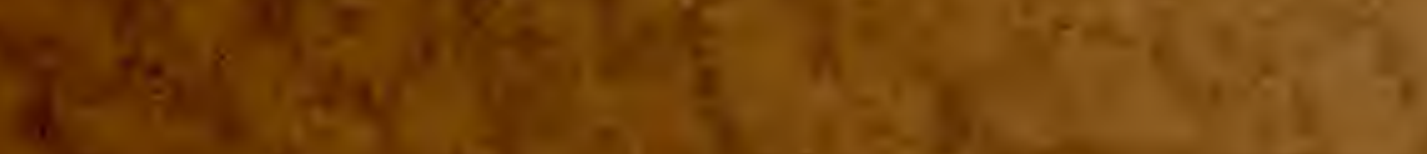

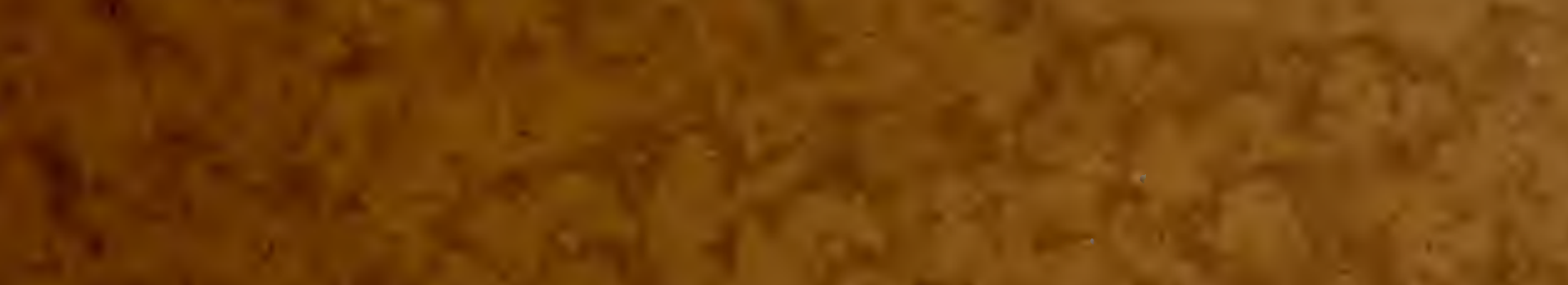

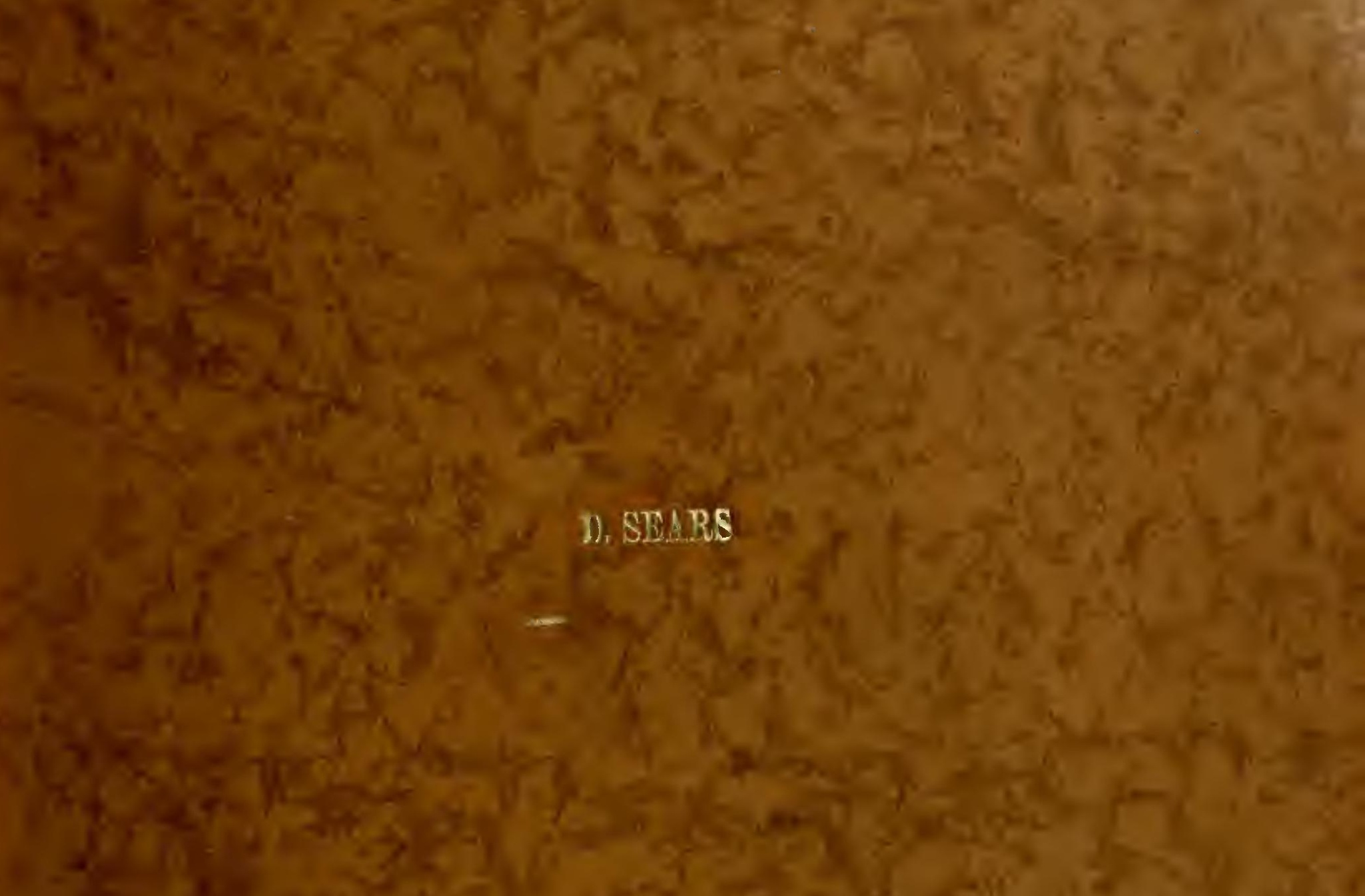

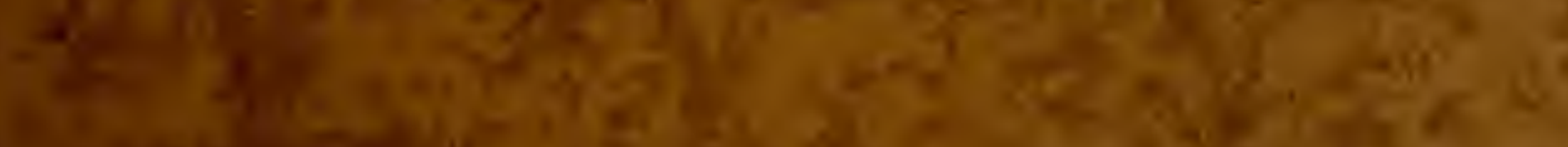

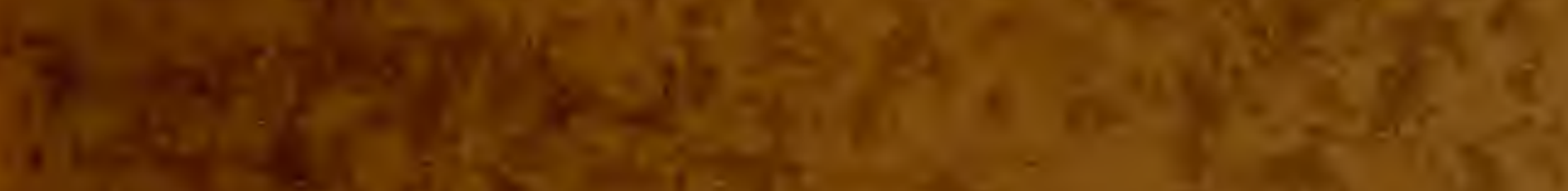

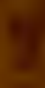
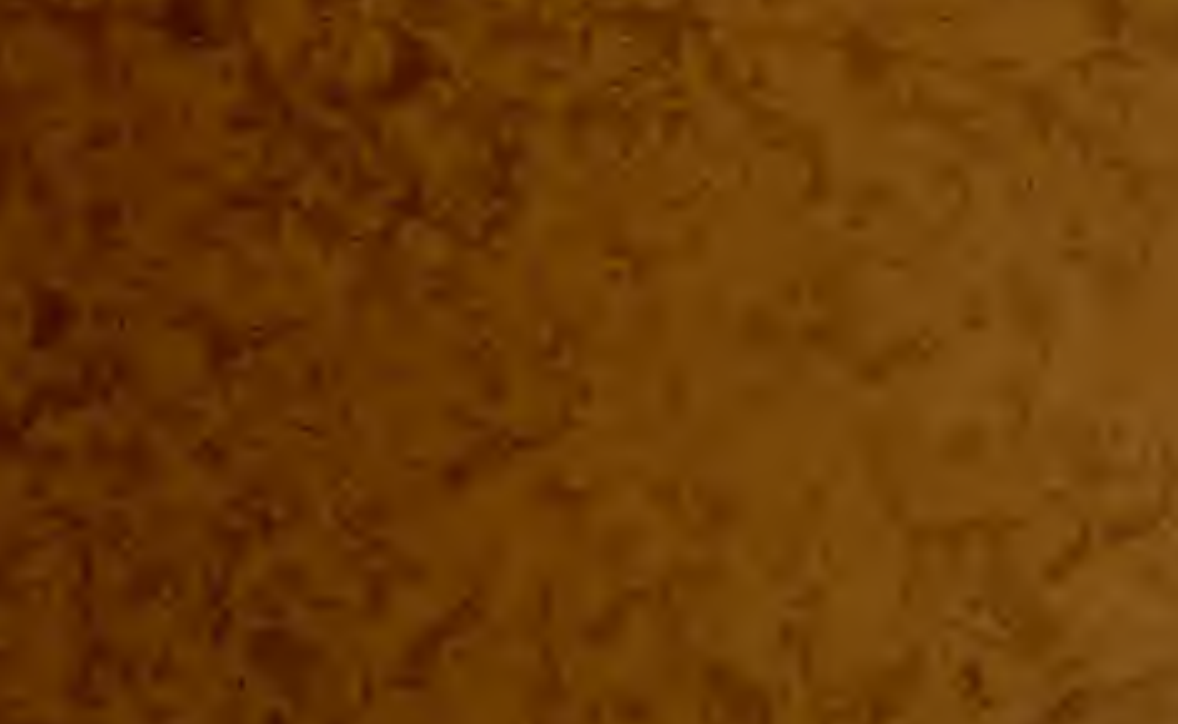



\section{Digitized by the Internet Archive in 2011 with funding from}

Research Library, The Getty Research Institute 



\section{ENCYCLOPEDIE METHODIQUE, OU}

PAR ORDRE DE MATIERES;

PAR UNE SOCIETE DE GENS DE LETTRES, DE SAVANS ET D'ARTISTES;

Précédée d'un Vocabulaire univerfel, fervant de Table pour tout l'Ouvrage, ornée des Portraits de MM. DIDEROT \& D'ALEMBERT, premiers Editeurs de l'Encyclopédie. 


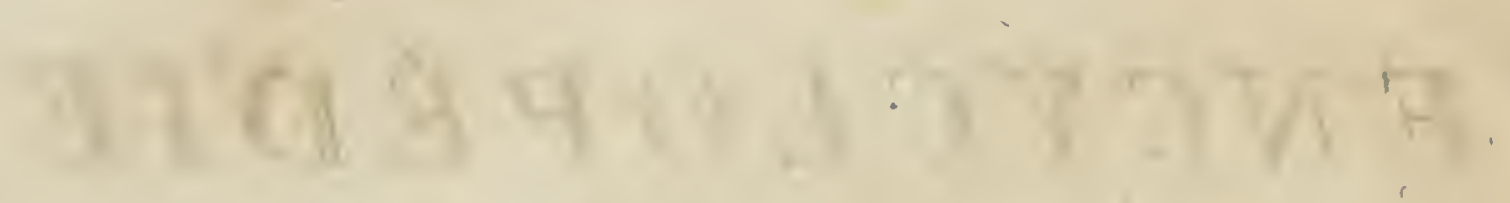

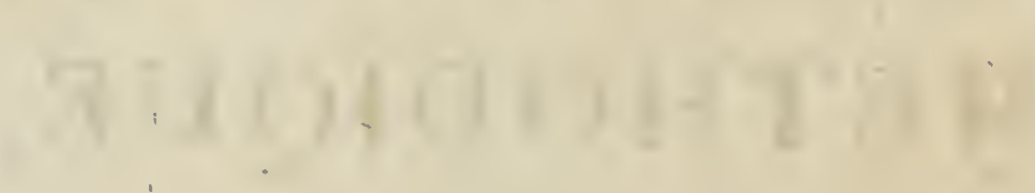

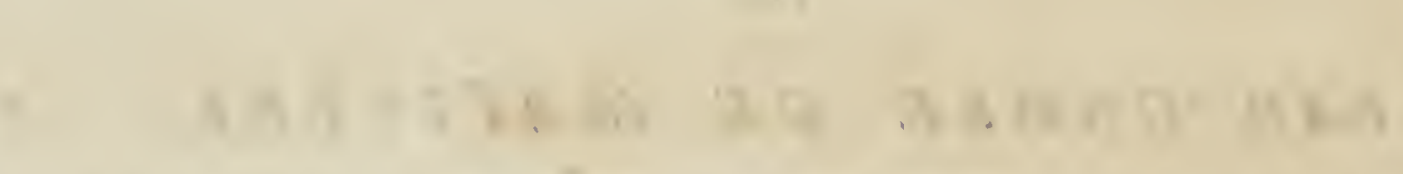




\title{
ENCYCLOPEDIE METHODIQUE.
}

\section{HISTOIRE NATURELLE \\ DES VERS,}

\author{
Par BRUGUIERE ET DE LAMARCK, \\ CONTINUÉE \\ PAR $M^{r}$ G. P. DESHAYES, \\ MEMBRE DE PLUSIEUTS SOCIÉTES SAVANTES.
}

\section{TOME SECOND.}

\section{A PARIS,}

Chez Minc veuve AGaSSE, Imprimeur-Libraire, rue des Poitevins, $n^{\circ} 6$.

M. DCCCXXX. 


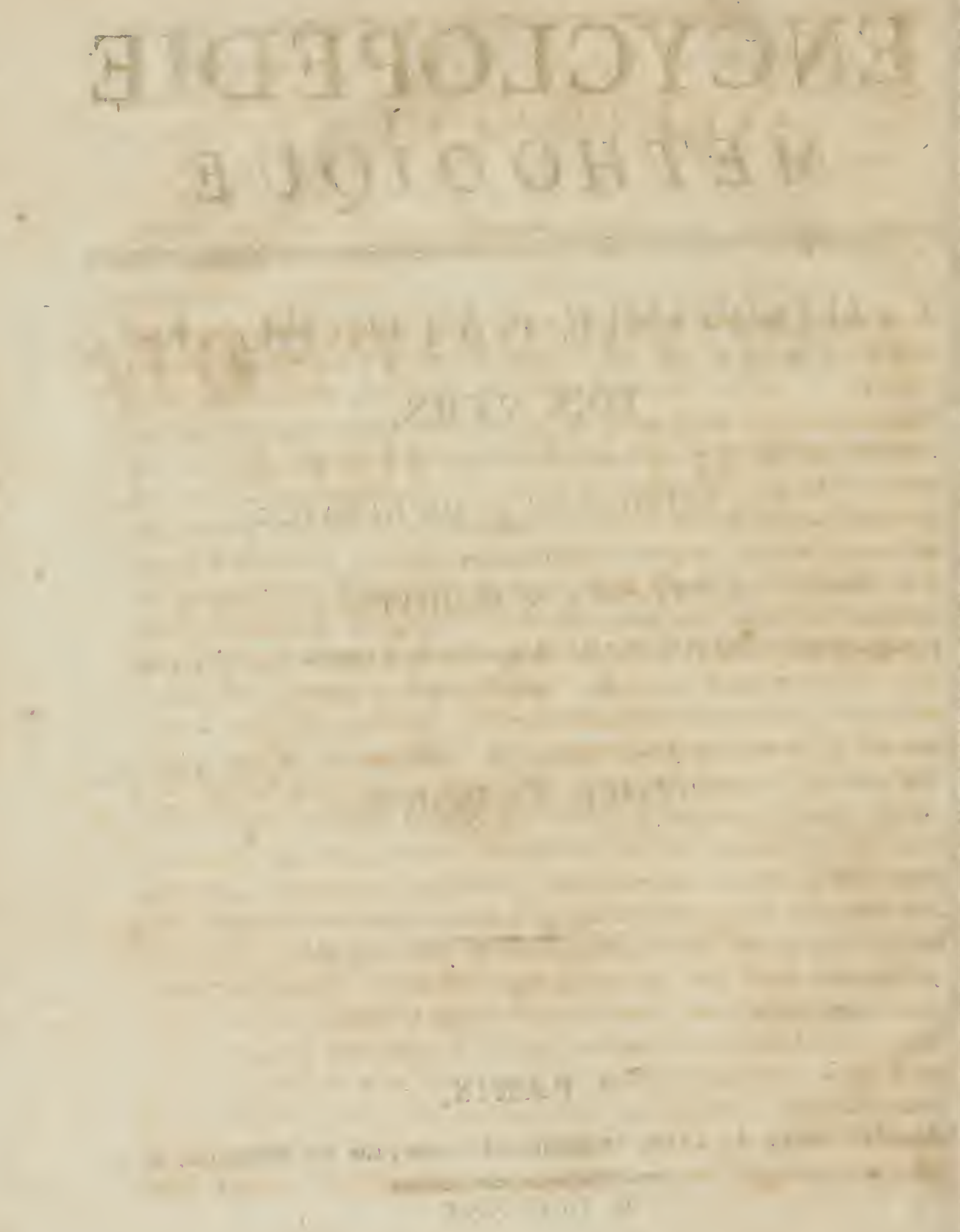




\section{AVERTISSEMENT.}

Lonsque Bruguière, il y a à peu près quarante ans, commença l'Histoire naturelle des Ver's, pour l'immense entreprise de l'Ency. clopédie, la science sortoit à peine des mains de l'imınortel Linné. L'impulsion donnée par un si grand génie avoit inspiré pour ses travaux une telle vénération, qu'elle étoit devenue une sorte de culte de la part de toutes les personnes qui s'occupoient alors de sciences naturelles. On auroit regardé comme sacrilége la main hardie qui auroit voulu toucher à l'édifice construit par le grand homme: il n'y avoit qu'un esprit juste, un bon observateur qui osât, en respectant l'ouvrage de son maître, y apporter les améliorations devenues nécessaires; et ce fut Bruguière le premier qui donna cet utile exemple pour la partie dont il avoit à traiter. S'il s'attira d'abord le blàme des imitateurs serviles, il acquit la gloire d'avoir montré la route des améliorations que réclamoit la science, et si une mort préinaturée l'empêcha de mettre à exécution le plan qu'il s'étoit tracé, du moins il trouva des hommes prêts à l'imiter; car le génie a toujours en de nombreux échos en France. Lamarck, dont le nom ne pent se prononcer qu'avec une profonde vénération, Lamarck, qui vient de terminer sa longne et glorieuse carrière, avoit Ihérité de ce génie linnéen, étoit doué de cette sagacité profonde qui se retrouve dans tous ses ouvrages méthodiques : comme Linné, observateur infatigable, tout ce qu'il fit fut le résultat de ses recherches. Après s'être acquis une réputation impérissable par ses travaux en botanique, dont il a laissé un beau monument dans cette Entreprise encyclopédique, il s'est livré pendant vingt ans à l'étude minutieuse de la partie la plus difficile de la zoologie : l'histoire unaturelle des animaux sans vertèbres lui est redevable de travaux d'mne 
telle importance, que nuus n'luósitons pas à los placer, pour notre époque, à la même hauteur que le furent ceux de Linné pendant la sienne.

C'étoit un tel homme qu'il falloit pour continuer et pour terminer l'Histoire naturelle des Ver's de l'Encyclopédie : lui seul étoit capable, par l'étenduc de son savoir, d'embrasser comme Bruguière l'universalité de la science, quoiqu'on un petit nombre d'années elle füt devenue immensément plus vaste. Interrompu dans ses travaux par une fatale cécité, il ne put rien faire pour cette partie de l'Encyclopédie, quoiqu'il se fùt promis de l'achever, et qu'il eût surveillé la confection des dernières planches.

Si nous avons continué une petite partie des travaux auxquels un Bruguière, un Lamarck s'étoient consacrés, nous ne l'avons fait, pour ainsi dire, qu'en tremblant, en nous défiant toujours de notre foiblesse devant la tâche que nous nous étions imposée, cherchant aitant que nous avons pu, à nous rapprocher de ces maîtres de la science. Nous sommes loin d'eux, nous le savons, et on aura plus d'une occasion de s'en convaincre : du moins pourra-t-on reconnóître aussi les efforts que nous avons faits pour être utile à la science; et cela seul nous en dédommagera.

Pour reprendre le travail de Bruguière, abandonné depuis si longtemps, il étoit indispensable de donner un Supplément qui le mît à la hauteur des connoissances actuelles : par suite des progrès immenses que la science a faits depuis le commencement de ce siècle, le Supplément s'est trouvé, lorsqu'il fut acleré, plus considérable que ce que Bruguièré avoit laissé sur la Conchyliologie proprement dite. Les démembremens nombreux qui se firent successivement aux dépens du plus grand nombre des genres traités par Bruguière, en les disloquant pour ainsi dire, en détruisant leur ensemble, exigèrent des développemens sur chacun d'eux, qui furent assez considérables pour que nous dussions regarder les articles du premier volume comme le complément des nôtres : nous allons nous faire comprendre par un exemple. Bruguière comprenoit dans son genre Buline des coquilles avec lesquelles Lamarck et d'autres auteurs firent six ou huit bons genres : ces genres, comme les Agathines, les 
Ampuldares, les Clausicies, etc., devinrent pour nous le sujet d'articles spéciaux qui furent traités d̀ leur place. Mais pour rendre utiles les excellentes descriptions spécifiques données par Bruguière, nous y avons constamment renvoyé, en indiquant les numéros du genre Bulime qui correspondent aux espèces des genres Agatinne, AmpulLAIRE, etc. etc. Cet exemple indique ce que nous avons fait pour tous les autres genres de Bruguière, parmi lesquels il n'y en a que deux ou trois qui n'aient pas éprouvé de unodifications. Ces motifs nous ont déterminé à placer notre Supplément au commencement et non à la fin du Dictionnaire; nous l'avons fait aussi pour rendre les renvois plus exacts, puisqu'ils se font des premières lettres sur les suivantes; et enfin parce qu'il nous a semblé que les recherches seroient plus faciles dans une seule série alphabétique. 


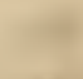

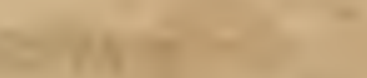

4

$$
4, x=0
$$

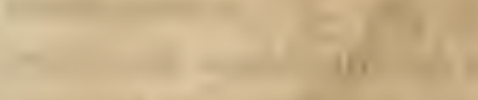

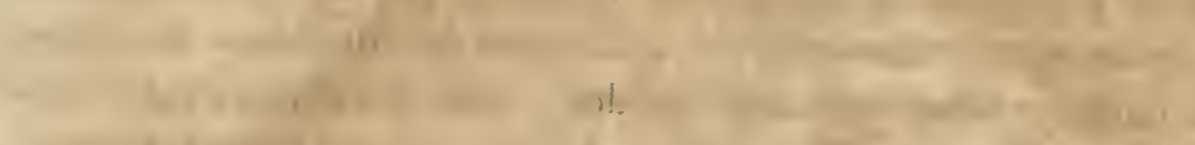

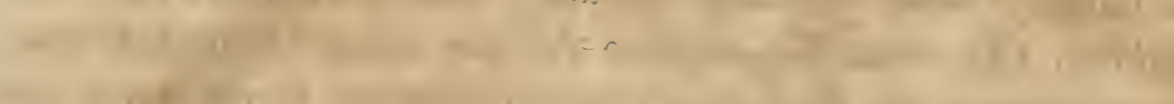

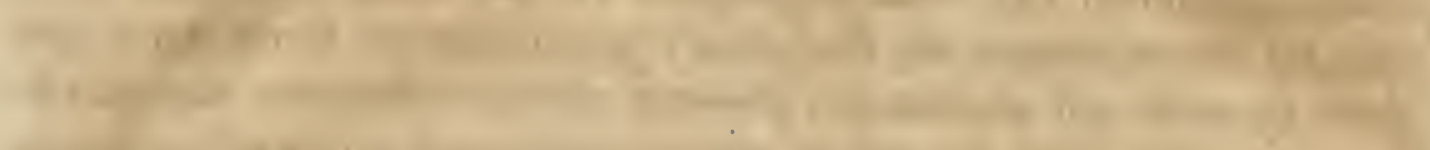

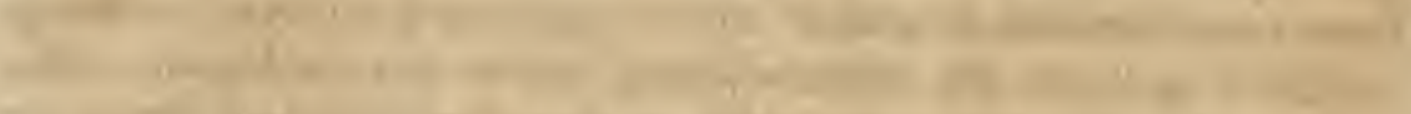
(20)

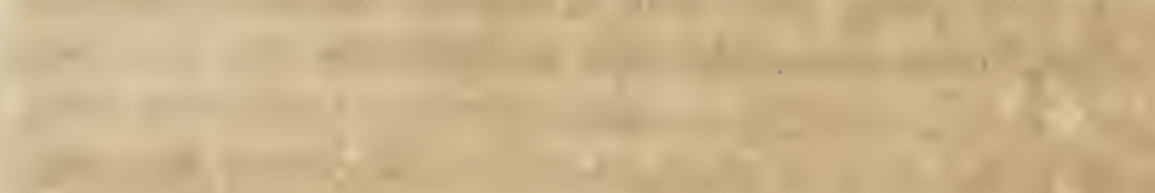

$\sqrt{2}$

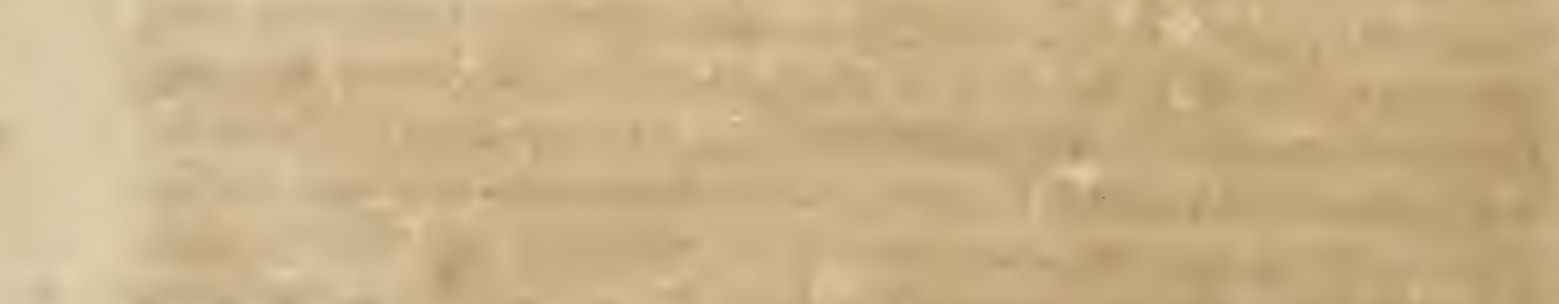

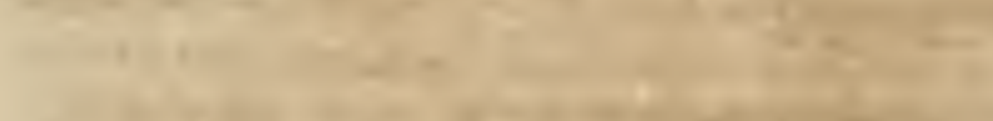

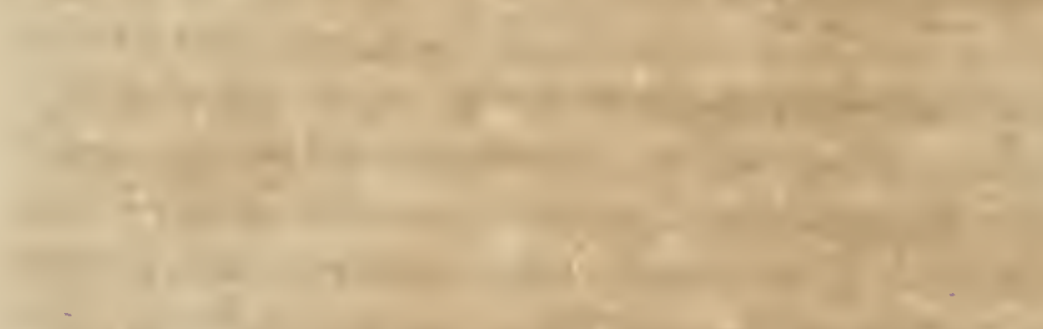
.

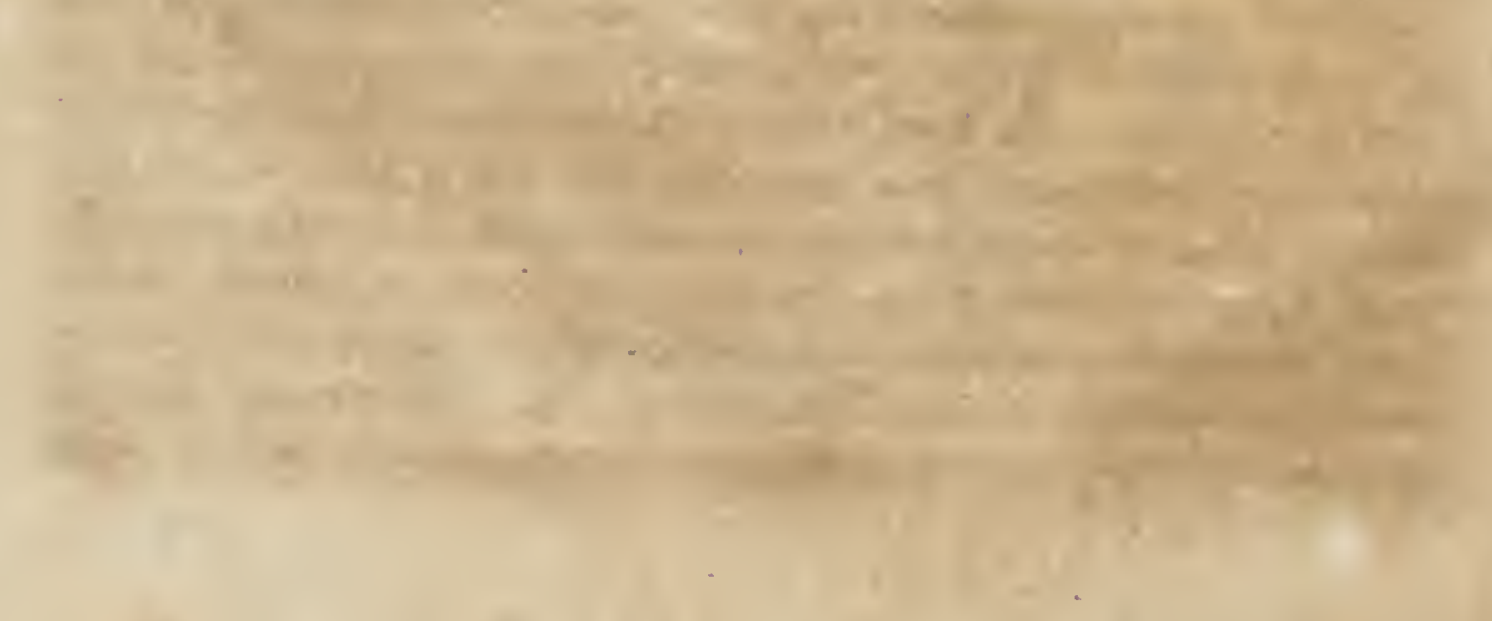




\section{HISTOIRE NATURELLE}

DES VERS.

\section{ACAne. Acamas.}

Genre proposé par Denis Montfort dans sa Conchyliologie systématique (lom. I, pag. 374) pour une espèce de Béleuınite doni le sommet tronqué offre dans le nilieu un pore étoilé, entouré de petits tubercules. Quand même ce caractère seroit constant, il ne suffiroit pas pour sépurer ce corps des autres Bélemnites, puisque du reste il en présente la forme et la structure : aussi M. de Blainville pense- - il que celle dispositiun particulière pourroit bien ètre le résultat de l'usure. Nous n'avons jamais vu la coquille dunt il s'agit; nous ne pouvons donc point appuyer ou désapprouver l'opinion de $\mathbf{M}$. de Blainville, mais nous sommes d'accord avec lui sur ce point, qu'il doit faire partie du genre Bélemnile. Voyez ce mot.

\section{ACARDE. Acardo.}

Bruguière, confiant dans les ohservations du cćlèbre royageur Commerson, proposa sous le no:n d'Acurde un nouveau genre de coquilles bivalves; mais trompé par ces observations, il prit pour des Concbilères, des corps que l'on a reconnus depuis pour des épiphyses de Cétacés. Le genre Acarde auroit donc dú être rayé de la liste : il u'en a point été ainsi, parce que Bruguière lui-même, dans les planches de ce Diclionnaire ( $p l .17^{2}$ et 173 ), rapporla à ses Acardes les $\mathrm{Or}^{-}$ thocératites de La P'eyrouse, et un corps dont M. Lamarck a lait depuis le genre Sphćrulite; de sorte que quelques personnes ayant rejclé les épiphyses des Mollusques, conservent le nom d' 1 carde pour les seules Orlliocératites de la Peyrouse; quelques autres, et M. Lawarck luimême, appliquèreut le nom de ce genre à un corps qui en est entièrcmem différent, et dont il a fait depuis un genre sépaté, auquel il a donoé le nom d'Ombrelle. Voye\% ce mot, ainsi que celui Acarde, dans le premier volume de ce DiclionDaile.

\section{Histoire Naturelle des Vers. Tome II.}

\section{ACASTE. Acasta.}

On doit à M. le docteur Leach l'établissement de ce geare; il le démembra des Balanes de Lingé. Adopté et bien caractérisé par M. Lamarck, il fut consacré par la plupart des zoologistes, qui le conservèrent dans la famille des Balauides qui correspond aux Cirrhipèdes sessiles de $\mathrm{M}$. Lamarck. (Voyez Cirrhipèdes et Balanides.) Ce savant a placé ce genre dans la première division des Cirrhipèdes sessiles, ceux qui ont un opercule quadrivalve, immédiatement après les Balanes, a vec lesquelles il a en ellet beaucoup de rapports. M. de Ferussac, dans ses Tablecurx des Mollusques, a adopté sans aucun changement les rapports indiqués par M. Lamarck; mais M. de Blainville ne les admit pas entièrement dans son Traité de Malacologie: les Acastes pour lui ne sont qu'une division très-secondaire des Balanes, dans lesquelles elles forment la troisième sous-division. Les Familles naturelles du règne animal prouvent que M. Latreille a adopté comme M. Ferussac l'opioion de M. Litmarck; seulement i! éablit en fanilles les divisions fondées sur le nombre des valves de l'opercule. Il nomase quadrifores la première, dans laquelle se trouve le genre Acasie.

$$
\text { CARACTÉRES GÉṄÉRIQUES. }
$$

Animal inconnu. Coquille sessile, ovale, subrnnique, composée de pièces séparables et symétriques. Cône formé de six valves, deux imparires symétriques sur Ja ligne mćdiane, et des quatre aures, deux de chaque côté absolument semblables, ayant pour fond une lame orbiculaire concave au rôlé interne, et ressemblant à une patclle ou it un gobolet. Quatre valves operculaires. Lank. Anim. s. vert.

I.es Balanes se fixent aux corps solides, y adhèrent par la totalité on une partie de leur base. Ics Aeastes ont d'autres habiudes; elles s'implanteut dars les éponges, s'y eufoucent par leur base 
rui prend nne forme conique patellöde, sur laquelle les valves viennent s'arriculer. Ces valves ont uue organisation semblable à celle des Balanes, et on ne trouve que pen de différence dans leur mode d'adlísion; elles sont au nombre de six, quatre latérales parfaitement paires et symćtriques, et deux médianes qui sont également symétriques. Il resulte de celte disposition que les Acastes peuvent être divisécs en deux parties parfititeasent égales el semblables. La hase patelloide qui supporte les valves a dô être sounise à la loi de syméric qui a présidé à l'arrangement régulicr dies valves : aussi c'est ce que l'nbservalion confirme. L'opercule se compose de deux parres de valves qui on beaucoup de ressemblance avec celles des lialancs.

Les deux premières espèces qui furent connues ont été coafoudues daus le genre Balane: l'une, sous le nou de Bulanus spongiosus, a été décrie par Montagu dans le Supplémeal aux lestacés britanniques, et la seconde a été découverte par Poli qui la foura dans son magnilique ouvrage, sous la dénomination de Lepas spongites.

1. Acaste de Montagu. Acasta Montagui. I. ЕAсH.

1. testâ albâ; valvis acutis, transverse strialis, extus spinulis ascendentibus muricatis.

LAys. Aninu. s. vert. tom. 5. p. 398. $n^{\circ}$. 1 .

Balanus spongiosus. Munt. Test. brit. sup. 2. tab. $17 \cdot f i g \cdot 4 \cdot 5.6$.

Cette coquille est blanche; sa base est lisse, tris-conique ou patelliforre; les valves sont aiguës à leur sommet, de sorte que l'ouverlure supéricure semble déchirée; ses valves sont striées transversilement el hérisscées de petites épines. On la trouve a Meymouth en Angleterte, dans les éponges.

2. Acаsте gland. Acasta glans. LАмк.

A. lestâ ovali, rubescente, supernè spinulosâ, transvorsim striatâ, valiâ baseos cyathyformi, margine sexdentutî.

Lamk. Aninz. s. vert. loc. cit. no. 2.

Lidcaste gland prend quelquefois d'assez grandes dimensions comparativement aux autres espèces. Il y a daus la colleclion du Muscium des valves inférieures qui servent de base a la coquille, qui ont dix-sept millimètres de longuenr sur quinze Ge large. Celle espèce se dislimgne par sa forme ovaluire assez ćlargie supisientement, par sá couleurd'un rouge obscur; li partic supéricure tes pic̀ces est chargrie d'ćpines font comtes; c'est aussi vers celle parlie que se voienl des stries twansverses qui diminueut insensiblement vers lat base. Jue somatel des preces est poinlu, triangulaire et fortement séparé de snn voisin, de solle que. J'ouverture supérleure esi découpćc en six parlies bien distinctes et symétriques. Ta base est patelliforme, un pen plus longue que large, śpaisse au cenlre, assez mince vers les bords, où l'on voil six petites apoplyses saillantes qui correspondent à l'endroil de la jouction des pièces; exicrieurement elle est ornée de stries concentriques très-lines. Les valves operculaires, au nombre de quatre, présentent entr'elles des diffírences : les antérieures sont plus épaisses, chargées de stries lamelleuses très-servées, crépues, tra sverses. J.cs valves postérieures sont beancoup plus minces. substriées; les stries sont beaucoup plus distante. $c t$ à peine sensibles.

Hab. L'île de King.

3. Acaste spinnleuse. Acasta spinulosa. Nor.

A. testâ ovato-conicâ, supernè rosế, infernè albâ, spinosâ; spinis minimis ad bism oblquis; 'alvâ haseos patellıformu depressâ.

Cetle espèce a des rapports avec. l'Acaste gland, mais elle eu diflère par plusieurs caractères principaux : elle est de couleur rose au sommel seitlement, car la base est tout-à-fait blanclie; le: pièces, surlout celles qui sont médianes, el por coiséquent symélriques, sont beaucoup plus triangulaires; toute la coquille, et surloul supáricurenient, est couverte de petiles épiues courres, obliques, dirigées vers la base de cocuille : elles sont heaucoup plas nombreases que dars l'Acaste gland. La valve de la lase est patelliforme, a ses stries concentriques tres-lines extrrieurement, el elle est très-díprimf́e plus que dans aucune autre espèce. Elle a douze millinètres de diamètre à la base, el quinze de lauteur.

Ilab. Ia Nouvelle-Hoilande. Coll. du Muséum.

4. Ac. sтe sillonnée. Acastu sulcutu. L.А и.

A. testî̀ oblongẩ, longitudinaliter sulcatiu, albida, supernè roseo tinctâ; sulcss scubrusculıs; valvầ buseos pocullutâ, margine crenulutâ.

LAsx. Anim. s. vert. loc. cit. $n^{\circ}, 3$.

La fornc sing̣mlière de celte espece l'éloiguc un peu des priciédentes paur les rapports; elle est en uffer subtubulense. Outre que les valres de la coupille sont alungées, la valve de la hase ellewềne l'est aussi notablenent, et resscruble à une (:i) ule tres-prolonde, de sorte que dans son ensemble la corjuille est comme tubuleuse. I,es strices qui sillonnerit la coquille longiludinalement à l'exrérieur sout assez larges, peu serrées el rudes suronut vers lexllćmilé supérieure des pieces, on wlles sont légrirement t́pumeuses. Celle móme parlie de la coquille est d'un rose paile. La valve de la base est fort profonde, striće longitudinalement conme le reste de la caquille; mais ce cru la dislingrue des aures especres, c'est que son bord est crónelé assez profondémcnt : ces créuelures sirticulent arec la base des pieces du cóne, qui a 


\section{A C A}

liukérienr offrent des crénelures réciproques et correspondantes. Loogueur, dix millimètres. La valve de la base a quatre millimètres. Largeur à la partie moyenne, à la suture de la base el du cûne, qualte millimètres.

IIab. La baie des Chiens-marias. Rapportée par Yérou. Coll. du Mus.

5. Acaste inbuleuse. dcasta tubulosa. NoB.

A. testấ elongatî, tubulosâ, parte superiore roseá; valvis transperse striatis; valvâ baseos profundissimâ, longitudmuliter laxed striatâ; murgine integrâ.

Cclle-ci a beaucoup d'analogie arec la précédcute, quoiqu'elle en soil parfaitemeut distincte; elle est beaucioup plns tubuleuse, les pieces sont alongées, striées longitudinalenent ì l'intórieur el Irunsversalement à lextérieur; leur sommet est lisse et teiuté de rose briqueté. Les stries extéricures sont très-fines, assez régutières, et plus appareutes à la base des pièces qu'au sommet. La valve de la base est beaucoup plus prolonde que dans l'autre espèce; elle est toute blanclue, miace, cassante, strée légèrement en longueur. Le bort est eulier el sans crénelures.

Les grands individus de cette espèce ont pu avoir vmgt millimètres de longueur. La moitié de cette dimension étant occupée par la valve de la base, á l'endroit le plus large de la coquille, qui est celui de la suture des pièces supérieures et de la base, on trouve six millimètres de diamètre.

On doil cette espèce aux naturalistes de l'expédicion du capitane lireycinet; elle est dans la cullection du Mluséum, sans indication de l'habitat.

6. Aesste naine. Acasta nana. Nob.

A. testâ ovatâ albidâ; salvis incequalibus substriatis; aperturâ obliquâ, sexdentatâ; 2 alpà busens pateiliformi, stris concentrucis exiguis ormultâ.

Jolie petile espèce que nous avons découverte dans une éponge rameuse de notre cullecuon: cile est pente, blanche, uvalaire; les valves du cône sont inégales; la valve antéruente esı la plus grande, la postérieure a plus cuurte, et les deux uuyennes diminuent iuseusiblement, ('e cui dume à l'ouverture beaucoup d'obliguté d'alvant en arrière. Cette ouverture est découpće en six pointes bien séparées, une pour claque valve : celles-ci cont à peine striées eu travers, sice n'est cans les aires latérales, où lés stries sout bien régulicres et bien sensibles. Le cône supérieur est séparé de la valve de la base par une vive arćte; cetle valve est jatelliforme, chargée de stries concentriques très-tiues. Les deua vilves opertulaires anterreures sout épaisses, sulides, orrées de s.ries lamelleuses transverses, et en dehors les deux postérieures, minces et lidjiles, ont des stries jeu
A C A

sensilules; elles sont pourvues latéralement d'une perite apophyse. Longueur, cing nailliàètres. Largeur à la base, quatre millimètres.

7. Acrste spongite. Acasta spongites. Lamk.

A. lestâ ovutâ, violuceâ, irregulariter sub-

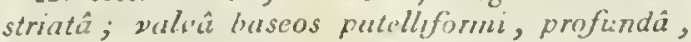
quatuor ridlis porum instiuctâ.

L.амк. Anim. s. vert. loc. cit.

Balunus spongites. Pour, T'est. des Deux-Sic. pag. 25.tab.6. fig. 3. 4. 5.6.

Cetle espèce se distingue très-bien de tontes celles du niêrae genre par une particularité fort renarguable. La valve de la hase qui est conigue, patelliforme et assez profonde, oflre quatre rangées rayonnantes du som:act à la base de pures disposés régulièrement sur trois lignes. Ce caractère, à délaut de tout autre, est bien suffisant pour faire dislinguer celte espèce, qui est, nous le crojons, lis senle qui le présente. Le cône se compose de six valves faciles à séparer; elles sont irrégulièremeut strices, violâtres, sans épines ni tubercules an sommet : ce sommet est pointu, de sorte que l'ouverture de la cocjuille est assez profondénent dćcoupée. Liopercule est strié transversalenent, rugueux, surlout sur les valves autérieures. Longueur, dix à douze millimcitres.

Hab. La Míditerranée, daus les éponges commuues, où elle anuonce sa préseuce par des tubercules en forme de pustule perforée au centre, où l'on aperçnit l'opercule.

8. Acaste glindiole. Acasta glundiola. Nob. A. testầ opato-uculâ, alhâ, inflatâ, lievigatâ; zulvis basi plicatis; valiâ busens putclliformi, comco-acutù, lowgatâ, margme volvis separatî.

Il existe quelques rapports entre rette espèce et celle que unus avons nommée Acastu numa: elle est beaucoup plus crande, la valve de la base beaucoup ples prolonde el plus pointue.

LiAcuste glaudiole est toule blanche, ovale, pointue, lisse, si ce n'est à la hase du cône où on vat deus: ou trois stries ou plis transversanx : elle n'est point aplatie latéralement; elle senuble au conzlzaire commé souftlée, tant elle est arrondie. Les urois valves antérieures sont beaucoup plus larges que les trois postérieures, qui occupent à peine le liers de la circonférence. l'ouverture est in réguliereruent ovale ou subcarce; son burd est profondéouent partagé en six lobes formés par l'extrénité supérieme des six valves. La valve inférieure est cébordíc par les valves du cône, de sorte que celui-ci est comme posé sur les lourds de cette valve qui est palelliforme, toute lisse, prolunde, pointue an sumnet. Les valves opesculaires sont striées transversalement; elles A 2 
sont blanches comme le reste de la coquille. Longueur, douze millimètres. Largeur à la base du cône, huit millimètres.

Hab. Inconuve.

Bruguière, à l'article Baraxe de ce Dictionnaire, a décrit une espèce d'Acaste que nous ne reproduisons pas ici; il l'a nommée Balane des gorganes, Balanus galeatus, tou. I, pag. 170, n०. 16 . Nous y renvoyons.

\section{ACCOUPLEMEYT.}

L'accouplement dans les Mollusques est une fonction encore peu connue; elie n'a été observée que dans un petit numbre d'entr'eux, et surfout parni ceux qui sont ierrestres ou fluviatiles. Nous jenvoyons à l'article Moucusque, où nous traiterons de cette question.

\section{ACCROISSEMENT.}

L'accroissement dans les coquilles a été le sıjet parmi les naturalistes du siècle dernier, de discussions assez vives qui ont été terminćes par les expériences conciuanfes de Réaumur. Bruguière a présenté celle question dans tout son jour. a l'aricle Copurle de ce Diclionnaire. (Vojez ce mot.) Ce sarant adople l'opinion de Réauuur; elle avoit été admise du temps de l'illus!re acadénicien, et elle l'esı encore aujourd"hui, parce quelle repose sur des faits incontestables, que les plus simples observations peuvent mettre en évidence à chaque moment.

\section{ACÉPHALES.}

Dans son Tableau élémentaire d'histoire naturelle, publié en 1798 , 11 . Curier se servit de ce mot Acéphale pour désinner un ordre particulier dans les. Nullusques, ordre que Linné et Bruguic̀re nommoient Coqurlles bivulues, à l'esemple de presque tous les aulears anciens. Le mot choisi pour celle parie des Mollusques est parfaitement conrenable, puisquii est viai que lous ceux qui y furent conpris sont dépourrus de lête. D'après ce caractère bien saillant, $\mathbf{M}$. Cnvier rangea daus sa nouvelle classe des êtres qui, après un examen ultérieur, dủrent en ètre exclus. Les Acéphales sonı divisés en six sections d'égale valeur : Io. les Acépbales aus (les Ascidies); $2^{\circ}$. les Acépbales testacis, saus pied et à coquille inéquivalve; 3o. les Acciphales iestacés, muis d'un pied, jvalves égules, à wanteau ourert par-devaut; $4^{\circ}$. les Acépbales testacés, pourrus d'un pied; à valres égales, à coquille ouverte par les deus bouts; a manleau fermé pur-devani; 50. les Acéplates testacćs, sans pied, niuuis de deux tentacules cbarnus, culiés, roulés en spirale; 60. les Acŕphales ieslacés, munis d'une anultilude de tentacules articulés et cilićs, rangés par paires (les Bulanes et les Anatifes). Il rćsulte nécessaire- ment, d'après cela, la destrnction de la division tıès-anciennement établie el perfectionnée par Linné, de mulivalves, bivalves et univalves, syslème qui ne pouvoit souflil un examen approfondi sans être renversé. Quelques années après, M. Lanarck employa le mème mot pour désigner les mênes êtres. Sans adopter toutes les dirisions de M. Cuvier, il parlage les Acriphales en deux grandes divisions principales, les Acéphales nus et les Acéphales conchifères : cers derniers sont ensuile partagés eu ceux dont la coquille est équira!re et en ceux qui l'ont inéquivalie; çestdans celles-ci que se trouvent, dans la deruière section, les Auarifes et les Balanes. Ainsi, à part la méthode de distribution, les Acéphales des deux auteurs que nous renons de ciler contienneat les mêmes animaux. Les divisions principales aroient élè senlies el indiquées.

MI. Duméril le premier, dans son Trallé élémentuire d'histoine naturelle, sépara d'abord en classe particulière les deux dernières divisions de U. Cuvier, et leur imposu le nou fort bien approprié de Brachiopodes (voyez ce mol), qui réunissent avec les Liugules, Orbicules, etc., les Anatiles el les Balanes. De Ruissy (Buffon de Sonnini) a conserré les Acéphales de M. Cuvier dans leur intégrité. M. Lamarck lui-même, dans sa Philosophie zoologique, ne conserva plus les premic̀res divisions du systéne. En élablissant des familles parmi les Acéphales, qui forment dans cet aurrage le premier ordre des Mollusques, il en sépara en classe particulière les Cirrlipèdes pour les Anatifes et les Bulanes, qu'il relira des Brachiopodes de 11. Duméril. Celle classe ne fit plus parie des Mollusques acéphales; elle fut élevée dès-lors à un degré égal aux. Mollusques. Les Mollusques acéphales fureut parlagés alors en treize lamilles. Les Brachiopodes forment la première, el les Acéphales nus des auteurs, sous le nom d'Ascidiens, constituent la dernière de cet ordre. Ces familles se présentent daus l'ordre qui suil : $1^{\circ}$. les Brachipodes; $2^{\circ}$. les Osıracées; $5^{\circ}$. les Byssifères; $4^{\circ}$. les Camacées; $5^{\circ}$. les Nuades; $6^{\circ}$. les Arcácées; $7^{\circ}$. les Cardiacées; $8^{\circ}$. les Couques; $9^{\circ}$. Les Mactracées; $10^{\circ}$. les Mjaires; Iro. les Solcnactes; $12^{\circ}$. les Pholadaires; $15^{\circ}$. les Ascidieus. (Voyez tous ces mots.) Ce savant cunserva la mène distribution des-Acéplates das l'extrait de son cours; seulement il rerint à rue division établie dans le systeme de sćparer en deus sections les Acéphales, la prenière pour ceux qui sont lestacés, la secoude pour ceux qui sont nus. Dans son deruier ouvragre il sépara la famille des Ascidiens en ordre purticulier, qu^il éloigna considérablemenı des Mullusques acéphales; il substitua à ce nom celui de Mollusques corchifères : et on ne troure plus en ellet daus celte classe ŕtêce au méme degré que les Mollusques, d'animaux dépourvus de coquille.

M. Cuvier a suivi une marche un peudifíreate: 


\section{A C E}

jl sépare des Acéphales et les Brachiopodes de Duméril et les Cirrhopodes de Lauarck; il divise toujours les premiers en lestacés et en nus, de manière que les Bıachiopodes par exemple, qui ont beaucuup plus d'aualogie avee les autres Acéphales yue les Ascidies, se truavent plus fortement séparés, puisquilils sont au même degré que les Molluscues céptralopodes, acéphales, elc., de la mélbode. Nous traiteruns à l’article Molcusque, de l'imporlance que l'un doil allacher au degré des livisions principales.

M. de Ferussac, dans ses Tableaux systématıques des animaux-mollusques, divise les Acéplaales en quatre grandes clas es, les Cirrlipodes, les Brachiopodes, les Lamellibrauches el les Tuniciers. Il y a une antioration d'avoir fait une classe à part de ces demiers, mais ce cliangement est dù à M. Lamarck. Cette grande classe des Acéphales se relrouve composée des ouêues éléviens, à peu près dans les nêmes rapports que dans le premer ouvrage de Cuvier, Tableau élémenturre d'historre naturelle, dont nous avons parlé au corntnencement de cet article. Ce qu'il y a de singulier dans l'arragement proposé par 11. de Fer'ussac, c'est la place qu'occupent les Cirrhopodes, qui n'ont point de rapports avec les Mollusyues céphalés yqui précèdent, et guère plus avec les Nollusques acéphales yui suivent. Daillcurs l'anatonie bien counue de ces animaux conduit a les mettre beacoup plus a aturellement à la fin des Mollusques acépbales, pour les rapprocher des arimaux articulés, avec lesquels ils ont un assez grand nombre de points de ressemblance: ils sortent mêtue tellement du plan d'organisalion des autres Mollusques, que M. de Blainville, dans son Truité de Mulacologie, en a fait un sous-lype a part des autres Mlolinsques. Chez cet auteur, les Acéphates ont reçule nom d'Acéphalophores. Ils sunt divisés en qual:e ordres : le premier renferme les Brachiopodes, sous la dénomiaction de Pulliobrunches; le second comprend les Rudistes; le troisieme, les Lamellibranches, contieut la presque totalité des Mullusques acéphales; le qua. trième enfia rassemble les Hétérobranches ou Ascidiens de M. Lamarck. Ainsi la móllode de H. de Blainville dillére de celle de M. Cuvier, qui admact les Cirrhopodes parmi les Mollusques; de celle de M. de Ferussac par la place qu'il leur tait occuper, et de l'un el de l'autre par la créalion d'un ortre nouveau, celui des Rudisies.

M. Latreille (Fumilles naturelles du régne animal) comprend avec les Coarchilères de M. Litmarck, dans sa seconde section des Alollusçues, les Agames, tous les animaux qui n'ont point d'accoupiement. Il est obligé de faire daus celle section deux divisions principales : la prenière, les Exocéphales, reoferme les Haliotides et tous les Tectibranches de Ml. Cuvier, ainsi que les Cyclobranches du inêtue savant. Celle division qur sert d'satercuédiaire pour ainsi dire entre les Mollus- ques cŕphalés ct les Acéphajes, ayant, par les animaux qu"clle contient, heancoup plus de rapporls avec les Mollusques céphalés qu'avec les Acéphales, auroit dî être placée en dehor's du cadre de ceux-ci.

Les Mollusques acḱphales des anteurs ont reçu le nom d'Endoctephules, et ils forment dans le systeme de 11. Latreille la seconde division des Ayames; ils sont divisés en deux classes; les Bracliopodes el les Conchifures : ces derniers renferment quatre grands orilres, fondés, à la manic̀re de Poly, sur la forme du maieau. Le premier contient les Acéphales à manteau ouvert; le secoud, cenx à manteau biforé; le troisième, ceux à manteau triloné; le quatrième enfín, ceux i manteau tulauleux. (Voyez ces mots.) Dans ces divisions ne sout point compris les Cirthipèdes et les Tuniciers. M. Latreille cousidere les premiers comue intermédiaires entre les Acéphales et les animaux articulés, et les seconds comme plus voisins des Actinozonires que des Mullusques, suivant en cela l'opinion de M. Lamarek. Al'article Molousqe nous reviendrons sur la classilication des Acéphales, sur l'eusemble de leur organisation, et nuus discuterons la question inportante de leurs rapports naturels avec les êtres euvironnans. Voyez Mollusque.

\section{ACÉPIIALOPIIORES. Acephalophora.}

Dénomination employée par MI. de Blainvillo pour la grande classe des Mollusques, auxruels M. Lamaick a donné le nom de Conchiferes, et tous les autenrs modernes celui d'Acéphules. Vojez ce mol et Mollosqoe.

\section{ACÈRE. Akera.}

C'est à Muller que l'on est redevable de celle déominatiun qu'il employa pcur une espèce dı genre Bulle, dont il laisoit son Akera bullata. Cet animal entra dans le geore Bulle de Linné et des couchyliologues modernes. D'après ce cliangemeot, le mol Akera auroit dû clisparoitre; mais par uoe substitution qui n'est pas sans exemple, il fut appliqué d'abord par. M. Cuvie. à un genre dans lequel l'skera bullutu n'est pas compris, et ensuite par M. Felussac à uQte faraille tout entière, à larpuelle M. Lamarck a donné le nom de Bulliens. (Voyez ce mot.) M. Ferussac partace celle limille en cinq genres, qui sont : Doride, Bullée, Bulle, Bulline et Surmel : ces denx derniers nenres sont nouveaux. Les Bullines sont Lien voisines des Bulles pour la coquille; elles ont aussi heaucoup de rapports avec plusieurs espèces de Tornalelles; l'aninal dilfere de celui des Bulles pur les tentacules : arus croyons qu'il a besoin d'être mieux connu. Quant au genre Sarmet, il est pris d'Adanson. M. Cuvier n'a pas cru nécessaire de le séparer des Bullées. Nous pensons que ce gente, comme beaucunp 


\section{A D E}

d'autres, a besoin d'être cxaminé avec soin pour que l'on puisse lui assigner des rapports naturels. VOJe Z BULLEES.

\section{ACÉRÉs. Acera.}

Nom que M. Latreille a donné à la famille que M. Ferıssac a nonimée les Acères et $M$. Ldmarck les Bulléeus. M. Isatreille divise la famille en deux sections, les Acérés qui out une coquille, los genres Bullée, Bulle el Sormet, et ceux qui sum suns cuquille, le genre Dorde (Doridium) de Meckel. On ne trouve pas ici le genre Bulline de MI. Ferussac. Voyez Acèke el Bulléens.

\section{ACHELOÏTE. Achelois.}

Genre proposé par Montfort (Conchyl. sjst. tom. 1. pag. 558) pour une coquille cloisunnée pétrifiée, yui doit fuire partie du genre Orthocère de Sow. (Voyez ce mot.) M. de Blainville, qui place ce genre dans les Conilites, pense que ce pourroit bien élre me alvóle de Bélemnite, opinion que nons ne partageons pas.

\section{ACOCHILIDES. Acnchlides.}

M. Latreille at divisú les Céplalopodes octopodes en deux fauilles (Fum. nat. du règ. anim. pag. 168), les Acochlides et les Cyıbicochilides. Cette prenière fanille est caractérisée par na aninal qui a'u poina de coquille et qui, dums son intérieur, renteruse deax petites pièces cartilagineuses. Les gemres Pou!pe, Elfédone et Leachie sout les senls upui y soient placés. D'Orbigay, dans sun travail sur les Céplalopodes . n'a point adopté cette division qui nuas semble pea nécessaire. Voyea Cépnalopodes el Octurjanes.

\section{ACT EON. Actoon.}

Quelques Aplysies encore imparfaitement connues sous plusieurs rapports, qui ont seulement deux teutacules, les yeux placés en arrière, et qui ont autour du pied des appeadices fort larges, ont serri à M. Ocken pour établir ce noureau genre sur la supposition aussi que ces animaux sont pulmonés, ce qui les rapprocheroit des Ouchidies. Mais comme il mancyuc des observations précises à l'égard du mode de respiration, on doit toujours, à l'exenple de M. de Blanville, conserver les espèces de ce genre incertuin parmi les Aplysies, en en lurmant uae petite section à part. Foyez Aplysie.

\section{ACTÉON. Áleon.}

Geare uon adopté de Montfort (Conch. syst. tom. 2), parce que M. Lamarck l'avoit déjä fait sous le nom de Tornatelle pour le Voluta tornatilss de Linné qui lui sert de type. Voyez TonATELIE.

\section{AC'TINOBOLE. Actinobolus.}

Klein, dans son Nova method. Ostrac, a proposé de róunir dans a seul genre toutes les coquilles bivalves qui ont des strics ou des côtes rayonoantes. On doit penser qu'un caraclère exlérieur de si peu d'importance ne pouroit faire un bon geure : anssi celui-ci, comare la plupart de ceux du même autenr, n’a point été adopté.

\section{ACYONEE. Acyoncea.}

Leach a prupusé ce nom pour les espéces de Scalaires dout les tours de spire ne se toucheat pas, comine daus le Scalaria pretiosa. On seot combien un tel geare est inulile. Vojez Scalaike.

\section{ADÉLOBRANCHES.}

M. Duméril, le créateur de ce mot et de la clusse de Mollusques anxquels il l'a appliqué, lni avoit donné uue extension considérable et il fant dire mal fundée, pinisque sons ce caractère si général d'u voir les organes respiratoires non visibles iu dehors, ce sivvant professeur rassembla un grand nombre de Mollusques de dilférente nature, pensant, à ce qu'il pratuit, que tous res iroient P'air immécliatement. Ainsi dans celle classe on tronve avec les Ilélices et les Limaces, les Aplysies, les Sabots, les Nérites, etc., la plus grande partie ea un mot des Mollasques qui ont eutière l'ouverture de lis coquille. Il a été impossible, lorsque l'olsservation est venue détruire ces rapprochemens, de conserver les Adélobranches, qqui fureor successivearent déwembrés et entin entièremeut rujetés.

\section{ADÉLOPNEUMONÉS. Adelopneumana.}

Aucuu des auteurs qui, dans ces derniers temps, ont proposi puur les Vullusųues de nouvelles classifications, u'a manqué de former avec les animaux de celle classe yoi respirent lair en ualuse, uue fawille ou au groupe daus lesqueís ils vat éle mis en rapports plus on nuvins naturellemeat. M. Gray dans sa classitication des Mollusques, d'aprés la structare iuterne (Bulletin des sciences naturelles, fívrier I 824 ), en lint une souscilasse sous le uous de Pneumobranclasa (voyez ee mot), et il la divise en deax oruses: le prenuer est celui qui nuas occupe; le second porte le nom de Phaneropneumona.

Les Ailéiopneamodés représentent assez bien les Pulmonés de M. Cuvier; ils renterueat les getares suivans:

a. Tentacules rétractiles. Terreftres.

Linax ou Limacidece, Onchidium, Plectrophorus, Testucella, Fatrina, Achatum, C'lausila.

b. Tentacules cylindriques, contractiles. Amphisuss. 


\section{A D E}

Auricula, Carychium, Phytia.

c. Tentacules comprimés, contractiles. Aquatigues.

Limna'a, Planorbis, Ancylus.

Voyez lous ces mots, PuLarosés et MoluusQUES.

ADÉLOSINE. Adelosina.

Genre proposé par M. d'Orbigny dans son ordre des Céplaalopodes foraminiferes, famille des Arathistègues (zoyez ce mol), pour plusieurs Coquilles microscopiques qui ont loutes été fignrées par Soldani. Quand elles sont adultes, il paroit quielles ont beancoup d'analogie avec les Qiaqueloculines, et on sera bien forcé d'en convenir, lorsque l'on aura comparé les caraclères suivans, donnés à ce gente par 1l. dorbigny, arec ceux du geare Quinqueloculine : coquille commencant par" use grande loge arrondie, ayant un prolongement an bout dnquel est une ouverture munic d'uu appendice; sur celle première Inge viennent se placer des loges en pelotonnemeat, de manière ì lormer avec l'àge un eruroulenent sur cinq faces, comme dans les Quinqueloculiaes. M. d'Orbigny ne dit pas si, dans ce genre, les ring Inges sont apparentes comme daus les Quinqueloculines: il est a présumer que cela rest pas ainsi, car alors il ne resteroit plus la muindre dillírence emre ces deux genres. Si aous eu jugeons d'aprćs les ligures de Solutani, nous soumes nhligres de conrenir, ou qu'eiles sout mal f.tiles, ce yul est pen probable, ou que les caractères donnis par MI. d'Orbigny ne snat point sullisans, ou bir a yue les figures dont il est question ne représentent que de jeunes individus. Celle dernière conjecture nous semble la plus prohahe. Pourceux gui n'ont point vu en nature ces petiles roquilles, il es: fort difficile de résoudre la question et de fuire accorder entrelles les objections que nọs venons de proposer.

\section{ADESHACES. Adesmarea.}

La dernière famille du Iroisième ordre des Mullusques, dans la méthode de $\mathbf{1 1}$. de Blainville (Truit. de Malac. pag. 577), a reçu ce nom; elle renlerme presque tous les genres que H. Lamarck avorit placés dlans sa lamille des 'Tubicolées. Il est certain qu'elle russenable des animatux qui ont entr'eux beauconp d'analogie, à l'exceptun du genre fistulane, qui, d'âlès nutre manière de voir, ne saurrit y rester. Voici les caractères que 31. de Blainville donne à celle famille: "Corps ovale, alongé, subcylindrique ou vermiforme; le manteau complatienient fermé et tubuleux, ouvert en avant pour le passage d'un petit pied cont, très-peu saillant à la surface de la masse abdominale, et terminé en arrière par deux siphons unelquefois lort courls, mais toujours réuais en un seul tube; bonche rnédiocre, à
A G A

lères simples, et appendices labiaux per considirables; branclies lamellenses, Inngnes, aiguc̈s, se prulongeant dans le tube, et lihres à leur extrémité. Coguille ordinairenent ovale-nblnuene, quelquefois comme tronque, constamment Jilanche, non ou très-rarenent épidermર́, équivälve, inéquilatcirale, ne pouvant jamais recouvir rout le corps de l'animal, tant elle est biillante à ses extrémilés: charnièe sans engrenage ni víritable lizameni corné; une impression nusculaire unique, quelquefois avec une impression palléale fortement sinueuse en arricre."

Quelgues parties calcaires accessnires servant a aurmenter l'útendue de la conquille ou prenant la forme d'un tube qui la contient.

Celle famille contiont les quatre genres Pholade, 'Térédine, Fistulane el Cloisonnaire. Foyez ces mocs ainsi que 'l'ubicolées.

AGLÉE. Figlou. Voyez Égrí.

\section{AGANIES. Agam:s.}

Seconde branche des Mnllusques dans le système de M. Latreille qui len" a imposé ce non, parce que dépourvus d'ormane copulatenr mâle, chaçue individu se féconde lui-même. Ces Molliscques soat d'ailleurs fons aquatigues el ne respirent que par des branchies.

Les Aranies sont divisés en denx sections : la première porte le nom d'Exocéplaales, et la seconde celin d'Endocéphales (Foyez ces mols.) La prenière section se pallage en deux ordres, les Scutibranches ct les Cyclubraoches, qui euxmèmes sont divisés en plusieurs familles. La seande section renferme tous les Conclifères de M. Lamarck, les Acéphales des auteurs; de sorte que dans le même embrancheqent des Mollusques on trouve de véritables Céphalés à coquille ercose touraée en spirale, et des Aciphales a coquille composée de deux parties. Ces animanx cepearlant n'ont de resscmblance que d'une maniêre lnrt éloignéce, et sous le rapport senlement des fouctions de la grínération. Les premiers sont intimement liés avec les Molluscues céplialés, dont il est impossible de les séparer; ils ne !e sont poial autant avec les Conchiferes. Cette question de classification ne pourra êlre disculée dans son crisemble, ef compatrativement avec les antues systcmes, qu'à l'article Hollusque, ancquel nous renvuyons.

\section{AGdNiDE. Aganides.}

Genre établi par Montfort pour les Nautiles dont las clnisons sont plus ou moins simueuses. A l'arlicle Nautile nous avona fail dans ce igenre une petile section, dans laquelle ces espèces viendent se ranger. Voyez NAUTizr.

AGANON.

Rundelet, dans le premier livre des Foissons 
couverts de test dur, page 12, dit que les Grecs, de sun temps, nommoient ainsi vulgairement le grand Concha imbricata que les cénobites d'Arabie désignent par le nom de Tridacna. Ce dernier mot a été conservé par les conchyliologues modernes, qui ont fait le gente Tridacne avec le Chama gigas de Linné. Voyez Tridacne.

\section{AGARON.}

Adanson, dans son Traité des coquillages du Sénégal (pag. 64, pl. 4, fig. 7), nomase ainsi mue espèce d'olice qui est une variété de l'oliva hiatula de NI. Lamarck, que l'on trouve fossile aux environs de Bordeaux. Elle a élé nommée duns cel élat Oliva plicaria. Voyez Olite.

\section{AGATHINE. Achatina.}

Les auteurs anciens qui ont connu les coquilles de ce genre, ne les onl meutionnées dans leurs écrits que pour en fuire comnoître le volune, qui leur parut extracodinaire pour des coquilles terrestres. Pline et Varrou rapportent que quelquesunes peuvent contenir quatre-vingls quadrans. On supposoit, el c'étoit le sentinient de presque lous les comnentateurs, que le quadran étoil une snesure de capacité, d'aì il résulloit des supposilions nombreuses par rapporl aux coquilles dont il est question. Ainsi il auroit fallu qu'elles fussent autrefois d'un volume triple de ce qu'elles sont aujourd'bui. Il faudroit cruire que nons n'uvons las encore retrouvé celte énorme espèce, quoigue nons counussions beaucoup mieux l'Alrique sa patrie que les Auciens, on il faudroit parlages le sentiuent de quelques personnes qui pensent que depuis l'époque de Pline el de Varron, l'espèce a dégéuéré au poinl de ne s'r.ffrir à nos locgards que daus des proporlions beacoup moindres. Ces diverses hypolleses ne sunt point adnissibles, car des observatious nonbreuses prauveraient que la seule graude cspèce auroil dégénéré, tandis que les autres du aêene pays seroient restées dans les dimensions aì nous les voyons maintenant. Eu admellant l'expliciation de Mi. de Ferussac on aplanit toutes les difficultés, et les observations des Anciens rentrent dims l'oritre nalurel des choses. Cet auteur prétend que le guadran éloit une pièce de monnoie de la grandeur de nos saus, el il u'est pas difficile de trouver dans nos collections de grauds iudivicus de l'Agallime d'Afrique rui puissent contenir qualrevingls de ces pièces.

lies atuleurs q̨ui avant Linné conuurent les coquilles de ce genre, les placèrent parmi les Buccras et la confondirent uéme avec les cuquilles mariues. 11 laut cependant excepter Lister, qui, en conservant le num de Buccins pour des coquilles terrestres, l'appliqua aux A gathines, qu'il sépara trés-bien des cooquilles malines. Linné, exulararassé sans doute de placer convenals!emeni ces coquilles, ne voulant point créer un trop grand nambre de genres, les jeta pour ainsi dire au Lasard dans le genre Bulle, d'on Bruguière les prit pour les placer dans son genre Bulime, oì elles sont heaucoup. mieux placées, quoique ce genre lui-même ne sait guère meilleur que celui de Liané. (Voyez Bucime.) Bruguière, dans son article Buline de ce Diclionnaire, eut soin de faire une section parliculière pour les Agallines, qu'il caractérisa par la Ironcature de la columelle, de sorte que M. Lamarck trouva déjà rassemblés et bien groupés les élémens du genre Agathine, qu'il proposa dans le Système des animaux sans vertébres, 1801. M. de Roissy adopla ce genre (Buffon de Sonnini, tom. V. des Moll., pag. 353 ); il le place eutre les Ambrettes et les Maillots, s'écartant en cela de $M$. Lamarck, qui le mettoit à la suite des Bulimes. Lorsque ce savant créa la famille des Colymucées daus la Philosophie zoologique, le gen re Agathine dut en faire partie, et an le trouve dans les rapports indiqućs par M. de Roissy, c'est-ä-dire entre les Ampbibulimes, qui esı le même geure que le Succinea de Draparnaud et les Maillots ; il laissa subsister ces rapports sans presque y rien changer dans ses autres nnvrages, l'Exirait du Cours et l'Histoire des cinimanx sans vertébres. Montfort s'empara de ce genre pour le démenubrer à sa mauière, comme il le fit pour presque tous ceux qui furent proposés avant lui; il en sépara les Polyphèmes et les Rubans, tous deux inuliles, qui peuvent lout au plus former des sous-divisious ou des groupes dars le geure : aussi nous ne connoissons paint d'auteur qui les ait adoptés.

Il est ussez difficile de deviner pour quel motif les genres Bulime et Agratline ayant élé très-bien circonscrits par M. Lainarck, M. Okeo les réunit et doune i cel ensemble le no:n de Pythia. On ne peut penser autre chose, que MI. Oken ayant aperçu un passage entre les deux geures, il aura cru pouvoir les réunir. Ce passage existe sans coutreait, mais point encore aussi fortement que dans quelques autres, oi il est impossible ruisonuablement de fixer la place de cerliaines espèces plusôt dans l'un que dans l'autre.

MI. Curier (Règne unimal, toun. II , pag. 409) a conscrvé le genre Ayalbiue dans son iuléplité, et ì titre de genre il fail partiedes Pulmonés terresites avec les Limaces, !es Escitrgols et les Clausilies. Ce savant professeur cousidérant la troncature de la base de la columelle comme un commencement on un rudimeut de l'échancrute de beancoup de coquilles inarines, place ce genre a la fin de cette famille pour le rapprocher aulant que possible de ces cocqui!les à véritab!e échaucrure; car il est à remaryuer que les Agathines, malgré celle troncalure remarquable, ve luissent pas yue d'a voir l'ouverture entićre. Cette manière de voir étoil en quelque sorte adınissible alors que l'on ne connoissoit poiut l'anianal des $\Lambda$ ga- 
thines. Aujonrd'hui que l'on sait que cet animal n'a rien de plus que les autres IÍ́lices, qu'aucun organe particulier ne passc par ecte sorte d'échancrure, il en résulte qu'on ne peut plus considérer les Agathines conme un passage à d'autres geu:es. M. Ile lerussac, dans son vouvel arrangement du gence Hélice, n'a point cu tout aduis le genre de M. I aimarck; il l'a fondu, counne beaucoup d'autres, dans le genrc Ilélice : il en fait denx sous-genres, anxquels il donne les nons de Cochlitome et de Cochlicupe; il les pliace dans la section des Cochloides. Il divise le premier eu deux groupes, le premier pour les espéces dont Montfort a fait le penre Liguus, et le secoud pour le reste des A rathines de II. Lamarck. los Coclnlicopes sout également divisćes en deux sectious: la première pour les espèces dont Montfort a fait son genre Polyphème, $\mathrm{ct}$ la seconde porte le nouı de Stiloides, à cause de leur losne alongée. Ces clıngemens proposćs par M. de Ferussac n'out point été adoplés et ne pouvoient lêtre, parce quil n'étoit pas nécessaire de créer de nouveaux norns génériques pour les substituer à ceux qui existoient déjà, et ensuite parce que les Agathines forment une série continue, daus laquelle les passages d'un groupe à l'aulre se filisant d'une manicre insensible, il est fort dillicile de poser des limites, et les motils qui ont détcrminé les conchyliologues à ue point adopter les démenbremens de Montfort, subsistent puur rejeler les divisions de M. de Ferussac.

A l'exemple de MIM. Cuvier et Lamarck, M. de Blainville a adoptć le gerre Agathine, tt il le place entre les Buliases et les Clausilies, ce qui le recnet dans les rapports indiquués par. N. de Roissy. M. Latreille (Fam. nat. du Rég. anim. p. 180), en adoplant le geure, en a fait uue sectiou à past dans sa famille des Géococlılides. M. Gray, dont la classification est antérieute aux denx que nous venons tle mentionner, a séuni dass la première section de l'ordre gu'il nomme Adelopneumona, les yenres Limace, Onchidie, Plectrophnre, 'Testacelle, Vitrine, Hélice, Agathine el Clausitie, ce gui conserve an gemre qui nums occupe, les mêmes rapports à peu près que ceux établis par M. Lamarck.

Jes $A$ gallines se trouvent surlout dans les contrées rhitules des deux contiuens. Les espèces qui hibilent les régious tempérées sont trés-pelites, et nous pourrions citcr à l'appui les deux gui sont propres à l'Europe. Lianimal ne dill'ère pas d'une manière très-sensible, à ce qu'il paroit, des autres Ilílices; cepenclant M. de Blamville, qui en a exacniné une grande espèce rapporléc par NiN. Quoy et Gaymard, fait remarquer quil y an we sorle d'interruption du collier à l'endror de la troncature columellaire, el que cette troncalne cllu-mêne doit soo exislence ì une saillic prorticulière du nuscle columellaire. D'un autre cólé, 11. Say, gui a donné la description de l'animal de
l'Achatina glans, indique dans les tenlacules une inflexion partisulière, ce qui déterinine nécessairencnt une linme différente de celle des tentacules des llálices : il paroit aussi que les appendices labiaux sont lrès-grands. Il pournoit arriver qu'eu faisant l'analomic complète de cet animal, on trouvat des molits suffisans pour en farre un bon gente.

\section{CARACTERES GÉNÉRIQUES.}

Coquille ovale, oblongne, quelque fois turriculée. Ouverture enticre, plus !nngue que large, à bord droit tranchant, janı is rélféchi. Colume!le lisse, asscz fortement excavée, tronquée et ouverte is sa base.

Bruguière, dans la troisième section da genre Bulime de ce Dictionnaire, a décrit quatorze espèces qui doivent faire partie du gente $A$ grathine. Nous renvoyons à ces descriptions, parce qu'elles sont bonnes el bien failes.

N. Lamarck a ajouté cinq espèces nonvelles à celles de Bruguière, ce yui fait dia-neuf. M. de Ferussac, dins son Prodrome, e: indicque scize dans le suns-genre Cochlitome et vingt dans le sous-genre Cochlicope, ce qui porte à treute-six le nombre des espèces connucs. Il faut y ajoutel le Bulla helicoides de Brocehi, qui se rencontre fossile en lialie, et dont l'analogue vivant est connu, et notre Achatina pellucida fossile des environs de Paris.

Nous allons iudiquer les espèces les plus remarquahles qui ont été répandues daus les collertions depuis Bruguière.

I. Agaturie immaculée. Achatina immaculata.

A. testî̀ maximia , ovato-oblong $\hat{u}$, ventricos $\hat{a}$, longitudinalıter sulcato-rugosâ, fülíâ, apice albidá ; aperturá suirâ longrore; columellá roseo tunctá; labro inlus albo, margine interiore fusco. LAML.

LaMr. Anim. s. vert. tom. 6. part. 2. pag. 128. $n^{\circ} .3$.

Fer. Hist. nat. des Mtoll. terr. et fluv. $20^{\circ}$. Lu. pl. 127.

Cette coquille est une des plus belles clu genre; elle eft presqu'aussi grande que l'Achatina perdix (Bulimus achatinus, Brug.). Sa torase est ovale; elle est icntrue, et son so:nmet est blanc et ubtus. Ce qui la distingue cominemment des autres espèces du mêue gente, ec sont les sıllens longiludinaux qui ornent sal surfäce exterme : ils sont réguliers é indiquent les atcroissemens suc,cessifs de la coquille. Lat spire, composée de huit tours légèrearent conrexes, est plus courte que l'ourerture. La suture est simple au sownet; elle est subuarginée vers les deus derniers tours. 
Comme son nom l'indique, ccite Agathine est d'une conlenr nuiforme, d'un faure foncé blanchissant vers le sommet; en dedans clle est blanche. Isa columelle est rose, et le bord droit, qui est nince el tranchant, est brun à l'intérieur. Longueur, cinq i six pouces. On ignore sal patrie.

2. Agature llammigère. Achatina flummigertz.

A. tesiâ clongutâ, ovato conicấ, fulsầ, basi fuscâ, apice albidâ, flammis longitudinalibus fulvo-fuscis ornatấ; columellầ albidâ ; labro intiss fulvo subalbido; anfractibus octonis. Noв.

Helix Rammigera. Fer. Prodr. pag. 49. $n^{n}$. 341. Hist., nat. des Moll. terr. et fluv. 12e. liv. pl. 118. fig. 5. 6. 7 .

Buccinum. Lister, Syn. conch. tab. 9. fig. 4 .

L'Agalline flanmigère étoit connue, comme on le voit, depuis la publication de l'ouviage de Lister; mais comme elle est restée très-rare dans les collections, le auteurs ne l'ont pas medionnée. Depuis cel!e époque, MI. de Ferussac en a donné une excellente figure dans soz ouvrage. Les personnes qui ne possèdent pas celle cognille, s'en fetont une très-lonne idće ca consultant cette figure.

Cetle espice a la forme alongće et subtorriculée de l'Agathine ruban (Bulimus virgincus, Brug.), mais elle est plus grande et ses tour's de spire sont moins arrondis; elle est ovale-eonique, composée de sept à buit tours de spire à peine convexes: la suture qui les sépare est simple et peu profonde. Sur un ford faure clair se dessinent des flammes nombreuses et serrées, d'un fauve plus foncé, ordinairement brunes à la base. La base du dernier tonr est marquée d'une large zône d'un brun foncé qui est tranchćc net sur la coquille; les flammes dans cetle partie sont presque noires. Le sommet est blanc. L'ouverture est beancoup plus courte que la spire; la lèvre droile est mince et tranchante, et faure en dedans, mais cetle couleur est ligèrement teintée de hlanc. Quoique par sa forme celte espèce doive se placer près de l'Agathine ruban, elle s'en éloigne cependant parla forme de la colnmelle, qui oe présente pas dans son milieu une forte excavation et à sa base une profonde échancrure. La partie antérieure de la lèvre droite dépasse de beatcoup la longueur de la colnmelle, ce qui n'a pras lieu dans l'Agathine ruban et les antres especes qui en approchent, desorte que l'espèce dont il est question peut servir de liaison entre les rrandes espèces d'Agatbines, comme l'Achatina perdix, eic., et celles dont Monifort a voit fait sou grenre Ligurs. Il en est de même du Bulimus exaratus de Broguière, à la description duquel nous renvoyons.

\section{Agsthise rose. Achatina rosea.}

A. testá or'ato-oblongía, roseâ, longitudinaliter tenuissimè striatâ, apice acutâ; aperturâ ov'atoncutâ, angustâ; labm terui acuto sinuato. Noв.

Helix rosea. Fer. Hist. nat. des Moll. tert. et fluv. $21^{\mathrm{e}}$ liv. pl. 135. fig. 1. 2. 3. 1bid. Prod. pug. 50. $n^{\circ} .356$.

Il y a heaucoup d'aralogie entre cette espèce et le Bulimus glans de Brwguierce. Sa spire est composée du mème nombre de lours, mais elle est plus alongée, car l'ouverture est à peine la moitié de la longueur totule : ses tours sont légcèreneat convexes, séparís parl noe suture simple, submargincic dans quelques individus; le sommet est médiocrement pointu. Toute la coquille est recouverte de stries loogitudinales tres-fines, serrées, profondes, légèrement sinueuses comme le bord droit de l'ouverture; elle est tout-i-fait sans taches, d'un rose pâle blinchátre en deloors, un peu plus foncé vers le sommet; à l'intérieur. elle est d'un rose légèrement fanve. L'onverture est ovale, obloogue, assez étroite, surlout pastírieureauent; la columelle est légèrement simueuse, fortement trooqnée ì sa base, et de fort peumoins langue que le bord étroit.

11. de Ferussac a figuré comme variété de celte espèce une coqquille subturriculée que l'on sépareroit volontiers comme espèce distuncte, mais qui est sans doute liće an type par une série non interrompue de variétés de plus en plus alongées. Longueur, soixante millinètres.

Celle espèce fort rare vieat des Florides. Nons la possédions depuis long-temps, lorsque M. de Ferussac en a publié la figure.

4. Agatane du Pérou. Achatina penviana. LAMT.

A. testâ cylindraceo-fusiformi, tenui, pellucidâ, longitudınaliter tenuissinè strutâ, strits transiersis subdecussatâ, albâ, fanmmulis lineolisque rufó fuscis zariegató; suluris subcanuliculatis; ultimo anfructu spirâ longiore, costulis incumbentibus instructo. LAvE.

L.suk. Anim. s. vert tom. 6. part. 2. pag. 132. $n^{\circ} \cdot 14$.

Helix pretiosa. Fer. Hist. nat. des Moll. terr. et fluv. liv. 21, pl. 135. fig. 4 .

On peut considérer l'Agatline du l'érou comme une des plus jolies coquilles qui exisie; elle est ovale, subcylindracée, lormée de huit loursde spire légèrement conrexes, fortement sćparés par une suture profonde, subcanaliculée, un peu nargiaée, surlout surle dernier lour : celui-ci est beancoup plus grand que toute la spire. En dehor's cette coquille offre sur toute la surface des stries longitudinales très - fines, très-serrées, qui sont coupées transversalement par d'autres un peu 
moins régulières, de sorte qu'elle se trouve couverte d'un réseau très-délical. Sur un lund blane, qui se clange en fauve vers le sommel, se desninent les llammules lauves ou bruues, qui sur le dernier lour se divisent vers la base en plusieurs linéoles de la mîure conleur. livaverture est ćtroite. Le bord droit eit simple, tracchant, ne déprassant presque pas l'échancrure columeilaire; la columelle est fortcmeat excavée vers son tiers :ılćrieur.

Cette coquille rare et précieuse vient du Pérou; clle a quarante-cinq mollimètres de longueus.

\section{Agaturne de Marmin. Achatina Marmini.} กов.

A. testâ ovato-oblongầ, subfrsiformi, tenui,

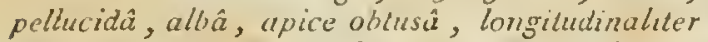
plicutâa ter crenalis. Nов.

Cette jolie espèce nous a élé conmuniquée par M. Marmin, analeur distingué, anupel nuns nous praisons de la dédier : e'est une des coquilles rires de sa charanante collection. L'individu qu'ii posside, le seul yui are soil connu, jcune encore, cst très-tnince, diaptrase, tlanc, sans ancune tathe, de lorme ovalaite; le dernicr tour est beancoup plus grand que le reste de lit spire, yui est composée de hait tours; lo sommet est lisse et fort obtus. Les tours sont peu convexes, chargés de plis longitudiuaux bien distiucts, réguliers, plus saillaus vers la spire qu'a la base de la coquille, oì ils descendent en diminuan insensiblemenl. Chacun de ces plis, en aboutissan sur la suture, y lorme une crénelure, de sorie que la sulure est crénelée régulic̀rement et ćléryanment d'un bout à l'autre. L'ouverture cst étroite, plus longue que la spire, assez semblable à celle de I'Achatina rosea; le bord droil cst mince el iraur:hant, et ne dépasse pas la troncature de la columelle a sa base : celle-ci est excavée dans sou nailieu.

On ne conuoit pas la patrie de cette coquille. bille a cinquate-trois asilimitres de longuenr. Cabisel de M. Marmin.

\section{Agatnine olive. Achutina oleacea.}

A. testâ ovato-oblongâ politussimâ, diaphanâ virescente, apice aculá; aperturấ ungustâ, spirâ acyuati; anfractitus octonis, convexiusculis; columellâ basi zaldè contortá, compressiâ, albat; kbor dextro sinuato. \ов.

Hcli.x oleaceu. l'en. Prod. pag. 5o. $n^{\circ} .560$.

M. Ferussac n'ayant donné que le unm de relle espère, sans y ajouter de figute ou wne descripjtion, il nous aurvil élé impossille de la reconnoilie, sans la complaivauce de Ml. Iramin, ciui co a délerminé un malivín de sa collection dans celle de .II. de Ferussac :outre qu'elle a à peu ju'śs la forme, elle a aussi la couleur du fruit de l'olivier. Elle est ovale, pointue, lisse, polic, brillante, pirtout din vert jaunătre; quelques llammules il'ua jame obscur se remarquent sous le dernic-2 tourvers l'ourerture, dont elles sont les anciennes traces. Laspiretst poinaue, conique, counposée de luit lours peu convexes, dont le dernier est plus grand nu au moins aussi graud que lous les autres. l'ouverture est presçue droite, élroite, surtoul postérieurement. Ia columelle est lorteuncut contournće en dedans, an liers antérieur de sa longuear; clle s'aplatit à la base el devient blanche : la live droite est mince el sinneuse. On présume que celle eyèce vient des Antilles. Elle a vingt-lutit à trente uillimètres de longueut.

7. Agntane demi-sillonnéc. Achatina semisulcatu. Nов.

A. testâ clongatâ subturritâ, apice obtusâ, fulvâ, flcmmulis distuntibus fuscis instructâ, regulariter striatâ, basi lavigalâ; aperturâ minimầ subtriangufuri; columellâ maximè contortâ.

Nous ac connoissons mulle part de figurc ou de description qui ait quolque lapport avec l'espèce que nous caractérisons. Lille est alongée, conique, et d'après cola elle peut for bien étublir le passage cutre les especes glandiformes et celles que M. de Eerussac noume les styloides, parce qu'elles sont fort alongées. Sa spire est composéc de huit lours lénèrement coavexes, séparés par une suture simpie; ils sunt striés longriludinalement. Lés stries sont simples, régulieres, peu serrées, surtout sur le dernicr lour, on elles s'alténuent vers le milieu et disparoissent colaleuent is la base de la coquille qui se trouse lisse dans cet endroil. Cette coquille est de conleur lauve clair ou chamois, plus foucé vers le sommel "qui i'sl presque bran. Sur ce lond se dessinent quatre on cing flammules brmes sur chayne lour : ces raies brunes sont longitudinales, étroites, et couséruemment as ez éloiguíes les unes des aulres. Liouverture csl courte, suhtulangulane. La columelle est fort oblique, fortement sinuense vers te milicu el contoulnée sur elle-mêne à la base vù elle est aplatie. La lèvre druite est inince, trauchante à la Lase; cllc a'est guire plus longue que la troncature de la colunelle.

Nous ignorons la patrie de cente espèce, gui est de notre cullection. Longucut, trente-sepl milli. meltes.

8. MGateinc turritellée. Achatina turritellata.
Noв.
A. testá turritâ, elongutâ, angustá, canaidissinsâ, laviguratí; apertuni brevissimấ; columellấ medo smusti, basiobliqué truncritá; aprce obtusuusculo.

La forme de celle coquille est fort différente de B 2 
la plupart des espèces du genre; elle a l'aspect d'une petite vis, mais étant terrestre elle ue peut eutrer dans ce genre. Elle est lurriculée, alongée, étroi!e à la base, légèrement obtuse au sommet; elle est toute blanche, sans aucuues taches, lisse, polie, brillante. La spire est formée de dix tours légèrement convexes; la suture est peu pruforde et simple. L'ouverture est très-yelite, un peu plus Iongue que large, occupant un peu plus du rquart de la longueur de la coquille. La columelle est fort ublique, recourbée dans son milieu et ćchancrée à sa base, mais obliquement ef pas aussi profondément que dans la plupart des espèces. La lèvre droile est simple, mince, tranchaote, un peu évasée à la base, où elle ne dépasse presque pas la troncature de la columelle.

Nous ignorons l'habilat de cetle espèce qui pa. roît forl rare; nous ue connoissons que le seul individu de notre collection : il est long de trentetruis millimètres et large de neuf millimètres à la base. L'ouverture a juste la longueur de ce diamètre de la base.

Nous rapportons aux Agathines un petit genre de M. Risso que nous aurions pent-être mal compris sans la communication yne nous en a faite en nalure M. Mlarmin. Le genre Vediantius dnit donc être supprimé, poisqu'il est un double emploi du genre Agathine. Liespèce qui a scrvi de type à ce genre est cerlaiuement nouvelle. M. Risso lui a donné le nom de Eristalizss qui n'a aucune signification; mais nous pensons quil y a erreur involontaire, et que c'est Eristalis que l'auteur a voulu melıre. Quoi qu'il en soit, pour éviter toute équivoque, nous lui donnons le nom du savant qui en a fait la découverte.

\section{Agathine Risso. Achatina Risso. Nов.}

A. testâ panulâa, ovatâ, pellucidâ, corneâ, lcovigatâ, apice obtusâ; aperturâ spinâ longiore; columellî̀ contortâ, busi albâa, rectâ.

Cette petile coquille est de forme ovale, un peu obtuse au sommet; elle est de couleur brune ou cornée, un peu foncée, diaphane, sans laches, entičrement lisse. Les tours de spire, au nombre de cinq, sont peu convexes; le deruier est plus grand que tous les autres; la suture qui les sépare est simple et superficielle. L'auverture est oblonfue, assez étroite, surtout postérieurement; elle est plus longne que toute la spire. La columelle es! oblique, fortement contournéc à sou tiers antérieur; eile se redresse à sa base, devient droite dans le sens de l'axe; elle est profondément tranyuée à la base el entièrement blanclie. Le bord droit est très-mince, tranchant, évasé à la base de la cocquille, ò̀ il dépasse notablerneut la troncature de la columelle. Les deux individus que nous arons sous les yeux n'ont que quatre à cinq millimetre: de longueur, un peu plus de deux lignes. Ils sont des eavirons de Nice. Noв.

10. Agatrine maculcé. Achatina maculata.

A. testâ ovato-oblongâ, v'entricosâ, obsoletè striatâ, apice obtusá; anfractibus octonis, ultimis fulvo fuscis; maculis fuscis majoribus vel strigis longitudinalibus ornatis, superioribus albidescentibus, flammis fuscatis instructis; aperturá spirâ breviore; columicllâ contorta, albâá labro intius albo, margine interione fusco.

Nous ne trouvons nulle part la description ou la tigure de cetie espèce qui ne nons semble cependant pas Irès rare; il seroit possible que $M$. de Ferussac lui ait imposé un nom dans son Prodrome, mais comme elle ne s'y lrouve pas décrite, ni figurée dans son grand ouvrage, nous ne pouvons saroir quel est ce nom. El!e a des rapports a vec la plupart des grandes espèces; elle s'en distingue au premier aspect par sa forme plus alongée, muins ventrue, une ouverture beaucoup plus courte, des tours de spire plus longs et plus convexes, un sommet plus poinlu; elle présente en outre des couleurs particulières. Revêtue de son épiderme, elle est d'un brun-verdàtre interrompu par des zônes blanches ou brunes foncées, longitudinales, irrégulièremeut distantes : vers le sommet, la couleur du fond se partage davantage, alterne avec des zónes blanches plus nonibreuses et se change insensiblement en flammes brunes, qui dimivuenl peu à peu jusquà disparoître toul-à-lait au sommel qui reste blanc. Les tours de spire sont au uombre de neuf, convexes, arrondis, lisses ou présentant quelques stries obsolètes et longitudinales. Liouverure est plus courte que la spire; elle est évasée, tonte blanche à l'intéricur, si ce n'est le bord droil qui est très-mince, tranchant et de la même cunleur que l'extérieur. La columelle est toute blanche, fortement sinueuse dans son milieu; la troncalure de la base n'est pas très. profonde; la columelle est plus courte que la parlie antérienre du bord droil.

Cetle coquille est longue de treize millimètres et demi, près de cinq pouces. Nous ignorous quelle est sa patrie.

\section{AGATHISTĖGUES (les).}

M. d'Orbigny fils, dans son arrangement systématiqque des Cépbalopodes foraminifères, a créé cetle famille pour y placer les coquilles don les loges se pelotonnent les nnes sur les autres de différentes manières; les Milioles présentant seules ce caractère, ce sont elles qui y sont rassemblées; elles y fornent plusieurs genres, basés principalemeot d'après le nombre des loges apparentes.

Cette famille est fort naturelle, et eile clevra être conservée : tous les gentes qui en font partie sont liés eatr'eux par des rapports que l'on ne peut contester; ils suni exprimés par les caracières suivans : loges pelotonnées de diverses manières sur un axe commun, faisant chacune dans leur 
enroulement antour de l'axe, la longueur tolale de la coquille; par ce moyen l'ouverlure se trauve alleruativement à une extrénité ou à l'autre. L'ouverture est loujour's munie d'un appendice; lest blanc et opaque.

Les six genres qui constituent celle famille sont des démenubremens du genre Miliole des autenrs. On remarque que parmi les espèces placées dans les Milioles, il y avoit des formes particulières, constantes, dépendant de l'arrangenienı des loges Ics unes par rapport aux autres; ces formes qui sont déterminées par le nombre des loges visibles au dehors, ont servi dans presque tous les cas à grouper le gente; nous disons dans presque tous les cas, parce que, dans le genre Quinqueloculine, par exemple, M. d’Orbigny, entrainé par le caractère des cinq loges apparentes, a fait entrer dans ce geare deux formes bien distincles et quil faudıa séparer. Sans doute que le nombre des loges apparentes est un caractere important, mais il n'esi pas de première valeur dans notre manière de voir. Les genres de celte famille sont les suivans : Brloculine, Spiroloculine, Triloculise, Articuline, Quinqueloculine, AdéloSINE. T'oyez ces mots.

\section{AGATIRSE. Agathirses.}

Par un de ces rapprochemens bizarres qui ont caractérisé la plupart des rapports indiqués par Deris de Montfort, la Siliquaire épineuse fossile de Grignon est Iransfurmée en coquille cloisonnée placée à la tiu des Polythalames, comme intermédiaire entrelles et les coquilles uniloculaires qui doiveot suivre. Nous ne réfulerons pas une telle idée, le moindre examen altentif suffit pour la détruire. Vojez Siliquaire.

\section{AIGIJE ROYAI.}

Nom vulgaire d'une grande et belle espèce d'Agatbine, Achatina bicarinata Lamk., qui est toujours sénestre. Il y a quelques années qu'on nen connoissoit que trois individus dans les callections d'Europe. On en a répandu depuis dans le conmerce. Bruguière a décrit cetle espèce dans ce Dictionnaire suus le nom de Bulimus bicarinatus. Nons renvayons à sa description.

\section{AILÉS (les).}

M. Lamarck a rangé dans une seulc famille, à laqnelle il a donné ce nom, toutes les coquilies dont la lèvre droite est plus ou mains dilatée en aile, ou prolongée en digitations variables pour le nombre et la longueur. Il y réunit les genres Rostellaire, Ptérocère et Strombe. (Voyez ces mois.) Nous pensons que prur rendre ce groupe plug naturel encore, il faudra y joindre le genre Struthiolaire, qui nous semble plus voisin des Ptérocères que des Ranelles ou des Tritons. M. de Ferussac $n^{2} a$ point adopté cette lamille; il a placé le genrc Rostellaire dans sa faraille des Pourures, et le genre Strumbe daus la suivante. L'animal des Rostellaires n'élant point connu, on ne peut savoir quels motifs ont pu dirigcr l'arrangement de M. de Fer'ussac, qui auroil dú se laisser conduire par l'analngie des cnquilles. MI. de Blainville a suivi une marche analogue, en plaçant le genre Rostellaire près des Fuseaux et des Pleurolomes, daus sa famille des Siphonnstomes, tandis que les Strombes en sont séparés par tonte la ś́rie des coquilles canaliculées à la base, ģni sont rassemblées non-seulement dans la famille que nous renons de citer, mais encore dans celle des Entomostomes, qui passe avant celle des Angistomes, qui contient les Strombes. Cet arrangemeat ne nous semble pas naturel : il rompt les rapports évidens qui existent entre ces gentes cl sans molifs sulfisans, puisque l'animal des Plérocères nest poiat connu. Ioyez Struthiolatae, Rostellaire, Ptérocère el Strombe.

\section{AJAR.}

Dans son Voyage au Sénégal (pag. 222, pl. 16 , fig. 2), Adaason donne cc nom à une coquille de son geare Came. Bruguière, en décrivant cette coquille dans ce Dictionnaire, sous le nom de Cardite ajar, a commis une erreur en la considérant comme l'analogue vivant d'une de nos espèces fossiles des environs de Paris, la Venericardia insbricata laak. Ce rapprocbement indique que cette coguille ne doit pas rester parmi les Cardiles, mais faire partie du genre Véncricarde çui cn a ćté démembré. Vayez ce ual.

\section{ALASVIDES. Alasmidia.}

Dans sa monographie des coquilles bivalves de l'Ohio, insérée daus le tome VI, page 287 , des Annales générules des sciences naturelles, M. Rafinesque a élabli des sous-divisions nombreuses dans le genre Unio de Lamarsk : il en fait une fawille qu'il partage en cing sous-familles, dont celle-ci est la quatric̀me. Les caractères sur lesquels ces sous-divisions reposent, sont de si peu d'importance, quon ne pent les admeltre à titre de sous-familles; à peine suffiroient-ils pour conslituer des sous-genres. Voici les caractères que Rafinesque donne à cette furnille : cocguille transverse; une dent primaire antérieure; point de dent lamel. laire. Celle sous-famille ne contient qu'un senl genre nommé Alasmidonte. Voycz ce mot el $\mathrm{Mu}-$ LETTE.

\section{ALASMIDONTE. Alasnidonta.}

Ce genre est le seul de la sous-farnille des Alasmides. (Voyez ce mot.) Si la sous-famille ne per:t ètre adoptée par le peu de valeur de ses caractères, à plus forte raison on ne pourra admettre le genre qui en dépend. Ce fut M. Say d'abord quil l'institua dans le Journal de l'Acadénie des 
sciences naturelles de philudelphie (lom. I, pag. 459 ). Il sembleroit plus nécessaire de conserver ce gemre d'après Mr. Ralinesque, parce qu'il ćlablit un passige entre les Mulettes el les Anodontes, parce que la longue dent cardinale postérieute des IIulettes manque, et qu'il ue teste plus it la clarnière qu'une seule denl antericure qui u’est pas très-grosse; naris si l'un considère que depuis lonry-lemps on a fondn en un seul les deux - cures Mlulelte et Anodonte de M. Lamarck, on ne devia alors admettre celui-ci que comme une sous-division générique très-secondaire. Voyez Muj.etre.

\section{ALA'A IAATA.}

Genre sixième de la farmille des Alata de Klein (Ostruc. pag. 100). 11 est lormé de quelques espèces de Stronibes yui ont le bord droit assez largetuent clévroloppé. Ce genre a’at point été adopté, ayant élé fiat sur des caractères de peu de villeur. Voyez Stroube.

\section{ALATITES. Alatites.}

Nom donné par Wralch aux coquilles fossiles des genres Ptírocire, Rostellaire et Stroube. Voyez ces mols.

\section{ALECTRION. Alectrion.}

Genre inutile, proposé par Houtfort (Conchyl. syst. tom. 2. pag. 566) pour un Brecin de la seclion des Nasses de Lanarck, Buccinum pupillosum Linn. Le grene Nasse nayant poiut ét: atdopté par l'insuffisance de ses caractères celuici duit être rejeté ì plus forte ritison, puisqu'il repose sur de plins toubles encore. Fojez Boccrs.

\section{AliEXE. Subula.}

D'uprès les olservations de NI. de Blainville, on seruit forcé de partager le genre Vis en deux gemes bien distincts, daprès les caraclères des aแialax. Ce savant anatumiste ayant pu examiner l'animal du 'éebra muculata, et l'ayan comparé avec la description que donne Adansoa de sun Mran, il n’a point hésiée is étaldir le genre Alene, pour tontes les coquilles qui se rapprocheut à Terchra maculatar, c'est-í-dirc pour la presque tolulité des especes du genre Vis de Lanarck, laissant sous celle dénumination uac ou deur espèces. Nous croyons yuue MI, de Bluiuville auroit dú lave le contratre ef conserver le geure Vis pour le plus grand woalure des especes, juisgue depuis luns-temps ce genes etuit consacré par 11. Lamarel. Quelines persones pens jicnt que 11. Jamarck avuil eu tort de placer parnil les Vis le 'lerebrestlata, qui d'après ses caracteres auroit dî rester patmi les Buccins. Nous partageons d'autant uicux colte opinion, que uons

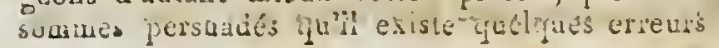

dans les déterninations de M. de Blaiuville. Sous olserverons que la coquille que M. de Blainville nomuse Vis muran dans son Traité de Malucologie, page $406^{\circ}$, et qu'il figure dans l'allas de cel ouvrage, pl. 16 , fry. 3 , sous le num de $V$ is Buccin, est la même que celle indiquée par M. Lamarch (Arim. s. vert. $t$,m. 7, pag. $291,7 n^{\circ} .24$ ), sous le wom de Vis buceiuéc, Terebra prittuta, wais n'est pas du tuat la méme qua le Miran d'Adausun.

Nous pussédons celte dirniòre espèce que nous avens reçue du Sénégul; elle serapporte parfuitemeut avec la description d'Adanson : elle a tellemeul !es caractères des Buccins, que M. Lamarct na point hésité à l'y placer. Il lui a dunocé le nom de Buccin poli. Il ne lui donne aucune synonyule, mais on peut facilement vérifer ce que nous disons, dars la collection que possède $M$. de Rivoli. Celle première erreur recourue, la question change déjia, et elle change bien davantage si lon compare l'animal du Mran d'Adanson à celui du Barnet quil place dasis les-Buccins, où il doit rester. On ne liouvera de dilféreuces véritablement esscritielles que dans le clélaut d'opercule, et il seroit possible quäl ail échappé à Adanson, guaique cela suil peu probable.

Nous caservernus encore qu'Adanson affirme positivement que les auimaux de son geare Tis sont absulurnent semblables, et on sera uécessairement furcé de convenir gqual se trompe, puisgr'il y a une corjuille que tous les conchyliologues, a l'exemple de M. Limasch, rangerst parmi les Fuseaux, le Fusus mifut, deus aurs's qui apparlicunent au nouvcau gemre qui nous occupe, et que M. de Blainville a séparé lui-méme du Miran, les deux autres espèces qui restent dans le genere Vis d'Adanson. Nous scriuns purtés a suivere l'exemple de MI. Lasnalck et à les rauger dans les Buccins, leurs coquilles en uffrant tous les caractires, ou hen en laie un petit gence à part, si on le croit absolument nécessuire.

Ve ce que nuus venons de dire, il nous semble que nous pouvons cunclure : $1 \%$ que les ol:servations de 11 . de Blainville sur l'animal du Terebra maculatu ne font que contirmer le genre Vis de M. Lauarck; 20 que ce genre devient trés-bon et bien naturel, aussitót quion en òte alussi bien le dliran que la Vis bucciuce pour les trausporter parmi les Buccins; $3^{\circ}$. que l'on doit, d'apris ce yui précerfe, cunserver le genre Vis de Lamarck en mudiliaut ses caractères'd'après l'a. nimal, et ne point adopter le genre Alène qui n'est gu'un duable emploi inutilc. Fojez V'ss.

\section{ALGERIENAE on HOULE D'ALGER.}

Now que les inarcliands donnent encore quelquelisis au hy trlas ungulatus. Voyez Move.

ALUÏDE. Alordis.

Genre proposé jar M. Mïgerle pont ane co- 


\section{A L V}

ruille que Chemnitz aroit ligurée depuis longtemps daos son Conchylien cerbenet ( $10 \mathrm{~m}$. X, ta!r. 172, lig. 1670 el 1675). En examinant celle figure ef en la comparant avec ce que N. Nhéserle dit de son nouveau genre, on peut sans atucun doute la rapporter aux Corbules, dunt elle ollie les caractècs. Foyez Consure.

\section{ALTÉOLINE. Alveolina.}

Fortis dévivit le premicr, dans ses Mémoires pour servir i l'histoire naturelle de l'Italic (tom. II, pag.112), des coquilles muliloculaires, ovoicles, presque microscopiques, yu'il confondit on ne sail pourquoi, et d'après quels rapmorts, avec les Nummulites, quil nomna Discolithes. (Foj. (ce mot.) Ces corps d'une structure singuliere furent placés par Ficlitel et Moll dans lem grand yenre Nautile, dans l'ouvrage quils publičntant en j 305 , une anvée après celui de l'ortis. Iinné, clui avoit rapporté ì son genre Naulile presque toules lus coquilles polythalames, fut imité par les auteurs gue nous venons de citer, et ces Discolitlies de Vortis recurent deux le aom de Nautilus Melo. M. Roissy, dans le Bullon de Sonnini, ne confondit pas ces coqnilles avec les Nummulites on avec les Aautiles; ces deux grenres sunt bien groupés; mais conservan sans doute quelgrues incerlitudes sur ces corps, il n'en lit pas mevion, el en cela il ne fut point imite par N!. Bosc, qui en fit avec juste raison un genre parliculicr sous le non d"Alvéolite. Il lail le sujet d'un Mémuire inséré tlans le no. 6 ? du Bulletin des sciences de la sociéte philomatique, oì les deux espèces sont bien liururées.

ll sembleroit qu'un genre nécessaire, élabli d'une mauière si positive, auroit dî être aloplé par les auieurs qui ont suivi; mais on va roir quil n'en a pas élé ainsi, e! qu'il en est peu, parmi les Mloblusques, qui aient suli aulant de changenens que celui-ci. Il semble ane les auteurs qui depuis M. Bosc ont traice de ce genre, aient pris à lache d'ignorer son cxistence et ce que les autres avoient déjit priposé. Mlontlort, qui ve publia sa Concilyliologic sysiénatique yu'en 1808 , au lieu d'adopter le sente de $\mathbf{1 1}$. Bose, én lil autant que d'espices : il instilua les genres Burćlie, Miliolite el Clausulie, saos ciler Forlis m M. Bosc. 11 ne fant pas confondre ce genre Miliolite de Moutfort avec le genre Miliolite de M. Launarck, dont il dilfère entièrement. Que dirons-nons de Mi. Duvernoy qui, dans son aricle AiréoLlTe du Dictionnaire des sciences nuturelíes, coufond le genre Alvéolite de M. Lamarcli, qui est un polypier pierreux à réseau, avec le gcure Mlvciolic de M. Bosc, élabli pour une coquille? Duns son arlicle supplfmentaire du même ouvrage, M. Defrance n'a pas comballu le rapprochement de M. Duvernoy, mais il rectifie lit synonymic en cilaal les ligures de liorlis. Nous signalens ce lint, parce que nous allons bientôt voir M. Detrance oublier aussi ses propres antécédens.
Malgré ces tritraux, qui éloient suffisans pour domner des curpss tont il s’agit, une idée satisfaisan:e, el qui ne devoient print laisser ignorer que dojit ils couslimoient des genres, lamarck, prohablement sans les comoilre, iustilua son genre Miélonic daus levirait du coms puhlice en 1812 , sans faire altention que dejit Mnulfort aroit employé un rom seublable pour un genue voisin des Lenticulites, et quil rapprocle des Nauliles: voilà un donble emplci anisible par la conlucion qu'il peut occasionuer entre deux genres dilférens. Ce genre Mćlonie de B. Larnarck se trouve

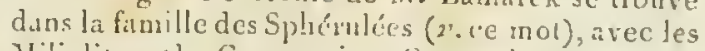
Milioliles eıl les Gyrugronites. Comme les noms génériques de ce cullebre zoologisle prévalurent, celni-ci lint lientôt adoptéct d"a!jud par M. Cuvier, qui, dans le Règne aloimal, le plaça comne sous-ø̈eare des Camérines (20)es ce mol), en y ríunissant avec juste rison les trois genres de Montfort. M. de Herussac, dans ses tẩlearix systémaliques des animanx-mollusques, suivil exactement l'opinion de M. Curier. On retrouve le gente Mélonie dans le dernier ourrage de H. Lamarck, encliainé dans les mêmes rapports que dans l'extrait du cours. Ce cuili a le droit de surprendre, c'est que le célèhre autenu des animaux sans vertébres ignore cucore los tratrax de ses derancicrs ct dise quil ne connoil ces coquilles que par les figues qu'en a donnćcs M. Fichtel.

Nous avons v lu pécódemment que M. Defrance connoissoil lidenlilé des coquilles de Fortis et de M. Bosc, mais il ne s'aperçut pas sans douie qu'elles étoient aussi les mèmés que les Mćlonies de M. Lamarck, puisque, pour séparer les denx genres Alvéolice confoudus par M. Duvernoy, il proposa pour celini qui apparlient aux Mollusyues, son genre Uryzarie a l'arijele HabUlatre du Dictionnaire des sciences natuelles. Cet article parut en 1320, et lorpu'en $182+$ il publia l'article Mélone, il ne mentinnal que le genre de Montfort et nulleacut celui de W. I.xmarck. Il avove qu'il ue comnoil pas cn wafure le wenre de ce derner auleur, et cepreudant il l'a nommé Oryzaire et l'a luil figurer suus ce nom; il fail judicieusement olserver cu'il n'y a aucuns rapports eutre les coquilies qui porient le wirtue nom dans ces deux auteurs. It. de Blainville re in ?as plus que M. Defrance. A l'article Blénonf di mếme ouvrage, il ne mentionne gue le yenre de Montlort. A I'article Molnuseue, ou dans son Tratice de Malacologie, le renenre de Monifort est oublié, tandis que celui de M. Iamarck, anquel il rapporte seulement les Borílics de Monifort, est adopté. Ce grense tait pirtie de la larsulic des Splićrulacées, adopiće de M. Lamiark. Le grenre Gyrogronite, qui est une graine de Clatra, eo a élé supprimćc et remplacéc par les geare. Suracéraire el'lexlulaire (rojez tes mols), proposés par M. Deliance.

1. Latreille (Fumilles nat. du règ. animal) 
proposa la faraille des Milléporites, dans laquelle on Irouve un groupe particulicr pour le genre Melonie, anquel sont rapportés les trois geares de Muntfort.

M. de Ferussac n'ayant noint parlé du genre Alvćolite de M. liosc dans le Dictionnaire clussique d'histoire naturelle, il est ì présumer quil en ignoroil l'existence. Celle omission uons lorça en quelque sorte à traiter ce genre à l'arlicle Mécone, lorsque plus tard nous nons clargesimes des articles de conchyliologic du mine ouvrage : aussi, ici qu'aucun inolif ne peut l'empécher, nums préférons le genre de M. Bosc, parce qu'ii a été institué le premier : quoigue ce fiit depuis loug-tems notre opinion, nous avons ¿́é précédés par 11. d'Otligny fils. Ce laborieux observaleur, auquel la science est reslevable d'un bou rravail sur les Céphalopodes microscopiques en parliculier, changea le nom d'Al'ćolite en celui d'Alvéoline, que nous avous aussi préféré, parce gưon en connoit maintenant uue espèce vivante. 11 plare ce genre disus sa dernière famille de l'ordre des f'oraninilères, à laqquelle il donoe le mna d'Zntumostègues. Voy'ez ce mot.

\section{CARACTÉRES GÉİRIQUES.}

Coquille ovale, oblougne dans le sens de l'axe de la spire; spire centrale; loges assez nombreuses, partagées en un grand nombre de cavités capillaires par des séparalions transrerses; ton:rs de spire très-serrés, le deruier envelopplant tuus les itutres; onverture loogitudinale présentant un grand nombre de pores.

lal structure des Alréolines es! fort singulière el s'ilvicune seusiblement de celle de la plupart des roquilles formuiaifères : l'axe de la coquille est central et placé dans le plus grand diamètre: des tonrs de spire nombreux, lrès-serrés, puisque nuas en avous complé jusqu'à quinze dans une cuquille d'une demi-ligne de diamètre, s'enroulcut les uns sur les aures, de manière à ce que le dernier les enveloppe tous; des cloisons longiindinales, au noml re de six ou de huit, partagent les lon's assez égulement; ces cloisous ne sont pis perlorćes; l'inlervalle qui existe entre chacume d'elles, est rempii par une série de canaux capillaires, séparés les nurs des aulres par ane petile chison transrersale rris-liae, de sorle que dans are conpe longiadinale, celle coguille a t"apparence d'un osselet criblé de porcé. La faroi extériture est fort nouce; clle s'use facilement, et quand elle a disparu, une coquille qui aurvit çû che lissc, paroil striće transversaleurent, parce qualors les lubes capillaires sonl ouverts dans turle leur longuen. D'après las structure de ces coquilles, il est bien à présnmer qu'clles sont intéreures, analogues en cola is la coquille des sichits. Lang-lemps on ue counut les coynilles de ce genre qu'à l'état fossile. M. d'Orlignny est lo premier qui en ait indiqué une vivante, venunt de la Nouvelle-Ilollande; elle est assez grande pour qu'un puisse espérer qu'un jour on pourrad en étudier l'animal. MI. d'Orjjigny, diıs le travail que nons avons précédemment cilti, en indique sept espices : la premièie senle, Alveolina bulloides, n'esl pas connue de nous; elle est fussile aux environs de Iitx. Nous l'avons jusqu' $\grave{3}$ présent inulilerient chercliée dans les sables de colte localilé célèbre par ses beaux fossiles.

\section{Antéoline melon. Alveolina melo.}

A. testù sphoricá zel spharoideấ, longitudinaliter octo ad decem lobos divisâ; tumsversim striatâ; aperturâ longitudinali, lineari, serie unicâ foraminum disfrositâ.

D’Oraig. Mlém. sur les Céphal. microscop. Ann. des scien. nat. tom. 7. fag. 306. nº. 2 .

Melonites spharica el Melonites spharoidea.

LАмк. Anim.s. vert. tom. 7.pag. 615. $n^{\circ}$. 1.2 .

Cleusulus indicator et Borelis melunoides. Montr. Conclyl. syst. lom. 1. pag. 178 et 170 .

Mielonia spharica el Melonia spharoidea.

Bhanvinee, Trait. de malucol. pag. 36g. pl. 7. fig. 2 et 3. Encyclop. méthod. pl. 469 . 1 . it - 1 . et fig. 29. y. h.

An Discotillus spharicus? Fortis, Mém. tom. 2. pag. 112 . pl. 3. fig. 6. a. L. 7 .

A l'exemple de M. d'Orbigny, nous réunissons en une scule !es deux espèces de MM. Lamarck et de Blainville. Il n'y a cle lifférence en efict que dans un pea plus d'aplalissement dans l'axe de l'une delles: a peine si ccla pourroil suffire pour élablir une variélé entre des curps que l'on troure darıs le's mêmes lieur. C'est à quoi nous n'aviuns pas suftisament luit altention, dins nutre article MIÉlonie du Dichonnaire classique d"histoire naturelle, où nous séparànes aussi les espèces, à l'exemple des auteurs que nous aroas cilćs dins notre symonymie. C’est avec doule que nous rénnissuns à celte espéce la Discolitbe sphérique de Foris : il lui indigue six cuies, lorsque les ligures

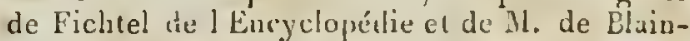
ville en indiquent huit ou dix.

L'Alvéoliue Melon est une petile coquille d'une dem-ligne ou d'une ligne de diamètre : elle est parfaitemeul gloluleuse ou légèrenent déorimée dans le seus de l'axe; chaque lour de spire présente luvit on dix cluisons simples, longitudinales, næu perlurées; les Iulies capillaires qui sont langés en re ces cloisons ue sont qu’ì un senl rang d'épaisseur pour chaque lour de spire; ils son demi-circulaires daus leur coupe trausversale, et grand, dans une coupe transverse de la coquille, on ouvre un de ces tubes, on peut guclyuelurs le suiyre dans toute sa longucur, depuis !e sou- 


\section{A L V}

auet de la spire qui est ceutral, jusquu'à son ouvertruc extérieure.

res localilés les plus certaines sont les environs de Moutolicux d'apiès M. d'Orbigny, et en Honfric, à Steiufeld et à Grusbach, d'après Piclatel.

\section{Atvéounve oblongue. Alseolina oulonga.}

A. Lestâ nvalo-oblongâ, crxtremitatibusobtusis; forumimbus rolundatis, serie unicâ dispositis; octo lobos dirisiti. Аов.

D'Oвви. loc. cit. $n^{\circ} \cdot 4$.

Melonia Fortisi. Ков. Dict. class. d'hist. nat. tom. 10. pag. 55e.

Discolithes spheroideus oblongus. F'оnтis, Mém. sur l'liculic, tom. 2. pag. 115. pl. 13. fig. 8. c. d.

Fuscioliles. Parsinson, tab. 10. fg. 28 à 31 .

Cette espèce est ovale oblongue, obtuse à ses extrcunitćs, divisée longitudinalemeat pur huit cloisons indiquées par ume liğne déprinée; les tours de spire sont très-nombreux, ; cu épais, formés comme daus l'espèce précédente, d'un seul rang de tubes transverses qui sont tout-à-fait ryliudriques daus leur coupe Iransverse. Qaind cette coquille n’est point usée, que la surtace eslárieure est bieu conservée, elie offre des stries transverses peu profundes; mais si elle a été roulie, elle est alors fortement sillonnce, parce que les tubes son! ouverts dans toute leur longucur. Forlis avoit en celle espéce, des environs de Vendemies dans le ei-cievaut Roussillon, ou elle se trouve dans un caleaire brunàıe. Depuis long-temps nous l'avons nouvée dans les sables a numulites du Suissonnois, on $\mathrm{M}$. d'Orbigny l'itgieque aussi : elle a deux lirnes de long sur une de large.

\section{Alvéolixe de Bose. Alveolina Boscii.}

4. testâ ovato-elongatâ, extremitatibus aculâ, lievigalâ, in octo labos divisâ; aperturí sinuatâ, serwe unici foruminium instruclá.

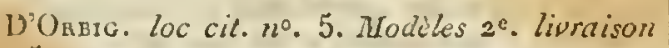
$n^{\circ} .5$.

Alséolite grain de Félusque, Bosc. Bull. de lu soc. pkil. $n^{\circ} \cdot 61$. fig. 5. a. b. c.

Miliolutes sabulosus. Movrr. Conch. syst. 10m. 1. pug. 174 .

Discolithes sphorroideus, gracilis, apicibus aculis. Iorts, Viems. sur l'ihalic, elc. lom. 2. pug. 114. p.l.3. fig. 1031.

Melonia Boscii. Nun. Dicl. class. d'hist. nat. loc. cit.

Oryzariu Boscii. Defrance, Dict. des scienc. nat. Lom. 16. $17^{\circ}$. cahier de l'Allas, pl. fig. 4. a. b.

Coyuille extrêmement commune dans presque toutes les loeúlités des environs de Paris, strrlout dans les ealcaires grossiers. Sa lorme la rend bien facile ì reconunitre; quoiqu'elle varie nu peu,

\section{Histoire Naturelle des Vers. Tome II.}

elle est ovoide, étroite, pointue à seэ extrémités. Quinul elle n’est pas mulce, elle est toute lisse; ou n'aptrouit les traces des tubestrausverses qu’'it l'aide d'un fort n'ossissement. Les eloisons sont le plus ordinairement au vombre de lunit; elles sont légèrement siuneuses dans le nilieu; elles sont peu iudiquées par une dépression linéaice it peine sensible. La dernicre cluison est sinucuse eomme les autres; sur quelques iudividus clle reste lisse, sans ancune trace douvertures; Jaus dautres on en voit me série umique s'ajpuyant contre le retom de la spire; lés tubes soni tris-fias, nombreux et presque earrés dams len coupe transverse. Les tours de spire sont trit-peu épais; il y en a quinze dans me cocprille yui a me deni-ligne de large dans sa eoupe longiudiuale : quelques individus ont justuat trois lignes de long sur une de large.

4. Arvéorine alongée. Alveolina elongata.

A. Lestâ ovalo-ıcutâ, substrialì, clongalâ; extremilutibus aculss; octo vel novem lobos divesâ, spirâ umaci serie lubulorum formatà; bulis rotundutis exilussimus.

D'Oraigny, loc. cit. no. 6 .

Celte espèce est la géante du genre. Sa taille, qui est de onze millimètres de lovgueur sur trois de largeur, pent servir à la liure reconnoltre parmi ses congénères; nous n'en avous vu que des individus un peu roulés, la localité d'où ils vieunent ne présentant gnère de fossiles qui ne soient daus cel état. Les lialunières de Valognes, quelque riches qu'elles soient en espèces, sonı en cela intérieures a celles d'uulres pays, par la mauvaise eouservation de ses fossiles. Nous ignorons si cette espèce éloit lisse on striée; nous ae connoissons pas non plus la dispusilion de la dernière cloison; éloit-elle perforće? Au clílaut de ces deux caraetères, it en reste plusieurs anties, sullisans pour désigner cette espèce. Nous avons vu qu’elle éroit plus grande quae les autres, qu'elle ćloit alongée et plus étroite proportionncllement. Ses eloisous sont au nombre de huit à neuf; les tubes capillitres transverses qui la composent, sont extrêmement fins, très-serrés, et un scul rang lorme les tours de spire, de sorte que ceux cı sont 1:ès-nombreux, relalivement an pelil dianètre Iransversal de la coquille.

Si la localité de Valognes avoit ollert plusieurs espèces clu même genre, il anroit peut-être été assez dillicile de rapporter l'indicalion de M. d'Orbigny à l'une plutôt qu'à l'autre; inais enmme elle est la seule, on ne peut douter que ce ne soit elle que MI. d'Orbigny a conute.

5. Alvéolne de Quoi. Alveolina puozii.

A. lestâ elongatâ, cylindricâ, extremitatibus obtusâ; aperturi curvalât, extremilatibus dila- 
latatâ; poris numerosis, irregulariter dispositis.

D'Orвтух , loc. cit. fig. 11. 12. 13.

Celle espèce est li seule vivante qui soit connue; elle est très-distincte de toutes celles qui sont fossiles : el'e est de forne alongrée, cylindracée, fort grêle, obtuse à ses extrémités; l'ouverture, étroite dans le milieu, se recourbe aux extrémités, où clle se dilate de manière à cacher les axes de la coquille; la dernière cloison qui la ferme est couverte de pores disfosés irrégulièremen!; la surface extérieure oflice les Iraces de sept à buit cloisons furt rapprocliées, qui sont coupées transversalement par des stries irès-fines. La longueur de cetle espèce, rare dans les collections. est de dix à douze millimètres; elle a ćté trouvée ì Rawac a la Nouvelle-líollande.

\section{ALYKRUIK On ALIEKRUCK.}

Nom vulgaire batave du Turbo littoreus de Linné, et appliqué ensuite à quelques espèces voisines, conme le Turbo maricatus, Turbo olearius, elc.

\section{AMALTHE. Amaltheus.}

Montfort a proposé ce genre parmi les coquilles cloisonuées (Conchyl. sy'stém. tom. 1. pag. 90), mais il se tait sur un des caractères les plus esseutiels. Les cloisons sont.elles simples? sont-elles articulées? Si elles sont simples, el que surtout le siphon qui les liaverse soit effectivenent placé comme Montfort le représente, c'est un Nautile, et le genre devient inutile. Si les cloisons sont sinueuses, alors le siphon n'est pas convenablement placé, et le genre appartiendroit aux Amnonites; il seroit encore inutile. M. de Ferus:ac dit dans le Dictionizuire classique, yue ce genre ne peut être séparé des Discorbes. M. de lierussac se trompe, puisque le geare Discorbe a été établi par M. Lamarck pour uue coynille microscopique des eavirous de l'uris, qqui u'est point siphouitère comme celle-ci. Cette erreur avoit déjà été litite daos les tableaux systémaliques dn mène auteur. M. de Blainville a mieux connu les véritables rapports de ce genre, quil confond jusiement avec les Ammonites. On peut le cousidérer aussi conme identiquement le mêtae que le genre Orbulize de MI. Lamarck, yenre que l'on ne peut aujourd'tui séparter des Aisianouites. Voyez ce mol el Orbulite.

\section{AMBLĖME. Anblema.}

Un gecre qui n’a pour caractè es gque ceux tirés de la torase extérieure de la coquille, ne peur être adoplé, quand cetle forme n'entraine pas des modilications dans l'organisabion de l'animal. C"est ce qui a lieu pour les gemes proposés par Ratinesque. (Monographue des Bu'calves de l'Ohio. Anr. génér. des Scienc. plyjs. de Bruxelles, sept. 1020.) Iís n’ollien! que dés déuembremens inu- tiles des Mulettes, dont ils présentent tous les casactères, et dont l'ainimal ne diffère en ancune facon. (Voyez MIU.ETtE.) Ce genre qui nous occupe fait partie de la sous-famille des Emblémides ( voyez ce mol) du même àteur, sous-famille qui fervil à peine ua bon sous-genre.

\section{AMBLÉMIDES (les). Ablemidia.}

N. Rafinesque a nommé ainsi la deuxième sonsfamille de ses Pédifères. (Voyez ce mot.) Le's Pédileres correspnodent au genre Miuletle des auteurs, el à peine pourroit-on considérer celle sous-famille comme un sous-grenre des Muleties, auxquelles nuus renvoyons.

\section{AMBREE OU l'AMPHIBIE.}

Genffroy, dans son pelit Traité des Coquilles des environs de Paris, nomme aiusi une coqnills: mince, transparente, fragile, que Nluller avort rangée dans le genre Hélix, snus la dénomination d'Helix succinara. Celle coquille a servi depuis ì Uraparnaud pour l'établissement de son genre Aubretle, qui a élé généralement adopié. Voyez AMBRETTE.

\section{AMBRETTE. Succincra.}

On doil ce genre à Draparaaud, qui l'a élabli avec une coquille que Linoé et Mul!er rangevient duns les Hélices, et qui éloit conoue bien avant eux par Lister, Gualtierri, el surtout Geolliroy. Ce dernier, dans soa excelleut potit Traité des Cuquilles des environs de Paris, lui avoil donné le nom d'Ambrés ou d'Amphsbie. Bruguière, dans le premier volume de ve Dictionnaire, la lira des Hélices pour la placer dans son genre Bulime; ce ne lut quaprès cela que Draparazud proposa le gedre Ambrelle dans son Histoire des Mollusques terrestres et fluviatiles de France. M. de Roissy fut un des premiers qui l'adopta (Buffon de Sonnini, tom. V. dés Moll. pag. 350), en changeunt le nom d'Ambrette contre celui de Succinée. II le plaça entre les Iimares el les Agathines, counme inlermediaire sans doule entre les Mnllusynes pulmonés, lacustres et les terrestres. La nêtme anwée, M. Lamarck décrivit dans le one VI des Annules du Muséuni, une coquille fort rare pour laquelle il iustitua le genre Auphilualime, quisqu'il reconnùl son identité générique avec l'Aminie de Geollioy. On ne sait pour quel unolit ce savant u'adopta pas le nom de Drapanaud. Dans la l'hilosophie zoologique du même auteur, un retrouve le senre Amphibulime laisant partie de la famille des Colymacées, ealre les Bulianes et les Agathines.

Montlort préféra la dénomination de M. Lamarck à celle de Draparaaud. On ne sait d'aprcs quels rapports il plaça ce genre et selui de la Parmarelle entre les Crépidules et les fissurelles. Certes on ne peut trouver entre ces genres la 
moindre analogie, quelle que soit la bonne voIouté que l'un puisse aroir. Dans l'extrail du Cours, M. Lamarck n'a rien chaogé, ni ì li dénomination, ni aux risports qu'il avoit établis précédemment dans la Philosophie zoologique; te ne fut que dans son dernier ourrage quil reudir justice á l'antériorilé du nom donné par Draparnaud, et qu'sl l'adopta. Dans cet invrage il lait toujours partie de la famille des Colymackes; il en rermine la première section avec les Arablines. M. de lierassac se fondant, comme Draparnand, sur les carractères lirés de l'animal, arrive à une cunclusion différente, puiseque, contre le sentiment de lous les auteurs que nous avons cités, il réuuit ce gente aux Ilélices, suirat en cela l'opinion de Linné el de Mhaller, avec celle dillérence cependant qu'il en fait un sousfrence bien distinct des Ifélices; i] lui clonne, dans sa snćlhode, pour l'arranrement de ce graud gi ure, le nou de Cochlohydre. (Fovez liénce.) It est le seeond de la ser:tion des Helices redondintes, lormant à lui seul le groupe des Evolutatco Cochloides. Nous viruns a l'arlicle Hértce, pour quels mosits on u'a pas adiuis les divisions de l'auteur rue nous cilons. M. de Blininville; daus son Tranté de Malacologie, a suiviles rapparts indiqués par M. Lamarch; seuleneat conase sa méthode eat concue daus un sens inverse, le genre Anbretle commence la famille des limaciens ( voyez ce mol), el il est suivi des geures Bulime el Agathine. Dans son derricer wuvrage M. Latreille, sans adupter la norucuclature de M. de F'russsac, a conservé néanuoins son arlaugement aćlhodicgue pom la liaison des genres. Il lail partie de la fumille des Géucoclalides, oii il est imleraćdiaire entre les Vitriues el les Iftilices propreurent dites.

l.es aniuiaux de ce genre sont trop grands pont rentrer complétement dans leur coqquille; 1 ls ont, yuant à leur organisation, une res,emblance trisgrunte avece ceux des Hélices; ils en dilierent ceprentant pur les tentacules qui sout proportionneiremeat plus couris, el surtout les inléricus. Lat pirtie postéreure de leur corps est enrublie d'une taanière particulière, d'uà résulie une corcyulle d'une lollue bien caractérisée; clest aussi de celle conquille que les auleurs ont liré les caracteres les plus appréci.l.les de ce geare.

Comme :ous les Mollusque; terresires, les Ambrenes peuveut rester guelgue teinps dans l'eau sans y nérir, mais elles tue sont pas anphibses plus qu'eux, comine un le crinyoit assez ácuéralatuent. Ce squi as pu donner lieu is celec cprinion, riest qu'un les rrouve toujours diuns les lieux hunides, an bord des riviéres el des ruiseseax, duns les endroits marécageux, nù clles viveut sur les planle's aqualiques. Les orgunes générateurs élanl semblables at cen $x$ des Itrilires, lu génération doib se faire de la mêtne raniere.

- Nous ne donnerons sur ce genre aucuns délails anatomiques, nous nous réservons; à l'article Hźuner, d'entrer à cet byard daus des dérails où nous anrous suin de noter les foibles difírences qui existent entre les geares qui avoisineat le Lúlices el les IÍlices etles-mênes. Nous renvoyous le lecteur à cer arlicle, ainsi grúc celui de la lamille des Culymacées, oì nous coupareruirs entrelles les diverses classifications moderaes, de lancien genre Helix de Liuné.

\section{CARACTERES GENERIQUES.}

Auinal semblable à celui des IIćlices, trop grand pour sa coquille; paire iuférieure dés tenlacules très-courte. Coquille mince, translucide, ovale on ovale-coniegure; ouverture auple, enlière, ovalaire, plus longue que large, un peu oblique; bord droit tres-mince, Iranchant, non rélléchi, s'unissant inferrieurement à une colunelle lisse, arquée, amincie et lranchante.

Quoique peu nombreux en especes, ce genre esi répandu dans loules les parlies du Monde; quelques espèces se trouvent également sur plusiemrs conlinens; le Succinea amphibia surtout en est un exemple firtprant. Si vu en croit se que dit M. de Ferussac, el en aduleuant toules ses variétés, celle coquille seroil presqu'universelle. Il seroit possible que quelqques-unes de ses variélés tussent de véritables esperes. Il faut dire que l'on passe de l'une a l'autre par des nuances si peu seusibles, qu'il seroit bien difficile, ponr ne pas dire impossble, de poser des linutes entr'elies; celis ne seroit faisable qu'autant que les animaux eux-mènes présenteroieut quelques caractères constans. M. Lutnarck ne vite que trois espéces dans ce genre, et MI. de Blainville, d'après hi, n'en comple pas davantage; cependant leur nombre est plus considérable. M. de lerussac en fail counoilte neut, el nuns ponvens en ajonter ane disième qu'il n’a pas doncaće, ni taus ses planclies, ni dans sa nomenchalure. 'Toutes les especes de M. de Ferussac sont-elies bien des Ainbrelles? Nous conservous du doute puur de'ux d'entre!les, l'angularis el le sulculosa, qui sunt bezuconp plus glubuleuses et plus raccourcies que tontes lés autres. Deux de ces especes ont élé conuues de Brugnière el décrites par lui, l'une, l’Ambrelte sapuchon, Succinea cucullata (FER. Moll. terr. et fluv. pl.11.fig. 14. 15.16.et pl. 1 1 A. fig. 12.13), sous le nous de Bullmus patulus; l'autre, la flus conumue de tontes, l'Ambrelle amphibie, Succinea amplabia Lasix. (Fen. Luc. cit. pl. 11. fig. 4 a io et $1 \bar{j}$, et 11 A. fig. 7 i 10 ), suus le dénominumun de Bulimus succincus. Vuyez Bunare, n:s. 15 el 18 du Ier. volume de ce Dichonnaire.

Ce genre n'a point encore cécé truuvé a l'ćlat fossile.

1. Azвn eтre tigrioe. Succinea tigrina.

S. testâ orali, pellucidả, loevigutâ, tenuissiC 2 
mâ, subvirescente, maculis minimis subrufis aspersâ ; aperturî̀ ingentissimâ, ovatì ; spurâ brevissimâ.

Helix tigrina. FER. Hist. des Moll. terr. et fluv. prod. pag. $26 . n^{\circ}$. 6. pl. $11 \mathrm{~A}$. fg. 4 .

Espèce des plus remarquables par sa forme et l'évasement cnnsidérable de l'ouverture. Elle est rérulic̀uement ovale, très-mince, subdiaphane, lisse, d'une couleur verdâlre et toute parsemée de petiles aches diun brun funve; elles sont fort nombreuses. Lionverture est ovale, point oblique, près de cing fais plas graude que toute la spire, qui est conposée de trois touts légèrement convexes; le bord droit est wès-mince. tranchant; fragile; le gauche, quaiqn'nn peu plus solide, esi bien tranchant aussi, et on aperccit son enroulement en regartaut la coquille par la base.

Cette coquille vient de l'ile Saint-Vinceat; elle a été envoyée par M. Lesneur. Sa longueur est de dix-lıuit à vingt millimètres.

2. Ambrette ovale. Succinea ovalis. Sar.

S. testâ ovatâ, limmoformi, pellucidâ, tenui, subsulcutî́; aperturá ovali, obluquâ; anfractibus guatuar convexis; spirâ brevi.

$\mathrm{S}_{\mathrm{A} Y}$, Journ. de l'Acad. des Scienc. nat. do Philadelphie, tom. 1. pag. $1 \mathrm{j}$.

Helix ovalis. Fer. loc. cit. $n^{n}$. 8. pl. 11 A. fig. 1 .

Plus que les autres espèces du même geare, celle-ci a l'aspect d'une pelite Limnée; elle est ovale, subglobuleuse, transparente, mince, fragile, d'une couleur de corne un peu brunâtre; Fouverture est grande, mais propostionuellement à la spire, beaucoup moins que dans l'espèce précédente; elle est ovale, un pen oljlique, eı les bords sont tres-nituces et tranchans. La spire est conrte, composce de quatre touls, dont le premicr est à peinc sensible; ils sont globulcux, séparćs par une sulure simple, assez profonde; le dernier tour ollie, surtont vers l'ouverture, des sillons d'accroissemún tqui se répètent à lintériénr, à cause le la grande nuncenr de la cocruille. Ellé n'a que donze à quatorze millinıètres de longueur.

Elle labire les Etats-Unis.

3. Ambrette oblongue. Succinea oblonga. Drap.

S. testầ ovato-oblongầ, tenui, longitudinaliter struatâ, ulbidh; anfiactibus quatuor convexis ; suturis subexcavulis; aperturâ spiram vix superante. Lasix.

Succineu oblonga. Drap. Moll. terr. de France, pl. 3. fig. 24. 25. ibid. LАмк. Anim. s. vert. tom. 6. pag. 135. $n^{\circ} .5$.

Helix elonguta. Fer. Hist. des Moll. terr. et fuv. pl. 11. fig. 1.2.3. et pl. 11 A. fig. 2.3 et 11.
Draparnaud le preınier découvitit cetle espèce duus le widi de la l'auce, et la décrivil dans sou ouvrage su: les Nollusques terrestres et lluviatiles de ce pays; cependant elle ne se trouve pas la seulement. D'aurès MI. de Ferussac, elle habiternit anssi la Suisse, MAllemagne, et deux de ses varićlis habilent la Guadeloupe et même le Cap de Bonne-Espérance, d'où elle a été rapprortíe par len Lalancie. Dans ce pays elle se plaít près les marais salés, tandis qu'en lirauce elle préféce le bord des fontaines.

L'unimal de celle espèce est grisâtre ct toujours plus petit que celui du Succinea amphibia. Lu coquille suit nécessairement les proporions de l'animal; elle se disingue des autres especes par sa forme plus alongée et plus étroite; la spirc, qui esi presqu'aussi longue que l'ouverture; celle-ci est oblique, assez régulièrement ovale; les tours de spire, au nombre de qualre, sout convexes et hien séparés par une suture simple et profoude. Cente coquille d'une conleur blancue, grisátre on jaune d'ambre, est finement strie longitndinalement, et porte quelquefois un perit bourrelet à l'intérienr du bord droit.

Sa longueur est de six à douze rillimètres, $t$ quelquefois un pen plus.

4. Ambrette rouggâtre. Succinea rubescens. Noв.

S. testâ ovatâ, tenui, fellucidì, nubesceníe, substriatî; upenturâ ovalı, amplissimâ, oblıquй; spirâ brevi, obtusâ.

Nons ne connoissons de cette espèce que les dea $x$ individus de notre collection; nous les avons acquis d'un marchand qui nous a assuré qu'ils venoicnt de la Guadeloupe. Ils ont des rapports avec le Succinea cucullata Lamk., Bulumus patulus Brug., et surtout avec les jeunes individus de cetle espèce remarquable; mais la conlenr et la forme les distingnent suflisamment.

Cesie coquille est ovale, ventue, d'un rongeviueux peu foncé, diaphaue, mince el cassante; son onverture est forl ğrande, oblique, régulicrement ovale, trois fois plus longue que toute la spire; les bords de cette ouverture sont minces; la columelle s'enroule assez largement, pour qu'va la voic d'un bunt a l'autre de la spire, en la regardant par la base de la coguille; la spire est formée de truis tours, donl le dernier est bear coup plus grand que tous les autres. A l'ceil au, cette coquille semble lisse, matçuée seulement de quelques stries d'accroissement; mais vne à la loupe, elle est couverte de stries très-fines, longiludiaales et assez régulic̀res.

$S a$ longuenr est de vingt-deux millimètres, dix ligues à peu près.

Nous devons à la générosité de M. Lesson, l’un des naturalistes de la corvette la Coquille, qui a fait si heureusement le tour du Moude, une cu- 
quille de re geare qui vieut dè îles Malouines, et qui a les plus grands rapporls avec la variété $d$ de l'Helir putris de M. de Ferussac. Cente variété vient des iles Mliquelon et Saint-H'ierre, près 'Terre-Nenve d'après ret auteur. Elle s'éloime, quant à la forıne et à la couleur, du type de l'espèce, ce qui nous fait penser quion la sćparera pour en lormer une espece distincle.

\section{AMINOVE. Aminonus.}

Ce genre a été établi par Montfort (Conchyl. syst. pas. 326. tom. 1) pour un corps qui ne paruit elre aulre chose, d'après l'opinion de M. Cuvier el de lit plupart des conchyliologues, qune pile d'alvéole de Béltanite courbée ainsı accidentellemeat. MI. de Blainville ne semble pas parlager celle manière de voir, car, dans son Traité de Mulacologie, ce genie forme une des sons-divisions des Couilites. Voyez ca mot et BéLearite.

\section{AMiral.}

Nou spécıfque et vulgaire d'une trìs-lelle coquille du geme Cóne, Conus amiralis, dont les noabreases varićlés ont reçu des épithètes caractéristiques que Bruguière a citćes dans la description de celie coquille. Foyez Cône dans le premier volume de ce Dictionuaire.

Plusieurs autres espèces de Cônes ont aussi recu des marchands le nom d'amirai. Aiasi le Conus cedo nulli a été noımé Amirul C'edonelli, Amiral de Curaçan, Amiral de la Trinité, etc.

Le Conus maldious, Amiral espatgaol.

Le Conus malacanus, Amiral portugais.

Le Conus miles, le Faux-inmiral.

I.e Conus siumensis, I'Amimal chinois.

Le Conus genuanus, Amiral de Guinée.

Le Conus acuminatus, l'Amital de Rumpbins.

Le Conus omaicus, l'Amiral d'Oma.

Le Conus granulatus, l'A miral d'Angleterre.

Le Conus aurantiacus, l'Ainiral d'Orange.

Le Conus dux, l'Aariral de Hollande.

\section{AMMONACÉES. Ammonacea.}

Daus son Traité de Malacolagıe, M. de Blainville a nomaé ainsi une launille de coquilles multiloculaires; elle est la qua!rième de l'urdre des Polytbalawacécs (zoyez ce mot), et elle se compose des yeures Discorlsite, Seaphite, Ammonite et Simplegade. De ces genres, le premier n'a aucon rapport avec les $\Lambda$ inmonites; il a été fait pour une coquille microscopique des environs de Paris qui n’a point de siplion, et dont les cloicoas ne sont jamais découpées. Le dernier est un double emploi inutile des Ammouites; il représente Je genre Orbulite de $\mathrm{M}$. Lamarck. Ce qui est étonnant, c'est que M. de Blainville y ait rapporté le genre Ammonie de Moatfort (voyez ce ce mot et Nadrice), fait pour le Nautilus umbi- licatus, et les genres Planulite. Cllepsolite et Amullú du même, tous dímembiés saus nécúsitú des Ammonilus, où jis forment des degrés mos on moins arancés dans l'Claryissemeat de l'ombilic, Ml. de 13lainville confondant ainsi sub le caractice pen esienticl de l'oubilic onvert, cies genres aussi diliéruns que los Amnonites et les Tuutiles. Celte famille ne correspond prestupin ruen à celle des Ammonées de M. Lamarck. Voyez ce mot.

\section{AMMONELS (les).}

On doitl'établissemeul de celte famille à M. L.amark, qui la proposa pour la prenicre fois daus l'extrait du Corurs, pullié en 1811.

Précédemment, il avoit compris dans la filniille des Nautilacées, créé dans la Philosoplie zoologique, lous les genres qui composent aujourd'lui la linuille des Ammonces; elle rassenbla d'abord les cinq genres suivaus: Ammonite, Orbulite, 'Turrilite, Anunonocératite el Baculile. Le genre Ammonite, dans la classificanon de M. Curicr (Regne animal, tom. 2), correspond a la famille des Ammonées de M. Lamarck; seulement on n'y voit pas le geure Amronocérati'e, qui est resté long-temps inconau.

La famille qui nous occupe resta la mème dans le deraier ourrage de M. Lamarck; elle conserva les mêmes rapports arec les familles environnantes, précedée, comnc dans l'extrait du Cours, des Naulilać́es, et tesminant la grande série des Céphalopodes polylhalames. M. de Ferussac suivit un ordie inverse à celui de MI. Lamarck. Nous trouvons la lamille des Anmonées adoptée de ce savant, au commenceunent des Céphalopodes décapoles; elle se compose, daus l’ordre qui suit, des six gentes Turritite, Oilsulite, Aumonite, Scaplite, Hamile, Baculite. $O_{\Omega}$ renarquera que les deux genres Scaphite el Hamite sont ajoutés à la lamille, tandis que le genre Amuonocérate eu est exclus fatte de le connuitre; cependant en examinant avec altention la caractéristique el la description des deux espèces du Systène des animaux sans vertèbres (lom. 7, pag. 644 et 645), on est lurcé de convenir que ce genre esı le mêne que le genre Haraile de M. Parkinsun; mais cumme le genre de M. Lamarck est pustérieur à celui de l'autear anglois, il sera juste de ne pas l'adopler. (Voyez Asmosocérate.) Quant au genre Scaphite, il ćtoit nécessaire, et appartient a la turaille des Ammonées, où il doit se trouver dans les rapports incliqués par M. de Ferussac.

Nous ae trouvons aucune trace de cette famille dans la métlode de M. Gray (Bull des scienc., février 1824); il comprend dans un seul ordre, qui porle le nom de $N$ autilophora (2ojez ce mot), tous les genres des Céphalopodes décapodes des auteurs. M. de Blaiuville, guidé par no autre prin- 
cipe que celui des auleurs que nous arons cités juscju"a prúseut, a dispersé la plupart des genres qui entrvient natu ellemeal daus les Anmonées, et a'en a consersé qu'un pelit noubre daus la fumille qu'il nomue Ammonacées. Il y lait entrer des corps qui unont aucune analogie avecles Ammonites, fel que le gente Discorbite (vojez re mol), un geure simpligade de Momfort, qui pourroit a peine fuire une sous-alivisisn des Amwonites, et corrane section de ce gomre le's Ainmonies du ấme autenr, qui ne sont aure ćose que le Nautile ombilipjué: avec deux gones que nous renons de citer, se truuvent duns les Ansmonacies, l's Scaphites el les Ammonites. Les Orbulites, genre inutilement sípuré des Ammonites, font parie de la famille des Nautilacies; lu genre Turrilite lait à lui seulla famille des 'Turriculatićcs; les genres Anımonocérale el Hamice, tous dewa conservís, quoique formant dousle e uploi, comme nous l'avous dil, lorment la seconde sechua de la famille des Lituacés; le genre Baculite enfin est posté daus la famille des Orthocérés, ua il lail une sevtion à part. On ne pent donter, dapris ce rue nous venous de dice, sque II. de lil ansille ai éléconduit à un arrangement aussi pen nalurel, par un principe qui lai a lait prélécer la forme de la cuguille à sa structure, principe essentiellement faus, que le savant jrofesseur a démié jar le fait dans le reste de sa mélihode, wì l'arungement des genres est basci sur ce qu'il y a de pius pusitif, linatouic des animanx, a laquelle il n'a rémi que secondaireanent la forme de la coguille. On peut répondre à cela qu'ici l'anatomic ne peut être utile a rien, fuisque la limille des Aaumourées est cumposée de coquilles pútrilices; suns dente, natis si l'unatomie manque, la structure si remaryuable de ces

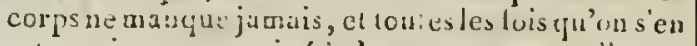
est servi, co cst itirive a des coupes nalurelies.

Les auteurs yai ont truilé des Céphalopodes, à l'excepion de M. Iatreille, nonl punt unité 11. de Blainville; its n'unt pa apporter Leancoup de changeneus dans la fanille, telle sine M. Litmarc's l'avni laiss!é. M. de Haan a propose? quelyues genıes dévecubrés des Ammonites, et l"u parlagúe en dęux groupes bien dịsliucts; séparés d'apes la torne dés cluisous ferlement récoupées dans le premier, et undulcuses ou angulenscs dans le secont; mais ce seroud groupe n'ist pount andmissible au méme clegrí çucelui des $\Lambda$ unumées, il rentre uatusilenent ciars les Naubles, romus nous le verrons a ce mot, ainsi qü is NAurtLoictiEs.

1., lamile des Ammonces de M. de Hilan est divisće en deux parlies; dans la preuicre suni comprises toutes les coyuilles it cluisons découpeies er en spirale; on y voil daus autant de soussectious, le's quatie geres suivans, Turrilie, Glohite, Planite et Anmonitic; la seconde contiant les coquilies qui, avec les wémes clusums, ac sont point tournées en spirale, tels que les Hanites et les Baculites. M1. de Jian ne connoissoil pas suffsamment, sans doute, le genre Scaphile, puisurüil l'a placé daus la famille des Nuullies; sill eúl su que les coyuilles de ce genre ont les cloisuns découpté comme les Anuruanites, il n'est pas douteux cin'il ne l'cút conjpris dans sa tamille des Ammonées, foudée principalement sur ce caractère. Les deux nonveanx genres que M. de Hun a proposís, on: le défaul que l'on a justenont repioclié au genre OrLulite de M. Lamarck, et l'un d'eux, Globite, en est un double emploi; l'autre est plus inulile encore, puisqu'il est fondé sur le déveluppement iusensiblement gradué de la coquille, çii reste beaucoup plus j!ale que dans les autres $\Lambda$ inmonites, qui s'épaississenl beaucoup plus rapidement. Ces curacteres ne sont point suffisans, yaand il s'agil de faire de bons genres : cenx-ci n'oul point cité adoptés.

11. Latreille, Fumilles naturelles du regne animal, est combé dans lá même faute que $\mathrm{M}$. de Blainville : emporté par les rapports de forme extéricure, il a iransportó dans civerses familles les genres qui composeul celle-ci; c’est ainsi que quelques-uns se rouvent daus la tribu des Polycycliques, ce s nt les'Turrilites et les Ammonites; d’autres das la tribu des Orthocírates, ce sunt les Bacalites et les Hamiles, rapprochées des Bacolites et des Tirauites de Monifurt. Les Batolites sunt des coquilles bivalses du genre IIippurite, et les Tiranites soat un double emploides Buculules. Nous donnerous de plus amples délails sur les rapports que M. Latreille a établis entre cis geares el cenx yui les euvitounent, aux articles f'olycychlques el Onthocérates.

M. d'Orbigny, en rétablissant la fumille des Aumonóes de M. Lamarck dans sun intégrité, en l'arlogulant suas restriction, a agi sapenient et a bieu couprois cjue les caracteres employés par cet ilinsire nuluraliste étoient les seuls converuables pour ar sires a un arrangernent viainent uaturel; il a bieu senti aussi que les genres qui $y$ sont rasseublés ne peuvent y foimer qin'une série unique, corume M. Laniarck l'avoul tegalement fail. II. d'Urbig:ly suppriuce d'ubord le grurc Orbulite, et en celi il a raison; il ajouce le gente $S$ caphite, it lexeruple de M. de Ferusiac, el on ne peut que l'approuver. L'ordre propusé par Mi. d'Orbigny nucis semble le plus convenal: le, numsl'avons adupté sans aucune modilication; cést le ouivant: Baculite, Hanite, Scaplute, Aumonite el Turrilike. Iojez cles mots.

11. Lamarck a caractérisé celle famille d’unc manipe moins complcle que M. d'Olbigny, en ce yunil n'it pas meutionné le siphon, partie dont la position est toujours la méme chus celle firambe, a rel proint yue sur l'irispection de ce cuructere, on pent décider en toute assurance si nuc coyullie lui appartient ou non, lors tréme in'on r'ipercevroit, par un accident quelcós- 
que, ancune trace des cloisons. Vurci ces caraclicres:

'l'est simple, spiral ou droit; cloisons découpées; cavilé sapérieuse à la clemière cloison grande el engaiuante; siphon nargitual (dorsal sur la carène). D'Orbig.

Les genres qui composent cette famille ne se trouvent plus qu'a l'état de pétrification; on ne voil que très-rarenient leır lest qui est d'une très-fuible épaisseur. Celle ténuité cle la coquille avoit lait penser à quelyues auleurs qu’elle étoit conlenue daus l'épaissenr de l'auimal; qu'elle étoit, par conséçuent, intérieure. l'lusieurs motifs peuvent donner une opinion diftésente que nous croyons plus viaie : $1^{0}$. on voit des coquillts excessivement oninces, les carinaires, par exeal1 ! ’e, qui ne sont point intérieures; $2^{n}$. les coyuilles insélieures ou demi-inléricures nont pas hesuin d'une grande cavité terminale, puisque l'auimal ne pourroity rentrer complélerneut : dans les Amnoncés, celte cavité est trés-grande; elle l'est assez pour qu'un animal puisse y rentrer et s'y abriter; 30. dans les coquilles intérieures, les bords de l'ouverture sont tnujou:s très-ainces, tranchaus. On sait aujourd'hui que daus lia plupart des Ammonées, et les Ammonites surtout, il existe un bourrelet marginal qui borde l'ouverture à l'état adulte; celté ouverture a d'ailleurs une forme gui lni est propre, selon les espèces, plus ou moins sinueuse, plus ou noins avancée, pour s'adapter au passage des parties de l'animal.

Ia forme des coquilles de cette famille est trèsdifférente selon les geores : lanlôt elle est parfaitement droite et conique, tanlôt tournée en spirale dont les tours ne peuvent jumais se toncher, tantôt enfia, en spirale dont les tours sont contigus, soil que les coquilles soient discoïdes, soit qu'elles soient turriculées. Parmi les discoïdes, il existe divers degrés de contiguité qui se tondeut insensiblemeat, de sorte qu'il est in possible de déterminer précisément où l'un commence et oì un autre finil. C'est cette lusion qui reud impossible l'établisserneat de geares aux dépens des Ammoniles, d'après ce seuì caractère. On voit en effet quelques espicces dont les tours ne sont qu'accolés les uns aux autres, mais on en ubserve d'autres dont les tours deviennent de plus en plus embrassans, et à tcl point, qu'à la tin de la série, le dernicr rour caclie tous les autres, de manic̀re à ne laisser aucune Irare d'ombilic, comme dans la plupart des Nantiles.

On áa pas eacore observé une seule coquille de ces genres is l'ćlal vivant; il est à présumer que lenr race est perdue : ou suppose généralement qu'ellesexistent sans doute dansla plus grande prolondear des mers; mais s'il en est ainsi, ce ue sernit pas un obslacle invincilsle à leur observation, car les animanx céphalopodes sint aageurs. Surpris par une violeate teinpête hors de leur deroure babituelle, le basard, après plusieurs sièrles dohservations, auroit pa en jeter quelques-uns, on an inoins leurs coquilles, on quelques lirangeris de leur rocguille sur les plages, où des observaleurs, occupés presqu'exclusivement de lit rechlerche des conguilles, n'auroient pas manqué de les rencontrer.

l'arai les coquilles qu'il est inportant au góologue de connoitre, ceelles-ci oecupent une des premières places; distribuées en grénéral d'une maniere analogne dans les conches semblables, less espèces peuvent servir de moyen pour recunnoille ces couclues. l.es umes soni propres au calcaire du Jura, les autres is l'nolite, les autres à lid craie, elc.; mais ce qui est rematrquable, ef ce qui peut fortement appuyer l'opinon que ec's genres sont perdus, c'est qu'ils ne se sont pas cncure rencontrés dans des terrains lerliaires, sur la nature et la posilion géologiqgue desquels on ai: aucune incertilude

\section{AMMONIE. Ammonites.}

Montfort voulant trouver dans le Nautile ombiliqué le type vivant des Ammonites, en fit un grenre à part sous ce nom dans sa Conchyliologie systémalıque, tom. I, pag. 75. Cetle opinion n'a point été adoptée, et ae pouroit l'être, puisque re Nautile is a aucuo des caractères des Anmonites. Voyez Nautracées el Nautile.

\section{a Mhonocérate. Ammonoceras.}

Genre de la famille des Ammonées, proposé par M. Lanarck daus l'Extrait du Cours (1811), pour des corpuilles polythalanes qui sont interwéliaires entre les Baculites et les Ammonites. Déjà ce genre, antórieurement à cette époque, avoit été fait par M. Parkinson, dans l'Organic remains of a former $W$ orld, elc., sous le nom de Hamite, qui a été généralement adopté, et auquel aous renvoyons.

\section{AMONOCERATITES. Anonoceratites.}

M. Lamarck, dans l'Extrait du Cours, avoit d'abord donné ce nom au genre que M. Parkinson avoit proposé sons le nom de Hamite, et que MI. Jausarck, dans son deruier ouvrage, conserva sous celui d'Ammonocérute. Voyez ce mot.

\section{AMPHIBIE.}

Nom dommé par Genllroy (Traité des Coquilles des ensirons de paris) à une coyuille commune snr les bords de la Seine, ò elle vit sur les jultates aqualiques. Cette liabitude de vivie si près de l'can avoit fait penser que ce Mollusque éroit amphibie; on a reconnu depuis que c'étoil unc ericur el qu'il est terrestre. Ce Mollusque a servi

Draparnand de type pour son geuse Arabrelte, Succinea. Voyez ce mol. 
$24 \quad \Lambda$ MP

AMPHIBULIML. Amphibulimus.

M. Lamarck a proposé sous ce nom un genre auquel se rapportent les Ambrettes de Draparnaud. Le genre de cet aneur étant anlérieur à celui de Nl. Lantack, a diù être arloplé de préférence, el c'est ce "un'it fail M. Làmarck lui-شiême dans son dernier ouvrage. Vo jez Ambrette.

\section{AMPIIDES.1E. Amphidesma.}

On est redevable de ce genre it M. Lanarek; avant lui, le peude aquilles qui en font parlie et qui ćloient counues, éloient coulondues avec les 'Telliues, a vec icsinuelles eiles ont quelgue ressembance, el d'autres avec les Mactres, dont elles séloignent cependant assez notablement. Ce reare fut d'ubord proposé sous la dévomisalion de Donacille daus l'Extrait du Cours; il lut neglige par M. Cuvier, qui ne le menisuma pas duns le Régne ammal, el M. Launarck changeal bientôt ce premier nom pour celus d'smpluidesme un'il a couservé; it est même beancoup plus généralement adopté sous ce deruier nom que sous celui de Lignle, quoique ce dernier soit plus anciennetnent donné au unêtre genre par Noatagn. M. de I'erussac est presque le senl yui ait préfíré le nom du savant anglais.

Dès l'origrine, ce geure fir parlie de la famille des Conques (2royez ce mot), entre les Donaces et les 'Telliues. Laus son Histoire dos sinimanx sans zertebres, Il. Lamarck changea nolablement ses rapports; il le remonta dans la famille des Mlactracées, oú il est placé le demier daus la deroière section de cet e famille, avec les genses Onguline et Solémye. MI. de Ferussac (T'ablecaux sysiématiques des iloll.) conservia la familie des II actracíes ( $20 y e z$ ce mot) en y fuisaut des changemens considérables. Le genre qui nous occupe y resta cependast, placé entre le's gr nures aliacire et Lavignon. M. de Blainville, lou de conserver ce genre el ses rapports, jugea convenable d'en faire une section de son genre Luciue, qui luimêne fail partie de la fumille des Cunclacés; tel quil est composé, ce gente Lucine ne nous semble pas naturel, puisqu'à cóté de la section des Arsphidesmes, on en trouve une pour le genre Corbeille; aussi nous ne pensons pas que cet arrangeneut soit jamais adopté.

M. Iamarck a confondı dans ce genre des coguilles qui cerlainement ne lui apparticnues! pas. Si on considere l'Amphidesue donacite comme le type du gente, on sera forcé d'én rejeter plusieurs especes; si au contraire c'est l'Amphtdesme panaclié que l'on prélère, le genre se conıposera de quelques espèces bien groupées, mais il faudra en exclure l'Amphidesue donacile. Déji M. Soweriy, ' dans son Genera; a senti que celle rélorme éloil nécessaire; il ne láissa dans le genre Amphidesune que les espèces analogues à l'Amphidesme panaché, el crut rencontrer dans l'Au-

\section{A M P}

phidesme donacile les caractires du genre Erycine de M. Lanarck, erreur purdonnable puur ceux qui ne connoisseal ni l'espèce vivanle, ni les espèces fossiles des euvirons de Paris. (Íojez Erycise.) M. Latreille est fort doigne de lopinion de N1. de Blainville; non-seulemeut il trouve des molifs suffisans pour conserver le genre $A m^{-}$ plidesme, mils encore pour en faire une petite famille composée de re genre seul; cette famille porte le nom d'Aniphidesmite. (Toyez ce mot.) Elle est priacée dins sa múllocie entre celle des Mactracées et celle des Myaires.

\section{CABACTÉRES GÉNÉRIQUES.}

Cocquille trausverse, inćquilaterale, subovale on ar ondie, quelquefois peu bâillante sur les cốés. Charuiere ayant une ou deux deats sur chaque valve, et uue fosselle alongée, ćtroite, obliçue, purr le ligament interne; uve deut latérale de chaque cốé de la charuiere. Linament donble; un exlerne fuible et court, un interne fixé darus les fosselles cardinales.

L'Amphideswe donacile que uous avons signalée n't-st pas la seule que lou donve rejeter du gente; par un duinble emploi dificile à expliquer, on y trouve anssi, dans l'ourrage de î. Lamarck, deux foris la mére coguille sous les noms d"Amphidesme lactée el d'Amphidesme lucinale; ce qui est plus étoonant, c'est que cette coquille riest point du grenre Aotphidesne el appartient aux luciues, où elle est bu: troisième fois menlionuće suns le aom de Lacine lactée. 11 est biéu à présumer que le rapprochement que MI. de Blainville a fait de ce genre avec les Lucines, vieut de celle erreur de M. Lamarck; ce qui, le pronve, c'est que M. de Bluinville, après avoir cité la Lacine lactée, Téllna lactea Linn., comme exemple de la seclion des Lucioes foripedes, lit reproduit une seconde fois ì la section des Lucines amplidesmes. Ces errenrs, malheurensenent trop fréquentes, soot unisibles à la science, jellent daos un grand embarras ceux qui commencent is l'étudier, et on ne saurvit trop les signaler ct les rectilier lorsque cela est possible. Outre ces espéces, if en est encore d'autres qui, par leur grande aualogic arec l'Anphidesme donacile, doiverut être écarlées du geure. Les trois suivantes, que nous avons pu examiner, sçnt dans ce cas: Anphidesmes glabrelle, cornće, bimaculée.

1. Amphidesue panachée. Amphidesma vaỉegata. Lamk.

A. testâa suborbiculatâ, tenuissintè striatâ, convexo-depressí, tenui, ulbido-purpurascente, maculis litturaformibus spadiceis; natibus contogus rudatis.

LAsx. Anim. s. 2'ert. t. 5. pag. 490. no. I. 
Sotrerby, the Genera of Shells, $n^{\circ}$. 9. fig. I. Tellina. Encyclop. pl. 291. fig. 3.

Coquille ovalaire, suborliculaire, inéquilatérale, mince, finement striće sur tonte la surfice; le cóté postérieur porte ua pli comme les Tellines; sa couleur est blanche, devenant d'un violetpourpé sur les croclsets, où cette couleur est géuérulement irradiće. Des taches irrégulières se voient sur le reste de la surface extérieure; en dedans, elle a toujours une grande tache médiaae de la mème coaleur que les crochets; ceux-ci sont petits, peu saillans, fort rapproclés, pointus; le ligament cxterne est petit et très-fuible. Cette coguille a trente-cing à quarante millimètres de large. On ignore sa patrie.

2. Aspuidesme réticulée. Amphidesma reticulcta.

A. testâ orbiculutâ, depressâ, strïs lamellosis, erectis. transversis, et longitudinalis exilissimis. reticulutâ; albidâ, intus flavescente; lunulâa munimâ, excavatô, rubescente.

Tellina reticuluta. Lisw. Gmell. pag. 3240. $n^{3} \cdot 67$.

Amphidesma reticulutum. Sow. loc. cit. fig. 2.

Cette espèce est lenticulaire, presçñaussi longue que large, blanche en dehors, d'un jaunetendre en dedans; elle est courerte de stries lamelleuses, transverses, très-fines, assez écartées, plus saillantes vers le bord inférieur cles valves yue vers les crochets, sur lesquels elles disparoissent insensiblement. Ces stries sont coupées perpendiculairenent par d'autres longitudinales extrèmement fines; on ne peut les voir. qu'ä la loupe. I.es crochess sunt petits, peu saillans; la luoule est plucée sous eux, elle est fort petite, enlincée et souvent d'une couleur ronge; le pli, surle còté postérieur, est trés-prononcé. Longueur trente-cinq ì quarante millimètres; largenr cuarante a quarante-cing.

V'après Linué, celte espèce se trouveroit dans la mer des Indes.

Wous ne donuons que ces deux espèces, par l"iacertitude que nous conservons sur la plupar des autres. L'A mphidesme alebelle est une Lulraire de la section des Ligules ou Lavirnons; les autres, surtont celles des cóes d'Auyleterre, ne sont point eacore dans nos collections, et elles aturoient besoin d'ètre examinées arant d'être délinitivement admises ou rejetées du şenre.

\section{AUPHIDESMITES. Amphidesmites.}

11. Latreille, Fumilles naturelles du rigne animal (pag. 22:), a proposé cette famille pour le genre Anphitesme lui seul; elle est la huitiène de la sectiun des Ćnconques, dans l'ordre des Acíphales a munteau tubuleux. M. Latreill : assimile sa nouvelle tamille au genre Lavignon de Histoire Naturelle des Vers. Tome II.
M. Cuvier; mais nous pensons que c'est à tort, car les Amplidesmes et les Lavirnons appartiennent à des geures dillérens, à moins que 11. Latreille n'ait en l'intention de les réunir, mais il se serait expliqué clairement à cet égard. Les caractères de cette famille sont exprimés par la phrase suivante : Le ligament cardinal est donble; l'uu est exlćricur et l'autre interne. C'est en vain que nons y cherchons des inotifs sutlisans pour l'élablisscment d'une famille, car dans le cas où ou l'adopteroit, le geare Amptidesme ne devroit pas y rester seul, car plusieurs autres, les Solemyes, les Ungulines, etc., ont aussi deux ligamens.

A l'égard de cette famille, il faut, ou faire l'applicalion rigoureuse de ses caractères, et y rassembler toutes les coquilles qui les présentent, et alor's ou doit l'adopter; ou bien ces caractères sont insuffisans, et alors il taut les rejeter: nous avons celle dernière opinion. Foyez AMPHIDESJIE et MactracéEs.

\section{A.JPHSTEGGINE. Amphistegina.}

Geure nouvellement créé par M. d'Orbigny fils, pour plusieurs coquilles microscopiques soit vivantes soit fossiles, que l'on u'avoit pas conun avant lui. Ce genre est le premier de la famille des Enthomostègues (voyez ce mot), également proposée par le mème auteur dans l'ordre des céphalopodes forauinifères. Ce geore singulier ne semble pas avoir tous les rapports désirables avec ceux de la mênue lamille, elle ne contient, en eflet, que des coquilles cellulaires ou subifèrés, qui ont par cela beaucoup d'analogie avec celie des sèches: ici on trouve des coquilles aautilordes quant à la forme, cloisonvées régulièrement comme les nummulites, par exemple, seulement, entre chacune de ces cloisons, il en existe une autre qui n'est pas complète et qui la divise eu deux parties qui peuvent conmueiquer entr'elles. Telle est du mons la disposition que nous avons pu comprendre après l'exauten d'une espèce vivaute que nous pnssédons, aussi bien que d’après les modèles et les ti ñures de 11 . d'Orbigny. Ce naturaliste ajoute à son genre d'autres curracteres que nous laavons pas renconırés sur les espic̀ces que nous avons examinées. Le plus important est celui de divisions transversales aux loges qui ne paroissent que d'un seul côté de la coquille; il paroit mème que ce caractère est plus essentiel au genre gue celui dont nous avous déja parlé clans la caractéristique. Nous voyons que ees deux sortes de coquilles ne sont liées entr'elles que par une circonslance unique, celle d’avoir une seule ouverture seui-lunaire, du còté le woins buinbé, et contre le retour de la spire; de cela, il résulte pour nous que le genre Anuphistégine el le suivant Hétérostégine ( voyez ce mot), dillèrent hien essentiellement des autres de la mèze famille, en cela, qu'ils sont dépourvus de 
pores à lourertnre. Nous ne ronlons pas ici discuter les rapports que MI. d'Orbigny a établi, c'est à l'arlicle Exтво votons, que nons entrerons dans ces détails.

Nos observations sur le double caractère dı genre n'en subsiste pas moins; nous ajouterons que cela indique ordinairement un groupement pen naturel des espèces, et nécessite quelquefois leur séparation en plusicurs genres, surtout lorsque le caractère qui les unit n'est pas de première valeur, on ne peut dire que celui d'une ouverture sur le cóté le moins bombé de la coquille soit suffisant, car il se renconlre dans une foule d'autres genres. Il faut donc s'en rapporter à la disposition des loges, et, à cet égard, nn retombe dans le double caractère que nous arous signalé.

\section{CARACTÉRES GÉXÉRIQUES.}

Divisions transversales anx loges, ne paroissan! que d'un seul côté de la coquille, quelquefois des divisions parallèles aux loges, paroissant également de chaque cóté, ouverlure unique, semi lunaire, du cóté le mains bombé et contre le retour de la spire qui est embrassante.

M. d'Orbigny a indiqué huit espèces dans son nouveau genre: parmi elles, nous nien arons reconnu que deux, une vivante el une fossile, que nous avons dans notre collecion. D'après les localités, il est à présumer qu'elles ne sont uouvelles ni l'une ni l'autre, la première venant dı sable contenu dans une coquille de l'Ile-deFrance, est l'Amplistégine de Lesson; l'autre commune dans les sables de Bordeaux, est certainement l'Amphistégine vulgaire.

Anphistígine de Lessou. Anuphistegina Lessoni. d'Orb.

A. testâ orbiculatâ utroque latere incequaliter convexâ, ulbidâ ; centris diaphanis; septis numerosis, alternatim brevibus internutis et longioribus continuis, reflexis; aperturí semi lunuri elongatá. Мов.

D’Orв. Mém. sur les Céphalopodes. Ann. des scienc. nat. mars 1826. pag. 304. no. 5. pl. 17 . fig. 1. 2. "3. 4 .

Ihid. Modèles de Céphalopodes, $4^{\mathrm{e}}$. livr. $n^{\circ} \cdot 9^{8}$.

Cocpuille lenticulaire, inégalement convexe, toute blanche, brillante, polie subcarénéc dans son contour, les centres sans former de mamclons se distinguent du reste par leur transparence el la couleur blanc de lait de la coquille se chañgeant en malic̀re vitrée; le denier lour embrasse tous les autres de manière à les cacher conmplétement. I.es cloisons sont nombreuses, elles se dirisent en deux sortes, les plus grandes qui sont continues, après avoir été droites jusçue vers les deux tiers de la circonférence, se courbent subite- ment, s'infléchissent de l'autre cỏté nù ellès se terminent aux cloisons: de ce côté, entre chacune de ces cloisons principales, on en remarque une autre en sayon qui s'srrête à l'endrnit où les autres se recourbent. La dernière clojsnu est convexe en dehors; d'un côté et tout-à-fait contre le retour de la spire, elle est percée d'une ouverlure alongée, élroite, sub-semilunaire.

Cétle espèce a quelquefois deux millimètres de diamètres, mais le plus sourent beaucoup moins, elle vient de l'Ile-de-France.

AnpHistégre vulgaire. Amphistegina v'ulgaris. d'Orв.

A. testâ orbiculatâ, utroque latere inaquoliter convexâ, albido-squalidâ; centris witreis, altero prominulo; septis numerosis, incuratureflexis, inegulariter inter se confuentibus. Nos.

1) Onвтg. loc. cit. $n^{0}$. 8. Modeles de Céphalopodes. $2^{\mathrm{e}}$. librais. $n^{\circ} 40$.

Celle-ci est à pen près de la onêrne taille que l'autre; mais étant fossile, elle a perdu sa blancheur pour prendre une teinte ocracée, les centres moins grands sunt transparens comme du verre et en ont le brillant; l'un d'eux, sous forme de mamelon, est cependant heaucoup plus saillant; c'est de sou côté que se roit la singulière disposition des cloisons. Dans les coquilles jeunes, elles sant régulières, onduleuses, comine dans le Nautile de Dax par exempie; mais à mesure que la coquille rieillit, ces cloisons, tout en restant onduleuses, le sont d’une manière bien moins régulière, de sorte que les courbures finissent par se toucher dans les points les plus saillans, ef les cloisons semblent se traverser : la surface de la coquille est alors couverte d'un réseau irrégulier de nervures souvent confoudues que dessinent les cloisons. La dernière est un pen moius convexe que dans l'espèce précédente, ct l'ourerture est aussi un peu plus grande et plus semilunaire.

Ou la Irouve assez abondamment dans les sables des environs de Bordeaux e! dans ceux des bords de l'élang de Tau, d'après M. d'Orbigny.

\section{AMPLExE. Amplexus.}

Nom donné par M. Sowerby, dans son Minéral conchology, a un corps pétrilié, strié dans sá longueur, qui a par sa structure beaucoup d'analogie avec certaines Orthocératites fort alnngées. quoique l'Amplexe ait des caractères qui lui sont assez particuliers, ils ne sont cependant point suffisamment I ranchés pour quion adopte ce genre, car par le même principe, il faudroit en farre un pour presque toutes les espèces. Vojez Orтвосвhatites el Jipporite.

\section{AMPOUL.E.}

Fom que l'on donne rulgairement ainsi que 
ceux de Gondole, œufs de Vanneau, de Muscade, a une espèce de bulle commune dans les collections Bulla ampulla. Voyez Burce.

\section{AMPULLAIRE. Ampullaria.}

l'armi les auteurs anciens qui ont figuré des Ampul|aires, Lister est celıi que l'on doit surtout remarquer; nous royons en effet, daus le viste recueil de ligures de cet auleur, qu'il avoit fort bicn sai,i les caractères d'ensemble des Ampullaires, all point gue la section particulière dans laquelle il les place, pourroit être considérée comme l'origine du genre. Notre opinion peut facilenent se vérilier par l'examen des planches 125 à 1.51 de son Synopsis conchylionum. Après Lister, nons voyons plusienrs autres auteurs ignorer que les cuquilles dont il est question son l llu. viatiles, et par suite de celle ignorance les confondre surtout avec les coquilles terresites. II seroit pen utile à la science de compter ces erreurs; il fuit remarquer cependant qu'elles exercent souvent une fatale inlluence sur les plus lieaux génies. Si Linné eut appris de ses devanciers dans quel milieu babitent les Ampullaires, il ne les auroit point confondues dans sun immense genre Hélice. II faut dire aussi gu'il aurcit probablement établi un plus grand noubre de genres, s'il eut pu se livrer à l'étude des détails uninutieux; mais les connoissances encore peu approfond es à son époque, devoient le rendre sobie de cetie espece de division, dont nous sommes devenus trop prodigues; son vaste génie, d'ailleurs, embrassant la mature tout entière, ne pouroit s'arrêter à des caractères considérés comme de peu d'importance alors, et il devait se tronver satisfait d'avoir lracé d'one main aussi harde qu'laabile les principales dirisions des trois règnes. l.es grands gentes de linné sunt une conséquence de l'état des sciences à l'époque où il écrivit.

Auller en associant les Ampullaires aux Népiles fit sentir déjà la faute de Linué; il comprit bien "qu'ii valloit mieux qu'tles fussent près de coquilles poar le plus grand nombre d'eau douce que parmi des terrestres. Bruguière neut pas la mene opinion, il se conlenta de changer de place les Ampullaires; des Hélices il les transporla dans ses Bulimes, ou certes elles ne sont pas davautage dans leurs rapports naturels, puisqu'il retomise dans une confusion semblable a celle du genre Hélice de linusé.

M. Lamarck, des la pul, lication de ses premiers travaus, sentit la nćces,ile de porter la réforme dans ce genre de Bruguière, et les Ampullaires cqu'sl proposa en sont enlièrement extraites. Plusieurs espèces d'Ampullaires ont la pliss grande analcyie arec les Planorles; seulement le premier de ces gemres est opercul'́; le second ne l'est pas: aussi Ji. Larvarck mit ces cleux genresen contact, dans le Systente des ammaux sans vertebres, quil publia en 1801 . Depuis celte époque ce genre fut généralement admis; il n'éprouva de variations que relativement à la place qu'on lui fit occuper dans les diverses méthodes. Ml. Lamarck, qui commença à former des familles ou des groupes de genres, dans sa Philosophie zoologique, lui conserva les mêmes rappor!s que daus le systćue. Il est conupris dans la famille des Orbacées, avec les Cyclostomes, les Paludines et les Planurbes. Ce savant zoologiste s'aperçut bientót que cette famille n'étoit point naturelle, a cause du genre Cyclostome qu'elle renfermoil; on ne doit pas douter que cela ne soit dú à la publication de l'excellen l travail de Mr. Cuvier sur le Vivipare d'eau douce d'après lequel il est impossible de conlondre désornais les Cyclostomes et les Ampullaires comme on le faisoit avant celle époque. Il fut donc forté de réfurmer celle famille des Orbacées, ce qu'il fi: dans l'extrait du Cours. Dans l'intervale, MM. de Roissy et Denys de Nontfort publièrent leúrs travaux: le premier la fin des Mollusques du Buffon de Sommini; le secood son Systène conchyliologique. Le premier de ces auteurs rapprocha des Aupullaires, outre les Planorbes, comne l'avoit fait M. Lamarck, le genre Valvéc, que Draparnaud, son créatenr, avoit placé entre les Cyclostomes et les Núrites. Quant á Montfurt, il crut trouver les ćlémens d'un genre nouveau qu'il nomma Laniste, dans une coquille qui ne diffère de ses congévères que parce qu'elle est sćnestre; il conserva le gente Ampullaire pour les autres espèces. M. Lamarck, comme nons l'avons dit, réforma la famille des Orbacées dans l'extrait dı Cours; il plaça les $\mathrm{Cy}$ clostomes dans les Colimacées, les Planorles dans les Limnéens et les Ampullaires dans les Péristomiens, avec les Paludines et les Valvées. Ce dernier genre ful rapproché, à l'imitalion de M. de Roissy.

N. Cuvier, qqui ne connoissoit pas encore l'animal des Anpulluires, lors de la publication du régne animal, dit cependant qu'il est probatle qu'il a assez de ressemblance avec celui des $\mathrm{P}_{u-}$ ludines; malyrés celle présomption bien juste, ce savant zoulogiste place !es Ampullaires a titre de sous-genre diass les Conchylies avec les Mélanies, les Phasianelles et les Janthines. L'animal des Ampullaires, aujourd'hui assez conna, ne laisse plus de doutes sur la place qu'il doit occuper. II. Lamarck ne le connuissoil point encore, et dans son dernier ouvrage, il conserva dans son entier la famille des Péristomiens de l'extrait da Cours. MI. de Ferussac est le premier, parni les zoologistes modernes, qui ait eu occasion d'observer l'animal des Ampullaires; d'après sa manière de voir il confirma en quelque sorte l'opivion de 11. Cuvier, c'est-i-dure qu'il lui troubu plus de rapports avec les Nérites et les Truchus qu'avec les Palndines et les Valvées; aussi rangea-1-il les Aupullaires dans la famille des Tro- 
chus, avec les Nérites, les Janthines, les Mélanopsides, ctc. MI. Gray, dans sa classification naturelle des Mollusques, vit lant de ressemblance entre les genres $A$ mpulaire et Paludine, quil n’hésita pas à les rémnir en un seul qui constilue la cinquième famille de son troisième ordre, les Ciénobranches. Cette opinion, M. de Blainville la partage complétement, comme on peut s'en assurer à son article PALUdine du Dictionnaire des sciences naturelles, $10 \mathrm{~m}$. XXXVII, pag. 301, où il dit: "Ce genre (Paludine) n'est pas aussi facile à séparer des Ámpullaires, et l'on peut même à peu près assurer qu'ils devront être réunis, tant il y a de ressemblance dans l'animal el l'opercule. Il n'y a donc que la forme plus ventrue et ombiliquée de la coquille, qui puisse servir à distinguer ces denx genres dont les animaux ont du reste les mêmes habitudes et vivent également dans les eaux douces.

Malg:é cette opinion, M. de Blainville établit, dans son Traité de Malıcologie, des rapports qui sout loin d'en être la conséquence; cependant ce savant anatomisle connoissoit l'animal des Ampullaires qu'il a fort bien caractérisé. Ce genre, dans la méthode de M. de Blainville, fait partie de la famille des Ellipsostomes, où il est associé aux NIélanies, aux Rissoaires, aux Phasianelles, aux Hélicines et aux Plenrocères. Il suffit de nummer ces genres, pour laire voir qu'ils ne sont lićs entr'eux par rien de naturel; qu'ils n'ont pas ces rapports que lous les esprits comprement lorsqu'il est facile de les concevoir.

M. Latreille a lui-même disırait les Ampu|laires de leurs rapports natorels en les écartant des Paludines, pour les placer a l'imitation de II. de Ferussac, dans la facoille des Turbinés avec les Turritelles et les Turbo.

M. Lamarck, dans un de ses cours, avoit proposé un genre Ampulline qui ne fut jamais autrement publié, et qui paroit avoir été créé dans l'intention de rejeter hors du genre Ampulaire un certain nombre de coquilles fossiles qui ne peurent évidemment y rester; mais si ces coquilles ne doivent plus faire partie des Ampullaires, il n'est pas nécessaire pour cela d'en établir un exprès pour elles, puisqu'elles peurent fort bien se classer dans les Natices. Il est viai, comnie nous le verrons à ce genre, que ces coquilles sout dépourvues de la callosité ombilicale, inais nous observerons que quelques espèces vivantes manquent aussi de ce caractère, quoique par l'auimal elles soieut de véritables Natices. Nous observerons encore que M. Lamarck a abandonné celte opinion en dernier lieu, puisque dans le tome VII de sun dernier ouvrage on voit encore dans les Ampullaires fossiles les coquilles avec lescurelles il se proposoit de faire le genre Anıpulline. 11. Lefroy, direćteur de l'école rayale des mines, qui a rassenublé avec un zèle bien digne de louinge uue très-belle collection de co- quilles à cet utile établissement, nous a fait apercevoir un caractère qui, faute d'autres, pourroit servir à sćparer les Nacices des $A m p u l l a i r e s ; l e$ voici : si l'on place une Anpullaire de manière à ce que son axe soit dans un plan vertical, on verra que le plan de l'ouverture est parallèle ou le même que celui de l'axe. Si l'on fait prendre la même posilion à une Natice, on reconnoitra que le plan de son onverture est toujours oblique à celui de l'axe: c'est à l'aide de ce caractère ajouté à ceux déjà connus g̣ue nous rejetons la plupart des Arapullaires fossiles que II. Lauarck avoit cru pouvoil y metlre. Quoique MI. de Ferussac prélende qu'il n'existe pas de véritables Ampullaires fossiles, nous avons cependant réservé pour ce genre des coquilles qui en préscntent pour la plupart les caractères.

L'animal des Ampullaires n'a point encore été complétement decrit; on ne le connoil que par. les caractéristiques de 1131 . de Ferussac et de Blainville; elles diffèrent assez notablemeat l'une de l'autre. 11 . de Ferussac par exemple, dit qu'il y a quatre tentacules, considérant comme tentacules distincts les pédoncules qui portent les yeux. MI. de Blainville n'en compte que deux; il dit en elfet, com me cela a lieu dans beaucoup de genres, que les yeux à la base des tentacules sont pédonculés, c'est-à-dire portés par un pédicule court soudé à la base des tentacules.

\section{CARACTÉRES GÉENRIQUES.}

Animal renflé, globuleux, spiral; le pied ovale, court, avec un sillon transverse à son bord antérieur; la tête large, tentacules supérieuis fort longs, coniques, très - puiatus; les yeux situés à leur base externe, et purtés sur nn pédoncule très-sensible; Louche verticale située entre deux lćvres disposées eu fer à cheral, et formant uuc espèce de muffle; point de dent supérieure; un ruban lingual hérissé, mais non prolongé daos la cavité abdominale; la cavité respiratrice fort grande, partagcée en deux par uue cloison horizontale incomplète.

Coquille mince, globuleuse, ventrue, ombiliquée, quelquefois planorbique; la spire courle; le dernier tour plus grand que tous les aul:cs; ouverlure ovalaire plus longue que large, á bords réunis; la lèvre extérieure tranchante, sans callosite.

Opercule corné, darement calcaire, mince, ovalaire, non spiré, à ćlémeus concentriques, à sommet submarginal inféricur, dépassant obliquement le bord droit de l'onverlure, mais colle cuntre le gauche.

Les Ampullaires sont des coquitles d'eau douce qui haloicont dans les deux bémisphères les régions les plus chaudes, elles ae se trouvent píus ex Europe; l'Asie, les lndes, le centre de l'Ainérique, une parlie de l'Afrique, sont les pays ò̀ 
il faut les chercher. Elles vivent dans les rivières et dans les laes à la manière des Paludines dont elles ont à ce qu'il paroit les mours el les halitudes. On sait que dans guelçues marais samaitres des

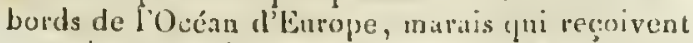
une plus ou moins grande quaulicé d'ean deuce, il n'est pas rare de rencontrer des Pahndiues vivaut comme lans l'cau donce pure: les Ampullitres, an rapport dı savaut Olivier, présentent aussi quelguefois la mème habilude; il en a tronvé ahondımunt une espèce, la mène que celle des (asis, dins le lac Mareotis, avee un assez graud no:ubre de coquilles ararines. Ce lait explique pourquoi dans bien tes localités un trouve les Ampullaires fussiles dans des terrains marins, comuc anx environs de l'aris par exemple.

11 est peu d'Ampullaires qui ne soient ombiliquées, it en cst même quil le sont au point de ressembler ì des Planorbes; depuis cet état, jusqu'au manclue presclue total de lombilic, on tronve une dégradilion inseusible qui lie entrelles tontes les lormes. La même règrle se remarque daus la position plus ou uoins oblignae de l'ouverture, et cette posilion est dépendatate de la grandeur de Pombilic; ainsi daus les espèces planorbiques louverture í sun diaunètre perpendiculaire ct ce diametre sublique d'antant plus, que l'ombilic se rétrécit davanlage.

Nous avons dit que Bruguière avoit confundu les Armpullaires dans son genre Buline; mons renvoyons en conséqueace ì Ṕrticle BuLne du premier volume de ce Diclionnaire. Les quatre premières espèces qui y sont décrites appartiennent an geare qui nous uccupe; ce sout : les Bulimes ail-damunon, cordon bleu, idule et vitré. Nous ajonterons quelıgues espèces que Brugruiète ne connojssuit pas.

1. Ampullatre corne de Bélier. Ampullaria comu crietis. Sow.

A. testâ sinistrorsâ, solidấ, superne planoconcuvâ et albâ, subtus lizte ombilicatâ, rufofucescente; anfructibus cylindraceis, lievibus; ultimo fusciis castaneis cinclo; operculo cornco, nigro.

Plunorbis comu arietis. I.ай. Anim. s. vert. tom. 6. $2^{\mathrm{e}}$. part. pag. $152, n^{\circ}$. 1.

simpulluriâ cornu arietis. Sow. The genera of recent and fossil shells. $n^{\circ}$. 4. $\mathrm{pl}$. fig. 3 .

Helix connu arietis. Isx. Gmell. pug. 3625. $76^{\circ} .4 t$.

Phenorbis contrarius. Mlocler. Verm, pag. 152. $\pi 2^{\circ} \cdot 34 \%$.

Liszer. Sinop. Conch. tab. $14 \mathrm{l}$. fig. 40.

Cнезият. Conch. cab. t. 9. tab. 112 . fg. 952 et 953 .

ENCYcLOpÉde.pl. 460. fog. 3. a. b.
Var. a. Ков. Teslú fuscovirescente, intus ulbıdu; fusciis nullis.

Avam que l'on ne sut qué celte coquille étoit operculće, il éloil bien pernis de la placer dans les planorbes, elle en a prespue tons les caractères; discoïde comme eux, alle il louverture un peu oblique, ses tours de spire sont cylindracés; en dessous elle est largement ombiliģucée sarus que cepentant tous les tours se voient dans l'ombilic, ce qui u'a pas lieu dans tous les l'lunorbes, mais ce qui se voit dans quelques espèces, te Planorbe coné par exemple; le dessus cst plan-concave, ie sommet est sitillaur et pointu, ce çui n’a pas lien dins les Planorlses. La couleur de celte coquille est blanche tlans presque laute son élendue : sur ce fund, on voit sur le dernier tomr, six à sept bandes assez variables pour la largent, d'une couleur brun-fauve; en dessous tout l'onbilic est de lat même conleur que les bandes.

Nous possédons une fort helle variété de cetle espèce : elle est remarquable en ce quelle est compléteneat déponrvuc de handes colorées ; elle est tonte blauche en dedins, en deluors clle ent couverte de son épiderme d'un brun verditre qui est partout de la nếne couleur; du reste, pour lar forme et l'opercule qui est cormé et d'une couleı. noir-bruu, il n'y a aucune dill'rence aver les antres individus, ce qui nous a porté i la considérer comme une variété seulement.

Quelques personues pensent que cette belle espèce vient du Brésil et d'autres de la Chine.

Sun diamètre est de quarante-denx à quarantetrois millias., plus de deux pouces et deuni.

\section{Aarpulaire carénée. Ampullaria curincelu.} LAMK.

A. testâ orbiculato-ventricosâ, sinistrorsi, latè umbulucatâ, tenui, rufescente, in medio unica $\hat{z}$ on $\hat{a}$ albấ fasciatâ; spirce brevi; anfracitibus transwerse striato-rugosis; umbilico spureliter curinato. Lask. Loc. cit. $n^{\circ} .8$.

Cyclostoma carinata. OLIvier. Doy. ali Lepant, pl. $3 \mathrm{I}$. fig. 2. $a$. b.

Ampullaria curinata. Calluav. Voygge ell Égypte, tom. 2. pl. 60. fig. 9 .

On ne connoit celte espèce qne depuis le royage d’Olivier au Levant, ill'a trouvée chus le Nil, ò̀ depuis M. Caillaud l'ir retronvéc. Ello est toujours sénestre, c'est-à-dire touruée ì gauche; elle est orbiculaire, veutrue, plus large que liaule; compośe de cinq lours de spire cunvexes, dont ie deraier est de beanconp plus grand que cous les aurres; la spire est peu saillante, son sımmet est oblus, quand il n'est pas rongé; on rewarque que les tonrs qui le formeut sont carénés dius le milieu; cettc carèe sarrondit insensiblement et dispartuit dès le second ou le conumencement du truisicue toar. Ea dessous il y a um ombilic finte 
grand, à travers lequel on voit tous les tours de spire, il est pourvu, à son bord externe, d'une carène saillante qui descead avec lui jusqu'au sommet. Les premiers tours de la spire sont lisses, mais le dernier est couvert de stries ou de sillons ireçguliers qui indiqueut lesaccroissemens successifs de la coquille. La cuuleur est d'un brun clair passınt au châtain au sommet; plus funcées en dessous qu'en dessus, ces deux nuances sont séparées nellementsur le dernier tour, par une fascie blanche qui en marque le milieu.

L'ouverture est presque roude, les bords en sont minces, comme tout le resie de la coquille, le druit occupe plus des trois quarts de la circonférence, î́ se renverse à l'endruit de la columelle qui n'existe réellement pas davautage que dans les Planorbes. Le bord gaucle est très-cont, il s'applique sur le retour de la spire, il est si mince 'ju'on voit la couleur de la coquille à travers. Cictle espèce par sa forme peut très-bien, ainsi yue l'Ampullaire cii-d'annon, servir d'inlermédiaire entre la première espèce et celles qui, ćlant beaucoup plus globulenses, n'ont presque point d'ombi.ic ou en sont totalemeat dépourvues.

Habite le Nil et les enux douce d'Égypte. Diamère quarante millimètres, dix-buit ligues environ.

\section{Ampullatre pJgnmée. Ampullaria fjogmara.} L.A K.

A. testâ sinistrorsâ, discoideo-globosâ, lapvigatâ, tenui, fragilissimấ, basi lastè umbilıcalâ; spirâ planáa ; suturí canaliculatâ; apertuná ovatú, basi elongati. Noв.

L.4 tom. 8.pl. 61.fig. 6. a. b.

Ibid. Anim. s. vert. tom . 7. pag. $547 \cdot n^{\circ} .1$.

Defr. Dict. scienc. nat. tom. 20. pag. 446.

Deshayes, Descrip. des coq. foss. des env. de Paris. 12e. livrais. pag. $147 . n^{\circ} \cdot 7 \cdot p l$. 7 . Jig. 15. 16.

Quoique se trourant toujours dans les terrains marins, les caractères de cette petile coquille fossile sont tels, qu'il servit impossible de la placel dans tout autre genre; elle est prar sil forme subplanorhulée, intermédiaire entre les espèces qui ont tout-a-fait la forme des planorbes et les autres plus glnbuleuses, mais qui ont la spire saillante et l'ombilic moins largement ouvert.

Cette très-jolie et très-petite coquille, constaminent tournée à gauche, est très-mince, trèsfragile, blanche el iransparente; elle est presque discuide, a cause de l'aplatissement de la spire; celle-ci est composée de quatre à ciuq lours, don! le dernier est beaucoup plus grand que tous les autres, arrondis et séparís par une suture cana- liculée mais simple. Louverture est ovale, fort alongée longi:udinalemeat, mais snrtout a la base; les bords sunt très-minces et très-tranchans; le gauche s'applique sur l'avant dernier tour où il s'aperçoit à peine; il se continue sur la columelle, derrière laquelle on voit un ombilic large et profond.

Lougueur deux à trois millimètres.

On la trouve fossile à Grigoon el à Chaumont.

4. Ampuldaire sphérique. Ampullaria spharicu. Nов.

A. testá globosâ, ventricosâ, epidermide fulwo virescente, pustulis minimis rotundatis opertâ; fasciis numerosis, sub fuscis, transversulibus; aperturâ ovatâ, incrassatá; hmbo aurantio.

Ampullaria rugosa. Sow. The genera of shells. loc. cat. fig. 1 .

Ce nom d'Ampullaria nigosa ayant été donvé par M. Lamark à l'Ampullaire ídole, et cette espèce étant parfiteaseat distincte de celle que M. Sowerby nomme de méme, nous sommes dans l'obligation de changer sa dénomination pour éviter tuute confusiou.

I'Ampullaire pustuleuse que nons possédons est tout-ä-fait semblable à la figure qu'ea donne M. Suwerlyr; elle est globuleuse, arondie, obtuse à son sommet; clle se compose de six tours de spire, dont le dernier est beauconp plus grand que lous les autres, jls sout arroudis et séparés par une sumure simpla. L'épiderme d'un brun verditre qui couvre cette coquille a cela de parliculier, de présenter une fuule de petites pustules $\nabla e ́ s i c u l e u s e s q u i$, renant a se détucber par le frottenent, laissent voir à leur place le test à nu. Si ces pustules n'étoient disposées dans le sens des accroissemers, et si elles ne se remarquoient sur toute la coquille, on pourroit supposer qu'elles sont dues a un accident, mais mous ne pensons pas qu'il ea soit ainsi. Au-dessous de l'śpiderase on voil que la coguille est pourvue de banctes élroiles, distautes, brunâtres, au nombre de quatorze ou guinze, et que l'on voit aussi de la méme couleur en dedans de l'uuvertnre. Celle-ci est ovaluire, oblicjue, et épaissie dans tont sou pourtour par un bourrelet blanc qui se remarque aéme sur le bord gaucbe. Il paioit destiné a recevoir l'opercule qui, étant calcaire, ue doit pas s'enloncer plus loin; la columelle est solide, renversée ansi que la base de l'ouverture; le limbe est d'une belle conleur orangée. L'ombilic est en partie cucbé par le rencersement du bord gauche, il a'est pas très-graud, un peu en Tente. M. Marmin. a reçu de Ponclichéri un jeune inclividu de celle espéce; il eșt à présumer que les grands que nous pusséduas eu vieaneat aussi.

Longueur cinquade millimètres. 
5. Ampeluare marron. Ampullaria castanea. Nов.

A. testâ globulosâ, ventricosâ, castanea, , lèvigatâ, basi umbilicatâ ; an fractibus senis, spiritis; apertume aurantiâ; limbo incrassato.

Il est bien facile de reconnoitre celle espice qui est la senle vivante que nous connoissions qui ait autour de la spire un méplat assez large et en rampe. De cettc rampe partent tout autour des stries irrégulières qui se perdent sur le dos de la coquille, pour reparoilre vers la base. Celle base esi perlorée par un ombilic arrondi assez ouvert, mais plus on moins selon les individus. La spire est peu élevée, pointue, raremeut ron née; elle se compose de six tours globulenx. L'ouveriure qui cit ovale, est orangée à l'iutéricur, ses hords sont tranchans, quniqu'à l'intéricur elle soit épaisse et solide. Le bord gauche est fort mince, collé au relour de la spire et de la mêne couleur que le droit. Ia columelle est arrondie, épaisse, renversée en delors aussi bien que la base de l'ouverbure. La coquille est partout d'une coulcur brua marron, et quelquefois noiralre. Longueur quarante-cinq nillim. Largeur is la base trente-huit. l'atrie ignorée.

\section{Amperifire ovale. Ampullaria ovata.}

A. testâ ovato globulosî, tenui, irregulariter sub striatâ, apice erosâ, castaneo visente, aperturâ magnâ, marginibus acutis, intus alhido-rufeis; umbilico nuinino, obliquo.

Olitier, Voy. au Levant, tom. 2. pag. 38. tab. 31. fig. I.

Ampullarila ovata. Callead Voj. en Égrpte, tom. 2. pl. 60. fig. 10.

Ihid. Ferussac, Dict. class. dhist. nat. tomı. 1 . pag. 304.

Coquille peu épaisse d'un brun verdître, beaucoup inoins globuleuse que les précédentes, d'une forine ovalaire, ses tours de spire, au nombre de quatre ou cinq, sont assez alongés, bien arroudis, striés longitudioallement el irrégulièrement. Le sammet est obtus dans le plus grand nombre des individus parce qu'il est ordinairement carié, mais dans ceux quine le sont pas il est fort pointus. La base est percée d'un ombilic médiocre, oblique, en partie caché par le bord gauche. L'ouveruure est grande, nvale, oblique, ayant le limbe d'un blanc fanve. Tont-à-fait ea dedans on remarqne, surtout vers la base de la coquille, uo assez grand nombre de 20taes d'un brun foncé qui iranchent sur un brun plus clair, tandis que supérieurement la couleur de l'intérieur est toute blancbe. L'opercule est calcaire, bleuátre à sa face interne, où se voit un nucleus submarginal. Longuenr cinquante-deux millim., largeur quarante.

C'est cette espèce qu'Olivier a trouvé dans le lac Mareolis arec des coquilles marines, et Caillaud dans la plupart des eaux douces de l'Egypte. Nов.

7. Ampuldane d'Olivier. Ampullaria Olivieri.

A. testâa outatn-globosât, solidâ, epidemide fulvâ, fascïs rufis, cinctô, uperturis magnâ, albidulá; coluniellâ solidâ; umbilico nullo, detecto.

Cette espèce à une forme qui lui est particulière, elle est ovale, globuleuse, le demier tour surlout est très-convexe el beancoup plus grand que les autres; le second et les autres sont plus petits proportionnellement arec le premier que dans les autres espèces. Ia coquille qui n'a pus plus de cinq tours de spirale est anssi plus épaisse; elle est revêtuc ordiutiremeut d'un épuderme brun faure à travers lequel on voit bien distinctenent six à dix bandes transverses, étroitcs, fort bien séparées les unes des autres. L'ourerlure est fort grande, hanclie en dedans, quelquefuis brune, mais rarement; sur cette coulcur on voit se répéter les bandes fauves de l'extérieur. Le hord droit est irancliant quoiqu'à l'intérieur il s'épaississe; la columelle est très-solide, blanche, et cache inut l'oubilic. L'opercule est d'un brun d'écaille, il est corné et llexible. ls ait.

Longueur quarante-cinq inill., larger trente-

Elle vient de Cayenae, naus la devons a l'obligeauce de M. Marain.

8. Ampolinare polie. Ampullaria polita. Nob.

A. testâ ovatâ, globulosâ, tenui, politâ, virescente; spirâ productiusculâ, apice obtusâ; aperturi obali, purpurascente; umbilico minimo.

Ampullaria virescens. Nов. Dict. class. d'hist. nat. 5e. livruis. de pl.fig. 2.

la crainte de roir confondre avec l'Ampullaire verte de M. Lamarck, notre Ampullaria virescens, nous changeons cetle dénomivation contre celle-ci qui ne laissera plus d'équivoque. Cetie coquille est une des plus belle du genre; elle est ovalaire, ventrue, un peu rétrécie ver's la base; la spire composée de sept tours est assez élancée et pointue, quelquefois rongée et alors elle est un -peu plus obluse; les tours de spire sont arrondis, le dernier est très-grund, couparalivement aux autres. Tuute la surface extérieure de cette Anpullaire est d'un vert brunàtre, uniforne; elle est polie et brillante, ce qui est rare chans les corguilles d'eau douce. Le sommet est d'une couleur brun foncé, rougeấtre; la base qui cst assez rétrécie, est percée d'une fente ombilicale furt étroite, cachée en partic par le bord gauche qui se réfléchit sur elle. L'ouverture est grande, ovale, oblique; les bords sont minces, tranclazos, un 
peu épaissis par un bourrelet marginal intérieur: ce bourrelet est d'un rose un peu rembrani sur le bord droit, beaucoup plus clair sur le gauche; la colurelle est eutièremeat rose. A l'intérienr, elle est d'un brun rougeàtre, obscure à la base, qui passe insensiblement au rose terue, puis au blanc vers le côté opposé; toute la coquille est mince et légère.

Nous ignorons sa patrie. Sa longueur est de soixante-quatorze uill., deux. pouces neuf lignes, et sa largeur de soixante millim, deux pouces deux lignes.

9. Aspullaine de Bruguière. Ampullaria BruEиieri. Ков.

A. testâ magnâ, sub ovatâ, globosâ, tenuissimâ; fusco fusciatâ, sub epidemide virente; spira brevi, acutâ; anfractibus motundatis, suturú profundâ, canaliculatâ separatis; aperturû ‘mplissimâ, intus castaneâ.

Cette coquille a de l'analogie, par quelques-uns de ses caractères, arec l'Mupullaire canaliculée de M. Lamarek, unais elle en dillère par tant d'autres qu'on ne sauroit les coafundre. L'Ampullaire que nons consacrons à la ménoite du savant naturaliste, qui a commencé cet ourrage, est fort grande el très-mince; elle est sub-ovalaire, tres-ventrue, surtout le dernier tnur; ils sont au nombre de six, arrondis, globuleux, séparís les uns des autres par une sulure profonde et canaliculće. Dansles individus bien entiers, le sommet est ussez pointu et rougeâtre, mais dans ceux ‘ni l'ont rongé, ce qui est fréquent, il est obtus et d'un brua funcé. La base de la coguille est large, elle présente un ombilic arrondi assez grand, un peu couvert par le bord giluche. Toute Pi surluce extérieure est couverte d’un épiderme verdâtre, quelquefois, el surtout vers l'onverture, d'un brun roux; au-dessous de lui ou voit gue la coijuille est orucie de bandes transversales bruues, dont le nombre et la largeur sont assez variables; il y en a ordiuairemenı donze ou quatorze. L'ouverture est fort grande, ovale, à peine modifié par l'avant-dernier tour; à l'iutéricur elle est d'un hrun marron très-foncé, on y aperçoit cependant, parce que leur couleur est plus foncée encore, les bandes transrersales. Les bords sont tres-minces, tranclıans, sans bourrelet à l'intévienr. La culumelle est peu épaisse, arrondie, renversée en dehors et toute blancle. Le bord gatuche est Irès-court, très-mince et formé d'une matière diaphane, qui laisse roir en desscus la couleur de l'éviderme.

Nous ignorons d'où vient celle coquille 1emarquable, wous pensons quelle peut renis de Cayenue.

Lougueur soixaute-dix millimétres, larigeur soixaule.
NoB.

A. testâ ovato-elongatâ, acuiâ, crassâ, solidâ, sub epidermide fuscâ, candidissimá ; transversim substriatú; anfractibus sextis, convexis, scaluriformibus, suturâ ponfundî, canaliculatâ valdè separatis; aperturá ovuto-acutú, basi effusá, intus caudidissimâ; umbilico minimo.

\section{Paludinu crassa. Sar.}

Nous ne partageons pas l'opinion de M. Say, qui range cette coquille parmi les-Paludines, elle n'en a pas les caracières essentiels, elle ne s'en rapproclie que par l'alongement de la spire, du reste, elle a tous les caractères des Ampullaires, son épaisseur et sa forme la rapproche surtout de quelques espècics fassiles des environs de Paris, dont il sera question un peu plus tard.

Cette coquille est ovale, alongée, printue au sommet, arrondie à la base; elle est épaisse, solide, pesante, couverte d'un épiderme brun, quelquefois verditre, très-nince, sons lequel la coquille est partout d'ua blanc de lait pur. La spire est alongrée, conique, scalariforme, furmée de six tours conrexes, séparés profondément par une suture canaliculée; des stries transverses, yeu profondes, se remarquent a la surlace des indiridus non roulés. L'ouverture est médiocre, elle n'est point, comme daas les Paludines, obl1que à l'axe de la coquille ni arrondie el à péristome contiuu comme dus ce genre; mais elle est ovale, rétrécie à son sommet, vù elle est anguleuse conrue dans piesque toutes les Ampullaites: élargie à la base vù elle turme un large sinus peu protond; elle a encore cela de commun avec plusieurs Anıpullarres, ce gui n'a jamais lieu dans les Puludines; entin la têrre droite est légèrement recourrante, ce qui est encore propre a plusicurs especes du genre oì nous la jilaçons. Le bord droit de l'vurerture est trauchini, il s'épaissit bienió sans avoir un hourrelet intérieur; vu de profil, il est légèrement sinueux sultout a la base; le bord gauche est épais surtout vers l'angle postérieur de louverture, il est oblique el applitué sur l'avant-dernier tour à la base duquel il se confond arec la culumelle, qui est arrondie, épaisse, et renverscée en dehors; derriere elle il y a une pelite tente onbilicale.

Cette coguille vient de l'Obio et de la plupart des rivières de l'Amérique septentrionale; elle est longue de quarante-cinq in cinquante millimetres.

11. Aspolatae pesante. Ampullaria ponderosa. \Ṓ.

A. testá os'ato-rentricosâ, crassá, fonderosú, trensver:m substriatá; spira bresi, acutú; antfractibus rotundutis, suturá, profundá separatis; 
aperturâ ovato acutâ, basi eflusâ; umbilico aperto.

Ampullaria pondernsa. Nов. Descript. des coq. fossles des envir. de Paris, tom. 2. pag. $140 . \mathrm{n}^{\circ}$. j. $p l .17$. fig. 15. 14 .

On pourroil avoir quelques molifs pour penser que cette espèce est marinc : son épaissenr, sà solidicé et son gisseuteut pourroient le faire présumer, mais par l'excuple de l'espèce précédente, qui est trés-épaisse quoique lluvialile, aussi bien que par les antres caracteres génériques aui saccordent parfaitement avec ceux des Ampullaires, il nons semble impossible de rejeter celle coquille du genre pour la mettre parmi les Natices. Eille esi ovale, globuleuse, ventruc; lit spire est assez courte, paintue, lormée de liuit ton's arrondis, dont le dernier est beancoup plus grand gue tous les autres; ils sont couverts, surtmut le dernier, de stries triusverses peu profondes e: un peu onduleuses, elles son coupées longitutinalement par qualques sirics d'accrorssement qui se multiplient surtont vers l'ouverture, elles représentent les péristomes précédens, par des étévations onduleuses qui, dans cet eodron, reudent la surure pen régulièse; du seste, elle est simple el présente un caual trés-étroil qui sépare chaque tour. l'ouverture est ovale, aigue a son cxtrémité postéricure; le bord droit est tranchant, s'ćptississant promptemcut i l'inté:ieur, il est un peu sinueux daus sa lougueur; le gauclie esi fort oblique, épais, presque droit, il cache en partic l'onbilic qui est une feute médiocremeut ouverte; la columelle est rearersće en dehors ainsi que la Lase de l'ouverture.

On tronve cette coquille fossile aux enviroos de Paris, à Monneville, localité d’aulant plus remarquable, que les fossiles sont répandus en asscz yrand nombre dans la terre labourable, ce qui indique quảs ont éfé abandonnés à la surface cuu sol.

Longueur cinquante millim., largeur quarante.

12. Ampelane de Wiliemet. Ampullaria IVIllemetii. Мов.

A. testâ nvato ventricosî̀, lavigutâ, spirîa brevi, acutá; anfractibus septem, roturidutis; suturâ pnofundâ, subcaraluculatî́; aperturấ ovutì, magnầ, basi effusià; umbilico munimo.

ヘов. Descript des coq. foss. des eno. de Paris, loc. cil. $n^{0}$. 6. pl. 17 . fig. 11. 12 .

Dans notre ouvrage sur les fosiles des envirous de l'aris, nous avous consacré celle espèce à nolre estinable ami W. Willenet, dont le nom est comu en botanique, qui a cnrichi celle belle science d'intéressantes observatioos, et qui en a liit égalemeat sur les Mollusques.

Cetle coquille ovale, gloluuleuse, à spire courte el pointue, ešt lisse et brillante; elle est tonjours plus petile que la précédente, avec laquelle elle a assez de rapports; clle est plus mince, la spire est plus ćlancéc, plus régulière et pins conique; ses lours au nombre de sept sont arrondis; la suture qui les sépare est enfoncée, subcanaliculée; le deinicr tour est plus graad que tous les autres; l'ouverture qui le termine est grande, ovale, it bords minees el tranchans, fortement ćvasée il la base; le bord gauche est presque droit, moins pourtanı que dans l'espèce précédente; il laisse à découvert une petite fente orbbilicale.

Longneur trente-cinq nillim., largeur vingtsept.

Lille est fossile dans bien des localitís des environs de Paris, à Mlonchy, l'arnes, Dameric, Courtagoon, Montmirail, Senlis, ete.

13. Ampulatan conique. Ampullaria conica. Nor.

A. testâ ovato-conich $\hat{\imath}$, turgidulâ, luvigatâ; spirâ productâ; anfractibus conpexts; uperturấ ovatâ; umbilico minimo sublecto.

LAnt. Ann. du Mus. Com. 5. pag. 50. $n^{\circ} .3$.

Ibid. Anim. s. 2.ert. tom. 7. pag. 548. no. 3.

Ibid. Der. Dict. des scienc, nut. 10m. 20. pag. 446.

Ibid. Nов. Descript. des coq. foss. de Paris, loc. cit. $n^{\circ} \cdot 4 \cdot p l .17 \cdot$ fig. $7 \cdot 8$.

Coquille ovale, conique, qui peut servir d'intermédiaire eutre les Ampullaires et les Paludines par l'alongement de sa spire, ayant assez bien l'ouverlure de celles-ci avec la torme de cellesli. Elle est entièrement lisse, ses lours de spire sont conveses, séparés par une suture peu profonde, 2u nombre de huit; ils forment uce spire saillante et pointue, dont le dernier tour est assez grand et reullé. L'onverture est ovale, oblique, beaucoup moins aliondic que dans les Paludines, aloogée et versante à la base comme celle des Ampullaires; l'avant-dernier tour fail à peine saillie dans l'ouverturc; la lèvre gauche s'applique en laissant entrouvert un petit ombilic; la levre droite es! simple et tranchante. Celle espece très-rare u'est connue qu'à l'étal fossile, elle a été trouvée à Betz aux eqvirons de Paris. M. de Frauce qui a bieu voulu nous la communiquer est le seul qui ea possède dcux iodividus.

Longucur, trentre-trois millimètres, largeur, vingt-ua.

14. Aspuldare de Guyane. Ampullitia Guanensis. L.AMK.

A. testầ ventricoso-globosâ, solidâ, longitudinaliter et inequuliter striatî́; epidermide fuscú; anfractibus senis; ultimo maximo; aperturầ uUantia. LAMK.

LAsk. Anim. s. vert. tom. 6. 2e. part. pag. 17. $n^{n} \cdot 1$. 
Listea. Sinop. Conch. tab. 128. fig. 28.

Grande et belle coruille qui approche, pour le volume, de l'Ampullaire idole Bulmus urceus Batg. Iais qui en diffère d'uue manière assez notable pnur quan puisse la dislinguer an preunier aspecı. Elle est ovale, ren!rue, globuleuse, solide, assez épaisse, composée de cinq is six tours convexes, séparés par une suture simple. Le sommet est rouge, ce quile rend oblus et raccourcit la coquille. Le dernier tour est très-grand, lisse dans quelques indiridus et dans d'autres, surtont les plus grands, convert de stries rugueuses, langitudinales, irrégulières, qui ne ressembleat point du taut aux sillons réguliers de l'Ampullaire idale; ici ce re sont que des traces de l'accroissement lent des plus vieux individus, car dans les jennes cela ne se remarque jamais. A la base de ce dernier tour on remarque, derrière la columelle, un onbilic assez large, arrondi et profond. L'ourerture est fort grande, ovalaire, ablique; le bord drait est mince et trauchant, sans bourrelet intérieur, sinueux supérieurement el à la base de l'ouverture, qui est versante; le loord gauche est mince, assez court, formant àpen-près le cinquième de la circonférence de la coquille, il se réunit obliquement à la cclumelle, qui est larre, solide, arrondie, fortement renversée en dehors aussi bien que la base de l'uuverture. Tout le bord interne de celle onverture, la columelle et méme le bord gauche, sont d'une canleur orangée-pourprée très-belle. Naus possédons deux jeunes individus de cetre espèce, ils sont très-minces, fragiles et oraés de bandes branes transverses, au uombre de huit à douze: l'un d'eux est pourvo d'un opercule corné trèsmince. A l'intérieur elles ne sont point cacore pourprées comme dans les individus adultes, mais d'un blanc terne à travers lequel se dessinent les bandes de l'exlériear.

Nous devons à l'obligeance de M. Marmin la connoissance en asture de celle belle coquilie, qu"il a bien roulu nous communiquer: il en aruit reça plusienrs individus de Cayenne.

Longuenr, huit centimètres, Irois pouces environ et quelquefois davantage.

15. Ampelaaje oviforwe. Ampullaria oviformis. Гов.

1. testà osutâ, globosá, bruneo-virescente, longitudinaluter substriatâ; spirá brevi, vuldè emsì, upertuñ magnâ, ovuiá, intus nigro-fuscâ, margmabus albidesi entibus; umbrlico nullo detecto.

A en juger d'après la descriplian et la figure que donne Brugnière de son Bulime de sinanuri, daus le Journal d'historre nuturelle (tom. 2, pag. $5+2, p l .18, f_{n} .2$ el 3.) L'espece que nons caraclérisons ici a avec lui beaucoup d'analogie, suz trois caractcoses surtuut, les antres n'élaut plus les mémes. Ainsi, dans l'une et !'autre espèces, la furme est à peu près la méme, la spire est toujours rongće el il n'y a point d'ombilic.

L'A mpullaire ovitorne, comme l'indique sin nom, est ovalaire, globuleuse, rétrécie à la base: composée de qualre à cinq tours, dont les deux ou trois premiers sont rongés, celle circonstance la fail paroitre heaucoup plus courte qu'elle ne devroit être; elle est de couleur brune ou verdatre, et dans les plus jeunes individus on apercoil en dessous de l'épiderme quelques légères lascies transverses, brunes, qui appartienuent sans donte à la coquille. Toute la surface extérieure est substrice : nous avons ceperdant sous les yeux un individu entièrement lisse. L'onverture est grande, ovale, oblique, un peur rétrécie au sommet et fort large à la base où clle est versante. Le bord droit est tranchant, à peine sinueux; le gauche assez alongé, mince, blanchátre, diaphane; il se rétrécit insensiblement vers la base de la coquille où il cansre l'ambilic et se confoud avec la columelle, qui est arrondie, peu large, solide, non renversée en dehors et blanche. La base de l'onverture est clle-mème à peine érasḱe; en dedans elle est d'un brun foncé, tirant sur le noir, le péristome est d'un blanc nuancé de fauve. Cette espèce remarquable nous a été communiquée par M. Narmin qui l'a reçue de Cayenre. Elle est longue de soisante millin. et large de quarante-huit.

Oulre les espèces fossiles que nous avons indiquées, il en est plusieurs antres qui, sans avoir absolument tous les caractères des Ampullaires, n’en dilfèrent que si peu, yuion ne paurroit les mettre dans aucun autre genre.

16. Amperiare scalariforme. Anipullatia sculariformis. Nов.

A. lestâ ovato-conciâ, magná; spiru pymmiduli; anfrucíbus duodecim, inferioribus rofundatis; superioribus marginatis, spiratis; aperturá ovatâ; unbilico obtecto, columellas bipartitâ.

Noв. Descript. des coq. Joss. des env. de Paris, tom. 2. pag. 1 58. $\pi^{\circ}$. 1. pl. 16. fig. 8. 9.

'Très-grande et très-belle coquille extrèmement rare aux environs de Paris, dont nous ne connuissous encore entiers que trois individns dont nous possédons les deux plus beaux. Eile est ovale, conique, lisse; la spire est pointue, pyramidale, composíe de douze tours réguliers dunt les premiers sont convexes, arrondis et sans rampe, tandis que les quatre a cing derniers, sont forlement carćnés et présentent une rampe spirale d'autant plus large, qu'elle s'apprache du dernicr tour. Celui-ci est forl grand, il occupe à pen pics la moitic de la lonuneur tolale; il présente quelques silluns assec éloignés les uns des autres; ils iudiquent les derviers accruissemens. Lionverture 
cst ovale, oblique, à bords minces, tranchans; le gauche peu épais appliqué sur l'avant-dernier tour, cachunt l'ombilic et se confondant à la base avec une columelle épraisse, solide, assez large, renversée en dehors et divisée en denx parlies inćgales par un sillon assez profond. La base de l'ouverture est beaucoup plus large que le somulel, et elle est légc̀rement évascée. Le tust de celte coquille n'est pas tries-épritis, ce qui la rapproclie de la plupart des Anipullaires.

l,ongueur, treize centimètres, environ cing pouces; eile se trouve tossile a Panes. LANK.

17. Ampulata à rampe. Ampullaria spirata.

A. testầ ovato-ventricosâ, lavigatâ ; spirâa brevi, rectâ; anfracthius octo, margine separatis; aperturî̀ ob'atâ, basi effusa; umbalıco aperto.

LAмк. Ann. du Mus. tom. 5. pag. 50. no. 6 et tome. 8. pl. 6t.fig. 7. a. b.

Ibid. Anim. s. vert. tom. $7 \cdot$ pug. 549. $n^{\circ} \cdot 6$.

Defrasce, Dict. sc. nut. tom. $20 . p a g .4+6$.

Nов. Descript. des coq. fos. des env. de Paris, loc. cit. $n^{\circ} .2 . p l$. 16 . fig. 10. 11 .

Nous sommes foin de partayer lopinion de M. Defiance qui, dans l'ouvrage cque nous venons de citer, croit pouvoir réunir én une seule espère et celle-ci et l'Ampullaire hybride qui est une coquille de la grosseur du poing. Elles différent entrolles au priut qu'elles ue peuvent appartenir au àène genre, l'Ampullaire hybride devant faire partic des Natices. Il sultira de courparer les liggures cque naus avous donné dans nalre onvrare, de ces denx coruilles, pom se convaiucre à l'unstant mềme qu'elles n'appartienuent point a' moins à la même espèce.

L'Ampullaire a rampe est une coquille qui reste toujours d'une taille nédocre; elle est mince, fragile, globulense, ventrue; la spire est assez courte, conique, pointuc, composée de huit tours dont les premiers sont arrondis, les antres sunt munis d'une raupe plate, on légérement inclinée en dehors, séparée chu reste par un angle assez prononcé. L'onveriure est grande, oralaire, un peu rétrécie vers le sommel. Le burd droit est tranchant, trecs-mince, coume le reste de la coqnille; le gauche est cont et fort mince, aussi arrivé à l'ombilice et avant de se confondre avec la columelle, il lorme une petite échancrure; la colu:nelle est arrondie, assez mince, et fortement renversée en dehor's, ainsi que la base de l'vuvelture qui est légèrement versante. La base du dernier tour est percée d'un ombilic médivcre, arrondi, du centre duquel part une pelite còie sullanle qui descend se contondre avec le bord colimellaure : les plus grands individus de cetle espéce nout pas plus de treute-un millinetres de longrueur. On la trouve assez fréquemment à Grignon, ì Parnes et à Moncliy.

18. Ampelatre acumiuće. Ampulluria acuminatu. Lана .

A. test.i ovato-ucutâ, ventricosâ, spivâ clongatí acuminutâ; anfractubus mlundates, stris superficialibus, longitudinalibus et transversulebus clathrutis; suturâ profiundâ, simplici, subcunaliculatâ; aperturầ orutấ; umbileco tecto.

Lамк. Ann. du Mlus. loc. cit. no. 5. tom. \&. pl. 61.fig. 4. a. 1).

1bid. Anim. s. vert. loc. cit. no. 5.

DEF. Dict. des scienc. nat. tom. 20. pag. 446.

Nов. Inc. cit. $u^{\circ}$. 5. pl. 17. fig. 9. 10.

I.es individas que l’on trouve à Grignon, à la ferme de l'Orme et dans les autres Jacalités qui environuent celle-ci, sont généralemert plus pelits et ne présentent le plus souvent gue des stries longitudinales; cependint on en voit yuelquefois qui, quoique d'un petit volume, offient anssi bien les lonuitudinales que les transversales. Dans d'autres localitís cette coquille prend un plus graud volume. Cetle coquille est d'une lorme ovalaire, alongée, ventrue, surtont pal son delnier 10ur, qui ne guère plus grand que le reste de la spire; celle-ci est conique, assez alongée, pointue, couposíe de buit tours arrondis bien tréguliers, séparés entr'eux par une suture simple, mais profunde, subcanaliculée. 'Tonte la surlace de la corguille est couverte de stries transverses jeu prolondes qui le sont plus cependant que les longiludinales qui sont à peine inarquées. L'ouverture est très-urande, ovale; son bord droit est tranchant, fort mince comme toute la coquille, it fait avec le bord gauche un angle onvert. Le bord gauche est fort mince, appliqué, assez grand, recouvrant l'ombilic yui est complétement cacbé, et se confondaut par sa base à uue columelle aşsez large, aplistic obliquement. La base de l'ouveıture est à peine évasce.

Les plus grands iudividus ont cinquante willimètres de longuenr el quarante de large.

On tronve celle espece à Grignon, fa ferme de l'Orme, Parnes, Liancourt, Moncliy, toujour's daus les terrains masins.

19. Ampulzame de Vulcain. Ampullarica Vulcani. Brosg.

A. testâ zentricosâ, ovatâ, longitudinaliter striatâ; spirâ brevi, acutâ; arfractıbus rotundutis, suturâ simplica separatis; aperturâ ovatoacutu, obliqua basi effusâ; umbilıco mnimo subtecto. Noв.

Brovg. Mém. sur le terr. cal. trap. sup. p. 57. pl. 2. fig. 16. a. b.

Grosse coquilie globuleuse, ventrue, it spirc li 2 
courte, pointuc, conposée de six tours arrondis, sulurc simple, jamiis creusée en canal, surface cxlérjeure malqué de slries langiludiuales régulières, fines, serrées, pen profondes; le dernier tour beancoup plus grand que tous les autres, terminé par uue ouverture assez grande, ovalaire, rétrécie aú sommet, élargie, évasée, versante à la base; bord droit, mince, tranchant, s'épaississant insensiblement; le gaucle très-nuince d'abord et prenant insensiblement p'us d'épraisseur jusque rers l'ombilic qu'il caclie en partie; la coIumelle est épaisse, arroudie, courte, renrersée en dehors ainsi que la base de l'ouverlure.

Longueur, cinquante-cinc millimètres, largeur, cinquanle.

On la trouve fossile au Val-de-Ronea près de Véronne.

20. Anpoldare strialule. Ampullaria striatula. Noв.

A. testâ ventricosâa, crassâ ovatâ, acuminatâ, transversim stria; spirutî̀ brevi, acutâ; anfractibus senis, rotundatis, angustè canaliculatis; aperturâa ovato-acutâ, basi effusâ, umbilico obliquo, subtecto.

Ainpullaria crassatina. VAr. a, Basterot. Ménz. sur les env. de Bordeaux, pag. 55. $n^{\circ} .2$.

Nous avons lait figurer dans notre onvrage sous le nom de Natica crussatina, l'Ampullaire crassatine de M. Lamarck; il suffita je pense de comparer avec celte figure qui est fort bonne, la coquille de Dax que M. Bustérot, dans son iutéressant mémoire, a confondu avec elle; on reconnoilra bientót l'erreur dans laquelle est tombé l'anteur que nous citons en confoudant deux coquilles qui n'out entr'elles que peu d'analogie.

LAmpullaire crassatine des environs de Paris est remarquable par la largenr de sa base, occupée par uu tris-large calus convexe, qui couvre constamment l'ombilic; biev qu'elle ait la spile cawaliculée, elle est marquée de slries longiludinales régulières et serrées. Ia lèvre droite qui dans les Ampullaires est dans le plan de l'axe, est daus celte espece coupée obliquement à l'axe, direction qui suit toute l'ourerluse. Aucuns de ces caractères ne se retrouvent dans l'Ampullaire striatule, elle a nne forme globuleuse, ventrue, elle ıst épaisse, solide, composée de sept tours arrondis, slriés légèrement eu travers el séparís entl'eux par nne sulure canaliculée, enfoncée. L'ouverture est médiocre, ovalaire, élarugie à la base oi elle est rersante el nu peu évasée, aiguë et anguleuse au sommel; la lèvet droite est tranchante, un peu sinueuse, la gauche est assez longue, échancrée vers la fente ombilicale qu'elle laisse a décourer?. 1) milieu de cette lente part un sillon qui descend en formaut un deni-cercle qui circonscrit d'une manière nette el trancluéc un petit bourrelet columellaire. La columelle est fort épaisse, arrondie, courte, formant avec le bord gaucbe une ligne presque droile. Celle coquille vraiscmblablement ne restera pas dans les Ampullaires oi nons la plaçons Iransiloirement. On la trouve fossile à Dax.

Lourneur, soixante-cing nillimètıes, largenr, cinquaute-huit.

Błruguière a décrit dans le premier volume de ce Dictionnailc une coquille assez singulière à laquelle il a donné le nom de Bulimus avellana. M. Lamarck, qui possédoit dans sa collection cetle coquille très-rare, pıessentit qu'elle étoit lluvialile et non marine, comme Brugnière l'atvoit dil, et par suile de celle opinion, la rangrea dans les Anpullaires sous le nom d'Ampullaria avellana. Nous possédons aussi celle espèce el nous arons appris posiliveneut qu'elle est marine; scu ouverture oblique ainsi que la plupart de ses caractires la porle däns les Natices, mais elle a un aspect qui lui est propre el qui nous fait présumer que plus lard, si on en découvre l'animal, on en fera un grenre particulier.

\section{AIIPULIINE. Ampullina.}

M. Lamarck dans uu de ses Cours aroil proposé ce nouveau genre pour un certain nombre de coquilles fossiles des environs de Paris, qüil plaçnit parmi les Ampullaires. M. Lamarck ne publia jamais ce genre autrement, il paroil même qu'il t'a abandonné, puisque dans le tom. 7 de son dernier ouvrage, on trouve les coquilles qui devoient conslitmer le renre Ampulline lowjours dans les Ampullaires; elles ne peurent cependant y rester, elles doivent se ranger parui les Natices. Fojez Aupuldaire et Natice.

\section{AMUSILN.}

Genre proposé par Klein (Ostract. pag. 154.) daus sa seconde classe des Diconcha arrita poux le Pecicn pleuronectes. Ilest à présumer que Klein a emprumté celte dénomiuation à Pethiver el à Rumphius, qui l'emploient comme specilique pour la mèue coquille. Qnoique ce geure de Klein ne repose sur aucuu bou caractere et qu'il n'ait élé adopté ni par Linné el ses successemrs, 1I. Megerle cependant l'a reproduit en 18 I I sous le méme nom dans le Magasin de's curieux de lu nature de Berlin, pag. 59, et MI. Silslothein daus son Petzefactenkinde sous celui de Pleumnectite (poyez ce mol). Le genre Amusium de Klein n'élant pas admissible, on ne peut non plus admettre celui des deux aulen's que nous verons de citer, les coquilles qu'ils y placent doivent faire partie du genre l'eigne dont on ne peut raisonnablement les separer. Tojez Pergre.

\section{AMYGDALE, Amygdalum.}

Saus ce nom, M. Negrerle propose un genre qui correspond parfailement au gemie modiole 
de II. Lamarek; il fait par conséquent un double emploi inutile puisqu'avant 1811 gue date le genre de .M. Negerle, M. Lamarck avoit institué le sien; on doit le prétérer puisqu'il a l’antériorilé. Voyez Modrowe.

\section{ANADARA.}

Nom donné par Adanson ( ójez Sénég. p. 148, pl. 18), ì une coquille du grence Arche, srice antiguna. Bruguicre, dans le premier volume de ce Victionance, pag. $103, n^{\circ} .12$, lui a couservé le nom dunné par $\mathbf{A}$ dauson. Nous renvoyous à lit descriplion.

\section{ANTIEE. Anatifa.}

les progrès que les sciences ont fitites depuis ticute-ciug ans que le premicr volume de ce Dictionnate est publié, uous rend indispensable l'obligation d'ajonter ici ce qui a été fait sur le genre Analife dont Bruguière est l'auteur.

C'est avec juste raisou que ce savant naturaliste sćpara des Balanes sun geure Analife. Eubli sur de bons caracièces, il ne pouvvit manquer d'êlre adopté. Bruguicre avoit déjà entrevu les rapports gui existent entre les Anatifes, les balanes et les animaux articulés, cependalat dans ses tableaux d'arrangement inéthodigue, ils sont contondus avec dautres oeures non moius hélérogènes dans ce groupe informe des Multivalves. iH. Cuvier, dans son tableau élémentaire du liègne animal, commença ì débrouiller ce culhos sans adnetre les Muluvilues, il sépara les deux genres Anatife et Balane dans la sixième section des Acćphales, il les caractérisa d'après les rentacules ciliés et articu!és don l'animal est pourvu. Les belles anatomies publićes par Poli dans son grand ourrage coutribuèrent sans doute a opérer ce changement remartyable dans les rapports de ces êtres. M1. Lamarck, daus ses premiers travaux, suivit l'exentple de M. Cuvier, il créit pour les Anatifes et les Balanes une petite section qui termine les Acéphales et rapproche ainsi ces auimaux de ceux qui soat articulés, qui commencent immédiatement après. H. de Roissy, dans le Buffon de Sonnini, imila complérement M.M. Cuvier et Lamarck. Ce fuı MI. Duméril le jremier qui rassenbla, sous la dénomination de Cirrhopodes, des genres dont on avoit cntrevu les rapports, sans les lixer d'une naniere précise. 'Tout cenx que l'on avoil reconnu ĉtre pourvas de bras ciliés y furent compris : ainsi avec les Anatifes et les Balanes an trouve les Lingules, les Térébralules el les Orlricules. Cetle espèce de désordre de Ml. Duviéril en créaut de nouvelles idées, favorisa un atrangement beaucoup plus rationel, et c'est à 11. Launarck qu'il est dîn, il le proposa dés $180 \mathrm{~g}$ dins sa Philosophie zoologique, où l'on voit les Cirrhipèdes bien circonscrits, sans aucun mélange, constituer une des grandes classes du Régnc ani- mabentre les Annélites el les Mollusques. Dislore les grenres Iingule, 'Térébratule, crc., sont restés dans les Mollnsques acépliales, el les gu'mes Anatife et Balane, ainsi que les Coronules et les Tubiciaclles qui en sont démcubrés, consituent les Cirrlipèdes (royez ce not anupel nous triiterons de celte classe considérée ditus son ensemble el d'une manière générale). Il fiaut remarquer que dans loxtrail du Cours (1811) M. Lamarck partigea les Cirrhipeddes en denx groupes dont les Auatifes a clles seules lorment fe second: ce gence ì celle époque, est enrore tel que J3ruguière la laissé; il al conservé sa premiere intégrité. 11 ne tarda pas à être démenuluré par un savant zoologiste anglais, leach, yui rendit de véritables services i la conchyliologic. Ces dénembremens ne fureut faits qu'après la publication du Regne amimal de H. Cuvier. Nous devons done conslater que dans l'onrrage du savanl prolesseur, les Cirrhipides snut formés des mênes gentes el dans des rapports seublialles. à ceux proposés par 11. Lamarck antélientement. En même temps que Leach, M. Lamarck proposa son genre Poucepied pour les espèces qui ont treize valves et plus; l'auleur anglais le nommoit Scalpellum. 11 renferme les espèces que Brnguière avoit tont bien groupées dans la seconde section de son genre Anatite.

Le Lepas aurita de Linné avoit élé décrit à la fin des Anatites dans ce Dictionnaire, Brugnic̀re déjà pressentoit qu'il ne punroit rester dans le genre, et il ne l'y laisse que futute d'en trourer un plus convenable; sans donte aussi qüil craignit d'en élablir un exprès. Cctle indication fut suivie par Leach qui proposa le geare Otion adopié par M. Lamarck, il institua aussi un genre voisin de celui-ci, le Cinéras, que M. Lamarck adopta ainsi que lautre, com une on pent s'en assurer dans sun dernier ouvrage. Voili done le gcure Anatife partaré en quatre genres et ces quatre genres, par lenrs rapports évidens, servant à former une famille que MI. Lamarck nomme Cirrhipedes pédonculés. Les Analiles furent réduites aux espèces comprises dans la première section de Bruguière.

II. de Ferussac ne fit aucun changement daus l'arrangement de M. Lamarck. M. de Blaiuville ne resla pas comme lui imitateur, il changea loute la nomenclature: sous le nom de Peutalépe, il réunit en dewx sections les genres Anatifes et Poucc-pied, le premier tel que M. Lamarck l'a conça el le second démembré, c'est-à-dire ne contenant plus les Scalpellum de Leach, il en fait en ellet de ceux-ci un geare à part sous le nom de Polylèpe.

Tels sout les principaux changenens que le genre de Brnguière a éprouvế depuss sa création; pour en avoir une juste idée, il ne faut plus y rattacher que les qualre premières espèces qu'il a dé- 
crites, et changer les caractères suivans contre ceux qu'il a donnés.

\section{CARACTÉRES GÉNÉRIQUES.}

Corps recouvert d'une coquille et soutenu par un pédoncule tubuleux et lendineux. Bras tentaculaires, nombreux, longs, inégaux, articulés, ciliés, sortant d'un côté saus le somnel du corps.

Coquille comprimée sur les cólés, à cing valves : lcs valves contiguës, inégales; les inférieurs des côtés élant les plus grandes.

Nous renvoyons pour les espèces à la premic̀re section des Analifes de Bruguiere, la seconde comase nous l'avons vu formant un autre gente anquel nous reuroyons également. (Voyez PoucePIED.)

\section{ANA TIFÉRES. Voyez CoNQUES AXititiéres.}

\section{ANATIXE. Anutina.}

Ce genre fut publié pour la première fois en 180y, par 11. Lamarck, dans le premier volume de sa philosophie zoologique, il lait pariie de la famille des Myaries dans layuelle se ironve, avec celui-ci, les genres Mye et Panope. Dans l'E.rtraut du Cours du mêae auteur, le genre Analine fiait toujours partie de la lamille des Myaices, mais elle n'en contient plus que deux, les l'anopes ajant été transportís dans la famille des Solénacées. L'antéri rité du genre Analine de M. Lamarck lui est sullisamnient acquise, sul le genre Auriscalprum de M. Mégerle, qui exi est un doub.e emploi que l'on ne peut adopter. Le Solen unatinus de Linné qui servil de type au nouveau genre, n'étoit pas la seule coquille qui put y cntrer, quelques autres du genrc Bjye de Chennitz pouvorent en faire partie. Cependant elles ny furent point réunies par M. Ochen qui les laissa parai les Hyes, re que lit égalemenı H. Scliweiger. M. Cuvier (Régne animal), loul en.réunissaut les Anatines aux Myes eut le soin de les con. server en sous genre; ce savant nituraliste avoit for bien senti, comme M. Lamarck l'a coufirmé depuis, que le genre Rupicole de M. Fleurian devoit se confond:e avec les Anatines.

I'ar l'ensemble des especes comprises dans les Anatines, on se fait une jusle idće de quelle maniere le savan auteur des Animaux satw veriébres conçut ce genre d'après les caracicres qu'!! lıi assigne, ainsi que par dautres analogies, il auroit dis y placer aussi une pelite coquille, Mya solemyalis Lasx., quin examen pen approlond ou furl sur des indivichus incomplets, iont porté a 1 ranger de prélérence dans ses Myes. Nous avons proposé cetle l'éumon comme nous le verrons bientô:.

II. do Ferussac, dans ses Tableaux syslématiques, en adopiant la tamille des Myaries, y a ajouté les Lutraires et les Soléuyes, de sorte que les Anatines se trouvent en rapport avec ces genres, ce que M. Lamarck n'avoit pas fait, mais cela a voil éré indiqué par. Ml. Cuvier. M. Latreille dans son arrangement de la famille des Myaires, ne dillere de MI. de licrussac que d'un seul poiut; il rejelle le geure Solécnye, mais il admet les trois autces: Jes Auatines se trouvent par lit entre les Lutraires el les Mjes.

On voit d'apres ce que nous venous de dire que l'opinion des zoolonistes a été peu variable rclativement a la place que le genre gui nous occupe devoit avoir dans la série; effeclirement, tet quili étoit convu, on ue pouvoit lui chercher d'aulres rapposts.

Un lait curieux que nous avions obseıvé depuis assez long-temps, avoit dirigé purliculiérement botre allention et nos recherches vers le gense Analiue : ce lait gue nous arous conmuniqué at 1]. de Blainville, avant la publication de son arlicle Molnusque, dans le Dictionnaire des scienc. naturelles, wì il l'a consigué ainsi que dans son Trailé de Nulacologie, consiste à a voir observé que l'Analine trapezosde, Lamk., avoit un osselet mobile, cunéilorme, placé daus la charnière dans l'angle formé sur les deux cuillerons intérieurs qui donnent allache au ligament. Ce singulier caratiere devoit laire sorbr celle coquille du gente Aualine, et d'aures encore pouvoient y èlre ajoulés pour contirner celle opiaion; tels que l'iućgalité des valves, la disposition du ligameat el la forme des iupressions musculaitcs.

Ce luit isolé en faisunt connoitte un nouvean mode dunion dans les charméres, deroil faic présumer que, daus d'untres coquilles analogues, on pourrout trouver quel jue chose de semblable. Nous dirigeîmes nos recherches vers cet objet et uous liumes assez beureux pour faire quelques dcicuuvertes qui, une fois bicn connues, mellront les observaleurs à même de les augnenter. Nonseulement l'Anatiuc trapezorde nous a ollert un osselet libre à la charnière, mais encore l'Auatine myale, l'Anatine longirostre, ainsi que plusieurs aurres esficces. Nous avons loutes les présomptrons pour peuser que les coquilles du greare 'Tluracie, onl également un osselel caduc; nous arons en effet truuvé sur elle des traces certaines de sa position, mais nous ignorons sa forme, car celle coquille très-rare dont nous ne connoissons que le seul individu que nous possédons, a voit le ligament rompu lorscue nuas en fimes l'acquisilion: il seroit donc nécessaire de l'observer duns son intégrilé.

Les osselets cardinaux dont nous venons de parler, quoiqu'analogues sous plusieurs rappnrts aux pieces dursales des pholades, surlont par leur forme symérrique, en dillërent copendant par $l_{2}$ place gu'ils occupent, par leurs usiges, lenr's rappouts avec l'animal el leurs connexions. Ils font partie intégrante et vécessaire de la charnicre, ielenus en place par le ligament des valves ou 


\section{A N A}

par un ligament particulier, et on n'en rencontre jamais yu'un scul daus cbaque esprice. Ce seroit a tort cepeudaut quion confondroul ces ossclits avec les dents cardinales des autres cuquilles bivalves; il existe entre ces partic's des lillérences assez notables pour les dislinguer par nue dénomination particulic̀re, et nous arous adopté celle d'Osselet, Ossiculum. Si on se souvienı que les dents cádinales sunt des érninences solides, lixcs, du bord dorsal, qui sont reçues dars les cavités proportionuclles de l'autre valve, on verra que celle délioitinn ne peut nullencent saccorder arec celle de l'osselet, el, si l'on vouloit couserver is celtc partic le nom de Dent candinale, il faudroil nécessairement modilier celte délinition, modiliration qui la rendroit tres-rayne et incertaine daus sun applicatiou. Il est plas convenable, et mous admettins en principe que l'on doit donner un nouveau non à un objel jusqu'alors inconnu.

Des observations que nous ayoos pu faire sur toules les especes du genre Anatiue, ainsi que sur plusieurs aures que M. Lamarck n'a point mentionné, il résule pour uous la nécessilé de démembrer le neure Aualine, nous proposons même de faire, avec les nouveaux genies yui en sont pour la plupart exlraits, une famille qui les rasseable tous daos leurs rapports naturels, famille que nous diviserons en deux grompes pom y placer les genres: dans le premier, ceux qui ont le plus d'analogie avec les 1$]_{y}$ es. el dans le second ceux qui se rapprochent le plus des Curbules; celle nouvelle famille que nous nommons les $O s$ trecorises (vojez ce inat) pouvani servir d'iutermédiaire entre celles des Myes et des Corbules.

J.e genre Anatine tel que nous le considéroas maintcuant, ne contient plus que trois espèces, les irois prenières de $\mathrm{Ml}$. Lamarck, Anatina latema, Anatina trancata et Anatina subrostruta; elles ont entr'elles beaucoup d'aualogie. Les caractères qui en font un genre distinct sont les suivans:

\section{CARACTÉRES GÉNERIQUES.}

Coquilie transverse, subequivalve, baillanle aux deux cótés; crocliels fendus; fente close par une meabraue; uoe deat cardinale élaruie en cuilleren, saillante incérieurement, donnaal atlaclie antérieurenent, par un liganent unique, à un osselet ricuspide. Une laue ou une côte ea faulx, adnce, obliqueneul coulante, soutenant les dents cardinales daus lesquelles sinsère le ligauxent.

Outre la forme de l'osselet qui esı bien particulière à ce genre, il y a encore un caractère des plus remarcjuable, cest la fente des crocluets. Celle fute est presuue parallèle it la côte en arciboutanı qui soutient le cuilleron; elle n'esı lormće que par une nembraue fort mince qui n'empéche pas ses deux bords de se recuuvrir larsqu'on les lire ligirement en scns inverse, en proliant de l'álasticilé du lest. l'resqu'aussi lanarne que l'arcboutant dost il vieut d'étre question, celle fente aboutit au sommet qui est trés-nijnce et toujours percé d'un trou rond tout près du bord cardiual, qui lui-même est éralemont feudu. Dans les coquilles bien conservées, on roit yue retle ouvcrture des crochets est ciose par une expansion du linganent interne inséré dans les cuillerons. Aiusi rél que nous le modilions, le genre $A$ ualine conserve de bons aaractères généricues qui uous semblent suffisans pour qu'on ne puisse jamais le confondre avec aurun autre, quand même il arrivcroit, comme cela est ordinaire dans les collections, qu'on ne trouvervit pas l'usselel cardinal en place, car il riste evcore pour le reconnoitre la leove et la perforation des crochets, ot la faux en alc-boutant qui soulieut les cuillerons.

1. Axatrixe lanterue. Anatina latema. Iawk. A. testâ ovatâ, tenuissimá, pellucidâ, fragili, utrinque rotundatá.

LAnк. Anim. s. vert. tom. 5. pag. 465. no. 1 .

Ax. Mya anserifera? Chen. conch.cab.tom.11. pag. $19.5 .2 \%$ g. 20. A. B. Mala.

Coquille tròs-mivce, très-fracrile, gonfléc, équivalve, équilatérale, plus arrondie antérieurcment que postólieurement; elle est toute blanrhe, du-dejans d'un blanc nacré argenté, en dehors d'un Jlanc mat, elle est toute couverte de fiues granulations, el ses crochels sont finement et rígulic̀rement striés; lorsque les valres somt rasienlulées, on voit que la coquille es! baillante des deux cốćs plus postérieurenent quiantérieurement. Le crochet est percé d'un peitit trou roud çui se conlinue avec le bord cardinal qui est interrompu dans cet endioit; dans ee trou abuntil aussi la lente du crochet qui descend perpendiculairement presqu'aussi loin que le support du cuilleron. Celui-ci est fort obliquement rejeté postérieurement; il gagne cependant le dessous du cuillerou pour le rendre plus solide. Ce cuilleron est horizontal, d'une rúdiocre graudeur, il est creusé d'une goutière triangulaire qui doune insertion au ligament.

Nous u'avons pas vu l'osselel de celle esjèce, nous n'en sommes pas moins persuadé de son existence : on voit très-Jien sur le cóté antérieur des cuillerons la trace de son adhérence, cefle coquille a d'ailleurs tous les autres caractères du genre, el crlui de la fente du crochel qui tient à la manic̀re dont l'osselel est placé, pourroil dispenser à la rigueur de tous les autres. Celte coquille est fort rare dans les collections, on la nomne vulgairenient la Lanteme; elle vient de la ner des grandes Indes. Lindiridu que oous avons sous les yeux, qui appartient à la collection du Muséum, à quarante-trois millimétres de larare et vingt-trois de long. 
2. Aratrive subrostrée. Anatina subrostrata. LAMK.

A. testâ nvatâ membranaceâa, inflatâ, albâ submargaritacê, utroque latere hiante; latere postico attenuato, subrostrato.

Lams. Anim. s. 2ert. tom. 5.pag. 403. no. 3.

Blaivv. Traité de MIalac. pag. 564.pl.76. fig.6.

Solen anatimus. Lir. Gmell. pag. 5225. $2^{\circ} .8$.

Coemuitz, Conch.cab. tom.6. tab. 6. fig. 46 et 48 .

Rонан. MIts. tab. 45. fig. O.

ENccrlop. pl. 228. fig. 5. a. b.

Cette coquille quoique fort rare est cependant celle du genre qu'on roit le plus frégrienment daus les collectiuns. Elle est assez grande, ovalaire, bombée vers les crochets, iuéquilutérale, le côlć poslérieur le plus currt allénué, en bec très-bailtant; le côté untérieur arrondi et baillant aussi, mais beaucoup moins que le postérieur. 'Tonte la coguille est lisse, blancbe en dehors, d'uue nacre peu brillante en dedans; elle est excessivement mince, moius que du papier, par couséguent elle est très-fragile, la feute apiciale n’est pas aussi longue que l'arc-boutant qui soutient le cuilleron. Cêlui-ci est médiocre, placé absolument au-dessous du crocliet. Quoique nous n'ayous pas observé l'osselet de celte espèce, nous ne inettous nullement son existence cn doute; la parfaite analogie qui existe entre ces deux premières espèces et la suivantc, sur laquelie nous arons pu l'observer, ne nous laisse aucun doute à cet égard. longueur, cinquante mi!liwètres, largeur, vingtcinci.

Cette espèce se trouve dans l'Océan iudien, à Amboine et à la Nouvelle-Hollande.

\section{Axatrine tronquée. Anatina truncata. Lami r.}

A. testâ ovatâ, tenui, irregalariter transverse striatâ, postice subtruncutá; punctis mınimis, promimulus extus asperatâ; rimula apeciali magnat.

LAMK. loc. cit. $n^{\circ} \cdot 2$.

C'est sur cetle espèce que nous avons obserré pour lit première fois losselet tricuspide qui caractérise ce genre. La coquille u'avoit point été ouverte et cel osselet étoit retenu en place par le ligament qui, remplissant les cuillerous, les díbordoit pour adhérer à la face iuterne de l’osstelet; il est comme nous le disions, tricuspide, en forme d'étoile a trois branches; il est placé à la clarirnière de manic̀re a ce que l'une des branches est horizontale, entre les cuillerons, et sert de point d'atlache au ligament; landis que les deux autres à cheval sur le bord cardinal dans l'endroit où il est fendu, s'enfoncent dans les crochets où elies adhèrent, au moyen d'un ligament membritseus, qui est une continualion de celui qui ferme les feutes apiciales et qui lie aussi le bord de l'osselet au bord cardinal dans l'eudroit du contact.

Cetle coquille est de lorme ovalaire, moins juéquilatérale que la précédente, mais comme elle, wiace, trausparente, hlanclie, subnacrée à l'intérieur. Le côlé postćricur est baillant, mais point en bec, il est subtronqué : le coté antérieur est arrondi, baillant, mais moius que le postérieur, les deux valves ne sunt point parfaitement égales: leur inéralité se remarque surtout postérieurement. La surface extérieure est marquée par des accroissemens assez réguliers, et si on la regarde à la loupe on la voit touverte de ponctuations numl reuses et suillintes. Le seul individu connu de celte coquille a été communigué à M. Lamarck par MI. Aubry qui l'a trouvé près de Vanues dans la Minclie. Cetle coquille appartient maintenant à MI. de Rivoli, daus la collection duquel nous l'avons exaninée.

Longueur, cinquante nillim., largeur, vingtcinq.

\section{ANATONE. Anatomus.}

Genre proposé par Montfort (Conchyl. syst. tom. 2. pag. 278.) pour une petite coqualle qu'il a observée cu grand nombre altachée au Fucus natans. Ce geure qui d’après MIontfort auroit a l'ouverture de la coquille une fissure profonde, est restć incertain pour plusieurs raisuns, d'abord parce qu'en fait de découvertes on sait que Montforl ne se faisoit gnère de scrupule de tromper; cusuile c'est que jusqu'a présent personne n'a retruuvé cetle coquille; qu'on olsserve au contraire venant des nèmes régions, le Fucus natans convert de spirorbes qui, détachés, présentent quelquefois une fissure sur le côté plat. Ml. d’Orbigny fils, qui s'est spécialement occupé des petites coquilles trochordes a fissures quil a réunies en genre sous le nam de Scissurelle, n'a point observé la coquille de MIontfort, qu il lunt rejeter des Mollusques on tout an moins la considéres comme très-mal figurée. Vojez Scissurelies el Pleuhotomatre.

\section{ANAULACE. Antzulax.}

M. de Roissy, pou éviler la confusion qui pourroil résulter de deux dénominalious aussi voisines que celles des genres Ancyle et Ancille, avoit proposé le nom d'Anauluce pour ce dernier, ce fut daus le Buffon de Sonnini qu'il opríra ce clangement; mais MI. Lamarck ayaut douné le now d'Ancillaice au genre Ancille, peu de temps après la dénomiantiun da savant prolesseur jréralut et on vublia aussi bien Ancille qu'Auaulace. Yrojez Axcillaire.

Alicilie. Ancilia.

L'atuteul du Musénm geressianum a créé sous 


\section{A I C}

ce nom un genre entièrement inutile démembré des Calyptrées. Le Calyptraca throcoüdes Dillw., a servi de type. Foyez Carrptrées.

\section{ANCILI.AIRE. Ancillaria.}

La seule coquille vivante que l'on connoissoit du tenups de Limue fut placce par lui et par Gmellin dans le genre Volule, ce que firent égalenent ses imilateurs jusqu'au moment où M. Lamarck porta la réforme dans ce grand genre et créa à ses dépens un grand nombre de coupes dont celleci lait partie. On trouve pour la premiere fois ce genre dans le Traité des Animaux sans vertèbres (1801), entre les genres Olive et Volute, arec lesguels il a effectivement les plus grands rappors, et il porte le nom d'Aucille Ancille. M. de Roissy, pour éviter la confusiou de ce nun avec celui du genre Ancyle Ancylus, avoit proposé la dérsotnination d'Anaulace qui ne fut point adoptce, parce que peu de temps après M. Lamarck lni-même le changea coutre celui d'Ancilluire. Ce ne fut pas encore dans la Plulosophie zoologique qu'il fit ce changement, mais seulement dans les Annales du Muséum, et par suite dins l'Extrat du Cours (1811). Dans ces deux onvrages, la fumille des Euroulées contient le geure qui nous occupe dans ses rapports naturels avec les Olives, les 'I'arrières, etc.

Dans l'intervalle de ces deux ouvrages, Montfurt pulslia son Truité systématique $\hat{d e}_{0}$ Conchyliologie oì il conserva ce genre sous sa prinative dinumination d'Ancille. Les autenrs systérnaliques allemands ne tinrent pas compte, a ce gu'il paroit, de la création de ce genre, du moins an ne le lrouve ni dans Ocken, ui dans Schweiger. N. Cuvier a fait le même oubli dans le Règne animal, puisqu'on ne le trouve mentionné nulle part dans l'ouvrage de ce savant aaturaliste.

Comıne dans ses précédens onvrages, M. Lamark conserve, dans son Truité des Animaur sans vertébres, les mêmes rapports à son genı Ancillaire et le laisse dans la mêue famille, celie des Enroulées (zoyez ce mot): il fut en cela ì peu près imilé par. H. de Ferussac (Tableaux méthod. des Anim. moll.) qui, en admettant dans l. fumille des Enrunlées les genres Maruinclle et Volsaire, les y plaça de telle sonte que les Ancillaires se trouverent entreux et les Olives, ce qui change un pen, mais pas d'une manière bien innportaule, les rapporis de ce genre.

Quoique NI. Latreille (Fam. nat. du Règ. animal, pao. 197.) ait divisé en trois la famille de M. Lamatick, le genre Ancillaire, qui se trouve dans celle des Olivaires ( voyez ce mol), n'a pas changé d'ane manière notable dans ses rapports aaturels, étant avec les Olives et les 'Turrières.

M. de Blainville, Traité de Malacologie, laissa bien les Ancillaires avec les Olives et les 'Tar- rières, mais les mit aussi cn contact avec les Mitres et les Yolutes qui, avec plusieurs autres genres de la famille des Enroulées de M. Lamarck, font parlie de la sceonie secion de la liamille des Angristomes (voyez te wot); celle section ne ralssemble que des coquilles saus opercule. MI. Sowerby conserva dans ses deux ouvrages, le Minéral conchology, et the Geners of Shells, te premier non de M. Lamarck, celui d'Ancille, guoiq̨u'ils fussent publiés postérieurement au changement que ce suvant apporıa lui-même à celle dénominatiun.

\section{CARACTÉRES GÉNÉRIQUES.}

Animal tout-il-fait inconmu.

Coquil e oblongue, subcylindrique; ì spire courte, non canaliculce aux sutures. Ouverlure longitudinale, à peme éclancrée à sa base, versante. Un bourrelet calleux el obli fue au las de la columelle. laamk.

Quoiqu'on ne connoisse pas l'animal des Ancillaires, les coquilles sulliscut pour établir leut analngie avec les Olives; elles n'en dilfèrent en cflet que par le défaut de canal à la sutnre et un bourrelet columellaire en général plas saillant. Ces différences sont saus doute de peu de valeur, et elles deviendroient encore bien moindres si l'animal avoit une eutiere ressemblance arec celui des Olives, mais cela nous semble peu proba1.le; daus ce cas se réaliseroit l'opinion de M. de Ferussac, qui présume que les Ancillaires formeront par la suile un suns-gente des Olives. Comme dans ce deraier gente, l'animal des Ancillaires doit avoir un très-ample mantean qui cache tous la coquille et la polit constamment.

Si le défaut de canal sur les sutures distingue les Ancillaires des Olives, le bourrelet colunellaire empêche de les confondre, soit avec les Tarrières qui ont la columelle lisse, suit avec les Bucins qui sont généralement plas renllés et ont égalemenı la columelle simple.

Les $A$ ncillaires sont toules marines, on n'en connoil qu'uo pelit numbre à l'élal frais. Les terrains terliarres à lossiles en contiennent un plus grand nombre.

1. Anciziarne cannelle. Ancillaria cinnamomea.

A. testâ oblongầ, ventricoso-cylindraceâ, custaneo-fulvâ, anfractibus supernè albido fascicttis; varice columellari rufo, substriato.

Lamk. Anim. s. vert. tom. 7. pag. 413. no. I.

De Braswv. Trait. de Malac. pl. 28.fig. 3.5. a.

Anaulax cinnumomea. Rorssx. Buff. de Sonn. Moll. tom. 5. pag. 431, no. 1 .

Chesrs. Conch. cab. tom. 10. pl. 147. fig. $158 \mathrm{r}$. Encyclop. pl. 3g5. fig. 8. a. b. 


\section{A N C}

Cette espèce est une de celles qui sont le plus répanducs dans les collections; elle esı ovale, oblongue, subcylindracée. La spire est courte, peu pointue, chaque tour porte une zône blanche, assez large sur le deraier; chacun d'eux est séparé par une petile ligne fauve qui iudique la suture.

Toule la surface extérieare est lisse, polie, de couleur cannelle. Vers la base de la coquille on remarque un double sillon qui pait de la partic postérieure de l'ouverture, se dirige obliquement sur le dos de la coquille pour aboutir et se terminer à l'an rle antérieur de la lèvre droite. L'ouverture est plus longue que large, évasée à la base, el!e se rétrécit au sommet; la lèvre droite est siuple, obtuse posiérieurement, un peu tranchante antérieurement. La lèvre gauche n’est point bordée, elle se compose de denx parties distinctes, l'une oblique postérieure, l'autre cylindracće est perpendiculaire, elle constitue le bourelet; il est fauve et à peine strié.

On ignore la patrie de cette coquille qui n'a que vingt-cinq à trente millimètres de longuear.

2. Axcillaire ventrue. Ancillaria ventronsa. $\mathrm{L} A \mathrm{ATK}$.

A. testâ ovato-ventricosâ, aurantio-fulvâ ; spira apice obtusiusculâ; varice columelari ulbo, lceviusculo.

Lask. Ann. du Mus. tom. I6. pag. 304. $n^{0} \cdot 2$.

Ibid. Anim. s. vert. loc. cit. $n^{\circ}$. 2 .

Ancilla marginata? Sow. The Genera. $n^{\circ} .5$. fig. 1 .

Nous pensons que la figure de M. Sowerby appartient bien plutôt à cetle espèce quà l'Ancilluvia marginata de MI. Lamarck, car cette dernière est toujours toute blanche, tandis que la figure cilée représente une coquille fauve dont les caractères s'accordent très-bien avec la phrase caractéristique du savant professeur.

Cette espèce a beaucoup d'analogie avec la précédente, elle est à peu près de la même couleur et sa forme présente aussi de lia ressemblance; cependant elle est toujours plus ventrue; la spire est plus courte, dépourvue de la zônc blanche; les sulures sont complétement cachées, et les tours sont tellement fondus qu'il est impossible de les compter. La surface extérieure est lisse et brillante, le sillon de la base est simple, il est beauconp plus antérieur, et il se termine sur le bord droit par une dent à peine saillante. Ce qui caractérise encore fort biea cette espèce, c'est qu'elle a constamment le bourrelet columellaire tout blanc et légèrement strié.

On ignore égalcment la patrie de cette espèce qui a vingt-cinq millim. de longuens.
A M C

3. Axcillire bauche. Ancillaria candida. LaMr

A. testâ elongatâ, seni cylindraceâ, politâ, candidi, suturis obsoletis; varice columelluri obliquo, striato.

L.ank. Ann. du Muss. loc. cit. $n^{\circ}$. 4. Ibid. Anin. s. vert. $u^{\circ} \cdot 4$.

Anaulax ampla de Rosss. loc. cit. $n^{\circ} .2$.

Voluia ampla. Lin. Gmel.pag. 3467. $\imath^{\circ}$. 116. Chemsitz, Conch. cab. tont. 2. tab. 63. fig.722.

Encyclop. pl. 3g3. fig. 6. a. b.

Il est tirs-facile de distinguer cette espèce de ses congénères; elle est toute llanche, alongée, cylindrique; la spire est courte, pointue, les lours en sont caclićs, toule la surface extérieure est lisse; elle est divisée vers la base par un double sillon, le supérieur est le plus profond, et l'intervalle qui les sépare est assez large et déprimé. L'ouverture est très-longue, étroite; la lèvre droite est simple, séparée du bord grauche au sornmet de l'onverture par un léger sinus. Le bourrelet columellaire n'est pas tnul-à-fait drvit; comme dans les autres espèces, il est un peu cordu dans son milieu, il est élroit et sillonné. Cette coquille dont l'habitat est ineonna, a quelques rapports avec l'Ancillaire à gouttière fossile des environs de Paris.

Longueur trente millimètres.

4.Axcillane éburnée. Ancillaria eburnea. Ков.

A. testâ ovato-acutâ, candidâ, intus flases. cente; spira exerciusculí, acutâ; varice colssmellari minimo, albo, striato; labro dextro basi dentifero.

Pclite coquille d'un blanc d'iroire, c'est-ì-dire jaunâtre; ovalaire, pointue au sommet, ses tours de spire sont confoudus; elle est loute lisse; cn voit à la base un double sillon étroit et déprimć qui aboutit obliquement sersl'angle du bord droi?, où il donne naissauce à une petite dent assez saillante. La spire est alongée et lourerture assez courte, étroite, peu évasće à la hase; le bourreles columellaire est d'un blanc plus éclatant, il est petit et strié. Un dépôt calcaire se remarque sur la columelle à l'angle postérieur de l'ourerure; en dedans celte coquille est d'ua fauve très-pàle.

Patrie inconnue.

Longueur, dix-sept millimètres.

5. Arcruraine glandifurme. Ancillaria glandifomis. IAarr.

A. testâ ovatâ, ventricosiusculâ, subacutâ obtusâve, subtus callosâ; callo apice aperturce cunaliculato; suturis anfractumm occultatis.

VAr. B.) testâ niajore, latione spinî conicâ, acutâ. 
VAR. C.) testâ angustiore; spirâ elongatâ. VAR. D.) testâ subconoüdeâ ; spirâ brevissimâ. Lask. Ann. du Mus. tom. 16. pag. 305. $\pi^{n}$. I. Hid. Anim. s. vert. loc. cit. Especes fossiles, $n^{\circ}$. I.

Ancillaria inflata. Borson. Orjctog. pedemontanat, pag. 25. no. 5. tab. B. fig. 7 . a. b.

Anaulax inflata. Brove. Vicent.pl. 4. fig. 12.

Ancillaria infata. Bast. Mém. géol. sur les env. de Bordeanx, pag. 42. no. 2.

Ancilla glandiformis. Sow. Genera of Shells, $u^{n} \cdot 3 . f_{g} .3$.

Nous conservons de préférence le num donné par M. Lumarck à cette espèce, parce çu’il est le plus ancien. La coquille à laquelle il s'applique est ovalaire, ventrue, le plus souvent obtuse au surmet, presque également rúlrécie à ses deux extrémilés. La spire est assez saillanse, mais it est impossible de compter les cours qui la compose à cause de la couclse calcaire qua la revêt et la cache complétement. Ia base de la coquille oftre un sillon large et peu profond, qui descend obliquemeut vers la base du bord droit, où il se ternune par une petile dent. Louverlure est ova1.iie, plus longue que large, mais plus large au nitieu qu'à la base et au sommet; la lèvie dioite est peu obtuse, si ce n'est postérieurement vers l'a ogle de l'ouverture, où elle s'éparssit et où elle est séparée du bord gauche par un sinus assez profind qui se continue en uu sillon creusé jusque - vers le milien de la spire, dans l'épaisseur de la callosité. La columelle est arquée, chargée de matières calcaires, qui se fondent avec la callosité. Le bourrelet columellaire est oblique, épais, sillowné, heaucoup plus court gree le bord droit; ii est séparé du reste de la surface exlérieure par un sillon profond qui en suit extérieurement le cunlour.

Notre variété B est de Bordeaux; elle est beaucoup plus grande, sa spire est plus courte, plus conoide, et présente un agugle assez pronoucé duos l'eudroit de sa jonction avec le reste de la curpuille.

La variété $C$ est plus cylindrique que le type de l'esoèce, sa spire est plus alongcé, s:an ouverture proportionuellement plus courte.

La viricié D est très-remarquable, sa forme approche de celle d'un cune, sa spire est courte, conique, et fait un angle très-prononcé duns l'endruilde sa jonction avec le reste de la conguile. Ces deux dernières variélés vienneut des fíluns de la 'Tonraine.

Cetle espèce ne s'est encore trouvée que fussile; no la reucontre à Bordeaux, ¿̀ Dax, à Turin, aux euvirons de Vienue en Autriche, et dans les liblunières de la Tuuraulue. Les plas grads indivi- dus ont cinquante-cinq millimètres de longueur, environ deux pouces.

6. Axculane buccinoïde. Ancillaria buccinoïdes. lamk.

A. testâa ovato-elongatâ, acutâ, ad basim spiramque nitidissumâ; aperturâ magnầ ; columellâa callo sub marginat,; varice columellari striato.

L.A us. Ann. du Mus. loc. cit. $n^{\circ}, 2$.

Ibid. Anim. s. vert. loc. cit. $n^{\circ} .2$.

Encyclop. pl. 393. אig. 1. a. b.

Ancilla Buccinoüles. Lамк. Ann. du Mus. Lom. 1. pag. 475. et tom. 6. pl. 44. fig. 5. a. b.

Ancillus buccinoïdes. Mostront. Conchi. syst. tom. 2. pag. 582 .

Anaulax buccinoüles. Rorssy. Moll. tom. 5 . pl. 56. fig. 7 .

Fuvanne, pl. 66. fig. H. 1.

Lister. Conch. tab. 1034. fig. 8?

VAR. B.) Мов. testâ angugtione; spinâ longiore; aperturâ minore.

VAr. C.) Ков. testâ subturitî́; aperturâ $a b$ breviatâ.

Ancillaria subulatı. Lamk. loc. cit. no. 3.

Encyclop. pl.593. fig. 5. a. b. Mala.

Ancilla subulata. Sow. The genera of Shelis. $7 i^{\circ}$. 3. fig. 2 .

Ibid. Sow. Mineral conchology, pl.333. fig.3. 4.

Krorr. Foss. tom. 2. pl. 45. fig. 18.

Quand on a sons les yeux un grand nombre d'individus des lenx espéces que nous réunissons, il est impossible de les séparer réellement : en ćlablissani une série de furmes et en precant les extrêmes, on pourra assez facilement les distinguer comme espèces, mais on ne le pourra plus aussitôt qu'on y ajoutera les iatermédiaires; il faut donc considérer celle espèce daus toutes ses morifications će localités, yui influent souveat sur la forme et daos tontes ses varićtés. On la trouvera depuis la forme buccinoide ventrue, jusqu’a la forme subulée prescine turriculée : on ver'a l'ouverture diminuer de longneur graduellement à mesure que la spire s'alonge. En examinant ensulle comparalivemeut un individu quelconque de la série avec le type de l'espèce, on lui retrouvera ronjours les caractères spécifiques indépeudaris de la forme.

Ia coquille est de forme ovalaire, pointue au sommet qui est fort aigu; la spire est plus ou moins longue, mais les tours qui la composent sont converts d'une couche mince, d'un blate de lait, très-lisse, très-polie el fort brillante, mais point nacrée, comme l'a dit M. Lamarck. Cette concbe couvre une parlie du derniel tour de spire, passe sur la lèvre droite qui est plus obtuse 
dans cet endroit, et devient un bourrelet columellaire plus ou moins épais sur le bord gauche. 'Tous le ventre de la coquille quoique lisse n'est point couvert de cetle couche brillante qui revêt la spire; a la base, on retrouve encore une bande de la mếae nalure, elle se divise en deux parties distinctes: l'une est comprise entre deux sillons dont l'un indique le commencement de la bande, et l'autre moins profond aboutit au milieu de l'échancrule; l'autre partie est comprise entre le bourrelet et le second sillon. La levie droite est mince, trancliante, exce sté dans l'endroit de sa jonction arec le loord gauche oi elle est plus obtuse et ordiuairement échancrée en goullì̀re peu profonde. Le bord columellaire est hordé par une lèvre peu saillante formant une callosité vers l'anyle de l'ouverture. Le Lonrrelet de la base est gros, arrondi, tordu, garni de six à sept plis réguliers, obliques; il est séparé du côlé externe par un sillon profond; il est toujours plus court que le bord druit. Nous possédons un jeune indiviclu de cette espèce qui a conservé ses couleurs; le milieu de la coquille est hlanc, ses tou's de spire sont indiqués par une zône de taches d'un brun rouge, la base de la coquille est de la même couleur, mais sans taches.

Cetle espèce se trouve en abondance dans les terrains de calcaire grossier des environs de Paris; elle se trouve aussi à Valognes. Ia longueur des plus grands individus est de cinquante-deux millimèlies, environ deux pouces.

\section{Axcizlaire renflée. Ancillaria inflata. Noв.}

A. testâ ovato-acutâ, ventricosâ; spirâ subbrevi, conicâ, acutâ, nitidissinıâ; aperturâ subtetragonâ; columellâ callosa; varice columellari brevi, striato.

Quoique voisine de la précédente, cette espèce s'en distingue assez facilement; quelques personnes cependant l'ont confondue avec elle, et M. Sowerby, dans le Mineral conchology, ne les a pas distinguées; il les a représentées toutes deux dans la planclie 333, ce qui donne un moyen bien facile de les distinguer. Ce qui nous confirre dans l'opinion que l'os doit admettre notre nouvelle espèce, c'est la comparaison que nous avons pu fuire de leur coloration, qui est fort dilférente, conme nous le verrons bientôt. L'Ancillaire renflée est toujours d'un moindre volume cque la buccinoïde, elle est ovale, atténuée aux deux extrémités, elle semble composée de deux cônes soudés base à base; celui formé par la spire est régulièrement conique, pointu, très-lisse, étant couvert d'uu enduit brillant qui cache les sutures; il forme un angle oblus à l'endroit de sa jonction avec le resle de la coquille: l'autre a son sommet à la base de la coquille; il est curviligue, il comprend un pea plus de la moitié de la longueur totale; le ventre de la coquille n'est point lisse comme la spire, il est marqué de slries un peu obliques, iriégulic̀rement espacées, qui indiqueat les accroissemens. La lase est revêtue d'une bande oblique divisée en trois autres par deux sillons; la premic̀re est comprise entre le bourrelet ef un sillon superficiel qui aboutit an milieu de l'échancrure de la base; la seconde est au-clessus de celle-ci, le sillon qui la sépare de la troisième est quelquefois à peine sensible, il est cependant plus marqué vers la columelle que vers le bord droit, où il disparoît entic̀rement dans quelques individus. L'ouverture est la moitié de la longuenr de la coquille, elle est subquadrangulaire, plus large daus le milieu qu'à ses extrémités; la lèvre droile est mince et tranchante daus toute son éteudue; à sa jonction avec le bord gauche, elle présente un siuns lien prononcé : dans cel endroit la columelle est garnie d'une callosité assez épaisse, lisse et polie; cetle callosité descend en s'amincissant sur la columelle jusqu’à l'origine du bourrelet; celıi-ci est médiocie, il est garni de quelques sillons; sa longrueur égale presque celle du bord droit, ce qui n'a pas lieu dans l'espèce précédente.

Nous passédons un individu de celle espèce qui a conservé des traces bien sensibles de la primitive coloration; la spire est d'un blanc jaunâtre, cette conleur a une teinte plus toncée vers les sutures; la callosité columellaire est de la même couleur, mais le bourrelet est blanc teinté de jaune à la base. Le ventre de la coquille est d'un gris cendré. La bande de la base est d'une belle couleur orangée, et le pourtomr de l'écluancrure est d'un blanc jaunâtre très-clair; à l'intérieur, elle est blanche et le limbe est jaune. Nous le faisons remarquer encore une fois, cette coloration est tolalement différente de celle de l'espèce précédente.

Cetle coquille est fossile des environs de Paris; on la trouve surtoit dans les grès marins, à Ermenonville, à la Chapelle près Senlis, à Valmondois, à Monenville; on la reucontre aussi nais rarement dans les calcaires grossiers, à Monchy. Les plus grands individus nont que lreatre cing millimètres de longueur.

\section{Ancrlzara conoïde. Ancillaria conö̈lea.} Noв.

A. testâ coniforni, lavigatâ; spinâ toto callosâ, depressầ subplanâa, margine angulatâ; basi attenuatâ; aperturâ ovatâ callosà; varice columellari obliquo, uniplicato.

Voici sans contredit la plus singulicre et la plus remarquable espèce du genre, elle a complétement la forme d'un cóne à spire aplatie, forme jusqu’à présent inusitće dans le genre qui nous occupe. La spire est trés-courte, aplalie, revêlue d'une couche épaisse, lisse, qui en cache conplétement les cours; elle se joiut pa un angrle 
assez saillant avec le reste de la coquille; la couche calleuse déborde cet angle pour s'appliquer sur le dernier tour, el elle devient très-tápitisse à l'angle postérieur de l'ouverture, sur le bord droil ainsi que sur le gauche, où elle s'érale davantage. La callosité du bord droit est séparce de colle du bord gauche par un sillon assez profond, qui continue le sommet de l'ouverture. I.e ventre de la coguille est lisse, il est borné a la base par une baude divisée en deux parties inćgales; la première est uo sillon assez large qui part du tiers postérieur de l'onverture pour' se diriger obliquenent vers l'angle antérieur du bord droit; l'autre partie est toute lisse, elle occupe le reste de la base de la coquille. L'ouverture est ovale, allénucie à ses deux extrémités, large au milieu; sa lèvre droite esı mince, teraunée antériemenent par un angle un peu saillant; le bord c.lumellaire est arqué presque en demi-cercle; il est trc̀s-calleux au sommet, et il se termine nar un bourrelet oblique, étroit, séparé du reste de la coquille par un sillon prufond : duas toule son étendue, il n'en ollie lui-mêtae qu'un seul.

Celte coyuilie vient des faluaières de la 'louraine, oì elle est rare; elle a vingl-cinq inillimètres de loogueur, près d'un pouce, el vingt unilliàètres de large à la base de la spire.

9. Axcincaine olivule. Ancillaria olivule. I. A. testâ cylindraceâ, mucronatâ; labro basi unidentato; columells callosi; varice minimo angristo, striato.

Lask. Ann. du Mus. tom. 16. pag. 3o6. no. 4. Ancilla olivula. Ibid. Ann. du Mus. tonz. I. pag. 475 .

Anaulax olivula. Rorssr. loc. cit. $n^{\circ}, 6$.

Encyclopédie, pl. 393 . fig. 4. a. b.

L'Ancillaire olivule est rès-facile à distinguer des autres espèces, sa forme cylindracée la caractérise; sa spire est arrondie, presque en manelon, terninée par uoe pointe aiguë; elle est peu régulicere dans les vieux individus, à cause de la callosité qui n'est pas d'une épaisseur égale; celte callosité cache tous les tours de la spire, ils paroissed confondus quoiqu'ils ne soient que rachés; celle couche calleuse occupe un peu plus de la moitié de coute la coquille, elle couvre une partie du deraier tour; elle est lisse, polie, brillante. Le ventre de la coquille est lisse mais terne; Ia base est rétrécie, et comrue la spire elle est couverte d'uoe couche polie, qui ue commence quian-dessous d'un sillon étroit et enfoncé, qui aboutic à la base de la lèvre droite, où il se termine par une dent saillaole. L'ouverture égale la rnoilié de la longuenr totale; elle est quelquefois plus courte; elle est ovalaire, aiguë au somnet, qui se termine par une petite goultière creum sée duns la lève droite, à l'endroit de sa jonction avec la gauclie; le bord ganche est gami diune callosilé au sunumel de l'ouverture; il est d'abord oblique el se termine par le bourrelet columellaire, qui est droil, étruil, strié el aussi long que le lrord droil.

Cetle espèce se trouve abondamment à Grignou, à Couragnon ct it Moachy, où clle prend un peu plus de volume. Le plus grand individu de celle dernière localité â vingi-six millimètres de longueur, pris d'un pouce.

10. Ancrllatre donluuse. Ancillaria dubia. Nor.

-1. testâ orato-conicâ, subuentricosâ; spirầ regulariter conicấ, acutá, aperturầ oyato-acut.., elongatâ, basi dilutatá; varice columellari oblequo, minimo, substriato; labro basi unidentato.

Cette espèce a de l'analogic avec la précédente, mais elle ea dilfere assez pour que nous la séparions provisuirement; nons disons provisoirement, parce qu'il seroit possible qu'on trouvât quelques individus intermédiaires : alors celle-ci ne seroit qu'une variété de l'autre; elle est à peu près de la même taille, inais elle d’est pas cyliudracée; pour la forme, elle se rapproclue de l'Ancillaire bucciooïde; elle est ovalaire, pointue au sommel; la spire est régulièrement conir̨ue, elle n'est point chargée de callosilés irrégulières; la couche qui la revît est mince et brillante, elle ne descend pas aussi bas sur le ventre de lat coquille; la zône de la base est la mèıne; elle est surmontée d'un sillon qui se termine sur le bord droit par une dent fost saillante dans quelques individus. L'ouverture est plutôt triangulaire qu'ovale, elle est dilatée à la base, pointue an sommet, oì on ne trouve qu'une petite callosité peu épaisse; tonte la columelle est oblique, un pen arquée dans son milieu; le bourrelet columellaire suit sa direction; il est étroit, petit, strié légèremeut et presqu'wussi long que lé bord droit.

Nous avons recueilli cette espèce à Beaucbamp daus le grès marin, et daus les calcaires grossiers de Grignon et de Monchy. Elle est longue de vingt-cing millimètres. กов.

11. Axcillatre alongée. Ancillaria elongata.

A. testâa ovato-elongat $\hat{a}$, utrâque extremitate altenuatâ; spiri prelongâ, obtusâ; aperturâ ovatầ, mediocri; columeliâ rallosâ, arcuatâ; varice angusto unistriatu.

Ar. Buccinum obsoletum? Brqceri. Conch. foss. subapp. tab. 5. fig. 6. a. b.

Notre espèce a beaucoup d'analogie avec celie de Brocchi que nous venons de ciler, cependant elle n'est pas tont-a-lait semblable, ce qui nons a délerminés à la séparer. L'Ancillaire alongée est fort longue, fort étroite, peu callense, rétrécic 
à ses deux extrémités, ce quii lui donne la forme d'un oviale très-long et fort étroit. La spire occupe plus de la moitié de la longuenr totale, elle esi couverte d'une couche lisse qui en cache tous les tours; son extrénité eit arrondie et obluse. la base est séparée en de'ux parties inégales par. un double sillow yui descend de l'ouverture au bord droit ; lintervalle entre les deux silluns est le plus étroit. L'ouverlure est oviluire, rétrécie à ses deux extrćmités; elle est plus courte que la spire, et clle est it peine calleuse sur la columelle; celle-ci est arquée médiocrement el teminée à la base par un bourrelet oblique, étroit, le plus souvent lisse on préscntant une slrie seulement. La base est échancrée, mais celte échancrure est médiocre. Elle vient des fuluns de la Touraine oì elle est fossile. Sa longueur est de trente-trois millinètres, et sa plus grande lirgem de douze seulement.

12. Axcretaire à gouttic̀re. Ancillaria canaliferu. LAuk.

A. testâ cylindraccâ, nutrcronatú; labro dextro, columella, canali disjuncto; varice columella, obliquo, contorto, angusto, sulplicato.

Ancilla canalifera. Lанк. Ann. du Muséum, tom. 1. pag. 475 ; et tom. 6. pl. 44. fig. 6. a. b.

Anaulax canalifera. Rorss . loc. cit. $\pi^{\circ}, 5$.

Ancilluria canalifera. I.amk. Ann. du Mus. tom. 16. $n^{n} .5$.

Olisa canalifera. Lask. Ann. du Hus. tom.16. pag. $327 \cdot n^{\circ} \cdot 1$.

Ancilluria canalifera. Ibid. Encyclop. pl. 593 . fig. J. a. b.

- Ibid. Anim. s. 2'ert. loc. cit. $n^{n} .5$.

Ancillaria canalifera. BAst. Mém. géol. surles env. de Bordeaux, pag. 42. $n^{\circ}$. 1.

Ancilla turritellata. Sow. Mineral conch. tab. 99. fig. 1. 2.

Par une erreur involontaire, sans doute, MI. Lamarck a reproduit deux fuis cette espèce, dans deux genres différens, dans celui-ci et dans les Olives; il est certain que ce. ne pent élre une Olive, car elle a tous les caracitires des Aucillaires; elle a même heancoup de rapports avec l'Ancillaria candida, dont nous avons parlé précédemment. Celle-ci est subcylindricue; la spire est conique; les sutures quelquefuis visibles son fort souvent cachées par une callusité longue ct assez ćpaisse, qui passe aussi sur le sommet du bord droil et l'épaissit notalilement. I.a couche caleaire qui cache les tours de spire ve furme pas une bande tranchée sur le dos de la coquille, comme cela a lieu dans la plupart des especes; elle se fond insensibiement et disparoit de manière à laisser apercevoir duns presque toute leur lougueur les stries d'accroissemens, quelquefois peu régulières, qui se remarquent sur la face externe de la coquille; elle est dilatée à la base et ouverte par une très-vaste éulancrure; celte base est pourvie d'une bande oblique, polie, çui part du sonmet de louverture, dans la plupart des individus, ou d'un peu plus bas pour se rendre a l'angle du bord droit. L'ouverture est alongée, triangulaire, calleuse au sommet; c'est daus cet endruit et dans l'épaisseur de la callosité, qu'est creuséc une gontlicre qui sépare le bord droit du gauclie. Ce bord gauche esi oblique dans toule son étendue; il est formé en grande partie par le bourrelet columellaire qui es! Iongr, étroit, lordu sur lui-même, composé de deux parties bien distincies séparćes par un sillon en goultière; il est beaucoup plus court ciue le bord drort.

Cette corgnille est connue à l'élat fossile seulement; elle est commune aux environs rle Paris, i Grignon, Courlagnon, Parnes, Monchy et Acy en Mulitien, dans le grès marin supérieur; on l'observe aussi idealiquement semblable à Barton dans l'argile de Londres, ainsi qu'à Bordeaux et à Dax. Les plus grands iudividns ont rente-trois millimètres de longueur, un pouce rois lignes.

\section{ANC.YLE. Ancylus.}

Le genre Aucyle, créé par Geolliny et adop!é par Miller, est un de ceux qui ont le plus varié dans la place el dans les rapports que lui ont donnés les auteurs systémaliques. Linné, malgré la création de ce genre avant ses deruiers travaux, le conlundit avec les Patelles; Bruguière ne suivit pas l'exemple de Miller'; aussi on ne voit pis le yenre Ancyle ligurer daus les Tubleaux methodiques de cet auteur, et si l'on cherche dans !e premier volume de ce Lictionnaire, on trouve le mol Axcrae arec un renvoi aux Putelles, ce qui prouve que ce conchyliologue, d'ailleurs si judicieux, avoit adopté de préférence l'opiuion de Linué. N1. Lamarck, un peu plus tard, ne fit pas de même; sans adopter le gemre de Geoflioy, il en prit le nom avec une ortungraphe diflérente, pour l'appliquer à un nouveau genre voisin des Olives. Ce ful donc Draparnaud, le premier parvi nous, qui reprit le genre Ancyle, oublié pendaut loug-teaps, et qui le rélublit sur les caractères de Geollroy et de Miiller. Cet excellent observaleur n’hésila pas alors de rapprocher ces animaux des Planorbes, des Iimnées el des Plyyses, dans ane section séparcée de ses Gastéropodes.

Cependant en 1809 M. Lamarck u'avoit point encore admis le genre Ancyle, comme Draparnaud lui en aroit donué l'exemple, et l'on voit encore, daus sa Phalosophie zoologigue, le mot Axcılle appliqué au geure dont nous arons déjà parlć.

Avant cela, M. de Roissy, dans le Bufforl de Sonninz, Innt. 5 des Mollusques, pag. $25.5(1805)$, avuit aussi, comme Draparuaud, qu'll ne cite ce- 


\section{A N C}

pendant pas, rétabli le genre Anegle de Gcaftroy, et it le place à côté des P'atellc's, avaut les k'jssurelles, en faisant observer très-judicieusement qu'on le mentooit plus tard dans d'autres rapports, mais qu’il devoit èlre bécessairement séparé des Paréles. Mlalgré ces antécédens, Montfort cornservaut l'opinion de Bruguiere, on plutôt n'ayaut pas trouvé le genre formé dans les ouvrages de Ml. Lamarck, lui trouva, quiant is la coquille, beaucoup d'aualogie avec filusieurs espices de Patelles dont il fit le genre llelcion placé entre les Pavois (Parmophore) el les véritables Parelles. NI. Cuvier ne tit pas entrer d'abord ce genre dans la classification générale, il ne le unentionua que dans les additions ef corrections de son ouvrage ( $R$ ègne animal), e: indiqua sa jlace parmi les Pulmonés, ce gui vient ì l'appui de l'opioion de Draparnaud. Après avoir eacore oublié re genre dans l'Extrait du Cours, N. laumarck le fit entrer entu dass son ciernier ouvrage; il élabłit, il esı vrai, avee beaucoup de séserve, des rapports qui se rapprocheut assez de ceux de Linné et de Brugnière, puisque c'est arec des geures tous démenibrís des latelles de ces auteurs qu'il est assucié. Il fail parlie de la famille des Calyptraciens dont tous les autres genres sont Branchileres et l'ecinibranches. Celfe opimon, quoique motivée d"après quelques caractères, ne fut pourtant point admise généralemcui, ct nous pensons, avec beaucoup d'autrés zonlogistes, yu'elle est erronće; nous voyons, en effet, d'un côté, NI. P'feiffer les ranger parmi les Cyclubranches de M. Curier avec les Patelles et les Oscabrions, ce qui fervit penser que le savan allemaud a trouvé un systeme branchial semblable à celui des l'atelles et des Oscabrions, ce qu'il ne dit purturtant pas. D'un autre côté, nous voyons MI. de Ferussac reproduire l'opinion de Drujarnaud et de N. Cuvier, en les admettant au nombie des l'ulmonés aqualiques, ce qui au moins est molivé sur l'observalion des moeurs de l'animal el sur quelques traces d'organisation. Ealin, M. de 13lainville, dans son Fraité de Malacologie, étahissant encore de nouveaux rapports d'apiès la place des organes de la respiralion, en lait, avec les Ilaliotides, la famille des Otidés (vojez ce mol); il pense que l'Ancyle est peclinibranche et que la branchie est situće sur lé cóté qauche. Si cela existe ce seroit le seul point de contact qui s'uffiroit entre les deux genres de celte famille, car du reste ils n'ont aucune ressemblance. Ce seul fuit du savant auatomiste infirme, ou au moins read plus donteuse encore, la question des Ancyles, et vient détruire touies les conjeciures que l'ou avoit pu faire sur ce genre considéré dans loutes les opinions que nous venons d'exaniner. Il résulte de ce qui précède une suite de variations assez notables : créé par Geoffroy, ce genre est confondu avec les Patelles; il est extrait des Patelles pour faire partie des Gastéro- podes (Draparnaud); il reprend place comna genre distincl conte les l'alclles et les Crépidules (Roissy); il c'st coufondu de nouveau avec une section de vétilables l'atelles (Montfort); puis il est compris dans les P'ulannés aqualiques (Curier); i! passe parni de vérilables pecrinibrauct!es datus la famille des (alyptraciens (1.amarck); il est transporté bientôt atpris parmi les Cyclobranches (Plciller); il revient parmi les l’ulaionés (Ferussac); et culin est transporté parmi les Suctibranches dans la famille les Otidés (Blaiaville). Nous termioons ce résumé en faisant observer que 11. de Blainville, dans les dernières corrections el additions à son Traité de Mulacologie, rejelte P'opinion qu'il avuit d'alord manitestée, pour proposer de meltre actuellement le genre Ancyle dans son ordre cles Monopleurobrauclues (20yez ce mol), sans doute dans la fauilie des Patelloides, ce cutil ne spécifie pas; conduit à ce changenént par l'observalion d'une nourelle espèce qu'il a reçue de Ténírife de $M 11$. Quoi el Gaymard.

De coutes ces opinions, il n'y en a qu'une seule qui soit sanctionnce par plusicurs zoologistes, c'est relle de Draparnaud, adoptée par M. Curien. et M. de Ferussac, qui considérent les Ancyles comme pulenonies et les placent en consiquence avec les Liannées, les Planorbes et les Plıyses, dans une même lamille. De cette diversilé d'opinions et de leur dirergence, il résulte un fait, le senl qui soil incoutestable pour tout esprit jusle et inipartial, c'est que les Ancyles ne sont point cncore assez connues pour les flaces invariablement dans leurs rapporis naturels d'organisation. Plusieurs obstacles sopponeront pelıt-être longtempseneore à l'étude aprolondie el compléte de ces animaux; le plus grand, le plus insurmontable, est leur petilesse. Si on ajoute une grande acollesse dans leur contexture, et quelques autres difficultés non moios grandes, on se fera une idée des soins et des peines auxquels devra se résoudre le zoologiste qui voudra éclairer la question. Les caractères génériques onl dû varier relatiremeut aux opinions de ceux qui les ont donnés; $11 . \mathrm{L}$ amarck les exprime de la manière suivanie.

$$
\text { CARACTÉRES GÉXERIQUES. }
$$

Corps rampant, tout-à-fait recouvert par une coquille. Denx ientacules compritaćes, trorquées, ayant les yeux à lem base iutcrne. Pied court, elliptique, un peu moins large que le corps.

Coquille mince, en cône obliçue, à sommet pointu, incliné en ar'icère, nou aurarinal, ouverture ovale ou arrondic, ayant ses bords trèssimples.

Toutes les Ancyles sont d'eau douce; e!les aiment les eaux stagnantes ou peu courautes; elles babitent même de petits élangs susceptibles de se dessécher pendant la saison chaude; elles se tiennent peu éloiguées des bords, s'attachent 
aux pierres, mais de préférence anx plantes aquatiques, le long desquelles elles aiment à wonter jusquà la suifice de l'eau; M. de Ferussac dit qu'elles y viennent souvent, et qu'alors elles font jaillir un petit canal qui prend l'air nécessaire à l'acte de la respiration.

M. de Blainville, dans la caractéristique de ce genre, entre dans dea détails que nous croyous devoir rapporter pour compléter davantage la connoisance des animaux; le mantean a les bords minces, déponru d'apjendices tentaculaires, il ne déprasse pas la lête qui est fort grosse; les tentacules sont peu conlractiles, elles out à leur cûté externe un appendice loliacé. La bouche est toutà-fait inférieure, ouverte dans une masse boccale, considérable, prolongée de chaque côté en une sorte d'appendice. Líanus cst du côté gauche, Lranchics latérales, daus une sorle de eavité située au milieu du côlé gauche de l'animal, entre le pied el le manteau, et lerace par un appendice operculaire.

Il existoit une grande confusion parmi les espèces, parce que, comıe la judicieusement observé $M$. de Ferussac, chaque auteur en trouvaul une nourel!e espèce, l'a rapportée à l"une des plus connues, parce que leur descriotion n'était point suffisanment exacte. Liauteur gue nous remons de citer dans som article Axcres du Dickonnaire classique d'Histoire nuturelle, rapporte meuf espèces vivantes, quoiqu'il ait exclu 'Ancylus spina rusce de Diaparaud, que l'ou a recomnu depuis appartenis i un Entomostracé du gente $C_{\text {ypris. }}$

$11 y$ a peu d'annces ciue lon ne connoissoil pas encore de coquilles de ce genve à l'élat fossile. M. Desmarest, le premier, en signala une jolie espèce, hien distincle des vivantes connues; elle est décrite et ligurće daos le Nouveau Bulletin de la Société phrlomatique, janvier 1814 . Depuis nous en avous dtécourcrt deux antres espèces aux environs de Paris, l'ue que nous avous décrile dans notre ouvrage sur les fossiles des environs de celte capitale, elle vien des Silex meulières; l'autre ne nouś a ćté comue que depuis, elle est des marnes blanches d'Epernay. Eulin MI. Schlotheirn, avec l'analog've do l'Ancylus lucustris, en a trouré une autre espece toujuus fort épaisse dans les tufs culcaires de la 'Thuminge, non loin de Bourigt sna.

1. Ancrle des lacs. Ancy/his lacustris. Drap.

A. testâ conoïde $\hat{a}$; semiovatâ, membranaceâ; aperturú ovatia, suboblong $\hat{\imath}$; vertice subcentruli.

Patella lacustris. Lin. Gmr. pag. $3710 . n^{0} \cdot 97$. Ancylus lacustris. Muder , Ferm. test. pag. נ99. $n^{\circ} .385$.

Ibid. Drap. Hist. des Moll. pl. 2.fig. 25, 27.

Patella cornea, Porret. Prod. Fag. Io1.
L'Ancyle. Georf. Coq. des env. de Paris, p.122.

D'ARgexv. Conch. pl. 27. fig. 1 ; et Znomorplose, pl. 8. fig. I.

Coquille pelite, très-mince, très-fragile, ovale, oblnnque, de couleur de corne, très-lisse, quelquefuis un peu itrégulière; le sommet un peu postírieur, incliné sur Je côlé, par conséquent la coquille n'est point symútrique; elle est ı̀ès-lisse, ses bords sont très-enliers, très-minces et trèstranchans. Cotre espèce n'est pas rare, on la trouve dans tonte la parlie tempérée et chaude de l'Europe, dans les ruisseaux el les eaux douces peu courantes.

Sa longueur est de six á huit millinètres, sa largeur est de deux ou trois seulement.

2. Axcru. lluvialile. Ancylus fuviatilis.

A. testî conoïda, mucrone zerticis executrico; aperturấ ovatâ.

Ancylus flusiatilis. NuLL. Hist. verm. p. 201. $n^{\circ} .586$.

Lister. Anim. angl. tab. 2. fig. 52.

L'Ancyle. Geoffrox. loc. cit.

Patellufuriutilis. Lis. Gmel. p. 3711. n०.98.

Ancylus fuviutilis. Drap. loc. cit. $\mu l$. 2. fig. 25. 24.

Ibid. LaA M. loc. cit. $n^{\circ} .2$.

Ancylus riparius. Desanaest. Note sur les Ancyle. Nonveau Bulletin des sciences, 1814. pag. $19 \cdot$ pl. 1. fig. 11.

Ancylus Juviatalis. Pre1f FER. pl. 4. fig. 45.44.

Elle est patelloïde; assez élevée, à sommet excentrique et strié, pointu, recourbé ponstérieurcment, et renversé ni à droile ni à gauche, la coquille restant parlaitement symétriçue; elle est d'uu blanc jannatre ou verdâtre, assez solide et plus calcuire que la précédente; elle est moins alongcé, quoique restant ovale. Elle est assez valriable dins sa furme el ses proportinus, se trouvalit dans presque toules les eaux doures de l'Europe; elle peut éprouver quelques rnodilications locales. Elle est longue de huit millimètres el large de six.

5. Axcrle déprimé. Ancylus depressus. Ков. A. testâ conoïdù, depressissimâ, lavigutâ; vertice excentrico, recurvo; aperturâ ovatooblongâ.

К̈ов. Descript. des coq. foss. des env. de Paris, tom. 2. pag. 101. pl. 10.fig. 13.

Cette petite coquille, qui paroît être très-rare, se distingue des autres espéces par son extréme aplatissement; elle est ovale, oblongue, toule lisse; son sommet n'est point central, il esi postérieur, non symétrique, inclioé à gauche; sa surlace extćrieure oftre quelques stries concentri- 
ques qui sont dues aux accroissemens. Les bords de l'onverture sont simples et tranchans, celle-ci est ovalaire; elle est intermédiaire pour la forme entre l'stncylus lacustris et l'sincylus fluviatrios des auteurs. Nous l'avons trouvée dans uu Stlece liacustro de Jouy : il appartieut à la seconde fornation; elle est longue de quatre milliuètres et demi et large de trois, sa profoncleur n'est que d'un millimetre.

\section{A NDROMlí)E. Andromedes.}

Genre propesé par Mon:fort (Conchil. syst., tom. 1. pag. 38), pour une coquille microscopigque que MI. Lamarck a depuis comprise au nombre de ses Vurticiales; M. de lerussac l'a placée dans le gente Léticuline, et M. de Blainville, plus justeusent et a l'exemple de M. I anarck, daus le genre Vorliciale. M. d'Orbigny fils, daus son travail sur les Céplualopodes microscopiques, a reuui en un sen! les denx genres l'olystomelle et Vorticiale de M. Lamarck, et les Anchromèdes s'y trouvent naturelleneut conprises. Voyez PoLYSTOMELLE.

\section{ANE.}

Par ce nom vulgaire les marchands de coquilles désignent quelques-unes d'entreiles : ils nommeni P'etit ane le cyprad Asellus; la PeAu d'axe le cypnea Caurica; voyez Poncelaixe. Ils nomnient aussi l'ANe raYe ou le Zèrre, l'Achatina zebra. lask. Bulimus zebra. Bruguiére. (Voyez

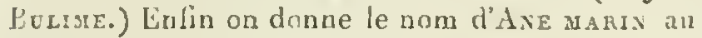
Poulpe (voyez également ce mol).

\section{ANGLE. Angulus.}

N. Mégerle a proposé sous cetle dénomination un genre dans lequel sont groupées par petites sections, les coquul!es que 11. Lamarck avant lui avoit fait entrer pitus naturellearent dans le genre Telline et dans le genre Psanmobie; en tratiant de ces deur: genres nous pallerons des divisions secondailes de M. Mégerle. Vojez Térixe el YS.AMOBIE.

\section{ANG YSTONE. Angystoma.}

Genre informe de Klein (Tent. ostrac. pag. 1o.) qui renferue des coquilles associées la plupart su" le caraciere de l'étroitesse de l'ouverture reudue plus petite encore par des denis gui en obstruent l'entrée. Suns se conformer à ce caractere exclusit, Klein lait eatrer dans son genre des coquilles qui ae le présentent pis du tout, comme la Jantline, THélix laciea, aspersa, el mème un 'Trochus. Est-il besoin, apres ce que nous venons de dire, d'ajouter que ce geure est tombé dars l'oublı?

\section{ANG YSTOMES. Angystoniata.}

Nouvelle famille créée par M. de Blainville dans Hisloire Nalurelle des Vers. Tome II. son Traite de Malacologie ( pag. 413), pour rénnir sous un caractere comman el pen important selon nous, un assez grand nombre de genres divers que les conchyliulogues avant lini avoient groupés d'une maniére toute différente.

Cette famille est divisée en deux sections distinctes d'après la présence ou l'absence d'un op ercule. La première comprend les genres Strcmbe et Cône, auxquels il faudra joindre le genre Mlitre, qui est aussi pourvu d'un opercule rndimentaire. Dans la seconde section, on trouve les genres Tarière, Olive, Ancillaire, Mitre, Volute, Marginelle, Péribole, Porcelaine et Ovule. Daprès celle énumération, on voil dans celle famille des genres qui constituent plusieurs familles de M. Iamarck. Ainsi les Stronbes font parlies des Ailées, les Cónes des Euroulées avec les Tarières, les Olives, les Ancillaires, les Porcelaines et les Uvules; enlin les Marginelles, les Mitres et les Tolutes, lunt la plus grande partie des Plicacées.

Le genre l'ćribole, comme l'a reconnu un peu plus lard M. de Bliunville lui-mêare, a été lormé I par Adanson pour de jemes Porcelaines; it deI vient conséqucument inutile depuis que ce fait est bien connu.

Si les deux genres Strombe et Cône ne sont rapprochés que dlaprics la coquille, il est certain qu'il n'y a entreux que très-peu d'analogic: il est vrai que presque tous les Strom!es dans le jenne âge ont la neéue lorme que les Cônes; mais nous croyons qu'on ne peut établir de bons rapports par la comparaison de jemnes individus d'un genre avec les individus adulies d'un autre. On sail que daus bien des genres il existe une énorme diflérence entre des coquilles d’àges diflérens, à tel puinl qu'on a pu, arant que les observations fussent assez multiplices, faire denx genres pour deux âges dans les mênes coquilles. Le genre Strombe est un des esemples les plus saillaus de ce que nous venons de dire; nous croyons quon ne peut proposer de bons rapprocbemens que par lia comparuison entue des coquilles de même àge, sins cela on tomberoit dans de graves erreurs. Du reste, jl existe des dillérences assez notables entre les animaux des denx gentes, pour qu'on puisse les séparer sans inconvéniens daus deux fimilles discinctes.

Quant au genre Vitre, il s'éloigne des Strombes plus encore que les Cûnes et n'est point susceptible de conposer une coupe nalurelle arec ces deux genres; il a (rop de rapports avec les Volules pour qu'on puisse raisonnablement les en sépartr, surtout de celles qui forment la seconde secition de M. Lamarck. Les leux genres Mitie et Folute s'éloignent d'aillenrs notablemeat ites Olives, des Porcelaines, des Ovules et des $A_{11}$ cillaires, qui se réunissent par un caractère bieu tranché, le poli, le brillant de la coquille, qui lient à la mauière dont le manteau se développe sur elle, pour la polir et y sécréier des couches 
de matières souvent bien différente pour la couleur, du test de la coquille tans le premier age; peut-être, Jes genres Marginclle et Volvaire devront-ils encore se joindre à ceux que nous venons de citer, car comme eux ils sont conslaminent lisses et polis. Nous reviendrons eneore sur ces questions en traitunt les familles et les genres que nous avons cilés dans cet arície el auxquels nous renvoyous.

\section{ANGULITIIE. Angulithes.}

Montfort est le créaleur de ce genre inutile fait avec les espèces de Nautiles munis d'un carène dorsale; l'espèce qui sert de type au genre est pétrifiée et peut-être appartient-elle aux Ammonites; ce qui nous le fernit croire; c'est que, dans la localité d'où vient celle coquille, on trouve assez fréquemment une Ammanite de la seetion des Orbuliles qui est carénée, et jamais depuis Montfort, du moins à notre cunnoissance, on $\mathrm{n}^{\circ} \mathrm{a}$ retrouvé son Nautile. Fojez Nautilaées et Na TILE.

\section{ANNEAU.}

Nom vulgaire de la Porcelaine anneau, Cypraca annulus. Limk. Voyez POHCELAiNe.

\section{ANODON.}

M. Ocken, dans son Traité de zoologie, donne ce uom latin au genre Anodonte de préférence it Anodonta, consacré long-temps avant lui. Yoyez Mulette.

\section{ANODONTE. Anodonta.}

Genre que Bruguière a établi sous le nom d'Anodontite dans les planches de ce Dictionnaire, et que 11. Lamarck, et presque tons les zoologistes, ont adopté sous le nom d'-Anodonte. Ce genre, par les animaıx, n'offre pas la moiudre différence avec les Mulettes; et, par les coquilles, il y a eutr'eux une telle fusion, qu'il est impossible de les séparer netterient; ces motifs nous ont déterninés à les réunil pour les partager en groupes d'espèces. Vo; ez Mulette.

\section{ANODONTIDES. Anodontidia.}

N. Ratinesque a établi, daus si Monographic des coyuilles de l'Ohio, celte rroisic̀me suus-tawille qui correspond rès-bien au geure Anodonte des auleurs, dès quion ne peul adinellre le nenre à ce litre, à plus furte raison une sous-famille qui le représuute; elle ne conlient que le genre Anodonle lui seul, et il est partagé en trois sousgenres, Auodoute, Struphite et Lastène. (Voyez (:es mots el Molette.)

ANODONTJTE. Anodontites. Dénominalion employée par Bruguière dans/l'lle-de-krance. les planehes de ce Dietionnaire pour un genre de coquil!e qui a été consacré sous le nom d'Anodonte par tous les auteurs qui lui ont succédé. Voyez ce mot et Mlouette.

\section{ANOMALINE. Anonalina.}

Genre établi par M. d'Orbigny fils dans l'ondie des Microscopiques foraminifères, fumille des IIélicostèyues nautilöides, pour un petit nombre de coquilles soil vivantes, soit fossiles, qui n'avoient point été connues avant lui; elles ont la forme Nautilöde; mais elles se disıuguent, ainsi que les Vertébralines, des autres geñes qui ont une forme analogue, par l'inégualitédes côtés dont l'un est plus bombé que l'autre, de sorte que les coquilles de ce genre ne sont pas synéiriques.

Nous ne counoissuns de ce genre que les deux espèces représentées par M. d'Orbigny, el nous ne les conuoissons que d'apres lui. Niayant jamats $\nabla u$ des coc uilles de ce greure en nalure, nous n'ivons pu les comparer avec quelques coquilles ches enviruns de Paris qui, par le plus grand nombe de leurs caraclères, pourroient entrer dans be genre qui nous occupe : un seul pourroit cependant les en exclure; elles sont toul-à-fait aplaties d'un côté, lorlement carćnées sur le dos, et nous pensons, d'apres quelques indices, qu'elles ont pu être adlı́rentes; nous n'en avons cependant jas la certilude.

$$
\text { CABACTÉRES GÉNÉRIQUES. }
$$

Coquille discoïle, sans tours apparens; à un seul rang de loges; côlés inćgaux, l'un bombé !'autre plat. La méme furme ì tous les âges; orrverture latérale, en fente, placée contre l'avanodernier lour de spire.

1. Avomanise pouctuée. Anomalina purcinlata. d'Onв.

A. testấ opato-descoïdeâ, undiquè puncticur latú; latere convexo et umbilico calloso, alteri) plano, umbilico subaperto; aperturât minamâ, semilunari.

D'Orn. Mém. sur les Céphal. Microscop. Arn. des scienc. nat. tom. 7. mars $1816 ., p l$. $15 . \mathrm{fi} .1$. 2. 3.3 his.

Coquille Nauliloide dont le dernier tour caclıe tous lís autres; il est composé de luit loges bicn dislinctes, un peuvésiculaires, et toutes couvertrs a l'extéricur de ponctuations nombreuses et irrégulic̀res; sur le côtú le plus convexe, l'ounbilic est recouvert par une callosité arrondie, andis qu'il est presciu'ouvert de l'autre côté. L'ouverture est on fente semi-lunaire plus sur le côté le plus plat que sur l'autre. Celte coquile vient de 


\section{A NO}

ANOMALOCARDE. Anomalocardia.

Genre composé par Klein (Tcnt. ostracol. pag. 141.) de toutes les coquilles bivalves, condiforincs, telles que Bucardes, Petuncles, Arclics, etc., et mème le gente Gulatbée de N. Lamarck: ce geare ne pouvoit être adopté.

\section{ANOMIA.}

M. Ocken crés inutilement ce genre qui, bieu long-temps avant lui, avoil été tormé par Ml. Lamarck sous le nom d'dicule que son autériorité a fait conserver par tous les zoulogistes moderues. Voyez Avicule.

\section{ANOMl'TES. Anomites.}

Autrefois quand les lérébratules faiscient parlie des Anomies on leur donaoil plus parliculierement le nom d'Anomit.s; aluourl'hui que ces coquilles en sont séparécs, on ne peut plus lcur appliquer le même nom, el il devroil sester pour les vraies Anomies à l'élal fossile; mais on n'ernploic presque plus maintenant la terminaison en ite pour les espèces fussiles d'un genre connu à l'état vivant, de sorte que celtc expression toun he en désıétude et disparoitra bientot de la science, oi elle est inutile. Voyez Axoure el 'T'ÉrébraTULE.

\section{ANOSTEOPIIORE. Anosteophora.}

Dans la nouvelle méthode de M. Gray la clisse des Céplaalopodes est partagée en trois ordres: le premier est celui qui prorle ce nom d'Anosteophora; il ne renferme que le seul genre Oclopode aurguel nous renroyons, aiusi qu'í $\mathrm{C}_{1}$ bbalopodes.

\section{A.TOSTOME. Anostoma.}

Lister est le premier, à notre connoissance, qui ai liguré la éoquille q̧ui a servi depuis î l'élalissement du genre Auostome; il l'a fort bien séparé des autres Ilólices dans une séction partirulière, la onzième et deraière de ses coquilles terrestres, caractérisée par le renversement de l'onrerture, et par les denis qui en garnisient l'entrée. Le genre est dunc bien indigué dans Lister, car il ne faut que substituer genre it section pour l'élablir; ceperdant comme cette coquille est terrestre et qu'elle a beaucutp de rapports avec les Hélices, on la confundit coujours avec elles, cl Liuné lui-mêne ae l'cn sépara pas; en cela, l'auteur du Systema natures ful innité par ses successeurs jusqu'a Montfort, qui fut le premier qui sépara le genre Anostome des IIélices de Linué. Il lui donua le noa de Tomogère que beaucoup plus tard, et dans son deruier ouvraure, M. Lamarck changea pour celui d'Anostome plus généralement adopté. MI. Lamarck plaça ce gense dans sa lamille des Coliwacées (voyez ce mol), immédiatement après les Hélices dont il seroit impossille de les séparer.

M. de Fernssac fit rentrer les Anostomes daus le gene Ileitice; il fuit, avee les autres espèces qui out l'ouverbure garnic de dents, un sousgeare auquel il a donne le nom d'Hélicodonte (vuyez ce mot et HÉLıCE). N1. de Blaiuville, en adoptaut ce gemre, lui a conscrvé le nom dooné par Mlǫutfort, ei l’a placé daus des rapports analogues à ceux indiqués par M. Lanarick. M. Latreille enfin s'accorde encore à l'égard de ce genre arec la célélure autem des Animaux soms vertèbres, sur ti place tue les Anostomes devoient occuper dans la série.

\section{CARACTÉRES GÉNERTUES.}

Coquille orbiculaire, ì spire convexe et obluse; ouverture semi-lunaire, dentée en dedaus, grimaçante, retournée en laant ou du côté de lá spire; bord droil ayant son limbe réfléchi.

Animal iucounu présumé voisiu de celui des IIélices.

Si on admet que ces caracteres sont absolument nécessaires pour ce genre, nous connoissons quelques conquilles qui, sans les aroir tous, ont celui qui paroit le plus essentiel, le renversement de l'onverture ver's le dos de la coquille; mais celte ouverture est simple et sans clents à l'intérieur. S'il est aussi cossentiel q̧u'une coquille, pour faire partie des Anosiomes, ait le double caractère des dents à l'ouverture, et du renversement de celle-ci sur le dos, il s'ensuivra gue les coquilles dont il est question devront constituer un nouvean genre. Nous le proposernus sons le nom de Stropgostume, Strophostoma, auquel nous renvoyons, ainsı qu'à Ilélice.

Les Anostomes sont des coquilles terrestres qui ont l'ouverture disposée d'une manière fort extraordinare, on peut mêtre dire presquiuique parmi les Mollusques. Les tours sont régulièrement en spirale coonme dans les autres Ilélices, mais le dernier lait no coucle pour se diriger ver's le bord oin il se renverse pour présenter l'ouverlure du côté de la spire ou da dos de la coquaille. L'ouverture n'est poiut ronde comme l'a dit M. Lamarck, elle est semi-lunaire, et les deux extrémités du péristome s'avancent sur la coguilie jusque près de la suture de l'avant-dernier tour. On ne connuit encore que deux espèces de ce genre; elles ont une fintine su!ngiobuleuse; elles soni fort rares dans les collections; les marchands les conuoissent á cause de leur liaut prix et de leur forme iusolite, qui leur a valn le nom de Lampe antigue.

I. Anostose déprimé. Anostoma depressa. LANK.

A. testâ suborbiculari, utrinquè convexâ, depressiusculâ, obtusé carinatâ, imperforatô, glus- 
brâ; rufâ, subitùs maculis castaneis pictâ; supernè lineâ circulari rubente; aperturâ quinque dentatá; labro rubescente valde reflexo.

L.syx. Anim. sans vert. tom. 6. 2e. part.pag. $101 . n^{\circ} . r$.

Lister. Conch. tab. 99. fig. 100.

Boxasis, Recreat.fig. 350.331.

Dargexville, Conch. tab. 28. fig. I"3. 14.

Favaxie, Conch. pl. 63. fig. F. 10.

BоR. Mus. coss. vind. tab. 14. fig. II. 12. 920 .

Chemsitz, Conch. tom. 9. tab. 109. fig. grg.

Helix ringens. Lix. Gnell. pag. 3018. no. 22.

Ibid. Noller, Verm. pag. $17 \cdot n^{\circ} \cdot 216$.

Tomogeres ringens. Moxtr. Conch. syst. tom.2. pag. $55 \mathrm{~g}$.

Helix ringens. Feraus. Moll. terr. et fup. pl. 55. fig. 3. 4 . 5. 6 .

Tomogenus depressus. Buarsv. Trait. de Malac. pag. 459. p!. 39. fig. 4. a.

Coquille assez grande, globuleuse, également conrexe des deux côtés, subcarénée daus son milieu par un angle fort obtus dans les individus adultes, beaucoup plus aigu dans les jeunes. La spire se compose de six tours régulièrement en spirale; ils sont peu globuleux; ils sont séparés par une suture simple qui est bordée par une bande unique d'un brun-fauve. Les premiers tours sont d'un blanc laireux, rougeătre, qui passe insensiblement au faure qui est la couleur du dernier tour; celui-ci est plus grand que tous les autres, il occupe tout le dessous de la coquille, où quiltant la direction spirale, il se projette en ligne droite en traversant la moilié du diamètre de la coquille pour se termiaer sur le bord par une ouverture qui regarde le dos ou la spire de coquille. Ce deruier lour, sur un fond lauve, offre noe multifude de taches irrégulières d'un rougebrunâtre qui le rencen! cowne marbré. L'ourerture est semi-luaaire, versante, à péristome épaissi, renversé, plus épais sur le bord gauche que sur le bord droit; !e bord yauche se prolonge jusqu'it la suture de l'avant-dernier tour, tandis que le droit se termine sur le bord de la coquille et est plus court que l'autre; tout le péristume est d'un rouge-fauve. En dedans, l'ouverture est garnie de cinq dents d'inégúles grandeurs, deux sont columellaires, l'une grande et l'autre petite; des trois autres la médiaue est la plus grosse, celle du côté gauche la moyenne, el celle du cóté droit la plus petile de toules.

Quand celle coquille est bien fraiche on remarque sur toute la surface des stries absolètes, longíludinales et assez régulières.

Longueur, quarante à quarante-cinq millim.; langeur trente-six à quaraute. Elle habite l'Inde, ò elle paroît rare.
2. Avostoure globuleux. Anostoma globulosa. LASIE.

A. testâ subglobosâ, ob̉soletè carinatâ, inmperforatâ, glabrấ, supernè nifâ, subtìs albâ, maculis rufis marmoratâ; anfractibus omnibus, lineâ rubrâ distinctis; aperturâ sexdentatâ; lubıo albo, margine reflexo, sinu instructo.

LA.rx. loc. cit. $n^{\circ}, 2$.

Helix ringicula. de Fentss. Moll. terr. et flup. prod. $n^{\circ}$. I1 4 . pl. 53. fig. 1.2.

Espèce très-facile à distinguer de la précédente; elle est toujours d'un plus petit volume, plus globuleuse et subcarénée dans son milien; ses deux cûtés sont presqu'égaux, à peu près aussi convexes l'uu que l'autre, quoique celui de der sous le soit un peu plus. La spire est formée de cinq à six tours, à peine conrexes, dont la suure simple est indiquée par ude baude rouge qui en suit les contours; en dessus elle est d'un fuve - ilanchâtre, quelquefois elle est toute blanche; en dessous le dernier tour est presque toujours blanc, marbré de taches rousses peu nombreuses surtout vers l'ouverture; à l'endroit où ce dernier tour après avoir fait le coude gagne directement le bord de la coquille, on remarque du cólé gauclie un renllement assez nolable. L'onverture est très-remarquable par le nombre et ta graudeur des dents qui se voient à l'intérieur ot qui laissent entr'elles si peu d'espace, que l'on conçoil à peine comment l'animal peut passer à travers tous ces obstacles. Le péristome est tont blanc, épais, renversé; à gauche il ne toucbe pas à la suture de l'avant-deroier tour, mais à droite il forme un sinus fort singulier à l'endroit de son adbérence à la coquille. Les dents sont au nombre de six, deus columellaires fort grandes dont l'une est tuilée et peu obtuse, et l'autre arrondie en un bourrelet épais; des qualre du bord droit la plus petite est vers l'angle droit de l'ouverluie.

Cette espèce, qui vient ćgalement de l'Inde, est plus rare dans les collections. El!e est longue de riugt milliunètres et large de quinze.

\section{ANSATA.}

Denxième classe des Monoconcha de Klein (Ostrac. pag. I I 7.), qui renferme toutes les coquilles patelloides assez voisines des Patelles pour la forme; il se divise en quatre genres qui sont les suivans: Calyptraa, Cochlearia, Mitra ungarica et Cochlolepas, presque tous des démembremens inutiles des Cabochons. Voyez cos divers mots.

\section{ANTÉNOR. Antenor.}

Montfort, dans sa Conchyliologie systématique (tom. I, pag. $7 \mathrm{r}$ ), a établi ce geure pour une
petite coqnille microscopique de l'ordre des Cé- 
phalopodes; il a été adopté par quelques zoologistes; les uns l'on placé parmi les $\Lambda$ mmonites, les antres parmi les Nautiles, d'autres parmi les Lenticulines, ce qui rejette cette petite coquille loin de ses rapports naturels. M. d'Orbigny tils, apprès un examen approfondi, l'a fail entrer dans le gence Robuline, qui fail partie de son orde des livaminifères, famille des Agitlistègues uautiloides. Voyez Robulise.

\section{ANTIIOBRANCHE. Anthobranchia.}

Déjà M. de Blaiuville, dans le Bulletin des Sciences (1816, pig. 93), avoit établi sous le nom de Cyclobranche un ordre dans lequel plusicurs Mollusques nus étoient rangés d'après la disposition des organes de la respiration : antérieuremenl, M. Cuvier avoit aussi donné le nom de Cyclobranche à un ordre, mais renfermant d'autres Mollusques que les Cyclobranches de H. de Blaiuville; on pouvoit, d’après ce double emploi, ètre eutraîné à des erreur's graves. MI. Goldfuss, pour éviter toute confusicu, a conservé les (yyclobranches de M. Cuvier, et a substitué le nom d'Ant?robranches aux Cyclobranches de M. de Blainville.

3. de Ferussac, dans ses Tableaux systématiques, a adupté le nom de M. Goldfuss pour le premier sous-ordre des Nudibranches qui ue conlient que la famille des Doris. Voyez ce mot, ainsi que Nudibranchb el Crclobanache.

ANTLIO BRANCHIOPHORES. Antlio brachiopliora.

Dénomination qui a le défant d'être trop longue, que M. Gray a proposée dans sa Classification naturelle des Mollusques, pour la première classe qui correspond complétement anx Céphalopodes des auteurs. Celte classe se compose de trois ordres : $1^{\circ}$. Anosteophora; $2^{\circ}$ Sepiafora; 3०. Nautilophora, auxquels nous renvoyons, ainsi qu’à Céraalopones.

\section{ANTI-BARILLET.}

Nom donné par Geolfroy, dans son Traité des coquilles des environs de Paris, à une petite espèce de Maillot, Pupa quadriens, que Bruguière a rangte dans le genre Bulime sons le nom d'Antibarillet. Voyez Bulime, pag. 351 , no. 91 du premier volume de ce Dictionnaire.

\section{ANTI-NONPAREILLE.}

Nozn donné par le même à une autre espèce dn genre Maillot, Pupa cinerea, que Bruguière a également décrit sous le nom de Buline antinonpareil daus l'endroit que nohs venons de citer ${ }^{\circ}$. 92 , anquel nous renvoyons. Voyez aussi MALLOT.

\section{ANUS.}

Ce mot a deux acceplions différentes selon l'application qu'on cn fait; auatomiquement, c'est comme dans tous les autres animaux, l'extrémité postérieure du tube intestinal; mais dans les coquilles Bivalves, c'est l'impression plus ou moins profonde qui est au-dessous des sommets et que l'un nomme plus comnuuément lunule. (Yoyez ce mal, Mollusque el Cogulle.

\section{APALOSIA OU APLOSIA.}

Il semble que M. Rafinesque ail eu l'intention d'employer ce nom à la place de celui de Mollusque, ce qui n'a pas étć adopté. Voyez MorLOSQOE.

\section{APLEUROTIS.}

Genre indiqué par M. Rafinesque, mais $\mathrm{rop}$ peu caractérisé pour quou puisse rien statuer it sun égard; il a ćlé démembré des Térébratules. lojez ce mot.

\section{APLODON. Aplodon.}

Genre iutilement démenbré des Hélices par 11. Rafinesque, pour une espèce qui a la bouche arrondie, la columclic unidentée et ombiliquée. Beaucoup d'aulres Hílices présentent ce caracic̀re qui est hien insuffisant pour l'établissement d'un genre. Fo, ez HĖstce.

\section{APLYSIE. Aplysia.}

Dans un Mémoire très-bien fait sur les Aplysies et inséré dans les Annales du Muséum, M. Cuvier est cntré dans des détails curieux sur l'bistoire de ce genre dont il a fait aussi une excellente anatomie. Nous avous mis ce travail a profit ponr les recberches que nous avions le projet de faire, recherclics qui, au reste, ne nous out conduit comme lui qu'à la connoissance des erreurs nombreuses el des préjugés, soit des Anciens, soit des Modernes sur ces animaux.

Parmi les Mollusques, il $\mathrm{y}$ en a fort peu gni aient été aussi anciennement observés, et il n’y en pas qui soient devenus le sujet de préjugés populaires et de croyances plus absurdes. Les anciens nommoient les Aplysies laṫvae Marin, Lepus marinus; ils lui a voient donné ce nom à canse de la forme que ces animaux ont lorsfu'ils son sans mourement à foud de la mer : lenr léte, pourvue de deux longs tenlacules auriculiformes, donne encore plus de ressemblance avecun lièvre. Cetce comparaison, quelqu'ineracte qu'elle soit, ne peut se comparer aux verlus ou aux propriétés que l'on a attribućes au lièvre marin. Il suffit, comme l'observe très-bien NI. Curier, qu'un animal ne puisse servir à la nourriture de l'homme pour que déjà on ait contre lui quelques préventions. On a bientót dit qu'il est nuisible si, arec 


\section{$5+$}

une forme peu agréable, il offre une odeur repoussante, et si surtaut il répand une liqueur. plus ou moins âcre dont l'a pourvu la nature pour le protéger coutre ses ennernis; mais bientôt celte adeur, cette liqueur et l'animal tout entier, sont transformés en poisons violens, par un peuple grossier, qui ne manque pas en outre de lui altribuer des vertus extraordinaires, quelquefois oppostes. Plusicurs ouvragres de l'untiquité, tels que ceux de l'line par exeuple, peuvent étre considérés comme un miroir fidèle sur lequel viennent se réflćchir les traditions et les erreurs vulgaires qui ont acquis, par leur longue durée, la lorce de la vérite. Nous nous abstiendrons de rapporter les conpoisonnemens altribués au lièvre toariu, nous ne dirons pas non plus qu'on le considéroil comme une cause d'avortement; nous n'exbumerons pas des memiers trailés de médecine les listes assez longues de médicamens dans lesquels le lièvre marin entroit comme substauce héroique contre plusieurs tnaladies. Ne seroit-il pas ridicule aujourdbui de discuter la question de savoir si un lomme qui regarde un lièvre marin peut en nourir comme on l'it cru en Italie, ou si c'est le lievre marin lui-méme qui périt comme c'est la croyance des Hindous? Cepentaut ces prójuarés, accrédités par l'ignorance, se perpéturrent lursque la moindre expérience auroil suffi pour les délruire; rapportés par les Auciens, ils trouvèrent au renouvellement des lettres des hommes crédules disposés à les recucillir, à les adopter et à les propage: de nouveau comme l'altesteut les conits d'Aldruvante, de Rondelet et de quelques autres.

Un animal qui inspiroit tant de dégout et tant de crainte ne purvont être examiné d'une manière conterable parr ceux-là mêmes qui le redontoient; aussi si d'un côtć on lroure beaucoup sur ses soidisaut qualités, d'un autre on ue trouve rien sur ses maiurs, sur sa forme et son organisation.

Aristote malheureu emeut n'a pists parlé de ces animaux, nous disuns matheureusement, parce quail étoit capable, plus que les autres naturalistes de l'antiquité, de domer sur eux d'utiles renseignemens, et d'en laire une description suffisante. Pline, qui en parle beaucoup, qui rapporte longnement les propriétés du liève mariu, se contemte de dire quil est comme une uasse de chair intorme. Dioscuride e compare à un petil Cálinar, el celle comparaisun est loiu d'être exacte. Elien réussit mieux en lui trouvaut de la ressemblance avec uu limaçon saus caguille; celle comparaison est la plus judicieuse, etle rapproche des êtres d'uue mine classe, d'un mếne type, et elle pent conduire à des rapprochemeos lieureux. Mais de tous les auteurs ancieas, Apulée est le seul qui ait reconu une particularilé renarguable de l'organisation du lievre m.rin; ćcal la stracture de l'estumac, daus lequel il décourrit le premier des o.sselets qu'il compara à ceux des pieds de cochon.
A P L

Depuis Apulée jusqu'au renouvellement des lettres, on ne trouve rien concernant le lièvre marin. Rondelet, dans son Traité des poissons, au livre $17^{e}$, est le prewiel qui en ait douné une ligure reconnoissable quaique grossière, et qui en ait fait une description an moyen de laquelle on peut furt bien le reconnoître; il remarque judicieusement que cel auimal n'est pas symétrique, ce qui peut aicier singuličrement à le faire distiuguer d'autres analogues. Le même auteur décrit ct figure une seconde espèce qui appartient incontestablement an genre Aplysie, puis une troisièue qui ae lui peut convenir puisque e'est une Tritonie (voyez ce not).

Aldrovande et Lesner recopièrent les figures de llundelet, et le premier y ajonta deux espèces dont une est douteuse et l'autre appartient inconrestablement au genre Doris. Il paroit que depuis ces auleurs jusqu'à Linné, personne ne s'oceupa des Aplysies, du moins on rien trouve pas de trace dans les auteurs intermédiaires. Inové luimếme, à ce qüil juroit, conuut lort peu ces animaux, qu'il range clans ses premières éditions parmi les Lernés. Bohadsch, pendant le même temps, décrivuit avec soin el même avec une exactitude font remarquable, les Aplysies que Linné laissait loujours dans le genre lutrné, mais dont il séparoit le geare Téthys fait avec la troisième espèce de lièvre marin de Roudelet, don l'histoire avoit été rendue plus complète par $\mathrm{Fa}$ bius Columna. Ce fut senlement dans sa douzième édition que linué sépara les Aplysies en genre distinct des Lerués; il le nomwa Laplysin, sans doute par suite d'une laule d'impression, comme le lait judicieusemeut remarquer MI. Cuvier, car Laplysia na aucune signification, tandis que Aplysia veut dire qu'on ne peut laver, et cela s'applique parlailement bien à ce genre. Gmeliu, daus la treiziène édition de Linné, rectilia ce nom, et le genie Aplysie fit parlie de la classe des Molluscir placée entre les Limaces, les Doris et les 'l'étlozs. A l'imitalion de Linné, Bruguièı rangea les Aplysies dans la classe des ver's Mulluscrues, cntre les Daris et les Limaces, mais il adcpta de préférence le nom de Laplysie. M. Cuvier, daus sun Tubleau élémentaire d"histoire naturelle, démembra avec juste raison les vers Mullusques de Linué el de Bruguièce, puntrapporter Jes dilléreus animax qui les composoieut à leurs vélitables types d'organisation; c'est ainsi que les Limaces, les Télligs, les Aplysies, las Doris, les Tritonies, etc., fureut compris dans la classe des Mullusques et rangés parmi les Gastéropodes; ce fut une très-grande amélioration dans le systeme de clussification. M. Lamarck en adopta le principe, el dans son premier ouvrage, le systène des Animaux suns z'ertèbres, il en lit l'application; il divisa les flollusques nus en deux sections, la seconde commence par le genre Laflysie et contient les onze geares de MIollusques 
nus Gastéropodes connus alors. Ce fut peu de temps après que H. Cuvier publia, daus le lome deux des Annales du Muséum, le Mlémoire dont nons avons déjà parlé; il compléta, par une savante anatomie, ou plutôt il introduisit dans la science, la conuoissance complète de l'organisation des Aplysies. Dès-lors leur place el leurs rapports ne devoient plus varier beaucoup; et c'rst effectivement ce qui arriva.

M. de Roissy (Buffon de Sonnini, tom. 5.), adopta le premier arrangement de M. Curier, en introduisant les nonveaux genres proposés nouvellement; les Aplysies font parlie des Gastíropodes nus et sont eutre les 'T'éthys, les Scyllées et les Liunaces. M. Lamarck bientôt aprís (Philosophic zoologique, tom. 1. ) perfectionna la classification des Mollusques, comme de plusienrs autres jarties des Aniniaux sans veriębres, en y introduisant des familles. Jusque li on n'aroit pas assez senti combien il étoit nécessaire de sćparer les animax qui respirent l'ean de ceux qui respireut l'air; M. Lamarck alteignit ce but ea érablissant la famille des Laplysiens, qui séprara les Aplysies et les Dolabe!les, qui en sont trés-voisines, des Linaccs et d'autres genres pulmonés qui furent compris daus la famille suivante celle des Limaciens. M. Lamarck avoit compris dans la fanille ćes Laplysiens les genres Bullée el Siralet, dont le dernier s'éloigne assez notalylement des Aplysies el des Dolabelles. Dans l'Extruit du Cours, les Laply'siens sont divisés en deux sections, la première contient les genres Arèse, Bullce el Bulle, et ía seconde les genres S:caret, Dolabelte et Laplysies. La composition al larrangement de celte lamille sernient convevables sans les Sigraets qui ne sont pas il leur véitable place.

B. Cuvier a conservé celle fanille dans le Règne animal, en lui donuant le nom de Tectibranclies, en $y$ incroduisant le genre Notarche, et en y laissant les Aceres qui ont pour sonsgenres les Bullées, les Bulles et les Acéres propres. Cependant M. Lamarck peo salisfait de l'arrangement de sa famille les Laplysiens dans l'Extrait du Cours, el ciuvique M. Cuvier en ait adoplé les rapports, y opcre cie notables changeruens dans sun dernitr ouvrage; nous avous ruo çue cette famille éloit divisée en deux sections, la première servit de base ì une nouvelle famille de Bullćens ( voyez ce nor), laudis que la seconde, débarrassée du geme Sigaret et ne contenant plus par conséqueut que les deux genres A lysie et Dolabellle, constilua la famille des Laplysiens, telle que M. Lamarek la conçut en dernier lieu. M. de Ferussac n'imita pas completement le savint auteur des Animaux sans vertébres, il introduit dans sa famille des Diceres, qui correspond assez bien aux Laplysiens, quatre genres: les Aplysies, les Actron, gui en sont démembiés, les Dulabelles et les Nolarches. On ne sait pourguni II. Iamarck n'a point adopté ce deruier gente, sans doute que dans ce cas il l'auroit mis dans la famille des Laplysiens, conme l'a fait M. de Blainvil'e ('Trait. de Malac. pag. 471.); mais outre celui-la ce savant ajoule encore denx autres, les Bursatóles et les Elysies (voyez ces mots), qui sont mis en rapports avec les Dolabe!les et les Aplysies. M. Latreille, qui nomme Tentaculés (voyez ce nol) la famille des Aplysiens, ia divise en deux secions; dans la première se trouvent les genres Phyllirhoe et Notarche, et dans la secoude les genres Aplysie, Actaon, Dolabelte e: Bulline.

Telle est l'histoire abrógée de ce genre aussi singulier par les erreurs ciulil a fait naître que par son organisation; il ne nous reste plus maintenant, pour teminer ce qui a rapport aux généralités, que d'entrer dans les délails auatomiques, saus lesquels on ne saurait avoir une connoissance complète de ce genre.

Les Aplysies sont des anirnaux limaciformes, ovalaires, plats en dessous, où est un pied long et étroit, boubés en dessus et assez régulièrenent convexes, termicés postéricurement par une pointe peu alongéc, quelquefois nousse, qui est la terminaison du pied comme dans les Hélices; u a vant le corps se prolonge en un col plus ou moins long qui pent s'alunger ou se raccourcir à la volonté de l'animal, e: qui porte une tête assez grosse à son extrémilé antérieure. Celle lête présente une bouche longitudinale; elle porte en avant deux mrands teniacules nembrameux assez variables pour la longueur et pour la forme, et qui sont le prolongement d'une sorle de voile ou tentacule bucate; en arricre il y en deux antres cylindriques flus courts, ployés en deux à leur extrémité, de unarič ì ce qu'sls ressemblent assez bien à l'oreille d'un anirval quadrupèrie; ils sont oculés à la base, intérieurement; ils ne sont point complétenent rélraciles; ils sont suscepiibles de s'ulonger el de se raccourcir à la volouté de l'aninal. Le point oculaire est noir et fort peiit. Le mateau est lormé de deux lanes charnues, dont l'une est ordiaairement plus courte que l'antre; ces deux lames sont libres vers le dos de manière a laisser voir sons elles uue pièce mobile, produile par une duplicalure de la peau, qui contient une coquille cartilagineuse et rudimentaire, libre dans la cavité qu'clle forme, carité qui est ouverte parun trou on complétement ferucéc selon les espèces. Cette parlie, qui est l'opercule branchial, est fixíe par soa cisté gauche de manière à être complétencut libre dans tout le reste de son étendue. Il semble, par la maniere dont elle est mobile, qu'elle soit atlachée jar une charnière; c'est au-dessous d'elle qu'on aperçoit un grand peigne branchial, l'anus et l'issue rtes organes de la génération disposés comme nons le verrons un peu plus lard.

Les Aplysies, comme un assez grand nowbre 
d'autres Mollusques, ont la facilité de répandre une liquenr d'use couleur foncée, destinée à les cacher a milieu de l"eau aux a oimaux qui veulent en faire leur proie. Ceste liqueur est rejetée à la moindre crainte qu'épronve l'animal; il faut çu'elle se sécrète avec assez d'abondance; il ve paroit pas qu'elle ait un canal particulier pour être répandue au-delıors. D’après les observations que II. Cuvier a failes sur des animaux vivans, lexcrétion de la liquear se leroit par exudation sur le bord de l'opercule braucbial. Celle liqueur a été soumise à queiques recherches climiques, qui sont insuffisantes pons' en connoitre la composition exacte : ce sont MM. Cupier el Fleuriau de Bellevue qui ont lait ces expériences. D’ubord cette ligueur n'est poirt mallaisante, comme l'ont cru les Anciens; elle ne donne ancune sensalion désagréable à la peur il paroit même gu'elle n'a pas la propriété de laire tomber le pout comme les Auciens l'a roient dit el comme linué le répète. Lilie est de mème nature que la liqueur pourgre des rochers, et elle pourroil peut-être devenir usile dans la teinture, car elle est fixée par les acides, et surınt par l'acide sulfurique.

Le système de la digeslion comneuce par une bouche longitudinale, coniverte en partie par le roile de lu iête qui y forme des livvres épaisses el rillées, ce qui donne à l'entríe de celte ouverture guelque ressemblance avecu un spincter. Sil'on fend longitudinalement ce voile, on a provoit une fente buccale, étroite, linéaire, dont les deux lèviessubcartilagineuses, luanches, légètrement plissées, sont plus saillaotes inférieuremcint, on elles furment nue espèce de saillie pointue et recourbée en avant. En continuant de lêndre la pear de la tête, on troure use masse huccale cousiciéruble, arrondie, chanue, formée d'un grand nombre de finsccaux thiseux qui l'enveloppent de toutes parts. Lai peau n'y est point adhéreste, si ce n'est auturi des levres sur lesquelles elle est lixie par un grund nombre de petits muscles, qui ront eu rayomant s'altaclier à la peán à peu de distance de leur point d'altache. En péuétraut dans celle cavité, on la tronve garuie de deux plugues coruées ou cartilagineuses, d'un Jarun-rouge, iplacćes rerticalement, et dont le bord antérieur, suilluws, forme les lèvres dont nous avons parlé. Elles out uue forme de lozange, elles sun: lisses et réuuies supérieurement el inférieurement par une meinbrane blanche et mince. La litce interne de ces flaques, celle qui aduère aux parois de la bouche, sout linement strices trunsversalement. Au fund de la bouche on anercyil une misse chanue, conicue, qui est couverte pur les parois buccales, counue par une sorte de cajuchon; cette masse, yue l'on pourroil nommer linguale, n'est pas tcndue en arant, mais bien en dessus, el celle lente, qui naboutit qu'à un trou, est garnie de deux lèvres cornées, cunrexes, brunes, couvertes d'aspérités assez dures; ranjées régulièrement sur des ligues obliques; c'est au-dessus de celte masse linguale que l'on trouve l'onverture œscphagienne et sur ses parties latćrales; mais daus l'épaisseur des parois buccules que l'on remarque l'ouverture des canaux salivaires.

Cet osoplage charnu, médiocrement long, aboulit is un estomac membraneux en forme de cornemuse, qui a quelques boursoufflemens et qui est très-grand. Cet estomac est séparé d'un second par un érraglement pylorique, courl, épais et cbarnu; le second estomac est beancoup plus jelit, subcylindrique, arrondi aux deux bouts el partagé dans le milicu par une zone large, beancony plus clarnue que le reste; elle domne allucbe à l'intérieur à des osselels nombreux qui triturent les alimens après une première digestion. Ce qu'il y a de remurquable, c'est que cet eslomac, dams le reste de son élentue, est compléteneat membraneux, et peut-être plus mince encore que le prenier. M. Cnvier considere comule un troisieme estomac la portion meubraueuse qui suit la zone charnue qui donne insertion atux osselets; mais nous nadmeltons pas celte distinction, puisça'il n'exisle pas entre ccs faulies nu álranglement qui en pút motiver la séparation. Celle portion du second estomac u’est pus moius singuliere cine l'autre; elle présente à lintéricur des crochets cartularincux qui paroigsent destinés à ralenir encore lintroduction des sulstances alimentaires dans les inteslins. C"est dans cetle partie el nou loin de l'orjgine des inteslins que se ruient les obilices des canaux biliarres el celui d'un intestin gricle et fermé à son extrémité, et que pour cela on a comparé avec un cacum. Les iulestius cummencent aprés ce dernier rentlement stomacal; ils sout cylindriques, font dans la masse du foie quatre ou cinc grandes circouvolations; le reclum gagne le hord de l'ovare, s'accole $\dot{a}$ lui et va percer la peau dars 1a cavité branchiale a l'altache postérieure el cu dessous de in brancbie.

La masse intestinale, le foie et l'ovaire, sont renfermés dans un suc membranenx, véritable pélituine, qui se détuche très-fucilement, gui est inince, trausparent et d'une contexture solide. Le f.rie est très-gros, d'un brun-verdâue; il envelople presque ton l'intestin et fournt deux canzux biliaires assez gros qui débonclient dans l'estomae ¿l l'endiroil que nous arons indiqué.

Nous avons va quiau-dessous des deux lobes da manteau se trouve postárieurement un disque membraneax, ovale, composé de deux feuillets entre lesquels se développe un rudirnent testacé, qui reste toujons à l'étut corné on cartilagioeux. Ce disque scrt dopercule anx organes de la respiratiun; il est nobile au-dessus d'eux, et sa purtie postérieure complítement charnue, se ploie pendau: la vie de l'aniuali ea une sorte de lube ou cle gocttière, qui fait saillie entre les lobes du manteau el dome accès à l'eau jusque sur les 


\section{A P L}

branclies. C'est des bords de cet opercule branchial que séchappe la liqueur rouge 'qui est contenue dans un grand nombre de cellules creusécs dans l'épaisseur de la pean qui l'eutoure. Une glande triangulaire, fort grande, qui a des connexions intimes arec les cellules dont nous veuons de parler, et qui est placéc sous la base de l'opercule, est considérée par M. Cuvier comme ayant la destiaation de fuuruir a la sécrétion de la liquen rouge.

L'organe de la respiration est composé d'une seule branchie fixée dessous l'opercule par une altache longiudinale, et elle a la forme d'un deri-croissant dont l'extrúmité la plus petite est divigée en arrière; elle est cnmpuséc d'un graud nomibre de feuillets'à peu près parallèles, qui se sous-diviseut en feuiliets plus petits et latéraux, el ceux-ci encore en d'autres. Deux gros vaisseaux se rendent à cet organe, l'un est placé au bord concave du deni-croissant; il apporte le sang de toutes les parties du corps puur être vivilié par la respiration, e'est l'arlère branchiale : l'autre est convexe, il prend le sang des branchies pour le porter au caur, c'est la veine pulmonaire.

Un fait des plus remarquables dont nous avons douté, malgré l'autoritć imposante du nom de N. Cuvier, jusqu'au moment où nous avons pu le vérifier par nons-tuêmes, est celui relatif à la libre communication encre l'artère branchiale et la cavité qui contieat les vistères. Nous ne pouvons mieux faire que de rapporter textuellement la description que fait M. Cuvier de celle disposition, car elle est d'une graude exactitude, conume nous nous en sommes assurés par la dissection de cinq à six Aplysies de deux cspèces.

- L'artère brancliale, dit ce savant, qui sert 'aussi, si l'on veut, de veine-cave, puisqu'il n'y a pas de ventricule droit, est autrement disposée; sa slructure est nıême peut-èıre le fait le plus extraordiaaire que la physiologie des Mollusques m'ait encore ollert.

- Après avoir reçu, ou plutôt avant d'avoir donné les artères particulières des feuillets, par plusieurs trous semés sans ordre, elle resle quelque tenps lisse et entière; mais une partie se courbe à gaacbe derrière l'allache de l'opercule, et une autre à droite, vers la base du bord saillant de ce côté. Ces deux branches se nortent ainsi en arant et preaneat sulintement une texture bien singuliére. I,eurs parois se trouvant formées de rabans musculaires, transverses et obliques, qui se croisent en loute rorte de sens, mais qui lasssent enir'eux des ouverlures sensibles à l'ail, et perméables à tontes les espèces d'injections, et qui établissent une communication libre entre ces vaisseaux et la cavitć de l'abdomen, de manière que les lluides contenus dans celle-ci péuètrent aiséıneut dans ceux-là et réciproquemét. L'extrémité antérieure de ces deux gros vaisseaux ou de ces deux veines-cares, se cootood mème absc- lument avec la grande cavilé générale; quelques rubans musculaires éloignés les uns des autres, et qui n'iaterrompeut nulfement la libre communicalion, sont les seules liraites apparentes qui distinguent ces veines.

"Celte communication est si peud'accord avec ce que nous connoissons dans les animaux vertébrés, que j'ai voulu long-temps en donter; et même, après l'avoir fait connoille à l'lustitut, il y a quelques annćes, je u'osia pas d'ulrord faire imprimer mon mémoire, lant je craigaais de moêlue trompé; enfin, je suis oblirré de céder ì l'évidence, et dans ce noment oì je peux disposer d'autant d'Aplysies qu'il me plait, je viens de m'assurer par toules les voies possibles, 10. qu'il n'y a poinl d'autres vaisseaux pour portci le sang aux lranchies, que ces deux grunds condrils musculaires et percés que je viens de décrire; $2^{\circ}$. que toules les veines dı corps aboulissent médiatement ou imaédiatement dans ces deux grauds conduits.

"Or, comme leur communication avec la cavilé abdominale est évidunte et palpuble, qu'on les appelle veines-caves ou cavités analogues au ventricule droit, on enfin aréres branchiales, car on voit qu'il's remplissent les fonctions de ces trois organes, il résulte toujours que les lluides épanchés dans la cavilé abdominale peuvent se mèler directement daus la masse du sing ct être portés aux branchies, et que les veines font l'o fice des vaisseallx absorbans.

"Cetle vaste communication est sans doutc uo premier acheminement à celle bien plus vaste encore que la nature à élablic dans les insectes, où il n'y a pas même de vaisseaux pour le lluide nourricier; et nous en avons déjà un vestige cians les Mollusques cépbalopodes, où, comme je le montre à leur article, certains corps spongieux portent aussi le lluide abdominal dans lia veinecave.

"C'est d'après ces faits que j'ai pensé riue le système absorbant cesse entièremeut dans les Mollusq̧ues, et à plus forte raison dans les animaux situés au-tessous d'eux dans l'échelle. ”

Ce que nous venons de rapporter de M. Cuvie! suffit pour nous dispeuser de toute réllexion i l'égard de celle organisation particulière des Aplysies.

La veine branchiale, placée au bard convexe du croissant, formce par les branchies, perce la peau daus l'angle formé par l'opercule, puur gagoer l'oreillelle placée ainsi que le cœen daus an péricarde mince, assez grand, qui contient aussi lorigine des gros vaissenux. L’oreillette, mérlio crement grande, offre une structure particalière, les fibres musculaires qui entrent dans sa composition, formant des anastomoses nombreuses, qui Ia font ressembler à on rćseau à mailles inégales, mais assez fines, ce réseau est enreloppé par que membrace. Cette oreillet:e est adhérente ̀̀ la base 
du coeur et n'en est pas séparée par un étranglement; elle est munie de deux ralvules milrales gui s'opposent au retour du sang vers les branchies. Le cœur est couique, d'un petit volume, un peu aplati, placé obliquement de gauelse à droile, d'avant en arrière et de bas en hiut; ses purois élant peu éljaisses, sa cavilé est encore assez graude proportionnellement à la grossear de cel organe. De la pointe naîl un tionc aorlique très-court, fort yros, qui se divise en trois troncs principaux à sa sortie du péricarde. Le premier, qui est à ganche, gagne le bord antérieur de la zone charnue du second estomac, ou elle se divise en plusieurs brauches dont guelyues-unes se dirigent vers le pylore du premier estomac, et de lia a la petite courlsure pour se répandre sur lui; d'autres, rélrogrades, prarcourent le second estomac, arriveut anx inlestins auxquels elles se distribuent.

Le second trone artóriel pourroit être considéré comme une division da troisième ; dian, assez gros, gagrie le foie sans douner une seule branclie, et se divise dans cet organe en nn grand nombre de branclies dout une priucipale 6e porle sur l'ovaire.

Lé Iroisième tronc est de tous le plas considerable; if se porle à droile, mais avant de sorlir du péricarde il oflie deux crètes charnues, peu épaisses, formées de vaisseaux très-pelits, qui sartent du tronc, se courbent et y rentrent jmmédialement: on ignore à quel usage est destinée nne structure aussi singulière. Ce tronc en sortant du péricarde est accolé au ganglion nerveux de l'abdomen; il done d'abord nne branche pour. les organes de la génération, puis une autre qui relourne en arrière se porter à l'opercule et aux partics postérieures du corps, et enfin une troisième pour les parties postérieures et diroites. Le tronc, notablement dimiaué de volume, se porte en avant, snus l'œsophage, où il dome quelques branches pour les parties gauches du col et du corps, d'autres pour le có:é droit, et parvient à la masse buccale, où il se divise après avoir fuurai un ramean à la verge.

Les organes de la génération sont doubles dans les Aplysies, c'est-à-dire que chaque individu est mále et femelle tout à la fois, comme cela a lieu, au reste, dans un Irès-grand nombre de Mollusques.

Les organes máles sont composés d'une verge isolée à la partie anlérieure du corps, sur la tête, a d'un testicule, et ses annexes, situć irès-loin de là derrière le cour el la masse viscérale, ne communiquant en aucune manière directe à l'intérieur et seulement au-debors par un sillon catané peu profond, qui s'étend sur le côté droit du corps depois l'ouverture des organes de la génération jusqu'à la verge sur laquelle il se continue. La verge est d'un médiocre volume; elle sort audessous du tentacule droit antérieuz au moment de l'accouplement ou pendant l'agonic de l'animal; elle est rylindracée, un peu comprimie et pourvue d'un sillon sar le côté. $\Lambda$ près la mort de I'aninaal, cet organe paroit oblus et percé au sommet, mais il u'en est pas ainsi; se développant à la maaiere des tentacules des limaçons, il reste à moilié dehors et l'extrénité est en dedans reployée sur elle-même : celle extrémité se pelotonue pour ainsi dire en dedans sur la partie supéricure et droile de la tête, el peut se développer sans olsstacle; lorsqu'elie est complétement élendue, elle a la longueur de la moilié du colps au moins; plus grosse à sa base, tlle diminue insensiblement jusqu'au sommet, qui est extrêmetnent allénué. Cet organe est creux probablement dans toule son ćtendue, nous l'avous trouré ainsi aussi loin qu’il nous a élé possible de le fendie; il est muni de deux faisceanx nusculaires assez considérables, les fibres réunies an point d'allache s'isulent à nresure qu’elles s'attacbent à la parui înterne de la verge; le plus gros de ces muscles se lixe à droile et iuféricurement vers le bord du plan locomoteur avec lequel il semble se coulondre: l'autre, beaucoup plus petil, est simple; il se tixe à la peau au-dessous du second teniacule droil el gagne la verge sans se diviser vers son tiers antérieur, el s'y coufnud.

Le teslicule esl gros, alrundi, nvalaire, légère. ment aplali des deux côtés et comne tourné en spirale, parce qu'il est gami d'un canal excréteur en ruban aplati clui affecte celle forme. Ce ruban est composć de deux parties, l'une striće ct vasculaire; l'uutre formant un caval aplati qui, au sommel du testicule, se joint au eanal de l'ovaire. Il en suit les inllexions aprés avoir laissé un lacis semblable à l'épididyme: peu avant de percer la peau, il reçoit le canal fort petit d'une vésicule dont l'usage n'est pas encore déterniné.

L'ovaire occupe la portion la plus reculée de la masse viscérale; il fournit de son milieu un oviducte très-mince qui se dirigre vers le bord, se place tout près du reclum, forme, dans son trajet, pendaut lequel it augmente iusensiblement de voIume, un grand noinbie de plis, et parvenu an lesticule, s'amincit subitemeat, se contoume un graod nombre de fois, et se termine au canal déférent dans lequel il débonche après s'y être collé quelque temps. Mais avant de 'y ouvrir, cet oviducte reçoit le canal fort étroit d'une pelite vésicule pyriforme qui pourroit être l'aoalogue des vésicules multifides des limaçous; on n’en counoît pas l'asage.

Les deux canaux réunis de l'ovaire et da teslicule resteat d'abord séparés, mais bientôt il y a une libre communicalion par une fente qui règne entr'eux, et qui est rendue plus étroile par une crète membraneuse qui indique le point de contact : c'est ạinsi que réunis ils gagneut la peau en avaut et à droite de la tache anlérieure de la branchie où ils s'ouvreat, et c'est à cette 
ouverture que commence le sillon crai va jusqu'à la verge.

Le systène nervenx est fort considérable; il est composé de ciuq ganglions dont quatre placés i la têle concourent ì l'anneau cesophagien que l'un est convenu de nommer le cenvecu dans les anitnaux mollusques. Le ganglion antérieur est placé sous la masse buccale; it est elliplique et fournit des branches priucipalement à la tête et a la masse clarnue de la boucbe; ces branches sont au nombre de quatre de chaque cólé : une cinquième paire descend en dessous de l'resophage pour s'anastomoser au granglion impair sus-cesophagien; celui-ci est subquadrilatère, il recoit à ses angles antérieurs les branches d'anastomose dont nous venous de parler, et donne de chaque có:ć quatre puires de nerfs, trois se distribuent aux parties la ćcrales du cou à droite et à gauche, nuais à droile quelques filets se portent à la partie antérieure de la verge; la quatrième pare part dis ceutre du grangliun et se dirige tout entière aux tentacules postérieurs. I.es angles postérienrs de ces gauglions donnent naissauce à deux troncs lurt courts qui aboutilleut a deux ganglions placés en arricire du premier et sur les parries latérales de l'arsuphage. Chacun d'eux fournil un grand enmbre de nertis, les uns plus nombreux se perdent dans les dillírentes parties de la peau el du pied. Enfin une paire de chaque ganglion se dirige à droite vers le caur et l'ouverture des organes de la géuération, et se jette dans un ganglion assez gros qui est le cimquic̀ne. Les eganglions latéraux somt rísunis parun très-y ros trone qui complètel'anneau nerveux au milieu durquel passe l'osophage. Le ciu-

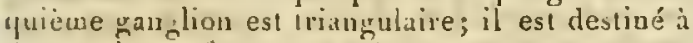
duuner tles nert's aurour ef a ses annexes, et surtout aux orgunes de la géníration; à fournir des filets au fuie, aux iutessins, à l'estomac et en général à tous les viscères. C'est donc a vec juste raison que M. Cuvicr cumpuse celle partie du systcme nerveux au grand sympathique des animanx vertébrés.

'lous les muscles sont cutunés, excepté ceux de de la bouche el de la rerge; ils forment une enveloppe générale dans laquetle le pied lui-même - es compris; celle enveloppe, lorsqu'elle a été un peu unacérée, ollie un lacis iuextricable de petits fuisceaux fibreux qui allectent loutes les direclinus possibles; cependant, on voit de chaque cúcé du corps deux bandes libreuses qui vont vers la léic. C'est à l'aide de ce système musculo-culaué que les Aplysies ramprent à la manière des Limaces, nargent en ondulant leur curps, et se renversent à la surface de l'eau la léte en bas comme les Limnées, les Plasurbes, etc.

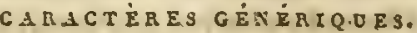

Corps rampant, ollong, convexe, bordé de chaque còlé, d’un unanteau large qui, dans l'inaclivan, recouvie le cou, "2üte porice sur uo con; ayant quatre tentacules, dont deux supériears et auriformes, et les deux autres près de la boucbe. Ieux sessiles, très-perits, en avant des tentacules auriformes. Un écussan dorsal demi-circulaire, subcartilagyineux, fixé par un côté, yecouvrant lí cavilé branchiale. Anus derrière les brancbies. Lamk.

Les mocurs et les habiludes des Aplysies ne sont guère connues; on sait quiclles se lieunent le plus ordinaireacent daos le creux des rochers où elles s'auritent aiasi des daugers qui les entourent; on sait aussi qu'elles pullulent en tri'sgrandes quantités au printemps; que c'est aussi P'évoque de leur accouplement, mais cet acconplement a'a point encorce été observé. Ce Mollusque nu, sans déléce, dont les nouvemens sont très-lents, ne peut altaquer d'autres animanx ou plus agiles que lni, ou plus protégés; il est donc réduit à se nourrir de petits Mollusques jui vircot sur le sable el qui ne peurcat manquer, pilr leur impuissance, de devenir la proie des Aplysies et d'autres animaux semblables.

La Méditerranéc, lOcéan d'Europe, sont les mers dans lesque!les on a jusqui à présent trouvé le plus grand nonire d'Aplysies; cependant on en a obscrvé aussi dans les mers de l'lude, et MII. Quui el Gaymard en ant rapporté quelquesunes des mers Australes. Quelques espèces ont ce caractère particulier propre à lés distinguer facilement: la membrane qui envcloppe le rudimeat testacé est percée en dessus. Une autre esjèce, l'Aplysia virides de M. Busc, n'a pas la paire postérieure de tentacules, les yenx sunt derrière les tentacules buccaux: M. Cuvier pense quäi cause de cela clle pourroit lien constituer un autre genre; aussi $\mathrm{H}$. Ochen en a proposé un pour elle sous le nom d'Actcon, 'tue M. de Ferussac a a adopté, mais que $M$. de Blainville a rejeté comme geare el aduis conme petite section des Aplysies.

II. de Blainiville a aussi placé dans le genre qui nous occupe un animal qui oflie de notables différences, et avec leque!, comıne il le présume, on fera un nouveau geare : c'est son Aplysia limacina qui a la forme d'une testacelle el qui n'a ni coquille ni bouclier pour cacher les branchies, celles-ci se trouvat daus une cavité assez antérieure, creusée sur le dos et couverte par les lobes fort courts dis matuteau. Cet animal offre donc un caractère bien parliculier sulfisant, à ce que nous pensons, pourl'cxclure comane l'Aplysic viridis de M. Bosc du gcare Aplysie.

Après ces réformes le genre resteroit oncore composé de huil espèces que M. de Blainville a sommairement décriles dans une Monographie des Aplysies, insérée dans le tome $96^{6}$ du Joumab de physique (juin 1825). Plusieurs caractères penvent être utilement einployés à la distinction des especes : la proportion des lobes du manteau, qui sope plas ou moins longa, plus ou moins larges; 
la forme et la nature du rudiment testacé et du bouclier operculaire qui le contient, qui est percé suṕricurement dans quelques espèces et qui ne l'est jazais dans d'autres; enfin, la coloration de l'animal qui paroit assez constante pour qu'on puisse utilement s'en servir, quand ce caractère scrt encore à appuyer les autres.

I. Apreste clianeau. Aplysia camelus. Cuv.

A. corpore nigro, elongato, ovali, gibboso; cervice prielongo; testâ tenui, corneâ, pellucidâ. Cuv. Ann. du NIus. tom. 2. pl. 1. fig. 1.

An. Aplysia mulgaris? Buainv. Monographie des Aplysies, Journ. de phy. tom. 96. pl. fig. 1. 2.

Grande espèce qui prend des formes assez diverses, et dout la lête est portée sur un long col. Son corps est ovalaire, bombé en dessus; les lobes du manteau sont larçement fendus d'un bout à l'autre, sans bride postérieure; le lube gauche ést plus large que le droit. Le pied épais et subcaréué en dessus, se prolonge postérieurement en une sorte de queue. La membrane supérioure de lopercule n'est point percéc. La coquille qu'elle contient est mince, cornée, peu profondc.

2. Aptrsie fasciéc. Aplysia fusciala. Lrs.

A. corpore nigro; membranorunt tentaculonmque margine coccineo.

Ap!ysia fasciata. Guex. pag. 3103. $n^{\circ} .2$.

Polrex, Voy. en Barb. pag. 2.

Cuv. Ann. du Mus. tom. 2. p. 295.pl. 2. 3. 4 .

Toutes les analomies ont élé failes sur celle espèce.

Blainv. Monog. loc. cit. $n^{\circ} .2$.

Aplysiafasciata. Lawk. Anim. s. vert. tom. 6. pag. 41. $n^{\circ} \cdot 2$.

Cette espèce est aussi grande que la précédeate; elle se trouve quelquefois avec elle dans les mémes lieux; mais elle se distingue facilement en ce cue tous les bords de ses membranes, de son pied, de ses tentacules et même de sabouche, sont burdés de ronge vif. Cette couleur se passe assez vile quand on conserve cette espéce dans l'alcool. Poiret l'a trouvée le premier sur les côtes de Barbarie; elle se rencontre aussi sur nos côtes de la Manche d'où nous l'avons reçue. La cocjuille est fort grande, assez épaisse, subquadranguluire, membraneuse sur les bords.

3. Aprysie margincé. Aplysia marginata. BuAINV.

A. corpore osato, crasso, nigro, maculis albidescentibus marmorato; pallio tuberculis rotun. datis, nininis, operto.

Buainv. Monog. loc. cit. fig. 3. 4.

Cosps épais, ovale, gibbeux; pied étroil, ridé; les lobes du manteau sont minces, bridés postérieurement, mais peu baut peudani la vie de l'animal; ces lobes sont converts de tubercule. sphériques qui s'effacent après la mort. Le houclier operculaire n'est point percé, la membrane en est grande comparativement à la coquille qu'elle coutient postérieurement; elle se prolonge d'une manière notable, et forme une goultière ou un canal qui déborde les lobes du nantean. La coquille est mince, llexible, cornće, submembraneuse, de forme ovalaire. 'Tout l'animal sur un foud noir est marbré de laches d'un blanc verdâtre ou livide, surtout vers les bords du manteau; elle a quatre à cinq pouges de long, et on la trouve à la Rochelle.

4. Aprysiz dépilante. Aplysia depilans. Lis.

A. corpore livido, fusco-nigricante, postice obtuso.

Laplysia depilans. Lrv. 120. édit. p. 1682. $n^{\circ}$. 1 . Aplysia depilans. Gмгц. pag. 3 105. $n^{\circ}$. 1.

Lernaca. Вонадsca. Anim. marin.pl. 1. 2. 3.

Encyclop. pl. 83. fig. 1. 2., et pl. 84. fig. 1. 2.

C'est l'espèce la plus anciennemeot conune, celle à laquelle on a attribué tant de propriétés; celle qui a été bieu vue par Apulée, ensuite par Roindelel : c'est la premic̀re espece de cet auleur et d'Aldrovande, qui l'a copice d'après lui. Cetle espece est grande, fort convexe, i pied assez étroit et ridé tıansversalement, la masse viscérale portée en arrière; le pied dépasse à peine l'extrémité posiérieure di corps qui, dans cel endroit, esı subtronqué. Les lobes du manteau sont assez grands, réunis postérieurement de manière ì couvrir un peu l'opercule branchial; celui-ci a la membrane supérieure pertée daus le ceatre; tont le corps est d'une teinle livide d'un fauve noirâtre. On trouve cette espèce dans la Méditerranée el sur nos côtes à li Rochelle. Lorsqu'on la touche et qu'on l'irri!e, elle laisse suinter une viscosité blanche, d'une odeur nauséabonde, ì laquelle on attribue la propriété de faire tomber le poil, d'où est venu le nom spécifique donné a cetle espèce.

5. Apt.rsie ponciuée. Aplysia punctata. Cuv.

A. corpore nigro-purpurascente, punctis sparsis pallidis notato.

Cuv. Ann. du Mus. loc. cit. pl." 1. ffg. 2. 3. 4.'

Laplysia punctata. Laur. Anim. s. vert. Joc. cit. $n^{0} .3$.

Buariv. Monograp. loc. cit. no. 6.

M. de Blainville olsserve que cet auimal pourroit bien n'être qu'une variété de l'espèce précédente, mais il ue dit pas sur quoi il fonde sa présomplian. Elle acquiert à peu près le même volume; elle est très-bombée et fort courte quand 
elle est contıactée; la masse viscérale est portée en arrière et le corps est subtronqué postérieuremeni; les lobes du manteau paroissent réunis beaucoup plus haut et convirir divantage l'écusson operculaire. Comme dans l'espèce précédente, sa membrane est percée au centre; elle s'en dislingue aussi par la coloration, celle-ci étant toujours d'un noir rougeâtre et toute parseméc de petites taches pâles et blanchâtres irrégulièrement disposées. M. Cuvier a abservé celte espèce à Marseille, et elle se trouve aussi à la Rochelle.

6. Aptrste unicolore. Aplysia unicolor. Brarn.

A. corpore albido-rifescente, gibboso; pallio antice aperto; testâ profundâ, latâ.

Bramiv. Monog. loc. cit. fig. 9. 10.

Cette espèce n'a pas plus de dix-huit à vingt lignes cte long; elle se distingue facilement:, elle est toute lisse, d'un blane un pen brunatre; la masse viscéralc est Irc̀s-proéminente, placée postérieurement de nanióre à ce que le pied ne la déborde presque pas; le manteau a les lobes petits, réunis très-Jaut postérieurement, de mauière à couvir une partie de l'opercule et a la brider; mais antéricurement le manteau est fendu presque jusque sur le cou. Les tentacules autérieurs sont plus cylindriques que dans les aurres espèces d'Aplysies. La coquille est plus arrondie, plus profonde; elle est très-mince, flexible, cornée et transparente. Nous avons reçu cette espèce de la Méditerranée. Mi. de Blainville l'a observée dans le cabinet de M. Brongniart qui l'a recueillie a Bayoune et à Toulon.

\section{APLYSIENS. Aplysiana.}

Famille de Mollusques proposée pour la première lois par M. Lamarck, dans la Philosophic zoologique, sous le nom de Laplysiens qui, n'ayant aucune signification, a été abandonné par M. Cuvicr et presque taus les zoologistes. Celle famille lint composée d'abord des quatre genres I،aplysie, Dolabelle, Bullée, Sigaret, et placée entre les Pliyllidiens et les Limaciens ( murs). Des genıes qui la constitue le dernier seul, dont on ne connoissoit pas suffisamment l'anatomie, est burs de ses rapports. Dans l'Extrait du cours du même auteur, il fut pourtant maintenu; mais la famille s'augmenta dos genres Bulle et Acère, et fut partagée en deux sections de trois genres chacune : dans la premic̀re sont les genres Acère, Bullée et Bulle; et dans la seconde, les genres Sigaret, Dolabelle et Laplysie. Les rapports de toute la famille furent changćs, du moins par rapport aux Phyllidiens, entre lesquels fut interposée la famille des Calyptraciens.

Il étuit moins pardonnable à M. Lamarck de laisser eucore le geure Sigaret dans cette famille, à l'époque de la publication de l'ourrage que nous venons de ciler, parce que M. Cuvier avoit publié l'anatomie de ce genre dans les fmnales du Muséum ; aussi ce savant ne fut pas la mème lante. Saus adopter le nom de Laplysiens de M. Lamarck, M. Cuvier composa sa famille des 'Tectibranches ( vojez ce mot) des mênes élúnens; aux Sigarets, il substitua les genres Pleurobranche et Notarclue. Les rapports de cette fanille sont les mêmes que ceux indiqués par M. Lamarck dans sa Philosophie zoologigue, c'est-it-dire que M. Cavier la place entre les Phyllidies et les Limaces.

Dans son dernier ourrage, M. Lamarck réforma sa famille des Laplysiens; il forma à ses dépends la lamille des Bulliens, en rejeta les Sigarets, et $n^{3} y$ fit entrer que deux genres qui ont entr'eux, il faut le dire, bcanconp d'analogie, les $\Lambda$ plysies et les Dolabelles. Voyez ces mois.

M. de Ferussac, Tableaux systématiques des Animaux molluscjues, en donnant à cette famille le nom de Diceres (voye z ce mot), y a introduit deux genres, les $\Lambda c$ crons et les Notarches. M. de Blainville à préféré, en la corrigeaut, cunserver la dénomination de M. Iamarck. Ia famille des Aplysiens, dans le Traite de Malacologie, fait partie de l'ordre des Monopleurobranches, et elle est entre les sub-Aplysiens et les Patelloides, mots auxquels nous renvoyons. Elle est composée des genres Aplysie, Dolabelle, Bursatelle, Notarche et Elysie. Voyez ces mots.

M. Latreille, dans ses Familles naturelles, a donné le nom de Tentaculés à la faınille qui reoferme les Aplysies; il parlage cette famille en deux parties, lune ponr les genres Phyllirhoë et Notarche, et la seconde pour les genres Aplysie, Actreon, Dulabelle et Bulline. Il nous a été impossible de deviner pourquoi le genrc Phyllirhö se trouve dans celle lamille avec laquelle, il faut le dire, il n'a presqu'aucuns rapports.

M. de Blainville a caractérisé cettc famille de la manière suivantc : corps non divisé, on lormant une seule masse molle, charnue; quatre appendices lentaculaires constamment bien disliucts, aplatis, auriformes; bouche en fente verticale, avec deux plaqques labiales, latérales, snbcornées, et une langue cordiforme bérissée de denticules; yeux sessiles cntre les deux paires de tentacules; les branchies couvertes par une sorle d'opercule; los orifices de l'appareil générateur plus ou moins distans, et réunis entr'eux par un sillon extérieur. Coquille nulle ou incomplète, constamment interne.

\section{APOLLE. Apollon.}

Genre on ne peut plus inutile proposć par Monifort (Conchyl. syst. tom. 2. pag. 57o.), pour quelques Ranclles qui ont le bord gauche un peu saillant, et derrière une fente ombilicale. Voyez Ranille et Roceza. 


\section{APORRHAIS.}

Des coquilles uniralres ont été indiquées sons ce nom par Aristote; on est resié dans l'indécision pour savoir à yuoi appliguer cette dénotainztion; on a peasé qu"Arislote aroit voula désigracr des Rochers, et Rondelet, ainsi qu'Aldrovande, peosent qu'un peus l'appliquer à une coquille qui fait aojourd bui prarie da genre Plérocère. Klein, en adoptant le genre Aporrbaīs, $n^{\prime}:$ a pas conpris la roquille gu'Arislole semble avoir isdiquée; elle est comprise dans sun gente Hepiadactyle. Voyez Strovis et Ptírociriz.

\section{APTERIGIEIS. Afterigia.}

11. Latreille nomure ainsi, dans sa Nethoke conchyliologigue (Fam. nut. du Règne animul, pay. 1-0.), sa secoude grande divisaon des Mollusques. Dans la preaniere nomace Ptérigiens ( vogezce mo1), soni rassemblés lous les animan de celle classe qui n'ont poiut de pied pour ramrer, el la seconde renferme tons ceux qui ont un pied. " La plupat de ces Mlcllusques, dit ce -zvant, rampear a morea d'ua prolongemeal reatral, ea forme de pied, ou bien soar fixés, soil par un pédicule ou un lijusus, soit par lear coquille; les autres peurent aager ou llotter arec direrses parties de leur corps, mais ils n'ont jamais de bras ou de tentacules à la téte propres à exéculer ces mourenens, ai de nageoires sar les coíts du col. Les yenx manqueri ou ne se mon'rea: que sous la forme de poiuts colorés, et ne peurent servir à ha risioz. La plupart encore ont une coquille gégérzlement tubulaice et eu spira!e, cu bien formée de deax ralres réunies jar u ligarsen:, et dont nos huitres, anx direrses modifications génériques près, nous offrent le modèle. Dans quelques-nas, elle est remplacée par une rangée de lámes dorjales. „ Ce n'est pas sass iategtion que noos arons rapporté les paroles el'es-mémes de 11 . Larreille pour qu'on re puisse dopter de son in:ention de réunir par ce caracićre exclusif du pied presque tous les Molluscques céphalés et acépbales dans une seule section. Nous crojous que ce caractèrc est trop secondaire pour établir sur loi de nrandes divisions rraiment naturelles. M. Latreille l'a bien senti, car les divisions dont nous parlons ne sont qu'use sorte de superfétation à sa distribution générale, qui ponrroit fort bien s'en passer, et n'en sercit, à notre avis, que plas simple et meilleare, car il re doit y aruir rien d'inuille dans one métbode. Nous en appelons à M. Latreille lui-mème, à ce rétéran de la science, dont les trarau si saramment anaJy iques, ont contribué plas qu'aucuns antres de ce siècle, à l'avancement de l’entomologie.

\section{AQUARIA.}

Le genre Arrosoir, établi depais lorg-lemps par M. Lawarck, reçut cegendani de Péry le nora
d'Aquaria qrui n's pas été adop̣té. Voogez Anacsora.

\section{ARABIQUE.}

Nom vulgairenent donné à une Porcelaine que l'on désigne aussi sous celui de Farusse arlequrre. C'est une des esprece les plas communes da geure Porcesaria. Iojez ce mot.

\section{AQTILLE. Aquillus.}

Genre fait avec beaucoup trop de légèreté par Modifort (Conclyl. syst. pag. 5-8.). pour le Murex cutuceus de Linné, qui last aujourd'bui partie du geme Triton. Lojez ce mot.

\section{ARAIGIÉE.}

Nom rulgaire donaé par les marcbands d’bistoire aaturelle à la plupart des coupailles du genre Plérocère, $\in l$ à quelques-unes da genre Sirombe. Ce nom, accompagné d'uoe épirbète caractéristrque tirée du nombre des appendices da bord droit, a servi à caraclériser quel yques espèces; il s'est glissé beuocoup d'erreurs et quelques doubles explois gu'il es? a ujourd'tui isutile de chercher

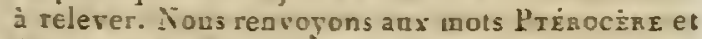
STROXBr, cà zons donverons les noms vulgaires des espéces lorstre nous les croirons autheniques.

\section{ARAPĖDES.}

Selon d'Argueville, on nomme ainsiles Patelles sur les cóles de prorence. Vojez Patelis.

\section{ARCACÉES.}

Chemnitz paroit éire le premier qui ait senti les rapports qui lieat hes genres de cette famille; il en a fail trois gronpes, le premier pour les genres Cucallée, Arcbe et Nacale, qui a'étcient point neliemeut séparés alors; le second pour les Pétoncles, et le troisième ponr les Yernes, qui s'éloignent assez notablement des premiers. Linné, ¿ l'exception des Pernes, a tout réni dans son genre Arcbe, en quoi il fat suivi par presque tons ses inilateurs, et notarment par Broguière. M. Lamarck le premier démembra ce genre et proposa les geores Iucule. Péloncle et Cacallee : qui, arec les Arcbes et les Trigonjes, faren: mis en rapports dès 280 t dans son Truité des animaux sans vertebres. II les conserra intégralement en formant avec enx la famille des Arcacées dans les Tubleaux de Ia philosnphio zoologique, où ils soat préseatés daus l'ordre suirant : Nucule, Pétoncle, Arche, Cucullée et Trigonie. Dans l'Exiridit du Cours elle resta absolument la wéme, et conserra, arec les fámilles roisines, les Nayades et les Candiacées, les mérnes points de contact. M. Cuvier n'a pa: adopté la farrille des Arcacées; II rétablit le geore Arclae de Linaé dacs son iná́g rilé, e: 1 ll 
le partage en cinq sous-genres qui sont les mémes que ceux qui forment les Arcacécs de M. Lamarck. Ce genre Arche, dans la mélhode de M. Cuvier, termine la famille des Ostraclís à deux muscles qui contienneat encore les gemes Aronde el Jambonneau; ce qui change singuliérement la disposition de M. Iamarck. Celuici, dans sun dernicr ouvrage, persista néanmoins à conserver la famille des Arcacées dont il sépara ì tort, d’après notre opinion, le genre Trigonie, qui au reste n'est pas assez connu daus son analosuie pour qu'ou puisse ricu statuer de positit' a son égard.

11. de Ferussar a adopté celle famille telle que M. Lamarck l'a élablic dans sa Pholosophe zoologique, mais il la iaisse, à lexcmple de M. Cuvier, dans les Ostracés. M. Latreille a suivi à peu près la même opinion, dle fail parlie de l'ordre des Nanteatux ouverls (2'oye ze mol) : elle y est placée dans la seconde section qui porte le now de Plugimyone, et elle est la seule de celle section. Elle est composée des rinq genres dout nous venons de pulter. C'est inntilement que M. Druuet a proposé d'adjoindre à celte famille le genre Néithée, formé avec guelques Peignes fussiles dont les caracières fureut mal compris.

M. de Blainvi'le ne laissa pas les 'Trigonies daus celle famille, illes transporta dans sa famille des (amacées avec les genres Came, Dicérate, Ahcrie, 'Tridacne et Isucarde. Le gente Cucullé ful supiriacé el confoddu avec les Arches, de sorte que la famille des Arcacécs ou Polyodoules se trouve réluite aux trois genres Arche, l'étoncle et Nucule. Quant à ses rapports généraux, ils sont à peu près semblables à ceux indiqués par M. Cuvier et par M. Latreille, c'est-i-dire qu'elle est cntre les Jambonneanx de la lamille des Mytilacés et les Mulettes qui commencent celle des Submytilacés. En admeltant dans la famille des Árcacces le gente 'Trigonie, les caractères devront en être exprimés de la manicre suivante : mantean ouvert dans loule la circonférence, si ce n'est sur le dos, sans trou ni lubes; pied assez variable; deus muscles adducteurs des valpes; denis cardinales, nelites, nombreuses, entrantes, et disposées, sux l'une el l'autre valve, en ligne, soit droi:e, soit arquée, soit brisée, ou seulement au nombre ae deux, striées profondément et perpendiculairement.

Dans les genres de cclle famille, deux nous paroissent a'en avoir pas lons les caractères: ce sont les Nucules et les Trigonies. Il ne suffit pas a'avoir un grand nombre de dents à la charnière, il faut encore que le ligament soit semblable; dans les Nucules, il est interne, porlé sur un cuilleron, et dans les Trigonies, il étoit cxlerue, à en juger par la positiou des nymphes. Cependant comme l'organisation de ces deux genres n'est pas assez connue, bous les rapportons à la lamille des Arcacées en altendant de nouvelles olsservations. Foyez Cuculdés, Arcae, l'étoxcle, Nucule el 'íngonie.

\section{ARCACIITE. Arcacites.}

Lorsqu'autrofois on donnoil une termiuaison diffireule aux e-pèces fossiles d'un genre, on nommoit Arcacites les especes d'Arche qui sont dans cet élat, et qui éloient comprises dans le gente de linué avant son démenubrement. Anjourd'hui les Arelies seules devroient porter re nom, mais on l'a abandonné comue cffraut de l'inutilité. Voycea Arcur.

\section{ARCIILS (Les).}

Quclques zunlogisles onl préféré celle dénomiration a cetlle l'Arcacées pnur désigner la même famille composće des mèmes genres. On remarque cepentant que $\mathrm{N}$. Ocken a rassemble sous ce nom quatre groupes de coquilles bivalves qui n'onl guc̀ı de rapporls entr'elles, puisqu'on y trouve : $1^{\circ}$. les genres Irus, Loripes, Ethérie; $2^{\circ}$. Glossus, Bucarde, Isncarde, Carelissa; 3․ l'élonile, Arche, Trignnie; 4º. Mulette, Anodonte et Cardite. Il suflit d'émumérer ces genres pour qu'on s'ipperçive rès-facilement 'Tu'il's sont riunis pour ainsi dire an hasard, ou, s'il en est aulrement, frar des rapports qui sont restćr jusqu'á présent inallerçus aux observateurs. Fojez Ancacées.

\section{ARCIIIDIE. Archias.}

Une coquille microscopique figurée par Fichtel et Moll, et copice maladroilement par Montfort, a servi de type à nn noveau genre de cet auleur; il lui a donné le nom d'Archidic elans son Traité systématique des coquilles (tom. 1, pag. 190). Elle appartient indubiablement au genre Orbiculine. Voyez ce mol.

\section{ARCIIONTE. Archonta.}

Montfort raconte qu'après un conp de vent de l'équinoxe d'automne, il recueillit sul la plage de Dunkerque une pelile coquille qui s'y trouva en liès-graode quantité. Depuis cetic époque personne ne la revit; il auront été ljien intéressant cependant de la retronver, puisque Montfort la fit servir de type à un nouveau genre auquel il a donvé le nom d'Archonte. (Conchyl. system. Iom. I, pag. 5o.) II est à présumer, d'après le caractère bien conuu de Mlontfort, qu'sl s'est contenté de copier à sa manière la figure que Soldani donve de celle caquille, cı que, par sa prétendue découverle, il a cru éviter qu'on ne l'accusât de plagial. Ja coquille de Soldani n'a point été revae depuis sa publication; elle appartient probablement au 
genre IIyale et peut-étre au gare Cléodore. Foyoz ces mols.

\section{ARCINELIE. Arcinclla.}

Nom donné vulgairement à une espèce du zenre Came (vojez ce mot), et qui a été appliqué à un genre établi par M. Ocken dans son Traité de zoologie. Ce genre n'est point uu démembrement des Cames comme on pourroit le penser, mais un double emploi du genre Cardite de Bruguière et de M. Lamarch. Foyez C.Ardte.

\section{ARÉNAIRE. Arenaria.}

M. Megerle a proposé ce genre lorsque déjà relui que Jlonlagu a nomané Ligule éloit élabli depuis long-leaps. Ces genres Arénaire et $\mathrm{Li}$ gule sont les mêmes que les Iavignons de II. Cuvier. MI. Lamarck range les coquilles qu'ils renferment dans son gente Lutraire. Fojez Ligote, Lavigios et Luthatre.

\section{ARÉTHUSE. Arethusa.}

M. Dorbigny qui, depuis Soldani, est celni des zoologisies qui s'est le plus occupé des coquilles microscopiques, na pu déteraniner le geure dans lequel la caquille qui a servi de type au genre Aréthuse de Monifort doit étre placée. Cette cocuille n’est connuc que par la ligure de Soldan, et il seroit nćcessaire de l'abserver en nature pour se décider ì son égard.

\section{ARGOBUCCINUM.}

Gcnre établi par Klein (Hist. ostrac. pag. 44) pour une seule coquille converte de petits tuhercules arrondis que linné a placke dans le genre Murex sous le nom de Murex argus. Cetle coquille fait aujourd'hui partie du genre $R_{2}-$ nulle de MI. Lamarck. Toyez ce mot.

\section{ARGODERHE. Argoderma.}

Dénomination générique employée par-Poli (7est. zitriusque Sicil.) pour les coquilles de son reare Argus. Poli considéroit isolément l'unimal et la coquille d'un taème genre, et pour distinguer celle-ci, il ajoutuit au nom générique le mot quma, qui signifie peau, parce qu'effectivement la coquille est une partie sécrétée par la peau des Mollusçues. Maintenant que la coquille entre pour beaucoup dans la formalion du genre, on a sejeté de la nomenclature les doubles noms comane embarrassans el supertha. Fojez Argus.

\section{ARGONAUTE, Argonauta.}

Ce genre est un de ceux qui ont été connus des Anciens; l'animal quil l'halite est décrit par eux dans un style poélique : ses maurs, sa navigation, orbellies par leur féconds imagiaztion, furent peintes sons les cauleurs les plus brillanles, et le Poulpe de l'Argonaute, presque divinisé, fot présenté comme le premier modèle de la navigation. L'homme, imitateur de l'admirable industrie de cet animal, devint navigateur: il construisit une barque, y déploya une voile, se servit de rames, tixa un gouvernail, et s'aventurant sur. les abimes des mers, if en devint le dominateur.

Une question d'uu haut intérêt, agitée par les savaus de ce sic̀cle, a été délallue avec un talent remarquable. Les deux opinions qu'elle a enfantées ont éte soutenues par des argumens spécieux, et on a cherché à les appuyer du témoignage des écrivains antérieurs. Il a donc fallu se livier à de miuutieuses techerches, et il en est résultć une histoire aussi intéressanle que bien faite de l'Argonaule et du Poulpe qui l'habite. Nous pensons d'apres cela qu'il seroit supe:llu de douner ici celle histoire, dans laquelle nous pe pourrions ajouler aucun fait important. Nous renvoyons le lecteur au travail de Montfort dans le Buffon de Sonnini, et particulièrenent au savant llémoire de M. de Blainville. Nous uous contenterons de tracer d'une manière rapide, les faits les plus im, portans concernant ce genre depuis l'époque où Broguière en tecrivit dans le premier volume de ce Diclionnaire.

Bruguière, comme an peut facilement s'en assurer, rnodifia sensiblement l'opinion de Linné; celui-ci avoit placé l'Argonaute avec le Nautile, en tête des Coquilles univalves, sans en faire une section à part. Bruguière, en faisant dans son Systeme une juste application des divisions de Monohalamus e: de l'olythalamus proposées par Breyme, fut entraîné à laisser les Argonautes parui les Coquilles uuiloculaires, et de les séparer ainsi des Nautiles qui, démembrés en plusieurs geures, lerminèreut la série des Ilollusques au liea de la comnencer; mais comme Bruguière sentoit, en admeltant la vérité des rapports de Linné, que les Argonautes ne devoient pas s'éloiguer des Nautiles, il les placa tout a la fiu de la série des Coguil!es uniloculaires, de manière à se trouver le plus près possible des Nautiles.

M. Cuvier apporla de nombreux changemens dans la disposition des genres de Bruguière; rénnissant sous le nom de Céphalopodes tous les animaux semblables ou vo sirs des Poulpes el des Sèches, il lut obligé d'y comprendre aussi les Argonautes, en adoplant, conme Bruguière, l'opinion de Linné; c'est ainsi que, dans une même classe, sc trouvèrent lout i la fois des Coquilles simples et des Coquilles claisannces, ce que Bruguière a voit voulu éviter; mais il étoit naturel que cela futt ainsi, pour que les pribcipes zoologiques de M. Cuvier fussent rigoureusemont appliqués.

Dans son premier système, M. Lamarck fut plas ixitatenl de Braguiere quo do M. Cuvier. 
Comme dans les tableaux de ce premier le geare Argonaute est à la fin des Coquilles uniloculaires, et les Nautiles suiveot après dans la section suivaute, qui contient tous les multiloculaires. Cependaot sil est vrai, conune le rroit M. Lamarck, que le Poulpe de l'Argonaute soit le véritable p:opriélaire de l'élégante coquille dans laquelle on le tronve, pour être con ćçıent avec lui-mè we, il faudroit que ce genre se irouvit dans le Système, dans la méme classe que les Poulpes et les Nauti'es, puisqu'il a tant de ressemblance arec eux; aussi celte opinion ne fut point adoptée, et M. Lamarck lui-méme un peu plus tarul la réforma.

Un an après la publication du Système de M. Lamarck, c'est-á-dire en 1802 , Montfort dona l'histoire des Argonautes dans le Buffon de Sonnini. Cet auteur étoit tellemeot convisincu de l'opinion que le Poulpe esi le constructeur de la coquille, qu'il ne balança pas à décrire les Argonates comme des coquilles de Céphalopodes, et a les comprendre parmi eux. Il est fáchcux que le savant continuateur de Montfort o'ait pas eu occasion de traiter de ce genre, quoiqu'il soit à présumer que M. de Roissy ait eu alors l'opinion des savans qui l'avoient précédé.

Nous avons dit précédemmeat que M. T.amarck a voit lui-même réfurmé sa première cpinion. On trouve en eltet de notables changernens dans sa classilicetion. Les Céplialopodes, dans sa Philosophic zoulogique, sont partagés en trois seciions, selou qu'ils sont multiloculaires, uniloculaires ou sans coquille. C'est dans la seconde section, comme on l'a déja deviaé, que sont les Argonicules; mais ce qui surprendra sans doute, cest de les y trouver avec les Carinaires. Ce rapprochement, yui pourroit être consi léré par quelques personnes cowme une erreur, nous fail voir que M. Iswarck, l'homme qui, après Lioné, a été doué de ce gévié quii fuit deviner les rapports, a été entrainé à mellre en contact deux genies qui ont, quant à la coquille, lant de rapports, quil faut, pour les séparer, être conduit par un système ou une opiniun faite d'arance. On pourroit dejà de là liser liuduction, que ni la Carinaire, ni l'Argonaute ne sont ì leur véritable place.

i. Ockeu, dans son Traité de Zoologie, moditie un peu la manière de voir de ses prédécesseur's sans hanger la question. Il range le grenre $A$. gonaute daus la famille des Seiches, ce qui le laisse toujours parui les Céphalopodes. N. Schweiguer présente un ordre qu'il sera aussi dilficile d'adopter que d'exp!i.juer, puistu'il range les Céphalopudes daus le genre Arronante, de sorte que ce genre représenteruil vérilablement un ordie tout entier, avec des. divisions qui représenteroient assez exactemen! les geare compris duns les Céphalupodes. Dans l'Eatrait du cours et dans sou dernicr nuvrage, M. Lamarch rejetal la Cariuaice des Céplualopodes, et le genre Argonaule à lui seul en constitua la seconde section.

Hisfoire Naturelle des Vers. To:ne II.
Dans l'intervalle de ces deux ouvrages de M. Lamarck, M. Cuvier publia le Régne animal; on y troure les Argonantes à la fin des Céphalopodes, ce qui est conforme à la premrère opinion du savant prolesseur, opinion qui est calle de Limné, conne nous l'avons va précédemaen. M. de Ferussac, imilaleur de M. Cuvier dans presque toule sa méthode, s'en écarta, non juant á l'opinion sur les Argonaules, mais quant à leurs rapports avec les genies analogues. Au lieu de les séparer des Puulpes et des Seiclics par toute la série des Céphalopodes, comme l'a fuit M. Cuvier, il les rapprocla a contraire a la manière de Léach, et il termina les Céplialopodes par la famille des Octupodes, qui rassemble les Poulpes et les Arronaules. Avant lia publication de l'uuvrage de NI. liernssac, M. Rafinesque ayant trouvé daus la Méditerrance un l'oulpe à deux bras palmés, et dépourva de coquille, nageant comme les autres Poulpes, innorant de plus que ce fút le Poulpe qui liabite l'Argonaute, en fit un genre qu'il nonma Ocythoé. Ce furt, d'une grande importance, resta quelque temps dans l'oubli, ou plutôt fut inconnu pour avoir négligé d'analyser les caractères dounis par Rafinesque à sou nouvean genre. M. de Mlainville fut le prenier qui le découvrit, et le comwuniquant à Léach, il convainquit ce savant, ainsi que plusieurs autres non moins recommandables de l'Angleterre, que le Puulpe a'éloit pas le constructeur de la coquille dans laquelle un le trouve.

Un excellent Mémoire que M. de Blainville publia dans le Journal de Physique, vient ì l'appui de celte opinion; il y rasscmbla tous les faits pour et contire, et s'appuyant autaut des observations faites jusqu'alor's que des priocipes les plus certains de zoulogie, il chercla à démontrer er démontra en ellet, pour un grand nombre de personnes, que le Ponlpe est un parasite qui s'em. pare d'une cocfuille étrangère. Les judicieux raisonnemens du savant prolesseur et les conclusions qui en découlent, trouvèrent des contradicteurs qui vinrent se prísenter dans l'arène avec des arnues, si ce n'est éuales, da moins furaidables. 11. Razzani, zoologiste distingné qui honore l'Ilalie, répondit au hiémoire de M. de Blainville; il chercha par des argumens coustraires à délruire ceux de son adrersaire, et saus vouloir faire prévaluir l'opinion linnéenne, il espéra prouver que la question étoit tuajours dans le même état, que les mèmes doutes existoieut, muilgré ce que l'on avoit dit de part el d'autre sur ce sujet.

Dans le nếrne tenaps, M. de Ferussac ayant reçu cle M. Pisso de Nice, un individu du Poulpe pris vivant dans la coquille de l'Atgonaute, et par constífuent très-bien conservé, lira de ce nouveatu fait tout le parti qu'il put, en appuyant par l'observalion directe les raisumemens qui fuuvoient furtifier l'opinion de Linué, qu'il parlage ayec MM. Cuvier, Ranzaui, elc, Les con- 
clusions du Mlémoire de M. de Ferussac furent à peu près les mêmes que celles de M. Rauzani, malgré le tait nouveau qui é est le sujet; aussi M. de Blainville, loin d'abandunuer le terrain sur lequel il étoit si avantageusement placé, rassembla toutes les preuves pour el contre, les mit en regard avec bonne foi, et les donna une dernière fuis à l'urticle Poudpe du Dictionnaire des sciences naturelles.

Nous avons présenté les principaux travaux qui ont élé publiés dans l'inteution d'éclairer l'importante question des Argonautes; nous allons maiutenant entrer dans la discussion entière des deux opinions qui parlagent encore les savans depuis Aristole.

Les Anciens, qui avoient observé l'admirable industrie et la savante navigation du Poulpe de l'Argonaute, mais qui n'avoient aucuns principes cerlains de zoulogie, pouvoient croire que ce Poulpe étoit le véritable arlisan de sa lécère et élégante nacelle; ils n'ignoroient pas qu'il pouvoil la quilter pour venir paitre, comme ils disoient, sur le rivage; celá leur paroissoil d'antant plus daturel quils croyoient qu'il en éloit de même pour les autres Mullusques; les Limaces pour eux éloient les mêmes animaux que cenx des Colimaçons, anxquels ils attribuoient la faculté de quitter à volonté Jeur coquille : l'art d'observer étoit encore dans l'enfance. Quoiqu'clles ne s'étendissent pas au-deli d'un cercle furl élroit, on a voulu cependant trouver daus les observations des Anrieos, des argumeus en faveur de l'une et de l'aulre opinion; mais, comme on le voit, c'étoit vouloir sappuyer sur une base bien fragile. Les observations des temps reculés ne peuvent aujourd'hui serrir que par leur nombre; nous voulons dire par là qu'un cerlain nombre de personnes ont vu un Poulpe dans ane coquille d'Argonaute; elles constalent anssi ce fait hien important, que le Poulpe de l'Argonaute peut cquiller sa coquille, ce çui nouvellement a encore été observé.

La question en discnssion est celle - ci : le Poulpe de l'Argonaute est-il ou n'est-il pas le constructeur de sa coquille?' Un certain nombre de personnes pensent quilil en est le constructeur; et elles ont de leur opinion presque tous les Anciens, et plusieurs des zoologistes modernes les plus illustres. Elles appuient leur manière de voir sur les fails suivans:

I ${ }^{\circ}$. On a vu un assez grand nombre de Poulpes d'espèces d'ifférenies, constamment dans des espéces dillirientes d'Argonautes.

$2^{\circ}$. On ne trouve que très-rarement ce genre de Poulpe sans coquille.

$5^{\circ}$. Il est contenu dans cette coquille, il est vrai, saos aucun muscle qui l'altache à lui, mais avec tant de justesse qu'il reçoit, et garde plus ou moins long-temps l'impression des côtes et autres accidens de la coquille.

$4^{\circ}$. Quand l'animal est contracté, ses bras sont reployés régulièrement, de manière à ce que les ventouses de l'uue des paires correspondent aux tubercules de la coquille.

50. Le Poulpe de l'Argonaute ne s'atlaclie à la coquille par aucuns muscles, aussi on n'y remarque aucune trace de l'ioupression musculaire.

$6^{\circ}$. Plusieurs zoologistes très-distingués affirment avoir recomnu une coquille d'Argonate, dans les œufs du Poulpe.

Il.est vrai que toutefois que l'on a trouvé de nouvelles espèces d'Argonaules arec des Poulpes dedans, ils formoient eux-mêmes des espèces distinctes de celle qui a ćté observée dans la Mléditerranée. Ce fait a paru d'une grande inportance aux personues qui croient que le Poulpe est le constructenr de la coquille. Celle concordance, comme l'a fort bien observé M. de Blainville, prouve que clans la mème mer, il y a une espèce d'Argonaute et une espèce de Poulpe. Si duns un licn quelconque de l'Océan on observoit deux ou trois espèces d'Argonaules, habilées constamment et sins mélange, par deux ou trois espèces de Poulues, que le même Poulpe se relrourât loujours dans la même coquille; c'est alors que le fail dont il est question prendroit une très-grande importance, sans pourlant pouvoir à lui seul décider la question.

Depuis Aristole jusque dans ces derniers temps, on n'avoit pasobservé le Poujpe navigateur sans lá coquille de l'Argonaute, on en avoit conclu assez naturellement quil ne pouvoit s'en passer, et par une conséquence tout aussi naturelie, qu"il en étoit le véritable habitant. Celte circonstance étoit une des plus favorables, et qui fournissoit un argument trc̀s-puissant en laveur de l'opinion de Linné ; mais l'observation faite par Rafinesque, qui a trouvé ce Poulpe dépourvu de coquille, et qui a fait avec lui le genre Ocylhó parce qu'il ollioit des caractères particuliers que Rafinesque n'a point reconnus pour ceux du genre Argonaule de Linné, quoiqu'ils fussen! cependant les mêmes, pronve que ce Poulpe pent se passer de coquille. Ce seroit en vain qu'ou objecteroit à celte observation qu'elle seule ae peut en détruire un grand nombre de coatraires, el que probablement le Poulpe observé par Ratinesque avoit perdu sa coquille par un accident. Quelle que soit la manière dont il l'a perdue, on u'ea conclura pas moins qu'il peut s'en passer, puisque le naturaliste que uons cilons, l'a vu nageani à la manière des Poulpes et sans coquille, et sans avoir l'air d'en être plus incommodé: que l'on compare cela ì ce qui arrive à un Mollusque que lon prive de sa coquille; qu'on le compare même à un Pagure que l'on arracheroit de sa deméure, on verra que le Mollusque est vouéa une mort certaine, et que le Pagure n'aura point d'autre soin que de trouver un abri qui lui est nécessaire pour cacber la partic poslérieure de son corps. L'observation de Rafinesque ne fait que confiraser ce que les Anciens 
avoient dit des babitudes du l'oulpe de l'Argovaute; ils savoient en eflet, qu'il porsvoit quitter sa coquille à volonté pour venir paitre sur lc rivage. Counoissant la manière peu approfoudie doni les Ancicns faisoient leurs observations, on purroit, arcc quelque raison, penser qu'ils avoient pris quelqu'autre espèce de Poulpe pour celui de l'Argonaute; mais aujourd'bui celte erreur paroît moins probable.

Nous voici arrivés à un point important de la discussion; et il faut l'avouer les raisundemens en faveur de l'opinion de linoé sont bien faibles, tandis que ceux en faveur de l'opinion contraire prenneut une force presque irrésistible.

'Tontes les observations faites d'un Poulpe dans Ia coquille, ont mis hors de doute qu'il n'y est lić par aucun muscle, qu'il n'y est retenu par ancun organe. S'il est vrai que le Poulpe est réellement le proprićtaire de la coquille, il présenteroit le seul exemple d'une semblable anomalie : il n'existe aucun Mollusque ayant une roopuille extérieure, qui ne soit lié à cette coquille par un muscle. Comment sans cela concevroit-on la sécrétion réRulière d'une coquille parfaitement symétriquę? Un accident quelconque, le moindre dérangement de l'animal, détruisant les rapports actuels de son corps avec la coquille, quels moyens au:a$\{-i l$ de se replacer juste comune il étoit, pour cuntinuer à la former d'une manière si régulière? Mais bien mieux, lorsque volontairetrient il aura quilté complétement celte coquille, en supposant yu'il ait l'inslinct de la retrouver, pourra-t-il s'y replacer arec une telle précision, qu'il soit iupossible d'apercevoir sur elle aucune trace d'irrégularité? Cela nous semble d'autaut plus i:upossible en raisonnant par anologie, que tous les aures Mollusques à cocquille, quels qu'il soient, laissent sur leurs coquilles, qui devient quelquefuis monstrueuse, des traces iudélébiles des clian- gemens ou des mutilations qu'ils ont éprouvés. i)'ailleurs pour qu'un Mollusque puisse sécréter une coquille régulière, il faut non-seulement quai $y$ soit atlaché, mais encore qu'il ail pour celte sícrétion les organes propres, les organes sans lesquels elle ne peut se laire. Or il est évident que le l'oulpe de l'Argonaute n'a point de mantcau, ce fait est incontestable; donc il ne peut sćcrétcr une coquille : il est si évident que là où un organe manque, ce qui en résulte toujours doit unanyuer aussi, que nous n'iusistous pas davantage sur ce point. A ce raisonnement, qui est lié à ce que la zoologie a de plus positil dans ses principes tondamentaux, on opposera en vain que le corps du l'uulpe prend el couserve l'impuession de toutes les côtes ou aulres accidens de la coquille, gu'il existe eutr'elle et lui un contact si iamédial qu'ıl en résulie une sorte d’adbérence, qui est bien capable, dit-on, de remplacer celle d'un muscle, et qui estassez intime pour favoriser la sccuétion de la coguille. Lous répondrons à cela que limpression des cóles de la coquille sur le corps de l'animal, ne pronve vien dans cette queslion, si ce n'est que le l'oulpe est un animal inou; ce qui vicut à l'appui, c'est que, non-seulement le corps mais aussi loules les autres parties prennent les mếmes impressions, ainsi les bras, suivant leur position, les on aussi. Nous avons fait sur ce sujet quelques expériences, qui feront voir le peu d'importance que l'on doit altacher à l'impression des accidens sur le corps de l'animal : nous arons pris une Aplysie que nous avous introduile dans une coquille d'Argonate, elle y est eutrée par son propre poids; nuus l'arous placéc dans un vase rempli de liqueur, et nous l'avons ainsi laissée une huilaine de jours; en la retiruot, toutes les parties qui étuient en contact avec la coquille avoient contracté une sorle d'adbérance, et présentoient l'impression des côtes de la coquille ainsi que des tubercules de la carène. Nous avons répété cetic expérieuce avec l'animal du grand l'eigne de nos côtes, ainsi qu'avec relui de l'Jlaliotide, et elle nous à égalentent réussi.

Le corps du Poulne a une forme qui n'est, en aucune mavière, en larmonie avec la forme de la coquille; ce quile pronve le mieux, c'est le vide qui exive ì la partie postérieure de la coquille, vide qu'il scroit impussible à un corps en forme de sac arrondi de remplir complétement. Ceci est encore nue anomalie des plus surprenantes pour cet animal, puisque rien d'aualogue n'existe dans uu seul Mollusque à coquille externe. C'est dans celle partic la plus reculée de la coquille que sont placés les organes essentiels à la vie de l'animal, le thic, l'oraire, les intestins, elc. : ici lien de semblable. Cel espare vide reçoit les œufs au moment de la ponte; aussi est-il bien remarquable, que l'on tronve beaucoup plus de femelles dans les coquilles que de mâles.

La relation intime qui existe dans tous les Mollusques entre la forme du corps et celle de la coquille est telle, qu'elle est devenue une loi, un principe tellement constant, qu'on ne connoit jusqu'a présent ancuu fait qui soit contradictoire; le Poulpe de l'Argonaute seroit le seul, mais comme on le voil, il est loin d'ĉtre ansez constant pour servir de preuve. Le principe etabli sur tout ce qui existe sert au contraire de preuve contre le Puulpe de l'Argonaute.

Un autre fail montre, comme le précédent, qu'en admettant que le l'oulpe sécrète la coquille vì on le trouve, on est entouré de difficultés impossibles à résoudı d'une manière satisfaisante; il est relatif à la coloration du Poulpe, loul-à-fait ciillérente de celle de la coquille : celle-ci, comme on sait, est toujuurs blanche, plus ou moins vitreuse et Aransparente selon les espèces. On est torcé d’admettre dans l'hypothièse, que c'est le corps du Poulpe qui sécrète la cnquille; or ce corps a une coluration qui lui est propre, il en est de même, pour la coquille; donc celle coquille 
nest pas celle du Poulpe. Si nous ne prenions celte conclusion, il faudroit encore admellre une nouvelle anomalie, et par conséquent la destruction d'un principe fondé sur l'observation de taus les Mollusques, qui est : que tous les Mollusques à coquille externe ont celie coquille colorée en raison de l'organe qui la sćcrète. Nous ue pensons pas qu'un seul fait puisse ĉtre allégué contre cette lui. Ainsi dans l'liypothèse que soutienneut les sectateurs de linnce, on est furcé de dire : le Poulpe de l'Argnnauie a uue coquille, mais il n'a point d'organe sćcréteur qui puisse la former; il a une coquille dont la forme n'est point une relation avec celle de l'animal, il a une coquille qui est blanche et vitreuse lorsque le corps qu'elle revêt est d'une tout autre coulenr. Ne doit-on pas reculer devint de telles contradictions? Elles suffiroient pour terminer une discussion zoologique; il en existe cependant quelques autres non moins fortes, sur lesquelles il faudroit se résandre de passer.

Nous avons vu que la régularité quaffecte le Poulpe navigateur daus la manière dont il dispose ses bras lorsqu'il se contracte dans sa coquille, qui est telle, dit-on, que les ventouses de deux des bras correspondent aux tubercules de la carène de la coquille, a servi de preuve et d'argumen! en faveur de l'opinion de Linné et de ceux qui l'adoptent: cependant si quelques observations sont favorables, d'autres peuvent contre-balancer celte assertion d'une manière bien puissante, car en elfet, il est rare de trouver deux Poulpes dont tontes les parties soient disposées d'une manière semblable par rapport à la coquille. Si on compare la description des auteu's entr'eux et leurs figures, on ne trouvera presque aucun accord; il y en a encore mains si l'on observe par soi-même quelques-uns de ces animaux. Quant à la correspondance des ventouses aux tubercules de la coquille, fait qui n'a été observé qu'un trc̀s-petit nombre de fois, il semble qu'on en veuille couclure que ces tubercules sout sécrétés par les parties de l'animal qui leurs correspondent. Pour admettre une pareille hypothèse, il faudroit trouver quelque chose de semblable dans d'autres Mollusques et établir un raisonnement par analogie; mais ici, comme dans toutes les questions que nous avons cxaminées, il n'en existe aucune. Connoît-on un seul Mollusque dont certains organes sécrètent nne partie de la coquille, tandis que certains autres, quoique destinés à des mouvemens continuels et irréguliers, produisent une autre partie de cette même coquille? Et ce qui est plus étonnant, c'est que ces parties résultant d'organes différens soient tellemeat unies, tellement fondues, ont une telle correspondance dans leurs stries d'accroissement, qu'il soit impossible de les distinguer. Mais ce qu'il faut admettre, et ce qui est contradictoire avec toutes les observations sur les Mollusques, c'est que des organes essentiellement destinés à la locomotion, à la préhension de la proie, et souvent il la défense de l'animal, sont aussi des ory̧aues de sécrétion, et d'une sécrétion admirablement réguliçre. Le raisonnement seul, comme on le voit, peut suffire pour faire rejeter une supposition si contraite à ce qui est possible; mais ce qui doit la détruire entièrement, et ruiner un des argumens que l'on a crus favorables à l'opinion de Linné, est le fait du Poulpe de la collection de M. de Plainville : il manque à cet individu un des bras palmés, que l'on suppose être destiné à la formation des tubercules; on voit que la cicatrice de cette mutilation accidentelle est ancienne; s'il est vrai que les bras palmés contribuent à la formation de la coquille, il est évident qu'elle a dú devenir irrégulière dès l'instant de la perte d'une des parties qui la sćcrète. Ce n'est cependant pas ce qui a eu lieu; la coquille est tout aussi régulière : donc les bras ne sont pas des orgranes de sécrétion, ils n'out donc aucune inllueace sur la formation des tubercules de la coquille; ce que déjà nous avions pu conclure par analogie et par le raisonnement.

Le Poulpe de l'Argonaute n'est pas lié à sa coquille par un muscle; il n'est pas surprenant, diseut les personnes qui soutiennent l'opinion dé Linné, que l'on ne découvre sur elle aucune trace de l'impression musculaire; ccla pronve donc que la coquille appartient au Poulpe. La conséquence de ce raisonnement seroit rigoureuse et incontestable, si la caquille de l'Argonaute étoit la seule où le muscle d'attache ne laissât aucune trace de son impression; mais il n'en est pas ainsi : la Carinaire et en général les coquilles virreuses, comme celles des Hyales, des Cymbulies, des Chodores, etc., et qui sont, counme tout le monde sait, altachées à l'ani. mal par un muscle, n'en offrent cependant point l'im. pression. Si parmi les Mollusques que nous venons de citer, il en est.que!ques-uns auxquels on pourroit, faute de les connoitre assez, conlester l'existence d'un muscle d'attache, du moins on ne peut leur refuser un manteau destiné à la sécrétion de leur coquille. Une circonstance nous porte à croire qu'il doit en être de même de l'animal inconnı de l'Argonaute; dans le jeune âge la coquille est couverte d'un épiderme, ce qui prouve d'une manière bien'incontestable l'existence du manteau : or le Poulpe de l'Argonaute n'en a point; donc il n'est pas le véritable propriétaire de la coquilie qu'il babite.

Quelques zoologistes ont prétendu avoir reconnu la coquille dans l'veuf du Puulpe de l'Argonaute; si le fait étoit incontestablement prouvé, la discussion seroit terminée : mais il y a une difficulté, c'est que les mêmes œufs examinés de nouveau n'out plus ollert de trace de coquilles; ainsi provenant d'un nıême individu, pris dans la même coquille et à la même grappe, les œufs de ce Mollusque ont servi le pour et le contre dans cette question. Plusieurs personnes ont récemment 


\section{A R G}

olsservé avec soin de ces ceufs, et ils n'ont point vu de coquille. On peut donc aflirmer duns l'éta actuel de nos conpoissances qu'ancun observateur n’a prouvé, par une série d'expériences faites à différens âges de l'aninıal, que la coquille existât dès la sortie de l'œuf. C'est tà, mais là seulement, que, par des observatious biea faites par un loume digne de foi, on pourra trouver les clémens nécessaires pour la solution de la question.

Nous pourons dire que, quand même la question au lieu de se résoudre en faveur de l'opinion de MI. de Blainville prouveroit évidemment le contraire, nous avons raisonné d'après des bases lixes, d'après les lois et des principes incontestables qui découlenı de toutes les observations fuites sur les Mollusques : nous arons raisonué suivant les regles de la logique qui veut que, ponr disculer une telle question, on marche du connu à l'ioconnu; que pour éclairer un point duuteux, on se serve des parties analogues d'une inême science sur lesquelles on n'a aucun doute, et qu'en élablissantensuite une comparaison on en tire unc consćquence. Si l'observation directe prouve que cette consćquence présumable est fausse, c'est que la science n'aura pas de principes, ou du moins que ce que nons appelons principes aujourd'hui, ne le sera plıs dès-lors que ce nouveau fait sera dereuu incontestable. I.es adversaires de M. de Blainville nont pas le même avantage que lui; de quelques fails cunlestés, appuyés plus sur des raisonnemens spécieux que sur l'observation, ils en out conclu l'admission d'une chose contraire à tout ce qui est connu, qui renverse ce que la science a de plus positif, et sont forcés ainsi de prendre pour raisonoer des bases peu solides. On ne peut disconvenir que celte marche ne soit peu rationnelle.

Ea conclusion de ce que précède, et dans l'élat actuel de la science, on peut dire que l'auimal de l'Argonaute n'est connu que par les rapporis des coquilles. Il y a plus à croire qu'il doit être voisin des Carinaires que de tout autre type de Mollusques; que pour décider la question. il faut des observations directes et bien faites, lesquelles manquent. On ne peut donc devancer les faits, car ce sont eux qui font la science: le temps n'est peut-être pras éloigné où celte question, qui louche à ce que la science a de plus certain, sera complétement décidée.

\section{CABACTERES GÉERIQOES.}

Auimal incounu.

Coquille univalve, uniloculaire; involute engaînarte, subnaviculaire, très-mince, à spire bicarinée, tuberculeuse, rentrant dans l'ouverture.

Linné el Brugaière son imitateur ont confondu plusieurs espèces dans one seule, l'Argonauta urgo. M. Lamarck en a distiogué plusieurs, et
A R G

qquelques antres espèces y ont été ajoutées. M. de Ferussac, à son arlicle Arcosaute du Dićtionnaire classique d'histoire naturelle, donne la nomenclalure de sept especes dont une est douteuse. M. de Blainville, dans le Dictionnaire des sciences naturelles, donne lgalemeat sepi espèces; mais ccmme la synonymie est moins complète, et scs descriptioos plus couttes, il y a deux d'entrelles qu'on ne peul rapporter d'une manière cerlaine à celles de M. de Iierussac. M. de I3lainville distin. gue de l'Argonauta argo de M. Lamarck Ics grands individus de la mer des Indes, qui ne diffèrent de ceux de la Médilerrance que par la taille qui est plus grande, et la lorme plus comprimée latćralenen!.

Nous ne pensons pas que ces différences soient suffisantes pour ćtablir une espèce, quand $\mathbf{d}$ reste il y a une identilé parfaite pour la couleur, la disposition des côtes.

Bruguic̀re, comme nous l'avons dit, a confondu trois espèces avec l'Argonauta argo. Il ne les a dislingućes qu'à tilre de varićlés, mais elles sont assez exaclemeat décrites pour qu'il nous suffise de les indiquer ici, et de renvoyer le lecteur à l'article Anconaute du premier volume de ce Diclionnaire.

La variété $\Lambda$ est l'Argonauta argo. LAmk.

La variété $\mathrm{B}$ I'Aigonauta tuberculata. Id.

La variété C l'Argonauta nitida. Id.

Nous n'avons pu voir ni connoître en nalure les aulres espèces décriles soil par M. de Ferussac, soil par M. de Blainville. Nous élant fail une loi de ne décrire jamais d'apr'c̀s des figures, nous nous contenterons d'indiquer ccs espèces, parmi lesquelles nous croyons quil existe des doubles emplois fails sur des variétés d'âtges.

1. Angonaute à côles rares. Argonauta raticosta.

Blaivv. Dict. sc. nat. tom. 43. pag. 213 .

Argonauta cranchii. I.ÉAcH, Philosop. irans. juin 1817 . pag. 296. pl. 12. fg. $1-6$.

Ibid. Ferussac, Diction. class. d'hist. nat. tom. 1. pag. 552 .

11 est à prósumer que cetle pctite coquille est trop jeune, pour décider si elle doit faire on non une véritable espèce. Elle vieat du golfe de Guinée.

2. Argonate gondole. Argonauta gondola.

Dillw y. Descript. cat. pag. 335.

Ibid. Fenussac, loc. cit. pag. 383.

Argonauta argo. Var. E. Linn. Gmel. Favanke, pl. 7 . fig. A. 7.

Martini, $t a b .18 . f_{g}^{g} .160$.

M. Lamarck, comme on le voit par-la'synonymie, ne distingue pas celle espèce de I"Ar- 
gonauta tuberculosa. Nous partageons complétement l'opinion de M. Lamarck, et nols nous demandons sur quel caractère de quelque valeur on pourroit maintenir cette espèce.

3. Argovate profonde. Argonauta haustrum. Diclwyx. Descript. cat. png. 355.

Argonauta argo. Var. B. Lins. Gures. Favasie. pl. $7 \cdot$ fig. A. $\overline{3}$.

Martixi, tom. 1. pag. 258. Vic. pag. 221. fig. 2 .

Coquille douteuse, probablement monstrueuse, mais très-rare à ce qu'il paroit : elle est jaune, ses oreilletles sont bica développées et son ouverture est très-imple.

4. Argotadte gondole. Argonauta cymbium.

Lixy. GMEL. pag. $3568 . n^{\circ} .3$.

Ibid. Ferussac, loc. cit.

Ibid. Br.arvilue, loc. cit. pag. 215.

Carinaria cymbium. Last. Anim. s. vert. tom. $7 \cdot p a g .674 \cdot n^{\circ} .5$.

Guarti, Test. tab. 12. fig. D.

Fivaxie, Concl.tab. 7.fig. C. I.

Martixi, Conch. tom. 1. tab. 18. fig. I61, $16 \mathbf{2}$.

Cette coqnille est donteuse; quant au genre, ce z'est point une Carinaire, car son sommet n'est point tortillé; ce n'est point non plus une Argonaute. Elle est intermédiaire entre les deux genies, mais appartiendroit cependant ì celui-ci de préférence à l'autre.

\section{ARGONAUTIER.}

Nom que M. Lamarck avoit donné au Poulpe de l'Argonaute. Voyez ce mol.

\section{ARGONAUTITE. Argonautites.}

Montfort, dans le Buffon de Sonnini, a dislingué par cette dénomination les espèces de coquilles fossiles qn'il attribue au genre Argonaute, mais qui ne lui appartiennent pas. Voyez ArgoNAUTE.

\section{ARGUS. Argus.}

M. Poli dans son magnifique ouvrage (Testac. des Deux-Sicil.) a institué ce genre duns lequel, d'après les animaux, il admet les Spondyles et les Peigues : comme on fait entrer maintenant la coquille pour quelque chose dans la détermination des caractères génériques, on rà pu admettre dans son entier le genre du savant que nous citons. Ioyez Sponotle \& Peigie, où nolis donnerons de plus amples détails.

\section{ARION. Arion.}

\section{$A R \cdot R$}

Quelques légères différences dans la pofition de l'ouverture branchiale et des organes de la ghenération, ainfi que l'existence d'un pore muqueux à l'extrénité postérieure du corps, ont déterminé M. de Ferussac à démembrer les Limaces en deux genres. Il a nommé Arion celui qui offie ces caractères particuliers; ils ont paru insuffisins, car le genre dont il s'igit n'a point été adopté. Voyez Lrace.

\section{- ARLEQUINE.}

On donne ce nom à une espèce fort rare de Porcelaine, Cyproca hiflrio L. On nomme Habut $d^{3}$ arlequin ou Fausse arlequino une autre Porcelaine très-commune et dont les variélés sont nombreuses, le Cyprea arabica. Voyz. PonceLAINE.

\section{ARMINE. Aminia.}

On ne connoît ce genre de M. Rafinesque que d'après une très-courte plırase caractéristịue qu'il a donnée dans son Prodrome. Elle est ainsi cunçue : corps oblong, déprimé; bouche nue, rétractile; les llancs lamelleux; l'anus à droite. Il est à présumer que ces animaux aroisinent les Linguelles de M. de Blainville et enirent daus la famille des Pleurobranches; mais il est impoffible avec ce que l'on en connoit de placer convenablement ce genre dans lequel il y a deux espèces. Elles ont élé observées dans les mers de Sicile. Il fant attendre ì leur égard de nouvelle; observations.

\section{ARONDE. Avicula.}

Bruguière, dans les planches de ce Diclionnaire, avoit donné le som d'Hironde à un genre qui a voit pour type le Mytilus hirundo de Linné, autour duquel il avoit groupé d'autres caquilles analogues que plus tard cependant on en dénembra. II. Cuvier donna a wême genre le nom d'Aronde, que M. Lamarck clangea pour celui d'Avicule qui a été généralewent idopté. Voje= ce mot.

\section{ARROSOIR. Afpergillum.}

Lorsque'Bruguière traita ce genre dans le premier volume de ce Diclionnaire, il s'en falluit de beaucoup qu'il êtt loules les données nécessaires pour le faire d'une manière complète. Il est vrui de dire que ce savant naturaliste a pris la science dans un moment où elle étoit encore dans l'enfance, comparativement à ce quelle est aujonrd'bui; il faut dire anssi que Bruguière s'est placé au-dessus des conchyliologucs de son époque en moditiant et en perfeciionuant le système de Linué, anquel personne n'osoit toucher, et la création dn genre Arrosoir qui lui est clue, ainsi que celle de 


\section{A $\mathrm{R} R$}

plusients autres, alteste d'une manière bien évidente ce que nous venons de dire.

Liuné aroit mal à propos coufondu l'Arrosuir avec les Serpules; Bruguiere le reprend arecraison de celte erreur qu'il étoil si facile d'ćviter par la création d'un genre: c'est ee qu'il fit; mais il éloit bien dillicile de le placer convenableuseut, et le fatx rapprochemeal que Bruguière en fit est bisn pard nuable pour le temps où il écrivit. En ellet, ce venre se troure daus sa Métbode parmi les coquilles univalves sans spires rígulières, entre les Serpules et les Siliquaires, avec les Fissuvelles, les $\mathrm{P}^{2}$ utelles et les Dentales. M. Cuvier, dans son Tableau élémentaire des Animaux ( 1795 ), n'adapla pas l'opinion de Bruguière; loin d'admetre le genre Arrosoir dans les Mullusques, il en lit un sous-gente des Sirpules qui fout partie de la classe des Vers. M. Lamarch au contraile, daus sou Système des animaux sans vertébres, publié quelques années plus tard, sentit l'amćliorution apportée par Bruguière et l’adopta eu la nıdifiaut. Eubarrassé sans doule de placer ce genre convenableneot, ne lui conooissant pas encore d'affinité avec d'autres espèces, il le jela à la tín de ses Mollusques céplialés arec quelques autres non moins incertains que celui-ci. C'est ainsi qu'il s'est trouvé entre Jes Siliquaires \& les Carinaires. M. Jamarck ne tarda pas à revenir sur ce grenre ri à lui assjgner d'autres rapports, en trailimt des fulliles des environs de l'aris daos les Annales du Muséum. Il dit à propos du genre Fistulaue (come VII, pag. 426, J806) qu'aplès aroir pris le tube testacé des Fistulanes pour la pièce priucipale, il avoit reconnu son erreur; il ful convaiocu alors que la véritable coquille de la listuline consistoit uniquement dans les deux valves 'ppotées et égales, entre lesquelles se trouve l'unimal, et que le fourreau qui les contient, n'est qu'un accessoire destiuć à former la cavité daus quelle l'animal doit vivre. Nous allons rapporter textuellement les deux phrases suivantes de M. Latoarck : elles sont importantes pour décider à qui appirtient cette heureuse idre dut rapprochement des Arrosoirs avec les Fistulanes. "Je sentis en* suile, dit M. Lamarek, qu’il en eft de même ^ pour le Taret et pour la Pliolade, \& que ces dif- férens genres apparticnnent évidemment à la * division des coquilles bivalves \& équivizl'es; n les tubes enveloppans soit du'Taret, soil de la * Fistulane, soit même de l'Arrosoir, et les pieces "accessoijes des Pholades, étant des objeis indé- pendans du caractère général qui doit servi: - au classement de ces animaux, et devant seu-

w lement être employés à la distinction de leurs $n$ gerres.

* J'exposai ces considérations daus mon cours » del’an 10 ( 1802 ) pour redresser Jes détermin vations publiées dans inon $S_{y}$ stène des animaux n sans vertebres, pag. 128 , \& jen fis part à ceux n de mes amis qui siutéressoient à ces ohjets. "
$\Lambda$ la page suirante, MI. Iamarck ajoute, apris avoir comparé les listulanes avec les'larets: "Les "valves sunt ordinairement libres, et ne tiennent "nullement au forreau; quelquefois cependant „ l'une d'clles adbère au fourreau et mêne sert à " le compléter d'un côté, de sorte qu'elle en fiait " partie; quelquefois enfin l'une et l'autre walye sont incmstécs dans le fourreau et enfont par" tie comme dans l'Arrosoir."

Ce lut donc en 1802 , l'année qui suivit celle de Ia publication de son syslème, que Lamarck professa el répandit parmi ses amis l'upiuion qu'il avoit qu'il falloit rapprocher les Arrosoirs des Fistulanes el les placer conséquemment parmi les coquilles bivalves régulières. Il eft bien évident d'après cela, qu’i M. Lamalck appartient le ı́érite de cetingénieux rapproclsemenl el uon à Me Roissy, comnie l'ont prétendu quelques personnes et tout nourellement encore. M. de Roissy en ellet ne publia qu'ed 1805 la suite du Buffon de Sornini, parlic des Nollusques, ourrage dans lequel tut adoptée pour la première fois l'opiuion de M. Lamarck, et appropriée à un système complet. Aussi II. de Roissy, se conformanı aux idées de M. Lamarck, flaca le genre qui nous occupe entre les Fislulanes \& les 'I'arets.

Quelgues années après, 1 . Lamarck rangea les Arrosoirs dans sa lumille des Pholadaires, jnstiiuée dans sa philosophie zoologrique; elles se trouverent en rapport avee les Pliolades, les Tarets et les Fisiulanes. Quelques-unes des coquilles de ce dernier genre avoient élé remarqułées par $\mathbf{M}$. Lamarck, dans les Annales du Muséunt, comme nous l'avons vu précédenent; il avoit olservé qu'une des valves est libre dans le tube, tandis que l'autre eu fait partie et y est fixée. Ces cocquilles devineat le motif d'un d'un nouveau genre internuédiaire entre les Fistulanes et les Árrosoirs, et il leur duma le nom de Clavagelle. (Toyez ce mot.) Ce geure lint publié dans l'Extrait du cours, placé duns la famille des Pholadaires eutre les Fistulanes el les Arrosoirs. Les rapporis de ces genres furent dès-lors fixćs, car presque tous les zoologistes les adoptèrent. Il faut en excepter cependant M. Cuvier qui, conservant sa première idée, la reproduisit dans le règne avimal. Sans doute justgu'an moment où l'animal de l'Arrosoir. sera conau, ce qui ne tardera pas à ce que nous pensons, il restera du doule [ur le rang qu'il doit teniu dans l'échelle organique; ce qui augmente ce doule enccre, c'est la mauic̀e dont l'Arrosoir a été figaré plusieurs fois par des anteurs dignes de croyance. Ils ont fait roir le tube se terminant postćrieuremen par une poinle très-aiguë, tortillée et adliérente aux corps sous-marius. Cetle pointe n'a aucune ouverture. Si le fait eft vrai \& qu'il se vérifie, lopinion de M. Cuvier \& son rapprochement avec les Térébelles seront confirmés; dans le cas contraire, ce seront les erremens de M. Lamarck qui prévaudront. Il est peu proba- 
ble que l'opinion de M. Cuvier se vérifie jamais, puisque M. Savigni a trouvé dans la mer Rouge une très-belle espèce d'Arrosoir dont le tube reste loujours ouvert et libre par son extrémité postérieure.

Comme on doit bien le penser, M. Lamarck conserva sa manic̀re de voir daus sou dernier ouvrage. MNI. de Ferussac, de Blainville et Latreille l'adoptèrent et la unodifièrent us peu, comme nous le verrons en traitant de la lamille des lubicolées (yoyez ce mut), que H. Lamarck a uréé pour sćparer les Arrosoirs et autres geures analogues pourvus d'un tube, des Pholades et des Gastrochènes.

Les caractères assigoés à ce genre par Bruguière étant iacomplets, voici de quelle manière ils doivent être exprimés pour êtro cn hármonie ayec les connoissunces actuelles.

\section{CAR}

Arimal iucounn.

Coquille bivalve, rśyulière, beaucoup plus longue que large, ovaluire, à crochets saillans et sirit's, fortement bâillante, saillaute en dedans du tube et portant deux impression's musculaires, obliques, presqu'en forme d'un 7 et bien symétriques de chaque côté des crochets. Bords des valves complétement adhérens à la partie antérieure d'un tube calcaire conique, claviforme, un peu irrégulier, ouvert postérieurement à son extrémité, atténuée et terminée antérieurement par un disque convexe dont la base est entourée d'un rang de tubes serrés et le plus souvent fort longss, et lui-même percé d'un aflez grand numbre cie trous ronds, placés irrégulièrement autour d'ane rimule centrale dont les bords sone saillans en dedans.

Pour compléter autant que possible les caractc̀res de ce genre, nous arons sacritié un bel individu de l'Arrosuir de Jasa de notre collection, nous l'arons caffé au-dessous de l'insertion des valres, et nous avons reconnu qu'elles ont un bord saillant en dedans. Les crochets des valves bombés en deliors sont remplis d'un matière calcaire qui couvre aussi les bords cardinaux, de sorle quil est impossible de s'assurer s'ıl y a eu one charnière articulée avec un ligament. Cest de chaque còté des crocbets \& placées bien fymétriquewent que fe remarquent deux petites inpressions mufculaires, une dans chaque valve, élroites, récourbées postérieurement de manière i représenter affez bies un 7 de chilfie un peu grussier. Nous n'avons vu aucune trace d'impres. sion palléale échancrée postéricurement, jndiquani l'exiftence des siplıóns.

Sil'analogie ne guidoit on peu, on seroit fort embarrallé de savoir cnmment se fait l'accroiffement du tube de l'Arrosoir et surtou: de son disgue. Oa sait que le Taret et quelques efpèces de
Fistalanes ne ferment leur tube antérieurement que lorsqu'ils ont pris tout leur accroissement; il est très-probable quil en est de même pour les Arrosoirs qui développent leur tube et la coquille quïls portent sur le dos, et qui ne les couvre presque pas, que lorsqu'ils sont parvenus à un certain áge; celte coquille elle-nême est alors tixée dans le tube; l'animal devenu immobile quant à toute sa malle n'augmente plus son tube que dans les pruportions que permet le développement de ses parties antéricures, sur lesquelles se moule cette surle de corolle qui bien probablement est membraneuse, ou cartilagineuse au moins dans son disque, avant d'être calcaire et parfuitement solide. $\Lambda$ quels or granes les tubes du disque donnent-ils passage? A yuel usage est destine la rimule du centre? Ia seule connoissance de l'animal ponrra faire répondre d'une manière salisfaisante à ces questions, qu'il seroit oiseux de chercher à résoudre par des liypothèses.

Bruguiire a décrit deux espèces de ce genre à l'article Arnosor du premier volutae de ce Dictionnaire, ce sont les Arrosoirs de Java et de la Nouvelle-Zélande, à la defcription defquelles nous reuvoyons; depuis quelques autres esperces ont été décuuvertes. Nous allons en donaer les c'a. ractères distintifs.

1. Arrosorr à manchettes. Aspergillum vaginiferum. Lam

A. vaginâ longissimâ, subarliculalá, ad arliculos 2'aginis fóluceis auctâ; fimbria discianlacl, brevissımâ; rimula magnâ, subcentrali, tubulis mintinis, recurvis, purtiu tectâ.

Laxx. Anim. sans vert. tom. 5. pag. $430 . n^{\circ} .2$.

Savicit, Grand Ouvrage de la Comiss. d'Egyp. part. d'hist. nut. pl. 70. fig. 91 .a. 99 .

Nous ne croyons pas que la figure de Lister se rapporte à cetle espeçce comme l'a cru $\mathrm{M}$. Lamarck, il est vrai, avec quelque duuse; elle a bien plus d'analogie avec l'Arrosoir de Java, a laquelie Bluguière la justement rapportce. L'Akrosoir à manchettes eft une coquille trés-belle et très-ctrieuse, elle acquiert une longuenr furt considérable. M. Savigay, d’après ce que dit M. Lamarck, en auroit rapporió des morceaux de plusieurs pieds de longueur. L'individu qu'il a figuré dans l'ourrage que nous avous citć est long de huit pouces et deau; il se termine antérieure. meat par un disque hémisphérique dout la base est forméc par un rang circulaire de tubes placés les uns près des aurres, d'une médiocre loguncur, mais plus lungs cependant que ceux qui couven: conte la surface du disque. Celui-ci, d'aprís la figure de M. Sayinny, serort dépourry de la tente rimulaire, mais elle existe cependant dus deux individus que nous avons vns; elle était en partie caclué par un grand nombre de petits tubes subcapillaires, 
capillaires, courts et obliques, disposés de tnanière à se croiser sur la fente et à la cacher presqu'entièrement; son absence nous auroit d'autant plus surpris que nous avions remarqué qu'elle est toujours dans des rapports déterminés avec les valves de la coquille. Au-dessous du disque se voit insérée dans le tube nne petite coquille bivalve, ovalaire, saillante, et autour d'elle, une impressiou triangulaire, siuucuse à son bord postérieur; cette impression réunie à celle de l'autre côté produit nuefigure en forme de losange; elle se dessine en creux eu debors et elle est fort saillante en dedans. An-dessous de l'impression le tube se rélrécit sensiblement, et reste cylindrique dans presgue toute son étendue, en dimiauant un peu cependant vers l'extrémité postérieure : celle-ci se termioe d'une manière des plus singulières; elle s'évase en entonnoir dont les bords sont élégaumeat plissés et dentés; darıs ce premier, s"u insère un second un peu plus graud, et dont les deutelures sont plus profondes; daus ce second un troisième, quelquefois jusqu'à cinq et même davantage à ce qu'il paroit. Ces entounoirs s'élargissant successivement, et le dernier présentant louverture ovalaire du tube, ne pourroit-ou pas trouver dans ces sorles de mancheltes, de l'analogie arec les cloisons quelquefois très-nombrenses et perforées que certaines Fistulaues font à l'intérieur de leur tube, et à la méme place que dans celle espèce d'Arrosoir?

Un fait qui zous paroît des plus inexplicables dans l'état de nos connvissances sur les Mollusques, qui est cncore plus inexplicable, en admettaut que l'animal de l'Arrosoir est un cbétopode, est relatif à l'existence d'une cloison complète, soudée à l'intérieur du tube, vers le tiers antérieur de la longueur. Celle cloison, quoique criblée de petits trous, rendroit diflicile à comprendre la formation de la partie postérieure du tube, sans laquclle l'animal ne pourroit se développer, si on ne supposoit que cette cloison n'existe qu'i certaine époque de la vie de l'animal, car cons les jndiridus ne la présentent pas. Nous en avons va deax dans la collection de $\mathrm{M}$. le duc de Rivoli, et ils n'en ont pas la moindre trace. Le test da tube est solide et assez épais pour purmettre quelquefois à certaius vers malins de le rouger et de le dédoubler pour aiasi dire, ce que représentent saus doute les figures 96 et 97 du grand ouvrage d'Egyple.

2. Arrosorr agglutinant. Afpergillum agglutinans. LuMk.

A. vaginâ rect $\hat{a}$, subsymetricâ, aliquantisper waric curvi, corpora aliera agglutinante; fimbriâ disci regulari, magná, infundibuliformi; disco hemisphonco; tubulis minumis rregulariter dispositis; rimulá subcentrali. LAwk. loc. cul. $\pi^{\circ} \cdot 4$.

Histoire Nuturelle des Vers. Tome II.
Si l'on compare notre plarase caractéristique à celle de M. Lamarck, on sera bien étonné, salis doule, de la grande dilférence qu’on y remarquera; cela tient uniquement à ce que M. Lamarck a fait cette espèce arec un scul individu gêné dans son développement et avorté pour ainsi dire, qui appartient à la collection du Muséum, landis que nons le rectitions sur deux beaux individus de la collection de MI. de Rivoli, et un troisième de la même collection, semblable et mêne plus irrégulier que celui du Jardin du Roi.

L'Arrosoir aggluliuant a un tube droit, régri:lier, subsymétrique, enllé en massue antéricurement, alténué et ouvert postérieurement; lit masse antérieure avant de se terminer se réllécıt un peu et elle donne naissance à un disque dont la base, comme dans tous les autres Arrosoirs, est entourée d'une sorte de corolle formée de tubss assez longs; ici ils forment nne sorte d'entonnoil pak leur disposition oblique es rayonnante. Le disque: central est parfaitement circulaire; il est hérisś́ de lubes très-petits, grêles, peu saillans, fell serrés et irrégulièrement disposés. La rimule est subcentrale, mérliocre : ce qui ncus a paru trèsremarquable dans celte espèce, éest la manièrt dont les valres s'insèreut sur le dos du tube; elles son' petites, saillantes, réunies et confondues par le bord cardinal, ce qui doune à leur ensemble lit forme d'on cœur de carte à jouer, dont la pointe dirigée en avant se confond avec le tube, tandis que tou t le reste da con tour, saillant, se dessine aladessus d'un petil enfoncemeut qui pénètre an dessous des valves et les isole pour ainsi dire sur nne sorte de pédicule qui leur serl de soutien. L'impression de ses valves est beaucoup plus bas snr le tube en dessous du disque que dans les antres espèces du même genre. Dans les individus irréguliers ou chargés d'une grande quantité de sable, on voit plus difficilement cette disposition des val. ves dont nous n'avons pu apercevoir de traces sur les deux individus que nous avons vas; ils présenteat du reste assez de différences pour les signaler ici, ils sont contourués sur eux-mêmes, terminé; en massue, mais cctle massue n'est pas couronr ́́e régulièrement, le disque est ovale, il manque même presque tout-à-lait dans l'iullivida de Ml. de Rivoli ; les tubes de la base sont placés irrégulièrement, iuclinés diversement et implantés sur la massue au-dessus du rétrécissement; l'endroit de ce rétrécissement est toujours dépourvu de corps étrauger. L’individu du Muséum vient de la Nouvelle-Hollande, d'où il a été rapporté par Péron et Lesueur; il a soixaute-douze millimètres; il est taut couvert de sable, de fragmens de ccquilles, de madrépores, etc. Les trois individus de XI. de Rivoli sont moins chargśs de corps étrangers, surtout ceux qui sont réguliers: l'un d'eux est presque uu, l'autre est couvert de sable sans cc. quilles. On n'en connoit pas la patrie : le plus grand a plus de douze centimètres de lunguenr. 
Nous présumons qu'il sera nicessaire de distinguer comme espece, les individus irréguliers que faute de métériaud sulfisans nous avons réunis.

II y a cnviron une amce que M. IIæningloans de Crefeld communiqua aux amatcurs d'listoire naturelle la figure el une courte description d'une espèce d'Arrosoir trouvée foffile aux environs de Burdeaux. Quelqnes doutes s'ćlevèrent pour conlister l'étal fossile de celte coquille, mais depuis sa publication MI. Itreninghans étant venuà Piris, il uous a été possible de prendre de nouveaux renseiguemens de cei estimable sarant. Il nous a assuré plusicurs fois gu'il ne doutoil. (n aucune façon que l'Arrosoir en question ne füt parfaiteuneut lossile. Ises doutes devroient encore heanconp? dimioucr : si les caractères donnés à celte espèce sont bien ceux qui lui conviennent, ce seroit uoe espèce vraiment distincic, puisqu'clle offiriroit l'exemple unique jusqu'à présent d'avoir le disjuo dépourvu de lissure; elle présenteroit encore cela de particulier d'être agghutinant: non-seulerocat sur le tube, mais encore sur le disque. Ce qui offre un caraclère non moins important que le premier.

N'ayant point cette coquille sous les yeux, nous nous contenterons de l'indiguer par le nom et la phrasc caractéristique de M. Houinghans.

Arrosorr de Lćognan. Aspergillum Leognamum. Hensa.

A. v'aginầ subclus'atî; corpona aliena agolutinante; disco tubulis frequentious echinato, etiam corpora alcena agglutinante, fimbriâ et fissurâ destituto.

Le tuyan et le disque sont reconverts en plusieurs parties de sible et de petits cailloux. Tout le tube est rempli de sable semblable à celui de Lćognan, localité des environs de Bordeaux où l'on trouve un grand nombre de beaux fossiles.

Avant de terminer ce qui a ripport aux Arrosoirs, nous dirons que nous arons observé dans I'Arrosoir de Java, que les iubes de la circonférence du disque se bifurquent à une cerlaine époque de leur a coroissement, et que plus tard, en s'alongcant davantage, chacuue de ces bifurcations se divise elle-mếnc en deux tubes plus grèles. Nous avons trouvé une première bifurcation dans l'Arrosoir agglutinant, et nous n'avoos pas vu le même fail se répéter dans les auires espèces du même grenre.

\section{ARTHEMIIDE. Arthomis.}

Nom que M. Poli (Test. utrius Sicil.) a donné à un genre de Mollusques bivalves, et çu'il introduit dans sa quatricme lamille. Ce genie est proposé pour une seule espice des Vénus de Linoé et de Bruguière, qui a élé comprise depuis, par Lamarck, dans son genre Cythérée, sous la dénomiuation de Cytherea exoletu. M. Oulien a
$A R T$

adopli: le genre dont il cst ques'ion, tandis que 3. Nónerie lui a donné le noin d'Orbicule, ce qui perterout indubiablement a commetre quelque erreur, prisque ce nom a élé aussi emplnyé par M. Jamarck pour des coquilles fort différentes. Les autres coquilles du genre Cythérée que M. Poli a connues étoient rangées par lui daussou greare Callista. Voyez ce mol el Cirtuénés.

ARTIÉMIDERME. Aithemiderma.

1)'apres le principe éralsli par M. Poli pour la dénominalion des genres de coquille, re nom s'appliqne anx cofiuilles du gene Arthémide. Voyea ce mol el Crtasiś.

\section{AR'YICULATIONS.}

Ce mot s'emploie de iserz manières dans la classe des Mllnsçucs; dans ceux qui sont acéplıales et pourrus de deux vilres, on dit que ces vilves sont articulćes par la cliarnière, et celte articnlation est ginglymoidale. Dans les Mollusques céphalés, on ne trouve de coquilles articulćes yue dans les Cíphalopodes dont ies coquilles sunt formées de loges superposées dont les bords sont tantôt simples, tantôt plas ou moins sinueux on même lascinićs profondément, comme dans les Ammouites, elc. Celle articulation est immobile, elle est par constiquent synarthrodiale. Toyez Copurale el Molzuspee.

\section{ARTICUIANE. Articulina.}

Petil genre proposé par M. d'Orbigny fils, dians la famille: des Agathistègues gui tuil parlie des Céphalopodes foraminiferes. (Mém. sur les Céphal. Ann. des scienc. nat. janvier 1826.) Les coquilles qui le constatuent sont microscopiques, et assez rares: Elles présentent cela de singulier de commencer par un pelotonnement semblable i celui des Triloculines, puis d'abandoneer ce mode de développement, el de projeter plusieurs loges en ligne droite. Celle circuostance qui ne se rencontre dans aucune coquille de la nuême famille méritoit bien l'établissemement d'un genre, et cela devenoit d'aulant plas raisonnable, qu'un autre car'actère d'une assez crrande impor'tance ajoutoit de la force au premier: loutes les Milioles out l'ourerture garnie d'une dent plus ou moins saillanie qui en parlage l'entrée, iei l'ouverture est bordée diun bourrelet assez éfais; elle est ronde, parfaitement entière et sans dents.

$$
\text { CARACTERES GÉรẼTQUES. }
$$

Loges opposées et pelotonnćcs sur trois cûtís; laissant à un certain âge ce mode d'accruissement, et projetant uae à trois loges cyliadriques surl'ase primitif; onverture ronde, marginéc, saus den:s. 
M. d'Orbigny n'a fait conncilre ou pluiôt u'a indigué qu'une seule cspèce dans sun gente Articaline. Les recherches nombreuses que nous avons fuiles dans les sables des curirous de P'aris où il l'a découverte, nous l'a procuce ainsi yu'une antre qui en est assez voisine; elles vitunent toules deux de Grignou.

1. Anticunine élégaute. Arliculina nitiáa. d'ORB.

A. lestî̀ elongatî̀, conichầ, rectî́, eleganter striata; striis longiludinalibus; upice mumimo, trslobuto; articulis tribus. Non.

D'Orbicir, Mém. sur les Céplual. (Ann. des scienc. nat. mars 1826. pagr. 300.). Modéles, ${ }^{100}$. livruis. $n^{\circ} \cdot 22$.

M. d'Orbigny a va celte coquille moins avancée gue nous dans son développenient; sur le sommei pelotonné et trilobé il ne place que deux loges, l'individu que uous avons en a troislicudistinctes. Cette coquille microscopique est droute, cunique, obtuse au sommet. Ce sommet est composé de trois loges apparentes pelatonnées sur trois cótés; sur l'ouverture de la iroisième loge, se placent perpendiculairement et dans l'axe primitil de la coquille, deux ou trois loges ovalaires très-distinctement séparées par un érranglement, tellement que sans l'enroulement du sommet, on prendroit cette coqulle pour une Nodosaire. 'l'oute la coquille est éléganment el linement stríe longitudinalemeat; elle se termine à la partic aurérieure par une ouverture ronle asses grande, bordée d'un bourrelet lissc fortemeut renversé en deliors.

Fossile à Grignon.

2. Articentre arquée. Arículina arcuala. Nob.

A. Lestâ elongatâ, subcylindrich, arcutû, striis longiludinalibus ornutâ; apice mugrno, obtuso, trilobalo; articulis duobus.

P'eut-être celte coçuille n'est-elle rju'une variétcé de J précédente, elle s'en distingue cependant par plusieur's caractères qui nous oni secublé suflisans pour la séparer; elle est arquée, subcylindracée, cest-à-dire que le sommet a un diamètre presque égal à celui de la dernière loge: ce sommet est beaucoup plus gros que dans la première espèce; it présente bien distınctement trois luges dont la plus interne est lisse; la dernière est pourrue d'un pelit bourrelet marginal sur lequel s'insère Ia loge qui suit : la dernière est la plus grande, elle se termine par une ouverture plus petite que rlans l'autre espece, elle est bordée d'un bourrelet beancoup plus large. Les stries don! cette coquille est converte son semblables à celles de la précéclente: qunique n'ayant que deux loges, elle est pourtant de la mème grandeur.

Fossile de la même localité.
ARTOIONE. Arolun.

Il est lort dillicile de décider si ce genre quo Monturt décrit aves assurace appartient aux Mollusques ou anx Aunélides; comne il n'ti pits ćlé retrouvé depuis, il est inpossil,le de se fixes a son cigard, ce 'fu'cu dit l'autcut élant lait pous jcler plutót dans l'embirras yue pour en faire sortir. Nous athandomous ces geures incertitis jusqa'ì de nouvelles observations, ne voulant pas a loute lorecy trouver ce qui i'y est probableaseat pas.

ARVAN.

Celte corquille, fort sincrulière, qu'Adansen (Voy. au Sénég. lab. 4. fig. 4.) a rangrée dans sın feure $V$ is, a reçu de lui ce nua. Il est à présainer que celte coquille, dunt l'ouverture est entière, seulement largement évaséc à la base, n'appartient pas à ce genre, mais entreroit bien plulut dans les 'Turruelles, dans la section des Prolo de M. Defrance. Voyez Proto et TunaTELLE.

\section{ARYTULiNE. Agthoena.}

M. Orken donne ce nom sans aucume nécessitú à un genre établi bien lonrr-temps avant par Brugruière, celui qu il a nommé Arrosoir, et qui a étć adopté sous ce nom par tons les zonlogistes francrais. Cependant celle dénomination du zoologisle allenand a élé préférée par MM. Scliweigger ét Goldluss. Ce servit à tort que l'on suivroit un tel exemple, car on arriverrit is ignorer le preinier auteur d'ut genre, en substrtuant ainst un autre nou à celui qual a donné, et ce nom füt-il unanvais seroit encore préférable à celui bieu meilleur qu'on voudroit lui substituer. Vojez Arresurr.

\section{ASIIHONOBRANCHES. Asiphonobran-} chiall.

Désxième ordre des Mollusques paracéphabophores dioiques du Système de Malacologie de 11. de Blainville. Cet ordre correspond à une parlie des Trachélipodes pbyliphages de M. Lamarck, et assez bien aux Pectinibranches trochoides de M. Cuvier. Caractérisés aussi bien d'après les organes de la génération que de ceux de la respiration, les Mollusques de cet ordre étant diorques, comme les Siplunobranches ( vayez ce mot), ont dû, par ce rapport bien aaturel, les suivre dans l'ordre méthodique, mais y constituer un ordse facile à distiuguer par le manque de siphon branchial a l'animal, et de canal ou d'échancrure à la base de la coquille: ainsi presque toutes les coquilles à ouverture entière sont placées dans cet ordre, excepté celles qui, comme dans les Hélices, par exemple, apparliennent à des atuimaux hermaphrodites. Ml. de Blainville a caractérisé de la manière suivanie K. 2 
l'urdie des Asiplionobranches. Les organes de la respiration constamment formes par une ou deux branclies pectinitormes, silućes obliquement sur la partie antérieare du dos, el contenues daus nue cavité dont la paroi supérieure ne se prolonge pas en tube, mais qui offre quelquefois un appendice ou lobe ioférieur qui en remplit l'office. Coquille de forme extrêmement variable; ourerture constamment entière, et tonjours complétement operculé, c'est-à-dire ferméc jar un opercule corné, et le plus souvent calcaire, projortionuel à celte ouverture.

M. de Blainville a formé dans cet ordre les cinq familles qui snivent et auxquelles nous renvoyons: e!les sont f́tablies principalement d'après la forme de l'onverture de la coquille : $1^{\circ}$ GoniosIornes; $2^{\circ}$. Cricostomes; $3^{\circ}$. Ellipsostomes; $4^{\circ}$. Hémicyclostomes; 50. Oxystomes. Voyez ces mots.

\section{ASPIDOBRANCHIATA.}

M. Schweigger a donué ce nom à un gronpe de Mollusques qui, excepté le genre Ombrelle qüil y a ajonté, correspond aux Scutibranclies de M. Cuvier. Foyez Scutrbraxches.

\section{ASTACOLE. Astacolus.}

Petit genre établi par Montfort (Conch. syst., tom. I, pag. 262), pour le Nautilus crepidulus de Ficlutel; il nous semble que cette coquille doi faire partie des Cristellaires. (Voyez ce mot);

\section{ASTARTE. Astarte.}

La justice vent, quand un genre a été proposé par deux anteurs, gre ce soit l'antériorité qui décide leqnel des deux noms on doit préféres. D'après ce principe, nous n'hésitons pas d'adopter le now d'Astarté donné par M. Sowerby, et non celui de Crassine que M. Lamarck a proposé plus tard. C'est en 1816 , dans le MIineral conchology, que ce genre fut proposé pour la première fuis. M. Lamarck, comme nous veuons de le dire, l'adopta en lui donnant le nom de Crassive. Nous ne savons d'après quels rapports ce savant rangea ce genre dans sa tamille des Nymphacées telinaires, non loin des Donaces et après les Capses, avec lesquels il n'a qu'upe analogie ધloignée. Celle opinion est cependant plus admissible que celle de $M$. de Ferussac qui, dans ses tableanx des animaux mollusques, fait de ce genre et des Crassatelles, une famille qu'il range dans son systeme, non loin des Arclies et des Noules; mais depnis, M. de Ferussac, dans sou article Astanté du Dictionnaine classique d'Histoire naturclle, a reconnu son erreur, et il convient que les coquilles de ce genre out plas de rapports avec les Vénus qu'avec toute antre. N. de Blainville partage la même opinion; il va même plus loin, car ponr lui les Astartés sont de véritables Vénus, dont il lait, dans ce grand genle, une pelite section caractélisée principalemeul d'a près l'impressiou palléale simple.

M. Latreille a suivi presque complétement la mavière de voir de M. Lamarsk; le genre qui nous occupe fait partie de la fawille des Tellinides (vojez ce mot), oǹ, accolé aux geures Corbeille, Lucine et Loripes, il fait un petit groupe dont les élémens ont hesoin d'être examinćs avant qu'on adopte définitivement lear rap. proclienient. De ces diverses opinious, celle qui nous semble la plus couvenable, est celle de M. de Blainville, en la modifiant un peu, c'està-dire en conservant le genre Astarté, dont l'auimal n'étant pas connu ve pent être définitivement admis ou rejeté, et en le plaçant dans la frmille tes Conques immédiatement après les Vénus. 11 est à présumer que ceci éprouvera cependant des cliangemens par la suite, parce que biea prolsablement l'animal des Astartés est semblable à celui des Vénus; on est conduit à le penser par la grande analogie qui existe entre les coquilles des deux genres el la manière insensible dout se foudent leurs caractères. Nous allors d'abord donner la pluase caractéristique de M. Sowerby, avant d'entrer dans la comparaison que nous roulons en faire avec celle des Véuns.

$$
\text { CARACTÉRES GÉNÉRIQUES. }
$$

Coquille suborbiculaire, sourent transverse, équivalve, inéquilatérale: cluarnière ayan denx fortes dents divergentes sur la valve droite; sur la valve gaucbe une seule dent, et à côté une antre obsolète. Trois impressions musculailes sur chaque valve; deux latérales, oblongues, simples; la troisième très-petite et postćrieure; ligament externe.

Quant aux formes, on sait que les Vénus les affectent presque loutes, il y en a d'orbiculaires, de transverses, etc.; clles sont tontes éqnivalves et presque toutes inéquilatérales. La charnièrc est aussi très-variable; quelques espèces ont truis dents à une vilve, quatre à l'autre; d'autres ont trois dents a chaque valve, c'est le plus grand nombre; quelques autres en ont trois d'un côlé et deux de l'autre; on en trouve anssi qui n'ont que deux dents à chaque valve, et plusieurs qui avoisineot les Astartés qui ont une de ees deux dents ordinairement avortée. La troisième impression musculaire dont parle MI. Sowerby, se retrouve sans exception dans toutes les Vénus, les Cytbérées, les Vénéricerdes, etc.; elle indique l'endroit où s'attache le muscle rétracteur du pied. Un autre caractère, qui a cependant quelque valeur, et dont M. Sowerby n'a parlé que dáns ses observations genciales (the Genera of recent and fossil shells, $n^{\circ} 4$.), peut être pris de l'impression $d u$ mantean; elle est toujours simple dans les Astartés; elle ne présente postérieurement aucune sinuosité. Cette sinuosité est pro- 
duite par l'insertion d'un muscle aplati, le rétracieur des siphons : l'exis:ence de l'un entritine nécessairement celle de ceus-ci. Ce caractćre seroit des plus concluans, si l'un n'avail lia ce:titude que les siplıors peuvent exister aiusi que leur muscle rélracteur, sans laisser sur la coçuille la moindrc trace. Les Iridines en donnent la preuve convainquante et les Vénus elles-nuêmes. Si dans quelques espèces, celle impression sinueuse est très-profonde, on peut en trouver où elle l'est beaucoup moins, el établir une série ot on la voie diminuer insensiblement d'étendue, et enfin disparoitre complétement. Plusieurs des espèces où elle n'existe plus ne sont pourtant pas des Astartés, puisqu'il y a trois dents cardinales à chaque valve. On pourrait conclure de lis, comme l'a fait M. de Blainville, que le genre qui nous occupe ne devroit pas être adonté; c'est aussi ce que nous ferions, s'il n'avoit un facies particulier, s'il n'étoit épidermé, et enfin si l'on en connoissoit l'animal et qu'il fát semblable ì celui des Vénns : jusque là nou croyons convenable d'admettre ce genre provisoirement.

On ne compte encore qu'un petit nombre d'espéces vivantes d'Astartés. Il y en a davantage de fossiles, elles viennent surtont d'Angleterre dans les terrains tertiaires. M. Lajoukaire, dans une notice jusérée dans les Miémoircs de la Société d'histoire naturelle, en a fait connoitre d'aulres fossiles de la Belgique. Des coquilles assez. communes dans l'oolite de Caen et de Bayeux, et que M. Lamarck, par l'aspect extérieur, avois rangées parmi les Cypricardes, doivent venir augmenter le nombre des espèces du genre Astarlé. Sow.

1. Astanté crassatellée. Astarte danmoniensis.

A. testâ orbiculato-trigonâ, brunneo fulvâ, transwersè rugośa, rugis parallelè striatis, scalarifonnibus; intus alba ; marginibus crenatis.

Crassina danmoniensis. Lasr. Anim. s. vert. tom. 5. pag. 554 .

Venus danmonia. Montag. Ani. Angl. Suppl. pog. 45. tab. 29. fig. 4.

Venus danmoniensis. Brssst.Trait. de Mulac. pag. $557 \cdot p l .75$. fig. 7 .

Sowerв , The genera. $n^{\circ}$. 4. pl.fig. 1. 2. 3.

Coquille d'une taille médiocre, ovale, subtrigone, inéquilatérale; les crochets sont petits, jointns et fort rapprocbés; la surface extérieure est d'un brun-jaunâtre, quelquefois verdàtre; clle est tonte converte de sillons transverses, réguliers, convexes, et striés dans leur longueur; la lunule est ovalaire, peu profonde, toutel lisse; le corselet est lancéolé, il contient antérieuremeut no pelit ligament externe qui s'étend jusquo an somrnet des crochets; en dedans cette coquille est blancbe, et ses bords asscz épais sont finement crérelés; son test est épais, solide et se rapprocbe par la de celui des Crassatelles. Les plus grands individus de celle espèce ont 55 railliu. de large; on la trouve dans les mers britanniques sur la còte du Dévonshire.

Astanté d'Omalius. Astarte Omalii. La Joxx. A. testâ ovato-trigronâ, subcordutâ, lavigratî, natibus solùm rugosâ; lumulà ovatâ, excavatâ; marginibus cremulatis. Nов.

De la Jonkilre, Note sur le gente Astarté. Mlém. de la Soc. d'hist. nat. de Patis, tom. 3. pag. 129. pl. 6. fg. 1. a. b.

Cette espèce est ovale-trigone, épaisse, intequilatérale; ses crochels sont petits, pointus, saillans, obliquement recourbés vers une lunvle cordiforme, ovalaire, lisse el assez profonde; la surface extérieure esı lisse dans presque tonte son étendue, marquće senlement de quelques stries d'accroissement, mais les crocliets sont ornés de sillons récruliers, coucentriques gui s'ólargissent, s'aplatissent promptement et disparoissent. Lais lame cardinale est épaisse, assez large; elle porte sous le crochet, à la valve droite, une très-grosse dent striée latéralement, et à la valve ganche deux denis divergentes plus petites. Les bords sont taillés en biseau, queiquefois assez épais et finement crénelés en dedans.

Celte coquille, qui a 25 à 50 millimètres de large, se trouve fossile aux euvirons d'Anvers et en Angleterre.

3. Astartélisse. Astarte nitida. Sow.

A. testâ orbiculato-trigonâ, depressâ, lavigatâ, nitidâ; nusibus prominulis, tenuissimè strutıs; niarginibus crenulatis.

Sow. Miner. conch. pl. 52 1. fig. 2.

Quaique voisine de l'espèce précédleale, elle s'en distingue néanmoins facilement; elle est ovalaire, moing transverse, plus longue, jlus équilatérale; le crochet est pointu, peu saillunt; le côté antérieur est presquue droit, il présente une lunule lancéolée, peu profonde; le corselet est étroit el pen creusé. La surface extérieuse est lisse et polie, si ce n'est sur les crochets où l'on voit des stries régulières, fines et concentriques, qui disparoissent promptement. La dent cardinale de la valve droite est moins grosse et moning saillante que dans l'espèce précédlente; elle est également striée, mais les stries sont plus fues. Son bord est crénelé en dedans.

Celte coquille est comranne dans le Crag de Suffolk en Angleterre, oì elle est à l'état fossile. Largeur 32 à 35 millimètres, longueur 20 à 30 .

4. Astarté bipartite. Astarte bipartita. Sum. A. testâ trigonatâ, subcondatâ, ouliquâa; na- 
litu: acutis, balde recurvis, sulcis regularibus irofundis, ornatis; lumulis ovalâ, profundâ, livvigutai:

Sówerat, Minetal. conchol. pl. 52 r. fig. 5.

Val. a. lestî latiore margine cnenato. Мов.

Asturte oblonga. Sow. loc. cit. fig. 4 .

Nous réunissons eu une seule ces leux espèces de $\mathbf{A l}$. Sowerby, clles ne dillërent véritablement que par le bord qui est crénelé dans l'une et pas duas l'autre : si l'on remargue dans les ligures une plus grande dillérence, cela tient à ce que l'auteur anglais á fail ligurer de jeunes individus de l'Oblonga, cqui par cela seul sont couverts de sillons daus tcute leur élendue.

Celte espèce est subovalaire-triangulaire, presque aussi longne que large, corditorme, bossue; ayant les cruchets saillans, pointus, obliques et vilargés de huit ou dix gros sillons qui disparoissent pour lajsser le reste de la coquille enticremeat lisse. Cette circonstance, qui lui a sans doute valu son nom, se tronve dans la variété qui ne dillère vtriablement qu'en ce que les sillons désceudent un peu plus bas, et par les bords qui sun simples; mais ce dernier caractère est de peu d'inportance pour les espèces, car il se montre assez rariable.

Longueur 26 millim. largeur 2\%. De Suffolrk datus le Crag en Aogieterre.

5. Astanté corbulö̈de. Astarte corbuloides. LA Joxis.

A. testâ subtrigonâ, inflatâ, cordiformi, regu. Eulariter sulcatâ; natibus prominulis; lunulâ excavatá, ovatâ, levigatá; margine crenato. Noв.

LA Josx. loc. cit. $n^{0} \cdot 2$, pl. 6. fig. 2. a. b. c.

Coquille moins grinde que les précédentes, très-facile a distinguer par sa forme subrrigone et ea cceur; ses crochets sont grands et saillans, cbliquement reoourbés vers uoe lunule ovale, profoude el entièrement lisse, lorsçue tont le reste de la coquille est convert de sillons convexes, concentriques et fort réguliers; le corselet est petit el lancéolé; la lame cardinale est assez large, wlle porie deux deuts cardiales bien distinctes sur chaque valve; le bord est crénelé, mais les crénelures sont plus grosses que dans la plupart des espéces. Celle-ci, qui a 18 à 20 millin. de largo et un peu plus de long, vient des eavirons d'ADvers où elle fossile.

\section{Astanté épaisse. Astarte incrassata. Noв.}

A. testâ solidáa, subtriangulî, infutû; natibus transversum rugosis; latere antron leviter inflexo, margine sappus denticuluto; candinis dentibu's binis salidis, ulsero un dextrî̀ valuầ minimo. Broccer.
Tenus incrassata. Broccur. Conch. foss. sub app.pag. 557. n०. 23. pl. 14. fig. 7 .

C'est à tort que M. Brocchi a rapporté celse espèce au genre Capse de B. Lamarck, elle sse loi appartieut unllemeat, mais bien à celui-ci dorat elle présente tous les caractères. Elle est cle forme snbtriangulaire, enllée, vn peu cordilume; ses crochets sont petits, courbés, très-rapprocliés, ils sont linement sillonnés, ces sillons sont transverses, peu nombreux; ils disparoisseat bientôt et tout le reste de la coquille est lisse : on y voit cependant quelques traces des accroissemens. La luuule est alongée, ovalaire, enfoncée, séparée du reste par une arête asscz vive; le corselet est petit el un peu profond, les bords sont le plus sonvent crénelés, ils soul quelquefois lisses, ce qui prouve qu'il ne faut pas trop s'attacher a ce caractère pour distinguer les espèces.

Celle coquille, dont le test est épais, est large de 18 millim. et un peu moins. On la tronve fossile dans le Plaisantin et au Val d'Audone.

Parmi les espèces fossiles d'Italie, citćes par NI. Brocclii, et les autres que nons avons rues, celle-ci est la seule qui appartienue véruableweni aus Astartés.

\section{Astarté étagée. Asturte scalaris. NoB.}

A. lestâ trigonâ, depressâ, sulcis subregularihus, scalunformibus, ornatá; umbonibus acutissimus, necurvis; curdine angusto, dente cardinali dext1o bifido.

Var. a. Testâs suicis tenuioribus, numerosioribus.

Celle coquille s'approche un peu de la Nucule nacrće pour la forme; elle est subtrigone, trans. verse, très-inéçulatérale, couverte extériemtement et dans toute son étendue de sillons subaigus, concentriques, scalariformes, bien réguliers sur les crochets jusque vers le milien des valves, et devenant plus arrondis, moins réguliers vers les bords; les crocluets sont petits, très-aigus, pen recourbés vers une lunule ovale, alongée, peu prolonde et très-nettement dessinée par un anghte aigu. La coquille est déprimée, aplatie, peu épaisse, ses bords sont finement crénelés; la charnière est portée sur une lame cardinale étroite. Dans les indivirlus bien conservés, on voit trèsfacilement que la grosse dent cardinale de la valve droite est inégalement partagée par nn sillon. La variété se distinnue par les sillons qui sont beaucoup plus nombreux, plus rapprochés et conséruemment plus fins. Nous avons trois individus de celle espèce, le plus grand a'a que it millimètres de large. Fossile des environs d'Angers.

8. Astatí striatnle Astarte striatula. Noв. A. testâ orlíiculuto-trigonâ, cordatî, exilis- 
sind striatâ; umbonibus magnis, w'ilue recurvis, "cutis; marginibus tenué crenululis.

Jolie corquille hien distincte de toutes les esreces conaues; elle est de lorme suborbiculaireirigoue, condilutene, trés-bombéc, convexe, converte dans tonte sun élendue de stries lrèslines, profondes, un peu oblicjues, les dervières aboulissant sur le bord, e: ne lui étaul pas paralléles dans toute son ćlendut; croclıcts saillans, furtement recourbés, a sommet pointu, inclinés sur la Iunule; celle-ci esi ovale, protonde, la ligne médiaue qui la partage, et qui résulte de la réunions des deux valves, est sinuense dans son milieu, de sorte que la partic de la lunule qui apparticnt is la valre gauche est plus large que l'autre; la lame cardinale cst assez larare, elle supporte une cliarnière dont les dents sont épaisser et saillautcs. Lo test est solide et épais; les bords sont crénelés fincment : les jeunes iudividus paroissent déponrvus de ce caractère.

Celle espèce a les mêmes dimensions en lnngneur et en largeur, 20 millimètres. Fossile des invirons d'Angers.

9. Astanté solidule. Astarte solidula. Noв.

A. testâ orbiculato-trigonâ, crassâ, solidâ, condato-gibbosâ; umbonibus acutis, recurvis; mullisulcatis; tribus quatuorvo sulcis latissimis, depressis, valvas obtegentibus.

On distingue facilement celte petite espèce par sa forme orbiculaire-subtrigone, cordiforae, l'épaisseur de son test qui est considérable pour sou volume, et la disposition des sillons qui se voient à son extćrienr : ces sillons sont finq sur le crochet, ils se terminent assez brusquement pour faire place à plusieurs grossillons convexes-aplatis; lisses un légèrement striés les premiers seulenent, et accupant le reste de la surlace de la coquille. Le crocbet est petit, pointu, urédiocrement saillant et courbé; la lubule est ovalaire, pelite et fort profonde ainsi que le corselet, qui est Gtroit et lancéolé. Te bord des valves ost tantòt lisse, tanlôt finemenl crébclé.

Jargeur 14 millimètres.

Fossile des faluns de la Touraine. Nor.

10. Astanté modiolaire. Astarte modiolaris

A. testî̀ ovato-oblongâ, tumidîa, striis transsersis arcuatis ornatâ ; lunulâ ovato-cordiforni, profundâ, margine valdd crenato.

Cypricardia modiolaris. LAMr. Anim. s. vert. tom. 6. $1^{\text {re }}$ part. pag. 29. $n^{\alpha} .5$.

An Astarte excavata? Sow. Min. conch. pl. $23 \overline{3}$.

M. Sowerby est certainement dans l'erveur lorsqu'il donoe ponr l'Astarte modiolaire une coquille qui 'n'est pas la Cypricarde unodiolisire de
M. Lamarck; car si M. Sowerby y cut pris garde, il auroil vu gque par celle espéce H. Lamarch a entenda une coqquille striće, et celle représentée par M. Sowerlyy est elieierement lisse : pour tou: dire, l'auteme andugis a flymél la Cypricarde oblique Lamk. sous le num de Modiolaire. Is.dstarte cxcasata Sow. a ciuelquanalogie avec celle-ci, mais elle offre des diférences assez notables pour qu'on ne l'y rapporle qu'avec donte; on en jugera eu comparant ce que nous allous dire, avec la description et la figure que nous avous citées.

L'Astarté modiolaire est une coquille transversale, ovale-oblongue, oblique, très-inéquilaterale, car les crochets sont presque aussi saillant que le bord droit; loute lis surface extéricure est sillonnée; les sillons 6ont étroils, régalicrs, conceutrigues; les crocliets sont petits, obliques, inclinés sur lit lumule qui est ovale, condiforme, lisse, très-profonde; le corselet est aussi très-profond. Nous sommes parrenus arce de la persévérance à dígarger complétement une charnière de celte coquilie, et nous pourons affirmer qu'elle apparticut bien au genre Astarle; la cavité du crochet est profonde en dessous tio la lame cardinale, ce qui n'a pas lieu ordinairement dans ce genre oì cotte cavité est remplie par la matière de la coquille. Les crénelures des Lnrds sont grosses et distantes. Largeur 50 ì 55 millimètres.

Cetse coquille se treure à l'état de pétrification dans l'oolite de Cuen et de Bayeux. Noв.

A. lestâ ofato-oblonĝ́â, depressiusculâa, striis transuersis cxilibus omatâ; lunula lanceolatâ, superficiuli; margine tenuissimè crenato.

Nous distinguons celle espèce, quoigue firt voisine de la précédete; clie a une forme à pen - près semblable, ovale, oblongue, une jen moins inéquilatérale; les stries concentriques qui couvrent la surface extérieure sont plus noubreuses, plus fines, plas serrées, plus saillantes antérieurement que postérieurement; mais ce qui la distingne surtout, c'est la lunule qui est à peine séparéce do reste de la coquille tant elice est superficielle: elle est ovale alongée, laucéolée, tonte lisse; le corselet n'est point enfoncé non plus, la nywnhie qui le termine vers le crochet est au niveau du Lord; la lame cardinale est beaucoup moins large, et la cavité du crochet est remplie par la maticre de la coquille. Elle est plus solide et plus épaisse, et ses boìds sont finement crénelés. Nons dédinos celle espèce à la númeire de notre ami, le savaut et honnête Ménard de la Groye, enlevé trop tôt aux sciences qu'il culiivoit avec un zèle et une délicatesse bien honorables.

Largeur de cette coquille 50 millimètres. 
Des earizons de Cacn. On la tronve dans la méme couche que la précédente.

12. Astarté ablique. Aslarte obliqua. Nов.

A. testá obliquè cordatâ, convexâ, sublceviSatâ; margine superiore rotundato, alteris intìs subcrenulitis; lunulâ ovatâ, vix depressâ.

Cypricardia obliqua. Lamк. loc. cit. no. 6.

Astarte planata? Sow. Min. conch. loc. cit. pl. 257

Astarte modiolaris. Sow. The genera recent and fossil. shells, no. 4. pl. fig. 4 .

Var. a. Testâ ombonibus striatis.

Var. b. Testá majore, depressá, umbonibus minimis.

Var. c. Testâ rotundatâ, marginibus non crenulatis.

Comme on le voit par notre synonjmie, cette espèce a Ćté prise par M. Sowerby pour le Cypricardia modiolaris de M. Lamarck qui est l'espèce précédente ; celle-ci est très-commune dans l'oolice ferrugineuse des environs de Caen et de Bayeux. Eille se reconnoît à sa forme ovale, ì sa griude obliquité, qui est telle que le crochet dépasse le bord droit dans presque tous les individus; elle est conséquemment très-inéquilatérale; son bord supérieur ou dorsal est arroudi, convexe; le bord antérieur est assez court, il présente une luuule peu marquée, peu profonde, ovalaire, sur laquelle s'incline le crochet qui esi petit el pointu; les bords sont tantôt simples, tantôt crénelés en dedans. Cette espèce est assez variable dans sa forme; elle est plus ou moins ovale, quelquefois presque circulaire, d'autres fois très-tzansverse : la première variété est remarquable par les stries régulières et fioes qui sont sin les crochets, et plus ou moins loin sur le dos des valves. La variété b. se reconnoît à son extrómité postérieure qui est plus pointıe, à ses crochets plus petits, un peu plus courbés, clle a aussi un plus grand nombre d'accroisscmens matrqués. Eufin la variété c. est presque orbiculaire, tant ses contours sont arrondis. Les dimeusions de cette corquille sout assez variables, les grands individus ont presque Go miltim. de large. On la trouve surtout aux environs de Caen et ì Bayeux.

13. Astanté trigone. Astarte trigona. Noв.

A. testî̉ cordato-trigonâ, subangulatâ, $a b$ breviatâ; striis tiansversalıbus tenuissimis, reguluribus. Anus lunulâque distinctiusculis; margine crenato.

Cypriacardin t.igona. Lamx. loc, cit. $n^{\circ} \cdot 7 \cdot$

Coquille subovale, subtrigone, cordifurme, inćquilatérille, mais moins gुue les especces pré- cédentes; elle est assez épaisse et ses crochets assez longs, se reploy ant vers la lunnle, lui donnent la forme d'un cour; le corselet est peu profond, la lunule l'est davantage. Elle est ovalaire, lancéolée; le bord supérieur est arrondi, oblique, ke postérieur est le plus court; l'antérieur fait un angle presque droit avec le supérieur, il est presque aussi long que lui; toute la surface extérieure est couverte de stries 1 rès-fines, rapprocbées, régulières et coucentriques. La charnière est supportce par une lame cardinale peu large mais épaisse; le test lui-même est solide et épais; les bords postérieurs et inférieurs sont crénelés, l'antérieur ne l'est pas.

Moins grande que les précédentes, 3o millim. de large. Celte coquille vient des mêmes localités, mais elle y est plus rare. NoB.

A. testâ inflato-condatâ, subtrigonâ, eleganter striatâ, subequilaterâ; umbonibus magnis recurvis; lunulâ motundatâ, excavatá; marginibus crenulatis.

Cette petite coquille est, de tontes les espèros de ce genre, celle qui est le plus cordiforme; elle est enflée, subrrigone, presque équilatérale, le côté postérieur étant un peu plus grand que l'autérieur; les crochets sont grands, saillans, recourbés; la lunule est circnlaire, assez grandé et creusée; le corselet est profond, lancéolé, séparé du reste de la coquille par un angle aign. La surface extérieure est chargée d'un grand nombre de stries trausverses, très-régulières, saillantes, aiguës, qui s'eflacent un peu vers le côté postérieur; la charnière est portée sur une lame cardinale épaisse mais étroite; les bords sont créuelés assez finement, cependant les crér nelures sont plus grosses vers le milieu du bord inférieur que jartout ailleurs.

Celle petite coquille, fort rare, se tronve avec les précédentes à Bayeux dans l'oolite ferrugineuse. Elle er aussi longue que large, 14 millimètres.

\section{ASTROLEPAS.}

Ce genre de Klein, établi pour le Lepas testudinarza Lin., Cononula testudinaria Lamk. , correspond assez bien au genre CoHonole, quï est géuéralement adopté. Voyez ce mot.

On donne aussi le nom d'Ostrolepas à une coquille du genre Patelle. Voyez ce mot.

\section{ATLANTE. Atlanta.}

On troure ì la planche 63 da Voyage de Lapérouse, et indigutes sous le $10 \mathrm{~m}$ de cornes. d'Awnou, de petices coquilles transparentes qui appartiennect au genre Ailante, et que Lamanon, 
ce mallieureux compagnon d'un illustre royareur, prit pour le type vivant des Ammoniles. Sil étoit facile de se prémunir contre une pareille erreur, il l'étoit plus encore de citer l'auteur de cette découverte, lorşue M. Lesueur proposa l'établissement d'un geure nouveau pour les unêmes objets. Nons supposons que M. Lesuear a iqnoré ces antécédens, nous lui connoissuns trop de boune fui pour ne pas en être assuré. Lamanon, il est vrai, ne connut janais l'animal de sa corne d'Ammon; Lesueur eut sur lui l'avautage de le reucouser, et il en donua une description assez détaillée et des figures assez bien faites dans le tom. 85 du Journal de Physique (novembre 1817 ). M. Lamarck ne connut pas sans doute ce travail de II. Lesueur, car il ne mentionna pas le genre Atlante dans son dernier ouvrage, quoique publié deux ans après. Dès l'origine, ce genre fut placé parmi les Mollusques ptéropodes, et il y fut aduis par M. de Ferussac; dans les Tubleaux systématiques de cel auteur, il forme, avec le genre Limacine, la famille des Limaciues, la seconde des Ptéropodes se trouvant de celte manièı avoisinće par le genıe Cymbulie, dépendant de la famille cles Hyules, et par le genie Clio, appartenant à lis fauille des Clios.

Les nouvelles observations fai:es par MI. de Blainville sar les Ptérupodes, le purtèreat à clianger cousidérablemeut l'ordre systématique adopié avaut lui : il ne laissa plus dans les Ptéropodes véritables que trois genres dout celui-ci est le premier, et sans doute que cel habile anatomiste ne l'y anroit pas laissé, s'il avoit pu exalniner l'animal de ce genre; mais il ful obligé de se servir des matériaux donnés par M. Lesueur, et s'il s'est trompé daps ses rapports, c'est à l'auteur du genre qu'il laut l'attribuer, puisque c'est lui le premier qui a commis quelques erreurs. M. Latreille, à l'égard de ce genre, suivit la marclie de ses prédécesseurs; il n'avoit pas plas qu'eux les élémens nécessaires pour opérer des changemens dans la méthode, aussi trouvet-ou le genre Allante dans la famille des Procépbales, la première des Pléropodes, formalt avec les Limacioes une peite section, qui est suivie de celle qui renferme les Clios, les Cléodores el les Cymbulies. Telles éloieat les connoissances acquises su. le genre curieux qui nous occupe, lorsque M. Rang, observaleur habile, publia un mémoire particulier parmi ceux de la Suciété d'histoire nalurelle de Paris (tom. 3, pag. 572,1827 ), qui est entièremeut consacré á l'histoire et à l'anatomie des Atlantes. Ce trivail, fort bien fait, indique des erreurs dans les descriptiuns de M. Lesueu;, it tel point, que les Mnllusques dont il s'agit deviont passer des Ptéropodes parui les Gastéropodes, puisqu'ils en ollirent plu.ôt l'organisation. Après avoir comparé la phrase caraciéristique de M. de Blainville, avec celle qu'il propose d'y substituer comme plus exacte, M. Rang

Histoire Naturelle des Vers. T'ome II. entre dans des délails anatomicques qui sont trop importans pour que nous n'en donnions pas une courte analyse.

L'animal, comme tous les Alollasques en spirale, se compose de deux parties distincles, une antérieure et l'autre postélicure, concuarúe en spirale comme la cocpuille : la partic antérienre ollie trois organes principanx, le premier la tête, le second la nageoire on le pied, le troisiène est un appendice de ce mênı pied destiué à porter un opercule.

La tête est alongée en trompe, courlíe postírieurement, ouverte à sun extrémité antériente, qui est atténuée, par une bouche petite, qui présente à peine des rentlemens labiaux. Yer's le quart postérieur, à l'endroit le plus large de la face sipérieure de cette tête, se voient deux tubercules peu saillans, ayant à leur parlie interne un très-petit appendice, et portant dans leur milieu des yeux grands et noirs, en avant desquels naissent deux longs teatacules cylindriques, qui restent presque constamment appliqués le loag de la trompe.

Le pied quii est ici transformé en nageoire est médian, ovalaire, grand, aplati latérulement, muni de plis transverses coupés par des stries longiludinales très-lines et régulières, que l'on auroit pu prendre pour une disposition vasculaire destinée à la respiration; le bord postérient de cette nageoire est muni, vers son milieu, d'une petite ventouse, au moyen de laquelle l'animal peut se fixer aux corps flottans, puisqu'il lui est impossible de ramper. A la base de l'organe locomoteur, se voit un appendice mobile, pointu, qui dans l'état de développemeut de l'amimal, purte en dessous une opercule corné, vitreux, très-mince, et qui a exactement la forme de l'ouverture de la coquille. Celte troisième partie de l'animal est comparable avec l'extrémité postérieure du pied des Gastéropodes, destinć aussi à porter l'opercule: ici, comme dans les animaus que nous citons, l'opercule est retenu par un muscle qui laisse une irapression.

D'après la disposition particulière de ces diverses parties, on pent déjà assurer que le mollusque de l'Allante n'est point un Ptéropode, mais bien un Gastéropode, dout le pied a élé modifié pour la natation. Les organes de la digestiou commencent par une ouverture buccale d'une médiocre élendue; à l'intérieur de la bouclie se voit nn petit prolongement lingual, derière lequel commence un cesophage long, cylindrique, accompagné latéralement de causux salivaires extrêmement minces, qui naisseut de deux glandes alungrées, placies a la bauteur de l'estomac; celni-ci, qui est d'une grande éteudue relativement au volune de l'animal, est fort alongé et de conleur noirâtre, l'intestin qui en naît n'esı pas d'une égale dimension; après plusieurs circonvolutions, dans le fuie probablement, ce que M. Rang ne 
dit pas, il revient en avant el se termine à une sorte de pavillon llottant qui a la forme d'un entonnoir, et qui est placé à drojle au-dessous de l'origine de la tête.

NI. Rang nous laisse ignorer la position de la cavité branchiale, il est donc à croire qu'elle est situce au-dessus du col; elle contient, lixée à sou plafoud, un seul peigne branchial, counposé d'une douzaine de feullets en formes de paletles disposées sur un seul rang. Le coeur est placé non loiu de la branchie; mais M. Rang n'indique ni sa place précise, ni la disposition générale du systène vasculaire.

Le système nerveux a été mieux connu, quatre ganglions composenc la masse encéphatique; ils embrassent l'osopluage lant en dessus qu'en dessous, et doment naissauce a un grand nombre de filets dont les antúlieurs se distribuent à la téte et aux parties postérieures dr corps, tandis que dins d'autres la distributiun et les rapports ne sunt pas connus; cependant par analogie on peut supposer, avec M. Rang, qu'il existe un ganglion viscéral uni au cerveau par un filet plus gros que les autres.

Les orgaues de la génération ne sont pas conaus dans tous leurs aétails et leur connexiou : il y a un ovaire qui occupe, avec le fuie, la partie la plus reculée de la coquille, et un organe excitateur placé au côté droit sur le rềme tubercule d'où sort l'anus. On peut donc conclure de l'existence simulianée des deux sexes sur le même iudividu, que les Allantes sont Lermaphrodites.

Il n'est pas douleux, d'après les nouvelles cnnnoissances acquises sur le genre Allante, que l'on ne doive saltendre à voir ses rapports éprouver de nolables changemens. Désornais on ne pourra plus admellre ceux que l'on avoit élablis avec la Limacine. (Voyez ce mot.)

Il devra nécessairement sortir des Ptéropodes pour entrer dans les Gasléropodes; mais on éprouve un bien grand embarras quaud on reul lui trunver des connexions naturelles avec les Gastéropodes aperculés, s'il y a quelqu'analogie pour un pelit nombre de parties, il y a plusienrs autres motifs pour les éloinner. Si on veut l'introduire dans une famille ou un ordre des métlades déjà établies, il est cerläin, comure l'a lort bien fait sentir M. Rang, qu'il pourra eutrer dans les Hétéropodes de Ml. Lanarck; mais nous ne pensons pas, avec le même auteur, que re genre puisse faire parlie des Nucléubranches de M. de Blainville, bien qu'all l'y ail en effet placé; mais M. de Blainville croyoit ce genre dépourvu d'opercule, et il est bien is présunier que celle nouvelle condition d'orgauisation lui étant cunnue, il pe conservervil plus la même opinion, car la présence ou l'absence de l'opercule, dans les Mollusques, a toujours ćté considérće comne d'une haute importance dans leur classilicalion. M. Rang dit, en parlant des Hétéropodes, que c'est bien un ordre distinct, mais qui, de même que le genre Anomie d'autrefois, sert de réceptable à tout ce dont on est eubarrassé. Nous croyons juste d'observer yue celte comparaison n'est pras exacte: l'ordre des Héléropodes n'est composé que de trois genres; deux de ces genres sont si voisins, les Cárinaires et les Firoles, que jamais personne, pas unème M. Rang, n'a songé à les séparer. Quant au genre Ihylliroé, M. Lesueur en avoit donué ane description trop peu complète, comme on l'a su depuis, pour que M. Lanarck eût pu commettre une erremr, que tout autre a sa place aurost été dans l'obligation de faire aussi en se servanl des mêmes matériaux que lui. Il est donc vrai que nuns avions de justes raisous de reprocher celle comparaison a M. Rang, puisque le geure Anomie de Linné étoil un assemblage monsirueax des genres les plas disparates et les plus éloignés.

M. Rang propose de rapproclier les Allanites des Carinaires et des Firoles, et d'en fuire un ordre auquel on conserveroit le nom de Nucléobranche. Nous ue cruyons pas que le rapprocliement des Allautes et des deux autres genres soit naturel, 1\%. parce qu'ils portent des branclies sériales sur le dos, non conaprises dans une cavité respirarrice, ce qui n'a pas lieu daus les Allantes; $2^{\circ}$. la forme clu corps, du pied, et la proportion relative de la coquille avec l'animal, qui permet ì celui qui nous occupe d'y reutrer complétement, sont d'atures motifs bien graves pour rejeter les Allantes du voisinage des Carinaires; 30 . ce qui éloigne ces genres, c'est surlout l'opercule, qui ne peut se trouver dans un Nucléolranche: car, qui dit Nucléobranclie, comprend des animaux qui ont plusieurs organes groupés sur le dos en une sorte de nucléus, dont la masse est si peu proportionnée à celle du reste de l'animal, qu'ello en lait à peine la dixième partie. Ces motils nows semblent suffisans pour ne pas admetice les Allantes parmi les Nucléobrancles, et puur croire qu'il sera nécessaire d'en faire une petile famille iutermédiaire entre les Gastéropodes véritables et les Nucléobrancbes.

\section{CARACTÉRES GÉNÉRIQUES.}

Corps conchylifère, comprimé, spiral, pourva d'un pied en nageoire, médian, fuliacé, assez grand, et portant une ventouse à son bord postérieur; têle en trompe; deux tentacules cyliudriques en avant d'yeux fort gros, comme pédiculés à leur base; bouche à l'extrémité de la trompe; les organes générateurs mâles au cûté droit, implantés à la base d'un tube très-grand, qui se termine en avant par l'orifice de l'anus; branchie pectiniforme au plafond de la cavilé pulmonaiice.

Coquille enroulée longitudinalement, trèsinince, diaphane, forlement carénée, à ouverture 


\section{A T I.}

Échancréc ou fendue antérieurement, à bord tranchanl; spire terminće par uu bouton au fond dc l'ombilic ulu côté droit.

Opercule corać, vitıeux, à élémens concentriques.

Les animaux de ce genre sont nageurs, aussi est-ce en pleine mer gu', n les rencontre, et ils $y$ sout en quantités nuombrables; leur petitesse, leur transparence, ont été des causes bien suffisantes pour qu'ils échappent aux recherches des naturalistes. C̈est dans la mer du Sud et dans le graud Ucéan indien que les Atlantes se sont trouvés jusqu'à présent : les coquilles sont d'une transparence de verre, elles oul quelques caractìres qui ont échappé aux investigatıuns de Lesueur, tels que le bouton qui comaence la spirc ef la fente de l'ouverture. Cetle dernière circunstance surtout est importante à observer; il est bon de noter aussi que l'animal est lié à sa coquille pur un muscle longiludinal fort puissant, à l'aide duquel les mouveneus de coulrac ions sopèrent facilement, et cependani on ne trouve aucune trace de son adbérence dans la coquille lorsque l'auiraul en est séparé. Cé fail est constant dans toutes les coquilles minces et vilreuses, et il vient ذ l'appui doun sentiınent qui a été rejeı́e, il y a peu de temps, à l'éuard de l'Argonaule : de re que l'on ne trouvoit poiut d'infression musculaire dans cette coquille, on eu a conclu qu'clle ne devroit être liée par aucun muscle à l'animal qui l'babite. Il nous semble que par l'uuiversalité des fuits on aurait dî tirer une conclusion cuntraire.

1. Atrante de Péron. Allanta Peronii. Lesu.

A. lestâ descoideâ, depressî, hyalinâ, lavigatâ; anfractibus in medio carnutis, carina junctis; aperturâ ovatâ anticẻ in medio fissâ. Ков.

Corne d'Ammon. Lamsxox. Foyage de Laperouse. pl. 63. fg. 1. 2. 3. 4 .

Atlanta Peronii. Lesuér. Journal de phys. 6. $85 . \mu l .2$. fis. 1 .

Ibid. Busixv. Trailé de Malac. pl. 48 bis. fig. 9. 9 a.

lbid. Rawg. Mém. de la Soc. d'hist. natur. de Parls, tom. 5. pag. 38o. pl. 9. fig. 1.2. 3. 7 .

L'animal est d'un blanc transparent, sno pied en nageoile est grand, et la veatouse proporlionuellewent fort petile; la tête est plus attéuıée anténeuvement que dans l'autre espèce; la parlie du corps realermée dáas la coquille a une teinte jaunâtre, à ce que dıt MI. Rang, ce qui est dû prubablenent à la grande étendue du fure et de l'ovaire, organes qui ont très-souvent celle coluration dans les Muliusques. La coquille est symétrique, wince, vilreuse, aplitie, et formée de deux ou trois tours de spire; le dos, dans son milieu, est lortement caréné, et cette carène si fragile sert d'appui aus cours de spire. L'ouver-
A I L

tare est d'une médiocre étendue; elle est ovulaire, mais plus évasée postérieurement qu'aalérieurement, oi elle se termine par nue lissure mediocıe, profunde et droite. Lojucrulc est vitreux comue la coguille; il est altaché par son milieu au wuscle de l'appendice postérieur du pied; il est juste de la grandeur el de la forcuse de l'ouverture.

Les plus grands individus n'ont pas plus da buit millimetres. De l'Océau indien el aastral.

2. Atcante de Kéraudren. Allunta Keraudienii. Lesv,

A. testâ hyalinâ, descoideâ, larvigatâ, subinflatâ, subirmoluta; anfiuctibus bins, postherno carinato; aperturá ovato-transversi, anticè in nsedıo fissá. N̄ob.

Lesueur, Journ. de phys. tom. 85.

Rang. Mém. de la Soc. d'hist. nat. de Paris, loc. cit.pl. g. fgg. 4. 5.6. 8 .

Rien n'est plus facile à distinguer que cette deuxiène espèce; elle est toujours plus petite que l'autre et toujours plus enllée, plus ylobuleuse; ce qui la caraclérise, au reste, le plus, c'est la carène, qui est moins ćlevée et qui ne se voit que sur le dernier tour, ainsi que ld manière dont l'avaut-dernier tour rentre daas l'ouverlure comme cela a lieu dans les Nautiles; le dervier tour est conséquemment beaucoup plus enveloppant que dans la première espèce. La forme de l'ouverture et de l'opercule ont dì éprouver des nudilications en raison de ces dil:lérences générales. L'ouverlure est ovalaire, mais plutôt transversalement que longitudinalement, et elle est readue siuueuse dans le milieu par la saillie qu'y fait l'avant-dernier tour : quant à l'opercule, sa forme est en tout semblable à celle de l'ouverture et la ferme exactement. A la partie antérieure dc celle ouverture, il y a aussi uue fi:sure, mais elle est plus large et moins profonde que dans la première espèce.

Lidilante de Keraudien est beaucoup plus rate que l'autre; elle est d'une couleur jaunátre, et elle a'a que 4 mıllimètres de diamètre; elle baLite les mers équa toriales.

\section{ATLAS. Atlas.}

Ce genre a été établi par M. L.esueur en même cmps que le précédeat, et dans le nuême recneil, pour un Mollusque sans coquille, lort petit, trèsvariable dans sa forme par les contractions dont il est susceptible, et présentant nne organisation qui lui paroit particulière, mais qui n'est cerlainement pas assez connue dans ses détails pour pouvoir statuer d'uue manière invariable à son égard. Il est d'ailleurs à craindie que, comme dans le genre Atlante, M. I.esueur nait pas tout vu, et l'incertitude où l'on est sur la posilion des L 2 
branclies, donne quelque force à ce que nous venons de dire. M. L.esueur indique cependant ces organes, ce sont des cils qui couronnent la masse antérieure de l'animal; M. de Blainville a aclopté d'abord celle opinion, d'où l'élablissement de l'ordre des Ciliobrancbes proposé par ce savant pour le genre noureau; il indique la place de cel ordre dans les Gastćropodes. M. cle Ferussac, en conséquence de celle manière de roir, propasa, dans ses Tableaux systématiques, un ordre incertain à la suite des Inférobranches, augruel il conserve le $110 \mathrm{~m}$ proposć par M. de Blainville. 11. Lalreille, embarrassé sans doute de placer d'une manière convenable un genre incertain, le mit provisoirement, à ce que nous pensons, dans sa famille des Bilaribraucbes (voyez ce mol), arec les geare Phyllidie et Diphyllide. M. de Blainville enlin, abandonnant sa première iléc, proposa, dans son Trailé de Malacolngie, d'introduire le geare Atlas dans la famille des Acères, et de le metre ainsi en rapport avec les genres $G$ astérophère, Surmet, Lobaire, etc. Ce changement vient de lit supposition faite par M. de Blainville, que les cils du manteau pourroient fort bien ac pas ètre des branchies, et qu'il est à présumer, d'a près la position de l'ants, que cet organe de la respiration pourroit être situé dans nne cavité propre, non loin de la teruninaison de l'intestin.

On roit par ce gui précède combien ce genre est enreloppé d'incertitudes : comne l'animal qui en fait le sujet est extrèmement pelit et qu'il n'a point été reru depuis M. Lesueur, on concevia facilement la grande réserve que nous mettons à l'admeltre dans la méthode. Nous nous contenterons donc, obligés que nous sommes de mentionner tous les genres, et de fixer surlout l'attention des zoologistes sur ce qui est incomplètement conna, pour exciter leurs recherches, de rapporter les caractères génériques tels que $\mathrm{M}$. Lesıeor les a donnés, et de rappeler la seule espèce qui se rapporte au genre.

\section{CARACTERES GÉXERIQUES.}

Corps globuleux, formé de deux parlies séparées par un étranglemeat; l'antérieure déprimée, circulaire, pourvue antérieurement d'un pied ou discrue pour ramper, et bordée par des cils branchif́ces; l'autre ovalaire, sacciforme, postérieure, contenant les viscc̀res.

La caracléristique donnée par M. de Blaiurille est fort dillérente de celle-ci, nous croyons utile de la rapporter dans son eatier: " Corps partagé $n$ en deux parties réunies par une sorte de pé$₫$ doncule, à peu près comme dans le genre Gas" téroptère; la postérieure ovalaire; l'antérieure " dilatée circulairement et ciliée sur ses bords, " raais poursue d'un très-petit pied distinct en " dessons, et d'une paire de très-petits tentacules n auriformes en dessus; l'anus au milieu da cóté n droit de la masse postérieure; les organes de * la respiration inconnus, ainsi que la terminai„ son de ceux de la génération. "

Ce genre ne comprend qu'une seule espèce que M. Lesueur a nommée:

1. Atras de Péron. Atlas Peronii. Les. Jouın. de phys. tom. 85. pl. 4. fig. 2.

Ibid. Bu.sirince, Trailé de Malac. pl. 45.fig. 6. a. b.

On ne connoit pas la patrie de celte espèce singulière de Mollusque qui a à peine quelques lignes de longueur.

\section{ATTACHES MIUSCULAIRES.}

On nomme ainsi les points où les muscles d'un Mollusque s'attachent à la coquille; dans presque toutes les coquilles, ces points d'attache sont marqués d'une manière plus ou moins forte, et on les nomme alors impiessions musculaires. Elles varient pour le nombre, la forme, la place qu'elles occupent, comme nous le verrons ì l'arlicle Moluusque.

\section{ATYS. Atys.}

Montfort, dans sa Conchyliologie systémalique (tom. 2. pag. 342), a élabli ce genre inutile pour quelques coquilles démembrées du genre Bulle. Vojez ce mot.

\section{AULUS.}

M. Ocken, dans son Traité de Zoologie, a proposé de démembrer le genre Solen, et de donner ce nom générique aux espèces 'Tellinoïdes, ce que MI. Niégerle avoit aussi tenté avant lui. Nous ne croyons pas que le geare Solen, tel que M. Lamarck l'a constitué, soit susceptible de divisions solidement établies sur des caractères zonlogiques; ces nouveaux genres ne peuvent étre aduis que comme des sous-divisions ou groupes d'espèces propres à faciliter leur classement et lears rapports dans un genre nombreux. Vojez SOLEx.

\section{AUMUSSE.}

Nom vulgaire, devena scientifique, d'une espèce de Cốne, Cunus vexillum, décrit daus le premier volume de ce Dictionnaire. Nons renvoyons à l'article Côre no. 82.

\section{AURICULACÉS. Auriculacea.}

II. Lamarck, le premier, employa celle expression, dans la Philosophie zoologique, et l'appliqua à une famille dans laquelle le genre Auricule étoit compris arec les Mélanopsides, les Mélanies et les Limnées. M. Lamarck abandonna bientôt cette réunion de genres, lorsqu'il 


\section{A U R}

s'apercut qu'elle mettoit en conlact des Pectinibranches et des Puloobranches; on ne retrouva plus cette famille ni aucune autre qui la représente daus ses autres ouvrayes.

M. de Blainville, dans son Traité de Malacologie, s'empara du nom seulement, pour l'appliufuer a unc lamille qui correspond assez exacteuneul à celle des Auricules de M. de lierussic. ( $V$ oj. Auricules) ; il placa cette famille dansl'ordre des Pulmobranches, entre celle des Limuacés el des Limaciués; il la conıposa de trois genres duns lespucls lurent introduits, comme sections, les genres de la famille des Auricules de M. de Ferussac; ces trois genres sont: Pićtin, Auricule et l'yramidelle. Dans le premier, se trouvent les'I'vrnarclles et les Conovules; dans le second, les renres Scarabe et Carycbie; le troisième n"étuit point susceptible de changemens. Depuis la puLlication du Traité de Malucologie, M. de Blainville fut obligé de changer dopinion relativement aux genres Tornatelle et Pyramidelle, lorsyu'il sut, d'une manière positive, que ces geures sont operculés, coume MI. Lamarck l'avoit si judicieusewent prévu. Dans les additious et corrections, il conviut de son erreur et la rectifia, de sorte qu'a lien dire, la famille des Auriculacés fut réduite aux seuls liétins et a dont il fallut relrancher une des sections. Telle yu'elle est aujourd'hui, cette famille est plus natulle; nous croyons cependant que MI. de Blainville sera forcé d'y apporter non d'autres réformes, mais un arrangement nouveau dans les genzes qui y sont restés. Yojez Piétris. Auricule el SCARABE.

\section{AURICULAIRE.}

Nom que quelques anciens oryctographes donnoient à des coquilles de forme auriculaire, mais qu'ils ont si imparfaitement représentées, qu'il est impossible de pouvoir déterminer à quel genre elles appartiennent.

\section{AURICULE. Auricula.}

Plusieurs coquilles du genre Auricule furent connues avant Linné et fignrées dans quelques ourrages sans que les auteurs aient cherché a les réuair. Klein paroit être le premier qui en ait fait un genre dans sa Méthode de conchyliologie, page 37, sous le nom d'Auris midae; et, ce qui nest pas ordinaire à cet auteur, dont les genres sont formés des coquilles les plus étrangères les unes aux autres, on ne tronve, dans celui-ci, que des Auricules et une Tornatelle. Martini, dans son grand ouvrage, et Humphrey, dans lé Museum calonnianuni, ont beaucoup mieux entcndu ce genre que Linné, qui le confondit tout eutier dans ses Volutes. L'auteur du Systema natura fut entrainé à cette errenr par la seule considération des plis columellaires, ne tenant pas comple d'un caracière d'une plus laante importance, le défant d'échancrure à la base de la coquille; mais alors Liuné sortoit la science conchyliologique du cliaos: de telles erreurs sont pardonnables à son inmonse gúuic.

Muller, eo confondant ces cocuilles parmi les Hélices, fit un rapprochement plus heureux gue celui de Linné; ce savant zoologiste sut apprécier la valeur du earactère de l'ouverture nou écliancrée que linné, duns plus d'une occasion, avoit méconuu; il se rapprochoit donc davantage des bons priucipes zoologiques, et la scierce n'étoit point cncore assez atvancée poul permette des coupes que la sagesse de Linné, si juslement respectée, avoit limilé à un pelit nombre. Bruguière ne peut donc être sérieusement blàmé d'avoir suivi l'esprit de Muller, en raugeant les Auricules dans son genre immense des Bulimes, quoique ce ne scil pas une aucúlioration par le lail, puisque, placés dans une section à part destinée à toutes les espéces qui ont l'ouverture dencée on plissie, elles s'y trouvèrent avec les Clansilies, les Maillots, etc. Lorsque II. Lamarck créa ce genre Auricule d'une manière plus précise que ses devanciers, il y laissa cependant un mélange de coquilles terrestres marimes et des rivages, ce qu'il étoit difficile de corriger alors que l'habitation des espices éloit à peine connue; aussi, a mestre quelle le fut, et que la zoolorie eut fail de nouveaux et rapides progrès, AI. Lamarck lni-méme et d'autres concbyliulogues portèrent la rólorme dans ce genue. Draparuaud adopta le geare Auriculc le premic après sa création; il le caractérisa principalenent d'après l'animal de l'Auriculu myosotis, ce qui en donnoit une excellente idée, mais il $y$ introduisit une espèce terrestre, qui probablenıert ne doit pas lui appartenir. Ce mólange fait par un aussi bon observaleur qne Draparnaud, et sanctionné un peu plus tard par Lamarck, be pouvoit manquer d'entraver notablement la correction de ce genre.

MI. de Roissy, dont les ouvrages sont si judicienx qu'ils méritent toujours d'être consultés, fut le premier qui, dans le Buffon de Sonnini, exprima l'opinion qu'il ne falloit point admettre d'espeecs marines dans ce geure, opinion qui fut oublice ou ignorée, et à laquelle on est furcé cle reveniu aujourd'luui; mais, dominé par les écrits de Draparnaud, le savant que nous citons laissa dans les Auricules les espèces d'Hélices qui ont quelque chose de leur forme et de leur caractère : tant i? est viai de dire que ce n'est que lentement, tris. leatement même quelıuefois, que se lout les progrc̀s dans les sciences.

M. Lamarck, qui d'abord dans l'ordie múllodique de son Système (1801) avoit rangé les Auricules entre les Pyrawidelles et les Volvaires, s'aperçnt bientôt que ce dernier geure ne pouvoil rester dans ces rapports; il l’éloigna en cllét, dars 
sa Philosophie zoologique, de la famille des Auriculacés ( voyez ce mol) qui ne contient plus que des coquilles terrestres; cependant il est probable qu'à cette époque, l'illustre professenr a porté dans les Aucicules une réforme qui ne s'y trouve pas plus lard.

Mlontfort, cet auteur dont les travaux sont pour ainsi dire plulôt l'elfet du hasard que d'un savoir mis en pratique, fut pour les Auricules uu peu plus heureax yue pour d'autres genres qu'il voulut démembrer. 'Tuut en couservant le genre Auricule, il proposa les geures Scarabe, Nélampe et Actéen. Ces geures, en sćparant des types d'oryaDisation particulic̀re, devoient être conservés; mais telle est la défiance que $\mathbb{M}$. Lamarck avoit pour les travaux de Montfort, qu'il ne voulut pis les consulter; d'où il résulıe que 21 . Lamarck proposa sous d'autres noms des genres déjà établis: ce qui arriva non pour le genre Scarabe qu'il n'adopta pas, mais pour les Milampes et les Actéons, dout il lit dans l'Extrait du cours (1811), du premier, le genre Conovule, et du second le gence 'Tornatelle. Dans l'ouvrage que nous citons, Pa famille des Auriculacés n'existe plus; le genré Auricule lait partic de la seconde section de celle des Coliunacćes, il avoisine les genres $\mathrm{Cy}_{-}$ clostome et Verligo; tandis que les Cunovules. yu: ont tant de rapports avec elles, sout placés dans la fanille des Limnéens avec les Pbyses, Limnées et I’anorbes. Les Toraulelles réumes aux Pyranidelles dans une mème fámille, les Plicanées, sont rejetées rers la fiu de la série des coquilles à ouverture entière, au uilieu de genres lous operculés, ce qui n'a d'abord été adoplé de personne: cependant des abservations récentes ont fait voir que ce tact qui caractérise les travaux de M. Lamarck ve s'éloil pas ici démeuti, car ces dcux grenies sont operculés:

M. Cuvier ne tint pas compte de l'opinion de M. Lamarck, il rassembla les Auricules avec les Canorules, les 'Tornatelles et les Pyramidelles, a la fin de sa famille des Pulmonés aquatiques, et laissa le genre Scarabe de Montfort dans le genre Hélice a litre de sous-genre. Si M. de Ferussac u'iatila pas complétement M. Cuvier, du moins il en suivit la marclıe, et dérigea ses cflorts jour améliorer la nuéthode de ce grand zoologiste; et s'il eut soin de ramener le geure Scarabe a ses véritables rapports, il ne sut pas profiter des indications de M. Lamarck : aussi les Tornatelles et les Pyramidelles se trouvent-elles dans la famille des Auricules. Ce dermier genre, comme dans l'ouvrage de M1. Cuvier, ne cotalieu! plus d'espèces terrestres, de sorte que, débarrassé d'un cólé de celles qui sont lout-à-lait marines par M. de Roissy, d'uu autre des terrestres par I. Cuvier, ce genre Auricule ne présenta plus qu'un assemblage bien naturel, et dont les espèces ont entr'elles une aoulogie incontestable.

Quant à l'animal des Auricules, il n'a que deux lentacules, ce qui le dislingue essentiellement des Hélices qui, avec une fornıe alongée, ont aussi une ou deux dents à l'ouverlure, ce qui le sépare bien nettement des 'Tornatelles et des Pyramidelles. M. Latreille, dans les Familles naturelles dis Règne animal, eut le bon esprit d'adopter ces amélioralions el de M. de Ferussac el de M. Lamarck. Cet exemple sera certainement suivi par la suite, il est liaclieux que MI. de Blainville ne l'ait pas inité; il ne se cantenta mêne pas de mettre les Turnatelles dins la famille des Auriculacés, il les contundit dans le genre Piérin aves les Conovules, de sorle que lorscgue M. Gray aunonça que le genre Tornatelle est operculé, et lorsigue nous pûmes mous convaincre qu'il en est de mênue pour les Pyrauidelles, M. de Blainville fut olfigé de revenir au sentimeut de M. Lamarck, comme on le voit dans les additions et corrections au Traite de MIalucologie. Ce suvant fit entrer le genre Curychum de Muller, ainsi que le genre Scarabe de Montforl, dans les Auricules, il fit de l'un et de l'autre une pelite section; mais par une erieur de citalion, sans doute, il donna l'Auricula myosotis comme teprésentat: le genre Curyctite, landis que c'est uu vérilable Auricule. Les seules Caryclies connues en Frauce soni celles que Dlaparnaud a décrites suus les noms d'Auricula tineata el minima. Ces corguilles sont toul-à-fait terrestres; clles n'ont que deux tentacules, et les yeux sont silués sur la tête derrière les tentacules. Ces légères dilléreuces sont-elles suffisantes pour conserver ce genre et le séparer des Auricules? Nous croyons yu'on peut en faire une pelite section sous-géaérique.

Le Scarabe, quoiquencure imparfaitement couna quaut à l'animal, pourroit plutót conslituer uu bon genre que le précédent. Il ne differe des Auricules que par les tentacules qui sont poinlus, par la position des yeux silués au-dessus de la têle et a la base des tentacules, et surtout pa: la posilion de l'orgaue pulmonaire et de son orifice.

II. Lesson, qui pendant le cours de son voyage autour da Monde vit l'animal de l'Auricule de Midas, et en prit un très-bon dessin sur le vivant, a eu la bonté de nous le confier avec cette obligeance qui décèle dans ce savant dislingué le desir d'ètre utile ḋ la science avant tout : cet animal a assez l'aspect d'un Hélice. Il est d'un bruurougeâtre, et toute sa surface dorsale est chargric de tubercules aplatis, semblables à ceux que l'on voit sur la Limace rouge. Le pied est aplati en dessous, et plus élroit que dans la plupart des Hélices; il est lisse, libreux.el d’un Llunc-jaunàtre; il ne paroit pas sćparé du dos par un sillon, il sc termine postérieurement en poiute; antérieurement il est urrundi, ẹt il est séparế de la tête par un sillon: celle-ci est obtuse, assez large, fendue antérieurement et en desious, ce qui partaye la lèvre supérieure en deux parties égales qui ue 


\section{A U R}

ressemblent en aucune manière an mufle proboscidifurme que Draparnaud mentionse dans l'animal de l'suricula myosolis. C'est au iond de celle fente que se trouve la bonche. La téle ne porte que deux tentacules cylindriques, rugneux, comme le reste de l'animul, et teruinés antérieurement en uu bouton arrondi semblable à celui les grandstenlacules des Ilélices. M. Lesson nous a assuré que c'étrit là où éto:ent lés yeux de l'animal, et non à la base des tentacules ou sur la tête. Quoigue uous ayons la plus grande confiance dans les observalions de M. Lesson, nous avons de la peine à nous persuader gu'il en suit ainsi : sans duute gue ce savant voyageur voyant les tentacules teruinés en massue, sans étendre plus lin ses investigations, en aura conclu par anaJogie avec les Hélices et les Limaces gue t'éloit 14 qu'étoicut les yeux. Tout ceci n'est qu'une hypotbèse gratuite de notre part, et nous ne la faisous que dans la croyance que nous avons que cet animal tue doit pas s'éloigner beacoup de celui décrit par. Draparnaud. La position de l'ouverture pulmonaire nous semble bien singulière; elle est à gauche presque à l'extrómité postérieure du pied, et cn clessous de cet orgaue. Il nous semble que celle disposilion ne s'est pas encore rencoulrée dans les Mollusques de l'ordie, où se trouvent les Auricules. A cel égard, le dessin de M. Lesson ne laisse aucun doule, puisun'll a représeuté l'animal en dessous ex près pour marquer d'une manic̀re iocontestable la place de celte ouverture. Le pédicule qui joint la partie antérieure à la partie postérieure de l'animal, constamment contenue dans la coquille, est assez gios; il est enveloppé comme dans les Hélices par un collier épais et blanc à travers duquel l'animal est obligé de passer, quandil rentre dans sa coquille. Le muscle columellaire paruiı divisé en deux parties inégales, qui sans doute correspondent aux plis columellaires.

Quant à la disposition des viscères de cet animal, nous ne connoissons absolument rien, et M. Lesson n'a fuit à ce sujet aucune observation. Ce savant voyageur n'a vu l'animal en question que peudant l'liver; il s'enfunce daus la terre non loin du rivage, et se blotlit sous les racines d'arbres: on l'y iroure en très-grande abondance, et à une certaine profundeur. Celle babilude est semblable à celle de nos Hélices et des Liwaces, qui passent ainsi la saison froide on la saison des pluies dans les climats plus chauds.

C'est à la nouvelle Guinée, au bavre de Dorelıy, que M. Lesson a va ce Mollusque en grande abondance : il est fort bon à manger à ce qu'il paroit, du moins au goût des Papous qui en sont friands, et le recherchent pour leur nourriture. D'après ce qui précède el en n'adrnellant pas encore, comme cerlaine, la place que M. Lesson assigne aux points oculaires, les caractères de ce genre pourront s'exprimer ainsi.

\section{A U R \\ CARACTÉRS GÉERIQUES.}

Animal Gastropode prrtant à la tête deux tentacules terminés antérieutement par un tubercule non oculifie, jeux à la base interne des tentacules; orilice de la respiration à gauche, a l'extrémilé postéricure du pied et en dessous; poiut d'opercule.

Coquille épaisse, sulide, ovalaire ou conoïde; ouverture étroile, longiludinale, trés-entière à la base, rítrécie postérieurement et interrompue; columelle charpéce d'un on de plusieurs plis; lèvre droite soit fort épaissic et lisse, soit tranchante et quelqueluis strice en dedans.

Nous ne pensons pas gue le genre Scarabe, composé aujourd'hui de trois espèces Jien dislinctes, doive rester confondu avec les Auricules, il a des caractères qui !ui sont particuliers. (Foyez Scarabe.) Nous croyons qu'il est aussi nécessaire de rejeler des Auricules, I'Auricula dombeiana Lam., Bulimus dombeianus Brvg. no. 66. Si l'on compare cclte coquille avec les autres Auricules, on s'aperçoil bientôt qu'elle n’a arec elles que fort peu d'analugie, landis yue l'ampleur de l'ouverture, gui n'a ni plis ni bourrelet sur la lívie droite, linclinaison de celte ouverture sur l'axe de la coquille, la forme et la position du pli unique de la columelle, tout indique qu'elle doit entrer dans le genre Limnée. Si on jette les yeux sur les ligures 6 . el 7 . de la planche 459 de l'Encjclopédie, on ne peusera jamais que les deux coquilles qui y sont repursentées appartiennent à des genres dillérens; on seroit cependaut forcé de l'admettre si on suivuit l'opinion de M. Iamarek, puisque l'une est l'Auricule de Doubey et l'autre la Limnée staguale de cet auteur. Ce qui a sans doute porté M. Lamarck et plusieurs autres zoologistes à placer ainsi cette coquille, c'est que son tcst est plus épar que dans les aulres Limnées; nous croyons que ce motif est bien insulfisant pour l'opposer avec avaulage aux caractères réels du genre.

Nous avons vu que l'on avoit confondu des Hélices véritables avec les Auricules. M. Lamarck, dans son denier ouvrage, a maintenu ce mélange, qui n'est plus admissible dès que l'ou connoîl l'animal des Auricules; Bruguiere rungevit tout cela dans les Bulimes. Nuus renvoyons $\grave{a}$ cet article dans le premier volume où l'on trouvera décrites les espèces suivantes gui sont de vérilables Auricules: Auricula mider Lasn. Bulinus auris mide Bn OG. no. 76. Auricula judae L a к. Bulimus auris juda Brca. n० 78 . Auricula conyformis La MK. Bulmus conifonnis Brug. no 72 . Auricula nitens Lank. Bulmus ovulus Brvg. $\mathrm{n}^{\circ}$. 71. Auricula monile L.am. Bulimus monile Brug. $\mathbf{n}^{\circ} \cdot 7^{\circ}$.

M. Lamarck réunissant maintenant les Conovules avec les Auricules, sur un molif mal fondé, mais ce rapprochement étant devenu vécessaire 
par les rapports ialimes qui les anissent, il a été hénéralement adopté, ce que nous faisons aussi. Nous pensons d'après cela qu'on pent partager les Auricules en trois groupes bien tranchés, daus le premier les Auricules proprement dites, davs le secoud les Conovules, et daus le troisième les Carychies.

Nous conncissons des cspìces fossiles qui se rapporlent aux deux premiers yroupes. Il est à présumer que les petites espéces qui ont un seul pli à la columelle, comme l'Auricula miliols, I'Auncula hordeolu, etc., appartienuent à la section des Carychies, quoiqu'ou les trouve habituellement dans les terrains marins. Les espèces fossiles que nous counoissons vieunent toutes des terrains tertiaires, où en général elles ne sont pas aboudantes. 1)ans notre ourrage sur les Coquilles fossiles des envirous de Paris, nous avons décrit dans le geare Auricule une coquille singulière, anbiguë, qui a la plupart des caracteres de ce genie, mais qui ea offie quelques autres qui lui sout particuliers; nous vouluns parler de l'Auricula ringens, que l'on a promenté, pour ainsi dire, de geure en genre, et qui nous paroit devoir entrer dans celui-ci de préférence, jusqua au moment oi liaimal étant counu on pourra définitivement le placer.

La séparation des Conorules et des Auricules n'est pas aussi aelle qu'on pourroit le croire; il y a un passage eutre les Auricules à spire élevée jusciu'a celles qui out cetle partie la plus aplatie, de tclle sorte que celle distiuction est établie plutút pour faciliter la recherche des espc̀ces qu'elle n'existe véritablement.

I. Aurrcule myosotc. Auricula myosotis. Drap.

A. testâ ovato-conicâ, apice acutâ, tenuiter striatâ, corneofucescente; anfractıbus convexis; columellà triplicatâ; lubro murgine albo, reNexo.

Dr.ap. Moll. terr. et fluv. de France. pl. 3. fig. 16. 17 .

LAMk. Anim. s. vert. tom. 6. 2. part. pag. 340. $n^{\circ} \cdot 9$.

Ibid. Ferussac, Prod.pag. 103. $n^{\circ} .8$.

Auricule pygmée. Buarn. Trait. de Malac.pl. 37. bis. fig. 6.

Var. a. Testâ columellä bidentatâ.

Var. b. Testâ labro dextro incrassato, unidentato.

Var. c. Testâ angustiore, alb:descente.

Fossilis, Mancel de Serne, Note sur le gissement de quelques coquilles. Bull. des Scienc. 1314. pag. 17. pl. 1. fig. 9 .

Cette coquille, qui est d'une peti!e taille, se trouve fréquemment sur nos côtes de l'Océan et de la Mléditerranée; elle est de forme ovale alongée, pointuebau sommet, de couleur corné brunâtre, peu opaque; la spire est composée de buit à neul tour's convexes, lisses, quelquefois submarginés près de la sulure; celle-ci est simple, peu enfoocéc; si on l'examine à une forte loupe, on la trouve plissée très-finement sur quelques individus; le dernier lour est plus grand que tous les autres réunis; l'ouverıre est ovale, pointue, plus large à la base qu'au sommet, où elle se termine par ua angle aigu, formé par la réuaion du bord droit a l'avant-dernier tour; la columelle est oblique, munie de trois plis inégaux : le postérieur est le plus petit, il maaque quelquefuis, comme dans la variété $A$; c'est plulôt une dent qu'un pli; le moyen est le plus saillát, il est presque lamelleux; le troisic̀me où l'aniérieur est large et épais à la base, il produit à la columelle une sortc de troncature; le bord gauche ne s'aperçoit qu'à la base de la columelie, il se reuverse, s'ćlargit, et cache ainsi une très-petite fente ombilicale; il est blauc ainsi que le bord droit qui se rénnit à luj. A la base de la coquille, ordinauremert ce burd droit est simple, plus miace postérieureuncut; il se charge diun bourrelet a rondi et renversé en delıurs antérieuremeut el latéralement; ordinairement la lèvre droite est lisse en dedans, et quelquefuis elle est nunie d'une dent peu saillante qui correspood à l'intervalle qui sépase la dent columellaire postérieure de la moyenne. Cette disposition est celle de la vavićté $\mathrm{B}$.

$\mathrm{L}$ a variété $\mathrm{A}$. se distingue, comme nous l'avons vi, par la Columelle qui n'a que deux plis; le bord droit est aussi moins épais, et il est toujours simple. La variété $C$. est remarquable par sa forme et sa couleur; elle est plus alongée, plus étroite et toujours d'un blanc-jaunâtre passant à uac teinte plus foncée vers le sommet. M. de Ferussac cite deux variétés qui soat probablement des espèces distinctes; il ne les donue quavec doute : nous ne les conuoissons pas. Les indıvidus fossiles ne dillërent à ce qu'il paroît en rieu de ceux qui sont á l'ćtat fiais. N. Marcel de Serre les a observés dans une marne bleuâtre, a Bois-Vieil, département des Bouches-du-Rbône. Habite les bords de l'Océan en France et en Angleterre, les bords de la Méditerrance en Corse, et probablement daus les îles dé l'A chipel.

Lougueur 10 iे 12 millim.

Noв.

2. Auricole de Brocchi. Auricula myotis.

A. testâ ovato-acutâ, tuigidulâ, lavigatâ ; columellâ triplicata; labro dextro unidentuto; anfructibus convexıusculis; suturâ marginatâ.

I'oluta myotis. Brocc. Conch. foss. sibap. tom. 2. pag. 640. pl. 15. fig. 9 .

C'est à tort que M. Brocchi a blâué Gmelia d'avoir rapporté à l'Helix scarubeus la cuquille 
figurie par Lister $\left(t a b .577 \cdot \int_{1} g .52.\right)$, et copice par Klein (Ostrac. tab. 1. $\sqrt{2} g .24$.$) ; ct v'ust en-$ core plus à tort qu'il liu trouve de la ressernblauce arec sou toluta myotis, les figures dont il esl question représentaut une cspèce distincte de Scarabe (2oyez ce mot), taudis que la coquille fossile dont il est question est une véritable Auricule très-voisine pour ses rapports de l'Auricula myosotis.

Cuquille ovale, pointue, heaucoup plus large que la précédente, lisse et épaisse. La spire, terminée en pointe aiguë, est composéc de sept à huit tours peu convexes; la sulure est accumpaguée d'une strie; le dernier tour est plus grand yque tous les autres. L'ouverture cst ovalaire, rétrécie d'une manière notable par trois dents colasnellaires, par l'épaississement du bord droit qui en outre porte une dent obtuse vers son tiers postérieur; le bord gauche est assez épais, il s'applique sur l'avant-dernier tour de spire, s'ílargit et se reuverse à la hase de la coquille, de manière à caclier presque complétement la fente ombilicale; il se continue ensuite avec le bord droit.

Longueur 17 millim., largeur 10.

Fossile dans le Piérnont et au val d'Audone. Nons devons cette espèce it l'ubligeance de Mi. Bunelli, snvaut professeur de zoologie a l'Académie de Turin.

5. Aoricure de Saint-Firmin. Auricula Firnunii. YАYR.

A. Testầ orato-acutâ, comeo-ful'ô, fasciatâ, vallidè striato-punctatấ; aperturầ ov'atâ; columellá triplicatá; labro dextro aculo.

Payrauneau, Catologue desc. des Ann. et des Moll. de Corse, pag. 105. no. 229. pl. 5. fig. 10.

Celte cocjuille est de la taille de l'Auricule myosote; elle s'en distingue loujours et très-facilement; elle est ovale, pointue, formée de sept ì huit tours dont le dernier est plus grand que tous les autres; la spire est conique, pointue; les tours qui la composen! sont aplatis, séparćs par une suture marginée; ils sont, aussi-bien que le deruier, couverts de stries trinsverses et longitudinales régulières ponctuées dans l'endroit de l'entrecroisement; de clacune de ces ponctuations s'élève, dans les individas hien frais, un poil épidermique court que l'on ne voit qu'it une forte loupe. L'ouverture est ovale, poiulue aux denx extrémités; la columelle offre trais plis saillans, lamellens; la lève gauche v'est pas sensible, si ce n'est à la base où elle se r'cnver'se en s'elargissant un peu; la lèvre droite est simple, unince et tranchante. La couleur de cette coquille est le fauve coiné, passant ì uue teinte plus foncée au sommet. Elle a uue fascie transverse, obtuse daus le milieu du dernier tour.

Longueur 10 millim., largeur 4.

Habite en Corse, où elle est assez rare.

Histoire Naturelle des Vers. Tome II. Nob.

4. Auricule ombilique. Auricula umbilicatu.

A. testâ orrato-conicâ, turgidulâa; spirâ conica, acutâ, anfractibus convexis, marginatis; umbilico infundibuliformi, angulo basi scparato; aperturâ angustâ; labro dextro crasso; columellâ triplicatâ.

L'Auricule ombilignée est une jolic coquille fussile parfaitement caractériscée. Elle estovalare, rentrue, lisse ou presque lisse, le dernier tour olliant quelquefois une ou deux carenes transverses et obtuses; la spire est conicgue, pointue, compośe de six à sept tours convexes, fortemeut séparés par une suture bordée, quelquefois simple. La base de la coquille oflre un ombilic trés-évasé antérieurement, fort rétríci postérieurement; il est séparé du reste de la cornilbe par un angle saillant, qui aboutit is l'angle antírieur de l'onverture ou sa base; cette onverture eśt longitudinale, fort étroile et rélrécie encore patr trois plis columellaires, et un bourrelet fort ćpais de la lèvre droite, bourrelet qui se temine postirieurement par une dent obinse; le pli columedlaire postérieur ne se prolonge pas à l'intérieur de la coquille, ce n'est à bien dire qu'une dent; le bord ganche s'applique d'abord sur l'avant-der nier tour, il est dans cet endroit fort mince et pen sensible, mais vis-i-vis l'oubilic, il s'épaissit, s'arrondit, couvre un pen la fente orbilicale, et se continue en s'infléchissant versle bord droit.

Longuem 13 millim., largeur 7 .

Fossile assez rare des faluns de !a Tonraine.

Non.

5. Auricure oblongue. Auricula oblonga.

A. tcstâ ovato-oblongâ, lavigatî̀; spirâ acutiusculấ; anfructibus depressis, ultimo mirgno isd suturam sinuato; aperturâ ovalî̀, magnâ; columellầ biplicatâ.

Quoicu'ì peu près du méme volume que l'Auricule ombiliquée, on l'en distingue par sa forme plus étroite, filus alongée; sa si ire est plus courte, un peu plus obuse, formée de cinág tours aplatis dont le dernier est sinueux vers la suture; cette suture est simple, non marginće et très-superticielle; le dernier tour est trés-grand, il occupe près des truis quarts de la coquille, il est convexe, oblong, et tout lisse, comme le reste da test; l'ouverture est grande relativenent alu volume de cette espèce; elle est ovalaire, évasée dans presque tout son pourtour; le bord gauche, quoique nince, se distingue fort bien, il s'élargit à la base et couvre ainsi complétement l'ombilic, le bord droit est épais et sans dents; la columelle n'a que deux plis qui la suivent dans toutesa louguems.

Longuear 15 millim., largenr 7 . 
Elle se trouve avec la présédentc dans les faluns de la Touraine.

6. Auricure pisoline. Auriculi pisolina. Ков.

A. testâ ovato-acutâ, glohulosî, luvvigatâ; spuâ elongatâ, acutâ; anfractibus convexis, sutunî̀ marginatâ sepurutis ; aperturâ abbreviatâ, ơatâ; columellî́ tridentatâ.

Celle-ci est fort rapprochée des denx précédentes; elle est constammeut plas petite et plus globuleuse; la spire est alongce, pointue, foruaée de sept à huit tours peu convexes; la suture est peu profonde mais màrgiace. Le derniel tour est court à peu près de la moitié de la longueur totule; il est ventru, globuleux, tont lisse comme tout le reste de la coyjuile; l'ouverture est fort courte, plutôt snlsquadraogulaiıe qu'ovale, évasée à la base; la columelle est garnie de trois plis saillans, lamelleux; le bord gauche est mince et sépaissit à peine à sa base, de sorte que la fente ombilicale, trc̀s-petite, res!e à découvert; le bord dioit bien arciué est simple et saus bourrelets ni dents.

Longueur 44 millim., largeur 7:

Fossile dans les faluns de la Tuuraiue.

7. Auricule ovale. Auricula ov'atc. Lans.

A. testâ orato-acutâ, subventricosâ, utroque latere submarginat $\hat{\imath}$; lubro dextro crasso, in medio subsinuato; columellâ obliquá, marginatâ; plicis duobus tribusz'e instructâ.

LAмк. Ann. du Nus. tam. 4. pag. 43j. no. $n^{\circ}$; et tom. 8. pl. 6o. fig. 8 a. b.

Ibid. Anim suns vert. tom. 7. pag. 538. $n^{\circ} .2$.

Ibid. Nов. Descrip. des Coquilles foss. des environs de Paris. tom.2. pag. 68. $\% l .6$. fig. 12. 13.

Espèce remarquable, eacore rare dans les collectious : elle est ovale, ohlongne, sa spire est aiguë, plus alongce que dans la plupart des espèces précédentes, le dernier tour de spire présente constamment deux bourelets opposés, qui font paroître la coquille aplatie. Quelques iadividus, semblables en cela aux espèces du genre Scarabe (voye se mot), ont des bourrelets opposés à lous les cours de spire; l'ouverture occupe un peu plus de la morité de la longueur de la coquille; sa lèvre droite, épaissie en dedans, non rélléchie, est légèrement sinuée vers son milieu; le bord gauche est mince, appliçué sur l'avant-dernier iour, il ne devient saillant qu'à la base, oì il s'arrondit, et cache une trc̀s-petite lente ombilicale; la columelle n'olfre que deux plis sublamelleux, et quelquefois une dent postérieure fort petile. Les plus grands individus a'ont pas plus de 20 millim. de longueur sur 10 de large.

Cette coquille est fossile aux environs de Paris à Grignon, Maule, Mantes, etc.
3. Aunicule fasciće. Auricula fusciata. Nob.

A. testâ ovato-conicâ, turbinatâ, basi attenuatâ, licvigutâ, nitidî, albido-cœrulescente, fulvo-fascialấ; spirấ brevissimâ; colum llấ yuadriplicatâ; lubro dextro dentuto.

Celle coquille est biea voisine de l'Auricule conilorme (Bulinus coniformis Breg. no.72.), mais elle se caraclérise constamment d'une manière si tranchée, que nous ne pensons pas qu'ou la confonde avec elle. Sa taille est petite; elle est de forme ovalaire, conique, plus large à la base que la plupart des Conovules, parce que son ombilic, furtement évasé, occupe un assez graad espace; la spire est courte, régulièrement conique, formée de buit à nenfs toursaplatis, très-rapprochés; l'ouverture est longitudinale, fort étroite postérieurement, un peu plus évasće antérieurement; la columelle présente quatre plis, dont les inférieurs sont les phus gros; le bord ganche n'est sensible qu'à la base de la columelle, il se renverse au-dessus de l'ombilic en le laissant ouvert; le bord droit est trunclant, s'épaississant un peu en dedans; il est chargé vers l'ouverture de quatre ou cinq dents assez saillantes, et il a'est pas strié. Toute la coquilie est lisse, polie, brillante, de coulenc blanc-bleuâtre, interrompue par quatse on cinq zones bruues, régulières et transverses.

Nous ignorons sa patrie. Elle a 15 millimètres de long sur 9 de large.

9. Aunicule cornée. Auricula comea. NoB.

Á. testâ ovato-conifomi, translucidâ, transversim substriatâ, corneo.griseâ; spırâ brevi, obtus.î, scepè erosâ; aperturâ angustâ, elongatâ; columellâ biplícatâ, basi albâ; labro tenui, acuto.

Coquille qui, comme la précédente, appartient a la section des Conovules; elle est ovalaire, coniforme, à spire ua peu plus alongée que dans l'espèce que nous venons de décrire, peu épaisse et translucide; sa coulear est celle de la corne un peu brunâtre; sa surface, qui est brillante et qui paroît lisse ì l'œil nu, est souvent couverte de stries superficielles, transverses, peu régelières, coupées longitudinalement par des accroissemens.plus ou moins serrés. La spire raccourcie est composće de sept à huit tour's; elle est obtuse au sommet, parce que cette partie est rongée, comne cela a licu dans beaucoup de coquilles d'ean douce, ce qui nous fait présumer que celle-ci y vit aussi; les sutures sont simples et superficielles; l'ouverture est longue et étroite, elle se termine postérieurement par un angle fort aigu; la columelle est munie de deux plis simples et peu saillans, l'intérieur se contione avec le bord gauche qui devient alors saillant à la base de la culumelle, il est blauc dans cet endroit; la 


\section{A U R}

livre droite est mince et trauchante, sans stries ui dents à lintérieur.

Longueur 11 willimètres, largeur 5. Habite New-Yorck.

10. Auracole livide. Auricula livida. Nob.

A. testâ conoideâ, lavvigatâ, albido-lividî̀ vel nfescente; spurầ brevi, conicâ; aperturâ clongutâ, angustâ; columellì quadridentatâ; busi custaneâ, labro dextro intiss multidentatu.

Nous ignorons l'habitut de celle espèce, elle auus a élé communiquée par M. Murmia avec son obligeance accoutumée: elle a la forme d'un cône et sa taille approche beaur:oup de celle de l'Auricule coniforme (Bulimus coniformis Brug.), mais elle s'ea distingue constamment; la spire, régulièrement conoide, est courie et pointue, elle fait à peu près le quart de li longneul totale; elle est formée de neuf à dix tours très-serrés, aplatis, séparés par une suture superficielle. Le deruier tour, fort grand, est lisse et poli comme la spire elle-même, il est alténué a la base. L'ouverture est longitudiaale, étroite, plus large à la base; la columelle est chargée de quatre plis dont le postérieur est le pluspetit; le bord gauche ae se voit pas sur l'avant-dernier tour, ce n'est qu'à la base de la columelle qu'il se montre épais, arrondi, bien lisse, brillant, et toujours culoré ea brun chàtaio; il n'y a puint d'ombilic, le bord droit tranchant sépaissit en đłedans, où il présente un assez grand nombre de dents sailluutes blanches. La coulcur de cette coquille est le pius ordinairement le blanc fanve, livide et peu foncé, passant à une teinte plus obsiure au summel; quelquefois, mais rarement, sa couleur reste partout d'un brun obscur, mais la base de la columelle reste loujonrs de la même couleur.

Lougueur 18 millimètres, laryeur 1 I. Il $\mathrm{y}$ a des individus d'une plus grande taille. Noв.

11. Atricene à deux plis. Alricula biplicata.

A. testâ conicâ , turbinatâ, lavigatâ, castaneo. fuscâ; spirâa brevi, conicâ; aperturâ longà, ad basin dilatatá; columellâ biplicatâ; labro dextro acuto, intùs obsolete striato; umbilico infundibuliformi, partin obtecto.

On ne sauroit confondre celle espèce avec aucune de celles qui font partie de la section des Conovules; clle acquiert la même taille que l'Auricule conilorme, mais elle a des caracteres particuliers dans la coluration, la furme, le nonbre des plis columellaires, qui la distinguent parfaitement. Elle cst rénulicrement canique, mars plus étroite et plus longue que les prúcédentes relativerweut à la tuille; sa spire est fort courte, coni jue, pointue, ne présentant que sept tours dont les sutures, superficielles, sont peu régulières; celie spire occupe à peu près le cinquième de lí

coquille; le dernier tutir, qui est fort grand, est largemeut ombi'iqué à la base; ce: ombilic, infoudibuliforme, cost en jartie cauvert par la lèvre gauche, et il est séparé du reste de li surface par un angle obtus qui le limite nettement. L'ouverture est fort longue, rétrécic postćrieurement, elle s'évase à la base; la columclle cst munie de deux plis seu'emeat, dont l'un, le postérieur, est fort gros, blanc el subdivisé à la loase, l'autre antérieur est peu saillant et se voit à peine. Le bord gauche n'est sensible qu'á la base de la columelle; il s'élargit considérablement; se renverse au-dessus de l'ombilic sans le boucher, et s'amincissant ensuile, il se courbe à sa base pour se joindre au bord droit; ce bord est mince, tranclant, s'épaissit à l'iutérieur où il est garni de plis peu saillans et nombreux. La couleut de cette coquille est partout d'uu brun foncś an peu grisâtre, excepté la dent culumellaire, lis plus grosse, qui est blancbe.

Longueur 22 millim., largeur 12. Nов.

12. Adrucete de Tours. Auricula turonensi:

A. testâ conoideâ, turbinatâ, levvigatâ; spirí brevi, obtusâ; apcrturâ elongatâ, angustâ; columellâ triplicatá; plicis minimis; labro dextro intus multiplicato.

Nous ae croyons pas que l'on ait cité jusqu'a préseat une seule espèce d'Auricnle fossile qui pût se rapporter ncllement, et sans laisser de dontes, à lis section des Conuvules. Nons en possédons depuis quelque teups nue espèce qui vient des fuluuières ale la 'Touraiue, oú el!e puroit bien rare, car nous n'arons jamais vu que le seul individu que nous possédluns et que nous avons acquis avec beancoup d'autres fossiles de lat mème localité. Cette espèce est d'une perite taille; la spire est couique, courte, obtuse, conposée de six tours fort courts et aplalis, sŕparés par une sulure simple, régulière et peu profunde. Le dernier tour présente 育 peine à la base une trace de la fente ombilicale; l'ouverture est fort éiroite, un peu évasće antérieurcment; la columelle ollic trois peits plis peu saillans, les denx postéricurs sont fort rapprochés l'un de l'autre, l'antérieur est plus isolé; la levre droite, un nen obtuse, est striće à lintérieur dans toute sa longueur. Toure la coquille est lisse et polie, sa longueur est de 11 millimètres, sa largeur de 7. Fossile en Touraine.

Nous observerons que cette espc̀ce a Jeaucoup d'analogrie avec une variété de l'Auricule coniforme; on pourroit la considérer comne un subanalogue.

Les quatre espèces que nous allons décrire appartiennent à uce petite sectiou bien distiucte des Cnnovules, quoiqn'elles en conservent la forme. M. de Ferussac avoit fail, avec les desx MI 2 
seules espèces quil connoissoit, la section des Cassidules, placée à la suite des Conovules dans le genre Auricnle. Ce petit groupe, que nous croyons lluviatile ou des eaux saumâtres, pourroit bien, par la suite, lorsque l'animal sera connu, constituer nu petit geure caractérisé par deux plis columellaires fort gros; la lèvre droite très-élargie et épaissie en dedans, à bourrelet tronqué postérieurement, pour douner vaissauce à une échancrure assez profonde entaillée dans le bord droit; une côte obliquement décurrente à la base de la coquille, circonscrivaut un ombilic.

L'Auricula felis Lank. (Bulimus auris felis, Brug. $\left.12^{\circ} \cdot 77.\right)$ figurée dans l'Allas de ce Dictiounaire, pl. 460. fig. 5. a. b. peut donner une juste idée do groupe des Cassidules et offrir le moyea de juger les autres par aoalogie.

\section{Aoricule noyau. Auricula nucleus. Fer.}

1. testâ o'ato-conicâ, fusco-nigricante, alicunntisper albo fisciatî, temuissimè striatâ; spirî̀ conicât exertiusculît, obtusiâ; columellâa biplucatâ; labm dextro valde incrissato, postice risecto.

Ferus. Prod. pag. 105. $n^{\circ} .26$.

Nantrn. Univ. conch. t. 2. tab, 67. fig. exter.

Cogfuille ovalaire, conoide; à spire urédiocre, conique, obtuse au sommet, cumposée de six à sept tours aplatis, plus larges que dans les Conovules proprement dis, séparés par une suture régunlière moins superficielle. Le dernier tour est beaucoup plus grand que tous les autres réunis, il torme les trois quarts de la coquille, il est strié transiersalement ainsi que la spire; ces stries sont fines, peu profoudes, régulières, serrées; la base de la coquille est alténuće, mais moius en général que dans les Conovulcs; il y a uo ombilic circusscrit par une côte oblique, saillante, blanchátre, qui, partant du bord gauche vis-ilvis l'espace qui sépare les deux dents columellaires, aboutit à la base de l'ouverture; celle-ci est alongée, longitudinale, rétrécie, plus large antérieurement et postérieureasent que daus le unilieu; le bord gauche, très-mince et peu sensible postérieurement, se détuche vers le milieu de la longueur de la colunelle, reste plitt, et comme dans la plupart des Casques, par exemple, forare nue lame qui couvre l'ombilic; c'est dans cet endroit, et sur la columclle, que se voient deux plis simples et obliques, peu saillans et obtus; ce bord ganche, aprés être descendu perpendiculairemeat jusqu'à la base de la coquille, se joint an bord droit en formant un arc de cercle et sans changer de largeur. Le bord droit est garai d'un bonrrelet sailiaut en declans et en dehors, il est aplati et partagé distincteweut en deux parties; la plus longue upiforméusent de la mêase largeur, el se terminant par une troncature où le bord s'amiacissant subitement, forme une échancrure arrondie, entièremeut entaillée dans son épaisseur; cetle entaille termine le bord à l'endroit desa jonction à l'avaut-dernier tour. Toute celle coquille est d'un brun foncé obscur, quelquefois un peu grisâtre; plufieurs indiviclus sout ornés de quelques bandes blanches au nombre de trois ou quatie; le bord droit et le gauche, jusqu'au second pli, sont de conlcur fauve clair.

Longusur 16 millim., largeur 10.

Nous ne connoissons pas son habitation. Martyn la dit d'Otaïti. Noв.

14. Auracole de Belette. Auricula mustelina.

A. testâ ovato-conoidecâ, subventricosá, tenuè striatâ, albidâ, quatuor zonis rufis, incrqualibus cinctấ; aperturî longitudinali, angustutâ medio; columellầ biplicatâ; plicis magnis; labro dextro nuarginato.

Cette jolie coquille avoisine pour sa taille l'suricula filis; elle est plus grande que l'espece précúdente, sa forne est semblable; la spire est un peu moins saillante et cependant moins obtuse, elle est régulièrement conique, et formée de sept tours aplatis; le dernier tour est tresgrand, terminé par une ouverture aussi haute que lui; il est orné, ainsi que tous les antres, de stries fines, régulières, superticiellcs; atcúnué à la base, il est, conunse dins l'espèce précédente, muni d'un ombilic étroit, circonscrit par un angle saillant tout blanc. L'onverture a la même forme, rétrécie dans le milieu et lougitudiuale; la columelle porte deux gros plis obliques en sers inverse, saillans, sublamelliformes; le bord gauche est fort large, le droit, moins large à la base, augmente insensiblement, postérieurement et en dedans, où il fait une saillie considérable dans l'ouverlure et la rélrécit d'uue manière notable; il se termiae brusquemen crure profonde, parlagée en deux parties inégales par une petite de ut. L'Auricule de béletle est agréablement ornée de qualre zones brunes de largesir inégale sur un fond blanc de laiı; la plus érroite de ces bautes brunes est placée au bord de la suture, de sorte qu'elle se voit sur conte la sprre; les borrls de l'ouverture, ainsi gue les plis columellaires, sont d'un blanc rosé d'une grande fraicheur. Cette jolie espèce, encore fort rare daos les collectious, est longue de 18 millim. et large de 12. Sa patrie est inconnue.

15. Auricule labrelle. Auricula kibrellu. Noв. A. testî́ ovato-acutî, tenuiter striatâ, griseofulva, basi attenuatâ; spirâ elongatâ, ucutâ; anfructibus rotundatis, marginatis; columella biplicatî; lubro incrassato, marginato.

Nous soupçonuons que celte espèce est la auèno que colle quc M. de lierussac a nommée Auriculu 
fabu dans son Prodrome; il l'indique de l'lle-deFrance, et celle que nous possédons en vient aussi; il la croit inlermédiaire eutre les Conovules et la section des Cassidules, nous croyons qu'elle doit faire partie de celle dernière. Comme II. de Ferussac ae clonne ni description, ni figure de celte espèce, il ne nous a pas élé possible de nous assurer positivement si nous la isions un donble etuptoi. L'anricule labrelle est fort renarquable; avec tous les caracic̀res des deux précédeutes espices, elle a celui bien particulier d'avoir une spire beauconp plus alongée, ce qua la reud plus ovale er plus longuc; sa basc est aussi plas étroite et plus alténuée, quoique présentant aussi un movilic circonscrit par un angle saillant et blaac, lorscue le reste de la coquille est d'un brun grizâtue un pen plus foucé à lit spire. Cette partie csi composéc de six tour's arrondis, finement stliés et marginés; le dernier tour, plus grand que tous les autres rúunis, est subglobuleux, lineuneut et régulic̀rement strié comme les premiers; l'ouverture est pelite, lo bord gaucbe est sensible dans toute son éteudue, et saillant seulement à la base, un peu avant de se réunir au bord droit; l. colnmelle est oblique et munie de deux gros plis; le borcl droit, très-épais, forme en dehors un bourrelet arrondi; en dessus, il est aplati et suillaut en dedans, il rétrécit beaucoup louverture dans le milieu; il est tronqué postérieurenucat, et l'échancrure qu'il forwe n'est point arrundic comme daus les deux espèces que nous "vons décrites.

Longueur 12 millim., Jargenr 7 .

Habite à l'He-de-Frauce. Elle est probablement lacustre. Nò.

16. Auncule angistome. Aüriculiz angistoma.

A. testî̀ ovato-elongatî, lavigatâ, nitidî,

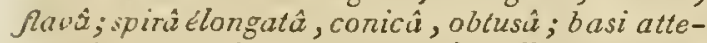
muat $\hat{s} ;$ aperturî̀ a ngustat $\hat{\imath}$; columellầ bidentat $\hat{i}$; lubro dextro valde intius marginato, crenato, postice internuto.

Coquille ovale-oblongue, à spire alongée, olstuse, formée de sept tours à peine convexes, mais assez larges, it sulore simple très-superticielle. Le dernier tour est un pen plus grand que la moitié de la coquille; il est légèrement atténué à la base, et il est dépourvu de cet angle circonscrivant un orbilic : ici i peine si l'on voit une fente ombilicale converte par le bord gauche. L'onverture est longitudinale, très-étroite, grimaçante; la cotunulle offie à sa base deux plis saillans et asliques; le bord gauche, très-mince sur l'avantdervier tour où il s'applique, s'arrondit, s'épaissit, et s'ćlargit a la base où il se courbe ponr gagner le bord droit. Ce bord n'est point marginé audehor's, comme dans les espèces précédentes, son bomrelet est fort saillant en dedans, il est troncué postérieurement, mais l'échaucruse qni en résulte est très-pelite; ce bourrelet, de couleur blanche, a cela de remarquable, d"c̀tre denté dans lonte sa longueur. La coquille est tonte lisse, polie et brillante; elle est partout d'un fauve clirir plus foncé au sommet. Elle a 16 millim. de long sur 7 de large. Nous irgorons sa patrie.

17. Aurtcule conovuliforme. Auriculi conosulifornits. Ков.

A. testâ ovato-ventricosî̀, subglobulosî, temissime striatâ; spirî conico-depressí; aperturî́ semilunari; luoro dextro crusso non repli. cato; columelầ marginutá, aliquantisper unıplicatâ.

Nов. Descript. des Coq. foss. des env. de Paris, cont.2. pag. $67 \cdot n^{\circ} \cdot 1$. pl. 6. fig. 9. 10. 11. 16 .

Nous sommes restés dans le doute à l'égard de cetle coqnille qui arec la forme des Conovisles, n'en présente pas la plupart des caracières : malgré cela nous ne voyons aucuns genres où ellc convienne mieux qque celui-ci, ì moins que d'en établir un exprès pour elle, ce qui nous semble peu nécessaire. Elle estovale, globnleuse, terminée par une spire pointue surbaissée, composée de huit ì neuf tours rapprochés; le demier est plos grand que lons les autres, allénué à la base et dépourvo dombilic; il est finement strić dans toute son étendue ainsi que la spire; ces stries transverses sont fines, serrées, régulières, peu profondes, on les roit à peine à l'œil nu. L'onverture est grànde, semi-lumaire, évasée ì la base, rítrécie au sommet; la columelle n'a le plus sonvent ni stries, ni plis. Nous avons nn individu qui offic un pli peu saillant à sa base. Le bord droit est épais, arrondi, lisse, non marginé en debors et dépourvu de dentelnies ou de stries, comme daus quel gues Conovules. Longueur 19 millim., largeur : 3 .

Fossile aux environs de Paris, à Parney particulièrement. Celte coquille est rate.

\section{Aonicule pygmée. Auricula minima.}

Drap.

A. testâminimâ, ovato-ablongâ, apicè obtus $\hat{a}$, tenuissime striatâ, diajhanâ, albidì; columullî̀ uniplicatâ; labro bidentato reflexo.

Carychium minimum. Musx. Verm. pag. 125. $n^{\circ} .321$.

Helix carychimu. Lins. Gues. pag. 3663 no. 156.

Auricula minima. Draparvado, Moll. de France, pag. 57.pl. 5.fig. 18.19 .

Ibid. Lamx. Anim. s. 2'ert. tom. 6. pag. 140. $n^{\circ} \cdot 10$.

Carychiun minimum. Feruss, Prod. pag, 100. $n^{\circ} .2$. 
Ibil. Prenfreat, Coquilles terr. et fuv. de Prusse, pag. 69. $p l$. 1. fig. 5. 6. et pl. 3. fig. 40. 41.

Nous croyons que c'est à lort que M. de Ferussac a compris saus y mettre de doute, daus lit synonymie de cette espèce, le Bulimus mimimus de Bruguière; n'ayant pas lu la description et les citations de cet auteur, et s'en rapportant à la seule analogie du nom, il n'a pas vu que le Bulimus de Bruguière étoit une cocquille d'eau douce, la même çue l'Helix ninutı de Muller (Verm. pag. 101. $1 \iota^{\circ}$. 299.), foltt diflérente du Carychium minimum du même auteur (pas. 125. $n^{\circ} .521$ ), et que Bruguière u'a mentionné nulle part. Celte erreur devient d'autant plus sensible que Bruguière dil qu'il a trouvé son Bulims minmms dans la Seine, tandis gue Muller et Drapardaud donnent pour habitation du Carychium minimum les lieux liumides sur les feuilles poinries. Nous doutons que cette coquille, qui a un aspect particulier, et qui vit loin de la ner, soit une Anricule vérilable comme l'a pensé M. Lamarck d'après Draparnand; elle doit donc faire une petite section à part, ainsi que quelques autres quilui sout analogues, et que nous n'avons pas sous les yeux. M. de Blainville dit dans son Traité de Malacologic, nouvelles additions et corrections, pag. 654 ., que les espèces de la section E. du geore Amicule, espèces qui sont turriculées, et sans plis a la columelle, ne dojven! pas rester parmi les Auricules, parce quielles sont operculées; que M. Gray et d'autres savaus anglais lui ont aftirmé ce fait.

Il est certain que l'Auricule burinéo de Draparnaud, que M. de F'erussac a rangée parmi les Carychies, n'a en aucune façon l'aspect de ce genre, et encore moins celui des Auricules; aussi M. Lamarck a-t-il eu soin de ne pas l'y adonettre. Cette coquille appartiendroit an genre Cyclostome, et non aux Paludines, s'il esi yrai, conme le dit Diaparnaud, que son animal vit dans les bais sur les mousses. Il est à présumer que les personnes qui rapportent celte espèce aux Paludiues se trompent, ou il faut supposer que Diaparnaud, d’ailleurs si exact daus ses cilaliuns, a élé iniduit en errenl sur sa manière de vivre, 'Teutes ces incertitudes nous démontreat qu'il est nécessaire d'olserver de nouveau ce genre Caryclie, et la pelitesse des aniuaux, les plus petits peut-ctre des Jullusques uniloculaties, n'est pas un des moindres obstacles qui puisse s'opposer à décider enfin leurs rapports.

Si l'on compare la phrase caraciéristique que nous avons donnée de l'Auricule pygmée avec celle de M. Liamarck, on s'apercevra que nous y avous apporté quelques changemens; aprés un examen altentit a une forte loupe, uous avoris reconnu que la coquille dont il est question est striée longiludinalemen, quoique ceperdant quelques individus soien! lisses; mais on reconnoit que ceaxlí sout roulés. Cette coquille, qui a à peine uue ligne de longueur, est ovalaire, alongée, obiuse au sommet; la spire formée de six ou sept tours est plus longue que le dernier; ces lours sont arrondis, bien sćparés par une sulure assez profonde. Le dernier tour est court et globuleux, à peine ombiliqué à la base; l'ouverlure est arrondie, le bord gauche est épais, étalé sur l'avant-dernier tour, il se relève à la base de la columelle, et se prolonge en s'arroudissant au moment de se courLer pour se joindre au bord droit; il s'élargit un peu et donne naissance à une dent; la colunelle est oblique, et elle ne présente qu'un seul pli assez saillant; le bord droit épais, renversé en dehors en bourrelet marginal, est pourva d'une dent plus saillante que celle que nous avons mentionnée. Les plus grands individus de cette espèce n'ont pas deux millimètres de long sur un de larghe. Elle habite en France, en Prusse, en Suisse, etc.; dans les lieux humides, sous les pierres, les bois ou les feuilles pouries.

29. Aonicore grimaçante. Auricula ringens. LAMik.

A. testâ ovatâ, turgidulâ, transversim striatá; striis tenuissimis, regularibus; columellâ obliquâ, marginatâ, basi truncatâ, biplicatâ; labrodextro obliquo, reflexo, in medio inflato et dentato.

LAmк. Ann. du MIus. ton. 4. pag. 435.; et tom. 8. pl. 6o.fig. 11. a. b.

lbid. Anim. s. vert. tom. 7. pag. 539. n०. 5.

Nов. Descrip. des Coq. foss. des env. de Puris, pl. 8. fig. 16.17 .

Marginella. MÍnaro de ua Grote, Ann. du Mus. tonz. 17. pag. 33 1.

Lor'sque nous donaâmes la synonymie déte cette espèce, dans notre ouvrage sur les crquilies fossiles des environs de Paris, nous confundimes, comme M. de Ferussac l'avoit également fail, plusieurs espèces à tilre de variélé; aujourd'hui, que nous avons fait de nouveau un examen approfondi de ces coquilles, nous croyons qu'il est possible de douner de bons caracteres pour les distiuguer. Les variations continuelles dans lesquelles se sont tronvés les auteurs, relalivement à ces coquilles singulières, nous avoit donné l'opivion qu'elles pourroient bieu former un petit genre; cette idée devieat plus probable pour nous, lorsque nous voulons trourer des rapports réels avec des grenres dans lesque!s on a voula essayer do les placer. Nous ne sommes cependant point encore assez éclairés pour le proposer défiuitivement, la connoissance de l'animal étant une condition indispensable, quand il existe tant de rapports avec des genres très-éloignés appartenan à des familles et à des classes différentes.

Nous pensons que les seules coquilles qui doi- 


\section{A U R}

rent rester dans l'espèce de M. Lamarck, l'Auricula ringens telle qu'il l'a connue, sont celles qui provieunent des eavirous de Paris et de $\mathrm{T}_{\mathrm{a}}$ lognes.

De toutes les espèces de ce groupe, eelle-cj reste constamment la plus petite; elle est globuleuse, pointue, formée de cinq lours arrondis, doot le dernier est beaucoup plus graud que tous les autres; le sommet est pointu; la suture est simple et médiocrement profonde, toute la surtace extérieure est régulièrement et finement striée; les stries sont simples, arrondies, étroites, lisses, et l'intervalle quiles sépare est lisse auss?. L'ourerture estoralaire, subtrigone, rélrécie par deux plis columellaires très-siillans situés à la base de la columelle, et sonveot une dent oblique placée à sa partie postérienre. Le pli autérieur se renverse en dehors en se contournant sur lit columelle, disposition qui produit une sorte d'échancrure comparable à celle de quelques liuccins; le bord gauche est épais, largeweut étalé, mais bien nettement circonscrit ; il se comourne a la base de la coquille, borde en delıors l'échancrure gui s'y trouve, et se continue avec le bord droit; celui-ci, bien arrondi en bourrelet, s'épaissit et devient plus saillant dans le milieu, ce qui contribue à rétrécir notablement l'ouverure, il descend plus bas que la columelle : ee qui est un des bons caractères qui distinguent cette cspéce.

Longneur des plus graods indiridus 5 millim., largeur 3.

Très-commune aux environs de Paris dans les sables da calcaire grossier; non monins répandue dans ceux de Hauteville, près Valogues.

20. Aonicone buccinée. Auricula buccinea.

A. testâ minutâ, subovatî, inflatâ, lavigatâ; spirâ brevi, acutâ; colunsellâ triplicatâ; plicis acutis; labro serestro expanso, adnato, altero marginato, in medio inflato, non crenato.

Voluta buccinea. Broceri, Conch. subap. tom. 2. pag. 3ig. no. 23. pl. 4. fig. 9 .

Ibid. Sow. Min. conch. pl. 465. fig. 2.

Auricula ringens. Var. a. Fer. Prod. pag. 109.

Ibid. \ов. Var A. ei B. Descript. des Coq. foss. des env. de Paris.tom. 2. pug. 72.

An eadem? Yoluta pisum? Brocc日, loc. cit. pag. 642. pl. 15. fig. 10.

Cetle coquille est certainement distincte de la prérédente; nous avons réuni les deux espèces de II. Brocchi, parce que son Voluta pisum, établi arec une coquille cassée, nous a semblé, d'après la description et la figure, identiquement semblable au Voluta buccinea. Cetre coquille est toujours benucoup plus grande que l'Auricula ringens; elle est globuleuse, à spire conrte, pointue; ajant sis tours de spire seulewent, ils scat arrondis el sćparés par une sulure jeu profoude et simple. Le deruier tour est très-globuleux, arrondi, ventru, beaucoup plus grand que tous les autres, il cst compléteuent lisse comme eux, l'ouserture qui le teruine est étroite; la columelle oblique offre à sa base deux plis, dont l'anıérieur forme l'échancrure, un troisième plus épais, calleux, se remarque à la partie postérieure; le bord droit arrondi, margiré en dehors, se zonfle au milieu, mais il n’est ni crénelé ni uenté; le bord gauche s'élargit et s'amincit, il est moins visible que dans l'espèce précédente; il se joint pourtant an bnurrelet marginal qui borde la base el le bord droit de l'ouverture.

On troure cette espèce à l'état fossile daus le Plaisantin, daos les faluns de la 'Touraine, et aux environs d'Angers: dans cette dernière localité ils sont un peu plus alongés.

Longueur 8 nillim., largenr 5 .

\section{Aonicule de Bonelli. Auricula Bonelli.} Nов.

A. testâ ovato-abbreviatî, turgidulâ, elegunter striatâ; striis tenuibus, numemsissimis, angulis ninimis lateralibus imbricatis; columellá triplicatâ; lab́ro dextıo incrassato, valdè marginuto.

C'est à M. Bouelli, savant professeur de Tnrin, que nous derons la connoissance de cette jolie espèce, voisine pour ses rapporls de l'Auricula ringens et autres analogues. Elle s'en distingue constamment, et par le volume qui est plus considérable que dans aucune des autres espèces, et par la forme beaucoup plus globuleuse. Oulre ces deux caractères saillans, elle a la spire trèscourle, pointne, formée de cing tours arrondis. dont la suture est simple; le dernier tour est très-grand, globuleux, ainsi que la spire striće transversalement dans toute son élendue; les stries sont fines, dentelées des deux còtés de manière à ce que les dentelures de l'une entrent dañs les angles rentraus de l'autre, et réciproquement : celle disposition est sembluble à ce qui rísulteroil tle l'entre-croisement des dents égales de deux lames de scie. L'ouverture est ovaleirigone, longitudinale, siuueuse et versante à la base. La columelle est chargée de trois plis saillans, les deux antérieurs sublamelliformes, le postérieur, plus épais, se confond par une base élargie arec le bord gauclie; le bord droit est arrondi, épais, forteureot marginé en debors et renflé vers sa base, vis-à-vis les dents columellaires.

Longueur 9 millim., largeur 7. Fossile des environs de Turio.

IOB.

22. Aonicele marginée. Auricula marginaia. A.testâ ovato-2entricosâ, larvigetij; spirâ 
acutâ; suturâ subcanaliculutâ; labro sinistro latissmo; columellâ triplicatâ, callo repando posticè instructâ; labro dextro sub callo marginato; in medio valdè incrassato.

C'est encore ì l'obligeance de M. Bonelli que nous derons cette espece remarquable; elle est petite, ovale, jointue, rentrue, toute lisse; les tours de spire au nombre de cinq sont arrondis, el netlc aent séparés par nne sulure assez profonde subcanaliculée; le dernier tonr est beaucoup plus grand que tous les autres; il est globuleux, et se termine par une ouverture qui seule caractérise fort bien cette espèce. Le bord gauche est très-large, il s'étale sur presque toute la face inféricure chu demier tour. Il est mince, et sa lianite seroit difficile à apercevoir s'il n'étoit plus lisse, plus brillant que le reste de la coquille; il se, contourne à la base autour de l'échancrure, très-petite, qui s'y trouve; il est ordinairement dans cet eudroit chargé de plusieurs sillous irréguliers, et il gagne le bourrelet du hord droit. La columelle est munie de trois gros plis saillans, et de plus postérieurement d'une callosité longitudinale un peu recourbée, saillante, et couvrant l'ouverture cu s'approchant du bord droit, entre lequel elle ne laisse qu'une fente étroite, une sorte de petit caual, terminé par une légère éclsancrure du bord droit dans l'endrcit de sa jonction sur l'avant-dernier tour : c'est en clessous de cette callosité qu'il fuut chercher le troisième pli columellaire que l'on ne verroit pas sans cela. Le bord droit est arrondi, marginé, et largement bordé en dehors, il s'élargit iuférieurement vis-ì-ris les plis de la columelle; il s'aplatit et devient presque tranchant à son bord interne, qui est subtronqué an térieurement. Cette coquille curieuse, que l'on trouve dans les sables d'Asti, n'a que 6 millimètres de long et 4 de lar.se.

\section{AURICULES (les). Auricula.}

M. de Ferussac donna le prearier ce nom à la famille qui rassembla les dirers genres qui aroisinent celui des Auricules, d'où elle a tiré son nom. Si l'on consulte l'article Auriculacées, on verra que M. Lamarck avoil eu le premier l'idée d'une famille de celte nulure, idée qu'sl abandonua par la suite parce quil ne troura pas qu'on eût des données suffisantes pour admettre ou pour rejeler défnilirement plnsieurs des gemres qui devoient entrer dans sa composition. C̈́cst ainsi, comme nons l'avons dit a l'article Aunicure (voy. ce mot), que les genres Scarabe et Caryclic, l'un et l'autre terrestre, furent rapportés aux Auricules, et le Pietin, qui appartient à un mollusque marin, fut rejeté loin d'elles arec les 'Tornatelles. Cette marcke, celte distribution ne parut pas naturelle; persoune ne l'adopta, elle n'avoit pourtant besoin que d'être perfectiounée. Le temps, qui a conduit à de nouvelles obserrations, a fait counoître que M. Lumarck avoit eu parfailement raison d'éloigner des Auricules plusieurs des genres que, walgré cela, M. de Ferussac a corbpris dans la famille des Auricules. Nous derors rendrc celte justice à cet auteur, que ce n'est qu'arec doute qu'il les y a laissés : doute qu'il a manifesté dans son l'rodrome aussi-bien qu'it l'article Auricule du Dictionnaire classique.

M. Lümarck, comme nous l'avons ru, ne sen boit pas la nécessité de cette famille des Auricules, parce qu'il n'admeltoit pas les genres qui y sont aujourd'hui. N. de Ferussac, qui les adopte tous, a cherché un arrangement convenable qui $l_{\mathrm{s}}$ mette en rapports. Cette famille fait partie du quatrième ordre, lcs Pulmonés sans opercules, et constitue à elle seule le second sons-ordie, lés Gélyydrophyles ( vojez ce mol); six genres la composent, ilśs sont disposés dans l'ordie suivant: Carychie, Scarabe, Auricule, Pyramidelle, 'Turnatelle, l'iétin. Voyez ces mots et surtout AURzCULE.

\section{AURICULITE.}

M. Bosc, dans le Nouveau Dictionnaire dhistoire naturelle, dit que l'on donne vulgailentent ce nom il une espèce de Gryphées. Laquelle? nous l'ignorons, car il ne fait aueune citation.

\section{ALRIfÉRE. Aunifera.}

11. de Blainville avoit créé sous ce nom $\mathrm{mm}$ genre de Cirlhipèdes que Léach a proposé sou la dénomination d'Otion pour le Lepas aurita de Linné. Bruguic̀re, dans le premier volume de ce Dictionnaire, pag. 66., a bien fait sentir la différence de cet animal arec celui des Analifes, mais il a'ed a pas fait un genre. Le mêrme animal it reçu le nom de Brante par Nl. Oken. Le nom de MI. Léach ayant été adopté de préférence, c"est à lui que nous renvoyons.

\section{AURIFORNES. Aurifornes.}

II. Lamarck a établi une famille sous le nom de Macrostomes (2.oye ce mol), pour y rasseub bler les genres Haliotide, Stomate, Sionatelte et Sigarei. M. Latreille en éloigna jusıment ce dernier, et au nom de Macrostomes substitua celui-ci. Celte famille des Auriformes est la promière des Scutibranches : en traitant ce mot, nous examinerons la valeur des nouveaus rapports que M. Latreille a proposés eutre cette litmille et la suivante.

\section{AURIS,}

Dénomination latine employée par quelques auteurs, surtout les anciens, avec une épithćte plus ou moins caractérisque, pour désigner les coquilles qui ont une forme analogue à celle de 


\section{A V I}

l'oreille humaine ou de quelques animax. Vojez OreILLE.

\section{ACRISCALPIUI.}

M. Lamarck aroit dơjà créć le genre Analine, lursque M. Mrigerle, dans le Magasin de Berlan ( 1811 ), le proposia de noureau sous ce nom d'sluriscalpium gui ne devoit pas étre adopté. toyez Axarise.

\section{ATAGNON.}

Nom vulgaire employé sur nos côtes de l’Ocćan pour désigner des corquilles qui s'y mangrent, comare les moules. On fuit aussi usage du mot Lavigzon, que Al. Cuvicr a adopté, pour l'appliyuer a uu genre lurmé de ces cogyulles. Il faut remarquer quavaut la crénliun de ce genre, Mégerle l'uvoit établi sous le nom d'Arénaire (yoyez ce unot), et Montagu sous celui de Ligule (voyez aussi ce mot), et depuis M. 'Turlon lui a domné relui de Listera anujuel nous reovoyons, aiosi qu'à Nactre et à Lutraise.

\section{AVELISE.}

Les marchands donnent ce nom, ainsi que celui de Scircube ou de Gucule de loup, is une coquille fint resarqualsle par sa furme el ses dents noa1 reuses, qui obstruent son ouverture; c'est l'Helix siurabcus de Linué, Aunicula scarabeus de Lawn. Uarila, dans son Cataluguc, a aussi donnć le nom d'Aveline an Tomutilis fascialu Lamk. Voyez Scarabe el Turnatelle.

\section{ATICULE. Avicula.}

Si nous recherchons parmi les anciens anteurs de conchyliologie l'origine de ce genre, nous le rrournas mentionné, pour la prenière lois, par Aldrovande (de Testucess, par. 459.); il le désigne, à cause du peu d'úpaisseur des coquilles, sous le nom de Testacea tenuis teste; il en donne nne notion très-courte, et le compare aux moules qui se fixent par un hyssus de la mêne manière. Langius, dans sun Tĺraité, si bien litit pour le temps ou il parut, ne le distingua nullement, et à cet énard Lister le suivis. Guatierri lut le premier, ce nous semble, qui ail indiqué ce genre d'une asanicre nelle et tranchée; il le désigne par le nom carastésistique de Cochlea aliformis, et la planclie 94. de son ouvrilge reprèsente, sans aurun mélunge, les espères qu'il connuissoil : ainsi Klein, en críant the nouveau ce genre sous le nom qu’il porle encore aujourd'hui, u'eut pas le mérite de l'invention, et il ne fut pas mieux circenscrit, car, comme lui, Guallierri en avoit séparé les I'utadines, exeurple que M. Lamarck suivit plus tard.

Adanson ne connut quine seule espèce de ce Histoire Nuturelle des Vers. Tome II. genre; entrainé par des rapports mal appréciés, it le rangea dans le geare Jambonoean, qui ressemble à un incertie sedis bien plutôt qu'i un genie, puisqu'on y rouve lesgenres Piane, Monle, Ilodiole, Cardile el Avicule. linné, sans imitrs ce mauvais exemple quadanson donna si rarement, rassembla en une seule espece toutes les Avicules qu'il commua el la plaça parai les Muules sous le nom de Mytilus hirundo. Bruguière ne vit pas d'abord la nécessilé de séparer les Aricules des Mloules, ce ue fut 'fu'après la publication du premier volume de ce Victronnaire, dans l'arrangement des planclies quil'accompagnent, qu'il songea à une réfurme nécessaire; il comprenoit dans son genre IIironde, Avicula, non-seulement les Aricules de Klein, mais eucure les Marteaux et les Pioladines.

Dès ses premiers Iravaux, M. Lamarck réforma le genre de Brugnière en séparant les Marteaus; il cût fallu s'arrêter là peot-être, car les Pintadines ont avec les Avicules de tels rapports, qu'il est impos ible de les séparer nellement. Compris dans la lamille des Byssifères de la philosophie zoologigne, ce genre se relrouve dans l'Extrait du Cours, mais alors les Pintadines en sont séflarées. M. Cuvier n’a pas admis celte séparation, nais au lien de les ranger dans les Acéplates monomyaires, coome M. Lamarck, il les met dans les Dinyaires, à cause de l'exisrence d'un second muscle adducteur, extrêmement petit, dont on retronve les traces su. les coquilles. Ce genre, arec les Jambonneanx et les Arches, constitue la seconde lamille des Osıracées, curaciérisée par deux muscles. Mialgré cetle opinion du célébre zoologiste dont nons venons de parler, M. Lamarcl conserva sa manière de voil' a l'égard des Avicules; dans son deraier ouvrage, en ellet, on les trouve dans sa famille des Malléacées, dómembrée de celle des Byssifères, de l'Extruit du Cours : el!es n'ont pas changé de rapports d'une manière noiable, sculement au licu d'êre séparces des Pintadines par les Marteanx, elies sont en contact iunaédiat.

M. de Ferussac n'a adoplé ni l'un ni l'autre des arrangemens que nous venons de mutioner: a côté de la fitruille des Malléacées se trouve celle des Avicules, dans l'ordre des Ostracés dirnyaires; le genre qui nons occupe se voit entre les Crénalules el les Pintadines. Bien peu de tcmps après la publication de ses Tableaux systématiques, M. de Ferussac, daus le Dictionnaire classique d'histoire naturelle, revint a la premiére opinion de M. Lamarck, à celle de N. Cuvier, en ríunissant les deux genres Avicule et Pialadine. Mr. de Blaiuville, dans son Traité de Malucologie, adop!a complétement celte manic̀re de voir, mais donna au geure d'autres rapports en le plaçant dans la lanille des Margaritacés. (Voyez ce inot). La famille des Oxigrones de M. Latreile 
(Fam. nat. ¿du Reg. anim., pag. 211.) correspond nettement à celle des Malléacées; on y remarque cependant le genre Pinne qui nous semble avoir plus danalogie avec les Huules quavec les Mollusques des Avicules.

Le magnifique ouvrage de Poli nous a dévoile l'anatomie d'une espèce d'Avicule assez commune dans la Méditerranté ; c'esı d'après lui que nous allons donner quelques détails sur son organisation.

Le manteau, pourvu d'un double rang de cirrhes, est ouvert dans toule sa longueur et formé, comme dans presque tous les Mollusques de celle famille, de deux lobes égaux; un prolougement postérieur est placé eutre les deux appendices qui terminent de ce côté la base de la coquille; deux paires de branchies lanelliformes sont placées de chaque côté du corps et en dedans du znanteau; elles son t plus courtes que lui. La masse abdominalè est pelite; elle se terınine antérieurement par ua pied cylindrique, alongé, pourvu à la base d'un byssus à soics rudes, agglomérées et nombreuses. L'ouverture buccale est médiocre, tout-i-fait antéricure, transverse; les deux lèvres qui la forment sont papilleuses ei garnies le.ch aque côté d'appendices labiaux, striés et tronqués au summet. Laaus, libre et flottant, passe derrière ce muscle adducteur des valves, auquel il est adhérent dans uue grande partie de son élendue; le unscle esı cylindrique, assez alongé, il laisse sur la coquille des traces de sa présence, ainsi yue le muscle rétracteur du pied qui s'insère uon loin du premier. Le système vasculaire ne paruît pas différer bien notablement de celui des Moules.

Daprès ce qui précède, il n'est pas douteux que le genre Avicule ne doive être conservé; outre une forme particulière dans sa coquille, il offie aussi, dans son organisalion, quelques particularilés qui le distinguent des autres genres avoisinans; ainsi la terminaison de l'anus, par exemple, est tout-à-fait dillérente de celle des Moules. La masse abdominale est beaucoup plus courte, et le byssus est d'une structure fort dillérente de celle des Moules el des linnes; an lieu a'être composé d'un faisceau de soics isolées, dont chacuue s'altache séparément, toutes ici sont réunies par une sorte de membrane cornée, fort dure, au-dessous de laquelle se voient des fibres en faisceaux plus ou moins gros qu'il est impossible d'isoler. Ce byssus, par cette disposition, ressemble à un large empâtement couparable à celui de certains Polypiers llexibles.

11 existe un passage insensible entre les Avicules et les Pintadines, de telle sorte qü il est impossible de décider si quelques espèces dépendent plutôt d'un genre que de l'autre; ce unotif est suffisant pour réunir en un seul genre $t$, utes les coquilles qui ont entre elles tant d'anaogie, el, quoiqu'on ne connoisse pas encore l'a-
A V I

nimal des Pintadines, il est bien à présumer qu'il ne diffère pas de celui des Avicules d'une manière notable.

$$
\text { CARACTERES GENERIQUES. }
$$

Animal lamellibranche; deux paires de brancluies synúlriques; corps petit, terminé par un piced cylindroide vermiculaire; un byssus à fibres grossières, réunies, allaclić à la base du pied; anus lluttant derrière le muscle adducteur postérieur; nuscle antérieur, pelit, presque rudimentaire.

Coquille inéquivalve, le plus souvent mince et fragile; à base transversale, droile, une échaucrure d la valve droile pour le passaye du byssus. Charnière linéaire, sub unidentée, quelquefois saus dents; facelle du ligament marginale, large, oblique, en canal.

Le nom de ce genre indique suffisamment qu'il ne le duit qu'ì une comparaison assez juste de sa forme avec celle d'un oiseau dont les ailes sout élendues ou dans l'action de voler, surtout lorsqu'on ouvre les valves sans les écarter. Celte forme ne se trouve pas dans tnutes les espèces, elle n'appartient qu'à celles de la prenière seclicun, encore il $y$ en a plusieurs qui, pur la dimiuntion graduelle de l'appendice pustérieur, ne peuvent plus recevoir cette comparaison.

Toutes les coquilles de ce genre sont nacrés en dedans; il y a quelques-unes qui, par leu: épaisseur, leur grandeur et l'éclat de leur nacre, sont l'objet d'un commerce particulier, et d'une pêche très-active dans certains parages de la mer des Indes ou de l'Océan austral : celle pêche a d'autant plus d'atrait qu'elle forrnit la plus grande parlie des perles répandues dans le commerce; nous reviendrons sur ce sujet intéressant à l'article PerLe. 'Toutes ces coquilles sont marines, iuéquivalves, souvent écailleuses en dehors; elles sont compasées de deux parlies bien distinctes, nue corticale qui prend sur les bords un développement beaucoup plus considérable que dans beaucoup d'autres genres. Nous avons observé que cette couclue corticale avoit, dans ce genre, une structure semblable à celle des Pinnes, c'est-à dire fibreuse perpendicalairement; nous avons observé ce fait aussi bien dans les Avicules proprement dites que dans les Pintadines. Il pourra peut-être par la suite être d'une assez grande utilité pour fixer définitivement les rapports des divers genres qui l'offient.

Nous diviserons les espèces du genre Avicule en denx groupes, le premier pour celles qui constituent les Avicules de M. Lamarck, et le second pour le genre Pintadine du même auteur. Nous disposerons les espèces de manière à ce que l'on passe insensiblement d'une section à l'autre par 
le raccourcissement successif du prolongement postérieur du bord supérieur : ce bord supérieur est aussi le bord cardinal; dans les Avicules et plusieurs Piatadines, il est muni d'une dent placée sous les crochets, celte dent est fort peu saillante, elle ne peut donc pas être d'uoe grande utilité pour la solidité de la charnière.

Limpression musculaire qui se voit dans l'intérieur des valves, a'est pas placće au centre, mais sur le côté postérieur; elle est composée de deux parties bien distinctes, la plus petite, qui est l'antérieure, donoe attache au muscle réltacteur du pied. Uoe autre impression beaucoup plus petite, à peine visible dans quelques espéces, est placée antérieurement en dedans des crochets; elle indique, comme nous l'avons viz, la position du muscle adducteur autérieur des valves, lorsyu'il existe.

$$
\text { Ire. Section. Les Avicules. }
$$

IAA $\mathrm{K}$.

Avicule macroptère. Avicula macroptera.

A. testâ maximâ, extùs fusco-nigricunte, intùs ulhıdo rubescente; alâ amplissimâ, obliquè cursù ; caudâ longiusculâ, lata, subucutá.

LAnk. Anim. sans vert. tom. 6. pag. 147. $n^{0} \cdot 1$.

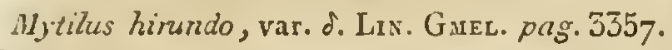
$n^{\circ} .2 \%$.

Gualtiert, Test. $p l .94$. fig. A?

Kivar. Vergn. 6. tab. 2.

Nous unettons un point de douse à la citation de la figure de Gualtier, paree qu'elle représente une ispéce dont le prolongement postérieur est beaucoup plus grand qu'il ue l'est dans les iodividus de la cullection de M. Lamarck el de la nôtre. Cetle upice, la plus grande du genie, est plus longue que large, oblique, très-inéquilatérale; le sious de l. valve droite pour le passage du byssus est profund, il est placé assez bas dans la longueurdu bord untérieur; l'appendice postérieur est peu alongé, assez large surtout à sa base. A l'intérieur, celte cocguille est diune nacre brillante rougeâtre trèsbel!e; la partie nacrée est débordée tont autour par la couche corticale, bruue el subcoruée : à l'extérieur elle esı d'un brun foncé, quclquefois à peine écailleuse, mais plus souvent couverte de lames écailleuses lascinićes irrégulic̀rement, plus nombreuses, plus saillantes vers le bord inférieur des valves que partout ailleurs. Duns le jeune âge, on voit sur les crochets des raies blancliâtres longitudinales rayonnantes qui, dans quelques individus, se prolongent fort loin sur les valves. C'est de cette espece don le loyssus remarquable a été cité précedeunent: elle acquiert jusquà vingót centiuètres de longueur. On ignore sa patrie.
2. Avrcure demi-Hlèche. Avicula semisagitta. LA3X.

A. testâ obliquâ, longissimè caudatâ, extùs nigrâ, rudiatim squamulosâ; squantulis minimis, acutis, imbricatis.

Lister, Conch. tab. 220. fig. 55?

KNor r. Vergn. 4.tab. 8. fig. 5. et5. tab. 10. fig. 1. 2.

Cette espèce est remarquable aussi bien par son appendice postérieur fort long que par la disposition paricnlière des écailles qui couvrent une partie de sa surface extćrieure. Elle est très-oblique, obliquement subcarcúce dans le milieu des valves par une gibbosité obtuse qui les partage en deux parlies presqu'égales. Toute celte corjuille es ld'un noir foncé à l'extérieur, ainsi que le limbe iulérieur des valves qui déborde la substance nacrée; elle est couverte dans presque toute son éleodue, surtout la valve droite, de rangées rayonnantes d'écailles petites et pointues qui partant du sommet s'élargissent jusqu'au bord inlérieur des valves où elles aboutissent. La charnière, outre une dent cardinale bifide médiocre, offre en outre sur la valve droite une dent latérale fort longue, reçue dans une cavité correspondante de la gatrche. A l'intérienr, cetle coquille est d'une nacre blanche un peu bleuatre. Longuenr quarante-un millimèures, largeur qualre-vingt-cinq Nous ne savons de quelle mer elle vient.

3. Avicure vespertilion. Avicula vespertilio. Nов.

A. testâ griseo-fuscatî, inaquivalvi substriatû; alâ latá, rolundatâ, vix obliquâ; cuudà elongatâ, angzest $\hat{a}$, fragili.

Coquille d'une taille médincre, et l'une de cette section qui est le moins oblique; elle est en dehors d'un brun - grisâtre, toute couverte de stries peu régulières, peu profondes, qui indiquent des accroissemens; la valve droite est plus petile que la gauche et l'échancrure pour le byssus est assez prolonde; l'appendice postérieur est long, étroit, grêle, fragile, et contraste avec la largeur des valves, qui sont, coinme nous l'avons dit, peu obliques et arrondies. La charnière a une dent cardinale Irès-petite, et off'e à peine la trace de la dent latérale que nous avons signalée daus l'espèce précédente. A l'intérieur, la nacre est blanche, avec des rellets rougeâtres et cuivreux, et la matière corticale la dóborde fort peu. Nous ignorons d'où vient cette espèce, qui a trente-cinq millimètres de longueur el cinquante-sept de large.

4. Avicule de Tarente. Avicula tarentina. LaMx.

A. depressâ, obliquâ, griseâ, fusco-radiatâ, $\mathrm{N}_{2}$ 
irreguluriter striatâ; striis infornè squamulosis; ulâ lutấ; caudì variabili, sapius elongatâ.

Mytilus hirundo. Polr, Test. des Deux-Siciles, pag. 65. pl. 23. fg 9 .

Laмs. Anim. sans vert. tom. 6. pag. 148. $n^{\circ} \cdot 7$.

Une des variétés de cetle espèce est l'Aviculız falcata Lass.

Cette espèce, assez commune dans quelques parties de la IIéditerranée, est celle qui a servi aux anatomies de Poli, dont nous avons eu occasion de parler. Elle est variable quant à la forme et à l'épaisseur; elle se reconnoît cependant facilement à certains caractères qu'il seroit difficile de méconnoître. Eille est souvent nince, ce qui dépeud probablement de l'àge, car nous en possédons plusieurs d'épaisses et de fort solides. L'appendice postérieur dépasse ordinairement les valves eo longueur dans quelques individus; il est même fort long, grêle, très-liagile; le corps des valves est assez grand, ovalaire, oblique; l'extrémité antérieure est étroite, alongée, à base beaucoup moins large que dans les autres espèces, et ce qui lui est particulier, c'est que le sinus pour le byssus cst creusé également dans les deux valves. Le bord cardinal est droit, peu épais, et n'ollire qu'une deat très-petite et pas lis moindre trace de la dent latérale que nous a vons signalée dans les deux espèces qui précèdent. La cuuleur en dehors est d'un blauc-jaunâtre ou grisitre, avec quelques rayons d'un brun obscur; en dedans elle est d'une nacre argentée, largement débordéc, surtout postérieurement, par la substance corticale. Quelquefois cette corfuille est lisse, arec quelques stries irrégulieres qui marqueut ses accroissemens; d'autres fois, et c'est le plus souveut, ces stries sont Jamelleuses et leur bord libre découpé assez profundément en dentelures irrégulières et aiguë:

Cette espèce paroit particulière à la Médilerranée, et surtout abonder dans le golfe de 'liarente et les mers de Sicile. Elle est longue de cinquante-cinq millimètres, el large de quatrevingts.

5. Avicole safianée. Avicula crocea. Lasix.

A. testâ glabrâ, luteo-croceâ, immaculatâ; alâ obliquè divaricatâ, caudâ latâ, trianguluri; cardine, dente laterali magno, instructo.

Lasu. Anim. sans vert. loc. cit. $n^{\circ} .6$.

L'́ACH, Miscel. zool. pl. 114.

Var. a. LAm r. Caudâ longiusculâ, attenuatâ.

Var. b. Caudâ brevi, alam non superante; alà ohliquissinè fulcatâ. Noв.

Celte espèce remarguable se reconnoit à la premicre vue par sa couleur qui est peu variable et sans mćlangre : cette coulcur est le jaune de sa- fran. Cette coquille n'acquiert jamais une grande taille; très-obliquc, elle est aussi très-inéquivalve, sa valve droile étant non-seulement plus petite, mais encore moins prolonde que la gauche. L'appendice postérieur est large à sa base, triangulaire, terminé én pointe plus ou moins aiguë, plus ou woins longue, mais en général plus longue dans les jeunes que dans les vieux individus, et dépassant en longueur l'extrémité postérieure des valves; celles-ci sont très-obliques, subyibbeuses daus le milieu, et étroites. Cette coquille paroit lisse, mais vue à une forte loupe, on y voit des stries très-fines, très-régulières, et longitudinales; en dedans elle est d'une nacre blanche argentćc, très-belle; la charnière est remarquable en ce que la dent latérale est très-saillante. La variété A. se dislingue par la longueur de l'appendice postérieur; la variélé $B$., au contruire, l'a beaucoup plus conte, mais par la lengneur des valves, leur oblicjuité el leur conrbure, elle ressersble à une faux.

I.ongueur de cette varité, soixante-cinq millimèlics; largeur, soixante.

\section{Avicore de Savigny. Aviculı Savignyi.} Nos.

A. testâ tenui, fra gili, fusco-nigricante, obliquâ, undiquè transversim striatâ; striis tenuissimis, antice subsquanosis; caudâ brevi, ulum vıx superconte.

Aroisinant pour sa couleur l'espèce que onu; avons désignée précédemment sous le norn d'sit'icula semisagitta, celle-ci s'en dislingue parlailement; ellc est arrondie, oblique, courbe, équivalve quant aux dimensions des contours, mais inéquivalve quaus à la profondeur des valves, la gauche l'emportunt sur la droite à cel égard. L'extrémité postérieurc est courte, large, à peine plus lon. grue que l'extrémité des valves; l'extréwité antérieure est assez longue, triangulaire, munie ì sa base ct surla valve droite seulement, d'une profonde échancrure pour le byssus. En dehors, cette coquille est d'un brun-noirâtre; on voit cependant sur les crochets, mais sur la valve ganche surtout, quelques rayons blanchâtres qui disparoissent dans l'épaisseur de la couche corticale; car si on interpose la coquille entre l'œil et la lumière, on distinguera, à l'aide de sa transparence, uu grand nombre de rayóns blaochătres dans tonte son étendue. La surface extérieure des deux valves est finement striće en travers; ces stries, vers le bord inférieur, se relc̀vent en lamelles Irès-minces, fauves et écailleuses antérieurement. Le bord cardinal est mince, la dent cardiaale est petite, et il $\mathrm{y}$ a à peine un indice de la dent latérale. La nacre de l'ıntérieur est blanclıe, avec des reflets métalliques bleux et rouges; un large bord de substance corticale circonscrit la tacbe nacrée de liatérieur. 
Celte coquille est voisine, pour ses rapports, de celle fgurée dans le grand ouvrage d'Egypte (ipl. 11. fig. 6.) par le savaut auquel nous I 3 dédions. Il existe des différences assez notables pour qu'elle doive en ètre distinguée.

Longueur quaraute-cinq milliwètres, largeur soixanle-dix-huit. Nous ne connoissons pas son habitat.

7. Aricule allantique. Avicula atlantica. Lank.

A. testî̀ fuscat $\hat{\imath}$, substriatû, alà latâ, rotundutâ, vix ubliquâ; corudî̀ elangatâ, ungustì; valvis mugnitudine inargutibus.

Avicula atlantica. Lass. Anim. sans vert. loc. cut. $u^{\circ} .8$.

Gutatierr, Test. 94. fig. B.

Mytilus hirundo. Lrx. Gmell. $3557 \cdot n^{n} \cdot 22$.

Yar. a. Testá albu-radiutá. Encyclop. pl. I77. fig. 9?

Ceesivitz, Conch. tato. 81. fig. $7^{22}$.

Var. b. I'estâ latiore; caudâ longâ, trianguluri.

Le Chumon, Adsxs. Voygg. au Sénég. pl. 15. fig. 6.

Les figures des coquilles de ce genre sont en général manvaises dans les auteurs qui en ont tonué; ce n'est qu'avec une grande circonspection qu'il convient de les citer; cclles de l'Encyclopédie sont malheureusement de ce nombre, et ellcs nous font seuiir, aussi-lsien que les autres, la nécessité d'une bonne monographie de ce genre; elles sont d'ailleurs la plupart recopiées de Chemnilz.

L'Avicule atlantique est une coquille d'une taille moyenue entre les espèces du genre. Elle est brune, et quelquefois rayonnće de blanc, surtont dans les individus qui n'ont pas acquis tout lear développement, ce qui n'est cepeudant pas constaut; les valves sunt ovales, peu obliques, substriées, inégales quant à la profondeur, minces fragiles; l'échancrure pour le byssus, sur la valve droite seulement, est profonde. Le prolongenent postérieur est assez variable, il dépasse cependant tonjours la longneur des valves; il est plus ou moins étroit, grẻle et fragile, ce qui tient sans doute à l'âge, comme nous avons pu le remarquer dans d'autres espèces. La variété A. à laquellenons rapporterons ¿vec doute la figure citée de l'Encyclopédie, est remarquable par les rayons blancliâtres qui l'ornent. La variété $B$. est caractérisée par la forme des valves qui sont courtes, à peine obliques et terminées par un appendice triangalaire assez long. 1.a longueur de celte espèce est de quarante à quarante-cinq millimètres, et sa largeur de soixantedix à qualre-vingts. Elle provienı des mers Allantiques chaudes et du Sénégal.
8. A
LADI.

A. testâ crassá, lentricosà, subobliquí, loevigat.i, subcaudatoi, intus margurituce ì; epidermide lutescente, maculis rufis irregularibus ornato; cardine edentulo.

L,A AnE. Anim. sans vert. loc. cit. $n^{\circ}, 15$.

Basterot. Mém. sur les foss. de Bordeuux. Mím. de la Soc. d'hist. nat. de Puris, fom. 2. pag. 75 .

Les auteur's que nons venons de citer n'ont pas conna complétement cette coçuille, comme l'itltestent leurs descriptions; ellc est fort in icressan:c cependant: elle esi la plus yrande fossile conuac dans ce genre, et peat très-bien servir à lies le genre Avicule au genre Pinadine, par le raccouscissement de l'extrémitć postérieure.

Cette coquillc est épaisse, solide, pen oblique, arrondie inlérieurement, pcu éclancrée postérieurement et terminée de ce cólć par un apperdice très-court. L'anricnle antéricenr est plus long, pointu, excavé, mais fort peu à la lase, jour lé pasáage du byssus. La valve droite est morns pro. londe que la grauclie, mais clle lui est égale dans les authes dimensions. Dans les vieux indiridns, le bord supérieur on cardiual oflie un talon assez large sur lcquel cst crcusce bicn nellement la goullière du ligament. Ce qui u'est pas moins remarquable dans cette coquille, e'es! le nancjue absolu de dents à la charnière, ce qui la rapproche davantage encore des Pintadines. Nous po:sćdons deux individus conplels de celte espece; l'un des deux est précieux en cela qu'jl a conservé prescrue toute la couche épidermique, avec des traces de couleur : il est d'un blanc-roussutre, parsemé de taches nubéculeuses de brun peu foncé. tonguenr soixante millimètres, largeur soixantedix. On la trouve assez communément à Bordeaux, mais presq̣ue toujours mulilée. Noв.

9. Avicule à quene contle. Avicula breviculudu.

A. testâ tenui, fragili, nigricante, substriatâ, ubliquá; caudá brevissinuá, obtusâ; auriculá niinimâ.

Coquille anssi longue que large, le bord sujérieur se tronvant diminué de la longueur du prolongement postériear, qui ici manque presqu'entièrement. Les valves sont obliquewent courbées en arrière, inégales, assez minces et fragriles; l'oreillette antérienre est médiocre, obtnse, subqnadrangulaire; l'échancrure de la base est pen profonde, elle existe dans les deux valves, mais inégalement, étant plus petite sur la valve gauche. Lappendice postérieur est court, obtus, Iriangnlaire et ne dépasse pas l'extrémité des valves. I,e bord cardinal, assez épais, est pourvu d'une dent 
apicale assuz grosse, et d'une dent latérale plus grusse eacore ; tllte est beaucoup plus cour:e tt beancoup plus solide que daus tuules les espèces dt geure. En debors, celle coguille est lisse, zarquée d'accroissetoeus per réruliers; elle est d'uu brum-noirâtre. Sa longueur et sa largeur sont de quarante-cing nulliméres Nuus la crcyues de la wer Rouge.

10. Aricrie à cúles. Avicula costala. Sow.

A. testí uvato-rotunduti, incrquivalis; sulva dextrú pihsuusculâ, rudialurn stuatâ; vulvá strustra profunda, costes sirnplicibus elesistrs, iadia-

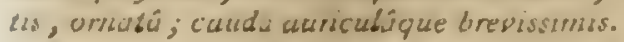

Son. Marh. Courkh. Fl. 244 . fig. 1.

Coquille singulière par la disparité de ses valves ei leur extrécue intigalité dans toutes les proprorions. Llle est arruadie, peu oblique; l'ureillette auterieure est tres-jelite, triangulaire, proinine, síparce par un profind sirus trangulare qui la seprare jusqu it sa base dans la valve drote, sur la nauche elle est moius excarée. Le prolungewrent postérieur est firt court; triangufaire el de dépassatus pas learrétuité des valvés; celles-ci smut tres-iucigales, la droite est lico-ajlatie et retlement disproperrivancé arec la ganclie, gu'il faut avois des ndividus complets pour croirt yo'elle puisse apparenir à uv wảe indridu. Sa surlace exléreure est couverte de s'ries élevées, tayounantes, plus ou ravius aumbreuses selur les individus. Lat valve droite est profunde, veutrue, chargée cxlírieuremeal de buil à onze cốres saillavtes, rayonuanteg, se lerwinaut sur Je bord patr des poivtes aiguës, ee jui découpe ce bord par atulam de deutclures youl y a de cóles; la valve druite est simple au coutrire daus son bord. Celle

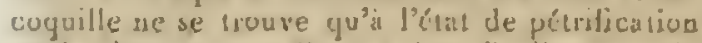
eu Angleterre at co lisance daus loulite lerragineuse. Celles yue nous possldous vienneat des curirous cle Cueu el de Bay'cux. La valve inférieure c'st lougue de varo-tuit evilizeetres, el large de treute-ciag.

\section{Secoude section. Les Pintadrnes. Lank.} Nov.

8. Avreve Écailleuse. Avicula squarmosa.

A. Lestâ subquadratś, inferred mituridutâ, posticè subsiruato-cuudulá, fusco-ziolascente, ulbo obscurè nadiatsi, harnellesu-squarnosa.

Cetre coguille tient eucore a la section precedeate par plusieurs caracteres; elle o'a poivi d'al" peadice postéricur, wais un legur siuus du bord posicrieur indigue un cow we acewers, uu ruditocat de cette partie : ce qui la lie encure aux autres Avicules, c'est la clarraière, gui est pourvue d'ue deat cardisule et d'us rudiwest de deat
Latérale. Les individus de cette espèce qque ours connoissons sont dun exéducre roluvie, lus ralres surt d'inigale profondeur, piesque carrices, peu obliques. L'oreillelle de la valie droite est coujours Large à la base, pourrue d'u sious petil, peu enfance. La couleur de celle coquille est le urus-violacé obscurément, rayumée de Llasc du suzacoet a la hase par 1:ois un quatre ligracs dous les écailles sout un jeu plus saillanies. "Tuute lat surface est curertede lawes suillartes, conceatrignes, rigulières, plus fréqueutes rers les burds et tercomées par dé écailles miaces, fragiles et printues. Ln dedins, la nacre est duo Dlave brillaul; elle est eutourée d'un liwbe peu large, de substance corlicule. Nous ue coupriss"as pras la palrie de celle corquille, qui est ausoi lougue que large: veote-ciug wrllisebres.

1\%. Aricule rayounie. Áricula radicia. Nob. A. testísubquadiats, infernè rotundatí, paslice obliqua, leriui, fragili, fusco-rubescerile, Lneis albis rathatë, hamellosa, squaniosá.

Plusieurs caractères dislinguent cetle coquille; elle apparient encure aux Avicules de la prewate se criou pas la charulere, mais par la forate aux l'iotadisics paran lerguelles elle dart preada. place. On ve sauruit la coulundre avec la précedente, elle est loujour's plus grande, flus miace. son bard suptrieur est beaucoup plus court, it sur le posténear, a pcise sil existe uve figire inflesion qua iedique ua rudirueut d'appetdice pusténeur. Les valves suot inégales guaut a la prufuedeur, la droile est la plus ajla ié; l’ureillete de celle valpe est courte, mais fort larme, quadraggulare, le sinas qui da circunscrit iofi-

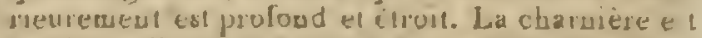
érrvite, elle ue présente gu'un rudimeut de dent cardivale, et un autre ruditaeus de dent latérale; Le buad cardinal est court, l'iulérieur est folus graud, raince et arrondi ea deliors. Celle cuyualle est courerte de lawes concentriques ab briyutes, écalleuses; sa couleur est brun-rougeálke. iolerrowpue par un assez ghrimd nombre de rayur. blancs. Lu dedius la tacre est d'uu blape-revilsire, et elle est eriluarce diue large burd de substance corricale. Lorgueur 55 wilim., largeus 43. Patrie sacounue.

13. A vicese albine. Aviculo ulbina. Lank.

A. testá subquadrati, degressá, albido-luté. irridatá, squamosá; latere postico fiarum persirnato.

Meleagrina albina. Lamk. Anirr. s. zert. tom. 6. rag. 15\%, $n^{\circ}, 2$.

Kusн. Mlus. 2ab. 47. /ig. B?

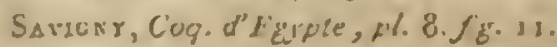

Cette especte est dacilexent recocuussulis, 


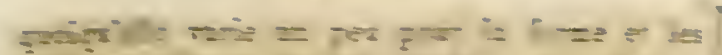

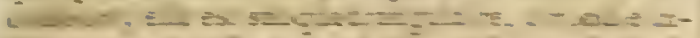

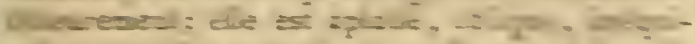

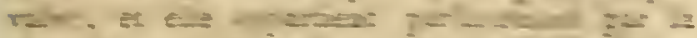

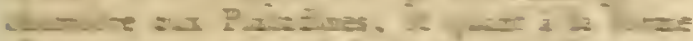

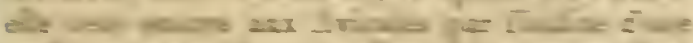

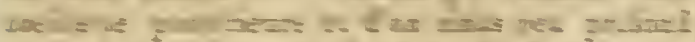

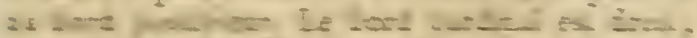
asse: exp: :

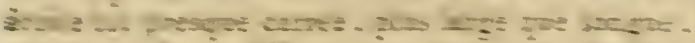

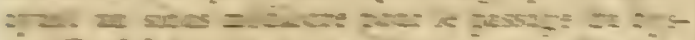

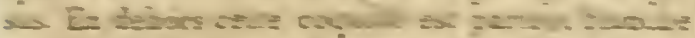

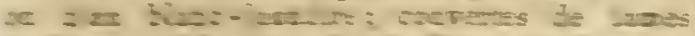

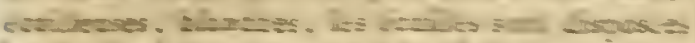

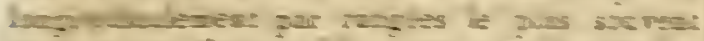

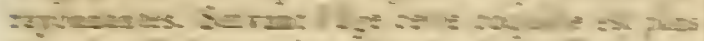

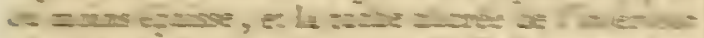

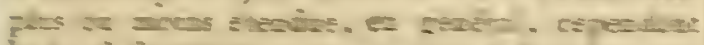

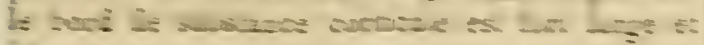
ites:

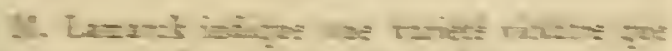

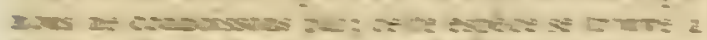

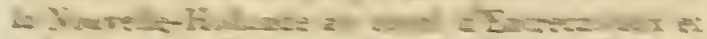

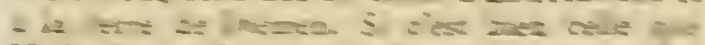

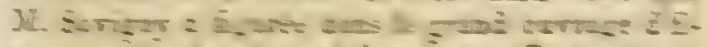

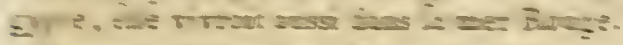

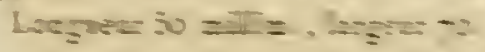
$-2-1$

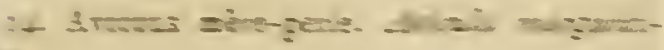

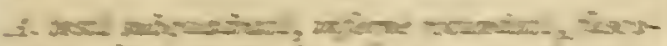
3.

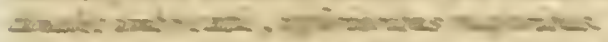

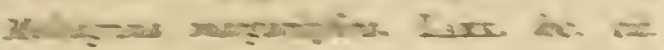
$x^{2}-1$.

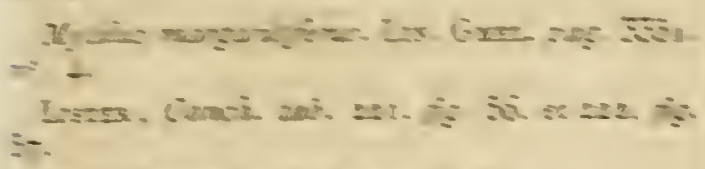

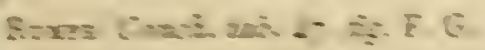

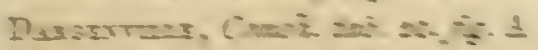

S$x+2$

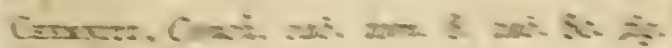
$-1+-2,-13-2$

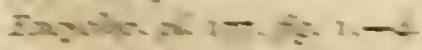

=

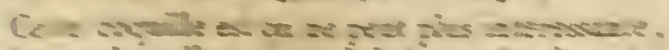

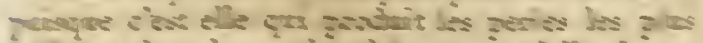

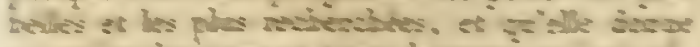

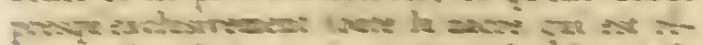

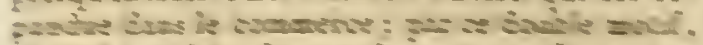

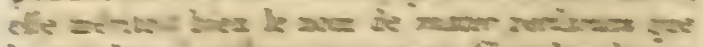

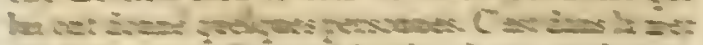

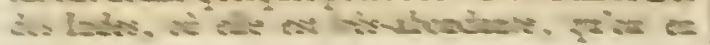

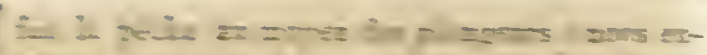

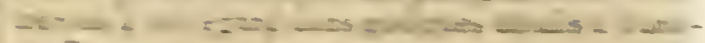

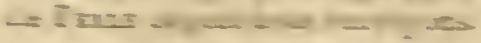

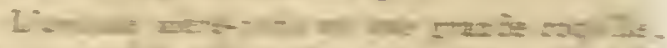

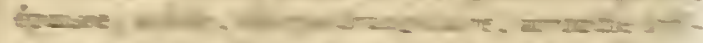

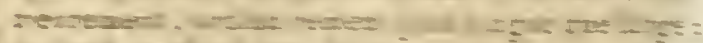

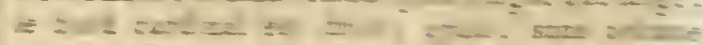

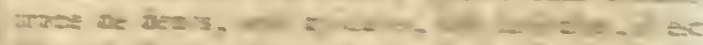

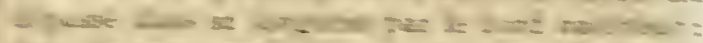

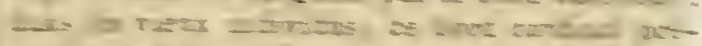

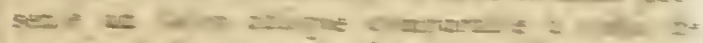

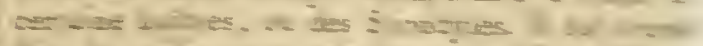

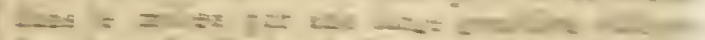

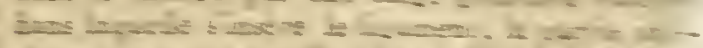

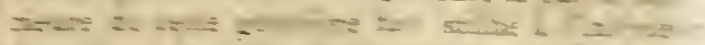

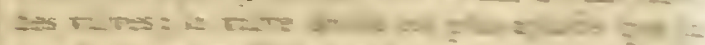

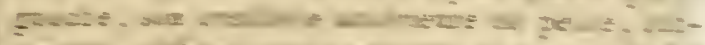

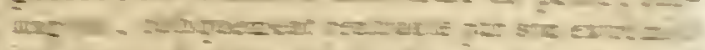

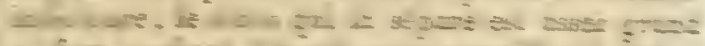

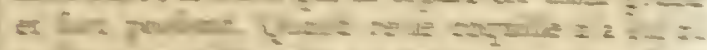

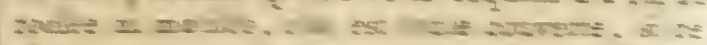

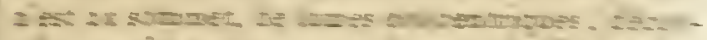

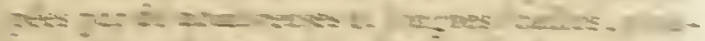

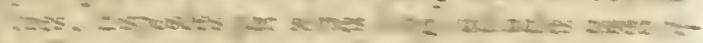

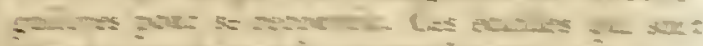

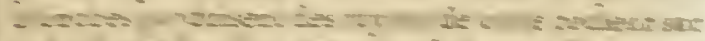

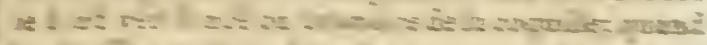

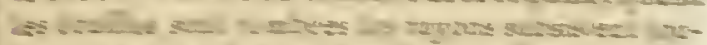

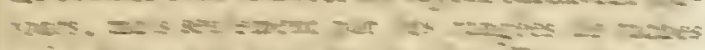

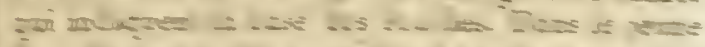

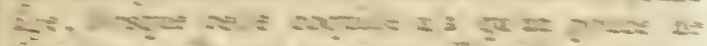

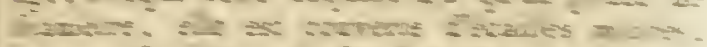

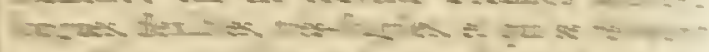

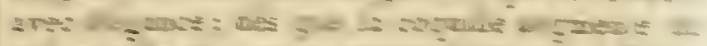

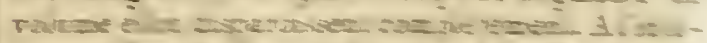

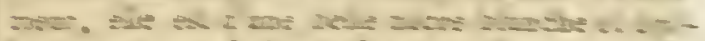

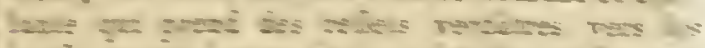

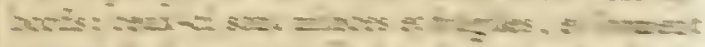

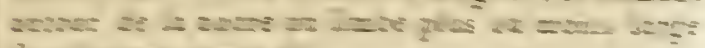

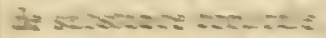

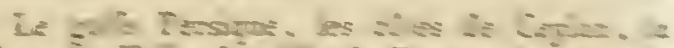

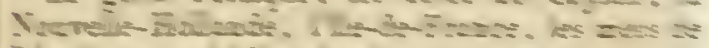

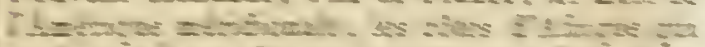

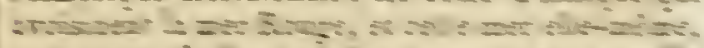

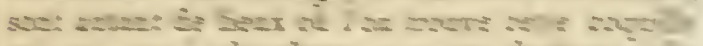

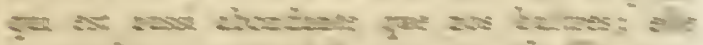

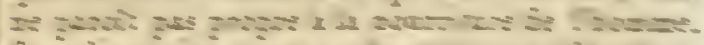

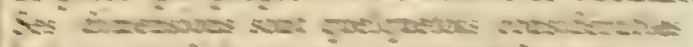

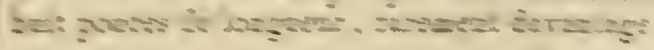

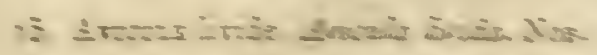

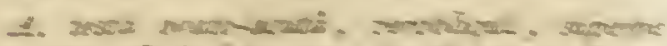

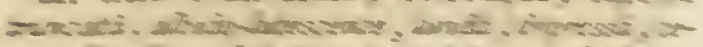

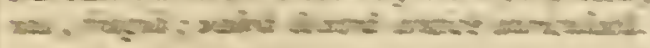

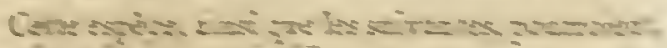

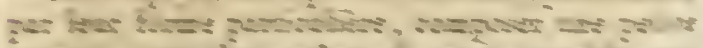

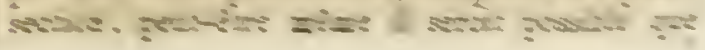


$10 ?$

par la suite on en fit un petit genre, ce que nons ne croyons pas nécessaire, quaot à préscent, que l'anatomie ae pourroit nous servir de guide; nous n'en arons pas fait non plus une section, parce que ces espèces ne different de celles qui précedent que par leur grande obliquité et le raccourcissement du bord cardinal.

l'Avicule dont il est ici question est d'une petite taille, mince, fragile, tres-comprimée; sa torme est un ovale alongé dunt le grand diamètre est très-oblique arec l'axe de la coquille, il est trongré supériemrenent par le bord cardinal qui est droit et court; le bord anté:ieure est oblique, arrondi; le postérieur est presque droit, el lait, arec le supérienr, un angle très-ouverl; si charnière est simple et sans dents; lit ralve gauche est la plus profonde; la droite porte une tries-pelite oreilletle antérieure, sćparie pár une éclancrese ćroite, mais profonde. Eo dehors, celle cociville est toute lisse, dun Llanc sale, jaunitre ve russitte; en dedans se voit un espace nacré, peli!, bordé largenteut, surlout ver's la partic pustérieure, par la substance corticale. Grand diamétre, 50 million. P’atrie inccunue.

16. Atrcere papïiunacée. Aviculu paprlionacell. Lams.

A. lestû ovato-obliquissimi, rubro-violuscente, wpace albá; rudus viridulis, ad basim evanescentibus, albo fuscove gutlatis, punctis per series tongitudnales disposits.

L.A. Anims. s. wert.pag. 149. $n^{\circ} \cdot 10$.

Cïssitz, Conch. tom. 8. tab. 31. fig. 726.

Encjclop.pl. 177.fig. 5. ex Chensitz.

Les auteurs qui ont par.é de celte espèce paroissent ne l'aroir connue que dans solı jeune age, ils nont donc pu en douner une description cuxplète. Juus en possédons un individu beau:u plus grand, en voici la description:

De torme obliquement ovale, poinlue postérieirement, trunquée supérieuremeut par le bord carciinal, qui est lout dioil, pas la noindre apfarence de prolongenent postírieur comme dins l'espèce précédente; bord antérieur, arrondi, déjussant le supérieur; bord postérieur, droit, trèsoblique, et turasat, par sa jobetion arec le supúriem, un angle tres-ouvert; oreilletle de la ralve droite, lies-petise, triangulaire; le siuus pour le byssus médiocre, assez prolund, rrianyulaire aussi. Les crochets sou blaacs, cette conleur pase iusensib!enent au rougc viceux, gui devient obscur el brunátre inférleurement et poslérieuremeat; sur sa partie blanche commencent des rayons de taches d'un teau rert, qui disparoissent peu ì peu, is mesure que la conleur ronge devient plus obscure. Sur ces taclies rertes ou dans leur interralle $C D$ roit dics ragées rayonnantes da sommet à la base, de pelits points blancs on jaunâtres. En dedans la nacre est d'un blanc rerdatre, circonscrile par un large bord uon nacré, de la mème couleur que le dehors de la casuille. Elle csi rare et vient de la Nouvel!eHollande. Le grand diamère est de 60 millim.

17. Avicule lingulée. Avicula lingulata. NoE. A. testí ovato-obliquâ, depressá, nigrî, solidulí, lavvigatú.

'Très-voisine de l'espèce précédente pour la forme et la taille, on de sauroit cependaut les conlundre, celle-ci élant plus solide, moins oblique, plus arrondie intérieuremeni, et partout d'nue couleur noire miforme. Le bord cardiail est assez ipais, mais lort courl; il a, avec le postérieur, une disposition semblable à celle des deux au!res esféces. La valrc droite est plate, quelqueluis convexe en dedans; son creillette est triangulaire et pelite; le sinus d'une lurme pareille est assez gurud; la partie vacríe de l'iutérieur n'a que fren ciéteddue, elle est cntource d'un large burd noir.

Patrie inconnue. Grand diametre, 60 millim.

Des coquilles pétritiées diun assez grand rolume, que l'on rencuntre surtont dans l'oolite ferruginense de Caen el de Bayeux, ainsi gee dans l'oolite blanche de Siriat-libiel, sont placées dans presqure toutes les collections à la suite des Pintudiaes, et conséquemment des Avicules. Plusieurs molifs nous ont portó a les ranger pluti: a la suite des Limes: ces curuilles mamyuent de l'écldaticrure pour le passage du byssus; elies aont pius ou moins baillantes auterrienrenent, et ce báalleuent a lieu audessous d'oreillettes sem. blables à celle des Limes. Les bords ne sont pas simples comwe dans toutes les Avicules, mais garms de dentelures réciproques, qui sont produites par des cótes saillantes, et rajonnautes da somaret at la base des ralves. Le bord cardinal est lort cula: tei méficcre, ce qui read ces toquilles presque équilatérales, les éluigne encore des Ariculees et les rapproche des Limes. Foyez. ce mol.

\section{ATICULEES (les).}

MI. de Ferussac a proposé de faire cetre famille aux dépens de celle des Byssilères de H. Lamarck (vojez lìssprirrej), établis dans la Philosophre zoologique et l'Extrait. du Cours, puis démeonbrés en trois familles, dans l'Histoire d's Animaux sans verlébres, les Mytilacées, les Malléacées et les l'ectinides. La faruille des Avicules de ii. de Ferussac correspoud a celle des Ilalléaccíco de II. Lamarck, si ce n'est qu'il y a ajouté le genre Pinne que ce savant range plus naturellement, ce nous semble, dans les Myulacćes. Voyez ce mot et UALİAcies. 
AXIMEDE. Aximedia.

Dans son travail sur les Mluletles de l'Ohio, M. Rafinesque a partagé ce genre ca plusieurs sous-genres; celui-ci est de ce nombre, mais n'étant fondés que sur de trés-fuibles caractères, ils sont inadaissibles comme nons le verrons it it larticle Mluetre auruel nous renvayons.

\section{AXIN. Aximus.}

M. Sowerby s'est hasardí, dans son Minewal conchology, il proposer ce gente pour des cuquilies biralves pétriliées tlont un be connoît que le unoule et pas la moindre tace de charnière. On conçoit facilement qu'il est impossible d'adopter ing genre anssi incertain, et il est fáchenx gue dars la science on mette si peu de scrupule i introduire de unuveaux genres aussi peu nécessaires que celui-ci.

\section{AXINEE. Axinca.}

Le célèbre Puli a dounć ce uon à un geme dont les animanx nual connus, à élé, à cause de cela, conlondu par linné parmi les Arches; depuis il fut rélabli par M. Lauritrek sous le nom de Pétoncle (voyez co mol), qui a élé gn'néralement adopté. Dans son systère de nonsencliture, Poli designoit par un nom particulier les animanx et les coquilles: culles de son geure Axinée portent la dénomination d'Axinoderme, qui n'a point élé adopiće plus que la premiere. 


\section{B A C}

\section{B ACUijte. Baculites.}

Les Baculites, comnues seulenent is l'élat de pétrificalion, furent justement comparées avec les Ammoniles prar le plus grand nombre des observalcurs. Ceux qui précédèrent Isamarck, sans en former un genre distinct, avoient jugé, par sa structure, quil se rapprochoit des cornes d’Ammon. Scheucluzer, Klein, Bournet, Langius, Walch et Knorr furent de ce sentiment. Les dénominations variées que ces auteurs donnèrent à ces corps, ne les ont jamais cmpêchr's de les comparer et de les rapprocher des Aminonites. M. deJupsch, dans un Ml'́noire intéressant, confirma celte opinion. L'auteur, par une comparaison approfondie de plusieurs coquilles cloisonnćes, fut le premier, en 177 t, ¿̀ établir des rapports que personne peut-être alors n’apprécia convenablemeat, puisque ce ne fut que longtcmps après qu'ils furent reconnus d'une grande justesse. M. de Jupsch, en elfet, douna comme conclusion de son travail, que les Orthocératites sant des Nautiles droits, coume les Baculites sont des Ammonites droiles. Faujas qui, dans l'Histoire naturelle de lit montagne Saint-Pierre de Maestricht, rend comple de l'opinion de M. de Ilupsch pour la conbattre, fait de vains ellorts pour trouver cet auteur en contradiction, et il ne peut y réussir, car il a tellement raisonné juste, qu'il est impossible de rejeter ses conclusions. Ar reste, Faujas n'ćtoit pas un jugre compétent dans cette occasion. Son opinion efoit qu'll ne falloit pas faire un genre distinct des Baculites, mais le faisser, ainsi que les 'Turrilites, parmi les $\Lambda$ inmonites. Il se irouvoil par là en opposition avec Lamarck, yai venoit définitivement d'ćtablir le genre Baculite dans le Système des animaux sans veríbres, publié en 1801 . Füjas u'enipecha pas le gente de Lamarck d'être grénérulement adnpté; el de Roissy, dans le Buffon de Sonnini, en donna le premier exenple; nsais, entraîué comme Lamarck par des rapports de lormes, il n'élablit pras plos que lui cerx indiqués par. N. de Hupsch. Une errear que ces auteurs accréditèreut, dout on doit la rectification incomplète à Alnutfort, est relalive a l'existence du sipbon. On croyoil que cetle partie importante des corjuilles claisonnées n'existoit pas daus les Bacutiles. Montfort afruma le contraire; mais on a droil de deander d'après quelle observation il a pu dire tyue le siphion est central, puisqu'il est prouvé qu'il est latéral. Defrance, le premier, à ce qu'il paroît, rectifia l'errear de Mlontfort, et bien desper'sonices fureut à même de la vérifier, par la découverte que fit Ml. Gerville d'une nouvelle espice dans les anvirons de Valognes.
II. I.amarck créa dans la Philosoplice zoologique la famille des Nautilacées, qui n'auroit par la suite éprouré aucun changenent, s'il lui eût donné celui d'Ammonées et en avoit ôté le genre Nautile: ce genre c'st le seul en ellet qui ne soit pas complétement en rapport avec les autres. M. Lamarck ríforma hienlút lui-même celte famille. Daus l'Extrait du cours, on 1 rnuve celle des Amuonfes; elle est termince par les Baculites, qui se trnuvent maturellement près des Hamites, des 'Tumilites el des Ammonites. Il n'y changea plus rien par la suite.

l.e célc̀lse auteur du Regne animal et de tant d'autres onvrages qui ont donné une si vive impulsion an sciences naturelles, it su apprécier la justesse des rapprochemens de M. Lamarck, et il les a conservés. Son genre Ainmonite, qui comıprend qualte sous-genres, contient les mêmes objels et dans la mếme distribution que dans la lausille des Aumoníes. On peut donc regarder ce genre Ammonite comme l'équivalent d'une famille. Nous avons vu ì l'article Ammoneres, auquel nous reavoyons, comment MIN. de $\mathrm{Fe}-$ russac, de Blainville, Latreille, de Haan et d'Orlsigny ont compris son arrangement, et combien avnient étć ulites pour arriver à un classenent naturel les caractères dont s’étuil servi $M$. Latralck. Le genre 'lirannite, que Montfort crén sur une ligure de Kuorr, n'ayant point ćté observé depuis lui, quoique, suivaut son assertion, on le trouve fréquemnent à la montagne Sinte-Catberine de Ruven, a jelé dans l'embarias les zaolo. gistes qui se sont occupés des Baculiles. La plupart Pe rapproclicient des Baculites, d'autres en firent un sous-geure; les plus prudens, ceux qui savoieut le nieuxi apprécier les travaux de Mnntfort, ne le mentionnérent qu'avee doute; M. Desmarest est du nombre. On auroil méme pa le rejeter, car il a élé lazt avec des indiviàus usés de Baculites.

Dans un lrès-beau Mémoire, instéré dans le Joumal de Physique, 1817, ce zonlogiste din grand oćrite douna des observalions sur les $\mathrm{Ba}-$ culites, et une description avec de bonnes figurs's des espèces qu'il connat. Il crut être le premier ì recilier l'erreur de Montfort sur la place da siphon, mais Defrance l'avoit fait plus d'une année avant lni. Les caractères dont se servit M. Desmarest pour la distinction des espèces étoient peutêtre de trop peu de valeur, ce qui les lui a fait multiplier de manière à considérer comme telles de simples variélés.

Maintenant que le genre Baculite est bien connu, que ses rapports sont incontestablement bien éta ljlis, qu'on en a séparé destronçons de Haunites- 
qui y étoient confondus, on pcul exprimer les caracières génériques de la manière suivante:

\section{CARACTÉRES GÉNÉRIQUES.}

Auimal inconut.

Coquille droile, uvale dans la coupe transierse, quelyucluis un peu déprancé, forl longue, rénnlierement conique; cloisons sinueuses, dont les lourds sont découpés en feuilies de persil, peu distantes, la deraicre furt grande, engatioante; le siphun margiaal.

Les Baculites ne se son: encore troovées qu'à l'état de pélrification dans les terrains de erase; nous n'en counvissons antune provenaul de terraios soil supérieurs, suit inférienrs à ceux-la. la furmation craycuse a celle singulière proprićté, de dissoudre le test de presque toutes les coujuiles qui y ont Été enfouies; c'est pour celle raison que l'on n'y rencontre jamais que le moulc ia érieur des Baculites. On peut juger cependant, par l'jnteavalle qui séfare le anoule de l'empreiute extérieure de la coquille dans laquelle il esi quelquelois libre, que le lest de ces coquilles doil êlre très-anince. Dans quelyues localités, les inoules conserven les rellers Dacris, ce qui indique que la cugulle elle-méme l'éloil anssi, conme cela a en lieu dans lieaucoup d'Aumunics.

Les Baculites sont régulièrement cuniques, Irèsalungées et terminées en pointe. (N) a calcule, par la frrogression dins l'augmentalion du diamérie de In base, ' 'u'une conguille qui alloil dix-huit lignes de diancire à l'exırémité antérieure, aurniı plus de deux pieds de longucur. Il a dû exister des iadividus plus lungs que cela, à en juger prar quelques tronçons de ce geore. Les articulations sont nombreuses, plus rapprochées au sommel qu'à la base; elles sout onduleuses et parfaiteınent symélriques. Les saillies placées sur les bords sout taillées en queve d'aroode ct terminíes de manière à se reteuir fortement, quoique par la disparition du test, elles devicnneut quelquefois mobiles les uoes sur les aures. Les denteiures des bords des cloisoas sont beaucoup moins profondes que dans les Hamiles, ce qui peut fort bien servir à distiaguer les deux genres, lorsque la courbure de relui-ei n'est point assez complète ponr le caractériser autrement.

Quelques auteurs ont indicqué des Baculites partuilemeat cyliudriques; nous n'en connoissons point qui aient celle forme : loules celles que nons avons observées jusqu'à present éloient ovales. liespèce qai se trouve à Valogaes a cela de retoarịuable, d'avoir un cóté beaucoup plus aigu que l'autre; c'est celui qu'occope le siphon. La derùère loge est assez grande, engaíaante, et il est bieu à présumer qu'elle ne pouvoit contenir qu'une pelite partie de l'animal. On ignore comment son ooverture se terminoil; on peut supposer, par saalogie avec la spirule, qu'elle étoit dépourvae de bourrelel, (qu'elle ctoit simple, mince et fragi'e. Snus n'atrons janais rien vu dans les colleclurno qui jül nousendunuer une idće satisfaisante.

Dans le Mémnire de M. Desmarest que nous avons cilé, on truave la descripliou de quatre especes: la preasicre, par la forme de ses digitalinns, afpartient lien certainement an genre IIamile; la seconde, la Baculite de Kinori, paroit fort doutcuse; c'est elle clunt Montfort a fait le type de sun genre Tiranite : nous avous dit pour quelles raisons na devoit le rejeter el considéres l'espèce comme doulcuse. La troisième espiece, que N. Nesmarest no:nase Baculie dissemblable, Baculites dissimilas, nous semble jaadmis. sible caractérisée comme clle l'est. I'un cóté, dil ce savant, les lobes des cloisons snat découpés en fcuilles de persil, et de l'autre ils sont siuples: les fignres quii accompagneet son Memoirc te reprísenient. Nous avons quelyues raisons de croire que cela est accideutel, l'ayant observé assez frécrueminent sur la Baculite de Valognes. Comme les persillagesdes cluisons soou trés-superliciels, un foible lrotlenent suffit pour les laure disparuitre; il arrive méme que celle circonstance peut avoir lieu par le remplissaze incomplet de la coquille lors de son enfuuissement, et nous en avons sous les yeux la preuve mutérielle. La ggasIrième espèce en compread leux rjue nous croyons distinctes, et que M1. Desmarest a confondues. La Baculie dissenblable apparlieat bien probablement à l'une d'elles, celle à laquelle nous consesvoas le nom de Baculite de Faujas, donné par Lamarck. Quant aux trois espèces de eet anteur, les deux prealieres nous sont connues; l'autre, qui est cylindrirjue et qui vieat d'Angleterre, es'elle de ce genre? Il est is présumer que c’est un tronçon de Illaaite qui a servi pour la caracteriser.

I. Bacurite de Iaujas. Baculites vertebralis. LAMK.

B. testî̉ rectî, lateribus oppositis leviter depressí; suturis lobatis, denticulatis.

Lsin. Anim. sans vert. tom. 7. pag. 647. $7^{\circ} 1$.

Faujas, Hist. nat. de lu Mont. de Suint-Pierre, pag. 140 pl. 21 . fig. 2.3.

Baculites vertebrulis, Mosтront. Conch. syst. tom. 1. pag. 342 .

Ibid. Desmarest, Joumal de phys. tom. 85. pag. 49. pl. 2 fig. 7.8.

Celle espèce est moins communémcnt répandue dans les collections que la suivante; c'tst elle probablemeat que Langius a figurée, \& que Bour. guet a rendue presque méconooissable en la recopianl; mais on ne peutavoir aucune cerlitude is cet égard. Celle qui a été découverte par Faujas est généralemeat d'un volume peo coosidérable; elle eft aplatie également des deux côtés, ce qui la rend régulièrement ovale, le côté du siphon 
n'étant ni plus aplati ni plus caréué que l'autre. Les cloisous sont très-rupprochées, pirtailement régulières, à den!elnies peu profondes.

C'est à Maestricht surlout que se trauve celle cspèce; quelqueluis elle $y$ est à l'état siliceux. M. Duchastel nous en a lait voir un tronçon venant de Cipli, dans un terrain semblable à celui de Maestricht. Oa ne la connoit point entière, rais, d'après quelques fragmens, on peut supposer qn'elle pouvoit avoir 8 à 10 pouces de longueur.

2. Bacelite glidiée. Baculites anceps. LA:Ax.

B. Testá rectâ, compressiusculâ, ancipiti, lavi; uno lutere subacuto, altero crussiore, obuso; siphone nuarginuli ad latus acutum.

LAנk. loc. cit. $n^{\circ} \cdot 2$.

Buculites veriebralis. Def. Dict. des Scien. nat. tom. 3. pag. 160 du Supplément.

An Baculates dissimilis? Desua RET, Journ. de phys. tom. 85. pag. 43. 720. 5. pl. 2.fig. 4. 5. 6.

Baculites veriebralis. Buswv. Tiait. de Maluc. D.. 12.

Il est nécessaire de faire alteotion à la phrase descriptive que nous avons copiée dans l'unvage de M. Lamarck, pour qu'on se fasse une juste idée de quelle unanière uous circonscrivons cette espece.

Uue Baculite a été tronvée par Faujas; elle a été nornmée vertebralis; elle u'est jamais anguleuse. Une autre lut découverte plus tard à Valognes et, à ce qu'il paroit, en Anglelerre; elle est constammeut subcarénée du côlé du siplion. 'Tour les auteurs, à lexreption de M. Lamarck, la confondent arec la première : nous voulons éviter celle confusion, \& paur ceia, nous avons rectifié la synonymie coume on vient de le voir.

La Baculite gladiée acquiert lonjours un plus grand voluae que la premic̀re, et elle s'eu disingue en outre par l'angle obtus qui régro dans tonte sa longueur, du cólé du siphon.

Les articulatious sont nombreuses, rapprochées, smrlout au somuet, \& s'ćloiguent insensiblemen! à $3 a$ base; celle-ci est farmée par nue loge fort grande qui, dans les vieux individus, conserve souvent des oujulations plus ou unoins régulières qui indiquent des rétrécissemens et des élargissemens successifs de l'onverlure.

Chaque articulatious a, du côté de la base, sept apopluyses, et du côté du sommet, six seulement : les plus sailiautes, sont les latérales; elles sont absolument semblables d'un còté et de l'autre daus le nombre \& la forme des denielures; des apophyses moyennes, celle où est le siphon a'est pas deutelée, elle est tronquée et peu saillante; celle du côté opposé est fort peu saillante aussi, elle iest en dessous divisée'par une très-petite anfractuosité médiane, et ea dessus, à la mème place,
( se troure une trìs-pelite suillie qui correspond d la cavité de la cluison suivante.

Cette espèce se rencontre principalement aux environs de Valogues, départemeut de la Manche; c'est à II. de Gerrille qu'on en doit la déconverte. D'après M. Lamarck, elle se trouveroit ausis en Angleterre.

\section{B.AIGITOIRE.}

Nom spécifique enployé par quelques auteurs pour des cngulles fart différentes: l'une est le triton lotorium Lanik., dont Monifort a fait uu genre inuile (voyez lotorre el Tritus); l'autre est l'Avicule macroptera que l'on nomme aussi Baignoire cuivrie. Vujez Aricele.

\section{BAJET.}

Brugnière, dans le premier volume de ce Dictiounaire, n'il pas mentionné ce nom douné par Adinson (Yoyage au Sénigal, pag. 201. $p l$. $14 . f i g .14$.$) à une espèce de son genre Huílıe,$ Ostrea crisicata Lamk. Voyez IIvitae.

\section{BALANE. Balanus.}

Comme nous l'avons fait pour l'article Aratire, nous allons indiquer les cluangemens qui sont survenus, dans le genre Balane, depuis le travail de Bruguic̀re dans le prenicr volune de ce Dictionnaire.

Cet auteur le premier institua ce genre en lni dommant le noin de Balunite, qui ne fut puint adopié, parce qqualors s'élablit l'usage, abandonné depuis, de désigner les espèces lossiles de chacue genre par la terminaison en ite, du nom générique. M. Lamarck consacra le nom de $B(\downarrow-$ - Lane en adoptant ce genre dans son Systène des Animaux sans vertebbres ( 1801 ). Cet exeaple fut bientot suivi par tous les zaologistes qui sentireut loule la nécessité du démembrement du geare Lépas de Linné. M. Lamarck ne tarda pas ì rendre ce démembremeat plus complel en créaut les genres Curnnules \& Tuhicinelle (voyez ces mots) dans le premier rolume des -1nnules du Muséum. M. de Roissy les adopta le premier, ainsi que M. Duméril ; le genre Balane se trouva donc simplitié, et quoiqu'il contienne excore plusieurs espèces qui pouvoient en être séparées, il resta sans changemens pendant long-temps; la Philosophie zoologique, l'Extrait du Cours de 11. Lawarck, le Régne animal de 11 . Cnvier, démontreut cet état siationnaire. Léach le premier teuta d'établir de nouveaux genres avec plusieurs espèces de Balanes, tels sont cenx qu'il a noumés Acaste, Pyrgome et Creusie (voyez ces mols); c'est ainsi que l'ancien geare Balane de Bruguiere fournit cinq coupes nouvelles et devint, dans le dernier ouvrage de M. Lamarck, le type d'une famille, ainsi que le genre Auatife qui suivit une marche à peu près analogne. M. de Ferussac, 
dans ses Tableaux des Arimanx mollusques, n'apporta aucuns changemens ni dans les rupjorts ui dans le nombre des genres gue nous avous éaumérés. Cependint, pout pasyer son trilunt d"in. novation, M. de fiernssac, a l'article Balane du Dictionnuire chassique d'listoine naturelle, proposa un arrantreurent aćlludique des genres qui ne diffère guere de celui de MI. Lamarck, et ajoutale nom de deux grenres qui sont restćs inc:onnus; l'un d'eux, dídié à Bosc sous le nom de Boscie, n'a pas été mentiouné à sa place dans la suile du même ourrage : est-cc oubli de la pirt de l'auteur? a-t-il reconnu que ce genre étoit inulile? c'est à çuoi il nous scruil difficile de répondre.

M. Ruvzani publia un peu plus tard la première décade de ses Mémoires sur la Zoologie; il s'en trouve un sur le genre Balane, dans lequel il propose plusieurs démembremens, dcux entr'auires poar les Coroubles, qui me seroat probablement plas adoptés.

Deux autres greares faits avec des Balanes propreuent dites, sur lesquels it existe encore quelgues dou!es, onł ćté adoptés par M. de Blainville, ce soat les genres Cbulamale et Ochlobosic. Lé genre Conie, créé par Léachl dans le Supplément de l'lincyclopédie d'Edimbourg, geare qui corres. pond à celui nommé Asemus pac MI. Ranzaui, a été aussi adopté par M. de Biainville; il n'eu a pas éıé de même de celui nommé Octomeris par MI. Suwerby, dans son Genera, pour les especes qui sont formćes de luit parties. (Joyez Cuta.1Male, Ochthosie, Conie el Octoaneris.) D'aprc̀s ce qui précède, il est ualurel de croirc que le renre Balane, ainsi récluit et rectifié, ne subira plus de notables changemeus : cependaut M. de I3laiuville propose d'y réunir le gente Acaste, qui, comne nous lavous $v u$, a des caractères sullisins pour êtıe adopté; il en a d'aussi bons certainemeat que le genre Conie; aiusi, si l'on admet l'uo, pourquoi rejeter l'autre? En principe, nons croyons que les genres formés uniquement, comme la plupart de ceux que nous avons citćs, d'après le nombre des valves de la purtie coronaire, ne sont pas de bous genres, zoologiquement parlant, puisfue les animaux sont semblables à celui des Balanes proprement dites. Ua changement qui seroit favorable ne consisteroit pas à rejeter tous ces nonveaux genres, mais à les ramener à leur juste valeur, celle de sous-genre ou simplement de groupes, c'est alors seulcment que le genre Acaste pourroit êtré englobé comme les autres. De cette manic̀re les Balanes deviendroient un. genre naturel, caractérisé par l'animal et l'opercule, et composé de plusieurs groupes:

$1^{\circ}$. Puur les espèces à trois parties, genre Ochthosie;

20. l'our les espèces à quatre valves, geare Conie ;

"3?. Your les especes qui ed ont six, geare Balane tel quon le caractérise maintenant;
4". Pour les espices qui ont huit parties, gemre: Octonseris.

Le genre Acaste, qui rit dans les éponges, comue les Pyrgonces dans les l'olypiers, pourroit soit à litie de gemre, soit conme yroupe des Balanes, servir de passige à ce dervier, d'ailleurs Jiea caractérisé par son opcrcule. Avant que lon introduise dans la srience ce flue venons de proposer, voici de quelle manière il cunvieut de circonscrire le geare Balane.

$$
\text { CARACTÉRES GÉNÉRIQUES. }
$$

Animal sessile enferme dans une coquilie operculée. Bras nombreux, sur deux rangs inćraux, articulés, ciliés, composés chacun de Jeux cires sonteuts frar un pédicule ct exserriles hors de l'opercule. Bouche sans saillie, ayant quatre michoires transverses, deatécs, et en oulre qualie appendices velus, ressemblant is des palpes. Lamarck.

Coquille sessile, fixée, conique, ironquée au sommet, fermee au fond par une lame calcaire, cuelguefois membraneuse, adhérente; cone furmé da six pièces distincles, une antéricure el l'itutıe postcrieure, médianes, deux paires de latérales; opercule intcricur, quadrivalve, forman! unt pyramide suillante dans l'unvertule.

Bruguière ayant donné des détuils fort étendus sul la structure et l'accroissement des cuquilles des Balanes, détails sullisans, et qui font voir combien il étoit bon observateur, nous y renvoyons le lecteur, ainsi qu’à la description dés especes, qui peuvent suffie poul downer du seare une iclée juslc et précise.

'Toules, à l'exceprion de celles que nous alluns indiquer, apparticanent véritallement at çesce qui nous occipe.

Le Balanus 2erruca $a^{\circ} .13$, nayant que trois valves, appartient, comme nous le verions, «u geore Ochthosie.

Le Balanus squamosus $\mathbf{x}^{\circ} .17$ n'a aucune trace d'aires latérales; il est très-celluleux et trèsépais; il appartient incontestablement au gen:e Conje.

Enfin les Balanus diadema et testudinurius ont servi depuis fort long-temps, comme nons l'avons $\nabla u$, au geare Coronule.

\section{BALANIDES. Balaridea.}

La famille ì laquelle M. de Blainville danoe ce nom correspond à celle que MI. Lamarck a instituće depuis long-temps pour le genre Balaue de Bruguière el ses démembremens. M. de Blain. ville la considère aussi de la même manière; mais il $y$ a introduit des genres que M. Lamarck a'a pas connus, et il la divise en deux sections d'après la position de l'opercule, vertical dans la première, horizontal, dans la seconde, les genres Balane, Ochtlosie, Conie, Creusie et Chtla- 
male, forment le prewier groupe, et le second ne contient que le seul genre Coronule auquel est ríuni celui des Tubicinelles. Nous renvoyons a ces mols de genres, et surtout à Cirrbipédes, nì uous parlerons de noureatu de la famille des Bualanides.

\section{BALANITE. Balunites.}

Nom que 13ruguière, daus le prenier volnme de ce Dirtionnaire, imposa à un genre qu'il venoił de créer dans les Lepas de Linné. M. Lamarck lui a donné le unom de Balane qui a été adopté de préféreace. Yoyez BaLAne.

\section{BALISE.}

Nom vulgaire que les marchands donnent encore quelquefois au Cérite télescope, Cerithum zelescopium. Yojez CÉnte dans le premier volume, no. 17.

\section{BARBELLE. Barbala.}

Dans le Iruseum Calonnianum, Hemphrey a donné ce nom à nne coquille précieuse renant do la Chine: Solander luí avoil donaé celui de Mytilus plicatus, et il l'assimile an Mu'el d'Adanson. Ce rapprochement pent servir à indiquer le sente de la coquille nommée Barbelle, le Mutel "lant très-probablement une Iridine; il est croyable que le nom de Burbelle s'applique at même greure. Voyez Irinive.

\section{BARNET,}

On tronve, dans le prenier volume de ce Diclionnaire, un renvoi de Barnet à Buccin oculé; nais a l'article Buccin on ne lrouve ni le Buccin oculé, wi rien qui ait rapport au Barnet, de sorte yue cette petite corquillc, depuis Adarison (Voy. uu Sénég. pag 146.pl. 10.fig. 1.), n'a ćlé mentronuée par aucun auteur; elle méritoit cependánt bien de l'être, car l'animal, bien décrit, est le premier que l'on ait donné comme type au genre Buccin. Nous ne la conuoissons pas.

\section{BASE. Basis.}

Depuis Linué on a donné diverses définitions cle ce mot, ccpendant elle étoit la plus simple et la plus facile à comprendre; Bruguière l'a adoptée, el nous n'arons pas bien compris celle que propose M. de Ferussac daus le Dictionnaire rlassique d'histoire naturelle. Nous verrons à l'article Coquicte s'il est nécessaire d'y apporter des chaogemeas.

\section{BATEAU.}

On donne vulgailement ce now à une Patelle mince et profonde, Patella compressa LaxARcE. Fojez PAIELLE.

\section{BA'TOLITE. Batalites.}

B I C

l'imagination de Montfort alloit quelquefuis très loin d.uns les covjectures qu'il formoit sul les dimensions des genres : là oì l'observation manquoit son esprit y supuléoit, son genre $\mathrm{Ba}$ tolite, gui n'est autre chose qu'une Hippurite (voyez ce mot), nous en offre un exemple. De ce qu'il a vu ua troncou d'Hippurite de qualre pouces de diamitre, il en conclut qu'eile avoit dû avoir cinquante-quatre pieds de longueur; il dit on avoir va cians les Alpes qui avoient trois pieds de long sur un pouce de dianètre à la base. Nous pouvons affirmer que Montfort a cru voir, ce qui lui est arrivé dans plus d'une occasion. L'observation prouve qu'a l'exception de l'Ilippurite, dont cet atcur a fait le genre inadmissible qu'il nomme Balotite, toutes les autres Hippuites sont en cône dont la terminaison est queliquefois très-brusque. Ce qu'il y a de particulier, c'est que M. de Ferussac, dans le-Dictionnaire clussique, cite ces extravagances de Alontfort sans les réfuter, et admelte encore ce genre aiosi que les IIippurites parwi les Céphalopodes décapodes. Nous verrons à l'article HippUrite combien étoil peu juste celte opinion.

\section{BATONNET.}

Nom vulgaire d'une jolie espèce de cóne assez rare dans les collectious. Bruguicre l'à décrit sons ce nom au no. 127 de l'article Cône. Vojez ce wot tome ter.

\section{BATTANS.}

Adanson, dans son ouvrage si remarquable sur les Coquilles du Sénégal, employuit ce mot pour désigner les valves d'une coquille; ce mot n'a point été aclopté, on lui a préléré celui de valves. Voyez ce mol et Coquilie.

\section{BEC. Rostrum.}

Ce mol a diverses acceptions qui, pour la plupart, sont tombées en désuétude pour la science, ou sont entrées dass le domaine du vulgaire. C'est ainsi que les marchands disent nue coquille à bec pour désigner celle qui à un canal court et recourbé à la base; ils nocoment aussi becs les sommets des coquilles bivalves, quand ils sont longs et en forme de crocbet. Enfin, en ajoutant vue épithète plus ou moins caractéristique, ils désiguent plusieurs coqnilles de genres différens.

Le bec de canard est la Lingule anatine d'apres Favard d'Herbigny; le mêtue mot s'applique à l'Anatime subrostrée Lamk. Le bec de llute est le Douax scortum, le bec de perroquet le Terebratala psittacea Lank. ( $V$ oyez les genres que nous venons de mentionner.)

On a comparé très-jndicieusement les mandibules des Sèches, des Calmars, etc., au bec d'un perroquet, et cette ressemblance, qui est fort 
exacte, a fait conserver le nom de bec aux mâchoires de ces animaux. Voyez Cérualupodes.

\section{BËCASSE.}

La conupraison que l'on a fuite dı canal de li base de quelques cognilles, vm to bec des viseaux nommús becasses, a déterminé les atuciens conchyliologues et les marchands à appliquer é nom, avec une dipibète caractéristique, a plusieurs coquilies qui rentrent dans le genre Rocher. Voyez ce mot. lum.

La TÈre de bécasse, est le Murex haustel-

Ia Bécasse à ramages, le Alure.x comulus.

Ia Bécasse épineuse, lo Murex crassispina.

La grande BÉcasse épiueuse, le Murex tcmuispinat.

La BÉcasse à courte épines, le Murex brandaris.

Bruguière a fait un renroi de Bécasse épineuse an genre Pourpre; unus ne pouvons nous l'expliquer, il faut voir le not Rocaer.

\section{BELLEMNITE. Belemnites.}

Nous avous toujours élé surpris que ce genre, connu depuis si long-temps, et désigné par le non de Bélemnite, bien avant la publication du premier volume de l'Encyclopédie, n’y ail été aicnlionné d'aucune manière, pas mêne par un renvoi. Il est à présumer que, suivint lés erremens de l'immortel auteur du Systema natura, Bruguière le compreusit dass le genre Sautile, co qui anjourd'hui n'est plus admissible.

Ce genre, intélessant tcul i-la-lois la zoologie et la géolngie, méritoit bicn d'altirer l'altention des savans modernes; cela ćloit d'autant plis nécessaire, qu'a jurès a voir occupé les naluralistes de presçue lous les âges, après avoir élé le sujet d'une foule de préjugés et d'erreurs parmi presque tous les peuples, il éloil resté à peu près inconuu jusque dins ces dernier's temps. Pour ce qui a rapport aux espèces, et à leur déiermination rigoureuse, deux travaux furent entrepris dans ce but, l'un de M. Faure Bignet, l'autre incomparablement plus complet de M. Blainville, dans lequel on trouve, avec une histuire Irès-Lien faite du genre des considérations d'un liaut in térêt pour la zoologie et la géologie. Naus citerons encore l'article BÉLemsite de M. de Ferussac dans le Dictionnaie classique d'histoire nuturelle, article incomplet, paisqu'il ollire seulement la partie la moins imporlaute pour le naluraliste, la parlie bistorique, qui, tout altrayante qu'elle puisse être pour l’écrivain érudit et le lecteur, ne peut être considérée que conme une introduction à l'étude des espèces d'un genre. Nous nous sommes trèsulilement servis des travaux que nous venons de citer, ainsi que d'un Mémoire de Guettard, qui conticnt beaucoup de bomes observations, peur remonter aux sources et vérifier, antint gue cela nous a été possible, les liats qui y sont cunsignés. Quoique nous n'ayons-rien de lien important at ajouler à l'bistoire curieuse des Bélemnites, clir est trop intćressante pour que nums ne la trarcions pas le plus possible en abrégé.

On a prétendu que le prenier anteur qui ait parté des lićlenuites éloit l'héoplraste; on it rapporté un passage où il fait menlion d'une pierte provenant de l'eudureissement de l'urine de Jynx; mais il est impossible, conune Hill la fort judicieusement dit dans ses Commentaires sur Théphiraste, d'assurer que eet ancien ait vouln désigner des Bćlemnites, sa descripiton ue s'uccordint en aucune façn avec celle d'un corps de cetre espire. M. dé lerussac el M. de Blainville sout de ee sentiment, que nous partageous d'autaut plus volontiers, qu'il n’y a véritablement aucune resscablance cnlle le lyncurium et une Bélemuite.

Pline, après avoir rapporté le passage de Thlóo. phraste, vie que l'urine d'un animal puise se clsanger en pierre; on ue peut que l'approuver de manifester une opinion conforme a la nature des faits. Cependant, après avoir dit que le lyncurium néloit pas connu, en parluat du lyux, dans son Trailé des animaux, il rappelle sans critique la nanière de vui: de 'Tlicuphrasle, la rend plus obscure, en donnant à croise qu'il a voulu parler du succin, substance qui a bien quelques-anes des proprićtés du lyncuritum, mais glui ne les possède pals toutes. Il est plus probable qua les idaei dactuli de Pline qui, dit-il, se trouvent dirns l'ile de Cilndic, on nae couleur ferrugineuse, et ont la torue du punce humain, appartiennent plutôl à ce genre que le lyncurium. Celle déternination, quelyu'incumplète qu'elle soit, établit une comparaison qui, malyré son peu de justesse, est cependant plus déteminante que celle que l'on a faite avec le texte de Théophraste. II rien est pas de même d'un antre passage de Pline, que l'on a appliqué aux Bélemnites, mais qui laisse quelques doutes puisquon peut l'entendre de deux manieres. En lorcant le sens pour l'appliquer aux Bélemnites, plusieurs personnes ont cru trouver une preuve que pline a connu ces corps; mais on doit dire que ce passage ne peut s'appliquer convenablewent qu à l'étul des pierres précieuses qui jettent la lumiere en rayonana. Nous passerons sous silence Dioscoride et Solin, qui n'ont rien ajonlés aux ouvrages de 'Théophraste et de l'line, el nous observerons que le mot de Bélemnite a'a pas été donné par les Anciens, el qu'il est assez croyable gu'ils n'ont poiut connu ces corps, le passage de Pline sur les idaci dactyli étant le seul qui peut faire naître quelques doutes à cet égard.

Isidorc de Séville au sixième siècle, dans ses Origines, a coutribué beaucoup à faire coufondie 
112

B E L

Ie lyncurium avec le succin; it en parle dans un autre chapitre gue l'idoeus ductylus, sur lequel, du res!e, il ne dit rien de plus quie l'line. Ici commence un long interralle pendant lequel ou cherche en vain des documens sur l'bistoire du genre qui nous occupe; ce n'est qu'an renourellement des lettres au quirzieme siècle que les minéralogistes et les personnes qui s'occupoient de matiêre médicale surtout, recherchèrent le Iyncurium de Théophraste, s'imaginant, cumme le croit avec vraisemblance M. de Blainville, que proreuant de l'urine de lynx, cette sulsstance deroit avoir de grandes vertus pun la gućrison des pierres et des calculs vésicaux; tais il falloit trouver le lyncurium. Dans quelques endroits de la Prusse, on trouve en assez grande abondance du succin dans ua diluvium, dans leสguel il n'est pas rare de rencostrer des morceaux de Délemniles de la craie, qui ont anssi une couleur d'amlore, d'où a pu naître daus ces temps d'ignorance la confusion entre ces corps et le succin. Jusqu'à Agricola, on ne troure rien de raisounable sur les Bóle moites; c'est donc à lui, dit M. de Bluinville, que l'on duit les premières bonnes observations et un peu étendues sur ce genre. Il paroît aussi que c'est lui le premier, en 1546 , dans son ouvrage rraiment remarquable porar celte époque sur la cause et l'origine des corps fossiles, qui employa le mot de Bélemnite; dans les recherches qu'il fit sur ces fossiles, il s'unquiéta peu de leur origine et de leurs rapports, it nadop!a pas les préjugís de son lemps sur ses vertus médicalcs, il rejeta l'idée d'analogie alors reçue avec le lyncuriuu, et il les décrivit assez cotaplétement, puisquinil parle de l'alvéole logée dans la cavité de la base. Ce ne fut que sept ans après que Belon, dans le quinzième chapitre de ses Singularités, adapta le nom de Bílemnite: il suit, du reste, l'opinion d'Agricola; mais il regarde comme certaine l'analogie du dactylus idarus de Plime arec la Bélemaite; il affrrue positivement qu'elie se trouve en Crète de la mêtre manière quau mont Sxiut-Jean auprès de Luxembourg, oì, d'après ce qu'il a vu, on en trouve en très-orrande quantité. Nous ue parlerons pas de MIalioli qui n’a tai: que commenter Dioscoride, et qui u'a rien dit d’iutéressant sur les Bélemniles, et nous arrirons à Kentmann et à Gesner qui, en $156 j$, clonnèrent la première ligure de Bélemnite qui soit consue, et don: on auroit pu tirer quelqu'arantage, pour les rapports, sil eût été possible alurs d'en établir. En surrant rigaureusement les dates, rous devons parter ici de l'opiniou de Mcreati: cet auteur, qui mourut en rógà, avoit lerıiné avant cetle épuque son Mietiallotheca vaticana; encore que sou manuscrit n'ait été iupprimé et publié que plus de deux cents ans après, ce ne seroit pas un motif de ne le citer qu'à cctte époque; ses opinions ne servient plus en relation arec le ternìs do cette publication. Cette opinion erronée
B E L

se ressent do temps où elle fut produite, quoique de bier meilleu es l'uient étŕ avant elle : elle consiste à traduire dactylus par datte, et à supposer que Pline à cumparé les Bélemnites au noyan de ce fruit. Une objection sérieuse peut être faite à cela, c'est qu'il ne croît point de dat? tiers en Crète, et qu'ils n'y sont même pas cu'tivés; ainsi il nous semble évident que Pline na pu comparer les Bálemnites aux noyaux de dattes du mont Ida, puisqu'il n'en existuit pas dans cet endroit. Nous ne devons pas oublier Césalpin, qui écrivoit dans le même temps que Mercati, el qui fint le premier qui rechercha lorigine des Bélemnites; elles proviennent de la Pinne-marine, dit-il, ou de quel qu'antre coquillage. 11 avvit donc bien seuti, chose remarquable, que cétoil à cette classe d"étres qu'il fálloit la rapporter : c'étoit sans doute une opinion basartće, mais qui ne manquoit pas d'une certuine jus!esse.

Avant d'aller plus loin, résnmons en quelçues mots ce qu'il y a de plus esseutiel dars ce que nous venuns de ciire: Agricola est le premier gुui fait de bonnes observations sur la béleunite, Gesner en doune la première tigure, et Césal pin fait entrevoir pour lis première luis quels rapports on duit lui chercher. Cette progression mérite certainetnent d'être remarquée.

Nous vuila parvenus, avec Imperato, à l'anncée 1599 ; il ne mériteruit pas d'être mentionné si sun ouvrine, consacré plus spécialement à la minéralogre, ne lui aroil acq̧inis quelque célébrité: il dit que les Bćle:nnites ne sunt que des stalactites. O.1 nous dispensera de rapporter les preuves qu'il en donue.

Buetius de Boot doit être excepté de la liste des auteurs que nous ne citons pas, parce quilis n'unt fuit faire à la science aucuns progrés; non qu'il ait rien dit d'important sur ces corps dans son I'raité des Pierres et des Gemmes, nuais parce qu'il a élé le sujot d'une inéprise de M. Bendant, qui a cru quilil avoit été le premier qui ait eusployé ce mot de Béleunite, dont l'origine est beaucoup plus ancienne, comme nous l'avons dit. Depuis 609 que parut l'ourrage de Boetins de Boot, jusqu'en 1673, que lister publia le sien, on truuve une dixaine d'ouvrages qui, dins uae histoire d'un genre aussi inportant que celui-ci, ne mériteut d'ître notés que pour indiquer d'une maniëre générale l'iupulsicu des esprits. C'est à cette époque que commença le gnít des collections el cqu' on rassembla les productions nuturelles comna oljets de pure curiosité. Les pliarmaciens furent les premiers qui firent des collections et ciui en propagcient le goût; aussi presçue tous les ouvrages qui parureat ilor's ne sont que des descriptions de musíums plus ou moins remarquables. A l'appui de notre opinion, nous pourrions citer. daus l'espace d'une quarantaiue d'an. nées, le Muséum de Calceolari, celui d'Aldrn, 
vande, celni de Wormius, celui de Lachmund, et celui d'Olearius, dans lesquels il est question des Bélemuites, sans y comprendre ceux vir elles ue sont pas mentiounées.

Lister, médecin de la reine Anne, éloit un lomme remarquable pour son ćpoque, son grand ouvrage de conchyologic est la prenve qu'il avoit devancé ses coutemporiuns dans l'étude de celle science : ce fut à la fiu de son Truité des animaux d'sngleterno gu'il donna la description de deux Bélemnites; il les admet au nombre des corps oryanisés, dans sa seciou des laprides turbinati non spirati, non loin des Oursius, sans justutier sun opinion. Césalpin avoit eu lat mème pensée; mallieurcusement elle resta long-temps encore avau de prévaloir, les anciennes théorics trourèreut des délicnseur's dans ceux-lii nuènes qui, ayant rassemblé de grandes collections de ces curps, auroient dî être plus capables de les jugrer.

Arant Luyd, il existcil une opinion assez répandue et que nous n'avons pas ellcore rappurtée; elle trouva quelques auteurs qui plas tard la soutiurent, malyré son peu de fondement: elle consiste à regarder les bélemnites comme une come lirontale de certains poissons comparables au narval. Il étoit fort dilicile de concilier celte manière de voir avec liaxistence constatée de l'alvévle placée dans l'intérieur; anssi Luyd ne liadopta pas, il en prétéra nne autre qua n'est pas plus recevable. Les Bélemuites, disoil-il, étoient le résultat d'une matière minérale monlée dans l'intérienr de quelque ube mariu, ce qui le déterarina à les ranger parmi les pétrilicatious. II ful le premier qui donna le nom d'alvéole aux concamérations qui se voient dans l'inlérieur de la cavité des Bélemnites, et ce rapport, qui avoit léjłà été entrevu, lut défioilivement mis hors de doule far celui-là même qui le contestoit. W Woodward, qui connut un très-grand nombre de Bélemniles, qui les avoit rassemblées de diverses lucalitís, en aperçut assez bien les diflérences, et les rangea néaumoins, dans son Histoire naturille de li Terre, parai les minéraux réguliers.

Depuis l'année 1702 jusqu'en 1724 , il existe un certain nombre d'ouvrages dans lescyuels il est question des Béleranites; 1untót en suivant des upinions reçnes, on les plaçit, comme Schenchzer, parmi les minérux; d'ausres les rapportèrent au rìne animal; d'autres entiu se contentoient de les rassembler en grand nombre, de les figurer et de les décrire, sans entrer dans uue discussion approlondie sur leur nature.

Ce fut en $172+$ que parnt une dissertation fort importante, puisquà cette époque Elırliart, son auteur, par une discussion fort approlondie, indigaa, a vec une justesse bien faite pour donner de la conliance, la place que doivent occuper les Bélemnites; il a démontré que ce sonl des coquilles marines voisines des Nautiles et des Spirules, scrvant d'enveloppe à ce que Luyd avoii nouné alvéole; il s’aperçut anssi qu'elles s'accroissoient par l'addition successive de couclses extérieures, et qu'enliu leur composition chinnique dévoilait leur origine auimale. Il éloit in possible d'arriver it de meilleurs résultats: ils sont tellemeut justes, que l'opinion qui en découle est celle qui est universellement ad loplée maintenant, qu'elle a éié sanctionnée par la connoissance, si nécessaire pour celit, de l'anmal de la spirule. Eluhart croyoit que l'animal des Bólemuites étoit contenu dans la portion de leur cavité laissée libre pat l'alvéole; celle croyance fut celle de tous les zoologistes, nou-sculement pour le gemre yui nous occupe, mais encore pour tons les autre; qui lui sont analognes par l'organisillion, jusqu'au moment ou la découverte de l'animal de la spirule vint jeter une vive lumicre sur cette ques-

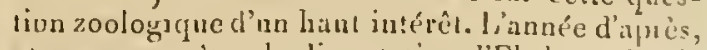
el sans connoitre la dissertation d'Chrhart, Rusinus arriva de son cóté au mème résultat, ce qui auroil dû avoir uue grande inlluence, si à celle époque on avoil su apprécier celle concidence. Cependant il a'en ful pas airsi, plasieurs anteurs consertèrent les anciennes erreurs, et Bonrgnet entre autres, qui jouit d'une certaine célébrité, loin dialmellre les véricés incontestalles de ces deux autenrs, doma encore une nonvel e opinion sur les Bílemuites; il prétend, dans ses Lettres philosophiques, il croit aême le prouver, que les Bélemuites soni des dents de cacbalo: ou de quelque grande espèce de cétucés; mais douze ol treize aus après, en publiaus sun Traité de Pétrifications, il montra des doutes sur la validilé de sa premiere opinion.

Klein mentionna d'ahord, sans s'expliquer, les Bélemuites parmi les tuyan marias; al étoit permis de croire, d'après cela, que c'étoil avec eux quil leur trouvoit de l'affinité; mais quel(ques années plus tard, daus le temps que la dissertation de Breyne sur les Polythalames aroil pu le taire reveuir d'une opinion erronce, il dit, dans sor Trarté sur les Oursins, पृu'il croyoit, a vec Rosinus et Elurhart, les Bélemnites voisines des Nauliles; et cependant, par une bizarrerie diffirile is expliquer, if conserva, parmi les pointes d'Oarsins, celles qui, par une cause queleonque, n'oat jamais de cavité. Il persista dans cette opinion long-temps après, comme on peut s'en assurer dins l'édition de la sciographie lithographique de Scheuchzer, qu'il pulslia en 1740.

La disscrtation très-estimée de Breyne, de Fo4thatamis, est une juste applicalion des nouvelles idées à la classitication des coquilles, et celle disinction fondiamentale de cocjuilles rounothalames et polythalames, est une conséquerce des résultats obtenus par librhart. On croiroit peut-être que les opiuions tundées sur cie bonnes observations, conduisant à des cluangemens lavorables dans celte parlie des sciences, ont été sn:le.champ adoptées. L'esprit huraain n'est point 


\section{14}

B E L

ainsi fait, il s'allaclye long-temps eacore à l'erreur, aux inuovations les plus dénuées de preures, lorsque la rérité a été trourée et qu'il ne faudroit que la suivre. Ainsi nous trouvons Capeller, qui prétend que los Bélemsiles sont des Holoturies, ¿iui ont étú pétriliées au moment où elles a valoient uae cocprille qui est reslée à demi-ditrérée; il veut parler de l'alvéole. Le minéralogisic Wallérius, peu compétent pour juger une pareille opinion, l'adnet sass la disculer heacoup. Nous voyous Dacosta revenir à une idée abandounée dejpuis plus d'un siècle, que les Bélemnites sont des stalactigues, et Bromel les nonuner encurc pierres de foultes. A côlé de ces erreurs dont nous pourrions augmenter bcaucoup la liste, cंest arec jlaisir que nors citous les ourrages de quelques autcurs qui ont su les íviler: ainsi Baker place les Bélemnites près des Orthocères, arec lesyuelles elles ont certajuement beaucoup d'analogie. Brauder admet ce rapprochement, et a le boa esprit d'adopter la manière de voir de Rosious el d'Elırbart. De plus, il cherche à prourer, ce que l'on u'aroit pas fuit arant lui, que toutes les Bčiemnites qui n'ont point de cavité ne le du'vent qu'au jeune age; ce qui est incontestab!e pour presque toutes, car il y en a pas p'us de deux qui soient sans casités à tous les àres.

Allioni, dont l'ory clonraphie piémontaise a conservé une juste répulalion, adopte sur les Bélemaites le sentiment de Breyne, et il annonce d'après Bozzeti qu'il existe une Bélemnite virante dans le cabinet du chanoine Capponi; mais cela paroit bien peu probable : ne seroit-ce pas plutôt, comme le croit aussi MI. de Blainville, une haguelte d'Oursiu?' On doit regrelter néanmoins que ce corps n'ait pas été figuré avec soin.

Malgré tant de travaux sur les Bélemnites, maluré les opinions si judicieuses d'hommes d'un grand mérite, malgré l'aủhésiun de linné à ces opinions, on trouve encose des uaturalistes en pe:it nombre, il est vrai, qui s'altachent à d'anciennes erreur's, et enchérissent sur clles d'une manière ridicule. Peut-un qualilier autrement l'opinion de Bertrand, qui en $179^{\circ}$, dans son Dictionnaire des Fossiles, veut rajeunir celle de Capeller en l'embellissant par de faux raisunuemens? Celle de Lemonnier qu'on trouve daus le nème ouvrage mérite d'c̀tre traitée de mème, puisigu'tlle veut prouver que les Bélemnites ne sont que des stalaclites, comme Dacosta et avaat Ini Langius l'avoient cru. Celle de la Tourette peut se metire au mème rang que les précédentes; elle a cela de particulier d'avoir été aussi recneillie dans le Dictionnaire des Fossiles de Bertrand. Cet auteur croit que la Bélemnite est une espèce de Polype, et l'alvéole une anire articulé indépendañ du premier, et qui cependant virroit dans sa cavité. De telles erreurs n'ont pas besoin d'être réfutées.

Nons louchons enfio au moment où nuus noan- rons plus la púnible tâche de signaler des erreurs; le temps des vacillations a fait place à celui d'ane fixité beaucoup plus grande. I,a vérité, apıès àvoir été sonvent méconnue, présida presque seule aux travaux que uous allons mentionner. Les opinions d'Ehrhart et de Rosinus prévaluren: enfin, et on de chercha plus ru’à les perfeclionaer. Dans an Ilérnoire inséré dans les Transactions philasopliques, Platt donna beancoup de développement a ses idées; considérant que dans certains Mollusques, la coquille reçoit un accroissement extéricur par superposition de couches, que dans les P'orcelaines, par exemple, cela est dú à la disposition des lolies du manteau, il en conclut par anologie que l'accroisemeut des Bélemnites se fuisunt par le dehors, l'animal devoit aussi étre pourru d'un unanteau, si ce n'est semblable, au moins analogue. Cette thcorie élojt certaiaement très-salisfaisante pour une éporue oì rien encore re provuit faire présumer une analogie arec les Siclies. Ce ae fut pas long-tenus après cenendant que ces nouveaux rapports furent entrerus à luccasion d'une observation faite par Firmin, en 1767 , d'un corps qu'il prétendit ćtre rne Bélemnite vivante, ce que Bernard son ami soutiut anssi. Mais un auteur anonyme (Pallas) démontra que ce n'étoit qu'un calmar mutilé. Cette observation, tout incomplète quelle étoit, pouvoit cependant conduire à une idée lunineuse.

Un chapitre de l'ouvrage de Knorr sur les pétrificalions est entièrement consacré à l'histoire et à la distinctinn des Bélemnites. Walch s'est rendu cúlèlure par cet ouvraye dont le texte lui appartient. Ce clapitre des Bélenunites est vraiment remarquable, et peut entrer en parallèle arec le Mémoire de Guetırd que nous menlionnerons bientô:. liauteur douma une analy:se fort étendue de ceax qui l'ont précédé, et se montra judicieux en adoptant l'opinion que les Bélemnites sont des coquilles analogues aux Nauliles, forts différentes cependant des Orthocératites que Bianchi renoil de déconvir à l’état vivant. Telle est linlluence malheureuse des noas et la confusion quils entraînent, que ce mot Ortbucératite changé en Orthocère appliqués à des corps fort différens devint parmi les auteurs une source derreurs et de faux rapprochemens qui ne sont dus qu'à la ressemblance du nom : e'est ainsi, pour en donner un exemple, que furent rassemblées des Orthocères rivantes, qui ne sont aurre chose que des Nodosaires, coquilles microscopiques, avec les Orthocères fossiles, qui sont de véritables Nautiles, droits, cloisonnés et siphonifères, avec les Orthocérates de la Peyrouse, qui sont des coquilles bivalves. Cette confusion, qui existe encore dans les auteurs les plus modernes, n'est pas la seule due à la méme cause que nous pourrions citer. Ainsi cette Orthocératite rivante de Bianchi n'étoit pas comparable avec les Bélemnites; et Walch l'aroit très-bien senti. Cet 
auteur en distingua plusicurs espèces, mais malheurcusement sans les définir d'une tuanic̀e riguurense et précise : l'exemple de Limné u'ćtait point cacore généralement suivi.

Dans une dissertation trùs-aprofondie que l'on trouve dans le cinquicme volume de scs Múmoires, Guctarl, en 1785 , fil usage de celle a agacié qui lui était particulic̀re en fuisaal l'examen crilique de toutes les opinions de ses devanciers; Walch, comme nousl'avons vu, a voit fait de môme huit ans avant; mitis telle ítoit la lenteur des communications scientiliques, qu'il est presque cerlain que Gueltard ne connoissoit pas l'important travail de l'atleur allenand. Il arriva à ce rósulat imporlant, que les opinious d'Ebrhart, de linsiuus, el de cenx qui les avoicut suivies, éloient les senles vraies, les seules qu'nl liit permis disormais d'adopter, et avec linné, il pense que la bélemnite est un Nantile droit on se rapproche de ce genre par un grand nambre d'analogies. Bruguiere, se rangeant de l'opiuion le linoé, ue les sépara par, à ce rüil patoîl, des Nautics, camare cela scuble probable par la définition quil dona de ce gense, el liabsence absolue de toute indicalion particuliere des Btlemailes, daus le prenicr vulunic de ret ouyringe.

T'ulle est la séric forl longuc, comme on le roit, des ouvrages qui ont été fails sur les Bélemnites, et qui ont précédé les auteurs de ce siécle. lci me progression rapide va se montrer, el le court espace de vinert-sept années aura été plus prolitable à la connoissance exacte et complète rles Bólenuiles, gue juresque lous les écrits que nous avons mentionnés. Dès 1800 , une poléruique qui ne fut pas imuile s'éleva entre jucsase et I) prítendoit que les Búlemnites ne sout que ries noyaux d'Orthocéralites; le second a contraire rue les Orthocératites ne snnt que des piles d’alrévles appartenant aux Bjélemnites. Maluré cettc divergence, on voit que ces denx savans uvoient apprécié les rapports qui lient les deux genres, et quils ne difíroieul yue dans la maniere de les envisayer. Delue s'éloit fait une fausse idée de l'alvéule, il croyoit que les cloisuns fort épaisses se touchoient et ue litissoient entre elles aucun espace vide; d'oì il fut conduit it rejeter l'exis!ence du siphon : il we litlloit cependant "ju'avoir des jeux pour s'assurer facileueat du contraire.

Dès son entrée dans la carricare zoologique, MI. Comarck, dans son $S_{y}$ steme des animaru.x scins

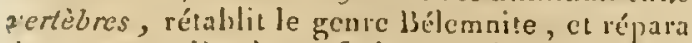
de celte manicre la confusion de linné, de Burgaière et de plusicurs antres aulem's. $\Lambda$ celle époquc, M. Lamarck ne forma qu'une seule séric parmi les coquilles cloisounces, en commoncant par celles yui sont discoides, pour finir par celles qui sont droites. Nons ne savaus si ce savaut con- fondit les Orthocératites avec les Orthocères; ce qu'il y a de certain, c'est que dans ce derniev ğrnre, qui est le seul mentionné, il n'a donné pour excmple que le Nautilus raphanus, coquille microscropique qui u'a que des mapports furt ćloignés avec les bélenmiles, et qui sen trouve cependant rapprochre ainsi yue les lippuriles, que la Peyrousc a:ril anssi nommées Orlhocéralites, quoique ce soient des coquilles bivalves.

MI. de Roissy, dars le Buffon de Sonnini, adopla complètement l'opinion de $\mathrm{N}$. Lamarck, ot ne comprit dans le cromre Orthocè güil rapproche aussi des Búlemultes, qque des cónuilles micresenpiques, ce qui devorit produire d'aulant plas liscilement la conliusion que Lesage, sous le orense

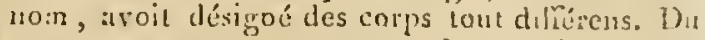
reste, cet autcur se contente de rappeler fort e: abrégé el tres-incomplélemenl quelegues opinions, sins se prononcer plus pour l'une yue pour l'autre, ne jugreant jas gne la scicnce posséldit anse/ de malériaux pour se décider, présumant cefendant que la bólemnile devoit être placte a l. partic postérieure d’un anional céphalopode. (u toul ou cu parlie couverte par le mancau; mas nous avons eu occasion da le dire, cente maricire de voir n'est pas nouvelle.

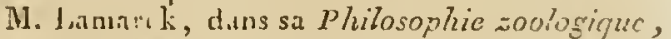
opéla des changemen: avantageax daus la clistribution gúnérale des Céphalopodes; mais les 136́lemniles, quviquappartenant à la famille des l.:tuolacées (zoyez ce mol), n'en luren! pas fisicux placées dans la série, puisquielles furent licauconp urop élnigrnóes des Nauliles.

Lal Conchyliologie systématioue de Mortfor:, qui trop long-lemps inspira de la confiance aux sìvaus, vint leur ollir, en 1808 , une ofvinion ì laquelle il n’étoit gnuère permis de s'aticndre à celic époque, après les discussions apprafondies dont les Bélennites avoicnt élé le snjes. Cet alulear prótendit que l'avénle n’appartenoil poinl à la lićlemnile, que céloient deux corps entièrencut iadépendans que le hasard scul reumisnit que!queluis, mais ne ponvoit convenir à un nicme animal. Il fut donc conduil ì former de la Délemnite un genre, et ua autre avec l'alvéole. Ce qu?al y a de particulier, el ce qui est inconciliable, cest que Mlonllort, fout en soutenant son hypollicese, liaissa les Bélemnites parmi les coquille's rloisounées. Ou les Bélemnites ne sont pras clcisoonics, el alors pourgnoi les laisser parui les Cúplatonodes? on elles le sout, el pourruoi faice un senre Callyrhö avec les alvéoles qui s’y lrouvent?

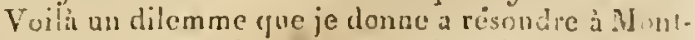
ful et à cenx qui scroient lentés de l'imiter. Dans un genre où les especes ćtoient it peinc connutes, cet auteur, lúcond cu genres nonveaur, lyuma moyen d'en démembrer sur les catritelèes de la plus anince valeur, et souvent purament accidentels, les gemes quil nomme l'aclitc. 'Thalamule, Callyrhoë, Célocine, Acane, Carjsarire, Itabo- 
lite et l'orodrague. Aucuns de ces genres ne furent adoptés; ils ne méritoient pas de l'être.

Nous avons vu que M. Lamarck avoit amélioré la classification des Céphalopodes dans sa Philosopthie zoologique, sans que cependant les Bélemnitcs eussent changé de place : il n'en est pas de mène dans l'Extrait du Cours; dans cet ouvrage eiles commencent la série des Céphalopodes à coquille droite et à cloisons simples, qui sont renlermées dans la famille des Orthoccres, la première de celle classe : les Nodosaires sont séparées des Orthocères, mais sans amélioration pour ce gente, qui ne contient toujours que des coquilles microscopiques, ayant peu d'analogie par conséquent avec les Bélemnites.

Klein, dans son Traité des Oursins, avoit confondu quelques espèces de Bélcmulites sans cavité, soit accidentellconent, soit naturellement, avec les baguctes ou pointes que porte le test de ces animaux; il étoit peu probable que celte opinion erronée que l'on a voit justement blàmée, trouvât des sectateurs. M1. Beudaut crut cependant pouvoir la reproduice en la géuéralisant et l’appliciuant indistinctement à toules les espèces.

11. Beudant n'a véritablemeut qu'un seul fait rui paroisse concluant en sa faveur, il est relatil it une espèce de Bélemnite qui n'a jamais de cavité; il nous semble qu'il est difficile d'un fait comue celui-là de conclure que toutes les Béleunnites sont des bagueltes d'Oursins : aussi, à l'égrard de celles qui ont une cavité plus ou moins profonde, M. Beudant reste dans le doute, croyant que les opinions de ses devanciers sont toutes sur ce point extrêmement incertaines. Le Mlémoire de 1 . Beudant, publié en 1810 dans les Annales du Mruséum, n'a pas besoia d'une sérieuse réfutation; les Bélemnites sont aujourd'hui trop bien connues pour que cela nous arrête davautagre.

M. de Blainville a élé alans l"èreur lo:squ'il rapporte l'ouvrage de M. Faure Bignuel à l'année 1810 ; ce n'est en effet qu'en 1819 qqu’il a paru. Ce pretil traté de bélenınitologrie est précieux, on y trouve un grand numbre de détails curieux sur la structure des Bélemnites, et une comparaison de l'accroissement de ce corps avec la coquille calcaire des Limaces. Ce naturaliste confirma ce lait avancé par Lesinge, que les loges de l'alvéule correspondent aux accroissemens de la coquille. Mais M. Faure Biguet, comparant le siphon des Búlemnites avec celui des Ammonites, ou des Baculites, est conduit à croire qu'il n'avoit point une structure scmblable, qưil n'étoit point complèement calcaire, aussi-bien que les cloisous 'jui devoient être membraneuses. Quelqques faits tris-pen probaus sont les seuls appuis que l'auteur trouve à ce système, qui, dans notre maniere de vojr, n'est pnint vraisemblable : la partie descriptive du travail de M. Faure Biguet est beaucoup plus complète que dans tous les au- tres traités. 11 divise les vingt espèces qu'il caractérise et décrit d'une manière suffisante, en trois sections : la première pour les espèces comprimées; la seconde pour celles qui sont cylindriques; la troisième enfin pour celles qui sont coniques. Il n'a parlé que des espèces de sa collection sans ảomer de synonymie.

11. Cuvier, Règne animal ( pag. 371 ), dislingua trćs-nettement les Orthocératites de Breyne des Orthocères et des Nodosaires de M. Lamarck, et ne les confondit pas; il les rapproche des Bélemites, et en effet aucuns corps n'ont plus d'analogie avec elles. M. Cuvier fut le premier qui vil la coulusion et la voulut détruire; l'indication de ce grand zoologiste, quil auroit fallu snive et pertectionner, ne fut pas prise en considéralion par N. Lamarck, qui, dans son dernier onvrage, persista dans sa manière de voir à l'égard des Orihocères. Quant aux Jélemnites, il ne changea rien aux rapports établis dans l'Extrait du Cours. Dins sun ouvrage intitulé Organic remains, M. Parkinson donna quelques considérations sur les Bélernnites; après plusieurs observations, il arriva à ce résultat, que l'état actuel des Bélemnites est dû a la cristallisalion spathique et non a l'organisation, ce qui est peu probable; cat il a fâllu pourtant q̧ue l'organisation ait aussi son influence dans l'arrangement des mollécules cristallines, puisque cet arrangement se rencontre presque exclusivement dans les Bélemnites.

Le traité des pétrifications de N. Scblotheim ne peut être d'une grande utilité pour l'ćtude des Bélemnites; presque point de synonymie, aucune firue, une indication nominative accompagnée d'une description très-insulfisante, voila ce que l'on trouve dans cet ouvrance, du reshe fort ntile pour la connoissance de beaucoup de pétrificalions te l'Allemagne. M. de Ferussac, dans ses Tableaux systématiques des animaux mollusques, a lait avec le seul genre Bélemnite une tamille qui conserve aussi ce nom. Elle est placée entre celle des Hippurites et celle des Orthocères; de sorte que ce genre se trouve entre les Hippurites et les lchibyosarcolites. Nous navons pur répondre d'une manic̀re satisfaisante aux deux questions qque cet arrangement nous a suggérées : quels rapports y a-t-il entre les I3élemnites, les Ilippurites et les Ichthyosarcolites?' Pour'yuoi élablir une famille exprés pour les Bélemnites seules lursque leurs rapports avec les Orthorératites sont tels qu'on ne peut éloigner ces deux genres? M1. de Ferussac y a répondu dans sun anticle BÉlemNite du Dictionnaire classique, cn avouant qu'il s'étoit trompé; il faut donc, comme il le dit, regalder comme non aremue celtc partie de ses tableaux systémaliques. Larticle que nous venons de citer est trop important pour que nous ue nous y arrêtions pas. Après avoir donné une listoire du genre, et en avoir critiqué les détails d'une manière convenable, MI. de Fe- 


\section{B E L}

russac discule les opizions les plus récentes, et adopie celles qui sont seules dans ce cas, parce qu'elles ont été sanctionnées par l'observatiou; il prend judicicusement ce qui est bon dans les ilćmoires de Lesage, Deluc, Beudait, etc., et, en y joignant ses propres observations, s'en sert utilemeat pour développer la formation des Bélemnites et assigner leurs rapports avec les genres les plus voisins. M. de lerussac admet, probablement d'après Faure Bignet, que plusieurs especes de ce genre ont le siplon central, ce qui ne paroit pas exister; il croit anssi que dans quelques espèces le centre de la coquille est ouvert par un canal étroit qui règne dans toute l'étendue e! communique arec le siphon. Nous ayous élé à mẻme de nous assurer que cela nexiste pas. MI. de Ferussac fait aussi sentir combicn seroit inportante l'étude des Bélemnites appliquéc à la géologie, et il déplore qu'on n'uit poiut encore une monographie bien faile de ce geure qui réclame, à plus d'ua titre, de fixer liallention des savans.

Nous avons ru jusquà présent que rien de biea satisfaisant n'avoit été fait pour classer les Béleunites daus leurs rapports les plns naturels; une des causes qui ont le plus contribué à donner de fausses idées, c'est la cuufusion générale qui a résulić du rapprochemeat des coguilles polythalames microscopiques des véritables Séphonifères : le geare Orthucère, qui est Je plus voisin de celui qui nous occupe, a été ur des prenier's soumis à cclte fâcheuse crnfusion, et tanı qu'elle a existé la classilication s en est ressentie. Ml. Sowerby (Ainerul conchology) a commencé à ne douner dans le gen:e Ortbocératite que des es. péces grancles à siphon central, celles en un mot que lireyne avoit indiquées sous ce nom. On oublia pendant quelque temps celle indication de l'auteur anglais, mais elle ne fut pnint perdue pour II. de Haan qui, dans son excellente mooographie des $A$ mmoniles publiée eo 1325 , dona enlin une très-banne classification des coquilles cloisonnécs. Cet auteur s'aperçut du passage insensible qui existeentre les Iélemnites et les Orihocératites: aussi il n'ea lit qu'un seul geure auquel il conserva cette dernićte dénomination. C'est à $M$. de Ilaan, comme nous le verrons en traitant des Céphalopodes, que l'on doit cetre heureuse séparation des coquilles mulriloculaires à siphon de celles qui u'en out pas, distinction que M. d'Orbinnny établissoil daus le même temps sans connoitreles travaux de l'iluteur liollundais. Quelle que soit la graude analogie qui existe eatre ces deux genres, il y a de bons caractères pour les séparer et les distinguer facilement: aussi nous n'admettons pas la réunion de $\mathrm{M}$. de Haan; du reste il plaça plus cnnvenablement ce genre que ses devanciers. Il fait partie de la famille des Nautiles, entre les Hippurites et les Conilites. Les Ilippurites sont des coquilles bivalves; mais ce fail n'úloit pasalors prouvé comme il l'est aujourd'hui.

M. de Blainvile ne connut pas le travail de MI. de Itaan, il ne put en profiter, et sa classilication s'en ressentit. La famille des Orthocìres, ea tête de laquelle se trouve le genre Bélemnite, est diviśce en deux sections : la prenière pour les coquilles droites à cloisons simples, la seconde pour celles qui avec la nuêrne forme ont les cloisons découpées (les Baculites); ainsi dans une même farnille se trouvent réunis les types fort différens d'organisalion; les Bćlenıniles soul suivies des genres Conulaire, Conilite et Orthocere. (Toyez ces mois.) Ces deux premiers genres son: douteux, surtout le second, et celni des Orihocères n'a épronvé aucune aúlioration.

La classiticatiou de M. Iatreille (Fanilles naturelles du Règne animal, page 162) n'est guère plus salisfassante sous ce rapport que celle de Mi. de Blainvile. Comprises dans la famille des Orlhocérates, les Bélemnites forment le premier groupe avec les Caliirhoës de Hontfort ct les Ichthyosarcolites. Nous arons vu que ce genre de Montfort avoit été fait avec une pile d'alvéales de Bélemnites; cest donc un double emploi qui a'est pas 'e seul, puisque le savant cutomolcgiste admet tous les déurcmbremens de Moniforl, clont il fait de petits groupes, et il fruit, comme l'ont fait ses prédécesseurs, au moins pour la plupart, par mettre dans la neèrne famille aon-seulement les Baculites, mais de plus les IIamies, les Molosses, les Hortoles, les Lituites, les spiroliwes, etc., ce qui ne s'étoit point encore vu.

M. d'Orbiguy' fils ne publia son travail sur les Céplualopudes qu'un an après ceux que nous venous de mentionner. Il est tont eutier dans le torne 7 . des Annales des sciences naturelles. Ce jeune savant, qui s'est occupé plus spécialement des coquilles microscopiques, a donué une classification générale qui a beancoup d'analogie, quant aux Siphouiferes, avec cel!e de M. de IIaan. Ces deux autcurs élant parlis des mèmes priacipes devoient nicessairement se rencontrer en plusieurs endroits; ils diffèrent cependant pour ce qui a rapport aux Bélennites : si MI. de Ilaan eut le tort de les confondre arec les Orthocératites, M. d'Orbigny ent celui plus grand, selon nous, dc trop les en écarter. Il leur assigna des rapporys qui ne nous semblent pas naturels : qu'y a-i-1) de commun, en eflet, entre ce genre et l'I clulilyosarcolite? La fauille des Péristellćes (vojez ce mot), composée de res deux greares, he sera certainement pas conservée. La classificaliou de 11. d'Orbinny auroit été beancoup plus parláte, si le geurc bélemcite avoit terminé la fauille des Nantilacées en contact immédiat avec les Orthocérates, el si le genre Ichtbyosarcolite avoit is lui seul formé la famille des Péristellées : ce que nous disons ici ne seroit applicable quen raisounant daus le système de II. d’Orbigny, et nous 


\section{IIS}

verrons bientôt par quels motifs il doit subir de notables changemens.

$\mathrm{Ce}$ fut à peu près à la méme époque, $18 \% 6$, que parut, dans les Mlémoires de la Société géologique de Londres, un Mlémoire très-important sur les Bélemuites par M. Niller. Nous derons ea rendre ua compte détaillć.

M1. Miller partage son travail en plusieurs parties : la première est consacrle a l'histoire du gense dans ses rapports avec la géologie. Considérée de celle inanicre l'hisioire propremcut dile, comme on l'enlend ordinairement, n'a puint élé laite, mais MI. Miller est arrivé a des données générales furt ntiles pour la distribution des BClemnites dans les divers terrains. Entrant ensuite daus des considérations purement zoologiques, il examine le cône chambré que nous nnmmons l'alvécle; ; il le troure d'une stracture lamellaire, et il suppose que dans un certain numbre d'espèces, le siphon cst central. Toutes les observations fintes jusqu'il ce jour dérnentent celte assertion. Il suppose égaleinent que l'alrúole dépasse à la hase le test de la coquille, ou tou au moins le remphit complútement. Nous ne partageons pas cette upinion de M. Mliller; l'observation maneque sur "थ point, el nous ne la remplacons janais par me therie, quelque filusible elie paroisse; elie est d'ailleurs coutraire au but que remplit me coquille dans le corps d'un animal, elle protége les organes les plus essentiels, ct clle ne preut le firre eflicacemeut guen les courrant, ce qui ici deviendroit impossible. On oljectera sans doute le Belemnites plenus qृui n'a aucuae cavité; mais c'est un fail isolé sur cinquante autres qui en dilfèrent. Il seroit possible que dans un certain nombre d'especes, la dernicre loge ue liut pas plus grande que lus antres; mais encore, avant d'admettre celte manière de voir qui cst plus plausible que la première, fandroit-il qu'elle suit constatée par de bonnes observations.

NI. Niller suppose cncore que la Bélemnite pendant la rie de l'animal ćtnit telle que ncus la irourons a jourd'hui; quatelle n’a cliangé ni de poids ni de structure. II. de Blainville rejetie complétemenl, comn:e nous le verrous bientòt, cetce opinion de l'auteur anglais: aons ne suirons pas son exemple, parce que nous admettons que la structure libreuse el rayounante dépend de l'organisation el non de la spathification; mais nous croyous aussi que le séjour dans la terre a permis l'imbibition d'une malière calcaire dans un test poreux et léger qui a dûn nécessairement en clan. ner la pesanteur d'une tasrière notuble: ce chan-

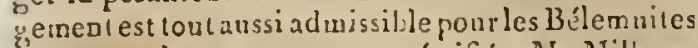

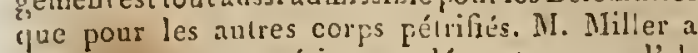
beau, par une expérience, dónootleer que l'a!réole ride suffit pour tenir dans nne postion verticale dans l'eau une Bélemnite Eossile, cela ae sulfit pas, car il est peu présumable par acalocie que l'animal, surtou: celui cite représenle
M. Niller, nageat dans une position verticale, ce que l'on sernit forcé d'admeure en supposant la Bélemaite aussi lourde qu'elle l'est anjourd'Juin. Puisque Mr. Miller admet une aussi grande analogie eutre l'auimal des Bćlemnites et celui des Cilmars ou des Séches, pourquoi détruire une partie de celte anologie, en supposant une tatation dillérente pour une coquille qui $n^{2} a$ plus qu'une ressernblance éloignée dans sa siructure?

M1. Miller termine ses considírations générales par des conjectuncs snr l'animal de la Béleminie; il va méme jusqu'à le faire tigurer, ce qui rend bien plus lacile a concevoir l'opinion quäil sen est faite : nous y voynus la finnre d'un Cifmar dans le dos claquel est placé une Béleınnite, uais ancun o:gane n'est indiqué. Ce yui nous a faru peu probalule dans Ilyypollèse de M. Miller, c'est que le mantean sercit fendu au lieu de contenir la coquille dans un sac complétenent fermé, comme crla a lien daun les Sèches et les Calmars. Cette division din mantean expligqueruit, selon M. Niller, la furmation de la raioure; mais celia ne peus ètre, puisque la rainure est toejours rentrale, qu'il en existe trís-rarement une dorsalc, et quielles sont quelcquelois lalírales lorsqun y eu a plus d'une. On feut croire avec M. Miller gue l'animal des Bélemniles étoil très-roisin des Calmars, mais on ne sanruit affirmer leur anaIngie positive. Quoi quil en soit, on roit que cet auteur a voit judiciensement senti des rapports qqui lient les J3élemnites aux Sèches, rajports qque II. de Blainville a ceulirmís d'une manière micontestable. Quant au travail des espèces, M. MIIL. ler n'cn a conas quius trop pesil nombre nour les établir d'une manière ccriane; son travail de ce côtú est très-imiparfait : il a séparé les espècrs pleines pour en faire an genre à part sous it nom d'Actino-camax, quii u'a pas les caractères suffisans pour un bon genre.

Enfin, pour compléter celle histoire des Brilemuites, il nous reste a examiner le traté ie plus complet qui existe sur ce gonre et que rient de prblier, en 1327, MI. de Blainville. Ce snvants cmbrasse rout ce qui a rapport au genre qiu'ti taaite , el il partage son travail en autant de sertions que son sujet l'exige : la prenière est consacrée à l'histoire da genre; la seconde, à la nature des Bélemnites et à la place qu'elles doiver.t occuper parmi les ètres organisćs; la truisien e. Iraite des modifications cque les Bélemmites ont dlü éprouver dansle sein de la lerre; la quatrième est destinée it la distribuann géographlique et gróolngique des ix́lenunites; la cinquiurne, une des plus importantes, comprend la description des espeées; la sixieme donme les rísuliats génćrax el les applications à la góologic ; la septicne, et rlernière, renlerme daus l'orclie chronologique la liste des au!eurs cilés.

L'histoire des Bélemnites que donne Mi. de Blaiville est certainement la plus complète, nous 
y arons puisé de précicux malćrianx pour le rísumé que l'ou vient de lire; cepeuclant, et ce ¿qui doit surprendre, c'est que cet estimable savant ne rend pas comple des clissilications importantes les plus nouvelles que nous aynns, soit sur les Mullusques en général, soit sur les Céphalopodes en praticulier; ainsi il ne meotionne, ni le demier ouvrage de Latreille (Fam. natur. du Regn. anim.), ni le sien propre, le Traité de Yulucolugie, wi ccux bien importans de de Haan et de d'Orbinny. Ces ourrages sont cependant an. térieurs à celui de $\mathrm{M}$. de Blainville, puisgue celui de d'Orbigny, entr'aulres, est cilé dans le cours de l'ouvruge à l'occasion du genre béloplère. Quvi qu'il en soit, celle histoire est fuite arec une grunde imparialite et une saine critique; c'est une source précieuse ponr ceux qui vandront éludier complélenent ce genre.

Dans la seconde section, MI. de Blainville, apris avoir dércloppé la structure des Búlemnites el résumé les laits curieux constalés par l'observilion, tire la conclusion, qui découle alissi de l'applicalion des principes de la zoologie, que l'animal des búlemuites éroit un Céphalopode puit et symitrique, que la coquille étoit complétement intrieure, comme le prouvent les accroissemens; que, comme l'os de la Sèche, elle étoil dorsale et terwinale, et que lia deraière loge, toujours plus grande que les antres, it un trés-petit nombre d'exceptions près, étoit desfinće à supporter quclques viscères, comme ceux de la génération, el probablement une partie de ceux de la digestion. Le sillnn qui cxiste dans un graut nombre d'espèces est ventral et il correspoud toujours au siphon. I a place des Bélemuites dans le corps de l'animal, déterminéc avec autant de précisinn que l'analogie judicieusement employée peut le permettre, on parvieut plus facilement à indiguer les rapposts de ce genre avec ceux qui l'avoisinent. Un corps que Guetrard a connu et figuré dans le tome 5 de ses Mémoires, parmi des dents de poissuns, et que nous avons retronvé aux environs de l'aris, a été très-utile puur lier les Bélemnites aux Sèches. Depuis longr-temps nous avions apprécié limporlance de ce corps par les nouveaux rapports qu'il indiquoit, et anns lui avions donné en couséquence le nom de Béloptère avanı de l'avoir commuaiqué à $\mathrm{N}$. de Blainville, auquel nous fimes part de toutes nos observations à ce sujel. I.e Béloptčre est un corps très-singulier; il est pourvu antérieurement d'une cavité conique, daus faquelle on trouve des traces évidentes de cloisons, en tout semblables à celle des Bélemnites, et d'un siphon ventral; celte parlie a même lá texture fibreuse et rayonnante. De chaqne côté se voit un appendice aliforme, inclioé sur l'axe, et qui a la plus grande analogie avec le corps de l'os de la Sèche; enfin, postérieurement, le Béloptère se termine par un bec émoussé, obtus, épais, qui a çuelques rappo:ls avec l'appendice posic:ieur de l'os de la Siche. La comoissance complére du Jélopicre, dont Guellard n’a pas connu limportance, est devenue pour nous et M. de Blainville un t:ait lumineux, qui à dû déterminê" enfin d'une manière précise les liens qui unissent les Bélemnites avec les autres Céplailopodes. On sentira davantage la justesse de nos obscrvations si l'on compare Ies résuliats obtenus jar M. de Blainville ding son Traité de Mralucologie, a ccux du grand travail sur les Bélemniles; li elles sunt ćloignáes des Séches, ici elles en sout rapprochées. Ce notable changenent, dans l'opinion de ce savart, vient certaidement de la connoissance qu'il avoit récemment acquise du $B e^{-}$ loptère de notre collection. Ainsi, pour nous et pour M. de Blainville, il n'est pas dnuleux que la famille des Sèches ue doive se terminer par le Béloptire, et celle des Oriliocìres, ou des Niutiles, suivie imméliatement et commencer par le genre Bélemnite.

La troisième section de l'ouvrage de M. de Blaiarille est consacrée à l'ćclaircissement d'une question qui doest pas sans intérêt. Déja M.Parkinson, el quelques antres naturalistes, en avoicat traité, mais d'une manière peut-être moins complète. Il s’agit de savoir siles Bélemnites durirent leur élat fibreux uniquement à lear séjour dans les couches de la terre, ou hicn si celle sliucture appartient entierement à l'animal, qui au moment de sa destruction aumit laissé sa coquille tolle que nous la trouvons anjondthai. M. de Blainville pense que la structure première de la coquille a été telle pendant la vie de l'animal, qu'elle a pu facilement s'imprégner de carbonalc de chaux, qui s'est cristallisé en aignilles rayonnantes à mesure que la niatic̀re auinale, par sa destruction lente, a abandonué la coquille nolécule à molécule. Cette opinion, que nous ne partageons pas complétement, est la mére que celle de M. l'arkinson. Mi. Niller ne l'admet pas, il crnil roir dans lit Bélemnite pétriliée la coguilie telle que l'a. nirnal l'a laissće. Cet auteur exagère certainenent la vérilé; on ne peut supposer, car on n'a aucune induction pour le faire, que l'animal de la Bélemnite portoit uoe cocjuille d'une pesanteur si peu proportionnéc avec celle de la Sèche, par excmple, qui peseroil vingt fois moins à vnlume égal. Nous présenterons un pen plus tard l'opinion que nous nous sommes faile, et nous dirons par quelle analogic nous nous sommes rapprochés de celle de MI. Miller, tout en la modifints.

La cjuatricme scction est importante, par cela qu'elle dounc des moyens, si ce n'est cumplets, du moins plus parfails que ceux que l'on possédoit, d'appliquer la connoissance des Bélembites à la distioction des terrains d'où elles pruvienneat. Mallseureusement M. de Blainville n'a pas assez de documens exacts pour décider plusieurs points importaus; il v'a pu préciser encore, par exemple, 
les esfices qui apparliennent exclusivement à cerlaivés couches et qui pourroient les caractériser partout oì on les rencontreroit. Ce résultat ne pourra s'obtenir que lentement et à la suite te nombreuses observalions directes. Si celte partie du travail de 11 . de Blainville présente quelque lacune, cela n'a pas dópendu de lui, mais de l'état actuel de la science, qui manque encore d'observations importantes; elle n'en sera pas moins cousultéc avec un grand avantage par les géologues, qui y trouveront un résumé assez complet de lont ce qui a été dit sur ce sujer, avec les notes que l'autent a recueillies par Ini-mềne.

La section suivante, la cinquième, est la plus importante pour la zoolorgie, puisquon y trouve la description des espéces el lenr distribution en Inuit groupes. On regrelloit singulièrement qu’il n'exislât aucune monographie du genre Bélemuitcs; les travaux entrepris étoieni si peu complets, qu'on pouvoit, al l'exception de celvi de MI. Faure Biguet, les iegarder comme non aveuns; on sentit, d'un autre côté, loutes les difficulıćs dont ce genre est liérissé, par le peu de bons carnctères pour distinguer les espèces. 11 est résulté de tout cela que ce genre ae pouvoit être atilement traité que par un homme habile, depuis long-temps versé dans l'élude de l'bisioire valurelle, ct qui sût meltre à profit, avec sagacité, le peu d'élémens de distinctions spécifiques dont il est possible de se servir. Nul, plus que M. de Blainville, ne rassembloit à un plus baut degré res précieuses qualités; aussi nous croyons qu'il y aura fort peu de rectificalions a faire dans celle parlie de son travail. M. de Blainville caraclérise et donne la figure très-lied fitie de quarantesix espèces, nombre beaucoup plus considérable qu'on auloit pu s'y allendre, d'après le petit numbre qui en étvil cauuu. Puur arriver plus facilement à leur distinction, l'autcur les a parlagcées eu huit groupes, dans l'ordre suivant:

\section{A. Espèces sans cavité.}

B. Espèces à cavité très-petite, fissurée surle bord et sans cloisons.

C. Espèces à cavité graade, fissurée sur le loord et sans cloisons.

D. Espèces à cavité grande, cloisonacie, siphonnée, avec une gonltiçre rentrale plus ou moins évidenle de la base au sommel.

E. Espèces à cavilć grrande, cloisonnée siphonnée, sans fissure ni gouttièrc à la base, deux sillons latéraux au sommet.

F. Espèces à cavilé très-grande, cloisonncé, sipluonnce, sans fissure ni gouttière à la base, ni sitions au sommet.

G. Espèces à cavité heaucoup plus grande pro- portionnellement, cloisonnée, siphonnée, sans fissure, cannelure ai sillons.

\section{Espèces mal ou incomplétement connues.}

Comme on le voit, H. de Blainville suit une progression, depuis les espèces les plus pleiuey ou saus cavité, jusqu’a celles qui l'ont triss-grande et qui par lá avoisinent les Orthocères. Nous ferons obserser que le troisième groupe, formé des espèces de la craie, n'est point admissible. Quant au caractère des cloisons, dont M. de Blainville nie l'existence, nous sommes persuadés du contraire, non par l'olservation directe, mais par analogie et parce que nous savons que celte substance a la propriété de dissnudre complóicment cerlaines parties des coquilles don: la nature dilfère du reste. Ainsi on ne retrouve jamais que les parties corticales, celles qui sont le plus animalisées, et personne ne doute que les cloisons, et une couclie interac de la cavité des Bélemnites, ne soient d'une tont autre nature que le reste. Cetle partie a subi la loi commune des coquilles de la craie, elle a disparu par la dissolution.

I a sixième section est un résumé, ou sert de conclusions zoologiques et géologiques de re quii précède; elle est suivic d'un supplément, dans lequel Mi. de Blainville a caractérisé plusieurs genres qui avoisinen! les Bélemniles, ce sont les genres Bélopic̀re, Pscudobèle, Rhyncholite et Conchorhynque. (Voyez ces mols.) Après ces genres, l'auteur donne des additions et correcinons, et enfin termine son ouvrage par une seplième section, qui n'est composée que d'une liste des titres des ouvrayes cités dans le cours de ce Iravail.

Tel est le résumé historique úu genre curieux qui nous occupe. Noos avons clierché à mettre en saillic les auteurs qui ont elé véritableracat uliles à la bélenunitulogie. Ce sont ceux-lì dont il faut retenir les noms, et cerles cerx de Luynd, d'Elirbart, de Rosirous, de Brander, de Breyne. de Walch, Guellard, Deluc, Miller, Faure Biguet et Blainville ne seront jumais oubliés dans la description de ce gemre important, dont ils ont complété de plus en plus la concoissance.

L'histoire de ce genre nous offre l'exemple de ce qui a cu licu pour presque toutes les connoissances bumaines, et particulièrenent pour ce qùi a rapport à celles de l'histuire naturelle. Que nous appread-elle? On trouve dans l'antiquité des traces incertaines d'un genre; il devient moins problématique, et enlin il est constaté; mais des sic̀cles s'écoulent avant qu'on ait clierché à en détermirer les rapports. Cenx que l'on présente sont presque tous laux ou très-éloignés; cependaut quelques-uns se rapprochent davantage de la vérité, et il existe une lluctuation des esprits entre le plus on moins d'erreurs et de faux xapprochemens, jusqu'i ce qu'un bomme, douć 
de plas de génic et de perspicacité que ses contewporains, découvre et dévoile la vérité; c’est alors qu'il s'établit entre le vrai et le faux uce lutte inégale; les opinions erronćes sout sontenues par le plus grand nombre, mais la rérite, après un combat long el pénible de quelques hommes yui lui sont dévoués, apparoít entio dans toute sa splendeur. Une nouvelle carrière est oaverte; les théories s'établissent sur des faits qui sont discutés; elles deviennent alors presqu'inélıranlables; mais il manque encore gunelque chose à toules ces connoissances, un complément indispensable pour en faire une jusle ct rigourcuse application, les spécialités; c'est alors quion s'en occupe el que paroissent les bonnes monographies, et ce n'est qu'après elles que l'application d'une science à une autre peut se faire avec sécurite.

Donnons un exemp'e de ce que aous venons d'avancer, et nous pouvons le preadre dans le genre méme qui nous occupe. I.a connoissance des l̉élemnites peut être trís-uile à déterminer certains terrains; certaines espèces sont peut-être propres à certaines couches. On a rassemblé des mattriaux, mais la zoologie ne les a pas élaborés; ils deviennent une source d'erreurs pour la géologie, ils en sont une aussi pour cetle première science, wuis de beaucoup rocins grave; ou tourne ainsi dans un cercle derreurs muluelles qui cesse tout-à-conp lorsque les espéces sont bien dérerminées. C"est alors que le géologue, les connoissant parfaitemeat, les note sans hésitation parlout oủ il les trouve, et rend possible enlin l'applicatios de la conchyliologie a la science qu'il éclaire d'une inanière ellicace. Les nouveaux matériaux qu'il donne, la zoologie s'en empare de nouveau, pour élabiir celle succession élonnante des êtres ferdus dans les cuuche de la terre, et dont les rares détruites laissent des vestiges de leur passage par leurs antiques dépouilles.

Déji, par ce qui précède, on a pu acquérir ginelques idées exacles sur ce que l'on doil entendre par les B́leconites; cepeodant quelques points importans de leur siructure n'ont poinc été examinés. Nous allons leur donuer quelques développemens nécessaires.

La Beilemnite est une coquillo composcie de deux partics, de denx coones placés l'un dans l'autre et se réunissant par leur base. De ces parties, l'une est externe, el l'aulre interve; toutes deux ont une structure qui leur est propre, et qunil est nécessaire de bien connoître. La partie la pins considérable de la Bélemnite est l'estérieure; elle est de lorme variable, mais d'une structure semblable dans tontes les espèces. Il paroit démontré que les jeunes bílemnites, en soriant de l'œut', étoient pourrics d'une coquille poigtue anx deux extrénuités, el dépourvue de toute espèce de cavité; du moins tel est l'úlat où s'olfrent les jeunes indivillus bien connus de plusieurs espéces; on s'asșure eocore que cela étoit ainsi, en décomposant les Bélemniles, en les plangeant incandescentes. dans de l'eau froide; leur exfoliation devient facile donne ce résuliat : on l'ob:ient eacore en sciant en deux des Belemnites et en polissant leurs surfaces; on parvicat, dans quclques individus, à découvrir le noyau central Jont nous parlons. Ces fails sout confurmes à ce gu'ont observé N1M. Faure Biguet, de Blainville, Miller, etc., et nons-ménes. C'est sur ce noyau central, dont la luase correspond an sommet de la cavieć future de la Bélemnite, que se depose successivemen:, a mesure que l'anital grandit, des couclies extérieures, minces, de plus ea plus grandes, et s'empilant les unes sur les autres comme des cornets de papier. 'Yrouvant dans la présence d'un organe particulier, auruel le noyau est allachi, nnobstacle pour leur réunion à la base de la cnquille, les lames d'accroissemeut se ason'ent sar lui, et donnent naissince à une cavité plus ou moins profonde, sel un les espèces, dans laquelle it est possible de voir les traces des accroissemens; on conçait pourquoi ici ils sunt intérieurs et nnn extéricurs, puisque, comme on le voit, les accroissemens se font à liurerse des aures coquilles. En méne temp's que s'agrandit la cavité de la base, les organes qui y sont contenus se déplacent et produiseni derricie eux des cloisons plus un unoias rapprochées, dont ils ont besoin pour trouver. un point d'appui; mais ils n'y adherent pas, et l'anional ne servit pas lić a sa coquille, si l'organe tendineux, probablement, qui s'attache au noyau central, ne conservoit un passage à travers les cloisons et ne donnoit naissance à ce que l'on nomme siphon, et qui ici se voil sur le borl des cloisons, du cóté ventral ou inférienr, et correspondant à la rainure ou à l'ćchancrure, lorsqu'elle existe.

On est convenn de nommer alvéole l'empilement des clvisons; elles ont toutes la forme d'un verre de montre; el!es sont excessivement minces, et, comme dans les Niantiles et les auties coquilles cloisonnées, el!es laissent entr'elles un espace vide. Les anteurs qui onl cru que les cloisons éloient épaisses, solides et inuédiatement en contact, ont été trompés par une fausce apparence prodaite par l'état de fé́rification cù l'on troure les Béleminites.

'Trois circonstanres se présentent relativement à l'alvéole : ou elle est délruite, co la place qu'elle devoit occuper est remplie de la pile de la roche daus laquelle la Bélemoite a été pétrifíe; ou elle s"est couservée, minis la finesse de la paite, ou une circonstance qu'il n'est pas toujours possible d'apprécier, lui a permis de siuterposer entre lez cloisons san, les d'ranger; ou bien enfin, les cloisons intactes, laisśes en partie ou complé ement vides, sont deveuues un centre de cristallisalion pour le carbonate de claux qui s'y est introduit par infliration, et a revéta la cavité d'une cristallisation régulière, ou l’a remplie par 
une cristullisation confuse. Dans le premier cas, on a pensé qu'il existoit plusieurs espèces de Bélemnites qui, bien que pourrues d'une grande cavité, n'éloient cependaot jamais cluisonaées, ce qui est une erreur. Les denx aulres circonstances ont donné lieu à la supposition que Deluc et quelques autres persozues avoient faite, quil nexistoit aucun intervalle entre les cloisons, hypothèse qui n'est pas plus juste que la prenière. M. de Blainville, cependant, a cru pouvoir affirmer que les Bélemnites de la craie, purvues d'une profonde cavité, n'avoient cependant point d'alvéole, admettant ainsi partiellement une opinion qu'il a voit justement combattue. Nous savons que dans les Bélemuites donl il est question, on n'a jamais va les cloisons; mais nous ne croyons pas que ce soit une raison pour admettre détiniđivement qu'il n'en existât jamais : on pourra même avoir uue forte présouption du contraire, si l'on fait altention à la singulière propriété dont jouit la craie, de dissondre certaines parties calcaires des coquilles, en respectant celles qui paroissent le plus aniunalisées, puisqu'on n'y recroure jamais que la partie corticale, ce qui a conduit naturellement les observateurs à avoir, des corps placés daus celle circonstance particulière, de très-fausses idées. Aussi nous sommes bien persuadés que la règle générale n'a point ici d'exception, et nons présumons que quelque jour la découverte de craic un pen plus périfice, pourra conserver les traces des cloisons des Bélemnites qui s'y trouvent.

La plupart des zoologistes pensent que dans tontes les Bélemnites, la dernière cloison est placéc assez haut dans la cavité de la base pour laisser nu espace vide assez considérable. Celle opinion esi juste pour un certaiu nombre d'espèces, et ne l'est pas pour plusieurs autres; d'où il suit gu'on ne peut la prendre comme caractère générique. Nous avous sous les yeux la preure matérielle de ce que nous disons, et nous croyons qu'il existe, à cet ésard, une grande varialion selon les espèces.

On s'est beaucoup occupé de la structure rayonnante et cristalliue des Bélemnites. Deux opinions se sont établies et se sont étityées de quèlques faits; ceux qui sontiennent la première, prétendent que l'animal a construit sa cociuille telle que nous la trouvons anjourd'hui; qu'elle étoi fornée de fibres rayonnantes qui n'ont point changé de nature malgré le long séjour de la coquille dans le sein de la terre. Les personnes qui défendent l'autre opinion, sont persuadées que l'état actuel de la coquille est dâ à la cristallisatiou du test, augoel l'animal n'auroit jamais donaé une organisation fibreuse : cette structure auroit donc été indépendante de lui et purement accidentelle, ce qui est peu probable. On s'est servi, pour soutenir cette dernièreopinion que partage M. de Blainville, d'un fait qui paroit assez concluant: tous les Oursins fossiles ou pétrifiés, quels que soient les terrains où on les observe, sont changés en spath calcaire cristallisé en rliombe, ae peut-on pas dire, par analogie, qu'il est arrivé de même pour les Bélemnites par leur cristallisation rayonante?

Quoique l'un soit porté à répondre alfirmativemeat à culle question, nous ferons observer, $1^{\circ}$. que les Oursins el les parties qui en dépendent sont très-poreux, et que la cristallisation du carbonate de chaux qui s'est introduit daus les pores a pu entraîuer facilement celle du test lui-même ; $2^{\circ}$. il existe un certain nombre de coquilles qui ont uae structure filureuse analugue à celle des Bélemnites, et jamais on n'a mis en doute qu'elle dépendit de l'animal el non d'une cristallisation fortuite, indépendante. Ces caquilles se rencontrent aussi daus les terrains divers, et pourquoi n'a-t-on jamais dit que leur état dépendoit d'une cristallisalion? parce que l'ou connoissuit parmi les coquilles vivantes une structure anulogue; matis si l'élat fibreux de ces coquilles dépead de leur organisaliun premiere, ponrquoi n'en seroitil pas de même pour les Bélemuites qui se trouvent pétrifiées dans les mêunes couches et placées conséquemment dans les mênes circonstances? II nous semble que, par analogie, on doit conclure en faveur de la première opinion plutôt que de la seconde; elle a besoin cependaut d'ètre modifiée, en cela que les Béleminites ont dû changer de pesanteur par l'jmbibition du carbonate de chux, qui, en se combinant avec la matière du test, à dú aécessairemeat le rendre beaucoup plus lourd. Il est peu croyable, comme semble le penser M. Miller, qu'un animal ait porté une coquille aussi lourde cı aussi compacte, elle seroit le seul exemple qu'on pourroit citer. L'alvéole étoit destinée, dinsles Bélemnites, comme les cluisons dans les autres Céphalopodes, à rendre la coquille plus légere et à la mettre en équilibre dans l'eau de telle sorte que son poids ue soit pas une gêne pour l'animal. Il est incroyable que cela ait pu avoir lieu pour les Bélemnites, en supposant quelles f́toient originairement aussi lourdes que nous les trouvous maintenant; cela est inadnissible, suriout pour un certain nonalse d'espéces dont l'alpiole est trés-petite relutivement au reste de lit coquille. Une autre analogie vient appuger encore loppinion que nous adoptons de prélétrnce, elle est prise du Béloptère dont nous avons déjà parlé : nue de ses parties est fibreuse de la même manic̀re que les Bélemnites. On ne pourroit pas l'attriluter à la cristallisation, persomne n'jugure que janais à Grignon on a trouré de coquilles cristallisées; les Oursins ne le sout mème pas, comme il nous est possible de le démontrer. Le Bélaptère seroit donc une exception unique; ce que nons n'admettons pas; nous pensons, au contraire, que l'état filsreux du Béloptẻre est dû à l'anional, puisqu'il est vrai que cette coguille n’a pu être cristallisée, et, par analogie, 
nons concluons qu'il en a été de méme pour les Bélemnites.

Ce seroit ici le lieu de parler de la place que doit occuper le genre Bélemnite dans la série des Céphalopodes et d'en iudiquer les rapports, si déjà nous ne l'avions fait en pardant de l'opinion de Mi. de Blainville, qui est aussi la nôtre; nous n'arons rien de plus à ajonter.

Les Bélemnites sont généralement calcaires, et cette matière a dans ce geure des qualités particulières dont jouisseut aussi les autres coquilles filsreuses; ainsi il n'est presque jamais dissous, quelle que soil la nature de la rocbe qui l'enveloppe. Les contre-empreintres de Bélemnites sunt très-rares, elles ne se trourent que dans les silex de la craie; alor's la cavité qu'occupoit la Búlemnite est rempllacée par la matière siliceuse, qui ae conserve que très - rarement des traces de l'organisation de la coquille. Si l'on casse on si l'on frolle une Bélemnite, elle répand une odeur particulière comparable à celle que lon perçoit des narbres puans : elles ont ue couleur qui est peu variable, c'est le brun plus ou moins foncé dans les terrains plós adciens que la craje, mais d'une couleur jaune ambrée dans ces derniers terrains.

M. de Blainville a remarqué avec une grande sagacité que la cavité des Wus graude qu'elles se rapprochent par cunséquent d'autant plus des Orthocératites, qu'on les observe daos des terrains plus anciens; tandis que dans les terrains les plus noureaux qui offrent ce genre, sont disséminées les espèces sans cavité, ou dont la cavité est très-petite.

\section{CARACTÉRS GE NÉRLQUES.}

Coqnille droitè, conique, pointue an sommet, tronquéc à la base, où elle présente le plus souveat une cavité courte et conique, contenant une séric de loges iransverses, simples, perforées par un siphau contiuu, ventral. Cuvité de la base quelquefois nulle ou extrêmement courle, et ne contenant probablement dans ce cas, ni cloison, ni siphon dout on ac voil aucune trace. Ouverture ronde ou ovale, sunveut évaséc, très-mince, tranchante, transverse et droite.

Ia géologie peut tirer un bon parti de la conpoissance des Bélemnites qui, paเ leur constance dans certaius terrains, et mêne dans cerlaines coucbes, peuvent fort bien les caractériser et les faice reconnoitre; mais cette science n'a point encore obtenu de ce côté des lésultats qui puissent actuellement lai être d'un grand secours, il fant augmenter le nombre des observations pour soumeltre leus masse is l'esprit d'analogie et en tirer des conclusions géaérales. On a maintenant pour point de départ le résnmé géologique de M. de Blainville : il a rassemblé tous les faits épars daos un granal nombre d'auteurs, ainsi que ceax qui lui ont été commaniqués, encore inédirs, par plusieurs géologues distingués; malyrú tout cela on sent l'iasuffisance de ce qui existe, et il est facile de s'apercevoir que cela tient certainement a l'impossibilité où ont été les géologues de noter avec précision les espèces qu'ils rencontroient; ils les rapportoient presque toutes à đleux cu trois espéces, ce qui a dú jeler dans un grand embarras les zoulogistes qui ont eu à mette en ceuve de tels matériaux. Cet ouvrage étant exclusivement consacré à la zoologie, nous ise pouvons, sans manquer son but, entrer dans de grauds délails sur les conséquences géologiques de l'étude des ljélemnites, nous renvoyons il cet égard al l'uuvrage de M. de Blainville.

La distiaction des espèces du geure dont nons nous occupons est tiès-dillicile. Si quelques-unes se distingucat au premier coup d'ceil, il y en a un grand nombre dout les formes et les autres accrdens extérieurs sont si voisins les uns des auties, qu'il est presqu'impossible de poser des linites entre ces especes. M. de Blainville a reconuu lui-nếne ces diffi ultés, et il a cherché à les surmonter en éludiant avec soin les cirractères les plus constans, au moyen desquels on peut parvenil à distinguer les cspèces véritables, et à ne pas prendre pour telles de simples variétés. Voici, à cct égard, ce que dit l'auteur que nous citons, et auguel nous empruntons textuellement ce qui suit:

" La forme générale du corps de la Bélemnite est d'une assez grande importance; cependant il ne faut pas croire que l'on pnisse en tirer des caractères rigoureux et sulfians pour distinguer les espèces, et à plus forte raison pour les réparti: en sections. En ellet, la mêrne espèce est quuelquefois cylindrique, subfusilorme et même un peu liastée ; quelcuelois son appointissement esten arrière, insensible ou plus rapide, et son évasement ver's l'ouverture commence un peu plus tôt ou un peu pins tard.

" La considération du sommel est d'une valeur plus grande, mais pour cela il faut l'enrisager dans sa position normale, et en ayant égard à ses rapports avec l'axe de la coquille, ainsi qu’à la manière clont les lignes ventrale et dorsale contribuent it le former. Son prolongement mucroné ou non, la forme de sa poivie, les stries simples ou donbles que l'on remarque dans ses ligues ventrale ou dorsale, fuminissent d'assez bons caraclères, mais de moiudre valeur que l'absence ou l'existeuce des cannelures de ses côtés, qui peuvent cependant être plus ou moins marquées.

„On trouve si rarement les Bélemnites avec lenr base complète, que je n’ai pu employer la considération de l'ouverture que dans ụn très-petit nombre de cas. Il ne faut cependant pas nier que es caractères qu'elle fournit ont noe véritable Q 2 
124

B E L

importance, suivant que sa forme est ovale, ande, subtriquètre ou mềne subtélragonale.

"L'intégrité ou l'échancrure plus ou moins prononcée, c'est-a-dire fissurée et canaliculée, de son bord, niont fourui des caracleres de premier ordre par la grande constance de celte modification.

"La forme de la lissure ou de la cannelure, qui part ainsi du bord de l'ouverture d'une Béletunite, fournit de fort bons caractères, suivant que elle est arrêtće brusquewen!, ou continuée et perdue avaut le sommet, ou prolougée jusyu'au sommet.

* La cavité d'une Bólemnite a'est pas non plus à aégliger, et il faut la considérer, non-seulemeni dans sa furme générale, conique, évasée, dans la position de son sommet par rapport avec l'axe de la coquille, mais eacore dans sa proportion relative avec la coquille en totalieé. Je ne dois cependaut pas cacher yue, si dans certaines espèces celle proportion est assez fire, il en est d'aulres où elle est sujelte à un assez grand nombre de variations; alors le sommet est ce que j’ai appelé plus ou moins surchargé. J'え̌ d'abord que cetle proporiou étoil fixe, ou ne varioit du unoins que dans des limites assez rapprochées, mis de nombrenses observatious mont parfailemeut convaincu du contraire.

^Je ne puis dire si la forme des cloisons, leur nombre, ainsi que la position du siphon et sa forme, fourniroul de bons caractères, ce qui se peut concevoir'; mais on trouve trop rarement ces parties bica conservées, pour qu'il m'ait été possible d'acquérir à ce sujet quelque certitude.

- Quarat à l'alvéole, on peus faire l'observation quelle tradisit fort bien la cavité dans laquelle elle s'est formée, et que l'on peut aussi s'en servir ponr connoitre celle-ci, mais sans autre iupertance.

n Eufin, il ne faut pas non plus entièrement néçliger l'élat minéralogique de la Bélemnste, ćest-à-dire sa structure lien radiée ou plus on moins spathique, non plus que la conleur et la transparéace, car les espèces les plus ancieunes me paroissent èrt les moins fibreuses, les moins blundes ct translucides, tandis que les plus modernes le sont au contraire toujours bien davantaje. "

Telles sont les considéralions importantes et les justes observatious dont .1. de Blainville a fait précéder la description des espèces, dans le bean travail dout nous avons eu si souvent occasion d'apjrécier le mérite. Nous a vons cru, dans l'intérêt de la scieace, ne pouvoir mieux faire que de présenter sans changemens ces considéralions, qui doivent servir de priacipes fondamentaux pour la distinction des espèces, et que nous avons nis utilement en pralique pour les espèces que nous aillons décrire. M. de Blainville, comme nons l'arons dit, en a fait connoitre plus de cinquante es-

\section{B E L}

pèces dans sa monographie; ne les ayant pas toutes sons les yeux, nous n'en décrirons qu'uu nombre suffisant pour donner une bonne idée des diverses sections élablies dans le genre. Nous admettons celles proposées par II. de Blairiville, à l'exception de la troisicme : nous avons dit pour quelles raisons nous la rejetions.

\section{$\dagger$ Espèces sans cavité.}

I. Bézemite pleive. Belentnites plenus. Braist.

B. testâ fusiformi; basi angustâ, obsoletè bicanaliculutá, convexâ, plenâ, radiatin subreguluriter striatâ. Nов.

Buarso. Mém. sur les Bélenmites, par. $5 \mathrm{~g}$. no. 1.pl. 1. fgg. 6.6. $a$.

MirLer, Ml'm. sur les Bélemnites, Mém. de la Soc. géol. de Londres, juillel 1326.

Ранкікso», Organ, rem. tom. 3. pl. 4. fig. 19.

Beudant, Observ. surles Bélem. Ann. du Mus. tom. 16. pl.3. fg. 8. 9 .

Cette espèce est la senle qui puisse eutrer dans celle première section, elle est très-facile à distioguer de ses congénères; elle est fusiforme, pointue au sommet, rétrécie à la base, où elle est pourvue de deux cannelures peu profondes, obsolètes, qui s'ellicent assez pro:aptement sur la longueur du test. Sa base est on ne peut plus remarquable, non-seulement elle est dépourvue de cavité, mais elle est convexe, et quel que soit son áge, on la troure toujours dans le mêue état. Du centre de celte base partcat en rayounant des sillons subréguliers et presque symétriques. L'axe de cette coquille est presque central dans toute sa longueur. C'est d'après cette espèce, qui d'ai!leur's a tous les autres caractères du geare, que II. Beudant s'étoit fat l'opinion que les Bélemnites sont des pointes d'Oursins. M. Niller, non content de rejeter l'opiuion que nous venous de rapporter, croit pouvoir proposer pour cette seule especce nn genre particulier, a uquel il donne le nom d'A rrixocasax, que M. de Blainville z"a puint adopté, ct que uous n"adopterons pas non plas, parce quil ne présenie pas de caractères suffisans pour un bon gemre.

t† Espèces a carité très-petite, fissuréb sur le

2. Béteunite de Scanie. Belemnites Scanice. Bensvv.

B. testâ elongato-conicâ, obscurè triquetrî̀, basi subangustatû, vix excuvatâ; aperturâ subtriangulari; mergine ventrali fissunì mediocri, angusiâ, diviso; apice acuto, foramirus ofato teminato. Nов.

Blarvv. loc. cit. no. 2. pl. 1. fig. $7 \cdot 7 \cdot a$.

Brouen, Minér. et Lithog. suec. pag. 5̆. 
Coquille obscurément triangulaire, peu alténuée a la hase, quoiqu'elle y soit plus rétrécie que dausle milieu; cette base est un peu oblique, elle est creusće par ane cavité peu profonde, dunt les bords sont épais; elle est subtrigone, et sun ceutre, très-enloncé el très-étroit, gagae assez lıat l'intérieur de la coquille; il eu part une lente étroile, peu profonde, plus rétrécie eu dedans que vers la surlace extéricure; en dehors aucune strie ou sillon n'y ahoutissent. Depuis la base jusque vers les deux tiers, les diamcires de cetle bélemnite augmentent insensiblement et dimiauent ensuite assez promplement jusqu'nu sommet; celui-ci, assez aigu, se termine par un pore uvale, excavé dans le milieu.

Celte curieuse espèce n'a élé lien connue que depuis le voyage en Scanie de MI. Bronguiarl; ce sarant géolugue en a recueilli un assez grand aumbre d'individus de divers âres, dans la crraie, à Ignaluerga; il a eu l'extrếme bonté de nous la comusniquer.

5. BiLeMxite granulée, Belemnites grarulatUS. DEF.

B. testú crlindraceâ, granulosâ; basi subattemuati, brevifissâ; apice obtuso, mucronato, aluquantisper placato. Ков.

Buaixr. loc. cit. no. 5. pl. 1. fig. 10. 10. a.

On doil la connoissance de celte espece interesiante aux recherches assidues de $\mathrm{N}$. Giaves, qui fait à Benuvais une collection fort remalquable des fussiles du départexent de l'Oise; il l'a conmuniquée à II. Defrance et à nous, et cest par ce savant qu'elle est veune à la connoissance de Ml de Blininvillc.

La Búlemuile granuléc est rylindroide, à peine rélrécie à la base; elle augmente de volume jusque passé la moilié de la longuenr; elle diminue ensuilc peu à peu pur se terminer par un somuet arrondi, olsus, mucroné dans le centre, qui se termine parfois par ua pore dont la base est lógèrement froncée. 'Tonte la surfice extéricure esi fivement chagrinée, ce qui fait reconnoitre l'espèce avec une extrếme facilité. La base de certe coquuille présente une cavité peu profonde, quii l'est plus cepentant que dans la précédente; s in bord uflie une fissure très-petite, qui se continue par un léger sillon.

On la trouve dans la craie des environs de Beauvais.

4. Bézenatr striće. Belennites striatus. DEF.

$B$. testâ elongato-conicâ, gradatin attenuatâ, striatô; striis longitudinalibus tenuissimis; cavitate minimâ, subtriquetrá. Nов.

BLaIst. loc. cit. $n^{\circ} \cdot 6 . p l$. 1. fig. 11. 11. $a$.

On ne conuoit de cette espèce qu'un seul incliridu iucomplet de la collection de N. Defrance, qui l'avoit rès-bien distingué el lai avoit donné le nom que M. de 13lainville a adopté. Cet individu ćtant wutilé à sa partie postérieure seulement, il a été possible d'en caractériser l'espèce de manière à la reconnoitre facilement. Elle est alongée, conique, plas large à la base que partout ailleurs; sa coupe transverse est ronde, aussi bien que son ouverture; celle-ci a les bords tranchans et sans aucune fissure; la cavité de la base est peu prolonde, obscurément tiiangulaire et ressemble beancoup à celle de l'espèce précédente, si re n'est qu'elle n'a point de fente à son bord ventral; tonte la surface extérieure est finement striée en longueur. Comme le sommet est tronqué, on ignore si les stries s'étendoient jusqu'à Inì.

l'ossile dans la craie de Chimey, en Champagne.

$$
\begin{aligned}
\text { tft Espèces à cavité grande, cloisonnée, } \\
\text { siphornée. }
\end{aligned}
$$

\section{Une filure sur le hord.}

5. Bélenvite mucronée. Belemnites mucronatus.

B. testâ elongatâ, conicâ, apice acutâ, :mucronatầ; aperiurcî rotundutâ, delatatấ; fissurấ tenuissimâ, sulco brevi continuatâ; sulcis vascularilus irnegularibus impressis. Nos.

Branv. loc. cit. $n^{0} \cdot 7 \cdot p l \cdot 1 \cdot f g$. 12.12 a. $12 \mathrm{~b}$.

Ihid. Cur. et Broxg. Géol. des env. de Paris. pl. 3. fig. 1. a. b.

Ihid. Schlotreim, Petrefuct. $n^{\circ} .4$.

PARMinson, Organic remains. tom. 5. pl. 8. fig. 10 et 12 .

Manted, Geol. of Sussex. pl. 16. fig. 1.

Belemnites electricus. MrLLER, Mém. sur les Bélem. dans les Mérn. de la Soc. géol. de Londres, juillet 1826. pl.8. fig. 18 à 21.

Var. B. Testâ majore, subgranulosâ, sulcis 'ascularibus numerosioribus.

Fadjas, Hist. nat. de la montagne SaintPierne de Maestricht, pl. 52. fig. 5.

Nous ne partageons pas l'opinion de M. de Blainville, qui croit que celte Bćlemuite, ainsi que la seni-caniculé, est dépourvue de cloison ct de siphon: quoique l'on en ait pas encore trouvé de trace, nous sommes conraincus que equelqne jour une circonstance plus heureuse fera découvrir l'existence de ces parties. Depuis long-temps que nous étudions avec beaucoup de soin, et dans unbut particulierles Fossiles de la eraie, nous nous sommes aperçus que certaines parties intérieures des coquilles qui s'y trouvent, disparoissent constamment; et il est d'autant plos difficile d'en constater la première existence, qu'elles se rédnisent presque toujours en une poudre blanche, qui 


\section{6}

B E L

se confond très-facilement avec la sabstance de remplissarrc qui est elle-même sous cette forme. 11 paroit au reste que MI. Miller a rencontré cette espèce de Bélemnite avec des cloisons et un siphon; il en parle d'une manière non équivoque. 11. de Blainville croit que c'est par analogie et par conjecture : nous ne royons pas pourquoi M. Miller auroit indiqué des parties qu'il n'auroit point vues.

Ia Bélemnite anucronée est certainement l'espèce la plus communément répandue dans la formation de craie. Elle est alongée, conique, quelquefois subcylindrique; la coupe traosverse est arrondie, son diamètre se rótrécit vers le quart antérienr', et s'élargit un pen vers l'ouverture et quelquefois vers l'extréunité opposée, mais cela est peu ordinaire. L'onverture a les bords extrêmement minces: uussi il est très-rare de la trouver entière. Ell e est parfaitement ronde dans un individu enlier que nous possédons. La cavité de celle Bélemnite est griude et profonde; dans son intérieur, et aux extrérnités du diamètre dorso-ventual, on remarquue deux silluns qui se dirigent vers le sommet; l'un d'eux est plns superticiel, l'autre, plus profond et plus étroit, aboutit antérieurement à une fente qui divise lc bord; cette fence est fort étroite et partage tonte l'épaisseur du test dans une étendue de plus de dix millimètres, et elle se termine en delıors par un sillon étroit, profond qui a un peu plus de longueur qu'elle et qui s'arrête bruiquement. On remarque sur les parties latérales deux silloas profonds qui s'éleadent depuis la base jusqu'à plus de la moitié de la lanteur : ils se sous-divisent en un grand nombre de brauches qui, parleurs noubreusesanastomoses, présentent l'aspect d'un réseau vasculaire, dont ces sillons sont certainement les traces. Dans quelques vieux individus, $c \theta$ résean s'étend sur toute la surface de la coquille, et les anastomoses sont si maltipliées qu'elle semble cbaurrinée; c'est ce que l'ou remar'que surtout dans les individus de Maestricht et cle Cypli, ce qui, joint à leur taille constammeat plus grande, nous a déterminés à en faire une varićté dont nous avons vu déjä plusieurs individus. Le sommet arrondi, obtus dans le plus grand nombre qui sont probablement incomplets, se teruiuse en pointe aiguë au sommet de lacjuelle un trouve un très-petit pore arrondi et assez profond.

Longuenr go à 100 millim., diamètre de l'ouverture i 5 à 18 .

Longueur d'un individu entier de la variélé 132 millim., diamètre de l'ouverture 20 milliza.

On trouve celte espèce dans la craie à Mleudon, Mantes, etc. , à Ilsebourg en Prusse, à Aixla-Chapelle, ì Oldenbourg, dans l'ille de Rugen, dass celle de Blasberg, aux envirous de Bruxelles, de Grodno, etc. eté. La variété paroît jusqu'à présent provenir exclusivement de la moatagne Saint-Pierre, près Maestricht, et de Cypli; celles
B E L

de celte deruière localité nous ont été commaniquées par MI. Duchastel de Versailles.

6. Béleantre semi-caniculée. Belemnites semicanaliculatus. Braivv.

B. testâ elongato-acutâ, lateribus depressâ, basi subattenuatâ; aperturî ovatâ, margine fissâ; fissurî minima, sulco ventrali in medio cochlea evanescente, terninatâ. Noв.

Bц.1nv. loc. cit. $\pi^{\circ}$. 8. pl. 1. fig. 13. 15. a.

Cette cspèce qui se trouve dans la craie chloritée a autaut de rapports avec: les suivantes qu'avec. l'espèce qui précède, et si M. de Blainville n'avoit été conduit à penser qu'elle étoit dépourvue d'alvósle, il l'auroit cerlainement rangée dans sa quatrième section, Elle est de forme alougée, conique, atténuée à la base, déprimée latéralement, ce qui donne une forme avale à sa coupe transverse, ainsi qu'à son outerture; depuis la base jusque ver's son liers postérieur, elle augracnte peu it pen de volume et se terwine easuite par un sommet puintu: la base est percée d'une cavité simple et profonde dont le bord est fendu, mais peu profondément. Celle fento en debors aboutit à un sillon étroit d'abord, et qui s'élargit et s'aplatit insensiblement jusqu'au nilieu cle la coquille on il disparoît. Elle se trouve à SaintPaul-'Trois-Chitteaux; elle est longue de 8 à 9 centinètres.

7. BÉLeutite d'Altdorf. Bolenonites Altorfensis. BLainv.

B. testâ elongatâ, conici, apice acutâ, subquôdriluterâ; latere ventrali latrore, sulco lato, de basi usque apicem instructo.

An Belemnites canaliculatus? Scuцоти. Pe= trefuct. $\pi^{c} \cdot 7$.

Schnater, Einleint. 4. tab. II .

Belemnites sulcatus. MiLnen, loc. cit. pl. 8. fig. 5.

Buanvillee, lac. cit. no. 9. pl. 2. fig. 1. 1. a.

Il est peu douteux que le Belemnites canalicu. latus ne soit la même espèce que celle-ci; mais nous pensons que c'est arec justice que M. de Blainville a changé ce nom pour empècher la conlusion, puişu'il pourroit être appliqué à plusieurs especes distinctes.

Lia Bélemuite dont il est ici question est assez grande, et d'une teinte qui paroît assez coustamnieut d'un brun foncé; elle est rígulièrement conique et subquadrangulaire dans sa coupe transverse; de ces faces, la rentrale est la plus large, la dorsale la plus étroite et la plus arrondie. Sur le milicu de la lace ventrale, on remarque un large sillon qui s'étend de la base au somauet; celui-ci est assez aigu ou peu porté en arrière dans les vieux individus, et paroît dépourvu de pores et 


\section{B E L}

de sillous; la base n'est connue qu'imparfaitement à cause des matilations. Dans un jeune individu de notre collection, elle se dilate assez sensiblement el dome lieu à une onverture ovalaire plus litrge que haute; le sillon ventral s'ilplabl el a une tendauce à s'ellacer à mesure qu'il en rapproche. M. de Blainville rapporte à celle espere des individus des euvirons de Caen qui ont la plupart de ses caractères; cependaut plusicurs nous semblent assez iunportans pour mériter d'en faire une esjuèce distincte, parce que, $t^{\circ}$. le sillon ventral es beaucoup moins large el ne va pas jusqu'au sommel; $2^{\circ}$. le sommel est beancoup plus aigu, sub-mucroné; $5^{\circ}$. le sillon loin de s'ellicer à la base devient au contraire plus proloud, et se ternine par une feule étroite, qui divise toule l'épaisseur du bord. Si nous avons été dans l'erreur en séparant ces deux espèces, il faudra tout au moins faire de celle deruiére ane tris-furle variélé de celle-ci.

Louguenr 1 l cenlimètres, diamètre de la hase 21 millizn. On la truave en Suisse, el communéwient en Allemagne daus le puj's d'Cuningen et de Closterlsanz.

3. Bélemite aiguë. Belenuites acutus. Buarvv.

B. testá elongato-conicu, acutissumá, luteraliter subcompressí; sulco unico, angusto, 2'enmalide busi ad apicem decurrente; margino fisso? N̈ов.

\section{BLainv. loc. cit. no. 11. pl. 2. fig. J. 5. $a$.}

11 nous semble que M. de Blainsille a compris au moins deux espèces dans celle-ci, et dans la description qu'il en donue, on s'en aperçoil en comparaut ce qu'il dit à la fin des individus quil a vus dans la collection de M. Roissy avec ce qu'il dil au commencement sur ceux de la coliection de II. Desnoyers. Nons nous trouvons cucore dans un autre emluarras : en s'en rapportaut iniquenent à la figure clonuce par M. de I3lainville, nous n'izzorons pas guels sout les Búlemnilcs que nous devons y rapporle:; mais des individus d'une espèce bridemneul distincle, et dont H. de Blainville a eu la possession pendaat son travall, nous ont élé rendus portant sur

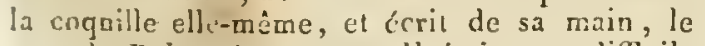
nom de Belemnites acutus. Il b́nil assez difficile de se détcrminer entre ces deux Bélemuiles; nons croyous quall esl conrenalale de conserver le nom à celle qui a élé tignrće, car dans l'incerlinde où laisse la descriplion, ce serala fiutre qui décidera. Nous someses obligés de donner ces délails prèliminaires, ponr faire apprécier le inntif de la différence, entre notre description el celle de B1. de Blainville.

La Bélemnite aiguë ne paroît pas atteindre un grand volune; elle est alongée, subfusitorme, légèremon: dilatée à la base, et terninée en cóne aigu. Le sowuet aigu, mucroné, 'h'a ni stries ni pore, est parfaitement central. Parla coupe transresse on voit que celle coquille est hicu arroudie, cepeudant clle est un peu aplatie latéralement, mais Q'une manière à peine sensible. Un sillon médian, profond à la base de la coquille, parlage la lace ventrale jusque près du sommet, ou il disparoît : il occupe les liois quarts antérieurs de la coquille, ou un peu plus, mais il n'alteint pas le sommet lui-même. Dans un individu assez complet, et encore jeune, le sillon partage prescjue complétement le bord de l'ouverture qui, quoique casséc dans cel endroit, nous laisse la conviction meque certaiue qu'elle avoit me lissure élroile ct courte. Sa calití est assez grante, son sommet est central; elle office un sillon médiau qui suit la direcrion de celui du dehors. Les individus gue uons avons de celle espèce vicunenl de liayeux, près Caen. Le plus grand a gualre-vingres nillim. de longueur, et qualorze de diametre à la base.

9. Bézenvite hastéc. Belemnites hastatus. Bi..

B. testâ clongatâ, fusịfurmi, postice compressá, inflat $\hat{x}$, ad basim attenuatâ, angustatâ; uperturâ. dilatatâ; sulco unico, in medio profundo, triangulari, ad aperturam et apicem evanescente. Nos.

Buariv. loc, cit. no. 12. pl. 2. fig. 4. 4. $a$.

M. de Blainville n'a comu gue des tragnens de celle espóce, depuis la publication de sun trdvail, nous en avons acquis plnsieurs beaus iudividus qui viennent de Bayeux; ils ont près de sept ponces de longueur, el la base cst inconplète; mass un lragment dont nous ignorons la lucalité nous l'ollie presplue entière. Celle coquille est fusiforme, eullée postéricurement, beancoup plus ŕtroite dans son nilien, et entin dilutée de nouveau à la base; mais celle base n'a pas un aussi grand diamèlse que la partie postélicure; elle a en un mot assez bien la forme dun fer de lance. Sa base offre une onverture dom les bords minces sont dilatés d'une manière notalsle; cile est ronde ou prescue ronde. Sa cavilé est peu connue, élant ou cassce ou remplie d'une matière très-dure dans les individus yue nous arons vas; on sait cependaut qu'elle e'st ussez courle, et que son sommet est central. Après cellc dilatation de la base la cocuilie diminue peu à peu de volume jusque vers son tiers inferrieur; elle resie à pen prćs cylindrique dans loul ce trajet, counrence anguenter de nouveau en s'aplatissant un peu, el son diamètre devient plus considerable cju'il n'étnit ì la base; elle augnente ainsi graduellemen! jusejuaux Irois guarts de sa longueur, et se termine enfin on poinle aiguë, siaple, avec une petite troncature, ou un pore lrès-superficiel. Un sillon superliciel à sa base, profond et triangulaire dans le milieu, dininuant ensuite jusqu'au quart postérienr où il se termine, partage la face rentrale en deux parties cgales. 
Longueur dix-sept centimètres et demi, le plus grand diamètre viogl-deux millim.

A Bayeux, anx Vaches-Noires. En Angleterre.

10. BéLe uñte de Blainville. Belemnites Blainvillei. Nов.

B. testâa elongato-conicâ, acutâ, lcevigatâ, depressâ; sulco unico, ventrali, angusto, de apice ad basim continuo.

Nous avous dit, en parlant des Belemnites acutus, pour quels motifs nous en avions relevé quelques individus qui doivent faire une espèce distincle. N'ayant trouvé aucune indicalion qui pût s'y rapporler, nnus la regardons comme nouvelle, et nous nous plaisons à la dédier au savant auteur de la Bélemnitologie.

Nous ne connoissous que deux individus de celte espèce : ils sont tous deux de même taille, et paroissent adules; ils sont courts, et plus lar'ges à la base que partout ailleurs : le diametre ne diminue que très - insensiblement jusque vers le tiers postérieur, et ensuite assez rapidement en pyramide dout le sommet est très-aigu. Ils sont comprimés latéralement de manière a ce que les cótés présentent deux neéplats bien sensibles à la vue et au toucher; cette compression latérale donne à lit coupe transverse de celle espèce une forme subquadrilatc̀re, ou plutôt ovaliire. Sur la face ventrale se voit depuis la base jusqu’à la poiute une rainure étroile el peu profoude, qui diminue graduellement, et qui se termine au sommet arec la coquille elle-même. L'ouverture n'est point dilatée; la cavité est assez profonde, sou sommet est au centre, el elle n'est point ovale comme la cocfuille, mais arrondie, ce qui se roit très-bien par la dillérence d'épaisseur du test des côtés avec celui de la face dorsale ou ventrale.

Longuene soixante-cinq millim., graud diamètre de la base treize inillita.

Elle se trouve assez rarement à Vieux-Pont, près de Bayeux, dans une coucle argileuse.

\section{Noв.}

I. Bélemine bipartile. Belemnites bipartitus.

$B$. testâ minimâ, elongato-conicâ, lateruliter d:pressia; sulco unico, profundo in utroque latere de basi usque apicem; altero minimo abbreviato, yentrali; catritate angustâ, profündâ.

Pseudobèle biparlite. Pseudobelus bipartitus. Blairv. loc. cit. pig. 115. $n^{\circ}$. 3. pl. 5. fig. 19. 19. a. 19.6 .

Il est probable que M. che Blainville n'a connu ce corps que très-imparfuiteunent de toutes les manieres: d'abord, il n'a pas reconou sa structure fibreuse, ce qui l'a délerminé à le placer dans son gence Pseudobèle; eusuite il n'y a reconnu aucune çapité aualogue à celle des Bélemaites, et n'ayaut eu à sa disposition que des troncons incomplets, il n'a pas vu le sommet.

Celte petite Bélemnite est fort singulière; elle est alongee, conique, aplatie sur les côlés, terminée au sommet en pointe aiguë. Dans le milieu de chaque face latérale on voit un sillon étroit et profond, mais plus à la base qu'au somwet, qui s'étend daus toute la longueur; comme ces deux sillons se correspondent, ils partagent la coquille en deux parties, donc la dorsale cst un pen plus épaisse el un peu plus large. Sur la face ventrale a la base seulement, et sur une étendue du quart de la longueur totale environ, il existe ua petit sillon bearcoup moins profond que les autres, il diminue peu à peu, el disparoît à l'endroit que nous avons dit. La coupe transverse est subtétragonate, plus large que baule. Nous ne connoissons pas l'ouverture dans sou intégrité, mais nous croyons qu'elle a'est pas dilatée; la cavité n'est pas tou-à-fait centrale, elle est arroudie, coniçue et profonde pour une aussi petile espèce.

Longueur trente-quatre millim., grand diam. de la base cinq millim. Il y a des individus un peu plus grands.

M. Elie de Beammont a trouvé celte espèce à Chadres, au sud ce Serres, dans les Hautes-Alpes. M. Marmín nous ea a comrouniqué un indivi:lu venant de Castellane; c'est celui que uous venons de décrite.

$2^{\circ}$. Espèces sans gouttière à la base ou sur lune desfaces, mais avec des sillons au sommet.

12. Bélemarte bicanaliculée. Belemnites bisulcallus.

B. te:tâ elongatâ, crassâ, cylindruceo-conicấ; aperturá subdilutatâ, rotundutâ ; upice ob̉tususculo, sulcis duobus, lateralubus, bipartito; pate dorsali majore. Nов.

Brainv. loc. cit. no. 19. pl. 2.fig. 7. a. b. c.

Cette espèce est bien certainement une des plus communes en France, cu Allemagne et en Angleterre. Sans acquérir un bien grand volume, on en trouve qui ont près de cin'q pouces de Innugueur : ils sont alongés, coniques, plus larges à li base que partout ailleurs; leur coupe lransverse est ronde. Quelques individus, les plus vieux surtout, duniuent d'abord peu sensiblement, ce gui les rend subcylindriques dans une parlie de leur longueur; le sommel, terminé en une pointe un peu obtuse, olfie toujours deux sillons en goutcière qui s'elfacent en descendunt, ct qui se parlagent en deux parties inégales; l'une ventrale, plins petite el moins épaisse, l'alitre dorsale la dépasse de beaucoup et la cache complétement si lou regarde la coquille du cóté du dos. L'ouvertare est ä peine dilatée, les bords en sont minces; la cavité est peu profonde, ellẹ se di- 


\section{B E L}

rige un pen vers le dos Lors de la dircction cen. trale.

I.ongueur douze ì treize centimètres, diamèwe de la base vingt-deux à vingt-rjualre millim.

On la trouve aux cnvilons de Nancy, dans les Ardennes, aux environs de Cueu, de Bayeux, à Mendes, départeraent de la Lozère, etc. etc.

15. BÉLeMsite unisillonnée. Belennites unisulcatus.

$B$. testầ elongatâ, angustầ, snbcylindrace $\hat{\imath}$, acutâ, busi subdilatatâ; sulco unico, dorsali, postico, terminali; duobus alteris anterioribus, superficiulbus, bipartitis, lateralibus.

An Belemnites unisulcutus? Brainv. loc. cit. $n^{\circ}$. 20. pl. 5. fig. 21.21 . «.

1.a localité d'où viennent les individus que Dous possédons nous fait croire, ainsi que quelques caractères qui s'y accordent, qu'ils sont de la mème espice que ceux qui furent communiqués par M. de Roissy à M. de Blainville, et auxquels il donna le now de Belemmites unisulcatus. Cet auteur la caractérise surtout par sa forme alongée, étroite, obscurénent subquadrilatère, sa base un peu évasće, son sommet pointu qui olfre un seul sillon peu profond, dorsal, qui descenct assez bas sur la coquille, et par un autre sillon ventral qui va de la base jusque ver's le sommet. Ce qui est parliculier, c'est que ce sillun est formé de deux très-fins sépurés par une carène étroite. Ces caractères suffisent certaiuement pour bien distinguer celte espèce.

Nous possédons plusienrs individus qui ont une forme absolumeut semblable à ceux cue 11 . de Blainville a décrits; ils provienuent du nême lieu, et au lieu d'avoir un sillon dorsal et terminal, ils en out deux latéraux superliviels qui s'étendent de la base jusque vers le sommel, et qui sont l'un et l'autre bipartites, comme le sillon unigue indiqué par M. de Blainville. Ces deux sillons, qui sout bien symétriques, ne partagent pas la bélemuite en deux parties égales, la partie dorsale étant la plus grande. Malugré les dillérences que nous venons de sigaaler, il servit possible cependant qu'ils appartinssent à une seule et nềme espèce, et voici sur quoi nous nous fondons, c'est qu'il n'est pas rare de rencontrer des iudividns un peu roulés, ou usés d'uo côté seulement, de manière à ce qu'ils ne présentent plus que la partie apicale de l'un des sillons latéraux, d'où est venue probablement la description de $M$. de Blaiaville. Nous dunnons ceci comme un doute, et nous a'avons pas tous les élémens nécussaires pour le lever. Dans le cas où il se changervit en certilude, le nom donné par MI. de Blainville devra être changé, car il pourroit occasionuer des erreurs; dans le cas contraire, les individus que nous possédons devront constituer uue espéce distincle.

Hist. Nat. dis Vers. Tone II.
Longuear 50 millim., diamètre de la base 7 millim.

Des environs de Caen et de la Pissole, près Fontenay, département de la Vendée.

14. Béleiuntte de Miller. Belemites Millori. Non.

B. testâ crassâ, conicâ, subelongutâ, basi latiore; apice subacuto, sex sulcis instructo, duobus longioribus et lutioribus.

Cette espèce est si bien caractérisće, qnuil est impossible de ne pas la distiugruer au prenier alourd. Sa laille considćrable la rapproclie de la Bélemnite comprimée, ou de la Bélernnite gigantescjue. Elle se distingue cependant de l'ure et de l'autre; elle est épaisse, régulièreınent couique, assez courte relativement au diamètre de sa base. La base ést la partie la plus large, la coquille diminue graduellement, et elle prend la forme f'un cône régulier, dont le sommet est un peit incliué vers la face ventrale; elle est légèrement déprimée sur les côtés, ce qui donne ì sa coupe transverse nae forme à peine ovale, puisqu'il u'y a qu'une ligae de dillérence dans la longueur. de's diamètres. Le sountnet, assez fortement comprimé, se termine, dans un individu bien entier de ce côlé, que nous possédons, par un assez grand pore ovalaire auquel aboutissent six sillons parfuitenient symétriques, rrois de chaque côté, aucun n’étant impair ou médian. De ces sillons uue paire est dorsale, ce sont les plas petits; la seconde paire est latérale, ils sont plus profonds que les deruiers, tt plus ver's le dos que vers la face veutrale de la coquille; entin, la troisième paire est ventride, profouds au sommet, ils s'élargissent, deviennent superficiels et descendent à peu prèr jusqu'au ticrs de la longueur-de la coquille. La cavité est assez grande, el l'alvéole qu'elle renferme a les cloisons irès-serrées: nous en avons compté trente-quatre dans une longueur d'un ponce et demi. Quoiçue par le sommet elle se rapproche de la Bélemnite quiuqué-sillonaée de M. de Blainville, elle ne peut cependant se confondre avec elle; il sullit, pour s'en assurer, de comparer les deux descripiions.

Longueur 13 centimètres; elle devoit avoir au moins quatre centiuc̀tres de plıs, à en juger par la troncature de la base: grand diamétre de la base 58 millimetres.

Des eovirons de Besançon, du Jura.

I5. Béledntte compinée. Belemnites compressus. Bratwv.

$B$. testâ magnâa, elongatâ, conicâ, lateribus compressî̀, busi subdilatatâ; capice acuto, centrali, bisulcato; sulcis lateralious, sensim cyanescentibus.

Brasvv. loc. cit. no. 24.pl. 6. fig. 9. 9.a. 
KNorr. Monum. Suppl, pl. 4. fig. 15.

La B celles de ce gevire qui acquièrent le plus grand volume; elle se distingue cependant et de la précédlente qui ne paroît pas alteindre une aussi grancie taille, et de la Béleminite giwantesque, qui n'a plus les niêmes caractìres. Celle-ci est fort alongée, conique, diminuant inscnsiblement de la base, qui est la partie la plus large, justye vers les trois quarts de sa longuenr, dans cet endroil; du moins dians les vieux iodividus que nous avons vas, la diminution devient píns subile, et la coquille se termine en pointe assez aiguë. Le smmet est sulcentrul, un peu a plati, et présente deux sillons, un de claque côté, d’abord étroits et assez profonds, s'élaryissant ensuite et s'ellacaut peu it pet en descendant jusque sur le quart de la longueur. La base est notablement dilatée, et clle ollire une ouverture presque roude, beaucoup moins ovale que la coupe tranverse de la cuquille faile au-dessus de la cavilé. Cetle cavité cst grande, conique; sour. sommet, qui est trèsnigu, ne se dirige pas vers le centre de la coquille, mais va obliquenent à l'uxe, qui lui-même n'est pas ceutral. Les cloisons que celte cuvité renferme sont très-rapprochées, surtout au sommel. Nous possédons tros morceaux de cetre Bélemnite; le pius grand a plus de luit pouces de longrueur ; il est cassé au sommet et à la base : en supposant ce qui lui manque, il doit avoir plus d'un pied de long. Quoique sa base soit tronquée assez liaut, elle ne laisse pas que d'avoir près de vingt lignes dans son grand diamcitre. Cette espèce se trouvc à Bayeux et à Caen, dans l'oolite ferrugineuse, et à Auerbach en Bavière.

\section{BÉctuntre de Prevost. Belemnites Pre- vosti. Nor.}

B. testì elongato-conicâ, angust $\hat{a}$, subclavatâ, levigatû; apice ucuto mullustriato; stris teruissimis, profundis.

Nous dćdions celle espèce remarquable ì notre ımi M. C. Prevost, géologue distingué. Le sommet de celte coquille li rend vraiment remarquable; aucune autre des espèces que nous connoissons, soit en nature, soit par les descriptions, ne présente rien de semblable. 11 est strié dans tonte sa citconférence; les stries sout fines, nombreuses, longitudinales, d'autant plus profondes, ฯu'elles s'approchent davan tage du sommet, \& tellement profoudes quand elles sont parvenues à son extrémité, qu'elles le divisent dans toute son épaisseur; ces stries, qui sont au nombre de vingt, a arriveat pas toutes à l'extrémité, six principales y parvienneat, et le parlagent en six lobes égaux et symétriques. La base est un peu dilatée, l'ouverture cst arrondie et la cavité est petite; au-dessus de la base, le diamètre diminue légèrement, et il augumente ensuite peu à peu jusqguau tiers posté-

\section{B E L}

rieur. Toute la coquille est grêle, cylindracée complétement lisse hors le sommet. Elle a 55 mil. limètres de longueur, sur 5 seulement de diamètre à la base. Nous ignorons d'où ellè vient.

17. I3Écemnite alène. Belemnites subulu. Noв.

B. testâ elongato conicâ, lavigatâ, apice subulatâ, trisulcatâ; sulcis duobus lateralibus obsolitis, terfio dorsali, longiore et profondiore.

Cette espèce, que M. de Blainville n'a pas comnue, à ce qu'il paroît, se distingue très-facilemenı. Nous nien connoissons print qui ait le sommet plus aigu. Louverture et la base nous sout in connues, les individus que nous avons étant tronqués de ce côté; depuis celle troncature jusqu'au sommet, elle diminue graducllernent; elle est aplatie sur les côtés, ce qui rend sa coupe transversale avale. Son sommet est, comme nous l'avins dit, extrèuement aigu; il est partagé en trois parties par trois sillons, deux latéraux, superficiels et peu prolongés, el un troisièrue múdian, assez profond, étroit, descend du sommet jusque près de la moitié de la longueur. Le plus yrand morceau que nous ayons de cette especce a $6 j$ millimètres de lougueur, et il est cassí au-dessus de la cavité. Il a II millimètres de diamètre. Nous ne savons d'où il provient.

19. Bílemnite épée, Belemnites gladius. Bu. B. Lestâ praelongâa, angustâ, depressâ, conicâ, basi ovatí, aperturî subrolundí, cavitate nuinimá; apice subacuto, lateribus bisulcato.

Blainv. loc. cit. $n^{\circ} \cdot 25$. fig. 10. 10. $a$.

Celte espèce est une des plus remarquables du genre, élant extrêmement longue et fort étroite. Elle forme un cône alongé, terniné par une pointe assez aiguë, qui offie de chaque côté un sillon superficiel qui ae descend pas loin; elle est comprimée latéralement et assez fortement, aussi sil coupe trausverse présente un ovale alongé; elle est beancoup plus comprimée au sommet qu'à la base; celle-ci est la partie la plus large, et malgré l'inégalité de ses diamètres, l'onverture de li cavité est presque circulaire. La cavité est petite, courte, obliquement inclinée vers le côté ventral; clle n'a qu'un septième de la longueur totale, ce qui ne se voit pas dans les autres espèces de celte section.

Nous ne connoissons jusquà présent qu'un seul individı complet de cette belle Bélemnite, c'est celui de notre collection. M. de Blainville l'a fait figurer dans son entier. Il a 24 centimètres de lon. gueur, 9 pouces, et seulement 21 millimètres dans son grand diamc̀tre de la base. En indiquant les Vaches-Noires comme la localitéde celte espèce, M. de Blainville avoit sans doute oublié que nous lui avions dit positivement qu'elle vient de VieuxPont, près Bayeux. 
5.. Espèces qui n'ont ni sillons ni rainures à la base ou au somniet.

19. Bélemarte courte. Belennites bnevis. BL.

B. testâ conicâ, brevi obtusâ basi subdilutatá, lateraliter depressâ, uperturầ uvutî.

Busist. loc. cit. $n^{\circ}$. 6 . var. C. pl. 3. fig. 3.3. a.

La Bélemaite courte, telle que M. de Blainville l'a définie arec ses trois variétés, ne nous semble pas une espèce naturelie. Nous trouvons uoe si grande dilférence entre la variété A et la variété C, que nous ne ponvons nous persuader qu'elles appartiennent à la méue espèce. Que l'on jelte les yeux snl la figure des trois variétés dans l'ouvrage de 11 . de Blainville, et l'on s'assurera que nous avons quelques raisons de duuter. Anssi, pour éviler toute méprise, nuus cunservons le nom de Belemnites brevis à la variété C. pl. 3. fig. 3. 3. a. de louvrage précilé. Cette variété a en ellét des caractères si tranchés, qu’àl sera toujours facile de la distinguer bien plus certaineruent que les autres. Elle est ćpaisse, solide, déprimée latéralement; clle forme un cone cunt, olstus, plus large a la base, diminuaut graduellemeut jusquau summet qui est arrondi cl mousse; l'ourcrture est lígèrement dilatée, elle est cirande, ovalaire; ses lucrds sont minces et tranchans. Nuus ne connoissons pas la cavité qui est remplie d'oolite ferrugrineuse à grains fius et fort durs. Certe espèce est lingue de 80 millimètres; son grand diamètre de la base en a 3 . Elle se trouve aux envirous de Nancy.

MI. de Blainville a rapporlé, il est vrai avec doute, à son Belemnites brevis, une coquille crue Montlort a fait entrer a tort dans les Pobthalames, suus le nom générique de Pyrgopole; ce corps n'esi autre chose qu'une dentale que nous n'arons pu déterminer, et dont MI. Defiance a fait le genre Lutale. Vojez Pyggopole.

20. Bélenvite ovale. Belemnites ovatus. Br.

$B$. testâ elongato-conicâ, basi dilutatâ, depressâ hateraluter; apice subacuto, valde depresso; aperturâ ovato-elongatá.

BusIsv. loc. cit. $n^{0} \cdot 27 \cdot p l .3$. fig. 4. 4. $a$.

Coquille singulière et très-bien caractérisée, formant, sans aucuajdoute, une espèce bien distincte. Si M. de l3laiuville n'a pas trouvé l'ouverture parfitement sysétrique, cela vient de ce qui'elle a cédé à la pression de la cuuche où elle étoit enfouie, comme le font voirles fentes qui sont d'un câté. Cette bélemnite n'est pas lort longue; dilatée à la base, elle s'anténue insensiblecuent jusqga'au snmmet; la dilatation de la base a cela de pariculier, d'avoir lieu antérieurement et pustérieurement, et d'être presque aulle sur les côtés. Ces côtés sont déprimés, aplatis, ce qui donae à la coupe transverse une forme ovale. Le somuet est assez aigu, aplati comme le reste, mais il est subcaréné par le fait de cet aplatissement. Longueur go millinètres; le grand diamètre de la base en a 25 .

Cetle especce a été établie sur un bel individu de notre collection; il vient de Nancy, dans l'oclite ferrugineuse.

21. Béleusite pénicillée. Belemnites ponicillatus. Sснцот.

B. testâ brèiusculî, elongato.conicâ, depressâ, ovatâ; apice abtuso, multrplicato.

Scrlotherm, Petrcfict. no. 10.

Ibid. Blainv. loc. cit. no. 29. pl. 3. fig. 7 . $7 \cdot a \cdot 7 \cdot b$.

An Acamas polyforatus? Moner. Conch. syst. tom. 1 . pag. 575 .

An Cetocis gluber? ibid. loc. cit. pag. 37!.

Kxовn. Petrif. part. 2. pl. 1. fig. 1. 2. 3. 4.

MI. de Blainville ayant caractérisé celle espèce d'après les individus de notre collection, il nous est facile de faire aujourd'hui quelques observalions que nous croyous nécessaires. Nouns pensons que parmi les individus que $\mathrm{N}$. de Blainvilte a nommés Relemzites pericillatus, il y a deux espèces distinctes, l'ume, qui est constanment dépourvue de plis, a la plus grande analogie avec le Belemnites digitalis; et l'autre, constumment plissée au sommet d'une manière assez rígulière, paroit suffisamment caraclérisée : c'est celle dernière seule que nous conservons diuns l'espèce gui nous occupe. Ce n'est qu'aver doute que nous admettons comme lai appartenant les diyures de Knorr, sur lesquelles Monifort a fait les deux genres Cétocine el Acame, qui ne sont pas plas utiles qu'une foule d'autres qu'il a créés de la même manière.

La Bédemnite penicillée que nous possédons en $^{+}$ aue coquille courle, régulièrement conique, pilus large à la base que partout aillenrs; elle dimmute graduellement jrisqu'au sommet, qui est obius, arrondi et cliargé d'un grand nombre de plis presque symétriques qui ne sont pas liès-profonds $\epsilon t$ peu prolongés sur la coquille. La base est ovale, non dilatée et percée d'une ouverture circulaire; aussi l'épaisseur da test est inégale dans cetle partie, beaucoup plus considérabie à la fare dors?le que partont ailleurs.

Celle espèce, fort remarqualle et trc̀s-rare, vient des eavirons de Nancy; elle a 60 nillimètres de longueur, et 16 de diametre a la base.

22. Bélennite cylindripue, Belemnites cylindricus. Blaisv.

B. testâ rectî, longissimâ, ‘nggustâ, aperturâ minimâ, rotundatâ; apice obtuso?

Blasiv. loc. cit. $\pi^{\circ} \cdot 76 . p l .5$. fig. 10. 10. $\mathrm{co}$ $R_{2}$ 
An Bclemnites Longissimus? loc. cit. pl. 8. fig. 1. 2.

Ibid. Bunisr. loc. cit. n०. 55. pl. 4. fig. T. Cop. de . Willer.

Nous a rons la conviction presqu'entière que les Belemnites cylindricus et longissinus, que .I. de Blainville a séparés, sont de la méme espèce : que l'on snppose le Belemnites longissinus ircnçonné à la base et à la pointe, comme étoient les indiridus du Belennites cylindricus de 11 . de Blainville, et on rerra qu'il existe une aualogie telle, qu'il sera bien difficile, peut-être méme ionpossible, de les distinguer.

Les fragmens que nous possédons de ceite esjèce, et l'un entrantres qui est presque complet, viennent des environs de Nancy, dans le lias ou Jes argiles de cette formation. Ce morceau est de la grosseur d'une plume à écrire, alongé, plus large à la base, s'altémuant très-insensibleneut jusque vers le sommet qui est tronqué. La hase n'est pas entičre; on y roil cependant nue ourertore arrondie, petite, q̧ui communiq̧ue arec une cavilé fort courte probablemeut, puisqu'une cassure que II. de Blainville a faite à six lignes de la base ue l'zlteint pas. Le sornonet, d'après MI. de Blainville, seroit obtus, ce que nons ne sanrions confirmer, puisqu'il mauque dans les individns que nous possédons. Longueur 65 willimètres, diamètre de la base 6 millimètres.

25. BÉcexrite ombiliquée, Belennites umbilicatus. Buartr.

$B$. testâ elongutâ, angustá, subcylindricâ, hastatá, basi dilatuti; apice obluso, umbilicato.

Buastr. loc. cit. $n^{\circ}$. 57. pl. 5. fig. 11.11.a. 31. $b$.

Cette espèce est bien distincle de toutes celles que nous coonoissons; ; elle cst alongée, assez étroile, subcrlindrique, à peiue subquadrilatére, légère nent dilatée à la base, se rébrécissant uu peu au-dessus pour s'accroilre de noureau, et se terminer enfin par un sommet obtus. Ce sommet offre cela de particulier, d'aroir un grand pore au centre en forme d'ombilic, et d'étre dépoursu de stries ou de sillons. La base, un peudilatée, comme nous l'arons dit, prúsente une ourerture ronde; la cavité est assez conrle et son sommet correspond à l'are qui est central dans toute son étendue.

Longueur 65 millimètres; diamètre de la base so milliàètres.

Les enrirons de Caen et de Bayeux, ViensPont.

24. Bélenvite claviforme. Beleniniles clavatus. Braist.

B. testâ lavigatî, elongatá, angustâ, basi subdilatutâ, clavatâ, ucuminatâ; striis et sulcibus destitutâ; apice subacuto.
Busstr. loc, cit. $n^{\circ}$, 38. pl. 3. fig. 12, 12,-a. 12. $-b$. $12,-c$.

Cette espèce a, quant à la forme, une grande analogie arec la Bélemnite hastée, mais elle s’en distingue en ce qu'elle $n^{\prime}$ a jamais le grand sillon médian qu'offre toujours celle-là. Sa base, légèrement dilatée, a one ouverture arrondie; sa carité est régulièrement conique, centrale et assez courte rers le milieu de la cognille. Après un rétrécissement notable elle se dilate en s'aplatissant un peu, et elle se termiue en un somret obius dans quelques individus, et beaucoup plus pointa dans d'autres, surtont dans les jeunes. On ne voit ni stries ni sillous sur la surface de celle coquille. Elle est longue de cinquante-deux millim., et large de buit à la base. On la trouve aux enriruns de Naucy et à Mendes, département de la Lozère.

25. BËLravite dilatée. Belemnites dilatatus. Beaist.

B. lestâ abbreviatâ, compressissimâ, clavatá, spatulutí, basi angustá; a pice mucronato.

BL. loc. cit. no. 40. pl. 5. fig. 15. 15. a-15-b. 15.-c. 15-d. 25-e., el pl. 5. fig. 18. 13.-a.

An Beudant? Uén. sur les Bélemn. planch. fig. 10.

Var. a. Testâ elongatâ, compressâ, hastatâ, upice sentrali.

Tar. b. Testá compressiore, apice obliquo, mucronato.

Var. c. Testâ latissimâ, ad basim dilatatá, apice oblusissino. Nов.

Coquille extrémement aplatie, fort remarquable par sa forme, et très-rariable à ce qu'il puroit. Nous en possédons plusieurs execoplaires; ils sont d'une taille médiocre, très-alténués à la base, s'élargissant beaucoup vers le summet en forme de spatule, et se terainant par nne pointe saillante qui n'est pas tuut-i-fait dans le centre du sommet; ce somunet est simple, lisse et sans stries, ainsi que tout le reste de la coquille. Sa base est fort étroite, elle offre une ourerture orale à bords miuces, conduisant à une carité fort petite qui s'arrondit rers son somaet.

La variété $A$ est beancoup plns grêle, et $50 n$ sommet est central, ce qui tient sans doute à son jeune áge.

La variété B a arec la première beaucoup d'analogie; elle est plus large, plus épaisse, et son sommet acuminé est incliné. M. de Blainville comprend dans cette variété une coquille fort dillérente selon nous, à moins qu'elle ne soit une monstruosilé de l'espèce.

La rariété $C$ est la plus remarquable par son grand volume, son aplatissement considérable, son sommet très-surchargé, qui est très-obtus 
arrondi, et eafin par la base, qni est dilatée, ce qui lui donne quelque ressemblance avec la Bélemnite hastée, malgré le manque total de la cavité par suite d'une mutilation. Cette variété est longue de soixante-dix millimètres, et large de vingt-cing; les atures ont un voluobe benucoup unoindre. Cetie coquille se trouve aux environs de Castellane, dans les Basses-Alpes, et à Esnandes, Charente-Inférieure.

\section{BELLEROPIIE. Bellerophon.}

Montfort a institué ce genre (Conchyl. System. tom. 1. pag. 5..) pour uue coquille nautilitarme qu'il donne comme cloisonnée et siphonnéc, et qu'il rapproche en couséquence des Nautiles.

Tromp's par cet auteur, les zoologistes qui out parlé de ce genre coüncident dans cette opinion quil doit être réuni aux Nautiles. Cependaut, la manière bien connue dont Montfort faisoit la plupart de ses genres, nouvoit jeter quelzue doute sur celui-ci, et en effet $\mathbf{1 1}$. Defiance fit connoitre l'errenr el la mauvaise foi de Alontfort dans une note insérée dans le prewier volume des Annales des sciences naturelles.

Ce savant possède, dans sa riche collection, un indiridu de Bellérophe qui provient de celle de Nontfort; peut-être est-ce lui qui a scrvi de type au genre. Ne voyant à la surface extérieure ni siphon ai traces de cloisons, il se détermina à le scier en deax, et il s'assura qu'il n'existoit ni cloisons ni siphon; il fut done évident pour lui et pour les autres conchyliologies, que llontfort avoit pris ces caractères dans son imagination. M. Defrance chercha à trouver de nouveaux rapports pour ces coquilles; il en aperçut avec les Argonautes et avec les Bulles, ce sont en effet ceux des genres dont elles se rapprochent le plus. MI. Sowerby, dans son Mineral conchology, fit connoitre de nouvelles espèces et adopta le genre Bellérophe, recifié d’après MI. Defrance. Préférant l'analogie avec les Bulles, M. de Blainville rangea ce genie entre les Bulles et les Bullées dans sa famille des Acères. (Traité de Maluc. pag. 477.)

Duns les Fam. natur. du Règn. anim., p. 168 , M. Latreille adopte l'analogie avec les Argonautes, et le place dans sa famille des Cymbicoclalides, et cette analogie nous semb!e prétérable, surtnut s'il es! viai que l'animal des Argonaules soit trèsvaisin de celui des Atlantes; le genre Bellérophe deviendroit alors in termédiaire entr'eux. Voici sur quoi nous fondons notre manière de penser : aucune Bulle n'est symétrique. Le Bulla naucum, la seule espèce qui puisse se rapprocher des Bellérophes, ne l'est pas complétenient; le bord dionit de l'ouverture est incliné sur l'axe, c'est-à-dire qu'il est oblique; la base de l'ouverture est élargie beaucoup plus que le sommet, et la columelle y préseute un pli tordu sur lui-même. Rien de tout cela ne se présente dans les Belle. fig. r. rophes, ils sont parfaitement symétriques; l'onverture n'est pas oblique sur l'axe de la coquille, elle n'est pas dilatée plus d'un côté que de l'autre; enlin, une Irace on un indice de carène, ou une carène obtuse, médiane, abontissant à une écbancrure du bord drait de l'ourerture, indique ane forme très-analogue a celle de: Atlautes, et l'on voit que, dans certaines espèces, l'ćchancrure de ce bord étoit profonde, at en juger au moins par la forme des stries d'accroisseruent aussi-bien que par l'impression de la coquille sur le moule. Le seul point sur lequel il y ait de la dillérence eutre les deux genres que nous comparons, est l'épaisseur des coquilles. Dans quelques espèces de Bellérophes elles paroissent fort ćpaisses; dans d’antres, au coutraire, elles sont minces, mais toujours beaucoup moins i proportion que celles des Atlantes. Il nous semble n:turel, d'après ce qui précède, de placer les Bellérophes près des $\mathrm{Ar}$ gonautes et des Atlantes pluiôt cịue près des Bulles.

$$
\text { CARACTERES GENERIQUES. }
$$

Animal inconna. Coquille aauliloide, à cavité simple, monollalame, synćlrique; ouverture ovale, transverse, recevint dans son milien le retour de la spire; bord droit, miuce, trauchant, sinueux ou lendu dans son milieu.

Les Bellérophes sont des coquilles que l'on ne connoít encore qu'à l'élat de pétrilication, et elles ne se rencontrent que ditus les terrains anciens. Le premier auteur qui en ai! parle est de Hlupsch, quiles coufondit avec les Nautiles; il les trouvi aux environs de Juliers, qui est uue localité fort intéressante par le grand nombre de belles pétritications qu'on y recueille.

M. Sowerby, dans l'ouvrage que nous avons mentionné, a ajouté plu-ieur's espèces fort in/ćressantes à celles que l'on counoissuit déji. Il les partage en deux groupes; le premier pour les espèces qui n'ont point un sillon ou une carène centrale, le second pour celies qui le présenteut; mais nous observerons que dans cette prenière section, M. Sowerby n'a placé que des moules intérieurs, bien qu'ils paroissent appartenir à des espèces distinctes. Nous ne croyons pas que celu soit suffisant pour les établir et les admettre définitivement: aussi, comme elles nous paroissent douteuses, nous ne les mentionnerons pas.

r. Belzérophe fendu. Bellerophon liulcus. Sow.

B. testâ globulosi, tenuè striatî̀, utroque

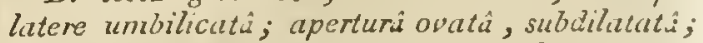
striis regularibus, sulco mediano, lato, interruptis.

SowERв $\mathrm{x}$, IIineral conchol. pl. 470. fig. I.

Nautilites hiulcus. Marris. pet. derb. tab. 40. 
Coqaille globuleuse, nautiloïde, légèrement ombiliguée; onverture ovale, peu évasée sur les côtés, recevantl'arant-dernier tour qui l'a modifie; bord droit tranchant, formé de deux ares de cercle dont la réuaion au centre y occasionne une lente assez profonde dont le centre cortespond a u sillon médian carénal peu saillant, assez large, çui partagre la coquille eu deux parties égales. La surface extérieure est courerte de strics saillantes, sublamellenses, fines, assez serries, et régulières; elles sont transverses et forauent une sinuosité semblable à celle du bord droit. Elle a $=5$ à 50 millim. de diamètre trausrersal et longritudinal. Elle se trouve dans le Derbyshire.

\section{Belérorde petite fente. Bellerophon tenui-} fascia. Sow.

L. testî́ spheroide $\hat{s}$, utroque latere umbilicatî, tenue striatî, in medio subcarinat $\hat{z}$; sulco mediano angustissino elevato; aperiuru semilunari, virr dilutatis.

Sor.. loc. cit. pl. 470 , fig. 2. 3.

Nicutilus hiulcus, var. c. Martrir, Arrang. sjơtén. des pét. du Derl. pag. I 5.

Cette espèce se distingue neltement de la précédente; elle est presque sphćrique, largenient unbiliquée au ceutre, de claqque cóté; l'ouverture est semi-lunaire, pers comprimée d'avant en arrière, et peu dilatée latéralement; le bord droit, mince $f t$ luncluant, est fendu dans le milien et con. rexe de chaque côté de la fente, mais cetıe fente cst moins profonde, clle correspond au sillon médian qui est très-étroit et saillant; il produit par conséquent aue carc̀ne sur le pcurtour de la coquille; coute la surlace est triée transversalement, les stries sont fines, non stillintes et fort serrées; le test de cclte cocfuille est fort mince. Elle acquiert un volume au rnoins double de la première. Elle se trouve comme elle dans la Derbyshire et de Jlus ì Kenda! duns le Yorkshire. C'est duns celle dernière localité qualle prend un plus grand volume.

5) Belcéroraz costulé. Bellerophon costatus. Sow.

B. testî̀ subglobosá, expansâ, umbilicatâ, subcarinatid sulco mediato lato, elevato, costis lamellosis, distantibus, valdè recurvis, transiersis, in sulco convergentibus; aperturi transversá, arcuat $\hat{s}$, profundè fissá.

Sowerbi, loc. cit. pl. 470. fig. 4.

l'Ansirscr, Organ. rem. tab. 10. fig. 6. 7 .

Non moins bien caractérisće que les précédentcs, cette espèce se reconnoit facilement; elle est subglobuleuse, mais plus transverse; les axes, ombiliqués assez largement et profondément, sont plus saillans; louverture, beacoup plus trans- rerse, est beaucoup plus étroite d'avant ca arrière, plus dilatée latéralcment; le bord druit est mince, prufondément fendu dans le nilieu et se relevant en demi-tercle de cliaque côté de la fente ; celle. ci, conıme dans les autres espèces, correspond an sillon central qui est saillant, assez large, et produit une carène obtuse sur le pourtaur de la coquille. La surface extérieure est ornéc de cóles lamellenses, transverses, fortement arquées et convergentes vers le sillon mídian. Celle jolie coquille se rencontre avec les précédentes, et elle a à peu près le mêue volume.

\section{BÉLOPTĖRE. Beloptera. Nов.}

Nous avons Gubli ce genre daus notre collection depuis le moment oú nous avons pris la rís jlution de publier le résultal de nos reclierctes sur les fossiles des environs de Paris; il y a douc au moins cinq années que nous l'avions caractérisé. Dès que nous en eûmes fuit la découverte, nous senlines ses rapports avec les Bélemnites d'une part et les Sèclies de l'autre. La forme de la coguille et scs rapparts avec les Bélemnites, noas déterminèrent duns le choix du non générique.

Nous comınuniquâmes ce genre à M. de Blainville, dans lc temps qu'ıl complétoil les matérizux de la seconde édicion de son article Monzusece. Malbeureusement les documens que nous lui donnâmes ne purent eatrer dans le corps mêtne de l'ouvrage, et ce ne fut que dans son premier supplément qu'il Irouva sa place. Par un uubli bien involontaire, M. de Blainville ne nous cita nullement í celte occasion; nalis dans son Tratité de Bélemnitologie, dont nous avons fait mention it l'article BÉLEMsite, a vec tout l'éloge qu'il mérituit, M. de Blainville a réprá celle omission de manière à ne nous laisser aucun regret. Cepeodaot, ce survant analomiste a modilic notre genre, en y introluisant des corps que nons n'y avions pas compris, et que, contre son opinion, hous cunsidérons comme des Sèches, et non comme dies Béloplères. A l'érarard des premiers, M. Cuvier s'éloit prononcé, il les avoil reconnus pour des restes de Sèche; quant aua seconds, il ne les connoissoit pas.

M. d'Orbigny et M. de Ferussac, dans la premic̀e partie du Mémoire sur les Csubalopodes (Ann. des scienc. nat. tom. 7. puov. 156.), nonsenlenent n'adoplèrent pas notre genre, mais encore crurent et direnl qu'il étoit le résultat d'uu équivoque. Nous pouvons assurer que l'équivoque est seulenent du côté de ces messicurs, qui n'uat pas conou ou qui out fort nial compris notre genre; aussi pour résultat, ils l'ont confondu avec les Sèches, et c'est là le rérilable et singutier Equivoque. Ils ont sapposé que ni M. de Blainville ni nous ne connoissions les espèces de Sciche dont le rostre est alungé, que c’étoit de là que provenoit notre crreur. N'est-ce pas ane dérision, 
quand à la ligne d'après on en cite nne description faite par M. de Blainville lui-méme dans sa Malacolngie, et quion a la bonne foi de ne pas mentionner la figure quil en dome planch. 11 du mène ouvrage! Nous aurions bien le droit, ce nous semble, de nous pilinin lre de l'extrême légyereté de cos messieurs; nous nous contentons de réclamer pour l'avenir un peu plus de justice et le maturits dans le jugenent qu'ils porteront des faits yu'ils ne connoissent qu'imparlaitement.

11. de Blainville a partarró le gente Béloptère tel qu'il l'a enteuda, en deux groupes, le premier prur l's espèces qui ont rapport aux Sictics, et Tu'il nomme Srpiostaires, et le second pour la senle espèce de Béloptère véritable; c'est celle-là seule el ses analogues, si l'on en trouve, que nous admeltons dans noure genre, pensant que les esperes du premier groupe appartientient plutut aux Siches, cnmme nous le disions tout à l'lieure. D'après res changemens, voici de quelle manière wums croyons convenable de caractériser notre getme.

CARACTÉRES GÉXÉRZQUES.

Animal complétement inconau.

Cuy uille composée de deux côaes réunis sommet à somuet, pourvae de clsaque côté de deux appendices aliformes, obliquenent inclinés; cône postérieur obtus, fibreux et fendillé longiludinaleınent; cône antérieur lisse, composé le sulsstance fibrense rajonnante comme daus les Bélemnites, creusé d'une cavitć arrondie, conique, dont l'ouverture antérieure a les bords minces et tranchans; dans celle cavilé, des restes évidens de clnisuns trausverses percés par uu siphon ventral.

Nous ne dontons pas que quelque jour le liasard ue fasse trouver cette coquille avec les cloisons bien conservées, ainsi que le siplson. Quoique nous a'ayons pas vu ces parties dans leur intégrité, d'après ce que nous conaoissons, nous avons la conviclion qu'elles existoient pendant la vie de l'auimal. Sur plusienrs individus, nous avons vu des indices si évidens, que nous pouvons concevoir facilement la structure entiere de ce genre, qui a, comme on pourra le juger, du rapport avec les Bélemnites et avec les Sèches, ce qui le send on ne peut plus précienx pour fixer délinitivement dans la série les Bélemnites. M. de Blainville a su l'apprécier, et il l'a déterminé daus le rapprochement qu'il a fait des Sèches et des Bélemnites aux pages 50 et $3 r$ de sa Béleninitologie. Ses raisonuemeus, fondés sur des analogies incontestables, nous semblent si évídens, que nous ne croyons pas qu'il soit possible désormais de les combattre avec quelqu'avantage.

Il n'existe encore qu'une seule espèce de ce genre, à laquelle M. de Blainville, à notre insu, a eo l'extrême indulgence de donner notre now.
Non: allons la décrice d'une manière assez connplere pour que l'on y trouve une enlic̀re comoissance du genre.

Béloptére Desliayés. Beloptera Belemniloidea. BLAIst.

3. testá ovato.elongatí, longitudinaliter recưvâ mosticè rostro cblusissimo, subbipartito terminatâ; cavitale anticá, conicà, septiferâ mtusudut $\hat{i}$; appondicibus rotundatis, inclinatis, lıter.libus.

Dent de poisson? Guetrand, Mćm. div. sur les scicuc. Lom. 5. pl. 2. fig. 11. 12.

Sepia parisiensis, n'Orв. Mćm. sur les Céphal. Ann. des scienc. nat. tom. $7 \cdot$ pegg. 157 .

Beloplera Beleminitoidea. Bu. Malac. Suppl. pag. 6i2. pl. 11.fig. 8.

Béloptère Deshayes. Ibia. Traité de Belemmitologie. pag. 111. pl. 1. fig. 3. a. 3. b.

Celte coquille est composéc de plusieurs parties clistinctes; dans son ensemble, elle est alongée, ovalaire, recourbce longritudiuslement, et l'inclinaison des ailes ou apprendices latéraux la réndcut tectiforme. Flle se compose d'uu cône postérieur en missue incliné sur l'axe, très-obtus postéricuremen', oì il est souvent partagé iransveralement en deux parties du côté du dos; il est fendillé, et si on le casse longitudinalement, on voit qu'il est formé de fibres longitudinales rayonuantes du sonımet à la base. Ce cône, par son sommet, se soude au haut de la calvicé conique ausérienre, en lormant avec elle nn angle peu onrert du côté du dos. Cette cavité conique antérieure est plus ou mnius grande, seion l'iuge ou la conservation des individus. Le cône antérieur est creusé dans sa longuemr par une cavilé conique, semblable en tont à celle qui se voit à la base des Búlemnites; les bords de l'ouverture sont minces, tranchans, et forment un péristome circulaire complet. Dans l'jutérieur de la cavité; on voit d'une manière bien évidente les restes des cloisons qui sont indiquées par des lames quelquefois assez saillantes; elles s'inlléchissent daus la ligne médiane et ventrale, et laissent li des traces non équivaques du siphon. La réunion de deux cônes sommet à sommet auroit peu de solidité : ici elle se trouve consolidée cl'une part pal l'épaississement du corps de la coquille du côtó du dos, et de l'autre par deux ailes latérales dont la base, fort épaisse, s’insère moitié sur les côtés du cône antérieur el moitié sur les côtés du cône postérieur. Ces deux ailes s'inclinent sur l'axe, s'amincissent sur leur bord, qui est demi-circulaire. A la jonction de l'aile avec l'extrémité postéricure du corps se voit l'empreinte d'un vaisseau dont les ramifications nombreuses se dessinent sur le dos de la coquille; on ne peut douter que cela ne présente une grande ressemblaace avec ce qui 
existe sur la Bélemnite mucronée, dont les vaisseaux, par leurs anastomoses fiéfyuentes, ont lajssés un réseau sur la cnquille : il en est à peu près de même dans le Bélopière. Tout le cône antérieur et les ailes sont fortués de substance fibreuse rayonnanıe, semblable ì celle des Bélemnites; celle structure rend très-fragiles ces parties, qu'il est assez rare de trourer dans leur entier, surtout l'ouverture du cóue antérieur. La partie postéricure de la coquille est fibreuse aussi, mais les fibres sout longitudinales, à l'inverse des premicres.

Longueur 55 à 40 millizn., largeur 25 à 28.

fiossile assez rare aux environs de Paris, à Parne, Grignod, etc., dans le calcaire grossie!:

\section{BEREERI.}

Les anciens conclyyliologues donnoient ce nom, à l'exemple d'Alhénée el d'Aldrovande, à l'Avicule mére-perle. Vojez Aricure.

\section{IERXACLE.}

Dans la croyance que les canards, nommés Eernacles sur nos cỏies, taissoient spontanément des groupes d'Anatile, on a donné, par extension, le même nom aux Aratifcs elles-mêues. Loyez AลATITE.

\section{JBERYICLE.}

Sur quelques codroits des cótes de l'Océan on dome ce nom aux Patelles qui s'y rencontrent aboudamment. MI. Bory de Saint-Vincent dil que les habitans de Bonrbon et de Mascareigne notamment appliquent celle dénominatiou vulgaire au Navicella elliptica, qui vit daos l'eau douce. Toyez Navicerle el Patelie.

\section{BERTIIELLE. Beriñclla.}

Ce genre fut établi par Léach pour un Mollusque gastéropode, qui est extrêınement voisin des Pleurobranclies. MI. de Blainville l'a adopté das son 'Traité de Malacologie, el ensuite, dans le Dictionnaire des sciences naturelles, il l'a réuni au Plinrobranche. Mluni d'une coquille conme lui, nous ne croyons pas qua en effet il puisse en être séparé autremea! que conme sous-genre. Voyez Pieurobraiche.

\section{BIAPHOLII.}

Léach avoil fait un genre sous ce nom; il n'est conau que par la citation qu"en fait M. Lamarck, et il paroît qu'il est un double emploi du geore Hiatelle. Voyez ce mot.

\section{BIFARIBRANCHE. Bifaribranchia.}

Tel est le noin que M. Lalreille donne, dans ses Fam. nat. du Règ. anim. ( $\rho .175)$, à une fa. mille qui correspond aux Iaférobranches de MI. Cuvier. Par un rapprochement dont nous nous rendons compte dificilement, l'auteury joint le genre Allas ( voyez ce mot), qui est encore très-doutenx. En supprimantl'Ailas pour le porter dass un incertoe sedis, la fumille de MI. Latreille devra reprendre le nom d'Inférobranche, qui a la priorilé. Voyez INTÉROBRANches.

\section{BIGÉNÉRINE. Bigenerina.}

Petit geore institué par M. d'Orbigny daus son trarail sur les Céphalopodes microscopiçues, pour des corps sinutiers en cela, que les loges commencenl par étre alternatires à l'origine de la coquille et à double rang, et fizissent par ôtre simples et en ligre druite, comme dans les Nodosaires. (Joyez ce mut.) Ces coqguilles présenten!, par cel arrangement de leurs loges, une organisation intermédiaire entre les coquilles droites avec une série umique de logres, et celles qui, plus compliquées que celles-ci, out des loges alternautes sur deux rangs, de la base à la pointe.

11. d'Orbingy n'a pas cru devoir faire de ce genre une fanille à part, et nous pensons qu'il a eu raisun en le plaçant, suriout comme il l'a fail, le premier de la faraille des Enallostègues (2oyez ce mol); en établissaut la série des genres d'apres la disposition des loges, il éloit naturel que celua qui nous occupe entrât plutôt daos cette familte que dans la précédente.

\section{CATACTERES GÉNEIQUES.}

Coquille microscopique, alongée, droite ou légèremeut arquée à l'origine, conique, formée de loges alternantes, sculewcnt dans le ;eune âge, et se terninant par une suite de loges simples. Ouverture ronde, centrale ou marginale.

M. d'Orligny ne compte encore que quatre espèces dans ce genre; toutes soal vivantes el viennent de la Médilerranée. Quelques coquilles fossiles des environs de Paris sont Lien voisiues de celles-ci, mais elles s'en distiuguent par la dispositiondes loges du jeune âge, qui, au lieu d'ếtre sur denx rangs, sont sur trois et se termident aussi par une série unique.

Selon que les espèces out l'ouverture centrale ou rargiuale, M. d'Orliguy les distribue en deux sous-genres. Cet observaleur, d'après notre maaic̀re d'euvisager les coquilles de cetle série, donac peut-être trop d'importance au mode d'empilement des loges, et pas assez à la lorme et à la place de l'ouverture; de sorte quil est probalble pour nous, que le second sous-genre des J3igénérines, auquel $\mathrm{N}$. d'Orbigny donne le nom de Gernmulines, pourra bien, par la suite, constituer no genre à part; et dans le cas où la forme et la place de l'ouverture seroient le caractère essentiel du genre, on pourroit réunir à ce sousgenre les coquilles fossiles dont nous parlions 
tout is l'heure, et former arec cet ensemble an geare naturel.

Nous ae connoissons pas en nature les espèces de ce genre, il nous est done impossible de les décrire; nous nous contenterons de les indiquer d'après M. al'Orbiguy.

1. BlC Évérıne nodosaire, Bigenerina nodosaria. D’Onв. Mlén. surles Céphal. Ann. des scicnc. nat. tom. 7. pag. 261. pl. 11. fig. 9. a. 12: 1bid. Modeles, $\mathfrak{x}^{\mathrm{e}}$. livruison, $n^{\circ} .57$. De la mer Adriatique.

2. BıG ÉNÉRINe tronquée. Bigenerina truncata. Ihid. $n^{\circ} .2$. De la mer Adriatique.

3. BนG ÉNÉnNe lisse. Bigenerinalcuigata. Ibid. loc. cut. no. 3. Soldani, test. micros. tom. 2. tub. 103. fig. D. La iner Adriatuque.

4. Bigésérne digitée. Bigenerina digitata. D'Orb. loc. cit. $n^{\circ} .4$. Ibid. Modèles, $3^{\circ}$. livrais. $n^{\circ}$.58. La Méditerranće.

\section{BIGNI.}

'Tul est le nom qu'Adanson (Yoyage au Sénég. pl. 9 . fig. 27.) donne à une petite corfuille de sun genve prourpre. Quelques auteurs ont jensé qu’elle appartenoit au yeure Buccin, et qu'elle étoil identique avec le Buccinum nitidulum de Linné; nais cela n'est pas, el Bruguière a eu tort de faire ce rapprochicment. Il n'est pas donteux que le Bigui n'appartienue au genre Colombelle. Voyez ce wot.

\section{BIGORNEAU. Bigourneau.}

Nom que l'on donne sur quelqnes parlies de nos côtes de l'Océan au Turbo littoreus de Linné, qui a servi de type au genre litlorine de M. de Ferussac. Vojez lurbo, Litroma el Paludine.

\section{BILLE DITOIRE.}

l.es marchand donnent encore ce nom à ane Luciue très-épaisse et d'un blanc éclatant lorsqu'elle a élé polie; c'est la Lucina pensyluanica Lank. Foyez Lucixe.

\section{BILOCULINE. Biloculina.}

Marrui les espèces du genre Miliole de MI. Lamarck, il en est une fort remarquable, et par son ouverture et surtaut par lit disposition de ses loges. Si l'on a oliservé le Miliolites ringens de cet auteur, on aura remarqué saus doute cqu'il n'y a jamais que deux loges visibles à l'extérieur; que ces loges s'ajoutent les unes aux autres par cuboitement, et que la dernière seulement ollic une ouverture assez grande, médiane, symétriçue, rétrécie par une dent bifurquée, sailHistoire Naturelle des Vors. Tome II. lante, dans la ligne médiane de l'ouverturc. Ces caractères, qui distinguent nettemen les coquilles qui les offient de toutes les autres Miliolites, ont paru suflisans à M. d'Orbigny pour l'ćtablissement d'un genre qu'il a nommé Biloculine, el qui, à cause de la simplicité de son mode d'iccroissement, comparalivement ì d'autres gentes analogues, a été rangé le premier de la famille des Agathisiègues. (Voyez ce mot et Cépmalorodes.) M. Defiance est l'auteur d'un pelit genre qu'il a nommé Pirgo, et qu'il a caractérisé dans le $41^{\circ}$. volume du Dictionnaire des sciences naturelles. 11 paroîtroit, d'après ce que dit ce savant, cque la coquille du Pirgo n'auroit qu'une seule loge, et pal conséçnent ne devroit puint fitre parlie des Polythalames. D'après cette observalion de M. Delirance, M. de Blainville, en adoptaat ce genre, l'a placé parmi les P'téropodes, it côté des Cymlualies, dans la famille des Tluécosomes. (Voyez ce mot.) Cependant, M. Deliance n'a pas tiré la rirourense conséquence de son opinion, en rangeant, comme il l'a fait, son genre Pirgo dans la famille des Cri-tacées, entre les genre Cristellaire el Orbiculine, avec lesquels il n'est guère possible de hui trouver quelques rapports. Si, en effet, comme on le voit par les caractères génériques dunnés par M. Defrauce, le P'ingo n'a gu'une seule loge, pourquoi le metreavec descoyuilles qui toutes sont multiloculaires? Il y a lis uue évidente contradiclinn. M. d'Orligny, et en cela nous suivons son opinion, a reconnu daus le genre dont nous parlous une analogie assez grande avec les Biluculines, pour le comprendre au nowbre des espèces.

\section{CARAETÉrES GÉNÉRIQUES.}

Coyuille ovalaire, polythalame, microscopique, formée d'une série de loges s'emboitant les unes sur les autres dans le mêne axe; deux loges apparentes, la dernière prćsentant une ouverture ovalaire, terminale, dirisée en deux parties égales par une deat saillanle, siaple el quelquefuis bifide.

Les coquilles de ce genre sont fort petites et ressemblent beaucoup aux Milioles, avec lesquelles elles étoient confondues. Elles se reconnoissent en ce qu'elles sont ovalaires, ylobuleuses et toujours symétriques, et qu'elles nont jamais plus de denx loges apparentes; louverture est ferminale, semi-lunaire, médiane et symétrique; elle ollie toujours une dent saillante, rquil la rétrécit e! la parlage en deux parties ćgales. Cette dent, quelquefois litide au sommet, est lixíe par sa bise sur l'avant-dernière loge.

On ne connoit pas encore un bien graud nombre d'espèces de ce geme; M. d'Orbigny en indirne sept; tontes ne nous sont pas conures, nons dé. crirons sculement celles que nous possédons. 
1. Brooculine bulloide. Biloculina bulloides. D'Orв.

B. testẩ minutissimâ, ovatâ, inflatî, lavigati, simplici; uperturì semilunari, dente simplici muniti. Мов.

D'Ord. Mém. sur les Céphal. Ann. des scienc. nut. tom. 7. pag. 297. pl. 16. fig. 1. 2. 3. 4.

Ibid., Modèle's de Céphal. 4e. livruis. no. 90 .

Frumenturia ovata. Soldan, Testuc. microsc. tom. 3. pl. 153. fig. R.S?

Prsucus, de Concl. min. not.pl. 11. fig. 4 .

Coquille extrêmement petite, ovalaire, globuleuse, presqu'aussi hante que large, toute lisse; la dernière lugre débordant l'autse tout autour, mais la dépassiut beaucoup plus postérieurement qu'antérieurement; l'ouverture est semi-lunaire, petite, non bordée, à péristome von coutiau, et divisée par une dent sirnple, obliquement dirigée en avaut et un peur saillante en dehors. Celte coquille n’a pas no demi-millinetre de diamètre; on la trouve vivante dans la mer Adriatique, et fossile aux environs de Burdeaux et de Parlis, suitout à Mouchy-le-Chàtel et à Parne.

2. Brooculne grimaçante. Biloculina ringens. D'ORB.

B. testí ovato-globulosí, umpullaceâ, lavi-

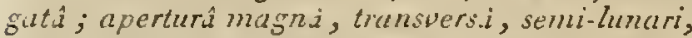
dente magno bipartıto prominente muniti. ов.

Mriliolites ringens. La a к. Ann. du Mus. tom. 5. pag. $551 . n^{\circ}$. 1. et tom. 9. pl. 17. fis. 1. a. b. SHulu.

Ibid., Anim. sans vert. tom. 7. pag. 6 r2. no. 1. Parxinson, Org. rem. tom. 3. tab. I1. fig. 11. D'Orbign, loc. cit.'no. 2.

Cette espèce est la plus grande du ganre et l'une de celles qui sont le mieux connues; tlle est ovdlaire, globuleuse, lisse; la dernière loge délzordaut l'autre plus antérieurement que postérienrement ; ce qui est l'iuverse dans la première espèce. Louverture est grande, transverse, semilunaire, coupée un peu obliquement; les extrímités du péristome se rejoignent avec la base de 1. dent, en se recourbant assez brusquement; cette dent, dont la base est fixée sur l'avant-dernière loge, est grande, saillante en dehors de l'ouverture, et son sommet est partayé en deux appendices' creusés en goultière dans leur longueul:

Celle coqnille, assez rare, a deux millimdres de diamètre. On la trouve à Grignon et à $\mathrm{Va}$ lognes.

3. Binocunive armée. Biloculin 2 aculcatiz. D'Orв.

B. testî ovatí, globulosí, lovigatutâ, utroque latere tricuspidatâ; operturâ subrotundutâ; dente brevi, simplici, acuto.

D’Orbignt, loc. cil. $n^{\circ} .3$.

Ibid., Modèles de Céplal. $2^{e}$. livrais. $n^{\circ} .31$.

Espèce fossile fort remarquable, elle est ovalaire, globuleuse; la dernière lnge beasucoup plus grande que l'autre, ne formant pas une saillie considérable à l'endroit de sa jonction, mais gagnant par un plan oblique la face supérieure; cclle-ci est déprimée, assez large ; latéralement, daos le lieu où elle se réunit avec les faces latérales, elle est munie de chaque côté de trois émiveoces ou dentelures. Livuverture est médiocre, un pen plus haute que large ; elle olfie une petite dent simple, poiatue, qui la divise en deux parties égales. Cette coquille, très-petite, se trouve fossile à Pauliac, à douze lieues de Bordeaux.

4. Biloculine opposée. Biloculina opposita. NOB.

B. testâ ovato-elongatia , lavigatâ ; loculis pyriformibus, oppositis; uperturi rotunduti, dente magno, bifido obturatî; margine continuo.

Une pnire, que l'on couperoit cn deux parties longitudinales et inégales, et que l'on disposeroit de manière à ce que le côlé large d'une moitié correspondít au côté étroit de l'autre, douneroit assez exactement l'idée de la forme de cette coquille. Les deux loges que l'on roit sont d'une forme semblable; la dernière plus grande que l'autre; elles sont beaucoup plus enflées et beaucoup plus larges du côté postérieur que de l'antérieur, et elles sont disposées de aranière que le côté le plus lar'ge de l'avaut-dernière loge correspond au cóté antérieur le plus étroit de la dernière, et réciproquement. Cette dernière loge se termine par une onvermme arrondie, à péristume contiou; elle est obstruće par une dent médiane, bilide, large à la base et saillante au-dehors.

Cette coquille, qui a à peine un demi-millimèrre cle lonunueur, se trouve fossile à Mouchyle-Châtel. Elle est rare.

\section{BIPLEX.}

Double emploi du genre Ranelle de Lamarck. C"est P'éry, qui, daus sa Conchylıologie, proposa le démembrement du genre Murex de Linné, d'après le uumbre des varices. Voyez RAxelze et TIOCRER.

\section{BIROSTRITE. Birostrites.}

Ne connoissant pas les rapports du moule intérieır des Sphrérulites et des Radiolites avec la coquille elle-mêne, ignorant aussi que ce moule en sortit, M. Lamarck proposa pour lui le geure Birostrite, qui fut adopté par presque tnus les zuologistes; ce n'est que dernièrewent que l'on a ds- 
couvert sa nature et ses rappoits. Fojet Rodistes et SPRÉRulite.

\section{BISIPLITE. Bisiphites.}

Montfort, qui ne portoit pas un examen fort approfondi aux coquilles qui lni servoient de type pour ses genres, a cru trouver deux siphons daus une espèce de Nautile pétrifié qui a'a qu'un enfoncement médian à la partie postérieure des cloisons, et un siphon réritable; cet eufoncement, donné sans preuve conne un vérilable siphon, a occasionné ce gense, dont nous reparlerons at l'article Nautre auquel nous reovoyous.

\section{BITO.JE. Bitomus.}

Une coquille rnicroscopique snr laquelle il est fort difficile de staluer yuclque chose, a été copiée daus l'ourrage de S sldani par Monlfort, qui l'a donoéc comane type du genre Bitome. Cet auteur qui, comme le premier que nous venons de citer, n'a donné sur ce corplos que des détails insuffisans, prétend l'avoir trouvée en grande abondance daus la Manche, ce qui nous semble peu croyable, car persome depuis lui ne l'y a retrouvée.

Il faut abandonner ce genre jusqu'à ce que l'on ait sur lui de pourclles observations.

\section{BITUBUI,ITE. Bitululites.}

Blumenbacl, dans son Specimen archorologive telluris (pag. 23. tab. 2. lig. 9.), a désigné pur ce nom un corps fort singulier, qu'il a raison aussi de nommer problématique, car il cot dillicile de décider sil appartieut aux Mollusques ou à toute autre classe. Lopinion de M. Schlatheim, qui le rapproche des IIippurites, est au moins hasardéc. Nous ne pouvans bous pronoucer arec le pen de docuaseus que nous avons sur ces corps.

\section{BIVET.}

Bruguière, dans le premier volume de ce Dictionnaire, renvoie de Bivet au geare Buccin, oủ il décrit celte coquille ligurée par Adanson. (Voyage aù Sénégal, pl. 8, fig. 16.). Aujourd'hui elle fait partie du genre Cancellarre, ćrabli depuis Brngnière, ce qui lnécessite un second renvoi a Cancellaire, où il sera encore question du Bivet d'Adanson.

\section{BOBI.}

Le bubi d'Adanson (L'oynge au Sénég. pl. 4, fig. 4.) nocst point une Volute comme l'a criu Bringuére; c'est une Marginelle, Mlargzinellar lineata Lamk. Voyez Marginelie.

\section{BOIS DE CERI.}

Les marcliands donnent re nom au Rocher scorpion, et M. Lamarck l'a appliqué a une es- pèce tonte différente de la Nourelle-IIullande. Vojez Rocher.

\section{BOLBOTINA.}

Nom qui fut cliangé par une fonle de copistes, et qui est le même, sclon toutes les apparences, que bolitaine. Vojez ce mot.

\section{BOLIN.}

La plupart des auteurs, à l'excmple de Linné, donnent Je Bolin d'Adanson (Voyage au Sénég. $p l .3 f_{g} \cdot 2 . a$ ) romme la mêne coyjulle que le Murex cornutus. Il nous semble quili a plus de rapports arec le Murex brandaris. Voyez RoСLER.

\section{BOLITAINE.}

Sous ce nam Aristote mentionne un Ponlpe, mais trop vägueneut pour être reconuu. M. de Blainville pense que par une erreur de copiste le mot Bolbotina, que l'on trouve dans Achénée, et beaucoup d'antres, s'appliqueroit au même animal que le Bolitaine d'Aristole.

\section{BOMBIX.}

Noa donné par Hamplirey dans le Museum calonnianum, à un genre auçuel il ne donne aucune désignation capable d'iudicguer is cuelles coquilles il a voulu l'appliquer.

\section{BORÉLIE. Borelis.}

Genre fort inulilement établi par Montfort (Conclyl. syst. tom. 1. pag. 170.) avec le $N_{\text {cut }}$ tilus melo de fichiel. Coyulle qui reutre dans le genre Mélovie de Lamarck, et par conséquent dans les Alvéolines de Bosc. $L^{r}$. ces derniers mots.

\section{BOUCARDE.}

On donnoit autrefois ce nom à des roquilles que l'ou désignoit aussi par le nom de Cazur de bouf: elles reatrent aujourd'hui dans le grenre Bucarde. Iroyez ce mot dans le $j^{\mathrm{er}}$. volume de ce Diclionnaire.

\section{BOUCARDITE.}

Les ancicos oryctographes donnoient ce nom a tontes les coquilles lossiles on pétritié juir ont la forme d'un caeur; la plupart appartiennent aux Bucardes et aux Isucardes. Voyez ces mots.

\section{BOUCHE.}

Ia boucbe d'un Mollisque est l'onverturc par laquelle la nourriture est prise et traasperléc daus l'estomac. Ce mol, dans ce cas, a la même acreption que chez tons les antres animaux. Par une extension un peu forcée, les conclyyliolognes noment bouche l'ouverture de la coquille. FoyeOupertuke el Coquile. 


\section{BOUFERON.}

Num que les pêcheurs et les habitans des côtes donnent a la Sèche. Voyea ce mot.

\section{BRACHIOPODES. Brachiopoda.}

M. Duméril, daus son Truité élénentaire d'histoire naturelle, proposa le premier de réunir, sous cette dénomination, dans une classe particulic̀re, des animaux appartenant à deux types fort distiucts d'organisalion. Cet auteur s'étoit appuyé en partie sur un très-bon travail de $M$. Cuvier, qui, en dévoilant l'anatomie des Lingules, a vait fait pressentir la nécessité d'un groupe pour ves animaux et d'autres quiles avoisineat; mais il étoit trop judicieux pour en rapprocher les Bulanes et les Anatifes, comme M. Duméril l'a fait. M. de Roissy, dans le Buffon de Sonnini, adopta les idées de M. Duméril, sans admeltre cependant une classe particulière pour les Brachiopodes, qu'il plaça ì la fin des Mollusques acéphales. MI. Lanarck, dès 1809 , dans sa Philosophie zoologique, fut le premier qui démenobra les Brachiopodes. Il créa la classe des Cerrhipèdes pour les anciens genres Lepas et Anatifa, el fit avec les Lingules, les 'Térébratules et les Orbicules, la fumille des Bracliopodes, qui cowmence les Mollasques acćpplales. Cetle amélioration nolable ne pouvoit maựuer d'être adoptée; et, en effet, on la retrouve clans l'ouvrage de M. Oken. M. Lamarck conserva cet artangement dans l'Extrait dı Cours, et celit n'empêcha pas Bosc, en 1816, dans le Nouveau Dictionnuire d'histoire naturelle, de reprodutre encore dans leur intégrité les Brachiopodes de M. Duméril. L'annće suivante, M. Cuvier', dans le Règne animal, non-seulement adopta en principe la division de M. Lamarck, mais encore fit des Bracbiopodes un ordre au même degré que les Acćphales et les Cerrhopodes; ce qu'il mutivoil sur l'anatomie des animaux.

M. de Ferussac, quelques années plus tard, imita MI. Cuvier dans les Tableaux systéwaliques des animanx mollusques, et au lieu de trois genres il en ajouta plusicur's, quel'on avoil à tort Taissés parromi les Huilues on rangés dans les Rudistes, cowme les Cranies et les Cilcéoles, el de plus y rallacha le genie Mitgas de M. Suwerby, el le genre 'Thécidée de M. Deliance.

Dans son nouvel ouvrage, M. Latreille fit, avec la lin des Mullusques ei le commencement des Acéphiales, wu ordse à part, quil considéra comme intermédiaire eutre ces deux grandes divisions; il le divisa en deux sections, et la seconde, yui porte le nam d'Endocéphale (noyez ce urat), représente les Bracbiopodes des auteur's ; ce prendant ce nom est réservé pour une classe, liı cinquiène de toute la série, et qui nous seubie êlre en suratsondance dans la section des lindocéphales. Nous examineruns celte yuestion i l'ar- ticle Muenosqur. Cetle classe est divisée en deur ordres, $1^{\circ}$. les Pédonculés, qui compreunent denx familles qui ne renferment shacune qu'un seul genre, la première les Lingules, la seconde les Térébralules; $2^{\circ}$. les Sessiles, composés d'une seule famille pour les genres Orbicule, Cranie, et avec doute $A$ carde et Spbérulite. Ce qui nous surprend, c'est de ne trouver ici aucun des genres nouveaux, qui rentroient uaturellement dans le cadre de cette section, et d'en voir deux qui en dépendent sans aucun doute, les Calcéoles et les Productes dans les Ostracés, oì ils sont éloigués de leur's riapports.

M. de Blainville (Traité de Malacologie, pag. 5og), en adoptant les Brachiupodes, en fit un ardre subordouné des Acéphales; ce qui ne fait que modifier légèrement l'opinion de M. Lanarck, dont il se rapproche Leancoup plus ugue de celle de MI. Cuvier. Il change aussi le nom de Brachiopodes, depuis long-lenups consacré, pour celui de Palliobranches, et place cet ordre le premier des Acéphales, comme M. Lamarck l'avoit fait depuis long-lemps.

M. de Blainville a'y établit que deux sections, la première pour les coquilles symétriques : elle contieut les genres Lingule, Térébralule, 'Thécidée, Stropliumène, Plagiustome, Dianchore et Podopside. La seconde pour les coquilles non symétriques irrégulières el consta moneutadhérentes: elle rénferne les genres Orbicule et Cranie. Nous ne pensons pas que l'urdre des Palliobrancbes, tel que M. de Blitinville l'a proposé, soit adopté, el en voici les raisons. Au genre 'Térébratule sétrouvent joints plusieurs genres distincts proposés dans ces deruiers lemps par M. Sowerby. tels que Pentamère, Spirifère, Magas et Productus. Duns le genre Tbécidée il $\mathrm{y}$ a des espèces irrégulières, adhérentes, et d'autres régulières, qui ne paroissent pas avuir été fixées à une époque certaine de la vie de l'animal. Ce geure, qui est daus la première section, pouroit être aussi bien dans la seconce que les Cranies, qui sont dansle inçme cas. Le gerre Strophomène nons semble un double emploi des Productus. Quant aux genres Plagiostome ou plntôt Pacbile, Dianchore et Podopside, ils n'appartiennent en aucune manière à cette fumille. Pour les deux dernières, nous sommes cerlains que ce sont des Spondytes, et nous avons de fortes présomptions pour croire que le prewier en dépend aussi. Nous ne trouvons. pas ici le gemre Calcéole, rangé à turt parmi les. Rudisies. Vuici comment nous croyons yue l'on. pourroit arranger les genres qui doivent faire partie des Brachiopodes.

† Coquilles adhórentes par un ligansent tendsneux plus ou moins long. (B:ach. pédunculés, LAT.)

A. Ligament cardinal. 


\section{B U C}

Lisgule, Térébratule, Spinifére, Strygocérhale, Productos, Magas.

B. Ligament passant par noe fente centrale de la valve inlérieure.

OrBicole.

t† Coquilles médiatement adhérentes, quelquefois libres à l'etat adulte.

Гhécioéz, Chanie, Calcéole.

Nous reovoyons à tous ces mols de genres, où nous donnerous de nouveaux détails.

13RANCHIFERES. Branchifera.

M. de Blainville, daos son Traité de Malacolngie (pag. 498), divise l'ordre des Cervicobuaches (yoyez ce mot) en deux familles : la première, les Rétilères, comprend le gemre latelle; et la seconde, les Branchifères, renterme les genres Eissurelle. Emarginule et Parnophore. (Voyez ces mots.) Nous nous abstenons, dans ce moment, de discater l'arrangemeot de celte famille, nous propnsant de reprendre cette question a l'article Scotibanche.

\section{BRANTE. Branta.}

M. Oken avoit donné ce nom à un gente séparé des Anatifes; c'est le Lepas aurita de Linné qui lui a servi de type. Mais M. Leach lui ayant donné le nom d'Otion, que M. Lamarck a adopté, les auteurs qui ont suivi l'ont égalenent préféré. Voyez Otron.

\section{BRILLANTE.}

Ce nom fut donné par Geoffroy à une petite coquille que Bruguière, dans le premier volume de ce Dictionnaire, décrivit sous le nom de $B u-$ limus lubncus. Celle coquille appartient au genre Agathine. Loyez ce mot et Burrare.

\section{BRONTE. Brontes.}

Genre composé par Montiort, dans le tome ze. de sa Conchylualogie systématique, pour quelques Rochers gue l'on ne peut retirur de ce grenre très-naturel, tel que M. Lamarck l'a réformé. Le genre de Moutlurl, dout le Hurex haustellum est le type, n'a point été adoplé. Foyez Rocnen.

\section{BRULEE OI POURPRE BRULÉE.}

Nom vulgaire d'une belle espèc:c du.geare Roclier, et nou des Pourpres, comare l'avoit cru Broguiere. Yoyes Roches.

\section{BUCARDE. Cardium.}

Bıtugière ayant traité d'une manière assez complète -e géare, pour qualil ail été cuaservé dans son intégrité, et qu'on n'y trouve d'ailleurs parmi les especes que de viritables Bucardes, nous renvoyons à l'article Borarde du prewiev volume de ce Dictionmaire.

\section{BUCARDES (Les).}

Celle famille fut proposée par M. de Ferussac dans ses Tableaux systématiques des animaux mollusques; elle est composée d'une parlic des genres de la famille des Cardiacées de M. Iainarck (voyez CARDracées), et elle nous semble plus naturelle, en ce quelle rejctie près des $V \hat{c}$ néricarles, les Cardiles et les Cypricardes, qui s'en distinguent à peine, au moins quant at premier de ces grenres. Cette famille compleand trois genres, Bucarde, Isocarde et Ifémicarde. (Voyez ces mols.) Ce dernier est certainement jumtile, présentant tous les caractères des Bacardes..

\section{BUCARDITE.}

Les anciens oryctorgraples donnoient ce nom à des coquilles cordiformes pétrifićes, yu’elles appartiussent on non au genre Bucarde : ćtoit alors la forme qui décidoit du gente. Vojez Bucarde.

\section{BUCARDIER.}

Dans sa première nomenclature syst́́marique, 11. Lamarck avoit proposé mue dénomination particulière dérivée de celle du genre, pour l'appliquer aux animaux de ce gonre même, en suivant à pen près l'exemple donné par l'oli.

Ces noms de Bucardier, Buccinier, Naticiers, etc. etc., étvient ceux des gentes Bucarde, Buccias, Natices, etc. Cette numenclature a étó complétement abandounée et par sou autear et par tous les autres zoologistes. Foyez MoLLUSQUE.

\section{BUCCARDIUII.}

Le genre Isocarde avoit été Établi depuis langtemps, lorsque M. Megerle le proposa de nouvean, en 1811 , sous le 1 om de Buccurdium, qui n'a point été adopté. Toyez lsocarde.

\section{BUCCIN. Baccinum.}

Les nombreux changemens qui ont été opérés dass le geare Buccin depuis le wonent aù Bruguière lui-même avoit porté la réforme dans le genre de Linné, reudent nécellaire un article supplémeataire, à l'aide duquel on pourra se faire une illée de ce que l'on entend aujourd'bui par le gente Buccin. Si an lit ce qu'en dit Bruguicure dass le premier volume de cet ouvrage, on verla que cet auteur a été le premier à porter la réfurme dans le grand genre Buccin de Linné. Il en sépara les Vis, les Casques \& les Pourpres; et malgré cela, le genre Buccin rcsta composé d'un grand nounbre d'espèces. Dis sou début dasas 
la carric̀re zoologique, MI. Tamarck, dans son S)stème des Animaux sans vertébres, opéra de grands cliagremens parmi les Buccias de Bruguiere; c'est ainsi qu'il en sépara d'abord les geares 'lonue, Marpe, Eburne et Nasse. Ces démembremens, aussi-bien que ceux de Bruguière, furent adoptés par MI. de Roissy dans le Buffon de Sonnini. Il fut en cela imité par Mluntfort (Conchyl. systén.), qui, malgré ces nombreuses dirisions, troura uroyen d'en ajouter trois de sa façon sous les noms de d'Alectrion, de Cyclope et de Phos. Ces geures, qui ae different en rien des Nisses, n’on point été adoptés. Ce fut dans le mime temps que M. Lamarck, dans sa Philosophie zoologique, en proposant la farille des Purpuracées ( z'ojez ce arot), eutièrement composée des clémenbremens des Buccins de Linné, en ajuula eocore deux autres non moins nécessaires que les premiers, ce soat les genres Concholépas et jionocères; de sorte qu'z cetle époque, on put comper dix genres sans sortir du senl genre Buccin du Systema nature.

Le geurre qui nous occape, dejja consiárablemeat réduit, étoit bien limité, quant anx Buccins froprement dits, et il nétoit plas possible d"u exiraire de nourcaux genres. Il n'en a pas ér de mẻme des Casques et des l'ourpres, qui ont fourni les uns et lẹs autres un genre nouveau, T:a l'on troure pour la prenière fuis dans l'Extrait dot Cours (1811): ce sout les Cassidaires et les Ricinules.

Loin d'adopter :ons les démembremens des Buccins, 11. Cuvier (Règne onimal) rétablit an conraire ce geure à peu prés sel quil étoit dans Bruguic̀re, et il y rapporte, comrre sous-genre seclement, les genres Eburne, Tonne, Harpe, Nasse, Pourpre, Casque, Cassidaire el Vis; de sorle que l'on pourroit rcgarder le genre Buccin pluiót com une famille équivalenie de celle des l'urpurifères de MI. Iamarck, qne comme un genre réritable, $\in t$ c'est l'opinion qu'ont eue la plupart des zoologistes qui ont snivi l'illustre ana:omiste.

Les Nasses sont très-roisines des Buccins; il y a, quant aux coquilles, un passage insensible d'un genre à lautre, et les animaus ne diffèrent pas enfr'eux de manic̀re à rendre nécessaires ces dleux counes. D'après ces motit's, M. Lamarck, qui le premier avoit proposé le jenre Niasse, fui aussi le premier, dans sun dernier ouvrage, à le réformer, et a le réuair definitivement aux Baccius. H. de Ferussac n'adopia pas ce sentiment; non-seulement il ranzea les liasses dans un autre geu:e, mais encore daus une famille distincle, ce qui ne nous semble pas mo:ivé, d'après l'état ces connoissances.

I. de Forussac ne troura point dibitatenrs. 11. Latreille, dans ses Fanvilles nuturelles du Régne animal, pag. 196 , partagea la famille des l'urpuriferes eu plasieurs autres, et l'une d'elles,

\section{B U C}

sons le nom de Buccinides (voyez ce mot), fut consacrée aux genres Nasse, Buccin et Eburne. II. de Blainsille (Trait. de Malac.) suivit ure autre marche que celle du sarant entomologiste. Le genre Buccin lait partie, dans cette classification, de la seconde section de la famille des Lntomostomes, et les Xiasses s'y trourent rénuies à titre de section on de gronpe daos le genre.

Brugnnière ne connoit les animaux des Bnccins que par quelques figures d'Adanson, les seules qui méritent guelque coufiance, ainsi que celles de Muller; il fut réduit à ne parler que des oryanes extérieurs, puisque la science ne possédoit pas encore d'unatomie un pen complète de ce genre. Cette lacune, vivement sentie, fut remplie par un excelleut MÍmoire de M. Cuvier; il fut inséré parmi ceux du .Iuséum, et reproduit dans le Recuenl des IIémoires anatomiques sur les Mlollusques, dont la scierce est redevable à ce grand znologisie. Ce ne sera pas sans truit qu'on le consultera. Une questiou d'nu assez baut intérêt, éloit de saroir distingner d'une maniere rationnelle les Fnseaux à queue crarie des Buccins. Muller ea avoit lait voir la difficulté en représentant un anicall tu Fusus antiquus Lasix. , qui est absolument semblable a celui du Buccinum undatum. Ce fait, qu'il n'est pas possiule de rúvoguer en doute, puisque nous arons surs les jeux les anizoaux dont il s'agit, z'a pas élé apprécié par 11 . Lamarck à sa valeur, car il auroil dú l'engager à rapprocher darantage les deax genres. M. de Fernssac pense qu'il faudra reporter dans le genre Buccin tous les Fuseaux dont le canal est trés-conrt; mais cela esı d'uxe excessire difficulté dans une aussi grande série d’espèces. Les transitions sont si peu sensibles, que nons ne voyons aucune limite possible, à moins qu'elle ne soit arbitraire, comme elle l'est déjà dans l'ourrage de M. Lamarck. Il faudroit que tons les animaux des Fuseaux nons lussent connus, pour décider quels sont ceux d'entreux qui doivent passer dans les Buccins.

Apres les nombreuses réformes dont le genre Buccin a élé le sujet, et en y admeitant, à l'exemple de M. Lamarck et de M. de Blainville, les Nasses, roici de quelle manière il conviendroit de les caractériser.

$$
\text { CARACTÉRS GÉSÉ⿴囗Q QES. }
$$

Animal spiral, orale on alongé; pied court, ovale, moins long que la coquille, ojercnlifere; manteau simple, siphonné en arant de la cavité branchiale; celle-ci grande, oblique et dorsale. Tète aplatie, pourrue d'une sea!e paire de tentacules, portant un point oculaire externe snr un renllement placé dans le milien de leur longueur; bouche armée d'ure trompe sans deut labiale; sexes séparés, les individus náles portant nue rerge longue et tonjours saillante sur lc côté droit du col, sonrent cachée daus la carité palléale. 
Coquille orale, ou ovale conique, à ourerture longituclinale, raremeat aussi large que baule; coluaclle sizuple, arrondie, ayant quelquefuis un seul pelit plis à la base; base de l'ouverture écliaciée et sans caaal. Opercule cornce, ouguriforme, à élémens concentriques; sommet margimal et supérieur.

Les Buccius sont des coquilles de tontes les mers; on en Irouve aulli-bien dans les zones gliciales que dans celies tonjours brülantes, iniertropicales. Cependant, dans ces rérrions, les especes sont plus nombreuses et plus rickes en couleurs que dans les premières; elles u'ont pas en géaćral un grand volume: il y en a méme uu plus grand nombre de petiles espèces que daulres.

Les Buccins dont M. Lamarck a voit fait le genre Nasse ac se distinguent des autres que par la forme de l'ouverture qui est géuéralement plus carrée, plus courte, el toujours garnie a l'iutéricur, au sozımet, d'un bourrelel décurreut placé surl'a vantdernier lour, el formant une goultière avec le bord droil. Dans celle section des Tasses, il s'en présente une antre bien caractérisée par les callusités calcaires du bord ganche qui s'éierd sur la lace ialérieure, el quelquef is enveloppe pres. que louse la coquille; le Buccin casquillon el onze aurtres espèces la couıposent.

Nous possédons plus de ceat espèces de l3uccins dans notre collection, sans $y$ compreadre plus de cinquaute autres à l'élat fóssile, et nous sommes loin eucore de possćder toutes celles yui sout commes. Ce ne sera pas exagérer que de croire qu'il existe deux cents espices dans un genre ou Bruguière en a indiqué soixante, en y joignant celles qui entrent unaintenant dass les cinq genres qui en ont élé séparés, nombre que M. Lamarck a laissé le axêne. Parai les espèces fossiles on remarque six analogues, incontesiables arec cles espèces actuellement rivantes. Brugricère ayant décril plus de quarante espèces de vériables Buccins dars le premier rolume de ce Diclionnaire, elles serriront diexemples à ce geure, ct nous y renvoyous, spécialement à celles qui forment sa secondé el sa troisième section.

\section{BUCCINE. Buccinn.}

Dinominarion quemplojoient quelcines antcurs anciens prur dísigner des coquilles turbinées qu'il est difficile de rapporter à un genre délermiuć. Marlini dans son grand onvrage l'a appliquée au geure Buccin de Linné. Foyez ce mot.

BUCCINEI.LE. Buccinella.

D: cble emploi du geare Turbinclle de $\mathbf{~ I ~ L a - ~}$ marcí; il a éré fuil par M. Péry, dans sou Truité de Conchyliologic. Vojez Turnarente.

BUCCINTER.

Noz deanć par 1L. Lara:ck dans le Sysieme des Animaux sans vertebres, 1801 , ì l'animal des Buccins. Fujez ce mol.

\section{BCCCINOIDLS (t,es).}

Nom que 11. Cuvier (Règne animal) donne it la seconde dirision de ses Mollusques pechinibranclies : elle rassemble tous ceux doni la coquille est canalicule ou f́chancrée ì la base, par consequent la plus yrande partie de celles qui sont conuucs. F'OYez l'ECTIMIBRAscBes el MoLLuSQUES.

\section{BUCCINUTLU.}

Quelques auteurs ont eajlloyé ce nom pour les perites espèces de Jỉacins. Vojez ce mot.

\section{BTCCIXUII I,ACERL'II}

Klein (Nov. meth. ostrac. Fag. 45 ) a rassemblé sous ce nam générique les caquilles de la classe des Buccins, qui on la lèvre drnite frangée dans loute sa longueur. Un tel genre ne pouroit étre adoplé.

\section{BUCCINUN MLRICATE.U.}

G. nre proposé par Kiein pour un certain sombre des coquilles de la classe des Buccius, qui sont cliargées de unbercules: on y troure des Trilons et un véritable luccin. Cé genre est loabé daus l'oubli.

\section{BUCCINUAI 'TRITONIS.}

Toules les grandes coquilles des genres Triton on Strombe, ou de tout autres qui, chez différens peuples, servirent de trompelles, forent rassemblés par Kleio (Ostrac. meth. pag. $4 \bar{j}$ ) en un genve auquel il donna ce nom. Il a'a point été adopté.

\section{BUJIS.}

liose, dans le Noureau Dictionnaire d'histoire ruturelle, dit que ce nom est l'un de ceux cle lat. Porcelaine cauris. Yoyez Puncenans.

\section{BULLIE. Bulimus.}

I! existe une si grande diffédence entre le genre que Eruguièse forina sous le uom de Bulime, et ce que pous compreuons aujourd'bui sous celle dénomination, cyu'il n'est pas possible de passer sous silence les nombreuses modifications ciüil a Éprourées par suite des amćliuratious qui se sont introduites successivement dans la science.

Lins avons vu aux articles Agstrixe, AypurLasne el AURICCLE, comment Bruguière, d'après un caractère de peu de valeur el pris trop cxulnsirement, avoit élé entrainé ì faire un fort manvais genre de ses Bulimes; comment, déterminé par la forme de louverture de la cocpuille, il y avoit rasseablé des Mollusques terrestres pul- 
monés, aquatiques pulmonés ou branchifères. Nous avons fait observer, ce que d'autres d'ailleurs avoient fait avaut nous, que ce genre étoit un véritable clsaos, auquel il éloit prélérable, en quelque sorte, d'adopter le genre Ifélice de Linné, d'où les Bulimes avoient été extraits sans amélioration pour la science. Dès que M. Lamarck, en s'occupant des animaux sans vertèbres, iutroduisit dans celte partie, si intéressante des sciences nalurelles, ce tad et cet esprit d'observation qui caractérisent ses nombreux travaux, il ae balança pas à porler la réforme dans le gente Bulime de Bruguière : il en sépara d'abord (Syst. des Anim. sans vert. 1301 ) les genres Maillot, Agrathine, Liminé, Mélanie, Pyramidelle, Auricule et Ampullaire, c'est-à-dire sept genres dont aucuu n'est inutile. L'année d'après, Draparnaud, cet excellent observateur, auquel on est redevalble du traité le plus complet des coquilles terrestres de France, détacba encore trois gerres des Bulimes, les Physes, les Ambreltes et les Clausilies : déjà ce premier genre aroit été indiqué par Adauson, suus le nom de Bulin. (Voyez ce mot.) Dès cetle époque, comme on le voit, les Bulimes éloient considérablement réduits, el ne contenoieut déjà presque plus que des cocpinilles terrestres, que M. Lanarck avoit caractérisćes d’après lcs animaux : aussice fut avec des animaux terrestres, daus la famille des Co'ymacées, que M. Lamarck plaça ce genre dans sat Philosophio zoologique; il lui conserva les mêmes rapports dans l'Extrait du Cours. Dans l'intervalle de ces deux ouvrages, Monifort (Concliyl. syst. tome 2) tronva encore dans les Bulimes les élémens de son genre Mélampe, que N. Lamarck proposa de nuuveau sons le nom de Conovule, qui füt plus généralement adopté; mais ce gente Jentre naturellemeut dans les Auricules. (Voycz ce mot.) M. Cuvier adopta le plus grand nombre des démembremens des Bulimes, qu'il distribua suivant leurs rapports dans divers groupes, et les Bulimes enx-mêmes, compris comme sous-genre du genre Escargol ou Hélice, conservèrent eutre les Vitrines et les Maillots des rapports qui déji, comme nous l'avons-dit, avoient élé appréciés et indiqués. Nous ne mentionuerons pas le dernier ouvrage de M. Lamarck, dans lequel on retrouve sa précédlente manière de voir, pour arriver à ceIni de M. de Ferussac. Coume cel auteur s'est spécialement occupé des coquilles terrestres, son opinion, pour ce qui les concerne, a besoin d'un exameu plus approfondi. Nons verrons aux arlicles Hélue et Molnusque comment M. de Ferussac a rassenblé sous le genre Hélice presque tous cenx qui en avoient été démembrés depuis Linné, et cornment, rassemblés en sous-genres, ils reçurent des dénominations particulieres et systémationes sans un avantage réel pour leur circonscription, puisque l'on peut dire, à quelques exceptions près, que les noms seuls furent changés,
Pour ce qui a rapport aux Bulimes, les espèces connues et décrites par M. Lamarck sont comprises dans le sous-genre Cochlicelle. (Voyez ce mol.) En traitant du genre Auricule, nous avons vu que M. Lamarck y avoil confondu deux sorles de Mollusques fort différens : les Auricules dont les animaux n'ont que deux tentacules, et un certain nombre de corquilles appartenant à des Mollusques à quatre teutacules, et qui par conséquent ne pouvoient rester dans ce genre, quoique leur ouverture fûl garnie de plis ou de dents comparables à ceux des vérititbles Auricules. Ces coquilles dont nous parlons, par leur forme, rentrent fort bien parmi les Bnlimes; néanmoins M. de Ferussac jugea convcnable d'établir pour elles, el pour plusieurs autres ana!ugues, un sous-genre roisin des Cochlicelles, et quil nomma Cochlogène dans son systène de nomenclalure. Voyez Coculogíne.

M. Latreille n'a point adopté celle nomenclature; il la blâme avec raison en ce qu'elle apporteroil de la confusiun daus la synonyurie déji si compliquée, el parce que les sons-geures de Mi. de lierussac correspondeot à des genres depuis Iongtemps sanclionnés dans la science. I.e genre Bulime, dans la méllode de M. Latrcille, fuit par(ie de sa famille des Géocochlides ( $20 y$. ce mot), où il conserve les rapports indigut, jar tous les zoologisles. M. de Blainvil'e, le deruier des nomenclateurs que nous ayons à mentionner, n'a pas non plus adopté le système de M. de Ferussac, il a conservé le genre Bulime, qui se trouve dans la première section de la famille des Limacinós ( voyez ce mol), entre les genres Anbrelte ct Aqalbine. Nous observous avec peine que M. de Bluiuville n'a pas tenu compte des rélormes de MI. de Ferussac, puisqu'on ne Irouve dans le Traité de Malacologie, aucune secion qui, dans les Bulimes, pût correspondre au sous-genre Coclilogène.

D'après ce qui précède, on ne sera pas surpris des cliangemens que doivent avoir éprouvés les caractères du genre Bulime. Voici de quelle manière ils peuvent être maintenant exprimés.

\section{CARACTÉRES GÉNÉRIQUES.}

Animal à quatre tentacules semblable à celui des Hélices.

Coquille ovale, oblongue, quelquefois subturriculće ; ouverture entière, plus longue quye large, à bords inégaux, désunis supérieurement; bord droit, simple ou bordé d'un bourrelet extéricur; columelle lisse, simple ou pourvue d'un ou de plusieurs plis sans troncalure et sans évasement a la base.

Les Bulimes sont caractérisés de manière à n'admettre que les espieces terresires; elles se distingueut desIlélices proprement dites par la forme ovale, alougie, quelquefois turriculéc; par la disposition 


\section{B U L}

disposition de l'ouverture qui est parallèle au plan de l'axe de la coquille, ou qui s'incline très-peu sur lui, ce qui n’a pas lieu dans les Hélices, qui ont toutes l'ouverture très-oblique. On ne sauroit les confondre arec les Agathines, puisque dans ce geure la colunelle est tronquée a la base, ce qui n'a jamais lieu dans les Balimes; cependant on voit combien ces deux geures sont voisins par l'hésitation que l'on éprouve à ranger certaines espèces plutót dans l'un-que dans l'autre.

Malgréles réductions nombreuses qu’a éprouvées le genre qui nous occupe, les découverles que l'on a faites depuis la publicalion du premier volume de ce Dictionnaire, ont augmenté considérablement le nombre des Bulimes réritables. M. de Ferussac, dans son prodrome, en comple plus de qualse-ving's, ce qui dćpasse de beatucoup le nombre des espèces du genre de Bruguière.

On a cru long-lemps, et c'est M. Lamarck qui a accrédité celle opinion, qu'il existoit des Bulimes fossiles. Plusieurs auteurs, conliant dans les travaux de l'illustre naturalisle, décrivireat des coqnilles fossiles sons ce nom; il en résulıa pour la géologie des applications qui manquèrent de justesse, puisqu'il est vrai de dire, après un examen approfondi de toutes ces cofuilles, quelles appartiennent aux genres Paludiue ou Mélauie (2.0yez ces mols); de sorte que les terrains qui les renferment, associés avec des coquilles lacustres, n'oat plus rien d'équivoque et d'embarrassant, et leur nombre quelquefuis prodigieux, qui seroit iuexpliquable si elles étoient terrestres, n'a plus rien d'ćtonnant lorsgu'on les a rendus a leur genre, dont les espèces, dans certaines cirçonslances, se multiplient beaucoup.

Les espèces de Bulimes peuvent se partager en leux grandes sections : $1^{\circ}$. celles qui ont l'ouverture garnie de plis ou de dents; $2^{\circ}$. celles qui out l'ouverture simple. Ces sections pourront ensuite se sous-diviser d'après la forme plus ou moins turriculée de la coquille, la forme de l'ouverture dont le bord est tantôt tranchant, tantôt margiué, selon les espèces; enfin, d'après la présence ou l'absence d'un ombilic : ce caraclère est un des derniers à eaployer, puisqu'al se inontre ou disparoît dans la même espéce, selon l'âge où on l'observe; il y en a quelque-uns cependant qui l'ollirenc à tous les âges. Ce qui nous a tonjaurs surpris, c'est que M. Léach, zoologisie d'ailleur's fort dislingué, se soit servi de ce foible caractère pour établir, sous le nom de Bulimule, un geare particulier. Personne ne l'a adopté.

Bruguic̀re ayant décrit un assez bon nombre de Bulimes pour servir d'exemples à ce genre, nous renvoyons au premier volume de ce Diclionnaire aux naméros suivans de l'article que nous venons de citer : Bulimus ovatus, ${ }^{\circ} .33$. Bulimus ablongus, $\mathrm{n}^{\circ} .54$. Bulimus undatus, $\mathrm{n}^{\circ}, 38$. Bulimus inversus, $n^{\circ} .28$. Bulinus citrinus, $n^{\circ}$. 27. Bulimus ovoideus, ${ }^{\circ}$. 64. Bulimus.interrupHist. Nat. des Vers. Tome II. tus, $\mathrm{n}^{\circ}$. 5o. Bulimus perusianus, $\mathbf{n}^{\circ} .37$. Bulimus Kambeul, $\mathrm{n}^{\circ} .40$. Eulimus calcareus, $\mathrm{n}^{\circ} .50$. Bulimus decollestus, $n^{\circ}$. 49. Bullunus radiatus, no. 25. Bulimus gucudulupensis, no.26. Bulimus octonus, $\mathrm{n}^{\circ} .47$. Bulimus acutus, ${ }^{\circ} .4^{2}$. Bulimus hordaceus, no. 62. Bulimus auris Sileni, $\mathrm{n}^{\circ}$. 81. Bulimus unris leporis, 4º. 82. Bulinus bovinus, עo. 80 .

\section{BULIMINE. Bulimina.}

C'est à M. d'Orligny que l'on doit la créalion de ce genre parmi les Céplialopodes microseopiques. Il appartient ì li famille des Jlélicostègues de cet auteur, et il est compris dius la première section, celle des 'Turbinoides. (Voyez HébicosTÉGUEs.) Il étoit nécessitire de distinguer ces pelits corps dont la forme s'approche, conme leur nom l'anuonce, des Bulimes, par la même raison que dans un autre orclre on a séparé les 'lurrililes des Ammonites. Dans le genre Buliwine, nous trouvous un groupe qui nous semble naturel et gui sera probiblement conservé, car il est caractérisé d'après le mode d'accroissement, aussi-bien que d'après la posilion el la forme de l'ouverture. Nous a vons observé, et nous ferons eacore seutir à l'article Cépa a Lopone, que dans un assez grand nombre de ses genres, M. d'Orbigny n'a pas assez tenu compte de cette ouverture, qu'il a considérée à tort comme caractère secondaire.

$$
\text { CARACTĖES GÉNÉRIQUES. }
$$

Coquille multiloculaire, spirale, turriculée; spire alongée; ouverture virgulaire et latérale près de l'angle supćrieur de la dernière cloison.

Ne connoissant pas en nature les espèces du genre Bulimine, nous ne pourrons pas en faire la description. Nous citerons a vec conliance les figures et les modeles de M. d'Orbigny, qui en douneront une idée sulfisante, et qui suppléeront d̀ notre ignorance.

\section{Buhrune marginée. Bulimina narginata.}

D'Onв. Mlém. sur les Céphol. Ann. des scienc. nat.tom. 7. pag. 26g. no. 4. pl. 12. fig. 10. 11. 12.

Elle se trouve à Rimini.

\section{Bulinine élégante. Bulimina elegans.}

D’Onв. loc. cit. no. 1о. Modèles de Céphal. Ire. liviais. $n^{\circ} \cdot 9$.

De la même localité que la précédente.

\section{Bummine caudigère. Bulimina caudigera.}

$\mathrm{D}^{\prime} \mathrm{O}$ в, loc. cit. $n^{\circ}$. I6. et modèles $3^{\circ}$. livrais. no. 68 .

De la mer Adriatique, près Rimini. 
BULIMULE. Bulinulus.

On trouve ce geare dans les Miscellanea zoologica de M. Léach, tom. 2. II est établi pour celles des espèces du genre Bulime, qui ont lom. bilic ouvert, comme cela a lieu daas le Bulimus guadalupensis de Bruguière. On conçoit facilement qu'un geare fait sur des caractères aussi insuffisuns n'a pas été adopté. (Voyez Burisiz.)

\section{BULIN.}

Adanson, dans son Voyage au Sénégal, a décrit sous ce nom une petite coquille avec son animal. Cette coquille a la plus grande analogie avec le Bulinus fontinalis de Broguière; aussi cet observateur l'a décrite dans le premier volume de ce Dictionnaire (voyez Burine, pag. 103), en parlant du Bulimus fontinalis des environs de Paris, Depuis, Draparaaud a fait avec celte espèce et d'autres semblables son genre Physe, qui a été généralement adopté, et dans lequel doit se ranger le Bulin. (Vojez Pryse.)

\section{BULLAA.}

On trouve dans ce genre de Klein (Nov. methostrac.pag. 82 ) la réunion de presque toutes les Bulles connues de son temps; malheureusemen: il y confond une espèce de Marginelle, ce qui empèche de lui attribuer la réforme du geare Bulle de Linné, ce que l'on doit à Bruguière, comme on peut s'en assurer en consultant l'article Borte dans le premier volume de ce Dictionnaire.

\section{BULLE. Bulla.}

Brnguière, à l'article Bulle de ce Dictionnaire, a complétement séformé le genre Bulla de Linné. Depuis, tous les zoologistes ont adopté le genre ainsi modifié, qui a'a plus varié que quant à la place qu'on lui a fait occuper dans les méthodes. Nons reviendrons sur ce sujet à l'article MorrusQUE. (Voyez ce mot et Burle, tom. I, pag. 370). Un genre en a cependant été extrait par M. Lamarck, qui lui a dunné le nom de Bullée ( voyez ce mo1), pour montrer la grande analogie quil a avec les Bulles.

\section{BULLÉENS (Les).}

La famille des Bulléeas a été créée par M. Lamarck dans son dernier ouvrage, et il auroit pu sans inconvénient luj donaer le nom d'Acères, qui étoit déjà consacré par plusieurs zoologistes avant $18 \mathrm{r}$, époque à laquelle M. Lamarck rassembla dans les Aplysiens les élémens de la famille qui va nous occuper. Les geares qui la constituent étoient fort éloignćs les uns des autres; 'c'est ainsi que dans la Philosophie zoologique, on trouve les Bullées dans la famille des Aplysiens, et les Bulles dans celle des Hétéroclites,

\section{B U L}

qui se trouvent, l'uae au commencement et l'autre à la fin de la longue série des Gastéropodes sans siphon.

La publication des travanx de M. Covier sur les Acères dureat modifier les opinions de M. Lamarck, et l'on voit, en effet, qu'il profita des précienses indications de son savant collègue. Les rapports des Acères avec les Aplysies se trou. vant hors de doute, M. Lamarck, dans l'Extrait $d u$ Cours, fit une seule famille de tous ces geares et la partagea en deux sections. Plus tard, la première section, composée des trois genres Acère, Bullée et Bulle, fut transformce en ane famille distincte, qui reçut le nom de Bulléens; elle fait partie des Gastéropodes, et elle est dans des rapports intimes avec la famille des Aplysies. II. Curier (Règne animal), dans l'arrangement des Tectibrancbes (voyez ce mot), coïncida presque complétement avec celui de la famille des Aplysiens de MI. de Lamarck (Extrait du Cours); seulement, au lieu d'adopter les trois genres de la première section, il en fit autant de sonsgenres de son genre Acère : de sorte que ces Acères représentent complétement la famille des Bulléens.

En modifiant la famille des Tectibranches, 11. de Ferassac n'y apporta pas de changemens confidérables; il l'éleva au titre d'ordre, et le partagea en deux familles, les Dicères et les Acères, qui correspondent assez bien anx A plysiens et aux Bulléens de M. Lamarck. On trouve dans les Acères deux genres de plus que dans les Bulléens: ce sont les Bullines et le Sormet. (Voyez ces mots.) Le premier de ces genres étoit inconau à M. Lamarck; et il ae devra pas ètre adopté; le second est trop douteux pour le fixer définitivement dans la méthode. Un autre chaggement que l'on remarque dans les Acères est relatif au sous-genre Acère de $M$. Cuvier, auquel M. de Ferussac a préféré , à cause de son antériorité, le genre Doridium de Mékel. MI. Latreille (Fam.'nat. dus Règn. anim. pag. 177) a adopté sans changemens importans la famille des Acères de M. de Ferassac; seulement le genre Balline, qui est pourvu de tentacnles lorsque les antres genres des Acères en sont dépourvus, termine la famille précédente, les Tentaculés ( voyez ce mot), et le genre Sormet se tronve par là plus rapproché des Bullées et des Bulles. Nous croyons atile le changement proposé par M. Latreille, et nous l'adoptons d'autant plus volontiers que déjà depuis longtemps dans notre ouvrage sur les Fossiles des environs de Paris nous l'avons indiqué.

M. de Blainville (Trait. de Malac.) ne suivit pas entièrement la marche de ses devanciers dans Ia disposition de la famille des Acères, et dans ses rapports arec les familles environnantes; c'est ainsi qu'entre les Aplysieas et les Acères est interposée la famille des Patelloïdes, qui comprend les genres Ombrelle siphonnaire et Tylo- 
dinne. (Yoyez ces mots.) Les Acères contiennent un plus grand nombre de genres, ils sont disposés dans l'ordre suivant: Bulle, Belléroplee, Bullée, Lobaire, Sormet, Gastéroptère et Allas. Nous avons dit pour quelles raisons le gente Bellérophe ne pouvoit rester dans celte fanille, mais se ranger à côté des Argonautes. (Voyez B BLLÉnop日e.) Naus ne trouvons pas le genre Bulline de BI. de Ferussac, qui n'est mentionné que comme une division secondaire des Bullées; cependant ce genrc differe des Bullées et par la cuquille et par l'animal : ce que nous exposerons à l'article Buchise, auquel nous renvoyons. Le genre Lobaire est le nême que le Duridium, et le Bullidium de Mćkel est le même aussi que le gemre $\Lambda$ cère de M. Cuvier. Le Gastíroptère a saus doute de l'analogie avec les Acères, mais est-il cuflisamment conou pour resicr lans celte fauille? A plus forte raison pouvons-nous faire cette question pour le genre Ailas.

Ainsi, en résumć, il n'y a de bien connus que les trois geares mentionnés dans la famille des Bulléens de M. Lamarck; le genre Bulline ne devant pas y rester, cette raison nous l'a fait prétérer ì toutes celles qui ont été proposées depuis, et qui paraissent plus complètes : elles ne le seront véritablement qu'au moment où il n'existera plus de doule à l'égard des genres qu'on y a introduits. Nous examinerons cependant tous les geures que nous arons mentionnés, et nous y renvoyons: ceux que nous admettons dans la famille dés Bulléens sont les suivans: Gastéroptère?' Lubaire on Acère, Bullée et Bulle.

\section{BULLÉE. Bullaa.}

Quoique l'on ait généralement attribué à Plancus la première description et la première figure de l'animal des Bullées, il est pourtant constant que c'est Fabius Colunna, qui le prewier l'a fiait connoitre sous la dénonnination de Concha natalis minima exotica. Il est vrai de dire que Fabius Columna prit les pièces stomacales pour l'opercule de la coquille; et que la figure de Plancus est tellement mauvaise, qu'il falluit avoir un autre point de comparaison pour la rapporter à son geare. Il n'est donc pas éconnant que plus tard Ascanius, qui observa l'animal, ne le pû́t comparer aux tigures déjà faites et lui ait donné un nom particulier, le premier générique qui lui ait été imposé, phylline quadripartita, qui fut longtemps oublié, et que Muller, presqu'en même temps, lui ait donné celni de Lobaria quadriloba. Voilà, sans aucun doute, un gemre bien établi, autant d'aprè la cannoissance de l'animal que sur' celle de la coquille. On peut donc reprocher à Linné de ne l'avoir point adopté, puisque déjà Abildgaard avoit reconou l'analogie de la figure de Plancus avec celle de Mluller; mais on s'étonnera duvantage de voir Gmelin, daus la $13^{\circ}$. édition du Systema naturee, placer d'abord le Loba- ria à cóté des Clios et des Lernées, et la coquille parmi les Bulles. Ce double emploi est ua nouvel exemple du peu de critique que Gmelin avoit lorsqu"il s'agissoit d'almettre ou de rejeter les genres. Bruguière ne tomba pas dans la míme faute, el cependant u'adojta pas le geure Lobaria de Muller, et conserva, à l'exemple de Limué, la Bullée parmi les Bulles, sans nentioner dans sa synonymie, ordisairement si complète, ni le Phyllioe d'Ascanius, ni le Lobaria de MIuller, et pourtant il iodicua la ligure de l'lancos.

Dès l’année 1800, M. Cuvier publia, dans le Bulletin de la Sociéte philomatique, une nole sur le mollusque de la Bullée; il fic apercevoir les rapports qu'il a avec les Aplysies, et en donna peu apiès une description plus détaillée dans un excellent Mémoire qui fait partie du premier volume des Annales du Muséun. Alors M. Lamarck, ve tenant pas compte des noms donnés ì ce genre avant lui, proposa, sous la dénomination de Bullée, le genre de Muller, et ce noun prévalut parmi les conchyliologues, comme l'atlesteat les Iravaux de.MM. de Roissy, Bosc, et un peu plus tard ceux de Montfort. Daus l'intervalle, Draparnaud décrivil les pièces stomacales du Bulla lignaria, en dévoilant le mensonge de Gioeni relatif à ces pièces ( voyez Char); et comule elles se trouvoient aussi dans le Bullaca apcrita, on se servit de ce rapport pour rapprocher ces denx espèces dans un même geure, et d’après ce!le seule induction, Montfort se servit du Bullal lignaria comme type de son genre Scaplandre, qu'il proposa de substituer aux Bullées, pour éviter, disait-il, la confusion qui devoit résulter des deux norns analogues très-voisins. Quoique l'ouvrage de Montfort n'ail paru qu'en 1810, il paroit qu'il a'a pas eu connoissance de celui de Monlagu, publié cinq ans avant. Cest dans ce dernier ouvrage que l'on trouve l'iodication exacte de tous les travaux anlécédens sur ce sujet, et en même temps une très-bonne figure de la Bullée. Un pen plus tard, $M$. Cuvier donna un travail général sur les Acères et parla de nouveau du genre qui nons occupe ; il le mit en rapport avec les Aplysies et d'autres genres voisins. Aussi M. Lamarck, qui, dans le Systemedes Animaux sans vertebres, a voit d'abord beaucoup séparé les genres Bulle et Bullée, les rapprocha dans une même famille, les Laplysiens, dans l'Extrait du Cours, el finit, dans son dernier ouvrage, par créer pour enx une famille, saus le nom de Bulleens (voyez ce mot), qui, dans sa méthode, est la plus voisine des Aplysies, dont elle a été démembrée.

M. de Ferussac a conservé, dans ses Tableaux systématiques, un arrangement analngue, quoique moditié (voyez Acènes), daos les rapporis des familles des Aplysies et celle des Bulles. M. Latreille a adopté presque complétement l'ordre proposé parM. de lerussac. On trouve donc les Bullées avec les Bulles dans la famille des Acères. 
II. de Blainville adopla la famille des Acères en la rendant plus considérable, mais il l'ćloigua des Aplysies. Le genre Bullée (Traité de Malacol. pag. 477) est nuêrme séparé des Bulles par le gente Bellérophe, sur les rapports duquel nous croyons que M. de Blainville s'est trompé; mais bientôt, s'apercevant qu'un autre arraugement est préférable, le savant professeur propose la réunion des deux genres en un seul, comme on pent le voir dans les additions et corrections, page 625 du même ouvrage. Sans adopter ni l'une ni l'autie opiuion de M. de Blainville, nous croyons, comme la plupart des conehyliologues nous en donnent l'exemple, qu'on peut admettre le genre Bullée, et le placer immédiatement à côté des Bulles, dans la même famille, soit que l'on préfère celle des Acères ou des Ijulléens.

Nous avons menlionné, dans le résumé hislorique qui précède, les ouvrages principaux où il est question des Bullées. Parmi eux, les Mémoires de M. Cuvier doivent être consultés de préférence, sil'on veut connoitre avec quelque détail l'organisation de ce genre; nous y renvoyons le lecteur, car nous serions obligés d'emprunter à M. Cuvier ces détails, si nous voulions les donner ici.

\section{CARACTÉRES GÉNERIQUES.}

Corps ovale-alongé, un peu convexe en dessus, divisé transversalement en partie autérienre el en partie postérieure; les lobes laléraux du pied, à bords un peu épais el se réfléclissant en dessous; tête peu distincte, point de tentacules; branclies dorsales placées sous la partie postérieure du manteau; coquille cachée dans l'épaisseur de ce manteau, au-dessus des branchies, et sans ad̉círence.

Test très-mince, partiellement enroulé en spirale d'un côté, sans columelle et sans spire, ì ouverture très-ample et très-évasée.

Le nombre des Bullées est très-borné, on n'en connoissoit jusqu'à présent que deux espèces bien constatées, l'une vivante et l'autre fossile; depuis nous en avons découvert une troisième bien distincte, fossile, d'Italie. Elles sont toutes excessivement minces, papyracées, fragiles, ovalaires, peu profondes, à peine involvées, et par conséquent très-amples. On a découvert depuis quelque temps, et on l'avoit déjà dans quelques collections, une pelite coquille verdâtre très-mince, qui a beaucoup de rapports avec les Bullées, et qui s’en distingue néannoins par quelques caractères bien saillans. La spire est beancoup plus complète, et l'ouverture, bien que très-ample, est entière, par la réunion du bord droit au gauche supérieurement. Les tours de spire sont visibles seulement à l'intérieur, où ils forment une spirale saillante; mais ce qui est particnlier, c'est qu'il esiste ì l'intérieur un appendice en forme de cuilleron, comparable en cela avec celui des Pholades, mais fort analogue sans doute, quant à l'usage, à la lame perpendiculaire qui se voit daus un certain nombre de Calyptrées. Cette coquille constitueria bien probablement un genre, lorsqu'on en connoitra l'anional.

\section{Bullée'striéc. Bulloca striata. Nов.}

B. testâa ovato-truncatâ, depressâ, tenuissimâ, supernè angulatâ; spirấ intics perspicuâ, striis lenuibus, depressis, elegaritibus.

Nов. Descript. des Coq. foss. des env. de Paris, tome 2. pag. 37. pl. 5. fig. 1. 2. 3.

Bullcea aperta. DEF. Dict. sc. nat. tom. 5. Suppl. pag. 133.

Ou doit s'étonner de trouver entières, à l'ćtat fossilc, des coquilles aussi minces et aussi fragiles que celles de ce genre, car leur épaisseur, vers le bord le plus solide, égale à peine un sixiène de millimètre; néanuoins, les deux espèces que nous conuoissons en constatent la possibilité.

I,a Bullée striće est ovale, tronquée du côté de la spire, d'où le bord supérieur' se délaclie fortement en un angle assez aigu; clle est peu concave, mais encore l'es!-elle un pen plus que la Bullaca aperta. Sa spire est aplatie, composée d'un et demi à deux tours de circonvolution; à l'intérieur elle est lisse, et à l'extérieur striée élígamment; mais les stries ont une disposition fort remarquable, elles sont aplaties, carrées, semblables à de pelits rubans posćs sur une surface lisse.

Longueur 15 millim. largeur 11.

Elle est très-rare et fossile à Grignon et à Mouchy-le-Châtel.

2. BuLLEE ouverte. Bullaa aperta. LAM.

Bulla aperta. Brug. Voyez la descript. de cette espèce, tom. I, pag. $375, \mathbf{n}^{\circ} .7$ de ce Dictionnaire.

\section{BuntéE rostrée. Bullaa rostrata. ов.}

B. testâ subrotundatâ, depressâ, obliquissime vix involutâ; margine dextro valde separato, supernè angulato, rostrato.

Celte jolie coquille ne nons est connue que depuis peu de temps; nous l'avons trouvée dans un Casque fossile du Plaisantin, qui l'a mis à l'abri de la destruction. Elle est d'une taille pen considérable, peu profonde, et à peine tournće en spirale. D'un côté, cette spirale, très-oblique, fait à peine un tour, et elle se termine bientôt au bord gauche, qui est arrondi et fort évasé, aiosi que le droit, qui devient extrêmement mince. Le bord supérieur, en se détachant de la spire, au lieu d'ĉtre droit ou un peu oblique, se projette 
en avant, et se joignant avec l'extrémilé du bord droit produit un angle fort saillant en bec : disposilion particulièce que nous n'avons jamais remarquée que dans cette espèce. Cot angle fait une saillie de plus de deux milliucetres en deliors de la coquille, qui, du reste, n'en a pas plus de dix dans ses autres dimensions; elle ollie quelgrues stries d'accroissement; du reste, elle est toute lisse en dedans et en dehors.

fussile en Inalie.

\section{BUIIIER.}

M. Lamarck a nommé ainsi, dans le Systeme des Animaux sans vertèbres, l'aniual des Bulles. Ioyez cc mot.

\section{BULLIN. Bullinus.}

M. Ocken, en rlbangeant l'orthogiaphe du Bulin d'Adanson, a fait sours ce nom uu genre assez singrulier, composé des Plyyses et des Ancyles, qui certes ont des caracleres suffisans pour rester séparés. Foyez Puyse et Axcrie.

\section{BULLINE. Bullina.}

Cic petit genre; démembré des Bulles de Bruguière el de M. Lanarck, fut créé par M. de Ferussac dans ses Tableaux systématiques des animaurx mollusques, et caractérisé à l'article BoLI.Ix du Dictionnaire clussique dhistoire naturelle. Les espèces que l'auteur a comprises daus son geare sont celles qui olfient ce caractère, d'avoir constanment la spire saillante, les autres Bulles ayant cette partic ou tronquée et aplatic, ou complétement intérieure. On s'apercoit facilement que ce genre ne repose que sur un caractère artificiel et de très-peu de valeur; car par la mème raison on pourroit en faire un avec les espèces dont la spire est aplatie et tronquée, et extérieure, et enfin nn troisième avec celles qui ont la spirc complétement intérieure, \& lorsqu'on aura établi ces trois coupes sur des caractères de la même valeur, il sera fort difficile de les trancher nettement, lorsque l'on aura une grande série d'espèces sous les yeux. Si en suivant le principe de M. de Ierussac, les deux démembrenens que nous avons proposés momentanément sont évidemment inutiles, il faut convenir que celui de cet auter ne l'est pas moins : mais ce qui le pronve d'une wanière incontestable, c'est que l'auiual trouvé par MM. Quoy et Gaymard, et décrit par eux dans la partie zoologigue de leur ouvrage, animal sur lequel M. de Ferussac comptoit en quelque sorte pour achever les caractères de son genre, quoique différent sons plus d'un rapport de celui des Bulles et des Bullées, porte néanmoins un coquille dont la spire est complétement intérieure: de sorte que sil y a un démembrement à faire dans le genic Bulle, ce ne pourra être que d’apres les animaux, et l'on couccura saus peine que pour l'élablic il est absolument indispensable d'en connoitre un assez grand nonbre; ct c'est précisćment celle condition londamenta'e qui manque. Nous admettons cependant que l'animal décrit par MHI. Quoy ct Gayaud, qui est tentaculé, qui n'a point d'alnure stomacale, dont le manteau divisé en denx petils lobules antérieurs libres, cacliant une foille partie de la coquille, diffère issez sensiblemeut des 13 ulles, et il n'est pas doutcux qu'il ne doive constituer un genie a part, si on peut $y$ joindie quelques autres espices.

\section{BULLINS (Les).}

M. Ocken a proposé sous cette dénomination ume lanille qui, par les genres qu'clle contient, a beaucoup d'analogie avec celle que M. Lamarck avoit nomaćc Ar.riculacés dans la Philosophie zoologique. M. Ocken proposat de réunir les quatre geures Planorlie, Bullin, Limnée et Mlarsyás. (Voyez cos mots.) Nous observerons que ce genre Bullia est composé des Ancyles et des Pliyses qui a'ont que fort peu de lapports, comme o: eh conviendru. Le genre Marsyas est composé des Auricules et des Scarabes, et ils sont pulmonés terrestres, et ue peuvent en couséquence rester avec les Planorbes ct les autres geures mentionnés.

\section{BUREZ.}

On écrit Buris par erreur sans donte dans quelques Dictionnaires. Au rapport de Rondelet, on donnoit ce nom sur les côtes du Languedoc a la coquille nommée Murcx brandaris par Liná et Lamarck. Voyez Rochen.

\section{BURGAU.}

Nom donné par le vulgaire et les marchands à quelques coquilles du genre Turbo de Lamarck. Le Turbo marmoratus, qui est très-grand, recoit particulièrement ce nom lorsqu'il a été décapé : il présente alors la nacre la plus brillante.

Le Turbo cornutus Lamk. a reçu le nom de Burgo tuile ou épineux, el le Tubo sannaticus celvi de Burgo perlé. Voyez Tunвo.

\section{BURSA.}

Quelques anteurs ont donné ce nom latio à quelques coquilles d'une forme oblc ague, surtout des genres Casque et Cassidaire : c'est it Buonani, Petiver et Gualtierri que l'on doit cette dénomination qui n'est plus en usage.

\section{BURSATELLE. Bursatella.}

Genre que M. de Blainville forma pour un animal remarquable qu'il observa dans la collec. 
150

B U R

tion du Musée britannique, et dont la description et la figure devoieat être publićes dans le Supplément à l'Encyclopédie britannique. Mais oet ourrage a'a point été achevé, de sorte que nous ae connoissons le genre Bursatelle que par une très-courle notice, insérée dans le tome 5 du Dictionnaire des sciences naturelles, pag. I38 du Supplénent, et par les caractères génériques que l'auteur lui a donnés dans son Traité de Malacologie, où l'vn tronve aussi une figure qui donae de l'animal une idée plus complète.

M. Raug, dans sa Monographie de la famille des Aplysies, a admis le geare Bursatelle daos des rapports analogues à ceux indiqués par $\mathrm{M}$. de Blainville, mais avec un doule convenable d̀ un genre incomplétement connu. M. Rang pense, saas vouloir cependant l'assurer d'une manière trop positive, que le genre Bursatelle est le mème que celui qui a été nommé Elysie. II trouve entr'cux des différences qui tienaent, à ce qu'il pense, à ce que l'un est beaucoup mieux connu que l'autre; aussi il ajonte qu'il n'a adopté la Bursatelle à litre de genre que dans l'intention de le mettre en évidence avec les iacerlitudes qui l'entourent, et provoquer par ce moyen les recherches des ualuralistes.

A l'exemple de $\mathbf{3}$. de Ferussac, dans le Dictionnaire classique d'histnine naturelle, et de M. Rang, dans la Monographie des Aplysies, nous allons copier textuellement les caractères génériques de M. de Blainville, et la courte description de l'unique espèce consue dans le genre.

\section{CAR $\triangle$ CTE்RES GÉSÉRIQUES.}

Corps sabglobuleux, offiant inférieurement un espace ovalaire circonscrit par des lèvres épaisses indiquant le pied; supérieurement une fente ovaluire à bords épais, symétriques, formée par la réunion complète des appendices natatoires du manteau, et communiquant dans une cavité où se trouvent une très-grande branchie libre et l'anus, quatre tentacules leadus, ramifiés, outre deux appendices buccaux.

Aucuae trace de coquille.

Borsatelle de Léach. Bursatella Leachii.

Buaiv. Dict. des sc. nat. toin. 5. pag. 138. Supplément.

Ibid. Fenussac, Dict. clas. dhist. nat. tom. 2. pag. 588.

Bisint. Traité de Malac. pag. 473. pl. 43. fig. 6.

RANG, Monog. des Aplys.pag.78.pl. 23 . fg. 2. ex BuarNt.

Cet!e espèce, la seule du geare, a été décrite par M. de Blainville daus celle courte phrase:

\section{B I S}

* La Bursatelle de Léach est presque grosse comme le poing, d'une couleur d'un blanc jaunâtre, comme trauslucide; tout son corps est parsemé de pelits appendices tentaculiformes irrégulièrement disposés, ce qu'on nomme, peutétre à tort, des tentacules dans celte famille, et le bord de la tête en ont de plus longs. "Elle vieat de la mer de l'lade.

\section{BURSULE. Bursula.}

Mauvais genre proposé par Klein (Ostrac. pag. 175) sur une mauvaise figure copiée de l'ouvrage de Buonani. Il seroit dilficile d'affirmer d'une manière positive à quel gepre appartient la coquille qui sert de type à celui-ci : on pent cependant présumer que ce n'est autre chose que la valve supérieure de l'Anomia ephippium, qui par basard a le crochet fort grand et un peu recourbé.

\section{BYSSIFËRES (Les).}

M. Lamarck créa cetle famille dans sa $F / i$ losophie zuologique, et y rassembla tous les auimaux conchifêres qui ont la propriété de s'attacher au fund de la mer au moyen d'un byssus. (Voye: ce mot.) 11 la reproduisit dans l'Extrunt du Cours ( 1811 ), et il la composa alors des geares Houlette, Lime, Pinse, Moule, Modiole, Crénatule, Peroe, Marteau et Avicule. Depuis le savant professeur s'aperçut que d'autres genres appartenant ì des familles fort difterentes avoient la même faculté de filer un byssus. Il abandonna donc ce caractère dans son deroie: ouvrage, ce qui lui permit de distribuer plus naturellement dans d'antres familles les genres des Byssifères : ils sozt compris maintenant dans les Mytilacées, les Malléacées et les Pectinides. (Voye = ces mots.) M. Goldfuss (Handb. der zool. pag. 604) a adopté la famille des Byssifères en la réduisant aux trois genres Vulselle, Marieau et Perne. La raison qui a fait rejeter la famille des Byssifères de MI. Lamarck suffit pour ne pas adopler celle-ci, quoique les genres qui y sont rassemillés aient évidemment beaucoup de rapports entreux.

\section{BYSSOMIE. By'ssomia.}

Genre institué par M. Cuvier pour le Mya byssifera de Fabricius, qui ae dillère pas sen:iblement des Saxicaves par la coquille et pur l'animal, si ce n'est que celui-ci porte un perit byssus au-dessous du pied. (Voyez Saxucatr.)

\section{BYSSUS.}

Un cerlain nombre de genres parmi les Conchifères ont la faculté de s'altacher aux corps sous-marins, à l'aide de filamens plus ou moins nombreax, cornés, flexibles, quelquefois soyeux 
ou taudineax : tous ces filamens partent d'un méme point du corps de l'animal, et leur réuvion a recu le nom de byssus. On avoit cru pendant quelque temps que certains animaux inférieurs de l'ordre seuls avoient un byssus; M. Lamarck employa ce caractère pour créer la famille des Byssifères; mais depuis on sat que les Tridacnes, les Hyppopes? certaines Saxicaves avoient aussi cette partie, d'où vient la nécessité d'abaodonoer cette dénomination de Byssiferes.
Le byssus est placé à la lase du pied daus les animaux qui en ont un : ce pied presque rudimentaire est flexible, et paroit destiné à diriger et a fixer les fils du byssus. Parmi les geares Byssifères, le plus remarquable, le plus anciennement connu est le gevre Pinne : lorsque nous en traiterons nous donnerons de nouveaux détails sur le byssus, aussi-bien qu'aux geares Vulselle, Marteau, Perne, Pintadine, Avicule, Moule, Modiole, Peigue, Houletle, Lime, Tridacne et Saxicave. (Voyez ces mols.) 


\section{A B}

\section{Cabochos. pileopsis.}

Il est à présumer que Bruguière, à l'exemple de Linné, confondit les Cabochons dans le genre Patelle : il est probable que, comme lui, il en auroit fait une section sćparée, et en cela il n'auroit fait qu'imiter Lister, qui fut le premier qui forma des groupes naturels dans le genre Patellc. ( Vojez ces tnots.) Lun d'eux ae contient que des Cabochons, et l'on pourroit à la rigueur y trouver l'origine du genrc qui nous occupe. Linné et Brıguière ont imité Lisler : M. Lamarck les a suivis daus ses premiers travaux, puisque dans les $A n$ nales du Muséum il décrivit sous le nom de $P a$ telles les Caboctsons et d'autres coquilles séparées depuis des Patelles. Ce fut Montfort qui le premier proposa le genre Cubochon; il est du fort petit nombre de ceux de cet auteur qui on: mérisé d'être conservés. MI. Lamarcck l'adopta le premier daus l'Extrait du Cours, où il fait partie de la famille des Calyptraciens, et un per plus tard M. Cuvier, clans le Régne animal, l'introduisit dans la famille des Scutibradoch non symétriques.

MI. de Ferussac en admettant les Scutibranches les modifia notablemen: : il $y$ tit entrer la famille ces Calyptraciens de 1I. Lamarck ì titre de sousordre, et créa sous le nom de Cabochons une famille composée des genres Crépidule et Cabochon. Jnc observalion très-curieuse que M. Defrance aroit faite, aroit coustaté d'une manière irrérocable, que plusieurs espèces fossiles de $\mathrm{Ca}-$ bochons sécrètent une base qui s'altache comme les huitres anx corps sous-marins, qui est recouverte par la coquille, qui la ferme aussi exactement que le feroient les deux valves d'une coquille bivalve. Ce qui est particulier, c'est que l'animal est fixé à ce support par le mème muscle en fer-à-cheval qui s'attache à sa coquille : de sorte qu'il lui est impossible de jamais clanger de place comme le font les Patelles. Ces mohts dérerminèrent MI. Defrance à former un genre particulier sons le nom d'Hipponice, arec les espèces de Cabocbons qui ont un support. 'Toutes les espèces rue M. Defrance connut étoieut fussiles; les espéces vivantes de Cabocbons counues jusqu'à lui sont dépourvoes de support, quoiqu'il soit bien probable qu'eiles ne changent pas de place. On pouvoit croire par analogie que les animaux des Cabocbons et des Hipponices étoient semblables : en conséquence de celle opinion, 1I. Lamarck jugea convenable de réunir les deux gences, tout en conservant dans une section iे part le genre de M. Deliance.

Conduits par les mêmes raisonș, MI de Ferussac et nous-tnêmes, dans notre ouvrage sur les Fossiles des environs de Paris, suivimes l'opiaion du savant professeur : nons cherchåmes à élayer notre manière de voir par des analogies qui nous sembloient concluantes, et qui cependant nous ont trompés; car depuis cette époque M. de Blainville ayanı obscrvé l'animal d'un Cabochon à support, il l'a trouvé assez différent de celui des Cabochons saus support, pour conserver le genre de 11. Defrance, tout en reconnoissant qu'il existe entreux de grands rapports : nous renvoyons eu conséffuence a Hipponice, où nous donnerons !es détails convenables sur ce genre.

L'auimal des Cubochons ue nons est connu que par la courte description qu'en a dunnée M. Cuvier dans ses Mrémoires sur les Mollusques: coume il scruit difficile de dire en moins de mols ce qu'il est nécessaire de savoir sur l'animal du genre, nous allons citer textuellement ce que ce savant eu a dit.

- L'uuimal est attaché à sa coquille comme celui des Pulelles, par un muscle circulaite, interroupu seulement en avaut par le passage de la tête, et pour l'entrée de la cavilé brancbiale. En elfet le Cabochon n'a poiut les branchies le loug des cótćs de son pied, comme la Patelle, maıs daus une cavité au-dessus de la tête, comme le grand noubre des l'ectinibranclses; mais ce qui le distingue des autres, c'est que ces branchies, couriposées de beaucoup de lames étroites et longitudinales, adhèrent par une seule rangée transversalc au plafond de leur cavié; le cocur, auquel elles euvoieut le sang qui a respiré, est en arrière sur l'extréruité gauche de cettc rangée, et le fond du cône de la coquille est remplí par l'abdomen et par les viscères qu'il contient ordinairement, et dont je n'ai pas pu faire un examen pariculier.

"Le Cabochon se dislinguc eucore des genres voisins par les ornemens de sa téte; sa bouche est une trompe susceptible d'un certain prolongement, et creusée en dessus d'un sil:on profond; ses tentacules portent les yeux à leur face extérieure, vers leur base, et sur une partie renIlée. Sous la gorge et en avant du bord antérieur du pied, est uue sorte de liaise formée par de nombreux replis d'une double membrane, qui, dans l'ćtat d'extention, sert peut-étre a prolouger le pied en avant, et à faciliter la reptation de l'animal.

„L'anus est vers le côté droit de la cavité branchiale. L'individu unique dont j'ai pn disposer ne m'a point fait voir d'organe du sexe mâle; mais je n'oserois dire que ce genre n'en ait point, car je lui trouve dans !'ensemble de 


\section{A B}

son organisation au moins autant de rapports arec les Sigarets et les Buccios ya'avec les $\mathrm{P}_{2}-$ telles, les Fissurelles, etc. ’

Malgré ce que dit ici M. Cuvier en terminant, il est incontestable que les Cabochons n'aieut de grands rapports avec les Crépidules et les Calyptrées; M. Cuvier le reconnoît pour le premier de ces genres seulement, parce qu'il ne connoissoit pas le sccond. Plas heurenx que lui, nous en avons fait l'anatomie, qui a confirmé les prévisions de M. Lamarck sur les rapports de la plupait des genres de la famille des Calyptracieas.

\section{CARACTÉRES GÉNËRIQUES.}

Animal conique, quelquefois à peiue spiral, à pied subcentral, épais au centre, aminci sur ses bords; tête proboscidiforme alongée, divisée par uo sillon médian supérieur; les tentacules, assez courts, sout oculés au côté externe sur un renllement médian; branchie unique, transverse, composée d'un grand nombre de lames. Anus s'ouvrant à droite dans la cavité branchiale.

Coquille épidermée en cône oblique, courbée en arrière, à sommet aminci presuju'en spirale, à ouverture ovale, ayant le bord postérieur plus court, aigu, souvent sinueux; une impressiou musculaire arquée en fer à cheval, interrompue antérieurement.

La séparation des $\mathrm{H}_{y}$ ponices et des Cabochons a réduit considérablement le nombre des espèces de ceux-ci, surlout celles fossiles de nos terrains tertiaires, qui ont presque toutes des supporis. Quant aux espèces virantes, il y en a plusieurs qui paroissent devoir entrer dans les Hyponices; mais l'observation manque à leur égard, on ignore leur manière de vivie. Il en est d’ausres quı, au lieu de se fixer sur un support, s'attachent aux coquilles, et creusent dans leur épaisseur une surface à laquelle elles s'adaptent parfaitement, qui préscale une impression mufculaire semblable co tout à celle quel'on remarque sur le support des Hyponices. Sans doute que ces espèces, qui sont au nombre de quatre ou cinq, devront entrer encore dans ce deraier genre de préférence aux Cibochons. Si ces espèces en eflet ne forment pas un support, limpression quelles laissent met hors de doute leur analogie arec les $I_{3}$ ponices quant ¿ la manicie de vivre.

Plusieurs espèces de Cabochons se trouvent fossiles; l'une d'elles est remarquable en cela qu'étant tres-aplatic elle cherche les parties concaves des coquilles turbinées pour y vivre et s'y atlacher sans laisser aucune trace de son séjour. La manière dort elle est contournée, ses stries diaccroissement annoncent qu'elle a vécu à la unême place, semblable en cela à la Crépidule unguifurme, mais ne pouvant se confondre avec elle. Celte manière de vivre ainsi invariablement fixée

Histoire Naturelle des Vers. Tome II à la même place, sans laisser ni support ni impression, indique bien ses rapports avec lles $\mathrm{II}_{\mathrm{y}}$ pouices, sans que cependant il soit encore possible de rapporter cetle espèce à ce genre. Nous pensons quelle doit rester dans celui des Cabochons: c'eft par ce passage gradué des espèces d'uı genre à l'autre, que uous nous étions déterminés, à priori, à les réuair en uı seul.

1. C.aBochov bonnet bongrois. Pileopsis ongarica. LA $\mathrm{in}$.

P. testâ conico-acunvinatâ, striatâ; vertice revoluto, spirato; aperturâ tranverfirr latione; intìs 1oseấ, vel albâ.

Patella ungarica. Lis. Gmed. pag. 3709 . no. $8 \mathrm{~g}$.

Lister, Conchyl. tab. 544.fig. 32.

Gualteri, Conch. tab. q. fig. V. V.

Favavie, Conch. pl. 4. fig. E 2 .

Kконя. Verg. 6. tab. 16. fig. 3.

Вокм. IIus. cces. vind. pag. 414. vignette, fig. $\mathrm{D}$.

Msntixi, Conchyl. cab. tom. 1. tab. 12. fig. $107,108$.

LAMx. Anime sans vert. tom. 6. $2^{\mathrm{c}}$, part. pag. 17. $\pi^{\circ} \cdot \mathbf{I}$.

\section{Fossilis.)}

Broccer, Conchyl. foss. subapennina. tom. 2. pag. $257 \cdot n^{\circ} \cdot 4$.

Var. a. Testâ fossili angustiore minore, apice ad marginem magis inflexo.

Var. b. Testâ conico-elongatâ, subrectâ.

Gisissi, tom. 2. tab. 3. fig. 24 .

Celte espèce, très-commune, est fort intéressante par la manière dont elle est répaodue à l'état frais et fossile. Elle est conique, large et dilatée à sa base; son sommet peu élevé se recourbe postérieurement, sinfléchit et forme un commercement de spirale; il ae touche pas le bord postérieur, il est toujours placé au-dessus de lui, mais pas d'une manière constante, c'est-à-dire qüil est plus ou moins haut; de ce sommet parient en rayonuant juscju'i la base uo grand nombre de stries peu saillantes, interrompues transversalement par des accroissemens presque toujours irréguliers. Lonverture occupe toute la base; ses bords sont minces tranchans, irréguliers, et on voit netlement sur certaios individus qu'ils se sont monlés sur l'irrégularité de l'endroit qu'occupoit l'auimal; cette irrégularité, répétée par les stries d'accroissement, prouve, d'une manière non équivoque, que l'animal n'a pas changé de place pendant Ia plus grande partie de sa vie. A l'intérieur, cette coquille est lisse et polie, et présente toujours vers le miliea de sa hauteur une impres- 
sion musculaire en fer à cheval; sa couleur est rose, quelquefois d'un rose pourpré, et d'autres fois blanche. En debors elle offie les mêmes couleurs, aıiis cachées par na épiderme lırunâtre.

La variété $A$, qui est fossile, se distingue en ce qu'elle est plas étroite, plas petite, moins dilatée à sa base proportionnellemeat, el son somznet est plas postćrieur et plus infléchi sur.le bord.

La variété $B$ a une forme différente, elle est élevée, alongée, et son sommet peu infléchi est moins ea spirale. Elle se rapproche, pour la forme, de l'IIyponice corme d'aboudance.

Cette coquille nous préseute un exemple de l'identité parfaite eatre les individus vivans et fossiles de diverses localités : cette identité a été reconnue par M. Brocchi, par Faujas, Menard de la Groye, et par toutes les persunes qui ont voulu comparer.

Cette espéce se troure vivante dansl'Océan, dans toute la Méditerranée, et, dit-on, dans l'océan Allanticue. Nous ne connoissons pas les coquilles de cette deraière localité. A l'ćtat fossile, dans les terrains subapennins de toute l'Italie et de la Sicile; on la tronve également à Dax et ctans les faluns de la Touraioe: daus ces denx derniers eadroits elle est modifiée, elle constituc notre première valiélé. La seconde variélé est fossile d'Italie.

La base de cette coquille a jusqu'à deux pouces de diamètre.

2. Cabochos feuilleté. Pileopsis milrula. LAMK.

P. testâ ovato-rutundatî, obliquè conicâ, solidâ, albidâ ; lamellis transversis laxe imbricatis; vertice adunco; margine repando. LAwn.

patella mitrulu. L.is. Gare. pag. 5708. $n^{\circ} .82$.

Lister, Conch. tab. 544. fig. 3i.

Fataise, Conch. pl. 4.fig. F I. F 2.

Martisi, Conchy\% cab. tom. 1. tab. I2. fio. III, 113.

L,AMr, loc. cit. $n^{\circ}, 2$.

Coquille épaisse, en cône oblique, à base plus ou moins large, couverte du sommet à la base de lames trausversales trabchantes, lisses, imbricutes, heaucoup plus nombreuses et plus froes uu sommet qu'à la base; le sommet est assez aigu, quelquefois obtus, courbé en crochet, mais jamais tourné en spirale postérieurement et dépassant toujonrs le bord postérieur, lorsque la coquille est placée horizontalement sur sa base; la base est circonscrite par un bord épais, ovale, arrondi, peu régulier. Cette coquille est toute blauche, et presque toujours roulée : il seroit possible qu'elle vécút sur uo support; la ressemJlance qu'elle a avec certaines espèces fossiles nous le feroit supposer. Elle n'acquiert jamais un grand volume; 20 millim. de diamètre à sa base dans les plus grands individus.

3. САвасвох à trois cótes. Pileopsis tricostata. Nов.

$P$. testí ovato-oblongâ, aỉbâ, solidî́, lavigutâ, tricarinatî́; apice obtuso, obliquo, $a b-$ breviato incumbente.

Patella tricostata, Grex. $n^{\circ} \cdot 27$.

Ibid. LAs1 . Anim. sans vert. tom. 6. pag. 335. $n^{\circ} .43$.

Cаемritz, Conch. cab. tome. 10. tab. 168. fig. 1622. 1623 .

Jolie coquille fort rare et fort remarquable. Sa forme est oblongue, longitudinale, obliquement conique, à somnet surbaissé, oblus, jeu saillan:, et ue dépassant pas, le bord postérieur qqui est fort court : de ce summet il part trois côles saillantes, aiguës, dorsales, qui gagnent en rayonnant le bord antérieur; tout le resie de la surface extérieure est lisse ainsi que l'intervalle des cótes. Dans quelques individus le bord postérieur offre quelques stries obsolètes; la base est ovale, longitudinale; le bord est épais, postéricurement plus mince, plus tranchant antérieurement. Ea dedans, oì elle est blanche comme en dehors, on remarque une impression musculaire semblable à celle de tous les autres Cabochons. Elle a ¿5 à 30 millim. dans son grand diamètre de la base.

Nous ignorons quelle est sa patrie : on la dit de l'Inde.

4. Caвochon tortillé. Pileopsis intorta. Lass.

$P$. testâ ovato-rotundatâ, obliquissimè conic $\dot{a}$, albidâ; striis longitudinalibus ubsoletis, subdecussatis; vertice porrecto, laterali, spiraliter intorto.

LAMK. Loc. cit. $n^{\circ} .3$.

Fataxie, Conch. pl. 4. fig. B.

Cette coquille ne prend jamais un grand rolume, et elle est toute blanche en dedans et en dehors. Elle a la forme d'un cóne oblique surbaissé, dont le sommet fortement incliné à droile et postérieurement, préseate un commeacemen: de spire d'un tour et demi de circonvolution. Les stries dont elle est converte rayonnent du soramet ì la base; elles sont peu profondes tt comme treillifies par les ponctuations nowbreuses et peu profondes qui existent dans leur intervalle. Ces stries sont souvent bifurquées di cóté droit de la coquille, oì elles sont aussi plus larges qu'à gauche; de ce côté elles sont simples et beaucoup plus fines. La base est arrondic ainsi que l'ouverture; les bords en sont obtus, mais pen épais.

Nous ne savons d'où vient ce joli Cabochon, 
qui n'a que 16 ou 18 millim. de diamètre à s. base. Lasiz.

5. Caвochor roussâtre. Pileopsis subnifu.

$P$. testâovato-rotundutâ, obliqued conicâ, albâ, rufo roseoque nebulosia ; striis longitudunulibus, strus transversas decussuntibus; vertice porrecto, inflexo, subspirato; epidernide subrufó, squairdo, piloso.

l.ister, Conch.tab. 544. fig. 30.

KLEIN, Ostrac. tab. 8. fig. 9 .

Martisi, Conch. tom. 1. tab. 12. fig. 113.

Lasк. Anim. sans vert. loc. cit. $\mathrm{n}^{\circ} .4$.

Espèce bien distincle et très-facile à reconnoitre : elle est un peu moins grande que la précédente; sa forme est en cône oblique surbaissé, se terminant par un sommel pointu, en crochel, incliné postérieurement vers le bord, et quelquefois en spirale. Il dépasse fortenent le côté pustéricur au bord duquel il tonche quelquelois; des s ries serrées, nombreuses, assez fines el longitudinales, desceadent du sommet vers le bord; elles sunt coupécs à aogle driil par des stries transverses plus grosses, serríes et arrondies. Quand cene coquille u'est pas roulće, elle est couverte, stirtout í la base, a'un épiderme brunâtre trèsvelu; en dessuns de cet épiderme elle est de couleur blanche au soinmet, et rougeâtre passant au ruse sur les bords et sur le dos : à l'intérieur elle présente les méuıs teintes. Sa base est ovalaire arr.uadie, à bords épais et ubtus : elle a 14 ou 15 millim. de diaruètre à la base. Des mers d'A mírique?

6. САвосвол spirirostre. Pileopsis spirimstris. LAME.

$P$. testì obliquè conicâ, basi dilatatî, eleganter lanuellosá, longitudinaliter striatâ; z'ertice infle.ro, spirali, sublatcrali.

Patella spirirostris. Laßx. Ann. du Miss. tom. 1. pug. $311 \cdot n^{\circ} \cdot 6$.

Pileopsis spirirostris. Ibid. Anim. sans vert. loc. cat. $11^{\circ} .5$.

lbid. Nов. Descrip. des Coq. foss. des env. de purts.tom. 2.pug. $26 . n^{\circ}$. 6. pl.5.fig. 13. 14.15.

Ce Cabochon est le plus beau et le plus élégant du greure; il a la furıne d'un cône oblique, à base arroudic et très-large, le somatet en crochet prolungé, commençani par un tour et dewi de spirale, dépasse de beacoup le bord postérieur sur lequel il s'iucline fort pen; toute la surface extéricure est couverte de lames transverses, saillantes, ininces, relevées et chargées, ainsi que l'intervalie qui lés sépare, de stries liues et lungitudinales; de ces stries les unes moins nombrenses sont plus grosses; les auties, au nombre de deux ou trois, entre les premières, sont beaucoup plus fues. Le bord postérieur est fort court, ce qui tient à la forte depression générale de la coyuille : elle est mince, fragile, asscz régulière, et son ourerture est suborbiculaire.

Son diamètre à la base est de 23 millim. Elle se trouve lossile a Grignon, l'ernes et Muuchy.

7. Caвосноr empenné. Prleopsis pennata. LAMK.

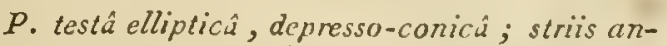
ticè sıuamosis, undulatus, subimebricatis; vertice cernuo, spiruto.

Patella pennatu. Lamx. Ann. du Mus. loc. cit. $n^{\circ} .8$.

$\mathrm{L}_{\mathrm{A} \mathrm{A}} \mathrm{K}$. Anim. sans vert. loc. cit. $n^{\circ} \cdot 7$.

Noв. Descript. des Coq. foss. loc. cit. $n^{\circ} \cdot 7$. pl. 3. fig. 5. 6.7.

Coquille déprinée, surbaissée, à base large subrégulière, ovalaire, à forme conoide, à sommet petıt, à peine saillant, incliné lortement vers le burd postérieur, présentant un tour et demi ou deux tours de spire inclinés à droite. Cette coquille lısse sur les cótés devient la melíeuse sur le dos; ces lames se relévent en écailles imbriquées sur six ou sept rangées rayonnantes, qui descencient da sommet à la base. Celte coyuile trèsrare n'a que 15 millim. de diamètre à la base. Elle se trouve fossile à Maulette, près Houdan.

8. Cánucron à côtes. Pileopsis sulcosa. Nов.

P. testâ oúto-conicâ, depressâ, obliquî, septem octove costuti; costis acutis, rugoses, undulutis; vertice spinuto, valie inflexo; marginibus crussis untice crenutis.

Nerita sulcosa. Broccer, Conch. foss. subapennma. tom. 2. pag. $296 . n^{\circ} .4$. pl. 1.fig. 3. $a$. $b$.

M. Broccbi a commis une double faute selon nous, en plaçant cette coquille dans le genre Stomate de M. Lamarck, et en'rapprochant beaucuup le genre lui-même des Nórites an point de l'y réunir au lieu de le laisser avec les IIaliorides, comme Linné et Gnelin l’avoient liait.

Nous avous sous les yeux la coquille dont il est questjon, et nous pouvons allirmer qu'elle n'appartient point au genre auquel M. Broechi la rapporte, mais à celui-ci : elle en a tous les caracières

Elle est ovaluire, conique, un peu oblique, déprimée ; sor sommet pointu s'incline forlcuent jusqu'au nireau du bord postéricur, sans cependant le toucher, et se ternine par un tour de spire sur le còté droit; le côté pustérieur par l'inclioaison du sommel devient losizontal dans le plas de l'ouverture : ce qui donne à la coquille vue du cûté de l'ouverture l'apparence d'ètre séparée en deux par une cloison, un peu 
comre dans les Crépidules. Cette face postérienre, ici inférieure par exception, est couverte de la mes irrégulières qui indiquent les accroissemens; sur le dos on remarque sept ou huit côtes saillautes, aiguës, un peu onduleuses, rugrueuses et saillantes sur le bord antérieur : de sorte qu'il est crénelé, tandis qu'il est lisse et arrondi latéralement, mais surtout postérieurement. A l'intérieur cette coquille est lisse, et présente l'impression musculaire comme dans toutes lus espèces du geore Cabochon : elle n'est point wacrée, il u'y a donc aucun molif de la placer ailleurs. Les plus grands individus ont 28 millim. de longueur, dn sommet au bord antérieus. Cette espèce rare se trouve en Italie, à Asti et daus le Plaisantin, à l'état fossile.

9. C.авосвоn striatnle. Pileopsis striatula. Noв. $P$. testâa ovato-conicâ, depressâu, obliquâ, striatâ; striis numemsis, bipartitis ; vertice obliquo, arcuato, lateraliter spirato.

Cette coquille a de l'analogie, quant à la forme, avec le Cabochon tortillé, mais elle en diffère par la disposition des stries. Il est de forme conique, oblique, terminé par un sommet crochu, formant un tour et demi de spirale, fortement incliné à droite, et inféri eureaneat vers le bord. Le côté postérienr est fort court; le dos de la coquille est bien arrondi, peu élevé; la base est ovale; le grand diamètre est antéropostérieur. La surface extérieure est couverte de stries rayonnantes du somwet à la base, interrompues irrégulièrement par des accroissemens : ces stries sont élevées, assez fines, et toutes sont divisées en deux par un sillon médian pen profond; dans l'intervalle de ces stries, on en voit d'autres à la loupe qui sont beaucoup plus fines el véanmoins bipartites comme les premières. Cette jolie coquille n'a que 12 millim. de longueur à la base. Il paroît qu'elle est assez rare à Dax, où on la trouve fossile.

10. Cabocron en écaille. Pileopsis squanoformis. Lamk.

P. testầ irregulariter ellipticâ, complanatâ, irregulariter striatâ; vertice minimo, spirali, depresso, marginali.

Lank. Anim. sans vert. loc. cit. $n^{\circ} .8$.

Ibid. Nов. Descript, des Coq. foss. loc. cit. $n^{\circ}$. 8. pl. 3. fig. 11 . 12.

Patella squamaformis. Liмk. Ann. du MIus. tom. 1. pag. 311. no. 9.

Nous avons déjà mentiondé cette coquille singulière at commencement de cet article; on ne pourroit croire qu'elle appartient au genre $\mathrm{Ca}$ bochon si on ne l'étudioit avec soin : elle est tellezent comprimée qu'on la preadroit plutôt pour la valve operculaire d'une coquille bivalve; mais son sommet en spirale incliné d droite et postérieurement, la forme de l'impression musculaire, la manic̀re de virre à l'intérieur des autres coquilles, sont les moyens par lesquels on décèle le véritable genre de celle espèce. Elle est gévéralement ovalaire, quelquefois irrégnlièrement contournée pour s'adapter aux accidens de la place qu'elle a occupée : elle est tantôt un peu concave ou convexe en dessous, lisse, brillante, avec une très-petite cavité qui correspond au sommet; en dehors elle est lisse et quelquefois irrégulic̀rement sillonnée par les accruissemens. Cette cocpuille est très-mince, fragile, et se met à l'alsi dans lintérieur des coquilles, profitant de leur concavité pour se loger plus facilement. Nous en avons trouvé une dans l'intérieur d'une 'Turritelle, où elle étoit encore en place; elle n'y a point laissé la moindre trace de sa présence: elle ría donc point de support, quoiqu'clle vive fixée. Jongueur 25 millim. Fossile à Perbes, Mouchy, la Chapelle, Soissuns.

\section{CABOCIIONS (Les).}

MI. de Ferussac a formé sous cette dénomination une petite famille composée des deux genres Cabochon et Crépidule : en comprenant dans ce premier le genre IIyponice de MI. Delirance, sous avons vu à l'article $\mathrm{C}_{\mathrm{AB}}$ ocros pourquoi on doit le séparer. Cette petite famille fait partie, dans la méthode de M. de Ferussac, du deuxième sousordre des Scutibrauclies, lequel sous-ordre purte le nom de Calyptraciens, et représente assez bien la famille que M. Lamarck a proposée sous le même nom. (Voyez Camyptraciens.) Nous ne voyons pas poutquoi le genre Calyptrće est dius une autre famille que celle-ci, et pourquoi ayant une aualogie incontestable par la coquille et l'animal avec les Crépidules, il s'en trouve séparé dans une autre famille par quatre genres. La famille des Cabochons ae présentant point les caractères d'un groupe aaturel n'a pas été adoptée.

\section{CADRAN. Solurium.}

Les conchyliologues qui écrivirent avant Linné confondirent tous les Cadrans avec les 'Trochus, ou ce qu'ils aommoient coquilles turbinées. Liané lui-mème trouvant la plus graade analogie entre toutes ces coquilles, ne les sépara pas des Trochus, et en cela il fut imité par tons les auteur's qui suivirent sa métliode, et Brugnic̀re est du nombre. Le genre Cadran fut établi par M. Lamarck, lorsqu'en débutant dans la zoologie ce savaut rendit de si grands services à la partie des scieaces, qu'il cultiva depuis arec tant de snccès. Dès 1801 le genre Cadian est placé dans la méthode entre les Tooques et les Turbos, avec lesquels il a en effet de grands rapports. Depuis le genre Cadran fut adopté par tons les zoologistes, et tous furent d'accord sur la place qu'il devoit 


\section{A D}

occaper; elle resta la même que celle indiquéc par H. Lamarcl.

Quelques coquilles fossiles des environs de Paris, que MI. Limmarck ne connut peut-être pas dans len integrité, fureot rangées par lui dans le grenre Cadran, lorsqu'il décrivit dans les $A n-$ nales du Muscium les coquilles connues alors daos cette célébre localité de Grignon. Dans son dernie. ouvrage ces coquilles sont conservées dans ce geare, et il n'est point de conclyyliologues qui ne leur donne le uom générique que M. Lamarck leut a attribné : cependant ayant eu à notre disposition plusieurs individus lien conservés de ces coquilles, nous les trouvámes tellement dissemblables d'avec les Cadiaus pour leurs caractères cssentiels, que nous prînes la résolution de faire un noureau genre que nous avons nonmé Onalaxc (Omalaxis). ( Vojez ce mot.) Ce genre a pour type le Solarium disjunctum, et conticut díjà qualre ou cinq espèces.

On ne conooit pas encore l'animal des Cadrans, et malgré cela on peut avoir la conviction que c'est un bon genre, car il se distingue nonseulemcat par les caractères que lui out assigutis les naturalistes jusqu'a présent, mais encore par un autre qui étoit resté inconnu; il est relatif à l'opercule qui diflëre d'une manière très-norable, et de celui des Trocbus, et de celui des Turbos. Nous devons la connoissaoce de cet npercule à M. Herbert de Saint-Simon, capitaine de raisscau, qui aux Antilles le recueillit avec soiu, et voulut bien nous le communiquer.

Cet opercule est corné, conique, diminuant bien régulièrement de la base à la pointe : la base est arrondie, lisse, et présente à son centre un axe saillant, sur lequel s'insère le muscle d'attache. En dessus la lame cornce qui sert de base se détacbe, se lourne uo grand nombre de fois en spirale en diminuant régulièrement, se relevant un peu vers le bord libre, où elle est subfrangée: elle est fixée à l'axe de l'opercole. Cette structure est parfaitemeot comparable au serpeut de corne dont samusent les enlans, avec cette différence cependant que les lames spirales sont fixées par le centre dans l'opercule. Le nombre des tours de spire qu'il présente n'est point en rapport avec celui des tours de spire de la coquille : ainsi l'opercule que nous possédons a 16 à 17 tours, lorsijue la coquille d'où i! sort n'en a que sept.

\section{CARACTÉRES GÉNÉRIQUES.}

Animal inconnu.

Coquille orbiculaire, en cone déprimé, à ombilic ouvert, conique, le plus souvent crénelé à son bord interne, quelquefois lisse; ouverture subquadrangulaire; point de columelle; opercule corné, conique, formé d'nne lame spirale, contioue, enroulće sur un axe saillant à la base.
Les Cadrans sont de jolies coquilles marines, qui presque toutes sont aplaties à la báse, qui est ouverte plus ou moins fortement par un ombilic crénelé dans toutes les espèces que M. Lamarck a introdnites dans le geare; mais M. de Blainville ayaut voulu joindre aux espèces le genre Maclurite de M. Lesueur, qui est le uncme gue le genre Evompliale de MI. Sowerlyy, at été obligé à cause de cela de nodilier la caractérislique, et de dire ombilic crénelés ou nou. Nous avons suivi en cela M. de Blaiuville, et nous peusons comme lui qu'à celle petile modification près, les livomphales conviennent parfaitenent aux Cadraas sous tous les aulics japports.

M. Lamarck n'a indiqué que sept espices $: i-$ vautes dans le genre Cadran, el luuil fossiles, eu y comprenant plusieurs coquilles qui fout aujourd'hui partie de notre genre Omalaxe. Nous conuoissons ouze espèces vivantes, vingt-ders fossiles, sans faire entrer daus ce nombre quatre Evomphales, ce qui porte à trcale-sept les espèces du genre Cadrau.

10. Espèces dont l'ombilic est crénelé (gente Cadran Lask.).

1. Cadran strie. Solarium perspectivum. LANE.

S. testâ orbiculato-conoideâ, longitudinc:liter striatâ; albido-fulvâ; cingulis albo et fusco aut castaneo articulatis prope suturis, umbilico magno, profundo, canaliculato, valde crenato.

LAMx. Anim. s. vert. tom. 7. pag. 3. no. I.

Trochus perspectivus, Lin. GuEL. pag. $3566^{\circ}$. no. 3.

Lister, Conch. tab. 636. $f g .24$.

Ruмрн. Mis. amb. tab. 27. fig. I.

Goantierri, Testac. tab. 65. fg. 0 .

Bonann, Recreat. mient. part. 5. fig. 27.23.

D'Argenville, Conch. pl. 8. fig. M.

Fatanne, Conch. pl. 12. fig. K.

Bons. IIus. cos. vind. pag. 326. vignetle, fig. $\mathrm{B}$.

Chemitz, Conch. cab. tom. 5. iab. 172. fig. 1691 à 1696 ; et tom. 11. tab. 196. fig. 2884 . 1885.

Encrclopéde, $p l$. 446. fig. 1. a. b.

Var. B.) Ков. Testâ minore, cingulis niyris, continuis; unbilico minore, crenulis majoribus.

Var. C. ) Noв. Testâ, cingulo unico instnuctä, maculis latis distantibus, albis et rufis ornato.

Cette espèce est celle qui acquiert le plus grand volume : elle est de forme conique, assez aplatie, 
tuut-a-talt plane en dessous; elle est formf́c de liuit à neuf tours de spire; la suture, qui est un peu profonde, est indiquée par une bande blanche cui la suit : au-dessous on en remarque une antre brune ou fauve, quelquefois nou interrompue, nats le plus souvent subarticulée par des taches blauches plus ou moins nombreuses; une large haude d'un blanc fauve nccupe le mileu de chayue tour, qui à la base offie une zone brune coustamment interrompue. L'augle du derbier tour est formé par une carène obtuse, qui est accompagnée en dessus d'une seconde semblable, séparéce seulement par un sillon élroit. Au centre de la base, qui du reste est lisse, se voit l'nmbilic; il est profond et conique, canaliculé latéralement. L'angle de cliague tour y est marqué frar un bord saillant en dedans, crénelé en dents le scie; ce bord est séparé par un sillon d'un cordon granuleux gui le suit dans lintérieur de 'ombilic; la surface extérieure est striée longitudinalement; les stries sont plus profondes sur. les premiers tour's de spile : de sorte que lit coguille au sommet est granuleuse, et elle l'est d'aurant plus que deux stries transverses sur chaque tour sont plus profondes et plas prononcées, ce qui tient a $1 x$ individus, car il en est où elles sont peu senfíles : louverture est perpendiculaire a la base; elle est preque quadrangulaire, et son angle interne présente uve petile goultière sur le dernier tubercule du bord crénelé de l'ombilic. La va. riété $B$, plus petite, est remarquable par ses handes noires; la supérieure de chaque tour n'étant point interrompue, ses stries sont peu sensibles, peu profondes. Nous présumons que c'est avec cette varićté un peu plus grande, un peu plus conique, et dont les couleurs étoient en partie ellacées, que M. Lamarck a fait son Sularium lavigatum, qui cerlainement n'a pas de caractères sullisans pour cunstituer une véritable espèce. La variétć C n'a pas la baude blanche sul la suture, elle est renplacée par une zone plus large qui est indiguée, et par une strie et par des taches brunes alternant arec d'autres blunchâtres : elles sont touies laryes, et par conséquent peu nomlsreuses.

M. Lamarck indique celle espèce dans l'Océau indien : notre ami, M. Lesson, a rapporté la variélé 3 de 'l'aiti.

Diamelre de la base 45 millim.

Il $\mathrm{y}$ a des individus qui ont jusqu'à 69 millim.

2. Cadrax grinulé. Solarium granulutum. L. $A$ K.

S. testá orbiculato-conoideá, alhido-fulvî, undique maculis rufis sparis notatâ; cingulis pluribus granosis; umbilico coarctato, dentibus crassis milncato.

I. A ux. loc. cil. $n^{n} \cdot 2$.

Irster, Conch. tab. 65 f. fig. 22 ,
ExctcIOPÉDIE, pl. 446. fig. 5.a. b.

Le Cadran granuleux se dislingue très-facilement du précédent; il lui ressemble quant à la forme et à la taille, mais il en differe sur tout le reste; ses tours de spire au nombre de huit sont striés Iransversalemeot; ces stries sont profoudes, dislantes et au oombre de cinq on six : elles séparent autant de zones transverses qui sout granuleuses, et surtout la première, la plus large qui borde la suture. Sur celte zone on remarcjue une série assez régulière de taches bruves, d'aulres taches de la niême couleur, mais beaucoup plus petites, sont irrégulièrement répandues sur toute la surfice extérieure. Liangle inférien du dernier lour est moins furteunent caréné que dans l'espèce précédente. La base est aplatic : ou y remarque quatre cordons granuleux, le premicr vers l'angle, les trois autres entourent l'ombilic; celui-ci est profond, étroit, canaliculé, obstrué pour ainsi dire par des crénelures fort grosses et très-larges : l'ouverture a la même forme que dans le Solurium perspectivum.

Nous ignorons de quelle mer vient celte coquille : elle a quaraule willimètres de diamitre à la base.

3. Cadran tacheté. Solarium hy bridum. Lamx.

S. testâ orbiculatâ, abbreviato-conoideâ, lavigatâ, luteo-rufescente, albo maculatâ, subtìs fasciaîa ; aperturâ subtrianguları; umbılico an. gusto, crenuto, marginato, cumalıculato.

L.s 1 . loc. cit. $n^{\circ} .5$.

Trochus hybidus, Lix. Girex. pag. 3567. $n^{\circ} .4$.

Chems. Conch. tom. 5. tab. 175. fig. 1702 à 1705 .

ENCYCLOPÉDIE, $p l$. 446.f. 3. a. $b$.

Cette coquille est assez variable, ce qui explique la dillérence que l'on iruuve entre c'c qu'en dit Guelin et la courte desiription de M. Lamarck: le premier dit qu'elle est tonie blanclic: en dessous, le second qu'elle est lascife dias cet endroit. M. Lamarck prend la conleur lauve pout la dominante : on pour roit aussi bien prendie la couleur blanche; car dans certains indiviclus c'est clle qui donine. Maln'ré ces variations, on réconnoit toujunrs celte espèce, en ce quelle est couslamment lisse, que les tours de spire sout légèrement convexes en dessus el cn dessous, que le dernier a l'angle saillant, caréné tans les jeunes individus, bien arrondi daps les plus vicux : celle carc̀e est suivie cn dessus el en dessous d'une sirie pen profonde. L'ambilic est étroit, canaliculé luléraleuent, et bordé par un doulle rang de crénelures, donc le plus interne cst le plus large. L'ouverture dans les jeunes individus est subtriangulaire; tlle est presyut roude daus les rieux, hes couleurs, coms.e acu. 


\section{A D}

l'arons dit, sont variables : ce sont le plus souvent des flammules longitudinales, fauves, traversées par une fiscic iransverse de même couleur : elle manque cependant quelquefois; quand plle garne la suture, elle cache toute la partie superieure des llammules, elle est alors deutée infórieurcment. Ea dessous celte cspèce est quelquelois inule Jrune, à l'exception du pourcour de l'umbilic; d'autres fois elle est flammulée ou lascié, quelquefois entia elle est tonte blauche. Gmolin el M. Lamarck diseut que celle coquille vient de la Méditerranée : nous ne l'avons jamais renarquée daus les collections qui en provennient. Diametre de la base, viugt-trois nilliviuètres.

4. Cadran Jigarré. Solurium variegatum. I.A3E.

S. testâ orbiculato-subconvexâ, transversim sulcutâ, longritudinaliter striatâ, albo et fusco artaculatim varnegatiz; angulo marginali bipurtuto; umbilico medocri crenulato, bicanalsculato, lineâ albi curcumduto.

L.А х. loc. cit. $n^{\circ} .6$.

Truchus variegatus, Lix. GuEL. pag. 3575 . $n^{\circ}$. bo.

Cuemsitz, Conch. tom. 5. tab. 173. fig. 1708. 1709 .

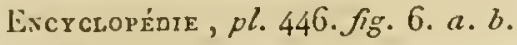

Var. B. ) Fossilis. Testâ striis nunzerosioribus, minùs basi depressâ.

Trochus variegatus, Bnoccнг, Conch. subap. tom. 2. pag. 360. n०. 16.

Quand ce Cadran cst jeune il est fort aplati; il devient un peu plus conique en vieillissant. Les individus qui sout long-temps restés sur les rivages ont uoe antre couleur que ceux qui sont bien frais : ceux-ci sont d'un brun funcé, avec des tarhes blanches, surtout vers la partie inferieure des tours de spire: ceux-là sont fauves, pales, avec des taches blanches plus nombreuses ct plus grandes : c'esi daus ce deraier état que celte espèce a élé connue de M. Lamarck. La spire, de forme conique surbaissće, est composée de sept à huit tours striés transversalement et Inngitudinalcment; les stries transverses sont plus profondes que les autres, leur eatre-croisement rend toule la surface granuleuse; le hord du dernier tour est bimargiaé, et c'est suriout sur lui que se voient les ta. hes blanches régulières qui débordent un peu en dessus et en dessous. La base est peu convexe, son centre est percé d'un ombilic assez grand, creusé latéralement d'une double gouttière, et crénelé a son bord, à double rang. Cet ombilic est bordé de blanc, tandis que le reste de la base est brun; l'ouverture est arrondie.
La variété fossile qui se trouve en Italie, dans les terrains tertiaires, se dislingue par ses stries transverses, plus nombreuses, sa base moins aplatic, et ses siries longritudinales plos profondes et plus serrées, ce qui rend la coquille plus granuleuse; le sillon marginal du dernier tour est un peu moins profund.

Celle espèce, assez rare, vient des mers Australes, d'après Al. Lamarck. II a quioze i dix-huit millimètres de diamètre.

5. Codpran jaunâtre. Solurium luteum. IAă.

S. testâ parulâ, orbiculuto-ronoideâ, glubrâ, ad peripheriam bisulcatá, lutế, sulcis sulurisque mbm punctatis; umbuluco angusto, crenis albis cincto. LAM .

LAмк. loc. cit. $n^{\circ} \cdot 7$.

Quoique cetle espèce ne soit pas figurée, elle est iellement distincte que nous l'atvons reconmue d'après la phrase de M. Laurarck, que nous venons de rapporter. Cette coquille est petic, toute lisse, conique, aplalie à sa liase, de coulcur jaune partout a lextéricur. L’angle du dernier tour porte deux petits hourlelets síparćs par un sillon: ces bourtelets sont blancs et marqués de points rouges assez serrés; la suture est roarginée et nıarquíc par un donble rang des mênes taches; l'ombilic est petit, canaliculé el bordé par des crénelures blanclies; l'ouverlure est arrondie, anguleuse inférienrement et à la partie interae. Celte jolic coprille, qui n'a pas plus de 13 ou 34 millina., vient de la Nouvelle-Hollande.

\section{Cadran d'Herbert. Solurium Herberti. Nor.}

S. testâ orhiculato-conicâ, tiochiformi, transversim sulcatâ, longitudinalıter striatâ, nigmfuscâ; umbilico minimo, crenuluto, intǐs trisulcato; aperturâ rotundutâ.

Coquille trochiforme, conique, forméc de sept tours de spire arrondis: ils sont sillonnés transversalement et striés longritudinalement; l'entre-croisement de ces siries et de ces sillons la rend toute granuleuse; les granulations sont très-fines, et plus marquées au sommet qu'à la base : celle-ci a'est point autant aplatie que dans la plnpart des espèces, elle est sillonnée comme le reste, et présente un ombilic fort petit, profond, crénelé à son liord et pourvu latérialement de trois sillons, qui séparent autant de bourrelets qui s'enfoncent en spirale daus l'iutérieur; l'ouverture est arrondie, non modifićc par l'avant-deroier tour. Toute celte coquille est d'un brua fauve noirâtre, marquée de quelques taches blanchâtres dans le jeuue âge; mais elles disparoissent ensuite.

C'est celte espèce que nous avons connue par M. Herbert de Suint-Simun, qui nous l'a cu- 
voyte avec l'opereule très-curieux que nous avons décrit précédemment : nous nous sommes fait un plaisir de la dédier à ce zélé collecteur, que ses voyages mettent à même d'être utile aux sciences.

Cette espèce se trouve à la Martinique : elle a 16 millim. de diamètre à la base, et autant de havtenr.

\section{Cadran cordelé. Solarium tessellatum. Nod.}

S. testâ orbiculato-conicâ, trochifomni, transversè sulcosâ, longitudinaliter tenuè et obliquè plicatú; suturâ lineâ albâ notatâ; anfractibus maculis albis et nigris alternis trifariam notatis; umbilico angusto, crenis albis cincto.

Celle jolie coquille est à peu près de la méme taille et de la même forme que la précédente; sa spire est eependant moius élevée, et les tours sont bien moins arrondis : elle est aussi plus aplatie à la base. Les tours de spire au nombre de six ont chacun quatre bourrelets transverses, arrondis, séparés par des sillons profonds; ils sont finement plissés obliquement et d'une manière fort régulière, ee qui les fait ressembler i) autant de cordelettes posées les unes près des autres avec soia. La premiere est toute blanche, elle suit la suture, les autres sont alteraativement marquées de taches carrées, noires et blanches: de sorte qne celte coquille ressemble véritablement à un damier. En dessous les mêmes taches se montrent aussi, mais les blanches sont plus obscures, et toutes sont plus petites : l'oubilic est étroit, crénelé, bordé de blanc, et présente à l'intérieur deux goultières profondes; louverture est arrondie, bicanalieulće ì sou bord, interne ou columellitire.

Nous ne savons d'où rient cette jolie eoquille qui paroît fort rare; elle a 14 millimètres de diamètre.

\section{Cadran trochoide. Solarium trochoides.} Nов.

S. testâ orbiculato-conicâ, elongatî, undiquè granulasâ, allido-griseâ; umbilico minimo, tenuè crendio, intus bisulcato.

Nous nummons ainsi cette coquille à cause de sa forme qui se rapproche de celle des Troques plus qu'aucune des autres que nous connoissons. Ia spire, composée de six tours aplatis, se termine par un sommet assez aigu; ehaque tour est garni de quatre rangs de granulations; le rang infericur qui touche aux sulures est le plus élevé et a les graius plus arrondis; la base est aplatie, granuleuse comme le reste, et percée d'un ombilic étroit, crénelé et garni sur sa paroi de deux cordons granuleux : l'ourerture esi petite, subquadrangulaise. La coulcur de cette eoquille est uniformément grisâtre; à la base des tours on aperçoit des traces de taches un peu plus foncées.

Longueur 11 millimètres, diamètre de la base 9 et demi.

Nous ne connoissons pas la patrie de cette espèce.

9. Cadran carocollé. Solarium carocollatum. LAMK.

S. testâ orbiculato-conoideâ, subdepressâ, transversim sulcuti, longitudinaliter striati, ultimo anfractu acutè angulato; ombilico pervio, crenis crassis, sulco profundo separatis, obvallato.

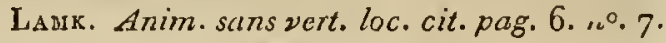

Ibid. Basterot, Mém. sur les fossiles du sudouest de le France, Mém. de la Soc. d'hist. nat. tom. 2. pl.2. fg. 12. a. b. c.

Cette coquille fossile s'approcbe beaucoup quant à la forme et à la grandeur du Solarium perspectivum. Elle en diffère par ses stries trausverses plus" nombreuses, par les longitudinales plus profondes, ce qui rend le sommet beaucoup plus granuleux. Le bord du dernier tour est fortement caréné en dessus et en dessous; cette carène est accompagnée d'un cordon saillant; l'oubilic est assez grand, canaliculé, couvert en partie par des crénelures larges et assez grosses, sur un seul rang, et séparées du reste de la base par un sillon étroit et profond. La base est aplatie, légèrement plissée dans les jeunes individus, mais lisse dans les vieux. Cette coquille se trouve fossile à Bordeaux, à Saucats et à Léognan : elle a 55 millim. de diamètre.

10. Cadran de Bonelli. Solarium pseudo-perspectivum. Broce.

S. testâ orbiculato-conoideấ; anfractibus lavibus; maroine suturali circinatim sulcato; sulcis elevatis duo vel tribus crenulatis succincto; umbilico mugno, canaliculato, crenato, crenulis sulco disinctis.

Brocchi, Conch. sabap.tont. 2. pag. $35 \mathrm{~g} . \mathrm{pl}$. 5. fig. 18. $a . b$.

D'après la citation que M. Brocchi fait d'une figure de Marlini, et que M. Lamarck, aiosi que nous, rapportons au Solarium hybridum, il sembleroit que cette espèce a suz analogue vivant; noas ne croyoos pas cependant qu'il soit connu, et bien que cette espèce se rapprocbe, comme la précédente, du Solarium perspectivum, elle s'en distingue uéumoins facilement. Les tours de spire sont lisses aussi-bien au sommet de la coquille gu'id la base; ils sout sćparćs par une suture biosarginée, qui le plus souvent est légèrement plissée, d'autres fois lisse; le dernier tour se termine par un angle assez aigu, formé par un triple cordon, un médian sur l'angle lui-même et le deux autres 


\section{A D}

plns pelits; l'un est supérieur et l'aulle inférieur, ou tout-a-fitit au-dessous de la coquille. La base est assez aplatie, onverte par un omlilic mésliocre caualicule, bordé par une assez large liande crénelće, séparée du reste de la base par un profond sillnn.

Celle espèce, assez commune à l'ćtat fossile dans le l'luisantiu, à Asti, à Brancano dans le loolonais, à Dax el les lislunières de la 'Touraine, - lrouve anssi d Salles, à 12 lieues de Burdeaux; mais dans ces deux dernières localités, il dillère de ceux d'ltalie en ce que les sulures ue sont ui crénelćes ni plissíes, el que dans le jeune âge on voil quelques stries longindiuales. Vingrt-huil ì trente millimètres de diamitre.

I1. Cadpar mille-grains. Solarium millegranum. LAM

S. testầ orbiculuto-conuexâ, at peripheriam compressá, angulato-curinutî, scabrâ; striis sulcisque transwersis, granulosis; infurnấ fucie

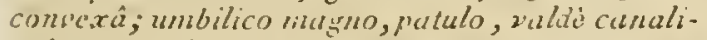
culato, crenis carnnfirmubus caicumatoto.

I. $\mathrm{xk}$. loc. cit. $n^{\circ} .8$.

Troclus canaliculistus, Broccri, loc. cit. $n^{2} \cdot 14$.

M. Lroechi a confondu celte r liarnante espèce avec le Solurium caraliculatum de MI. Tamarch. Sun-seulement on trouve cette ciration daus sa svoungmie, mais encore celle d'une ligure de Brauder, pl. 1. fig. 7. 8., yui, reprísentant u víriable Solurium canaliculatum, ne peut cu ancune manière tonvenir à l'espice d'llalic : e'cst done une andognie entre fossiles do pays éloignis, qüil lisut ellacer de lis liste. Comme nous avons - ous les yeux la coguille d'Italie. celle des environs ile Paris et celle d'Angletere, il nous est facile de decider celle question d'une manière jostlive. L'espice d'llalic est parfuitement distuncte; elle esi arrondie, peu couique, composíe da sept à liuil tonrs de spire convexes, sếparés par une suture canaliculée, dans les grauds individus surlout, les jeunes prúsculant moins c: caractire; la sulure.cst en outre indiquée par une raugre de granulutions plns grosses que celles qui couvrent le reste de la surface; le dernier lour s'aplatit vers la base, s'anuiucit el se prolonge en une catène saillinnle légèreraent den.. telće : la base de la coquille est arrundie, eliatróe comme tout le reste de lines grauulations irosrénulières. Celle hase est vuvelte pal un lièsErand ombilic profundéruent canaliculé littóaleneal, séparé par une carène aiguë et cú́nelfe, et outre cela granulé dans lonte son érendue. f'ouverture est arrondie el nullement modilíc par les carénes du bord et de l'omhilic. Cette coquille, d'après M. Brocchi, nest pas rare is Caslel-Arqualo; cependant on la voit Irc̀s-peu dans les collecrious. Le plus grand individu que nous

Histoire Nabrelle des F"ers. Tome 11. conanissons a 27 millimètres de dianètre à sa base; il vient du Mlaisantin.

12. Cadrax ćvasé. Solarimu patulaturiz. I. Anz.

S. testâ orbiculuto-conser $\hat{a} ;$ arıfiactibus plunulatis, sublavibus; marginibus carinatis et crenulatis; unbsico nuarno, patulo, simplici, wi. crenuluto.

Ibid. Lasie. Ann. al Mus. tom, 4. pag. 55. $n^{\circ}$. 1. et tom. 8. pl. 35. fig. 3. a. b.

Solarium paicllatum, ibid, $n^{\circ} \cdot 7$.

Ihid. Lasn. -1nim. sums vert. loc. cit. $n^{n} .1$.

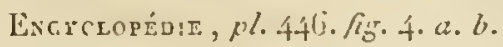

Parmi les especes qui se trouven lossiles aux environs de l'aris, cclle-ci est la plus graude; elle est arroutie, couique, jen élevée, lolmée de huit $\vdots$ nenf lours de spires lisses, aplalis, carrés dans la coupe transversale, et purrvus it la base d'une carenc saillante et crénclée sur le bord qui marque la suture; l'ombilic est trèsgrand, évasé, "eoniıue, non canaliculé, lisse ì l'intéricur el bordé par un rauğ de créneluses fort petiles et peu apparentes yui ne sont point saillautes en dedans. Nuus rapportons sans liésitalion le Solarium patellatum a cette espece : cen est évidemuent le jeuse âge.

Celle espèce, parfaitement distincte, se troure fossile à Grignon et à Parnes. Les plas grands individus ont 24 millinètres de diamètre à la bise.

15. Caprani canaliculé. Solurium conaliculutum. Lasik.

S. testî orbiculato-convexâ, suprà infiàque sulcis transw'ersis, granulosis sculpî́; umbilico crenato, ad latera canaliculato.

Lanx. Anim. sints vert. loc. cit. no. 3. Ibid. Ann. du Mus. loc. cil. $n^{\circ} .5$.

Turbo, Brander, Foss.hant. tab. 1. fig. 7. 8.

Celle cocpuille est conique, surbaissée, forméc de sept a huil tours aplatis en dessus, convexes en dessous; la sulute cst marquée par un peli: canal peu profond, hordé par le rang supérieur des granulations, qui est un peu plus saillaut que les autres; la circonlírence du deruier lour c'st sabearénte ; la base estarrondie el nuverte par un très-grand omililic crénelé à son entrée el caréné dans son milieu par un rangr de grauulizions saillanles: c'est en dessous decelle ciarse incidiane que se truave le canal listéral qui, comme nous l'avons v'r, existe dans un grand nombre d'espéces. Licuverlure est arrondic, non inodifice ; el!e est prouvue sur sa face latúrale interue el cu dedans, de deux pe:iles goullières qui correspondent aux deux rangs de crénelures de l'ombilic. Toute la surface extérieure de celie coquilie est couverio de stries tines, graubleuses, dont les grains sout 
pxlrênement firs en dessus, el un peu plus süillaus et plus gros en desseus. Le Gaclian canaliculé n'est pas rare aux environs de l'aris. On le trouve a Grignon, Parnes, Munsliy-le-Claitel, Courtaguron, etc., dans le calcaire arossicr. Les plus grands individus ont 15 milius. de diametre.

$2^{n}$. Espèces dont l'ombilic large i'est jumais crénelé (genre Evounphale Sowerur).

Nous n'admetions pas au nombre des espices du weme Evomplate toutes celles que M. Sowerby a décrites; plusieurs sont cles 'lurbes dont l'ombilic est renpli par une cällosité. Les autres sont cles Dunpuinules véritables : et le plas petit nombre scut des Evomphales; ce sont celles-là seulement, au nombre de trois, que nous décrirons comme ponvant entrer dans le geure Carbun. Le genre que M. Lesueur, dans les Annales de lu. Société des sciences nuturelles de Philadelphie, a instirué sous le nom de $M I a-$ clurite, ue dillire en rien des Evomphinales, et doit fuire parlie de la section du genre Cadran, dans laquelle ce genre lui-méme est compris.

14. Cadran pentagulaile. Solutrum pentagu. látum. Noв.

S. testâ discoriteâ, lavigatâ, utroque latere depresso-umbilicatà; anfructibus supemè in medio carinatis, subtìs subangulatis; umbilica magno-simplici; aperturâ rotundatâ, subperitugulutâ.

Eumphalus pentugulatus, Sow. Min. conch. pl. $45 . f i g$. 1. 2.

Cette coquille n'a pas la spire saillante, elle est conséquemment discoïde; sa forme peut se comparer à celle des Planorbes : car la spire, quoicpue place, est cependaot plus saillante d'un côté que de l'autre; lous les tours yu'elle forme, au nointre de six ou sept, sont en dessus carćnés par un aogle assez aigu, qui les parlage en deux parties presqu'égales; en dessous l'ombilic est très-graud, il est circonscrit par un augle trèsarrondi, qui se ditingue surtout vers louverture. Cet ombilic n'a ni stries, ni granulatious; il est lisse comme le reste de la coquille : l'ouverture est arroudie, subpentagonale. Le diamètre transversal de cette espèce est de 45 ì 50 millimètres, quelquefois davantage : elle se trouve pétriliée dans les calcaires fétides trèsancieus des envirous de Dublin. NoB.

15. Cadran petit plat. Solarium catillus.

S. testâ discoideâ, lavigatâ; anfractibus subtrigonis, utroque latere in medio angulatis; umbilico simplici, ingentissimo; aperturâ subtrigonâ.
Eumphalus catillus, Scw. loc. cit. pl. 45. fig. 3. 4 .

Tris-voisiue de la précédente, celte espèce s'en distingue facilement par l'angle saillant, qui parlage en dessus et en dessous tous les tours de spire: res angles ne sont pas dados le nuiliea, mais plus vers le dos de la coquille; cente partie se rronvant la plus large, et en méne tenps un peu déprimée, tandis que le cólé columellaire est lies-étroit : eetle disposition donne aux tours de spire une forme triangulaise, fort prononcée dans la coupe transverse; c'est aussi celle de l'ouverture. L'ombilic est tris-grand, siuple, pyramidal. Toute celle coquilte est lisse ou marguce de stries daccroissement : elle a la même laille que la précideute. On la tronve a l'élal de pérrilication à Winster et Burton, dans le Derbyshire, en Augleicre.

16. Cadran noneux. Solarium nodosum. Nos.

S. testâ discoideâ, loevigatâ; anfractibus sulpernè in medio angulatis, subtius nodosis; nodis depressis, ovatis, magnis; unhilico ingentissimo, nodis cucumdato; aperturâ subrotundutá.

Semblable anx prícédentes, quant à la forme : celle coquille est bièn caractérisíe d'ailleurs, et par sa plus grande taille, et les larges granulalions de la lace inférieure de ses tnurs de spire. Vue en dessus, on la prendroit volontier ponr le Solarium pentugulatum, les tours de spire élant divisís en deux parlies presqu'égrales par un anghe saillant; mais en dessous, au lieu d'être partagée par un angle, ils le sont par une série unique de gros tubercules ovalaires aplatis, qui circonscrivent sur le dernier tour un très-large ombilic. Cette coquille, qui a 60 millim. de diamètre, se trouve avec la précédente dans le Derbyslitie, où elle est pétrifiće mềue à l'état spatbique.

\section{CALCAR.}

Nom latin du genre Eperon de Montfort. Voyez EPEnon.

\section{CALCARINE. Calcarina.}

De jolies coquilles multiloculaires microscopiques, qui ont la forme élégante des Trochus, que l'on nomme vulgairement Eperons, sont devenues le type d'un gente nouvellenent établi par M. d'Orbigny fils, dans son MIémoire surles Céphalopodes niicroscopiques. Cet au eur rapporte à son geare une espèce que M. Lamarck avolt rangée dans les Sidérolines (voyez ee mot), ainsi que la plupart des auteurs qui le suivirent. Elle étoit connue dès le temps de Gmelin, qui lui donna le nom de Nautilus Spengleri, dans la 13 e. édition du Systema naturæ, nom qui fut adopté par Fichtel et Moll. 
Montfort, au moyen de celle coquille, put satislaire son goûl pour les nouveaux gentes; il créa pour elle celui qu'il numma Tinopore, cout en conservant le genre Sidéruline, et créau! co mèıe temps cclui quil uomma Cortale, qui est resté douteux, mais qui paroit bron devoir se placer daus celui-ci. $₫$ peut être carac!́́risé de la manière suivante.

\section{CARACTERES GẼÉRUES.}

Coquille spirale, troclifurme, rugueuse on ćpincuse; la carène du deruier tour découpce en appendices rayounans; spire quelqueluis masquée, mais jamais de disque onbilical; ouverture en fente longritudinale contre l'avant-dernier lour de spire.

Nous nous rendons compte diflicilement du molif qui a déterminé M. d'Orbigny à compuendre dans le genre Calcuriue le Sidenolites calciintpoides de M. Lawartk, Nautilus Speng!eri Gmelin. Quand on examiue un certuin nombre d'individus de celle coquille, on en tercontre, il est vrai, quelques-unes qui prisculent une ouverlute trćs-superficie!le, milis qui n'a pas constamment la même furme; nous clu avous ru de triangulaires, d'ovaliires, de plus cu moins Éruiles, et d'aulies vil il n'y en it plus du tout. On ne peut disconvenir que luules ces coquilles, avec ou sans ouverlure, onl une si grande analogie, et pour la forme et les accidens extérieurs, la grande variabilité dans le nombre et la lonøneur des épines, qu'il est impossible, à moins que de le faire arbitrairement, de marquer la $l_{1}-$ uite entie celles qui appartiennent à uu genre ou a l'autre. Ce qu'il y a de reararquable, c'est que par le fail de la classilication, les Sidérulies à ouvertures, qui sont les Calcarines pour M. d'Orbigny, sont irès-ćloignées des autres, et séprarées dans deux lamilles par une série de dix-huit genres.

Nus ve comprendrons donc aucune Sidéroline avec les Calcarines; encorc que nous considérions ce derrier genre comme artificiel, nous ne roulons y placer que des espéces yui, par leur aoalogie avec celles qui out serri de type, peuvent furmer un petil groupe qui puisse ĉlre conservé, soit à litre de geure, ou de sous-genre. Nous disions que nous croyions ce genre artificiel, parce qu'en eflet il ue présente point de caractère liondameatal : plusieurs genres voisius ont l'ouverture en fente contre l'avant-dernier tour de spire; ils sont trochiformes : ils ne diflèrent donc que par ce fuible caractére, de n'avuir pas la careue davisće en épines rayonnantes, et ils out puur la plupart un disque ombilical; mais cette dernièse circonstance n’es! pas plus déterminante que la première, puisque ce disque ombilical, il est vrai très-petit, se trouve daus la première espèce du geare. Pour peu que l’on ait étudié avec quelque soin les corquilles microscopiques, or $s^{3} a p e r c ̧ o i r$ que ce caracière a peu de valeur ábsolue. Anssi nous pensons qu'un genre qui se composcroil de toules les coquilles multilaculaires truchiformes, avec une ouverture en fente placéc sur la dernic̀re cluison contre l'avant-dernier tour de spire, serait nalurel, et pourtoit lacilement se diviser en plusieurs scctions, dans lesquelles se rangreruient les espèces, soil épincuses, soit sans épines, avec on sans disque ombilical, elc. Nous navons pas, quant à présent, assez de matériaux pour opérer le changement que nous indiguous: nous allons donc en allendant décrire les espèces que nous connoissons, et qui appartien:acul aux Culc arines de $\mathrm{M}$. d'Orbigny. Cet auteur v'en at indiqué que six, dont il fuut retrincher le Nautilus Spengleri Ginelin. Purmi les cinq qui restoicnt, deux seulement sont ligurces ou modelées, les trois autres ne sont indiquées que par un nom; il est donc impossible de les déciire, quand même nous les anrions sous les yeux.

\section{Calcarise ćperun. Calcarina calcar. $\mathrm{D}^{\circ} \mathrm{OrB}$.}

C. testî trochiformi, depressâa, subtùs convera $\hat{a}$; anfractubus margine carinatis, spins crassis, trevbbus, pyramidalibus armatis; aperturî̀ minimâ, elongaltâ, subarcuatâ. Ков.

D'Овия. Mćm. sur les Céphal. Ann. des scienc. nat. tom. 7 . pag. $276 . n^{\circ}$. 1 .

Ilbid. Modeles de Céphal. $n^{\circ} .34$.

La Calcarioe éperon est sénestre, c'est-à-dire enroulée de drorle à gauche dans le sens inverse du plus grand noubre de coquilles; elle est trochilorme, peu ćlevée, composée de deux ou trois tours, doni le bord carémé est fortement découpé eo larges pointes pyramidales, rriangulaires. Chacune de ces pointes correspond a une loge; les loges sont séparées extérieurement par un sillon assez protond, et lort large en dessus, superticiel en dessous. Chaque luge est rayomante, aussi-bien que les intervaltes qui les séparent: eo dessous ils aboutissent au centre, qui est indiqné par un très-petit disque ocobilical. D’apres les caractères énoncés par $\mathrm{N}$. d’Orbigny, ce caracıère devioil exc:lure celle coquille du gente; uais il a bien seuti quil avoit peu de valeur, puisque lui-mêue l'y a introduite. Cette coquille n'a pas nu millimètre de diamètre : elle est toute ilanche, el se trouve assez communément dans les sables de l'Ile-tle-France. M. d'Orbigny dit quelle se rencontre également i la Martinique el i Madagascas.

2. Carcarine de Defrauce. Calcarina Defrancii. D’Опв.

C. testâ trochiformi, depressâ, subdiscoideâ, utroque latere equaliter convexá; anfractibus $\mathrm{X} 2$ 
carinatis, spinis elongatis, gracilibus, cylindraceis armates; apice aliqurmtioper grunuloso.

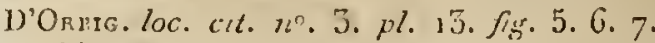
rt 7 . bis.

A peu prés de la mêre laille que la précédente, colle espice s'en distingue trie-lucileneat; sa spire, conposce d'nu nombre tgal de tours, est beaucoup plus aplatie en dessus, el un peu phus convere crn dessous; la carèue du dernier tour, lort trachante, est très-prulondément divisce par us nombre assez variable d'ćpines rayounanies, longucs, dioiles, cyliudracées el fort glêles : chaque ćpine indique une loge de la coquille; elle cst nluctée sur son centre; un sillon superliciel en dessus, ur peu plus profond en dessous, indique la place de la cloison. Celle de la denivie loge est convere, et ollie nne très-pelite onverture en fente, uu peu plus Jurre an milien qu'aux extrénitús. Celle espéce, très-ćlégante, les épines comprises, n’a pas plus d'un ruillin. de diaustre; elle vient de la mer Rouge. Nor.

5. Calcanise :are épine. Calcarina rarispina.

C. testâ lasigatî, utroque latcre conoide $\hat{u} ;$ spirâ oblusâ ; carinâ acutâ, rarispinalâ ; spinis mininis acutıs, rectis; aperturi minimâ.

Cocquille presque aussi élevée d'un côté que de l'autre, présentant deux côncs âlatis, réunis base à base : !e côté de la spire esi encroûté de manière à ce qu'il est impossible de savoir de combien de rours elle est composće; elle s'enroule de gauche à droite. En dessous on distingue bien facilement cinq à six loges subvisiculaires, triangulaires, séparćes par un sillon assez profond qui se dirige eu couvergeant vers le centre, qui ollre tantôt quelques graunlittions, tantôt un disque ombilical, nuédiucre et saillant. Chacune des loges présente à la curène une petite épine, droile, aiguë qui ne s'appuie pas sur le centre de la loge, mais sur la partie qui avoisine la cloison. Les deux deruieres loges soul quelquefois dépourvues d'épines, on ne les présentent que fort courtes ou rudiatentaires. La dernière loge est un peu plus vésiculaire que les autres; l'ouverture que l'on y voit est très-petite, un peu plus large dans son milieu qu'aux extrémités. Celte coquille est tout-à-fuit microscopique; elle n'a pas un demi-millimètre de diamètre. On la trouve fossile dans les grès marins de Senlis, où elle est assez rare.

\section{CALCINELLLE. Calcinella.}

Une coquille connue des anciens conchyliologues, et entrantres de Belon, fort commune sur Les côtes de la Méditerranée, où un la nomme Piperone, Biverone, Peveraza, Calcinella, etc., a été

\section{$C A L$}

retrouvée sm les côtes du Sínígal, à l'embnuchure du Niger, par $\Lambda$ danson, gui lui a conservé ce nom de C'alcinclle. (Foyuge au Sénégul, pag. 252. pl. 17. figr. 18.) (elle conquille liail partie du genre ligule des stutems angriais, et des latlaires de Mi. Lamack. (Jojci Ligure th LuTHALIE.)

\section{CalliRHOE. Callithoe.}

Gene instilué par Montfort pour une nile d’alvéoles de Bélemuites, sćpattée de la encuille. Ce genre ve pouroit être adopté. (Foyez biLEM $\triangle$ ITE.)

\section{CALIISTE. Callista.}

Poli (Test. utmusque Sic. tom. 1.) a voit élabli ce genre sur des caracties trop étendus des aniuaux. 11 y róunissoil ceux qui appartienoent aux genres Mactre el Cythérée de M. Lamarck, que persmne nit conlindus depuis. Ce genre ne pouvoil êlre aloplé. (Vojez hactue el (Titiente.)

\section{CAIIJSTODERIIE. Callistodema.}

Poli a donué ce nom aux coquilles de son genre Calliste. (Voyez ce nut.)

\section{CALLITRICHE. Callitrichus.}

'Tous les Mollusques conchifères qui n'ont qu'une seule ouverture en forme de trou à la parlie posterieure du manteau ont ilé compris daus ce geme, institué fiar. Poli daus son bel onvrage sur les testacís des Deux-Siciles. II renlerme les genres Moule el Modiole de M. Laimarck, et Lithodome de M. ('uvier. (F'ojez ces mols.)

\section{COLLJTRICODERME. Collitricoderma.}

Nom applique seulement aux coquilles du genve Callitriche par Puli dans l'ouvrage précité. ( $V^{\prime} o y$. Colitriche.)

\section{CALCÉOLE. Calceola.}

De Ilupsch et Knorr firent connoílre et par de bonoes tigures et par des descriptions détaillcies une singulière coquille bivalve dont linné fit une Anomie sous le nom d'Anomia sandalizm. Ce genre Anomie (vojez ce mol) étoit, dans le système linuéen, composé d'un grand nombre de coquilles extrêmement différentes entr'elles. Bruguière $\mathrm{y}$ fit quclques changemeus, mais ne songea pas aux Calcéoles. Il ne les fit pas figurer, il ne les décrivit pas avec les Anomies; de sorle qu'il est à présumer qu'il les avoit oubliées, ou qu'il ne les connoissoit pas. Ce fut M. Lamarck qui, continuant les réformes du genre Anomie de Linné, créa le genre Calcéole dans le Systćme des animaux sans vertèbres: il est placé fort judicieusement à côté des Térébratules. Peu de 


$$
\text { C } \perp \text { L }
$$

$16 \mathrm{mps}$ apres aroir été citubli, ce genue fut a dnpté, d'abord par Busc, el ensuite pal B]. de Rivisy; mais re dernier zoologiste ne conprit pus sans done l.i justesse des rapports incliqués par Mt. Latmack, car il les changea notablearent, eu conservatit les Cialcíoles avec les Ariales el les Radialiles au commatucenent de lit tisse des derplitles, tandis que les l'ribrallules el autres genres amalogues sout à la lin de celle longue série. Celle opinion d'uu savant forl dislingué n'eut point d'influcuce, a ce y u'il paroil, sur celle de II. Inanarcl, yui, lans sa Phrbusophse zoologropue, tout cu comprenant les Culcioles dans su tamille des Ostracés, ne les flujölla pas de celle des Bruchiopudes, et les laissá d'ailleurs cotre les Raldiolites el les Cuanies. Cet arrungeu. cut resta le mêne dans l'Extrait du Cours, mais épronva des clinggemens importins dins l'Historre dos animaux sans vertibres. I.a fumille des Usiracós lue rélormíe, et celle des Rudistes fut créce. Oa peut se convaincre, par les observalions yue nous arons fülles sur les Hippurites, les Rudiclíes el less's hérulites, elc. (20y. Rudis'es), corblien celle lisidle est peu nalurelle, rir clle ne pourra plus désorwais consriver un seuldes genres qu'elle contient mainicnaut. C'elui qui nous octupe t'n fall partic, et il ne devril pas y rester plus yue les autses. M. Cuvier ( $K \dot{e}_{\ddot{b}}$. nnim.) ne mentionua nulle puri le genre Calcévle. M. de lierussic ne comba pas dans le uểoue oulli ; ayant aduplé la famille des Rudisles dans ses lubleaux systematiques, le genre Calcéole ful couservé dans ses fiux rapporis avec des gremes mal connus.

Disus ses Familles naturelles du Régne ammal, 11. Latreille, luin d'ameliorer la classilication a l'égard des Cinlcéoles, reproduisil à jen pris, mais d'one manière moins lavorable, la première opinion de M. Lamarcli, en replacaul ce gemreclans la liamille des Ostracés, arecles Ǵyphées, les Judawies, les Huî́l'es, les Tulselles, les Productus, les l'odopsideset les Anomies, assecoblayeassez bizarre de genres appartenant bien évidemment à des lamilles fort différentes. M. de Blainville ne nous semble pas avoir été plus licurcux que ses prédécesseurs, puisqu'il conserve les Calcéoles au nomLre des Rudistes.

Après un examen très-approfoudi de la fumille des Rudistes, M. Deswoulius, tout en y apportant une sage réforme, y conserva néanmoins lés Calcéoles, dont les caractères ne peuveat s'acicorder sur aucuns poiats avec cenx donnés à la lamille elle-même. Nous étant occupés d'uae maaière spéciale des Rudistes, nous sommes enfin parvenus à découvrir leur nature, et il nous sera fucile, comme nous le ferous à l'article SphÉrulite, de démontrer quon s'est complétement mépris sur leur nature et leurs rapports; quils doivent former une famille voisioe des Cames, dans laquelle, comme on doit le prévoir, les Calcéoles ne sauroieat entrer.
C. $\& T_{d}$

165

Torsque l'on examine ce gerre ct rivon le compare aux Cromics el anx aulaes genres compris aujund'hui dans la firmulle de's Brachiopudes, on ne jeul se délendre de lai truuver des analogies incontestables. Culatines Camics ont le talon de

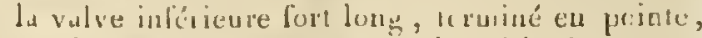
sur laquelle on remartue yuclyuefuis des traces d'atheirence, nais qullpueluis aussi on il es! in posible d’en aperevoir la moindze; cela se semarque aussi daus les l'lucicilees : le talon de Ja grande valve te la calcéole est bien conparabie a relui des genres que nous cilons, mais on re

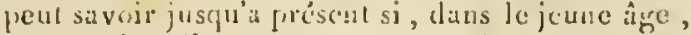
il y aroil adherence atux corps elratigers, lows les individus que nous avons vas étant usés dans cetle partie de ananière à nons laiscr dans le doule à rel igard. Louverture de la gramile ralur est oblique comme daus an granel noastre de lérébratules; le bord postérieur est garni de finas denielures, dont une médianc, pius grosse, phis saillan!e, eo forme d'apoplyse, s'aricule elle seule avec la valve supérieure cu s'entonçan daus une: cavité correspondantc.

lid valve supérieure est aperculifurme commo dans renains l'ruductus, coune dans les Tirécidées; en dedius, elle est paltagce en cieux patlies Éales par une lame saillante à l'extrémité postérieure de liqquelle se voit la petite cavité correspondaate a la denl de l'aulre valve; le bord calldiual est, du resie, droit et linement dealelé. Sur les parlics lidérales, cl ce sont probablenera des impressions musculaires, on renarque trois ou qualle gros plis qui se terainent par de perits sillons qui gaguent en s'arondissant le ford autcrieur de la valve; loul le reste de la surface intérieure le celle valve cst strić linement, surloul sur le bord aulcieur. Les injpressious musculaires no: se distinguent pas bien nellement dans la valve iuléricure; nous cıojons cependaut qu'on ne peul atltribuer a aulle chose qu'a des muscles les impressions pelites et nombremses que l'on voit dins les angles qui résultent de la face inférjeure arec les larérales. Il esı très-probable que, comme cela a lieu dans les lérébratules et dans les Cranies, la lame médiane de la valie supérieure sert de joinc d'allache aux muscles qui partent de la valse inféricure. Ainsi, en résunant, on ne l'ouve dins les Calcénles ni charnière, ni trace de ligancu, ni une seule eu deux impressions musculaires; na on lui trouve nu test synúlıque strié, épais, dont une valve est plus grande que l'autre, caractères qui saccordent parfailement avec ceux de la lamille des Brachiopodes, et nullement avec ceux des Rudistes. Ce que nous avoos dit prićcédemment peut justifier l'opinion nouvelle gue nous avous sur les rapporls de ce genre.

\section{CARACTERES OE் ÉRIQUES.}

Coquille bivalve, symétrique, régulic̀re; valve 
inféricure grande, conique, courbée, pline ex dessous, convexe en dessus, ouverte obliqueneni, fort épaisse; vallve supérieure peu convexe, operculiforme, striée en dedaus et partagée dans le milieu par une lame perpendiculaire; charuière droile, mulidentée sur la valve inféricure, arliculće arec la valve supérienre par une seule deat moyenne, conique, intrante, plus grosse et plus saillante que les autres.

Ce genre curieux que, dios notre manière de vuir, nous plaçons à la fin des Brachiopodes, ue se compose encore yue de deux espèces; leur forne ressemble assez a celle d'une sandale dont os auroit coupé le talon: l'une d’elles, ancienneaeal connue, est beaucoun plus grande que l'antre que M. Defrance a fail connoốtre daus l'Allas du Dicfionnaire diss scrences nuturelles, et igue M. de Blininilie a reproduite daus sun Traité de ilalacologie.

1. Cancéon sandaline. Culceolu sandalina. l. AMX.

C. testâ conicâ, subtùs planâ, supernè conעexá, posticè recurrâ, crassâ, undiqué subluvigeatá.

Laxx. Syst. des anim. sans vert. pag. 13.jg. Ihid., Hist. des anim. s. yert. tom. 6. pag. 253 .

MARTINT, tom. 2. pag. 547.

Anomia sandalium. lix. Gorer.. pag. 3349.

Conchita anomia juliacensis, Hursca, Mus.

Knour, Petrif. tom. 3. Sup. tal). 9. d. fg. 5. 6 .

Bose, Coq. tom. 2. pag. 217. fl. 8. fg. $2 \overline{3}$.

De Rotssy, Buffon de Sonnini, Coq. tom. 6. pas. 186. pl. Go. fig. 9 .

SOWER BY, the genera of recent and fossil. shells. $n^{\circ} \cdot 16 \cdot f_{g}^{g} .1 .2 .5$.

Busisv. Traité de Malac. pl. 52. fig.9.

Cocpaille d'un médiocre volume, conique, recourbée lérc̀rement au summet de la value inlérieure, qui est beancoup plus grande que lia supirieuie; celle-ci resscmble it un opercule; ni l'uue ui l'autre ae présentent des cótes, des sillons ou des stiies, soil longitudinales, soil transverses, si ce n'est quelques stries irrégulières qui indiquent des accroissemens. Celle coquille, assez sare, est, à ce qu'il paroil, assez variable dans sa furwe; guelques individus sont étroits et alongrés, c'autres, au contraire, sont très-élargis; l'ópicisseur du iest est considérable, ce qui rend la cavilé incérieure petite; elle n'es pas plus longue gue les deux tiers de la longueur totale. Celte espèce ne s'est encore rencontrée qu'en Allemigne, dans le duclsé et aux enviroos de Juliers; clle est longue de 55 niillimètres, el large de 50 . Nous avons un individu lung de 40 millimètres, el large de 45 .
2. Calcéore bétéroclite. Calceola heteroclita. Defrasce.

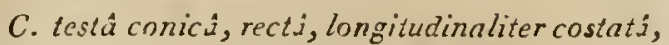
posỉicè pluntấ, costâ unicâ, tongitudinali munitâ. Nов.

Derr. Atlus du Dict. des scienc. nut.

Busav. Traté de Malac. pl. 56. fig. 5. 5.-a. 3.-b.

Celle espire cst heaueon! plus petile que la précédinte, el il est impossible de la coutonire avec clle; les deux valves sont extérieurement pourvies clesix grnsses càles rayonaables dir sommel al la base; les cieux médlianes sont beaucoup plus !arres que les antres; ces cótes se terminent sur le burd par autan: de denflures qui coriespondent à cellés de la valve supérientis. Le cuté postérieur est plat dans la plus grasde prartie de sa sulfare; il est parlagé én deux par une cáte silillante, longitudisule, qui correspond au sommet de la valve suṕrieure. Celte coquiile diflère encore de ha précédente, en ce qu'elle n'est point courbće rers son sommel, qui est loul drait. Nons ne connoissons pis la localité de cette coquille, qui na que 7 on 8 nillim. de longeur.

Des cociuilles pétrifices d'Angleterre, que M. S:werby, durs sm Nimeral conchology, a rangtes daus sun gente Spirifer sous le nom de Spivifer cuspidertus, nous semblent devoir entrer dunsle gente Calcéole; ne les ayan! jaunais rencontrćes clans les collections de Paris, il nus est inpossible de le dire positivcuent.

\section{CAlMaR. Loligo. (Vojez Loligo et Cá- PHALOPUDES.)}

CAIMARET. Loligopsis. (Vojez Longopsis el Ceiphalopodes. )

\section{CALPURNE. Calpurnus.}

Nontforl (Conch. Syst. tom. 2.) a fait ce genre avec une caguille du genre Ovule, l'Ooula yerracosa, parce qu'elle porte au-dessus des échancrures deux perites verrues. De si fuibles caractires devoieal faice rejeter ce genre. ( Voyoz Ovule.)

\section{CALITTRA.}

Comme presque tous les genres que fit Kleit: (Nov. Mleth. ostrac. pag. ıô.), cclui-ci est un assemblage de cocjuilles diverses, quelques Calyptries véritables, des l'atelles eldes Cabocbons. Tol gu'sl étnit, ce genre ne pouvail être conservé; sun norn seul a pu être transforme par M. Latnarck en celui de Calyptraca; mais on doit toujours réserrer au savint professeur la priorité sur l'élab) lissemcnt du genre Caly ptrée tel qu'li est aujourd'hui. (Voyez Calypriś.) 


\section{C $A \mathrm{~L}$}

\section{CALYPTRACÉES (les).}

Nom que M. Iamalek avoil d'abord donné à la famille qu'i! anmma plus tard Callyprariens, et qui a chté aduptie sous ce derniter nom. Nous y reu yoyous.

\section{CALYPTRACILNS.}

Ce Cur d'ulsord sous le aom de Culyptracées que 11. Lamarck instilua cetle funille. II l'uvoil conıposés d'une manicre asse\% sinzulière; clle cnmenoit seulement les qualre genres Cripidule, Culyperce, Cadran el 'l'roclus : elle termine la longue súlie des Grastéropodes sans siplano. Les proirres que fit la concly liologie, al l'aile des ex. celiers travanx de M. Cuvier, ne permirent pas que cet arrangement subsistât longo-terngrs. M. Ladluack lni-mùne ful le premier à le modifier de loules les manières, aussi bien daus les ripports te turte la famille que dans les genres qu'il y introdusit. Illui donna le nom de Cialypetaciens, la rait au conmcacenent de la classe des Moilusques sums siphon, an lien de lu laisser ì la fin, la stpara nellement des Catrans et des Troyues, gui font partie de la fatrille des 'Turbinacées, et enlin ne la composa que de genres qui ont entreux de grands rapporis. 1ls sont au nombre de cinq, dans l'ordre suivant: (Gahochn, Fissurelle, Enarginule, Calyptrée, Crépidule. Quoiquiil y eút encore dans un nème groupe cles coquilles symérriques, el d'autres qui ne le son! junais, on ne peut contester la grande anćlioration que les Cillyptraciens éprouverent. M1. Cuvier ne les adopla pas. Les genres que nons venons de menlionoer sont répartis avec d'autres dans les Scutibrancibes. (Voyez ce mot). Parmi enx et à côté des Crripidulus, se lrouve le genre Navicelle, que M. de licrussac institua sous le nom de Septaire, pourvu d'une pièce operculaile, et ayant au reste une grande analogie avec les Nérites. M. Lamarck le sépara tout-à-fait des Calyptraciens; NI. de lerussac, au contraire, persista a le laisser dans des rapports que rien ae pouvoit justifier. Cet auteur, dans ses Tableaux systématiques, fit de la famille des Calyptraciens un sous-ordre des Scutibranches. Il le partagea en deux familles, la première pour les coquilles non syuétriques, la seconde pour celles qui ne le sont pas. Ces caractères distiuctifs éloient très-bons, mais cncore fulloit-il en faire une juste applicalioo, et cest ce que M. de Fernssac ne fil pas, puisçn'il sépare les Calyptrées et les Navicelles, quill croit syonétriques, des Cabochons et des Crépidules. Or ni l'un ai l'autre de ces genres ne sont syinétriques; douc il étoit plus naturel de les mettre dans la même famille que les Cabochons et les Crépidules. Le genre Navicelle, comme nous l'avons dit, n'appartient point anx Scutibranches, la pièce operculaire, bien que rudimenlaire, suffiroit à clle seale pour décider celte question.
Nous reconnoitrons núanmoins dans l'arrangement de M. de Ferussac nne ilie tris-lionne, relle de la sifatration des genres des Calyptraciens, d'après la symérie ou la non svmétrie de la coquille. MI. de Biluinville, dans sun Trailé de Malacologie', fit de ce principe une apllicalion rigoureuse, qui eat pour résulat une conposition plas naturclite de la famille des Calyphraciens. Elle ne conlient plus en eflet que les genres uon symétriques de lia lamille des Cailyptraciens de M. Lamarek. Les rapports ciủil trouva entre les Hyponices el certaines conquilles bivalves, les rapports qui exislent néamoius entre ce gente el les autres de la familie qui mons wecupe, out dílerminé M. de Blainville à termicer par elle senle la série des Mullusques criphatós. On y trouve les cinf pentes Crépidule, Calyptríe, Cabochon, Hyponice et Notrène; ce dernicr, institué par M. Rafuesque, est touteux, et uous ne l’admeltons pas. Un antre, qui est beancoup mieux connu, et que $\mathrm{M}$. de Blainville mul á coić des Onbrelles, nons paroit devoir eutrer dans les Calyprraciens; nons voulons parler des Siphonaires, ¿que l'irrégularité de lenr coquille, la torme coniqua de quelques-nmes, et d'antres caricières tivís de l'aninal, rapprochent d'nne manière évidente des Cabochons.

Tout en n'adnetlant avec M. de Blainville ciue des coquilles non symétrigues dans cette fanille, tout en adoptant les caractères qu’il lui donne, nous la modilions en cela que nuus rejetons le genre Notrème qui est à peine connu, pour y mettre le geare Sipbonaire. Voici l'ordre yue nons proposons pour les cinq geares que nous adtneltons.

\section{a. Point d'appendice interne.}

Hyponice.

Citbochon.

Siphonaire.

b. Un appendice ou lame interne.

Calyptrée.

Crépidule.

Nous renvoyons à ces mols de genres ainsi cqu' it MIoncosque, où nons donnerons les caractères des ordres et des familles.

\section{CALYPTRÉE. Calyptrcece.}

Quelques Calyptrćes répandues ataus les mers d'Europe, furent connues de la plupart des anciens anteurs; Bucnani, Lister, Rumphius, etc., en font mention d'une mavière particulière, et tout en les plaçant parmi les Patelles, jls firent sentir qu'elles cn dilléroient par la lame ou l'appendice qu'ils remarquèrent à l'intérieur.

Lister n'en connul qu'no petit nombre; il les sépráa néanmoins des vraies Patelles, comme il en sćpara aussi les Cabochons, les Fissurelles et les Crépidules, ce qui pouroil donner aux auleurz 
cuit suivirent guelques indicalions pour former de chacune de ces divisions autant de genres stépirís; nais nous royon qu'il n'en a jus é:é ainsi, cal linnć se conlenta de swive lister, en partageant son genre Palelle en sections, el réfúta we qui avoir été fait avant lui. Bruguiere, Jui. néme, quile preuser donma l'exenple des rélormes daus le systène limnéen, ne pruposa dans le premier rolune de ce Dictionndire, quua senl dómendrement des Pulciles, le genre lissurelle, qui fut génćrilenent aduis. M. Latearck proprosa le premier de sciprurer chacune des secrons du r̆cure Patelle de linuć en autant de coupes gésé. riques, et il $y$ lroura en outre les élémens de plusieurs genres qu'on $y$ avoit ronfondus : ainsi nous voyons, dès 301 , dans le systeme des animarex sans vertébres, ligurcr, a coté des l'alelles et des Fissurelles, les genres Emarginule, Crépidule et Calyptrée. MI. Lamarck a situs doute einl' uuté ce dervier nom générique à hilein (Ostrac. f'(rg. 118 ), yui lo premer a emplogé le mol C'aiptra pour les coquilles du genre qui nous occupe, lequel lut reproduil par Hamphrey dans le Museum calonmianmm, ou il en fit une applicalion plus distincte et mieux molivée.

B1. de Rrissy, duns le come 5 des Mlollusques iu Buffor de Sonnini, pense que cellaines (ia1) plices, celles qui onl ure linne spirale et nac spile extérieute, oal tant d'analogie par leur fume aver certains 'l'roques, qu'on devia les en a approcher. Nloutiort, saisissunt cettc idée, fit ivec le Culypirad trochiformis, en y joignanu le Iroclias concavas, el guclates autres analognes, son genre Infundibulum. Ce gente ne ful point aduis, et il ne pouroit l'ëre; cur les ćĺmens en sant hrétrogènes: la scule cousidérution de l'opercule pouvoit en décider; on n’y til aucune altention, el celle bégligence lut cause sans doute que M. Suwerby dui seul conscrva le geare de Nontfort dans son Minesal concholsgy.

M. Lawarck, eı 1811 (Exlat du Cours), zeproduisit, sous le nom de Calyptraciens, la tarille des Catlyptidcées de la Philosophie zocloहैique, en y apportant de norables changeareus; Il la sépara, avec juste raison, des l'alclies, sur la diférence des branchies, el il la composa des genres Cabochon, lissurelle, Emarunula, Calypltrée et Crépidule. On doit altributres r-piorts nuveaux, indiques par le savan M. Lanark, aux travaux anatomigues d'un homme à jatuais illustre dans les sciences nalurelles: M. Cuvier, cu ellel, dijà à celle éproque, avoit publié un arnad nomble d'excellens Hicuvires dans les Anyules du DILséum.

'lel ciloil l'clat de la science, lorsque parut le gégne animal, que liun dili ì ce savanl zoolugiste. On Irouve dans cet ouvrage la famil!c des Sicutibranches, divisic en Scutibranches symérri. ques et un Siulibranclies nou syurétriques. C'est frarui les genies de celle deracie division, qui a du resie de lana!ogie ares los Calyptraciens de 11. Lamarck, que l'on trouve le grenre Calyptrée. Ce fut quelques aunces phlus lard que M. Litmarck publia son dernier ouvrage sur les animaux sans vertibres; il y conserva la lamille des Calyptraciens, sans d'autre clangement que l'addiliun du gente Parmophnre, que M.de Bluinville, appuyé de la connuissance de l'animal, reproduisit du Scutus de Mont lort. i1. Isanarck opérid alors, dans les Caly!nlues, la division indiquée par M. de Russy, cisi-j-dire, que re zoologiste, Irompé sans doute par une analogie de fon mes, plaça avec les Trogues de Cabptrit: trochiformss, sous le now de Tinchus calyptraformis, saus tullc allenlion anx aulres caracleres, el strfunt a ceibi de l'opercule. Il éroil imponssilile d'atmetie ce vluargement, clomt il est dilhcile d'ancrecroir les moiils. Un conviendra lacilement, forsque l'on aus a olsservé les passayes insensibles qui exisient entre toutes les Cillyprices, que cel arrangcuent délruil des rapporis nalurels.

On a dû remarquer que justüa présent il n'a pas éló question de l'animal des Calypulées; c'est qu'en ellet fous les aulcurs gue nous venons de culer ate le commurent pas. Ce ne fill qu'en zovembre 1824 que parul notre Mlensire anatomique sur le Culyptra'u sinensss dans les Ammes des sciences maluralles. Ce Miémoite ent pour risulat de lever lous les doules a l'égard durente Calyptrée, et de lixer délinitivement des rapporls cqui néaunuins avoient élé dé erminés d’une manierc asscz juste par la p'upirt des zoologistes. Dans le mêne texips, M. Deslougrehamps publinic un Mcinoire moins étendu que le nôtre sur le môme aninal daus les Ménuoines de la Socieile linnéenne åu Caloados; il est acrumpagné de fignres lic̀s-mídiocres, qui we peuvent clre d'ullcunc ulilite. 1)ans sun suvrage inlilule Familles maturelles du Régne animal, M. Lalicille suivil,

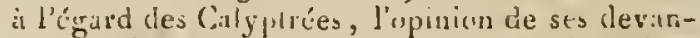
cicors cn lés rangeant à côté des Cuépidules, dans saliam le des L'iléiturases. ( $P$ oyez ce mal). M. de Blainville, en adoprant la finille des Calypraciens de M. Lamark, y tit des cbangeneas jnportius qua nous aduptons volcutiers. Elle ne contient plus en elfet que des coquilles non synétifyes, doul les animaux onl cull'cux des rapporis évileus; du reste, les rappurts du genre Culyptrie sont les rüires que dans M. Ladmarck, puisqu'ıl se voil entre les Crépidules ei les Cubochoris.

Lanimal yue nous avons dicrit appartient at Culypirata sinensis, Patella sinensis Lin. Oil le iruave quelguefuis sur nos côtes de la Mlatclue. Il ne sera pas inuile le rappelu les rail. principana de soa croanisalion.

La téle de cet animal est petile, aplatie, diviséc con dessus en deux perits lubes. qui se continucul à la face inlésieure, ou ils sont séparés par uu sillon arédian assez profond, au baut dutjuel 


$$
\text { C } \perp \text { I. }
$$

se trouve la bouche: elle est munie de chaque cûlé de deux lèvres charaues, longitudinales, ipaisses, ce qui donne à celte lace inférieure de la rète l'appareuce quadrilolóe. De chaque cólé et antérieurement, šinsèrent sur la tète deux tentacules, assez grands, pointus, coudés dans leur nilieu, et oculés extérieurement sur un béger renllement ì l'endruit mcme de la courbure da tentacule. Celle tète est soutenue par un col assez long, triangulaire, très-déprimé et muni de cliaque côté de raembranes très-minces quile font paroitre plus large qu'il n'est réelleasent.

Au-dessus du col se trouve une grande cavité branchiale, furmée par le manteau qui est largement ouvelt dans cet endroit; celle portion du mantean est mince, transparente, et forme un sac assez irrégralier par son insertion posićricure au reste de l'animal.

lies branchies sont composées d'une multitnde de tilamens cornés ou cartilagineux, éluftiques, creux à l'inléricur, fluttans par une extrémité, pectiués, traversau la cavité branchiale obliquemeut de gauche à droite, insérés les uns près des antres a gauche de l'animal dans un épaississement demi-circulaire du mantcau. On veil à leur origine, un peu au-dessous de leur insertion, le vaissean branchial qui donne un pelit ramean à chacun des filameus. On apercoil dans celle méme cavité branchiale, une portion de l'intestin, le rectum, comprise dans l'épaisseur de l'insertion du mantcan a corns de l'animal; son extrémité libre ou l'anus est follante sur le côté droit de l'animal, en avaot du wuscle qui l'ultache à sa coquille. Le rectum est presque toujours rempli de petits fragmens ovoïles, grisities, de matière fécale que l'on troure quelquefois rejetés dans la cavité des branchics où est l'autrs. Outre ces parties que nous venons de mentionner, on remarque encorc dans le sac branchial l'o-ifice de l'organe génératenr femelle qui se prolonge jusque pres du bord droit du pied. Cel urifice se conlinue en un ovaire assez grand qui passe derriére le rectum, devient plus postérieur et va gayner le bord postérieur clu foic auquel il s'insère.

Le pied est un disque charnu, adhérant an ventre par un pédicule court et large; il sembleroit quiil n'est pas dans la ligne médiane de l'inimal pris dans son ensemble; on croiroit qu'il est rejelé plus à droite, mais ccla est dû à l'extension latérale granctie de la cavité branchiale.

La bouche est terminale, sans trompe, placée entrc les deux lobes antérienrs de la têle. V'ues à une fortc loupe, les lèvres présentent quelques petits crochels carlilagineux. Par la transparence de la paroi buccale lupérieure, el mienx aprés l'avoir coupée en denx Inngitudinalement, on apercoit uoe petis appareil lingual formé de pièces cartilagincuses brunes, hérissées et subarticulées. L.l cavité buccale est assez graude, elle se rétrécit en un œsophage plus long que le col; il
$\mathrm{C} \perp \mathrm{L}$

(i)

s'insère sur un estomác ovalaire, médiocre, it parois ridées à l'intérieur et assez épaisses; de son fond part un intestin qui descend dans le foie; en $y$ arrivant il recoit les vaisseanx biliaires, puis il se prolonge, enveloppé dans cel argane, jusque vers l'ovaire où il pénètre un peu; c'est li, sur le bord postérienr du luie, qu'il se replie, remonte en s'y enfoncant de nouveau, cl après quelques circonvolutións, parvient à son insertion dans la carité brancliale où il se termine comme nous l'a vons vir. Lee foie n'a qu'un seul lobe assez grand; il est séparé du reste du corps parce qu'il occupe tout l'espace compris entre la cogquille et sa lame oblique interne. Cet organe est couvert en dessous d'une membrane jaunâtre, au travers de laquelle on voil des vaisseaux assez gros; en dessous il est brun, marbré de jaune verdầtre; on aperçait sur cette surface les vaisseaux bilidires qui se réunissent en un seul tronc qui s'introduit daos l'iniestin lorsqu'il sort de l'estornac.

L'organc excitalcur mâle est très-pelit, placé au côté droit du col au-dessous du tentacule; lorsqu'il est rétracté, on l'aperçoit quelquefois se prolongeant jusque vers la troitié da col, en s'intléchissant un pen; son extrême ténuité et la pelitesse des animanx de celle espèce, ne nous ont pas permis de le suivre davanlage dans ses rapports. Mais ce qui est essentiel à noter, c'est l'hermaphroditisme de ces animaux qui portent tous un organe mille et un organe femelle.

Les organes de la circulalion se composent d'un cœul' avec son orcillelte, d'un vaissenu bran. chial ou artère pulmonaire, el d'un système vasculiuire général.

Le cour est pelit, placé dans an péricarde au cóté gauclic de l'estomac et un peu au-dessons de lui au côté gauclıe de l'animal à peu près à la base du bourrelet qui porte les branchie: it n'est séparé de l'oreilletle que par un étranglement fort court. L'oreillette est subtriangulaire, elle donne nuissance, par son angle antéricur, au vaissean branchial qui parconrl coute la base du peigne branchial el fournit un grand nombre de rameaux; de la base du ventricule mait nue aorte qui se divise en deux troncs, l'un qui se distribue aux parties autérieures, l'autre aux postéricures.

Le système nervenx nous est peu connu : nous avons va sur le cólé gauche du col un ganglion assez gros gui fournil un filet entaculaire, un lileı buccal, quelques autres postérieurs, et de plus, un plus gros lacéral qui passe au-dessus de l'esophage pour s'auastomoser avec le ganglion du côlé droit: il est à présumer qu'il existe un ou denx autres ganglions sous-asophagiens comme daus tous les autres molluscques de celte classe.

Quoique nons ne connoissions qu'imparfaitement l'animal des Crépidules, nous conviendrons ponrtant qu'il offre a vec ceux des genres voisins, et surtout avec les Cabochons, des rapports assez intiaes; mais ces rapports sont plus wrands en- 
core peut-élre arec les Calyptríes. Ces deux geares se distinguent néamoins et par la pusition des yeux et par la forme de lit branchie, en panache dans les Crépidules, on peirne dans les Calyptrées; les coquilles ont rlailieurs des resserublances incontestables, ce qui clome plus de force atux allinités indiquées pour ces rnenres.

\section{CARACT它RESENERICUES.}

Animal conique ou díprimé, ovalaire, spiral ou engainant; manteau fort mince, simple, dépassant un pied subcirculaire, peu épais sur ses bords, bealicoup plus à son centre qui donre naissance au muscle unique qui se fixe an somnet de la coqulle; lête large, aplatie, pourvue de deux grands lealacules triangulaires, pointus, portani les yenx sur un reullement placé au milieu du cóté externe; cavité Lranchiale très-gnande, largement onverte, oblique et contenant uoe braachie pecliniforme, conjunsée d'un yrand nombre de lilumens roides et exsertiles; anus llottant à l'extrémité du rectum, sur le còté drnit, clans la cavité branchiale; oviducte s'ouvrant plus à droite dans la mème cavité; organe excitatear mâle sur le cóté druit du col, au-dessous du reutacule de ce còlé.

Coquille connïde, non symétrique, irrégulière, quelquefois spirale, à sommet verlical ou incliné, non perforé el postérieur; cavité munie on d'une lame spirale ou d'une languelle en fer it cheval, on d'une lame en cornet, ou entin dune simple languetle saillante sur. le cóté; inpression unusculaire unique, de forme variable sur la langueltc.

I.es Calyptrées sont des coquilles marines, non symétriłpues, souvent jrrégulières, quel quefuis épilermfes et cqui affectent des formes assez singulières : les unes sont patelliformes, les antres trochiformes. Dados les preničres on pourroil élablir plusieur's sous-divisions: 10 prour celles qui ont sur le cólé un appendice lrés-petit, rudimentaire; $2^{\circ}$. pour celles qui ont cet appendice plus saillant, oblique et subspiral; $3^{\circ}$. pour les especes qui ont une lawe en fer al cheval, desceudant du sommet jusque près de la base de la coquille fixée seulement pur le somaret; $4^{\circ}$. enfin pour celles qui ont une lame en cornel complet, formanl un cône compris dans la cavité conique de la coquilie : ce coraet est lixé, non-seulement par sou sommet, mais encore latéralement par une lame de jonction. Les espèces trochiformes ne sont pas susceptilles de se partager, elles ne different entrelles que daus les limites des autres coquilles, et leur diaphrañme est composé suivant l'âge et les espèces d'un plus ou moins grand nounbre de tours de spire.

Plusieurs espèces de Crépidules sont voisines, quant à leur forme extérieure, de quelques Calyp- trées : ainsi le Crepidula aculeata, par exemple, dont le sommel s'mclio sur le hord et se ton rne ea spirale sur le còlé droit, ne diflère des Calyptrées Irochitormes que par cetre inclinaison du sonimel; il est une autre coquille, le Culvptroea crepidularis lamk., que l'on trauve fossile aux environs de Paris, qui est très-voisine de la Crépidule que oous venons de mentionner, mais $s^{n n}$ somtrel est un peu moins marginal; nous croyous que ce!te inclinaison du sommet dait décider à lis ranger au nombue des Crépidule; alors les caracetére, que nous avons assignés au gen:e recevrunt leur enticre application dans loules les espèces.

\section{Espèces trochiformes}

1. Camprtrór péruvicune. Calyftráa peraviena. Хов.

C. Leslî̀ obbiculuri, depressî, t:ochifonni, nóbidis vel lutescente, costis sulmodulosis, dislantibus, elev'atis, radintis, ornalià, subcis concrviá; verlice subcentralt; epidermide lamelloso , fusco.

Havaxiv. Conch.pl. 4 , fig. A. 1. A. 2.

Celle grande et bel!e coquille est très-remarquable; elle u'erl pas régulière comme les'Troques, el'e ne doil dooc pias y être conlondue plus que la suivante que M. Lamarck y avoil placée. Elle est orbiculaire, conique, peu ilevée, tormée de quatre it cinq tours, dnnt le dernier est plus graut que tous les aulres. Le bord droil se termine obliquement el cu diminuant peu à peu de manière à se confond:e avec l'angle de la base, qui est saitlantel augmente nolablemeut la concavité de cel'e base. 'lous les tours de spire sont omés de cô.es rayonnantes du sounmet à la base; ces cótes sullantes, subrégulières, quelquefois un peu nuduleuses, sont arroudies et coupées obliquement p.ul" des accroissemens irrénuliers, quelques-uaes sinples vers les sutures, se bifurquent plus ou norins liaul, tandis que loutes les autres sunt simple's: en dessous cette cocpuille est concave, blanclie, quelquefais d'un jaune-orangé sur le bord drrit; le bord libre du diuphragme est sinuenx, for mince comme lout le reste de celte partie : il $n^{\prime} y^{\prime}$ a point d'ombilic, et ce que l'on pourmit nnmacr colunelle, ou pluiót l'axe de la coquille, n'esı pas ceotral. Nous possédons un individu, jeunc encore, qui est couvert d'un épiderme brun, tin et lamelleux. Celte coquille vient des cútes du l'írou; les plus grands individus ont 55 millinètres de diamère à la base.

2. Calyptrée de Lamarck. Calyptroea Lamarkii. Nos.

C. testâ orbiculato-convexâ, apice mamilluti, licvigatâ, albâ, superne lutescente; infermâ facie concavâ; lamellâ seplıformi tenuissimâ, cavitatem formante. 
Trochus Caljptreformis. Las к. Anim. s. vert. tom. 7. pag. 12. $n^{\circ} \cdot 7$.

Nous emprusions à M. Iamarck la plirase caracléristique, mais nous n'admetluus pas avec lui que cette coquille duive tuire partie des'l'rayues; nous ue crnyons pas non plus qu'on duive lit regarder comene l'analugue clu Calyptrea trochiformis de Grignon, ce qui nous a enragré, pour éviter toute coufusion, ä changer le nom de celte espèce pour lui consacter celni dn suvant professeur, et ue pas altórer la synunynie de l'espèce lissile adoplée depuis lnug-lemps.

La C.I Iyptrée de Lamarck est une coquille d'un volume aiedincre, blanclie ou jautuâ! re, toute lisse, quelquetois légèrement strićc par des accroisse. mens assez ríguliers. Se: tours de spire, au nombre de trois ou quare, sunt convexes, arradis, - sparís par une suture simple mais cufoncée; le soinmet, qui n'est pas central, est saillant et mameloné. Le bord droit est très-mince, tranchant "oume le reste de la base avec laqquelie il se con foul insensiblement. Cenlc base est cuncave, toujours polie, hlanche, luisante; la lame septiforme yue l'on y' remaryue est sinuerse à son bord libre, tres-mince, translucide, et luisse it l'are sur lequel elle lourne une iress-petite lente ombilicales, oblique, en parlie recunteria. Cette coymulle, rare encure duus les colleciliuns, ricol de la Nouveliellollande; elle à de 20 à 25 milhır. de diamètre a la base.

NuB.

3. Calyptrée radiée. Calyplnza radiuta.

C. testî rotundato-conicâa, elutâ, trochi.formi, spiratâ, albî́; anfructzbus planis, sub distinctis, costulis numcrosis, tenuthus, valde sepanutis, rudiantibus, oncutis; subtis concasia.

On ne sauroit comprendre celle espèce avec aucunc de ses congréueres. Ses tours de spire, al noubre de trois ou quatre, sont aplatis et peu distincts, la suture se confondant avec le tour urícélent; la lase cst arrondie, et le snmmet sulldant el élevé cst presque ceulral; ce sommet est fort fouvent toujours lisse, mais le reste de la coquille est cuuvert de petites côtes rugnueuses, Iroutes, simples, rayounantes, saugmentant daus leur épaisseur et leur largeur du somener a la base. En dessous, relle coquille est très-concalve plus que les précécentes; le bord qui rermine la base est moins tranchant et cuafondu avec li lève droile; la lume sepliforme est ruace, sinuense à sinn bord libre. épaise vers laxe, clle laisse ujercevoir une tres-petile lente onibilicale ablique. Celle coquille, tute b!anche a quel. fue ressemblance avec le Caljptrea costuria Grat. Eussie i Dax. Elle s'en disciugue facilement maintenau; il seroit pussible cependunt que ce n'en soit qu'ume variété, ce que lon ne pourra élablir, au reste, que par des passages. Nous ign rons la parie de cetle espèce y qui a jo millim. de diamcitre à la base.

4. Calyptaie trochiforme. Calyptrace tmchiformis. LA SIK.

C. testầ orbiculutâ, convero-turgidulù, spinosâ, subconiciá; vertice subcentrali, lizvigalo; spurá perspicuâ.

Lamk. Ann. du Mus. tom. 1. pag. 385. $n^{\circ}$. I. et tom. $7 \cdot p l .15$. fig. 3. a. b. c. d.

Tinchus Calintrefornis, lan K. Anim. so vert. tom. 7 . pag. $558.71^{\circ} \cdot 9$.

Infundibulum echinulatum. Sow. MIin. Conch. $n^{n} \cdot 18 \cdot p l \cdot 97 \cdot f i g .2$.

Inf indibulum spinulosum, ibich. loc. cit. fig. 7 .

Infundibulum tuberculatum, ib. loc. cit.fig. 1.

Trochus apertus et opercularis, Brayder, Foss. hant. tab. 1. fig. 1. 2. 3.

Var. b. Noв. T'estâ clatiure, deformi, spinis obsoletis.

Var. c. Noв. Titstâ elatiore, scriatim et spiratim irregulariter tuherculato-striatâ.

Var. d. Noв. Testâ depressá, spinis raris, minimis.

Calyptraca trochiformis, Nов. Descript. des Cor. foss. des environs de Paris, tom. 2. pag. 30. $n^{\circ} .1$. pl.4. fig. 1. 2. 3. 4. 11.12.13.

Var. e. Noв. Testâ majure rugosâ, spinis rarioribus obsolcts, subtuberculfformibus.

Grateloup, Tubl. des Cog. foss. de Dax, Bulletin de lu Soc. lin. de Bordeaux, tom. 2. pug. $8 \mathrm{~s}$. $n^{\circ} \cdot 17$.

Espèce très-variable et très-remarquable en ce qu'elle se trouve dans un grand nowbre de localités. Elle est orbiculaire, trochiforme, à tour's de spire cunvexes, séparés par une suture bien apparente. Le sommet n'est jamais central, il est submamelonné, pointu, presque toujours lisse, lendis que tout le reste de la coquille est épineux; les épines sont tantôt très-nunbrúcuses, el tout-áfait ea canal, d'autres fors plus rares, seulement en ćcailles ou en guuttières, quelquefois mème changées en tubercules. Dans le premier cas, l'intervalle des épines est presque lisse; daus l'autre, au coatraire, le test devient d'autaut plus rugucux yue les épines sont plus rares, p'us courtes, plus inberculilormes. Ces diverses nudificatious nous ont engagrés à étallir une série de variétrés dont la dernière, qui vient de Dax, est la plus élnigncée du type principal de l'espèce. L? spire est variable cquant à sa forme el à son ćlévalina; elle est conique, quelquefnis fort ćlerée, d'aures fois très-déprinée, ct l'on tronve tous les internédiaires entre ces prints extrètres. La cavilé de la base varie aussi en raison des clangemens de a 
spire, elle est d'autant plus profonde que la spire est plus saillante; l'inverse a licu lorsque la spire cat déprimée; les bords ea sont simples, tranchans, le droit se continue saus interruption sur lit base. I.e diaphracrme est mince, fraule, sinueux à son bord libice, plus épais vers l’axe, et présentant derrière cet axe une fen:e oblique en partie cachée et plus ou moins grande.

La coquille que nous regardons comme type de celte espèce esı cellc qui est tout épincuse, et que nous avons représentée lig. 1. 2. 3. 4., de la planche 4. de notre ouvrane sur les Fossiles de Paris : elle est propre aux environs de Paris, du moins nous ne la connoisions pas ailleurs. La variété 13 est moins régulière, plus élancée : elle se distinune surtout par lcs épines courtes et rares. La variété C est plus élaucée que la précédente; son test est rugueux, ses épines sont courtes et rares, et elles sont disposées par rangées obliques el en spira!e. Celle variété se trouve à Dax, unais plus déprimée, el à spire plus excentrique que daas celie de lauris. I a varrété $D$ est trésdéprimée; les tours de spire sont peu sensibles, les épines qui s'y voient sont courtes et trèsexiguës; le test est presque lisse dans l'intervalle des épines. La variété E est la plus grante : elle est plus épaisse, ses épines sout plus luberculeuses, et le reste de la surface du test est rugueux. Peut-être celte variété constitue-t-elle une espèce. On a trouvé cette coquille aux environs de Paris, à Grignon, Parnes, Yalmondois, Senlis, Beauchamp, etc.; aux environs de Dax, à Crastetcrabe, à Cabanes, Mondillot, à Tuco, à Saint-Paul, etc.; en Angleterre, à Barton et l'ile de Wight. Les plus grands individus ont 35 a 58 millim. de diamètre à la base.

5. Calrptríz lisse. Calyptroea loviguta. Noв.

C. testâ orbiculato-conicâ, laevigatâ, trochijformi ; spirâ vix perspicuâ.

Noв. Descript. des Coq. foss. des env. de Paris, loc. cit. $n^{0} .2 . p l .4$. fig. 8.9. 10. 14 . I5.

M. Lamarck n'a pas mentionné celte espèce, qu'il a confondue peut-être avec la précédente; elle se reconnoît pourtant avec ane grande facilité, car elle n'a ni tubercules, ni épines, ni stries obliques et interrompues; ses tours de spire, au nombre de trois ou quatre, sont peu visibles; ils sont aplatis, à peine convexes, presque toujours lisses, quelquefois légèrement striés; le sommet est pointu, subcentral, terminé en mamelon; eu dessous elle est concave, assez profonde, le bord est circulaire, mince et tranchaul; la lame septiforme est miace, fragile, et à peine sinueuse sur son bord libre; la fense ombilicale placée à l'axe est presque toujours obstruée.

Nous avons trouvé à Moucliy-le-Chatel un individu de celle espèce qui, ayant vécu sur une coquille striée, a répélé les mêmes stries sur toute sa coquille, et seulement dans un sens qui éridemment n'est pas celui de l'accroissement de l'animal : ce fait prouve que cet individu a vécu constanment à la même place; on peut mêne juger qu'il étoit posé sur des stries longitudinales d'une coquille bivalve, lesquelles étoient rayonnartes du sominet à la base. Nous avons fait représenter ce singulier accideut aux figures 14 . et 15 ., de la planche précitée. Cette espèce se trouve aux environs de Paris, à Parnes, Mnuchy, La Chapelle près Senlis, Tancrou el Valmondois: elle a 25 à 28 millimètres de dianètre à la base.

6. Cartptrée lamelleuse. Calyptraca lamellosa. Nuв.

C. testâ orbiculato-depressâ, lamellosâ , l.smellis obliquis, erectis; apice mamillari, subcentrulz; spinầ vix perspicuâ.

An Calyptraca trochiformis, var. B. Lauk. Ann. du MIus. tom. 1. pag. 385. no. I; et tom. 7. pl. 15. fig. 4. a. b?

Nов. Descripi. loc. cit. no. 3. pl.4.fig. 5. 6.7.

C'est avec doute que nous rapportons à celle espèce la variété que nous venous de citer : elle est déprimée, mais elle ne paroît pas, ou presque pas lanelleuse, ce qui la sćpareroil d'une nuanière très-nette. La Calyptrée lamelleuse est orbiculaire, déprimée, conoïde, formée de deux à trois tours de spire seulement, qui sont peu distincts, presque confondus, le sommet est subcentral, droit, mamclonné; la base est large, arrondie, peu concave; le diaphragme est trèsmince, très-fragile, légèrement convexe, quelquefois même saillant au-dessus du bord. Son bord libre est assez fortement sinueux, surtout à l'endroit de la jonction avec le bord droit; it s'ćpaissit vers l'axe sur lequel il laisse onverte une fente ombilicale étroile. La surface extćricure, excepté le sommet, est couverte de lames minces, obliques, saillantes, plus ou moins serrées, selon les individus; il est rare de les trouver entières, le moindre frottement suffit pour les détruire. Celle espèce se trouve fossile aux environs de Paris, à Parnes et à Mouchy-le-Chatel. Elle a 30 millim. de diamètre à sa base, et 8 ou lo sculement de bauteur.

7. Calrptríe d côtes. Calyptraza costaria. Grat.

C. testâ orbiculuto-conicâ, rugosâ, costatâ ; costis longitudinalibus, scabriusculis; vertice subucentrali, mamillari, obtuso.

Gratelour, loc. cit. $n^{\circ} .18$.

Celte espèce est bien distincte de toutes celles que nous connoissons à l'élat fossile; elle se rapproche, comme nous arons dit, dune espéce vivante, la Calypticea radiata, que nous avons 
précédemment décrite. Celle-ci est assez grande, orbiculaire, couique, composée de trois à quatre lours de spire peu convexes, peu séparís les uns des autres, cerminés par un sommet manselonné et obtus; ce soumet est lisse, taudis que le res!e de la coyuille est couvert de cotes longitudiuales feu obliques, rayonnautes, tubcreuleuses dans lcur lougueur, quelquefois subsquanueuses; ces côtc's soút plus ou moins nombreuses, selon les individus, mais le plus ordinairement elles sont bien séparées. L'espace qui est eotr'elles est rugueux, chagrinć el laisse apercevoil quelquefois des stries d'accroissement irrégulic̀res et assez grossières. La base présente unc carité peu profonde; lc diaphragme est miuce, fragile, sinucux à son bord líbre; l'axe, solide, ollic uoe feute ombulicale, plus grande que dins les espéces précédentes. Cetie coquille rare se trouve fossile à Saint-l'aul , anx environs de Dax. Elle a jusqua'à 40 millin. de diamétre.

\section{$2^{\circ}$. Especces patellifornes.}

a. Tne languelle en entonnoir.

8.

Calyptrée ombiclle. Calyptraca umbrella.

(․ testâ orbiculuts-depressâ, patelliformi, lute.i, radiatin costatâ; vertice subcentrali, porrecto; costis irregularibus, margine lasciniantibus; sublùs concavî, albido-lutescente; lamins infundibulifonni, basi patulâ.

Cette section, dans les Calyptrées, est fort remarqquable; la lame, au lieu de se fourner en spirale comme dans la précédente, est fixée seulemeat au sommet de la coquille el se développe perpendiculairement en un eutonnoir complet ou en cônc crenx, dont la base libre, dans tunte sa circonférence, correspond à la base de la coquille, tandis que le somnet est scul adhérent. Quelquefois ccite espècc de coraet est ad̉bérent latćralement à la paroi de la coquille; d'autres fuis, plus détaché, il est soutenu par une arćte saillante; d'autres fois, enfin, il est complétement libre : c'est ce qui a lieu dans l'espèce qui va nous occuper.

La Calyptrée ombrelle est une coquille patelliforme sur laquelle on n'aperçoit aucune trace de spire; elle n'est ni irrégulière ni symétrique, elle cst orbiculaire, de forme conique, mais dépriméc; le sommet est subceatral, assez aigu, saillant et presque lisse; il en part en rayonnani un assez grand nombre de côtes saillantes, arrondics, subsquammeuses, aboutissant sur le bord où elles se terminent en pointes saillantes, de sorte que ce bord est découpé. Celle disposition donae assez bien à celle coquille la forme d'une petite ombrelle cbinoise. La cavitú est élargie et peu profonde; elle est lisse, brillante; à son sommet cst altachée la lame inlundibuliforme, qui est lilre dans toutc sa circonférence; sa basc, llc̀sélurgie, très-mince, présente unc large carité couique dans la cavité de la coquille clle-mème, de sortc qu'il scmble qu'il y ait deux coquilles l'une dans l'autrc. En deloors, cettc coquille est blanche vers le soamet et roussâtue dausle resie de son étendue. En dedans, elle cst hlanche, avec une tcinte brunátrc peu foncéc, qui s'apercoil surtout vers le bord. Nous ne possédons qu'un individu de celle espèce, nous ignorons d'oú il vient; il a 44 millim. de diamètre à la base, et seulement 15 millim. de hauteur.

NoB.

9. Calpptrée chagrinée. Calyptraca mgosa.

C. testâ orbiculut $\hat{a}$, conicâ, elatâ, subregulari undiquè rugosâ, albido-fulvâ, lineis bruneis irreguluriter sparsis, intus albá; rugis minimis longiludinalibus, irregularibus: vertice subcentrali, porrecto, ob́luso; margine simplici, integro.

Coquille orbiculajre, conique, en cône élevé, patclliforme, presque régulièrc, aon symétrique; à sommet saillant, ordinairement arroudi, quelquefois poiotu dans les jcunes individus, toujours excentrique el un peu incliné postérieuremen: Toure la surface extéricure est rugucuse, les rides sout itrégulières, longitudinales, interrompues, très-fiaes; le somme! est lisse, dun blanc sule ou jaunâtre, ainsi que le reste de Ja coquille. Sur celte couleur se dessinent des ligaes irrégulières d'un brun-rougeâtie, qui s'entrecroisent et forment une espècie de réscau; d'autres fois ces lignes sont plus larges, plos rares et affectent plus la dispositiou longitudinale. Ces conleurs soni le plus ordinaireneut masquées par une coucbe épidermique mince et bruae. La base est circonscrile par un bord simple, miuce, tacheté de blanc et de brua. Toute la cavité est blancbe, lisse, et présente fixée à son sommet une grande lame infundibuliforme, un pen oblique, ovale, munie d'une crète latérale qui se soude dans une partie de sa longueur à la paroi du test. Nous présumons que celle coquille vieat du Pérou; elle a été envoyée avec d'autres venant de ce pays. Elle a 36 à 40 millim. de diamètre à la base, et 18 à 20 de hauteur. Nов.

ro. Cartptrée radiole. Calyptraea radiole.

C. testá orbiculato-conicâ, irregulari, albâ, maculis rufis, raris notatâ, multicustatâ; costis rugosis, radiantibus, elevatis; apice subcentrali, mucronato; margine crenulato; intùs candidissimâ.

An Fatanve, Conch. pl. 4. fg. $\mathrm{B}_{2}$ ?

Quoiqu'ayant de l'analogie avee la Calyp!rée 
ombrelle, celle-ci, plus perite et plus irrégulicre, sen distingue encore par d'autres caraclères. Elle est orbiculaire, conique, à sommet saillant et subceatral; des côtes nnmbreuses, Iugueuses, - aillantes, serrées, descendent en rayounant du sommer à la base; elles se terminent elu autant de crénelures aisự;, assez courtes, qui dícnupent le bord; ce hord est mince et crénelé. La carité est peu prolonde; à son somnet est altachée la lame en calonnoir qui descend jusque près da niceau de sa base. Cetle latue ovalaire est munie d'une crite latírale, elle est 10 smince et Irès-fracrile. En dehors, celte espièce est d'nu blanc laitcux parsemé de petites taches d'un runge obscur; elles sont peu noubreuses. En dedans, elle est partout d'un blanc mat très-pur. Nous ne counoisons pas sa patrie. Elle a 20 millins. de diaunètre à sa base.

B. Une languelle en fer à cheval. I.A3ik.

C. ¿estâ suborbiculari, convexo conicj, irregulari, tenui, pelucidi, alhâ; struis lunguludinulubus acutss, undulutis, subtuberculatis, wersis marginem majoribus; sertice subacuto, cuna.

Laxк. Anim. s. vest. tom. 6. pag. $21 . n^{\circ} .3$. Patella equestris, Lrx. Grex. pag. 3691. $n^{\circ} .1$.

Listsa, Conch. tab. 546. fig. 38.

Rовген. Mlus. ant. tab. 40. fig. P. Q.

GusLT. $t a b \cdot 9 \cdot f i g . Z$.

D'Argenvilue, Conch. $p$ l. 2. fig. K ?

Fatasse, Conch.pl. 4. fig. B. 3.

Martini, Conch. tom. 1.tub.13. fig. 117.118.

Cette coquille est bien facile à distinguer : outre 1. forme de sa laue interne, yui caractérise cette section, elle est reconnoissable aussi à son peu de rćgularité, ஷ̀ sa forme orbiculaire conique, à sun snmmet pointu, saillant, excentrique, incliné postérieurement. Elle est exlérieuremeut couvcrte de cûtes très-nombreuses, longitudinales, ouduleuses, très-étroiles, tranchanles, noduleuses, surtout vers la hase. Daus les interstices des côtes, se voient des stries lrès-fines; le bord est souven! irrégulier, il est mince, tranchant, légéremeut crénelé, les créuelures correspondaut aux côtes du dessus. Eu dedans elle présente, fixée à sou sommer, un grand appendice ou lame érasée, un pen oblique, Irès-saillanie, en forase de goutlieve oo de fer à cheval. Cette lame en goultic̀re e: libre daus toule son élendue, si ce n⿳est à sno suminet, par lequel elle se tixe dans celui de la coquille. On trouve retie espèce daas l'Océao indien; elle a 35 à 40 millim. de diauètre à la base. Les irrégularités de celle coquille font sup- poser qu'elle vit sur les rochers et constamment 2 la mêrne place.

12. Caip ptréz toit chinois. Culyptrcra tecturn sinensG. LAAYS.

C. testi orbiculari, obliqué conicâ, tenui, lamellis tranjpersis contabulatâ, albâ liteolàve, trinslucida; vertice obtuso.

Patella tectum sinense, Спемriтz, Conch. cab. tont. 10. tah. 168. fig. 1650. 1631. - Ibid. tom. 1. $t a b \cdot 13$. fig. 125.126.

Favanie, Couch.pl. 4 , fig. B. 1.

D'Argentrie, Conch.pl. 2. fig. S.

Lask. Anim. s. vert. loc. cit. $\pi^{\circ} .4$.

Coquille fort singulière, petile, à base arrondie ea cóne oblique, quelquelois assez élaucéce. Son sommet, saillant et obtus, est toujours excentrique; des lames yrandes, saillantes, uniuces, burizontales, inbriquées, iudiqueut les accroissemeas de la cuquille; elles soni peu nombrenses el successivement plus grades dir soaınet it la base; elles sont biell disliucles, un peu onduleuses, et lout-a-fait lisses en dessaus; le bord est fort large, il est furmé par la deruière lane d’accroisseu:est. La calité est pe'ite, conique, et à son sommet est atlacbie une petite languetle en gouttière, semblalle en pelit à relle que oous avuns mentionnée daos l'espèce précé. dente. Celle pelíe espèce, furt rare dans les collections, est loule blanche al presque transparente : nous en uvous vu un individa d'ua jaune pâle s.ıfiané.

On Ir. uve crelle espèce amx iles de la Sonde et daas l'Ocía des Grandes-1ndes. Elle a 15 à 18 millia. de diamètue à la base.

C. Une lame oblique tixée par un de ses bords.

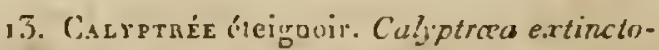
rium. bis.

C. testí conico-a_uth, orbiculuri, basi artgustâ, eluti, ulbo-griseầ vel fuscâ, lorvigatid; cinculis incrqualibus, subspiralibus; intis fuscatâ, lamellà minimâ obliquâ, replicutâ, insstruct:

Blainv lee, Truit. Le Malac. pl. 43. fig. 8.

Aneadem species? Lask. loc. cit. $n^{\circ}$. 1 .

Nous n'avins pas vu la coquille à laquelle U. I amarck dnnoe ce nom, mais nous connois-

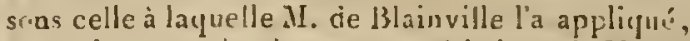
et yunique, parla phrase caractiostique de M.laaaurck, on puisse jnger qu'tl y a en!l'elles une grandle amalngie, ceperdaur, comme il nous tesic du doute sur leur idenuté, nuns avous dî le manitevter.

La Calyptrée éleignoir n'est jamais d'un grand rolume; elle est éltuite à la base, qui est circu- 


\section{A L}

laire on oralairc; elle est conique, pointue, irrónulière; le sonımę est élevé, poiutu, subcentral, il se terminc par un tour et deni de spire oblique; ce commencement de spire ne se voit qu'a l'aide d'une loupe et sur les indiridus bien conservés : pour peu qu'ils soient frollés elle disparoit cotnplétement. La cavité de celle coquuille cst conique et profonde; elle est lisse, bruve, et présente toujours sur ane de ses parcis, à nartir du sommet, unc lan aretle oblique, Iriangulaire, légèrement inclinée vers ellc; allachée à cctle paroi par son grand cólé, libre daus tout le reste de son étcodue, le hord interne et libre se reploie surlui-même, de manière à laisser un canal conique, très-étroit dans l'endroit de la duplicatol'e.

En deliors, cetle coquille est d'un blanc-grisâtre, avec quelques zones iransverses brupcs, chliques ou sulsspirales. Si l'on rapproche cette coquille de celles que l'on trouve fossiles à Bordeaux et it Dax, et qui sont décrites sons le noin de Calyptruect deformis, on ne pourra discouvenir qu'il n'y ait cutr'elles de très-grands tapports, surtont si l'on compare des individus de mêne laille. Nous avons soin d'indiquer celte circonstance, parce que le Calyptrea deformis prenant souvent un bien plus grand développement, la comparaison en devient uoins facile. D'après celle très-exacte que nons avons faite, nous ponvons dire yue ces espèces sonl subanalognes.

Les individus que nous avons de la Calyptrée éleignoir nout que 17 usillim. de diamètre et à peu près autant de hauteur. Nous de sarous d'où ils viendent, L.A. X.

14. Colytroté diff arme. Calyptreca deformis.

C. Lestâa elevato-conicâ, traniversè rugosit, upice mucrone curvo, spivato terminatâ; modò basi suborbiculati, obitâ, modo luteraliter depressi, intis appendiculo minimo, simplici, instructâ.

B.sтевот, Coq. foss. du sud-ouest de la France. Mém. do la Soc. d'hist. nut. de Paris, tom. 2. pag. $71 \cdot n^{\circ} \cdot 1$.

Lasr. Anim. s. vert.ton. 7. pag. 532. no. 1 .

Griteloup, Cat. des.foss. de Dax. Bull. de la Soc. lin. de Bordiaux, tom. 2. pag. 84. nº. 23 .

Cetle coquille, comme nous l'avons dit, a beau coup d'analngie arec la précéden'c lorsque l'on compare des indivilus égaux quant à la taille: cependabt, coume l'espece fussıle tevient rèsgraude, et qu'elle offre d'ailleurs des différences coustanies, quoique pen importantes, nous pous sommes décidés à séplarer les leux espèces, tout en persistant à dire qu'elles sont subanalnunes.

La coquille qui nous occune cst patelliforme,

alde, conique et ovuluire lorsqu'elle est le moins irrégulière, naais nrdinaitement elle est countimíc, crntourníe diversement, lantól d'on cốć, tantôt de l'autre; son snmmet pointu rt saillant est incliné à gaudte et postólicurement. Les jeures individus nat ce sonımet terminé, comme dans l'espèce préćdente, par une petite spire que l'on aperçoil a l'aride de la loupe : ce caractère, qui se détruit facilement par la moindre usure, ne se tronve pas, par celle raison, dans les vieux indivilus, et manque quelquefois dans les jeunes. M. Grateloup, qui l'a observé, s'en est servi pour étallir une varił́lé que nous n'avons pas conser'scée, et d'après ce quii précède, on doit en senlir la raison. La surface extérieure est couverte de sillons ou de stries irréguliers gui indiqueat les accroissemens; le bord est mince, tranchant, irrégulier dans son contour; en dedios, la surface est tout-à-fait lisse, quel quefois polie et brillante. Sup la paroi postérieure se voit une lame trics-pen sillante, trignne, oblique, plus petite que dans l'espèce précédente, et solide dans toute son étendue : clle ne présente an borl libre ui goutière ni canal, elle y est senlement un peu plus épaisse qu'à son bord d'insertion.

Celle espèce fossi'e se tronve, dans son plus grand déreloppement, aux environs de Bordeaıx; na la trouve aussi à Dax, mais d'un moindre volume; enlin, clle s'amoindrit et devient naine daus les faluns de la Touraine, où elle est $f$ n rare. Les individus de Bordeanx ont 48 unillim. de largeur; ceux de Dax 25 à 30 , et cellx de 'Turaine 10 à 12 seuleuneut.

15. Cangptrée chapeau chinois. Caliptras sinensis. LamK.

C. lestá orbiculari, depresso-convexi, tenui, lipoiusculi ; striis tiansiersis remotiusculis, spiraluter corcinatis; verlice acuto, cernuo.

Caliptran lavigata. Lasx. Anim. sans zeri. tom. 6. pag. $21 \cdot n^{\circ} .2$.

Calyptrcea sinensis. Noв. Mtén. anat. sur la Caljptrée. Ann. des scienc. natur. tom. 3. pag. 535. pl. 17. fig. 1. 2.

Patella sinensis, Lax. GmeL. pag. $3692 . n^{n} . \bar{J}$.

Lister, Conch. tab. 549. fig. 39 .

D’Argexvilie, Conch. tuh. 2. fig. F.

Boxuxxr, Recereat. purt. 1. fig. 12. Iiculit.

Bous. Wus. cass. Vindob. pag. 414. vig. frg. a. $b$.

Martrit, Conch. toin. 1. tab. 15. fig. 121 a 124.

Fossilis.

Putella sinensis, Bвосcв, Conch. foss. subup. ton. 2. pag. 256. $n^{n} \cdot 5$.

Coquille circulaire, patelliforas, conique, dé- 
primée, à sommet presque central mamelonné, aigu, ierminé par nne spirale très-petite; de cc sommet on voit partir un scul sillon peu profond en spirale, qui descend jusque vers la woitie de la liantenr de la coquille; ce sillon indique l'insertion de la lame interne; toute la sublace est lise, marguréc sculement par des stries irregulic. des d'accruissement. Le bord est entier, mince, tranchant, guclelucfuis étalé; la cavité intérieure est conique, lisse, jolic, prostérieureraent est attachée une litrue sulsspirale, abliqgue, mince, triangulaire, lixée senlement par un de ses bords libre clans le reste de son étcudne, formant uvec la corpuille a sa base une ́́chancrure profunde, excavie a son bord interne libre, tui est fpaissi par une duplicature qui $y$ est soudée dans jresque toule sa longucur.

Celte coquille est ordinairement foute blanclie, ou légèrement jaunâtre. Nous possédons plusienrs individus rqui ont en dedans, 3 !a base, une large zone couleur de cliair; elle se tronve vivanie dans toute la Méditerrinćc, sur nos côtes de la Manclie el de l'Ocían. D'iljurces I inné, elle seroiı

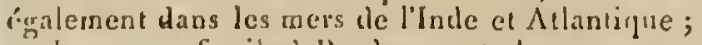
ou la rrouve fossile i Burdeaux ef dans presque tontes les collines subapenuines de l'balie el de la Sicile. Ies individus fossiles paroisseul généralement plus grands gue les autres, 30 millim. de diancitre; les vivans en ont 20 ou un peu plus.

\section{BAS'.}

16. Canprtáe muriquée. Calyptraca muticata.

C. testâorbiculari, conoideẩ, subdepressâ, terum, intus lutcâ, extiss albido-squalids; squamulis mininis irreguluriter dispositis, muricala; werlice manilluri spiraliter intorto.

Calyritraa muricata, Bastr. Móm. loc. cit. pag. 71. $\pi^{\circ} \cdot 3$.

Patella muicala, Jnoccit, Conch. foss. subap. tom. 2. pus. 254. $2^{0}$. 5. pl. 1. Jig. 2 .

Calyptica punctata, Giatelcup, Mén. loc. Gil. $n^{\circ} .22$.

C'est toujours arec peine que nous voyons changer les noms spécifiques consacrés, conlue d'autres qui sont ainsi introduits arbitrairement dans la science; cette pratique a pour résultat de rendre la synonymie plus conopliguee, ce que l'on devroit sutlout chercher ä éviter. M. Gruteloup a deumé un nom nouvenu is celle espèce, lorsque cléja M. Basterot et M. Brocchi avant lui en a voient rousacré un; il citoit tum naturel de conserver le flus ancien: il $\mathrm{J}^{\mathrm{a}}$ la plus grautle analngic cure celtc espèce et la précédenic, méme forme, míme taille, lort peu de diflérence claus la lame interne, gui nous semlile daus celle-ci un peu plus grande. las surface extéricure esı hérisséc de petiles écailles disposées irréculièrement, plus saillantes et plus nombreuscs vers le hord giue sur le des!e de la co- quille; le sommet en est ordinairement dépeurva: celui-ci est pelit, nıamelonné, terminć en une tres-petite spire. En dessus celle compille est blanche et grissitre; en dedans clle est lisse, polie, partout d'une coulcur lauve tendre. Cette especre ne s'ćtoit trouvée jusqü it present qua'it l'état fossile : nous en possédons deux individus vivıns parfaitenent ilfentigues; ils sunt cependant un prea jlus ovalaires, mais on sait que la forme varie selun la place fanecupoit l'aumal peudant sa vie. Les individus vivans vienaent de la Méditerrance; les fossiles du l'litisantin, de Dax, de bordeaux et des faluns de la l'ouraine. Les plus grands ont 30 militio. de diamésre, quelquefois in peu plus.

Nor.

7. Canpráe écaille. Calyptráa squamu.

C. lestî̀ orbiculari, conico-depressissimá, lavigatâ, translucıdâ, subluteolî; marămo tenuissimo, superné repando; apice inumullais, miuino, centrali, telorto; lanelli internas minimâ subspirali, prominente.

De iontes les Calyp!rícs que nons connoissons, celle-ci est la plus aplaric : clle l'est tellement, qu'on pourroil la prenulre prour une écuille dé puisson, dont clle a aussi lit couleur; cllc est orbiculaice, très-mince, lígèrement conigue, trisdéprimée, foute lisse, diaplane, d’un blanc jaunûtre comé. Ie sommet est central, poitutis, matmelonué, lourné en spirale : les bords, ràs-minces et très-fratriles, sont étalís et légèrenent reover'sés en dessus, ce qui rend la coquille concave dins cet endroit, et un pou convexe en dessous : de ce cúté la cavité est si peu profonde. que l'on conçoit dillicilement comment un anitral a pu s'y loger. Da centre de celle cavilé part une lanclle oblique, qui ressemble beaucoup a celle di Calypera sinensis; elle est seulentent plus diroile et plus saillante : son extrémité dépusse la liautent des bords. Celle espicice, furr rase, vicnt de la Méditerraníc, des cótes rie la Sicile; clle a 18 a 20 millim. de dianactre : elle a à peine 3 millin. de hauteur.

18. Cartprné auriculaire Calyptora auricalaris. Nos.

C. lestâ orbiculari, conicâ, irregulari, radiatims costatâ, insuper altido-grisea, in lius roseo-purpisreâ; lasnellâ replicalâ, lateruli munitá; murargine crenata; apice acuto, retrocerso.

Jolie coquille dont nous ne trousuns nulle part la figure on la description. Sa lase est orbicinlaire, peu réguliere; clle s'élive en cóne irrígillier assez élevé, terminć par un somnel poiutu lenversć en arrière, mais non cn spirate; des cótes rayonnantes, nonbreuses, arrondies, ondisleuses, irrégulic̀res, partent en rayounant de ce sommet et aboutisseat au bord, ou clles se termi- 


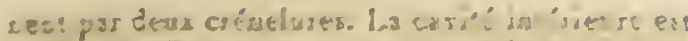
congue, elle paterese cerse sugnalas te diaruis

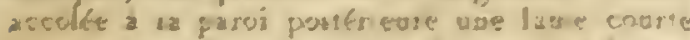

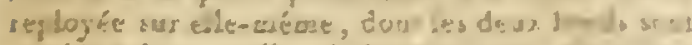

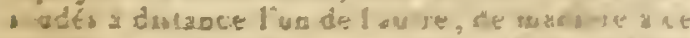

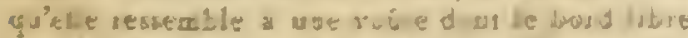

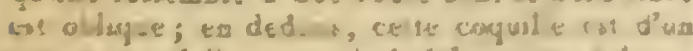

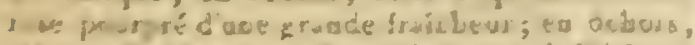

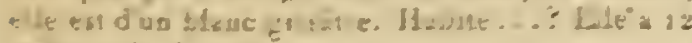
Live. de diseaside.

\section{CAI:AEES (1e-s).}

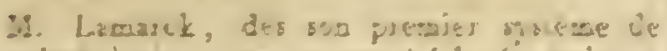

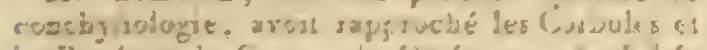
les Pand res der Cares, dib Daciales el des lathi-

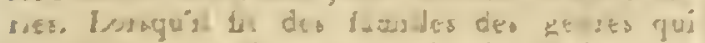

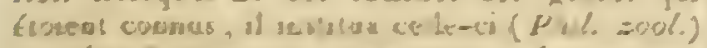

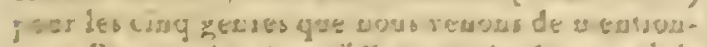

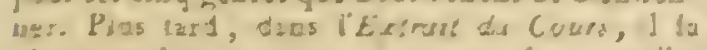
biparz ea deux secioos. I voe pour les coegulles

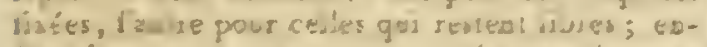

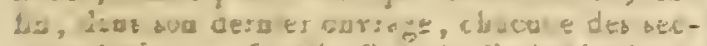

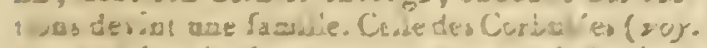

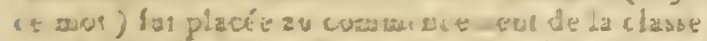

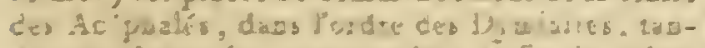

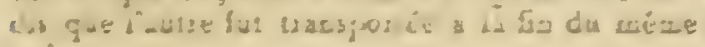
cadie.

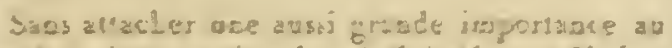

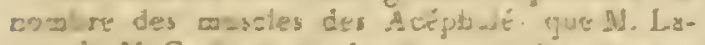

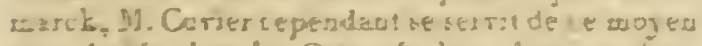

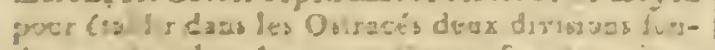

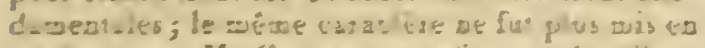

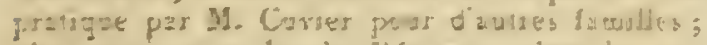

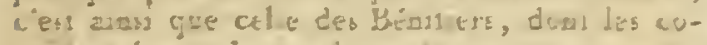

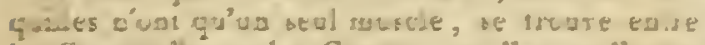

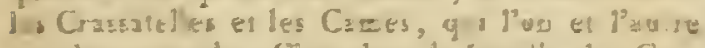
voi deax zuscles. C'est daes 14 I-eadle des C.r. diacés, arec les loocardes, Bucaroes, Luales, Cocludes, Telraes, Vewas, ec., Ee., que se

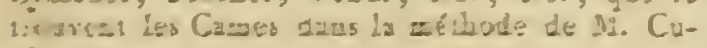
rie:

11. Le Ferussac yoi, camze toes aross eq d jù

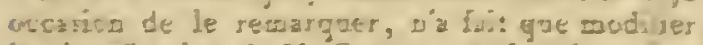

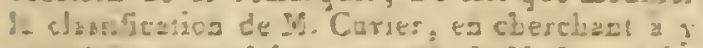

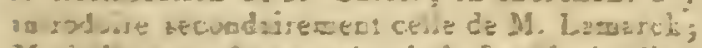

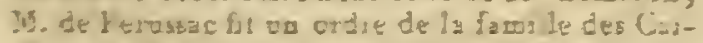

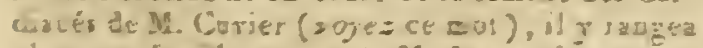

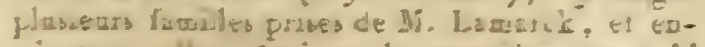

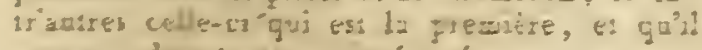

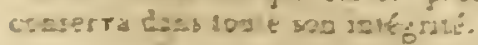

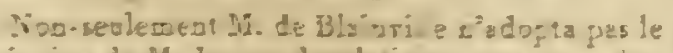

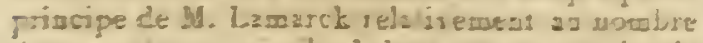

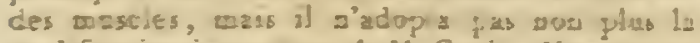

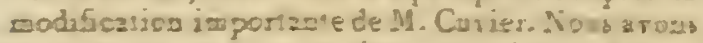
to que ce krand actociste aront istadui use

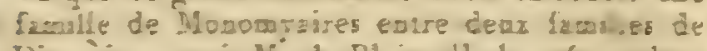
Diagrizes, pais $\mathbb{L}^{\circ}$. de Blaiorale les ruass dass

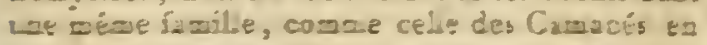

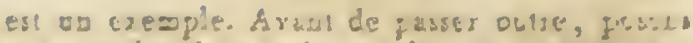
ual: yuestion de pr scije, juj prorra, far sa bolui os, nous cugdure a adep ea cu a 1ejeles la

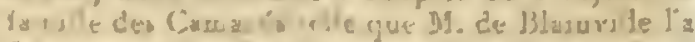

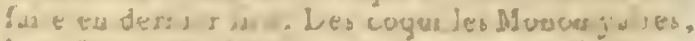

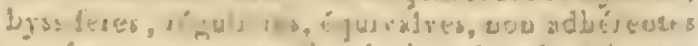

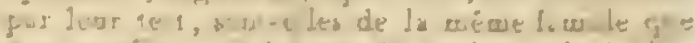

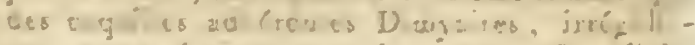

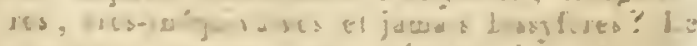

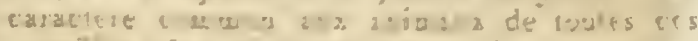

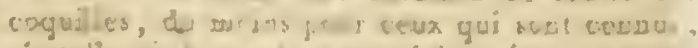

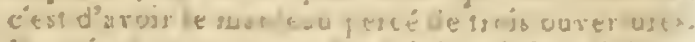

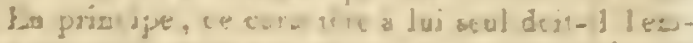

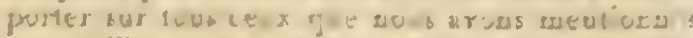

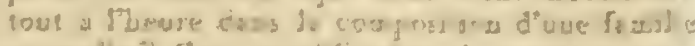

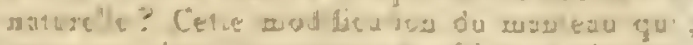

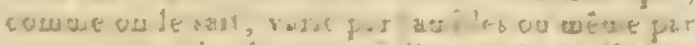

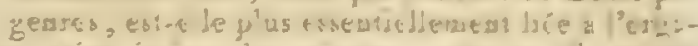

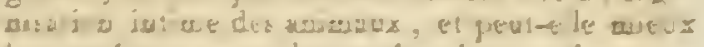

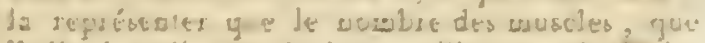

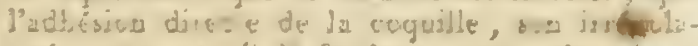

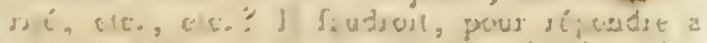

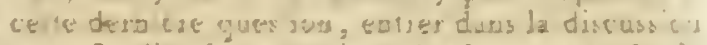

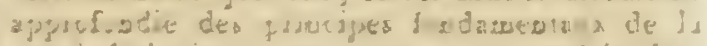

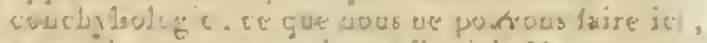

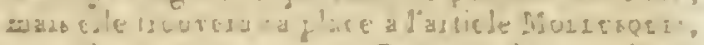

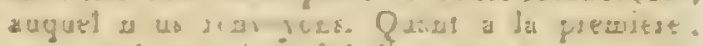

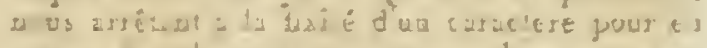

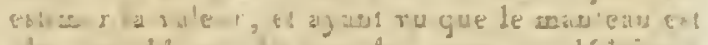
plus rarable que des is usc'ses, aous ea déduir.r,

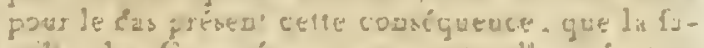

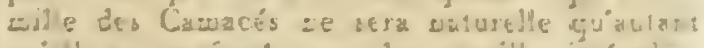

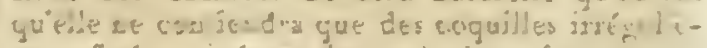

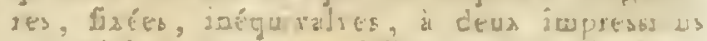

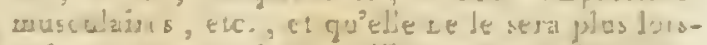
quo'us I luctsa deb co juilles mosory yises, ri-

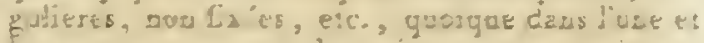

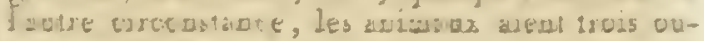

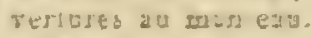

i-pres ce gui frécede, il est dacile de prítors

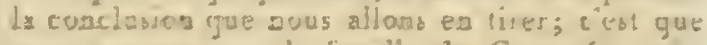

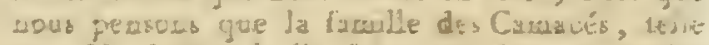
gue MI. Lizizact l'a laste, est beauecup fluo

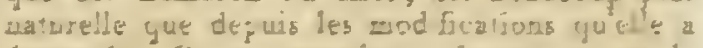

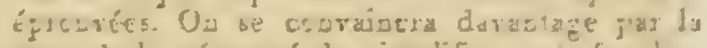

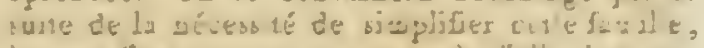

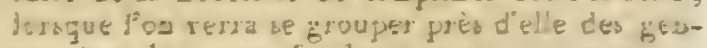

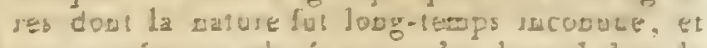

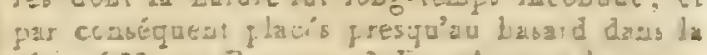

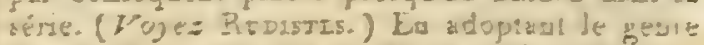

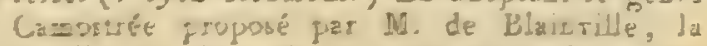
facille der Cumacis se cosposerun des yquatse

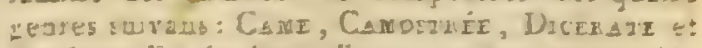

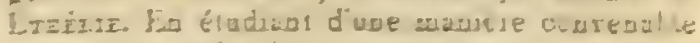

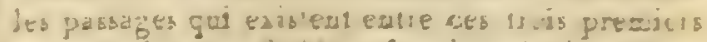
ger res, if exi probable qu'ca les foviry es la

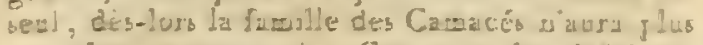
que deux gevres, Jes Cazes e! leb Libines.

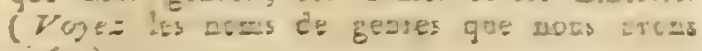
cises.) 
CANBRY. Cimber.

Moutfort a fait ce genre dans sa Conchyliologie systématique pour la coquille connue d'abord sous le nom de Patella borbonica, avec laquelle M. de Ferussac a faic son genre Septaire, et M. Lamarck sou geare Navicelle. (Vojez ces mols.)

\section{CAME. Chama.}

Bruguière fut le premier qui réforma le geare Came de Linné. Il contenoit un grand nombre de coquilles qui ne pouroient Jui convenir. Depuis cette époque il n'a subi aucun changement, si ce n'cst que le nombre des espèces s'est acciu. Comme il en a élé décriı neuf dans le premicr volume de ce Dictionnaire, cela est bien suffisant pour qu'on se fasse une bonnc idée du geure. Nous $y$ renvoyons le lecteur.

\section{CANIE. Chaina.}

Le genre qu'Adanson (Vnj. au Sénég.) nommoit ainsi avec les anciens conchyliolorues, n'a aocun rapport avec celui que Linné el ses successeurs ont instituésous le mêne nom. Adauson n'y comprenoit en effet que des coquilles appartenant aux genres Cy thérée, Vénus, Mactre, Vénéricarde, etc., c'est-i-dire des coquilles régulicies, taudis que maiutenant le genre Came des méthodes ne contieal que des coquilles adhéreules irrégulières, elc., dont Adauson avoil fait son genre Jalaron. (Voyez ce mot et Casz dads le premier volume de ce Dicrionnaire.)

\section{CAMOSTRÉE. Camostroa.}

Ne connoissant pas la coquille arec laquelle M. de Blainville a fait ce genre (Traité de Malacol. add. et corr. pag. 63i), nous ne pouvous rien décider à son égard quaut à présen!; nous remalquerons seulement que la Cane arcinelle présente la plupart des caractères indiqués par M. de Blainville pour son nouveau genre. Il le mel à la suite des Cames, avec lesquelles il paroit avoir de trèsgrauds rapports : malhcureusement il n'est point figuré, ce qui nous ôle loute espèce de mnyen de le juger dans ses analogies.

\section{CAMÉRINES.}

Bruguière avoit élabli un genre Camérine ponr des coquilles que Guetlard disignoil sous le nom d:Hélicite. M. Lamarck changea le nom Camérine pour celui de Nummulite : ce deruier seul a été adoplé génériquement. M. de Ferussac, dans ses Tableaux s; stématiques, a fait une famille assez vatorelle sous le nom de Camérines, dans laquélle il a rassemblé plusieurs geares. Ceste faubille, après un examen attentif de ses c̉lémens, peut presque se réduire à un seul genre; lursque nous en laiterons (vojez Numutres), nous re-

\section{A N}

viendrons sur celle famille des Camérines. ( $F$ "oy. aussi CËPHALOPODES.)

\section{CAMIILLE. Camillis.}

Genre que l'on doit a Montfort (Conch. syst. tom. 2. pag. 442.); il l'a proposé pour une pelice coquille presque microscnpique dont il a copić la liguie dans l'ouvage de Sultani. Depuis l'observalion de ce célébre micrographe, certe coquilie n'a pas élé recueillie el de se truuve dans aucunc collection : elle esı uniloculaire, canaliculée à la Lase, et paroil voisine de quelques Cérites à canal druit.

\section{CANALIFĖRES.}

On trouve pour la premic̀re fois cette famille daus la Philosophie zoologique de M. Lamarck. Il y rassembla toutes les coquilles dont la base se termine par un caual droit, plus ou nuvins alongé : elle commence la section des Mollusques siphonés, et dans l'origine elle n'est composée que des buil yenres qui suivent : Célile, Pleurotonie, 'Turbinelle, Fasciolaire, Pyrule, Fuseau et Mnrex. Dans l'Extruit du Cours cette famille fut conservée par son aulcur, daus les mémes rapports; mais elle fut atumentie de trois genres, Clavatulle, Ranelle el Siruihiolaire. Plus tard, exlin, M. Lamarck, dans son deruier ouvrage, sunprima justenent le genre Clavatulle, qui ne dillëre pas essentiellement des l'teurotomes, et aupmenta encore cetre famille des Canaliferes, ríc deux geares, les Cancellaires et les 'Tritons : il la partagea en deux sections, d'après la présente on l'absence d'un bourrelet à l'ouverture. A l'exceplion d'un pelit nombre de geares douteux, on ne peut disconvenil que la farille qui nous occupe ne soit naturelle : elle n’a pas été adoptéc, il ext vrai, par les zoologistes, mais ils en out fait d'autres avec les mêmes élémens. Nous pourrions dire que les geures Cérite el Rocher de M. Cu:vier représeoten! cette famille : nous n'en retrouvons riea de suivi dans les tableaux systémaliques de M. de Ferussac, qui a fait des Echancrées et des Canaliculées un singulier mélange; mais nous la retrouvons presqu'entic̀re sous le noun de Siphonostomes, dans le Traité de Mulacologie de M. de Blainville. Enfin elle constitue deux lamilles, la septième el la neuvième des Gastéropodes pectinibranches de M. Latreille (Fam. nat. du Regn. anim. pag. 192) : elles portent les nous de Fusiforntes et $\mathscr{V}$ uriqueux. (Voyez ces mots, ainsi que Siphosostouss.) Nous disions précćdemmiat qu'à l'exception d'un petit numbre de genres la lacialle des Canaliferes étoit assez nalurclle : celui des Struchiolaires, par exemple, nous semble avoir plus de rapprorts avec les Rostellaires qu'avec les Ranelles; lc canal de la base est coum. el à ['eine creusé en gumltière, ou la goutlière est très-étroitc, ce yui 


\section{$C A N$}

\section{A N}

n'arrive jamais daus les Ranelles ef les Rochers, tandis que cela est cunstant dans les Rostellaires.

Le genre Triton ne repose que sur de lien loi hles caracières; l'animal cst semblable à cclui des Rocliers, el nous ne vnyons pas ponrquoi on ne l'y leroit pas entrer. Un autre genre encore, qui peut-ètre n'est pas à sa place, est le genre Cancellatice : cependant comue on n'a aucune conboissance de l'aninul, qu'on ne sait rien sur la forme de l'opercule, on est obligé, quelle que soit la place qu'on lui accorde, de la dérider arbitrairement; peut-être se rapprocheroit-il de is famille des Plicacés de M. Ianarck. Si l'on adnet la famille qui nous occupe, elle pourra être composée de la manière suivanle :

10. Point de bourrelet constanı dans les espèces

$\begin{array}{ll}\text { Cérite, } & \text { Fasciolaire, } \\ \text { Plenrotome, } & \text { Fusean, } \\ \text { l'urbinelle, } & \text { Pyrule. } \\ \text { Cancellaire, } & \end{array}$

20. Un bourrelet constant sur le burd droit dans toutes les espèces
linelle,
Rucher,
Iriton. Foyez ces mots.

\section{CANCELLAIRE. Cancellaria.}

Les auteurs qui précédèrent Linné, conlondirent les coguilles du genre Cancellaire avec celles qu"ils nommoieat Buccins ou Pourpres. Adauson lui-même, qui en conust quelques espèces, les plaça daus son genre Purruse. Les pli, yu'elles porlent sur la columelle dícidèrent dans quel genre de Linné elies devoient eatrer. Ois vuit dans le Systema natura, que toutes les coquilles, snit échancríes, sutt à canal court, soit nuème à ouverlure entière, mais qui on! des plıs à la columelle, funt toutes parlie da genre Voluta. On peut juger, qu'élant 'tabli seulement sur un caratelère de peu d'imporiance relativement à d'autres, ce genre ne ponvort offrir qu'un asseinhlage peu naiurel de coquilles de fuuilles el de clusses fort différeates. Bruguière commença a le vélormer, mais ce fut M. Lamarck qui y ît le plus de clsangenens. C'est lui qui en a exlrait le fenre Cancellaire, qu'il caractérisa dans le Système des animaux sans zertebres: on le trouve dans cel ouvrage, entre lus Marginelles et les Nasses. M. de Roissy, duus le Buffor de Sonnini, tonie 6. des Mollusques, adoptil le geure Cancellaire, el le laissa duns les rapports que lai avoil donnés M. Lamarck. Le savaut protesseut ne les clangea pas non plus dans sa $P / u$ l sophie zoologique. Les Cancellailes sont en tete de la famile des Colnmellaires, fort rapprochíes par corsíquent des Nasses, qui terniment la précćdente, colle des Purpuracćes. (L'oyez ces muts.) Montfort adopta aussi le greare, et d'en chanöea pas non plus les rapports, ce qui doit surpreades, place de ce genre dans la série parvissoit décidée; i1. Iamark, dins l'Extrait du Cours, n'y a voit rien changé; et M. Cuvier, en le considérant comme sous-genre de ses Volules, l'avoit mis le dernier, de manière il le rapprocher antant que possible des Buccins, lur: gue M. Lamarck, s'apercevant enlin gue les Caucellities sont canaliculćes à la base, les rransporta dans sa fumille des Canalifères (yoyez ce mol), à côté dles 'l'mbrnelles et des liascioluires, autre genre caualiculé el portan! des plis sur la columelle.

1,a lauille des l'ourpres de M. de Ferussac nong semble avoir élé courdonuéc arec une précipitation qui aua empécbé sans doule son autcur de se rendre compte des rapposts qu'il élablissoit. Pour ce qui concerne le geare (iunccllaire, il n'est pur distıngué des Pourjures; il y est inlroduit avec les Conclioléfas et les Monucéros: d'après quels cirracteres, sur quels rapporls? nons liunorons. mille on tronve le genre Colombelle entre les Pourpres et les Roclser's, le genre Struthiolaire entre les Ricinules et les Cassidaires, tuns trois considéré nerque les Cauccllail es suient conlundues a vec les l'ourpres propremeut dites, n'cul fussen! pas mèue un sous-yenre? Les auteur's qui vinrent après MI. de treille adop!a la manière de voir de M. Lamarck; il conserva les Cancellaires clans sa famille des Fusiformes, entre les lisciolaires et les Cérites. M. de Blainville, an contraire, les rapprocha davantage des l'ourpres, dans la Irnisicme section de sa lamilie des Eutomostomes. (Voyez ('e aut.) ("est d'après Adauson que M. de Bliuiuville lit ce rapprocliement; naais doit-on avoir une confiance absolue dans les travaux de cet excellent observa. teur? ne doit-on pas convenir que, dans ce geare Pourpre d'Adanson, il y a an grand nombere de coquilles étrangèses à ce genre : on peut s'en assurer par ce qu'il en dit lai-même. On peut lire a la page 100 de son Traité sur les coquilles du Sénégal, yque les caracteres des animanx councident avec les divisions quil a faites daus les Punrpres; quil a prélicré se servir de la coquille pour les qui ne connoissent pas les auimaux et qui ne sont pas à mêne de les observer, mais qu'il servil lacile de former la mène divisiun a vec eux. "L'nne "fait voir d’ahord les aniasux dont les yeax snnt " placés an nilicu de la longueur des curves; elle "présente ensuite ceux qui les ont placés un peu nau-dessous; eutin ceux qui les portent au-dessus "du milieu des mêmes curues. "Nous citons ici les mols propres d'Adanson, pour litire sentir que cet observatem si profund savoit lui-même yual 11. elloit des animand divers dans le uáne genre; cela n'est point Ćtonnant, quand on se reposte a puisque cela ne lui arriva presque jamais. La ( Voje = P'ourpas.) Quand dans celte nû́une lacomme sous-gerrescles l'ourpres, doit-on s'étonFerussac, ne suivirent pas son exeinple. M. Laćtablir, atin d'en rendre l'étude plus fucile à ceux 
l'śporguc oì son ouvrage fut publié, époque oil il n'existoit pas encore de principes dans dans la science, oi elle manquoit de base. Ceci justifie le doute que nous conservons sur le genre Cancellaire; c'est pousser peul-être un peu loin le scrupule, mais nuus croyons qu'il vaut mieux s'abstenir quard on n'a pas tous les élémens d'induction ou de conviction direcle, que de jeler entore one hypothèse an milieu de celles qui existent. Celte que nous ferions, instinctivement, pour ainsi dire, seroit de rapprocher, comme nous le disions précédemment, les Cancellaires de la lauille des Plicacés de 11. Lamarck. Cetle opinion peut ث̂tre noins foudre que celles que nous avons rapporlées, mais elle a pris plus te furce dans motre esprit depuis rue l'on sait d'une manicre posilive que.les gemes de certe famille sont operculés. Nous donnons au reste, comme on doul le voir, celte opinion pour ce qu'clle vaut, et sans $y^{\prime}$ illacher la moindre importauce.

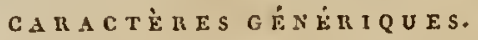

Animal inconnu, ayant un opercule corné et ovale, d'apress Adanson.

Coquilie ovale ou lurriculée; ouverture presqu'cutière, à peine canaliculfe il la base; lo cianal trés-superficiel, plus ou moins long quelquetois presque nul; colunielle rarnice de deux à gnatre plis obliques; bord droit olslique sur l'axe, sillonné à l'intérieur.

Une coquille très-rare, que l'on nomme vulgaitement le Bordstrope, a ćcé rangíc par M. La. marck dans les Dauphinules. Ayani pu examine. celle coyuilla dans la riche collection de M. de Rivoli, il nous a clé facile de nous assure. que c'est une vérilable Cüncellaire. Elle a denx plis à la columelle, et clle a un canal trèssuperficicl à la base. Ces caractères avoient schappé à MI. lamarck, saus aucun doute; on ne pourroit pas, sans cela, se rendre comple du molit qui l'a déterminé à la mentionner dans le geme Dauphinule. Nous sommes diutant plus convaincus de la justesse de nolre opinion, gue nous avous une esprece fossile de Cincellaive absolument semblable an Bordstrape, et pour l'ombilic qui traverse loute la conuille, et ponr la disposition des plis de la colunielle et le cantal de la base. D'autres espèces, de moins en moins ombiliquées, servent de passage à celles qui no le sont plus du tous.

Unc autre conuilleque M. l amarck a iutroduite dans I: ponre Cancellaire, et cola lien à lort, scirun usin, esal le Nurex senticosus de linns, qui est un veritalile Buccin de la scrolion des Nasses.

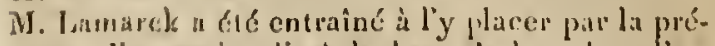
sence d'un protit plis a la baso de la columelle; mais sil avoit lat attention gue cotte coquille est fortement échancre at la hase, qu'elle n'a pas l'onverture oblique, et s'il avoit remargुus surtout que presque loutes les espèces de Buccins de la seclion des fisses sont pourvues de ce pli, il auroit reporté le nturex scrnticosus dans les Buccins, parce qu'il auroit bion senti que toutes les Nusses ne pouvoicui être inlroduites dans le geure Cancellaire. En exiuniuant les coquilles du genre Cancellaire de la collection du lluséum, nous avons étŕfort surpris d'y rencont?er des espèces appartenant à d'antres gentes, me Mlitre, un P'eurolome el une Turbinelle. Nous arons également remarque, que pour le plus grand nombe clles portent des noms qui ne se trouvent plas dans le Traité des animaux sans vertèbres. Nons nous expliquons celte circonslance; les nor.s dunt il s'anit sont ceux qui furent donnés avant la publicalion de louvrage que nous renons de citer, et depuis on n'a pas mis d'accord les ancienues arec les nuvelies dínomianalious.

Ies Cancillaires sont des coquilles marines d'une lorme ćl'chante; elles sont trés-recherchées dians les collections, et lil plupart sont fort rares. II eu existe un alssez grand nombre de fossiles qui s $n$ t propres anx terrains tertiaires. Leur ćléfrance ne le cède en rien à celle des espèces visantes: $0: 3$ un corupte près de trente duns cet élal; quelque:unes sont analognes, snit à des especes viran!es, soit à des especues fossiles de locialitís diverses. Nurs allons intiquer les especes que uous connoissons, cn commençant par culles qui we some pas ombiliques du rout, pour passer graduellemeat à celles qui le sont le plus.

\section{Caṇcelatine lactée. Cancellaria laction. Yin.}

C. testâ avatâ, ventricosâ, acutä, đnu. +

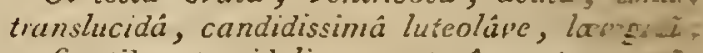
anfractibus turgidulis; aperturâ ovato-arz:labro tenui intùs non striato; columellâ tripoucatâ.

\section{Var: B. Testâ lutescente.}

Coquille d'ua médiocre volume, ovalaire, sub globulcuse, formée de six à sept lours de spire. dont le dernier est plus grand que tous les autres réunis; ils sont arrondis el sćparćs par une suture sinple; l'ouverture es: semi-lunaire. Ia columelie śant presque droite ou a peine aryaric : elle se iermine a la base en formant, ares la bond droil, nu canal peu profoud, nou échaurere. Ceetle columelle est garmie do trois plis ebliguts prestgu'é-

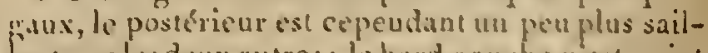
Pant quele's deux autres; le bord gatehe nest point saillant, il se confoud aresta columells', si ce n'est il sa base, où on l'aperçuit un peu: le bord droit cst simple, mince, tranchant, jamais épaissi en bourelet, et toujours depourvin de siries on do sillons. Toute la liace exterme est lisst, aussibien que l'interne. Celle copuills cost diun blant: pur, ce quelquelois, mas ratruem, jaunitre : co

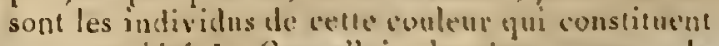
notre variété La Camcellaire lactic est prescyue la 


\section{$\mathrm{C} \perp \mathrm{N}$}

seule dans le gente gui soil lisse et sams buarteld

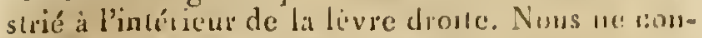
noissons pas sa paltrie : elle a 22 il 25 millim. de longe, sur 15 is 15 de lisrege.

2. Canceldarne bifasciéc. Cuncelluria bíascinle. Ков.

C. lestú ovato-elongatû, uthî̀uce extremilate acuminatâ, striss tenuibus, longiludinalibus ol trunsversalibus clathralä; anfraclibus convexis, ulimo majore aurantio-luleo, zonis duabus albis ornato; columallâ tripliculá.

Jolie espèce bien distincte de toures celles que nous connoissons. Ellic est ovale, alengric, printue aux deux extrémilés, pen verulrue, furméc de six lours de spires convexes indiqués par unc nuture simple assez profunde, mais non canaliculéc. 1.ouverture est semi-lunaire; la columclle cst pies fue droile, tronguće à la base el munic de trois plis, doal le supéricur est le pliss gron; le bord gaucle est sensilile daus toute sa longuenr; il se dirlache un peu vers la base de la corjuilla, mais il ne forme fas un ombilic; ce mime l,ord, en se réunissant an droil a la base, foruc un pectil canal court et peu prolund, sans cichancrurc; le bord droit est asse\% épais et strite en dedans. Dr:s stries Iransferses fines, nounreuses, acrrécs, peu sailiantes, entre lesquelles il en existc unc l, reaucoup plus fine, sent croisćes à angle druit par des siries longritudinales siangles; eces stive comprseat un réseau trés-fin qui couvre ton'e la surluce exlf́rieure de celle coquille. Sa conleur ent jaurzorazo, assez iolense sur le deroicr Iour snrtsul: c'est sur ce deraier que se vojisa d'unc manterc bien traacliée les deux bandes Llanchen transverses. Cet:e cuçuille paroil forl rare; srub ün arans jaraais ru d'auires qus le seal individa y u nogs possédocs: noes izucroes d'cull vieat. II a 22 willim. de longet 13 de larze.

5. Curcezisiza de Mí!!et. Cancellariu Milleti. Sicz.

C. tertá noato-turziłulá, apice acuminatá, eleEarter deczuatá; aperisiá uqatá, anzurú; co-

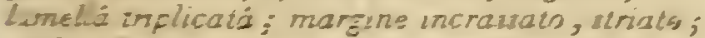
anfiartubu conpexz, swórí angusle canaliculstú g* $=2 \pi \leq i s$

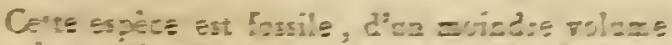

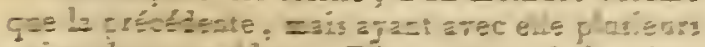

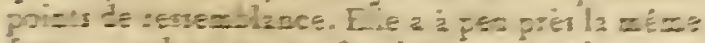

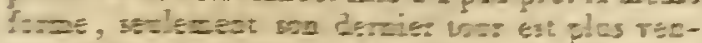

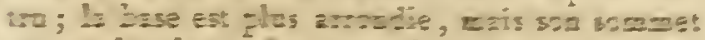

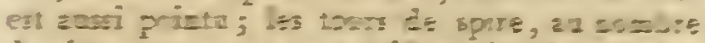

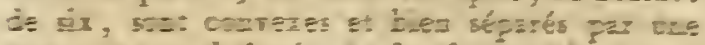

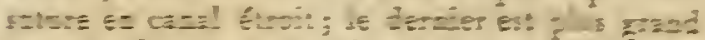

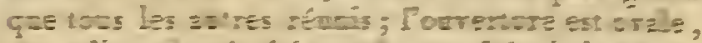

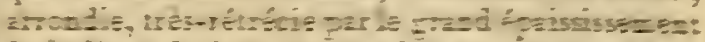

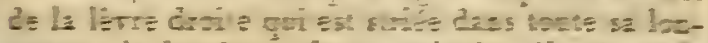

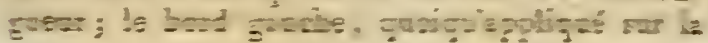

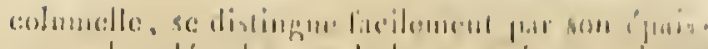

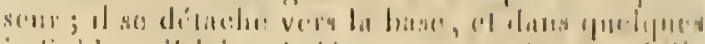

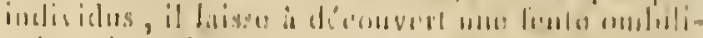

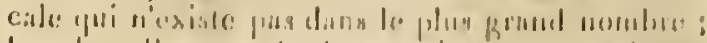

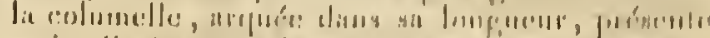

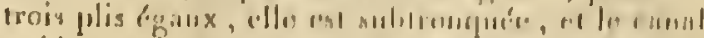

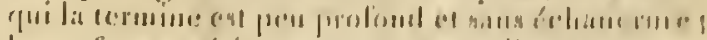

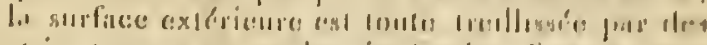

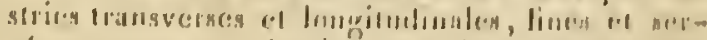

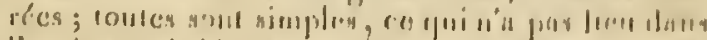

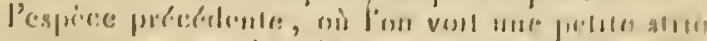

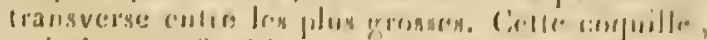

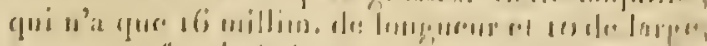

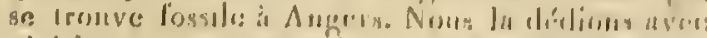

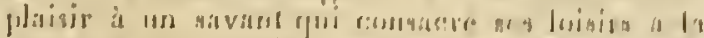

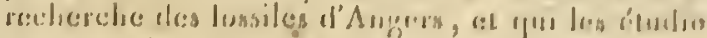
avec suriciss.

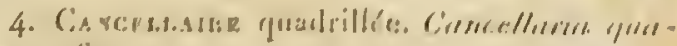
dicula. Siss.

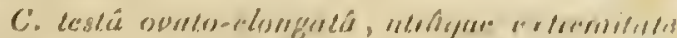

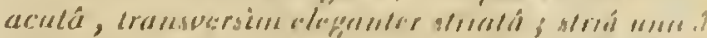

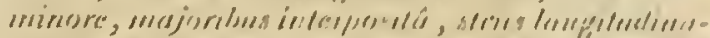

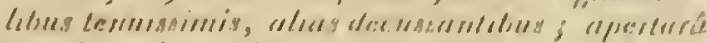

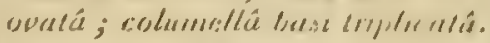

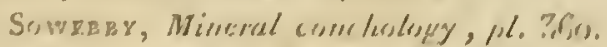

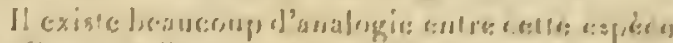

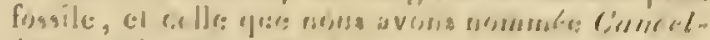

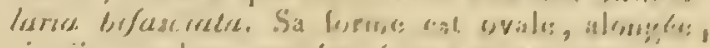

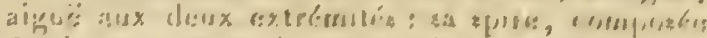

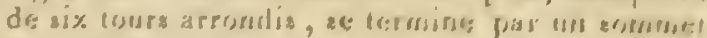

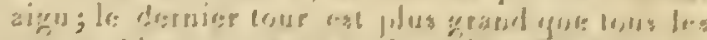

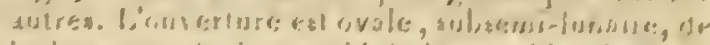

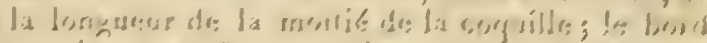

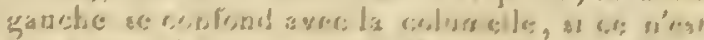

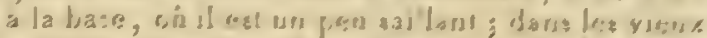

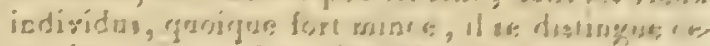

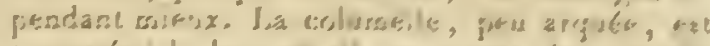

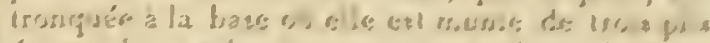

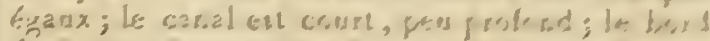

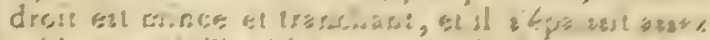

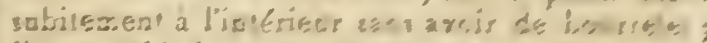

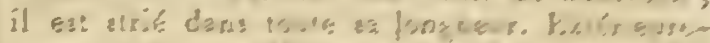

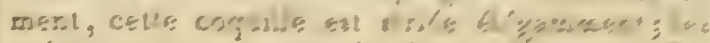

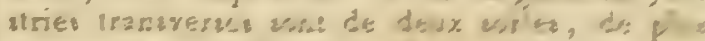

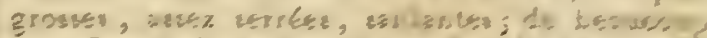

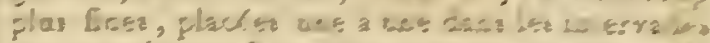

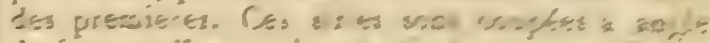

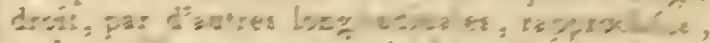

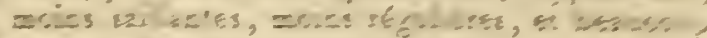

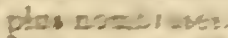

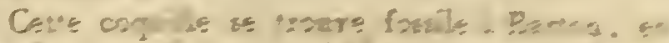

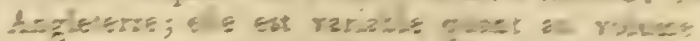

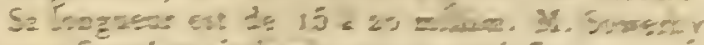

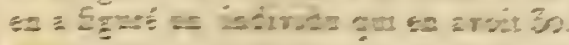

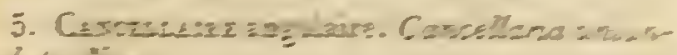
द्ista. His.

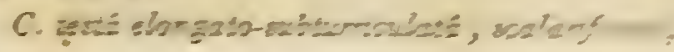


acutâ; anfructibus shpernè spiratis, vaiủe angulato-serratis, costis longitudinalibus, distantibus, ornatis; aufractu ultimo ad basim sulco unico circumdato; aperturâ abbreviatá; columellầ subtriplicatâ.

Cette cuquille est élancée, turriculée à la manière de quelques Cérites ou de quelque Scalaire à base un peu large. Les ton's de spire, au nombre de sept à huit, sont forternent séparés entr'enx par l'aplatissement de leur partie postérieure, qui forme une espèce do rampe un peu oblique, qui monte jusqu'uu sommet : celte rampe est sćparée du reste pur un angle aigu, découpé élégamment en festons, dont les pointes soul formées par les cótes qui descendent longitudinalement, et daus l'endroit où eiles passeat sur la carcèe. Ces côtes sont simplés, distantes, régulièrement espacécs, lisses aussi-bien que toni le reste de la coquille; elle offre cependant quelqueluis plusieurs stries d'accroissement assez régulières. Le dernier tour est moins long que cous les autres révois; il présente vers la base un sillon unique, transverse, saillant, qui coupe transversalemeut toutes les côtcs. L'ouverture est petite, subtrigone; la columclle cst droite, terininée en pointe; elle porte daus le milien deux ulis obliques, et à la base un troisième, per élevé et peu sensible: il n'y a aucune trace d'ombilic.

Celte espèce, d'une forme très-ćlégante, se trouve fossile à Asti et dans le Plaisantia. Elle est longue de 20 à 25 millimètres.

\section{Canceleaire en lyre. Cancellaria lyrata.} Broc.

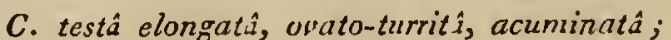
anfractibus convexis, tenuè striatis, in medio carinutis, spinosis; costis longitudinalibus, obliqus, ornatis ; columelli triplicutd; labro incrassato, intiss striato.

Broccur, Conch. foss. subap.tom. 2. pag. 311. $n^{\circ}$. 9. pl. 3. fig. b.

W C. $4 . f i g .1$.

La Cancellaice en lyre est une coguille alongée, ovalaire, pointue aux dicux extrémités; ses tours de spire, assez nombreux, sont distans les uns des autres; ils sont convexes, et partagés en deux parties presqu'égales par une carène peu salante. Des côtes longiłudinales, obliques, saillantes, rescendent d'une suture à l'autre ou jusquà dà base, et donnent naissance, à leur passage sur la carc̀ne, à un tubercule, quilquef is à nne épine. Liı dessus de cette carène, les tours de spite sont striés en travers; ces stries sont très-lines, égales et très-scrrées. En dessous au contriaire, outre celles-là qui se continuent, on en voit plusienrs de saillautes, qui rendent les côtes rugricuses ed passant sur elles; l'ourerture est assez grande, elle est semi-lunaire, et sa lèvre droite, fort épaisse, est entourée d'un bourrelet maryinal extérieur; en dedans elle est striée. Le bord gauche se disingue facilement dans toute sa longueur; il sc délaclıe seulement à la base, et laissc entrevoir une petite fente omlilicale. La columelle, presque droite, offre trois gros plis dans son miliea; le postérieur est le plus gros, il en présente quelquefois uv petit it la base; il est beaucoup moins oblique que les deux autres, qui sont aussi moins gros. Le cand qui termine la base de"la coquille, est assc' $x$ alongé, peu profond; au lieu de se renverser posterienrement is gaucbe et en dessus comme dans les Buccins, elc., il s'incline légèrement en dessus et is droite. Nous remarquons ane disposition semblable dans plusieurs autres espèces : celle-ti n'est conmue quà l'élat fossile. Elle se trouve dans les terrains terliaires de l'Italie, où il paroit qu'elle n'est pas rare. Sa longueur est de 53 à 58 milliuètres.

\section{Cancetratne variqueuse. Cancelluria vari-} cosa. Broc.

C. testâ ovato-turrilâ, elongatâ, apice acuminatâ, transversìn tenuissimè striulâ, longitudinaliter costatâ; costis distantitus, rotundatis, tubenculis minimis, acutis, exusperatis ; aperturi ovatâ; basi acutâ, labro incrussulo, intùs strusto; columellâ leviter ancuatâ, biplicatâ.

Voluta varricosa, Ввос. Conch. subap. loc. cil. pl. 5. fig. 8.

Var. B. Testâ majore; striis elatioribus, distantibus, inter alias regulariter interpositis.

Coquille alongée, plus turriculée que la prícédente: ses tour's de spire, au nombre de sept à luvit, snut arrondis, convexes, séparés par une suture simple, profonde, onduleuse; des côtes longitudinales, obtuses, arrondies, au nombre cle sept à neul sur les derniers tours de spire, desccudent obliquenent; elles sont, aussi-bien que le resic de la coquille, courcrics de siries lransverses, lines, régulicères el égales. Le dernier tour est plus petit que les autres réunis; il se termive par une ouverture courte, ovale, pointue à la base; sa lèvre droite, lort épaisse, est garnit: d'un bourrelet extérieur formé par la derniète côte, et quelquefois d'un épaississcment intérieur qui est couvert de sties dans toute sa longueur. Le bord gauche s'applique dans presque conte sa longueur sur la columelle, il en reste cependarat hien distinct; il se releve un pen vers la base dans quelques individus, surlout les vicux, et laisse ainsi à découver vne fente ombilicale. La columelle est légèrement arquée, elle n'a que denx plis vers le milien. M. Brocchi dis cependunt qu'il $y$ en a trois; nous avans examinć dix ou dunze individus de celle espèce, et nous n'en arons jamais vu que deux. Nous pensons que M. Brocclii aura pris pour un pli, la termiaaısun de 
la colomelle au-dessus du canal per: profond et fort court de la base. La variélé que nous distinguons paroit constante, elle ne dillère esseulielfement que par des stries plus Gievties, distiuctes, eatre lesquelles les stries fines dont nous avons parlé se voient bien distinctement. Celte coquille n'est connue qu'à l'état fossilc. Elle vient des mêmes lieux que la précédente, et acquiert presque la même taille, 40 à 45 millimètres de longueur.

8. Cancerlaire pelites côtes. Cancellatia costulata. Lasi

C. testâ ovato-elongatâ, apice acuminatâ, longitudinaliter costuta; costis crebris, simplicibus, levvigatis; unfructibus convexis, sutura profundâ canaliculutiè separatis; aperturì oputâ, basi canaliculatâ ; columellâ triplicutâ.

LAMK. Ann. du Mus. tom. 2. pag. 63. nn. I. et tom. 6. pl. 44. fig. 11. a. b. Vurietate exclusa.

Itid. Anim. s. s'est. tom. 7. pag. 117. no. 6 .

M. Lamarck, à ce quil nous semble, confondit me seconde espece avec celle-ci; elle s'en distingue ceprendant par des caractères constans. Les coquilles auxquelles uous conservous le nou de Cuncelluria costulata, sont d'une taille médiocre, ovales, alongées, subturriculíes, ornées de còtes lungiludinales, nombreuses, lisses, peu ubliques, et presque jamais iraversées par des strics, si ce n'est au soinmet, où on eu remarque de transverses qui disparoissert promptement. Les tours, au nombre de huit ou neul', sont convexes, sépul'ćs par une sulure profonde, cnaaliculée; à la base de la coquille, les côtes longiludiales sont remplacées par quel fues stries trausverses. Cette coquille prósente ce curactire particulier, d'avoir, coume les Tritous, des vasices persistantes et irrégulièrenient disposées sur ses tours de spire. louverture est ovalaile, la lèvre droite est épaissie par un bourrelet saillant en dedans et en dehors; il est fincasent strié daus toute sa longueur; le bord gauclie est oblique, appliqué le long de la columelie, qui a'est point ombilicuće, et qui offre ¿ la base irnis petits plis rapprocliés. Le canal est jus creusé que duns les espèces précédentes; il n'est cependant pas écliancré. Celte coquille se Irouve fussile aux environs de Paris, à Parnes, Grigoon, Mouchy, etc. Les plus grands individus ont 23 asllius. de longueur.

\section{Caxceldare granifere. Cancellaria grani-} feru. Nов.

C. testâ os'atîs, acutâ utrâque evtremitate, vuricosâ ; varicitus numerosis, trregulanter dis. positis, aliquando oppositis; costults longitudinalibus, angustes, graniferis; striis transversis decussatis; onfractibus convexis, suturi profundi canaliculatî̀ seperatis ; aperturí ovato-acutâ; colusuellis triplicutâ.

\section{An Cancellaria costuluta varietas?}

Lamx. Ann. da Mus. loc. cit.

Cetle espèce est la seule dans le genre Cancellaire qui ait des varices depuis le jeune age jusqu'ì l'état adulte: ces varices, au nombre de deux sur chaque tour de spire, sont éparses irrézulièrement commedans les'Trions; d'autres fois ellessout opposées absolument comme dans les Ranelles, ce qui donne à cette espèce l'apparence d'une coquille de ce genre. Elle est de forme ovale, poinlue aux deux extrémités; elle a huit tours despire, ils sont convexes et séparés par une suture profonde et canaliculée; ils sont oroés de côtes trèspetites, étroites, peu saillantes, longitudiaales, ainsi que de stries transverses, très-fines, tégulières, trìs-serrées; elles sont interrompues ì des distances régulières par d'autres stries également transversales, plus saillantes. De l'eatre-croisenent de ces stries, plus grosses avec les côtes longitudinales, il résulte un réseau régulier, dont les points dentre-croisentent sont oicupés par de petits grains noduleux. Celle disposition se reaırugue parliculièrcmeut sur les premiers tour's de spite, calr il y a des iadividus qui ont celte particularité, d'avoir le dervier tour presque lisse, tandis que d'autres au contraires conservent des nodusilés daus une graode parlie de leur étendue. L'ouverture est alongée, ovale, assez longue; sa levre droite est épaisse, clle est garnie d'un bourrelet externe et d'un autre interne strié daus sa longucur. Li columelle est à peine arquée et grarnie claus le milieu de trois plis égaux; le bard gauche n'existe qu'à la lase de la colurnclle; il s'y upplique complèlement : il n'existe pas la cooindre tracc d'ombilic. Le caral de la base es! plus alongé que dans l'espièce précédcrite el moins proford. Nous pensons que cetle esfèce cst sulfisamment caractérisée pour ètre conservée. lible se trouve avec la précédeute, et acquict la mème taille.

so. Canceliajre de Brander. Cancellisia cuulsa. Sow.

C. testî ovato-turgidulì, apice acuminatá, longitudinaliter costuta, transversim striata; stms asperis, distantibus; anfiactubus convexis; varicibus ruris, muntis; apertura subrotunduto, abbrevati; columellí uncuuti, contortâ, hasi triplicatâ.

Sowerв , Min. conch. pl. 36r. fig. 2. 5. 4.

Buccinum evulsun, BAANDER, Foss. hant.pl. 1 , fig. 14 .

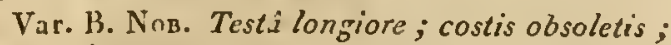
striis minoribus, numerosioribus.

On avoit cru long-temps que celle espéce étoit propre à l'Angleterre oin elle est fossile; depuis quelques annces elle a été bécourtile aux envi- 

$18 ;$
C $\perp \mathrm{N}$

rous de Paris, et nu pent dire que les individus de ces deux localités lort éloignées sont identiquement de la même espèce. Celte coquille est ovale, oblongue, pointue au sommet, ventrue à la base; les lonr's de spire sont au nounbre de sept ou huit, ils sunt convexes et courts, séparés par une suture profonde mais non canaliculce; ils sont pourvus de côlcs numbreuses, arrondies, longitudina!es, qui sont coupées en :ravers par des stries ondulenses el suilluates; on remarque sur les tours de spire, mais a de graudes clistances, des côtes plus saillantes, de vétitables varices; linuverture est peite, courte, arrondie; sil livvre ciroile est très-ćpuisse, garnie d'uis bourrelet a l'intérieur, lequél est strié dans sa longueur; le bord gauche se confond en orande parlie avec la columelle, il n'est seasible qu'à la base; il ne se relère pas. Ia columelle est forlement arquée ciaus le milieu, à sa base ou remarque trois plis ćaus; le canal de la base est court et si peu profuad, qu'on pourroit dire que l'ouvertule est entière comne dans certaines MIélanies; il n'y a auctroe trace d'umbilic.

Nous avons distingué une variélé constante, les côtes lonuitudiunles sout peu nombreuses, presque eflacées, et les stries transperses sont plus rnultipliées, mais moins saillantes; il servil possible que celte variélé ait élé distinguće comme espèce par M. Sowerby, sous le nom de Cancellaria laviuscula. On ne connoìt celle espèce qu'à l'élat fossile : on la trouve en Angleterre í Barton, ct en France aux envirous de Paris, à Senlis dans les grìs marins. Nous possédons un individu de cette dernière localisé qui a 32 millim. de longueur; c'eft le plus grand que nous ayons jumais vu : il a 18 millim. de large.

11. Cancellaire réticulée. Cancellatia reticulatu. Lasix.

C. testatâ, ovatâ, ventricosâ, crassá, transversims rugosâ, longitudinaliter striatì, retuculatâ, a!bo, lutes nufoque subzonutî; anfructibus convexis; suturis courclatis; columellâ busi triplicaíi, umbilico obtecto, murgine obtuso circumduto.

Folutu reticuluta. Lriv. Gased. pag. 3446. $76^{n} \cdot 34$.

Lister, Conch. tab. 830. fig. 52.

Bonaxir, Recreat. 3. fig. 52.

D'argent. Conch. pl. 7 . fig. M.

Kiorr, l'erg. 5. $a b$. 18 . fig. 7 .

n!artisi, Conch. cab. tom. 3. tab. 121 . fig. 107 à 1109 .

LAsх. Anim. sans vert. loc. cit. $n^{\circ}$. 1 .

Mitre, Encjclopédie, pl. 575. fig. 3. a. b.

Celte coquille est une des plus grandes du genre; elle se distingue particulièreruent par sa forme ovale, ventrue, par la disposilion de ses stries, sa coloration \& la forme des plis columellaires : les tours de spite sunt au nombre de huit; ils sunt arrondis, convexes, surtoul vers la sulure qui $\in$ ll simple, mais un peu eufoncće; ì la base du dernier tour, un remarque un bourrelet saillant, arrousli, qui entuare uu o:abilic infundibulifurme, $p \in \mathbb{E}$ profond, et en graode partie cache par le bord gauche qui le couvre. 'loute la surface extéricure est couverte de stries trausverses assez grosses, séparées par un sillon plus étroit; ces stries sout coupées à augle droit par des cóles longitudinales; ces côles, d'abord aussi saillaules que les stries dans le jeune âge, commencent à s'ellicer peu à per ver's le qualrieme tour de spire, e! elles sont remplacées vers l'onverlure par dics stries daccruillement peu régralières, yjui, par leur profundeur, rendeal les stries trausverses rugueuses. L'ouverture est semi-lunaire, assez élroite, obstruce d'ut cólć par trois plis columellaires fort gros, el d'un autre par uiz bourrelet iuterne lort épais, crénelé dans toute sa longueur. Des plis colunsellaires, le postérieur est le plus saillant, il est quelquelois bipartite, le second est moins gros el simple, le troisieme esi le plus petit de luus. Le canal de la base est assez pruloud, oblique el subéchan. ré. Celte cornilie est tachetće de brun assez loncé, passaut au luure et au blanc, mais d'une manière peu réguliçre; quciques individus présentent deux zones blanches et transverses. Daprès M. Lamarck, la Caucellairc réticulée viendroit de l'Océan allantique austral; elle a 55 millim. de longueur et 30 de large.

\section{Caxcelasine rosetie. Cuncellaria cancel-} lata. Lams.

C. testâ ovato-acutá, valdè ventricosâ, subcaudatâ, longitudinaliter etobliquè plicutâ, trans-

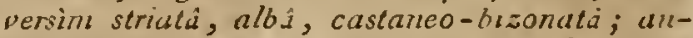
fructrbus convexis; spirâ brevi; columelli tri seu quadriplicatá, busi umbilicatá; unbilico patulo, margine circundato, obluso; labro incrassulo.

Vuluta cancellata. Lix. Gmev. rag. $3448 . n^{\circ} .59$. Gualtierri, Testuc. tub. 48. fig. B. C.

Le Bivet, Adaxisos, Sénég. pag. 133. pl. 8 fig. 16.

K NorR, TYerg. 4, tab. 5. fig. 5.

Bons. Mus. cas, vind. tab. 9. fig. 7.8.

Mrrae, Encyclopédie, pl. 3-4. fig. 5. a. b.

Fossilis.)

Вносси, Conchyl. foss. subapenn. tam. 2. pug. 307 .

Bastenot, Terr. tert. dusud-ouest de la France, Mém. de la Soc. dhast. nat. de Puris. Iom. 2. Lab. $47 \cdot n^{\circ} \cdot 7$.

La cancellaire roselte est une jolie corquille ovale, rentrue, pointue au sommet, composén 
de six à sept tours de spire arrondis, chargés de côtes ou de plis obliques, saillans, au nombre de 10 à 13 sur le dernier tour; ils sont conpés transvi alement par des stries trunchantes, bien séparées les unes des autres el ea nounbie viariable; if n'y a jamais d'autres stries dans les iatervalles qui restent lisses. L'ouverture est ovale, pointue aux deux extrémités; elle se termise à la base par un canal assez long, recourbé en dessus et un petr à sa droite, nov échancré. Cette ouverture est rétrécie par trois gros plis columellaires, obliques, dont le premier on le postéricur est le plus saillant et le plus gros, et le dernier le plus petit; la lèvre droite est fort épaisse, elle est bordée extérieurement par un bourrelet épais, at à l'iulérieur pur un autre non moins salllatut qui est strié dans toute sa longueur. Lc bord gauche est appliqué supérienrement et peu disliuct, mais à la base il se détache, s'éplaissit et convre en partie un ombilic nédiocre, creusé à la base de la columelle; il est inlundibuliforme et eatouré par un bourrelé saillant, cuutourné obliquement. Cette coquille cst de conleur blumche, orace de deux ou trois zones d'un brun rougeitte. Eille se trouve vivante dans les mers du Sénégal, dans la Mléditerranće, surtout dans les parties méridioniles; les terrains tertiaires de l'Italic, de Bordeaux, de Dax et des environs de Vienne, en recèlent des individus fossiles abso'umeut identiques aux vivans. Les plus grands individus que nous ayons vus dans l'un ou l'aulce ćtat on 40 millim. de long et 28 de large.

15. Cancellare aspérelle. Cancellaria asperelke. Lank.

C. testâ ovato-acutâ, ventricosî, transversim sulcatî, longitudinaliterstriatâ, cancellatâ, scabriuscula, rufo fucescente, aliquandd griseo bifasciata; suturis profundè canaliculatis; columells excabata, triplicatâ; umbilico mediocri, vi.c obtuso.

LАн. loc. cit. $n^{\circ}, 2$.

ExCYCLOPÉdie , pl. 374. fig. 3. $a . b$.

Coquille rare jusqu'ù présent daus les collections; elle est assez grande, ovale, ventrue, pointue au sommet, à spire courte luruée de six tours, dont le dernier est de beancoup plus grand que tous les autres, ils sont convexes; la suture qui les sćpare est caniculée, profondéuneut étroite, et le bord qui la couronue est crénelé dans toute son érendue; ces créuelures se continuent par des côtes longitudinales, peu saillantes, assez écartées, obliques, entre lesquelles se voient des stries trìs-lines qui suiveut la wème direction; ces stries el ces cùles sunt traveısées à augle droil par des stries transverses dout les unes, plus grosses et plus écartées entrelles, forment avec les cóles longitudinales un réseau à mail es carrées el lurges, dont les Hist. Nat. des Vers. Tome 11. points d'intersection sont occupés par nne aspérité; d'autres stries transverses plus fines que celles-ci sont interposćes. L'ouverture est griande, ovaluire; le bord droit est inince et tranchant, sans bourrelet, soit à l'extérieur, soil ì l'intérieur, il est cependant strić dans cet endroit; la columelle est concave, elle porte trois plis dont le supérieur est le plus élevé et le plus gros; ces plis se continuent souvent jusquau bord de la levvre gauche ea s'amincissant el en prenant des directions plus ou moins obliques: quelquefois ente ces plis véritables se trouveot une ou deux rides que II. Lamarck a prises pour des plis, mais eiles ae dépassent pas la face extérieure de la columelle. Le bord gauche est élalé supérieurement, il se rétrécit vers la base, s'épaissit ut se relève; il luisse à découvert presque totalement un ombilic uńdiocre, infundibuliforme, limité par un bourrelet saillant et arroudi. La couleur de cette coquille est ordinairement d'un brun-fauve; un iudividu de la collection du Musénun présente sur le dernier tour denx fucies d'un blanc-grisâtre. Nutus croyons que celle espéce vieat des mer's de la Nonvelle-Zélandre; clle a 40 à 45 millin. de longueur sur $3 j$ de large.

14. Canceldatae spenglérienne. Cancellaric spengleriana.

C. Testâ ovato-aculâ, ventricosâ, longitudinaliter oblique costatî, trunsversin striatî, albido-lutế, nufo maculutî; anfractibus convexis supernd angulatis, supriz planis, unicu serie tuberculonum coronutis; columellâ triplicuta; labro incrassato, striato.

Cette belle espèce de Cancellaire vient du cabinet de lisbonue; elle appartient maintenant a Ia cullection du Jardin du Roi; elle est ovale, alongée, pointue aux deux extrémités, ventrue dans le milieu; le dernier tour de spire est plus grand que tous les autres réunis, ils sonat convexes, ornés de côtes longitudinales, obtuses, régulièıes, écartées, ua angle aigu les sépare supérieurement en deux parties inégales; la plus petite est plane ou peu oblique, elle torme une sorte de rampe qui monte en spirale en suivant lid suture; en aboutiffaut à cet angle, les côtes donnent naissance à des tubercules saillans qui couronnent tous les tours de spicic; des stries écartées, assez prufondes, fines el transverses, se voient sur toute la partie inférienre des tours de spice; sa partic plane est occupíe par des stries plas fines encore, très-serrées el lort nombreuses. L'ouverture est grande, ovale, pointue aux deux extrémités, lerminée ì la base par an canal superticiel assez longo, légèrement relevé en dessus et à gauche. La columeile est excavée dans le milieu, elle oftre trois plis écartés, le supérieur eat le plus gros el le moins obliguce; $\in \mathrm{n}$ dehors des plis on remarque sur la columelle dix a donze granu.

$$
\text { A a }
$$




\section{6}

\section{A N}

lations peu saillantes. Le bord gauche est élaigi supérieurement, plus étroit à sa base, il est plus épais et cache en grande partie un ombilic rétréci, borné par un bourrelet suillant et arrondis. Nous ne savons d'où vient cette coquille; elle a 45 millim. de long et 25 de large.

\section{BAST.}

15. Cancelzaire tordue. Cancellaria contorta.

C. testâ ovato-rcutâ, in medin ventricosâ, utroque extremitate acuminats, longitudinaliter costatâ, transversim striatâ; anfractıbus rotundatis; aperturâ magnâ; labro incrussato, striato; culunsellì excavatì, triplicatâ.

Bastenot, Mém. de lit Soc. d'kist. nat. de Paris, loc. cit. pl. 2. fig. 3.

Var. B. Noв. Testâ angustiore; striis numerosioribus; columelli bast subtruncatâ.

La fignre que II. Basterot a donnée de cette espèce, est lurt bonne : il dit gu'elle est contourvie. Nous ne royons pas qu'elle le soit plus que beaucoup d'autres; elle l'est moins certainement yue les Cancellaria trochlearis et acutangularis, dont nous parlerons bientôt. Cette coquille se distingue néanmoius facilement de toutes ses congénères, elle est ovale, alongte, pointue aux deux extrémités, un peu oblique par la manière dout l'ouvertare se dirige; elle est compóée de six ou sept tours arrondis, convexes, chargés de cotes longitudinales, obliqges, variables par leur nombre et l'élévation, quelquelois légèrement anguleux vers leur sonmer; cet angle indiquant un aplatissement peu prononcé qui borde la suture. On remarque, sur toute la surface de rette coquille, des stries transrerses, nombreuses; les unes, plus saillanies, sont distantes entre elles, et l'intervalle qui les sépare est occupé partrois stries plos fines, dont celle du milieu esi cependant plus saillante que les deux autres. Louverture est grande, ovalaire ou subtrigone; le canal de la base est large, peu profond, el se confond insensiblement avec le bord droit: celui-ci est épaissi et strié en dedans daus toute sa longueur. Le bord ganche est étalé supérieurement, heaucoup plus étroit inférieuremen!; il se relève un per et laisse ì découvert une petite fente ombilicale; la columelie est légèrement arquée; elle présente dans son milieu trois plis écartés, dont l'an. térieur est obsolète. Nous avons compris dans cette espèce, à titte de variété, une coquile d'Italie qui diffère par l'ombilic qui est un peu plus grand, par les stries qui sont plus rapprochées. Des trois interwédiaires, les deux plus petiles ont disparu. Enfin, par la columelle tronquée à la lase par le dernier pli qui la coupe obliquement : ce pli n'est pas moins saillant que les deux antres. $\mathrm{Ne}$ pourroit-on pas faire de ces individus de l'Italie une espèce particulière? Les différences

\section{A N}

que nous venons d'indiquer, et qui sont assez considéiables, lienuent-elles uniquement aux localités? Nous ae pouvons réscultre celte question, n'ayaut point assez de coquilles d'I alie pour lever les doutes que nous avons. C'est surtout anx envirous de Burdeaux que l'on trouve cette espece dạns son plus grand développewent; on la rencontre encore it Dax et en Italie. Elle est longue de 50 millim. et large de 23 . La variété est plus petite que les individus de Dax.

16. Caveeclathe noduleuse. Cancellaria nodu. Losa. Lanx.

C. testâ ovato-acutä, ventricosâ, longitudinaliter costutâ, tmunsversim striatâ, albido-rufescente; costis per totam longrtudinem nodulviss; anfractubus convexis, supernè angulatis, supri planis; lubro sumplici, intùs rufo; columelli rectá, obsoletè biplicatí; umbilsco menimo, infundibulformi, pmfundo.

LAм к. loc. cit. $n^{\circ} .5$.

An Buccinum piscutorium? Liv. Gres. pag. $5496 . n^{\circ} \cdot 116$.

Le Solut, Adassos, Voy. au Sénég. pag. 122. fl. 8. fig. 15.

Martixi, Conch. tom. 4. tub. 124.fg. 11 ĭ: 1152 ?

M. Lamarck rapporte à cette espèce le Bucc:num piscutorium de Gmelin; mais nous croyons que c'est a tort, cal Gmelin cite une tirure de Lister qui représente une espèce de Córite, et il ne mentionne pas la figure de Marlini : il ne parte pas non plus du Solal d'Adansnn; M. Lamarek paroit l'avoir oublié. Cependant, si la coquille qui, dans la collection du Muséu no porte le nom de Cancellaire noduleuse, est bicn la même qৃue celle que 13. Lamärck a nommée ainsi dans son ouvracre, ce que nous croyons, il est évident qu'elle ne dilfe:e en rien du Sulat d'Adauson, aucant qu'on preut en être assuré d'après la description et la figure.

Cette coguille est d'une taille médiocre; elle est ovale, alongée, forınéc de six tours de spire, anguleux supérieurement et plats en dessus; ils snni couronnés par un rang de tubercules pointus, placés dans l'eodroit où les côtes longitudinales passent sur l'angle des tours de spire. Ces côtes, assez nombreuses et oblinues, mais peu saillautes, sont traversées par des stries peu nombreuses supírieurement; it l'endroit ric l'intersection des côtes et des stries s'élève uı tubercule pointu, de sorle que, survant que les cótes ou les stries pridomineront, les tubercules se trouveront rangís trausversaleroent ou longitudinalement. L'ouverture est ovale, pointue à la base; la lèrre draitc, siruple et tranchante, est lisse en dedans et sans bourreler. La columelle es! peu arquée, presigue 


\section{A N}

droite; elle a one tache brune dans son milien, dans l'endroit où s'ćlève un pli peu saillant, alldessous duquel il en existe un second à peine sensible. Le bord gauche est blanc, étalé supérieurement, détaché ioférieurenient, au-dessus de l'umbilic; celui-ci est en entonnoir, étroit, perforé, et horné à l'extérieur par un bourrelet oblipue, arrondi et saillaut. Le canal ae la base est assez profond, recourbé en dessus et sans échancrure. Eo dehors, celle coquille est d'un Jlanc-grisitre supérieuremeut, et o:née de deux larges zones bruues; sur le deraier tour, ces zoves sunt souvent voilćes par uoe teinte blanchâtre qui les obscurcit. Cetle coquille, rare encore dans les collections, se trouve refendaut trés-aliondaument au Sínégal, au rapport d’Adrosuu. El'e a 27 à ¿̇o mullım. de lungrueur.

17. Cascelcaiae aspérule. Cancellaira asperula. Nов.

C. testà alhâ, ovato-acutá, ventricosissima, longitudinaliter plicald, transverim striati; anfractions rolundatis, supenid spinis cononatis, canaliculatis; aperturâ ovato-ucuti, vix basi canuliculatâ; labro incrassato, striato; columelli triplicati, basi truncati; umbalico n:inimo, pevforato, pingiundo.

Jolie coquille ovale, très-ventrue, son dernier tour est beaucoup plus grand que tous les autres réunis; ces tours sont au nombre de sept : ils sont convexes, canaliculés en-dessus près de la suture, et couronnés sur le bord du canal an sommet des spircs par une rangée de tubercuies épineux; ils indiquent la aaissance des côtes nu des plis longitudinaux, obliques, trancbans : ils sont rendus uppres an toucber par de petites den. telures ou aspérités aiguës qui naissent sur le bo:d, dans l'endrait vù s'entre-croisent avec eux les stries transverses qui sillonoent toute la coquille. Elles soot numbreuses, peu saillantes et régulièrement espacćes. L'onverture est assez grande, ou pourroit dire qu'elle est entière, tant est peu jrofond le canal de la base; la lèvre droite est bo:dée extérieurenent d'un bourrelet tort épais, et b:eu distincl des plis lougitudinaux. Eu dedans, el ae eot garnie d'un autrebourrelet strié, mais beancoup moins suillant que celui de l'extírieur; la columelle est concuve dans le milieu, et chargée vers la base de trois plis égaux, dont l'autérieur, saillant au-dessus de la columelle, la trunque obliquement dans cet endroit. Le bord gatuche se délache inlérieurement an-dessus de l'oulpulic, qu'il laisse bien à déconvers; it est petit, aı roudi, perloré et profond; il est séparé par un angle à peine saillant. Cetle coquille est toute blanche en dedans el en dehors; nous iganroos quelle est sa patrie. Elle est longue de 22 millim. el large de 15.
18. Cancelcarke ridée. Cancellatia rugosa. LAM E.

C. testû ov'ali, z'entricosá, abbreviatâ, longitudinaliter costatà, trimsversinn sulcalî̀ griseâ, nufo bizonatâ; costes crassis, ngaformibus; labro dilatatn, rugoso, incrassato; columelli acuatâ, triplucatá; umbilico patulo, obluso.

Laak. loc. cit. " $^{\circ} 11$.

ENCYcLopéde, $p l .575 . f_{3} .8 . a . b$.

$\mathrm{Si}$ l'on suivoit rigoureusement les indications de NI. Lamarck, on ne comprendroit dans cette espice que des corpuilles alosolument blanches. S'il y en a de blanches, nous croyous yue c'est prarce quelles unt perdu lcurs couleurs : nous possédons en ellet plusieurs individus de cette espèce, qui les ont conservés; ils sont d'un blanc-grisåtre, oroés de deux zones brunes étroites, l'une près des sutures, l’autre vers le milieu du dernier tuur. Dans leur jutervalle, et séparée par deux ligues blanches, se voit une zone plus large, occupée par une multitude de points irréguliers, fauves ou bruos, qui pâlissent et se perdent dans le blanc qui est le fond de la conleul. Outre ceste colnration particulière, senle capable de distinguer celte espèce, elle présente d'autres caractéces quall faut connoitre pou: ne pas la confondre avec dillérentes coquilies, dans le cas oi elle en seroit dépourvue. La Cancellaire ridée est pen ovale, très-ventrue, raccourcie, it spire fort courte, composée de cinq tours seulewent; ils sont convexes, arrondis, un peu aplatis supérieurement : c'est sur cet aplatissement une se voit la première zone brune; elle est pourvut de huit à neul' côtes longitudinales, arrondies, obtuses, qui sont traversées par des sillons transverses assez rapprochés et arrondis, nu nombre de luuit ou nent' sur le dernier tour. L'ourerturc est assez graode, évasée à cause du bord droit qui est fortement arqué; il est épais, marni d'un bourrelet extérieur, crénelé et strié à Printérieur. La columelle est arquée, et garnie vers la base de trois plis obliques rapprochés et inéganx. L.c canal de la base est plus profond que dans aucune autre espèce; 11 se recourbe en dessus, et se termine par une échancrure. Le bord gauche, élalé supérienrement, est épais et ridé dans les vieux individus; il se relève presque droit à la base, d'autres foisil est moins relevé, s'applique eo partie sur J'ombilic qu'ıl cache presqu'd noilié : cet ombilic est évasé, peu profond, ap̧lati et borné par un bourrelet furt saillant et obtus. On de connoit pas la patrie de celte espèce; les plus grands individus que nous connoissions ont 22 millim. de long et 18 de large.

$\mathrm{NoB}$.

19. Canceliatue obluse. Caticellatia obiusa. C. testâ spharoïleâ, obtusâ, spirâ hrevissinấ, A a 2 
transversim nigosî, luteâ; aperturâ mas̆nâ, ovuto-ucutô; columells biplicatà, arcuatiz; umbilico paiulo, minimo.

Coquille des plus remarquables et des plus rares : on u'en connoil encore dans les collections de Paris que le senl individu que nous possédons; il est presque sphérique, ghlobulcux, très-oblus au sommel; quatre tours constituent tuute la spire, qui est extrênement courle; le dernier tour est en conséquence beaucoup plus grand que tous les autres; ils sont convexes, bien arrondis, séparés par uue suture simple; le deroier préseate extérieurement douze sillons assez prolonds, transverses, plus larges à la base que vers le sommet : ils sout simples et non interrompus par des cótes on des stries longitudioales. L'ouverture est grande, ovalarre, poiutue à la base, la lèvre droile est dépourvue de bourrelet, soit à l'intérieur, soil à l'extérieur : on remarque seulement à l'intérieur, et supérieurement, quelques rides assez courtes. Le bord gauche est élalé, épais, subcalleux supérientement, se rétrécit bearcoup à la base, et ue dépasse pas la colunalle; celle-ci est arquee, et ne porte que deux plis inégaux dans son milieu. L'ombilic, trèsaplati, à peine fendu, est circonscrit par un bourrelet arroudi, fort épais; le canal de la base es très-court et très-peu profond: en dehors celte coqnille est d'un jaune-orangé, peu foncé; en dedans, elle est blancbe. Nuus ignoruns sa palrie; elle a 29 millim. de longueur et 24 de large.

20. Cascellaire hérissée. Cancellaria hirta. Broc.

C. testâ ovoto-ventricosâ, longitudinaliter sulcatâ; squamis foliaceis, transversim per series dispositis; spirâ exsertâ, acutâ, supernè canaliculatâ; columellâ biolicatâ, basi umbilicatâ.

Voluta hirta, Broccni, Conch. foss. subap. pl. 4. fig. 1. a. b.

1I. Brocchi a été induit en erreur en attribuan un seul pli columellaire à celte espèce : nous en avoas vu six ou huit individus, et nous avons toujours observé deux plis; il est vrai que dans les plus vieux le second, celui de la base, devient plus obscur. Cette coquille est ovale, ventrue, composée de sept ì huit tours de spire, sćparés par une rampe assez large, légèremeat canaliculée; toute la surface extérieure est couverte de cótes lougitudinales et de séries transverses, d'écailles ou d’épines écailleuses plus ou noins serrées qui naissent à l'entre-croisenent des côtes longitudinales avec les stries transverses. L'ouverture est ovalaire, subtrigone, à peine canaliculée à la base; le bord droit est assez épais, s!rié en dedans dans toute sa longneur; le bord yauche est sailtant dans toute son étendue; il furme une callosité à la partie supérieure, s'épaissit et se relève rers la base de la coquille, et laisse à découvert nn ombilic assez grand, mais peu profond, yui est borclé extéricurenent par un ljonrrelet crénelé daus toute sal longuenr. La columelle est presque droite, ì peine arquée supéricurement : elle oflie dans son milicu un pli aflez gros, \& als-deffous un second moins saillan:. Celte coquille, fort remarquable, se trouve fossile en Italie, à Asli, en Piémont : elle a quelquelvis 55 ınillim. de longueur.

21. Cancelisire acutangle. Concellatia acutangula. Lanz.

C. testâ orato-acutâ, transversim striatâ, longitudinuliter et obliquẻ costatâ; anfractibus superne angulutis, suprì planis, ad angrulum dentibus comonatis; coluniellâ valde asusatî́, obliquatâ, subtriplicatâ, umbilicatî.

L.A мr. Anim. sans vert. pag. 116, no, 2.

FAUJAs, Arin. du Mus. tom. 3. pl. 10. fig. x. a. $b$.

Bustв́rot, Mém. de lu Soc. d'hist. nat. de paris, tom. 2. pag. $45 . n^{\circ}$. 1. pl. 2. fig. 4 . a. $b$.

Cette coquille, excessivement commune aux envitons de Bordeaux, est facile à reconnoitre, quoiqu'elle soit assez variable et pour la forme et pour quelgues autres de ses caraclères. Oralaire, veutrue, composće de supt à huit tours de spire peu bombés, si ce n'est le deroier; celtc coquille est couverle de stries transverses, étroiles, dont quelques-unes, à des inlervalles variables, sont plus grosses et plus sailiantes; les tours de spire sont aplatis supérieureruent en une rampe spirale assez large, courunnce sur l'angle qui la sépare du reste par une série de tubercules épineux qui uaissent avec les cótes longitudinales plus ou muins serrées, qui descendent de la base au sommel de chaque cour. Dans les vieux individus surtout l'ouverture est oblique et díjelée vers le côté droit, ce qui lui donne l'apparence d'êtıe tordue; cetle ouverture est grande, subtrigone, presque entière a la base, tadt est snperficiel le caual qui s"y voit; la columelle, inclinée ì droile, est fort arquće; elle porte dans son milieu deux gros plis et un troisicme presqu'eflacé in la base; le bord gauche esı fort éprais, et arqué comme la columelle, il forme supérienrement une callosité à sa jonction avec l'avantdernier tour; il couvre en partie un ombilic large it la base, flroit et profond supérieurement, circonscrit à la base par un bourrelet arrondi fort gros, irrégulièrement foliacé; le bord droit est plus ou moins épais suivant l'âge, le plus souvent lisse à l'intérieur, quelquefois strié dans toute sa longuenr. Celte espèce se troure abondamment aux environs de Bordeaux, où elle est dans un état de conservation admirable; les plus grands individus ont jusqu’à 60 millim. de longuenr. 


\section{C $\mathrm{A} \mathrm{N}$}

22. Casicelasing calbestan. Cancellaria troch?'earis. liassk.

C. test.î ovato-oblongô, ventricosâ, transversmu rugosá; costis longitudinalshus obliquis, ob- oletis; anfructibus supernè value canuliculutis; columellis biplicat $\hat{s}$, latè umbilicatâ; aperturî̉ magni, trigonald, subintegrâ.

l, $\mathrm{u}$ к. loc. cit. $n^{\circ}$. 1 .

liaujas, loc. cit. pl. 10. fig. 2. $a . b$.

BAstéRot, loc. cit. pl. 2. fig. 2、

Cette espìce se trouve avec la précédente, mais elle cst beancoup moins commune; elle acquiert le mêtuc volume et se dislingue très-facilement; elle cst couverte de rides transverses, larges, separées par des sillons étroits, au fond desyuels on remarque quelquefois une strie ioterunédiaire; ces rides sont readues légèrencut onduleuses pat des cótes longitudinales, obliques, peu prononcéés, qui descendent du sommet a la buse de chanue tour; ceux-ci convexes sont furtement séparís par uae suture largement et profondémeat caualiculée. L'ouveriure est grande, liigone, à peine canaliculće à la base; le bord droit est Irauclıaut, lisse co dedans; la columelle est fortement arquuée, déjetée à droite et garnie de deux gros plis dans son milieu; en ảehors elle est bordée par un bord gauche étalé et calleux supérieurement, relevé et déconvrant un large ombilic à la base; cet ombilic est rrès-graud, strié a l'iatérienr et bordé extérieurement par un bourrelct arrondi pen saillant, quelquefois lamelleux, mais irrégulièremeat. Cette liclle coquille fossile se trouve particulièrement à Burdeaux; elle a 55 ruillin. de longueur.

22. Canceldare scalarine. Cancelluria scalarina. LAxк.

C. test $\hat{\imath}$ elongat $\hat{i}$, acut $\hat{x}$, subturrit $\hat{i}$, fulvâ, longitudinaliter costatâ; costis crebris, obliquis, inansversè tuberculosis; tuberculis albidis; anfractibus convexis, suturá canaliculatá separatis; margine anfructum tuberculis albis coronato; coliunellis rectâ, triplicat $\hat{s}$; umbilico profundo.

An Cancellaria scalarina? Laмк. loc. cit. pag. $113 . n^{\circ} .3$.

Nous avons sous les yeux une coquille nommée dans la collection du Muséum Cancelluria scalurina. Elle dillere en quelques points de celle décrite par M. Lamarck, et comme nous a'avons pu véritier dans la collection du savant prolesseur si les dilfërences pouvoient constitucr une espèce, nous avons dú ne citer qu'avec doute la Cancellaire qu'il a décrite. Celle-ci est alongée, subturriculée, scalaroïde; sa spire est pointue, composée de sepi tour's convexes séparés par one sulure canaliculée profondément et couronnée sur l'angle par une rangée de tubercules blancs. Des côtes nombreuses, aiguc̈s, obliggues et rugueuses, descendent du sommet it la base de chaque tour; elles sont traversées par des stries saillantes distanles, qui, eu passant sur les côtes, forment les rugosités dont nous avous parlé; dans l'intervalie de ccs côtcs et de ces stries, on remarque un réseau extrêmement lin de stries entre-croisćes. Certe coquille est partout d'un brua-marron; les tubercules gui couronnent la spire, ainsi que ceux qui divisent les côtes, sont d'un blanc pur. L'onverturc est médiocre, de la même couleur que le reste de la coquille; le canal de la hase est très-court et peu profond; le bord droit est trancliant, assez subitement épaissi et strié dans toute sa longucur; la culumelle cst droite, ce présente à la base trois plis et quelques rides; le bord gauche est petit, relevé devant un oubilic, nédiocre, mais profond. Longneur 28 milim. Patrie incomnue.

\section{Canceldatre tonne. Cancellaria dolio-} latis. Bast.

C. testá globosâ, abbreviatî; spirâ depressâ, profunde canuliculatî, rugis elatts, rolundalis opertá; striầ unicâ, minimâ, rugis interpositâ; aperlurî̀ ovuto-acutâ, cóumellâ rectâ, biplicalâ; umbilico mugno, patulo, infundibuliformi, profundo, maiginato.

Bssténot, loc. cit. pl. 2. fig. 17.

Par sa forme arrondie et globuleuse, cette coquille fort remarquab!c a de l'analogie avec notre Cancellaria obtusa précédemmeat décrite, mais elle en diffère par tous les autres caractères spécifiques. Cille-ci, commc son norn l'indique, ressemble à une petite tonue; sa spire de cincr tours est très-obtuse, à peine saillante; la suture est profondément canaliculée, et toute la surface extériemre cst clargée de neuf ì dix grosses rides ou côtcs, cunvexes, transverses, séparées par ua sillon presque aussi large qu'elles, et laissuat a percevoir dans son milica une strie élevéc parallèle aux deux côtes entre lesçuclles elle marche. L'ourerture est presque aussi haute que la coquille elle-mème; elle est ovale, pointuc; le bord droit bien arqué est festonné et strié en dedans dans toute sa longuenr; le bord gauche, subcalleux supérieurement, se détache ct se rudresse au niveau de l'ombilic, sans se renverser sur lui; la columelle arcquée se porte un pou ì droite par sa base, elle est munie dans son milieu de deux gros plis; le canal de la basc est assez profond, un peu relevé vers le dos, mais non échancré; l'ombilic, qui perce cet!e coquille dans son axe jusqu'au sommct, est grand, infundibuliforme, très-profond, élargi et bot'dé à la base par un bourrelet crénelé : en dedans cet ombilic est strié. Cette coquille fort rare se trouve fossile aux environs de Bordeaux. Elle a 33 millirò̀tres de longucur et 28 de large. 
$1 ; 0$

$$
\text { C } \perp \mathrm{N}
$$

25. Caxceldatre ampullacéé. Cancellaria ampullacea. Ввос.

C. testâ avato-ventricusâ, confertim transversè striati, costis subtetragonis, crassis, munitâ; anfractibus rotundatis, valuè sepranatis, supernè planulatis, ad angulum carinato-crenulatis; aperturî́ ovato-acutì; columelli triplicuti, ; umbilica profundo.

Valuta ampullacea, Ввоссиг, loc. cit. pl. 5. fig. 9. $a . b$.

Cette espèce est des plus élésantes; d'une forme ovale raccourcie, sa spire de six tours seulement est peu saillante, le dernier tour est beaucoup plus graud que tous les autres réunis, Inus sout convexes et fortement séparés les uns des autres par un large aplatissement de leur partie supéricure qui forme ane rampe spirale qui gagne le sommet; cette rampe est séparée da resie des tours de spire par un angle subcariné couronné par un rang de tubercules qui naissent à l'origine de chaque côte. Celles - ci sont longitudinales, légèrement obliqques, subtétragones et torcrinées supérieurement par un tubercule saillant; toute la surface extérieure de celte coquille est dlégamment striée ea travers; les stries sont s.iillantes, trc̀s-régulières, arrondies, un peu ruguerses ou obscurénent grenues; dans le milieu de l'intervalle qui les sćpare, ou remarque une strie très-fine et saillante. L'ouverture est ovale, pointue, le canal de la base est peu profond, le bord droit est épais, garni en deloors d'un bourrelet et en dedans de stries pou prolongées; le bord gauche est calleux supérieurement, se détache au-dessus de l'ombilic en se renversant un peu sur lui; la columelle, arquée ulans sen milieu, porte trois plis furt gros. Derric̀re le burd gauche on remarque un ombilic peu évasé, mais très-profond, burclé à sa base par' un bourrelel saillant et arrontli. Cette coquille fort rare se trouve fosile dans le Plaisantin. Ėle a 40 millim. de longneur et 30 de large. Nos.

26. Cazcellaire scabre. Cancellatia scabra.

C. testâ ventricasú, transversè mgosá, longithálinaliter subcostatâ ; rugis cons'xis, squamulıs minimis erectis, nunierosis, apertis; anfructihus conu'exis, supeinè canaliculatis; apertúa subintegrâ, ovato-acutâ; columellá biplicatâ ; umbzlico magno, infundibuliformi, profundissimo.

Norus n'avons jamais va de cette espèce remarquable que le seul individu que possède la collection du Musćum; il s'y tronvoit sans aucune dénomination spécificue, seulement avec l'indiration de la localité. Nous disons que cette coquille est très-remarquable, et en effet on la prendroit facilement pour une Dauphinule, si ce n'étoient les deux plis de la columelle et le canal peu pro-

\section{A N}

fond et tris-court qui termineat l'ouverture à sa base. Cetle coquille est ventrue, globuleuse, à spire courte, formée de six tours arrondis séparés par une suture largement canaliculée; touıc leur surface extérieure est couverte de gros sillons Iransverses, convexes, interrompus obliquement par des cótes longitudiaales peu saillantes, quelqueluis variqueuses, qui descendeal du summet à la base de cliaque tour; les sillons transverses sonl chargés d'un graad nombre de petites écailles serrées, imbriquées, qui rendent loule la coquille rude au toucher; l'intervalle qui sépare les sillons est occupé par une ou deux stries śyalement écaillenses. L'ouverture, qui u'est pas lurt grande, est appnyée seulement par son augle interne et supérieur contre l'avant-dernier tour; elle ressemble par là beaucoup à celle des Dauphinules; son bord gaucbe est entièremen! libre, et il n'y a véritablement pas de columelle, camme cela a lieu dans les coquilles que nous venons de citèr; le bord droit est très-épais, festonué sur son tranchant et fortement strié en dedans dans tou:e sa longueur; le bord gauche, wince et tramebant, libie dans toute sa longueur, est fortement arqué vers la droite; à l'intérieur il porte deux gros plis; il se reuverse un peu en dehors, en dessus d'un ombilic très-graud largement ouvert à la base de la coquille el la traversant jusqu'au sommet. Cette coquille est précieuse par le passage qu'elle établit avee les Dauphinules, mais bien plu ó: avec la coquille nommée Bordstrap, que II. Lauarck avoit placée à tort dans ce dernier gemre. L'espèce que nous allons décrire, en conscrvant des rapports évidens avec celle-ci, eı a bien davantage avec le Bordstrap. La Cancellaire scabre est fussile et vient du Plaisantiu. Elle a 45 millim. de longueur et $\mathbf{3 8}$ de large.

27. Cancelgare perforée. Cancellatia umbilicaris. Broc.

C. testâ oc'ato-acutâ, scalariformi, transversé rugosá, longıtudinaliter costatâ; anfructibus convexis valdè separatis, supernè planulatis, angulutis; spinismagnis, recurvis, coronatis; aperturit subintegrî, trigonâ; umbilıco magno, usque ad apicem pervio.

Вноссаг, loc. cil. $n^{\circ}$. I1. pl. 3. fig. 10. It.

11 existe les rapports les plus incontestables entre celte coquille fossile et celle que $\mathbf{M}$. Lamarck a nowmée Delphinula trigonostoma; sans circe de la uiéme espèce, l'une doit atcessairewent entrainer l'autre dans le uême geàre. Celle qui nots occupe est fort belle, orale, alongee, scalariforme, coin posće de sept lours de spire furtement séparés par une large rampe oblique qui monte avec eux jusqu'au sommel; cette rampe est due à l'aplatissement de la partie supéricure de chaçue tour; elle est sćparée du resle par un angle aigu couronné par un rang d'épines élé- 


\section{$C A N$}

Mantes recourbées ters la spire; ces f́pines sont à liorigine des côtes lungritudinales et obliques qui rlescendent du sommei à la base de chaque tour. Cas cutces sunt subvarriqueuses, ćtaut cliargées d'écailles ou de petils tubercules plus gros que dans le reste de la cocpuille. Les sillous transverses, lont aous avous parlé, sont plus ou moins saillans, pius on moins écailleux, selon les individus; entre chacun des plus grus, on en remalque toujours un très-fin. Louverture est pelite et tout-à-fait triangulaire, presque entière, et plus que dans l'espèce précédente, car le canal cot très-court et à peine marqué par une légr̀re dépression; la livve druite est assez épaisse et striéc ey dedans dans toute sa longueur; il n'existe pas le columelle; le bord gauclie est librc dans rouse son éleuduc, il cst mểme tranchant et numi à 1 inlérieur de deux plis airus parallèles et égaux; il se renverse un peu au-dessus d'un grand omlific lisse eu dedans, conique et traversant la :arruille de la base au sornmet, un angle aigu circonscrit cel ombilic à la base. Celle belle coquille fossile du l'aisantin a 35 williw. de lon¿neur el 20 de largeur.

\section{C.ANCRIDE. Carcris.}

Genre propósé par. Mnntfort pour une coquille microscopique que $\mathrm{M}$. d'Orbigny rapporte, ainsi que beaucuup d'autres, au genre Nonionine. Voyes ce mol.

\section{CANISTRLU.}

Klein a inslitué ce genre (Ostrac. pag. $5 \mathrm{l}$. ) pour mettre les coquilles dont la lome approche des petites curbeilles d'osier que portent les temmes; c'est parmi les Bulimes quil tronve de quoi furmer son geme. li ne les y aduet pas tous, mais en revancle on $\mathrm{y}$ trouve yuelques $A$ gathines et une Maillot.

\section{C.INOPE. Eanopus.}

Genre très-incertain, établi par Montfort (Conch. syst. tom. 1. pag. 29o.) avec une coquille wultiloculaire, clont la description est tcllemeat incomplète, qu'il a été impussible jusquà prúsent de savoir à quelle groupe, à quel geure elle apparlient.

\section{CANTHARE. Cantharus.}

Autre geure de Monifort (Conch. sy'st. torn. 1. frg. 398.), non mains indéterainable que le préccident. M. d'Orbigny observe qu'il est établi sur une coquille cassée en deux : Suldani a dunné la ligure de celle moitié; recopiée par Montfort à sa asanière, elle est devenue le type d'un genre.

\section{CANTHARIDE. Contharidus.}

Une clarmante coquille appartenant au genrc 'roulus des auteurs, le 'Trochus iris, a servi de tȳpe au genre Cantharide Ctabli par Montlort (Conch. syst. tom. 2. pag. 250.) : quviqu'1l n'ait pas été adoplé, on ne peut disconvenir cependant que ce geme ne dilfere sensiblement des Troques, mais il peut entrer dans les Litorines de Ml. de fierussac. Foyez Lirtonises.

\section{CANTHROPE. Cunthropus.}

L'habitude quavoit Mlontlort de décrire souvent les objets d'apiès son imagrination, J'impossibilité vù nous sommes de retrouver une coquille qui ressemble à celle qui a servi ì re gente, nous liat supposer que Montfort ayant trouvé quelqu'ammonite roulée sur la plạ̈c de Boulorne l'áura donnée comme un Nautille, +1 Iui aula trouvé un siphon ventral aussi facilement qu'il avoit détermué celui des Bellérophes et d'au!res, ou il ne l'avoit jamais vu.

\section{CAPRAIRE. Caprinus.}

Les espèces d'Hélices de la scction des Carocolles, qui out deux dents sur la lèvre droite, ont été séparécs en genre, sous le nom de $C_{(z-}$ praic par Denis de Mlonifort. (C'onch. syst. tom. 2. pugr. 1f2.) Si l'on vouloit établir des genres sur des caracières d'aussi peu de valeur, parmi les nombreuses espèces d'llélices, on pourroit facilement en fare plus de trente, qui ne vaudroient pas mieux que celui-ci, et que l'on adopteroit pas plus.

\section{CAY'SE. Capsa.}

Un genre fut élabli par Bruguicre sous ce nom, mais il ne le caractérisa pas; il fit représenter les coquilles qu'il vuuloit y laire enirer daus les planches de ce Diclionuairc $(\rho / .251)$. MI. Lamarcle l'adopla dans ses Animaux sans vertébres (18:1) sans y rien changer, eu donnaut pour type du genre le Capsa rugosa (Venus deflorata Lin.) que Bruguiere en ellet comprenoit dars soll genre. Dans l'ouvrage que nous venons de ciler, II. Lamarcls proposa un genre Sanguinolaite pour le Solen sunguinolentus Liu., et plaça dans sa série immédialement après les Capses. On verra un peu plus tard pourquoi nous mentionnous ici ce geure Sanguinolaire.

Lorsque M. de Roissy mentionna ce genre dans le Buffon de Sonnini, il n'avoit pas sans doute les plancbes de l'lincyclopédic sous les yeux, puisqu'il allribue la création de ce genre à II. Lamarck. Il adopta aussile genre Erodone de Daudin ( voyez ce mot), sans taire attention qu'il étoit fait avec des coquilles du genre Capse de $\mathrm{Br}^{\mathrm{r} u-}$ guière. Il est impossible de savoir, si M. Lamarck, en plaçant les Capses dans la famille des Conques de sa Philosophie zoologique et de l'Fxtrait du Cours, y lit des changemens; ce qui est certain, c'est que, dans son demier ouvrage, le 
192

$$
\mathrm{C} \wedge \mathrm{P}
$$

genre Capse a'a plus le moindre rapport arec ce qu'il étoit originairement, tandis que l'espece qui lui avoit servi de type d'abord, le Venus deflorata, a été transportée dans le genre Sanguinolaire, qui tien: lieu à bien dire des Capses de Bruguière. Il est à présumer cependant que ग. Lamarck, jusqu'à la publicalion de sou dernier uurage, n'avoit rien changé anx Capses, puisquilil avoit créé un genre Dunacille pour une coquille que l'on confondoit avec les Douaces, et ì Iaquelle il donua en dernier lieu le nom du genre de Bruguière.

En pous résumant, le genre Capse est créé par Brusuière, adopté dans son intégrité par M. Lidmarck, Lُuvisé par Daudin par la créalion da cenre Erodone, tous deux adoptés par M. de Roissy. Ml. Lamarck joint les Citpses à ses Sanguinolaires; le mot Capse devient dès-lors sans application, mais pour l'employer, il abandonne le nom de Donzcille, pous donner de prélérence celui de Capse à ce genre nouveau, qui n'a plus le moindre rapport avec les Capses de Broguière.

M. de Ferussac reclifia ia synonymie générique de ces divers groupes; mais cela neurpêcha pas que l'on ne contiuual à suirre M. Lamarck, et $\dot{a}$ adopter les genres tels qu'il les a donnés. M. de Blainville (Trait. de Maluc.pag. 543.) a réuni le genre gui nous occupe avec les Duuaces; il n'en différe en effet rque par le détaut absulu de dents latérales.

Mi. Sowerby, dans son Genera, a joint au genre Cupse une corquille de lis Manche que l'on royoit dans les Donaces, et que Montagu aroit aussi rungúe dins ce genre sous le no:n de Doncax complanata. Nous possédons, bien conserrée dans la liqueur, cette cspèce avec son animal; nous arons pu le comparer arec le Donux trincatus, gue nous possédous ćyalemeut, et nous pouvons assurer qu'il n'existe pas la moiudre dillérence générique entre ces deux animaus. Nous ajunterons, qu'en examinant allentivement la charnière dn Donax complanata (Capsa complunata Sow.), ncus arons vu une dent latérale fort petice et postérieure, et nul'e trace de la dent latérale antérieure, comme cela a lieu, au reste, dans plusieurs espèces de Donaces et notamment dans le truncatus, de sorte que nous ne partageons pas l'opinioa de M. Suwerby : nous croyons que sun Cupsa complanata n'est qu'une Iubace, dout 13 charnic̀re, tiès-élroile, lusse apercevoir muins facilement ses caractères.

On ne connoil point encore l'animal des Capses; on peut présumer qu'ii est très-voisin de celui des Donaces; mais jusquau moment oi on aura décidé de son identité, nuas pensons qu'on peut le conserver, car le contlaire pent aussi avoir lieu : ses caracteres peureat tra exprimés de la maaière suivante.

\section{A P}

\section{CABACTÉRES GÉXERTQEES.}

Animal inconna

Coquille trausverse, équivalve, inćquilatérale, non baillante; charnière ayant deux dents surla valve druite, une seule bifide et intrante sur li gauche; point de dents latérales; ligament extérieur saillant sur le côté le plus court ou postérieur.

Le geare Capse ne s'est pas encore rencontré à l'état fossile, et on n'en connoit que deux espèces vivantes; elles ont, quant à leur forme, beancoup de rapports avec les Donaces; elle sont épidermées, inéquilatérales et le ligament est sur lc côté le plus court, comme cela a lieu également dans les 'Tellines. On ne peut disconvenir qu'elles n'avoisinen I beaucoup ces genres. Des deux espèces décriles par M. Lamarck nous n'en connoissons qu'une, celle du Brésil ; la seconde de nos espèces est le Dorax ringens Lamk., qui appartieut sans aucun doute aux Capses. Il y auroit donc trois espèces daus ce genre.

1. Capse du Brésil. Capsa brasiliensis. Lamr.

C. testŝs oblongo-trigoná, incequilaterá, propè latus posticum valde depressâ, transversim longitudnaliterque striatá; albidá natibus violaceâ, subepidermide virescente.

Last. Anim. s. vert. tom. 5. pag. 553. $n^{\circ} .2$. Sогевв, the Generu $n^{\circ}$. 10 , genre Capse, fig. 1.

Donax, Bвоg. Encycl. method.pl. 26 I. fig. 10.

Donu.x brasiliensis, Bцагзу. Trait, de maluc. pag. 549. pl. 71. fig. 3.

La Capse du Brésil est une coquille transverse, triqone, assez épaisse, inéquilatérale et poiat buillinte; elle est assez épaisse et gonllée vers le milieu; les bords sont simples, lisses, plus ou unvins épais selon l'äge; les crochets, peu saillans, s'inclinent l'un ver's l'autre et se touclient: ils sont presque toujours dépouillés d'épiderne, et sont tein és d'une coulcur violette intense; on y remarque ordiuairement quelques rayons blanchiares; le reste de la su:face est blauc lorscjue l'épiderine minque, elle est verditre ou brube lorsqu'il existe eucore; le bord inférieur est assez forteneut sinueux rers l'angle pustérieur; des stries irrégulières, plus ou moins lines, vont en rayounant des cruchets jusqu'au bord inlérieur; elles coupent, à angle droit, d'autres stries trèslines et transverses. En dedans, celle coquillo est toute blanche lorsqu'elle est vieille; d'un blanc-violâtre lorsqu'elle est jeune : on y visit une impression palléale très-profondément sinueuse postérieurement; le bord cardinal est étruit : il prúsen:e sous le crocliet deux dents sur la ralse gaucle; l'antérieure es! la plus grosse, wt 


\section{A P}

une seule sur la valve droite. Elle est accompagnée, sur le côté antérieur, d'une petite saillie que l'on peut regarder comme une seconde dent cardinale : la priacipale est toujours bifide et oblicyue. lies grands individus de cette especce ont 67 millim. de large et 48 de long. Elle se trouve au Brésil, où elle n'est pas rare.

\section{CAPSE grimaçante. Capsa ringens. Nов.}

C. test $\hat{\imath}$ ovato-trigonâ, albido-violascente, intìs violaceâ, posticè gıbbâ, undato-rugosâ, scabrâ; margine crenulato, posticè sinuato, subringinte.

Donax ringens, Layк. Anim. sans vert. tom. 5. pug. 549. $n^{\circ}$. 16 .

Cиemiтt, Conch. tom. 6. tab. 25. fig. 251. 252 .

\section{Excrclopédie, pl. 260. fig. 3.a.b.}

Il est pour nous incontestable que cette coquille appartient au geore Capse : elle en a lous les caractères, quoique sa forme la rapproche cependant des Donaces. Elle est ovale, Lrigone, inéquilatérale, le côté postérieur étant le plus court; elle est peu bombée, ses crochets l'ort petits sout très-rapprochés, opposés, non incliués; ils soat marqués de quelques rayons violets. Comme dans l'espèce précédente, le bord inférieur est légèrement sinueux postérieuremeat, il est crénelé dans toute son étendue, et laisse ì l'angle inférieur et postérieur un petiı bâillement grimaçant. Le cóté postérieur porte un ligament gros, arrondi, fort saillant, supporté par des nymphes courtes mais épaisses. 'Tout ce côté postérieur est couvert de rides onduleuses, rudes au toucher: elles se terminent brusquement dansl'endroit de la jonction, du cólé postérieur, aves les laces latérales; cellesci sont lisses ou a peine strićes longitudinalement: elles sont d'un violet obscur vers les crochets, et blanc:hes ou d'un blanc légèrement teinté de violet dans tout le reste de leur étendne; en dedius celte coquille a une large bande violette çui suit les bords. Les impressions musculaires el une partie de l'espace compris dans l'impression paléale sont de la méme couleur qui, dans quelques individus et fort intense; le reste de l'intérienr eft blanc. La charnière ne dilfëre en rien de celie de l'espèce précédente; sur la valve droite, on troure teux dents divergrentes séparées par une fossette qui reçoit la dent bilide de la valve zauche. Celte belle coquille nous a été communiquée par M. Gućrin, eutumologiste fort distingué, l'un des collaborateurs de ce Diclionnaice : elle a 50 millim. de long et 70 de large. Elle vient des mers de l'lnde, d'après M. Lamarck; mais nous savons que c'est au cap de Bonne-Espérance qu'elle se trourte assez communément, à ce qu'il paroit.

Histoire Naturelle des Fers. Tome II.

\section{CAPSOIDDE.}

Nom que M. de Blainville, dans son Traité de Malacologie, a donné à une sous-division du geure Psammocole. Voyez ce mot. .

\section{CAPSULE. Capsula.}

Depuis long-tempsle genre Capse de Bruguière, ou Sanguinolaire de M. Lamarck, étoit établi lorsque M. Schumacher proposa de nouveau le méme geare sous le nom de Capsule. Il ne doit pas ćtre adopté. (Voyez Sanguivoladme.)

\section{CARAFE. Lagena.}

Déjà Klein avoil institué un genre Lagena que personne n'a adopté. M. Schumacher, en le reproduisant avec de nouveanx caractères, ne l'a pas sendu meilleur, et nous ne pensons pas qu'on doive l'admettre; il est un double cmploi des Fasciolaires ou des Turbinelles. Voyez ces mots.

\section{CANARIS. Canarium.}

II. Schumacher a proposé sous ce nom un genre démembré des Strombes; il a pour type le Strombus canarium. Nous ne voyons pas en quoi cette coquille dillëre assez notablement des autres Strombes pour en faire un gente. (Voyez Strorbe.)

\section{CARDIACÉES (les).}

On trouve l'origine de cette famille dans la Philosophie zoologique de M1. Lamarck, cllc y porte le nom de Cardiadées : elle est composée des. cinq genres 'Tridacne, Hippope, Cardite, Isocarde et Bucarde. Dans l'Extrait du Cours, elle prit le nom de Cardiacées, et fut augmentée du genre Hyatelle. Elle fut placée, dans l'ordre systématique, entre les Arcacées et les Conques. M. Cuvier, dans le Règne animal, établit aussi une famille sous le même nom que celle-ci, mais eile ne lui ressemble nullement, élant composée d'autres genres; elle correspond assez complétement à une autre famille de $\mathrm{M}$. Lamarck, les Conques. (Voje z ce mot.) Celle famille de M. Cuvier, contient un grand nombre de genres (Cames, Isocarde, Bucarde, Donace, Cyclade, Corbeille, Telline, Loi ipède, Lucine, Yénus, Cythérée, Capse, Pétricole, Corbule, Mactre, el Laviguon), dout l'organisation est quelquefois trop dilférente pour constitaer une famille; il faut la considérer platôt comme un ordre, et encore en éloigner quelques genres qui ne peuvent $y$ rester.

Nous remarquerons que la famille des Cardiacées de M. Lamarck est loin d'être vaturelle: on y trouve un mélange de coquilles monom yaires, dimyaires, qui ne pouvoit pas long-temps subsister. 11. Cuvier sut éviter celte confusion, en créant sa liamille des Bénitiers. NI. Lamarck mit

$\mathrm{BL}$ 


\section{I $)^{\prime}+$}

C A R

à profit cette indication; dans son deraicr ouvrage, il fit la lamille des Tridacnés, aux dépends de celle des Cardiacées qui se trouva réduite aux einq genres Bucarde, Cardite, Cypricarde, Hyatelle, Isocarde. Malgré la réforme nécessaire dont nous venons de parler, celte fanille n'est pourlant pas encore. naturelle; aussi, par nne conséquence facile à concevoir, si ou la retrmure dans les auteurs, ce n'est pas sans avoir subi des modificalions plus ou moins nombreuses. M. de Ferussac, dans ses Tableaux sy'stématiques, en unet une partie dans la fatnille des Cardites, et réserve Irnis genres, les Isncardes, les Bucardes el les Hémicardes, pour la famille des Cardiacérs. Il la place dans le système de telle sorte, que les rapporis entre les genres indiqués par M. Cuvier ne saient point changés. La manière dont M. de Blainville a envisugé l'arrangement des acéphales, est gévéralement et snrtout pour cette partic, tolalement dillérente de ce qui avait été fait avant lui. Nous le ferons remarquer à l'article Mollusque, ainsi qu'aux articles Subniytilacés et Camacés. Voy'ez ces mots.

M. Latreille adopta presque sans changemens In famille des Cardiacées; il en ôla les Hyatelles, el $y$ mit les Hémicardes et les Vénéricardes : il étoit nécessaire de rapprocher surtout ce dernier geare des Cardices; ce que M. de Ferussac, seul, avoit fait jusqu'alors.

Malgré tous ces changemens, nous ne croyons pas que l'on conserve le groupe dont nons nous occupons : les Isocardes et Bucardes ont entre pux de l'analogie-, cela est incuntestable, on trouve dans l'an et l'autre deux siphons postérieurs, et une ouverlure grande pour le passage du pied; mais dans les Cardites et les Vénéricardes il n'en est pas de mème, le manteau est fendu dans toute sa longueur, et ne présenteroit qu'une bride postérieure, à peu près comme dans lès Nulettes; de sorte que l'on auroil danz celte fitmille, d'une prart, quelques yenres se rapprochant des Conques; et d'une autre, le reste se liant avec les Mulettes, qroique bien séparé d'elles. Il est donc impossible désormais d'adopter la famille des Cardiaccées de MI. Lamarck.

\section{CARDIADÉES.}

Nom que M. Lamarck avoit donné à une famille, qu'ıl a nommée depuis Cartiacée. Voyez ce mot.

\section{CARDIOCARDITE.}

M. de Blainville a donné ce nom à une•secrion des Cardites: il y renferme celles qui sont ovales, le bord inférieur droit ou pen bombé, crénelé, et complétement fermé. Voyez Cardire.

\section{CARDISSA.}

M. Ocken, ignorant saasdoule l'exi stence du

\section{A $\mathrm{R}$,}

genre Vénćrirarde, a changé cette-dénomination adoptée pour celle-ci, tandis que M. Mrogerle l'emploie de son côté pour les coquilies tont M. Cuvier a fait son genre Hémicarde. (Vojez ce mot et Vénéricande.)

\section{CARDITE. Cardita.}

C'est à Bruguic̀re que l'on doit ce genre : il l'a proposé dans le premier volume de ce Dictionnaite, et est resté depuis dans la méthode, mais en éprouvant de grands el d'utiles clangemens. M. Lamarck lut le premier qui les proposa. D'aboril on trouve le genre Isocarde séparé des Cardites dans le prodro'ne d'une nouvclle classification dess coquilles, inséré dans les Mémoires de la Sociefé d'histoire naturelle de Paris, publiés en 1799; puis le genre Vénéricarde, deux années apres, dans le Système des Animaux sans zertébres; et enlin les deux derniers démenubremens pour les genres Cypricarde et Hyatelle eurent lieu dans le dernier ouvrage du célèbre professenr: de sorle que ce genre Cardite de Bruguicre prósenta les élémens de quatre genres, et se réduisit à un fort petit nombre d’especes. Brnguière en effet ne compta que treize espèces dans toul sun gemre Cardite, el si on retire celles qui apparlieunent aux genres que nons avons cilés, il n'en reste plus que six pour les Cardites, telles que M. Lamarck les caraclérise aujourd'hui. Depuis la publicatiou du travail de Bruguière le nombre des Cardites s'est :onsidérablement augmenté; M. Lamarck en indique vingt-cinq taat vivantes que lossiles, et certainement il y en a davantage.

Si l'on compare avec soin les deux genres Cardile et Vénéricarde, l'on se demunde ponrquoi II. Lamarck les a séprarés dans deux families, car il est impossible en eflet que deux genres soient pius voisins que ceux-ci; ils ont tellement d'analugie, que l'on pourroit se demander aussi pourquoi M. Launarck a séparé les Vénéricardes, car nous ac voyous pas les caractc̀res de quelque valeur qui justitient cetle séparation : nous tronvons une telle liaison, un passage si insensible enirc les deux genres, que nonus croyons rju'il est per nécessaire de les admeture tous deux; mais comme c'est le genre Cardite le plus ancien, c'est sous celte dénominalion que nous réunirong les deux genres. La comparaisun que l'on punra faire des caractères génériques de l'un el de l'autre -fera voir le peu de différence qui existo entr'eux: on s'assurera que la principale est dans la forme générale, car la charnière de certaines Vénéricardes ne differe en rien de celle des Cardites: il y a daos l'un et l'autre genre des espèces dont la dent cardinale antérieure est droite, et non oblique comme dans le plus grand nombre des Vénéricardes. Dans l'un et l'autre aussi la dent antérieure est avortée ou rudimentaire, ce qui confirme encore l'analogie des deux genres. 


\section{A R}

Eu farcur de l'opiniou que nous manifestons ici nous pourrions nous étayer de celle de M. de liainville, qui est à peu près conlorme à la nôtre; car conme nous il réunit les Vénéricardes aux Cardites, mais y joint de plus les Cypricardes, re rue nous n'adoptons pas pour plusieurs ratisons. (Fojez Cypricande.) Non-seulement M. de H3aiuville a opéré la réunion des deux genres qui nous uccupent d'après les rapports des coquilles, uais encore sur la convicliou de la ressemblance farfaile qui existe entre les animaux. Puli dans sou bel ouvrage (Testacéa utriusque Sicilia) crut meltre ce fail hors de doule, et M. Lawarck auroit dû ne pas l'oublier lorsqu'il clémembra les Cardites de 13ruguière. Si l'on en croit Poli, l'animal des Cardites différeruit pen de celui des Muletles; il a en tllet le asanteau ouvert dans toute sa longueur, retenu postérieurement par une bride transverse au-dessous de l'anus; if n'y a point de vérilables siphons, et sous ce rapport il est évident que ce geare est bien séparế des Bucardes et des lsocardes, et quiil ne sauroit désormais resier dans la famille des Cardiacées de W. Lainarck. Le pied, les branchies sont aussi à leu près semblables à ceux des Muletles : de sorte que par une conséquence un peu lorcée de celle ressemblince, qui ue fut point assez approtiondie, l'uli tit des Mulertes et des Cardites un seul genre qu'il nouma Limmaca. (Vojez ce auot.) (ielle nanière de voir ne lut point adoptée : M. Cuvier (Règne ammal) n'a point adwis le genre Vénérucarde, $\epsilon l$ il laisse le genre Cardite tel à peu près que Bruguière l'a caractérisé; mais il place ce genre cout à côté des Mlulettes, dans sa lànille des Mylilacés. M. de Ferussac, dans ses Tableanx systénatiques, fit du genre Cardite de M. Cuvic: une famille qu'il rangea immédiatement ajrès celle des Muleltes, daus l'ordre des Myidacés: de sorte yu'il n'a fallu, pour avcir cet arrangement, que changer les mots genre et famille pour ceux de fumille et d'ordre, saus que la méllode y init beauconp gagué.

M. de Blainville (Truité de Mulacologie) aduet entièrement l'opinion de N1. Cuvier, en nellant l'un près de l'uulre el daus la même tamille les Subartalacés (voyez ce mut), les teux genres Cardite et Nlulelte : en cela il ne lant que asodilier légèrement l'opinion de l'oli, car ce sont les lravaux de ee savant analomiste y̧ui le guidèrent, aussi-bien que les auteurs dont nous venous de parler.

Contuit par les rapports des coqnilles plus que prar ceux des animaux, M. latreille, daus ses Familles du Règne cuimal, n'a tenu compte ni de l'opinion de l'oli, ni de celle des autres auteurs qui l'ont admise en la modiliant : il est dunc eut:ainé à placer des animaux sans siphons dans son ordre des Concliferes à manteau tubuleux, ce qui, aiusi que dans la méthode de M. Lamark, ruupt évidemmeat les rapporis naturels.

\section{C $A R$}

195

S'il cst vrai qüil existe une grande analogie entre les animaux des Mulettes et des Cardites, if ne seroit pas impossible cependant de trouver des dillérences sulfisantes pour justifier la séparativa que lon en a laite. lour les personnes qui n'out jas sous les yeux les animaux des deux genres, il leur suflira de comparer dans l'ouvrage dé Poli les ligures qui les représentent en détail : elles pourroat sissurer bien lucilement que les animaux des Cardites et des Mulettes out des différences notables dans des points essentiels de leur organisation. Dans les Cardites l'oúverlure buccale est garnie de trois ou quatre paires de contacules buccaux, il u'y en a jamais que deux paires daus les Muielles, l'osophage est longr, l'estomac globuleux; dans les Mulerles, à peine s'il y a un ósophage, et l'estomac est beattcoup plus cylindrace. Le cour el sos anneses présenteut d'autres dillérences plus essentielles : ainsi dans les Cardites le ventricule est très-court, ylobulenx, et les oreillelles, au lieu de s'ouvrir dans toute leur longueur dans les artères branchiales, s'appuient sur elles, et fournissent de leur partie antéricur un vaisseau gros et court, qui se jelle obliquement dans le vaisseau branchial. Celle disposition dillëre entièrement de ce qui a lieu dans les Hulelles, qui ont d'ailleurs le ventricule fusitorme.

C"est ainsi que des dillér ences qui ne se voient d'abord que dans la coquille, se manifesteot aussi dans ce que l'orgauisation a de plus caché, lorsqu'au contraire les parties extérieures de l'animal paroissent lout-à-fait semblables à celles d'autres animaux voisins. Une autre considćration importante, is laquelle Puli n'it pas liat asiez altention, est relutive à l'habilation des deux genres que nous comparous; les Muletles, comme on le sait, vivent toutes dans les eaux douces, les Cardites habitent invariablemeat la nes : il y a done de très-bons motif́s pour les séparer, et peut-être y en auroit-il de sullisans pour les porter dans deux familles distinctes : néanmoins on les conservera Lien probableuent dans la mème, car ils on analoyies incontestables.

\section{CARACTÉRES GÉNÉRIQUES.}

Animal suborljiculaire ou transverse, épais, ayant le manteau ouvert daus toute sa longuet:: anus séparé par une bride lransverse postérseure; point de siphons rérulables ; pied petit, lancéolé; ouverture buccale garnie de trois ou quatre paires de tentacules.

Coquille suborbiculaire on transverse, équivalve, inéquilatérale, non baillante, le plus souvent garuie de côtes ou de stries rayounantes du sommet a la base; deux dents cardinales, la postérieure toujours oblique sous le corselet, l'antérieure quelquefors oblique comme 
la première, quelquefois droite, quelquefois avorlće.

Par les modifications que nous avons apportées dans les caractères du genre, les Véméricardes peuvent très-bien y être introduites, et nous le laisons avec d'autaot plus de conliance que nous savons par Poli lui-même que les Cardites qui ont les deux dents cardinales obliques ont les animaux semblables à celles qui ont la dent antérieure droite ou aulle. Les deux animaux quil a décrits appartiennent, l'un an Condita sulcata Brug., qui est une vérilable Vúnericarde de M. Latnarck, et l'uutre au Cardita squamosa Jaank., qui est au contraire une Cardite de cet auleur.

La forme des Cardites est variable, plusieurs sont grandes, suborbiculaires, d'autres sont un jeu plus transverses et obliques, et d'autres cafin sont tont-à-fait iransverses, prennent la forme des Modioles, et sont par conséquent très-iuéquilatérales : en général plus les espèces deviennent trausverses, et plus la dent antérieure devient droite ou s'avorte. A l'exception d'un très-petit nombre d'espères, et nons a'en connuissons encore qu'nne seule qu'on doive excepter, toutes sont couverles de côtes plus ou moins numbreuses, tantôt lisses, le plus sonvent écailleuses ou noduleuses : en abontissant sur le bord des valves elles le découpe en uombre égal de crénelures qu'il exisie de côtes. En général les espèces du genre Cardite sont épaisses, solides, bombées, subcordiformes; les crochets sont souvent grands, proéminens, renversés sur une lunuie presque toujours profonde. Ce genire contient un tort grand nombre d'espèces fossiles, presque toutes des terrains tertiaires; quelquesunes offirent de l'intérêt par la manière dont elles sont répandues daus cerlaines couches avec proIusion. Nous diviserous tontes les espèces, dont nous avons plus de cinquante sous les yeux, en plusieurs groupes, de la manière suivante :

\section{A. Bords crénelés.}

10. Espèces dont les deux dents cardinales sont obliques (genre Véuéricarde Lamk.). $2^{n}$. Espèces transverses très-inéquilatérales, la
dent antérieure nulle ou droite.

B. Bords entiers.

30. Espices modioliformes, ies deux dents cardinales rupprochées et obliques, lisses ou presque lisses.

Nous n'avons pas l'intention de décrire tontes les espèces de Cardites que nous connoissons; nous renverrons d'abord le lecteur aux descriplions de Bruguière. A l'article Cardite du premier volume de ce Dictionnaire les espèces sui- vantes lui seront suffisamment connues. Carmite cannelée, Cardita sulcata, $10^{\circ} .3$; Candite ajar, Cardita ajar, no. 4; Candrte trapézoïde, Cardita trapezia, no. 5 ( Encyclop.pl. 234, fig. 7); Cardite lachetée, Cardita variegatu, no. 6 (Cardita calyculata Lin. et Lamk., Encycl. pl. 233 , fig. 6); Caruite jeson, Cardita jeson, $\mathrm{n}^{\circ} \cdot 7$ (Cardita crassicosta Lamk., Encycl. pl. 234, fig. 5); Cardite chambrée, Cardita concamerata, $11^{\circ} .8$; Cardite brune, Candita semiorbiculatici, $\mathbf{n}^{\circ}$. Io (Cardita phrenetica Lamk. , Encycl.pl. 233, fig. 4); CARdite pétoncle, Cardita pectunculus, $\mathrm{n}^{\circ}$. 12 : c'est probablement la même espèce que la Cardita rufescens Lamk.; car cet autenr, sans citer Bruguière, indique la mème figure que lui dans Lister, mais avec $u$ point de doute. Les espèces que nous venous d'indiquer, appartenant pour le plus grand nombre à notre seconde section, et l'une d'elles à la troisième, nous nous attacberons principalement à la description de celles de la première, qui constituent le genre Vénéricarde des auteurs. Les Candita sulcata et ajar Brug. appartiennent à celte première section.

\section{A. Coquille à bords crénelés.}

I $^{\circ}$ Espèces dont les deux dents cardinales sont obliques (genre Vénéricarde Lamk.).

\section{Candite bicolore. Cardita bicolor. Lamx.}

C. testâ ovatâ, condiformi, turgidulâ, albâ, maculis nufis irregulariter sparsis rotatá; costis latis, lowibus, antice rugis, transversis, subsquamosis; cardine altero brdentato.

LAMk. Anim. s. vert. tom. 6. pag. 23. no. 10. ENCYCLOpÉDIe, pl. 233. fig. 3.

Il n'est pas étonnant que rapportant la figure de cette espèce au Cardita sulcata Brug., M. Lamarck ne trouvant que fort peu d'accord, lui ait donné l'épilhète de mauvaise. Il est vrai cependant que la figure de l'Encyclopédie est fort bonne, seulement il falloit la rapporter à l'espèce qu'elle représente.

Cetle coquille est ovalaire, subtransverse, cordiforme, enflée, garnie de vingt à vingt-deux côtes longitudioales, convexes, larges, lisses, si ce v'esi les autérieures qui sont chargées de petits tubercules transverses, subsquammeux. Les crochets sont grands et saillans, obliquement recourbés sur une lunule petite et profonde. Les bords sont crénelés, mais le postérieur l'est beaucoup moins que les autres, ce qui vient de ce que les côtes postérieures sont moins grosses que les autres. Le bord cardinal est étroit, sur la valve droite il porte une seule dent cardinale trèsoblique et fort longue; sur la gauche, il y a deux dents séparées par une losselle très-large et trèslongue pour recevoir la dent de l'autre valve; 
la dent postéricure est mioce et fort longue, l'anréricure oblique, trigone, est très-courte. En dedans celte coquille est d'uo blanc laiteux; en dehor's elle est couverte d'un épiderme brua, au-dessous duquel elle est blanche, et parsenrée irrégulièrement de taches carrées, fauvefoncé, toujours sur les côtes les intervalles restant blanc.

On ne trouve pas fréqueumznt celle coquille: les plus grands individus ont 40 millinede long et 50 de large. M. de Blosville, officier de marine, a trouvé des valves détacliées de cette espèce à Ceylan : il n'eft pas douteux ıpue c'est de là que provienneut les individus complets yue nous a vons rus, ou que aous possédons sans indication de patrie.

2. Cardite déprimée. Cardita depressa. Lanx.

C. testâ obliquâ, orali, depressâ, alîa ; costis confertis, latis, convexa depressis, postice absoletis; lunulà minimâ, angustissiniâ.

Lam. Anim. sans vert. tom. 6. pag. 23. $n^{\circ} .11$.

Var. B. Fossilis. Noв.) Testâ minis obliquâ, turgidiore.

M. Lamarck a établi celte espèce sur deux valves roulées, rapportées par Péron : ces valves, qut nous avoos sous les yeux, sont toutes deux du côté gauche; elles sont ovales, transverses, obliqques, très-inéquilatérales, comprimées, assez épaisses et solides: elles sout couvertes de seize ou dix-sept côtes, larges, convexes, peu saillantes, serrées, séparées par on sillon étroit et siasple; elles sont lisses, et les postérieures beaucoup moins élevées et plus étroites sont presque effacées. Les crocbets sont pen saillans, et la luvule sur laquelle ils s'ioclineat est cordiforme, très-étroile et très-courte La charnière peu large oflie deux dents cardiuales obliques, médiocres, séparées par une fossette triangulaire fort grande, dans laquelle doit s'insérer la dent cardinale de la valve droile que nous ne connoissnns pas. Ces valves étant roulées sont toutes bianches en dehors et en dedans; il n'est pas à dire cependant qu'elles fusseat originairemea dépourvues de conleur.

Nous rapporterons à cette espèce, à titre de variété, des valves fossiles des faluns de la 'Touraine, qui ne nous ont oliert que de très-foibles dillérences : nous les considérons comme subaualogues ì l'espèce vivante; elles sont un peu moins déprimées, un pen moins obliques, et par suite un peu moins inéquilatérales; les côtes sont semblables, mais il y en a une on deux de plus, tous les autres caractères restent absolument semblables. Longueur 26 millim., largeur 35 . Les fos. siles sont un peu plus grands.
3. Candite enlíe. Carlila turgida. Lauk.

C. testâ ovato-transversâa, obliquâ, cordatâ, tumidâ, fulvâ; latere antico brevissimo, obtuso; costis longitudinalibus, convexis, crenatis; lunulî minimâ, condatî̀, profundâ.

LasI . loc. cit. pag. 22, $n^{\circ}, 3$.

Ceennitz, Conch. cab. tom. 7. tab. 48. fig. 490.49 i.

La figure 2 de la planche 233 de l'Encyclopédıe, que M. Lamarck iudique comme représentant mal celte espèce, ne lui appartient en aucune manière : nous peusons qu'elle convieut plutôt à la Cardite ajar, dont elle présente la forme et les divers caractères extérieurs. La Cardite enflée est ovale, transverse, lrc̀s-inéquilätérale, très-gontlée, cordiforme, épaisse, solide, à crochets saillans, obliquemeut recuurbés sur la lunule; celle-ci est cordiforme, profonde, aussi large que haute; des sommets partent en rayonnant seize à dix-sept côtes, saillantes, arrondies, séparées les unes des autres par des sillons assez lal'ges et profouds, à l'exception des quatre ou cinq dernières qui se touchent; res côtes sont chargées de tubercules transverses, peu régaliers, obtus et arrondis. Le côté antérieur de celte coquille est très-court et arrondi; il dépasse peu les crochets. Les bords des valves sont fortement crénelés, le bord cardiual est assez étroit; il porte sur la valve gauche deux deats obliques, d'un volume médiocre, séparćes par une large tos. selle; la valve droite n'a qu'une seule dent fort longue, elle est reçue dans la fossette de l'autre valve. En dehors cette coqualle est partunt d'un fauve-lırunâtre, avec quelques fascies transverses plus foncées : elle est longue de 32 millim. et large de 47. Elle vien: des ner's de l'Inde, d'après M. Lamarck.

4. Cardite de Jounnnet. Cardita Jouanneti. Noв.

C. testâ ovato-lransversâ, obliquâ, cordatâ, turgidulâ; costis conferlis, planiusculis, latis; lunulâ profundissimấ, cordatâ, sulco profundo separatâ. Nов.

I'cnericardia Jouanneti, BAst. Bassin tert. du sud-ouest de la france. Mlém. de la Soc. d'hist. nat. de Paris. tom. 2. pl. 5. fg. 3.

Grande et belle coquille, oblique, cordiforme, transverse, inéquilatérale, subovale, beaucoup plus arrondie antérieurement que postérieurement, épaisse, solicle, couverte de vingt còtes arrondies peu saillantes, lisses, si ce n'esi sur jes crochets où elles sont légèremeat tuberculeuses: elles sout séparées par un sillon étroit. Dans les vieux sadividus cette coquille est strice en travers, seulemen! vers les bords des valves; ceux-ci sont largement crénelés, mais peu profondément : 
les crochets sont saillans, obliques, très-rapprochés; la lunule est cordiforme, très-profondément enfoncée sous les crochets, et séparée du reste par un sillon très-profond; la charnière est large et très-forte dans les moyens d'union; il y a deux dents cardiaales sur chaque valve, et le ligameat étoit supporté par des nymphes trèsépaisses et fort solides; sur l'une et l'autre valve la dent postérieure est striće ed travers sur une de ses faces seulement.

Celte coquille ne s'est encore trouvée que fossile : elle se trouve en Italie, aux environs de Vicnne ell Autriche, et aux environs de Bordeaux, et surtout à Salles, cù elle paroit fort commune. Les plus grands individus on 50 millin. de long et 75 de large. Nos.

\section{CARDIte à côtes plates. Cardita planicosta.}

C. testá ovato-obliqui, condatá, crassissimâ, longitudinaliter costats; costis planulatis; apice aliquantisper granulutis; lunula profundissmi , latu, condata; margine crenato; dentibus cardinalibus binis tenuissimè striatis.

fír. , Petrif. part. 2. tab. 23. fig. 5.

SEв. , Thes pl. 106. fig. 36.

I'enericurdiu planicosta, Layr. Ann. du Mus. tom. 7. pag. 55 ; et tom. 9. pl. 51. frg. 10.

Ibia. Anim. sans zert. tom. 5. pag. 669. no. 1 . SUWErsy, Min. conch. pl. 5o.

Venericundia planicusta nobis : Descrip. des coq. foss. des env. de Paris, tom. 1. pag. 149. pl. 24. fig. 1.2. 3 .

Cette grande et bclie coquille se reconnoit arec la plus grande facilité : elle est presque aussi longue que large, fort oblique, ea caur; les deux crocbets sont grands, saillans, inclinés l'un vers l'autre sans se toncher, au-dessus d'une luaule cordiforwe, profonde, plus large que laaute, séparée par un sillon profond. La surtace extérjeure est courezte par vingt-cinq ou trente cótes aplaties, peu saillantes, plus aiguës sur les crochets, et s'aplatissant insensiblemen (jusque vers les bords oì elles disparoissent : dans les vieus individus elles sont remplacées par des stries transverses, nombreuses, irrégulières qui iodiquent les accroissemens de la coquille. La lame cardinale est large, solide, épaisse : elle poite sur la valve droite denx deuts obliques, dont la postérieure se confond en parlie aree la nymphe; sur la valve gauche la dent antérieure est plus courte, et In nostérienre entièrement séparée de la nymphe: ces dents cardinales sont striées latéralemeot. Les impreisions musculaires sont grandes, et quelquefois assez profondes : au-dessus de l'aatérieure (in en remarque une troisicme petite, à l'origine du loord antérieur de la lame cardinale. Tout le bord est crénelé, mais les crénelures sont peu saillantes; il y en a autant que de cótes.

Cette coquille, connue à l'état fossile, se rencontre en abondance aux envirnos de l'aris, à Grignon, Parnes, Valmondois, etc., etc.; elle se tronve aussi en Angleterre ct en Belgique, aux portes de Gand; M. Lamarck la cile dans le l'iémont \& aux environs de Plaisance : nuas avons cherché à nous assurer de la réalité de ces indications \& nous sommes persuadés que MI. Lamarck aété trompé. Longueur 9 cent., largeur 10.

6. Cardite pétonculaire. Cardita pectuncularis.

C. testî orbiculari, mugná, subaqquilaterá; costis latis, depressis, obtusis, luterahbus muricatis.

Venericandia pectunculuris, Lask. Ann. du Mus. loc, cit. $n^{\circ} .6$.

Ibid. Arim. s. vert. loc. cit. $n^{\circ} .2$.

Venericurdic pectuncularis, Ков. descript. loc. cit. $n^{\circ} \cdot 2$.

Vénus de l'Oise, Cанввт, du département de l'Oise, pl. 7. fig. 1.

Celte coquille est la plus grande connue dans le genrc; elle a assez bien la forme d'un grand pétoncle; elle est presqu'équlatérale, orbiculaire, aussi longue que large, présentant extérienrement vingl-quatre ou vingt-six rôtes peu saillantes, arrondies, obtuses, plus aplaties vers les bords que sur les crochets. Antérieurement, ces còtes sont imbriquées un muriquées \& elles sont doubles, c'est-à-dire, qu'il semble qu'il y en ait uue plus petile posće sur le wilieu d'une plus large; deux on trois des postérieures sont tuberculeuses, mais irrégulièrement; les crochets sont petits, peu saillans, fortement inclinés l'un vers l'autre, et se tauchent lorsque les deux valves sont réunies. La charnière es: supportće par une lame cardinale, large et fort épaisse, à l'extrémité de laquelle se voit la troisième impressiou musculaire qui est oralaite et profonde. Les denis cardinales sont grandes et fortes, il y $\mathrm{en}$. a deux sur la valve gauche \& une seule, trèsgrande et fort large, sur la droite; une autre poslérieure, reste arortée et canlandue avec la aymphe. On conpte sur le bord des valres autant de crénelures larges et peu profondes, qu'il $y$ a de cótes à l'extérieur.

La Ténéricarde pétonculaire n'est conaue que foffile et aux environs de Paris, seulement dans les sables de Bracbeux et de Noailles, nou loin de Beauvais. Elle est longue de ro contim. et large de 10 et demi.

7. Cardite à côtes nombreuses. Candita multicosiata. Nos.

C. lestí subrotundatá, obliqué cordatá, crassá, 
multicostali; costis converis, scparutis, nodulnsis, antice bipartntis; umbonibus magnis, recunvis; lunulá mininấ, triangulari, prefuntdissimâ.

Tenericardic multicostata, Lauк. Ann. du Nus. loc. cit. $\pi^{\circ}: 2$.

Quoiqu'ayant des rapports avec les denx prérédentes espèces, celle-ci s'en distinguc cependant assez facilement; sa taille n'acquiert jamais le même développemen:; elle est suborbiculaire, oblique, cordiforme, enllée, garnie extérieurement de vingt-huit i treute côtes serrées, séparées prar un sillon profond et étroit; elles sont conrexes, mais en appruchant des croctsels elles deviennent peu ì peu anguleuses, et le sont tout-à-fatil sur cette partie. Lè côtes qui se voient sur la partie antérieure de la coquille, sınt beaucuup plus aplaties que les autres et divisées en denx par un petit sillun peu profond; quelquefois il $\mathrm{y}$ cu a deux et alors la coute est partagéte en trois; loutes les côtes sont uberculeuses; les tubercules sunt iransverses, plus ou moins saillans uu nombreax, setun les individas. Dans le jenne âge, ces iuberi:ules sont subsquamıneux et imbriqués; la lunule est petile, ties-profonde, triangulaire, elle ne se partage pas en deux paries freses sur claque valve, la valve droite la porte presque tout entière. Ia lame cardinale est large et épaisse; elle présente sur la valve garchie deux dents épraisses, striées finement, sur la face latérale et postéricure seulement. La valve droite présente aussi deux dents, mais la postérieure, avortće, se cantond avec la nymphe.

Cost daus les sables d'Ahhecourt, de Noailles et de Bracheux que l'on trouve celle coquille, dont les grands individus out 67 millim. de longneur et 70 de large.

8: Cardite imbriquée. Candila imbricala. BuAist.

C. testâ suborbiculutâ, cordiformi, subobliquâ; costis numerosis, convexis, profundd separutis, imbricato-squamosis; linulà profundissina obliquâ.

Lister, Conch. tab. $497 \cdot$ fig. 52.

SEBA, Thes. pl. 106. fig. 39.40 ?

Chemnitz, Conch. cab. tom. 6. tab. 30. fig. 314. 315.

Venus imbricata, Liv. Guen. pag. 3277. $n^{\circ} .34$.

Vénus Encyclopédie, pl. 274. fig. 4.a. b.

Venericundia imbricata, Lamk. Ann. du Mus. loc. cit. $n^{\circ} \cdot \cdot 3$.; et tom. 9. pl. 32. fig. I.

Ibid. Anim. s. vert. tom. 5. pag. 610. no. 3.

Ibid. Non. Descript. des coq. foss. des environ de Paris, pl. 24. fig. 45.

\section{Brasw. Trait. de Malac. pl. 68. fig. 3.}

Purmi les coquilles assiles des environs de Paris, il u'y eu a guère de plus communes que: celle-ci; aussi est-ce une des plus anciennement figurées: elle l'a été d'uoe manière bien reconnoissable par Lister, puis par Seba, mais trèsmal; enfin par Matini, Bruguière, etc. Cette coquille est orbiculaire, peu oblique, corliforme, enllẹe; le test en est épais, solide, extéricurement recouvert de cútes nombreuses, serrées, séparées par des sillons étroits el profonds; elles sout convexes et chargćes d'écuilles tuilées, se reculvirant; postéricurement, les côtes sont moins larges, plus tranchantes, et sout armées de tubercules en dents de scie; les crochers sont peu ubliques, assez saillans, inclinés sur une !naule trc̀s-petite et obliquement enfoncéc au-dessons d'eux. Les dents de la charnière sont disposies de la même manière que dans l'espéce précédente; elles sont stricies très-finement en travers et sur les deux côtés; les bords sont fortement découpés par des crénelures, en nombre égal aux cóles de l'extérieur. Celle coquille est extrêmenient commune dans tons les calcaires grossiers du bassin de Paris, à Grignon, l'arnes, Iiancourt, Monchy, Saint-Félix, Montmirail, Courtagnon, elc.; "t ̀े Orglandes, près Valogne. Les plus grands individus on! 45 milliun. de longueur et 43 de large.

9. Cardite à côtes étroites. Cardila angusticusta. ов.

C. testầ suborbiculatî, obliquá, tumidì, cordiformi, crebricostatî, costis angustis triangularibus, squamoso-serratis, anticis duplicatis; lunulì mediocri, griblosa, non excavatâ.

A peu près de la arêne taille que la précéderte, celle-ci ne sauroit se conlondre avec elle; elle est suborbiculaire, oblique, enllée, corditorme; son test est assez mince, et la cavité des valves plus profonde proportionnellement que dans les antres espices. Ia surface extérieure est chargée d'un grand nombre de côles étroites, triangulaires, trancluantes, prolonclément séparées par des sillons en goultière; ces côtes, bipartites antérieurement, sont Iranchantes et terminces par des écailles subimbriquées, et en dents de scie plus saillantes et plos grandes postérieurement; les crochets sont saillans, obliques, recourbés l'un vers l'autre au-dessus d'une luaule cordiforme, aussi large que haute, convexe, bossue, superficielle, non enfoncée comme dans les espèces précédentes; la lame cardinale est courte et étroite; elle présente sur la valve droite une seule dent triangulaire, fort oblique, à peine si la dent postéricure se distingue de la nymplue; el sur la valve gauche on remarque deux dents obliques, dont la postérieure est très-étroite. Le bord esi profondément crénelé; les crénelures sont trian- 
gulaires et se prolongent peu à peu à l'intérienr des valves. Les impressions musculaires sont superficielles, et à peine si l'on peut apercevoir limpression du manteau.

On trouve cette espèce aux environs de Paris, à Grignon, la ferme de l'Orme, Parnes et Chaumont. Elle a 37 millim. de long et $4 \mathrm{r}$ de large.

ro. Candits à côtes aiguës. Cardita acuticosta. Nob.

C. testâ rotundatî, subobliquâ, depressiusculâ, costatá; costis distantibus, angustis squamosonodosis; cardine unidentato, altero bidentato; margine undato-crenulari.

Vonericandia acuticosta, LaMr. Ann. du Mus. loc. cit. $n^{\circ} .4$.; èt tom. 9. pl. 32. fig. 2. a. b.

lbid. Anim. s. vert. loc. cit. no. 5.

Var. B. Non. Testâ tumidiore, crassiore, costis angustioribus.

Var. C. Nos. test î obliquiore, costis numerosioribus, gramulatis.

Coquille assez variable, orbiculaire, déprimée, peu épaisse en générul, inéquilatérale, peu oblique, cordiforme; elle est couverte de cốtes rayonnantes au nombre de dix-hnit à vingt-deux; cés côtes sont distututes, aiguës, étroites, écuilleuses, en dents de scie, peu élevées. Sur les bords, ces côtes correspondent à autant de créselures larges, peu profondes et onduleuses. Oa remarque entre les côtes, outre des accroissemens bien marqués, des stries très-fines, régulières vers les crochets, et plus irrégulières et onduleuses vers les bords. Le crachet est petit, peu saillant; il se racourbe au-dessus d'une luaule cordiforme pen enfoncée; la lame cardinale est étroite; elle présente une seule dent sur la valve droite et deux sur la valve gauche; l'antérieure est petite, conique, oblique; la postérieure, fort étroite, se conlond en fartie avec la nymple, it laquelle elle est adossée.

Notre première variété a son test beaucoup plus épais et plus solide; la coquille est plus obliçne et plus enflée; sa lame cardinale est plus largé et ses côtes plus étroites. lá seconde variété est un peu plus ovale et plus oblique; ses côtes soṇt plus nombreuses, plus searées, et les écailles sont plus épaisses et presque changées en tubercules. Nous connoissons cette cspèce fossile dans le bassin de Paris semlement, à Grignon, Chaumout, Parnes, la Clapeile près Seulis, Beauchamps, Pontoise et Valmondois. Longueur 32 millim., lurgeur 30.

\section{$2^{\circ}$. Espèces dont la dent antérieure est droite ou nulle.}

Nous avons terminé la première section avec une espèce sur laquelle on observe déjà une anomalie qui la rapproche de celle-ci; elle n'a plus qn'uue dent sur l'une des valves. Les espèces décrites par Bruguière appartiennent à cette section. A ces espèces bien connues, nous en ajouterons plusieurs qui méritent d'être mentionnées, soit parce qu'elles se trouvent dans nos mers, soit parce qu'elles ont leur analogne fossile loin du lieu où elles vivent actuetlement.

11. CARD1TE intermédiaire. Cardita intem media. LAmk.

C. test $\hat{\imath}$ ovato-transversâ, cordatâ, turgidá, incequilaterali, costatá; costis separatis, rotundatis, crenatis antice, bisulcatis laterahter; latere antico brevissimo.

Lasix. Anim. sans vert. tom. 6. pag. 23. $n^{\circ} .6$.

- Chama internedia, Broccur, Cancl. foss. subap. pag. 520. pl. 12. fig. 15.

Venericardia intermedia, Bast. Bass. tert. dn sud-ouest de la lirince, Mém. de la Soc. d'Hist. nat. de Puris, tom. 2. pag. $8 \mathrm{o} . n^{\circ} .3$.

Coquille fort remarguable, en ce. qu'elle se tronve fossile dans presque tous les terrainstertiaires de l'ltalic, et vivante dans les mer de la Nouvelle-Hollande. Nous pouvons constater celle ideulité, dont on a fort peu d'exemples dans des mers si éloignées, avec d'autant plus de facilité que nous avons sous les yeux les deux valves détacbées de la collection du Muséum, les seules connues vivantes, el que nous pouvons les coulparer avec onze individus fossiles, de dillérens lienx de l'Italie. Celte comparaison nous conduit à dire que l'identité est parfaite.

Lil Cardite intermédiaire est ovale, oblongue, trcss-oblique, transverse, renflíe, cordiforme, se rapprochant sous ce rapport de certaines $\mathrm{Bu}$ cardes; le test des individus adultes est épais, fort solide; les crochets sont très-protubérans, fortement inclinés; il en part en rayounant dixhuit à viugt côtes arrondies, bien séparées, larges à la base, tuberculeuses; les antéricures sont divisées en trois patties, par une stric de chaque cóté à la base des tubercules; les postérieures non divisécs, sont plus étroites, les nodosités souvent ellacées, \& quelquelois, surtont dans les jennes individus, elles sont écailleuses et tuilées. Lu lunule n'est pas enfoncée; elle est cordiforme, lisse et assez grande. La charnière est partíe par une lame cardinale étroite, coudće dans son milieu; noe seule dent cardiuale se voit à la valve droite; elle est longue, courbée, conique, épaisse : sur la valve gauche il en existe deux, l'antéricure est couique, petite, obliquement inclinée en avant ; la postérieure est mince, longue et dirigée en arrière. Dans les jeunes iudividurs on remarque une petite dent latérale a l'origine de la lanule. La coquille vivante a'a pas plus de couleur que les analogues foșsiles; elle est d'un 


\section{$C A R$}

gris-hlanchátre, ce qui provient vraisemblablement de ce qu'ello est restée long.temps sur la plane, expusće à tortes les vicissitudes atmospuériques; elle est pesante, transparente, son bord est en dedans dine conlcur janne de calcédoine et il eu a la translncidité. Cette coquille est longue de 35 millim. et large de 42 ; il $y$ a Aes individus un peu plus grands. Elle se trouveroit aussi fossile aux eavirons de Dax, d'après M. de Basterot.

12. Candrte grossière. Cardita crussa. Lastk.

C. testî ou'uto-transversi, obliquissimâ, tumidí, gibbosí, posticd subsinualí, costati; costis crussis, hatis, rolundutis, imbricatn-sipumosis; squamis obtusis; latero antico abbreviato; lunuli nulli.

Var. A. Testâ angustione, costis numerosiorious. NoB.

Yar. B. Testâ obliquion, vald sinuatâ.

Coquille fossile, remarquable par son abondauce dans les conches coquillières de la 'louraine; elle est noe de relies qui caractérisent le mienx cette localité si célèbre. Eille acquniert quelquelois un rolume considérable; elle est cordiforme, très-oblique, très-inéquilatérale, le crochẹt étaut à peine dépassé à l'extrémité antérieure. I.e ervehet est peu saillint, très-oilique, som sumnet s'incline sur l'urigine d'un sillon fort obliaue el très-profond, qui remplace la lunale; à l'extérieur, on compte treize a dix-huit côtes rasonuantes: les postérieures sont les plns larges, et elles rout graduelie ment en diminuint jusqu'à l'extrimité antérienre; ces cỏ!es postćrienres sont chargées l'ćcailles rares, alais épaisses et saillantes; les cóles moyennes sout lisses ou a peine tuberculeuses, landis que les antérieures sont courertes d'écailles droites, nombreuses, on de iubercules qui les représenteot. Le bord cardinal cst oblique, sinueux dans le milieu, portant sur la valve droite une seule grande dent oblique, séparée par one lussctle étroite et longue, d"une aymphe enfnncle au-dessous du bord du corselet et peu visitle an-dehors lorsque la coquille est fermée. I a valie nauche a une dent postérienre droite c: une dent antćrieure presque rudimentaire entre lesquelles existe une large losselte triangulaire daus larpuelle est reçue la dent de l'autre valve; 1. burd est crénelé el quelquefois subéchuncré vers le milieu, de manière à laisser un bâillenutnt lorigne les dinx valves, sont réunses.

Lod varié:í: A, que l'on tronve a Dax, esl plus Éroite, nojas ublique, suldétrugonale, alongée et buillante, comme si l'animal eút pousto un tysaus. La varifté I) ext plus large postérieurevieat qu'dulciriearenent, le hord infórieurest sinueux. Cenc coquille ste trouve fossile dans les faluns de I ' Touraine, a $D_{\alpha \lambda}$, et à $A s t i$, eu Italie. Auus en prosséclars uee valie que l'on nous a Histoire Nuturelle des Vors. Tonie II. assuré provenit des environs de Paris. Le plus grand individu que nous ayons vu a 60 unilin. de long et 80 de large.

13. Carditr citrine. Cardita citrina. Iank.

C. Lestâ ovato-transversâ, luteấ, obliquissimấ, longitudinaliter costatâ; costis in dorso latioribus, squamulosis; latere antico brepissimo; cardine angustissimo, unidentato.

Ladx. Anim. s. vert. loc. cit. $n^{\circ}, 21$.

Nous ne conmoissons de celte espèce que le seul individu de la colleclion du Muséum; il est petit, ovalaire, très-oblique, ayant assez de raf:ports avec les jeunes individus de l'espèce prícédente. Le crochet est Irès-petit, peu prononci, et fort oblique; il est au nivean du bord antérieur, qui est extrêmement court, ce quii rend cette coquille très-iuéquilatérale et presque modioliforme. En deliors, clle est d'un jaune citron et couverte de còtes longitudinales, dont les trois dorsales sont les plus larges; antérieurement it postérieurement elles sont plus étroites, et les écailles qu'on y remarque sont plus droiles et plus nombreuses que sur les côtes du milien. Lu dedans, celte corquille est blanc de lail; la charnière est très-étroite et n'a qu'une seule deat trèsoblique sur charque valve. On trouve celle coquillc à la Nouvelle-1 follande; cllc est large de 18 millínètres.

14. Cardite sinuée. Cardila sinuata. Lask.

C. testâ ovalo-transversâ, obliquissimâ, albidâ, lutere postico intus rufescent:; margine inferiore sinuato; costis crebris, imbricato-squamosis.

LamE. loc. cit. no. 18.

Tar. B. Ков. testâ magis sinuatâ, anticd subrostrulâ.

Cetle Cardite se distingue très-nettement de ses congénères, quoiqu'elle conserve la forne transverse et irès-oblique de la plupart des espices de celle section; elle se reconnoil par ses côtes au nombre de quioze ou dix-luit, plus larges et plas saillantes pustérieurement, et chargées d'écailles plus grandes et plus nombreuses que sur les côtes antérieures qui, aplaties et trauchanles; sont ou tuberculeuses on couvertes de petites écaillcs, selon les individus. Le crochet, gui est très-petit et fort oblique, est dépassé par l'extrémité da côlé antérieur; le bord inlérieur est quelquefois droit, mais le plus soureat il cst siaueux, exravé el tonjours crénelé. Le bord cardiual est assez ćiroit et truaqué postérieurement; il ne purte sur claque valve gu'une seule dent plus épaisse sur la droite. Eu dehors, cetre coquille est d'un blanc sale, et en dedans d'un blanc plus pur, si ce n'est postírieurement où elle est marqué d'une grande tache d'un brannoiratre. La variélé se distiague net:ensent par 
sa forme; elle est très-sinneuse dans le milieu, ce qui, en atrincissant l'extrémité antérieure, lui donne la forme d’un bec. Les individus de la variété sont plus petits et n’ont pas inujours la tache lamne intérieure. Nous croyons celte espèce de la . Iéditerranée; clle est large de 27 million.

15. Cardite hippope. Cardita hippopca. Bast.

C. testâ ovato-transwersâ, subequilaterâ, infatâ, duodecin costutú; cosís latis, distantibus, convexis, subtuberculosis, duobus posticalibus carinatis; candine angusto, unidentato, altero Bidcntato. К̄ов.

Basterot, Bass. terl. da sod-ouest de la France, Niém. de la Soc. d'hist. nat. de Paris, torn. 2. pag. $79 \cdot$ pl. 5. fig. 6.

Le nom que $\mathrm{N}$. de Basterot a donné à cette coquille indique la ressemblance que sa forme présente avec celle d'un Ilippope; on croiroit en effet que c'en cst nn en minialure. Les caractères ceperdant sont ceux des Cardites: ovale, oblougue, enflée, transrerse, celle coquille se distingue de toutes celles de la méme section en ce qu'elle est presque équilatérale, peu oblique, subcordiforme. Elle est munie à l'extérieur de douze ou treize côtes longitudiuales, convexes, séparies par les intervalles presque aussi larges qu'elle : elles sont légèrement tuberculeuses. The curselet est grand, séparé par une côte plus saillante et caréuée qui aboutit à l'angle inférieur el postérieur. La lunule est petite, arrondie, peu profonde; la charuière cst éroite, elle a une seule dent sur la valre droite et deux peities sur la gauche. Cette jolie coquille, fort rare, ne se trouve qu'à l'élat fossile aux convirons de Bordeaux, a Sancals, et anx environs de Dax. Elle ést longue de 20 millim. ct large de 30.

\section{Especes lisses, le bond entier.}

16. Caninte lisse. Cardila sublavigata. Lamz.

C. ¿esía ovuto-oblongấ, obliquá, depressâ, albo et rufo zonatâ, subradtiatá; striis transwersis tenuissimis; margine integerrimo.

Lsirk. Loc. cit. $n^{\circ}, 22$.

Celle coquille, avec Ja Cardite brune que Tirnguière a décrite dans le premier volume de ce Diclionnaire, sont les seules qui soicut déponrvucs dés côtes longitudinales que uous avons rewarquées sur toules les aulıes espèces. Celle-ci est ova!c-oblongue, tmusrerse, plus large postérieuremeat quantf́rjeuremeut; elle est irèsobliçue, el son crocbet petit et contourné s’incline fortement. II fau: regarder celte coquille it la loupe pour apercevoir les stries très-fines et transverses qui couvrent sa surface extérieure, qui est ornéc aussi de zones fauves el blanches irrégnlières, et de qnelque rayons blanchátres qui descendent da crochet sul la partie postírieure. En dedans, dans la cavité des crochets, on roit une grande tache fanve: le reste est blauc de lait arec quelques zones d'un faure peu foncé; les bords sont parfaitement lisses, linférieur est légèrement sinneus dans le milieu. La charničra est très-étroite el présente sur chaque valve denx très-petites deals.

Celte coquille, extrémement rare, vient de la collection du stathonder. On ne connoil encore que lindividu de la collection dis MInséuts: il est large de 20 cuillim. On ignore sa parrie.

\section{CARIXAIRE. Carinaria.}

On connnissoit les Carinajres avant que le genre en fút établi; la coquille seule étoit parvenue à la connoissance de Linné, qui, trompé par certains rapports, la plaça dans son genre l'alelle. Il oe falloit pas un examen bien approfondi pour s'apcrcevoir de l'erreur qui atoit conduit Lioné au faux rapprochement que nous vennns de signaler. Guclia, dans la treizième édition du Systema naturce, indiqua le premier un rajprnchement plus aiturel en confondant la Carinaire arec les Argonautes, sous le nou d"stgonauta vitreus. Brugnière, à l'arlicle $A_{R}$ goxiote de ce Dictionnaire, sans mentionner ce cluangement de Gmelin, persista à regarder celle corguille comme une Patelle; mais sou opiuion ne prévalut pas. MI. Lamark, en ćtablissant le geare dans le Systeme des Animaux sans vertébres ( 1801 ), le démembra des Argonautes et le laissa imaédialement à côté d'cux. Depuis re monent tous les zoologistes adoptèrent le genre Carinaire; mais tous de furent pas te l'avis de M. Lawarck, de le mellre en rapport avec les Argonautes.

Nous avoos vu qne les Aruonantes avoient '́té le sujet d'une vive et intéressante discission, qui toucbe dans sa solulica ana principes fouclawentaux de la scicuse. La division dopinions qui s'est élablie à celie occasion entre les zoologisles, a ea une grande influcnce sur lis classifiealiou de la Carianire et sur les rapports gu'on lui a assignés dans diverscs méthodes. Cenx qui out admis que l'animal de l'Argovaute est uc Cépbalopode ont dú cn éloigner considérablement Ja Caricaire, dont l'animal bien connu appartient à un tout autre ordre, tandis que ceux, au contraire, qui, avec M. de Blainville, professent une opinion toute diflérente, se trouvent entrainés tout naturellement au rapprochement de .11. Lamarck. Ce qu'il y a de remarquable dans les ouvrages de ce dernier auteur, si bien conar par la sagacité arec laquelle il ćlablissoit les rapprocheuens, cest que jumais il n'éloigna les Carinaires des Argonaures, bien cu'il conunt l'animal de la Carmaire el quail 


\section{$\mathrm{C} A \mathrm{R}$}

altribuât la coquille do l'Argonaute à un Cépbalopode.

Il est difficile, sans contredit, de justifier le rapprochement que .I. Limarck tit de l'ordic des Ilétéropodes avec les Céphalopodes; mais on peut le regarder comme le résultat d'une analogie quil rrayoit si naturelle qu'il be la dérruisit pas, malgré l'excmple yui lui en lut donnué plusieurs foss par d'autres zooloyistes; on pecut douc admettre que ce fait est plntôt fuvorable à l'opinion de M. de Blainville quà celle de ses adversaires, qui s'en sont pourtant servis contre lai.

L'animal de la Cariuaire fut trouvé el décrit pour la première fois par MJ. Bory de St. Viucent, dans sou Voyage aux quatre iles principales de l'Afrique. Depuis, une autre espèce fut trouvée dans la Méditerranée par Péron et Lcsueur, et elle devint le sujet d'un Mémoire qu'ils publièrent dans le tome is des Annales du MIuséum. Dans le mème tempis M. Cuvier décrivil aussi, daus les Annales du Mluséum, un genre qu'il nornma Plénotruchée, et gui n'est autre chese, de son aris, que le genre Carinaire, mais mutilé el saus mucléus. Malgré ceste circonstance délavorable, M. Cuvier put voir assez de l'orgauisation de l'auimal pour juger qu'il appartenoit aux Gastéropodes el non aux Ptéropodes. Nous faisons remarquer ce fail parce qu'ou l'a donné comıne nouveau dans ces derniers temps. La classification que M. Cuvier proposa pour la Carinaire dans le Regrne animal, est la conséquence de l'opinion que ce grand aaturaliste avoit manifestée à l'ćgard de la P'érotracliée. On trouve en effet la Cariuaire dans les Gastćropodes scutibranches, eatre les Navicelles el les Calyptrées.

Il n'est pas donteux qu'on ne puisse donner une place plus naturelle au geare qui nous occupe. W. Latreille n'essaya mếme pas de la trouver, car il reproduisit sans changernent, dans les $F_{C l-}$ milles naturelles du Regne animal, l’arrängement de M. Cuvier. Il n'en lut pas de mème de \$1. de Blaiuville, qui, possédant l'auimal catiel qui avoit servi à la description de P'ćron et Lesueur, pnuroit micux que personue déterminer la place de la Carinaire. On avoit recounn que le genre Firole de Péron et Lesueur, adopté par M. Lamarck et rous les naturalistes, n'étoit autre chose que la Pićrotrachée de Forskael et de Gmalin, et non me Carinaire mutilée, comme l'avoit préjugé M. Cuvier. Les rapports des deux genres sun tellement éridens fine porsonne ne put les rontcster. M. Lamarck, le premier, entraina les Firoles à Ia suite des Carinaires, et depuis cette époque le sort des deux geares devint semblable.

M. de Blainville partagea les Gastérópodes en plusieurs ordres; celui des Nucléobranches ( $\nu 0 \%$. oc mol) contient deux familles: la première, les
Neclopodes, coatient les geares Firole ef Carinaire; et la seconde, les Ptéropodes avec plusicurs grentes, oflire celui de l'Airgouaute que .11. de Blatirville, par une analogie autrement foudćc que celle de M. Lamarck, rapproche ainsi des Carinaires. M. de Blaiaville, dans son Traite de $M$ halacologie, souleva une autre question; il jugea, par analogie el d'ilurès la prosition des orgaues, que la Carinaire devoit nager, nos pas combe P'eron l'avoit dit lal coquille peudanle, mais dans un sens inverse, la porlant sur le dos et ayant la nageoine en bas. On ne pouvoit s'empêcher d'admettre la théurie; rependant des observations faites depuis sont contradıctoires: c'est ainsi que M. Custa, de Niples, qui a publié son observation dans les Annales des Sciences naturclles, dit avoir vu plusienrs jours une Cariuaise aageant dans la position que M. de Blainville indiçne, à priori. D'un autre côlé, M. Rang, éralenent dans les Ain:nales des Sciences naturelles, décri: une nourelle espèce qu'il a frouvéc dans les wers de liadagascall. Il dit en avoir olservé quatre individus pendan plusieurs lueures, et tous nageoien la coquille en dessnus, comme l'śron l'avoil dit. la inanière de aager, chez ces animaux, peut-elle dépendre de l'espèce? Cela n'est pas à présumer, du moins cela formeroit une caception unicjue parmi les Mollus jues. On duit concevoir l'embarras du naturaliste eatre deux opinions appuyćes l'une et l'autre sur des observations directes donućes par des hornmes également dignes de confiance.

On ue conncit pas encore tonle l'organisation des Carinaires; quelques détails uıt écé donnés par M. Cuvier el depuis lui, rien de complet n'a été présenté. Nous nous sommes occupé de ce sujet, el nous pouvons domer ici un extrait de nos obsetvations.

l’animal de la Carinaire est alongé, subfusiforme, un peu courbe sur lui-nièise antérieurement, ct plus épais dans son milieu; il est presyue lout gélatineux, subtransparent, chagriné au tuberculeux dans toute sou élendue; il est trongué antérieuremeut el tertainé ì sat partie postérieure par une sorte de quene aplatie, munie d'une nageoire dorsale dans coute sa longueur, el d'une autre beaucoup p)lus petite au-dessus; ces nageoires sont placées daus la ligne médiane de l'animal. A la réuniou du liers postérienr avec les deux liers antérieurs, on remarque un pédicule chatau qui supporte, dans la ligue médianc el dorsale de de l'animal, un assemblage d'organes recouverts d'une coquille extrèuement mince. On nomme nucléus-celle rénnion d'organes; nous y reviendrons plus taru. Dans la ligue aiédiane, ventrale et eu rpposition avec le nucléus, se voit une large nageoire charnue, coriace, fibreufe, aplatie, latéralement mince et tranchante sur les bords, et ayant à la partie inférieure et postérienre une ventouse qui sert à l'animal pour se fixer. Cet organe, d'un rouge pâle, est, on n'en pent douter; une $\mathrm{C} \mathrm{C}_{2}$ 
ınodification du pied des Gastéropodes, qui, étant destiné à la natation, a pris dans la Cariuzite une forme particulière, tout en conservant, par la partie que nous nomunus ventouse, les caractères da disque locomoleur des Gastéropodes.

La tête est tormée par deux parties cyliudriques, de diamètre diflérent; la plus petite, à l'extrémilé de laquelle est placée l'ouverure buccale, est enchâssée pour ainsi dire dans la plus grande, qui est forméce par la pean; à la jonction de la tête avec le corps et en dessus, on remarque deux longs tentacules pointus, dont la base s'insère dans uue légère duplicature de la peau, et qui portent à.la partie extérieure de leur insertion des yeux sessiles noir's assez grands et assez *ailluns. L'ouverture buccale est toul-ì-fitit terminale : ellc est à l'extrémité d'une masse charnue cylindroide, comme nous l'avous dit, qui est de ioules les parties de l'auimal la plas coriace et la plus solide; lorsque l'auional est contracté, cette masse rentre complélenrent en dedans; alors la tĉte, racrourcie considérablement, est réduite à l'une des parties cylind:iques. Cette masse boccale est d'un violet foncé, composée surtout de muscles disposés dans deux plans dillérens; le premier cxtérieur est formé de faisceaux longitudinaux parallèles qui s'insèrent autéricuremeat aı pourtour de l'ouverture buccale, et postéricurement se confondent avec le plan fibreux sous-cutané général, dont nous parlerons bientôt; ils s'y insèrent dans l'eudroit de l'étranglement yui sépare la tête du reste du corps. Ces muscles, qui forment aurour de la unasse buccale une sorte de tunique fibreuse, sont destinés à la faire rentrer en dedans : deux muscles postérieurs et latéraus s'attachent à la parie postérieure de la masse buccale, et se rendent à la partie antérienre de la peau; ils ont pour usage, sans aucun doute, de porter en avant l'ouveriure de la bouche. Les unuscles intrinsèques de celle partie forment deux nasses principales et latérales, d'où partent des muscles dans diverses directions : entre deux de ces muscles antérieurement el de chaque côté se voit l'iusertion des canaux salivaires placés su. les parties latérales de l'osopliage, se plongeant le long de l'estomac, et aboulissant à deux fort petites ylandes salivaites retenues daus l'abdomen par un tissu cellulaire, rare et lâche. L'œsophage lui-même part de la masse buccale, ayant de chaque côté les canaux salivaires dont nous vewons de parler : cet uesophage est très-mince et fort court; il se termine à un estomac cylindrique assez épais et coriace dars son état de vacuité, un peu plus gros qu'une plume de corbeau. Cet estomac, ainsi que la portion d'intestin qui en naît, et qui a uu diamètre beaucoup plas petit, est placé daos la ligne médiane : ils soxt par conséqueut pairs et symétriques; l'intestin grêle se dirige en ligne droite vers le pédicule qui supporte le nucléus. Ce pédicule est un cyliadre

\section{A R}

cont et creus; lintestin, accompagné de vaisseaux et de nerl's, $\bar{y}$ péuètre, passe à tiavers uı diaphragme musculaire sopérieur, et se rend ainsi dans le fuie, qui occupe toute la partic postéricure du nucléus et de la cognaille qui le recouvre. L'intestin eu arrivant dans le foie s'amincil considéraljlement; il fait dans ce vilcere plusieurs circonvolutions, pendant lestjuelles il reçoit, prar des cryptes bíans, la sécrélion de l'urgane qui l'enveluppe, et se termine par un anus un pen saillaut à la partie antérieure et gauclie du pédicule du nucléus, un peu en aviant du pli que produit son insertion sur le nuclétis.

Un appartil de mastication considérable, et d'une structure singulière, se trauve dans la masse charnue de la lête : cet appareil revếl l'intérieur de la louclie, il est formé de chaque côté d'uue sćrie, de vingt-quatre à trente raugfées de crochets cornés, assez longs, fort aigus, dout toutes les pointes sont dirigées en dedans; nae gonttière médiaue assez large sépare ces deux séries de crochets; le fond est couvert d'une série d'écailles cornées, tuilées et simples. Ces diverses parties s'iusdrent dans deux plaques cornées flexibles qui s'attachent aux deux masses musculaires, a leur tace interne. Cet apparcil, qui se termine antérieuremeot à l'ouverture de la bouclie, peut, à ce qu'il paruît, sortir en partie pour saisir la proie, et l'entrainer en la déchirant jusque dans l'oosophage, où elle ne pénc̀tre que broyée par ces mâchoires compliquées. On pourroit les comparer dans leur action à deux cardes mises en wouvement l'une contre l'autre.

Les organes de la circulation sout difficiles à étudier dans la Carinaire, à canse de lenr transparence el do lcur pen cle consistance. Le cœur, placé à la partie antérieure du nucléus, mais à droite, est petit, charmu, subgylobuleux, déprimé de haut en bas; à sa pirtie antérieure se voit une oreillette ablongue, mince, séparíe du ventricule par uu cour't étranglewent. Ces deux parties principales de l'appareil de la circulation sont contenues dans un vaste péricarde, dont les parois extrêmement minces laissen! facilement apercevoir le cœur. De ía partie postérieure du ventricule naît un tronc aorlique qui, avant de franclirir le pédicule dn nucléus, donne une petite branche à l'ovaire, et une autre plus grosse au foie, dont plusicurs rameaux se distriJuent sur les intcstins. Après avoir traversé le pédicule ce tronc donne une branche cutanće, postérieure, s'avance vers lintellin, suit sa direction, donne quelques rameaux à l'estomac, aux parties latérales de l'enveloppe commune, et gagne en se bifurquant les parties latérales de la lête, où il se distribue, ainsi qu'd la masse buccale. Le sang est repris par des veines d'nu tissu peu deuse, dont le tronc commun part de la partie postérieure de la masse buccale, descend dans la ligne médiaue jusque vess l'origine du 
pied, où il reçoil en divergeant plusicurs branches qui viennent les unes des parties latérales de l'enveloppe musculn-cutauce, et les autres de la parlie postérieurc. Le tronc principal, grossi de loules ces branches, pénèrre jusqu’à la partie auterieure du nucléus, où il forme un grand sinus veiveux qui sert de point d'insertion aux branchies : ce vaisseau forme un arc de cercle, sur lequel les feuillets branchiaux ne sont pas disposés, comme on yourroil le croire, d'une manière symétrique et cn nombre énal de chaque côté du nucléus, uais cumposemt dans leur enseable une branchie pectiaée, daut les feuillets sont assezzétroils el pendans. Le sung, après avoir parcouru les branchies, est repris par des reines pulmonaires gailient les feuillets branchianx enir'eux par le milieu : ces roines se réunissent cn un tronc commnn fort caurt, gui se jotte dans loreillette à l'entrémité antérieure. Ic sang ainsi vivifis rentre dans le ventricule, el de lì dans la circulation générale.

Des organes de la génération nous ue counnissons qu'un oraile d'un médiacre valuare, placé cutre le foie et le péricarde; l'oviducie est placé sur le bord antérieus, a l'endroil de l'insertion du 1)éricarde; après s'être un pen contourné il se dijige etr avaut et à gauche, et aboutit entre deux feuillets brauchiaux, où il se termiae par un petit tube llollaat. Lee système nerveux est considérable : on trouve deux petits ganglions asophagiens antérieurs, desquels partent des filets paur les diverses partics de la tète, pour les tentacules, et particuliercment pnur les yeux; deux lilets priacipaux descendent le long de l'estomac et de fintestin, et établissent une communication avec deus gauglions postérieurs : ceux-ci douneut des branches cutanés, latérales et postérieures, ainsi gue des tilets qui pénètrent dans le nucléus, en stivant linteflin.

Il eft facile de se convaincre, par ce qui prúcide, que toute l'organisation des Carinaires est celle des Gastéropodes monoïques; que cette organisation a été modifiée, il est vras, par cette circonstance particulière où se trouve l'auimal de nager loujours an lien de ramper cnume presque tous les Gastéropopes; wais walgré cello modificasion, on reconnoit sans peiuc le véritable type orgavique auquel les Cariuaires appaitiennent.

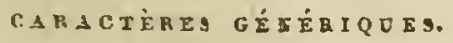

Animal : corps alangé, symb́riune, fusiforare, terminé antérieuremeut par une tête praloscidiforme, Ironquée, et follérieurement par une queue a platie coupce obliquement, et porlunt en dessus une nageoire verticale, $\&$ en dessous one autre beaucoup plus petite; nucléus enveloppé dans nn nanteau un peu lobé antérienrement, \& recouvert par une coquille très-mince; anus en avaat
\& à droile du pédicule du nucléus; ouverture de l'ovaire plus anterienre \& is gauche; pied comprimé en nagcoire, pourvu d'un disque postón rieur fort pelit servant de ventouse.

Coquille très-mince, transparente, ritrbe, cassaute, conique, compriméc latćralcment, éluréc, sommel poslćrienr un pen tourné en spirale, muaie sur le das d'une cricte dentce irèsmince; ontertare ovalaire, entière.

Arant de quitter la lićdilerranéc pour le grand vogage quil venoit d'entreprendre, M. Galymard, ayant observé la Cininaire, a voil essayécle donncr quelques détails analomiqnes, qui malbeureusement ne parraut citre que da fort peu d'utilité pour la scieuce : mampant sans daute des moyens dobservations, ce naluraliste, anquel la science est redevable de tant de travaux ntiles, s'est mépris au point de prendre l'estomac poar une nlande salivaire. Il est vrai qu'il ne le dic gu'avec doute : il donne d'uue manière isolée un système nervenx, dont la distribution ne coincide pas avec ('e que nous avons vu, et nous nous sommes derandé comment il se fuisoit que $M$, Gaymaril âvoil vu ce système, d'uilleurs clifficile à disséquer, dans des détails anssi minutieux que ceux qu'il dounc, et n’avoit, dans la même dissection, reconnu ni l'estomac, ni l'intesina. M. Gayraard a anssi donné des détails sur la struclure de la masse buccale \& de son armure, et mous y tronrous plusienrs choses qui ne sascordent en aucune manièrc avec ce que nous avons va: de sorte que nous croyons qu'il ne faut prendre le travail de M. Gaymard qu'avec une extrême réserve.

La Carinaire, dont on ne conuoil encore que trois espeeces, est un animal qui vit dans les hautes mers; prescque toujours bageant, il ne se repose que rarement en se lixant, à l'aide de la ventonse de sou pied, an fucus natans, ou à d'autres corps flottant à la surface de l'ean. Il paroît se nourrir de matières animales : on ne sait rien du reste sur ses meurs el sa repruduction. La coquille gui reconvre son pucléus est tellement mince et fragile qu'elle se brise au moindre cloc: aussi est-il irès-difficile el très-rare d'en avoic d'entières. Cette coquille ne porte aucuue trace d'impression musculaire : nous pensons cependant que le manteau, épaissi antérienrement, s'y attache par des libres musculaires, car nons avons détaché avec beaucoup plus de peine de celle partie des fiagmens de test que des autres points du nucléus.

1. Carisabre vitréo. Carinaria vitrea. Lanx.

C. testâ tenui, hynlinầ, transpersìn sulcatì; dorso carinâ dentalâ instructo; spirâ conoidea altenuatâ; apice minimo, involuto; apcrtur. versus carinam angustati. 
Lars. Anim. sans verț. 2om. 7. pag. $67 \overline{3}$. $n^{\circ}$. 1 .

Patolla cristates, Lix. Grex. pag. 3710. $n^{\circ} \cdot 96$.

Argonauta vitreus, ibid. fag. 3568. $n^{\circ} .2$.

Datertile, Conch. append.pl. I.fig. B.

Favavie, Conch.pl. 7. fig. C 2.

Martwi, Conch. cab. tom. 1. tab. 18. fig. 163.

Cettc cogruille est la plus rare et la plus précieuse de celles qui sont connues : on n'en compte que trois ou quatre dans les collections de lEurope, et elles ont une haute valeur dans le commerce. Le Muséum de Paris en possède un trèsbel exeroplaiı, qui fut donné par M. de la Réveillère-Lépaux, qui la tenoit a:ec des recommandations spéciales de M. IIuon, qui apres la zaort d'Entrecasteaux commanda l'es pédition qui alla à la recherche de Lapeyrouse. Celle coquille est assez grande, transparente, us peu opaline, cannelée transversalement, très-régulièrement oruée sur le dos et dans la parlie médiane d'une crêtle festonnée très-mince et très-fragile. Soo sommet, incliné légèrement en arrière, devient lisse, et furme un tour de spire incliné à droite à son extrémité. l,ouverture occupe toute la base: efle est ovale, oblongue, arrondie postérieurement, angnleuse, ftioite antérieurement. Cette espèce, qui vit dans les mers de l'Inje et saus doule dans le grand Océan allaniqque, a 15 ou 18 lignnes de longueur à lá base.

2. Camisare de la Méditermuée. Carinatia mediterranea. Ков.

C. testầ tenuissinz $\hat{a}$, hyalinâ, conico-depressî, transversinn plicatí; carinâ elevatí, subdentata, dorsali munitâ; apice reflexo, spirali, lavigato.

Carinaria frugilis, Laмк. Anim. s. vert. loc. cit. $n^{\circ}, 2$ ?

Lesueve, Ann. du Mis. tom. 15. pl. 2. fig. I 5 .

Carinaria vitrea, Costs, Ann. des Scienc. nat. tom. 16. pl. 1 .

Carinaire de la lléditerraníe, Qcor el Garuan, Alın. des Scrienc. nat. tom. 16. pl. 2.

ExcrсLOpÉde, pl. 464. fig. 3.

An eadem? Bohr de Sarxit-Tixcext, Voy. aux illes d'Afr. tom. 1. pl. 6. fig. 4 .

Nous avons dî citer M. Lamarck avec doute, puisqu'il dit dans sa phrase caractélisingue, que la Carinaire fragile a'a point de carene dorsale; cependant, dans sa synonymie, il cite des ligures aù cette espèce est représentéc arec cette parlie. M. Lamarck a été couduit a cette contradiction par la fignte el la description de l'espico tinuvie dans les mers d'Afrique par M. Bory de SaintVineent, qui pourroit peut-être présenter des caractères spécifiques particuliers, co que nous ne saurions dire positivement, puisque nous n'avuns pu comparer les individus de l'Afrique et de la isediterrance. Si l'on arrive plus tard a décider cette question, de manière is séparer eu deux espèces ce qre nous réunissons en une, il est certain qu'il faudra exclure de la synonycaie de celle-ei, les dens auteurs que zous renons de cites. C'est par erreur que Bi. Costa a donné le nora de Carincine vitrée à celte coquille; celle quil a représentéte appartient bien évidemment a celle - ci.

Mloins rare que la précédente, elle est cependant fort préciense, son extrême fragilité la rendunt exirônement difficilo à recueillir et à dótaclier de l'azimal sans la briser. L'animal est celui rgui a servi a la lescription que nons avons laite et aux recherches anatomiques dont nous a vous donné l'extrait; il est donc inutile de répéter ici ce cule nous avons dit aillears. Quant à la coquille, ello est consiamment beaucoup plns petite que la précéderie; elle est moins élevéo perpendiculaircreat, relativement à la largenr de la base; le sommet, olliquement incliné es arrière, tombe assez bas vers le bord; il devient lisse, sincliue à droite et courae en spirale. Une carène élérgante, saillante, très-raince, un peu dentelée, ist placée sur la partie médiane et dorsale depuis la base jusque près du sommel. Cette cocruille est beaucoup plus mince que la vitrie; elle est d'uce fragilité telle yu'à peiue on pear la toucher sans la briser, sa substance étant vitıense et sans élusticité. Eille a 20 à 22 milliro. de longueur à la base et 12 ì 14 millim. de hauleur.

I, Carinaire gondole Lamk. ne nous est pas sufisamraent connue, non plus gue la Carinaire déprimée de H. Rang, que nous n'avons jauais rue et que nous ue conooissons que par la seule phrase calactéristique qu'il eu a donnée dans le tome 16 des Annules des Sciences naturelles.

\section{CAROCOLLE. Camcolla.}

Ce genre, institué par M. Lamarck poor les Hélices dont le dernier tour es! anguleux, ne pouvoit ètre adopté, reposant uniquement sur cc caractère de fort peu de valeur. Voyez Ilézice.

\section{CARREAU. Fulgur.}

Genre que Montfort a démembré des Pyrules, et qui sercit, selon lui, intermédiaire entre ce genre et les lasciolaires; mais les caractères qu'.l lui donne sent de-juu d'importance, puisqu'il ne dillèré des Pyrules que par an pli columellaire ou plutót un cordon saillant qui termine 
la columelle à sa base: il u'a pu ctre adupté. Voyez Praule.

\section{CARYCHIE. Carjclium.}

Ce genre a été iutroduit par Muller dans la science; il contient deux fort pelites coquilles terrestres que la plupart des autenrs ont cunfondues parmi les Auricules. lilles n'en differcat pas assez notablemeat pour qu'on conserve ce genre. Vojez Auracule.

\section{C.ISQUE. Cassis.}

Ce genre ayant éte traité d'nne manièrc assez complète par Bragnidre, dansle premier volume de ce Diciionnaire, uons y renroznns le lecienr, en faisaut observer que, depuis, il. Lamarck en a exirait les Cassidaires ( voyea ce mot); et que, par suite de ce changernent, les espèces décrites sons les auméros 15.19 .20 .21 . appartiennent aux Cassidaires. Nuus en reparlerons en traitant de ce genre.

\section{C.ASSIDAIRE. Cassidaria.}

C'est en 1811 , pour la première fois, dans l'Extruit du Cours, que M. Lamarch Mroposa le renre Cassidaire. Montfort, il est vrai, l'avoit établi, quelques années avant, dans le second volume de son I'raité systématique des coquilles, el lui a roil donoé le nora de Heurslme (Morio), qui ne fut point adopté; celui que lui iruposa II. Lamarck, au contraire, fut saactionné par tous les anteurs quile suivirent.

Dís son origine, placé dans la famille des Purpuriferes, ionnédialement après les Casqucs, ce gente ne pouroit être mis dans de meilleurs rapports : ils furent conservés, soit qu'on ait gardé le genre, soit qu'on ne l'ait considéré que comme sous-genre des Casques. M. Cuvier, dans le Règne animal, ne l'a reçn qu'à ce titre; M. de Ferussac, dans ses Tublecux systématiques, a rassemblé, dans le grenre Pourpre, presque lon: les genres de la facille des Purpuriferes de M. Launarck, et en a fait autant de sous-genres : c'est ainsi que les Casques et les Cassidaires y furent crapris. Ce quil y a de parliculier et d’a peu près inexplicable pour nous, c'est que les Strubliolaires sont mises en rapport immédiat avec les Cassidaires, ce qui n'est point admissible.

MI. de Blainville (Truite de Maluc. pag. 401) se rapprocha davantage de NI. Lamarck; il adopta le genre Cassidaire, yn'il rangea à cuté des Casques, des Tonnes, des IInrpes, des IRicinules, etc. A l'exemple de M. Lumarck, il avoit séparé ce genre d'après la coquille; seulement, et peu de temps aprés, il put se convaincre qu'il y aroil dans l'opercule un orotif de plas, puisqu'il ne ressemble aucuuement à celui des Casques. II. Latreille, dans ses Fumilles matruelles du Regne animal, tit une famille dus Cassidites, dans laquelle il ne mit que trois genres, démemhrés des Purpurifères de M. Lamarck : ce sont, les Casques, les Cassidaires el les Riciaules. M. Lamarck avoit déjà, en quelque sorte, établi cetle farmille, ens síparant en deux sections celle des T'urpuriferes; dans l'une d'elles se trouvent les gearcs Casque et Cassidaire: la famille des Cassidites seroit, sclun nous, plus naturclle avec ces dellx genres, car le troisième a beaucoup plus de rapports arec les Pourpres.

Le genre Cassidaire, composé d'un fort petit nombre d'espèces, ne paruissoil pas susccptible de division. M. Sowerty cependant proposit daus son Generu de fuire, avec le Cassidarsu oniscus et quelques antres espèces analognies, un genre Ouiscic, Oniscia, que M. de Blainville n’a point admis, et que nous pe sommes disposé à adoper qu'autant que lauimal présentera des différences sulhisantes pour justifier les faibles caractères de la coquille.

Quelques zoologistes ont dit, d'après $A$ danson, que l'animal des Cassidaires ressenbluic à celui wes Buccins on des Pourpres; mais on n'a pu le dire que par induction: puisqu'Adansou a" parlé que des Casques et non des Cassidaires, on a préjugé que les Cassidaires ressembloient aux Casques, e! tons doux aux Buccins. Le fait est que l'on u'a rien de positif à cet érard. On ne counoit les Cassiclaires que d'après la Gigure mal faite qui se voit durs la zoocorphose de Dargenville, et que liavanne s'est contenté de recopier en fisant descendre les yeux au-dessous des tentacules.

Lorsquil revint de son voyage en Corse, M. Puyratteau nous conımuniqua l'anirnal de la Cassidare échinophore, qui se trouve abondammeut sur les côtes de cette île et dans tonte la Míditerranée. Cet animal a en ellet de la ressemblance avec celui des Buccins; sa tète, qui est aplatie, porte antérieurenent deux tentacules coniques et poiutus, à la base desquels, et du còté externe, sont placés les yeux, sıppoités sur un reallesoent à peine apparent : ils sont petits et noirs; la boucbe est placée en desscus de la tête, sous un petul roile membranenx qui joint les deux tentacules à la base. Le pied est mince et plat; plıs grand, à proportion, que dansles Buccins, il esi accompagné d'une expansion du manteau, qui, en s'érendast, produit le bord gauche de la coquille : ce manteau est largemeat ouvert au-dessus du cou; il donne entrée par li dansla eavité branchiale, qui est tris-vaste; elle conlient un grand peigne brauchial, qui est lixé à sa paroi supérieure, el cqui !a parcourt d'arant en arricre dans toute sa longuenr; an foud de celle cavité s'ouvre l'aniss a l'exuréwité diun rectum lloltant dirige à droite. L'orga:re excita!cur mâle cst fort grand, moins déve!oppú ce;endant que datus les Buccins; il est lisse, dépourvo des strics trasverses et nonbrenses 
gui se roien: par cet organe dasa les fuccios: dacas liétat do repes, il se reglie dass la carité lrancbiale.

\section{chkACtines cisingezs.}

Aaisal roisia de celui des Buccies, arano na pied large el plat, i l'extréraitś duçuel est

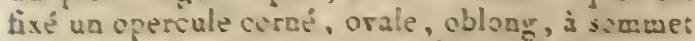

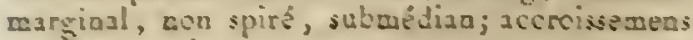
num conceutriques.

Coguille orvile cu orsle, cblocpaes curer-

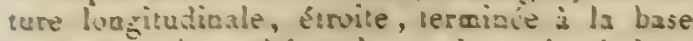
par ua caasl courbs, subasceadant; bord drout couai diuu repli ou dun bourrelet; bard gauche élalé, applijué sar la coluselle, de plas souven: ruke, grauleux , blerculeux ou ri.l!.

Ou ne conacit eaccre qu'un petit acmbre a'es joes daus ce gerre; el es 3021 unarives et it y ea a de rivantes et de lusilles. Eles perven: se diriser ea deux secions, luse pum les Cassidaires proprexeat dites, et la secoude pour le genre Osiscie de X. Siwerby. Les cociulles de Is prexière section soat aiuces, orsles. s!obuleases, tresi-enllées. celles de la seccade sout y่us épaisses; la srire est gécḱra!ement plus courte. et le canal de la base est plas cocrt.

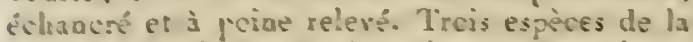

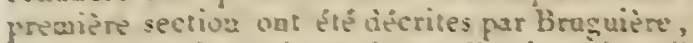
dus le preaier voluse de re Dictionazire; if les cozpreacit das sja geare Csigue : ce saut les auziéros 10. 90. et =1., et par cositqueat

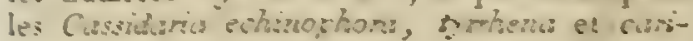

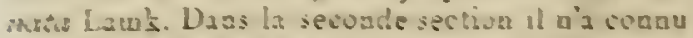
quiuze espece, le Cacizaria crosurs, qui esi décile su nüáro 15 da anese article. suquel nous rezroyous le lecteur, ne devaut pus repredui e ici des especes deili décrites. Nous ferons obser-

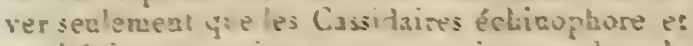
urrbánievac, qui se troureut rivaetcs dues la 3itediterrabie, out leur analogue le plas partait fosile en Irabe es es Sicale.

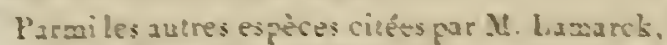
zous remarquous use Cussidaise cerclée. cqui prob-hlemeat cappartient pas au gुeure. St la

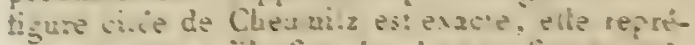

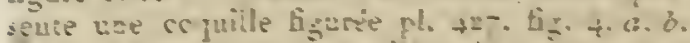

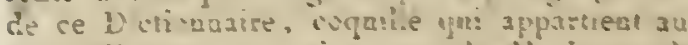
geterz tinseau, of qui a reçu de II. Lamearck

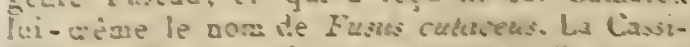

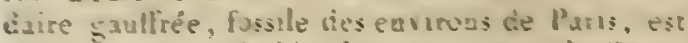

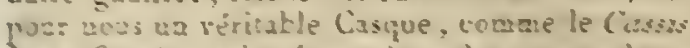

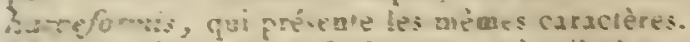
Anaj, sar les especes de M. Lumarck. il ay ea

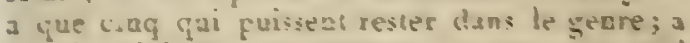

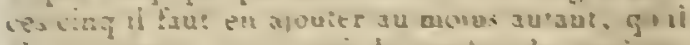

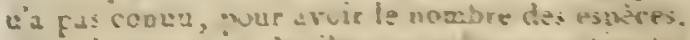

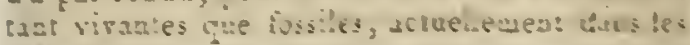
collestives.

\section{C is}

L.225.

1. Campans strife. Ciscriazriz sonishb.

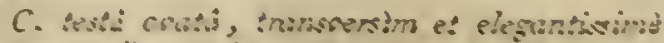

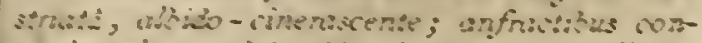

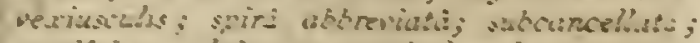

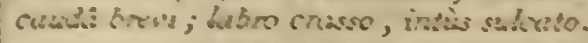

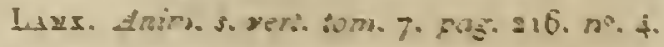
Excres. F! \$05. f.j. 2. 6.6.

Coçuilic fort rare, qui, pas sa forme et le racconrsissemej: de sca cazal, fait le passajo eatre les Cassidaines propremeat dites e: les Oriscics : ol!e es: orale, oblongue, altéuuce anx deux estrézist; sa spire est conrte, elle so coapose de six tours arruedis, peu conrexes, sinares par une su:ure simple; le dernies ton: eit beancoup polus sorand cime tous les autsos

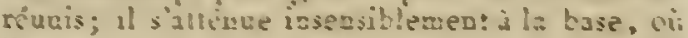
il se termiä par ua casal fort court; tout co Liernier tour, arsi que le reste de la spire, scm: couverts de stries times. ines-régulières et fort

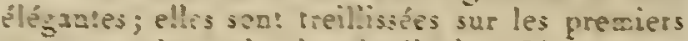
tours par des stries longirdiasles. Lourercuro est aloggée. Étroi:e; la livre gamehe es! peu sillaute. eais appliguse sur la colucaelle daus prescue icule sa ive iuenr; le bord drot est frais. dent in:śrieurement. "Toute l'oureriure est diun

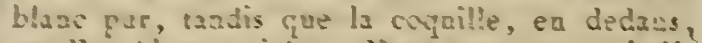
est d"un blanc-crisitre. lous areas ra un jadividu qui écoi: cros de deux razes de taches ciusdrangulsires fares. Oa ignore la parrie de cetse esprice, qui es: lowgue d! \у2.

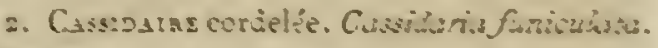

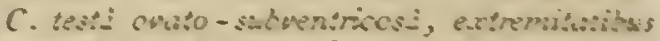

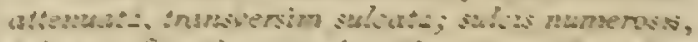

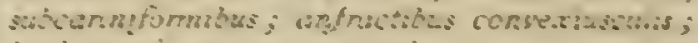

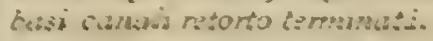

Cente cajuile, fossile des eavirons de Paris, en rraiwent rewarguable: elle se rapproche par

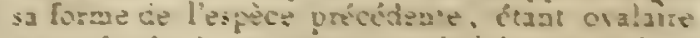

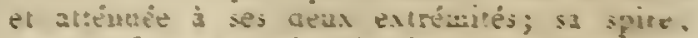
courte, forme a peine le liers de la languen: totale; r.te es: très-pwinlue, th tes preaien te u.s,

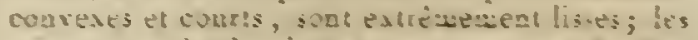
sarvass, et le dernier surticut, sent erots cus graad navabre de sillons trabsverses, szilisas,

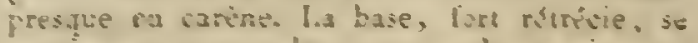
tercine par ua casal court et terda, torsion yast

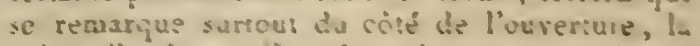

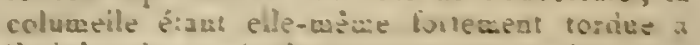
l'origive du caus!; 'onvesture est grasde, coraIaire; is colacuclie. ea are de cerile. revil le bord suble, qui sophligue sur tle; le cant

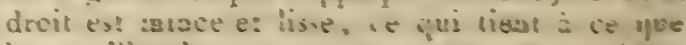
de coquille n'a pas eucor arygus ton: 3 :a dew.

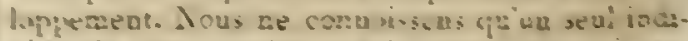

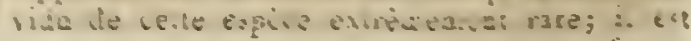


fossite des cavirons de Paris; il est lung de 5o callian.

\section{Cissraniag cournunée, Cussichriu comonalu.} \ов.

C. tesli ovalú, infalin, striis transversulibus numerosi.sinus ornals; urifraclibus ungulutrs;

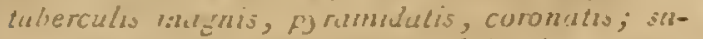

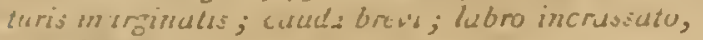
2ix derilato.

On dis'ingue fucilement celle espece de tou!es sus congémeres; sa forme ovale, globuleuve, la rupprocle an peu de l'Eehinoplore; sa spire est lormée de six lcurs aplatis supérieurenaedt, angaleux dans le miliea, el cuuruarés daus cel cudroit par an rang de gros tui.creules poiutus, pyranidaux, bieu espacés; entre eux et la sulure, qui ess bord ie el fincroent plissie, se trouve un cordon perlú qui régne sor toute la sprirc; sur le dernier tour, au-dessous dis prenier rars r de turercules, on en voil ao sec o I de Leavicoup fi..s petils $\in$ ol):us, mais cu tio che numbre que li.s autris. Toute la surfáce de celte corjuille est couverle dune ralliale de stries iri-tines,

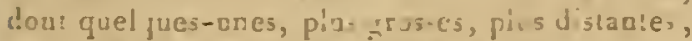
s.ni gronulcules; le cuald de l. ba:e est wéniv :e, peu relevé. Jouster are est assez griade; le bord gaule, frr n.iace, se díacle a la lase; le werd comis, ipdissi far un bourrelet a frine den::, est aplaii en asaut, cl toon arroudi, corace dans la flapurt des espéces : celle-ci, co. nae fossile scul autal, est extrétiement rare.

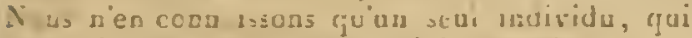
vent de laners, n, n de loin de Vleaus, en

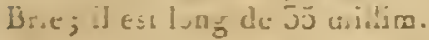

4. Cassidane harpe. Cakilariz cythure. Nob.

C. testi obovati, Inngitsidualuter co:latu,

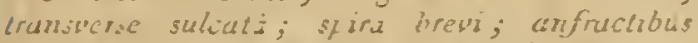
purte upenare excuvalis, sithnodulasis; uner-

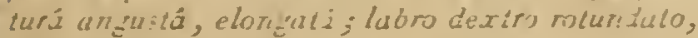
untis dertuin, altén culloso, repando, allquarttisper grumulojo.

Buccimun cythara, Brocisa, Conch. ofss.

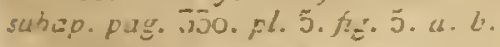

Oniscis cytharu, Sows. Geners, $n^{5} .24 \cdot f_{i}=5$.

J.i c cryalle fnssi.e apparteant cerlanemeui aux Cusoidaires de la serande section, ou au genre Onixie de 1. Soweris : e le es: ovalaire. a s; re hes-cuarte, w wivieuse, chague tour

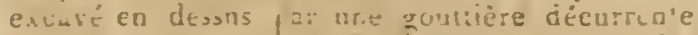

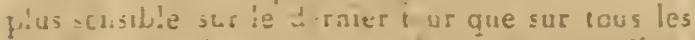

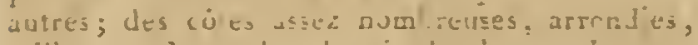
saildaries, descenden: log giludualemeat cu sorsme: a la base de la co puilie en se conionraara un 1er; elles son: irarersées par des sillodi iransrerses, distans, tres-régu'jers el peu profonds. Le cansl de la base est court, se selere ar feu

Hist. Nat. dis T'er. Tome II. ca se ccutouma:t; l'cuverture est fort alongre, trés-étroite; son bord ganche, étalé sur toute la face inferieure, est fort Epais el calleux; dans y.eelques indlividos il est lisse, daus d'autres il es: chayriué; le bord droit es! fort épais, renverse en dehors, arrondi, dentelá é dedins. Cetic entruille, condue a liclat fossule, se ircuse d Betforte, a la Superga, pris "lurin, et aux ensirors de Dax. Les grands isdividus out 40 coillim. de longueur.

\section{CASSIDIE. Cussileat.}

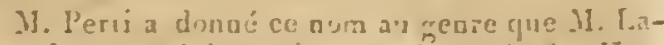
Barcl, avant lui, avoit uomaé Cossizuire. Vuy. ce mo:.

\section{CASSIUITES. Cas̆sidites.}

W. Latreine. dans ses Fumilles nulurelles du Réne unimal, a pronosé de pormer ce le irm.lle avec riuclyues nenres des celle des Purpuritures de 11. Lamarck: Éle se corapose de trois feor-s senlement, les Casques, les Cassidaires et les Ricioules. Sints ferons observer d'atorl yute les Ricioules roat pas de rapporis iumédia's arto les deux autres yenres; elles se rapirsul cut d.jen darantage des Pourpres, $\in$ : dans le cas oir l" n rondroit admeltre la farille des Cassilites, il budroil commencer par en ćózger les Rici-

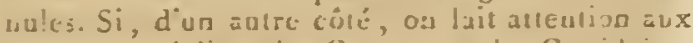
rappures qui lierat les Casynes et lés Cussirlaires a certaines Nasses ef as que? juts Buccias, or sera woins portć à aduet!re uoe lauslie qui re repose pas sur des caractices sulfisaus, soit cyion reuille les preadre de louguaisalion dus ancmaux, s jit qu'oo les cherche daus les cos fuilica elles-mén.es. Voryez Caspez, Cassidataz, Ruckacie el l'tratRIFERE.

\section{CASSIDULIIE. Cussidulina.}

Lne seule espèce de coquilirs nitroscopignes a sulli - .1. dOraigay pour éla lir ce gence. "ui Est viaimen: singulier. Ia cortale tet pridir-

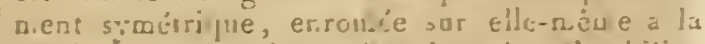

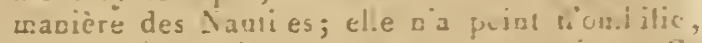
ef lase d'earoulentut est taci-encentrigne. Co

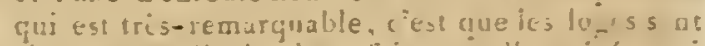
alternantes: liasisal en fair use diun cuté, qui

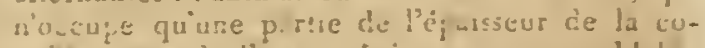
quile, ; to de l'ualre cúlc une ausre semblal e

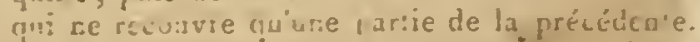

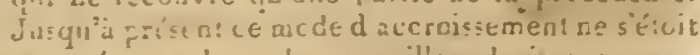
noniré giue diens des copuilles droi is cu noa

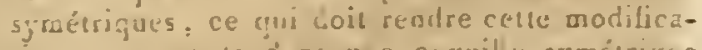
fion suspretante disas u.le ccruilde symétriqce comme l'est cele-ci : ce qui étonce davantage enense, cest gue l'curerbre quĩ perce la der-

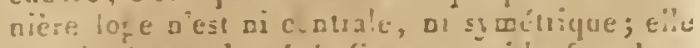

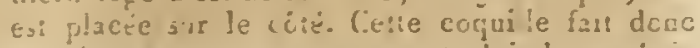
ua des rures excél :so: al celie loi de sjacirie D d 
et d'harmonie, par laquelle une coquilie paire rt symétrique daus son mode d'enroulement doit l'être dans tout le reste.

\section{CARACTÉRES GÉNÉRIQUES.}

Coquille microscopique, nauliloide; spire cmbrassante, symétrique dans son enroulement, tormée de loges alteruantes, sur deux axes, la dernière percée dans son milieu, mais nnn dans le centre de la coquille, d'une petite onverture ovalaire.

Lia seule espèce de ce geure ne nous est connue que par la ligure qu'en a donnée M. d'Orbigny, et le modèle qui se trouve dans son bel ouvrage sur les Céphalopades nicroscopiques : noris en donnons seulement lindicalion.

\section{C. testà nautiloideâ, ovato-rotundatâ, subde- pressâ, làvigututâ.} D'OrB.

1. Cassidurine lisse. Cassidulina Invigata.

D’Ore. Mém. sur los Céphal. Ann. des Scienc. nat. tom. 7. pag. 28z. no. 1. pl. 15.,fig. 4. 5 .

Ibid. Mlod. de Céplach. $2^{\mathrm{e}}$. livrais. $n^{\circ} .4 \mathrm{t}$.

M. d'Orbigny ignore la piltrie de celle coquille; il l'a recueilife dans un sable de délestage.

\section{CASSIS.}

Ce genre, élabli par Klein (Tent. method. ostrac. pag. 91), n'es! point naturel et ne peut être considéré comme l'origine du gente Casque, puisquil contient, avec les Casques véritables, des Cassidaires, des Buccios et des Pourpres.

\section{CASSIS - BICORNIS.}

C'est ainsi que Klein (Tent. method. ostrac. pag. 96) nomme un genre qui comprend quelques Ruchers tuberculeux. Ce gente ne ponvait ôtre adopté.

\section{CASTALIE. Castalia.}

Nous ne croyons pas que ce genre, élabli par M. Lamarck avec une espèce fort rare de Mulette, puisse être adopté. Bien que cetic caguille présente à la charnière une dent cardinale compliquée et s!riée, nous ne pensons pas que ce caractere sulfise, quand on songe aux voubreuses modifications de celte partie dans diverses espies de l'Ohio. Poyez Mulette.

\section{CATILLE. Catillus.}

M. Lamarck ne connut jamais ce genre, qui fut proposé, pour la première fois, par MI. Bronguiart, dains son 'Traité de Géologie du b́assin de Paris. Fondé sur de bons caractères, utile au géologue pour reconnoîle avec certitude la formation crayeuse, ce genre devoit atre in roduit dans les mélhades qui suivirent celle de MI. Latmarck; et en elfet nous le trouvans cité dans celle de M. de Blainville, celle de M. Latreille, et loul nouvellement dans colle de N. Rinn. C s antenrs saccordent en relat avec MI. Bronguiari, que ce grence drit ôtre rapproché des Pernes; des Crínalules, et antres enentes dont la charnière, crénclée, étuit destisée à recevoir un ligrament mulliple.

MI. Brongniart a cru nécessaile de séparer de snn genre Catillus quelques coquilles qui ubilient d'autre différence que lit lorme, qui se ritpproche assez de celle d'une Iongue Moule, d'ou le nam de Mrytiloides quil propusal mais tons les autres caractères étant identiquement semblables it ceux des Catillus, nous n'admetrons pas le genre ot nous le réunissons à celui-ci.

11. Snwerby, dans son Mineral conchology, a adopté le geure Catillus, et a signalé, sons le nom de Pachimya, une graude copquilie venture, alongće, inéquilatérale, qui, par sa structure, se rapproehe heancoup des Cutillus, ce qui nous porteroit à y joindre aussi ce genre; nous y serious d'autaut plusentraîne, que nous avons vu une espèce de Catillus provenant des couches de craje blanche de la Belgique, qui avoit nue forme très-analogue a la Pachinge de MI. Sowerlay. Comme ce Catilius, qui appartient à la collection de M. Duchastel, étoit très-bicn conservé, il nous a élé lacile de juger de sou analogie avec la coquille de NI. Sureiby.

11 résulte de ce qui précc̀de que le genre $\mathrm{Ca}$ tillus, rel que noụs l'admellans, rćunit les geures Myliloide de M. Brongniart el Pachimye de M. Sowerby : nuus les regardons seulemeni comme des modifications dans la forue de coquilles dépendantes d'un même groupe d'organisation.

\section{CARACTÉRES GERRIQUES.}

Animal inconnn. Coquille ovalaire, plus on moins aplatic, tris-inéquilatérale, équivalve, à crochets saillans et bombés, quelquelnis cordiformes; charnière droile, préseutant, derrière un bourrelet marginal, une série de petites cavilés étroiles, destinćes à donuer insertion à un ligament muliple; test fibremx.

Les Catillus ne se sont encore Irnuvés que fossiles, e! l'on éprouve bien des difficultés pour les juger complétement, à canse de l'élat où ils sont. Provenant des couches de craie où les corps organisés ont élé dissous en tolalité on en partie, tout poile à croire que ces coquilles ont élé dépouiliées de leur couche interve, et que ce que l'on en connoíl maintenant n'est que la partie corticale. Ce qui nous le prouve, c'est que la coquille est excessirement mince itu crochet et beaucoup plus épaisse vers les bords, ce qui ne peut avoir lieu, comme on le verra it l'article 
l'Juorsioe; ct ce qui nous le proure encore, c'cst que l'on n'ia jumats va la mondre trace des impressions unusculaires. La structure libreuse de la coupuille et la disparition de sa couche interne sont des circonslancers qui la rendeut très-fiduile; il est extrumement rare de rencontrer des valves cnticies ou seulemeut portant quelques partics de la chamière. On ne coanvit de mienx conservés que les iudvidus qui ont élé remplis de silex, et, dans ce cas, si l'on ne peut plus voir l'intérieur de la coquille, du moius jeut-on juger de son earemble : ce qui est impossible d'aprics des fragmens.

Qusique l'on ne connoisse pas dans la famille des Nullíacées, dans laquelle on range le genre Carillus, d'autres coquilles libreuses gue cellesci, on est bien obliné, malgré le défaut com. plet d'analogie, de l’admeltre sur celle qui a le plus de valeur aux yeux du coachyliologue. La clarmicre crénelíe, si voisine de celle des l'ennes et des Crénatrales, suffit, liute de l'ensemble des "caractères, pour déterminer la place du genre.

hes Catillus sont des coquilles ovaluires, trèsinćyuilatérales, plus ou arisins aplatres ou globuleues, quelyuctuis cordifurmes, à crocheis protubérans, subspirés; queliguefois lirt alongées, déprituées et nuytiloides. La cin annière cst étroite el s'llargit it mesure qu'elle s'uccroil postérieuremest; elle se compose, comme dans les Yerues, d'une série: unique de petites cavités longitudirlales, pe: prof niles, el destinées, saias aucuu dute, a recevoir l'insertion d'un liganent muiipple. Comase dans les l'ernes, ce ligament étoit séparé de lintéricur de la coquille par un petit bourrelet saillaut et décurrent sur le bori.

Noyant à molre dispostion qu'un très-petit no:ulire d'espèces, ce seront celles là seulement que nus décriruns pour servir d'exemple au hente.

1. Catrue de Lamarck. Catillus Lamarkii. Brong.

c. testás ovati, abbreviatia, cordato-inflatâ, nugis nugnis, subreguluribus, scalurifommbus, trunsuersulibus ornatá.

Cur. el Broxg. Géol. des environs de Paris, pl. 4 . fig. : $0 . \mathrm{B}$.

Inocertmus Bmngniarti, MaXiter. Geol. of Sussex, pug. $214 . n^{\circ} .85$.

Inoceramus Lamankii, Ibid. $n^{\circ}$. 84.tab. 27. fig. I.

Inoceramus Brongniarti, Sun. Min. conch. pl. 441. fig. 2. 3.

Coquille très-ventrue, ovale, courte, cordiforme, à charnière droite et subturriculée postérieurement; les crénelures cardinales snnt petites, placées dans uae raiaure assez profonde, elles sont presuue égales; les crocliets sout peit suilians, mais ils sont gonllés, opposés ct inclinés i la partie antérieure de la coquille, ce qui la rend très-inéquilatérale; de larges sillons subrégulicrs, transverses, concentriques, se voient sur tnutc la surface extérieure, qui, du reste, ne présente incur autre accident. Cette coquille caractérise la cruie blaoche; on ea rencontre des fragricros prestyue partout.

2. Catrute coyliloide. Catillus mutiloides. Nos.

C. Lestî ovalo-elongutî, depressî, apice obliquè subtruncati, irregulariter sulcatá; cardine recto, tennè sulcato.

Inoceramus mytiloides, Mantel. loc. cil. tab. 28. fig. 2. 3). ct tab. 27. fig. 5 .

Ibid. Sow. loc. cit. pl. 442.

Mytiloides lubialus, Cor. el Brosu. Géol. des environs de Paris, pl. 3. fig. 4.

Celle espece a la forme d'une Moule, ce qui lui a valu le nom générique que M. Brongrniart lui a douné. Nous avons dit pour quelle raison nous n'adoptions pas ce genre; vous ne pensons pas non plus qu'on doire la laisser, comme MJ. Siwerby, purmi les Inocéranses. Cette corguille est alougée, ovale, présentant à son extréuité supérieure une sorte de troncalure oblique, produite par la cliarnic̀rc; elle est dominée par le crochet, qui est peu saillant, et composée d'une série de tines crénelures lovgritudiuales. Tonte la surlace extérieure est couverte de gros sillons concentriques, on plutôt de plis onduleux. C'est dans la craje que se trouve celle coquille, qui est fort rare entière; elle a jusqu'à 6 pouces de longueur.

\section{CATINUS-LAC'TIS.}

On pourroit trourer, dans ce genre de Filein (Tent. method. ostrac. pag. 19), l'uri rime du genre Sigraret; cas c'est une de ces coyaniles, la seule prabablement que l'un connit alors, qui servit de rype au genre aujnurd'hui oublie de Klein.

\section{CATOLINE. Cavolina.}

On doit ce grenre à Bruguière, qui l'a proponsé dans les planches de ce Dictionuaire, et qui paroit depuis l'avoir abandonné. I! a en effet tropl d'analogie avec les Eolides pour qu'on puisse l'en séparer. Voyez Eorroe.

\section{CÉLIBE. Chelibs.}

Ce genre a été établi par Moblfort, et décrit par lui d'une manière si peu satislaisante, qu'il est presque impossible de savoir aujaurd'bui si on le rapportera comme lui aux Céplialopodes 
racroscopiquez on 3ux Polspiers. II. d'Orilicay a celle dernitre opinion, que nous ne partageous pas entierement; il nous sewhle que iInntiort a eu sars les jeax une cotuille mutiće ane औ. d"Orbigny comprend dans san genre Giobigérice. Fojez ce rot.

\section{CELLULACÉS. Celluluscer.}

Dans sou Traité de Malacozie (pзg. 569), II. de B'ainville a élathli cet ordre, qui correspond ea petite partie aux Céplıalapojes foraminifres de M. dOrliguy; mais ne rassemblant qu'ua pertis nambre de ces corps, et les autres élant ir distinctement répandus arer des cornilles sintrouifres dass un grand nombre de genres, on ne pourra pas adunetre cet ordre, sur lequel nous revieadrons à l'article Céphal opodes. IToye ce mot.

\section{CELLLI.IE. Cellintiuts.}

Ce seare, proposé par Montfort (Conch. sysi. tom. 2. pag. 20\%) . a’a point Ćté adupté. I! seatre dars le genre Polystomelle de M. Lamarck, conserré el radifié par il. dorbigng. Foyez Porss. TOMIILE.

\section{CÉPHALÉS.}

Les deux principales dirisions établies dans les Mollasquzes reposant sur l'absence ou la pré. sence de la tète, on a nonumé Acciphulés les Mol. lusques biralves qui n'ont peiat de téte, et on 3 duanéle rom de Céphalés à tous les autres qui ea sjut pourrns. Comme cette dis.inction touclie à la classification gréćtale des Mullusques, c’est à l'article Morersque que nous donaerons des ditails que nons ae ponrrious que répéter ici.

\section{CÉnHALORHORES. Cephalophors.}

II. de Blainrille, dzus sou Traité de Mlukucologgie ( pag. J0̈千), a changé le mot Céphaéa , depais lung-temps adupté, conire celui-ci, qui a la mése valeur et la Lème sigritication. Voyez Nolitsqee.

\section{CÉPHLLOPODES. Cephalogoda.}

De tous les animaux mollusques, les Cépbalopodes sont cenx qui sont les plus arancés en organisati.n, ceus qui se rappracbeat par consćquent le plas des animaux rertébrés. Libres, prompts dans leurs mouremens, habiles nagenrs, jonissant plas qu'aucan autre de la faculté de roir el d'enteadre, ces animaux méritoient bien d'a!lirer l’atteation des naturalistes, et d'exciter surtout les recberches de ceux qui se sont spécialement occupés des mollusques. Lenr forme singulière, I disposition plus singulière encore de leurs longs bras masculeax anton: de la téte, leur grandeur e? leur force, qui les a rentus quelquefois redou- tables à l'hamane lui-méme. ce prodige si merseilleua de l’unimal parasie, de l'Argenaule, enseiznant par son admirable manouvre l'art de naviguer, lant riv circonstances ont fait diriger vers les $\mathrm{C}^{2}$ f hulupodes les regarỏs des observateurs de tous les iesups.

lious trouvons dans la liaule antiquité, dars

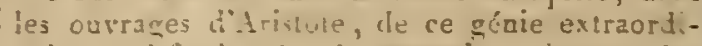
anire, qui ful!e frie de t.ules les sciences, dus indicalions próvieuses sur les Céphalopodes. D:puis cette ép rque jusqu"à nos jours, il n'est presque poiat de natrivalises qui ne les ait neutionnés duae maniere spéciale, el flusieurs se sost appiitiués particulicement à leur ílude. Il cst réstlé de ce cracours dez conajissances trésapirufudies sur celle classe d'aninaua; mal zré cela les ousrages dotristate peurent è re eacore consultés aver eraalage, tant il portssa lonin !es recherches méme anatorniques sut nes ilohsques : il les divisa en piusieurs gentes, d'apn, la disposition des rentouses el le nombre des hr.1. caractéres encore employés dans les'inélhuiles les plus nourelles. Il tisui sans douie altriber à cel'e perítian, dans tes cunuoissances des Ciphalupotes l'étal stationajire dans lepual ils resiereut lunz-temps; au lieu de les perfecionusr, on répila ce quavoit du Arislote, par cel'e r.ison probable, que lou croyait a l'impossil ifité

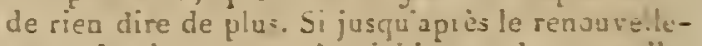
went dis le:tres on neariclit pas de nourelles ubserrations l"uistuire antarelle des C'phalupodes, du muins on aj ru:a a leur bistoire, et on recaeilli: arec sin les récits fabuleax auaquels ils dunnèrent liea. Ce ser it sans utilité pourla scicate que auas réluteriuns ces viteilles erreurs, car il n'ist plus persanre qui y cruie. Laissant de cỏté les vavrayes diElien, de Pine, d'Aldrovacie, de Gesaer, de Jurston, etc., nous citerons en passaat Rondelet, qui le prercier lit conavite un animal dont on a luis le geure Sépiole, puur arriver a l'nuvrage de Summinerdam. Ce savant liollandais fut le premier qui, dans son Biblisa musturx, donsa sur la Siche des dérails plus complets que ce que l'on aroit en jusulalurs, quaiquils contiennent plus d'une erreur.

Ia coquille du Naurile étoit bien conaue depuis long-temps, mais un iguoroit quelle appartía: à un animal céphalopode. Rumphius donua à cet égard de précieuses indica'ions, qui engagèrent les zoologistes a laire des rapprochemens. auxquels arant cela on u’aroit pas songé. Par une analogie biea simple, on compara les Ammonites aux Xautiles, et par une conclusion díduite de la ressemblance, on les attribas à des Céphalopodes doat les races étoient perdues. L'ourrage de Breyne sur les Polythalames, si atile dailleurs, fut remarequable en cela qu'il introduisir défiaitivenent les coquilles cloisonnées parmi les Jiollusques: éétoit uue conséquence forcée, pour aiasi dire, de la décourertede Rua- 
phius. Gualtierri, dans son Inder testanam, imita Hieyne, clde plus mentionna el plas'a, a cólé les Niautiles, des coqgilles microscopiques cloismmées, yui malhemeusement pont la múllode furent coustimancul, depurs, rapprochées des Nautiles el de tous les autres grands Céphalopodes.

Si d'un côlć l'úlude des coquilles cloisonnées s'anćlioroit d'une alanière trés-ulile, d'un autre les analouistes ne úgligeoient pas d'accroitre les comoissances sul I' ryanasation des ćtres qui lcs ploduisent; c'est ainsi que Minnto, Scarpat, et p'us nouvellement M. 'Tilesius, soccuperen! de recherches lurt importantes, q̧ui furent bientôt suivies des incinurables Iravaux de MI. Cuvier dans les llémoires du Musium, et de ceux thèsremarguables de M. Savigny, dius le grand ouvrage d'Égpte, malkenreusenent resté iucomplet par suile de la cécité de ce gradod observateur.

Revenuns maintendut aux travaux des classificatents. Linnó, comme Breyue el Guallieri, rangea dins les Mollusques tesiacés les Nautiles, auxquels il rapporta routes les coquilies cloisonnées conuues de sen temps. Il les init immédiateraent en rapport arec les Aigonautes, et, par une singrulicre contradiction, après avoir carictórisú ce genen par ces mots, Ariua sepra, Testa conivaluis, etc., il en sépare néanmoins le genre Supia lui-moine, ruil met hors de ses rapports natu:cls dans la clusse des animanx mollusques, et qui rissemlloit, avec les auimaux mous les plus simples, ceux qui, ayaat la acume mollesse, on: cependun! une organisalion bien supéricure: c'est ansi que ce caractère, mal apprécić daus son imporlauce, détruisit en cela, pal une lausse application, l'larmonie du système, si admirable d'si.leurs, de Linné.

Des travaux d'un grand intérêt, qu'il appartenoil senlement á des hommes d'une grande patience d'entreprendre, furent exécutés d'abord par Jean Bianchi, connu davanlage sous Je nom de Junus Plancus, sur les coquilles microscopiques multilocinlaites, corpuilles que Linné et ses iuitaleurs ne firent entrer quea rrop pelit nomLra dans la mélliode, et qu'ils coufondirent dans le greare Nautile. Cetle direction, imprimée par J'immeuse génie de Linaé, eut un fâcheux résultat pour la science, en ce quiil détoura l"atlention des oliservaleurs de ce monde en miniatare, eatrevu par Plancus et mis a découvert par le célèlıe Suldani : saus cet oubli, certaiuemeat yue l'ouvrayge si admirable de ce dernier en̂t $\mathrm{eu}$, dès sou début, toute l'iullueace scientifique qu'il n'a acyuise que beaucoup plus tard. On pourroit dire aussi que ce n'elt que depuis peu d'années que l'ouvlage de Soldani est deveau utile, autant qu'il pouvoill'ètre, une fois que l'inlluence linnéenne a été tout-i-lait détruite sul celte partie de la classification; car nous regardons comme une suile de celte inlluence la confusion ๆui régaa dans les nóphodes jusqu'ì la publication des travanx cte Mill. de llain el d'() bigny.

Binguicire fit une lieureuse innovalion en séparaut netteront les coquilles polythalames des aulres dans une scctiou composec seulement de quatre genres (Camérine, Aumouite, Nantile, Orllucérate); mais il n'évila pas celte fante de Linné, Je séparter les Sèches des autres Mollusques céphaloporles, et il en commit une nonvelic en lisiant le genre $\Lambda$ rogonaule avec les coquilles monothalames, tout en admettant quil est hibitó par un animal semblable ì celui de la Sécbe; il lil d'ailleurs comne Linur, el laissa dans le genre Sepira tous les Céphalopodes uous ou à corfuille intérientre.

Ce que nous venons d'exposer prouve d'un: manière irrecusable, ce nous semble, cue l. science n'étoit poiut arrivée an point oil l'un peut établir des principes invariables; il est évident que Błngière el Liuné lui-même ne s'en étoient joint proposé, du moins pour celle pallie de la science. Si la connoissance des animanx duil déterminer les rapports, pourunoi séparer les Sèches des Argonatutes et des Nautiles? ct si de boumes inductions sont utiles daus la scieace, pourcjuoi séparer ces divers genres dans des classes dilinctes? Nons ne voyons guc̀re la possibilité de répondre d'une unaricre salisfuisante à ces objections.

M. Cuvier, dans son Tableau élémentare du Règne animal, publié en 1793, donna le picnié le nom de Céphalopodes aus animaux yni nous occupent, et introduisit dans la méllode cc principe dunt nous reprocions l'oubli tout it l'heure à Linné et à Bruguière. Ainsi, dans les MIollusques céphalopodes, se trouvìrent réunis les Sèches, les l'oulpes, les Argonautes et les Nautiles: association heureuse pour le temps ou elle fut proposée; elle mit Jes zoologistes dans aue nouvelle roule, la seule qui pût être suivie désormais pour perfectionner la science: celle indiçuée par Linać ful dès-lors abandonnée.

On tronve, daus le même recueil, les Mémoives de la Société d'Histoire nuturclle de Paris (1799), deux travaux remarquables de MI. Lamarck: clans l'un, qui traite spécialement des Céphalopodes aus, ce savant, suivant les iodicalions d'Aristole, établit dans ces animaux trois genres fort bien caractérisés, Sèche, Calmar et Poulpe. Ce que l'on doit remarquer, c'est qu'a la fin de ce Mlénoire, M. Jamarck ajoute une note sur les Argonautes, dans haquelle il rejette l'opinion que le Poulpe que l'on trouve dans celle coquille en soit le constructeur : il le regarde comme un parasite. On verra, en consultaut l'article Argoñdte, que M. Lnmirck a rejeté depuis celle première opinion. Le second lravail de M. Lamarck olfie une classificatien nouvelle des coquilles; il augmenta le nombre des genres rloi- 
sonaés; et, par un oubii fort extraordinaire, il ne mentiona pas dans sa nouvelle classificalion les Cépbalopodes ous, qu’il venoit de décrire quelques pages auparavant. Les cacpuilles multiloculaires son! nettement séparées, et elles comprenaent dix genires de plus que daos Braguière; ce sont les stivans: Nautile, Nautilite, Ammuaite, Planorbite, Camerine, Spirule, Baculite, Orthocère, Orthocératite et Bélemnite. Parmi ces geares, nous rewarquons les Nautilites et les l'lanorbites, qui, par leurs caractères, font double etuploi avec les Nautiles et les Ammonites, et le geare Orthocératite, pris de Picot la Peyrouse, el qui n'est autre chose qu'une coquille bivalve.

Deux anoées plus tard, lorsque le Tableau clĺmentaire du Règne animal de $\mathrm{M}$. Cuvier étoil connn, \& lorscu'il auroit fallu suivie la marche qu'il aroit tracée, M. Lamarck, daus le Système des Animaux sans vertebres, qui parut en 1301 , répara l'uuhli qu'il avoit lait des Céphalopodes nus dans sa méthode précédente; mais, par une opiuiva assez bizarre et dont on ne peut pas se rendre compte, il mit les Mollusques céphalopodes ous en lête de la preccière section, qui renlerme les Mollusques céphalés uus, et les sépara des coquilles multiloculaire par la série loute entière des Mollusquez univalves. Les uultilocularies furenl augmentés d'un seul genre nécessaire, celui des Turrilites; \& au lieu de conserver le nou d'Horlocéralite, gui pouvoit produire quelque confusion avec celui des Orthocères, it le changea contre celni d'Ilippurite.

A peine M. Lamarck avoit-il publié l'ouvrage que nous renous de citer, que parurent en nıème temps le Mémoire si remarquable de M. Cuvier, dans les Annales du Muséum, \& la partie du Buffon de Sonnini qui a rapport aux Mollusques. Cette partie, confiée d'abord is Moutlort, lut terminée par M. de Roissy. Aulant nous Evitons soirneucenent de citer les travaux de Nontfort qui sunt estachics de mauvaise foi, autant nous avons de plaisir a rappelel ceur de son continuateur, qui a su reoferuner toute la conebyliologie dans un cadre resserré en la traitant en véritable science, tandis que Montfort avoit pu à peine épuiser quelques yeures dans quatre volumes. Il est vrui qu'il falloii bien faire passer, à l'aide de longs discours, el le Poulpe colossal faisant sumbrer un uavire de haut-bord, et l'his. toire du Kraken.

M. de Roissy ne revint pas sur les six genres Sèche, Calmar, Poulpe, Argonante, Carinaire et Nautile, traités par Nontlort, et telmiual'histoire nalurelle des Céphalupodes par les genres indiqués par M. Lamarck, Spiule, Ammonite, Planulite, Turrilite, Baculite, Orthocère, Ilippurite, Bélemnite, Numuulite et Rotalie : ce demier genre venoit d'ütre créé par M. Lainarck dans les Annales du Muséum. N. de Roissy fut le premier qui fit coanoitre, arec queligues dé- tails, l'animal de la spirule, qui veuoit distle rapporté par Péron. C'est sans contredit l'un cies farts les plus importans dont la scieace se sout enrichie, que celui relatif à la Spirule; les doutes gue lion pourait conserver sur la nature de beacoup de gentes, par suite de la connojssance iaparfaile de l'aniual du Nautife, devenoieut disormsis inpossihles. La connoissance de ce lait entraíua nécessairement à des considératious nouvelles sur les Cépralopodes, et dut apporter aussi des changemens daus leur arraugement méthodique : on s'en apercut d'abord a la nuvelle classilication que douna II. Lawarck. daus sa Philosophic zoologique.

Pour la première tois arrangés en familles, les Céphalopodes furent accrus d'un grand nombre de greares; pour la premiere fois aussi M1. Lamarik revial de son opiuion sir: les Argonautes, et les admit, ainsi que les Carinaires, au milien des Céphalopodes. Ils lurent partagés en trois groupes ou urdres, d’après la coquille : ceụx à coquille multiloculaire, ceux à coquille uniloculaires, et ceax euliu qui n'ont point de coquille. Les deox deruiers groupes ne contiennent chacnin qu'une fanille : les Argonautacées pour les deux genres Argonaute el Cirrinaire; les Sépialées puur les gences Poupe, Calmar et Sèche. Quant an premier groupe, il reaferane tross tumilles: 10 . les I,enticulacées, qui couticnt les genres Miliolite, Gyrogonite, Rotalice, Rivulite, Discorbite, Lenticuline et Nummulite, qui prezque tous venoient d'êt!e nouvellement élablis dans les Némoires du Auséum; $2^{\circ}$. les Jituolacées, pour les genres Liluolite, Sprroliuite, Sprrule, Or: thocère, Hippurite et Bélemnite; $3^{\circ}$. les Nautilacées, qui renterne les genres Baculite, Turrilice, Amorouocératite. Ammonile, Orbulite et Nautile. Voila duac le nombre des grenres plus que duablé, et cependant encure lon de répunute au besoin de ta science, si l'on avoit eabrassé tout ce qu'elle contient; mais l'ouvrage de Soldani, celui de Plaucus, et celui bien plus uonveau de ficbtel et Nool, linent oubliés.

Monturt le premier, il faut lui rendre cene justice, attira sub eux l'altention des naturalistes; mais, à l'exceprion d'uu trecs-petit nombre da genles qui lurent conservés, e'est là tout le mérite que l'on trouve dans le premier volune du Tranté systématique de Conchyliologie de cet auteur. (ent geures lui turent nécesvaires pour distribuer tous les Céphalopodes; mais, guidé jar un faux priucipe, il ne s'allacha qu'ì la forue extérieore de la coquille: cela seul le dirigea dans les rapports quill proposa; d'ou il résulta d'abord un aćlange des coyuilles les plas diverses, de coquilles ì Cloisons siumples, à cluisuns persillées, el de coquilles microscopicques. II en r'́sulta aussi que certaines especes rui chaogent de forme avec l'igc, servirent de type jusqu'ia trois fois pou: trois dilférens geric. 
Enfun des germes don les espeeces nombrenses one des formes assez varialjles, mais qui se lient entre clles far des caractères comstons, servirent is l'álablissement de huit ou neul geures; il ćlaWlissnit neêue ses garuser arec tant de léprèreté, "üil domma comme: roismnces des coquilles qui we le sont pas, on des corps étrangers aux Mol. luse[nes, soil (1!'il l'ait lait de mauvaise foi, soit que ce soit par ume nénligence blámable. De tels travaux ne pouvant inspirer de conliance, .1. Lamarck, qui les avoil bien jugés, ne Jes Cita jamais, \& nous amrions tait de nuéme si, dans les classilications les plus nouvelles, nous n'avions vu adopls le phlus grand rombre des gemres de Monifort.

En 1812, M. Lamarrek jublia l'extrait de son cours, opuscule dins lequel il donna une nourelle classilication des Mollusques; les Céphalopodes éprouverent des changemens notaliles: le genre Curinatre en fut extrait, plusieurs genres nourcaux furent ajnutcs, et de vingtquatre ils furcnt purtés ì trente-nn. Les truis divisions pruncipales restèrent les mèues, mais le nombre des familles de la première lú augnienté, el les rapports des genres entre eux furent guelquefois moditiés. Cés fanilles se présentent dans l'ordre suivaut: $1^{\circ}$. les Orlhocérées, 20 . les Liluolées, $3^{\circ}$. les Cristacées, $4^{n}$. les Splacirulées, 5 ?. les Ridiolées, $\widehat{0}^{\circ}$. Les Nautilacées, $7^{\circ}$. les Ammonies, 80. les Argonautes, $9^{\circ}$. les Sćpiolées. l'lusieurs de ces familles sont naturelles, celles des Ammonérs et des Sépiolées cntre autres; quant à celles qui conticnnent les coquilles microscopiques, elles ne peuvent l'être, puisqu'il est vrai que M. Lamarck ne connoissoit qu'un trop petit nombre de ces corps pour les circonscrire et les lier d'une manière définitive. Nous n'cntrons pas, quant à préseat, sur ces faurilles dans d'autres délails, puisque nous les lraitons dans aulant d'articles séparés auxquels nous renvoyons, al que nous les reproduirons dans leur ensemble dans les tableaux qui accompagnent l'arlicle Monzosoue.

Entre cet opuscule de $\mathrm{M}$. Lamarck et la publication du Regne animal de MI. Cuvier nous ne urruvous rien sur les Céplaalopodes; les auteurs ćtrangers, eucore atlachés à la lettre de Limné, auivoient sans changearent la mélhode de ce srand naturaliste dans leurs ouvrages de conchyIiologie; nous verrons qu'i?s ne tarderent pas à suivre une autre marche, et adoptèrent les travaux de .H. Lamarck et de M. Cuvier.

Les (Céplialopodes, dans la méllode de M. Cuvier, commencent les Mollusques ct en forment l'une des six divisions principales; ils sont parlaguís ell six grands genres, qui eux-mêmes renferment, a tilte de sous-genres, trente-un des genres de MI. Lamarck ou de Montfort. Les six geores principaux sont disposés dans lordre suivant : les Sèches, qui contieaneat les Ciphaloporles nus des auteurs; les Nautiles, qui. onlre les vrais Nautiles, renfermenl comme suusyenres loule's les rognilles uricruscopiques bauliloides à cluisons simpries, ainsi gue celles qui commencent par un caronlonent spiral el se terminene en ligne droite, comme les lituites, auxqueiles sunt jointes les sous-genres Ilurtole, Spiroline, Nndosaire et Orlliocératice, qui n'ont entre pux que des rapports fort éloignés; les remes Bbieunite et Hippurite, qui suivent, nollient aucune division. On sail maintenaut, a n'en plus douter, yne les llippurites sont des coquilles hivalues. (royez Hlippurirr.) Les Anmonilos forment avec leurs sous-geure's un grupe naturel qui correspond exactement à la famille des Anmonées cle M!. Lamarck. Les Cancérines forment le dernier gemı, séparées des Ienticulites, comprises lans li lamille des Nautiles, lorsque ces deux genres ont tant d'analogie quil est impossible de trouver un bon caractere pour les séparer: cela démonire que $M$. Cuvier n'a pas connu les intermédiaires qui les unissent. Outre ce défaut, le genre $\mathrm{Ca}$ mirine cn a cncorc un autre, c'est de comprendre dans son ensemble des corps qui n'ont avec lui que lort pea d'aualogie : il nous suffira de ciler les genres Miliole, Polloule et Aréchuse, gui certunement n'ont, avec les Camérines on Nommulies, aucune ressemblance de forme et de structure.

M. Léacl porta son attention sur un caractère qui, juscyu’alors, n’avoit pias élé assez apprécié. Dans la disposition méthodique des Céplaalopodes nus, il employa d'une manière fort avantageuse le nombre des bras, d'où vint la déromination de deux familles qu'il proposa, les Octopodes et les Décapodes; il muliplia les genres, surtout aux dépens des Calmars. Cette division de II. Léach étoit trop naturelle et trop simple pour ne pas étre adoptée; elle le fut d'abord pat 11. de Ferussan, dans ses Tableaux systématiques : ces deux familles terminent chez lui la grande série des Céphalopodes, ce qui a droit de nous étonzer, puisque, dans sa métbode, M. de Ferussac a suivi l'ordie descendant.

Cet auteur, dans l'ensenble de sa méthode, a suivi celle de MI. Cuvie:, mais il en a changé considérablement les détails; cbaque genre devient des familles, et plusicurs antres leur sont ajonlées; elles sont disposées dans l'ordre suivant: $1^{\circ}$. les Ammonées, $2^{\circ}$. les Hippuriles, $3^{\circ}$. les Bélemuites, $4^{\circ}$. les Orthocères, $5^{\circ}$. les Lituites, 6.. les Discorbes, $7^{\circ}$. les Nauliles, 8०. les Camérines, $9^{\circ}$. les Milioles, $10^{\circ}$. les Sèches, $12^{\circ}$. les Puulpes.

La famille des Ammonées, placée la première, feroit supposer, dans les zoologisies qui la disposent ainsi, qu'elle appartient aux Cépbalopodes les plus simples; rependant leur structure et la coa- 
noissance de la Spirule, qui sert d'internédiaire, conduisent à noe opinion opposée. Celle fauille, suivie d'autres contenaut les coquilles microscopiques, qui elles-naêmes sont suivies par les Céphalopodes aus, qui terminent la grande série de ces animaux, ve nous semble pas un orlye baturel; nous pensons an coutraire, eu raisunnant comme ou le fuisoit avaut le travail de II. d'Orbigny, qu'il étoit valurcl d'aller du convu à l'iuconur; et, en conséquence, de placer les Céphalopodes nus en tête de la clirse, et de faire servir le geure Spirule d'intermédiaire entre eux et les renies a coquilles.

I a famille des Ammonées de MI. de Ferussac est une imilation de celle de M. Lamarck; on y troure de plus le gevre Scaphíte, que ce sâvaut a'avoit pas conar : le geure Haraite est substitué à l'Aumonocérate, genre qui est resté douteux jusçu'au moinent où la collection de N. Lamarck put être examinée. Cette fimille est suivie de celle des Hippuriles, qui contient les denx seu!s grea es Batolite el Ilipparice. Il n’est pas dillicile de démontrc que ces deux genres n'en lont çu'us, et que le démembrement des Batolites, proposé par Nontforl, est un double comploi. (Voy. Mrproritr.) En supposant que les Hippuriles suient des coquilles de Céplualopodes, nous demanderons, quant on aura examiné leur structure, quelle analogie peut les lier arec les $\mathrm{Am}$ monées d'un côté, el avec les Bélemnites d'un antre. 11 est ćrident qu'en raisonnant selon l'hypothèse que ce sont des Cóplatopodes, quils doivent lormer un groupe iudépendant; mais aujourd'hui on ne peut plus admeltie de telles sup. position;, puisque nous avous prouvé que les IIipparites étoieut des coquilles bivalves.

La famille des Bélemuites ne contieuı que le seul geure dont elle at empruaté le vors; cependant ce * Fne se lie avecles Orthocères; mais M. de l'erussac forme de ce verure et de quelques autres une tamille à part, youvient im!nédiatearent aprés ce!le des Búlemites. Cetie lamille des Orthoceres rassemble quatre gemres qui, on pouroit le dice sans exagéraliou, soul étunnés de se rencontrer : ce son les Ichihyosarcolites, les Raphanistres, les Orthocératites et les Nodosaires. Les Ichthyosarcolites, nous en ayous la preuve, ne soul gue des parties dérachíes el mal examinées de cuquilles livalves. L.e Riphanistre est une Tlippritile runlée, décrite par Moutfurl et ì sa manere. Le genre Oithocératite est un bon gente, si on l'adinel it lit manièıe de MI. Sowerby, c'csta-dice, ne renfermant que des coquilles druites, à cloisons simp!es el percécs au centre par un siphon; mais it nen seroit pas de mèse si on voulun le prendre tel que M. de Ferussac l'a composé; l'assemblage des sept groupes qu'il y propose est une chose si bizarre, que l'ou a clruit de se demander si c'est sérieusement que l'auteur l'à donné: nous supposons plutòt qu'il a vuulu exercer la sagucité de ceux qui desiroient approfondir sa michude. 11 rous sullira, pour justifier ce que nous venons de dire, de citer ces sept groupes, parmi lesquels le scul qui représenle le gence Orthocéralile peut être conservé : ce sont les gentes Toxérite de Ratiuesque, 'Télúboile Montfori, Conulaire et $\Delta$ mplexus $S$ siverby, Misile et Canthare Mnatfort. Nous prions le lecteur de consulie. ces diflérens inots, ne voulant pas, pour éviles une répélition inutile, redire ce que coutiennent ces articles. Le quatriène gente de la lamil!e des Orthocères est celui des Nudosaites: noves ve l'examinerons pas ciunt à présent; il nons sufira de dire qu'il appartient a un autre ordie, fuisqu'il n'est pas siplıoné.

La cinquièue famille, celle des Lilnites, conlient conine la précúdente un mélange de génes siphonés et sans siphon; mais, comme nuus l'avous fait diju obscrver, ce mélange se retrouvant dans tnutes les méthojes, riéloil que la suile d'une fuusse direction, dans laquelle on resta trop long-temps. Les cuatre genres de ret.e famille sont : Canope, Limole, Spiroline et Sp:rule. (Joyez ces muts.) Quantà la sixième litmille, celle des Discorlses, elle est plus baturelle, en ce qu'elle contient miquement des coquilles microscopicues saus siphon : elle ne ienlerme que les trois gonres Cristellaice, Discorbe et Rotalie, dont chacun est sums-divisés en un graud nombie de grupes, gui se composent, pour presque tous, de l'un des genres de Muntfort. C'est en traitant de ces trois geares que nous verrons quelle valeur an doil leur d nner.

Après cette lamille se présente celle des Nantiles, et nous retronvons le wême mélange que dans les premières: deux genres seulement lid composent, ce sont les Leoticulines et les Niuliles. Dans le premier genre, on truare qualle groupes dans lescyuts sont rassemblés un assec grand nombre des genres de Montfort; mais pris dans cel auteur, sans discussion el sins crilipue, leur moindre défant est d'étre, pour le plus urima nombre, iualuissibles. Ce gende Lenticuline, $t \in$ que l'avoil conça M. Lalmar.k el débarrassé conséquemruent de tons les sous-renres quon $y^{\circ}$ a

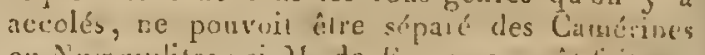
ou Nummulites: si M. de liertissac y eûl litit attention, el si, avaat d’établir samélhode, il cn cut exarnivé avec foiu el discnté les élémens, il auroit a perç un passage insensible entre res deux genres, et il les auroil rónis an lieu de les mettre duns deux fatrilles sć, iarícs. Le même reproche peur être ado"essé a la composition du genre Ninulie, genre si simple, si naturllewent circonscrit, de daus lequel MI. de formsac place, con diffirens groupes, les Bisiplitites, les Cantrupés, les Phatrames, ícs Clisipliontes, les Angulites, les Auk nor, les Sporulies, les Bellérophes, lows yenres inadmissibles ou à rejeter des Xautiles tels yu'un

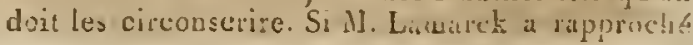


dans une micme famille des grenres cnire lesquels l'observasion a démontré plus tard qu'il n'uxistait point de rapports, du moins n'a-ton pas à lui reprocher celle élonnante confusion de coquilles si diverses dans un mème cadre générique. Chaque genre pris isolément comme un tout est bien faractérisé: si les rapports changent, il faut que le gente tout enticr subisse ce changement; il n'en est certainement pas te mêtme de ceux de 11. Ferussac, puisqu'il faut les démembrer pièree d pièce pour en conserver une fraction, la seule dont l'enseuble puisse être ramené à des caractc̀res raisonnables. Que M. de Ferussac essaie de donner unc caractéristique d̀ son genre Nautile tel que aous le trouvous dans ses Tiableaux systématiques, et il verra, ì l'impossibilité dans laquelle il se rronvera de répondre à celte demande d'une manière saiisfaisante, que son geare n'est point admissible.

Nous avons dit que le genre Nummulite ne patsvoit être séparé des Lenticulines, par conséquent ce genre, ainsi que les Sidćrolites, doit être retiré de la lamille des Camérines qui, dans l’ordre de M. de Ferussac, vient après celle des Vautiles. I,es deux genres qui resıcnt, Orbiculine et Blélouie, appartiennent ì une organisation différente de celle des Numunulites el doivent fiaire partie d'autres lamilles. Ainsi celte famille des Camérines se trouve détruite par le senl lait d'un atrangrement dillérent et très-préférable.

La famille des Milioles étoit nécessaire, et toute defectueuse que la présenle M. de Fertussac, elle pouvoit être conservée, par cela seul rquelle contient le genre Miliole de M. Lamarck, genre gui, daus les unains bubiles de M. d'Orbigny, est deveau une fauille nalurelle. On pe peut disconveair que le genre Rénuline nc soit à tort compris dans la famille des Nilioles, puisqu'il se rapproche des Pénćroples et se confond avec elles. Le gence Glabulite de M. Defirance nous est resté ioconuu, et (puant à l'Arélluse de Montfort, il est indéterminable; ainsi dans cette famille reste le geare Miliole et ses démembremens actucls. Après elle et sans aucune transition, comme nous l'avons fait remarquer, viennent les deux familles de Céphalopodes octopodes et décapodes dont nous avons déjà parlé.

Après l'examen de cette parlie de la métlode de M. de Ferussac, examen que nous aurions pu étendre bien divantage si nous avions voulu relever tontes les erreurs de détails, mais qui seroit fostidieux, puisque ces délails se trouvent à chacun des arlicles des genres que nous avons cités. A près cet exameo, disons-nous, nait une réGexion qui en est la conclusion : c'est que M. de Ferussac, dont nous admirons la vaste éruditinn, a admis sans discussion les élémens dont il s'est sorvi, les prenant de toutes mairs, sans faire atlention si lous devoient inspirer la mème contiance. Ces élémens, groupés en geares et en fa-

Hisloire Naturslle dos Vors. Tome II. milles, d'après des observations mal faites et des rapports fort doutcux, ne pouvoient présenter 'y'uı ensemble incohérent, résultat nébsessaire de toute métlode créé avani l'examen mioutieux et très-détaillé de tous les faits qui doiveut lui servir de fondement. On peut dire, dans ce cas, que l'imilation est un inalhenr pour l'avancenseat de la scieace, car on we fait que changer de place ce qui auroil besoiu d'être mieux observé, et la science u'existe que par les filits.

Daus les familles naturelles du Règne animal, 11. Lalreille a poussé encore plus loin la conlinsion parmi les coquilles des Cépbalopodes: admettant prescque sans restrictiou les travaux de Montfort, de M. Lamarck et de Ml. de Ferussae, n'ayant qu'un guide bien incertain et souvent illusoire au milieu de ce dédale, donı l'accès est déjà si difficile, il étoit impossible qu'il ne s'y égarât pas. Nous savons bien če que l'on r’épondra a nos olsservations : qu'elles nous sont bicn faciles, puisque nous pouvous nous guider d'après les travaux. récens de M. de Haan et de M. d'Orbigny, qui n'étoient point encore pullićs lorsque pirturent les métlodes que rous critiquons. Cetle réponse paroît juste, nous la regardons comme spétieuse; elle a'cst cn quelque sorte qu'uue excuse atu moyen de laquelle on passe à cólé de la difliculié; et la difficulı́, la voici : c'est que pour créer une bonne méthode dans une scicace, il laut que l'ubservation ait douné une lougue Inabitule de tnus les liais de celte science, qu'elle ait permis à l'espit et au jugearent de s'exercer viurt fois sur cbacun d'eux. Si un fait douleux se présente, il fant le véritier, et pour la circonstance présente, puisque l'ouvrage de Montfort éloit si peu digne de confiance, pour quelques points depuis long-temps reconnus, il falloit s'armer, conme M. d'Orbiguy l'a fait, de la loupe et du microscope, vérifier Pouvrare dans son entier, et en reconooissant une eireur presque à chaque geore, on seroit arrivé à les abandonner, mais riclıe de laits nouveaux capables de remplacer avec un immense avantage un travail vicieux dans toutes ses partics.

Ne devons-nous pas nous souvenir de ce qu'il fait le grand Linné : ce n'est qu'après avoir vériGé les faits connus avant lui, ce n'est qu'après y. avoir ajouté ceux que sa longue observalion lui avoit appris, qu'il se hasarcla a créer une méthade, el?! quelle admirable métlode! Si elle a élé si supéricure à celles qui l'avoient précédée, il l'a dú aulant à ce qu'il avoit tout vu, tout examiné, qu"à ce tact si sûr, à ce jugement profond, à ce génie enfia dont la nature l'avoit doné. Si un exemple est à suivre, le voilà : il n'existe point d'autre moyen pour l'arancement des sciences. Nous le disons avec une sarte d'orgueil, si en France naus avons de grands naturalistes, des législatcurs de la science, des Cuvier, des Lamarck, des de Blainville, des Geoflroy, des Latreille, c'est parce que cet immense génie de Linué les a

E e 
dominés sans cesse : loin d'être de serviles adorateurs, ils sout devenus ses émnles en suivant ses préceptes. Ces préceptes, en définitive, se réduiseat it un seul, observer pour juger. Qu'est-ce qu'une múthode?' N'est-ce pas uoe suite de jngemens, de conclusions plus on moins généralisées et déduiles des faits nbservés? La condition d'une bonne mélbode est renfermée là tout entière; il ne faudroit que jeter un coup d'œil sur les méthodes spéculatives de l'Allemagne pour être bientôt assuré qu'on s'égare dans une autre route; elles n'ont rien produit qui puisse être l'équivalent d'une boune olsservation, $c^{3}$ est au basard guelles doivent quelques traits lumineux, et si plusieurs púlices peuvent être de quelque utilité, c'est qu'elles ont été conçues sous l'intluence de l'observation de la nature: hors d'elle qu'y a-t-il?

l'our examiner complétement la méthode de M. Latreille, il y faudroit consacrer un espace considérable; nous pensous qu'il suffira d'indiquer la marche générale de l’antear et de renvoyer, pour les dérails, au tableau de sa méthode que nous donuons a l'article Molrospoe. Les CéphaInpodes sont divisés, d'après la manière de N. Léach, en Dérapodes et en Octopodes. Par une idée qui appartient à M. Latreille, il comfrend daus ce premier orde, et dans deux familles distinctes, toutes les coquilles cloisonnées dont les animaux nous sont restés inconnus, et les Céplialopodes nus décapodes. Cet arrangeneut peut être bon, et un y est conduit par la Spirule; mais rien jusqu'à présent ne peut nous assarer que le plus grand nombre des genres Multiloculaires ont été en effet produits par des animaux décapodes. Cette manière de voir a conduit M. Latreille a ne plus laisser en dehors des deux grandes divisions fondamentales celte foule de geares, comme cela a lieu dans les autres méthodes : ce seroit sans aucun doute une graude amélioration, si l'ou pouvoit douner quelque chose de certain à cet égard, et malheurensement il n'en est point ainsi.

La première lamille, celle des Décapodes polythalames, est partagée en quatre tribus: la première, celle des Orthocères, coulient tous les genres à coquille droite ou senlement un peu courbée, ou d'abord en spirale et terminée en ligne droite. Si cbacune de ces formes avoit donné lieu à uoe section ou à une division quelconque, du moins, tout en produisant de la confusion dans ses rapports naturels, on pourroit dire qu'elle est le résulıat de l'application d'un moyen artificiel, et qu'il existe an certain ordre au moyen duquel on pent arriver facilement à ce que l'on cherche; mais la méthode de M. Lareille n'a pas même cet avantage, que Mlontfort avoit su donner à la sienne. Les rénnions de gexres sont faites d'après les caractères les moins imporluas; c'est ainsi que les trois genres Bélemnite, Callirboé et Ichiliyosarcolite sunt réu- nis, purce gru'ils sont coniques; mais il faut observer que le Callithoé est le moule de l'alvéole de la Bélemnire, el que l'I chthyosarcolite forme, dans son développement, une partion de spire. Une autre section renferme les geares Hibolite ("t Porodrague, deux démembremens inuliles des Búlenuites; la sectina qui suit est composée de trois genres de Montfort, qui font eacore double emploi des Bélenınites, de sorte que ce genre Búlemnite se reproduit sept ou buit tivis inutilemes!. Si uous examinons une autre section, nous Irouvons le genre Batolite, qui n'est qu'une Hippurite, associé aux 'liranites, aux Baculites et aux Haniles. Nous devous faire remarquer que le genre 'Tiranite a élé fail par Montfort avec un morceau usé de Baculite, et que le geare Hamite recourbé en spirale disjointe se lie aux Ammonites par les Scaphites.

Dans la seconde tribu, les Polycycliques, sont rassemblées une partie des coquilles euroulées; mais il a peu importé que leurs cloisons fussent simples ou découpées, qu'elles fussent tarriculées ou discoildes, que les luurs de spire fussent rénnis ou disjoints: par une conséquence toute simple, nous devons retrouver la méme confusion que dans la tribu précédente, puisqu'on observe la mêrne absence de puincipes de classification. Les Nautilites et les Milléporites, qui formest la troisième et la quatriène tribu, ne sont pas plus vaturelles que les deux autres: l'uue termine les coquilles enroulées, đfui, dans la pensée de M. La. treille, ont nne ouverture, conme les Nautiles, par exemple, et la dernière ne contient que celles qui n'ont plus cetre partie, ou qui l'oult plus on moius décomposée. Cependant les Miliolites qui $s^{\prime} y$ trouvent ont tomtes une onverture bica distincte et unique, ce qui les éloigne certainement des Mlélonie ou Alvéolites, près desquelles on les roit. On observe nou loin delles le geare Rotalie comme étanı une coquille rayunnée, ce qui pronve avec la derniére éridence que $\mathrm{M}$. Latreille $a^{2}$ a pas connu ce genre, pas plus que le Licophru ct la Discolite de Monifurt, qui sout des Polypiers, et que l'on roit cependant associés aux Sidérolites et aux 'Inoprores.

Nous savons combien est difficile à coordonner cetle partie de la mélliode que nous venons d'examiner dans l'onvrage de M. Latreille; il auroir fallu un long trarail sur les corps inicroscopicjues pour éviter la confusion qu'il a mise, et à laquelle il a été porté par les travaux publiés avant le sien. Il a, selon nous, un :ort inexcnsable quavoient su éviter quelques-uns de ses devauciers, celui d'a roir adais presque sans examen les gem es répétés deux on trois fois, el quelquefois davantage, pour les mêıes corps. Si nous avons été dans l'obligation de critiquer de cetie manière celte petite partie de la méthode du savaut entomologiste, nous nous faisons un vrai plaisir de reconnoître que dans le reste on trouré des idées 
neures qu'on s'empressera d'adopter, et d'ailleurs une vasie érudition et un savoir acquis par une langue observation.

La Tanille des Entérostés est la seconde des Céplaalopodes décapodes de M. Latreille; elle est formée de cing genres : ce sont les suivans, Sèche, Calinar, Sépiole, Onizie et Cranclie. Celte fumille a été conservée depuis, counme nous le verrons bienlòt, presque sans changement : elle est en effet bien laite.

L'ordre second, celui des Octopodes, est partagk en deux familles : ccux sans coquilles on Acocblides, et cenx qui ont une corguilie, les Cymbicochlides. Dans la première liunille nous trouvons les trois geares Poulpe, Elédone et Léachie : ce dernice est incertain; et, dans la seconde, un nombre égal de gemres, qui sout: Ocythoé, Argouaule et Bellérophe. Nous observerons que, uicme eu altuettant avec M. Laireille que le Poulpe que l'on trouve dans l'Argonaute en est le constructeur, l'un des deux gentes Ocythoé et Argonaute est inutile : il suffira de se souvenir, pour s'en convaincre, que ce genre a été établi, par M. Ralinesque, pour l'aniral de l'Argonante trouvé sans coquille. II est impossible de conserver un genre pour un animal et un autre pour la coquilie; si, au contraire, on n'idmet pas cette opinion, et que l'on rulopte celle qui lui est opposée, dés-lors cette lamille des Cymbicochlides est détruite, le geure Ocytboé rentre das celle des Acochlides, et les geares Argonaute et Belléroplıe, se joiguant aux Carinaires, constiluent dans les Gastéropodes une fimille très-naturelle.

Tout en divisant les Céphalopodes à peu près comme M. Latreille, M. de Blainville propose rependint, dans son Truité de Malacologie, un arrangemeal tout différent des familles et groupes des genres. Nadmellant qu'avec beaucoup de doutes les coquilles polythalames au nombre des Céphalopodes, il les rejelte dans un ordre à parl, s'éloignant en cela de la manière de voir de N. Latreille, qui fut !e premier, au contraire, à les renfermer dans les Décapodes; spécifiant ainsi, par une analogie bien contestable sans douse, la nature d'un grand nombre d'animaux inconuus et probablement, pour beaucoup, à jamais perdus. Quand ou songe i l'éloigaement qui existe entre les coquilles l'olythalatnes microscopiques et celles intéricures des Cíphalopodes counues, on est porté à douter, avec 11. de Blainville; aıais on ve devra porter son doute que sur ce qui est réritablement incertain, et c'est ce que n'a jas fait l'auteur de la Malacologie; lrouvaut parmi les genres de coquilles wlythalames un bien plus grand nombre pour les microscopiques que pour les autres, il a porté un jugement sur la masse, sur l'ensemble, sans faile atteation qu'il falloit, avant tout, dis- - tinguer et séparer les deux sortes de cor [s conpris dans les Multiloculaires.

Les Céphalopodes, que MI. de Blainville nomme Céphalophores, sont parlagés en trois ordres: le premier a reçu le nom de Cryptodibranches; il contient en deus familles les Octocires ou Octo. pudes, et les Décacères ou Décapodes. Dans la première on me troure que le seul genre lovipe parlagé un deux groupes, les Elédones pour l'un, "L les Ocythoés pour l'autre. Cet arrangement, beaucoup plus satisliaisant que ce que nous arors vu, ne permet aucin double emploi, et rejette des Céphalopodes, les Argonautes el les Belleroples. M. de Blainville réduit la farnille des Décacères ì deux genres, les Calmars et les Sèches; il est vrai qu'il divise ce premier genre ca six groupes, ce qui lui permet d'admettre, ¿t ce titre seulearent, lit plupart des yenres qui ont été proposés prarmi les Décapodes : e'est ainsi que les geares Sépiole, Cranchie, Onychoteutbe, lorment les trors premières divisions, qui sont suivies des Calmars, Illèclıes, Piéroteutlies et Sépioteullies. Ce grenre représente donc à feu près la lamille des Eutérostés de MI. Latreille, moias les Sèches. Ce même geore, qui est le secoad des Décacères, ne comporte aucune division. M. de Blainville, clans les additions et correetions au Traité de Malucologie, propose d'ajouter aux Décapodes notre geure Béloptère (royez ce mo1), qui, tel que nous le concevons, fant évidemuent le passage entre les Séches et les Bélemuites. Quand on songre à ces rapporls et à ccux qui s'élablissent par les Spirules, qui sont écralement Décapodes, il nous semble qu'il y a un moindre inconvénient à joindre les coquilles polythalames siphonifères aux Décapodes, qu'a les en éloigner. Nous savons bien que, ponr certains genres dont les types sont perdus, on aura loujants du donte sur leurs araimaux; mais c'est ici lecas, ou jamais, de faire usage d'une sage analogie, qui est toujour's préférable a une simple lyypotièse. Pour la mettre en pratique avec avantage, il fandroit n'arnir pas ì s'embarrasser des coquilles polythalames wicroscopigues, dont le mélange avec les autres a été toujours un obstacle ponr l'améliuration de la unétbode. Nous en allous trouver ici, clans l'ourruge de M. de lilaiuville, un dernier et nouvel exemple.

La second ordre des Céplialopodes de M. de Blainvilte a reçu le sou de Cellulacés, et il ne contient que des coquilles microscopiques : il est partagé en trois familles, les Sphérulacés, les l'lanulacés et les Numbnlacés. Dins la première on trouve quatre genres: ce sont les BIilioles, les Mélonies, les Suracénaires et les 'l'extulaires. Ces genres, pris eu prarticulier, sont bons, leur réumou en nae même fumille est défectueuse, parce qu'ils u'out entr'eux aucune analogie de structure, ni mêne de torme, et que tous qualre doivent être distribués dans autant de faunlllies, E⿺ 2 
où ils trouvent de nombreuses analogies. La fami!le des Planulacés est beaucoup plus nalurelle que la prcuic̀ie, mais elle n'est point complète, puisqu'elle ne conticat que les deux genres Rénuline et l'énérople, qui ont entr'eux de l'analogie, quoique M. d'Orbigny les ait séparés daus sa métbode; mais il existe plusieur's autres genres qui doivent se joindre à ceux-ci pour former une fanille. Si, daus la famille des Nummulacés, les genres n'étoient formés de groupes composés de genres de Munifort, qui, pour la plupart, sont inadinissibles, on n'auloit que peu de réformes à y faire; elle demanderoit seulement à êlre complétée, composée comme elle l'est des six genres Nummulite. Hélicite, Sidérolite, Orbiculine, Placentule et Vorticiale. Nous ferons remarquer que les denx premiers genres font double emploi, l'Hélicite n'étant que de certaines espèces de Numnulites. Le genre Orbiculine est déplacé, puisqu'il coutient des coquilles celluleuses comparables aux Mćlonies on Alvéalites, et devant en conséquence entrer dans la nêue famille.

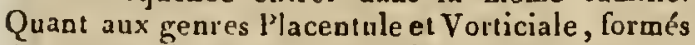
de genres de Moplfort réunis sur des caratères mal appréciés, ils ne peuvent être adoptés, par celte raison, que les groupes qui les constituent ne peuvent supporter un examen approfondi.

Dans son troisiène ordre des Cépbalopodes, nomué Polythalamacés, M. de Blainville n’a point été heureux dans le choix qu"il a fait des moyens dunion entre les genres et les familles; guidé par le caractère si artificiel et de si peu de valeur de la forme extérieure, il a manqué au principe dont il a fait une si sage et si boune application dans le reste de sa méthode; principe par lequel tout caractère organique doit l'emporter sur tous les autres. La connoissance imparfaite de plusicurs genres, comme M. de Blainville se plaît à l'avouer lui-même, a été la principale cause qui l'a déterminé à ranger les genres d'après leur plus grand développement spiral : c'est ainsi que s'est tronvé détruit le petit nombre de rapprochemens naturels proposés par MI. Lamarck, et qui aveient passé intacts, ou à pen près, à iravers le chaos des classifications; c'est ígalement de cetıc manière que se sant trouvées confondoes les coquilles micioscopiques avec les grands P'olythalames.

On compte sept familles dans cet ordre : celle des Orthocères se présente la première. Elle contient deux divisions, les genres à cloisons simples et ceux à cloisons sinneuses : les Bélemuites et ses nombrenses divisions; les Conulaires, genre fort incertain; les Conilites, qui rentrent en partic dans les Bélemnites et en partie dans les Orthocères; enfín les Orthocères forment la premic̀re division. Dans ce derajer genre se voient mélangées les caquilles siphonifêres droites et les caquilles microscopiques sans siphon et Egalement droites, telles que les Nodosaires et les Réuplages. Ja seconde secion nous oftre le genre Baculite lui seul démembré bien à tort de la fauille des Ammonées, à lacunelle il est jnint par des caractères bien esseutiels, le sipbon dorsal et la lurme des cluisons.

Dans la lamille des Lituacés nous trourous la nuêne division, d'après les cloisons simples on découpces ; c'est aitusi que les genres Ich thyosa:colite, Lituole et Spirule sani dans la première section, et les gentes Hamite et Anunonocéralite daus la seconde. Nous ne sommes point élonné de rrouver le genre Iclithyosarcolite ici, puisque l'on ne savoit point encore qu'il a ppartint à une coquille bivilve : les geares Litnole et Spirule ont de l'analogie; mais 'il n'est pas nalurel de rapprocher des Spirules le genre Spiruline, formé de coruilles microscopiques. Ia seconde section ne devroit présenter qu'un seul genre, puisque le genre Ammonocérate de M. La. marck est le mênue gue relui des Hamites do M. Sowerly : il faut adopter l'un ou l'autre. Nous remarquons encore ce démembrement nouvean de la fituille des Ammonées, fait malgré les raractères que nous avons indiqués pour les $\mathrm{Bacu-}$ lites, et qui se trouvent être ici absolument les wềnes.

La troisième famille, celle des Cristacés, u’est gnère plus heureusement conçue que les précédentes, car elle est composée de trois genres de caquilles microscopiques, dant deux, Óréade et Linhthrie, peuvent se joindre anx Cristellaires, et le troisième, Ciépiduline, furmé de trois groupes, a besoin d'être démembré. Chacun de ces groupes appartient à des gentes dillérens.

Naintenant que nous avons déjà vu des démembremens de la fauille des Ammonées répandus dans dillérentes fitmilles, on ne sera sans doute pas surpris de la trouver réduite et dans un état défectueux, comme toules les autres. Nous y trouvnns d'abord le genre Discorbite entierement formé de coquilles microscopiques, tontes dépourvues de siphon et tontes à cloisons simples; ce genre est suivi des Scaphites, dont l'enroulemeñt est incomplet d'un côté et dont les cloisons très-découpées les rapprachent des Ammonites; puis vient le genre $\Lambda$ numonite dans sun intégrité et tel qu'il esi généralement adopté; il est enfin lui-même suivi du genre Simpligade, dans lequel M. de Blainville, par un clangement dans l'alranyement de Montfort, met le Nautile ombiliqué lui senl, tandis que les autres Nautiles, cenx saus ombilic, ont pris place dans une autre famille et dans un autre genre. Telle est la cumposition de cette famille des Amınonacés, qui ne saurait être conservée dans aucune de ses patties.

Nons ne voyons pas davantage la possibilite de conserver la cinquic̀me famille, celle des Nantilacés; les genres Orbulite, Polystomelle et Lenticuline qui s'y trouvent, accompagnant les Nautiles démembrés, comme nous renuas delo voir, 
ne présentent pas un assemblage naturel. Le grerre Orbulte, conme on le sait, a été proposé pour la premicre fois par 11 . Lamarck, pour yuclques Ammonites dont le dernier tour enveloppe totalement tous les autres. Rejeté de lis móthcde comme inutile, le noun seul fut recueilli par 3. de Baanville, gui l'appliqua ì la réunion de deux des genres de Monifort, Agrauide et Pélaguse, le premier furt incertain et le second appartenant aux Anunonices. Quant aux deux genres Polystomelle et Lenticuline, ils sont inaduissibles tels qu'ils sont constitués; ils ne sont point ì leur place, el le genre Lemticuline surtout, se lianı aux Numnulites, comme dóji nous l'avous dit en parlant de la uxétlode de M. de Ferussac, ne sauroit être séparé davanıage de ce genre, et ne pourroil aduellre dans tous les cas le plus grand nombre des urroupes furmés d'un des genres de Moatfurt que M. de Blaiaville y a placís.

Les deux genres Cibicide et Rotalite, qui forment à eux seuls la fanille des Turbiancés, qui est la sixiène, ont bien entr'eux quelqu'aualogie, puisqu'ils peuvent eutrer dans une mêne lamille; nais ils sunt ici trop isulés ponr qu’ils constituen؛ une famille naturelie, guand on songe surtout aux nenres de Montfor que M. de Blainville a rattachés aux Rotalites. Nous arrivons enfin i la septieme el deruière famille de $\mathbf{M}$. de Blainville, uons y trouvons le seul geure Turrilite, qui termine d'une manière singulière celte série des Mollusigues céphalopodes, si singulièrement coordounés d'après un principe que l'auteur a eu soin de ne jatudis mettre en pratique daus le reste de la ualacologie.

C'est avec plaisir que nous voyons se terminer la tảche pénible que nous nous sommes imposée dans le seul but d'éclairer la scicace; cet examen critique des méthodes étoit nécessaire pour que l'on puisse éviter à l'avenir les écueils que nous a vons signalés: c'est là le seul objet que nous nous soynns proposć. Nous apprécions trop bien les difficultés sans nowbre qu'il faut vaincre pour créer une bonne mélhode; nous avons trop d'estime pour les savans qui en ont doté la science pour que l'on puisse nous supposer ici lâ moindre intention bustile à leur égard: on en sera d'autant mieux couvaincu, que nons reportons plus haut l'origine de la confusion ga'ils ont Irouvée toute établie dans le principe et qu'ils n'out fait que continuer.

C'est à Linné en effet que nous rapportons la premicre confusion; c'est lui qui rassembla indistincternent tous les Polythalames quil connut dans le genre Nautile: les auteurs qui le suivirent proposèrent d'abord des démembremens du genre Nautile, comme le firent Bruguière, Fichlitel et Moll, etc., qui cependant se tinrent davantage dans l'esprit de liuné que leurs snccesseurs. N. Lamarck et MI. Cuvier lui-méme, dans leurs premiers travaux, tout en chereliant à secouer le joug de Linné, crouvant une roulo Hacée, ne lentèrent pas d'en sortir. Après avoir mulliplié de plus en plus les démembremens des Nautiles, ils en viureat à l'établissement de lamilles et d'urdres parmi eux, en conservant toujours les rapports dont ils s'étoient d'abord servis. Les zoolugistes qui tentèrent après cux de nouvelles méthodes n'ayaut point fait de nouvelles observations, furent dans la nécessité de prendre pour les établir les roatériaux qu'ils trouvèrent, et furcut conduits presque malgré eux ou à l'imitalion ou à une confusion d'autant plas lächeuse qu'elle fut présentée sous l'apjparence de l'ordre.

Des observaleurs laborieux ont ouvert depuis quelques années une nouvelle carrière à l'étude des Céphalopodes, élude qui seroit aujourd'hui bien plus avancée si la roure qu'ils ont suivie eít été trouvée lorsigue la concbylioiogie prit un grand essor à la suite des traraux des zuolugistes franciais.

Lè noms de MM. de Haan et d"Orbigny sunt inséparables, par la réforme qu'ils proposècent presque en ruême temps dans l'arraugement des Céplialupodes; cependant, pour procéder avec plus d'ordre, nuus examinerons séparément les mébodes de ces auteurs, en commençant par celle de M. de Han qui a précédé celle de M. doubigny. M. de Itaan, daus sou ouvrage (Monographice Ammoniteorum et Goniatiteorum specimen), eut pour but principal l'urrangement mélbodiçue des coquilles cloisounées puurvues d'un véritable siplion; unais avaut d'eu venir à celle spécia!ité, il examiue les méthodes yui ont élé publićes avant lui, et après des observalions souvent très-judicicuses, il en vint à proposer, dans l'universalité des Céplıalopodes, un arrangement nouveau, qui, encore défectueux suns quelques rapporls, est cependant infininient meilleur gue tous ceux que oous avons vus. Nous cn donnons ici une copie exacte.

I. Animal contenu dans une coquille ou qui y est - tixé par un ligament...... a DHEREvitis.

A. Cloisons perforées par on ou denx siphons....... Siphonolde.

1. Cloisons à bords persillés. Ausonrtes:

3. Cloisnns à bords anguleux ou onduleux..... Gomatisea.

3. Cloisons entières....... NACrutes.

B. Cloisons sans siphons..... Asiphonoipea.
1. Tours de spire simples, test non foliacé...... Mrcroscoprca.
2. Tours de spire cornposés de lamelles recouvran- tes............. Contaburata. 
II. Animal dépourvu de coquille, ou n'y étant pas attaché Iorsqu'il en a une....... LJBERA.

On voit d'abord que cet arrangement est le résultat de l'emploi des caractère de premier valeur dans les Céplalopodes; quelques-uns sans doute n'ont pas ćté appréciés comme ils devoient l'être, mais il seroit injuste de vouloir une méthode parfaite d'un premier jet. Les Céplıalopodes adhéréns ct libres correspondent sans aucun doute aux Décapodes et aux Octopodes des autenrs. C'est dass cette première division que $\mathbf{M}$. de Haan ragge tous les Céphalopodes à coquille, quelle que soit cetle coquille, et c'est, comme nous l'avons $\nabla u$, ce qu'a fait aussi N1. Latreille: mais ce que personae n'avoit essayé, et ce qui est pour nous le priacipal mérite de la classilication de M. de Haan, c’est qu'il a bien justement séparé les coquilles siphonces do celles qui ne le sont pas, et a par cela seul fait cesser le chaos qui régnoit dans les Céphalopodes; le reste de l’arrangement devient facile. Il n'est pas douterux que cette classe des Asiphonoides ne soit défectueuse, puisqu'elle met en contact et les coquilles microscopiques et les Mollusques sépiaires; ces derniers surlout, sous le nom de Conlabulatis, réunissent ces trois groupes, les Calmars, les Sèches et les Nummulites. Certainement si N. de Haan eát mieux couna les Nummulites et quelques genres voisins qui les lient aux autres coquilles microscopiques, il les en̂t rejetés de celle famille, et peut-êtue ce lien détruit, il aurvit pu sćparer et des Octopodes et des Décapordes loutes les coquilles microscopiques, comme l'a fait si judicieusement M. d'Orbigny. Le travail de M. de Hixan ayant eu pour but priacipal l'arrangement des coquilles siphonées, nous allons examiner la classitication de cette partie, après en avoir présenté le tableau exact. Ce tablenu ne comprend dans son développement que la classe nommée Siphonoidea par M. de IIuan.

A. Cluisons découpćes, foliacées el lobées.............. Ammonite..

1. Coquille en spirale.

a. Coequille turriculée..... 'Terriltte.

b. Coqquille discoïde.

«. 'Tours de spire invo!vés. ............ Grobite.

f. Tours de spire aon involvis.

1. S'éprassissant peu à peu.......... P'unitte.

2. S'épaississant rapidement. ...... Asraronite.

1I. Coquille non spirale.
a. Courbée en deux parties égales............ II Aarte.
b. Droite conique....... Baculite.

B. Cloisons auguleuses ou onduleuses.............. Goviatitea.

I. Coquille spirale.

a. Tours de spire leuni-enveloppés.......... Cératite.

b. Tours de spire tout-a-fait cnveloppés......... Goniatite.

II. Coquille droite non spirale. Rrabdits.

C. Cloisons très-entières....... Nactra.

I. Coquille spirale, tours enroulés surle mềne centre.

a. Tours complétement enveloppés......... Natutríos.

b. Tours non complétement enveloppés.

๙. S"épaississant peu à pen. Discite.

ß. S'épaiss. rapidement. . Ompranie.

II. Coquille iofléchic en spirale de l'un et de l'autre côlé.............. Scaptite.

III. Coquille spirale, le dernier tour projeté cu ligne droite.

a. Le dernier tourtrès-court. Sprnuze.

b. Lederniertourfort long.. Liture.

IV. Coquille non spirale, droite.

a. Formée d'une gaine soluble et d'un moule intérienr (aucléus).

b. Nayant ri gaine ni oucléus.

*. Cananx Iongiludinatix au nombre de deux. Hiprurite.

\&. Point de caraux longitudiazux.

1. Coquille cylindri-
que........... Onthocératite.

2. Coquille anguleuse, pyramidile ..... Conitite.

Trouvant dans les trois fauilles quil propose une analogie évidente entre les genres qui les composent, relativement à la forme extérieure, voici comment $\mathrm{N1}$. de llaan en établit la coïucidence : 


\section{E P}

A.Y.YOYTEA. GONTATITEA. 10. Planites.

20. Ammonites. Ceratites.

piscites.

Omphalia.

$5^{\circ}$. Globites. Goniatites.

Nuutilus.

$4^{n}$. Baculites.

Rhubdites.

Orthoceratites.

Ce parallélisme est la conséquence naturelle de l'établissemeut de trois familles et de plusicurs rouveaux geares; il dénontre, quand mêne il ne pourroil êlre adopté que pour deux fauilles, dans quelle grave erreur sunt tombés ceux des acteurs qui, dans des séries bien distincles, uen ont vu gu'une seule, et ont cherché des rapports immédials entre des corps qui ne pourrunt janaais en avuir yuc de plus éluignés.

La famille des Ammonites est composée, comme on peut la voir, d'un plus grand nombre de genres que duus II. Lamalck; on trouve de plus les genres Planite et Globite : ce deruier est absolumeat le mêrne que le genre Orbulite de M. Lamarck, et par la raison yu'il est iualmissible, celui de .I. de IIaun le duit être aussi. Il laut irrévocablement rejeler d'une bonne mélbode tous les genres qui ne sunt pas fondés sur des caractèrés invariables el d'une valeur délerminée. Nous voyons les geures 'Turrilite, Buculite, IHamite, fuudés sur des diftérences de formes bien caractétisées; nous les adinetıons au même degré dans la méthode, mais nous ne devons pas accepter les genres Globite et Planite, qui ue sont que des mudilicalions d'uoe aceme forme, celle de l'enruulement spiral dans un même plan; mais nous adopteruns le gente Ammonite, parce qu'il a aussi, comme ceux que nous venous de citer les premiers, une forme qui est ì lui : que dans celte forme l'enroulement soit plus ou moins rapide, que les tou's de spire soiemt, plus ou moins embrassans, peu importe puisqu'elle persiste. Il n'y a plus de parité eatre les genres de la famille de M. de Haan, dès que leurs caractères ne sont poin d'une même valeur.

Ia famille des Godiatites ne nous semble pas adinissible: composée de deux genres démembrés des Ammonitcs et du genre Ribabdite, qui est le ineme que l'lchihyosarcolite de M. Desmarest, elle ne peut supporter un examen approtondi. Il est évideut que M. de Haza n'a pas conau l'I chthyosarcolite, car personne n'iguore que cette coquille n'est pas droite, comme il le croit; il n'est pas douteux non plus que l'un des deux genres Cératite ou Gouiatite est de trop, et que celui des deux que l'on conservera reatrera, soit dans la famille des Ammonites, foit dans celle des Nautiles, selon que le siphon qui traverse les loges sera ou dorsal, on médian, on ventral. On ue sait pas encore, dans les coquilles placées dans ces genres, oì se tronve le siphon; on ne peut donc point cncore se décider : pous serions porté à croire cependant, par analogie, que les corguilles du מ̆crue Cératite sont des Ammonites, et celles du genre Goniatite de la famille des Nautiles.

La fa mille des Nautiles sle MI. de Haan présente, sous le rapport de gquelques geures, les mêmes délauts que les précédentes, parce que les caractères qui ont servi ì leur élablissencnt sont de trop peu d'importance. Nous atvons dit pout quelles raisons nous rejelions les rentes Globite et Planite de la famille des Ammonées; elles subsistent dans celle-ci pour nous empécher d'adopte: les genres Discites et Omplalia, qui sont pour nous des Niutiles plus au tuoius aplatis, à ombilic plus ou noins auvert. Quaut au genre Scaplite, qui se trouve au nuilieu de la famille des Nautiles, il est bien certain qu'll n'a pu yêtre placé que par suite d'une erreur; il appartient, comme tout le monde sait, is la famille des Ammonites, et par la forme de ses cluisons, el par la position du siphon.

Le geare Spirule est toujours embarassant à placer dans une méllode : soit qu'on en lisse une famille, soit qu'à l'exemple de MI. de Haan on !e nelle dans celle des Nautiles, il se remarifue toujours une lacune, une interruption yqu dérange un peu les iclées systématiques. Ycut-on le considérer comme une liaison entre les Nautiles el les Ortlocérales, et dans ce cas le laisser dans la fumille des Nautiles? ou bien doit-il former un type à part, une famille en debors de la première? Nous préféruns celle première mauière de voir, quoique les coquilles de ce genre ne soient pas engainantes comme toutes celles des Nautiles, et q̨u’elles olfient aussi une forme particulière.

Nous présumons que c'est par oubli que le trenre Bélemnite ne se trouve pas dans le tableau de II. de IIan; sa place est préparée et marquée entre les Lituites et les Hippurites. Nous ne pouvous criticguer ces s'apports, qui cependant ne sont pas naturels, et cela pour plusieurs raisons; d'abord, parce que notre genre Béloptère, qui lice les Bélemnites aux Sèches, n'étoit pas connu, et en second lieu, parce que l'on avoit cru que les llippurites éloient des cuquilles cloisonnées, tandis qu'elles ne le sont pas et appartiennent à la classe des Conchyfères, comme nous l'avods irrérocablement prouvé : ces deux circonstances sulfisent pour justifier les auteurs qui, ne les ayant pas connues, n'ont pu faire les changemens qui en découlent. Nous ne dirous douc rien du genre Hippurite, qui se trouve interposé entre les Bélemnites et les Orlhociératites; celles-ci sont dos Nautiles droils, comme les Baculites sont des Ammonites droiles. On auroit pu les rapprocher davantage des Nautiles. Quant au genre Conilite, qui termine cette série des Céplalopodes, il nous semble bien douleux; des cloisons irrégulières dans lesquelles jusqua'a présent on n'a vu aucune trace de siphou, une forme pyramidale, anguleuse, iosolite, daus les Céphalopodes, nous don- 


\section{4} C E P

nent de tels doutes, que nous préférons ne pas mentionner ce genre que de le placer dans les Céphalopodes, dont il ne présente aucun des caractères distinctifs.

Les légères erreurs que nous avons fait remarquer dans la méthode de M. de Maan ne sont rien quand on compare leur foible désavontage à la grande utilité qu'un arrangemen! aussi nouveau devoit avoir pour la scieuce; il faut se souvenir, poor l'apprécies', du désordre que nous avons fait remarquer dans les méllsodes qui ont précédé eelle-ci.

M. d'Orbiuny a, comme M. de Haan, le mérite d'avoir porté la réforme au milieu des méthodes; ruais ayant sur M. de Haan l'immense avautane d'avoir revu cous les Céphalopodes microscopiques, et d'avoir fail sur eux, avec une admirable patience, une longue suite d'olsservalions, il a pu embrasser dans son enlier tout ce grand ordre des Céphalnpodes, et proposer pour lui une méthode plus parfaite. M. d'Orbigny cependant, nous devons lui rendre celte justice, ne put profiter du travail de M. de llaan, quoiquil ait été pulslié avant le sien, parce que l'intervalle qui existe eotre les deux publications a été trop court pour lui permeltre des modifications dans une parlie dont les principales divisions étoient firées depuis long-temps. Ainsi, comme M. de Haan, M. d'Orbigny est créaleur de sa classification; il la doit comme lui à l'observation, et toutes deux prouvenı ce que nous disions précédemment, que pour juger ou färe une méthode, ce qui csı la mênı chose, il faut bien connaitre tout ce gui doit en faire partic. I! n'y a que l'observation qui puisse nous mettre dans cette condition nécessaire : elle est donc, en conclusion, la base fnndamentale de toute science et de l'ordre que l'on y peut établir.

Nous donnons ì la fin de cet article une copie exacte du lableau méthodique de M. d'Orbigny; il est iudispeusable pour abréger l'examen que nous en voulons livire, examen qui nous semble nécessaire seulement pou' les parties que nous croyons susceplibles de cliangemens avantageux. Nous adopterons tout le reste, nons y ajonterons les résultats de nos observations, et nous cluercherons, autant que nous le ponrrons, à améliorer celte classilication, dont les bases sout honnes, ainsi que le plus grand nombre des détails. Jes changemens que nous proposerons se remarqueront surtout dans les deux prewiers ordres de M. d'Orbigny. Nons donnerons les motifs qui nous ont détermivé à les proposer; aa moins par là nous éviterons, autant que passible, d'être accusé de les avnir fails au liasard.

Les ohservalions que nous allous présenter sur la classification de M. d’Orbigny seront de deux sorles: les unes générales, qui s'appliqueront ì l'ensemble du système et à ses divisions principales; les autres de détails sur les rapporls des geares et leur adusission.
C E P

Nous l'avons dit, et nous ae cesscrons de le répéter, parce que nous croyons que c'est un des moyens les plus sûrs d'améliorer la méllıode, il faut que les caractères des divisions que l'on établit dans me grande série d'êtres oryanisés soient d'une égale valeur, ct le plus sonvent comparables dans les divisions du même ordre. Puar que ces caraclères soient comparables, il faul nécessairement qu'ils soient pris dans les mèmes organes : quand ces organes sont importans, et quile sont la condition núccssaire du mode particnlicr de toute l'organisation, ils peuvent servir à Conder les classes ou les ordres, selon la prédoninance qu'on leur accorde; mais une fois que l'on a clioisi celte série pour élablir un ordre, on ne peut plus prendre une autie sérje pour fortaer l'ordre suivant apparleaant à la même classe.

Que l'on ail clioisi, par exemple, les organes de la respiration pour former les ordres dans lez Mollusques gastéropodes, on devira, pour que chacun des ordres ait lit même valeur, les établir sur les modifications des mêtnes organes, el non pas faire des oidres tantôt avec les organes de la respiration, tantót avec ceux de la génération ou de la loconsotion, elc. C'est au zoolouiste à déterminer, avant de faire ses coupures méthodiques, les organes qui derroni prédominer par lcur constance et les modifications tranchées quils présentent; il les prend alors aves sécurité pour circonscrire ses ordres : d'iutres moins imporlans se présenten ( pour les familles et les genres. Raisonnant d'après ce principe pour ce qui a rapport aux Céphalopodes, nous wous apercevous bien facilement cu'il n’a pas été mis en pratique par 11. d'Orliguy. Son premier ordre, en effel, emprunté ì MI. de Blaiuville, les Cryptodibranclies, est fondé sur la nature des organes de la respiralion; le second et le troisième, au contraire, sont formés sur l'existence ou la non existeoce d'un siplion dans la coqguille, caracière qui n'a plus lo moindre rapport avec les organes de la respiralino, qui on servi pour le premier ordre. La classificalion est douc fautive sous ce rapport, que la valeur des ordres n'est pas égale el a élé prise arbitrairement.

Le résulıat de cette marclie vicieuse étoit nécessaireaicnt l'établissemeot de familles mal circonscriles sur des caraclères également arbitraires : ainsi, pour les deux premiers ordres, cest le nombre des bras qui les séparent; dans l'une il y en a huit, dans l'autre dix. Dans la famille suivaute, celle des Spirulées, appartenant au second ordre, on trouve également dix bras commo dans la seconde liamille du premier ordre; mais ce caracière n'a plus la mêrne importance, ceux qui constituent celte fumille sont lirés de la nalure de la coquille el de la longueur de la derniérc loge, ainsi que de la place occupéc par le siplion; ce qui, dans cet ordre des Siphoniferes, devient de première valeur pour la formation des familles. 
Ce défaut capital que nous venons de signaler n'existe plus pour les genres qui présentent, pour le plus grand nombre, des caractères équivalens, arais leurs anports mutuels ont dû se ressentir de la manière dout les ordres el les familles out été fitils; c'est ce que nous allons exaininer.

Nous tronvons d'abord dans la première famille les genres Argonaute et Betlérophe; nous avous dit piécédemment, et en trailant de ces genres à leur place, pan quelles raisons nous ne les adnetlious pas au nombre des Céphalupodes. Nous ne reviendrons pas ici sur celle question que nous arons épnisée ailleurs. Des trois autres yenres, l'oulpe Elédon \& Calmar, nous rejetons !e dernier comme incertain, et nous le remplacons par le geure Ocythoé, qui a ćté établi pour l'anitoal parasite de l'Argonaute.

Dans la famille suivante, celle des Décapodes, les cinq preniers genres sont liés entr'eux, nonseuleueut parce qu'ils portent des bras sur la tête, mais encore par la nature el la positiou du rudiment testacé dont jis sont pourvus. Quant au genre Sècbe, uous croyons que la nalure de sa coquille le sépare nettement de cette famille pour se joindre à notre Béloptère, que M. d'Orbigny a mal connu, ou u'a pas conau du tout, malgré ce ţu'il en a pu dire. Ce genre Béloptère est évideniment un passage entre les Sèches et les Bélemaites. Participaut de la nature de l'un et de l'autre de ces genres, M. d'Orbiguy auroit pu tirer un très-bon parli de son étude plus approfondie. Yojez Beloptére.

Le genre Spirule constilue à lui seul la famille des Spirules; il est isolé, sans aucun doute, de lous les autres du même ordre, mais par certains caractères seulement; car s'il est Décapode, il se lie par là áux Sèches. Il est séparé des Nautiles par un caractère qui, selon nous, n'a pas assez de valeur, et dont M. d'Orbigny n'a pas tenu compte dans sa famille des Périftellées. Par exemple, nous savons que la Spirule est une coquille demi-intérieure; nous savons aussi que sa dernière loge ne peut contenir et protéger l'animal, mais nous ne savons pas si les Nautiles et autres genres de la famille des Nautilacées ne sont pas dans le méme cas; tout porte a cruire que la $\mathrm{Li}-$ raite, malgré sa dernière loge plus grande proportionnellement que dans la Spirule, étoit placéc dans l'animal de la même mauière que celle-ci. Ne peut-on pas faire la même conjecture pour le genre Orthocérate et ponr le Nautile lui-mêne, dont l'animal nous est si peu connu? En nous lais. sant guider par l'analugie, et sans cepeudant abuser de ce moyen si utile pour nous faire juger de l'inconnu par le conna, nous arrivons par deux moyens à présumer que les Céplualopodes sipboniféres apparteuoient à la division des Décapodes. Nous avons d'un côté le Béloptère, qui se lie tellement aux Sèches par sa forme et la position qu'il devoit aroir dans l'animal, qu'on peut lui suppo-

Hist. Nat. des Vers. Tome II. ser nne organisation très-analogue; comme d'un autre côté il se lie aux IBćlemnites, il introduit, pour ainsi dire, ce genre et les Ortliocérates dans les Dérapodes. I a Spirule appartenant clle même à ces Décapudes, elle y cotraine les Lituites et les Nautiles; ces derniers, il faut en convenir, avec raoins de probahilite.

On voit par ee qui précède que nous n'admcltons pas la famille des Naurilacées teile que $\mathrm{Nl}$. d'Orbigny l'a compusće; il y a eutre les lbélemnites et les Urthocérates une liaison fvidente, ce qui nous empèche aussi d'admeltre celte fanille des l'éristellées, forraće des denx genres Bélenınises et Ichthysoarcolite; elle se déruit delle-même des que l'on sait que ce dernier genre a été fait avec les débris d'une coquille bivalve, et que lun aperçoit des rapports naturels aux Bélemnites.

La lamille des Ammonées est tellement naturelle qu'elle a pu traverser sins altérations toutes les mélhodes, à l'exception de celle de $\mathbf{M}$. de Blainville. M. d'Orbigny l'a mieux comprise que I. de Haan en la restreignant aux seuls genres admissibles. Aucun animal de celte famille n'est connu; on ne sait donc, en aucune façon, s'ils sont Décapodes ou dépendant d'une tout antre organisation; l'ignorance complète où l'on est à cet égard fait que l'on peut placer celte litmille à peu près arbitrairement. Cependant la liaison qui existe entre les Décapodes nus et les Nautilacées ve peut être rompue; il faut donc la placer, ou à la suite des Ociopodes, sans que l'on ait pour cela le moindre motif, ou à la tin des Décapodes, ce qui yous paroit plus raisonnable, puisque, comme dans les genies dépendaut de ccux-ci, l'aninsal étoit liếa sa coquille par un siphon.

La discussion qui précède, sur la méthode si re. marquable de II. d'Oı bigny, nous a forcé à exposer les principes que nous croyons favorables à l'arran. gement de celle partie des Céphalopodes. N'ayant pas trouvé de parité eutre les ordres et les familles, parce qu'il n'existe pas dans la valeur des caractères une similitude convenable, nous avons dù chercher d'aures bases pour le groupenient des ordres et des familles, et nous les avons trouvées non dans les organes de la respiration, qui restent les mênes dans les Octopodes et les Décapodes, mais dans le nombre des bras, qui coincide ayec l'absence ou l'existence d'une coquille. Ce caractère, comparable dans tous les cas, uous semble de prenière valeur, et nous l'employons à la formalion des ordres : les caractères pris sur les mêmes organes ont l'avantage d'être d'égale valeur. Deux ordres vaturels se présentent done dans les Céplialopodes uon furaminifères, les Octopodes et les Décapodes; les Ociopodes n'ont point de coquille, ınus les Décapodes en ont uue : !a nature de celle coquille et la place qu'elle occupe relativement à l'auimal détermine les familles. Dans la preaière des 
Décapodes, par exemple, nous plaçons tous les genres qui ont, dans une lacune dorsale, une coquille iuterce, mince, en forme de plume ou de dard aplati; dans la seconde, ceux qui ont dans le dos une coquille ossense interne; dans la troisic̀me, tous ceux qui ont cette coquille subiaterne on exte:ne, mais toujours à cloisons simples et à siphon central ou ventral; la quatrieme enfin contient toutes les coquilies à cloisons découpées et à siphon dorsal. La grandeur considérable de la dernic̀re loge fait supposer, arec quelque raison, que l'animal pouvoit être entièrement contenu dans sa coquille.

Liordre que nous venons d'indiquer ent celui que nous avons suivi dans le tableau suivant; il nons a paru prefférable à ceux que nous avons examinés : nous avons clierché au moins ì lo rendre tel. Nous le summetluns d'ailleurs, ainsi que les observalions qui précèdent, à la critiģı des conchyliolognes.

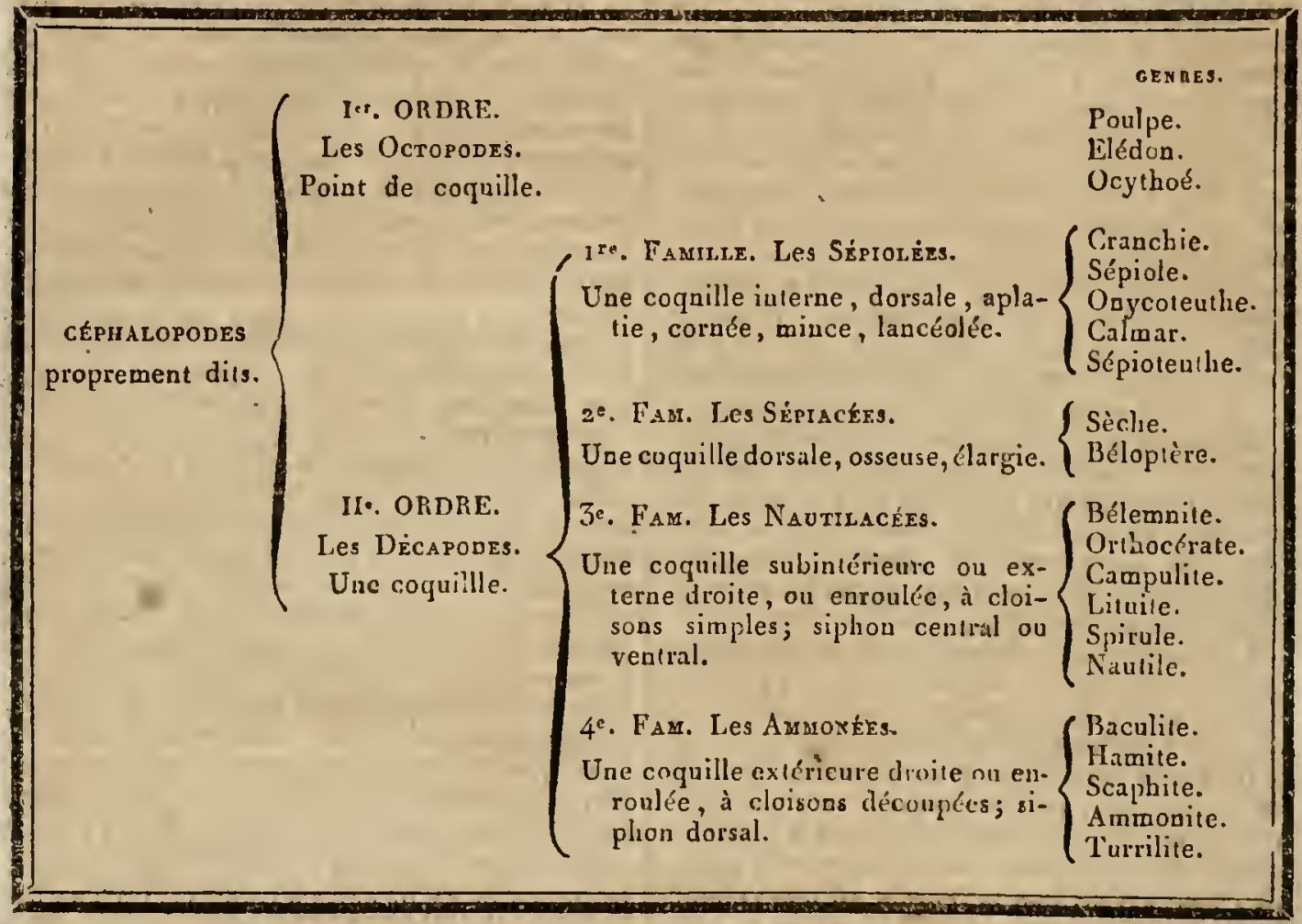

Dans la série des genres qui composent le tableau qui précède, deux seuleunent sont nonreaux : le Béloptère, que nous avons décrit, ct le Campulite, qni n'est point encore connu. (ie genre est aux Nauliles à perr près ce que sunt les Hamiles aux Ammoutes; il lie les Orthocérates, qui sont des Nautiles droits, aux Lituites et aux Nautiles, en ce quil offire des coquilles courbées en demi-cercle, à cloisons simples, peu convexes et percées d'un siphon placé enlre le centre et le dos, ce qui différeocie suftisamment ce genre de tous ceux compris dans la famille des Nautilacées. La dernière loge est plus grande que les autres, et elle ressemble ea cela à celle des Orthocérates.

Ia partie des Céphalopodes qui nons reste ctuellement à examiner est, sans contredit, nno des plus difficiles de toute la cubchyliologie par les obsiacles sans nomlre que l'on rencontre dans l'ohservation directe des objels qu'elle contienr. Quand on songe que M. d'Orbigny comple pris de huit cents espèces de Céphalopodes microscopiques distribuécs dans cinquante-deux gentes, on n'est pas étonné de limmensité de travanx qu'il a fallu faire pour coordonmer ce mond nouveau; mais cet étonnement sera pliks grand lorsque l'on saura que ce jeane observateur a dessiné, avec le plưs grand soin, tout ce quil a vu, et, de plus, qu'il a scalpié en relief des modèles en pierre, sous un grossissement déterminé, des types des principaux genres modèlcs qu'il eut l'heureuse idée de couler en plâtre, pour les livier au commerce et faciliter anx autres, de cette manière, une étude qui lui avoit Eté si péuible, ft qui arouit exigé de lari plusieurs aanées d'assiduité. 
Quoique anus ayons examiué un gränd nounbre de ces corps microscopiques, que nous ayons pris le soin de dessiner et de réunir en collection presigue tous reux qui se trouvent aus eavirons de l'aris, et le nombre est de plus de cent vingt espèces, que nous ayous vu beauconp de cenx t!c la Méditcranée, qui nous furent généreusemeut communiqués par M. Michelia, dans des - Ables de Rimini, nous ne crayons pas cependant possćder encore assez d'observalions el de fuits pour discuter tous les points de la aréthode de N1. d'()rbigny. L'lusieurs genıes importans. usus sont iriconnus : ce sont des lacunes qui rompent malyré nous la sćrie des rapports, que l'un ne pent d'ailleurs bien élablir qu'après avoir tout vu; nous pourrons cependant exaciner l'encemble de Ia méluode pour les corps microscopiques, et la soumetre dans ses principales divisions aux raisonnemeus qui nous ont guidé dans la première partie.

Uue question se présente, et sans dıate qualle sera agitíe par quelques zonlogistes nous devons nous expliquer à son sujet. Le's Céphalopudes foraminiferes, tels qu'ils snut circnascrits jar M. d'Orbigny, sont-ils, eo ellet, des Céplalopodes, el aicume sont-1ls des Mnilusques? Il ent certain que, dans l'état actuel de la science, il est bien dificile, pour ne pas dire itopussible, le répondre d'une manière absolne à rettc question. l.es observations se contrediscut; d'un ḉć, M. d'Orbigny assure quayant vu !es animax de quelques genres microscopiques, ils sont pourvus de bras nombreux et apparliennant aux Céplualopodes; d'un autre côté, M. de Jlainville, qui a vu l'animal de la Miliole, assure 'pu'il est dépourvu de bras et qu'il a'a point la structure des Céphalopodes, qu'il n'est point en tehors de la coquille, mais placé en dedans. l'our nous, qui a'avons à opposer aucune ohservalion directe à l'une ou à l'antre de ces observations, nous sommes forcé de les abandonner jusqu'a ce que l'une d'elles soil confumée, el nous ne pouvons naus guider, dans celle diffirulk, que par le raisonnemeat et l'analogie.

Tous les zo.logistes conviennent qu'll existe l.eaucoup d'analogie entre les Numbulices, les liabulaites, etc., et l'os de la Sèche : cette analogie existe en ellet, mais a un certain degre, daus la structure seulement, et par la place présumé que devoit occuper la coquille daus l'animal. L'analogie fundée sur ces caractères n'est pas, sans doute, de premicre valeur, mais, latute d'anlres moyens, vaut-il encore micux lemployer que de rester dans le doute absolu. 1)ès que l'on aula adınis ce rapprochemeut, tout fluigné qu'il paroisse, tous les lioraminifères suivrout le sort des gentes que oous avons cilés: prar la fusion qui existe entre les geures, ils sont liés de telle sorte qu'il est impossible d'ea briser la sírit.
Nous remarquons d'abord que la dénomination de Céphalopodes foraminiferes convient bien, wise en opposition avec celle de Siphoniferes; atais nil'une ni l'autre ne s'uccordent avec celle de Cryptodibranches, appliquée au preuier ordre. Ccla tient, sans ancun doute, à ce que les ordres sant élablis sur des caractères non comparables, ce qui vicie nécessairement la méthode; c’esı paur cela que nous avons proposé de preadre les caracières des ordres daus des organes invariables quant à leur existence. Ces organes, par lear présence, servent de eachet pour lous les Céphalopodes. Le nombre des bras nous a para préférable à tout autre caraclère, et, suivant la même marche, aprìs avoir fait les ordres des Octopodes et des Décapodes, aous préferons la dénomianion de l'olypodes à celle de Foraminiferes, ponr les coquilles microscopiques, puisquil paroit, d'après les observations de II. d'Orbigny, que les anicnaux qui produisent ces corguilles soat munis d'un grand nombre de bras.

Nous trouvons cing familles dans cet ordre des Foraminifères ou des Polypodes, et nous observons que les quatre premières sont fondéc: principalemeat d'apres la forme extérieure de la coquille, et la cinçuième d'après la struc!ure. Déjà, dans plus d'une occasion, nous avons chercbé à dérnontrer que l'on établissoit presque toujours de faux rapports lorsque l'on se laissoit guider par la forme des coquilles, prise commo caractère principal. Il suffiroit, pour se convaincre de cette vérité, d'examiner les méthodes fondées d'après celte maoic̀re de voir; et certes les exemples ne mauquent pas. Si l'on admetioit en principe celle marche vicieuse pour le reste de la cunchyliologie, on retomberoit à pea pres dans la méthode de Kleia, qui n'est, comme tout le monde en convieat, qu'un véritable chaos.

La première famille des Foransinifères de M. d'Orbigny est celle des Stichostègues; elle comprend toutes les coquiiles droites, sans trace de spirale, et formćes de loges empilées les uncs. sur les autres et sur un même axe. II n'est ici question, comme on le voit, ni ile la forme, ni de la position de l'ouverture, ef il peut y en avoir plusieurs : ces caractères sont réservés pour les genres, et par conséquent ils sont considésés par M. d'Orbigny comme d"une moindre valeur. Eu cela nous pe:ısons tout le contraire, pour êtue conséquent avec les principes que hous avons exposés pour la formation des genies dans les Décapodes : nous les royons tous fondés d'apres la forme des coquilles, pour ceux qui eu odt, et les mêmes formes se représenter dars les deux principales familles. Comme M. de Haan l'a très-bien exposé, ces familles sont caractírisées par la forme des cloisons, la position dn sipbon, etc., en un mor, par la structure. Nous espéruas nưuil ae seera pas impossible, à force 
de travail, et puissamment aidé par ce qu'a fait N. d'Orbigay, de présenter dans la suite une classification des Céphalopodes polypodes fondée sur le raisonuement que nous venons de laire.

La farnille des Stichostègues est formée de huil genres : le premier, Nosodaire, représente celui nommé Orthocère pirr M. Laınarck el les auteurs qui le suivirent; il est composé de cinq sousgenres dont deux uous paroissent douteux, comnie nuus le verrons à l'ullicle Nodosarne. Le gente Frondiculaire, qui le suit, n'est pas lì à sa place, juisque, comme nous eu sommes assuré, il comunence par une Spire et se rapproche par ce caracière des Rénulines et des Pérénoples. Le genre linguline, qui est le troisième, nous semble déja s'éloigaer par la furme de l'ouverture, qui cependant reste centrale; mais la Rimuline s'en éloigue bien davantage, car l'óuverture u'est plus centrale; elle est très-longue, latérale, la coquille n'est plus droite, et les cloisons ne sont plus trans: verses. Ce genre est suivi du cinquième, qui porte le nom de Vaginuline. Il présente une petite ouverture ronde sur le côté, de sorte que le genre précédent se trouve réellement isolé par ses caractères. Nous ne voyons pas en quoi le genre sixième, Mlarginuline, diffère des Vaginulines, si ce a'est que l'ouverture est porlée sur un petit prolongement : ce caractère est de lien peu de valeur, il faur l'avouer. Dans ce même geare il existe un autre défaut, c'est que l'on y trouve des espèces qui ont évidemment, d'après Ml. d'Orbigny lui-même, la plus grande ressemblance avee celles comprises dans le şous-genre Dentaline, des Nodosaires. Le genre Planulaire, créé par M. Defrance, est le septième: ne le counvisant pas en nature, comme les précédens, nous nous abstiendrons d'en parler. Quant au dernier genre, celui des $\mathrm{P}$ avonines n'es! pas à sa place, et sa présence daus celle famille montre mieux que quoi que ce soit qu'elle n'est point aaturelle. Cetle coquille, qui a à peu près Ia forme d'un écusson, est cumposée de loges concentriques qui parcourent presque les trois rjuarts du cercle; la dernière cloison est percée d'un grand nombre d'ouvertures ou de trous ronds. Celte disposition est Irès-analogue à ce que l'on voit dans les Pulystomelles et les Rénuliues, c'est donc près d'elles que ce geare devruit se trouver; mais il ne s'y trouve pas, parce que le sommet n'est pas tourné en spirale : encore il est probable que si l'on étudioil ce gerre, comme nous avons fait de la Frondiculaice (voyez ce mot), trouveroit-on la spire cachée en dedaus et couverte par un empatement calcaire.

La seconde famille, à cause de l'alternance des loges des coquilles qui la composent, a reçu le nom d'Enallostègues; elle est peut-être moins baturelle encore que la première : c'est ainsi que nous voyons dans un même genre des coquilles à ouverture centrale et $d$ ouverture marginale, caractère qui aroit servi à distinguer les genres de la première famille. Nous trouvons des genres dont toutes les loges sont alıernaules, en séparant d'autres qui ont quelques loges alternantes an sonmet et qui se termineut en ligne droite, comme les Nodusaires. On y voil un genre Polymorphine dont les loges alternantes snnt irrégulièrement pli:cées, el enfin un genre Sphéroidine qui a inliniment plus de rappur's avec les Hilioles quavec toule autre famille. Ce qui est assez dillicile a expliquer, c'est que la fauille suivan'e commenco par des genres qui sont aussi, comme ceux de celle-ci, composés de lnges allemantes, avec cetto seule différence qu'ils sont disposés sur trois axes d'ume manière asscz régulière, de sorte qu'its senblent, par cette disposition-là même, toumer en spirale, lorsque véritablement il n'en est rier. C'est ainsi que les genres Clavuline, Uvigérine $\mathrm{t}$ Valvuline, déparent celle troisiène famille, qui sans ccla se trouvcroit assez maturelle, en ce qu'clle n'offiriroit que des coquilles vétitablement enroulées, soit trochiformes, soit nautiloïdes; e:1core voudrions-nous en ôler le genre Cassiduline, qui, malyré l'enroulement spiral de la coquille, appartiendroit plutôt à la seconde famille qu'à lả troisiène, à cause de l'alternance de ses loges.

Celte alternauce des loges est certainement un bon moyen de fuire uue lamille paturelle, mais il faut en faire l'application rigoureuse, y rangur toutes les coquilles qui ont ce caractère, quelle que soit leur forme : c'est d'après celle forme seulcment que les genres pourront être circonscrits.

La troisièwe lamille, dunt nous venons déja de signaler un défant, a recu la dénomination d'Holicostègues, parce qu'elle ne renferme que des coquilles spirales; elle coutient à elle seule ving tsix genres distribués en trois groupes priacipatid: les Turbinoïdes, les Ammonoides et les Nautiloides.

Dans la premièı section, celle des Turbinoïdes contieat, comme nous l'avons déjà fait remarquer, des geures qui ont de tels rappuris avec cenx de la famille précédente, quil est iupossible, selon nous, de les en séparer. Quant à ceux qui suivent, à cońmencer au genre Rosaline, ils présentent, il est vrai, des coquilles earoulces ou commençant par une spire pour se terminer en ligne droile; mais il s'en faut de beaucoup que leurs rapporis soient établis sur des caractères naturcls. On ue trouve aucuue suite dans les caractères : tanlòt ce sout des coquilles symétriques au milieu de genres qui ne le sont pas, tan:ôt des coquilles à ouverture terminale, à côlé de celles qui l'ont inférieure ou ventrale; quelquefois on trouve des genres à coquille projetée en ligne droite et percée de plusieurs ouvertures, au milieu de genres enroulés à ouverture simple. Nous ne vonluns pas pousser plus loin, cquant à présent, l'examen de ces genres; nous le ferons ed les traitant en particulier. Si nous considérons maintenanc les deux dernières fa- 
milles de M. d'Orbygny, nous les trouvons infiuiment plus naturelles que la précédente : ce qui dépend sans ancun doute du choix des caractères qu'il leur a donnés. Ia quatriène famille porte le nom d'Agathistegues; elle est presque uniquement composée des coquilles que Mi. Lamarck placoit dans le genre Milisle. Ni. d'Orbigny, en le démembrant en cing genres, a rempli une indiration nécessaire : il falloit tốt on tarld qque cela se fit; on en voit l'utilité aussitôt que l'on éludie un peu ce genre Milınle de M. Lamarck. M. d'Orbigny a jnint ì ces cing genres celui qu'il nomme Adelosine, et qui est une des conbinaisons des plus singulières: après avoir produit une grande loge en spirale semblable i un petit Nautile, une autre lnge se projetie obliquement sur le côté plat, de manière à l'emlurasser en partie et à présenter la lorne et la terminaison d'une dernière loge de Nilinle. Les cinq autres genres de cette lamille sont les suivans: Biloculine, Spiroloculine, Triloculine, Articuline et Quinqueloculine. Pour nous, nous y ajnuterions un septième ğenre, celui des Splaćroidines, que nous avons Qéjà mentionné en parlaut te la seconde famille.

La cinquième et dernière famille, celle des Entomostçgues, est à notre avis la meillcure de loutes, en ce qu'clle est formée d'une manière rationnelle, d'après la structure de la coquille, et les genres d'après la forme, ainsi que sur le nombre et la place des ouvertures. Peut-ètre auruit-il fallu la diviser en deux sections, l'une pour les coquilles a une seule ouverture, et l'autre pour celles qui en out plusieurs. Quant à la place que cette famille occupe dans la série, nous crnyons qu'il vaudroit mieux qu'elle fút la première, la plus rapprochée des Céphalopodes du second ordre, parce que, de toutes les coquilles microscopiques, ce sont celles qu'elle contient qui se rapprochent le plus, quant à la structure, de l'os de la Sèche. Pour suivre cette continuité de rapports, nous placerions immédiatement après elle une famille qui commenceroit par les genres Nummulite et Sidéroline, et nous rapprocherions la faunille des Agathistègues de celle des Enallosiègues.

La famille dont nous nous occupons daus ce moment est composée de cinq genres: les Amphistégines, les IIérérostégines, les Orbiculines, les Alvéolines et les Fabulaires. Nous avions cru, sans les avoir assez examinées, que les Pénéroples viendroient se ranger dans la famille des Entomostègues à côté des Órbiculioes; mais nous avons élé détrompé en usant surune pierre à rasoirs une Pévérople, et nous avons reconnu que claque luge, bien que percée de plusieurs ouvertures dausla cloison, est pourtant simple et non divisée.

Tel est l'ensemble du système de DI. d'Orbigny. Quoique bien supérıeur à tous ceux que nous vas, nous avons remarqué cependant qu'il laissoit encore à desirer; et, malgré ses imperfections, nous rendons à son auteur toute la jus- lice qu’il mérite, puisqu'il avnit tout à faire, lout à créer clans celle nonbreuse classe des Céphalopodes, que ses devanciers avoicnt mise dans un désordre élounant, lout en croyant y élablir des lamilles maturelles. Quand M. d'Orbigny n'aurcit pas cu le mérite d̈observer lonerteuips plus de huit cents especes de coquilles microscopiques, d’en créer les genres, en réformant irrévocablement lous ces mauvais genres de Montlort, il mériteruit encore d'obtenir la reconnoissance ales amis de la science, par cela seul quil a nettement séparé les coquilles microscopiques des autres l'olythalames.

D'aprés la discussion que nous venons de faire sur la ałéthode de M. d'Orbigny, on s'est apercu sans doute quelle marclue nous suivrions, si nous voulions subslituer un arrangement nouveau à celui de cet observalenr. Les caractères tjui lieut lcs Pulypodes ou Foraminifères anx Décapodes se trouveot daus la structure des coquilles; car, jusqu'à présent, la conooissance des animaux nous manque à peu près complétement, puisque les observations se contredisent d'une manière égale et absolne : c'est donc par leur moyen seulensent, et, il faut en convenir, d'une mauière plus on moins artificielle, que leur. ordre peut êlre délerminé. Aussi, dans une telle cisconstance, quand les premiers moyeus nous éclappent, il faut recourir à l'analorgic, et se tracer des règles déduites de l'observation, aussi complète gruion peut le faire, de tons les êtres compris dans l'ordre uu la classe dont on s'occupe.

Nous avons vu que, de tons les Foraminifères, c'élcient ceux compris dans la famille des Entomostègues qui, par la structure de leur test, se rapprochent le plus de l'os de la Sèche. Ii nous semble que ce sont enx qui doivent être placés les premiers de l'ordre, pour se rapprocher le plus possible des Décapodes : retle famille seroit suivie de celle qui comprendroit toutcs les coquilles enronlées, symétriques, semblables à de petits Natuliles, et présentaut une ouverture, soit ventrale, soit médiane, snit dorsale, simple et symérrique corume la corquille elle-même. Les genres Nummuline e! Sidéroline, qui, a vec l'âge, perdenı l'ouverture de la dcrnic̀ré cloison, pourroient faire dans celte famille uu groupe particulier, et devroient la commencer, ou peut-être conviendroit - il mieux de former les sous-familles d'après la position de l'ouvertare, car ce caractère est furt peu variable. A la snite de celte lamille, il s'en présenteroit uoe troisième qui rassembleroit toutes les coruilles etrroulées, non symétriques, et qui, par consईquent, n'ont pas non plus l'ouverture symétrique relativement à la coquille dans son ensemble; mais elle peut l'être relativement à la loge. Le plas souvent celte onverture est placéc contre le retour de la spire, à la face inférieure de la coquille ou à sa base. Les coquilles subturriculées et 
véritablement involvées tronvent leur place dans welte famille, que l'un pourruil sous-diviser comame la précédente, d'a près la forme et la posilion de l'ouverture.

Une difficulté se présenie actuellement : les eoquilles qui commencent par un enrouleruent régulier et qui sont terminécs eu ligne droile, qui restent cependant paires et symétriques, cluivent-elles être placées après notre seconde famille, ou bien venir ici préluder, pour aiusi dire, ia no nouvel ordre de choses qui teud sans cesse is s'établir? Nons retrouvons cette teadance surtout dans les familles suivantes, et nous somenes porté, par cette raison, à placer cle préférence ici ces coquilles symétriques entre deur familles de coquilles qui ne le sont pas.

Celte petite famille seroit composée de pen de genres divist́s d'une manière assez naturelle on deux groupes : dans le premier ser ient compris ceax ilont les cloisons sunt percées d'un grand norabre de pores, et le second renfermerbit ccux qui n'ont qu'une seule onverture. Ces deux groupes, qui présentent des cojuslies de formes dillérentes, pourront peut-étre par la suite lormer deux lamilles disinctes.

Nous adopterions, pour notre ciuquième fs-

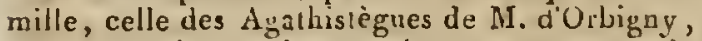
ny introduisant dautre cbangemeut que cy actonetre le genre Sphéruidioe. Cette tamille, par la structure des coquilles, est fort nalurelle, et présente d'un côté des rapports avec la famille précédente par un genre dont l'extrémité se projette en ligne droite, et avec la suivante, par le singulier pelotonnement des loges, qui, daus les Spiroloculines, par exemple, est une sorte d'alsernance qui conduit à la famille qui suit.

Ici viendroit se placer la famille des Ena:lostègues de M. d'Orbigny; mais, assez considérablement modifiée par les raisons que nous avons exposées jrécédemment, celtc limille auroit besoin, comme les précédentes, d'être divisíe en plusieurs sous-familles, et on pent les lormer par plusieurs moyens, suit en prenant la forme et la position de l'ourerture, qui est ou centrale ou latérale, soit en prenant l'aliernance cies loges, qui se joignent trois à trois ou deux à deux. buffin, on arriveroit encore à un groupement assez nataicl eu rénnissant loutes les coquilles dont les loges sont alternautes de la base au sommet; puis celles qui, après un certain nombre d'alticınances à deux ou lrois loges, se lermineal en ligne droile par une suile de loges simples: ce dernier groupe conduiroit d'une tranicre louic aisurelle à la dernicie famille, celle des Sichosrègues de $\mathbb{M}$. d'Orbigny. Cette lamille, comme on le-sait, De contient que des coquilles droites ou presque droiles, formáes d'use seule sírie de boges, dont la dernière présente une ouverlure eentrale ou latćrale loujours ronde. II conviendroit peut-être, pour ve pas rompre ces carae- lères naturels, de former une famille de plus pour le seul geure Rimuline, dont la forme des loges, et surtout celle de l'ouverture, qui est fort longut el latérale, justiliervil assez l'ćtablisseneul. Une autre famille nous sembleroit nécessaire pour la placer l'avant-dernière; ells ne comprendroit nou plus qu'un très-petit nomlore de genres fort singuliers, que nous n'a vons encora observés quaux environs de Paris : ils se composent de globules réunis sur trois, quatre vu cind rangs; claque globule est percé d'une nuverture inlérieure, soit arrondie, soit semi-lu. naire. Ces coquilles sout droites, alongées, $t$ t semblent étıe produites par trois, quatre ou ciny Nodosaires adossés et agglutinés les uns aux autres d'une manière régulière.

Dans le tableau suivaut, en nous servant presque exclusivement des genres de $\mathrm{N1}$. d'Orbigny, el quelquefois de ses fautilles, en les inoditian selon le besoin, nous présenterons dans son ensemble l'arraugement que nous proposons; arrangement que nous ne considérons que comme un essai et non comare une méthode définitive. Nous sentons de plus en plus la nécessité de multiplier davantage les observations sur les coquilles microscopiques, et, bien que nousen connoissions dejja un fort grand nombre, cependant nous ne croyous pas avoir lous les caalériaux nécessaires pour présenter, dans ce moment, une classification définitive.

Noıss croyons nécessaire d'ajouter quelgy!es observations à celles qui précèdent, pour justifier quelques-uns des changewens que nous avons apportés dans la disposition in térieure de quelques genres. C'est ainsi, par exemple, que dans lo genre Nonionine de M. d'Orbigny, nous ne laissons que les espèces qui ont l'ouverture en fents semi-lunaice contre le retour de la spire; nous réunissons celles qui ont l'ouverture ronde areo quelques espèces du genie Nuntonline, dont II. d'Urbigny avoit fail le sous-genre Assiline, t en lui conservaut celle déucmination, nous faisuns de celle réunion un genre dislincr. Nous en rap. procbuns le genre Operculine, sans faire attention que lcs tours de spire ne son t pas recouvrans, $\infty$ caractere étant dune trop petite importance relaiveruent aux autres.

Nous avons exinminć plusieurs espèces de Polystomelles, et nous en avous usé quelques-unnes sur une pierre à rasoirs pour en découvrur l'intérieur, el voici ce dont nous nous somunes assuré : le test est épais à l'extéricur, et l'on reconaoit qu'il est composé d'uu grraud nombre de cellules; cependant les cloisuns sunt simples, très-nombreuses, et elles séparent des loges comparables en perit à celles du Nautile. Lorsinie les individu: que l’on obscrve nont pas la deruière loge complète, on roit sur la iranche du bord un graud nombie de pores, el au centre une cavité plus ou unoins grande, qui ost celte de la loze elle- 
méme; mais lorsçue la cloison csl complíte. on ne voit aucuns pares, mas seulement, et encore on ne la trouve pas loujours, une seule pelite nuverture contre le rebord de la spire: celle circoustance nous a dès-lors décidé a placer ce genre à cốlé des Rohulines.

Dans la famille des Trochiformes, nous arons introduil un nouveau genre que nous dédious à M. d'Orbigny, an jeune savanl anyuel la science est redevalule des changemens méinorables quil a introduits dans la classification des Céphalopodes. Ce grenre est formé avec celles des compilies trochiformes qui nnt la dernicre cloison percée contre le relonis de la spire d'uue ouverture ronde, re qui les disingne éminemnent des Rolalies, parmi lesyuelles elles érnient confondues. le genre Dorbignyor est, relaivement à la famille des "I'rochilormes, ce qu'es: le genre Assiline pour la prétédente. I,e genre Dendritiae n'est jlacé a la lin de celle famille qu'avec donte, el curarue na incerta sedis. Nous ne le connoissons que d'après M. d'Orbigny, el cesle particulitrité ci'une nuverture non sy:uétrique dans nue cofjuille qui proir lètre parfaitement, nous semble un fait si peu en rapport avec ce que nous connoissons, que nous arons lesoin de roir ce genre en nalure pour nous décider à son ḱgart : î seroit possibfe que ce ue soil quine Polystomelle.

II nous a paru uécessirire de démembrer le genre (Huinqueloculine de M. d'Orbigny. Il y a en effet une grande difference entre les especes aplaties yui se rapprochent des Spiroloculines et celles qui sont cylimiroiques; non-seulement elles dillèrent par la forme des loges, qui sont très-aplaties dans ces dernières, mais encure par l'uuverlure, qui eal dopourvae de lappendice gui barre l'ouver- lirre des aulies Quinqueloculines, et meme dn plus grand nnmbre des genres lćmerubrís des auricunes Nilioles. Ce genre nonveau, que nums nommons Saxicoline, a pour type le Miliolites saxorum de M. Lanumati.

Ce cui nous a surloul délerminé à changer l'ordomance de la fimille des linallnstègues, et à y placer plusieurs les gemes de la famille des IÍlicoslègues, c'es! qu'il nous a paru que M. d'( ()rbigny avisil rompu les rapports naturels pour un molif de bien pen d"iaporlance. Qu"importe, en ellet, que lempileneut des loges sur deux m trois anes ail lapparence de tnurner en spirale, loraque leur alicruance est ćvidente, lorsque lour forme, leur seructure, la position de l'ouverture, appellcnt ces coquilles a faire parlie de rroupen naturels el d'une fausille formie avec de bons caractères?

Si, comme on dait le desirer, ou se live davantage par'la snite à l'étude el à la reclierche des coquilles microscopiques, il csi à presumer que l'un découvrira des passages entre les denx genres de notre nouvelle timille e: les Nodosaires d'un côté, e! avec les Glohigérines de l'autre; c'est alors seulement gue l'on pourra sans doute rasserbljer en un seul groupe toules les cotuilles conposées de globules : elies sout certuinemen les plus simples de tontes celles qui sont comprises dans cet ordre des Polypodes.

Nous nous alostieadrons dians cel article de donner des considćratiuns générales sur l'organisation des Céphalopoủes; elles pourrout se dédnire facilement après la lecture des arlicles Poolpe et Sìcry, dans lesquels nous exposerons toul ce gui esl comu en analomic sar ces animaux: nous donnerons aussi quelgues a perģus a l'arlicle Mouxesqer. 
Quelquefois na test monothalame ou un rudiment testacé interne, mais jamais de coquille polythalame.

Quatre ou cinq paires d'appendices tentaculiformes à la tête, et entouraut la bouche.

\section{Ier. ORDRE.}

LES CRYPTODIBRAXCEES. Blainv.
A. Huit bras sessiles, munis de rentouses. Iro. Famile. - Les Octopodes, Léach. Feruss. Décacènes, Blaiñ.
B.. Iluit bras sessiles et deux bras pédon- culés, ordinairement repliés dans le sac, tous munis de ventouses. 2e. Fay.-Les Décapodes, Léach. Feruss. Uécacteres, Blaing.
1. Cranchie. 2. Sépiole. 3. Onycoteuthe. 4. Calmar. 5. Sépinteutbe. 6. Sèclie.

1. Argonante. 2. Bellérople. 3. Poulpe.

4. Elédon. 5. Calmaret?
Un test polythalame interne ou partiellement recouvert par l'animal, qui peut alors rentrer à volonté, en tout ou en partie, dans une loge supérieure à la dernière cloison. Siphon tonjours continu d'uneloge à l'autre. Dix appendices tentaculaires ou plus eatourant la bouche.

\section{II॰. ORDRE. IIS SIPEONIYL̀RES. D'Orbigny.}

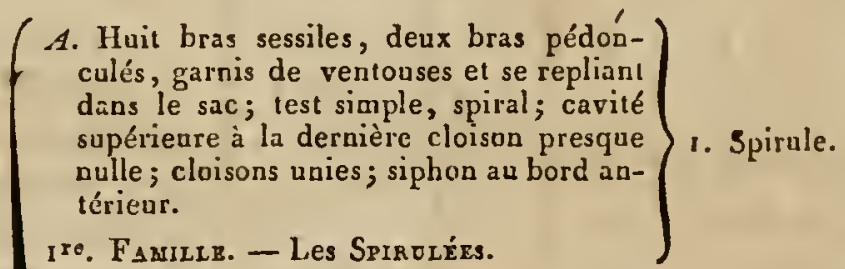

$B$. Une série très-nombreuse de bras sessiles dans les animaux connus et eutourant la boucbe; ventouses? test simple, spiral ou droit; cloisons unies; cavité supérieure à la dernière cloison, grande et engaî. nante; siphon central ou situé au bord antérieur.

2e. Fars. - Les NaUtilacízs, d'Orb.

C. Bras? ventouses? test simple, spiral on droit; cloisons découpées; cavité supérieure à la dernière cloison, grande et engainante; siphon marginal (dorsal sur la carène).

3е. FAm. - Les Amroxís, Lamk.

1. Nautile.

2. Lituite.

3. Orthocéralite.

1. Baculite.

3. Hamite.

3. Scaphite.

4. Armonite.

5. 'Turrilite.

D. Bras? ventouses? test présumé toul interne, composé d'un boyau divisé en loges et d'uue enveloppe souvent trèsépaisse, formée par un résean présuiné analogue à celui da rudiment teftacé des Sèches; cloisons unies; cavité supérieure à la dernière cloison peu profoude; siphon communément margiual.

$4^{e}$. Far. - Les Primstrziris, d'Orb.
1. Ichthyosarcolite. 2. Bélemnite. 
Un lest po'ylualame 10talement inlerne; dernière cloison terninale; print de siphon, mais sculernent uae cu plusicurs onverlures dounant communication d'une loge à l'antre. bras.

Un grand nombre de III. ORDRE. LES FORAMINIFERS. d'Orbigny.

\section{MOLLUSCUES CEPIIALOPODES.}

† Ũoe seule cavilé par loge (A plostègues.)

A. Loges empilées ou superposées sur un seul axe, bout ì bout, soit qu'elles débordeut ou non en se recouvrant plus ou moins latéralement; point de spirale.

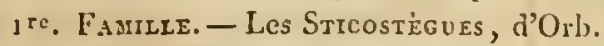

$B$. Logres assemblées en tout ou en partic par alternance, ou enfilćes sur denx ou trois axes diftinets de diverses manières, mais sans former de spirale régulière el nettement earactériséc.

$2^{e}$. Farr. Les Exalcostéges, d'Orbigr.

(

C. Logres assemblées sur un ou deuxaxes distincls, mais formant une volulespirale, rćgulière et nellement carractérisée, turriculće ou discoidale.

ว̋. Fasr. Les Hélicostc̀gues, d'Orbig.

Test libre ou fixé; loges empilées sur. un seul asc; spile plus ou moins élevée; tours apparens d'un seul côlé.

$1^{\text {re. Section. }}$

Turbinoïdes.

T'est libre on fixé dis. coïdal; loges enfi-

$2^{\mathrm{e}}$. SECTION.

Ammonoüdes. GEYRES.

1. Nodosaire.

2. linguline.

5. Frondiculaire.

4. Rimuline.

5. Vaginuline.

6. Marginuline.

7. Plannlaire.

8. Pavonine.

1. Bigenćrine.

2. Textulaire.

3. Vulvaline.

4. Dinorpline.

5. Pulymorphine.

6. Virguline.

7. Spléroüdine.

1. Clarnline.

2. Uviférine.

3. Bulimine.

4. Valvuline.

5. Rosaline.

6. Rotalie.

7. Calcarine.

8. Globigérine.

9. Gyrnidiue.

10. Troncaluline.

lées sur un scul 11 . Planuline.

axe; tours de spire I2. Planorbuline. apparens de cha- 13 . Operculine. que côlé. 14. Soldanie.

Test libre ou assem- (15. Cassiduline.

blé sur un ou denx 16. Anomaline. axes distincts, allernans ou non; spire embrassant en lout on en partie; poirt de lours visibles.

\section{3e. sectiox. \\ Nautilöides.}

17. Vertébraline.

18. Polystomelle.

19. Dendritine.

20. Pénérople.

21. Spiroline.

22. Roluline.

23. Cristellaire.

24. Nonionine.

25. Numbuline. 26. Sidéroline.

I. Biloculine.

2. Spirolocaline.

3. 'Triloculine.

sur un axe commuo.

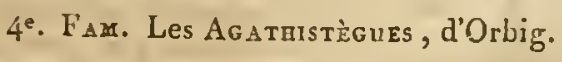

4. Articuline.

5. Quinqueloculine.

6. Adélosine.

†† Loges divisées en plusieurs cavilés et $\int 1$. Amphistégine.

2. Hélérostégine.

3. Orbiculine.

4. Alvéoline.

5. Fubulaire. 


\begin{tabular}{|c|c|c|}
\hline 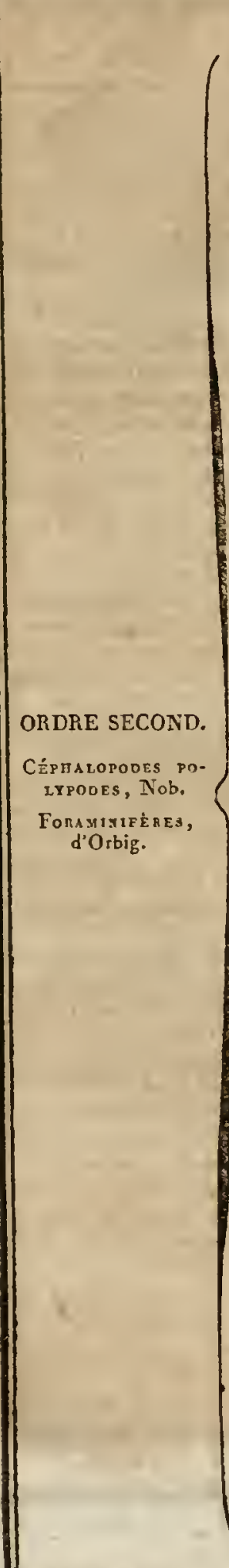 & 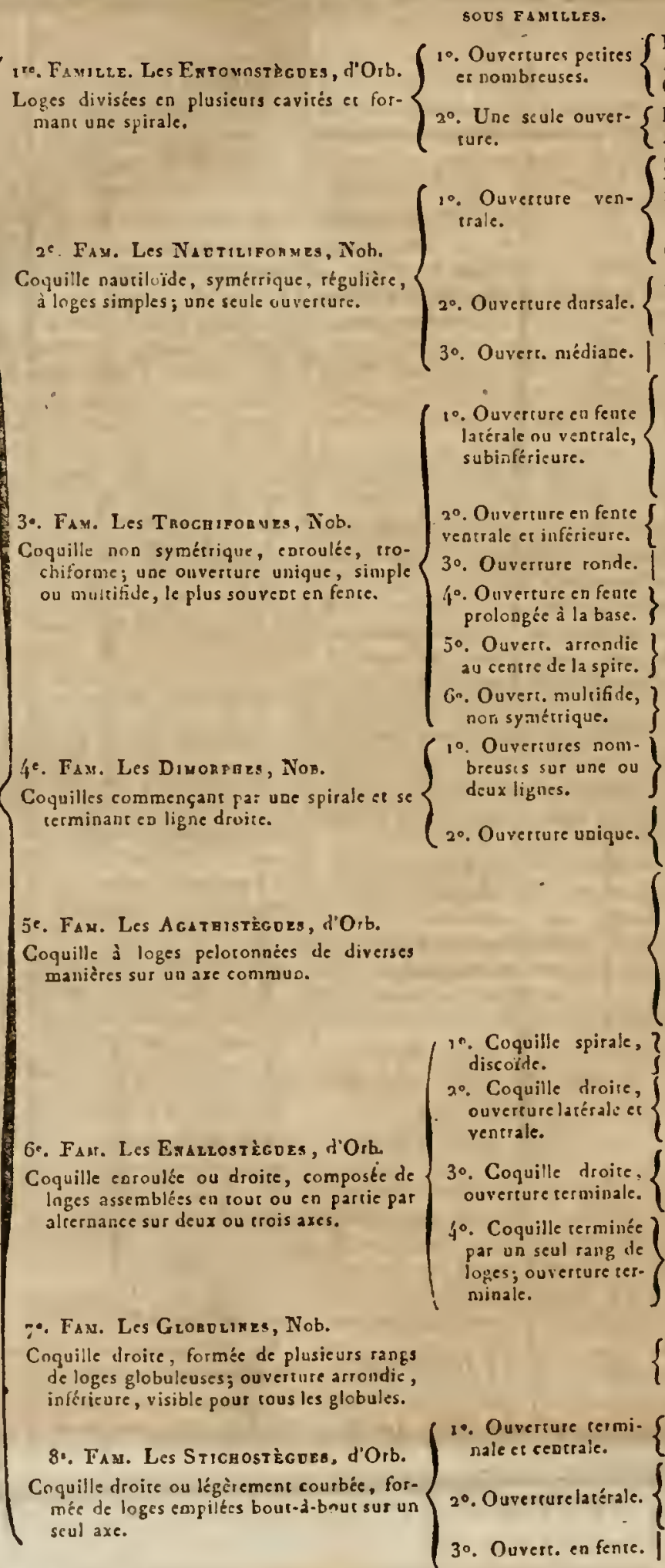 & 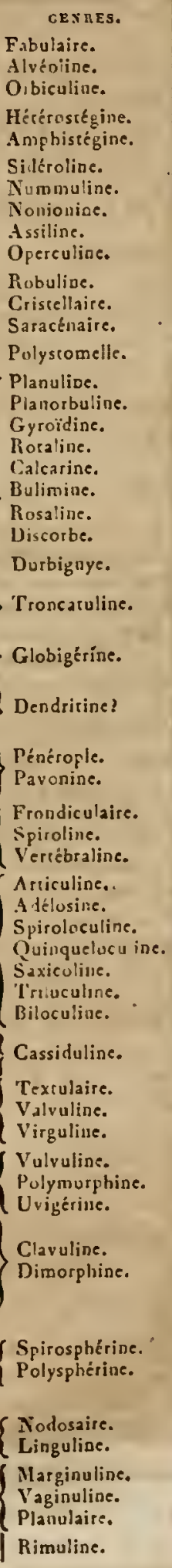 \\
\hline
\end{tabular}




\section{CÉPOLE. Cepolis.}

Genre proposé par Monifort dans le tome 2 de l. Conchyliologie systimatique, pag. 150 , pour une Hálice qui a une dent sur le bned druit. Ce genre ue peut être adopté. Vojez IIÉltce.

\section{CÉRASTE. Cerastes.}

Dans son bel ouvraye sur les Testaces des DeuxSiciles, l'oli a nommé ainsi les animaux da genre Carzlium de Linué, et par suite de son système de nomenclature, il a donuć le nom de Cérastaderar aux coquilles de ce geure. Foy. Bucande.

\section{CERITL. Corithium.}

C'est Adansna le premier, dans son Traité des coquillugés du Sénégal, qui átabli ce bon gente, que Liuné, malyré cela, laissa dans les Mlurex. Ce genre ayant élé traité dains le premier volume de ce Dicliounatre de mauière à n'exiger aucune réforme, nous y renveyons le lecicur. Voyez Cïrite.

\section{CERITLS (les).}

M1. de Ferussac avnit propesé, dans ses Tubleaux systématiques, une liumille, qui est la troisième des Pecrinibranclies hémipomastomes, pour le geure Cérite lui seul. Ne sachant quels out étéles molifs de l'auteur pour la séparation de celle lamille, nous ne l'adoptons pas, ne pouvant devioer sur quels caracticres on pourroil la fonder.

\section{CERVICOBRANCHES. Cenicobranchiala.}

C'est ainsi que M. de Blainville a nommé le second ordie des Paracéphalopliores hermaphrodiles dans son Traité de MIalacologie. Il le divise en jeux f.umilles, les Réliféres el les Branchifères. (Voyez ces mols.) Cel ordre correspond ou pluiô a quelyu'analonie avec celui nommé Trachelobranches par NI. Gray, qui, en détinitive, se rapportent assez bien l'un et l'antre aux ('alyptraciens de M. Lamarck. Voyez tous ces mots.

\section{CE'TOCINE. Cetocis.}

Démenbrement inulile proposé par Montfort (Conch. syst. tom. I. pag. 57o) puur une Bé-

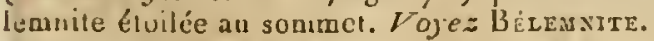

\section{CII.1DET.}

La roquille qu'Adianson fait connoîle sous ce now (T'oy. an Senég. pl. เo. fig. 4) appartient an gente Cérite; mais comme celle coquille ne s'esi pas selruavíc, on ne peul avoir la certifude yn'elle uppartient au Cerathum elurneum de Bruguière. loyea Cintre dans le prenier rolume de ¿e Diclionnaire.

CIIAMELFA.

Genre lormé par Klein (Tent. Meih. ostrac. pag. 15ı) avec des Vénus, des Bucardes, des 'Tellines, elc. Il cis tombé dans l'oubli.

\section{CHAMCETRACH ЖA.}

Mauvais geare proposé par Klein (Tent. Mcth. ostrac. pag. 149) pour des coquilles bivalves, rugneuses el siuneuses. Ce genre, actuellement oublié, renferme des Bśnitiers, des Arches, elc.

\section{CIIANON.}

Dans son Voyage au Sénésal (pl.16), Adans'n nonme de celle manière une $A$ vicule, l'Avicule allautique Lamk., que nous avons précédemment décrite. Voyez Aviculi.

\section{CIIARYBIDE. Charybs.}

Genre élabli par Mnntfort dans sa Conchyliulogie systématrque (tom. 1. pag. 106), avec une sprorbe copiée daus Soldani et qu'il donne comme cloisonnée, yuoique Soldari l'ait placée parmi celles qui ne le sout pas et l'ait iudiquéce en conséquence. C'est arec celte légèrelé que Mon:for't fabriquoil lis plupart de ses genres.

\section{CIIENILLE. Vertıgr's.}

Cest sous ce nom yue MI. Schumaclier propose un démembrement dans le genre si naturel des Cérites; à peine si ce geure pourrét constiluer une sous-division ou groupe d'espèces. Il est inadmissible comme gence. Voyez Cémтte.

\section{CUICORACÉ. Chicoreus.}

Démearbrement des Rochers proposé par Manıfurt (Conch. systém. tomi. 2. pag. 6ro) pour cenx des Rochers qui, tels que le Miurex rimosus Lin., ont la queue conrbe te les varices armées de longues éplines divisées. Ce genre n'a point l'té aduis et ue pouvoit l'être. Vroyez Rocuer.

\section{CIIMERE. Chimara.}

Non que Polia donné dans snn enrrage sur les 'T'estacés des Dena-Siciles à l'auimal du genre Pinna de Linué, el il a proposé celui de Cuñ roderae, Chimaroderma, pour les cuquilles du mìue gence. V̌oyez l'rxis.

\section{CIIIONE.}

MI. Mrovele, ne connoissant pas sans doute le grente Mérétrix de NI. Lamarck, a proposé de déinembier'sous ce porn les Cythérées des autres Vénus. Voyez Vénus et Crteéaé.

\section{CHISMOBRANCHES. Chismouranchiatu.}

M1. de Blainville a proposé cet ordre dans son Traité de Rolucologie ( pag. 466), pour y place. les genres Coriorelle, Siuaret, Cryptostome, Oxynoć, Stomatelle et Vélutine. Nous nous pro$\mathrm{G}_{\mathrm{g}} 2$ 
posions de disculer ces genres et l'ordre lui-mème dans leurs rapports, wais des comnoissunces nou. relles étant venues depuis la publication de l'on-viage de M. de Blainville, nous y reviendrons ì i'article Mollusque, el nous renvoyons aux genres que nous veuons de citer.

\section{CHITONELLE. Chitonella.}

II. de Blainville (Traité de Malcucol.) a substilué ce nom à celui d'Oscabrelle que M. Laruarck avoit donné depuis long-temps à un geure voisin des Cscabrions. La dénomination de M. Lamarck doit être préférée à cause de la priorité. Voyez OscaBRELLE.

\section{CHIENA.}

M. Ocken donue ce notn an genre Gastrocliène de Spengler. Cette dénomination ne peut être adoptée, puisque celle de Spengler est depuis plus long-lemps aduise. Voyez Gastocaine el Fistulane.

\section{CHOTIN.}

Le Chotin est une coquille du genre Cóne qu'Adanson a décrite sous ce nom (Voyage au Sénég. pl. 7.fgg. 6); c'est le Còne d'Adauson de Hi. Lanarck, Côue que Bruguière, dans le premier volume de ce Dictionnaire, regardoit comme une variété du Conas jamaicensis, $\mathrm{n}^{\circ} .90$. Voyez Cône.

\section{CHRYSAORE. Chrysaor.}

Genre inutilement établi par Mloutfort (Conch. syst. tom. 1, pag. 376 ) pour quelques espèces de Bélemnites. Yoyez ce mot.

\section{CHRYSOLl: Chrysolus.}

Genre de coquilles microscopiques placé par Montfort près des Nautiles dans son Traite systématique de Conchyliologie (tom. 1. pag. 26.): Ce genre n'a point été adopté; il rentre dans celui unmmé Nonionine par M. d’Orbigny. Voyez ce mot.

\section{CIBICIDE. Cibicides.}

Le genre Cibicide, de Montfort, auroit pu être conservé s'ilavoit été mieux caractérisé, et sil'auteur ne l'avoit pas reproduit nae seconde fois sous un autre nom. La coquille qui lui a servi de type appartieut au geure Troncatuline de M. d'Orbighy. Vojez Trovcatuline.

\section{CICLOPHORE. Cy'clophones.}

D'après la fignre donnée par Montfort (Conch. syst. tom. 2. pag. 29o) et les caractères qu'il assigue à ce geare, on pouvoit croire qu'il présealoit, sons ce nom, un démembrement des $\mathrm{Cy}$ clostomes; mais il s'agit d'une Paludine, et le démembrement a’en est pas meilleur. Voye $=\mathrm{P}_{\mathrm{A}}$ LUDINE.

\section{CIDARIS.}

Geare caractérisé seulement d'après la forme qui, selon Klein (Tent. Meth. ostrac. pag. 21 ), ressemble à un Turlso. Les cocquilles de ge genic semblent appartenir à quel fue petit 'Turba, ou peut-être à des Nérites.

\section{CIDAROLLE. Cidarollus.}

Il est assez dillicile de savoir ce que c'est que ce genre de Montlort (Conch. syst. tom. 1. pa: 110) incomplétement caractérisé; ce n'est qu'uvec doute qu'on peut le rapprocher des Rosalines. Voyez ce mot.

\section{CIRCÉ. Circe.}

Quelques auteurs, en comparant les genres Vénus eı Cyıbérée de MI. Lamarck, avoient trouvé dans quelques espèces une variabilité telle dans les caractères de la charnière, qu'on les trouvoit tantòt Vénus et tantôt Cythérée. On remarquoit également un passage entre les deux genres par la manière insensible dont s'ellace la dent latérale dans certaines Cythérées. Oa avoit justement conclu de ces deux modes d'induction que l'uu des deux genres n'étoit point nécessaire; on s'appuyoil eucore de la ressemblance des animaux. M. Sclumacher a procédé tout autrement, il it créé autant de genres quilil a trouvé de légères modifications; celui qui porte le nom de Circé, et qui a pour type la Venus scripta Lin., en esi un exemple. (Voyez V́́vos.) Ce geare ne sera pas adoplé.

\section{CJRRHOBRANCHES. Cirriobranchiato.}

C'est par cet ordre que M. de Blainville cosmence la troisième sous - classe de son arrang(ment méthodique dans son Traité de Mulacologie. Il l'a formé pour placer le genre Dentale lui seul, qui, en effet, a une organisation si différente de celle des autres Mollusques, qu'il falioit bien le séparer de tout ce qui étoit cọnnu. M. de Blaiuville a fait suivre cel ordre de celui des Cervicubranches, qui commence par le genre Pate!le. Sans doule qu'en considérant la furme symélrique des Dentales, elles se rapprochent en quelques points des Patelles et des Fissurelles; unais l'aoimal des Patelles n'étant point cervicubrabclue, comme M. de Blaioville le croit, cette analogie entre liss Cirrhobraaches et les Cervicobrauches devient plus éloignée que M. de Blainville re l'a voit pensí, et nous-même d'après lui. Après avoir fait récenıment de nouvelles recherclies à ce sujet, nons somenes porté à croire que l'ordre des Cirrtiobranches et le genre Dentale qui s'y trouve, formeront un type d'organisation intermédiaire entre les Mollusques et les Annélides. 
CIRrilcs.

Genre proposé par M. Sowerby pour des coquilles fessilcs qui ne diflèreut pas assez des Turlos pour qu'on les doive séparer. Quelyues - nncs des espices apparlienuent probablenentaux Pleurotomaires. ĺojez ce mot el 'Turbo.

\section{CITHARA.}

Eu réunissant les coguilles de ce geure d'après la position des cóles, il est arrivé que Klein (Tent. Meth. ostrac. pag. 97) a fait par hasard un genre naturel qui est le uséme que celui nommé Harpe par 11. lamarck el les auteurs moderues. Voyci IIARTE.

\section{CI.ADOPODES. Cludopoda.}

M. Gray, daus sa Methade de Conchyliologie, réunissani en un seul ordre les geures des Tubicolées et les Pholadaires de M. Lamarck, a donné à cet ordre le nom de Cludopodes. Nous n'adoptons pas cet ordre, parce que si, d'uu côté, les genres Arrosoir, Clavagelle, Fistuiane, funt une famille uaturelle; dun autre côté les gentes 'Taret, T'ćrédine et Pholade eu forment une autre uon noins distincte et bien séparée. Voyez Tomicolées, phoradalies el Mollusque.

\section{CLANCULUS.}

Non sous lequel Nuntfort a établi un genre que M. Lauarck nouma Monodontc. Celte deruière dénotnination a été conservće. Voyez MoNoDoNte.

\section{CLATHRUS.}

MI. Ocken a donné ce nom au genre Scalaire de L. Lamarck. Comwe il tait double emploi, il n'a pas été adupté. Voyez Sc.ıLainz.

\section{CLAUSULIE. Clausulus.}

Moatfort (Conch. syst. tom. 1. pag. 178) a fait re gente inutile pour une coquille du geure Mvéoline. Voyez ce mot.

\section{CLAVAGELLE. Clavagella.}

Le geure Clavagelle est, sans contredit, l'un des plus curieux et des plus iutéressans par le singulier passage qu'il nous montre entre les Arrosoirs $\epsilon$ t les autres Conclyyfères tubicolés : il cst évident, aujourd'bui plus que jamais, par la lícouverte de plusieurs especes, que ce geare cst voisin des Arrosoirs, comme M. Lamarck l'avoit dit, lorsqu'il proposa le genre dans les Annalcs du Afuséum. Depuis, presque personne ne contesta celte opinion; M. Cuvier ne l'adopta pas, aimant mieux, ne connoissant pas l'animal, le laisser parmi les Annélides tnbicoles, dont quelques-unes, garaies de nombreux tentacules sur la tête, les couvrent de tubes revêtus de grains de sablc. L'analogie justilioit, en quelque sorte, l'opinion de IJ. Cuvier, mais l'analogie des Arrosuirs avec les Claragedles cst bien plus forte et plus entrainante. Lorsugue M. Lamarck créa le genre, il u'avoit pour se décider qu'un pelit nombre d'espèces assez éloirgúes des $\Lambda$ rrosoirs par la forme et la position des tubes : il est permis : en quelque sorle, de douter, parce que ces coquilles présentoieut anssi beaucoup dianalogir avec les Fistulanes, partui lesquelles elles a voierr: été quelque teuips confondues. Nous arons fait remarquer ailleurs, dans notre ouvrage sur les fussiles des environs de Paris, que les Clavatrelles préseutoient plus ou moins d'inalogie avec les Fistulancs ou les Arrosoirs, selon la maniers de vivre des espèces; ainsi celles qui, comme les Arrosoirs, vivent dans le sable, preonent quelquelois absolument la forme des Arrosoirs; leurs épines tubuleuses, longues et bifurquées sont placées en couronue au sommet, et au milieı du disque libre, on voit une rimule irrégulière. Dans les espèces courtes et pyriformes la disposition des épines est diffẻrenı ; elles sont épar'ses sur. le tube, et la rimule disparoît. Dans les espèces perforantes, on retrouve quelquefois des traces de tubes spinifurmes, mais le plus souvent ils disparoissent complélement. Il arrive aussi, dans ces espèces comme dans les Fistulanes, que lit cavité dans laquelle vit l'animal a'est revêtuc qu'à la moitié par la couche calcaire du tube.

Quelque attention que nous ayons mise ì lirs ce que M. Brocchi dit des Clavagelles qu"il it observées, nous n'avons pu nous rendre comples des faits qu'il annonce, ni les faire accorde: avec rien de ce que nous connoissons, soit sur les Clavagelles, soit sur d'autres genres. Nuus ne concevons pas comment, daus une même especce de Clavagelle, il a pu se tronver des coquilles appartenant à différeus genres, tels çue les Vémus, les Saxicaves et les Myes : nous ne concevons pas davantage, en supposant, comme M. Brocchi, que l'animal de la Clavagelle est parasite, comment, en s'emparant d'une coquille étrangère, il a pu en fixer une valve daus ur: tube assez épais, en laissant l'autre libre et la réservant sans doute pour son usage. Mais it ‘quel usage pouvoit-elle être destinée? S'il est vrai qne, dans plusieurs, son contour correspond exactement à celui de la valve iucluse, il a fallu que leur accroissement se fit sicoultanément : et comment expliquer cet accroissement dass um animal parasite qui noccupe qu'une coquill. étrangère? On voit qu'il est impossible de résoudre ces questions.

Voici actuellemens quelle est notre opinion sur les faits rapportés par MI. Brocchi, et luimême en l'indiquant semble assez disposé d li partager: nous croyons que, dans un tole de Clavagelle déjà abuadonué par son animal tuort, 
il est tombé ou il s'est introduit une jeune soquille perforante des genres P'étricule, Vénérupe ou Saxicave; que, par son accroissemeut, la valve libre de la Clavarrelle a été dissoute, et qu'ainsi s'est trouvie, dans ce tube de Clavagelle, une coquille qui lui est étraugère el qui pourtant y a vécu de la même manière que dans le trou qquelle auroit creusé dans la pierre. lioverse aura pu également avoir lier, c'est-ádire, 'Tu'une Clavagelle, à l'élat d’œuf, a pu tomber dans nue cavitê creusée par uà genre perforant, et développer son lube dans l'iutérienr d'une coquille qui lui est complétement étrangère: c'est de cette wanière ciue nous expliquı ns le: observations du savant I talien, en ajoutant toutefois qu'll cst bien certain qu'il a vu la valve véritable de la Clavagelle; c'est elle cin'il rapporte au genre Mye, étant nacrée el fuliacée. Cela nous suffit pour la reconnoitre à l'aide des observalions qui nous sont propres.

Par suite des abscrvations de M. Brocchi, M. de Blainville, sans les discuter, paroit dis. posé à rejeter le keure Clavageile, quoiqu'il avoue ne le connoitre que d'une manière lort iucomplète; cependant il !e juge comıne un genre artificiel, qu'il convieudroit de repotter à côtá de ce qu'il nomme les r’énus irréguliéres, c'esta-dire, les Pétricoles et les Vénérupes. A cet égard nous ne partageous pas et nous ne partagerons jamais l'opinion de M. de Blainville, la rólre ayant élé lixée dès le moment que nous svons pu observer la Clavagelle couronnée, qui ne permet plus de mettre en clonte les rapports des Clavargelles avec les Arrosoirs.

II. Rang, dans son Munuel de Conchyüologie, partage complétement notre manière de voir, et, par ure couséqueoce nature!!e, il place le gente qui nous occupe entre les Arrosoirs et les Gustrochenes dars sa lamille, mal circonscrite selun nous, des 'Tubicolćes. M. Rarng pillage le genre en trois graupes : les deux premiers peuvent être conservés; le troi-ième, qu'il rérurde comme dauleux, micux connu, dail rentrer duss les Fistulanes; et nous rempliıçons ce troisične groupe par des coquilles que M. Rang est porté a rejeter des Clavagelles, parce qu'il ne les connoit gu'imparfailement. Nous aurons Lientót occasion d'cn parler.

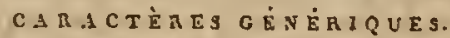

Animal inconnu.

Coquille bivalve, baillante, dimyaire, à cliarmicre dorsale, linéare, drnile, subarliculéc, róunie pár un ligrament extérieur alongés sur le lere; une valve libre, laure incluse thans léplisseur d'un tube calcuire au elle est immobile; ce tube, tantôt libre es orné d'ónines tubuleusen, tantôt inclus el dépunurva complálement ou presque coia ì étedent d'épines.
MI. de Blainville, cherchant à se reudre compte de l'usage des épines fistuleuses qui couronuent le disque des Arrosoirs, a pensé, pelt-être avec beaucoup de justesse, qu'ils devoient donner passage à un byssus destiné a fixer l'animal dans l'endroit où il doit vivre. Celle idée, que M. Rang a prise comme ponvanl s'appliquer anx Clavagelles, se fortitie en ellet par les observalions que nous avons faites précédemment; c'est que le nornbre des épines tubulenses diminuo dans ce genre à mesure que l'inclusion du lube se lait d'uue manière de plas en plus solide dang les corps sous-marins, jusquar moment où la fixité de l'anitual étant entierement assurée, par la solidité du corps dans lequel il se loge, les tubes deviennent iuutiles el disparoissent ainsi cont-it-fait. Néanmoins, comme on ne connoit pas du cout l'auimal des Clavagelles, et que l'on ignore également de quelle nalure est celui des Arrosuirs, on ne sitil pas en quoi consiste l'organe destiué à passer à travers ce grand nombre de tubes spiviformes, et nous n'en raisonnons que par conjecture.

Nous faisions observer que M. Rang aroit rejeté des Chuvagrclles une coquille trouvée dams la Méditerranće, dont lo tube, inclus dans les corps sous-marius, se levune à l'extérieur par nn prolongement giani de lamelles circulaires el orrès-minces semblalles à celles de l'Arrosoir à wanchelles; l'extrímilé opponsée du lube, celle qui comient la coquille, s'iduiucit peu ì peu, et laisse à nu, dans la parlic postérieure, ure assez grande surface du corps dans lequel il est fixé; on ne voit aucune trace d'épines, mais la coquille qui est contenue dans ce tube a une de scs valves allérente aux parois de ce tube, et l'autre y est parfaitement libre; et, quoique la furne des values differe un peu de celle des autres cspèces, lous les autres caractères restaut ceux du genie, nous l'aclmeltons au nombse des Clavagelles, et nous en formons une section dont on pourra peut - étre élablir plus tard an geno discinct.

La Clavagelle lihiale, doot M. Rang aroit fait le trusiease groupe du genre, groupe qu'il regarduit avec raison comme dloutenx, est une coquille qui appartient anx Iistulaues, anssi bien que le I'eredo bacillum de M. Brocchi, que M. Litmarck prend it lart ponr une 'T'́rédine.

Nons avans pu étudier la manière dont s'accroissent les Clavagelles sur de très-l eaux individus de l'esirece lussile nouvellement découverte en Sicile : il n'est pas douseux que cente coquille ne s'accroisse du còté le plus large, où est placíe la conronne d'épines tubuleuscs. Cela liil supposer, quand on songe it la grande taille do quelques individas, que l'aninal peut dissoudie la partie supérieuse de son tube, et la reproduice plisieurs tois. Cependant, comme rien ne pourroil expliquer comment se lait cetle singulica 
općration, il est assez croyable que le tube ne se complète que lorsqu"il est parvenu à tout son déreloppement. Mais celle manière de voir n'est pas confirmée par l'olservation; car, quel que suienı l'äge et la taille de ces corguilles, du moins quant à celle dont nous parlons ici, on les trouve tuujours pourvues de leur's épines.

l'endant plusieurs apnées on me connut les Claragelles qu'ù l'ćtat fossile: M. Sowcrby en fit connoitre une dans sbn Genera; elle est la unéne que cel!c que possède M. de Rivoli, et qui vient de la Méditerranće. M. Rang en a observé une seconde espèce à l'lle-de-France; elle parvit appartenir au second groupc. Eufin, nous en possécons une égalemeni des mers de l’Inde, qui a la plus grande aualogie avec celle de la Méditerrunce, et qui probablement n'en est qu'une rarib́te. Nous comptoos déjà sept espèces lossiles, sillus y comprendre la Clavagelle tiliale que nons regardons actucllement cornme une Fistulane.

\section{† Espèces teminées antérieurment par un disque aplati, fendu dans le nilieu.}

1. Cravagele couronnéc. Clavigella coronata. Non.

C. tubo recto, elongato, clavato, spinis furcatis coronato; disco ninimo; valvâs inclusâ, sabundulutâ, ovutî, alterâ tenuissimâ.

Nов. Descript. des coq. Joss. des env. de Paris, toni. 1. pag. 8. $n^{\circ}$. 1. pl. 5. fig. 9. 10.

Sowerв , Mineral conch.pl. $430, f_{i g} .1 .2 .3$.

Coquille curieuse dont le moule sculement sous fut connu. Lorsque nous la décrivinues la première fois, nous rapportions à la mêose espèce des coquilles trouvées à Pauliac, mais qui nous paroissent actuellement être de la même espèce que colle de la Sicile. MI. Sowerby compléta la connoillance de notre espèce par une description ct nne figure faite sur un individu bien conservé, de sorte qu'on peut la regarder actucl!ement comme sulfisamment counue.

La Clavagelle couronnéc ne prend pas, à ce guiil paroît, une grand taille; elle est alongée, droite, étroite, lerminće en massue; son disque, - petit, arrondi, fendu au bord postéricur par une lissure quelquefois bilide, est borné circulaire'ment par un rang d'épines an nombre de sept à huit, qui, d’abord simples, se bifurqueut une preunière fris à chacune des branches; clles-mêmes se divisent à leur tour; la valve incrustée dans l'épaisseur du tube est reudue onduleuse par des accroissemens, l'autre value est de la méme forme; elle esi très-mince, vacrée comme la première, et toutes deux présentent denx impressions musculaires comme dans tous les conclyferes dimyaires, et de plus une impressiun palléle profondément sinueuse postérieurcoent, ce qui aunonce bien évidemment l'existence de sipliuns. Nous ne connoissous pas la charnic̀re de celle espèce, qui bien probalulement est semblable à celle de l'espèce suivante; celle-ci, longue de 45 millia., ne s'est trourćc qu'tine senle fois aux environs de Paris, près de Meaux, et une fois en Angleterre, à Barlon, avec toutes les coquilles de l'argile de Londres.

2. Cravagele bacillaire. Clavagella bacillaris. Nов.

C. tubo subrecto, clongato, angusto, tenui, antices spinis numenosis dichotomis caronato; disco magno, fisso; fissurầ bifurcatâ; v'alvâ liberâ, ovato-clongatâ, tenuissinâ, margaritaceấ dopressâ; cardine edentulo.

Grande et magnifique espèce de Clavagelle; elle est la plus grande du genre, et l'une de celles qui montrent le nicux le passage aux Arrosoirs. Cette coquille se compose diun lube fort grand, druit ou un peu torlueux, alténué postérieurcment, claviforme, et terminé à son extrémité antérieure par un disque aplati, an milieu duquel se voit une fissure communiquant libreneut avec l'intérieur. Cette lissurc commence au côté droit et superieur du bord du disque, et se bilarque en s'avancant vers le milieu, de sorte qu'en eflet elle a la forme d'uo $Y$ dont les deux branches sont tres-ouvertes. Les épines naissent de la circonférence du disque; elles sont nombreuses, irrégulièrement placécs, et elles se bifurquent promptement; cliacune des branches se bifurgue à son tour, de sorte que l'on peut dire que les ćpines tubuleuses sont dichotomes. Ja valve, incrustée dans l'épaisseur du tube, est placće tout près du disque; elle est ovale, courte, presque aussi longue que large, et son crochet lorme une saillie a laquelle correspond une saillic "plposée produice par le tube; cetie proéninence dans le tube produit en dedans une cavité qui reçoit le crochet de la valve libre. Celle-ci est avale, alongée, aussi large que l'autre, mais heaucoup plus longne; clle est mince, nacréc, fragile, peu profonde, et présente lien distinctement les deux impressions musculaires et l'impression palléalc. Dans l'intérieur du unbe, le bord cardinal de la valse adhérente fait sajllie dans l'endroit de l'articulation avec la valoe libre; derrière cette saillie se trouve nne petite cavité qui sert à loger le ligament qui devoit être fort petit, à en juger par la nymplie qui lui donnoit inserion; la claarnicre est sans dents, senlement au-dessous du croclict on remarque une légère dépression. Si l'animal pouvoit être contenu dans l'espace formé par les deux valves rapprochées, il devoit ĉtre fort petit relatirement à la grandeur de sou tube.

Celte coquille, dans le jeune âcee, étnit toujours agglutinante, tandis que parrenue à un 
242 C L A

qui, en s'agrandissant de plus en plus, finissent par être disccïdales et s'empiler les unes sur les autres. Dans le jeune âge, lorsque l'empilement des loges se fait encore trois à trois, l'ouverture est toul-à-fait placée comane dans les ligénérioes, c'est-à-dire quelle est latérale, appuyée contre la lnge précédente; à mesure quie la coquille grandit, elle devient de plus en plus centrale, et après avoir été alougée, demi-circulaire et séparie par un petit osselet, elle se présente à la lin tout-ì-fait ronde et toujour's garnie de son osselet latéral.

Le nombre des espèces n'cst pas encore considćrable. Al. d'Orbigny en cite quatre, dont une fossille des environs de Paris; nous cn connuissons denx autres qui souı égalemeat des sables la bassin de Paris. D. ORB.

1. Chatuline ie Pais. Clavulina parisiensis.

C. testá rectâ, lavigatâ, extremitate lanceolato-clandats, di parte superiore separatâ strangulatn; loculis superioribus depressis, simpliczbus. Nов.

D'Orbigxr. Mlén. sur les Céphal. Ann. des Scienc. nat. tom. 7. pug. 268. et Modeles de C'sphal. 3e. livrass. no 66.

Coquille microscopique qui a à peine une demiligne de longueur; elle est lisse, étroite; son sommel pyramidal est síparé du reste par un ¿́tranglewent, et les loges qui lui sont superposées deviennent sur-le-champ régulic̀res el percées au centre; elles ressembleut de petits disques aplatis, arrondis par le bord libre. L'ouverture est fort perite, el l'appendice qui s'y ruit a la forme d'une petite virgule. Cette coquille se trouve à Mouchy-le-Cbâlel et à Palnes. Noв.

2. Chavolaxe irrégulière. Clavulina irregularis.

C. testâ breviculâ, non clav'atâ, rectâ, larrigat $\hat{a}$, extreritale puramidali regulari; luculis inferioribus primo megulurier dispositis, duo iresve superioribus regruluritus; aperturâ mininá; ufwerndice minimo, recto, extus prodiente.

Commençant par une painte régulière en pyramide triangulaure, comme l'espècc précédente, celle-ci ne présente aucun érranglemeıt, elle est conique de lá base au sommel; au-dessus de la poinie les loges deviemnent itrégulière, de plus cu plas grandes, et les deux au trois dernières sculemeut sunt discoïdales, complètes el réguliires. La dernière est percée d'un trés-petit trou dans lequel s'aperçoit un appeodice droit qui part d'un léger tubercule qui est sur le bord de louverture. Cetle coquille, toute lisse, est large i la base; elle se tronre dans les sables de Grignon; elle a à peine un millimitre de longueur.

\section{L E} NoB.

3. Cuaruraz rongée. Clavulina corngata.

C. test $\hat{2}$ elongatâ, angustâ, subrectâ, undiquß et irregulariter corrugatd.

C'est la plus grande espèce du genre, car elle atteint plus d'une ligne de longueur; elle est fort étroite, souvent coutournée sur elle-mêrne; son extrémité est, comme dans les autres, en pyramide triangulaiıc, non séparée par uo étranglement, mais surmontće de quelques loges irrégulières qui sont suivies de six ou huit loges discoïdales, complètes, superposées régulièrement; la deruière est percée d'une fort petitu ouverture, dans laquelle se voit un appendica qui va presque d'un bord à l'autre: il se recourbs en crochet. Tuute la surface de celte coquill est comme roygée, ce qui la rend irrégulièroment granuleuse et rude; elle se tronse a Parnes et à M̂louchy.

\section{CLÉODORĖ. Cleodora.}

Ce genre, créé par Péron et Lesueur, dans lis Annales du Muséum, a élé généralement adopł et placé parmi les Plćropodes par presque tous les auteurs. 1]. Cuvier d'aloord (Regne anunal) le mit entre les Clios et les Cymbulies, où il est dans des rapports très-naturels; aussi M. Lamarck n'y cla angea rien en l'admettant, comme DI. Cuvier, dans les Ptéropodes. M. de Ferussac divisa len Ptćropodes (20yez ce mot)en plusieurs familles: dans la première, celle des Hyales, se trouve le gerue Cléodore, entre les Hyales ct les Cyıbulies, rapports peu différens, au reste, de cenx que nous avous déjà mentionnés. Dans le Traité du Malacologie, la place de la famille des Ptérnpodes fut changée, ou plutôt la famille ellc-mêare fut détruile el tut comprise dans les Gastéropodes. Un ordre particulier, les Aporobranclies ( $20 y .1$ mo!), fut limité pour les anciens l'téropodes ct divisé en familles: la première, celle des 'Thécosomes, est la mêue que celle des Hijăles de M. de Ferussac, seulement elle contient de plus le genre doutenx des Pyrgos.

M. Rang, dins son Manuel de Conchyliologu, en adoptant les rapports indiqués par ses devanciers pour les Cléodores, a divisé ce genre en plusieurs sous-genres, d'âprès les'observations nouvelles qui lui sunt propres. Ces sous-genres, an nombre de trois, sont les Cléodores propremen dites, les Créseis et les 'Triptères. Ce dernier sous-gente paroît avoir une grande analogie aree le second. Il est à présumer, comme le croir M. Rang, que, micux connu, il en fera partie. Cesavant, avant la publication du Manuel, donna des renseignemens précieux sur ce gente et quedques-unes de ses sous-divisions, dans le lome XW des Annales des Sciences naturelles: ils sont d'autant plus indispensables gu'ils tlonnent la facilité de juger et d'apprécier les innavations de Ml. Ranh. 


\section{L, E}

Nous lescroyons utiles et núcesiraires, mais nous pensons qu'il auroit été préférable peut-être de taire un geare à part du sous-gene Créseis, dout la lorme tunte particulière s'ćloigne d'une unanière uolable de celle des Cléodores proprement dites. Cette ol,jection n'a ancune valeur, s'il est vrai, comme le croit M. Rang, que les animaux des deux sous-genres sont semblables. Il reste cependant du doute à cet égard, et c'est à cause de ce dıute même qu'il auroit mieux valu séparer des Cléadores les Créseis et les 'Trijtiores.

En allendant que de nonvelles observaticos anatousiqnes vienneat contirmer le rajproclsement de M. Rang, nous caractériseroas le genre d'a près lui, el nous admeltrons deux groupes on souspeures, an moyen desquels il est facile de cléteriniaer et rapprocher les espèces assez notalureuses qui y sont comprises.

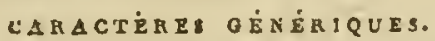

Animal de forme oblongne or alongée, tauni d'un lobe intermédiaire demi-circulaire, nuais n'ayant point d'expansions latérales; le m.inteau ouvert en avant; les branchies et les organes de la génération incomplétement conurs.

Coquille fragile, vitrće, en furme de gaîze ou de corvet plas ou moins aigu postéricurement, el toujon:s close de ce côté; ouverture le plas souvent linge, sins lente et sans appendices latćraux, quelquefois plus rétrécie et simple.

Les animaux des Cléodores ont heaucoup de rapports avec ceux des Ilyales, et certaiaes coquilles, par leurs foranes, ollient un passage -utre les deux genres.

Parmi les coquilles rapporiées au nombre des Clíodores par MI. Rang, nous irons vu avec surprise le Dentalium gadus et le Dentalium coarcsutun. Nous avons examinó avec une alteation minuticuse les inotifs de M. Rang, qui, en deruière analyse, se réduisent à un seul. Une des conditions du geure Cléodore, aussi bien qque des Hyales, c'est que la conquille n'est jamais perlorée justćrienrenent, à moins que par accident. Les Dentalium gadus et coarctatum, au contruire, sunt coujours ouverts aux denx extrcimités.

M. Rang n'a vu, daus la perforation de l'extrémité postérieure de ces corps, que le tésultat d'une fracture souveat répétée sur leur partic la plus liragile. C'est de cette manière on'il a contredit notre oninion, et quil a aflirmé que les teux lentes postérieures et latćrales que nous avons uentionnées dans le Dentalium coarctatum étuient le résuleat d'une cassure, gu'elies ne présentoient janais rien de régnlier. M. Rangr a même assuré yue ces foutes, ou ce que nous avions pris pom elles, puuvoient se reproduice à volonsé par de nouvilles cassures.

Conpplant que M. Rang, avant de publier ses

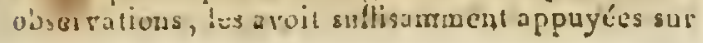

des faits, entrainé aussi par les ripports qui sembloient lier les corps dont il est question aux autres Clćodores, saus revoir, conme nous eussions dû le Iaire, les Dentales que aons venons de mentionner, wous nous sommes rangé à l'opiuion do M. Kang, et avons rejeté, comme on pourra le vuil, ces espices dn genre Deutale (yoyez ce mot ); mais, en recherchant les matériaux vécessaires pour traiter le geure Clécdore, nous avons examias aver le plus grand soin, el it l'aide d'un très-fort grossissenent, les cocjuilles qui font le sujet tle la disenssion.

Nous possedons deux individus très-frais du Dentalium gudus, qui vit it ce qu’il paroit dans les iners dingleterre. Celle petite coquille t beanconp d'analogie avec le Dentalian courctatum, inais en dillère sons plusieurs rapports. Ce qu'il laue noter ici, c'est que sun extrémitú postérienre est ouverte, et que celtc ouverture, épaisse et arrondie sur le bord, n'ollire aucure trace de cassure on peut au contraire lit regardes comme bien entiere et bien naturelle. Pour ceci déjà, il nous paroît que M. Rang s'est trop hấlí, mais il s'est bien évilemment trompé pour ce qui it rapport an Dentalium coantatum. Nous possédous un nombre considérable de cetle coquille, provenant de diverses localités des environs de l'uris, de Bordeaux, de Dax et d'Italie; leur examen zons a fail voir une chose il laquelle nous n'avions pas fait attention dans le principe. Un certain nombre d’individus, généralemeat plus grçles que les autres, présentent constanment, conme nous l'avons dit, deux lentes à l'extróraité postéricurc. Ces fentes sont latérales et jarfaiteaent symétriques. D'autres individus, non-senlement ont ces lentes latérales un per plus étroiles, mais ont le bord de celte ouverture divisé en neal" lobes symétriques: trois dorsaux et six qui appartiennent a la face inférieure. Le plus grand des preniers est impair, plus saillant que ions les autres, et tout-à-fait médiun; les denx antres sont trèspetils el séparés par une lissure peu frrafonde. Ces trois loles sont séparés des autres par les denx grandes fentes latérales. Jes lobes de la partie inférieure consistent ca petiles dentelures égalcs: truis de cliaque côté de la ligne médiane. Si ca que nous venons de dérrire ne s'étoit v'll que sur un seul individu, nous anrioas du donte; mais nous en avons plus de cinquante qui sunt absulument semblables. On ne peut done plus altribuer cetle structure ì un accident, d'autant plus gue les individus ov̀ on n'oloserve pas l'une ou l'aurirc disposition, olfrent des traces évidentes de rassurc. Ce qui, pour nous, met la cliose plus hors de dontc encore, s"il est possible, et ce qui nous prouve que c'est a l'animal qu'on doit celte disposition, cest que le bord des lobures s'anincit considérablement, ce qui a lieu par un biseau poli et assez court, formé aux dépens de la partie interieure; cela produit un érasement II $\mathrm{h}:$ 
qui ne pourroit avoir lieu avec constance par suite d'une cassure.

Il résulte des observations que nous venons de faire, que les deux Dentales, ćtant naturellement perforées aux deux extrémités, we peuvent entrer dans les Cléodores, et il seroit bien possible qu'elles ne pussent rester dans les Dcntales, dont aucunc espèce ne préseute des caracières analogues. Il résulte ausside ce qui précède que probablement on confondoit, dans une seule, deux espèces qui nous semblent sulfisamment caractérisées par la différence dans la forme générale, ct surtout par le nombre des lobures et des fissures.

Nous trouvant complétemeut en npposition avec M. Rang, et ayant dans nos observations toute la ceritude possible, nous ne craignons pas d'offitir, à quiconque conservera des dontes, les preuves malćrielles de notre conviction: elles se trouvent dans notre collection, que nous avous tonjunrs misc à la disposition des persunnes qui peuvent en avoir besoin. On pourra facileluent vérifier, sur les matériaux qui nuus ont servi dans cette discussion, de quel còtć est l'erreur. Si nos obserrations se confirment, il sera évident que M. Rang aura ajouté d'imauination unc pointe recourbée et ferméc à des coquilles naturcllement tronquées et ouvertes, lorsqu'il auroit dô, ce nous semble, les représenter telles qu'il les voyoit.

Les coquilles des Cléodores sont très-fragiles, ninces, vitrées, coniques, pointues et fermées postéricurement, plus ou moins dilatées antérieurement, quelquefois munies d'appendices stytoides à l'ouverture, d'autres fois ayant celle ouverture simple. Elles conliennent des animaux d'une organisation assez simple, mais encore incomplétement connue. Ils sont nageurs, et ne se rencontrent que loiu des côtes, au milieu des grandes mers, où ils sont quelquefois en grande quantité. Ils sont pourvus à leur partie antérienre d'une paire de grands appendiccs aliformes qui servent de nageoires, an nilieu desquels se voit nu petit lobe intermédiaire, ntile aussi ì la natation.

On ne connoit encore qu'un petit nombre d'espèces daos les collections. M. Rang en compte scize distribuées dans ses trois sous-yeures; elles se réduisent à quinze, si nn n'admet pas le Dentalium gezdus.

Nous dunnerons seulement le petit nombre qui sont à notre counoissance : elles serviront d'exemple au geare.

$\dagger$ Espdces à ouverture large, anguleuse et urmée dappendices aciculaires, ou dentée sur le bord.

(Cléodores proprement dites, Rang.)

1. CLĖodore lancéolée. Cleodora lanceoluta. Lesueun.

C. testí lanceolatá, levigatâ, pyrumidali, triungulari, tenuissinâ, apice acutissimâ; cuper-

\section{L E}

turí depressá, trigoná, dilutatâ, obliqud truncutâ.

lesveur, Nouv. Bull. de he Soc. phil. no. 69. mai 1813 .

En Cleodoracaudata? Lamr. Anini. s. vert.t.6. $2^{2}$. part. pag. $290 . n^{\circ} .2$.

Nous avons snus les yeux une Cléodore dont les caractères spécifiques s'accordent si bien avec ceux donnés par M. Lesueur à sa Cléodore lancéotée, que nous n'avons pas le unoindre doute sur son identité : aons n'avons pas la certitude que ce soit la même espèce que celle nommée Cleodora candata par M. Lamarck.

Cette coquille est longue de six à huit lignes; e!le est excessivement mince et transparente comme du rerre; sa forme est cellc d'une pyramide triangulaire, à base dilatée et coupée obliquement. Cette base représente l'ouverture, dont les angles sont saillans et terminés en pointe. L sommet est atténué en pointe très-aiguë et parfaitement clos. Toute cetle coquille est lisse ; celle que nous possédons nous a été communiquée par notre savant ami M. Lesson, qui l'a recueillie dans les mers du cap de Bonne-Espérauce. Elle est longue de 12 millimètres.

$\dagger \dagger$ Espèces étroites, non dilatées à Couverture, qui est le plus souvent simple ou n'ayant qu'un seul appendice; l'extrémité postéricure druite ou courbée. (Sous-geares Ciéseis et Triptère, RANG.)

Le genre Triptère fut établi par MII. Quoy ct Gaymard, dans la partie zoologicgue de la relation du voyage qu'ils firent autour du Monde.

Ce gyenre ne diffère des autres Cléodores de ce groupe que par l'animal, qui paroît avoir le lobe intermédiaire antérieur presque aussi développé ণque les nageoires elles-mêmes. Ce caractère, de très-pcu d'impartance, ne nécessite même pas, selon notre opinion, un groupe ou un sous genre. Noв.

Cléodone Etranglée. Cleodora strungulsus.

C. testâ elongato-yentricosâ, apice acutâ, depressá, ad aperturam coarctatâ, lcevigatâ; aperturâ trunsversâ, subovatâ, conıpressậ, utroque latere sinuatâ.

Nobis, Dict. class. d'Hist. nat. art. Créodonr. Dandrs, geore Vaginelle.

Vaginella depressa, BAst. Bassin du sud-ouest de la France, Méns. de la Soc. d'Hist. nat. de Paris, tom. 2. pag. 19. $\pi^{\circ}$. 1.pl. 4.fig. 16.

lbid. Bowder, Clins. of conch. ${ }^{\mathrm{re}}$. part. pl. 3. fig. 10.

Cleodora strungulata, Gratelovp, Bull. de hi Soc. linn. de Bord. tom. 2. pag. $7^{5} . n^{\circ} .2$. 


\section{L I}

Cruscis viginella, RAsc, Mém. sur les Clèndores, Annules des Sc. nat. tom. 13. pag. 3oy. $n^{n}$. 1. pl. 18. fig. 2 .

Chaque auleur, ou à peu près, a dunné un nom particulier à celle coquille. Nous l'avons le premier rapportúe à son véritable geure, et il nous étoit permis de lui donner un nom spécilingue nouveau en lintruduisant parmi les Cléodores. M. Rang auroit dì, ce nous semble, puisqu'il ne la changeoit pas de genre, adopter le nom que nous lui avions imposé, au lien d'angmenter encore la symonymie d'un nom inutile.

La Cléodore étranglée est droite, alonorée, ventrue, déprince de haul en bas, terminée poslérieurement en pointe aignü, se rétrécissant vers l'ouverture en une sorte d'étranglement ou de col, après lequel l'ouverlure, plus'déprimée cocore que le reste de la coquille, se dilate, surtout láéralemed. Cette ouverture, en fentc subovalaire, est déprimće el subcausliculée de chaque côté, eı elle est un peu anguleuse à la commissure des deux lc̀vres. Cette corjuille, connue à l'état Cossile seulement, se tronve ea abondance à Bordeaux et à Uax. Elle sert de jonction cutre les clenx yroupes des Cléodores et des Ciéseis. Les plus grands individus ont 7 millim. de longueur.

\section{CLIO. Clio.}

Ce genre, indiqué par Bromne (Hisiaria natur. jum. pag. $386^{\circ}$ ) pour les animuux auxquels l'éron a donné le nom de Cléodore, lut éfabli postérieurement par Pallas sous le noa de Clione; et, quoique Martini l'ait lait firnter dans son Voyage au Spitzberg, Liuné néanmoins ne coamença it en parler qu'à sa dunzième édilion, eu y comprenant, ainsi que dans les suivantes, et la Clio figurée par Martini et celle indiquéc par Browne. M. Cuvier, dans uu Mémoire inséré dans le premier volume des Annales du Muséum, donna sur l'animabde la Clio des dérails analomiques lurt curieux, et fit pour ce genre, ainsi que pour quelques autres avoisibans, la seconde clasie des Mollinsques, les Ptéropodes. (Voyez ce mot.) Le genre Clio fat placé aaturellement dans celte classe des Pléropudes, à côté des Iyales et des Cléudores. II. Lamarck ne cloangea rien aux rapports indiqués par M. Cuvier; M. de Lerussac les modifia en érablissant dansles P'iéropodes une famille pour le genre Clio lui seul : cetle famille n'a pas été adopiće, et ve poivoit l'être, à cause des rapport qui lient ce geure it ses voisins. Ml. de Jlainville, dans le Dictionnaire des Sciences naturelles, a donné à son article Clio des détails fort impurtans et très-intéressans, au moyen desquels on peut beaucoup mieux caractériser les Clios. Dins son Traité de Malacologie, regarchat les P'téropodes comine des Gastéropodes, ou une de leurs modifications, les y plaça sous

\section{Is I}

le nom d'Aporobranches. (Voyez ce mot). Il les distribua en deux familles, et la seconde, qui porle le norn de Gymuosomes, contient les geares Clio el Pneumoderme. M. Rang, dans son Munucl de Conchyliologie, adopte la lamille de M. de Blinville, mais lui donae le nom de Clio, emprunté à M. de lierussac, quoique M. de Ferussac u'ait pas proposé sous ce nom de Clio les mêmes rappurts que M. de Blainville. Nons ne signalons celle iudvertance que pour rembe à chacun ce qui lui appartient.

MII. Quoy el Gaymard ont proposés ua geure Cliodite qui est encore imparfitiemeat connu; il a de l'analonie avec les Clios : il seroit, selon ces auteurs, dépourvu de tentacules, et le tronc séparié de la lêté par un étranglement ou une sorle de corselet. M. de Blainville, et aptès lui 11. Rang, ont réuni ce genre aux Clios. l.es Clios peuvent être génériyuement caractérisées de la unaière suivanle, d'après M. de Blainville.

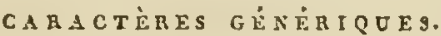

Corps nu, gélatineux, lilse, plus on moins alougé, un peu dépriné; une têle distincte, surmontéc de six tentacules rétractiles, longs et coniques, séparés en deux faisceanx de trois chaque, qui rendent la lềle bilobée lorsqu'ils sont contractés, et penvent être entièreıneat cachés dans uue sorte de prépuce, porlant luimème un pelit tentacule à son côlé exterue; deux yeux à la partie supérienre de la tûte; bouche lerminale, verticale; deux nagcoires opposées, branchiales, iusérées de chaque rôlé i Ii base du cou; l'anus et l'orifice pour la généralion s'ouvrent au côlé droit, près du cou, sous la nigeoire.

Le syslèco nerveux est composé d'an cervea bilobé, duruel partent deux lilets qui aboutissent sous l'œsophage, où ils se reoflent en ganglions. Ces uranglions fournisscnt eux-mémes deux autres filets, lesçuels donnent encore un ganglion chaque, qui se réunissent an-dessus de l'assophage par un filet intermédiaire; les nerfs des aulres organes partent en rayonnant de ces divers ganglious. La respiration est branchiale, ses $0 \mathrm{l}^{\circ-}$ gaues font partie des aageoires; c'est pont cela que M. de Blainville propose le nom de Pterodibranche, que depuis il a changé pour celui d'Aporobranches pour l'ordre qui rénnit les Pléropodes de M. Cuvier. De chaque branchie nait un vaisseau qui se rénnit à son congénère andessus du cour, pour donncr naissance à un lronc unique, lequel se rend directement à cet orgaoe. (Voir, pour d'antres détails anatoaiques, le Mémoire de M. Cuvier, Ann. du Mus. tom. I. p. 242. $p l .17$.$) Tous les organes internes des$ Clios sont enveloppés d'une tunique musculaire, recouverte elle-même parune peau transparente, à travers laquelle on roit la ciirection dus libres 
tusculaires. M. de Blainville, comme on peot lo voil par li caractéristique que nous lui avons empruntée, a douné, dans son Truité de Makacologie, un dessin de la Clio qui paroit plus exact que tons ceux que l'ou connoit déjjà; la forme et la position des tentacrales y sont déterminées d'une maoière fort dillérente de ce que l'on avoit déji vu, soit dans la figure de Bruguière clans ce Dictionnaire, soit méme dains celle de M. Cuvier. Au reste, ces naturalistes ont représenté nn animal contracté dans la liqueur, et personne n'ignore cembien les Mollusques nus s'ullèrent el cbangent de forme dans celle circonstance. Le nombre des espèces de ce genre est fort limité. Une seule étoit conane autrefois; Brtacuière en a décrit une nouvelle daus le premier volume de ce Diclionnaire, nous y renvoyons le lecteur.

\section{CLIODITE.}

Genre que jroposèrent MM. Quoy et Gaymard, pour un pelit aninal voisu, à ce quars] paroit, des Clios, toais encore trop jen connu pour ètre admis. M. de Blainville et M. Rangr ont réuni ce geore aux Clios. Voyez ce mot.

\section{CLIOS (les).}

11. de Ferussac a proposé de former du genre Clio lui seul une famille a laquelle il a donué ce nom; elle n'a poiut étć adoptće. M. de Blainville fit aussi une famille pour les Clios, mais il y joignit les I'oeumodermes, et uomma Gymnosomes celte rúunion des denx genres. M. Rang adopta cet artangement dans son Maruel, mais lui conserva, on De sait pourquoi, le nom de la famille de MI. de Fer'ussac, laissant croice par la que c'est à cel auteur que l'on duit le rapprocbement proposé par Mi. de Blainville. Voyez Crumosomes et Chio.

c

\section{CLISIPHONTE. Clisiphontes.}

Ce genre fut proposé pal Montfort, dans sa Conchyliologie systématique (tom. 1. pag. 226), pour une coquille microscopicque nauiloide que M. d'Orbigny range au noobre de ses Tobulines. Voyez ce not.

\section{CLITON. Clitor.}

Montfort, dans le second volume de sa Conchyliologie gyslématique, a proposé ce genre pour les espèces épineuses de Néritines : à peine si lou peut conserver le geure Néritine, à plus forte raison ce déprembrement de Muatfort. Foyez Nerte ch Nizitine.

\section{CLOISONNAIRE. Septatia.}

C'es: à Rumphins que l'on doit la première figure do la coquille qui a servi is l'établisse-

\section{L O}

ment de ce genre; on la trouve dans son Mirséum d'Amboine, où elle a reçu le nou de Soler arenarius. Avant Linné, ce mnt Sulen signifioit coquille tubulense et ćlvit appliqué à toutes les Serpules, luyaux marins et coquilles bivalves, étroites el langues. Ce fiat lui qui restreignit cette expression, eu l'appliquaut spécialement aux coquitles bivalves qui portent encore ce nom: par suite de celte réforme, lous les tuyaux marins furent compris par Linné dans le geare Serpule, et celui-ci comme les antres. Il resta oublié pour aiusi dire jusqu'an moment où M. Lamarck, dans sou dernier ouvrage, le retira des Serpule. pour en faire un genre qui, par ses rapports, avoisine les Fistulanes et les Tarels, commo cet auleur l'a judicieusement annoncé. Depuis ce moment, ce greme se trouve dans toutes les méllodes el dans les rapports que M. Lamarck a voit incliqués. Nous n'entrerous pas à cet égard dans plus de détails; il nous suffira de dire quo les auteurs de ces nuéthodes ont raogé ce genre dans la fanille des'Tubicolís (Ferussac, Latreille, Rang), ou celle des Pylridés (Blainville). Voyez PrLoridés et Tubicúlés.

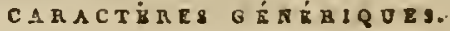

Animal inconnu.

Tube testacé, très-long, insensiblement atténué vers sa parlie postéricure, el comme divisá intérieurement par des cloisons voùtées, incomplèłes, résultant d'actroissemens irréguliers ; cxtréunité postćrienre divisće à lintérieur en deux trous daus lesquels on voit des cloisons nombrcuses, circulaires el ouvertes daus le milieu: sur cluacuns de ces trous s"insère une longute calamule calcaire, arliculée, non cloisonnée.

On ne connoit, comme on le voit, que le tube calcaire très-consiclérable qui seul it sumi pour caractériser le genre et le veltue dans ses rapports naturels; ni l'animal, ni la coquille qni doit êre contcme dans l'extrémité la plus élargie du lube, nont ćlé olsservés jusqu'a ce jóur. Jusqu'au moment oì celle lacune aura dispará, on pent douler si en effet ce tube de la Cloisonnaire cst celui d'une liisfulade exagérée. comme le croit M. Lamarck, ou celui diun Taret gigantestrue, ou bien s'il appartient à un genre distiuct de l'un et de l'autre.

D'après l'exarnen que nous avous fait des beaux individus cle Cloisonnaire de la collection da Musélum et de celle de M. de Rivoli, nous serions assez de lopinion que ce genre differe des Fistulanes et des 'Tarets. On sait que toules les Yistulanes qui vivent dans un tube libre on toujours ce tube fernié à l'extrémité la plus large : on sait aussi que dans ce genre, si l'extrémitú postérieure se divise quelguefois en deux trons, elle est toujours dépourve de tules articulás. 


\section{L O}

Jans les plus grauds individus de Cloisonnnire que nous avons vus, rien n'annoncoit qu'ils duscont se fermer par lextrémité la plus large; s'aniacissant insensiblenent, ils prósentent un bord tranchant, plitô! recourbé en dehors qu'en dedans. Les 'Tarets, il est vrit, restent presque toujnurs ouverts à leur extrémilé anléricure; mais, outre quils ont nne manic̀re particulière de vive, s'enfonçant dans les bois plongés dans la mer, on n'en connoit pas encore nn seul qui - oit pourva de calamules arliculées semblables à celles des Cloisonnaires. Cependant, conme les animax des 'Tarets sont pourvus à leur extrémité postérieure de palcolles de formes diverses, nous leur trouvons plus d'analogie avec les Cloionnaires que n'en ont les listulanes; aussi, dans l'arrangement que nous proposerons pour la lamille des Tubicolés el celle des Pholadaires, re sera dans cette dernière, et à côté des 'l'arets et des 'Térédines, que nous placelons le geare yui nous occupe.

On ne connoît encore qu'une seule espèce de Cloisonnaire, qui est restée rare jusqu'at présent dans les collections : sans doute que sil manière de vivre entoncée dans le sable, où elle reste niême après la mort de son habilant, est ce qui a empèché qu'elle ne soit plus complétemeat observée et plus généralement répanduc.

\section{LAMK.}

1. Clorsonsarae des saljles. Septaria arenaria.

C. tuho longissimo, crusso, solidn, postice bjpurtito, duobus tubulis articulatis instructo. Nos.

LA An. Anim. sans zert. tom. 5. pag. 437 . $n^{\circ}, 1$.

Serpula polythalamia, Lix. GaEL. pag. 374z. $n^{\circ} .13$.

Solen arenarius, Rustpa. Huseun amb. tab. 41. fig. D. E.

SÉBA, Mus. tom. 5. tab. 94. (Tubiduo majures.)

Martivi, Conch. cab.tom. 1. tab. 1.fgo. 6 et 11 .

Le tube de la Cloisonnaire est très-grand, très'pais, solide, en cône très-alongé, subcylindrique, ayant i la base une ouverture ronde, dont les horủs sont atnincis à l'extrúnité postérieure; le tube se divise, et cette division commence par une sorte d'épecon qui parlage à l'intérieur le lube en deux autres lubes égaux, qui, d'abord ovalaires an-dessus de l'éperou, $s$ arrondissent de plus en plus jusqnà leur extrémilé, qui donne jnsertion aux calamules articu!ées.

La Cloisonnaire vil dans les mers de l'Inde, et notamment à $\Lambda$ mboine; elle a quelquefois plos de trois pieds de longueur.

\section{CLONISSE.}

Nom vulgaire que l'on donne sur nos cóles t la Venus zerncosa l.1. Adanson (Voy, au Sénégal, pl. 16. fig. 1) a conservé ce nom spécilique pour la même coquille. Voy. Véxus.

\section{Clotilo. Clotho.}

Iaujas ayant observé dans des coquilles perforantes fossiles, qu'il attribue au gente Cardite, et qui sont des Cypricardes, une autre espèce de coquille bivalve, qui, cn parasite, étoit venue se placer dans la cavité des valves de la première, a cra reconvoitre, dans cette singulière parasile, un genre nouvean qu'il nomua Clotho, el qu'il décrivit dans les Annales da Muséum. Nous arons inentionué un fait senblable dans le Dictionnaire clussique d'Histoine naturelle, mais, pour d'antres cocpuilles; une listulane conteroit nne coquille d'ua autre genre el diflérente des Clothos. Entin, nous pouvons ajouter que vous avous olsservé des Modioles lithoplages dans un Polypier, contenant cntre leurs ralues des Cypricardes, et quelquefuis deux Cypricardes placées l'une dans l'autre éloient conlenues dans une seule Modiole. Ces fails nous conáuisent it perser que les diverses especees de coquilles perforantes qui vivent dans une même localitó peuvent êlre des Clochosles unes par rapport anx autres, sins que pour cela cette circonstance les ronde d'un genre pariculier. dinsi le genre Clotho de Fanjas nous paroit être une Saxicave : la coquille contenue dans la listulane est diun genre houvean dont nous counoissons déjà plusieurs espéces (2'oy'cz Quorie), et notre troisiẹme observalion montre que les Cypricardes qui avoient été envahies par le Clollas de Faujas, sont derenues à lear tour envahissantes et parasites des Modioles lithodomes.

\section{COCHLEA.}

Jans sa Mélbode, Kilein nomme aiasi uno classc clans laquelle il range quelques-unes des coquilles spirales, qu'il distribue en huit genres caractériscís à sa manière : ccs buit gentes sout, Cochlea lunaris, Cochlea crelata, Cochlea petholata, Olearia, Tigris, Fornax, Trochocochlea et Saccus. Ln cousaltant ces mots, on s'assurera combien les familles \& les genres de cet auleur, maladroit critique de liunc, sont défectueux.

\section{COCHIEA CELATA.}

Genre proposé par Klein (Method. ostric. pag. 59) pour une coquille appartedant au gento Tuxbo.

\section{COCHLEA IUUNARIS.}

Klein (Method. ostmc. pag. 3g) donne co 
aom à un genre actuellement tombé dans l'oubli, comme il le mérite, formé de quelques 'Turbos.

\section{COCHLEA PETHOLATA.}

Démembremeat inurile du genre Turbo, proposé par Klein (Tent. Alethod. ostrac. pag. 40), et non adopté. Il coutient le Turbo petholatus et quelques autres coquilles du coême geure, présentant une coloration à peu près semblable.

\section{COCIFLEARIA.}

Petit démembremeut que Klein (Tent. Mcthod. ostrac. pag. 118) propnsa pour quelques pelits Cabochons à coquille épaisse. Il ue pouvoit être adopté. Voyez CaвосипN.

\section{COCHILICELLE. Cochlicella.}

Sous-genre proposé par M. de Ferussac, dans 3 on arrangemeut des llélices, pour quelques $\mathrm{Bu}-$ limes alongés, dont le demier tour est plus court que la spire. Cé sous-genre a'a pas été adoplé

\section{COCIfLICOPE. Cochlicopa.}

Daus son système de nomenclature et cle division dn grand gemre Helix (yoyez ce nol), M. de Ferussac a dlonné ce nom à un sous-genre formé de quelques Agathines, dnut Musifort avoit déjà forné un genre Polyphêase, qui n'a pas ćlé adopté. Vojez Agatuine.

\section{COCiHLIS COMPOSITA.}

Daus sa Méthode de Conchyliologie, Kilein donne ce nom à la seconte section de ses coquilles spirées. Il rassemble ici en plusicurs classes toutes celles qui, telles que les Cônes, certains Fuscaux, ctc., ont l'apparence d'étre composées de deux coquilles coniques, soudées base à base. Fondée sur un caractére de si peu d'importance, celte division est depuis longtemps abaodoanée.

\section{COCHLIS FORNICATA.}

La classc que Klein (Tent. ostrac. pag. I2) nornme aiosi contient, en plusieurs genres, tous défectueux, les coquilles dout le deraier tnur, fart élarri, a nu diaaètre plus graud que l'ase de la coquille. On conçoit qu'uu tel caractère a'a pu donner lieu quä des rapprochemens peu anturels.

\section{COCHLIS PLANA.}

Klein rassemble dans selte première classe (Tent. ostrac. pag. 2) toutes les coquilles discoides distribuces en plusieurs geares, sans trop? faire attention si elles sont simples ou cloisounées.

\section{COCHLIS ROSTRATA.}

Tel est le no'n que Klein (Tent. MIeth. ostrac. pag. 59 ) donne à la première classe de la secriun des Cochlides composita. Cette classe, divisée un plusieurs genres, renferme les coquilles canaliculćes à la base, telles que Fuseaux, Pyrules, Rochers, etc., souvent confondues et souvent divisées sars molits.

\section{COCHLIS SIMPLEX.}

Klcia avoit réuni sous cette dénoninutinn, en une première sectiou, un mélange bizarte do coquilles à onverture enlière ou échancrée, ou à canal cnurt : elles étoient introduites dans l'un des nombreux genres de celle section, pourvu qu'elles fusseu! ventrues et globuleuses.

\section{COCHLITOME. Cochlitoma.}

Sous-geoue proposé par M. de Ferussac pour une partic des Agalliues de M. Lamarck : ce sous-genre a'a pas été adoplé. Il étuit d'ailleur inutile; car, si l'on veut partager les Agathines en deux groupes, on doit conserver le nom "i'Agathine, et adopter celui de Polyphême de Monıfort, de préférence à une nomenclature nouvelle, qui s'adapte à des divisions seublables, ou à peu près, à celles autérieurement élablies. Toyez Agatrixe.

\section{COCHLODINE. Cochlodina.}

I.1. de Ferussac a proposé ce sous-genre ponr des coquilles de son gente Hélice, caractérisécs surtout par la présence d'un osselet operculaire (cluusitium) fixé sur la columelle. Draparnaud s'éloil déjá servi avec avantage de ce curactère pour lormer son genre Clausilie, auquel correspond à peu près le sons-gente non adopté de il. de Ferussac. Voyez Crausilie.

\section{COCHLODONTE. Cochlodonta.}

Ce sous-genre de M. de Ferussac, carrespondant complétement au geare Maillot de M. Lawarck, n'a pas ćlé adoplé. l’ojez Maltzot.

\section{COCHL,OGENE. Cochlogena.}

Ce sous-irente de M. de Ferussac contient ceux des Bulinies de DL, Lamarik qui ont le dernier tour plus loug crie le reste de la spire. Le passage insensible qui se remarque entre les espèces lets plus tumiculées et celles qui sont courtes ct ventrues s'oppose à l'adoption de celle division de $M$. de l'ernssac, qui, au reste, a amélioré le genre Buliase, en y introduisant clans une petite seclion ceux qui ont des plis à l'ouverture, el que M. Lamarck, sur ce caractere, avoit mis à tort parmi les Auricules. Foyez Hésics et BuLIME.

\section{COCIflö̈DE. Cochloides.}

\$I, de Ferussac nomme ainsi, dass sa nomenclature 
clature du genre Ilélice, la seconde division, qui conticnt coutes les conuilies subturriculécs ou turriculées et élancécs; celle division renterme les sept sous-gemes suivans : Cochlostyle, Cochlytome, Cochlicope, Cochlicclle, Cochlo-

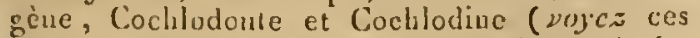
nots); ils cortespondent ponr lit plupart à des grures érablis par M. Lamarck, cl qu'il eñt écé beauconp plus siuple et plus juste a la bis d'idopter. Voyez Il'Éuce, où nous prósenterous, dans sun cnsemble, le sysiène de .IJ. de Ferussac.

\section{COCIILO-LÉPAS.}

Dénembrencnt inutilc ćlabli par Klein (Tent. Method. ostruc. patg. 119) pour une espèce de Citbochon à sounud incliné. Voyez Casocas.

\section{COCIILOSTILE. Cochlostitt.}

Ce sous-genre, dans la mébluode de M. de Ferussac, représente un déarenubrement des bulimes de M. Lamarck : il conticnt celles des coquilles de ce genre qui ont la colnuclle en filet rrès-aminci. Ce sons-g,ente n'a pas été adopté. Voyez liugiase et IlËLICE.

\section{CODOK.}

Le Codok d'Adanson (Ioy. au Sénég. pl. 16. $f_{i}$. 5) est une coqui'le que limné a placée dans sun genre Vénus, sous le nom de lenus tigerinu; H. Lamarek l'a comprise dans son genre Cyltérée, et nous la regurdons comaie une Lacine. Voyez ce mot.

\section{COEUR.}

Les auteurs qui, avant Linns, voulurent faire counoitre des coynilles, s'allachèrent pour la pluparr à les désigner par leur furme, la compirant à une forme déterminée el connac : c'est nirsi que toutes les coquilles cordilormes, quel yue suit d'ailleurs le geme auguel elles appattienuen, furent classécs daus un geure, sil'on pent nomner ainsi un pareil arsemblage, et reçurent des noms divers, qui devinrent vulgaires. Un nomic :

Cour de Vínus, le Cardium cardissa.

Caur de Dinne, le Cardiun retusum.

Caur en snufflet, le Cardiun hemicardict. La même coquille reçut aussi le nom de double Ceeur de I'énus.

Cueur de bœuf luilé, le Curdium isocardia.

Cour épineux, le Cand un echinalum.

Curur arué de cils, le Cardiun ciliare.

Cour de bauf á grosses siries on Cour humain, le Curdium tuberculatum.

Cour de canard, le Candium edule.

Caur de Harmara, le C'urliun rusticum.

Hist. Nal. des IVers. Tonse II.
Cerur de Jauus, lc Cardium pectinatum.

Curur alongć de Carbagnène, le Combium elongatum.

Cour d'autructic, le Curdium scrulum.

Conur de bélier ou coulcur d'crange, le Cardium favurn.

Creur de serf on Cocur jaune, le Cardium muricatum.

Cicur enflé, le Curdium latum.

Dins d'autres genres l'Isocarcie fut nomnsé Cour de berils ou C'our it volutes.

$P$ armi ics Arches, quelques espicces recurent aussi le nom de caur.

Cour de la Janainue, l'Arce senilis.

Conur des lucles, l'Aru fuscu.

Coeur en arche, l'Ara antiquata.

Cour en rarène, l'Arca Noe.

Enfin, parmi les Maclies, le Mactra stultorum fut désigué par le nom de Coeur de singe.

\section{COFAR.}

Nom qui Adanson (Voy. au Séróg. pl. 9. fig. 22) a donné à nae espèce de Murex que lanné ril]porte à son Miure.x pommm. (Yoyez Rocher.) M. de Blainvilie dit, dans le Dictionnaire des Sciences nuturelles, que le Cofar est le Buccinum rostratum de lister : nous lerons observer, pour éviter loule erreur, que Lister ne uonate pas un Rocher spécialernent de colle maniere, mais emploie celle expression ponr défigner une section de ses Buccins, ypi conlieat presque tous les Murex de Linné.

\section{COLIMACÉES.}

M. Lainarck créa celle famille et la proposa, pour la premiere lois, dans sa Philusophie zoologique. Dès ce moment on vit que le savant prolesscul avoit lintention de séparer les 'Trachélipodes des Gastéropodes" et celle division est indiquéc: elle est marquíe entre la fanille des Limaces et celle qui nous occupe. Sans donte que c'est à peu près lì où commence la série des Mollusques dont l'extrémité, lournée en spirale, est couverle d'une coguille; mais le passage yui a licu entre ces animaux el les Gasléropodes j"nprenienl dits, passage qui prélude par diverses loranes aussi bien dans les Mollusques uarinz que dans les terrestres, ne permel guère d'admeltre celte division (voyez Gastriropodes, Tracuelpodes el Holiusque), dont un des graves inconvéniens est de séparer dans deux ardres deux familles telles que celles-ci, qui se touclient par tous les points, de telle sorle que l'on ne sait si certains genres ne conviendroient pas plutôt à l'une gu'a l'autre, et réciproquement.

Ućs l'oijuiae, celle famille des Colimacées 
fut composée de six genres : Hélix, Hélicine, Buline, Amphibulize, Agathine et Maillot. Depuis, dans l'Extrait du Cours, elle fut augmeutée de plusieurs genres et partagúe en deux sections, diaprès le nocnbre des tentacules. -Le geare Hélicelle fut ajouté aux six précédens; jls formèrent la première section des Colimacées a quatre tentacules: la seconde section, celle des Colimacées à deux tentacules, fut composée des genres Cyclostomes, Verrigo et Auricule. il. Cuvier n’adopta pas celte famille, qui est représentée presque tout entière, moins la seconde section, par son genre Escargot et ses nombreux sous-genres.

M. Tamarck, dans son dernier ouvrage, reproduisit sa famille des Colimacées, cri conservan! ses deux divisions, qu'il eut le tort de ne pas former d'après l'opercule. Dans la première section, on trouve daus l'ordre suivant les neuf feures Hélice, Carocolle, Anostome, Hlélicine, iilaillo, Clausilie, Bulime, $\Lambda$ gathine et Amlrelle; dans la seronde section on trouve les deux genres Auricule et Cyclostome. Le genre Carocolle n'élant fondé que sur une légère modification de la forme de ccrtaines Hélices, n'a pasélé adopté: le genre Ilélicine, étanı operculé, devroit étre daus la seconde section; mais M. Lamarck ignoroil ce fuit.

II. de Ferussac, dans sun ouvrage général des Mollus.jues terrestres, n’a admis aucun des genres proposés a vaut lui daos !es Hélices de Iinné. II les rassembla daus son genre Ilćlice (voyez ce mot), et les distribua en plusieurs sous-yenres que personne n'a adoplís, paree qu'eo elfet ils corres!ındent, pour lu pluparl, aux geares établis et admis dans la scicnce avant le travail de M!. de Ferussac. Cet auleur eut snin, et cela arec toute raison, de séparer des Hélices les Hélicines, les Cyclostomes el les Auricules.

M. Latreille nomma Géocochlides (voyez ce mot) la famille des Culimacées, modifíe d'après les indications de M. de Ferussac.

M. de Mlainville ne trouvant aucune limite assuréc entre les farnilles des Limaces el des Colimacées, les rénuil en une seule, à laquelle if donna ie noın de Iimacinés. Celte manière d'envisager l'ensemble de ces animaux nous semblat la plus uaturelle et la plus en rapport avec les principes d'une bonne classification, nous adoptons celle tamille, à laquelle cous renroyous pour plus de détails.

\section{COLIMACONS.}

On nomme vulgairement de cette manière les coquilles du geare Hélice. Vojez ce wot.

\section{COLOMBELLE. Colombella.}

Linué confoodoit les coquilles de ce genre purmi les Volutes, gyoique certainemeot elles מ'er aient pas tous les caractères. Autant quion en peut juger par les planches de ce Dictionnaire, I3ruguiere les traosporta des Volutes dans Ics Mlities, sans que pour cela la classilicalion ait beaucoup gagné; car il fulloit diviser à leur tour les démembremens que Brnguière avoit faits aux dépens des Volutes de Linné. Ce fut MI. Lamarck qui fit ce démembrement, et le geare Colombelle fut l'un de ceux qu'il proposa des premiers dans la classificalion qu'il donua dans les Mémoires do la Société d'Histoire naturelle de Paris, 1797. II plaça ce genre entre les Mitres et les Marginelles, non loin des Volutes, et le caractérisa de manière à faire penser que les coquilles qu'il renlerıne sunt munies de plis à la columelle. II lui conserva les mèmes rapports dans locs ses autres ouvrages, mêrne lorsquäil l'introduisit dans la fantille des Columellaires. Voyez ce mol.

Quoique M. Curier n'adoplat ce grenre qu'i tille de sous-gente des Volutes, il le licissa entre les Margiuelles et les Mlires, à peu près clans les mémes rapports que M. Lamarck, peosaut avec lui que la columelle est munie de plis.

Mi. de Fernssac, dans ses Tableaux systématiques des Mollusques, est le premier qui ait uieux juné le gemre Colombelle, el qui l'ail placó d'une ruanière plus cunforme à ses vérilables caractères; on le voit en ellet dans la fanille des Pourpres, dans laquelle s:e naturaliste le plare eutre les Rocbers et les Pourpres. M. Lalreille n'inita pas M. de Ferussac, et laissa ce genre à la place marquée par M. Lamarck, et daus la lamilla des Columellajes, adoptée de lui.

En plaçant le geare Colombelle dans la famille des Siphonostomes (voyez ce mol), M. de Blairl. ville se rapprocba assez de l'opiaion de M. de Ferussac:, sans cependant s'accorder entièrement avec lui : ce genre se voil an commencement de la seconde section des Siphonosiomes, don la premiere est termince par les 'Turbiaclies; il tst suvi des geares 'riton, Ruuelle, etc., et en général de foutes les coquilles dont la lévre drnice est ćpraissie en bourrelet. Ce changement volable dass les rappurts du genre qui nous occupe n'es: pas Lasé, comnie nous aurions pn le croire, sır l'alssence des plis columellaires, car on les trouve indiqués dans la caractéristique donnée par .1I. do Blainville. M. Pung a suivi, saos y rien clianger, l'opioion de M. Je Blainville, et, comme lui, dit que la columelle es! un peu plissée. M. Sowerby, daus son Genera, n'indique plus de plis à la columelle des Colombelles, et l'on voit, par les nourbreux exemples qu'il dunue de ce genre, qu'il en rejette toutes les espéces a plis.

Lorsque l'on examine le genre tel que M. Lamarck l'a laissé, on y trouve des coquilles de deux sortes: les unes, ielles que la Colombelle bizunale, ont de véritahles plis columellaires. l'onr nous, malgré le renflement du bord droit, cessut des Mitres. D'antres, qui n'ont jaraais de plis à la columclle, mais qui on! quelquelois, et dans quel- 


\section{O L}

ques espècesseulement, quelques petils tubercules sur la base de celle partic, lubercules yüil ne faut pas confondre avec les plis coluuellaites qui tournent en spirale avee elle jnsqu'au zominet de la coguille, ce qui n'a jamais lieu pour les tuber. cules on les dentelures dent il est jei question. Ia réunion dans un wéine genre de coquilles appartenant à deux geores diflerens, expligure d'où provient la divergence d'opinion que nous avons fuit remarquer entre les auteurs : Jes uns, ayant observé des coquilles à columcle plissée, out laissé le grenre dans les Colunullures; les antres, ajaul vu celles sans plis, ou ayunt pris les !ubercules pour les plis indiefur's par M. Lamalek, out trausporte le geure près des'livions.

Tollt en riformant le geare, nous pensnos yu’il est plus voisin des Buccios que des'l'rilnos, de telle sorte que quelques especes sont indécises entie les deax genres : ce pissage prouve yüjls sunt bien voisins. Voici de quelle maniére nous caractérisons actaellement les Colombeller.

\section{CARACTÉRES CÉNËRIQUE3.}

Animal incomplétenient cunnu, portant sur la tére denx teuracules oculés à la l,ast.

Cuquille ovale-oblongue, épidernée, à spire le plus souvent coute ct priutue. Ouverture longue, froite, cclancrée ¿ la base, à burd droit, Ejassi el denticulé, et à borrl gauclic suns plis, snueus, quelquelonis ayant quelyues derstelures ou quelques jetils inbercules a la base.

Opercule Ires-petil, cornc et fort mince.

Les Colombelles sont des coquilles marines épaisses, solides, couvertes d'un éj,ilerme plus ou moins epais, brun ou verdaire, assez fucile à dítaclier. Elles nut un aspect qui leur est particulier : elles le doivent en général au raccourcissement de la spire, qui est cependant pointue. Quelques esjucees ont cette partie alongle c: subturriculéc; unais elies se recounoisseat a la forme de l'ouverture, qui est roujuurs lort étrcite, et rendue sinucuse par l'épaississement cousideralile dı bord droit, épuississement pui correspond à la sinuosité du bord gauclie : de scirte gue, tout en se contournaat, l'ulivertare reste en fente d'une latgeur presque egale dans toute sa hauteus.

Le nnmbre des Culombelles esi encore pea con. sideralle. M. Iamarck en comptedix luitespèces, doot il faut retranclier denx on trois, qui sout des Mitres. Maintenant, daas les collections, on peut en compter plus de trente espèces, sans y rounprendre irois especes fossiles que M. Lamarck ne conout jansais. Un pourroit diviser ces espèces en deux groupes, daprés l'alongement de la spire, ou pent-çtr: mieux encore d'apres le plus uu moins grand épaississement de la lèvre droite. Il est certain qué arrangeaut les espéces dans un ordre décroissant relativement à l’épaississencat du bord droil, ou passcruit aux Buccins presque sans s'en apclecevoir.

les Colomlelles appatiennent, pour le plus frand nombre, aux mers chaudes; cependant doux espèces les plus ancicuncucul connues vivent daus la Jédicerranḱr:; mais clles n'unt pas, à ce cu’il parrit. leurs analogues fossiles.

Bruguière, ayant décrit quelques-unes des especes de ce grure parmi ses liuceins, nous renvoyons à ses Buccinum Ravum et Buccrnum punc-

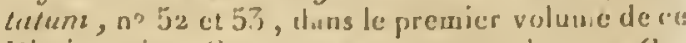
Jictionnatre. Cors especes correspoudent au $C^{\circ} O$ lombellu fluidu et scrmb-punctuta.

1. Cozombrziestrombiforme. Colombella strum . bifommis. I,A 31 .

C. lesti ovato-turhinatd, subuluta, Laviusculd, castaneu, strigls allis longitudnalibus breonusculis ornutû ; anfractıbus supermic angulutis; spiri exsertiusculi, labro mojusculo, crusso, intios denticulato.

LАмк. Anim. s. vert. tom. 7. pag. 97. $n^{\circ}$. I.

I3r.sisv. Malac. pag. 39g. pl. 29. Jiğ 3. 3 a.

An eadem, Coslombella strombjormis? Sow. the Goneru of shells, $n^{\circ} \mathrm{g}$. fig. 1.

Possédant rette corjuille, et l'ayant comparéc ¿ l'individu de la collection du Muséurn, qui a servi pour la ligure dunnce par M. de Blajuville dans son Trunté de Mulacologrie, nous inarilleztons quelques doules á l'regard de ceede que l'on tronve dens l'ouvrage de M. Sowerlyy, purce quelle ne présente ni la mécue coluration, ni lout-a-last la méme lorme.

La Culombelie strombiforme est ovalaire, à spire courte et a tours arrondiset serrés. l.e dernier est élargi sapéricurenent, cet dunnce ả la spiice une large laise ; il silténue inseasiblement à l'extrimité antírieute, cù il est pnurvu de sept a luait stries regulicres et oljliques; l'échancrure de la base est peu profonde. liouverlurcest ilongce, étroice, sinucuse, blanclue en dedans, el rétréu supericurement, ois tlle se relćve un preu à la maniere de celle des Strombes. Sur ur fund brin, cellc copuille presente des linnes longuludinales blanches, onduleuses, à contours arronlis, et quelqurefoispres qua droiles. Cellecopquille, e ic:ere rauc darsles collections, vit sur les cuiles du pir su. lil'e a un pouse de longueur d'apres .1. laurarek: l'individu que nous possédons, eacore jeune, que dix iignes.

2. Cozonberze Gtoilée. Colombella rusticu. LA IIX.

C. lesti ovalo-turbinalä, lavvi suadicenrue reliculula, prope suluras miculis allis angouluribus stellutis ornuti; labr, entus dinteculutn; columella basi dinteculati el intus callo bistnuulo instructâ. 


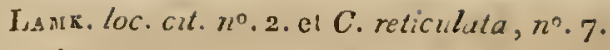

Voluta rustica, Linn. Guer.t. p. $5347 \cdot n^{\circ} .36$.

Lister, Conch. tab. 825. fig. 44. el tab. 826. fig. 46 .

Petiv. Gaz. tab. 3o. fig. 6.

Gualt. Test. tab. 43. fig. e.g. h.

Adans. Sériég. pl. g. frg. 28 , le Siger.

KNonn. Tergn. tom. 2. tab. 44. fig. 4 .

Martint, Conch. tom. 6. 1ab. 44. fig. 470 .

Excrclop. pl.375. fig. 2. a. b.

Les figures de cctle espèce très-commune sont généralement mauvaises, et M. Sowerby, dans son Genera, donue pour elle une cocquille d'une autre espèce, qui n'a mêtue avec celle-ci aucune analogie. La Colombelle étoilće est nne coquille trèsvariable, surtout dans la contur. Lorsqu'elle a alteint lout son développement, (lle est grande, ovalaire, asser érroite, à spire conique trés-pointue, composće de huit à neuf tour's aplatis, dont les premiers sont striés transversalement. I,e dernier, ventru supélicurement, s'atténue vers la base, où il est marqqué de quelques stries très.fines et larigemeot espacées. Louverture est aussi longue que le dernier tour: elle est étroite, sinucuse, prescyue en arc de rercle; lu lèyre droite, fortement épaissie dans le milieu, est ordioairenent eu deliors d'un brun-fanve, el porte en cledaus, dans loule sa longueur, des dentelures blanches qui", daus quelques individus, sont séparcées par un poiut brun. La columelle, sinueuse dans le milien, ollie à la base quelquues granulations dentiformes, et au-dessous, plus profondémeut, une callosité aplatie et longitudiuale divisće par une, deux, et rarement trois petiles éclancrures. Suus un épiderme brun et lanelleux, on trouve un réseau formé d'un grand noubre de linéoles brunes, diversement entre-croisces, sur uu fund blane ou jaudâtre. On aperçoil, vers la sulure, une fascie étroite, plus claire, foruxée de taches blanches, espacées et étilées, et souveut, sul le clernier lour, une autre fuscie obscure, formée par des taches hlanches plus nombreuscs. Les taches brunes se confondent quelyucfois de tcile caluiciore que la coquille ollre à peine quelques taches blanches; d'autres fois elles sont beaucoup plus rares, et le fond blanc domioe. Nous possédons nne varićlé qui est loule jaune. Les grands iudividos, qui viennent de Sicile, ont jusqu'à 30 millimètres de longueur.

\section{Colonbelle commune. Colomhella merca-} toria. Lamx.

C. testâ ovato turbinatâ, transiersim sulcatâ, "lbi, lincolss rufo-fuscis transversis sul fasciculitis picti, interdiun fasciata, iubro mitis denticulato.
L.A ज . loc. cit. $n^{\circ}, 3$.

Volutu mercatoria, Lisn. GaEx. pag. 3446. $n^{\circ} .55$.

Lister, Conch. tab. 824. fig. 43.

Bonvani, Recr. 3. fig. 36.

Petiv. Gaz.tab. 9.Jig. 4 .

Gualt. Test. $l a b .43$. fig. $l$.

A dass. Sénég. pl. 9.fig. 29 , le Staron.

Kaon . Vergn.tom. 4. tab. 12. fig. 5.

Mantini, Conch tom. 2.tab.44.fig 452-453.

Excres. pl. 375. fig. 4. a. $b$.

Cogruille qui, en ellet, comme lindique son nom, est une des phis répanducs dans les collections. Elle est aussi l'une des plus faciles à reconnuître, élan la seule du genre sillonne régulièrement de la base au sommet : ces sillons sunt arrondis, scrrés et égaux. La spire, formcée de sept à huil tours anguleux, est élagée, conique, et à peu près du ticrs de la longuenr de toute la cogrille. Le dervier tour, trés-ventru el larve à soll summel, se terunive à la base par une fechancrure assez prolonde. L'ouveriute est longrine et ćtroite, lontement siuneuse dans le tnilien, et termince supérieuremeat par une saillie sinueuse subauriculaire de son extréurité à l'endivit de son insertion à l'avant-dernier tour. La lève droite devient très-épaisse dans le milieu : elle estblanche, souveat bordće d'une ligué fiume en delıors, et dentelée en dedaus dans toute sa longueur. Li columelle, sinueuse dans le milieu, offie à sa base une rangúe de perits lubercules, ordinaireuret au noubre de sept. Au-desious, et beaucoup plus en dedans, se voit un bourrelet columellaire, trunqué inlérieurenueut, et creasé d’un scul petit siaus. Ja conleur de celte coquille est trcis-vasriable : on pourvit par ce mojen compter sept ou huit variétés. Quelques individus seut tom blancs, et leur fraicheur indique que ce n'est pas is un accident qu'ils doivent celle con!enr" ; d'autres s ut unilurmérmeal faures : naais les individus cque l'on rencontre le plus ordinairement sont marqués de taclies inégulières ou de ponctuatious, oranurics on grisitres, loncées ou brunes, sur un loud blink: Cette coquille, trìs-commune dans l'Otéan allan. lique, dans les mer's des Autilles et au Sínézial, se trouve aussi, dit-on, clans la Méditeranéc. Fille est lungue de 9 à 10 lignes ( 20 à 22 millin.).

4. Colonarle panthérine. Colonbellis pardalinc. Lami.

C. testî̀ opali, 'ávi, basi striatâ, alb $\dot{i}, \mathrm{ma-}$ culis rufo-suscis pictá, columella obscuré plicul..; labro dextm albo, subincrassato, denticulas.o.

Làk. loc. cit. $n^{\circ} \cdot 9$.

Celle coquille asser rare, à ce qu'il parait, eat uvaliaire, a tićnucie a ses extréuilés; sa spire, assez 
longne, coniquc el pointue, esi composéc de six ì sepi lours aplatis; le dernier, plus grand que lous les autres, est ventru supéricuremeut et strié à la hase; la coquille est din reste toute lisve; l'vurverture cot asscz courte of un peu plus large proporliunaelleurent que dans les espèces précéclenles, ce qui lient is ce que le boid druit, qnoique renllé, l'est cependaut moins; les dentelures, pen nombrenses, sunt aussi peu saillantes. la columelle est lisse, pen sinueuse et toute blanche conme le reste de l'inléricur de l'ouverture; eu deliors, sur un fond blanc tris-pur, se dessine un réseau de taclies brunes qui, vers la base du dernier tour surtuat, formeut des mailles arrondies et quelqnefois risgulières. Nuus ignorons qu'elle es! la pälrie de ce!cc espèce, qui est longue de 15 nillicu.

\section{Colosbele luisante. Colombella nitida. I.AMr.

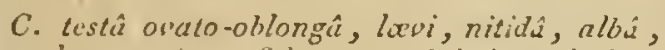 maculs punctisque fulvis aut rubris irregularibus fictî; plicis columella obsoletis. \\ L.AMK. loc. cit. $n^{\circ}, 12$. \\ Lister, Conch. lab. 827. fig. 49. b. \\ Colombella nitidula, Sowевв , Genera, loc. cil. fis. 7}

Jolie coquille forl commune, ovale-oblongue, peu ventrue, pointue au sounet, altinuée à la bise, sans aucune strie, lisse, polie, bril ante, coune le seroit une cocpuille inićrieure. La spile, furmce de six it sept tours un pen canvexes, esi ronique, et oscupe le siers de la longueur de la roquil!e; le derrice lour, un peu reullé dans le milien, se termine par une onverume alongre, étroite, s'elargissat peu à peu vers la lose. Lat columelle est abliçue, à preiue sinueuse, el ne présente qu'uu très-petit renllement inférieus. Le tord droit, légèrement ćpaissi, et garni de petires douts nbsolètes, semble se rẹlier en-dledaus. En delors, toute la surface est couverte de taches irrézuhires, ca réseat ou en portutuations lirunes on rougeatlres sur on lund blanc: une tache bruac, plus princle que les autres, occupe le dos de la coquille dans le plus grand nombre des individus. Cetle caquille vit dians ia mer des Autilles, où e!!e est lure commuae; clle est lungue de 17 milliucitres.

6. Comomerefécrite. Colombella scripla. Lamx.

C. testî overli, lavvi, busi slrinti, albi, litluris fuscis minimis fuscrutin cinctin; columellis lidkentulâ, extìs denticulalî.

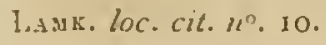

Julie perice enguille equi, par sa forme, a de l'suslogic avec la C'olombelli mercalorio, mais yui s'eu distingue furileurent en ce que, d'abord, elle n'est pas sillonace dans loute son étendue, ua ais l'est sculcunent à la base du dernicr tour, en ce qu'elle est constarnment plus petite, et enlin par la disposilion de ses couleurs. Celte coguille a la spire combe, fururce de cing il six tours subanguleux el élagís; le deraier, beaucoup jlus grand que lons les atutics: cst renlle supéricurement; il s'atténue vers la base, où il est strié transversalemeul et terminé par une petite ćchancrurc. l'ouverlure est étroite, et elle forme une sinuasití profoude it son ungle supérieur. La columelle c'st simeuse dans le nilieu; sa la ase est clargéce, à sa partie superlicielle, d'un rang de fines gramulalious, an-dessous desquelles se voil un bourelet columellaire bipartite. Le burd droit est Jlanc, épais, arroudi, el linement denlelé dans lonte sa longtieur. Sur un fond hlane sont parsents un grand nombre de points bruns ou orangés, qui, Ic plus ordinarement, se réunissent eu liuéules longitudiuales sur deux ou trois ligues transverses, ce qui danue un peu ì celle disposilion l'apparence de lignes écrites imégulièrement. Nous posséduns une varićlé où les points sont plus gros tet régulièrement parsemés, et une autre où ces poinls forment des lignes reublées en zig-zan. Celle petile corpuille, longue de 14 millin., vit clans l'Uecian indien.

\section{Cononbelie ovuléc. Colombella or'alatu.} LasiK.

C. testấ nouli, mitidâ, trunsversim et minutissime striutá, mfo-cistunedi ant nigricante; maculis colles irregulunbus sparsis omatâ; sprma brevi, oblusiusculat ; apuce albido.

LAäK. loc. cil. $n^{\circ}$. II.

Coquilie regulièrement ovilaire, allćnuée aus deux extrémités, à spire courte, quelquefois poinlue, et le plus souveut olsuse: on y comple six ou sept lours arrondis el caurls, dont les precniers sout loujums blancs; le dernier, qui forme les trois-quar's de la corquille, est renflé dans le milien el auéunć ver's lit base, où il oflie une échancme truspepte. Toute la sulfice extérieure de la coquille ess luisame, el uéamwoins converte d'un grand nombre de stries tris-lines, sertées, reguliêres et neu profondes. I'ourerture est très-étroile, longue, peu simucuse, a columelle simple ou à peine denticulie it sa hase; lo burd droit est Jui-nême pen épaissi el legèrenıent dentelé. Eu delors, sur un lond brun-châtain, et quelquelors noirâtre, un voil de grandes laches rrrégulières, blanches, suvventríliculées par des linéules trés-lines. Celle coquille vieut de la met. des Iudes; elle a 17 uilitim. de longueur.

8. Colorache fudroyante. Colombelle fuigumuns. Lasin.

C. lestâ nuatia , durso lovvi, basi striuiâ, svotdiceo-nigricante; strigis albus longitudinudibus 
aiguluta-flexuosis fulmen cemuluntibus; spirá brevi, obtusâ; apeiturâ ringente, subviolaceâ.

Peтіт. Gaz. tab. 49. fig. 9. 10.

Lxcrcuop. pl. $374 \cdot$ fig. $7 \cdot a \cdot b$.

L.sux. loc. cit. $n^{\circ}, 13$.

Coquille courte, ovale, vearrue, le plas souveut cibtuse au sommet, à spire courte, à laquelle on comple sept à huit tours rapprocbés, peu convexes; le dernier, très-renllé supérieurement, se tcrmiue en cône court : sa base est siriée en travers, mais tout le seste de la coquille est parlaiteanent lisse. L'ouverture est singulière et comme grimaçaute; elle est très-rétrécie, surtout dans le milieu, el un peu élargie à sa base. La columelle est forlement sinueuse à sal partie supérieure, el devieat ensuile presque droile à la base : daus cette partie, dénuée de granulations superficielles, elle est garuie profondémeut d'un bourrelet court, quelquefois simple, quelquetuis parlagé par un sillon. Le burd droil est violet comme le reste de l'ouverture; il est épaissi dans le molieu, mais son bourrelet, taillé en biseau tranchaul, a son bord strié en travers et tronqué à ses deax extrémités, caractère qui, fauce d'autres, pourroit seul faire reconooiltre cet!e espèce. La coloration n'est pas moins remarquable : sur un lund d'un brun très - foucé se dessinent des lignes onduleuses blanches, plus ou nioins nombreuses, qui descendent du sommel à lit base des lours. Nors possédons une variété qui est lanve. Celle cocjuille vieut, comone la précédenie, des nuers de l'inde, oì elle paroit assez rare; elle est longue de 15 ì 18 arllim.

9. Conomerze rubanée. Colombella mendicuria. Lam $\mathrm{x}$.

C. lestâ ovatâ, ventricosí, nodulosî, transwersin striati, taniss alternè nigris et albis aut luteulis cinctâ, aperturâ suhcinnumomeá; lubro crasso, dentato, supernè truncato.

Voluta mendicaria, Lis. Garl. fag. 3448. $n^{\circ} .38$.

Listea, Conch. tab. 826 . fig. 47.

Petiv. Gaz. tab. 11. fig. 5.

Gualt. Test. tab. 52. fig.e.

Knonr. Yeign. tom. 4. tab. 16. fig. 3. Bona.

Martini, Conch.t. 2. tab. 44. fg. 460.461 .

ENCYcx. pl. 375. fig. 10. a. b.

1. $\Delta \mathrm{x}$. loc. cit. $n^{\circ}, 14$.

Sowенв , Genera, loc. cit.fig. 4.

Julie coquille courte, ventrue, épaisse, à spirt courte, poivtue, conposée de six à sept tours: les preniers manquant presque coujours, la spire paroît obtuse au sommet; le dernier tour est très-ćlargi au soramet, et se termine en cỏne court vers la base, qui est érroilo el terminée par uae écbancrure oblique peu profoode. L'ouverture est violelte et fort rérrécie dans son ruilieu et inférieurement, mais élargia à sa partie supérieure. La columelle, fortement échaucrée supérieurement, est garnie à la baso d'un rang de grauulations superficielles, dont lis supérieure est beancoup plas lougue que roule. les autres. Au-dessous, el mufondément, se voik le bourrelet columellaire, qui, dans cette espèce, est très-saillant, mais non divisé. Le bord droit est remarquable en cela, que son épaississement cst court, plus supérieur que dans les autres espèces, el tronqué à ses extrémités; son bord libro est friblement deutelé. Lorsque celle coquille n'ä pas été roulée, et qu'on l'exauine à la loupe, on la trouve couverte de stries très-tiues, très-nourbreuses, dont quelques-upes, à la base, sont plus grosses et plus espacíes. La couleur de la coquille cousis!e en rulans alieraalivenent noirs ou brun foncé et blancs ou jaunes, le plus ordinairement au nombre de trois sur le dernier tour. Lia Colombelle rubanéc vil dans l'Océan indien; elle eat longue de 15 à 18 milliur.

10. Colomerune courterelle. Colombella turturina. Lam K.

C. testầ ovato-turbinatâ, supernd lavigatá, inferne transversimstriata, alba, lineolis punctisque fuli's prictâ; spirâ brevi; apertura rirgente, subroseá.

lincycros. pl. 374. fig. 2. a. b.

LAMX. loc. cit. $n^{\circ} \cdot 15$.

La Colombelle tourterelle est l'une des plus singulicires espéces du genre : elle est la plus courte, la plus ventrue; elle est globuleuse; $s 2$ spire, conique, pointue, courte, a base large, est furmíe de six à sept tours aplatis; le dernier, très-grand, très-venuu, est armudi dans tous ses coulours; il est strié à sa base, ainsi que le bord droit, en dlehors, dias tuute sa longueur: le resle de la cocfuille est lisse. L'ougerture est étroite, fortemeni contonmée, d'un rose tendre icinté de violet. La columelle ollire a la base, à la place de la saillia da burd gaucbe, une rangío de fines denielures blanchies, en dessous desqueilers se voit le bourrelet columellaire, qui, dans relle espèce, est constamaent trilobé. Le bord droit, Ir's-épais, semble se renverser en dedaus; il cstdentelé dans laute sa longueur. La coleration de cette cspèce est asser. variable; clle est quelquefois presque touie blanche, quelquefois marquée de larges taches irrégulières brunes ou jannes, mais, le plus souvent, elle est ornéc de linéoles orangées, onduleuses, un peu rextiles. Celle Colombelle, eocore assez rare dans les cullections, se trouve dans les mers de l'lude. Les plus grauds individus a'ont pas plus de 15 willim. de longueur. 
11. Cozombelle ponctúe. Colombella punctutu. LANK.

C. testi ovato-turbinatâ, infernè transs'crsinu striat $\hat{u}$, in fundo spadiceo-nigricante punctis albis laxé dispersis pictâ ; spirû brevi, oblısâ ; labro crisso, dentuto.

1.ג $\mathrm{MK}$. loc. cit. n०. 16.

Petrv. Gaz. tab. 18. fig. I.

Martini, Concle. tom. 2. tab. 4f. $f_{g} \cdot 471$.

k.xcrce. $p l .374$ fig. 4. a. b.

La coquille à laquelle M. Sawerly donne le nom de Colombella punctatu ćtaol dune tout autre espèce que celle de M. Lamarck, nous ne la citons pas daas notre synonymie. Pour s'assurer de la vériléde ce que nous disons, il sullira de compare. les ligrures que aous indiquoas avec celle de MI. de Sowerby.

La Colombelle ponctuée est une coquille ovalaire, renlléc dans son milieu, acuminée aux deux extrémités. On comple six ou sept tours à sa spire; elle est conique, pointue et coutte; le dernier tour est élaryi supérieurement, il est strié a la base : ces stries son! les senles qui se voient sur toute la cogrille. L'ouverture est très-étroile, siqueuse, d'un rose-violâtre. La columelle présente à la base, à la place du bord gauche, un rang de dentelures très-tines, et si serrées, qu'elles se confondent par lenr base. En dessous, et beaucoup plus en dedans, se voit le bourrelet columeliaire, qui est creusé, à sa parlie supéricure, d'ua s’ul sillou. I.e bord droit est aplati en dessus, garni d’un bourrelet deatelé en dedans et sublronquí à ses deux extrémités. La coquille, en dessus, est biune ou fisuve loncé, et couverte de laclics sparses, ordinairement arrondies, ifuelquefois anyuleuses : celles qui sont à la parlie supérieure des tours sont longucs et obliques; elles sont toutes blanclies. Cette jolie coquille vieut de l'Inde; elle es longue de 17 milion.

\section{COLONXE. Columna.}

Une coquille tcrestre, rare et précieuse, connue dans le commerce sous le nom de Colonne torse, et qui appartient at genre Agatbiue (voy. ce mot), est devenue poul M. Schumacher le type d'un nouveau genre, qui ne sauroit ètre ailmis dans la méthode.

\section{COLUMELI.AIRES.}

On trouve l'origine de celte famille, dont M. Lamarck est auleur, dans sa Philosophie zoologique; elle est composée des cinq genres Cincellaire, Marginclle, Colombelle, Mitre et Vulute. Elle fut augmentée du genre Vulvaire, duns l'Extrait du Cours, et ensuite diminuée du genre Cancellaire, daus le dernier ouvrage du sitvant professeur. M. Latreille, dans ses
Familles naturelles, l'adopta sans cbangemens. Si nous admettions ce groupe, nous en rejetteriors deux grentes : le genre Colombelle, qui n'a point de plis columellaires, et qui a beaucoup plus de rapports avec les Buctins et les Ricinules qu'aves: les Volutes, et le genre Vulvaire, qui se fond tellement avec les Marginclles, quil a'est pas pussible de les distinguer. Voyez Mozcosque et les diver's geares que nuus venons de ciler.

\section{CONCHACÉS.}

M. de Blainville, dans son Traité de Mulus cologie, a donmé ce nom à une lanille tres. nonibreuse de Mollusques acéphales, qui correspond en parlie aux Conques de M. Litmarck, on qui présente plutôt un mélangre te plusiears lamilles de cet auten. Colle famille des Concliacés est partagée en trois sections: dans la prenière, se trouvent tous les genres dout la coquille a dus dents latérales; dans la seconde, loutes celles qui sunt dépourvnes de dents latérales; ct dans la troisième, les coquilles diles irrégulières. On voit dans la premiere les genres Bucardes, Donace, 'Tulline, Lucine, Cyclade, Cyprine, Mactre et Erycine; dans la seconde, les geares Crassatelle et Vénas; et daus la troisière, les genres Vénérupe, Coralliophage, Clotho, Corbule, Splic̀ne et Onguline. Il nous semble que, dans celte fanille, les rappnrts que lon regarde habituellement comme naturels n'ont pas été couservés: des coquilles avec un ligament cxtérieur sont dans la méme sectiou que celles qui l'ont à l'intérieur; on y Honve des animaux dont les siphons sont trèscourts, aree d'autres qui ont les siphons trèsalongés. Le genre Crassatelle qui, par l'impression simple du manteau, semble s'éloiguer des Vénus, en est ici rapproché; enfin le genre Onguline, qui est trís-voisin des Lucines, se trouve rejeté à côté des Corbules et de leur inutile démembrement, le Sphène; genres qui eax-njênes sout placés, quoique inéquivalres, loin des Anatines, Thracies, ele., et tout a côté des Vénérupes. Nous pensons quil est impossible d'admettre Ia funille des Conchacis, et les détails que nous donnons, sur claanu des genres que nous venons de citer, feront partager, nuus l'espéruns, notre conviclioo.

\section{CONCHIEERES.}

M. Lamarck, trouvant une grande dillëreuce dorganisation entre les Mollusques univalves ou céphalés et les Mollusques bivalves ou acépbalés, crut quili étoit pécessaire de les séparer en classes distiactes et au même degré, dans le Règne animal, que les Radiaires, les Vers, etc. Mais cetie distiaction anssi tranchée n'a pas étéadoptée, parce qu'en ellet les Acéphales appartieuneni par leur organifation au type des Mlollusques. Les 


\section{0}

$$
\text { C i) it }
$$

Mollusques, cansidérés dans leur ensemble, formeat deux grandes coupes dans le méme type; mais chacune d'elles ea peut être séparée. Déjà Bruguière, dans le premier rolume de ce Dictionnaire, a donné de précieux renseignemens sur les Mollusques, et par conséqnent sur les Conchifires, dans son article Copuris. On en houvera de nouveaux à l'article MIILesqua, auquel nous renvoyons.

\section{CONCIIOLÉPAS. Concholepa.}

La seule coquille que l'un coanoit dans ce geare étoit placée autrefois dans les Patelles ou dans le voisinage de ce genre, parce qu'en effet sa furme est tellement patelloiche el voisine de celle de certaius Cabochons, gunil falloit toute la sagacié́ et tou! le savoir de Bruguiere pour apprécier plus justement les rapports de cette cofuille. Ce fui lui en ellet, le premier, qui la plaça daus le genre Buccia, dans lequel il comprenoit les Pourpres : cet!e idée lumineuse ne fut pas perdue par M. Lamarck, gui vit ha nécessité de faire du Concholépas un genre à part, que ses rapports uaturels plaçoient à cólé des Pourpres, démenbrées des Buccins. Depuis relte époque, qui dale des premiers travanx de II. Lamarck, le grenre Concholćpas a été adopté, el a été invariab]lement fixé dans ses rapports, qquoiqu'ils ne fussent élablis que sur des a aalogies lic̀s-foodées. La conaoissance de l'aniual inanquoit, et maintenant qu'il est connu, on l'a trouvé semblable á celui des Pourpres, et muni d'un opercule d'aue structure analogue à celle de l'opercule des Ponrpres, tout en conservant une forme qui lni est propre; d'où il suit qu'aujourd'hui un seroit plutôt purté à rejeter le geare Concliolépas pour en iuire nne seclion des Pourpres, que de l'admettre pour le placer loin de ce genre. Nous croyons nécessaire rependant, avant d'opéier ce chanyement, que l'on connoisse un passage entre les deux geures; et, si
$\mathrm{C} O \mathrm{~N}$

l'on a déjà quelques P'uur pres qui avoisineut le Concholépas, il reste encore entr'enx trop de distauce. M. Rango, qui a va l'animal du Concholépas, le donae pour semblable à celui des Pourpgres.

\section{CARACTÈ RES GÉX́LIQUES.}

Animal semblable à celui de la Pourpre. Coquille épaisse, ovale, bombée, sillonnée en dehors, à somurel court et peu spi:al, forlemeut incliné vers le bord gauche; ouverture ample, longitudinale, subentière, oblique, ayaat inférieurement nne légère échancrure; deux deuts a la base du bord droit.

Opercule corné, trausoarent, |rapézoidal, à sozamet marginal et à ćlémens concentriques.

On ne connoit qu'une senle espèce de Concholépas, qui vil très-abondamment sur les côtes du Péron; il y est tellement nombreux, que les habitans le ramassent en assez grande yuantité pour eu faire de la chaux. Celte coquille est cependant restée très-rare dans les collections, et s'est maintenue d'un prix élevé dans le comnerce : depuis quelques anntes elle est devenuc beaucoup t lus commune. Bruguière ayant décrit celte coquille sous le nou de Buccinum concholepas, dans le premier volume de ce Dictionnaire, nous renvoyous le lecteur au $0^{\circ}$. $10 \mathrm{de}$ l'article Buccix.

\section{CONCHOLHORA.}

M. Gray, dans sa nouvelle classificalion nalurelle des Mollusques, donne ce nom à sa troisic̀ne classe des Mullusques. Elle correspoud aux dcéplialés testacés de M. Cuvier, et dillere des Cuncbifères de X. Lamarck, en ce que II. Gray en a sćparé, pour en faire une classe à part, les Rndis!es de cet anteur. Nous ne pensons pas que celle inaniere de roir pnisse èltc adoplée, comme bous le vericus a larticle Molnusqu, auquel nous renvoyons. 


\section{HISTOIRE NATURELLE}

\section{DES VERS.}

\section{C}

Conélix. Conalix.

Genre proposé par M. Sowerby dansson Genera, et avant lui par M. Srhumaker, dans le Syfteme de Conchylinlogie sous le nom d'imbricana, pour quelque coquilles qu'on ne sauroit séparer des Mitres, dont elles ne diffèrent que par la forme. Yoyez Miтhe.

\section{COXES (les).}

M. de Ferussic a proposé pour le genre Cône lui seul, une lamille à laquelle il donue ce nom; il la place après celle des Strombes daus son sousordre des Jiérnipomastomes. (Voyez ce mot.) Nous ue pensons pas que cette famille soit admissible, yuelle que soit la place que l'on donne au genre qu'elle renferme. Voyez Monuseues.

\section{CONIE. Conica.}

Léach fut un des prenier's qui se servil du nomure des pièces dont sont composés les Cerrhipèdes sessiles pour l'établissement des genres. Il en proposa plusieurs; celui qu'il nomme Conie mérite d'être conservé : il est démembré des Balanes de Linné, et rassemble celles qui sont formées de quatre pièces seulement au lien de six que l'on voit dans les autres.

Ce genre o'a point été adopté par M. Lamarck, qui a continué de le confondre avec les Balanes. II. de Blainville a senti qu'il étoit nécessaire de l'introdurive défioitivement dans la science, et après s'être assuré par un individu conservé dans la liqueur, que nons lui avons communiqué, qu'il ne diflère presque en rien, quant à l'aniaul, des autres Balaues, il lui a donné les caractères suivans:

$$
\text { CARACTÉRES GÉNÉRIQUES. }
$$

Animal semblable à celui des Balaces, coquille conique, dúprimée; la partie coronaire formée de quatre pièces seulemeat, plus ou moins dis- tinctes, presqu'égales, et ordinairement strićes tle la base au sommet, a vec ou sans aires distincles; support plat, fort mince ou membracux; opercule articulé, pyramidal, composé, comme dans les Balanes, de deux pièces de chaque cóté, mobiles ou soudées entr'elles.

Les coquilles de ce genre sont épaisses, poreuses, et se rapprochen par là des Coronules; mais, du reste, leur manière de vivre et de se grouper entr'elles est alssolument semblable ì celle des Balanes. Les espèces, quoique fort peu nombreuses, peuvent se pariager en denx petits groupes, comme l'a proposé M. de Blainville. Dans le premier sont les espèces qui ont des aires latérales, et daus le second, celles qui en sout déponrvues : il paroit aussi que les espèces de cette seconde division ont les pièces de l'opercule soudćes, de manière à ce qu'il n'est que bivalve. C'est d'après ces deux caractères que M. Ranzani a fait son genre Afemus, qui n'est point admissible.

1. Conie radiée. Conia radiata. Brainv.

C. testâ conico-depressâ, radiatìn fulcatâ, symietricâ; operculo quadrivalvi. Nов.

BuaInv. Trait. de Nlalac. pag. 598, pl. 85. fig. 5. 5. $a$.

Espèce d'un médioere volume, formée de quatre parties symétriquement disposćes; l'antérieure est la plus grande, les latérales sont pourvaes l'une et l'autre d'aires latérales, et la postérieure, la plus perite de toutes, en a une de chaque côté. Ces diverses pièces sont couvertes de sillons de la base an sommet; l'opercule subgibbeux a une apophyse basilaire à la pièce antérieare; il est formé de cquitre parties articulées.

2. Conre stalactifère. Conia stalactifera. Br. C. testâ conoideâ, obliquâ, infernè crassiore, cellulosâ; extus sulcis. fillformibus creberrimis, adpressis; radiis nullis; aperturâ coarctatâ. LAMK. 
An lepas porofa? LIx. GuEL. p. $3212 . n^{\circ} .19$. Balunus squamosus, Brug. Dict. $\pi^{2} \cdot 17$.

Encyclop. pl. 165 . fig. 9. 10.

Blasvv. Truit, de Malac. loc. cit.

Nous citons celte espèce pour rectifier quelques erreurs de synonymie, et pour faire observer que Bruguière s'est trompé en disant qu'elle est composée de six parties, lor'squ'il est vrai qu'elle n'en a jamais que quatre. Du reste, sa description est fort exacte, et nous y renvoyons, tome ler. n 0.17 .

\section{CONILITE. Conilites.}

Sous ce nom générique, M. Lamarck, Anim. s. vert. $t .7: p .598$, a séparé des Bélemnites el des Hirpurites des coquilles multiloculaires pétritiées, yui paraissent se distinguer parfaiiement de ces deux genres. Il sembleroil que les coyuilles qui doivent y ĉtre comprises sunt rares, ou sont restées coulondues avec les genres voisins; aussi MI. Lamarck n'a proposé ce gente que pour signaler ces corps et en donner un bon exemple. Toici les caractères par lesiuels il les sépare : coquille conique, droite, légèrement inclinée, ayant un fourreau mince, distinct du noyan quil contient; noyau subséparable, multiloculaire, cloisonné transversalement.

D'après ces caractères, il est évident que ce renre Conilite de 1I. Lamarct est absolumeat le mème que celui nommé aulérieurement Orthocérate, par MI. Sowerluy, dans son Mineral conchology, et admis depuis par M. d'Orbigny fils sous le nom d'Hortocératile. On verra, en consultant ce dernier mot, cumbien il y a eu de confusion à son égard, et ce que l'on doit enfir entendre par ce genre.

\section{CONIVALVES.}

NI. Cuvier, dans ses leçons d'anatomie comparée, avoil proposé un groupe pour placer les coquilles univalves coniques et patelliformes; depuis il l'a abandouné, et les geures Fissurelle, Patelle, Crépidule et Cillyptrée, qui le composoient, sont coupris dans les Scutibranches ou la famille des Calyptracicns. Lasx. Voyez ces mots.

\section{CONO-COCHLIS.}

'lel est le nom que Klein (Tent. ostrac. pag. 25.) donna à la cinquièrue classe des cuguilles univalves. Celle classe, composée de seize genres, renferme toutes ou presque toutes les coquilles en spirales, régulières et coniques. Depuis long-temps on a abandonné celte division fondée sur ane méthode absolumeat artificielle.

\section{CGNOÏDES. Conoidea.}

M. Latreille, en adoptant la famille des Cônes de M. de Ferussac, a cliangé le nom et les rapports que cet autcur lui a voit donnés. Il la place dans son système ( $F a m$. nat. du Régne anim. pag. 197) entre la famille des Columellaires et celle des Olivaires, ce tui se rapproche de la manière de voir de M. Lamarck. Voyez Cóse.

\section{CONOTROCHITES.}

On trouve dans les anciens autears celle déromination appliquée aux Volutes fossiles avec lesquelles les Cónes se trouvoient confondus. Cetle confusion se remarque encore dans les ouvrages qui ont précédé Linné de peu d’années. Il servit possible que ce nom, qui cunrient mieux aux Cônes qu'aux Volutes, leur ait été plus spécialement appliqué.

\section{CONOYULE. Conorula.}

II. Lumarck avoit proposé ce genre pour celles des Auricules qui ont la forme d'un Còne et qui paroissent habiter de préférence les eaux douces ou saumatres. Ce geure inutile a été justement abandonmé et par son auteur el par les autres conchyliologues. Voyez Auriccle, au Supplément.

\section{CONQUE.}

Nom anciennement employé par Aristote pour désigner en général toutes les coquilles bivalves, el adopté par Laugius, dans sa méthode pour indiquer les mêmes objets; mais depuis il a élé applicjué à des cocpuilles de différens genres, et il est devenu familier aux marchands, qui, sous cette dénomination, rassembleut pour la plupart des coquilles qui n'ont entre elles aucume ressemblance. C'est principalement parmi les Coochiferes que l'on trouve cette application vulgaire, el sultout daus le genre Venus de Linné. C'est ainsi que l'on nomme CoNQte DE VÉvOS MaLÉFICIÉE la VénULS verrecusa lin.; Conque de V'́nus orientale la Vénus dyse"a; Cosqoe de Vévus épineuse la Vénus Dione. On donna également le now de Conques à des coquilles du genre Cardium; le Cardium pectinatum lin. reçut celui de Covere. de Vénus saxs pointes, le Cardium isocurdia celui de Corque turlée, el le Cardium costutum celui de Cosque exotrque. L'Hippopus maculatus Lamk. fut nommé CoNQue oxglée, et on alla même jusqu'à appliquer le mot conque à des coquilles univalses; le Murex tritonis el le Purpura persica, le prenier nommé Conque de triton, el le second Conque persique, en sont des exemples.

Les Anciens donnoient le nom de Couque de Vénus à toules les coquilles du genre Porreláne, et Rumphius l'appliqua, on ne sait pourquoi, aux 'Trigonies fossiles. 


\section{$\mathrm{C} O \mathrm{~N}$}

La Conque anatifère n'est autre chose que l'Auatile. Voyez ce mot.

\section{CONQUEFORMES (les). Conchoformia.}

Quatric̀me division établie par M. Sclıuınacher daus son Système de conchyliologie, pour ceux des Mulivalves qui se rapprochent le plus des Conchilc̀res, dans l'opinion de l'auteur. Ce qui paroít singulier, c'est de trouver réunis les genres I'bolade, Analife ctses sous-divisions. Il y alongtemps que celle question de la séparation des Cir. rlipjèdes et des Mollusques a été décidée par les Poli, les Lamarck, les Cuvier, etc. Voici dans quel ordie les genres de cetle division se présentent: Pholade, Ramplidione, Aualile, Sénoclite et Malacolte. Voyez ces mols.

\section{CONQUES (les).}

M. Lamarck proposa cetle famille dans sou deraier unvinge; il y rassembla, dans deux sections, tous les genres qui lureut démembrés du grand genre Vínus de tiané. Les animaux qui y sont compris, soit fluvialiles, soit marios, ont ce cal'actère conımun d'être pourvus postérieurewaent de denx siphons courts et d'un pied sécurifura:e aplati. Ils se ressemblent anssi sous beaucoup d'autres points de leur organisation, de manierc quils présentent un groupe fort naturel d. nnt il ne faudra exclure quiu seul genre, commo nous le verrons tout à l'heure. Les anteurs qui ont suivi 11. Lamarck ont adopté, sans y apporter de grands changenens, les rapports quiil avait indiqués. II. de Ferussac, par exemple, fait une famille pour chacune des sectious; mais on ne doit regarder cetle circonstance que comme fort secondairc, puisqu'elle ne touche pas à ce qui est essentiel dans ane bonne classitication, les rapports des genres. M. Latreille conserva les denx fumilles de M. de Ferussac, mais changea leur nom (poyez Crcladine et Vénémides) en transportant les Cypriaes, qui sont marines, dans la première famille, qui ne contient que des coquilles fluviatiles. M1. de Blainville changea le unot Conque en celui de Conchacés ( voy. ce mot), et conçul celle famille d'une autre manière que MI. Lamarck. Nous pensons que si quelques genres ont pu y être introduits justement, il en est plusieurs qui ne sont pas à leur place, comme les Corbules, les Sphènes, les Mlactres, les Erycines, etc. etc.

Ccmme nous l'avons dit, M. Lamarck avoit élabli deux sections pour la famille des Conques; la première, pour les Conques fluviatiles, contient les genres Cyclade, Cyrène et Galathée. La seconde, pour les Conques marines, renferme les genres Cyprine, Cytbérée, Vénus et Vénéricarde.

Ce dernier genre, comme on pourra s'en assurer en consultant l'arlic!e Cardite, n'appar- lient point à celte famille; mais il pourroit êtle remplacé par le genre Astante (voy. ce mot), qui a cerfainemeut heaucoup d'analogie avec les Vénus. (Voyez les muls Cycrade, Cyreve, Galatuée, Cyprine, Crthérée, Vénus, Astarté et Cardite.)

\section{Les Conques Ruviatiles.}

Outre l'habitalion particulière de ces Mollusques, on les dislingue cncurc par des caracic̀res qui leur sont propres. C'est ainsi que, comme les coquilles qui vivent dans les eanx donces, elles sont pourvues d'un ćpiderme persislant, verdâtre ou bruâtıre, qui est seulenent rongé sur les crochets, comme cela a lieu dans les Alulettes, etc.; leur charnic̀re, qui préseute constamment des dents latérales, u'cst pas moins un très-bon caractère poar les distinguer des Conques marines; ce caracière des deuts latévales leur est commun avec plusieurs autres greures de différeutes lanilles : iclles sont surtout les Mactres; mais on les reconnoûtra par la position du ligament qui, dans les Mactres, est intérieur, lorsqu'il est extérienr dans les Cunques.

Un autre genre avec leçuel elles ont aussi beancoup d'analogie quant à la charnière, est le genie Donace; mais la position du ligament sur le côté le plus court, le défaut d'épiderıne et le peu de cunstance des dents latérales, qui d'anlleurs som beancoup plus pelites, sont de bons moyens pour les séparer facilenent. Un fait très-singulier, qui résulte des observations faites avant nous dansle bassin de Paris, et qui ne pouvoit être expliqué d'une manière salisfaisante, esı le mauque absolu de Conchifères dans les terrains purement lacustres. Il devoit paroitre fort singulier, en ellet, de ne pas rencontrer dans ces conches les compagnons naturels des Lymnées, des Paludines et des Plaoortes qui s'y trouvent si abondamment répandues. Jusqu' i présent, en eftet, nou-seulement les Mulettes et les Anodontes ont manqué, mais encore les Cyclades et les Cyrènes, à l'exception de quelques espèces de ce dernier genre, dont la première, la Cyclas deperdita, a été rapportée aux Cyclades par M. Lamarck, avant la création du genre Cyrènc, et les autres figurées par M. Herussac dans son ouvrage des Mlollusques terrestres et fuviatiles. $\mathrm{Si}$, plus heureux que nos devadciers, nous avons pu ajouter parmi les fossiles de Paris des coquilles bivalves lacustres, elles appartiennent à la famille des Conques et nou à celle des Naïades, dont nous ne connoissons pas encore d'exemple.

- Nous adojtons complétement la famille des Conques, telle que M. Lamarck l'a fajte, et , on cela, nous ne faisons qu'iuiler les auteurs qui nous ont précéde, à l'exception d'un pelit nombre, 
car presque lous, sous les noms de Cyclades, Cycladés, Cycladines, elc. (voyez ces mols), l'unt admise, se conteutant de changer le nom, sars rien rlanger à la composition de la famille. Il nous semble qưil auroit été couvenable, puisgu'ou aduptoit celte fumille, de lui conserver le nom que lui avoit imposé pour la prenière fuis le savant Lamarck.

On ne peut contester qu'il n'existe les plus grands rapports encre celle tamille et la suivaute, les Cunques marines; elles sont liées entrelles par le geme Cypriae, qui appartient aux Congues marnes; d'un autre côté, elle se rattache un peu a la lamille des Nalades par le genre Iridine, qui est pourvo de siphons comae daus les Vénus, ainsi que nous l'ävons fait voir dans un Mémoire spécial, el comme nous le dirons de nouveau au mot Irintes, auquel nous reuroyous. les Cunques flurialiles se composent, dians l'ordre suivant, des genres Cyclade, Cyrène et Galatbce. Voyez ies mols.

\section{Les Conques marines.}

De tous les Conchifères dymiaires réguliers, la famille des Conques marines de M. lamarck renferme les geares les plus beaux et les plus nombreux en espèces. Cetle famille représente assez bien aujourd'bui le gente Vénus de Linné. Ce genre, dans le Systema naturae, préseule un très-grand nombre d'espèces, à la délermination desquelles il est souvent très-dificile de parrenir. M. Lamarck, en le sous-divisant en plusicurs coupes génériques, quoiqu'elles snient artificielles, a renda cependant un très-grand service an conchyliologue, en l'aidant par l'indication de caractëres faciles à saisir. C'est ainsi que le genre Cythérée, d'abord, partagea les Vénus de Sinné en deux groupes, et que le geare Cyprine, for voisin des Cyrènes, en détacba encore quelques espèces, qui ne pouvoient convenir ni aux Vérus ni aux Cytbérées.

Quml aux Venéricardes, que M. Lamarck a placées à la tin des Conques, pour servir de passage aux Cardiacćes, elles paroissent avoir plos de liapports avec cetle deruière famille quavec les Conques; elles se confondent en effet a vec les Cardites, au point qu'il est souvent difficile de décider la place de certaines coquilles ambiguës, llottantes, pour ainsi dire, entre ces deux genres, ce qui nous a décidé à les réunir. (Voyez CarDITE.) La disposition rayonnante des cólés des Vénéricardes les placenı d'ailleurs t:ès-naturellement dans les Cardiactes, dont les genres présentent égalemeut le même caractère.

Les genres Cxprine, Cyitérée, Yénus cons= titaent les Conques marines, et presque tous, très-nombreux $\in$ ul espèces vivantes, le sont aussi ca espèces fossiles; il n'est aucun d'eux que l'on ne troure dans le bassin de Paris et les autres lieux à fossiles connus. A ces genres que nous renons de ciler, nous pensons ciu'il sera convenable d'y joiudre les Astartés, qui ont certainement arec les Vénus beaucoup de rapports, el qui, par l'impression palléale, toujours simple, peut servir de coujonction à la famille des Curdiacées, telle qu'on doit l'entendre maintenant. Nous renroyons le lecteur aux mots de genres que nous avons cités dans le cours de cet arlicle.

\section{CONTRE-LIIQLE.}

On a gévéralemest donné ce nom à toutes les coquilles qui tournent à gauche au lien d'être à droite, comme le plus grand nombre; nais ce mul s'applique plus particulièrement à celles qua son! à gauche accidentellement et qui offirent dans une mềue espèce la coquille à druite et à gauche.

\section{CONularRe. Conularia.}

Gente f́tabli par M. Miller pour nne coquille pétritiée fort singulière, que l'on place parmi les Céphalopodes (yoyez ce mol), parce qu'elle se termine par quelịues cloisons irrégulières. Adopté par M. Sowerby dans son Mineral cunchology, il l'a été également par M. de Blainville, gui le place entre les Bélemnites et les Conilites; mais il n'a cerlainement point de rapports arec eux. Nous peasons que ce genre est encore trop douteux pour qu'on puisse l'admettre défiuilivenent; ce qui le pronve, c'est une nole que MI. de Blainville a placée dans les adiditions et corrections de son ouvrage, et sa non admission dans le travail de MI. d'Orbigny.

\section{CONUS.}

Le genre Cône est tellement naturel, qu“il n'e:t prescue point d'auteurs qui ne l'aient netlement sépacé, mêtne avant Linné. Klein (Tent. ostrac. pag. 64), en l'admellant, n'a pas manqué de fuire ce qu'il avait déjà lait pour presque tous les genres, un mélange sourent bizarie de coquilles diverses. Pour les Cônes, on ne peut lui reprocher que d'y aroir admis des Olires. Voyez Cône dans le premier volume de ce Diclionnasre.

\section{COPEAU. Assula.}

Nontfort aroit fait un genre Scaphandre avec le Bulla lignaria; au lieu d'adopter le nom de Muntfort, M.Schumacher en donne un autre pour le mème genre; mais ce genre étant inutile, celle erreur devient moins préjudiciable. Voj. Burle.

\section{COPHINO-SALPINI.}

Genre établi par Klein (Tent. ostrac. pag. 44) sur des caraclères extérieurs de nulle imporiance. 11 rassemble les coquilles treillissées terminíes à la base par un canal plus ou zooias long. On con- 


\section{O Q}

çoit qu'un tel genre pourra admeltre des Buccins, des luseaux, des Murex, etc. etc. Il pe pouvoit êlre adopté.

\section{COQUITIAAGE.}

Les écrivains du dernier siècle nommoient ainsi tous les Mnllusyues it compille. Celle expression n'est prescue plus en usage; elle est remplacíc par colle de coquille, lorsque l'on entend parler ale coquilles saus les amiuaux, et par celle de mollusques lorsque l'on vent désigner tout à la fois les coquilles, les auimanx gui les habient elceux qui son: dépourvus de têt, kais que leur organisation place dans celle grande classe d'êtres. $V o y$. Coquille el Moluusque.

\section{COQUILLE. Cochlea.}

A prendre ce mot dans son acception la plus rignureuse, on doit le délinir de la tnanière suivaate : corps corué on crétacé, fornić d'une ou de plusieurs parties, convraut lout ou partie d'un animal mollusque, et servant à le protéger, ou au moins les oryanes les plus essentiels à la vie. Bruguière, dims le premier volume de ce Dictionnaire, a traité, à l'article Coxchy liologie, tort ce qui a rapport à la coquille. Quoique faite depuis long-temps, celte partic de l'article de Bruguilère a’a presque pas vieilli, parce qu'elle a été rédigće avec un grand soin : nous engareuns le lecteur à la consulter, pour prendie des idées exactes de la nomenclature technologique de la conchyliologie.

\section{COQUILLE DES PEINTRES.}

L'Unio piciorum, le Mytilus edulis, le Mactra stultorum, et en général toutes les coquilles un peu grandes qui se trouvent en alsondance sur les rivagus de nos rivières ou sur les côtes, ont reçu ce un.m du vulgaire, parce qu'elles sont utilcreent employées a mettre des couleurs, qu'à cause de cela on nomme dans le commerce coulcurs en coquitles.

\section{COQUILLE DE PHARAON.}

On nomne aiosi une copuille qui a déjà plusieurs autres noms vulgaires: c'est le Trochus pharaonicus de linné, yui appartient au genre Munodonte de Lamarck. Voyez ce mot.

\section{COQUILLE DE SAINT-JACQUES.}

Toutes les coquilles du genre Peigne ont reçu ce nom vulgairc, parce qu'elles éloient portées autrelois par les pélerins qui se rendoient à SaintJacques de Compostel; elles servoient surtout à garnir le camail qui faisoit une partie nécessaire de l'babillement de ces royageurs. Dans le commerce, le num de coquille de Saint-Jacyues on de Pélerine s'applique particulic̀rement au Pecten jacoucus. Voyez Percine.

\section{CORBEILLE. Corbis.}

Les Anciens connoissoient les corpuilles de ce genre; on en roil une espèce fignréc dans Lister; Gualticri, Rhumphius, d'Argenville, elc., la représentèrent. Klein (N1éthod. ustrac. pag. 148) aroit établi un gente pour les Canes des Anciens, qui ont leur surface couverte de lames lrausverses, coupcés par des sillons longiludinaur; il lui avoit donné le nom d'Omphalo clathrum, c les Corbcilles en font partie; mais celte rénnion d'espèces ne reposant sur aucuns bons caractères, ou peut la considérer comme rulle. Linné raugea dans son genre immense des Yínus, sous le uom de Venus fimbriata, la Corbeille counue des Anciens. Genclin, dans la treizième édition du Systema nature, en a donné la syanaymie d'une maaière peu exacte, ed citant à faux Lisler et Rlumplius. Bruguièe, en caractérisant le genre Vénus plus rigoureusement, dut en éloigner les Corbcilles. Il avoit créé lé genre Lucine, il crut pouvoir les y placer. MI. Lamarik les y laissa jusqu'à la publication de son deraier ouvrage. M. de Ruissy, dans le Buffon de Sonnıni, suivit san exemple. Cependant, M. Mégerle sépara d'une manière précse le geure Corbeille sous le nom de Fimbria. Il est à p:ésumer que M. Cuvier ne connut pas le genre de cet auteur, lorsque, daus le Règne animal, il proposa le même genre avec la dénomination de Corbeille, qui fut généralemeut adoplée depuis, d'abord pay" M. Lamarck dins son dernier ouvrage, et par II. de Ferussac daos ses Tubleaux systénnatiques des Mollusques. Si l'on consulte l'article CorBEILLE di Dictionnaire des Sciences naturelles, on verra que son auleur a considéré le genre comıme distioct, mais il renvoie à Fimbria poar donner sans doute de nouveanx détails, et malheureusement ce mot ne se trouve pas. Quoi qu'il en soit, M. de Blainville, dans son Traité de MIalacologie, replace les Corbeilles dans les Lucines, en les séparant en unc section des Lncines proprement lites. Nous ne voyons pas pour quels motifs ce savant a proposé ce cliangement, qui ne peut ĉtre admissible, dans tous les cas, que lorsclu'on connoítra l'organisalion de l'animal des Corbeilles; sans cela, ce rapprochement ne sauroil être aduis, car les Corbeilles, quant aux coquilles, sont fort distinctes des Lucines. Autant la charnière des Lucioes est variable, autant celle des Corbeilles est constante; dans les premières, nons trouvons des coquilles orbiculaires très-rarement transverses, plates ou peu bombées, n'ayant presque jamais les crochets opposés et en ceul, et prúsentant constamment cette grande impression musculaite si remarquable, qui caractérise si bien les Lucines.

$$
\text { CARACTÉRES GÉNÉRIQUES. }
$$

Coquille transverse, équivalve, sans pli irré- 
gulier a bord antérienr; ayant les crochets courbés en dedans et opposés; deux dents cardinales; deux dents latérales, dont la postérieure est la plus rapprochée de la charnière; impression palléale non écbancrée postérieureinent.

Animal inconnu.

Les Corbeilles ont des rapports, non-seulement avec les Lucines, mais encore, de plus éloignés sans doute, avec les Tellines, dont elles nout plus le pli irrégulier. Cepeadanı M. Duclos, qui possède l'individu du Corbis fimbriata de la collection Yalenciennes, nous a fiut remarquer qu'il présentoit un pli irrégulier très-marqué sur l'angle postérieur. Nous a vuns observé la unême anomalie sur une valve de la Corbeille pétoncle, fossile des environs de Paris; et malgré ces rapports, nous pensons que les Corbeilles son t plus éloignées des Tellines que des Lucines, car celles-lì présenteat toujours dans l'impression du manteau celte profonde échancrure, qui indique l'existeace des siphons, tandis que celles-ci ont cette impression très-simple: ce que l'on retrouve également dans les Corbeilles.

On ne connoit encore qu'un petit worabre d'espìces de Corbcilles, une vivaute et deux fussiles. Nous allous les indiquer.

1. Corbejlue reullée. Corbis finbriata. Laur.

C. testâ transversè ovali, gibbì, longitudinaliter striat $\hat{u}$; sulcis trunsversis, undulatıs, margine crenulato. Lasr.

Ienus fimbriata, Lis. GMeL. p. 3275. nº. 25 .

Corbis fimbriata, Cur. Regn. anim. tom. 2. pag. 481 .

Снемхтт, Conch. tom. 7. pag. 3. vignette, et tab. 45. fig. 444.449 .

Lucina fumbriata, Buans. Malac. pag. 551. pl. 62. fig. 4 .

Lucina Encyclop. pl. 286. fig. 3. a. b.

Celte coquille toute blanche, enflée, épaisse, solide, est encore rare et lort recherchée des collectionneurs. Elle est couverte dans toute son étendue de sillons transverses, onduleux, plus écrasés et plus ellacés dans le milien, suburanuleux postérieurement, et fort élégamment lamelleux daus le jeune âure; ces sillons transverses sont coupés à augle droit par des sıries longitudinales assez tiaes, plus prononóes sur les purties latérales que dans le milieu; les bords épaissis sont crénelés, el sonveat de couleur orangée. LIMK.

2. Corberzic: pétoncle. Corbis pectunculus.

C. testâ subrotundatâ, zentricosâ, crasiâ, cancellatô ; lamelhs trinsversis, crebris, ad latus posticum plicato-crispis, serratis.

Lamx. loc. cul. Anim. sans yerl. nº. 5 .
1EF. Dict. scienc. natur. tom. 27. pag. 270. Article Lucine.

Nов. Descrip. des coq. foss. des env. de Paris, tom. 1. pag. 87. $n^{\circ}$. 1. pl. 13. fig. 3. 4. 5.6.

Celle-ci est la plus grande des espèces connues: elle a beaucoup d'analogie avec l'espèce vivante; el!e s'eu disingue cependant assez netlement, non-seulement elle est plus grande, mais elle est plus arrondie, plus épaisse, les sillons transverses sont plus larges, plus séparés, granuleux antérieurement, et lanelleux sur le côté postérieur. Cette belle coquille, dont nous possédons un individu complet, a d'abord eté découverte par M. de Gerville dans les faluaières de Valognes: depuis, elle a été retronvée sux environs de Paris. Elle a jusqu'a cent deux millim. de large, et quatre-vingt de long.

\section{Conbejzer lamelleuse. Corbis lamellosa.} LAME.

C. testâ ellipticâ, cancellatâ ; lamellis transversis, elevatis, antice crispis, remotusculis; striis longitudinalibus, creberrimis intrá lamellas; lunulâ prǫfundá, minimâ, lanceolatâ.

Lucina, Brug. Encycl. pl. 28. fig. 2. a. b. c.

Lucina lamellosa, LAmк. Ann. du MIus. tonı. 7 . pag. $257 . \pi^{\circ}$. 1 ; el tom. 12. pl. 42. fig. 3. a. b.

Corbis lamellosa, La ик. Anim. Bans vert. loc. cit. $n^{\circ} \cdot 2$.

Chemartz, Conch. cab. toms. 6. tab. 13. fig. 137 et 138 .

Var. B. Testâ crassioro margine spisso, lamellis numerosioribus.

Ibid. Nов. Descript. loc. cit. $n^{\circ}$. 2. pl. 14. fig. 1. 2.3.

Coquille très-belle et irès-élégante, très-abondamment répandue dans le bassin de Paris, et surtout dans le calcaire grossier. Elle est ovale, inéquilatérale, peu épaisse, couverte de Iaurs transverses, minces, élevées, élégantes, un peu obtuses sur le dos de la coquille, crépues et festonnées antérieurement et postérienrement; ses stries longitudiuales sont fines, très-rapprocbées, et placées dans l'iatervalle des lames; le bord est assez mince, crénelé, la lame cardinale étroite et présentant des dents cardinales, petites et inégrales; des dents latérales l'antérieure est très-près de la charnière, la postérieure s'en éloigne beaucoupplus. Ia variété se distingue, et parson épaisseur plus grande, et par le plus grand nombre de lames transverses qui la couvre; la charnière est aussi plus épaisse, et les deats cardinales et latérales, tout en couservant la mème position, sont plus fortes. Il arrive quelquefois que, par suite d'un accident, cette coquille se dédouble, toute la couche extérieure se sépare et ne laisse plus qu'un têt convert de stries longitudiaales très-régulières: 
dans cet élat, on pourroit la preadre pour une espèce disliucie sil'on n'étoit prévenu de ce singulier accident, tjue nous avons reconnu par des dédoublemens partiels.

Cette espèce est longue de $\mathbf{4 2}$ millimètres, et large de 64 . Elle se trouve dans toutes les localités où le calcaire urnssier est désaurégé, aux environs de l’aris, à Grigoon, Coultagnon, l'arnes, etc. etc., ì Valmonois, et la variété se rencontre à $A$ bliecourt et à Bracheux, près Beauvais.

\section{CORBICULE. Corbicula.}

Genrc que M. Mleger'e proposa de démembrer des Cyclactes de Bruguière. Ce grenre est absoluunent le uème que celui des Cyrènes, établi par M. Lamarck, et généralement adopté. Voyez Crnexis.

\section{CORBULE. Corbula.}

Bruguière le premier institua le genre Corbule lorsqu'il fit dessiner les plauches de l'Encyclopédic; il n'en avail point eu commoissance prubablement lorsqu'il traça les tableaux qui cummencent le volume que cet illustre naturatiste nous a laissé; il ne put donc le caractériser, mais on voil par la place qu'il lui a assignéc dans la série générique, counbien il avoit sasi juste ses véritables rapporis, puisque, depuis lui, les conchyliologrues ne tenant jas compte de cette idéc, aprês avoil inutilement tâtonné pour le placer, ont enlin fini par le remettre là où Bruguière l'aroit mis depuis long-temps. Ce qui dut embarrasser, r'est l'inégalité des valves à laquelle on donna plos d'importance qu'il ne falloit, et c'est sans doute pour ceite raison que M. Lamarck le plaça d'abord à côté des Houlettes el des Anomies, puis duns les Camacées; que M. de Rui-sy le unit près des Gryphćes; que M. de Blainville le laissa dans les Camacées. Cependanı lorsque M. Cuvier publia son Règne animal, on s’aperçut qu'il s'étoit rapproché de l'idéc de Bruguière, qu'il avoit enfin placé les Corbules arec les Conchyferes réguliers, et que du unoins, en les plaçani à la fin des Cardiacés, tout près des Nactres et des Myes, il avoit montré leurs véritables rapports. Aussi N. Lamarck, qui a l'esprit trop juste pour tenir à ses premières idées, lorsque de meilleures lui sont offertes, suivit M. Cuvier, el, tout en les séparant cornme lamille, les laissa pourtant à peu près à la même place dans la série. Enlin M. Gray, qui a éludié avec beaucoup de soins les travaux les plus récens sur les Mollnsques, a adopté l'idée de Bruguière et a placé les Corbales immédiatement après les Nyes. Ce rapprochement nous semble três-juste, et $j$ l est motivé sur une très-grande analogie dans le mode d'articulation de la charnicere, surtout lorsqua'on $y$ est conduit par le genre 'Thracie et plusicurs autres de notre famille des Ostćodesmes. Voyez ce mol.

CARACTERES GÉXERIQUES.

Animal inconuu.

Coquilie régulière, inéquivalve, inéquilatérale, point on presquc point bálllante; une dent casdinale sur chaque valve, conique, courbée, ascendanle el à côté une fosselle; dent cardinale de la petite valve, plus grande, quelguefois aplatie, lamelliforme; point de denis latérales; ligament intéricur fixé dans la fosselte de la valve inferiente el sur la face extcrne de la dent de la válve sufurieure.

Nous avons élé forcé de laire quelques changeruens daus l'ínoncé cles caractères génćriques; nous y avons éić concluit par l'oloservation que nous uvons faite, qu'il étoit impossible que le ligament s'insérât dans les fossettes des deux valves, puisque cclle de la valve ganche sert à recevoir la dent de la valve droite: il faudroit donc cu'il y ait deux fossettes à celle valve gauche, l'unc pour le liganent et l'antre pour la dent de la valve droite, ce qui n'existe pas; tandis que l'on voit, au lond de la fosserte de la valve droite, une cavité profonde, qui porte l'impression du ligament situé sous le crocbet.

Le second changement porte sur ce que le geare seroit limilé beaucoup trop, si on s'astreiguoit à n'y mettre que les cocfuilles qui ont sur chaque valve une dent conique : oi placeroit-on, en ellet, un assez grand nombre d'espèces qui ne diffèrent des Corbules qu'en ce qu'elles ont la dent cardiuale de la valve superieure lamelliforme, quel quefois même décurrente sur le bord?" Le genre Sphéna de M. Turlon, qui co uprendroit cés espèces, dillère trop peu des Corbules, pour qu'on puisse les limiter netlement; car on peut passer insensiblemcut depuis les espèces qni ont les dents les plus couique et les plus pyramidales, jusqu’à celles qui sont les plus lamelleuses.

Les Corbules sont marines; cependant ou a assuré qu’on en avoit trouvé en Amérique daus les eaux douces, et M. de Ferussac indiegue ce fait daus ses Tableaux systématiques des animaux mollusques, mais il ía énoncé avec un point de donte, et nous pensons en ellet qu'il a besoin d'une coulirmation authentigne.

D'après ce que uous avous pu roir dans la collection du Mlusénar, M. Lamarck a confonda parwi les Corbules plusienrs coquilles qui ne sont point de ce genre, el cntrautres la Corbule ausirale. Les espèces fossiles sont tres-nombreuses, on en comple vingt cspèces aux environs dé Paris seulement, et dix ou douze dans d'autres lieux; ce qui porte au moins a quarante les espèces de Corbules connues dans les collections. Nous iodiquerons seulemeut les principales espèces. 
1. Coretre sillonnée. Corbula sulcata. Lasiz.

C. ¿estâ subcordatâ, transverim sulcatâ, obsoletè radiata; natibus gibbis, purpurascentibus.

Corbulcr sulcata, Lasr. Syst. des anim. sans vert. pag. 137.

Corbula, Excrclopéde, pl. 230 . fig. 1. a. b. c.

Jolie coquille très-solide, eullée, cordifor'ne, régulièrement sillonnée en travers; les sillons de la valve droite sont plus gros que ceux de la gauche. Les crochets, en dedans, sont d'uce belle cculeur pou:prée, et l'on voit, sur la valve droite, plusieur's rayous de la mème couleur, sur le fond gris-ceadré de la coquille. Les valves sont épaisses, solides, et la charnière très-lorte. Cette coquille, fort rare, vient, dit-on, des mers de l'lode; eile est longue de 14 à 16 willim. et large de 20 ì 22.

2. Corbule noyau. Corbula nucleus. Lazí.

C. testâ globoso-trigonâ, transversim striatâ, subantiquat;; umbane altern gibbosione; natzbus rubris.

Lamк. luc. cit. no. 6.

'Turtos, pag. 3g.tab. 3. f.g. 3. 9. 10.

Iir) a inaquivalvis, DisLwrs, pag. 55.

Mostagu, pag. 38. tab. 26. fig. 7 .

Mlatox et R.sс⿰етт, pag. 40. tab. 1. fig. 6 .

PAYKAUDEAU, Catal.pag. 52. $n^{\circ} .44$.

Soweri. Genera, n०. 18. fig. 1 .

Excrelor. $p l .230$. fig. 4. a. b.c. d.

Petite coquille fort remarquable, élegamment et fiuemeut striée dans sa largeur; les crochets sont rouges, quelquefois rayunnés de cette couleur; la ralre gauche est aplatie, beancoup plus pelite que li droite et dépassíe beaucoup par elle, to dedans elle est d'un rouge-brun. Cette coquille, qui se trouve vivante dans l'Oséan europét et dans la Méditerranéc, a sou analogue fossile en Italie, en Sicile, à Dax el dans tes fuluus de Touraive.

5. Corbere à grossillous. Corbula exarata. Nов.

C. testâ ovato-transversí, tumidâ, valvá dextrâ sulicis pmfundis exaratâ, sinistrâ sublcevigatâ, costulis subprominulis, longitudinalibus radiats.

Ibid. Гов. Dict. class. d'hist, nat. tonz. 5. atlas, pl. 5. fig. 4 .

Ibid. Descript. des coọ. foss. des env. de Paris, tom. I. pag. 48. no. 1. pl. 7. fig. 4. 5.6.7.

Fort belle coquille remarquable par la disparité de ses valves dont la droite, la plus grande et la plus profonde, cst aussi fortement sillonnée, lorsque la gaucbe, beaucoup plus petile et aplar tie, est toule lisse ou presque lisse, et traversfe longitudinalemeat par denx ou trcis côtes à peine sailluntes et rayonzantes; les crochets des deux valves se touchent, mais ils sont très-inégaux, celui de la grande valve étant beaucoup plus saillant et plus contourné. La dent cardiuale de la valre gauche est fort yraude, presque perpendiculaire sur le bord, et divisće en deux parties inégales par une saillie oblique. Cette belle coquille, conuue seulemeat fossile et aux eorirons de Paris, à Mouchy-le-Châlel et à ChàleauRouge pres cle Noailles, est longue de 26 milliun. et large de 33 .

4. Corbule gauloise. Corbula gallica. Lanк.

C. testá ovato-transversí, valvá majone turgida, ad nates tenuissimè striatá; umbone leviusculo; valvá sinistrì costellis longitudinalibus radiatî.

Corbula gallica, Làk. Ann. du Mius. tom. 8. pag. $466 . n^{\circ} .1$.

Corbula pro valvâ dextrî, Anim. s. vert. loc. cit. $n^{\circ} \cdot 10$.

Id. costulata, pro valvâ sinistrâ, Lیмк. ibid. $n^{\circ} .11$.

Corbule uaie, Bosc, Dict. d'hist. nat. pl. 6. 25. fig. 7 .

Excrclop.pl. 230 . fig. 5. a. b. c.

Cortulu gallica, Ков. Descript. loc. cit. $n^{n} \cdot 2$. pl. $7 \cdot$ fig. 1.2 .3$.

Sowerby, loc. cit. fig. 2.

M. Lamarck, dans les Annales die Muséum, avoit pensé que les valves supérieures que l'on trnuve à Griguon, et qui ont de petites côtes rayonaantes et irrégulières, appartenoient ì la Corbule gauloise, et il avoit raison; n'ayant point vu réuuies les deux valves de cette coquille, il pensa depuis que cette valve devoit appartenir à une autre espèce, qu'il caractérisa, dans les Animanx sans vertèbres, sous le nom de Corbula costulata. Ncus avons eu depuis occasion de nous assurer que M. Lamarck avoit été dans l'erreur à cet égard; nous arous pu examiner un grand nombre d'iudividus complets de cette espèce, et nous nous sommes assuré de l'ideatité parfaite des deux espèces de 11 . Lamarck. La Corbule gauloise est grande, bombée, reuflée, à crochets proéminens, surtout celui de la valve droite, il est lígèrement strié en travers; le reste de la surface est lisse, marqué seulement de quelqnes accroissemens irréguliers. La valve sn périeure est plus petite, plus aplatie, lisse, marquée de sept à huit petites côtes ou plis irréguliers, longitudinaux, rayouvans, quelquefois bifides. La dent cardinale de celte valre nait du bord, elle est très-yrande, conique, pyramidale, perpendiculaire au pláa de la coquille, séparée en deux parties 
partics inćgales par un sillon profond et marqué tres-sensiblement par l'iupression du ligament.

Cetloespèce, la plus grande du genre, est furt commune aux environs de Paris, dans lous lus calcaires grossiers, dans le grés marin infúrieur, à Beauchamp, Senlis, Valmondois, Eimenonville, etc., ainsi quà̀ Grignon, Parnes, Mantes, etc. etc. Elle est quelquefois large de 48 nillim.

LAar.

5. Conbele dent rouge. Corbula erythrodon.

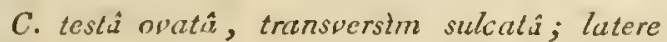
antico productiore, subaculo, maryine interno purpurascente.

Lasx. Anim. s. vert. loc. cil. $n^{\circ} .3$.

On ne connoit encore qu'une siule valve de celle coguille, et e'est la droite; elle sullit pour bien caractériser l'espèce. Ellle est assez grundẻ, bombée, profonde; strn crochet, fort suillant, se renverse un peu au-dessus du bord cardinal; celui-ci est assez épais, d'une coulcur rouge foncé; il porte une dent en crochet d'un médiocre volume, et is côlé une fossctte, ou plutôt une goultière, qui s'entonce sous le crochet et qui reçoit la grande dent cardinale de l'autre valve. L'angle postérieur est un bec assez saillaut el aigu.'Toute ia surface est profondément sillonuée; les silluns sont arrondis, oblus et assez larges; la valve supérieure n'élant pas connue, on ze sait si elle étoit sillonnée on lisse. Cette coquille, que l'on cruil de la Chine ou du Japon, est large de 30 million. Elle est très-rare, et seulemersi au Nusćum.

6. Coвbure donacine. Corbula donacina. Nrs.

C. test $\hat{i}$ ovalo-trigonâ, levvigalî, transpersie, inarquilaterali, griseo candidi, intùs candidissima; latere antico, brevi, rotundato, postico, subrostrato.

Certe espèce, que nous ae irouvons mentionaće aulle part, est bien facile à dislinguer de toutes ses congénères; elle est oblongue, transverse, trigone, ayant un peu la forme des Donaces, étant par conséquent inéquilatérale; elle est peu enflée, et ses valves sout presqu'énales quant it la profondeur, mais la droite est plus large que l'ustre et la dépasse inférienrement. La coulen. est d'un blanc laiteux en dedans, et en dehors d'un blanc-grisittre ou de corne; les deux valves sont érralemeut lisses. Le ligament est contena dans nne gouttière, qui partage en deux la deat cardinale de la valve gauclie. Cette deut est solide, conique, épaisse et reçue dans une gonttière entre les deux saillies de la valve druile. Celte coquille vient du Brésil, de Rio-Janeiro. Elle a 20 i 25 millim. de large.

Hist. Nat. des Vers. Tome II.
7. Copbue porcine. Colbula porcina. Lamk.

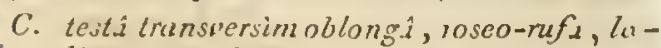
viusculi, subequiluterâ, posticè rolundatî, anticé subrostratî, truncatâ.

L.А кі. loc. cil. $n^{\circ} \cdot 8$.

ExcrcLOPÉDIE, $p l .230$. fig. 3. $a . b . c$.

M. I amarck n’a connu cette espèce que morle el altérée par son sćjour sur la plage, antant du moins que nous en pouvons juger par les individus du Muséum et ceux quac nous possédons. Cette petite coquille est ovalaire, oblongue, transverse, presque équilatérale, toute lisse, trèsaplalie, inéguivalve, arrondie du côlé antérieur, angnlense et tronquée postérieurement. Elle est partout d'un fauve-rosatre et blatschâtire en dedans; quelques individus sont beaucoup plus páles. La dent cardinale de la valve gauche est saillante et creusce en goutlière dans sa longueur. On croit que cetle petite espèce vient des mers Australes. Elle a 9 à 10 millian. de large.

3. Condure aplatie. Corbula complanata. Sow.

C. testâ orato-subtetragonâ, trunsversâ, dcpressid, lavigutis; umbonibus subnullis; dcnte valua inferioris conico, solido, superioris depresso, minimo.

Sowerв , Mncral concliology, tom. 3. p. 86. pl. $562 \cdot \mathrm{fig} \cdot 7 \cdot 8$.

Erycina trigona, LAux. Ann. du MIus. tom. 6. pag. $413 . n^{\circ} .3$.

Var. B. Nов. Teslâ minimâ, multó transversiore.

Nов. Descript. des coq. foss, loc. cil. $n^{\circ}, 4$. pl. 7. fig. 8.9. 13. 14. 15 .

Nons avons douté de l'analogie qui existoit entre les individus de celte espéce, trouvée en France et en Angleterre; maintenant que nous en possédons de localités diverses, après un examen scrupuleux, nous pouvons assurer qque celte espèce de coquille se trouve répandue en Frauce, aux environs de Paris, dans les falunières de la Tourraine, à Dax et à Bordeaux, et en Angletcre dans le crag, où elle est fort abondante.

Celle coquille sort de la forme habituelle des Corbules, beaucoup plus aplatie qu'elles ne lè sont, elle a assez l'aspect d'nue petite Mye. Elle est fort inéquivalve, déprimće, solide, épaisse, subquadrangulaire, un peu báillante aux extrénités. Les crochets sont très-petits, peu saillans. ha lame cardinale se confond avec le bord; sur la valve droite est une deat conique fort grosse, et à côté une fossette entaillée dans l'épaisseur de la value, au fond de laquelle est placé le linament. Cette fossette reçoit la deat conique et saillunie de la valve gauche, qui elle-mếne est munie d'une fossette superticielle, dans laquelle 
s'articnle la dent de l'autre valie. En dehors, celle coquille est toute lisse. On lat trouve à l'état fossile seulement, et, comme nous lavons dit, daus plusieurs localiés fort éloi znées les unes des autres. Sa largear est de 30 à 30 millim.

\section{Consure striée. Corbula striata. Lask.}

C. testấ ov'ato-transversî, subrostratâ; strïs transversis, tenuibus, e'egantissimis.

LАзк. Ann, du Irus. tonz. 8. pag. 467. $n^{\circ} .3$.

Ibiu. Anim. s. vert. loc. cit. no. 15.

Nов. Descript. des coq. loc. cit. no. 8. pl. 8. fig. 1. 2. 3. et pl. 9. fg. 1. 2. 3. 4. 5.

On ponrroit citer un grand nombre de variétés de cetle espèce, qui, se trouvant fossile dans un grand nombre de localités, varie presque conslamenent dans chacune d'elles. Presque tontes ces variélés se trouvent aux environs de Paris, à Griguon, à Parves, Acy-en-HIultien, Longjameau, Valmoninis, etc.

La Corbule striće est une pelite coquille ovale, globuleuse, clégamment el récuulièrement striée en trarers, sur les deux valves, ayant le tôté postérieur assez large et pea en bec, et l'anlérieur arrondi; la charnière est médiane, ainsi que les crochets, qui, dans les vieux indiviclus, sunt presqu'égaux et subcordiformes; la valve droite est plus grande que la gaucbe, et, quand l'individu est vieux, les bords s'épaississent et les stries en disparvissent. Outre les localitćs que nous avons mentionnées, on peut encore indiquer Dax, Bordeaux et Angers, où cette coquilie se trouve. Largeur 10 à 12 millim.

\section{Conbure anatiue. Corbula anatina. Lamk.}

C. testí ovatn-ellipticâ, tmunsversè striatâ; rostro obtuso, subtruncato; dente cardinali lamelloso.

Lasux. Ann. du Mus. tom. 8. pag. 468. $\pi^{n}$. 6 .

Noв. Descript. des coq. foss. de Paris. tom. 1. fag. 60. pl. 7. fg. 10. 11.12.

ExстCLop.pl. 230. fig. 3.

Cette coquille a "plus d'ua rappnrt avec les Anatines; fort mince el transverse, plissée transversalement, presque équilatérale, inéquivalve, bâillante, elle ne diffère du genre que nous rezons de ciler que par la charnière, qui est toutà-fair celle des Corbules, encore celle dernière la rend intcrnédiaire entre les Corbules proprement ditcs et le genre Spliène des auteors anglais, car la dent cardinale est aplatic et lamelleuse, snbtrigone et saillante hors du bord cardinal. La Corbnle anatine ne s'est encore trourée quanx environs de Paris, à Gringnon, Houdan et la ferme de l'Orme. Elle est large de 21 millin.
11. Coxbule ridée. Corbula rugosa. Lay

C. testá ovato-ventricosâ, gibbosâ, brevissime rostratä; sulcis transversis, grossiusculis.

Lamk. Aun. du Nius. Loc. cit. $n^{\circ} .2$.

Ibid. Anim. s. vert. loc. cit. $\pi^{\circ} .12$.

Nов. Descript. coq. foss. loc. cit. no. 5. pl. 7 . fig. 16. 17. 22.

An Solen ficus? Braxder, Foss. hant. $n^{\circ} \cdot 105$.

Tellina revoluta? Broccu, Conch. subap. tab. 12. fig. 6.

Corbulie revoluta? Sow. Miner. conch. tab. 209. fig. 8. 13.

Il nous semble plus probable aujourd'lui, qu'a l'éproque de la publication des premières livraisons de nolre ouvrage sur les fossiles du bassin de Paris, que les individus d'Italie et cenx d' $\Lambda$ ngletęrre appartienuent à des espèces différenies de cellc-ci. Il ponrroit bien en être de même de celles de Bordeaux, de Dax et des faluns de la 'Touraine, qu'on y rapporte ordinairemenl, quoiqu'elles officnt des différences assez notables et constantes.

Cette espèce est globuleuse, renfléc; ses crochets sont saillans, cordiformes, opposés et se touchent lorsque les valves sont réunies; ils sout médians el au-dessus d'un bord cardinal assez étroit, dans l'épaissear duquel est crensée la clarnière : elle se compose, sur la valve droite, d'une dent en crochet, d'une cavité postérieure à côté, et sur la valve gaucbe, d'une dentégalement en crochet, mais plus pelite, et d'une cavilé à củté, qui, avec la dent de l'autre valve, reçoit aussi le ligamenı. Jamais, quel que soit l'áge de cclle coquille, elle ne devient rostrée postérieurement; loute sa surface est couverte de sillons transversaux, plus profonds et plus nombreux sur la valve supérieure que sur l'ioférieure. Dans les vieux individus, nous avons remarçué que les impressions musculaires derenoient saillantes; nous avons également observé que cetle coquille, et quelques autres du même geare, éloient composées de deux conches distinctes, que le choc peul séparer, de sorte que si l'on n'étoit averti de cetle particularilé, on pourroit facilement faire deux espèces pour une, l'une avec la partie interne, laulre avec la parlie corticale. On trouve celle coquille communément aux eovirons de Paris, Grignon, Parnes, Mouchy, etc. Elle est large dc 44 millim.

12. Conburz anguleuse. Corbula anguluta. LAMX.

C. testâ transuersim elongata; latere postico, rostrato, biangulato; striis transverialibus, obsuletis.

Lamr. Ann. du Alus, loc. cit. $n^{\circ} .4$. 


\section{$\mathrm{C} \mathrm{O} \mathrm{R}$}

Nobis, Descript. des coq. foss. Woc. cit. $n^{2}, 11$. pl. 8 . fig. 16 ì 20.

Cette espèce se distingue très-facilement par sa forme subtrigone, trasverse, fort alongíe postérieuremeat en bec sourenu par deux angles qui fragnent ea convergeant les crocbets; ceux-ci ont petits, pnintus, opposés; le côté antírieur est arruadi. En dehors, celle coquilie est irréguli rement striée par des accroissemens; cllc est déprimće et la cavité intérieure est lort petite. La charniere se compose, sur la valve droite, d'une petite dent plate, el à cóté une losserle triangulaite, tailléc intericurement en biseau, qui recoil une petite deut cardinale de la valve gauche : cette valve a également une fusselte ublique prise dans le bord cardiual, dans laquelle, outre le ligament, se place aussi la dent cardinale de la valve droite. Ce mécanisme de charniire, qui est en tout analogue it celui des grandes espéces, présente néanmoins celle dilfírence, d'avoir sur une valve unc fossetue interno-externe, taillée en bisenu : ce que nous ubscrverons encore sur d'auties espices. Celle-ci, qui se trouve à Crépy", à Senlis, à Lourres, etc., eat petite. Eille est large de dix millin. seulement.

13. Conaude en bec. Corbula mostrata. Lam .

C. testá tenuissimé, pellucidâ, transiersá; latere antico, elongato, mstrato, subangulato; strii; ohsoletis.

L.ам . Ann. du Mus. loc. cit. $n^{\circ} .3$.

Nов. Descript. des coq. foss. loc. cit. no, 12. pl. 8. fig. 21 वे 25 .

Avec une forme analogue à celle de la Corluule anguleuse, celle-ci s'en distingue nćannmins avec une grande facilité; elle est plus transrerse, plus nuince, son bec postérieur est plus lonir; il est dépourvu de ces deux angles saillans qui caractériscut l'autre espèce; la cluaraic̀re présente aussi des différences, la dent cardinale de la valve droite est plus sur le bord; elle est trèscamprimée et partagée en deux parties inégales, 10: un sillon; la dent de la valve gaucbe esi conoids, en crochet et assez proémineute. Celte coipuille, ainsi que la précédeute, appartiendroit an renre Splùne si on l'adoptoit. Eille se tronve ¿ Grignon, Chaumon:, Mouchy, elc. Elle est hicge de 9 millin.

14. Conbule maine. Combula minula. Nob.

C. tcstâ minimá, subquadratâ, depressá, aquilatemali, tenui, laviguti, postacé biangulatj; curdine unidcnuto, altero bidentato.

Nobis, Descript. des coq. Soss. loc. cit. $n^{\circ}$. 15. 17. 8. fig. 51 a 35.

Coyuilie très-jelite et forl commune, que sa petilesse aura sans doute fail échapper aux re- clierclies des persounes qui se sont occupées avant nous des lossiles du bassin de Paris. Elíe est remarquable par sa forme subquadraugulaire, ses c!eux angrles oblicpues, postéricurs, el surtout par sa charnière, qui u'a quine seule dent sur l'unc des valves el deux sur l'autre, de maivire à recevoir entr'elles la dent nuique en crochet de li valve droite. Nous navons janais vu d'autres espéces de Corbulcs prísenter ce caractète : du reste, celle espère est lisse, miuce, transparente et déprimie. On la trouve à Senlis, Acy, Cicigruon, larues, Tilmondois, etc.; elle ira que 4 millira. de large.

15. Contule argentéc. Corbula argented. Lasix.

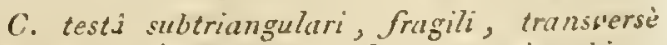
plicatâ, intìs argentế; latcre postico bicurinato.

LAM . Ann, du Mus. loc, cit. $n^{\circ} \cdot 7$.

Noв. Descript. des foss. de Paris, loc. rit. $n^{\circ} \cdot 14$. pl. 8. fig. 26 i jo.

On ne connoil pas une senle espèce vivante du Curbule qui soit nacrie, celle-ci esi la seule lossile qui présente ce caractère; elle peut doac, à cause de cela, se reconnoilte facilement. Celte coquille est petite, mince, fragile, diaphane, inćquivalve, mais les valves presque également creuses des deux côtés. Le côté autérieur est arrondi; le postérieur, un peu en bec tronqué auquel viennent aboulir deux carènes élevées, qui partent en diveraneant des crochets. Toute lit surface exterieure est finement plisác. Ces plis vécrulicrs, et qui se terminent ¿ l'angle antérieur, se répitent à l'imtericul des vulves à cause de l'extrème línuité de la coquille. La cbarnic̀re se compose, sur chacue vilve, d'une petite dent triangulaire, el à côté d'une pelite fossette de méme luine, dans laquelle la dent de la valve opposée vient s'insérer. Cette jolie coquille se trouve à Parnes et à Chaumont; elle a 8 millim. de large.

16. Corbude 1reillissée. Corbula cancellata. LAMIX.

C. testa fragili, nostrata, striis minimis et obliquis decussulim cancellatâ; rostro attcnuato; dente cardinali lamelloso, prólongo.

Lauk. Ann. du Mus. loc. cit n ${ }^{\circ} .8$.

Nов. Descript. loc. ‘it. n०. 19. pl. 9. fig. 9. 10.

Celte petite coguille est fort remarquable par les stries très-fines et irc̀s-flégrambient croisées sur sa surface extérieure; eile est subtrigone, se nrnlongeant en bec postérieurement: ce qui la distingue epcore unanimement des autres Corbules, e'est la dent cardinaie laneliforme qui se prolonge postéricurcnient dars presque toute l'étendue du bord cardinal. A l'exirémité aatéB 2* 
rieure de celte lame se voit scus le crochet nne pelite lossette triangulaire pour le liganteat, et sans donte pour une dent de l'antre valve. On rencontre très-rarement celle coupuile dans les sables de Grignon, Parmes et Mouchy; elle est lurge de 4 millia.

\section{CORBULEES (les).}

Depuis long-temps MI. Lamarck avoit associé les prenuiers élénens de celte lamille : dès 1801 , il avoit rénnis les genres Corbule et Pandore; mais il les avoit placés dans nue série où ils ne pouvoient rester. Les Corbulées sont dimyares, les Ostracées, avec lesquels ils étoient jéuais, sont monomyaties. Cependaut, quelques annćes après M. de Roissy, daus le Buffon de Sonnini, sépara les deux geares, plaça le premier entre les genres Dicérate et Griphée, oi il est cerlainement liors de ses véribables rapports, qu'il sait considéré seuleunent comme dépouille, comme tết ou comme habité par un animal organisé; et le second entre les Solens et les Samgunaulaires, où il est en rapport avec des grentes tres avoisinans. Depnis les travaux de Poli et la pailication de son magnifique ouvrage, les Testucés des Deux-Siciles, on a connu l'organisaton de la Pandore, et alors les zoologistes ont séparé ce genre et l'ont placé avec les Solens, M. Cuvier, dans sa famille des Enlermés, M. de Blainville, dans les Pyloridés. N. Lamarck, qui a voit d'abord placé ces genres catre la Houlette et l'Anomie, vit plas tard, qu'ils n'étoient point à leur véritable place. Les deux impressions musculaires dont ce zoologiste s'étoit servi pour faire, parmi les Conchyfêres, deux ordies distincts ne devoient point lni laisser d'luésitation; mais l'inégalité des valves lui sembla suffisante, abstraction des autres caractères, pour les placer dans les Camacées, dont elles formèrent alors (Extrait du Cours, 1811) une section sons le simple caractère d'une coquille libre, lorsque toutes celles de la même famille sont fixées; mais plus tard, M. Lamarck changea encore d'opinion sur ces deux genres, et, saisissant alors leurs véritables rapports, il sentit qu'il falloit non-seulement les placer non loin des Solens, des Mactres et des Lutraires, mais encore qu'il étoit aécessaire de les en séparer, ne pouvant nalurellement se confoodre parmi ces genres; c'est pourquoi il en fit une fauille. Cette famille dut venir se ranger à côté des Mactracées; peut-être auroient-elles été plus convenablement à côté des myaires : mais les myaires ont lous de très-longues trachées on sypbons, tandis que la Pandore, que nous connoissons très-bien par la description de Poli, n'en a point d'aussi grands, ainsi que la Corbule, ce que l'on présume avec assez de certitude, par le peu de profondeur de l'échancrure antérieure du manteau. Ces raisons nous seablent assez bien motiver la réunion de ces deux geares; il est vrui de dire que nous ne connoissons point encore l'auinal des Cuibulcs, et qu'il est permis de doutcr de sa place jusqu’à sa contruissance parfaile; ce qui permet aussi bien de les placer parmi les Saxicaves (Fernssia), que parmi les Camacées (Lamarck), on les Cardiacées (Covier), ou les Conclacés (Blainville), ou à côté des Myes (Gray, 132I).

De tontes ces opinions, la dernière, qui est aussi a per prés celle actuelle de M. Lamarck, loit être, ce nous semble, préférée. On pent aujourd'hui d'autint moins la contester que l'on councîl le geure 'Thracie et quelques autres, dont nous formons la fanilie des Osléodeswes (zoyez ce mol), intermédiaire sans aucun donte d'une part entre les Corbules et les Myes, et d'une autre entre ces mêtmes coquilles et les Lutraires.

\section{CORDELIERE.}

Nom que l'on donne vulgairement à des coquilles qui, sur uu fond blanc, présentent une ou plusieurs séries de uœuds ou d'aspéritées d'une couleur foncée, comparant ainsi celte dispusition à la corde qui servoit à ceiodre les cordeliers:

\section{CORDIFORMES.}

Ce not ue s'ipplique qu'anx coquilles bivalves très-globuleuses, et dont les crochels, recourbés l'un vers l'autre, donnent à la coquille la torme d'uu cœur de carte à jouer.

\section{CORDON-BLEU.}

Les marchands donnent ce nom à une belle espèce dn genre Ampullaire. Yoyez ce mot.

\section{CORET.}

Un petit Planorbe, très-abondant dans les eaux douces du Sénégal, a été nommé ainsi par Adanson. (Loy. all Sénég. pl. 1). Vojez Planorde.

\section{CORIOCELLE. Coriocella.}

Nous connoissons ce genre d'a près M. de Blain. ville, yui l'a établi dans son Traité de Malacologie. L'animal qui lui sert de type parvît fort voisin des Sigarets, sans que cependant on puisse le confondre avec eux, puisqu'il n'a ancune trace de coqnille et le mauteau énormément développé. M. de Blainville a caractérisé ce genre de la maniète snivante : corps elliptique, fort déprimé, ayant les bords du manteau trèsminces, écbaocrés en avant, télbordant largement de toutes parts; pied ovale, très-pelit, et la tête pen distincte; deux tentacules cachés sous le bouclier, assez gros, courts, contractiles; les yeux à la base externe des tentacules; le dos peu bombé, sans trace de coquille estérieure ou intérieure 


\section{$\mathrm{C} \mathrm{OR}$}

Il n'est pas domeux, d'ajuds cette caractérislique, gue ce genre ne soil tres-voisin des Sigarels: on peui dire que c'cst un Sigaret sans coquille, avec un ample nantean; et M. de Blainville l’a placé dans la uéthode d'une manière conforme i celte idée. Il est le premier des Clismobranches et suivi des Sirarets et des Cryptost jenes. Vojez ces mols.

On ne counoit encore qu'une srule espèce de Coriacelle; c'est celle que M. de Blainville a indiquée dinos son 'Traité de Malucologie. Il l'a nommée Cnriocelle noire, Coriacella nigrn, et fait ligureı pl. 42. lig. 1. Elle vient des mers de l'lle-de-lirance. Cet aniunal est long de 45 à 50 millim.

\section{CORIS ou CAURIS.}

Noms vularitires d'une lorcelaine qui sert de monnuie en Guinée, pour l'achat des esclaves; elle porle aussi le nom de monnaic de Guncé: c'est le Cyproca moneta Lamk. Voyes PonceLAINE.

\section{CORNE. Cornu.}

Dénomination générique sous laquelle M. Schu. macher a caractérisé des coquilles qui appartiennent au genre Carinaire, établi antérieurement. Joyez Carivarre.

\section{CORNE D'ABONDANCE.}

Nom vulgairement donné d l'IIuître plissée et à quelques grands 'I'ritons.

\section{CORNE D'AMIION.}

Les anciens conchyliologues appliquoient ce nom aux coquilles planorliques que l'on nomme aujourd'hui Ammonile. (Voyez ce mot.) On sail aue celle dénomioation de Corne d'Ammon, vient de la comparaison que l'on a faite de ces coquilles avec les cornes de bélier que les Anciens plaçoient sur la tête do leur Jupiter Ammon.

I"iufortuné Lamanon avoit trouvé daus son voyage à llavers le grand Océan la coquille de l'Alante, et l'ayant prise pour le type vivant des Ammonites, quoi qu'elle n'eût point de cloisons, lui donna, par suile de celte erreur, le nom de Come d'Ammon. Voyez Mtusits.

\section{CORNEE. Cornea.}

Ce genre fut proposé par M. Mégerle pour des coquilles dout on aroit fait avant lui le genre Cyclade. Voyez ce mot et Cxrène.

\section{CORNET.}

Autrefois, et c'est d'Argenville qui l'avoit pour ainsi dire cousacré, on donuoit ce nom à loutes les coquilles du genre Cóne; on l'appliquait aussi quelquefois à des olives. Il n'est pas névessuire de dive que ce nom avoil ćlé douné par la ressemblance que l'on trouvoit entre un coruet de papics et la forme de ces coquilles.

Les labilans des hords de la Maclie nomment aussi Cornets, les Calmars. Vojez ce mot, ainsi que CôNe.

\section{CORNET CHAMERE.}

\section{CORNEI DE POSTILLON.}

\section{CORNET DE SAINT-IIOBERZ:}

Ces trois noms vulgaires s'appliquent à nue seule ec même coquille, la Spirule. Poyez co mol.

\section{CORNU AMMONIS.}

Klein, dans son Nova method. ostrac., a donné à tort ce nom à la Spirule. Voyez ce nut.

\section{CORONULE. Coranula.}

Ce genre étoit resté confonda avec les Balaues, et tous les anciens conchyliologues le placoient parmi les Multivalves; M. Lamarck (Anim. suns vert., $10 \mathrm{~m} .5$, pag. 385), apercevaut des caractères propres à eu fuile un genre distinct, le proposa et le plaça parmi les Cirrlipèdessessiles, à côté de la 'Tubicinelle, a vec lıquelle il a beaucoup de rapports. Léach, qui fit subir de nouvelles divisions aux Cirrbipèdes (voyez ce mot), adopta !e genre de M. Lamarck, mais il fit avec lui et deux autres la larnille des Coronulides, qui est la première de son second ordre. M. de Blainville, dans son Truité de Malucologic, a rejeté avec raison la famille des Coronulides, et a compris les Coronules dans la famille des Balanides ( $20 y$. ce mot), en y joignant les geares Chélonobie de Léach, Célopire et Diadème de Ranzani, ainsi que la 'Iubicinelle de M. Lamarek. Ce dernier genre est le seul qui mérite d'être conservé, et et nous y renvoyons.

L'auatomie des Coronules n'a pas encore été complétemeut faite. On pent jugcr, par analogie, que leur animal ne doit oflir que peu de dillérences avec celui des Balanes. M. Lamarck l'a caractérisé de la manière suivante :

$$
\text { CARACTÉRES GÉNÉRIQUES. }
$$

Corps sessile, enveloppé dans une coquille, faisant saillir supérieurement des bras, petis, cétucés et cirrheux. Coquille sessile, paroissant univalve, mais réellement fornıée de six pièces soudées, suborbiculaire, conoïde ou en côse retus, tronqué aux extrémités, à parois trèsépaisses, intérieurement creusées en cellules rayounantes. Opercule de quatre valves obtuses. 
Les bords de la coquilfe ne présentent jamais lé bourrelct qui forme les bords de celle des 'I'ubicinelles, ut cocore moins celle série d'anneaux circulaires et horizontaux qui composeot celles de ces dernières. L'ouverlure est ovale, arrondie, fermée es partie par l'opercule, rui est trop petit pour la remplir, et en partie par uue membrane mince quíatlière an pourtour. La cavité iutérieure est conique et entièrement tapisscie par le manteau; la lame qui recouvre les cellulosilés, et qui dans les Balanes est loujours incomplète, est ici entière el descend jusqu'au fond. Ou a remarçué que l'un des caractères des Balanes est d'être leronés inlérieurement par une lame testacée adluérente. Dans les Curunules, l'ouverture inléricure est simplemeut close par mue membrane assez épaisse. La roquille, dunt l'épaississemeat va ena augmentant ver's la base, est composée d'une multitude de lames rayonuantes, dont les unes sont coinplètes, c'est-ddire qu'elles s'étendent de la paroi interace à la paroi externe, tandis igue d'aulres intermédiaires partent de lit parin tealeme, pout ne s'avauces que jusqu'au milien de la cavitée que laisseu: eutre elles les preuières. I.es Cormules suot toutes adherentes par leur bases; te plus grand nombre se fixe sur la peau des grand's anibisux marins, s'v enfonce de quelques lignes et s'y montre quelquefuis en grande abondance; dautres se tixent sur les corlues, méme sur loule espèces de corps durs suus-1uarins, comme des coquilles, etc. C.e geure est peu nombreux en especes, lruis seulcueal sont conates : ce sant les suivales.

\section{Coronore diàdême. Coranula diadema.}

I.Asc. Anim. s. vert. tom. 5. p. 387. ñ. 1 .

Hruguicerc a très-bien décrit et domué une syvonymie fort bonue de celle espéce, quil nomine Bulumie diademe, dans le premier volume de ce Dichonaaire, pag. $171,1^{\circ} .18$. Nous y renvinuas.

2. Corosule rayounere. Cononulu buluriars.

C. testí orbiculato-convexâ, rudiis sex antEu-fis transserse strublis; interstitiis sulcatis; sulcas rildiantibus.

iАмк. loc. cit. $z^{\text {b. }} \mathbf{2}$.

Lepas hahenaris, Lik. pag. 3208. no. 5 .

Pediculus balcenaris, Curms. Conch. t. 8. pag. 93. $f g .845$ el 846 .

Batunus balanaris, Виче. Encycl. pl. 160 . fg. 17 et 18.

Celle-ci se distingue facilement de la précédente; elle est orbicnlaire, conrexe, aplatie, purrue de six rayons étroits, striés trancersalemenı: les intervalles gai séparcat les rayons soa ógrilecueat striés, inais le stries soat dayuanialos en partaut du sommet pour se diriger \& la base. linné dit que lopercule est seulement formú de deux parties et qu'il est presque membraneux.

\section{Corosure des tortues. Coronula lestudina-} ria. Lask.

C. testâ elliptico-convexâ; radiis sex angustis, trunsierse strutis; interstitiis hevibus.

L.sur. loc. cit. $n^{\circ} .3$.

Lepas testudirariu, Lis. loc. cit. $n^{\circ} .6$.

pediculus testudinarius, Cumsixz, Conch. $t .8$. pl. 99 . fig. 847 et 848 .

Rempnos, Mus. tab. 40. fig. k.

Bananite des turtues. Balanus tesludinarius. Encycl. pl. 165. fig. 15 el 16.

Cette espèce est généralement plus aplatie que les deux autres; clle est convexe, blanche, scin nuverture est ovale, fermée par un opercule quadrivalve; elle préseute six rayons élroils, striés tranversaleneut, et séparés par des espacies lisses; la cavité iutérieure est plus grande ioférieureunent que supérieurement : c'esi le contraire dans la Corunule diadéme.

\section{CORONULIDES. Coromulidea.}

M. Léach a proposé celle famiile pour circonscrire quelques genres placés avani tui dans la limillecies Balaades. Les caracières que M. Leach lui clomise sont insuftisans; its reposcnt seulenent sur la coquilite et nullement sul l'animal, qui est trop sermblable à celui des Balanicles, pour quon puisse ainsi élablir une lamil.e suns nécessité. II I a cumposoit des genres Coronule, Tubiciselle et Clićlonobie (voyez ces mots), qui peuvent faire uae section de la famille des Balanes.

\section{CORSELET.}

Par ce mol on eutend daus les coquilies bivalves, la parlie oǹ s'insère le linameut lorsçüil est extérieur. Voyez l'article Concarococis daus le premier volume de ce Diclioonaire.

\section{CORTALE. Cortalus.}

Genre proposé par Montfort (Conch. syst. tom. 1, pas. 115), pour une cogullie micrascerpique qui, n'atyaut pas été retrouvée, reste dnitteuse. Il. d'Orbigny, daus son grand Iravail sur les Céphalopode's, a mis ce gemre, avec un point

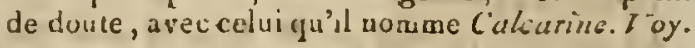
ce mor.

\section{CO'MAN.}

Nom qu'Adanson (Voyage au Sénémul, $p$. .24́) donoe à la Venus exoleta de Linné, qui appsilient au genre Cydiéric de M. Lamarcl. Fojez (그는. 


\section{R A}

\section{COTIQLE BLANC.}

C'est ainsi que l'on nomme vuigairement, et dans le commerce, le Cyproza annulus. Voyez Porceratsi.

\section{COULEUTRE. Colubrarica.}

M. Sclunnaclier a douvé ce nom à un démembrement inulile des Ranelles. Vuyez ce mot.

\section{COUPET.}

Nơn qu'Adanson a donné au Còne hébraique. Trajez le mo: Cóne, au prenier volume de ce Dictionmaire.

\section{COURLI.}

Nom que les marchands donnent an Murex hausicllum Lin. Foye: Rocuer.

\section{COURLI EPINEUX.}

I.e .Murex hrandaris Lin. est ainsi nommé par les marclands. Voyez Rocher.

\section{COURONNES (les).}

M. de Ferussac a lormé eette famille avec un démenbrement des Volutes de 11. Lamarck; il n'y mit que celles qui. élant minces et fort anples, avnient été séparées par les anteurs à titre de sections dans le genre. Il nous semble que celte famille u'est pas plus admissible que le seul genre qui la compose. Vojez Vulvte.

\section{COUTEAU. Cullellus.}

En démemlirant le genre Solen, M. Schamacher a poussé peut-êtré un peu loin le desir de faire des noureaux genres; celui-ci pourroit en Atre la preuve, car il ne repose que sur de bien foibles caractères : il ue doit contenir en eflet que les espèces de Solens qui, coume le Solen cultellus, sont recourbés dans leur lougueur. Tojez Sole.v.

\section{COUTOIR.}

Sur nos côtes, on donne rulgairement ce nom à la Vénus clonissc. Voyez Vévus.

\section{COVET.}

Dans le Vojage au Sćnégal (pag. 114. pl. 8. fig. 9.) Adanson donne ce nne au Buccinum condor Lin. Voyez Buccis.

\section{CRANCHIE. Cranchia.}

Genre instilué par Léach, qui divisa les Céphalopodes décapodes en deux familles, les Sépiolidées et les Sépiacées; c'est dans celte preière que se trouve le geare Cranchic qu'il dédlia a-Crancl, vojageur anglais, qui a montré le plus grand zćle pour la zoologie. Ce genre, iris-voisin des Calmars, ne fut point adopté à litre de genre. N. de Ferussac, dans ses Tuhleau.v sistématiques, en fit un groupe du genre C.alcnars. M1. cle Blainville ne le sépara pas d'une autre manière, il en fit aussi un groupe des Calınars. M. d'Orligny a pensé néanmoins que ce genre avoit des caracières suffisans, et il l'a unuservé dans son Tableau méthodique des Mollusques céphalopodes (2oyez ce mol): d'uprès ce que nous connoissons de ce genre, hous pensons qu'ul est trop peu distinct des Culmars pour quinn puisse en faire un genre. V̌oyez Calmars.

\section{CRANIE. Crania.}

Le genre Cranie, instilué par Bruguière, aroit été confondu par I.inné parmi les Auomics : il ne connoissoit quiunc seule espèce qui püt se rapporter au genre de Buguière; c'est l'Anonin craniolaris. Depuis Bruguière presque lous les conchyliologues ont adois ce genre : MIII. Lamarck, Mínerle, Ocken, Defrance, de Blainville sont de ce numbre. N. Cuvier n'en fait pas menlion; il ne le cile méme pas parmi les Anomies : quoi qu'il en soit, ce genre ne doit plas être p!acé parmi les Multivalres, comme le pensoit Bruguière, car il n'a avec eux aucun rapport de forme et de structure; et ces trous, doni la valve inféricure paroissoit percce ponr l'insertion les muscles sur des osselets analogues à ceux des Anomies, est un fail que l'observation a détruit. Les Cranies n'ont point de charnière: déponrvues de ligament et de dents propres à retenir les deux valves, il est fort rare de les trouver ensemble. Dans les espèces fossiles surtout, on fi: long-temps à ne connoitre que la valve inférienre de la plupart des espèces; aujourd'lui, comae nous le verrons bientôt, ellez sont plus compléte. mont décrites.

Placé d'abord parmi les Multivalves, ce genre fut transporté par M. I amarck dans la famille des Rudistcs, et mis en contact avec les Discines, les Birostrites, les Calcéolcs, les Radiolites et les Spilcérulites. On verra à l'article PioDisTE combien celte fumille a bosoin de cluangemens, cl nous chercherons ì démontrer quelle devra se réduire aux seuls geures OrBicule, Crame el Calcéole. Vojez cos mots.

Il manquoit une lionne monographie des Cranies; MI. Hoeningliaus, en se chargeant de ce travail, a rendu uu grand service à la science. Nons-seulement il a réuni les élúmens dispersís daus les ouvrages et a complété la synonymie, mais encore il a ajouté un assez grand nombre d'espèces nouvelles et fait micux connoître rguelques-unes qui éloient iocertaines. Toutes les espèces sont représentées avec un soin et une variété qui ne laissent rien à desirer : ces bolles 
figures prouvent que la. lithographie peut, dans des maius labiles, rivaliser avec ce que la gravure sait faire de mieux.

\section{CARACTÉR GÉXंतIQUES.}

Coquille inéquivalve, suborbiculaire, préscntant $\ddot{\mathfrak{a}}$ l'intérieur de chaque valve qualre impressions musculaires ou fosseltes calleuses; valve sapérieure obıuse, conique, $\dot{a}$ sommet excentrique; valve infórieure aplatie, plus ou moins adbérente.

Nons avions pensé, avec flusieurs autres zoologistes, que les Cranies pouvoieut avoir de l'anaPogie avec les Ilipponices; celte analogie est iucontestable quanta la manière de vivre, aiusi quä la forme de la coquille el à la nature du support, mais c'est lí où se borwent lcs ćlénens de ce rapprochement; il devient impossible de te pousser plus Inin, lorsque l'ou compare les animaux qui appartieunent à deux types d'organisation bien diffírcute, el que l'on examine los carractères des coynilles et les iupressions qu'elles offent. Cependant, dans une bonne classification, nous pensons que l'arrangenent proposé par M. de Ble.nville dans son Truité de Malacologie sera adopté, car par son moyen, il conserve des rapport certains sans contondre des animaux de classes cilliérentes. Foyez Cazochos, oil nous arous lraité cette question.

Lorsurue l'on observe les Cranies vivanies et fossiles de differens terrains, on aperçoit entre elles des différeaces qu'il est nécessirire d'indiquer pont en faire apercevoir la cause. Ainsi, daus les espèces vivantes el fossiles des tertains tertiares, on tronve tonjours les impressions unusculaires pen profondes, quelquerois neême elles sont saillantes, et dans aucun cas ne présement des perforations ou des cavités profondes. 1)aus celles qui proviennent de la craie, an contaire, on irouve toujours les impressions musculaires profondes, coniques, quelyuefois en goutticres obliques. Si l'on lait alteution à la nalure des iunpressions musculatices, on reconnuít bientôt qu'elles ressemblent à celles du support des Ilipponices, c'est-it-dire, qu'elles sont formées d'une inatic̀re calcaire dissoluble, lorsque le reste de Ia valic estinsoluble; et si lon sé survient que, daus la craie, eerlaines parties des coquilles disparoissent toujours, que ees parties sont préciséneut aualogues, quant $\dot{a}$ la structure et aux autses propriétís, aux impressions musculaires des Hipponices el des Cranies, on devia en conclare que, dans les Carinies de la craie, ces partes ont subi la loi commune de la dissolution.

1. Cansie en inasque. Crunia personaiz. Lank. C. Jalpa inferiore avato-orbiculari, posíce retusa, cicatricibus posterioribus, obliquis, subren!formibus, anterioribus in unam orbicularem confuentibus tuberculosis; rostello nullo; aisco palmato, radiato; limbo antice incrassato; valós superione ablusâ, conica, irregulari, subsquamosí, rubrá.

LAмx. Anim. s. vert. toin. 6. pag. $238 . n^{\circ} .1$.

Crania Brattemburgensis, Retzius, Sch. der Berl. Gesel. tom. 2. tab. 1. fig. 2. 3.

Encyclop. $l a b .17$ 1. fig. 1.2.

Haningaus, Monogr. des Cran. pag. 2. $n^{n}$. 1. fig. $a . b$.

Les conchyliologues qui, depuis M. Lamarck, ont oliservé des Cranies vivantes, les ont rapportées à celte espèce sans faire trop allention si elles ne portoient point de caractecres suflisars pour les dislinguer. M. Ifoninghaus, après uu examen plus atientif, a séparé deux espèces bien distinctes. Celle-ei est orbiculaire, adliérente par loute la surface inférieure de sa valve, plaue á l'intériear ; celle valve présente des impressions limbiformes, étroites et profondémen: séparées; daos la partie moyenne et postérieure une daulale impression arrondie, assez grande, quelquefois tuberculcuse, et derrière elle, de chique côlé, une iurpression plus petite, ovale, réniforme eb oblique. Le limbe est épaissi et très-finement poneuré; la valve supérieure est patellitorme, cunique, peu iparisse, d'un ronge olscur en dehors, blanche et ponctuće en dedans; ses bords sont minces, tranchans, el ses slries d'accroissetnent irrégulières sont un peu écailleuses. Cette coquille, très-rare Iorsqu'elle est complète, se se trouve duns la Mléditerranée; elle a 12 a 15 uillim. de diamètre.

2. Cranie grimaçante. Crania ringens. II $\alpha$ s.

C. lestâ suborbiculari, valvâ in feriore, postice retusá; cicatricabus posterioribus, subtrungularibus, irunsversis, anterioribus in unam trunsversalem confluentibus; rostello nullo; disco pedato; limbo anteriore, incrassato.

Crania personata, Buanv. Dict. des Scienc. nat. Állus, 5e. cah. fig. 2. d.

Idem, Malac. pl. 5g. fig. 2.

Anomia turbinata, PoLr, Test. ulr. Sical. tom. 2. tab. 50.

Haning. loc. cit. $n^{\circ}$. 2. fig. 2. $a, b$.

On ne connoit pas encore la valve supérieure de celte espècé; on ne peut douter cenendant qu'elle ne se distingue très-nettemeul de la précédente: sa valve inférieure cst narquéce dans sa ravité d'impresions irrégulières, llamboyanues; limpression médiane est peu profunde, ovale, transverse, toute lisse; les deux postérieures sont triang"laires, transverses aussi, ou du moins peu obliques 
ollicgues postérieurement; cette value est mince, taadis que son bord autéricur est épaissi et taillé en biseau. 'Toute la face interue est ponctuée, ct les ponctuations, plus grosses sur le bord, se confondent assez souvent, ou sont dispostes en séries et dunuent l'apparence de stries. P'lus petite que la prócédente, elle se trouve aussi dans la Méditerranée.

\section{Crasie rostrée. Crania rostrala. IIexisg.}

C. valuá inferione suhorb:culari, posticè retusia; cicatricibus posterioribus suborbiculutis, anterioribus in unan cordiformem confluentibus; rostello acuto; disco simusto; limbo antice arregulart, incrassato.

Hexisganes, loc. cit. $\pi^{\circ}$. 3. fig. 3. a. b.

Anomia creniolaris, Caess. Conch. tom. 8. tab. 76. fig. 687 . a. b.

Crania persoruata, Sow. Lssx. Transact. tom.13. tab. 26. fig. 3.

Ibil. Genera, no. 12. fig. 12?

Patella distoria, Mostage, Liss. Tiansact. torn. 2. tab. 15. fig. 5.

Coquille orbiculaire, à peu près semblable, quan i la foruce, aux précédentes, mais parlaitereat dislincte par tous ecs autres caractores. Les impressions musculaires dont la réunion en produit une seule ceatrale, sont séparécs ou indiqufes par une apophyse saillante, odtuse: médizue; celte ianpression est cordiforme et $\mathrm{eu}-$ tourée, a sa partie inféricure surtont, d'un large bourreler, qui, dans la ligne médiane et longiludioule, se prolonge en poivte jusque sur le bord. Les deux iupressions pastéricures sant arrondies, assez fortement séparées par un espace creusé en rountiere stuperficielle, subtrianguluite, qui aboutit an rostre de limpression médianc. 'Toute la surface intérieure est ponctuće, wais les ponctuations sont plus grosses et moins nombreuses que dans les deux espèces précédentes. Celle-ci acquiert la unêrae taille et elle vit dans la Méditerraoée.

4. Crayie ancienne. Crania prisca. Meevisg.

C. lesti valuá inforiore orb 'culari, postice integri; cicutricibus posterioribus subobliquis, ovatus, anterioribus didymis renifornibus, rus. te'lo acuto bifido subseparatis; disco radris obsoletis, parallelis.

IIcxisgasts, loc. cit. no. 4. fig. 4. a. b.

Cette coquille, que l'on troure dans desterrains plus anciens que la craie, est remarquable par son gissement d'abord, puisque long-temps on a cru que les Cranies fossiles ne se tranvoient pas au-dessous de la craie. Comme espèce, elle ne peut se confondre avec aucune autre: l'in- pression masculaire moyenne est profonde. iransverse, étroite, surtout dans le miliea où cile est dominćc par une saillie bilide, ar rondie surles cìlés; les impressions postéricures sont grandes, ovalaires et placécs obliçuemeut. Les impressions du limbe sont régulières, rayonoantes, et vont toules du bord vers l'impression médiane. Le bord simple et rérgulier, est mince postérieurement et épałs antérieurconeat. Celte coquille sest trouvée, d'après M. Ileninghaus, à Dusseldorf, dans la Grauvake. Elle a I 8 willim. de long.

5. Canane monnaie. Crania nummulus. Lasz.

C. valu.i inferiore orbiculuri; foveis penetrantibus, posterioribus subtnquetris bipartitis, anteriorbus didymis, dissepmento obluso discretis; 10 stello bifido; disci impressionibus radiantibus, obtusis; linmo incrasiato, convexo.

IIcsivg. loc. cit. $n^{\circ}$. 5. fig. 5. a. b. c.

LAš lor. cit. $n^{\circ}$. 2 .

Nirsow, Act. Acad. Holmice, 1825. tab. 2. fig. 1. et Petref: suec. tab. 3. fig. 11. A. D.

Anomia craniolaris, Lixx. Faun. suecica, pag. 520. Ibid. Sj st. nat. pag. $5340 . n^{\circ}$. I.

Nummulus orrttemburgensis, Sтов жus, Dissent. epist. Limboe, J73̈. - MaxlikoRt, Broksaxs, Eprst. itin. cent. 2. epist. 38. pag. 3go. tab. 17 . fig. 10.

Ostracites nummismalis, Вечтп. Julice et mont. subterran. pag. ז5̄o. $4 a b \cdot 7 \cdot n^{\circ} \cdot 46$.

Crania numnulus, Sow. Gener. loc. cit. fig. 4.

La Cranie monnaie, nommće vulgairement monnaie de Bruttcmbourg, n'est connue quà̀ l'ćlat fussile. Elle est tout-i-lait circulaire, épaisse, adhérente seulcment par le sommet de la valve inférieure. Les iapressions musculaires sont profondes el traversent toute l'épaisseur du têt, ce qui lient certainemeat à ce que la substance qui les remplissoit a été dissoute. L'impression moyenne, formée de deux impressions distincles, est ovale, transverse, divisée en deux parties égales par un bourrelet longitudinal, au-dessus duquel domine un rostre largement fendu : les deux impressions postćrieurs sont également transverses et divisées en deux parties iuégales par une arête. On remarque daus le limbe des stries régulières et rayonnantes, qui se dirigent de l'impression muyence jusqu'uu bord : celui-ci est épais, furtement granuleux, mais ces granulaLions sorıt souvent conflnentes par séries, surtout vers l'extrémité de ce bord. Diam. I5 à 18 millim.

\section{Cranie antique. Cranie antiqua. Derr.}

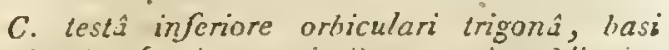
productá; foveis posterioribus ovatis, obliquis, marginatis, anterioribus didjmis, dissepiniento 
acuto discretis; rostello bifido, acuto; disco sinualo-lobalo; limbo granuloso; valvîs superiore regulari, patelliformi, lavigatá; apice acuto, posticè incurvo.

Defr. Dict. Sc. nat. tom. 11. $5^{\text {me }} \cdot$ fasc. de plunc'l. fig. I.

HIexivgaus, loc. cit. no. 6. fig. 6.a. $-f$.

I AME, loc. cil, $n^{\circ} \cdot 4$.

Sowerit, Truns. linn. soc. tom. 13. pl. 26 . fig. 4. et Genera, loc. cit. fig. 7 .

M. Hounghans a signalé trois variétés principales qu'il rapporte à celle espèce. A ne considérer que les excellentes figureś de cet autear, on pourroit croire qu'elles appartiennent à autant d'espèces distinctes; mais on est bientôt désaluusé quand on peut examiner un bon nombre d'individus de celle espèce : on les voil alors passer d'une variélé à l'autre. Elle se distingue par le long talon de la valve inférieure, anquel on remarque en dessons une tiès-petite trace d'adhérence. L'impression moyeane est ovalaire, transverse, séparfe en deux par un bourreleı aigu qui correspond el souvent est reçu entre les bords du bec fendu qui domine cetle impression; elle est entourée inférieurement d'un bourrelet qui se termine en une poiate desceodant le plus souvent jusque sur le bord. Los deux impressions postérieures son! ovales, obliques el légèrement échancrées au bord externe et supérieur; le bord est épaissi el tonjours granuleux. La valve supérieure est de la forme d'un petit Cabochon symétrique, à sommet pointu, inclioé postérieurement; elle est toute lisse. Celle coquille se trouve daus les terrains de craie moyens et inférieurs.

\section{Crante tuberculeuse. Crania taberculosa.} NiLs.

C. testâ orbiculuto-ovatû, posticè retusâa, extìs subliliter granulatâ; valvîs superiore convexâ, intùs rudiatim striato-granulatî̀; vertice excentrico; valos inferiore planulatâ; disco intùs et limbo parùm incrassato, tuberculatis.

HœNivgaus, loc. cit. no. $7 \cdot f g \cdot 7 \cdot a .6 . c . d$.

Nilson, Act. acad. Holn. 1825, tab. 2. fig. 3. a. b. c.

Ibid. Petref.tab. 3. fig. 10. a.b.c.

Cuenisz, Conch. tom. 8. tab. 76. fig. 687. $\mathrm{c}$.

Craniolites: brottemburgensis, Schlotueim, Petref. tab. 28. fig. 5.

Lncyce. pl. 17 I. fig. 5.

Espèce très-facilement reconnoissable : elle est la seule qui ait à l'intérieur des deux valves de gros tuber"cules répandus non-sẹulement sur le-lyord, mais encore sur tout le reste de la face interne. Elle est ovalaire, sans talod postérieu. ì sa valve inférieure, aplatie et rayonnée; cette valve offire une double impression médiane; transverse, étroite, parlagée par une arete mogenne, aiguë, couverte par un rostre saillant et prolondément bifide. Les impressions postérieures sont ovales, écartées, et ont leur grand axe presque perpeudiculaire : des stries rayounautes partent de limpression centrale et se dinigent vers les bords. La ralve supérieure est de la mème taille que l'autre : elle est patelliforme; sou sommet est excentrique et postérieur; en delors, cette valve, ainsi que l'intérieure, est couverte de granulations très-tines el très-serrées. Celle coquille, qui a 12 ou 13 unillim. de long, se tronve aux environs de Copenhague.

\section{Cratre épaisse. Crania parisiensis. Defr.}

C. testâ urbiculari, posticè truncatâ, cicatricibus posteriobus val'ce inferiors orbiculatoos'etis; anterioribus in unan transversalems confuentibus; rostello late marginato; disco scrobiculato, radiis impressis subparallelis instructo; margine valde incrassato; valvâ superiore conicu, elatâ, apice obluso, postice inflexo, intus duabus apophy'sis divaricatss instructa.

Høing. loc. cit. fig. 8. a. b.c.d.

Laмx. loc. cit. no. 3.

Defr. Dict. Sc. nat. loc. cit.

Sow. MIin. conch. pl. 403.

Broxg. Géol. de Paris, pl. 3. fig. 2.

II y a un inconvérient de donner à une espèce un nom de localité, et celle-ci en est un exenple, puisquelle se trouve ailleurs que dans le bassin de Paris. Elle est la plus grande du genre, el, quoiqu'assez commune duns la craie de Mleudon, on ne connoissoit pas eocore la valse supérieure il y a quelques anzées. M1. Michelin, amateor distingué, fut le premier qui la posaćda à Paris; depuis, elle a été retrouvée plusieurs fois par M. Duchastel, qui a mis nn zèle iufatignable à la recherche des fussiles de la belle localité de Cypli.

l.a valve inférieure est aplatic, épaisse, trunquée postérieurement, peu concave, et le plus souvent adhérente par toute sa surface aux corps sous-marias. La double impression musculaire moyenue est d'une médiocre étendue, ovalaire et lransverse, dominfé par un bec largemeat lendu. Les impressions postérieures sont distantes, arrondies, ovales, un peu obliques. Sur le limbe on remarque des impressions droites et profondes, subrayonnantes, profondément découpées depuis le bord jusque près de l'impression moyenne. laa valve supérieure est patelliforme, conique, poinlue, à sommet ceotral et un peu incliné postérieurement; elle est lisse à l'extérieur ou marquée seulement par des accroissemens : en dedans elle est pourvae de deax apophyses saillantes en forme de V, dont le sommet est dans celui de la coquille; ces apophyses donneat altache aux 
muscles antérieurs. Nous arons sous lcs fetix un indisidu de cette espèce qui a 31 millim. de large, et M. Duchastel nuus en a montré un fragment qui arnonçoit une corguille d'au moins 45 millin. de diauètre. Cette coquilie se trouve à Meudou ot a Cypli, près Mac̈stricht.

\section{Crasie strife. Crania striata. Defr.}

C. testós libcrá, orbíulatá, radiatine striatocostatá; valv. inferiore depressâ, cicatricibus postcrioribus rotundutis, unterioribus minimus, (sp) roxumatis, nostello integro, elongato, acuto, curmato, separatis; disco pectinuto; limbo grumuioso ; valva superiore patell formi, conicá; apice postico, recto.

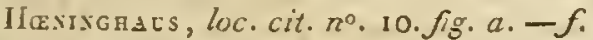

LAsts. loc. cit. $n^{\circ}, 5$.

DEFr. Dict. Sc. nut. tom. $1 \mathrm{r}$.

NiLsor, Act. Acad. Holm. 1825, tab. 2. fig. 4 .

Ibid. Petr. stuec. tab. 5. f.g. 12, $a$. d.

Crania egnabergensis, Retzios, Schrifi. der Bchyn. gesellsch. tom. 2. pag. 75 . tab. 1. fig. 4 à 7 .

Nummulus minor, Stozaus, Opusc. pag. 51. fig. 3.4 .

Cranuz costata, Sow. Genera, no. 12. fig. 6?

Excres. pl. $171 \cdot$ fig. 6. 7 .

Très-julie espère, pelite, déprimée, arrondie, subqualrilatère, sans aucune trace d’adlérence à la valve inférieure, élégamunent striée en dessus comme en dessuas; les strie; des deux vaives sont serablables, layounantes du sommet au bord; elles sont fines, serrées, et n'aboutissent pas toctes a sommet: il s'en trouve entre celles qui $y$ parvienneat, de plus courtes, intercalaires; je sommet est excentricque, postérieur, mais croil. En dedans, la valve inférieure oflie à peu près dans son milieu deux très-petiles impressions musculaires, arrondies, séparées par une apophyse saillante, pointue, droite, entière, qui faut saillie hors de la valve lorsqu'on la voit de profil. Les deux impressions postérieures sont tout-â-fuit rondes, assez grandes, bien séparées et un peu saillautes. Le limbe présente une impres. sicn profondément lasciniee; le bord, épaissi et aplati, est couvert de granulations. La valve suptrieure est concave; son bord cst fort large et granuleux comme dans l'autre valve: elle est patciliforme, régulière, symétrique et élégamment striće. Celle coquille a 10 millim. de diametre; elle se trouve en Scarie, a Bulsterg et à Charlottenlund.

10. Cranie ì cótes. Crania costata. Sow.

C. testâ subquadranguluri, radiatìn regulariter costuti, dentatí; walvá inferiore vertice subcen- trali; cicatricibus posterioribus ovatis, obliquis, unterioribus didymis; instello acuto; disci inpressionibus integris, lunatis; linbo granuloso.

Sow. Genera of sliells. no. 12. fig. 6.

II Exisg. luc. cit. fig. 11, a. b. $c$.

Pelite coquille dunt on ne connuit eneore que la vilve inférieurc; elle est arrondie, subquadranguluire et saos trace d'adhérence; son sumuset, olstus, est presque central; il en part en rayounaut dix â douze côtes arrondies, dont quatte, plussaillanies, se dirigent vers les angles ét se terminent sur le liord par des prolongemens assaz suillans; les autres côtes, en aboutissant sir.le burd, le découpent en dentelures woius saillantes. A l'intérieur", on trouve dans le milieu une apophyse aiguë, pró́minente, reconrbée en bec de perroguet, et séparant deux petites impressions obliques et superficielles; les deux impressions postérieures sont beaucoup plus grandes, ovalaires, obliques. L’impression du limbe est simple en croissant; le hord, assez large, épaissi et aplati, est couvert de nombrenses granulations dont les postérieures sont les plus grusses.

\section{CRAPEAU AILÉ.}

Les marchands donnent ce nom au Strombus latissimus Lin. Vojez Strombe.

\section{CRAPAUD. Bufonaria.}

C'est absolument le même geare que celui que II. Lamarck avoit nommé Ranelle et Monifort Bufo. En le présentant sous un ruisième nom, MI. Schumacher a fait un double emploi nuisible, puisqu'il multiplie sans nécessité la synonymie généique. Voyez Ravelle.

\section{CRASSATELLE. Crassatella.}

Ce genre, que M. Lamarck avoit d'abord fait connoître sous le nom de Paphie, paphia, dans la première édition des Animculx sans verièbres, reçut de lui le nom de C'rissatelle, d'abord dans les Annales du Muséum el ensuite dans la seconde édition des Animaux sans vertèbres. C'est cette seconde dénomination qui a été adoptée par les conchyliologues. Autant ce genre est peu nombreux en especes vivantes, autant il se troure abondamment fossile; mais, comme le remarque 11. Defrance (Dict. des Scienc. nat.), il ne se rencontre jamais dans ta craie ou dans les terrains qui sont au-dessous d'elle; on ne le voit que daus les terrains tertiaires et surtout dans cenx des environs de Paris, quoiqu'il y en ait aussi quelques espèces en Angleterre dans l'argile plastique de Londres, qui remplace, par la position geologique et la natnre des fossiles qu'elle renlerme, nos terrains parisiens. Quelques espèces de ce genre avoient été connues de Chemnitz, de Grelin, de Bruguicre; maís les deux 
premiers les avoient confondues avec les Vénus, et le demier avec les Hactres, arec lesquels eiles ont eflectivement bien des rapporis. Mais on n'aroit ancune idée de ces belles Crassatelles si rares et si précieuses, qui furent rapportćes dans ces derniers temps de la Nouvelle-Hollande, et qui se voieut dans la magnifique collection du DInséum : espèces d'autant plus inléressantes, que l'une d'elles nous offre l'analogue d'une de nos plus communes coquilles aux environs de Paris. Ce firit, ainsi que celui relatif au Cérite géant et quelques autres semblables, font penser que ce pourroit bien être daus ces aers éloigncés que l'on devroit chercher, non pas tous les analogues de nos espèces fossiles en général, mais peut-ĉtre une quantité sullisante pour en tirer des conclusions satisfaisanles, qui tendroient à prouver un changement notable de température, quelle qu'en soit la cause première. Quoi qu'il en soit de ces considéralions générales, qui, si elles étoient appuyées d'un grand nombre de faits, pourroient bien servir de véritables bases à l'histoire de la terre, voici les caractères qui distinguenl les Cressatclles des genres voisins :

\section{CAR $\triangle$ CTÉRES GÉRÉRIQUES.}

Coquille inéquilatérale, suborbiculaire ou transrerse; valves non bâillantes; deux dents cardinales, subjivergentes et une fossette à côté; ligament intérieur inséré dans la fossette de chaque valve; dents latérales nulles.

$\mathrm{Si}$ nous considérons quelle place doit occuper les Crassatelles dans la série des genres, nons verrons d'apiès les caractères énoncés, qu'elles doivent se rapurocher beaucoup des Mactres, dont elles ont le ligament inléricur, et des Erycines, dont quelịues cspèces se rapprochent assez pour avoir été confondues dans ce deruier genre par. quelques conchyliologues.

II. Cuvier ( Reg. anim. tom.2.pag. 474.) place les Crassatelles à côtć des Cardites et des Vénéricardes, quoique dans ces derniers genres lü position du ligament et la disposition de la charnière soicat bien difiérentes. Il dit : "Je ne doute » guère que ce ue soil encore la place des Cias2) satelles, que l'ou a rapprochées, tantôt des " Iactres, tantôt des Vénus. "El plus bas : "Leurs valves deviennent très-ćpaisses avec l'âge, » et l'empreinte des bords du manteau donne à » croire que, comme les précédentes (les Car„ dites et les Vénéricardes), elles n'ont pas de " tubes extensibles."

Cetle manière d'énoncer avec doute et arec une grande réserve les caractères qui pourroient le mieux servir à placer convenablement ce genre, font penser que M. Cuvier avoit lui-méme peu de données, et que ce n'est que par une analogie éloignée, qu'il l'a provisoirement placé comme cinquième genre des Mytilacées.
M. de Ferussac ( $T a b$. syst. des anim. moll. pag. 42) établit nne fumille pour les Crassatelles, en y joignant le genre Crassiue. Ces deux genres, sils onl entre eux certains rapports, manquent de ceux rclatifs à la charnière et à la position du ligameut.

Les Crassines se rapproclent, comme tout le monde en convient, des Vénus, tandis que les Crassatclles s'en éloignent davantage. Cependaut dans ces derriers tempa, M. de Blainville, dans son Traité de Malacologie, trompé sans rloute par un faux rapprocbement, mit les Crassatelles tout à côté des Ténus, les sénarunt des Miactres, des Erycines et autres geures à ligament intérieur, parce qu'elles n'ont point de dents latérales. L'impression du manteau étant simple, on peut supposer avec quelque raison que l'a aimal des Crassatelles est dépourvu de siphons, sans qu'on prisse cependant l'assurer, puisqu'il pourroit arriver qu'elles fussent semblables à I'Jridine sous ce rapport. Parmi les espèces vivantes citćes par 1I. Laurek, il en est plusieurs qui devront sortir du genre, car elles se rapportenl aux Erycines de II. Suwerby, ou aux Amphidesnues de M. Lamarck. Voyez ces deux mol

Le nombre des espèces connues vivantes n'est pas encore considérable; celui des espèces fossiles le surpasse de beaucoup. Nous nous conienterons de citer les espèces suivantes, qui sont les plus intéressautes à connoîtue.

1. Crassatelle de King. Crassatella Kingicolcz. Lamx.

C. test $\hat{\jmath}$ avato-orbiculat $\hat{a}$, subgibbâa, fuscâ, intùs albida, duabus muculis rufis lateribus munitâ; stris transversis, exiguis; nutibus plicatis.

Laxarce, Ann. du Mus. vol. 6. pag. 408. - Anim s. vert. tom. 5. pag. 48 r. no. 1 .

Sow. Generc, n०. 3.

Cette Crassatelle, rare et préciease, est revêtue d'un épiderme brua, qui disparoil vers les crochets. Elle est orale, orbiculaire, Epaisse, enflée, d'un bluuc-jaunâtre, obscurément rayonnée, et orzcé à sa surface de stries très-fines el trèsserrées, quelquefois irtégulières, présentant plutôt des traces d'accroissement; les crochets sont plissés, peu proéminens. Celle coquille, large de 2 pouces 9 lignes, se trouve dans les mers de la Nourelle-Hollande, à l'ile de King. Nous en possédons un jndividu maguifque, qui a 110 millim. de large, quatre pouces.

2. Crassatelze sillonnée. Crassazella sukcata. LAMS.

C. testâ ovato-trigonâ, valdè inaquilaterá, gibbâ, transversim sulcato plicata ; latere antico angulato, productiore. 
LAsx. Ann, du Mus. pag. 408 et 409. $n^{\circ} \cdot 2$. pour la fossile.

Anim. sans vert. loc. cit. $n^{\circ}, 3$.

Fassilis, Noв. Descript. des caq. fass. de puris, tam. 1. pag. 35. n०. 2. pl. 5. Jig. 1. 2. $\overline{3}$.

Celle-ri est uue des espèces les plus intéressantes, puisqu'elle nous ollire l'analogue d'une de nos espèces fossiles que l'on tronve abundamcent aux environs de Beauvais, à Bracheux et à Albeconrı. C'est uoe coquille ovale, trigone, très-iućquilatérale, un peu enflée, éléramment slilonuée transversalement; le côté antérieur est anguleux, proéminent; les sillons, diminuant de yrosseur vers les crochets, devienusent des stries fires qui fiaissent par disparoitre an sommel; la lunule et le corselet sont bien marqués et enfoncés. Celle espèce, qui vient đes mers de la Nourelle. Hollaode, à la baye des ChiensMlains, présente plusienrs variétés. Isa première ne differe que par le volume, c'est la fossile de Bracheux: la secoude est moins arrondic, bięn plus transverse, mais plus épaisse et plus globuleuse, presque bossue ; également fossile de Braclieux et d'Abbecourt : la troisic̀me eufin est plus dćprimée et présente des silious ou des plis plus rúgulitrs, ce qui rend la coquille plus élégante.

3. Crassatelee scutellaire. Crassutelle srutel Lanu. Nов.

C. testâ avato-trigonâ, depressâ, angulutâ, irreguluriter sulcatâ; lunulî̉ henceolatâ, prufundi; unbonibus minimis.

Nов. Dict. class, dhist. nat.

Jbid. Descript. loc. cit. $n^{\circ}, 11, p l .5$. fig. 1. 2.

Cette grande coquille, ovale, trigone, aplatie, dont le lêt est très-épais, a le bord st:périeur anguleux, subrostré. De la lunule et du bord postérieur partent des sillons qui s'aplatissent sur la surlace de la coquille et qui disparoissent vers le milieu; la lunule est très-enfoncée; le corselet l'est aussi, et il est circonscrit par une côte saillante; les crochets sout peu proéminens; la lame cardinale est large; l'impression du ligament est grande, irrégulièrement triangulaire; le bord inférieur des valves est crénelé. Elle est longue de 2 pouces 3 lignes et large de 2 pouces 9 lignes : nous l'avons décuuverte à Abbecourt, is deux lieues de Beauvais, dans une localité semblable à celle de Bracheux, mais plus importante, car elle pourra servir à décider l'äge et la vraie position géologique des fossiles de cette dernière localité.

\section{Crassaterle enflée. Crassatella tumida.} Lami.

C. Testâ ovato-trigonâ, atate gibbâ, crassissimzâ, antico latere anguluto; natibus transversd sulculis; margine intus denticulato.
Venus ponderosa. I.r. Ga ar. pag. 328a. $n^{\circ} \cdot 54$.

L, यи. Ann. du Mus. tom. 6. pag. 408, et tom. 9. pl. 20. fig. 7. a. b.

Ibid. Anim. s. vert. loc. cit. $n^{0} .12$.

Nов. Descript. loc. citat. $t^{\circ}, 1, p l$. 3. fog. jo 11 .

Sow. Genera, $n^{\circ} \cdot 3$.

ExсчсLOPEDIE, pl. 259. fig. 3. a. b.

Cette espece fossile est une des plus grandes du grenre; elle n'est poilut l'analogne de la Kingicula, quoiqu'il y ait entre les deux espèces Leaucoup de ressemblance pour la forme et la taille; muis il reste assez de dillúrence entre elles pon' que l'on dislingue sans peine les deux espèces. Célle-ci est grande, enllée, surtout en vieillissant, lisse cu seulemeal marquée par des accroissemens vers les bords cl légìrement plissée ou sillonnée sur les crochets. Les bords sont épais et crénelés, la lame cardinale, très-large el fort épaisse, porte une charnière très-puissante qui se compose sur la valve droite d'une dent cardiuale pyramidale, triangulaire, trèsépaisse et un peu en crocliet, de chaque côté de laquelle se trouve uue fossette profonde; a côté de celle qui est postérieure se voit une fosselle triangulaire superlicielle, dans laquelle s'insère le ligament. Sur la valve gauche, entre deux dents obliques, se voit une cavité triangulaire, profonde, dans liqguelle est reçue la dent cardinale de lautre valve; à côté de la dent postérieure se trouve la fosselte du ligament. Les crochets sont petits, pen saillans, peu courbés an-dessus d'une lunule lancéolée, ova: wire et profonde.

On trouve abondamment cette coquille aux environs de Paris, à Grignon, Paraes, Mouchy, dans le Soissonnois, etc. etc. Elle a jusquà 120 millim. de large.

5. Crassaticue lamelleuse. Crassatella lanellosa. Lam

C. Testâ transversc̀ oblonğà, pluniusculà, lamollis erectis tiansversulibius remotis, postice angulatis, ornatâ; margine crenato; lunuli profundî, lanceolatú.

Lajn. Ann. du Mus. Loc. cit. $t^{\circ}$ 3. et tom. 9. pl. 20. fig. 4.a.b.

Ibid. Anim. s. vert. loc. cit. $n^{\circ}, 16$.

Tellina sulcata, BRANDER, foss. hant. tab. 7 . fig. 69 pro 89.

Var. B. Nов. Testâ turgidiore, transversint breviare.

Lorsqu'à l'article Mocuusque nous traiterons la question si intéressante de l'espèce, nons verrons combien il est important de constater avec soin les analogues fossiles dans diverses localités 
éloignées, el de faire remarquer les changemens qu'ils éprouvent, pour ensuite en lirer des conséquences plus générales. La Crassarelle larnelleuse, qui se trouve en Angleterre et aux environs de Yaris, sans qu'il y ail de différences appréciables dans ces denx localités éloignées, se retroure encore près de Talogues ópépartenent de la Mauclee, oà elle n’a pas non plus éprouvé de changemens.

Cette coquille est fort inécquilatérale, transverse, alongree; coupée obliquement postérieurement, et arrondie antérieurement; elle porte un angle oblique sur ce côté postérieur, qui aboutit à l'angle postérieur du bord. A l'extérieur, elle est couverte de lames longitudinales saillantes, distantes, simples el tranchantes. En dedans, les hords sont crénelés, l'impression palléale superficielle, et la cavité des valves peu profonde. Les crochets, petits et poiritus, et la charnière peu large. La lunule est profonde, lancéolée et ordinairement lisse.

Longueur 32 millim., largeur 51 . Elle est ordinairement moins grabde. Nó.

6. Crassatelne sinueuse. Crassatella sinuosa.

C. testá ovato-inflatâ, posticè angulatâ, sinuatâ; sulcis numerosis iiregularibus, lcevbus; murgine crenato; lunulá profundâ, ovatâ.

Noв. Descript. des coq. foss. loc. cit. $n^{\circ} .8$. pl. 5.fig. 8. 9. 10.

Coquille très-enllée, prergue cordiforme, olllongue, transverse, ioéquilatćrale, anguleuse postérieurement, couverte de sillons arrondis, peu réguliers, qui aboulissent à l angle postérieur ef s'y terminent. Le bord sinueux postérieuremeni, daos les individus adultes, se termine alors par un angle saillant; il est crénelé dans toule son étendue. La lunule est assez grande, protonde et ovale, lancéolée. Celle coyulle, a l'état fossile seulement, se trouve à Chaumont et a Monnerille. Elle est large de $5 z$ millimèrres.

7. Crassaterie fines-stries. Crassatella tenuistria. Nов.

C. testá ovato-transversá, tenui, gibbosá; striis tenuibus, regulanbus; umbonibus depressis; lumulà ovats; margine integro; cardine angusto.

No B. Descript. loc. cit. no. 9. pl. 5. fig. 13. 14.

Cette Crassatelle est petite, ovale, oblongue, transverse, presque équilatérale, concave, finement stivée sur toute sa surface; les stries des crochets sont plus fines que les autres; e!les sont un per arrondies, régulières, profondes; les crochets sont peu saillans, la lame cardinale étroite, -et les dents de la charnière sont petites; la lunule est large, peu profonde et orale. Cette petite coquille est rare; elle se trouve fossile a Chaumont, et n'a que 20 millim. de la:ge.
8. Crassatelle rostrée. Crassatella rostrata. Nов.

C. testâ transtersá, depressâ, ovato-rostnuti, crassis sulcis exeratâ; margino postico arcuuk.

Nив. Descrift. loc. cit. a $^{\circ}$. 3. pl. 5. fig. 6.7.

Coquille fossile bien distiacte de ses congénères par sa furme subtrigone el prolongée en bec postérieureasent. Lille est très-iuéquilatérale, transverse, iurt aplatie; ses crochets, peu courbés, très-ninces, pointus, opposés, dominent une peit te lunule lancéolée, profunde; la surface extérieure est sillonnée trausversalement; les sillous sout arrondis, réguliers, distans, et aboutissans au côté postérieur où ils se terminent. La chitrnière ne présente que deux fort petites dents, et une fossette aplatie à côté pour le ligauieal. On irouve celte espèce daus les grès marins, principalement à Senlis, et rarement dans les calcaires grossiers a Mouchy.

-9. Crassatelle trigonće. Cirassatella trigonata. LAлז.

C. testi parvilá, orbiculato-trigonâ; transversim eleganter striatí; natibus laviusculss; margine integerrimo.

LA 3 . Anim. s. 2'ert. tom. 5. pag. 485. $n^{\circ} .17$.

入ов. Descript. des coq. foss. loc. cit. $\pi^{0} .5$. pl. 5. fig. 4. 5 .

Crossatella trianguluris, L.а мг. Ann. du Mlus. tom. 6. pag. 411 . et tom. g. pl. 20. fig.6. a. b.

Cette Crassalelle est une des plus petites du genie, et sa forme subtriangulaire, aussi lon:rue que large, la rend très-facile à reconnoitre. Elle est ćquilatérale; les crochets, qui sont très-plats et puintus, font le sommet d'un angle presque droit, dont les côtés sunt formés par les cótés antérieur et postérienr de la coquille. Extédienrement, elle esi striće finement et régulièement. Les stries des crochets sont tellement lines, qu'on a de la peine à les apercevoir à l'oil nu. Il a'y a sur la charnière que deux petites dents trèsétroiles et une fossette pour le ligament. Cette coquille est commune aux environs de $\mathrm{Paris,}$ Parnos, Griguon, etc. Elle a 18 millinuetres de longueur.

10. Crassatelle comprimée. Crassatella compressa. Lask.

C. testí or'ato-orbiculatâ, planiusculâ; posticè angulati; sulcis transversis tenubus, sculariformibus.

Laмк. Ann. du MLus. loc. cit. $\pi^{\circ}$. 4. et toni. 9. pl. 2o. fig. 5. a. b.

Ibid. Anim. s. vert. loc. cit. $n^{\circ}, 15$.

Var. B. Ков. Testá postice latione, striis ad. nates exiguioribus. 
Nollis, Descnpt. coq. foss. loc. cit. no. 6.pl.5. fig. 8. 9 .

Nous avons réuni dans cette espèce, à titre de variété, une corquille que probablement on siparera conme espece distincte; c'est elle que nous avous fait représenter $p l .5$, fig. 3 et 4 , dans notre ouvrage sur les coquilles tossiles des envirens de Paris. Elle est constamment plus large et présente d'autres caractères. Quant à la Crassalelfe romprimée, elle est subtriyone, transverse, inćquilatérale, obtuse, arrondie antérieurement, subrostróe postérieurement, couverte dans touie son étenduo de stries lamellenses transverses, plus écartices sar les crochets que vers le Lord des valves, qui est peu épais et légèrement crénelé; la lunule est fortétroile, enfuncée, ainsi que le curstlet. La variélé que nous avens indiquée se reconnoit à sun côté postérienr plus large, sesstries plus fioes et aussi rupprochées sur les crochets que sur le reste. Celle corquille, qui se trouve à Grignon et autres lieux, a 30 millim. de large.

11. Crassatelle bossue. Crassalella giobosulci. Lasir.

C. testí ovatâ, tumido-gibbosâ; angulo posticò emmente; lamellis trunsversis, crrguis, prominentibus et postice tuberculo minimo seriatim internutis; lunulâ profondè lanceolatî.

LА⿱一⿻上丨日. Anu. du Mus. loc. cit. no. 5. 6. 7 .

Noв. Descript. loc. cit. $n^{\circ} \cdot 7 \cdot p l .5$. fig. 5.

Cette espèce, assez graude, est gonllée, bossue, sabcordiforase, transverse, trìs-inéquilatérale; la partie postérieure séparée du rcste de la surface par un angle assez saillant. Elle est toute couverte de lames minces, élevćes, tranchantes, rérulièrement espacées et interrompues sur le nullicu dn cóté postérieur par uu petit inbercule pointu. La lunule est profonde, lancéolće, toute lisse et petite. Le bord interne des valve's est crénelé, mais les crénclures sont plus grosses postérienrement. Cette coquille, que l'on trouve aux environs de Paris, à Chaumont et à lluudan, est large de 54 millim.

\section{CRASSATELLES (les).}

Famille que M. de Ferussac proposa dans ses Tableaux systématiques des animaux mollusques, pour réunir reux genres qui ont bien entr'eux quelque analogie, mais qui offrent trop de diflérences, quant à leurs caractères essentiels, pour quils restent ensemble. Celte famille a'a point été adoptée. Voyez Crassatelie.

\section{CRASSINE. Crassina.}

MI. Sowerby avoit établi ce genre sous le nom d'Astarté, lorsque N. Lamarck le reproduisit sons celui-ci, ignorant sans aucun doute qu'il existât déja; il est de toute justice de lui conserrer le nom de son premier auteur. Voyez Astanté.

\section{CRATIUM.}

Ce mot est accompagné de l'explication suivante dans le Dictionnaire des Scicnces naturelles: "Dargenville nomme ainsi l'Ostrea frons " de Linné. "Nous avons fait observer à ce sujet, dans le Dictionnaire classique d'Histoine naturelle, que le mot Cratium ne se trouvoit dans Dargenville pas plus que l'Ostrea frons dans Linné.

\section{CRÉNATULE. Crenatula.}

Ce genre fut créé par M. Lamarck ( $A n n$. du Mus. vol. 3. pag. 25) et adopté par presque tous les conchyliologues. Les coquillages que. renferme ce geme préscutent des particularités remarquables, tani duns leur manière habituelle de virre, que par la disposition du ligament, qui en fait un passage bien évident du genre Pinne, compris dans la famille des Mytilacées de Lamarck, a vec ceux de la suivante, les Malléacces (Perne, Marteau, Avicule). En effet, ce genre présente un ligament marginal continu, étendu sur le bord; landis que dans les Crénatules, on voit le lirament divisé dans des échancrures du bord cardinal, et, par cela même, commencer à se montrer multiple. Dans les Pernes, il est toutà-fait divisé par portions bien distinctes non continues et sur un très-large bord. Lianimal des Crénatules n'est point connu, mais vivant dans les éponges, et n'ayant jamais été vu que dans celte circonstance d'habitation, cela donue à penser, yu'outre les modifications qui se remarquent sur les coquilles, il a dâ lui-mème en épronver de particulières, en relation au moins avec sa manière de vivre.

\section{CARACTÉRES GÉNÉRIQUES.}

Coquille subéquivalve, aplatie, feuilletée, un peu irrégulière; aucune ouverıre latérale pour le byssus; charnière latérale, linéaire, marginale crénelée; crénclures sériales, calleuses, creusées en fosselles et qui reçoivent le ligament.

Bruguière avoit connu une coquille de ce genre, mais il l'avoil confondue avec les Monles, comme on le voit par la figure 2 de la 216 e. planche de ce Dicionnaire.

N1. Cuvier (Règn. anim. tom. 2. pag. 466 ) l'a adopté et l'a placé entre les Arondes (Avicules, Brug.), les Pernes et les Jambonneaux. M. de Ferussac (Tableaux sjst. des anim moll.), dans sa famille des Aviculées, place le premier le genre Crénatule, qui, comme Lamarck l'a dit le premier, sert de passage des Pinnes et des Inocérames de NI. Sowerby (Catallus, Brong.) aux 
Perves; cufin, il a été adopté par MM. Schweisuer, Ocken, Bliinville, etc.

Les espèces du genre Crénatule sont rares et encore peu connues; elles habitent les mers chaudes, et il n'estopas venu à notre conaoissance quion en ait rencontré is l'état fossile. Parrai les espèces que nous citerons, nous choisitons de préférence celles qui out été tigurées, la description le mienx faite ue pouvant quelquefois suppléer entièrement à une figure, mème wúdiocre. laris.

1. Caknature aviculaire. Crenatula avicu-

C. testâ rhomhen-rotundatí, compressá,

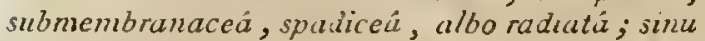
baseas nullo.

Lamk. Ann. du Hus. tom. J. pag. 29. tab. 2. fig. 1. 2. - Anim. sans vert. ton. 6. part. 1. pag. $137 \cdot n^{\circ}$. 1 .

Schrceter, tom. 9. fig. 6 ?

Sow. Genera, no. 8. fig. I. 5.

La Crénatule aviculaire est une coquille rhomboidale, arrondie, comprimé, trés-mince, presque membraneuse, rouge, arec des bandes rayonnautes blanches surla surface. Elle se trouve dans les mers de l'ímérique raéridiúnale.

2. Crévatule verte. Crenatula viridis. Lamk.

C. testâ glauco-virente, subirregulari, ovato-

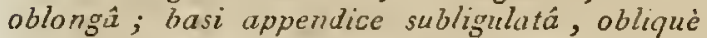
producti, natibus terminatá.

Lamk. Anint. s, vert. tom.6. part. 1. pag. 10.7. $n^{\circ} .5$.

Cetle espèce singulière mérite d’être cilce, à d'abord comme la plus grande du genre, ensuite cause de l'appendice linguiforme qui prolonge les crochets. C'est une coquille peu régulière, ovaleoblongue et présentant des appeadices terminaux, des crochets obliquement proéminens. Elle est Inngue d'un décimétre environ, en y compreanat l'appendice des crochets. Elle se trouve dans les mers de l'Asie australe.

3. Crénatule mytiloïde. Crenatula nutiloides. LAIK.

C. testâ ovato-oblongâ, basi acutâ, temui, violaceá, obscuré radiat nicatis, intus farctis.

LAMr. Arin. du JIts. tom. 3. pag. 30. pl. 2. fig. 3. 4. - Anim. sans vert. tom. 6. part. I. pag. $158 . n n^{\circ} .6$.

An Pinna picta? Fовкк. Descr. Anim. p. 125.

Sow. Genera, $\pi^{\circ}$. 8. fig. 2.

Celle-ci est petite, ovale-oblongue, aiguë vers les crochets ef abscurément rayunaée. Elle se reconnoît surtout par des lames voúlées qui garnissent intéricarement les crochets. Elle vient de la mer liauge.

M. Savigny, dans le grand et magnifique cuvrage d'Euyple, a fait Lyurer plusieurs espèces de Crénatules; mallieureusement, il n'a pu $y$ juiadre les descriptions ni la moindre indication, de sorle qu'll est presque impossible de les raphporter a des especes déja connues, ou de décider si elles souı nuavelles.

\section{CRÉPIDULE. Crepidula.}

Ce geure, fait par Bl. Lomarck aux dépens des Patelles de Linnć, s'en distingue en eftct d'une manière bien trancliée, ainsı que les Cilyptries et quelques autres qui y étoient confondus; placées dans la famille des Calyptraciues, les Creppidules sont mises dans l'ordre le plus convenable de leurs rapports; et la connoissance de !animal, sur lequel Adanson (Voyag. au Sinégal, pag. 38.pl. 2.nos. 8.9. I0) nous a donné quelques aélails, ainsi que M. Beudant (Nouv. Bullet. des Sciences, pagr. 257. $n^{\circ} .4^{2}$ ), doiveui nuss coutiraer de plus en plus dans l'upinion de Il. de Lamarck sur ces animaux, touchant l'ordre et la famille où ils doivent être placés. Marchant sur un disque rentral, l'animal des Crépidules ollire des organes respiraloires qu'Adanson avoit indiqués, suas qu'on pút trop les reconbuitre, mais que les olservalions de M. Beudant sur l'animal rivant, ainsi que celles de MI. Lamarck sur un animal couservé dans l'alcool, ont fait connoitre exactement. Cependant, les caractères énoncés par M. Cuvier diffërent un yeu de ceux dosnés par M. Beudant et par MI. Iauarck, ce qui liendioit peut-être à ce que l'auimal observé par le célèbre auteur du Régne animal étoit d'une autre espèce. Quoi qu'il en soit des légers changemens qui peuvent se remarquer selon les diverses espècei dans le nude respiratoire, tous ces animaux nous ollient les caractèıes propres à la lamille, et taus ceux qui sant nécessaire; pour former un gevre bien tranché. M. de Blainville, en adoptant la famille des Cályptraciens de N]. Launarck, n'a apporté aucun cliangement dans les rapports d s Crépidules, qui sont Évidemment très-voisines des Calyptrées, et pour l'animal et pour la coquille. M. Latrcille, dans les fumilles raturelles du Règne antmal, a suivi la même opinion, et l'on ne peut contester la validité des rapports établis, quand on les voit sanctionnés par tous les zoologistes. M. de Blainville ayant donné les caracteres génériques les plus complets, c'est d'après lui que nous les reproduirons.

\section{CARACTÉRES GÉXÝRIQUES.}

Corps plus ou moins déprimé, ovale, à peine 


\section{R E}

3piral postéricuremeat; maulean fort mince, sans tcntacules marginaux; pied peu épais, surtout en arrière, trachélien ou sc portant fortemeut en avant, par une partie distincte, auriculée de chaque cỏté; lĉle bounbée, bordćc antérieureunent par une lèvre bifide, de chaque bilurcation de laquelle part une pelite membrane décurrente, allant se teraniner au point de jonction du corps et du pied; deux tentacules presque cylindristucs, gros, obtus, peu contractiles, portant des yeux á leur tiers inférieur ; carité branchinle for: grande, oblique de gauche a droile, s'ouvrant largeracut et cuntenant une petite bianclue turbinée á gauclıe, et à droite ui faisceau de longs filamens brancliaux.

Coguille ovale, oblongue, a dns convexe, concarre en dessou; ; à sommet bjen marqué, non symétrique, presque droit on contonrué en spi. ra!e, nais toujonrs aluaissé sur le bord postérieur; cavité fort grande, partagée en deux paries par une cloison lovizontale, qui se place entre la masse des visceres et la partie postrieure du pied; hords irréçuliers; inpressiou unsculaire en fer à cheval.

Les Crépidules sont des animanx sédeutaires qui vivent à la manière des Calyptrícs et llos Caboclions, lisées à peu de profonderr sur Jes rocliers, qui suurcnt en soni courerts, et nieue elles vivcnt les unes sur les autres. Les esprices passent iusensiblemeut aux Ciljyplrées, sans ccpendan: se conf ndre avec elles; uiusion pourrcil les disposer daus un ordre tel, que commençant par celles qui ont le sommet droit, il fibiroit par celles qui ont plusieurs cours de sprire à la parlie nostcilienre et latérale, et si, comine uous le jen. sons actuclleınent, dat Calypórée crénidulare fos. sile des enviroas de Paris doit pasicr au gren:e Crépidule, on anra nn passage plus évident encore avec les Cialypirćes.

Le nombre des especces de ce genre n'est pas très-considérable; M. Lamarck in a donré six vivautes, et M. Defrance en indique un nombre rgal de fossiles. De ces deruières, nous a'en connoissons pas autant, inais uous en possédons davantage des prewières.

1. Crépidule poicellane. Crepidula porcellana. Lassk.

C'. testâ ovali, posticè acutê, recumvî, dorso rotundutâ, griseo-albì, maculis mifis triangularobs aspersi, labio posteriori plano.

patella porcellana, Lix. Gaes. pag. 36ga. $n^{\circ} \cdot 4$.

Crepidula porcellana, LАнк. Anim. sans vert. torn. 6. pag. 24. $n^{\circ}$. 1 .

Lister, Conch. $1 a b .545$. fig. 54 .

Rumpнivs, Mus. amb. tab. 40. fro. 0. Hist. Nat. dei Vers. Tome II.
Gualtierar, Ind. Conch. tub. 69. fig. 5.

Le Sulin, AD.sxsox, Toy. au Sónég. pl. 2. fig. 8.

Martisx, Conch.tom. 1. t.7b. 13. fig. $127 \cdot 128$.

D'après Gualtierri, un natmaliste, Petro Mlichelio, auroit nommé celte espèce Patella crepidula, d'ou il est bien probable que l'on a pris depuis re nom rénérique, de spécifque qu'il étoit. Cetle coquille est ovale, oblongue, son sommet cst recuurhós sur le hord; sa conleur est le plus sourent ओiache, parseunéc de taches triamolaires roussiltes ou brunes. D'apres la finnre d'Adanson, elle auroil jusqu'à un pouce ei demi de longueur. () is la tronre dans les mers de l'Inde et à lile de Gorée, où il paroil quelle est asscz componne. Elle adhite aux rochers, et s'y fixe avec tant de forec, quion casse quelquelois la cocjuille sans avoir délaché l’auimal.

\section{Cópidure de Goiće. Crepidula goreensis.} Nír.

C. lestâ ovali, planấ, tenui, albâ, nitidâ, exterius lamellosá. GuEx.

Palellu gorecnsis, Laxie, pag. 369 f. no. 10.

Le Jenac, Adsxsox, Poyag. au Sénég. p. 41. tab. 2. fig. 10.

Adanson donne pour l'animal de cette espèce des détails assez curieux. Ses tentacules ont, vers lcur extrémité, des petits lubercules blancs qui les font paroitre chagrinés; le pied et le manteau le sont éralement; du roanteau et vers le derrière de la tête, on apercoit luuit flets cylindriques assez longs, qui, d'après M. Cuvier, seroient les branchics sortant hors de la cavité brancliale. Ceue espèce, longue de 5 à 6 lignes, se trouve sur les rochers de l'île de Goréc, mais elle y cst rare. Elle est blanclue, lisse, très-mince, ovale et ìes-aplatie.

5. Crépidele voútée. Crepidula fornicata. LAAMK.

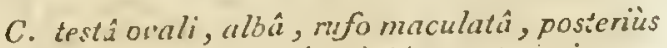
"culâ, obliquè recunicí; labio posteriori concavo.

Patellafornicata, I.x. G.⿲丿⿺. pag. $36 g^{3} . n^{\circ} .5$.

Lister, Conch. tab. 545. fig. 33.

Ккова. Vergn. 6. tab. 21. fig. 3.

Martina, Conch. tom.1.tab. 13. fig. 129.130.

Dargenville, Concli.tab.2.fig. N.

W s cсе. Naturf. I v. pag.78.tab. I.fg. 3. 4.

Cette coquille, très-bombée, très-bossue, est fort commune dans les cullections. Elle est ovalaire, un peu plus pointue postéricurement, oì est le sommet, inclinée un pen obliquement sur le bord. La lame médiane est blanche ou brunátre, et concave en dessous. En celnors, celle $\mathrm{D} *$ 
coquille est blacche, arec des taches ou des rayons faures; quelquefois, elle est toule de telte couleur. Elle se trouve dans les uiers de l'Inde, la Néditerranée et autres lieus.

4. Créprdere linéolé. Crepidula lineolata. Nов.

C. testá ovato-oblongit, convexo-gibbosi, lineis fuscis internoptis ficti, apice albo univadiutâ, intùs fucescente; margine aloo; seplo magnu, plano, nurgine subsinucto.

Coquille bien distincte de toutes celles du méme genre; elle est ovale, oblongue, assez large, peu oblique, très-couvexe en debars; clle est warqué de lignes faures, tremblantes, interrompues, nombreuses, sur un fond blancjauaatre: on remarque, partant du sommet, un seul rayon blace, étroit, qui se dessine jusque vers le onilieu du dos on il disparoil. En declans, cette cognille est d'un fauve bran, si ce n'est vers le bord qui est tout blanc, ainsi que la lame en cloison, qui occupe en longueur lis moitié de la cavité; son bord libre est mince et un peu exr:aré dans son milien. Celle jolie espèce est longue de 38 millim., et large de 25 elle rient des wers Australes.

NOB.

5. Caśpinole déprimée. Crepidula depressa.

C. testâ ovato-subrobtundî, depressâ, irreguhiti, fusco violascente, intus albo et fusco mamboratá; seplo triangulari, albo, vahiẻ sinuato.

La Crépidale déprimée est d'une taille médiocre; elle est peu bombée, plus aplatie que la plupart des autres especces; elle est presque anssi large que longue, et se termine en pointe au sommet; son bord est irrégnlier, ce qui tient sans doute à l'habitude qu'a l'animal de s'appliquer sar des rochers irréguliers. En debors, elle est d'an brun-violátre obscur; en dedans elle est brillante et marbrée de celte couleur, mais moins foncée, et de blanc; quelquefois elle est, soit presque toule blanche on presque toute brune; la lame septiforme est blancbe et concare; son bord libre est forlement sinueux, surtout à droite. Cette coquille à 25 à 50 millim. de long et à peu près autant de large; elle se trouve sur les cótes du Pérou. Nas.

6. Cópinere sandaline. Crepidula calceolina.

C. testâ oratâ, postice acutâ, depressissimâ, alỏa , imnaculatâ, translucidá; lamellí tenui, cxtús convexá, extra margines prominente.

patella crepidula, Lix. Gyex. pag. $36 g$ j. $\pi^{\circ} \cdot 17$.

Grast. tab. 6g. fig. H.
Fossilis. - Fatells crepidula, Broc. Conch. foss. supab. ton:. 2. pag. 253.

Crepidula itulica, Derr. Dict. des Scienc. nat. lom. II.

Crepidula unguiformis, Bast. Bass, tert. du sud-ouest de la France, Mém. de la Soc. d'hist. nat. de Paris, tom. 2. pag. 70. nº. 1.

Espèce intéressante qui laabite nos mers et quise Irauve fossile dans plusieurs lieux : elle est la p'us aplatie de laules les espèces; elle l'est tellement que sa cloison, légèrement convexe, fait saillie en deliers de la coquille; sa furrae est ovale, oblongue, pointue au sommet, qui est droil on à peive incline; elle est toute lisse en dehors, mais plus encore en dedans, nù elle est polie et brillanle; sa lame interne, mince el tranchasie I son bord libre, est légèrement canvexe, avec un petit sinus vers l'extrémilé droile. Quand celle coquilie vit sur les rochers, elle est droite et légèremeat convese, mais lorsqu'elle s"introdiat daus la cavité des coquille's pour y vivre à l'ahri, e'lle se moule alors sur le lieu qu'elie liabile et prend des formes accidentelles assez irrégulières. Les indiridus fossiles, aussi bien que les vivans, présentent les mêmes acoidens: il est impossible de nier l'jdentité la plus parfaite entre les individus fossiles et virans de cette espèce. On la trouve dars presque loute la Méditerranée et la mer de l'Inde, et fossile en Italie, en Sicile, aux enrirons de Vienne, de Bordeaux et dans les faluns de la Touraine. Elje est longue de 25 à 30 millim.

\section{\ов.}

7. Créprdole bépatique. Crepidula hepaticu.

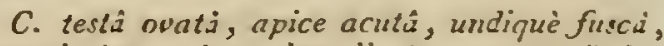
irregulariter striato-lamellosî; septo albido, plano, subsinuato.

On distingue celle-ci par sa conleur, qui, ansi bien en debors qu'en dedaus, est d'un brun foncé sans tacbes; elle est ovale, assez large, peu convexe; son sommet, petit et pointa, se dirige ubliquement vers le bord, sur lequel il s'incline en le dépassaat un peu; des stries daccroissemens nombreases, serrées, sublamellenses, se roient en dehors; en dedans, elle est polie et luisante. La lame septiforme est blanche, mince, bien torizontale, et partage en deux parties Égales la carité de la coquille; son bord libre est mince, un peu sinueux dans le milieu. Nous irgnorons d'où vient celte coquille; elle est longue de 20 millim. et large de 16 : elle est quelgaefois un peu plus grande.

8. Crépidere à cótes. Crepidula costata. Nó.

C. testó ovato-elongaiá, radiatim costatz; cos. tis distontibus, convexis, fexuosis; intus albi, 
lincis longitudinalibus fuscis, radiuntibus pictá; margine antice fexuoso.

Charmante espèce que nous devons à l'amitié de N. Lesson, qui l'a recueillie à la NouvelleZélade, où il paroît qu'clle est asscz rase. Ovale, oblonguce, elle est plus pointue au sumaet qu'antérieurement; ce sommet, un peu oblique et recgurbé, donne naissauce a dix on duze cútes arrondies, rayonnantes, distantes, onduleuses, qui gagnent le bord et le lesionueut; elles sont blanches, brunátres à la base, el les intervalles qui les séparcut sont d'uu brun funcé. En dedans, celle cequille est blanche et marquée de cinc a six rayons bruns; la cloison est miace, blanche, toute plate, et sun bord libre est droit, sans aucune sinunsité. C.ctte julie et curieuse espèce est longue de 30 millim. et large de 20.

9. Crépidure élargie, Crepidula palula. Nов.

C. testá irregulariter mondalia, convex $\hat{a}, p a-$ luli, albo ct fiusce variegata; intus alba vel fucescente; lamella alba, margine inlegro, valdè sinualo, contorto.

Celle corpuille liut rapportée par N. Lesson de son vnyave antour du monde. Il la rencontra sur les contes de 'Tuili, ois elte paroit assez commune. Su forare est le plus souveut irrégulierement arrondie, rarement plus longue que large, hossue, convexe; son soumt, incliné sur le bord postérieur, se tourne lígèremeal en spirale, il est fort petit el le dipasse ratement. En dehors, celte coquile est irrégulièrement striée par des accroissemens; elle est marbrée de taches fauves, quise londent avec le blanc, 'jui est la couleur dominan'e. Eu dedans, elle est blanche, si ce n'est sur le bord, oì elle est lauve. Quand elle est jeune, elle est d'un fauve pur en dedans. La iane médiane ressemble beancoup à relle de quelques Calyptrées; elle est fortement reconrbée dans son burd, sa partie moyeane élant saillante el sćparce du bord droit de la coçuille par un sinus profond du cóléganclie : à l'endroit de sou insertion, elle présente aussi un sinus, mais plus lurge et moins prolond que le piemicr. Cette espéce a 45 i 50 millim. de long.

io. Cápidure bossne. Crepidula gibbosa. Def.

C. lestì ovatî, irregulari, contortia, rugosâ, gibbosiá; lamelli magni, simplici, rectu.

La Crépidule bossue est une des plis grandes espices du genre; elle est ovale, oblongue, souveot aplatice, irrégulière; d'autres fuis, bossue el convexe, couverte de stries irrépnlières, rugucuses, trc̀s-serrces. Le sommet, incliné sur le bord, est épais et obliqque; en dedanś, la cavité est assez profonde; elle est parlagíe en denx parties ćgales par la cloisun, qui esı asıez épaisse, un peu convexe cn dehor's, et ayaut son bord libre droit on presque droit, prescntant seulement dans son milieu une légère inflexion. Les bords de la coquille sont itréguliers; ce qai a dépenda, comme le prouvent les accroissemens, de la manière de vivre de l'animal. Cetle espèce se trouve fossile dans les falans de la Touraine. I.es grands individus ont 47 millim. de long et 34 de large. Nors avons une coquille vivante, qui malbencusement est roulée et dont nons ae pauvons juger complétement, puisque nons a'en avons gu'un seul indiviou. Nous pouvons dire qu'elle a avec la fossile la plus grandé abalogie daus ce que nous en connoissuds.

11. Créridure Épineuse. Crepidula aculeala.
Lask.

C. lestâ ov'ali, fuscâ, vel fusco radiatâ; striis aculeatis exasperatí; vertice spirali, sublaterali, marginali.

L.sмк. Anim. s. vert. tom. 6. part. 2. pag. 25. $n^{\circ} .3$.

Patella aculeata, Iris. pag. $369^{3} . n^{\circ}, 6$.

Favane, Conch.pl. 4.fig. 3.

Dacosta, Conch. lab. 2. fig. 2.

Cnesurtz, Conch. Lab. 168.fig. 1624. 1625.

La Crépidule épinense se reconnoît très-facilement; clle est ovale, aplatie, son sommet fait un tour de spire environ, il est couché vers le bord gauche; elle est blanche, avec des flammules roussatires, et chargéc de petiles côtes peu régulières, qui porlent des épincs ou des écailles. Elle a 11 ou 12 lignes de longneur. Elle habite les ners de l'Amérique méridionale, où on la tronve rarement.

12. Créproure calyptréifurme. Crepidula calyptraiformis. NoB.

C. testì ovato-mlundatâ, gibbosî, nufescente, longiludinaluter striuta; stris rugosis, ad marginem evanescentibus; apice obliquo, spirato.

Cette coquille, ainsi que la suivante et celle qui précède, fait le passage des Crépidules et des Calyptrées. Sun sommet, tourné en spirale, s'élevant un peu au-dessus du bord, mais n'étadt puint encore central, ne laisse qu'une très-foible distance entre les denx genres, et probablement que des intermediaires serviront à la remplir. Elle se dislingue des antres especes par sa forme ovale, ses strjes assez nombreuscs, peu saillantes et rugucuses, rayonnant du sommet jusque vers les bords, où elles disparoissent peu à peu; elle est d'un fauve pále, et les stries sont d'une coulear un pea plus foncée. Ea dedans, elle est lisse, pulie, unarbrúc de blanc et de fauve; la lame est blanche, diapbane, obliquement inclinée el indicpuast un commencenent de spire; son bord libre est mince, tranchant, sinucux à ses points 


\section{$\mathrm{C} R \mathrm{E}$}

d'insertion à droite et à gauche : ce qui rend $\operatorname{son}$ centre plus saillaut. Nous igrorons d'où vient cette coquille, nous supposoos qu'elle vient du Pérou, l'ayant trouvée dans le commerce avec d'autres coquilles venant de ce pays. Elle a 26 millim. de long et 22 de large.

13. Créproule parisienne. Crepidula parisiensis. Nов.

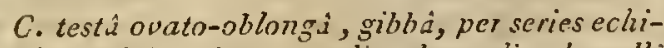
natá; spirâ submarginali, lateruli; lamelli tenui subcontortì, bisinuatâ.

Calyptrcea crepiduluris, Lamx. Ann. dü Mus. zom. 1. pag. 585. $n^{\circ}$. 2.

Ibid. Nов. Descript. des coq. fuss. des env. de paris, tom. 2. p. 32.no. 4. pl.4.fig. 16. J7. 18.

Iorsque nous avons rangé celle espèce parroi les Calyptrées, nous avons manilesté le doule que mous éprouvions à l'égard du genre où on devoit Ia placer; nais aujourdhui, que nous l'avous examinée de nouveau, et comparativement avec plusicurs autres crépidules voisiues, nous ue pouvons plus douter qu'elle appartient aux Crípidules. Elle est ovalaire, oblnngue, régulièrement convexe, et couverte d'écailles disposćes en lignes longitudiuales et rayonnantes du sommet à la base. Le sommet, incliné sur le côté droit, n'est pas tout-à-fait marginal, il forme deux tour's de spire légèremcat convexes et un peu saillans, ce qui nous a clélerminé, ainsi que MI. Lamarck probablement, à placer celle coquille parmi les Calyptrćes. La lame postérieure est très-mince, légèrement conlouraée et uu peu relevée en son bord vers son angle clroit, de manièe à indiģuer de ce côté un fảit ombilic. De chaque côté, elle prísente un pelit sinus, ce qui rend saillante la partie moyenne deo son bortl libre. Celte petite coquille, fort nuince et très-frutwile, se trauve à Griguon, où elle est fort rare. lille est longue de 12 on 14 millim.

\section{CREIPIDULINE. Crepidulina.}

M. de Blaiuvilie a proposé ce genre, qui ne sera pas adoplé, parce qu'il réuoit plusieurs genres de Monttort, qui eux-mêmes ne sont point admissibles et rentrent dans le genre Nonioniue de M. d'Orbigny. Voyez ce mol.

\section{CRÉSÉIS. Cresis.}

M. Rang a propesé de former sons ce nom un sons-genre dans le penre Cléodor. C"est dans lc IManuel de Conchyírologie que l'on doit au zélé voyageur, tguc l'on trouve celte indication sur laquclle nous reviendrons à l'arlicle Cléodone: auquel nous renroyous.

CRI:TAIRE. Cristaria.

La coquille arec laguelle M. Schumacher a établi ce genre, paroit avoir appartenu an genre Moule. If faut șivoir que sous celle dernière dénomination, l'anteur ne tenant pas cornpte des démembremensfaits aux clépens des Moules, rassemble daus ce genre les Modioles, les Lithophages el les Mlulettes. Ce scroil alors à ce dernier. genre quil faudruit rapporter les Crêtaires. Voy. Nulette.

\section{CREUSET'. Crucibulum.}

M. Schumacber, dans son Systeme de Conchyliologie, a donné ce nom à un genre furmé aves: celles des Cályptrées qui ont à l'intéricur ure lame en cornet ou en enlunnuir. ('e geare n'est point adaissible. Voyez Calyptrée.

\section{CREUSIE. Crensia.}

C'est à 11. Láacl que l'on doit le genre qui va naus occuper. Déjà Brayuic̀re, à l'article BaLANede ce Dictionuaire, en parlant du Balames veriuca, avoit fait sentir la singularité de celte coquille el indiqué les différcocés qui la séparent des véribibles Balanes. Le gene de M. Lúach Ćloil nécessaire, aussi fut-il bientôt actmis par N. Lamarck dans son Traité des Animaux sans vertèozes, el depuis, il ful géuéralement adopté, parce qua'en effel it repose sur de bons carac!ères. Les rapports qu'or lui a donnés avec les Acastes el les l'yromes (2oyez ces mols) sont naturels, et ils on élć admis par MM. de l'erussac, Latreille, el plus intinement encore par Mi. de Błainville, puisqu'il a réuni les Pyrgomes aux Creusies dans un seul genre, auquel il a conservé ce dernier nom.

$$
\text { CARACTÉRES GEXERIQUES. }
$$

Aumal ayant le corps sessile, subglobuleux, enfermé dans une coquille operculée. Trois on qquatre paires de bras teutaculiformes. Bouche sans saillie à la partie antérieure et supéricure du corps.

Coquille sessile, fixée, orbiculaire, convexeconique, composée de qualre valves; les valves iuégales, réunies, distinctes par leur's sutares; opercule intérienr bivalve.

Ce petit genre, peunombreux en espèces, a été réduil il y a peu de iemps par M. Ranzani, qui a proposé son genre Ochihosic pour le Lepas stroemia de Mluller, qui, d'après lui, ne seroit composé que de trois parties. Nl. de Blainville présume au contraire qu'elle en a quatre, et néannowins admet le genre de l'auleur italien. Au reste, cette espèce différeroit bea ucoup des aulres Crensies, puisqu'eile b'auroit pas, combe elles, l'halilude de s'enfoncer dans les masses madréporiques. Ics Creusies se composent de deux cînes base a base, dont l'un, extérieur, beaucoup plus aplati que l'autre, forme au-dessus de la surface du madrépore vre espèce de pustule ovaluire, 


\section{R I}

tandis que l'autre còne, très-profond, s'enfonce daus son épaisseur puti k:ontenir l'animal. On peul, sous ce rapport, comparer les Creusies aux Acastes, qui senfuncent dans les épunseses, tout en conservant cependant la pluparl des caracletes des Balanes, raudis qu'ici ils commeuceul id disparoitre davantage.

Creusie spinuleuse. Crensia spinulosa. Léach.

C. lestî lurininatì, conicerâ, suturis quatuor signuta; sulcis mininuis, raduantibus, spinulosis.

LEACH Cirh. acampt.

I.s $3 \mathrm{k}$. Anim. sank vert. tom. 5. p. 400, $n^{\circ} .2$. 13zasv. Truité de Mulac. pil. 35. fig. 6.6 a.

Coquille diun médiocre volume, ayant l'apparence d'une verrue sur un madrépore; mais si on vient it la casser, on s'aperçoil qu'elle s'enfonce profondtónent : on voit bien distinctement les qualre parties synétriques dont cilla est formie; mais il est rare de rencosirer l'opercule, qui est bivalve et obliquement pyramidal. Celte cuajuille vient, dit-on, des mers de l'lade.

Pour la Creusie verrue (C'reusia remucosa, Léacl) notss renvoyons à la descriplion de biuguière, qui l'a fort bien décrice sous le nom de Bulanusveriuca, $1^{\circ} .15$, daus le premier volume de ee Diclionatre; nous renvoyous également à la ligure donnée par M. de Blainville, Malucologie, pl. 85. fig. $7 \cdot 7$ c. 7 b.

\section{CRICOIPIIALOS.}

Klein (Tent. Mcthod. ostrac. pag. 146) a réuni sous ce nom générique, depuis long-lemps abandonné, toutes les coquilles bivalves qui ont une lunule irès-enfoncée. La lunule éloil nomméc pa. lui ombilic, et l'on doit sentir qu'un genre ćlabli sur de pareils caractères ne pouvoit manquer de tomber daus un juste oubli.

\section{CRICOSTOMA.}

Ce nom de Cricostome, qui semble entrainer ares lni l'idée d'une ouverture ronds, a ćté employé par Klein (Tent. Meth. ostrac.posg. 12) pour un genre dans lequel on trouve quelcues petils Turbos de la section des Liltorines, ainsi que des Trochus à base aplatie et épinease sur le bord. Vojez Troque et Tuabo.

\section{CRICOSTONES. Cricostomati.}

Ce mot, que Mi. de Blainville a emprunté à Klein et à Dargenville, a étć appliqué d'une manière restreinte, dans son Thaitú de Malacologie, à une famille qui représente assez bien le geore Turbo de Lianć; elle contient tout à la fois les Péristomiens, les Scalarines et une perite partie des 'Turbinacés de M. Lamarck. (Voyez ces mols.) Par l'établissement de cette famille,

\section{R I}

M. de Blainrille súpire denx genres exfrèunemeul roisios, que M. Lamarck et pres(jue lous les anteurs out eu soin de rassembler dans un prëme groupe; sous ce rapport, la famille des Cricos. tomes ne pourroit être adoptće saus cluagernens. Joyez Molluspue.

\section{CIRIOPODER UE. Criopodenma.}

Nom donné par Poli à la coquille du Criopus. Voyez ce mot.

\section{CRIOPUS.}

Peli, dans son bel ourrage sur les Testacés des Deux-Siciles, a donné ce nom à l'animal de la Terebrutula caput serpentis, et non ì celui de liz Cr:nic comone N. de Blainville l'a cru daus le Dictionnuire des Sciences naturellos.

\section{CRISTACES.}

On trouve ce mot employé, pour la première fois, par M. Lamarck dans l'Extroit du Cours, pour une petice famille de coijuilles muliloculaires microscopicjues, composée des trois gentes Réunlile, Crislellare, Orbiculine. L'élude nouvelle que l'on a fuile des corps de même nature, ne perrael plus d'adopter celie famille.

M. de Blaiuville, en adoptant le nom proposí par H. Lamarck pour une fimille de coquilles microscopinues, l'a composée de genres dillérens; ce sonı les suivans : Crépiduline, Oréade et Linhavie. Celle fanille n'est pas plus ailmissible que la précédente. Nous renvoyons aux mols de zenres que nous avons cilćs el à Cristellaire.

\section{CRISTELLAIRE. Cristellaria.}

Comprises autrefois parmi les Nautiles, les $1: 0-$ quilles de ce genre en furent séparées par M]. Lamarck daus l'Extmil du Cours, el depuis ce genre Cristellaire lut adoplé par tous les zooloristes, çui ne furent pas laujours d'accord sur la place quon devuil lui donner dans la série. Avanl la création de ce genre, Montfort, dans le premier volume de sa Conchyliologie systémalique, avuit élabli plusicurs coupes, dont uue seule auroit sufli. Des coquilles voisines de celles-lì et qui appartienaent, pon* la plupart, au grenre Nouionine (royez ce unot), servirent également de prélexte au même auteur pour l'établissement de plusieurs genres, qui, à cause de leur analogic, furent rapprochés pa. les auteurs et diversement groupés, soit dans des fumilles, soit dans des genres plus on moins en rapport les uns avec les aulres.

N. Lamarck plaça d'abord les Cristellaires dans sa fanille des Cristacés, entre les Rénulites et les Orbiculines. M. de Ferussac fit une famile des Orbiculines, dans laquelle il introduisil les Crislellares, quil composa de sepl genres de Mon:fort, qui tous ne sont point jamissibles et dont quelques-uns ne convicnnent nullement aux Cris- 


\section{R I}

ıllaires. M. de Blainville a démembréles Crisfellajres de M. Lamarck, il a porté plusieurs espèces dans le gcare Pénérople, et d'auıres fort loin de la, dans une autre famille, les Cristacés, dans le genre Crépiduline, où ellés ne sont point naturellement placées. M. Latreille a, comme M. de Blainville, abandanné les indications de M. Lamarck; il a eu beaucoup trop de conliance dans les travaux de Montfort, el les genres de ce deraier, qui rentrent dans les Cristellaires, furent compris dans la famille des Polycicligues, le premier, les t)réades, eutre les Spirules et les Gésites dans le premier groupe; les autres, Scortime ét Linthurie, dans le second, qui es! termiué par les l’ériples, genre fort douteux.

Il résulte de celle divergence, que l'on n'avoit pas encore déterminé d'une manière rigoureuse les caractères de ce genre; chacjue auteur les envisargeait à peu près à sil maniè e, ne s'arrêtant pour ainsi dire qu'à des caracteres extérieurs, et surtont à celui d'une carène tranchanle et assez élerée qui parcourt le dos de ces coquilles.

Lorsque M. d'Orbigny voulu caractériser les Cristellaires, d'ap'ès ses priucipes, il ue trouva pour base de son trarail que le geure de M. Lamarck, dans lequel il lut encore ublizé de faire des changemens, relativement aux espèces, dont plusieurs avoicat été fuites sur des individus non adulıs. Cepeudant, malgré l'amélioration que le ceure a éprouvé par le travail de M. d'Orbigny, nous croyons que les caractères génériques peuvent ea recevair encore quelques-uns. Mais il est nécessairc pour cela d'écarter le saus-genre que II. d'Orbigny a proposé de taile dans les Cristellaires, arcc les Saracénaires de M. Defrance. Ce sous-genre, en effet, nous semble suffisamuent caractélisé pour être conservé a lilie de genre (yoy. Saracénarre) ; car, aprés avoir pris duns le jeune âge la forme d'un Nautile à spire courte et à ouverlure Irès-évasće, il se projelle en ligue droite en vieiliisant: ce qui n'a pas lieu, à beanconp près, daus les Cristellaises jroprement diles.

\section{CARACTÉRE GÉÉRIQUES.}

Coquille oautiloide, dćprimée, à cloisons trèsobliques dans l'état adulte; la dernière, fermée par un diaplirayme plat ou à peine convexe, et termicé à l'angle dorsal par une ouverture petile, ronde, le plus sourent cntouréc d'un peiit bourrelet. Uue carc̀ne dorsale daus presque tuures les espèces.

Avaul que Ml. d'Orbigny n'cxaminâl, avec toute l'attention qu'ii y a mise, les coquilles de ce genre, M. Lamarck et la plupart des auteurs avoieut pris pour des espèces clistinctes des ieses rifí́reus d’unte môme espèce. Cela ne paroillib pas élonnaut si l'ur fait attention au peu de ressemblance qui existe entre ces corps encore jeunes oil ayant atteint tout leur développeraent. Lorsque l'on ne vil que les points exlrémes diune série,

\section{R I}

il est extrêmement facile de sc tromper : ce que l'on concerra sans peine. Pour quelques espèces, la synonymie ancienne a reço de fortes modificttions, comme on pourra s'eu assurer, car nous citerons ces espéces de préférence, étant les seules qui aient été bien tigu:tées.

1. Cristelcalne casque. Cristellaria cassis. D'ORB.

C. testâ ovato-elongat $\hat{a}$, lateraliter depressá, dorso valde carinatâ; carinà acutâ, elevatà, simplici; disco radiatim granuloso; articulls numerosis, simplicibus, postremis obliquissimis; aperturìminimâ, marginatâ; margine plicuto.

D'Onв. Ciphal, Ann. des Sc. nat. toin. 7. p. 2yo. $n^{\mathrm{C}}, \overline{3}$. el modéles $n^{\text {os. }} 44$ el 83.

Nantilus calcar, Lis. Guel. pag. 5370 .

Soudaxı, Test. micros. tom. 1. tab. 56.

Nautilus cassis, Fischtel et Moll. pag: 95 .

Martisi , Concli.cab.tom. 1. tab. 20.fig. 182. 185.

Yar. A. Fich. et Moll. tab. 17.a. b.c.d.

Plancus, tab. 1.fig. 2.

Cristellaria fapillosa, L.s1 x. Anim. s. sert. tom. 7. pag. 607. $n^{\circ}$. 2 .

Linthuris cassis, Buasvv. Maluc. pag. 384 .

Cristellaria cassis, Excrcoop.pl. $467 \cdot \sqrt{\prime g} . \overline{3}$. a. b. c. $d$.

Var. B. Fich. et Moll. tah. 17.fig. e.f.g.

Linthuris cassidatus, Moste. Conch. syit. toin. 1. pag. 254 .

Cristellariet producta, Esicrcoor. pl. $467 \cdot$ fig. 5 . e. $f . g$.

Var. C. Fich. et IIoll. tab. 17.fig.h. i.

Cristellaria serrata, Excrccop.pl. 467. fig. 4 . a. $b$.

Var. D. Fich. et Holl. tab. 17. fig. k. l.

Cristellaria lavis, LAM . loc. cit. no. 5 .

Cristellaria papillonacea, Esicxczop. pl. 467. fig. 4 . c. d.

Var. E. Fich. et Moll. tab. 18. fig. a. b.c.

Cristellaria undata, Excrcuop. pl. 467. fig. 5 . a. $b$.

Parkinsoi, Oigan. rem. tom. 2. tab. it. fig. 3̄o.

On voit, par relle syuonymie, combien celle espece cst variable; les erreurs dont elle a été cause n'ont donc lien qui doive surprendre dans des auteurs qui nont pus vu un nombre assez considérable d'individus pour apprécier les passages qui se voient entr'eux et enire toutes les varićlćs. Sil'on jelle un cnup d'cail sur les ligures que nous arous citees, ct surtout celles de ce Dictionasire, 


\section{R I}

on reconnuitra facilement que les distictions spéciliques de M. Iamarck reposen! sur de trop foibles caractères, et qüil tiut, à l'exemple de 1]. d'Orbigrny, réunir ce qu'il avoil séparé.

La Cristellaire casque est aplatie, contournée en spirale à son somnet, et se continuant presyrieu ligne draite en vicillissant, sans cependant yue ses cluisons cessent de gagner le ccurpe les dernières sunt trìs-obliques. Une carìne aigü̈, tautòt culic̀re et simple, tantât onduleuse ou dícoupée, parcourt le dos de la coguille et la parlage en denx parties égales. Te centre, plus épaissi, et le plas souvent granulcux, soit que les granulations suient irrégulicirement disposées, soil qu'tlles suivent le bord des cloisous en sćries simples. lionverture est dorsale et termine la dernicre cloison par une petile saillie, au milieu de laquelle clle se remarque; elle est ovaluire, el le bourrelet yui l'eatoure est lécrèrement plissé. Celle coquille, que l'on trouve vivante à Rimiui, et fossile a Sienue, a jusquäa 5 ou 6 willim. de diamètre.

\section{Cristeluatre lisse. Cristellaria galaa.} D'Ors.

C. testî ovatâ, depressissimâ, cassifomi, la'igutâ; urticulis distuntibus, imbriculis; carinầ dorsalı tenui, elevatâ ; aperturâ minimâ, ovatâ, sublineari, margine plıcato circundatâ.

Noutilus galara, Fichtel et Moll. microsc. pl. 18. fig. d.e. f.

Cristellaria lavis, Lan r. Anim. s. vert. tom. 7 . pag. $608 . n^{\circ} \cdot 3$.

Cristellaria galaa, Excrcsop.pl. $467 \cdot$ fig. 6. I a. b.c.

D’Oввасту, loc. cit. $n^{\circ} .6$.

Celle-ci, moios variable que la précédente, s'en distinuse bieo nellement; elle n'a jamais sun centre granuleux; elle est très-déprimée latéralement et composée de cloisons moins nombreuses et plus éloignées. Le bord des loges étant saillant postérieuremeut, semble recevoir ou t'ecouvrir la loge qui précède; les demières sonl fort obliques, trés-longues et dépassant le sommel. La crête dorsale est lamelleuse, nince, tranchante, élevéc et légèremsint festonoće sur son bord libre. liouverture ça la corjuille est placée à l'augle dorsal; elle est pelite, ovale, oblongue, presque linéaire, catourće d'un bourrelet, liuement striée longitudinalement. Cette coquille, de 3 à 4 millim. de diamètre, se trouve à la Coroncine.

3. Comstellaire à cótes. Cristellaria costata. D’Овв.

C. testâ ovato-acutâ, depressâ, longitudinaliter costatä; costis quinque, simplicibus, distantibus, anticè evanescentibus; septisobliquis, numerosis, vix perspicuis.
D'OrbIGNy, loc. cit. $2^{\circ}$. 10. et Modeles, $4 "$. livreis. $n^{\circ} .84$.

Espèce fort remarquable, ovale, alongéc, pointue anćrieurcment, se terminant par l"angle dorsa!, où se reıuarque une très-petite ouverture arrondie, non nıarğúce ni plissée. Posı́rieurement plus épaisse, celle cuquille s'earonle en spirale, mais la suire est cachée par des callosilés recouvertes elles-mêmes par ciuq ou six côles peu saillantes, simples, lisses, qui disparoisseat sur la partic autérieure de la coquille, tandis qu'elles sont plus élevées sur la partie postérieure. Une crête peu saillunle ct assez épaisse règne le long du das et partage la coquille en deux parties symétriques. Les cloisons sont simples; les deruières, très-obliques ct plus marquées qua les premières, qui s'efficent sous les côtes. Cette coquille, très-petite, se trouve à Rimini.

\section{Cerstelladre polie. Cristellariz levoigata. D'ORB. \\ C. testâ ovato-elongatâ, spirali, dorso angu- latî, posticè radıatim costatá; umbilicis obtusis, callosis; aperturâ simplici, rotundâ, posticali. \\ D'Onbignt, loc. cit. $n^{\circ} .19$; et Mtodeles, $2^{\circ}$. livrais. $\pi 2^{\circ} \cdot 47$.}

Cette coquille, dont le dos est dépourvu de carcene, paroîi, au premier aspect, étrangère au genre Cristcllaire; on Jui retrouve cependant les caractères qui doivent l'y placer. Elle est conlournće en spirale postérieurement, et ornée de côtes rayonoantes, assez nombreuses, plusélevées vers le centre gue sur le bord, où elles disparoissent. L'ombilic, de chaque côté, est recouvert d'une callosité arrondie, mamillaire. Comme dans uo assez grand nombre de coqnilles micruscopiques nautiliformes, les deux côtés se rejoigneut sur le dos en formant un angle assez aigu dépourvu de earène. Les dernières loges, un peu globuleuses et comme élranglées, sont lort obliques, et la derzière, fermée par un diaphragme convexe, est percée à son angle dorsal d'une pelite onverture toute ronde dépourvue de bourrelet et de rides. Celte petile coquille se trouve dans les calcaires des environs de Caen; elle pourroit servir de passage entre les Cristellaires et les Saracénaires, s'il existoit encore d'autres intermédiaires, qui jusqu'à présent sont inconaus.

5. Camstercaire anrieulaire. Cristellaria uuricularis. Lawr.

C. testâ ovalâ, globulosî, lavigatâ, dorso

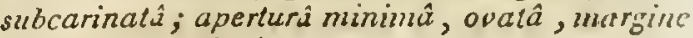
plicato circumdatá.

D'Orbic. loc. cit. no. 23.

LAII, loc, cit. $\pi^{\circ} \cdot 4$. 
Naitilus acutauricularis, Fichtel et Moll. tab. 18. fig. 9. h. $i$.

Oreas subulatus, Montr. Conch. syst. tom. I. pag. $n 4$.

Itid. , Blatrv. MIulacol. pag. 585.

Cristellaria acutauricularis, Excrcu. pl. 467. fig. $7 . a$. b.c.

Orale, globuleuse, toute lisse, plutôt anguleuse sur le dos que carínce, celle petite coquille se distingue par ses loges simples, assez nombreuses, grandissaut prouptement et devenapt de plus en plus obligues à niesure gguon sapproche davanage des demicres; le bord de la dernière est un peu contouraé el elle n'est pas fermée par un diaphragme convexe, majs par un concare, et l'ouverlure, petite, orale, enlouréc d'un bourrelet, trèstinement plissíc, est saillante el portée sur une sorle d'apnpliyse sululće. C'est dans la Mléditerranće que l'on trouve celle coquille, qui a it peine 2 aillim.

\section{CRYPTOBRANCHES. Crjplobranchia.}

La deuxicme classe des Mnllusques de la Méshode de M. Gray, qui rorresiond à la grande division des Gastéropodes de M. Cuvier, a élé diviscee en deus sous-classes; la premiere contient 1ous les Mollusques qui respirent l'air en nature; la seconde, ccux qui respiront l'eau, el qui, par couséquent, sont pourvus de bram lizes. Celle scconde division a reçu le nom de Cryptobranches, et contienl, divisée en dix ordres, la plus grande parlie des Mollusques. Voyez ce urot.

\section{CRYPTOCEPIILES. C'ryptocephala.}

Famille proposíe pa: M. Latreille (Fam. nat. duRègn. amm., pag. 169) pour le genre Hyale Ini seil. On sent combien celle famille est inutile, quand on fait atlention anx rapports quilient los Hyrales aux Clios et iutres çenres des Pı́ropodes de M. Launarck : genres que l'on range maintenant, cl avee raison, tout près des Gastúropodes. Togez Hyales el Noliusque.

\section{CRYPTOCOCHLIDES. Cryptocochlizes.}

M. Latreille a donué ce unm ì la seconde section qu'il a élablie dans l'ordre des Peclinihranclies. Celle scrtion ne contieut qu'uue seule famille, relle des Macrostomes, qui n'a presque de ressemblance que le nom avec celle que iI. La. marck avoit nowence ainsi. Nous verrous, à l'article Moltusque, si celle section étoit nécessaise.

CRYPTODIBRANCHES. Cryptodibranchiata.

Bl. de IBlainvil.e a propos de former, sons relte dénomination, un premier nrdie daus les Céphalopodes, lequel tenfermeroil tous les aniualis que Linué comprenoit dans son genre
Sèclue, e’est-à-dire les Céphalopndes, Dérapndes el Octopodes des auteurs. M. d'Orbigny a adoplé celle division, qui est très-bonue, comme nous le verrons à l'arlicle Céphazopodes, auquel nons renvoyons.

\section{CRYPTOPLACE. Cryptoplax.}

Dénomination que M. de Blainville proposa de donner à un fenre que M. Lamarck, avant lui, avoit nommé Oscabrelle. Vnyez ce mot.

\section{CRYPTOSTOMk. Cmptostoma.}

Ce genre, que M.de Blain.jlle a ćabli pour des animax mollusques d'une lorme tròs-singulic̀re, qui ont les rapports les plus évidens avec les Sigarets, doit se ranger prés d'eux dans les méihodes de classification; c'est dans le Dictionnaire des Sciences naturelles que nous a vons pris connoissance des observatious qui concerncnl le noureau genre; l'article Moususque de l'Encyclopédie dídiabourg le mentionna pour la premiere fois, et il fut reproduit depuis par son auieur dans le Traité de Malacologie, ou il prit place dans l'ordre des Chismolsranches, à cóté des Sigarets, arec lesquels il a une trés-grande analogie; si grande, en effet, ciue nous doulons quil soit par la suite conservé, car la principale différence arec les Sigarets seroit daos l'ampleur du manteau et du pied, el la grandenr rela:ive de la cocuille. M. de I3́ainville a carictérisé ce genre de la manière suivante:

\section{CARACTÉRES GÉNÉTIQUES.}

Corps glossriide, formé en très-grande partie par un pied fort lonğ, très-épais, plus étroit en arant, canaliculé de chaque côlé et débordant de lieaucoup la masse cortillée des viscères, qui est fort pelite, peu convexe en dessus, el icconverle dans son tiers médian par une coquille intérieme, en tout seublable à celle des Sigarels proprement dits; bouche très-petie, cacliéc scuus le rehord antérieur el supérieur du pied, ver's laquelle couvergent ses quatre sillons; deux leuticules comprimés el appendiculés à leur hase; yeux? un seul grand peigne branchial; anus au côté drnit du bord iibre du manteau.

L'animal aplati, un peu plus convexe posterieurement qu'antérieurement, ayant la bouche cachée sous le rehord auléricur du manleau, et caractérisé surtout par la grandeur dn pied, qui est énorme, proportionellemeat au reste da. corps, dont ì a qua!re à cinq fois les dinensions. Les yenx sont placés à la base des leniacules à leur partie externe. A la partie postérieure el la plus élevée de l'animal, on remarque wue coquille qui est inléricure el qui, comme dans les Sigarets, est destinće it protéger les organes de la respiration. N1. de Blaiprille, aux articles cites 
ci-dessus, donne, sur la structure de l'animal, des détails étendus, auxquels nous renvoyons, n'ayant pas eu nous-même occasion de voir les corps dont il s'agit: il nous sufira d'ajouter que la coquille ressemble tellement à celle des Sigarets, yne l'on seroit porté de la placer avec eux, si on ne conuoissnit pas l'animal qui les parte. Il n'y a encore que deux espèces de Clyplostomes de connues, ce sont les siivantes que nous indiquons d'après M. de Blainville.

1. Carptostoue de Léach. Cryptostoma Leachi. Bearve.

Bussv. Encycl. d'Edimbourg et Dictionnaire des Sciences naturelles.

Ibid. Truité de Mlakac. pag. 467.pl. 42. fig. 3.

Cetle espèce est ovale, oblongue, plus alungíe que la suivaute; les tentacules sont perits, plus cunirgues, plus étroits et plus distans; les appendices de leur base sont plus petits, la partie antéricure du corps plus longue que la postérieure.

2. Cryptostowe raccourci. Criplostoma breviculume.

Blisvilee, loc. cit.

Celui-ci est large, plus arrondi, la partie antérieure presqu'égule à la postćrieure; les tenacules sont grands, larges et dépriniés; les appendices de leur base y sont proportionnés et conséguemment plus grands que dans la première espèce. Quoique da corpuille du Cryplostonse raccourci De soit paiul conuue, M. de Blainville pense qu'elie doit préseuter des différences au moins dans le volume.

\section{CTEXITE.}

On trousc ce mot daus les ancicns oryctograplies qui désinnoient ainsi les coquilles fossiles du genre l'eigne. Vojez ce mot.

\section{CTÉNOBRANCHES. Clennbranchia.}

M. Gray es! un des conchyliolngues qui ont le plus éudié les opercules; il s'est servi très-utulement de ce moyen pour élablir des groupes on des familles dans les Pectinibranches que, daus sa meibode, il nomme Ciénobranches. Conme le not Pectimbrunches, appliqué d'une manière conrenable, est consacré depurs lonen-temps dans la science, no:us pensnns guril est nécessaire de la conserver. Voyez Pecrisibanaches.

\section{CIÉNOÏDES.}

Suns ce nom Klein (Iéthod. ostrac. pag. İít.) avoit séparé des Peignes de linné des coquilles dont la rémion en genre étoit utile. Depuis, liruguière l'a élabli de nouveau sous le non de Lime. Ce genre a été adopté par הl. Lamarck Hist. Nat. des Vers. Tome II. et le plus grand nombre des zoologistes, Vojez LIME.

\section{CUCULLĖE. Cuculláa.}

Les Cucullćes, les l'étoncles et les Nucules ont été séparcis du geore Arclie de Iinué, parmi lesquels ou les avoit long-temps rangés. C'est a M. Lamarck (Anim. s.vert. ire.édit.pag. 116) que nous devons celte ulile réforme, qui ue permettra plus la confusion dans des coquilles qui, quoique préseatant des rapports, ont pourtant entrelles des dillérences assez grandes; il faut dire cependant que les Cucullées sont parni ces genres celles qui présenturat le moins de caractères Iranchís. En ellet, elles ne diffèrent des Arclies que par des dents latérules transverses en plus ou moins grand nombre sur les angles antétérieurs et postérieurs de la charnière; du reste la disposition des crochets et du ligament, ainsi que la forme générale, teudroient à les confondre dans le dernier genre. Plusieurs concliyliologues, et nous soumes de ce nombre, admettent le geare Cucullée avec celte resiriction, qu'il est nécessaire de connoitre l'uuimal, ou au moins d'avoir sur lui quelques notions qui puissent faire vorr quelques différences organiques entre lui et celni des Arches, que Poli a si bien décrit et si bien liguré sous le nom de Daphné.

M. Curier et M. de Blainville noont adopté ce genre qu'à titre de section secondaire des Arches. Comme ces coquilles sont parfaitenueat closes, qu'elles ont des ion pressions musculaires saillantes, qu'elles sont très-lonbées, et cepeudant fort minces, nous croyons qu'un peut les admellre au mons comme sous-genres, en attendant gue l'auimal soit connu.

Voici au reste les caractères que l'on pent lui donner; u'en connuissant que les coquilles.

\section{CA A $\triangle$ CTÉRES GÉNÉRIQUES.}

Coqquille équivalve, inéquilatérale, irapéziforme, ventrue, a crochets écartés, séparés par la lacette du ligamenl; impression musculare antérieure formant une saillie à bord angulenx ou auriculé; cliarnière linéaite droite munie de petites dents transverses, et ayant à ses extréinités deux à cinc côles qui lui sont parallèles, ligament tout-î-lait extérieur.

Les coquilles qui appartiennent à ce genre sont généralement très-renllíes, yrosses, épaisses seu. lement dans les espèces fossiles. Le côlé ablérieur est séparé du resie par une sorte d'angle obtus qui coupe la coquille, ce qui rend le corseler lort large. Ises impressions musculaires, qui dans la plupart des autres Conclaylères sont entoncícs, ici présentent des ćlévations, des saillies plus ou moins considérables, surtunt pour l'impression antérieure, qui prend quelquefois la tome ciane $\mathrm{E} *$ 
languette auriculiforme. Ce genre se compose d'un très-petit nombre d'espèces, une seule vivante ou à l'élat frais, quelques autres fossiles et généralement dans des terjains anciens. M. Ménard de la Groye nous a dit en avuir trouvé des moules et des impressions dans un calcaire oolitique des environs du Mans. M. Basterot en a trouvé également, mais aussi peu reconnoissables que les premières, à Lances près Rliétel, dans le sable vert: celles mème des environs de Paris paroissent devoir appartenir aux plus anciens dépôts qui se sout formés sur la craie, comnie quel ques observations qui nous sont propres tendroient à nous le laire geoser.

T. Cucultée auriculifère. Cuculloza auriculifera. LAmx.

C. testâ obliquè cordutá, ventricosâ, decus. suthm striatâ, fulvà; candine utrinquè subbicostato.

lanx. Anim. sans vert. torn. 6. part. Ire. pag. $34 . n^{\circ} .1$.

Arca auriculifera, Businv. Maluc. pl. 65. fig. 4 .

Arca cucullata, Lis. pag. 5311.

Cиеmitz, Conch. tom. 7. tab. 53. fig. 526 et 527 .

Arca concamera, Bnug. $n^{\circ} .11$.

Excrcs. pl. 304. fig. 1. a. b. c.

Elle se distingue facilement, comme espèce, par les attaclies musculaires, par les stries tresfines qui se croisent sur la surface, par la couleur fauve-cannelle en dehors el violâtre en dedans, surtout vers le cóté antérieur, ainsi que par lä charnière qui ne présente qu'un ou deux còtés transverses : on la nounie vulgairemen le Coqueluchon; elle vient de la nuer des Indes, où elle est fort rare. Elle acquiert quelquefois jusqu’à trois pouces huit lignes de largeur.

\section{Cuculdè crassatine. Cuculloea crassatinu.} L,A MIK.

C. testâ subcordatâ, ventricosâ; sulcis longitudinalibus, interniptis, interdiun subnullis; auriculo interno brevissinio; cardine utrinquè ter ad quinque constato.

Lamk. Loc. cit. et Ann. du Mus. tom. 6 . pag. 338.

Kxonn. pag. 11. $t a b, 25$. fg. I. 2.

Celle-ci présente quelquefois plus de longneur que la précédente : elle a jusqu'à quatre pouces de large; elle se distingue en outre par les impressious musculaires, qui, quoique saillantes à J'intérieur, ne présentent point un appendice auriculiforme; les côtés de la charnière, plus larges, sont munis de quatre à cinq côtes transverses. Ce qui est surtont remarquable dans cette espèce, c'est que, par la disposition des stries, on pourruit en faire deux; ('ar l'une des valves a les siries tiansverses très-fortes, tandis que sur l'uutre ce sont les longitudinales qui sont les mieux marquées. 1l fulu avoir eu souvent occasion de les voir encore réunies, par le sable qu'elles renterment, pour s'en faire une plus juste idée. On la tronve fossile aux environs de Beauvais, à Brachenx it à Alubecourt, où elles sont très-communes, mais aussi très-friubles.

\section{CUCUNIS.}

C'est ainsi que Klein (Meth. ostrac. pag. $7^{\text {8.) }}$ nomme un genre quil propuse de faire aux dppens des Volutes de Liané; il ne contient presque que des Marginelles, et auroit été sans donte adopté s'il n'ê̂t renferné que des coguilles de ce genre. Voyez Marginele.

\section{CUILLER.}

Quelques coquilles du genre Cérite ont reçn des marchands ce nom, quils accompannent d'une épilhète pour désigner des espèces diflirentes : ils nomment Cuniner a pot le Cersthium palustre Lamk. Brug., Petite coileEr a POT le Cerithium sulcalum, et CuILLen d'ébìne le Cerithium ebeninum. Voyez Cérate dans le premier volume de ce Dictionuaice.

\section{CUILLER D'IVOIRE.}

Est le nnm que l'on donne vulgairement au Pholas dactylus, qui devient quelquefois folt grand. Voyez Prolade.

\section{CUL-DE-LAMPE.}

La plapart des coquilles dn geare 'Turbo qui ont la spire courte et arrondie, sont nommées rnlgairement Cul-de-Lampe. Cette démominatiun impropre est presque abandonnée.

\section{CULOI'TE-DE-SUISSE.}

Quelques marchands nomment encore de cetre manière le Murex lumpas de Linné, ainsi que le Turbinella pyrum, qu'ils désigneni aussi par le nom de Culotte-de-Suisse Slanche. Vujez Murex et Tohainelle.

\section{CUNEUS.}

A la manière dont M. Mígerle exprime les caractères de ce genre, on cruiroit, si l'on en connoissoit le type, que c'est tout autre chose : en effet, des Concliyfères dont les coquilles pirsentervient six dents cardinales et trois dents latérales seroient pour nons tont-a-fait nonvelles, si nous ne savions que cet auteur compte en méme temps toutes les éminences des deux valves; alors, dans notre manière d'énoncer les carac- 


\section{U V}

ieres, ce seront des coquilles qui ont trois deats cardiaales sur chaque valve, et une dent latérale qui, sur la valve opposée, est reçue dans une cuvité dont les deux cûtés plus saillans sunt comptés comme des denls. Les caraclères, ailısi réduils à leur juste valeur, se rapporteut parfuileuent à ceux d'un genre fait depuis lougternps pir N. Lamarck sous le nom de Donace. Vojez ce mol.

\section{CUVIr̈RIE. Cuvieria.}

Genre nonvellement proposé par MI. Rang, dans son Manuel de Conchyliologie, pour deux Mollusques vuisins des Cléodores, et que très-probableanent on conservera dans la Méthodc. Dans l'arran:zensent de l'auteur que nous citus, ce gemre est compris daos Ia famille des llyales, qui est la première des Ptéropudes, el placé eurre les genres Cléodone el Euribie. (Vuyez ces mots.) Il est caracterisé de la nisuicre suivante :

\section{CARACTÉTES GÉNÉETQUES.}

Animal alongé, muni de deux nagecires assez prrandes et d'ua lohe intermédiaire demi-circuParre; les Jrancluies extérieures, siuces à la base du lulse intermédiaire; lorgane de la génération incompléle:neal conus; la louche, nunie de pic̀ces dentiliurunes propres à la mastication.

Coquille en forme d'étui, cylindrique, un peu aplditeprès de son ouverture, yui est cordiforare, et dunt les bords sont tranclians; extrémilé puslírieure fermée par un diaplsráne convexe a l'extérieur, non terminal, étaul débordé par les parois du cyliudre. (Rang.)

D'après les caractères que nous venons Ilexposer, nn ne peut donter que ce genre ne dillere ctes Clćodiras el d'autres genres voisins; on duit dunc l'adopter, el le places dans les rapports que M. Rang indique.

Dans les Annales des Sciences naturelles, AI. Rang a donné des détails analomicjues sur ree netre; il a reconnu les or:yanes digestifs, qui sont rres-simples, les orgines de la génération, et quelques traces dn système nerveux. A sal partie antérieure, cet animal est pourva de deux nageoires assez grandes, en furme de leville de myrte, qui se réunissent en convergeant sur un pédicule coun tendu, qui se termue postérieuremeat par un long muscle en ruban qui va saltacber au fund de la coquille : c'est daus la fente du pidicule que se trouve l'auverture buccale, qui est petile, et aboulit is un aroppliage lous et iris-grêle qui s'eulle en un estonac fusiforme, en grande prarlie enveloppi, ainsi que le court inlestin qui en nait, dans un foie assez rulumineux. Cel intestin, aprés un petit uombre de circonvolutions, se reporte en Laut, en avant et is droite, et se termine dans uu petit pavillon flotant, auquel aboulit aussi l'organe de la génćration; celui - ci, très - simple, se compose d'un uvaire for singulier, qui occupe le fond de la coguille; il est ennique, aplati, creusé d'une goutlicre à sa facce ventrale, et foraré de segmerrs empilés, de l'un desquels el du milieu de lit gontliée palt un oviducte très-mince et tresgrçle a son crigine, qui se renlle dans son tnilieu, s'amincit de nuuveau el s'inllécluit plusieurs lois avani de se jeler daus le pavillon commun. $\Lambda u-$ dessnus de l'osoplage, se voit un ganglion arrondi, ducjuel partent en rayoumant des lifets netveux qui ont une telle ténuité, qu'il a été impossible de les surve un peu au-deli de leur origine.

La brauchic, très-petite, est altachíe au pédicule antérieur; elle est irrégulière et peudante au-dehors, lorfque l'animal est nageant. Ce qui est fort singulier, c'est que le cœur, extessivernent pelit, est placé au fond de la crefuille, an-de:sous de l'ovaire et forl loin, conséquemment, de la branchie, ce qui n'est pas ordinaire chez les Mollusques, où le cœur est presque toujours à la base de l'organe de la respiration. Lat transparence des vaisseaux et du liquide qu'ils contiennent, s'oppose à co qu'on puisse les dislinguer des organes daus lesquels ils pinètrent.

N. Ratag a'indique que deux espèces dans son genre, l'uue vivante, et l'autre fossile: la première ayant été la senle figurée et nommée, c'est elle que nuus allons indiquer comme type du genre.

Coviéne pelile colonne. Cuvieria columnellu. RANG.

C. testá tenuissima $\hat{a}$, hyalinâ, rectí, clongati, posticè truncatî, rolundatâ, septo clausâ; in medio leviter turgescente; aperturá ovato-depressi, subtrigona.

Rang, Ann. des Scienc. nat. tom. 12.pl. 45. fig. I à 8 .

Ibil. Munuel de Conchyliologie, pag. 116. pl. 2. fig. 4 .

Pelite coquille transparente, vitreuse, trésmince, très-fragile, druite, trouquéc à ses deux extrémités, sulscylindracée, un peu ventrue dans son milien; l'extrénuté postérieure est fermée par un diaphragme Iransverse, convexe, qui prísente cela de siagulier, d'être placé an-dessus du bord, el débordé par les parois da cylindre. l'ouverture est transverse, subirigone, el ressemille, sous plus d'un rapport, à celle de quelgues Clćodores. Cente coquille, lengue de 10 à 12 millim., se trouve en aloudance dans les mers de l'lle-de-France et de Madagascar.

CYCLADE. Cyclas.

Les aufeurs qui ont précćdé Linné, et Linać E*2 
lui-même, ont confondu ce geure, soit avec les Tcllines, soit avec leurs Cames, soit avec ce qu'ils appeloient Pétoncles. Lister ne les distingue unllement des autres coquilles bivalves d'eau donct. Geoffroy, dans sa Conchyliologie des environs de Paris, en leur donnant le nom de Cames, les a beaucoup micux connues; on peut même dire que c'est lia l'origine du genre, on du moins que c'en est une bunne indication. Bruguière le premier l'élablit d'une manic̀re positive dans les planches de l'Encyclopédie; il y réunit coutes les coquilles Iluviatiles qui ont de la ressemblance avec les Cyclades. Ce gronpe, Itès-naturel, a élé ensuite sous-divisé par M. Lamarck, qui a donné an nouveau genre qu'il $\in u$ a extrait le nom de Cyrène. Toutes les coquilles épaisses qui out deux ou trois dents cardinales sur chargue valve, et qui faisoient partie du genre Cyclade de Bruguière, reutrèrent dans celui-ci. 'Yous les auteurs modernes ont adopté celte division, soit comme genrc, soit comme sousgeurc. M. de Blainville, dans son article Cycladr. du Dictionnaire dos Sciences naturelle's, thit observer, d'après M. de lierussac, qu'il existe des cspèces qui servent à furmer le passage entre les deux geares, et daprès cela il propose, tonjours suivant M. Ferussac, de diviser les (.yclades de Bruguière en deux sous-gentes qui sont : Corneo-cyclas pour les Cyclades de M1. Lamarck, el Cyano-cyclas pour lis Cyrines du mème auteur. Dans les Iableaux systématiques de M. Fe russac, publiés postérieurement à l'article que nons venons de ciler, nous ne retrouvons plus celle division, l'anteur y ayant renoocé, à ce qu'il paroit, pour adopter les deux geares de M. Lamarck.

M. de Blainville, depuis, modifia aussi sa manière de voir à l'égard de ces genres, comme on peut s'en assurer duus son Truité de Nalacologie, où il rénuit dans le seul grenre Cyclade, les genres Cyrène et Galathée de II. Lamarck, remplaçant de celle manic̀re la famille des Cycladés des anteurs.

\section{CARACTÉRES GÉNÉRIQUES.}

Coquille ovale, bombéc, transverse, équivalve, à crochets procubérans; dents cirrdinales rtis-petites, quelquefois presque aulles : lantôt denx sur chaque valve, dont ane pliée ea deux; tantòt une seule pliće uu lobée sur une valve, el deux sur l'autre; dents latérales alnngćes transversalement, cowprimées, latnelliformes; ligament extéitent.

Animal ayant le corps ovale et épnis; les loords du mantean simples, soudés postéricurenent et formaul de ce côlé deux lubes rémis, peu saillans; le pied large, coupriuć à sa base et terminé par une sorle de jambe ou d'appendice.

L'animal cles Cyclades est trop comoun daos nos rivières pour que nous croyions nécessaire de le décrire ici. Depuis long-lems ps figuré, ćtrdié avec soin par Geolliny, on ne conleste pas res rapports; mais il est bien ceritain pour acus çue le geore $P$ isum, que I.I. Pfeller en a démembré parce que les siphons sont un peu plus courts, ne mérite pas d'être adoplé.

II seroit possible qu'en réunissant un grand aorabre d'espèces de Cyclades et de Cyrènes, ou tronvât un passage entre ces deux genres : mais les matériaux manquenl, et l'on connoit trop peu d'espèces pour opérer celle rénaion, ì laquelle on pourra probablement revenir plus tard. 'loutes les Cyclades sont lluviatiles; elles sont petites, fragiles, épidermées, ovalaires, et avec une claraière qui n'a jamais la régularité et la force de celle des Cyrènes.

La Cyclade que nous avons trourée dans le bassin de Paris vient des marnes blanches qui sont entre la craie et les premiers dépúts de l'argile plastique, à la montagne de Bernon, prés Epervai; elle est accompagnée de Paludines, de Plyyses, de Planurbes et de Cyrogouites entières.

1. Cycrade lisse. Cyclas levigata. Nов.

C. testầ ovato-subtrigonâ, incrquilaterâ, obliquâ, inflatâ, tenui, pellucidî, lovvigatâ; dente cardinali unico, vix perspicuo in utrüque valva; dentiluus laterilus magnis.

Nов. Descript. des coq. foss. do Paris, tom. 1. pl. 18. $f_{0}$. 12.13.

Celte pelite coquille a assez d'aualogic avec le Cyclas fontinalis de Druparaaud; elle est cependant plus enilée et plus inćquilatérale; sa taille est à pen près de même. Elle est ovale, subtrigone, peu transverse; le côté postérieur furt Jarge et plus épais que l'antérieur; son crochet est peu proémioent; la charnière ne présente suos le crocliei qu'une très-petite dent cardinale sur chaque valve : celte dent est rudimentaire. Les denis latérales sont bien marquées; elles sont même plus épaisses et plus fortes quz dans les Cyclades vivantes de même taille. La postérieure est la plus longue; elle occupe presque toule la lougueur du corselet. L'antéricure est petite, et la place qu'elle occupe sur la lame cardiuale fait saillie a lintérieur' : coute sa surface extérieure est lisse; on y aperçoit souvent quelques stries d'accroissement. Longueur 4 millimèlres, largenr 5.

2. Crcrape des rivières. Cyclas rivicola. Laxk. C. testâ subglobosî, solidulâ, eleganter striati, corneo virescente, intùs carulescente; sulcis duo sive tres transpersis, subcoloratis. LaMr.

Lister, Conch. tab. 15g. fig. 14.

Cyclas cuinea? Drap. Hist. des Aoll. 


\section{Y C}

Defrance, pag. 128.pl. 10.fig. 1.2.3.

EscrcL. $p l .302$. fig. 5. a. b. c.

M. Lamarck a cru celte espèce rare en France; nous savons au contraire quelle est fort commune dans les rivières de la Bretagne. C'est la plus grande du genre et celle qui se rapproche le plus des Cyrènes, quoique sa charnière seu distingue cependant bien neltement : elle est ovalaire, assez solide, bombće, striće transversalanent et couverte d'ua épiderme brun, donı la tciate uniforme est le plus souvent interrompue par une ou deux zones droites de couleur cornée. Elle est large de 20 à 25 millim.; elle se trouve dans presque toutes les eaux dunces d'Curope.

3. Cyclade cornée. Cyclus corneca. Lank.

C. testî̀ subglobosâ, tenui, tenerrimè striatâ, pallide cornea; sulco subunico; zonta marginali lutescente.

Tellina cornea, Lrr. Gurs. pag. 3242. $n^{\circ} \cdot 76$. Sjn. plerisque exclusis.

DARGexville, Zoomorph. tab. 8. fig. 10.

Chemsitz, Conch. tom. 6. tub. 13. fig. 133?

Goalt. Test. tab. 7. fig. B. 4. 5 .

Cyclas rivalis, DRAP. loc. cit. pl. чо. fig.

Nous n’avons pas vu les variétés que M. Lamarck ajoute ì celte espèce; comme il les cile le l'A nérique scplentrionale, nous avons peine a les atmetue sans les avoir conırarées avec soin. Celle espc̀ce, que l'on trouve très-abondummeot en France, eu Allemagne et d'autres régions de l'Europe, est constamment plus petite que la précédente, loujours plus enflée, plus mince, irćs-fragile, d'un brun-grisâtre ou corné vers les bords; elle est couverte de strics extrèunement fines, régulières et lrès-serr'es; en dedans elle est d'un blanc livide et sa charnière n'a qu'uoe on deux deals peu pronuncées. DRAP.

4. Cycla de culyculée. Cyclas calyculata.

C. testâ orbiculato-rhombea, tenui, subdepressà, diaphaná, albo-Lutescente; natibus prominentibus, taberculosis.

DaAp. loc. cit. pl. 10. fig. 14. 15.

LarK. Anim. sans vert. $20 m$. 5. pag. 559. $n^{n} \cdot 5$.

Coquille d'un médiocre volume, moins globuleuse ‘ue les cspèces précćdentes, presque orbiculaire, un peu rhomboidale, fort mince, liansIncide, lisse, converte d'un épiderme fauve ou burua-jaunâtre; ses crochets saillans sont tubercaleux, ce qui la dislingne très-nettement de toutes les autres. Elle se iruuve en lirance, eo Augleterre et en Allewagne.
5. Crclade des fontaines. Cyclus fontinalis. Drap.

C. testâ globosâ, subdepressâ, subinaquilatcrali; umbone subacuto.

Drar. loc. cit.pl. 10. fig. 14. 15.

La Mк. loc. cit. $n^{\circ} \cdot 7$.

C'est sans contredit la plus pelite espèce counuc en Europe. Elle n'a que 2 mallim. de large; elle est toute lisse, très-nince, fragile, traosparcute; elle est arrondie, subglobuleuse, un peu déprimée, toujours d'une teinte grisâtre, un peu plus blunche en dedans. Ou l'a trouvée daas les liontaines des eavirons de Montpellier.

\section{CYCLADES (les).}

N. de Ferussac a reproduit sous ce non, et sans aucun cbangement, la lamille des Conques lluviatiles de M. Lamarck. (Voy. Cosques.)

\section{CYCLADÉES. Cycladia.}

M. Rafinesque, dans sa Monographie des coquilles de l'Ohio, insérće dans le tom. 5 des Annales des Sciences de Bruxelles, a proposé celle lamille pour les genres Cyréne et Cyclade, les seuls (qu'il conoút; elle est donc incomplète. (Voj. Cuxques.)

\section{CYCLADINES. Cycladina.}

En élablissant cette famille, M. Latreilic y introduisit d'abord les Conques fluviatiles de 11. Lamarck, auxquelles il ajouta le genre $\mathrm{Cy}$ prine, gui est marin, et qui se place mieus daos le voisinage des Cythérées. (Vor. CoxQUES.)

\section{CYCLAS.}

Klein a clonné ce nom i un greore composé principalement de Lucines et de quelyues autres coquilles; le nom seul, appliqué à um lon geore, a été conservé par Bruguicre.

\section{CICLAS.}

Le genre Cyclade éloit établi depuis longtemps par Bruguière; déjà nême MI. Lamarck, par une réforme ulile, en avoil séparé les Cyrènes, lorsque N. Schweigoer, dont nous ve conncissons pas les motifs, liansporta ce 1:00u aux Galathées, qui déja, elles-uêmes, avoient élé séparćes cn geme par M. ladmarth. ( Voj. Crclade et Galathee.)

\section{CYCLENIS.}

Genre imparfaitement connu, parce que son auteur, M. Ralinesque, ne l'a pas suflisamnont caractérisé; il paroîl cependant qu'il l'a fuil avec quelques Limnces; alors il sercit conijhtement inntile. 


\section{CYCLOBRANCHES. Cyclobranchiata.}

M. de Blainville a introduit cetle famille dans la science depuis 816 ; on la trouve dans la unéthode conchyliologique pabliée alnrs dans le - Tourral de Phisique. Il la démembra des Gastóropodes nuclitrancles de M. Cuvier, et la composa des trois genres Doris, Onchidore et Péronie. M. de Ferussac établit aussi une famille presque semblable à celle-ci, et lui donna le nom de Doris (Joy. ce mot). Dans le même terps M. Gray, dans sa Méthode des Mollusques, cruployoit le mot de Cyclobranches pour un des ordies des Gastéropodes, qui ne contient que le genre Patelle. Il suit de là un double enploi nuisible, et si la dénomination de $\mathrm{Cy}$ cobranclies reste dans la science, il fandra que ce soit avec l'application que M. de Blainville (n) a faite, puisque le premier il l'a proposée. Vuvez Molnusozo.

M. Latreille (Fum.nat. duRèg.anim.pag. 202) a a ussi formé un ordre de Cyclobranches; il se rapproche plus de celui de M. Gray que de M. de Blainville. Il le parlage en deux fumilles, La première, les Scutibranches (yoyez ce mot), cunticat les Ombrelies et les Putelles, et la seconde, les Lamellés (2rovez ce mol), renferme les ventes Oscabrion el Oscabrelle. Nous verrons à l'áticle Ombrelle, que ce genre d'est pas là duns ses rapports naturels.

\section{CYCLOPE. Cyclops.}

Gearc établi par Monifort (Conch. Syst. tom 2. paz̆. 570) pour le Buccinum nertteum de Linné, 'J'1, bien qu'ayant un port particulier, ne présente cependant pas des caractères suffisans phrt former un bon genre. Toyez Buccin.

\section{CYCLOHHORE. Cyclophora.}

'Genre inutile, proposé par Montfort ponr quelyues Cyclostomes. Toyez ce mot.

\section{Circlostone. Cyclostoma.}

M. Lamarck, qui a créé le grenre Cyclostome (Amm. sans vert. 130r), y cumprenoit alots tortes les coquilles soit terrestres, soit marines, yui ort la bouche ronde et le péristome continu, e! le type de ce geure étoil le Turbo delphinus de Iingé. Draparnaud circonscrit beaucoup mieux les Cyclostomes, en en éloignant les coquilles urarines; il n'y resta plus, d'après lui, que des soquilles fluviatiles et terrestres. M. Lamarck sersit que, des aninaas vivant dans des condituons si différentes, ne pouvoient rester dans la mêtne coupe générique. Dans les Anmales il les sépara cu proposant son genie Dauphiuule, qui reuferina alors les coquilles marines à bouches roudes; et, lorsque M. Cuvier eat fait connoître l'anatomie de la Vivipare ì bandes, M. Lamarck la sépara des Cyclostomes pour eo faire son genre Paludine. Monifort, outre les genres Vivipare et Cyclostume, quil caractérisa à sa manière, démembra encore des Cyclostomes son genre Cyclophore, qui ne sauroit être adoplé. II. Cuvier (Règne unimal), en admettunt les Cyclostomes, les a néanmoins laissés parmi les Sabols, dont ils forment un des nombrenx sousgenres, quoique ceux-ci soient de véritables Pertinibranclies, tandis que les Cyclostomes sont pulmonés. M. de Ferussac, dans ses Tableaux systématiques, a proposé l'établissement d'un ordre nouveau, sous le nom de Pulmonés operculés, pour les Hélicines et les Cyclostomes, qui forment chacun une lamille. (Voyez Hézrcine et Turatcine.) Les Hélicines n'ayant point do collier, comme M. de Ferussac l'a cru, on réunira sans doute les deux genres dans une méme famille, en les rapprochant des Hélices et des autres Pulmonées.

Maintenaut les Cyclostomes ne renferment plus que des cocjuilles terrestres, dont quelques-anes se distinguent assez difficilemeut des Paludines. Cependant celles-ci ont toujours l'ouverture tranchante, non renversée en dehors e! sans bourrelet; elles se reconnoissent, en outre, parl'anglo gue lorme l'ouverture à sa partie supérieure, dans lendroit de la jonction des deux lèvies. Cetıe ressemblance des deux genres nous a laissé du doute pour quelques-unes des coquilles que uous rapportons a celui qui nous occupe. Il est fort difficile de décider si les espèces que nous trouvons dans les dépôts marins sont terrestres, lluviatiles uu nariues, lorsque surtout on trouve parwi elles des passages insensibles de l'uoe à l'autre.

\section{CARACTÉRES GÉNล́RTQUES.}

Coquille de furme variable, à tours de spire arrondis; ouverture ronde, régulière, á bords riunis circulairement, ouverts ou réfléchis avec l'âtre; un opercule. On peut ajouter à ces caractères ceux tirés de l'animal qui a une téte pronboscidiforme, surmontée de deux tentacules seulement, cylindriques, un peu renllés à leur's extrémités el oculés au côté externe de léar base.

Le gissement des Cyclostones n'a rien de particulie:; seulement on les tronve plus fréquemment dans les couches de mélaugre, que dans lcs terrains unarins ou dans ceux äeau donce. Parmi les espèces citées par M. Lamarck, il cn est trois qui nuus semblent ne devoir point rester daus le venre : ce sont d'abord le Cyclostoma plur norbrila, qui est une coquille trop jeune peur dérider son genre; le Cyclostoma macrostoma, qui est peut-être uoe rnaustruosité; entin, le Cyclostoma turritella, qui est un véritable Sci. laire. 


\section{Y C}

Ootrouve eacore, aux environs de Paris, deux espéces que nous de connoissous pás assez parfaitement pour les décrire et ponr les tigurer; quelque soin que nous ayons mis aे les recherchier, il uous a été improssible jusqu'aujourd'bui de nous les procurer. La prenière de ces cspéces, est lc Cyclostome ciselé, décrit et figuré pù N. Brard, duss les Annales du Museium, tom. 15. pl. 24. fig. 12 et 13, quil a beatucoup de ressemblance avec le Cyclostome élégaut, mais qui est trop mal tiguré, soit pour élablir des rapports défunitifs, soit pour le décrire de nouveau. La scconde esi le Cyclostome géant, que le même auteur a fait conooitre dans le tome 72 du Journal de Physique, pag. 453; mais sa descriptiou, fuite daus des lermes douteux, d'après des moules iulérieurs ile coquilles déprimées, écrasées dans des couches vù elles lureat trouvées, nous a laissé daus un doute que les ligures n'ont pu détruire. Pussédant plosieurs moules de l'Ampullaria patula Lamk. dans un état semblable à ceux décrits par al. Brard, et ayant élé d’abord perté à les placer parmiles Cyclostonnes, par les mêrnes raisons que lui, nuais par suite les ayant partaitement recoonus, noos pensons que, n'ayant pas vu les individus que possède ce minéralogiste distingué, nous devons rester dans le doute, jusqu'à ce que de nouveaux matériaux nous soient venus sul ce вujet. Une troisièuıe espèce, que le nêtue auteur a comparée au Cyclostoma trincutulum de Draparnaud, et que M. de Ferussac, dans snn Mćmoire géologique sur les terrains d'eau douce, a admis dan, ce genre, n'est, d'uprís M. Brard lui-u’cme, qu'une coquille warine. Conse Draparnaud le laisse à penser, elle rentre dans les Puludines marines de $\mathbf{H}$. de Ferussac, dans un des sous-genres, soit Lillorine, soit Rissoa; ce que nous examiuerons arec plus de détails lorsque nous décritons les Paludiues.

Les Cyclostumes vivans sont nombreux en espèces, et il sont répandus à peu près sur toute la surface da globe, comme cela a lieu pour les Hélices. Les plus grandes espèces se reuconirent dans les rénions les plus chaudes des deux hémisphères. MI. Lamaı'ck a indiqué vingt-huit espèces de Cyclostomes; mais il en existe davautage, nous en possédions plus de quaruate et plusieurs fossiles. Ces coquilles soni variables dans leur forme; les unes, élaucées, turriculées, ressemblent aux Scalaires ou aux 'Turritelles; les autres, moins élevćes, deviennent trochiformes, et, s'écrasant peu à peu, prennent la torme des Planorbes.

1. Crccostone planorbule. Cyclostoma planorbula. Lasrx.

C. testâ anfractibus teretibus orbiculatim involutis, supernè planulatá, subtùs latè unabilicatâ, bizonatâ, suprà luteo-nufescente, infrì casiuned; aperturî̀ albá; labro margine reflexo.

\section{I C}

L.A M. Anim. s. vert. tom. 6. $2^{e}$. part. $n^{\circ}$. 1 .

An Helix cornu zenatarium? Liv. Ga EL. pü̈. $56+1 \cdot 2^{\circ} \cdot 227$.

Cuensitz, Conch. tom. 9. tab. 127. fig. 1132. 1135 ?

Fatanne, Conch.pl. 64.fig. P. I ?

Cyclostoma planorbula, LAмк. Encjelop. p\% $46 \mathrm{r}$. fig. 3. a. b.

Petiven, Gazop. tab. 1. fig. 6.

Grande et belle espéce, assez roal firurée dans les auleurs pour que nous ne les cilinon qu'arer: doute. La ligure dc l'Ency lopédie est fort bonne, elle en donne une idée suffisante. Sans ètre tontà-fait planorbiqne, celle coquille estcependant fort déprimée; l'ombilic, très-large, est peu prolond, et on y compte tous fes tours de spire. Il es entouré, sur le dernier tour, de deux bandes brunes foncíes; en dessus, la couleur est unifor nuérneat fauve; toute la surface est couverte de stries transierses très-fiacs. Cette coquille, lort rare, qui vient, dit-on, du Sénégal, a jusylu'it 19 lignes de diamètre, 43 villim.

2. Circrostone trotbifurme. Cyclostoma zotvulus. Lam $\mathrm{x}$.

C. testâ trochiformi, profunde umbilicata, trunsversim striata, albo, luteo el rufo variegata; spirá acuminatá; aperturí albi aut luteâ; labro margine neflexa.

L.Amx. loc. cit. $n^{\circ} .2$.

Helix volvulus, Lin. Gms. pag. $5658 . n^{\circ} .91$.

Ibid. Mullea, Venn. pag. 82.,no. 230 .

Lister, Conch. tab. 5o. fig. 48.

Petiv. Gazop.tab. 76 . fig. 6.

SEBA, Mus. tom. 3. tab. 40. fig. 18.59.

Borv. Mus. cass. vind. tab. 14.fig. 23.24.

Caesinz, Conch. tom. 9. tab. 123. fig. $100 \dot{q}$ d 1066 .

Excrclopénie, pl. 461. fig. 5. a. b.

Espèce un peu moins grande que lia premičre; à spire plus élevée, trochiforme, à tours dirondis, et ombilic étroit, quoiqu'oover dans toute la longueur de la coquille; ces tours de spire sont striés transversalenient dans leur moitié supérieure; en dessous, ils son: lisses. Il arrive tuelquefois que les cuuleurs se parlagent de la mème maniere, c'est-à-dire que la coquille soit colorće en dessus el pas en dessous, où elle est d'un blanc-jaunâtre. Ordinairement, elle est marbrée de brun et de fauve sur un fond blanc; les taches se coufondant, elle est quelquefois toule brune en dessus et marbrée en dessous. On ne sait oì se trouve celte espèce, quia 35 a 40 taillimètres de diamètre à la base. 
5. Crclosroxe cariné. Cyclostoma carinata. Lasx.

C.testá orbiculatá, subtrochiformi, pmfundè umbulicat $\hat{\imath}$, tenui, pellucidâ, multi carinatâ, allidi; anfractuum carinis procipuis subquinis eminentibus; spirâ breviusculi.

1,asr. loc. cit. $n^{\circ} .3$.

Turbo carinatus, Lrx. Garr. pag. $3601 . n^{\circ} .57$.

Ibid. Bors. Mus. cas. vind tab. 15. fig. 3. 4.

Coquille très-rare, mince, blancle ou jaunit:e, quelquelois taclietéc de brua, on marquée de quelques bandes obscures transverses de la mćme couleur; ses tours de spire, arrondis, sout cliargés de carènes ou cótes blanches assez varialules et pour le nombre et pour la disposition; mais it y ea a le plus sourent trois a cing principales, entre lesquelles il en existe de plus petites. Fin dessaus, se voit un oubilic médiocre et profond: l'ouverture assez ample, à bords minces, quelyuefuis renrersés en debors. On nous a assuré yae cette coquille se trouroit à liile de Cuba; nous a'en arons cependanı pas la cerílude. Elle a les mèmes dimeusions que la précédeute.

4. Crczostome usicarinc. CJclostoma unicarincia. Lajis.

C. testi trochiformi, umbilicata, transwersim striatâ, luteo-rubente; ultimo anfractu medio, carin: prominente cinclo; labro margine albo, wakle refiexo.

Excrccop. pl. 461, fig. 1. $a . b$.

- Cette espièce remarcuable est partout striée assez finement, et régulièrement trochiforne comue les précédentes; el!e est ombiliquée de mème. Elle est d'un faurc-rougeâlre ou ü'un jaune obscur. Ce qui la disirague facilement de ses congénères, éest qu'elle porte daus le uilicu du dernier tour une carène aiguë, à base assez large. Cette coquille a quelqueluis une ou plusieurs bandes étroites, brunes e: transrerses sur le dernier tour. Elle se troure a Madarascar, et elle alteint 36 milim. de diauètre.

Il est bien à présunier ilue le Cyclostome olssolète de M. Laniarck u'est qu'une variété sans caréce de celle-ci.

5. Crccostone grand-rehord. Cyclostoma labeo. LAsk.

C. testá ovato-oblongi, obtusí, umli icatú, pellucidí, decussatim strutía, albá uut rubente; maculis minimis, luteis, furcatis, transwersim serulis; labro margine refecro, a!bo, dilutato, catente.

I.sw5. loc. cit. no. 9 .

Turbo labeo, Lx. Gsex. pag. 50̄o5. $n^{\circ} .75$.
Lrst. Conch. tab. 25. fig. $2 \tilde{3}$.

Brows, Jam. tab. 40. fig. 5.

Bors, MIus. cces. 2ind. tab. 13. fig. 5. 6.

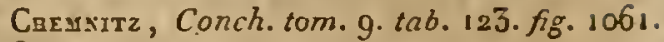
1062.

Excrchopédie, pl.46r.fig. 4.a.b.

Très-jolie espèce de Cyrlostome, facilement reconnoissable par sa forme alongée, obtuse au sommet, par le résean fin el des plus réguliers que produisent des stries fines et rapprochées, par les petites taclues brunes, bifurquées, disposées sur plusieurs lignes, el enfia, par l'ourerture bien ronde, garnie au-dehors d'un large rebord blanc. Tantót celte coquille est blanche, et taniót elle est d'un rouge obscur ou vineux. Les taches manquent aussi quelquefois, ou il n'y a qu'un seul rang médian. C'est à la Jamaïque que se trouve celle espèce, qui est longue cle 35 à 38 millim.

6. Crczostose éléçant. Cyclostoma elegans. Lanx.

C. tesiâ ovalo-conicá, perforatâ, striis elegan. tissimis cincti, alhido-cinereâ, anfractibus qunis, convexis; adultorum iabro margine refexo.

Laмx. loc. cit. $n^{\circ} \cdot 26$.

Cyclostonia elegans, Drap. Moll. terr. et fluv. de France, pl. I. fig. 57 .

Turbo elegans, Lix. Gxis. pag. 3606. $\pi^{\circ} \cdot 74$.

Nerita elegans, Mclea, Vern. pag. 177. $n^{\circ} .563$.

L'Eleganlestriée, Geofrar, Coq. de France, pag. $108 . n^{\circ} .1$.

Lister, Conch.tab. 27.fig. 25.

Gualtierri, $t a b .4 . f g$. A. B.

DARGrit. Conch. pl. 28. fig. 12. el Zuomopphose, pl. 9. fig. 9 .

Coquille très-commune en France dans les lieux secs et élevés, oì elle s'altache aux arbusles it aux Lerbes. Son animal est tout noir; la coquille, turbincé, ovale-conique, est ombiliquée, naais son oubilic est étroit; elle est fineonent sirici, transtersalement, et ces stries sont régulic̀tes at Clégantes; le plus sonsent, celte coquille est d'un gris-rougeátie, quelquefois riolette, et très-suuvent aussi marquée de plasienrs rangs de tactics de la mêcue coaleur, mais plus inteuse.

7. Crchostone élégant ancien. Cyclostoma elegans antiquum. Brosg.

C. testá obato-conici, perforatí, síriis enunsversis ele guntissinis cinctis; anfractibus quinls, 2alde roiundatis; umbilica mediocri, perforato.

Broxg. Ann. dn Wus. lom. 15. pag. 56j. pl. 22. fig. 1. 


\section{I C}

Ibid. Brad. Journ. de Phys. 1811 , tom. $7^{2} .1$ pag. 453 .

Cyclostoma elegans, Nов. Fass. des enu. de Paris, tom. 2. pag. $75.17^{\circ}$. 1. pl. 7. fig. 4. 5 .

Peut-être aurions-nons bien fait de joindre la syuonynie de ce Cyclostome à celle du précédent, puisqu'on peuı le regarder comme un analogue parfait de l'espèce vivante en France. De tels exemples sont si rares, ils peuvent avoir une telle inlluence sur les opiuions ǵćologriques, que nous avons établi cette séparation pour quon y porte plus d'attentiou. Nous n'avons vu qu'un petit nombre de ces fossiles, et nous pouvons dire quils ne dillèrent lles vivaus que par l’ombilic un peu plus grand et la base un peu plus dilatée. Ils se trouvent à Fontainebleau à la Table du GrandMaitre.

8. Crclostore bouche-d'or. Cyclostoma favulu. LasK.

C. testá cylindracể, puparforni, solidi, ghibrî, luteo-iufescente; infractibus octoris, convexiusculis, aperturi annulo aureo distnectí; lubro extis marginato.

LAsк. los. cit. $n^{\circ} \cdot 13$.

Helix cornea, Lis. Guse. pag. 3655. $n^{\circ} \cdot 243$.

Chésixtz, Conch. tom. 9. tab. 135. fg. 1253.

E.scrclop. pl. 461. fig. 6. a.b.

Cente coquille, plus épaisse que ne le sont ordinairemeat les Cyclostomes, pourroit étre prise pour une espèce lluviatile; mais deux autres espéces, qui vienment de Cuba, et que l'on sait être terrestres, nous contirment que celle-ci peut l'être également. Elle est alongée, lisse, obtuse, ses tours sont légèrement arrondis; la suture eft simple et peu profonde; le dernier tonr présente ๙े la base une petite fente ombilicale, et l'ouverture qui le termine, arrondie et marginée en deliois, est bordée de jaune d'or, tandis que toure la coquille est d'un gris pâle, passant quêlquefois au fanve. On trouve cette espèce à l'ortoRicco et à Ténérille. Elle a 30 ¿ 55 milliu. de longueur.

\section{I.A $1 \mathrm{~K}$.}

9. Crciostome momie. Cyclostoma mumia.

C. testá cylindraceo-conicá, transversim striatâ, ¿lriis longuludmolibus subtilussimis, aperturâ obliqué oricatis labro crasso.

Lask. Ann. du tus. tom. 4. pug. 1 15. no. 5. et tom. 8. pl. 37. fig. 1. a. 6.

DeEr. Dict. Sc. nat. tom. 12.

Brosgsiant, Ann. du Mus. tom, 15. $p l .22$. fis. 2.

Val. A. Nos. Testi ninjore, strits transucisis nunicrostoribus.

Hist. Nat. des Vers. Tonie II.

\section{Y G}

Tar. B. Testâ striis transversis distantioribus, obsoletis, longiludinulibus, subnullis.

Tar. C. Testi lavigatis; labro incrassato.

Tar. D. Testa tribus lineis nufis pictâ.

Var. E. Testì angustiore, clathrutâ; striis transucrsis, distantibus et longitudinalibus, ruris; labro refiero, rard marginato.

Cyclostome cies grès, Bнand, Ann. du Mus. tom. 15. $p l$. 22. fig. 10. 11 .

Comme on le voit, cetle coquille est très-rariable; quelqueliois toute lisse, le plus souvent elle est finement strife, mais ces stries sont variahles, elles sont même quelquufois quadrillées par des stries longiludinales, ce qui avoit déterwiné M. Brad à taile une nouvelle espdce, que nousn'admettons pas, puisque nous savons qu'elle est le résultat d'une moditication locale de l'espèce. Ce qui nous a surpris, c'est de trourer ì Chambord, entre Parnes et Chaumont, une viariété qui a conservé des traces de l'ancienne coloration de la conuille, qui étoit conleur lie de vin, avec trois zones de la même couleur, plus foncée sur le dernier tour.

Le Cyclostome momie est une cornille à lä quelle les géologures ont peut-ètre attaché trop d'importance; on avoit cru qu'elle éioil propre and terrains d'eau douce moyens, mais il est bien certain qu'elle se trouve dans lesterrains marins par excellence, tels que le calcaire grossier, le grès marin inléileur, ainsi que dans le supérieur. Un la rencontre également dans les terraios de mélange, et aussi d'eau douce, comme nous le disions précédemment; il paroit qu'elle s'est trouvée dans le gypse de Montmartre, mais qu'elle y est excessivement rare.

Si on n'avoit parmi les Cyclostomes vivans des espèces analogues à celle-ci, on pourroit présnmer qu'elle appartiendroit plutôt aux Paludines. Elle est alongée, turriculée, striée en travers d'nnt manière asse $z$ apparente; les stries, longitudinales, visibles seulement à la loupe, forment, avec les premières, un réseau très-fin. Le somntt est légérement olutus, les tours sont peu bombés, et les sulures, simples, peu profondes; l'ouverture est petite, ovale, un peu anguleuse supérieurement, ordinairement entourée d'un bourrelet plus ou moins ćpais, qui en fuit le bord; lorsque ce bourrelet n'existe pas, la levre est renversée en dehors; l'ombilic est petit, en partie caché par le bora gauche de l'ouverture. Nous ne crnnoissons jusqu’a préseut cette espèce que dans le bassin de Paris, où elle est abondammeni répandue. Nous lavons trouvée plusieurs fois at Grignon et a Maulle, dans le calcai:e grossier. Elle a jusqüà 36 million. de longueur; mais celte taille est tres-rare.

Par un double emploi inexplicable, M. Lamarck a donné le nom de Cyclostonic momic à une ej1* 
pèce vivante de France, qui n'est point l'analogue de l'espêce fossile. LAMK.

10. Crchostone fascié. Cyclostoma fusciata.

C. testâ cylindraceâa, apicc truncalâs, subperforati, levvi, pellucidì, albà; fusciis duabus sen tribus violaceo-fuscescentibus; aperturâ parvulâ, obliquá; lubro subreflexo.

Lank. loc. cit. $n^{\circ}$. 14 .

Favanie, Conch, pl. 65. fig. B. 10.

Chenn. Conct. tont. 9. tab. 136. fig. 1256. 1257.

EvcrcLop. $p l \cdot 461$. fig. 7 .

Coquille facile à reconnoitre, alongée, cylindracée, obluse ou tronyuće ar sommet, blanclse, lisse, transparente et oruće de fascies violatires ou fauves, au nombre de deux ou trois sur chaque tour de spire; quelquefois les fascies manquent cotalement, et alors on reconnoit l'espèce ì la forme do l'ouverture, qui est fort petite relativement à la grandeur de la coquille, qui est blanche et non janne d'ar, et dont le bord, au lieu de former un bourrelet marginal, se renverse un peu en dehors en s'amincissant. Celle coquille, assez rare, vient de Saiat-Domingue. Elle est longue de 30 millim.

\section{CICLOSTREMA. Cycóostrema.}

M. Mariol a établi ce genre pou* une coquille de l'Iude, qui peut se rapporter aux Cyclosioures. Voyez ce mot.

\section{CYLINDRE. Cylindras.}

Un genre démembré des Cônes a élé proposé snus ce nom par Mlonifort (Conch. Syst. Lom. z. pag. 39o). Il y plaçoit toutes les espèces cylindroites; mais, comme il existe un passage insensible entre elles et les autres, ce genre étoit inadmissible. (Voyez Côse.) Quelques anciens conchyliologues ont égaleıneut donné ce nom aux Côncs et aux Olives indistinctement réunis.

\section{CYMBE. Cymbium.}

Ce grenre avoit déja été proposé par Adanson, sous le non d'Yet. Montfort, en le reproduisint, n'a pas donné un seul fait qui pût eagiager à l'adopier. 11 est trop semblable anx Volutes pour qu'on en lasse autre chose qu'une section clans ce genre. Voyez Voivte.

\section{CYMBICOCHIIDES. Cymbicochlides.}

Cetle farnille est la deuxième des Céphalopodes octopodes de M. Latreille. Elle contient, avec le genre Ocythoć de Rafinesque, les genres Argonante et Bellérophe; il nous semble qu'il y a u, double emploi entre ces deux premiers genres puisque M. Tatreille doit supposer, avec les zooIngistes de son opinion, quel'Ocylloce est l'hiabitant el le constructeur des coquilles nommées Argonautes. Nous ne savons encore si l'opinion que partage M. Latreille prévaudra; on verra aux artiiles Argonaute, Poulpe et Céphalupode, pour quels motifs nous ne l'adoptons pas.

\section{CYMBULIE. Cymbulia.}

Ce liut dans les Annales du Muséum que ce gense, proposé par Péron el Lesueur, lut carac lérisé pour la première lois, et il faut l'avouer. d'une manière assez incomplète. Une figure, qui laisse beaucoup à desirer sur la struclure de l'animal, accompagne le Mémoire de cel auteur; et, comme elle étoit la seule, elle fut bieutót après copiée dans les planches de ce Dictionnaire. Les Ptéropodes, établis pour y placer ce renre et quelyues autres, furent introduits daus Ta Méthode par M. Cuvier, dont l'exemple tut suivi par M. Lamarck el dautres zoologistes. (Voyez Prénopons.) Cet ordre éprouva de nolables changemens, surlout depais les travaux récens de Ml. de Blainville, dont les résultats sont conuus par son Traité de Mlalacologie. Plusieurs des Pićropodes rentrèrent dans les Gastéropodes, et en général, ceux qui restèrent furent moins counus. Malheureusenent le genre Cymbulie, plus rute à ce qu'il paroit, ne fut point de nouveau sounis à l'nbservation, et on dat l'adopler tol qu'il itoil : c'est avec ces inuperfections qu'il se présente dans tuntes les méthodes, qui toutes l’admettent dans les ralpports it:diqués par M. Cuvier. M. Rang, auquel on doil de précieuses observalions sur les Ptéropodes, n’a pas été à même d'augmenter, par ses propres travaux, celles sur les Cymbulies; il s'est servi, pour les reproduire, d'un dessin que lui a communiqué M. Cuvier; dessin qui, bien que fait d'ajréy nalure sur un animal conservé dans la liqueur, laisse pourtant du doute sur plusieurs points importans. Les caractères suivans, empruntés ì II. Ring, le prouveront suftisamnent.

\section{CARACTÉRES GÉ NÉRIQUES.}

Animal oblong, gélatineux, transparent, muni de deux yeux?" de deux tentacules? et d'une bouche en forme de trompe? Deax nageoires latćrales, grandes et arrondies, porteut le réseau vasculaire des branclies; elles sont connées à leur base, du côté postérieur, par un appendice intermédiaire en forme de lobe alongé.

Coquille gélatinoso-cartilagioeuse, oblongue, en forme de sabot, entièrement revêtue d'une membrane mince et à peine visible, à ouverture supérieure, longue, fronquée à l'une de ses extréurités.

Nous ne nons hasardons pas à donner une 


\section{Y P}

arple description de ce geure, ne le connoiss.ut que d'apris les figures que nous avous menmentionnées, nous somues forcé de renvoyer i ce que Yéron en a dit, ainsi qu'i l'aricle C:YMbulie du Dictionnaje des Siciences naturelles, sats pouvoir assurer le lecteur qu'ii trouvera tout ce ciuil pourra desirer sur ce geare curieux.

1. Crarbue de Péron. Cymbulia Peronii.

C. testầ tenuissimâ, hyalinầ, echinatî, elongati, lateruliter compressí, calcejormis, antice iruncutâ, postice acutá; aperturâ elongutà, 'judrangulari; magine serrato, dentato.

Cjmbulio, l'irow el Lesoevn, Ann. du Mus. tom. 15. pus. 66. pl. 3. fig. 10 i 12.

Cuvieh, Règ. anim. tom. 2. pas. 580.

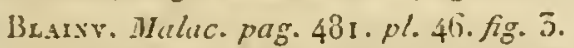

I.Aмk. Anim. s. vert. tom. 6. pras. 29.5.

Rsiv, Manuel de Conch. pag. I is.pl. 2.fig. 1. Escrec. pl. 464 . figr. 4. a. b.

Coquille très-jolie, wès-nince, transparcn!e corume du rerre, ayant la forme d'un sabot, lïgirenent compriméc Iatéralenent, et présentuat en dessus une grande maverture quadrangulairc, dont les bords sunt minces et découpés tu deuts de scie; postćrieurement ils se terminent pat deıx angles saillans. En debors, el surıout en dessus, on remarque des rangées longiludiriales, nombrenses, d'épines un d'écailles peu saillanles; l'extrémité postérieure se termine en pointe, vers laquelle se dirigent en convergeant presgue toutes les rungrées d'écailles. Cette coyuille, longue de 60 millin. et quelquelois duvantage, re s'est encore rencoutrée que dans la Nédilerracue.

\section{CI.TOLUNE. Cynodona.}

E.: trast des Tolutes de Liuné par II. Sclıumaclier, ce grenre correspond à celui que depuis

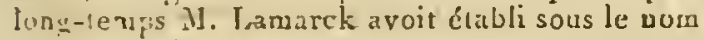
de Tubrnelle. Vuyez ce mot.

\section{CIPRICARDE. Cypricardia.}

Cuelques coquilles de ce genre furent conoues de Lirué; mais, prolrablement embariussé de les iappurter à un gesure bien déterminé, 11 les plaça dans le genre (áme, wi il y avoit raggé d'ailleurs hearcoup de coppilles de genres diférens, conme la Camia lippopus, caljculesta, cor, oblonga. binguière, le preanier, sous le nom de Curdite, seppilı des Caues des auteurs toutes les coquilles qui, avec des. deats cardiaales variables, présentoient constanument une dent latérale sons le corselet. Alors les Isocardes, les. Ilyatelles, les Cypricardes et des Véuéricardes furent renfermíes dans le inêne geure. Lamaick, dèsi 180 : (Syst. des Lnimn. s. vêt.) commença à réformer le genre da Bruguière, il en sćpara alors les Isocardes et proposa les Vénéricardes; ensuite, en 1812 (Extnut du Cours, pag. 106), il en séiara le genre llyalelle proposé par Daudin; et eulin, en 1819 , il troura cncore son gente $C y-$ pricarde parmi les Cardiles. Ce deruier genre resta néanmoins nombreux en espcccs; mais presque toutes lirent bien circonscrites pardes caractères tranchés et laciles à suisir. Le gente Vénéricade, comme nous l'avous vu à l'article Candite, fait seul double emploi et doit êre rejeté d'unc bonve mélhode.

\section{CARACTÉRES CÉNÉRIQUES.}

Coquil!e libre, équivalve, inéquilatérale, alungée obliquemeut ou transversaleınent; Irois dents cardiuales sous les crochets, et une dent latérale se prulongeant sous le corseler.

Quvique très-voisines des Cardites, les Cypricartes sen distingueut au premier aspect ; toutes celles connues jusqu'aujuurd'hui n'ont jamais présenté les côtes longitudinales si habituelles des Bucardes et des Cardites; si leur sniface, le plus souvent lisse, présente des lames ou des sillons, ils sont toujouis transversanx, c'est-à-dire dans lia direcion des bords. La cliarnière, d'ailleurs, est dilféréte, puisqu'elle présente constamment toois dents cardinales, au lieu d'une ou de deux, comme cela a lien dans les Cardites. Le nombre des espéces est encore peu considérable. M. Ia marck en indique sept; mais il faut eu ôter les trois fossiles qui appartiennent aux As:artés, comme on le verra en consnliant ce mot.

Quelques Cypricandes ont la faculté, comne beaucoup dautres Concliyferes, de percer les madtépores ponr s'y loger. En cassaut une masse de polypiers de la iner des Indes, nous avons observé des Cypriciardes qui s'étoient emparées de trous habités encore par des Modioles, s'étuient logées dansces Modioles, et s'y étoieut pour ainsi dire monlées, ayant pris toute la forme extérieure des Modioles, en conservant les caracières des cypricardes.

1. Crparcarde de Guinée. Cypricandia Guinaica. LAMK.

C. testá oblongẩ, obliquè angulatâ, decussutim striutâ, albo-lutescente; antico latere versis extremitatem compresso; apice rotundato:

Lask, Anine. s, vert. tom. 5. part. 1. pag. 28. $n^{\circ} \cdot 1$.

Chama oblonga, Lr.v. jag. 5302. $n^{n} \cdot 10$.

Chama guinaica, Marrist, tom.7.pag. 1.7.: iab. 5o. fig. 504. 505.

Excyclop.pl. 234. fig. 2.

Carlita carmata, Brug. Excyclop. tom. I. pag. 409. $n^{\circ} \cdot 9$. 
Elle est oblongue ei ressemble à one Nodiole; obliquement anguleuse, elle est treillissée par des s'ries fines; son côté postérietur est aminci, comprimé; les crochets sont arrondis et peo proéminens; a l'intérieor, elle est blacclie, à l'extérieur elle est jauaatre. Elle est longue de deux puuces environ; elle babite les mers de Guinée. Cette coquille est rare dans les collectiuns.

2. Crpricarne datte. Cypricardia coralliophaga. LAMK.

C. testô oblongâ, cylindraceâ, tenui, albâ, decussatim striutâ, anteriùs compressâ; striis marginalibus in laminas prominulis.

Laviz. loc. cit. $\pi^{\circ} .4$.

Broccar, Conchyl. subap. tom. 2. tab. 13. fig. 10. a. b.c.

Chama coralliophaga, LIs. Gues. no. 25.

Martixr, Conchyl.ton. 10.pag. Jög. tab, 172. 16-3. $167 \bar{t}$.

Bruguière ( Encycl. nn. 13. pl. 2334. fig. 5) l'a décrite sous le noun de Cantite dalle (Carditu ductylus). Quoique cette espéce, comme la précédente, ait l'aspect d'une Modiole, elle s'en distingue ceprendant ex ce gu'elle est plus cylindrique, plus élroite, plus mince; ses stries sont fines, les transversales, surınt celles qui sont vers les bords, se relèvent en lames. Les crochets sout moins arrondis, plus proéminens, terminés yar des taches pourprées. Celle coquille se tronve jarevient dausles collections; elie tabite, comme l'a dit Chemnitz, dans les masses madiéporiquez que l'on péche dansla mer des Indes, posir en faire de la chaux. Elle se tronve égralement dans les mers de Saint-Domingue, et fossile en Italie. Elle eat longue aje deux pouces environ.

3. Crpmeande cordifurme. Cjpricardia cordiformis. Noв.

C. testid ovicato transversa, inaquiluterâ, turgida, cordiformi, postice angulata, lavigatî; unbonibus magnis, obliquis, recurvis; cardine bidentato; dentibus luterulibus magnis; margine istegrn, posticè subsiruato.

C'est daas les couches de l'oolithe de Bayeux, près Caen, que s'est truuvée celte coquille remarqualle; elle est orale, oblongue, Irunsierse, très-inéquilatérale, fort obliqne, et semblable à nne Bncarde, quant à la furme extérieure; elle est lisse, et son còté postéricur est séparé du reste par" on angle assez aigu, qui descend du crocher jusqu'à l'angle pestérieur du bord. Le côté anićrieur esi court el arrondi, et ne présen:e aucune trace de lunule. La charnière est absolumeut celle des Cypricardes; deux deots cardinales, inégales, divergentes, el des dents latérales fort puissantes, dunt lit postérieure est plus longoe et pius écartée des cardinales que l'antérieure. Celte coquille, assez rare dans la localité que nnus avues indiquée, n'a pu être rigourensenent déterminée, quant au genre anquel elle appartient, que d'après sa charnière; et ce n'est qu'à furce de travail, que, sur trois individus, nous summes parrenu à débarrasser celle parlie de la pierre qui la recouvroit. Les grands individus ont jusqu'ì 98 millim. de large.

4. Cizpatcarne corbuloide, Cypricardia corbu. lotdes. ㄱoв.

C.testi panuli, subtetragonis, turgidi, incequiluteruli, posticè angulatá; umbonibus mininis, obliquis; cardine bidentatn; dente laterali postico, zalde separato, minimo; margine clenato.

On trouve celle pelite espèce, pút lifiće, avec la précédente dans la même couche; lorsqu'elle devient vieille, elle a assez la furme d'une petite Corbule, qui, dans quelques circonstances, it ses bords trés-épais et perpendiculaires, coume cela a lieu dans le Corbula striata de Bordeaux, par esemple; elle est di reste enflée, gibbeuse, subtétragone. Le côlé postérieur est séparé par un angle arrondi, mais saillant, gagnant le bord, en partaut oiliguement du crochet; celui-ci est petit, très-obliçues, incliué sur une très-petile lunule; le cótć antérieur est court et arrondi, et la sulface extérieure, hien qu'étagée par des accroissemens assez réguliers, est de plus strice en travers. La charnière est fort étroite; elie présente deux cents cardinales; la dent lacírale autérienre est obsolc̀te; la postérieure, lrès-petite, se voit pourtant facilement: le bord est crénelé dans toute sa longueur. Celte ccquille, comme nous l'avons dit, vient de l'oolithe de Baycux, ou de Saint-Vigror, près Caen, où elle est très-rare; elle n'a que 10 millim. de large.

5. Crpricarne oblongue. Cypricarda oblungua. Nor.

C. testâ ovato-transversá, inarquilaterali, ohliquâ, lovigatâ; umbonibus obliquis, recurv's; cardine angusto, bidentato; altero dente bifilu; dentibus lateralibus obsoletis.

Coquille étroite, transrerse, très-inégrilatérale, mince, bombée, à crochels médiocres, fort obliques; elle est tonte lisse, marquée quelquefuis de stries irrénolières qui indiqueut ses accroissemens; le bord est simple, mince, tranchant, el piesque toujours siuneux dans son milieu; le cóté antérienr est plus élroit que le poslírieur. La charnière se compose, sur la vaire droile, de deux dents simples, dont l'antérieure, conique, s'élève plus que l'antre, et sur la valve gauche. de deux denis, dont la postérieure, la pius épaisse, est frofcodéneat bifide : les derts 


\section{Y P}

Lutérales s'eflacent aver. l'itye, et sunt d'aillems presque toujours ohsolites. On trouve cette espèce fort rare daus le bassin de Paris, à Purnes, à Mourlıy et à Clhaumont; elle est guelquefois large de 67 millim. Nios.

6. Crpricarde carinée. Cypricardia carinata.

C. testî orkto-obliqui turgidì, posticè abliguè truncuts, angulatì, elegunter striata; striis tenuibus, iranswersis; dentibus cardinahbus binis, in alter unico, profunde bifido, lateralibus magris.

Cecte espece est ovale, oblongne, tronquée obliquement à son côté postérieur, yui est sćparé par un anchle saillant, subcaréné, quii part obliquement du crochet poù se rendre à l'angle postérienr du bord; le côté antéricur est arrundi et Irès-court; les crcchets, enflés et ea cueur oblique, domineut une charnière étroite, sublanelleuse, composíc sur la valve gauche de deux dents Irés-obliques, et sur la droite, d'une seule, plus épaisse, mais profondément bifide; les dents latérales sont grandes, mais la postérieure l'est plus que l'autre, et elle est plus éloignée des dents cardinales; le bord des valves est simple et trancliant; en dehors, cette coquille, enllće et cordiforme, est couverte de stries ćlégantes, liucs, arrondies et transverses. Cette espèce se tronve fossile aux euvitous de l'aris, à Chaumont; elle est large de 40 millia.

\section{CYPRINE.}

1, a seule coquille rivante de ce genre connue par linnc, et qui depuis a serri de type au genre Cyprine, est celle quil a nonmé Venus islandica. Une secunde espèce vivante, que possède M. Defrance, a élé décrite dans le rome 5 des Aninaux sums zeriebres, pay. 158, pa. M. Lamark. Ce sont les seules qui soient comnues jus‘u'aujourd'tıi à l'elat frais, un plus grand nombre d'espéces se trouvant fossiles. L'Tlalie, l'Angleterre et le midi de la France en avoient oflert sept à huit bien calactérisées. Les environs de l'aris sembloieut en être dépourvus; mais, en examinant de nouveau les espèces fossiles du renre Cythérée, nous y avons reconnu une belle Cyprine dans la Cytherea sculellaria, qui avoit été placée daus les Cythérécs avane la création da feme Cyprine, et que personne n'avoit songé depuis à rétablir dans sa véritable place.

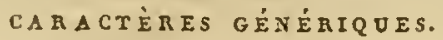

Coquille équivalve et équilatérale, en cœur oblique, à croclie:s obliquement rourleśs; trois dents cardinales iuegales, rapprochées à leur base, un peu divergentes supérieurement; une dent l.:térale écartée de la charnière, disposée sur le côlé postérieur, quclquefois obsolète; callositís nymphales grantes, arquées, terminées près des crochets pal une fosselte; ligament extérienr s'enfoncant en partic sous les crochers.

Les Cyprines, d'apiès l'opinion de M. Larnack, peuvent servir de terme moyen entre les Cyrònes et les Cythérées. Nous voyans en effet que la Cyprine d'Islande est pourvue, comme les Cyrènes, d'un épiderase d'un jaune-verdître ou brunâtre, persistant; que des dents latérales, l. moins force et la moins nécessaire est la seule qui ait disparu; que le liganeut qui s'étend jusqu'audessous des crochels occupe la même place dans les Cyrènes; enfin, que les Cyprines vivent ¿t l'emlouchure des lleuves, dans les eaux peu salées. Si nous les comparons aux Cyllérées et aux Y'́mus, nous trouverons ure forme analogne; nous oluserverons dans la forme et la position des dents eardinales cles poiats de ressemblance Lien érideos; mais atussi des dissemblances faciles ì saisir, en comparant les caractères assignés à clraque genre. Ce rqui les distingue Je mienx, outre la clent latrírale, e’est la fosselte placće sous le crochet el qui teranive les nymphes.

Le genre Cyprine a été établi pä M. Lamarck dans l'Extruil du Cous, et il l'a placé enlle les Cyrèncs et les Vémus. M. Cuvier ne l'a pas admis, nêrne comre sous-genre; cependant, M. de Blainville, daus le Dictionnaire des Sciences naurelles, ainsi que M. Deframee dans le mêrne ouvrige, l'adoplent l'un el l'atutre. M. de l'erussic en a aği de nuême dans ses Tulleaux systétnutiques, et M. I amalck a persisté el l'a conservé duus les mémes rapporis, dans les Cunques marines, inucédiatement après les Cyrènes. MI. L.atreille n'a opéré d’antre clangement, en établissant la famille des Cycludines, que d'y transporter les Cyprines et de les associer ainsi anx Conques lluviatiles de M. Iamarck : ce qui, par lc fait, it lort peu d’importace. MI. de Blainville, daus son Truité da Mulaculogic, a continué à adupter le genre qui nous occupe. Nous concevons bien qu'll vieune inmédiatement dans sa Métlode apjès le genre Cyclade, qui représeute les Conques IJuvianles de MI. Lamarck, mais nous demandons pourquai le genre Mlactre le suit, et nous faisons cette question parce que nous n'apercerons pas les rapports entre ces genres, tandis que nous les saisissins facilement atvec les Cyllérécs et Jes Vínus. Nous avons toujours élé surpris de trouver ce genre Mactre placé d'une manière si insulite an milieu des Conchacées (voyez ce not), lorsque ses rapports avec les Lntraires soat si évidens.

On ne connoît encore qu'un jetit nombre de Cyprines : deux vivantes et huit fossiles. Nous donnerons la description de quelques-unes poir servir d'exemple. 

l, AMK.

r. CYPRINE d'Ișlande. Cyprina islundica.

C. testâ condatâ, transversim striatâ, epiderme indutá; antico lutere subangulato; ano mullo.

L.ME. Anim. s. vert. tom. 5. pag. 557. no. 2. Tenus islandica, Lix. Gmes. $p .3271 . n^{\circ} \cdot 16$. Pexiast, Brit. zool. tom. 4. pl. 5j. fig. 47. Lister, Conch. tab. 272. fig. 108.

Fors. Mus. cers, vind. tab. 4. fig. I1.

Excrclop.pl. joi. fig. 1. $a$. $b$.

Coquille arrontie, subcordiforme, épaisse, à crochets proćminens, oblig̣uementrecourbés sur unc lunule à peine marquée, quelquefois mềne n'existant pas du tout; le ligrament est grand, suillant, adbérent à des nymphes très-forles, qui se terminent vers les sominets en une carilé oblongue. La surlace extéricure est couverte d'un cpiderme d'un brun-farve, quelquefois presque noir ; il est disposé par petites lamelles conceratrieques, qui suivent le nombre et la disposition des stries d'accroissement. Ln dedans, cette coquille est tcute blanclie, et sa charnic̀re, purtúe par une iame cardinale large et solide, présente trois dents inégales et une dent latérale obtuse el peu saillante. La Cyprine d'Islande se troure surtout dans les weers du Nord de l'Europe. On dit Iu'elle vil aussi cians la Méditerranée, mais est-ce licu la même? M. Lamarck dit qu'un la trouve fossile aux environs de Bordeaux. Nuns ne l'avons jumais rue de cette localité. La Cyprine sculellaire des environs de Paris a avec elle plus d'un rapport. NaB.

2. Crprise scutellaire. Cyprina scutellaria.

C. testá suborbiculatâ, obliquâ, solidí, subdepressấ ; striis transversis irreguluribus, dusluzltibus; dente laterali magno; fuveolis nympluali minimâ.

Cytherea scutellaria, L.suк. Ans. dis Mus. tom. 7 . pag. $155 . n^{n} \cdot 1$.

1tid. Anim. s. vert. loc. cit. pag. 581, nn. 5.

DEF. Dict. des Scienc. nat. Lom. 12. plig. 421.

Cyprina scuiellariu, Nов. Dict. chess. d'hist. nat. toin. 5.

Ibid. Nов. Descript. des coq. foss. de Paris, tom. I. pag. 125. $\pi^{\circ}$. 1. pl. 20.fig. 104.

Cirande cocquille, qui est d'un volume aussi considérable que celu de la Cyprine d'Islande, ef (rui a beancoup d'unalogie avec elle, am point quill sera possible, lorsqu'on aura pu éivdier un asser grand norabre d'individus, de las réunil à celle espéce comme une rariélé; nụis la rarelé de ces coquilles, et leur extrène fragilité, est une grande diffecté ì vaircte nour arriver 2 leur comparaison exacte et entière. La Cyprine scutellaire est orale, suborbiculaire; les crocliets sont grands, obliques, saillans, en caur, lorsquue les valves sont réunies. La coquille est moins épaisse que celle de la Cyprine d'Islande; elle. est toute lisse sur les crochers; des stries d'accroissement, peu régrulières, se multiplient vers le bord intérieur; suus le crocbet, on tronve lat fossette ny uiplaale, qui est fort petite, comparativement à la grandeur de l'espèce; la lame cardinale est large et sinueuse dans son milieu; elle porte trois dents cardinales, dont la moyenne est la plas grande; la nymphe est grande et saillaute, elle aboutit postérieurement à me cóle arrondie, qui se prolonge suus le bord posterient. jusqu'à la dent latérale, qui est très-distanie de, cardinales : elle est fort graode et constante dans l'espéce; derrière elle se voil une eavité en goultière, une fosselte qui reçoit la dent de l'autre valve; les iunpressions musculaires sont grandes, bien séparées ; l'impression abdomiuale a'est poini Echancrée postérieurement, et en cela elle ressemble it la Cyprine d'Islande, mais elle ditfère par: ce caractère de plusiẹurs autres espèces, qui ont cette échanciure très-profonde. Lonüucur, so milliui., largeur 95.

\section{CYRELEE. Cyrena.}

Comme nous l'arons dit à l'article Crcrade, M. Lamarck, le premier, sépara les Cyrènes des Cyclades de Bruguière; il en prit les principales diflérences dans la dispositiou de la charnière, dans la forme générale, ainsi que dans une plus grande épaisseur du tci. Ce geure fut également proposé par M. Mégerle, en 1811 , sous le nom de Corbicule; il ña point été adoplé par les conchyliolognes frimçais. M. Cuvier à point admis ce démembremeni, que $M$. de Ferussac a conservé eatièrement. M. de Blainville, daus ces derniers temps, a ramené le genre C.jclade à ce qu'en avoit fait Bruguière, el il propose méıne d'y faire rentrer lc genre Galaibée, yui nous semble cependant bien distinct des Cyrèoes, quoiqu'il ait avec eille des rapports bien évidens.

\section{CAก ACTÉRES GË ĖRIQUES.}

Coquille arrondie, trigone, euflée ou veatruc, solide, inéquilatérale, épiderunifure, à crochets écorchés; chanière ayant trois dents sur chaque valve, on deux sur l'une et trois sur l'autre. Les dents latćrales presque toujours au nombre de deux, don une souvent est rapprocbée des caldinales; ligament extérieur sur le cóté le plus grand.

Les Cyrines liabitant les fleuves ou les grands amas d'ean! dpuce, ne se trouvent plus en E:rope; elles y ont été détruites, a rec beaucoup d'aulres races de. IIollusques, par uae cruso, guce 


\section{Y R}

l'ub a quelque saison te croire ditre un changeneat notable de température. Quelle quée soit l'opinjon çue l'on ail a cet égard, il h'en est pas moins constant que ce genre y etrit attrelois tiès-alsondamment répandu; il y vivoit avec les Mélanspsides, les Palucines, les Illélanies, comme nos Cyclades et nos Mulelles vivent avec les l'aIndines et lès Planorbes. Des couches eutières sont composées presqu'uniquement de Cyrènes, de Hélanies el de Mćlanopsides; d'autres fois, comme à Mayence, leur masse e'st formée de Cyrènes et de Paludines; car ces soi-disaut Véuus de Hayence appartienneat, saos ancun doule, au yenre qui nous vecupe, ef hous en avons la preuve. D'autres lois, et c'eyt le plus grand 11.ubre de cas, elles sont mélangćes avec les coquilles marines, soil du caleaire grossier proprement dit, comme à lloudan, ou avec celles alu grès marin inférieur, comme à Beauchamp, et mêmo du supérieur, comme à Assi-en-Mulitien, à Hetz el probablement à Valmondois. Nous sommes surpris que des couches considérables, dans les environs de Paris, qui contiennent une si grande quantité de ces coquillages, n'aient point altiré l'attention des géologues on des conchyliologres qui s'occupent spécialement des terrains et des corpilles d'eau douce. Le nombre des cspèces vivantes est peu considérable, et quelquesunes sont assez grandes; mais il en existe une plus grande quantité de fossiles, nous co comptous au moins vingl-cinq espèces.

1. Crnise perdue. Cyrena depordita. Noв.

C. testâ ovato-ventricosâ, obliquâ, subtrigonû, locvigatâ substriatuve; umbonibus magnis, irflatis, recurvis; dentibus cardinalibus tribus vals's sinistrî̀, duobus dextrî̀; dentibus latcrilibus subcrqualibus, lervigatis.

Cyclus deperdita, LАмк. Anu. du Mus. tom. 7 . pag. 425.

Ibid. DEF. Dict. Sc. nat. tom. 12. pag. 280.

Non. Descript. des coq. foss. de Paris, tom. i. pag. $118.1 \pi^{\circ}$. 3. pl. 19. fig. 14. 15 .

Coquille très-abondammeot répandue dans les grès narius, soit supérieurs, suit inférieurs, et qui a été confondue dans les collections, soit avec les Mactres, soit avec les Vénus; c'est cependant one véritable Cyrène bien caractóriste. Ellc est assez variable daus sa forme; le plus souveat elle est ovale, pen transverse, subtrigone; d'antres fois, elle est plus transverse; quel q̧uclois, enfin, elle a presquautant de largeur que de longueur, et alors elle est d'une forme plus trigoue; elle est reoflée, cordiforme, à crochets proéminens, le plus souvent lisse, a vec quelques iodices de ses accroissemens; quelquefois assez régulièrement striée. La charnière est élroite, elle présente sur la valve gaucbe trois denis, dont la médiane est bifide; y il en a deux sur

\section{C $Y \dot{R}$}

la valve droite. tes dents latérales sont presqu'égales, l'anterievire cependant est la plus courte. Longuenl 16 milliu., largeur, 18. On trouve celle coquille aux envirnus de Paris, seulement dans les terralins de mólanne, i Pontoise, Beaucharap, Taucron et Valusoudois.

2. Cymese épaisse. Cyrena crassa. Noв.

C. testấ ovito-subtrigonâ, crassâ, levvigatá: umbonibus produclioribus, obliquis; curdire tridentato, ulter bidenlato; dentibus laterulibus abbreviaits, spissis.

Noв. Descript. coq. loc. cit. $n^{\circ} .4 . p 1.18 . \mathrm{fs}$. 14. 15.

Pelite coquille lisse, épaisse, prestau'aussi longue que large, subtrigone, à angles arrondis; ses crochets sont saillans, obliquement recourbés. cordiformes; luuule non indiquée; nyraphe courte et pen saillante; la surface extérieure est loute lisse, avec quelques strics d'aecroissemen!; lance cardinale large et épaisse, prúsentant daus sou milieu, sur la ralre droilc, deux deuts cardivales, et sur la gauclue trois, dont la postérieure se conluad par sa base avec la nyouple. Les denls lutérales sout courtes, surtoul l'antérieure; Ja postćrienre est plus longue, et elle est de la longueur dn corselet, toutes deux sont très-près des denls cardinales; les impressions musculaires sont petites, lorl écartées. On ne voit point d'échancrures dans l'impression abclominale, qui est simple. Longuear 9 nillim., largeur, 10 aullia.. Elle se trouve is Tislmondois.

\section{Craise antique. Cyrena cintiqua. Fer.}

C. testâ trigonî̀, contiformi, inciquilaterî̀, crassissumâ, turgidâ, lcevigut i; umbnribus obtrquis, magnis; dentabus cardinalibus tribus; luterulibus magnis, striatis.

Cyrena antiqua, Heruss.sc, Hist. des Moll. ter. el fuv. pl. suns numéros, fig. 5.

1bill. Nов. Descript. des coq. foss. de Paris, loc. cit. $t^{\circ} .5 . \mathrm{pl} .18$. fig. 39. 20. 21 .

Coquille remarquable par sa forme tricrone ci cordiforme, presque longisudinale, par la grande épaisseur de ses valves, la grandeur de ses crocliets obliquement courbés rers la lunale; par le corselet, qui est fort grand et séparé par une sorte de troncalure, qui forme le custé postríleir de la cocuille; la surtace extérieure ne présente: que des stries irregulières d'accroissement, qui sont assez serrécs, surtont vers le bord inférieur. La lame cardinale est úpaisse, plus large dites sa parlie lunulaire ou antérieure que dans la postérieure; clle est munie dans son milicu, et sous le crochet, de trois dents cardinales non bifides, dont l'antérieure est la plus petite; les dents lalérales sont fortes, strićes, assez près des cardi- 
nales, et surtout l'autćrieure, qui les touche; la postérieure est beaucoup plus longue, elle est aussi plos éloignée des dents cardinales. Les impressions musculaires sont petites; l'impression abdominale préseate une lésère échancrure vers l'angle ioférienr et postérieur. Longueur et larǵcur 35 millim. Jusqu'à présent, cette espèce ne s'est trouvée qu'à Epernay.

\section{Cyrìxe de Grave. Cyrena Gravesii. Nos.}

C. testâsuborbiculutĥ́, turgidâ, lavigatâ; umbonitus magnis, cordutis, recurvis; dentibus cardinulibus tribus, luteralibus magnis, curdine approximatis, lavigatis.

"Nobis, Descript. des coq. foss. loc. cit. $n^{\circ} .6$. pl. 19. fig. 3.4 .

An Cyclas diperdita?? Sow. Mineral conch. औu. 162. fig. 1.

C'est à M. Grave, salvant qui s'occupe avec soin à recueillir les fossiles du département de l'Oise, que l'on doit la connoissance de celtc luelle espece, et nous ne pouvious thoisir avec plus de plaisir l'occasion de lui témoigner notre reconnoissance de la bonté qu'il a eue de nous communiquer une grande quautité d'objets curieus, lors de uotre séjour à Beauvais.

I 1 Cyrène de Grave est grande, presque orbiculaire, subinéquilatérale, légèrement oblique, I Él épaisse, enflée; ses crochets sont grands e! saillans; sa face extérioure est toute lisse, marquée irrégulièrement de stries d'accroissement; lu lame cardinale est asser. étroite, elle porte sur claque valve trois dents cardinales obliques, non bifides; la nymple est courte et pen saillante; les dents latérales sont fort graades, et surtout la pustérieure, qui n'est éloignée de la dent cardinale postérieure que par une cléuression à peine scusible, de manière à pouvcir étre confoudue atee elle; l'antérieure est moius longue que la pustćrieure; toutes deux sonı lisses. Longueur, 53 unillim., largeur 38. Cette coquille prend de plus grandes dimensions, 45 millim. de large, raúis ces individus sont rares. On la trouve à (ilise-la-Mothe, départernent de l'Oise.

\section{Curnexe aplatie. Cyrena depressa. Nos.}

C. testáa ovato-obliqui. subtrigon.j, depressá, lovigata; accressionibus subrcgularbus rusticatâ; dentibus tribus in utrique valvâ, posticalibus bifidis; dentibus lateralibus magnis, sefaraits, lavigatis.

Nubis, Descript. des co.7. Soss. loc. cit. $n^{\circ} \cdot 7 \cdot$ 1\%. 18. fig. 16. 17. 18.

Wid. Dict. class. d"hist. nat. tom. 5.

Ceite belle et rare espèce de Cyrène est trèsreconnoissable ì sa forme obligue et subtrigone; id la surface extérieure e!le est lisse, próseatant quelquefois des accroissemensirréguliers; elle est peu épaisse, point aussi renllće que la plupart des autres especes; son crochet est oblique, peut saillant et pointu; la lunule n'est pas marquée; le corselet est assez grand, la nymplie n'est point saillante au-dehors. Dans les individus que l'on truuve comple!s, le ligament se voit encore ell place, comme, an reste, dans toules les coquilles bivalves dont les valves n'ont pas étć désunites avantl'enfouissement; la charaière a constanment trois dents cardinales, dont l'anlérieure est la plus pelite, la médiane el la postérieure sont bifides; les dents latérales sunt grandes et non strićes; l'antérieure est près des dents cardinales. la postérieure en est séparée par toute la longutur de la aymplic.

M. Desnoyers m'a communiqué cette espèce, trouvée à Vaugirard, près Paris, dans la couche de lignites qu'il a découverte entre les denx couches du calcuire grossier. Longueur 35 millim. , largeur 45. On la trouve aussì à Houdan et $\dot{a}$ Maule.

6. Cynève cunciforme. Cyrena cuneifornis. FERUSS.

C. test ì noto-transversâ, subtrigonâ, inaquilaterî, irreguluriter substriatâ, anticè truncatu; dentibus cardinalabus tribus valiâ dextrá, duo. bus in alterâ; dentibus lateralibus striatis.

FErus. Hist. nat. des Moll. ter. et fluv. pl. sans numéros, fig. 4.

Ibid. Nов. Descript. des cog. fuss. loc. cat. $n^{\circ}$. 10. pl. 19. Jig. 1.2. 20. 21.

Cyrena donacialis, Nor. Dict. class. d'Hist. nat. tom. 5.

Cycleas cuneiformis, Sow. Mincralconch.tab. 162. fig. 2. 3.

Var. B. Nов. Testî̀ nimis transversâ, minùsque obliquá.

Oa reconnoit facilenent cette espèce à sa forme transverse, ovale, sulurigone, à l'obliquilé de ses crochets et surlout it la troncalure de son cóté antéricur; ses crochets sout peu saillans; sa surfice extérieure est irrégulièrement marquée de stries d'accroissement; la lame cardinale est fort étroite; les dents cardinales sout conrtes, à peine bifides; on en voit trois sur la valve droite, deux seulement sur la gauclie, la troisienre ou la postérieure se trouvant confoodne avec la nymphe, qui est courte et saillante. La dent latérale posterieure est tor grande, séparíc des cardiuales par lat nymphc; l'autérieure est beaucoup plus courtc el touche aux dents cartinales; toutes deux sont linement strices, et surtout l'untérieure, çui l'est plus profondémea: Losgueur 20 millim., largeur 27. En France, cet:c comaille ne se trouve qu'aux environs de 


\section{I R}

Soissons, et ea Aoglcterre, à Clartion et à Headen-Hill.

7. Crrise teilinelle. Cyrena tellinella. Ferts.

C. testâ obuto-elongatá, transs'eria, inviuidluterî, laciguti, depressí : umbonibus monimis; dontibus cantuablus minimis duolus in utrique salidi, lateruluts magnis, oblique striatis.

Fencssac, Hist. nut. des . Moll. ter. et fulv. pl. suns nusméros, fig. 1.

Ihit., Хов. Descript. de's coq. foss. loc. cit. n?.11. pl. 19. fig. 13.19 .

An premier aspect. on prendroit celie pelite coquille pour une Telline; elle a me forme rewarquable et inusire dans les Cyrincs; elle est aplatie, ovale-oblongue, très-bransverse, inéquilatérale; elle est lisse à l'extériéur; son croched est petit el peu sailian!; la lame cardinale est étroise, surtout dans l"eadroit de linsertion des dents cardiuales; celles-ci sont for! petites, il Y eu derix seulemen! sur chaque valve, la iroisième ou la postérieure étant corfondue arec 12 uymplic. Les dents latérales sont fort grandes, proéminentes, la posírieure plus zrande que l'aatériture, tontes deux scat cbliquement et profundérzent strices. Longgueur 8 mallia., larseur 16.

8. CrRive de Ceylan. Cyrena cej Lonica. Lavi.

C. testi onato-cordati, turndit, inciyullater: epidennide damelloso, fusco rel migncante an-

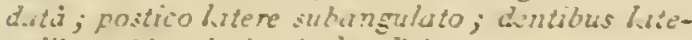
rulibus abbroviotis: intus a.ha.

LAMa. Anim. suns zert. som. 5. fag. 55 f. $n^{\circ} .11$.

Venus ceylunica, Caensisz, Conch. $60 \mathrm{~m} .6$. farg. $3 \overline{3} \bar{\jmath} \cdot \operatorname{tab} \cdot 32$. fig. $5 \tilde{3} 0$.

T'enus couxans, Lix. Guez. rag. Jँ2-8. no. 41.

Bestre. Ualac pl. $7 \overline{5}$. fg. 2.

Excrecop. pl. 50n. fig. 4. a. b.

Graadc e: belle coquille qui labile les feares de l'ile de Ceylan, où il paroit qu'elle est assea comaune : clle est subcordiforme, enllée, oblique, iáquilatérale, à crochets géuéralement petits et sourent rongés; elle est loote blanche en dedans, el servit au-dehors de la wéme coulenr, si elle n'étoit courerte d’na épiderme d'un janne-laure ou verdatre, quelquefois dina brun presque noir; cet épiderne se relève en stries concentriques. Ia melleuses, suurent caducgues. La charuic̀re rend cette espère facileaseat reconnoissable, quclque soien l les rariations qu'elle éprouve; constamment les deux deus cardinales postérieures, sur la ralre druite, et les deux antérieures, sur la gauche, sont bilides; la troisième dent est petite, presque avortée; les deats latérales sont simples et ires-courles. Celle coquilie alteiat assez Tré-

Hist. Nat. des Vers. Tome II.

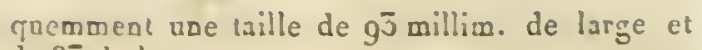
de $8 \overline{3}$ de long.

\section{Q. Cratie violelle. Cyrena yrolacea. l.aua.}

C. testás ob'at’́, obliquá, depressid, anticè urreguldriter plicati, epidernide fusco-lute i, intus violuced, vel mseo-cameis; devite laterali fostico pridango, síristo.

LAMx. loc. cit. $\pi^{\circ},-$.

An rarietus? Testio crussion; sublis anticis, regularibus.

Cyclas, Bave. Encyclof. pl. jor. fig. 1. $a . b$.

C'est à L.I. Lesson, Quoy et Gaymard, que l'ou doit la connoissance plus parfaite de cette belle espèce, dont M. Lnmarck ne prssédoit qu'un fort petil indiridu. Cente coqnille, crande, ovale, oblique, aflatic, es! constamuent converte à l'exlérieur d'un épiderme brun, sourea: Ćoruhé sur les croche!s; ceux-ci sont peu saillans et un peu en ceur andérieusement; on remarque sur la surface extérieure des stries ou des sillous irréguliers, qui s'interrompent ress le mulieu, qui est lisse, tandis que le còié postérieu présente des siries fines el lamelleuses, produites par la desquammalion de l'épiderme. Lorsque celte coquille est jenre, elle est en dedans d'ua beau riolel qui persiste quelquefois dans les in tiridus adulces, mais le plus surreat elle est dun rose-pourpré d'une fraicheur admirable. La charuière, très-solide, a trois cieats cardinales à chaque ralive et les dents latérales assez longies, striées; elle est néanmoins affermie par ur ligament très-saillant et conreve. La raricté se distiague par ses sillous antérieurs, qui saut plus réguliers el par son test, qui est plus épais, ce yni lient pent-etre à la rieillesse de liadividu. Cette coquille. large de 90 millim.. se troure dass les eaux douces de la Nourelle - Zélanảe et des Célèbes.

io. Crresie cozur. Cirena cot. Laja.

C. testi elongrato-cordati, inarquilaterô, tumids, scaluriter sulcudi ; nutitus prominentihus, involutis; dentionus laterulious magnis, strutis; intis siolucer.

L.s.ux. loc. cit. $n^{\circ} \cdot \mathbf{5}$.

Cyrena consobrima, Calliatd, Foysge en Esopte, tom. 2. pl. 61. fist. 10. 11.

Cirena fuscata, Lams. loc. cit. $11^{\circ} .4$.

Excrclorede, fl. jol. fig. 2. a. b. et jon. fis. 2. a.b.c.

Cynena arientalis, $\mathrm{L}_{\mathbf{A}} \mathrm{x}$. loc. cit. $74^{\circ} .2$.

Il n'est pas douteux pour nous gue ces trois espèce's de .I. Lamarck n'en soot quiune, et peutètre scra-t-ca olligé plus tard d’y joindre aussi une quatrième espéce, la Cyranci Auminea, qui 
présente quelques earactères qui la distinguent; mais comme nous n'avous vu 'qu'un seul exemplaire de cette coquille, il seroit possible que ces dillérences fussent inclividnelles.

11 n'est pas douteux que M. Lamarck n'ait fait les espèces gue nous venons de uentionner sur des âges différens de la mème coquille prise dans diverses lucalités; cela nous semisle tellement inconlestablc, que l'on peut relrouver dans une sćrie de la même localité toutes les variétés prises ponr des espèces, et il est, dans tous les cas, très-facile de les reconnoître ì certains caáactères qui restent invariables.

La Cyrène cocur est une coyuilie d'un volume mŕsliocte; elle est arrondie, subtritrone, enllée, fresegue equilatérale, presque aussi longue que large et un per oblipue; ses crochets, souvent écurchés, sont en cour peu inclinés; la surface extéricure, couverte d'un épiderme vert dans le jeune age, el brun dans les individus adultes, Jrésente aussi des stries transverses, plus ou moins nombreuses, selon les individus; caractères 'ini, joints à la couleur de l'intérieur des valves, qui n'est pas moins variable, ont délerminé M. Laimarcl à faire aver eux des espèeses. Celle couleur de l'intérieur est un violet assez intense, surtant ver's le bord, où elle forme une large bande d'une teinte plus foncée que le reste; dans les jennes individus celle bande n'existe pas encore, aussj la coulcur est-elle d'ua violé pâle ou blanchitre. Ce qui caractérise ensentiellement celte espèce, c'est sa lorme, ses stries et sa clarnic̀re; celle-ci se comprose toujours de trois dents cardinales sur chaque valve: elles sont entières, divergentes; l'antérieure de la valve droile tauclie ata bord supéricur de la dent latérale du même côté, tiudıs que sur la valve gauche, c'est Ia dent cardinale postérieure gui touche ì la dent latérale de ee côté. Les dents lat térales sont presque égales; la postérieure est cependant un peu plus courte et un peu plus écartée des cardinales; l'antéricure, an contraire, lcs touche; les dents latérales sout striées perpendiculairement dans toute leur longueur; la postérieure d'un côté senlement et l'antérieure souvent des deux côtés; le bord des valves est mince, tranchant et trèsentier. Ce qui est encore lort remarquable daus telte espèce, e'est qu'elle se trunve à de grandes distanees. Lalande l'a recueillie au cap de BonneEspérance; Olivier, dans les eaux douces de la P'erse; Lesclsenauli, dans calles de l'lude : nous savous qu'on l'a rencontrée en Chine, au Sénégal et en Euypte; il est donc à prísumer quelle habite les eatux douces de la région intertropicale de l'ancien Monde. Les iudividos de taille moyenue ont 25 à 50 millim. de large et presque autant de loug.

1.. Cyrièe ondée. Cyrena fuminea. Lanix.

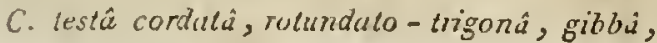

favn-virente; sulcis latis, doliaribus circumcincta, intus albo violaceoque variegutâ.

LAmx. Loc. cit $n^{\circ} .5$.

Tellina fuminea, Lin. GurL. pag. 5245̄. $n^{\circ} .80$.

Cuелмiтz, Conclu. tons. 6, pag. 321. pl. 30. fig. 322.523.

Coquilie un peu moins grande que la précédenle, trigone, équilatérale, cordiforme, enllié, solide et éfraisse, ornée de stries ou de sillon:s arroullis et distans; ses crochets, saillans, opjorsés, peu obliques, sunt souvent rongés; en dehors clle est converte par un épiderme vert-jaunâlre, et l'on remarque que la luaule et le corselet sont indiqués pall nue fascie obscure. La charnière, plus large ct plus épaisse que dans le Cyrena cor, a avec elle beaucoup de ressemlilance; nous remarquerons cependant çue les dents cardinales sont plus obliques, quil n'y en a que deux sur une valve et trois sur l'autre; quelcuelois ba dent antérienre est avortśe; la dent postérieuse est presque aussi longue que l'antẻrieure; lontes deux sont linement strićes, la postérieure des deux côtés. Cet!e Cyrèoe se trouve dans les caux douces de la Cline; mais on ne dil pas clat:s quelle région de cet inmense pays. Elle a 25 mi:limètres de large el autan! de longueur.

\section{Cynène australe. Cyrena austrulis. Nob.}

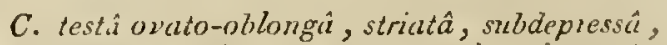
tenui, frugili, fusco-z'trente, intius uurantrâ: striis tenuissimis, transversalibus.

Jolie petite ençuille qui nous a été généreusement communiquée par aotre aini, M. Lesson, qui l'a recueillie à la Nouveile-Hollande : elle est ovalaire, presque équilatérale, peu épaisse, à erochets petits, rongés, peu obliques, oráe en deliors de stries fiues, concentriques, régurlières et recouverte d'un épiderme d'un noir-brun; en dedans elle a une large tache orangée. La cluaruiese a trois dents cardinales lort petites, et les dents latćrales, fort alongées, sont finement striées l'une et l'autre des deux cộtés. Celte coquille qui, comme nous venous de le dire, vient de la Nouvelle-Hoilande, n'a que 15 millina. de large.

13. CYRÉne tronquée. Cyrena truncala. Lasi. C. testà ovato-trigonâ, cordutâ, crassâ, inuquilatcrâ, obliquè tnucatâ, posticè angulatia ; sulcis transversis, irregukuribus; dente latcrali postico, obliquè striato.

Laнk. loc. cit. no. 6.

Il existe la plus grande analogie entre cerre espièce, qui se trouve fossile près de New-Yorck, en Amérique, et la variété de la Cyrène cunćiforme, fossile aux environs d'Epernay, dans le bassin de Paris. Cette analogie est tellement com- 
plète, que la value de New-Yorck, rapprochée d'une valve opposée d'Epernay, s'uccorde avec elle aussi complétcment que si elles avoient apartcou au meme animal. C'est tout nouvellement que nous avons pu constalce ce fuit trèscurjeux, en examinant les coquilles de la collection da Muscum, parmi lesquelles nous trouvàmes une seuce valve, qui servit ì M. Lamarck pour ćlablir sa Cyrene tronquée et la raractériser. Cétte valve provient de la collection de feu Vulenciennes, qui l'avoit reçue de M. Milbers.

\section{Crrixe de Faujas Cyrena Farjasiz, Nob.}

C. testí orato-rotunds, depressi, lievigatî, substrutive; umbonbus mimmis, recurous ; car. dine angusto, tridentato, dente laterule antico, brevi, angustissimo.

Tluns de Mayence, Fanjas, Mem. du Mus. tom. $8 . p l .58$.

Deluc aroit connu cette roquille et les circonstauces de son gissement; il lui avoit donué, avec les anciens conclyyliologues, le nom de Cume: il la croyoit marine. Faujas reproche a Deluc de n'avoir pus rapporté celte esfice au génre V'énus de Linné, puisqu'elle en présente, d'après lui, tous les caracteres: Fuujas, en conséquence, la croil marine, et ne fuit en cela qüirniter Deluc. Pour prouver que les petits Bulimes de Mayence sunt marins, il s'appuie sur le fait, gue l'on troure avec eux des Houles et des Huitres, tt de plus, la V'énus en ques:iun. Lorsque liaujas jublia le Mémoire sur les fossiles de .Mugence, il puuvoit protiter des travaux de Bruguière et de M. Lamarck; il auruit clonc pu, sil eût voulu y apporter plus d'altention, reconnoitre dans sa coquille tous les caractères du genre Cyclade (Cyrène, Lamk.); cela lui était d'autau plus facilé, quili dil avoir vu des valves détachées de celte cópulle; nous en possétlons également, et nous pouvons assurer qu'elles présentent tous les caractères des Cyrènes: ce sunt par conséquent des coquilles d'eau douce, d'où il suit que c'es soj-disant Bulimes ne sont bien probablement que des Paludices également d'eau douce; et quand dans ce vième terrain on trouve des Hélices et quel ques Huitres, on peut croire qu'il appartient à ces ciépóts de mélange qui sont produits par des maiériacx lluviatiles, iransportés et déposés dass Ia wer à l'embouchure des !leuves.

La Cyrène de laujas est ovale, olmoncle, peu Épaisse, déprimée, légèrement oblique, inćquilatérale, lisse an presque lisse, ne présentant gce les siries irrégulières de ses accroissemens; la charnière, supportée par une lame cardinale for étroite, se compose de trois deots cardicales, dont la moyenne est toujours bifide; les dents laiérales suat étroiles, lazaclleuses, et l'antérieure, lris-conrte, touche aux dents carlinales, tandis quela postérienre, beauconp plus longue, en est séparéce par tonte la longueur de la nymphe.

Celle coquille, counue à l'étut fossile sen!ement, se truuve eu abondance et pâr lits dans les collines dOppenheim et de Weisnau, prés Mayreace Elle a 20 nuillim. de large.

14. Crasse de Brungniarl. Cyrena Brongniatti. B.ist.

C. testâ subtrigonâ, obïiquâ, incequilaterâ, infuto-cordıformi, liansverse sulcatá; umbo"ubus magnis, recunvis; cantine subtridentato, dente luterali antico conico, crisso, brevi.

B.sт. Mém. de la Soc. dHist. nat. de Paris, tam. 2. pag. 84. $n^{\circ}$. 1.

Mactra cyrence, $\Lambda_{\mathrm{L}}$. Brosic. Mém. sur le $V_{i-}$ cent. pl. 5. fig. 10.

Tar. B. Nob. Testá minore sublavigalâ.

Cyrena Sowerbyi, B.ssr. loc. cit. no. 2. $p l .6$. fig. 6 .

Après avoir vu un assez grand nomlue d'individus des deux espèces que nous cilons, nous avons élé convaincu de leur identité et de la nécessité de les rémair en une seule, celle que II. Basterot a Dommée Cyrena Soswerhyi, n'étiunt, selon nous, que les jeunes indivitus de la Cyrène de Brongniart. Il a'est pas douteux que l'autcur du Mémoire sur les terrains calcarco-trapéns du Vicentin n'ait pas reconnu le genre d'une coquilie gu'il nomme Mactua cyrena? Cepentaat, la seule figure qu'il en donne sulfiroit pour lever rous les doutes, car ćest une véritable Cjrène qu’elle représence.

La Cyrène de Brongnialt est de toutes les espèces fossiles celle qui acquiert le plus grand volume; clle est ovale, subtrigone, subsinueuse postérienrement, très-conrexe, en!lée, cordiforme, a crochets saillans et obliyues; elle cst inéquilatérale, le plus souvent lisse sur les crocliets, et couverte, dans le refte de son étentue, de sillons assez régnliers et lansverses, plus saillans sur le côté antérieur quze sur le postéricur. La clianière, large et très - furte dans la plupart des individus, offie sur chaque valve trois deats cardinales: clont une, l'antérieure ou la postérieure, est peu prononcée. Les dents latérales sont courtes, usais épuisses, coniggues \& lisses, \& sont recues dans des cavités currespoodantes dont les bords épaissis deviennent saillans dans l'iucérieur des valres.

On tronve cette espèce à l'état fossile aux environs de Bordeaux, dans les terrains marins, mélangée avec toutes les conuilles qui les liarment, aux cuvirons de Dax el au Val-de-Roncr. Les grauds udividus ont 71 millim. de lor.gueur. 
15. Cyrèse de Geslin. Cynena Geslini. Nos.

C. tesìi rotundat $\hat{\imath}$, depressî , substriatâ, obliqui, incrquilaterali; umbonibus minimis; cardine tridentuto, allero bidentato; dentibus bifidis, latemalitus, brevibus, compressis.

Cuquille remarquable qui a quelqu'analogic avec notre Cyrena depressa, fossile des environs de Paris; elle eft arrondie, inéquilatérale, un peu ułlique, sublenticulaire, déprimée; le lếl est jeu épais el marqué en deliors de stries irrérulières, concentriques; les croclies sout petits, à peine saillaos; la charnière présente trois dents divergentes sur la valre droite, les deux postérieures sont bilides, l'autéricure est petite el plis courle yue les autres; sur la ralve gauche la dent postéricure disparoît presque complétemeut, tandis yue les deux antérieures sout bitides; les denis liatérales sont courles, et la postérieure eft fort élojgncée des cardinales à l'extrémité du corselet. Cette coquille se trouve fossile aux environs de Dax; elle a 50 milliur. de lougueur et de largeur.

16. Cyrève subovale, Cy rena oborata. Sow.

C. testî uvato-subtrigoni, obliquè condata, gibbosulì, crassia, lcevigatí, posticè angulatâ; cardine budentato, altero tridentato; dentibus bifidis, dente latéruli postico, prcelongo.

Cyclas obovata, Sow. Min. conch. pl. 162. fig. 4. 5. 6.

Espèce que l'on trouve assez communément fussile cu Anchleterre, à Barion et surtout à l'ile de Wight, daus un ierrain où clle est mélangée avec des coquilles marines; elle est ovale, subtrigone, enllée, cordiforme, fort oblique \& inćquilatéra!e; en dehors, elle est lisse ou substriée par des accroissemens qui sont plus marqués sur le côté postérieur, celui-ci est indiqué par un angle obtus. La charnière, assez étroite, présente trois dents cardinales sur la valve droite et deux sur la ganche. Les dents latérales sont étroites, alongées, rapprochées des cardinales; la postérieure est la plus longue, clle s'étend dans toute la longueur du corselel; dans quelques individus, ces dents latérales sort finement striées. Les plus grands individus de cetle espèce que nous ayons vus n'ont que 20 millim. de largeur et presque autant de longueur.

17. Cyrìxe demi-striée. Cy rena semi-striata. Nor.

C: testâ ov'ato-trigonâ, obliquè cordatâ, incequilaterî, posticè angulatu, anticè regulariter striatio; striis transversalibus in medio evanescentibus; cardine bidentato; dentibus latcralibus, brevibus, conicis, oratis.

Coquille qoi, par sa forme ovale, trigone, très-inéqquilatérale el oblique, a de l'analogie aree lit Cyrena cunezformas, wais qui sen dis- lingue très-facilement : elle est mince, assez fragile, cordiforme, lrombée, à crochets pointus et saillars. Dans les individus bien conservés, la surface extérieure présente, sur le côlć antérieur seulement, des stries transverses, arrondies, régulières, qui disparoissent sur le milieu de la coyuille, qui devient lisse dans le reste de son étendue. La cbamière caractérise fort bien celle espèce; eile n'a que deux denis cardinales sur cliaque valice, les dents latérales, presque égales, sont courtes, coniques et ovalaires. Cette cojuille, conuue à l'élat fossile seulement, ne se renconlte qne daus une couche de sable quartzenx avec des coquilles marines. On reconnoit facilemeat que tous les corps organisés contenus dans celie couche on: été roulés et transporlés; ce qui explique pourquoi la plupart des individus que l'on trouve sont devenus lisses, tandis que les autres, moins usés, présentent tous leurs accidens extérieurs. C'est à Klein-Spauneu, près Maëstricht, que celle corguille se trouve; elle est large de 25 is 30 millim.

\section{CYRTODAJRE. Cyrtoduriu.}

Daudin, dans le Joumal de Physique, avoit étaljli ce genre porr une coquil!e que M. Lamarck nomma depuis Glycimére, nom qui a été généralement adupté. Voyce ce mol.

\section{CYTHÉRÉE. Cytheroa.}

M. Lamark avoit d'abord créé ce genre dans les Animaux sans vertébres, en 1801 , sous le mom peu convenalule de Meretrix; depuis, en 1807 , il lui donna la dénominatiou de Cythérée, lorsque, dans les Annales du Muscum, il décrivi les espèces fossiles des environs de Paris; à dater. de cette époque, ce nom est resté à ce genre. Antérieurement aux travaux de $\mathrm{M}$. Lamarck, Linné et Bruguière firent, avec les Cycthérées et les Ténus, un genre immense, dans leque! il étoit presqu'impossible de retrouver uoe espere; maintenant, que le genre est divisé en deux partics presqu'égales, celle difficulté reste à peu près la uéme, tant à cause du graud nombre d'espéces nouvelles découvertes dans les derniers temps, que par le graud nombre de nuances, de fornies, de couleurs, qui les rapprocheat el les confondent.

Tout en conservant le genre linnćen, $M$. de Blainville, dans son Truité de MIalacologie, a cherclié à le diviser en un assez grand nombre de sectious, pour rendre plus facile la recherclie des espèces. On pourroit adopler plusieul's de ces groupes, dout les caractères principaux sont pris dans la forme, et sous ce rapport, comme sous celui des couleur's, le genre Cythérée est très-variable. Il y a peu de genres parmi les Conebyferes, qui offreut autant de variétés pour les couleurs, et coume toutes les espèces sont dépourvues 
d'śpiderme, et qu'clles jouissent naturellement d'uu brillant qui sowvent n'est qu'artificiel dans d'autres genres, ces corpuilles, à cause de cela, sout presque toutes fort reclierchées des aunateurs. On trouve à l'état fossile, à Bordeaux, Dax, et dans le Plaisantin, plusieur's espèces qui sont encore actuellement vivantes, soit dans la Méditerranée, soit dans les mer's de l'Inde. Nous nous allacherons surtout à décrire ces espèces, parce qu'elles pourront plus tard servir de watériaux à la géologie.

\section{CARACTÈRES GÉERIQUES.}

Coquille équivalre, inéquilatérale, suborbiculaire, trigone ou triasverse, quatre dents cardinales sur la valve droite, dont trois divergentes rapprocliées à leur base, et une tout-i-fait ısolée située sous la luuule; trois deuts cardinales divergentes sur l'antre valve, et une fosselle un peu écartée, parallèle au bord; dents latérales nulles.

Les Cythérées, anjourd'hui très-nombreuses en espèces vivantes, le sont moins en espèces fossiles, quoique leur nombre soit encore assez considérable. Les environs de Paris sont, à cce quill paroît, de tous les terrains tertiaires, ceux qui en fournissent le plis. MI. Sowerby, daus son Aincral conchology, n'en décrit qu'un petit nombre, et Brocchi lui-mème ne rapporte yue six espèces de son genre Vénus aux Cytlérées de NI. Lamarck. Parmi les espèces rapportées par Brocchi, il $y$ en a une quil considere comune l'aualogue de la Venus rifescens, et en même temps comme celui de la Cytheráa lovigata de II. Lamarck, que nous trouvons très-abondamment aux environs de Paris. D'apsès la figure citée de la Venus rufescens de Linné, il est impossible dela confondre arec la Cytherce lavigata, à moins de supposer que la figure est excessivement mauvaise. On pourruit suupconner, dit Brocchi, que ce sont de jeunes individus de la Venus chione; mais on servit dans l'erreur, car elles sont toujours plus aplaties et le bord est plus déprimé à l'endroit de la lunule. On pent donc être convaincu, d'après la description de Brocchi, et d'après l'analogie qu'il lui trouve avec la Venus rifescons, que ce n'est pas l'analogue de notre lossile.

M. Brongniarl, dans ses travaux géognostiques sur les environs de Paris, a nommé deux espéces de Cythérées, trouvées dans les marnes du gypse, la première $C_{y}$ thérée bonbée, la scconde Cythérée pkine. Nous avous vu un très-grand nomibre de ces coquilles, et, après les avoir examinées avec une scrupulense attention, nous sommes forcé d'avauer que nous n'avons pu parvenir à déconvrir des caractères géué:iques, et on conçoit que cela doit présenter de graudes dillicultés, puisqu'on ne trouve que des empreintes ou des moules, et si, par lasard, on aperçoit quelques vestiges de têt, c'est pour constater son extrême friabllité et son peu d'épaisseur. M. Brongniart néunmnins a rangé ces coquilles parni les Cythérées, d'après l'ensemble de la forme et d'autres inductions qui ne sont pas plus solides. Nons ne saturiuns doner de motil's sullisans pour dapporter cescoquilles aux Cyllérées plutôt qu'à tout autre: genre. Ce qui rst tort remarquable, c'est que les valves sont placces les unes à côté d's autres, toutes tournćes, comme à plaisir, d'ut mínt: cóté. Nous possédons une plaque de marne de Montmartre, sui laruelle it y a quarante-siny coquilles tournées en dessus, saus aucuue exception. Il est une autre reforme gue nous proposons. dans le genre Cythérée, et que nous croyons nécessaire; nous l'avons indiquée à l'article lucrae du Dictionnaire classique d'Histoire nuturelle. Si l'on cxanine les Cytbérées tigérine et bord-rose, ainsi que quelques autres espèces fossiles qui en sont roisines, on reconnoîtra ruue lat charnière est tout-à-fait serublable à celle des Lucines; on leur trouvera de plus ce caractère, propre aux Lucines seulement, d'avoir l'impression musculaire antérieure trìs-longue, et d'avoir l'impression du manteau non échaucrée postérienrement; enfiu, l'intérieur des valves est ponctué comme dans les Lucines : ce qui n'i jamais lieu dans les Cythérées. D'après cela, nous pensons qu'il conviendra de porter dans le: genre Lucine (voyez ce mot) toutes les espèces de Cythérées qui, comme celles que nous venons de sigualer, présenteroient les mêmes caractères.

1. Crtriérée des jeux. Cy thercea lusoria. Lank.

C. testâ ovato-cordatâ, lacui, albâ; zorris castaneis medio interruptis; dente cardinali antico, cunaliculato, struto.

LaMs. Anim. s. z'ert. tom. 5. pag. 561. no. 1.

Venus lusoriu, Chensitz, Conch. tom. 6. tab. 32. fig. 340 .

Excres.pl. 270. fig. 1. a. b.

Coquille assez grande, ovalaire, subcordiforwe, épaisse, solide, toute lisse et luisante; elle est ornée sur un fond blanc, de zones brunes interrompues dans le milieu; sa charnière est puissante et la dent postérieure est bien sensiblement strite. Cetle espéce, qui se trouve abondamment sur les cótes de la Chine et du Japon, a recu le nom qu'elle porte aujourd'iui, par ce qu'elle sert daus le pays à certains jeux, après ạvoir étć peinte en dedans.

\section{LAME.}

2. Cутне́rés pétéchiale. Cytherea petechialis.

C. testâ ovato-cordutâ, tumidâ, levi, ulls 
glaucescente; maculis parvis, punctiformibus, subsparsis; latere postico angulato.

Lanx. Anim. s. vert. loc. cit, $n^{\circ} \cdot 2$.

Excrce. pl. 268. fig. 5. b. elfig. 6 .

Cette espèce est toute blanche à l'intérieur; en dehors, elle est d'un blanc-jaunàtre, glauque sur la partie postérieure, séparée da reste par au angle assez aigu; toute la surface est lisse et chargée de mouclsetures brunes, irrégulièrement rípandues. Elle est très-voisine de la précédente, quant à la forme; ses crochets, assez saillans, subcordiformes et obliqurs, s'inclinent sur la partie antérieure, qui est la plus courte, cette coquille élant inéquilatérale; la lunule n'est pas suarquée. Cette espèce, fort rare dans les collec:tions, vient de la mer des fudes; elle est large de 68 millim.

3. Crthérée impudique. Cytherea intpudica. Lidir.

C. testí cordatî, lcevi, crassî, albido-fulvî, subradiata; vulvâ livido-carulescente, angulo laterali obtuso separutî.

LAsr. loc, cit. $n^{0} .3$.

Cangnitz, Conch. tom. 6. tab. 35. fig. 347. 548 et 349 .

Excres. pl. 26g. fig. I. a. $b$.

Cette Cythérée est assez variable dans ses conleurs; tantót elle est d'un blanc fiture, tantôt d'un blanc-grisattre ou brunătre avec ou sans fascies, brumes, rayonnantes; cependant on ea trouve presque toujoars des traces sur les crocuets : son côté postérieur, séparé par un angle obtus, est'souvent d'un brun-jaunâtre, quelquefois d'un brun tirant sur le noir, et d'autres fois, mais plus rarement, à peu près de la même cuuleur que le reste; elle est toule blanche en dedans, ćpaisse, cordiforme, presque aussi longue que large, iuéquilatérale, à bords simples, mais épais. Ceite espèce vient des mers de l'Inde où elle n'est pas rare; elle a 7 I millim. de large. LAMK.

4. CYTrtérée graphique. Cytherea graphica.

C. testî trigono-rotundati, lavi, griseâ, fusco-radiati, aut lineolis flexuosis pictá; vulvis ovali, glauciní; ano oblongo.

LAHE, loc. cit. $n^{\circ} \cdot 7$.

Casms. Conch. tom. 6. tab. 54. fig. 55 g à 56 i?

An Venus nebulosa? Lix. Gres. $n^{\circ} .46$.

Eкстѐ. $p l$. 266. fig. 5. a. b.

Coquille subtrigone, arrondie, toute lisse, inéquilatérale, peu bombée, onnée sur un fund grisâtre de deux rayons bruns ou de linéoles llexueuses; quelquefois ces deux caraclères existent ensemble, et quelquefois ausil les deux rayons manquent; la lunule est ovale, oblongue, et le corselet, ovalaire, se distingue par sa couleur glauque et son élévation médiane.

C'est dans l'Océan indien que se tronve cette coquille, qui est large de 38 millim. seulement: elle est assez rare. Nous croynas que l'espèce que MI. Lamaick a nommée Cythérée morphine, u'est qu'une variété de celle-ci : nous ne lui trouvons nul caractère spécifique suffisant.

5. Cytuérée chasie. Cytherea casta. Lani .

C. testá cordato-mtundatî, substriatâ, gibbâ, crassâ, albâ; pube annque owatis, convexis, glaucessentibus, intùs violaceo maculatâ.

Lank. loc. cit. $n^{\circ} .10$.

Venus casta, Lin. Gmez. pag. 3278. $n^{\circ} .42$.

Cuems. Conch. tom 6. tab. 33. Jig. 346.

Espèce rare, blanche, presque lisse, ayant cependant des stries longitudinales, peu apparentes, tachetées de violet en dedans, surtout vers les impressions musculaires; elle est cordiforme, arroudie, gonflée, épaisse, à bords lisses et épais; la lunule est grande, ovale, supeifi. cielle, marquée seulement par une strie, et convexe, auss bien que le corselet, qui est souvent violâtre, proéminent el oviluire. L'Océan indien, l'un des points les plus riches en belles coquilles, est la patrie de celle-ci, qui a 45 à 48 willim. de large.

6. Cтthérée corbicule. Cytherea corbicula. Lamk.

C. testầ trigonâ, glabrî, albidâ, aut fulví, rufo subradiató; umbonubus argustatis; uro magno, subcordato.

LAMi loc. cit. $n^{\circ}, 1 \mathrm{I}$.

Venus corbicula, Lin. GmeI. pag. $3278 . n^{0} .39$.

Lister, Conch.tab. 251. fig. 85.

Kхов,. I'erg. 5. tab. 15. fig. 2 et 6.

Chess. Conch. tom 6. ta\}. 31. fig. 326 .

M. Lamarck indique une variélé que nous ne connoissons pas. Cette espèce est trigone, presque inéquilatérale, conıme tronquée de chaque côté; les crochets sont étroits, saillans, cordiformes et légèrement inclinés vers la lunule, qui est grande, cordiforme et superficielle. Cetle coquille, toute blanche en dedans, l'est également en debol's : quelquefois elle est fiuve, et sur celte couleur on voit des rayons bruns plus ou moins marqués; quelques individus, d’aprè Mi. Lamarck, en seroient complétenent dépourจus. Celte Cythérée vic dans l'Océan américain; elle a 45 millim. de lirge.

7. Crтtánée tripline. Cytherea tripla. Laxk. C. testầ trigon $\hat{\imath}$, laevi, albidi aut fulv $\hat{\imath} ; \mathrm{um}$ - 
honibus tumidis, angustatis; radiis subnullis; culo ovuto, magno.

I, MK. loc. cit. no, 12.

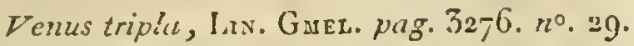

I.Ister, Conch. tab. 252.fig. 86.

Cukux. Conch. tom. 6. tab. 5̇. fig. 530 à 53 ı.

lisona. Vergu. 6. tab. 6. fig. 4 .

Exčyci,op. $p l .26 g \cdot f g .4 \cdot a . b$.

II seroit possible que cetle espèce ne fût qu'une varićlé de la précédente : sa forme est la nt:ane; clle est lisse, blanche ou fauve; les crocliets, presque symétriques, saillans, curdiformes, sort étrvits, ils n'ont pas autaut de rayons bruns, cependaat on eu trouve des traces; la lunnle est grinde, ovalaire, superficielle, semblable à celle de l'espèce précédente; en dedans elle es t presque toute blanche, si ce u'est dans les croclıcts ou clle est viulatre. L'Océan atlantique est sa patrie; elle a 55 ì 50 milliur. de large. Elle est plus petite que la précédente.

8. Cytuérée géanle. Cythena gigantea. Laux.

C. testî̀ mitrimầ, ovatî, sublividâ, làvigatâ; rudiis numerosis, interruptis, fuscis uut contescentibus; ano impresso, ovato.

L. мк. loc. cit. $n^{\circ} \cdot 13$.

Venus gigantea, Lis. GreL. pug. 3282. no. 9. Chens. Conch. tont. 10. tab. 171. fig. 1661.

Favasie, Conch. pl. 49. fig. Ii.

Excreior. pl. $280, f g .3 . a . b$.

Celle-ci est la plus grande du genre; elle est uvile, trausverse, inéquilatérale, toute lisse, marquée, surtout ver's les bords, de stries d'accroissement; elle est aplatie, ses crocliets, assez saillans, sont peu gonllés; ils dominent une lunule ovale, lancéolée, prolonde. En dehors cette soquille est diuu blanc fauve et grisâtre, et toute couverte de rayons interrompus, inégaux, de coulcur brune; eu dedans elle est toute blanche, son lêt est mince et cassani. Cette coquille, rare et précieuse, se trouve à l'ile de Ceylan; elle a jusqựà 22 centimètres de large, c'est-à-dire plus de 8 pouces. LА Мк.

9. Crthérée cedo-nulli, Cytherea erycina.

C. testấ ovatîn, aurantio-fulvì, variegat $\hat{\imath}$, fusco rediatî; sulcis transversis, obtusissimis; lunulù ovatâ.

L.s K. loc cit. $n^{\circ} \cdot 14$.

Venus exycina, Liv. Guet. pag. 3271. n०. 13.

Lister, Concl. tab. 268. fig. 104.

Kковr. Yergn. 4. tab. 3. fig. 5.

Chems. Conch. tom. 6. tab. $32 \cdot f i g .337$.
Farsaxe, Conch. pl. 46. fig. F.

ENCYCLOPÉdE, pl. 264. fig. 2. a. b.

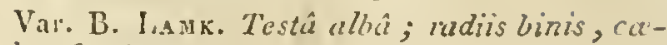
ruleo-fuscis, fube immacalatú.

Var. C. Lask. Testâ albidâ, supenè violuscente, radiis numernsis, fusco-violaceis.

Var. D. Nов. Fossilis. Testâ depressiñ, oblongiore sulcis numcrosioribus.

Bast. Bass. tert. du sud-onest de la Franre, Mém. de la Soc. d'hist. nat. de Pams, tomi. =. pag. 89 .

Ibid. Brocent, Conchiol. subap.

On ne peut contester l'analogie qui existc entre cetie espèce vivante, actuellement dans les aners de l'Incle, et les iadividus fossiles que l'on tronve en abondance aux environs de Dax, de Bordeaux et dius presque toute l'lalie.

La coquille vivante est recherchée daus les collections à cause de le beaulé et de l'harmonie de ses couleurs: elle n'est pas très-rare; sa forme esi ovale, subtransverse, assez bombée, inéquilatérule; ses crocliets sont saillaus, obliques, corditormes; la lunule, qui est au-dessous, est ovale, pointue, légèrement enfoncée, et séparée par uu sillon peu profond. Elle est d'un beau jaune-orangé et toute lisse, tandis que toute la surlace extérieure est régolièrêment sillonnée; les sillons sont larges, obtus, arrondis, très-fins sur les crocbets, et angmentant graduellement ver's les bords. Sur un lond d'nn heau jauneorangé parsemé de taches étroites, brunes, se voieut des rayons plus on moins nombreux d'un brun funcé. Les variétés vivantes signalées par M. Lamarck sont constantes : elles paroissent dépendre d'une modification de localité. Le type de l'espèce se trouve dans les mers de l'lade; il a été recueilli récemmeut par MMI. Reyoaud et de Blosville, à l'ile de Ceylan, taudis que les variétés sout propres aux mers de la NouvelleHollaude. Quant à la variété fossile, elle ne diffère tue par un peu plus d'aplatissement et par le nombre de ses sillous transverses, qui cst plus considérable. Cette coquille a 60 ou 70 willimètres de large, et non 34, comme M. Lamarck l'a dit, probablement par suite d'une erreur: les variétís sont un peu plus petites.

o. Crthéré lilacine. Cytherca lilacina. LAMK.

C. testâ ovatâ, fulvo-lividâ, obscurî, radiatî; margine intissque violascentibus; ano bvido.

Lanx. loc. cit. no. 13.

Chems. Conch. toni. 6. tab. 32. fig. 338.359 .

Excrez. pl. 264. fig. 5. a. b.

Coquille fort rare, ovale, inéquilatérale, cordilorme, sillonnée, d'un fauve clair et souveut 
violitue, obscurément rayonnée, surtout sur les crochets : quelquefois elle est couleur de bois, passant peu à peu au violet; ver's les bords, cette conleur, d'une teinte plus vive, pénètre dans l'iotérienr des valves; les crochets, assez protubérans et enflés, sont obliques et recourbés audessus d'une lunule livide, peu profonde. Le bord, très-entier, est épais; tout le têt est solide el épais, aussi bien que la charnic̀re, qui repose sur une lame cardinale étroite, mais epaisse. Habite l'Ocćan des Grandes-Indes; elle est large de 55 milliw.

11. Crtakee fauve. Cytherea chione. Lank.

C. testầ ovato-cordatâ, levi, fulvâ, subradiatâ; sulcis transversis, obsoletis; ano sublanccolato.

L.셔․ loc cit. $n^{0} .22$ :

Tenus chione, Laxi. Guel. pag. 3272. $n^{\circ} \cdot 16$.

Ibid. Polr, Test. utr. Sicil. tab. 20.

Jister, Conch. tab. 269.fig. 105.

Gualt. Test. pl. 8o. fig. A.

Favane, $p l$. 47. fig. B.

1) ARgenv. Conch. pl. $2 \mathrm{I}, f g . \mathrm{C}$.

livorr. Vetgn.6.tab. 4. fig. I.

Chenn. Conch. tom. 6. tab. 32. fig. 343.

Ficrec. $p l$. 266. fig. 1. $a$. $b$.

Var. B. Nов. Fossilis. Testâ majore, sulcis rants in medio internuptis.

Il est assez remarquable que celte espéce se trouve autant dispersée vivante que fossile ; ainsi, elle vit dans l'Océan européen, dans la Méditerranée, dans l'Océan atlantique et aux Antilles. Nous la connoissons fossile dans les faluns de la Touraine, anx environs de Bordeanx, en Sicile, et dans tous les terrains tertiaires d'Italie. Elle varie peu, malgré́ l'éloignement des localités qu'elle habite.

Cette coquille est ovale, transverse, cordiforme, un peu déprimće, subéquilatérale, à crochets assez saillans, obliques; elle est toute lisse, ayaut souvent quelques sillons transverses, irréguličtement espacés; la lunule, assez grande, est orale, laucéolée, légìrement déprimée : tout l'extérieur est de conleur faure, avec des rayons de la même couleur plus loncés, qui descendent des crochets jusque vers les bords; ces crocbets sont quelquefois blancbâtres et couverts de tacbes fauves, itrégulières; en dedans elle est tonce blanche, si ce n'est daus les crochets ò̀ elle est verdàtte. La variété fossile que nous avons indiquée, se reconuvil à la disposition de ses sillons, qui sont interrompus sur le milieu de la coquille : quelques individus ont de ces sillons, antéricurement et postérieurement, en assez grand uombre, et assez réguliers pour qu'on les premae pour une espèce disliocte, si l'on n'avoit des intermédiaires. Les individas vivaus ont 90 millim. de large; nous en avons de fossiles qui ont un quart de plus.

12. Cyтrérée tachetée. Cytherea maculata. LAM $\mathrm{X}$.

C. testầ "ovato-curdatâ, loovi, albidì, rufo tessellatim maculatá; vuló̀ subfísciatâ.

Laмк. loc. cit. $n^{\circ} \cdot 23$.

Venus maculata, Lins. G MeL. pag.3272. $n^{\circ}$. I7.

Lister, Conch. tab. 270. fig. 106.

Gualt. tab. 86. fig. I.

Kмовк. J'ergn. 2. tab. 28. fig. 5. - I'ergn. 6. tab. 20. fig. 3 .

Chems. Conch. tom. 6. tab. 33. gg. $^{\alpha} 45$.

Encrclop. $p l .265$. fig. 4. a. b.c. $d$.

Très-jolie coquille, qui a à peu près la taille et la forme de la précédente, mais qui s'en distingue parfaitement par la manière dont elle est tachelée; elle est aussi un peu plus déprimée latéralement et un peu moins cordiforme. Elle est toute blanche en dedans; en dohors, sur un fond également blanc, quelquefois rosâtre, se dessinent des taches subarticulées, dant celles du uilieu forment denx rayons imparfaits; elle est toute lisse à l'extérieur. Sa longneur est de 65 millim. On la trouve dans les mer's de l'Inde.

13. Cутнérée citrine. Cytherea citrina. Lank. C. testầ condato-trigonầ, transversim striatâ, citrinâ, latere postico fusco-rufescente; lunulá subcordutâ.

\section{L.A Ix. loc. cit. $n^{\circ} \cdot \mathbf{2 4}$.}

Cette coquille, encore rare dans les collections, vient cle la Nuuvelle-Ilollande; ce qui est remarguable, c'est que l'on trouve aux environs de Paris une espèce q̣ui est extrêmement voisine, et que l'on pent regarder comme une simple variété. - Nous l'avons décrile sous le nom de Cytherea. incrassata, dans notre ouvrage sur les fussiles de Paris; la vivante est subtrigone, corditorme, inćquilatérale, finement striée en travers, d'une belle couleur jaune citron et bruu postérieurement. En dedans elle est également jaune, et postérieurement, d'uue belle couleur bruu-rougeâtre, se nuançant el se fondant insensiblement dans la cuuleur jauae; la lnnule esi cordiforme, superficielle, marquée par une strie.

Celte coquille se trouve daus les mers de la Nouvelle-Hollande. Les grands individus sont lajges de 44 millim.

14. Crthéré inmescente. Cytherea lata. LAIIK.

C. testâ cordatâ, tuniidâ, albidâ, semira- 
diats; radiis fandicantilus, superne interruptis; lunuld subovicâ.

I.cnus lota, Lixi. G мег. pag. 3273. no. I9.

Kхоня. Le'rgn. 4. tab. 24. fig. 2 et 6. tab. 10. fig. 5?

Cnems. Conch. tom. 6. tab. 34. fg. 353. 354.

Evercr. pl. 266. fig. 4. a. b.

Espèce commune, cordiforme, enflée, blanche ou jaunátre, lisse, polie, lirillante, rayonnée tantôt de blanc, tantôt de fauve ou de brun; les rayons sont uonbreux, interrompus vers les bords et quclquefois vers les sommets, qui sont souvent couverts de petiles taches brunes ou rousses; la lunule est blanche, déprimée, ovale et marqquée par une strie; elle se relève inférienrement en un angle suillanl et aigu. Cette coquille, qui u'a que 55 à 60 millim. de large, se trouve dans l'Océan indieu et dans la Méditerranée, d'après Gmelin.

15. Crтuérie point de Hungrie. Cythereacastrensis. Lamk.

C. testẩ mtundato-condatâ, ventricosâ, albâ; lineis angularibus, transversis, spadiceis, hinc fimbriatis; ano cordato.

Venus castrensis, Lins. Guex. pag. 3273. ne. 20 .

I.1ster, Conch. tub. $262 . f_{g} \cdot 98$.

Guast. Test. tab. 83. fig. H.

Kкона. Vergn. 1. tab.21.fig. 2.5. - tab. 20. fig. 2 et b. - tub. 6. fig. 5. 6 .

Cuearn. Conch. tom. 6. tab. 35. fig. $367 \cdot 368$ es 37o. - tom. 10. tab. 171. fig. 1662.

Excres. pl. 27j. fig. 1. $a . b$.

Coquille fort jolie, et encore assez rare dans les collectinns; tlle est variable, mais tonjours reconnoissable par la disposition remarquable de ses couleurs, qui consistent en lignes angulenses brunes sur un lond blanc; ces lignes, diversement entre-croisées, font ressembler assez bien les dessius qu'elles forment au plan d'un camp, sur lequel se verroit de profil un grand nombre de tentes de diverses grandeurs. Les lignes brunes sont quelquefois simples, quelquefois fiangées; souvent tuême les triangles qu'elles forment sont remplis de ligues transverses, entre-croisécs par d'autres, longitudinales ou obliques; quelquefois, mais plus rarement, le sommet des angles est llammulé, ce qui donne un aspect parliculier à celte variété, La taille de celte coquille est de 40 à 50 milliàetres. Elle vient de l'Océan indien.

16. Cyтпіве peinte. Cytherea picta. Lamk.

C. testí rotunduto-trigonâ, albâ, maculis Hist. Nat. des Vers. Tome II. lineisque "Ifs: aut spadiceis diversissimes pictâ, intis lutescentc.

LAsk. loc. cit. $n^{\text {n. }} 33$.

Lister, Conch. tab. 259. Jig. 95.

REGENF. Conch. tom. 1. tab. 1. fig. 2. 4 .

Caemsitz, Conch. tom. 6. tab. 35. fig. 573 et 376 à 381 .

Excrcu. pl. 273. fig. 2 et 3. a. b.

On ne sauroit confondre cctte coquille avec la précédeute; elle est toujours plus petite; bien que que sa coloration ait de l'analogie, cependant elle a aussi des dissemblances constantes: sur un fond blanc-rosátre sc dessineat une multitude de lignes souvent anguleuses, qui, par leur entre-croisement, font ressembler toute la coquille à un tissu; en dedans elle est rose ou jaunàtre : elle a une forme ovalaire, cordiforme; les crochets, assez saillans, sont obliques; la lunuie est peu prolonde: toute ceite coquille est lisse et brillante. Elle a 25 à 30 millim. de large. Elle babile l'Océan indien.

17. CттнÉRÉ jouvencelle. Cytherea jứnilis. LAM K.

C. testâ orbiculari, convexâ, albâ, nifo maculatâ; nutibus obliquè prominulis; sulcis trunsversis, concentricis, anterius et posterius lamellatis.

Laux. loc. cit. $n^{\circ} \cdot 36$.

Venus juvenilis, Lis . Grex. pag. 3287. $n^{\circ} .84$.

Chems. Conch.tom. 7. tab. 38. fig. 405.

EncrcL. pl. 280. fig. 2, $a . b$.

Jolie coquille orbiculaire, gonflée, tonte blanche, avec des points bruns ou des taches fauves, irrégulièrewent parsemés; les crocheis sont grands, obliques, cordiformes; la lunule, petite, est en cœur et profonde. Fu dehors on voit sur cette coquille des sillons concentriques, assez gros, moins saillans et plus arrondis dans le milieu de la corjuille, unais lamelleux et se relevant davantage antérieurement et postérieurement; quelquefois, au lieu de se terminer par des lames, ces sillons aboutissent à des rides. On trouve cette coquille dans les mers de l'Inde; elle a 28 millim. de large.

18. Сүтне́ве́ épineuse. Cytherea dione. JАмк.

C. testầ obliquè cordalâ, roseo-purpurascente: sulcis transversis, elevato-lumellosis; mutio vulvâque ad murgines spinosis.

Lamк. loc cit. $n^{\circ} .39$.

Venus dione, Lin. GMex. pag. 3266. no. 1.

Lister, Conch. tub. 307. fig. 140.

Guslt. Test. tab. 76. fg. D. 
Dargexifile, Conch. pl. 21 . fig. 1.

Livorn. Vergn. I. tab. 4. fig. 3. 4.

Снемx. Conch. tont. 6. tab. 27. fig. $27 t$ ¿े $27 \bar{\jmath}$.

Excres. $p l .275$. fig. 1. $a . b$.

Coquille bien connue des amateurs, qui la nomment Conque épineuse ou Conque de Vénus; ils la recherchent par la singulière disposilion les couleur's et des épines sur le côlé postérieur; clle est non moins remarquable par la finesse et l'élégance des lames nombreuses et transverses qui la cnurrent: la lunule, qui est enfoncée sous les crochets, est rouge. Ou trouve cetle espèce anx Antil!es et dans presque lout l'Océan auséricain.

19. CxтнÉné exolète. Cytherea exoleta. I.A us.

C. testâ orbiculari, subaquilaterâ, albidi, aut rufescente; maculis, lineis rudiisve rifis picti; striis concentricis, suthdetritis; lurula corditâ, impressi, lamellosí.

f'enus exoleta, Lix. G GrL.pag. 3284. $n^{0} \cdot 7^{5}$.

LAM x. loc. cit. $n^{\circ} .48$.

Lister, Conch. tab. 291. fig. 127 . et tab. 292. fis. $1: 8$.

Gualt. Test. tab. 75. fig. F.

lionx. Mus. cers. vind. taì. 5. fig. 9 .

Cuess. Conch. ton. 7. tab. 38.fg. 402.404.

M.ıто., Acl. soc. linn. ton. 8. tab. 5. fig. 1.

Ion, Test. utrusque Sic. tab. 21. fig. 9. I0. 11.

Lc Cotun, Adassoy, Señóg. pl. 16. fig. 4.

Evercl. $p l$. 279. fig. 5. et pl. 280. fig. I. a. $b$.

la forme de cette coquille est lenticulaire, bien arrondie, également convexe de chaque côtés; les crochets, pelits et peu saillans, dépassent de fort peu le bord postérieur; la lunnle est médiocre, enfoncée extérieurement. 'Toute cette coquille est ccuverte de stries régulières, concentriques, très-fines sur les crochets, un peu plus grosses vers les bords; les couleurs sont assez variables : sur un fond blanc-jauuâtre on voit deux ou trois rayons de couleur brun canolle; dans quelques individus, cette dernière couleur dounine et elle est coupée par des rayons blancs; des lacbes irrégulièrcs, linéaires, Lrunes, sont jetées à travers ces rayons sur queleques individus. Cette coguillese trouve sur nos côtes, au Sénégal, Cians la Méditerrauée rt dans l'Océan alantique. 42 millim. de diamécie.

20. Ciтиíré lustrée. Cytherea lincta. Lanx.

C. testi suborbiculari, obliqui, inequilateri, albida, innuaculatí; stris cuncentricis, confirtis, tenuisimis, levibus.
Lisx. loc. cit. no. 49 .

Lister, Conch. 'tab. 29o. fig. 126 .

M.atox, Act. sac. linn. tom. 8. tab. 5. fg. 2.

Fossilis, Bast. Bass. tert. du sud-ouest de la lirauce, Ménr. de la soc. d'hist. nat. tom. 2. p)sg. 10. pl. 6. fig. 9o. $n^{\circ} .3$.

Coquille toute blanche, suborbiculaire, un pcu plus longue que laruge, inéquilatérale, à crochets pelits et obliques; elle est peu épaisse et toute converte de stries liès-fines, concentriques, extrêmenent régulièrcs. La lunule est cordifurme, profunde et presque lisse; le corselet est assez saillan! en delıors des nymplies pour que le ligatuent soit entièreunent caché. Les bords sont simples et la charniùre, assez étroite, est coudée dans son milieu. Non-seuleuneat cette espèce se Houre sur les cótes d'Angleterre, mais encore dans la Méditerrance, en Sicile, etc. Son analogrue fossile, parfaitement identique, n'est pas raie aux envirnos de Bordeaux, de Dax; on le rencontre également eu Italie et daus les faluns de la Touluive, mais il est très-rare daus celie dernièze localité.

21. Ciтtнike concentrigne. Cytherea concentrica. LAMK.

C. test $\hat{\jmath}$ orticulari, convexo-depressâ, subcequilaterî, alló; striis concentricis, confertis; ano condato, impresso, lavi.

Lımx. loc. cit. $n^{\circ}$. 5o.

Venus concentrica, Irss. GMeL. pag. 3286.

Lister, Conch. tab. 26 t. Jig. 97. el tab. 288. fig. 124 .

Bors. Mus. cass. 2ind. tab. 5. fig. 5.

Le Dosin, Adansox, Toy. au Sénég. tah. i6. fig. 5.

Caexs. Conch.tom. 7. tab. 38. fig. 5g2.

ExcrcL. pl. 279. fig. 2. a. b.

Belle coguille, fort analogue pour la forme à celles qui précèdent; elle est tout-à-fait orbiculaire, lentiforme, déprimée, sulıéquilatérale, toute blanche, légèrement jaunâtre ver's les bords; elle est ornée de stries concentriques, zrrondies, fines sur les crocbets, plus grosses vers les bords, d'une régularité remarqualile. Les crochets sont peu saillans; ils s'inclinent sur une lunule enfoncte, oviale, cordiforme et route lisse. Elle est également blanche en dedans, et l'impression palléale, très-profonde, cst anguleuse. Elle habite l’Ocćan américain et indieu, la Méditerranée? Elle est large de 73 a 80 milliun. M. La marck indique une variété de la Nouvelle-IJollande; nous ae la conuoissons pas.

22. Cттне́в́s plate. Cytherea scripia.

c. tcst- lentifomi, complunatí, apice nn 


\section{Y T}

sulo reclo teminatá, transucrsim striatis, varie pictâ, seu lithumata ; nalubus compressis; ligamento extús conspicuo.

L.A $\mathrm{xK}$. loc. cit. $7^{\circ}, 57$.

Venus scripıa, Lıx. Grex. pag. $3286 . n^{\circ} \cdot 79$.

- Rомр日. Mus. tab. 42. fig. C.

Gusct. Test. tab. 77. fig. C.

DARGENV. tab. 21. fig. M.

Ksorr. Vergn. 5. tab. 15. fig. 5.

Cuear. Conch. tom. 7. tab. $40 \cdot \mathrm{fg} \cdot 420$ iो 426 .

Exeres. pl. 274 . fg. I.

Coquille très-facile à distinguer de toutes ses congénères; elle est lenticulaire, aplatic, striée transversalemeat, subéquilatérale; ses crochels, aplatis ct poinlus, font le sommet d'un angle droit, dont les lignes sont formées par les cótés antérieur et postérieur de la coquille; la lunule est euloncée, ovalaire, lancéolée; le corselet est fort alongé, profond, et le ligament, placé à sa partie supérieure, se voit à découvert dans toule son éteodue. La Cylbérée plate est variable daas ses couleurs; lantôt elle est d'un brun clair avee des lignes anguleuses d'un brun-noirâlre; tantôt elle est blanche avéc des lignes brisées d'un rouge brun on des taches éparses de la zême couleur; quelcruefois elle a deux ou Irois zones brunes sur un fond blane. On trouve celle espèce à l'ille d'Amboine et dans tout l'Océan indien; elle a 40 à 50 millim de large.

\section{LAบR.}

25. Cттив́né pectinée. Cytherea pectinata.

C. testâ ovatâ, albo spadiceoque variegatâ, sulcis granulosis, nedianis, longitudinalibus ; luterulibus, obliquatis, curvis, biffis ; lunulá ovutì.

I.s s x. lac. cit. $n^{\circ} \cdot 65$.

Venus pectinata, Liv. G srex. pag. $5285 . n^{\circ} 78$.

Iister, Conch. tab. 312. fg. 148.

Gosct. Test. tab. 72. fig. E. F. et tab. 75. fig. A.

Dargenv. Conch. tab. 21. fig. P.

Carmv: Conch. tom. 7.tab. 3g. fig. 418.419?

Escrer.pl. 271. fig. 1.a.b.

Celle espèce se trouve communément répandae dans les collections; elle se distingue très-facilemeat par sa forme ovale, subtransverse, et par les cótes granuleases qui la convrent. Les cóles moyennes sont longiludinales et rayonnantes; celles qui sont sur les còtés sont divergentes aux premières et bifurquées; la lunule est ovale, enfoncée; les crochets, ainsi que toute la coquille, sont peu goullés; ses couleurs sont assez constammeot des taches brines sur un fond blanc; les bords des valves sont crénelés, mais pen profundément. L'Ocćan indien est la patrie de cetle espéce, qui a $40^{\circ}$ millim. de lalge.

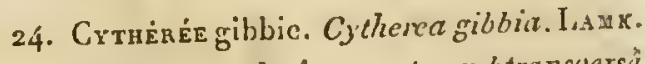

C. testâ subcordatâ, ovato-subtranswersâ, atale gibbosissimâ, albâ, rark naculatî; sulcis longitudinalibus, crassis, crenatis, antico latere oblique divaricatis.

l.isтен, Conch.tab.313. fig. 149.

Ḱnona. Vergn. 6. tab. 3. fig. 3.

Cnemnitz, Conch.tam. 7. tab. 39.515 .415$. 416.

Excrcuor. $p l .271 \cdot f g \cdot 4 \cdot a \cdot b$.

Espèce parfaitement distinetc de la précédente, avee laquelle on serait tenté de la confondre comme variété; elle se reconnoît à sa taille, spiri est pliss considérable; à l'épaisseur de son test, qui est fort solide; à sa forme, qui est plus transverse et plus ovale; enfin, à la disposition de ses sillons, qui sont plus gros, plus élerés et it crénelures moins nombreuses et plus grosses; cep sillons, longitudinaux su toute la partie antérieure et moyenne de la coquille, restent simples ct ne deviennent obliques et dirergens que sur lo côté postérieur. Cetle coquille se distingue encore par son renflement, rui est tel, lorsqu'elle est vieille, qu'elle devient presque cylindracke Les plus grands individus ont jusqu'à 54 millim. de diamètre. Elle habite, a ce que l’on présume, la mer des Indes.

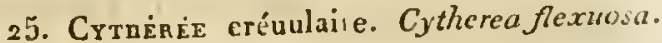
LAMX.

C. testâ condato-trigonâ, latere antico productiore; rugis transversis subcrenatis ; pube luriluque impressis, litturatis.

LA $\mathrm{s}$. loc, cit. $n^{\circ} \cdot 7^{\mathbf{3}}$.

Venusflexuosa, I.1м. Guะx. pag. 3270. $n^{n}$. 12 .

Rомге. Mils. tub. 44. fig. M.

Gusct. Test. tab. 83. fig. I.

Bors. Mus. cas, vind.tab. 4. fig: 10.

Caemisz, Concle. tont. 6. lab. 31. fig. 5.7i). 334.

Exстсцор.pl. 266. fig. 6. a.*b. et 7 .

Très-variable dans ses couleur's, cetle coquille se reconnoît par ses stries iransverses, sublamelleuses et crénelées, qui se partagen! en deux vers le corselet. Celui-ci est séparé du reste par unc: arête assez aiguë; elle est retuse, lousse et strićc obliquement; la lunule est profonde, ovalaire et peinte de lignes brunes. La forme de cette coquille est snutrigone, curdiforme, inéquilatéralc, assez épaisse; quant ìla couleur, elle $t$ ' it blanche, ponctuée de brun, ou bien elle ust rayonnće, ou bien rlle est de couleur cendréu, H * 2 
avec des taches ou des stries d'un fauve obscur; quelquefois, enfin, elle est tonte blanche, n'ayant que la lanule et le corselet bruns ou noirs, avec les bords interne et cardinal bleus. Elle se trouve dans la mer des Indes. Elle a 35 millim. de large.

26. Cyтuénés lisse. Cytherea lavigata. Lamk.

C. testâ ovato-oblongâ, transversâ, incequilaterâ, laevigatâ, nitidâ; lunulì lanceolatâ; dente eardinali postico bifido.

LAMK. Ann. du Mus. toms. 7. pag. 134. et tom. 12. pl. 40. fig. 5. a. b.

Ibid. Anim. s. vert. tom. 5. pag. 582. $n^{\circ}$; 8 .

DEFr. Dict. des Scienc, nat. tom. 12.

Noв. Descript. des coq. foss. des env. de Paris, tom. 1. pag. 128. n०. 1. pl. 20. fg. 12. 15.

Cette coquille, l'une des plus communes des environs de Paris, se trouve dans toutes les formations marines; elle abonde principalement dans les calcaires grossier's et les grès marins supérieurs. Elle se rapproche, pour la forme et la grandeur, de la Venus textile Lank. ; mais ces denx coquilies sont de genres différens. La Cythérée lisse est assez grande, ovale, oblongue, transverse, inéquilatérale, à crocbets petiis et peu suillans. Les dents cardinales sont au nombre de trois, les deux antéricures sont rapprochées, lamelleuses etsimples; la postérieure est plus forte, alongée sur le bord et profondément bifide. La lunule est petite, superficielle, ovale, lancéolée. Cette coquille est large de 48 millian. A Senlis, où elle se trouve assez souvent complète, le ligament est parfaitement conservé.

27. CYтнÉRÉE subérycinoïde. Cytherea suberycinoides. Nов.

C. Lestâ ovato-transversâ, subdepressâ, regulariter sulcatâ; sulcis rotundatis, numerosis ; lunulâ minimâ, lavigatâ; candine tridentato; dentibus divaricatis; dente postico bifido, laterali minimo.

Noв. Descript. des coq. foss. loc. cit. $n^{\circ} .2$. pl. 22. fig. 8. 9 .

Une coquille qui a beaucoup d'analogie avec la Cythérée érycinoz̈de Lamk., qui est si abondamment répandue aux euvirous de Bordeaux, et dont l'analogue vivant existe sous le nom de Cythérée cedo-nulli, se trouve très-rarement aux environs de Paris; nous l'aurions indiguée en décrivant cette dernière espèce, si nous ne lui avions constamment trouvé des différences qui nous semblent sulfisantes pour qu'elle reste distincte. Elle est constamment beaucoup plus petite, plus transverse; son côté postérieur plus arrondi, et l'antérieur moins large; la lunule est plus lancéolée; sa surf́ace extérieure, couverte de sillnns arrondis, en présente un bien plus grand nombrc à égal volume : l'Erycinoïde treute-six à quarante, la nôtre environ saixaule; enfin, la lame cardinale est plus large, non sinueuse dans son bord; elle porte trois dents divergentes, dont la postérienre, bitide, est la plus large et la plus grande; l'antérieure el la moyenne sont plus sé-. parées, nous parallèles comne dans l'Erycinoïde, et la dent latérale moins graude et aussi plus séparée. Celte espèce s'est trouvée à Mouchy-leChâtel et à Acy-en-Multieu. Flle a 48 millim. de large; nous ne l'avons jamais vue plus grande.

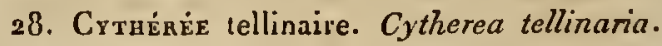
LAMK.

C. testâ ovato-subtranswersâ, trigonâ, la̛vigatâ substriatâve, posteriùs sinuata; lunula magnâ, ovato-oblongâ; dentibus cardinalibus tribus, anterioribus approximatis.

Lamk. Aun. du Mus. tom.7.pag. 135. $n^{\circ} .6$. et tom. 12. pl. 40 . fig. 4 .

Ibid. Anim. s. vert.loc. cit. $n^{\circ} \cdot 9$.

Ibid. Nов. Descript. loc. cit. $n^{\circ} \cdot 4 \cdot p l .22$. fig. 4. 5.

Var B. Noв. T'estâ posteriùs profundione sinuatâ.

Cette espèce fossile est une de celles qui se reconnoissent le plus facilement. Le pli siuneux, semblable à celui des Tellines, qui se remarqne vers l'augle postérienr, est un moyen infaillible de la distingner, puisqu'elle est la seule du genre qui présente ce singulier accident. Ia Cytbérée tellinaire est de taille moyenne, inéquilatérale, ovale, subtrigone, lisse ou irrégulièrement substriée. Elle est encore caractérisée par une grande luaule ovale, par des crochets peu saillans, et par la charnière, dout les dents antérieure et moycnue sont presque parallèles et très-rapprochées sur la valve droite. La variété ne diffère que pardes stries un peu plus régulières et par son pli postérieur, qui est heaucoup plus profond. Cette coquille, large de 25 millim., se trouve à Griguon, Parnes, Moucby, Courtaguon, Valmondois aux environs de Paris.

LamK.

29. Crthérée Clégante. Cytherea eleguns.

C. testâ ovato-orbiculutá, subtrigonâ, depressâ, inaquilaterâ, transversìm regulariter sulcatấ, lunulâ minimâ, ovatâ.

Lamx. Ann us.loc. cit. no.7. et tom. 12. pl. 40. fg. 8.. $d_{u} M$

Venus elegans, Sow. Miner. conch. tab. 422 . fig. 3.

La Cythérée élégante esı toujoars petite, ovale, subtransverse, inéquilatérale, à crochets petits, à peine saillaus, peu courbés; elle est couverte en dehors de stries assez distantes, rfogulières, 


\section{C $\mathrm{Y} \mathrm{T}$}

arrondies, et diminuant insensiblement des bords vers les crochets; la lunule est ovale; la charnicre, sur une lane cardinalc courte et droite, présente sur la valve druile trois dents cardinales; l'untérieure est fort petite, rapproclíe de la uroyenne, qui lui est presque parallèle ; la postérienre est bilide; la valve gauche nollire que leux dents cardinales, la postérieure se conlonraut avec la nympbe; la dent latérale est trèsr isine des cardinales. Coquille qui a 15 millim. de large, et qui est fort abondamment répanduc dans les terrains marins des environs de Paris.

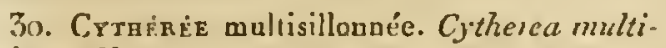
sulcuta. Nób.

C. testî ovato-rotundati, inaquiluteri , obli-

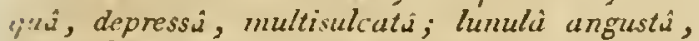
lanceolesi; ano profundo; dentibus cardinalubus tribus, divaricatis.

Аов. Descript. des coq. foss. loc. cit. $n^{\circ} \cdot 9$. pl. 21 . fig. 14.15.

On reconnoit fucilement cette espèce aux caractères suivans: elle est ovale, arlondie, peu transversc, inéquilatéralc, oblique, couverle de stries arrondies, assez régulières el unmbreuses; le crochet est pelit, acuminé, peu saillant; la lunule est étroite, lancéolée, subdéprimée; lı nymphe est assez grande, placée au fond du curselet et très-concave; la lame cardinale esi éltuite, sinueuse sous le crocbel; elle porte daus cet endrait trois dents cardinales diveryentes, et une deutlatérale wédiucre. Cette coquille ne s'cst jusqu’à présent trouvíe qu'à Chaunuat. Elle a 39 willim. de large. Хав.

51. Cутнв́ie sulcataire. Cytherea sulcataria.

C. testâ ovatâ, tumidi, inaquiluterâ, transversim sulcata; umbonibus ninimis, obliquis; luriulà magıâ, ovatâ; cardine tridentato; dente posticali bifido in valud sinistrô, dextri lamelloso.

Noв. Descript. des coq. foss. loc. cit. no. 10. pl. 20. fig. 14. I j.

La forme ovale-globuleuse de cette coquille, scs sillons mains réguliers, son épaisseur, ses crochets petils et obliques, la séparent sufiramment et de liespèce précédente et de toules les autres connues. La lunule est assez grande, non euloucée, indiquée seulement pas une strie; la lane cardinale est assez étroite, sinueuse dans le milieu; les dents cardinales qu'elle supporte sont an nombre de trois sur chaque valve; sur la valve droite, lis dents antérieure et mayenne sant presque parillèles, rapprochées et sublamelleuses; la deat pastérieure est large et bifide; sur la valve gauche, les denis sont beaucoup plus divergneates, el la postérieure est simple èt l.i- melleuse; la nymphe est assez grande et enfoncée sous le bord du corselet. Cetle espèce fossile des environs de Paris étoit cunfondue avec lit Cytherea nitidula Lamk., mais elle s'en distingue. Elle vient de Chaumont et de Purncs. Sia largeur est de 41 millim.

32. Cytaliée luisante. Cytherea nitidu! LAMK.

C. testî̀ ovato-rotundatî̀, tumidà, la'vigiztí, nitidi, obsolete transversim striati; striis ext-

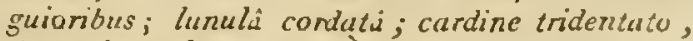
dente laterali nagno, conoideo.

La «k. Ann. du Mus. tam. 7. loc. cil. $\|^{n}, 3$. et tom. $12 . p l$. $40 . f i g .1 .2$.

Nalis, Descript. des coq. foss. loc. cit. $\pi^{\circ}$. 11 . pl. 21. fg. 5. 4. 5. 6.

Var. B. Noв. Testa transuersion, obliquiore.

Var. C. Noв. Testûs depressầ; lunulî̀ profundiore.

Cuquille extrèmement commune dans le bassin de Paris, et notamment dans les lieux où le cal. caire grossier est désagrégé, tels que Grignou, Chaumont, Parnes, Courtagnon, etc.; elle est assez variable dans ses formes pour que l'on soit porté à en faire plusieurs espèces, lorsqu'on ne voit pas une série complète, car tantôt elle est presçu'orbiculaire, tantôt plus transverse ct plus oblique; d'autres fois, se rapprochant de la forme triaugnlaire, elie est aussi plus aplatie; mais tautes ccs variétés se réunisseut par plusiends varactères invariables daus" l'espèce, ce sout les suivans: lunule cordiforme, peu profonde, indiquée par une strie; surface lisse et brillante, légcrement striée; stries superficielles, peu régulières, plus apparentes vers la lunule et le corselet que sur la partie mayenne des valves; crochets abliques, assez saillans, cordiformes; charnière supportée par ure lane cardinale asse étroite, siuneuse; elle présente constanımen t Irois dents cardinales sur chaque valve; la deat posrérieure de la valve droite est bifide et large; tle est simple et beaucoup plus droite sur la valve gauche. La nymphe est grande et cachée en partie sous le bard du corselet. Nous avons dit, clans notre ouvrage sur les fussiles des environs de Paris, que N. Defrance passédoit le subanalogue, et nous l'analogue vivant de cette espèce, sans qu'il $y$ ait entre le nôtre et les fussilles une identité parfaite. Les individus fossiles sont larges de 48 aillim. Nов.

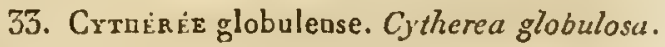

C. testâ ovato globulosî, subtransversâ, levigati; striis transversis, irreguluribus; lunulâ cordatâ; caldine tridentato; dente laterali minimo, conico. 
Nов. Descript. des coq. foss. loc. cit. $n^{0} .15$. pl. 21 . fig. 9. 10. II.

Cette espèce, rare aux environs de Paris, quoique présentant de l'analogie avec la Cythérée luisante, est pourtant facile à distinguer; elle est ovale, subtransverse, subéquilatérale, globuleuse; son test est épais, solide, lisse, luisant en dehors, où se remarquent des stries irrégulières d'accroissement, plus nombreuses rers le corselet; les crochets sont médiocres, recourbés sur une luaule ovale, peu profonde. La lame cardinale, qui est légèrement sinueuse dans son milieu, présente trois dents cardinales divergentes, et une dent latérale conique fort petite. Cette coquille vient de Chaumont; elle a. 26 millim. de large.

34. CrтกÉnÉE polie. Cytherea polita. Lamx.

C. testî́ ovalo-subtrigonâ, transversâ, depressî, politâ, nitidâ; natibus perparvis, acuminatis, recunvis; lunulầ minimu, lunceolutâ; cuntiré tridentato, dente luterali pralongo.

Lamк. Ann. du Mus loc. cit. $n^{\circ} .4$.

Ibid. Ann. s. vert. loc. cit. $n^{\circ} .6$.

C'est surtout à Hoodan qu'il faut rechercher' cette espèce; elle y est assez commune. Elle est facilemeat reconuoissable par sa forme ovale, subtrigone, transverse, équilarérale; par son a platissement et le poli de sa surface; par son crochet petit, pointu et recourbé. Sa lunule est fort étroite, assez longue, lancéolée ; le corselet est étroit et profond; la lame cardinale, épaisse et assez large, présente sur chaque valve trois deuts cardiuales, dont la postérieure est bifide, seulement sor la valve dioite; la dent latérale est peu élevée, mais alongée. Cette espèce se trouve dansle bassin de Paris, à IIoudan, Parne;, Acy, Valmonduis. Elle est large de 26 millim. 


\section{A U}

\section{ACtyle.}

Nom que l'ou donne vulgairement à la Nodiole lithodome. Pline, comne nous l'avons dit ì l'arlicle Bénanite, a nommé ces corps Dactili, les comparant, soit à la forme d'un doigt, soit à celle d'une dalte.

\section{1)ACTILUS.}

Klein a proposé sous ce nom (Method. ostrac. rog. 77) un genre renfermant loutes les cocguilles 'ylindracées et obtuses, par conséquent, des Ulives, des Mlitres, des Volutes, elc.

\section{DAIL.}

Les habitans de nos côtes nomment aiosi les I'holades et quelqueliois aussi les Modioles lithophages. F'oyez l'Horade et Modione.

\section{DAKI.}

l'etite coquille qu'Adanson ( Voy, an Sénég. pl. 12.fig. 3.) place dans son genre 'loupie, et qui appartient sans aucun douie au genre Littorine de M. de Ferussac. Iojez Litтoms.

\section{DALAT.}

Adauson (Voy. au Sćnćgal, pl. 12) nomme aiusi une variété du Trochusmagus. Voy. Tropue.

\section{DAMIER. DAMIER DE LA CHINE.}

Nom spécilique, devenu valyaire, d'une belle espèce de Cónes et de sa variété, Conus marmoieus, Brog.

\section{DAPIINÉE. DAPHNÉODIRME.}

Noms comployés par Poli ( Tesí. des Deux-siciles), le prenier pour l'animal, le second pour la coquille du geare Arche. Vojez ce mot.

\section{DASAN.}

La coquille à laqueile Adanson a donné ce nom (Voy. uu Sénég. pl. 2) est la Fissurelle en bareau, Fissulullic numbosa, Lasax. Voyez FissuBELLL.

\section{DATIN.}

Le Datin est une coquille fort curieuse, que l'un prendroil pour une Serpule, mais qui apparticot aux Mollusques par son auimal. Adunsun (Voy. au Senég. pl. 11 ), qui l'a fait connoître. l'a placé dans sun genre Vermet; ce utue nous fercas śralcment. V’ojez VER世?

\section{DATTES.}

Ce nom vulgaire s'applique indistinctement i un assez grand nombre de coquilles, soit univalves, soit bivalves; il sulli qu'elles aient dans leur forme quelque ressemblance avec le fruit du daltier, pour qu'on le leur clonne; c'ust ainsi q̧ue des Olives, des Moules, des Modivles, des Cardites, des Mitres, des Cypricardes, sont nommćes parle volgaire. On donue plus parliculièrement le nom de Datte à une belle especce de Cypricarde. Vojez ce mot.

\section{DAUPHIN.}

Les marchands donnent ce nom aux coquilles du genre Dauphinule. Voyez ce mot.

\section{DAUPHINULE. Delphinula.}

N. Lamarck, dans le Syst. des anim. sans vert., assimila aux Cyclostomes terrestres no certaiu nombre de coquilles marines que Linné a voit rangrées parmi les 'Turbots. Plus tard, dans les Mémoires sur les fossiles des environs de Paris, insérés dans les Annales du Muséum (tom. 4, pag 109), il propusa de démembrer son genre Cy.lostome, cl d'en séparer lontes les coquilles ularines épaisses \& nacrées qu'il y aroit d'abord confondues; ce fut sous le nom de Dauphinule, Delphinula, qu'il proposa le nouveau genre. Rien certainement n'ćtoit plus décessaire que sa séparation; il étoit impossible, avec la connoissance des modilications éprouvées par les animaux dans lenr organisaliou, d'après les milienx labilables, de penser que les uns \& les autres eussent la même organisation; les uns devaient rester parmi les Pulmonés puisqu'ils respirent l'air, les autres parmi les Pectinib anches puisçu'ils respirent l'eau. Depuis l'élablissement do genre Dauphinule, le plus grand nombie des conchyliologues l'aut aduplé, suil comare gente, soit comme sousgenre. C'est à tort que Mun!furt, Conchyl. syst. tom. 2, pag. 126, a séparé des Dauphiuules le Lippiste qui en a tous les caractères. MI. Lamarck a iudigué, comme a plparlenant à ce genre, upe coquilie des pilus ratres conuue dans le cummerce suus le noin de Bortstripe; celte espèce, que nous avons vue plusieurs lins, appartient sans aucun duulc an genre Cancellaire, \& quoique sa forme parvisue ıuusilée aus ce gente, on y est cependant conduit inseusiblement par des passages d'espèces fusiles yui s'en rapprochent de plus en plus. Vojez Cancellame.

\section{CAHACT⿱宀RIS GÉNÉRIQUIS.}

C qu.lle sub scride ou conique, ombiliquée, 
solide, à tours de sprire rudes on anguleux; onrerture entiere, roude, quelquelois trigone, à hords continus, le plus souvent fiaogés ou munis d'un bourrelet; ouverture fermée par un opercule.

I.es Dauphinules sont généralement herissées ou armées de longues épines; leur ormbilic est larges, et comme elles ont le péristoune coatinu (1) souvent entièrement libre, séparé du reste de li coquille, la columelle n'existe pas. On ne counoît quiuu petit nombre d'espèce de Dauphinules vivantes ou fossiles; quelques-unes som Iİ̀s-rares \& très-recherchées.

1. Dauphnute laciniée. Delphinulu laciniata. I.AM

D. testâ subdiscoideâ, crassâ, transversim sulcato-asperatä, appendicibus maximis, curis, laciniato-ramosis armatâ, rubro et fusco variâ; spiri retufâ.

L.1Na. Anim. sans vert. tom. 6. 2e, part. pag. $230 . n^{\circ} .1$.

Turbo delphinus, LrN. Gare. pag. $35 ّ g 9$. $n^{\circ} \cdot 44$.

Ruयрн. Mus. tab. 20. fig. H.

Gualt. Test. tab. 68. fig. C. D.

Dargext. Conch. pl. 6. fig. H.

Favanne, Conch. pl. g. fig. G $1 . \mathrm{G} 2$.

K vовп. Vergn. 1. tab. 22. fig. 4. 5. et 4. tab.7. fig. 23. tab. 8. fig. I.

Lister, Conch. tab. 608. fig. 45.

Carmatz, Conch. tom. 5. tab. 175. fig. 1727 ¿ 1735 .

ExcycL. $p l .451 . f g$. I. $a, b$

Cetle coquille est subdiscoide, épaisse; toute la surface est chargée de sillons écailleux ou gravoleux, dont quelques-uns plus gros portent des appendices laciniés, plus ou moins longs; elle est du reste élégamment colorée de rouge et de fanve. Elle vient de la mer des Indes, et a jusqu'a 25 lignes de diamètre.

\section{Dauphinule distorte. Delphinula distorta.} L.A $\mathrm{N}$.

D. testâ subdiscoideâ, crassâ, nubro-purpureâ; sulcis tıansversis, tuberculato-muricatis ; anfractibus supemè angulato-planulatis et longitudinaliter plicatis; ultimo disjuncto, separato.

LAMк. loc. cit. $n^{\circ} \cdot 2$.

Turbo distortus, Liss. pag. 3600. $n^{n} .46$.

Carma. Conch. tom. 5. tab. 175. fig. 1737 à 1739 .

Celle-ci, comme la précédente, est subdiscoïde et épaisse, wais elle cst colorée en rouge pourpre; ses tours de spire supérienrement sont anguleux et plissés longitudinalement; elle est silfonnée et les silloas sont tuberculeux; le dernier tour est constamment séparé des autres, comme dans quelques Scalaires. Elle est d'ailleurs dépourvue des appendices laciniés qui se voient dans l'espèe précédente.

3. Da

D. testâ orbiculato-convexâ, scabrâ, transversim striatî; striis squamulis, concavis, echinatis ; anfractibus Jubangulatis, teretibus; unztilico profundo, valde echinato.

LaMk. Anim. s. vert. tom. 6. 2e, part. pag. 251. $n^{\circ}$. 2. el Ann. du Mus. vol. 4. pag $110, n^{\circ} .2$.

BaANd. Foss. hant. tab. I. fig. 7. 8.

Celtc coquille est orluiculaire, convexe, épaissc, ayaut conservé sa nacre, quoìu'à l'état fossile; elle est sillonnée Irausversulement, et les sillons portent de petites écailles concaves; les tours de spire sont subanguleux, le sillon de l'angle étaut plus gros et chargé d'écailles plus grandes. M. Lar marck indique Courtagnon coume la lacalité oì l'on a trouvé celte coquille; nous l'avons eve d'une localité plus rapprochée, des envirous de Sealis, dans les grès marins supérieurs.

4. Da uphinofe à bourrelet. Delphinula marginata.

D. testâ orbiculato-convexâ; anfractibus lce vibus ; umbilici margine sncrassuto, subplicato.

LAuk. loc. cit. pag, 232. $n^{\circ}$. 4. et Ann, du Ius. tom. 4. pag. $111, n^{\circ}, 5$.

Coquille orbiculaire, convexe, à tours de spire lisses, ce qui ne se voit pas ordinairement dans ce geure; l'ombilic est marqué par un petit bourrelet granuleux. On trouve souvent cette coguille avec des restes de sa coloration; des taches faoves entourent la spire; elles varient daus leur disposition. Quelquetois on observe l'opercule, encore en place, fermant l'ouverture. Cette peti!c coquille, de trois lignes \& demie de diamètre, se trouve souvent à Grignon, à Parnes et duns presque toutes les localités à calcaire grossier.

\section{DE்CACÈRES. Decacera.}

M. de Blainville a nommé de cette manière, dans son Traité de Malacologie, une famille qui correspond à celle des Décapodes des auteurs. Foyez ce mot et CépHalopode.

\section{DÉCAPODES.}

Depnis Linné, qui avoit réuni tous les Céphalopodes aux seuls genres Poulpe et Natile, on en avoit successivernent démernloré un assez grand nombre de genres qui linirent par être réunis en 
DE N

deux familles; mais pen de temps s'écoula sans qu'elles fussent égalemert divisées en d'antres groupes, ct d'abord celle des Nautiles éprouva dans les maius de M. Launarck les plus yrands changenuens; la famille des Céplalopodes nus n’a élé divisée en deux que dans ces derniers remps, d'une nanière bien convenable et sur de lons caractires, pris dans le nonbre des bras, qui sont constans dans plusicurs geares; ces bras sont au nomlire de buit, ce sont les Octopodes (Octocéres, Brasnv.); dans dautres ils sont au nombre de dix, et constituen! la fanille des Décapodes (Décacères, Braisv.). Voulant traiter les Céphalopodes daos tout leur ensemble, c'est à ce mot que nous renvoyons pour les détails.

\section{1)ÉGON.}

Nom donné par Adanson (Voy. au Séneg. pl. 10) ì noe pelile espèce de Cérite qui paroit n'être qưune variété du Cérite ponctué de Bruguière. Voyez Cértte dans le ter volume de ce Diclionnaire, pag. 498.

\section{DENTALE. Dentalium.}

La forme alongée, tubuleuse, plus on moins courbée, pea symétrique en apparence, qu'offrent les Dentales, devoit présenter a l'esprit des observateurs des dounées incertaines, des ninyeus insuffisans pour les placer dans la série des êtres; aussi voyons-nous deux opinions qui ont peu varié parmi les auteurs qui se sont occupés de celle partie des sciences naturelles qui traite des Mollusques ou des aniunaux qui les avoisinent, soit pour les raltacher à ua syltème général, soit pour en faire le sujet d'études particulières.

La première et la plus ancienue de ces opinions eft celle de Rondelet. Il considéra les Dentales comme des Vermisseaux marins, et les confundit avec eux, en les indiquant cepeudant d'une manière particulière. Là seconde, moins ancieune, efl plutô indiquée qu'établie par Lister, qui unit les Dentales à la fin des Patelles.

Langius, daus sa Méthode, suivit à peu près la wême varche que Lister; seulement après les Patelles il fit une section séparée, dans laquelle, avec les Dentales, il ajouta tons les 'Tubes calcaires des Annélides connues alors.

Breyue qui, comme on sait, divisa le premier les coquilles en deux yrands ordres, les Mono thalames et les Polyulialames, conımença les preraiers par son genre Tubutus, qui contient les Dentales, les Entales et Solenes univalvi auctorıbus dicti. Ce genıre, ou plùâı celte section, se truuve séparé des Patelles par toutes les autres coquilles univalves comprises dans les Cochlidium, ainsi que par la série des Polythalames.

Luin de se trouver en rapport, ils sont donc éloigués de tout l'intervalle des Mollusques, Breyne ayant probablement considéré les Patelles comaue un passage des univalves anx bivalves, puisqu'il les met iuı́diatement avant elles.

'louluefort adopta à peu près l'idíe de Breyne, avcc ce scul changement, de mettre en tête des coquilles, les Patelles ou Lepas, et à la fin, avant les bivalves, les Dentales, les Eutales et les autres Tubes marins.

Le premier et le seul auteur qui jusqu'à ce jour ait donné quelques notions sur l'animal des Dentales, est Daryeuville dans sa Zoomorphose. Ces notions, trop incomplètes pour décider en rieo la question de la place de ces animaux, éloieut le résultat d'une note et d'uu dessin qui lui avoit élé envoyés de l'Inde. Quoique cet auteur ait dûu être plos instruit sur ces animaux que ceux qui l'avoient précédé, cela ue l'enpếcha pas de réunir les Dentales aux autres corps, dont l'assemblage bizarie el monstreux forme la troisième divisiun de son système, sous la dénomination de Mulivalves.

Enfin Linné, cetillust re réformateur des sciences nalurelles, qui en jalonna toutes les roules et qui en rendit lous les accès faciles, génie immortel qui embrassoit aussi bieu les rapports géuéraux que ceux des détails, qui s'est montré supérieur. à son siècle en devançuant par ce lact particulier des rapports des êtres les temps d'un savoir plus approfondi, Linué moura la place que devoient occuper les Dentales en les rangeant près des Patelles.

Bruguière, l'imitateur de Linoé, et ģui commença à apporter quelø̧ues changemens dans son système, couserva avec juste raison les rapporis indiequés par le savant auteur du Systema natura; il faut dire gne Bruguière, aussi bien que Linné, eu tort de mellue à côté des Dentales les Serpules, les 'Tarets, les Sabelles et surtout les Arrosoirs, qui s'éloiguen beaucoup des uns et des autres.

Après les travaux de Bruguière viotent ceux d'un savant que son grénie a placé à côté de Linné, et lui a juftement acquis le titre de Linné Francais. Lamarck va marquer l'iulluence de ses opiniuns sur celles de ses contemporains, el alors elles seront presque les seules reçues. Dès $180 \mathrm{or}$, dans son Systènie des Animaux sans vertèbres, séparant dans une classe diflérente les Vers d'avec les MIollusgues, et mellant en rapport les Dentales avec les T'rébelles et autres geores analogues en apparence, il les eniraina dans cette nouvelle coupe, rien que d'après des rapports extérieurs.

Plus tard, dans sa Philosophie zoologique, il sépara la classe des Vers du système en deux autres clisses, et fornıa les Anuélides avec la section des Vers exlérieurs; il bleva celle nouvelle division assez liaut dans la série des invertébrés, la présence d'un cour et d'une circulation la rupprochant des Mollusques, tandis que les Vers, bien inféricurs en organisation, restèrent entre 


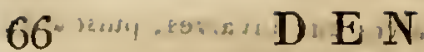

les Radiaires mous et les Insectes. C'est dans celte nouvelle classe que nous trouvons les Dentales dans une mêne serition que les Serpules, les Spirorbes et les Siliquaires. Cel aprangementresı le méme dзas l'Extrait du Cours publié en 1811 ; mais daus le grand ouvrage des Animaux sans vertebres, MI. Lamarck profita des ilavaux de M. Savigny. D’après. la cousidération ré l'empalement en forme d'entonnoir qui termine l'animal des Dentales, d'après ce qu'eu avọit dit Dargenville, ét trompé aussi par les communinations que lui fit M. Fleuriau. de. Belleyue, il considéra les Deutales comme fort vuisizes des Clymènes, et les plaça dans la famille des Maldauies de M. Savigny.

Les auteurs syfémaliques qui ne connureat, comme M. I,amarck, que le tube des Dentales, suivirent son opinion; celle de M. Cuvier y eft conforme, puisqu'il les range dans les Annélides tubicoles, avec les 'Térébelles, Serpules, etc.

M. Savigny cependant, dans son Systeme des Innélides; donna une description sommaire de l'animal des Dentales, descriptiou Irop inconplèie pour décider la question, cependant sulfisante pour détrosire ce çu'en avoil dit M. lileuriau de Bellevue.

Lé Dentalium entalis, qui fut envoyé par Léach à ce savant ohservateur, lui suffit pour dire qu'il n'avoil aucune trace d'anneaux, quil n'avoit point dc soies sur les parties latérales du. corps, qu'il étoil esseutiellement musculeux, et qu'il ne pouvoil rester parmi les Chélopodes. On verra bientût combicn 1]. Savigny avoil raison, et nous devins regretter que cet babile naturaliste ne suit pas éniré alors dans plus de délails.

Tel étoit à peu près l'état des connóissances sur les Dentales, lorsqu'en 1825 acus publiâmes, dans les Mémaires de la Société d'histoire nuturelle de P'aris, l'anatomie el la monographie de ce genre. On a dú remarquer, par ce qui précíde, que lion. n'avoit sur l'urganisation des Dentales que des notions fort incomplètes, avec lesquelles il étoit impossible de rica décider sur la place définitive de ce genre; nous avons cherché à remplir celle lacune, el uous avous dû, par suite de nolre 1 ravail, adopter celle des deux opinions que nous avons mentionnées çui rapproclie les Dentales des Mollusques: opiuion qui na été admise que par le plus pelit nombre des auleurs.

M.,de Blainville, anquel nons communiquâmés notre travail, dans, le temps de la publication de son Traité de Malacologie, pdopta notre manière de vair sur les Dentales, et en fit dans les Mollusques one famille particulière, commenous le verrons plus tard.

La Dentale qui a été l'objet de nos recherches est de la même espèce que celle qui a été envoyéé à M. Savigny; c'est la Dentale lisse, Déntaliun cntalis, qui se trouve aussi bien sur nos cótes que
D, E, N

súr cellès 'd'Angletérre et dans la Méditerrance. Elle' a une cóquille lonǵne "d'un pouce' et demi éviron, conique, lisse ou seulement marquée par des accroissemens; elle est blanche ou grisâtre, el souvenı teintée de rose pâle au somnet; célui-ci est le pliss souvent aign, toujours percé d'un' lrou fort petit et jamais fendu, mais souvent très-finement strié en long; d'airtres fois'ce sontmèt est ironqué, à sa place il existe une'sarface plane, nne sorie de diaphragme solide percé daris. son milieu; on roit quelquélois anssile trou de cetté surface se prolonger en va petit tobe d'un dímètre beaucoup plus petit qu'elle, et qui remplace en quelque sorte la partie qui manqure. Lonve:ture occupe toute la base; elle est un peu oblique, roude, entière, mince, tranclian!e dàns ses bords: En dedans, la coquille est lisse et brillante, quoiquion ait supposé que l'animal n'adhéroil point a la coquille, qu'il pouvoit la quitter et y rentrer à volonté, supposition qui; n'étant appuyce d'aucun fait positill, et qui auroit été facilement détruite si on s'étoil donné la peing de couper en deux une Dentale d'un assez grand volume, doit être désoimais abaridonnée.

Nous avons fail, pour plusieurs espèces, diffí. rentes coupes, soit dans le sens de la coirbure; soit 'sur la convexité, soil' sur la concavité, et nous avon's trouve une impression musculaire en fer à cheval, embrassaut toút le contour de la cavité, mais plus large autérieurement ou dir cóté de la face abdomiuale que du cóté de la face dorsale, où elle n'est point interrompue; c'est un anneau musciuleux qui a laissé son impression; elle est située vers'l'è trémité postérieure, à peu près au cinquiène de la longueur, à parlir de celle cxtrémilé.

L'avimal contenu dans celte coquille conique et iubuleuse, esıl lui-même d'une forme conique, alougrie; il y est placé de manière à ce que la face ciórsale réponde à la convexilé de la coquille, et sa face "abdominale 'à sa concavilé. Il est lisse', trońqué olliquement antérieurement, présentant au ceutre une légère saillie pyramidale, qui est l'extréraité du piéd; postérieurement, il est'plus aminci, paroît moins musculeux, et le plus souvent est termicé par un empalement en forme d'entonnois : c'est le pavillon, qui, dans certains individus, est formé et bien développé; 'tandis 'que dans d'au'tre's il est mou, afíassé, et si peu apparent, qu'il semble ue pas exister. Lorsquil esi développé, il est séparé du reste du corps par un étranglemenı bien marqué. C'est au-dessus de cèt étranglemént que l'on apercoit un anncau musculaire, plus large du côté de la lace abdominàle que de la dorsale; il sinsère dansla coquille, y atlachè l'animal; et donne lieu à l'impression que nous $y$ avons renarquee.

La face dórsale ṕrésenle, vers le tiers autéricur, une légère élévation qui indique l'endroit où est placée la tête; an-dessous le reste de celle sui- 
face est occopé par deux múscles de cliaque côté; ils sont symétriquemen! placés, aplatis, se dirigeant obliquement des pariies látérales dípied ou bous les reverrons in pei plus'tard, puur gaguer insensiblement la lace dorsalé el parvenir à l'extrémilé pustérieure, oì il's se confondent avec le muscle d'insertion. Les parois abdorainales étant très-minces et transparentés, ces mus. cles, qui y sont compris, se voient paifaitement sans aucune dissection.

La face abdominale nous offre également, vers le tiers antéricur et de chaque côté, deux organes 1-rfaitement semblables, profondénent laciniés; is sont d'nne coulcur' brun foncé : c'est le foie. Au-dessus de cet organe, et à l'aide de la transparence des parvis abdominales, on voit des granulations contenues dans un ovaile irès-grand, gui remplit presqu'a lui seul toute la cavilé de labdomen, aipsi que l'intestin qui déscend en droite ligne vei's le pavillon, où il se termine par uo anus médiau.

Toute la parlie antérieure de l'aninal est énveloppée d'une membrane miuce et fixée à l'origine du pied postérieurement, libre antérieurement, et Epaissie dans cette partie en un bourrelèt percé a son centre : c'est ce que l'on est convenu de nomwer manteru. Ce bourrelel, qui lórue une sorte de collier, est formé par un muscle cunstricteur circulaire, qui, dans son étal dé contraction, fronce la peau, embrasse dans son ouverture l'estrémité du pied, qui lui sert de bourchon, et soppose ainsi à toute espèce de cońmunicailion avec l'extérieur: ielles sont les parties que l'on aperçoit sans le secours de la dissection, lorsque l'on examine l'auimal contracté el conservé dans 1. liquenr.

N'ayant jamais eu l'occasion d'éxaminer l'animal des Dentales pendant sa vie, il nous étuit impossible de le représenter ei de le décrire dans son état, d'expansion ou de dilatation. C'est une lacune que nous aurions laissée à regret daus un travail comme celui-ci. M. d'Orbigny fils, qui, pendant plusieurs années, a consacré ses loisins à Pétude des Móllnsques de nos côtes, qui les a presque tous dessinés sur lc vivant, n’a pas négligé les Dentales; il en a fail deix dessins, qn'il a eu la bonté de nous communiguer pour en prendre copie, et il y a joint, avec une rare complassance, loutes lcs observations qu'il'a eu occasion de faire sur les habitudes de ces aniraaux. Nous as parlerons plus lard. La première de ces ligures représeute l'animal' au moment où i) fail sortir de la coquille son pied, dout il'dilateles lobes. Dans cei étai, cetic partic représente assez bicu upe lleur dont la corolle ondulée et peu élendue porteroit. à son centre un pistil renllé dạs sor milieu, fusiforme et pöinitu a son exırénilé libre; celte ligure dóna l'idée de la belle couleur de l'animal. Celre conlenir au réste, est variable dinș le Dentalium.cnlal $s^{\prime}$, qui a servi aux observalious; de M. d'Orbigny; il est d'un bean rose, quelguelois briqueté, lorsque la coquille elle-móme est.de celle conleus; il.est d'aulan! plus rose que la coquille l'est davantage; mais aussi il palit comule elle, de sorte que lor'squ'elle est blanche, l'animal est blanc ou à peine rosâlre : il servit curicux d'ubserver s'il en est de mêrne pour loutes les autres espèces vivantes, et cela nous scable probable. La seconde tigure représeute l'animal concole vivant, duns son étal de coutraclion; la coçnille a élé cassée intérieurement, pour faire juger de la profondeur à laquelle il alleint lorsqu'il se contracte.

Pour apercevoir les autres parlies de la Denlale'; nous alloos d'abord feudre le mantean, en dirigeanl l'incision sur la ligne médiane el clorsale; nous le délacherons à gauche et à droite de son insertion, ponr le renverser en bas elà droite; alors nous aurons suns les yeux le pied, la tĉte ct les branchies.

Le pied est alongé, subcylindrique, un peu conique, aplali de haut en bas; if est entièrement charnu, placé il la partie inférieute ct anlérjeure de la lête; la face supérieure el la face inlećrieure présentent dans leur milieu une gouttière pen profonde; l'extrémité anlórieure est la plus grosse; sa partie moyenne est occupée par une sorte de mamelon congue, gui a une large base, converte en partic par deux petits lobes latéraux coupés en festons, dont les échaucíu:es correspondent aux goultières que nous venous de mentionner. L'extrémité postérieure paroît se bifirquer, parce qu'elle donue allache aus unscles réiracteurs; c'est sur les parties latérales qu’ils s'y insèrent. La partie moyenue fait une légère saillie; daus le sac abdonitinal elle sert d'appuia l'estumac: et aux autres principaux viscères. Ce pied, qui n'a aucune resseublaucé avec le plan lucumoteur des autres Mollusques, ne pent avoir les mémes usages. Lés Dentalés, vivant enfoncés dans le sáble, la petite extrémité en liaut, comme nous l'appread M: d'Orbigny, leur fúed ne peut leus: servir qu’a anitér le sahle envircinuant, pour metre en monvement les corps ruileur servent de nourriture. Il peul êlre anssi destiné, comme lé jíed des Solens, arec leçicl il a beauconp d'anilogie, a opérér dans des trous crensés par l’animul, des monvemens d'ascension ou de descente. - Lia têté, qui n'est conyosée que d'une bouche, est campanulıforme, aplatie d'avan en arrière; elle est situé supérieureneot ver's l'extrémilé postériéure ilu pied; clle a une face antérieure convexe et lisse, et uue lace postérietre convexe aussí. On voil'ver's les parties latérales et à travers les párois, deux points noirs que l'on pourroit prendie prour des yeix, mais ce sont des, uáchoires: Le bord supéricur; est composé de deux lèvrés protondément décompées, on plutùt pourvues de tentacules labiaux an nomiore de truis pairés pour"chaque lc̀vre; ceux de la lèvre pos. 


\section{$\mathrm{DE} \mathrm{N}$}

térieure sont les plas grands, et surtout la paire moyenne. Ces tentacules sont symétriqnement déconpés, et font ressembler assez lien l'enscmble de la tćte à une corolle. La lèvre antérieure a un espace nu dans le milieu; cet espace indique l'ouverture de la bouche; de cbaque côté, celte lèvre est munie de trois petits tentacules simples. En écartant les lèvres, on voit dans la ciavité huccale deux petits corps splériques qui sont tixés dans les parais; jls sont noirs, carnés, chagrinés à leur surface extérieure, fendus dans leur milieu, ayant assez bien la forme d'une très-petite coquille bivalve: ce sont les máchoires, dont les bords entrouverts et tranchans sont libres dans la ravité buccale et destinés, sans conlredit, $\dot{a}$ coutondre et ì lacérer les matières nutritives.

- Celle bouche se rélrécit en un csophage court et charnn, qui forme une sorte de col, qui aboutit Jientôt à un estomac pyriforme, à parois épaisses, s'appuyant et adbérant fortement à l'extrémilé postéricure du pied, et conteuant dans son intćrieur on appareil dentaire assez compliqué, placé à son ouverture caıdiaque. Les alimens, pour pouvoir parvenir à l'extrémité pylorique de l'estomac, sont olbligés de passer à travers cet appareil, quileur fait subir une seconde mastication.

A la hauteur de l'estomac, et de chaque cólé des parois abdominales, on remarque deux organes biuns , profondément découpés et parfaitemont scmblables : c'est le foie, divisé en deux lobes symétriques, qui versent le produit de leur sécrélion dircclement dans l'estomac, chacun par un vaisseau biliaire qui lui est propre; l'estomac, après avoir reçu les vaisseaux biliaires, se termine inférieurement en on intestin grêle, trausparent, droit, médian, qui se rend sans détour au pavillon, où il se termine par un orifice extérieur. Cette position médiane de l'anus a la partie postérieure de l'animal, est le seul exemple qu'on puisse citer jusqu'i présent dans les Mollusques; celui-ci présente donc plus qu'aucnn d'eux des parties paires el symétriques, même daus les arganes qui le sont ordinairement le moins, ceux de la digestion.

Des organes de la circulaticn, nous avons reconnu le ccur, qui est symétricque, placé audessus de l'estomac dans la ligne moyenne; j] est contenu dans un péricarde pyriforme, subdivisé inféricurement par un rapisé moyen, d'où partent quelques rides transverses régulières. A la pariie antérieure de ce sac, on voit un tronc vasculaire qui se dirige vers le col, en se divisant en deux grosses branches; pour cliacun des paquets branchiaux, ils se subdivisent ensuite en quatre rameaux dans lenrs pédicules. Nous ne connoissons rien du reste de la circulation, mais il est bien probable qu'elle a beaucoup d'analogie arec celle des autres Mollusques.

\section{E N}

Les branchies sont paires, placées sur les parlies latérules et postérieures du col, où elles sont supportécs par un pédicnle divisé, on mieux par une membrane branclifère en forme de jabot; elles sant formées par une mulitude de filameus tentaculaires, très-fins, mous, llexibles, terminés en massue et devant remplir, d'après leur posilion, deux fonctions, celle de retenir les mnlécules alimentaires et de les diriger vers la bouche; la seconde, et la plus importante, de donner an lluide sanguin la dose d'oxygène nécessaire à l'entretien de la vie. Celte seconde fonction est å a $^{\text {a }}$ lant plus celle de ces organes, que le cœur, qui en est tout voisin, y envoie de gros et de nombreux vaisseaux.

L'appareil de la génération nous est fort pen connu; un ovaire, qui remplit presque totalement la cavité abdominale, et qui probablement a son orifice extérieur dans le pavillon, est le seul organe que nous ayons pn reconnoitre. Quant à l'organe mâle, s'il existe, quoique très-important à connoître, si ce n'est dans tous ses détails, au moins dans sa position et ses rapports, il a entièrement échappé à nos moyens de rechercbe. Une observation que nons avons faile, et qui múrile d'être vérifiće sur un grand nombre de ces animaux, c'est que les individus qui sont pleins d'œufs, sont ceux dont le pavillon est bien développé, tandis qu'il semule s'affitisser et même disparoître, à niesure quc le nombre des cufs diminue, ou qu'il n'y en a plus dans l'ovaire; d'après cela, cette partie sembleroit destince à remplir quelque fonction inconnue pendant la génération. La pelitesse de l'espèce que nous avons soumise à nos observations ne nous ayant pas permis de pousser nos recherches sur cetle partie aussi loin que nous l'aurions desiré, nons sommes forcé de laisser une lacune que la connaissance de plus grandes espèces pourra seule fermer. Le système nerveux est encore plus difficile à observer que les organes de la génération; cependant, nous avons bieu reconnu la forme et la position du ganglion cérébral; il est petit, quadrilatère, fort alongé et placé longitudinalemenı sur la partie moyenne de la face postérieure de la téle; de ses angles inférieurs partent deux filets très-petits, qui se contournent sur l'oesophage, où nous n'avons pules suivre, mais qui bien probablement passent au-dessous des bianchies, se dirigent à la partie antérieure du col, pour former l'anneau nerveux qui existe dans tous les Mollusques céphalés. Si les Dentales eussent êt un système nerveux semblable à celui des Annélides, c'esı-à-dire unc moelle longitudinale noueuse, il auroit été facile de l'apercevoir; mais celte moelle n existant pas, elle est certainement remplacée par un systćne ganglinnnaire comıne dans les Mollusques, et la connoissance seule du ganglion cérébral en donne la conviction.

lés animaux lont nous renons de développer 


\section{E N}

les traits principanx d'organisation n'ont point de rapports arcc !es Cliétopodes, n’ajaut jamais le corps annelé, ne présentant ni soies, ni lubercules latéraux; ils a'en conservent que la forme extérieure, et quoique les branchies semblent avoir de l'analogie avec celle des Amphitrites, lour forme et leur position les en disingue facilement.

I.es Dentales étant de vériables Jollusques, il est essentiel de rechercher ì quel:e classe, à quel ordre elles doivent appartenir, ei voir parmi cenx-ci le type d'organisation qui peut présenter le plus d'analogic.

Si par la cumparaison du test, qui est syméirique, anus trouvons quelques rapports, ce sera arec les Patelles et notanment avec les FissuJelles, qui sont aussi percées au sonımet : c'est là le rapprocliemeut de Lister, de Liané et de Bruguière; mais si nous faisons altention fue l'ouverture de la Fissurelle ae reçoit pas directement l'anus, qu'elle correspood à une ouverture du manteau, lequel forme la cavité brancbiale; celte différeuce nous suflira, ainsi que la nou existence d'yeux et de tenticules, pour les en séparer. Si nous recherchons les points d'analogie qui existeut entre les Deutales et les Nucléobranches, nous trouverons un plus grand nombre de rapports, surtout pour le groupement, sur la partie dnrsale et médiane des principaux organes; mais au lieu de trouver une petite cocjuille engainaute pour le nucleus sculement, nuus en trouvons une gui renferme l'animal tout entier; mais au lien d'une tète pourvue d'yeux bien organisés, nous la trourons dans une autre position, et sans ces nrganes essentiels : d’autres différeoces s'observent encore dans la forme et la position des branchies, et surtout celle de l'anus. Néanmoins, malgré les anomalies siogulières des Dentales, nous pensons qu'on ve peui les meltre en rapport qu'avec l'un ou l'antre des groupes que nous venons de mentionner et pent être avec tous deux, en plaçant la famille que les Dentales formeront désormais entre l'une et l'autre.

Telle cst pour ceci l'opinion de M. de Blainville, qui, ayant eu connoissance des premiers matériaux de ce travail, a fail des animaux qui nous occupent un ordre nouveau de la sousclasse des Paracéplialophores, sous le nom de Cirrhobranches, qui leur convient parfaitement et que nous avons adopté. Ce fut d'abord à l'arlicle Molnosqoe du Dictionnaire des Sciences naturelles el ensuite dans son Traité de Malacologie, que M. de Blaiuville a établi les rapports que nous venons d'indiquer.

L'ordre des Nncléobranches, dans la méthode de M. de B!ainville, termine la sous-classe des Paracéplalophores monoigues et la sous-classe suivante, les l'aracéphalophores bermaphrodiles, commeaceat par les Cirrhobrancbes, ordre établi, comme aous l'avons va, pour le geare Dentale lui?

\section{E N}

seal; l'ordre qui suit inmediatement celui-ci renferme le geare Palelle, de sorte que dans la siotie, les Dentales se trouvent entre les Carinaires, Arvonantes, etc., et les Patelles. Il nous semble évident que dans ces rapports il existe de part et d'autre une lacune d'organisation trèsforle, dans laquelle nous ne vnjons aucun point intermédiaire qui serve de lien plus immédiat; malgrré cet hyaus, nous pensous uéanmoins que M. de Blainville a bien saisi les seuls rapports que l'oa puisse donner aux Deatales.

\section{CARACTÉRE GEXERICUES.}

Animal. Corps alongé, conique, tronqué antéricurement, enveloppé d'un manteau terminé antérieurement par ua bourrelet splincteorojde, frangú ou plissé; pied antérieur, proboscidiforme, terminé par nn apnendice conique reçu dans une sorte de calice à bords lestonnés; tête distincte: pédiculée; lèvres mnnies de tentacules; poini d'yeux ni le tentacnles oculiéres; branchies cirrheuses, en deux paquets cervicaux et syméiriques; une paire de máchoires latérales, cornées, ovales, fendues; anus ternival, médian, dans une sorte de parillon iofuadibuliforme, postéricur, pouvant sortir de la coquille; organes de la génération formés du seul ovaire?

Coquille régulière, conique, alongée, symétricpe, plus ou moins courbée; concavité venirale, couvexité dorsale, ouverte aux deux extrémitcs; ouvertare antérieure plus grande, simple, le plus snuvent oblique; la postéricure beaucoap? plus petite, quelqnefois continuée par une fente la plus souvent médiane et dorsale.

D'après ce que nous avons dil de l'anatomie des Dentales, il reste constant que ce genre doit maintenant faire partie des Mo!lusques. Considéré dans ses nuuveaux rapports, on ne pent plus le caractériser comme il l'étoit arant ce cbangement, et la rectilication des caractères les rendant plus rigoureux, il est désormais nécessaire d'en òter plusieurs corps qui ne peavent plus y rester; c'est ainsi que d'abord nous en ćloiguerons le Dentalium comeum I.inn., qui n'esi pas la même espèce que le curnerum de N1. L2marck, qui a été reconnu par M. d’Orbigny et d'autres pour être l'étui d'une larve de Frigane; a ralions et tous les renseignemens que nous avons pu nons procarer sur ces corps, que c'est toujours dans les eanx douces qu'on les trouve, quelquefois tixés les uns aux autres par une sorie d'appendice de l'anional, et entièremeat clos aux deux extrémités, lorsque la larve est devenue nymphe ou chrysalide. On reconnoit cette soi-disant Dentale à sa coulcur bruaâtre, à la flexibilité de ses bords et à leur élasticilé. Sowerby, Irompé comme le plus grand nombre de ses devanciers, a figuré dans son Gertera of schels deux de ces Éluis d'in- 
sectes parmi les Dentales; il est vfai qu'il ne les y place qu'avec doute. C"est d'après les mêmes raisons que nous, rejelerons également du genre Dentulel'espèce que M. Lamarck a nommée Dentalium nigrum, Japportée par Péron; elle a la uxême tanlle; la uêne couleur, senịement plus doncée; elle est élastique, llexible, cornée, tuule. serablable en un auu au comeum de Liuné. MI. Lamarck avoit eru reconnoitre son analoyue fossile dans une, espèce trouvée par $M$. Dulresue. en Bourgogne, mais. on ne peul admeltre cette anaIogie.

Une secoude espèce que l'on doit reporter aux Serpules, est le Dentalium radiculä de M. Lamarck; nousl'avons examinée avec, soin, et comme elle est contournté a La tnauic̀re des Serpules et par conséquent qu'elle n'est poiut symétrique, nous avons dû l'éluigner du genre, puisque ses, varactères n'y trouveat pas leur application.

Une roisiène espèce, le Dentulium deforme Lamk.; se trouve daus le mème cas que le précédeat, c'est-i-dire quil doit se repurter paruai, los Serpules et pour la mème raisun.

Nous peusous que le Dentulium pellucidum de Linué, qui est flexible et corué, doit être, comme „un Devidalium corneum, rejeté des véribables, Mentales.

Un assez grand nombre d'erreurs se trouve dans Lit syuonymie des Dentales, nous allons sigualer les principales : pour le Dentulium elophanitinum, Guelin, dans lia 13e. édition de Liuné, contond arec lai ane espece bien distincte, ea citaut toms les auseurs qui oul liguré l'ua ê l'autre, à l'exception de Gualtierri, duat il réserve une ligure pusur laire.le ype de son Dentulium recunvum, ce coi indique un double eaplai, puisque les figures de même espèce des autres auteurs vint édé rapportées au Dentalium elephantinum. Ceci a besoun d'une explication précise pour ne poiat uouner lieu it l'erreur: ainsi Gracliu cite les figures de Lister, Buonani, Burnn, Dargeaville, elc., qui ont donné pour la mème espèce tantôt l'une, tantût l'autre, ou qui les ont représentées toutes deux en les contondant. De ce numbre esi Gualne:ri; muis. Gmelin, puur celui-ci, preud seulerpeut une de ses ligures pour le Dentalium elephantinum, et réserve l'autre pour son Deñtulum recurvum; celle dernière espèce étant bien distinctc do l'elephontinum, nus l'avons conservée, seulement aous y avoas rapporté toute sa synonymie. M. Lanarck est tombé dans la méae erreur, et M. Sowerby en a commis une autre en donisuu, dans son Generu, le Dentialum sexansulure comme l'analogue fossile du, recursum, y't prend pom l'clephluntinum. Celle erreu!', it liati te dire, est occasiunuée par M. Hrocchi, qui, au lieu de faire firurer le Dentalizm sexan"gedura dans soneatier, u'a fait représeuter que l'eurrmité postérieure, drouqụce clạns l'endroit où les suies iale:midiaire; ne se son! point encore montrées; nous renvoyons pour le reste aux descriplịons dés dillérèntes espècés.

Une autre errem, nun moins palpable que la prẹmière, est relative au Dentalium aprinum; Gmelin eite seulement la figure 4, B de Mirtum, pl. 1, et rapporte lí figure 5, 13 du même aúteur, qui est a! sulument la mêrme; vue d'ua au re côté, is son Dentälium striatulum, pour lequel il ajoute la tigure de Lister. M. Lawarck a rectifie la syponymie, mais il u'it jas recomu le double eurploi, puisçu'ıl ne liadique "pas; il laisse uêtue dans le daute a l'égard du Dentalium aprinum de Gmellin, quil ue japporle au sien quavers hésitation. Le Dentalium coarctaturni de M. Lasmarck' a ćté le sujet d'une erreur de la part do M. Brocchi, qui a cru le recunuuitre daus l'áalogue du Dentalium corneaim de M. Lumarck, que nous nommóns Dentalium stiangulatum, pour ae plus laisser le moirdre rapport avee te corneun de Linné. M: Suwerby, dans sou Genera, a représenté le véritable Dealále rétréci de M. Lamarck, mais il lui a donné le noon de Dentalizm gadus. Au resle, cette espèce napprartieat prohablement pas au"genre Dentale, conume nuas l'aviuns cru avec tous les autres 'autevirs: les découvertes nombreuses que M. Rang a litiles dépuis la pusticalion de nistre travaif, tans la luuille des Pléropodés, nous font parląrer l’opinion qu'il a donsée que ce Dentulium devolt entrer dans sun geure Creseis; un y est conduit par des rapports de forme avec d'aulres espèces qui sout nouve:leueñt connues.

Un duable emploi se remarçue clans l'ouvrage de 11. Lamarck; il est relatil aux Dentuliuns noven costatum el fasciatum, qui applarlieunent à des indiviclús de wême espècé, dans delix ćlals dilléreus l'un mort, roulé dans la vase et ayant chingé de couleur, l'autre frais ct ayant conservé toutes les sienues. Le tóne autear a lait un autre double emploi pour le Dentaliuin tarentinum, qui est à peine une variété du.Dentalism entulis. Nous pourrions ajouter aux erreurś que nuus vemons de signaler, quelques autres d'uñe rgoiadre impartance; nous les indiqueruns 'dans nos descriptions, et criles reconnoitra aux changemens que nous avons apportés dans la synonywie de plusieur's d'en'tr'elles.

Plusieurs bons caractères peuvent servir à étrblir dan's le genie Dentale trois coupes principales: dans la prenière seront placées les espèces qui n'uat aucune lissure a'leur extrétnité; dins la seconde celles qui sunt plus oú móns profondément teudues; dans la "roisièràe seront réunies toutes celles qui sout étraínglées ou rétrécies à leur onverlute auĺcievire : les deux prewiers groupes pourroient être, si cela deverioit aécessaire parr le grand nuubre des "espèees, sous-divisés e:1 especces à côtes' ou ì stries, et en espèces lisses. Nuus noús sumeses servi de ces inayens pout élablir les rapports eatre les éspéces." 


\section{E. N}

On rencontre quelquefois des Dectales qui, ayaut élé cassécs a leul extrémile, présentent un petit prolungement tubuleux que l'animal a formé après l'accident. Ce mode singulier de réparation s'est perpétué dans une de nos pelites espèces fossiles, dont l'extrúuité postéricure scmble forurée de deux tuyaux engagés l'un dans l'autre, et dint le plus perit feroit sallie bors du plus grand. Uite siruclure analogne eu apparence se remarque dans le corps que 1I. Defrance a nommé Entale. l.orsque l'Entale est entière, on voit un pelit tube sorlir par l'extrémité d'un plus grand; niais lorsyule l'on vieut à casser celıi-ci, un s'aperçoit que le plos petit est libre et nullement soudé crmme dins les Dentales. 11 sembleroit résulter nécessinirement de ce fait, que l'animal qui habitoit les Entales devoit ĉtre furt dillét ent de celui des Deutiles. Cumme les Eutales ne sont encore counues que fossiles, dans des couches crayeuses He Mac̈striclat, et que ces couches, duns cortains endroits, renferment de ces corps en très-trande quantité, on ausoit pu croire que le hasard avoit doonć lieu à l'iutroduclion de deux tubes l'un daus l'autre; mais on sera détrompé facilemeat par plusieurs raisons : la première, est le grand nombre qu'ou en l1'suve avec les deux tobes; la seconde, c'est qu"il y a lovjours ua de ces tubes flus court et plus mince que l'autre, c'est celui yui est intérieur; et la troisième, c'est que ce unbe iutéricur n'est pas de la même structure que l'extérieur, et que, vu isolément, il devroit conslitaer une espèce dillérente. Celle struclure sinyulière n'a rien de semblable dans les Dentales, et cependant pent s'explituer assez bien aujourd'bui que l'on connoit, à n'en pas douter, la sinyriiière propriété qu'ont les ierriius de eraie de dissoudre certaines parties des coquilles, en laisount les aulres dans leur intécrité, et nous donnerons, à l'article Podopside, les preuves les plus irrécusables de se fait. Tout nous porte à croire, par les Dentales que nous avons vues de Cyjply, el que nous a comnuniquées Mi. Duchastel, une la détluublure des Dentales de Maëstricht est le résultat d'un accident semblable. Un assez grand roubre de Jentales présentent une fente postérieure.plus on unoins profonde, plus on moins large, suivant les espèces, mais qui est constante pour chacune d'elles. Celte fente ést presque constamment placće sur la ligne núdiaue et dorsale de la coquille, c'est-à-dire sur sa face conrexc. Nous en pnssédons une espèce qui a celle feate sur le milieu de sa face concave ou ventrale; doil-on supposer que l'aninal est reiourné dans sa coquille, saus autre changement de la position de ses organes, on bien que l'organe qui passe par cetle fente el quí la produit est dans une direclion inverse? On ne pourra répondre à ces questions qu'uprès l'examen des animaux de cette espèce.

Parmi les auteurs qui ont parlé des Dériales, hous ne trourons que M. Lamarck "qui ait menliouné la 'ferite qui en caractérise un certain nombre; eicorctil paroit que ce roologiste altachoit pén d'importance à ce caractère, puisqu'il né l'a pas indiqué pour son-Dentalium striatrm, qui en présente cependaut'une très-large et trèsprofonde, comme nous nous en sommes assuré par l'examen des judividus de sa collection, individus que nous arons figurés. Celte omissiona a dá nécessairement jeler dans l'erreur les ituieurs qui ont clierché, d'après la phrase caractérislique de M. Lamarck, à reconnoître le Dentahum striatum; et il est tacile de concevoir'(gue celle erreur est de loule manière indépendante de leur savoir et de leur sagacité.

Les Dentales qui sont rétrécies à leur ouverture forment un groupe bien nalurel, non-seulewent sous le rapport de ce caractère commua, mais cncore par un facies gui leur est particulier; elles u'ont point de stries longitudinales; elles ue présentent que des traces souvent pen régulières de leurs accroisseanens. Le Dentalium coarctatum ne doit point faire partie de cclte section; il ne portc aucun des caractères qui puisse l'y faire admeltre; son ouverture, yuoitjue rétrécie, n'est pas munie d'un bourrelet.

Les caractères spécifiques dans les Dentales sont pris principalement daus Ja courbure, la forme générale, le nombie et la disposition des cótes ou des stries; la coule rr, qui eśt assez constante pour les espèces qui en ont; enliu, la taille qui, dans les espèces, ne dépasse pas certaines liailes. Ces caractères génćraux peuvent servi. pour toutes les sections que nous arous ćtablies dans le genre; nais chacune d'elles ea préente de particuliers, auxquels l'observateur doit s'altacher de préférence; puur la première, il u'y en a point d'autres que ceux que nous venons d'énoncer. Dans la seconde, ontre ceax-là, on a de plus la lente postérieure, qui, le plus souvent, on peut mêrue dire généralement, a une forme et des proportions de profondeur el de largeur parliculicies à l'espèce, de manière que ce caraclère, faute d'autres, pourroit suffite a leur dislinction. Dans la troisième section, outre les caractères généraux qui ont leur application, la forme, la longuear du bourrelet, et surtoul la propurtion de l'ouverture par rapport à la lonpueur du têt et à son épaisseur, sont les moyens les plus certains pont arriver sáns erreur à la dislinction des espèces.

Pour quon puisse facilement arriver à la connoissance des especces, et reconnoître ce que nous avous dit de chacune d'elles en particulier, il est nécessaire qu'on les examine dans la même position que nous, et voici de quelle manière: bous les a vons placées devant nous sur un plan horizontal, la grosse extrémité ou la base en avant, la petite extrémité ou le sommet en arrière; la 
face coucave ou ventrale en bas, la face conrexe ou dorsale en haut; alors nous nommous antérieure la grande ouverture de la coquille qui occupe toute la base; nous nommons postérieure la petite qui se troure au sommet. Nous trourons quatre faces, l'une inférieure qui est la veutra!e, l'autre supérieure qui est la dorsale, et deux latérales, l'unc droite et l'autie gauche.

Cette distinction de faces, qui paroit pućrile en ce qu'elles n'existent réellement pas, puisque les corps sur lesquels on en fait l'application sont arrondis, est cependant très - utile à bien établir, pour reporter dans des plans connus el déterminés les parties que l'un décrit. Cette méthode, aduptée géuéralement, abrége beaucoup les descriptions, en ce qu'elle rend inutiles des circonlocutious ou des périphrases souvent lastidienses. Comment exprimeroit-on, par exemple, que la fente postérieure est supérieurc, infiricure vu latérale? Comment pourroit-on dire qu'un certaia nombre de cótcs sont dorsales, qu'un cerraiu nombre d'autres sont lutérales, etc., si on ne s'est pas entendu d'avance sur la position respective de ces régions?

Nous navons que fort pon de détails sur les mueurs des Dentales; elles préferent, d'après ce que nous en a dit M. d'Orbigny, les planes saLlonneuses entremélées de rochers, oú elles se tienneat au niveau dos plus basses marées; elles sont entoncées perpendiculairenent duns le sable, à peu de profondeur; elles n'y peuvent plus renl'er une fo:s qu'clles en sont sorties, alors elles contirueat de vivre dans une position horizonlale. Nous ignorons dans qnel temps de l'aunée - tait la poale des aufs; nous sarous seulement que dans certains eadroits, les Dentules s'y multiplient considérablement; aussi voit-on leur coqunlle en tres-zrrand nurabre rejelće sur les plinges. Lianimal paroít très-liwide, comme la piupart des Mollusques; il se retire dass la coquille an noindre mouvement, au moiudre 'choc qu'dl érouve; il reste tres-long-temps sans se remontrer; il rentre dans la coquille avec une extreme rapidité, et il paruit qu'il en sort avec unc rapidité non moins grande.

1. Dextaze éléphautiae. Dentalium elephantimum. Lin.

-D. testi duadecin custat 2 , angulutâ, subrectí, aibidi, costá minore unicu inter alias.

I.IX. Gmel. pas. 3736. no. 1. - Dentalium recium, pag. 3758 . no. 12 .

l.ıтter, Sinops. Concl. tab. 547. fig. I.

Uargenvilge, la Litho!. et la Corich. pl. 5. fig h. $h$.

Bosann, Mus. Tirker. el Recreat. part. I. fig. 3 .

Guszt. Index testar. tab. 10. fig. li.

\section{D $\mathrm{E} N$}

Scruld, la Vana, Specul. tab. 18. fig. 6.

Fossile, Broccur, Concli. subap. pag. 360. $n^{\circ} .1$.

Fossile, Mercart, Metallo. vat. pag. 502. fig. $S$.

DARgerv. Zoomoiph. tab. 1.fig. $h$.

Androv. de Test. pag. 283. $n^{\circ}$. 1.

Martixi, Conch. cabin. tom. I. tah. 1. fig. 4. $a$.

Guettand, Mén. sur les Arts et les Scienc. tom. 1. pl.6g. fig. 7 , copiée d'aprés celie de la Zoomorphose de Dargenville.

An Bourguet, Petrif. pl. 56. fig. 384?? (pessinus.)

Cominient. Bowasy. tomi, 2. purt. 2. pag, 296. fig. 6. 9 .

Petrver, Amboin.tab. 16. fig. 33.

Ibid. Gazophil. tab. 15. fg. 9 .

Knовr. les Délıces des yeux, part. I. tab. 29. fig. 3.

Scheucrzer, Piscium querela, pl. 5.

Var. A. Nor. Testâ costis $a b$ origine aqualibus.

Nobis, Mlonogr. du genr. Dent. pag. 27. pl. $\overline{5}$. fig. 7 .

Gmelin, daus la treizième édilion de Linné, a éviderunient coutondu plusicurs espéces avec celle-ci, et fuit plusieurs dububles ensplois : ciest aiusi qưil élablit le Dentaliun rectum et le Derttalium recury'um, aux dépens de l'elephantizum, que, malgré cela, il donue pour le cicrnier dars la syuonymie des deux atutres, et qu'il y dapporte des figuies yui appartiennent bien certaioment à l'un at á l'autre. Si on óte du Deñtaluum elephantinum le Dentalium rectum et le Dentalum recurvum, il ne restera plus ricn pour l'elephantinum. Nous n'avous pu adupier de pareilles esreur's; et, sentant la nćcessité de séparer l'uue des deux espèces, nous avons adopté le Dentalium recunium, et nous avons laissé le Dentulium rectum pour servir de base à l'elephantsnum : en tomparant wos fjures el en véritiant notıe synunymie, un rerra facilement la dislinction que nous laisons, et oll l'apprécicra davautage en comparant nos descriptions. Let Dentalium elephuntinum, tel que nuos l'entenduns maintenant, est une grande coguille tubuleuse, assez lurge i la base, presque droite ou fort peu arquíe, blanchc, d'aprés les individus que nous avons rus, avec des zones transversales, d'un vert pàle, suivaut les auteurs, préscalant constamaient au soumet douze côtes bicn symétriquement disposérs, et un peu au-dessus, $O D$ apeıccict l'origine d'uue côte plus petite qui vieut sialéposer entre cliacune des prewieres, $\in$ qua 


\section{1) $\mathrm{E} N$}

a la base presque aussi grosse quelles; alors, duns cet endroit on en compte vimgt-quatre. Le véritable aualogue fossile de celle espèce se trouve en Jalie, à Saint-Miniato; et ce n'est pas lui que Suwerby a figuré daus son Genera, $n^{\circ}$. 15, fig. $^{2}$, cet autcur ayaut, comme plusieurs auties, confondu le Dentalium sexungulare dans son enticr développerneat a vec celle-ci. D’apres la collection du Mluscum, ćliquetée de la uain de M. Iamarck, ce savaut seroit tombé dans une erreur non moins grave, en cousidéraut le serangulare comme l'analogue fossile du recunvum. Naus devons à $\mathbf{M}$. Boué la conmoissauce de natre variélé; elle est fossile, et elle a été découverte par ce savant géulogue, à b.ıden, près Vienne en Autriche : elle se distingue liacileneut par un pen moins de volume, et par les côtes, qui sunt au nombre de vingtquatre dés le sommet; elle sont un peu mous ıégulièremeul disposćes, et on en voit quelquefois d'antres plus perites in erposíes, ce qui ang'mente leor noabre à la base. Les individus vivaus se Irouvent dins les mers de l'Jude et daus la Médiserranée; ils ont 80 à 90 millim. de lonir, et 13. a 15 milliu. de diamétre à la base.

3. Dextale arquée. Dentulium urcuatum. Lis.

U. testâ albo-virescente, arcuntâ, decem costuta; costis inferioribus mujorbus; strià unicá unter costas.

Lix. Gusc. pag. 3338. no, 16 .

Dentalium elephantinuni, L.sux. Anim. sans v'ert. tom. 5. pag. 345. $n^{\circ}$. 1.

Dentalium elephantinum, Sow. the Genera, m. 15. fig. 1 .

Gualt. Ind. test. tıb. Io. fig. G. I.

Rимне. Mus. tab. 41. fig. 1 .

Martixt, Conch. cab. tub. 1. fig. 5. a.

Bann. Test. Mus. cas, vind. pag. 450, vign.

Var. A. Noв. Testâ novem costati.

Nobis , Monugr. du genr. Dentalium, pag. 29. no. 2. pl. 2. fig. 5. 4.7.8.

On verra facilemeut, d'après ce que nous avons dit du Dentalium elephantimun, que celui-ci doit fairc une espéce bien distincte. Il existe plusieurs espèces admises depuis long-temps parmi les auteurs, et qui reposent sur des caractères de woindre valeur; celle-ri est grande, arquée, rerte, et warquée de vert toncé a la base, blanchillce on d'un vert-jaunatre atu soumet. Dans le pus grand nombre des individus, on remarque entre chaque côle une strie peu prononcée; les côtes soat saillantes, au nowbre de dix, et de neut' pour la variété; celles qui sout dorsales sont aplaties, écrasces; celles qui sont veutrales, ou dans la concavité, sout beacoup plus sailIantes; les coupes transversales de la coquille

Hist. Nat. des Vere. Tome 1 . indiquent cette disposition. Le sommet n'est pas très-áigu : il est eatier; les bords de l'ouverture sont minces, tranchans et festonnés en dedaus par des éclyancirures qui se rematiquent dans chaque côte. Nưs ne connoissons point celte espèce ì l'étal fossile; elle est vivante dans les mers de l'Iude et à Amboioe, d'aù notre arui, M. Lesson, l'a rupportée; elle est longrue de 80 inillim. et plus, et son diamétre à la base est de 11 millim.

3. Dentale sexavgulaire. Dentalium sexangulare. LAMK.

D. testâ tereti, arcuatâ, subuilutî, duodecim costatû; costis sex eminentioribus; striis transversis, minimis.

Lauk. Aninu. sans vert. tom. 5. pug. 344. $n^{\circ} \cdot 8$.

Mencati, Metall. vat. pag. 302. flg. infírieule?

Dentaliunt sexangulum, Livvé, pag. 373 3 . $n^{\circ} \cdot 21$.

Ibid. Broc. Conch. subap. pag. 262. $n^{\circ}$. 4 . pl. $15 . \mathrm{fg} \cdot 25$.

Krorr. Petrif. tom. 1. part. 2. pl. J. a. fg. $5 . b$.

Dentalium elephantinun, Sow. the Genera, $n^{\circ} \cdot 15 . f i g .2$.

Var. A. Noв. Testâ niinore, costis minus eminentibus.

Var. B. N⿴囗в. Testâ minore sex costatî, strïs binis vel tribus inter costas.

Nов. Monogr. du genr. Dent. pug. 3о. $n^{\circ}$. 5. pl. 3. fig. 4. 5.6.

Celte espèce a encore donné lien à plusieur's erieurs; la manière dont M. Brocchi l’a ligurée a contribué à les propager, et si nous n'avions pas eu sous les yeax un grand nombre d'individus de tous les âges, nous aurions pu nous Iromper comale nos devanciers. Celte coquille commence, lorsqu'elle est très-jeume et qu'elle n'a que 6 lignes de longueur, par piésenter six côles saillantes et aiguës; lorsqu'elle prend plus d'accroissement, elle produit entre les six premières côtes, six autres plus petices, qui finissent, lorsque l'animal est adulte et la coquille dans sou développement, par devenir presque égales aux premières. M. Brocchi n'a figuré que le premier âge, ou peut-être, et cela nous semble plus certain, un morceau de l'extréruité. Il n'est pus étonnant, d'après cela, que 11. Lamarck, qui a parfistement recomnu. l'espèce, n'ait rapporté qu'avec doute le Dentaliun sexangulum de Ganelio, tandis que M. Brocchi le doone avec certulude dans la synonymie; mais on-doit être surpris que M. Sowerby ait confondu celte espèce avec le recurvum de son 
Genera, car elle est très-facile à distinguer : elle est très-grande, étroite, assez forlement arquíe, préseataut constanment douze côtes, dont six sont plus proéminentes et prolongées jusquià l'extréraité, tandis que les six aurres ne naissent que plus tard et restent presque tonjour's plus pelites.

Quêtquefnis les côtes deviennent striées, s'eftacent et disparoissent insensiblement vers l'onverure : cela a lieu dans les vieux indivilus; des stries trausversales, très-fines et peu régulières, indiquent les accroissenteus; , le sommet est assez aigu et constamment hexagone; l'ouverture est oblique; les bords sont tranchians et simples. Ia variété $A$ est tonjours plus petite, un peu moins courbée et les côtes beancour moins saillautes; elle est aussi plus grêle. La variété B est t́galement plus petife, et d'autant plus remarçuable, qqu'elle n'a dans tonte sa longueur que six côtes, tet que les six antres sont remplacées par deux on trois stries bien marquées. Celle modification lieat sans doute à la localité, car elle vient de Baden, près Vienne : la première m’a été conmuniquée par M. Michelin, et la seconde par M. Boné. La longueur des plus grands indivielus "st de 10 ou II centimètres, et le diamètre de louverture de 10 on II millin. La variété B n'en a que 40. Celle espèce ne s'est encore Irouvée que fossile, principalement dans le Plaisantin, où elle est commune.

4. Dentale coine de bouc. Dentalium caprinum. Lis.

D. testâ virescente, tereti, subsulcati, decem costatî; striis transversis nulls; apice acumiacato.

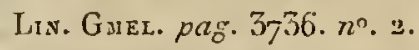

LAuk. Anim. sans vert. tom. 5. pag. 343 . $n^{\circ} .2$.

Lister, Syz. Conch. tab. 547. fig. I. (Inférienre.)

Martini, Conch. cab.tumi. 1. tab. I. fig. 4 B. ct $5 \mathrm{~B}$.

Broc. Conch. subap. pag. 264. $\pi^{\circ}$. 10.

Var. A. Testâ duocedin regulariter costatâ, albidâ.

Var. B. Nов. Testâa undecin costatâ; striâa unicâ inter costas.

Dentalium striatulum, L1N. Gmex. pag. 3738 . ino. 13.

Noв. Monogr. du genr. Dent. pag. 31. $u^{\circ} .4$. pl. 2. fig. 18. 19.

Le Dentalium striatulum de Linné ne peni être considéré antrement que comme une variété de l'espèce qui nous occupe; c'est un des nombreux doubles emplois qu'on remarque dans le Linné de Gmelin. Quoique cette espèce ait beau- coup d'analngie aree le Dentuitisen arcuatum, elle s'en distingue cependant avec ficilité; elle est plus courbće el plus étroile; sa conleur veite cst moius foncré ; son extrémité postérieure, plns acumiuce, conserve la même teinte que le reste; ses còtes, variables depuis dix juscqu'à douze, son bien symíriques, étroites, régulièrement espacfes, aussi saillantss sur la lace convexe que sur la face concave; elles sérendent du sommet à la base; quelques stries transversales, peu nombreuses, iménulières, indiquent des accroissemeos; ces stives sont ordinitirement accompagnées de zones transversales d'un vert pluz foncé; le reste de l'espace qui est entre ces côtes est entièrement lisse. La variété $\mathrm{A}$ se distingue par douze côles régulières et par sa blancheur, mais celle couleur paroîı dépendre de ce que la coquille est inorte. La variété $\mathrm{B}$ est de la nême couleur que l'espèr e; outre qu'elle a onze côtes, elle se recunnuî̀ à une strie pen saillante qui se remarque entre chaque côte principale, ce qui a clécidé Gı́elin à en faire une espèce séparée. M. Brocchi cite celle espèce fossile en Italie; nons a'avons pu la voir pour la comparer, mais on doit s'en rapporter avec sécurité au savoir du conchyliologue italieo. Elle se trouve vivante dans les mers de línde et dans la Méditerranée, d'apiès Renieri. Elle est longue de 67 millimètres, et son diamètre i la base est de 5 millim. et demi.

5. Dentale oclogone. Dentalium octogonum. Lamk.

D. Testầ albidâ, lacteâ, subarcuatâ, octogonô; costis octonis; duabus tribusve friis inter costas.

LaMk. Anins. sans vert. tom. 5. pag. 344 . $n^{\circ} .5$.

Var. A. Nobis. Testâ septem costatâ.

Noв. Monog. du genr. Dent. pug. 32. no. 5 . pl. 2. fig. 5. 6 .

Espèce que $\mathrm{N}$. Lamarck a fait connoître lc premier, et qui n'a point été figurée par les auteurs. Elle est blanche, subdiaphane, médiocrement courbée, d'une taille noyeune, présentant huit còles irégulières qui s'étendent du sommet à la base; elles sont étroites, arrondies, bien symérriques, et dans leur intervalte on voit deux et quelquefois trois stries fines; it n'y a poiat de stries transve:sales, si ce n'est quelcyes-unes qui indiquent les accroissemens. Le sommet est pointil, percé d'un trou fort petit; l'ouverture est régulic̀rement octogone, trancliante et peu oblique. La variété est en tout semblable, si ce d'est qu'elle n'a que sept côtes : c'est M. Duclos qui wous l'a fait connoître. Longueur 45 millin., diamètre de l'ouverture 5 millio. Elle se trouve dans les mers de la Chine. 
6. Dextale raccourcie. Dentalium abbreviatum, Noв.

D. Testâ minutâ, abbreviatâ, subrectâ, extremitute recurvâ, septem angulutâ, crassâ; aperturâ rolundî̀, rectâ, incrasssutâ.

Nов. Mronog. du genr. Dent. pag. 32. $n^{\circ}, 6$. pl. 4. fig. 21.22.

Celre espèce, que uous avons découverte daus les sables des environs de Suissons, ponrroit servir de passage entre celle section el la dernière. Sans avoir d'êlranglement au-dessous de l'ouverlure, les bords en snot cependant épaissis et non tuuchans; elle est droite ou peu courbée lorsru'elle est petite, mais lor'squ'elie alteint luut son développensent, elle se courbe davantage, surtout vers soo extrémitée postérieure, qui est fort pointue et entièrentent lisse : c'est un peu andessus que se voil l'origine de sept angles sailla as, bien symútriçues, dont le médian se tronve sur le dus; ils se terminent sur le burd. L'ouverture est ronite et droite; ses bords sont espatssis, obtus, sans tormer de brurrelet unargidal; tout le lest est épais. Longueul 11 millim., dianètre de l'ourerture 1 millim. et deıi. Noв.

7. Dextane variable. Denulium variubile.

D. testâ tereti, subcrscuatâ, albidì luteolâve, quinque adnovem costulâ; striis exzgitss, trtcer. postitis.

Nов. Monog. du genr. Dent. pag. 32. no. 7 . pl. 2. fig. Jo.

Nous sorumes obligf's d'exprimer vaguement des cardctères qui som tres-variables, el à tnoins que d'établir une variétć pour chaque légèce nodification, ce qui les nultipliroit prestgu'a l'infini, il est impossible de caructériser autrement celle espece; elle est d'une taille petite, léperement arquée, ondinairement peu puintue, le plus souvent d'un blanc laitenx", assez rarement jaune serin peu foncé; les côtes, au nombre de ciuq à un uf, soul généralement plus pruérnineates sur la face concare que sur la convexe, aussi elles son: les dernieres qui disparoissent vers l'ouverlure; taniót elles persistent et se montrent jusque sur le bord; lantót enfin les dursales sont disparnes lorsque les ventrales, au numbre d'nne, iruis on ciny, existent encore; ces cótes, dans'les individus bieu frais, olficul des séries de peints I'un blanc-grisatre, sur le fond hlanc laileux de la coçuille; des stries variables, en raison du linobre des côtes, snni d'autunt plus' nombreuses qu'il y a nuins de celles-ci, et réciproquement: elles sont d'abord très-tines, s'accroissent el devienneot presque égalus et même cégales auxicôtes arece lesguelles on pout les confondre; elles.persisient loujours jusqu'à l'ouverlure. Cetle corquille; sue jai Irouvée chez ua marchand aroc bean- conp de petites coquilles de l'Iude, pourroitêtre de ce prays. Elle esı longue de 25 a 30 millimètre.

8. Dentale à peliles cútes. Dentulium dentalis. Lrsix.

D. tcstâtereti, subarcuatâ, costellutâ, nubrá; costellis actodcnis ant vigenti, alternis minoribus. LAME.

Lанк. Anim. sans vert. tom. 5. pag 344 . $n^{\circ} \cdot 10$.

L.INS. GMEx. pag. 3736. n०. 3 .

OLIv. Zool. adriut. pag. 19 !. $n^{\circ}$. 1 .

Вกnxr. Mus. caes, vind. tab. 18. fig. 13.

lloмрн. tak. 41 . fig. 6 ?

Inoccal, Conch. sub. pag $261.7^{\circ} .3$.

Ax. Kмоня. Petrif. tom. 1. $2^{\circ}$ part.pl. j. a. fig. 3. 4 ?

. Mercatr, Mclal. 2at. pag 302. fig. in mediu.

Var. A. Testâ majore, costis majoribres pilanulatis.

Var. B. Testâ duodecim ad sexdecim costutâ.

Dent. altenuatum, SAY, Ménr. sur les foss. du Marylhund, Juurnal de l'acadimie de Phulat. tons. 4. pag. $154 . p l .8$ fig. 3 (lussile).

Nubis, Monog. du genre Dent. pag. 35. $n^{\circ} .8$. pl. 2. fig. 9. 10.

Coquille rouge, arquée, subulée, présentant dix-buit à ringl côtes rapprochées, salllautes: eutre clancume d’elles on en voit une plus peizle. Ces cûtes se prolorgent le plus souvent de la pointe à la base, sur quelgues iudividus elles diminuent insensiblement et disparoissent vers l'ouverture; elles sunt saillantes, arwondies et régullières; le sommet est aiğa, subulé, percé d'un Irès-pelit lrou; l'ouverture est arronde, un peu oblique; les bords sont très-minces ct très-tranchans. La variéti A est fossile; elle est plus grande yue les individus vivans que mous avons vus: le nombre des côtes est le mếne, elles sont aplaties. Elle se trouve dars le Piémont. C'est a Ml. Mérard de la Groje que nous en devons la counoissauce.

M. Say a dérrit daris son Mémoire sur les rossiles diu.Mern thand, inséré dans le Journal de la Société des sciences naturelle's de Philadelphice, une espèce de Deutale qui, d'après la ligare et la descriplion, peut ét:e considérée comme la variétéde celle-ri. Ce fait, quoique fort étonnant, le paroitra moins lorsqu'on sania yu'ua assez. grand nombre de fossile du Marylhand retrouveut Peur analogue parni cenx de l'Íalic. Oatre la Panopée et l'Isocardia cor, nous poutrions citer encore plusieurs Cyllrérées et deux Buccius. L'a' Dentale à petites côtes se trouve vivante dans la"$\mathrm{K} 2$ * 
Néditerranće; elle est loague de 50 million., et a 4 millin. de diamètre à la bale.

9. 1 .

D. testâ suliancuatâ, subulutâ, costatá; costis reguluribus, continuis, sexdecim.

Lası. Anim. s. vert. tom. 5. pag. 34.3. $n^{\circ} .3$.

Nobis, Mlonog. du genr. Dent. pag. 54. $n^{\circ} \cdot 9$. pl. 4 . fig. 15.

Dans la phrase caractéristique, 11. Lamarck anza coufondu avec celle-ci quelque autre espèce, car nous avons complé les côtes sur plus de quinze indiridus, et nous les avons constamment trouvées au nombre de seize. Celle erreur de II. Lamarck nous seroble d'autant plus probable, gue nous avons reconnu parmi les Dentales de la collection du Muséum, plusieurs individus d'une autre espèce accolés à̀ quelques-uns de ceux-ci, et porlant le mêrne nom. La Dentale sillonuée a beaucoup d'analogie arec le Dentalium dentalis, quant à la disposition des côtes; elle est petile, pointue, peu courbée, assez large à sa base, élégamment et régulièrement couverte de seize côtes, obtuses, continues de la base au s.ommet; dans la moitié antérieure se voit entre chaque cóte une strie peu prononcée; l'uuverture est très-niuce, trancliante et festonuée par les côtes qui $y$ aboulissent. "Nous ue connoissons cette espèce qu'à l'état fossile. C'est à Griguon principalement qu'elle fe trouve; on la rencontre aussi, mais plus rarement, à Parnes et à Mouchy-leChàiel.

30. Dentale fossile. Dentalium fossile. Lis.

$D$. testâ vix arcuatâ, longitudinaliter striatâ, crebris striis, regulanbus, obiusis, equalibus. Noв.

Lins. Garex. pag. 3738. no. 14 .

Broccr. Conchil. subap. pag. $26 \mathrm{I}, n^{\circ} .2$.

Scrretea, Eint.in verst. 4. tab. 5. fig. 7 .

An Dentalium costatum, Sow. Mineral. conch. pl. 70. fig. 8.

Nobis, Monog. du genr. Dent. pas. 55. $n^{\circ} .10$. fl. 3. fig. 12.

Quoique très-voisine de la précédente, cette espece est cependant bicn distincte. L'individu que nous avons figuıé nous a śté commaniqué par M. Mémard de la Groye. M. Lamarck, qui a voit consulté la collection de ce-savant, a'a point reconoa, à ce qu'il paroit, cette coquille pour l'espèce à iaquelle elle appartient, et il l'a regardée comme l'analogue de son Dentalium striatuma, qui est ane espèce entièrement dillérente, paisqu'elle est largement fondue à son extrémitte, lorsque celle-ci est constamment entière. Nous arons cru d’après cela qüil étoit ntecessaire de rétablir 'e Dentalium fossile de Linné. Il est d'une taille médiocre, peu courbé, plus large à sa base que le dentalis; il est aussi moias acuniné au summct. Cette partie reste lisse; les stries prenaen! leur origine un peu plus haut insensiblement et saccroissent avec le resle de la coquille, et, arrivées vers l'ourerture, elles conservent tonte leur élévation; elles snat nowbreuses, sercées les unes près des autres, arrondies, séparies seulement par un sillon étroit; on n'apercuit d'autres stries transversales que quelques-unes, en pelit nombre, qui indiquent des accroissemens. Elle se trouve fossile aux environs de Sienne en 'Tuscane, d'après M. Ménard, et à Loretto, d'après Brocchi. Elle est longue do 45 millim., et a 5 willim. de diamètre à sá base.

11. Dex̃tale de Boué. Dentalium Bouei. Nob.

D. testâ tereti, subarcuatâ, longitudinaliter tonuissmè striatî, striis transversulibus decussatô.

An Dentalium decussatum? Sow. Min. conch. pl. 7 . a. fig. 5.

An Dentalium intemptum? L1кx. Gare. pag. $3759 . n^{\circ} \cdot 19$.

Nobis, Monog. du genre Dent. pag. 35. no. 11. pl. $4 . f g .8$.

Les nombreuses ressemblances que nons trouvous entre notre espèce et celle des auteurs que nous citons, nous font penser que c'est probablement la même. Cependant, la figure de Sowerby étant insulfisaute, puisqu'elle ne représente qu'un fragment, rous ne pourons l'admettre gu'arec doute, et nous devous également en conserver pour celle de Linné, dont la phrase caractéristique dillère un peu de la nôtre, et ne peut s'appliquer daos toutes ses expressions aux caractères de notre espèce. C'est aux infatigables recherches de M. Boué que l'on doit la connoissance de cette belle Dentale. C'est avecile plus grand plaisir que nous la dédions au savarrt géologue dont les travaux ont puissamment conlribué à l'avancement de la géugnosie.

Le Dentalium Bouei est grand, légèrement arqué, étroit, subulé, atténué à l'extrémité postérieure; la surface extérieure est couverte de stries fines, peu saillantes, serrées; elles sont plus élevées à l'extrémité postérieure que ver's l'ouverture, où elles disparoissent quelquefois; ces stries sont cuupées transversalenent par des stries non moins fines et plus serrées : ce qui furme sur la coquille un réseau très-fin. Oulre ces stries transversales, on en voit d'autres plus grosses, plus enfoncées, placées irrégulièremerı! ; elles indiquent des accroissemens. Cette coqnille vient des argiles bleues terliaires des enviroas de Bade, piès de Vienne en Autriche. Elle est lnngue de 80 à go millim.; son diamètre est de $7 \dot{a} 0$ williw. 


\section{E N}

12. Dentale à ueuf cóles. Dentalium novem costatum. L. $\mathbf{~} \mathrm{k}$.

D. testầ subarcuatâ, roseâa albidâve, nor'cm costutâ, bast sublizvigatá.

L.s uк. Anim. s. vert. tom. 5. pag. 544. $u^{\circ} \cdot 7$.

Dentalium fasciatum, ibid. pag. 343. $n^{\circ} .4$.

Var. A. Eadem albidâ, decem castatá. Nов.

јов." Monog. du genre Dent. pag. 36. no. 12. pl.2. fig. 11. 12.

En examinant comparativement le Dentalium novem costatum et le fasciutum, on s'aperçvit bientôt que ce sont deux étals dillérens d'une mêrue espèce. Elles ont tontes deux le tnểe nombre de côtes, la mème forme, la mếne longueur; sculement l'une, le fasciatum, présente uue coquille morte, dont les couleurs sont altérées par suile de son séjour prolungé daus la vase. En réunissant ces denx especes, nous ne craignons pas d'être contredit par les personnes qui auront ju voir un assez grand nombre d'individus de celle espèce. Elle est d'une taille múdiocre, peu courbée, ayant constamment ueuf côles peu sátillaates, continues depuis le sommet jusque vers les deux tiers de sa longuear; plus saillaules au sommet, elles diminoeat insensibleasent et fivissent par disparoitre vers l'ouverture. Quand elle est bien fiaicbe, cette coquille est d'un rose un peu briqueté, avec des zuwes transversales de la urème couleur, plus foncée, qui acconıpagnent ordiuairement des stries irrégulières d'accroissement; d'autres fois, elle est d'un blanc-grisitre unitorme, et souvent elle est rose au sommet et blanche à la base. Le sommet est ordinairement trouqué, et on y remarque quelquefois un petit prolongement tubuleux, semblable à celui que nous arons fait remarquer daus d'autres espèces. Iıa variété est blanche el elle a une côte de plus; nous n'en avons vu qu'un seul individu, sur plus de treute que nous avons eus à notre disposition. Oa trouve celte coquille vivante dans la Manche, aux environs de La Rochelle et dans la Méditerranće ; son analogue vient des faluns de la Touraine. I.es plus grands individus ont 40 millim. dé longueur, et 4 millim. de diamètre. సов.

13. Dextate de Lesson. Dentalium Lessoni.

D. testâ subrectá, tereti, albido-griseá, octo ad decent costutî ; costis obtusis, depressis, ad uperturum evanescentibus.

Nobis, Monog. du genre Dent. pag. $37 \cdot n^{\circ} \cdot 15$. pl. 2. fig. $1 \overline{3}$.

Ceıte Dentale nous a été donnée par notre estimable ami, M. Lesson, qui a rapporté de la Nouvelle-Guinée un collier a quatre rangs qui en étuit cantièrement composé. Nous nous empressons à payer a cet iulialigable el savaut baturaliste notre tribut de reconnoissance, pour les nombreux oljets enticrement nouveaux dont ses recherches ont eurichila science. Celle espèce, quoique voisine du novem costatum, s'en distingue par su forme aussi bien que par sa courbure el la disposition de ses cóte's; elle est plus étroite, plus Inngue, moins courhćc, constumment d'un blanc. jaunàtre uniforme, sans zones transviersales; ses cúles, au nowbre delıil, neufou dix, se touclient par la hase, s'élèvent médiocrement el s'arrondissenı; elles sont plus Clevées vers le somme?; elles diminnent insensiblemen: et disparoissent ver's l'nuverture; elles sunt interiompues par quelques stries d'accroissement; l'ouverture est étroile relativement à la longucur de la coquille. Elle est longue de 50 millim., el son diamelre est de 4 millim. seulemenı.

14. Dextsue il cúles aiguës. Dentalium acutıcosta. Nuв.

D. testấ tereti, subarcuatâ, subulatâ, duodecin ad sexdecim costatâ; costis tenuibus, anoustis, acutis, ad aperturam evanescentibus.

Dentalium striatum, Sow. Mineral conch. $p l$. 7o. fig. 4 .

Nolsis, Monog. du genre Deni. pag. $57 \cdot n^{\circ} \cdot 14$. pl. 4. fig. 3 .

Nous sommes dans l'obligation de donner un autre nom à celte espèce, M. Laurarck ayaut dẻji emplnyé la même dínomiuaion pour une autre entièrement différente. Celle-ci est alongrée, étroite, pointue, lisse vers l'ouverture, converle de côtes dăıs le resı́e de son éleodue. C.es cóles, au nomblre de douze ì seize, sont petites, étroites, peu élevées, aiguës, assez distantes; elles diminuent inseusiblement da sommet vers la base, ou elles linissent par disparoilte plus ou moins promplement, suivant les individus; des stries transverses d'accroissement sont assez molliplices; la longueur des plus grands individus est de 75 millim.; ils n'en on la base. On ae connoît encore cette espèce qu'à l'état fossile, et elle paroit particulière à l'argile de Londres: c'est à Barton principalement qu'elle se rencontre.

15. Devtale psendo-sexagone. Dentalium pseudo-sexagonum. Nов.

D. testâ tereti, subulatâ, subarcuntâ, griseâ, tenue striatâ; c.xtremilate posticâ sexangulutâ.

Nobis, Monog. du genre Dent. pag. $38 . n^{\circ} .15$. pl. 2. fig. 14.15 .16 .

Celte espèce présente des caraclères bien difficiles i saisir; clle est d'un blanc-grisülre, demiIransparente, peu courbéc, pointue; le somwet présente constamment six angles, assez saillans et bien réguliers. Entre chacun de ces angles naissent un grand nombre de stries qui comvient 
la coquille; les angles disparvissent promptement vers le quart ou le tiers inférieur. Nous avons cherché ì exprimer cette dispositiou par les tigures que nous avons données dans notie $M I O-$ ingraplize. La première présente la coupe transversale vers. l'ouverture, et la seeonde une coupe vausversale vers l'exirémilé. On remarque des slies d'recroissement assez tiues el sonvent regulières, qui coupent transversalenent les stries longiturinales. Nous possédons plusieurs individus de celte espece. Nous ignorous sa palrie. Lille est longue de 45 à 50 milliui., et son diatnètre est de 4 millias. a la base.

16. Dextare à stries nonbreuses. Dequtalium multistriatum. Nов.

D. test.i lereti, subrectî, albidî, mullistriata; striis tenuibus, confertissinis, altquantasper seriatim submaculatis.

An Dentuliun fascialum? Lisi. Gaes, pag. $373 ; \cdot n^{\circ} \cdot 10$.

7cs. Mlonog. du genre Dent. pag. 53. $n^{\circ}, 16$. p.. 4. fig. 11.

Cutle espére est pelite, élroite, généralement $p=u$ conthée, Llanche, jaunatre ou urisutre; elie «s entièrement couverte de stries lines, serrées, coutinues de la base au sommet. Daus quelques individus, ees stries sont un peu plus grosses, acins serćes, et alors il uaît cnurelles une strie tres-bue; dans le plus arand noabre elles sont égales, arronclies, quelquefois assez régulièrement tachées de gris ou tic blanc iranslucide sur un blanc mat. Le sommet est ordinairement inousse; les stries y sont souvent plus profundos ciu'it la base; l'ouverture est légèreneat oblique, les bords sont Iranclians. Nuns avons Irouvé cet!e espice avee notre Dentale variable. Nous présuzuons qu'elle est de liInde. Elle est longue de jo zosllim.; son dianctue a la base est de 5 millin.

17. Devrare faussc Eolale. Dentalium pseudoentalls. l,ask.

D. testis lereli, suburcusldi, ucuminatí, antice lovorgati, pusticé sulcalt.

L.Asix. Anim.s. vert. tom. J. pag, 345. $n^{n}$. II.

Niobis', Monog. du genre Dent. pug. $58.12^{\circ} \cdot 17$. pl. 3. fig. 21 .

31. Defrauce, davs le Diclionnaire des Sciences zaturslles, tome ij, article Dritale, eu parlaul de celle-ci'; dit 'qu'elle est fendre à sor extrézxité posiérienre. Cela prouve gue M. Defrance a pris me espece de la, section survale pour celle qui r.cus occupe, puisçu'elle ra juasuis la lente josténieure: La Deniale fuusse Eulale a beaucoup ae :apgons a avec l'e.ipèce suivante, la, Dentale lisse, aigis.outre quelle ts: tonjours plis petile

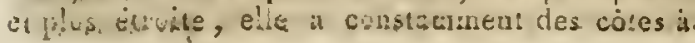

son extrémité, lorsque l'autre est quelquefuis simplemeat suriée an méme endroil. Ces cóles, eu uombre variable, sont aiguës et plus f́levées à l'extrémité; elles dimiuuent insensiblement el se perdent vers le tiers de ia longueur; dans quelques individus, elles se eoptinueut jusque vers le milien, mais cela est rare. L'ouverture est parfiilemens ronde, peu obligue, et ses bords sont lieo tranclians. Nons ne connuissons pas celte esrèce à l'élal vivan!; mais nous la possédons de Grignon, des faluns de la Touraine, desenvirons de Bordeaux, de Sabcalz particulierement. Elle est longue de 25 à 50 millim.

18. Deatart lisse. Dentalium entalis. Lix.

D. testâ tereti, subarcuuld, laevigatâ, continud, albầ vel rubescente.

Lis. Gses. pag. $5736 . n^{\circ} \cdot 4$.

LАак. Ainim. s: vert. tom. 5. pag. $345 . n^{\circ}$. 13 .

Oniv. Zoul. adriul. pag. 192. $n^{\circ} .2$.

Gras, Adratut tom. 2. tub. I.

Pexsaxt, Zool. britan. tom. 5. tab.9. fig. 154.

Listek, Synops. concle. tab. 547. fig. 2. (pessime) et 1056 . fig. 4 .

Bonassi, Mlus. kirk. et recreat. part. 1. fg. 9 . Petтве, Gazuphil. tom. 1. tub. 65. fig. 9 .

Gositierni, Ind. tesl. tub. Io fig.e?

Dahgeville, Conch. tab. 3. fg. K. el tab. -g. fig. a...? ( Fossilss.)

BORxN. Hils. cas. vind. pag. 432. nP. 4.

Mantix:, Conch. cabın. lub. 1. fig. $t$.

Broccur, Conch. subap. pug. $263 . n^{0} .8$.

Scrila, la Tana specul. tab. 15. fig. (mferiore dextrú). el pl. 18. fig. 7.8.

An Dentalium entalis?" Sow. Miner. conch. iab. 7o. fig. $\overrightarrow{3}$.

Buntro, Orycliol. desenv. de Bruxel'es, pl. 8. fig. 'T. An eadem species, fig. 5. et pl. 17. hg. O?

Jaxus Plancus, Conch. min. not.tab. 2. fig. 2.

An Króra. Petrif. tom. 1. part. «. pl.j. a. fir. 1?

Var. A. Noв. Eadem apice mbescente.

Denlalium tarentinum, LAмx. Anim. sans. vert. tom. 5. pag. 345.n $n^{\circ}$. 14 .

Var. B. Eadem albida, rubescente apiceve.subtilissimé struta.

Nahis, Monog. au gentr. Dent.pag. 3j. no. 18. pl. I fig. 7. et pl. 2. fig. 2. (Tres-yrussie.)

Nous avons sous los yeux des cocuilles qui unt servi i .M. Lanarçk pour élahllir le Dentcibum tarentinum; c'est M. Niénard de la Gruye çui tes lui avoit communiquces. Ce savant professear a Lien voulu uous. Ies conlier pour les exarainer de 
nouvcan. Après les avoir compartes ninutieusement, nous avons inutilement cherché leur caracic̀re spéciliłue, ct nous n'avons (rouvé cqu'une reinie rosíe plus forte et pius prolongée vers l'extrémité, tout le reste étant absulunient semblable. Si uous ajoulons yue sur nos cóles de la Manche on de l'Océan on tronve très-souvent rette variẻté rose de la Dentale lisse, pêle-mèle avec un tres-grand nombre d'individus de l'espèce, et enfia, si rous disons que unus arons vi l'animal de l'un el de l'autre, el yu'oo n'y aperceoit pas la plus petice dillérence, on sera forcé de convenir qu'il Éloil nécessaire de réunir les deux espuèces.

Une antre espece, que l'on jninòra probablemeut aussi à celle-ci cornne variété de localité, est le Dentalium arietimun de Linué, que nous n'avons pu nous proenrer, et que nous n'avons trouvé dans aucune colleclion. Mlais daprès ce qu'en dit Ginclin, elle ne paruit en difféces essentiellement que par la taille, jui est beancoup moindre, ainsi que par un pen plus de courhure. La Dentale lisse est de taille médiocre, assez tortement courbée, assez large à la base, blanche on grisattre, sonvent eintée de rose au sommet; elle est cutièrement lisse, présentant ynelquefois des stries d'accroissement; son extrémité postérieure, le pius souvent acumince, est quelquefois tronque e, alors une surlace plane s'y voit, et sur quelques indivilus, on rexarque un petil tube qui fait saillie hors de l'ouverture, et

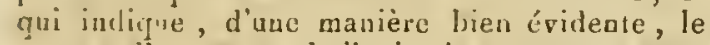
passage d'un organe de l'auimal par cette ouverlure. L'ouverture de la base, qui est assez grande, est parfaitemeat circulaire; ses bords sout tranchans.

I,a variélé $B$, que M. Lamarck avoit indiquée par son Dentalium tarentinum, se troùve aussi bien dans les individus entic̀rement blanes, que dans ceux qui ont l'extrémité rose : ce qui donne un molif de plus pour contondre les deux espèces. Celle variété se reconnoil aux stlies longitudinales très-lines, visibles seulement à l'aide d'une loupe, qui sont à son extrémité postérieure. Cette espèce, à l'état frais, se trouve dans presque tout l'Océan europécn et la Néditerranée. A l'ćtal fossile, elle se trouve en Italie, dans le Plaisantin; en France, aux environs de Bordeaux et à Dax, dans les fáluns de la Touraine, à Hauleville près Valognes, et aux enviróns de l'aris à Grignon. Ce lait d'analogie parfaile viendra augmenter la liste de ceux que l'on connoit déjä. Celte espc̀ce est inugue de 44 willita., et large de 5 à la base.

19. Dextale polic. Dentalium politum. Irsis.

D. testâ teneti, suburcuatá, albidà; striis anmularibus confertissims, tenuissinis.

Liss. GuEL. pag. $37.77 \cdot n^{\circ} \cdot 7$.
LA木к. Anim. sans vert. tom. 5. pag. 549. $n^{\circ} \cdot 17$.

Onw. Zool. adriat. pag. 192. no. 3.

Mantrir, Conch. cab. tom. 1. tab. 1. fig. 3. $a$ ?

Guactigra, Ind. lest. tub. 10.fig.f.

Rumpa. Mhus.tab. 41.fig. 5.

Bonns. Tést. mus. casar. 2'ind. pug. 433. $u^{\circ} .5$.

Nolis, Mlonog. du genr. Dent. pag. 4r. $2^{\circ} \cdot 19$. pl. 2. fig. 17 .

Grande ci Lelle T)entale assez furtement courbé, pointue, polic el brillante, d'un Jlabe de lait pur, subdiaphane. Quoique Groelin dise quielle est quelquefuis rosátre on présentant des auncaux repts et blancs, nuns n'eu avons jamais vu de ces conleurs. Nous en avons cependant exaniné un assez nuand nonise pour pourvoir constater ces nuances si elles enssent existées. Des stries trèsuombreuses, lransverses, sensibles à l:ocil tu, courrent toute la coquille depuis la base jusçu’au sommet; elle ne sont print rígulièrement espacries, les unes sont plus grossičics que les atutres, ce qui fait voir qu'elles sunt dues à des accroissemens murlipliés; le sominet est fort aign, ue prérente jamais de stries longitudinales; Pouverture est oblique, les bords sont très-traurhans e! minces. Celle espece, qui se trouve particulièrement dans les wers de l'Inde, est longue de 67 millim. ( 2 ponces et demi); son dianiètre à lit base est de 6 millim.

2o. Dentaíe de Dufresue. Dentalium Dufresnii. Nов.

D. testâ tereti, ancuatì, larvigatâ, continuà, acuminatâ.

Nов. Monog. du genr. Dent. pag. 42. $n^{\circ} \cdot 20$. pl. 3. fig. 18.

C'est à M. Dufresne, préparaieur en chef du cabinet du Nuséum d'histoire naturelle, que l'on doit la connoissance de cetle espèce, et nous nons plaisons à la lui dédier. M. Lamarck avoit cru y tronver l'analogre de son Dentalium nigrum, mais par les motifs que nous avons exposés précédemment, le Dentalium nigrum étant corné et bien probablement l'élui d'une larve d'inscete, nons l'avons rejelé du genre. L'espèce prise pout son analngue est une véritable Denale i test calcaice, nous la conservons : elle est de taille médiocre, fortement courbée, pointue, lisse, sans aucunc trace de stries soit longitadinales, soit transversales; elle est éltoite el sa base est peu large; l'ouverture est parfaitement circulaire, à bord minces el tranchans; elle est fossile de Marcigni en Bourgogne. Elle est longue de 22 millim., et large de 2 et demi ì sa base. 
zI. Dextale translucide. Dentalium translucidum. Nов.

D. testâ tereti, subrectâ, translacidâ, hyalinâ, glalierrimâ, nitidâ, subviridulâ.

Nов. Monog. du genr. Dent. pag. 42. no. 21. vl. 2. $f_{g} g .26$.

Quoique vitrée et transparente, nous ne ponvolns rapporter à cetle espicie que le Dentalium sitreum de Linné, qui est lossile et que nous ne conuoissons, aussi bitu que M. Brocchi, que d'après l'ouvrage de Schrieter, où elle est indiquće d'une nanière trop impartaite pour qu'on puisse la rapporter à unc espèce conuue. Ta notre est vivinte, et nous la comuoissons par la collection de M. Duclos, qui a bien voulu nous la confier; elle est de taille médiocre, brillante, transparente, d'un jaune-verdattre comme de la 'corue blande; elle n'est point élaslique, llexible ni comée; la matièce est calcaire et solide, sans stries quelconques. Sa patric m'est inconnuc. Filie est longue de 25 millin.; son diamètre à la lrase est de 2 millim. el dewi.

22. Dentale lactée. Dentalium lacteum. Noв.

1). lestâ tereti, subarruatâ, lacpigatissimâ,

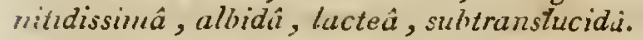

Noв. Monog. du genir. Dent. pag. 42. no. 22. pl. .. fig. 28.

Cetre espèce se reconnuit assez facilement, uruaiquon soit porté à la coufuadre a vec la Dentalium entalis, étant lisse comme elle; pais ce caractère stul ne pelt sullire, et on la distingucra à sa taille, qui esı taujours moindre; ì son diamètre, qui est proporlionnellement plus pelit; * sa couleur laiteuse et subtransparente invavialsle, ce qui ae se voit janais dans l'entulis; au peu d'épaissem de son lest; entin, en ce qu'elle ue présente jamais de stries à son extrémité, conne la variélí de l'entalis, et qu'elle est constanreat lisse et brillante. Cette coquille vient de de l'Inde, et celle différence de localité est un molif de plus pour la séparer de l'espèce avec liqquelle nous venons de la comparer. Elle est lougne de jo milliw.; clle n'a que 2 millim. et de ui à sa basc. Noв.

23. Dextare inceraine. Dentaliun incertum.

D. testâ lereli, angustâ, subarcualâ, apice acutissımi i, lovigatí, nitidâ.

An Dentalium nitens, Sow. Miner. conch. pl. 7o.fig. 1.2?

Nов. Honog. du genr. Dent. pag. $42 . n^{\circ} \cdot 2 \overline{5}$. p.. 5. fig. 17 .

Nous ne connoissons celle espèce qu'à l'état fossile : c'est surtout aux environs de Bordeaux gqu'elle se trouve abondamment; gous l'avons aussi renconirée aux environs de Paris, spécialemenl à Naulclle près Houdan. Ses caraclères sout assez vagues et assez incertains; elle a presque la lorme du Dentalium pseudo-entalis, mais elle n'en a pas les stries; elle est lisse comme l'entalis, mais clle est beacoup plus ćroite, plus courbée et plus pointue; elle a aussi des rapports avec l'especce précédunte, cependant elle s'en dislingue par plas de conrbure, pal une plus grande arille, par un sonutet plus aign et pal plus d'épatisseur dans le tesi. 'Toutes ces ressemblances on dú laisser du donte dars notre délermination, et il est probable que, lurscyu'on aura en asse\% grand nombre le Dentalium lacteum, qu'on y réunira celui - ri comme variété, ce que nous n'avons pu taire, n'ayaut eu de ce dernier qu'une Irop petile quanité a notre disposilion. Longuest 45 millim., largeur is la base 3 millia.

24. Destale rongeâlte. Dentalium rubescens. Noв.

D. testû tereti, subarcuatâ, translucidá, rubescente, lorigatá, acuminatâ; extremitate intùs sulco dorsali.

Nов. Munog. du genr. Dent. pag. 43. $n^{r}, 24$. pl. 2. fig. 23. 24 .

La Dentale rongcâtre pent servir de passage ì la section suivante, où sont réunies les espéces Cendues postériearement; la fente n'existe pas encore ici, mais elle est in diquée à l'iutérieur par un sillon dorsal médian, as ez court, qui est creusú dans l'épaisseur da test saus le fendre à l'extérieur. Celle disposition pent servir à fuire reconnoîtrc l'espèce avec la plus grande facilité; elic est de plus d'un rouge briqueté peu foncé, translucide, trẻs-lisse et lic̀s-billante; la courbure est peu considérable; sun ouverture bien arrondie, un peu oblique et ses bords très-lranchans; on n'apercoit sur toute la surface aucune race de stries, soit lungitudinales, soit transversales. Ayant trouvé cette espèce avec le Dentulium dentalis et d'autres coquilles de la Méditerranée, nous pensons qu'elle est de cette mer. Elle est longue de jo millim., sa base à 3 millim. de dirmètre.

25. Dentale double. Dentaliunt duplex. Defr.

D. testâ teneti, angustissimâ, subcylindricî, exinemitate duplicatis.

Defasuce, Diction. des Scienc. nat. tom. 10 . pag. 71 .

Non. Monog. du genr. Dent. pag. 45. $n^{\circ}, 25$. pl. 4. fig. 9. 10.

Nous avons fai: observer, en parlant du Dentalium entalis, qu'il arrivoit quelquelois que la coquille étant cassée à son extrénité pustértenre. l'animal reproduisnit un petit tube qui sembloit I sortir du plus graud, mais qui est soudé an pour- 
tour de l'ouverture postérieuro de celle-ci : ce qui n'est qu'icciclentel dans celte espèce devient un caractcie constint dans celle qui nous occupe. Elle est très-étroite, aciculaire, subcylindrique, le plus souvent tronquée an sommet, et de cette troncalure nait, de l'ouverture postérieure, un tube cuaıt, d'un dianètre beancoup plas petit et qui semble sollir du plus grand. Celle coquille est entièrewent lisse, pen coubée et diminuant très-peu de la base au sornmet. Nous ne la comoissons que fossile des environs de Paris, à l'aruez et ì Mouchy-le-Clıâtel, daus le calcaire grossier. 11. Delirance dit qu'il iguore si elle est onverle aux deux bouts; uous nous en sommes assulé en passant un crin au travers. Le plus grand individu que nous counoissons a 20 unillim. de longuenr, et I millim. de diamètre à sa base.

26. Dextale bicariuée. Dentalium bicarinatum. Nos.

D. testi tereti, angustissima $\hat{a}$, subrectij, ovatosubcylindricâ, intius duabus carinis oppositis instructis.

N⿴囗в. MIonogr. du genr. Dent. pag. 44. pl. 4 . fig. 16.17.

Voici une des espèces les plus singulières que nous connoissions; elle est petile, très-élroite, presque aussi large au sommet qu'à la base; sa courbure est presque nulle; elle est lisse, brillaate, marcquée légèrement par des accroissemens; elle n'est point ariondie, mais ovale, dans son conluur, et quoique l'extrémité postérieure, a ssez large, se termiue par un trou unigue, on voit dans sa coupe Iransversale qu'elle est muaie dans toute sa longueur de deux carènes opposćes qui répondent à l'aplatissement des deux còtés. Ces carènes sont plus proéminentes vers l'extrémité fostérieure; elles diminuent insensiblemént jusque vers l'ouverture, où elles disparoissent. L'ouverture est ovale, oblique, très-mince et àt bords tranchians. Nous avons découvert cette espèce singulière dans les sables de Parnes et de Monchy-le-Chitel, où elle est assez rare. On pourroil cruire que l'organisation de cette Dentale est le résultat d'un accident individuel; mais nous pouvons aflirmer çu'il n'en est pas ainsi, puisque nous en avons vingt individus. Le plus grand d'en!re eux a 18 nillim. de longueur, et I millim. dans son grand diauetre à la base.

27. Dextans striće. Dentaliunt striatunı. LАак.

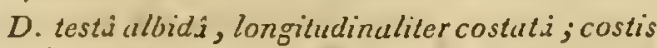
crobris, obtusis, subaqualibus; extremitale postici profunde fiss.i.

LAur. Anim. sans vert. tom. 5. pag. 344 . $n^{\circ} \cdot 9$.

Nов. Monog. dugenre Dent. pag. $44 . p l .4$. fig. 4.5.

Hist. Nut. des Vers. Tome II.
Il étoit impossible de confondre plus long-temps le Dentalium fossile, đui n'est janais feudu postéricurement, el celui quil l'est constamment. Les autres caracteres sont tellement dillérens, que leur séparation est des plus faciles. C'est à la complaisance de M. de Rivoli que anous devons d'avoir pur rectilier cetle erreur, car d'après la collection du Muséum, les coquilles fossiles qui sont éliquctées sous le nom de Dentalium striatmm sunt dillérentes, non-seulement de l'espéce vivante, mais encure du Dentalium fossite que M. Iamark y rapporte. liespèce qui nous orcupe est grande, blanche, presque droile, présentant douze à qualorze grosses cótes continues du sommet à la base; elles sont arrondies. Entre chacuae d'elles se remarque une côte plus petite ou seuleurent une strie pen saillante; le sommet un peu pointu; il présente sur la parlie médiane el dorsalc une fente large et prolonde, plus large antérieurement que postérieurcment; ses bords sont coupés ubliquerent aux dépens de la face interae; l'ouverture est grande, peu oblique, ses bords sont peu tranchans; quelques s'ries transversales indiquent des accroissemens. Celle coquille est longue de $7^{3}$ millim., et large de 5 à la base.

Nов.

28. Dentase grande taille. Dentalium grande.

D. lestâ magnâ, tereti, subarcuatâ, striatâ; striis uumerosissimis, confertis, tenuibus; fissur. posticali profundi, angustâ.

Noв. Monog. du genre Dent. pag. 45. pl. 3. fig. 1. 2. 3.

Ce sont des tronçous plus ou moins complets de cette belle et grande espèce, que A. Lamarck a pris pour la même que la précédente. Il esı bien certain que si, comme nous, M. Lamarck en̂t eu quelques individus entiers, il les auroit bien dislinguls de tontes les espćces connues. Celle-ci, qui pirvieut à la plus grande taille, est bien facile à reconnoître; elle est peu courbée, conte couverte de stries fines et nombreuses qui s'aplatissent vers l'ouverture, oì elles sont tonjours moins saillantes qu'au sommet; elles ne sont point coupées par des stries transversales, si ce n'est quelques-unes assez rares qui marquent les accroissemens. Le sommet n'est pas très-pointu; il l'est plus que dans l'espèce précédlente; il présente coustamment une fente dorsale médiane profunde, mais étroile et également large dans tuute son élendue. L'ouverture est légèrement oblique; ses bords en sont très-minces et très-tranchaus. On ı eraarque sur quelques iudividus de cetie espèce ua appendice au irou postérieur' elle replésente le peit tube que nous arons fait observer it l'exirénité du Dentalium entalis; seulement, supérieurement, cet appendice est fendu de la méme manière cyne le reste. Nous retrouvous la wéme disposition dans d'autres espèces; cela est L * 
accidentel et non spécifique. Le Dentalium grande est long de II centimètres; il n'a que 9 millim. de diamètre à la base. Nous ne la counnoissons que fossile et senlement des environs de Paris, de Grignon, de la Chapelle près Senlis et de Valmondois.

29. Dexraze à courte fente. Dentalium brevifissum. Nов.

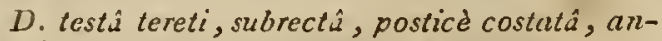
ticè lcevigati, costis tredecim ad sexdecim, obtusis, extremifate eminentioribus; rimulấ angustî, abbreviatî.

Noß. Monog. du genre Dent. pag. 46. pl. 3. fig. 15.14 .

Cetle espèce est grande, peu courbée, assez large à la base; son sommet est un peu pointu; elle est chargée de treize à seize côtes coutinues du sommet juscrue vers l'ouverture; plus élevées au scamet, elles s'élargisseat et s'aplatissent insensiblement, et elles disparoissent entièrement avant d'y parvenir; elles sont lisses, arrondies et obtuses; des stries transverses d'accroissement sont éparses irrégulièrement dans la longueur de la coçuille; elles se multiplient beaucoup vers l'ouverture, à mesure que les côtes disparoissent; elles sont très-fines, à peine perceptibles à l'œil 17u. Nous avons l'obligation à MI. Defresne de placer convenablement celle coquille dans la section qui lui appartient. Nous n'en avions eu que des morceanx incomplels; nous en avons trouvé un bel individu dans sa collection, nous l'avons fait figurer. Il nous a appris que l'espèce étoit fendue; la feute est dorsale, fort courie et fort étroile. Celle espèce est lougue de $6 \mathrm{i}$ à 60 millim., et large de 6 millim. à la base. C'est aux environs d'Anger's principalement que se rencontre celle espèce. On la trouve aussi, mais en manzais état, dans les faluns de la 'Touraine. Nов.

Ђ̆o. Dentale substriée. Dentalum substriatum.

D. testâ tereti, subrectá, anticè laevigatâ, poslice leviter striatâ; striis nsinutissimis; rima $a b$. breviutî, subangustâ.

Dentulium fissura, Sow. the Genera, $n^{\circ} .15$. fig. 3. 4 .

Nсв. Monog. du genre Dent. pag. 46. pl. 4. fig. 1. 2.

L.e Dentalium fissura de M. Lamarck étant une espèce entièrement lisse, beaucoup plus petite et d'une contbure diff'́rente, il est évident que le défisut de figure aura trompé M. Sowerby, qui n'anra cu pour se diriger que la phrase caractéristique; elle dit cependant : testí lcevi, subarcuculá, ce qui auroit pu l'empêcher de confondre nue coquille presque droile et striée au sommet. C'est iudubilablement l'espèce que nous allous décrire, que M. Sowerby a prise pour la fissura. Elle est grande, peu courbée, étroite, tout-à-fait lisse dans les deux liers antérieurs de sa surface, présentant des stries fines et peu saillantes à son extrémité postérieure, plus ou moins nonbreuses, plus ou moins prolongées, selon les individus, mais passant rarement le tiers inférieur de la longnear. Une fente plus large et un peu plus profonde que daus l'espèce précédente, se voit à l'extremité sur le milieu de la face dursale. On vait, par la figure de Sowerby, qu'elle est susceptible, comme le Dentalium grande, d'avoir des appendices. La longueur des plus grands individus est de 80 à 85 millim.; ils ont 7 millim. de diamètre à la base. Nous ne connoissons cette espèce qu’à l'état fossile, et seulement dans le basin de Paris, à Parnes, Chaumont el la ferme de l'Orme.

31. Dentale demi-striée. Dentalium semistriatum. Ков.

D. testầ tereti, subarcuatâ, extrenitate posticè recurvâ, striatâ; parte anticâ, lavigatâ; fissurî̀ profundî̀, angustâ.

Nов. Monog. du genne Dent.p. 3. fig. 15. 16.

La forme de cette espèce lui est toute particulière: presque droite dans sa partie antérieure, elle se courbe fortement vers son extrémilé. Elle offire constamment huit à dix stries très-fines, peu saillantes, qui parviennent, en diminuant, jusque vers le milieu de la coquille on un peu plus baut, où elles disparoisseot eutre ces stries principales; à l'aide d'une forle loupe, on en aperçoit deux ou trois beaucoup plus fines, qui disparoissent a rant les premières, ou qui, sur quelques individus, se prolongent jusque vers l'ouverture. Celle-ci est assez grande, un peu oblique, ayant des bords très-minces et très-tranchans; la fente est parfaitement médiane et dorsale; elle est assez profonde, mais fort étroile; l'extrémité est priatue et fragile, et lorsqu'elle est cassée an-dessus de la fente, ce qui se voit quelquefois, on seroit alors porté à confondre ces individus mutilés avec le Dentalium pseudo-entalis, qui n'est jamais fendu. Celle espèce se irouve fossile, avec la précédente, à Parnes, Chanmont, Moucliy et Senlis. Elle est longue de 40 nillim.; sa base est large de 5 millim.

32. Dentale coupée. Dentalium sectum. Ков. D. testâ tereti, angustâ, subrectâ, albid $\hat{i}$, subtranslucidi, posticè tenuissintè striatì, obliquè sectâ; rimá angustá in sectione.

Nов. Monog. du genre Dent. pag. 47. pl.4. fig. 12.13 .14 .

Il sera loujours impossible de confondre cette espèce avec une autre, lant ses caractc̀res sont tranchés et faciles ì saisir; elle est peu courbée, 
Étroite, subcylindrique, blanche, translucide, trìs-finement striée postérieurenent, lisse antérieurement; stries nonbleuses, serrces, capillaires, imperceptibles à l'ail nu; extrémité postérieure non pointue, coupée obliquement da côté du dos; une section oblique, beaucoup plus petile du côté du ventre, vient rejoindre la première; la lénte postérience ne dépasse pas la hauleur des deux seclions; elie se voil foiblement sur la fuce ventrale, parce que la section est très-courte; elle esi plus prolungée sur la face dorsale, parce rue la section de ce côté remonte flus haut; l'ouverture est étroite, mince et tranchanle dans ses bords. Nous présumons que celte espèce vieut des Iudes, l'ayant eue avec d'auires espèces et des cocuilles de ce pays. Elle est longue de 26 uillim.; elle n'en a que 2 de diamètre à lo base. I,IN.

53. Dextale ivoire. Dentalium eburneum.

D. testâ tereti, subarcuatâ, nitidâ, acutissimâ, striis annularibus, regularibus, plus minusve remotis; apice fissurî tenuissima praelongâ. Nов.

Lis. GaeL. pag. $3737 \cdot n^{\circ} \cdot 9$.

1.asx. Anim. suns xert. tom. 5. pag. 346. $u^{\circ}, 18$.

Ax Schreter, Einlhint. in conch. tom. 2. tab. 6. figs. 17?

Sowersy, the Generis of schells, etc. $n^{\circ} .15$. fig. 6 .

DeFr. Diction. des Scienc. natur. tom. 15. $p a g \cdot 72$.

Var. A. Nов. testá angustiore; striis annularibus, creberrinis; fissurâ longziore.

Dentalium arcuatum, Sow. loc. cit. fig. 5.

Nов. Mlonog. du genr. Dent. pag. 48. pl.5. fig. 8. 9. 10. 11 .

Si on examine avec quelque soin les deux fizures citées de Sorverby, on s'apercevra bientố qu'il a donné un nom spécifique à une simple variété de l'espèce, ce cqui nous permet de l'admettre à titre de variété seulement. Le Dentalium eburneum est sans contredit un de ceux qui se distingnent le plus facilemen : il est assez grand, arcjué, brillant, poli, pointu, assez étroit, blanc de lail, subdiaphane, composé d'une série d'anneaux subiransverses, obliques, séparés les uns des autres par une strie assez profonde, bien apparente, oblique, transverse comme eux; l'extrémité, qui est très-pointue et très-profondément fendue, a quelquefois un tiers de la longueur totale; cetle fente est capillaire, ì peine sensible à l'œil ou. La variété diffêre en ce qu'elle est laujours plus étroite et que les anueaux dont elle est formée son' plus étroits et beauconp plus multiplićs; la fente est aussi un peu plus profonde.
On troure celte espèce vivante dans les mers de l'Inde, er son analogue identicgue a Grignon, I'arnes el beaucoup dautres licux dus envirous de Paris. Nous ne connoissons la variété qu’à l'etat fussile; les grands individus ont jusqu'à 55 milliuı. de longuens", un diamètre de 4 unillim. is la base. La varićté a une longueur presqu'égale, mais elle n'a pas tout-i-lait 3 millim. de dianètre.

34. Dentale entaille. Dentalium fissura. LAMK.

D. Testâ tereti, subarcuatâ, angustî̀, subulatâ, lavissimâ; fissurâ temuissimâ, dorsali posticá.

Lasrk. Anim. sans vert. tom. 5. png. 856. $n^{\circ} .20$.

Nов. MIonuğ. da genr. Dent pus̆. 43.pl. 4. fig. 6.7 .

Le Dentalium fissura, anquel nous ue ponvous rapporter le fissura de M. Sowerhy, comme nous l'avons dit précédemment, est une coquille de taille médiocre, entièrement lisse, brillante, légèrement arquée, très-pointue, étroite, subtrausparente, ne présentant pas même de stries d'accroissement; son extrémité est fendue dans la parlie médiane de la face dorsale; la fente est prolonde et étroite. Dans quelques individus elle est prolongée par le tube fendu que nous avons remarqué à plusieurs autres espèces; l'ouverture est petite, peu oblique, très-mince et très-fragile. Lindividu qui a servi à M. Lamarck pour établir l'espèce, est fossile de Grignon : c'est cet individu qui, grace à la complaisance de M. le duc de Rivoli, est figuré daus nos plancbes. M. Michelin, amateur dislingué, nous en a communiqué depuis quelques inclividus du dépôt coquillier de Monbmirail; et enfin, nous possédons l'analourue vivant que nous avons trouvé avec des coquilles de l'Inde. Cette espèce est longue de 32 millim. , elle est large de 3 millim. à la base.

35. Dentale acumiuée. Dentalium acuminatum. Noв.

D. testâ tereti, minutâ, subrectâ, acutissimâ, lavoigntấ; fissurâ capillari, profundí.

Nов. Monog. du genr. Dent. pag. 49. pl. 3. fig. 19. 20.

Cette petite espèce est folt remarquable; nous avions élć d'abord porté à la regarder comme de jeunes individus de l'espèce précédente, mais en ayant vu un certain nombre d'individus constamment les mêmes, nous avons reconau gu'ils pouvoient conslituer une espèce distincte; elle est pelite, Irès-lisse, brillanie, pointue comme une iiguille postérieurcment; la base est assez large, bien plus large proportionnement que dans de plus grandes espèces; l'extrémilé, quoique trèsfine, est néanmoius converte par une fente méL $2 *$ 
diane et dorsale. Celle fente est profonde, mais trc̀s-étroite, capillaire, nou visible à l'œil nu. Nous arons trouvé celle coquille dans les sables de Parues et de Mouchy-le-Chátel, dans le J)assin de Paris. Elle est longue de 15 millim., et large de 1 millim. et demi à la base. LiN.

36. Deñtale nébuleuse. Dentalium nebulosum.

D. testâ albidù, lcevissimâ, subarcuatâ, extremilate posticâ maculatâ, viridulì, subtilissimè striat $\hat{\text {; }}$ maculis albidis, opucioribus; fissurî postic $\hat{\imath}$, laterali.

Lis. GmeL. pag. 3738. no. I1.

Nов. Monog. du genr. Dent. pag. 49. pl. 2. fig. 20.

Nous conservons quelques doules sur l'ideatité parfaite entre la coquille que nous signalons ici et celle indiquée par Linné; comme il ne cite aucne figure, nous a'avons pu nous guider que jar sa plirase caractéristique, et elle n'indique pas le caractère essentiel. Elle est d'uo blanc laiteux, subdiaphane, peu courbée, lisse, brillante, ayant ì son extrémité des stries courtes, excessirement fines, visibles seulement à une forte loupe : cette extrémité est plus souvent d'une teinte légèrement verdátre ou jaunâtre; elle préseate sur cette couleur des taches en zig-zag plus ou moins régulières, d'un blanc opaque; ces taches grossissent en se confondant insensiblement ou en se perdant vers le milieu de la coquille, et quelquefois plus laut, et disparoissent tout-àfait. Louverlure n'est pas fort grande; elle est 11ès-mioce et ses bords sont tranchans. Par uue singularité étonnante, qui fait voir dans presque toutes les circonstances que la nature emploie des transitions insensibles pour arriver d'un élat à un autre, nous trouvons dans cette espèce que la fente postérieure, au licu d'être dorsale et médiane, se trouve rejetée sur le cóté droit. Si nous n'avions eu qu'un seul exemple de ce fait, mous l'aurions regardé comme une anomalie; mais plusieurs se trouvant semblables, ils font voir le passage à l'espèce suivante, qui a la fente postérieure médiane, mais sur la face ventrale au lieu de la darsale, éest-à-dire dans une position dianétralemeut opposée. Linné indique cette espèce des mers de la Sicile. Les individus que nons possédons vienuent à ce que nuus présumons des mers de l'Iode, les ayant trouvés avec des coquilles de ces régions. Elle est longue de 35 à 40 millim., et large de 3 à 3 millim. et demi à la base. Noв.

37. Dextale inverse. Dentalium inversum.

D. testì tereti, subarcuatâ, subulalâ, angustâ, hjaliná, posícè tenuissimè striatì, nubescente, anticè lavigatâ, albidá; fissurâ angustissimbi, profiundi, ventrali.

Nов, Monog. du genr. Dent. pag. 5о. pl. 2. fig. 21. 22.

Nous arons ainsi nommé celte espèce par la singulière position de sa lente postérieure; nons avons vu dans toules les especces fendues que la fissure est sur la face dorsale, et qu'elle est constamment médiane; elle iodique le dianètre perpeudiculaire de la coquille. Nous venons de remarquer dans l'esfrèce précédeule nne anomalie qui fait une premic̀re exception à la règle; celleci en présente une plus forle, dont la première nous a en guelque sorte averti, puisque la lente se tronve sur la face concave ou ventiale de la coquille : elle est donc dans une position diamètrulement opposée à ce qu'elle devroit étre. Outre ce caractère de première valeur, celle espèce en présente d'autres qui pourroient la faire reconnoitre si elle avoit l'extrúmité rompue; elle est d'nn blanc laiteux, subdiaphane à la base, et cette couleur, vers le ınilieu, se change insensiblement en rouge påle, briqueté, également transpareni; de plus, on commence à apercevoir, un peu au-dessous de la jonction des deux couleurs, des stries très-multipliées, mais excessivement fines, qui se voient jusqu'au sommet, qui est trèsaigu; la fente qui est au sommet est profonde, mais élroite; la coquille en géuéral est étroite et assez fortement courbée. Nous en ignorons la pairie. Nous en possédons une vingtaine d'individus qui constatent l'espèce irrévocablement. Elle est longue de 35 millim. et large de 2, ou un pen plus, suivant les individus.

3g. Dextale étranglée. Dentalium strangukztum. ов.

D. testá tereti, subarcuatá, cinereâ, intertuptí, opacá; apertuia courctatâ; tubi mu'gine untico inflexo.

Dentalium comelm, LAмr. Anim. sans vert. tom. 5. pug. 345. $72^{\circ} .15$.

Dentalium coarctatum, Broccri, Conch. subapen. pag. $264 \cdot n^{\circ} \cdot 9 \cdot p l .1$. fig. 4 .

Scirsa, la Vana specul. pl. 18. fig. infer. sinistrorsum.

Plascus, de Conch. min. mot. tab. 3. fig. 2.

Dentalium incrassatum, Sow. Min. conch. $p l$. 79. fig. 3. 4 .

Nobis, Monog. du genne Dent. pag. 52. pl. 2. fig. 28.

Les différens noms qui ont été donnés à celle espèce ont été pour nous un premier motif de n'en adopter aucun, ponr éviter à l'avenir coute especce de confusion. Un second motif plus puissaut encore, qui nous a fait prendre cette délermination, c'est que le Dentalium comeum de M]. La- 


\section{E N}

marck n'est pas du tout la mème espèce qure le corncum de linne; tet comne cèlui-ci n'est autre chose qu'un étui de larve d'insecte, qu'il doit par cela seul être rejeté du genre, nous u'avons pu conserver un num qui auroit indubitablement conduit a l'erreur dans laøuelle M. Lamarck est tombé, et qui ne peut procluire autre chose que de la confusion. Nous avons reconou que le Dentulium strangulatum étoit l'analogue vivant du Dentalium cuarctatum de Brocchi et de l'ancrassatum de Sowerby. Les personnes qui pourront, coume nous, nou-seulement comparer les figures de ces divers anteurs, mais encore les coquilles elles-mêmes, ce que nous avoos fait pour élablir notre opinion, recondoîliout avec nous qu'elles appartiennent à une seule et mêrue espèce, qui a éprouvé quelques légères modilications locilles, d'vì sont venus les dillíreus noms gu'ou lui a dounés. Celte espéce est peu courbée, d'une couleur gïs-cendré, allćnuée à son extrémilé postérieure, rétrécie rers l'ouverture, qui est garnic d'un bourrelet plus ou moins obtus, quelquefuis ayant les bords mousses, et d'autres fois en biseau et tranchans; des sties transverses, serrées, trèsfines, plus ou moins régulières, quelquefois assez grossiêres, interrompent l'unilormité de la surface. L'ouverture antérieure n'est point oblique. Les individus vivans ont été rapportés par Yéron de son voyage aux 'lerres-Ausirales, et les fossiles se trouvent en Italie, à Dax et à Bordeaus; en Angleterre, dans l'argile de Higligate, et très-communémeut aux euvirons de Paris, dans presque tous les lieux vì le calcaire grossier se trouve désagrégé. Sa longueur est de So millim. Scilla en a représenté de plus grands, unais nous pensous que ses figures sont grossies. Noв.

40. Devtane subulée. Dentalium subulutuni.

D. testâ tereti, arcuatâ, angustâ, subulatâ, acuminati, albido fuscâ; muculis nebulosis, fuscis; aperturâ coarctatá.

Nов. Mlonog. du genne Dent. pag. 55. $\mu l .2$. fig. 29.

Quoique cette espèce ait beaucoup d'analogie avec la précédente, on ne sauroil cependant la confondre avec elle; elle est plus grande, plus pointue, plus arquéc, plus étroite; l'ouverture, rétrécie, $\mathbf{n}$ 'a pas un bourrelet si court et si gros; après le bourrelet, Ia lèvre, au lieu de se renverser, se continue, s'amincit et derient tranchaute. Le sommet est beaucoup plus aigu et percé d'un trou plus petit; la couleur est aussi fort différente. Le strangulatum est d'un griscendré uniforme; celui-ci est blanc au sommet, d'un fauve clair dans le reste de son étendue, arec des taches nébuleuses irrégulières de là même coulcur, plus foncée; la surface extérieure est entièrewent lisse; on n'y aperçoit uncune strie, soit longitndinale, soit transversale. Cette espèce, qui vit dans la Néditcrancé, est longue de ji willim.; elle a 2 williw. et demi i la base.

\section{Dextazépaisse. Dentalium crassum. NoB.}

D. testâ arcuatâ, abbreviati, crassâ, septem costuta; aperturé coastati.

Noв. Mlonog. du genre Dent. pag. 53. pl. 4. fig. 20 .

Celle espèce, fort recoarquable, se trouve, avec la suivanie, fossile à Cypli, prés Mons, dans une craie semblable à celle de Mäestricht. Llle a été rapportée derniérement par M. Ducluastel, de Versailles, qui a eu la conplatisance de nous da communiquer ; elle est courle, arquée, épaisse, solide, ayant une litrge base, qui est due plutút i l'épaissenx du test yu'à la grandeur de l'ouverlure; elle prósente sept côtes saillantes, grossières, bien symétriques, dunt l’impaire est sur la ligne médiane dorsale. Ces côtes parviennent dans tonte leur liauteur jusque près de l'onverture, où elles s'eflacent promplenieut dans le bourrelet marginal. Le bourrelet est gros, élroit et sćparé du resie par une légère clépression; antérieurement, il samiucil, devicnt cu hiseau anx dépens de la circonférence externe, et donne lieu à des bords tranchans non retléchis. Des stries irrécrulières et transverses indiquent les accroissemeus de la coquille. Flle a 21 milliun. de longueur, 7 millien. de largeur au bourrelet, et 5 millizo. de diamètre pour l'ouverture.

\section{Drvitale massue. Dentalium cluva. Lains:}

D. testầtereti, clavatâa, subarcuatâ, crassâ; striis transversis, inaqualibus; aperturî̀ cinctà. strictiore. LAMK.

Laмк. Anim. sans vert. tom. 5. pag. 346. $n^{\circ}$. Ig.

Nobis, MIonog. du genre Dent.pag. 54. $\mu l .4$. fig. 19 .

Cette coquille, qu'on trouve avec la précédente ¿ Cypli , aux environs de Mrus, a une forme qui lui donne la plus grande ressemblance avec unc pelite corne de bauf. M. Ménard de la Groye a eu la complaisance de nuus confier, pour le taire dessiner, le plus bel individu de sa collection; depuis, M. Ducliastel nous en a communiqué plusicurs autres du même endroit el de plus graude taille. Elle est assez fortement courbéc; son test est épais, mais moins proportioonellcment que dans l'espéce précédente; le sommet est peu aigu; l'ouverture qui s'y trouve est pttite; la surface extérieure présente des stries irrégulières, inégales, plus ou moins multipliées; un étranglement, surmonté d'un bourrelet margina!, accompagne l'ouverture; ce bourrelet est antérieurement coupé en biseau, pour donner lieo i un bord droit et tranchant. La longueur de cetie 
coquille est de 39 millin. ; son diamètre à la base est de sept millim.; son ouverture a 4 millim. de diamètre.

\section{DENDRITINE. Dendritina.}

Petit genre établi par M. d'Orbigny, dans sa famille des Hélicostègues nautiloides, đui fait partie de l'ordre des Céphalopodes foraminiferes. Remarquables par la forme de l'ouverture, les coquilles de ce genre méritent d'être mises à part, car elles sont les seules qui présentent de tels caractères. Euroulées ṛégulièrement comme de petites Nautiles, dont le dernier tour embrasse tous les autres, elles se terminent par une dernière cloison qui, au lieu d'une ouverture simple, en offre une composée d'un grand nombre de ramifications, qui rappellent assez bien quelques Dentrites que l'on voit sur les agates ou sur les pierres fendillées. $\mathrm{Si}$ on ne voyoit plusieurs espèces de ce genre, on pourroit croire que celte ouvertare est due à quelqu'accident fortuit, d'autant plus qu'elle n'est pas symétrique lorsque la coquille l'est au contraire parfaitement : c'est une anomalie ̀̀ la règle de symélrie dans les coquilles, règle qui jusqu'à présent ne s'est point trouvée en détaut.

\section{CARACTHEES GÉERIQUES.}

Cocquille discoïde, nantiliforme, régnlière, à ombilic simple et nu; la dernière cloison aplatie, yercée d'une ouverture longue, brancliue, muliifide, non symétrique.

Ce genre curieux n'étoit pas conniz arant 11. d'Orbigny; c'est une combinaison de plus dans ces petites coquilles microscopiques qui furent dédaignées si long-temps malgré l'immense travail de Soldani, el dans lestuelles l'observateur troure cependant une fuule de faits intéressans pour la science zoologique. M. d'Orbigny a signalé trois espèces dans son genre Dendritine; nous n'en mentionnerous qu'une seule, celle qu'il a figurée et modelée, les autres nous étant complétement inconnues.

Dendritre arbuscule. Dendritina arbuscula. D'ORB.

D. testá discoideâ, subcarinatâ, dorso angulatô, regulariter tenuissimè striatâ; striis longitudinalibus, concentricis; aperturâ angustâ, ramıusculosû.

D'Orsigry, Mém. sur les Céphal. Ann. des Scienc. nat. tom. 7. pag. 285. $n^{\circ}$. 1. att. $20 \mathrm{~m} .3$. pl. 15. fig. 6.7 .

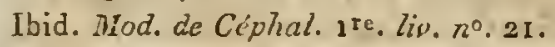

Celte coquille, tout-à-fait microscopique, a tout au plns un tiers de millimètre de diamètre; elle est nautiloide, aplatie de chaoue côte, et. parfaitement symétrique; les deux faces latérales se réonissent sur le dos en formant un angle assez aigu; les centres sunt marqués par un ombilic peu protond, simple, dans lequel les tours précédeus ne s'aperçoivent jamais. Les loges, au nombre de dix ou onze, sont un peu étranglées par autant de cluisons simples et arquées; cliaque loge étant bombée sur le dos, découpe cette partie en festons réguliers; la dernière cloison est aplatie; bordée par le test, qui paroî fort épais, elle présente à peu près daus le milieu, uue fente longitudinale, un per onduleuse, a laquelle viennent aboutir d'autres fentes latérales, multifides, non symétriqnes : toute cetie coquille est couverte de stries fines, régulières, concentriques et peu profondes. Celle espèce se trouve fossile à Bordeaux; les deux autres espèces mentionnées par MI. d'Orbigny sont vivantes, l'une dans la siéditerranée et l'autre aux Antilles.

\section{DENTS.}

Les conchyliologues entendent par ce rnot, toutes les éminences cardinales des Conchyferes, et l'appliquent aussi à celles qui, dans quelques coquilles univalves, se trouvent sur le bord droit. Vojez l'article Coxchylologre dans le premier volume de ce Dictionnaire.

\section{DERMATOBRANCHE. Dematobranchus.}

Geare décourert sur les cótes de Jura, par M. Van-Hasselt, mais !rop incomplétement connu pour le mettre dans la Méthode. M. de Blainville, çui le crite dans les additions et corrections de son Truité de Míalacologie, pense qu'il pourroit se placer à côté des Yolybranches. Voyeá ce mo1.

\section{DIADÈME. Diadema.}

Un démembrement des Coronules fut proposé, par M. Ranzani, pour séparer des deux autres especces la Coronule diadême; ce qui ae nons semble pas aécessaire. Vojez Coronore.

\section{DIADÊME. Diadema.}

Dans son Essai d'une méthode de conchyliologie (pag. 54.), M. Schumacher a proposé de nouveau le genre Coronule, institué depuis longtemps par M. Lamarck sous le nom de Diudéme. Vojez Coroxule.

\section{DIANCHORE. Dianchora.}

Tel est le nom que M. Sowerby a donné à un genre de coquilles bivalves, que nous regardons comue un double emploi des P'odopsides. Voye ce mat et Spoxidis.

\section{DICERATE. Diceras.}

Deluc, le premier, décourrit les singulières 
coquilles qui ont servi à former le genre qui va nous occuper: ce fut daus les couches calcaires du mont Salève qu'il les trouva. Saussure ( $V o y$. dans les Alpes, tom. I. pag. 190. pl. 2. fig. 1. 2. 3. 4.), en faisant la description de cette monlagne curieuse, rapporte les observalions et les figures qui lui furent communiquées par le savaut naturaliste génevois. Depuis, M. GiletLaumond eut occasion de retrouver des cocpuilles analoyues, et dans des circonstances semblables, à Saiut-Mihiel en Lorraine. En juillet 1823 , dans un royage que nous entreprimes pour visiter cetle localité intéressanle, nous en̂mes occasion de voir que les coquilles de Deluc s'y trouvoient avec les mếmes assemblages de corps marins pétriliés, des Polypiers, des Pinnigènes, des 'Térébratules, des Encrinites, etc., avec cette seule différence, que la pâte calcaire qui les denler'me étant plus friable dans quelques - unes de ses parties, on en extrait plus facileusent et plus nettement les corps pétrifiés.

Nous ne pourrions dire si la position géologique des couches qui renferment les Dicérates au mont Salève, est semblable à celle de Saint-Mibiel; mais nous pouvons affirmer que dans celte dernière localité, les couches dépendent de la partie supérieure de la grande furmation oolitique du Jura. Dans d'autres parties de la France, dans les départemens de la Sarthe, de l'Orne et peutêtre du Calvados, on observe une conche contiaue sur plus de vingt lieues d'étendue, où on trouve une Dicérate toujours plus petile, bien probablement d'une autre espèce, et dont on a'a eu jusqu'à présent que le moule intérieur accompagné, si ce n'est des mêmes lossiles qu'au Salève et à Saiut-Mihiel, au moins de celui qui est le plus caractéristique, la Pinnigène. Ce qui est très-remarquable daos ce dernier gissement de Dicérates, c'est que la position géologique est la mêrue que celle de Saiut-Mibiel. 'Tels sont les trois endroits, les seuls connus à ce que nous pensons, oi l'on ait remarqué des Dicérates, et, comme on le voit, ils nappartiennent pas aux plus anciennes couches du globe, comme l'a dit MI. Defrance, dans le Dictionnaire des Sciences nuturelles.

Depuis long-temps Favanne avait figure ( $p l .80$. fig. 5.) une Dicérale, à lacquelle Cliemnitz senl fit attention, encore pour la rapporter maladrojtement au Chama bicornis de Lindé, lorsque - Bruguière, qui avoit vu les types qui ont servi a la figure de Favanne, pensa que l'on pouvoit en faire une nouvelle espèce duus le genre Came; et ce fut sons le nom de Came bicorne, Chama bicornis, qu'il décrivit cetle coquille dans l'Encyclopédie, ne connoissant pas sans doute celle décrite par Deluc et figurée par Sanssure, dás son Voyage des Alpes, trois années auparavant. Lamarck ne crut pas d'abord nécessaire de créer un geure particulier pour les Dicérates, aussi il n'en est fait aucune mention dans le Système des Animaux sans vertebres; nuais un peu plus tard il le créa dans les Annales du Musćum. (vol. 6. pag. 300. pl. 55. fig. 2. a. b.)

11. Cuvier (Règne animal) ne l'adnuit pas, pensant qu'il préseutoit trop peu de dillérence pour le séparer des Cames.

Cependant MM. Schweygner, Defrance, de Ferussac, le conservèrent. Nous ne voyous pas de motifs suflisans qui nous le fasse rejeter, surtout en modifiaut les curactères donaés pát M. Lamarck.

\section{CARACTÉRES CÉNERIQUES.}

Coquille inéquivalve, adbérente, à crochets conioues, très-grands, divergens, conlournés en spirale irrúgulière; lime cardinale très-large, fort épaisse, portant postérieurement sur la valvé droite une forte dent conique, et devant une grande fossette profonde; sur la valve gauche, une fossette posiérieure recevant la dent postírieure de l'autre valve, et devant clle, une grande dent épaisse, concave, subauriculare, reçue dans la lossette de l'autre valve. L'impression muscuculaire le plus souvent est auriculiforme, et se continue en carcene saillante juscyu'il l'extrémitú des crochets.

M. Defrance a cru pouvoir faire de la Dicérate dn mont Sulève, une espèce distincte de celle de Saint-Mihiel; nous ne sommes pas dı mêwe avis, nous la regardons corome une simple variété : il n'en est pas de mêtre du moule de Normandie dont il n'a presque rien dit, et qui nous sembleroit devoir former une espèce distincte. Les Dicérates, avec la forme générale des Isocardes, ont l'irrégularité des Cames, vivant comme elles, et lixées aux corps sous-marins par un des crochets, le droit ordinairement, qui est aussi le plas grand et le plus irrégulier, et sur lequel on aperçoit l'empreinte de l'adhérence qui lixoit la coquille. Nous possédons une valve encore adbérente à un antre corps marin.

1. Dicérate ariéline. Diceras arietina. Lain.

D. test.î ovato-globusâ, crassî̀, pondenosí, condiformi; umbonibus magnis, contortis, utrinquè divaricatis

Lank. Anim. s. vert. tom. 6. pag. 9 t.

Denuc, Voyage aux Alpes, par Sulussure, pag. 19o. pl. 2. fig. 1. 2. 3. 4.

Favanne, Conch. pug. 8o. fig. 1.

Celte coquille est grande et épaisse; elle a les crochets très-grands, tourués en spirale, non carénés sur une de leur face. Nous avons examiné plns de vingt individus de Saint-Mihiel, tous sans exception étoient fixés pa. la valve droite; il en est de même de ceux du mont Salève, quenons 
arous eu occasion d'observer dans différentes colIccions. La dent cardinale gauche est tres-yrande, concare; l'impression musculaire subauriculiforme se prolonge en carène jusqu'au sommet des crocbets. On remarque souvent a la surlace de ces coquilles des parties lisses; cela vient de co quine partie de la concle extćrieure, gui eal r'igueuse, obliquenent_strice, s'est écaillée ct s'ust delaclace ca séparant la conguille de la pierre oit elle éloit incluse.

lous considérerons la coçuille de Srint-alihie!, Lu unvins celle que l'on y troure le plas counoniníracul, comae une rarićlé de celle-ci; tlle n'én dillere réellewent que par la dent cardiunle gुui est moins grande, et par les crochets, qui sout dans un certaia nomlre d'individus moins surbaissés que dans celle du mont Salève. Nuus possédons des individus qui ont jusqu'id 4 pouccs de large au-dessous des crochets.

2. Dicénate gauche. Dicoras sinistra. Nов.

D. testá oblongü, cordıformi, postice subangulutá; umbonibus mininis, inversis; cardune oblique bideritato.

Non. Dict. class. 2'hist. nat. all. $n^{\circ} .8$. fig. 1. a. b.c.

J'avais d'abord pensé que cctte espèce a'étcit qu'uue varićté de la précédeute; l'ayaul observie avec plus de soins, je reconnus anon erreur, et vorci sur quoi je me tonde pour l'établir: elle est plus petite; les crochets ne sout jarpais plus saillaus que les bords; ses valves, el surtuut la plus petite, sont séparées en deux parties iuérales par nue caréne assez aiguë. Elle est a l'iuverse de la Dicérate ariétine, car si l'on met les grandes valies du mèce cóté, les crochets de luae vont de droite á gauche, c'est celle-ci; ceux cle l'iulre voat de gaucle it droite : chez la prewière, c'est par le crocliet de la grande valve, qui ici est du cóté gaucbe, que la cuquille est thace : c'est l’ioverse dans la Dicírale autélide.

Ces caractices seroient sulisans puur itablir celte espéce, mais la charnicre nous en uffre de bien plus certains encore; ce sont méme cenx-lá quii uous ont décidé à faire noe nouvelle cspèce. Uaus la Dić́ralc ariéciae, la cliarnière de la valve gauche présente une grande dent, et à cóté une fossetle de peu de grandeur. Dans la Dicêrate gauche, la mème valie présente deux dents cardiuales; une très-grande, trouquée dans son extrémité antérieure par ume petile fosselte, et qui suit la direction du corsclet; l'autre est placée derrière elle, mais elle est bien plos petite, tt derrière elle est une petite fossette conique, prolonde; la ralse droite ollre, sous le corselet, une fossette, à l'extrémitć de laquelle se trouve une dent isolée, arrondic, en forme d'un petit mamelon; un peu postérieurement se voit une petite fosselte, séparée de la première par uae lérère Elévation : ces deux cavités sont destinfes a recevoir les deux deuls cardiuales de l'aulre valve; derrière elles, et sous la lunule, se trouve une grande deot pyraniclale, subtriangulaire, qui est reçue dans la fusselte correspondante de la valve gauclie.

Arec des caractères aussi tranchés que ccux que nous veauns d'exposer, il seroit ditlicile cle se refuser d'admellre celle espèce, puisque la cbarniere seule, abstraction faite de la torme générule de la coguille, sulfirnir pour la consialer. Nous ne posséduns que deux individus de cetle espéce; l'un dont les ralves sunt réunies par la püte calcaire; l'antre, que je suis parvenu ¿ ouvrir el à vider en grande partie, et clont je posside par couséquent la charnière entière. Le plus grand individu a 2 pouces de large et 3 de long, Ia longueur étant prise au point le plus élevé du crochet de la arinde valve. Nuus aroos recueilli i Suint-Mibiel quelques moules intúrieur's de Dicérates pour les comparer avec ceux de Normudie; quoiqu'ils préselllent des dilfúrences, elles ne wous semblent point sulfisuntes pour établir une truisième espéce : il laudrcit cyue des portions de charbière, ou au moins la lorme da test, vinssent aider is la déteruianalioa.

\section{DICĖRES. Dicerata.}

M. de Blaiuville a proposé celle famille, pour placer des Polybranclies qui riont que deux tentacules : ce sunt les genres Sryllée, 'Tritonie et Thélys. Vojez ces a:irts et Pulybriscars.

\section{DIMORPIISE. Dimarghina.}

M. d'Orbigny a proposé ce geure daus la famille dos Luallostegnes paur une coqualle microscopique singuliere, qui se trouve dans la lléditerranée, el que Solduni avoit figurée parmi les Ortocères; elle présente celle siugularité, de commencer par deux loges alteinantes, et de se terminer par une série unique de loges; toute la coquille est droite. Nous avons observé daus les sables des environs de Paris des coquilles microscopiques fort analogues i celles-ci, mais au lieu d'avoir deux loges alternantes, il $z$ en a truis, égulement surmontées d'une série de liges simples. Devia-1-ou sur d'aussi foibles caractères former un genre pour les coquilles que nous sigralons? Sous ue le pensous pas; cepeudant, en attendant un exumen complet des genres de liéphalopodes microscopiques, dans lesquels nous propuseruns plusicurs changenuens (yoyez CśpaLORODEs), voici les caractères que M. d'Orbigny donue iu geure.

\section{CARACTÉRES GÉXERIQUES.}

Coquille droite, dont les premières loges seulement soat alieranates dans la jeuncsie, et em- 
piléez les unes sar les autres dans le même axe, daos l'äge adulte; ouverture ronde au sommet de l'axe.

M. d'Orbigny n'a indiqué qu'une senle espèce dans son genre.

Disorpaine tuberculeuse. Dimorphina tuberosa.

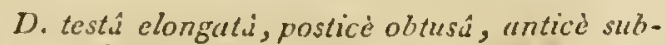
acuti, loculis globosis, lavibus, pusticalibus alternantibus, oppositis, anticas simplacabus, vesicularibus.

Petite coquille microscopique, alongéc, obtuse posléricurement; elle est composée de plusienrs loges obliquement alteraaules : elles sont vésiculaires, globuleuses et surmontées par yuelques loges siaples, Iorizonales, superposćes l'une sur l'autre comme dans les Orthocéres, ee qui indique doux modes d'accroissement dans celle petite coquille, qui a une forme quand elle est jeme, et nue aure lorsqu'elle a pris tout son developpeasut; la dernicre luge se lermioe antérieareasent par an prolongement en poiate, qui porte à son extrémité une très-pelite ouverture ronde. Celle coquille se truave dans la Médilerranée.

\section{DICONCIIA.}

Dans la Métlude de K̈lein, ce mos s'applique à toures les coquilles bivalves. Il représente une association naturelle dans sou ensemble; matis les coupures qu'il y a faites ne sout plus recevables. Les gentes sont désignés dans celle classe par deux mots; le prcmier, D.concha, répété, désigne la fawille, el le secoad le genre : méthode qui u'est plus suivie maintenant daus les bonnes classifications d'histoire naturelle.

\section{DIMYAIRES.}

Dans son deraier ouvrane, NI. Lamarck a partagé les Conchyferes en denx grandes divisions, d'après le nombre des impressions musculaires; if $y$ en a assez constamment une ou deux, d'où les noms de Monomyaires et de Dimyaires. Quoique par ce moyen on rende facile à déterminer la place de beaucoup de genres, il en est un certain nombre, comme les Noules, Avicules, Modioles, etc., qui échappent, pour ainsi dire, à cet arrangement, parce que, quoiqu'il y ait deux muscles, le second est si peth et latisse si rareroen: son implession, que M. Lamarck el ses imitateurs les rangent dans les llonomyaires, tandis que dautres zoologis!es les mellent dans les Dimynires. Cet inconvénient n'est pas le seui de celle division, car elle éloigra beaucoup certaias genres, qui ont des rapports d'organisation arec les Iluitres, par exemple, si ce n'est qu'ils n'ont qu'une inpression musculaite. Lorsque ces Hist. Nat. des Vers. Tome II. geares en ont deux, de là s'elève une question assez iuléressante, doat nous aurons à nous occuper à l'aricle Morrosque, de savoir si ce callactère de derzx nuscles, daus les Molúsques conchyfères, duit lemportersur d'autres, s'il traduit mieux l'organisation que tout autre. Voyez Mollusque.

\section{DIOÏQUES. Dioica.}

A pen près dans le même temps, MM. de Bluinville et latreille jutroduisoient daus la science des Molluscrues cette dénominatiou, quails ont appliquée à ceux de ces arimaux qui ont les denx sexes séparćs daus les individus différens. TYoyez Mollosque.

\section{DIP.}

Un petil Buccin blanc, que les auteurs nont point mentionné dans leurs calalogues, a été

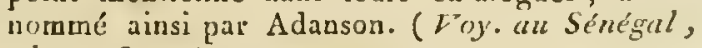
pl. 10. fig. 7.)

\section{DIPIIYLLIDE. Diphyllidia.}

Nous ne counoissons ce genre, proposé par II. Cuvier, que par la conte description quilen a donuée claus le Règne animal (tom. 2, p. 3g5). Elle nous semblc insuffisante pour placer ce geare.

\section{DIPSACCUS.}

Ce genre de Klain (Ostrac. pag. 36) représenteroit assex bien celui nommé Eburne par les allteurs arodernes, si l'auteur a'y avoit introduit quelques Buccins; il l'avoit d'ailleurs caractérisé d'après des principes inadmissibles, la forme extérieure de quelques parties, indépendamment du reste.

\section{DIPSAS.}

Geare proposé par NI. Léach pour dérnembrer des Anudontes quelques coquilles qui ne s'en distinguent que par des caractères d'une trop foible valeur pour constituer un genre. Voy. $\Lambda$ sodonte el Mulette.

\section{DISCINE. Discina.}

11. Lamarck, en atablissant ce genre, a Ǵvidemment fait un double emploi, puisqu'il est le même que celui qu'il avoit proposé sous le nom d'Orbicule. Voyez ce mot.

\section{DISCI'TE. Discites.}

Geare yue nous croyons inutile parce qu'il ne dillère des Nauliles que par son large ombilic, dans lequel on vait tous les lour's de spire. Comase ce n'est que graduellement, par transition insensible, que l'on passe, dans les Nautiles, de ceux qui n'ont point d'ombilic à celux quil'ont très-ouvert, il s'ensuit que, d'après le même 
principe, il fandroit un genre pour cliarge degré, ou, ce qui nous semble infiniment mieux, il ne faut qu’un genre bien caractérisé qui réunisse toutes ces moditications. Foyez Nautre.

\section{DISCOLITE. Discolites.}

Depnis long-temps Mercati (Metallotheca saticana, pag. 240) avoil figuré un corps discoïle que l'on doit japporter à ce genre. Guettard (Mlémoires surles sciences et les arts, tom. 3 . pl. 15. fig. 51. 32) en avoil aussi fait nention, les rapportant aux Camérines, sous le nom d'Hélicites. Burtin (Oryctographie des environs de Bruxelles) en a fiuré uise qui paroil srmblatle à celle de Grignon ( $p l$. 20. fig. 1. a). Fortis (Journ. de Phys. tom. 52. pug. 106. Lettre à Hermann), qui aroit recueilli surles Discolites et les Nummulites un grand nombre d'observations, et qui les regardoit comme des corps intériculs, observalions quil reproduisit dans les Vémoires sur l'Italie, tom. 2, fit menticn, d'une mauière toute particulière de l'espèce que l'on trouve à Grignon. Faujas (Hist. de la mont. de SaintPierre de ilaèstricht, pag. 186.pl.5 f.fig. 1.2), après avoir émis l'opinion des écrivains qui le précédèrent, et après avoir observé que M. Lamarck avoit séparé des Camérines de Deluc, de Fortis, de Guettard, etc., le corps aplati avec lequel on l'avoit mis, pour en faire un polypier, pense que le fossile trouvé à Maëstricht, ayant la même structure, devioit faire parlic du nouveau genre de Polypiers de 11 . Latnarck. Ce savant (Syst. des Anim. sans yert. 1801, pag. 357 . 576) Établit, dans le tableau des Polypiers, un genre $n^{\circ} .19$, sous le nom d'Orbulite, et pag. 370 , dans l'exposition des caractères dı genre, il lui donne le nom d'Orbitolite; et il donne, comme type de ce genre, l'Orbitolite plane, qui est commun à Grignon. M. Lamarck sculit donc l'inconverance de laisser avec des Numaulites des corps qui s'en distinguent éminemment. On ne peut çu approuver sa détermination, et la place qüils occupent est la seule qu'ils doiveat avoir. Ón devra s'étonner, après ce que nous venons d'exposer sur l'historique des Discolites, que Nontfort (Conch. syst. tom. J. pag. 186) donne ce corps comore nouveau. Il est curieux de voir cet anteur, en 18 ro, s'étonner lui-même de ce que las conchyliologues modernes n'ont point parlé de cette coquille fossile, qu'on trouve si fréquemment a Grignon. Nais on admirera mieux l'assurance de Moutfort, quand on saura que c'est à Fortis, et en citant l'ouvrage même où ce: auteur a donné une descriplion trèsexacte de la Discolite de Grignon, qu'il a emprunté le nom de Discolitbe, dout il u'a changé que l'or:bographe.

Nous avons blàmé M. de Blainville, à notre article Discolite du Dictionnaire classique d'Histoire naturelle, d'avoir admis le gense de Mont- fort sans critique et sans observation, comme on peut le roil dans le Dictionnaire des Sciences naturelles; si l'on songe aux grands travaux di ce savant zoologiste, une négligence compe celle-là se concevra facilement, et elle n'en sera que plus excusab!e.

Les Discolites étant de véritables Polypier's, nous en avons parlé parce que, par suite des erreurs que nous avons signalées, ce genre a elé introduit dans les MInl!usques, el que nous avons dû dormer les mnlifs ţui nous le font rejeter. Adınis dans les Polypiers sons le nom d'Orhulite, c'est à ce mot que nous renvoynns, dans le troisième volume de ce Dictionnaire.

\section{DISCORBE. Discorbite.}

Genre que M. Lamarck avoit établi d'abord dans le Système des Animaux sans vertèbres, sous le noin de Planulite; reproduit depuis sous celui de Discorbe, il fut adopté par presque tcus les zoologistes et cnuservé par. MI. d'Orbigny, comme sous-genre des Rolalies. Voyez ce mui.

\section{DISSIVALVE.}

Nontfort a proposé cle donner ce nom à une famille de Mollusques exiraits des Mulivalves des auteurs linnéens. 11 donne le Tarel comme exemple de ce groupe, qui rentre dans la farnille des Tubicolés de M. Lamarck. Celle division de Montfort a'a point été adoptcée.

\section{DITROCIIUS.}

Klein, en instituant ce genre, prit pour caractère la forme en double cône de quelques coquilles, saus s'inquiéter si ce moyen le conduiroil à une coupe naturelle; celle-ci paroil füite avec de jeuries Strombes.

\section{DOFAN.}

Le Dofao d'Adanson (Voy. au Sénég. pl. 11) est une coquille singulière, que Linné et la plnpart des autenrs ont placće dans les Serpules, et qui, d'après Adanson appartient anx Verwels. Voyez ce mot.

\section{DOLABELLE. Dolabella.}

Genre dont on ne connut long-temps que la coquille, ou la figure assez peu reconnoissable de Rnmplius. La cocpuille, d'une forme singulière inusitée parmi les Mollusques, embarrassa, à ce qu'il paroit, les auteurs qui précćdèrent 11. Lamarck, carril n'en fireat nulle mention dans leurs travaux. L'auteur que nous citnas fut le premier qui reconnut les rapports de cette coquille arec celle des Aplysies, quniqu'il a'en connût pas l'animal; mais cette analogie étoit si évidente qu'il a suffi de l'indiquer une fois, pour que tous les zoologistes en reconnussent toute la justesse. 
Le genre Dulabelle fut créé dans le Système des Animaux suns vertebres (1801), el placé dans les Gastéropodes nus, immédiatement après les Aplysies.

N. de Roissy, dans le Buffon de Sonnini, adopta le genre Dolabelle; mais, ce qui nons étonue, cest que le conmoissant mienx que la plupart des zoologistes, puisque l'éron lui avoit conmmiques nae uate furt exucte à son sujet, il l'ait néanmoins séparé des Aplysics par le grenre liunace interposé.

A peu près dans le méxe temps, M. Cuvier publivit, dans le tome 4 des Annales du Musérum, se's observations sur. les Dolabelles; il prouvoil d'une manière incontestable qu'elles ne diffèremt des Aplysies que par un manteau plus serrés sur le dos, et parla cogpille, qui est calcaire au lieu d'être comée; le reste de l'urganisation est tellement semblable, que M. Cuvier a jugé inulile d'appuyer ce lait par des dessins allalomiques, qui naaroient été que des répétitions te ce qu'il ¿ $\nabla$ il déja fait pour les $A_{\text {gl }}$ josies.

On ne lint presque aucun compte du travail de M. Cuvier. H. Lamarck persisia à conserver les deux genres quil plaça dans sa familie des Laplysies de sa Philosopitic zonlogique, avee les Sigarets el les Bulles, it laguelle il rapporia que peu de changemens daus l'Extrail du Cours, el qu'enlin, plus éclatrés sur la nulure du Sigarel et des autres genres, il réduisit aux deux seuls genres Ap! jsies et Dolalielle dans son dernier auvrage. M. Je Btainville, dans ses divers travaux sur les Mollusques, adopta le genre qui no:ıs occupe, tout en convenant qu'h a une prande analogie avec les Aplysies. MI. Cuvier, ébranlé peut-ét:e par lés opiuions de ces denx zoologistes, changea sa premićre inanière de penser pour adopier la leụr, et admeltre les Dulabelles à tiire de genre dans la famille des Tectibranclues, eatre les Aplysies et les Nutarches. M. de lierussac, dans ses Tableaux systémutiques des animuar mollusques, érigea les 'lectibraoches en ordre, et fit des quatre genres Aplysie, Dolabelle, Nolalche et Actéon, sa famille des Dicères : nous-mime, entrainé par les travaux de tors les auteur's que nous venons de citer, avons conservé au genre Dolabe!le sa valeui générique, lorsque nuns coopésâmes ì la rédaciion des arliciles du Dictionnaire clussique d'His. corre naturelle. Depuss, deux auseurs justement estimés dans la science, l'un dalas ses Familles malurelles du Règne animal, l'autre dans son Thuite de Alalacologie, ne firent que unors contirner de plus en plus daus lopinon gínćraleinent aduise, puisqu'elle étuit également la leur. C'est en snivant ces erremens que nous fimes, dans ce Diclionnaire, l'article Apqusie, depuis l'impression daqquel a été publié une belle monographie de la famille des Aplysies par M. Rang.

L'iuteur, sur des faits nombicux et nouveaux quo l'ın duit à ses recherches, revient à la prewièere idée de M. Cuvier; et, ruontratat un passagre inseusible entre les deux genres, il est conduit à les réunir par l'impossibilité oi il se trouve de pouvoir les sćparer nellement. La tran. silinn enlre les deux gentes se remarque nonseulenent dans la forme des animanx, qui deviennent de moins en moius tronqués postéricurement, mais encore dans la forme el $l_{2}$ consistunce des coquilles, qui, de presque entièrement culcaires qu'clles éloieut, devienneut d'abord cornces, puis pellucides, et linisscut par disparoitre.

Nous avons dit dins plus d'une occasinn, que ce passage, insensible dans les caractòres d'animax yui ne different que par des accilens de peu de valeur, étoit la meilleure prenve quiils formoient duns leur ensemble un groupe ou un genre bien naturel. C'est en fiisant de continuels efforts pour tronver ces pasanges. pour former de ces groupes, que diantres liens liennent entre cux, que l'un finira par simplilier et rendre taturelle la Méthode, gui, encore anjourd'bui, présente un grand nombre de ces lacunes que plus turd des iravaux serublables à cenx de MI. Ring combleront.

Si nous avions connu le travail de M. Rangr plus tôt, nous aurions traité nolre article Apussie. sur un autre plan : à l'exemple de M. Rang, nous $y$ aurions mis les Dolabelles. Pour ne point laisser de lacunes diuns l'étude de ces animax curicux, nous caractériscrons ce genre comme section ou sous-genre du premier, et nous indiquerons les especes assez nombreuses qu'il contient.

\section{CARACTÉRES GÉNERIQUES.}

Animal semblable pour l'urganisation à celui des Aplysies, ayant le corps renllé en arrière, Lronque ou terwiné en pointe. Les bords du unanlealu serrés, courts el impropres à la natation. Coquille calcaire, dolabriforme, subspirale, triangulaice ou suligguadrangulaire.

Les Dolabelles se distinguent des Aplysies, quelques-unes par deux caracières, les aulres par un seul, ce qui a délerminé M. Rang à les partager en deux sections: dans la première, il place celles qui ont la partie postérieure du corps lort épaisse el terminée par une troncature large, oblique et circulaire; ces espèces sont celles dont la coquille, très-calcaire, est triangulaire. Dans la seconde section, lanional se termine postérienrement par un prolougemeut pointu, et ressemble par consécruent tout à-fait aux Aplysics; il en differe seulement par la coquille, qui est calcaire et subquadrangulaire.

Les mours des Dolabelles different de celles des Aplysies, en ce qu'elles ne nafent pas comme elles, cqu'elles n'ont d'antre locomotion que celle 
que leur procure un large pied; elles ont beaucoup moins d'activité, se cachent dans le sable ou la vase, où elles se mettent à l'abri de leurs ennemis, et recherchent les petits animaux marins qui, avec les parties tendres des fucus, font leur nourriture.

I. Dorabelle de Rnmphius. Dolabella Rumphii. Cuv.

D. corpore scabro, hirsuto, obscuro-yirescente; disco fimbriato; testâ dilatatá, suprì luteâ, subtìs albâ, rostro subspirali, crasso, calloso. Rang.

Runph. Amb.pl. 10. fig. 6. et pl. 40. fig. N.

Doris verrucosa, Liv. Guel. pag. 3103.

Dolabella Rumphii, Cuv. Ann. du MIus. tom. 5. pl. 29. fig. i.

Dolabella Rumphii, Lamx. Anim. sans vert. tom 6. part. 1. pag. 41. $n^{\circ}$. 1.

Dolabella Peronii et Rumphii, Nов. Dictionn. class. d'Hist. nat. art. Dolab.

Dolabella Rumphii, Bц.1nv. MIalac. pag. 473 . pl. 43 . fig. 5.

Aplysia Rumphii, Ranc, Monng. des Aplys. pag. 46. $n^{\circ}$. 1. pl. 1 .

A l'exemple de $\mathrm{M}$. de Blainville, nous avions pris ponı uue espèce ce qui pouvoil être considéré comme une simple variété; nous avons pu nous en convaincre par l'examen de plusienrs individus de diltérens âyes. L'animal est alongé, conique, terminé postérieurement par une large troncature, dont la partie inférieure se prolonge en une petite queue qui indique la terminaison du pied. 'Tout le corps de l'aninal, à l'exception du pied, est couvert de petiles aspérités charnues, molles, simples et coniques, qui s'affaissent lorsque l'animal est hors de l'eau; le discque postérieur est lui-même entouré d'une rangée de ces aspérités, rui en découpent le bord. La couleur de l'animal est d'un vert obscur, domnant des éclats métalliques pendant la vie.

La coquille devient assez grande : elle est triangnlaire, légèrcment contournée en spirale au sommet, qui est chargé d'une callosité épaisse et courte; elie est toute calcaire, couverte sur la face dorsale d'une couche épidermique assez épaisse, el qui déborde en avant la matière calcaire, r(ui, dans cet endroit, s'anincit beaucoup. Le côtć gauclie de la coquille est lisse, arrondi en bourrelet décurrent, qui se confond postérieurement avec la callosité.

L'aniınal, d'après MI. Rang, auroit jnsqu'à 15 et 14 pouces de longueur. Ce géant des Dolabelles halite Ics Incies, aux Moluques, à 'limor, à Waigion, Ranach, ainsi qu'ì l'Ile-de-France; sa coquille a 50 à 60 millim. de longueur.
RANG.

2. Dorabetre écourtée. Dolabella ecaudata.

D. corpore ecaudato, sublevigato, virescente, disci margine undulato; tentaculis posterioribus, hasi approximatis; testâ translucidâ, suprà pallido-lute $\hat{a}$, subtus albì; rostio subspirali, crasso, subtìs calloso. RANG.

Raxg. Monog. des Aplyfies, loc. cit. $n^{\circ}, 2$. pl. 2 .

Outre que celle-ci est toujours d'une moindre taille que la premiere, elle se reconnoît encore en ce qu'elle est toujour's dépourvue de ces appendices ou aspérités cbarnues qui caractérisent trèsbien l'autre; le disque postérieur n'a pas le bord frangé mais seulement mince et ondulenx, il ne se termine pas inférieurement par un prolongement caudal : caractère qui a valu à l'especce le nom qu'elle porte. Les tentacules postérieurs sont fort rapprochés à leur base, et les antérieurs, larges et épais, ont la forme de grandes oreilles de lièvre. La conleur de cette espèce est d'un vert sombre comme la précédente, et sa coquille, entièrement calcaire, couverte à sit face dorsale d'unc couche épidermique jauuâtre, dillère très-peu, quant à la forme, de ce!le de l'espèce précédente; elle est seulement toujours plus petite el sa callosité plus épaisse en dessous. Cette espèce a été trouvée à Waigion et à Rawack, par MM. Quoy el Gaymard; elle a iz centim. de longueur, el sa coquille a 22 millim.

\section{Dolabelne Térémidi. Dolabella Teremidi.} RANG.

D. corpore subecaudato, scabro, hirsuto, virescente, annulis albis nigrescentibus in medio; disci margine fimbriato; testâ elongatâ, su-

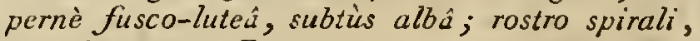
margine crasso. Raxg.

Ranc. Monog. des Aply's. loc. cit. no. 4. pl. 3. fig. 1. 2. 3.

Très-belle espèce à laquelle $M$. Rang a conservé le nom que lui donncnt les naturels des íles des Amis, qui la maugent. Elle est de la même taille que la précédente; son disque postérieur est aplati, peu oblique, circonscrit par un bord mince et firangé, il ne se termine pas à sa partie inférieure par un prolongement caudal. Le corps, qui est revêtu d'une peau dure et coriace, est cbagriné, et sur un fond vert peu foncé, marefué d'ocelles grandes, irrégulièrement disposées, formées d'un point noir entouré d'un cercle blanc et quelquelois d'un cercle lauve. La coquille, proportionnellement plus grande que dans l'espèce précédente, ressemble à la Dolabella Kumphii; mais elle est plus alongée et plus étroite, sit callosité postérieure est .plus épaisse el plus en spirale, son épiderwe est d'un bruu fituve. Cette espice, qui 


\section{$\mathrm{D} \mathrm{O} \mathrm{L}$}

vient des iles des Amis, est longue de 13 centim.; la coquille est longue de 5 I millim.

4. Dolabelle géante. Dolabella gigas. Raxg.

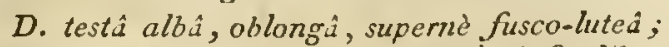
rostro spirali, valde dilatato, subtus infundibuliformi, frusque exiguis notato; apice callosissimo.

Raxi, Monog. des Aply. loc. cit. $n^{0} .5 . p l .5$. fig. 4 .

Quoique l'on ne connoisse que la coquille de cette espèce, elle est tellement distincte de toutes ses congénères, qu'il est fort difficile de ne pas la reconnoitre, quand même elle we seroit pas encore parvenue à son développement; elle est grande, épaisse, fortcment contournée en spirale au sommet, qui porte nne large callosité sur le bord, callosité qui est obliquement infundibnliforme et dont la cavité est tournée du côté concave de la coquille; outre celle callosité, le bord gauclie, ordinairement simple et en bnurrelet décurrent, présente en debors une seconde callosité qui s'étend clepuis à peu près le sommet jusqn'au milieu de sa longueur; cette callosité, mince et trancbante, se joint à la partie postérieure de son bord avec la callosilé postérieure. L’angle droit et postérieur de la coquille est fort saillant, et remonte à la bauteur do sommet, ce qui ne se voit pas dans les autres espèces. Outre ces caractères, déjà suffisans pour distinguer cette espèce, il en existe un antre qui ne se remarque que sur elle, c'est qu'elle est striée a l'intérieur. Elle est recouverte en-dlessus d'un épiderme mince et jaunâtre.

Cette coquille, la plus grande du genre, suppose un animal fort grand, surtout si l'on prend la Dolabelle de Rumphius pour terme de comparaison; alors on peut croire qu'il avoit au moins 18 pouces de longueur. La coquille est longue de 10 i millim. Elle vient de la mer des Indes; on n'en connoit encore qu'un très-petit nombre daus les collections.

5. Dolabelle de IIasselie. Dolabella Hasseltii. FERUS.

D. corpore conico, ecaudato, scabro, valde hirsutn, virescente; maculis fiscis, nigrescentibus in medio; disci margine inapualiter firmbriato; nimâa dorsi ad extremitates dilatatâ; testa invognitú.

R.ax. Monog. loc. cit. $n^{\circ}, 5$ bis.

MI. Rang n'a connu cette espèce que par un dessin qui fut communiqué à M. de Ferussac par MM. 'Temminck et de Haan; ce dessin provenoit da royage de M. Van Hasselte à Java. Cette espc̀ce trés-crrande a la lorme d'un pain de sucre à base un peu oblique; la base est occupée par le disque qui cst arrondi, fort large, entièrement
$\mathrm{DO} \mathrm{L}$

dépourvu d'un prolongement candal et séparć par un angle aigu qui se termine par un bord frangé irrégulièremeut; tout le corps, aussi bien que le disque, sont couverls d'un grand nombre dappendices charuus, saillans, diversement déconpés et irrégulièrement distribués sur la surface; ils sont mous et fort sensibles, et paroissent servir de tentacules i l'animal, dont la peau du reste est épaisse ct coriace. Tout cet animal cst d'une couleur verle asscz brillante, et parsemé de nombreuses et grandes laclies d'ua brup foncé, irrégulières, le plus souvent arrondies et noirrâtres au centre. Ce qui caractérise le mieus cette espèce, ce sont les ouvertures du manteau; la postérieure, qui est presquau centre du disque, est légèrement dilatée pour le passage du siphon; mais l'ouvcrture dorsale l'est hien davantagc. Elle est en forme d'entonnoir et laisse. un large passagre a l'eau qui se rend sur les branclies.

On ne connoît pas la coquille de cette grande et belle espèce. M. Rang pense arec raison que la Dolabelle géante pourroit bien lui appartenil. Celle espèce est longue de plus de sepl pouces; elle vient de Java.

\section{Dorabelre dolabrifère. Dolabella dolabri-} fera. Cuv.

D. corpore hirsuto, virescente, maculis nigris prasertim ad marginem notato; testá albi, subtranslucidì, recurvâ, angustî, in nuedio intenduim crassá; rostro valiè calloso.

Cuvier, Règ. anim. tom. 2. pag. 398 .

RANg, Monog. des Aplys. loc. cit. $n^{\circ}, 6 . p l .4$. fig. 1. a. 6 .

Pour la formc, l'animal ressemble à une petile Aplysie, l'cxtrémité du corps n'étant point tronquée postéricurement, mais bien terminée €n pointe en forme de queue; il diffère des Aplysies en ce que le manteau, très-pelit et serré sur le dos, n'est point propre à la natalion; il dillère encore par la coquille qui est calcaire. Ainsi, malgré sa forme, il appartient incontestablement a la section des Doluluelles, et il peut servir, de même que les cspèces suivantes, dc passage enlıe les deux groupes. L'animal de cette espèce est alongé, ovale, pointu à chaque extrémité, légèrement couvexe et largencut gastéropode; la jonction de la face dorsalc avec la ventrale s'opere sous uu angle forl aigu, ce qui produit un bord mince et tranchanl. 'Toute la surface supérieure est couverte d'aspérités claruues en forme d'épines; sa couleur esı d'un rort-jaunâure obscurci par une grande quantilé de pelites taches noires qui devicnnent plus nombreuses vers les bords. Isa coquille est alonerie, fort étroite, blanclie, translucide, peu contornée, non spirale au sommet, qui se termine par une petile callosité un peu courbée vers lia face ventrale; clle 
est assez épaisse dans le milicu et furt mince postérieurement. Celte espèce curieuse a été trouvée par M. 'Rang à l'lle-13ourbou où elle est très-commune; elle a go millim. de long, et sa roquille 9 millim. seulemen!. Raxa.

7. Dohabere ascifère. Dulubella ascifera.

D. corpore luten-fuscato, verruculis rotundis

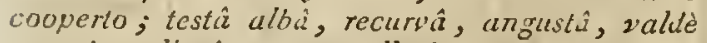
crassí, callosî́; rostro callosissimo. RAxG.

RANG, Monog. des Aply. loc: cit. $w^{\prime \prime} .7 \cdot p l .4$. fig. $7 \cdot a \cdot 9$.

Sernblable pour la taille et pour la forme au précédent, l'animal de celle especce en dillère notamment par sa couleur, qui est dun brun fauve, et par les tubercules verruqueux qui le couvrent, au lieu des aspérités épineuses qui se voient sur l'autre; les tentacules antérienrs sont aplatis et se conlondent à la base avec le voile de la bouche. La coquille, plus large que la précéilente, es: subquadrilitère, épaisse, blanche, busllante, comme éaraillée, terminée par une callusilé assez épaisse, un peu oblique et placée presque dans la direction du bord droit; le centre est fort épais et très-calleux. Cette espitce a ćté recueillie par feu Richard père à Saint-Jeau de Cagenne; elle est longue de 85 millim.

8. Dorabelce pétalifère. Do'abella petalfera. RANG.

U. corpore lovi, virescente, aperturi dorsi lasiler dextratí; testâ alhâ, concavầ, dilutats, exili.

Ranc, Monog. des Aplys. loc. cit. $n^{\circ} .8 . p l .5$. fig. 1.2.5.

Espèce curieuse d'un médiocre volume, toute lisse, toute verte, et ayant la fente dorsale porté un peu à droite; sa forme est semblable anx deux précédentes, elle est cependant un pent moins large et un peu moins aplatie; ses tentacules postérieurs sout coudés dans leur tiers supérieur, ce quí leur donne une forme caractériftique. Pour cense espèce, la coquille qu'elle contient dans son opercule branchial est fort iderressante en ce qu'elle est beaucoup moins quadrangulaire gne les deux autres espéces, qu'elle s'arroudit an contraire et pread presque lout-i-lait la forme de celle des Aplysies; elle est cependant calcaire, blanche en dedans, mais couverte en dessus, ver's le bord, d'un épiderme épais et solide. Cetle espèce intéressante a 55 millim. de lungueur, et sa cocguille 9 millim.; elle se trouve duns la mer de Nice, d’oit elle a été envoyée au Nluséua de Paris par M. Risso.

1)OLIAIRE. Doliaria.

Famille que AI. Latreille a proposćedans ses

\section{O N}

Familles naturelles du Règno aninal ( pag. 196). Il y rassemble les genres Harpe, Tonne, Licorne, Coneholépas el Pourpre. La séparation de ces genres des Buccins ne nous semble pas suffisamment justifiée, et nons pensons gue cette famille ne sera pas adoptée.

\section{DONACE, Donax.}

Il est probable que, snus la dénomination de Telline, les Anciens confondirent un grand nonibre de Mollusques différens. Les Donaces, si voisines des'Tellines, furent sins doute du noublise, et il est possible d'en reconnoitre une dins la première espèce de 'Telline de Rondelet. Celle opinion paroît preodre quelque certilnde lorsque nous voyons les auteurs plus modernes, et Lister notamment, appliquer spécialement le nom de Telline unx cocquilles que nous nommons $D_{0-}$ naces, en les mélangeant il est viai avec quelques vérilables 'Tellines, mais en petit nombre, ainsi qu’avec quelques Vénus.

Bien postérieuremeat à Lister, Adanson nomma aussi Telline le genre dans lequel il ne resiembla que des Donaces, leur conseıvant ainsi la dénominution que leur avoient donnéc les Anciens. Mais Linné, auquel nous devans le genre qui nous occupe, a'a point suivi les mêmes idées. Il donna le nom de Donace aux coquilles qui laisoient la plus grande parlie des Tellines des Auciens, pour conserver ce dernier nom à des coquilles ripandues parmi leurs Pétoncles, ieurs Canes et en fuible partic dans leurs Tellines. Ce zente fut génćraleucul adopté, et comme il prúsente dans son enseuble des caractères facile a saisir, et que d'ailleurs il est restreint à des espèces fort a alogues, il n'éprouva que trc̀s-peu de changerneus; nous n'en comnoissuns nême que deux rqui puissent être mentionnés : le premier est le genre Capse de M. Lanarck, ot l'aurre le genie Cunens de M. Mégerle. Ce dernier genre, lormé avec tontes les especes qui sont moius tuansverses, généralement plus aplaties et qui n'ont gu'une seule dent latérale, ue mérite pas d'eire conservé comme genre, si l'on fuit atteulion aux passages qui lient lonles les nuances de formes et de dispositions dans la charnière. Quant au genre Capse, quoique les dillérences soient plus constantes et mieux trancluées, nous crayons, avec M. de Blainville, quion Jevia le réunir aux Donaces, car nous royons que les caractères de la charniere, sur lesquels se genre est fondé, varicut tellement, ‘u'on trouve véritablement un fort pelit nombre d'espèces dans lesquelles ils se rencontrent à la fois.

\section{CARACTERES GÉ ÉRIQUES.}

Coyuille transverse, équivalve, inéquilatérale, à côté postérieur très-court et très-obtus. Deux dents curdinales, soit sur chaque vulve, soit sur 
une ecule; une ou deux dents latérales plus ou moins écarlées. Ligament extérieur court, sur le rôté le plus court de la cocpuille.

Oı a dit géaéraleneui que le ligament des Donaces n'étoit point à la même place que dans les autres Cunchyfères; quil occupoiı la lunule au lieu d'être dans le corsclet. Cette opinion s'est forméc probablement d'aprés la manière dont l'animal des Dunaces est figuré dans l'ouvrage d'Adanson, où il est représenté bien évidenneust à l'iuverse de ce quill doit ètre, c’est-à-dire que les siphons, dirigés vers le grand côté de la coquille, devroient l'être vers le plus petit; ce qui fait prendre lc côté postéricur pour l'antérieur, et vice versâ.

M. de Blainville avnit signalé celle erreur rien que diaprès la considération de la position de l'impression du manteau : cette impression, en ellet, indique toujours la direcion des siplions, et peut remplacer jusqu’à un certain poiut l'animal lui-mẻme, au moins pour ce qui concerne la posilion de ses lubes. Naus avons dans ce moment sous les yeux les animaux de plusieurs espèces de Dounces, et nous pourons confirmer l'opinion de M. de Blainville. Un autrc lisil auroit pu conduire avec quelques certiludes au même résultat, si l'on ne s'étoit attaché à le regarder également comme une anomalie : c'est la direction des crochers. Dans tous les Conchy feres dymiaires, ils sont dirigés vers la lunule, à un très-petit nombre d'exceptions prises daus les Cames, par excmple, et guelques autres analogues; daos les Donaces, ils sout inclinés vers la lunule que l'on a prise pour le corselet, paree qu'elle se trouve sur le grand côté de la eaquille, ce qui est l'inverse dans les Vénus, les Cythérées, eic. : il suit de là quiil n'existe aucune anomalie dans les Donaces, que tout eft y bicnà sa place, le ligameut dans le corselet et le siphon dirigés postérieurement. Les animaux des Donaces et des Tellines ont beaucoup de rapports entr'eux, à tel point que Poli, dans son grand et magnifique ouvrage, les a réunis dans un seul et rocme genre, celui quil a nommé Peroticoderma. Cet animal a un pied aplati, coudé ou sécuriforme; ses tubes assez longs sont séparés comme dans leg Tellines, et fort grêles; le mantcau assez mince au bord l'est bieu daraniage au milicu des valves, il est ouvert daus toute sa longueur, si ce n'est à l'eudroil des siplions oì ses deux lobes se soudent. L'onverture buccale est petile et garnie de deux paires de palpes lriangulaires.

I.cs espèces de ce genre, assez nombreuses, sont toutes littorales et vivent dans le sable, les siphons dirigés en baut : quelques-unes sont ornées de riches couleurs, d'autres sont d'une assez grande taille et rares; dans les cabinets, on en compte un ecrtain nombre de fussiles, parmi lesquelles on aroit cité une coquille singulière, Donax irregularis, dont on a fait depuis un genre à part, dédié à M. Gratelonp, sous lo nom de Grutclupia. (Foyez ce mot.)

Une espère fort belle, qui vient du can de Bonne-Espérance, le Donax ringens, apparient rertairement aux Capses où nous l'avous décrite. (Voyez Capse.) Malyré ees rélurmes, le genre Donace ne laisse pas que d'être noublureux, car nous y comptous plus de quarante eş̧èces, tant vivanies que fossiles.

1. Donace bec de flute. Donax fortun. Lis.

D. testú triangulari, anticè acutî̀, decussatin striati: postice corduti, angulatâ, planá; marginibus subnullis.

Lin. GMei. no. 1.

LАмк. Anim. sans vert. tom. 5. pag. 546. $\pi^{\circ} \cdot 2$.

Lister, Conch. tab. $377 \cdot$ fig. 220.

Borv. Mus. caes. vind. tab. 4. fig. 1. 2.

Cerara. Conch. tom. 6. tab. 25. fig. 242 is 247.

Excrcl. pl. 260. fis. 2.

Celte coquille est une des plus grandes du genre; elle est brunâtre on d'un blanc-violâtre vers les crochets; elle est ornée de stries lines longitudinales, et d'autres transverses plus grosses qui les coupent à angle droit; le corselet est aplati, fort grand, sćparé par une carène aiguëe, quelquefois un peu tuberculeuse; toute la coquille cst enflée, subcordiforme; anguleuse à son extrémité antérieure; en dedans, elle est violette et sou bord est finement crénelé. Celte eoquille vient de l'Océan indien, à Amboine; elle a 55 ì 60 millia. de large.

2. Donace pubescente. Donax pubescens. LiN.

D. testâ triangulari, decussatî, lamellosâ, posticè cordatá, planî, angulatâ; angulo spinyfero; marginibus lamelloso serratis.

Lin. GMer. loc. cit. $n^{0} \cdot 2$.

Ibid. LAMK. loc. cit. $n^{\circ}, 2$.

Cresin. Conch. tom. 6. tab. 25. fig. 248.

Encrer. $p l .260$. fig. I.

Celle-ci a infinimeut de rapports avec la prumière; elle n'en est peut-êtue qu'une variété; elle est plus petitc; ses stries sout plus fines, bifurquées, et l'angle postéricur qui sépare lé curselet du reste est plus aigu et chargé d'une sćrie d'épines assez longues, un peu en gouttière; les croehets, petits et peu saillans, sont opposés et légc̀remeut inelinés vers la lunule qui est à peine marquéc, laucéolée et fort longue; le ligament est court. En dedans cette espèce est violâtre et ses bords sont crénelés; elle vient de l'Ocćnn indien, et elle cst large de 40 à 45 millim. 


\section{$\mathrm{DON}$}

3. Donace en coin. Donax cuneata. Lrs.

D. testâ trigonâ, compressâ, cuneiformi, rufá, albo radiatí; striis longitudinalibus exilissinits; posticé convexa, rugo/a.

Lin. G Hex. $n n^{\circ} \cdot 7$.

Ibid. Liנr z. loc. cit. $n^{\circ} .5$.

Lister, Conch. tab. To2. fig. 231.

Kivar. Vergn. 6.tab. 7. fig. 3.

Cuears. Conch. tom. 6. tab. 26 . fig. 260 .

Fiscrci.pl. 26r.fig. 5.

Coquille beaucoup plus comprime que les prícédentes, en furme de coin, sulstransverse, d'une coulcur fáuve peu foncé, rayonuée de llanc el couverte de stries longitudinales trésfines; elles aboutissent à un bord lisse plus épais antérieurement que postérieurement. Tout le côté postérieur de la coquille, qui est le plus court, est ridé trunsversalement; les rides sont irrégulières et pou élevées. Cette espèce, qui vit daus l'Océan indiem, à 45 millim. de large; ellc u'csi pas jare dans les collectious.

\section{4.}

\section{Dorace comprimée. Donax compressa.}

D. testâ cuneiformi, compressâ., basi acutâ, carnco-fulvâ, irrudiatâ; vulv.i subrugrosá; marginibus angulutis.

Lisn. loc. cit. $n^{\circ} \cdot 4$.

Encrenop. pl. 262. fig. 6. a. b.c.

Cette coquille est l'une des plus faciles à distingue!, elle est une des plas aplaties; sa forme est triangulaire, ses crochets, petits et pointiss, dominent le corselet qui est court; il contient un ligament arrondi et il occupe la partie supérieure du côté postérieur; celui-ci est séparé du reste par un angle olıtus; il est court et ridé transrersalement; la surface extérieure est lisse, marquée de quelques accroissemeus irréguliers d'une couleur de chair tirant sur le fauve, quelquefois subrayonnée de teintes plus jû́les. Cette cocuille, assez rare dans les collections, vient des mers de l'inde, à ce que croit $\mathrm{N}$. Lamarck. Elle a 40 millin. de large et 30 de long.

\section{Dosice subrayonnée. Donax vitata. La arz.}

D. testí ovato-trigonâ, transversè striatá, $a l$ bidi ; rudiis rufis, perpancis, infernè latescentibus, intuis rubro trifascicta.

LAMK. Loc. cit. $n^{\circ} \cdot 14$.

Jolse coquille qui n'est pas rare et fort distincte des espéces qui précèdent, avec une forme amalogue an Donux cuneata; elle s'en distingue en ce qu'elle est plus épaisse, ses stries tranversales sont plus grosses; elle est peinte de couleurs i peu prés semblables, et de plus, elle est teintce de rouge violet ou de rosé sur les crochots; en dedans, elle a constamment deux ou trois rayous assez larges de rose pourpré, d'une grande traicheur, sur un fond blanc; le côté postérieur au lieu d'être ridé transversalement, comme duns la Donace en coin, est striéobliquement. On ne conncît pas la patrie de cette coyuille, qui a 35 à 40 milliu. de large.

\section{Doxace ridée. Donax rugosa. Lix.}

D. testâ triangulari, inflatâ, posticè obliquè iruncatu, \{sulcis longitudinalibus, creberrimis, rugosâ; v'ulvâ cordutá; marginibus angulatis.

Lis. GueI. pag. 3262. $n^{\circ} \cdot 3$.

LАMк. loc. cit. $n^{\circ} \cdot 17$.

Gualt. Test. tab. 89. fig. D.

Chems. Conch. tom. 6. tab. 25. fig. 250.

KNOR, Vergn. 6. tab. 28 . fig. 8.

Excrelop. pl. 262. fig. 5. a. b.

Coquille triangulaire, assez grande, moins aplatie que la plupart de celles du même genre; elle est inéquilatérale, le côté postérieur est le plus court, très-aplati, séparé par un angle aigu du reste de la surface; il est fauve on violâtre, et couvert de stries longiludiuales, nombreuses, profondes et très-régulic̀res; la surface extérieure est blanche, ornće de stries rayounantes, aplaties, qui descendent jusqu'au bord, qui est épais et crénelé en dedans; les crochets peu saillans sont subcordiformes et opposés; la couleur de l'intérieur est d'un violet teadre sur toute la partie antérieure et moyenne de la coquille, elle devient d'un violet toncé et obscur sur le côté postérieur. On trouve cette coquille aux Antilles, dans l'Océan américain, et une variété qui nous est inconnue à la Nouvelle-Holkande. Elle est large de 40 millim.

\section{Donace alongée. Donax elonguta. Lamx.}

D. testu trunsversim elongatâ, longitudinaliter sulcatô, postrcè obtusissimá, valva sulcii subdenticulatis.

Lasik. loc. cit. $n^{\circ}$. 19 .

Le Pamet, Adans. Voyage au Sénég. tab. 18. fig. 1 .

Gualt. Testac. tab. 39. fig. F.

Caesn. Conch. tom. 6. tab. 26. fig. 253.

On connoît de puis long-temps le Pamet d'Adanson; c'est une coquille alongée, trigone, trèscourte postérieurement, très-inaquilatérale, striée longitudinalement; les stries partant du crochet et aboulissant en rayonnant au bord qui est dentelé en dents de scie, et tout-i-fait intérieurement; en dedans, cette coquille est tachée de violet, et en dehor's, elle présente une teinte blanchitre ou grise, quelquefois violacée, par- 


\section{D $\mathrm{ON}$}

courue par deux rayons d'un violet brun; ils sont fort larges, l'un couvrant tout le cóté postérieur el l'autre une partie de l'antérieur. Sous le nom de Donax bicolore, M. Lamarck a fait une espèce qui n'est bien évidemment pour nous, qui l'avons examinéc dans sa collection, qu'une variété de coulcur de celle-ci, lous les autres caracteres restent absolument identiques. Ml. Busterot a donné comme analogue de cette espece une coquille fossile de Bordeaux, qui a avec elle beaucoup de rapports, mais qui n'est quiun subanaloguc; elle est toujours plus longue et moins large; les crénelures du bord sont plus grosses et moins nombreuses; enfin la nymphe qui porte le ligament est superficielle an lieu d'être très-cnfoncéc comme dans la vivante; il en résulte que la dent latérale postérieure, qui est à l'extrémité de cette nymplie, ne présente plus la même forme, les stries du côté postérienr sont plus funes. On a fait des espèces sur de moindres caractères. On la trouve sur les côtes du Sénégal. Elle est large de 55 millim.

8. Dosace denticulée. Dunax denticulata. Lis.

D. testâ posticè oblusissimầ, albầ, cerulaeo aut purpureo radiatâ; striis longitudinalibus, impresso-punctatis; labiis transverse, mgosis.

Lis. Gsex. pag. 3263. $n^{\circ} .6$.

LАM . loc. cit. $n^{\circ}, 20$.

Lister, Canch. tab. 376. fig. 218.219.

Le Nusar, Anaxs. Sénég. pl. 18. fig. 5.

K.мon. Vergn. 2. tab. 23. fog. 2 à 5.

Caемxiтz, Conch. torn.6. tab.26. fig. 256.257 .

ExcrcLop. $p l .262 . f i g \cdot 7 \cdot a \cdot b$.

On ne peut confondre celle espèce avec aucune autre; ses stries longitudinales, nombreuses et profondes, sont finement ponctuées, ce qui ne se voit dans aucune autre espèce; elle est ćpaisse, très-abtuse, aplatie postérieurement; son bord, denticalé dans tonte son étendue, l'est plus profondément à son angle postérieur; sur uı foud blanc, on voit sur cette coquille dix ou douze rayons violets on poorprés; en dedans elle est d'un viulet-noirâtre. Elle habite la Mlédilerranée, le Séntgal, etc. Longueur 25 millim.

9. Dovace à réseau. Danax nieroe. Laxk.

D. testâ ovato-trigonâ, compressî̀, transwersim parallele striatâ, lineis purpureis subreticulatis pictấ; vulvâ excavatâ.

Lasx. loc. cit. $n^{\circ} \cdot \mathbf{2 2}$.

Yenus metoe, LIs. Gxel. no, 22.

Lisren, Conch. tab. 378. fig. 221.

Cneys. Conch. tomı. 7. tab. 43. fg. 450 à 452 .

Evcrcs. pl. 261. fig. 1. a. b.

Var. B. Noв. Testá lineis fuscis pictâ.

Hist. Nat. des Vers. Tome $I I$.
D O N

Très-jolie coquille qui n'est pas rare; elle est ovale, oblongue, subéquilatérale, tıc̀s-aplatie, régulièremeut striée en tratvers; les stries sont distantes, bien régulières, peu profundes; le côté postérieur, plus court que l'antérient, est arrondi, non tronqué; il présente à sa parlic supériemre un corselet très-profond, qui contient le ligameur placé au-dessous des crochets et tont prics d'eux; ceux-ci sont pelils, el sensiblemeat tourués vers une lunule superficielle, blanche, alongrie, lancéolée; un réseau de lignes angulcinses, plus ou noins larges, d'unc conleur pourprér, couvre toutc la surface cxtérienre de celte coquille, qui, en dedans, est d'un blanc laileux, avec unc large tache violette au milieu. La variété ne dillère que par la couleur des lignes qui formeut le réseau; elles sont d'un beau fauve au lieu d'êrre pourprées. Cette coguille se trouve dans l'Océan indien; les grands individus ont 50 willim. de large.

10. Dovace tronquée. Donax trunculus. Lis.

D. testâ transversim elongatî; striis longitudinalibus, minimis; intìs violaceâ; latero antico lavi, brevissino.

Li.y. GreL. no. 6 .

L.A 1 . lac. cit. no. 24.

Lister, Canch. tab. 576. fg. 217.

Le Gafet, Adans. Sénég. tab. 18. fig. 12.

Kvora. Vergn. 1. tab. 7 . fig. 7 .

Borv. Mus. cas. vind. tab. 4. fg. 3. 5.

Casm. Conch. tom. 6. tub. 26. pag. 253. 254.

Sow. Genera of shells, no. 10. fig. 2 .

Il est impossible, d'après M. Lamarck, de distinguer cetle espèce du Donax anatinum; il y a entre ces espèces une confusion qui se reIronve dans la collection du célèbre professeur, comme nous avons pu nous en assurel de visu: les principales distinctions reposent sur le côté postérieur, plus court dans l'une que dans l'autre, et su. la grosseur relative des stries; mais après avoir va une quantité cunsidérable de ces coquilles provenant de diverses localités, nous pouvons affirmer que ces deux caractères se perdent par des transitions auxquelles il seroil impossible d'assigner des linites. Dans ce rrand nowbre d'individus que nous avons examinés, nous en avons trouvé quelques-11na qui présentent des caractères constans, et comme ils provienneat des mêmes lieux, nous leur avons conservé le nom de Donax anatinum.

La Dunace 1ronquée est très-variable, et ses variétés peuveut se distinguer en deux sortes: celles qui sont rayonbées el celles qui ne le s'nt pas; les preuières sont généralement violálres, avec les rayons blanes, et les secondes sont jaunâtres ou couleur de corne. Cette coquille est oblongue, transverse, subtrigone, inéquilatérale, 
à côlé postérieur comrt, obliquement tronqué, arrondi, lisse. On remarque extérieurement des stries longitndinales, pen sensilles, plus on moins larges, mais tonjours peu prolondes; elles manquent quelquefuis; en dedans, clle est très-rarement blanche, presque toujnurs tachetee de violet ou de rose violet : quelles que soient les variétés, la charnière reste toujours la nême; elle est étroite, avec deux dents cardinales sur la valve gauche; une grosse dent bifide sur la valve droite avec une toute petite à côté; les dents latérales sont obsolètes. Celle coquille, lrés-commune, se troure sur nos côtes et dans la Méditerranée. Les grands individus ont 47 millin. de large.

1 1. Donace cardioide. Dona $x$ cardioides. Lamx.

D. testâ trigonâ, turgidá, longitudinaliter sul. cutâ, posticè lacviusculâ, albâ, rufo maculutâ, mtùs albâ luteâve; latere postico subplano, medio gibbo.

LAMK. loc. cit. $n^{\mathrm{D}}, 2 \mathrm{I}$.

Coquille trigone, enflée, cordiforme, assez épaisse, tronquée postérienrement; les crochets upposés, peu obliques, assez grands, se contournent en cour; il en part en rayonnaut des stries nombreuses, plus grosses postérienrement que sur le côtć antérieur, oǹ elles disparaissent peu à peu. Le côté postéricur est fort large, sćparé par un angle; il est presque lout plat, se relevant seulement un peu dans le inilieu. La coluration de cetle espèce est pen variable; elle est presque toujours blanche en dessus, avec quelyzues points bruus, el le côté postérieur est marqué de lignes brunes ou de taches ondulenses de la wecme coulenr, gui quelquefuis se confondent; en dedans elle est blanche on d'un jaune heurre lirais, surtout lorsqu'elle est jeune. Notre ami, M. Tesson, nous a communiqué le premier cette espêce, provenant du Port-Prialin el de 'I'aiti, on elle reste petite; depuis, M. Quoy l'a retrouvée aux Célèbes, où elle prend une taille beaucoup plus grande. 3o millim. de large. Nов.

12. Donace à trois rayous. Donax triradiata.

D. testâ ovato-trigonâ, crussâ, solidâ, depressî, albi huteâve, roseo aut violaceo triradiatá; ano rotunduto, striis rugosis transversalibus ornato.

Cette espèce a le test épais el solide; elle est ovale, subirigone, presque aussi longue que large, inéquilatérale, lisse ou presque lisse, laissant apercevoir quelques stries d'accroissement coupées par des stries longitudinales extrêmement fines, qui n'existent pas sur tous les individus; elle est blanche on jaunatre, quelquefuis d'une. teinte violitre; elle est traverśe, du crochet jusque vers la base, par trois rayons d'un rose pourpré ou vinlet, dont le postérieur descen:1 le long du corselet. Eu dedans les mèmes rayons se répètent sur un lond blanc el de la méme confeur, mais plus inteuse el pulus pure; le côtó postéricur, plas cocrt, est couvert de stries transverses, obligues, ruguenses et ondulerises. Nous ignorons d'uù vient cette espèce, dont les grands individus unt 35 millim. de iarge et 29 de lang.

\section{Donace obscure. Donax obscura. Noв.}

D. testá ôlato-subtrigonâ, depressá, subtuliter striatá, posticè subtruncatâ, rugosâ; striis rugisque longitudinalibus; extùs fusco-nigrà, intius violucea.

Après avoir examiné avec soin, et comparativenuent avec le Cuneata, dont elle se rapproche le plus, Jes individus de celle espèce, nous avons été dans la nécessité de les séparer, ne pouvant se coufondre avec aucun de ceux qui sont connus. Cetre coquille est ovale, subtrigone, suluransverse, aplalie, ayant le test épais et solide; ses crocliets, en pointe, sont petits et forment le sommet d'un angle, dont le côté postérienr est le plus court; ce côté postórieur, arrondi, est couvert de sillons granuleux, tandis que le reste de la surface n'a que des stries extrêmement fines et superficielles, qui ne s'apercoivent qu'a la lonpe; le bord est entier et la chámière, assez forle, a ses dents latérales fort f́cartées et bien distinctes. En dehors cette coquille est partout d'un brun foncé avec des zones transverses et une teinte moins obscure; en dedans elle est d'un violet très foncé, surtont dans le milien des valves. Nous ne savons oǹ vit cette espèce; elle a 32 willim. de large.

i4. Donace aplatie. Donax complanata. NOB.

D. testâ ovato-oblongâ, transversâ, lavigatâ, albidisub epidermide virente, postice uniradiatu; radio lutescente, duabus lineis fuscis murginato; margine integro, intus violascente.

Capsa complanata, Sower. Gener. of shells, $n^{\circ}$. 20. fig. 8 .

Nons avons dit à l'article CAPSE, que l'on pent consulter, pour quelles raisons nous n'admeltons pas celle espèce dans ce genre, mais bien dans les Donaces, dont elle présente les caractères; clle est ovale, oblongue, comprimée, mince, fragile, toute lisse, blanche lorsqu'elle est dépourvue de son épiderme, et verdâtre lorsqu'elle en est couverte. Ce qui la distingue esseotiellement, c'est un seul rayon partant du crochet et gagnant la base, placé vers la partie postérienre de la coquille; ce rayon est jaune et bordé de chaque côté par une ligne brune, un peu irrégulière, souvent formée par une série de taches nuageuses, plus larges sur le côté autérieur que 


\section{$\mathrm{D} O \mathrm{~N}$}

sur le postérieur du rayon. Les erochets sont petits, souvent teintés de rose vif ou de violet olsscur; en dedaus cetle coguille est viulette. Cette espèce remarquable vit dans la Manche, aussi bien sur les côtes de france que sur celles d'Angteterre; elle est fort commune daus cerlains endruits sablonneux. Elle a $36^{\circ}$ williw. de lung.

15. Doxace de Lesson. Donax Lessonii. Nов.

D. testâ triganâ, depressâ, laevigatî, subarqui-

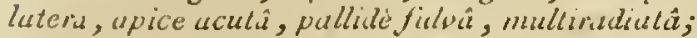
radis fuscis, interruptis; intus ulbudo-fuscî; murgine anlicè lianle, integermo; dente lateruli untico, praclongo.

Nous connoissons celte espèce, rare et belle, par M. Lessỏn, auquel nous nous plaisons de la dédier; elle est triaugulaire, presque aussi longrue que large, et à peu près équilatérale; elle est grande, aplatie, toute lisse, d'uue conleur fauve pàle, ę ornée de rayons nombreux de la nuême cunleur, anais plus liuncés, et sonvent interrompus à l'eadroit des principaux accroissemens. Le bord est simple, lisse, légèremeat dépriné antérieurement et postérieurement, de manière à laisser entre les valves, lorsqu'elies sont réunies, un birllement étroit; en dedans, celte coquille est fauve, passant au blanc vers les crochels, et au brun vers le câté postéricur; la charnière est remarquable, en ce que la dent latćrale antérieure est foul longac, et semblable en cela it la plapart des Mactres. Cette coquille vient de l'ile Bourou (Muluques); elie est large de 55 millim. et longue de 46. Nous a'en connoissons que deux individus dans les collections de Paris, lun dans celle de M. le duc ue Rivoli, et l'autre dans la wótre.

\section{Dovace ondée. Donax scripta. Lamk.}

D. testâ ovato-subtrigonâ, compressi, lavvi, lineis purpureis undatis scriptä, intùs violace $\dot{a}$; ano vuldè excupato; lunulâ proelongs, lunceolatâ; marginibus acutis, tenuè crenatis.

LaMK. loc. cit. $n^{\circ}, 23$.

Lister, Conch. tab. 379. fig. 22. el tab. 380. fig. $22 \hat{\mathbf{j}}$.

Kхови. Velgn. 6. tab. 7. fig. 45.

Chesistiz, Conch. tom. 6. tab. 26. fig. 26 s. à 2605 .

Lixcyceop. pl. 261. fig. 2. 3. 4 .

Nous pourrions tacilement compter six ou hait variétés daas cette épèce, dont les couleurs n'unt presque rien de constant; mais malgré ceite grande variation, les formes restent toujours les mêmes : ce sont elles qui fumraissent les meilleurs carac:ères. Ovale, oblongue, subtrigone, aplatie, a crochels petits et pointus, cette espèce se recontaoil encore à son còté pos-
$\mathrm{D} O \mathrm{~N}$

térieur, le plus court, arrondi, prósentant un corselet excavé prufondément, et portant un ligament court à sa partie supéricure; clle a sa lunule lancéaléc, très-longue, superlicielle et toujaurs d'une teinte olsciure; en dedans cette coguille est toujours violette.

Quant aux conleurs extérieures, ou peut en préseater une série de valiétés commençant par des taclies trigones et rares, passant à des lignes nomlarenses, anguleuses, quelcuefuis ondulenses; elles sont peintes sur m fund blanc, elles ont ensuite une tendance à se coufondre, cel le fonct en est obscurci; bientüt elles sont tellement confondues, que le fond est devenu de la couleur des lignes, et en laissce néanmains apercevoir encore quelques traces des plus foncées; elles finissent entin par disparoitre complétement, et le fond, de blauc qu’il étoit, a passé aú violet-grisàtre d’abord, puis au viulet-pourpré ubscur. Longueur 35 aillim. Elle habite l'Océan indien.

17. Doxice des canards. Donax anatinum. LAMK.

D. testi iransversim oblongâ, niliduli, allidis, cornea, vel pallidé rubente; shizis longitudinulibus, exilissunis, medio transversalibus clathratis; latere postico, obliquè truncato.

Laмk. loc, cit, $n^{\circ}$. 16. syn, cxclusis.

Très-voisine de la Truncalu, quaut à la lorme, cette espèce s'en distingue facilement : elle est encare plus transverse et sca côté postérieur plus alongé; elle est tunjours blanche à l'intérieur, tandis que la Trancata est violette; elle est aplatie, revêtue d'un épiderme verdâtre, trèsfin, à travers lequel on aperçoit les nuances violâtres ou rostitres du test. Les crocliets, qui sont petits et peu saillans, sunt ordinairensert blancs; sur la partie postérieure et módiane de la coquil e, et de charjue côté, on voit des stries transversules fines et régulières qui, partant du trard postérieur, gagnent le nilieu de la coquille, où elles s'arrètent subitement; d'autres stries longitudiDales et non moins lines que les premières les croisent à angle droit, et cessent sur la partic moyenne, là où les premières s'urrêtent, de manicre à laisser parfaiteuseat lisse coute la partie astéricure de la coguille : celle disposition remáquable des stries suffiruit à elle seule pour distiuguer cette espèce, qui se trouve dans les mêmes licux que la Truncata. Loog. 32 millim.

18. Donace corbuloijde. Donax corbuloides. ов.

D. testâ trigonâ, gibbosâ, cequiluterâ, politâ, condsformi, albo-roseâ, lineis luteis, undutis, pulcherrimè pictá, intüs rubro fucescente.

A voir les valves isolées de cette coquille, on 
les prendroit ponr celles d'une Corbule, tant elles sout borbées; cependant elles dépendent du genre Donace. Celte coquil!e est cordiforme, trigone, équilatérale, peu transverse, a crochets opposés, médians, droits, d'une belle couleur rose-pourpréc ou blancs. 'Toute la sniface est lisse, polie, brillitnte, d’un blanc-rosé tıès-päle, sur lequel se dessinent des ligues transverses duu jaune pur, ondulenses, conlinues, quelquefois un peu angulenses, mais toujour's assez régulières. Eu cledans, cetie coquille est d'un rose-brunâtre ou pourpré; les bords sont lisses et tranchans, et la dent cardinale antérieure est longue et étroite. Nous ignorons la patrie de celle coquille, dont nous ue connois ons que les individus de tutre collection; ils sont larges de 17 millim.

19. Do: Ace transverse. Donax trinsversa. Nos.

D. testì ovato-oblongî, trunsversâ, angustá, incrquiluterali, losiguti, posticè obliquè truncil â et eleganter abliyué striatâ; margine crenato.

Donc.x anatinum, BAs.r. Bass. tert. du sudouest de la Frauce, MIÉm. de la Soc. d'hist. nat. de Paris, tom. 2. pag. 83. pl. 6. fig. 8.

Il faut toujours mettre une excessive réserve, avant de se prononcer, sur l'aualogie entre des coquilles fossiles et virantes; lorsque lion veut en tirer des inductions par les chiffies, les erreurs devienneut doublement préjudiciables. M. Basterot a donné cette esfrèce coorme l'analogue fossile du Donax anatinum, nous avons vı que cette espèce étoit fort mal déterminée, et nous avons été forcé d"apporter des changemeus notables, puisqu'elle se confond avec la Truncata; mais en rapportant l'espèce de MI. Basterot à la Truncata, on ae trouveroit pas davantage d'ana. logie; nous sommes donc fundé à dire que M. Bastero: a commis unc erreur.

Cette espèce se distingue fucilement par sa forme orale, oblongue, transverse et droite; elle est inéçuilatérale, subtronquée postérieurement, ayant le corselet circouscrit par un angle assez airu, ce qui ne se voit pas dans l'espèce vivante; le côté postérieur est élégamment strié; les stries sont fines, obliques, el se terminent à l'angle; tout le reste de la conuille est lisse, poli et brillant; le bord est crénelé et la charnière, très-étroile, a la dent latérale autérieure avortée, taudis que la postérieure est bien prononcée. Cette coquille reste constamment beaucoup plins petite que celle vivante, a laquelle ou l'a comparée. Elle est fossile à Bordeaux: Dax et les falnns de la Tonraine; les plus grands individus a'ont que 20 willim. de large.

BAST.

20. Donace triangulaire. Donax triangularis.

D. testí triangulari, aquilaterâ, sublavigatâ, atate postice rostratâ, utroque latere carinatí; lunulî̀ magnâ, lineâ superficiali circumdati; cardine tridentato, posteriori, carioso, laterali, unico, magno, anticio.

\section{B.sт. loc. cit. $n^{\circ}$. 3. pl. 6. fig. 3.}

M. Basterot n'a connu, à ce qu'il paroit, que de jeunes individus de cetle espèce, autant qu'on peut en jujer par sa courte description et la figure qui l'accompagne. Cette coquille est triangulaire, éqquilatérale", lisse ou marquée seulemeut par ses accroissemens; ses crochets, pointus et saillans, sont opposés, légèrement iuclinés vers la lunule, qui est ovalaire, grande, lissc et marquée par une strie saillante qui l'entoure. Le côté autérieur, ainsi que le postérieur, sont aplatis et séparés din resie de la surface par un aninle assez airru; le côté postérieur, à sa jonction arec le bord iuférieur, forme, dans les vieux individus, un prolongement en bec, aussi prolongé pour le moins que dans le Donax scortum; dans les jeutes individus, ce bec n'existe pas: les bords sont lisses, non crénelés, et la charnière, assez épaisse, pourroit à clle seule fort bien caractériser celle espèce; on y voit trois dents cardinales, dont la postérieure, se confondant avec la nymplie, est comme cariée. La dent latérale postérieure est avortée, landis que l'antérieure est grande et bien séparée des cardinales.

On ne connoît encore cette espèce qu'à l'état fossile : c'est à Bordeaux et à Dax qu'on la rencontre, mais assez raremeat. Les plus rieux individus ont 46 millim. de large, et 35 de long.

21. Donace luisante. Donax nitida. Laux.

D. testả minimâ, ovato-trigonâ, transversá, pellucidi, lovigatissimâ, nitidâ; lutere postico abbreviato, aliquantisper striato; dentibus lateralibus perspicuis, cardinalibus binis.

L.AMк. Ann. du Mlus. Lom. 7. pag. 231. no. 4 . et tom. 12.pl. 41. fg. 6. $a . b$.

Defr. Dict. des Sc. nat. tom. 13. pag. 424.

Nов. Descript. des coq. foss. des environs de Paris, pag. 112. pl. 18. fig. 3. 4.

Petite coquille très-transverse, très-inéquilatérale, subtronquée postérieurement, extrêmement lisse, brillante et sans stries; quelquefois on en aperçoit de fort régulières sur le côté postérieur; vers l'angle inlérieur elle est mince, aplatie; son bord est entier, non crénelé ou denté; la charnière est parfaitement caractérisée: elle présente, sur une láme cardinale très-élroite, deux dents cardinales fort petites, et deux dents latérales bien pronuncées. Cette espèce est fort rare; elle n'a que 4 millim. de long sur 8 de large. Elle est connue à l'état fossile seulement à Grignon el à Damerie, près Epernay. 


\section{O N}

22. Doxace obtusale. Dunax obtusalis. Noв.

D. test $\hat{i}$ ovato-subtrigonâ, depressâ, tenui, fingilissima ; latere postico obtuso, longitunaliter striesto; nymphis magnis.

Nов. Descrip. des cog. Soss. des env. de Paris, pag. $109 \cdot \mu l .18 . \operatorname{fig}_{\mathrm{g}} 7 \cdot 8$.

Celle Donace très-rare est nne de cclles qui se distinguent le plus facilement; sa forme ovale, subtrigonc, Iranswerse, ses augles obtus, aiusi que son obliquité générale, hui donnent un aspect particulier; elle est très-mince, fragile, lisse en delıors, excepté sur le bord postérieur, où des stries profondes et divergentes la sillounent longiludiualeaneut. La cbarnière présente sous le crochet, qui n'est pas saillant, deux denis cardirales fort petites et divergentes; il n'y a acune race de deuts latérales; la nymphe est fort sail. lante; l'inpressinn abdominale est comme dans toutes les Donaces. Longueur i m millim., largeur 17. Nous l'avons recueillie à Beauchamp, près Pontoise; elle y est rare.

23. Donace émousséc. Donax retusa. Lamk.

D. testî cuneifarmi, truncatâ, transversî, trunss'erse substriatâ; striis tenuibus; murgine inferiore postice inflexo; marginibus integerrimis.

LAMK. Ann. du Mus. tom. 7. pag. 250. no. 1. et tomr. 12. pl. 41.fig. 1. a. b.

DEF, Dict. des Scienc. nat. tom. 13. pag. 424 .

Noв. Descript. Loc. cit. $n^{\circ}$. 1. pl. $17 \cdot f g \cdot 19 \cdot 20$.

M. Lamarck cilc une autre localité que Valmandois, celle de Purnes, près Pontoise; mais Parnes élant ì huit lieues au moins de Pontoise, et celte espèce appartenant ì ce qu'il paroît aux grès marins, cela nous fait douter qu'elle ait jamais été rencontrée dans cet endroit, où l'on ne trouve que le culcaire grossier. Cette espèce est la plus grande que nous ayous dans le bussin de Paris; sa forme triquètre, son bord inférieur sinueux vers l'angle postérieur, l'aplatissement des valves, aiusi que leur surface extérieure lisse ou seulement marquée par des stries d'accrissement, sont des moyeus laciles pour la reconaoitre. Elle est très-rare. Longueur 20 millim., largeur 28. Fossile fort rare trouvé à Valmondois, entre Pontoise et l'ile Adaw.

\section{Noв.}

24. Dovace de Basterot. Donax basterotina.

D. testû ovato-trigonâ, compressâ, cuneiformi; striis longitudinalibus vix perspicuis, distantibus, latere postico profundioribus; dentibus luteralibus obsoletis; marginibus integerrimis.

Var. B. Testâ minimâ, lovvigatâa; dente lateralipostico, perspicuo.

Noв. Descript. des coq. foss. des env. de Paris, pag. $110 . p l .17$. fig. 21.22.
Celle coquille a beancoup de rapports avec la Donax cuneata; elle est plus transverse et les angles sont plus émoussés; clle est ovale, trigone, rrès-inéquilatérale, cunéilorme; son côté pastériemr est très-comrt et plus fortcment strié que le reste de la coquille qui semble lisse, et qui est cependaat muni de stries superficielles, irrégulières et distanıes; le croclıet est peiit, à peiac saillant hors du bord; la charnicre a deux dents cardinales sur la valve gauche, une seule sur la droite; les deuts latérales sont obsolètes on uulles, la postérieure est rudimentaire. La variété ne dillère que par une plus pelite taille, par le manque de stries, soit sur la surface, soit sur l'extrémilé postérienre, et par la dent posté:ieure un peu plus marquée. Longueur 13 millim., largeur 2o. Celle espèce, fossile dn bassin dé Paris, se trouve à Maulette près Houdan, et à Damerie près Eperuay.

\section{Donace oblique. Donax obliqua. LAмк.}

D. testâ ovato-obliquâ, incquilaterali, lavigatâ; curdine bidentato, allero unidentato; marginibus integerrimis; dentibus lateralibus obsolets.

LAмк. Ann. du Mus. tom. 7. pag. 231. $n^{\circ} \cdot 6$. et tom. 12. pl. 41 . fg. 4 .

Der. Dict. des Scienc. nat. tom. 13. pag. 425.

Nов. Descrip. loc. cit. $n^{\circ} .4 . p l .18 \mathrm{fg} .5 .6$.

Petite coquille fort rare dass les localités que nous cilons; elle est très-reınarquable par sa forme oblique et parce quiclle esi moins transverse que les autres espcces du âcme genre. Elle doit indubitablemeut se ranger parmi les Donaces; sou ligancut est placé de mêune; il y a deux dents cardioales sur une valve, une seule sur l'autre, comme on le voit dans un assez grand nombre d'espèces; les dents latérales sont unlles ou pres(jue nulles, l'antérieure seule étant quelquetois perceptilile, quoiqu'à l'état rndimentaire. En dehors, cette petile coquille est toule lisse; les bords sont emliers et non denlés. La figure citée de M. Lavarck est très-mauvaise; on a représenté sous ce nom uue coquille trigone, striée eu dehors el à bords crénclés, ce qui ne s'accorde en aucne fircon avec la description. Cette espèce curieuse se trouve à Grignon, la ferme de l'Orme el Moucliy-le-Cluâtel; elle est large de 7 millim.

26. Donace incomplète. Donax incompleta. LAsx.

D. testâ ovato-trigonâ, incrquilaterâ, lavigatì, latere postico abbreviato, rotundato; dentibus cardinalibus binis, lateralibus nullis.

LAMk. Ann. du Mus. tom. 7. pag. $230 . n^{\circ} \cdot 2$. et tom. 12. pl. 41. fig. 3. a. b.

DEr. Dict. des Scienc, nat. tom. 13. rag. 424. 
Noв. Descrip. descoq. foss. des env. de Paris, pag. 111. pl. 18. fig. 1.2.

Coquille trigone, inéquilatérale, obtuse, sułcunéilorme, a crochets airns quoique peu saillans; l'ancrle pos!ćrieur cst arrondi, l'antérieur est plus saillabl et plas poinlu; les bords snnt très-eutiers et non créuelés; l'impression abdominale est bien profonde et bien marquée; la clacriere offire deux dents cardinales sur chaque valve; à la base de la dent cardinale postérieure il y a en dehors une petite émineuce horizontale qui est une nyuphtre fort petite et per: saillante: elle iudique que le ligament devoit ểre très-court. la surface extérieure est lisse, présentant quelques stries d'accroissement. Longueur 11 millim., lärgeur 13. Elle se trouve fossile a Beyne, à Vulmondois et à Beauchamp.

27. Donace tellinelle. Donax tellinella. Lank.

D. Testâ ovato-transversâ, subtilıssimè striatá, tenui, pellucidi; dentibus lateruhbus perspicuis, distuntibus.

L.sis. Ann. du Nius. tom. 7. pug. 230. no. 3. et tom. 12. pl. 4 !. fig. 2. a. b.

DEe. Dict. des Scienc. nat. tom. 13. pl. 424.

Noв. Descrip. descoq. foss. des env. de Paris, pag. :11. pl. 10 . fig. 9.10.11.

Un troure cette peite coquille clans presque tous les endroits où le cilcuire grossier est désagrégé; elle est assez commune, el on pourroil !a coulundie arec les Tellines, si l'on ae fuisoit allemliou qu'elle est toujours dépourvae du pli sinutux qui caractérise celles-ci. lille est ovale, très-mausverse, presque équilatérale; son croLhet est à peine sensible; sa charuière a deux dents cardinales sur la vilve dioire, une senle sur la gauche; elle préseate deux dents latérales lıen seusible, et surtut sur la valve droite; le bord n'est point rrénelé, il est lisse; en deliors, ou aperçoit, à l'aide d'une forte loupe, que coute la surface est couverte de stries transversales trèsfices. Lon rueur 4 millim., largeur 9. Fossile is Grignon, Parnes, Moucby', Courtagnuy, etc.

\section{DONTOSTOMA.}

Dins ce grenre de Klein (.Meth. ostrac. fag. 16), on trouve russemblées un graad nombre de coquilles cliverses, qui ne se réunisseot quue par ce seul caractère, d'avoir des dents a l'ouverture. On conrevra sans peine qu'un tel genre ne peut èire couscrvé, puisçu'il contuent des espèces de cinq ou six genres uillérens, des Nírites, des Auricules, elc.

\section{DORIDIE. Doridium,}

M. Mekel a proposé ce geare, qui n’a point été adopté, pour les Acères de M. Curier. Íogez Arterts el Bellésexs.

\section{DORIS. Doris.}

Ce genre, dont nous devons la connoissance à Buhadscl (Anim. mar. tab. 5. fig. 5), sous le wow d'Argo, lut adopté par Linué sous le nom de Doris, arqquel il réunit tous les Mollusques marins yui rampent au moyen d'un disque ou d'un pied charuu placé sous le ventre; il sentit cependant que le genre Doris ne ponvoit les admettre tous, puisqư ils présentuieut des caractères variables : ce quilui fit créer les geares Scyllée, Tritouie et 'Tétlyys. Braguière, conduit comme Liuné par la cousidéracion de la place qu'occupe l'organe de la respiration, en sépara encore yaeiques espéces pour former le geure Cuvolius; et eutin, M. Cuvier, se fondant sur les mêmes caracleres yue ses prédécesseurs, proposa eacore les genres Eolides et Tergipes. Linué plaça lé genre Duris parmi les Thollufca pterolrachea, Luut le curps est percé d'une ouverture lutérule. Les Limaces et les Duris se trouvèrent daus la même furmille. Bruguière suivit à peu près l'ordre de Limé, il changea les familles, en se fondant sur l'absence ou la présence de deux tentacules; c'est ainsi que les Aplysies, les Doris et les Limaces lureut encore en contact.

Lamarck, daus le Syst. des Anin. sans vert., 1801 , après avuir séparé les Mullusques céphalés ea deux ordres, plaça les Doris encore avec les Limaces parmi ceux qui rampent sur le ventie. Il est Étonnant que jusciu'alors on n'ant pas senti qu'un anizal qui vit a l'air et qui le respire, devoit essentuellemeat dillërer de celni qui respire l'eau. M. Cuvier tut le preuier qui, dans les $A$ hnales du Mluséum, ćloigna, sur des caracteres ćvideus, les Doris et les Aplysies des Limaces. 11. Lamarck lui-mème, reccifiaut ses idées d'apres les laits exposés par M. Cuvier, seutit que ces auimaux éivient trop dilférens pour rester clésormais voisins. On vit done, pär l'Extruit de Cours, 1811 , qu'il a vuit adopté l'opinion du savint auteur de l'Anatomie compurée : opiniou dont tous les nąiuralistes resterent convaiucus et qui a prévalu, comme les Tableaux de MH. de Ferussac, de Blunville, et la auuvelle classilication de M. Lámarck dans l'Histoire des Animaux suns vercubres, le prouveut avec évidence. Voici les caraltères que les zoolugistes domment a ce geure.

\section{CARACTERES GËÉRIQUES.}

Corps rampant, nageant quelquefois, oblong, tantôt plauulé, tantôt convexe et subprismatique, bordé tout autour d'une membraue qui s'étend jusqu'au-dessus de la tête; bouche antérieuse tit eu dessous, ayant la forne d'une trompe; quatre tentacules, deux placés autérieurement sur le corps, reotrant chacun dans une fossette ou ane espèce de calice; deux autres situés près de to bouche. Anus vers le bas du dos, entouré par les b:anchies, qui sout silllantes, laciniées, tran. 
gées; ouverture pour la génération situéc au củlé droit.

Le dos des Doris est presque toujours chargé de tubercules plus ou moins gros; ì la partie antérieure on apercoit deux cavités destinées à coutenir les tenticules extérieurs; ces tculacules, variables daus leur lorme, suni quelquefois composés d'une série de petils globules que Boladsch avoil pris pour autant d'yeux, d'où le nom d'Argo qu'il avoit proposé ; mais le p!ıs souvent ce sont de petites lunules semblables des cieux côtés; les teux autres tentacules sont coniques, placés en arant sous le rebord du mauteau, sur les parties lalérales de la bouche; elle est furmće d'une petite trompe contractile, daus l'intéricur de laquelle se trouve une petite laugue cartilaginense, rounie de petils cruchets. L'osophage est assez lonğ, replić sur lui-mème, il entre dans l'estonıac non loiu du pylore; l'estomac est membraneux, presqu'entic̀renent enveloppé par un toie trèsvilumineux, qui verse dans son intérieur, par plusieurs ouvertures, une quantite notable de bile; le canal intestiaal cst court, se dirigeant vers l'anus, qui s'ouvre a la partie supérienre du corps, au milieu du disque branchial. I.cs Doris sont bermaphrodites, elles ont un double accouplement réciproque. Un ovaire contenu dans le foie, uo oviducte qui s'élargit en forme de matrice : voilà les organes générateurs femelles. Un gros testicule, nn canal déféreut, une verge fort loogue, repliée sur elle-même, qui sort peu ell arriçre du vaỵin : voilà les organes générateurs inâles. Une sorte de vessie qui s'adosse à la matrice et qui y aboutit est un ormane sur l'usage doquel on n'a aucuoe donnće. Les organes de lit respiration ou brauchies, placés comme nous l'avons dit précédemment, sc composcnt d'arbuscules de furmes diverses, de nombre variable, mais toujours symétriques, tquclquefuis unis a l'extćrieur, d'autres fuis cachés dans une poche qui a une ouverture extérieure arrondie. Ces branclies, comme tous les organes destinés à la respiration, sont composées de deux orliles de vaisseaux; les veines pulmonaires aboulisseat à une oreillette qui verse le sang daos un cœur en furme de croissant situé près de l'anus; il donne naissance à deux aortes.

Les Doris sont marines, elles habilent à diverses profondenrs et surtout dans les lieux où il y a beaucoup de vase, dont elles paroisseat faire leur vourriture. 11. Cuvier a disposé les espèces d'après la forme du corps, ce que MI. Blainville a ígalemeat fait dans le Dict. des Sciences nat. Nous allons donner quelques exemples dans chacune des divisions du genre.

10. Corps subprismatique; le manteau débordant à peine le pied.

1. Doris bords-noirs. Doris atro-marginata.

D. carpore elongato, subprismatico; dorso prominulo, lineâ nigní lateribus distincto, po:tucd acuto, subcaudito.

Cuvier, Ann. du Mils. tom. 4. pag. $47 \overrightarrow{5}$ pl. 2. fig. 6.

Doris candale, Lask. Anim. sans yert. $20 \mathrm{~m} .6$. part. 1. pag. 3ı.

Le corps est alongi, subprismatique; le des élevé et marqué postérieurement d'une ligne d'un très-beau noir : le corpss est terminé posiérieurcment par uue poiute aigü̈ ou une sorte de queue.

\section{Corps subhemispheirique, débondant le pied.}

\section{Donis verruqueuse. Doris verrucosa.}

D. corpore ovato-oblongo, convexo, vermcoso ; tentuculis superioribus intrì lamellas ducis eminentibus.

LINX', pag. $3103 . \pi^{\circ} .1$.

Lasix. Anim. sans vert. tom. G. part. 1.p.311, $n^{\circ} .3$.

Covier, Ann. du Mus. tom. 4. p.7g. 467. 7 l. I. fig. 4.5.6.

Le corps de cette espèce est ovale, nlblang, convexe, chargé de lubercules hómispluériques, saillans, lisses, dont les plus gros sont à la partie la plus élevée du dos. Les tentacules supériens sont placés entre deux feuillets charnus, et non dans une savité fcyalhiforme, comme dans la plupart des espèces. Longueur 1 pouce. On la tronve à l'Ile-de-France.

\section{3․ Corps comprimé; le mantean dépassunt beaucoup le pied.}

3. Donis argus. Doris argus.

D. corpore ovato-oblongu, planulato, lavi; tentaculis superiorihus clavatis, subverrucosis, $\dot{e}$ fovcis nudis exserentibus.

Laxr. Anim. sans vert. tom. 6. part. 1.pag. 3 ro. $n^{\circ} .2$.

Doris argo, Lin. Gures. pag. 3107. $72^{\circ} .4$.

Argo, Boyadsce, Anim. mar. pag. 6j. tab. 5. fig. 4.5 .

Exctclopédie, pl. 82. fig. 18. 19.

C'est une des espèces le plus anciennernent connues; la forme el la disposition de ses tentacules la distingue snffisamıent; en effet, ils présentent ce caractère singulier, d'ĉtre formés d'un série de petits globules posés sur on pédicule. Son corps esi ovale, oblong, déprimé, lisse, écarlate en dessus, bleuâtre en dessnus. Les branchies sont découpées au nombre de six au huit arbuscules, dans deux trous latéraux; elles peuvent rentrer dans la carité branchiale à la 
$104 \quad \mathrm{D} R \mathrm{~A}$

volonté de l'animal. Longueur 3 pouces et demi, largeur 2 pouces. Elle vient des mers de Naples.

\section{DOSIN.}

Nom qu'Adanson (V'oy, au Sénég. pl. 16) donue à une coquille que Lamarck nomme $C_{y}$ thérée concentrique. Voyez CrtréréE.

\section{DOTEL.}

Adanson (Voy. au Sénég.pl, 15) nomme ainsi le Mytilus mger. Voyez Modu.

\section{DO'TO.}

Nom donné par M. Ocken à un démembrement des Doris, pour celles qui sont étroiles. Ce genre, foiblement caracterisé, nous semble trop douteux pour qu'on l'admette actuellement dans la méthode. Voyez Donis.

\section{DRAGONNEAU.}

TTom rulgaire d'une jolie Porcelaine, que M. La. marck nomme Téte de Dragon. Elle est rare. Tojez Porcratine.

\section{U N}

\section{DRAP.}

Ce mot s'entend de deax manières: ou on l'applique à la coloration particulière des coquilles qui semblent couvertes d'une étoffe, comme le Cóne drap d'or, le petit drap, le drap d'argent, etc.; ou bien on l'emploie pour désigner l'épiderme dont une coquille est couverte: on dit alors qu'elle a son drap marin. (Voyez Coxcr YIIOLOGIE.)

\section{DUCHON.}

Adanson (Voyage au Sénég. pl. 4) a fait connoitre sous ce nom une petite coquille que quelques auteurs ont rapportée au genre Porcelaine, wais à tort, selon nous, car elle appartient anx Marginelles et à celle que M. Lamarck a nommée MIarginelle interrompue. (Voyez $M_{\text {ARGINELLE. ) }}$

\section{DUNAR.}

Une Nérite a reçu ce nom d'Adauson (Voyage au Sénég. pl. I3); Gmelin en a fait une espèce particulière sous le nom de Nerita senegalensis. (Vojez Néritr.) 


\section{E B U}

\section{EBurane. Eburna.}

Dès 130 r, M. Lamarck créa ce genre aux dépens des Buccins de Linué et de Bruguière, il le plaça dans le système des animaux sans vertébres, entre les Buccins et les Vis, et lui conserva par la suite les mêmes rapports, soit qu'il l'ait introduit dans la lamille des l'urpuracées de la Phylosoplice zoologique, soit dans celle des l'urpurifères de ses méthodes suivantes. Basé sur des caractères de peu d'importance, M. Cuvier ne le sépara des Buccias que pour ca faire un sons-gente, ce que MI. de Ferussac imita. M. Latreille divisa celte famille des Purpuriferes de II. Lamarck en plusienrs autres, dont celle des Buccioides contient les trois genres Nasse, Buccin et Ehurae, et comme lia famille suivante, les Subulées ne conticnneul que le arenre Vis; il s'ensuit que les Eburnes, dans cette méllode, n'ont pas réclleasent clangú de place et de rapprors. Ceux présentís prar .i. de Blainville, dans son Traité de Macologie, snut absolument les wères, mais dans un ordre renversé.

Quoique l'auimal des Elsurnes ne soit pas connu, et que preique tous les auteurs reconnoissent le peu de baleur des caractères génériques, cependant les coquilles ont un fucies si particulier que presque tous, et suriout les auteurs des méthodes les plus modernes, l'ont athis suns modifications; il n'cu a pas été de mêrne cle çuelques zuologistes anglais, yui, aprés avoir examiné quelques espèces el leu: avoir reconnu surs plusieurs rapporis des ressemblances incontesiables avec les Ancillaires, n'ont pas bésilé de rékuir à re genre cesespéces, et à remettre les autres avec les Buccios, laisan! ainsi disparoitre de la nomenclature ce geare sur de simples présoaptions. Ces prísomplions peuvent ĉtre fortes, il est vrai, en laveur de la réturne, muis il nous semble que rela ue suffit pas, puisqu'elles sont conire-balancées pal des présomptions contraircs. On ré pourra se décider que lorsque l'on conncitra lianimal du genre, qui probablement est operculé er est pourvo d'un assez ample manteau pour couvir en grande parie sa cocjuille, puisquolle cst lisse et brillante comane celle des Anwillaires, des Olives, elc.

$$
\text { CARACTERES GÉSLRIQOES. }
$$

Anitnal inconnu.

Coquille ovale ou alongíe, à boril droit trèssimple, oblique à l'axe de la cuquille; ouveriure lougiludinale, écúancrée à sa hase; columelle ombiliquée dans sa partie supérieure et caniculée sous l'ombilic. Lamk.

Hist. Nut. des Vers. Tome II.
Les corfuilles du genre cuil nous occupe se parlagent en denx sortes, comrne nous l'avous fait oliserver tout à l'heure, celles qui sont alongíes et peu ventrues, et celles qui sont ovalaires, ventrues; ces dernières, en plus grand nombre, se rapprochent des buceins. Les premières sont lisses, brillantes et nat la suture converte d'une callosilé ansez ćpaisse, comme dans les Ancillaires; leur columelle est fort singulière, onverle supérieurement en une assez large lacune, terminée par un sillon qui se continue jusqu'a la base et qui la parrage eu deux parlics presqu'égales; elle est bornće en debors par un autre sillon plus profond qui se contourne a la base: Dans les aulres espèces la columelle n'est pas bipartite, mais simplement perforće et ealourće d'un bourrelet marginal; ce qui a lien, comme on le sait, dans un assez grand nombre de coquilles de genres divers.

Quelques personnes avoient cru pouroir ranger dans les Fiburnes une coquille fossile de Dax et de Bordeaux; mais ayant l'ombilic couvert d'une large callosité, on doit la laisser parni les Buccins, dont elle a tous les caractères.

1. Ebunne alongée. Eburna glabrata. Lamx.

E. testâ ovato elongati, basibisulcatî, lavissimâ, nitidi, pallide lute. vexiusculis, superne confuentibus; suturis callosis, tectis.

Buccinum glabratum, Lix. Grex. pag. 3489 . $n^{2} .8 \mathrm{l}$.

LАМ̆. Anim. sans vert. tont. 7. pag. 280. $n^{3}$. I.

Lister, Conch. tab. 974. fig. 29 .

lioxwaxi, Recr. 3. fig. 149.

Gualt. Test. tab. 43. fig. $t$.

DABGEXv. Conch.pl.g. fig. g. ad sinistram.

Havaxise, Conch. pl.31.fig. f. 1.

K.ховк. Vergn, tom, 2, tab. 16. fig. 4. 5.

Martivi, Conch.tom. 4. tab. 122. fig. 1117.

Buccinum glubratum, BReg. Encyclop. $n^{\circ} .28$.

Excrct. pl. 40 t. fig. 1. $a . b$.

Sowerby, Genera, n'. 19. fig. I. 2.

Coquiile ovale-alongée, polie, ayant ses sutures couvertes par un dépốt calcaire, qui se termine a l'onverture par une callosité assez épaisse, placée au-dessus de l'ouverture de la colnmelle. Cette colnmelle est profondément inllécbie, comme tordue, ouverte à la partie supérieure et

$$
0 *
$$




\section{6}

divisée en deux par un sillon longitudinal, qui part du fond de lombilic; elle se termine par un bourrelet semblable à celui des Olives et aes Anciliaires, seulement il n'est pas strié. Au uiveau de l'angle supérieur de l'ouverture part un double sillon, qui descend obliquement jusqu'à l'angle inférieur du bord droit, où il se termine par une petite dent. Toute celte coquille est d'une belle coulenr jaune-orangé, quelquefois púle, quelquefois très-foncée. On la trouve assez communément dans $1^{2} O c e_{a n}$ acnéricaia. Elle a jusqu'à $7^{\circ}$ millim. de longueur. LAME.

2. Enunne de Ceylan. Eburna zeylanica.

E. test $\hat{\imath}$ ovato-conicâ, apice acutì, larvi, alb $\hat{\imath}$, macalis luteo-fulvis pictî́; anfructibus convexis, suturis distinctis; spirâ apice corale $\hat{y}$; columelle canali squaminiferv, violuscents.

Lister, Conch. tab. $9^{32}$. fig. 42.

Kre1s, Ostrac. tab. 2. fig. 47 .

Gualt. Test. tab. 51 .fig. 6.

Martini, Conch. tom. 4. tab. 122.fig. 11'g.

Buccinum zeylanicum, Bruc. Dict. $n^{\circ} .27$.

Eburna zeylanica, Encrcs. pl. 401. fig. 3. a. b.

Lamx. Anim. sans vert. loc. cit. $n^{\circ} \cdot 2$.

Espèce fort belle, graode, enflée, composée de sept à luuit tours convexes, séparés pai nne suture simple, uon canaliculée el ornée de taclies d'un fanve-bruu sur un fond blanc; les taclies qui touchent ì la suture forment un rang assez régulier; elles sont plus grandes que les autres, qui généralement sont arrondies; les premiers tours sunt d'up brun très-foncć et obscur. Liouverture est ovalaire; la columelle, régulièrement arquée, est simple, lisse, un pen saillante au-dessus d'un large ocnbilic, qui la perce à la base; à l'intérieur, cet oubilic est d’un bean violet et orné d'une rangće de lames saillantes de la même couleur; en dehors, il est circonscrit par un bourrelet qui se termine à l'échaocrure de la base, et qui n'en est que la trace. Cette jolie coquille, très-fitcile à distinguer, vient des mers de Ceylan, oì elle n'est pas rare. Elle a 75 à 80 millim. de long.

\section{Eburane canaliculée. Eburna spirata.}

E. testâ ovato-acutâ, ventricosâ, lavi, albâ, naculis luteo-fulvis pictâ; anfractibus supernè canaliculatis; canalis margine externo acuto; spirâ apice caeraleâ; callo columellce unbilicum partim obtegente.

Buccinum spiratum, Lis. Gres, pag. 3407. $n^{\circ} .70$.

Lister, Conch.tab. 983. fig. 42.c.

Bonsani, Recr. 3. fig. 37 o.

\section{E B U}

Ruмr. Mus. tab. 49.fg. $d$.

Peтrt. Gaz, tab, 101. fig. 13. el $a m b$. tab. 9 . fig. 21.

Dargen Conch. pl. 17 fig. $n$.

Favande, Conch. pl. 33. fig.e. 1.

SEBA, Mus. tom. 3. tab. 73. fig. 21. 22. 24. 25 .

Knora. Verg. tom. 2. tab. 6. fig. 5. et tom. 3 . tab. 3. fig. 4 .

Martini, Conch. tom.4. tab. 122.fig. 118.

Buccinam spiratum. Var. A. Brug. Diction. $n^{\circ}, 26$.

Eburna spirata, ENcYcL. pl. 401 fig. 2. a.b. LAMr. loc. cit. $n^{\circ} .3$.

Lorsque l'on voit cette coquille encore jeune, et qu'on la comprare avec des individus adultes, il y a une si grande diflérence dans la columelle et l'umbilic qui la traverse, qu'on est en droit de se demander si ces individus sont de mêne espèce; daus les premiers, l'ombilic, ouvert audessus d'un sillon quil le partage en deux parties, comme dans l'Eburne alougée, en vieillıssant, non-seulement cet ombilic se bonche, mais il est encore totalement recouvert par la callosité du bord gauche, qui s'étend du sommel à la base de l'ouverture, au lien de s'arrêter à sa partie supérieure, comme duns le jeune âge. Cette espèce est ovale, ventrue, assuz courte, formée de huit à neuf tours, dont les premiers sont bruns; ils sont convexes et bien séparés par une suture fortement canaliculée, bordée par une rangrée de taches obliques, alougées, fauves, plus graudes que celles arrondies qui se voient sur le reste de la surface; toutes ces tacbes se dessinent sur uu fond blauc assez pur. L'ouverture est ovalaire, garnie d'une callosité épaisse sur son bord ganche; elle est d'une belle couleur de rose. Elle vit dans la même ner que la précédente. Elle a Go zillin. de longueur.

\section{Ebunne parquetée. Eburna areolata. LAsx.}

$E$. testáovato-ventricosâ, lavi, alba , nmculis rufis quadratis triseriatis tessellata ; unfractihus superne angulatis, suprà planocavis; angulo obtuso; spirâ apice albâ; columellae conali nudo.

Lister, Conch. tab. $9^{81}$. fig. 41.

Bonnani, Recr. 3. fig. 70 .

RuMPH. Mus. tab. 49. fig. c.

PETiv. Amb. tab.9. Rg. 20.

SEBA, Mus. tom. 3.tab. 73. fig. 23.26.

Favanne, Conch. pl. 33. fig.e. 2.

Martint, Conch.tom. 4.tab.122, fig. 1120. 


\section{E B U}

Buccinum spiratum. Var. B. Brug, Diction. $\boldsymbol{n}^{\circ} .26$.

Lars. loc. cit. $n^{\circ} \cdot 4$.

Grande et belle espèce, très-distincle de toutes ses congínères; elle est ovale, veutrue, formée de huit lours de spire convexes, dont la suture est canaliculée, wais peu profondément; le bord antéricur du canal est arrondi, tandis qu'il est fort aigu dans l'espèce précédente : caractère qui, à defaut d'autres, pourroil servir à les distioguer. La disposition des coulenr's n'est pas moins rewarquable; sur un fond d'un blanc laileux le plus pur se dessinent trois rangées de taches d'un brun clair; elles sont carrées, alongées, distāutes el bien nettement séparées. L'ouverture est grande, ovalaire, blanche en dedans; le bord gauche est pourvu, à sa partie supérieure, d'une callosité épaisse qui s'interrompt au-dessus de l'ornbilic. Celui-ci est for grand, sinple, tout blancet bordé en dehors par un bourrelet décurrent, assez large et épais. Cetle corjuille, fort rare, vient des mers de la Chine. D'aprés .I. Lamarck, elle a 80 williun. de long, près de trois pouces.

\section{Ebure boneuse. Eburna lutosa.}

E. testá ovato-acut $\dot{i}$, subventricosá, lorvigat $\dot{i}$, squalide albidi; zonis duabus aut tribus obscure fulvis; anfructibus supernè angulo obtusissimo pruditis; unbblico semiobtecto, aliquantisper patulo.

ENcres pl. 401 . fig. 4. a. b.

I,AMK. loc. cit. $n^{\circ}, 5$.

Formée de sept à huit cours de spire convexes, artundis et formant une rampe obtuse, cette coquille, ventrue et ovale, n'a rien de bien remarquable, surtout pour les couleurs, qui sc composent de trois rangs de taches carrée;, oblougrues, souveat confondues, d'un liauve très-pále sur uo fond blunc sale. L'ouverture est ovale, oblon rne, garnie au côté gauche et supériententent d'une callosité épaisse toute blanclie, qui s'arrète au. dessus de lombilic; le bord gauche est épais, coutblanc, et laisse derrière lui un ombilic assez variable pour son étendue, selon les individus; quelgurefnis il est très-grand et très-ouvert; d'autres fois il est très-petit, prestu'entiẻrement caché par le bord gauche el par la ciallosité; dans tous les cas, il est bordé en deliurs par un hourrelet lort épais; le bnid droit est mince et trancliant, il se détache du gaucbe, à sa partic supé. rieure, par un sinus assez protund, qui॰nest indigué dans les autres espèces que par une inflexion. Nuus i nnnorons où vit ceite coquille, qui est fort rare dins les collections. Elle a bo millim. de long.

Dans son Genera, Sowerby a figuré une coquille de ce geure, dunt il a fait à cort, selon nnus, une espèce distinete de l'Eburna glabrata; elle en a absolument tous les caracières, si ce n'est qu'elle porte sur le dos une côte décurrente et arrondie : cet accident se rencontre dans plusieurs espèces d'olives et ne peut y constituer que des variétés.

\section{ECIIIDNE. Ecliidnis.}

Geure que Montfort, dans sa Conchylialogic systematique (tom. 1. pag. 354), proposa pour un corps pérrilié, qui doit rentrce dans les Orthncérales, puisqu'il n’en dillère en aucuve manière. Joyez Orthocérate.

\section{ECIINODERME. Echinoderma.}

Poli, dans sou ouvrage des Testacés des DeuxSicrles, donne ce uom a la copjuille de son genre Echion, qui correspond au genre Anonsie de M. Lamarck. Voyez A vome.

\section{ECIIINOPHORE.}

On nomme vulgairement aiosi le Buccinum echinophorum de Lioné, qui appartient actuelle. ment au genre Cassidaire de MI. Lamarck. Vojez CassidatRE.

\section{ECHIONE. Echion.}

Genre érabli par P'oli pour l'animal des Anomies véritables, telles que les conçoivent MII. I,amarck, Cuvier, elc. Voyez Axomie.

\section{ECLAIR.}

Les habitans de nos côtes et nos marins donnent ce vom à des Anomies qui, à ce qu'il paroit, jettent une vive lumière phosphorescente pendant la nuit.

\section{ECORCE DE CITRON.}

\section{ECORCE D'ORANGE.}

Noms vulgaires de deux helles espèces de Cônes. Ces mots sont deveaus specifigues. Voyez Côse dans le premier volume de ce Dictionnaire.

\section{ECORCIÉ.}

Les marchands et les amateurs nomment ainsi une fort belle espèce de Cône, le Conus striatus. Voyez Cóse dans le premier volume de ce Diclionnaire.

\section{ECRITURE ou COQUILLE ECRITE.}

On emploie vulgairement indistinctement ces mots pour désigner des coquilles couvertes de lignes bizarres, qui ressemblent grossièrement à des caractères d'écriture; ainsi on nomme de cette manière des coquilles de différens genres, la Venus scripta, la Cytherea castrensis, l'oliva 


\section{8}

scripta, etc. On donne le nom d'Ecriture hebrä̈que au Conus habrers, et Dargenville nomme Ecrite une des noubreuses variélés de l'Oliva hispidula.

\section{ECUSSON.}

On donne ce nom à la grande pièce dorsale des Pholades et des Térédines. Voyez ces mots et Coquille.

\section{EGËONE. Egeon.}

Genre qui est un des doubles emplois que Monifort (Conch. syst. tom. 1. pug. 166) a fait dans le genre Nummulite, qu'il a reproduit sous quatre noms dillérens. Voyez Numulis.

\section{EGÉRIE. Egeria.}

M. de Roissy, dans le Buffon de Sonnini, avoit prop.ssé de substíluer ce nom à celui de Galathée, donné p̧ar Bruguière et adopté par M. Lamarck, à une coquille démembrée des Cyclades. M. de Roissy se fondoit sur ce qu'il existoit déjà , dans les Crustacés, un gente Galathće. Ce motit'n'a pas prévalu, et d'ailleurs, depuis, on a établi un genre Egérie dans les Crustacés. Voyez GaLathé.

\section{EGOUEN.}

Nom qu'Adanson (Voy. au Sënég. pl. 4) donne à uue coquille du genre Narginelle, Marginella corulescens Lamk. Vojez Marginelle.

\section{ÉLÉDONE. Eledon.}

Ce genre ne se distingue des Poulpes que par un caractère de peu d'importance et qui nons semble insultisant. Les Pualpes ont deux rangées de ventouses sur chaque bras; les Elédons, q a n'en diffèreat en aucune autre manière, u'en ont qu'une. Voyez Cépanzopodes et loulpe.

\section{ÉLE்GANTE STRIÉE.}

Geoffroy, daus son petit Traité des coquilles des environs de.Paris, a donné ce nom à une espèce de Cyclostome, Cyclostoma elegans lamk. Voy. Cyclostour.

\section{ELLIPSAIRE. Ellipsaria.}

M. Rafinesque, dans sa Monographie des coquilles de l'Ohio, insérée dans les Annales des Sciences de Bruxelles, a proposé la division du genre Mulette en plusieurs genres et sous-genres qui tous ne reposent que sur des caracières insuffisans. Le sous-genre Ellipsaire est du nombie et n'a pas été adopté plus que les autres. Voyez MULETTE.

\section{ELLIPSOLITHE. Ellipsolithes.}

Une Ammonite, que l'on trouve très-sonvent

\section{E M A}

compriméc, et rendue ovale par suite de cet accident, est devenue pour Montfort (Conch.syst. tom. I. pag. 86) le sujet d'un genre qu'il uomme ainsi. Comme il est assez ordinaire de trouver celte espèce dans cet état, d'autres auteur's causervèrent ce genre sur ce caractère de la forme, mais nous croyuns qu'on ne peut le séparer des Ammonites. Voyezce mot.

\section{ELLIPSOSTOMES. Ellipsostomata.}

M. de Blainville a proposé cette famille pour rassembler plusienr's genres, parmi lesquels il s'ea trouve de lerrestres, de lacustres et de marins, qui, pour la plupart, ont des caractères qu'il est difficile de concilier, aussi nous pensons que cette famille ne sera pas adoptée ; elle se compose des genres suivans : Mlélauie, Rissoaire, Plassiauelle, Ampullaire, Hélicine ct Pleurncère. Voyez ces mols.

\section{ELPHIDE. Elphidium.}

Montfort, dans le tome jer, de sa Conchylio. logie systématique (pag. 14), a élubli ce genre pour une coquilie microscopicjue gui ne dillére pas des Polystouilles. Voyez ce mot.

\section{EI.YSIE. Elysia.}

Genre fort douteux, que M. Risso a proposé sans avoir probablement assez examiné l'animal qui lui sert de type. Cet animal paroit être le même que celui nommé Actéon pa: M. Ocken, et que malheureusement le zoologiste allemand n'a caractérisé que d'une manière incomplète; ainsi, ces deux genres, qui probablement u'en font qu'un, très-voisin des Aplysies, ne peuvent être encore introduits dans la méthude.

\section{EPIARGINULE. Emarginula.}

Les Emarginules, que M. Lamarck a séparées des Patelles de Linné, pour en fairc un genre, se distinguent en eflet d'une manière trés-remarquable de toutes les antres l'atelles; et çuoique M. Lamarck n'eût point connu l'auimal de ce genre de coçuille lorsqu'il le proposa, il avoit assez bieu saisi les rapports pour le placer dans l'ordre le plus convenable et pour en avoir tracé les caractères aussi bien que la connoissance seule du test pouruit le permettre. Depuis quel'on a eu occasion d'observer lanimal, en coulirmant les rapports établis par M. Lamarck, on n’a pu ajouter que des caractères anatomiques : ce qui ne laisse plus de doute sur l'apivion quon doit avoir sur ce genre.

Les Enargininules ont, d'un côté , beaucoup de rapports avec les Parmophores, surtuut si on en rapproche celles dont l'échancrure est pen profande, et, d'un autre, arec les Fissurelles. Ces rapports sont mĉue si intimes, que MI.de Blain- 
ville jerarde les. Mollusques de ces genres comme semblables et mantrant un mêtne ordie duns l'organisation et dans la place de l'ouverture branchiale, qui est au sommet dans les Fissurelles; yui est interı́cliaire entre le sommet et le bord dans l'Eurmginule douteuse de M. Defrance; qui devieot marginale dans les auires Enarginules; qui ne laisse plus qưune légère échancrute dans I'Émargiuule subérnarginéc de AI. Blainvilie; et enfiu, 'qui n'est plus quiun sinus assez large dans les Parinophores, dont quelques espèces nème sont tout-il-fail dépourvues : c'est ainsi que, lorsugue les rapporss qui lient les geures sont nalurels, et ne rompent point les convenances organiques, si je puis parler ainsi, ils doivent passer insensiblement de l'un a l'autre, et qu'ils peuvent servir de preuve a celle loi gćućrale de l'enchatuement des èlres.

\section{CARACTÉRESं GÉNE்IQUES.}

Corps ovale, conigue, pourvu d'un large pied occupant lout l'aldonen, el débordé par lé taanteau, qui a une fente antérieure qui correspond à celle de la copuille pour la comanuicalina avec la carité branchiale; tête pourvue de cleux tentacnles coniques, oculés à leur base externe; branchies parfaitement symélriques; coquille synétrique, conique, à sommet bien distinct et dirigé en arrière, fendue à son Lord antérieur pour sa comunuicalion avec la cavité branchiale, ou n’ollianı quiune légère échancrule à l'extrémité d'un sillon interne.

L'uninal des Emarginules $n$ 'a point encore été décrit àue manière complète; on le connoit assez copendant pour qu'il u'existe plus de doute sur lesrapports intimes qu'il a avec les tissurelles et les Parmophores; son pied et grand est aplati en dessous comme dans tes Patelles, soutenaut le corps par un large pédicule, entre lequel et le wanteau il existe une goutlière entièrement nue. Le manteau est assez épais, flexueux sur son bord, qui se relève pour couvrir une partie de la base de la coquille; il est lendu antérieurement au-dessus de la tête, el cette fente correspand a celle de la coquille ; cette même fentes'ouvie duus la cavité branchiale, qui est cervicale, et où l'on trouve deux petits peignes branchiaux triaggufaires, parlaitement symétriques; à droite de celle cavilé branchiale se remarque un orifice un peu saillant : c'est la terminaison de l'anus et de l'o:gaue de la génération. La tête est petite, aplatic, portaol deux teutacules coniques, contractiles, d'une médiocre longueur et oculés à la base au côté externe.

Les Emarginules sont des coquilles marines d'un petil volume, généralement minces et cassantes, toujours reconooissables par la fente ou l'échancrure du bord; toutes sont ornées de côtes rayonantes, et le plus grand nombre treillissées avec la plus grande régularité el beaucoup d'élégance. M. Lanuarck n'en a connu que denx espèces vivantes, auxquelles $\mathrm{H}$. de Blainville en a ajouté deux autres. M. Payraudeau en a incliqué une cinquième, quili a découverte sur les cûtes de la Corse, et que nous avons ene de la Sicile. Nous en connoissons deux autres espèces encore inédites: ce qui porte à hmit le nombre des espèces vivates. Quant aux fossiles, il y en a davantage, au moins douze: ce qui porte is ringt le nombre total, qui n'éloit que de crnq pour M. Lamarck.

I. Enarginule échancrée. Emaginula emaryinata. Bralvv.

E. testî̀ ovatâ, conicâ, patelliformi, costatâ; albâ vel albo-virescente, antice intùs canaliculatâ, margine submarginatî́; costis octo em.nentioribus.

Busux. Diction. des Sc. nat. tom. 14. p. 382. 1lid. Malacologie, pag. $501 . p l .48$ bis. fig. 2 et non fig. 3.

Coquille patelliforme, ovalaire, ì sommet à peine incliué postérieurement; il est subcentral, et il en part en rayonnant huit côles principales, saillantes, rugueuses, dont deux, l'antéricure et la pnstéricure, partagent la coquille en deux parties parlaitenent symétriques. En dedans de la côte moyenne antérieure, on remarcue une goullière assez prolonde, qui, en aboutissant sur le bord, y laisse une échancruse peu profonde. Entre ces cates principales, on en remarque plusieurs autres en nombre peu variable, qui est ordinairement de trois; quelquefois l'ume d'elles est plus grasse, et les deux autrés sont très-petiles; d'autres fois elles sont presqu'égales, mais dominées par les cótes principales; enfín, et cela est plus rare, la coquille devient plus conique, plus élevée, et tontes les cótes sont presqu'égiles; on distiugue cependant les huit principales, qui sont plus larges. Cette coquille est d'un blaocverdâtre en dehurs, el de la mênue couleur , mais un pen pius insense, en dedaus. Elle a 50 millin. de long. Nous ignorons le lieu de son habitation.

2. Earanginule deprimée. Emarginula depressci. Brainv.

E. iestâa patelliformi, albî, ovato-oblongâ, lateraliter depressâ, costatâ; costis novem eminentioribus; striis transversis, clathiatis.

Busrvv. Malacol. loc. cit. pl. 48 bis. fig. 3. 3 a. etnonfig. 2.

Coquille voisine de la précédente, mais biea distincte, toujours comprimée latéralernent, ce qui lui donue une forme ovale fort alongée; ses bords, épais, sont coupćs longitudinalement en arc de cercle, de sorte que, placée su: un plan horizontal, celte coquille a'y touche que par deux 
points; son sommet est subcentral, bien visiblement incliué en arrière; il en part un assez grand nounbre de côtes, dont neuf principales plus saillantes que les antres; il y en a deux ou trois plus petites dans lintervalle de chacuae; toules ces côtes sont coupées en travers par d'autres transverses, qui ne les dépassent pas et qui forment sur la surface extérieure un réseau assez grossier à mailles carrées. L'échancrure du bord est fort petite, un peu plus profonde cependant que dans Pespèce précédente. Celle espèce est tout-à-l'ait blanche. Elle est Inngue de 25 millim. Nuus avons quelqque raison de croire qu'elle vit sur les côtes de la Martinique, car nous l'avons trouvée daus le commerce parmi d'autres coquilles de ce pays.

3. Esarginude élégante. Emarginula elegans. Dera.

T. testâa ovato-oblongâ, conicâ, eleganter costatî, leviter clathratî, vertice recurvo; fissurú minimá, marginali, extrenitate sulci $1 n-$ terni. Nов.

DEFR. Dict. des Sc. nat. tom. 14. pag. $38 \mathrm{z}$.

Nов. Descript. des cog. foss. des environs de Paris, pag. 16. pl. 3. fig. 1. 2. 3. 4 .

Sow. Genera of shells, $n^{\circ} \cdot 21$. fig. 4 .

De toutes les Emarginules fossiles, c'est celleci qui a l'entaille la moins prufoude; celle fissure est placée sur le bord, à l'extrémité d'un sillon intérieur qui se prolonge jusqu'au sommet; ce sillon est marqué au-dehors par une cóte saillante, sur lag̣uelle s'aperçoivent très-bien les traces d'accroissement indiquées par de petites écailles; le sommet est courbé, élevé, subcentral; il en part en rayonnant un graud nombre de côtes, qui sont traversées par des stries peu prononcées, ce qui rend très-sensible le léger rreillis qui couvre le debors de la coquille : son burd est mêue crénelé. Longueur 13 millim., largeur 9 uillim.

Cetie coquille ne s'est encoré trouvée que fossile: M. Defrauce la recueillit d'abord à Parnes, dans le bassin de Paris, où elle est très-rare; depuis, M. de Gerville la découvrit à Valognes, où elle est plus commune. Elle sert de passage entre les espèces précédentes et celles qui saivent, car son échaacrure, encore fort petite, est pourtant plus profonde, et commence aussi par un sillon intérieur. LABK.

4. Emarginule radiole. Emarginula radiola.

$E$. testá ellipticâ, subdepressâ; verlice subcentrali; costulis crebris, squamulosis; fissur $\hat{\imath}$ anticâ, minimấ.

- LaNE. Ann. du Mus. tomi. I, pag. 384. $n^{\circ}, 3$.
Iljid. Anim, s, vert. tom. 6. part. 2. pag. 8. $n^{\circ} .5$.

Defa. Dict. des Sc. nat. tom. 14. pag. $38 \%$. $n^{\circ} .3$.

Nов. Descript. des coq. foss. des environs de Paris, pag. 16. $\mathrm{pl}$. 1. fig. 25.29 et 33.

Cette jolie coquille n'est point commane aux environs de Paris : elle est très-mince, très-frágile, ovale, alongée, quelquefois déprimée perpendiculairement, d'autres fois lateratement, et alors son sommet est peu proéminent, peu courbé; il en part ane trentaiue de côtes rayonnantes, entre lesquelles, vers le bord, on en voit une plus petite : dans les individus bien conservés, ces côtes sont chargées de petites écailles. Elle se distingue de l'espèce précédente, par les côtes plus serrées et plus nombreuses, par sa furme plus alongée et son soumet peu recourbé el peu saillant. Longueur 15 millim., largeur 7 .

\section{Emarginule fissurée. Emarginula fissuiata.} Sow.

E. lestâ ôtatâ, conico-depressâ, regulutriter radiatim striuta, extùs rubiâ, intùs albâ; striis tenuibus, transversis, alteras decussantibus; fissurá brepi.

Suw. Genera, $n^{\circ} .21 . f g .5$.

An Emarginula rubra? LAм5. Anim, s, vert. tom. 6. part. 2. pag. 7. $n^{\circ}$. 2 .

Nous n'avons pas la certitude, que l'espèce figurée par. M. Sowerby soil la même que l'Emarginule rouge de M. lamarck; la phrase caragí́ristique de ce dernier ne peut s’appliquer complétement à cette espèce : celle-ci est en dehors d'un rouge foncé saus nuances; elle est ovale, arrondie, conique, mais peu élevée; son sommet, excentrique, porté en arrière, s'y incline assez fortement; il donne naissance à un yrand numbre de petites côles rayonnantes, setrées, étroites, arrondies, qui parriennent sur le bord, qui est légèrement crénelć; sur la ligne médiane anté rieure de la coquille se voit uue côte'un peu plus large et plus saillante que les autres; elle est résulièremeut écailleuse et se termine vers la bord pal une petite échancrure peu proluncle, mais qui l'est cependant un peu plus que daus les espèces précédentes; des stries transverses, très-fines, régulic̀res, forment, avec les côtes, un risseau fin et régulier. Celte jolie coquillc, fort rare dans les collections, proviendroit, an dire de quelques personnes, des mer's d'Eurupe; elle a 15 à 18 millim. de long.

6. Emargrnule Ireillissée. Emarginula fissura. LAar $\mathrm{k}$.

E. testí ovali, convexo-conicá, costellis longitudinalibus striisque transversis cancellatá, 
albidâ, vel intùs roseâ; vertice curvo; nargine crenuluto.

Patella fissura, Lix. Gsex. pag. 57-29. $n^{\circ} \cdot 192$.

lank. loc, cit. $n^{\circ}, 1$.

Mullek, Zool. danic. tab. 24. fig. 7 à 9 .

Lister, Conch. tab. 543. fig. 28.

Pexisixt, Brith. zool. tab. go. fig. 151.

BUR. Mus. cas. 2ind. tab. 18. fig. 12.

Mart. Conch. tom. 1. tab. 12. fig. 109.110.

Fossilis. Emaroinula reticula, Sow. Min. innch. tab. 53. fig. 5. 4 .

Var. B. Non. Testa inties roseâ, eqidermide fusco extus induti.

Emarginula rosca, Belr. Zool. jour. $n^{\circ}$. 1. pug. 52. $\mu l .4$. Jig. 1.

Var. C. Noв. Testi minore, mugis conica, elatione; apice extis margine recurvo.

Celle espèce, quoique la plus commune du ycnre, est cependant l'uue des plus intéressantes, se trouvant dans nos eners et fossile dans plasieurs lieux : clle est ovale, patelliforme, très-conique; son somanct, incliné en arrière, est pointu, non central; des côles rayonantes, lisses, nombreuses, en descendent; ane plus petite est interposée dans l'espace assez étroit qui, les séplarant des stries transverses, bon moins régulièıes que les róles, les coupent à angle druat, el produisent sur la surface un résean d'une grande régularité, très-fin, à mailles carrées et profundes. L'entaille du bord est profonde, mais moins que dans les espèces que nous allons indiquer : le plus souveat Llaocbe cu dedans et en dehors, elle est quelquefois rose en dedans, ce qui ne vaut pas la peine de faire pour cela une espèce, comme l'a pensé M. Thomas Bell, les autres caractères restant d’ailleurs les mêmes. La variété C' est constamment plus petite, plus conique, plus haute; et son sommet, fortement incliné, dépasse le bord poslérieur. Cette espèce se trouve dans les mers d'Europe, e! fossile à Angers, les fuluos de la Touraine et le crag d'Angleterre; elle a 15 millim. de long et 10 de haut. I,ASK.

7. Emargixude à cóles. Emarginula costata.

E. testâ obliquè conicâ, costatâ; costis carinatis; vertice adunco.

Lamr. Ann. du Mus. Loc. cit. tons. 6. pl. 43. fig. 6. a. b.c.d.

Ibid. Anim. s. vert. loc. cit. no. 1.

Defr. Dict. ibid. $n^{\circ}$. I.

Noв. Descript. des coq. foss. des environs de Paris, pag. 18. pl. 1. fig. 30.31. 32.
Emarginula scalaris, Sowerby, Min. Conch. pl. 5 เg. Jig. 3.

De toutes les Emarginules, celle-ci est celle qui a le sommet le plus proúminent et le plus loin du centre; cllc ressemble au premier aspect à un petiı Cabochon; clle cst coniquc, élevée en cône, courble et cluargéc de treize à quatorze cótes en arêtes, qui rayonnent du sommet a la base; entre les cotes, on olsserve des stries relcvées, serrées et sublauelleuses; la lissure est bordée par deux lames en arêtes, qui vont depuis le bord jusqu'au sommel. Celte pelite coquille, yui a seulenient, dans les grands individus, 4 ou 5 millim. de longueur, ne se trouve à Grignon qque dans les couclies supérieures du dépôt coquillier. Nous comptons une cóte de plus dans les individus trourés en Angleterre; c'est la seulc diflérence notable que l'on puisse observer, et cependant cet analogue, avec le fossile de Grigoon, appartient à l'oolite; ce qui a lieu de surprendre, car on ne pourroit citcr un second fuit semblable à celui-ci.

8. Esangixule curvirosire. Emarginula curvirostris. \ов.

E. testa ovatâ, conicâ, albâ, translucidâ, longitudinaliter costatâ, transversim striatû; apice peracuto, valdè inflexo, recurvo.

An Emarginulu fissuru? PAYr. Cat. des Ann. et des Moll. pag. $9^{2} \cdot n^{0} \cdot 37^{2}$.

Emarginula conica, Buassv. Malac. $\mu l .48$. fig. 4 .

Jolie coquille mince, fragile, que l'on ne sauroit confondre arec aucuacs du même genre; elle est blanche ou jaunatre, ovale, conique, a sommet très-postérieur, incliné, recourbé en crochet pointu; vers lui convergent un grand nombre de cótes rayonnantes, dont les unes, plus saillantes, laissent entre elles des espaces assez larges occupés par trois côles plus pelites; des stries transverses, fines et nombreuses produisent sur tout le test un treillis d'une grande linesse et d'une régularilé admirable. Le bord, augnel se readent loutes les côles, est finement crénelé, et l'entaille qui se voil sur le bord antérienr est étroile el profonde; elle se continue jusqu'au sommet par une cóte médiane, écailleuse. C'est dans la Méditerranée que se trunve cette espèce, qui est longue de 16 millimètres.

9. Euargivole treillagée. Emarginula clathrata. Noв.

E. testá minimâ, conicâ, obliquè recurvâ, elegantissimè decussatâ; apice recurvo; fissurî̉ marginatâ, profundâ.

Nов. Descript. des cog. foss. des environs de, Paris, pag. 17. pl. 1. fig. 26. 27.28. 
Je n'ai jamais vu de cette espèce, que l'individu de ma collection : elle est petite, mais d'uue forme élégante, et les cùtes nombrenses, rayonnantes et verticales, coupées par d’autres longitudinales, qui couvrent toute la surface d'un réseau régulier, la rendent très-remarquable; dans l'intervalle de cbaque côtes on ea remarque une plus pelite; le somnet est courbé, et fait à pen près trois quarts de tour. La lissure est profonde, marginée par deux crêtes qui se continueat jusqu'au sommet; dans leur intervalle, on voil de petites écailles qui marquent l'accroissement, et qui correspondent aux côles Inngitudinales. Lon rueur 5 millim., largenr 3 millim. et demi. Cette jolie espèce, très-fragile, ne se trouve que très-rarement a Parnes, et on oe peut l'avoir un peu entière, qu'en la cliercliant dans les sables qui remplissemi les grosses coquilles.

10. Enangmere en bouclier. Emarginula clypeata. Lams.

E. testâ elliptic $\hat{\imath}$, depress $\dot{i}$, striis decussatis cancellat $\dot{i}$, dorso canaliculatí, bicarinatâ; vertice submarginali.

L.Aмк. Ann. du MIus. loc. cit. $n^{\circ}$. 2. et tom. 6 . pl. 43. fig. 5. at. b. c. d. e.

Ibid. Anim. s. vert. loc. cit. $n^{\circ} .5$.

Defr. Dict. ibid. $u^{\circ}, 2$.

Nов. Descript. des coq. foss. des environs de Paris, pag. 17. pl. 1. fig. 20. 21. 22. 23. 24.

Jusqu'à présent on n'a tronvé cette belle coquille qu'à Grigunu, où elle est très-rare; elle est mince, fragile, déprimée, élégamment treillissée à sa surface; son bord est frangé; la fissure antérienre est peu profonde, assez large, bordée latéralement par une clête trancbante, qui se cuntinue depuis le bord jusqu'au sommet, et qui forme ainsi noe soite de rigole qui trarerse tout le dos de la coquille. Dans le fund de ce canal, un remarque de petites écailles courbées, qui marquent les accroissemens et tes déplacemens de l'organe gui passoit par la fente, dont il n'est que l'indice. Rien n'est plus éléçant que le réseau de siries qui couvre la surtace de celte coquille, fort remarcfuable d'ailleur's par son aplatissement et la manière doat son sounmet se courbe sur le bord postérieur, qu'il tuuche, comme cela a lieu dans les Crépidules : cente espèce est très-rare. I,ongueur 15 millim., largear 10 ou 11 millimètres.

\section{EMPEREUR. Imperator.}

Genre que Montfort a proposé dans sa Conchyliologie systématique (tom. 2. pag. 190), pour une coquille très-belle, très-rare, qu'on ne doit pas séparer des 'Troques, dont elle at tous les "caractères. Voyea Thoque.
ENALLOS'TEGUES.

Dans son Mémoire sur les Céphalopodes fora. miaifères, M. d'Orbigny a donné ce uom à une famille composée de sept genres sculement, qui tous offient ce caractère, d'avoir une coquille formée de deux ou plusicurs séries de loges agglomérées par alternances et régulièremeat, sans jamais tormer de spire neltement caractérisée. Les sept genres suivans, Bigénérine, Dimorphiae, Polymorphine, Sphérordine, T'extulaire, Valvuline et Tirguline, constituent la famille des Enallostègues. Nous renvoyons à clıacua de ces mots, ainsi cql'à CÉPHALOPODES.

\section{ENDOCÉPHALES. Endoceptuala.}

M. Latreille, dans ses Familles naturelles du Regne animul (pag. 203), a donné ce nom a la seconde section de ses Mollusqnes, lacpacile correspond aux Acéphales des auleurs. Foyez ce mot et Moliusque.

\section{ENFERMÉS. Inclusa.}

Nom que M. Schumacher donne à la troisiène division de ses Multivalves; celte division comprend les deux genres Tarel el Histulane. ( $T$ ror. ces mots.) La manière peu philosophique doni le système de l'aulenr que nons cilons a été conçu, nous oblize de renvoyer le lecteur à l'article Multivalie, où nous verrons cumbieu il e.l à desirer que cetle classe articliciclle soit enlin rejetée des méthodes.

M. Curier a aussi employé la même dénnmination, ea l'appliquant à une tamille de Mollusques acéphales, dunt le manteau, á peine ouvert pour le pussage d'un pied rudimentaire, semble enfermerl'aninal dans celte enveloppe charnue. Composée d'un grand nombre de genres, celte tamille n'a point élé conservée; M. de Fernssac en a fait un ordre, dans lequel it a introduit des cbangemens nombreus; $\mathrm{H}$. Lamarck a répari les nèmes genres en plusieur's familles, dont la disposition semble préférable, comme on puarra en jurer à l'article Morruspere.

\section{ENROULÉS (les):}

Des coquilles qui ont le caractère commun d'êtue enroulées de manière à ce que la spire soit presque complétement cachée ou peu saillaute, telles que les Porcelaines, les Olives, etc., ont été rassemblées en une faraille unique, par M. La. marck : elle se compose des genres Ancillaire, Cône, Olive, Orule, Porcelaine et Tarrière; if y a entre ces genres, à l'exception des Cönes, un caractere cerlain, c'est que les animaux ont un manteau assez giand pour envelopper leur coquille et la polir consiamment. Si celle circonstance organique ae se trouvuit que daas ces genres, sans loute que ce servit un excelleut moyea de réunion; 
Ifunion; mais il se tronve aussi dans d'autres, qui ont les caractères d'une famille voisine, dont le's genres portent des plis à la columelle : lequel de ces caractères doil alors l'emporter?" duit -on luisser les Marrinelles et les Volvaires dans les Columellaires (2royez ce mol), purce qu'elles ont des plis ì la columelle, ou doit-on les rangrer dans les Enronlés, parce que la coquille est coustaument polie? il serout possible que, yunud méac cellc question secoil rés lue, on n'arrivât pas à une classilication délinitive, puisque parmi les genres que nous avons cités, il y en a d'operculés et d'autres tui ae le sont pas, et, comme l'operçule est un caractère d'uue plus grande importance dans la méthode naturelle, ce sera d’après lui qu'on devra se décider. Voyez les muls des genres que hous avons mentionnés, airsi que Mlowusque.

\section{ENTAILLES.}

Vulgairement on nomme ainsi les coquilles du genre Emarginule. M. de Blainville, dans sun Trueté de Mialacologie, a douné cetle dénomination à un pelil groupe des Lnarginules, celles doni la fente très-courte commence en delans par un sillon antérieur dont l'orignine remonte jusçu'zu sommet. Voye = Emargivele.

\section{ENTCALE. Entalium.}

Nuus avions d'abord pensé que le genre Eutale différoit assez des Dentales puur en être séparé; nuus n'avions en cela que suivi l'auteur du geure, M. Defrance, qui l'a proposé dans le Dictionnaire des Sciences nuturelle; matis ayan! eu l'occasion de l'examiner de nouveau, depuis surlout que nuus connoissons certains phénomèmes propres aux fossiles de la craie, nous avons dû changer d'opision, et considérer les Entales comme une véruable Dentale, dont une partié du test se trouve décomposée. Voyez Devtal.E.

\section{EVTÉROSTES. Enterostca.}

M. Lalreille a donné ce nom à sa seconde famille des Céphalopodes décapodes; comme nous traitons en détail, à l'article CÉrenLopode, de ce qui a rapporl à ces animaux, nous y renvoyons parce que l'on y trouvera un examen des diverses métbodes dont ils ont été le sujet.

\section{ENTONOSTÉGUES.}

Famille fort naturelle proposée par M. d'Orbigny dans l'ordre des Céphalopodes foraminilères, pour les coquilles doat les cloisons sont composées d'un nonbre plus on moins grand de cavités, le plus souvent tubuleuses, agglomérćes, ce qui donne à ces coquilles, d'ailleurs tournées en spirale, de la ressemblance avec l'os de la Siclie : ceci nous porteroit à commencer l'ordre Hist. Nat, des Vers. Tome II. parcelle famille, au lien de la terminer par elle, comme l'a fait il. d'Orbigny. Cetie linnille se compose des cing genre suivans : Amphistigine, Hétérostégine, Urbiculine, Alvéoliue et Falsulairc. Voyez ces mots el Céphalopodes.

\section{ENTOMOS'FOMES. Entomostomata.}

Seconde famille du premier ordre des Paracéphalophores dioiques de 31 . de Blainville. II l'a propusée dans son Traité de Alalcicologie, et l'a divisúe en quatre sectious: dans la prenière se trouvent lcs yenres à coquille turriculée, ce sont les Cérites, les Mélanopsides, les l'lanaxes, les Alènes; dans la seconde sont vangées les coquilles Turbinacécs buccinoïles, elle comprend les genres Vis, Eburne, Buccin; la troisième renlerme les corguilles ampullacées des genres llarpe, 'Tunae, Cassidaire, Casque, Ricinulo, Cancellaire et Pourpre; la quatrième enfiu est destiuće à un seul geare, le Coucholépas. Il est à présumer que l'arrangement de cetie famille subira des changemens notables, déjà nous en avons noté un à l'article AlÈne; les Cuncellaires paroissent s'en éloigner, comme nous l'avons vu eu traitant de ce genre, les 'l'ounes we sont point operculées; les lfarpes ne le sont pas davantage. II faut donc retirer ces genres d'une famille dont tous les animaux portent un opercule. Ces changewens, nécessaires dans cette famille, nous portent à ne pas l'admettre. Voyez Mollusque et les mots des genres que nous avoas meationaés.

\section{ENTONNOIR. In fundibulum.}

Le trochus concavus, qui ne diffère des antres espèces de Troques que par la concavité de sa face inférieure, est devenu pour Montfort le sujet d'un nouveau genre, gui a'a point été adopté ( Loyez 'Thoque); par suite d'une fausse apprécialıon des caractcres, il a confondu dans ce genre des Calyptrúes trochiformes, ce qui n'est pas adwissible.

Vulgairement on nomme Entonnoir les Fissurelles profondes et les Patelles les plus coniques.

\section{EOLIDE. Eolides.}

Un opercule de Gastéropode, figuré dans Soldani, fut copié par Montforl daus sa Conchyliologie systématique (1om. I. pag. 142), el décrit par lui avec une rare assurance comme une coquille cluisonnce el perforée au centre; il est vrai que les cloișons et la pertoration ne furent jamais que daus l'imagination de cel auteur, aussi jeu scrupuleux que véridiquac. La description de Soldani sulfit pour dévoiler le mensonge de Montfort.

EOLIDE. Eolidia.

Les Mollusques de ce genre avoient été cou$\mathrm{P} *$ 


\section{IIf}

E O L

fondas parmi les Duris. Linné en aroit coanu d'abord deux especes qu'il ne distingua pas; mais $\mathrm{Gmelia,} \mathrm{qui} \mathrm{eo} \mathrm{rassembla} \mathrm{da} \mathrm{rantage,} \mathrm{prit}$ plaisir, pour aiosi dire, à en faire un singulier melange, à confondre les espèces el à en repruduire quelques-unes trois ou quatre fois dans une syoonymie remplie d'erreurs. Braguière, sans rien cbanger dans le genre Doris, auroit prabablement corrigé les fautes de Guclin, car il avoit fait copier avec heanconp d'exactitude, dans les planches de ce Diclioonaire, les figures originales des auteurs qui avant lui avoieat fait connoiltre ces animanx.

C'est à M. Cuvier que l'on est redevable d'un travail qui a débroullé le chaos que Gmelin avoit fait; non-sculement il créa le genre qui nous occupe, ce qui étoit nécessaire, mais encorc ce qui n'étoit pas moius utile, il rétablit la synonymic et fit entrevoir la conrenance d'un nonveau genre pris daus le même type d'animaux, et qu'il réalisa plus tard sons le nom de Tergipède.

Un geure Cavoline a élé créé par Bruguière dans les planches de ce Dictionáaire; il a sans contrediı !es plus grands rapports avec les Eolides; BI. Cuvier l'y joignit, et ea cela il fut imité par la plupart des zoologistes.

M. Lanarck mentionaa d'abord le genre de M. Cuvier dans sa Philosophie zoologique; plusienrs années après sa publicalion dans les $A n-$ nules du Muséum, il les rangea daos sa famille des Tritoniens, avec les genres qui depnis servireat à établir les Nudibranches des autenrs. Depnis cette époque, M. Lamarck coulioua d'adopter le geore Eolide et le laissa coos!amment dans les mêmes rapports, et comme M. Cnvier confondit avec Iui les Cavolines de Braguière, il fit olsserver cependant que si l'on vouloit on ponrroit établir parmi elles plusieurs geores, en saisissant pour les caractériser les diverses formes des brauchies; mais il regarda ces distinctions comme inuriles, et la raison qui lui fit rejeter le geare Tergipède, l'empécha d'admeltre les Cavolines. M. Lamarck eut raison d'en agir ainsi; il tiroit de celle manière la conséqueace d'un principe admis. $N$. de Ferussac ne fit pas de nıéme, il adopta les Tergipèdes de $\mathbf{1 1}$. Cuvier, et laissa réuaies les Cavoliaes et les Eulides, les distinguaat seulement en deux groupes; mais il anroit pu certainement en faire d'autres en employant des caractères de même valeur.

Ce que M. Lamarck avoit voula éviter d'autres le tentèrent, el uotamment M. de Blaioville, dans son Truite de Malacologie: on y trouve en effet, dans sa fumille des Polybranches tétracères, les ırois genres Tergipède, Cavoline et Eolide. M. Rang.s'est contenté daus sou Manuel de diviser les Eolides en deux suns-genres, les Eolides proprement dites et les Cavolines, ce qui se rapproche de l'arrangement de M. de Ferussac.

11. Cuvier put examiner une espèce d'Eolide, et il donna la description de ses parties extéricures, mais il n'entra dans ancun détail anato. mique : leur voisinage des Tritonies et des Scyllies peut fuire concevoir pour elles nne organisation, si ce n'est eatièıement semblable, dn moins analigue; ce que l'on en connoit suffit d'ailleurs pour bien caracteriser le genre.

\section{CARACTÉRES GÉ NE⿱R⿴囗QUES.}

Animal limaciforme, sans mantean oi cujrasse, plat en dessuns, convexe en dessus; lecte dislincte, fortant quatre on six tentacules. Branchies saillantes, molles, en lânes écailleuses; papilles ou cirrhes dispusées sur le dos en ranyées longitudinales ou iransverses; auus et orifice de la génération réunis sur un seul tubercule antériear et du cóté druit.

Le pelit nombre d'espèces que l'on connoit dans ce geare a ćlé le sujet de plus d'une erreur, comme hous l'arons annoncé au commeacement de cet article, el il ne sera pas sans intérêt de citer ici lextuellement une demi-page du Mémoire de M. Covier, ount il a élé fait plusienrs fois meotion. Voici ce qu'il lit pag. 18 :

"Linnacas paroil être le premiér qui ait décrit une Eulide, d'après Marlin, l'un de ses élères, qui l'avoil trouvée dans la mer de Norwège; c'est le Liniax papillosus de la Fauna suecica, $2^{e}$. édil. 1761 . Il a en dit antre chose, sinon qu'elle est grande conme un grain de riz, toute couverte en dessus de petıtes papilles aiguës et molles, avec quatre grands tentacules.

* Baster en décrivii, l'année d'a près 1762 (Opuscula subcesiva, tom. 81.pl. 10.fg. 1), sous lo nom de Doris, noe des cótes de Hollande, longue de deux ponces, ayant aussi qualre tentacules, le milieu du dos au et les côtés couverts d'une très-grande quantité de pelites écailles molles; le pied large et plat.

"En 1766 , Linræus regarda l'animal de Bagter comme le mème que le sien, et les réunit (Syst. nat. édil. 12) sons le nom de Limax pafillosus, demandant toutefais si ce ne seroit pas plutôt une Doris.

* Ea 1770 , Gnanerus, évêque de Dronbeim, redonna l'auimal de Baster sous le nom de Doris bodoensis. (Mém. de l'Acad. de Copenhague, tom. 10. pag. 170. pl. sans no. fig. 1-i3; celle dervière figure est copiée dans les planches de ce Victionnaire, $p l .8 z$. fg. 12.) C'étoit sur les côtes de Notwège qu'il l'a voil troavé.

"Gmelin réudit ces trois syaonymes sous son Doris papillosa, et quoique celui de Lionæus paroisse déjà différea des deux antres, il en ajouta encore denx non moins différens, savoir : le Limax mininus de Forskabl (Descrip. anins. 


\section{E O L}

ciab. pag. 100. e! Icon. 25. Hh 1. et h 2. copiee fig. 10 et $11 . p l .82$ de ce Dictionnaile), trouvé dans la Méditerranée, à quatre tentacules trèspelits comme celui de Linnaus, le milieu du dos est comme celui de Baster et de Gunner, mais à éciilles beaucnup moins nombreuses, et à pied en forme de sillon; el la limace épincuse de Bommé (.Mém. de Flossingue, tom. 3, fig. 2), des côtes de la IIollande, aussi très-petite, à dos entièrement garui d'écailles, peu numbreuses et à six tentacules.

- Au tort de confondre ainsi au moins trois espèces, il ajoute celui de doubler une des trois, celle de Forskabl; car apłès en avoir rappotté la firure à son Doris papillosa, il en cite la description comme fundart sur elle l'espèce du Doris minima.

Une fois averti des erreurs de Gmelin, il sera facile à l'avenir d'en éviler de semblables, et la synonymie de M. Lamarck a dû se resseatir des judicieuses observations que nous venons de rapporter.

Nons diviserons les espèces de ce genre eu quatre groupes, d'après la forme et la position des brauclies; ils ne contiendront la plupart quine seule espèce, mais il est à présumer que le nombre s'en augunentera lorsque l'on aura recluerché les espèces encore douteuses qui sont des mers d'Europe, et que les voyágeurs s'occuperont à les recueillir dans les régions lointaincs.

t Espedces dont les branchies cirrheuses sant disposés en rangées transverses sur le dos. Cisvo. lines, Baug.

1. Eoude pélerine. Eolidia peregrina. Lıнк.

E. corpore lacteo; circhorum ex fusco caruleorum in dorso seriebus decem trunsversalibus.

Cavolin. Pal. mar. tom. 3. pag. Jgo. tab. 7 . fig. 4 .

Doris peregrina, G G EL. $n^{\circ}$. 16.

Lanx. Anim. sans vert. tom. 6. part. 1. pag. $303 . n^{\circ} .5$.

Cavolina, Busixv. Malac. pl. 46 bis. fg. 7 .

Cavolina, Excrct.pl. 85. fig. 4 .

Animal limaciforme, subcylindracé, terminé en pointe à son extrémité postérieure, porrant sur la î́te six teotacules, dont les moyens sont trèsalongés; les branchies, en forme de filamens longs, grêles et pointus, sont placées sur le dos en ranuées transverses régulières, au nombre de cinq d'après M. de Blainville, et de six d'après Brugiicre. Cet animal, long de plus d'un ponce el demi, est d'un blanc laileux, et ses branchies snnt fauves oujaunâtres. Il lıabite la Méditerranéc sur les fucus. $f+$ Espèces dont les biranchies cirrheuses sont disposées en rungées longitudinales sur les parties laténales du dos.

Lamx.

2. EoxIde fasciculée. Eolidia fascjculata.

E. corpore oblongo, postice attenuato; papillis dorsi acutiusculis, subferrugineis; tentaculis quatuor.

Limax marinus, Fonst. Descr. an. pag. 99. $n^{\circ}$. 3. et $I c$. tab. 26. fig. 9.

Doris fasciculata, Grex. pag. 3104.

Lasx. loc . cit. $n^{\circ}, 2$.

Escrcrop. pl. 82. fig. 13.

Espèce oblongue, cylindroïde, voisioe de la précédente quant à la forme el pouvaut servis de passage entrelle et les espèces á écailles, car scs branchies en lilamens pointus et mous sont rangées longitudinalemeni de clıaque côté du dos, au lieu d'être placées en raggées transverses comme dans l'espèce précédente, dont on a fait le genre Cavoline. Celle-ci est longue d'un pouce, pointue postérienrement, blauchâtre, avec les branchies de coulear de rouille; sa tête, obtuse et peu distincte du corps, porte quatre tentacules longs et pointus. Cet animal habite la Mtdilerranée.

\section{t t + Especes dont les branchies sont en écailles.} Eolides proprement dites.

3. Eolnde de Cuvier. Eolidia Cuvierii. Lamr.

E. corpore subovato, suprà lanellis serialibus proclongis deorsim incumbentibus; tentaculis sex.

L.Ax . Anim. sans vert. tom. 6. part. 1. p. 302 . $n^{\circ}$. 1. Synonym. exclusis.

Si l'on admettoit la synonymie que M. Lamarck doune à celle espèce, on retomberoit presque complétement daas les mêmes fautes que Gmelin. Il est bien certain que le Limax papillosus de Linné, qui est très-pelit et qui n'a que quatre tentacules, est différent de cclui-ci, qui en a toujours six et qui a un pouce de longueur. Il est bien certain aussi que l'espèce de Baster el de Gunner diffère, et de l'espèce de M. Cnvier et de celle de Linné. La Doris papillosa de Gnelin, qui est l'assemblage de cinq espèces, doit donc être rejetée de la synonymie. Quant à l'animal finuré sous le nom d'Eolide de Cuvier, dans le Traité de Malacolngie par M. de Blainville, la simple conparaison des figures suffit ponr démontrer évidemaent que ce n'est pas la méme espèce, mais peut.être le Limax papillosis de Linné, ayunt absolument Ia même taille qu'elle et n'ayant également que quatre tentacules. II résulte des observations précédentes que nous g'admettons daas l'espèce qui nous occupe que

$$
\mathbf{P} * 2
$$


celle qui a été figurée par M. Cuvier. Elle est longue d'un ponce; ses écailles branchiales sont disposéés en plusieurs rangées longitudinales; elles sont fort longues, surtout antérieurement et ne s'implantent pas au milieu du dos, qui reste constamment au; les tentacules, au nombre de six, sont inégaux; la paire postérieure est la plus longue. Cette espèce vit sur nos côtes de l'Océan.

4. Eolide grisâtre. Eolidia minina. LaMr.

E. corpore pallide cinereo; seriebus papillarun dorsalium quatuor; tentaculis ninimis quatuor.

Lina.x minimus, Forsa. Desc. an. pag. Ioo. et I c. tab. 26. fg. h.

L.s x. loc. cit. $n^{\circ} \cdot 3$.

An Eolidia Cuvierii? Busisv. Malac. pl. 46 bis. fg. 8.8 a.

Excycl. $p l$. 82. fig. 10. 11 .

Toujou's plus petite que la précédente, celleci est dun gris-cendré; ses lamelles branchiales, arraugées sur qualre rangs, occupent plus de place sur le dos, de manière à ne laisser dans le milieu qu'une zone étroite qui en est dépourvue. Ce qui doit surtout empêcher de confondre celleci avec la précédente, c'esl qu'elle n'a que quatre teatacules, caractère qui, se retrouvant sur l'animal de NI. de Blainville, nous a déterminé à le rÉnir avec celui de Forskahl. L'un et l'antre, longs de 4 à 5 ligues, se sont trouvés dans la NIéditerranée; ce qui est une présomption de plus pour croire qu'ils son! de méme espèce.

$† \dagger+$ Espèces à branchies en mussues, terminées supérieurement par une ventouse? Six branchies de chaque côté. Genre Tergipède, Cuv.

5. Eoride lacinulée. Eolidia lacinulata. Lnn.

$E$. corpore minimo, albido, subovato, papallis dorsi abovatis utrinque sex.

Limax tergipes, Forsx. Fuun. arab. pl. 99. et I c. fig. E. I. 2.

Doris lacinulata, Gaex. pag. 3105.

Tergipes, Cur. Règ. anim. tom. 2. pag. 394.

Tergipes lacinulatus, Buarv. Malac. pl. 46. fig. 6. 6 a.

ExcrcL. pl. 82. fig. 5. 6.

Ce petit animal est celni qui a servi à M. Cuvier pour l'établissement de sou genre Tergipède; il est alongé, limaciforme, et porte de chaque côté du dos six branchies sur un seul rang; elles sont claviformes, tronquées supérieurement et terminées, à ce qu'il paroît, par une petite ventouse, qui permet à l'animal de se servir de ses douze branchies comme de pieds; la tête est assez grosse, arrondie; elle porte quatre tentacales, dont les postérienrs sont les plus longs. Celle espèce, toute blanche, n'a que 2 lignes de longueur. On ignore où elle vil.

\section{EPAULÉE.}

Les marcbands donnent encore ce nom dे une belle espèce de Telline, Tellina anguluta Lamr. Voyez Telise.

\section{EPERON. Calcar.}

Genre inutile et inadmissible proposé par Montfort (Conch. syst. tom. 2. pag. 134) pour les 'Troques qui, comme le Trochus calcar, ont le bord découpé en pointes plus on mojus longues. VOJez'TROQDe.

\section{EPIDRONIS.}

Des Nasses, des Strombes, des Buccins, des Tritons, rassemblés d'après un caractère de furme extérieure, constituent pour Klein un genre auquel il donne ce nom, emprunté de Rumphius.

\section{EPONIDE. Eponides.}

Montfort, dans sa Conchyliologie systématique (tom. 1. pag. 126), a proposé ce genre pour le Nautilus repandus de Fichtel, qui est resté inconnu et indéterminable depuis la publication du miçographe allemand.

\section{EQUERRE.}

Une jolie espèce de Perne, qoe l'on nomme aussi quelquerois l'Enclume, le Perna isogonum, a reçu celte dénomination des marcbands et des amateurs.

\section{EQUIVALVE.}

On entend par cette expression nue coquille formée de deux parties principales, consiamment égales dans toutes leurs dimensions. Voyez Conchyliologie dans le premier volume de ce Dictionnaire.

\section{EQUIVALVES. Equivalvia.}

1I. Latreille, dans ses Familles naturelles du Rigne aninzal, a forrué sous cette dénomination la première fawille des Brachiopodes (voyez ce mot) pour le genre Lingule lui seul. Peut-être fera-t-ou bien de conserver cette famille, car, comme on le verra à l'article Lingure, ce geare diffère sensiblement des Térébratules et autres analogues.

\section{ERODONE. Erodona.}

Genre établi par Daudin pour deux coquilles que Favanne possédoit dans sa collection. Ne connoissant celte coquille que par la description 
et les figures de Bosc et de M. de Roissy, il est assez difficile de les juger. Cependant, comme M. de Roissy a admis ce genre et que cel autem. n'en a décril que de certaias, il est bien à présumer quil le connoissoit assez pour le placer dans la série. Néanmoins, M. Lamarik ainsi que 13. Cuvier n'en lisent pas mention. M. de lerussac replaça ce gente avec les Myes, avec lezquelles ils a beaucoup d'analogie; seulement il paroit, cornme l'indique son nom, que la dent cardinale est comme rongée et que les valves sont inégales, ce qui les sajprocheroit des Corbulées.

\section{ERYCINE. Erycina.}

II. Lamarck, anquel nous devons ce genre, le regarde comme éyuivoque par la dificulté que l'on êprouve pour bien en établir les caraclères. Sons ce rapport nous sommes du même avis que le célèbre zoologifte que nous venons de citer: cepeudart, sil en est aiosi, pourcquoi conserver \& admellre un geure que son autenr lui-même regarde peut-être comme mauvais? Ce genre n'est défectucux qu'autant qu'on y a rassemblé presque tantes les petites coquilles dont on n'a pas bien reconau le geare; en ellet, nous y avons trouvé une Cyrene, des Tellines et une Corbule. Ces erreurs ont certainement rendu difficiles les déterminations génériques ou spécifiques, ce qui a dû aścessairement porter Ml. Lanarck à dıre que son genre étoit équivoque. Maintenant que nous avons ajcuté d'avoir aussi bjen la fossette du ligament à côté des dents cardinales qu'entr'elles deux, et de plus, de ne réunir dans le genre que les cocquilles qui ollient limpression da mantean échaucré en arrière, ce qui indique l'existence des siphous et leur direction de ce câté, nous avons rendu ce genre plus naturel en en éloignant tont ce qui ne pauvoit recevoir rigoureusement les caractères, ce qui nous a wis ì mêne d'y faire rentrer quelques coquilles douteuses dans d'autres genres, ou qu'on n'avoit point encore observécs. Si je n'avoís eu occasion de voir, dans la savante et riclie collection de M. Defiance, les coquilles qui ont servi de type aux figures des Vélins, et par suite, à celles des Annales, il m'auroit élé inpossible de juger plusieurs des espèces que j'ai sigualées comme ne devant point appartenir au gemre Erycine; en eflet, ce n'est point avec des figures comme celles que je viens de citer qu'il seroit possible de lever le moindre doute : elles sont trop défectueuses; il seroit impossible d'aflirmer, par exemple, que l'Ericina lavis est une Cyrène, que l'Ericince trigona est une Corbule, si on devoit ve s'en rapporter qu'à elles seules. Voici les caraclères que nous lui donnons.

\section{CARACTÈRES GÉNÉRIQUES.}

Coquille transverse, subinéquilatérale, équi- valve, rarement bâillante; denx dents cardinales inégales, divergentes, ayant une fusselle intcrposée ou à côté; deux dents latérales oblongues, comprimćes, courtes, intrantes; ligament intérieur lixé dans les fossettes; impressiou du mauleau éclıancrée en arrière.

Long-temps on ne connul que des espèces fossiles dans ce genre, ce n'est que claus son dernier ouvrage que $\mathrm{H}$. Lamarck en signala une vivante, qui lut rapportće par Péron dn port du roi Georges, où il n'en tronva qu'un seul individu sur le sable; depuis, M. Payraudeau en doma une seconde qu'il découvrit dans la MEditerranée, et qu'il figura dans san Catalogue des Annélides et des Mollusques de Corse.

'Toutes les Erycines sont marines et d'un trèspetit volume; leur chamière, assez difficile it étudier, est bien caractéristique, présentant cons. taminent une très-petite fosselte cntre deux dents cardinales ou à côté d"elles, et de plus, une dent latéralc de chaque côté, comme dans les Teélines. Ces caractères, qui ont été mal appréciés par. MI. Suwerby, lui ont fait prendre pour des Erycines des coquilies tout-à-fait étrangères it ce genre, coquilles que MJ. Lanarck aroit contondues partic dans dans les Crasatelles, partie dans les Amphidesmes, et qqui doivent constituer un geure à part, qu'il est impossible de confondre avec ies Elyciaes une fois que l'on connoit quelques coquilles qui appartiennent à ce genre; par leurs rapports, elles avoisinent les Mactres et les Crassatelles bien plus que les Ongulines, car celles-ci se rapprochent des Lucines, et peut-être serat-il difficile de les en sćparer.

M. Basterol, daus son Mérnoire sur les fossiles de Bondeaux, a donué comme une Erycine une coquille qui n'appartient point à ce geure; c'est "ue Nlactre jeuse encore, dont la charniere, un peu fruste, n'a point été reconnue par l'auteur d'une manière sulfisante.

1. E $\mathrm{Y}$ С $\mathrm{N}_{\mathrm{E}}$ cardioide. Erycina candioides. LAMK.

E. testâ ovato-orbiculari, parvulì, albì, decussatim striatî; striis transversis, remotis, longitudinalibus, crebeminis, tenuissimis.

LAMK. Anin. sans vert. tom. 5. pag. 486.

Blarsy. Malac. pag. 554. pl. 73 . fig. $7 \cdot 7 a$.

Petite coquille extrêmement rare jusçù préseat dans les collections. Oa ne connoil yue l'individu du Muséum et lcs cinq que nons pos. sédons; clle n'a rien de bien remarqquable, d'un blanc-jaunatre ou grisatre; elle est ovale, subtrigone ou suborbiculaire; elle est ornée de stries lamelleuses, transver'ses, dislautes, relevées, et dans leur intervalle, on voit nu grand nombre de stries rayonnantes très-fines, très-rapproclućes qui descendent jusqu'au bord; celui-ci est simple; 
a l'intérieur on voit distinctement l'impression palléale échanerée postérieurement. Celle petite coquille se trouve dans les mers de la NouvelleHollande, au port da roi Georges; elle a 10 mill. de large et 7 de long.

2. Erxerne de Geolfroy. Erjcina Geoffoyi. Patraud.

E. testâ parvầ, ovato-trigonâ, tenui, compressî, nivế, pellucidî, nitrdâ, subaquilaterâ, trunsversim luviter striat $\hat{a}$, lineis purwulis, fuscis longitadinalibusque concisis ornatá.

Paynaud. Cat. Ann. et Moll. de Corfe, pag. Jo. $\pi^{\circ}$. 40. pl. 1. fig. 3. 4. 5 .

Très-jolie espèce, dit M. Payraudeau, d'une forme triangulaire, arrondie, subéquilaterale, excessivement mince, liagile, luisante, transparente, d'un blanc de neige finement strice en travers avee de petits traits tronqués et longitudinaux, d'une couleur bruae et qui semblent être incruslée dans l'épaisseur du test. C'est à M. Geolfroy Suint-Hilaire lils que cette espèce a été dédiće; elle est bien distincte de la précédente, et, à ce qu'il paroit, aussi rare qu'elle. C'esi dans le golfe d'Ajaccio, en Corse, que celle espèce a été découverte; elle est large de to à 12 millim.

3. Erycine fragile. Erycina fragilis. Lamk.

$\boldsymbol{E}$. testâ ovato-trunsverfâ, pellucidâ, lavi, nitidâ; cardine bidertato.

Lamx. Ann. du MLus. tom. 6. pag. 4ı3. no. 5.

Der. Dict. des Scienc. nat. tom. 15. pagi. 264.

Noв. Descrip. des coq. foss. des env. de Paris. pag. $40 . p l$. 6. fig. 4. 5.6.

Cette eoquille porte bieu le nom qu'on lui a donné; elle est excessivement mince, Iransparente et si fragi'e, que M. Defiance a élé obligé d'enduire de yomme, des deux côtés, l'individu qu'il possede; sa charuière est tris-petite, on y voit denx dents cardinales à côté desquetles il y a une fossette oblongne pour l'insertion da ligament; il n'y a point de dents latérales, ce qui doit laisser quelques doutes pour son genre, et nous l'aurions éloignée des autres Erycines si l'impression da mantean, ćchancrée par derrière, ne nous en̂t porté à l'y laisser jusqu'à ce qu'on en ait vu un assez grand numbre d'individus pour en juger diffuitivemeot. La coquille que possede M. Defrance est loograe de 19 millim., et large de 26 .

4. Errycine rayonncé Erycina nadiolata. Lamx.

E. testâ ovato-compressá ; natibus minimis; striis longitudinalibus, radiatis; cardine brdentato, foveolis in risedio; dentibus lateralibus subperspicuis; margine crenato.
Lask. Ann. du Mus. tom. 6. pl. 418. to. 11. et tom. 9. pl. 31. fig. 8. b. a.

Def. Dict. loc. cit.

Nов. Descrip. des coq. foss. des eno. de Paris, pag. 41. pl. 6. fig. 1.2.3.

Jolie petite coquille très-mince, transparentr, elliplique, aplatie; sa lane cardiuale est si peu large qu'on croiroit qu'elle u'existe pas; son crcchet est presque nul; sa surlace extéricure ollira des stries transver'sales qui sont coupées par d'altres longitudinales, un peu onduleuses; la charvière à deux dents cardinales très-divergeates, et au milieu une petite fossette pour le ligament; on observe de chaque côté des rudimens do dents latérales. Elle est longıe de 7 inilliu. et large de g. Elle se trouve à Griguon et à Mouclig.

5. Enтсыкe elliptique. Erycina elliptica. Lask.

E. testâ subrotundâ, depressiusculâ, tenuissind striatâ; striıs lamellosis; dentıbus cardinalibus bonis.

Lamx. Ann. du Mus. tom. 6. pag. $414 \cdot n^{\circ} .6$. et tom. 9.pl.31.fig. 6.a. b.

Drr. Dict. Loc. cit.

Nов. Descript. des coq. foss. des env. de Paris, pag. $41 . p l .6$ fig. 16.17 .18$.

On reconnoit celte espèce à sa forme ovale, orbiculaire, déprimée; à scs stries très-tines, relevées en lames courtes; à la forme de son crochet peu saillant; enfin, à sa charnic̀re qui, outre deux dents cardinales bien appareutes, a côté desquelles il y a une fosselte pour le ligament, présente encore deux deuls latérales bien prononcies dans le plus grand nombre ajiudividus. Elle est longue de 15 millim. Et large de 19 . Celte espèce se reucontre à Beauchamp.

\section{Erteine él'́gante. Erycina elegans.}

E. testâ ovato-transiersá, pellucidû, eleganter tenusssime striatia; candine bidentuto; dentibus lateralibus obsoletis.

Noв. Descript. des coq. foss. des env. de Paris. pug. $42 . p l$. 5. fig. 13. 14. 15.

Je ne connois de celte espèce qu'uve seulo valve que j'ai trouvée à Valmondois : elle oftro les caractères principaux des aulres Erycines, seulement les dents latérales sont obsolètes. Ites dents,cardinales sont au mombre de deux; ell ss sont pelites, divergentes, et à côté il y a une fossette pour le ligameat. Le crochet esi petit, acuminé; toute la surface extérieure est chargée de très-fines stries arrondies, qui diminueol régulièrement depuis le bord jusqua'an eroclet. Langueur 8 million., largeur 10 


\section{E R Y}

7. Earesse transparente. Encinu pellucida. LAMK.

E. testầ ovato-orbiculatâ, nitidi, subpelluridâ; curdine bidenfuto, dente laterä́ distuncto.

LAмK. Ann. du Mus. tom. 6. pug. 413. no. 2 . Dern. Jict. loc. cit.

N⿴в. Descript. des coq. foss. des enviruns de T'aris, pag. 45. pl. 6. fig. 19. 20. 21.

Ties-petite coquille appartenant certainement au genre Erycine: elle est ovale, suborliculaire, très-mince, tris-fragile, lisse, peu protonde; dans les individus hien conservés, on voit à la clrarnière deux dents cardinules, à cốcć desquelles se remarque une fetile fosselle pour l'inserlion du ligament, ainsi qu'une dent latérale, petite, stiparée, distincte sur lu bord. Celle coquille n'a que 4 à 5 miliar. de longr sur 6 à 7 de large. Elle vient de Mlouclyy.

\section{Nos.}

8. Enrcase orbiculaire. Encina arbicularis.

E. testâ pellucidâ, radiatìn subcostulutâ, orbiculutu, tenuissimi; dentibus cardunalibus binis, hiteraltbus nullis; altero complicato.

Erycina pellucidu, L.1 $\mathbf{x}$. Ann. du Mus. tont. 6. pag. $415 . n^{\circ} .8$.

Noв. Descript. des con. foss. des environs de Paris, mag. 43. pl. 6. fig. 27. 28. 29. 50.

Nous remarguons que M. I,amarck a donné, dans le uiême genre et à deux espèces différentes, une dénomination semblable. Nous avons conservé le nom d'Erycine transparento à la première de ces especes, et nous donuons t:elui d'orbiculaire à la seconde. En ellet, celte coquille est orbiculaire, petite, transparente, lisse, peu profonde; sa ct.arnière se coarpose senlement de deux dents cardinales, entre lesquelles il y a une petite fossette pour le litrament. Elle est longue et large de 7 millins.

9. Erycine tellinoide. Erycina tellinoides. Non.

E. testâ ovatâ, pellucid̀, lavvigatì; fossulầ obliquâ, minimâ, dentibus cardinalıbus adjectâ. LA $₫$.

Tellina pusilla, La xx. Ann. du Mus. tom. 7. pag. $237 . n^{\circ}$. 8. el tom. 12. vl. 42. fig. 2. a. b.

Nов. Descrivt des coq. foss. des environs de Paris, pag. 43. pl.6. fig. 10. 13. 12.

Pour caractériser cette espc̀ce, nous arons copié textuellement la phrase que M. Lamarck lui avoit appliquée, eo la plaçant parmi les Tellines. Mais, outre qu'il indique nne fossette à côté des dents cardinales, il ajoute en observation, que celte fosselte n'a pas pour usage l'insertion du ligament. Cependant, en observant un grand nombre d'individus avec soin, et a l'aide d'une tris-forte loupe, il nous a étf impossibls de reconoitre wie altaclie quelconque, extéricure, pour un ligament; d'où nous avons éf́ conduit à penser qu'il étoil iuséré dans la fossette carclinale, ce yui nous a porté à placer celle coquille parni les liycines. lies dents lalérales ne sont point conslantes; daus quelques individus elles unauyuent entièrement, dans d'autres elles sont très-visibles. Ce qui, sans doute, avoit engagé M. Lamarck à la placer' parmi les 'I'ellines, c'est le pli sinueux qui se remarque à l'aogle postírieut; mais à cóté des aulres caractères, nous pensons que celui-là cst de peu de valeur. Longueur 8 millim., largeur 11. Coquille commune, surtout dans les sables de Parnes.

10. Erycine miliaire. Erycina miliaris. I, мx. E. testä ónto-trigonâ, obliquâ, minimâ, infatâ, lavi; cardine unidentato.

Lank. Ann. du Mus. com. 6. pag. 415. $n^{\circ} \cdot 10$. et tom. 9.pl. 31.fig. 7. a. b.

Noв. Descript. des coq. foss. des envivns de Paris, pas. 44. pl. 6. fig. 22. 23. 24.25.

De toutes les coyuilles bivalves connues, celleci est la plus pelite; elle a à peine 3 millimères de longueur : elle est lisse, quelquefois étagíc par des acrroissemens; sa forme est subtriangulaire, ovale, oblique; ses crochels sont courbés, petits; la charnière est petie, composée sur une valve, seulement d'une dent subconig̣ue, ¿̀ cóté de laquelle se trouve ure petile fossette pour lo ligament; sur l'autre valve, il $y$ a deux fosseltes et une pelile dent avortée. Elle se trowve à Larme, aे Grignon et Mouchy.

\section{ESCARGOT.}

Nom que l'on donne vulgairemeni aux coquilles du genre Hélice. Voyez ce mot.

\section{ESPLANDIAN cu TOIIE D'ARAIGNEE.}

Nom vulgaire que l'on donnoit autrefois à une belle cspèce de Cône des côtes de Ceylan. Bruguière l'a décrit, dans le prenier volume de ce Diclionnaire, sous le nom de Cûne esplandian. Vayez Cônz.

\section{ESSAN.}

Très-petile espèce de Pintidine, qu'Adanson a décrile et figurée sous ce nom ( Voy. au Sénég. $p l .15)$, el qui n’a été ni retrouvéc ni mentionaće depuis lui. Voyez Prixadise.

\section{ETHÉRIE. Etheria.}

Genre établi par M. Lamarck dans sa famille des Camacées, et généralement adopié; M. de Blainville ne le mentionna pas dans lè Dictionnaire des Sciences naturelles, et M. Cuvier n'en a point parlé dans le Règne animal. Ce geore 
pourtant repose sur de baus caracteres, et il devient d'autunt plus nécessaire à couserver, qu'ou l'observe mieux : aussi M. de Ferussac (Tabl. syst. des anim. moll.) l'a-i-il adxis, ainsi que 1I. Schweiger et Ocken. Cet eremple ful iurié par M. de 13! ainville, qui l'admit dans la serie dans son Truile de Rlulacologic, ou il est placé dans la fumille des (iamacées, daus les rapporis que H. Lauaruk lui a assignés a côté des Dicérates et des Cames. Il est évideut que ce geure apparticnt aux Canacées, dont il présente tous les caractères principaux : les deux impressians rusculaires, limpression du masteau, la firité de la valve inférieure, sant les rails principaux de ressemliance; ainsi, comme celui des Canes, l'habitaut de l'Éthérie doit avoir le manteau ouvert seulement duns deux endrois : l'une de ces onvertwes est destince au passagge du pied, et l'autre au passane des siphons; neaumoins il se clistingue des autres genres de iu raéme tamille, par les curactères suivans:

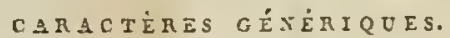

Coquille irrégulièıe, inéquivalve, adhérente, à crochets courts, comme cutoncés daus la base des valves; charmieie sans dents, oudíe, subsinuée, inçgale; deux impressions musculaires, cistantes, latérales, oblongues; impression du manteau simple, non écluancrée; ligăanent exté- zieur enfoncé dans un petit espace lijangulaire, divisant en deuä paties le talon de la ralve iuférieure, et se prolongeaut ditus toute sa longueur.

Ontı ces caractères, les Elluérie se recuanoissent cucore au lrillaut de leur mare, et aux singulières boursauflures quise voient il l'intérieur des ralves. On a été tort lang-lemps ì ignorer l'existence de ces coquillages: leur fixité à de glaudes profondeurs dans la mer, dit M. Lamarck, eu a étć la cause priucipale. Mais est-il bicn certain gne les Ethéries soieut mariues, ou au moins que toutes le suient? D'après les noureaux et intéressans renseignemens que $\mathrm{M}$. de Ferussac a donnés, d'apres M. Cailliaud, sul ce genre, il n'est point douteux que plusieurs espècés trouvées daus le Ail, nou lain de son embouchure, ne soient lluriatiles; et les espèces trouvées daus ce tleure se rapporteut indubitablearent i celles que pussédoit laujas, et qui out passé depuis dans la collection त๕ Muséum. Mais M. Lamarck, dans le tow. 6 , des Animaux sans veriébres (par.. I. pag. 100) mentioune, d'après san premier travail sur le greure inséré dans le tom. Io des Annules du Âséum, deux espèces qu'jl regarde comme murines et dont il doune même l'zubitat. Ces Eibéries malines se distinguent aussi des lluviatiles par le dćlaut de callosités insérées daus la base de la coquille; il paroîtroit douc hors de doute que, dans ce geare, on trouva des espèces tluviatiles et dautres marines, ce qui, quoique n'élant point sans exemple, a besoin d'étre con. fromé par de nouvelles observatious.

Un lajt très-curieux, el que nous avons pu constater sur un grand nombre d'iudividus de même espèce, c'est que ces corguilles s'attachent indifléremaenl par la valve droile et par la $v$ a!re gauche; ce qui n'a lien d'uue manière authenlique dans aucun aulre genre. Dans les Cames, on troure des espèces à droile et à gauche, ce qui indique ordinailement l'adluérence de valves dilférentes; mais on ne trouve pas que cela ait lieu, comme dans les Eibéries, pour la wéme espece.

Daus une Notice qui a pour but de faire caunoitre les coquilles rapportíes de la Haute-Egypie par M. Cailliaud, M. de Ferussac, après l'examen des espèces, a cru pouvoir les réduire à lrois seulement, en réunissant en une seule les Ethérics elliplique et rigonule de M. I,amarck. M. de Ferussac ne propose ce clangement que sur la variabilité de ces coquilles, qui, dans l'espéce du - Vil, est Irès-grande, et qu il suppose être la même dais les aulres esjeces. Si, par l'examen d'un nombre suflisant d'iudividus, on pouvuit s'assurer que cette variation a lien dans les deux espèces de M. Lamarck, au point d'avoir la certitude de leur identilé, il ne faudroit plus bésiter à les réunir : mais il n'en est pas ainsi, et daus ce cas le doute doit être permis.

Ainsi que l'a proposé M. Lamarck, nous séparerons les espèces, en ceiles qui sont pourvues d'une cullosité, et en celles qui n'en présentent point.

\section{Une callosité ablongue dans la base de la coquille.}

1. Eтне́rie elliptique. Etheria elliplica. Lasix.

E. testì ellipticî, complanutâ, versus apicem dilatatâ; nulubus vix remotis.

J.A wx. Ann. du Mus. Com. 10.pag. 401 . pl. 29 . el $31 . / g .3$.

Ibid. Anim. s. vert. ton. 6. part. I. pag. 99 . $n^{\circ}$. 1 .

Brarvv. Maluc. pag. 545. pl. 70 bis.fig. 2.

Eile est grande, elliptique, aplatie, fart dilatée vers les crocheis, qui, eur-mémes, sont peu éloigués; son test est épais, feuilleté et d'une nacre très-brillante. M. Lamarck indique avec doute la mer des Indes comme le lieu de sou babitation; uais il est plus probable qu'elle vient du Nil ou de quelgu'autre rivic̀re d'Atrique. Elle a 7 ou 8 pouces de long.

2. Eтнerie trigonule, Etheria trigonula. LA мx.

E. testâ sublrigonâ, gibbosulà, supernè basique allenuats, nati inferiore productione ranotissimâ. 


\section{E T II}

Lasx. Ann. du Mus. loc. cit. $p l$. Jo et $\bar{x}$. fig. 2 .

Ibid. Anim. s. vert. loc. cit. $n^{\circ} .2$.

Celle-ci, consue lindique son nom, est subirigone, bossue, rétrécie supérienrement et vers la base; sun crochet inférienr es! fort grand et fort écarté de celui de la valve supérieure, tandis que dans l'esperce précédentc les deux crochiets sont très-rapprochés; du reste, il y a entre clles beaucoup danalogie, et probablement que par la suite on n'en fera qu'une seule espc̀ce : nıais il est nécessaire pour cela qu'on en connoisse un assez grand nowbre d'iudividus. FER.

3. Eraéme de Cailliaud. Etherici Cailliaudi.

E. testî ovato-oblongâ, extùs virescente, intis argentch; umbonibus magnis, prcelongis, ucutis.

Fenus. Mléms. de la Soc. d'hist. nat. de Paris, tom. 1. pag. 35g. $n^{\circ} .2$.

Ibid. Cailliaud, Voyage cil Egypte, tom. 2. pl. 51 . $f g$. 1. 2. 3.

Coquille ovale, alongúe, dont le talon, trèsgränd, droit, un peu incliné, se termine en jointe; la charnière est littérale, tautôt à droite, tantò! à gauche, selon la valve qui est adbérente; son test, furt éprais, est extrêxement feuillcté et boursoufllé, d'un vert obscur, brunatre à l'extérieur, d'une nacre tlanche et argentée à l'intéricuı : peut-être celle espéce u'est-elle qu'une variélé des précćdentes. Elle vit à la manière des huîtres, se groupant sur les rochers ou les nnes sur les auties : nous en avons vu un groupe de plus de vingrt individus, altachés de cette manière en un seul bloc de plus d'un pied de diamètre. Cette coppille est très-commune dans le haut Nil et ses aflluens; elle a 17 ou 18 centi. mères de long et 8 ou 9 de large : quelquefois elle est proportionne:lenıent plus étroite.

\section{Point de callosité incrustée dans la base de l.s coquille.}

\section{LABIE.}

4. Etnغ́rie semi-lnnaire. Etheria semi-lunati.

E. testầ obliquè ovatâ, semi-rotundatâ; latere postico reclo; mutibus secundis, subaqualibus.

Suw the Genera of shells, no. 1 .

Lask. Anini. s. vert. tom. 6. pag. 100, no. 5 .

Cocquille obliqge, ovale, demi-circulaire, bossue, ayant son còté postćrieur droit ou presque droit; les crocliets sont presque égaux; la nacre est verdảtre. Eile a été retrouvée sur les côtes de l'ile de Madagascar, d'après M. Lamarch; mais il est plus probable quelle vient des eaux douces de cetle île.

Hist. Na!. des Vers. Tome 11 .
5. Eтие́ а в transverse. Ethenia transpersa. LIAIX.

E. testâ ovato-trunsversâ, subgibbosia, natibus inaqualibes.

Layr. Ann. du Mus. tom. 10. pag. 404. tab.32. fig. 1.5.

Ibid. Anim. s, vert. loc. cit. no. 4 .

Coquille ovale, transverse, oblique, subgil,beuse, à crochets iníganx; sa nacre est égaletneut veruâtre, mais sa furme générale, et celle des croubets en particulier, la listingue des autres espèces. Elle est moins griande, el a élé tronvét avec la précédente. Nous avons vu plusieurs individus qui peuvent se rapporter à cette espdce, qui, probablement, n'est qu'une variélć de lit précédente, qui pruvenoildu Niger, où ils aroicut été recueillis non luin de son embouchure.

\section{EUNËLE. Eunzelus.}

M. Rafinesque a proposé ce genre poor des animaux voisins, it ce qual paroil, des Onchidies; mais l'ayant caractérisé d'unc manière insuffisante, il est impossible de ladmettre avant de nouvelles observalions.

\section{EURIBIE. Euribia.}

II. Rang a cru devoir élablir ce genre, qui présente encore quelques incertitudes, dans la lumille des Mollusques plérupodes; voisin, sons quelques rapporıs, des Cuvicries, des Psychís e! des Cléodores, il a besoin d'étre revu avec soill, puisqu'on ne connuil point sun organisation, et qu'il pourroil bien, lorscu'il sera connu, sorti" des Molluscrues; cependant cela est peu probable.

Rien de l'organisalion n'est connu : ni les organes de la respiration, ni ceux de la circulation, gui, ordiuairement, s'a perçoivent les premiers, a'ont été examinés, ct cétoit, comme M. Rayur lui-mćuse l'aura sebli, une coudition essentielle, quand da reste on n'a rien ou presque rien d'anat loyne quant aux formes extérieures.

Ne connoissant ce genre que par la courte description que M. Rangen a donnée dans le tome 10) des Anncales des Sciences naturellé, nous répúterons ce qüil en a dit pour engager les maturialistes à farre de nouvelles reclierches à son bgard. I’animal, globulenx, est muni de denx naseoires horizortales, opposécs, à la base descyuelles est siluée la buaclbe et un erès-petit lobe intermédiaire; il est blane, un peu transparent; les natgeoires sont ovales, élroiles à la base; l'ourerture buccale est noire el les viscères bruus.

La coquille, carlilagino-membraneuse, est très-mince, régulière, llexilıle, à ouverture ronde et très-évasée, bémisplatrique ou cn furme de calotic : elle est de couleur junne.

Cet animal, qui habite l'Ocean atlanlique, a 
été figuré dans l'Atlas des Annales des sciences naturelles, tom. 10. pl. 45 . fig. 9. 10. 1 I.

\section{EVOMPIALE. Eumphalus.}

M. Sowerby, dans son Mincral conchology, a établi sous ce non un genre qui étoit trup voisio des Cadrans ponr qu'on ne l'y réunisse pas. Nous a vons fait avec cette cognille une section des Cadrans. Foyez ce mot.

\section{EXOCÉPHALES. Exocephala.}

Liordre des Mollusques agames, établi par 11. Latreille dans ses Familles naturelles du Règne animal, a été divisé par lui en deux sections, les Exocéphales et les Endocéplaales : celte première section contient des MIollusques gastéropodes, qui terminent la grande série de ces animaux (les Scutibranches Cuv.), tandis que la second renferme tout les Mollusques acéphalús, bivalves; ce qui, suivant nous, tend it trop rapprocher des types bien distincts, qui n'ont entre enx que ce seul rupport, de n’avoir quiun même organe de géućration, l'organe femelle; mais, il faut le dire, l'auatomie des animaux placés par M.Latreille dans les Exocéphales esı peu avancée, et nous avons toutes les présomptions de croire qu'étant mieux étudiée, on reconnoitra quils sont pourvus des deux sortes d'organes générateurs, et se séparent par conséquent, par ce point, comme par tous les autres, des Conchyfères. Nous avons fait voir daus une anatonie de $l_{\text {at }}$ Calyptrée que l'animal de ce genre portoit un organe excitateur; ne doit-on pas, par analogie, le supposer cbez les Crépidules, les Caborchons, etc., qui ont avec lui tant de ressemblance?

'Tout porte à penser que la classification de M. Latreille ne sera point adoptée sur ce point. (Voyez Molnusque.) Celte section a élé divisée en denx ordres, par M. Latreille, les Scutibranches et les Cyclobranches, qui, enx-mêmes, contieuneat dans deux familles, les premiers, les Auriformes et les Piléiformes, et les seconds, les Scatiformes et les Lamellés. Voyez tous ces mots. 


\section{F A B}

Fabulatre. Fabularia.

On trouve aux eavirons de Paris ua petit corps fort singulier, que queiques personnes a roient pris pour un polypier. M. Defrance en ent une autre opinion et le siguala définilivement sous le nom qu'jl porte encore anjourd'hui; il le rangea, a vec juste raison, parmi les cuquilles multiloculaires, vì, en cllet, il troure à se meltse en rapjort avec d'antres genres analogues quant à la structure. Si l'on ne tronroil sur ces coquilles des traces non équivoquns d'un accroisscanent semblatjle à celui des autres Foraminifères, on seroil tenté de les prendre pour des osselets criblés de pores irrégulicr's; inais quand on les examine avec soin, on reconuoit bieutut gu'clles sont parfaitement symétriques et composées d'une suite de lopes enronles sur le grand axe, à la manière des Milioles, et plus pariiculièrement à celle des Biloculines ( vojez ce mot), puisure, comme elles, elles n'ont rue deux lorres apparentes: la dernière loge enurasse une partie de la précérente, et l'ouverture est placée, comane dans les Biloculines et parle fait de l'aorroissenent, alternatirement aux deux extrémités du grand axe de Í coquille. L'onverture, ou plütôt le point d'ąraclie de lanimal i la coquille, est placée à l'estréuité de la dernicre luge, dars un espace subcirculare, le plus souveot oralaire. Elle ollire ua grand nombre de pores irréguliers, qui comanunicjuentavec des cinaux nombreux et tortueux, lesquels snireat la direction des loges et les remplissent; ils y produisent une ztruciure très-comparable is celle de l'os de la Sèclic.

\section{CARACTERES GEXERIQCIS.}

Connille oralaire, déprimée latéralcueut. formrie de loges opposécs, erubrassantes, pelotonnces sur le mème plan er dans le grand are; deux loges risibles a l'extérieur; loges puptäées en un rand nombre de cubes longitudinaus imégulier; aboutissant dans la dernière aux ourettures irrégulieres du point d'insertion; celui-ci, placé alicrnativenent à l'un el à l'útre extrémité de la coquille.

les : apports des Fatalaires sont, d’après leur structare, fuciles a satisir, et M. d'Ortiony, lis place à la fin cle sa litmille des Enthomostéglies (zoyez ce not). qui elle-mème termiue 12 prencle série des Mullniçues céplaulopodes furaminiferes. Quoigne le geure dont nous parlons ait Gíćlabli depuls loner-temps, ancun auteur rerencl. nt ne l'a unentiouré. Les figrures gui en arucut édc concées far M. Defiace sulfisotent pour fuire roir qu'il étoit nécessaire el qu'il reposoit sur de bons caractères.

On ne coonoît encore gquine seule espèce appartenant is ce genre; on la rencuntre tres-aliondamment dans les ralcaires grossiers des enviruns de Paris et de Tálognes. Elle est une des corguilles qui caractérisent le nicux cette lormation.

\section{DEF.}

Fabodatre discolithe. Fabulutia discolithes.

F. testí ovato-depress $\hat{\imath}$, Levigat $\hat{\alpha}$, aliquantasper substriatâ; loculis ducabus opposalis, impressione porosi terminatis.

Defr. Dict. Sc. nat. tom. 13. pag. 105. Allus, fig. 5.

D'Orsicsy, Mém. sur les Céphul. Ann. dus

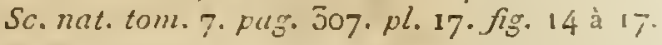

Inid. MIodèles de Céphal. $4^{\mathrm{c}}$. linuis. $7^{\circ} .100$.

Cetle coquille est une des plus grandes de la famille à laquelle clle apparitent. Elle est oralaire, deprimée lacéralement, lisse ou foiblement striéc daos sa longueur; les loges, assez grandes et pyriformes, sont opposíes dans le même plau clembrassantes, de sorte ru'il n'y a jamais que les deux dernieres de visibles; clics sont patuitement symétriques el disposécs de maniere $r_{j}$ the l'ouverture teruinale se trouve alternativement aux extrémités du grand axe de la cocquilic. Comne nous le disions tont it lieure, cette cor yguille, longue de 6 à 3 millimétres, se troure en alondance dans les calcaires yrossiers des envirins de Puris cut de Talogues.

\section{FAGAN.}

Dins son Toyage au Sénégal ( $\mathrm{nl}$. 18. fig. 5 ), Adunson nomua ainst'slece sentis, quil ranie arec des Bucardes daus le geure l'étoncle : venae qui depuis a subi des réformes considiradies.

\section{F.IS.1N.}

Les marchands d'histoire naturelle uomment encore de cetie maricre les coquilles autrefuis

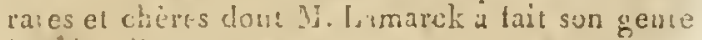
Phasicelie. Ioyez ce mol.

\section{FALIER.}

Adanson a commé de cctte maniere une peite coctuile çuil place dians son genre Nandelct, ruii a ćiélait, comme on le szit, pour le jeune üue des Porcelanes. (Foyez ce mot.) Cente corinille nappartient pas au gecre Portelaine, muis licu a celui des Folvires: ce réprouve, de la part 


\section{4}

F A S

d'Adanson, une crreul qu'il est nécessaire de rectifier. Le Falier n'est autre close, autant qu'on peut en juger cl'après la description et la figure, Iue la Volvaire byaline Lauk. Voyez Vorvarre.

\section{FANEL.}

Cette coquille, fignrée et décritc dans l'ouvragge d'Adanson ( Voy. uu Sinég. pl. 13. fig. 3), appartient au genre Nérile de Liuné et Natice de lamarck : c'est le Natica millepunctata de ce dernier. Voyes Natice.

\section{FAROIS.}

11 est érident, d'après la description d'Adanson (Voy. cuu Sénég. pl. 9. fig. 54 ) que la coquille ণৃu'il uonme ainsi n'appartuent ni aux Volutes ni aux fruscaux, comme les auteurs l'ont lous répété. Adunsou dit que la lèvre droite est profondément échuncríe à sa jonction avec íavant-dernier tuur, ce qui constilue le caractere essentiel des Pleuroturnes. Quant à l'especte, nuus ne la conouissons pas, et il paroît qu'elle n'a pas été retrouvée depuis Adanson. Voyez Pleurotodie.

\section{FASCIOLAIRE. Fasciolaria.}

Avanı Linné, qui confondoit les coquilles de ce geme parmi les Mure\%, plusieurs anteurs, Lister, Bonnani, Rumphius, Gualierri, etc., eu avoient lait connoître plusieurs espèces. Leurs caractères différoient trop de ceux des Murex, pour qu'elles pussent rester daus re genre. Dans une mélhude mieux perleclionnée, Bruguière, lans le premier volume de ce Dictionnaire, en séparant des Rochers les l'useaux, entraina avcc. eux les Fasciolaties, qui furent beaucoup mieux placéeś, et peut-être auroit-il étć convenable de les laisser dans ce greare. Cependant, MI. Lamarck, sur un caricière d'assez peu de valeur, les plis obliques de la columelle, créa le genre qui rons occupe, dans ses premiers travaux, et continua depuis à le reproduire dan ses diverses rnélhodes; extrait des Fuseaux, ayant avec eux la plus parfaite analogie, ce fut constamment près d'eux que ce genre fut placé, considéré assez justement comme un intermédiaire avec les 'Iurbineiles.

Quand on considère le peu de valeur des caractères des Fasciolaires, on ne doit pas être ćtonné que ce gemre n’ait été admis que par un fort petit nombre de zoologistes, qui presque tons ne i'ont mentionné que cornme sous-genre ou section des liuseaux. $\Lambda$ cet égard, nous partagerions complétement leur opinion, si la connoissance de l'ariual des Fasciolaires confirmoil cetintine raprort; tontes les fois qu'il faut réforaser les travaux de ZI. Lamarck, en derantrerl'larmonic, on ne doit le faite gu'avec une très-grande circunspection, car un a vu, dans plus d'unc occasion, d'habiles zoologistes proposer des changemens dans les rap-

\section{F A S}

ports, et êlue forcés bientôt aprècs à revenir à ceux indiqués par M. Lamarck, parce que la connoissance des animaux est veuue presque toujours les conlismer.

Les Fasciolaires se distinguent des Rnchers, en ce qu'ils n'ont point de varices longitudinales, et des Fuseaux, par les plis columeliaires; on peut. les regarder comme des litiseaux à plis. Mon:lort, qui a exagcíré l'appréciation des caractères génériques, avoit proposé, dans sa Conchyliologie systématique, la création d'un genre Fulgur, pour le placer a côté des Fasciolaires et pour contenir celles des Py'rules qui ont à l'origine du canal de la base un pli ou un bourrelet décurrent sur la colunelle. Ce genre de Nontfort n'ćtoit pas admissible comme celui de $\mathrm{II}$. Lamarck, car il se perd graduellement en passant d'une espece à d'aulres, tandis que les plis des Fasciulaires sont constans dans les inêmes espèces, et ne sc perdent pas insensiblemcal : ce qui leur donne plus d'importance pour caractériscr le genre.

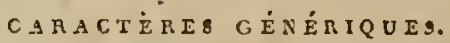

Animal inconnn. Corguille fusiforme, sans bour. relet persistant, canaliculće à sa hase, ayant près du canal, presqu'à son origine el sur la coluticlle, deux ou trois plis très-obliques.

Les Fasciulaires, comme nous l'avous vu, se distinguent des liuseaux par les plis columellaires; mais il esi un autre genre, les Turbinelles, qui contient aussi des coquilles fusiformes, gui ont également des plis columellaires, avec lesyuclkes on pourroil les confondre; oulre un fascics un peu dillérent, on les séparera facilement sil'on fart alenliun que les plis, dans les I'asciolaires, sont très-obliques, placés a la basc de la columelle et à l'oriugine du canal, tandis que dans les 'Turbiuelles ils sont transverses, plus uombreux, plus petits et sourent plus aédians.

Lorsque BI. Lamarck fit connoître les Jiverses espèces de fuseaux fossiles que l'on trouve aux enrirons de P'aris, il fit observer que quelquesuns avoieut des plis sur ba columelle, et qu'en conséquence ils poumoicul bien entrer dius le geare Fasciolaire. MI. Detrance eflectua celte mforme dans le Dictionnaire des Sciences maturclles. Nous présenterons à ce sujet gruelques olsservaliuns. D'abord, nous ne pensons pas, avec ce naluraliste, que la Volutco bulbula doive être placée parmi ies Fasciolitires; elle u'a pas la forme de cescorguilles, et la base, au lieu de se terminer far un canal, fiuit par une échancrure; semblable cu cela avec les Vulutes, elle en porte du reste tous les autres caractères, el dans la forme de la columelle ci dans la disjosition des plis.

Quant aux autres espèces que M. Dofrance rapporte aux Fasciolaires, après les avoir examioées, yous ne pouvons y leconnoitre les caractires de 
ce genre; elles u'out plus la même forme, et les plis calumellaires, au nombre de uu ou deux, sout transverses et placés de manière que, pour être visibles, il faut que la lèvredroile soil cassée, et que, par ce moyen, la columelle soil mise à découvert dans une partie de son étendue. Nous f.ensons, d'après cela, qu'il convient de laisser res coquilles parmi les fuseanx, on bien de les unetre de préférence à la suite des Turbinelles, avec lesquelles elles ant plus de rapports.

\section{Fascroraire tulipe. Fasciolaria tulipa.}

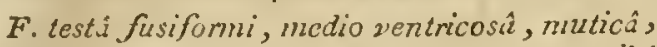
l.evigatî, nunc aurantio rufescente, nunc alba et spudiceo-marmorutâ; lineis fuscis trunsversis incequaluter confertis; anfractibus walue cons'exis; suturis manginuto-funbriatis; caudi sulcatá; lubro intùs albo, striato.

Lasr. Anin s. vert. tom 7. pag. $118 . n^{\circ} .1$.

Murex tulipa, Lix. Gmé. pag. 3550. $n^{\circ} \cdot 9^{1}$.

Bovxani, Récréat. 3. fig. 187.

Iaster, Conch. tab. 911.fig. 2.

Ruмri. Mlus. tab. 49. fig. 11 .

(josct. Test. tab. $46^{\circ}$. fig. A.

DaRgevv. Conch. pl. ig. fig. K.

Favaxie, Conch. pl. 54. fig. L.

SEEA, Mus. tom. 3. tab. 7 1. fig. 23-32.

Kковn. Vergn. 5. tab. 18. fig. 5. 6. el tab, 29. fig. 1.

Mantixi, Conch. tom. 4. tab. 136. fig. 1286. 2287. et tab. 137. fig. 1283 is 1291 .

Fusciolaria tulipu, Evcres. pl. 431.fig. 2 .

Grande el belle espèce fort commune daus les collections, fusitolme, ventrue, lisse, si ce n'est à la base, sur le dos du canal, où elle est sillonnće nbliquement, et vers les sutures, qui sont ridées longitudiualement et accompagnces de deux on trois sillons protonds plus ou moins rapprochés. lille est assez variable pour la couleur; tantót tle est marbrée de fauve-brun sur nn fond Janc, d'autres fois ces warbrures sont orangees; tantôt toute la coquille est uniforáment brub-fauve, ou orangée sans antre muance, et, quelle que soit la coulcur du fond, tous les individus sont marques de lignes brumes transverses, et assez rapproclices les uaes des autres. Liouverture est blanche, et la lcvie dioice est stríe dans loute sa longueur. lille vit daus l'Occua des Autilles, où êlle est fort nommune; sa longurur est quelquefois de 7 pouces.

2. Fascrozane distante. Fasciolaria distans.

$F$. testî̀ fusifomi-turritu; 2rnericosâ, inuticâ, levi, albî, strigis longitudinalibus undutis luteoroseis pictâ; lineis nigris, transversis, distantibus; anfractibus convexis; suturis simplicibus; cuud.ì onviusculì, sulcatâ; labro intis striato.

I. Ам. Alim. s. vert. luc. cit. no. 2 .

Listen, Conch.tab. $9^{1} 1$. fig. r.

Quoique très - voisine de la précédente, on ne sauroit confoudre cclle-ci avec elle : elle est tonjours beaucoup plus pelice, un peu moins ventrut, et son canal esi plus conrt; ce gui la dislingue éminemnent, c'est que la suture est simple, non plissée, et jamais accompagnnée de sillons. Elle est agréablement llammulée de rose sur un foud blauc, et traversée, sul le dernier lour, par luit à neuf lignes brunes, egales, diftanles, taudis quiou en voit vingt-liuit à trevte-deux sur la Iasciolaire tulipe. Cette coquille, très-lare, vient de la baie de Campêcle; clle a 4 pouccs do longueur.

3: Fasciolaine robe de Perse. Fasciolurial lal. pezium.

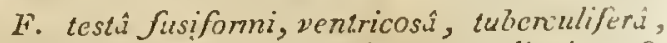
laviusculi, albi aut rufescente, lineis mis cinctâ; tubenulis conicis subcompressis in anfructuum medio uniseriatis; colunzcllíf fulvo-rubentc, labro ivtius eleganter striato; strits rubris.

I. Axк. Anim. s. vert. loc. cit. $n^{\circ} .3$.

Murex trapeziun, Lis. Gatel. pas. 3552. $n^{\circ} \cdot 39$.

Bonvan, Ricriat. 3. fig. 287.

Lister, Conch. tab. $931 . j i g .26$.

Rumpr. Mus. tab. 29.fig. E. el tab. 49. fig. K. Guatr. Test. tab. 46. fig. 6.

Danoerv. Conch. pl. Io.fig. $f$.

Iiavañe, Conch.pl. 35. fig. b. 2.

SeBd, Mus. tom. 3. tub. 79. figurce duce in angulo superiore et exteriore puginarum.

Kxiona. Vergn. tom. 4. tab. 20. fig. 1.

Manmixi, Conch. tom. 4. tab. 139. fig. $129\{$. 1299 .

Fasciolaria trapezium, Excyclop. pl. 4.ंगt. fig. 3. a. b.

Coquille tres-commune, fusiforme, ventrue, couronnée par un seul rang de gros tubercnles. druils, coniques el obtus. La spire, compusíc de dix à onze tours rapprachís, est paintie et strice au sommet; les deruiers tours soat enticrement lisses; le canal de la base, à sa partie externe, présente quatre à cinq rides saillantes et obliques. Quand cette coquille est encore converte de son épiderme, elle est brune; mais quand l"épiderne est ealevé, elle est blanche ou orangéc. Sur ce fond se dessineal un grand noulbre de lignes transverses, le plus souvent par paire: elles gaguent le bord droit et aboutissent, dans 
120

\section{$F+5$}

les rieux individus, à zatant de dentelures saillastes a l'iotérieur. Ec dedans, la columelle est dian bean bru-rongeátre : elle porte rois plis. La lèrre droite, éléganzent stríée de roage su: un food Llasc-ronsátre, est siuple dars les jecoes iadiridos el deutelée dans les rieux, qui unt quelçuefois 7 pouces de lugrueur. Ceite éspéce riex: de l'Ucian iadiez.

\section{Fuscressisz oraggle. Fasciolaria auman-} zacu. Lak $\pi$.

F. tes:i subfusifomi, rentricosi, contukuLin's, tukerculato-nodosá, transsersion rugosi. uibo e: auranio vaviegaía ; anfractibus moedio angulatis, ultua angulum Flaridutis; angul.) t:tenulufero; caudi breviusculi:; aperatu albá; Litro insus strato.

Lexs. Gnim. s. 2ert. Loc. cit. $\pi^{3} \cdot 4$.

Dszesst. Conch. F. . 10. fig. 11.

F.TAXse, Conch. Fl. 54. f.g. 11 .

L.screz. fl. $450.7 . g .1 .6 . b$.

Caquille très-rate, remarçuble par ses nombreus tubercules $\epsilon:$ par sa ccloraticu : clle es: fuíforme, très-rectrue, ̀̀ canal assez court; lts $10 a 15$ de spire sont dirisis dans le milieu far 2 a rang de gros tubercu!es; et ils sont, en dessus, o. -licuez ent étagés et seulement striés; le deraier tuir cat cocroneé par on seul rang de tubercries stapériecrs, et sillonné dans tant le reste de sor éte-due; plusiecrs de ces sillors, de cirq à sepi,

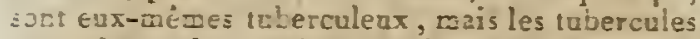
sout plus felits que les sopérieurs. La colozation consiste ea marbrares blascos, Gai se roient jircinalezent sar le ragy supérjev: de tuberccles, sar ca fuad crangé pea forcé; en ceúas col:e coquilie est tonte biascte; la lerre droite, giace ê franchante. est sillcnnée irassversaleEert dans luate sa looguea. On crei: qre crite coçuille es! de l'Océan des Grandes-lndes; elie a 10 ì Ii certim. da longuter.

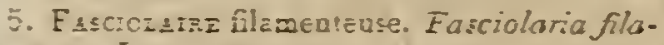
micnosios. LAute.

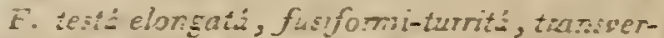
- sy salcciá, cibź, siricis curnntio-rufis lonziiubraclibus racholim ficts: anfractious nedio subanguktas: tuberculs compressis brevibus cc-

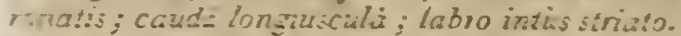

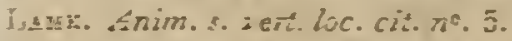

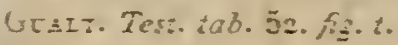

Dencest. Conch. pl. 10. fs. $h$.

Patzise, Coñt. Fl. Jis. f. h.

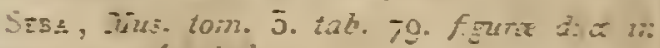
- tre sugremín sutulix.

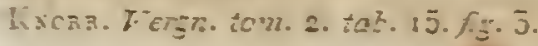

\section{$F+5$}

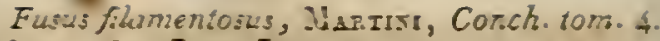
tab. 14. f.̃. 15:0. $15 \overline{1} 11$.

Easciolaria flumentofa, Escrcics. pl. \$24. fig. 5 .

Cetle espece est heanconp plus fosiforme que les nitcédentes: elle est alonzée, peu rentrie. i spire longue et poinlue, plus langue que le canal de la hase; les tocrs, an nombre de dir, sout partagés en denx parties égales par uce carèe assez aisuë, peo ssillan'e, garsie d'cr rang de tubercules peu élevés, aplatis, corrat piacés; ionte la surface est coorente de sillons serrés, combreas, azrcrdis, fluz saillans et presque raguear sur le dos, ou ils sont fort obliques; ces silloos, ea aboutissan: sur le lord droit, produisert actar: de crébelures ou de dentelfres peu saillantes. La couleur de celte ccqrilie, lorscqu elle est encore ccurerte de sod éri. derse, est un beua obscriréced rcugeätre, aree des lactes blactiotres sor la spire; lorsquelle Est cépccillée de son enrelopre na:ure!le, elle

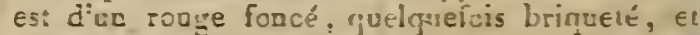
liviersalle des tajercues es: Lla rouge-janaitre trés-püle. Allintíriear, cet:e cocuille eat d'u a blanc-risi. et la lerre drcite es: ficemed stiće de roure dass toute sa longuecr: il ga trois wlis a la cclumelle ’ liaférieur est trèsszillac: Habite l'Ucéa inuien. Longुषed 4 pouces.

\section{Fisctclalse gouronté Fasciolariz coro-} rata.

F. test: fur-form, 2entricosú, transwersim

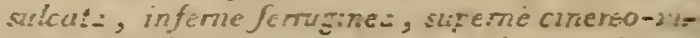
rex.s: anfruct? us niedio tubercula:j-riocosis, ultumo superne istenulis eninetióntíns coro-

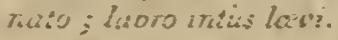

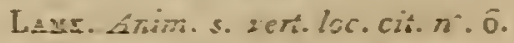

Es sèce encore peu ccanue, rais irès-dis'incte de icuites ses con- atere; el!a se raprocbe de certaines Pyrules puta la tcrme, ćar: rectrue e: arant la spire neu alunzée; el.e a crelça'zz-

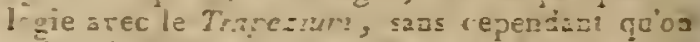
ruisse la confocare arec thi; e le est :or.ie sil-

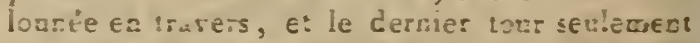
est courcuzé par co seul rang ce gros ivhercli:es peu saillars e: obius: elle es: cccien:e öca f́njderme brun fort adhérec:, si ce a'ts: scr les foeLiess iorers de soire cui son: d"ua blacc-grisüire, parce rüis en son: cefcuillés; sus l'épiderme, ie derzier tom es: cin fare gale arec des linges travirerses nombrerses ce la wize ccu's. wa

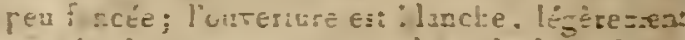

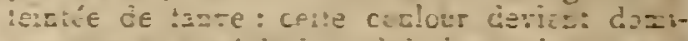

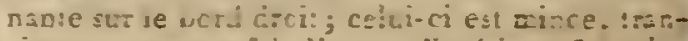

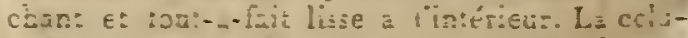

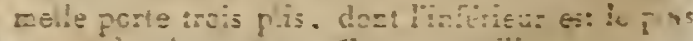

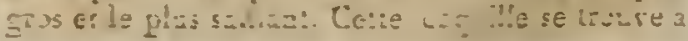


la Nouvelle.Hlollande; elle acquiert jusqu’à 6 pouces de longueur.

\section{FASCIOLITE. Fasciolites.}

M. Yarkinson, dans son Organic remains, nomme aimsi un genre que Bose avoit fail depuis long-temps suas le nom d'alvéoline. Voyez ce inot.

\section{FASIN.}

Nous trouvons décrite sous ce nom, dans l'ouvrage d'Adanson (Voy. au Sénég. $\mu l .7 . f i g .7$ ), une coquille que Luaué nomme Buccinum senescalicum, et que M. de Blainville rapporte a tort au gence 'Tonne, car ce n'est qu'un jeune iudividu du Cassis fascialum de bruguière et de lamarck. Voyez Casper.

\section{IVATAN.}

Le liatan d'Adansou (Foy, au Sénég. pağ. 251. 1\%. 17) est une Mactre, et bien probablement le Mactra plicaria Lamk. C"est dunc à tort que ismelin a placé celle coquille dans le genro Vénos, cas il sullisoit de lire sa description pour s'assurer qu'elle ue lui upratrtenost pas. Voyez Mactae.

\section{FAUXE. Faunus.}

Montfort, dans sa Conchyliologie systématique, a proposé ce genre pour une coqualle du genre Múlanopside de M. de leerussac, et Pyrène de M. Luararck. (Loyez ces mols.) Ce genre, conme on doit le peuser, faisant duable crnplui, n'a point teté adopté.

\section{EAVAL.}

Adanson a bommé ainsi une coquille de son genre Vis, Térebra, qui a été adopté par BI. Lamarck, et reproduit sous le non d'Alène par. 11. de 13lainville. (Voyez Vis et ArÈne.) L'espice dont it s'dyit est le Terebra subulata lawk.

\section{FELAN.}

La coquille qu'Adauson (Voy. ausenég.pl. 16. fig. 8) a numuće de cette manière a reçu de Guelin lo nom de Venus dicuphana, daus la 13e. édit. du Systema naturre. D'aprés la description même incumplète d'Adansun, il nous semble que celle coquille conviendroit mieux au genre Lucine : ce que vous ne saurions affirmer ò ure unanière positive, ne la conuvissiat pas. Vojez LucuNe.

\section{IERUSSINE. Ferussina.}

Daus la descriptivo que .1. Grateloup a faite des iossiles de Bordeaux et de Dax (Bulletin de la Soc. linn. de Burdeaux), il a nommé de cetle unanière un genı nonveau, que de notre côté, et sans avoir cu connoissauce du travail de M. Grateloup, nous nowmions Strophostome. Malgré l’antériolité du nom donné par le naturaliste plein de savoir et de zèle que nous venons de citer, nous conservons ì ce gremre la dénomination que nous arons choisie, parce que nous savons que depuis long-temps M. d'Orbigny fils avoit atilli dédié un genere de Mollusques i M. de Fcrussac; forcé d'oplar entre deux dédicaces, ce naturaliste prélérera, sins aucun doute, celle de M. d'Orbigny, puisçu'elle est la première tt Gu'elle a lieu précisément dans un travail que MIM. de lerussac et d'Orbigny doivent publier cn commun. Voyez Stropgostome.

\section{FIROLE. Pterotrachea.}

Forskael, quitit le premier connoitre les arimax de ce genre, Jenl avoit donné le nam d'e Pterotrachea, et l'on ne sait pourquoi Brusuè̀ dans les plinaclies de ce Dictionnaire, changeit ce nom pour celui de Firole, Firola ; qui a été adopté par les zoologistes français. Depuis Bruguière, qui plaçoit ces auimaux entre les Holoturies et les 'Ihalies dans sa classe assez inforace des Vers mollusques, M1. Iamarck, qui a commencé à cébrouiller ce clias, transporla les Firoles dans les Moliusques proprement dits, et les separa ainsi fortement des Radiaires que Bruguière contondoit dans le mćme ordre. Ce lut dans le Systène des Animaux sans veriebres qu'il opéra celte réforme; on y trouve en ellet les Firoles dans l'ordre des Céphalés mis avec les Céplanloprodes", entre les Lernées et les Clios. Quelque défectueux que soient ces rapports, cependaut ils étoient bien préférables à ceux antérieurement établis, puisqu'ils ramenoient los Firoles parmis les Mollusques. Une fois placécs dans la classe d’auimatix ì laquelle elles appartiennent, clles ne pouvoient par la suite qu'cprouver d'heureux clangemens dans leurs raplports : c'est ce qui arriva à l"instant où M. Cuvicr, formant l'ordre des Pléropodes, indiqua contae probable l'ictrodaction des firoles parmi cux. II. de Roissy, dans le Buffon ace Sonnini, effectua ce que M. Cuvier n'avoit 'ju'indiqué, et les Firoles cerminereut les Ptéropudes. Nous ue pourons nous rendre compte des motils qui ont déterainé N. Lamarck a omettre le grenre qui nous occupe dans les Tablecuux de lia Philosophic soologique, où l'ou trouve adaise la fawille des Ptéropodes: cela se compread d'autant moins qu'il a voit été le premier à l'introduire parmi les Mollusques. Plus tard, il répara cet oubli; mais sa mémoire dut être sollicitée par les travaux de Péron et Lesueur, aiasi que par ceux de N. Cnvier dans les Annales du Muséum : encore ynue co dernier ait pris une Carinaire mutilíc pour vae 


\subsection{8}

Ptérotracbée, cela n'ernpeccle pas quiil n'ait fixé l'atlention des zoologistes sur ces animatex, ce que frrent plus spécialemeut l'éron et Lesneur par leur Ménnoire sur les Ptéropodes. Ce Mémoire démontra d'uue manière érideate la liaison des Carinaires el des Firoles, et bien qu'il ait luissé des lacunes considérables dans la connoissance de ces animaux, il a étć véanmoins d'une grande ntilité à la classilicalion. C'est d'après lui que BI. Lamarck (Extrait du Cours) proposa l'ordie dies Ilétéropodes, que suivat une fausse apprécialion de certains trails de l'crganisation des animaux quil y rangea, il crul ceroir mellre le dernier des Iollusiues comme plus voisin des auimaux verlébrés que les Céphalopodes euxmiêanes, les Héléroppoes se coniposirent de truis semres, Caricaire, Furole el Piayliroć. D'un autre côté, M. Cuvier, conduit à un autre extrême par wotil's dillérens, ranjea bien les Carinaires àvec les Gastéropodes, dont elles out en effet presque lou:e l'organisation; nais il les plaça d'uae manière singuhère daus sa famille des Scutibrauches symétriques, entre les Navirelles ct les Calspltrées, qui ne sonl point sýciétriques, pas plus que la Carinaire elle-mére. De plus, M. Cuvier nadopla pas le grenre firole, qu'il ne mentionne que daos une note placée an bas de la page 450 du lome 2 du Regne aninal; elle est concue en ces icraes: « Je ne doute pas qu'il " ce faille rapporter à des individus mulilés de - direrses Carmaires les Pterotrachea de liorsk. "el Gael., ca les Firoles de Brug. et de Péron." Apres avoir donnć une Cariuaire muliĺce pour nne Firole, M. Cuvier, sans avoir sans doute porié tonte son altention sur ce genre, croit que elles sant toules dans le aneme cas, et que le geure Firole doit être en conséquence rejeté de la méthode. Celle erreur de 11. Cuvier ue se proy ragea pas, ce qui est dù probablemelat autao: aux travaux que ncus avons citćs cin'à ceux de MI. Lesueur, qui les publia daus les dunales des Sciences de Phalabelishie; non-seulemeut cet auteur décrivit des especes nouvelles, mais il donna de plos des déluils anatomiques très-iuléressans, qui complètent d'une maniere satisfaitante les conooissances analomiques nécessaires pour établir déficilivement les rapports du geore. lis resteront sans doute tels que MI. Lanarck les a proposés depuis long-lemps, arec les Cariaaires, sans admellre néanmoins ceux arec les Pbylliroés, eisans adopier les Hétéropodes el la place ciu'ils accupent dans la mélbode de ce savat, gui, dans son dernier ourrage, ria subi alicun chavgement relativement au zeare qui nous occupe. Surs adopler ui la méthurie de Y. Curier, ni ceile de M. Lamarck, 31. Gray nous semble avoir é:é le premier qui rupprocha l'une manière conrenable les Ptérotracliées des Gustéropodes tus ( Na libranches Cov.) d’un cúté, el les Ptércpudes de l'autre, se trouvant ainsi placćs comue

\section{F I R}

un passage entre les deux ordres. Cette idće, qui nous semble la meilleure, a élé confirmée par ies observalions qui ont été faites depuis sur les P'téropodes par M. Raug.

Le systéme de 11 . Cuvier ayant servi de base Cundanentale a la eacithude de $\mathbf{3 l}$. de lerussac, il ue lialluit pas s'alteudre a truaver dans les tableaux de cel auleur de nouveaux apperçus; il se contenia en ellel d'adopter le geure firole, de le piacer entre les Cariuaires \& les firolordes, \& de constituer avec ces trois geures la fatnilte des Plérotraclices, la seule du sous-ordic des Hétéropodes, sous-ordre qui fait parlie des Scatibraoches Cuvier, el qui laisse ces animaux d'une organisation si particulièrc au milieu d'aulres (Calyptrées, Patelles, etc.) qui n'ont avec cus aucune analogie.

M. de B!ainville, qui connut la classitication de MI. Gray, sea rapirocha beaucoup dans sun Traité de Malacologze. Les Firoles \& les Cari. naires constituent la familie des Nectopodes, ta première des Nucléobranches : elle est suivie de celle des Ptéropodes, et toutes denx font gartie des Gastéropodes.

N. Latreille n'a pas compris la classification de la méme mantère que ses devanciers : nous doyous dire d'abord quall ful le seul zuologiste qui rejela le genre Firole, à l'exemple de M. Cuvier, el cela dax anuées aplès la pulilication du Régne animal, \& aprés celle des diver's travaux que nous vecons de meationuer, dans lesquels on trouve si irrérocablenent tout ce qui est nécessaire à sa cunservation. Ayant regardé les Firoles comme dies Carinaires mutilúes, hous ajoulerons que ce yeme lait partie de la famille des Crobranches asec les-genres Doris, Polycères et Onchidiore, combinasou dont i! est tres-dilficile de se rendre cumpte, et que nous ne chercherons pas à expliquer.

I! ve nous reste plus a mentionner que la méthode de II. Rang. (Manuel de Conchyliolngie.) Les P'ćrrojudies sout cunservés, ils formeul la seconcic classe des Mlollusques, el elle est placéc entre les Céphalopiodes et les Gasteropodes. Cas deıniers commencent par les Aucléobranches, qui eix-mêcues commencent par la famille des lirulides ( vojez ce mot) : clle se compose des geares Firole et Carinaire; vieut ensuite la launilie dics Allantides pour le genre Allante tui seul, el entin la série des Nudubranclies, ce qui conserve ce ce córé les rapports indiqués par II. Gray et M. de Blainrille, avec celte dilference que l'ou troupe ici ces animanx in conmencernent de la grande série des Molluscrues, tancis yu'ils scrut a la tiu de la aceae série dass les múluudes de ces deux zoologistes. C"elt anx articles Nuciéobranthes, Ptéropodes et Mollusques que nous pourrous discuter l'enscanble de ces opiaions; dous y reuroyous le lecicur. 


\section{CARACTÉRE CÉNÉAIQUES.}

Corps libre, alongé, gélatincux, trinsparent, terminć postérieurenent par une queue, el mun d'une ou plusieurs nageoircs; ba auchies en torme de pauache liotlant librenseut en delsurs, et groupées avee le ceur sulas le ventre vers l'origine de la queue; tête distinctc; deux yeux; des máchaires cornées; point de tentacules.

Les Firales ont beaucoup du rapports avec les Carinaires, dont elles ne dillerent cssentiellement qu'en ce que les branchies et le caur ne sont poiut protégús par une corguille; la tôte cst ununie untérieurement d'une trompe ì l'intérieur de laqualle se voient de petites uhiblucires rétraćlıles, laterales, à ce que disent l'írou et Lesueur, pourvues en dedans et de chaque cúté d'uue sérue de prointes corrćes, courbées, pectiollurmes, surmuntices d'un autre rang de plus petites; $2 u$ lund de la cavité buccale ainsi armée, on voit deux espèces de palpes articulés. Quoique l'on n'uit point encore reconnu de véritables tentacules aux firules, $\mathrm{M}$. de Blainville pense pourtant que 'on pourruit regarder comme aualugues les tentacules qui se vuieat cn avant des yeux el sur la partie antérienre de la tête. Les yeux sont grands, situćs à la réunion du corps et de la trouıe; d'après Lesucur, il parvitroit qu'ils sont placés à l'extréaité de pédicules très-cuurts. De la cavitć buccale part un asuphage qui va aboutir à l'estumac, qui est long et cylindrique; il se termine par un intestiu qui va au nucleus; cette partie saillante, sur la partie postérienre et médinne du dos, contiont, outre les branchies et l'intestin, le foie et le cceur; l'intestin, à ce qu'il paroît, se termine à l'extérieur au cóté droit de la cavilé Lranchiale. Le corps est alongé, renllé dans le unilieu, revêtu d'une peau transparente et gélatineuse; eile se continue sur le nucleus, mais il paruit qu'elle y prend une autre structure, car elle est irisće t.ès-agréablement lorsque l'animal est plongé dans l'eau. Les organes lucomoteuis se composeut d'une sorte de pied ou de asasse charnue, mince, comprimée, fixée au curps par un pédicule assez large vers le unilieu de la face abdominale : ce pied forue une véritable nageoire; c'est vers le milieu du bord iulérieur de cette nageoire que Forskabl a observé une petice ventouse destiuée à fixer l'animal au foud de la mer. Il paroît que P'́ron et Lesueur u'ont paint aperçu cette partie essentielle qu'il anruit ćté nécessaire de constater de nouveau; la partie postérieure ou la queue, qui a son origive an nucléus, est terminée par un aplatisseunent ou aageoire bifurquée : c'est sans doute de cetre tageorre que sort un filament plus ou moirs longr, cumposé d'une série de tuljercules, et dont l'usage est inconnu. Une question qu'it auroit été fort ualéressant de décider, est celle relative à la position des organes de la génération : mais il paroit que l'extréme délicatesse de ces organes a empêclié juscju”it présent les habiles observateurs gui se sunt uccupés cles liroles d'avoir autre chose que des présomptiuns qui paroissent aéanmoins assez bien fundées. Lesueur a observé au cúlú droit du corps un appeudice vermiculaire, qui paroit ètre l'urganc excita!eur nâle. Il sembleroit d'après les observations du même naturaliste que les firules ne sont point liermaphrodites, et celi paroitroit conlirmé par l'évidence des oviductes dans les individus qui n'ont point l'organe vermiculaire des aúles; mais cet oviducte auroit sun onverture au côté gauche, dans une position contraire à celle de lorgane mâle: vuilit les trails priucipaux de l'organisation des Firoles. Nons ajouterons que lés branchies sout symétriques, composées de deux faisceaux de duuze ì seize filanens; et nous reuvoyons pour le reste an Mémoire de M. de Blaiuville, inséré dans le Bulletin de la Société philomatique, ainsi qu"à celui de Péron et Losucur dans les Ann. du MIus., tome 15, et celui de Lesucur daus le Journal de l'Académie des Sciences de Philadelphie, 1817 .

Nous renvoyons ainsi aux auteurs qui ont décrit des especes, parce (1ue, ne les ayant pas sous les yeux, il nous est impossible de les décrire de nouveau. Il manque ì la science une bonne monograplie de ce gremre, et nous ne possédons pas les matériaux pour la faire; aous engageruns donc les naturalistes ì s'occuper d'un genre aussi curieux qu'intéressant.

Nous indiquerons, pour servir d'exemple au genre, quelques-unes des éspeces les mieux connues.

J. Finole couronaće. Fteralrachea coronate. Fonsk.

P. ventre caudáque pinniferis, capitis proboscidè tereti perpendiculari; frontis coronulâ acule is decern.

Forss. Faun arab. pag: $117 \cdot n^{\circ}$. 41 et Icon. tab. 54 . fig. A.

LIN. GHeL, pag. 3137, $\pi^{\circ} \cdot 1$.

Lauk. Anint. sans vert. tom. 7. pag. 676 . $\pi{ }^{\circ} \cdot \mathrm{l}$.

Excre1. pl. 88. fig. 1.

Cette espèce est la plus grande de toutes; elle se reconuoit fucilement en ce qu'elle est couronnée de dix pointes sur la tête, et que sa trompe, longue et cylindrique, est pendante. Le corps est sabcylindrigue; le pied, ou plutôt la nageoire, est aplatie, coriace, et ounie à son bord d'une petite ventouse comme dans les Carinaires. La queue est séparée du corps par un érranglement; elle est triangulaire et bifide à son extréruite. Cet animal, d'après $G$ meliu, auroit 8 ou so ponces de longueur. Il habite la Mléditerranée. 
2. Firole hyaline. Pterotrachea hyalina. Fonsk. $P$. capite elongato, lovvi ; pinnulí centralis.

Forsk. loc. cit. $n^{\circ}$. 2, et lcon. tab. 34. fig. B. Lin. Guec. pag. 3137. $\pi^{n}, 2$.

Lamx. loc. cit. $n^{\circ} \cdot 2$.

Encrccop. pl. 88. fig. 2.

'l'oute petite espèce, longne d'un pouce, trèsétroite, transparente, atténuće aux deux extrémités; elle rentre:oit par consćquent dans le genre Sagitelle de M. Lesueur, si ce genre Cloit adraissible. Sa queue est un peu conprimée et sa nagreuire ventrale fort petite, et presque dans le milieu du corps, est fort mince et lort aplatie latéralement. On ignore la patrie de celte espece, gui prohablement est de la Méditeranée comme la preaijère.

5. Frnose à grrande gorge. Pterotrachea pulmonata. lorsx.

$P$. capite obtuso, hyalino; intestino respiratorio plumis ciliato.

Forse. loc. cit. $2^{\circ}$. 3. et Icon.tab. 43. fig. A.

Liv. Gane. pag. $3137 \cdot \pi^{\circ}, 3$.

LAMK. loc. cit. $n^{\circ} .3$.

Excrclop. pl. 88. fig. 3.

Celle-ci est alongée, cylindrique, simple, à tête courte et obtuse, mais sa queue esı longue, aplatie et pointue. En dessous, dans la ligue médiane, depuis la tête jusqu'à l'origine du pied, on roit voe large membrane pendante qui lui donne l'apparence d'avoir une double gorge; une large nageoire demi-circulaire munie d'uue petite rentouse aplatie de chaçue côté, se voit au cen- tre de l'animal. Il est longr de plus de 4 pouces. On ne connoît pas sa patrie.

\section{FIROLIDES.}

M. Rang a partagé les Nucléobranches en deux familles. (Manuel de Conch. pag. Izo.) La première, à laquelle il a donné ce uou, contient les deux genres Firole el Cariuaire; ces genres, comme rous l'avons vu dans les arlicles spéciaux u ù nous les avons traités, out des rapports ttllement établis que tous les zoologistes les ont rapprochés, et quelques-uns même n'en ont fait qu'un seul greare.

Avant M. Rang, M: de Ferussac avoit élabli la même famille sous le nom de Ptérotruchés. L'antéviorité de cette dénomination doit nous la faire préférel. Voyez Ptérotrachée, Frrole el CariNAIRE.

\section{FIROLOÏDES. Firoloides.}

II. Lesueur a proposé ce genre pour celles des Firoles qui ont le nucléus tiès en arrière, et qui, immldiatexent après lui, se termivent par une sulite troncalure et wue queue giêle non fendue. Ces caractères ont trop pen de valeur pour faire admettre ce geare. Vojez Firole.

\section{FISSURLILLE. Fissurella.}

Ce genre est un de cenx que depuis très-longlemps Lister sépara des Palelles, ainsi que plusieurs auteurs après lui, et que cependant Linué confondit avec elles. Eminemment distinctes che ce genre, les fissurelles se reconnoissent au premier abord par la pertoralion du sommer. Aussi est-ce d'uprès ce caractic̀e si lacile qu'elles ont été groupées. Bruguière fut le prenier à les séparer en genre, el depuis lui elles fureat cons. tanıment couservées au unêrue titıe dans luutes les mélbudes. Il varia génćralement furt peu dans ses rapjorts; Bruguiere, dans les Tablecuux du premier volume de cet ouvrage, le mit en lête de de sa troisieme section, an-dessus des Patelles. 11. Lamarck, dans le Système des Animaux sans vertèbres, 1801 , anćliora ces rapports par la création du genre Entroninule et d'autres tirés des $\mathrm{Pa}_{2}$ relles, au milicu descyuels les Fissurelies furent placées. M. de Ruissy (Buffor de Sonnmi) moditia l'opinion de M. Lamark, en interposint, a tort, entre les Patelles et les Fissurelles le genie Ancyle, composé de petites coquilles lacisires, qqui depuis, il laut le dire, ont embarrassé presque tous les nomenclateurs.

Lors de la formation de la famille des Phyllidéens, dans la Philosophie zoologique, M. Lamarck y rangea les Fissurelles, eurre les P'atelles et les Emarginules; mais, un pen plus tard, dans l'Extrait du Conrs, il modilia d'une uanière avantageuse les rapports de ce gremre. On songea eutin à comparer les animaux des Patelles et des Fissurelles, et il ne fulluit que recounoître la grande dissemblatace dans l'organe branchial, pour les séparer. La création de la famille des Calyptraciens, bien qu'elle contint des aumaux à cotyuitte symétrique et d'autres non symétriques, eut cet avantage de séparer lien nettement et de groulper d'ude manicre beaucoup plus naturelie des genres que l'on a voit jusın'alors rapproclués.

Celte famille des Calyptraciens de M. Lamarcik, dans laquelle se trouvent les Fissurelles, entre les Cajochons et les Emarginules, servit de point de départ à $\mathrm{N}$. Cuvier (Règne animal) pour la formation cle sa famille des Scutibranches. (Voyez ce mot.) D'ilprès un excelleut principe, il divisa cette fanille en deux parties, pour síparer les cołpilles symélriques de celles qui ae le sont point. Il iutroduisit dans la section des Scutibranches symétriques, outre les Fissurelles et les Emarginules, trois autres genres, qui n'onı pas

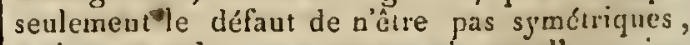
mais encore de ne pas appartenir, pur l'organisalion, à la famille ou ils se trouvent. Il sullit de 
noramer les genres Navicelle, Carinaire et CaIyptrée, pour justitier ce que nous venuas de dire.

M. Lamarck auroit pu am(liorer les iapports du penre qui nous occupe, en séparant en deux sa fanile des Calyptraciens, qu'sl augrumata sculewent du genre Paruophore; du reste, les Fissurelles ne changèrent pas de rapports.

M. de Ferussac, qui dans sa lléliode inata si sourent.M. Cuvier, ne conserva pas la base d'après laquelle les Scutibranches devoreut être rélurućs. Il fulloit laire les groupes d'aprés la symétrie ou Ia nun symétrie des coquilles; céluit le seul snoyen de furcaer des liarilles nacurelles : it ne le lit pas, aussi trouve-t-on les Fissurelles à côté des Éaparinues, des Navicelles et des Calyptrées.

A part ce défaut, d'avoir tiop stéparé les Calyptríes et genres voisins des limarginules et des Fissurelles, M. Gray est le preuier gui ait nis en pratique d'une manière convenable le principe indiqué par M. Cuvier daus sa Classificalion naturclle des Mollisques; il lit en ellet un ordre sous le uoaude Dicranobranchia, dans lequel il rangea tous les vrais Scutibranches symétriques, lissurelle, Parmophore el Enarninule. Vuilà, saus contredit, une fumille ualurelle yui restera dans la science. Si un veut cbanger ses rapports, il fuut que toute la facoille soit soumise en masse a ses cliangemens, car les rapports de détails ne peuveut plus être altérés.

La classitication de M. de Blainville (Traité de Mlalacol.) vient sur ce point contirmer ce que nous venous de dire. Revenant à des r'apports depuis long-temps abandonnés, voulant rapproclier les Scutibranches symétriques des Patelles, il enIraina toute la fanille, sans que les rapports des truis grenres qui la cunstituent suieut altérés. M1. de Mlaiaville, aussi bien que 11 . Latreille, nont pas Lit assez altention dans leur classification ( voyez Mollosede), dont les grandes divisions sont basées sur les organes de la génération, à ce que nous avous dit des Calyptrées; ils ne les auroient pas rangées alors dans les Agames, puisqu'il est vrai qu'elles ont les deux sexes : ce qui rend la même organisation très-prubable daus les genres qui nous occupent; d'où il suit qu'lls doivent étre reportés dans l'ordre dẹs Paracéphalophores dioiques : ce qui les sépare des Patelles par de puissantes raisons. Non-seu!cuneat MI. Laireille a commis cette négligence, maisil est aussi tombé dans la faute de M. de Ferussac, ayrant mélangé dans une mêune lamille (Pilérformes, voyez ce mol), et sans distinction, basé sur la sycuétric ou la non symétrie, presque tous les geares des Scutibranches de M. Cuvier, dont plusieurs, comme nous l'avous vu, be peuvent rester dans ce groupe. Le genre Fissurelle est dans une méme section, avec les Ilipponices, les Cabochons, les Emarginules et les l'armophores.

Cumme nous le verions aux arlicles Scuti- branche el Jolrusqoe, M. Rang nous paroíl avoir saisi le micux les rapports d'ensemble entre les fauilles des Scuribranches, tout en ayaut égard a la loi de symétrie, au moyen de laquelle il a réuni, daus Ia famille des Putelloides ( voyez ce mol), les trois genres que M. Gray a voit déjà si bien groupés dás celle des Dicranabranchia.

$$
\text { CARACTERES GÉNÉRIQUES. }
$$

Animal ovalaire, conique en dessus, plat ea dessous, muni d'un large pied, épais, dépassé daus toure sa circonférence par Ies hords épuissis et liangés d'un manteau, ouver! antérieurcmeut all-dessus de la léte et au somanct par une ouverture ovale correspondant a celle de la corjuille et communiquant dans la cavité brancliale. Deux grands peignes branchiaux, égraux, se portant très en avaut et naissant de clatuue côté du plancher de la cavité branchiale; lête large, aplatie, munic de chaque côté de deux tentacules coniques, porıani les yeux, très-saillans à leur base extéricure.

Coguille ovale, conique, palelliforme, concave en dessous, sans aucuuc trace de spire, perforéc à son sommet; trou rarement rond, ovale ou oblong.

Les caractères génériques détaillés que nons venons de donner, d'après l'animal, nous dispeusent de pousser plus loin sa description. Ce que nous en avons citit est sullisan! pour faire connoitre son analogic avec l'animal des Ecoargiualcs et des Parmophures.

Les Fissurelles vivent à la maoière des Putelles, attaclices en plas ou moins graad nombre sur les rochers, qu'elles ne quittent, à ce qu'il puroit, que pendant la nuit pour chercher leur nourriture, et revenaat aussi, comme les l'atelles, se fxer à la même place. C'est principalement daus les mers chaudes des deux bémisplic̀res qu'clles habiteat; on en trouve deax espeeres dans lia Méditerranée, el un petit nombre de fossiles dans les diverses localités de France, d'ltalie, d'Angleterre, etc.

M. Lamarck n'a indiqué que dix-neuf espèces vivautes dans ce gonre, et une seule fossile. Nous en connoissons près du double des premières et huit des secondes; parmi elles, il s'en trouve quelques-unes qui ont leurs analogues vivates, uous les sigualerons de préférence.

1. Fissunele de Magellan. Fissuralk picta. LAMr.

F. testâ ovali, convexú, solidâ, albidhî, radiis undulatis, violaceo purpurascentibus cosisque longitudinalibus separatis; foramine oblongo, lateribus angustato.

Faranie, Conch. pl. 3. fig. a. 4.

Mantisi, Conch.tom. 1. tub. I1. fig. go.

D) vidas, Catalog. tom. 1, pl. 3. fg. C. 
132 F I S

Patella picta, Grex. pag. $3729 \cdot n^{\circ}$. 190.

Lasik. Anim. s. vert. tom. 6. no. I.

Cette coquille, assez commune dans les collecions, est une des plus grandes du gente; elle est ovalaire, un peu plus étroite antérieurement que postérieurement; elle est conique, épaisse, peu déprimée; son sommel, qui est un peu antérieur, est percé d'un trou ovale-oblong étroit. En dedans elle est d'un blanclaiteux, et en dehors, sur un fondblanc-jaunâtre on grisâtre, se dessinent quatorze rayons plus ou moins larges, violets et guelquefois d'un violet très-obscur; dans quelques individus, à peine si l'on voil quelques stries longitudinales; dans d'autres, au contraire, elles sont nombreuses, et aiors le bord est légèrement crénclé : re qui a'a pas lieu-dans les preciers. Cette coquille vit aux îles Malouines, au détroit de $\mathrm{Ma}$ gellau et presque dans tout l'Océan austral. Elle a quelquefois 85 millim. de long sur une largeur de 54 .

2. Fissorelce en bateau. Fissurella nimbosa. LaIIK.

F. testâ ovato-oblongâ, convexá, albo-lutescente, radiis fusco-violaceis pictû́, striis longitudinalibus crebris, conferlis; margine crenulato; foramine oblongo.

Lasr. Anim. sans vert. loc. cit. $n^{\circ} .2$.

Patella nimbosa, Lix. Guex.pag. 3729. $n^{\circ}$. 196 ?

Lister, Conch. tab. 528. fig. 4.

Bonaxi, Recreat. 1. fig. 3.

Go.altierni, Test. tab. 9.fig. q. r. s. $t$.

Dargentille, Conch. pl. 2. fig. C.

Adaxs. Sénég.pl. 2. fig. 6. Le Dasau.

Martini, Conch.tom. 1. tab. I $2 . f g \cdot 9^{\mathfrak{r}} \cdot 9^{2}$.

Si nous lisons la description qu'Adanson donne de son Dasan, el si nousla comparons avec ce que dit Grelin du Patella nimbosa, et M. Lamarck de sa Fissurella nimbosa, nous serons portés à croire que chacun de ces auteurs a en en vue une espèce différente. Celle opinion prendia d'autant plus de force que clacun des autenrs ne cite aucune variété : ce qui ne peut laisser croire qu'ils ont successivement décrit des variétés d'une même espèce. D'un autre côté, les figures citées par les auteurs sont si médiocres, qu?il est presqu'impossible de les rapporter d'une manière certaine et absolue plutôt à l'uae qu'à l'autre des coquilles décrites. On en sera bien convaincu si l'on fait altention que cette synonymie est restée la même et s'est prêtée d'une manière fort élastique à la description des trois espèces données comme le Nimbosa.

La Fissurella ninibosa de la colleciion du Muséum se rapporte exactement à la courte descrip.
F I S

tion de MI. Lamarck. Pour ériter tonte espèce de confusioa à l'avenir, nous allons donner la description la plus exacte que nons pourrons de celte coquille, qui est celle que M. Lamarck a nommée ainsi, et nous-même d'après lui.

- Cette coquille est orale, oblongue, conique, élevée, à sommet un peu antérieur, percé d'un trou ovalaire, unn iucliné, quelquefois uo peu rétréci latéralenient; des cốtes nombreuses, sulségales, peu saillantes, arrondies, serrées les unes coutre les autres, en partent en rayonnant \& parviennent au bord, interiampues seulement quelquefois par des stries d'accroissement; le bord est légèrement créaelé, ou plutôt plissé, daus toute sa circonférence. En dedans, cetle coquilte est d'un vert tendre plus foncé vers le sommet, aì l'on voit un bourrelet assez large, aplati, qui entoure l'ouverture apiciale; en debors elle est rayounéc alternativement de violet obscur et de fauve-blanchàtre ou rongeâtre; les rayons violets sont plus larges que les autres, qui noccupent qu'une seulc" còte. Celle coquille se trouve, à ce qu'il parnît, dans l'Océan d'Afrique, et nous summes cerlain qu'elle vit aussi dans la Méditerranéc, où elle paroit assez rare; tlle a 37 millim. de long et 26 de large à la base.

3. Fissurelce à grand tron. Fissurella macrochisna. Sow.

F. testầ ovato-elongatâ, angustâ, conicâ, lateraliter depressâ; vertice antico, obliquissimé perforato, foramine subtriangulari, pralongo, ad marginem incumbante; margine antico, crasso, elevato. Nов.

Sow. Genera of shells, $n^{\circ} .21$. fig. 5 .

Coquille des plus remarquables par la forme el la position singulière de l'ouverture du somme!; de forme oblougue, ovale, étroite, elle est comprimée latéralement, obliquement conique; snn sommet est trìs-antéricur et percé d'une grande ouverture subtrigone, arrondie antérieurement, fortement inclinée, et pour ainsi dirc tombant sur le bord; celui-ci se relève fortcment, ce qui le rapproche encore de la fente et diminue l'intervalle qui les sépare : on peut regarder avec juste raison cette disposition comme un passage aux Emarginules. Le bord antérieur lui seul est épaissi, les aulres sont minces, tranchans et ì peine crénelés. On remarque à l'extérienr un grand nombre de petites côtcs rayonnantes, ioćgales, un peu ondulenses, plus régunlières sur les côtés, et daus cet endroit seulement, coupées en travers par un grand nombre da stries fiocs et récrulières qui ne s'aperçoivent plus sur le côté postérieur. La couleur est assez variable, lantôt grisâtre, tantôt d'un brmn rauge en tiraot sur le fauve. Celtc coquille, très-rare, nous a été communiquéc par MM. Quoy et Gaymard au relour de leur second voyage, qui aura pour la science 
đ'immenses résultats; elle a été recueillie à la Nouvelle-Zćlande. Elle est longue de 30 milliu. et large de 10.

4. Fissurele hiantule. Fissurella hiantula. L.A $1 \mathrm{IK}$.

F. testî̀ oblongo-ellipticâ, conve.xo-depressî, extremitutulus elevatis, fornicatis ; striis tenuibus; verticis forumine maximo, prolongo; margine integro.

Borx. Mus. pag. 414. vign. fig. $f$.

Lask. Anim s. vert. loc. cit. $n^{\circ} .12$.

Coquille remarquable par sa forme et la grandeur du trou du sommet, de forme oblungue, wralitire, un peu plus étroite antérieurement que postéricureuent; elle est conigue, peu élevéce, compriméc latéralement; son bord, contiuu, épais et simple, est taillé en portion de cercle de chaque côté, se relève en avant et en arrière, de manière que la coquille, placéc sur un plan liorizontal, ne le touche que par deux points. Le somınet est un peu antérieur; il est percé d'un très-rriand trou ovale, non rétréci sur les côtés. I.a Fissurelle hiantule est, de toutes les espèces du genre, celle qui proportiounellement a ie plus graud trou; de cette ouverture partent en rayonbant un grand nombre de stries fines et serrées, et le plus sonvent donze ou quatorze rayons d'ur brun clair, et assez larges, sur un fond blanc; d'autres fois, la coloration consiste en linćoles irrénulières, brunes sur un fond blanc-grisàtre; en dedans elle est toujours toute blancbe. Cette coquille, rare dahs les collections, vieut de la mer des Indes; elle a 40 millim. de long.

כ. Lirsunele pustule. Fissurella pustula. Lairx.

F. testâ rotundatâ, ellipticâ, depressâ, antcrius

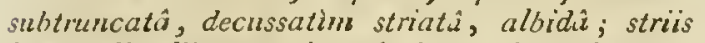
longitudinalihus, eminentioribus; foramine excentrali, parvulo, lincâ roseâ cincto; margine crenulato.

Patella pustula, Lis. Gares. pag. 3728. $n^{\circ} \cdot 194$.

1,1st. Conch. tab. 528. fig. 3.

Petiv. Gaz. tab. 3. fig. 12.

Canss. Conch. tom. 10. tab. 168. fig. 1632. 1633.

LAMx. Anim. s. vert. loc. cut. no. 13.

Sow. the Genera, $n^{\circ} .21$. fig. 3.

Cette coquille est, de tontes celles du genre, la plus comprimée; elle ressemble, en effet, comme son nom l'iudique, a une large pustule : elle est arrondie, tronquée antérieurement, et quelquefois un peu sinueuse, relevée de ce côté, ainsi que postérieurement, de la même manière, à peu près, que dans la Fissurclla hiantula. La fissure du sommet est antérieure; elle est remarquable en cela, qu'élant alongúe, étroite, elle sélargit subitement dans le milica, comme si au centre d'une lente étroite on eût percé un trou rond; le bord antéricur de celte fente est marqué, au-delors, par une ligne rose, et il en part quelquefois des rayons de fa même couleur, qui forment autour d'elle une sorte d'auréole, car très-rarement ils s'avancent jusqu'au bord. Cette coquille est du reste toute blanche, couverte en dessus d'un grand nombre de petites côtes simples, rayonnantes, qui, en parvenant sur le bord, y produisent des crénelures peu prononcées. Cetle coquille vient de la mer des Indes; elle a quelquefois jusqu’à 30 millim. de long sul 25 de large.

6. Fissurelde fasciculaire. Fissurella fuscicukeris. I.AMK.

$F$. testâ parvulâ, oblongo-ellipticâ, depressiusculi, cillo-flavescente, lineis fasciculatis fuscis radiatî; striis confertis; foramine elongato, lincî̀ rubrâ cincto.

LAMr. Anim. s. vert. loc. cit. $n^{\circ} .14$.

Sow. Genera of shells, $n^{\circ} .21$. fig. 6 .

Coquille qui a beaucoup d'analogie avec la Fissurelle pustule, nais qui s'en distingue cependant avec une grande facilite : elle est ovale, oblongue, rétrécic antérieurement, mais jamais tronquée et sinueuse de ce côté, comme la pustule; son sommet est presque central, il est plus élevé, ce qui rend plus conique cette espèce rue celle à laquelle nous la comparons. Le bord, crénelé dans toute son étendue, se relève antérieurement et postérieurement. L'ouverture du sommet est étroite, alongée, élargie senlement. daus le milieu; elle est, en dedans, bordée d'uu cercle rouge, et en dehors elle est le point d'où partent en rayonnant un grand nombre de côtes, arrondies, saillantes, espacées, un peu rugueuses. D'un rouge éclatant au sounet, cette coquille est ornée de buit à dix rayon's alternativement d'un brun pâle et d'un brun beaucoup plus foncé; quelquefois ces rayons n'existent pas, et alor's elle est toute brune, d'une nuance plus ou moins foncée, assez raremeut rougeâtle. Il est trèsprobable que cetle espèce vient des mers de l'Inde; elle est longne de 22 millim. et large de 15 .

\section{Fissurelde rude. Fissurella rudis. ов.}

F. testâ ovato-rotundatâ, conicâ, depressâ, squalidè albit, fasciis obscuris rufis subradiatâ, costatá; costis numerosis, radiantibus, separatis, rugosis; foramine minimo, ovato.

Coquille assez grande, ovale, obronde, en cône peu élevé, à sommet droit, un peu antérieur, percé d'un très-petit trou ovale, non 
oblique. Elle est couverte, en dehors, d'un grand nombre de côles rayonnantes, rugueuses, peu régnlières, tantôl arrondies, tantố déprincées, toujours distantes, quelquefois rendues ondulenses par des accroissemens irréguliers du tesı. l.e hord est large, aplati, ̇̀ peine crénclé et distinctement formé de la couche corticale de la coquille, qui se distingue par une couleur d'un banc sale ou grisâtre, tandlis quen dedans elle est d'un blanc de lait pur; sur celle teinte grisâtre de l'extérieur, se montrent onze ou treize rayons d'un bruu-roussitre. Le trou du sommet est très-petit relativement à la grandeur de la coquille : il est ovalaire. Cette coquille nous fut communiquée d'abord par notre ann Lessou, qui la trouva à Péita, at Péron; depuis nous l'avuns trouvice dans le comarerce, provenant également dı Pérou; elle est longue de 55 millim. et large de 43. Nous possédons une g:ande coquille, que ne rapportons à celle-ci quavec doure, parce qu'elle est polie, qui a 76 millim. de long et 62 de large.

8. Fissurezle épaisse. Fissurella crassa. Lamx.

F. testî oblongo-ellipticâ, convexiusculî, crussấ; margine integro, crasso, sursimm revoluto; foramine oblongo; lateribus coarctatis, utrinquè unidentatis.

An Patella avellana? Liv. Gmes. pag. 373ı. $7 n^{\circ} \cdot 206$.

LAmx. Anim. s. vert. loc. cit. no. 3.

Grande et belle coquille qui a de l'analogie, pour la forme, avec la Fissurella pictc : elle est ovale, oblongue, égalemenı large des deux côtés, très-épaisse, très-sulide, mais surtout ver's le bord, qui sarrondit en dehors, du reste il est simple ou un peu onduleux dans les vieux individus; une couche corticale, épaisse, de couleur brune cornée, couvre extérienrement toute la coquille, qui est tonte lisse, marquée seulement de quelques accroissemens irriguliers; en dedans elle est toule blanche vers le bord; mais au-delà de l'impression musculaire, on remarque une large tache d'un rouge vineux-blanchâtre, dans laquelle se voient un grand nombre de sillons irréguliers, longitndinaux, qui partenı du pourtour du bourrelet de la tente supérieure, et qui paroissent être des impressions vasculaires; ce bourrelet est épais, blanc, découpé à son bord et percé à son centre de la fente apiciale, qui est fort large, rétrécie clans le milieu par des dents latérales fort saillantes au-dehors. Cette conuille remarquable vient des côtes da Pérou; elle a 85 millin. ( 3 pouces i ligue) de long el 55 de large.

9. Fissurelie noueuse. Fissurella nodosa. Lamx. F. testâ ovali, convexo-pyramidatâ, albidâ, transversim annulata; striis longitudinalstus nodosis; nodis valdè elevatis, hateribus compressis, apice fissis, externis longioribus; foramine oblongo, lateribus courctato.

Patellw nodosa, Bors. Mus. pag. 4=9.

List. Conch. tom. 1. tab. 11. fig. 94 .

Nartini, Conch. tom. 1.tab. I1. fig. 94.

Patella jamaicensis, Guents, pag. 5730. $n^{\circ} \cdot 200$.

Lamx. Anin. s. vert. loc. cit. $n^{\circ}, 5$.

Coquille d'un mediocre volume, ovale à la base, élevée, conique, à sommet central percé d'une onverture oblongue, rétrécie latéralement; de ce sommet il part en rayonaant dix - neuf $\dot{a}$ vingt-une côtes saillantes, régrulières, symétriques: chargées de gros tubercules aplatis latéralement el fendus a u sommer. Le Lord est crénelé; il y a une crébelure pour chacune des côles, qui sont d’ailleurs représentćes en dedans par antant de sillons superficiels. En dedaus comme en dehors cette coquille est toute blanche, quelqivefois un peu grisâtre ou jaunâtre à l'extérieur. Elle vient des Antilles; sa longueur est de 30 millin. et sa largeur de 23 .

10. Fissuorelez cancellée. Fissurelles greeca. Lami.

F. testâ ovato-obbong. $\hat{i}$, convoxâ; striis elevatis, cancellatis, ad sectiones tubenculatis; furamine pano, intùs cincto, margine crenulato.

Lank. Anim. s. vert. tom. 6. pait. 2. pag. I1. $7^{\circ}$. 4 .

Patella graca, Lin. Gmex. pag. 3728. no. 195.

Fissurella graca, $\mathrm{P}_{\triangle \mathrm{Y}}$. Cat. des Ann. et de's Mull. de Corse, pag. g3. $n^{\circ} .181$.

Dorset, Cat. pag. 52. tab. 23. fig. 5.

Donovan, tom. 1.tab. 21. fg. 3 .

Lister, Concli. tizb. 527.fig. I. 2.

Bonani, Recreat. 1. fig. 6.

Gualt. Test. tab. g. fig. N.

Dabgenville, Conch. pl. 2. fig. I.

Adanson, Voyage au Sënég. pl. 2. fig. 7.

Aldrov. de Testaceis, pag. 546. fig. 4.

Fussilis. Patella graca, brac. Conch. subap. tom. 2. pag. 259. no. 8.

Noв. Descript. des coq. foss. des enw. de Paris, pl.2. fig. 7. 8. 9 .

Cette coquille n’avoit encore été trouvée fossile qu'en I talie, ę e!le offrit l'analogie la plus co:uplète avec l'espèce vivarrt actuellement dans $l_{a}$ Mléditerranée et dans l'Océan atlantique. Il est donc très-curieux et drès-étonnant ì la fois de retrouver aux environs de Paris un analogue fossile 
ct un analogue vivan! dans la même coipuille; ce fait est d'aulaut plus intéressant qu’il est trés-rare de rencontrer quelqu'analogic cntre les fusales d'Italie el ceux des envirous de Paris, et qüil est plus rare encore de truuver des analogues parfaiis entre nos fussiles et les Mollusques vivans. Quoique ce ne sult pas moi-mème qui di recucilit ce fossile, je niu suis pas moins convaincu cya'il a élé trouví a Grignon; c'cst feu Laubotiu, qui s'est occupé pendant très-longr-lemps de ranuaser des fussiles de Grignon, qui a eu la bonlé de me le communiquer, en y joiguant la note de l'éporue a laquelle il lut trouvé. Cette coquille, très-cumzune dans les collections, est ovale, oblongurue, à sonme: un peu antćrieur percé d"une ouverture raediocre, inclinée, uvalaire, souvcnt rétrécie dus son milien, el bordce an-dehors d'une ligne Irunc ou bleuâtrce. liouverture cst le point de dépurt diun graud uouj)re de côtes rayonbantes, arrondies, traversćes par d'autres transverses régulières qui produisent sur les premiures un tulocrtulc ou unc écaille au puint d'intersection, et comme elles ne sont pas moins réuulicres rue les premieres, elles couvreni toute la coquilie d'un réseau très-régulier, d̀ mailies carrées assez grandes. Le plus ordinarement liuit zones brunes, rayounantes, se dessinent symútriqguement sur là surluce blanclie de celte espèce; sun bord rst crénclé. On la tronve vivante dans la Méditerrance, les incrs d'Europe, d'Afrique et de l'Inde, et fossile en Italie et aux environs de Paris, oi tlle cst extrêmewent rare. Elle est longue de 40 millim. Noв.

11. Fissunelle obionde. Fissunella subrotunila.

F. testî̀ ovato-motundì, conicâ, elevatâ, striis longitudinalibus obsoletis ornuts, rubro et ulbo radıtu; upıce subcentrali; fissurî. minimá, rotunduts.

Coquille très-peu ovale, presque coute ronde, conique, élevée, à sommet subcentral élevé, la cuquille étanı régulièrement conique; ce sominet est percé d'un trou méliocre, presulue rund: il donne origine à un assez graud noubre de petites cóles légerement rugueuses, a peine saillantes, et qui palviennent ea rayoubaut sur le bord qui reste entier. Cetle coquille est, en dehor's, rayou. née d'un rouge très-loncé et tiês-obscur, surtout dans le jeune âne, sur un fond ronge un peu moins intense; en dedans elle est toule blanche, ct le bourrelet qui curconsrit la fente est légèrement ridé. C'est au Pérou que se trouve cette espèce; elle est longue de 52 tuillim. et large de 28 . NoB.

12. Fissorelle à cótes. Fissurellı costaria.

F. tesíi oblongo-ellipticá; dorso convero-conicà; lateribus subdepressá, costis radiantibus, crehris, strias timsincisas subsquamulosus decussuntibus; margine cienulato; formminc oblongo, inclinato.

Non. Descrint. des cou. fossil. des cnviruns de Perrs, pag. 20.pl. 2. fig. 10.11. 12.

Je dois la connoissance de cette conuille it 11. Duchitel, de Versailles, qri m’a assuré l'avor louve a Grignon on dans une des localités qui avoisinent celle-ci; tlle cst d'aulant plus remaiquable qu'elle offie une prarlaic analogic avec unu Fissurelle vivante que l'on roit assez snuvent daws les collections, et qui "1'a puint cucore flé nomnúe par les couchyliolognes; elle a itussi beancoup de rapports avec la Fissurellu itculica Detr. Elle esi cumulue, olilique, ćlevée; son ouverturc supérieure est inclinée, nou contrale; il en part, un rayunnat, vinğ-six grosses côtus, cntre lesquelles on en voil d'une di trois plus fuctics ; toules ces cótes sont un peu écailleuses, ou plutút coupces longitudinalt nent par un grand numbre de stries circulares; a l'intérien, l'ouverture sirpérieure est cuvionuće d"un bourrclet comira. Sa couleur est partout d'un jaune fauve en cleliors; elle est blanche en dedans, et son bord est crénelé. Ellc estlongue de 30 willimètres, et large de 18 . Nos.

13. Fissurelde \{́cailleuse. Fissurella squamora.

F. testiovato-depiessi, costis crebris, cepressis, radiuntibus, costas eleganter squamosu-apers; foramme ovali, obliquo, intus marginato; margine laviguto.

Noв. Descript. des coq. foss. aes env. de Pars, pag. $21 \cdot p l .2 . f i g .1 .2 .3$.

Depuis long-temps j'avois séparé, comme espèce, deux petites cocpulles de ce genre que j’avois recueillies a Gijunon, lorsque jeus occasion de m'en procurer une autre plus graude du méme lieu, avec laquelle il m'a été possible de caractériser décidément cellc copèc. Le grand individu que je possède a conservé des uäres de son ancienne coloration, \}ui cousistent en 1rois larges bandes rayonnantes dun lature-rougecitre, dalss l'iutervalle desquelles on en voit une ou deux plus petiles; elles sum écailleuses; ces écailles nultipliées reudent la coyuille rude au toucher et fort élégante. L'ouverture supétieure est oblique, assez grande, ovalc, surmonlće postérieuremeni par uue pointe un pea coubée, cumme dans quelques individus de la Fissurelle labiće; a l'intérieur elle est bordéc.

longueur 40 millim., largeur 26 ; il y a de plus petits individus.

14. Fisscanle labiéc. Fissurella habiata. Lamk. $F$. testi̊ ovato-oblonga, conico-depressâ, stritis 
tenuibus, decussatis, subsquamosis, foramino; obliquo, intics labiato.

Lamk. Ann. du Mus. tom. 1. pag. 312. $n^{\circ}$. I.

L.ank. Anim. s. vert. tom. 6. 2e. part. pag. 16. $n^{\circ} \cdot 20$.

Nов. Descript. des coq. foss. des env. de Paris, pag. 21. pl. 2. fig. 4. 5.6.

On reconaoit celte coquille au premier aspect; Iu liuesse de ses côtes, qui ue sont que des stries assez tines élígamment chargées de très-petiles écailles qui se continuent sans interruption dans l'intervalle qui les sépare, les stries longitudinales elles-mêmes, qui sout très-lines et très-rapyrochées, la forme plus ovale da trou, et surtont la sorte de lèvre que forne postérieurement le bourrelet intérieur qui, dans le reste de son étenciue, est presqu'eflacé, sont des caractères bien suffisans pour distinguer cette espèce de la précéduate, surtout si on ajoule une moindre taille el une forme orale plus alongée. Cotte coquille est assez commune; le plus grand individu que j'aie va a 3t millim. de long et 18 de large. Elle se trouve a' l'etat fossile anx euvirous do Paris et de Valogues. Noв.

15. Fissurele multifide. Fissurella multifia.

F. testầ ovato-oblongâa, depressâ, conicâ, radiatim multrcostatí; costis numerosissimis ntundatis squanulis angulatis serratis ornatis; margine in onnibus costis profunde fisso.

Nous ne connoissons celte coquille qu'à l'état fossile; elle est orale-oblongue, conique, déprimée, à sommet un peu antélieur et incliné de ce côté; l'ouverltare qui s'y voil est ulongée, étroite, subcarrée; il en part en rayonnant un grand nombre de côtes arrondies, éyales, serrées, peu saillantes, tontes chargées d'écailles courbes, relevées vers le sommei, anguleuses, surtuut vers les bords. En arrivant sur le bord, chaque côte, et surtout les postérieures, est divisée en deux parties égales par une fente étroite et assez profonde, et que, jusqu'à présent, nous n'avons remarquée dans aucuue antre espèce; le bord est peu épais et crénelé dans toute son étendue. La grande régularité des côtes et les fines écailles qui les couvient rendent celte corguille remarquable par son élégance; ella a 20 millim. de long. On la touve lossile aux environs d'Angers.

16. Fissurelde douce. Fissurella mitis. Nob.

F. testâ ovato-oblongâ, conicâ, anticè angustiore, crassî, costis squamulosis, numerosissimis, uqualibus, ornatú, squanulis mininnis, appro$x$ imatis, numerosissmis, subimbricatis; margine crenulato.

Coquilie ovale, oblongue, assez épaisse, un peu plus étroite antérienrement çue postérieusement, à somaet son central, percée d'uu ouverture ovale, rétrécie latéraleuntent et inclinée obliquement en avant. 'Très-r'́gulière et peu élevée, cente coquille est cuuverte d'un grand nombre de cútes arrundies, serrées les unes contre les autres, peu saillantes, conpécs par nue multitude de stries transversales, qui deviennent légèrement écailleuses en passant sur les côtes; elles forment avec celles-ci un assemblage bien comparable i un fin tissa d'osict. Le bord, assez épais, est liacment crénelé dans toute sa longueur. Nous connoissons cette espèce fossile seulement en Iralie et dans les falnas de la Touraine; elle est longue de 34 millim. et larage de 21.

17. Fissurelle radiole. Fissurclia radiola. Nub.

F. testî ovato-oblong. $\hat{z}$, conico-depressâ, régulariter costellatâ, eleganter albo et violaceo radiatu, margine leviter crenato; fissuri magnâ, lateribus coarctatá.

Jolie coquille très-distincte de loutes los autres espèces du même genre : elle est ovale, oblongrze, à peine plus étroite antéricurament; son sowouet subcentral antérieur présente une girande ouvetture oblongue, rétrécie dans le milieu de chaque côlé; en deduns elle est bordée par un bourrelet étroit, finement strié; pn clebors, cette cocpuille est converte de côtes lines et rayonnantes, subégales, arrondies, peu saillantes, coupées par un grand nombres de stries transverses, ondu leuses, qui paroissent être le résultat d’accroissemens multipliés et réguliers; sur uu fond blanc. grisâtre se dessinent sejze à dix-huit rayons violet foncé, parlaitement symétrignes. Le bard est tinement créuelé, et présente, à l'endroii des layuos, des-tacbes oblongues, alteraativement blunches et violettes. Cette coquille, fort rave, se rouve sur les cútes des iles Malouines; elle nous a été communiquée par notre ani M. Lesson.

18. Fissurelde rayonnée. Fissurellı r.ldiata. LAMK.

F. testî́ ovato-oblong. $\hat{u}$, convexiuscultâ, albidi, fasciis spadiceis radiatá; costellis radiantzbus laxis; foramine minino, obovato; margane subcrenato.

LAask. loc. cit. no. 10.

Petrv. Gaz. tab. 8o. fig. 12.

Scaroeter, Eint. inconch. tom. 2. tab. 6. fig. 15.

An patella angusta!" Girr. pag. 3733. $n^{\circ} .210$.

Coquille assez variable dans ses couleurs, mais to ujurs reconooissable à ses accidens extérieurs: 


\section{F I S}

elle est ovale, oblongue, un peu rétrécic abtéjieurement, conique, à sommet piesque central, droit, percé par un trou d'une médiocre grandeur, ovalaire et simple; des côtes nombreuses en partent en rayonnanl; les unes, plus grosses et en moindre nombre, laissent entre elles des espaces plus ou moins larges occupés par d'autres, plus petites, au nombre de une à trois, mais sans constauce el sins régularić, el quelquefois sans symétrie; dans les vieux individus toutes ces côtes sont arroudies, saillautes, quelquefois méme écailleuses. On pourroit, d'après la distribution des couleurs, établir tacileovent trois variétés : A. coquille toute rouge arec quelques rayons blanchátres très-obscurs; B. coquilie rayonnée de rouge obscur et de blanc, \& souvent maculée de brun vers le sommet; C. coquille rayonnée de brun et de blauc: les rayons bruns formés quelquefois par des taches irrígulières et nombreuses. En dedans, cette coquille est toute blanche, et son bord est crénelé dans toute son étendue. Nous ignorons sa patrie; M. Lamarck croit qu'elle vient des Antilles. Elle est longue de 30 millimètres et large de 20 .

19. Fisstrelce verdâtre. Fissurella viridula. LAXK.

F. test.î ovato-oblongâ, conicxiusculî̀, virescente, costellis albis radiatâ; foramine oblongo, inclinato, lineầ subcceruleâ cincto; margine crenulato.

LAs x. Anim. s. vert. loc. cit. no. II.

Coquille orale, oblongrue, couvexe, conique, élevée, à sommet un peu incliné el antéricur, percé d'une petite fente étroite, un peu plus large dans le milieu, et entourée; en dedans comme en dehors, d'une petite zone d'un blanc obscur; cette ouverture est fortement inclinćc en avani. La surface extérieure est couverte d'un graud nombre de côtes serrées, onduleuses, alternativement plus grosses; quelquefois il $\mathrm{y}$ en a deux ou trois très-fines entre chaque grosse, au lien d'une seule; dans tous les cas les grosses cótes sont blanches et les autres sont vertes. Le bord est fuement crécuelé et de la même couleur que l'extérieur. En dedans, cette coquille est toute blanche. Nous ignorons d'où elle vient; elle est longue de 25 à 28 millim.

20. Fissuretre de la Barbade. Fissurella barbadensis. LauK.

F. testî ovato-oblongî̀, convexâ, albidolutescente, maculis rufis subpictâ; costis radiantibus, incequalibus, squamoso-nodosis; foramine motundo; margine crenato.

lusster, Conch.tab. 528. fig. 7 .

M Intini, Conch. tom. 1. tab. 11.fgg. 93. et 36. 97 .

Hist. Nat. des Vers. Tome II.
Patella burluadensis, Guel. pag. 3729. $\pi^{\circ}$ 199.

IAak. Anim. s. z'ert. loc. cit. n’.9.

Coquille ovale, oblongue, rétrécic antérieurement, conique, élevíe, quelquefois un peu irrégulière par son mode d'accruissement; elle est chargée de côles nombrcuses, élevées, inégales, arrondies, ondulenses, rudes, ruelquefois grossièrement écalleuses; toules partent en rayonmaut dn sominet ct lont saillic sur le bord, qui est épais et fortement crínelé; le sommet est central, occupé par une ouverinre ronde, dont le bord est presque toujon's marqué par uoe ligne rougeâlre; ell dedans, celle onverture est entourée d'un large bourrelet strié très-légèrement et toujours verl; en deliors, celte coquille est d'uu blanc-grisâtre on fauve, matquée, surtout sul les côtes, d'un grand nombre de taches irregulières, de coulcur brunc ou rougeâtre; eu dedans, elle est d'un blanc-verdâtre, et sourent elle montre, vers le bord, une large zone verte. Cette espèce, longue de 37 millim., se trouve ì la Bardade, comme son nom l'indique.

21. Frssureste lilacioe. Fissurclla lilacina. Lank.

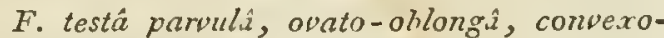
conicâ, albidî, roseo-corulescente nebulosâ; striis longitudinalibus, exiguis creberrinis; foramine ovali; margine integro.

Laмк. loc. cit. no. 7 .

Coquille qui ne pread jamais un grand volnme : elle est ovalaire, très - rétrécie antérieurement, conique, élevée, un peu déprimée sur les côtés, et percée, au sommet, d'un trou petit, ovalaire, arrondi; les stries qui en parlent sont nombreuses, simples, saillanics, rayonnantes, mais peu régulières : les couleurs sont peu variables; elles consistent en rayons obscur's de coulcur ronge-violâtre peu foncé, sur un fond blanc; quelquefois les rayons se rapprochent, se confondeat, et le fond blanc disparoît. En dedans, cette coquille est d'un vert tendre, et le tron du sounmet est entouré d'une zone assez large, de la même couleur, un peu plus intense et légèrement brunâtre. Le bord est simple, à peine crénelć. D’après M. Lamarck, cette coquille viendroit des mers de la Guiane; elle est longue de 30 millim. et large de 19.

22. Fissorelle de Cayenne. Fissunella cayennensis. LaMK.

$F$. testâ oblongo-ellipticâ, dorso convexoconic $\hat{i}$, lateribus subdepressấ, albidì; striis longitudinalibus, crebris, strias transversas exiguas decussantibus; nargine crenulato; foramine oblongo, inclinato.

Laur. loc. cit. no. 6. 
Nous avons vu daus la collection de M. Lamarck la coquille qui prorte ce Dom, el nous arons pu nous assurer qu'il avoit confond a avec clle, à titre de variélé, deux espères hien distinctes: nous avons dí, en conséqueace, sup primer celte variélé.

La Fissurelle vle Caycune est une coquille fort rare: elle est ovale, très-conique, épaisse, tonte blanche, ì sommel un peu antérieur percé d'un trou orale, et fortenent incliné aotéricurement; un graud nombre de petiles côtes rayounantcs descendent du sommet à la base; elles sout couvexes, pen flevécs, presqu'égales, régulières et coupécs trasversalemenl par un grand nombre de stries fiucs, sublamellenses, trèsrapprochéce ef non moins régulières que les puemièrcs. Si on exabine relte espèce à la loupe, on remarque gu'entre chacune des stries transverses il s'on trouve deux on trois autres cxtrêwemeut lines que l'on ne peut distingner à l'neil nu. Le bord estépitis, arrondi, finenent crénelé daus loute son cilendue; en deduas, le bourrelel de l'ouverture du somuel est lriangulaire, alongé, Ct préscnte du côté postérieur une petite lanie. Daprès M. Lamarck, relle coquille vil it la Guiane; elle est longne de 35 millim. et large de 25 . Nов.

23. Fissurille aégligée. Fissurella neglecta.

F. lestâ orato-ohlongấ, anicicè angustî̀, conicâ, costatí, firscu zirescente et alho radiutá; costis inaqualuhus, striis transwersis numerosissimis, decussutus; apice aníico, obliquè perforato; margine crinsto.

Var. B. Nпв. Fossilis. Testá elatione; striis transversis, lamellosis.

Coguille très-communément répandoe dians les collections, el qui, se trouvant dans la Méditerranée, a été conlondue avec la Fissurella graca: quoigu'elle s'en distingue constamment, l'erreur s'est propagée pour l'espèce à l'élat fossile, on l'a tonjour's rapportće à la Fissurclla sraeca, qui cst aussi fossıle dans les mênes localités. Cétle coquille est ovale, oblongue, rérrécic antérieurement, tandis que la Fissurella graca est régulièrement ovale; le somne! est loujours plus éleré, plus antérieur et percé d'un trou ovalaire; toujours très-obliquement incliné antérieurement, ce trou est rétréci dans son milieu par deux carènes lalérales, obtuses. Les côtes rayonnantes de la surface soot fort différentes de celles qui se roient à la Fissurella graca; nous avons vu çu'elles étoient grosses, saillantes, une plus petile interposée entre cliacuoe des grosses, et toutes couptes en travers par des lames transyerses qui découpent toute la surface en un réseau à grandes mailles carrées : ici les côles sont de deus sortes, les unes sont les plus saillan'es et les anoins nombreuses, et régulièremeut disiantes entie elles; les autres, plus fines, sout interposées au nombre de trois entre chacrune des premières, de sorte que, sans exagération, on peut compier, sur l'espèce qui nous occupe, denx fois autant de côtes que sur celle avec laquelle nous la comporons; les stries traosversales sont nombreuses, fioes, serrées, pen saillantes et elles produisent, seulemeat au sommet, un réscau régulier à pelites maillıs carrées, réseau qui s'efface insensiblement à mesure que les côtes longitudinalcs l'emporienı en rolume sur les stries iransverses. Celte coquille est quelquefois d'un brun-verdâtre uniforme; le plus souvent elle est ornée de dix ou douze rayons blancs, frroits, qui vont de la base an sommet; en deduns, elle est d'un blauc lógèrement verdû́re, el le bourrelet du tron du somanel est érroit, saillant en dedans, et d'un blanc ́́clatant; il est de forme triangulaire; le bord est finement et assez prolondément crénelé. La variéré qui se trouve à l'état fossile est toujours plus conique, plus étroice latéralement, el les stries transverses, quoique tris-nombieuses, sonl plus sailluntes et presque lamelleuses. Celle coquil'e se trouve vivance dans toute la Miciterraúe, et fossile en Italie: en Sicile, daus les luluns de la Tuuraine et aux environs d'Angers; elle est longue de 40 aillim. et large de 27 . Nous avuns vu un individu fossile, a a moins du double, dans la collection de M. Dusgale.

24. Fissurelee naive. Fissurella minuta. Lanx. F. test.â minimâ, oblongo-cllipticâ, converâ, albâ, lineis nigricantibus exilibus radiutim pictu; strus tenuissimis, decussatis, longitudinalibus, sulgranosis; foramine exiguo, excentrali.

LAßK. Anim. s. vert. loc. cil. no. 19.

Elle est la plus petite des Fissurelles et en même temps une des plus élégantes : uvale. oblongue, conique, nince, son sommet est anlérieur, oblique, ioclioé; il est percé d'un trou ovalaire très-petit, ua peu ćlurgi dans le milieu, comme clans la Fissurelle puslule; la surface exlérieurc est couverte d'un grand nombre de petiles côtes rayounanles, sej'rées et couvertes de granulations Irès-lines et d'uve grande régularité; celle régularité est telle que, soit qu'on examine ces grabulations en rangées longitudiuales, soit en rangées transversales, on les trouve toujours disposées de mauère à former uu réseau d'une grande élígance. Ses couleurs consistent en petites lignes noires ou d'uu bruu très-foncé, rayounantes, plus ou moins nombreuses, et rapprochées dirersemeut. Ea dedans, cetle coquitle est loute blanche et son lord est finement crénelé. On ignore sa patrie; les plus grands individus n'ont que 10 millim. de diamètre longitudival à la base. 
FISTU1.AIE. Fislulina.

Tel qu'il est caractérisé aujourd'lui, ee genre ne peut plus renferuer des coquilles très-différenies, comme cela a voit lieu pour les Fistalanes de Brugruière el ce même genre de II. Lamarck, qui contennil encore, il y a peu d'années, les rudimens de tons cenx que circonscrit maintenant la fumille des 'tubicolées; ainsi on n'y verma p'us ligurer les Clavangelles et les Térédines, mais wus nous eflorcerons de fuire voir que, s'il éluit núsessuire d'un cóté d'en séparer queleques geares, il étoit inclispensable d'un autre de rappeler coulien les Gastrochenes ont avec elles de rapports, rapports que nous croyous si intimes, que nous regardons comme indispeasable la réunion des deux grenres.

Jusqui a présent on a voit pensé que la présence d'ua tule complet ćloit nécessirice pour earactériser suffisamment les firistulan's; c'est mème en l'admeltant lizoureusement qu'on a exclu quelqques espèces pour les rangrer parmi les Gastrochènes. Cette distinction, yui n'est d'ancone valear, conduiroit indubiliblement à plarer indistinctement, lantôt dăs un genre, laurout dans l'autre, les mêmes cspèces, sếlon qu'on les aura recucillies avec plus on moins de suin, ou qu'elles aturont vécu dans des circonstances plus ou moins favorables au développenent da tulie.

Cela prouve, ce nous semble, que l'un des lienres est mauvais; ce qui lient, sans aucun iluute, à ce que ces genres ont été arill observés. En effet, nous voyons le genre Gastrochène, que Spenyler a proposé le premier, n'ètre formé que de listulanes, et principaleasent de celles qui, au lieu d'habiter dans un tube libre, ont la propriété de percer les corps sous-marius et de revêtir d'un tube plus ou inoins complet lit cavité oì elles sont logées; l'adhérence du lube à ces corps a dû le faire négliger, lorsqu'en les cassant on en a extrait la coquille : et cela est si vrai, qu'il est bien constaté, même depuis long-temps, et dernic̀rement par' Turton (Conch. des lles Britan. pag. 17), que le Gastrochène cunéilorme, qui a servi de type au genre, est conslanment pourva diun tube plus on moins complet qui revêt l'intérieur de la cavité quiil Jiabite. J'ai eu occasion moi-même d'observer plusieurs fuis des sui-disant Gastrochènes en place dans des masses madréporiques; j'ai répété mes observations aussi bien sur les espèces fossiles que sur les vivantes, et je n'ai vu manquer le iube complétement que très-rarement : je l'ai abservé, aı contraire, presque toujours complet, on manquant, seulement à sa partie pastérieure, dans un petil espace. On contestera cela d'autant moins que Spengler (Nova Acta danica, ınm. 2. pag. 177) a lui-nềne rangé parmi ses Gastrochenes toutes les Fistulanes des auteurs, dianrès la considération da tube; ce qui fait penser que ret aneur exact avoit olservé celui du Gustrochène cuncilorme, aussi bicn que ceux de toutes les antres espèces quil rajportoit à son gente : ceci nous porte à croire qu'il y a cul ufuligence de la part da zoologiste qui a rétabli le grence Gastrochène, puisulu'il n'a point fast mention lu tube, que Spengler regardoil comme caractòre essentiel, ce qui a induit en erreur M. Lamarck, qui a admis le genre, ce qui est arrivé égilcment à M. Defrance, à MI. de Terussats el at beaucnup d’autres zoologistes. Ainsi, ce geure Gastinchène, que l'on a constamenent rapproché des Pholades dans une antre famille que les listalanes, est donc d'aloord mal placé si on veut le conserver, puisisu'il a na tube, et ensuite ne repose plus :" sur un caractère de rès-peu de valeur, quíscruit l'incrustation du lube dans l'épaisseur des corps sons-narins; ct encore ce caractère devient-il nul si un fait attention que celui qqui sera incrusté dans un corps friable pourra deveuir litre, et conséquemment passer dans le genre listulane, taudis q̣ue celui qui adlic̀re ì des corps durs, ne ponvant plus, par aucuns moyens, devenir libre, resteroit dans le genre Gastrochène; et, comme: ces circonstances peurcut avoir lieu ou se reproduire pour la mêcre espéce, il s'ensuivroit qu'elle occuperoit deax places dillërentes, ce qui mest pas admissible: il ne resie done plus aux Castrocliènes que le lisillement considérable des valves, mais ce baillement n'est pas plas grand que dans les listulanes à tube libre.

De toules ces observations, it doit nécessairement résulter la sappression du grenre Gastrochène, puisque les caractéres sont détruits o:s renirenl entierement dans ceux que l'ou donne aux Fistulanes : v'est ce qui nous a porté à modilicr les cariclères génúrigucs donnés par M. Lamatr.k.

\section{CARACTERES CENÉRIQUES。}

Fourreau tubnleux, le plus souvent teslaci. soit libre, soit incrusté dans l'épsisseur des corps sous-marins, plas renflé et lc plus souvent licrmé postérieurement, alténué vers sun extrémilé ilutéricure, ouvert à son sominet, contenant une counuille libre et livalve; les valves de la coquille érales et très-bâillantes lorsqua elles sont réunies; le ligament calérieur droit; jamais de cuillerons internes sous les crochets.

Les Fistulames sout assez nombreuses en espèces, soit virantes, soit fussiles, et, dans l'un ct l'arire état, nous les ietrouvons dans les denx circonstances d'labitation qui en out fait deux genres; mais, comme les tubes de celles qui vivent dans le sable acquièrent une grande fragilité en devenant fossiles, il n’est pas étonnant de tronver quelquefois leurs valves séparées dans les sables à fossiles. l’armi les espèces à 
tube libre, celle que l'on troure le plus ordinairement aux environs de Paris avoit la singulière propriété d'agglutiner à son tulse les grains de sable qui l'environnoicat, propriété qui lui est commune avec quelques espèces d'Arrosoir. Les valves des Fistulanes, quaique fortement réunies entre elles, à l'état frais, par un ligament, n'offrent jamais de dentelures à la cliarnière; cette parlie est ordinairement droite ou légèrement arquée, très-mince, quelquefois arrondie par un petit bourrelet décurrent sur le bord.

Aux observations précédeutes, il faut en ajouter une qui n'est pas sans intérêt. M. Lamarck a caractérisé le Taret sur son habitude de conserver son tube ouvert aux deux extrémitćs, et de l'enfoncer dans des bois pourris. Les valves présentent, sours les crochets, de petites palettes analogues à celles des Pholades, mais, d'après l'observation d'Adanson, lorsque le 'Taret est arrivé a tout son développement, il ferme fon tube à l'extrémité la plus large; et alors, sous ce rapport, il ressemble à plusieurs espèces de Fistulanes. D'uu autre côté, nous voyous parmi celles-ci un véritable Taret qui vit dans les bois pourris, qui a seulement celle différeuce, de clore toujours son tube; cependant les valves sont pourvues, comme l'autre, de paletles intérieures; mais elle ont la même forme : le lube lui-même présente cette irrégularité, ces sinuosités si communes aux Tarets. Tout nous porte donc à penser que la Fistuluna grezata des auteurs, la seule qui présente ces caractc̀res étrangers aux véritables Fistulanes, doit passer au genle 'laret, et ainsi rentrer dans le groupe dont elle porte les caractères. Il étoit essentiel de développer les motifs qui m'ont fait ajouler aux caractères génériques du genre qui nous occupe, de ne jamais présenter de palettes intérieures, caractère qui devient plus essentiel que la considération du tube, lorsque, dans cette famille de Tubicolées, on ne pent arriver à aúcune juste détermination sans l'examen attentif des coquilles, sur lesquelles on trouvera toujours les caractères fundamentaux.

M. de Blainville n'a pas eu, sur les Fistulanes, la même opinion que nous, et on le concevra facilement en consultant son article FisTuLANE du Dictionnaire des Sciences naturelles, ainsi que ce qu"il dit de ce genre dans son Traité de Malacologie. Sentant qu'il étoit nécessaire de séparer la Fistulana gregata des Fistulanes véritables, au lieu de la reporter dans les Tarets, où est sa véritable place, il fit, avec cette coquille et quelques autres très-douteuses, comme nous le verrons, le geare Fistulane, leportant dans les Gastrochènes toutes les vraies Fistulanes, et conservant, par double emploi, le genre Taret.

Dans ses Familles naturelles du Règne animal, N. Lalreille n'a apporté aucun change- ment utile dans les rapports des Fistulanes, et n'a point admis leur réunion avec les Gastrochènes; ce qui produit, comme dans M. Lamarck, deux genles pour un seul : et à l'exemple de cet anteur, M. Latreille place dans deux liamilles dillérentes ces parties d'un tout; au lieu de réunir les Gastrochèues aux Pholades, il les joint aux Solens et antres genres analogues, de la famille des Salénides. Ce que nous avons dit précédemasent suffira sans doute pour convaincre que M. Latreille a été dans l'erreur.

M. Rang (Mraniuel de Conch.) a confondu daus la Fánille des Tubicolés, les Pholades, les 'Tarets, les Arrosoir's, les Gastrocliènes, les Fistulanes, etc. : nous proposerons aux articles $\mathrm{P}$ но LaDrs ct 'T'UBtcorés les changemens que nous croyons utiles dans l'arrangement de ces fimilles. M. Rang a bien senti qu'il existoit un double emploi entre les Fistulanes, les Tarets et los Gastrochènes : ce savant modesle, se défiant trop de son savoir, ne voulut pas supprimer le genre inutile; d'où vient que, dans sa méthode, se retrcuvent les mêmes defauts à peu près que dans celle de M. de Blainville.

Nous avnns fait remarquer, dans le Dictionnaire classique d'Histoire naturello, à l'article Fistulane, une singulière erŕeur de M. Lamarck qui, dans les planches de ce Dictionnuire, a pris la figure de l'animal de la Fistulana gregats pour celle de la Fistulana corniformis; cette erreur nous semble d'autant plus incompréhensible, qu'il ne fallait qu'une foible attention pour l'éviter.

'Toutes les fistulanes vivent dans la mer, ezfoncées dans le sable, ou logées dans les cavites qu'elles se creusent, dans les pierres calcaires, les madrépores et même les coquilles; lorsqu'elles vivent dans le sable elles sont pourvues d'un tube calcaire, complet, plus ou moins solide, ordiuairement droit ou légèrement contourné; lorsqu'au contraire elles creusent des corps plus ou moins aurs, le tube revêt la cavité d'une mauière dautant plus complète que le corp; est moins susceptible de poli.

Le nombre des especes n'est point enenre considérable; elles sont vivantes et fossiles, tt peuvent se partager en deux sections, d'après la forme des valves, qui sont longues et étroites dans les unes, beaucoup plus larges et plas courtes dacs les autres.

\section{t Espèces dont les values sont longues et étroites.}

1. Fistulane massue. Fistulana clava. Lame.

F. vaginâ tereti, clavatâ, rectâ, tenuissinı $\hat{a}$, fragili; testæe valvis elongatis, antice contortis, uncinatis, regulariter striato-plicatis.

Laxx. Anim. sans z'ert. tom. 5. pag. 4055. no. I. 
Gastrochena, Spexcler, Nov. Act. dinica, tom. 2. pag. 174. fig. I à 7 .

Pavane, Conch.pl.5. fig. K.

Busisv. Malac. pl. 81. fig. 3.

Sow. Genera, $n^{\circ} 27$. fig. 1 à 5.

ENcrcL. pl. I67: fig. 17 à 22 .

Coquille fort rare dans les collections, et trèsremarquable par ses valves minces et longues, qu'elle contient dans nu fourrean tubuleux, teslacé, blanc, papyracé, très-fragile, alongé, toujonss élroit, conique, en massue, ouvert à sa Fetite extrémité, obtus, arrondi et complétement clos à son extrémité la plus large, marqué dans toute sa longueur par des stries d'accroissement; les valves contenues dans ce tube sont longues, itroites, comme tordues légèrement dans toute leur longueur; elles sont minces comme da fin papier, et extrêmement fragiles; elles ont la forme d'un carré long, un peu plus étroit antérieurement, où on remarque une sinuosité sur le bord; lorsque les valves sont réunies, ce sont ces sinuosités qui produisent le grand bâillement qu'elles présenteut antérieurement. Le bard postérieur est droit, un peu plus épais, surtout à l'endroit de l'insertion du ligament; les crocbets sont à peine indiqués. L'extrémité antérieure se recourbe fortement en arc de cercle, et est couverı, à l'extérieur, de sillons assez nombreux, qui partent du crochet pour gagner le bord en rayonnant. Cette coquille, d'aprês M. Lamarck, viendroit des grandes Indes; le tube est long de 10 centim. et demi, et les valves de 32 millim.

\section{NoB.}

2. Fisturane alongée. Fistulana elongata.

F. tubo incognito; testâ elongatâ, angustâ, parte superiore uncinatî, recurvia $\hat{a}_{j}$ valvis hiantissimis, subquadrilateralibus, in medio sinuosis.

Nов. Descript des coq. foss. des env. de Paris, tom. 1. pag. 15. pl. 4. fig. 17. 18. 19 .

Quoique nous ne connoissions pas le tube de cette coquille fossile, elle présente tant d'analogie avec la précédente, quant à la forme générale, que nous ne doutons pas qu'elle ait été contenue dans nn tube semblable, proportionné senlement à la graudeur des valves.

Nous avons caractérisé cette espèce, d'abord sur ane seule valve de la collection de MI. Brongniart, depuis nons l'avons rendue plus certaine par une seconde valve trouvée, comme la première, dans les sables de Grignon. Cette coquille, alongée, subquadrilatère, très-mince, très-fragile, contournée dans sa longueur, est terminée antérieurement par une extrémité recourbée en crochet court, très-aplati en dessus et lisse. Le bord postérieur est arqué, arrondi, tandis que l'antérieur est fortement sinueux et très-mince, de sorte que la coquille est très-bâillaute lorsque les valves sont réunies. Cette corquille, extrêmemeat rare, n'a que 13 millim. de longueur; ce qui supposeroit un tube de 59 millim. de long, dans lo cas où il seroit avec la coquille dans les mêmes proportions que l'espèce précédente.

3. Fistulane bâillante. Fistulana hians. Broc. F. testì ovato-elongat $\hat{u}$, angustâ, subcylindricâ, substriatâ, hiantissimâ; valvis subcontortis, parte superiore depressis, vix uncinatis. Noв.

pholas hians, Broccur, Conch. Soss. subap. pag. 5gz. pl. 11 . fig. 14.a.b.

Tout en rapportant le pholas hians de Liuné à cette coquille, M. Brocchi reconnoît cependant qu'il y a des différences qu'il trouve assez considérables pour le déterminer à en donner une figure. A cet égard, nons allons plus loin que le savant italien, nous avons sous les yeux le Pholus hians de Liuné, qui est la même coquille que le Gastrochena cuneiformis de Spengler; nous avons égalewent la coquille fossile, et, après une coinparaison exacte, nous pouvous assurer qu'elle constitue une espèce bien distincte de la première. C'est pour cette raison que nous avons excln la synonymie de hiunć, qui appartient à une autre espèce.

$C^{2}$ est probablement par suite de cette confusion, que M. Brocchi a dit que le ploolas hians vivoit tantôt dans un tube isolé et tantôt dans un lube inclus dans l'épaisseur des corps sous-marins. Nous présumons, d'après la forme des valves, que c'est celle-ci qui vit dans un tube libre, tandıs que le cunéiforme est constammeat inclus.

La Fistulune biillante est alongée, étroite, mais moins, à proportion, que les espèces précédentes; son test est plus épais et plus solide et marqué de stries d'accroissement assez régulières; le bord antérieur est peu sinueux, et cependant, lorsque les valves sont réunies, le bâillement qu'elles présentent est considérable et se remarque dans tonte leur longueur. L'extrémité antérieure se termine aussi en crochet; mais il est beaucoup moins grand que dans les deux premières especes, de sorte que l'on peut considérer celle -ci comme un passage à la section suivante. Cette coquille, longue de 18 à 20 millim., se trouve fossile en Italie et en Piémont.

\section{t† Especes à values ovalaires; te tube presque toujours inclus.}

4 Fistulane de Provigny. Fistulana Provignyi. Nов.

F. vaginá inclusâ, tereti-clavatâ, ad aperturam crassâ, bicarinatâ, tenuissimâ, et soxpe non clausâ parte postoriore; testa valvis inagnis, 
I午 2

opatis, anticè oblique sectis, apertis; aperturá magná, cordutâ, extìs striulo-sublumellosá.

Nов. Mént. de la Soc. d'Hist. nat. de Puris, tom. 1. purt. 2. pag. 251.pl. 15. fig, 2.

Nов. Descript.des coq. foss. des enu. de Paris, tom. 1.pag. 17. pl. 1. fig. 16.19. 21.

Lorsque nous avons dé:rit, dans les deux ouvruges précités, celte bul e espèce de Fisiulane, nous ne possédinas pas eucore une espèce vivaule del'Inde, que l'on peut regarder cumme le subanalogue de celle-ci; nous iguorions égulement que son identi,jue lóssile se trouvât à Dax. Aujourd'hui que ce fait est pour nous rertain, nous le constatous d'une manière précise, pour qu'al puisse être ulile plus lardà la géulonie. A l'épợue où oous décourvines celte espièce fossile a Valmondois, elle étoit la plas grande connue; nous en trouvâmes trois individus duı l'épraisseur d'une masse madréporique, el cous trois élvient con:enus dans un lube testacé adhérent à la cavilé, trèsépais anlérieurement e. bicariné vers l'ouverture; très-mince et manquaut à lit parlie postérieure. La cociuille est orale, oblongue, báillante antérieurement, où elle est comme coupée ou trongluée obliquement. La surlace extériture est, cuuverte de stries larnelleuses élégantes, révulièr.s: qui suivent exactement le contour des valves. Le bord pastérieur est assez épais, arrondi et sans ancuue trace de dents cardinales; il se termine au-dessus du crochet par un angle peu saillant. Cotle cocruille, mince elfrasile, se trouve fossile à Talmonduis, près Paris, et à Dax. Elle est longue de 40 willius. et large de 20. Les individus de Dax ne paroisseut jamais alleiodre une aussi grandè taille.

5. Fisturane géante. Fistulana gigantea. Noв.

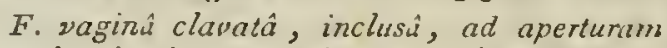
crassâ, bicarinata; test $\hat{\imath}$ ovato-oblong.r, tenui, fragili, eleganter striato-lamellosâ, valde hiante margine antico recto, umibonibus non terminulibus.

Très-belle et très-grande coquille, la plus grande dü genre, qui a, comme nous l'avons dit, la plus grande analogie avee la précédente; celle de Provigny, en effet, ne diflère que par une légère sinuosité du bord antérjeur et par une forme plus quadrangulaire; le crochet est placé plus bas sur le bord. Ces différences, jointes ì celles de lu taille, nous onı déterminé à séparer ces esjèces. On ne sauroit confondre la Fistulane géante avec le Gas. trochène cunéiforme de Spengler, qui, aalgré l'analogie qu'il a arec celle-ci, s'en disliugue néanmoins facilement. Le tube de la Fistulaue géante est ordinairement inclus dans l'épaissenr des polypiers picreux de la mer de l'Inde; il devient fort épais vers l'entrée, qui est loujour's bicutinée. La coquille est ovale-oblongue, alongée, pointue astérieurement el largement bäillumte; le bâillement a près des quatre cinquièmes de la longueur de la coquille. Les croclseıs ne sont point terminaux, ils sont peu saillans. En debor's, celle coquille est converte d'un grand nombre de slities lauselleuses très-fines, qui suivent le contour des valves. Elle est loule blancbe en dedans et en dehors; on remarque dans l'intérieur très-distinctemeut les deux impressions nusculaires; l'anterieure, très-petite, plicée sur l'extrémité poiutue qui dépassele crochel; la puslérieure, lrès-grande et triangulaire. On remarque égalemeul l'ı apression palléale lortement échancrée postérieurement. Cente coquille, longue de 57 millim., près de deux pouces, vienl de la mer des Iades.

6. Fisturaxe cunéiforme. Fistuluna cunciformis. Nов.

F. vaginâ tereti-clavatâ, inclusâ, ad aperturane incrussutst, bicurinatu; testá ovutâ, cuneiform, turgidulâ, apertissimâ, stricito-lamellosâ, alhâ; umbonibus minimis, anticis, terminalibus.

Gastrachena cuneiformis, Lauk. Anim. sans vert. tom. 5. pag. 447. $n^{\circ}$. 1 .

Gastrochurna, Spengler, Nov. Act. dun. tom. 2. fig. 8 à 11.

Pholus hiuns, Lix. Gmex. pag. 3217. $\pi^{\circ} .12$.

Cuensirz, Conch. tom. 10. tub. 172. fig. 1678 iे 1679 .

Gastmchcena cuneiformis, Sow. Cenera, n०. 11 . fig. 3.4 .5$.

La figure de Spengler suffiroit à elle seule pour leadre lacile la distinction de celle espèce de toutes les aurres du même genre. Son tube, qui est toujours inclus dans l'épaisseur des masses madréporiques on des pierres calcaires des rivages, s'attén!e postérieurement el manque le plus souvent dans celle partie de la cavité; dans sa partie antérieure, au contraire, il devient très-épais et il est muni eu dedans de deux carènes opposées. Lia coguille est oblongue, subtrigone, élargie tt ovalaire postérieurcment; obliquemen! tronquée antérieurement, où elle présente une grande onverlure, qui s'élend dans presquo toute la longueur; le bord cardinal est linćaire, arqué daus sa longueur; le crochet, petit, est terminal et tout-à-fait antéricur; en dedans, el dans la cavisé même du crocliet, on remarque sur le bord une callosité irrégulière; ca debor's, celte coquille présenle des stries plus ou moins régulières, sublamelleuses, qui suivent exactement le contour des valves et indiquent leurs accroissemens. L'impression musculaire postérieure est ovalaire, et célle du manteau est très-profondément sinueuse. Celte coquille est blanche ou jaunatre; elle se trouve dans les mers de l'lade et de l'Arérique. Elle est longue de 27 à 50 millim. 
7. Fistorare modivline. Fistulana modiolini. Lavix.

F. vaginâ pyriformi, contort $\hat{u}$, ad aperturan bicarinatâ, crassâ; lestâ ovato-oblonģâ, angustâ, striatâ, untice simuati; natıbus unte basim prominulis.

Gastrochurna modiolina, Lawr. loc. cit. $n^{0} .3$.

Myca dubia, Persist Zool. brit. tom. 4. pl. 44 . fig. 19 .

Sowerby, Generu, $n^{\circ}$. II. fig. 1. 2.

Exctclopéde, pl. $219 \cdot f g$. 3. 4. Pessima.

Petite espece mince, blanche, cunéiforme, alongée, élroite, largement báillunte anlérieurement dans presque foute sa longuenr; le bord antéricur est sinueux ver's l"exirémité des valves, ce qui les rétricit daus cet endroit. Celle extrémité antéricure des valves est lógçrement alrondie, très-courte et tellement surbaissée, que les crocliets sont tout-i-fait termioaux. Ja surface extcrieure est striće, et les stries qui suirent le roncourdes valres sont le plus souvent arrondies, plus saillanies et moios nombreuses que dans la pluprat des cspèces. Cette petite coquilile est contenue dans un tule tastôt inclus, tantôt libre, mais rarement dans ce deraier clat; il est pyriforme, souvent contourné, ordinairement complet; épais antéricuremeat, où il préseute une ourerture ovalaire, bicarincée. On trouve relle coquille dans l'Océan entopéca, das la Méditerranée et même dius l'Octén iulien. Elle a de l'analcgic avec lis Fistulance hions, mais elie ne lui est pas identique. Sa logruemr est de 12 à 15 inillicn., dans un tube de 25 à 30 millim. de long.

8. Fislorase étroite. Fistulana angustu. Ков.

F. vaginâ tereti, angustâ, glubrâ, integrầ, anticè allenuatí; aperturi ov'utu-depressâ, duu-

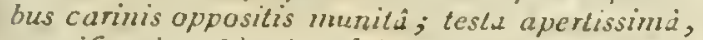
cuneiformi, sublavi, sulcis accretionis rusticati.

Méntoires de la Socicité d'hifl. nat. tom. I. $2^{\mathrm{e}}$. part. pag. 251 . pl. 15. fig. 5.

Non. Descript. des coq. foss. des env. de Paris, pag. 16. pl. 1. fig. 11. 13.14. 15.

Elle se distingue de l'espèce précédente par sou tube lisse, sa coquille plus grande, très-báillante, mais dont l'ourerture est plutôt cordilorme, se terminant inférieurement en pointe, elle n'a jarais ic sinus qui caractérise l'autre espèce; elle est rustiquée ì l'extérieur, et, rue ¿ la loape, elle oflie des stries très-lines. Nous avons également trouvé cette espèce produisant un tube tantôt complet et tantôt incomplet, selon le lien d'habilation. C'est ainsi que cinq ou six individas, trouvés dans un calcaire tendre d'eau donce, un'ont offert le tube très-entier, tandis que tous les autres, observés soit dans des masses madrépoliques, soit dans d'autres corps durs, aroient constamanent le tube incomplet. Ia longueur du tul e cll de 29 anillinètres, et celle de la corguille de 16. liossile de Talmandois.

9. Fistucase contournée. Fistula contortu. NuB.

F. vagint clavalî, angulo subrecto contorts ; testá parvulu, ovato-elongatî̀, tenuissimis stris accrebonıs orna'â, likntisi imá; aperlura ovali, acuti.

Memoires de la Socivte d'histoire nat. tom. I.

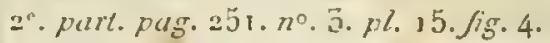

Nов. Descrip. des coq. foss. des cnv. de Puris, pag. 16. 1 l. 1. fig. 24. 25. 27 .

Nous uesommes point certains que cette corquille doive faire une espice distincle, car clie ue diffíre essentiellement de la Fistulaue étroite que par ses st:ies plus fines, sa forme plus ovale et le plus grand bailloment de son ouverture. Elle prisente celte particularité, cost que les trois cubes que nous avons oliscrvís fonl, près de leur ouvesture, un anzle prescrue droit. Ils sont insérés dans l'épaisseur d'une arche; ils ont 6 millim., et la coquille n'en a que 4. Fussile de Grigaon.

ro. listurane ampullaire. Fistuluna anpulLuria. lanzs.

F. arenulis obduch, 'aginâ ampullercế, continui, apertum intus bicarinato; test $\mathbf{s}$ ovati, hiantissimî, ruggosá, sinuute, strictâ, ovali.

Favjas, Géolog. vol. 1. pag. 93. pl. 3. fig. 1. 2. 3.4 .5 .

LAsк, Ann. du Mus. tom. 7. pag. 428.

Idem. Anim. sans vert. lom. 5. pag. 436. no. 5 .

Nов. Descript. des cuq. foss. des env. de Paris, pag. 15.pl. 1. fig. 17. 18. 20. 21.

Cette Fistulale a la propriété de vivre dans un tube lilre, anquel elle agglutine les grains de sable qui l'environnent, ou de s'enfoncer dans des corps sous-matins où on la troure quelquefois, \& surtout dans les portions du Cérite géant. Quand la Fisıulane anpullaire vit enfoncée dans le sable, elle se fait un tulje complet; lorsqu'au contraire elle vit dans l'épaissear des corps durs qu'elle a percés, son tube est très-mince el disparoit a la partie postérieure, el il est d'autast moias complet, quc le corps est plus compacte et présente une surface plus lisse, ce qui fait voir quel degré d'importance on doit donuer aux caractères tirés du tube, la coquille seule devant servir de guide. Celle-ci se reconnoîl Irès-facilement, c'esi même uoe des espèces les mieux tranchées; le bâillemeat des valves est ovale, arrondi aux deux extrémités; des crochets part un léger sious qui s'avance en s'élargissant jusque vers les bords. 


\section{4}

Longueur du tubo 16 millim., largeur de lu coquille 8 millim.

\section{FISTULANE. Chana.}

M1. Schumacher, malgré les travaux de plusienrs auteurs et surtout de M. Lacnarck, realerme ce genre dans la mème division que les Tarets, quoiqu'il en dillère essentiellement. M. Schumacher ue comprend dans son genre que de véritables Fistulaues, il en rejette la $F$ istulana gregata, qui n'est qu'un Taret, comme nous l'avous dit aussi à l'urticle Fistulane du Dictionnaire classigue d'Histoire naturelle, avant que louvrage de cet auteur füt connu en France. Voyez Fistulane el Tanet.

\section{FLORILIE. Florilus.}

Montfort a créé ce genre dans le tome premier de sa Conchyliologie systématique (pag. 135). Il est inutile et v’a point été adopté par M. d'Orbigny, qui l'a compris dans son geure Nonionine. Voyez ce mol.

\section{FONET.}

Adanson (Voy. au Sénég. pl. 15. fg. 4) a nommé ainsi une coquille de son geure Jumbonneau, qui contient des espèces de plusieurs genres très-distincts; celle-ci est du genı Moule : c'est le Mytilus lovigatus de Gmelin. M. Lamarck ne l'a pas mentionné dans son dernier ouvrage. Voyez MouLe.

\section{FORAMINIFÈRES.}

Dès que l'on eut senti la nécessité de séparer d'une manière nette et tranchée les Céphalopodes microscopiques et sans siphons des Céphalopodes siphonifères, il en est résulté une immense avantage pour la science. Depuis ce mowent a dû cesser celte confusion déplorable, pour ainsi dire, qui régnoit dans cette partie des Mollusques. Conduits seulement par des rapports de formes et non de structure, tous les auteurs ont coustamment fait un singulier mélange des genres les plus différens.

Montfort, dont les travanx furent malheurensement plus estimés qu'ils ne méritoient, en déligurant les coquilles microscopiques et en les mélangeant d'après leur forme avec les tests des siphonifères, eut mae fácheuse influeace sur les auteurs méthodistes, et contribua beaucoup à les tenir dans la fausse ronte.

Il est vrai que Linné, Broguière et M. Lamarck lıi-même avoient donné l'exemple à Montfort. Mais MM. Lamarck et Cuvier, qui ont fait faire a la science tant de progrès, laissèrent subsister dans leurs écrits les plus récens la confusion que nous venons de signaler. Les travaux de MIN. de Haan et d'Orbigny, qui parurent presqu'en même temps, fureal les premiers daus lesquels on trouva les plus utikes réformes. Ces deux zoologistes se rencontrèrent sur un même point en suivant des routes opposées; M. de Haan, en examinant les coquilles siphonifëres, en rejeta les coquilles microscopiques, qui n'ont point en ellet de siphon, et en fit un ordre à part sous le nom d'Asiphonoidec. II. d'Orbigny au contraire, procédant d'abord par l'examen minutieux et approfondi des coquilles microscopiques, tira la même conséquenco que M. de Iaan pour leur séparation des siphonilères.

M. d'Orbigny eut, sur M. de Haan, l'avantage d'embrasser dans son travail tous les Céphalopodes connus, de sorte qu'il a pu établir parmi eux des groupes véritablement naturels, reposant sur des curactères aussi f́aciles à reconnoîlue qu'ins. porlans. (Vojez Cíphalopones.) Ces caractères, après avoir été négligés, sont rẹgardés aujourd'hui comme d'uue telle valenr, que quelques zoologistes pensent que l'on devra par leur moyen rejeter les Céphalopodes microscopiques, nonseulement de la graude famille où ils sont actueblement, mais mểne de la classe des Mollusques. Cette opinion peut être la meilleure, mais rien jusqu'à présent ne la justifie d'une manière sutgsante; on ne peut en ellet s'appuyer que sur nne note communiquée par M. de Blarnville à l'Aoadémie, par laçuelle il sembleroit que l'animal de la Mliliole, qu'il a observé sur les cốtes de la Méditerranée, seroit déponrvu de bras et de tentacules, et n'appartiendroit couséquemment pas à l'ordre des Céplatopodes, comme on le croit le plus ordinairement. D'un autie cóté, N. d'Orbigny a fait également sur la Miliole et quelques autres Microscopiques foraminifères des côtes de La' Rochelle, une suite d'observations eatièrement opposées à celle de M. de Blaiuville. Ce jeune observateur, qui a su de bonne heure manier habilement le microscope; aflirme posilivement avoir $\nabla u$, pendant la vie des animaux, saillir des tentacules nombrenx de leur partie antérieure; mais ils disparoissent aussitôt après leur mort. Sur le portoobjet du microscope, la vie de ces animaux est à peine de quelques secondes, ou du moins d'une très-courte durée, ce qui rend très-difficiles les observations que l'on peut tenter sur eux.

Non-seulement à cause des recherches de M. d'Orbigny, mais encore par suite des liaisons évidentes qui existent entre certains Foraminifères et quelques Céphalopodes sépiaires, nous pensons que l'on doit préférer l'opinion de II. d'Oıbigny jusqu'au moment au moins où nous posséderons une suite d'observations capables de la détruire.

Nous pouvons facilemeat readre comple des motifs qui déterminent notre choix entre les opinions que nous avons mentionnées : personne n'a contesté jusquà présent les rapports de struc- 


\section{F R I}

ture qui existent entre les Nunmulites, les liabılaires et l'os de la Séche. Si l'on fait atlention cusuite que les Séches sunt inlimement lićes pa. l'organisation aux Spirules, il Paudra bien reconnoitre entre les foraminifères que nous venous de citer, les Sèclies el les Spirules, une double liaison. Il serail facile, dira-t-oo, de súparer des Foruminilères les gentes qui, conne ceux-ci, ont des âfinités avec les Céplualopodes, pour les en rappruclier et en éloigner tout le reste; mais une plus grande dilficulté nous arrête, les rapports des Nummulites, des Fabulaires sont plus intines encore arec les autres Foraninifares quavec tous les Céplıalopodes, quels quiils soient, de sorte que si l'on veut, dans l'état actuel des connoissances, toucher a cette partie de la classilication, on se trouve enire deux écueils, puisqu'il faut détruire l'un ou l'autre des rapports que nous venons d'indiquer.

Nous croyons, du moins tels sont nos principes, que dans une telle circonstance il est convenable d'avoir autant de prudence que de circonspeclion, et d'altendre du temps et de l'observation les élémens nécessaires puur se prononcer.

Ayant traité à larticle Céphazopones de la classilicalion générale des Foramiuilères, nous y reuvoyons le lecteur.

\section{IOOSSAR.}

Il est nćcessaire de faire remarqner à l'égard du K'ossar d'Adanson (Voyage au Sénég. pl. 13. fig. 1), que la coquille qu'il nomme ansi a été bren a tort placée dans le genre Naiice, puisque c'est une veritable Nérite. L’animal de cetle espece ayant été liguré par $\Lambda$ diason, il est clevenu pour les auteurs mélhadistes le tyae du gente Natice; on concevra sans peine yue les rujprochemens qu'ils ont proposés ont dú se ressentir de l'erreur dans laquelle ils sont lombís involontairement. Nous reviendrons sur se sujet aux articles Natice et Nérite, auxquels nous renvuyous.

\section{FRIPIER. Phonw.}

Genre élabli par Montfort (Conch. syst. tont. 2. pag. 158) et que rien jusqu'a présent de justıtie. Il a été étubli pour ceux des 'roques qui ont la singulière faculté d'agglutiner à leur coquille les corps étrangers qui sont dans leur voisinage, et de se caclıer ainsi snus des débris étrangers. Voyez Troque.

\section{FRIPIËRE.}

On donne vulgaireuent ce oom aux espèces de Troques qui allachent à leur coquille des corps étrangers de toute sorte, de manière à se cacher snus les dépouilles des autres animaux u.arins. Toyez TroQuE.

Hist. Nat. des Vers. Tome II.

\section{FRONDICULAIRE. Frondicularia.}

Geure Établi par M. Defrance dans le Dictionnaire des Sciences naturelles, oì il a ćć fignuré, mais non décrit. Ml. de Blainville ue l'a pas adopté et l'a réuni au genre Rénuline, quoiqu'il en dilfere sous plusieur's rapports. M. d'Orbigny, dans son Mémoire sur les Céphalopodes, l'a idoplé, et par snite M. Rann l'a conservé dans son Mamuel de Conchyliologie. Dans la elassitication de MI. d'Onbigny, le grence lirondiculare lail partie de la facoulle des Sticostingues, la prenicre de l'ordre des Foraminifies (woyez Sircostrgues), famille qui ne contient ancuse coquille spirét. N. de Blainville n'a pas allaché à ce caraclère autant d'inporlace que M. d'Olbigny, puisiue dans la même famille, les Planulées, il flace égaleroent les Rénulines qu’il ne croit pas spirées, el les Pénércples yui le sont évidemment; brais prar un hasard heurcux, $M$. de Blainville a rapproché des genres qui sont tres-voisins, puisque, comme la l'énérople, la Rénuline est sjirie au sommet, el par conséquent se joint i ce gent: (voyez PExiroples), non-seulement il cause de ce caractere, mais encore par suite de la disposition des trous qui sont nombrewx. Un autre hasard a encore favnrisé M. de Blaiuville lors. qu'il a mis les lirondiculaires avec les Rénulines; il ignorvit en effet qu'elles fussent spirées au sommet de la mêne manière que les Rénulines, et il ne fit pas assez allention qu'elles n'ont qu'u?e senle ouverture centrale, ce qui les sépare sans retour de ce nenre, quoiqu'clles doiveat rester près de lui ditas uue lonnc méthorle.

Ce qui précède dénontre que M. d'Orbigny a ćlé dans l'erreur sur la structure du gente qui nous occupe; il l'aurait cerlainemevt placé dans le voisinage des Pénéroples sil leur avout reconau un sommet lourné en spiriale. 11 scruit possible, et cependant nous en doubng bcaucoup, que le: especies de frondiculaies qui ont servi de yje a M. d'Orbigny ne lissent pas spiries alu sun:me: : comme nuus u'arons pu veriticr le fait, n'ayant pas en nalure ces coquilles, nous ne pouvons maintenant décider celle questicn; nais ce clont nous snmmes cerlaias, c'test qu'une espèce que nous possćdons, et gui nous at élf́ commnaiquée par 11. Duchastel, nous a présenté ce caractère sur les six individus que nuus avons vus. Il faut mettre la plus grande alteution peur reconnoitre la farne du sommet, qui ressembie au premier aspect à un pelit mamelon un peu irrégulier; mais on reconnoît, à l'aide d'un lorte lentille, qu'il s'incliae sur le liorl, et on n'a plus aucun doute qu'il ne fasse deux taurs de spire lorsque l'on a usé à moitié la cogurlle sur une pierre à rásoirs.

Les Frondiculaires sont des caquilles très-aplitties, ovalaires ou subquadrangulaires droites et symétriques, si ce n'est au sommet; sur ce souT* 
met spiral s'empilent les unes sur les autres une sério de loges qui forment au centre un ungle plus ou moins aigu; cet angle se reproduisant exactement le même et dans la même direction d chaque loge, il représente l'axe de la coquille. ("est au sommet de l'angle des logres que se voit nue ouverture; M. d'Orbigny la représente ronde et simple. Sur l'espèce que nous avons observée nous l'avons toujours trouvée en fente transversale, ridée et sphinctóriforme, quelquefois obstruée ou complétement formée dans les vieux individus, sur lesquels on n'aperçuit plus qu'une impression obtuse, à stries rayonnantes.

On concevra facilement d'après ce qui précède que nous ne pouvons adinetlre les caractères génériques tels que M. d'Orbigny les a donaés, ils doivent subir de grandes modifications; nous proposons de les exprimer de la maDière suivante.

\section{CARACTĖRES GÉNÉRIQUES.}

Coquille ovalaire ou quadrangulaite, très-aplatie, composée d'une série de loges ployées à angle aigu dans le milieu, et superposées en ligne droite sur un sommet lourné en spirale; ouverlure ronde on en lente ridéc, placée au sommet de l'angle de la dernière loge, et diamétralement opposée au sommet; loges très-simples, nombreuses, à parois assez épaisses.

Le gente Frondiculaire étant ainsi caractérisé nous pensons qu'on le reconnoîtra toujours facilement et que l'on partagera notre opinion sur les rapports que nous !ui donnons actuellement. Il faut se souvenir, comıne nous l'avons déjà dit, qu'il diffère des Rénulizes, et, ce qui est la wême chose, des Pénéroples, en ce que celles-ci ont uı grand nombre d'ouvertures ou de pores ouverts dans le diaphragme de la derniere cloison, tandis que dans le genre qui nous occupe il $n^{3} y$ a qu'une seule ouverture ceatrale. Ce qui ne le distingue pas moins, c'est qu'après avoir tourać en spirale, il devient néannioins parfailement symétrique dans tout le reste de son étendue, ce qui n'a jamais lieu daus les Pénéroples.

Quelques espèces de Frondicalaires ont jusqu'à 2 ou 5 lignes de longueur, ce que l'on peut regarder comme un développemeat considérable parmi les Foramiaifères, qui sont généralement si petites. On en tronve do vivantes et de fos. siles, mais elles sont en pelit nombre; $\mathrm{M}$. d'Orligny n'en comple que sept $z$ comme nous ne les connoissons pas pour la plupart, nous décrirons seulement les deux espèces que nous possédons.

1. Frondicolasae rhomboidale. Frondicularia rhomboidalis. D'Orв.

F. testâ minimá, depressá, quadrangulari, loevigalâ; aperturä productiore, rotundutâ, simplici.

D'Onargnт, Mrén. sur les Céphal. Ann. des Scienc. nat. tom. 7. pag. $256 . n^{\circ} .1$.

Ibid. Modeles de Céplal. microscop. tre. liv. $n^{\circ} .3$.

Pelite cnquille blanclue, luisante, lisse, quadrangulaire, Irds-aplatie, dont nous n'avons trouvé qu'un seul individu mulilé au sommet, de some que nons n'avons pu nous assurer s'il éloit bien comme le représenle M. d'Orbigny, formant un petit pagnet de loges loncitudinales, non spirales, el prodaisant par lear plus grande épaisseur une sorte de mamelon; c'est sur ses parties latćrales que viennent s'accoler des loges qui se ploient dans le milieu en une angle aigu, et donnent un développement tout latéral à la coquille à mesare que de nouvelles se superposent aux anciennes; cbaque loge est iudiquée des deux côtés par une strie peu profoade; l'extrémité antérieure de la deruière loge est onverte d'un pelit Irnu arrundi, à bord simple, qui communique immédiatement arec la cavité de la loge. Celle petite coqulle vil dans la mer Adriatique, où elle paroît assez rare.

2. Frondicolarae ovaliaire. Frondicularica subovate. Noв.

F. testá ovato-subquadrangulari, deprossâ, lavigatâ; loculis numerosis, simplicibus; apice centrali, minino, spirali; aperturâa ungustì, radiatim rugosî.

Les espèces fossiles de ce genre aroient été recueillies jusqu'ii présent dans les sables d'Italie, qui appartiennent à l'une des formations les plus modernes. M. Ducbastel, qui s'occupe avec le plus grand soin de rerueillir les fossiles de Cyplı, nous a communiqué l'espèce que nous mentionnons ici, provenant de cette localité cólèbre, qui est une continuation de la craie de Maestricht. Ce qui est très-remarquable, c'est que cette eypèce de Cypli a le plus grand rapport, aulaut du moins qu'on peut eu juger par la figure, avec celle d'Italie, que M. Defirance nomme Frondicularia complanata. Elle est en effet fort aplatie, ovalaire, subquadrangulaire, quelquelois subcorditorme; les angles latéraux sont arrondis, il n'y a de saillans que ceux formés par le sommet, qui cst mamelonné et touraé en spirale, et celni ò se trouve l'ouverture, à l'angle de la dernière loge. Celle ouverture est transverse, élroite et marquée de rides rayonuantes. Les loges sont nombreuses, serrées, siruples, indiquées an dehors par une ligne d'un blanc transparent sur le fond blanc-grisatre et opaque du reste de la coquille. Quelques individụs ont 6 millim. de long sur 4 de large, 


\section{U S}

FUJLT.

Gmelio a réuni sons le nom de Trochus corallinus deux coquilles qu'Adauson (Voyage au Sénég. pl. 12. fig. 4 et 5 ) regrarde comme deux espèces distiactes; elles ollient cependaut pen de differences. Il les nomme Fujet et Sari (yojez ce mot), et elles appartiennent plutôl a Turbo qu'à celui des 'Troques. Vojez 'l'urbo.

\section{FUNON.}

Petite coguille alecrite par Adanson (Voyage au Sénég. pl. 10. fig. 5) et placée par lui dans son geare Buccin; elle n’a été mentionnée ni par Gurelin ni par M. Lamarck. Nous croyons quelle appartient au grenre Colombelle. Voyez ce mot.

\section{FUSEAU. Fusus.}

Le genre Fuseau, démembré des Murex de Linué par M. Lamarck, présente aue coupe assez naturelle, qui ollie d'uu côté des rapports avec les Pyrules, les Fasciolaires, les Turbinelles, et d'un antre avec les Buccins, avec Jesquels il est facile de cunfondre quelques - uns d'ealre eux. Cest en 1801, dans le Systeme des Anmaux sans vertèbres, que ce gente fut établi d'une manière positive : avant cetle époque, Lisler et Gualtierri avoient indiqué celte coupe en séparant, le premier, les Buccinis rostratis, claviculi productiore, et le deuxieme, en formant son second genre de la classe quatre de la troisième partie, sous le caractère de Strombus cunaliculutus, rostratus, ore simplici. Je genre de Gualierri est mieux circonscrit que celui de Lister, qui, outre de véritables Fuseaux, contient des Rochers, des l'usciolaires, des Pleurotomes, elc.

Qunique Linné les aient placés dans son genre Murex, il les a cependant assez bien séparés dans sa quatrième section snus-générique, désigncée sons l'épithète de Ciudigeri; jl est vrai que cetle section renferme encore des Fasciolaires et des Pleurolomes. Aủanson, qui en a mentionné quel. ques-uns, les a confondus dans son genre Pourpre, qui correspond assez bieu aux Murex de Linné.

II. de Roissy, dans le Buffon de Sornini, a admis le genre Fuseau tel que M. Lamatck l'aroit fait el sous les mêmes caractètes; en $8 \mathrm{r}$ :, dans l'Extrait du Cours, M. Lamarck a réuni en une seule famille, suus le nom de Trachélipodes canalifères, tous les genres qui ant avec celui-ci des rapports très-iatines: il a conservé la unêare division et les mểıes rapports dans son Hastoire des Animaux suns vertébres.

Mlonifort a fuit avee les Fuseaux ce ru'il faisoit avec presque tous les autres genres, c'est-à-dire, qüil en a séparé très-inutilement un genre Latire qui n’a point élé conservé. M. Cuvier a considéré les Fuseaux sculement come un des sous-genres d้es Murex; il leur a subordonné les Lalires, les l'leurotomes, les Pyrules, les Fascialaires et les Carreaux. M. de Ferussac a fait du sous-genre Fuseau de M. Cuvier un genre séparé des Murex; mais il y a laissé, comme sous-genre, tous ceux indiqués par M. Cuvier, ct, de plus, il a ajoutć les Turbinélles et les Clavalules.

M. de lerussac, dans sa famille des Pourpres (2oyez ce mot), réunit la plus grande partie des coquilles canaticulées ou ćchancićes à la base; ce qui est loin de présenter, pour la classilication, les avaranges de celle de M. Lamarck, qui avoit eu soin de séparer bes canalifòres en unc famille naturelle, au wilieu de latquelle se trowre le genre qui nous occupe.

Par la composition de sa famille des Siphonoscomes, Ml. de Blainville s'est rapproché beaucoup plus de l'opinion de M. Lamarck que de celle de M. de Ferussac : c’est dans cette famille, entre les Rostellaires et les Pyrules, yue sont compris les Fuseaux. Quoique nous ne parlagions pas l'opinion de M. de Blainville sur les rapparls des Rostellaires, nous admellons avec lui el les autres auteurs l'intime connexion qui existe entre les Fuseaux, les Fasciolarres, les Pyrules et autres genres voisins. Ces connexious sont devenues incontestables aujourdhui que l'on connoît les animaux du plus grand nombre des genres de celle famille el que l'on a pu étudier les opercules, qui sont un excellent moyen pour établir des rapports.

\section{CAIACTĖRES GÉNÉRIQUES.}

Coquille fusiforme ou subfusiforme, cabaliculée à la base, ventrue a sa partie moyenne ou inlérieurement, sans bourrelets extérieurs, et ayant la spire élevée ct alongée; bord droil sans échaucrure; columelle lisse et sans plis. Lamk.

Opercule corné, à clénens concentriøges, à sommet submédian, non margiual et non spiral.

Si l'on en croit Nuller, qui a liguré, le premier, lanimal du Fuseau du Nord, on ne devroil pas séparer les Fuseaux des Buccins, puisque les animaux seroient semblables. Nons ue pouvons nous empêcher de reconnoitre la justesse de l'observation, mais senlement pour ce qui a rapport a celle especce et quelques autres voisines, que l'on sera obligé, par la suite, de transporter dans le genre Buccin. Nous avons sous les yeux l'animal de Muller, ainsi que diverses espèces de Buccins, et nous pouvons constater leur identité; l'opercule lıi-mếme ne dillère pas de celui des Buccins, taudis çu'il oflire quelques diflérences arec celui des Fuseaux proprement dits. Ainsi, dans les premiers, nous vayons que l'opercule a le somnet lout-á-fait marginal; dans les liuseaux ce sominet est coujours plus ou moins ćloigné du bord. 
Les Fuseaux sont des coquilles marines, généralement alongées, à spire longue et canal grêle, non moins long que la spire, quelquefois raccourcies, faisant le passage aux Buccius; d'autres fois plus alongées, mais êlargies et préscntaut un passage anx Pyrules. Toutes les espèces sont cou. vertes par un épiderme plus ou moins épais, bran, quclquefois velu, qui cache des couleurs généralement assez brillantes; quelques espèces prennent un volume cunsidérable; ct on peut en juger pa: cclles représeutées par Lister. Un graud nombre est à l'état fossile, et on en connoît davantage maintenant de ccs derniers que de vivans. Toules ces espèces peuveat se partager en trois groupes privcipaus, d'après la forme el la longneur relative du canal de la base : dansle premicr aous placerons les Fuscaux à canal étroit, alongé, sabcylindrique; daus le secand se trouveront les espèces à canal long et large, comme dans les Pyrules; et dans le troisième, les espèces à cuual court, se rapprochant par là des Buccins.

Nous ferons olsserver que les Pyrules ne different des Fuseaux que par les pruportions de la spire, relativement un canal de la base : caractere de bien peu de valeur, qui ne nous auroit pas empêché de les rénnir aux Fuseaux si nous avions connu l'animal des Pyrules.

\section{$\dagger$ Especes d canal long et etroit.}

1. Fuseau élanch. Fusus longissimus. Lamk.

F. testâ fusiformi, prcelongấ, transversìm sulcatâ, pentitis candidâ ; anfractibus convexis, medio serie unicâ, transversim tuberculato-nodosis; caudâ gracili; labro crenukato, intùs sulcato.

Lamx. Anim, sans vert. tom. 7. pag. 122. $n^{\circ} .2$.

Murex candidus et longissimus, LiN. GMer. fag. 3556. $n^{\circ}$. I1 3 et $n^{\circ}$. 116 .

MARTINi, Conch. tom. 4. tab. 144. fg. 1339. ct tab. 145. fig. 1344 .

SEs. MIus. tom. 3. tab. 79. Figurae tres in parte inferiore tabula : unica centrali, duabus lateribus.

Il est évident, comme l'a très-judicieusement remarqué M. Lamarck, que Gmelin et Martini lui-même ont fait deux espèces pour la même coquille : il est impossible d'apercevoir la moindıe différcnce entrc les figures citécs.

I.e Fuseau élancé cst une des plus grandes coçuilles du genre : elle est tonte blanche, pen ventrue, à spire longue et pointue, terminée à la base par une queue longue, grêle, subcylindrique, presque anssi longuc que la spire; celleci est composée de dix à dluuze tour's convexes, chargés dans le milieu par un seul rang de tuber-1 cules arrondis au nombre de onze on douze. Sur chaque tour, dans le jeune âge, ou sur les cinq ou six premiers tours, ces tubercules sont remplacés par un nombre égal de côtes longitudinales, arrondies; toute la surface exlérieure est sillonnée transversalement; ces sillons sont plus gros et plus saillans sur les tubercules, et trèsobliques sur le dos du canal de la base, où l'on remarque une strie fine entre chacun d'eux. Ia lèvre droite est crénelée sur le bord et sillonáe en dedans. Celte coquille, assez rare, vient, d'après M. Lamarck, de l'Océan des GrandesIndes; elle a 25 ou 26 centim. de long, plus de 9 pouces.

2. Fuseso proboscidifère. Fusus proboscidiferis. J.Amx.

F. testâ fusiformi, ventricosâ, transversim sulcatâ, longitudinaliter tenuissimè striatâ, fulvo rufescente; anfractibus angulatis, suprà planulatis; angulo tuberculis nodiformibus coronato; spirâ parte superione cylindraceâ, proboscidiforme; apice mamillani; labro intùs lavigato.

Lasix. loc. cit. $n^{\circ}, 14$.

Coquille singulièrement remarquable par le commencement de la spire, qui au lieu d'être pointue, présente un cylindre de quatre ou cing tour's globuleux, lisses, égaux et rapprochés; il se termiue par une extréwilé oblase et maunelonnée, tandis que le dernier tour donne subitement origine à la suite de la spire, qui, daus le reste de son étendue, est sillonnée transversalement et ornée de stries longitudinales trèsfines; l'entre-croisement des stries et des sillons produit, sur loute la sufface, un réseau très-fin et très-régulier, surtout sur la partie supérieure des tours de spire. La coquille est ventrue, à spire longue, formée de six à buit tours anguleux à leur partie inférieure, et chargés, dans cet endroit, d'un seul rang de tulsercules aplatis sur le dernier taur. Au-dessous de la carène se voient deux côles saillantes, longitudiaales, et deux autres très-obliques sur f'extrémité du caual de la base; ce canal est presque aussi long que la spire, assez largement ouvert. Le bord droit est mince et tranchant, bout-à-fail lisse en dedans. Sous un éfiderme brun, tomenteux et caduc, cette coquille est partout d'un jaune fauve peu foncé. Ellc est rare el précieuse : on ignore sa patric. Un bel individu de la collection du Muséum a au unoins 7 pouces de long, 19 centimètres; celui de la collection de $M$. Lamarck a près de 4 pouces, et celui que nous possédons a 4 pouces 3 lignes (I 5 millim.).

3. Fuseav quenonille. Furrus colus. F. testâ fusiformi, angustâ, transversim sul- 


\section{$F \cup S$}

cat $\hat{s}$, alb $\dot{d}$, apice basique rufi; ventre parvulo; anfractibus convexis, medio carinato-nodulosis; caudâ gracili, longâ; labroi ntiss sulcato, margine denticulato.

Lusux. loc. cit. no. 3.

Murex colus, Lis. Guex. pag. 3543. no. 61.

Lister, Conch. tab. 918. fg. 11. a.

Roฌрв. Mus. tub. 29. fig. F.

Periv. Amb. tah. 6. fig. 5.

Gualt. Test. tab. 52. fig. $l$.

Dargent. Conch. $p l$. 9. fig. $b$.

Favanne, Conch. pl. 33. fig. C. 3.

Seв A, Mus. tom. 3. tab. 79. Figura duce in medio tabulce et laterales.

Kxorn. Vergn. toni. 3. tab. 5. fig. 1.

Martixi, Conch. tom. 4. tab. 144. fig. 1342.

Fusus longicaudi, EncrcL. pl. 423. fig. 2.

Var. B. Noв. Testâ minore; sulcis rurioribus; caudâ latiore, subcontortá.

Jolie coquille longue, étroite, élancée, a spire longue et pointue, formée de douze tours de spire arrondis, ornés d'un seul rang de tubercules aplatis, qui disparuisseat ordinairement sur les deraiers tours et qui se changent en côtes longitudinales sur les piemiers. De la base oaît nne queue longue et grêle, cylindracée, teintée de fauve foncé; le sommet de la spire est de la même couleur, qui forme des taches plus foncées entre chaque côte ou chaque tubercule, mais sur les premiers tours seulement, tout le reste de la coquille est blanc. Cette coquille est sillonnée dans toute son étendue; un sillon plns gros et plus saillant passe sur les tubercules, et les remplace lorsqu'ils disparoissent. L'ouverture est petite : la lèvre droite, assez épaisse, est denticulée sur le bord et profondément sillonuée à l'iutérienr; le bord gauche est mince et saillant. La variété est remarquable; elle est plus petite; la spire est à peıve tuberculeuse; les sillons sont moins nombreux, plns gros, plus distans, et le canal est plus large et légèrement contourne. Cette coquille vient des mers de l'Inde; elle est longue de 16 à 17 centim. : la variété a 95 millim. seulemeat.

\section{Fuseav tubercule. Fusus tuberculatus.}

F. testá fusifomi, transversim sulcatâ, albâ; ventro majusculo; anfractibus convexis, medio angulatis; angulo unicâ serie tubenculiferâ; interstitiis tuberculorum rufis; labro intis sulcato.

Fusus colus, Encrcx. pl. 424. fig. 4.

Lamr. Anim. s. vert. loc. cit. no. 4 .

Ce Fuseau est assez voisin, pour ses rapports, de l'incrassatus, bien plus que du colus, avec lequel M. Lamarck l'a comparé : il est alongé, ventru dans le milieu, trés-pointu au sommet, et formé de dix a onze tours de spire, ctargés dans leur milieu d'un seul rang de neuf tubercules saillans a la base, lirges et obtus a $50 \mathrm{~m}$ met; entre cliacun des tubercules on remarque une tache fauve; sur le dernier tour, au-dessous du rang de cubercules, on en remarque un second moins saillant, sur lequel on compte douze ou treize petits tubercules aplatis; des sillons nombreux, rapprochés, peu saillans, se voient sur toute celte coquille; ils sont traversés par des stries lougitudinüles, à peine visibles, tant elles sont obsolètes. 1.a queue de cette coquille est plus courte que la spire; elle est étroite, gréle. presque cylindrique. L'ouverture est ovalaire; sun bord droit est sillunné en dedans. A l'exceplion des taches fauves qui sont entre les tubercules, certe coquille est parfaitement blanche. Elle vieut des mer's de l'Lnde; elle est longue de 125 millim.

\section{Nusead de Nicobar. Fusus nicobaricus.}

F. testâ fusiformi, transversiun sulcatâ et strictâ, albà, rufo fusco nigroque variegató; anfractibus convexis, medio angulato tuberculatis; tuberculis eminentibus, acutiusculis; spir. $\hat{\jmath}$ conico-subulatá; labno margine dentato, intis sulcato.

Favanne, Conch. pl. 33. fig. A. 5.

Murex nicobaricus, Cuear. Conch. tom. 10. tab. 16o. fig. 1523 .

LAsx. loc. cit. $n^{\circ} .5$.

Coquille bien distincte de tontes ses congénères, et facilement reconnoissable : elle est alongée, peu ventrue; sa spire est longue et tiès-pointue, formée de douze tonrs anguleux dans le milieu, chargés dans cet endroit d'un seul rang de tubercules saillans et assez aigus, au nombre de onze sur chaque toar. Les sillons qui traversent cette coquille sont larges, aplatis, peu profonds, très-écartés, très-obliques, et au nombre de quatre ou cinq sur le dos du canal de la base; celui-ci est un peu woins long que la spire; il est grêle, droit et nn peu tordù ̀े son extrémité. Liouverture est petile, ovale, oblongue; la lèvre droite, fortemeat striée en dedans, est épaisse et denticulée dans toute sa longueur; le bord gauche se relève aussi dans touta sa longueur et devient lamelleux. La coloration de celle coquille est assez variable : sur an fond blanc se dessinent des flammules d'an brun plus ou moins foncé et plas on moins nombreuses; quelquelois ces taches sont moins foncées, et elles prennent naissance, pour la plupart, de taches plus foncées, qui sont entre chacun des tubercules de la spire; les taches qui sont sur le canal de la base sont quelquefois remplacées 
par des bandes fauves, très-obliques entre les sillons, et qui en suivent la direction. I,e nom de celle coquille indique sa patrie; elle est longue de plus de 14 ccntim. ( 5 pouces 4 lignes).

\section{Fuseau toruleux. Fusus torulosus. Lamx.}

F. tostì fusiformi, ventricosâ, trunsversim sulcatâ, tuberculiferâ, albo et rufo nebulosá; anfractibus convexis, medio tricarinatis, longitudinuliter plicatis; plicis apice tuberculo terminutis; apcrturi albâ; labro intius sulcuto.

Excycr. pl. 423. fig. 4 .

Lamk. loc. cit. $n^{0} \cdot 7$.

Rare et belle espèce, alongée, Ctroite, à spire pointue et à queue presque aussi longue que la spire; ses tour's, au numbre de neuf à dix, sont convexes : on y vait onze ou douze côtes longitudinales, peu élevées et arrondies, qui sont coupées transversalement par trois ou quatre carènes aiguës, médiocrement saillantes, cntre lesquelles se vuient des stries très-fines; sur le dernicr tour, outre les carènes dont nous avons parlé, il s'en trouve quelques autres plus petites qui diminuent graduellemeut, et il leur succède, à la base et sur le dos du canal, des stries trèsliues, très-nombreuses, serrées et fort obliques; l'ouverture est ovalaire, perite; la lèvre divuite est éfaisse, sillonuée en dedans, et la gauche est saillante dans toute la longueur non-seulement de l'ouverture, mais encure du canal de la base. Sur un fond blanc, celle coquille est ornée de llammules d'un fauve pảle; clle est luute Wancbe en dedaus; clle est longue de 15 centim. ( 5 pouces et demi). Oa iguore sa patrie.

\section{Fusead épais. Fusus incrassatus. Lamz}

F. testáfusiformi, solidâ, crassâ, plicato-nodosâ, transtersinz striata, albâ; anfructuum nodis posterius crassè plicutis; spinâ conicoacutá, ferè saóulata; labio crasso, denticulato, intis sulcuto.

LaMr. loc. cit. $n^{\circ} .8$.

Fusus longissimus, Mantint, Conch. tom. 4. tab. 145 . fig. 1343 .

Alurex undatus, Gusc. pag. 3556. nn. 115.

Fusus incrassatus, EscrcL. pl. 4ะ3. fig. 5 .

Coquille qui devient presque aussi grande que te Fusus longissimnes, qui est blanche comme lui, mais gui s'en dislingue par plusieurs caractères constans : elle cst ulongré, pointue, toute blanche, très-épaisse, pesante, formée de douze ou treize tours auguleux dans le milieu, et présentant, dans cet endroit, un seul rang de gros tubercules obtus, arroudis, au nombre de sept ou buit sur chaque tour; ces tubercules sont redressés du côté du sourmet, et se prolungent inférieurement en une côte qui descend jusıu'à la suture; la parlie supérieure des tcurs forme un plan oblique, ou est quelquefois crensée en une large gouttière peu protonde; des stries nombreuses, lines, rapprocláes et transverses, couvrent louse la surface extérieure de la cuquille, ainsi que le prolongement de la base; celui-ci est épais, arcins long que la spire; la lèvre druite est fortement sillonuée en dedans, et le tord gauche, saillant au-dessus de l'ouverture, descend dans loute la longueur du canal, dout il rétrécit la lente. Celte cnquille, tiès-rare, qui vient, d'après M. Lamarck, de l'Océan indiea, a justju'a 20 centim. de long ( 7 pouces).

\section{Foseat sillongé. Fusus sulcatus. Lam}

F. testâa subfusiformi, transversinz sulcat $\hat{a}$, griscâ; sulcis prominulis, spadiceis; anfraclibus valde converis, ultimo dempto longitudinaliter plicatis; cuudì recusvâ, spirá breviore; aperturâ albâ.

\section{ENcres. pl. 424. fig. 3. \\ Favaxie, Conch.pl. j3. fig. C. 4. \\ LaMr. loc. cit. $n^{\circ}, 10$.}

Les figures que nous citors ne représentent pas celte espece d'une manière satisfaisante, si nous en jugeons d'apıès les individus de la collection de M. Lamarck el de la nôtre. Celle coquille est alongée, peu ventrue, composée de huis tours de spire arroudis, convexes, sans tubercules, mais tous, à l'exception du dernier, plissés longitudinalement; ces plis, quelquefois, n'occuperat çue la partie supérieure des tour's, et, lo plus souvent, s'sleudent d'une suture à l'autre; un grand numbre de sillons transverses, rapprochés, subanguleux, couvrent toute la coquille; les espaces quil les séparent, et les sillons euawêues, soní finement striés, mais irrégulièremeot. La coloration de cette coquille est assez variable; le plus ordinairement sur un foud blanc-grisâtre ou jaunâtre, les sillons sont fauves, ou plulôt couverts d'un grand nombre de taches de cette conleur; quelquefois ces taches se rangent par bandes longitudinales, et marquent les accroissemens de la coquille tout en resiant sur les sillons; enfia elles s'étendent, s'enfoncent entre les sillons, et elles forment de grandes lianmules longitudinales placées surtout sur les cütes ou les plis. Le canal est plus court que la spire; il est largement ouvert, et le bord gauche, sailians et lamelleux, le borde dans toute sa logrueur, ainsi que l'ouverıure. Lá lèvre droite est crénelée 8nr le bord el silionnée en dedans. Longuear 11 rentim. On la dit des mers d'Aasérique.

9. Fuseav distant. Fusus distans. Lamr.

F. testâ fusiformi, transversim sulcatí ct tonnissime striata, ruféscente; unfractibus carná tuberculatû in medio cinctis; carinis inferı- 
ribus distantibus; columelli nudi; hebro intius sulcato.

Las a. loc. cit. $n^{n} \cdot 6$.

Le Fuseau distant est une jolie eoquille alongée, à spire un peu ventrue, "lès-poinlue au sommet, et rerminé a la base par un canal assez large, droit et presque aussi long que la spire; celle-ci est composée de aeuf a dix tours convexes; les premiers sont munis de dix à onze côtes arrondies, Inngitudinales, qui disparoissent peu à peu sur les derniers lours; nne carène salllanle, droile, aplatie, festonnée dans son bnrd, divise les tours de spire en deux parties égales; des sillons transverses, ríguliers, distans, au nombre de quatre à six sur cliaque lour, s'élèvent en carènes, mais beaucnup moins saillantes que celles du milien; ces sillons, ainsi que l'espace qui les sépare, sont couverts de très-fines stries très-régulières, dont l'une, entre les sillons, est plus grosse. Sur le deraicr lour les sillons se continuent à la base, ainsi que surle canal, qui la termine. L'ouverture est ovalaire; le bord droit, peu épais, est fortement sillonné en dedans; le bord gauche est $n$ ar, c'est - à - dire dépourvu de lane recounvrante. La couleur de celte coquille est partout d'un fauve pále; elle présente rarement des flammules un peu plus foncées, mais la carène est ornée de taches brunes entre chaque tubercule. On ne sait où vil celle espèce, qui est longue de Ir centin. (près de 4 pouces et demi). No8.

10. Fusea à larges cótes. Fusus laticostatus.

F. testâ fusiformi, elongatâ, angustâ, acutâ, albä; anfructibus convexis, medio tuberculatis, costatis; costis transversalibus, latis, depressis,

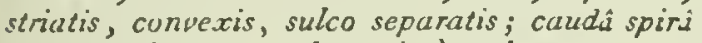
breviore; labro crenulato, intìs sulcato.

Coquille nouvelle, parfaitement distincte de ses cungénères, et dout nous ne connoissons encore qu'un très-petis nombre d'individus qui viennent de Ceylan; celui que nuus possédons nons a été communiqué par M. de Blosville, jeune officier de marine, qui s'est distingué d'une manière si honorable dans le voyage de la corvelte la cheorette.

La coquille que nons nommons ainsi est grande, alongée, étroite, solide, épaisse, toute blanche, à spire longue et pointue, formée de dix tours convexes, ¿̇ peine carinés dans le milieu, où ils présentent un rang de iubercules pen saillans qui s'elfacent sur les derniers tonrs et se changent en côtes longitudinales sur les premiers; chaque tour de spire est ınuni de sept côtes transverses, larges, aplaties, séparées par un sillon étroit et finenent striées dans tonte leur longceur; à la base du dernier tour se trouvent des côtcs semblables aux autres, mais celles qui sont sur le dos du canal sont étroites, saillantes, snbca- rénies, et beaucoup plus disıantes que les autres; le canal de la base est eylindracé, plus court qne la spire; en dessous il est bordé dans toute sa lnngueur par le bord gauche, qui est peu saillani. L'ouverture est petite, toute blanche ea dedans; le bord druit est subcaréné, sillonné et strié à l'intérieur. Longueur 13 centim. (près de 5 pouces).

11. Foseav verruculé. Fusus vemuculatus. Laxx.

F. testâ fusiforni, trunsversè sulcatî, pallidi refescente; sulcis dorso planulatis; anfractibus cingulo medio elatione vernucoso instructis; verrucis rufo-fuscis; labro intius lavigato; casedis subrecurvấ.

LAMr. loc. cit. no. 23 .

Martist, Conch.tom. 4. tab. 144. fg. 1341.

Fusus ocellyferus, Excrcc. pl. 429. fig. 7 .

Coquille alongée, subrentrue, à spire longue et pointue, à queue beaucoup plus courte et légèrement tordue; les tours de spire, au nombre de neuf à dix, sont convexes: les premiers le sont moins que les autres; ils snat pourvus de six còtes larges, aplaties, finement strices; celle du milieu, et sur:out dans le jeune âge, porte un rang de nodosit'́s aplaties, toutes marquées sass exception d'une lache d'un brun foncé; en vieillissant les nodosil'́s disparoissent, ainsi que les taches. Sur le deruier tnur, les cutes se contiauent à la base, ainsi que sur le dos du caoal; mais, dans cet endroit, chacune d'elles est séparée par une strie silillante, interméliaile; des siries longrtudinales, nombreuses, très-fines, régulières, en s'entre-croisant avec les transverses, produisent un réseau très-fin et très-dćlicat sur toute la sarface. Cette coquille est lc plus souvent d'un brun pâle, quelquelois blanchâtre, avec des tlammules plus on moins nombreuses, d'un hrun foncé. Le canal de la base est du tiers de la longueur totale; il est convïde, et sa forme établit un passage à la section des Fuseaux buccinoïles; l'ourerlure est ovale, étroite; ic bord droil est ruince, légèrement onduleux; le gaucbe: est pen saillant le long de l'ourerture, mais il se relève dans toute la lnngueur du canal, et en rétrécit le fente. Celte espèce ne paroit pas rare: on ne sait d'vù elle provient; sa longueur est dic 110 millim.

12. Foseat de Tarente. Fusus rostralus. Oxir.

F. testâ subfusiformi, scabri, longitudinaliter plicatî, transversìn sulcatá, albi, rufo nebulosâ; anfractibus convexis, medio cariná dentatâ cinctis; plicis remotiusculis, dorso scabris; labro intis striato, margine denticulato.

Fusus strigosus, L.s

Murex rostratus, Ourp. Zool. adriat. pag. 153. 
Grxsas, Adriat. tom. 2. tab. 7. fis. 56.

Fossilis, Bnoccrt, Cunch. foss. subap. pag. 416. $n^{\circ}$. 36. tav. 3. fis. 1 .

Nous sommes bien snrpris que 31. Lamarch ait dunné un nom nouveau à celle coqullle, coumue, comme on le voit, loug-temps arant lui, aussi bien rirante que fossile: la moindre recherche lui auroit fai: éviter ce double emploi. Le Fuseau de Tarente est une jolie coquille d'un faure pảle; elle est alongce, pointue an sommet, et termince à la base par un canal droil, étroit, cylindracé, presque aussi long que la spire : ceille-ci est formée de aeuf à dix tours très-convexes, séparés par une sulure enfoncéc; ils onl chacun boit à neuf cóles longitudinales, et de plus, ils sont divisis dans le ailieu par une carčne lamellecse, saillante, festounée, dont les parties les plus saillantes correspondent aux cóles longiludiuales. Des sillous nombreux, serrés, rugueux, transcerses, courrent toule la coquille; cenx qui sont sur le dos du canal de la base sout plus pelits el plus espacés. L'ourerture est petice, ovalaire; la lévre dioite est épaisse et fortemen? sillonnée en dedaus, la gauche se relèse el se contiaue le long du canal en rélrécissaut son ourerture. Nons connoissons une varićé de celle espice, elle est lossı!e de la'Touraiue; clle diffère en ce que la carène n'est quindiquée el qu'elle est placké plus haut. Celle espèce vit dans l'Adriatique, sur les cutes de Sicile, et se tionve fossile en Sicile dans lous les teriains tertiaires d'Ialie et dans tous les faluas de la Touraine. Elle est longue de 60 millian.

13. Fusent rủané. Fusus synacusanus. Lasir. $F$. ‘esiá fusifomi-turrita, longitudinaliter plicaia, transiersim sinata, allo et rifo alternie zonala; anfractshus superne angulurn-carnuars; carrinis tuberwiano-nociosis; cauda breviduculd: labro intiss struato.

LANE. loc. cit. $n^{\circ} \cdot 25$.

MIurex syracusanus, Lix. Gxel. Fag. 555.4. no. 104 .

losisuri, Récr. 3. fg. 80.

Carss: Conch. tom. 10. tab. 162. ffg. 1542. $15 \Varangle \vec{j}$.

Fusis syracusanus, Excrce.pl. 423. fg. 6. a. b.

Vаг. B. Noв. Testá minore, costis albidis.

Var. C. Nов. Testi minore, undiquè rufä.

Coqnille assez comaune dans la Médirerrance, d'ue taille coédiocre et pouvant serrir par sa forme de passage aux fuseaux bucciouides; sa spire, formée de huit à neuf tours, est pcintue au sommet el assez large à sa base; elle se termine par un canal couri a peine du tiers de tal longueur tolale de la cocquille. Les lours sont peu convexes, divisés en deux parties presque çarales par mu angle, et chargés de cútes loogiludinales, rénuliçes, convexes, serrées, coupées trausversalemeat par des sillons transverses, entre lesquels se tronvent des stries tiues qui ellesmémes, entre-croisćes par d'autres stries lon riludivales, forment sur la surface de la coquille un réseau liu, inais trés-régulicr. L'ourerture est ovalaire; le luord droit est miuce, tranchant et sirić en dedaus, le gauche se confond avec la columclle. Les tuurs de spire sont bruns ea dessus de l'aagle et blancs en dessous, le deraier tour au-dessous de la zone blanche a une seconde bande brune. Ces zones sont divisécs très-netlotencut; elles donueut à la coquille un aspect particulier. La premic̀re varićı́ est neltement tramclée; les contes longitudinales sont blancbes, ec les iaicrvalles qui les seppareut sont bruns; la rariété Cest plus petite, les lours sont moins anguleux, et la couleut est uaiformément brune. Celle cucquille est lougue de 50 millim.

\section{Fessau aciculé. Fusus aciculatus. Lasx.}

F. testâ fusiformi, angustissimä, thansversim striati, longitudunditer costulutí; caudi longa, strictis, subaculeats.

Excres. pl. 425. fig. 8. a. b.

L.4uk. Anim. sans vert. loc. cit. pag. 136. $n^{\circ} \cdot 11$.

Ibid. Ann. dus Mus. tom. 2. pag. 313. n०. 5. el tom. 6. pl. 40 . fig. 6 .

BraNDER, Fass. hant. tab. 2. fig. 36.

Fusus acuminatus, Sow. Viner. conch. ${ }^{3 l .274}$. $f_{i g} \cdot 1.2 .3$.

Fusus asper, ibid. loc. cit. pl. 274. fig. 4. 5. 6.7 .

1I. Sowerby, daus lourrage que acus renons de cilcr, a lair deux espèces pour une, el a changé imatilement le nom de Brander el celui de .I. Lamarck. Le Fusus acriculatius est une jolie coquille fossile qui, par sa firrase et la longueur de sa quene, se rapproche du Fusiss coius, sans cependant en ére l'analugue; la spire est alongée, élruite, Iris-pointue au sommel, formée de truize tours arrondis, conrexes, courls, séparés par une sulure siaple et profonde, charás de cótes longiludiuales plus ou moius aombreuses, un peu contournées el traversées par des sillons assez nombreux. Le canal de la base est plus long que la spire; il est grèle, cylindricuse, druit ct ne préseulc antćrieurement qu une fente très-źltoile. L'ouverture est scui-luaare; elle est petile, crénelée sur le hord droit, qui est mince, un pen sioueux el lisse en dedans. Celle jolie coqulle se troure aux eurirons de Paris, a Parnes, Mouclay, Grignon, et à Barton, en Angleterre; les 


\section{F U S}

plus griakds individus que nous ajons rus ont 65 tosllius. de longueur.

15. Fusenu cordelé, Fusus funiculosus. Lian. F. testâ fusiformi-elongatî, obsoletè costatá, decussuti, rugosû; rugıs transversis, alternis, mujoribus; columcllis subplicutie.

1. $\Delta$ мк. loc. cil. $n^{\circ} \cdot 12$.

Frsus funirulosus, Ann. ibid. pag. $586 . n^{\circ}$. 23. et tons. 6. pl. $40^{\circ}$. fig. i.. a. b.

Excres. $\mu l .428$. fig. 6. a. b.

Var. B. Noв. T'estï ninore, vix costati, tenue striats.

Coquille alungéc, étroite, Epaisse, solide, ayaul l'aspect de ccrtaines Turbinelles, et qui ca cllel s'en rapprocbe puisqu'elle.présente un ou deux perits plis sur la columelle, plis qui sont visibles seulement lorsque la lèvre droile étant brisée, la columelle se Iroure à découvert; c’esı pour celle raison que nous avons persisté a retenir cente cuquille parmi les Fuseaux. La spire alongíc, étroite, pointue au somroet, est formée de neuf a dix lours pen convexes, sur clacun desfuels se vnient neuf à dix cútes obluses, larges, arrondies et longitudinales; des stries également longitudinales, très-lines et assez résulicres, s'entic.croisent avec des sillnns transverses, subglanuleux, entre cbacun desfjuels se trouve une slic line. Le canal de la lase est moins loug yue la spire; il est conoïJe, assez large et recouvert dans toute sa longnem par le bord giturbe, qui ne laisse qu'une feote capillaire; dass l'ouverture, qui est ovalaire, il est p'us suillaal; le bord dioll est lranchant, à peiue strié en dedaus. La variété, toujours plus petite, est J'ewarguable en ce que les coites ont presgue disparu et que les sillons se sout changés cn stries Egales, tines, serrées et lisses. Certe coquille, connue à l'étal fossile seulenent, se trouve atax environs de Paris, à Purues, Girgnon, Courlaguon, Moucby, elc., daus les calcuires yrossier; elle est lourue qualquefuis de 56 milliw., mais il est rare de la trouver de celte tailie. Noв.

16. Fuseav à deuls de scie. Fusus serratus.

F. testî̀ fusiformi-elongatâ; spirî conoïdeâ ucutâ; anfiactıbus in medis curinutis, dentatoserratis; sulcis distantubus, trunspersis, ornatis; cauda grucils, spuri longiore, substriatś.

Non. Dicl. cluss. d'Hest. nut. article Fuseau el Atlas, $7^{\mathrm{e}}$. liv. Jig. $\overline{\mathrm{j}}$.

Ce Fuseau est sans contredit une des plus belles espèces fussiles des enviruns de Puris; elle est alongée, à spire conoïle, assez large à la base et têminée par une queue grêle, subcylindrique, plus lon nue que la spire; celle-ci est composée

Hist. Nat. des Vers. Tonze $I I$. de onze ou clouze trous convexes, divisés en deux parties égales par une carène tranchante, uniuce, festonnée; cbacun des angles de celtc carènc, colrespond à une côte longitudinale peu éloveś et plus saillante dans le milieu quà ses extré. mités. Des sillons élroits, distans, subcaréoés, se voicut au nombre de qualre ou cie cing sur chaque tour de spire; it la base du tervier, on reuarque des strics de pius en plus fines, qui tinissent par disparoitre a la partie supérieure du canal, qui reste lisse dans toute son ćtendue. L'ouveriure est petite, semilunaire, ì bord columellaice, simple, non saillabt, et à bord droit, tranchant, mon crénclé et lisse en dedans. Celte coquille est rare bien conservée, et surtout lorsqu'elle a alleint un graud volume, le peu d'épaisseur de la cfueue la rendant tiès-fragilc; elle se trouve a Purnes. Le plus grand indivitu que nous connoissiuns et que nous posséduns est lutg de 10 centin. ( 3 pouces 9 lignes).

\section{Fuseau longirostre. ERusus longinster. noc.}

F. testâ fusiformi-elongatâ, apice acuti; anfractibus convexis, longitudinaluter costatnnodosis, trunsversion sulcutis et striuls, sulits distantibus; cuudî̀ longâ, rectú.

Murex Longiroster, Broc. Conch. foss. subup. iom. 2. pag. $418 . n^{\circ} .57 . p l$. 8. fig. 7 .

Comme l'observe lrès-bien M. Brocchi, celle coquille a certaiuement de l'analogie, quant a la forme, avec le Fusus colus, mais elle en olfre davaulage encore avec le Fusus torulosus, sans que cependant elle soit l'aualogue fossile de l'une ou de l'autre. Ce Fuseau est alongé, étroit; sa spire, de onze ou douze lıous, est pointue au somrnet; elle est munie de còtes longiludinales, obluses, arrondies, rendues noduleuses par les sillons ćcartés qui les traversent; res sillons écartés, au nombre de ciuq ì huit, sont plus nombreax sur la partie supéricure des tours de spite: enti’eux se trouvent des stries tines, sertées, plus un moins noubreuses, selun l'écarteroent des sillons. Le caual de la base est presqu'aussi long que la spire; comme elle, il est couvert de sillons et de stries, il est élruil, subcylindique. L'ouverture est ovalare; le bord druit est foiblement sirié en dedaus, le lord grache s'applique sur la columclle et ne se releve quau commencement clu canai, au-dessus duquel il s'élève une lame perpendiculaje. M. Brocchi dil que cetle espèce a 3 pouce's 7 li - nes; wous en avons un individu qui a 4 pouces el demi, 12 centian. On la trouve en Italie et en Piémout.

\section{Fusead ridé. Fusus iugosus. Lasz.}

F. testâ. fusiformi, subcanccllatî; sulcis transversis, remotiusculis; costis longutudinalibns, distantibus, supremis nodulosis. 
An Mure.x porrectus, Braxder, Foss. hant. tab. 2. fig. 35 ?

Fusus rugosus, Ann. du Mus. loc. cit. pag. 316. $n^{\text {n. }}$ 1. et cont. 6. pl. 46. fig. 1.

Ibid. Lamk. Aninz. s, vert. loc. cit. $n^{0} .3$.

ENCrCL. pl. 425. fig. 6.

Favavie, $p l .66$.ffg. M $6 . \mathrm{M} 7$ ?

Testâ juniore, imperfectâ. Fusus clavellatus, LAנx. Ann. du Mus. loc. cit $n^{\circ} .4$.

Ihid. Anim. sans vert. loc. cit. $n^{n}$. 4. synon. exclusis.

M. Lamarck ajoute à la synonymie le Murex fossilis de Guelin (Sysicma naturee, $13^{\mathrm{e}}$ : edit. pag. 3555. $n^{\circ} \cdot 112$ ), en y mettant un point de doure; mais, selon nous, il ne pouvoit y avoir d'iacertilude, puisque Gmeliu cite les figures 1321 et 1322 de Martini, planche 141, figures qui évidemment se rapportent, aiusi que la descripltion, au Fusus uniplicatus Lam . Le Murex porrectus de Brander nous paroît une espèce bien distincte de celle-ci; comme nnus ne la connoissons que d'aprc̀s la figare, nous la conservons dans la synonymie en $y$ ajoutant un point de doute, ce que n'aruit pas fait M. Lamarck.

Ayant vu, dans la collection de M. Lamarck, les coquilles qu'il nomme Fusus clavellatus, nous nuus summes assuré qu'il avoit pris pour une espèce le jeune âge non-seulement du Fusus "mgosus, mais encore du Fusus Noce, lequel, dans cel élat d'imperfection, présente des ressemblanees qui justifient en quclque sarte cette confasion, oecasionnée fans doute par le trop pelit nombre dindividus que M. Lamarck a obfervés.

Le Fuseau ridé est one coquille commune aux environs de Paris; elle est alongée, an neu veotrue, terminée à la base par un cunal aussi long que la spire, mais !arge, conique et légc̀rement infléchi à son extrémité; la spire, assez variable dans sa longueur, commence toujurs par deux ou trois tours globuleax, cylindriques, ohtus, semblables en plus petit à ce que nous avons vu au Fusus proboscidiferus; les tours suivans grossisseat graduellemeut comme à l'ordinaire. Ces tours soat an nombre de six; ils sont légèrement converes; ils sont pourvus de côtes pliciformes, distantes, quelquefois étroites, quelquefois larges et presque toujonrs noduleuses au sommet de fa coquille; des siries nombreuses, peu régulières, également longiludioales, accom. pagncnt les eôtes et s'effaceni ordindirement sur elles; elles sont traverses par des silloos transverses, étroits, distans, réguliers, assez élevés, mais s'effaçant ordinairement en passant sur les côtes. L'ouverture est ovale, alongée; la lèvre Aroile, no peu siaueuse supéricurement, le devieat lavantage a l'origine du canal; le loord sauche est épais et peu saillant le long de l'au- verture, mais arrivant au canal, il se détache furterneat en lame mince et oblique qui reconvre ce cinal dans toute sa longuenr, en laissant une fente étroile. Celle coquille, longue de 85 millian., se trouve fossile aux environs de Paris. Une variété se rencoatre dans les fulunières de Valogncs; ellc nous a été counmuniquíe par M. de Gerville.

19. Fusea veatre lisse. Fusus longarus. Lamk. F. testâ fusiforni, reentricosâ, crassâ, anfractibus infinis dorso planulatis, lavigatis; margine superiore obtuso incurvo; suprenis striatis et plicato-nodulosis; culudi gracili.

Laмx. Anim. sans vert. loc. cit. no. 1 .

Dahgenv. Conch. pl. 29. fig. 6. Figurü quará.

Mantini, Conch. tom. 4. tab. $141 . f$ g. 1319. 1320.

Murex lavigatus, Garx.pag. 3555. $n^{\circ} .111$.

Murex longavus, Bнander, Foss. hart. fig. 37.38 et 93 .

Fusus longarvus, Ann. du Mus. yol. 2. pag. $3: 7 \cdot n^{\circ} .3$.

Excrci. pl. 425. fig. 3. a. b. el 4 .

Fusus clavellatus, ibid. $p l .435$. fig. 1.2. a. 6.

Les citations que fait M. Lamarck des figures 40 et 73 de Brander pous semillent mauraises en ce qu'elles se rapportent complètcment an Fusas scalaris Lamk. Les figures de re Dictionnaire qui représentent le Fusus clavellatus appartienvent sans le moindre duute au jeune áre de l'espèce qui nous occupe; nous arcns fail ollserver que de jeunes individus du Fiusus rugosus arvient élé confondus avec ccux-ci par N1. Lamarck, également sous le nom de Fusis clavellatus.

Le Fuscan ventre lisse est une coquille fpuisse, pesante, à spirc courte, conique, comaençant par quelegues tours cylinciriques, lisses, proboscidiformes; ceux qui les suivent sout coniques, noduleus, strjés ca travers; les stries et les nodosités se perdent pen à peu et disparoissent à wesmre que le bord de chaque tcur s'arrondit et devient de plus en plus saillant; les derniers tomrs sunt lisses, la hase se termine par uo canal long et droit, un pela moins long que la spire; le bord gauche ne tait ancune saillie, et le drnit est simple, non strié en dedans. Celle coquille, longue de 12 centim., 4 poucfs et demi, est conmune aux enviruns de Paris.

20. Foseau Noé. Fusus Nog. Laur.

F. testì fusiformi, apice basique transucrsin sulcatâ; spirâ costati, nodulosia; anfructuum margine superiore retuso, crispo.

L.1s. x. loc. cit. $n^{\circ}, 2$. 
Murex Noa, Cuess. Conch. tom. 11. tab. 212. fig. 20g6. 2097 .

Fusus Noc, Ann. du Mus. Ibid. n॰. 2. et tom. 6. $p l .46 .5 g .2$.

Exстсr. pl. 425. fig. 5.

Coquille fussile non moins commune que la prćcédeute aux enviruns de Paris; elle esi fusifurme, épaisse, solide, à queue médiocrement longue, large it la base et conique; la spire est également conique, de sorte que cette coquille semble formée de la réunion de deux cónes base à base. La spire, un peu obtuse, est mameIonnée au sommet; les tours sont au nombre de luit ou neuf, les cinq ou six premiers sont coniques et chargés de cútes longitudinalcs, arrondies, qui s'eflacent graduellement et disparoissent entièrement sur les derniers tours. Ceux-ci, coniques d'abord et à peine séparés par une suture superficielle, deviennent de plus en plus distincts, leur partie supérieure formant peu à pea une petite rampe qui rend les derniers tours aplıtis supérieurement vers la suture. Outre les cótes longitudinales que l'on remargue sur les premiers lours, on y voil aussi des stries transverses qui disparoissent sur le dernier tour : celuici est lisse ou un peu sırié supérieurement, il est court et cylindracé d'abord, et se teranine à la base par un canal coniyne qui porte sur le dos des stries nombreuses. L'onverture est ovale, oblongue; le bord droit est épais, simple, non sıcié é dedans; le gauche, bien apparent, ferme en partie la fente du canal de la hase. Cette coquille, coinmune daus tous les calcaires grossiers, est longue de 11 cention., 4 pouces.

\section{it Coquilles pyruliformes à canal long et large.}

21. Fuseau colossal. Fusus colosseus. Lamk.

F. testâ maximâ, zentricosâ, transversim sulcatá et striatí, pallidè fulva; anfructibus convexis, medio angulatis, serie unicâ, trans. versim nodosis; ultimo sonsim in caudism atte. nuuto; labro intìs leviter sulcato.

Lask. Anim. sans vert. tom. 7. pag. 122, $n^{n} \cdot 1$.

Havane, Conch. pl. 35. fig. B 4 .

Excrcr. pl. 427. fig. 2.

A l'exception du liuseau figuré par Lister, Gui est avec le Cérite gúant le colosse de conte la Conchyliologie, celui-ci est après lui le plus grand du anerre; if est alongé, venlru, d'un furve pále, uniforna en dedans et en dohors. Les tours arrondis, au nombre de sept nu linit, soot anguleux dans le milieu, et l'ang!e porte une seule série de tubercules épineux, quelıuefois plus on moins saillans, seloo les individus. Des sillons transverses, entre lesquels sont quel- ques stries, couvrent toute la surface de la coquille; le dernier tour ventru, plus ancruleux que les précédens, se termine insensiblewent en un canal large et conique qui finit en pointe. L'ouverture est très.grande et le canal de la base, largement ouvert, n'est indiqué à son origine que par une légère corsion de la columelle; le bord ganclie s'applique sur elle sans y produire d'ćlévation; le bord droit est mince, tranchant, festonnés par des sillons qui y aboutissent. On ignore d'où vient cette coquille, qui est assez rare dans les collections; elle a 30 centin. de lungueur, plus de i" pouces. Naus en avons vu un individu plus grand.

22. Fuseat de Blosville. Fusus Blosvillei. Nов.

F. testá oblongâ, pyriformi, ventricosâ, tramversin striati et sulcati, fuscá; anfiactibus medio angulatis, supernè suhplanulatis, longitudinaliter costatis, ultimo sensim in caudum attenuato; labro intis sulcato.

Celte coquille, que nous devons à l'oblineance de M. de Blosville, est presque la miniature de la précédente, lout en conservant cependant des caractères qui lui sont propres; elle a la furne de la précédente, alonóé, ventrue, furmée de six a sept tours convexes, anguleux dans le milieu, clargés de sept à huit cốles longitudiuales, sur chacune desquelles s'élève un tubercule à l'endroit de l'aogle des tours; la partie supéricure des tour's est aplatie en plan oblique et couverle de fines stries transverses, tandis que lenr partie intérieure, au-dessous de l'augle, est cliargée de silluns entre lesquels se voient quelques stries fines; loute la partie intérieure du dernier tour, qui s’attéuue inseusiblemenı, est muvie des mćmes sillons. L'ouverture est avale, oblungue, terminée inférieurcment par un canal largement ouvert. La columelle forme une petite torsion à son origine; le bord gauche est confondu avec la colucrelle, et le droit, très-épais, lirgement crénelé, est profoudément sillonné à l'intérieur. La couleur de celte espéce est uniformément brun funcé; l'nuverlure est d'un blanc-jaunâtre. Elle est langue de 35 millim.; elle a ćté trourée a Ceylun par M. de B!osvil!e, anquel nous nous faisons un plaisir de la dédier.

\section{Fuseau noil. Fusus morio. Lamk.}

F. testi fusiformi, ventricosá, transversè sulcatâ, mogrâ, fiusctss albıs binis inarqualibus cincti ; anfructibus angulats; angulo tuherculis plus minusve emineatibus coranato; caudâ latá, sensim attenuata; spiri breviore.

Fusus morio, Lasix. loc. cit. no. 16.

Fusus coronatus, ibid. loc. cit. $n^{0} \cdot 17$.

MIurex motio, Lix. Gare. pag. 3544. no. 62. 
Lister, Conch. tab. 928. fig. 22.

Dosmani, Recreat. part. 3. fig. 357.

SEBa, Mus. toin. 3. tab. 79. fig. tres, et tab. 80. fierd omines.

KNorr. Verg. I. tab. 20. fig. 1.

Martini, Conch. tom. 4. tab. 13g. fig. 1300. เว̄oı.

Le Niver, Adanson, Senég. pl. 9. fig. 3 .

Escres. pl. 430. pag. 3. a. b. et fg. 4 .

Malgré les raisons que M. Lamarck a données de la séparation des deux espèces que nous venons de réunir, nous ne partageons pas son opinion et uous revenons à celle de Linué, de Chemnitz et des autres auteurs. M. Lamarck a dunné cinq motifs qui l'ont déterminé à séparer le Fuseau couronné du Fuseau noir; elles peuvent être réfutées avec la plas grande facilité, et l'on s'en couraincra en réunissant quel ques individus à différens âues de ces deux espèces. $\mathrm{Si}$ on prend les individus jeunes, nous defions qu'on puisse les distinguer pendant les six ou sept premiers lours: mêtne forme, même convexité, même nombre de tubercules, même coloration, enfin, l'identité la plus parfuite; mais parvenue aux derners tours, la coquille se modifie selon les individus: dans les uns, les inbercules s'effacent et sont remplacés par des ondulations; daus d'autres, ils persisteut, muis ils restent petits et peu saillans; dans d'autres encore, ils deviennent plus grands, moins numbreux, et alors la partie supérieure du dernier tour s'aplatit; enfin, ces tubercules deviennent très-grands, comprimés de haut en bas, et c'est alor's que l'aplatissement de la partie supérieure du dervier tour est de plus en plus considérable; c'est alors aussi et par suite de cet aplatissement que la spire de ces coquilles à gros tubercules est plus courte. Ce qui est remarguable, c'est qu'au milieu de ces changemens dans la forme, tous les autres caractères spécifiques persislent. Les sillons qui couvrent toute la coquille sont les mèmes dans tous les individus, aplatis et larges, sur le deraier tour, ils sont plus saillans sur le prewier; la suture est toujours bordie par un bourrelet peu épais, derrière lequel se trouve une très-petite gouttière. La couleur varie du brun nair au brun fanve; deux raies blanches, inégales se voient à la base de tous les tours de spire. Le canal, large et plus court que la spire, $s^{3}$ atténue insensiblement; il est sillonné corame le reste; il est largement ouvert et iudiqué pa. une légère flexion de la columelle : celle-ci est arrondie, brune, pulie, dépourvue de Lord gauclie, le droit est d'un blanc-noirâtre, sillonné; les sillons supérieurs et inférieurs sont bruns. Cette coquille vit au Sénégal et aux Antilles. Elle est longue de 5 à 6 pouces.

\section{$\mathrm{F} \cup \mathrm{S}$}

24. Fuseau rampe. Fusus cochlidum. I.ama.

F. testâ fusiformi, transversè sulcrotô, rufü; anfractibus supernè angulatis, suprò planissimis, areà ambulacriformi et spirali amuluntibus; supremis angulo tuberculatis; aperturî̀ alsó; labro intùs lavigato.

LA $\mathrm{N}$. Anim. suns vert. loc. cit. $n^{\circ} .13$.

Mfunex cochlidium, Lin. Guez. pag. 3544. $n^{\circ} .63$.

DARGENT, Conch. pl. g. fig. $a$.

Favanne, Conch. pl. 35. fig. b. 3.

SEBA, Mus. tom. 3. tab. 52. fig. 6. et tab. 57. fig. 27.28.

Chems. Conch. tom. 10. tah. 164. fig. 1569.

Pyrula conchlidium, Excrcu. pl. 434 . fig. 2.

Cnquille voisine de la précédente, mais néanmoins distincte; elle est alongée, pyrulifortne; sa spire, formée de sept à huits tours, est conique, élagée; les preroiers tours sont munis de côtes longitudiuales qui se terminent par des tuliercules; ils couronnent la partie supérieure des tours, qui est aplatie en rampe horizoniale; sur le dernier les tubercules s'élacent et sout remplacés par une ligne onduleuse. Des sillons nombreux et transverses couvrent toute celk: coquille, un ou deux plus saillans tournent i $l_{1}$ partie supéricure des tours de spire dans le canal ou l'aplatissement qui s'y voit; les sntures sont plissćes lungitudinalement el bordées par l'un des sillons que nous venons de mentionuer. $l x$ : caual qui naî́t al la base est large, plus court que la spire et indiqué à l'intérieur pal une petite flexion de la columelle: celle-ci est lisse; le bord gauche se confond avec elle, le bord druit est siuple, non strie en dedans; il est blanc, tandis que tout le reste de la coquille est d'un brun foucé sans autres muin'es. Celle coquille rare vien! des wers de l'Inde; elle 3 ì 4 punces de long.

25. Tuseau mexicain. Fusus corona. Laxk.

$F$. testì abbreviato-fusiforni, ventricos $\hat{a}$, curonatá, rufo fúscî́, albo fascintá; unfracüibus supemè angulatis, suprà planis; angulo lamellis plicato-acutis ercetis spiniformbres comnato; caudá sulcatâ; aperturâ ulbidâ; labro intús lasigato.

La $\mathbf{x}$. loc. cit. no. 19 .

Murex coronu mexicana, Cвesr. Conch. to:n. 10. tab. 161 . fig. 1526.1527 .

Murex corona, Gıes. pag. 3552. 110. 161.

Fusus corona, Enctel. pag. 43o. fig. 2.

DAviLA, Catal. pl. g. fig. A.

Coquille avoisioant encore plus les Pyrules que les prérédentes; sa spire reste néanmoins pius 


\section{F U S}

longue que la qucue : caracicre qui, comme on lo sait, est le scul cn definitive qui sépare les Pyrules des Fuscaux. Le Fuscau mexicain est une espèce rare, recherchée des awateurs; elle cst alongée, ventrue, formée de six ou sept tours de spire, séparés en deux parties inégales par un angle suillant, couronné par un rang de grandes ćcailles épincuses, solides, aiguës, ployécs en deux et rapprocliées les unes des autres; en dessus de cel angle les tours sont aplalis, "juelquefois lamelleux daus cet endroit, mais le plus souvent lisses; cet aplatissemeut produit une raaspe un peu concave et de plus en plus élroite à mesurc que l'on arrive à l'origine de la spire. Des sillons transperses se remaiqueat i la base Ju dernier tour et sur le dos du canal, celui-ci est très-court, largerneut ouvert. L'ouverture est banche; la culumelle est simple et le bord droit, vime et tranchant, est lisse eu dedans; toute cette coquille est d’un bruu foncé, orué de deux raies blanches, enales et distanles; quelquefois des fascies blanches, lonvitudinales, irrécrulières se voient sur les dernier's couts: elles indicuent des accroissemens. C'est dans le golfe du Mexique yue se trouve ce I uscan, qui est long de go uillim.

26. Fuseso aurore. Fusus filosus. LAs x.

$F$. testâ fusiformi turritâ, crassâ, nodosì, lovigati, albido fulvi, lineis auranio rubris reberrimis cinctá; anfrictibus supernè nodosis; nodis hemispharicis; aperturä albâ; lubno intús striato.

Excres. pl. 429 . fig. 5.

An Martini, Conch. tom. 4. pl. 140. fig. 1308. 1309 ?

I, Аик. loc, cit, no, 2 เ.

Coquille ovale, oblongue, épaisse, solide, a spitc alongée, à qucue courte et large; sa spire, un peu obiuse au sommet, est composée de sept à huit tonrs légèrement convexes, séparés par une sninre superlicielle, marginée; huit ou neuf y̆ros tubercules courts, obtus, lúsonisphériques se voient sur chaque tour de spire, qui sont du restc tont-ì-fait lisses; ils sont parcourus transversaleacat par plusieurs raies rougeâtres ou orangé foncé, rapprochées ordinaircouent deux à deux sur uu fond orangé clair; le canal de la base est trc̀s-court, il s'atlénue insensiblement, il est indiyué à son origine par une très-petite fexion de la columelle. Liouverture est subtrigone, alongée; la columelle cse lisse, simple; le bord gauche se relève ì son cxtıérité seule. ment el laisse ouvert un ombilic assez large ct profond. La lèvre droitc est ćpaisse, solide, légèrement striée en dedans. A l'iutérieur celte coquille est d'un blanc teinté d'aurore; elle est rare dans les collections et habite les mers de la Nonvelle-IIullands. Longueur 75 millim.
27. Fusead coupé. Fusus excisus, Lasix.

$F$. lestâ ovalo-oblongâ, transversè rigosí, costis longiludinalibus obsoletis; columellá abliquè excisu; caudi brevi; labro mlis dentato.

I, AM . Anim. s. vert. loc. cit. no. 13.

Fusts excisus, Ann. Ibid. pag. 3ı. $\pi^{\circ} .1 \mathrm{t}$.

Encrce. pl. 428. fig. 4. a. $b$.

Ce Fuseau est d'un médiocre valume : i] ist élroil; sa spire est alongée, printue an soinmt ; son dernicr tour, un neu ventrn, se termine par un canal Irès-court; il est composé de sept tour: arrondis, sépar's par uue sutace simple, asse\% profonde; chacue tour est muni de sept à laujt côtes longitudiuales, contiaues d'un tour à l'autı elles soni arroudies, distantes, et accompagnées de strics longitudiuiles, trìs-fines at tris-se:"rées : elles sont traversées jar des sillons distans, saillaus, peu nombreux, entre lesque!'s se vaient des stries presque aussi lines que les premières. Cu treillis tin el délicat, qui orne toutc la partic supérieure de la spire, se continue à la hase et sur lo canal cui termue le deruier tour. Comme nuns l'uvous dil, ce cunal est tres - court, inciiquti ca de: dans à son origine, far un angle foras par la colıwelle; il est bordé par le bo:d rruclıe, qai fail, au-dessus de lui, une légire saillie. Louverıre est ovalaire; son bord druil, très-épaissi, est garui eu declaus de dentelures assez saillaates. Cette coquilie, connue à l'étal lossile sen'enent, se tronve a Griernon, Parnes, Courtagnon, ctc., aux euvirous de l'aris; elle est longrue do $2.5 \mathrm{mil}-$ limètres.

28. Fusea o spaissi. Fusus incrassaius. Noв.

$F$. testâ oblongó, subfusiformi, crassá, solidâ, longitudinaliter costato-tubercillatû, transversè ngosâ; rugis ad basin subnodosis; anfiactilus medio angulutis, suprà planis, tenuissimè striatis; striis longitudinalibus, tenuissinis, lamellatocrispis; colunella latá, basi umbilicat.

Coguille parfaitement distincle de toutes celles que nous connoissons : elle cst alongće, veutrue, épaisse, solide; sa spire, régulierenent conique, se termine en pointe aiguë; elle se compose de hai tours peu convexes, divisés, dans le milien, par un angle assez aign ; des côles longritudlinales, au nombre de six à huit, selon les iudiridns, se terninent par un tubercule aplati i l'angle des tours; des stries longitudinales, urè-fiocs, sublamelleuses, crépues, très-scricées et très-nombrcuses, se voient sur toule la surlace de la coquille; en dessus de l'angle des tours, clles sont traversies par dautres siries presque aussi fines; mais en clessous de l'angle, elles le sont par des sillons étroits, distans, subcariuiformes, qui deviennent souvent grauuleux sur le dos du caual; ce canal s'alténue peu à peu ; il est larrge, court, épais, ombiliqué à la base. L'ouverture 
est ovalaire, et le bord droit est fort épais, à peine crénelé. Cette coquille se trouve fussile à Beyne et Moucby, dans le bassin de Paris; les grands individus out 40 millim. de long.

29. Fosead subcariné. Fusus subcarinatus. LASK.

F. testâ ovato-oblongâ, ventricosi, transversim striatâ et sulcatâ; anfractibus abbreviatis, angulatis, costatis, nodulosis, parte superiore depressis; tuberculis plus minusve eminentibus, compressis, spiniformibus vel obtusis; caudâ spinú breviore; columellâ aliquandò umıbilicatâ. Nов.

L.AMк. Anim. s. vert. loc. cit. $n^{\circ} .24$.

Var. B. Nов. Testâ brevione, tuberculis magnis obtusissimis coronatâ.

Var. C. Nов. Testâ spirâ breviore, tuberculis divisis.

Var. D. Brosg. Testá latiore; tuberculis compressis, hutis, spiniformibus; anfractibus parte superiore obliquis.

Brang. MIem. sur les terr. calc. trap. du Vicentin, pl.6. fig. 1. a. b.

Coquille dunt on punrroit faire denx ou trnis especes si ou n'en royoit que quelques inclividus, mais si l'on en rassemble un grand nombre, ou élabliti facilement les passages pa. une série de variétés. Nous aurions pu en aunmeater le nambre, car il n'y a qu'une pelite yuantilé d"individus absolument semblables. Cetle coquille est généralement alongée, ventrue, a spice médiucremeal longue, poiurue au sommel, terminće à la base par na canal large et plus court que la spire. Celle spire est composíe de sept tours courls, ornés de côtes généruleasent peu saillantes el longiludiaales, parlayés ea deux par un angrle saillant, sur lequel cliaque côte devient raberculeuse, ce qui courona la coquille d'uae seule rangée de tubercules. En dessus, dans le flus grand nombre les individus, les loars sont aplatis, el présentent une rampe qui rourne avec eax; des siries longiludiuales, fines, nombreuses, serrées, irrégulières, se voieaı sur toute la cocuil!e : elles sunt crnisées par des sillons nombreux, plus on moins serrés, entre lesqnels sont plackes une nu plusieurs stries trèstines; les silluns disparoissent à la parie supérieure des Inurs de spire; on ne trouve li que des stries régulières, pllus ou mains rapprochées selon les individus. L'ouverture est assez grande, subtrigone, largemeat ouverte à la base; le canal est court, indiqué par une légère torsion de la columelle; celle-ci est lisse, simple, le bord gauche se confondaut avec elle guelquelois; cependant il se dérache a la base, el laisse a découvert uu large onlilic, qui, dans le plus graod nombre des individus, est seuleavent indi- qué; la lèvre droite est mince, tranchaule, lisse en dedans, et crénelée sur le bord dans loule sa longueur. Nous possédons une coquille de celle espèce qui, quoique jeune en apparence, a la lèvre droite très-épaissie en dedaus, et profondémeat sillonuée dans tonte sa longuenr.

La variété $B$ a la spire fort courte, à tel poiut qu'on la prendroit poar uae Pyrule, si elle ce conservoil les caractères de l'espèce à laquelle elle appartieat. Elle se reconnoíl de plus par les gros lubercules coniques, oblus, épais, qui conronnent les tours de spire, et surtout les deux ou qrois derniers : il faut observer que la partic. supéricure des cours de cette coquille reste en rampe horizontale.

Dass la varićté C la spire, un pea plus longue proportionnellement, est ornée de côtes et tubetcules nombreux; mais, à leur sommet, tous cers tubercules sont divisés en deux par un siltun large et profund. Enfin la variété $\mathrm{D}$, à laquelic M. Brongniart a donné l'épithèle de Roncana, parce qu'elle fut trouvée d'alsord à Ronca, se rencontre anssi aux envicons de Paris; elle eat renarquable en ce qu'elle est très-ven:rúe, que ses tours, fortemeat anguleux, ont lear partie supérieure furt oblique, et l'angle découpé en iubercules alongés, subspiniformes, moins nombreux que dans les autres individus, aplatis de baut en bas, comme sils avoient élé pincés dans un élat de collesse; au lien de se relever vers le sommet, ils s'ıclinent plutôt vers la base de la coquille. Celle espèce est abondante aux environs de Paris; c'est près de Senlis surlout qu'on la rencontre dans les grès marins; elle se trouve égulement à Cbanmont, Beyne ef all val de Ronca, près Vérone. Les plus grands individus on 80 millim. de long.

\section{$t+\dagger$ Espèces buccinoïdes à canal court et contourné.}

3o. Fusead du Nord. Fusus antiquus. Lamr.

F. testâ ovato-fusiforni, ventricosâ, mutica, transversim tenuissmie striatâ, albida, in junioribus rufescente; anfructibus valdè convexis; cuudì brevi, contortâ; uperturâ patulà, labro intus lavigato.

Lass. loc. cit. $n^{\circ} .11$.

Murex antiquus, LIN. GMex. pag. $3546 . n^{\circ} \cdot 7^{3}$. Null. Zool. daric. tom. 3. tab. 118. fig. 1. 3. Отн. Faвя. Fuun. groenl. pag. 397. $n^{\circ}, 396$. Buxsasi, Recreat. 3. fig. 190.

Iister, Conch. tab. 915.fig. 4. el 962. fg. 15. Sera, Mlus. tum. 5. tab. 3g. fig. 75 . tab. 85. fig. $\overline{5} 6$. el $t a b \cdot 9^{5}$. $f i g .3$.

Pesxaxt, Z ool. brith. tont. 4. tah. 78. fg. 98. Farsixe, Concli.tab. 32. fig. II. 
Nartisi, Conch. tom, 4. tab. 138. fig. 1292 et 1294 .

Fuste antiquus, Evcrcc. pl. 426. fig. 5 .

Fuscau veutru, à spire longue, à queue courte et un pen relevée vers le dos, formée de sept lours arrondis, dont les premiers sont obtus; ces tours, régrulièretneut convexes, séparés par une sulure simple, sout couverts de stries nombreuses, serrées, tines, régulières et transverses. liouverture est grande, ovale, toute blaoche en dedans; le canal de la base en est séparé par uue forte torsion de la columelle; il est court, largement ouvert et oblique; le bord gauche sc confond avec la colume!le; le bord droit est mince, tranchant, lisse en dedans. Tonte cette co quille est d'un blanc-jannâtre, ou loute fauve en dedans et en dehors. Elle habite les mers du nord, où elle n'est pus rare. Sa longueur est quelquefois de 6 pouces, mais celte taille se rencontre rarement. Nous avons vil l'analogue fossile de celle espèce, qui se rencontre assez fréty'jemment dans le crag de Suffilck.

31. Fosea duuble crête. Fusus despectus. LAxis.

$F$. test $\hat{s}$ ovato-turritâ, subfusiformi, ventricos $\hat{\imath}$, transpersinu striutá, albido lutescente; anfractibus convexis, medio bicarinutis; carinŝ unicâ, prominente, tuberculato-nodosá; caudâ brevi; aperturi alba ; labro intùs loviguto.

Lasx. loc. cit. no. 12.

Mfurex despectus, Liv. Garel. pag. $3547 \cdot \pi^{\circ} \cdot 74$.

Listea, Conch. mantissa, pl. 3. frg. 2.

Отн. ЮАв. Faun. groenl. pag. 396. n०. 375 .

Martini, Conch. tom. 4. tab. 138. fig. 1293 et 1296 .

Schroetter, Einl. in conch. tom. 1. tab. 3. fig. 5.

Fusus despectus, Evcrcsnp. pl. 426. fig. 4 .

Nous avions pensé d'abord que celle coquille n'étoit qu'uue variété de la précédente, et il nous sembloit que la suivante pouvoit s'y rémir éralement au même titre; mais, après un examen plus atrentif, nous avons cherché inutilement des passages que, suns aucun dinte, unus aurions rencuntrés entre ces variélis, si elles eussent appartenu en ellè à une seule espèce. Le Fusus despectus a la unếne forme que le précédent; il est cependant encore plus veutru; il est strié en travers; toais les stries sont onduleuses, plus ellacées, beaucoup moins norahreuses, el, sur le dernier tour, quelques - unes plus saillantes et furt distantes, an nombre de buit ou neuf, ressemblant à des carènes. Ce qui distingue encre celte coquil!e, cest que ses tours, au lieu d'être régulièrement convexes, sont angn. leux dans le milieu et conronnés par un seul rang de lubercules, plus saillans dans le jenne âge, remplacés par quelques ondulatious sur le dernier des individus adulies. La forme de l'ouverture et da canal qui la termine à la hase est semblable à celle de la précélente espèce. Comıne elle, elle vient des ners du Nord; elle a 4 pouces de longueur (114 millim.).

\section{2. liuseau cariné. Fushs carinatus.}

F. testâ fusiformi-turritá, transversim striat $\hat{x}$, cariniferi, fulvo-rufescente; anfructibus angrelatis, supia planulatis, bicarinatis; carina inferiore submarginali; spara apice mamillan; labro intùs albo, loevigato.

Lank, loc. cit. $n^{\circ}, 13$.

Mhurex carinatus, PesN. Brith. zool. turn. 4. tab. $77 \cdot 7 g^{\circ} \cdot 96^{\circ}$.

Anillartiv1, Conch. tom . 4. tab. 138. fig. 1295 ?

Lister, Conch. mantissa, pl. 3. fig. 1 ?

Espèce très-voisine doss précéclentes par ses rapports, mais ayant ses tours convexes dans le jeune áge seulement, et 110 peu aplatis ì leur. partie supérienre; la spire, obtuse an sommer, se termine par un bouton; tous les tours, all nombre de sept, sont striés transversalement, et, cie plus, ils portent dans le nilicu deux carénes saillantes et distantes, au milieu desquelles se trouve une strie plus saillante que les autres; it la base du dernier Inur, au-dessous des denx preanicres, on reuarque pualre ou cinq autses carènes yui aboutissent au bord droit. L'ouverture est grande, ovale, arrondie, bordée le plus souvent par un bord gauche un peu saillant, surtout à la base, où il laisse à découvert une feute ombilicale; le bord droit est assez épais er sinueux à la partie supérieure; le canal de la lase est fort court, et indiqué í son origine par une forte torsion de la columelle. Celle coquille est blanche en dedans, d'un fauve pâle en debors, avec les carc̀es d'un blanc opayue; ellc vient des mers du Groenland. Elle est de la mène taille que la précédente. Nous possédons l'idenrique lossile de celte coquille; l'identité ne pent être plus grande. C"est dans le crang de Suffolck ¡n'elle a été trouvée.

33. Foseav écourté. Fusus brevicaudâ. Nor.

$F$. testâ fusiformi, buccinoideâ, subventrscosâ, transversim sulcalâ, fulvo-rufescente: ailfructibus rotundatis, convexis; spiri elonguto-acutâ; lubro intús lasigato, parte siperoore sinuato; caudâ brevissima.

Coquille subturriculíe, à spire alungée, pointur, termine par un canal tres-court, ce qui done à celle espèce l'apparence d'un Buccion; les tou.s sont au nombre de huil; ils sont régulièrement 
$16(1)$

conrexes, assez longs et séparés par ane sutare simple, mais profonde. 'Toute la coquille est sillonnée transversalement; les sillons sont nombreux, réguliers, égaux, rapprochés, arrondis; ils deviennent obliques a la base du dernier tour, saus cesser d'être r'́guliers. L'ouverture est obronde, subcarrée, terminée par nn canal court et oblique, largement ouvert. La columelle est simple, ann bordée, un peu tordue à l'origine du canal; la lèrre droite est simple, tranchante, et assez profondément sinueuse supérieurement. Toute cette coquille est d'un brun fauve uniforme eu dehol's, et blanche en dedans; elle est longue de 55 millim. On nous a assuré qu'elle provenuil des mers du Nord.

34. Fusea d'Islande. Fusus islandicus. Lamx.

$F \cdot$ testâ fusiformi-turritâ, infemè ventricosâ, mutici, transversim striatâ, albida, anfractibus convexis; labro tenui, intús lovigato; caudî breviusculâ, subrecunvâ.

Fusus islandicus, Mantixr, Conch. tom. 4. tab. 141 . fig. 1312 et 1313.

MIurex islandicus, G Mez. pag. 3555. $n^{\circ} .1$ io.

Fusus islandicus, Excrcz. pl. 429. fig. 2.

L.A.ix. Anim. s. vert. loc. cit. no. 15.

Coqnille ovale, oblougue, alongée, peu ventrue, à spire alongée, à queue courte et légèrement inlléchie en dessus; elle est composée de neufs tours peu convexes, réguliers, séparés par uve surture peu profonde; les premier's sont alstus, th pelit nombre et tout-à-fait lisses; les suivaus sout orcés d'un grand nombre de sillons transrerses, réguliers, plus profonds sur les premiers que sur les dernier's; ces sillons sont convexes, simples, quelquefois, mais rarement, rendus légèrement grauuleux à la partie supérieure des tours de spile par des stries d'accroissement assez régulières et mulliplićes; sur te dernier tour, les mêmes sillons se continuent is la base jusipu'à l'extréailé du canal; celui-ci, fort court, quoique plus long ọue daus l'espèce précédeule, est tordu et un peu relevé en dessous par un angle yue fait la columelle à son origine. L'ouverture est orale, oblongue; le bord gauche est rarement marqué, el le dioit, simple et tranchant, est lis:e en dedans. Celte coquille est couverte d'un épiderme caduc, brun, assez épais; elle est toute blanche lorsqu'elle en est dépouillée. Sa longueur est de $9^{5}$ millim. Son nom indique sá patrie.

\section{Fusead perrers. Fusus contrarius.}

F. testâ sinistrorsâ, fusiformi-turitî́, contorta, oblique ventricosa, transversim substruta, fulvá; anfractibus valdè convexis; labro simplici, intüs levigato; caudà brevi, obliquâ.

Nurex contrarius, Iss. Gyex. pag. 3564 . $77^{\circ} .157$.

\section{F U S}

Lister, Conch. tab. 95o.fig. 44.b.c.

Favaine, Conch. pl. 32. fig. n. pl. 79. fig. $f$. et pl. 8o. fig. $r$.

Chenv. Conch. tom. 9. tab. 105. fig. 894. 8g5.

Fusus contratius, Excrcz. pl. 437 . fig. 1. a. b.

Toute la synonymie que rapporte M. Lamarck appartient, sans ancun doute, à l'espèce lossile d'Angleterre, dont nons ne connoissons pas l'an.zlyse vivant, espèce que l'on pourroit confondre avec une autre vivant dans la Mléditerrance ou dans la mer de l'Inde, et dont l'analogue fossile se trouve en Sicile. Le Fusus contratius est une coquille ovale, oblongue, rentrue, bucciniforme, à canal trćs-coult; sa spire, alongée, pointne au sommet, se compose de sept lours très-convexes, le plas souvent lisses, ayanı quelques stlies transverses, surtout dins le jeune âre; dans quelques individus, qui paurroient constiluer une variété, des stries très-fines, obsolètes, se voient sar toute la coquille. L'ouverture es ovale, obronde; la columelle, en arc de cerulc, est bordée par un bord gauche ì peine marqué; le bord droit est épais, simple et lisse en dedans; le canal est très-court, indiqué à l'intérieur par un angle de la columclle; muis il n'est point écluancré à sun extrémité, comme l'a dit M. Launark. Celte coquille, longue de 85 millim., se trouve fussile daus le crag au comté d'Essex, en Angleterie.

36. Fuseau contraire. Fusus sinistrorsus. Nub.

F. testâ ovato-acutâ, sinistrorsâ, ventricasá, albidâ, transuersìn striatî et sulcatâ; anfractibus iegularibus, convexis; caudâ latâ, brevi, contortu.

Favanne, Conch. pl. 52. fig. A.

Coquille jusqu'à présent rarissime dans les collections; nous n'ell connoissons que trois individus dans celles de Paris, doux dans cetle de II. le duc de Rivoli, et un dans la nó re. Ce Fuseau est grand, ovalaire, ventru, atténué is ses cleux extrémités, terminć il la base par nu canal fort court et ollique; il est composé de sept tours de sjire, le premier est mamelosis, et les suivans sont régulierement espacés, arrondis, conveses, à suture simple, mais profonte. 'Toute la coquille est couverte de silluns nourbreux, convexes, simples, rapprochés sur les premiers tours, plus distans et séparés par une strie iralerposée sur les derniers; ils sons géné. ralement plus tins el plus serrés à la partie supérienre des lou:s de spire, dans le voisinage de de la sulure. L'ouveriure est ovale, oblongrue, poiutue à scs dcux extrénutćs; infétieurement elle se termine par le canal, qui cst indiqué par une torsion de la coluralle; celle-ci est bordíe par le bord ganclie, mince et peu saillant, qui sépaissit et s'aplatit d'une manière notable, 


\section{F U S}

à la base, en laissant à découvert une fente ombilicale peu profonde; le bord droit est assez epais, sinple, lisse en dedans, et un peu sinueux a sa parlie supéricure. Ou trouve en Sicile, dans une couche peu élevéc au-dessus de la mer, et siluée aux environs de Yalerme, des individus fossiles de celle espèce idenıiquement seublables i ceux actuellement vivans; celle circonstance nous fait penser que ces deraiers vivent dans la Méditerrauce ou daus l'Océau indiea. L'indıvidu vivant de notre collection esi long de 95 millim. Nous eu avons un fossilc lung de 120 nullim.

57. Fuseau sinistral. Fusus sinistralis. Lask.

$F$. testâ sinistmors $\hat{a}$, fusifornit-turritâ, angust $\hat{s}$, transversim sulcata, longitudinuliter costatâ, albido-fulvî; unfractıbus consexis; caidâ brewiusculâ, mucromifonni; labro intùs sulcato, margine denticuluto.

Laur. loc. cit. $n^{\circ} .31$.

FataNe, Conch. pl. 3.3.fig.a. 6.

Fusus manccanus, Cиемn. Conch. tom. 9 . tab. $105 . f_{b} \cdot 8 g 6$.

Fusus maroccensis, Gmex. pag. 3556.fg. 132 .

Fusus sinistralis, Escrcc. pl. 424. fg. 1.a. b.

Petite coquille alongée, élraile, sublurriculée, poiulue au summet, terminéc par no cand un peu plus long que dans les espicies précídentes, mais tordu el oblique; ses tous's de sjuire tournent de droile à gauclıe, à l'inverse du plus grand nombre des coquilles, et cu cela elle se rap prioche des deux espèces que nous venons de mentiouner; mais elle n'a presque gue cela de combun avec clles; ses tours de spire, au nomire de liuit, soat Irès-convexes, courts, séparés plar une suture profoude, subcanaliculéc; des côles longitudinales, nonbreases, convexes, rapprockćes, se voient sur tous les cours de spire, qui, de plus, sont urnés de sillous lransverses, profunds, nombreux el très-réguliers. En aboulissaul à louverlure ils en rendent le bord droit créuclé dans loute sa longueur; cetlc ouvertute est pelife, avale, obronde; le canal qui la termiue inls:ricurement est indiqué à son orrgine pas une Jlexion de la culumelle : il est étruit, oblique, non borde. Calle pelile coquille, longue de 20 nillins. seulement, est rure dans les culiections, lille est d’un fauve-blanchátre; sa parric est la uner des Antilles.

38. Fusead marqueté. Fusus nifat. I,ank.

F. testâ fusiformi-turritî, lavi, albồ, maculis quadratis luten-rufis transversim seriulis picti; anfractibus convexis; cundia brevi, cmar. sinata; labro simplicissimo.

Lister, Conch. tab. 914. fig. 7 .

Adaxs. Sénég. pl. 4. fig. 3. le Nifat. Histoire Naturelle des Vers. Tonie II.
Favaxxe, Conch. pl. 33. fig. 1.

Martini, Conch. tom. 4. tub. 147. fig. 1357.

Buccinum nifut, Brvg. Dict. no. 56.

Murex pusio, Giul. pag. 3550. n०. go. Non Linnai.

L.Амк. loc. cit. no. 32 .

Ibid. Fusus scalurinus, loc. cit. n०. 36.

Exстсг. pl. 437 . fig. 2.

Nous avous vil, dans la collection de M. Lamarck, la coquille qu'il nomme Fusus scalurinus. Eile ne differe en rien d'esseutiel de l'espicte qui nous occupe; c'est pour cette raison que nuus l'y réunissons. Nous ne nous sommes même pais aperçu quil y ail un motif suffiant pour fare une variélé, et luous ne doutons pas que M. I.a. roarck auroit facilement évité ce double emploi s'il cût eu sous les yeux ua plus grand nombre d'iodividus. Il a sćparé le Fusus scalarinus sut ce caracière de peu d'impcriance, d'avoir les tours aplatis en dessus; mais jl est à remarquer qu'il y a des individus du Fusus nifut qui ont la moilié de la spire en rampe, el le resic arrondi, ce qui joint les deux espices daus un méme individu. II n'en liaut pas davan!age pous laire rejeler désormais la séfralation de Mla Iatmarck.

I.e Fuseau warquelé est une jolie coquille alongée, peu ventıue, à stiric longhue, pointue an sommet, composke de tienf à dix lours peu conrexes, aplatis, surloul dans le jeune âge, terwinés quelquefuis supéricuremeut eis mue rampe oblique. 'loure la coquille est lisse, polie, un pen cylindruccéc au dernier tour, qui se terunine a la base par un cunal court, un peu tordu, reuversé en dessus ct échancré. Sur un fond blanc lajteux se dessinent des taches subyuadrangulaires, disposfes sur le dernier tour en cinq rangées transverses. L'ouverture est ovalaire, pelite, a colunelle simple et à bord drcit Iranchaut, lisse en diclans. Celle coquille se trouve dans les mers d'Af:ique; elle est longue de 55 millim.

59. Ficsead raifort. Fusus nzhanus. Lamk.

F. testâ fusiformi-turritâ, ventricosâ, tenui, tnunsverse striota, ulbıdi, fulvo-nebulosá; anfructibus medio angulato-carnatis; ultimo bicarinato; camis onınibus tuberculuto-dentatis; afertuiâ alba ; labro intùs lavigato.

la dix. loc. cit. $n^{\circ}, 20$.

Manтris, Univers. conch. tom. 1. fig. 5.

Cakm, Cortch. tom. 10. tab. 163. fg. 1558.

Excycs. pl 455. fg. 1.

Parroi les espèces de ce genre, il en est peu qui soieut aussi bien caraciérisées que celle-ci, et aussi facile à distiujuer : elle est ovale, obloogue, ventrue, pointue au sommet, termince $\mathrm{X} *$ 
a la base par un canal court, conlourné el écbancrés, farmé de sepl à buit tnurs très-aggu. luud daus le milieu, ei courunoés dans cerre par'ie pur un seul rang de tubcrcules pointus el ornés dins loule leur étendue d'an grand nombre de stries régulières et traasverses. Sur le deroier lour, on remarque, au-dessous du premier, ua second rang de iubercules semblables. L'ouverlure est ovale, oblongue, acuminée sanéricareruent et terminte inlériearemeat par un caual largement ourert. Elie esi conte blanche, à culumelle simnle, à bord droit tracclant el lisse cn drdans. Toule celle ro ruille es: mince, légère, d'un fare pále, ciuelgytefois nuarcé de lábes nébuleases uo pea palus foocícs. Lille est rare, rechercbíe des amaleurs; sa longueur est de 6o millira. Elle labite l'Ocćan pacilique, à l'ile ces Anis, à la Nourelle-Hollande.

40. Frseav reiní. Eusus ligharius. Las x.

F. testis subturriti, acutj, crassivsculi, ghubri, abidz, rufu cut fusto venuluta; spirá parte superiore cosiellatu e: transversim strna! $\dot{0}$; sutura marginatá; caudá brevi, contorto; labro intùs sulcato.

L.Axx. Lac. crt. $\left.n^{\circ}, 2\right\}$.

Psirsud. Cnt. des Ann. et des Uoll. de Corse, pug. $147 \cdot n^{n} \cdot 292$.

Bnxsax, Recreat. 3. Fg. 72.

SESA, MUs. tom. 5. tab. 52. fg. 4 .

Excras. $p l .424 \cdot$ fig. 6 .

Fossilis, Broc. Conch. foss. subap. tom. 2. rag. 426. $n^{\circ} .50$.

Le Fasear reiné est une coquille cornmune dans la Méditerranée, et que nous ne connois. soos pas daus les mers du Nord: tlle est ovale, alongée, sablurriculée, un peu venirue, à spire looguecił canal tıè-court; sa spi:e ce compose de buit tours; les premiers, irès.courls, sont pourrus d'uo rang de nodosités, el suat striés en rravers, mais les deruiers soct en:jerement lisses, si ce a'est quelgnes stries qui se voient à la basc de la coquille a lorigine du ranal; les tons de spire soni per coavexes : horaés par une sulure simple, au-dessus de !aquelle règne coe gooltière quila suit. Liuurerture est ovalaire, violátre en dedans; la columelle est simple, t forme un angle à l'origine du canal; celui-ci est étroit, ublique, relevé rers le dos de la coquille et terminé par nae felite éclancrure; la lerre droile est Epaisse el sillorrée en dedans. La couleur de celte coquille consiste en reiooles plus ou mrins nombreuses, lraues sur an fond Llanc-grisátre. On troure eu Ilaiie, en Sicile et à Stlles, près Bordeaux, l'analogue fussi.e de celle espèce; on a quelques individus conserrés arec leur aucieane coloration. Longoenr 55 เพilliu.

\section{FLSIIOR.IES. Fusifomia.}

1. Iuatreille (Fans. nat. du Régne crim. pag. 192) a pruposé celte famille pour rasseunbler les genres suivans, que .Y. La:oarck comprenort arec d'aulres dans ses Canalifere, Pulauside, Cérite, Cancellaire, Fasciolasre, Carreau, Pleurolome. 'Turbiuelle, Fuseau, I.atire, Clavaluie et Pyrule. Nous ferons observer d'abord que, parmi ces genics, 1 en est piusiears qui ne soct plus adminiules: teis que, Putamide, qui reatre dans les Cérrtes, Carreau el Latire dans les Py. rules, et Ciaraiule dades les Pleurotomes; cuac: sux autres geares, i's ont, sans coatredit, $b \in a u-$ cuap d'aualogie tatrc eux. Mais préscoseut-ils des caractères sufisans pour les stéparer des Rocbers el autres geares roisias cazaiisulés? nnu;

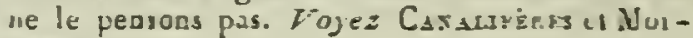
LโSQ $=\Sigma$. 


\section{G A D}

GADE. Gadus.

Geure proposé par Monlagn pour ure trìs. perite coquille que M. Siwerliy rapporte au genre Deutale sous le noro de Dentalium gadus. 1. Rang, dans sou Mamuel de Conchyliologie, la place dans le second sous- wenre des Cléudores, unais c'est ì to:t, selon nuus. V'ojez ĆÉodora.

\section{GADIN.}

C'est le nom qu'Adausou (Voy, au Sénig. pag. 3.j. pl. 2. fig. 4.) a donné à une peliie cyiece de conpuitle quil rapporte aux l'atelles. M. de Blainville, daus le Dictionncire des Scrences uaturelles, doule que ce soit une coquille de ce gerle : il pourroit se faire, en efliel, quielle appartint an genre Siphonaire, sans que cependumt on pût en avoir l'eutiere conviction, la figure et la description laissint à desirer sur les caractìres de cre grute nu des l'atelles. F́ayez SIPHONAIRE Cl l'ATELIE.

\section{(id:ЕT.}

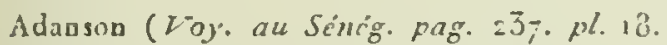
fig. 2) arnil donné le nom de Tellme anx Duriares de Liuno; celle-ci, qui est une "lerine pour lui, est le Donax trubculus des anteuts. Voyez JOAACE.

\section{GAIDEROPE. Guideropa.}

On nommoit aiof, on on donnesil le norn de pred dóne, qui est synunyme, à une corguille assez commune, que les anciens pliçrient parmii les Iluitres épineules, \& qui rentre injonirfthi dins le genre Spondyle, sons la dénersinution de sporidylus gaderopus. Voyez Spaxdrze.

\section{GALAI)ES. Galades.}

Les Anciens donnoient te nom a trontes lo inianilles bivalves blanches en dertans. Cet'e

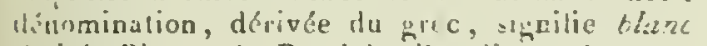
de lait. Plus tard, Rondelet lappliyua plus parliculiciement à des corpulles hlunibes et lisses. comme sont quelg̨u: Tellines.

\section{(iALATIEE: Gaiathate.}

Cienre indiqué par Brünicice dans Ia !1. 250 de l'lincyctopédie, allopié e! caricitrisé pir

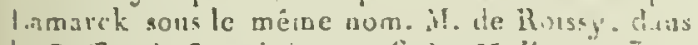
te Buffon de Sonnini, tom. 6 ches Moll. pugs . 124 , propesse de changer le no:n de Gulushés. quis a ¿: donné a un genre de Ciustatis, cont:a celui d'turierie, roalant par ce mnyen ériter les désa-

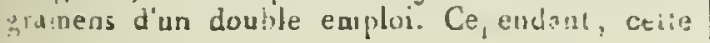

déuomination de Brnguière prévalut et fut consacrte à ce genre. Lainarck l'introduisit dans la méllode; dads sa Philosophie zoologique, il fait partie de la famille des Conques, ainsi que les Cyclides. La famille des Conques ayant été parlügée en deux dans l'Extrait du Cours, les deux genres Galathée et Cyclade composèrent celle sectlion, qui, plus tard, lut augasentée du genre Curèue démenbre des Cyclades. Les Galathées se (rnuvoient dès-lors dans des rapports oaturels. M1. Cuvier (Regne anim. tom. 2. pag. 480) trnuvant probublement insulfisans les caractères de ce genre, ne l'a point admis, et le rejinint aux Cyclades. M. de lerussac, dans ses Tableaux systématiques, adople le genre ainsi que les rapports yue lui donnc lamaick. M. Lutreille (Familles naturelles du Rigne animal, pag. 218) fait de mêne; sculement il en rapproclie les Cyprines, que tnus les conchyliolngues laissent de préférence à côté dés Vínus.

M1. de Blaiuville, dans son Trailé de Malacnlogie, ne differe ed rien de M. Cuvier; il n'admet en eller que le seul genre Cyclate, dont les Curcues \& les (ialabces devienuent des sections oit Houpes d'esicces. Tout en imitant dians son ensemble la mílhode de $M$. de lilainville, M. Ran: sut l'aruétinerer dans plucieurs prints, et iri luutout ex féparant, a l'exemple de lamarck et de Mi. de VHussac, les set:tions des Cyclates en genres disincts. Mi. Sorverby doune à regrel, dir-il, le nom de Polamophile à ce geare pnul éviter de le confondre avec le genre Galarhe, apparteoant aux Crullacés; naais si l'on vouloit opérer ви changement de onm, on a celui d'Egrérie, donné Jien antérieurcinent par M. de Rrissy: ce nom de listanophitile ne peut donc être adonis clans la nétloje.

\section{CARACTÉRES GÉNERTQUES.}

Coquil'e fort épuisse, équivalve, subrigone, recouverte d'un cpicterme verdatre; dents cardinales sillonuces, denx sur la valve droite connirentes a leur hase, trois sur l'autre valve; l'inlırıédıaire pyranidale, trigone, avancée, séfracéc deu's Gára!es écaltérs, à peine distinctes; li ratcent exsérieur court, saillant, boubé; ny njile unéminente.

On voil, par ces caractères, que les Galathées dillent nutamencu: des Cyrenes; les charnières

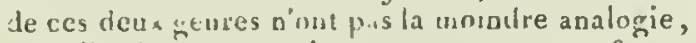
et celle du genre qui unm, occrpe a une forme et une dispresting inut-à fail à part de inat re que nous ronuoissons. Sur la valve druite, se vojent deux grindes deats convergentes en forme 
de V; le sommet de l'angle est entaillé par une cavité triangulaire lort pelite; de chaque côté des grandés dents et en debors il y a uuc cavité alongée, étroite, dont la postérieure est la plus cuurle : elle est tronquée par un rudiment de dent latérale. Sur la valve gauche ou remarque également deux grandes deuts cunvergentes, mais qui ne se rejoignent pras an sommet; ce sommet présente une petite saillie triangulaire, et l'intcrvalle qu'elles laissent entre elles est occupé jar une grande dent triangulaire, pyramidale, détacliée de toute part, portée en avant sur le loord. Le test de la coyuille est très-épais; les crocbets sont grands, saillans, et derrière eux est placé un ligament très-bombé, très-saillant, porté par tles ny mphes proéminentes. Les impressions musculaircs sont arrondies, profondes, et l'impression palléale, échancrée postérieurement, annonce que l'animal de ce gente étoil pourvu de siphons, comme cela a licu daus les Cyclades el les Cyrìnes.

Nous pensons que res caractères distinctifs sont bien suffisans, surtout lorsque la connoissance de l'animal y apportera quelque valeur. Nous croyons que l'animal des Galaihses diffère plus de celui des Cyclades ou des Cyrèues que ces deux geures entreux.

On ac connoit qu'une seule espèce de Galatliée qui vient des rivières de l'Inde ou de l'ile de Ceylan.

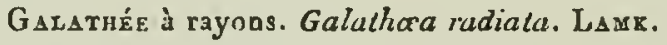
Lamк. Ann. du Mus. Lom. 5. pag. 43o. pl. 26 .

Ibid. Anim. s. vert. tom. 5. pag. 555.

Egeria radiata, Rorssy, Buffon de Sonnini, tom. 6. des Moll. pag. 327.

Venus paradoxa, Borv. Mus. cas. vind. pag. 66. tab 4. fg. 12.13.

Venus subviridis, $\mathrm{G}$ мег. pag. 3280. 329.

Caмsuтz, Conch. tom. 6. pl. 31. fig. 327 à

Evcrci.pl. 250. fig. 1. An Galathaea? variété.

List. Conch. tab. 158. fig. 13.

Potanophila, Sow. Genera, $n^{n} .3$.

Cette belle et rare coquille épidermifère est remarquable par son épaisseur, par sa tache violelle iuterieure sar un fond blauc, el surtout par ses rayons au nombre de deux à qualre, d'un beau violel sur un fnnd hlanc de lait, qui se voient à l'extérieur lorsque l'on a enlevé l'épiderme. La figure cilée de Lister est difficile à juger; seroil-ce une variélé ou une espèce distincte, c'est ce qu'il est furt difficile de décider. d'après la fiurure qui ne paruit pas exacte: au reste, les différences seroient principalentenı dans la forme des crocbets, e! peut-être dans celle de la lunule, qui seruit plus grande dans celle de

\section{G A S}

Lister. On donne ordinairement les heuves de I'Inde et de l'ile de Ceylan pour patrie de celle coquille, mais $M$. Gray nous a assuré qu'elle avoit été trouvée dans le tleuve de Congo, ce qui est confirmé par M. Sowerby.

\section{GALEA.}

Klein (Method. ostrac. pag. 56) réunit sous celte dénomination toules les coquilles qui ont plus ou mrins de ressemblance avec les Casques que portoient les Anciens. Dans ce genre, comme dans presque tous cenx de cel auteur, on trouve des coquilles fort différenles : des 'Ponnes, des Casques, des Cassidaires, des Porpres, des Can. cellaires, etc. e:c. Ce geare est counbé dans l'oubli comne il lo méritoit.

\section{GALIINULA.}

Genre érabli par Klein (Meth. ostrac. pag. 56) pour les coquilles que l'on compare à des poules qui couvent, parce qu'clles ont le bord dioit en furme d'ailes. On tronve, dans celle coupe principalement, des Strombes qui se rapproclient du Strombus carinatics, et des Volutes : tels que la Neigreuse, le Pavillon d'orange, etc. Ce genre n'est plus admissible.

\section{GARAGOI.}

Nom dobné par Rımplius et adopté paı Klein (Method. ostrac. pag. 55) pour distinguer une coyuille qui, d'après cet auteur, ressemble à un Buccin, lorsqu'on la voil du cồlé clu dos, mais dont la forme de l'ouverture l'en éloigne. Il est fort difficile de jurer celle question, puisqu'on ne cite que de nauvaises figures, et vues seuletnent du cóté da dos.

\section{GARIN.}

Adansnn donne ce nom à une espèce de cợuille bivalve qui ressemlile à une Plicalule : elle appartient rependant au geure Huitre, conme on peut le conclure de la courte destription et de la fonure incomplète d'Adanson (Voy, au Sénseg. pag. 200. pl. 14.fig. 2). Voyez Huiтre.

\section{GARNOT.}

Espèce de coquille du genre Crépidule décrile el tigurse par Adanson ( $\nu$ oy. au Sénég. pl. 2. fig. 9). Cette coquille est restée douteuse. Vojez Chepidule.

\section{GASAR.}

Une variśté de l'Ostrea parasitica Gmel. et Lamk. a reçu ce nnm d'Adanson. (Voy, au Sénég. pl. 14. fig. 1). Voyez Hoitre.

\section{GASTERROPODES.}

Dénominalion introdnite dans la science depais 


\section{G A S}

long-lempss par M. Cuvier, duns fun Tableau élémentaire du Regne animal, publié ì la tin du siecle dernier (1798). Celte dénomination très-convenable, qui exprime une unaniére d'šre des animaus auxquels elle s'applique, me pouroit manquer d'ètre adoptée, ainsi que les idlées systémaliques nourelles dont elle étoit la suite. Cette distunction des Mollusques en grands ordres, d'après les organes locomoteurs, entrainoit avec elle de toute nécessilé les changemens les plus remarquables dans le systèrue de Limné; on derout désormais abandonner celte dislinclion, dés-lors inadmissible, ae Mlıllusques i coçuil'es et de Mollusques nus ranirés dans des classes différentes, sur ce caractère de peu d'inportance de l'exislence ou de l'absence d'un curps lestacé protecteur: telle est l'influence du thoix que fuit le zoologiste des parties caractérisantes d'une classe ou d'un ordle d'animaax, qu'il parvieut par cela seul à une bonne ou à une mauvaise classificalion. Si nous n'avians le projel, à l'article Nozlusqoe, d'entrer dans quelyues délails sur celle questiou importante, nous trouverions daus les Gastoropodes un exemple des plus remarquables de cette unfluente. Elle n'es! pas superlicielle, conme on pourroit peut-être le croire si l'on n'y réllécbissnit pas assez; car, à côté de celle idée qui parnit si simple, d'un animal gastéropode, vient s'en grouper bcaucoup d'autres, qui sont le complément nécessaire el indispensable de la première.

Les cluangemens de classificalion résultant de l'établissement des Gastérupodes éloient trop iınportans et pouroient conduire à des résultats trop favorables à la science pour ne pas être adoptés. larmarrk qui, presqu'en même temps que 11. Cuvier, Iravailluit a une classification des Mollusques, parvenuit de son cátć et par d'autres moyens à perfectiunner cunsidérablement la mélhode (voyez Mollosque): dans ses premiers (ravaux il ne mentionna pas les Gastéropodes; il ne les adopta que danssa Philosophie zoologique, mais 11. de Rois.y, avant cela, avoit admis cette divisiun fondumentale dans le Buffon de Sonnini; depuis lors elle a été iutroduite dans toules les méthodes. Lamarck est le seul des zuologistes qui ait parlagé les Gastéropodes de M. Cuvier en deux parts : les Gastéropodes proprement dits, et les Trachélipudes. Celte distinction, il fant le dire, ne préseute aucun avantage; ellé est mêcoe nuisible, en ce qu'elle se fait précisément entre les deux las illes qui démontrent le mieux l'impossibilité de ce partage, celle des Hílices et des Limaces. Nous reviendrons sur les Gastéropodes à l'article Molnosqee, anquel nous renvoyons.

\section{GASTEROPTEROPHORA.}

Nom employé par M. Gray, dans la classification naturelle des Mollusques, pour sa troisième classe de Mollusques, qui ne conlient qu'un seul genre, celui des Plírolractićes, dans lequel sont compris les Cariuaires et los Argoniutes. Ce qui est rès-remar(yuable dans l'arrangement du savant zaologiste anglais, c'est la place qu'il donne i celle classo a la lin des Gastérupodes, is la suite de reus yui sont uns et immédiarement avant les pićropodes. Celle amblioration dans la méthode a été adoptée presque entiiremenI par M. de Blainville, duns son Tlaites de Mulacologie, comme nous le verrons à l'urticle Nolzosque.

\section{GASTROCHENE. Gustrochana.}

Genre institue par Spengler, dans les Nora Acla danica, ton. 2, pour quelques espoces de coquilles birulves qui ue se distingueat pas di's Iislulanes. Voyez ce mol.

\section{GASTROPLACE. Gastroplax.}

En 181 1 , Lamarck créa pour la Patella urnbeliata, vulgairement le Parasol chinois, le geure Unbrelle, dont on ne con:soissuit pas alors l'animal. M. de Blaiuville, l'ayant vo le preunier dans ie Muséun britannique, le fit cannoitre suns le nom de Gastroplax. Ce sera à l'article Orbrelle que nous ctonnerons quelques détails et sur l'animal el sur sa coquille. Nous lc ferons d'autant plus facilement que nons possédons un anirä bien eutier de ce genre, ronservé dans la ligiueur.

\section{GATAN.}

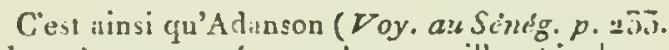
pl. 17) a nummé une des coguilles hivalves, qu'il placoit daos son genre Came, que Linué a désignée sous le nom rle Solen vespertinus, et dont Lamaick a fait la Psammobie vesperlinisle, Psanimobia vespertina. Voyez Psamaовг.

\section{GATEAU FEUILLETÉ.}

Nom vulgaire et marchand du Chama lazanus, l'une des espèces les plus communes du genrs Came. Voyez ce mol.

\section{GEHYDROPHILES.}

C'est de celle manière que M. de Ferussa: nomme le sccond sous-ordre des Pulmoués; il a vouln, par le nom de celte division, exprimer un des caractères des animaux qui y sont rassemblés, animaux qui vivent lantốt à l'air et tan!ôt dans l'eau, ou plulôt babitant des rivages maritimes, ils peuvent être momentanément couverts d'eau : c'est ce qui a lieu pour les animanx de la famille des Auricules, famille qui est la seule de ce sous-ordre. Woyez Auriculfs, Pulmonés el Mollosqua.

\section{GEMMULINES.}

M. d'Orbigny, dans son travail sur les Céplls. 
lopodes, a donné ce nom à un sous-geure des Bigénérines. Voyez ce mot.

\section{GÉNOT.}

Cette coquille, nummíe ainsi nar Adauson (Voy. au Sénég. pag. 145, pl. 9), a été plackée a tort dans le genre Voluta par Guelin. M. de Blainville lui trouve plos de rapport avec les Cônes quavec les Volutes, et nous croyons, apiès la lecture attentive de la description d'Adinson, quielle appartient aux Pleurotomes. Ioyez ce mot.

\section{GÉOCOCHLIDES.}

Tnus les Mollusques vivant a l'air libre ef a la surface de la terre, qui sant manis ti'une cequille spirale, ont été placris par M. Lalrcille daus les familles naturelles do rène animal, dans une mêuce fáaille à laquelle il a donné ce nom. Cette famille ressemble beancoup à cclle des Limaçons de M. de Ferussac, ainsi quì̀ celle des Colitoanés de Laararck. Poyez ces mols et Mollusque.

\section{GÉOPHILES.}

M. de Ferussac, dans sci Tableaux systématiques des Mollasques, partage les Pulmonés nun operculís en trris sous-ordres; Ie premicr, sous le nom de Grophiles, rassemble deux familles, celle des Limaces el celle des timicons. Voyez PuLSTONÉs.

\section{GÉOPONE. Geophanus.}

Montlort, danssa Conchyliologiesystématique, a tiabli ce genre poor une petite coquille de la Mréditerrance, qui vit, comme benuconp d'autres Céwhalupodes microscopiques, sur les fucus ou les polypiers. Celle coquille ne pouvoit constuber un yente, surtout a vec les caractères donnés par Mnuiforl; elle reatre daos les Polystomelles, dont elle ne preut se distingner. Vayez PosysTCuELre.

\section{GERVIJLIE. Gervillia.}

3. Defrance est l'anteur de re genre; il l'a dédié à M. de Gerville gui, par ses nombreuses recherches aux environs de Valognes, a décnuvert un grand nombre de corps organisés tossiles, el qui méritoil bien de vuir son nom aftzclé à un bon gevire. BI. Defrance ne connut d'ahord les Gervillies que par des nocules intélieurs d'une espèce répandue dans la craie ce Valognes; il caractérisa le genre d'aurè̀s ces matériaux incouplets, et on seut lien cuse les craractères durent s'en ressentir : cepentant cet auteur avoil bien saisi les caractires nrincipan. Pea de remps après la publication de M. Defunce,

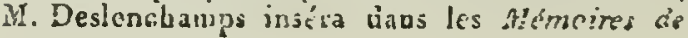

la Société linnéenne du Caluados (1om. 1. 1826). un Mémoire assez étendu daas lequel i] reclitiv les caractères donn's par M. Defrance, d"aprés l'examen de plusieurs espèces nouvelles dont if observa les coqnilles en nature et uon d'après les moules.

Le genre Gervillie, devenant moins incertain, ponvorit être adoprić, et il le fut en eflet par 11. de Blainvilie, dans son Trité de Mialucologie. par M. Laireille, dans ses Fumilles naturelle. du Règne animal; par.M. Rany, daus son Manuel; el entin par nous, dans le Dictionnare classique d'Histoire naturelle. I.es rappurls de ce' genre ont étć fixés dès sa créalion; on ne ponvoit y voir qu'nne modificalion des l'ernes, it il étoit impossible, par conséquent, de l'ell ćloigner. lies Gervillies furent done admises din: la famille des Malléacćes de Lamarck, el vinrent se placer entre les Pernes ot les Crin:tules : c'est la quon les trouve daus les ouvragte. que nous avons cités précćdeuıneut, el c'est th certaincınent où il res:eı, à noilts çu'on t:e le réunisse aux Peracs i litre de sous areure.

\section{CARACTERES GENEIQUES.}

Coquille biralre, inécuivalve, inéquilatéra!c, alongée, un pen arquuéc, sularansve'sse, trèjoblique snr sa base, non ballunle; rbarniète double, l'extérieure formée de sillons laruges. peu profonds, plus ou moins nambreux, oppin sés sar chaque valve, desinés à recevoir de. ligamens comme dans les Perues; lintérieurc it dents urès-obliqnes, alternes sur chaque valice et se recevant nutuellement.

Nous empruutons celle phrase caractéristique à N. Deslonchamps, parce qu'elle exprime, aus.i bien qu'on pent le ilesirer, les caractères dintinctifs iles Gervillies. Daus le Dictionnaire clis.. sique d'Histoire raturelle, nous avons jugé tos plancbes qui accampagnent le Mémoire de M. Deslonchamps plus sévèrement qu'tlles ne méritoien?: le hasard nons avoit fait comber dans les maill. de snanvaises épreuves, d'après lesquelles noc: avicns porté notre jugcment qui doit être rectitié, car il sernil à desirer que wuies les $l_{1}$ gures données par les naturalistes fussent ause: bounes que colles-ci, quoique cependant elles soient encore loin de la perfeclino. Les $\mathrm{G}(\cdot-$ villies sont des coquilles alongées, étroites, it charniive droite $t$ très-oblique par rapport à l'are des valves; celle charuièce ésl composíe, cotzme dans irs Pernes, d'une sírie de golittières longitudinales plus ou moirs nutnloreuss, scion les espèces, se correspundant dass li'; deux valves, ct donnant insertion à un liyau.cu! multiple : ces goutlières sont creuscécs da as l'épaisseur du talon des ralves. En dedaus de ces mềm('s goullicres, co tronve sur chaque ralve deax (") trois aents obligges très-lungues, fort étroites, 
- cble desqueilles sont des cavités olslongnes e! Litruites destinces à recevoir les dents suillaries de l'autre valve: c'est là le carautère le plus saillant et le plus distinclif des Gervillies. Leur forme n'esi pas constante: quelques-unes snnt pernoides et thrt alongtes, d'autres sont it lexléricnr tout-à-fait semblables aux Avicules, ayant un prolon:rement saudiforme postérieut. 'Toutes les espèces connnes jusqu'à présent tlans le geure qui nous occupe sunt fossiles el apparlienuent aux terrains secondaires: c'est dans i'oolite et les argiles qui en ispeodent quiclles se trouvent particulièremen:. Nous ne cileruns que quelylues espèces, n'ayant pas à notre disposstion toutes celles décrites par M. Deslonibarups, qui ne sont pourtant qu'au uoubre de cinq.

1. Gervilise aviculoide. Gervillia avicuioides. Sow.

G. testâ elongatâ, crasssá, obliquissimâ, subcylindracáa , anticè acut $\hat{i}$, subauricul $\mathbf{\imath} t \hat{a}$; auriculis integris; sulcis curdints externi magnis, numerosis; dentibus cardinis interni polymorphis, obliquissimis.

Perna aviculoides, Sow. Mirn. concle.pl. 66.

Gervillic aviculoides, ibid. Min. conch. pl. 511.

Genillia pernoides, Eudes Deszoncuamps, Mén. do la Soc. linn. du Calvados, tom. 1. pag. 126. n?. 1. ll. 1.2. 3.

Coquille longue, élroile, subcylindracéc, trèspointue antćrieurement, arrondie postírieurement el un peu arquée dans sa Iouguenr. Le lrord cardinal est très-alongé, droit, un peu relevé en aile aplatie postérieurement, il rorme avec l'axe des valves un augle très-uigu; les valves sont très-épaisses, sarlout dans la lungueur de la charnière, elles samincissent à leur extrémilú postérieure : elles snnt lisses oll presque lisses, ne présentant jamais que des stries d'accruissemeut. A l'intérieur elles sout polies, peu concares, el sont pourvues d'une impression musculaire, ovale, obronde, subcentrale, placie aul-dessous de l'extrémilé du hord cardinal irèsprès du bord. Sni la partic externe du hord ratdinal on conıpte sept ou huit goullic̀res, larges el peu profondes, pour l'insertion des ligauens; elles sont parallèles et perpendiculaires relalivement au bord. La partie interoe du bord présente quatre on cinq dents irrégulières, ondées, saillarites, à côlés desquelles sont rreusćes des cavités semblables pour les dents de l'autre valve.

Cette coquille, qui a quelquefois plus de deax décinètres de longueur, se trouve dans le calcaire de Caen arec abondance, mais dissoute, et n'offrant que la conche corticale et fibreuse, qui est Irès-nince. On la trouve aussi aux VachesNuires, mais complétement conservée, et enfin en Angleterre dans unc position géologiegue semblable.

2. Genvinhe solenoïde. Gervillia solenoides. DEF.

G. testi longissimâ, soleniformi, arcuntâ, angusta, tenui, anticè truncata; candine brevi, obliquissmo; sulcis quatuor; dentibus cardinis interni mumenosis, zariè dispositis.

Def. Dict. des Sc. nat. tons, 18. pag. 50.j.

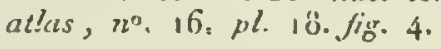

Deszoncr. loc. cit. $n^{\circ} 3$.

Sow, Mun. conch. pl 510. fog. 1 iो 4 .

Brainvilee, Traité de Malac.pag. 530. pl. (i). fig. 4 .

Cnquille lungue, étroite, mince, lout-i-fat solénilume, comne sun unn l'indirgue; elle est courbie dans is lungueur coume le Solen chsis, et devuit étre fort aplatie i en juger par les impressions quelle a laisstes. lue bord cardinal est rei!ement oblique quil devient presque paralièle a l'ase tes valves; il est tronqué arlérieuremsut el à peine relevé à son extrémilé postérienre. Ce bord est très.court, et ne présente janais sur le calon plus de trois orz quare sillons pour le ligament muliple. Sur le bord interne de lis chainière se trouvent les denis cardinales, peliles, alongees, obliquu's, étroiles, irrégulièrement lisposées.

OII ne comnoil celle espèce de Gervillie que d'après les uncules et les impressions. M. de Gerville la découvrit aux environs de Valognes, dans la craie, el depuis elle a élé retrouvée en Angleterre également dans le terrain crayeux. Celle coquille a quelquefuis donze ou treize cenlimètres de longuetr et seulement donze on quacorze millimètres de large.

Les autres espèces de Gervillies ne bous sont connues que par les fugures et les descriptions de M. Desloncliamps. Liune d'elles, comme ce savant naturaliste l'ulserve fort bien, n'a pas les caractères du genre: sa forme d'A vicule ne servit pas le seul nuulif qui nous feroit replacer celle espéce dans ce genre, car nous ne pensons pas que les plis irréguliers du bord cardinal puisse étre un obstacle à la juicdre aux avicules.

\section{GIBBE. Gibbus.}

Monifort, dans sa Cenchyliologie systématique ( $10 \mathrm{~m} .2$. pug. 302 ), a élabli ce genre à tort pour une coquille, il est vrai fort singulière, le Bublmus lyonetianus de Bruguière, décrit dans le premier volume de ce Dicliomnaire, anquel nous renvoyons. Lamarck a compris cette coquille an nombre des Mailinıs. Voyez ce mot.

GIOENIE. Gieonia.

Tons les conchyliologistes ont reconno avee 
Draparnaud la supercherie de Gioeni, qui a décrit, dans un pelit Mérnoire isnprimé à Naples ea $178 \mathrm{a}$, les labitudes, la manière de marcher d'un animal fabuleux qui n'étoil (pe l'estonac armé de pièces calcaires du Bulla lignaria. La description étoit tellement circonstanciée, que Bruguière et Retzius y fureot trompés et en firent uı genre sous le nom de l'auteur, qui, au reste, avoit eu assez peu de modestie pour se le dédier. Bruguière lui a donné le aom franęais de Char, auruel nuus renvayons.

\section{GIROGONITE. Girogonites.}

Tong-temps on fut trompé sor la nature du corps nommé aiosi par Lamarck; re savant le plaça dans ses méthodes parmi les Céphalopośes, ce que presque tous les zoologistes firent après lui. Léman découvrit la nalure de ce corps, qu'il faut reudre a la botanique, puisque ce a'est autre chose qu'une graine de chara.

\section{GIROL.}

Adanson (Voy. au Sénég. pag. 61, pl. 4) uurame ainsi une jolie espèce d'Olive que M. Iamarck, d'abord dans les Annales du Muséum, et ensuite dans le tom. 7. des Animaux sans verlebres, pag. $4=7 \cdot n^{\circ} \cdot 87$, nomme Olive glandiforme (Oliva glandifornis). Le Girol d'Adansou n'en est qu'une variété. Voyez Onve.

\section{GITON.}

Adanson ( Voy. au Sénég. pag. 124.pl. 8) piace sous ce nom, parai les Pourpres, une petite cequille qui n'a point été indiquée dans la synonymie des nouveaux auteurs, et qui laisse du doute quantà son genre, paree que la figure, qui est mauvaise, ue supplée pas suffisamment à la description. M. de Blainville la laissc dans les Pusurpres; ce poarroit ctre an Buccia de la section des Nasses.

\section{GIVAL.}

Nom donnć par Adanson ( Voy. au Sénég. pag. 37. pl. 2. $n^{\circ} \cdot$ 7) uu Patella graeca de Linné, qui est aujourd'hui, pour Lamarck, le Fissurella grapa. Voyez Fissorelle.

\section{GLADIUS.}

Dénomination tirée de la comparaison avec le puisson Xiphias gladus, que Kleio (Tent. ostrac. pag. 59) a appliquué à une coupe générique, qui is été établie de nouveau par I:anarck sous le nәz de Rostellaire. Vayez ce mot.

\section{GLANDIOLE. Glandiolus.}

Genre que Montfort étahlit dans sa Conchyliologie systématique (tom. 1. pag. 314), d’après lize figure de Soldani, pour an colps microsca- pique qui est resté doutcux; on ne peut done, quant à présedt, admellire le genre Glandiole, qui, selon la pensée de M. d'Orbigny, seroit une coquille jeune; aous ajontons, et peut-être mutilée.

\section{GLANDULINES.}

M. d'Oubigny donne ce nom an prewier sousgenie des Nodusaires Voyez ce mot.

\section{GLAUQUE. Glaucus.}

Connus depuis long-teraps, les Glanques ont été établis en geare par Forster, dans le tam. 5 du Mlagasin de Voigt; il a été ensuite admis par la plupart des zoologistes, qui, à l'exemple de Forster, l'out fait sortir des Doris, où Linné el Guelio l'a voient placé. M. Cuvier, Règne aninual, tom. 2 , le rage dans les Gastéropodes nudibranches, entre les Eolides e! les Suyilées : Bose les avoit coulondus avee ce dernier genre. Lamarck a considéré ces Mollusques, d’après leur habitude de nager à la surface de l'eau, comme un passage enıre les Híropodes el les Gası́ropodes; aussi le met-il le premier daus sa lamille des Tritnaiens (2ojez ce mot), qui commeace les Gastćropodes, et qui suit immédiatement les Héléropodes. M. de Ferussac a laissé ce genre dans les mêmes rapporte que $\mathbf{M}$. Cuvier; mais il en a formé avec lui une fumille séparée des Nudibranches polybranches sur le nonibre des tentacules. Il est à remarquer, avec $\mathbf{~} 1$. de Blainville, que, jusqu'à la publication de son Mémoire sur l'ordre des Mollustrues polybranches, inséré dans le Joumal de Physique, lous les observateurs qui ont mentionné ce Mullusque, ou qui l'ont liguré conme Blumenbach, l'ont lous représenté sens dessus dessous, ayant considéré sa surface abdnminale comme élant la dorsale, et vice versâ: Cette erreur a dì les porter à dire que les oritices de l'anus et de la génération soot situés à gauche; ce qui auroit été nnique jusqu’ì présent dans les Mollusques. En rétablissanı celuici dans sa vérilable position, il rentrera dans la règle générale. Il paruit aussi qu'on avoit vu cet animal d'une manière fort incomplète, car M. de Blainville, qui en a fait nne description fort détaillée dans le Dictionnaire des Sciences naturelles, a eu oceasion de rectitier plusieurs erreuts assez notables.

Nous ne suivrons pas cet aliteur dans sa descriplion détaillée el savante; elle pourroit faite le sujet d'un ménuire plutôt que d'un siasple article; nous anus cuntenterons d'en doaner $u$ extrail. Ce petit Mollusque, très-contractile, d'après les furmes que lui donnent les fuures $\mathrm{d}_{\mathrm{s}}$ : auteurs, comparées à celle de l'animal lui-méme conservé dans l'aleool, est revêtu d'une peilı qui est beaucoup plas a inple qu'il de le faut pour coulenir juste les viscères, qui sodt rassemblés en une pe:ite masse i la partie antérieure; le 
corlys, vu dans son entier, est triaggulaire à sa pariie antérieure où sa base est placée; la boucbe surmontée de quatre tentacules; la surface abdominale est aplatie et entièrensent occupée par un disque charnu musculaire, qui est le pied que l'on avoit pris pour le dos, l'animal ayant l'habitude de nager renversé; le dos est bombé et ne préscate rien de remarquable; de chaque côté, et ordinairement d'une manière symétrique, naissent quatre appendices digités qui servent de nageoires, et probablement à porter les branchies.

Les naturalistes gui ont vu cet animal vivant s'arcordent à dire qu'il est d'un très-beau bleu bordé d'argent, et les branchies sont de la wême couleur, mais plus vivement coloriées aux extrćuités qu'à leur origine. On peut caractériser le genre de la manière suivante.

\section{CARACTÉRES GÉNÉRIQUES.}

Corps alongé, subeylindrique, gélatineox, ayaut une tête antérieurement, et terminé postérieurement par une quene grêle, subulée; iête courte; bouclie probosciditorme, surmontée de quatre tentacules par paire, les plus grands étant sans doute oculés; nagcoires brauchiales opposées, palınécs et digitées à leur sommer, latérales horizontales, au nombre de truis on quatre paires; les postérieures presque sessiles; les ouvertures pour la génération el l'anus ouverts latćralement dı côté dinit.

On a prélendu qu’il y avoit plusieurs espèces de Glauques; on a pensé que le nninbre de paires de nageoires pouvoit servir pour les distiuguer, mais on s'est bientôl aperçu que ce caraetère pris seul était insuffisauı par son extrètne variabilité. Oa ae connoil donc encore que l'espéce suivaute.

Glavque de Forster. Glaucus Forteri.

LAnx. Anim. sans vert. tom. 6. 1re, part. pag. 30o.

Glaucus atlanticus, Вцамемвасн, fig. d'hist. nat. pl. 48., et Munuel d'hstoire naturelle, tom. 2. pag. 22.

Glauius, Perrox, Ann. du Mus. tom. it. pl. j. fig. 9 .

Scyllée nacrée, Bose, Hist. nut. des vers.

Glaucus Forsteri, Busivv. Malac. pag. 485. pl. 46 . fig. 3. a. b. c.

Ce Glauque est long environ diun pouce et demi; il vil très-abondamment dans les mers chaudes, et même dans la Méditerranée. On le voit en grand nonabre a la surlace de l'eau nayeant avec une graude rapidicé dans les temps calmes.

GLAUQUES (les).

M. de Ferussac, dans ses Tableaux sjsiémaHist. Nat. Wes Fiss. Tome II. tiques des Animaux mollusques, proposa cette famille, qui, dans son système, est la troisième des Nuclibranches; il y introduisit les geures I.rniogère, Glauque, Eolide et Tergipe. Cettc famille n'a pas étú adoptée. Voyez les geures que nous venous de ciler el Moliusque.

\section{GLOBIGÉRINE. Globigerina.}

On est redevable de ce genre à M. d'Orligny, qui l'a propusé la première fois daus son travail général sur les Céplaalopodes, inséré dans le 10m. 7 des Annales des Sciences naturelles. Mi. Rang qui, dans son Manuel, a admis sans changemens la méthote de M. d'Orbiguy, a laissé le geare Globigćrine dans les rapports qui lui fureni primitivenent donnés; il est compris duns la première section de la faoille des Hélicostègues ( voyez ce not), entre les geures Calcarine el Gyrnidine.

Nous peusons, comme MI. Rang, que le genre Globigérine est nécessaire et doit être conservé, duais nous eruyons que ses rapports pourroient êtue meilleurs, et e'est au moins dans l'intention de les rendre plus nalurels que nous les avons modifiés dias le Tableau que nous avons douné des Céphalopodes microscopiques à l'article Cépralopodes, a uquel nous renvoyons.

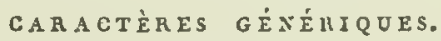

Coquille libre, trochoïde, irrégrulière; spirc plus ou moins confuse, fornće par des loges splériques plus ou moins distinctes; ouverture eu forme d'éehaucrure, plus ou moins profunde et arrondie, sicuée à la base de l'axe de la spire, à l'angle ombilical.

Dans les divisions que nous avons fuites dans les familles des Cépbalopodes microscopiques, nous avons choisi comme essentiel un earaelère auquel M. d'Orbigny n'avoit pas assez donné d'importance; nous voulons parler de la iorwe et de la position de l'ouverture. Le genre qui nous occupe méritoit sous ce rapport de furmer un groupe à lui seul, ay ant non-seulement une forme et une composition toute particulière, mais encore l'ouverture placée d'une manière qui est propreà ce genre.

Nons arons nomme Trochiforme la famille dans laquelle nous rangeons les Globigérines; eette famille, comme son nom l'indique, ne contient que des coquilles trochoides non symétriques, que II. d'O bigny a voient placées dans une même famille avec celles qui sont symécriques et nautiliforrucs. Quoique plusieurs espèces de Globigérines ne présentent qu'une spire obscure el quelquefois très-aulatie, le plus grand nombre est téllement trochilorme, et sert à détruire l'bésitalion que l'on pourroit avoir sur les precnières. Les Globigérios sont des coquilles extrêmement

$$
\mathrm{Y} *
$$


pelites, formées d'une série de globules enfilés sur un seul axe tuurué en spirale; chaque espèce est composée, dans l'état parfait, d'un nombre assez constant de globules; le derniel seul est nuvert, et 'ouveriure, coinme nous l'avons dit, a une position particulière au genre. M. d'Orbigny cite dnuze espèces dans le genre Glohigérine; le plus grand nombre sont vivantes, quelques-unes sont fossiles : Soldani, qui avoit si bien exploré les sables coquilliers de Rimini, en avoit figuré quelques espèces. N'ayant pu recueillir qu'un petit nombre d'espèces de ce genre, ce seront celles-lá seulement que nous décrirons.

I. Globigénine hullnïde. Globigerina bulloides. D'ORв.

G. testâ albâ, irregulariter subovatâ, depressâ, spirata; globulis distinctissimis, lavigutis ; aperturâ rotundâ. NoB.

D'On B. Mlémoire sur les Céphalopodes, Ann. des Sc. nat. tom. 7. pug. 277. $n^{\circ} .1$.

Ibid. Modeles de Céphal. 1re. livor. $n^{\circ} .17$ et 4e. livr. $n^{0} \cdot 76$.

Solani, Micros.tom. 2. pag. 117. tab. 123. fig. H. I. O. 1'.

Celle coquille microscopique est irrégulièrement ovale, subglobuleuse, un peu déprimée, forméc d'une série de sept ou buit globules disposés dans une ligue spirale; elle a un aspect particulier qui la distingue assez facilement des autres espèces que nous connoissons, à cause du plus grand nombre de ses globules; cbacun d'eux est très-nettement séparé de ses voisins, auxquels il est fixé par une petite partie de sa surface; tous les globules sont lisses, croissent successivement depuis le premier jusqu'an dernier, qui est le seul qui soit percé à la base de la coquille d'une ouvertare ronde. Cette coquille a à peine un demi-millimètre de longueur; on la trouve à Rimini.

2. Globigérane poncticnlée. Globigerina puncticulata. D'Orв.

G. testâ minutissimâ, depressâ, tres quatuorve globulis formatâ; globulis undiquè puncticulatis; aperturâ rotundâ. Noв.

D’Orbignt, loc. cit. $n^{\circ} .8$.

Coquille beaucoup plus petite que la précédente, ayant à peine un cinquième de millimètre de longueur; elle est jaunâtre, composée de trois ou quatre globules bien séparés les uns des autres et formant un commencement de spirale trèsaplatie, un seul globule forme le sommet, les trois autres lui sont inférieurs; ils sont tons cbagrinés et cotverts de pouctuations éparses et nombreuses. La dernière loge, qui est la plus grande, est percée inférieurement d'une très-petite ouver- ture ronde, gui nous a paru placḱe plus exlé. rieurement que dans l'espèce précédente. Ayant recueilli cette espèce dans les sables de Rimini, nous avons pensé que c'étoit celle que M. d'Orbigny avoit nounmće Globigerina puncticulata, son nom et sa localité s'appliquant bien à elle.

3. Globig ÉRINe triloculaire. Globigerina trilocularis. D'ORB.

G. Lestâ ovato-trigonâ, depressâ, globulis tribus lovigatis fornatâ ; aperturd minimâ, subovatá. Nов.

D'Orbignr, loc. cit. $n^{\circ} .2$.

C'est encore parce que nous avons trouvé cetle espèce dans la localisé indiquée par M. d'Orbigny, et qu'elle a'a, comme son nom le fait eutendre, que trois globules, que nous l'avons rapportée au nom de Mi. d'Orbigny, sans avoir l'entière conviclion que c'est bien la même que celle qu'il a vue. Cette espèce est très-petite; elle est subtrigone, aplatie, le premier et le plus petit des globules se trouvant dans l'angle formé par les deux autres : ces globules sont moins séparés que dans les espèces précédentes; l'ouverture du dernier est en dessous de la coquille; elle est petile et subovalaire. Cetle petite espèce se trouve fossile aux environs de Bordeanx. M. d'Orbigny annonce une espèce de ce genre aux environs de Paris; malgré nos recherches assidues, nous ne l'avons jamais rencontrée.

\section{GLOBITE. Globites.}

M. de Haan, dans sa Monographie des Ammonites et de: Goniatites, nomme ainsi un nouveau genre démembré des Ammonites pour les espèces qui sont complétement involvées. Ce genre, qui est un double emploi des Orbulites de Lamarck, ne pouvoit être adopté, d'abord parce que par antériorité celui de Lamarck seal devoit être admis, et ensuite parce que ni l'un ni l'autre de ces genres ne reposant sur de bons caraclères, ne pouvoient être reçus dans la móthode après un examen na peu aprofondi. Vogra Círalalopodes et Auxonite.

\section{GLOBULINES.}

Nom que $M$. d'Orbigny donne au troisième sous.genre des Polymorphines. Noyez ce mol.

\section{GLOBUS.}

Une Bucarde et quelques Cames d'ane forme globuleuse constituent dans l'ouvrage de Klein ( Tent. Meth, ostrac, pag. 173) un geare qui est tombé dans l'onbli.

\section{GLOIRE DE MER. Gloria maris.}

Nom que l'on donne à an cône extrèmement rare et recherché des amateors. Broguière l'a 
dúcril dans le premier volume de ce Diclionaaise. Voyez Còne, no. I 46.

\section{GLOSSE. Glossus.}

Daos son grand et magnifipue ouvrage des Testacés des Deux-Siciles, Y'oli dnnne ce nom aux a oimaux a'un genre qui correspnnd comnlétement à celui nommé Isocarde par Lamarck. Voyez Isocande.

\section{GLOSSODERMIE. Glossoderma.}

Nom que Poli donne aux coquilles de son genre Glossus. Ce geure est le même que celui nummé par Lamarch lsocarde. Voyez ce mol.

\section{GLYCMĖRE. Glycimeris.}

La coçuille qui servit a Lamarck pour établin ce genre ćınit placée par línné au norsbre des My'es; elle présente en effet quelques-uns des ca ractères de ce genre, mais elle en ollie aussi de particuliers que tous les conchyliologues reconnuren! avec Lamarck: le genre Glyciucere lut établi et caractérisé dans le fremier lavail de Lanarck sur les coyulles; il fait parlie des Méunoires de la Sociélé d'Ilistvile uaturelle de l'aris, publiés en l'an 7. Ce geme, dans celle pre:vière méthode, se tronve à tôté des Sulens, mais on doil remarquer qu'il n'éloit pas dans l'origine ce qu'il est anjourd'lui. Le Nya glycimerss de Linaé lui fut donvé comme type, et cette coyuille est devenue le type du genre $\mathbf{P a}$ nopée de Ménard de la Graye : on s'aperçul de ce changement lorsque Lanul k pubia, eu, 801 , son Systême des Animaux suns vertébres; "an" au lieu de contiuuer de donner le Myce styci meris cunme type, il donna le Mya suíqua de Cheaınilz, coquille que Daudın présenta conne ty pe du gente Cyrtodare. Ce cliangement de laamarck entraina traiseublablement M. de Roissy (Buffon de Sonnm ) à adacitre les denx cuciutlles dans le genre Glycimère, quoiqu'elles u'apartrassent pas, cumate on vient de le vuir, a un nième genie. Jusqu'au moneut vù Lainarck dola la science de son dernier ouvrage, ou ne sut comoreb il composoil le gente Glycinere quil aroit intraduit daos la famille des Solénacées. (I’oyez ce mol.) M1. Cuvier, Règne anmmal, u'adupla le geare quuà citre de sous-genie des Mycs, et il douna pour exemple le MIya siliqua seulement. Lamarck ne fit pas de mêue, il udidue trcis espèces de Glyrimères, et de plus renvie au Mya edentula de Pallas. Jusqu'au moment où la collection de Lamart, en devenant la proprété de Mi. de Rivali, pul êlre examuné, ii fut impossihle de savoir ce queétoient les deux nouvelles espcces de Glycimc̀re; ce ne lut pas sans étnnnement que nous nous assurâmes que l'une d'elles, la Glycimeris arctıca, étoit uue nonvel espece de Panopée, et l'autre, !a Gily- cincerc nacrée, fussile de Grignon, appartenoit au genre Saricave. Cel examen onus donna la certılude qu'il n'existoit gu'une seule véritalıle Glycimère.

Dans son Traite de Malacologie, M. de Blainville rangra les Glycimères dans la famille des Pyloridés à cólé des Panopées; mais dans les additiuns et corrections, il fait pressentir que ce genre pourroit font bien appartenir à une autre farnille et se rapprocher des Mulettes et des Anodnntes. Ce rapprochement ne nous semble justitié par aucun bon caractère, le molif de M. de lBhainville étaut l'irosion des croclıels dans les Glycimères comase dans les Mulelles et les Anodontes.

\section{CARACTERES GÉERIQUES.}

Animal pourvu de deux grands siphons posléricurs el ríunis, ayant le manteau fermé dans presque toute son élendue; une petite fente pallísale antéricure pour le passage du picd. Coquille transverse, très-baillante de cliaque còté, couverte d'un épiderare fort épais, corné; charnierce calleuse, sans denis ni fosselles; nymplios suillantes au-dehnrs, fortint un ligament externe tıès-saillant e! lart solide.

lin modifiant de cette manic̀re les caractères géníriques, il devient impossible d’admeture dans le gence d'autres coguilles que des Glycimc̀res. Tuule coquille qui ne scra pas lrés-baillante aux doux exırérnilés, qui ne sera pas couverte d'un épicierne épais, el cuai n'anra pas une charniere Epraisse, calleuse et suns dents ni fossetles, scril nécessairtunent exclue du genre; c'est paur celu que nous n'y admettons qu'une seule espèce qui est la suirante.

1. Grycimère silique. Glycimeris siliqua. LAMK.

G. testâ transversìm oblongâ, ovatâ, utrinquè h)antissumá; epidermide nigro; natıbus decorticatıs; valvis intus disco calloso incrassatis; posticé impressione palli exiguè emalginato.

l.aMr. Anim. s. vert. tom. 5. pag. 458. $n^{\circ}$. 1. Rorssy, Buffon de Sonnini, Coquilles, tom. 6. pag. 428. pl. 70 . fig. 5 .

Mya siliqua. Crems. Conch. cab. tab. 198. fig. 1934 . torr. 11.

Glycimeris incrassata. Lamk. Syst. des anim. sans vert. pag. 126.

Bosc, Hist. nat. des coq. tom. 3. pl. 17. fig. I. 2 .

Sun вRвт, Genera of shells, no. 8. (genre Glyciuere).

Coquille transrerse, ovale, oblongae, arrondie et fortement háillante à ses exirémités; elle 
$1 ; 2$

est: recouverte d'un épiderme noir, excorié sur les crochets, luisant et strié dans le milieu; il ne paroit pas dépasser le bord des valves, comme cela a lieu dans les Sulćmyes; en dedans, cette coquille est d'un blanc-grisattre. L'impiession du manteau y est indiquée par une ligne profonde, légèremeat échaucrée postérieurement; cetteligne d'insertion circonscrit la callosité qui se voit à l'intérieur et qui ajoute à l'épaisseur et à la solidité da test. Le bord cardinal est arrondi, couvert d'un bourrelet décurrent, se joignant postérieurement à des nymples épaisses, terminales, postérieures, très-saillantes et donnant insertiou au ligament. Les impressions wusculaires sont petites, l'antéricure est trèz-étroite et fort oblique; la postérieure est lout près du bord et se joint a l'impression du muscle rétracteur des siphons.

Les Glycimères vivent bien probablement à la manière des Myes el des Solens, enfoncées dans le sable; on sait aujourd'hui qu'elles se tronvent en grande aboudance au banc de 'Terre-Neuve. Cette cuquille a 75 millin. de large et 35 de long.

\section{GLYCIMERIS,}

Le genre que Klein (Tent. Meth. ostrac. pag. 170 ) institua sous ce nom, conlenant arec le Chama Glycimeris (Panopée) des Myes et des Lutraires, ne peut être regardé cumme l'origine dn genie Glycimère de Lamarck. Voyez Grycimér.

\section{GOCHET.}

Adanson (Voy. au Sénég. pl. 13. fig. 4) a donaé celte épithère à urse torl belle espèce de Natice, qui est la Natica fulminea de Lamarck. Voyez Natice.

\section{GOLAR.}

Dans son ouvrage sur les coquilles du Sćnégal (pl.19.), Adanson a nommé ainsi ane coquille plus conaue sous le, nom de Solen strigilatus. Voyez SOLEN.

\section{GONDOLE.}

Adanson (Ioy. au Sénég. pl. 1) a donné ce nom au premier genre des coquilles univalves. Ce genre contient le Sormet et une Bulle. Il n'a pas été adopté. Voyez Sormet et Bulle.

\section{GONDOLE BLANCHE.}

Nom marchand d'une belle espèce de Bulle assez commune dans les collections; Lamarck l'a nommée Bulla ampulla. La grande Gondole ou la Gondole papyracée est une autre espèce de Bulle dont Monifort a fait son genre Athis, et qui n'est autre chose que la Bulla nancum Lanik. Voyez Bulle.

\section{$\mathrm{GON}$}

\section{GONIATITE. Goniatites.}

Geare proposé par M. de Haan daus la famille des Goniatitées ( voyez ce mot) pour des coquilles à cloisons onduleuses ou subarliculées, dont les tours sout complétement involvés. Dans les caractères de ce genre, qui ne peut être adopté, M. de Haan fait passer en première ligne ceux tirés de la forme de la coquille et de son enroulement complet, ne tenant pas assez compte de la positiun da siphon et de la forme des cloisons. Voyez Nautile.

\section{GONIATITÉES. Goniatitea.}

Dans la classification des Ammonées, M1. de Hain a proposé de former une famille à laquelle il donne ce nom, pour y placer les coquilles cloisonnées, qui lient ou font le passage de celles qui ont des cloisons découpées et persillées d celles qui ont les cloisons simples; mais de ces coquilles, les unes appartiennent indubitablenient aux Ammonées et les autres aux Nautilacées: il n'y a pas de caractères constans, soit dans la forme, soit dans la place qu'occupe le siphon; dans les unes il est dorsal, et on trouve un engrainage des cloisons, te sout donc des Ammonites; dans les autres, il est central ou ventral, et les cloisons, bien qu'onduleuses, ne sont point articulées, ce sont donc des Nautiles. Ainsi se truave déruile celte famille, dans laquelle cependant M. de Haan a voit élabli trois génres qui ue sont point admissibles non plus. (Vojez Cématite, Goniatite et Rhabdite, ainsi que Céphalopodes et Molluspue.

\section{GONIOSTOMES. Goniostoniata.}

M. de Bluinville, dans son Traité de Malacologie, a séparé cette fanille pour deux gen:es que Lamarck comprenoit dans celle Ges Turbinacées. Cette séparation est fondée sur la nature de l'opercule, et en cela elle répond au but que M. de Blainville s'êtoit proposé: de séparer bien nettement en deux grandes divisious, abstraction faite de la forme, toutes les coquilles des anciens genres Trochus et Turbo de Linné : d'uu côté, Jans la familie des Gonioslomes, toutes celles qui on l'opercule comé, d'un autre, dans celle des Cricostores, toutes celles qui ont l"opercule calcaire.

Nous n'adoptons pas la famille des Goniostomes composée des deux genres Cadran et Troque, parce que nous croyons que les caractères sont insuftisans; si l'on veut faire atlention aux nombreux passages qui lient les Troques aux Turbos, on verra coubiea il est difficile de séparer ces deux genres dans denx familles : nous allons même plus loin, car nous peusons qual conviendroit mieux de les réunir en un sert. Nous savons bien quon nous objectera la nature de l'opercule, mais nous répondrons par 
l'cxemple du genre Natice, dans lequel on laisse sans difficulté les espèces à opercule corné et celles à opercule calcaire : par un raisunnement bien simple, nous demandons pourquoi, dans un genre, ce caractère de la nature de l'opercule a-t-il si peu d'importance, lorsqu'il en a tant dans l'autre? Il nous semble cependant, par une :nnséquence de principes, que celte valeur devruit être la même partout. Voyez Molnusque, Cadras el Troque.

\section{GOR.}

Gauelin, dans la 13 e. édition du Systema natura', a réuni à une seule espècc, le Trochus panthennus, deux coquilles qui appartienuent certainement à deux espèces bien distinctes : l'nne d'elles est le Gor, \& l'autre le Kachin d'Adünson. ( Voy. au Sénég. pl. I2). Nous en reparlerons à l'article Trocuss, auquel nous renvoyons.

\section{GORDET.}

A l'article Gordet du Dictionn. des Sciences naturelles, M. de Blainville dil que celle coquille d'Adanson (Toy. au Sénég. pl. 16 ) est la nềme que li Venus africana. C'est en vain que nous avons clierché dads les auteurs une Vénus de ce nom, et celte recherche nous a donné la conviction rue celle coquille du genre Vénus n'est citce uulle part. Voyez Vénos.

\section{GORON.}

Dénnmination sous laquelle Adanson ( $V o y$, au Sénég. pog. 206. pl. 14) a décrit et figuré une coquille très-commune, connue sous le nom de Spondyle pied d'âne (Spondylus gaderopus). Voy'. SPOXOYLE.

\section{GOSSON.}

Adanson ( Voy. au Sénég. pl. I) nomme ainsi une coquille du genre Bulle, la Bulla friata Brug. Voyez le no. 3 de l'article Bucle du premier volume de ce Dictionnaire.

\section{GOUMIER.}

Adanson (Voy. au Sénég. pag. 156. pl. 10) a nummé ainf uue espèce du genre Cérite. Celte espèce se trouve dans la Méditerrance \& sur les cítes du Sénégal, il y eft fort commun. On ne le trouve pas cilé dans la treizième édition de Linné, mais il eft dans l'Encyclopédie, article Cérite, no. 13, sons le nom de Cerithium vul. gatım, qui a été adopté par Lamarck. I] eft évident d'après cela que M. de Blainville a comnis une crieur en rapportant au Gourmier, dans le Dictionnaire des Sciences natirelles, le Murex fuscatus de Linné, qui elt une espèce fort diflërente, nommée Cerithium muricutum par
Bıruguière (Encycl. méthod., art. CÉnate, no. 27 ), adopté sous le même nom par Lamarck (Anim. sans vart. tom. 7. pag. 70. $n^{\circ} .13$ ). Voy. Cérite.

\section{GOUSOL.}

La coquiile qu'Adanson nomme ainsi (Voy. ars Sénég. pl. 9) appartient saus aucun doute au genre Mitre; elle n’a été citce daus aucun catalogue. Voyez Mitre.

\section{GOU'TIËRE.}

Nom vulgaire que l'on donne quelquefois aux Raulles-foyez ce mol.

\section{GRAIN D'AVOINE.}

Geollioy, dans sa Conchyliologie des environs de Paris, pag. 53, a nommé ainsi, à cause de sa forme et de sa grosseur, une petite coqnille mise par Draparnilud et Lamarck dans le genre Pupa sous le nom de Pupa nucleus. Voyez Mali.Lot.

\section{GRAIN D'ORGE.}

Nom vulgaire du Bulimusobscurus de Bruguièse et de Draparnaud. Voyez Busime.

\section{GRATELOUPIE. Grateloupia.}

Genre proposé par M. Desmoulins dans le Bulletin de la Société linnéenne de Bordeaux: dédié à M. Grateloup, savant distingué auquel la science est redevable d'excellens travaux, le genre qui nous occupe mériteroil à ce titre seul d'être conservé. Nous doutons cependant qu'il le soit, an moins à litre de génre, car il nous sem. ble qu'il manque de caractères suffisans et tels que l'on est en droit d'en exiger dans l'état actuel de la concty yliologie.

1، a coquille qui est le sujet da genre Grateloupia est le Donax irregularis de M. Basterot, fossile des environs de Bordeaux el de Dax. Celle coquille se rapproclie en effet beaucoup plus des Donaces que de tout autre geure. Les Donaces, comme on le sait, ont deux ou trois dents cardinales, et de clıaque côté une dent latérale sur cliaque valve; l'une des dents latérales, la postéricure surtoot, manque très-souvent, elle ne se Irouve junais dans le Donax triangularis, par exemple, et antres espèces voisines; de plus, dans i'es espèces, la dent cardinale postérieure se déconpose on se divise en dentelures inégales. Dans la Gratclnupie, celle dent postérieure se déconpose régulièrement en quatre ou cinq petites dents décroissantes \& divergentes. Les antres caractères de celle coquille sont ceux des Donaces. Elant équilatérale, le liganent ne pouvoit ètre sur le plus petit côté, il est un peu plus long que 
dans les Donaces. La dent latérale postérieure a laissé nne trace de son existence, landis que la dent latérale antérieure est fort grosse et plıcíe très-près des dents cardinales; celles-ci, vutre les quatre fou cinq postérieures, sont au nom!,re de deux, dont l'une, sur la valve droite, est fort épaisse; elle est la glus antériemre.

\section{CARACTĖRES GÉNÉRIQUES.}

Coquille équilatérale, équivalve, régulière, nn peu sinueuse postérieurement; charnière ayant deux dents cardinales simples, antérieures, ot de plus, à la place de lá dent postérieure, uu série de cinq ou six petites dents seriales, rhyulièrement décroissantes et divergentes; une dent latérale antérieure fort grosse, raltyrochée des cardinales; dent latérale postérieure, abonlète; iunpression palléale, profondénenı échaurriée.

Il est indubitable que les Grateloupies sont très-voisines par leurs rapports des Donaces et des Cythérées; nous pensons qu'elles se rapprothent plas encore de ce premier genre que du dernier, et en cela nous somines un peu contraire à l'opinion de M. Desmoulins, qui, à cause de la légère sinuosilé du bord infirieur des valves, plice un nouveau genre à côté des Tellines : un grand noubre de coquilles de genr's et de familles dillireus peuvent avuir une suuosité au bord inférieur ldes valves, saus que puur cela on les puisse rapprocher des Tellines; il est d'autres caractères dont la valeur l'cmporte de beaucunp sur celle de celui-lid.

1. Grateloupie donaciforme. Grateloupia donuciformis. DesaOUL.

G. testâ ovato-subtrigonâ, politâ, lavigutí, absolete rudultâ; margıne integro, postice sub. sinuuto; lunulâ lenceolutâ, impressa.

Desmoulins, Bull. de la Soc. d'hist. nat. de Bord. com. 2. pag. 24.). f.g. I d 5 .

Donax irregularis, B Аsтелот, Ném. sur lesterrains tert. des env. de Bordeutx. - Mém. de lo Soc. dhist. nat. de Paris, tom. 2. pag. 34. pl. 4. fig. 19.

Coquille ovale, subrimone, équilatérale, arrondie et large antérieurement, plus étroite et reraninée par an angle ohtus postérieurement; elle est toute lisse, polie, brillante, obscurément rayonnée longitudinalement, et présentant quelques s'ries transverses d'accroissement; les crochers sont petits, pointus, peu sulllaus, à peine inclinés vers la lunule; relle-ci est étroite, lancéolé, nuédiocrement profunde. Lc ligament est plus grand que dans les Vonaces; nous ne parluns pas des autres caracteres de celle cogulle, qui sont les mênies que ceux du genre. Celte espèce, la seule fui suil tonnue, se truuve aux cnvirons de Burdeaux el de Dax; les flus grands individus ont 57 million. de longueur et 57 de largeur.

\section{GRENAILLE.}

M. Cuvier (Règn. anim. tom. 11. pag. 408) avait séparé des Maillots \& des Clinsilies les espèces uvales dont l'ouverture, garnie de dents ou de lames sur le bord on plus jrolondément: ont la forme des véritables Bulimes. Ce sous-gense n'a point été conservé par M. Lamarck; il fait partie du treizième sous-genre des Hélices de 11. Ferussac, les Cochlodontes, qui répondent assez bien au Maillot des auteurs. M. de Blainville, duns le Dictionnaire des Sciences naturelles, en fail la deuxième division des Mailluls. Voyez ce mot.

\section{GRENOUILLE.}

On donne vulgairement ce nom à un Strombe assez commun dans les collections, Stronibus lentiginosus L. (Voyez Strombe.) Sous la même dénoninalion on indique aussi une véritable $R_{\text {in }}$ nelle, le Murex rana de Linné, Ranella crumenu Laub. Ioyez RanelLe.

\section{GRIFFE DU DIABLE.}

Nom vulgaire des Ptérncères à digizations recourbées. Poyez Ṕtínocìne.

\section{GRIMACE.}

Nom vulgaire du Murex anus de Linné, doct Montlort a fait à tort un genre síparé suus le

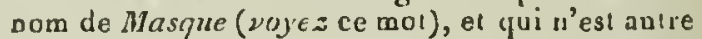
chuse qu'un 'Triton que M. Lacuarck a nommé Triton grinacrant ( Triton anus). Irojez 'Tritos.

\section{GRIVE.}

De vulgaire quil étoit, ce nom a été emplujé par Lamaick pour désigner le Cyproza turdus. Oa s'en sert erdinairement pour le N'erita exuvza Linué, que l'on nomne encore quelquefois Gruce a zhes arétes. Vojez Pohcelaise el N'́rite.

\section{GRYPUEE.}

Genıe que Lanarck a séparé des Huitres, mais (qu n'a pas de caractères suffisaus puur être conservé a litre de genre; nous en faisons une ser.tion dos Huitres. loyez ce mot.

\section{GU'T'TUI.INES.}

M. d'Orbigny donne re nom, chans snn ouvrage sur les Cépbalopodes, au second sous-genie des l'ulymorphines, Voyez l'e mot.

\section{GUTTURNIUN.}

Klein (Ostrac. method.pog. 51 Fb. 31. $\pi^{\circ} .64$ ) 
avoil proposé une pelite coupe génćrique dans laquelle il comprenoit cenx des Murex de Linaé qui sont cordonnés et qui ont le canal un pen relevé le type en étoit pris dans la figure H. de la pl. 24 de Rumphius. Aujourd'hui, celte coquille rentre parfaitement dans le genre Triton de Lamarch. (Voyez Triton.)

\section{GYMNOSOMES. Gymnosomata.}

Pelite famille proposée par M. de Blainville pour y placer deux genres de son ordre des Aporobranches ou Ptéropodes; elle contient les deux geares Clio et Pnenmoderme, qui ont en effet des rapports eatre eax, mais quil n'est guère possible, ce nons semble, de séparer des IIyales et autres genres voisins. Voyez Prénopodes. 


\section{H A L}

\section{H ALBARDE DE SUISSE. $_{\text {. }}$}

L'ú des noms donnés vulgairement au Rostellaire pied de pélican. Voyez Rostellahe.

\section{HALIOTIDE. Haliotis.}

Geure de la famille des Macrostomes de Lamarck et des Scuiilranclıes non symétriques de M. Cuvier. M. de Blaiuville les a placés dans le même ordre des Scutulranches, dans la famille des Oridies, qu'il a créée nouvellement. Plusieurs espèces de ce gente, abondammeul répandues dans nos uers, onl été connues des Aucieas, el pour la plupart figurćes par eux. Ils les ont presque tuutes rapprochéces des Patelles et les en ont séparies avec lacilúé; car il eft peu de geures qui suicat plus faciles à distinguer au premier abord.

Klein (Meth. ostrac. pag. 18.) paroît le premier a en avoir fait ce que nous nommons un genre, sous le nom d'Auris, paisé dans les écrivaius antérieurs à son époque, tels que Lister, Rumnhius, etc. Iinné forma eusuite ce gente sous le nom d'Halrotis, et il a été adop!é depuis sous la même dénomination par Adanson et lous Ies conchyliologues modernes.

Jamais les auteurs u'ont varié sur la nécessité ct sur la bonté de ce genre; mais il en est peu qui ail autaut varié de place. Nous royons en elfél Linné termiuer sa preunière division des coquilles régulières et à spire par les Haliotides, et commencer la section des coquilles sans spire par fes Patelles. Ce rapprochement avoit été senti et indiqué par les Anciens. Adauson lui-même mit ces genres dans un même ordre de rapports. Bruguière sépara beaucoup), dans sou cadre mérhodique, les Patclles des II aliotides; il mit les preunieres dans sa première division des corquilles sans spire réculière, avec les Dentales et les Serpules; les secondes, à la fin de la seconde division, entre les Nérites et les Argonautes. Ce qui est loin, comme il est fucile de le sentir, de présenter un ordre naturel dans lcs rapports. Lannarck, dans ses Animaux sans vertebres, 1801, avoit mis ce genre dans sa seconde siclion, celle qui réunit toutes les coquilles qui n'ont ni canal ni échaucrure à la base. Il se trouve évidemment à faux entre la Teslacelle et le Vermet. Dans la Philosophie zoologique, on le voit faisant partic d'une famille particulicre aver les Stomales et Stomatelles. Cette famille, à laquelle il donna d'abord le nom de Stomalacée, fui conservéc plus lard par lui (Extrait du Cours, 1811) sous te nom de Macrostones; mais il en sćpara alors le: Halintides pour les ríunir avec duule aux Palelles, aux Ombrelles et aux Oscabrions, daus la seugrde division des Phylliens. Enfin, dans son dernier ouvrage, le même auleur réunil de nouveau les Ilaliotides aux Stomates et Stomatelles, comaie dans la Philosophie zoologique, en conservant le nom de Macrostomes pour la famille à laquelle il a ajouté sans séparation le genre Sigaret. M. Cuvicr, dans ses divers travaux, n'a guère moins varié que Lamarck à l'égard des rapports de ce genre. Dans la première édition du Règne animal, nous le trouvons selon le système linnéen, entre les Nérites et les Paılles, à peu près daus les mêmes rapports dans le Cours d'anatomic comparée; mais dans la seconde édition du $R \dot{g} g n e$ animal, M. Cuvier réuuit les Haliolides aux Sionates, aux Cabochons et aux Crépidules, dans sa famille des Scutibraucles, dans la sous-division des non-symétrigues. M1. de Ferussac, dans ses Tableaux systématiques, a laissé ce genıe dans les mêmes rapports que M. Cuvier, sculement il a divisc les Scutibranches eu trois sousordres qui comprennent plusieurs familles : les Haliotides sont dans la première avec les Padolles de Mlonifort et les Stomates de Laniarck. M. de Blainville, dans son Traite de Mulucologie, a rapproché aussi les Haliotides des Calyptracines; il a fail, avec ce genre el les Ancyles, sa familie Jes Clidées. Quoique M. de Blaruville ait parfaitement comun l'ausinal de l'Jluliotide, il est lacile de s'apercevoir, par la séparation qu'il ea fait, et surtout par l'association avec les Ancyles, qu’il n’a point résolu la question, qui est d'autant plus difficile ì décider d'une manière salisfuisaute sins rompre les rapports des coquilles et des animaux, que ces animaux eux-mêmes préseuteu: un plus rrand nombre d'auomalies. Voici, au restc, de quelle mauière ce genre a été caractérisé.

\section{CARACTERES GENERIQUES.}

Corps ovalaire, très-déprimé, à peine spiral cn arrièe, pourvu d'uu large pied doublement frungé dans sa circouférence; tête déprinée; teatilcules un peu aplatis, connés à la base; yeux portés au sominet de pédoncules prismaliques situés au cóté externe des tentacules; mantesu fort mince, profundément leudu au côlé gauche; les deux lobes poin!us, formant, par leur réunion, une sortc dc canal pour conciuire l'eau dans la cavité branchiale situce il gauche, et renfermant deux treslonirs peignes branchiaux inégaux. Coquille nacrée recouvrante, très-déprimée, plus uu moins ovale, ¿ spire liès-petile, fort basse, presque postérieure et latérale; ouverture aussi grande que la coquille, à bords continus; le droil mince, tranchant; le gauche aplati, ilargi et tranchan? 
anssi; une série de trous, conplels ou incomplets, parallèle au bord gauche, servant au passaye des deux lobes pointus du manteau; une seule large impression muiculaire méliane el ovale.

M. Cuvicr depuis long-temps, dans un mémoire publié dans les Annales du Muséum, a donné des délails analouiques sur les Holliotides. Malgré leur abondance sur nos cótes, les animaux des llaliotides a'étoient que fort imparlaitement conutis pal une lignare assez mal laite dans la $Z$ somorphose de Durgenville, et par cclle meilleure, mais encore insullisante, d'Alansun.

Il est peu de Mollusques aussi élínamment ornés que le sout les Haliotides; leur pied, très-grand, discoüilal, ovalaires, est entonré d'un leuillet liangé qui, pendant la vie de l'animal, est ornć des plus lelles coulents. Cente frange est échancrée en arant, ct c'est dans son milieu que se próseme la têle, 1 s pied en dessous ne la délburde pas; cetle tête est alongée, épuisse, terminée autéricuremeut par une sorte de trompe it la base de lapuelle, el rle clanque côté, se troure un longr terulacule conique, pédiculé a la base; les pélicules, subcyliodracés, assezlongs et tronqués, portent les yeux à leur sommet; un petit voile très-mince, échanréé dans le milieu, couvre une parlie de la tê e et réuruit les tentacules en se soudaut à leur côté interne.

Le manteau, çuil ne faut pas confondre avec le Lord frange du pied, est simple, mince, et ne désorde pus lit coquille, si ce u'est quelequefius antérieurenent; il cst mince, tendmeux, lor large posićrieurement, où il s'mit en quelifues points à la unasse viscérale. Au centre, il aclliere au nuscle columellaire; il offre à gauche une longue cavité étruite, qui est celle des branchies: ce sac branchial présente une particularité fort remarquable, c'est 'pu'il eat feudu dans une partie de sa longueur, à sa partie supérieure et intérieure; celle fente pourroit se comparer i celle des limaryinules, mais elle n'est pas symérrirgue; elle s'éloigne de tout ce qui est connu daus les Mollusques. On remarque plusiears chioses dans le sat urinchial: d'aborl denx grands peiznes branchiaux subprisanaliques dirigis d'arricre en avaut, puis un long rectuat llottant torminé par l'ouvcrture anale, qui pribablement peut altemdre un trou de la corguille et rejete: au-tehors Jes résidus de la direstion. A cóté du rectum, on remaryute un orifice plus court et plus pesit qui est celur de l'oviducte; enfin, on voit parallèlement aux branchies et entrelles l'organe de la inucosité, çui se tronuve dans tous las Pectinibranches. La wasse viscérale est postéricuie à la cavité lranchiale et au muscle d'attaclie; elle est grisâtre, aplatie, et un peu tournée en spirale, corame l'est la coquille.

La cavité buccale présente de chaque côté une pliçue cornée, et au fond une langue hérissée de jetits crochets; elle se prolonge un peu posté-

Hist. Nat. des Vers. Tome II. rieurement el se bifurque. On voit de chaque cóté de la masse buccale une perite glande saliraire, elles versent dans la buuche le produit de leur sécrétion; l'isophage esi court, et il donue naissauce à un premier estomac, qui est alongé, pyriforme, enveloppé du foie ct placé profundément en dessous de la masse des risceres; il est finement plissé à l'intérieur, et vers son fond on voit plusieurs onvertures biliaires et un pylore muni d'uue valvule derrierc larjuelle cst le second estomac, qui est plus petit que le preıner, el qui oflie denx grands arilices lnliaires. De ce second cstomac naît l'intestin, 'qui remonte à cûté dn moscle, se recourbe en avant derrière la masse buccale, se ploie en denx pour redescendre parallèlement jusquen dessous le la parie la plus profonde du sac branchial, vers lecpuel il remonte en se courbant, pénètre d'abord dans le péricarde, et enfin daus la cavite branchiale ellemême, oì il se termiue comme nous l'avons vu.

Un trail des plus caractéristiques de l'organisation des Halintides, c'est que le rectum, cumme d:Ins les coquilles bivalves, traverse le cueur, et que cului-ci, ćgalement comme dans les mêines animaux, est pourva de ảenx orcillelles. Le système de la circulation se riapproche donc plus de celui des Conchiferes yne do celui des Mollus jues proprenear dits. Potar voir la disposition orgúnique dont nous venons de parler, il sulfit d'ouvrir dans sa longueur le péricarde, iqui est placé a l'extrémilé pustéricurc du sac branchial, entre lui et le comuencement de lat uasse viscérale. A l'extrémité antérieure des orcillettes aboutissent les veines branchiales, gui suivent le bord externe des branchies; les artères branchiales, qui sonı la continuation, pour ainsi dire, du trouc comaun des veines, parcourent le côté opposé des branclies, daus lesquelles elles apportent le saog des diverses parties du corps, qui, élaut vivitié par l'aste de la respiralion, est transmis au cour pal les veines branchiales. l.c rentricule est travcrsé, comue nous l'avous dit, par le rectum; de son extrónité iuférieure el postéricure nait l'artère arotle, cqui surt du péricarde en dessous; elle donne plusieurs fortes branches aux intestins, au foie et à l'oraire, irarerse le pédicule musculaire du muscle d'attache, et pénètre ainsi jusqu'a la masse buccale, ì latyuelle elle se distribue. Le foie est une ziante masse grisâtre qui enveloppe presuge compliteunent les viscères de la digestion et une grande parlie de l'ovarie.

L'ovaire est le scul or zane de génération connu juscqu'à présent daus les Halintıdes, ce qui est encore un point rle resse ablance entre ce genre et les Conchiferes. L'oviducte, qui naît de cet orraue, Iraverse une partic dil laie pour arriver à l'extrémité du sac branchial; il le Iraverse en s'accoliunt au rectum a côté duquel il se termine. On n'a jamais trouvé la moindre trace d'organe arćuéraleu: màle; nuus l'avous vainement recher- 
ché sur plusieurs individus de l'Ilalintide cornmune. Ainsi ce genre sernit encore plus voisin des Conchifères que les Calyptrées el les Crépidules, dans lesquelles nous avons découvert l'organe måle.

Le système nerveux, assez semblable à celui des autres Pectinibranches, offre cependaut une parlicularitć qui le rapproche de celıi des Conchiferes. Dans ces animaux, l'anncau œesophagien est très - grand, le ganglion supéricur se trouve au-dessus de la bouche el l'inférieur on sons-œsophagien, lié par des nerts lattéraux au premier ganglion, se trouve dessous le muscle adducteur posiérieur des valves. Dans les Halintides, le ganglion supérieur se trouve aussi au-dessus de lit bouche; mais l'inférieur, au lieu d'être inmédiatement audessous, se voit à la partie antérieure du muscle d'altache, et forme ainsi un très-grand auneau œsophagien.

Nous avnns cru nócessaire de donner ces dérails sur l'oryanisation des Haliotides, pour laire mieux sentir les nombreuses ressemblances qu'elles offrent a vec les Mollusq̧ues acéplaales, et pour faire voir que dans une bonne classification elles doivent former un chaioon entre les deux grands ordres des Mollusques. Quatre points priacipanx de leur organisation appuient fortement celle opinion : dans le système nerveux, la grandeur de l'anneau œesophagien; dans les organes de la digestion, le passage du rectum ì travers le cour; dans les organes de la circulation, les deux ureillettes, et enfin un seul organe sle génération.

Il est à présumer que les auteurs métlodistes auroient éprouvé moins de dillicultés à placer ce geare d'une manière convenable, s'ils avoient fait plus attention à l'ensemble de ces caraclères organiques. Nous les croyons si différens de ce qui est connu dans les Mollusques, que nous pen. sons quiil est nécessaire de taire une fumille à part des Haliotides; nnus n'admeltons pas, comme on le voit, la famille des Otidées de N. de Blainville, les Aacyles n'ayant pas, selon nous, assez de rapports avec les Hualiolides pour en être aı. tant rapprochées. Quant à la place des Haliotides dans la unélhnde, elles pe peuvent être trop rapprochées des Acéphales, et c'est pour celle ruison que nous en ferions la dernière tamille de la grande série des Mollusq̧ues céphalés.

Le genre Haliotide n'est point encore trèscombreux en espèces : quelques-unes, comme celles qui habitent sos côtes, se voient sur tout le littoral, depuis le Sénégal jusque dans les mers du Nord; ce qui prouve dans ces animaux une grande aptitude à supporter ces tempéralures différeates. Elles vivent, comme les Patelles, fixées en grand nombre snr les rochers, où elles s'attachent d'une manière Irès-solide au moyen de leur vaste pied. Quelques espèces prennent de fort yrandes dimensions; elles sont alors recherchécs des amalemrs cle coquilles, à cause de la

\section{H A L}

beaulé de la nacre intérieure, qui est sonvent colorée de la manière la plus brillinle de toutes les teintes de l'iris. La surface extérieure, couverte d'une croúte non nacrée et épidermifere, est rarement inlacte, le plus souvent rongée par différens vers marins; elle est aussi chargée de Selpules, de Balanes et de Madrépores.

Il n'y a qu'un pelit nombre d'années que l'on conooit le genre Haliotide à l'élat fossile; c'est M. Marcel de Serres le premier qui en fit connoilte une espèce, dont nons possédons un individu que nous devons à la générosité de lord Nortempton et de M. Lyell. Il a été trouvé en Sicile.

1. H.suotioe oreille de Midas. Haliotis Midar.

H. testâ rotundatâ, maximâ, crassî, ponderosá; dorso plicislongitudinalibus, undulatis, uno latere incumbentibus; spirá retusâ; mulgine dextro curvo, elevatissinio.

Laых. Anim. s. vert. tom. 6. pag. $214 . n^{\circ} .1$. Haliotis Midee. Lin. Gmex. pag. $3687 . n^{\circ}$. I. Listen, Conch. tab. 613.fig. 5.

Gu.sut. Test. tab. 6 . fig. 6.

KNORR. L"erg. tomi. 5. tab. 20.fig. 3.

Favanne, Conch. pl. 5.fig. A. 3.

Martini, Conch. tom. 1. $t u b .14$. fig. 136 , et tab. 15. fig. 141 .

Grande et belle coquille ovale, profonde, d'une belle nacre irisée à l'intérieur, ct ornée à l'exıéricur de plis nombreux et obliques. Ces plis sont saillans, sublamelleux, onduleux, irréguliers et se terminant brusquement à l'angle décurrent sur lequel les trous sont percés. Ceux-ci sont pelits, rapprochés, et loujours ouverts, au nombre de dix on onze; la spire est aplatie, formée de trois tours et demi on quatre tours. Limpression musculaire, qui est fort grande, est centrale et sruvent trćs-inégale et raboteuse. Celte coquille, assez rare, vient des mers de l'Inde et du cap de BonneEsprérance; elle a 5 pouces et denia à 6 pouces de longueur.

\section{Hatrotide iris. Haliotis iris.}

H. testâ rotundato-oblorgî, tenui, nugoso plicatê, ex viridi, rubro et carnuleo nitidissimè variâ; spirî subprominula, obtusâ; margine dextm elevato.

LAMx. loc. cit. $n^{\circ} .2$.

Forster, Catal. p. 193. $n^{\circ}, 1553$.

Haliotis iris. Martrns, Conch. 2. fig. 61 .

Favanne, Conch. pl. 79. fig.d.

Chemn. Conch. tom. 10. tab. 167. fig. 1612. 1613.

Haliotis iris. Guru. pag. $3691 . n^{\circ} \cdot 19$.

Celle coquille est recherchée des amateurs à 


\section{A L}

cause de la richesse des couleurs de sa nacre; elle est ovale, oblongue, d'un vert-noirâtre en deliors el d'une belle nacre iriśe en dedans; sa sjice, peu saillante, composée à peine de trois t urrs, est tuul-à-fail postérieure et presque margiusale. Dans les iodividus bien frais on remarque, vers le soumet, des stries longitudinales qui disfraroissent vers le liers de la longueur de la coquille; elles sont coupées obliquement par des rides obliques et onduleuses; les trons sont petits, rapprochés, il n'y en a jamais plus de ciug ou six d'ouverts; le bord droit est aplati, saillant el élargi, surtout à sa partie postérieurc. Celte coquille précieuse et recherchée vient des mers de la Nouvelle-Zélunde; les plus grands individus ont 4 pouces de longueur.

3. HAstotide tubifere. Haliotis tubifera. TAas.

H. testi ovali, hasi subacutâ, maximâ, crassiuscula, rugosâ, ex algenteo et rubro murgutitaceá; formminibus in tubos elongatos productis; spirs subprominula; inargine dextro elevatissimo.

L. AM $x$. Loc. cit. $n^{\circ} .3$.

Forsters, Catal. p. 193. $z^{\circ} \cdot 1556$.

Martivi, Conch. 2.fig. 63.

Haliotis gigantea. Cнваx. Cunch. tont. to. tab. 168. fig. 1611.1612 .

GNEL. png. 5691 . no. 18.

L'IIaliolide tulifere est l'une des espèces qui acquiert le plus grand volune; eile est ovale, ublongrue, un peu pointue à son extrémité antérieure; son test est épais, solide, couvert en dehors d'unc couclie corticale d'uu beau rouge de corail; elle est grossièrement plissfe et prósente des rides irrégulières d'accroissement. La spire, un peu saillante, est postérieure et à peine de trois tours; le côlé droit est élevé presque perpendiculaircraent, et l'angrle qui résulte de sa jonclion avec le reste de lia coquille est occupé par une série de trous prolongés en twhes saillans de plusieurs lignes, les qualue derniers resiant luujours ouveris. En dedans, cette coguille est dune nacre blanc-rougeảtre avec des rellets verts et rouges. Elle est assez rare dans les collecalions. Elle liahite les mers de la Nouvelle-Hollande; elle a quelqueluis plus de 6 pouces de longueur.

4. II Alotide concave. Haliotis excavala. L.M K.

H. testâ subrotundat $\hat{a}$, convexissimâ, striatoplicatú, intis valdè concavi, margaritaced; cavitute umbilicali subinfudibulformi, detecti; spiri promunente.

Var. Testá excavatione mediocri. Layx. loc. cit. $n^{\circ} \cdot 4$.

Coquille des plus remarquables dont la forme se rapproche de celle des Stomates et des Turbos; elle est très-concave, arrondie; sa spire subcentrale est saillante, à tours réguliers et assez nombreux, convexes, non anguleux; ils sont striés longitudinalement et subplissés transversalement; en dedans, la concavité est parcunrue par un angle spiral qui correspond i la suture; la nacre est blanche, irisfe de rouge el de vert. Celle coquille, très-précieuse et très-rare, vient de la Nuuvelle-Hollande et de Java, d'où Leschenault a rapporté la variété. Sa lungueur est de 2 pouces et 8 lignes.

\section{HALIOTDE australe. Haliatis australis. Lix.}

H. testá ovato-oblongú, latiusculâ, convexodepressí, rugosâ et plicuta, intús argenteo et rubro margaritaced; spiri promimuld.

l.AsK. loc. cil. $n^{\circ} .5$.

Chems. Conch. tom. 10. tab. IfG6. fig. 1604. $1604 a$.

Haliotis australis. GMEL. pag. 368g. $n^{\circ} \cdot 9$.

Cuquille orale, obronde, presque aussi longuc que large, sillonn'e longiludinalement dans tuute sun étendıe; les sillons sont nombreux, notuleux, el irrégulièrement décussés par des lides transverses; la coquille esi aplatie, sa spire est peı saillante, quoique bien marquée; elle est forméc de yualre tours sur lesquels on suit la sirie de Irous qui se voient sur la partie la plus saillade du côté gauche; les sept derniers trous restent tonjours ouverts. Le loord gauclie est aplati, fortement aigu, ct se continue à linlóricur par un angle saillant qui inurne en spirale. En dedans, cette coquille est d'une nacre argenté, et en dehors elle rest d'uo rouge obscir avec des flammules Jlanches on verditres. Sa longueur est de $76^{\circ}$ millin. et sa largeur de 58 ; elle se trouve dans les mers australes à la Nouvelle-Hollande.

\section{Haliotide commune. Haliotis tuberculata.} Lis.

H. leslìuvato oblongâ, convexo-depressâ, longitudinalıter stricatâ, transversè plicatâ; plicis inaryualibus, remotiusculss; fossulâ umbilicali perparva, labio partim tectá; spiri promimulá.

Haliotis tubenculata. I.I. Gser. pag. 3687. $n^{\circ} .2$.

Boxxant, Recr. 1. fig. 10. 11.

I.Isten, Conch. tab. 611.fig. 2.

Gusi,r. Test. Lab. (6g).fig. 1 .

Dargenvile e Conch. tab. J. fig. a.f. et Zoomoiph. pl. 1. fig. c.

FAvaxie, Conch. pl. 5. fig. a. 2.

K.овr. Vergn. tom. 1. tab. 17. fig. 2. 5.

Adans. Sénég.pl. 2. fig. 1. L'Ormier.

REGEX. Conch. tom. 1. tab. 8. fig. 20. 
Martisx, Conch. tom. 1. pag 174. vign. 6, et tab. 16. fig. 146 à 149 .

Var. B. Nов. Testà sablcev'gatâ.

Var. C. Noв. Testá striato-rugosá.

Coquille ovale, oblongue, déprimée, à test épais et solide; sa spire, cnurte el postérieure, est furatée de quatre tours; elle est presque marginale, légèrement suillanıe; le côlé gauche est pen proétuinent; le bord du même côté est large, épais, se contiuue avec le drait, et cache en grande partie la spire intérieure. Les trous sont nombreux, rapprochés, el ue sent pas sur une carçne, comme cela à lieu dans le flus grand nowbre des espèces, les six ou sept deruiers restent ouverts; au-dessous des trous se voit une légère dépression en righole qui esi suivie d'un bourrelet qui se continue jusqu'au bord, et sur lequel il y a de gros sillons. En dedans, celle coquille est d'une nacre argentće très-brillaute; en debors, elle est strice on sillonnée, et ces stries on ces sillons sout interrompus par des accroissemens norabreux et irréguliers; elle est souvent verdâtre ou rougeâtre, et quelquefois marquée de grandes taches anguleuses rouges ou vertes, sur un foud blanchâtre. La variçé $B$, qui est presque toute lisse, vient de nos côtes de la Nanche; la varićté C est très-rngueuse, elle vient des mers du Nord. Celte coquille irès-commune se Irouve sur tout le littoral, depuis les mers du Séncigal jusqn'en Norwège; elle est comnune aussi dans la Iléditerranée. Laraarck ajoute qu'elle babile aussi l'Océan allantique. Les plus grands individus ont I centim. el demi de longueur, plus de quatre pouces.

\section{Haliotide suriée. Haliotis striata. Lin.}

H. testá ovato-oblongâ, dorso convexâ, depressâ, longitudinaliter striatâ, transversìn rugosâ, ferrugineú; spiri subprominulâ.

L.A $\mathbf{x}$. loc. cit. $n^{\circ} \cdot 7$.

Haliotis strzata. Lix, G ssez. pag. 3688. $\pi^{\circ} .3$.

Marrisi, Conch. tomi.1. tab. 14. fig. 138.

Celte coquille se distingue facilement de la précédente; elle est plus aplatic, toujours plus petite, etconstamment siriée au-dehors; ces siries sont fines, serrées, légulières, quelquefois Iraversées par d'autres transverses qui les rendent léngèrereut écailleuses; le bord gauche est aplati, large, épais, et cache au sommet presque complétement la spire intérieure; la spire est trèscourte, non sasllante, à peine de trois tours; le dos est arrondi, et sur la partie la plus saillante à gauche sont placés les trous, qui sont petits, nombreux et serrés; les six ou sept derniers sont ouverts à tous les àges; les strics du côté gauche soot absolument les mémes que celles qui couvrent le seste de la coquille; il n'y a pas entre la série de trous et le bord ane dépression en gout- lic̀re, et ce hord n'est pas accompagné en dehors d'uu bourrclet sillonné. Ces diflérences sullisent pour que l'on ne confonde pas celte espèce avec la précédente. En dehors, l'Haliotide striée est d'un rouge-brun, et dans le jeune åge unarquée de graudes taches irrigulières d'un blanc sale; ̀̀ l'intérieur, la nacre est brillante, blanclıe, avec des reflets méralliques verts et rouges; les stries de l'extérieur se répètent en dedans. Longueur 7 millim. et derni. Elle vit dans l'Oréan indien.

\section{Haliotide en faux. Haliotis asinina. Lin.}

$H$. testâ elongatâ, angustiusculâ, subsulcatâ, lapvigata, viridi, fusca-manmoratî, intus margaritucea; striis undulatis, obliquis; spirá brevissims.

LAMKi loc. cit. $n^{\circ} .8$.

Huliotis asinina. Lrs. Syst. nat. pag. 1256. $n^{\circ} \cdot 745$.

Lister, Conch. tab. 6ro. fig. 1.

Rumpa. Mus. tab. 40. fig.e.f.

Gualt. Test. tuh. 69. fig. d.

Dargevv. Conch. pl. 3.fig.e.

Favavie, Conch.pl. 5. fig.a. 4 .

Kмонк. Vergn. 3. tab. 15. fg. I.

Regenf. Conch. 1. tab. 9. fig. 29.

MAatin, Conch. tom. 1. tab. 16. fg. 150.

Haliotis asinium. GuEr. pag. 3688. n०. 6 .

Parmi les espèces du renre, relle-ci est une des plus faciles à reconnoître, étaut la seule qui ait autant de longueur sur si peu de largen:; elle est ovale, alongée, étroite, arquće dans sa longueur, convexe, arrondie, à spire courte, peu saillante, obliqque, postérieure, ne dépassant pas en dedans la largeur du bord gauclie et postérieur qui la caclie; toute la coquille est mince, et le bord gauclue lui-même l'est autant que le reste, II se rélève et n'est poiut aplati comme dans les autres espèces; le sommet, formé de deux tours de spire, est orné de sillons longitudinanx, droits, qui s'eflacent rapidement; ils persistent sealement sur toute la longueur du côté gauche; tout le reste de la coquille est lisse, agréablement marbré de taches anguleuses, vertes, sur un fond blancjaunálre. En dedans la nacre est blanche et brillante; le côté gauche est percé de six à sept trous assez grands et ovalaires. Celle coquille, qui vient des mers de la Chine et des Moluques, est longue de 85 millim., plus de 3 pouces, et large de 38 millim.

9. Haziotide glabre. Haliotis glabra. Lir.

H. testâ uvali, convexo-planulatâ, glabrâ, tenuiter striatâ, albo et viridi marmoratâ; spirâ relusâ, internâ facie margaritaceâ. 


\section{$\mathrm{H} A \mathrm{~L}$}

L.AMK. loc, cit. no. 9 .

Favanie, Conch.pl. 5.fig. $\Delta 12$.

Haliotis glabra. Cerns. Conch. tom. 10. tab. 166. $f \mathrm{~g} .1602 .1605$.

Haliotis glabru. Liv. Gsex. pag. 36go. no. 14.

Haliotis glabra. Scnuber el WAgner, Suppl. au Chemnitz, pl. 224. fig. 3086. 3087.

Lamarck a, ce nous semble, commis une errenr en rapportant l'Haliotis virginea de Linné a l'Haliatis glabra qui en est parfailement dislincle; il est à présumer que Lamarck v'a en à sa disposition que le jeunes individus du Glabre, ce qui a facilité la confusion. MM. Sclubber el ITagoer, les contiauatenrs de Chemnitz, ont reclitié l'erreur de Lamarck, et l'out rendue à l'avenir impossible, en donnant une nonvelle figure de l'espece qui nous occupe.

L'Haliotide glabre est graode, régulièremeot ovale, aussi large à une extrémilé qu'à l'aulre; elle est profonde, arroudie, nnn angulense, il test épais; le cóté gauche arroudi, corane le resıe, es! indiqué seulearent par la rangéc de trous; ceux-ci sont pelits, serrés, nombreux; les sept derniers sont cuverts; la spice est très-courle, obluse et complétement cacliée à l'intérienr par l'exıłémité du bord gauche; ce bord est aplati, cpais, large, et tronqué obliquement à son extrémité antérieure. En dehor's, celle coquille est couverte d'une parlie corlicale épaisse, brune on noire, avec quelques laches blanclıâlres; dans le jeune ầre, le sommet est quelquefois lf́gèrement strié. En dedans, la nacre est très-belle; elle est blanche avec des rellets conlenr de feu. Celle coquille, longne de 12 centim. et deın, vient de la Nouvelle.Hollande. I,AIXX.

10. Haliotide lamelleuse. Haliotis lamellosa.

H. testâ ovato-oblongâ, convexo-planulutâ; lamellosâ, aurantio-rubente; dorso inaquali, longitudinaliter stivatâ; lamelhs transversts strias decussantibus, spirầ subprominuld; interni facte margaritaceâ.

Lasx. loc. cit. n०. 10.

Coquille d'nn médiocre volume, ovale, oblougue, aplatie, à spire très courte, un peu saillante, irc̀s-postérienre et contournée; le bord gauche est étroit, peu épais, arroudi, cachant une partie de la spire intérieore. En dehors, cette coquille est striée longitudinalement; les stives sont irrégulièremeot coupées par des lames multipliées, irégulières, ondulenses et transverses; des taches nombreuses, tantôt rongeâtres, tantôt vertes ou brunes, sur un fond blanc, se poient à l'extérieur. La coquille étant fort mince, on voit dans son intérienr la répétition des stries et des lames; les trous sont petits et nombreux, et placés sur une côle décurrente, obscure; les six ou sept delniers restent ouverts; la nacre est très-belle et triesbrillante. Celle coquille vit dans la Méditerranée, sur les côtes de Sicile, el pourrucit bién n'êtré qu'une forle variété de l'Haliolide cominune. If nous semble que l'Haliotis Philiberti fossile pourroil êrre anssi une variété de celle espèce. Iongueur, 65 millim., largenr 38 .

11. Hamotide canaliculée. Haliotis canaliculata. La $\mathbf{x}$.

H. testâ ornto-rotundatâ, convexo-depressí, decussutim stuala; costá singulari, notatá, ferrugineâ; interna facie margarituccâ, cunaliculo exurali.

LA\&. loc. cit. $n^{\circ}, 15$.

Haliotis parva. Lixx. Gnex. pag. 368g. no.7.

KNorr. Jerg. tom. 1. tab. 2o.fig. 5.

An Favane, Conch. $p l .5$. fig. d?

Mantivi, Conch. tom. 1. tab. 24. fig. 140.

Coquillc ovale, arrondic, déprimée, ì spire assez grande, proćnircule, furt distincte, composée de gualre lours; le bord gauche est relev: perpendiculairement, mince, arrondi, furtement arqué postérienrement et se continuant à l'intéricu par un augle saillant, en spirale, qu’indiquent les tours de spire. La face supéricase est partagcie en deux parties presqu'égales par une colle longitud:nale, arrondic; son ćlévation d'uo côté, el celle de la spite et du bord perluré d'un autre, produisent sur celle surface deux gonttières parallèles, dont la gauclie est la plus étroite; uu résean formé par des stries lougitudinales très-fines, et d'autres transverses non moins fines que les premières, se voil sur loule la face externe de cetle coquille, qui de ce côté est d'uoe couleur ronge de brique assez vive; en dedaos se trouve une gonttière médiane assez profoude, qui correspond à la côte du dessus; cinq ou six pelits trous arrondis restent ouverıs; la nacre est blanche et très-brillante. Cette coquille rare vient, dit-on, de l'Océan iodien; elle est longue de 45 à 50 millim.

12. Hactotide tricostale. Haliotis tricostalis. LAM $\mathrm{K}$.

H. testá rotundatî, depressâ, basi truncutâ; dorso albo-fermugineo, striato, subtricostato; Lamellis transversis, intra spiram et costam mediam; internâfacie obscuratú, canaliculo exaratâ.

LAMx. loc. cit. no. 14.

Scruber et W fig. 3088. 308g.

Dans l'onvrage que nous reaons de ciler, nous trouvons cette espèce sous le nom de la pré- 
rédenle: nous igaorons quels molifs ont porté a faire ce changement inulile et qui peut occasionner des erreurs.

l.Haliotide tricostale est une coquille trèsremarquable, assez grande, ovale, arondie, Cort dćprimée; à spire large, saillante, lornée de quatre tours; le milieu de la surlace extérieure tst occupé par une cô!e arrondie, aplatie; entre clle ct la suture se trouve une série de plis lanelleux, 1 rausverses, aigus, subréguliers, qui se cliangent en ondulations sur la côte en y aboutissant, et disparoissent ensuite; au-dela de la có:e médiane el à gauche s'en trouve une autre plus saillante et plus étroile, sur laquelle sout disposés, arec une grande régularité, des trous Iubuleux dont les six derniers sont ouverts; au-dessous de celte cóte, le bord gauche est marqué en deliors par uue carioe tuberculeuse, de sorte que la coquille es! garnie de rois côles sépartées par. des gouttieres parallèles; la surlice extérieure est de plus converte de stries longitudinales, rendues écuilleuses par ul grand nombre de stries transverses très - fiues et très-rapproclıfes; la couleur du dehors est verte, avec de grandes tackes rouges nuageuses et quelques blinclues; le lest est uds-mince, et on voil se répéler en dedans les accidens du debors; la vacre en est très-Lelle et très-hrillante. Celte coquille, trèsrare el très-précieuse, vient des mer's de Javi; el'e a 70 unilliu. de long et 52 de large.

\section{HAMITE. Hamites.}

Geare établi par M. Parkinson, poul des coquilles cluisonnées voisines des Baculites, et dunt quelque's-unes furent contiundues avec elles; elles présentent un caracière remarquable, qui n'est appréciable dans certaines espèces que lorsqu'on les trouve entières ou presque entières. Ce caractere est pris de la courbure de la sorle de crosse que fait la coquille lorsqu'elle est arrivée à une certaioe période de son accroissement; quelcyues autres espèces paroisseut uniformément courbées en portion de cercle, et ont en cela de l'aoalogie aver: le corps pétritié auquel on a donné le nom d'Ichthyosarcolite.

C'est avec nne de ces espèces qoe Lamarck fit, dès 1809 , dans sa Fhlosophic zoologique, le genre Ammonocératite, qui resta inconuu pendant long-temps, parce qu'il ne fut caractérisé que dans le dernier ouvrage de ce savaut. Nous avons dit, par suite d'une erreur que nous rectifions ici, que le genre Ammonocéralite (voyez ce mot) n'avoil été créé que dans l'Extrait du Cours. Un geure dont on n'a que le nom n'est pas détinitivemeat introduit dans la science, il n'est donc pas étonant que celui-ci ait été ıprésenté plus tard sous un autre nom. Ce nom de Hamile, quoique donné postérieurement par M. Parkinson, devoit être prétéré pour des raisons qui se déduiseot rrop fucilement pour qu’il sci: besoin d'iosister davantage. Ainsi, dès 1822 seulement, épocjne de la publication de l'Histoire naturelle des Animaux suns vertèbres, on a su que le genre Annomocératite étoit un double emploi des Hancites, et l'on a dú uéanmoins conserver ce deraier qui, depuis long-temps, éloit collsacré dans la science.

Ce gente a été adoplé par MI. Sowerli, dans son Mineral conchology, oú il en a liuil connoitre un assez grand nombre d'espèces, dont plusieurs sont Cor't curicuses. Jusqu'à présent il n'a pas été adopté par M. Cuvier. M. de Ferussac, dans ses Tableaux systématiques, a placé les 11 imites duns la famille des Ammooces, eutre les Scaphites et les Baculites; servant aiosi d'un échelon daus la série des rapports qui lient lous les Ammuréts dans leurs diverses furmes, depuis celle loula-lait droite sinas aucune spire, la Baculite, jusqu’a celle d'une coupulle entoulce soic tans le plan vertical, la Turrilite, soit daus le plao horizontal, les Ammonites, les Urlulites.

Duns son Traité de Malacologie, M. de Blainville a commis une erreur singulière en admetrant tout à la lois et les Hamites de M. Parkiason et los Amwonocérates de Lamarck; il est certain cependaul que les caractères sont identiquement les mêues. Ces genres, quiviu'ayant les cloisoos découpées et le siphon dursal, se trouverit cependaut dans la nème lamille que les Spicules et les Lituoles qui ont los cluisons simples e? le siphon central ou veotral; ils se trouvent ainsi éloignás des Baculites et des Aauaroites, et par conséqueut ils sont liors de leurs rapports vaturels.

Mi. de Ilaan et M. d'Orbigny, dans leur arrangement des Cóphalopodes, unt conservé ce geare dansla farmille des Ammonées, où Lamarck a voit aussi placé son genre Ammonocírate. Vojez AMMoNée el Cephalopodes.

11. Sowerly, dans l'ouviage que nous veoons de viler, a donné des caractères génériques qui nous seurblent insuffisans, car les Ilamitcs sont plutöt en pyranide très-alongée el courbée vers le milieu que lusifurmes, celte épitbète de fusiformes indiquabt ordiadirement uo renflement; les cloisuns soot uou-seulement ondées, mais elles sont arriculées pir des infractuosités profondes semblabies a celles des Ammonites; entiu le siphon n'est pas seulemeat près du bord extérieul, comme le dit M. Surverby, ce qui est difficile a concevoir quand il s'agit d'un corps cylindroïde, mais il est, comme dans tous les Aumonées, marginal el dorsal.

\section{CARACTERES GÉNÉRIQUES.}

Coquille conique, alongée, courbée dans sa longneur, fornabl quelquefois plusieurs tours de spire disjoints, quelquefois aussi commençant en spirale et se prujetant ensuite en ligne droite; 


\section{H A M}

cloisons nombreases, arlicultes comme celles des Ammonites, percées d'uu siplion unarginal et dorsal sur la cóle convexe de la courbure.

Les Hamiles ne se sont trouvécs jusqu'aujourd'hui que dans les terrains anciens au-dessous de la craie, ou dans la parlie inférienre de celte formation : c'est ordinairement le moule plus ou moins complet et dépourvu du test que l'nu rencoatre; quand le test existe, et cela dépeud à ce qu'il paroit de circonstances locales, il a une belle couleur nacrée, et on s'aperçoit qu'il devoit être extrêmement mince; on observe aussi le pea d'épaisseur que devoient avoir les cloisons elles-mèmes, qui, après être disparues, ne semblent avoir laissé aucun espace. Parmi les espèces, nous citerons de préférence les suivantes qui nous sont mieux connues.

1. Hamite arméc. Hamites armatus. Sow.

H. testá conicâ, elongatâ, lateruliter compressa, in medio inflexá, inansversim rugosí, dorso duabus seriebus spinanum armatá.

Sowerb , Min. conchol. pl. 168.

Espice fort grande et fort remarqualsle par le double rang d'épines qui sout sur ua des cốtés de la coquille. Elle est ployée en denx par un coude arrondi ; les deux parties droites sont à peu près d'égale longueur, elles sont sillonaćes r'sulièreıneot par de grosses et de petites côtes; les grosses sonl régulièrement distantes, il y en a entrelles deux ou trois pelites. Ces grosses côles portent sur la double crèle, d'un côlé, de gros inhercules arrondis, el de l'aulre, le double rang d'épines assez lungrues que nous venons de mentiunner. Ces garosses cótes présentent encole, vers la parlie interne, une série de lubercules arrondis qui se voient également des deux côtés.

I.a coguille est aplatie, comprimée, subquadrilatère, ce qui la distingue facilement de toutes les autres espèces connues.

C'est en Angleterre, au village de Roak, près de Benson en Oxfurdshire, que celle rare et irds-belle espèce a élé trouvéc.

2. Hamtre annuléc. Hamites annulatus. Noв.

H. testâ elongato-conicâ, biarcuatá, subspiratâ, costis annularibus numerosis dorso interruptis regularibus ornata.

Coquille remarquable par sa forme; elle est alongće, conique, symétrique, courlsée deux fuis dans sa longueur, de aıauic̀re a offrir assez exactement la forme d'un C. D'après un individu presque complet que nous possédons, le sommet se termineroit ex cône sans commencement de spire; la base est oblique, et il est à présumer que la forme de l'onvelture est indiquée par les cûtes transverses qui la répètent à des intervalles égaux; ces côtes sont nom-

brenses, lisses, d'une parfuile régularité ;elles sunt à peine saillantes sur la lace ventrale, mais elles s'élc̀vent graduellernent sur les faces latérales et vont ainsi en augmentant jusque sur le dos, où elles sont interrumpues subitement dans la ligne médiane. Celle coquille, fort rare, vient de foolite ferrugineuse des environs de Caen; elle est longue de 22 millim., la lougueur étant prise d'une courbure à l'autre et nou du sumanet a la base.

Noв.

I7. testâ prưlongâ, cylindricâ, elongatá, duobus cruribus suharqualibus incurvâ, transversim obliquè costutü; loculis numerosis, siphone minimo, marginali, dosuli perforatis; marginibus profunde dinticulatis, laciniatis, arborescentubus.

Baculites cylindracea. DEF. Dict. des Sc, nat. tom. 3. Suppl. pag. 160.

On ne connut d'ubord que des tronçons trep incomplels de celte especce pour quil fût possible de la rapporter a son véritable genre. II étoit naturel, comme l'a fait M. Defrunce, de la mellre au nombre des l3aculites, ou de ne la placer parmi les IIamiles que lursque $M$. do Gerville, continuant ses utiles recherties, eut déconvert un individu présentant une courbure entière; cet individu, que M. Defrance eut dans les mains, fut moulé en plâtre et se répandit dans les collections par la géuérusité de ce savant distingué.

Nous possédons un morceau de celle belle et rare coquille qui nous pennet d'en domner une description assez complète, aidé, comme nnus le sommes, par le moule de liudividu de la collection de M. de Gerville. Ce frarnment, qui est tronconbé à la base et vers le sommet, montre une ĺggère intlexion qui indique l'urigine de la courbure; il a pres de huit pouces de long, et ce. pindant il ucllie cneore aucune trace de la derniere loge, la conje trausverse est a peu près rylindriyue; le diamètre antéro-pustćrieur étant uu peu plus grand que l'aulre, les cloisuns sont numbrenses; elles sonl divisúes en cing labes priacipanx dont le postérieur, le plus petit, est le seul médian. Ise bord des cluisons esi décuupé en un grand noubre de devielures profondes sem. blables en tout à celles des Amuouites; elles sont eu feuilles de persil et tellemeut rapprochées et enchevêtries les unes dans les autres, qu'il est impossihle de distingoer celles d'une cluison d'avec celles de la suivante.

Un fragmeat de test conservé sur le morceau de aotre collection démontre que la coquille devoit être extrêmement mince et étoil ornéc de côtes transverses, lisses, régulières et na pen obliques. Le siphon est dorsal, marginal, fort 
petit et traverse toutes les cluisons. La disparition du test dans cet endroit le laisse à découvert daas loute son éleadue. Les deux parties de la coquille sont parallèles et réuaies par ure courbure $e n$ demi-cercle; clles sont à une distance de 40 millin., un pouce trois lignes. Tout ce que l'on connoit de cette coquille ac vermet yas encore d'en donner les dimensions; I'indiviclu de M. de Gerville a 18 ccntiar. de long. Cetle rare espèce se rrouve fossile dans la craic dure de Valogaes avec la Baculite.

\section{IIA.ILONIE. Hammonia.}

Nom que Soldani, dans son grand ouvrage sur les Céplalopodes micruscopiques, a donné dans un sens générique au plus grand nombre des coquilles aautiloïdes multiluculaires. Voyez C.éphalopodes.

\section{HANITS.}

Mlauvais genre étalıli par Klein (MIthod. ostrac. pag. 25) pour queiques espèces de Troques ou de Monodon:es; ce geore est mainteant oublié.

\section{HARPACE. Harpax.}

Gente établi à tort par 11. Parkinson, pour une coquille bivalve fussile que Lamarcli a placée parmi les Placunes sous le nom de placuna pectinordes: il n'avoit probablement pas vu la chasnière de cctte espece, car elle duit indu. bilablement appartenir a ux Plicatules (vojez ce mol); ainsi, que la coquille soit une Placuae on ane Plicatule, il reste constant que le genre Harpace est inutile.

\section{HARPAGO.}

Klein, séparant le Ptencera chiragra des actres espèces du même genre a lait de celie coguille (Tent. ostrac. $p .9^{8}$ ) un gevre inadmissible sous celle dénomiualiua. Voyez Ptérocíre.

\section{HARPE. Harpa.}

Linné, et à son exemple Bornn, Bruguière et les auteurs qui précédèrent Lamarck, confoudirent les Harpes avec les Buccins, et les rapportèrent presque toutes à unc seule espèce, le Buccinum harpa. Lorsque l'on tait attenliou à la constance des caractères des Harpes, à la ressemblance, sous certains rapports, entre les espéces, ¿े ce fucies particulier qu'elles préseutent, on est élonné que ces coquilles n'aient pas été séparées en genre plus tót, et que Bruguière, l'un des premiers rêformateurs de Linné, ae l'ait pas lui-même Éabli. C'est à Lamarck que l'on est redevable de ce genre. Dans sa première méthode il le plaça entre les Tonnes et les Casques, dans des rapports très-naturels, qui depuis furent conservés daus presque tous les arrangemens mélhudiques qui Cureut successivement proposés. M. de Rnissy, dans le Buffon de Sonnini, a cependant un peu modifié cel arrangemeat de Lamarck, cn plaçaor les Harpes entre les Tonnes et les Rochers. En établissant sa famille des Purpuracées dans la Philofophie zoologique, Lamarck ne changea rieb aux rapports des Halpes, qui restèreut entre les Casques et les Tonnes; nons les retrouvons à la même place et dans la wême fanille daus l'Extrait du Cours.

M. Cuvier comprit les IIarpes au nombre des sous-genres du grand genre Buccin; elles se trouvent entre les Tonaes et les Nasses, dans le voisinage des Pompres et des Casques : ce qui change très-peu la manière de voir de Lamarck.

Dans ses Tableaux syftématiques, II. de Ferussac transporta les Harpes des Buccins dans les Pourpres, modifiant ainsi d'une manic̀re peu importante l'ordre de N. Cuvier; dans le fond, les rapports restent ce que Lamarck les avoit faits, parce qu'en dérangeaul les Harpes, il enlraine avec elles les Tonnes, les Xiasses, les Casques, elc., entre lesquels elles sont rangées, et comme eux à titre de sous-geure.

La fumille des Entomostomes de Mr. de Blainville, dans son Traité de Malucolngie, rassemble un très-grand nombie de genres divisés en plusieurs groupes; le troisième renferme les Harpes à côté dos Tunnes el des Cassidai:es, ce qui est adopté de Lamarck. Mi. Latreille a conservé, dan. sa famille des Doliaircs, un arrangement assez semblablc : le genre IIarpe, qui cummence cet!e faınille, esı suivi des 'Tonnes, des Licoraes, des Concholépas et des Pourpres; re qui le rapproche un peu des rapports de M. de Ferussac, saus que cependiat ou puisse les regarder comme semblables.

Qnoique M. Rang ait connu l'animal du genre Harpe, il lui a cependant conservé à peu près les métues rapports. Placé dans la famille des Pourpres, entre les Buccins et les Pourpres, il est i peu près cname dans la raćllode de M. Latreille on celle ne M. de Fcrussac. Comme on a pu s'eu apercevoir, an reste, les variations de ce zenre sont de peu diuportance; tous les auteurs sunt d'accord en cela, que les Harpes ne peuveut être Éloignées des Buccins, des Tonnes, des Casquues et des Pourpres; tous ces genres sont liés par ttes ressemblances qui existeut, non-seulement dans les coquilies, mais encore dans les auimaux : de sorte qu'il importe peu que, dans la méthode, le genre qui nous occupe suit de prélérence is cólé de l'un d'eux.

L'animal de la llarpe est resté à peu près inconou jusque dans ces deiniers tecops, que M. Rejnaud, chirurgien-major de la corvelle la Chevrette, en douna une bonue descripion dans les Ménoires de la Société d'histoire naturelle. MM. Quoy et Gaymal'd 
Gaymard, de relour de len demier voyage de curcum-davigation, ont coolirmé ee fuit, que l'on regarda alors comne tout-à-fait neuf, el qui cependant éloir eonsigné depuis Inng-temps dans le bel ouvrage de Born ( Mlusceum Cicsaris vindolonensis, pag. 254), mais il étoit resté dans l'oubli le plus complet; il mériloil cependant d'être relevé, ear il est le plus renarquable de l'organisation des Ilarpes. Daus ces animanx, le picd a la faculté de se diviser eu deux, et l'une des parties, la postérieure, se détache Inrsque l'aniinal, se tronvant dans fjuelque danger, a bcsoin te se retirer profondément daus sa coquille. Par une conséquence toute simple de celle séparation de la partie postérienre du pied, un opercule devient inutile, puisquill seroit entrainé par la chute du pied : celle circonsıance du défau d'operćn!es'expliquant d'une unanière aussi nalurelle ve doil pas être un obstaele pour établir les rapports du genre avec d'autres qui sont opereulés, lorsque l'cnsemble de l'organisation s'en rapproclie d'une manière évidente, et séloigne au contraire des animaux qui n'ont point d'opercule, mais qui n'ont pas non plus, comone ici, uue cause physique gua soppose ì ce qu'ils en aient un.

Le reste de l'organisation de la Harpe seroit fuct analogue à celle des Buccins, d'après M. Reynaad. Dans aue grande eavité respiratrice cervicale ou tronveroit denx peignes branchiaux considórables fixés à la paroi supérieure; à côté de lui seroit l'orgaue aux mucosités, puis dans le fond un anus flollant, aecompagné de l'oviducic dans les femelles. Le cour seroit placé à la base de la branelie, en debors de la cavité branehiale, dans un péricarde renfermant aussi une oreilletie; le foie seroit très-considérable el occupervil la majeure partie de la spire, en enveloppant un large et long estomac et un intestin de pen de fungueur. Duns le mâle, la verye est comne celle des Burcins et placée de mêrne. Ia tête est Jurt petite, aplatie, partant de eliaque côté un tenracule conique, pen aloneré, oculé à la base externe. La bouche, placée en dessons, est fort petite et se distingue à peine sur l'animal conservé dans la liqueur.

CARACTERES GEXERIQUES.

Auional couni d'ane tête aplatie, portant nne paire de tentacules oculés à la partie externe de la base; bouche en dessous, simple, sans irompe; disque locumoteur fort grand, son extremuté postérieure caduque et dépourvae d'opercuic.

Coquille ovale, oblongue, plus ou moins bombée, généralement assez mince, émailiée, munie de côtes longitudinales, rérulières; spire peo élevée; ouverture grande, dilatée, fortement échancrée aotérieurement, le bord droit bordé par la dernière côte; la columelle simple, presque droite, poiatue en avant.

Histoire Naturelle des Vers. Tome II.
On ne peut lisconvenir que les II arpes ne suient de fort belles coquilles, d'une forme éléñaute, et ornées de vives couleurs agréablenıent variées. Leur nom vient sans contredit de la disposition régulière el oblique des côtes longitunales dont elles sont ornées. Ces coquilles sont maıines et habitent spécialement les mers des pays chands. Le nombre des espèces est pen considéruble : Lamarck en compte huit vivantes seulement et une fossile, et encore parmi ces premières on pourroit en refrancher quelquesunes yai font double emploi, telles çue la Jurpe iupsériale, par exemple, qui n'est qu'une variélé asscz constante de la llarpe ventrne. On en a la preave par un individa des plas remarquables de la collection de $\mathrm{M}$. de Rivoli: son dernier tola est moitié Harpe iopériale el moilié Harpe ventrue, portant ainsi les deux espèces. La Harpe striće nons semble aussi une variété d'âge de l'espéce précédente : on pourra s'en convaincre facilement; en faisant une série d'âges dillérens, on verra les stries cesser à nne certaine époque du développement de la cognille. Ce n'étoit done point trop à torl que Linné rénnissoil toutes les espèees de llarpes en une seule, et il faudroit encnre aujourd'hui suivre complément son exemple, s'il n'y avoit vérilablement plusieurs espèces bien distiucles el constantes dans le genre qui nons oceupe.

On ne connoil coujour's qu'une seule espèce fos. sile; elle est des environs de Paris.

\section{Hare ventule. Harpa zentricosa. Lamk.}

11. testâ ovato-ventricosâ; costis latis, distantibus, plus minusve numerasis et elatioribus, purpureo tinctis, apice mucronatis, mfnì mucronem subunidentatis; interstitiss albidis, muculis spadiceo-fuscis notatis; columells pupureo et nigı maculati.

Lank. Anim. s. vert. tom. 7. pag. 255. $n^{\circ} .2$.

Buccinum harpa. Liv. GMEL. pag. $3482, n^{\circ} \cdot 47$.

Bonnani, Recr. 3 fig. 285.

RомРн. Mus. amb. pl. 52. fig. K.

SeBA, Mus. loc. tom. 3. tab. 70. Absque numero.

Knон. Veign. 2. tab. 19. fig. 1. 2.

Regent. Conch. 2. tab. 6. fig. 5 r.

Favane, Conch. pl. 28. fig. A. 3.

Mantisi, Conch. cab. toms. 3. tab. Ing. fig. 1090.

Buccinum harpa. Bavg. Encycl. $n^{\circ} \cdot 9 \cdot($ Var. a.)

Excrenop.pl. 404 . fig. 1. a. b.

Var. A. Nuв. Testâ costis angustis creherrims. mustuctí, zonis internutis, luteo-rubescentibus ornatâ.

$\mathrm{Aa}^{*}$ 
Harpe inpériule. Harpa imperialis. Lssu. loc. cit. $n^{\circ} \cdot 1$.

Buccinum costatunt. LIN. Gmel. pag. 3482 . $n^{\circ} .48$.

Dargenv. Append.pl. 2. fig. F.

Matini el Chemnitz, Conch. cab. toni. 3. tub. 119. fig. $\log 3$, et tom. 10. tab. 152. fig. 1452.

Favane, Conch. pl. 28 . fig. $a 4$.

Buccinum harpa. Brog. Fncycl. tom. 1. $n^{\circ} .9$. (Var.e.)

Harpa multicostata. Sowerby, Gen. of shells. $n^{\circ}$. 3. fig. 1. 2.

Var. B. ов. Testâ griseâ; costis angustiorihus, distantioribus, albo nigroque articulutim maculatis.

IIarpe arliculaire. Harpa articularis. Laxx. loc. cit. $n^{\circ} .5$.

Guart. Test. tab. 29. fg. D.

M. ativi, Conch. cah. tab. 1 19. fig. 1092.

An eadem? Lием. Conch. cab. tom. to. tab. 152. fig. 1451 .

Excrcs. pl. 404.fig. 3. a. b.

Var. C. Nов. Testá costis angustis, renotis, instructâ, albo rufo et. fusco niaculatis; interstitiss transverse ftriatis.

Harpe striée. Harpa striata. Lamr. loc. cit. no. 8.

Sева, Muls. loc. tom. 3. tub. 70. Figura prima in serie ultima.

Escyclop. pl. 404. fig. 4 .

An eadeni species? Harpa cancellata. Cвesn. Conch. cab. tom. 10. tab. 152. fig. 1454.

Var. D. Nов. Harpe conoüdale. Harpa conoidalis.

LamK. loc, cit. $n^{\circ} .3$.

Testâ costis distantibus, inaqualibus, roseo tinctis, apice submucronatis, instructâ; spirâ conoideá, exsertiusculâ.

Nous réunissons, comme on le voit, quatre des espèces de M. Lamarck eu une seule; les personnes qui, comme nuus, auront vu un grand nombre d'individus de la Harpe ventrue, concevront facilement nos motifs et les approuveront. Voici ce que nous avons observ6 :

$1^{\circ}$. Sous le rapport'des côtes, elles sont lantôt larges, tantôt élroites, à nombre égal, avec la mêtme coloration; tantốt larges, taniôt étroites, en nombre variable, toujours avec la méme coloration; elles varient depuis dix jusqua"à quinze sur le dernier tour dans la Harpe ventrue proprement dite, elles vont jusqu'à trente ou trentesix dans notre variété A, Harpa imperialis, et il a fallu l'individu de la collection de $M$. de Sivoli pour nous convaincre qu'elle appartenoit is la méme esprice. Tuus les individas jetnes, apparlenanl a celle espèce, que nous avons vus, quels que soieor le nombre de leurs cốtes et leur coloration (roujours dans les limites que nous donnons à l'espèce), étoient sıriés en travers, d'autant plus fortenzent qu'ils ćloient plus jeunes, les stries disparuifiant insensibleneni avec l'àge. C'est aiusi que l'un concevra sans peine l'existence d'une variété striće pour chacume des mudifications de la coguille, snit sous le rapport de la coloration, soit sous celui du nombre des cô'es : pour nous, la coquille nummée Harpa striuta par Lamarck est le jeune îge de son Hapa articularis, qui est notre variété $\mathrm{B}$.

$2^{\circ}$. Sons le rapport de la coulenr, dans toutes les varićlés que nous arons compriscs dans celte espièce, nous retrouvons les mêmes élémens de coloralion : on remarque sur les côles de la Harpe ventrue, proprement dite, quatre bandes transverses plus foncées et assez larges; elles sout séparées par des lignes blanches et par des fascies intermédiaires plus étroites el plus pâles; le plus souvent ces quatre bandes sont bordées en haut et eu bas par des lignes brunes: dans la Harpe impériale il ne resie que ces lignes brunes; dans la Ilarpe articulaire ces lignes brunes sont très-foncées, mais le reste de la coloration persiste. Entre les individus qui n'ont point de lignes et ceux qui en sont pourvus au plus haut degré, on peut lacilemeut établir une súvie de variétćs, et avec l'inpossibilité de poser des liunites entre dos espèces, se joindra la conviction de la nécessité de lout réunir en une seule; cette conviction deviendra diautant plus forle que l'on aura vu une mêrne série de mo. difications dans un aulre caractère, celui du nombre des côtes, non moins variable que la coloration.

Nous ferons remarquer que dans la Harpe, comme au reste dans lous les geares de Nullusques monoiques, les coquilles rles mâles sont plus petites, plus étroites et oot la spire plus élancée. Ce sont ces individus mâles que Lamarrk a réunis en espèce, suns le nom de Harpe.connïdule, et qui constituent uotre dernière variété, que nous àarons mentionnée et conservée que pour que l'on puisse retrouver facilement l'espèce de Iamarck.

A près ces observalions nécessaires, nous renvoyons le lecteur à la description du Buccinum harpa de Bruguière, dans le premier volume de ce Dictionnaire, description rè̀s-bonne, dont nous retouchons les variétćs $b . c$. $d$. qui couslituent d'autres espèces.

2. HaRpe noble. Harpa nobilis. LaAr.

H. testá ovatâ, subventricosâ, giiseo-albo et fusco variô, maculis amplis purpureo-sanguineis pictâ; costis latiusculis; lineis nigris capil- 
larbus transwersim fusciculatis; spiri submuricatâ.

l.2ss. Anim. s. vert. loc. cit. $n^{n} .4$.

Listea, Conch. tab. 992. fig. 55.

Ruмрн. Mus. tab. 32.fig. $l$.

Goslt. Test. tab. 29. fig. c.e.g.

DARGexr. Conch. pl. 17. fg. $d$.

Favaxie, Conch.pl. 28. fig. a. I.

Kíona. Vergn. tom. 1. tab. 9.fig. 3.

M.antris, Conch. tom. 3. tab. 119. fig. $10 \mathrm{~g} 1$.

Buccinun harpa. Bnoc. Dict. no. 9. (Yar. c.)

Var. A. Nов. Testâ maculis latis rosets ornati; costis angustissmis, distantibus.

Hurpu rusea. Is ax. loc. cit. n. 6.

Martisi, Conch. cab. tom. 3. tab. 119. fig. 1094.

Buccinum harpa. Bnug. Encycl.n॰.9. (Var. b.) Excrez. pl. 404. fig. 2.

Var. B. Nов. Testi costis lutioribus instuct $\hat{d}$, maculis rosers lutis arnati.

Harpa nobils minor. Mantsxi, Conch. cab. tum. 3. $\mu l .119 . / \mathrm{g} .10 \mathrm{~g} \mathrm{~b}^{\circ}$

Nous pourrions facilement, cotame dans l'espèce précédente, établir les mèınes variétés ou a peu piès, et faire voir quelle varie presque daus les nèmes limiles; ainsi, à l'exceptinu d'une variété a côtes serries, que uous ne conunissons pas, nous trouvons des modificulions analogues fans le numbre el la grosseur des riles; danires, pour ce qui a roppout a la coloration; daulres enfin, relalives à lâne et au sexe. Ainsiles cótes varient eotre 9 et 15 sur le dernier tour, ce qui les reud plus ou moins serrécs; elles soni taniót fort étroites, lantò? beaucoup plus larges, a nombre égal sur les mèancs individus. 11 y en a de larges et d'étroite tont is la fuis; mais il est a remalquer que, quel que soil leur élat, elles ont toujours la mếme colnration dans toute leur loogueur, el sont toujours araquées de no:mbreuses lignes hrunes ou voires. Quant à l'élendue des laclies roses, elle est exl'êuenent variable; elles commenceut par ètre fort petites el finissert par envahir presque toute la face dorsale de la coquille. Ce que nous avons clit précédemment de lis Ilalpe ventrue doit nous fuire entendre facilemenc pour celle-ci, et pour sa description plus l:omplèe, nous runvoyons au Buccinum harpa (var. B et $C$ ) de Bruguière, daasle premier volume de ce Dictonatire.

3. Hanze alongúe. Harpa ninor. Lasik.

H. testís ovato-oblongâ, griseâ, fusco nuaculosi; costis angustis, distantibus, migro lineatis ; lineis geminatis; spiri exsertuscula.
Lasx. loc. cit. $n^{0} \cdot 7$.

Listea, Conch. tab. $994 \cdot f g .57$.

Rompa. Mus. tab. 32. fig. M. Harpa minor.

Petiv. Amb.tab. 15. fg. 10.

KLEIN, Ostr. tab. 6. fig. 105.

SEBA, Mus. tont. 3. tab. 70. In inferiore ordine utringue.

Martisi, Conch. tom. 5. tab. 119 fig. 1097.

Buccinum harpa, Baug. Dict. n॰. 9. (Var.d.)

Cette coquille, toujours d'une pelite taille et d'une coloralion particulice, nous semble suffisamment distincle pnur être conservée conme espèce; nous lui trouvons, tout en restant dans de certaines limites, la mêrne sćrie de variétís que dans les especes précédentes, ayant comme rlles des côtes larges et des côtes étroites, en numbre égal et en nombre variable. Quant ì la coloration, elle n'est guère moins variable que dans les espèces précédentes, passant du gris au blanc fauve, d'un grand nombre de linéoles sur les côtes à des taclies simples d'un fauve peu linncé, el des liugnes transverses subarticulées et élroiles à des zones et des taches irrégulières. Nous croyons que c'est à tort que Bruguiere a confondu celle espece all nombre des varićtés du Buccinum harpu; mais comme sa description est fort bonne, nous renvoyons le lecteur an lome ler. de ce Diclionnaire, Buccinum harpa. (Tar.d.)

4. II Rfe mlitique. Harpa mutica. LAsx.

H. testâ ovato-oblongij; costis acutis, di.tantibus, apice muticis; strits intercostalibus decussatis, longitudinalibus, mujoribus; spiri cxsertâ.

Harpa mutica. Ann. du Mus. tom. 2. pag. 16-. $n^{\circ} .1$, et tom. 6. pl. 44. fig. 14 .

Ibid. Anim. sans vert. loc. cit. $n^{\circ} \cdot 9$.

Sow скв у, Genera of shells. n०. 3. fig. 5 .

Celle espice est la seule connue jusqu'à ce jour ¿̀ l'état fossile; elle est à pen près de la taille de la Harpe alongée, mais généraleaca plus ventruc, elle est plus étroite a la base; son test est unince, fragile, oraé de onze ou douze côtcs longitudinales simples, ćtroites, jamais relevées obliqueuent, coucblés et trancbantes. Les intervalles qui les séparent sont larges, assez réguliers sous le rapport de la largeur, et toujours couverts de stries longitudinales liès-fines et saillantes, el de trausverses moins régulières, ce quii produit ua rése $\lrcorner$ assez régulier de mailles carrées. La spire, peu prolongée, se compose de six a sept tours arrondis, un peu aplalis $\mathrm{t} n$ dessus, mais non unuriqués; le sommet se forare de deux ou trois tours lisses et mamelonnés; l'uuverture est woius amples que dans les esA a $2^{*}$ 
pèces vivantes. La columelle, bordée par le loord gaucbe, étalé postérieurement et un peu rclevé à la base, est légèrement sinueuse dans son milieu.

Cette coquille, assez rare anx environs de Paris, se trouve \&galemeat à Valognes.

\section{HAULME. Morio.}

Et non Heaulme, comme l'écrit Montfort, par unc faute d'orthographe qui s'est répétée dans 1a plupart des ouvrages où se trouve mentionné ce genre, qui, au reste, est le même que le Cassidaire de Lamarck, plus généralement adopté. Voyez ce mot.

\section{HAUSTELLUM.}

Genre inftitué par Klein (Nov. Meth. ostrac. pag. 63) pour rangrer les coquilles à spire globuleuse, terminées à la base par on long canal grêle. Ces coquilles, telles que le Munex brandaris, comutus, haustellum, \&c., appartenaat spécialewent au geare Rocher, peuvent constiluer un groupe dans ce genre, mais non un genre à part, comme Montfort a tenté de le faire après Klein. Voyez Rocner.

\section{HĖBRAÖQUE.}

Nom vulgaire que l'on applique à la pluparı des coquilles qui ont des taches neltement découpées, plus ou moins semblables à des caractères. C’est ainsi qu'un Cóne, un Buccin, une Pourpre, \&c. \&c., ont reçu cette dénomination, qui, de vulgaire qu'elle étoit, est souveat devenue scientilique.

\section{HELCION. Helcion.}

Parmi les Patelles, il en est un certain nombre qui, quoique régulières et symétriques, ont le sommet en arrière, comme les Cabochons. C'est avec celle coupe des Patelles que Montfort proposa son genre. 11 auroit été admissible comme sous-geare ou mieux comme coupe secondaire si, par un rapprochcment très-peu fondé, il n'eút mis avec ces coquilles marines celles dont Geoffroy e! Draparaaud avoient fait le geare Ancyle, qui sont fluviatiles et qui doivent appartenir évidemmeat à une autre famille. Voyez Patelle el Anctie.

\section{HÉLE்NIDE. Helenis.}

Monifort ayant trouvé daos l'ouvrage de Ficl. tel et Moll la figure de quelques coquilles cloisonnées lort extraordinailes, les copizà sa manière dans le tome premier de sa Conchyliologie systématique, et en fit trois genres, Hẻlénide, Arebidie et Ilote, quoiqu'clles n'appartinssent bien évidemment qu'à un seul. Lamarck les réuuit en efiet sous le nom d'Orbiculine, et sui- vant les indications de Fichtel et Moll, il fit trois espèces, que les observations de d'Orbigny réduisireat à une seule, en prouvaut que Montfort avoit fait des genres et Lamarck des espèces sur des âges différens d'une même coquille. Voy. Onbiculine.

\section{HÉLICARION.}

M. de Ferussac a donné ce nom à un genre qui correspond parfailement à celui nommé $V_{i-}$ trine par Draparnand. Ce genre Vitrine étaat généralement adopté, il convient de le couserver. Voyez VITRINe.

\section{HÉLICE. Helix.}

Les animaux lerrestres, habitant les mêmes régions que l'bomme, ont été les premiers à êlre soumis à son observation, et parmi eux cenx dout la marche est la plus lente, et surtout qui se montrent la plupart en grand nombre, ont dô être les premiers à Je frapper. Les Hélices, et ea général cons les Mollusques terrestres, soni de ce nombre. II n'est donc point étonnant que les auteurs les plus anciens en aient parlé de manière à reconnoitre assez tien les espèces qu'ils ont mentionnées; et s'il est vrai, comue l'observe M. de Ferussac, dans le texte de la septième livraison de l'Histoire des Mollusques terrestres et fluviatiles, que les mots employés par la plupart des pcuples soient le résultat de quelques idées simples, ils font voir la baute antiquité de la connoissance, même assez délaillée, de quelques espèces d'Hílices, et que ce pelit nombre d'idées a été rendu dau, les différens langages par des mots dilléreus, mais équivalens. Ce n'est pas ici que nous devoos examiner ces étymolngies; nuus ne rapporterons pas et nous ne chercherons pas à disculer ce que les Anciens ont dit et ont écrit des Hélices, il nous sullit de savoir que Pline, Varron, Dioscuride, Aristote, les ont mentionnés d'une manière loute particulière; ce qui tient surtout, pour les auteurs latins, à ce que les Anciens en laisuient usage comme nourriture, et cherchoient les espèces les plus délieates et les plus facilcs à propager ou à élever près d'eux. Aussi nous voyons par dillérens passages de ces auteurs qu'on les rapportoit de liliyye, des iles de la Méditerranée surtout, et beancoup d'Alrique; la Sicile leur en furmissuit aussi un grand nombre. La manière dont les Aaciens ont désigné ces corjuillages a rendu plus facile la détermination des espèces qu'ils ont connues; l'usage qu'ils en faisoieat a pu servil aussi à faire présumer celles qu'ils recherchoient, et connoissant aujourd'hni celles des pays où ils allojent les recueillir, on a pu avancer, avec quelque certitude, que les liuıçons terrestres d'Aristute et les grands limacons d'lllyrie de Pline punvoient conveuir à l'Helix cincta, ct peut-être à 
l'Helix lucorum de Muller, comme le Pomatia de Dioscoride et de Pline et probablement le Coculia d'Aristote étoient l'Helix naticoides, très-commune en Italie, et non notre Pomatia, ‘ue quelques auteurs ont cru avoir été désignế par les Anciens. Depuis Aristote jusqu'aox écrivains du renouvellement des sciuces, nous ne trouvons presque rien de plus que ce que les Aaciens avoient écrit.

Les premiers travanx anatomiques sur les Limaçons ou Hélices sont ceux de Harder et de Rédi, qui précédèrent Lister, qui ne fit que les répéter.

Swammerdam et quelques autres auteurs parlèrent aussi de l'anatomie des Hélices; nous ne donoons pas dans ce momenc l'analyse de leurs travaux, devant un peu plus tard les mentionner d'une manière particulière.

Tonrnefort, dans sa Méthode conchylinlogique, dont Gualtierri tit usage le premier, a conlondu sous le nom de Cochlites une partic des IIélices, avec des coquilles mariaes qui leurs ressemblent plus ou moins, et a pourtant établi, sous la dénomination de Cochlites terrestres, un genre qui s'applique aux Hélices, et un autre encore, les Cératites, qui peuvent étre des Plauorbes uu des espèces d'Hélices planorbiques.

Nous ne eiterons pas l'ouvrage de Dargenville, qui a coufondu les IIélices tantôt avec une famille, tantôt avec une autre; ce que lit aussi Favanne dans la troisième édition du livre de Dargenville. Cependant ces auteurs eurent le mérite de donuer plusieurs espéces lort rares, qui nout point été retruuvées depuis eux.

Linoé, qui confandit daus sun genre Helix un grand nombre de coquilles qui y sont étraugères, y aroit placé des espèces terrestres, des lluviaililes, et mêtme des marines. On doit donc regretter que l'zuteur du Systema naturce n'ait pas profité des genres de Muller et d'Adanson, qui présentoient des coupes lien naturel!es, on peut même dire essentielles, d'iuprès la manière dont elles étoieut earaciérisées. Nous voyons en eflet, dans Adansan, le genre Liuaçon sćpuré d'après de bons curactères, ainsi que daus l'ouvrage de Muller, nit on trouve eo outre les genres Carichium e: Vertigo. Le seul clangrement que Bruguière ait liait dans les IIélices de Linné, eft la création de son geure Bulime, qui est presque aussi délectueus que le genre linnéen, puisqu'il conlient aussi, il est vrai un pen mieux séparées, des coquilles terrestres, fluviatiles et marioes. Lamarck commença à réformer ces genres, et créa d'abord à leur's dépens les Cyclosiones, les Miaillots, les Agathines, les Lyunnées, les Mlélanies, les Auricules, les Ampullaires, les Hélicines et les 'Testacelles.

Draparnaud, dans son Histoire des Mollusques terrestres el fluviatiles de Frunce, a encore ajouté plusieurs nouveanx genres, qu'il démembra aussi des Ilélices de Linné ou des Bulimes de Bruguière, à ceux que Lamarck avoit proposés. Ce sont les genres Ambrette, Clausilie, Vitrine et Pbyse. Monifort, dirigé seulement par !es formes extérieures des coquilles, a poussé encore bieı plus loin que Lamarck et Draparnaud les divisions génériques, et cela ne doit point érouner, cu faisant alteution, d'une part, au système adopté: par l'auteur, et de l'autre, \l'extrême variabilité des farares des coquilles des Hélices. Ontre les genres que nous avons mentionaés dans les denx auteurs précédemment cités, nous trouvons de plus dans celui-ci les suivaus : Cyclophores, Vivipare, Radix, Scarabe, Ruban, Polyplième, Ibère, Zonite, Carocolles, Acave, Capraire, Polydonte, Cépule et Tomogère. Lamarck créa encore une nouvelle coupe dans l'Extrait dus Cours, sous le nom d'Hélicelle, mais il ne l'it point conscrvée. M. Cuvier, daus le Règne animal, a forné de plus son pelit genre Greaaille. Léarb a proposé, il y a pen de temps, un nonveau genre, démembré des Bulimes, sous la dénomination de Bulimule. En résumunt tous les genres créés aux dépens des IIélices de Lioné, nous en trouvons trente-deux, entre lesquels se distribuent plus on moins bien les deux cents espèces d'Hélices de la treizième édition du Systema natura. Si tautes ces divisions reposoient sur de bons caractères, pias aussi bien des animaux que des coquilles, ce nombre de grenres, quelqu'exagéré qu'il parvisse, ne sernil pourtant poiut trop considérable pour séparer nettement et bien grouper lant d'objets dill'rens. Néanmoins, un grand service que la plupart de tes coupes out rendu à la science, a été d'abord de débarrasser les IÍlices des genres marins et lluviatiles, avec lesquels il étoit impossible de les laisser, et de plus d'avoir indiqué des groupemens d'espè̀es analogues, qui, sans être conservís comme genres, peuvent l'ćtre au moios comnce section générique.

M. de lierussac est le premier qui, après une étude soignée des Ilélices, ait proposé un sysicme d'ensemble ponr ce genre, dans soll ouvrage général des Mollusques terrestres et lluvialiles. Après a voir éloirné des IIélices de linné les genies marins ou lacustres qui ont élé formés par les auteui's prćcédens, à leurs dépens, it réunit tout le reste en une seule famille. les limaçons, qui au lieu d'une vingtaine de gexres urécédemment établis, cornme nous l'avons dit, n'en reul'erme plus que six, qui sunt : Hélixarion, unuvea genre créé par M. de Furussac; Hélicolimace, pouvelle dénnmiuation des Vitcines de Draparuaud; Helix, Pulyphème de Mootfurt; Verligo de Muller, et un nunveau geare qui est vivipare et auquel M. de Ferussac a donné lo nom de Partule. De ces genres, te plus nombreux, et conséquemment celui qui présente to 
plus de difficalés pour reconaoitre les espèces, est le geare Hélice circoncrit, comme nous le verrons bientôt avec plus de détails, de madière a y faire rentrer tous les Mollusques terrestres qui ont quatre tentacules, dont les deux supéreurs sont oculés au sommet. Tous les genres des auteurs qui offrent ce caractère ont dû́ rentrer dans le genre Hélice de M. de Ferussac; c'est ainsi que les Ambrelles, les Acaves, les Anołlomes, les Carocolles, les Rubans, les Agáthines, les Polyphèmes, les Maillots, les Claufilies, les Bulimes, les Bulimules, les Gremailles : les Capraires, les Cépoles, les Polyduntes, les Tumogères, les Ibères, les Zunites el les IÍlicelles en font maintenant partie.

i1. de Ferussac, réunissant lous ces genres et ayant eu connoissance, par suite de vastes relatiuns, d'un très-grand nombre d'espèces nouvelles, ce qui les porte à cinq cent soixante-deux, a bien pensé qu'il seroit absolument impossible d'arriver sûrement et promptement à la détermination des espèces sans des coupes reposaut sur des caractères plus ou moins bien fondés. Il auroit fallu arant tout un priacipe nouveau, qui auroit pu servir de point de départ, et en mêue temps de base fondamentale à tout le système. Détruisant les geores qui a voient servi à ses de vabciers, M. de Ferussac se trouvoit dans l'altemative de les remplacer par de nouveaux déduils de ses observations, ou de les employer eu les noditiant, en les couvrant du volle de la nouveauté; il fut obligé de se servir de ce deruier moyen, et nous verinns que les uombreux sous-uenres ‘u'il a établis dans le zeure Hélice se rappurten!, punr la plupart, aux geares antérienrement ćlablis, et n'ont de nouveau que la dénumination.

Les coquilles seules qui servirent à Modifort pour établir ses genres, sont aussi les moyens einployés par II. de Ferussac pour crfér ses sousgeores, avec celte différence, il faut le dire, que ce dernier auteur ayant à sa disposition uo nombre d'espèces bico plus considérable, a pu taire des groupes plus aaturels, des rappruchemens plus heureux, daus lesquels plusieurs des anciens genres vieuneat se confoodre iosensiblemem, au moyer de formes ou d'auties caracteres intermédiaires que l'uu ne connoissoit pas avant lui.

Pour élablir les grandes divisions du geare, un caractère naturel sest ullert à M. de fierussas: cerlaines Hélices ont une cocquille trop perite pour les contenir entièresoent, il en a tait une première section, et lui a appliqué l'épithète de Redundantes; d'antres Hélices, et c'est le plus yrand numbie, peuvent rentrer entièreasent daus Teur coquille, et mèrae elle est plus granie qu'il ae le taut pour quils la remplissent, ce sont celles-là qui forment la seconde section intitulé Inclusce.
Ponr élablir dans ces deux sections des counzez d'ua ordre iulérieur, M. de lierursac a easpliyé le mode d'enroulement de la spire; il a nommó Volutata, les coquilles dont les tours sont enroulés les nos sur les autres dans un plan borizontal, qui ont une forme planorbique ou subdiscoide, et il a nommé Evolutata celles qui sont enroulées dans le plan vertical, et qui sont alongées ou turriculées. Chacune de ces sousdivisions sont employées el dans la section des Redundantes et dans velle des Inclusa; se selvant ensuite des deux wots grecs helicos et cochlos comme d'uo racine, if en furme les mots helicoides el cochloides, qui lui servent à désigner chacune des sons-sections: it applique lia première aux Volututo, el la seconde aux Evolutata. Ces deux racines lui servent encore is fur" mer, dans clacune de ses qualle sous-sections, tous les sous-renres qui y sont contenus. Pour le, uns, c'est la raciue cochlos quiles tomenence; pour les autres, c'est helicns, avcc une terminaison qui leur sert d'épithèle caracléristıque. Vuici de quelle manière ce système est distriLué.

\section{Redundantes.}

Vuzutatж. Húlicö̈les. Helicoides.

Semude. Coquille perfurée ou umbiliquée.

Iilicopante. Helicopharta. Divisé en Virrinoides el en Vessies.

Evolutata. Cochloides. Cochloides.

Subreda. Culumelle en tilet solide.

Cocrlourone. Cochlohydra. Contenant les Amhretres et les Amplibulimes daus une seule section.

\section{Inclusce.}

Vouvtate. Húlicoïles. Helicaides.

Ombilic masqué ou couvert; quelquefois une counelle solide; coquille globuleuse ou surbaissée; péristume nun bordé.

Hélicogéxe. Helicogena. Divisé en grratre groupes, les Columellées, les l’erforées, les Acaves, les Surbaissćes.

Buuche dentéc; oubilic couvert ou visible.

IIÉlicodoxte. Helicodonta. Contenant cin: groupes, les Grimaces, les Lamellées, les Maxillées, les Anusloares, les Impressionnées.

Coquille carénée, quelquelois conique; ombilic couvert ou visible.

Hélucisone. Helicigona. Divisće en Cirorolles el en'luabilluns. Oubilic découvert; coquille sur. baissée ou aplatie; péristome rélléctii, sımple on bordé. 
Héricezr. IIelicolla. Cuntenant quatre grtonpes, les Lomastomes, les Aplostomes, les IIybromanes et les IJéliomanes.

Une columelle solide; coquille surbaisséc ou rrocbiforme; quelquefois des lames ou des dents.

Hélicostyez. Helicostylu. Il renferme égalelement quatre sous-divisions, les Apiostomes, les danellées, les Canaliculées et les Marginées.

Erolutate. Cocbloïdes. Cochloides.

Boucbe généralement sans dents; une colutnelle solide en filet non tronqué.

Cochlostrue. Cochlostyla. Divisé en Lomastomes el en Aplostomes.

Cilumelle plate, tronquéc; ouverture llar.jie; roquille conique ou vemtrue.

Cochutome. Cochlitoma. Il comprend les Rubans el les Agatbines.

Ouverture étroite; coquille ovoide ou turriculée.

Cochlicopa. Cochlicopa. Divisé en deux yroupes, les Polyphèmes et les Styloides.

Coquille perforée ou ombiliquće; dernier tous de spire moins long que les autres réunis.

Cocmutrelez. Cochlicella. Contenant uue seule sous-division, les Tuurelles.

Dernier tour généralenıent renllé et plus long que les autres réunis, rarement des dents.

Cochlocisx. Cochlogena. Divisé en six groupes, savoir: les Usnliliquées, les Perlurées, les Bulimes, les Helicteres, Ics Stomotoides et les Dontostomes.

Bouche géaćralement garnie de lames sans nouttières; péristome génćralement non coutinu.

Coculodonte. Cochlodonta. Il renferme les Naillots et les Grenailles.

Une on deux goullières; póristome généralement continu.

Cocanodine. Cochlodina. Il cst divisé en $\mathrm{Pu}$ poïdes, en 'Trachéloides, en Anomales et en Clausilies.

Tel est l'ensemble du syslème de M. de Ferassac pour les Hélices; divisées en qualorze sousgenres, elles sont distribuées en quarabte et un graupes.

Avant d'uller plus loin et de critiquer les diverses parties du système de M. de Ferussac, il est, nous le croyons, nécessaire de faire ici quelques observations générales sur la manière d’envisager le genre Hélice, pris également dans son ensemble à la manière de M. de Ferussac; ces abservations, que nous nons efforcerons de faire d'après la nature des faits, nous serviront á apricicier la valeur des yenres et des sous-yenres Ćablis aux dépens des fílices, soit par Ml. de Ferussac, soit par d'autres auleur's assez répandus pots exeicer une baute iulluence sur l'opinion des suvans.

Loi'sque l'on a rassemblé un nombie assez considírible d'espèces de coquilles terrestres, parmi les?puelles on a eu soin de recueillir les modificalions principalcs ga'elles ollient dans leurs caraclíres; lorsqu'on les a étudikes long.temps et consilencieusernem, on arrive, comme M. de Fernssac, à rester convaincu qu'il est impossible d’arlmettre dans cet ensublile wa grand nombre di? genres. Que l'on premue sucressivement tous lis caractères que l'on a observés, quin les suive dins toute la sćrie, et on les verrat éprouver une suite inseusible de inndilications, qui sera telle qu'il sera matériellemen impossible de marģucr une limite enire des caractères sensibles seulemerit anx deux points exliêanes de la série. Nous ne. parlerons pus de ha forme géaérale des coquilles, personne nignore qu'elles varient depuis la forare la plus discoide el la plus planorbigue juscun'a la plus turriculée. 'Benous pour exemple la forme de la columelle el de ses accidens divers qui pon:roient, avec plus de raison, ètre pris pour dés caractires de plus de valeur que les autres. Sous le rapport de son inclinaison is laxe de la coquille. nous la vayons d'ubord si courte et si oblique qu'à peine si on peut dire qu'elle existe; rlle se rapproche dans ce cas de la ligne horizonale, tt fait un anole droit avec l'axe perpendiculaire de la coquilie. Par des transitious iusensibles entre!es espèces, on la voit peu à peu se redresser à mesure que l'ouverture elie - mêne devient moins oblique, et se rapproclse davantage de la perpendiculaire. Entin, après a voir éprouvé tau!es l's variations possibles dans l'incidence de l'angle, elle parvient à la perpendiculaire et devient li prolungation de l'axe de la coquille.

Si ces variations dans la forme de la columelie entrainoient aussi avec elles des modifications dans les formes extérieures, que ces modifications fussent constantes, le problème seroit des plus faciles à résoudre; car, d'une modification columellaire donnée on en déduiroit la furme de la coquille, et, un goniomètre à la main, on élablirait les genres ou les groupes; mais il s'en faut de beaucoup que cela soit possible. Dans des espèces subturriculées, la columelle est tantót perpendiculaire, lantôt lrès-oblique; dans d'autres ylobuleuses el très-conrtes, la même variation de fa columelle apparoit. Ainsi, que l'on veuille former des groupes d'espèces, il sera impossiblo qu'ils suient établis sur les deux caractères à lit fois : dès-lors on sent l'embarras du conchyliologue, et cependant il s'augmente encore par de nourelles complications.

Les modifications de la colnmelle ne se réduiseot pas à la position relativement à l'axe de la 


\section{$1 \mathrm{~g}^{2} \mathrm{HE} \mathrm{E}$}

coquille : elle est quelquefois simple, quelquefois ombiliquéc ou perforée; quelquefois en filet trèsmince, d'autres fois épaissie; enfin, elle est tantût ou tronquée ou dentée. Faisons remarquer en passant que ces divers accidens, pas plus que ceux de la forme, ne coïncident avec ceux de la position de la columeile; souvenons-nous encore que pour faire de bons groupes ou des genres, il faudroit que tous ces accidens coïncidassent d'une manière constante et régulière.

Il est à remarquer que les accidens dont nous venous de parler subissent chacun pris isolément une suite de modifications dans la série des espèces telle unent gradućes, tellement peu sensibles dans chacune d'elles, qu'il est quelquefois impossible, et dans tnus les cas toujours très-difficile de leur assigner des limites certaines : c'est ainsi que l'ombilic, d'abord nul, commence par une fente capillaire qui s'agrandit successivement jusqu'à être infundibuliforme et très-largemeut ouvert; la forme générale de la coquille est plus d'accord a vec cetle modification qu'avec beaucoup d'autres. C'estainsi que si l'ombilic est aul dans qoelques espèces aplaties, il n'est cependant jamais, jusqu'à présent, largearent ouvert dans les espèces turriculées, mais bien dans les espèces subplanorbiques; néanmoins celle coïncidence de denx caractères échappe encore par son extrême variabilité. Il en est de même pour ce qui a rapport à l'épaisseur. de la columelle, à son évasement plus on moins considérable; elle cst réduite à un filet très-mince daus certaines espèces, et devient très-ćpaisse et calleuses dans d'autres: on trouve ensuile toules les modifications intermédiaires entre ces deux élats. Pour ce qui est des dents coln mellaires, elles suiveut absolunent la même loi d'accroissement ou de décroissement : elles commencent par être si petiles et si rudimentaires qu'il est impossible de dire si certaines espèces feront partie de celles saus dents ou de celles qui en ont; cette difliculié pourroit être tranchće arbitrairement, comne on l'a fait pour beancoup d'autres genres, mais c'est qu'elle se reproduit dans toutes les mudifications de forme et de position de la columelle, dans toutes celles de forme extérieure des coquilles; ce qui, comme on le voit, complique bien davantage la question.

Nous arrivons maintenaut à l'examen d'un caractère en apparence plus imporant, puisque Lamarck s'en est servi pour l'établissement de son genre Agathine; nous roulons parler de la troncature de la columelle de certaines Hélices. I! est bien certain qu'en isolant de ce genre tontes les coquilles qui se rattachent aux autres Hélices, on le trouve dans son enscomble caractérisé d'une manière plus convenable que la plupart de ceux que l'on avoit démembrés conme lui des Hélices. Les coquilles de ce genre ont en eflet beaucoup d'analogie entr'elles; leur forme, leur columelle, la forme pen variable de l'ouverture, sont des caractères assez constans nour que l'on puisse toujours rapporter à leur groupe les coquilles qui les offrent. S'il n'existoit aucun intertrcidiaire entre les Agathines et les Hélices, ce secoit à ban droil que l'on en feroit un genre; mais ces intcrmédiaires cxistent, sont même asjez nombreux, et montrent dans le caractère pritacipal une séric de passages entre les Bulimes on Hólices à spire langue ei les Agathines: il nouv suffira de citer le Kambeul d'Adanson, le Bulime. flaubé, l'Agathine colomnaire, etc., pour justifier ce que nous avauçous. Ainsi cetle modificaltion singulière de la troncature de la columelle u'est pais plus exemple, que celles que nous avons examinées, d'une graude variabilité, quila rallache au gence Hélice tel que nous le considéroas dans ce monient.

Ce graud nombre de caractères varialules que nous venons d'examiner ne sunt pas les sculs, nous n'avons pas encore parlé de ceux que peut fournir le bord droit; en créant son genre Hélicelle, dans l'Extruit du Cours, Lamar'k ne songea pas que pour être couséquent avec les caractères données, il auroit fallu établir un genre analogue aux dépens de ses Carocolles, un autre à ceux des Bulimes, puisque dans ces trois modifications principales des Ilélices, on trouve des coquilles qui ont la lèvre droite très-minte el tranchante. Iranarck s'aperçut bientôt du peu de fondement de son gente el le détruisit : on passe en elfel par des nuances insensibles, de. péristomes les plus minces à ceux qui sout les plus épais el bordés en deliors. Par celle raisun que nous ne trouvons pas dias ce caractére plus de vérité que dans les autres, nous ne lni accorderons pas plus d'iunportance qu'il ne mérite, quoique $\mathrm{M}$. de Ferussac, comne nous le verrons, l'ait employé fréquemment.

Les observations qui précèdent, qui sont le résultat des fuits eux-mêmes, eu même temps qu'elles démontrent l'étonnante variabilité de tous les caracières des Hélices, reudent facile is sentir l'impossibilité nù l'on est de les combiner de tellc manière qu'ils entrent tous pour quelque chose daus la composition des groupes; nous avons vu qu'il étoil impossible de coubiner deux caractc̀res de manière à les accorder constamment, à plus de raison ne pourra-t-on réussir s'i! faut en rassembler cing ou six de la mêne valeur. Dès que, par la nature des choses, on est force de conveuir de l'impossibité de ces combinaisons de caractères, on a reconnu le défaut de tous les systèmes daus lesquels on a fait des elloris, très-louables d'ailleurs, pour tenter ces combinaisons. Nous pouvons aunoncer à l'avance que l'on échouera constammeut dans de semblables essais.

Par une conséquence naturelle de ce que nous avons dit, nous croyons qu'il faut s'altacher it 


\section{H E L}

un seul earactère, clıoisi avec diicernement, de manière a ce qu'sl soit le plus important, tl ¿lablir autant de groupes qu'il olfrira de modificutions : il sera uécessaire de ne plus falre attention à tous les autres caractéres qui l'accom ragnent, ou du moins de u'en tenir compte que d'une manière très-secrnadaite. Si l'on se serl de Ia forme extérjeurc, on pourra firmer un ccrlain nombre de uroupes faciles a distinguer, tels que ceux pour les espèces globuleuses, les esprèces trochiformes, les espéces aplalies, lurriculées, e:c. etc. Lorsque ces gruupes aurout été déterwinés, former dans clacun d'cux des divisions dans lesquelles on rasseinblera les espèces à columelle simple, à colunielle dentée, celles à columclle droile ou oblique, à póristome simple, ou denté, ou tranchan!, ou bordé; les eipéces qui sont ombiliquées ou qui ne le sont pas puurront, dans certains ras, fitice de cos divisions du Iroisième ordre. La valeur que unus allribuons ici à la forme extérieure pourroil êlre donnée à toul aulre caraclère, sans que purs cela on soit olsligé de rejeler ces groupemens d'espères; ce seroil pent-ètre avec plus de raison qune l'on pren droit comout caractére de la plus grande valeur les zodifications de la columelle, et alors la forme extéricure ne seroit plus que très-secundaire.

Arec ces donaćes, qui sont des priacipes, ou peut juger en quoi les auteurs méltodisles unt été fautits, puisquils ont voulu rendre possilsle ce qui ne l'étuit pas, et se sunt épuisés en vains effurts devalut un obstable insurnootable.

Daus l'ensemble des coquilles qui loni le sujet des observations précédeales, nous a'avons pas campris celles que nous croyons devoir laire des freares à part, ou du moias des coupes l'une valeur plus grande que toutes les autres; c'est aiusi que les genres Ambrelle, Maillot et Clausilie se distingueat toujours nctlement et facilemeut de toutes les Húlices, et on peul y joindre, quniquue un peu moins sùrentent, le genre Anostume de lamarck, pour lequel on counoil quelques points de jonclion avec les Ilélices.

Les Ambrettes ont une manière de vivre particuliere: toujours sur les planles aqualiques, au bord des rivieres ou des marais, leur or ranisation a dú s'appropricr à ces circonstances, el nous croyons rque les différences qui en résulient, en comparant ce gence aux Hélices, sont plus fortes qu'on ne le pease ordinairenuent; nous en avoss la conviction par ce fail seul, que l'on ue trouve jusqu'a présent aucune jooclion, aucun passage enıre les coquilles des Hélices et des Am. brelles: ces dilfúreuces se traduisent encore en dehors de l'aniral par le raccourcissement considérable de ses rentacules inférieurs, la raccourcissement du pied, et l'ouverlure respiratrice un peu plus postérieure. Nous verroas bientót que l'organisalion iatérieure diflère, sous plusieurs apports assez importans, de celle des Hélices.

Hist, Nat. des Vers. Tome II.
Les mênes olsservalions se présentent pour les deux gentes Maillor et Clausilie, que probableanen: on réunira un peu plustard en un seul, mais qui, ne se liant par aucun point inlernédiaire aux autres Hélices, olfrent des caractères sullisans pour être cuaservés en genres.

Maiulenant que nous avons expliqué notre pensée sur le genre Hélice, considéré d'une manière à peu près aussi large que M. de Ferussac, gous allons examiner son arrangement systéunatique, et voir s'il éloit nécessaire, coume il l'a cru, de surcharger la science d'une nonencluture nouvelle, appliquéc à des coupes ou sous-genres qui currespondent pour la plupart à des coupes déjà proposćes; nous verrons s'il sera facile a 11. de fierussac de se justifier du reproche que quclques zuologistes lui on! déjà adressé, d'avoi: caracierisé ses sous-genres d'une manière tellement vajue, your la plupirt, qu'il est presque impossibie d'en faire l'application, et de les avoir conçus de telle sorte, qu'ils s'accordeat en boure parlie à des genres de Mlontfort ou de Lamarck, dont M. de Ferussac a justement blâmé l'iotroduclion dans la science. Ce quil y a égaiement de désavanlageux dans le systeme de nomenclature de M. de Ferussac, c'est que pour désigner in sous-genre apparleaant à une seclion dételminée, on est obligé d'employer quelquefois trois mots; ainsi le sous-genre Hélicoplante, pat exemple, appartient à la section des Redundantes volutato helicoides.

Ce sous.geare Hélicophante est caractérisé en partie par l'animal, loujours trop grand pour rentrer en enlier duas sa coquille, et par l'anspleur du dernier tour de celte coquille. Si toules les espèces ressembloient à l'Helix brevipes de Draparnaud, on pourroil a dmettre ce sous-yeure; mais nous voyons dans sa composilion les Helix camu-giganteum et magnifica, qui, ayant le péristome bordé, peuveut très-bien rentier dans d'autres groupes, et se rapprochent d'ailleurs beaucoup des Helix pulla, melanotragus, elc., que .11 . de Ferussac a placés dans un autre sousgenre. Dans ce sous-genre Hélicophante, nous ne conserrerions absolument que les deux premières espèces, et nous n'admellrions ce sousgenre dans les Hélices, et non dans les Vitrines, qu'àtaut que nous aurions complétement étudić les animaux.

Quanl au sous-genre suivant, Cochlohydre (Anibretle des anteurs), ce que nous avons dit précéderament suflit pour le moment; mais pourquoi ce nom nouvean, lor'sque celui d'Ambrette éto:t généralement adopté?

On a dú s'apercevoir que dans l'énonciation des caractères des sous-genres il y avoit quelquefois des choses iuutiles ou contradictnires, et c'est surlout dans la sous-division des Inclusce 2'0lutatce helicoideg que nous avons remarqué cela $\mathrm{Bb} *$ 
plusparticulièrement. Puur le quatriène sous-genre des Hélicodontes, les caracières sout : bouche dentée, ombilic couvert cu visible. 'Toutes les coquilles en général, et les Húlices consćquemment, qui ont le même unode d'accroissement, ae peuvent être que dans ces denx circonstances, d'un ombilic ouvert ou d'un ombilic fermé ou non existart. Si c'est une règle gćnérale, elle ne peut s'appliquer parliculièrement à une sous-divisıon d'une manière aussi vague. Il reste donc pour véritable caractìreà ce sous-genre d'avoir la bouche denlée. Montfort a étubli aussi plusieurs genres d'après ce seul caractère essentiel; tels sont les Capraires, les Polydontes, les Cépoles. Nous avons donc quel. que raison de dire que M. de Ferussac a employé les mêtraes moyens de division que ses prédéces. seurs; en voilà déjà un exemple. Daus le suusgence suivant nous trouvnns pour caractères: coquille carénce, quelquefois conique; ombilic couver et visible. Ce dernier câractère est aussi peu essentiel pnur ce sous-genre que pour le précédent, et d’après les mémes motits; la véritable distinction du groupe est donc dans ceci : coquille caréncee, quelquefois conique. Ces caractères ont été également employés par Montfurt pour son genre Carocolle. Voilà un second exemple de ce que pous avons dit précédemment. Passons au sous - genre suivunt, qui est le sixième, pour en examiner la phrase caracléristique; nous la rappelons dans son entier : ombilic découvert; coquille surbaissée on aplatie; péristome réflécbi, sinple ou bordé; ombilic rarement anasqué ou couvert, mais alors le péristome étant simple ou bordé. Nous trouvons en tête de la plirase, ombilic découvert, et dans le nulieu, ombilic rarement masqué ou couvert, ce qui fait deux membres de pbrases en contradiction; car, s'il est essentiel au sous-genre de renfermer des coquilles ombiliquées, jl lui est essentiel aussi d'en contenir qui ne le sont pas. Il auroil élé plus simple de dire : ombilic découvert on rarement couvert; mais on auroit septi plus facilement le vague et l'insuffisance de ce caractère, qui déjà se retrouve aux deux sous - genres précédens. Celle même phrase montre encore une parlie entic̀reınent iautile. Nous trouvons : péristome réfécbi, simple ou bordé, et plus bas: le péristorne étant simple ou bordé. Il nous semble que la première partie de la phrase, conteuant la seconde tont entière, celle-ci étoit à supprimer. En ôtant tont ce qui n'est pas nécessaire à cette phrase, on réduit les caractères à une plus simple expression que voici : ombilic convert nu découverl; coquille surbaissée ou aplatje; péristome rélléchi, sionple ou bordé. Nous retrouvons à peu près les tnêmes caracteres puur le genre Zoniles de Munifort, ou Hélicelle de Lamarck.

Nous a vons cluercbé, antant que nous l'avons pu, i bons readre compte du sixieme sous-genre, les
IÍlicosiyles; nous a'apercevons pas les motifs qui ont pu le faire séparer. Le principal caractère, d'après les espèces qui sont figurées, seroit, ce nous semble, la direction presque horizontale de la lèvre gruche dans des roquilles, tautót aplalies, taniôt trochiformes el élancées, mais ayant généralement la lsaie aplatie; cetle direction du bord gauche rend l'angle columellaire extrêmement aign, et dans cet angle il y a quelquefois une dent forl saillante, d'autres fois la columelle est simple, mais elle est tnujnurs drrite et sulide. Díja de sea!slables caractères se sont présentés dans d'autres sous-ryenres, et entr'autres dans les Hélirodontes; ce sous-geure, caractérisé ainsi, ne pourra être conservé.

Nous arrivons maintenant au second grand groupe des Hélices, à celles qui on la spire alorgée : déja nous avons fuit remarquer que dans les Hélices la spire sélevoit insensiblement de telle naanière qu'il étoit in prossible de dire si telles espèces appartenoicnt plutôt aux glubulenses qu'aux alongées. La lorme extériente a été, comme on le vait, le principal moyen de division dont M. de Ferussac s'est servi, et il al dù de toute nécessité faire ses coupes dinne unaière arbitraire. Dans le premier snus-gente de celle sons-division, on tronve des coquilles qui, de l'aveu de Ml. de Ferussac lui-même, prourroient, pour la plupari, entrer dans le deruier suus-genre de la pre:oière suus-division: dès-lors, où est dooc l'ulilité du sousgenre dint nous nons occupons? Le caractère de l'uclimaison de l'onverture, par rapport à l'axe de la coquille, auroit ju conduire a grouper un cerlain nombre d'espéces d'une munière assez nalurelle; nais M. de Ferussac s'cist allaché de prélérence a la position de la columelle, et anssi irouve-t-on de véritables Bulimes dans son sousgenre séparés des autres compris daus un des sous-genres suivans.

Pour avoir voulu séparer en deux sous-gentes l'un des groupes le plus naturel des Hélices, le genre Agathine de Lamarck; pour avoir roulu le caractériser à sa nanière lorsquill éloit si facile d'en conserver les caraclères simplenent et nettement exprimés par lamarck, M. de Ferussac les a rendns tellement vagues qu'il est presqu'impossible de savoir ce que c'est que son sous-geure. Pnur ne pas laisser de doule à cet égard, Dous transcrivons ici littéralenıent la cararıéristique de ce sous-genre Cochlitome: "Coquille conique nn "très-ventrue, solide, peu transparebte; volute " cruissant plus ou moins lortement; spire plus " ou moins élevée; lsord intérieur du cône spiral n Cormant une columelle plate, forte, solide, " repliée en dedans et plus ou moins tronquée à - sa base; unverture plus ou moins courte ou - longue, et droite, c'est-a-dire dans la di" rection de l'axe, mais élargie; bord exté" rieur plus ou moins dans la verticale; péristone " simple." 


\section{E L}

Quand uoe persoone étudiant la conchyliologie vicudra, une coquille a la main, chercher $\dot{a} \mathrm{da}$ rapprocher du sous-genre de M. de Ferussac, quel embarras n'éprouvera-t-elle pas en voyant des caractères countne ceux-là : volute croissant plus ou moins rupidentent; spine flus ou moins ślcvée; columelle plus ou moins tronquée à sa hase; ouveriure plus ou moins courte ou longue et droitc, avec un c'est-à-dise pour expliquer la pensée de l'auteur; enfiu, bond extérieur plus ou moins simple?

Nous regardons celle plirase caractéristique comme an type dans son genre; car il sernit difticile, quand on devroil y melire toute son attention, d'en faire une autre qui laissát plus de doute el d'inea actitude. La meilleure critipue que nous pourniuns en fuire sernit de mettre en regard la caracléristicjue du genre Agatbine de Lamarck. Elle est colicue de celle maniere : coquille ovale ou oblongue; ouverture entaere plus longue que large, à boid droit, tranchant, jumais réféchi; columelle lisse, tronquée a su buse.

On ne peut criliquer stírieusconent de pareilles choses, il laudruit pouvoir les passer suus silence: il eút ćté a desirer pour cela qu'clles restassent plus ignorées; mas l'ourirage de M. de fierussac ćlant duns les inains des personnes qui s'uc:cupeol des coquilles terrestres el fluviatiles, nous arons pensé qu'il étoit utile de les prémunir contre des tentatives en pure perie.

Nous ne diruns i ien du sous-gente Coclilicope, si ce a'est qu'il éroil complćlement inutile citaut démembré des Agalhines, celui de teus les groupes qui étoit le uroins susceptible de parläe.

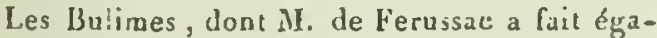
lement deux sous-geures, étoient peut-étre susceptilsles d'ètre plus uaturellement divisés. L.e sous-yenre Cochlicelle rassumble toutes les espè ces turriclées et étroi:es; cclui nommé Cochlogène cumpreud tuules les especces ventrues : elles sout partagries ea sis group.es. Nuus avons vu que quelques especes à coluruelie, légèrement lorses, avolentélé nises à tort, stolon nuus, dan, le snusgenre (Juchlnstyle : elles auruieut dû se trouver dans celui-si, qui, dans le desn.er groupe, contient plisteurs Mailors qui ae punrront y resicr. Nuus ric purlerons pas des deux deruiers sous - genres nonmés Cochlodonte el Cochlodine, ils correspondent aux Maillns et aux (lausilies des auteurs, et nous les conserierons en genres distincts. Nous arons dil puar quelles raisuos.

Il résulie des oloservalions que nons venons de présenter sur l'arrangenent : y lématique de $M$. de lierussac, $1^{\circ}$. que le sous - geure Héicophante pourra êlre conservé en n'y aduellant que la premiere section; $2^{\circ}$. que le sous-geare Cocblohydre devoit d'abord conserver son ancien nom $d^{\prime} \mathrm{Am}-$ brctte, et lirmer un geore distinct des Ilélices proprement diles; 33 . que les scus-genres Héli- cogène, Ilćlicodonte, Hélicigone, Hélicelle et Ilélicostyle, n'érant pas londés sur des caracières de mème valeur, el par conséquent nou-compa. rables, ne peuvent être adoptés, ayant d'ailleuts élé, pour la plupart, proposés antérieurement, et sous d'autres noms qui devoient être préférés; $4^{\circ}$. que les sous-genres Cuchlitome el Cuchlicope doivent être réunis de nouveau sous la dénoniination d'Agathine, et furmer un bon sous-geure des Hélices; 50. qu'après avoir ôté le dernier groupe des Cochlogines, on résunira ce sous-gente aux Cochlicelles pour rétablir, en le réformant d'une manière convenuble, le sous-nente Bulime, qui constituera un autre sous genre des llélices; $6^{\circ}$. eufin, yue l'on devra couserver les genres Maillot et Cluusilie, el ne pas les cunfondre arev les Hélices, puisquien collet il u'y a poiat de passage insensible entre les deux gentes.

Nous aurions pu, si nums l'eussioos voulu, pousser plus luin la crilipue de la distribution du genre Hélice par M. de lerussac; en descendant dansles délails, nous auriuns prouvé que rien n'y avoit élté fait d'apris des principes ar:êtés, ma:s qu'il avoit été produit en qquelque sorte au lasard et par inspiration.

Il n'en reslera pas moins à l'auteur le aérile d'avoir dooné dans son ouvrage unl grand nombre d'uspéces nouvelles, d'avoir montré des rapports jusque là inconnus, et surlou! d'aroir confié a des artistes lrès-babiles les confectious des planches, qui seront toujours citées comme les plus belles qui aient eucore été publiées dans ce zenre.

Les Hélices, que nous tronvons partout autout de nous, ont été, avec quelques autres Mollusques ann moias faciles à ubserver, les premiers a êlre soumis aux recherches des anatornistes.

Sévérinus, Muralt et Hardérus, les preniers, ont cherché à douner guelques notions sur l'organisation inlérieure de ces animaux; mais leurs truvaux se ressentent de l'imperfectiun des moyens qu'ils purent arettre ea usage et du pen de conuoissances que l'on avoit alors en anatomie comparcíe.

Rai ajouta quelques notions aux connoissabees acquises sur les Mollusques; il remarqua surtout le mode de sénération de ces animanx, leur accouplemen! réciproyue, en un mot leur herma. phrodilisne complet. (e mode extraurdinairs d'accouploment avail élé, à ce qua'al paroil, ol-scrvé depuis long-enups far les Persans; car le mot nermadech, enp!nyé pour les Ifélices, veut dire homme el femme, ou pour mieux dire exprime que chaque individu por!e les deux sexes. (Voyez la septième livraisnn des Mullusques terrestres et fluviatiles, par Ferussac.) Recti nit ce fait liors de dosure par les tigrures qu"il dom des organes de la génération, ituxquels al en ajoute 'puclques autres; mais ces figures incomplètes, $t t$ idailieurs rop arvisices prour dunner une idce BL 2 * 


\section{ryjo}

salisfaisante des parties, ne méritent pas de nous arrêter pour disculer ce qu'elles renferment.

Swamendam, dans son Biblia natura, publia aussi une anatoarie des Hélices. Il y commit quelques erreurs, mais son travail est bien plus complet que ceux qui l'avoient précédé, et wême que celui de Leister qui le suivit. On peut dire quavant les travaux de $\mathrm{M}$. Cuvier et des anatomistes moder eses, le travail de Swammerdam étoit le seul que l'on pút éludier avec fruit. Lister donna, dans son Synopsis Conchilionum, deux planclies avec leur explication sur l'anatomie des Hélices: on vuit, comue l'observe M. Cuvier, qu'il prit les glandes salivaires pour un épiploon, la vessie pour uo testitule, et la langue pour une trachée-arlère. M. Cuvier, auquel presque toutcs les parties de la zoologie sunt redevables d'excellens iravaux, donna aussi sur les Mollusques une suitc de précieux Mémoires, parrai lesquels il s’en Irouve un consacié à l'anatomie de la Limace et du Limaçon : des procédés anatomiques plus parfuits que ceux employés par les A aciens, de vastes connoissances en anatomie comparée, mettoient M. Cuvier à même de faire un travail fondamental ; on pent dire qu'il est aussi parfait qu'on peut le desirer, puisqu'il a firit connoitre l'organisation des Hélices dans les plus petits détails : anssi ce sera d'après lui et d'après les travaux de M. de Blainville que nous décrirons les parties principalcs de l'organisation de ces animaux.

Des expériences nombreuses ont été faites sur les Hélices; les plus curieuses, et qui ont eu les résultats les plus extraordinaires, sont celles des sections totales de plusieurs parties qui se sont reproduites ou régénérées après un certain espace de temps. C'est Spalanzani, le premier, qui a avancé qu'on pouvoit couper la tête aux Hélices, et qu'elles en reproduisoient une nouvelle. Ce fait, annoucé d'une manière positive par un expérimentateur anssi habile, a été contiedit par Adanson luimême, qui répéla ces expériences sur plas de quinze cents individus : il prétendit que cela ne réussissoil qu'autant qu'on n'enlevoit que les lèvres ou la partie supérieure de la Iĉte. L'opiaion d'Adanson fut confirmée par Colle, dans un article inséré dans le Journal de Physique (1774, tome 3). Les expériences eureat pour résultat, que les Hélices ne reproduisoient pas leur tête tranchée tout entière, et elles servirent à démontrer que ces animaux peuvent rester très-looglemps sans manger.

Valmont de Bomare, après plus de cinquante expériences infructueuses, prélendit, connme Adanson, que la reproduction de la tête ne se faisoit pas. Cependant Bonnet, nn peu plus tard, publia aussi le résultat de ses expériences, qui furent plus beureuses, et qui ne laissèrent plus le moindre doute sur la véracité de celles de Spalanzani. Ce Mémoire de Bonnet fut publié dans le Journal de Phyfique, 10m. 10; il l'ac- compagna de fiunres qui représeutent et les parties amputées et les parties reproduites : on voit par cela seul que, dirigeant son incision d'arrière en avant, il détuchoit les tentacules, la masse buccale et une pelite portion da pied. Il est fort curieux de suivre les progrès de cette reproduction, qui se fuit par une sorte de végétation qui n'arrive à son terme quaprès un temps plus ou moins long, et surtout lorsque l'animal a été placé dans des circonstances favorables; conditions sur lesquelles Bonnet insiste beaucoup avec raison, car d'elles scules dépend la réussile des expériences.

Un petit 'Traité de Cochliopérie, par Georges Tarenne, a été publié en 1808 . On trouve dans ce petit ouvrage des expériences qui confirment complétement colles de Spalauzani et de Bonnet, et qui sont même plus concluantes, en ce que la partie retranchée est plus considírable et mieux connue dans son anatomie; nous allons les examiner un peu plus en détail. Tarenne, apres avoir insisté d'une manière particulière sur l'indication des circonstances fuvorables où il falloit plarer les Hélices mutilées, circonstances qui doivent faciliter la nutrition de l'animal, ce que Spalanzani et Bonnet ne disent pas, quoiquils aient obtenu des résultats analogues, indique de quelle mauiere il pratiquoit l'excision de la tête. Armé de ciseaux bien trancbans, il les plaçuit perpendiculairement derrière les grands tentacules et sous le pied, et les fermant subitement, il euleroit d'un même coups les quatre tentaculcs, fa masse buccale tout entière, et, ce qui est le plus étonnant, le ganglion cérébral. Cetre opération faite sur deux cents individus, il les plaça dans un lieu ombragé et linmide, an fond d'un jurdin. 'Toutes celles qu'il relrouvi is la fin de la saison avoient reproduit une petite tête, ussez seublable, dit-il, à un grain de caté; cette tête avoit quatre tentacules fort petits, des lèvres et la mâchoire. L'anuie suivante, il les vit avec la tête entièremeut reproduite, a ussi grosse qu'elle l'étoit avant l'amputation, revêtne cepeudant d'une peau lisse, évidemunent cicatrisée : dans quelques individus, on pouvoir faculement voirle lieu de l'excision, qui se trouvoit marqué par une ligne enfoncée. Ces expériences, qui contirment celles de Bonnet, et qui sont plus étonnantes encore par la masse considérable des parties enlevées, manqueut d'une dernière preuve, l'anatomie des parties reproduites qu'il faudroit faire comparativement avec celles de la tête amputtée. On doit néanmoins être convaincu que la iète des Hélices a l'étonnante propriélé de se régénérer tout entière et dans toutes ses parties.

Cependant M. de Blainville conserve yuelques doutes, qu'il expose de la manière suivanie : "Nous concevons difficilement comment il se " peut que les filets nerveux, les muscles, les "vaisseaux, qui ont été coupés daas le milieu de 
- leur longueur, se raccordent avec les portions * qui poussent de la tête, devenue une sorle de » bourgeon; ou bien, en admeltanl que la régéわ nération partiroil des filets nerveux el muscu- laires eux-mêmes, commenl les filels nerveux, - par exerople, pousseroient el donneroient nais" sance au cerveau?" n Il est bien certaiu quon ue peat répondre à ces questious d'une manière satisfaisante; on ne le fera, comme aous le disiuns précédemment, qu'ea montrant des anatomies bien faites et compärafives des parties.

Nous allons maintenant examiner l'organisation des Hélices, et d'abord en décrire les formes extérieures. Your s'en faire nne idée nelte, dit M. Cuvier, daus le Mćmoire que nous avons cilé, il faut se figurer une Limace dunt le mantean a élé forlement distendu el aminci, dont les viscères ont été cliassés en parties lıors du corps dans celle espèce de sac et revêtus d'one coquille testacée : on aura presque changé la $\mathrm{Li}$ mace en Hélice.

Dans lus Hélices, aous avons trois choses à considérer, la tête et le picd, ou ce que l'on nomae le corps, le collier et la masse viscérale. Le corps est demi-cylindrique en dessus, plus éprais dans son milieu el autérieurement, plus large el plus aminci postérieureasent, où it se terrnine par un piolongement en forme de langue : c'esı la pariie postérieure du pied; en dessnus il est plat partout, essentiellement musculeux, el surtunt à la face inférieure, où les fibres, confondues avec la peau, sont destinées à opérer la progression. Le plan musculeux a reçu le nom de pied; il s'étend dejuis l'extrémité postéricure jusque sous la tẻte, dont il est séparé cependant par un sillon profond; il est lisse en dessous, rugueux ea dessus, et surtoul à la parlie antérieure, où on voit un graod nombre de iubercules saillans, dont on remarque sur le dos une raogée inoyenne; sur les parties latérales du pied, ainsi (yu'a sa portion postérieure, ils sont tuoins saillaus; la partie antérienre ou la tète est arrondie, séparée du pied par un sillon, mais confoudue arec le col. Elle porte quatre tentacules, dont les deux supérieurs sont les plus graods; ils ont la propriété d'êtrc complétezsent Jérractiles, en quoi il diffëreut de ceux de beaucoup de Molluscjues : ces tentacules sont terwiués par un léger renllement arroudi, qui offre dans son unilieu un point noir qui est l'œil; les teniacules infírieurs, plus courts et plus grêles, onl la mène lorme, saus avoir le pout ocalaire. Quelques personnes pensent qư'ils sont destioés ¿ l'orăane de l'olfaction. Entre les deux tentacules inféricurs, on roit un enfoncement un peu froncé, sublriangulaire; il indique l'orifice de la louche; en dessous et de chaque cólé il y a un appendice aplati, ce sont les appendices Luccaux. Quelquefois à la partie externe de la base du tentacule droit, on voit, avec assez de facilité, un pelite fente indiquée par un léger reuflemeal. C'est là que se terminent les appareils de la géuéracion.

La masse des viscères contenue dans me coquille spirale est spirale elle-nème; cette coquille la couvre et la prolége, car la peau extrêmement mince qui la recouvre auroil été insuftisante pour la grarantir des chocs extérieurs; un péoicule plus ou moins long selon les espèces, mais ordinairement assez court, lui sert de support el de lien avec le corps proprement dit; le pédicule nait vers la partie moyenne el antérieure du dos; ce pédicule est de loutes parts entouré d'un anneau clıarnu dont noe partie est aolérieure : c'est au milieu de cet auneau, qui porte dans les Hélices le now de collier et celui de manteau dans tous les autres Mollusques, que passe le corps larsque l'animal veut rentrer dans sa coquille; c'est aussj ce collier qui borde l'ouvertare de la coquille, el mème qui en fait la sécrélion; c'eft dans lé collier, latéralement et à droite, que se tronve l'ouverture pulmonaire, et un peu en arrière de celle-ci l'orilice extérieur de l'anus, qui a la forme d'une fenle verlicale.

L'accruissement des coquilles des Hélices se fait de la même manière que dans tous les Mollusques; c'est au moyen du manteau que leslumes s'ajoutent de dedaus en dehors, les anes anx autres, jusqu'à ce que la coquille soit arrivée à son élal complel; alors l'animal ne fait plus que l'épaissir. Lursque l'on a disculé le mode d'accroissement des coquilles, il y a eu deux opinions : la plus généralement adonise fut celle de Réaumur, qui démontra, par une suite d'expériences faites sur les Hélices, que la coquille se formoit par superposition de couches. L'aulre, qui étoit celle de Klein, mais qui avoit peu de sectatenrs, éloit fondée surdes hypothèses ou sur des rapporis fort éloignés, $t$ tre les coquilles et les os des vertébrés; dans cetle opinion, on croyoit que la coquille prenoit ses accroissemens comme un os, par des vaisseaux qui s'y disıribuoient; mais cette opioion esı évidemaenı lausse, tandis que la première, celle de Réauour, est restće la seule conforme aux faits el conséquemment à la vérité. Celte opinion de Réaumar est aujourd'bui hors de discussiou, et nous ne l'aurions mème pas mentionnée, si les Hélices n'avoient servi dans ce temps à argumenter pour el contre; nous aurons occasion, à l'article Mollusque, de revenir sur celle question. La peau des Hélices est ragueuse, les turbercales qui la convrent sont séparés entr'eux par des sillons plos on moing profouds, qui probablement sont destinés à répandre à sa surface le mucas qui doit la lubrifier; celle peau, constamment bumide, est molle, extrêmemeol sensible dans toutes les parties q̧oi peuvent sortir de la coquille, et extrènement musculeuse, comme celle de tous les Mollusques. La peau des tentacules paroit plus sensible eacore que celle 


\section{5}

HE L

do reste do corps; elle est plus fine et reçoit des filets uerveux assez considérables. La paire supérieure, comme nous l'avons dit, porte les points oculaires à leur extrémité. Swaumerdam, qui a fait l'anatomie de ces yeux, prélend y avoir trouvé toutes les parties vécessaiies à la visiou; cependant on sait que l'animal ne se gare des corps euvironnans que quand il les a touchés avec ses tentacoles. La démarche des Hélices, la manière dont elles portent leurs tedacules en avant pour explorer les corps environnans, fair penser que si elles ne sunt poiat aveugles, elles ne reçoivent que foiblement les impressions de la luniere. Les teatacules inférieurs paroissent plas particulièremeat destinés au tact. M. de Blainville pense que ce sont des organes olfactifs, et il s'appuie, pour rendre celte opinion probable, que les Hélices, aussi bien que les Limaces, sont altirées par l'udeur de certaines plantes qui leur plaisent. On n'a pas la prenve directe que ces parties servent à celte fonction; d'autres persones ont pensé qu'une peau muqueuse et molle, comme celle des $\mathrm{Nlol}$ lusques, pouvoit tout entière servir d'organe de l'odorat: ceci n'est encore qu'une conjeciore. Les Hélices sont insensibles au bruit, ce qui prouve qu'elles n'ont aucun organe destiné à l'audition.

Le système musculaire peut être divisé en général et en spécial: le générat est distriboé à la peau, et est si inlimement confondu avec elle, qu'on ne le reconnoît guère qu'à la faculté cuntractile de celte eaveloppe; les tilures du plan lucomoleur sunt plus nombreuses et plus distincles, aussi celle partie de la peau est-elle plus épaisse. Les tibres sont distribuées en faisceanx courts el longitndinaux; les autres muscles, destinés à des mouvemens spécianx, ont pris leur point d'altache sur l'endroit le plus solide de la cuquille. La columelle a un muscle principal qui relieıt lurteneut l'animal à sa coquille; c'esi le muscle columelLaire. Il suit la cclumelle pendant plosieurs de ses circonvolutions. Il est compusé de plusieurs lais. ceaox cbaraus; le plus considérable se dirige vers la parie médiane du pied où il se confond, par son extrémité antérieure, avec les fibres úu plan loconioteur. Il est desiné dans sa contraction à reployer le pied et a le laire rentrer dans la coquille a travers le manteau: ce musile $n^{\prime} a-$ git que quand les teatucules et la tête sunı déjä reployés en dedans. Une praire de muscles, qui part Ja colomellaire, se dirige le long du ivol pour s'inséver de cbaque côté de la masse bucrale; une autre paire de muscles, qui ont eacore leur origine an columellaire, se dirige vers les tentacules qu'elle tapisse il l'iatérieur Quand l'animal veut renirer dans sa coyuille, ces uuscles a'agisseat les uos quapres les autres; ceux des tentacules commencent et funt reotrer ces parties en les setournant sor elles-mênes; ceux de la massè buccale se contractent ensuite et produiseat sur la tête le même effet que ceux des tenlacules, e:
H E L

c'est lorsque la lête est contractée que le muscle du pied achève d'entrainer toule la masse du corps dans la coquille. Cependant ces mouvemens peuveat être jusqu'à un certala point indépendans les uns des autres : ce sont surtout ceux des tentacules qui le sont davautage; la masse buccale ne se coutracte pas complétemeni sans que les tentacules ne le soient eux-mêmes entièrement, et ceci suit une règle inverse lursque ces paries se dépluieat; elles ne peuvent le faire qu'au moyen des tibres cirruluires des tentatules ou des autres parties colanées. Un dernier muscle distiact est celui qui est destiué a la contraction de la verge.

Les organes de la digestion commencent à la bouche; celle-ci, placée comme nons l'avons indiqué préccidenuicut, est ovale et un peu transversale; son bord supérieur est assez régulièreauent plissé, il est arué en dedans d'un perit appareıl dentai:e, Lomıné aussi peigne dentaire, parce qu"il en a assez lı forme; il est corné el noirialre, composé d'un noinbre variable de dents suivagt les espèces. Dans la cavité buccale tt au food se trouve nn petit bourrelet auquel on a donné le uoin de langue. Quoiqu'elle ne soit point armée de pièces cornées, comme dans un trèsgrand aombre de Mullasques, elle reçoil l'action cle la mâcluoire, qui est enırainée en arrière par un muscle particulier dans l'acrion de la mastication. L'osophage est pelit, ties-inince, conmence à la partic supérieure de la bouche, reçoit un peu après la sorlie de celte partie les vaisseanx salivaires, qui sout fou nis par deux glandes yrumeleuses qui s'appliquent le long de l'estomar.

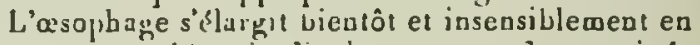
une cupacitć lon qiiudinale assez grande, terninée postérleureneas par un cal-de-sac bien prononcé: celle cavilé est considérée comoue l'estomac. Ce visière, qui se prolinnge jusque vers l'extrémilé de la spire, donne naissance latéralerneat à l’intestiu; à l'entroit de la jonction, on voit des hilures circulaires plus abondantes, qui pourroient ĉtre considérées i:omme nn pylore. Cet iutestin revient en avant apies one circonvolution dans layuelle 11 est einbrassé par le boie, gaune le plan. cher supérienr de la cavié de la lespiralion, et se lermune aaus le collier en arrière de l'orifice pulinonase.

Le fuie, divisé en irois ou quatre lohes, disnt un remplic avec l'ovaire l'extrérnité de la spire. est un urgane hrun, dont les produits de la sécrétion sunt versís dicectement dans l'estounac par les vaisseaux biliaires quail lournit, et qui s'y terminent vers le pylure par un caul unique. L'organe de la respiraliun se compose d'uur grande cavilé qur, à elie seule, oceupe presquentrèreutent le dernier tour de la coquil.e; elle est destiuße à recevoir lair directeoneat, cloù la décomination de cavité pulmunaire qu'on lui a donnée à tort, car elle ne renterue pas de 
véritables poumons; d'où encore la dénomiuation de Mollusques pulmonés paur taus ceux qui, comme les Hélices, respirent l'air en natırre. Vers celte cavité se dirigent loutes les reines qui naissent des diffírentes parties dez visic̀res et du corps; elles reauplissent les linctions de vaisseaux absorbans, comine cela à licu dans taus les $\mathrm{Mlol}-$ lusques. Ces veines réunies en quatre tronçs principaux se voient, le premicr et le plus considérable, à côté du rectum dont elle suit la direction; elle reçoit deux autres veines qui viennent des parties latérales du corps, et entin une troisième qui passe au-dessous du cour. 'l'oules ces veines se subdivisen: de nouveau sur les parois de la cavité de la respiration, et remplissent conséquenuneut les foncrions d'artères puluunaires. 1)e l'extrémilé capillaire de ces veines naisseut d'autres vaisseaux qus se ríunissent en troocs assez n̈ros, et qui furment avec les premiers un réseau vasculaice fort considirable; ce sont les veincs pulmonaires qui, réunies en uu gros tronc, se diririrent vers l'wreillelle, laquelle trasmet immédialenent lc Guide élaboré an cour.

Le cour est placé un peu obliquement, à ganche de la cavité respiralrice, et est contenu İans une enveloppe particulière qui est snn péricartie; il cst composé de deux parties, une oreillette et un veniricule, qui sont placés bout a bout, séparés par un étrungleasent qui marque la place de deux petites valvules. L'oreillette est scosiblemenı moins épaisse que le caur: celui-ci est ćpais, chamu, subtriangulaire; de son sommet nait un gros vaisseau aortique, qui se renlle un peu el se divise presqu'aussilòt en deux branclies principales: la première el la supérieure est deslinée à la masse des viscères, au foie, à l'ovaire, aux intestins, etc.; l'autre se dirige en avabt, elle est destince au corps proprenicol dil et aux parlies qu'il renferıne. Il est bien facile, d'après ce que nous avons exposé, de concevoir de quelle manière se fait la circulation, qui, en gẻnéral, dans les Mallusques, est réduite à une grande simplicité. Les veines servent de vaisseaux absorlians; elles trnuvent dans les produits de l'assimilation les matériaux nécessaires pour réparer les pertes des sécrétians et des excrétions. Le fluide absorbé n'a probablement d'autre sanguifi:alion que celle qui résulie de son passage dans l'oryane de la respiralion; il y arrive directement, et le système veineux général se change, sans aucun intermédiaire, en système artériel pulmonuire, qui se ramilie beaucoup, et donne origine aux veines pulmonaires, lesquelles se rendent à l'ureillcue, qui fournit au cœur le sang revivifié pour repasser dans le systène général.

Le système nerv.ux, fort développé dans les llélices, se compose d'un gaoglion cérébral au cerveau qui donne une assez grande quantité de filets ou de paires nervcuses. Ce cerveau est placé sur l'œsophage, un peu en arrière de la masse boc- cale; il paroit divisé dans sa ligne médiane par un léger silloo: c'est sans doute celle apparence de division qui a fait considérer ce ganglion cornme composé de deux parties réunies. Des parties latérales naissent un grand nombre de lilets verveux : d'aloord une fort petite paire est celle qui se rend aux reulacules inféricurs, la seconde se dirige vers la masse bucrale, une autre plus grosse va alux muscles propres de la massc buccale. Le plus gros filet parmi ceux qui out leur niggine au ganglion, est celui desuné aux rentacules supérieurs. Après être entré dans l'érui nu solte de gaine que forme le tentacule, il se tourne en spirale el se termine au point oculaire. A près cette paire, un nerf unique nait a druite; il est fort gros et destiné à l'ajpareil de la génération, auqquel il donne un gas. glion. Audessous de té filet, et de chaque côtŕ, vers l'angle inférieur du ganglion, on remarq : trois petits filets: le prearier se reploie sur l'aesoplage et furme avec son congénère un petit gauglion dont les lilets suivent l'oesophage et l'estomac; les deux antres, extrêmement grêles, se rendent aux parties de la peau qui avoisine la bouclie; enlin l'angle postévieur el inférieur se lermine par deux gros cordons, qui se dirigent ell demi-cercle au-dessous de l'osuphage pous rejoindre un gros gaoglion qui complè̀te l'auneaı nerveux qui se rencuntre dans lous les Mollusques. Ce ganglion inférieur est spécialement desliné à fuurnir aux muscles les nerfs nécessaires; c'est airsi que de sa face iulérieure il donne trois gros tilers qui se perdent imuédiatement dans le pied, d'autres se rendent aux muscles rétractenrs des tenlacules el de la bouche. Un filet impair, qui gagne l'arlère du pied, remonte en la suivani jusque vers le coeur, et de la les gros vaisseaux, a vec lesquels il se distribue, surtout à l'estomac et an resticule. Hlusieurs autres nerfs sont destinés au collier et à la cavité de la respiration.

Nous terminerons cet extrait très-abréné de l'anatomie des Hélices par un examen des organes de la génération; ils se composent trèsdistinctenient de deux sortes d'urganes: ceux du sexe mále el ceux du sexe femelle.

Je sexe femelle est composé d'un ovaire, d'un premier oviducte, d'une deuxième sorte d'oviducte nommée matrice par les auteurs, et d'ane vessie. L'ovaire n'est pas fort grand, composé d'un grand nombre de granulations; il est engage dans le dernier lobe du foie et remplit aves lui l'extrémilé de la spire; il est pourvu d'nn oviducte qui est blanc, mince, replié sur lni-même en zigzag et en diflérens sens dans toute sa longueur; il rencontre le teslicule, il s'y altache et devient si aunce, quon a peine à le distinguer et à le suivre jusqqu'a son entrée dans la matrice: on pent méme dire qu'on n'a pas encore bien va son orifice. La matrice ou la seconje partie de l'oviducte est beaucoup plus dilatte; clle forme 
des loursoufflures assez nonsbreuses, dépendant, à ce qu'il paroît, de la manière dont le canal déférent y adhère. Celle partie de l'oviducte est destióe à recevoir et à garder les oufs le temps nécessaire pour les envelopper de la malière gélalineuse, ce qui a fait douner à celle parlie le nom de matrice, quoique ce n'en soit véritablement pas une. L'orifice de cette pocbe se voit dans ce que M. de Blainville appelle le cloaque des organes de la génération. A côté de l'ouverture de l'oviducte, on tronve aussi celle d'une sorte de vessie que l'on présume être deslinée à recevoir la verge dans l'accunplemeat, mais sur. laquelle on n'a pas les données nécessaires pour en connoître les usages. Un organe pair, yui s'ouvre également dans le cloaque, est celui que M. Cuvier a désigné sous le nom de vésicules multifides; ces résicules, formées d'un grand + ombre de cauaux courts, cyliudriques, lernés à l'exirémité libre et aboutissant tous à un canal commua, ne sont point bien encore connues daus leurs usages. M. Cuvier pense, d'après la dénomination qu'il leur a donuée, que ce sont des vésicules séminales; M. de Blainville croit, au coulraire, que ce sont des prostates, purce qu'elles conlienaenı un liquide irès-blanc.

Un testicule, un épididyme, un canal déférent et one verge ou organe excilatenr, sont les organes qui constituent l'appareil géoérateur mâle. Le testicule est fort graod, plus grand que l'ovaire; il est formé en arrière d'un masse ovale, homogène, blanchâtre et assez inolle, que l'on trouve collée à l'oviducle, surtoul à commencer dans l'endroit de la jonction de l'oviducte. De ce testicule naît un organe variable pour le volume; suivant les époques où on l'exainine, il esl rugueux ou plissé. M. Cuvier le considère conme une contination du testicule; M. de Blainville pense que ce peut être un épididyıne. Celle partie, dans lous les cas, se conliuve et se termine par un canal unique et lisse, sans pli, qui aboutit dans l'eodroil où les denx parties de la verge se rejoignent: c'es: le canal déférent.

La verge est fort girade; elle resseable, dit M. Cuvier, à un long cordon; quoique non percée à son extrémicé, elle est creuse daus presque toute son étendue; dans l'état de repos, elle est Hottante dans la cavité viscérale. Elle sc compose de deux parties, l'une fililorme, que nous venons de mentionner, et qui se termine par un très-petit gonflement; l'autre, plus considérable dans son diamètre, est beaucoup plus coarte. La verge reçoil, dans son intérieur, et à la jonction de ses deux parlies, l'orifice du canal déférent, qui y forme un petit mauelon percé d'un trou; entre le mamelun et l'entrée de la verge, dans la bourse commune, on voit, d'après M. Cuvier, deux sortes de valvules ou prépuces, dirigés vers l'entrée du réceptacle common. Pour que la verge puisse remplir ses fonc- lions, elle est obligće de se retourner de dedaus en dehors, comme le ront les ientacules; tlle est munie d'un muscle rétracteur propre, qui est destiné à la replacer dans la cavité viscérale pendant son élat de repos.

Un dernier organe, dénendant de ceux de la génération et que les Hélices possèttent seules, c'est le darcl et la bourse qui le contient. La bourse est une poche musculeuse, arrontie, placée alu-dessus des vésicules inultifides; dans sun fond, il y a un perit mamelon charna; la cavilé est fort étruite, parlagée c'n quatre angles : ce manuelon, et peut-être loutes les parois de celle cavité, sécrètent uue ualière calcaire qui forme une pointe fort aiguë et quadrangulaire. Lioritice de cette porbe est placé au-dessous de celui de l'organe femelle; elle aboutit dans le cloaque. Le dard qu'elle contient peut se remplacer lursque celui qui y est vient à toniber on à être cassé. Larsque l'iustant de la copulativo approche, ces aninaux s'excitent mutuellement en se lançant le dard sur le col, où il reste quelquelois implanté. Celte tige calcaire ue se trouve dans les Hélices que vers la fin du printerujs, lorsque le temps de l'accouplement est arrivé: elle disparoît au moment de la ponte.

Après l'accouplement, l'ovare grossit d'une manière notable; les œufs, encore très-petits, passeut de l'ovaire dans la ma!rice au moyen de l'oviducte, et c'est li probablcment ou ils prennent lout leur développement a vaut d'être rejetés all-deliors.

L'organisation des Hélices élant bien connue, il sera irés-facile de la comparer avec celle des Ambrelles, des Bulines, des Ayallines, des Pall. tules, des Maillots et des Clausilies; pour ce qui a rapport aux Clausilies et aux Maillors, nous renvuyons à ce deraier not, et à l'égard des Partules, nous en traiterons à l'article de ce genre. Nuus allons actuellement revenir sur l'organisation des Acobrelles, que nous trailons ici parce que, au monent où uous parlions de ce veure, la saisoa ne vous permit pas d'en observer l'anjual vivant, ce que nous avons fait plus tard : nous avons pu en conserver us grand noabre daos la liquenr, et mulliphier ainsi nos observations anatomignes. Nous y ajouterons l'anaumie des Bulimes, que grace à l'obligeance de $\mathbf{M M}$. Quay et G iimard, nuus avons pu faire d'une manière assez complète.

L'auimal de l'Ambrelle à le corps plus court que les Hélices proprement dites, plus éprais el plus large; la peau parvit lisse à l'oil nu, tant ses tulsercules sout petits; les teatacules sont beaucoup plas petits proportionoellement que dans les Hélices de même caille, les inférieur's surtout suat excessivement courts. Derrière le grand teotacule droit et à sa base on remarque um point enfoncé qui indique l'ourerture commune des organes de la génération. Le trou pulmunaite. 
percé dans le collier ou bord du manteau, est un pen plus en arrière que daus les llúlices, et au-dessnus de lui se trouve, comme dans ce dernier genre, la terminaison anale de la l'appareil digestif. liextrémilé postérieure du pied est fort courte, et quand l'animal ararche, elle dépasse a peise le sommet de la coquille. la cuvité respiratrice est furt grande, elle occupe Ia plus grande parie du deroier tan: de la coquillè; sa parvi supérieure, très-miuce, s'élend d'un côté à l'antre de l'animal, ê préscnte un réseau vasculuire beaucoup moins cunsidérable que dins les Hélices; les troncs principaux se dirigent vers le côté gauclıe où est situé le cœur, qui est fort petit et contenu dans un péricarde proprorinané; il est fortement incliné de droite à gauche; l'urellette est mème menbraneuse, conoide, et communique avec le ventricule par un pédicule conrt. Le ventricule est conique, charnu; sa printe donne naissance a l'aurte, dont la disIribution, du moins pour ce gue nous avons va, ne differe pas d'unc maniere notable de celle les Hélices. La pelitesse des animaux ne nous a pas permis d'en examiner lous les dérails; cela éloit d'ailleurs peu aćcessaire all but gue nous nous proposions.

Lo système digestif offre des liftérencts assez notables. La dent buccale est ua cruissant, mais tile n’est pas pectiniforme et se termane postérieurenent par un appendice aplati, quadrilatire, qui se confond avec le burd cunvexe du croissant; l'œsophage, assez l.mg et giêle, est accompangé des canaux salivaires, qui passent avec lui dans l"anneau nervenx; les glundes salivaires sont pelites, alingúes, litures, plactés en dossous du renllement somacal et nou adliérea!es à ses parois; l'estomac est lusiforme, légèrenent cnntourné, d'une couleur noiratre; il se termiue parl'ın:esliu grềle et n'a proin de cul-de-sac à sın extrémilé postérieure, cuinue dans les Hólices. l.intestin, fort étrnit, ne latil clu une scule circonvolution de gauche à doute; il est enreloppé presque en entier par le tive, componsé d'un très. yrand lobe sen'eneat, l'yicrement subdivisé en deux : le produit de la sécrétion de ce dernier oruane est versó inmídiatcanent dans l'estonat, a T'uripioe de l'intestin, pal un canal bilidire très-court et asse\% coonsidérable. J,e rectum, court el grêle, granoe le proint de jonclion on l'angrle pruduit par la réunion au cốlé droit de la parai supéricure et inférieuie de la cavilé respirairice, el se lermine par une ouverture fint petite, placée un peu au-dessous de l'ouverture pulmonaire.

Les organes de la génération, que nous avons étudiés d'une manièré spéciale, offrent des dilférences encore plus reinarquables de ce qu'ils sont dans les Hélices: d’abord le cloaque, la poche du dard, les vésicules multifides manquent complétement; la jonclion de la matrice avec le

Hist. Nat. des Vers. Tome II. canal de la verge se lait sous un angle aign". a l'orifice extérieur des organes géniluux, de sorte qu'en dilatänt cet orilice, on voit gu'il est partugé par un éperon en deux ouverurres divtinctes, l'une pour l'organe mîle, c'est la plus antérieure, l'autre pour f'organe feme'le.

La verge dans l'élat de repos est contenue tout entière dans une gaine membraneuse, lénerement dépriunée, ovale, un peu renllée et arrondie à son extrémité libre; elle n'est pas furt longure et miluque de l'appendice postérieur et liliforme de celle des IÍlices. Le testicule es! une petite grlande ablongue, accoléc au sommet de l'orgaue nommé matrice par M. Cuvier; il y est uui par un lissu cellulaire assez serrí; de son exlréuité inférienre nait un canal, le canal délérent, qui est constamment dilaclué et lilse dans loute son étendue; il descend le long du burd de lat matrice, suit le vagin dans toute sa lonunuer , jusqu'i son puint de jonclion avec la gaine de la verge, n'étunt uni à ses parlies gute par un tissu cellulaire trés-láclue, s’applique an berd de la graíae de la verge, parvicnt juscra'a son sommet, le perce dans le centre, s'y iuiroduit et se tortille, se replie sur lui-même un granıl nombre de fuis, et comme il est cxtrêatement tin et filitorme, une yrande longuem se trouve ranzissée dans un pelit espare; cafia, il aboutı a lis verge, qu’al perce í son somuet, à cótú de liusertion de son auscle rétructeur, lequel s'épanouit sur son cưlé plar uue de scs extrémili's, et se fixe par litutre au sommet de la gaine. Ce muscle tronvelia un point d'appni suflisant, car la gaine elle-mètre est fisée par sun soirmet, aux urganes covironans, par des conmuaicalions vasculaires et ncrveuses, ainsi que par un tissu cellulaire asscz debse. D'après celle disposition particuliere du canal délísent, lorsque la verge eutre en érection, ce qu'elle ne peut iive qu'en se retomrnant, comme le font les Ienlacules, nous ue duutuns pas que l'ouverlure du caual défúrent ne suit portée à son extríanité, el que son pelotonnement dans la gaine ne soil destiné a furrnir librement à sou alongrement lors du développement de la verge daus le moment de la copulation; ainsi, duns ce cas, la verge ne seroil pas seulement un urgane excitateur, mais aussi un organe de transmisinn directe pour le iluide sperinatique.

D.uns l'animal des Ambrelles se trouve la démnnstration complète el évidente que le canal déférent ue comnunique ea aucuoe manière avec les orgaues femelles, ce qui est inportant is bien noler, puisque de ce lait découle de nouvelles dunnées playsiologiques sur les Mollusques hermaphrodites.

L.es organes fumelles ne présentent pas autant d'anomalies; ils se compusent, comme dans les Hélices, d'un ovaire, d'un oviducle, d'une matrice ou second oviducte, et d'un appeodice vési-

$$
\mathrm{Cc} *
$$


culaire, qui aboutissent plus ou moins directerent à an canal commun que l'on pourroit nommer yagin.

L'ovaire est assez considérable; jl occupe une grande parlie de l'extrémilé postérjeure du corps. Il esı jaune, un peu aplali, et plus éprais au cenlıe qu'à ses bords : il esi formé d'un grand nombre de lobules digités ou multifides réunis parailèlement par un tisso cellulujre lấclie et peu teuace; ces lobules sont cylindracés, obtus an sommel, et un peu convergens vers le centre de l'organe: c'est de ce centre que prend uaissance un canal très-ténu à son origine, lout avir, fortement el nn grand rombre de fois torlillé sur lui-mème, ce quii lui donne l'apparence d'ètre fort court, quoigu'en réalité il soil forl long. Il est filiforme, cylindrique, il se dirige d'arrière en avant, passe devant le icsticnle et aboulit à l'extrénilé postérieure d'une aulse cavité que M. Cuvicr nomme matrice. Cette portion des organes femclles est membraneuse, et ressemble, par ses plicalures molilipliées, à un pelit mésenière boursouffle; la cavité de cet organe est assez grande prour conleaiv une grande quantité d'œufs. Il est à présumer que c'est la que le vitellus est enveloppé de la matière albumineuse, et que se forme la nembrane envelıppante. Cet organe se termine à la partje antérieure par un canal étroit, ćpais, solide, contouı́né, qui s'insère sur l'extrénité postérieure du vagin. A cóté de ce canal s'en insère un aulre un peu grand quj lermine un organe que N. Cuvier a uommé la vessie.

Nous pensons que la dénomination de vessie, imposée à cet organe, est impropre et de lui cun. vient en aucune manière. En effet, 2 ce mot de vessie s'allache uncidée, une détioition qui, nous le croyons, a élé adunise par les analomisıcs; elle comprend daus ses termes un uppareil de sécrétion el d'excrétion annexé aux fonctions dinestives, mais iudépendantes des fouclions de la généralion. Ainsi, pour que l'organe dont il es: question fát one vessie, il laudioil le trouver dans deux conditions qu'il n'a pas, d'êlre dépendant des organes digestifs, el d'être pnurvu d'un organe glanduleux de sécrétion. Puisque ces deux conditionslui manquent, il faut donc qu'il se rattache aux fonclions de la génération, et le fait de son insertion sur l'extrémité du vagin en est la preuve la plus convainrantc. On conievia que dars les Hélices il étoit fort diffirile de dicider à quelle fonctiun appartennit cet organe singulier, puisqu'il s'insère dans un canal conmon, une sorle de cluaque dans lequel vienaent s'ouvrir plusieurs aulses canaux. Dans les Ambrettes, ce cloague n'existant pas, el l'nrgane nommé vessie subsistant et s'insérant sur le vagin, dont il parujt la conlinuation, il devient dès-lors évident que cet organe est dépendant de ceux de la génération, et, de plus, qu'il appartient essentiellement au sexe fenelle.
Nous donnerons à l'organe gui nons occupe le nom d'appendice vésiculuire. Il est composé d'uut pelite vésicule membraneuse, un pen oblongue on sphérique, se terminant par un canal grêle, moius long dans les Ambrelles que dans les Hélices; il se termine, dans le premier de ces genres, en s'élargissant un peu, et il se place dans ! direclion du varin qu'il semble continuer, landis que le canal du second oviducte est inséré obliquement et laléralement. Celle disposition, cel arrabgemeut, nous ont fait penser que l'appendice vésiculaire, dass l'accouplement, étoit destiné à recevoir la verge el à coplenir la liqqueur spermalique jusfu'au moment de la ponte: les a'ufs sont, cn eftet, furcés de passer devant l'orifice de l'a penentice vésiculaire pour parvenir du secord oviducle dans le vaghin; ils seroient imprégnés de liqueur fécondanie lors de Jeur passage, ei seroient bievlôt a près rejetés au-deliors. lia foncijon que novs allribuons à l'appendice vésiculaire nous semble lui appartenir avec d'auıant plus de prnbabilité que nous remarquons une proportion assez exacte entrela longueurde la verge et celle du canal de la vísicu'e. Dans les Hélices, par exemple, oì la verge est très-longue el trèsgiêle, le caual de la rćsicule est aussi très-long el étroit; dians les Arabrelles, où la verge est plos courte et plus grosse, le canal de la vésicule est éyalement plus court et plus large. 11 nous semble que ces rapports ue sont pas dus an hasald. Nous concevons que pour appuyer davantage notre hypo:hèse il faudroil un grand nombie d'observalions, el nous y avons insisté dans l'inteution de solliciter vers ce but l'alteulion et les recherches des ana:omistes et des ubservateurs.

On voil par ce peu que nous venons d'exposer sur le grense Aubrelle, qu'il ne suffil pas de s'altaclier uniquement à quelques caractçes isulés et exlérieurs ponr confondre dans un même gente des êtres dout l'uryanisation, scrutée plus prolondément, les en sépare pour toujours. On aurnil évilé celle erreur si l'on eûl fail altention que les corguilles des Ambrolles sont, par leur forme et leurs antres caractères, isolíes des Hélices; si l'on eúi donné l'imporlance convenable aux caractères des aumaux, on y auroil facilemeut trouvé la traduclion extérievic diune organisation différente de celie des Hélices sous plusieur's rapporı, mais appartenant hien certainement an même type, ou pour mieux dire à la même fumille.

Nuus avions présumé le résultat que nous venons d'oblenir eu conservant le genre Ambriete dans son inl'srité, comme on pourra s'en assures en consuliant ce mol. Voyez Ambrette.

Ninus venons de voir en yuoi les Auzbreltes diiférent des Hélices; nous allons indiquer en peu de mols les modificalions organiques que nous venous "liolserver daus les Bulimes.

Cest à MM. Quny et Gaymard que nous devons d'avoir pu analomiser plusienrs des iypes les plus 
importans des Iflices, grace a leur génerense communication de deux espèces de Bulimes de la Nonvelle-Hullande, et d'une autre de la terre dei Vau-Diénen. Nous pourrous readre leur histoire lseaucoup plu, complète qu'elle n'étoit avant nons.

Nous ue pouvons que difficilement préjuger de Ia forme géurérale du corps des Bulimes, les individus que uons avons eus ì notre disposition élant contractés el racorais par la liqueur; il nous semble rependant, ea les compariant is des Hólices placiés dansles métaes circunstances, que le corps proprement dit couserve dans ses rapporis de lungueur, d'épaisseur el de largeur a vec le Turrillun, beaucoup d'unalonie av'ec les Hílices. Lursque l'on examine l'animal hors de la cospuille, on remarque la brièveté da l'extrémité postérieure du pièl qui a’est pas dépassée par l'extrémité de la coquille, ainsi que le peu de lar eur de la mếme partie rolativeraent à la grandeu: de la masse des viscères.

Les organes divestifs sont en grénéral disposés de la méune manière que dans les II lices; une inasse buccale assez cunsidérablo contieal dans son intérieur ane dent buccale.

Celle masse buccale, lormée d'un nssez grant numbre de muscles propres, est retirce eu arrière par trnis muscles qui vout, en s'écartant un pen, b'insérer an pied. La cavité de la honclie se termine par un œsophage étruil, et elle reçair de chaque cólé les cautux salivaires, qui accompahaent l'ues phiare et passent avec lici dabs l'anaran céríbral. L'œsophage est assez lingr el grèle, il sélurit pea í per en un estomat: simple, sur lequel les plandes salivaires sont tixćes; elles o:cu. pent le cquart antérieur de la paroi de celte cavité; elles sont irréyulièrement altıclićes et découjiées en leuillets mobiles, et en petit nombre. les vaDanx s.livaires, placés un yeu en dessons de l'œsophane, sont un peu llexueux et l'uccoopaynent dans ioute sa longueur; ils s'ouvrent dins la bquclıe, daos les parois latérules postérieures.

I'esiomac est assez long, cylindracé, angmeutant progressivement de dianètre jusıjù sun extrénilé postériente, qui se reploie brus:juen:ent pous douner uaissauce à lintestin qui remon:e en saccolantimmédiatement is lui; par ce'te courbure sulite de l'intestin l'estomac s'armodil postérieuredent en nn cul-de-sac pen considétable vers lerguel vienneat converger les vaisseaux Liliaires, qui sont au nombre de deux principaux, un pour cluaque lobe. l'ialestin, comme nous venons de le voir, remonte dialsurd le long du burd droit de l'estomac; lorsqu'il est parvenu à peu près à la moitié de la longueur, il se dirigge a griache en formant un angle druit et en passant audessons de l'estomac circonscrit antírieurement; le bord du foie arrive à l'angle antérieur de cet urgane, il se porte en arrière après avoir fait de nouveau un angle presque droil, et circonscrit du côlé rrauclıe le lobe dufoie; il se courbe ensuite en arrière, passe derričre le cul-de-sac de l'estomac, ga zne le pelit lolse de foie, se rempluie derricie lovaire, passe dessous l'estomac et le premicr anse d'inlestin pour gagner bungle c'u dernier tour, as la jonction de la parni de la cavilé pulmonitie avec la masse viscérale : c'est en suivant la mème direction qu'il gagne l'auñle postérieur du bord du collier pour se terminer a' l'anus, qui est prercé lans cet angle un peu eu arrière de l'ourerture pul:nonaire. Celte nuverture, aussilien que l'autus, sont cacliés au fond d'une duplicáture diu mantean dont il faut rulever les bords pour hien les apercevoir.

Le foie est brun, granuleux et formé de deux lobes principanx auxquels se joint un Iroisieme petit lobe placé le longr de la partie de l'intestin yqui remonte aceole à l'estomac. Le premier lobe est compris dans l'anse intestiuale ; il est subqundrangulaire, bordé de toutes parts par l'intestin; il est uivce, aplati, et dans l'enroulement de !a masse viscérale il forme une cavité qui coatient, avec l'extrémité de l'estomac, l'extréraité de lá matrice. Le second lobe du foie est plus épais; il remplit les derniers lours de spire; il est alongé, étroit, et contient vers son railitu an ovare qui est dlun núdiocre volume : deux vaisseanx biliaires principaux, arparlenant anx deux grinds lobes du fuie, el un troisicue beaucoup plus petil descendast du petit lobe, se réunissent pour s'ouvrit en dessous dans le cul-de-sac de l'estomac.

l.es organcs de la grénéralion se distinguent trèsnettement et très-lacilement en deux sorles, et ne sont pas cependant semblables en tout à ceux de l'Arubrette. Les organes mâles et les organes femclles viennent se réuair en faisant un ande très-ning vers lear point d'insertion a la peau; ils souvient au-delors par un tron unique divisé en detlaus en deux ouvertares par un péron, l'ouverure antéicure aboutissant aux organes máles, la postérieure aux oriranes femelles.

Les organez feraelles sont composés d'un ovaire, d'un oviducle, d'une matrice, d'une résicule copulatrice, et alun canal commun ou vagin. Les orgranes máles ollirent, comme à l'ordinaire, un teslicule, uis canal déférent el une verge.

Liovaire est d'un médiocre volume; il est composé d'un grand unoubre de digilations cylindracćes, obluses, bifurquées, placćes les unes à côté cles autres parallélement ei perijendiculairemeat, el paroissant commuaiquer foules entr'elles : c'est du centre de cet orrane, dont la couleur jaune se tuit facilement reconnoilre au milieu du foie, que sort l'uviducle. Ce caoal, assez long, se torille beaucoup sur lui-mêrae, gagne la lice inférieure de la matrice, passe derrière le testicule el s'eufunce dans la matrice, dans l'eadroit nuêtre où le canal déféreat commence à y adhérer for- 
temeut. Uae fuis parvenu dans la matrice, l'ovidućle s’ulténue considérablement, de telle sorte qu'il est impossible de le suivre el de savuir précisément à quel point il aboutit.

La malrice est un organc membraneux forr grand, alongé, très-ınou, rempli de mucosilés, et se décsoposant en larges mailles, d'un tissu cellulaite qui se déctire facilement. Cel organe, diversement boursouffléselnn qu'il contieut ou non des œufs, et selon lear état de développenreat, dépasse postérienrement le testicule. Dans l'emrou. lement des viscères, avaut que la dissection ne les ait séparés, il a une siluation oblique de droite à yauche et d'avant en arrière, de manièrc à ce que son extrérnité postérieure vient se placer dans la cavité do lobe antérieur du fuie, à cóté ct audessus de l'estomac.

A l'extrémité antérieure la matrice se termine par un canal charau, droit nu isfléchi, un peu venflé dans le milien; ce canal ou vagin se dirige ver's l'ouverture commune de la génération, se jniat avec la base de la gaîne de la ceige en formant un angle airrs. Sur ce vagin, au sommet et à côté de l'insertion de la matrice, on rencontre ceile du pédicule de la vésicule copulatrice; ce pédicule, quoique d'un diamèlre moindre que celui de la malrice, parlage avec elle le sommet du vagin, et comme il farme avec cet oryane un angle très-aiñu, il peut étre, aussi-bien que lai, considéré corame la continuation du vagin.

Ia vésicule copulatrice est fort petite, spluérique, memliraneuse, furt mioce, et sou pédicule, tort alnagé, est llexueux, surtout vers son extrémité. Dans la siluation naturelle des organes le pédicule est accolé aux parois de la mairice audessous de laquelle il passe pour remoater eatre elle le burd du foie et l'estamac.

Les organes mâles présentent un testicule, un canal déférent et une verge.

Le testicale est un organe d'un médiocre volune; il est alongé, aplati, un peu déconpé sur ses bords, qui sont amincis; il est fixé à la face inférienre de la malrice, vers sun quart postérieur; il est, par ennsérquent, débordé par elle; il est uni à cet nrgane par un tissu cellulaire, assez dense. L'extrétnité antérieure du testicule se teruine en pointe, de laquelle surt un canal déférent, trc̀s-grêle, à l'origine duquel vieot aboutir la terminaison de l'oviducte. Ce canal déférent suit le bord inférieur de la inatrice, à laquelle il s'allache, se détache à l'arigine du vagin, descend jusquà sa jonction avec la base de la verge, fait un angle aigu pour remonter le long de ce dernier organe qui est fort alougé, se lie à lui par une mernbrane fort mince ou plutôt par un lissu cellulaire lìche, et le perce lorsqu'il est parvenu aux quatre ciaquičnes de la lougueur.

La verge est libre et flottante dans la cavité viscérale; elle est fort alongée, étroite, et res- seruble à un cordon diversement lortillti el contourné; elle est longuement conique, cylindracée, se jaint au vagin par sa base, en loralant un angle très-aigu. Celte réunion a lieu, cocome dans les Aubrelles, au point de sortie des orgitnes. Le muscle rétracteur du tentacule dinit pusse dans l'angle de jooction des organes mâles et fermelles pour aller se fixer ensuite dans les libres da plan locamoleur. Si l'on fend la verge dans sa lungueur, on s'assure qu'elle est formêe par un canal charnu dont la surface interne, dans le repos, devieat externe au moment de la copulatinn, la verge se retournant alors comme un doigı de gand.

Les organes de la respiration et de la circulalina sout disposés à peu près comme dans les Hélices: la cavité pulmonaire, qui est furt grande, occupe toute la partie a atérieure el supérieure du dernier tour de spire de l'asimal. Lorsque celui-ci a ćté déponillé de sa cocguille, la transparence des membraoes qui le revètent permet de voir à gauche du dernier lour, incliné de gauche à d:oile el d'avanl en arrière, le coenr, contenu dans un péricarde très-miace. Cut organe est composé d'une oreillcue meuluraneuse, conuide, qui se joiut an ventricule par un étranglement iriscourt. Le ventricule est plus large que l'oreillelle; il est cbarnu, assez épais, conique, sa base opposée à cclle de l'oreillette; il se termine par le tronc aortique, qui se pillage à sa sortie du péritarde en deux branches principales, une antérieure et l'autre postérieure, qui se distribue aux viscères.

Les veines se réunissent des divers poiuts du corps en un seulirunc qui est placé avec le reclun, daas l'angle produit par la jonction de la parui supérieure de la cavité respiratrice avec la inasse des viscères, cumpris dans le dernier tour de spire. Celle veine suit la direction de l'iulesion boustanment accolée à lui, et parvieut à l'atogle pustéricur dil collicr où est placé l'anus et le linu de la respiration; elle se recourbe subirenent et donne imosediatconeot origine à l'artère pulınouaire, dont les nombreuses ramificatiuns tapissent d'un résean vasculaire considérable toute la paroi supérieure de la respiratioo. Au-dessous du cour, et plus i gauche que lai, nn remarque une tache triangulitite, grisätre, strife : vue à la luupe, on reconnoil l'orirane des mucosilés, lormé d'un grand nombre de feullets divergens réuis par leurs parlies latérales en une seule masse aplatie.

Le système nerveux différe peu en général de celui des Hélices; lanncau esnphagien fournit, comme à l'ordinaire, de ses parties latćrales, des brauclies antérieures pour les tentacules, la masse bucciale, d'antres latérales pour les viscères, le cocur, l'estounac, elc.; insis de plus il donne oriyine, a droile seulement, a un ganglion assez cunsidérable dont les ramifications sont parliculiérement distribuées aux organes de la généra- 
tion. Les branches qui sorlent de l'anneau, en dessous de l'œsophage, se portent surtout dans la unasse musculaire du pied, quelques-unes pénètrent dans le muscle columelluire, ainsi que rlans les faisceaux charnus destinés à faire rentrer en dedaos la anasse buccale et la parlie autérieure du corps.

Dans le genre Bulime, comme on peut le vnir, il existe des différences nolables avec les Hélices, dilf:́rences qui ne se bornent pas seulement aux formes extérieures, unais qui se montrent dans une grande partie de l'organisme. En résumé, les principales diflérences se remarquent daus les glandes salivaires qui, quoique siluées a la parlie antérieure de l'estomac, ne sont point disséminíes, mais sont foliacées; daus la disposition des J lies du foie; dans la longueur du pédicule de la vésicule copulatrice et celle de la verge; llans la steparation jusqu'à leur point de sortie extérieure des deux appareils de la génération, qui manquent, du cloaque, de la poclse du dard el des vésicules nultilides. Dans les organes de lu respiration, on renarque que le réseau vasculaire aérien a une dispusition différente, que les vaisscaux ont un autre mode de distribulion : le cour lui-mème est beaucoup plus à gauche. Dans le système nerveux enfin, on remarquera le gros gangrlion des organes de la génération, gangliou qui est inliniment plus petit dans les Húlices, ct qui quelquefois n'existe pas du tout.

Pus terminer ce qui a rapport aux Hólices, considúrées en général, il ne nous reste plus g̣u"à indiquer sommairement leur distribution à lis surface du glabe, cl à présenter le mode de groupenent et de distribution que nous proposerons purr les espèces.

Les Hélices se trnuvent dans hutes les ríginns da globe el ì toutes les termpératures. M. de Ferussac, par la nature de son travail sur les Mollusques lerrestres et flcvialiles, a dú rassembler un graud nombre de docuneas sur les labitations diverses des Hílices. Curn:ne res coquilles n'enlrent daos nos collecions qu’en passant par les mains du commerce, il est irès-rare qu'elles y parviennent avec des indicatinns de localités sur I'autrenticité desquelles on pùt compter; en cons'quruce, nous emiprunterons á l'ouvrage de M. de licrussac le résumé fort alurégé qu’il donne page 22 de ses Considérations générales sur les Limacons.

"On trouve, dit cet auteur, des Hélices daos trutes les parties du plobe et sous toutes les zunes. Plusieurs de nos espreces d'Europe se retrouvent dans l'Amérique du nord, etc., telles que les Ifelix putris (Succinea amphibia DRA P.) hortensis, puchella, pisana, acuta, elc. Les Ambretles se rencontrent dans toules les parties du monde, du moins notre Helix putris (Succinea amphibia) vit à la fois aux Etats-Unis, dans l'Inde et anx iles Mariannes; l'Elonguta (Succinea elougata Drap.) à la Guadeloupe el au cap de BonncEspéranre; les Helix naticuides, aspersa, pisana, "ermiculata, candadissma, acuta, decollatu, vivent sur toutes les còtes el dans tontes les íles de la Mlédilerranée, en Europe, en Asie cl en Afrique; les Helix pisana el decollata se rencontrent mẻine aux Canalies; l'aspersa a été trouvée dins les lorts de Cayenne, au lisésil et au piesl du Chimboraçao; l'Holix candidissima a élé :encontrée aux iles Mlatiannes.

n D"autres espèces semblent réservées à certains pays : l'Helir lactaca babite exclusivement l'Espringe rt la côte opposée en Afrique; l'Helix alonensis l'ispagne, sculeraent vers la Mciditerranée; l'Helix gualteriana uniquemeat au cap de Gades; l'Algira en l'rovence, el sans doute en Afrique, mais elle n'est connue ni en Italie, ni ''n Espagne, el paroit avoir été portée à la Martinique; l'Helix zcnata descend des sommilés dles Alpes dans les plaines d'Italie, et jusque daus l'A rchipel, etc. etc.

"Quelques groupes paroissent particulicrs it cerrains pays : Ics Hólicodontes sont presque toules indigènes à l'A nérique septentrionale et anx Anlille's; les IÍlicelles byeromanes et háliomanes semblent plus propres i liurope ct aux iles de la Médicrrance.

"Les II licostyles et les Cnc?lustyles sont loultes exaliques a l'Europe. Dans les Cochlitunes (parlie des Agallines), les Rutans semblemi allectés at l'Amsitigue du sud el aux Antilles, è les Agathines a l'Alrirue cet aux iles de Madagasrar el de Frauce.

"les Ponyphimes el les S'yloïles (les Cochlienpes, de la seconde division des $\Lambda$ gallines de Lamarck) appartieunent en géoéral aux prays silućs autour du gulfe du Mexique el aux $\Delta n-$ tilles.

n l.es Cochlugènes (Bulimus Lask.) ondjiliquées soul toutes de la cóie occidentale d'Afrique; les Hélicteres, des iles Sandrvich et des Maridones.

n Dans les Cochlodiues (Clausilies purs Dnap. ) $_{\text {na }}$ les ['upoides som gúnérale:ncral des Antilles; le: Clausilies scoublent alfecties à l'Europe, et surtout aux còtes el aux iles de la Midilemanée. "

Les indicalions très-génćrales qui préciolcut sur la distribution des if́lices ne permullojient pas un grad nombre de deirils gui, tent curicux qu'ils peurent étre, ue doivent se lrouver qu'it la suite des descriplions spécifigues.

Nous arons vu qu'il étoit matériellenent impossible de faire cniocider plusieurs caractises it la fois daus les Hélices pour former des groupes d'especes; celle impossibilite une fois avoúe et reconnue, il deviendroit ridicule de tenter d'inıliles elforts pour produire un arrangement systé- 
sualique qui ne prourait raicux valnir que ceux qui existent déjà. lour un genre aussi nonslireux ģue l'est celui-ci en espèces, aussi variable quant il leurs formes, le zoologiste doil cliercher à atteindre deux buts : le premier est d'obtenir un neure naturel, netlement circunsuit, sur lequel in puisse facilement s'cniendre; le second, te'est d'arriver sûrement el facilemeut ì là connoissance de l'espèce. Quand les moyens de groupeusens a f"iide d'un ensemble de caractères lui ma:1quent, le znolngiste doit chercher parmi les muyrens arificieis des múllodes celui gui est le plus parfait et qqui oftre le plus d'avantage et de facilité. De tcus ces moyens, il est incontestable gue la méIn: de dichusomique ne duive être prúfértée, ę prour s'en convaincre il sufliroit de ciler l'admirable núlhode de Lamarck dans sa flore francaise, mélbode fondće lout enlicie sur ce principe.

Pour faire l'application de la diclootumie à la distribution des espèces d'Ifélices, nuas laisnas de l'ensemble de ces espèces une série unique d'après la furme seulemeut, comuneuçant par la plus a platic ou la plus planorbigne, pour finir par la plos Aancte ou turiculée; nous établissens celle série, nous le répélons, d'après la furme exlirieare, ibstraction faite de lout autre calactive. 1)ans cet:e longue série nous, lianitons a bitraireanent ciny groupes priacipaux détermines par les lurmes prédominantes: dans le premier, snotles espèces planorbiques; dans le second, les espcices Llobuleuses; dans le trosième, les esjices trochiformes; dans le quatrième, les subturviculées; et dausle cinquiènue enfio, les esprèces alongées. Nous prenons cliacun de ces groupes, le considéranı comme un tout, nous chercliours dans les espèces lous les accideus quelles penvent offirir; nous en trouvons qui ont un ombilic, d'autres qui a'en ont pass. Dans les premières el dans les secondes des topices qui uat dey dents, d'autres quí u'en utit pas, gui nat le hord trancliant, d'antres qui nut le buru narginé, elc.; et après avoir opposé aiasi deux ì deux lous les curactères, ou parvient, $r$ r les épuisint, à produire un nombre de groupes d'especes dans lesquels elles sont réunies parun caractice cousaun.

Un autre avantage de la dichotomie, yui n'est peul-chle pas le moins précieux, c'est de prévour lcs modificalions non encore connues, el de préparer a l'avance la place qu'elles doivenı occuper dans la súrie. Nous aous snumes assuré combien il étoil lacile de faire entrer daus les gruupes des nindificalions dont on n'avoil pas la connoissance matériclle. Ea établissant le rableau qui suit, nous nc ànoissions aucupe espèce quil pút se ranger dans la dernière division; oous la préparánes néanmoios conıme si nous avions dú y iascrire aulant d'esjèces que dans les divisions précécleates: c'est après ce travail que nous exaninatmes plusieurs collections, et ce fut dans celle de $\mathrm{M}$. de Rivoli que nous trouvâmes des espíces qui nous étoient jusque là restées inconnues, qui présentèrent les undilications que anus avinas prérues, el que nous d'eùmes plus qu'à inscrire a leur place déterminée à l'avance.

Le lableau que nous présentons ici est destiné aux Hélices plinorbiques seulement. Nous donnerons successivement ea tête de chacune de nos graudes divisions un tableau analogue; nous y téunissuns nuninativen ent loutes les espèces qui sunt yeuues à uotre connoissance. Nous ne les décrirous pas toutes, notre but élant seulcuent de présenter dans char.un des groupes des exemples à l'appui de la mélliode que nous enılliyons. En plaçant res tableaux en téte de chacune de nus grundes divisious, nons ne répélerons pas les titres el les caraclèes des groupes, les numéros des espèces técrites correspondant à cux x des tableaux. il sulfita de celle coinaridence pour les rapporier fucilement à leurs divisions méthodiques. 


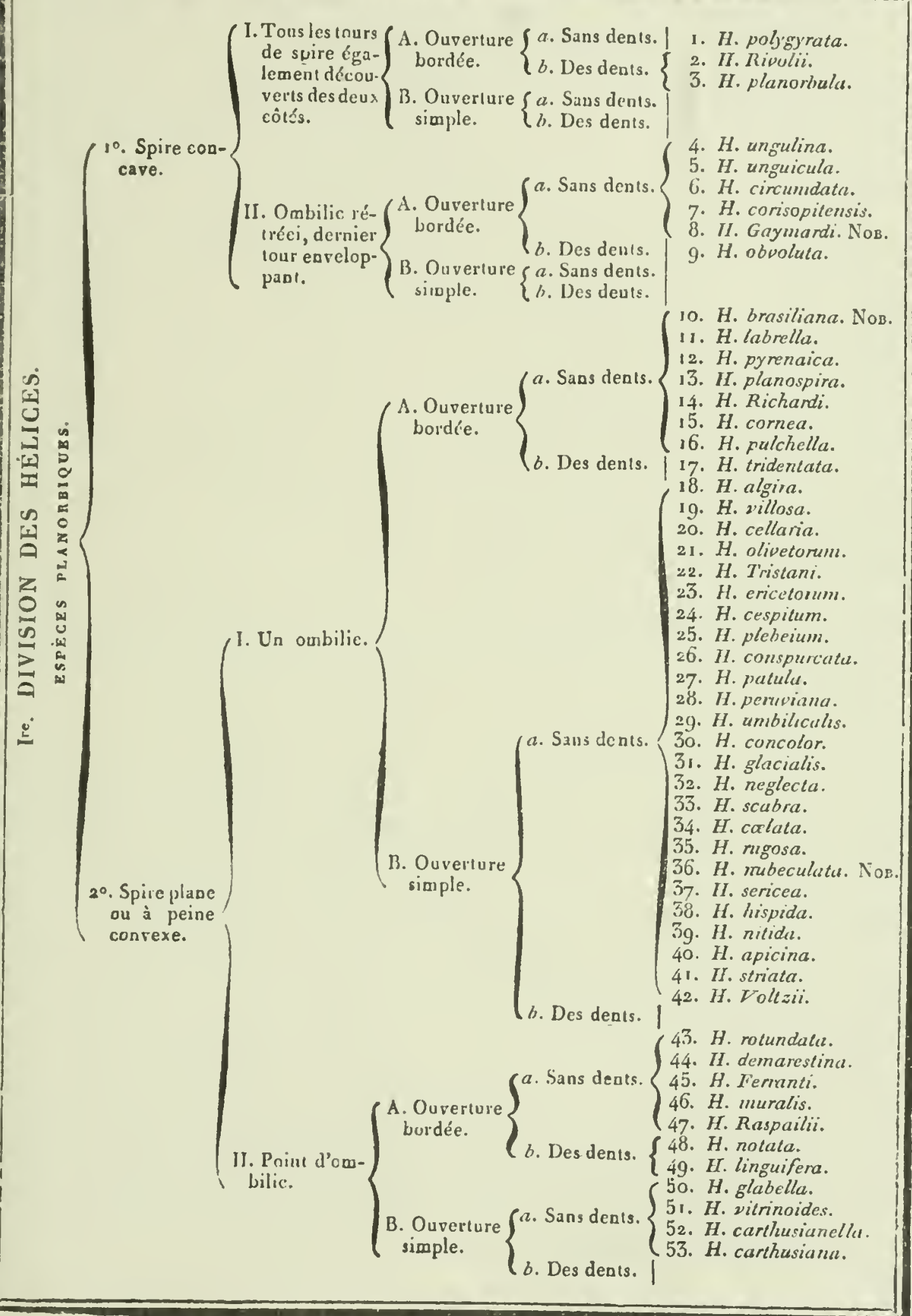


1. Hence polyngre. H, polygymata. Bors.

H. testâ orbiculatâ, discoidâ, supri planâ, subtùs latè concavâ, luteâ, tenuè striat $\dot{a}_{;}$un fructibus decem convexiusculis, anghstis; uperturú margmatá, obliquâ, senilunuri.

Bor., Mlus. carsar. vindob. pag. 1375. tab. 14. /ig. 19. 20.

Canx. Conch. cab. tom. 9. pl. 127. fig. 1124. $112 \stackrel{0}{3}$.

Lix. GNF. pag. 3624 . $n^{\circ}$. 233.

Ferus. Mist, nat. gén. des Moll. $n^{\circ} .194$.

Noous indiquons celle espèce d'après le bel onrrage de Buru, rayaut pu nous la procurer pour la décrire; elle est la seale que nons conaussions qui puisse cutrer dans la première de uns sousdivisions, comme étant la plus discrite des IIólices et la senle qui noffrit point de den's à l'ouverture. liHélice polygyre ressemble ì un trèsgiaud Planurbe; elle est plaue ou lígèreanent cuucave en dessus, un peu plus excavée eu dessuns. Leg tours de spire, qui sont cylindracés, s.on aussi larges en dessus quen dessous; on en comp!e dix, qui sont étroits el s'angmentent inseusiblement et proportionnelleavent: ils sont lézíre:ueut striús avec régrulatité, et leur surface ial simple. liuarerlure est semi-lunaire, oblifue, fren évasée, à péristome bordé, blanc et un peu riblléchi. (ielte coquille, très-rare, dont on iunore Is parrie, esı d'un fauve pâle cl'après Burn, blatn- hâlre atu sommet. Ellc a cinc ligues d’épuisscur a la circouférence, el un ponce dix lignes de (i. ancule.

\section{Hértce de Rivoli. Helix Rivolii. Non.}

H. testì albi, vitreâ, utmque latere concav'n. planulatâ, ellipsoide $\dot{i} ;$ spirí irregulari, supe:nè striatâ, infermè lavigats; anfructibus gymtis, ultimo mujore, ad aperturaln depressis; "upertuni rilatats, tubeformi obliqus, rotundutu-senulunari, intus quinque dentuti; dente columellari alieris longroue.

Coquille fort extraordiuaire, se rapprochant de la précédente par son apialiscement considérable et par l'élatgissenent de l'nomibilıc, 'Iui est tel, ¿ice !'on y voit aussi bien les lours qu'à la parrie supérieure de la spice. Elle est aplatie, concato Ges deux côtés, mais un preu plus inférieurement. La spire, formée de cinq à six tours, au lieu de s'curonler circulairenent dans le plan horizontui, senroule en furmant une ellipse, ce qui dunge un aspect fort particulier à cutte espèce, ci une physionomie gue l'on ne tetronve dans ancune autre du genre. Les tours de spire sunt sub1. glindrarés, enroulés irrégulièrement, c'est-àdire qu'ils ne préseatent pas un acrirnissement grıdué et propurtionné, mais ils s'enflent et se ítrócisseat ensuite à des intervalles ioéganx; le dernier laur, fius grand en punperlicn que les antres, est fortement déprimé avant le se turminer par l'ouverture. Celte dépression, qui a lieu sur la partie dorsale, rétrécit en l'aplatissan lat parlie de la cavité qui y corsespond. L'ouvertuie, un peu inclince intérienreaseat, est très-ubligue au plan de laxe de la coquille. Elle est la!érale, snu péristonıe est firtement rélléchi, évasé, "aI pell épaissi, el ressemlle au parillon d'une tronipelle. Lorsque l'on examine le fund de l'onverture, on renarque dans la partierélrécie dont uous avous parlé ciuy dents limelleuses fort élerées, dont la colunelluire, plus saillarie que lts autres, sivance jusclu'au niveau du périslome. Celte coquille est d'un blanc translucide ruorique laiteux : elle a le test très-mince et fort líger; coure la surface supérieure de la spire est linkment striće en long et un peu olsliquemeat. La circonférence et le dessous sont lisses.

Palrie inconuue.

Celle coquille, l'une des plus exıruordinaines que nuts connoissions dans le geare, méritou bien par ce molif, et à cause de son cxtrême ravelé, de parter le aom de son possesseur, qui. avec tant de bianveillance, livre à l'étude son imwease et uagnifique collection.

5. Hélrce planorluule. Helix planorbula. Lasa.

H. testà orbiculari, plano conicxâ, umbilicati, alba ; anfractibus octonis, trunsversinu et ucutè striatis; aperturd "U a.xe remotâ, lunarı; columellâ unilamellatá; labro margine reflexo, extus sinuoso.

Melix septem-zalva. DАU DEв. Hist. des Moll. $\pi^{\circ}$. 108.

l. Axx. Anim. s. vert. tom. 6. pag. 39. no. 86 .

Cette caquille exıraurdianire rossemble absolnment à un petıl disyue, étant plane et légèretuent concave des deux côtís; on pourroil la comparcer à unc lanic̀re peu épaisse, roulée sur elle-ıứme dutis un plan parfaitement horizuntal. Les tours dc spire se voient éfalement des deux rôtés, ct il, ont en dessus et en tlessous la mêtne éparsseur: ils ne sunt point arrondis, mais taillés carrémeat; ils sont soudés les uns aux auires sans s'euvelop. per, sani que le deruier soit moditié par le prícédent. Le's tours de spite sont au nombre de sept ou luit; ils s'accroissent avec une telle lenteur, qire les irvis un quatre derniers scmblout égaus. La suture qui distingue les tours de spire est simple el assez profonde en dessus; la coquille est assez fortement sillonnće longitudiualenient; les sillons, parvenus à l'augle supérieur du dernier tour, sy terminent sulvitement on se bifurquunt pour la plupart, et se changeant ainsi en stues aplaties et peu régulières sur le dos de la coquille et sar la face inférienre. L'onverture est lout-áfait latérale, étant placée sur le dos de l'avantdernier 
dernier tour: elle cst petice, fort oblique, arrondic, a puristome blanc, éprais, réfléchi eu delar"s, conlinu par une Jame columellaire relevée, qui jeritl ses points d'insertion; du milieu de cette linne colunellitie s'élève une petite dent pyramidale blanclie. Celle ouverture, vine de face, ressemble un peu à un cour de caric à jouer. Celle coçuille est partout brune, coméc, Iransparente, très-mince el très-[ragile; elle se trouve aux lilorides el atux Etats-Unis. Son diamètre est de six à sept lignes, et son ćpaisscul' d'une ligne.

4. Iléuce onguline. Helix ungulina. Jax.

H. testì orbiculatá, zentricosi, suprà depresso excavalá, infina concavâ, lutè umbilicutû, glubrâ, intensè rufí; lubro intùs albo, margine reflexo.

Helix ungulina. Lis. Gasi. pag. 3635. $n^{\circ} \cdot 75$. Mullea, Fcm. pag. 69. no. 265.

Rusрн. Nlus. tab. 27. fig. 2.

PEriv. Amb. tab. 12. fig. 13.

SeBa, Mus. 3. $t a b$. 40. fig. 11 .

Bons, Mus. tah. 15. fig. 11. 12.

Helix badia. Gmen. pag. 3639. nº 171 .

Helix ungulina, Dа Одев. Hist. des Moll. $n^{\circ} \cdot 192 \cdot p l \cdot 77 \cdot$ fig. 3.

LAयк. Anim. s. vert. tom. 6. pag. $75 . n^{n} .29$.

Celle coquille, ainsi que les suivanies, a une forme peu ordinaire dans lus IIélices. Quoiqu'elic soil beaucoup plus épaisse et presque globuleuse, le mode d'enroulewent de sa spire la place nécessairement diuns la méme section yu'ulles; les tuurs de spire s'entoulent dans le plan borizonlal; la spire est coucave, el formée de six tours, dont Ís cinq premiers sont très-ćtruits, et paroisseut enveloppés par le dernier, qui est tellenent grand qu'il fail a lui seul presque route la coquille; les tours sont convexes et séparḱs par une sutute simple assez prolonde; la base de la coquille est concave, et percée au centre d'un ombilic pelit et prolond, vers le bord duquel descend le bord grauclie pour s'y inserer. Isa circonférence du denier tour est réguliçrement convexe; elle se lcrmue ale cinaque cóté en dessus et en dessous par un angle tres-olsus, quı limite !es deux surfaces supérleure el inférieure. L'ouverture est arroudic, secui-lunaire, oblique, un peu sinueuse vers la terminaison du bord gauche; son péristome est réfléclii, arrondi, issez épais, blanc, cou'cur de chair, et quelquefois teinté de violet a liuláricur. La surfare extćrieure de la coquille est finement striée longiludinalcuent it des intervalles ircéguliers; quelyues stries sont plus snillantes ou plus serrées, elles indiquent des atccruissemeos; la couleur est partout la méıe, d'un beau jaune d'orange.

Celle précieuse coquille se trouve à Java.

Hist. Nat. des Vers. Tome II.
II $\mathrm{E} \mathrm{L}$

209

5. IILrice onguicule. Helix onguiculu. Fis.

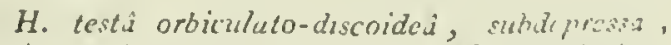

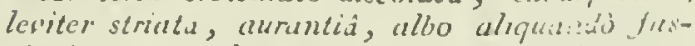
cintâ, utroque latere concavi; anfratilus ungustis, ultumo majore; aperturâs obligui, scrilllunari; labro albo, ieflexo.

lienus. IIist. nat. des Moll. $n^{\circ}$. 191. f?. C6. fig. 3. 4 .

Helix ungulina. Cnenv. Conch. tom. o. tai. 123. fig. 1098.1099 .

Cerle coquille a rertainement beancouf dimalogie avec lllelix ungulina, mais e!le cn cillite coustanment. Elle est orbiculaire, aplutie, concave en dessus el en dessous, plus cu moins épaisse à sa circonférence, bien arrundie, ne sc lermine pas en dessus t $t$ en dessous par un angle arrundi limitaut les denx surfaces supríriemre et inlérieure; les tours de spire, au nombre de six, sont moins enveloppans que dans les aulies espèces de la uêtue secliou, le dermer est cependant plus grand en proportion yucles autes; ils sont convexes el réunis par une sittilu simple, assez prolonde; cette spire est legirement concave, quique l'avant-dernicr tour soit plus suiltan! que le denicr; en ilessons, ha concavilé de la coquille est plus considérable; elle se contime par un unlitic méliocrement lutge, sur le bord duque! l'extrénité sinueuse da bord gatuche vient s'insérer. L'ouverture cst grande, semi-lunarire, oblique; ses bords, épuissis prar un boumelet blanc, sont renversés en dehors. Cen coquille est d'uu fauve orangé, el l'on remarque en dessus et en dessous une liscie blanche plus cu moins latrge. M. de l'erussac an signalé une varrécé dans láguelle il u’existo qu'une seule fascic blanche.

C'est des Grundes-Indes que uous vient cette rarce précieuse cójuille.

6. Hínice enveloppée. Helix circumảata. I'Eñ.

11. testi planorbulari, depressâ, utroque latere concava, lcevigata, albo-rufescente, faciis rufis, numerosis, angustis, regularibus ornuti; spira concavà, tenue et regulariter granulat $\hat{\text {, anf }}$ ractibus angustis, ultimo maximo.

Helix circumdalı. Fer. Hist. nat. des Moll. n०. 193. pl. 66. fig. 1, et pl. 77. fig. 1.

Vur. A.) Testâ gnises, mululineatấ, lineis pallidis.

Var. B..) Testî strictid.

Var. (..) Гов. Testu subtùs lineati, instuper fascia latissiná, fusciciornati.

Jolie coquille qui, ponr la forme, se rapproche beancoup des Helux ungulina et unguicula, mais toujours plus pelite ct plus aplatie qu'elles; elle se distingne d'abord par là, et ensuite par sa coloratiou el d'aulres curacteres propres à l'espece. $\mathrm{Dd}$ * 
Celle copuilic est discoijle, planmulare, peu épaisse, bien arrondic a sa circostérence el non subanaruaire comme l'Hclix ungulina; la spire est conoave, el.e est lormée de cincy is six lo:rs et demi, dont le deraier est proportinnnellement beaucnup plus grand yuc tous les autres; cenxci sont très-étroits, convexcs; la sulute qui les joint est simple et profunde; les deux premiers tours et quelquetuis une partie du troisième suat très-ljasment et très-lésulic̀reunent chagriaés, les suivans sun: lisses ou slrićs par des accroissemens assez réguliers. Cet accident de stries constitue la varièlé 13. En dessous la coquille est concave, el zon ceutre est ourert par un ounbilic urédincre, sur le bord duque! le borl gauche vient siusérer. L'onverture est asscz. grandr, un pen évasée par le renversenicnt du fúristume, qui est bordé et cependanl peu épais; le plan de l'onverture s'incline fort peu sur le plan de l'axe, el est par conséguent presque perpendiculare; l'extrémité gauclie du péristome, avant de s"insérer au borl de l'ombilic, forme un sinus peu échancré et se termine par vne pointe avancée sur le bord de l'omlilio.

Dans le plus grand nombre des individus la rouleur du fond est blasche, tirant quelque fois sur le fauve pâle; sur cetle couleur se desinent des raics ou des bandes transverses plus cu moins nombreuses, dix, douze et quelquefinis davantage; elles sont d'un fauve luncé et l'on ea voil jusque dans l'ombilic. La variété A, que M. de Ferussac a représentée pl. 66, fig. 1, nous semble être faite avec une coquille nunte et altérée; elle est d'un blanc-grisâtre, et les lignes nombreuses qui le cuuvrent sont d'un lauvre-grisâtre. La variété B ne differe que par les stries loogitudinales qui se roient sur le clernier tour. Quant à la variété $C$, elle est fort remarqquable, ioutes les lignes de la partic supérieure des tour's se ríuaisscat en une seule large bande qui or:c:spe toute la surface supérieure de la spire; au-dessous de celle large fascie on remarque quatre bandes assez larges, séparées par des lignes blanches capillaires. Cette variété, que nous posséduns, nous a été commuaiquée par M.M. Quoy et $\mathrm{G}$ aymard; elle vient des Mloluques.

\section{HÉLICE de Quimper. Helix corisopitensis.}

H. testâ discoide $\hat{a}$, planorbulari, depressâ; spirì excuvatá, corneo-fuscâ, tenui, pellucidi, frugili; umbilico mediocri, profundo; apertura magná, senilunari, peristomate albo, reflexo.

Helıx quimperiana. Fer. Hist. nut. génér. des Holl. terrest. et fluv. $n^{\circ}$. 17.2. pl. 66. fig. 2, et pl. 75. B. fig. 1, avec l'aniusal; fig. 2. 3, sans l'animal.

Nous ferons observer d'abord, pour justifier le clıangement appareat du nom de celle espèce, gue nous ne faisons an contraire que reslituer relni que 1I. de Ferussac at eus sans dnutc liniention de dnnner, ras quimperiance n'est pas lalin, et on ne peut disignel une espèce par un barbarisme, quand ou rouve le nom propre dans lous les dictionnaires.

lillélice de Quiuper est restéc inconuue à Drapirraaud, e'est cependant une des espèces les plus remaripables de France; clie ressemble toul. à-fait à unc l'lanorbe, la côté de la spire étant concave et eatoncé au lien d'être saillaot, conume cela a licu daus le plus grand nombie de nos esprèces. Célle - ci est discnidale, assez épaisse, aplatie des deux côtés, arronclie par la circonférence; elle est partout d'un brun-corné fonce, avec un, deux et quelquefois trois zones funves urargées; sur le dernier tour, zones qui indiquent lés anciens péristomes. La spire est composée de cinq tours arrondis, dont le dernier est plus grand proportionnellenent que les autres; la sulure qui les sépare est prolonde a linéaire; le somuce de la coquille, éest-à-fire le premier tour et la novilié du second, est finenent chagriné et d'une manière très.élégante; les tours suivans sout finement strif́s en longueur; vers le dernier luur, res stries deviennent de moins en moins-uombreuses et régulitres. En dessous, !a cociuille est peroce d'un oualilic arrandi, au bord duquel le bord gauche vient sinscirer; l'ouverture est grande, semi-lunaire, obligue, sublatólale; le péritoine, blanc et épaissi, est rélléchi, il est indiqué au-dehors par une fascie jaunàtre qui borde l'uuvesture.

On trunve cene corguille sur les bords de l'Odet, près de Quimper, en Bretagne.

\section{Ilélice de Gayaard. Helix Gaymardi. Noz.}

H. testa orbiculato-convexâ, subglobulosí, utm. que latere concuwi, luten-fusca; undiquè tenue et regulariter grunoso-punctati; aperturâ semilunari, subrotundutú; lubro albo, lutescerse, reflexo.

Cene coquille ressemble beaucoup en petit i l'Helix ungulira, dout clle ne diffère pas atu resice par la talle seuiement. Les tours de spire sont iovolvés, rélricis, le dernier, plus graod que tous le's autres, est drondi el légèrement déprimé à sa partie supérieure; la spire est à peioe concave; clle se compuse de cinq tours légèrement convexes, réunis par une suure sicuple; en dessous, la coijuile est concatve; la surface extcrieure est marquée par un angle à peine indiqué; an ceotre se vort un ombific arrondi et assiz graod, sur le bord ducguel vient s'apinger l'exirémité gaucle du bord de l'ouverture. L'ouvcrlure est assez grande, subseai-lunaire, arrundie, renilanu à la furme triangulaire; le pévistoute ent rélléchi et épaissi en un bourrclel arrondi, blane à sum inserion columellaire, d'un fauve pále rositre dans le reste de son éteudue. Coute la 
smiface cxtérieure de ectre coyulle e.t culorée urifurmémeut de roux-blauc, el elle est omée de ponctualious granuleuses, serrées el très-légulières.

Nous derons celte espèce à l'obligeance de MIN. Quoy el Gaymard, qui nous l'uat cummuniquće à leur retour du second voyage scientilique yu'its ont si gloricuscuncut acheré.

No I.L.

9. II ÉLICE trigonophore. Helix obvolutz.

H. testâ orbiculato-planâ, umbilicatâ, glabrâ, comco-ruféscentc; spirâ suhconcavâ; aperlüà triangulari; labro inargine albo, reflexo, - xtùs sinu distincto.

Heli.x obvoluta. Mvir. Term. pag. 27. $n^{\circ} \cdot 229$.

Guas.r. Test. tab. 2. fig. 5, et tab. 3. fig. r.

La veloutée à bouche triangulaire. GEOFF. Coq. pag. 46. $n^{\circ} \cdot 12$.

Helix trigonophora. Hax. Journ. d'Hist. nat. pl. 4 2. fig. 2 .

Helix obvoluta. Caess. Conch. tom. 9. tab. 127. fig. $1128 . a . b . c$.

Gmex. pag. $3634 \cdot n^{\circ} \cdot 71$.

DrAPARN, MIoll.pl. 17. fig. 27. 29.

DaUdeb. Hist. des Moll. no. 107.

Preiffer, Syst. anord. pl. 2. fig. 28.

LAsк. Anum. s. vert. tom. 6. Fug. 86. $n^{0} .76$.

Coquille planorbulaire, discoude, concave en dessus, légèrement convese en dessous, el arrondie à la circonlérence, cumme l'Helix conisopitensis; elle tst Corméc de six tours élroils, counne pressés ou serrés les uns contre les autres; ils sont convexes et séparés par une suture profonde; des stries longitudiuales, fines, serrées el profundes se voient sur toute la surface de la coquille; en dessous clle est convexe, perfurée d'uu ombilic évasé, au bord duquel vient s'inséter l'extrérnilé du bord gauche. L'ouverture est oblique, plus large que lianle, triangulaire, garnie d'un péristomé réfléchi, aplati en dedans, blanc ou furce et légèrement sinueux à ses extrémilés. Toute la coquille est subtransparente ct d'un brun corné lerne. Lursqu'elle est bien fraiche. l'épiclerme qui la couvre est Lérissé de poils qui sant lure caducs.

C'est dans les lieux ombragís, en France, cm Suisse, en Allemagne, qu'il faut chercher cette uspece.

10. Hér.tce du Brésil. Helix brasiliana. Nов.

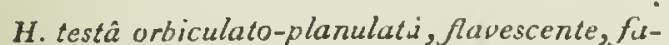
siis fammeis rubris albisque articulatis pictî, suhtus seriebus pluribus, punctorum nufescentiun umatô, sulplanorbulari, rotundutì, granulosâ, pilosi, sublis umbilicatif anfractibus converiusrulis; aperlurû semilunari; lubro alio, refe.ro.

Helix pellis setpentis. Var. a. Fer. Hist. nut. des Moll. $n^{\circ}$. 185. pl. 75. B. fiŏ.6; avec l'auiusal, 7. 8. 9 .

Nous ne croyons pas que celle coquille soit une varıéé seuleınent de l'helix pcllis serpentis; nous la voyons avec de's caructeres tellement conslans dans le jeune age conme dans l'age adulte, que nous a'hésitons pas à en faire une espeece distiucte, qui étanl l:es - déprimée, beaucunp plus que ne l'est l'Helix pellis serpentis, vient se placer au nombre des espèces planorbulaires, tandis que les autres restent parmi celles qui sont globuleuses.

D'après la figure de M. de Ferussac, l'animal de celle espèce sernit d'un gris d'ardnise funcó, a vec les tentacules rouges an sommet. La coquille ne differe pas seulemeut par la furne, mais aussi un peu par la disposicion des couleurs. Jjllélice peau de serpent est toujcurs plus grande que relle-ci, sa spire coujours plusélevée e! golobuleuse, el son dernier lour est partangé par une carèue, un angle assez saillant qui in inque constamment dans l'Hélice du Brésıl; l'uuverture est aussi moins sinueuse, elle est presque toujours d'une teinte violatre, tandis que daus l"uutre elle est blanche; la spire se comprose de six tours arrond:s, à suture simple et peu profonde; ces tours sont graduellenent croissuns : les premiers sont lisses, et tous les autres, en dessus comme en dessous, sout converts de fjues granulations très-nombreuses et très-régulières, de chacune desquelles nait un poil caduc, ce qui tend tnute la surlace de la coquille chagrinée et velue tout à la fois. Il est rare de voir celle coguille avec ses poils; elle les perd presque toujours dans son trausport du Brésil en Europre. La base est convexe el pertorée au centre par un ombilic assez grand, qui parcourt toute la bautcur de la coquille. L'ouverture est semi-lunaire, son bord, légèrement sinueux à sou extrénilé gauche, est réllécli, épaissi, blanc à la base seulement, et teinté de violel clair dans le reste de son étendue; à la partie supérieure de la spire, contre la suture, se voit une hande lormíe de taches blanches alicrnat avec d'autres d'un rouge brun; elles sout en arceau et nombreuses; au-dessous se voit une large bande formee de taches d'un rouge-bruu, qui es limitúe sur la partic la plus convexe du dernier tour par une bande élrovie, secoblable ì la premic̀re; en dessous, la coquille est blanchâtre et d'un roux clatir, et prísenle des lignes plus ou moins nombieuses de ponctualions alongées; ces lignes sont toujours plus larges que dans L'Hélices peau de serpent. Les plus yrands individus do cette espece n'ont que 43 millin. de diamètre. Ilabicie le Brésil.

\section{D d *}


11. HÉLnce labrelle. Helix labrella. LA

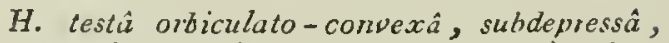

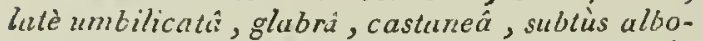
zonatâ, apice alba; labro valdè expanso, intis albo, margme reflexo.

Hetix sepulchralis. DAUDEB. Hist. des Moll. $n^{\circ}$. $183 . p l .75$. fig. 1.

IAiti. Anim. s. vert. tom. 6. pag. 73. no. 28.

Celte cocpuille, fort rare, ne s'est trouvée jusqu'à présent quı'à Mudagascar : elle est aplatic, compusíe d'un petit nombre de tours de spire, quatre ou quatie et demi, dont le deruier est beaucoup plus grand que tous les autres; ils sont convexes, lisses et séparés par ane sulure assez enfuncée; au-dessous de la suture ils sont creusés parallc̀lenent a elle par une gouttière sinuense riui s'accroit proportionnellement à eux. En dessous cette coifuille est ouverte par un très-large ombilic sur le bord duquel l'exiréuitć du hord gaucbe vient s'iusérer. Cet ombilic iofundibuliforme est catouré d'une côle saillante et blanche; l'ourcrture est très-oblique et fort grande, évasée et listenent rélléchice en dehors; le bord est épaissi par un bourrelet blade, plus épais sur le côté droit que sur le côté gauche. La coluaselle est garroie d'une lame appliquée blanche et mince qui joint les denx bords. Celle coquille est d'un jaune oran ré assez intense, le cordon ombilical luisunt est blinc. Un individu de la collection de M. de Rivoli est d'un jāune pâle, grisâtre, marçné de deux rangées de tuches irrégulières uvirâtrcs. Habite Madarascar.

12. Hélice des Pyrénée: Helix pyrenaica. DRAP.

H. testâ depressissimâ, orbiculatâ, tenui, pellucidì, substriut $\dot{\lambda}$, corneo-viridulà; aperturâ semilunari, obliqui, reflexá, peristomate albido circumdati; unbilico mediocri, profundo.

Drap. Hist. des Moll. pl. 131. fig. 7 .

lerussac, Hist. nat. des Moll. no. 170.

Jolie coquille d'une forme qui la fait facilement reconnoilre parm: les espèces de France; eile est tres-aplatie, planoridique; la spire est à peine saillunte, son contour est arrondi. La spire est furméc de cind tours légèrement convexes, dont le clemier esi proportiouné aux autres. La suture est -peu protonde, simple et linéaire; en dessous, elle cst convexe, aplatie, et percée au centre f'un ombilic uédiocre, un peu reconvert par le bord galacise, qui s'insère à son eatrée. I'ouverture est fo, th oblique, semi-lunaire, sublat rale; son prírstuone es! rélléchi, blanc, assez épaissi, et laisse un large intervalle entre ses points diuscrlion. La surlace extérieure est lisse on tiuemeot striée, mais ces stries sont peu constantes, citant plus on moins yrosses ou manquant par intervalle. Ta conleur est partout la autme, d'un brun-verelátre couleur de corue, à cause de la trinsparence du test.

Celle coquille assez rare vieal des Pyrénćes orieotales.

13. HÉlice pladospire. Helix planospira. Lamk.

H. testa orbiculato.depressâ, subtìs convexâ, umbilicatâ, glabrû, corneo-lutescente; spirấ planâ, ultimo anfructu fusciâ albida nufo marginatâ cincto; labio murgine reflexo, albo.

Gualt. Test. tab. 3. fig. o.

Helix zonata. Da udeb. Hist. des Molliasques, $14^{\circ} .165$.

L.мк. Anim. s. vert. toin. 6. pag. $78 \cdot n^{\circ} .48$.

Coquille qui a absolument la forue de l'Helix pyrenaica, étant loujonı's beaucoup plus grande, et préseniant des caractères qui lui sont propres; elle est arrondie, discoidle, aplatie, à spire ì peine convexe. Cette spire présente six tours peu convexes dont la suture est simple et superlicielle : le dernier est en proportion un peu plus grand que les autres cours. Les preniers tours, examinés à une tres-forte loupe, sint très-fideDıent et très-régulièrement thagrinés. Sur les tours suivans, les poncluations s'éluignent de plus en plus et fiussent par disparoitre. Le dernier cour est très-finement guilloché sur toule sa surface par une mulitude de ponctuations exırêtnement fines, beilucoup plas fines que celles des premiers tours, et que l'on n'aperconit qu'à l'aide d'uae forte lentille. En dessous, lit coquille est convexe et onverle it son ceatre par un oublilic un peu recouvert par l'évasement du bord gauche. L'ouverlure est uraude, obliçue, arrondie, semi-lunairé; le péristoure est blanc, fortement rélléclii, épaissi, en un bourrelet arrondi. Le bord gauche, à l'endroit de son insertion, s'avance cis s'élargissant el en se reuversabt un peu au dessus de l'ombilic. La couleur de celle coquille est le plus ordinairement me couleur janne de corne sur laquelle on voit, au-dessus du milien dn dernier tour, une raie blauche loordée en dessus par une ligne fuuve. Nons avons une variété verdatre et une autre brunâtre dans lacjuclle la luscie bianche, plus large, est divisíe en deux par la lirge brunc. Habile l'Iralie, la Sicile, les Alpes.

14. HéLtce de Richard. Helix Richardi. Fen. H. test.i orbiculato-convexâ, latè umbilicati, squalide alba ; anfinctibus transversè striatis; stris confertis, undulutis; labro maryıne albo, vuldi refle.xo, ad basim subunidentuto.

Helix Richardi. DAODEB. Hist. des Mollusques, $n^{n} .25$.

1.AMx. Anim. s. vert. tomb. 6. pag. $7^{2}, n^{\circ}, 25$. L'Hélice de Richard a quelque analogie, pour 
la forme de l'ouverture et la aature des stries, avec l'Helix albolabris; elle est constanument plus déprimée el ombiliqunée, l'umbilic mancue roujours dans l'albolabris. La spire de l'espece qui nous occupe est déprimée, peu saillante; elle se conpose de six tours peu convexes, stoparés par une sulure sinule, peu protionde. Le dernier est arrondi, un peu plus grand que les antres en propostion, el convert comme eux d'un grand nombre de stries fines, obliques, subrćgulic̀res et onduleuses; elles se conlinuent en dessous sul le dernier tour et convergent vers l'unshilıc. La face iuléricure de la coquille est convere; alle offre au centre un ombitic assez grand sur le bord duquel vieat s'irsérer l'extréuité du lurd gauche de l'onverture : celle-ci est assez grande, ablique, semi-lunaire. Le péristome, aplati en deviut, est blasc et refléchit ea clehors; s'épaississant un peu vers la base du bord gauche, il y produit une ondulation ou une dent pea prononcée. Il est difficile, d'ajrès l'individu de la colleclion de M. de Rivoli, le seul que nous ayons vu, de juger de la couleur de cette espece. Cet individa est d'un bluac sale, ce qui tient tièsproballement à ce qu'il a été recueilli long-temps après la mort de l'auimal.

\section{IIÉLIce cornée. Helix cornea. Drap.}

H. testâ orbuliculato-convexî, depressiusculi, umbilicat $\hat{\alpha}$, glabra, come $\hat{\alpha}$, rufo-subfasciat $\dot{j}$; spiri brevissimi, obtusa; labro inurgine albo, subreflexo.

Ilelix cornea. Drap. Moll. pl. 8. fig. 1. 3.

DAUDEB. Hist. des Moll. $n^{\circ}$. 161 .

I.A $3 x$, Anim, s. vert.tom. 6. pug. 90. $n^{\circ}, 9^{2}$,

Coquille déprimée, subconvese, arrondie à sa eirconféreuce, un peu carénée daus le jeune âge. Sit spire, peu élevée, est cie quatre à cing tours arrondis, conveses, dont la suture simple est assez profonde. La surface extérieute, ordinairetnent striée en long, est lisse daus quelques individus. Les stries suat inégales, peu cunstantes. Ea dessous, la cocjuille est un peu aplatie, son centre est ouve:t par un ombilic assez graud, un peu recouvert parle bord gauclı. L'ouverture est arrondie, ovalaire, trés-oblique et lalérale; elle ressemble un peu a celle des Cyclostomes par le rapprochement considéra!ble des poiols d'attache du píristome, qui laissent eolre cux un espace très-court, sur lecfuel on voit les traces d'un bord gauche qui sert à compléter l'ouverture. Le péristome est bordé, rélćclai en debors, et tonjours d'un roux pâle. Le lest est mince, bruu, corné, transparent, partout de la unème teinte, et orsé, à la circonférence du dernier tour, d'une baude ou faseie d'un rougc obseur, au-clessous de laquelle on en aperçoit quelyuefois une autre, mais à peine marquće et indiquée, surtout par la tache qu'elle produit sur le pédistome. Cente eoquille assez rare se tronve en France seu!ement, aux environs de Montpellier, l'érigueux et Castelline.

\section{Héltce unignonae. Helix pulchella.}

H. testầ minutissimâ, orbiculuto-depress $\hat{3}, u n:-$ bilicató, costutá, albs aut cinereâ; labro margine crusso, albo, ieflexo.

Helix pulchella, Mucu. Verm. p. 30. no. 252 .

Ejusd. Helix costata. Verm. p. 31. n $n^{\circ} 253$.

DARGEXv. Zoomorple. pl. 9. fig. 7 .

La petite striée, Georf. Coq. p. 35. $n^{\circ}$. 6 .

Helix pulchella. Gsies. pag. 3633. $n^{\circ} 67$.

Ejusd. Helix costata. p. 3633. $n^{\circ}, 68$.

Helix puichella. Drap. Moll. pl. 7. fig. 30, 32.

Dauneb. Hist. des Holl. $n^{\circ}, 173$.

Lamx. Anim. s. vert. tom. 6. pag. 94. n०. 107.

Helix costata. PFetfrer, Syst. anord. pl. 2. fig. 31.

Helix pulchella, ibid. fg. 32.

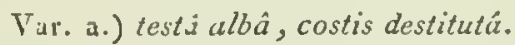

Vuici l'une des plus pelites espèces du geure, ca: elle n'acquiert jamais plus d'une ligne de dianitre; elle est aplatie, la spire est pen conique; elle se compose de quatre tous's arrondis, sćparés par une suture assez profonde el simple: le demier tour est sensibleneut plus grand que les autrcs. Vers son extréurtú, il se déjelte en dehors, de sorte que l'ouverture devient prosclue latcirale. Ea dessous, sette coquille est arruadic et largemeat ombiliquée; l'ouverture, un peu évasée, est presque ronde, l'intervalle qui sépare les points d'allache du péristume élaut extrênemeut conrt; ce péristome est blanc, fortement réflćclui en dehors, épaissi el arrondi. La corpuille est toute Jlanebe ou grisálie et elargée de côtes longiludinales plus ou noins serrées, de la même con!eur, et un peu liangées au loord libre. La varićté qui manque de ces rôtes a été distingucée comme espiece par cluelques auleurs; mais c'cs! is tort, tar il y a un passage cntre elle et celle qui a des còtes. Celle coyuilie est commune en lirance, en lalie, dans les lieux humides; elie se trouve anx Etats-Unis d'Amérique, d'apres: 11. de Ferussac.

17. Hinde tridentée. Felix tridentata. SAY.

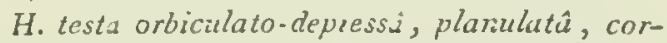
neo-luted, regulariter tenuè striatâ, umbilicatá; striis confertis, longitudinalibus, obliquis; aperturâ albà, tridentutá; latio plinulato, reflexn.

S.IY, Nicholson's encyclop. art. Conch.

Listen, Conch. tab. 92, fig. $9^{2}$.

Fervs, Hist. nat. des Moll. $n^{\circ}, 105$. 


\section{4 \\ II I L}

L'Helix tridentata est uue coquille d'un pelit volume; elle est déprimée, planorbulaire, a spire aplatie, un peu convexe en dessous, arrondie a sa circonférence; elle est composée de cint et dewi à six tours de spire; ils sont aplatis, peu convexes, et séparés par une suture simple et superficielle : le premier tour est lisse, luus les autres sont finemeut et régulièrement striés duns leu: longueur. Ces stries sont serrées, nombreuses, régulières, un peu onduleuses. L'ombilic, gini perfore le ceatre de la coquille, est pelit, arrondi, el on peu recouvert par l'extrémité du bord gauche qui se renverse au-dehors à son iusertion. l.'ouverture est petite, obligue, à péristoiac large, rélléchi, aplati en devant, et d'un blanc de lait pur. Soo bord interne, assez tranchant, est découpé en trois arcs de cercle, dont le médias, le plus rétréci, done aaissance à deux dents, prar la jonction de ses extrémités avec les arcs latéraux. L'ouverture est de plus rétrécie par nae dent columellaire, pyramidale, oblique, qui se prolonge à l'intérieur en une petite côle blauche. 'Toute la coquille est d'un jaune corné, transparent, si ce a'est à l'endroit du péristome, qui, en dehors, se manifeste par une bande d'un jaune-blanc entourant l'pu verture.

Cetle cuquille ne s'est trouvée, jusqu'a présent, qu'en l'ensylvanie el au Canada, dans l'Awériqué septentrionale.

18. Hílice peson. Helix algirs. LiN.

$H$. testâ orbiculato-convex $\hat{a}$, depressiusculi, latè umbilicatâ, rugulosí, griseo-favescente, immaculatá; labro fimplici, acuto.

Helix algira. Lan. Gesn, pag. 36 ,5. $n^{\circ}$. 11.

Helix oculus capri. MULLE, Verm. pag. 39 . $n^{\circ} .239$.

Iister, Conch. tab. 79. fig. 80.

Gualt. Test. tab. 3. fig. 9 .

Dargenv. Conch. pl. 6. fig. e.

F'avarve, Conch. pl. 6.5. fig. l. 1.

Bonn. Nus. tab. 14. fg. 3. 4.

Crems. Conch. t. 9. tub. 1:5. fig. 1093. 1094 . Helix agophthalinos. G MеL. pag. 361 4. $n^{\circ} .5$.

Helix algira. DRA PAKN. Moll. $\mu l .7 \cdot f_{g}$. 38.59.

Dacoeb. Hist. des Moll. pl. Ü. fig. 1, aevc l'aninıal.

LAMx. Anim. s. vert. tom. 6. pag. $77 \cdot n^{\circ} \cdot 45$.

Zonites algireus. Montront, Conch. syst. tom. ‥ pag. 282 .

L'Helix algira est une belle et grande coquille aplatie, subcliscorice, à spire obunse el peu saillan:e, convexe, percée en dessous el arrondie à sal circonfsrance, quoiqu'elle suit forteuseat carúnce lorsqu'elle est jeune. lics tours de spire sout au nombre de six ou sept; ils soat aplatis, si ce n'esi les denx derniers, qui sont un peu convexes; lit sulure est simple el superficiclle. En dessous, la cocjuille est ouverte par un ombilic grand et frroloud, sur le bord duquel vient s'insérer le bord gauche. L'ouverture est graude, semi-luuaire, arrondie, plus la:"ge que haute : ses bords sont minces, tranchaos à tous les àges, ct jamais garnis a l'intérieur d'un bourcelet. T'uute la partie. supírieure de la coquille esi couverte d'un ríseau chilgriné, qui résulle de l'entre-croisement de, stries longiludinales et transverses. Eo dessous. clle est lisse, sa coulear est d'un bruo jaune ou verdátre, quuelgुnefois ornce de lascies longitudinales plus funcées. Cette espjèce est propre à la France méridiouale, Toulon, Marseille, elc.

\section{Hélice velue. Helix villosa. Drap.}

H. testâ suhdepressâ , pallidé fuscâ, pellucidà, temui, fragili, longitudinaluter transversimque striatâ, hispidâ; umbilico magno; peristomuto simplici, intus margine nimimo, depresso, circumdato.

DnAP. Hist. des Moll. pag. 104. $n^{\circ}$. 56. pl. 7 . fg. 18. I9

Ilelix pilosa. Anten. taủ. 4. fig. 7.

Ferus. Hist. nat. des Moll. $n^{\circ} .266$.

Cette espèce est fort remarqualle par la longuenr des poils dont elle est couverte; elle se dintingue très-facileınent, par ce caractìre et d'autres quil lui sont propres, des autres eipeces velaes. Elle est déplimée, surtout an sommet de la spire qui est fort obtus; sa taille est plus grande que celle de l'Helix hispida, de laquelle elie se rapproche le plus; elte est partout d'une couleur fauve, légèrement brunàıre et peu foncée; son épiderme et les longs poils flexucux qui en partent sunt de la mème couleur; les tours de spire sont au nombre de cinq et demi ou de six; ils sont convexes, demi-cylindriq̧ues et séparés par une suture profonde et simple; ils sont linemen! striés longiludinalement; ces stries sont conpées par d'uutres transverses, onduleuses, excessivement lines, tiès-nomlueuses el tris-serrées, que l'cu we preut apercevoir qu'ia l'aide d'une tres-forte loape; la base est percée d'un ombilic fort graud, qui permet d'upercevoir lous les tours de spire juscju'au snminet. L'onverture est obligue, arrondie, l'extrémité des bords se riaprocochant beaconp à leur inserion; le péristnme rost simple, très-mince, renversé sculement à gauche audessous de l'ombilic: un petit bunrritet blanc, a peiae sensille, le borde a l'iutéricur. Colte espèce, assez rure bien conservée, se 'rouve eu Fraule, dans le Jura, ea Suisse el en Allenanglu.

20. Héuce luisante. Helix cellaria. Muna. 11. testấ orbiculato-consexiuscula, sudrtamu- 


\section{I! E I,}

lnlá, umbulicatâ, tcnui, pellucidi, tonuiter sllutu, snprà pullide comeí, subtiss lactcâ; lubro simplici, acuto.

Helix cel'urill. MuLs. Ferm. $\mu . \simeq 3 . n^{\circ} \cdot 230$.

Dangesv. Conch. pl. $28 . / \mathrm{jg} .4$.

la Luisanle. Genfr. Coq. prg. 36. $n^{n} \cdot 7$.

Cness. Cuncl. ionı. 9. 4 b. 127. fig. $11: 9 \cdot 1 \cdot 2$.

Garex. pag. 36.34 $\pi^{n} \cdot 7^{\circ}$.

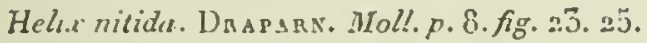

Helix cellaria. Davocb. Hist. des .11oll. $11^{\circ} .212$.

Var. A.) Testá minore.

Ilelix nitidbla. Dnay. Hist. des Woll pl. 8. fig. 21.22.

Ibrd. Ferus. Hist. des Moll. $n^{n} \cdot 21 \overline{3}$.

A l'Helix cellaria nous joignons l'IIclia nitidula de Draparnand, qui n'en est cerlainement yuune variélé d'ägre; on cunçoil qual est facile de sasurer de ce que nous disons en établissant une sírie d'individus pris à tuus les âzes.

L'Hálice luisaute est une coquille subplanorbique, discoille, ì spire peu converc, concave ea dessous, arrondie el peu épaisse sur sa circonferience. On comple six lours de spire peu conrexes, réunis par une suiure simple, superfu.ielle; le dernicr tour est propor!ionuel'eunent un peu plus grand que les aures, el se lermine par une ouverture peu oblique, assez grande, ser.i-lunaire, à périslome siarple, mince, tranchant, n’ayant jamais de bourrelel intélicur. En dessous, celle coquille cist non-seulement perforce dun ombilic assez grand, mais encore excavíc asez profundément. La coquille, vue à la loupe, est linement striée, surtout sur les premiers lours, mais d'une manière pen constante el irrégulière; la conlcur est le corué clinir roussátre, et en clessous d'ın blanc laiteus verdâtre. Celle coquille est mince, trasparente, polie et brillanie; elle vit dans le midi de la France.

21. Iİ́Lice semi-rousse. Helix olivetorum.

H. testâ orbiculato-conve.xâ, umbilicalî, teuui, pellucidx, suprà corneo-rufà, sublis alhidâ; spira obtuss; labro simplici, aculo.

Guact. Test. lab. 3. fig. 9 .

Helix olivetorum. Gues. pag. $5630 . n^{\circ}, 170$.

Helix incerta. DMAPAR Moll. pl. 13. fig. 8. 9.

Helix olivetoruin. DaUdeB. Hist. des Moll. $n^{n} \cdot 205$.

I,A s x. Anins. s. vert. tom. 6. pag. $7^{8} \cdot n^{\circ} \cdot 47$.

Jolie coquille qui, pour la forme, ressemble beaucoup à l'Helix cespilum, mais elle n'a que cela quila rapproche de celle espèce; sa forme est arrondie, subglobnlense, à spire un peu saillante, formée de cinq tours arrondis, dont le dernier est sensibleirent plus grand gue les aulres; ils sont subslriés lungiludinalement, et liur sulure saperfirielle cost sinpla et quslyuefoij ua peu p'issće. En dessons, celle :nquille est aryndie, percce alua unbilic assez grand, gui parvient jusqu'au sommel; l'ouverture, qui termine le dernier cour, est assez yrande, oblique, arrondie, ni évasée, ni renrerséc, muis simple, i péristome l:ancluant, tuujours dépouryu de bourrelet à l'intérseur. Certe coquille est brune, co:née, lransparcute, nićne vitrée, d'une couleur on teinse un peu plus pitie, tirant sar le virt a sa partie infúlieure. Eile habile en France. co Itulis, en Sicile, les plautations d'uliviers.

22. Hézice de Trislan. Helix Tristani. Вกохс.

I1. testà subglnbulosâ, lcevigatâa, anguluti; anfractibus qunque dapressis; spirât subprom$n u l a \hat{~}$

Broxg. Ann. du Mus. tom. 15. pag. 5̄-\%. pl. $2 \overline{3} \cdot$ fig. 8 .

Noв. Descrip. des Con. foss. des env. de Paris, pag. 55. pl. 7 . fig. 5. 6.

Nous ue savons si lon doit conserver celle espéce, rui pourroit bien n’être qu'un jeune individu de l'Helix Mnonguesi. En ellet, il laut se rappeler que les jeunes $\mathbb{1}$ élices prísentent très-souvert une carone obtuse sur le dernier tour, carène qui s'ellice à mes re que l'auimal grandil; el counue celle espèce ne se troure que daus les mémes endruils ytue l'Helix Homguesi, il serait bien à prósunicr que ciest la nièie espèce dont clie no diflère au resı que par le volume, ce qui la ren.l plus déprinće, et par la carène obtuse qui rène au inilieu de la circonférence de son deraier lour. Elle at 12 millimètres de diunètres.

\subsection{IÍ́lice ruban. Helix ericetorum. Mol.}

H. testầ arbiculato-depressâ, latè umbilicutâ, strialí, albidâ, rufo aut fusco fasciatí; labro simplici.

Helix ericetorum. Musl. Venn. pag. 33. $u^{n}$. $\approx 36$.

Le grand Ruban. Geoff. Coq. pag. 49. n०. 1.3. pl. 2.

Canss. Conch. tom. 9. tab. 132. fig. $119 \vec{\jmath}$ 1195.

G «L. pag. 3632. n. 65 .

Disанм. Moll pl. 6. fg. 16.17.

Daudeb. Hist. des Moll. $n^{\circ}, 28 \mathrm{I}$.

LAмк. Anim. s. vert. tom. 6. pag. 84. n०.6g.

Helix cespitum. PrEtFFer, Syst. anond. pl. 2. fig. 24. 25.

Var. A.) Testî̀ onnind albâ.

Var. B. ) Testì uni adquinque fusciatáfusco. 
Ta
tutâ.

Var. D. ) Testâ nigricante, duabus fascius latissinis instructá.

L'explication faulive de la pl. 6 de Draparaad, à l'sgat'd de rette espèce, des Helix neglectu et cespitum, a pu fäire commetire quelyues erreurs aux personnes qui ont fait plus allention aux fimnres qu'aux descriptions : c'est. ainsi que M. Pleiffer a donné l'Helix ericetorum sous le nom sle cespitum. Celle erreur, ni Lanarck, ni M. de Ferussac ne l'ont commise.

L'Hélice ruban csı une coquille fort rommune, que l'on trouve particulic̀reuent dans les lieux secs et arides, sur les gazons des colezux. Elle est asscz grande, discoide, aplatie; sa spire, peu saillante, se compose de six tours arrondis, séparés par une sulure simple et médiucrernedt protoude. Le promier rour est lisse et brun, les suivaos sont converls de stries longitudinales, aplaties, peu régulic̀res, plus on moins élevées; la circonfúrence du dernier tour est arrondie, si ce n'est dans le jeune âge qưelle est carúnée à la parlie supéricure. En dessous, celte coquille est largement ombiliquée; son ouverture, 1rcs-arrondie par le rapprochement assez considírable des points d'attaclue du péristo ñe, est légèrement Evasée en dehors, sans que cependaot le bord soil réfléclij. Le péristome est simple, tranclsant, et ordinairemenl garni à l'intérieur d'un bourrelet très-plat el très-étroit, hlaqc ou roussitre. La coloration de celle espèce est assez varable : sur un fond blanc sont disposées des bandes bruues plus ou moins nombreuses el plus on moins larges; noe seule, et très-rarement deux, se voicnl a la parlie supérieure de la spire. Ia suture ne suil le bord inférieur gue de manière à la laisser en de. lsors; lesautres, au nombre d'une à quatre, el quel. quefois cing, occupent la paric infúrieure du dermer tour: el clles sont conslamanent séparecics de cclles du ciessus par une zone blanclue.

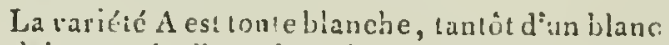
de lait, tanıöl d'un blanc-jannâtıe. La variété B compread cous les individus qui ont d'une à ciny bandes brumes, distiactes ct contitues, plus ou noins fiues et diversement disposées.

Daus la variété $\mathrm{C}$ sont disposés les individus qui, avec uu nombre variable de baudes, les ont, soil en dessus, soil en dessous, poncluées, inlerrumpues, confondues el marbrées de blanc. Dins la variété D deux larges zones brunes occupent presque loute la ciconférence du dernier tour.

Celte coquille se trouve dans presque toute l'Europe.

24. Hélice des gazons. Helix cescrium. Drap.

H. testâ orbiculatâ, convexâ, subdepressâ, latè umbilicató, tenuiter striatô, albâ aut hutescente, fusco fusciatá; spirá subproninulà; labro simplici.

Helix cespritum. DRА . Moll. $p l$. 6. fig. 34. 15. 1) AUDEB. Hist. des Moll. $n^{\circ}, 283$.

Helix ericetorum PFEIFF. Sy'st. anord. tab. 2. $f_{i, 5} \cdot 2 . \overline{3}$.

L.A. An. Anim. s. went tom. 6. pag. 84. n०. 68. Var. A.) Testâ albâ, peristomate albicante.

Var. B.) Testì rufescente, obscurè zonatá.

Var. C.) Testi superné unizonati, subtics bi ad quinque fiusco zonati.

Var. D.) Testi albá aut rufescente, parte superiore fuscati, albo vangatá, subtis zonatá.

Var. E.) Testi zonấ latè nigricante instuct.i parte superione; basi octo vel novem nigro fasciat.i

Var. F.) Testì omnino nigricunte, in medio zoná alba cinctá.

Cette espèce est plus épraisse, plus glubuleuse que ne le sont les Helix ericetorum et neglecta; elle se distingue aussi de ces espèces, et de la prenuière surtour, par une coloration fort différente. Elle esr arroncic, à spire un peu saillante, formie de six cours pen convexes, a sulure simple et peu profonde; ils sont suiés longiludinalenent, arais d'une manticre peu conslante: les stries sont p!us cu moins apparen!es. L'ombilic, qui se roit en dessous, est assez grand, évasć, surtoul dans les individus les plus dépritnés; il est plus rétréci dans ceux qui ont la spire sallante. Le deruier loux, plus grand moportionnellement que les aulres, se termine par une ouveriure assez ample, arrondie, ovalaire, a peine évasée, plus large que haule, ayant les bords plus désunis i leur exiréxilé qu'ils ue le sont dans l'Helix ericetorum.

Le péristome, mince et tranchant, est tantót blanc, taplól rosáire, on d'un ronge-violàtre; il est garni à l'intéricur d'un bourrelet de mérue couleur : ce bourrelet est plus ou moirs épais, mais toujours étroit.

Les variélús, comme on le voit, snnt nombreuses dans celle espèce comıne daus beaucoup d'isires; on pourroit facilencat les multiplice davontage cu s'uttacian: aux détails plus que nous uc läsons. La varićté $\Lambda$ cst inule blanche, sans tacl.es. La variété $\mathrm{B}$ est rausatre, présenle quelques liammules longitudinales, obscures, phus loncées, et des zones transverses, valiulles et peu mariques. La varitite $C$ est assez cunstanle; elle est la plus commune, el c'est elle qui se rapproche le plus de l'Helix neglecta. lifle a nise bande brune à la partie supéricure du dernier. tour, tlle est en dehors de la suture, et se roit sul tous les autres tour's jusciuan sommet. En dessous on compte deux à cinq, et quelquefois six baukies brunes, élroites, presque toujours ponc- 
tućes de blanc, ou laciuiées sur lears bords. La *riélé D se reconnoil a la large zone brune qui convre la partie supérieure des tours, cma tipi est poncluce de blanc; en dessous il y a, comme dans la précédente variété, des bandes brunes variables pur leur nombre. La variété $\mathrm{E}$ est fort remarquable : une large zone d'un brun noir, irré. gulièremcent marbrée de blanc, occupe la moitić supćrieure de lit coquille, et en dessous on compte huil ou neut lignes d'un bruu noir, continues et vettement dessinécs sut un fond blanc. Dans la dertière variélé, la large bande supćrieure persisie ct a moins de taches; mais toutes les bandes iul'érieures se véunissent en une seule, large, qui occupe la base de la coquille, qui devicul aiusi presque d'une senle couleur, les deux zones bruves étaut śparées seulement par tine ceinlure blanche médiane.

On trouve celte corgille dans toute la France méritionale, le Pićuront, l'lalie, la Corse, la Sicile.

20̈. HÉL1ce plébéienne. Helix plebeium. DnaP.

H. testú orbiculuto-convexâ, umbilicatâ, tenul, pellucidi, comej, hispidia ; spiri oblusâ; lubro margine albo, subieflexo.

Helix pleberum. Dnap. Moll. pl. 7. fig. 5.

Ds U DEв. Hist. des Moll. $n^{\circ} .26 g$.

L.s.u. Anim. s. vert. tom. 6. pag. 92. n. $9^{8 .}$

Especce qui a de l'analogic, quant à la forwe, arec l'Helux incarnata, dont elle dillc̀re, ail reste, par la taille et d'autres caractères. Elle est arrondie; sa spire, obluse, est ['cu saillante; el'e se compose de six tours arronds, striés lungiludinalenent; la suture est simple et peu approfondie; les stries sont nombrenses, serrées, irrógrulières, très-fines. L'ouverture est semi-lunaire, urroadie; son péristome est simple, reaversé un peu au-dessus de l'ousbilic: seulemeut, et bordé à "ialéricur d'un bourrécel liauc très-ilplati, qui paroit au-cleliors a cause de la iransparence de la coyulle par une bande fuuve on blanchatre. Toule celle eoquille est brune, mince, transpaleate, cornée, présentant sur le clernier tour une bande médiane, étroite, d’un lilunc pále; elle cst quelquelois revêtue d'un épiderue brun, velı, nuais tres-saduc. I, 'ombilic est petit, arrondi; on y apercoil facilement l'avant-dernich lour. Ceste coquille est d'un pelit volume; on la trouve cummuuément en France, en Suisse, en Allemague, dıns les lieax oulragés et lıumides.

26. IléLice sale. Helix conspurcata. DRAP.

H. testâ orbiculato-convexâ, subdepressá, umbilicati, strialâ, squaliuè albì, hispidulí; labro smplici. 25.

Helix conspurcata. DRAP. Moll. pl. $7 \cdot$ fig. 23 . Hist. Nat. des Vers. Tome II.
DAUDEB. Hist, des Moll. $n^{\circ} \cdot 277$.

L.A k. Anim. s. vert. tom. 6. pag. 95. no. 104.

Pelite espèce que l'on confundroit facilement avec de jeures individus de l'Hélice strice, mais qui cependant s'ea distingue constammeat par des caraclères invariables. Elle est toujours pelıle, tris-aplatie supérieurement, plus convexe en des.sous, assca forlennent carénée dans le jeune âge, subanguleuse seulemeat lorsqu'elle est adulie; l'angle carénal est situé à la parlie supérieure des lours; la suture se tait sous cet angle, c'est de lis que rósulte l'aplatisscancnt de la spife : celle-ci est furmée de quatre lours el demi, dont le dernier est proportionnellement flus grand que les autres. Eu dessous celte coquille esi convcxe, perforée au centre d'un ombitic rond, découvert et prnfond. Lonverture est assez griande et oblique; son péristome est simpie ct non bnrdé en dedans. Les stries longitudinales nulliplifies, fines é serrées, se voient sur toute la coquille; clles se bilinquent et s'anastomosent entr'elles. Celte coquille est d'un brun clair ou juunâtre, ou blanchâtre, parsemće de taclies irrégralières, ondulées, plus ou moins rapprouluécs, d'un brun plus funcé. En dessnus on remarque une ou piusicurs lignes de petites taches pâles. Un épiderme jaumàlre et velu recouvre la coquille; les poils sont llexueux, rúrés, longs et très-caducs.

Ou trouve communáment cetle pelite coquille en Suisse, en France et en Allemagne, dans les Luissoas, dans les fentes des rovliers.

27. Hélice évasée. Helix patula. Noв.

H. tests orbiculato-depressâ, corneo-fulvá, longitudinuliter striala, sublìs latè umbilicalâ; striis numerosis, angulatis, regularibus in umbilico con. tinuatis ; uperturầ minimâ, oblıquâ, simplci.

Il y a leaucoup d'analogie entre cette soquille, qui vient de l'Améric ue s'ptentrionale, et l'Helix rotundala, qui vil en lirance; núunuoios les deux cotjuilles restcot constammeut distinctes, et conslituent teux espèces bjen caractériscés.

hiHelix patula est perile. discoide, très-aplalie; la spile obluse esi higeremeat saillanie. Elle se compose de six à sepl tours étroits, arrondis, très-convexes, dout la suture est simple et profunde; les denx preniers tours sont lisses, mais les suivans sont tioement el profondément striés. En dessous, celle royjuille est fortenent évasće par un oabilic lres-large, dins lequel nu pent compler lous fes lours de spire jusqu'a celur du sommet. Le pourt, ur cst arrondi, jateais carene: en passant sur cette parlie les stries s'iullécl.issent un peu el sc contitueut cn dessous; elles gagnent lombilic, dans lequel e!les s'eufuucent en restant aussi fortes qu'en dessus de la coquille. L'ouvarlure est petice, arroulie, semi-lunaire, tuèsoblique, a péristoure simjle, traacliant, jamatis bordé ou renversé. Celle curguille est partoat d'une

E $c_{*}$ 
teinte unifome de brun tirant sur le janne: elle est mince, cornce, diapliane, gristitre et opaqu: lorsqu'elle a perdu snn épilerrue. On trouve celle espèce aux Elals-Unis, sur les plantes lierbackes et les mousses. M. Bory de Saint - Vincent nous l'a communiquie layant Irnuvée das un lierbier fait aux environs de New-York.

28. Hŕlice du Pérou. Helix peruviana. L. a ax.

H. testâ orbiculato-depressâ, latè umbilicutâ, tenui, nugulosâ, fulvo-rufescente, subtus albido griseâ; spirâ obtusâ; labro acuto.

Helix laxata. DA U DED. Hist. des Moll. $n^{\circ} .181$. Laмк. Arint. s. vert. toni. 6. pag. 76. n०. 41.

L'Hélice du P'́rou est une assez grande coquille qui a de l'unalogie avec l'Helix algira. Elle esi discoije, aplatie, formét de cinq à six lours arrondis, à sulure simple et assez profunde; les premiers soul lisses, et les suivans sunt en dessus jendus granuleux par un réseau de stries laausverses et longitudinaies sulurégulières, assez proforde. En dessous la cuquille est lisse, ou du moins ne présente que des sıries d'acruoissenent: de ce côté elle est Cort convexe, et l'ombiic qui la perce est très-grand et très-évasé; on $\mathrm{y}$ voit facilement tous les tours de spire. L'ouverture est grande et arrondie; les bords, à leur iusertion, se rapproclıenl et ont une tendance à se réunir; le péristoine est simple, trauthünt, lẹgèrement renversé à sou insertion au côté guauche au dessus de l'ombilic. La cuuleur de cetle cosjuille est, ex dessus, d'un jaane-fiuve ou orangé, et en dessous d'un blanc-yrisâtre. Celte espèce, qui vieut du Pérou, paroit rare. Nuus navoas jamais vu que l'individu de la collection de M. Lounarck. Elle a 25 millim. de diamètre.

29. HÉluce ombilicale. Helix unubilicalis. Noв.

H. testâ magnâ, fossili, orbiculato-depressâ,

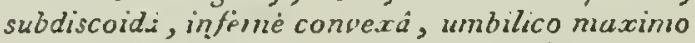
perfora!, lavigati, in medio subangulati; apertusâ magnâ, sımpllıci, rotundutâ, semilunari.

Nuus ne connoissous aucune espèce fossile que l'on puisse comparer à celic-ci qui se rapproclie, pour la forme et la taille, de l'Helix algira. On ne peut cependaut la regarder comme l'analogue fossile de cette espece. I'Ilólice ombilicale est discoide, assez épuisse, peu convexe en dessns, mais plus bonbée en dessnus. I,a spire, trèscourte, est romprosée de cinq tours aplatis: substriés obliqueneat et en long; le deınier lour est proportionnellement plus grand que les autres, bien arrondi vers l'ouverture; il esi subcaréné dans le reste de sun pourtour, la carène devenant de plus en plus aiguë en remontant vers le sommet. On peul êlre assuré que cetle coquille, comme l'Algina, éloit fortement sarénée dans le jeune ague. lionbilic que l'un voit à la base est très- fivast, infundibuliforase; sur son bord st fise l'extrénité dubón gauclie de louverture, yui se rever. arrondic, seni-lunaire, grande, aussi haute que lürge; son péristone est miuce, trancbaut, oi Lordé en deduns ni réfléchi.

Cette coquille, excessivement rare, ne s'est encorc trouvée une dans les faluns de la Tunraine. On en connoîl lrois individus; un dans la rollecliou de M. Duvau, l'autre dans celle de M. TrisIan, et le troisième dans la nôtre : ce deraicr a 35 millim. de dianı̀̀tse.

30. Hélice concolore. Helix concolor. Fer.

11. testi orbiculatö, plino-convexi, subtiss profundè umblicatì el fusco-castaneâ, supernè cinerea; ultimo anfructu subangulato; labro simplici.

Helix concolor. DAODED. Hist. des MTollusq. $n^{\circ} .208$.

LAas. Anim. s. vert. tom. 6. pag. 86. no.74.

Celle coquille a l'aspect et la couleur de certains l'Jaunrbes. Elle est très-subuisscé, léçèrement convexe du côlé de la spire, sulıanyuleuse à la partie inférieure de son pourlour. Elie est formíe de cing à six lours aplatis, donl la sulure, peu prolionde, est légèrement pliss(e. En dess uls celte corguille est concive el préseute ua l rès grand ombilic dans lequel on peut fucilement compter tous les tours de sprire. L'ouverture est simpice, trancliante, sans bourrelet intćrieur; cile est ollique, sublatérale, semi-lunaire, plus large yue haute. Tonte la coquille est d'uu brum-comé foncé, si ce n'est sur le sommet oi elle est un pou grisâtue; sa surface est lisse, narquée vers louverlure de quelques stries irréguliores d'accrnissement. Celte coquille vient de l'orlo. Ricco, oi elle a été découverle par MIaugé; ellu a 7 a 8 ligues cle diamctre.

\section{3i. IIÉlice glariale. Helix glacialis. Fer.}

H. testiorbiculatî, convero planô, subtus, profundè umbilicats, longitudinaliter striata, lined fuscâ circumdatá, virentc; aperburi rolundatû, semilunari, simplici.

lenos. Hist. nat. des Moll. $n^{\circ} \cdot 159$.

Cuquille d'un médiosre volune, d'une forme planorbulaire, aplatic, ayunt une spire rćpriance, formée de cincy tours légèrentent convexes, separies par uue sulure siuple, peu proliunde; ils augmenten! graducllencul. Les deux preniers lutrs sont lisses, les suivans sont cliargís de strits lingiludiuales, obliques, assez fortes, artondies, sulirégulières; elles sont plus flevíes en dessus qu'en dessous, vù elles disparnissent peu à peu avant de parvenir a l'ombilus. La face inférieure est régulièrement convexe, perćé d'un ombilic rédivcre, profoud, sur le bord duquel vient s'in- 


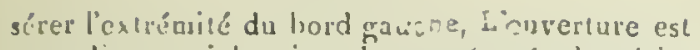
arrondic, seni-lunaire; les extrétuités du péristo De teudent à se rapprocher. Elle est trćs-oblique, un peu p!us large que liaule, simple, trancluante, lícgèreiuent évasée a sa base, garnie, vers le bord, d'un petit bourrelet blanc aplati. En dessus, cetle coquille est d'un vert ónscur, grisiłtre au surmet, avec quelques fascies bruses, irrugutičres et longiludimales, qui se contiuuent en dessous, où elles se distinguent micux sur un fond grisitte. Sur la partie moyenne et supérieute du deruier lour on voit une lisne brune foncée, continuc, suivie ou bordée eu dessous par une ligne blanche. On trouve celle coquille duns les Aipes piémontaises, prés des glaciers.

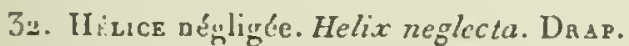

II. testâ orbiculato-convexâ, latè umbilicatâ, tenui, striutú, albidâ, nfo aut fusco fasciatâ; spirs pronunuli; labro acuto.

IIelix neglecta. Dnsp. Moll. pl. 6. fig. 12. 13.

D_UDEB. Hist, des Moll. $\pi l^{\circ}, 282$.

L.A sк. Anim. s. vert. tom. 6. pag. $84 n^{\circ} .67$.

Nous avons de la peine à distinguer celle esfière de l'IIelix cespitum, ses varićlís se rapprochaut beancoup de celles de celte deraicre. Un ue peut disconvenir cependant quelle n'ait un aspect ou un facies particulier, ce qui provient surtout de la forme extérieure un peu plusélancíe et du rélrécisscment de l’onbilic, qui est génciralement plus petit. Quaut a la couleur du périscome, nous lui trouvans des nuances semblables dans les deux especcs; elle passe du blanc au rouge, viaeux ou vinlatre. Le's priucipales diiférences existeot douc dans la coloralion extérieure, et il suffira de voir combien elle cst variable dans certaines cspéces, pour n'altacher à ce caructère ıjue l’inportunce qưil mérite.

Ceste coquille est globuleuse, un peu déprimée, Formée de six lourz armntis, dunt le premier esi lisse et bruu, et le dernier ua peu plus g:and que les autres proportionuellement. On remarcpue sur la spire des stries assez régulic̀res, qui le sunt moins sut le dernier tour, el qui disparoissent presyue complétement à la lase de la cucjuille. Cette base est percice d'un onbilic assez grand, mais moius évasé que dan les Helix ericetorum el cespitum. Louverture est arrontie, assez graude el oblique, son périsloue mince est garoi diun lonurrelet tantót blanc, tantót rosé, ou d'un rougge foucé. Sur un fond blanc ou roussatre on voil se dessinerdes bandes brunes plus ou inoins loncécs: une seule occupe li parlie supérieure de la spire, les autres, an nombre de deux à cing, se voieut cn clessous; elles sont guelquelois interro:npues, ponctuées dc blanc, el loujnurs réunies entre clles par des liģ, bes brunes çui vont de l'uue à l'autrc.
Mabile la lirance mé diouale, le Piémont. l'Italie.

33. HÉLICE scabre. Helix scabra. Làx.

H. test.i orbiculuto-depressî, late unbilicuti, striis elevatis crebis undutis scubri, albo et rufó alternè colnratâ, obscurd fasciati; uperturầ nufj; labro tenui, acuto.

An llelix rudiata? Mullen, Verm. pag. 25. $7 n^{\circ} .224$.

Lister, Conch. tab. 70. fig. 69.

PeTiv. Gaz. tab. 104.fig. 1.

Helix: rudiata. Gues. pug. 3634. $n^{\circ} \cdot 73$.

lielix alternata. DA U DEB. IIist. des RIollusques, $n^{\circ} \cdot 199$

I.Axk. Anim. s. vert. tom. 6. pag. 88. $n^{\circ} .83$.

Conulle très-mince et tròs-fiagile, qui semble être le jeune äge de quelque gran fe espèce, ç que cependant nous avous tuujours vue de mâmc et à peu près de la wême taille; elle esı dépriúcéc planorbulaire, lígerement convexe cn dessus cl en dessous. Là spire est oblıse el présenle cint tours ou ciuy lours et demi; ils sonl peu convexes, et lew suture simple cal assez profonde. l.e premie: tour cost lisse el tons les autres sont striés nu plutût plissés longiludiualement, et un pen oblicjuement: ces strics pliciformes sont nornbreuses, régulières, plus élevées ca dessous rien lessus de la corgille. On les vout en clipi jumiruer en approchant de l'utnbilic : celui-ciesi raud, arrondi et prolond. liuncuinte, as:ez ample, est arrondie, semilunaire. Ses bords sont winces, tranchans, frigiles, jamais épaissis par uu bourrelet. Cette cryuille it coute la face supérienre oruée de laches alieralivennent blanches et rouges. Ces aches sont Inngiludinales e! subquadrancrilaires. Le dernier lou offie, ì sa partie inférieure, deux laugées de taches dle mèrne coulenr, mais plus couries. On trcure celle espece aux Etats-Unis.

\section{3f. Hince ciselíe. Helix celutir. Fer.}

H. testâ orbicululo-depress $\hat{\text {, }}$ umbilicati, mi:ltistriutâ, tenui, corneo-rufescente; striis crebris, acutis; aperturi simplici, semilunari, obliqua.

Fer. Hist. nat. des $M o l l . n^{n}, 274$.

Va. B.) Striis minoribus.

Petice coquilie qui a de l'analogie aves l'Helix rotundatu, mais qui devient toujonrs plus grande et na janais les taches dont elle est uluée. Cutte caquille esı distostle, aplatie, à spire lic̀-déprimée, offiant six i sept tours convexes, à sulure simple et asiez prolonde. Les deux premiers tours sont lisses e! les suivans sont couverts de strics longitudinales, obliques, plicifor:mes, numbreuscs, aiguës, qui śépissent un peu en dessnus. La rilconlérence de la conuille est assez éndisse, arEc 2 * 
rondie. Les tours de spire sout étroits, serrés, et le dernier est proportion ué aux autres. I'ombilic, qui perfore la base à son centre, est assez graud, mais peu érasé, et on n'y distingue facilement que l'avant-dernier tour. Liouverture est petile, sublatérale, obligue, semi-lunaire, plus larne que baute, nen évasée, si ce n'est à l'insertion du bord gauche. Le péristome est simple, tranchant, légèrement épaissi à l'iulérieur. Dans quelques individus, celle coquille est uniforı́ment brune, cornće, transparente, mince, fragile; en dessous, vers l'oubilic surtont elle est na peu plus blanchâtre. La variété que nous a vons nntée ne diftere que par un oubilic uo peu plus réiréci et des stries moins saillantes; elle vient du Jura. Ce fut d'abord ea Suisse que celte espèce a élé découverte par M. Studer.

\section{Hérré rugueuse. Heli.r nigosa. Lank.}

H. testâ orbiculato-depressâ, subtìs convexâ, umbilicatâ, argutè striato-rugosâ, scabriusculà, cineren-rufescente; spirâ subplinulatà; labro simplici; margine inteliore rufo-rubente.

L.sir. Anim. s. vert. tom. 6. pag. 90. no. 91 .

Helix grojana. Feros. Hist. nat. des Mollusq. $n^{0} .276$.

C'est à Ménard de la Groye que l'on fut redevable de la connoissance de cette espèce; il la décuurrit en Italie, près de Sinigalia : depuis elle fut retrouvée en Sicile. Cettc espèce est discoïlle, fort aplatie, surtout en dessus. Dans le jeune âge, les tours sont fortement carénés, mais sur" le dernier tour des individus adultes, celte carène se réduit à un simple cordon saillant qui ne rend plus la coquille anguleuse et n'altéce pas la furme arrondic de l'ouverture. La spire, très-plate, est formée de cing it cinq tours et demi : le premier est tout lisse et d'un brun funcé, les suivans soat couverts de siries ou de rides lamellenses, longitudinales, ondulcuses, espacées irrégulièrement et quelquetois bifurquées. En passant sur l'angle caréual des tours, elles y occasionnent des iubercules assez réguliers. La suture suit en dessous la carène, de sorte qu'elle est bordée et crénelée par elle. Si cette coquille est Irès-aplatie en dessus, elle est beaucoup plus convexe en dessous, où elle est ouverle par un ombilic évasé. Liouverture est arrondie, non évascee, ai réfléchie en debors, mais garnie en dedans d'un bourrelet fauve ou rougeatre. Toute la coquille est diun janne sale ou d'un gris cendié. Nous avons une variété dans laquelle on voit plusieur's ligraes brunes en dessous. Cette espèce à 14 millius. de diamètre.

36. Hśrice aubéculée. Melix nubeculata. Noв.

H. lestâ orbiculat $\hat{\jmath}$, discoidû, lavigatá, suprà convexiuscula, albido-grised, maculıs longitudi- nalibuss nubcculatô, infernè albidulâ, umbilicatâ; apertura basi sinuutâ.

Cuquille que nons ne trouvans décrite ni figurée dans aucua des ouvrages que nous avons consultés, et qui est probablement encure inédile; elle a un peu l'aspect de l'Helix scabra, mais on l'en distingue avec la plus grande facilité; elle est discoide, assez epraisse, convexe des deux côtés. Sa spire est très-nbiuse, légèremeut convexe, formée de cinq tour's arrondis, dont la suture est simple el assez profonde. Les tours s'augmentent graduellement, et le deruier est proportionné à la largeur des précédens. Toute la coquille esı lisse ou du moins n'offre que quelques traces irrésulières d'accroissemeat. Én dessous, elle est convexe, percée au centre par un ombilic nédiocre, sur Je bord duquel s'avance et se renverse l'extrémité du bord gauche. L'ouverture est grande, un peu déprimée, plus large que haute, secoi-lunaire, et un pen oblique à l'axe de la coquille. Son péristome, mince et un pers évasé en dehors, est légèrement obtus à la base : le bord gauche, vers son insertion, présente une légère sinuosilé. Sur un lond blanc-urisátre ou jaunâtre, on voit sur les deux tiers supérieurs de la coquille des tacbes lougitudinales, nuageuse;, ondulées, qui se fondent par leurs bords dans la couleur du fuad; elles se terminent cependant d'une manière fort nette à la parlie inférieure, qui est tout-à-fait sans taches.

Nous ignorons doù vient cette coquille, de laquelle nous n'avons jamais vu que deux individus dont l'un de aotre cullection. Elle a 19 millimètres de diamètre.

37. Hélrce puhesceate. Helix sericea. Mult.

H. test isubdepressá, corneâ, fuscat.i, tenui frugili, pellucidi, basi perforatâ, hirsutû; aperturi, minimi, semilunari, simplici.

Helix sericea. Mur.ter, Verm. $n^{0} .258$.

DR Ap. Hist. des Moll. pag. 103. no. 34. pl. 7 . fig. 16.17 .

Pfeiffer, Syst. anord. tab. 2. fig. 20.

Feros. Hist. nat. des Moll. $n^{\circ} .272$.

La Veloutée. Grofrnor, Coq. de Paris, pag. 44. pl. 2.

Petite coquille subdeprione, à spire courte et obtuse, cornée, brunatte, nince, fragile, translucide, d'un bran peu foncé ou jaunátre, légèreasent strice dans sa longueur et couverte d'un épiderme brun, velu. Les poils épidermiques sont assez alongris, jaunátres, et recourbés dans lear longueur. Les lours de spire sont convexes, au nombre de quatre et demi ou de cinq, la suture qui les réunit est simple et peu prafonde; la base est convexe, légìrement déprimée, et perforce au ceatre d'un très-petit ombilic que caclse en petite partie le renversement du bord gauche 


\section{H E L}

L'onverture est petile, ovale, arrondie, oblique, plus large que baute. Sun píristome est mince, trancliant, non renversé, quelquefuis garni à lintćrieur d'uı petic bourrelet blanc, enfoncé, peu épais, ct qui paraît au-dehors à cause de la transparence de la cuquille.

On trouve cette coqnille dans presque toute l'Europe, dans les jardins, les lieux bumides, sous les pierres.

38. Héutce hispide. Helix hispida. Lis.

H. testâ orbiculato-convexâ, subdepressâ, umbilicatâ, pellucidâ, corneo-fuscescente, hispidâ; aperturi semilunari; labro tenui, subreflexo.

Helix hispidit. Lıx. Gu上x. pag. 3625. $n^{\circ}, 42$.

MULLer, Vern. pag. $73 . \pi^{\circ} \cdot 268$.

Petiv. Gaz. tab. 93. fig. 13.

La Veloutée. Geoff. Coq.pag. 44. $n^{\circ} .11 . p l .2$.

Caemsitz, Conch. tom. 9. tab. 122. fig. 1057. 1058.

DRA P. Moll.pl. 7. fig. 20 à 22.

DaUDEB. Hist. des MIoll. $n^{\circ} .271$.

Lasz. Anim. s. yert. tom. 6. pag. 92. no. 100.

Preiffer, Syst. anoid. $p l$. 2. fog. 17 .

Coquille brune, très-mince, fragile, transparente, finement striée dans sa longueur, déprimée, subcarénée à la partie la plus convexe du derniel tour. La spire est formée de rinq tours à cinq tours et demi : les deux premiers sont plus bruns que les autres et tout-à-fait lisses, le dernier esi proportionnellement plus grand. 'Toute la surface extérieure est cauverte d'un épiderme l,run, écailleux ou velu, dont les poils sont blancluátres et courbés : la base est percée d'un ombilic assez grand, évasé. L'ouverture est oblique, demi-ovale, arrandie, subsemi-luaaire. Snn péristome, simple, n'est ni renversé, ni bordé. 1)ans quelques individns on remarque cependant un iegrer bourrelet blanc qui le suit. Le loord gaucle est légèrenent renversé au-dessus de l'ombilic.

On tronve fréqnemment cette espèce en France, en Suisse, en Allemagne, en Belgique, dans les lieux huwides, au bord des ruisseaux.

59. Hélee lucide. Helix nitida. Monu.

11. testâ orbiculato-depressâ, unibilicatâ, tenui, pellucidia, minutissime striati, cornco-fuscâ; labro simplici, acuto.

Helix nitida. MULler, Verm. pag. 32. $n^{\circ} .234$.

Helix nitens. GuEx. pag. 3633. $\pi^{\circ} .66$.

Helix lucida. Drap. Mall.pl. 8. fig. 1:, 12.

Helix nitida. DAUDEB. Hist. des Moll. $n^{\circ} .218$.

Lasx. Anim. s. vert. tom. 6. pag. gr. n०.97.
Preiffer, Syst. anord. pl. 2. fig. 19.

Cette petite coquille nous semble s'éloigner bieu peu du jeune âge de l'Illix cellaria, dont elle ne dilfère à bien dire que par sa laille et les stries dont elle est arncie; ces stries se voyant aussi quelquefois au snenmet de l'Helix cellaria, de sorte qu'entre ces individus et l'espèce qui nous occupe il u'y a vérilablement que de trèspetites dillérences. Celte coquille esi déprimée, peu convere en dessus, plus plane en dessaus; elle est cornée, jaunátre ou brunâtre, mince, transparente, fragile, tiès-tinement striée dans sa longueur; elle est composée de cinq tonrs de spire fieu convexes, dont le dernier est plus grand que les autres : ils soul joiuts par une suture simple et per prolunde. La base, aplatie, est percée d'uu ombilic assez grand. L'ouverture est arroudie, subsemi-lunaire, plus large que haute; snn péristome est simple, tranchant, non renversé, et dépourva de bourreles intérieur.

D'après M. de Ferussac, on trourercit celte coquille non-seulement en Europe, mais aussi it la Guadeloupe.

40. Hélree apicine. Helix apicina. Lask.

H. testâs orbiculatâ, subtùs valdè canvexâ, umbilicatâ, suprà depressá, plunulatâ, argutè stnatá, albá; spinâ apice fuscá; anfractibus convexis; suturâ pmfunda, maculis quadratis, fuscis marginatá; labro tenui, acuto.

L.м к. Anim. s. vert. tom. 6. pag. 93. n०. 102.

Petise coquille qui, malgré la convexité de sa face inférieure cl l'épraisseur de son dernier tour, appartient par sa lorme, son ombilic et son mode deuroulement, à la section des coquilles planorbiques; elle est orbiculaire, sa spire est aplatie ou à peine conique, ou convexe, composée de cinq tours étroits, dunt le deruier tour est proportionnellement plus grand que les autres. Ces tours sont convexes et leur suture est profonde: les deux premiers sont lisses $\epsilon t$ d'un brun foncé, les suivans sont blancs et finement strices, mais les stries sont irrégulières, plus ou moius fines et rapprochées. Quelques individus sont tout blancs, mais dans le plus grand nombre les sutures sont bordées par uue seule série de petiles taches brunes, cuurtes, carrées, plus ou moins nombrenses, et disparoissant ordinairemect vers le milieu du deruier tour. En dessous, la caquille est très-canvexe; elle est percée d'un ombilic assez grand, profond: de ce côté, elle est toute blanche ou grisâtre. L'ouverture est grande, arrondie, aussi haute que large, et très-peu oblique; son péristame est simple, tranchant, non renversé ni bardé en dedans. Celle petite coquille a été trauvée d'abord par M. Latreille aux environs de Brives; elle est assez commune dans le midi de la France, et M. Payraudeau l'a tronvée en Corse. Elle a 8 ou 9 millim. de diamètre. 
41. Hélice striée. Helix striutu. DRap.

H. testâ globoso-depressâ, conoideâ vel plants. latâ, subtìs convexá, umbilicutâ, argutè striatâ, albidâ ad periphariam subangulatam, rufo fasciuta; labro simplici.

DARGENv. Zoumorph. pl. 9. fig. 6 .

La grande Siriée. Georf. Coq. pag. 34. $n^{n} .5$.

Ejusd. Le petit Ruban, pag. 49. n०. 14.

Helix striata. DRAp. Moll. pl. 6. fig. 18 à 21 .

Helix striata. DA D DEB. Hist. des Moll. n०. $27^{8}$.

LAмк. Anim. s. vert. tom. 6. pag. 93. no. 103 .

Helix caperatu. Mont.Test. brit. tab. 11 . fig. 11 .

Var. A.) Testì candidâ vel albo-fuscú.

Var. B.) Testâ parte superiore nigm unizonatâ.

Val. C.) Testi spirî productiore, unizonatâ; labro univel bisubdentato.

Helix thymorum. Alten. pl. 5. fg. 9 .

H. lix thymorum. PFEIFFER, Syst. anord. pl. 2. fig. 21.

Helix candidula. Feros. His!. nat. des Moll. $n^{\circ} \cdot 279$.

Var. D.) Testấ albì aut luteolầ trifasciatâ.

Var. E. ) Testâ supernè fascıá latâ, maculatá, instructâ, subtìs ulbâ.

Var. F.) Testâ supernè fusciatá, latè maculutá, subtús multizunata.

Var. G.) Testá fucescente; ultimo anfractu zonu angusta, albi, cincto.

A l'exemple de Iarwarck et de J)raparnaud, nous avons l'éuni à celle espèc:e l'Helix candıdula de M. de Ferussac, à lafjuellc uous ne rrouvous pas, jusquà présent, des caractères sullisans pour en faire uue espèce; il seroit possible que votı opinion fût erronée et que l'on trouvà plus tard des différences entre les animanx de ces coquilles.

L'Hélice striéce est géuéraleneul aplatie, quelquefois la spire est plus élevée tít la coquilie devient plus glubuleuse. Sa spire se cumpose de cing à six tours lícèremeul cunvexes, carénés, ou seulement anguleux dans le jeune áge. Lat suluse qui les joint est siuple, peu proloude lorsque la spire est proéminente, plus enforciée lorsqu'elle es: aplatie : le preanier tour esı toujours lisse el d'un brun louc:é, les autres sont lineoneo! et régulièrement striés; ils s'accroissent rígulièremènt, le dernier est cepeudant proportiounellement un peu plus g:and gue les autres.

La base est percée d'un ombilic médiocrement grand, dans lequel on ne voit que l'avaut-dernier. Lour. L'ouverture est oblique, arrnndie, les deux bords tevdant a se rejoindie à leur inseriou. Le péristome est nunce, trunchanl, toujours lilanc en dedans, et garni d'un bomrelel aplati de la usêne couleur : jamais i! ue se renverse en Jeliors.
Sous le rapport de la coulcur, celle coquille est très-variable; cl'e offre un exemple de plus du passage du blanc au noir, ou au lirun foncé, passage ifue l'on lemarquera dans d'autres es. pèces : Ilelix nemoralis, aspersa, arbustonun, vermiculuta, splendida, elc. La variélé A est toute blanche ou jaunâtre. Ces deux couleurs font indistinctement le fund des variélés suivantes. Lat variété $B$ n’oflie qu'une seule bande noire à la parlie supétieure du dervier tour : quelyuefois elle reste entièremenl en dessus de la sulture, et se voit jusqu'au sommet, d'antres fois elle est coupíe en deux ou est entièrement cachée pal elle. la variété C plésente une coloralion semblable, mais ses stries sont généralenent plus lines, sa spire plus cunique, et son péristome príseule en dedans près de son insertion, soit à droile, soil à gauclie, quelquefois des deux côlés à la fois, une petite dent peu élcuée. Daus les varićtés suivantes, on voit s'ajuultr successivemenl des bandes brunes à la prenière, qui se parlagent en deux laisceaux, l'uu à la parie supérieure des tours, l'autre à la partic inl'śreure et toujours séparés par une ligue blanche. Les lignes de la partie supérieure se coufunilent d'aboid en une seule large fascie tachetée de brun et de blauc; les ligues brunes du dessous, au nombre de une à cirr, linissent aussi par se conloncle peu à peu, en se mulipliaul el en s'ćlargissant, et l'on amive inseusiblement à la derniẹc varićlé, qui ne présente que ueux zones d'un b:un foncé yui occupent loule la suıfüce.

Celle coquille est très-répandue en lirancce, en Angleterre, en Aliemagne, dans loule lialie t les îles de la Médilerranée.

Nous pussídons une coquille qui a presyue tous les caractères de la striće, mais dunt le peristome est d'un rouge-brun très-intense. Elle vient de la Sicile. Esı-ce une espèce?

\section{Hélice de Volız. Helix Voltzii. Nob.}

H. test $\hat{\mathbf{A}}$ fossili, orbiculato.depressí, utroquè latere convexiusculâ, leviter striata; umbılıco putuło; aperturâ rotundatâ, semilunari, simplici.

Cutte coquille lussile est rès-vorisine, quaut is la lorne, de l'flehx nitida de ()rapa:maud; elle est cejendant loujours plus grande, et son cinlalic esi propurtionnellement moins evasé : éle a des stries anssi que l'espèce vivante n'a pas.

Celle espère est d'une taille médincre; elle est aplatie, discoide, légèrement convcia des deux cốćs. La spire obluse n’a gue cion on cing lours et demi; jis sont apla!is, joiuts par unc sulute superficielle, el tuement siriés dans len linucuenr. Les stries sonl plus saillantes en dessus cil' sous de la roquille; le dernier Inur, pruproticnné avec les auires, se termine par ure ouveriuc semi-luuaire, arrondie, simple, a hords trancliaus el obliques. In base de la coctuille est dé- 
primćc et ouverlo au centre par un ombilic évasé, frand, sur le bort sluquel vicot šiusérer l'extréwité du bord gauche.

On Irouve cette coquille fossile daus les terrains lacusires de Butureilleren $A$ lsace; elle a uix unil. lincatres de diamitre. Malưré la dureté de la pierte dans laquelle clle est comprise, on trouve cependant le test, qui a ordinairement une conleur jaube et conserve une partie de sis transparence.

43. HÉlice bouton. Helix rolundatâ. Moll.

$\boldsymbol{H}$. testâ orbiculato-depressâ, convexiusculi, latè unbilicutj, stricitâ, griseâ aut rufescente; spiri obtusissima; lubro simplici.

Helix rolundatu. Moll. Verm. p. 29. $n^{\circ} \cdot 23$ s.

DABGEXv. Zoomorph. pl. 9. figr. 10.

Le Bouton. Georf. Coq. p. 3g. $n^{\circ} \cdot 9$.

GazL. pag. 3633. $n^{\circ} .69$.

Drapans. Moll. pl. \&. fig. 4 à 7 .

UAпдев. Hist. des Moll. $n^{\circ}$. 196 .

LAsк. Anim, s. vert. tom. 6. pag, 92. $n^{n} \cdot 101$. Pegrfen, Syst. anord. pl. 2. fig. 33. 34.

Jolie petice coquille très-aplatie, subcarénce à sa circoufértence; elle est fort ressemblaute à uue lentille et pour la forme et pour la grandeur; ellc est lónèrenient convexe en dessus et eu dessous: elle se compose de six taurs peu convexes, étroils. Lien popurtionnés; ils sont fiuement el profondimeut striés dans leur longueur; leз stries sout réguliùres, un peu obliques, génćralement plus élevíes à l.d partie supérieure de la coquille qu'à sa base. Eu dessons elle est larrement ombiliquće, et se teruine par une pelite ouverture oblique, semi-lunare, un peu plus large que haute et lógèrement siuueuse dans son milieu; elle est simple, tranchaute et non bordée en dedans. La couleur de cclle coquille est jeu variable; elle esı d'un brun corué assez foncé, lianspareut, orné à la face supéricure ou sur la spuire de llammules rouges, à des espaces assez róguliers; il y a une variélı́ grise ou blancliâlre, à taches lrès-étroiles et mêne sans tache. Cette contuille se trouve sous les buissons, sous les fuailles mortes, daus presque touies les parties de l'Europe.

44. MÉlice de Desmarest. Helix desinarcstina. BRong.

II. testâ depressâ, planorbulari, lavigatâ; anfractibus sex confertis; umbilico magno.

Banng. Ann. du Mus. tom. 15. pag., 378. pl. 23. hg. 10.

Nos. Descrip. des Coq. foss. des env. de Paris, pog. $57 \cdot p l .6 . f g \cdot 7 \cdot 8$.

Daus la description que M. Brongniart fait de celte petile coquille, on remarque qu'il la rapproche avec juste raison de nolre perite Ifólice bouton, Helix rotundata, avec laquelle elle a effectivemenl beaucoup de rapporis quant a la forme el au volume, scu'ement elle est fonte lisse lorsugue l'Helix motundata est tonjonrs stricie; ses tous de spire sont plus serrés, plus rapprochés, el quoique l'ombilic: snit rrand, il l'esi pourtant n oins que dans l'łuélice vivante que nous venons de citer. Elle n'a que cinq millimètres de diamcetre ì sa liuse.

\section{Hécre de Feryant. Helix Ferranti. Nos.}

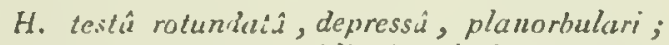
anfractibus ejunque, oblique striatis, non angulatis.

Nuв. Descrio. des Con. foss. des env. de Paris, pag. 56 pl. 7 . fig. 10.

M. Héricart-Ferrant a $\mathrm{vu}$, avec le plus grand snin, la formation d'eau donce supérienre dı Soissannais, et c'est dans ses recherches multiplires dans ces ranlous qu'il a trunvé l'especce d'Ilílice à laquelle nous doanons son nom. Cette espèce a de trés-grands rapports avec l'Helix mtundata; ses lou's de spile sont moins non:breux el moins rapprochés; la spire, un pen plus aplatie, el lc dernicr tum n'est ni auguleux, ni carèné; clle est strife irróguliènement et obliquement sur toute sa surface. Elie se distingue de l'Helix desmarestina, $1^{\circ}$. par ses stries, $2^{\circ}$. par sa spirt loul-à-fail plate, 30. par ses tou's moins nombreux et plus labes. Elle a huit millimètres de diaucitre.

\section{11'úce des murailles. Helix muralis.}

I1. testâ orbiculato-convexí, depressiusculâ, superforatâ, stivatâ, griseâ, maculis sparsis rufís aut fuscis insignatú; spiru prominulá ; lubromargine reflexo, albo.

L:ster, Conch. tab. 74. fig. 74 .

Goגı, Test. tah. 3. fig. I:

Carel. pag. $3664 \cdot n^{\circ} \cdot 155$.

Daudeb. Hist. des Moll. pl. 41. fig. 4 .

I.s м K. Anim. s. vert. tom. 6. pag. 9o. $u^{\circ} \cdot g 0$.

Coquille discoide, aplatie, líģèrement convesc des deux côtés, mais un peu plus du côté de la spire. Sa circonférence est bien arrondie; daus le jeune íge elle offre nne carc̀e ou no angle obius. Les tours de spire, au nombre de cinq, sout aplatis, très-légèrement convexes; les deux premiers, qui sont très - finement chagrinés, sont ordinairement d'uo brun foncé, les suivans sont strićs, d'abord assez régulièrement, mais les stries deviennent onduleuses, se bifurquent quelquefois ou se plissent irr salièrement dans leur longueur. Sur le dernier tonr, des stries très-Gnes, transverses, très-serrées, finemeat granuleuses, cou- 
vrent toute la partie inférieure de la spire, la face ialérieure de la coquille en est déponrvae; de ce côté les stries ou plis loogitudinaux se continuent et convergent vers le centre : celui-ci n'est point ombiliqué, il présente quelquefois une fente, mais souvent aussi elle est buuchée par le renversement du bord gauclie. L'ouverture est petite, resserrée, ovalaire, très-oblique; son péristome esı épaissi, rélléclii, garni d'un bourrelet blanc aplati à la base. L'ouverture est brune à l'intérieur. En deliors el en dessus cette cuguille est d'un blanc-grisâtre parsemé d’un grand nombre de petiles taches bruues, placées surtout dans les intervalles des stries. En dessous elle est loute grise ou blanche, et quelques individus out une bande brune détachée au-dessous du wilieu.

Habite l'Italie, la Sicile, dans les lieux secs. Fille a 18 a 20 millim. de diamètre.

\section{Héutce de Raspail. Helix Raspalii. PدYR.}

H. testâ orỏiculato depressâ, imperforatá, albido-olivace $\dot{r}$, lineis fusco-ruféscentibus zonatu; striis longitudinalibus, tenuihus; spirâ plunulati; aperturá lunari; margine albo, reflexo, basi planulato.

PaYraud. Cutal. des Annel. et des Moll. de Corse, pag. 10\%. nº. 21 9. pl. 5. fig. 7. 8.

A la voir en dessus on prendroil celte coquille pour noe varićté de l'Helix planospira; elle en diffère cependant, car etle n'a jamais l'ombilic oovert. L'Hélice de Raspail est graude, orbiculaire, assez fortement aplatie, à spire déprimée, à laquelle on ne cumpte qque quatre tours et demi ou cinq tours. Ils sont peu convexes et séparés par une suture simple el superficielle; les cleux premiers tour's sont globuleux, lisses, el d'un brunrougeâtre qui se conlinue quelquelois sur le troisième tour : celui-ci, aiusi que les suivans, sont striés longitndinalement; les stries sont très.tines, superticielles et obliques. Le dernier tour, pilus grand que les autres proportionnellenent, est orné de trois zones fauves ou brunes ì la partie supérieure, une seule de ces zones reste sur les tours suivans; le reste de la ciquille est d'un blancjaunátre ou olivàtre. La base est convexe, jaunis oubiliquée ou pertorée; l'nuverture est grunde, très-oblique, ovale, subsemi-lunaire; son péristome, blanc ou roussattre, est élargi el aplati sur le bord gauche; il est rélléchi et épaissi dans le reste de sa longueur. Cétte coquille, fort rare, a été découverte en Corse par MI. Payrandeau, qui nous l'a comrouniquéc avec la plus grande obligeauce. Flle a tété tetrouvée depuis en Sicile.

\section{Hétice nolable. Helix notata. Feros.}

H. testâ orbiculato-depressi, impeforati, traxslucidá, corneo-lutescente; longitudinuliter et transpersim striati; stris transversis, nunoribus; spiná planulatâ; appendiculo sublinguiformi, albo, obliquo, columellce adnato; labro margine albo, lato, depresso, reflexo, bidentato.

Ferus. Hist. nat. des Moll. $n^{0} .162 . p l .49$. A. fig. 5.

Celte coquille a la plus grande analngie avec la suivante. Nous indiquerons les dilférences qui la distinguent : elle est constamment plus grande et un peu nıoins déprimée du côté de la spire; elle est formée de six tours un peu plus convexes, dont la suture, simple, est aussi plus profonde. Les stries longitudinales, serrées et régulières, De sant point onduleuses sur le milieu du dernier tour, mais elles sont divisées en lravers par des stries très-fiues, nombreuses et prolondes, qui les partagent en denliculations d'une graode régularité : cette disposition se voit beaucoup mieux it la partie supérieure des tours de spire qu'à la báse de la coquille, où les stries transverses Iendent at s'tficer. Le péristome est blanc, réfléclii en debors, garni d'un bourrelet siillant, tranchant en dedans, a plati par devant; il est découpé, comase dans l'Hélice tridentée, en trois courbes, dont les points de jouction soni saillans : il est par conséquent lidenté. Une dent linguiforme, plus grance et plus saillante, se viuit sar la columelle à la méme place que dans l'cspèce snivante; il ny a également aucune trace d'owbilic, qui est re: placé par une légère dépression.

Cette coquille labite le Kentucky dans l'Anćririue septentrionale. Elie a 20 d 22 millitr. de diamètre.

49. Héltce linguifèe. Helix linguifera. Fen.

H. test à orbiculuto-depressá, imperforatí, pellucida, tenuiter striata, corneo-lutescente; spiró planulati; appendiculo tenu linguiformi, albo, obliquo, columellce adnato; labro murgine albo, reflexo, subbidentuto.

Fенus. Hist. nat. des Moll. no. 95. pl 49. A. fig. 3.

L.s к. Anim. s. vert. tonı. 6. pag. 9o. $n^{\circ} \cdot 9^{\bar{j}}$. Cuquille disccide, déprimée, aplatie à peu pıès également, un peu plus convese du côté de la spure : celle-ci ollie six tours, dunt le deruier est propurtiouné aux précédens; ils sont convexes et séparćs par une sulure assez prolonde en dessuus. La coquille est conrexe, tt sculenent déprimée au centre au lien d'être onbiliquée. L'estrémité du bord gauche s'insère dans celle dépression et la courre d'uue pelite callositéblanrolue. Toute la surlace de la coquille est couverte de stries très-fues, très-régulières, saillanıes, nonbreuses et longitudinales; sur le dernicr lour elles descendent un peu obliciuement de la sulure, et, parrenues sur le nulieu de la circonférence, elle's suilléclisseot assez fortement et gagnent le centre en s'alléunant. L'ouverture est abliçue, plus large 
que haute; le néristome, réflécl,i en dehor's, cist suillant et tranchant en dedans: il est découpú en deux sinnosités dont la médiane, la plus prolonle, est bornée à ses extrémités par une petite saillie. La columelle porte sur le milieu une dent oblique fort saillante, linguiforme, très-aplatie, barrant l'onverture et diminuat beaucoup la place qu'a l'arimal pour sortir de sa corquille. 'Tuure la corguille est trauslucide el d'un lauvebrunà țe, quelquefois jaunâtre. Laa patrie de cette espèce est l'Amérique septeotriouale. Elle a t7 ou 18 millım. de diamètre.

50. Hérice glabelle. Helix glubellu. Drap.

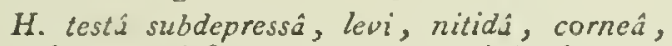
trinslucidi vel fucescenie, zoni albâ aliquuntisper circumdatâ; uperturî̀ senilunari, rotundistâ; peristomate submarginato, albo; umbulico minimo.

Dr.aP. Hist. des Moll. pag. 102, n’. 32.pl. 7 . fig. 6 .

Ferus. Hist. nat. des Moll. $n^{\circ}, 267$. An eadem species?" Helix glabella.

PFEIFr. Syst. anord. pl. 2. fig. 16.

Nous doutons fort que lit coquille donnée pour la Glabella par II. Piellfur suit en eflet de celte espece; elle nous paroit trop conique, et sou omlitic est trop grand po is queile puisse lui appaltenır. Cette Hélice glabelle a heatucoup plus de ressemblance avec l'Heltx carthusicenella yu'avec le Carshusiana ou tiout antite. Eile est d'une plus petite taille; sa spire est courte, a perue con:exe, conaposée de cinq à six tours arroudis, striés line. ment dans leur longueur, et ríunis pur une snture simple et peu profontie. Le thernier tour est subcarécé à sa partie supérieure, mais si fuiblement qu"̈̀ peine oo s'en aperçoit. En dessous, quarque convexe, elle est cepéndant dépriruée; elle est percée dans son cen're d'un petit ombilic parlus!ement rond. liouverute est médiocre, arrondie, semi-luaaire, un peủ plus latore que haute; I. fúristome n'est jamais renversé én dehors, il est çuelquelois simple, naais le plus souvemı ğurni eu dedans d'un petit bourrelet bianc, gui, a cause le id transparence de la coquille, est marqué en dehors par une zone blauche lort étroite. Cellc cociuille est transparente, mince, fragnle, coruce, juunâre ou brunàtre, cuelquelois ayant une luscie bianche et oiscure sur le dernier tous. Celte coyulle vit eo Frusce, aux cavions de lyon, en Silisse, en Allenague.

51. Hénce villinoide. Hehix vitrinoide: Noв.

I. testâ rotundato-depressi, tenuissimà, fragili, vitra's, translucidá, polita, laviguti, utroque latere convexiuscula, subtius imperforati; aperturi peracuti, ovato-semilunari; margine smmplaci, "cutissino.

Hist. Nut des Vers. Tome $1 \mathrm{l}$.
Celle coquille est excessivement mince, fragile, Iraniparente comme du verre, ligèrement et uniformément teintée de jaune ambiré : elle est parfaitement lisse, polie, brillante, sans la moindre strie : e!le est dépriúée, discoile à la manicre de l'Helix pyrenuica. Elle est légèrement convere de chaque cỏlé; la spire a cinq tonrs, dont le dernier est un peu plus grand que les autres proportionnellemeut; ils sont aplatis, et leur suture est très-superficieile. En dessous, cetıe coquille est imperforée, le centre est sculement déprimé et doune insertion à l'extrémité du lourd gancle. Louverture, assez grande, est plus large que haure; elle est semi-lunaire, presque droite; son péristome est siuple, mince, tranchant, nit évasé eu dehors, ni garni cn dedans d'un bourrclet. Le bord gauche, à son insertion, se contourse un peu.

Nous ne savons d'où vicnı celle coquille, que noas atvous depuis long-lemps dans notre colleclinn. liun des deux individus que nous possédions it été brisé; ils sunt les seuls que nous ayons jaimais vus: celui qui nons reste est le plus peri:; il a 15 millim. de diamètre.

52. Hédice bimarginíe. Helix carthusianclla. IIULe.

H. testí orbiculuto-convex $\dot{i}$, depressiusculí, perforati, lievi, pellucili, albo-comeá, obscurè fusciats; labro margine intus. fusco, extuis albo, subreflexo.

Helix carthusianı. Muclea, Verm. pug. 15. $n^{n}, 214$.

La Chartreuse. Geoff. Coq. pug. 32. $n^{\circ} \cdot 4$.

Caemitz, Conch. tom. 9. tab. 127. fig. 1130. 1151.

GiEr. pag. 3664. no. 1.54 .

Helix carthusianclla. Draparn. Moll. $p l .6$ fig. 31.52.

DaUDEB. Hist. des MIoll. $n^{3} \cdot 257$.

Coquille aplatie, lisse ou légèremen! strice, a spire obtuse. Elle est blubche, trunsparente, quelquefois teintée de fuuve, assez solide, quoique fort mince, formée de cing à six tours convexes, dout le dernier est proportionnellement plus graud que les antres; la suture est simple, pen proloade; en dessous la coquille est dépitince, convexe et perfurée an centre d'un ombilic fort petit, en partie caché par l'insertion du bord gauclie. L'oriverture est grande, uvale, subsemi-lunaire, obli. que; le péristome est mince, tranchant, à peine renversé en dehors : il est bordé en dedans frar un bourte!et blanc, aplati et étroit; en avaut de ce bourrelet: le bord est äun brun-rougeàtre, ce qui fait paruitre l'ouverture bimargine. Sul le dernier tour des indicidus teintés de fauve on rit une hande blanche obscure, et qui ne persiste pias dans toute la longueur du tour.

Ff * 
Cette espèce, trìs-communément répandue en France, se trouve surtout dans les champs, les prairies et les jardins, sur les herbes.

53. HÉlrce chartreuse. Helix carthusiana. Drap.

H. testâ orbiculato-convexâ, depressiusculâ, perforatâ, glabrâ, pellucidâ, albâa aut griseâ; spirâ brevi; labro margine subreflexo.

Helix carthusiana. Dr.s. Moll. pl. 6. fig. 33.

DAtdeb. Hist. des Moll. $\pi^{\circ}, 258$.

Laux. Anim. s. vert. tom. 6. prg. 85. $n^{\circ}, 7^{2}$.

Helix cantiana. Monts. Test. pag. 422.

Qui a $\nabla n$ l'espèce précédente peut facilement se fuire une idée de celle-ci, qui est toujours plus grande et un pen p'us boubée ; elles est orbiculaire, formée de sept conrs arrondis, luisans, légèrement striés, surtoat vers les sutures gai sont simples et assez profondes. Le dernier tour, proportionnellement plus grand que les autres, a souvent la surface un peu cbagriate : il est arrondi et convexe à la base, son centre est perforé et cet ombilic, quoique petit, est sensiblement plus grand que dans l'espèce précédente. L'ouverture est assez grande, aussi large que haute, arrondie, oblique, subsemi-lunaire; son péristome simple et tranchant est à peine évasé en dehors, si ce u'est à la base où il se renverse au-dessus de l'omlilic. En dedans, elie est garnie d'un pelit bonrrelet blanc aplati. La couleur de cette coquille est la même que dans l'espèce précédente : elle est donc d'un blauc laiteux, quelquefois grisâtre; son test est mince et cependant assez solide : on n'y remarque jamais la ligne blanchấtre plus opaque et dorsale qui est constante dans l'Hélice brmarginée.

Cette espèce se troave dans la France móridionale, l'Italie ct le Piémont. 


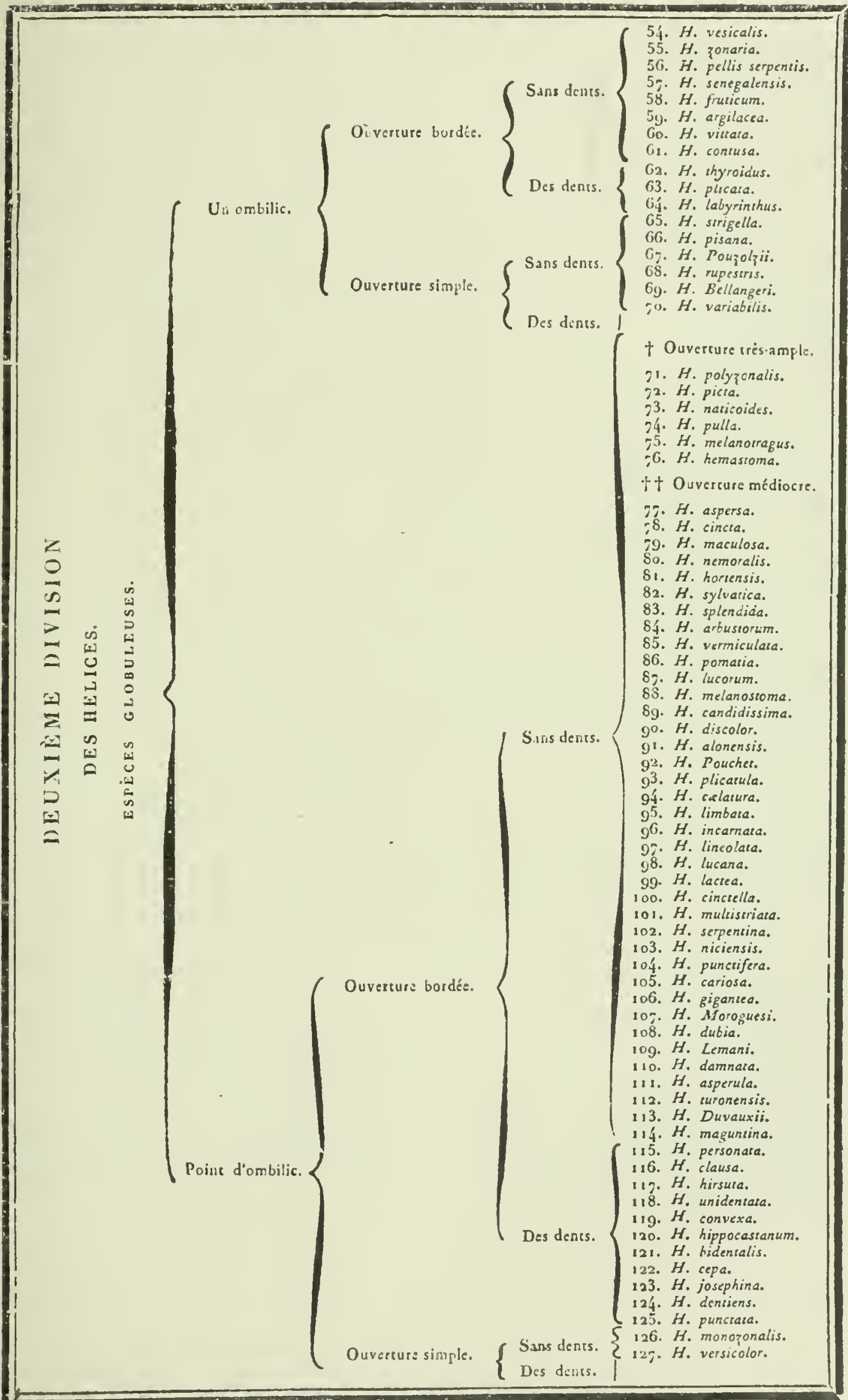

$\mathrm{Ff}_{2}$ * 
54. Hértce vésicale. Helix vesicalis. Laar.

$H$. testí suborbiculari, depresso-convexâ, perforatá, tenurusculd, lutco-rufescente, obscures zonatî; anfiactibus tiansverse striatis; kabro intis albo, margine reflexo.

Helix conu gigantcum. Canss. Conch. tom. I1. tab. 203. fig. $205 ̃$. 2052.

1)AUDEB. Hist. des Moli. pl. 10. Fig. 3. a. 1., c.

LAik. Anim. s. vert. tom. 6. pug. 65. n०1.

Celle espice est l'une des plus grande du genre; efle est arrondie, ovale, un per aplatie, formée de cind tours, doun le dernier est infuniment plas grand yue les autres: les trois premiers tours snnt lisses, le quatriène et la m vilié du demier sout lisensent chagrioés, et présenteut, de plus, yuclipues stries transverses obscures, et des stries jurégnlières d'accroissement çui, en se multipliant rers l'anverture, font disparuttre les slries iransrerses et les granulations. Le sommet de la spire est irès-obius, ct la suture est très-superficielle. Ein dessous, la eoquille oftre un ombilic assez graud, que le bord gauche couvre en partie par une callosité. L'ouveriure est très-grande, ovale, oblongne, très-oblique; les bords ont une grande tendance is se rejoindre a leur iusertion, et le bord columeliaire fort épaissi les unit et coraplète ajusi l'onverture. lee péristome est épaissi, bordé en dehors, il est blanc, ainsi que l'inlćrieur de la roquille; en dehors, elle esı d'un bean brun, plus toncé en dessous qu'en dessus: ces deux teintes sont nettement sćparées sur le milieu du dernier tour. Des zones lrausrerses assez nombreuses se roient sur toute la surface. Celte coquille est ordinairement très-mince el légère; elle s'épaissit assez notablement dans les vieux individus. Celle espèce rare vient de Madagascar; elle a 78 millim. de cliamètre.

55. Hélice zonaire. Helix zonaria. LIN.

H. testâ orbiculato-depressá, umbilicatâ, glabrî, albidì, fusco zonatî, muculis rufis adspers $\hat{\imath}$; spiri plunulatá; lubro expanso, margine reflexo, albo.

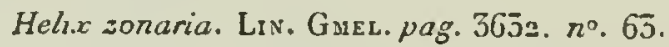

L.1мк. Anim s. vert. tom. 6. pag. $75 . n^{\circ} .37$.

MULLer, Verm. p. 35. $n^{\circ} .237$.

LJster, Conch. tab. 73. fig. $7^{2}$.

Gualt. Test. tab. 3. fig. L. L.

SEBA, MIns. tom. 3. tab. 40. fig. 52. 53.

Cuens. Conch. toru. 9. tab. 132. fig. I 188. 1 189. D. ODEB. Hist. des Moll. pl. $7^{2}$ el $7^{5}$.

Var. B. Testâ albidì, nitidâ, fusco bizonatâ.

SEBA, Mus. zom. 3. tab. 40. fig. 55.

KNORR, Velgn. tom. 5. tab. 21 . fg. 4 .
DaUdeb. Hist. des Moll. pl. 73. Fig. 6.

Jolie coquille sulgglobuleuse, à spire obtuse, dont les premiers tours sont tout-á-fait plats. Oiz conspte cing tours de spire, dont le dernier est, proportionnellement, plus granil que les autres: ce clernier tour est arroudi, plas épais, plus hlobuleux que ceux yui le précedent. la suture est simple et peu prolonde. En dessous, se trouve un onlsilic assez granil, profond, un peu recouvert par l'érasewent du bord ganclie; lonverture e:t ovale-oblongue, très-oblique, plus large que hall e; son póristoure est fortement évasé en deluns dans toute son étendue; il est blanc et un peu ‘pai ‘si a la base. Le test est mince, lravile, bui-iluil lisise; it est ormé, sur un lind blanc, d'un uontire plus ou moins grand de zour's brunes, dans l'intervalle desquelles il y a ordinairemem des taches nombreuses de la mềme coulcur, yuelguefuis confondues, quelquefois séparées. La variélé se distingue en ce que, sur le fond lolanc, il n'y is que deux zoues brunes. Nous possédons un individu que nous a donné M. Lesson, qui n’a qu'ane senle zone; il vient d'Anboine, habite les GrandesIndes. Elle a 30 millira. de diametre.

56. HĖr.rce peau de serpent. Helix pellis serpentis. CneMn.

H. testầ orbiculatí, convexâ, umbilicutâ, griseo-flavescente, fasclisflammeis rubris albisque prictá, subtùs seriebus pluribus punctorum rufescentium ornatâ; spiri abtusissimâ; ultimo anfiactu subangulato; labro margine albo, refiexo.

Lister, Conch. tab. 66. fig. 64.

Petiv. Gaz. tab́. 156. fig. I.

Favaxie, Conch.pl.63. fig. 3.

Helix pellis serpentis. Caen. Conch. tam. g. tab. 125. fig. 1095.1096.

Ejusd. Conch. tab. 208. fig. 2046. 2047.

GMEL. p. $3620 . n^{\circ} .254$.

DAODEB. Hist, des Moll. $n^{\circ}, 185, p l .75$. A. fig. 2. 3.

L.AMк. Anim. s. vert. tom. 6. pag. $7 \overrightarrow{3} . n^{\circ}$. 30.

VAR. B. Testá ultimo anfructu contusâ, irregulunter depressá.

En Irajtant de l'Helix brasiliensis, nous avons vu ponr quel anorif nous l'avions séparée de celleci. L'espèce nommée Hélice preau de serpent reste poirr nous ce qu'elle étojt ponr Lamarck et d'iutres conchyliologues. La coquille dont il s'agit est grande, arroudic, globuleuse, subanguleuse dans le milieu du dernier tour. La spire, obluse et saillante, est formée de six ou sept tours, rapprochés, arrondis, dont le dernier est proportionné aux aures. La suture est simple et nićdiocrement profonde. En dessous, la coquille est convexe, ouverte au centre par un petit ombilic, sur les limites 
duquel sinsile lextrémité du bord graclie: l'ouveriure ese midiocre, sem-lunairc, plus large que 1:atie. Le péistouc est blasc, lortement renversó (ir cehors, ci siuncux dans son comlout. Les p:emiers louls sont lisses, blanchaties; les suivans

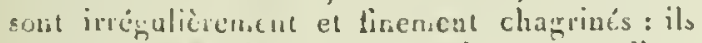
somt ornés, en dissus, contre la sulure, diunce sone de lacilies al ernativemcul lanues et blanclies; uhc: zone serablable, plus itroite, se voit sur le milieu du dernier tour; des llawnules nurbleuses, longitudinales, vout diune zonc a l'autre. En dessuus, sur un foad hrua, on voit un uowhre plus ou woins graod de liunces étruices lurmées pur des points ìin loruu loncé. l,a variété esc remarqualıle par la dépression irrégulière du dernicr lour à l'opposite de l'vavertare. Culle coquilla, large de 53 millim., sc truuve à Cayenne.

57. Hérice sinistrale. Helix senegalensis. Caeun,

H. testẩ sinistmorsâ, nrbiculato-convex $\hat{a}, u m-$

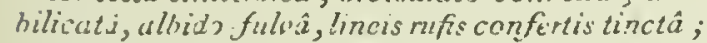
ullimo anfiuctu zons albi distuncto; lebru intús "lbo, margine reflexn.

Hclix sencgalensis. Cenms. Conch. tom. 9. tab. $\log$. fig. $917 \cdot 918$.

Daudeb. Hist. des Moll. no. 18g. $\mu l .78$. fig. 1. 2 .

Lask. Anim. s. vert. tom. 6. pag. 74. no. 31.

Conuille fort remarquable, et tolijonrs ficile à reconnoitue, élant du petit nombre de celles qui tomnent couslamment à l'inverse des autres, c'rsta-dire à guache. Cente coquille est moins grande que la précédente; clle esi arrondie, globulense; sa spire cst obtuse, courle, convexe, et cornposée de six lours arrondis, plissés prés de la suture. Celle-ci est peu profonde. Le dernier $t$ ur, proportionać aux autres, est legrèrement anguleux dans son milicu. En dessous, la coquille esı Irès-convexe et percée, au reatre, d'un ombilic élroil el profood, nn peu caché par le reoversement du bord gauclse. L'ouverture est semi-lunaire, peu oblique. Son péristone, épaissi et blanc, se rencerse en dehors, et surtout à son insertion sur le bord de l'umbilic. Les cleux premiers tours de spire sont lisses, les suivans sont plissés vers la suture. Le reste de lit surface est irrégulièrement cluagriné, ou plutôl convell de trés-petits plis dans divers seus; un grand noubre de lignes brunes llansverses se dessinent sur le fond, d'un faure clair, de la corguille; elles sont séparées en deux faisceaux pal uoe zone blanche nédiuoc. Cette coquille est lort rare. Quoiquion l'ait nommée Senegalensis, il n'est pas certain qu'clle vienue du Sénégal. Elle a 40 a 45 millim. de diamètre à In inse.

53. Hécice des arbustes. Helix fruticum. Molz. H. testà orbiculuto-convexâ, unbilicatâ, tenui, pcllucidj, obsolctes striats, albidâ, luteo-fascutu; spira subs rominub; labro murgine reflexo.

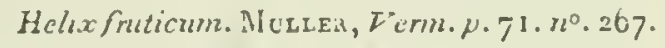

Cassx. Conch. tum. 9. tab. 133, fig. 1205.

GiE1.. pug. 36.5j. $n^{\circ} .77$.

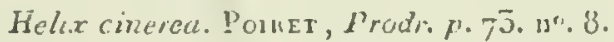

Helix fiuticum. 1) RA P. Moll. pl. 5. fig. 16.17.

DaUdẻ. Hist. des Mloll. $n^{\mathrm{D}} \cdot 25 \mathrm{~g}$.

l'feiffe: , Syst. renoid. tah. 2.j.g. 3. 4. j.

1. Auk. Anim. s. zert. tom. 6. pag. 85, n". tib.

Cenle coquille est usu de oos jolies esperess d'Europe : Draparnatud lui avoit donné le mar liraoguis de Trompeuse, parce quen ellet lorsegu'ou la tronve aver: l'animal, elle semble peirite de ruuleurs qu'elle v'a plus lorsqu'il en est ôté, la transparture de la coquille permeltaot que les couleurs vives de l'aninal paroissent au-dchors; il est ordinarement d'un jaune soufré, peintilli: de noir; il est quelquefois blanc ou roux, avec une bande brure on vinlâlre sur le collier. Lid rorguille est glolunlense, nince, diaplsane, composie de cinf lours convexes arronlis, sirites longitudinalement et nn peu ubliquenent: des stries treatblantes, ouduleuses, exlrémement fines, conjent les premières, à angle droit, et parviennent jusqu'à l'ouverture; celle-ci est arrondie, semiInuaire, plus large que haute. Son périslone, fort numce, se renverse en delurs, el s'épaissit lésèretnent en dedans. L'ombilic, qui est assez grand, est un peu recouvert par le bord ganche. Celle crquille est lantôl toule blancke, Iantót coute faure, et quelyuefois, sur l'une ou l'autre de ces couleurs, orníe d'use ceinture mfédiane de brun-rougncâtre ou violatre. Elle vit sur les arbustes des lieux ombragís un F:abce, en Snisse, en Allewagne, etc.

59. HÉLICE arrile. Helix argilacea. Fer.

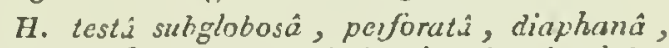
comen-rufescente; spirû brevi, obtusú; labro margine albo, reflexo.

Helix argilaceu. DA D. Hist. des Moll. $n^{\circ} .58$. pl. $26 . \mathrm{fig}_{\mathrm{g}}$. 3.3 .

LАМк. Anim s. vert. tom., 6. pag. 80. n०. 5.j.

Espèce qui, par sa forme, ruppelle notre Helix hortensis, ou plutôt une des variétés de l'Helix fruticum. L'Helix argl lacea est globuleuse, arrondie, à spire obtuse el peu saillante. Elle présente cinq tours convexes, séparés par une suture simple, mais profonde; le demier, plus graod en prcportion que les autres, est épais et convexe autant en dessous qu'en dessus; il est percé par un ombilic étroit et profond, en partie recuuvert par le bord gauche. Louverture est assez grande, semilunaire, arrondie, les extrémités de ses bords ayant une grande tendance à se rapprocher à leur 
point d'insertion : celte ouverture est remarcpuable par le renversement considérable du bord, qui est arrondi, épaissi, et surtout à la baseroù il s'élargit et s'étale au-dessus de l'ombilio. La coulen' de cette coquille est uniforme; elle est d'un fauve clair, et comme le test est mince et transfarent, cela lui donne l'apparence de la corne.

Cente coquille se trouve á 'Timor et aux Muluques; elle a 25 millim. de diamètre.

6o. Hérice macrostome. Helix vittata. Mull.

H. ¿estâ sulıglobosâ, perforatú, tenuiter striatâ, albá; spirá brevi, conoideá; apicc curuleo-nigri, aperturá fusco-nigricante; lizbro expanso, margine albo, reflexo.

Helix vitlata. Mucler, Verns. p. 76. $n^{\circ}, 271$.

Caems. Conch. tom. 9. tab. I32. fig. 1090. $10 g^{2}$.

Guec. pag. 3636. " $^{\circ} \cdot 79$.

Dsud. Hist. des Moll. $n^{\circ}$. 35. pl. 26. fg. 4. 6 .

LAus. Anim. s. vert. tom. 6. pag. 8o. $n^{\circ} .54$.

Coquille globuleuse, presque sphćrique, à spire obtuse, conile, formée de six tours peu convexes, réunis par une suture simple et superficielle. Les premiers tours sont d'un brun plus ou moins foncé, les suivans sunt d'uo blanc-jaunâtre ou grisâtre et tout-a-fait blancs : sur les individus bi:n frais se dessioent deux ou trois bandes transrerses d'un beau jaune, dont une seule se continue quelquefois près de la suture des premiers tours. En dessuus, celte coquille n'est pas moins convexe qu'en dessus; au centre, on trouve un petit ombilit arrondi, peu profond, en partie caché par le reaversement du bord gauclie. Rien que la forme ci la couleur de l'ouverture suffiroient pour faire reconnoitre cette espèce : elle est très-évasée, très-renversée en debors; le péristome épaissi en se reuversaut se termine par un bord mince et tranchant, qui n'est pas moins évasé a la hase que dans le reste de son contour. Cette ouverture est uvale, obronde, complétée par un bord columellaire peu épais; elle est partout d'un biuu foncé de café brúlé. Cette coquille est taute lisse, ou marqué par des stries d'accroissement très-lines: ello est assez rare, et se trouve à Java. M. Bc!lan. ger en a rapporté du mème lieu quelques individus.

\section{Héluce contuse. tirw $x$ contusa. Fer.}

H. testá globulosú, pellucidì, corneâ, multispiratź, subtùs unibilicata, obliqued depressâ, tenuè striatá; strïs longıtudinalibus, transversis, tenuissimis, decussatıs; aperturì nediocri; lubro incrassuto, neflexo.

DaUdEB. Hist. nat. des Moll. no. 41, pl. 31. fig. 1 ; et pl. 36. A. fig. 2. 3. avec l'anicaal.

l.'aniual de celle espece, d'après la figure don- née par M. de Felussac, est alongć, fort grêle, étroit, d'un beau juune-orangé, et ses deux teatacules inférieurs, aplatis à leur extrémité, sont palmés et subdivisés eo deux. Cel animal porte sa coquille sur l'estréınilé postŕrieure de son corps, ce qui ne se voit pas habituellement dans les espèces du grenre Hélice.

La coquille est arrondie, glubuleuse, à spire légèremeat saillanle et furcóe de lunit tuurs qui, dans leur cnroulement, se dépassent plus d'un côté que de l'uuire: cela se voit particuliérement au dernier tour dont la dépressirn opposée à l'ouverture est très-considérable. Ce deruier tour, à voir la spire par le sommet, ne liait presque point de saillie au-delà de l'avant-dernier, d'un côté, tandis que de l'autre il est proportionnellement beaucoup plus large. Les tours de spire sonl convexes, serrés, étroils, couverts d'un graud nombre de stries longiludiuales, fines et serrćes, régulières, roupées en travers par d'autres plus fines encore, et que l'ou ne voil qu'à l'aide d'une furte loupe. En dessous, cette coquille est fort convexc, toute lisse, percée d'un ombilic irrégulièrement évasé, se teruninzat par un petic trou qui suit la direction oblique de l'axe de la coquille. L'ouverture est médiane, semi-lunaire, oblique, un pen sinueuse inférieuremeol; son péristome est blanc, arrondi et renversé en ảebors. Celte coquille est d'uu blanc-jauuâtre ; elle est mince, transparente, cornée, légère. Elle vient du Brésil, ou elle paroît assez rare : elle n'est encore que dans un petit nombre de collections. L'individu que nous possédons est plus grand quaucun de ceux que nous ayons $\nabla$ os; il a 30 millim. de diametre $\dot{a}$ la base.

62. HÉLIce thyroïdienne. Helix thyroidus. Fer.

H. testâ orbiculato-globosí, correo-liuteâ regulariter, tenue striati; striis longitudinulibus obliquis; subtus umbilico minino; uperturisemilunari; labro patulo, albo; columella dento minimo, albo, instructá.

Lister, Synop. tab. 91.fig. 91.

Sсинстея, Einlingt. 2. pag. 192. " ${ }^{\circ} .60$.

Sar, Journ. of the Acad. Philadel. tom. 1. pl. 1. 123.

Daudeb. Hist. nut. des Moll. $n^{\circ} .96 . p l .49$. A. fig. 4 .

Coquille globuleuse, arrondie, mince, fragile, transparente, formée de six lours dont le deruier est proportionnellemeat un peu plus grand que les autres : ces tours sont convexes et séparés par unc suture assez profunde. Les deux premiers son! lisses, et les suivaos sont courerls de strits longitudinales, obliques, rombrenses, régulières, assez élevées, qui, sar le dernier lour, passent en dessous de la coquille, convergent vers le centre en s'affoiblissant peu à peu. En dessous, celte 
coquille est convexe, son centre est occnpé par un ombilic d'une médiocre grandeur, en partie couvert par le bord gauche qui vient s'insérer près de lui. L'ouverture est arrondie, semi-lunaire; sou péristome est blanc, épaissi, renversé en dehors et aplati par devant. La columelle présente sur son milien, au niveau de l'ouverture, une petite dent blanche, obtuse, un peu oblique et fort courte. "Toute la coquille est miace, translucide, d'une couleur jaune-cornće sans autres nuances. Cette espèce vit aux L̇tats-Uuis d' $\Lambda$ mérirgue. Elle a 20 à 25 millim. de diamètre.

63. Iİuree plissée. Helix plicata. Born.

H. testâ subolobulosâ, basi depressî, umbilicata, leviter striati, fulvâ, sabtìs albicante; aperturî̀ depressâ, trunsversim oblongâ, peristomate continuo cincumdatâ, plicis tribus instructâ.

Ferussac, Hist. nat. des Moll. no. $100 . p l .54$ 13. fig. I.

Carocolla labyrinthus. Lasx. Anini. s. vert. tom. 6. pag. 96. $n^{\circ}$. 4. Ejusdem labyrinthus. LAsx. Journal d'hist. natur. torn. 2. pag. 347. pl. 42. fig. 4. a. b.

Ksosn, Verg. 5. tab. 25. fg. 5. 6. 7 .

Helix plicata. Bonn. Mas. cas. vind. pag. 376 .

Coquille fort remarquable, que M. de Ferussac a justement séparée de l'Hélice labyrinthe avec laquelle Lamarck l'a confondue. Elle a incontestablement bestroup de rapports avec cette dernière espèce; elle s'en distingue cepepdant avec facilite, elle est toujours plus petite, son ombilic est plus grand, sa forme est plus globuleuse, et son ouverture a des caractères qui peuvent suffire à la séparer des jeunes individus du Labyrinthe.

Celte espèce est arronuile, subglobuleuse, à spire un peu saillante et obtuse, composée de six tours médiocrement convexes et séparés par uve suture simple; le dernier tour est proportionné aux autres; il est légèrement déprimé en dessous, où il est ouvert par un ombilic médiocre, évasé, sur lequel s'apance l'angle de l'ouverture; cette ouverture est transverse, beaucoup plus large que baute, sulsovalaire, à péristome contiou, formant un angle au-dessus de l'ombilic par la jonction des deux bords. Ce péristome est blanc, épais et renversé en dehors; trois dents sont placées à l'intérieur, l'uae est alongée sor la columelle, les deux autres sont sur le bord droit. En dessus, cette coquille est d'un fauve-orangé sans mélange; le dernier tour, qui a une tendance à être caréné, le paroit à cause de la ligne blanche qui parcourt son pourtour. En dessous elle est blanche, si ce n'est vers la circontérence où elle est teintée d'un fauve pâle.

Cette espèce est extrêmement rare daas les col- lections; elle a 30 à 35 millim. de diamètre. $O_{\Omega}$ croit qu'clle vit daas l'Inde.

64. Iİ̇ice labyrinthe. Helix labyrinthus. FEu.

H. testâ orbiculutî, utrinquè convexâ, latè umbilicatâ, glabrâ, més; apertará subquadmatu, plicis tribas incequalibus instructâ; marginibla connexis, reflexis, albis.

Kмов , Vergn. tom. 5. tab. 26. fig. 5.

Favanne, Conch. pl. 6.5. fig. f. I1.

Helix labyrinthus. CHEMn. Conch. tom. 13. tab. 208. fig. 2048.

Dauder. Hist. des Moll. no. 99. pl. 54. B. fig. 2. 3. 4. 5.

Excrelor, in-ful. Rec. de pl. tom. 6. pl. 34 . fig. 18.

Grande et belle coquille des plus extraordinaires, et l'une des plus précieuses du beau et graud genre Hélice. Peut-être par sa forme un pen surbaissée auroit elle mieux convenu à la première division, mais ses rapports intimes avec l'Helix plicata l'eutraîne à côté d'elle : elle est orbicnlaire, composée de six à sept tours arroudis en dessus, à suture simple ct peu profonde; leur surface est presque lisse, on $y$ remarque seulement quelques stries d'uccroisscment. Dans le jeune âge, le pourtour est anguleux, ce qui saps doute a porté Lamarcli i placer cette coquille dans son genre Carocolle mais dans l'âge adulie, l'angle s'elfice peu à peu et disparoil sur le dernier tour. En dessous, la coquille est ouverte par un ombilic médian lort évasé, et l'ouvertule qui la termine est fort singulière : elle est alongée, trausverse, rétrécie du côté interne en une vigole très-étroite, profonde et bordéc par le péristome qui s'enfonce dans l'ocnbilic; elle se coutinue du côté opposé en eutrant dans l'ouverture, et se prolonge sur si face columellaire. Le reste de l'ouverture s'arrondit, et le péristome pread naissance à peu prés au milicu de la longneur des bords de la $1 \mathrm{i}$ gole; il se renverse autous de l'ouverture. Le bord droit est échancré au milieu, et il porte en dedans trois deuts lamelleuses contournées, lort saillantes, qui obstrueut l'entrée de l'ouverture, de telle sorte que l'on a peine à concevoir comrnent l'animal pouvoit sortir de sa coquille : l'une des lames, la plus grande, est quelquelois dentée ou bifurquée.

La coulear de cette coquille est uniformćment la même; elle est d'un brun-fauve, peu fonct. On la dit de l'Inde; elle a près de 50 millin. de diamètre.

65. Hélree strigelle. Helix stigelia. $\mathrm{D}_{\mathrm{B} \text { A }}$.

H. testâ globosâ, tenui, fragili, albicınte vel corneâ, pelíacidâ, striutâ; umbilico magno, pro. 
fundo; aperturá rotundí; peristomate paiulo, intùs inarginato.

Drap. Hist. nat. des Moll. pag. 84. no. 11. pl. $7 \cdot f g .1 .2$.

Ferus. Hist, dos Moll, no, 265.

Var. B. Noв. Testâ minore, nugosiusculâ.

Jolie coquille que l'on trouve en France, et qui a beaucoup de rapports avec l'Helix fruticum. Elle est constamment plus petite; sa forrae est globuleuse, et sa spirc peu saillanie est formée de six tours étroits et convexes, dunt le dernier est proportionnellement plus grand que les autres. La sulure est simple, mais assez profonde en dessous. La coguille est convexe el présente au ceatre un ombilic grand et profiond. L'ouve:ture, qui est médiocre, est obliquc, arroadie; le péristome est simple, légèrementévasé ca dehurs, et garni en dedans d'un petit bourrelet peu saillant et d'uu ulanc de lait. Tunte la surface extérieure est courerte de fines stries longitudinales peu régulières, en furme de rides, un peu rugueuses. Comnie la coquille est très-mince, elle est, à cause de cela, translucide, soit qu'elle soit blancliâtre, brunâtre, on plutôt d'un corné clair. La variété que nous indiquons a été découverte anx enrirons de Lyon par un amateur zélé, M. Derillier, qui a bien voulu noas la communiquer. Elle est toujours plus petite et d'une teinie plus foncée; Labite la France, le Piémont, la Suisse, l'Allemagne et l'Espagae.

66. HÉlICE rhodostome. Helix pisana. Mole.

H. testí globoso-depressî, perforatâ, tenui, albidí, lineis variis luteis fuscisque interruptrs cinctá; labor simplici, murgine interiore roseo.

l. Aark. Anim. s. vert. toin. 6. pag. 82. $n^{\circ}$. 61.

Helix pisana. Murc. Verm. pag. 6o. $n^{\circ} \cdot 255$.

Petit. Gaz. tab. 52. fig. 12.

Gcalt. Test. tab. 2. Jig. 2.

lisers. Conch. tom. 9. tab̆. 132. fig. 1186. ग187.

GHer. pag. 363 t. $n^{\circ}$. 60.

Helrx rhodostoma. D凩ar. Moll. $n^{2}, 14$. fl. 5. fig. 13. 14. 15 .

Helix pisana. Fra. Hist. des Moll. $n^{\circ} .2$ go.

Var. a.) Drap. Anfiactu infino, fiscris quatuor compositis, margine lacerns notuto, duabus superioribus continuatis.

Var. \&.) Drap. Testi omnino fusciolis fuscis aut rufescentibus perfusi.

Va:. \%) Drap. Tcsta fosciis fuscis aut nufe:contibus laceris et interruptis seu maculis 2 'a negati.

Vir. d.) 1) Rap. Testí suprà albà, punctis nigricantibus adspersî, suliuis fasciatz.

\section{H E L}

Var. 1.) Noв. Testi fasciis pallidis omnind confusis notatú.

Var. ל.) Nов. Test $\hat{厶}$ albi, fasciis numerosis translucidis notatâ.

Var. ". ) Drar. Testá fasciâ unicâa, integrá, fuscâ, continuatâ.

Var. Ө.) Drap. Testâ omninò alhâ.

Celle espèce est, comme on le voit. très-variable aux six variétés intiquées par Diaparaaud. Nous en avons ajouté deux, et nous autions pu en noter daviutage, car on peut dire qu'il $y$ at presqu'autant de variélés que d'individus.

Coquille globuleuse, quelqqnefois un peu aplatie. Les tours de spire, an nombre de ciaç ou six, sont aplatis, conjoints; la suture qui les sépare est simple et superlicielle; leur suitace est trèsfinement et régulièrement treillisséc par des stries longitudiuales, et d'auires iransverses, numbreases et serrées. Lans le jeune ảge, les tours sont carénés à leur partie supéricure, et la sa:ure se fait sur celle carèce, rui disparuit sur le dernic. lonr des individus adultes. La base convexe est percée d'un oubilic petit et en partie recouvert par le bord gauche. L'ouverture est arrondie, son péristome reste mince, tranchant, et non renversé à tous les âges, si ce n'est vers l'oubilic, qu'il reconvre en partie. Un bourrelet fort aplati se voit à l'intéricur du péristome; ce bourrelet est d'ure belle conleur rose, quelciueluis noire, rarement il est blanc ou bleuâtre: la conleur rose se prolonge parfois assez lain daas l'ouveriure et se continue sur lit coluscelle, et le retour de la spire ou l'avant-dernier tour en est aussi leinté sur la partie comprise dans lionverture.

Cette coquille, sous le rapport de la couteur, ofire un grand nombre de variétés dont nous avons indiqué les priacipales : 10 . individus tout blancs de lait sans la moindre tache; $2^{\circ}$. individus plus grands, sans taches, mais jaunálres; 30. fund jaune plus funcé, quelques baades confusémen indiguées; $4^{\circ}$. trois landes d'un fance clatir sur ua fond blanc sur le dernier tour; 5". une liscie composée de poncluatiuns alongées, occupant en trois sérles presque tonte la surface du dernier tour; $6^{\circ}$. 1 rois bandes d'un brun clair, au milieu de chacune desquelles on distiugue i peine deux au trois linéoles plus foncées; $7^{\circ}$. trois bandes d'un brun-noir frangées sur lenis bords, indication d'une quatrième bande rers la suture p.:: quelques puncluations éparses; 83. ces tenis bandes netrement décomposées chacune en deu. on tronis linéoles continues; $9^{\circ}$. les trois bandes décompusées, quelguefuis fraugées ou subarticitlées, une qualrièuze à cóté de la sulure, formín de linéules longitudinales, rayonnantes, subaricnlées; $10^{\circ}$. cette quatrieme loute continue et simple; $11^{\circ}$. quatrieme fascic dícomposíe en deux ou trois linécles continues cumae les autres bande: ; 
des; $12^{\circ}$. un grand numbre de linéoles contiaues, a peine réunies par bandes, et couvrant, au uuinbre de quiuze, toute la surface; $13^{\circ}$. enfin, Ges individus fort remarquables qui viennent des íles Majorque et Miuorque, et que nous devors à l'amitié de notre collègue M. Cambessède, qui out un grand nombre de liaéoles transparentes sur un fond blanc de lait. Ce ne sont pas encore là coutes les variétés, car, parari celles dout les fascies sont décomposées, il y en a quelquełois une ou deux qui ae le sont pas; tantôt c'est relle de la base, et tantôt l'une des trois autrcs. Entiu, ces fascies sont formées indistiuciemeat de une, deux, trois et même quatre linéoles. Il lant encore ajouter çue toutes ces variétés se présenteat sur des individus tantôt d'un fond blauc, tantôt d'un fond fauve. Oa pourroit facilement, eu recherchant tuures les combinaisons, porter à vingtcinc ou trente le nombre des variétés de cette Espece.

L'Hélice rhodostome se trouve sur tout le littoral de la Méditerracée, en France, en Italie, en Corse, en Sicile, en Espagne, etc. Nous ne la connuissons pas d'Alirique.

67. Hécrce de Ponzolz. Helix Pouzoliii. Fer.

H. testá orbiculato-globosâ, fusco-virente, fasciis tribus subnigris curcumdutâ, latè umbilicatâ, striatá; aperturs motundato-semiiunan, labroob. tuso, simplici, albo, basi reflexo.

Hélice de Pouzolz. Paya. Cat. des Annél. pag. 102. $n^{\circ} \cdot 220$.

M. Pouzolz, amateur fort distingué, découvrit cette belle espèce en Curse, vì il par'uît qu'elle est très-rare. M. Payrandeau, malyré ses rechercbes, ne la retrouva pas, et il ne fit que l'inditguer dans son Catalogue des Annélides et des Mollusques de Corse, en disant que M. de Ferussac se propusoit de décrire cette coquille soas le aum de la personne qui l'avoit découverte. fyant eu de M. Puazulz lur-nème un individu de cette espece, nuus l'avions mis dans notre collection, sous le nom de cet estimable amateur, arec l'intention de la lui dédier, si, le premer, nutus avions occasion de la décrire. L'inlerrip:ion du travaii de M. de lierussac nous l'ullre aujuerd'hui; et c'est avec plaisil que nous saisissuns l'uccasion qui auus est ollerte, de témoiguer a N. Pouzulz notre gratitude des consmunications isieureillantes qu'il nous as failes dans l'iatúrêt de la concbyliologie.

L'Hélice de Pouzolz est grande, arrondie, globuleuse, subdiscurle, ajprochant un peu, pour la furae seulement, de l'Helix algira, sans cependaniêtre pius globaleuse qu'eile. Ldspire, arrondie et obtuse, est formée de sept tours, dont ie dernicr est proportionné aux autres. Ces tour's sont arronais, et leur suture simple est assez profonde. Les deux premiers tours sont lisses, les suivas

Hist. Nat. des Vers. Tome II. sont chargés de stries longitudinales, fines et irrégulières, qui résulteat des accroissemens. Outre ces stries, on en remarcque d'autres transverses sur la partie supérieure des denx derniers tours de spire; elles sont u'è-fines, rapprochécs, et ve sc voient bien quà la loupe. En dessous, ces stlies transverses manquent tout-d-fait, et les stries longitudinales ont aussi une tendance à disparoître. Le ceatre est occujé par un grand ombilic sur lequel vient se reaverser l'extrémité du bord gaucbe. L'ouverture est grande, oblique. Le péristome est readu obtus par un petit filet blanc qui le borde; il se renverse seulement à la base, et surtout au-dessus de l'ombilic. Cette cocpuille est d'une couleur sombre, d'un bru-verdâtre. Le dernicr tour est orné de trois zones d'un brun presque noir, dont la supéricure et l'iaférieure se fondeat, par leur bord exterae, avec la cunleur du fond. Celte coquille rare a 45 millim. de diamètre; elle a'a encorc élé trouvée qu'ea Corse.

68. Héluce des rochers. Helix rupestris. Dran.

II. testâ minimâ, globulosâ, fiuscâ, corneâ, translucidâ, tenuissimè striatâ; anfructibus convexis; suturis profundis, sepuratis; aperturá notundatâ; umbilico magno, profuncio.

Drap. Moll. de France, pag. 82. n॰.8.pl. 7 . fg. $7 \cdot 8 \cdot 9$.

Ferus. Hist. nat. des Moll. pag. 40. $n^{\circ} .201$.

Cette coguille est mise au nombre des plus petites espèces du genre : elle est en elfet d'un petit volume, les plus grands individus ayant à peine une ligne de diamètre. Ils sout arrondis, globuleux, à spire légèrement subconique : elle est composée de six tours étroits, bien gradués, fort convexes, striés, et nettement séparés par une suture profoude et simple. Les stries sont subrégulières, fines, nombreuses et serrées. Le deraier tour est convexe en dessous : a centre on voit un oubilic g!̣aud, évasé et profond. L'ouverture est arrondie, très-oblique, petite, à péristome simple, mince et trachant ; les bords du péristome tendert à se rejoindre à leur insertion: ils ae sont pas renversés an-dessus de l'ourbilic, et ronjours dépourvus à tous les àges dc bourrelet intérieur.

Toute cette coquille est unince, coraée, translucide, d'ur brun lancé, saus aucune autrc nuance : on la trouva dans les rockers, dans les mousses, en France, en Allemagne et en Angleterre.

69. HÉluce de Belanger. Helix Belangeri. Noв.

H. test i orbiculato-globulosá, subdepress $\hat{a}$, trans. lncide, rosed, subtius albicunte, ombilicati, insuper striis longitudinalibus et transversis omati; aperturu magná, obliquá; labro simplici.

$\mathrm{G}_{\tilde{n}}$ * 
Nous connoissions celle espèce avant que nons ne nous fussions clargé de la description des Mollusques qui doivent faire partie de l'onorage importunt que M. Belanger va publier sur l'Inde. M. Marmin avait eu la bunté de nous la communiquer, et dès ce moment, bien antérieurement au retour du jeune et savant vnyageur, nous avions consacré son nom à celle espèce, que l'on doit ì ses recberches.

Celte coquille est grande, globuleuse, subdéprimée, ì spire obluse et légèrement conique; elle est formée de six à sept luurs arrondis, dont le dernicr est, proportionnellement, plus grand que les antres. La suture qui les joint est simple et assez profonde. Dans les individus bien frais, les deux un trois premiers tours sont finement granuleux, tandis que les suivans sont couverts de stries longitudinales, très-fues, très-serrées, qui ae dépassent pas le milieu du dernier tour qui est lisse eu dessous. Ontre ces stries, quelyues individus en offreat d'autres transverses, plus fines encore, unais plus écartées et peu profondes: en dessous, la coquille est convexc. On voit au milieu un ombilic arrondi, peu considérable. L'ouverture est grande, ovalaire, arcondie, un peu sinueuse, et déprimée supérieurement. Le péristome est mince, non bordé, légèrement obtus. Celte coquille est mince et traoslucide, d'un rose pảle, ou tirant au fauve en dessus, passant au blanc en dessous, et surtont vers l'ombilic. C'est aux enviruns de l'ondichéri que cetle coquille a été trouvée; elle a 48 millian. de diamètre.

70. Héltce variable. Helix variabilis. Drap.

H. test $\hat{\hat{A}}$ orbiculato-conoideâ, umbilicat $\hat{\boldsymbol{A}}$, tenui, albidi, subfasciata; fusciis rufo-fusces; spirâ subconicâ, apice Juscâ; labro simplici, margine interiore rubro.

Goant. Test. tab. 2. fig. h. l.

Flelix subalbida. Pопиг, Prodr. p. 83. $n^{\circ}, 18$.

Helix variabilis. Duap. Moll. pl. 5. fg. 11. 12.

Daudeb. Hist. des Mall. $n^{n} .284$.

Helix maritima. DR. P. loc. cit.pl.5. fig. 9. 10.

C'est en rain que nous cherchons des différences entre l'Helix variabilis et l'Helix maritinut de Draparnand; nous voyons de contimuels passages entre les denx espèces, tant pour la coulear que ponr la forme et la largeur de l'ombilic. Draparnaud est obligé de convenir que l'Hélice maritime se rapproche de certaines variétís de l'Helix variabilis; mais elle s'en disingue, dit-il, par sa iorme un pei plus conique, par sa consistance plus solide, par sa caréne plus prononcée, par sa fietitesse roujours constante, par son trou ombilical plus citroit, et snrteut par la vivacité de ses couleurs. ():stre que ces diférences, comme on le voit, sont lo:t peu considérables, elles devienneo tinapprécia1 les rquand on réunit sculernent une vingtained"indi- vidus des deux espèces: ces molifs nous ont dé cidé à les réunir. Comme son oom l"indique, celte espèce est cn eflet très-variable ; elle est a rroudie, globuleuse, subconique, composée de six à sept loars arrondis, dont les premiers, ceux du sommel, sont lisses et bruns, les autres sont striés longitndinalemeat el un peu obliquement. Ces stries sont plus apparentes dans les jeunes individus que dans les vieux; elles devienuent obsolètes sur le dernier tour des plus grands. La face inlórieure est arrondie, convexe, percée d'un ombilic médiocre. Liouverture est arrondie; les deux bords se courbent l'un vers l'autre à leur inscrtion : le bord est brun à l'intérieur, et garni au-delà d'un bourrelet aplati d'un brun-rougeâtre. Les couleurs sont très-variables. La coquillé est tanlôt toute blanche ou grisâtre, avec yuelques indices pâles des bandes, soil inférieures, soil supérieures, tantôt tonte d'un brun clair, avec une ceinture blanche dans le milieu du dernier cour. Au milieu de celle teinte générale commencent ì paroitre des bandes brunes; ces bandes sont linéaires en dessous: une plus large en dessus se voil sur lous les tours, au-dessus de la sulure. Ces bindes dir dessous, an nombre de cinç ou six, finisscul parse toucher et se confondre en une large fascie noire. Cetre coquille se trouve sur le littoral de la Méditerranée.

7 T. Hérice polyzoaale. Helix polyzonalis. LABI $\mathrm{K}$.

H. testiarbiculato-ventricosi, oblique conoided, imperforata, fulvo-rufescente, albo zonato; ultimo anfractu maximo, zonis tribus inequalibus cincto; aperturi ampla; lubro margine interiore físco, subreflexo.

Helix magnifica. Daudeb. Hist. des Moll. $n^{\circ} .5$. pl. 10. fig. 4. a. b.

L.awn. Anim. s. verl. tom. 6. pag. 66. m?. 3.

Grande et belle coquille ovale, arrondie, trèsample, ventrue, à spire courte el obtuse, formie de quatre tours sculement, dunt le dernier est énorme comparativement anx autres; les preiniers tours sunt peu bombés, l'avant-dernier l'est assez considérablement. La sułare est simple et pen profonde: on ne voit, sur la sarface de la corpuille, et surtout sur le dernier lour, que des stries plus ou tnoins nombreuses d'accroissement. Ce dernier tour est très-convese en dessous; il n'est puint ombiliqué; l'ouverture qui le termineest trèsample, ovalaue, trc̀s-oblique à l'axe de la coquille: les extrémilés des bords ont une tendance à se rapprocher, et ils sont joints par un bord columellaire étalé, peu épais. Lé péristome est brun, rúlléchi en deliors: il resie assez mince dans toute son élendue, si ce n'est à la base de la columelle, oủ il s'élargit d'une manière notable. A l'extérieur, sur un fond d'un blanc-brunatre, on remarque une anllitule de raies étroites, parmi lesquelles 


\section{H E L}

il y en a trois plus larges et plus brunes. La prenuère de ces bandes, ou la supérieure, est la plus ítroite. Cette coquille rare et précieuse vit aux Grundes-Indes, mais on ne sait pas précisément dans quelle partie de cette vaste contrée. Elle a 65 millim. de diamètre à sa base, près de deux pouces et dewi.

72. Ilélıce peinte. Hclix picta. Guec.

H. testá subglobulosî, imperforatû, tenui,

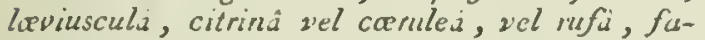
ciis variis longitudinalibus et trunsversis cruciatim distinctí; spirâ brevi, obtusí, labro simplici, acuto.

Hclix picta. Bons. MIus, tab. 15. fig. 17. 18.

Кковк, Vergn. 1. tab. 10. fig. 2.

Caess. Conch. tom. 9. tab. 130. fig. 1162 à 1165 .

GMeL. p. 365o. n०. 189 .

D.tuder. Hist. des Moll. pl. 11.a.fig. 14.pl.12, et 13. pl. 14. fig. 1-5, et pl. 25. fig. 9. 10.

Lewr. Anin. s. vert. tom. 6. pag. 69. no. 14.

Clsarmante coguille, l'nne des plus jolies du fenre, extrèmement variable dans ses couleurs, unime dans sa forme, mais ornée des couleurs les mieux en harmonie el variées dans les nuances les plus ayréables. M. de Ferussac, dans son grand ourrage, a rassemblé autant de variétés qu'il a pu: il en a lisit figurer trente. Celte coruille, guant à la f rine, ressemble beaucoup à l'Helix naticoides; elle est ylobuleuse, acapullacée, is spire courte, ne présentant yue quatre à cinq teurs, dunt le dernier est beaucoup plus grand que tous les autres: its sunt lisses, pulis, et ne présenient que des stries peu nombreuses d'accruissement. En dessus, la coquille est très-ventrue; sou onverture, trèsample, est arrondie; la culumelle est rentrante, c'est-a-dire que furmant la contiuarion de l'axe, elle est dépassée par la partie supérieure de l'ouverture lorsque l'on vient a placer la coquille perpendiculairement; le péristome est quelguefois mince, quelquefois épạissi, re qui lieat ì l’äge. Ce qui est particulier, c'est que le bourrelet, an lieu de se reuverser en dehors, est saillant en dedans. l,es couleurs sunt extrèmement variables: la coquille est antút jaune, mais bordée en dessus et en dessuus de lignes roses; tadot avec les fascies blanches, brunes, et quelquefois elle est blanclse, ou rose, on orangé, ou brune, on verte et mème violelte, tonjours a vec des zones de couleurs diverses, et toujuurs assorties à la couleur du fuod. Celte corguille, à cause de la beauté et de la fraicheur de ses couleur's, est recherchée des amatenrs. Quelques variétés sunt 'ort chères. Elle a de 25 a 35 cnillim. de diamètre. On ne sait où elle vit : on présume qu'elle vient de la Chine. 7j. IIÉlice natice. Helix naticoides. Drap.

H. testâ suhglobulos $\hat{A}$, ventricosâ, imperforatâ, temuissin i, fusco-virente; anfractibus tronsverse striatis ; aperturis ampla; labro simplici, acuto.

Gualt. Test. tom. 1. fig. f.

Helix aperta. Bonn. MIus. tab. 15. fig. 19. 20.

Helix nerituides. Cuens. Conch, tab. 9. tah. 133. fig. 1204.1205.

Helix aperta. Gar... p. 365 s. no. 192.

Helix nuticoides. Dra p. Moll.pl.u. fig. 7 à 20.

Feros. Hist. des Moll. $n^{\circ}$. 15. pl. 1 1. fig. 17 à 21.

LAark. Anim. s. vert. tom. 6. pag. 69. $n^{\circ}$. 33 .

Coquille glubuleuse dont le dernier tou est très-grand et la spire courte et obtuse; elle est formée de trois à quatre toul's convexes: ils sont ridés on striés irrégulièı ement dans leur lengueur, et leur suture simple est peu profonde. Eu dessous, la coquille est très-convexe, sans ombilic, et terminée par une ouverture très-graade, arrondic ou subovalaire, très-évasée à la base, un peu plus la aute que large. Le péristome, lrès-unince et tranchant, est garni en dedans, daus toute son étendue, d'un Lourrelet plat, blanc de lait. Ce péristome sc continue avec la columelle; celle-ci est rćduite à un lilet spiral extrêmement mince et trancliant. Le bord gauche ne se montre que dans les vieux individus: il consiste en une lame blanche, trèsmince, appliqué dans toute l'éteudue de l'avant. dernier tour qui sćpare les deux parlies du péristome. Celte coqquille est peu variable pour la couleur, qui est partout d'une teinte uniforme, soit brun-verdultre ou jaunâtre, soit vert tcinté de jaune d'ambre. Liépiphragme est remarquable, en ce qu'il est fortement bombé, et toujours appliqué sur la partie la plus externe du bourrelet du péristome : à gauclie il dépasse le bort de l'muverture, et se pose sur le contour nu bord ganche. Cette espèce se tronve en France, à Alger, en Corse, en Sicile, etc.

\section{Hélzce rousse. Helix pulla. GmeL.}

H. testâ subglobosi, ventricosâ, imperforat $\hat{a}$,

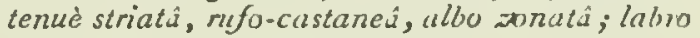
margine interiore albo, reflcxo.

List. Conchyl. tab. 42 fig. 43.

Kxonн, Vergn. 1. tab. 21. fig. 3.

Favaxe, Conch.p!. 63. fig. $m$.

Helix janä́censis. (намм. Conch. tom. 9. tab. 129. fig. 1140.1141 .

G MEL. pag. 3644. $n^{\circ} \cdot 234$.

Ejusd. Helix pulla. pag. 3650. $n^{\circ} .113$.

Helix janaäcencis. Dsuneв. Hist. des Moll. pl. 14. fig. $6-8$.

Lsur. Anini, s. vert. tom, 6. p. 66. $n^{\circ} .5$. 
Var. B.) Nob. Testá rufí in medio albo monozonató, zoní angustá.

Lamarck dit que cette coquille est toute lisse, a u point de ne pas y apercevoir de stries d'accroissement. Nous sommes persuadé, d'après ce que nous avons vu, que les individus que possédoit Lamarck avoient été polis artificiellement, comme on le pratiquoit autrefois sur un grand nombre de coquilles. Cette espèce a une forme très-analogue à celle de l'Hélice peinte; elle est globuleuse, trèsventrae, à spire courte, subconique, obluse, formée de quatre tours aplatis, peu convexes, réunis par une suture simple et saperficielle. Le dernier tour est extrêmement grand, très-convexe en dessous, où on ne voit ni ombilic, ai feate ombilicale. $\mathrm{La}$ columelle est reotrante, et elle continue l'axe de la coquille. liouverture est très-grande, ovale, arrondie, pourvue d'un péristome blanc, épais, renversé en delıors, et très-élargi, surtout sur la columelle. Ie bord columellaire est garni dune large callosité blanche, étalée, épaisse dans quelques individus. La surface extérieure est couverte d'un très-grand nombre de stries fines, serrées, régulières, qui, à l'iaveıse de celles qui se voient sur la plupart des espèces, desceadent obliquement des sutures vers la base et vers l'onverture, coupant ainsi les accroissemens à angle droit. Ces stries ne sont $\mathrm{ai}$ longitudinales, ni transverses, mais dans la diagonale de ces deux directions. En dehors, cette espèce est d'un bron-roux uniforme, avec trois zones blanches sar le deraier tour. Dans la variété, il n'existe qu'une seule zone médiane: Cette coguille est assez rare; elle vit à la Jamaïque, et elle a 57 millim. de ciinmètre.

\section{Hélice bouc noir. Helix melanotragus.}

$H$. testâ globoso-conoideá, ventricosâ, imperforatâ, castanen-fuscâ, inferne albo zonatâ, apice luteo; apertuná transversâ, fundo albo; columellà labroque nigris.

Helix melanotragus. Borv. Mus. pag. 388.

Helix haniastoma. Cuess. Conch. toni. 9. tab. 30. fig. I152. 1153. a. $b$.

Helix senegalensis. Excrcz. pl. 462. fig. 4.

Helix inelonotragus. DäDEв. Hist. des Moll. pl. 32. b. fig. 3. 4. 6 .

Lssx. Anim. s. vert. tom. 6. pag. 70. $n^{\circ}$. 17.

Très-belle coquille recherchée et estimée des amateurs, quoiqu'elle ue soit pas très-rare, à cause de la beauté et de la fraîcheur de ses couleurs. Elle est grande, globuleuse, subconique, formée de cinq à six tonis convexes, dont le dernier est infinimeat plus grand que tous les autres; la sutore est simple et pea profonde. La base de la coquille est très-convexe, non perforée par un crabilic. L'ouverture est grande, transverse, sa- hovalaire; son péristome, très-épais, est tout noir, ou d'un brun foucé ; il est fartement reaversé en dehors, à la base il se conlinue avec la columelle, qui est épaisse, arrondie et bordce par u bord gauche, unince et étalé de la même couleur que le péristome. En dedans, l'onverture est blauche. Sur un fond d'ua blanc-brunâtre, cette coquille est oruée de deux larges bandes brunes, de couleur café brûlé; le sommet, qui est obtus, est fauve ou jaunâtre.

On trouve cette espèce aux $\mathrm{G}_{1}$ andes-Indes, au pied des palmiers.

LiN.

76. Hélrce hémastome. Helix haemastoma.

$H$. testâ globoso-conoideâ, ventricosâ, imperforatî, rufo-castaneâ, inferne albo zonatâ; apice roseo; aperturâ latere dilatatâ, fundo albo; columella labroque purpureis.

Helix hamastoma. LiN. GasL. pag. 364 g. $n^{\circ} \cdot 112$.

Muller , Verm. pag. 78. no. 274.

SEBA, Nus. tom. 3. tab. 40 fig. 6.7 .

Favanise, Conch.pl.64.fig. a. 4.

Caemar. Conch. tom. 9. tab. 130. fig. 1150. 1153 et 3154 .

Schroetrer, Einl. in Conch. 2. tab. 4. fig. 5. 6.

D fig. 1.2 et 5.

Lамк. Anim. s. vert. tom. 6. pag. 70. no.16.

Très-jolie espèce, qui sembleroit n'être qu'une variété de la précédente si elle étoit moins constabte dans ses couleurs : la forme est à peu près la wême; elle a cependant la spire un peu plus courte, ce qui rend la coquille plus globuleuse; elle est formée de six tours arrondis, convexes, séparés par une suture profonde et simple. Le dernier tour, benucoup plus yrand que cous les autres, se termine par une unverture très-oblique, grande, évasée, subtransverse, ovalaire, peu modifiée par l'avant-dernier tou:; son péristome est très-épaissi, fortement renversé en dehors, d'une belle couleur rose pourpre. II se joint à la base à une columelle de même couleur : elle est arrondie, et séparée dans sa longueur du bord gauche par un sillon. Ce bord gauche est étalé, mince et de la mêue couleur que le reste de louverture, qui en dedans est d'un beau blauc. Sur un fond d'un brun fauve ou châlain, cette coquille est oruée d'une zone dun blanc pur sur la partie inférienre du dernier tour : on connoît une variété qui est toute brune. Cette espèce habite les Grandes-lndes.

77. HéLiće chagrinée. Helix aspersa. MoLl.

H. testâ globosé, imperforatâ, rugosiusculâ, 
griseo-lutescente, flammulis fuscis in zonas dispositis; labro margine interiore albo, reflexo.

Helix aspersa. MoleEa, Verm. p. 5g. no. 253.

Lister, Conch. tub. 49. fig. 47.

Goant. Test. tab. I. fig. $e$.

Darcevv. Conch. pl. 28. fig. 3.

Favann. Conch. pl. 63. fig. d. 3.

KNoRr, Vergn. 4.t. 27. fig. 3.

Le Jardinier. Georf. Coq. p. 27. $n^{\circ} \cdot 2$.

Scrroetter, Einl. in Conch. 2. tub. 4. fig. 7 .

Canan. Conch. tom. 9. tab. 130. fig. 1156. 3158 .

Gael. pag. $3631, n^{\circ} .58$.

Draparn. Moll. pl. 5. fig. 23.

DAudez. Hist. des Moll. pl. 18, et rg.pl. $21 . b$. fig. 6. 7, et pl. 24.fg. 3.

Var. a.) Noв. T'estâ luteo-fuscâ imnıaculatâ, fasciis destituti.

Var. b.) Nов. Testâ fasciis tribus vel quaternis lutescentibus instructi.

Var. c.) Noв. Testâ fiusco quinque fasciatâ, fasciis longitudinaliter albo maculatis.

Var. d.) Nов.Testâfusco quadrifasciatâ, fasciis dilucide distinctis.

Var. e.) Noв. Testî fusco trifasciatâ.

Var. f.) Nos. Testâ nigricante, bifusciatâ, lineis albis undulatis fulguratâ.

Var. g.) Noв. Testâ omnind nigrâ, inumaculatâ, ultinid anfractu lineà luteolâ, angustâ, rincto.

Varietates monstruose.

Var. h.) Testd sinistrorsâ.

Var. i.) Nов. Testâ suturis profundè canaliculatis.

Var. j.) Testì truchiforıni; spirâ productâ, non disjuncta.

Var. k.) Testi anfractibus disjunctis, cornuforni.

On pourroit peut-être encore joindre à ces variśrés uoe coquille de la Sicile, qui, quoique beaucoup plus conique ct converle de stries lamelleuses, longitudiaales, se rapproche de cette espc̀ce par des individus qui onl ane coloration analngue; déanmoins, ponr opérer celle réunion, il nous manque des passages de forme que nous crojons nécessaires.

Après l'Helix pomatia, celle-ci est la plus grande espèce qui vive en France; elle se trouve aussi dans toute la partie méridionale de l'Europe. Coquille veutrue, globulease, ayant la spire subconique, courle et obluse au sommet : cette spire est composée de quatre à cinq tours convexes, séparés par une suture simple et peu profonde; les deux premiers tours sont lisses, les autres sont couveris de petites éminences irrégulières, étroites, quelquefuis entremếlées daos le jeune âge de stries longiludinales; en dessous elle est irès-bombée, non perforéc par un ombilic. L'ouverture est graude, arrondie, subovalaire, plus haute que large; son péristome est blanc, épaissi, évasé et réflecbi en dehors; la columelle cst large, presque roujours aplatie, et quelquefois arrondic.

Il en est de cette espece, comme de beancoup d'autres, qui varient cousidérablement sous le rapport de la couleur, quelquefois même de la forme, et dont on réunit cependant toutes les variétés à un même type par les caractères iudélébiles qui sont propres à l'espèce. Dans celle-ci les individus que l'on trouve le plus habituellemen! sont orués, sur uu fond jaunâtre, de bandes transverses brunes, de trois à ciaq, le plus souvent interrounpues à des distances inégales par des tuches blancbes, longitudinales, inéuales, frangées irrégulièrement, ouduleuses. De ces individus ou passe, par des nuauces iusensibles, à des variétés que aous allons inciquer daus l'ordre de la coloration croissante. Var. (a). Coquille d'un jaune fauve, sans taches ni bandes: les aspérités paroissant un pen plus blanches, le fauve passe quelquelois au grisûtre, et wême à une teinte verdâtre.

A la variété précédente s’ajoutent quelques bandes brunes peu foncées, interrompues par des linéoles peu marquées, d'un jaune plus pâle que le fond: Ies individus qui offren I certe disposition constituent nolre variété(b). Isa variété (c), sur un food jaune, présente cinq fascies brunes, plus on moins loncées, étroites, bieı netrement séparées, interrompnes par des linéoles blanches, courtes et rares. Deux bandes se réunissent à la partie supérieure dı dernier tour: la seconde et la troisicme. A partir de la suture il ne reste que quatre fascies. dont l'uae est plus large que les autres: c'est lá variété (d). Dans la variété (c), les trois bandea brunes se réunissen! en une scule large fascie, qui occupe presque la moitié supérieure du deruier. tour; cetre large fascie es! toujours, comme dans les variétés précédentes, interrompue par les taches linéolées jaunes ou blanches. Dans aotre rariétć(f), non-seulement les trois baades supérieures restent jointes, mais encore les dcux inférieures se réuoissen! égalenent, et ces deux large fascies, qui occupent toute la surface du deraier tour, sont séparées par ane ceinture fauve médiane. Sur ces deux fascies, qui sont ordinairement trc̀s-foncées, presque noires, se dessinent trèsnettement les linéoles longitadinales blanches, qui, sonvent onduleuses, donnent à cette variété l'aspect des coquilles dites foudroyées. Enfia, notre variété $(\mathrm{g})$, la plus remarquable de tontes, sans contredit, variété que nous d'avons vu siter nulle part, a le deraier tour occupé par deux 
larges baudes noires, séparées dans le milié par une étroite ceinture jaune. Ces fascies sont continues, bulle part interrompues par des linéoles ou par des taches quelconques. Nous n'avons jamais vu de cette variété que le seul individu que nous possédons: il a été truuvé eu Piémont. Les variét'́s de monstrnosité sont au nombre de quatre seulement : la première, pour les individus sénestres; la seconde, pour ceux qui sont trochiformes, à spire non disjointe, mais fort élancée; la troisième, pour ceux qui sout scalaroides à tours disjoints, à des degrés divers de séparation; la quatrième entin, pour ceux qui ont la suture profondément canaliculée, d'une manière analogue à ce qui se voit dans l'Eburnea canaliculata, par exemple. Nous ne connoissons de cctte variété remarquable que le seul individu de notre collection.

Cette espèce se trouve dans toute l'Europe méridionale, en France, en Espagne, en Iıalie, ed Sicile, cic., daus les îles de la Mléditerranée, sur les côtes d'Afrique, à Alger. Nous la possédons de Cajenne. N1. de Ferussac la cite an Brésil : il est probable qu'elle a été portée dans le NoureauNinnde, et qu'elle s'y est acclimatée.

\section{Héltce ceinte. Helix cincta. Morr.}

H. testá globulosâ, ventricosâ, subtùs convexâ, imperforctá, fucescente, zonis duabus tribusve fusco nigricuntibus cinctí; spirá conoideâ, lonEltudinuliter transversìmque striatâ.

Helix cincta. Mulc. Verm. pag. 58. " $^{\prime \prime} .251$.

Gustrier, Test. tab. 2. fg. B.

D.unEB. Hist. nat. des Mall. $n^{\circ}$. 28, pl. 20. fig. 7. 8; el $p l .24$. fig. 1, avec l'animal.

Crefuille globuleuse, voisine par ses rapports r.e l'Heltx. melanostani de Draparnaud et de l'Helix pomctia; clle dilfiere cependant d'une manière sonstaute de l'une et de l'uutre : el!e est arrondie, Elolutleuse, à spice ubtuse, légèrement alongée, à laquelle un conpie six tours arrondis, conrexes, dont la sulure est simple et peu profonde : le somret, riui est d'un blauc-grisàlre, est tont-à-lair lissi. Sur les tour's qui suivent, on remarique d'alicrd des stries longiludinaies fart régulières, qui deviennent de plus en plus irrégulières à mesure quacin les examine jusqla $u^{2} a$ dernier tour, oủ elles ne sout plus que des traces i:régulières d'accruissement; les siries longitudiales, juscju'au dernier tour exclusivemeut, sont coupées en iracers par des stries transverses, fines ct profondes, assez rapprochées, et efui découpeat la su:face de la spire en perites granolations quadrangulaires, quel rquefois irrégulières; ea dessous la coquille est l'es-convese, sans ombilic ni fente ombilicale. Jouverinte est assez graude, arrondie, semi-lnniale, brune en dedans; son périslome, épaissi, lérérenient renversé en dehors, est d'un brun foincé, quelquefois violàtre; il est épais, surtout ì la base de la columelle; le bord gauche est arqué, peu élargi, assez épais, et de la même coulear que le péristome. Sur un fond d'un brunblanchâtre, ou grisâtre, ou jaunâtre, cette coquille est orrée en dehors de deux et quelquefois trois zones d'un brun foncé, dont la superieure, la plus nette et la plus constante, est la seule qui remonte sur la spire jusque près du sommet. $D^{\circ} a-$ près M. de Ferussac, celle espèce se trouve à Trieste, en Grèce, à l'íle de Chypre, à Constanti. nople et à Tripoli de Syrie. L'individu que nous possédons a été rapporté par Olivier. Longueur : 40 ì 45 millim.

79. HÉLICE maculeuse, Helix maculosa. BoRx.

H. testâ glaboso-depressâ, ventricosâ, subtìs convexâ, pefforatâ, albâ, fulvo maculosá; anfractibus trunsverse striatis; labro margine reflexo, albo.

Helix maculosa. Bons. Mis. t. 14. f. 15.16

GuEc. p. 3622. n०. 164 .

$\mathrm{D}_{\triangle \mathrm{D} \text { 口в }}$. Hist. des Moll. no. 45. pl. 28.f.g. 10.

Ejusd. Helix irregularis. Hist. des Moll. $n^{\circ} .44$. pl. 28. fig. 5. 6 .

Calulaud, Voyago à Miéroé, tom. 2. pl. Co. fig. 1. 2. 3.

Lams. Aninu. s. vert. tom. 6. pag. $7^{2} . n^{\circ} \cdot 24$.

Nous croyons que c'est avec juste raison que Lamarck a réuni les deux espèces que M. de Ferussac a séparées. M. de Ferussac doit eu être bieu convaincu maintenant que celte espćce, rapportée par M. Cuillaud en assez grand numbre, est deveaue commune daus les collections. Il s'établit des passages par un grand nombre de variétes enire les individus tout blancs et ceux qui sont tuut bruns, et dans toutes les nuances on retroure les variétés de forme qui ont valu à un certain nombre d'individus le nom d'irréguliers. L'Heli.x maculosa est une corjuille globuleuse, à spire ubtuse, plus ou moins saillante, assez variable dans ses proportions, se rapprochant quelquefois de 1. forwe de l'Helix globulus, et d'autres fois des individus aplatis de l'Helix vemiculatu; sa spire est cumposé de cinq lours arrondis, ronvexes, dont le dernier est plus grand que les autres; li suture est simple et peu profonde; tous les tours, si ce n'est quelquefois le dernier, sont striés fincment et régulièrennent dans leur longueur; las stries sont arrondies ei obtuses. En dessous, la con quille est trés-bombée; elle s'élère, et devient bossue vers le centle; l'ouverture est semi-lunaire, arrundie, médiocre, d'un beau jaune fauve en dedans; son bord est blanc, renversé en dehors, et épais, surtout à la base. Cette espèce est quelque. fois d'un blanc par, et passe, par des nuances insensibles, au brun chátain, coupé seulement par des lignes blanches, qui indiqueat d'ancicas pé- 
rustomcs. Parmi ces nuances, on en troove arec truis ou quatre bandes sur un fond bruo clair on sur le fond blanc : quelquefois ces bandes sont formées par des taches de grandeur variable. Cette espèce se troure dans toute l'Egypte; elle a 32 à 35 millim. de diamètre.

80. Héuce némorale. Helix nemoralis. Liw.

H. testâ subglobosâ, impevforat $\hat{a}$, tenuiter stria. tá, colore varià, nunc unicolore, nunc divertis. sintè fasciatí; labro niargine interiono nigro.

Helix nemoralis. Lin. Gres. p. 3646. no. 108. Mollea, Verm. p. 46. no. 246.

I,a Livrée. Grozf. Coq. p. $46 . n^{\circ} .3$.

Lister, Conch. tab. 57. fg. 54.

Dangenv. Conch. pl. 28. fig. 8; et Zoomorph. pl. $9 \cdot f g \cdot 5$.

Fataxiv, Conch. pl. 63. fig. h.

BонN. Mus. tab. 16. fig. 3 aे 8.

Chesrn. Conch. t. 9. tab. 133. fig. 1196.1198.

Draparn. Moll. pl. 6. fig. 3 à 5 .

D.sudeb. Hist. des Moll. pl. 33. a. fg. 2. pl. 33. 34, et Fl. 3g. a. fig. 3. 4 .

Pretrfen, $S_{j}$ st. anort. tab. 2. fig. 10.11.

Lasк. Anim. s. vert. tom. 6. pag. 81. no. 58.

On vorra, par ce que nous avons dit à l'occasion de l'Helix sylvatica, ce que nous entendons par les espèces nunımées Helix nemoralis et hortensis. Si l'un cansulte Linué, Draparnaud et Lamarck, on reconnoit que le caractère principal qui distingue l'Helix nemoralis de l'hortensis est la couleur du péristame, nair dans la première, blanc dans la seconde. II paroil que M. de Ferussac a pour distinguer ces espèces ua moyen qui nous a jusqu'à présent échappé, car on trouve des variétés de l'Helix nenoralis daus son grand ouvrage qui ont l'ouverture blanche, et dans son Helix hortensis une variété à bonche brune. Nous ue supposons pas que M. de Ferussac ait voulu distinuruer ces lleux espćces d'après la taille seulement; cet uhservateur sait trop bieu que le peu de cunstance de ce caractère le reud d'uuc applioution presque impossible et irrationnelle tout à la fois.

L'Lélice némnarale se distingue de la sylvatigue eu ce qu'elle a grénéralement les handes beaucoup plus netıes, et que son péristome est noir au lieu l'ître runget̂tre; elle se distingue de l'Ilélice des jardins par le péristome seulement, qui est blanc dans celle-ci et noir dans l'antre. Ces distinctions sont certainement très-faciles à opérer quand on r'a que des coquilles à boucbe noire, à bouche blanche, à bouche roséc et à bandes interrompues; mais que fera-ton d'une suite nombreuse de varićtés qui ont les bandes nettement Iraachées et qui ont l'ouverture rose, participaot ainsi anx caractc̀res de deux espèces? Nous ne royons dans ces variétés que des intermédiaires qui lient les deux espèces, et nous en sommes d'autant plus persuads, que nous observons une dégradation insensible entre les péritomes noirs, les roses et les blancs. Ces observations nous avoient conduit à la réunion en une seule espèce des Hélices aémorale st des jardins; nous avous été confirmé dans ce résnliat par les nombreuses dissections que nous avons faites if y a quelgues années, dans l'espérance de trouver dans les organes de la génération un caraclère qoi pût servir à les distinguer; nous pouvons assurer d'une manière positive qu'il n'existe pas la plus petite différence à cet égard entre les deux prétendues espèces.

L'Hélice némorale est extrêmement variable; on se rendra facilement compte de cc nombrt: considérable de variétés, si l'on veut faire alten:ion aux éléments de variations et à leur combinaison. On remarque dans la némorale deux couleurs de: fond bien distinctes: la jaune et la rouge; dans l'une et dans l'aulie on compte de une a cinc bandes brunes; quaud il n'y en a que quatre, c'est ou la première ou la seconde, en comptaut de has en haut, qui manque : ce sont cinq variétés à ajouter aux premières. Le même nombre se représente pour les variétés à trois, à deux et à une seule bande. A ces rariélés il faut juindre celles qui résultent de la place occupée par les bandes sur la surface de la coquille: s'il y a une seule bande, par exemple, elle jeu èıre en dessous, au milieu ou en dessus; s'il y un a deux, elles peuvent être coules deux en dessus, ou au milieu, ou en dessoms, ou bien l'uue en dessus, l'autre en dessous, ou bien encore l'une au milien, l'autre en dessus ou en dessuus. Les variétés se multiplient encore par les combinaisons entre trois et quatre bandes; Ia ais ce a est pas tout, les bandes varient de largeur, soil parce qu'elles se réunissen:, soit parce qu'elles s'élargissen: en restaot en mêune nombre. Quelquefois c'est une seule bande qui devient plus large; elle peut ètre on la première, ou la secoude, ou Ia truisième, elc. Si ce sont des bandes qui se réunissent, ce soul encore de nouvelles combinaisons, par couséquent de nouvelles variétís, ca. ce sont la preanière et la secondc bande qui se sont réunies, ou la seconde avec la troisième, onl la qualric̀ne avec la cinquic̀me : deux ou truis bandes peuvent être confoudues, soit en dessus, sout en dessous, et les autres manquer, soit totalement, soit l'une d'elles. On roit par ce que nous renons de dire combien sant nombreuses les combinaisons possibles, et combien par conséquent les varitit's se anultiplient. En arra:ugeant toutes ces variétcis dans un ordre déterminé, on voit l'Hélice uéumorale passer de la couleur du fund sans taclies à la couleur noire complète, qui résulıe de la jonction de toutes les bandes qui naissent et s'llägissen! successivement. Nous n'indiquerons pas, comm. 
240

H E L

on doit le croire, les variétés une à une; ce que nous avons dit doit suffire pour qu'il soit facile de les reconnoitre et de les arranger.

Cette espèce se trouve dans toute l'Europe.

\section{HÉLICE des jardins. Helix hortensis. LIS.}

H. testà subglobosâ, imperforatá, glabrâ, subdiaphanâ, colore variá, nunc unicolore, nunc dewersissimé fasciatá; labro margine interiore albo.

Helix hortensis. Mulder, Verni. p. $52 . n^{\circ} \cdot 247$.

Eon.. Mus. tab. 16. fig. 18. 19.

Chems. Conch. tomi. 9. tab. 133. fg. 1199 à 1201 .

GIEL. pag. 3649. no. 109 .

Draparn. Moll. pl. 6. fig. 6 .

Daudeb. Hist. des Moll. pl. 35. 36.

Lans. Anim. s. vert. tom. 6. pag. 81, $n^{\circ} .59$.

PFEIFEer, Syst. anord. tab. 2. fig. 12. 13.

Espèce non moins communément répandue et non moins variable que l'Hélice némorale; nous la regardons, au reste, ainsi que nous l'avons dit, comme une variété de cette dernière, don! elle ne diffëre, comme nous lavons vu, que par la blancheur du péristome. Nous retrouvans dans cette variété à bouche blanche toutes les combinaisons de coloration et d'accidens divers que nous avons fait remarquer dans l'Hélice némorale; nous observons une série de variétés commençani par le jaune pur et fanissant par le noir, produit par la naissance successive de bandes naires de une à cinq; leur élargissement, lear jonction, qui donne la leinte noire ou brune uniforme lorsqu'elle à lieu entre les cinq bandes. A côté de cette súrie, on en voit une autre analogue pour les individus qui ont le fond rouge au lieu de l'avoir jaune. linfin, il existe une troisicme série de coquilles fort scmarquables, qui, avec le lond jaune ou rosé, vat les bandes trausparentes an lieu de les avoil brunes ou noires : ces bandes sont du reste disposées et en même nowbre, comae si elles étoient colorées. Il est inutile de donner sur cette crquille plus de détails, ce que nous avouns dit des Hélices sylvatique et némorale devaat sullire, et nous y rer.royous.

Elle se trouve dans toute l'Europe.

82. Hélice sylvatique. Helix sylvatica. Drap.

H. testâ subglobosâ, imperforatí, minutissimiè stratá, subtiss lutoscente, supernè albida, fusco fascrata, lineis luteis interruptis cinctü; spirû ob¿usá; labro tenui, margine exteriore pallidè rubro.

Helix syluatica. Da apara. Mioll. pl. 6. fig. 1. 2. Daudes. Hist. des Moll. pl. 3o. fig. 4 à 9. pl. 32. fig. 7 , et pl. 32. a.f. 5 a 8 .
$\mathrm{H} \mathrm{E} \mathrm{L}$

LA Ak. Anim. s. vert. tom. 6. pag. 82. $n^{\circ} .60$.

Nous ne voyons dans cette espèce de Draparnaud, adoptée par les auteur's, qu'une variété sylvicole de l'Helix nenoralis, à laquelle il faut réunir l'Helix hortensis; nous sommes forcé de convenir qu'après avoir rassemblé un très-grand nombre de variétés de ces truis espèces, dans l'espérance de parvenir à les distinguer facilement, le contraire a eu lieu, et tous les caractères donaés pour les distinguer nous échappent de plus en plus, tandis qu'au contraire, cous trouvons dans l'ensemble de toutes les variétés du nemoralis, de l'hortensis et du sylvatica les caractères constaus d'une espèce extrếuement variable: les élémens de variations sont tels, ils penvent entrer en combinaison de tant de unanières, que nous avons la conviction que l'on finira par' rassembler au muins deux cents variélés de l'espèce telle que nous voudrions quion la considérât. Ce nombre de variétés nous semble d'autant moins exagéré, que, quoique nous soyons loin de posséder toutes les variélés connues, nous en avons rassemblé cependant, de quelques puints de la france seulement, près de cent cinquante, et nous ne connoissons ni celles de l'Europe septentrionale, Allemagne, Pologne, Russie, ai cclles de l'Europe méridionale, où elle est en aboudance, et où elle éprouve bien probablement, par suite des causes locales, des variations uon moins nombreuses que chez nous.

Nous sommes persuade que, plas tard, on $\in \mathrm{L}$ viendra a réunir les trois espèces dont nous parlons en une seule. Pour faire avec fruit ce chaugement, il faudroit entrer dans des détails que cet ouvrage, réduit cornmeil l'est, ne peut comparter; il faudroit aussi appuyer par des figures certaines choses qui pourraicnı être cuntestées, ce qu'il ne nous est pas permis de faire non plus. Ainsi, quoique nous donnions ici, comme nos prédécesseur's, les trois espèces dont il est question, nous ne le faisons pas dans le même esprit qu'eux, mais pour ollirir anx olsservateurs trois types principaux d'une même espèce, auxquels ils pourront plus facilemeat rattacher les nombreuses variétés qu'ils seront à mémc de rencontrer.

LiHélice sylvatique est ylobuleuse, mince, légère, et sulide cependant; striée longitudinalement d'une manière assez régulières, des stries trausverses nombreuses, peu sensibles, si ce n'est à uoe forte loupe, coupent les premières à angle droit. Il est des uadividus sur lesquels ces stries transverses ne paroissent pas. La spire a cinq tours arrondis, séparés par une suture simple et peu profonde : en dessuus, elle est légercment aplatie, nod jerforée par un onbilic. L'ouverture est médiocre, scmi-luarire; le péristome est à peine reaversé en deliors; il est brun, violet ou rose, et garni d'un bourrelet blanc en dehors: sur le bard gauclse, il s'aplatit, devient tranchant à l'extrénité comme s'il avoit étú pincé entre les doígts. La

colucselis 
columelle est cacbée par une callositć de la méme conlear que le péristome.

En dessous, cette coquille est habituellement janne, et blanche en dessus. Il arrive cependant cy'elle est on toute blancbe ou toute jaune. Elle est ornée de bandes on fascies transverses d'une à cinq, comme dans les Helix hortensis et nemoralis. Ces baades présentent cela de particalier, d'être presque toujours ou interrompues, et réduites par conséquent à des séries de ponctuations, ou frangées parles bords, ou la mmulées lorsqu'elles sont larges. Ces bandes ou fascics sont ordinairement d'un brun foncé lorsqu'elles sont un peu continues; elles sont pâles lorscyu'elles sont représentées par des séries de ponctuations.

Il existe, dans cetle espèce, comme dans beaucoup d'autres, des variétés monstrueuses, et entr'autres, une scalaroide signalće par M. de Feruisac. Cette coquille vit dans les foréts ombragées de l'Europe septentrionale.

83. Héntce splendidc. Helix splendida. Drap.

H. Testí orbiculuto-depressâ, impeforatâ, lovi, nitidi, albá, fusco lineatâ; spirí brevissins $\dot{x}$; labro margine interiore albo, senireflexo.

Helix splendida. Drap. Moll. pl. 6. fig. 9 à 11 .

Dav D. Hist. des Moll. pl. 40. fig. I ì 6.

LAirz. Anin. sans vert. tom. 6. pag. 82. $n^{\circ}, 62$.

Var. A. ) Testâ albá, translucidí, albo opraco cinclá.

Var. B.) Testâ albá, fusciü quinque vitreis ornalá.

Var. C. ) Testâ quinque fasciatü, unicá in medio fuscá, continusi, alieris punciualis.

Tar. D.) Testá fusco quinque fusciatá, fasciös continuis.

Var. E.) Testá trifasciatá, fusciá suiperiore latiore.

Var. P.) Testá trifuscialá ; fusciis fummulis nu'nerosis, junctis.

Var. G.) Testá omnind fusco, nigricante.

Jolic coquille mince, fragile, lisse, légère, díprimée, arrondie, à spire aplatie, formée de quatre cours peu convexes, don! la sulure est simple et superficielle. La base, peu convexe, est perforée; l'ombilic est caché par une callosité légèrement déprimée. Le dernier tour, assez grand, se termine par une ouverture arrondie, semilunaire, très-oblique à l'axe de la coquille. Le péristume est blanc, légèrement rêféchi en dehors, et bordé en dedans d'un petit bourrelet blanc. La coloration la plus babituelle de celle coquille est le b!anc, sur lequel se dessinent cinq raies brunes plas on moins foncées, quelquefoiz découpées sur

Hist. Nat. des Vers. Tome II. les bords; trois de ces bandes sont à la partie supéricure des tours et se continuent jusqu'au sommet de la spire, les deux autres sont inférlieures et plongent dans l'ouverture. Les variétés de cetle especce sont assez nombreuses; elles moutrent, comme dans plusjeurs autres, par des nuances insensibles, le passage du blanc au noir, ou de la couleur pure du fond a relle des bandes.

La première est remarquable en ce qu'elle est en dessus et en dessous d'un blanc-jaunâtre Iransparcat, et qu'elle ollie, dans le milieu du dernier tour, une ceinture d'un blanc-opaque, tres-tine et contiuve. La seconde variété est également blanche, mais opaque, a vec cint bandes étroitcs, transparentes, disposées de la mêıne manière que si elles étoient hrunes. Dans la troisiẻme variété une seule bande brune continue se voit sur le milien du dernicr tour, les quatre autres bandes sont in diquées par autant de séries de ponctuations d'un brun pále. La quatrieme variété est l'état le plus commun de l'espèce : elle offre cinq bandes brunes continues, plus ou moins foncles, quelquefois dentelées sur leurs bords. Dins la variété suivanle, qui est la cinquic̀me, il n'y a que trois bandes brunes, les deux inféricures s'élargissent, et les trois supérieures se sont réunies en une seule large fascic qui reste tonjours séparée de la suture par nne zone blanche. Parmi les individus à trois bandes, on en remarque qui ont ces bandes réunies par des flanmules qui passent de l'une à l'autrc; de sorte que les intervalles des handes sont articnles par des taches alternatives, blanches et brunes : celte modification, qui constitue notre sisième variété , fait le passage à la septic̀me, qui, ttant toute brune, oflire la junction des cinq bandes en une seule.

Cette coquille est commune en Provence, dars les Pyrénées, en Espagne.

84. HéLıce porphyre. Hélix arbustorum. Lis.

H. testá subglobosâ, perforatâ, solidâ, tenuiter striata, luteo-virente, maculis rufis minimis creberrinuis adspersá; ultino anfractu fasciâ fuscá cincto; spirâ urevi, conoideá; labro margine albo, reflexo.

Helix arbustorum. Lis. Gres. pag. 363o. $n^{\circ} .53$.

MoLLEn, Verm.p. 55. no. 248.

Lister, Conch. tab. 56. fig. 53.

Goalt. Test. tab. 2. fig. aa. $b$ b.

SEBA. Mus. tom. 3. tab. 38. f. 68.

Cuern. Conch. tom. 9. tab. 133. fig. 1202.

Drap. Moll. no. 16. pl. 5. fig. 18.

DaUdeB. Hist. des Moll. no. 40.pl. 25. fig. 5-8, et $p l .29$. fig. $1-3$.

Lasx. Anim.s. vert. tom. 6. p. 80. $n^{0} .56$.

PEEIEEER. Syst. anord. pl. 2 . fig. $7 \cdot 8$. 
Var. A.) NoB. Testâ albo rufescente, maculis albis adspersâ, in medio non fisciata.

$\mathrm{V}_{\Delta \mathrm{R} .}$ B.) Noв. Testấ luteâ, immaculatâ, lineâ nuf cinct $j$.

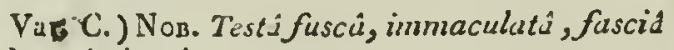
suźnigrì cinctâ.

Var D. ) Noв. Testá fuscâ, albo lutcove ma. culutâ.

Var. E.) Nuв. Testi nigricante, fusco maculata.

Coquille globuleuse, quelqnefois subconique, dure et solide, qunique peu épaisse, composée de six tours convexes, légrèrement plissés au-dessous de la sature, qui est peu profonde; les deux preraiers tours soat parfaitenient lisses et oblus, les saivans sont régulièrement striés en travers: les stries sout très-fines, rapprocliées, et ne s'ilperçoivent qu'à l'aide d'une bonne loupe. Le dernier tour, globuleux et arrondi en dessus comme en dessous, est percé à la base par une petite lente unbilicale, en grande partie recouverte par l'expansion da bord gauche. L'ouverture est d'une taille médiocre; son péristome est blanc, Epais et rélléchi. Les individus que l'on trouve le pllus comranérment sont d'un brun-verdàtre ou jaunâtre, parsemés d'an grand nombre de taches blanches, ou jannes et ornés, sur le deraier tour, d'une zone mécliane l'uo brun noir qui trauche nettement sur le lond. On tronve des individus ( Var. A) qui sont d'un jaune de corne, parsemés de quelques ıaçlies blanches, et dépourvas de la fascie noédianc. D'autres, vivant dans les Alpes, sont fanres, sans laches, avec la ligne brune: ils sont plus petits. La Variété (C) est brun foncé, sans taches, avec la zone brune. Notre Variélé (E) est d'une leinte presque noire, parsemée de taches brunes et ayant la ceinture très-foncée Elle se trouve en France et en Allemagne.

85. Hézice veruiculée. Hclix vermiculata. Nitu.

H. testâa subglobosi, depressiusculi, imper-

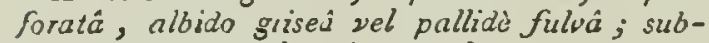
fascict $\hat{A}$, punctis lineolisque aibis minimis adspersi; spiri brevi; labro margine-interiore albo.

Helix vermiculata. MJLLER. Verm. Fag. 20. $n^{\circ} .219$.

Perry. Gaz. tab. 52. fig. 11.

Gu.1Lt. Test. tab. 1. fg. g. h.

Favasie, Conch. pl. 64. fig. k. 2. k. 3.

Caear. Conch. tom. 9. tab. 129. fig, 1148. a. b. c.

GMel. pag. $3616 . \pi^{\circ} \cdot 253$.

Dr.s. Moll. pl. 6. fig. 7.8.
DaUDEB. Mist. des Moll. $\mu l .37$, et $\mu l .39^{\circ}$ a.f. 5.6 .

LAss. Anim. s. vert. tom. 6. pag. 66. n०. 10. Var. A. ) ов. Testî albâ subrufescente.

Var. B. ) Nов. Testâ omanind grisen-fuscâ; subbizonatâ.

Var. C. ) \ов. Testâ quinque fusciatâ; fasciìs albo fuscoque articulatis.

Yar. D.) Nов. Test. quadrifusciati ; fasciis omnibus albo, fusco et luteo articulatis.

Var. E.) Noв. Testá quinque zonatâ; zoni superiore fusco et alḅo articulatâ, altevis nigricantibus integris.

Var. F. ) Noв. Testâ albâ, quinque zonatâ; zonis continuis nigricantibus, non interruptis nec punctatis.

Var. G. ) Noв. Testâ albâ, fusco-rigricante, quadrifusciutŝ.

Var. H. ) Noв. Testî spirâ productiore, triftusciatâ ; fasciâ superiore latissimô, albo maculatá el punctatî.

Vаг. I. ) Nов. Test ł̇ omnind subfuscá.

L'Hélice vermiculee est un peu variable pour la forme, majs elle l'est bien davantage ponr les coulenrs. Nous comptons nenf variétés, mais on ponrroil en faire un plus grand nombre, si l'on vouloit s'allacher à trop de minuties.

Si on reut en suivre la progression, on s'assurera qu'il en est de ceite espèce comme de beancoup d'autres, qui pissent du blanc, qui est la covileur du fond, au brun foncé, qui est celle des fascies. Malerré ces cliangements dans la culoration, il resie dans la forme et clans les couleurs elles-mèraes les caractères propres a l'espèce. Celle-ci est grande, glubulense, dépriı́é, ayant plitót dans sa forme de la ressemblance avec l'Helix nemoralis qu'avec l'aspersa. Formée de rinq à six tours convexes, dunt le dernier est proportionné avec les autres, la suture qui les sépare est simple et peu profoncle. Quand on examine cette coquille à une forte loupe, on voit que le sommet, qui paroit lisse, est cependant finement strić longitudinalement; rers le quatrième tour, ces stries disparoissent pour faire place à de petites aspérités irrégulières, pliciformes, contrarjés dans presçue tous les sens. La base de la cocquille est aplatie; ane callosité cache l'ombilic. L'ouverture, loute blancbe, est médiorre; elle est arrondie; les bords, à leur extrémité, tendent à se réunir; elle est très-oblique it l'axe, ì tel point que lorsque la coquille repose dess'as, l'uxe est peu incliné á l'borizon; le périslome est fort épais, évasé, renversé en dehors, sans être bordé en dedans. La coquille est blancbe, et dans le foud de l'ouverture on aperçoit les baudes brunes du dehors; le test est épais, solide, d’un blanc opaque, el orné le plus crdinairesent de quatre ou cing fascies brunes 


\section{H E I}

plus on moins foncées, gnelipuefris confuses, fivenent ponctuées de blauc ou articulées de la même couleur; lorsque les bandes sont confuses, alors toute la coquille est parsecó́c de ces punctuations blanches.

Notro variété A se compose d'individus blancs, légèrement teintés de fauve en dessus, sur lesđjuels on a'apercoit aucune trace de fascies ou de baades. Cette variété remarquable uous auroit paru le résultat d'une altération, si nous n'avious trouvé dans les coquilles les restes desséchés des animaux, ce qui prouve qu'ils n'ont pas Gté long-temps suumis aux iullueuces atmosphériques.

Dans la variété $B$, la coquille devient partout d'un gris-jaunâtre, et l'un commence à distinguel deux zones plus foncées; les ponctuations blanches commencent aussi is se montrer. La variété C oflie cinq bandes pales, si ce a'est l'iulćrieure, qui est linéaire et plus foncée. Cies bandes sont régulièrecient tachetées de blanc alteraant avec le brun; tlles sont deutelées sur leors bords. La variélé $D$ a les rroisième et quaırième bandes réunies, ce qui réduit à quatre leur nombre total. Les supérieures sunt páles, nuagcuses, mais les deux inférieures sont herdées de cliaque cỏlé par une linévele noire, tandis que, dans le milicu, elles sont arlicultes par des iaclics alternatives blauches et brunes. La variéte E est remarquable, en ce que Is baude supérieure seule est articulée de taches llapches el brunes, les quatre autres bindes Erant brunes, continues, netteuent trancliécs surle tuad Llanc. La variéte $F$ ue dillëre de la précédente que par cetle bande supérieure, qui devient taule brune conme les autres. Puur la varićté $G$, lis Laudes deviennent presque noires; la troisième ct la quatrieme, en comptant par le bas, se joiFnen:, et n'en forment yu'une plus large et aussi l.etce que les autres. Dès-lors, il ne reste plus cjue Guatre bandes sur le dernier tuul. La variété $H$ clfre les trois bandes supérieures réunies en une large fascie qui occupe la moitié supérieure du dernier tour: dans celte variété les bandes sont d'un brun châtain, el sont parsemées d'un très-grand nombre de ponctuations blanclies. Nous possédons uue undilication de cette variété, dans laquelle Is large fascie supéricure est toute d'un brun fancé, sans la moindre taclue blanche. Enlin, rutre dernière varićté(I), qui a le lest généralemeni plus petit, sewbleruit une modilicision de la variúté $B$, par lacpuelle la corfuille seroit devenue toute Lrune au lieu de yrise qu'elle étoit, les baudes Élant aussi peu apparcates dans l'une que dans lautre.

Cette espèce paroit répandue dans tout le littoral earopéen de la Méditerranée; c'est de la Sicile que provienuent les variélés blanches et à zones noires continues; la variété II vient de Majorque: r'est à notre suvant ami M. Cambessedes que nous In derons.
H E L

24.3

86. IIÉrice vigneronne. IIelix pomalia. Lis.

II. testâ globosâ, imperforatî, albidà wel pallide fulva; ; zonis tribus luteo-rufesccntibus cinctá; anfractibus transverse striatis; lubro margine subreflexo.

Helix pomatia. Lrs. Guer. pag. $3627 \cdot n^{\circ} .47$.

Mulier, Vemm. p. 43. $n^{\circ} \cdot 24 \overline{3}$.

Lister, Conch. tab. 48. Jig. 46. $a$.

Guadt. Test. tab. 1. fig. a. b. c. c.tab. 2 fig. 6.

Dangesv. Conch. pl. 28. $f$. et Zoomorph. pl. $9 \cdot f_{g} \cdot 4$.

Le Vigneron. Groff, Coq. p. 24. $12^{\circ}$. 1 .

Caess. Conch. tab. 128. fig. 1 !:38. a. b. c.

Drap. Moll. no. 15. pl. 5. fig. 20. 21. 22. 25.

Davded. Hist. des Mull. $\mu l .21$, el pl. 34 . fig. 2.

l'FeIfF. Syst. anord.pl. 2. fig. 9 .

LAsk. Anim. s. vert. tom, 6. p. 67. no. 8.

Var. «.) Testà sinistrors.d.

Var. ß.) Testì scaluri, infractihus disjunctis

Cette coquille est la plus grande des espères do France, el en nuême temps l'une des plus coin. munes; elle est arrondie, glubuleuse, renflée; som lest est mince, mais dur et solide. La spire, ub. tuse au sommet, quoique subconique, est composé: de cing ì six tours arrondis, séparís par une suírs simple et peu prolunde. I.es plemiers tours sont lisses ; les autres, et surtutit le dernier, sozt chargés de stries lougitudinales, pen régulières, qui sont le résultat des accroisseucos : ces stries longitudinales sont coupées en travers par des stries transverses très-fines, que l'on ne vor: bien qu"ä l'aide de la loupe. L'ouverture est grande, arrondie, le périsiome est d'un brun-violàtie pâle; 1l se renverse légèrement en delıors", urais il se coucourne en une columelle arrondie qui caclie une urande partie de l'ombilic. Cetle coquille est d'un fiuve-brun, plus ou moins foncé; elle oflíre trois a ciuq bandes bruncs, un pea conluses, mais bien. distinctes dans les jeunes individus. Pendantl'biver, le Mollusque se cior au moyen d'un épiphragme blanc et calcaire. Lat variété sénestre est fort rare; elle ne diltère des autres que par ce qu'elle tourae à gauche. La variété scaldriforme est plus rare encore; elle est fort longue et ressemble à une scalaire. Certe coquille habile en France, eo $\mathrm{Ao-}$ gleterre, en Allemagne, etc.

87. Hélice changée. Helix lucontm. Mulcer. H. lestâ globosî, perforatâ aut impeforatâ, zonis duabus rufis latis fusco maculatis cinctâ, albo fascialá; spirâ exsertiusculì, pallidè rufấ, lineatî; labro margine reflexn.

Helix castanea. Ouv. Voy. pl. 17. fg. 1. a.h. IIelix luconum. DAUD. Hist. des Moll. pl. 21. a. $\mathrm{HL} 2$ * 
Mulc. Vem. pag. 46. $n^{\circ} \cdot 245$.

Guast. Test. lab. 1. fig. c.

L.six. Anint. s. vert. tom. 6. pug. $67 \cdot n^{\circ} \cdot 7$.

Quaud on concrit l'extrême variabilité des coquilles sons les iuflluences locales, et même quelquefois dans les mêmes lieux, on est porté à établi: moins d'espèces qu'on ne le feroit si on a'avoit coustamment celte circonslance présente à la mémoire. Nous faisons cette réllexion à l'occasion de celle espèce, partce que nous sommes persuadé, sans en avoir la preuve matérielle, qu'elle n'est qu'une simple variété de l'Helix pomatia. Nous croyons que l'Helix pomatia fait le commencement d'une série dont celle-ci fait la fin, mais dont nous ne connoissons pas les points intermédiaires. Cette coquille est généralement plus grosse que la ponatia; elle est globulense, arrondie, à spire courte et obluse, foruéc de six tours, dont le dernier est plus grand en proportion que les antres. Les premiers tours sont striés longitudinalement, tandis que le dernier n'offre plus d'autres stries que celles de ses accroissemens. En dessous, la coquille est très-convexe, sans ombilic, ni fente ombilicale. L'onverture est assez grande, semilunaire, arrondie, à péristome épaissi et réfléchi, surtont à la base: ce péristome est d'un brun-rouge; l'onverture est en dedans de la même couleur, mais teintée de blanc; en dessus, sur un fond d'un fanve clair, se dessinent deux à quatre bandes, d'un brun plus ou moins foncé, qui souvent sont réunies par des flammules longiludinales, qui be sont interrompues que par la zone blanche du unilieu du dernier tour. Celle coquille se trouve à Constantinople, cn Sicile, cn Grèce, en Italie. Elle a quaelquefuis 57 millim. de diamètre. Drap.

88. Hélice mélanostome. Helix melanostoma.

H. testâ globosâ, imperforatâ, crassiusculâ, longitudinaliter striatâ, cinereá, subfasciatâ, aperturầ rufo fuscâ ; labro simplici, acuto.

Gualt. tab. 2. fig. c.

Helix melanostoma. DRAp. Moll. pl. 5. fig. 24 .

DaUdeв. Hist. des Moll. pl. 20.fig. 5. 6. 9, et pl. 24. a. fig. 1 .

Laxx. Anim. s. vert. tom. 6. pag. 71. $n^{\circ} .2 \mathrm{~J}$.

L'Hélice mélanostome est une coquille globuleuse, qui, pour le fucies, a des rapports avec I'Helix pomatia. La spire est courte, obluse, composée de cinq tours arrondis, irrégulièrement striés dans leur longueur. Ces stries sont les traces des accroissemens. La sulure est simple, peu profonde, quelquefois légèrement ridée par l'irrégularité des stries qui en partent. La base est trèsbombée, sans ombilic. L'ouverture arrondie, subsemi-lunaire, a le hord droit ordinairement simple et uo peu oblus, mais quelquefois aussi bordé en
H E L

dedans d'un bonrrelet peu saillant. I.e bord droit, en se confoodant avec le gaucbe, s'arrondit, et finit par se renverser sur la colnmelle : celle-ci est bord́e dans toute sa longueur par le bord gauche, étalé et plaqué dans toute sa longueur; tout le péristome, en dedans, et tout le bord gaucbe de cetle ouverture, sont d'une couleur brune foncle, café brûlé. La surface extérieure est d'un blancjuunâtre ou grisâtre, avec une assez large fuscie lorune sur la partie supúrieure du dernier tour jusqu'à la suture. Celte coquille, commune en Provence, aux environs de Marseille, se trouve aussi en Ëgyple et en Syrie.

89. Hérice porcelaine. Helix candidissima. Drap.

H. testâ subglobosâ, perforatâ, striat $\hat{x}$, subtìs planiusculí et lovviore, albá; spirá turgidulà, obtusâ; labro simplici.

Helix candidissima. Da ap. Moll. pl. 5. fig. 19.

Dauder. Hist. des Moll. pl. 27. fig. 9-13, et pl. 3g. a. fig. 2.

Laмr. Anim. s. vert. tom. 6. pag. 81, no. 57.

Coquille toute blanche en dedans, et en dehors; elle est arrondie, globuleuse, formée de six tonrs, dont les premiers sont presque plats, et les autres plus bombés et plus convexes. Les deux premiers tours sont lisses, les suivans sont strićs longitudinalement, et la suture est quelquefois crénelée dans les troisième et quatrième tours. Pour les deux derniers, la sutare est simple; en dessous, les stries sont moins apparentes. Il reste ordinairement une petice fente ombilicale, ouverte à la base; quelquefois elle est complélement fermée par une callosité aplatie, et assez large, du bord gauche. L'ouverture est médiocre, arrondic, semi-luuaire, simple, ì périslome épais et évasé légèrement en dehors. L'épiphragme est fort blanc, enfoncé, mince et fragile. Lorsqu'il vient à être brisé, l'animal en sefait un autre fort rapidement en quelques heures. Cette coquille est fort commune en Provence, en Italie, en Espagne, ainsi que dans les îles $\mathrm{Ma}$ jorque et Minorque, et en Sicile.

90. IÍLICE discolore. Helix discolor. FER.

H. testâ orbiculato, convexâ, imperforatâ, tenui, slriatâ, fusco-custaneâ; ultimo anfructu zonâ castaneâ albo marginatâ cincto; spirî̀ obtusá; labro marginc valdè reflexo, basi columellâ obsoletè trincatâ.

\section{Helix discolor. Rrchard.}

Daudeb. Hist. des Moll. no. 79. pl. 46. fig. $\overline{\mathbf{j}}-6$.

Lan x. Anim. s. vert. tom. 6. pag. 75. no. 35.

C'est quand cette coquille a été depuis lungtemps abindonnte par l'animal, et qu'elle a été 
exposée anx intempéries des saisons, qu'ellc prend une teinte d'un fauve pâle; mais lorsqu'elle est liaiclie, elle est d'un brun-chàlain foncé, plus foncé en dessous qu'en dessus, et lcs deux nuances sont séparćes neltement sur le milieu du deruier tour par une ligne blancbàtre, au-dessous de laquelle on en remarque souvent une autre d'un brun-noirâtre, qui la suit et la borde. Cette coupille est glubuleuse, arrondie, à spire obtuse et courte, à laquelle on compte quatre tours seulcmeat, dont le dernier est plus grand que tous les autres. Les premiers tour's sont a platis et lisses; le dernier et l'avant-dernier sont plus convexes: ils différent aussi des premiers par leur suture plos profonde, et surtout par les stries très-fines dont ils sont ornés. Ces stries sont longitudinaleset transverses; ce sont ces dernières qui, étant finement granuleuses, paroissent davantage. Le dernier tonr a un développement un peu irrégulier : il est an peu bossu à l'opposite de l'oaverture. En dessus, la coquille est très-convexe, et son ouverture médiocre, très-obliquue, est subovalaire et plus large que haute. Son péristome, d'un brun-viaeux, est fortement reuversé en debors; il est fort épais et arrondi : à la base il est plus epaissi encore que partout ailleurs; il se termine quelquefois à sa partie antérieure par noe légère troncature, de sorte que ce bord semble muni d'une dent. Cette soquille n'est pas rare dans les collections; elle vient de la Martinique et de la Gaddeloupe. Elle a 40 millim. de diamètre.

9I. HÉlice d'Alicaate. Helix alonensis. FER.

$H$. testâ subglobosâ, depressiusculâ, imperforatâ, albidî, rufo et fusco fasciatâ; spirû brevi; apertunâ lunari; labro subacuto.

Helix alonensis. D. Ап्в. Hist. des Moll.pl. 36. a.f. 4 , et pl. $3 g$.

Lass. Anim. s. vert. tom. 6. pag. 68. no. I I.

Coquille très-variable sous le rapport de la couleur; elle est globuleuse, un peu déprimée, composée de six à sept tours légèrement convexes, dont le dertier est proportionnellement plus grand que les autres; la spire est peu proéminente, les deux premicrs tours sont lisses, mais les suivans sont lonement striés en long, et dans un grand nombre d'individus, sur l'avant-dernicr lour, commencent à se montrer des striez transversales, écartées, et un peu plus profondes que les autres; elles parvienuent jusqu'à l'ouverture. Dans d'auircs individus, les stries longitudinales seules paraissent, et elles devienneut irrégulières vers l'ouverture. En dessous, cette coquille est convexe, et elle u'est ni ombiliquée, ni perforée; le centre est occupé par l'insertion un peu calleuse du bord de l'ouverture; celle-ci est assez grande, ova!e, subscmi-lunaire, très-oblique, évasée en debors, et garnie d'un péristome blanc et épais. Sa coulear est variable : taatôt elle est blaachàtre, avec plu- sieurs zones de taches fauves on brunâtres sabarticulées entre elles; tantỏt elle est d'un bran pále ct les zones sont plus coniinues, les taches étant plus grandes et moins séparées; quelquefois enfin, les bandes disparoissent presque complétement sur on fond qui est d'ua bran presque anssi intense qu'elles. Cette espèce se trouve en Espagne, aux environs d'Alicante; on nous a assuré qu'elle vivoit aussi en Morée.

92. HÉtice Pouchet. Helix Pouchet. Adans.

H. testâ orbiculato-globosâ, subdepressâ, imperforatâ, longitudinaliter striato-granulosâ, subtùs convexâ; aperturâ minimâ, peristomate albo incrassatâ.

Le Ponchet. Adanson, Séneg. pag. 18. nº.2. pl. 1. fig. 2.

Helix Pouchet. Fer. Hist. des Moll. no. 73. pl. 42. fig. 2.

Coquille globalense, arrondie, quelqnefois un pen déprimée, à spire courte et obı́ne, à laquelle on compte six tours convexes, dont la suture est simple et pea profonde; ces toars, à l'exception des premiers qui sont lisses, sont couverts de stries longitudinales serrées et nombreuses, qui presque toutes sont clagrinées irrégulièrement; le dernier toor, bien arrondi à sa circonféreoce, est convexe en dessous; son centre est occupé par une callosité assez Jarge, produite par l'insertion de la base du bord de louverture; celle-ci est d'une petite dimension dans les vieux individus surtont, où le péristome acquiert une épaisseur considérable; elle est très-oblique à l'axe de la coquille, de sorte que, plaće sur elle, elle repose presque verticalement; le péristome est tout blanc, fortement renversé en debors; la surface de la coquille est d'un brun marron foncé, d'une nuance uniforme. Nous avons une variété qui est jaunàtre en dessous, ct qui a une petite fascie poncticulée jannâtre contre la suture.

Cette coquille est fort commnne an Sénégal et dans l'ile de Ténérife; elle a 25 à 28 millin. de diamètre à la base.

93. HéLrce plicatule. Helix plicatula. Lask.

H. testâ orbiculato-depressâ, impeforatâ, creberrinè plicatâ, griseo-violacescente; plicis longitudinalibus, obliquis, acutissimis; labro expanso, margine albo, neflexo.

Helix plicaria. ExcrcLop. pl. 462. fig. 3. a. U. DAUDEB. Hist. des Moll. pl. 42. fig. 4.

LAsx. Anim. s. vert. tom. 6. pag. 87. $n^{\circ} .81$.

Cetie jolie coquille a beaucoup de rapports arec l'espèce précédente quant à la forme et à la coulenr, elle est cependant un peu plus déprimée; sa spire, conrte, arrondie et obture, est composée de cinq à six tours; le dernier est un peu 
plus graad que les antres en proportion; tons sout courexes, et séparés par une sulure fnement onduleuse; les deux premiers sont corsplétement lisses, tandis que les suivans sont couverts de belles côtes lamelleuses, étroites, longitudinales, obliques et lígèrement ondulenses sur le dernier rour; ces cótes lamellenses sont nombreuses et rapprochées, et leur insertion à la suture la read onduleuse; elles se continuent en dessous et conrergent vers le centre; celui -ci est occupé par uce callosité assez large que forme l'extrémité du péristome à sou insertion; l'ouverture est médiocre, fortement évasée, garnie d'un péristome blanc, épais, qui s'étale horizontalement, et produit un bord droit, aminci et tranchant. Toute cette coquille est diun bean brun, un peu plus pále en dessons qu'en dessus. Cette belle coquille vit à Porto-Rico, à Saint-Thomas, où elle n'est pas rare; elle a 25 millia. de dismètre.

\section{Hécice ciselée. Helix colatura. FER.}

H. testâ subglobosâ, imperforatá, longitudimnliter transversimque striatâ, intensè rufà; spirê exsertiusculâ.

Helix celatura. DAUDEB. Hist. des DIOll. pl. 28. f.g. 3. 4 .

LAHE. Anim. s. vert. tom. 6. pag. 71. n०. 22.

La spire de celte coqquille globuleuse est assez variable : tantôt subconique, tantôt frort dépriwée, elle est tonjours obluse au somnit et formée de six tours arrondis, cunvexes, à suture simple et pen enfoncée; ils sout couverts d'un Epiderme assez épais, cadoc, d'un brun loncé uniforme sur toute la coquille. Cet épiderrne est tiès-finement et très-régulièrement strié en long et axarqué d'ondalations transrerses; ces stries longitndinules sont très-nombreuses et tres-rapprochées, et si extrêmement fines, quon a besoin d nne loupe pour les bien voir. Si cette coquille ne conservoit ane forme constante, il seruit difticile de la reconasitre lorsquelle a perdu son Epiderme; car elle devient dun tlanc-rous, et tuutes les stries disparoisseat compléternenı. L.e dernier tour, qui est plus graud que les autres, est très-globalenx en dessoas, wais il est déprimé fortemeat à l'endroit de l'oubilic, qui est tout eatier occupé par l'insertion de la base du bord droit. L'ouverture est très-oblique, assez grande, subsemi-lunaire, souvent sinueuse; un la voit rarement complète : lorsqu'elle l'est, son péristome est blanc, épais, évasć et renversé au-debors; à la base il est toujours plus épaissi que dans le reste de son étendue. Celte coquille, ๆqui a 50 millim. de diamètre, vit à l'ile Bourboa, où elle est assez commane. Il en existe un individu fossile du Plaisantin dass la collectiun du Muséum.

35. Hétice marginée. Helix limbata. DaAp.

H. testí orbiculato-slobulosâ, subcarinat:,

\section{II $\mathrm{E} \mathrm{L}$}

tenuissimd striatâ, subtùs imnefforat's, albá vel fucescente; cariná albí; aperluní subsemilunuri; peristomate reflexo, marginato.

Dasp. Moll. de France, pag. 100. $n^{\circ} .29 \cdot p l .6$. $f_{\mathrm{g}} \cdot 2 \mathrm{~g}$.

FER. Hist. not. Moll. $n^{\circ}, 253$.

L'Helix limbata est une jolie coquille globuleuse, à spire obtuse an sommet, et un peu subconique; elle ce compose de sept tunrs asse: étroits, convexes, dont la su!nre simple est as-ez profonde; ils sont couverts de stries longitudinules nombreuses, peu profondes. En dessous la caquille est furt convexe, et à son centre on voit une petite fente ombilicale presque entièrement couverte par le renversecuent du bord droit de l'ouverture. Celte ouverture est d'une taille médiocre; elle est fort oblique, renverste en deLors, et garnie d'un péristome peu épais; la circonférence du deruier tour est légèremen: carúnce, et cette carène est occupée par uue fascie d'uu blauc opaque; le test est mince, transparent, fragile, tantôt blanc, tantôt d'un beau brun vineux ou rougeátre; le péristome est blanc lursque la coquille est de celle couleur, il est d'un rouge-violatre lorsqu'elle est brune. L'anicnal de cetle espèce est comme celui de l'Helix fruticum, il est orné de taches qui paroissent a iravers la coquille, mais qui ne laissent sur el!e aucnae trace. Celle espèce se trouve dans le midi de la France, ainsi que dans les forèts de la Norcoaudie, où elle est loujours plus grande.

96. Hélice bord roux. Helix incamata. Motu.

H. testâ suíglobosâ, depressiusculi, perforatâ, pellucidá, corneá; spirá prominula; labro margine rufescente, subreflexo.

Helix incarnata. Moux. Verm. pl. 65. $\pi^{2} .259$.

Caersitz, Conch. tom. 9. tab. 133. fig. $1200^{\circ}$.

G IrEL. pag. $3617 . \pi^{\circ} .17$.

Drapans. MIoll. pl. 6. fig. $30^{\circ}$.

DavdeB. Hist. des Mall. $n^{\circ} \cdot 254$.

PreiferR, Syst. anont. tab. 2. fig. 15.

Lamx. Anim. s. vert. tom. 6. pog. 91. $n^{\circ}$. 94.

Coquille globuleuse, un peu déprimé, dure, cornée-clair, iransparrate, linement stive, et ua peu carćnće; elle est recouverte d'un épiclerme caduc qui rend souvent la surface légèrement berissée de pelites lames membrancuses. Lorsqu'or l'esamine à la loupe, on s'aperçoit qu'e!le est ilégament sculptée ou chagrinée, ses stites $l$ ingitudinales urés-fines étaut coapées à angle droit par d'aures presciue aussi fines, ondulées, tremblantes. La spire est obtuse au sommet; elle est formée de six tours graduellement croissant, dout les deux preniers sont parfaiteraent lisses. Le dernier présecte ptesque toujours une bande obs- 
cure, Llanchátre sar la partic la plus convexe; Iu base est arroodie, perforéc au centre par un ombilic pen onvert. L'ouverture est oblique, plus large que haute, subovalaire. Son péristome, légrirearent reaversé en dehors, est burdé en dedans d'un buurrelet saillant, arrondi, rougeâtre o: ronx; en dehors, il est indique par une fascie ruugeatre qui catoure l'ouverture.

Celle coquille se trouve en France, en Allemagne et en Suisse; elle vit daos les foréts.

97. Hélice linéléc. Helix lineoluta.

H. testí globosâ, imperforatâ, luteo-rufescente, lineis fimbriatis confortis inarqualibus fuscis cinctí; spirâ apico albá; labro margine reRexo, intus alho.

Favaxxe, Conch.pl.64. fig.e. 1.

Helix undulata. Davd. Hist. des Moll. $n^{\circ}, 25$. pl. 16. fg. 3. 6 .

Lasz. Aninz. s. vert. tom. 6. pag. 67. $n^{n} .6$.

Coquille grosse et globuleuse qui, pour la forme e! la taille, ressemble becucoup à l'Helix pomtia; elle est ventruc. Sa spire ccurte et obtuse est formće de six tours dont le dercier est plus grand propertionnellemeat que les autres. Les lours sont médiocrement convexes, et leur suture est simple et peu profonde; ils soot lisses ou marqués sculement de qquelques stries d'accroissement. A la base, la cnquille a"est pas mnins convexe, son centre est occupé par l'extrénité du bord droit qui s'y insert en s'y étalant en uae callosité assez large. L'ouverture est grande, semi-lunaire, blasche en dedans et grarnie d'ua péristome de même coulear. Ce péristome est épais, arrondi, renversé en dehors; il se courbe, s'élargit et s'épaissit à l'endroit de son insertion à la base de la coquille. Le sommet de la coquille est le plus ordinaircmedt hlanc, et les autres tours le seroient aussi s'ils a'étoient couverts d'un épiderme bran, trèsmince el caduc, qui est orné d'un grand nombre de linéoles d'un brau plus foncé, onduleuses et transverses. Qnelques-unes de ces linéoles, à des des intervalles inégaux, sont plus larges et plas foncées. Celte coqquille n'est pas rare dans les collections; elle vit dans l'Amériłue méridionale vers l'embouchure du lleuve des $\Lambda$ mazones.

98. Héurce lucane. Helix lucana. Murx.

H. testâ globosá, umbilicatî, crassiusculi, glabrâ, infernè alba, supermè rubente; spirí breviusculs, conoideá; aperturi rifo-violacescente; labro margine reflexo.

Helix. lucana. Murxer, Verm.p. $75 . n^{\circ} .270$. Cheass. Conch. 9.tab. 13o. fig. 1355.

Grzz. p. $3636 . n^{\circ} \cdot 7^{8}$.

DАОдев. Hist. des Moll. $n^{\circ} .32 . p l .28$. fig. 11. I2, et pl. 32. Ag. 2. 3.
Larr. Anim. s. vert. tom. 6. pag. 71. no. 9.

On reconooit aisément celte coquille à sa forme globulease, à sa spire courte et obtuse, au sommet, et surtont à la forme de la fente ombilicale. On compte six tours à la spire : les premiers sout étroits et lisses, les suivaos sont plus larges et irréguličrement striés en longueur. Le dernier est beauconp plus graod quo tous les autres, et comme enx il esi strié, surtoul à la parlie supérieure. Fo dessons, il est très-convexe, et le centre offre une feate ombilicale demi-circulaire au-dessus de laquelle se reaverse la base du bord droit de l'ouverture. Cette ouverture est petite comparativement au volume de la coquille; elle est très-pen olılique, et son péristone, épais et arrondi, se renverse en debors et s'élargit à son iusertion à la base. Le bord ganche est marquá par une petite lame pulie qui joint obliquement les deux extrécnités da bord. Le péristome est d'un beau rouge violet, et l'intérieur de la $\mathrm{co}-$ quille est de la même conleur, mais plus foncét. En dessus, elle est d'un brun-rougeâtre foncé, arec une zone blanche près des sutures, et an: beaucoup plas large à la base. Cette coquille est très-commune au cap de Bonoe-Esspérance, sar les dunes.

\section{Hétice lactée. Helix lactea.}

HI. testâ arbiculato-convexâ, imperforatû, grise $\hat{a}$, refo vel fusco fasciata, punctis lactei. minimis notatâ; spirâ retusa, fuuce nigrâ; labru expanso, margine reflexo.

Helix Lactea. Mulen, Verm.p. 19. $n^{0}, 218$.

Lister, Conch. tab. 51. fo. 49, et tah. 95 . fig. 96 .

Petri. Gaz. tab. 153. fig. 8.

Cuear. Conch. tom. 9. tab. 130 . fig. 1161

Gire. pag. 3629. no. 237 .

Datdeв. Hist. des Moll.pl. 45.

Las. Anim, s. vert. tom. 6. pag. 75. n. 36.

A roir le nom de celle coquille, on croiroit qu'elle est blanche, mais on seroit dans l'erreur, car elle est presque toute noire, du moins quelques-unes de ses variétés, et clle n'est jamais toute blanclie. LiHélice lactée est une espèce qui a infinimeat de rujports, quant à la forme, la grandeur et mème la disposition des couleurs, avec uoe espèce que nous avons précédemment décrite sous le nom d'Helix verniculata: cette ressemblance est si grancíc dans quclques variétés qu'il seroit impossible de les distinguer si on ne voyoit l'ouverture ou résideat les caractères principaux des deux espèces. Nous a'avons pas mentionné la série de variétés de l'Hélice lactée; elle ressemble à celle de l'Hélice vermiculce. Nous dirons seulement que ce qui distingue les deux espèces, c'est que dans celle qui nous oc- 
cupe, la sarface extérieare du test, vu à la loupe, est finement striée transversalement, ce gai a'a jamais lieu dans l'autre, et que l'ouverture, dans toutes ses parties, est toujours d'une belle couleur brune café brûlé, tirant sur le noir, tandis que dans l'autre espèce l'ouverture est constamment blanche. Un autre caractère, qui est particulier a l'Hélice lactée, est pris du renflement dentiforme du bord droit à sa base. Cette espèce vit en Espague, en Afrique et dans les iles de la Méditerranée. Quelques grands individus ont 42 millim. de diamêtre autéro-postérieur.

100. Hélice cinctelle. Helix cinctella. Drap.

H. testâ orbiculatâ, subdepressâ, imperforatâ, glabrâ, corneâ; ultimo anfractu carinâ albâ cincto; spirá prominulâ; labro tenui, subreflexo.

LaIrs. Anim. s. vert. tom. 6. pag. $9^{r} \cdot n^{\circ} \cdot 9^{5}$.

Helix cinctella. Draparn. Moll. pl. 6. fig. 28.

Daver. Hist. des Moll. $n^{\circ} .248$.

Petite coquille de forme presque conique, déprimée, carénée, cornée, brunâtre, mince et transparente, légèrement et inégalement striée. La spire est composée de cinq à cinq tours et demi peu convexes; carène aiguë et marqute au dernier tons d'une ligne blancbe qui se continue sur le tour suivant. Ouverture semi-lunaire, anguleuse, plos large que haute; péristome simple: le bord gauche se rélléchit seulement ì son insertion, pour recouvrir le trou ombilical, qui est très-étroit et sonvent imperceptible. Nous empruntons à Draparnaud cette description d'une espèce que nous n'avons plus sons les yeux, les individus que nous possédions ayant été brisés par accident ; pent-être u'est-elle qu'une variété d'ầge on de localité de l'Helix limbata.

IOr. Hílice mul tistriée. Helix nultistriata. Now

H. testâ globulosá, tenui, fragili, translucidá, multistriatâ, cornế, in medio zonâ angustâ nubrî cinctâ; striis numerosis, regularibus, trans. versis; apertunâ semilunari; peiistomate albo, reflexo.

Quoique l'on ronnoisse déjà nn certain nombre d'Hélices qui sont striées, il a'y en à que bien pea doat tontes les stries sunt tiansverses et surtout aussi visibles que dans celle-ci. Elle est globuleuse, à spire obtuse et subconique, formée de six tours arrondis, convexes, séparés par une sutare simple et assez profonde; ils sont légèrement plissés longitudinalement à leur partie supérienre. En dessons la base est perforée au centre, mais cet ombilio est petit et en grande partie recouvert par l'extrémité du bord droit, qui se reaverse sur lui. L'onverture est petite, fort oblique, subsemi-locaire, ponrrue d'un péżistope blanc, ézasé, reqversé en décors el pęı épais. Les deraiers tours de spire de celte espèce sont couverts de stries transverses, arrondies, assez grosses, bien sensibles à l'œil; elles sont très-régulières et se voient en dessus et en dessons de la coquille; la couleur est d'un brun-corné clair et transparent; la circonfúrence du dernier tour est occupéc par une scule ligne étroite et rontinue d'un rouge obscur, qui se voit queloguefois a la base de l'avant-deraier tour, immédiãiement au-lessus de la snture.

Nous n'avons encore vu qu'un très-petit nombre d'individas de cette jolie coquille; ils venoien: de Cuba. Celui que nous possédons a 15 millim. de diamètre.

102. Hérice serpentine. Helix serpentina. FEs.

$H$. testá orbiculato-depressâ, subperforatá, tenui, glabriusculâ, albidâ, maculis minimrs rufo-fuscis inoequalibus creberrimis seriatim cinctâ; spirâ retusâ; labro margine subreflexa.

Helix serpentina. DaUdEв. Hist. des Moll. pl. 40. $f g \cdot 7$.

Lasix. Anin. s. vert. tom. 6. pag. 83. $n^{\circ} .6 \bar{\jmath}$.

II est facile de distinguer cette belle espèce d'Hélice de toutes ses congénères; elle est orbiculaire, arrondie, un pen déprimée dans le plus grand noubre des individus; la spire, conrte et ubtuse, est composće de cinq à six tours arrondis dont la suture est superficielle; le dernier est proportionnellement nn peu plus grand que les autres; en dessous, ce dernier tour est légèrement convexe, et son centre est un peu déprimé et déponrru d'ombilic ou d'une fente ombilicale; l'ouverture est médiocre, très-oblique, subsemilanaire, plus large que haute; elle est bordée et légèrement renversée en dehors; l'extrénité columellaire du bord droit s'élargit à son insertion, et il devient brun dans cet endruit; le côté gaucbe de l'ouverture est de la même couleur, tandis qque le bord droit reste blanc; la surface extérieture de la coquille est lisse, or y remarque seulement quelques stries d'accroissenuent; elle est ornée de plusieurs :angées de ponctuations brunes sor un fond blanc; dans quelques individus ces rangées sont distinctes, mais dans le plus grand nombre celles de la partie supérieure sont confundues pur les ponctuations, qui sont en grand nombre dias leurs intervalles; en dessous, il y a toujours une ou deux bandes nettement séparées. En Sicile on troure une jolie variété de cette espèce, das laquelle les bandes supérienres sont remplacées par une large fascie de zones longitudinales uniuleuses. Cette coquille se troure ea Corse, en Sicile, en Grècc et en Italie.

103. Hélice pourprée. Helix niciensis. Ferus.

H. testá orbiculato-convexá, imperforatâ, nitidul: : albs, linealis lutcis interruptis senatim 
cincti, seric mediand mujoribus fuscis; spirś breviusculu, fincc purpureo-violuced; lubro simplici.

Helix niciensis. DaUdeB. Hist. des Moll. pl. 39 . a. fig. 1, el pl. 40. fig. 9 .

Lamx. Anim. suns 2ert. tons. 6. pag. 83. in. 64.

Celle espèce a beaucoup de rapports avec la précéclenle; qquelques-unes de ses varićlís pourroient même se confondie avec elle par la disposition des cuuleurs. Celle espèce est orbiculaire, arrondie, à spire plus ou moins aplatie, à laquelle on couple cind lours peu convexes, dont là sutare est simple et très - superficielle. En dessous, le dernier lour est légèrement convexe, le centre donue inserlion au bard droit, et il est couvert par une petite callosité aplatie et un peu ¿́largie. Louverture est très - oblique, subsemilunaire, plas large que baute, bordée d'uu buurrelet renversé et évasé en dehors; à la base, il est un peu épaissi el quelquefois tranchant; en debors, cette coquille est lisse ou seulcuent striće par des accroissemens, sur un fond d'un blancgrisaltre. On comple ordiaairement sur le dernier tour cirq rangées de taches fauves ou brunes, pluz au moins rapproclsées; quelquefois les deux supérieures se confondeut en une seule parsemée d'uu grand nounbre de taches. Le péristome, airsi que l'intérieur de l'ouverture, soni d'un bea rose pourpré d'une grande fiaicheur; c'est ce qui, au freaier coup-d'ail, distingue celle espéce de la précédente. Elle se trouve à peu près daus les nénes lieux, aux îles Baléares, en Sicile et dans l'Ttalie méridionale.

$\mathrm{L}_{\mathrm{A} \Omega \mathrm{K}}$.

104. Hérice ponctifère. Helix punctifera.

H. testá orbiculato-conoideá, imperforatá, grise $\hat{2}$; stris obliquis, multipunctatis; punctis prominulis, granulformibus; labro intùs albo, inargine reflexo.

Helix linza. DaUdeB. Hist. des Moll. pl. 46. fig. 1. 2.

LAssr. Anim. s. vert. tom. 6. pag. 37. no. 80 .

Coquille globuleuse, à spire subconique et obtuse, formée de cinq à six tours peu convexes, dont la euture est simple et superficielle. Le dernier tour, un peu plus grand que les autres, est subcaréné dans le milieo; en dessous il est convexe, sans urabilic ni dépressiun au centre. L'onverture est d'une médiacre élendue; elle est extrêmement ablique à l'axt de la coquille; elle est ovalaire, substransverse, plus large que hante. Son péristome, d'un beau blanc, est fort épais et tiès-évasé; il est arqué à la base et calleua à son insertion; son épaisseur esi considérable, surtout ¿ I a base, ce qui rétrécit d'une manicire notatle 'oarerture par laquelle l'animal doit passer. Tuule Hist. Nat. des Vers. Tome $I I$ 。
Is surface extérieure de cette corquille est ccuverte d'un épiderme gris ou brunàtre, el elle est rendue ruguense par un grand norubre de granulations punctiformes, irrégulières, wais assez saillantes el blaucbes. Cctte coquille, encore rare dansles collections, a été rapportée de Porto-Rico par Maugé; elle a 28 milliun. de diamètre.

105. HÉLıee raboteuse. Helix cariosu. Ohır.

H. tcstâ arbiculato-convexâ, latè umbilicatâ, rudi, albá; spirâ obtusâ; umbilico margine splrali, acutungulo; latro subreflexo.

Helix cariosa. Orrv. Vog. pl. 31. fig. 4. a. b.

DAUDEB. Hist. des Moll. no. 149.

Lam K. Anim. s. vert. tom. 6. pag. 88. $n$ ㅇ. 84.

Espèce très-voisine de l'Helix candidissina, el qui u'en est pent-être qu'une forte variélé. Nous avons quelques passages entre ces deux espèces, mais nous n'en avons pas d'assez nombreux pour nous. décider encore à les réunir; nuus sommes persuadé cependant que cette réunion deviendra nécessaire par la suite.

Cene coquille est toute blanche, globuleuse, à spire subconique, à liqquelle on comple six tours régulièrement croissant, aplatis, carénés furtement dans le jeune age, et dont le dernier, daus l'âge adulte, est garni au milieu d'un bourrelet saillant, ce qui n'eupêche pas ce tour d'être réguli. rearent convexe. La sulure est très-superficielle, tlle a lieu sur la carène, et elle est crénelée des deux côlés; les crénelures sont fines, nombreuses et assez régulières. Les deux premier's tours sout lisses, mais les suivans sont couverts d'une multilude de petiles rides très-serrées, onduleuses, quelquefois anaslomusées entralles ou interrompues; elles sont obliques et longitudiaales; sur ic dernier tour elles disparoissent ordinairement, et il n'y en a jamais en dessous de lui. La base est convexe, dans le jeune âge, elle est percée au centre par un ombilic assez grand, qui est caché, dans l'état adulte, par une callosité demi-circulaire de la base de l'ouverture. Celle-ci est petite, très-oblique, plus large que haute, a péristome épaissi, mais peu renversé en debors. Ce!te coquille se trouve en Perse, en Sicile, en Grèce et dans les îles Baléares.

106. Hغ́lı́ géante. Helix gigantea. Lasix.

H. testâ orbiculato-convexâ, imperforatâ, solidô, alb $\hat{a} ;$ epidermide rufo-fuscô; anfractibus transversè striatis; aperturá patulá; labro intùs albo, margine reflexo.

Helix cornu militare. Lis. Gues. pag. 3620. $n^{\circ} \cdot 29$.

Krorr, Fergn. 6. tab. 32. fig. 2.

Farasie, Conch. pl 64.fig. c. 2. 
Helix malum terrie. Cness. Conch. tom. 9. tab. 129. fig. 1142.1143.

Helix gigurutea. Scopotr, Delic. insubr. tab. 25. fig. $u$.

G MrL. pag. $3646 . n^{\circ} \cdot 104$.

Helix cornu militare. Dauden. Hist. des Moll. pl. 15. fig. 5. 7 , el pl. 52. fig. 1 .

Lass. Anim. s. 2elt. tont. 6. pag. 6̆. no. 2.

Celle espèce est l'uue des plus irraudes du genre; elle est globuleuse, arrondic, légèremeat déprimée; sa spire, courte el obtuse, est formée de siz tnurs; ils sont peu conrexes, et leur suture es! simple et superlicielle. Le dernier tuur, proportioanellement plus graod que les autres, est bien arrondi; il est entouré daus le milieu d'une carène obluse, nu plulôt d'un léger bourrelel; $\mathrm{cn}$ dessous, il est fort convexe et dépourvu d'un ombilic. L'ouverture, qui le teraine, n'est que médiocremeat ablique; elle est graade, évasce, subsemi-lunaire, garnic d'un périslonse blance el épais, surlout à la base, où il est muni d'une callosité assez large à l'eadroit de son insertion. Un peu en avant de celle insertion, le bord devient un peu saillant, par la légère inllexion qu'il fait en avant. La surface de cclle coquille est lisse ou seulemeat marquée.par des accroissemens; elle est revétue d'un épiderme diua tran foncé, tautót unifurme, tantót divisé par zones ou baudes plus páles; la carc̀ne est blancheâtre. Celle espćce vit, à ce que l'on croit, en Amérique; clle a jusq̨u'à 75 ou 80 millim. de diamc̀trc. Brcas.

107. Hénıce de Morogues. Helix Moroguesi.

H. testâ globulosá, lơvigatâ, non angulalá; spirá subprominulâ, sexjes circumvolutâ.

Brosg. Ann. du Mus. tom. 15. pl. 23 . fig. 7 .

Nов. Descrip. des Coq. foss. des env. de Paris, ton. 2. pag. 54 . pl. 6. fig. 1. 2. 4.

Celle Hélice a qoelques rapports de forme arec motre Hélice aémcrale; elle est globuleuse et devoit ćtre lisse, à ea juger par quelqnes portions du test, qui se voient sur un des iodividas que M. Broagniart m'a commeniqués. On a'en Irouve ordinairernent que des moules dans un calcaire lacustre, grisátre, supérieur, d'aprc̀s l’opinioo de M. Héricart-Ferrant, qui termine le dépôt tertiaire du bassin de Paris, près d'Orléans, et que l'on observe particulièrement à Pithiviers el à Pontouraois, associés à des Lyonaés et des Planorbes.

108." Hélicy douteuse. Helix dubia. Noв.

H. teslí globulosá, subdepressá; umbilico minimo; anfractibus supernè planulatis, externo non arigulato.
Noв. Descrip. des Coq. Soss. des env. de Paiso, tom. 2. pag. 5j. pl. 6. fig. 3 .

J'ai nommé celte Hélice don!euse, non parce que je doute de son genre, mais parce qu'il est it présumer que ce n'est qu'une varicilé de l'Helix Mnoroguesi; elle en differe en ce que sa spire est plus plale, ses lours uu peu plus b́roils, et le dernier plus renflé vers l'ouverture. On voil qüil deroil $y$ avoir un ombilic fort petit. 11 est assez ćtonnant de trouver la mćrne cspèce a l'ile de IVight el également daus un terrain silicenx, ce qui prouve une aoalogie aussi parfaite eolre les coquilles terrestres qu'eotre les marines; wais ce qui est ici remarquable, c'est que, quoique irèsélnignćcs. ces deux localités les jurésentent dans le nème état. Celle coyuille a 17 millin. de diaunère. Je dois la connoissance de relte espèce aux environs de Paris à M. Duchastel, et à MI. Underwonl, géologue très-dislingué, celle de l'ile de Trighlu.

jog. Hélice de Leraún. Helix Lemani. Broxic.

H. testa subglnbulosi, lavigatî; spiri promimuli; anfructibus quinque, rotundatis; sulur.i perspicuá.

Broxc. Ann. du Mus. tom. 15. pag. 378. pl. 23. fig. 9 .

An Helix Cocquii? Brong. ihid.

Noв. Descrip. des Coq. foss. des env. de Paris, tous. 2. pag. 56 r. pl. 6. fig. 5.

Cclte julie espèce est parfaitement caractérisćc pas sa furne subglobuleuse, un peu déprienée, prar sa spire assez saillante, ses lours de spire arrondis et au nombre de cing: son dernier tour ne présente aucune carèo ni aucun aggle saillan: daas son conlonr. L'ouvcriure est engagie dans lit pierre siliceuse, mais on aperçoit un petit ombilic. 'loute sa surface devoil èıre presugue lisse; on n'y voit que quelques stries de ses accroissemens. Il est bien probable que l'Helix Cocquii de N\}. Brungniart d"est tu'nne variétci de celle-ci; elle a'en differe que par des stries d'accroisseraent plus nombreuses, par une forme un peu plus bombé, ainsi que par son dernier lour, comparativemeat plus volumineux.

ıo. Hélice damnée. Helix damnata. Brosg.

H. testá glabulosá, subconicá, apice obtusi, asperulá; anfiactious rolundutis; suluris marsinatis; aperturi depressá, ovali, obliquissimi; peristoniate incrassuto, continuo, neflexo.

Baonc. Mem. sur les terr. culc. trap. du Vicentin, pag. 52. pl. 2. fg. 2. a.b.

Ccile espèce fossile est remarquable par la forme de san oureriure, el facilement recnanuissable par ses autres caractères. Lille est globuleuse, subcouique, à spire oblusc et asscz sail- 
lante, dout les lours, au nombre de six, sont rapproclués, convexes: leur sulure e'st preu profonde el loordée par un petit sillon marginal. I.e dervier tour est ríguliètement convexe, non caréné, quoiytill le paroisse quelquefois, par suile d'un léger aplatissement que la coquille a éprouvé daus les couclies où clle est enfonie. En dessous, elle est trè-bornbie; tlle se termine par un ouverlure petite, ovalaire, extrémemeot oblique à l'axe, et beaucoup plus large que haule. Son péristome, qui esl épaissi e! renversé en deliors, cache l'ombilic par son insertion. Ses deux cótés ont uoe teodance à se rapprocber; nais ce qui rend celle ouverture remarquable, c'est que le bord gauclse es: saillant, aussi épais çue le péristome, el s'élend en rravers de l'ouverlure de manièse à la conpliler, comme cela a lieu dins l'llelix cornea et d'autres espèces. Eu deliors, la coquille est rugueuse et siriée ir. régulièrement par des accrnisseusens. Celle espece vient de Rnnca, et elle est noire comme tous les lossiles de cette localidé. Elle a 25 roillim. de diancelre.

31. IlÈultce aspérule. Helix aspenula. Nов.

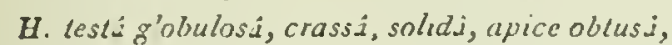
rugis irregularibus aspenuli; spirj brevi; anfiuclihus convexiusculis, sulura sinpóici separalis, "llimo subcurinuto; aperiurí mediocri, subsemilunari; peristomate incrassato, refexo, ad basım subcontorto.

'Très-belle espèce d'Hélice fnssite que liun iruuve en France, dans les faluas de la Touraine. Lille est stubuleue, à spire courie, un peu plus aplatie dans quelyues individus que daus $d^{\prime} a u$. ires; on y comple six tours peu convexes, dont Is suture est superficielle. Le dernier luur, plus graod en proportion que les autres, priseute dans sa parlie médiane une carène uu plutót un lionrrelet très-obtus, à peine saillant; en dessous il est bien convexe, el l'extréaité du horıl de louverlure sur le aentre cacbe entićreneat l'amlilic. L'ouverture est d'une mćdiucre élendue; eile est rès-oblique, semi-funaire, plus large que liaute, et bordíe par un périsiome épais fortement renversé en deliors, el quelquefnis saillant en dedans, de manière a rendre l'onveriurc p!us íruite. b.e bord droit, vers son inserlion a la base, ful une inllexion; une sorle de torsion légère, yui le rend flus saillant en dedaus, un peu liossu, quoique toujours arrondi comme dans le reste de son éleodue; a lexception des deux premiers inurs qui sont lisses, les autres sont converts d'aspérilés ircégulièrcs, très-comparables à celles 'pui so roient sur. i'Hclix asporsı; seulement elles sont plis rapprochices et plus saillitutes. Celle coquille, qui a jo millin. Je diaroère, plus d'un pouce, se trouve fossile dans les liatuns de la 'l'uraine, où elie est assez rare.
J 2. Hésice de Tours. Helix turonensis. Non.

II. lestá subglobulosá, laevigalû, vel leviler strıata-rugosá; anfractıbus convexis, sulurî simplici conjunctis; aperturi semilunari, obliquissimu, lubro reflcxo, basi rotundato.

Noв. Descript. de Coq. caracl. des terrains, pag. $13 g \cdot p l .1$. fig. 1. 2 .

l'Ilílice de 'l'nurs a à peu près la taille de l'Helyx memoralis, el elle est une des espèces fussiles du geure qui s'en rapproche le plus; tlle est cependant moins globuleuse, et sa spire, plus courte, est plus aplatie. Elle est lormée de cinq tours a cing lours el demi : ils sont peu convexes, arrondis, ct súparés par une suiure linéaire, simple el superficielle. Le deruier tuut est proporlionnellement plus grand que les autres : il est convexe en dessous, sans ombilic ni fente ombilicale. L'ouverture qui le termine est tres-oblique a l'axe de la coquille; elle est plus large que haute, semi-lunaire, plus déprimée proportionnellement que dans l'Ilélice némorale. Le borl esı épaissi, renversé en dehors et tranchant, si ce u'est a la base, oú il est arrondi eu lourruler, qui, assez épais el siuueux à l'extrćmilé, est léguerement noollé ou lussu dans le milieu. Une petile callosilé arrondic se vuit à l'endivit de l'inserion du bord, an cenire de la coquille. la sartice de cetle coquille est ordinairement lisse ou marquée de sıries irrígulières d’acrroissement, ou de quelques rides irrégulièıes. Ordinairenent celle coquille est toule blanche; on en trouve Guelques intividus qui ont conservé des traces de leur premiere coloralion : elle consisic principalement en une zome d'un jaune pâle sur le milieu du deruier tuur; quelyuelois on en compre truis à cint, el alor's elles sont plus élroiles; lorsqu'elies sonl an nombre de cinq, il $\mathrm{y}$ en a trois en dessus et deux en dessous. Eutre les quatre ou cing espèces d'Hélices que l'on trouve fossiles dans les faluns de la Touraine, celle-ci est la plus abondanmea! répandue; les plus grands individus ont 25 millim. de diamètre à la base.

\section{Ilérice de Duvau. Helix Duvauxii. Nов.}

H. testâ globulosâ, rotundatâ, leviter depressá, asperuli; anfractibus convexiusculis, ultino majore, aperturâ semilunari temninato; labro reflexo, marginato, basi intús acuto, recto.

Nous avons dédié celle espèce fossile d'Hélice à M. Duvau, savant aussi érudit que modesle, qui a contrilaú puissamment à faire conooitre les richesses zoologiques que récćlent les faluns de Ia Tuuraine.

Celle espèce a de l'analogie avec la précédente; on l'en distingue cependant en ce qu'elle est toujour plus surbaissce, que son tes! est plus mince, loujours linement graunleux sur coule la surface, si ce a'est sur les prewiers tours qui sont lisses. 
l'ouverture, qui est très-oblique, est plus large que baute, el elle diffère ce l'espèce précédente en ce qu'elle a la base du bord arrondie et nou trancbante. On obserre sur quelques individus des restes de la coloration, qui consiste en deux ou trois bandes trausverses assez larges d'un fauve très-paile sur lc fond blanc. Celle espèce a 28 millim. de diamètre à la base. Nos.

\section{Hélice de Mayence. Helix maguntina.}

H. testâ globulosí, apice obtusî, subdepressâ, lexvigatî; uperiurâ scmilunari; labro reflexo, basi lato, acuto.

Voici une es pèce fossile des environs de Mayence qui a la plus grande analogie avec l'Helix nemoralis; on peut la regarder comme soo subanalogue, et elle lui ressemble davantage eucore que l'Helix turonensis. Il existe en Sicile une espèce d'Hélice qui n'a pas encore été nommée par les anteurs, et qui seroit plutôt l'analogue de celle de Mayence qu'aucune autre; car', avec la même forme, elle a aussi le bord columellaire, aplati et trunchant.

Cette coqnilte est de la taille de l'Hélice néroorale; elle est globuleuse, lisse, à spire obtose, composée de cinq tours légèremeni convexes, dont la suture est peu profonde et simple. Ces tcurs de spire sont lisses; on y voit seulement ijuelques stries d'accroissement. Le dernier tour, plus grand que les autres en proportion, est conrexe à la base et non perforés dans celle parlie. L'ouverture qui le termine est médiocre, oblique, semi-lunaite, à péristome bordé et rélléchi. Ce qui distinğ ae celte espèce, c'est que le péristome est fortement aplati à la base, saillant en dedaus de l'onvertare, et tranchant et non arrondi, comme dans l'Hélice némorale. Sur un individu que nons devons à l'obligeance de M. IIcringhlıaus de Créfeldt, on voil trois zones transverses obscures sur le dernier tour. On troure cetle espèce anx environs de Mayeace, dans uue formation lacustre; elle a 20 millim. de diamètre d̀ la base.

15. Hécice grimace. Helix personata. Lamr.

H. testâ orbiculato-convexâ, subdepressâ, perforatâ, minutissimè striatâ, comeo-fucescente; apertur $\hat{\imath}$ subtriangula $r i$, tridentatá, ringente; $l a-$ bro malgine albo, neflexo, sinuoso.

Helix personata. Lasr. Journal d'Hist. nat. pl. 42 . fig. I. 158.

Helix isognomostomos. Gres. p. 3621 . $n^{\circ}$.

Helix personata. Draparn. Moll. pl. 7. fig. 26.

DaUDEB. Hist. des Moll. no. 103.

L.sux. Anini. s. vert. tom. 6. pag. $92 . n^{\circ} \cdot 99$.
Preirfan, Syst. anord. $p l$. 2. fig. 14.

Petite cocquille arrondie, déprimée, subplanorbulaire, mirce, transparente, d'un lirun-faure de la même teiute sur toute la surface; spire com. poséc de cinq tours étruits, proportionnés, distiugués par une sulure simple et assez profonde. Ua épiderwe velu, dont les poils sont gros et cassans, couvre toute la corinille lorsqu'elle est bien liraiche; en dessous eile n'est point perforée, mais seulement déprinuée à l'eudroit de l'oubilic. Ce qui reud celte espèce fort remarquable, c'est la lorme de l'ouverture : elle est pelite, fort oblique à l'ase, très-déprimće, et plus large que baule. Son péristome, renversé en dehors, est bordé en dedans; il est blanc ou faure, fort aplati, tranchant à sou bord interne, où il est décunpé en trois arceaux, dout le aúdian le plus étruit fait un demi-cercle parfait: la joncrion des deux courbes latérales avec la médiaue produit deux angles saillans ou dents marginales; une troisième dent lamelleuse, saillante, est placée à la base de l'ouverture, sur le retour de la spirc, et rétrécit considérablement l'ourerture en la barant; c'est le bord gauche relevé perpeudiculairemeut, et joignant les deux loords d'une insertion à l'autre. Cetle espèce, assez rare, se trouve dans le Jura, la Suisse, elc.

116. Hín.rce fernée. Helix clausa. Rar.

II. testí orbiculatâ, globulosî, leviter depressấ, tẹnuissimè granulosâ, griseo-fuscâ ; centro depiesso, calloso; aperturî minimá, subtransversia, dente clato instructí; labro incrassato, bidentato, albo.

Ferus. Tab. syst. pag. 34. $n^{2} \cdot 104$.

Cet!e Hélice singulière a quelque rapport avec I'Helix personata yui vit en Eurupe. Elle est de la même tuille, globuleuse, légèrement dépriacé, à contours arroudis; sa spire, obluse, est formće de cing tours couvexes, dont la suture est simple; en dessous, le centre est légèrement déprimé, couvert par une petite callosilé qui termine le bord droit de l'ouverture; la surface ex térieure est toute granulense; les granulations, très-fiaes, très-noubreuses et très-serrées, ont une très-grande régularité, surtout sur les premiers tonrs de la spire; elles sont interrompues par des stries d'accroissement vers l'ouverture; celle-ci, très-petite, trèsoblique, est tridentće; elle est rélrécie d'uue manière remarquable par une dent columellaire sublamelleuse, qui s'avance de manière à toucher presque le bord droit; elle est obliquement décurreate, et occupe taut lintervalle cntre les deux points d'insertion du péristome. Le bord droit est blanc, épais, bidente; les denx dents soot produites par les trois sinuosités qui le découpe dlune manière très-aualogue à ce qui a lieu dans l'Helr.r personata. 
Cette petite coquille se trouve dans l'Awérique sepitentrivale; elle a dix millirn. de diamètıe.

177. HĖure poilue. Helix hirsuta. Raf.

H. testầ minimâ, globulosi, pisiformi, rufí, diaphema, undique hirsuti, subtis converissima;

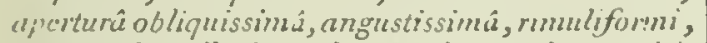
dcute columelluri pralongâ clussä; lubro trisizuuto, albo.

SAT, Journ. acad. nat. scien. tom. 1. page 17.

Petri. Gozopl. tab. 105. fig. 6.

Lister, Synops. tal. 93. fog. 94 .

Favaxie, Conch. p. 6.j. fig. 3.

Helix isognomostomos. I.I. pag. 36al. no. 158.

1bid. Helix sinuala. pag. 3618. $u^{\circ} \cdot 23$.

Fenus. Tub. syst. pag. 34. $r^{\circ} .101$.

Celle espèce cst une des plus singulières du genre, a cause de la forme si bizarte de son ouverture. Elle est lout-â-fail alobnlcuse, pisiforme, ;resqu'aussi convexe dessus qquen dessous. Sa spire, obtuse au sommet, est composée de six tour's coovexes ì suture simple; la surface extérieure, qui est d'un jaune-brun, est couverte d'un épiderme écailleux et velu. L'ourerture ressemble à une fente irréanculic̀ro extrêmcment étroite, à travers laquelle on concoit it peine comment l'animal peut passer. Sur la columelle existe une grande dent lamelleuse très-saillamte, obliçuewent décurrebte et rentrant daus l'ouverture vers son extrémitú droite; cetie deat s'élève à la hauteur du bord diroit, à une très-petite distance de lui; tlle est presque aussi longue que le bord lui même, e! se continue a la base atvec le péristone. Le bord (ỉroit, assez épais, est fortercent in!lecbi au-dedans de l'ouverture, et il est parallèle à la dent columellaire; son bord inlerne présente, dans sa longueur, trois petites siouosités, ou plutốt ćcbancrures, dont la médiaoe correspond à la saillie de la dent columellaire. Lette petite coquille ne pent être comparíc, pour la bizarrerie de son ouverture, qu'a l'Hclix labyrinthus. Elle vient des EtatsUnis, Amérique septeotrionale; elle u'a que sept ou luait millim. de diawètre.

\section{HĖuce convexe. Helix convexa. Raf.}

H. testầ convero-depressâ, sulıglobulosâ, diaFhani, rufescente, tenuissimè et regulariter punctatá; unfractibus convexis; centro depresso, subuperto; aperturâ obliquissina $\hat{i}$, angustá, dente columellari obliquo instructd; labro albo, basi sinuato.

Coquille qui a beancoup d'analogie avec la précédeotc; elle est moins globuleuse, et son ouverture, beaucoup moins étroite, suffit seule poor l'en distinguer. Sa spire, convexe et obluse au somaret, se comprose de six tours aplatis, doat la suture ust simple; le deruier est convexe en dessous, déprimé au centre, ò̀ l'on aperçoit une petite fente oubilicale du food de laquelle part le bord droit, qui en diminue l'étendue. La surface extérieure est d'un fauve pâle corné, trausparea!; elle est couverte d'une multitude de graunlations regulières, plus nombreuses que dans les espèces oĭ nous avous remarqué cet accident. L'ouvertuie est très-oblique, déprimće, beaucoup plus large que haute. La dent columellaire dout elle est pourvue reatre obliquement dans l'ouverture; celte dent est étroite, longue, peu élevée et opposée au bord droit de l'uuverture, qui s'infléchit en declans, en s'opposant à elle; le loord est blant: el siuueux, nais saos dent; son extrémilé gauclie s'insère dans la lente ombilicale, et c'es: un peı au-dessus de cetle insertion que l'on remarque une petite sinuosite, au-dessus de larpuelle le bord est bifide. Cette espèce, qui a dix millim. de diamètre, vient de l'Amérique septentriuzale.

19. II ĖLE unidentée. Helix unidentatu. Drap.

H. testâ canico-globosiâ, brunêa, corne $\hat{a}$, hispidî, striatâ, subtus convexî̀, perforatâ; anfractibus convexis, appmximatis; aperturâ contpressâ; peristomate marginato, unidentato.

Draparn. Hist. des Moll. pag. 81, $n^{\circ} .6, p l .7$. fig. 15.

Helix monodon de Ferussac. Prodr. pag. 35 $n^{\circ} \cdot 122$.

Pfeiffer, Syst. anord. tab. 2. fig. 1.

On servit porté à croire, tant est grande l'aualogie entre cette espèce et l'Helix edentula, que cette deraière n'est qu'une variétć dont la senle différcnce seroit dans le développement plus ou moins complet de la dent du péristome.

L'Hélice unidentće est perite, globuleuse, uu peu conique, arrondie à la base, ayant le bord du dernier tonr à peine subcaréné. Les tours sont au nombre de six ou sept, convexes, courts, pressés, striés longitudinalement, séparés par une sulure profonde. Le dernier tour se termine par une ouverture ua peu oblique à l'axe, très-déprimée, beaucoup plus courte que large, à péristome blanc, rélléchi rers l'ombilic, bordé de brun à l'extérieur, et se terminaot par une petite deat avant de se joindre au bord clooit. En dehors, le péristome est indiqué par une fascie jaune-faure. La coquille est brune, diaphane ou cornée, daos le reste de son étendue. Celle petite espèce se trouve en France dass le Jura, en Suisse et ea Allemague

120. Hélice marron. Helix hippocastaneum.

H. testầ subglobulosi, imperforatá, tenuissimi

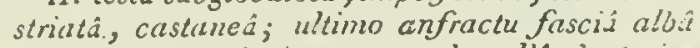
cincto; upcrturí ringente; columellâ dente in- 
crassato magno; labno margine interiore multidentato.

Helix hippocastuneum. L.sur. Journ. d'Hist. nat.pl. 42. fig. 3. a. b.

Favaviz, Conch. pl. 63. fig. 0 .

Helix nux denticulata. Caeas. Conch. tom. 11. tab. 209. fig. 2055. 2056.

Dat deb. Hist. des MIoll. $n^{\circ} \cdot 9^{3} \cdot p l .49 \cdot$ fig. 3 et 4.

Lيs1 K. Anim. s. vert. tom. 6. pag. 79. no. 51 .

Voici encore une espèce remarquable par la furme de son ouverture, el qui se rapproche par ses rapports de l'Helix hirsuta, que oous venons de décrire. Celle-ci est beancoup plus grusse, elle est globuleuse; sa spire, composée de six tours aplatis, est oloruie an sommet; la sulure est simple, ua ais superficielle; eu dessuus, la cunvexité est presque anssi grande que celle de la spire; la surlace, couverte, d'un épiderme d'un brun-marron, esi chagrinée irr'égulièreunent par un graod noubre de pelits plis diversement ioclinés; le milieu du derdier tour, qui est proportionnellement plus grand que les auires, est occupé par une zone blauche étroite. Looverture est grimaçanle, plus larue que baute, à bords con:inus; sa couleur est d'un fauveorange; le bord ganche est furné par une graode dent aplatie, pyramidale, fort saillante, quit occupe toute la longueur de la columelle, et se joint par ses extrémités aux deux points d'inserlinn dn bord droit : celle dent diminue d'une maniete très-remarqnable l'entrée de l'ouveriu:e, yui esı rendue encore plus étroile par la saillie du hord droit à l'intérieur. Ce bord, é $i$ ais et arrondi à ses extrémilés, est dentelé dans loute sa longueur; ses dentelures sont inégales, el ardinairement au nombre de cinq : les trnis qui sont à la base sont les plus petiles; elles s'efficent quelquefois presque complétement avec l'àge, et sont remplacées par un bourrelet seulemeni onduleux. Une large callosité réunit à la base de la coq̣uille le bord droit arec la dent columellaire. Cerle coijuille, assez rare et recherchée des amateurs, se numme vulgairement le Marron, ou la Noisette. Elle vit à la Martinigue, sur les rochers. Les plus grands individus ont 25 milliar. de diamètre. .

121. Hérice à denx dents. Helix bidentalis.

H. testâ subglohosâ, subties convexi, imperforatá, striis exilissimis subdecussat zonis fasciisque virentibus; spird brevi, conoidea; labro albo, reflexo, supernè bidentato, extis costẩ carinutâ in tructo.

I.Aux. Anim. s. vert. pag. 79. no. 52.

Helix malleata. Ferus. Hist. des Moll. $n^{n} \cdot 91$. pl. 48 . fig. 4 .

Celle cnquille a de l'analngie, quanı à sa lorme el à son volume, avec l'Helix hippocastaneum. Filic est globuleuse, is sire courte, obluse, cou- posće de cinq tuors légerernent arrondis et à suture simple el peu profonde; le deroier tour, lérérement caréné à sa circonférence, esl proportionnellement un peu plus grand que les autres. Il est très-convexe en dessous; comme les pr'ćcédeos, il est finement chagriné et couvert d'un épiderne d'un brun assez foncé; toute la coquilie est de la même couleur. La plupart des individus sont ornés de deux ou trois bandes d'un brun-noir; ces bandes sont transverses et élroiles. L'ouverture est très-oblique; elle est nódiocre, irrégulièremeot semi-lunaire, à périslume épaiset blanc : le priristome, légèremen! renversé en dehors, s'y termine brusquemeut el à vif-alête; il est sinveux dans sa lungueur, mais on rerarque surtout unc assez vaste échancrure demi-circulitice à sa partie cxlerne el supérieure, échancrure qui est bornie à ses denx extrémi:és par deox dents obluses et peu saillantes; ce bord druit, ainsi que l'intérieur. de l'ouvertire, sont blanes.

C'est à Ténérille que vit celte espèce, assc z rare daus les collections. Elle a 25 millim. de diamétre.

\section{HËLICE enfoncíc. Helix cepa.}

H. testâ orbiculuto-subconoidj, imperforatd, rufi, albo.fuscrutu; ulturno anfractu prope labrum profurde excavato et infia in dentem pro. ducto; labro margine roflexo, basi unitentato.

Helix cepa. Nurcer, Verm. pag. 7 f $^{\circ} n^{\circ} \cdot 269$.

Lister, Conch. tab. 88. fig. 89.

Nicolson, St.-Domingue, pl.5. fig. 9 .

GuEl. pag. $3619 . n^{\circ} .28$.

1) Aúrb. Hist. des Moll. no. I15.pl. 53. A., fig. 3.

Lasx. Anim. s. vert. tom. 6. pag. 74. $n^{\circ} \cdot 5 \bar{j}$.

Grande et helle coquille globuleuse, inince, iransparente, d'un brun funcé, avec une zone diun lauve clair a la parlie supérieure des tours de spire; celle spire est convexe, obtuse, formíe de cinq à six tours, dont les deux preme:s suut complétement lisses et ordinairement hlaucs. I,a suiure est simple et pen protunde ; le dernier lonr, pruporionnellement plus graud gue les autres, esi Irès-cunvexe en dessuur; il se cermine par vue ouveriure semi-lunaire à péristame éfrais, renrersé, amondi a la base, et pourvo d'une callosilé qui se joinl à s in autre extrénić, par un bord gauclie, élalé, très-mince. Celle ouverlure est d'une mídiucre érendue relativenent a la grandeur de la coquille; elle est urunie is la base d'uae grouse deut saillante, inlívieurement opposéc á une autre grosse deut pyranidale e! obluse qui se vi.jt cul chedans du hurd droil; cette dent resulie diune dépression de la partie latérale da test, yui, exlérieurement, est irrégulièrened enfoncé conurse si un accident, apués avoir blessé l'aninuil, l'eut Corcé à recurstruire ss coujuille irrégulicuereat. 
Toule l'ourerture est d'un fauve-rongeatre; snn pristome, épais et bordé, est simple dans presque inute son étendue. Celle coquille a tovte la surlire extérienre converle de stries longitudinales très - fines el très - nombreuses, simples sur les promiers tours, et irrégulièrement clıañrinées sur le dernicr. En dessous, ces stries convergent vers le centre, mais en diuninuant et s'allaiblissaut per à peu. Dans le jeune agre le dernicr tour est anguleux dans le railieu; mais lorsque les individus sont parrenus à leur enlier développement, cet angle s'ellace, et il disparuit complètement vers l'ouverture. Cefle coquille halsite Suiut-Domingne, oì elle n'est pirs rrès-rare; les plus siands individus ont 55 millim. de diasuctre. linn.

123. II ÉLCE Josephiue. Helice Josephina.

H. testî orbiculato-convexâ, subdepressî, sub- Lrinatâ, elegrenter striato-granulosa, virescente, maculis luteolis fuscusque alternuts; apertura obliquissimâ, cualá, minima, bidenlats; labm ininussuto, depresso, continuo, basi callasu, lineâ fiscû cincumdato.

Fer. Hist. des Moll. $n^{n}$. tas.

Celte espèce méritnit hien, par l'éléfance de ses couleurs, que $\mathrm{N}$. Ferussac la dédiźt à l'inpé. ratrice Josíphine. Flle est diune couleur peu commune parmi les Hélices; sur un fond vertclair deux zones d'un brun rougealle, intertompoes par des taebes llammulées l'un jaune d'or, parcuurent lous les tours de spire à la base et au somrat ; cestours, au nombre de cinci, sout orués, à l'exception du premier, de granulatious, un plutôt de stries granuleuses, obliques et ondulécs. En dessous la coquille est légèrement convexe; elle se termine par une ouverlure trèsoblique d'une médıncre grandeur, ovalaire, heaucoup plus large que haute. Son bord continu est ipais, renversé eu dehurs, blane ì sa partic interne, et loordé extêricurement par une ligne d'un brun foucé. A la base, el en dedans de l'ouveriure, on remarque deux denis pliciformes pyramidales, done la plus externe et la plus saillante est indiquée an-dehors par une léçire dépression "fui se voil immédiatement à cóté du péristoute. Les deux extrémités du bord druit sont réunies à leur insertion par un bord gauclie sitillant et de la même coulenr que le resie de l'ouverture. C'esi a la Guadeloune que vif celle jolic cuquille, qui a 20 ì 22 millins. de diamètre. Hen.

124. HÉlice polydonte. Helix dentiens.

II. testâ globulosî, fusca, lavigatâ subtìs, convexâ; aperiurâ semi-lunari, nmimâ, intìs denticulata, fusco-nigricante; labro refexo, inrassato.
Helix dentiens. Fieaus. Hist. des Moll. $n^{\circ} .88$. pl. 48. fig. 2.

Cuquille obtuse, globuleuse, furmée de cinq tours et dewi, a peine convexe; in suture simple, quelquefuis submargiace dans le jeune age, tnais toujours superficielle; le dernier tour, un peu plus grand gue les autres, esi convexe en deliurs; il est lisse coume les précédens, ou comme eux il est strié irrégulièreweat par les accroissemens. Il se terruioe par une ouverture extrêmement oblique, médiocre relalivement à la grandeur de la coquille. Une large callosité occupe le centre de la coquilie, et se continue d'une part avec le bord druit, et d'une autre avec le gauche, qui est appliqué et très-pen épais. I.e burd droit, renversé cu dedans a la base, et en dehors daas le reste de sacirconlérence, porte a la base deux petites dents, et eu lace, sur son autre partie, un bourrelet plus on unoius nrand selon les individus; ce bord droit, alusi que l'intérienr de l'ouverture, sont d'un brun quelquefois Irès-obscur, et quelyuefois aussi diune nuance moins foncée mais rougeatre. Toute celte coquille est d'une couleur urilorme, d'uu brü foncé, quelquelois passant au fauve. C'est à Cayenne, a ld Guadeloupe, à la Martinique, d̀ la Guiane que vit celle especte. Son dianétre est de 25 millimèıres.

125. Héstce ponctuée. Helix punctatu. Bовn. H. testî orbiculato-ğlobosî, subcarinatâ, superne fuscî, inferne albido virente el fusco unizonatâ, undiquè leviter punctatâ; aperturâ obliqué semilunari, marginatâ, refexâ, hasi bidentatâ, albâ; dente obluso, junctıone marginis dextri et colunellari posito.

Bors. Mus. Casurei vindebonensis, pog. 372. fig. 17 et 18.

Feros. Hist. des Holl. no. 8g. pl. 48. fig. "亏.

Il y a nue très-grande analogic entre celte espéce et la précétente, mais le caractère si constant de la dent isolće placéc a la joaclion de lextrémité antérienre du bord dioit de la columelle est bien sulfisant pour la distinguer au premier aperçu de toures les autres espèces de la mème section. Celle coquille est orbiculaire, arrondie, lígcienont dépriucée, jamais carćvéc, furmée de six tours peu convexes ponclués irèsfincment sur lonte leur surface; la suture est simple, superfuielle, quelquefois mais très-rarement subrnargiace dans le jeune âge; ea clessous, la convexité de la coquille est presqu'égale ḋ celle de la spire. L'ouverture, blanche daus presque toute son érendue, est bordéc par un péristome très-épais, continu, elargi et calleux a la base, et garni infúrieurement par un bou:relet saillant à liatérieur, brusquement terminć par une deat traochan!e; au-delit de ce bourrelet, 
i] se renverse considérablement en dehors, et $P_{i}$ end une teinte légèrement rougeâtre; arrivé it son insertion sur l'avant-dernier tour, a l'endroit où il se joint au bord gauche, il se tcruine par une dent conique et obiuse d'un rouge vineux; le bord gauche est blanc, assez suillant, et rend l'ouverture continue par sa jonction avec les deux extréunités du bord droit. En dessus celte coquille est d'un brun-rougeâtre ou noirâtre; en dessous elle est d'un fauve-verdâtre, et près de la circonférence ornée d'une bande transverse, étroite, de la méme couleur que le dessus. Nous possédons nne variété dans laquelle celte bande intérieure manque. Celte coquille n'est pas rare à Ja Martinique, où on la trouve spécialement. Son diamètre est de 23 millim.

126. Hélice monozonale. Helix monozonalis.

H. testâ orbiculato-convexâ, ventricosâ, umbilicatâ, pallide fulvâ; ultimo anfractu zonâ albâ angustiusculâ cincto; spirâ breviusculà; labro acuto.

Helix unizonalis. Excrec. pl. 462. fig. 6.a.b. Dauder. Hist. des Moll. pl. 91 . fig. 4.

LAMx. Anim. s. vert. tom. 6. $n^{\circ} .4$.

Cette belle et grande coquille est divisée en deux parties bien distinctes par une zone médiane étroite et blanche, qui lui a valu le nom donoé par Lamarck. Elle est discoidde, subglobuleuse, à spire obtuse et peu élevée, formée de cinq tours, dont le dernier est proportionnellement uo pen plus grand que les autres; ils sont lisses on marqués seulement par quelques accroissemens; en dessous, le dernier tour est légèrement concave vers l'ombilic : celui-ci consiste en une fente qui est obstruée par une petite callosité dans l'âge adulte. L'ouve:ture est trèsoblique à l'axe longitudiaal de la coquille; elle est serni-lunaire, simple, à péristome un pen obtus et lilet un peu renversé en dedans; le péristnme est blanc; un bord gauche étalé joint les deux parties du péristome. En dessus, cetle conquille est d'un brun-malron uniforme; en dessous de la zone blanche moyenne se voit une large bande d'un brun foncé, rqui orcupe seulement la partie supérieure de la base : celle base est toulc banche. Cette belle espèce, rics-rare dans les collections, a quelquefors 60 mill. de diamètre. On ignore sa patrie; quelques personnes pensent cependan: qu'elle vit à Madagascar.

127. Hélres de Baudin. Helix Baudini. Noв.

H. testâ orbiculato-convexâ, substriatá, pallide fulvâ; ultimo anfractu busi allo subcarinuto; aperturâ minimá, simplici, subrectâ; unnbilico minimo.

Nous devons à l'obligeance de II. Quoy la connoissance de celte espèce, qui a de grands rapports avec la précédente, mais qui reste constamment d'une taille beaucoup plus petite. Flle est subdiscoide, à spire legèrement conique, à laquelle on compte sept tcurs rapprochés a peine convexes, subsirićs, à suture superficielle et simple. En dessous, le ceutre est légèrement déprimé, ouvert par un onsilic très-petit et arrondi; dans cet onbilic, s'insère l'extrémité du péristome. L'ouverture est d'une médiocre étendue; elle est presçue perpendiculaire, obliquement semi-lunaire, plus large yue haute, simple dans son contour, un peu épaissie vers la base. La coloration de cette coruille a beaucoup de ressemblance avec celle de l'Helix monozalis; la spire est d'un brun pâle, netlement tranchíc à la circonférence du dernier tour par une lizgne d'uo brun un peu plus obscur; en dessous, la coquille est toute blanche. Cette espèce vient de la nourelle Guinée; elle a 22 millim. de diamètre. 


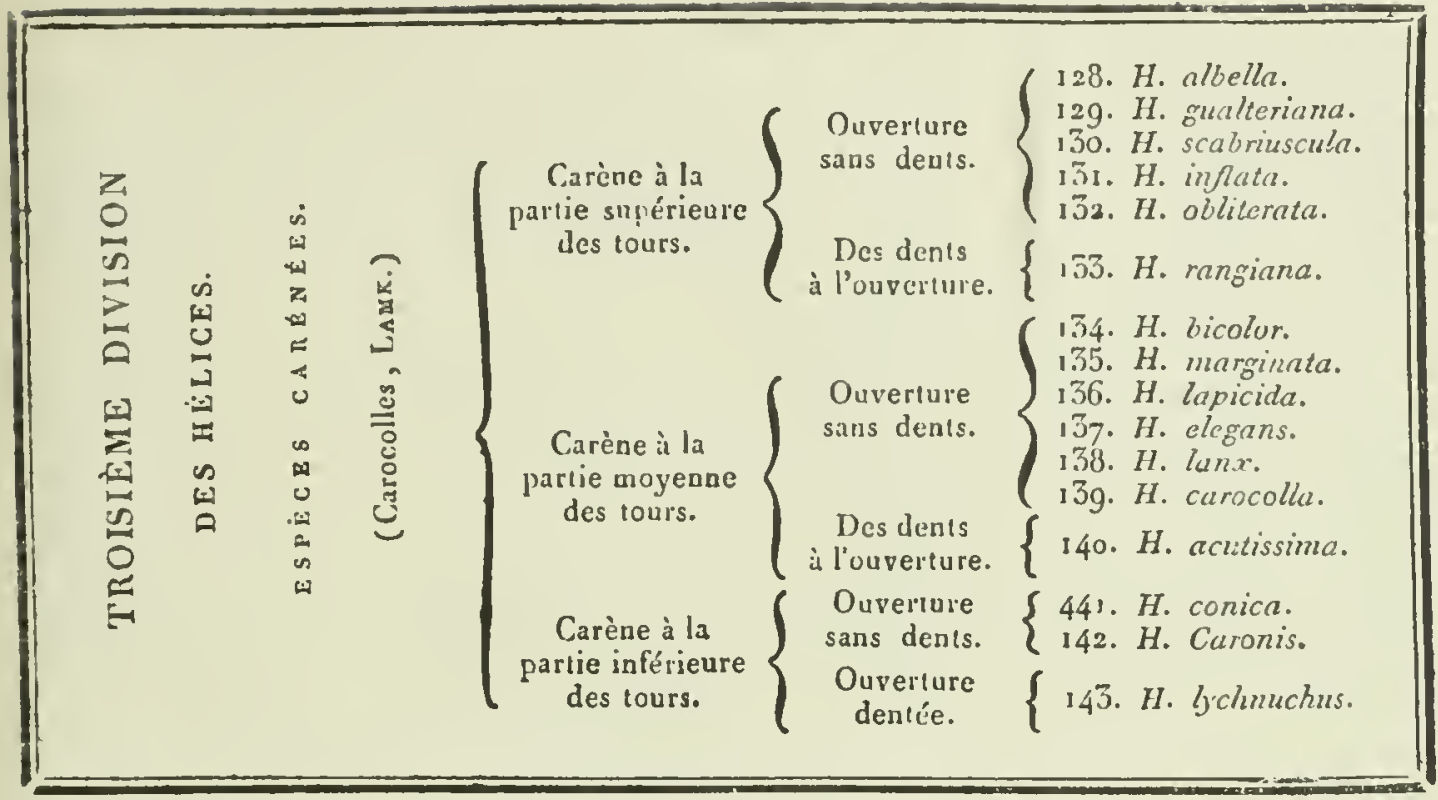

128. Hélice albelle. Helix albella. Liv.

H. testầ orbiculari, supnd̀ planâ, subtius conrexâ, late umbilicatâ, transversè striatâ, albâ aut lutescente; centro nigricante; labro simplici, acuto.

Helix albella. Lrv. Gmer. pag. $3615 . n^{\circ} \cdot 7$.

Helix explanata. Nuzz. Verm. p. $26 . n^{\circ} .228$.

Lisser, Conch. tab. 64. fig. 62.

Helix phnorbis marginalus. Caems. Conch. tom. 9. tab. 126. fig. 1 102. a. b.

Draparк. Moll. pl. 6. fig. 25.27.

Dsuder. Hist. des Moll. $n^{\circ} .296$.

Carocolla albella. Lasx. Anini. s. vert. tom. 6. pag. 100. $n^{\circ}, 17$.

Cette coquille est d'unc forme très-singalière; elle est planorbulaire, mais carénée à la parlie sapérieurc des tours, qui sont tout-à-fait plats dans cet endroit, et, au contraire, convexes en dessous; la jonction des tours se faisant sur la carène, il en résulte une spire très-aplatic et une surface supérieure plus large que l'inlérieure. Ou comple sur cette surface cinq tours de spire, dont les deux premiers sont lisses et bruns, les suivans sont d'an blanc-jaunâtre et finemeat striés dans leur longueur; ils s'accroissent graduellemeat, et sont proportionnés entre eux. La suture est simple et linéaire lorsqu'elle se fait sur l'angle carénal; elle est légèremeat bordée lorsqu'elle se fait un peu au-dessous de cet angle, ce qui a lien souvent. En dessous, celte cuquille est convexe, striée et de la même couleur qu'en dessus; elle est ouverte au centre par un très-large oasHist. Nat. des Vers. Tome II. bilic évasé dans lequel se voient facilement tous les tonr's de la spire. L'uuverture est ovale, subquadrangulaire, fortemeot anguleuse à sa partie supérieure et externe; son burd supérieur est droit, et l'inférieur, courbé eu anse de panier, le rejoint à l'angle supérieur; le péristome est simple, tranclsant, bordé ea dedans d'un bourrelet blanc.

Cette coquille se trouve sur le littoral de la Méditerranće, en France, en Italic et en Espagae.

129. HÉLıce scabie. Helix gualteriana.

H. testâ orbiculatà, suprà planá, subtis convexo-turgidâ, imperforatâ, scabrî, decussatim striata, sordidè cinere $\hat{a}$ spiri planissinsi; labro tenui, margine reflexo.

Helix gualteriana. Lis. Gmel. pag. 3621. $n^{\circ} .33$.

Guar.t. Test. tab. 68. fg. e.

Helix obversa. Bonn. Mus. tab. 13. fig. 12. 15.

Cвехx. Conch. tom. 5. pag. 237 . vign. 44. fig. $a . b . c$.

Scвноетter, Einl. in Conch. Lom. 2. tab. 4. fig. 2.3.

Helix gualteriana. DadDEB. Hist. des Moll. pl. 62. fig. 1 .

Lauk. Anim. s. vert. tomz. 6. pag. 97. $n^{n} \cdot 7$.

Cette coquille a beaucoup d'analogie avec les suivantes par l'aplatissemeut de sa spire; c'est une des belles espèces de l'Europe : elle est grande, discoïde, à spire très-plate, forméc de $\mathrm{Kk} *$ 
cint tours fortement earénćs à leur partie supésicure; la sulure, placéce au-rlessous de la carène, cost jrofonde et cachée suus elle; celle carène, très-aiguë, se relìve en dessus, el elle est créncléc daus toule son étendue; le dernier tour, proportionnellewent plus grand que les autres, est très-conrexc en dessous, il est dépourvu d'ombilic; l'ourer!ure qui le termine est pau ollitune, Iriangulaire, blanclie, calleuse ì la base, à hords épaissis el fartemeal tenversís en ichors. Tuute la surfacc prisente des stries longiludinales croisćes par d'autres transterses; ces stries, un pen lamelleuses et plus saillantes au point de l'entrecroisement, sout très-róntrilieres et très-clégantes dans le jeune âge, mais elles deviennent plus grossiètes et plus rudes sur le dernier tour, et surtout vers l'ouverture. la conleur de la surface extéricure est d'un faure t:entré blanchâtre : r'est en Espagne, vers Giliäliar, flue l'on troure celle coquille, dont les j'ins grands individus ont 45 ou 48 millim. de diaincilie.

3.̉o. HĖuıce scabriuscule. Helix scabriusculu. TiOD.

H. testâ orziculatí, cinerech, fusco maculatâ, "upernè plano-convexá, infernè convexo-turgida, imperforatá; striis laniellosis, irregularibus, lonsitudinalibus ornati, undique tenue granulosit; suturis marginatis; aperturi ovato-triangulari; lubro albo, valde reflexo.

Depuis peu de temps celte espère est conume; clle a élć rapportée de Sicile par M. Caron. Elle a beaucoup de rapporls arec l'Helix gualteriana, lant par sa forme que par les divers accidens extérieurs. Elle est orbiculaire, aplasie, moins convexe en dessus quien dessuls; sa spire est forméc de cinq lours tris-aplatis, fortement car'́nés à leur pourtour. Celte carène, se releraol cu dessus, cacbe la suture; en dessous, la coquille est régulièrement convexe; le ceatre, occupé par une callusité d'une médiocre granleur, donne insertion à l'extrémité du bord droit. L'ouverture est oblongre, subrriangulaire, plus large quue haute, ì péristome blanc, fortement rélleclii en debors, et surtont à la base. 'loute la surface extérieure de celte coquille est ornće de sıries longitudinales, pliciforme, irréruliéres, ondulcuses, qui, en passant sur l'angle des tours, y produisent de petiles crínclures. Ces stries, en dessous, convergent vers' le centre en s'alténuant. Outre ces stries, la surface est encore couverte jar un irès-grand nombre de granulations très-serties, qui, en dessous, se confondent avec les strics. La couleur est d'un lilanc-jaunàtre ou cendré, sur laquelle se dessine des taches d'un brun foncé, qui prennent quelquefois l'apparence d'une fascic trunsverse. Celie coquille n'est pas rare atua anvirons de Palerme el de Syracuse; elle vit sur les rocliers. Son diumèlre est de 25 willimètres.

131. Hixice enflée. Helix inflata.

H. testâ orbiculati, suprì convexâ, sulitus valde turgidâ, imperforati, obliquè striata, utringue albidê; unfiretrbus quatemis, duobus ullimis hatis; fauce trigona; labro margine reflexo.

Helix gualteriana. (неду. Conch. tom. 9. tab. 126. fig. 1100.1101.

Helix angulata. DandeB. Hist. des Moll. $n^{\circ} \cdot 134$.

Carocolla inflita. I.амк. Anim. s. vert. tom. 6 . pag. $97 \cdot n^{\circ} \cdot 6$.

M. Firussac a jus!ement sépraré de celle Heli.x infuta, l'espèce quiil nomme obliteratu, et qui nous semble, comme i lui, très-distincte de celleci. LiHelix inflata est une coquille furt remarqualle par l'aplatisscment de sa spire, et par la saillic considirable que le dernier lour frésente en dessous; clle est à l'inverse des autres flélices, sous re rappert, puisque c'est sa base grai est la partic la plus saillante. I a spire est furméc de qualie tours tres-aplatis, duat le dernier est próportionncllement plus grand que tons les autres. La sulure est légèrement bordće; elle est trèssaperliciclle. Le dernier lour porte, à sa partic supúrieure, une carčne très-ajguë, qui sert de base au conne peu ćleví que forme sia saillie. L'onveriure est très-ample, triungulaire, ¿̀ bords épaissis et renversés en dehors. La colamclle, aplatie, ćlargie en avant, se courbe, pour se joindre arec la base de l'ourcrture. le périsiome est blane, et la coquille l'est aussi, lurscju'elle est déponillíc de soúpiderme? rct épiderme est d'un fance paile el d'une couleur unifurme. Sur la susface extéricurio de colte especice il a'y a point de tuberrulc, mais senlement des stries d'aceroissement, caractère qui se juint très-bien avec tons les autres, pour distinguer celle espèce de la suivinte. Elle a 45 nilliaritres de diancritre; clle vit à P'orto-Rịçco.

132. Hélice oblitérée. Helix obliterata. Fen.

H. testâ orbiculatî, suprá subconvexá, subtìs valdè turgidi, imperforntú, granulosi, sul exidenne rufo: ulbicante; uperturi alba, triangulari, basi late callosi; lubro margine reftexo.

lierus. Hist. des Moll. $n^{\circ}$. ī̄6.pl. 6r. f.g. 3.

Les principales différences qui existent eutre ccllc espèce el la précídente, consislcnten ce guata spire est moins aplatie, que la curène qui partage le deroier tour est plus aúdiane, ct en ce que ta surface est toute chigrivée par unc foule de pelits lubercules arrondis, irrégulicirement disposis, mais suirant quelquefois la dircetion des strics l'accroissement. L'curerture est triaugulaire, 
l.linche, callense ì la base, à columelle licis. large et aplatie antérienrement. Le bord, fort épais, est renversé en dehors. Un épiderme d'un brun-fauve courre taute la coquille, qui devient blauche lorsqu'elle en est déponillée. Cetle espèce vit, avec la précédente. à l'ortoRicco. Les plus grauds individus ont 55 millia. de diamcitre.

\section{IĹtuce de Rang. Hclix Rangii.}

H. testí orbiculato-depressí, corneo-rubescentc, translucidâ, tenud et cleganter striatâ; stris longitudualubus, confortis; anfiactibus supcrnd planulatis, ultimo angulato, basi umbilcalo; aperturû angustissina, dentatij ; lubro intus contorto, flicato, supernì sinuato.

Petite coquille des plus singulières et des plus remarquables par la tormo bizarre qu'dteate sa levre droite, lorsyu'ulie est parvenue it fout son develofpement. Celte cociuilie est aplatie, diswide, wince, linsparente, cornée, d'un brunreogeatre, waitorase. Sa spire, tries-plate, se compose de sept tour's très-étroits, seriés, uu peu convenes, à sumre siaple; ils sont stricis longitudinalement, et fortenent anguleux is leur parlie supérieure, de sorle que la liase de la criguille est flus saillante que la spire. L'es stries cxccssivement lines et trunswcrses coupent, à innyle droit, les stries longitudinales, et ne s'a-

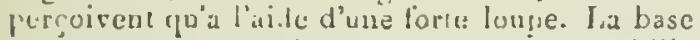
ess cuuvere, occupéc au centre par un ombilic

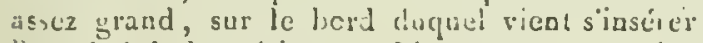
l'extrémilé da péristome. L'unverture est trisEtrcite, en forme de leutc longitudinale; elle est presique droite a l'axe de la copeille: la livre durvile, a la partie qui correspond í l'angle ratténal, se prolonge cn un crocliet tiès-airn, eontcurnć en dedans el treusé tn-dcssus d'une peitc gotutiire; ant-dessus de ce croclacl, le bo: d, tn se ienrersunt ca dehors, forme unc sinuosité iroturule en dessous. Cae dépression manilicse en delors procluit, en dedans du limbe, une den: suilian!e, au-dessous de laquelle le bord est denx fois enilé. Rien, jusqu'a prósent, parmi les Helices, at ponroit donner une idie de lat furme toute particulière de l'onverture de celle-ci.

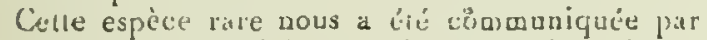
notre ami, M. Michaud, cficicr aussi dustiuguć far son carartere peensuncel gue par le ztle atdent qu'ul tret à l'ćlude de l'misione naturtie, et sorrout des productions de la liance. C'est it ses rechierchus que notle Faune francuise deva l'adition de celle espèce curieuse et de beaucoup d'autres. l.es plus grauds iuclivicus out 14 million. de diancilre.

154. Ijélce licoiure. Helix oicolor. L.sux.

H. tcsti orbiculuto-coroided, suotùs corvexấ, iniperforata, supià culba lateol.ve. subtüs rifo- fisci icl nigricante, ad suturas fusco fusciati. labro tcnui, aculo; columcllẩ incrassatä, "utbesceric.

Carocolla bicolor. Lank. Anim. s. vert. 6om. 6. pag. 97. $3^{\circ} \cdot 8$.

Helix inversicolor. Hen. Hist. des Moli. pl. 58. fig. $1-12$.

A l'exemple de M. de Ícrussas, nous réunissons le Curocolla muritiana Lamk. à cetle espéce; uras n'y royons gu'une variélé peu is:portante. A ígintid de toules celles qui sent

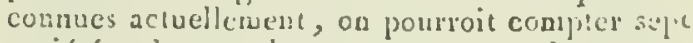
varićtés, dont quelques-unes serrent de passaje: a l'espèce que nous venons de citar. L'Líchx bicolor 'sl une coquille subdiscude, trachifurace, à spire plus cu moins saillanse, sclon les variélós; celle spire est conique, frointue; on y comple huit a neuf tours aplatis, aunt la sulure est simple et superficielle; la surlace de ses tours mont:e quelquelois des stries longi udinales sculement, quelquefois aus:i des strics trinsverses plus vi meins nond reuses, cini reudent leur surfice granu'cuse; le dernier hur, fortement cartue du:s l. milieu, est rénuliètement convexe ea dessurs. Dans le plus graud nombre des infividus, celte surfuce inlerieure est cilszamment quadrillée par l'entrecioisement de stries louritudiusles et trans.

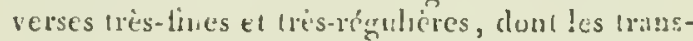
rerses sont grinétalement les plus espacécs. L'ouverture est subtrigune, asscz grande, simple, toujours a hords minces e! tranchins a tors les anes. La liase de la colnacllés"in pl ntc au centro de la bisc; clle est un peu a latie légerencont calleuse, ipaisse, arronde $c D$ dedias; elle se conlinue obliquem at en s'altinuant avec le lont droit, qui est légutemeut simmeux dans sa longueur.

Si celle uspece est varialile dans sa forme et daras sa taille, elle ne l'est pas moins rians sa coulenr : clle varie suns ce rapport depuis je jaurelinze jusquan bann-nuiratre lancé. D'antres variélís se montrent dins la disposition d'une ou deax bandes obscures qui se voient à la partie supérieure des tours, et des taches irrígalières, blanclälres ra jumbitres, Hannules ou ponctućes, qui suivent les sutures.

Lat disposition la plus urdinare consiste en ce gue la spire est d'on blanc-fauve ca grisitte et la base d'un lirus fonces. Ce n'est point seulement i l'lle-de-lirance fule l'on trouve celle espèce; cn la rencon!re aussi à la nouvelle Guinće, d'uú elle a été rapportée par MII. Quay et Gitymard. Les plus grands individus ont 43 coillion. de dia wetre.

35. Hërree marginée. Holix marginata. Mur.

H. iestì orbiculari, suprà convexá, infià convexo-planulati, umbalicati, alba, fusciis fuscis circtí; lubio margine reflexo, albo. 
Helix marginata. Muc.. Verm. p. 41, $13^{\circ} .241$. Bors. Mus. tab. 14. fig. 7. 8.

Chesn. Conch, tom. 9. tab. 125. fg. 1097.

GMEL. pag. 3614. $n^{\circ} .3$.

Ejusd. Helix marginella, pag. 3622. $n^{\circ} \cdot 162$.

Helix marginata. Daudeb. Hist. des Moll. $n^{\circ} .140$.

Lasr. Anims. s. vert. tom. 6. pag. 98. $n^{\circ} .11$.

Coquille discoide, ayant la spire plus saillante que la base; celte spire est conoïde, un peu obtuse au sommet, striée longitudinalement, et composée de sir tours très-aplatis, dont la suture est simple et très-superficielle. En dessous, le dernier tour est médiocrement convexe, un peu déprimé au centre, et garmi d'une callosité sur laquelle s'insère l'extrémité du bord droit. L'onverture est très-oblique, médiocre, opale, triangulaire, bordée d'un périslome très-épais, blanc, jenversé en dehor's, et se coulinuant sur l'avantdernjer ton' ca un bord gauche saillant, qui complète l'ouverture; le dernier tour est divisé par un angle très-aigu, ordinairement d'une coulear moins foncée que les bandes brunes qui sont en dessus et en dessous de lui. Sur un fond blanc passant quelquefois au fauve, se dessine, en dessus des tours de spire et à leur base, une large fascie d'un brun très-foncé; en dessous du dernier toul, une aut:e fascie de la même conleur en occupe tuate la circonférence, en laissant tout le centre blanc. Cette coquille n'est point rare dans les collections: on la distingue netlement de deux espèces voisines, parce quelle n'est jamais ombiliquée, et que son angle reste toujours très-aigu. Maugé a rapporté celle espèce de Porto-Ricco; elle a 35 milliu. de diamètre.

136. Hérice lampe. Helix lapicida. Lrv.

H. testâ orbiculari, supernè depressâ, subtìs convexiore, latè umbiüicatâ, tenuissimè rugosâ, griseo-comeâ, maculis rubentibus pictâ; labris margine continuis, reflexis, albis.

Helix lapicida. Lix. Guel. pag. 36,3. $n^{\circ} 2$.

Museer, Verm. pag. 40. $n^{\circ} .240$.

Lister, Conch. tab. 69. fig. 68.

Peтrv. Gaz. $t a b \cdot 92$. fg. 11 .

La Lampe. Geofr. Coq. pag. 41. no. 10.

Cirms. Conch. tom. 9. tab, 126. fig. 1107 .

Drapary. Mloll. pl. 7. flg. 35. 37.

Dauder. Hist. des Nisll. $n^{\circ} .150$.

Preiffer, Sjst. cinord. pl. 2. fig. 26. 27.

Carocolla lapicidal. Lask. Anim. s. vert. tom. 6. pag. 99. no. 16.

Jolie coquille onbiculaire, lentiforme, également convexe des deux côtés, et furtement cá- rénée dans son milieu, ce qui la place dans les Carocolles de Lamarck, genre inadmissible, comme nous l'avons vu précédemment. La spire surbaissée est composée de cinq à cinq tours et demi de spire, aplatis, peu convexes, dont la suture, simple et très-fine, a lieu sur la carène elle-même; en dessuns, cette coquille est régulièrement convexe, à peu près aulant que du côté de la spire, ce qui varie cepeodant selon les individus. Un ombilic assez large et évasé est placé au centre de celle surface. L'ouverture est trèsoblique, légèrement évasée, ovale et angaleose à ses extrémités antérieure et postérieare; le péristome, mince, blanc et réléchi, est contina, le bord gauche se soulevant en une lame mince, qui se joint au péristome. L'onverture de cetle coquille étant complète, peut être comparée à celle des Cyclostomes, mais sous ce rapport seulement. La couleur est partout d'un brun opaque, parsemé de flammules rouges, longitudinales, surtout sur la face supérieure. Lorsque l'on examine ce!te coquille à la loupe, on la voit cha. grióe par une multitude de pelites granulations serrées, qui n'ont point de directions déterminées dans leurs dispositions.

Habite en France, en Allemagne, en Suisse.

137. Hédice élégante. Helix elegans. Lis.

H. lestâ conicâ, trochiformi, pevforatâ, albâ, rufo-sulfasciatâ; striis niinutissimis, confertis; anfractibus planis; labro simplici, acuto.

Carocolla elegans. Lanx. Anim. s. vert. tom. 6. pag. $100 . n^{\circ} .18$.

Lister, Conch. tab. 61. fig. 58.

PET1V. Gaz. $\iota u b .22$. fig. 10.

Favanve, Conch.pl. 64. fig. 0 .

Cerss. Conch. tom. 9. tab. 122. fg. 1045. a. b. c.

Helix elegans. Gmex. pag. 3642. no. 229 .

Drapars. Moll. pag. 79. $n^{\circ} .3$. pl. 5. fig. 1. 2. DAUDED: Hist. des Moll. no. 303 .

Coquille de taille médiocre, que l'on prendroit facilement pour an Trogue ou pour un Cadran, étant de forme tout-ì-fait conique et carénée à la base du dernier tour; elle est plus ou moins Élancée, quelquefuis fort déprimée, et beaucoup moins haute gue large, d'autres fois fort elancke, et présentant des dimensions inverses. Les tours sont nombreux, aplatis, sépar'́s par uae suture profonde et marginée. Toute la surface extérieure est couverte de stries fiues, très-nombreuses, pressées les unes contre les autres; elles sont longitudiaales et un peu obliques; res mêmes stries se retrouvent en dessous, où se voit un ombilic assez large, qui occupe le centre de la base; cette face joférieure de la coquille ost un peu bombée. L'ouverture est subquadrilatère, plus 


\section{H E L}

large que haute, à péristome simple et tranchant. Souvent celte coquille est d'un blanc-gris avec lo sommet brun; quelquefois elle est ornée d'une large bande brune sur le milieu des tours, laquelle est parfois remplacée par les flammules de la même couleur. Celle espèce se trouve sur le littoral de la Méditerranée, ainsi que dans les îles de cette mer.

138. HéLice plat. Helix lant. Fer.

H. testâ orbiculari, utrinque convexâ, latè $u m b i i^{\prime} i c a t \hat{a}$, obliqued striatâ, castaneâ; aperturâ

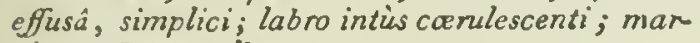
gine reflexo, albo.

Carocolla madagascariensis. Isux. Anim.s. vert. tom. 6. pag. 98. no. 10.

ExcrcL. pl. 462. fig. 2. a. b.

Feros. Hist. nat. des Moll. pl. 25. fig. 5 et 6.

Helix rhadama. Lesson, Cent. de Zool. no. 3.

Helix lunx. Fer. Hist. des Moll. no. 156.

II. Lesson, dans les Centuries zoologiques qu’il publie, vient de douner comme nouvelle celle espèce, qui depuis long-temps a voit été indiquée d'une manière précise par Lamark; il est vrai que ce savant auleur ne connut qu'un jeune individu de celle espèce, aussi rare que précieuse, de sorte qu'il n'est point étonnaut que M. Lesson ait fait un duable exploi, ayant sous les yeux une coquille qui, dans son entier développernent, est le double de celle de la colleciion de Lamarck: peut-être cette espèce ne devra pas rester dans la section des Carocolles, car l'ang!e qui partage son dernier tour s'elface insensiblement vers l'ouverture, et ne persiste que dans le jeune âge. Déjà nous avons pu remarquer qu'un graud nombre d'Hélices sunt dans le cas de celle-ci, et sont conservées dans d'autres sections; cependant l'Helix lan $x$ conserve plus fortemeat et plus longtemps que d'autres l'angle carénal qui divise son dernier tour. Cetle corquille es! discoïde, aplatie, éralement couvexe des deux côtés, à spire obtuse très-déprimée, formée de six tours à peine conrexes, striés irrégulièrement clans leur longueur et réunis par une suture simple et peu profonde; le dernier tour, proportionnellement plas grand que les autres, est convexe en dessous, caréné clans le milieu, et terminé par une graode ouverture ovalaire irc̀s-oblique, d'un blanc-bleuâtre en dedans, et bordée d'un péristome blanc un peu épaissi à la base et rélléchi cn dehors. Ces deux extrémilés se rapprochent à leur point d'insertiou, de manière à ne laisser entr'elles qu'un bord gauche très-court. Le centre de la base est occupé par un très-vaste ombilic infundibuliforme, dans lequel on peot facilement compler tous les tours de.spire.

Cette coquille est d'un bron-marron très-foncé, partout uniforme, si ce n'est on dessons of rers l'ouverture, où il devieat presque noir. On ne connoît encore qu"un pelit nombre d'individus de cetle espèce, qui ne s'est encore trouvé que dans les grandes forêts de Madagascar; elle a 60 milliu. de diamètre.

\section{3g. Hétice carocolle. Helix carocolla.}

$H$. testâ orbiculato-conoideâ, subtìs convex $\hat{a}$, impefforatâ, rufo-fuscescente; striis exiguis et obliquis, anfractibus sex; fauce alb $\hat{a}$; labro margino reflexo.

Helix carocolla. LiN. Güex. pag. $3619 \cdot \pi^{0}, 26$.

Moller, Verm. pag. 77. $n^{\circ} \cdot 273$.

Lister, Conch. tab. 63. fig. 61.

SEBA, Mus. tom. 3. tab. 40. fig. 9 .

Helix tomata. Boнs. Mus. tab. 4. fg. 9. 10.

Chemn. Conch, tom. 9. tab. 325. fig. 1090. 1092.

Helix carocolla. D $\triangle$ ODEB. Hist. des Moll. no. 131. pl. 59. fig. $1-4$.

Carocolla albilabris. Larr. Anine. s. vert. tom. 6. pag. 96. n०. 2 .

Plusieurs espèces ont été confondues avec celle-ci par Linoé et la plupart des autears. Dans le jeune âge, elle ressemble beacuup à quelques espèces qui n'ont jamais lis lèvre épaissie. Presque aussi convexe des deux cótés, celte coquille est discoïde, à spire obtuse, subconique, à laquelle on compte sept cours aplatis à suture simple et superficielle; le dernier tour est divisé i sa circonférence par une carène aiguë, devenant un peu obtuse vers l'ouverture; celle-ci est oblique, triangulaire, surbaissée, blanche à l'intérieur, et garnie d'une lèvre blanche épaisse renversée en dehors, surtuut à la base. En dessous, le centre de la coquille est un peu déprimé et occupé par une large callosité produite par l'inserticn du bord droit. Des stries nombreuses, rígulières, longitudinales, sillonoent toute la surface extérieure. Sous nn épiderme d'uu brun-verdâtre, Ia coquille est d'un brun-marron foacé, plus pâle à la partie supérieure de la spire. Les individus les plus grands ont 63 millim. de diamétre. On trouve celte coquille communément aux Antilles.

140. Héuxe disque. Helix acutissima.

H. testâ discoideâ, utrinque convexâ, iniperforatá, ad periphariam compressâ et acutissimè carinatâ, fuluâ; striis exiguis, obliquis, minutissime granosis; labro margine reflexo, inferne bidentato.

Ksorn, Vergn. tum. 4. tab. 5. fg. 2. 3.

Helix acuta. Excyczop. pl. 462. fig. 1. a. $b$.

Helix Lamarkii. DsuDED. Hist. des Moll. pl. $57 \cdot$ fig. 3 . 
C'aroculh acutissima. Lark. Aran. S. verl. tom. 6. pag. $9^{5} \cdot n^{\circ}$. 1 .

Coquil!e extrêmement rare, l'une des plus yrandes du genre Caruculle de Lamarck. Elle est discoìde, déprimée, prescju'éralement couvexe des denx cóltés; sa spire ubtuse est forarée de sept lours aplatis, doat le dernicr est partayé en leux partics presgu'égales par une carène très. aiguë. En dessous, le centre est la parie la plus saillante; il est occupé par une large callositó que forme le bord droit a son point d'unsertion. louverture, qui est furt ublique, est toul-à fuit triangulaire; elle est plus largo que Laute; son péristome, épais et bordé, est forlement réllèchi en dehors; deux deals copiques, pointues, sailLantes en dedans, sout placées à la base du bord droit. La couleur de celle coquille est d'un fauvohrunâtre, devenant plus clair sur le dernier tour. En dessous, le centre est tcinté de violet; l'uuverture est fauve comroe la coquille; les deux dents soul Llaaches. On ignore quelle est la patrie de cette espèce : M. de Ferussac la rroit de la Jamaïgue; flle a 60 millim. de diamètre.

141. HÉlice conique. Hell.x conica. Drap.

H. tostâ parvâ, conicâ, trochiformi, subtìs plunulutâ, nerfurutî̀, striatá, ulbâ, lineis fuscis cinctá; anfruc:ibus convexis; labro simplici.

Helix trochoides. Purnex, Itin. Barb. 2. p. 29.

Helix conica. Draparn. Mioll. pug. 79. $n^{\circ} .2$. pl. 5. fig. 3-5.

DaUdEB. Hist. des Moll. no. 305.

Helix conica. Lisix. Anim. s. vert. tom. G. : ag. 94. $2^{\circ} \cdot 105$.

Vuici une espèce carénée, trouliforme, que Lamarck place au nornbre des Héices, tandis yue l'Helix eleguns et d'aulres qui lui sont analogaes son comprises an nombre des Carocolics; cefait, et plusieurs autres dı inê ne gentre, suífiroient pour démontrer que le genre dunt il s'agit ¿n été fait de la manière la plus arbitraire, si déja un en a voit plusieurs istres preuves.

L'Hélice conicque est une jolie conpuilie gui a beauconp de rapports avec l'Helux conoides; elle s'eu distingte cependant nettement et cunstanment: elle est conique, trochilorme, ou phucut. turbiciforme, étant assez courte, at lours de spire étroiss, arrondis, convexes, sarént's à la base. striés finemeat dans leur longueur; la sulure esi marginée par la saillie de la caréae yu'éle suil. En dessous, cette rorguille est un peu convexe, pourvue d'un ombilic feu onvert. L'ouverture est àroite, plus large que baute, subadouleuse au bord druit, à liendroit qui correspoud is la carène; le péristome est tranchant, quelquefois zuni d'un petit bourrelet iutérieur. Les couleur's sont assez rariables: elle est, ou toute blanche, cu avec ure banje brune à la base, ou arec uue sir deux autrez baudes en dessus de claque tour; ua bien elle est llammulée de fauve, de brun nu de violätre. Celle espèce se trouve sur tou le littoral enropéen de la Médilerranée.

143. Hílicr de Caron. Helix Caroni. Noв.

$H$. testi conich, elongato-pyrumidatâ, trochiformi, Longitudinaliter stricts; striis confertis, sublumellosis; anfructibios numerosis, basi carinatis; cariná squamoss; aperturi depressa, quadranguburi, simplici; lubro tenui.

On prourroit facilement prendre cette coquille putr un Troque; hous ne concoissons aucune esprice qui en ait mieux la forme : sa spire, fort pointue et très-f́lancée, est conique, formée de douze tour's étroits, aplalis, doat la suture superticietle est bord́e en dessus par un angle auduleux ou écailleux; des stries nombreuses, sublamelleuses, assez régulières, descendeat da gamruet a la base de chaque lour, et produisent les écailles gui se voient sur l'angle de chacun d'eux; en alessuas da dernier tour, elles se conlinuent en couvergeant ress !e centre; la base est tou:$\dot{a}-l$ lat aplaile, percée d'un très-petit ornbilic, eu partie resivurert par l'extrémilé du bord droit. Louverture est petite, quasirangulaire, perpendiculaire, bearcuup, flus large grue haure, a périslome suince, liarchant, non réllécldi ni burdé a l'iuśs: ienr. En debors, ce!te cuquille est d'un blanc-grisalte, quelquefois fuve, préseniart sur ses tuurs des laches llamaulées, longitudinales, d'un Lrun peu foncé; le sninmet est urdinairewenl moir. Nous arons dédié cctie jolie esjèce is 11. Curon, gai l'a rappurtéc le prewier de la Sicile. Quoique livré un commerce, MT. Caron a earichi nos collections d'une grande quaulití d'especes malioes et terrestres, soit vivantes, soit fossiles, qui ont le double intérèt ne faire wieux connuitre la zoologie médicerranéenne et de donner des matćriaux importans à la gríulogif. Disnctre de la base 9 millim., longueur" : millim.

\section{Héuice connïde. Frelirl, chnuchiss.}

H. iesti orbiculato-conoide i, subtus cunnex?planulati, imperforatâ, rufí, obscuiéfuscrilí; sp:rs apice obtusid labro bidentuto, murgina albo, refexo.

Helix lychnuchus. MuLner, I'crm. pag. 81. $n^{\circ} \cdot 278$.

l.ister, Conch. áub. 90. fig. 90.

Helix licerna. Caess. Conch.tom. g. tath. 120 fig. I10ü. 1 10y.

Helix lychnuchus. Gust. pag. 36ig. $n^{2} \cdot 27$.

DAUDEB. Hist. des Moll. $n^{\circ}$. 126 .

Lank. Linim. s. vert tom. 6. pag. o, $n^{n} .12$. 


\section{H E L}

Celte coquille, assez variable, appartıeut à la section des wrochiformes; car l'angle du dernier tour la sépare en deux parties très-inégales, la sasllie de la spire lemporlant de beaucoup sur relle de la base : elle est de forme assez variable, cuclegueferis à spire très-conique, d'autres fuis ayaat retle partie tres-surbaissle; la spire, compusée de six tours, est obtuse au somatel; les tuurs sout aplatis, Ciroits, serrés; leur suture est siuple ei superficielle; des stries obscures et ji3 éculières descendent d'une suture à l'autre, et incrrompent les graublatinns fines et nombruses yail couvrent toute la surface. Ces grautalions sunt irrégulières, quelquefois transformícs en lides, et ne commentent à sc montrer que sur le second on irojsième tour; la lase de la conuille : : n est ealièrewent couverle : celte hase est rígulièrement confexe, et lurmíc d'une tnamiérc wès-lratichce par l'angle qui est à la circonfé rence du dernier tour. L'ouverure est médiocre, extrêmement oblique, oblongue, snlstriangulaire, blanche ou brunâlıe, ayaut à la base une large callosilé d'où part l'extréuité du bord droit; cclui-ci est épais, fortement renversé en dehors, et rouni à l'intérieur de deux dents aiguës, inc:gales, saillantes à sa partie inférieure, el dont la plus externe est la plus grosse. Celle dernière courespond à une dépression placée immélialement derrière le renversement du bosd droit. La couleur de cette espice est peu variable : tantôt d'un brun très-loncé, avec la base un petı plus pâle vcrs le centre; laniôt d'un brun-fauve avec denx tascics obscures de la unême couleur. plus foncée au snmmet et à la base tle clatque tour. Crlle: coquille, assez commune anx Antilles, a 30 willim. de diamètre.

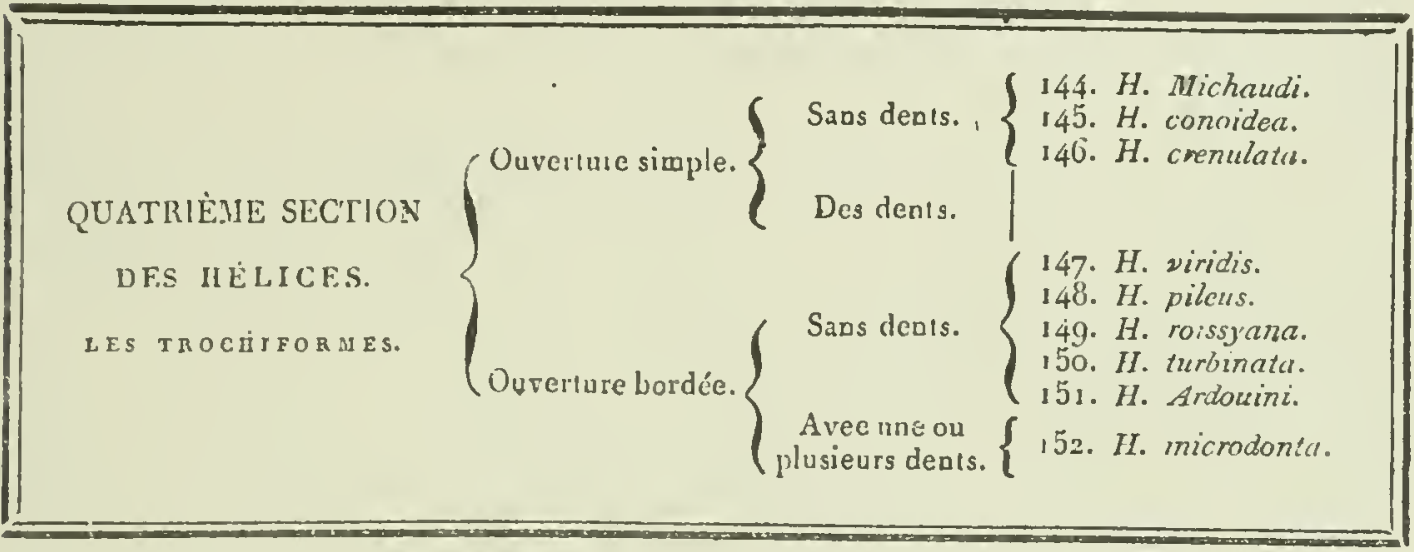
Jon.

144. HÉlice de Micliaud. Helix Michaudi.

H. testi urbiculato-corroideâ, apicc obtusî, turbiniformi, longutudinaliter striat $\hat{z}$; striis confertis, tenuibus, regularibus; anfractibus subplarulutrs, albidis, hneis nigricuntibus ornatis; aperturầ semilunıri; rosco tinctâ.

M. Michaud a en lı hicnveillance de nous comrruniruer celle jolie espcice, et uous ntus fuisons m plaisir de la lui dédier. Eile ressemblo, pour la forme, a l'Helix mirabrlis de $\mathrm{M}$. re [erussic, mais .lle est infiniment plus petite : elle est conoide, à spirı saillante et obiuse au sommet; elle est formée de six tours peuronvexes, à suture peu profonde at simple; le demier tour, un peu convexe en dessous, est arrondi dans son contour ctlerminé autéricurement par une ouverture sewilunaire, médiocre, très.pen oblique. Simple e légèrement teinte de rose à la base, toule la surface extérieure est couverte de stries nombrenses, assez régulières, longilndinales et obliques : sur un fond blanc-jaunaire se dessine, sur chaque tour, une bande jétroite, d'un beau noir lićs- funcé; en dessous dư dernier tour, on voit deux autres bandes semblables. Celle perite coquille, élégante, a élé truuvée ì Ténériffe. Fille a 7 millias. de tliamèire.

145. Hénce conoide. Helix conordea. Unap.

H. testî parvâ, conoide $\hat{i}$, trochịfomi, siblìs convexâ, umbilicat $\hat{x}$, albâ, fusco fasciati; anfractibus convexis; suturis imuressis; lablo smmplici.

Hclix solikria. Роглет, Prodr. pag. 85. no. 21. IIclix conoidca. Drap. Moll. pl. 5. fig. 7 . 3.

Diuder. Hist. des Moll. $n^{\circ}, 3-5$.

LAx s. Arrm. s. 2ch. tom. 6. pag. 94. $2^{\circ} \cdot 106$. Jolie petic espèce que l'on trouve tant en France cin'en l'ićmont, et dans presque toutes les iles de la Midi!er:anéc. Elle esi conique, alongéc, trocliforac, nou carćnćc a la base, ariondie en dessuus, et percée par un ombilic un pe: recouvert. Ises lours, an nombre de cinct ou! six, sont lefgirenent conrexes, couverts de stries fines et serices, et séparées par uae suture prc- 
fonde. Le sommet, qui est obtus, est ordinairement brun on corné, et toujours lisse. Cette coquille, sous le rapport de la couleur, présente plusieurs variétés : elle est quelquefois d'un blancgrisâtre ou jaunâtre, sinas bandes ni taches, avec Pa mème teinte gévérale. Elle a souvent, en dessuus du dernier tuur, une bande brune, quelquefois deux; mais cela est très-rare. Quelques individıs ont, en dessus, à la base des tours de la spire, une bande d'un bran foncé, qui suit la sulure jusqu'au sommet. Il arrive souvent qu'au lieu de bandes, la partie sapérienre des tours n'offre que des flammules fauves, ou des taches irrégulières. Cette espèce se trouve dans la France méridionale.

146. Héunce crénelée. Helix crenulata. Oniv.

H. testâ orbiculato-conoidea, turhiniformi, subpeforatâ, albido-cinereâ; anfractibus convexis, suturis profundis, separatis superne; et ad basim crenulatis, longitudinaliter striatis; labro tenui, acuto.

Laux. Anim. s. vert. tom. 6. pag. 88. $n^{\circ} .85$.

Oriv. Voy. au Lev. pl. 3r. fig. 5. A. B.

Fra. Hist. des Moll. $n^{\circ}$, 300.

Cette coquille a, par sa forme, de l'analogie avec l'Helix conoidea de Draparnaud; elle est toujours plus grande, et ses crénelures, ainsi que sa conlear, la distinguent suffisamment de tontes les espéces qui l’avoisinent. Celle Hélice ressenble à un petit Turbot. Sa spire est élancíe, conique, pointue au sommel; on y compte sept à huit tuurs convexes, séparés par une suture enfoncée, cachée, en grande partie, par l'angle caréné et tuberculeux qui fait la base de chaq̣ue tour de spire; à la partie supérieure de ces tours règne un second rang de crénelures aussi saillantes que les prewières, Le dernier tour, proportionnellement un pen plus grand que les autres, est arrondi et à peine crénelé dans son contour. Des stries longitudinales, irrégulièrement disposées, pliciformes, descendent du soumet à là base, et ront converger vers le centre du dernier tour. Le centre est ouvert par un ombilic très-petit, en partie caché par le renversement de l'extrénité du bord droit, qui vient s'insérer prćs de lui. L'ouvertare est peu oblique à l'axe; elle est obronde, un peu plus large que haute. Son péristome reste simple et traachant à tous les àges. Cette coquille, assez rare, se trouve en Egypte, aux environs d'Alexandiie. Son diamètre est de 13 mill. et sa hauteur de 15.

\section{Héluce verte. Heïx viridis.}

H. testâ turbinato-conoideá, apice obtusâ, locvigatâ, fasciis fuscis tribus ornatâ, albo-virescente; aperturâ obliquè ovatâ, basi leviter contortâ, callosâ; labro nigro, obtuso, reflexo; anfractibus convexis.
Long-temps on ae connut que deux ou trois individus de cette coquille, qui ne s'est encore trouvée jusqu'aujourd'hui que dans l'ile de Madagascar. Le voyage que vient do faire, dans cette région peu abordable, un jeune naturaliste plein de zèle, a donné anx collectionneurs le moyen de se procurer cette coquille remar'quable. Elle est turbiuiforme, à spire alougée, conoïde, dont le sommet est obtus; elle est fortaée de six tours arrondis, convexes, complétement lisses, dont la suture simple est assez profonde. Le deruier tour, convexe à la base, se termine par une ouverture oblique, ovalaire, plus haute que large, dont la columelle, légèremeut sinueuse, garnie d'une callosité externe et alongée, est arrondie et d'un brun-blanchâtre; clle se juint au bord droit en formant une petite sinuosité. Le bord droit est obtus, presque noir, renversé en delıors. Sur un fond d'un beau vert pâle se dessine, sur chaque tour, trois bandes d'un brun foncé : elles sont larges, très-nettes et très-régulières ; la dernière, la plus large, occupe la base. Cette espéce a des rapports incontestables avec l'Helix galactites; mais elle est conslamment plus petite, d'une autre couleur, et présente d'ailleurs à l'ouverture des diflérences qui la caractérisent suflisamment. Elle a 25 à 30 millimètres de diamètre, et 30 à 35 de hauteur.

148. Hélice bonnet. Itelice pileus.

H. testâ conicá, subtùs planulati, glabrî, alhâ, nufo et fusco fusciat $\hat{\alpha}$, inferná fuscie castunea; spiri apice subacutâ, rubellí; labro tenui, margine reflexo.

Helix pileus. Mullen, Vorm. pag. 80. $n^{\circ} .277$.

Bors, Mus. tab. 16. fig. 11. 12.

Trochus pileus. Chews, Conch. tom. 9. tab. 122. fig. 1046-1048.

Helix pileus. Gu上x. pag. $3637 \cdot n^{\circ} .89$.

Ejusd. Helix pileata. pag. 363g. $n^{\circ}, 173$.

Helix pileus. Datdé. Hist. des Moll. pl. $6 \bar{j}$. a. fig. 3-8.

La arx. Anim. sans vert. tom. 6. pag. $87 \cdot n^{\circ} \cdot 78$.

Celle coquille est une de celles qui se rapprocbent le plus des Bulimes par l'alungement considérable de la spire, mais elle appartient au type des Hélices par la forme de son ouverture, qui a de l'analogie avec celles de la plupart des especces globulenses. Sa spire alongée est puiatue au sommet et fort élancée, conique, formée de sept tours peu convexes, lisses, à sulure simple et superticielle; le dernier, un peu plus grand propurtionnellement que les autres, est arrandi dans son contour, et esi fort convexe en dessous, suns ombilic ni fepte ombilicale. Il se termine anibrieurement par nue ouverture fort oblique, ovale, semi-lunaire, un peu plus large que baute. Le 
bord droil de cette ourerture sinsète an centre et y produit une callosité aplatie. Le reste de son étendue est épaissi, arrondi, blanc ou légc̀rement teinté de fauve, et fortement reaversé en dehors. Sur nn fond blanc, les tours de cette coquille sout ornés de plusieurs bandes étroires d'un beau brun; les bandes sont variables dans leur nombre et leur disposition, et penvent être comparées sous ce rapport ì celles qui se voient sur nos Hélices des jardios. Celte coquille, tort rare jusqu'à présent dans les colleclions, esi remarquable par sa forme et l'élégance de ses couleurs. Elle a 25 millias. de diametre et 30 de hauteur.

149. IJ Élice de Roissy. Helix roissyana. Fen.

H. testâ orbiculato - conoideâ, turbiniformi, apice obtusâ, lavigatà, fascius fuscis variabilibus ornatá; apertunâ subsemilunari; coluniellâ rectâ, latâ, depressâ, albú; labro obıuso, nigro, 'ix reflexu.

FER. Hist. des Noll. pl. 104. fig. 2 et 3.

Nous rapportons à l'espèce donnće par M. de Ferussac, sous celle dénomination, des coquilles qui ne nous paroissent en être que des variétés. l.es individus que nous avons sous les yeux, variables quant à la couleur, ont une furwe identiquement la wême que celui dont nous venons dindiquer la figure; ils sont globuleux, a spire proéminente, mais obtuse au sommet, composée de ciuq à six tours, dont les premiers sont peu convexes et rénais par une suture tellemeat superficielle, quat peine on peut la distinguer. L: dernier tour, plus globuleux que les précédeus, est aussi proportiounellenent plus hrand qu'eux; il est en dessous Irès-convexe, el sa base, qui eu est la partie la plus saillanie, est occupée par une large callosité semi-circulaire, de laçuelle s'élève perpendiculairement. Ia columelle; celle-ci est aplatie par devant; elle est elargie, blanche, un peu tranchante à son borch interue, sur lequel on remarque une légère dépression un peu avaut son point d'insertion. Celte columelle se coufund un peu obliquement à sa base avec l'extrémité du bord droit. L'ouverture est semi-luaaire, médiocre, presque droite et garnie d'un péristome olstus, étroit, en thlet autant saillant en dedans qu'du-debors; il est noir dans toute sun étendue, tandis que la coquille est d'un blanc de lait pur à l'ıntérieur : en dehors elle est également blanche, ornce de plusieurs bandes d'un brun foncé, dont une presque noire est placée à la partie supérieure des tours de spire; une autre, de la méme nuance, entourant la callosité de la base; et les autres enfin plus ou moins larges, quelquefois deux et quelquefois davantage, sont situées eatre les premières. L'iadividu encore revêtu de son épiderme, liguré dans l'ouvrage de 11. de Ferussac, diffëre de ceux dont nous venons

Hist. Nat. des Vers. Tome II. de parler en ce qu'il n'a, sur le wilieu du dernier tour, qu'uoe seule zone brune, cl que son péristome, un peu plus évasé, est tout blanc : peut-être ces différences suffiroient - elles pour constituer deux espèces, si l'on ne trouvoit par la suite des variétés intermédiaires qui pussent les réubir. Cetıe espèce est l'une des plus rares des Hélices; elle se rapproche beaucoup de l'Helix gulactites, mais elle est moins conique. Elle a $\mathbf{3 2}$ millim. de diamètıe à la base; sa patrie nous est inconno.

150. İér, larbinée. Helix turbinata. Noв.

H. testâ conicâ, basi patulâ, convexâ, glabrâ, acutâ, ulbo-cinerescente fuscià unicú basi omatâ; anfractibus convexis; aperturá magní, ovatá; lobro tenui, suldé reflexo, albo.

On peut placer celte espèce à côté de Helix. pileus; elle a en effet avec elle de très-yrands rapports quant à la lorme conique el alongée de la spire; unais celle-ci, ayant la base proportiondellement plus large, la spire toujours plus couite et une coloration tout-a-fait dillérente, se distingue au premier aspect de toutes les especes te de la section à laquelle elle appartien. Cetle cuquille est alongée, conoïde, à spire pointue, formée de six lours très-convexes, sćparés par une sulure simple el protonde, le dernier proportionneilement un peu plus grand gue les autres, et très-arrondi dans sa circunlérence, fort contexe à sa base, et terminé antérieurenent par unc ouverture très-oblique, grande, oralairc, qui se rapproche beaucaup de celle des Cyclostomes par la terdance qu'unt ses bords à se rejoindre à leur. point d'insertion. lae péristome, très-titalé, furt large, est mince, trancbant, et lorlement renversé eo dehors. Il est tout blanc, landis que l'intérieur de l'ouverture est d'un brun-roussâtre peu foncé. La surface extéricure de cette cocpuille parait lisse; mais, examivée à une furte luupe, on la trouve clagrinée par un grand nombre de petites rides qui ont loutes une direction oblique. Sous une croûle d'un doir obscur, yui paroît être le résultat de la manière de vivre de l'aninal, et cai ressemble en quelque sorte à un épiderme, la coquille esı d'un blanc-roux ou brunctitre, d'une teinte nnilorme, "n peu plus pâle cependant au summet, mais jrésentant, vers le milieu du dernier tour, une bande élrojle d'un brun vieeux assez intense. Nous devons la connoissance de celte belle et précieuse espèce à notre savant ami M. Lesson, qui, avec toute la gébérosité de son estimáble caracière, nous l'a communiquée avec beauconp dautres coquilles recneillies daus le cours de son périlleux voyage. C'est à la NouvelleZélande qu'a été recueillie cette espèce, dont on ne compte encore qu'un petit nombre d'individus daos les collections. Fille a 24 millim. de diamètre à la base, et 23 de hautcur. 
150. IÉrace d'Ardouin. Helix Ardomini. Non.

II. testâ orbiculuto-conoileá, fuscâ, fuscî̉ lat í nigricante ornats, basi palulâ, perforaldi ; spiri apice acuti, proninuli, anfractibus planulatis, ultiino depresso; aperturî ovato-trensversâ, fuscâ, effusấ; labro tenui, lato, nigricante, vuldè reflexo.

Nous ue connoissons aucune description ni aucune tigure qui ait du rapport avec celle espèce. Nous devuns donc la regarder como nouvelle. Elle est trochiforme, et se rapproclse, pour le port, de l'Helix turbinata. Sa spirc, assez éievée, est conique, pointue an soumet, furmic de sept tours trc̀s-peu convexus, dont le dermier est proportionnellearent un peu plus grand yue les autres. Ce dernier tour forme une base trés-large à la spire; il est comme ćcrasci du hant en bas, et cependant son coutour reste arruudi; la base, légèrement coucave an centre, est perforée par un ounbilic assez grand, en partic caché par le renversement du bord droit au puiut de son insertion. L'ouverture est fort grande, oblique à l'axe, for. tement évasée en deliurs comme le pavillon d'une trompette; elle est plus large que liaute; son péristome est brun, mince, Iranchant, reuversé et disposé de telle surte que la coquille útant placée perpendiculairement, son extrémité supćrieure dépasse el cuuvre sa base. Cetle coquille est toule lisse, d'un brun funcé; le dernier tour seul est orné à son pourtour d'unc large bande dun"brun-noiratre, dont une parile rentre llans l'uuverture, et l'antre reste en dehors de la sulure. Nous ne connoissons encore que quatre individus de cetle belle espèce. Nous croyans quiiis onl élé rapportés par des officiers de la dernic̀re expridition scientifique de 'Astrotalie. Elle a 40 mill. de diamètre, et Jo de hateur.

Nous avons dedić celte loelle et rare espìce à N. Ardouin Michelin, amateur distingué, possesseur d'une belle collecion de coquilles, qu'il ouvre généreuserncut aux personnes qui soccupent de scieuces.

152. Hécıce microdonte. Helix microdonta.

H. testâ orbiculato-conoideâ, subtùs convexsâ, imperforatî, rufü; ultimo anfractu obtuse angulato, zonâ albidûa cincto; labro intùs albo, mustgine reflexo, basi unidentato.

Helix unidentaț. СвемN. Conch. tom. 11. tab. 208. fig. 2049. 2050.

Dauper. Hist. des Mull. pl. 104. fig. 8 el 9. no. 318 .

Lank. Anim. sans vert. ton. 6. pag. $7 \dot{4}$. $n^{\circ} \cdot 32$.

+ Celte granle coquille as la plus grande analogie, quant à la forme, avec un Turbo. Sa spire esi élancée, conique, obtuse an sommet, formée de sept tours, dont la suture est sinple et assez pro- fonde; leur surface est suréc irrécrulitirement dans sa longueur, eu dessrus le dernier tcur est régulièrement convese; le centre, qui est la partie la plus saillante, ust gatrni diusc callosité considérable : tlle donne insertion à l'extrúmilés du borr droit. L'nuverture est médiocrement oblique à l'axe; clle est assez grande, à bords épaissis, renrersés en dehor's, et se continuant à la base avec une columelle courte, élargie, arrondie, et portant dans son milieu une dent conique int. diocre telativensent a la grandeur de la coquille. Quant i la conleur, elle est peu variable dans celle espicce; elle est tnute brune ou toute blanclie. Nuus pussétuns une varićlé brune qui a une ceinture blanclie vers le milieu du dernier tour. Cette coquille, assez rare dans les collections, vient du Sénégal, à ce que l'on prélend. Les plus grauds individus on 47 millim. de diamètre, et 40 mill. de irautcur.

\section{IIÉLICELLE. Helicella.}

Genre dela famille des Colimacées, rue Lamarck ell: le tort de séparer des Hélices (Ext. dul Cours.) sur des caractères très-peu importaus. Ce savant a senti, plus tard, que ce genre ne pouroit rester, et il l'a sulpprimé dans son dernier ouvrage. Il rassembloit toutes les espices d'Ilćlices qui, comme l'A/sira, sure planorbulaires, et a bords toujours uninces ut tranchans. B. de Ferussac a employé la mêne dénanination pour un des sous-genres de ses Ilélicoiles, el lui a donaé des caracières plus iteudus, mais qui re sont pas plus reccoables que ceux de lamarch Ponr ête rouséguent it sa classificalion, M. de Ferussac anroil dî́ placer dans ce groupe ansi lien des Carrolles que cerlitnes csictecs globuleuses, et mêrne trochiFormes, yui ont le curactice d'une onverlure tranclante a tous les ages, el que cependant il a retenu sur d'aulres caractèes d'une érale valeur dans d'autres divisions de son systeme. Ceri prouve, coinure nous avons eu occasion de le laire sentir, en parlant précédcmment de lat valeur des caractè es des Hélices, qu'il nón est aucuus qui ne se reproduisent dans tous les groupes de lorme; ce qui fust voir que c'est principalcu.ent à la forme exićrieure qu'il faut s'allaclses pour former lcs grandes divisions: qquoique coule méthode suit arbilraire, elle est cependant plus satisfaisaute is ce que nous présumons que celle mise jusqu’à présent en pratique, Voyez llélice.

\section{HÉLICIGONE. Helicigona.}

Ce sons-genue de M. de Ferussac répond au genre Carocolle de Montfort, adoplé par Lamarck, ainsi qu'au genre lbère de ce nèue auleur: les coquiles quil renferme ont étć groupées aussi par M. Ucken, sous le nou de Vortex. Voyez CanoCOL.Le el HÉLICE. 
H E L

IIELICINE. Helicina.

Genre à peine conau des anciens concliyliologrues, figuré cependant par Lister, qui le conlondit avec les Ifélices, méconnu par Linné et 13ıguière, et proposé par Lamarck, dés 180 I, dans le systêune des Animaux sans vertèbres, et adoplé depuis par la pluparl des auteurs. Gray, dans le Zoological Journal, a donné une tiès-bonne monograplise de ce genre, dans laquelle on trouve III beatucoup plus grand uombre d'espèces qu'aucun auteur n'en avoit donné. l'lusieurs espèees, qui n'avuient point été décrites par les auteurs, ont un caractère que personne avant lui n'avoit encore observé, une funte, placée à la base de la columelle, doune à ces coquilles un aspect particulier.

Lorsque re genre fut proposé, on n’en connoissoit pout l'animal, mais nn savoit qu'il étoit operculc. C'est sans loule d'après celle considération que Lamarik le rapprocha d'ibord des Nériles et des Nalices, en fuisant aussi allenlion à la forme générale, et surtout à celle de li columelle. Depuis, dans la Philusophie zoologrique, Lamarek ayant établi la famille des Colimacées, y ranuea les Hélicines, eatre les Hlélices, los Buliwes, les Agathiues, les Aup, libulines el les Misillots, quoique tous ces genres soient dépourvus d'opercule. Il persista dansla méme opinion, dans l'Extruit du Cours, où on ruil ce geare placé dans les unèues rapports, et c'est encore celle qu'il canserva dans son dernier ouvrage. Mnntfort ne trouva pas convenalile le nom dounć par Lamarck; il vensa que ce nom avoil trop de rapport avec Hélice, et qu'on pourroit le confondre avec ce dernier : il proposa en consćquence de le nommer Pitonnulle; mais personne, que je sache, n'a admis ce chaıgement. M. de Ferussac, qui a possćdé le premier l'animal de l'Ilélicine, le comanuniqua à II. de Blainville, en lui assurant qu'il est pourvu l'uu collier; que l'ouverture de la respiration est à gaucle et l'anus à droite : ce qui paroit être le contraire, d'après M. de Blainville et d'apićs M. Say. Les observations de ces deux zoologistes out fait connoître sullisanment l'animal de l'Hálicine; il sera fucile dćsormais de le mellre en rapport avec les genres environnans; et, comme le dıl M. de Blainville lui-même (art. Hélicise, dı Dict. des Sc. nat. tome 20, page 455), ce sera auprès des Cyclostomes qu'il sera raugé. C"est aussi l'opinion de Ml. de Ferussac : mais, ayint cru apercevoir un collier, il a fondé sur ce caractère une famille particulière pour les Hólicines, quil met à cỏle des Turbicines, anire famille créce pour les Cyclostomes. Comme les deux savans observateurs dont nous avons parlé ne mentionnent aucunement le collier dont parle $\mathrm{M}$. de Ferussac, ce sera dans ane même coupe que les deux geares se placeront.

Pour compléter ce que nons arons à dire sur ce genre, nous ferons observer que $\mathrm{M}$. de Blainville, après ávoir dit (article HÉLICIsE dn
II E L

Dict. des Scienc. nat.) qu'on devra placer ce genre à cóté des Cyclostomes, l'en Cloigne cependant assez motablement dans sun systèue génétal ciéveloppé à l'article Moz lusque du mème ouvi'age. Nons voyons, en ellet, les Cyelostomes fuire partie de la fanille des 'lubus, nounués Cricostomes, el les Ilélicines ếre placées dans la famille des Eillipsnstomes, et séparées par les genres Mélanie, Rissar, L'hasianelle, AmpulPaire el Aupulline, de son genre le plus analogue. Nous ajoulerons, que nous croyons qoc ce sarant zoologiste a réuui les Ronlelles aux IIlicines, conduit par une analogie dans les formes : en supposaut quielle soit partaile el cnlière, ce qui n'est pas, il y a loujours une considéralion importante qui doit nous guider: c'est que l'un des genres est mariu el l'autre terrestre; ce qui suppose, dans l'urgauisalion des animaux, au moins dans celle de l'appareil respiratoire, des dillérences assez considérables pour tenir sépaŕs ces deux grenres. II en esı de ceux-ci comme des Cyclostomes et des Paludines, quel'on a été obligé de dislinguer, malgreé une bien plus grande aralogie dans les cuquiiles.

\section{CARACTÉnES G ĖẼRIQUES.}

Aoinal globuleux, subspirul; le pied simple, avec un sillon. naruinat ancérieur; tcie proboscidilorme, le mufle bilabié au somnet el plus court que les tentacules qui sout au numbre de deux, liliformes et poitant les yeux à la partie externe de leur ba:e, sur un l1:beicule; les organes de la respiration comme duns les Cyclostones lerrestres; la cavilé branchiale communiquant arcc l'extérieur par une labge fente. Coquille subglobuleuse un conoide, à spire bassc; ouverture demi-ovale, modilice par le dernier lour de spire; le périscome réllécli en bourrelet; le burd gauche élargi ; a la base est une large callosité qui recouvie enlicienent l'umbilic, et se joignant avec la columelle, qui est tranchante iufcrieurement, saillante el un peu tordue; un opercule corné, complet, à élémens concentriques.

Parmi les espèces actuellementassez nombreuses, nous citeruns les suivantes:

1. Hézrcine douleuse. Helicina dubia. LAmk.

H. testá semiglobosâ, larvi, nitidula; aperturá ovato-rotundatá; columella callosâ.

L.A м. Ann. du Mus. tom. 5. pas. 9 .

DEF. Dict. des Scienc. nat. tom. 20.

Noв. Descript. des Coq. foss. des env. de Paris, pag. 53. pl. 6. fig. 14. 15.

Quoiqu'il soit douteux que le genre où oo place celte coquille soit réellement le sien, on ne peut cependant l'en úter sans risquer de la placer plos LI 2 * 
mal qu'elle n'est; et si on la compare avec soin aux Héliciues virantes, on reconnoitra qu'elle a la plupart des caractères de celles-ci. Cependant le test est moins mince, l'ouverture plus ovale, la columelle moins droite, et l'angle inférieur plus arrondi : du reste, la colnmelle est de même calleuse, la spire aplatie, les sutures simples. Les individus les plus grands n'ont que 4 millim. de diamètre.

\section{Hélicive néritelle. Helicına neritella.}

H. testâ ventricosâ, globoso-conoideâ, glabrâ, albâ; labro margine reflexo.

Lam x. Hist. des Anim. s. vert. tom. 6. pag. 103. Lister, Conch. tab. 6 1. fig. 59 .

Grat, Mon. du genre Hélicine. Zool. Joumal, tom. 1. pag. 65. $n^{\circ}$. 2. pl.6. fig. 2.

VAR. B.) Testâ roseâ; columellâ lutescente; labro margine crassiore, reflexo.

Coquille lisse, ovale, déprimée, mince, fragile, conique en dessus, convexe en dessons; la couleur est quelquefois toute blanche, ou d'un jaune pâle, et quelquefois elle est oraée de deux fascies bruaes ou roussàtres; quelques individus ont la spire fasciée de rouge ponrpré. Le péristome est épaissi, réfléchi en dehors, d'un beau jaune, ainsi que la columelle, qui est pourvue à la base d'noe large callosité très-lisse. Cette espèce vit avx Indes.

\section{Hélicine fasciée. Helicina fasciata.}

$H$. testí orbiculato-convexâ, depressâ, tenui, pellucidâ, albido-corneâ, nufo fusciatâ ; labro margine interiore albo, subreflexo.

Lamr. Anim. s. vert. tom. 6. p. 103.

Grat, Monog. du genre Hélicine. Zool. Joum. tom. 1. pag. 65. no. 3. pl. 6. fig. 3 .

Petite coquille très-mince, pellucide, très. fragile, ovale, déprimce, fort cunvexe en dessus, moins boubée en dessous, où elle est légèrement déprimée. Son ouverture est oblique, semilunaire, à péristome épais, blanc, réféchi en dehors. La columelle est blanche, calleuse à la base, très-lisse et très-brillante. En dessus, cette coquille est ornée de fascies, de taches subarticulées rousses, on brunes et blanches; sur le partonr da dernier tonr, uae de ces zones est plas large, plus constante et plus blancbe; en dessous, on y roit des linéoles continues, rougeâtres. Celte jolie coquille, qui a à peine trois lignes de diamètre, vient de PorloRicco.

\section{Hélicrne verte. Helicina viridis.}

H. testâ minimâ, orbiculato-convexâ, depressâ, ad periphcerian angulato-carinatâ, lavi, nitidâ, viridi; labro simplici, acuto.
LaMx. Anins. s. vert. tom. 6. pag. 103.

GaA Y, Monog. da genre Hélicine. Zool. Journ. tom. 1. pag. 67. n., 7. pl. 6. fig. 7 .

Très-jolie coquille, d'une belle couleur verte, nuiforme, avec une zone blanche sur le milieu du dernier tour, qui est légèrement caréné dans cet endroit. Celte espèce est ovale, déprimée; à spire conique, peu élevée; !a base est convexe; son test est mince, lisse, briliant, translucide; son ouverture semi-lunaire, oblique, est bordée d'une lèvre un peu épaisse, réfléchie en dehors, d'uae conleur jaune, quelquefois teintee de rouge; la columelle, calleuse à la base, est courte et blanche. Cet te belle coquille, fort rare dans les collections, babite Saint-Dumingue, d'après Lamarck, et Cuba, d'après M. Gray; elle a deux ou trois ligures de diamètre.

\section{HÉLICINES ( Les).}

Famille proposée par M. de Fernssac, dans ses Tableaux systénatiques des Animuux mollusques, pour le seul genre Hélicine. Il est à présumer que cette famille ne sera point adoptée; car les caractères sur lesquels elle repose nours semblent encore douteux; et l'on pourroit bien réunir le geare qui la constitue aux Cyclostomes, malgré les différeaces assez notables qui existeut tant dans l'opercule que daus la forme de la coquille.Voyez HËLICINE.

\section{HËLICINIDES.}

- M. Latreille, dans ses Familles paturelles du Règne animal, en adoptant la famille des Hélicines de M. de Ferussac, lui a imposé celte nouvelle dénomiaation, sans rien cluanger dans ses rap. ports. Voyez Uízicises.

\section{HÉr.ICITE.}

Dénowioation employée par les anciens orychthographes, pour les coquilles fossiles auxquelles on a appliqué depuis le nom plus connu de Nummulites ou Nummulines. Voyez ces mots.

\section{HÉLICODONTE. Helicodonta.}

Sous.geare proposé par M. de Ferussac, dans son arrangement systématique des Hélices, pour une partie des espèces de ce genre qui ont des dents à louverture. Ne pouvant fuire nne application rigourense du caractère, M. de Ferussac a été forcé d'admettre celui des Hélicodontes dans plusieurs de ses autres sous-genres auxquels il a donné, d'uae manière arbitraire, des caractères qui , sans être d'une plus grande valear, out été preférés à celni-ci. Ce a'est point de cette manière, il fant en convenir, que l'on doit faire une classitication que l'on donne comme assez parfaite ponr classer d'une manière rationnelle tous les faits qui sont ccanus. Voyez Hélice. 
IIÉLICOGÈNE. Helicogena.

Sous-genre proposé par M. de Ferussac, dans le genre Hélice, pour un de ses plus nombreux groupes; il le divise en quatre sections : l'une d'elles représente le genre Acave de Montfort. Voyez ce mot el Hİ̉ice.

\section{HÉLICOLIMIACE.}

Le genre que Draparnaud a créé, sous le nom de Vitrine, en be considérant que la transparence de la coquille, a été nommé Hélicolimace, par M. de Ferussac. Cette dernière dénomination, quoique donnant une idée plus juste dn genre dont elle fait sentir les rapports, ne pouvoit être adopté. Voyez Vitrine.

\section{HÉLICOPHANTE, Helicophanta.}

Nouveau sous-genre proposé parM. de Ferussac, parmi les Hélicoïdes enronlées, pour celle des Hélices à forme planorbulaire ou subplanorbulaire, cl dont l'animal est beaucoup trop grand pour être entièrement canlenu dans sa coquille. II a donué les caractìres suivaus ì cette coupe: animal énorme pour sa cơuille; en général, la partie postérieure seule étant recouverte; volute rapidement développéc dans le sens borizontal; spire peu saillance, de trois a qualre tours, le deraier très-grand; ouverture très-ample, fort oblique par rapport à l'axe; bord intérieur du cône spiral portant plus ou moins sur la convexité de l'avantdernier tour, ce qui rend la coquille perforée ou ombiliquée. Les coquilles de ce saus-genre ont été confondues par les auteurs avec les autres Hélices. Cependau, en considérant que celles-ci peuvent servir de passage entre les Vitrines et les autres IIelices, il n'y auroit aucun inconvénient d'admettre le sous-genre de M. de Ferussac, qui réunit des espèces fort remarquables par la graudeur du dernier tour de spire comparativement aux autres. Dans un premier groupe, caractérisé par un péristame simple, et qu'il nomme les Vitrinuides, il y a deux espèces que Draparnand avoil, à tort, décrites parmi les Hélices de France; elles ve sy sont jacuais reucontrées; c'est à $M$. de Ferussac père, yui les a trouvées en Souabe, qu'on en doit la première connoissance : ce sont les Helix brevipes Drap., et Helix rufa Fra. Le second groupe, caractérisé par un péristame épaissi et subréfléchi, et nommé les Vessies, comprend des espèces beaucoup plus grandes, et, entrautres, l'Helix cornu giganteuni de Caemnitz, qui est li plus grancle espèce connue; les autres espèces sont l'Helix cafra. FER. MIoll. ten. et fluv. pl. 9 . a. fig. 8 ; et l'Helix magnifica FEr. pl. 10. fig. 4. a. b. La première de ces deux espèces a été rapportée par Lalande, de son voyage en Aírique; elle est nouvelle. La seconde vien! des GrandesIndes; elle a été figurée par Buonani, dans le Mluseum kincherianum, pl. 12. Ce deroier groupe
H E M

269

devra, par la suite, être séparé du premier; car tout porte à croire que l'animal de l'Helix cafra n'est point disproportionné avec sa cuquille au même degré que l'Helix brevipes. Voyez VITRINE.

\section{HÉLICOSTĖGUES.}

Famille faite par 11. d'Orbigny dans son important travail sur les Céphalopodes miscroscopiques; elle est la troisième de son arrangement systématique; elle reulerme tontes les coquilles qui, avec un ou deux rangs de loges, sont euroulcés en spirales tantôt irochiformes et tantôt discoides. Cette fanuille est partagée en trois sections : dans la première, les Turbinoïdes, sont rangés dix genres, dont la spire est plus ou moins élancée; dans la seconde, les Ammonoides, on comple quatre genres seulement, dont les coquilles, très -aplaties et symétriques, ont les tours de spire apparens des deux câtés; dans la troisième section, celle des Nautitoides, sont rassemblées toutes les coquilles discoïdales dont les tours embrassans ne laissent apercevoir ancunes parties de la spire. Ces coquilles sont distribuées en douze genres. Dans l'essai d'une méthode que nous avons donné à l'article Céphalopode de ce Dictionnaire, nous n'avons pas adopté l'arrangement de M. d'Orbigny, parce que des caractères que nous avons regardés comme de prenière valeur ne sont pour lui que secondaires. Voyez Céphalopodes.

\section{HÉLICOSTILE. Helicostila.}

Sous - genre établi par M. Ferossac, poứ un petit graupe d'Hélices qui ont une columelle solide, une coquille surbaissée ou trochiforme, quelçuefuis dentée ou lamellée. Comme le dit M. Ferussac lui-mêtue, ce groupe a besoin d'éprouver plusieurs changenuens; il est même à présumer qu'il ne sera jamais adopté. Voyez HíLICE.

\section{HÉMICARDE. Hemicandia.}

M. Cuvier (Règne anim. tom. 2. pag. 479) propose de séparer des Bucardes toules les coquiniles de ce genre qui sont fortement cumprimées d'avant en arrière et toujours carénées dans leur milieu, comme le C'ardium cardissa, par exemple, ainsi que le Cardium aviculane Lamk., espèce fossile de nos environs, que Sowerby, dans son Genera, place à tort dans le même genre que les Hypopes. Voyez Bucarde.

\section{HEMICARDIA.}

Dans son Ten. metho. ostr., Klein a proposé avant M. Cuvier le genre Hémicarde pour les mêmes coquilles que le savant anteur du Regne animal a séparées sous le même nom, sans citer le zoologiste allemand. Voyez Bucards. 


\section{2:0 H E R}

HENICTCLOSTONES. Hemyrgelortomats.

M. de Blaicrille, diss sza sjstème coocby: Liologigge, a cooué ce $c \mathrm{co}$ à are fraille quj répond fisfailezen: a celle que Laxarch aroil faile prếcédem=eo: soos le =o= de Nérilacées. Elle coupread teates les coguilles doc: le bord croil de l'ostertare foree to deci-cercle, el qui sca: pourrees dos cpercale ce=ple: : scil ccrá, soi calezire.

\section{HENDËCADACTILE.}

Expressica explopée astrefois pa: les coachrliologues poo: l'aze des coçcilles de lear grasd gezre Rochsi, et cri es: camplise a ajourd buj dazs le gezie Plérocère de Lazarch. Ce com eat

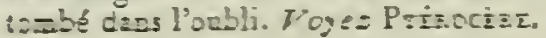

\section{FEPTADACTILE.}

Conze iz précéżeste, retle expression c'est plas exployee par les coscuydiclogues. El!e élou!

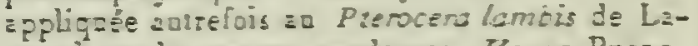
corch e: des apteurs zoderces. Voyez Prizocะis.

\section{HERCOLE. HeTro'es.}

Mozlfo:t, dass sa Corcharologie gyrtams. bigze, a proposáce genre pear ane peite caqulds ¿gorie, mais aro décrile par Soldzoi. (Tes. microccop.:-2x.18. 6.) Cente coquile, blancke $\in$ ?

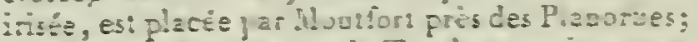
ce porrcis é:-e ca pe:i: Trockes, mais r= es?

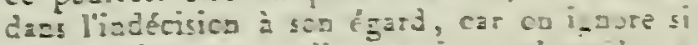
elle est clciscacte; elle es: roince, discrz!e, =

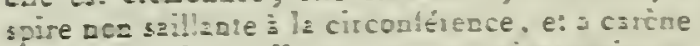

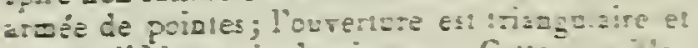
nog moditée par le dernierraur. Celle coculite, qee Decis Modifori $=0==e$ Hercoles ruzicuna,

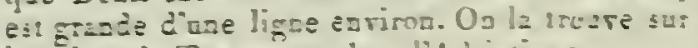
les cótes de Torcase e: dass!"A drintigue.

\section{HERIONE. EET:R.}

Macrais geare ézbli pat Mcalfori dezs le

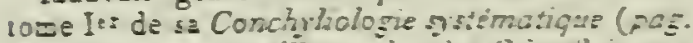
250) peo: cre coctille rolsize des Crisiellairze el comprise par d’Orbigaj dass soo geare Rodulise. Poye: $\mathrm{ce}=0$ :

\section{HÉRISSOY.}

$\mathrm{O}=$ zomxcil zinsi astrefcis todies les cocailles apires courertes d'épines plas on woios loegces; des Rockers, des Turkizelles, des Puarpres, etc., so iroercienl cemprises sous calte décorcinzis.a. : $x=b \dot{e}$ ajocidzei duss l'ocbli.

HERŨ.4PHRODITES. Bemraghogis.

La piexière sectica de la iroisiè=e classe ces

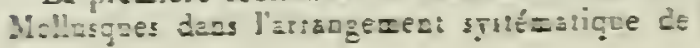

$\mathrm{H}$ E T

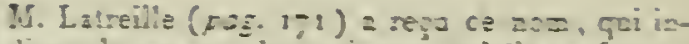

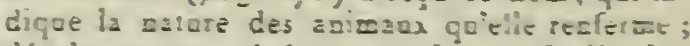
déla les cozzess fénératecrs el lect code diacli an zroient été e=plorés per M. de Blajorille $p$ is

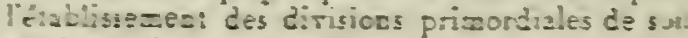
systè=e. 11 a explugé l'expressica équira'ente.

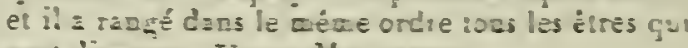
scar dierques. Jogez Xcrussirs.

\section{HERUES.}

To désezbrexes: da gezre Cone a reça ce noa de Mcotfort, gui à tori ez

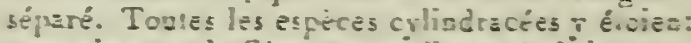
comprises, el le Cose tussaielle er ércii le trage.

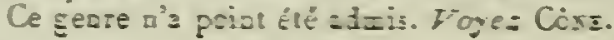

\section{HERMINE.}

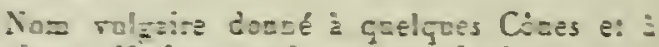
quelques lizlices, qui, sut co rood biscc ou

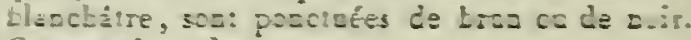
Ce act rest plas ea coige.

\section{HÉTEROCLITES.}

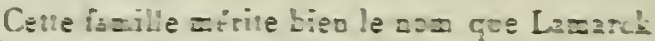

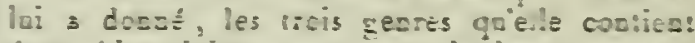

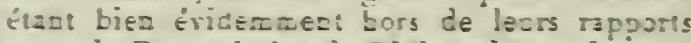

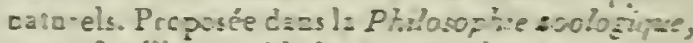
celre remille a sabi de gradu cbagexers; le geore Talraire a cié porté daes la facilho des Ýlicacées; le peare Balle, jois: zex aceres e: aox Butlées, eal dereac le type de la faxule des

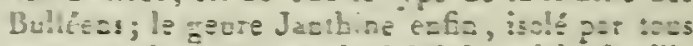

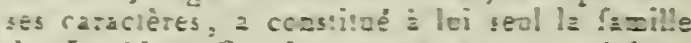

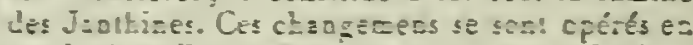
partie dacs l'Eximas du Cour e! es pa:tie dass

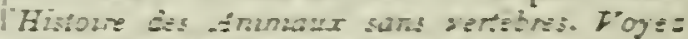
les trail davilies gue gous rezcas de cire:.

\section{HETEROPODES.}

Trzapé fat dae fasse a porécizlioe de carcc-

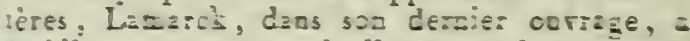
élab!i ox grcope particclier poct des zcissox

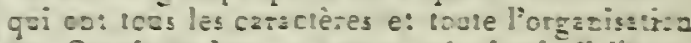

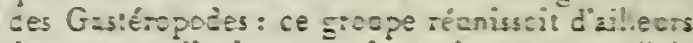
deux trpes c’azicar cua farcissen: assez éloisués; les Carizaires eíl les Pbrllirués re for:rolent étre réazies qu"zutad qué ce cervier gezre prósenieroi: des brzachies ccmparzbles z̀ celes dz prexier. Wzis il s"eo fac: bieq qu'il en toll

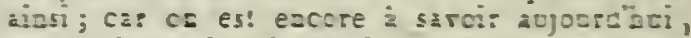
zalgié les reckerctes atsidces de picriears azasocis!es, quelles srs: les parries risibles de la Phriliroé qui serted à la respirziog. Vogez

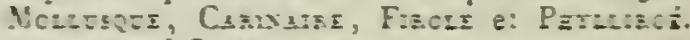
Vogezagsi Gaszezozo=zs.

HE'TEROSTEGINE. He:erosta etro.

Gere établi par M. ¿"Ortigct pon de peitis cogehles nicroicopiçoes, don: les carzzières!es 


\section{E T}

rapproclicnt des Amphistégines et de la plupart des genres qui constituent la lamille des lintomostögues. Dans celte famille des lintomastègues, M. d'Urbigny a joint deux types bien distincts de coquilles, réunis cependant par ce caracıère sommun de loges divisćes par une ou plusicurs aluisons; dans trois des genres, les cloisons aluutissent clacune à une ouverture, landis yue dans les deux aures, et c'est le cas du genre tuui nous occupe, il n'existe qu'une seulc ouverture : de ce fuit, il résulte la séparation nécessairc eu deux sections des geures de la famille des Eutomostcgrues. Celle séparalion est fondée de plos sur une clillérence de slruelupe qua est le résuliá de l'existence d'une seule ouverture.

Daus notre tnanicre d'envisager les rapports généraux des êlres, nous a vons dû rapprocber la liamille des lutomosicgurues des griands Cépbalopodes, et la mettre la première de la graude division à latuelle clle appartient; nous avous dû considérer aussi comine un passagge ealre la premicie section de celle faunille et la fauille suivante la secande section que nous $y$ avons ciablie, et qui coruprend les deux gucares Hétérosrégiue el Amplàiségine.

\section{C $\triangle$ R ACTÉRES GE் NÉRIQUES.}

Coquille aplatie, discoilde, à centre un peu julus élevé; lours apparens, divisés par un grand nowbre de logres transverses parlagées par un grand nombre de pelites cloisons longiludinales; la dernière logre percie d'une nuverlure unique, arrondie coutre le retour de la spire.

Le petit nombre d'espices gue l'on connoit actuelleusent daus ce reurc le rend assez dificile il observer en nature; mais les julis modèles que l'on doil à l'adresse de M. d'Orbigny peuven: sufire a l'observalcur scrupuleux qui veut Irouver les rapiorts des genres et les établit sur rous les raracieres observables. Nous indiquerons une seule des cieux espèces, donnéc par Ml. d'Orbigny dans sun Cialalogue.

IlĖtÉRกstéGINe déprinće. Hetcrostegina depressu. $\mathrm{D}^{\mathrm{O}} \mathrm{\textrm {H }}$.

11. testâ ovato-orbiculatâ, utroque latere depressissiná; anfiaclibus, planulatis, perspicuis, primis clutioribus, loculis mumerosis alcuatis septis longutudinalubus numerosissimis integris instructis; upcrlurî̀ minimâ, rotundutâ, puncliformi.

D'Ornigvт, Mlén. sur les Céph. Ann. des Scienc. nat. tom. 7. pag. 505. $3^{\circ} .2 . p l .17$. fig. 5. 6. 7 .

Id. Modeles de Céph. $4^{\mathrm{c}}$ liv. $n^{\circ} \cdot 99$.

'Très-peiile coquille qui a la lorac des Operculines, que l'on Irouve eu abondance aux environs de Bordcaux, mais qu'il sulfit d'examiner avec quelijue soin paur reconnoitre qu'elle ap. partient a un autre geurce. Elle est orbicalare, très-aplatie, symílrigue, un peu plus élevée au centre que daus le reste de sou f́condue; elle est diviste on un grand nombre de loges transverses, un peu obligues, convexes en dehors; toules cus Inges sont parlagées par un grand nombre de pelites cloisons longitudinales, qui rendent la coquille route cellulense el la peuvent faire conparec à l'os de la Sccche, quát à cette structure senlement; les petices cloisoas qui divisent les loges sont cumplètes, ct ne laissent aucune communication entr'elles. La deraičre cloison, lièsstroitc et tris-longue, est bombée en deliors; nue scule ouverlure se voil à son extrémilé inlérieure; celle ouverture est petite, alrondie, simple, et fail conmuniquer les loges entr'clles. Certe petile roquille s'est trnuvéc dans les sables de St.-Ilélène; nous avons pu l'examiner, ayant élé rapportće de la mêrne localité par MM. Quoy et Gaymard. Elle a à peiue 2 millim. de diaucire.

\section{IIEXADAC'TYLE.}

Dénomination anciennement employée pour désigner une varićlé du Ptcrocera millepeda Lawk. Vojez Pt́́nocéne.

\section{HIATELLE. Hiatella.}

Genre de la fumille des Enfermées de M. Cuvier el de celle des Capdiacées de Lamarck, créé pair Daudio paur de petites coquilles bivalves qui faraissent assez embatrassantes a bien placel dans la sćrie. Cunlondues par linné avec les Solens et les Caraliatées prar Brugaicre, Bosc, le premicr, les mentionna; Ml. de Roissy, aprés lui, adopta le genre yui les renferne, el c'est ce yuc lirent chalement Litmarck et M. Cuvies. Mais, en adneltant ce gente commenécessaire, ces autcurs onl cu sur lui des opriuions fort difiérentes. Celle de M. (uvier paroit pourlant prévalair; car MM. lerusiac: et de 33ajuville l'on entièrement adoplíe. Lille consiste à placer ce genre à còlé dés Sulens. Celle opinion s'appuie sur deux choses principales : la premiére, le bâillenent des val:es, qui r'existe que rarement dans les genres de lit famille des Cirrdiacies que Lamarck a voulu melle en rapport avec celui-ci; et la seconde seroil prise de l'laalitude qu'a l'animal de c:e genre, d'après M. Cuvier, de vivre enfoncé dans le sable; mais s'il est vrai, coume le dit Othon labricius, yue le Mlollusque soit libre, on sera lorcé de canvenir alors que Bruguière et Lamarck eurent quelque raisou de le meure jorès des Cardites et des Cypricardes. Quoi gu'il en soil, voiri les caractères yue l'on peut donner à ce grenre.

$$
\text { CARACTËRS GE் ÉRIQUES. }
$$

Coquille équivalve, très-inéquilatćrale, trans- 
verse, bäillante au bord inférieur ; charaic̀re ayant une petite dent sur la valve droite et deux dents obliqgues, on peu plus grandes sur la valve gauche; ligament extérieur.

Les Hyatelles different très-pea en effet, comme l'a dit M. Cuvier, des Saxicaves, et surlout des Byssomies; sa charnière, composée de deux petites dents, variables dans lenr grandeur et leur position, ressemble beaucoup à celle de quelques Pétricoles qui font le passage vers les Saxicaves; mais ce qui différencie les Hyate!les de l'un el l'antre de ces genres, c'est l'existence d'une petite dent latérale postérieure, assez semblable a celle qui existe dans les Cypricardes; les inpressions mnsculaires, l'impression du manteau et sa sinuosité postérieure, indiquent, d'une manière bien positive, que l'organisalion des Hyatelles a une très-grande ressemblance avec relle des Saxicaves.

M. Costa, de Naples, qui a examiné l'animal des Hyatelles, prétend avoir trouvé attachte à son pied ane petite coquille semblable à nae valve de Lime. Nous ne pouvons croire que celle observation suit exacte; elle meltroit cet animal hors de tout ce que nous connoissoas parmi les. Mollosques acéphalés. Avanl de croire un fait nouvean de celle imporlance, il faud roit an moins qu'il s'accordát avec quelques principes ou queiques observations an lérieurement fuiles. Il est bien à présumer qu'une petite coquille introduite par lasard dans celle d'une Hyatelle, aura contracté par la corupression quel que adbéreoce a rificielle que l'au teur aura prise pour aaturelle. L'animal de ce renre, d'après le méme autenr, seroit semblalıle à celui des Buccardes. Il est puurvu, dit-il, d'unc iracliée postérieure et d'une lente palléale antéricure pour le passage du pied. Celle comparaison a'est point eolièrement exacte, puisqu'il est rrai que les Buccardes on 1 deux onvertures postérieures au manteau, absolument comme cela a lieu daus les Yénus, les Isocardes, etc.; tandis que dans les Saxicaves, il n'existe véritablement qu'un seul siphon, qui réunit en une seule masse le tube anal et le lube de la respiratiou. Ce que dit 11. Costa de l'Hyatelle est donc conforme à l'opinion que nous arons, quoiqu'elle semble étre contre elle.

On ne connoit eacore que denx ou trois espèces appartenant à ce geare; elles sont de l'Océan européen. L'espèce donuće par MI. Costa se troure abondamment dans le golfe de Naples, et, à ce qu'il paroit, dans toule la Méditerranée. Nous indiquerons seulement l'espèce suivạute.

Hraterle arctique. Hyatella antica. Lanx.

H. testâ transwersim oblongâ, postico lutere longiore, apice truncato, valvarum angulis binis muricatis, altero valie obliquo; strus trans. versis.
I.Asr. Anim. s, vert. tom. 6. pag. 80. $n^{\circ}$. 1 . Mya arclica. Otнox Fabricios, Fau. groend. pag. 407.

Solen minutus. Cивщх. Conch. tom. 6. tab. 6. fig. 51.52 .

Escrcr. pl. 234 . fig. 4. A. B.

Cardita antica. Brug. Encycl, tom. 1. n०. 11.

Nons renvoyons, pour la description de celle espèce, à l'article Cardite, donné par Bruguière dans le preaier volume de cet ouvrage. Il sulfit ici de l'avoir indiquée, el d'en avoir cumplété la synonymie ponr la rapporter avec certitude au geare auquel elle sert de tyџe.

\section{HJBOLITE. Hibolites.}

Démeubrement proposé par Montfort dans le genre Bélemnite pour les espèces qui sont élargies el aplalies à la partie supérieure, ce qui leur donue la lorme d'un fer de lance. Ce geare u'a point été aduplé. (Voyez BéLesiste.)

\section{HIMAגTOPODE. Himantopoda.}

Nuus de concevons pas d'où peut venir celle mélhode singulicre qu'ont certains auteurs de substiluer des noms nouveaux à ceux introduits depuis lung-temps dans la science, el que l'habilude a sanclionués. M. Schumaclier, dans un grand nombre d'occasius, el dans celle-ci noiannen', a remplacé les noms géućriques de Lamarck par d'aultes que l'on ne doil et que l'on ue peut adopter. Ce genie Himantopude est le mérue que celui coonu sous le now de Marteau. Loyez ce mot.

\section{HINIITE. Hinnites.}

M. Defraoce est le créateur de ce geare que l'on Irouve pour la première lois dans le tome X.II du Dictsonnai.e des Sciences naturelles. Il l'a lurmé pour des Conchilères que l'un Irouve dius le Plaisantin, a Saint-Paul-I'rois-Châleaux, départemeot de la Dróme, el a la Cberrutière, départemeot du Finistère. Ces coquilles peuvent très-bien servir de lerme moyen un de passage entre les Yeignes et les Spondyles : adhérenites par leur valve iuféricure, elles sont auriculées comme les Peignes et irrégulières comme les Spondyles; elles ont un très-petit talou, le ligameot est placé dans une goultière largement ouverte dans loule son étendue, et elles n'ont point res dents cardina'es en crochels qui caraclérisent les Spondyles. De cetle comparaison des trois genres, il esı évident que celui-ci avait besoin d'ètre créé, puisyu'il ne peut rieliement fapre partic de ceud que nuus venons de citer. M. Delirance u'a connu que des espèces lossiles qui puissent s'y rapporter : cependant le Pecten inegularis des auteurs aurvit pu lui servir de type, car il en a cous les ceractères; en ellet, dans 
les vieux individus de celte espèce, le petit talon des autres Ilinniles, qui, dans les Spondyles, a un grand développement, et que NI. Defrance n'avoit point observé. De plus, conıone dans les Spondyles, il n’y a point d'ouverture sur les parties lintérales à l'origine des oreilleltes, comme cela a lieu dans le plus urand norulsedes Pcignes. On peutdonc mainlemant énoucer les caractères géaćriques de la aranic̀ce suivante.

\section{CARACTÉRES GËE⿱ERIQUES.}

Coquille bivalve, inćquivalve, parfaitemeut close, adbérente; crochets terwinés par un petit talon; ligameut placé daus une rainure profonde, largement découverte; point de deuts cardinales; oreilles latérales subégales, conrtes, nun baillantes.

Nous n'avons point ajouté, comme M. Defrance, la posilion de limapression da muscle, parce que celte position varie dans les Iluitres, quoique généralement elle soit placće ì l'uverse de celle-ci, c'est-ä-dire filu:ól postérieuremens qu'antérieurement, et nous n’avons puint mentionné non plus le caractère des stries on des lumes concentriques sur une valve, et rayonnautes sar l'autre, parre que ce caracrère n'est qu'accidentel, comme cela se vort dans les $S_{\text {, }}$ ondyles, qui ne produisent ces lames que paur rendre plus solide lcur adbésion aux corps envirounans, en aultipliaut les poiats de contact.

1. IIrxiteirrégnlière. Hinnitesirregularis. Nuв.

II. testâ ovatâ, irregulari, depressi, inequaliter sinuosâ, aurantio fusco et albo variegutia; striis raduantibus, undulatis, angustis, numerosis, scabris; walvi inferiore lamellis squanuefoimibus transversè instructá.

Pecten sinuosus. Lamx. Anint. s. vert. tom. 6. pag. $175 . n^{\circ} .49$.

Lister, Conch. tab. 172. fig. 9 .

DAcosta, Conch. brit., tab. Jo. fig. 3. 6.

Pennant, Zool. brit. tom. 4. tab.61. fig. 65.

Cette coquille, coofondue à tort par Lamarck parmi les Peignes, offre lous les caractires du geare aucuel nous lia rapportous. Il suflisoit de s'apercevoir qu'elle étuit constamment adhérente par l'une de ses valves pour être certain yu'elle ne pouvoil appartenir au genre Peigue. (Ce qui est remarquable dans celte espèce, et ce que nous avons pu conslater sur un assez grand nombre d'individus, c'est qu'elle reste libre et régulièrc dans le jeune âge, le crochet de la valve alluérente olfrant constamment lindice de celle résularité, de telle sorle qu'il sembleroit quiun même animal a vécu daos deux espèces de coquilles; mais on sait que, d'une part, cela est impossible, et, d'une autre, on est dirigé par la structure. de la valve supérieure, qui ne change

Hist. Nut. des Vers. Tonze 11. dans aucude de ses párlies. Irrégulićre comme loutes les toquilles adhérevtes, celle-ci il la valre inférieurc tantôt très-concave, tantồ t:ès-aplattie. Dans ce dernier cas, la valre superien:e devieut profoude, et contient presque tout l'animal. La valve inléricure est garvic en deliors d'un grand nombre de lignes lamelleuses et 1 ransverses, cunrtes, numbreuses, serrées, qui servenl à l. lixer aux corps suus-marius. $\Lambda$ u-delà decette adlıérence el versle bord, cesstries longitudinales reparoissent avec autant de réguharité que sur la v.lve sujérieure; celle-ci, généra!cmeot plas mince, operculiforme, est gúrnie, dans toute son étendue, de côles layonnanles, ćtroites, nombreuses, rapprochées, cliargées d'écrilles dans levi iongueur, el se terminant sur le bord par des crenelnres en aussi grand nombre qu'elles. Les orei!lettes sont peu alongíes, elles participent à l'iirégularité de la cocjuille; elles sont couvertes de slives rayounantes, tries lines sur la valve supérienre, remplacées sur la valve inférieure par un grand nombre de lamelles qui se joignent à celles †'11i serven! à l'adlérence. En dedaos, celle coquille est loutc blanche; les stries du dehors s'y répètent, surtout vers le bord, et lorscyulelle est jeune encore; en diliors, les valves sont ornées, sur un fund d'un blant:-toux, de taches un peu divergentes, d'un rouge vil, qui, se confondant vers le crochet, le teignent de cette seule couleur. Ia valve inlérieure cst quelquelois d'un blanc-jaunâtre uniforme. Celte curgulle curiense se trouve dans l'Ocćin européen, sur les côtes de France, aussi bien que sur celles d'Anglelerre. Les plus grituds individus out 40 milim. de longueur.

\section{Hinntre de Curtesi. Hinnites Cortesij. Def.}

H. testà orbiculatâ, depressâ, magnâ, crassâ, longitudinaliter costutâ, transversin lamellosâ, irreguluri; auriculis inaqualibus, minimis; sulco cardinali prelongo, profundo.

DET. Dict. des Sciences natur. tom. 21, art. HINNITE.

Grande et belle corjuille, que l'on ne conncitt encore quàa l'élat fussile. Ou la prendroit, au premier aspect, pour une grande Huitre, car ses oreilletles étroites el incínales lui donnent peu de ressemblance arec les Peignes ou avec les Spondyles; elle es! urbiculaire, aplatie, équivalve, toujours parfaitement close; son test est épais, solide, convert en dehors de côtes longitudinales bien distinctes sur les crochels, wais s'eflaçant peu à peu vers les bords, oủ elles sont à peine indiquées par le relc̀vement un peu plus considérable des écailles transverses au moment où elles passent sur elles. Lcs écailles sont trèsmultipliées, fort saillantes, irrégulic̀res; elles manqueat lout-à-fait sur les crochets; ceux-ci sont Irès-pelits, à peine saillans au-dessus du bord; à l'intérieur, les valves sont lisses; on re- 
mar.jue vers lenr centre une très-grande impression nusculaire comparable en tout it celle des Sipondyles : un talon prolongé et strié en travers termine le bord supérieur dies valres; il est semblalile à celıi des Limes, mais il est moios régulier; il est crensć dans sa longueur par un sillon trianguluire, alongé, très-prolond, et dumnant altache au limament. Celle arande espice se trouve ea Italie et dans le P'ićmont, dans des terrains tertiaires, mais surtout dans les sables jaunes des environs d'Asti. Elle a 14 centimètres de longrueur, et is peu prís autant de largeur.

\section{IIJPPOCRENE. Hippocrenes.}

C'est sous cette dénumination que Montfurt proposa, dars sa Conchyliologie systénutique, un démembrement de plusieurs espeices du genre Rostellaire, dont le Rostellaria macropteru ileviit servir de type; mais comme celle coquille ne differe des autres Rustellaires que par le díveloppeureat énorme de son bord dioit, développement qui est variable daus les espèces de ce prrure, ce caracière est insultisant pour qu'on puisse conserver le démembrement de Rlontfort. (Voyez ROSTEliatße.)

\section{HJPPONICE. Hipporix,}

M. Defrance avoil olsserréde puis long-!emps que certitincs espices rossiles de Caboclions étoient pourvues d'une base solide et Gxée, d'uu support sernblable en quelque sorte ì celui des (iranics. Cetie considération l'a engagé à faire, du sujet de son obserration, une note partit:ulière, qu'il communiģua à l'Académie, et qui lut inséréc dans le Tournal de Physique เ8ı. N1. Deliaoce propose, sous le nom d'Hipponice, l'úlablissement d'un uoureau gerre, dans lequel il range tous les Caisochons connus qui sont pourvus de support. lanarck a'a adanis ce genre que comme une division secondaire dans les (́alochons. M. de Blainville, au contraire, les maintient séparés; el, appuyć de lis connoissance de l'auimal d'ua Ilipponice, que MII. Quny et Gaymard oat rapporté dc leur voyage antour du nonde, il fait voir que ce genre sert de passage des Unirales aux Bivalses. Antérieurement à la publication de l'article Norqosque de M. de Blainville, nous avions cherclié, dans notre ouvrare sur les $C o$. quilles fossiles des environs de Paris, ì conlirmer, par de noureaux faits el par des raisonnemens appuyés sur des analogies, l'opinion de Launarck. Nous faisions remarquer que plusieurs espèces d'Hippouices rivans, au lieu de se développer sur un support, s'iacrustent pour ainsi dire sor les corps oi ils virent, s'y enfoncent, et y laisseat celte impression co fer à cheval qui se remarque sur la surface supérieure des supports. Nous avons également fait observer que les espèces qui paroissent être plus libres, qui,

\section{H I P}

à cel égard, à ce que l'on présume, ont une manic̀re de vivre analogue a celle des l'utelles, avoient pourtaut an bord irrégulier, taillé évidemmedt pour s'adapler aux sizuosilés des corps sur lesquels l'animal a pu vivre; irrégularité qui se remarque snuvent ì l'aide des strics d'accrnissement depuis le jeune âgc jusçu'à l'inslant de la mort, et qui tendent a prouver que ces animaux ont v'́cu à la même place comme le lont ceux qui sont pourrus de supports. Si de ccs obcervations il ne s'ensuit pas nécessairement la réunion des deux genres, cela donnnit au uoins de forles prísonptions pour les considérer comme très-vinisins, surtnut avant la connoissance de l'animal. Vuici de quelle manière $\mathrm{XI}$. de Blaiaville a caractérisé le geore qui nous occupe.

\section{CARACTÉRES GÉNÉRIQUS.}

Auimal arale ou suborbiculaire, conique ou dáprinı́; le pied fort mince, uu peu épaissi vers les bords, qui s'amincissent et s’ólargissent ì la mauic̀re de ceux du Alaniean, auxquels ils ressembleat complétewent; tête glal:uleuse portée a l'estrémité dune espece de cou, de chaque cólé duçucl est un tenlacule renllć a la base, et terriace par une petite poiate conique; yeux sur les rentlemens tcntaculaires; Louche avec deux pelits tentacules labiaux; auus au côté droit de la cavilú cervicale; oviducte terminé dans un gros tubercule à la raciue du tentacule droit; le muscle d'allaclice en fer ì theval est aussi unarqué en dessus qu'en dessous; coquille conoïde ou déprimée, a sommet conique ou peu arquí; ouverture a burds irrígulicrs, une empreinte misculaire en fer à cheval à la coquille, une empreiule de même forme sur le corps qui lui sert die support, et qquelyeelois is li surface d'un suppost lamelicux distinct du corps sur lequel il est lixé.

On peut díjä cilcr plusicurs especes virantes appartcuant à cerente, el un plus grand nomlse d"uspèces fossiles. Nous allons incliquer les principales.

1. Hipposice australe. Hipponix ustrulis.

H. tcstì tenui, obovati, dorso gibui, oblique conica, irregulari, rufescente, intus allâ muculâ luteolà ad apicem instruct.ì; strizs longitudinalibus, undulatis, scrpi mpartitis, crossiusculs, radiantibus; vertice acuto, infle.ro, postucali.

Patella australis. Labix. Anim. sans vert.t. 6. p. $535.7 \pi^{\circ} .44$

Confondan: celle coqnille irrégulière parmi les Patelles, dont l'un des caractères principanx consiste à présenter la plus grande symétric, Lansarck meltoil les conchyliologues duns l'impossibilité de reconnuitre crlte espèce. Il ne fut prossible d'en avoir connoissance qu'au motnenl oì l'on put exani ier sa collection réuuie à relle de M. de Riroli. Ur aroit long-lemps ignoré si celle co- 
quille, rapportice d'abord par Perron, devoit restur dans la yenre Cabochou, on fuite partie de celuides Ilipponices; les observations de MM. Quoy ct Gaymard ne laissent pas le aooindre doute a cet ‘́gud, l'ayant recueillie fréquemment lixée encore sur le support gui lui sert de point d'appui. Ce support est semblable en tout it ceux que nuus arons lait connoitre dans les espreces fossiles des environs de laris. Il est saillan, plus ou moins ćpuis, suivant l'igre de l'animal, blanc, ayant clans le milieu une impression musculaire en tw it cheval un peu saillante. La cogurlle placée sur le supprort esi conique, à base large, à sonmet prisulu lourné en spirale dans le jeune âge, et alors iaclinú à droi e. Le côté puslérieur de cette coquille est le plus conrt; il est presque perpendiculaire, el suuvent son bord est échancié, ce qui n'auive sans doute que lorsque la coguille est fosée sur un corps cylindroude. Du sommet part cul rayounant un assez grand nombre de côtes ajluties, peurlevies, souvent bililes, onduleuses, et produisus sur le bord des crénelures noaJreuses; un épiderme lin el caduc revót extérieurement la coquille. Sa couleur, souscel épidẹne, êsı d'uu blanc-jaunâtre passant au liauve. Au sommet, en dedans, elle est palie, luisinte, blanche vers les bords, et ornce d'uue gramde tache d'un beau funve dans toute la partic la plus profunde de sa cavité. C'est à la Nounvelle-Hollandeque se tronve celle espece. Elle a 20 millim. de diamètre à la base.

\section{II p porice rayenn'e. Hipponix radinta. Nue.}

II. testâ orbiculato-depressá, patellformi, irregulari, costis elatis irregularibus radiantibus ornalu, apice subicentrali; zmpiessione musculari unicá, arcuatá.

Orbicula crispa. Dep. Dict. des Sc. nat. 1.36. ग. 29.3 .

Nous ne savons sur quels caraclères. N. Defrance s'est fondé pour placer cente coquilie parmiles ().dicules; il suffisoil de voir une senle impressinn musculaire en fer à cheval pour ètre cerlain un'elle n'appartenoit pas à ce nomre. 'Tout le nunile sait que !es Orbicules, appartenant ì uı animal acépilale, présenteat coustamment duns l'iutérieur des valves quatre petiles inapressi ns musculaires placées au centre de ces mềnes valves. L'espiece qui rous orcupe est olliculaire, patclloide, irrégulière, à somaset subcentral, lisse, mamelonné, duquel part en rayonnant une vinğlaine de côtes trancliantes, lasuelleuses, élevées, fort érroites, eralre lesquelles dautres côtes plus petites et plus courtes vicarent se placer à peu près vers le milieu de leur longueur; d'aurres, encore plus petites, apparoissent vers le bord dans les intervalles que luissent les premières. Outre ces côtes, la surfice est encore orace de stries longitudinales trés- fincs el très-scrrées qui se coulinuent sur les parlices latúrales des cútes, et dont une quelquefuis est placíe à leur sommet. Lin dessous, le bord est aplati, crénelé; il es! limité postérieurement par l'impression musculaire en fer it cheval, qui se voit dans l'intóvieur et sur les parties latćrales de la coquille; sa cavité est peu prolonde. Nous présumous que cette esicce appartient nu gente ITippnnice; sa fornse, analogue is plusieurs espèce's des easiruns de l'asis, nous liail préféter de la placer ainsi, quoitguon ne connoisse pas sur support. Elle a 20 millim. de diamétre a la base. Fussile de Valogi:es, département de la Mauclue.

\section{IItppoxice sillonućc. Hipponix salcatus.} Bons.

H. tesî̀ ovato-conicî, pateliiforni, obliquit, apice obtusâ, sulcis longitudmaluhus et transversis clathrata, arregulari; marginibus integras.

Borsur, Mém. géol. sur le Piëmont.

Patella sulcata. 13ноля. Mém. sur le Vicentin, p. 76 . pl. 6. fg. 18. A. B. (..

Celle coquille a de l'analogic avec l'Hipponix australis que nous avons précédcument décrit; mais celie analogie n'est point complète, les stries longiludinales qui couvient la surlace de l'espéce quin nous occu pe élant toujuurs treillisseses par des stries transverses nombreuses. Cette coquille cst obliquement conigne, imcrgulière, ì sommet incliné postérieurenicnt, toujours obtus el lisse; il donne naissance ì un grand nombre dc côtcs lungindinales, serrées, élruites, sépariées par des snlons plus érroils qu'elles, jumais bilides et constammeal coupcis en travers par des stries numbreuses, surrées ('t plus lines que les sillans longiludinatux. Les bords sont trúuelés, souvent imignierenent unduleux, ce qui est produit par la ramière dent a vécu l’aninal, appliqué sur les corjos sous-mains tantól aplalis, tancôt irréguliers. Un ne comnoit pas le support de celte espéce, et peut-être étoit-elle dans le cas de colles que nous avous mentionnces, et qui se creusetat une inpression semllable au support des autres espices : nous fondons celte présoauption d'après des inpressions que nous arons observées sur quelques corjuilles de Dax, oì celte espèces se trouve assez fréluemrneut. Les plus grands individus ont 20 milliu. de diameire à la base. Ce n'est pas seulement à Dax que se rencoutre celle coquille fossile; elle est égaleant dans les faluas de la Touraine el ì la Superga, près de Turin. Ml. Bronguiart la cite parmi les especes du Vicentin.

4. Hipponice corne d'abondance. Hipponix cornu copice. LAN $\mathrm{K}$.

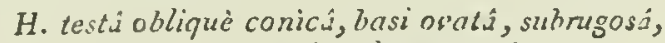
obsoletè decussubá; vertice clevato, adunco.

M 以 $2 *$ 
Knов, Petrif.tom. 2. $2^{e}$. part. tab. 13 I. fig. 3.

Patella comu copic. I,Aмк. Ann. du Mus. tom. 1.p.311. no. 5, et tom. 6.pl. 43. fig. 4 . c. b. c.

Hipponix cornu copia. DiF.

An patcllu unguis? Sow. Miner. Conchology, $n^{\circ}$. 25. pl. 139. fig. 7.8 .

Patella cornu copice. Вrосенг. Conchyl. subapenn. tont. 2. pag. 258, no. 6 .

Nов. Descrip. des Coq. foss. des env. de Paris, pag. 23. pl. 2.fig. 13.14.15.16.

On recounoitra facilement celle espèce par sa forme en cône ublique, par ses stries peu appareotes, par son ouverture fort large et la grande épaisseur du test; son somnel est obtus dans la plupart, et non en spirale, ce qui me porte à regarder avec doute la Patella ungzis de M. Sowerby comue analogue, car elle diffère de la nôtre par son sommet aigu et en spirale. Quan à celle que l'ou trouve en Italie, ne l'ayant jamais vue, nous devons nous en rapporte $r$ ì un observateor anssi exacle et aussi éclairé que M. Brocclii, et noter cetle coquille parmi le petit nombre des analogues fossiles que nons observons avec l'Italie.

Dans toutes les localités où l'on troure abondamment celte coquille, on y rencontre aussi en proportion des supports qui ne peuvent avoir appartenu qu'à celle espèce; on est d'autaut plus fondé à le croire, que $\mathbf{M}$. Defrance en ayint trouvé un en place, il n'est plus possible de se méprendre à cel égard. Cetle base est orbiculaire, à surface supérieure lisse, tantôt plane, tantồ concave, tanlôt convexe, suivant la furme du corps sur lequel elle adbère; face inférieure irrégulière, présentant des points d'insertion sur les corps sous-marins. Le bordantérieur est plus épais que le postérieur; l'insertion musculaire que l'on remarque à la face supérieure a la forme d'un fer à cheval dont les depx extrémités, plus larghes, se recourbent l'une vers l'autre, mais ne se touchent pas. Dans lez jeunes individus, ces deux extrémités se louchent sans se confondre, et leus partie étroite et postérieure est égallement séparíe, de manière que l'on voit évidemment que ce sont deux impressions qui se confondent postérieurement, et qui s'écartent aatćriemrement à wesure que l'animal prend de l'accroissemeut. Parmi les individus de cette espèce, il cn est qui prenuent un fort graot volume, comme M. Defrance l'a observé sur ceux de Valognes. Ceux que nous avons aux environs de Paris ont de moindres dimensions, 60 millim. du sommet au bord antérieur, et 38 de diamètre à la base.

5. Hipponice dilatée. Hipponix dilatata. LAMK.

H. testâ obliquè conich, depressiusculâ, ru- gosá; striis longitudinalibus, confertis, undulatss; verlice nutante; aperturi aniplissiniâ, patula, ovato-rotundatâ.

Patella dilatata. Lam K. Ann. du Mus. tomi. 1. pag. 3ı1. n० 4. tonı. 6. pag. 43. fig. 2. a. b. c. elfig. 3. a.b.

\section{Hipponix dilatata. Der.}

Nов. Descrip. des Coq. foss. des env. de Paris, pag. 24. pl. 2. fig. 19. 20.21.

Les forles stries onduleuses, simples, qui se dirigent du sommet à la base, qui sont coupees par des stlies I ransverses d'accroissement plus on moins multiplices, ainsi que le grand évasement de l'ouverture et l'aplatissement général de la coquille, sont des caractères tranchés an moyen desquels on reconooit facilement celte espèce.

M. Defrance l'a obserrée avec son support, qui a beaucoup de ressemblance avec celui de l'espèce précédente; sculement il est plus large, plus mince, et plus souvent adhérent par toute sa surlace inférieure. Il prend des dimensions beaucoup plus grandes que celles indiquées par Lilmarck, comme ou peul s'en convaincre par les ligures cilées, qui sont de grandeur naturelle. Celui de la fig. 2 I est le plus grand que jaic jamais ru; c'est pour cela que j'en ai fait dessiner le truit el une partic des détails, pour convaincre qu'il appartient à celle espèce.

Il a 70 millin. de longueur, et 40 de diamètre à la base.

6. Hipponice élégante. Hipponix elegans. Nов.

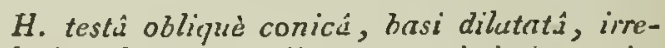
gulavi, eleganter striis nunierosissimis majoribus et tenuissinuis ornatá; apice recunvo, non spirali.

Nов. Descrip. des Coq. foss. desenv.de Paris, pag. 25. pl.3. fig. 16.17.18.19.

Celle espèce a quelques rapports avec le Spirirostre, mais on l'en distingue facilement; d'abord, ence qu'il n'est point lamelleux; que ses strics ont une disposition diflérente; qu'il est ginéralement irrégulier, ayant vécu sur des curp̧rs pen nuis sur lesquels il s'est moulé. Son sommet n'est point porté bors du bord, il n'est pas tourné en spirale; des stries, les unes sont plus grosses, les autres très-tines, an nombre cle trois à quatre entre les pretrières. Cette coquille, rare et élégante par la disposilion de ses stries, est quelquefois étagée par des accroissemens irréguliers. Il est évident, pour moi, d'apries les accidens des stries, que cette espèce vit toujours à la même place, et il est bien à présumer qu'elle avoit un support, mais gu'il n'est point encore conau.

Diamètre de la base 18 millias. 
7. Hipposice rétortelle. Hipponix retortella. LAsK.

H. testâ ovat $\hat{x}$, lavigatâ, basi substriatâ; vertice laterali, spirali, obliquato.

Patella retortella. LANк. Ann. du Mus. pag. 511. $n^{\circ} \cdot 7$.

Pilcopsis retortella.. Ibid. Anim. sans vert. com. 6. $2^{\mathrm{e}}$. part. pag. 19. $n^{\circ} .6$.

Noв. Descrip. des Coq. Soss. des env. de Paris, pag. 26. pl. 2. fig. 17.18. Un peu grossie.

Il est facile de reconnoître celle espèce : son sommet iucliné en spirale, les stries de la base, sa forme et sa taille, sont autant de caracières distinctifs. Il servit iumpossible de la confondre arec l'espèce précédente, dont elle n’a ni la forme ni les siries lamelleuses. Il est probable que celle espèce étoit pourvae d'un support, mais nous ne le cnnnoissons pas. Lamarck n'a connu que de jeunes individus de celle espćce, ce qui est cause qu'il n'en donne pas toutes les dimensions. Nnus en possédons plusieurs, dont le plus grand a 11 millim. de long et 9 de lurge.

8. Hrppoxice operculaire. Hipponix opencularis. Nов.

H. testâ orbiculari, extús concavî, intus convexâ, papyraceâ, sublamellosâ, squamoeformi; apice spirato, depresso, submaryinali; stris tenuissimis, irregularibus, internuptis.

Noв. Descrip. des Coq. foss. des env. de Paris, pag. 28. pl. 3. fg. 8. 9. 10.

Comme le Caboclion en écaille, celle espèce présente celie singularité d'être.aplatie conme un morceau de papier; mais elle a de plus que l'autre sa concavilé du côlé extéricur, ce qui est l'inverse de tou!es les cocuilles patelliformes. Elle est conséquemment convexe en dedans au lieu d'être concare, et l'on se demande avec juste raison oi pouvoit ếre logé l'animal. Dans l'espèce que nous vecons de ciler on le conçit encore, parce que, rivant daus lcs cocqualles spirales, l'animal prufie de la concavilú même qu'il clooisit pour se loger; mais ici ce ne doivent plus être les mênes haljitudes : si elles étvient semblables, la coquille en présentercit les traces, ce qui n'existe fas, car elles onl loules une tinrine régulière qui fait penser qu'elles se sunı développées librement. Mais comme dans !es métnes terrains on trouve, outre ces coyialles, un support fort singulier, lamelleux, très-concave, qui a été adhérent, et que nous avons fuit représenter, même planche, fig. $20,21,22$; que ce support seroil enlièrement inutile à nne espèce pourvue d'une coquille à ample concavilé, il est bien à présumer qüil a appartenu á celle espèce : du moins tout me porte à ?c penser, surtout si on fait attention à une disposition semblable des impressions musculaires dans l'un et dans l'autre de ces corps. Quoi qu'il elz soit de la justesse de ce rapprochement, on reconnoittra toujours facilement l'espèce qui nous occupe, et on la distinguera par sa forme circulaire, son aplatissement considérable, son sommet peu apparent en spirale, ses lanes peu élevées, nombreuses et très-finement striées; en dessous elle est lisse, présente une impression musculaire en fer à cheval. On y voit une petite coocavilé qui correspond au sommet.

Celte coquille est rare; elle a jusqu'à 25 millim. de dianètre.

\section{HIPPOРE. Hippopus.}

Une coquille que les Anciens plaçoient parmi leurs Cames, et que Klein sépara avec les 'l'ridacnes en genre particulies sous le nom de Chanicetrachea, avoit été confondue par Linné parmi les Cames; il lui avoit donné le nom de Chama Hippopus.

Binguière, à l'exemple de Klein, réuuit dans les plauches de l'Encyclopédie les Hippopes aux coquillcs vulgairement nommées Béniticrs, e! il en formil un seul genre, qu'il nomua Tridacne.

Depuis, Lamarck, tout en conservant le genre 'Tridacne, en sépara la coquille qui nous occupe, qui devint le typa du nouveau genre, qu'il proposa sous le non d'Hlipponpe. M. Cuvier (Tableaux: élémentaires de l' Histoire naturelle des Animau.r, ${ }^{1798)}$ ) mentionne a peine les Tridacnes, quil cunfond avoc les Causes, comme Limné l'avoit fait.

Mais plus tard, l'Illustre anteur du Régne animalnon-seulement aduil le gremre Tridacue, mais encore le genre Hippope, dont il fit un sousgenre des 'Tridacnes.

M. de Blainville avoit d'abord conservé le gente Hippope, comme on peut s'en assurer cl1 consulant larticle du Dict. des Scienc. nat. concernant ce gente. Ce savant ayant eu l’occasion de prouver qu'à l'état adu!te, les 'Tridacnes perdeat l'ouverture lunulaire, do mcins dans lit Tridacne gignatesque, il en conclut l'analogie avec les Ifippopes. Celle analogie est bien évidente; anssi nous trouvons à l'article MoncusQUe du Dict. des Scienc. nat. ces deux gentes fondus en un seu], dans lequel les Hippopes forment unc petite section à part.

Lamarck avoit placé les Hippopes parmi les Conchifères monomyair s; ellectivernent, nne grande impression musculaire, submédiane et assez facile à observer, n'avoit point laissé de doule.

M. Cuvier, le premier qui a donné quelqques notices sur l'animal des Tridacnes, n'a point menlionné deux muscles adducteurs. Cependant M. de Blainville, qui a vu aussi ces animaux, affirme avoir vu un second muscle, mais très-petit, ce qni l'a porte à les ranger parmi les Dimyaires. 
Le truit caractéristique principal qui a déterminé lamarck à la sćparation des Hippopes est le dúfaut cle l'ouverture de la lunule qui se remarque ¿ 1 des degrés diftérens dans les Tridacnes. Mais, coume l'a dil M. de Blainville, la Tridacne gigantesque perdant celle ouverture par l'âge, il s'ensuit que ce caractère est de peu d'impurlas:ce ¿t insulfisad pour l'établissement d'un genre. Plus tard, lorsqu'on connoîtra l'animal de l'Hippope, on pourra porter un jugement détinitil quil est impossible de donner d’après la considéralion seule des coquilles. Voici les caractères que Lamarck a assignés à ce geare.

\section{CARACTÉRES GÉNÉRIQUES.}

Coquille équivalve, régulière, inéquilatérale, transverse, $\dot{a}$ l'unnle close; charnière $\dot{a}$ deux denls compliunées, inégales, antérieures et renIrautes; ligament marginal extérieur; une seule impression musculaire.

Un ne conuoit encore qu'une senle espèce qui puisse se rapporter aux Hippopes; elle a été figurée dans presque lous les auleurs : Lamarck l'a nounmée.

\section{Hıppgpe maculée. Hippopus maculatus.}

Lask. Anim, s. vert. tom. 6. pag. 108.

Chana Hippopus. Lis. pag. 3300.

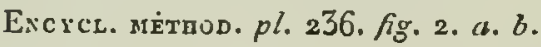
499 .

Chexx. Conch. tom. 7. tab́. 5o. fig. 498 et

Cette jolie coquille, qui nous vient de la mer des Indes, est commune dans les cullections; elle a l'aspect d'une 'Tridacne, elle s'en dislingue ficilement par la lunule close; elle, es: chargie de cóles rayonnabtes assez larges, qui correspondent aux découpures du bord. Ces ióles, dans les individus lien lirais, préseptent des aspérilés ou des épines plos ou moius régulières, yui se voient surtout lisns le jeune âge; lï lunule est très-grande, occupant fout le burd supéricur et antérieur, et séparée du reste de la surface extériebre par une carène dont les écailles sont régulièrcs. Toute la surface extérieure est tachetée de rose ou de rouge violaccé sur un fiond blanc. Les grands individus ont 5 ponces et plus de largeur.

\section{HIPPURITE. Hippurites}

Dans un Nlémoire que nuus avons publié en 1825 , dans le tome $V$ des Sciences naturelles, nous avons fuit sentir conbien avoil élé peu rationnelle l'opioion des auteurs qui placèrent le geore Hippurite parmi les Céphalopodes. Déeruvert en 1745 zux Bains de Rennes, dans les $\mathrm{Py}$ rínées, par Picol de Lapeyrouse, ce genre olfire des corguilles d'une structure fort singulière, e: qui présenlent des caractères qui rendent leur filace dilicile à assigner dans les classitications. Hruguière a compris, dans son genre Arcade, les Uilracites et les Orthocératites de Lipeyrous:" corps conaus aujourd'bui sous les noms d'Hippurite et de Rudiolite.

Lamarck reclifia le genre, le divisa en deux, clonna aux Osiracites le nom de Ruálolite, "t anx Orlhocératites celui d'Hippurite. Ces genrés furent conservés par lai dans ses différens uuvares sur les Mollusques; et nalyré les rapports qui existent entre cus, il plaça le premier dans la tamille des Rudistes (2'oyez ce mot), et le secund parn:i les Céphatopodes à coquille, saus spirale, eatre les Bélemnites et les Orthucères.

Tous les auteurs, sans exceplion, ont adopté la manière de vuir de Lamarck. NJ. Cuvier, lui seul, avois fait une observation dans son Règne animal, tendant à jeler quelque doute sur la valeur des raplporis indicués par Lamarck. Il corscrvá néamins, dans sa classification, ce qui avoit élé fait ivan! lui par l'auseur des Animaux saris vertébies. M. de Ferisssac, dont la méthode ñest le p'us ordinuirement qu'une copie de celle de N. Cuvier, le suivit pas à pas dans cetle occasiun; il unarifesta les niénies doutes que lui, et, comme lui aussi, ne fil alleur clangement da:is les rappnils des genres. M. de Blaidville, daus son arlicle Mlulicsque, du Dictionnaire des Sciences naturelles, embarrassé peut-être du genre llippurile, ou, ce qui est plus probible, l'ayan: oublié, ne le mentıunna pas du lout; ci cependant, après avoir purésenté à la Société philomatiyue nos ubscrvations sur re genre, IJ. de Blainville préleridit, dans san rapport, être arrivé zux mếmes résulıals que nous dans son Traité de Malacologie, gui n'ítuit poiut alors publié : nous devons dunc: conserver toute lis priuricé de notre lravail sur ce geure curieua. Si les auteurs qui nous ont précédé s’éioient souvenus des principes au moyeu desquels ces êtres peuvent être uis en rapport, et qu'ils euscént litit al:ention que les llippuriles u'ont aucun des ca. racières propres aux Céplualopotes, sans dou'e quils aurvient cherché à leur trouver des rapports plus nilturels; brais il semble que, confundaut lous les caracières les p!us essentiels à denx classes aussi distinctes quie le sout les cocpuil!us univalves et les coquilles bivalves, ils aient fait de continuels elforls pour se uretre en contrudtction avec cux-menses. De ce que les Hippurites son: des coyuilles alongrées, lubuleuses, coniques, il ne s'ensurl jas que ces circonslances de si peu alin:portance duivent les laire placrer à cúté des Orthnct resel des Bélenaniles, qui snnt counme elles alumgres et vonignes. Les llippurites ne snut jamais symertriques; elles snut loujours adheicnles, imruguliètement cuntournces, souvent foliacées i l'extéricur; elles scnt fermicus par tinc valre suptrienre, yüil cs: injossiule de con- 
parer avec les cloisons des coquilles multiloculaires; cl si, dans leur longueur, elles sont pourvues quelquefois de cloisons transverses, yuoique res cloisons aient plos de rapport quant it leur position a vec c'elles des C'éphalopodes, l'analogie, il s'en faut de bien, est loin d'être complète : d'aillenrs, entre la dernière cloison inlérieure el la cloison supŕricure, qui est pour nous la valve, il existe une arsez grande cavité dans laypuclic on ruconnoit l'labiatation d'un Mollusque qui ne puuvisil avcir d'action extćricure sur sa coquille, asmme cela a foujours liea dans les Céphalojordes.

La séparation des Ilippuriles el des aulres genres de la faunille de Rudivies est la chose cloni nous nous sommes occupé dans le Alémoilce que nons avons cilć; nous nous sommes allaché '́galement i démustrer quaurun des caracières des llippurites ne pouvout se concilier arec ceux de la classe dans layuclle on les a mis. Nous ablons ici reproduire les raisounemens it l'aide desquels les rappol's des genres ont éte modilit's.

Sil'un cumprare les cloisuns des $\mathrm{H}_{1}$ ppurites avec celles des Polylialanes, on trouvera de's dilfirences nolables. Ici elles ant une irrégularité constaote soit daus les espaces quolles occupent, suit mêroc dans leur inclinaison, comparable en cela, comme l'a dil précédemment M. Detrance, anx concamérations qui se rencontrent dans le tulon de cerlitines IIuitres qui onl celle parlie très-alongée. Ces cloisons sont bien cerlainement le résultat des accroissemens sucressifs de l'animal, accroissemens qui sont irréguliers dans toutes les Bivalves de la famille des Ostracées, ct méme de loutes celles qui, comme elles, contiennen des coquilles addiérenıs. Jci les accroissemens de l'aninal contenu dans une cavité alonsúe oul dû prendre uue manière l'éltre approprice il la nature toécue de son liabilation. Dans la nécessitć nì il se trouve d’augmenter d'un cồtć l'espace où il est compris, de lassser d'un autre cưlé cicriere lui l'espuce yưil ne peul phas habiter, el cependan: cle truurer un poiut d'uppui, il lorme une cluison pour le suppotter comme l'Huitre forme une nouvelle lawe a mesure quielle siscroit. La formation des cloisons irrégulières des Hippurites rentre donc daus la rèyle généralc, et s'explique très- bien par analogie.

Ces cloisons ne sont pas pefrées dun siphon comme quelques personnes l'ont prélenda; e.les sont simples, se cunlundent avec le test, sans qu'elles soicnt séparables comme celles qui se trouvent dans les coquilles clnisonnées. Ce que l'on avoit pris pour le siphun n'est rien aurce chose, sclon nous, yue les restes d'une charnière dont un ne connoit joint encure complétement lat ualure. Dans les Polythalames à siplion, telles que les Nauriles, les Ammoniles, les Spirules, les Bćleurailes, elc., le siphon est continu, non inlerrompu, quelquefois ariculé; il a pour usage de donner passage à un tendon on ligament qui s'y insère, et rui est diestiné a lier l'animal à sa crquille. Il fal faire allculion, en oulre, que le siphon est constant, et neéuc la condilion la plasessentielle des coquilites multiloculaires. Il estévident gue la parlie nommée siphon dans les Jippuries ira pu aveir le aéme usage, d'abord parce quil est lui-unême cloisonné par les accroissemens, et ensuile parce que son cxistence n'est poiat constanle dans le genre : ainsi on voit les espèces avec celle partie nommét siphon, el d'aulres qui en sont dépourvues. Cependant les uncs et les aubres sont garnies de cloisons, el précentent d'ailleurs les mêmes cüractères extérjeurs. Lo siphun des IIippuries consiste en mue ou deux aretcs remontant de la base vers le commet de la coujuille, fixćes is sa parui par un de lear côlú. Iorsqu'il $y$ eu at denx, elles sunt convergeutes, et laissenl cnue e!les une goutlicre assez profonde, dont les cloisons reunlilissent la sinuosité. Ces arêies, dans la coupe lransversale de la corpuille, paroisseut avoir bé creuses à lem parie supérieure, puistuon les troule cloisonnées parallèlement à la cavité de la roquille. D'a près de nouvelles observalious, nous a vons po nous convaincre que ces arctes lurment nne parlie coustituanle de la charnière, el recnivent uu ligamed puissant dans l'intervalle qui les sépare. L'usage de ces parlics, une lois iecomno, fait donc rejecer loule analogie quon pourroit supposer avec le sipbon des Céphialopodes.

Pour ce yui a rapport it la rabe superiene ou operculaire, il n'est aucune comparilison possible avec les coquilles polythalames. A-I-on jamais va une cortuille do cetle dernicre famiile cloisonnéc et opcreulée tout à la fuis? Il liudivit admettre celle combianison hizarre pou: pouroir introduire les lippurites dans celle classe d'animaux. La seule objection qui peut elre fuise, c'est qne celle valve supérieure des Hipluribs ve se montre jamais arec une charniere. Un a lonc pa la comparer avec la cernière cluison bombée en dehors qui termine la plupart des ccquilles micruscopiques; mais il futt encore revenir à une comparaison exacte des Hippurites et des Cépbalopodes, consolier avec quolque soin l'ouvrage de Lapeyrouse, pour s'assurer que colle valve des Hippurnes n'ofire aucune analogie.

Nous voyous que les coquilles muliloculaties qui ónt la dernière cloison bombée en delars sont complćtement cachées par les parties molles de l'animal. Cetle cloison est fixée soudée au pourlour de l'ouverture, qu'elle lerme d'une manière très-exacte. Celle tixilé est nécessaire à l'animal, poisque c'est là qu'il trouve sou point d'appus. Jl laut faire observer en ontre que, dans les coquilles cluisonnées dont il est ici question, loutes les cloisons sont semblables. Ia deruiere, ac dillérant de la première que par de plos grandes dimensious, il n'en est jas de même 
daus les Iippnrites, la valve operculaire ou dernière cloison est libre, el bien dilléreute en tous points des cloisons de l'intérieur, car elles sont filures et concares par leur surface externe, ot Ia dernic̀re, au contraire, est convexe. On vuil d'autant mieux que ce ne peut être une cloison, que souvent des Huilres on des Polypiers sint adhéreus sur la surface extéricure de cette valie: ce qui ne pourroit avoir lieu, si réellemeut elle remplissoit les fonctions d'une cloison. I.a valve supéricure a nne siructure gue l'on retronve daus toutes !es coquilles bivalves inéquivalves; elle est épaisse, poreuse, เaillée en biseaul aux dépens cle sa surface interne, pour s'adapter plus exactement sur l'ouverture de la valve inlérieure, et présentant toujours sur son bord toures les crénclures, les anfractuosités qui peuvent se remarquer sur les hords de l'autre valve. De ce que nous veuons de dire sur celte soi-disant cloison, on peut facilement conclure que ce n'eo est point une, mais seulement vne valve semblable à celle des Radiolites et des Splićrulites, ayant bien évidemment pour fonclion de fermer une coquille dans laquelle l'animal ét oit contcou. Une deruière considération est celle qui résulte de la disproportion qui existe entre l'cspace compris entre la dernière cluison el l'opercule et entre les cloisons entrolles; aulant celles-ci sont serrées et accumulées dans un petit espace, autant celte dernière est graude et spacieuse. Et a quoi serviroit une si grande luge, si ce n'est, comme nous disiuns, pour contenir l'animal?

La plus forte preuve, à notre avis, que les IFippurites n'ont point appartenu à des Céphalopodes, résulte que l'adhérence constante de leur coquille, soit anx corps sous-marins, soit à ellesmêmes, se prêtant ainsi, à la maničre des Huitres, un mutuel appui, tout anaonce, dans leur forme, leur irrégularité, leur non symétrie, qu’elles ne jeurent appartenir à celle classe des êtres si voisius des Vertéhrés par leur organisation compliquée, et par la hlierté entière dont ils jouissent comme eux. Celte adhérence des Hippurites, constatée dès le principe par licot de la Peyrouse, auroit dî éloigner l'esprit du rapprocluement quon en a fait avec les Bélemnites et les Orthocères, et détruire ainsi toutes les fausses idées que l'on s'étoit failes de ces corps.

Si mainteroant nous rapprochons les Hippurites des Radiolites ou des Sphérulites, nous leur trouvons une telle analogie, que nous croyons dilfcile leur conservatiun comme genre. Tout ce que nous avons dit à l'égard de la famille des Rudistes de Lamarck, dans une note spéciale, publiée ea 1828 , dans les Annales des Sciences naturelles, peut s'appliquer très-exactement au gevre Hippurite. Comme nous devons reveoir sur ce sujet, à l'occasion des Rudistes et des genres que cette famille contient, nous ne donnerons ici aucun des détails qui se trouveront mieux placés dans le travail d'ensemble que nous nous proposons de faire alors. Nous ajoulerons seulement, qu'il arrive assez fréquenment que l'ou trouve les Hinpurites avec un birostre semblable à celui des Radiolites, el qu'il nous a été possible, $2 u$ moyen de celle impression cxactc de l'intéricur des valves, de nous assurer de la grande analogitqui exisle dans la structure des deux genres. (Voyez Rudistes el Spatirulites.) Une dernière ubservation que nous ferons au sujet des Hippurites, c'est que l'on a rangé cerlaines de leurs parties, déduublées par suite de la fossilisation, parmi les ichthyosarcolithes. Ce dernier genre, composé de graods débris, comparé aux Spirules, a été fortné sur des tronçons telletnent incomplets, que l'on conçoit à peine comment il a pu être intruduit parmi les Césllalopodes, n'étunt en dernier résultat que le ınoule intérieur de certaines parties d'une graode coquille bivalve, conaue sous le nom de Caprine. Celle deruière, se rallachaot par ses caracières aux Radiolites et aux Splérulites, nous en traiterons en mếme temps que ces genies.

\section{CARACTERES GENÉRIQUES.}

Coquille along'e, tulunlense, composée d'une graude valve intérieure et d'une pelite valie supérieure, uperculiforme; test porenx, tantót lisse, lantót orné de côtes longiludiuales, et lantôt foliacé Irausversalement; vaive supériense operculiforme, plate ou us peu bombće en dessus, olliant le plus souvent denx cryples qui correspondent aux arètes de l'iutérieur; extrécoité de la grande valve remplie par des cloisons transverses, plus ou noins nombreuses; l'iulérieur de celle même valve muni ordinairement d'une ou deux arêtes longitudinales, entre lesquelles est situéc une goullière assez profonde; charniète forlement articulée, incompléternent connue; deux impressions musculaires.

J,es Hippuriles paroissent, jusqu'à présent, appurtenir d'une mauière suéciale aux terrains de craie. Quelques personnesont prétendu qu'elles existoient aussi daus les terrains tertiaires; mais lorsque l'ou est venu à examiner avec tout le suir convenable les terraius à Hippurites, on les a définitivement rapportées au grand système crayenx. Deux points restent anjourd'hui cuntestés : celui de Gossau, décrit par MM. Sedwichı et Murschisson, el celui de Sicile, qui n'a encore été examiné que d'une manière superficielle. Gossau appartient incontestablement, d'aprćs les observations de M. Buué, au systeme da grès vert.

1. Hipporite cornel de pasteur. Hippurites cornu pastoris. Desmourins.

H. testâ cylindraceo-elongatâ, conicâ, plus minusve contortâ, apice attenuatâ, longitudi. 


\section{H I P}

naliter coshuha; costis anguluribus; fusciis longitudinalibus, duabus inaqualibus elcganter striatis; striis obtusis; valvis superiore subplantâ, sublarbigatî radiatinve subplicati.

Dess. Mén. sur la fun. des Rudistes. Bull. d'Hist. nat. de la Soc. lin. de Bonteunx, tom. 1. pag. 288. $n^{\circ}$. 2. pl. 10. fig. 1. 2. J.

Celte belle espc̀ce, remarcjuable par la porositć bien évidente de son test, ne l'est pas muins par les deux fascies aplaties, larges et liremcnt striées, qui remoutent de la base au sommet daus luate sa longueur : l'une de ces fascies est plus étruite que l'autre; elles ne paroissent correspoultre is aucuuse des parlies de lu charnière. D'après un individu dans leyuel le birostre est en plitce, et au moyen duquel il cst par couséquent fucile de juger de la place qu'occupoit la charaière, on voit que la plus large liscie lui est diamétralement opposée : elle correspond doac au côté venlral de l'animal; la petite fascie est placée sur le coté gauche, et telle est le peu de symétrie de cette cuquille, que rien ne la représente sur le côté droit. Les sillous longiludinaux sont peu nombreux au sonmet, mais a mesure que la coquille -accroit, il s'en iuterpose de nouveaux entre les premiers; de sorle ciue dans les grands individus, ils se trourent trés-multipliés ver's les bords. Ceuxci sont épais, finement unduleux dans tuate leur circonférence: ondulation qui résulte des côtes extérieures, et qui se répète su: les bords de la valve supórieurc. Celle-ci est un peu bumbée eu deliors: loisqu'ellu se dédouble en se détachant de la roche, elle présente une surface lisse; anais lorsqu'ou la voil enticre, elle est on rée de cótcs rayónuantes peu élevées, interrompues par des Isinelles conceutriques. A l'iutérieur cette cuquille est lisso; unais on ne peut juger de l'état où elle étuit pendant la vie de l'aoimal, que parle moule intéricur qui s'y truave quelquefois, et antour duquel un espace vide indigue la dissolution de la partie intérieure du test, dout il dunne une seprésentalion exacte. Les porosités de cette cayuille se voient très-bien au moyen des cassures; elles sont semblables, comme nous le verrans, à ceiles des Spliérulies. Cette grande et belle espéce a été décuurerte aux enviruns de Périrrueux, daus une couche de craie furt puissante. Les grauds individus ont jusqu'a 2 déciniètres de longueur, et 6 a 7 centiacties je diamètre.

$\mathrm{DEF}$.

2. Hippuritr sillonnée. Hippurites sulcata.

H. testâ cylindraceo-attenuatâ, crassissimâ, longitudinaluter rugosá, sulcutá, bass truncuta; valva superiore plani, subradiutâ, foved, duplici instructâ.

DEx. Dict. Scienc, nat. art. Hippurite:

Nos. Dict. class. dHist. nat. art. Iitrgurite. Hist. Nat. des žors. Tome IÍ
Dess. Mém. sur la fum. des Rudistes. Bull. de la Soc. lin. de Bonteaux, torn. 1. pag. 292. $3^{\circ} .8$.

licot de la Peyrouse, Orthocératites, tab. 5.

Grande coquille irrégulic̀re conique, alangíe, à sommet pointu, présentant uoe trace d'adhisrence, et donaant origine a un grand nombic de côles rayounantes, oncluleuscs, carćoćes et anguleuses a leurs hords; celles du sommet iucomparablement natins nombrenses, de nouvelles s'iulerposant entrolles lorsque la coquille est parrenue à un certain degré de dévcloppement; et cet accroissement de côtes se faisant ainsi successivement, on en comple plus de trente vers les bords, lorsqu'il u'y en avoit a peiue que la unoilié au sounenet. Des stries transverses, peu apparentes, assez serres, conpent les cútes et les rendent rugueuses; elles sont plus ou moius appareates, selon les individus: dans quelqnes-uns, elles l'emporlent sur les côtes longitudinales. La valve supérieure est aplatie, concave en dessus, à sommet subcentral, orné de cûtes onduleuses et rayonuantes : vers le bord postérieur, elles sont interrompues par deux ocelles uvales rapprachées, et placées dans deux petits espaces lisses et triangulaires. Le teot est très-ćprais; il a en dedans deux carcines saillantes qui le parcaureut dans toule sa loggnenr. Du reste, ou ne connoit ni la charaière, ni le birastre, ni rieu de ce qui pomrloit donner une idée satisfaisable de sa sllucture. L'élat de pétrilisation de cette coquills s'oppose tnême a ce que l'on puisse juger si son test est poreux. Cetle espète se trauve dans les Pyrénces; elle a 10 ou 11 cent. de longueur, et 55 inillius. de dizmètre.

\section{Hippumire rayounanle. Hipupites radiosa.} Des.r.

II. testû elongato.conicû, crassâ, multicostatû, aliquando inegulariter contorti; valvi superiore plani, radiatimz clegantissimèque striati, ocellis duobus instructâ.

Dess. Mém. sur la fum. des Rudistes, Bull. a'list. nat. de la Suc. lin. de Burdeaux, tom. 1. pag. 288. $n^{\circ}$. 1. pl. 9. fig. 2.

Picot de Laptzinouse, Descrip. de plusieurs espèces d'Orth. pl. 9 ?

Cette belle espèce a ćté découverte par MI. Jouannet, aux envirous de Cendrieux, en Péritrord; elle nous senuble avoir beaucoup d'analogie arec celle des Pyrénées, firnurée par Picot de Lapeyrouse; il y a cependas: quelques dillérences door nuas ne pouvons pas afprérier actuellement la valeur, el fui silfiraient peut-être ponr disinguer deux. cspèces. Celle - ci eś conique, à base large; eille est assez réńulière, cauverte de côtes lougitudiaales peu ćlevées, rayannanies, nombieuses, qui, arrivant sur le bord, y produises: de peliles crénelures; deux larges côles näcourant toute lat 
longueur de !a coquille, et les deux sillons quiles indiquent au-debor's, sont la trace des arếlesintérieures placées sur les parois de la coquille; la valve supérieure est aplatie, operculiforme, trèsélégamment striće. Les stries partent du sommet, qui est central, et vont en rayonnant vers les bords. Deux ocelles alongées, subtriangulaires, sont placées sur les parties latérales de la valve sapérieure, et correspondent aux arĉtes interieures.

L'élat de pétrification de cette coquille a'a pas permis de l'éludier d'une manière complète. Un individu cassé ì dessein nons a montré un grand nombre de cloisons à sa partie la plus attéaucé, et nous a montré également la coupe transverse des deux arêtes; mais nous ne savons rien de la charnière des impressions musculaircs et de la po. sition que pouvoit avoir le ligament. Si lindividu figuré par. Lapeyrouse appartient à celte espèce, elle prendroit des dimensions assez considérables. Celui représenté par M. Desıoulius auroit 16 centim. de iongueur, et 10 centim. de large.

4. Hippunite corne dabondance. Hippurites cainu copice. DEF.

H. testâ elongato-turbinatâ, conoideâ, longitudinaliter tenud striatá, striis exilioribus trunsversis subdecussatâ; valvâ superiore planâ, regulariter textilliosâ, ,eticulatâ; carinis interionbus duabus obtusis.

Def. Dict. des Sc. nat. art. Hippurite.

Pl. du même Dict. 31^. cahier, fig. 1. a. b.c.

De Bratrv. Malacol. pl. 58 bis. fig. 1. a. b.c.

Desss. loc. cit. pag. $291 . n^{\circ} .6$.

Grande et belle cocjuille assez variable dans sa forme, mais le plus souvent alongée, conique, atténuée au sommet, et fort large à la base; son test est très-épais, diversement contourné, el offrant toujours, soit sur ses parties latérales, soit au sommet, des traces di son adkérence. Il ar. rive fréquemuent que p!usieurs individus sont groupés entre eux. La surlice extérieure de la grande valve est couverte d'un Irès-grand nombre de stries longiludinales, lizes, serrées, aplaties, coupées transversalernent par d'autres plus tines eacore, qui ne se voient bien que sur les partics du test qui sont dans ue bon état de conservation. Ces stries, soit longitudinales, soit transverses, sont souvent interrounues par des accroissemens irréguliers; la valve supérieure est lénèrement conciare en dessus : sa surface extérienre est vraimeut cirriense par sa structure; elle est couverte d'un réseau à mailles anguleuses, quelqne. ois aussi régulières que celles des Polypier'sà réseaux, à tei noint qu'il nous à fallu en examiner plusieurs poli: nous convaincre que cètle disposition lui aprartenoii :cellemen!. Dans quelques vieux individus, celte valve supérieurc est rayonncé vers les bords; à l'intérieur de la grande valve se tron vent les deux arêtes saillantes, dont la position est indiquée au-debors $\mathrm{p} r$ deux côles céprimées, clout l'une est plus large que l'antre. Cetle espèce, d'apiès M. Defrance, se Ironveroit aux environs de Naples. Nous en possédons un grand exemplaire qui vient des bords de l'étang de Caronta, non loin de Gap. Cet individn a plus de 2 décim. de long, et go millim. de diamc̀tre à l'ouverlure.

Quelques flagmeos uous indiquent que cette espèce a le test poreux.

\section{Hippuate bi-oculée. Hippurites bioculata. Lank.}

H. testâ elongatâ, cornuformi, conicâ ${ }_{4}$ busi planá, apice attenuatâ, sublowigatâ, transversin tenuè striatâ, valvà superiore concrivâ, undique porosâ, radiatim tenuissine substriatâ, ocellis duobus profundis laterulibus obliquatis instructâ; marginibus obliquis, rugosis.

Laux. Anin, sans vert, 1re. édit.

Def. Dict. des Sc. nat. loc. cit. 3ı. cahier, fig. 4. a. $a$.

DE Buanv. Malacol.pl. 58 bis. fig. 3. a. at.

Prcot de Lap. pl.6. fig. 4, el pl. 7.fig. 1. 2.

Espèce assez régulière qui a souvent la forme d'une corne; ellc est éltoite, cylindracée, conique, contuuraée plus on moins régulièrement daus sil longueur; son lest épais, coniinu, presque lisse, offrant des stries d'accroissement transverses, tines et assez régulières. Le sommel, ordinairement tronqni, présente l'impression irrégulière de l'adbérence. La valve supérienre est d'une tout antre structure; à la voir isolémeat, elle semluleroil appartenir à une autre esfièce; elle est concave en dessus, couvertc d'un grand nombre de pores ou de poinls cnluncís, nomhreux, assez rapprochćs et irrégulicirement parsemés sur elle; ils u'cmpêclient pirs la dispusition rayonnanie des stries extrêmemeal fines qui souvrent loute celte valve. Denx ocelles tres-profundes, qui scmbleroient devoir percer la valve. sont placées obliquement vers sno bord postérieur; les ocelles sont ovalaires, couvergent rers le centre, et correspondont exactement à la posilinn des deux arêtes qui sont dans l'intérieur de la grande valve. Ces deux arêtes sont fort saillantes; l'une d'elles l'est davantage, et l'on voit par la coupe transverse quelle est soutenue par une base rétrécie. La gouttière qu'elles laissent entre elles est très-profonde, plus large vers le 8 parois du test qu’à son entrée. L'appareil de la charnière éloit placé immédialement à còlé de larite la plus courte. Aulant que nons pouvons en juge: par des coupcs transverses faites à des hauteurs cis:erses d'uce même coquille, la chat- 


\section{I P}

nic̀re seroit très-puissante, et formke de deux grandes dents très-prolongées, dépendant de la valve supéricure, el de deux autres plus conrtes appartenant à l'inférienre. Celle espèce, comme la précédente, vient des Pyrénées; elle a 12 à 14 centim. de longueur, et 35 à 40 willia. de diamètre.

6. Hippurite dilaté. Hippurites dilatata. Def.

H. testâ conico-pyramidalâ, abbrevialî, dilatati, longitudinaliter tenuè costatí; walvi superivie salde concavâ, porosâ, tenuè el mirabiliter sculpti; ocellis duobus separatis paralellis instructu.

Det. Dict. des Sc. nat. ar. II pporite.

Dess. Essai sur les Sphenulites, pag. $29^{2}$. $n^{\circ} \cdot 9$.

Picut de Lap. $\jmath l .7$. fig. 5.

Coquille remarquable par son peu de lnogueur comparativement à la largeur de l'ouverlure de la valve inlírieure; elle est courle, conifue, pyramidale, à sommel tronqué par suite de l'adliérence; il en part en rayonnant un assez grand nombre de côtes peu pronuncées, obluses, inégales, qui ne sont iuterronpues que par des at:croissemens irréguliers; deux sillons divergens, un peu plus profonds que ceux qui sćpareut les cótes, indiquent à l'extćrieur la posilion des arêtes el la largeur de la gontlière. la valve supérieure est concave; ses bords sont très-minces, se joignent, en formant un bord tranchant, avec la vaive inféricure, et l'union en est si parlatice, ypuil est difficile d'en apercevoir la trace. La surface de celte valve est porease, mais les pores ont une strucure que nous n'avons jamais vue dans aocune autre espéce; ils oot de la ressemblance avec ces sculptures yui orneat sonvent les mnnumens de l'ordre dorinue. Les occlles sont assez grandes, parallèles, ovalaires presque sur le bord.

Celle coquille se trouve dans les Pyrínées, ni elle ne paroit pas commune. Nous ne l'avons jamais vue que petite; il seroit possihle rependant que le pen d'individu que nons connoissons fussent jenues, el apparín-sent á une especre devenant I eaucoup plus grande. Longueur 55 milim., diamitre 45. Nов.

7. Mbrurute dépriméc. Hippuiles depressa.

H. lestá elongutn-conicá, sublcrvigatí, transversirn urregulanter striatâ, subbilohutâ; valuâ superinre concava, argute strinto-punctuta, porosi, broculatui ocellısobliquis, nocatis, p'mfundis; carinis duabus obtusis interiorbus.

Coqnille qui a de la ressemblance avec l'Hippurites cormu copice, mais surtout a vec l'Hippurites biocula!a; se clislinguant de la preaicere, parce qu'elle n'a jamais de stries longitadinales, et de la seconde, en ce qu'elle est bilobée extérieurement el comprimée dans sa longueur, ce qui rend ovalaire sa coupe transverse. (Celle coquilic est presque lisse, alongée, conique, trèssouvent. contournée vers le sommet, par lequel elle est conjours adhérente. Sa surface est marquée par des stries d'accroissement irrégulièrement espacées; on y voit denx côtes longitudinales, aplaties, peu convexes, de largeurinégale, remontant du sommet vers les burls; elles indiquent, par leur position, celle des archies qui sout à l'intérienr. Ou en compte trois; elles sont inégales, et divisent une partic de la cavité en deox goultiòres parallèles. La valve supérieure est concave, très-poreuse, très-mince vers les bords, ayant, comme dans les espèces précédenles, les deux ocelles oblongues, ovalaires, convergenles, correspondant exactement allx deux arêles les plus saillantes. Les pores de la surface externe sont très-multipliés; ils sont alongés en forire de perites rides irrégulières, qui, vers le bord des valves, deviennent un pen rajonvantes. Liaplatissement de la valve inférieure, en rendaot sa coupe transwerse ovalaire, a valú à celle espèce le noun que nous proposons. Elle a étí trouvée aux environs de Gap, sur les bojds sle la Méditerranée. Eile a I décim. de longueur, ct 40 millim. dass son plus grand diacac̀tre.

8. Hopurite luyau d'orgue. Hippurites organisans. Desa.

H. testâ elongatâ, cylindraceâ, perangustû, apice aculâ, longrtudinaliter sulcatâ eq temuè striatâ, intus carinis ducebus approxinatis insiructi; valvâ superiore planầ, bioculatâ, subradiatâ.

Batolites organisans. Moxтr. Conch. syst. t. 2. p. 334 .

Fer. Dict. clas. d'Hist, nat.

De Brainv. Dict. des Sc. nat. t. 4. Sup.pag. 47.

Radialites. D’Oвв. Mém. surles Céphalopodes, Ann. des Scienc. nat. t. 7. pag. 169.

Orthocérafites. Picot DE LA PEYн. $p l .9$.

Desa. Essais sur les Sphérulites, p. 293. $n^{\circ} .12$.

C'est avec juste raison que M. Desmoulins a rapporté re corps au geme des Hippurites. Conduit cornue lui par des analogies incontestables, ncus l'avions r'galement remis à sa véritable place avant que le travail de cel auteur ećl ćltí publié.

De coutes les Hiprurites, celle-ci est la plus longue, proportionnellement à sun dizmetre; clle est très alongée, inbulilion me, cylindracte, trèlongucancol conique, allínuie el poiolue au soinmet, se groupant ct s'altacliant les unes aux autres par les paries latérales; toute la surface cxtćrieure est couverie de sillons nomlireux, ar- 
rondis, de grosseurs inégales, finement striés sar toules leur surface. Les stries sont longitudinales; la valve supérieure est fort petite, aplatie, quelquefois légèrement concave, garnie en dchars de côtes saillantes subporeuses et rayonnautes. Dear acelles obliques d'nue petite dimension sont placées vers le bord; les deux arêtes intérieures de la grande valve sant inégales, assez saillantes, laissant entre elles une gouttière très-étroite à son entrée, ce qui tient à la convergence et à l'inclinaison des arêtes; sauvent elles sout indiquées en dehors par un sillan plus profond que les autres. Cette espèce curieuse vient des Pyrénćes, de la localité illustrée par Lapeyrouse. Elle a quelquefnis plus de 2 décim. de longueur, et à peine 25 ou 30 millim. de diamètre à l'ourerture des valres.

\section{HIPTE்RE.}

Genre ŗu'a fait M. Rufinesque, mais snr lequel les détails manquent presqu'entièrement. On peut supposer que c'est un démeubrement ou un donble emploi du genre Firole. Voyez ce wot.

\section{HIRONDE.}

M. Cnvier (Règn. anim.) a introduit ce nom vulgaire pour l'appliquer an gente Avicule de Lamarck. Il n'a pas été adopté. Voyez A ricore.

\section{HIRONDELI.E.}

Nom valgaire employé par les anciens conchyliolognes, paur les caquilles du genre A vicule de Lamarck. Voyez ce mot.

\section{HOMOLOCERATITE.}

M. de Hubscb est le premier qui, après avoir observé uoe coquille dı genre Baculite, l'ait distinguée en genre anquel il avoit danné cette dénomination. Elle lut oubliée depuis, et reıplacée par celle de Baculite, donnée par Lamarck au mème corps, et qui a prévalu. Voyez Baconite.

\section{HORTOLE. Horiolus.}

Montfort, dans sa Conchyliologie sjstématique, a cru devoirséparer ce geurc des Lituoles, parce que les toni's de spire ne se touchent point comme dans la Spirule, landis que dans les Lituolcs, ils sont adhérens les nns aux antres. Nous ne croyons pas que deux degrés si voisins dans nne mềme organisation doivent être séparés en genres. Vojez Litudele.

\section{HOULETTE. Pedum.}

Geare de Conchifère proposé par Braguière, dans les planches de ce Dictionnaire, el établi d'une manière pasitive par Lümarck, dans le $S_{y}$ stème des Animiaux sans verlébres, en 1801 , et

\section{$\mathrm{HO} \mathrm{U}$}

depais adoplé par presque tous les cooclyyliolognes. Une coquille fart singulic̀re, placée par Linné dans -son geore Huitre, sert de type an genre qui a été placé dans les Osiracées par iI. Cuvier, dans les Pectinides par Lamarck, et cnfin dans les Subostracées par M. de Blainville. On ne connoit point enccre l'animal de la Honlelte, mais d'après la farme de la coquille et l'échancrure qui se voit à la valve inférieure, on pent supposer qu'il devoit être byssifere comme les Limes, les Avicules et les Pintadines; cette coquille se distingue pauratat éminemment de tous les genres enrironnans : on ne connoit pas encore de Haulette à l'ćtat fossile. Cependant, une coquille que l'on Ircave assez rarement à Grignon, et que Lamarck a nommée Huître à crochet, semble s'en rapprocher singulièrement, commc nous aurons occasion de le laire remarquerà l'article llvitre. (Voyez ce mol.) Voici les caractires que Lamarck donne au genre Houlette.

\section{CAR $\triangle$ CTÉRES GÉNÉRIQUES.}

Caquille inéquivalve, un pen auriculée, loâi\}lante par sa valve inlérieure; crochets inégaux, tercainés cn talons obliques, écartés; cliarničre sans dents; ligament en partic extćrieur, inséré daus une fasselle alangée el canaliforme, creusece daus la paroi iuterne des crochets; valve iuferieure échancrée pri's de la base pasiérieurc.

$D^{\prime}$ après ces caractères, il est facile de voir qu'il ne doit pas exister d'hésitation pour placer convea ablement les Houlettes. Leurs rapports avec les Spondyles diune part sont incontestables, par la forate des crochets et la position du ligament, wais elles diffèrent par la valve inférieure, qui n'est point adbérente; elles cat également les plus grauds rapports avec les Pintadines, par l'échancrure de la valve inférieure, destinée, sans contredit, au passage d'un byssus; enfin, leur analogie avec les Licnes, et par suite avec les Peigues, n'est pas moins certaiue.

Haveette spondyloïde. Pedum spondyloideum. $\mathrm{L}_{\Delta \mathrm{M}} \mathrm{E}$.

Ostrea spondiloides. Lisxé, $n^{n} \mathrm{I} g$.

Favaxe, Conchyl. tab. 8o. fig. K. 670 .

Сагмхтz, Conchy.l.tom. 8. tub. 72. fg. $669 \mathrm{et}$

ExcrсL. МЁтоD. pl. 178. fig. 1. 2. 3. 4 .

Caquillc trìs-rare et très-rechercliée, assez alongée; d’un rougc-violâtre en dedans, blaucgrisâtre sale en dessus; la valve inférieurc plus teiote de rouge foncé an violâtre, surtout vers le crochet; le tulan est petit, ollique, divisé obliquement par la rainure du ligameat, qui est plus enfoncée dins la valve inférieure que dans la supéricurc. Quand la coquille est fraíche, la valve 
supérieure présente des cốles peu apparentes, chargées assez régulièrement de petites écailles. Ces coquilles ont jusau'à 70 ou 75 millim. de lougueur. Lamarck indique uno variété plus petite, moins alongée, subquadrilatère, arroudie, à valve inféricure plus plate. Nous la possédoas, et nous croyons que c'est une varićtć d'âtge.

\section{HUITRE. Ostrea.}

De tous les coquillages counus, il n'en est pas peut-être qui le soient plus anciennement que les IIuitres. Utiles comne pourriture, l'liomme sanvage, comme l'homme civilisé, a dú en faire le sujet de ses reclıerches intéressées.

Les auteurs anciens nous rapporlent que les Alhéniens, d̀ leur origine, se servoient d'écuilles d'Hluîtres pour donner leurs suffrages, ou pour porter des sentences; d'où le noin d'ostracisme que l'on donnoit à ces sortes de votes populaires. Quant aux anteurs anciens qui ont traité d'lisvire aaturelle, soit d'une manière indirecte, soit spécialecnest, il n'en est qu'un petit nombre qui n'ait pas mentionné les Huitres. Nous ne chercherons point ici à rappolter ce ‘u'ils en out dit; qu'il nous sulfise de savoir qu"ils les avoient observées, et que les Romains ont été les premiers à les faire venir à grands frais des divers endroils où elles abondent ct où elles présentent des qualités préfúrables, el qui ont ionaginé de les placer dans des lifux aupropriés; à faire, en un mot, ce que nous nomnous anjourd'hui parquer des Huítres.

Les premiers travaux qui on été entrepris sur. les flûtres sont ceux de Willis, duns son ouvrage intitulé, de Anima brutorum, cliap. 3. Cet cxcellent observatcur tit conuoitre alors les oruanes principaux de l'Huitre; mais il restoit beaucoup à ajouter à ses observations.

Lister, daus son grand ouvrage (Synopsis Conchyliorum), cousacre deux planches, 195 et 196 , accompagnées d'explications, il l'anatomio de l'Huitre, en grande partie d'après IVillis. Cet auteur prend les lobes din manteau pour des muscles, et comunet encore d'autres erreur's.

Depuis, Dargenville, Adanson, Baster et surtout P'oly, dans les T'estacés des Deux-Siciles, unt conplété les connoissances sur les Huitres, auxquelles M. de Blainville a ajouté quelyues nouvelles observations.

C'est principaleuent à Poly que l'on duit la connoissance exacte et parfaite du systè̀ne artériel et veineux, qui n'avoit encore avanl lui été qu'entrevu; quant aux auteurs qui n'ont parlé que des coquilles pour les faire rentrer dans des systèmes de classification, nons voyons le genre Iluitre établi depuis long-temps, rétréci ousétendu, plus un unoins lien circonscrit, selon les sysic̀nes acloplés oul créés par eux.

Lister, que nous avons déjà cité, fit avec les
Kuitres seules, telles que nous les considérons an. jourd'bui, uue section bien séparée de ses Bivalvium imparibus testis. Cette section, dans laquelle il n'y a pas une seule coquille étrangetro aux Iluitres, répond parfaitement au genre Fluitre de Inamarck et des auteurs modernes. On peut donc considérer Lister comne le créaleur din genre, et il auroit úté à desirer que les conchyliologues qui vinarent après lui le suivissent rigoureusement. C'est ce que Langius sentit trèsbien, ct reportant les Huitres à la lin des Bivalves, it les conserva, comme lisier, saus mélangé d'autres coquilles. Cependaut, dans la section des Huitres, Latagius élablit quatre geares, qui ne peuvent être considérés maintenant que comme des sons-divisions génériques, étant iosés surdes caractères de formes extérieures.

Nous ne nons arrêterons point au systeme de Dargenville, ai à la manière dont il circonscrivit le genre Huitre. 11 y comprenoit, comme dans toutes les autres divisions qu'il a établi, des coquilles de genres fort dilfśreus, et qui avoient été bien séparces par ses devanciers.

Klein tomba ì peu près dans les mêmes crreurs que Dargenville; ainsi nous royons dans la classe des Fluitres de cet auteur plusieurs genres qui sunt faits comme ceux de langius, avec des caractères insuffisuns, et d'autres qui nont avec les premiers que des rapporls diloignés, et qui, de plus, sunt des mélanges de coquilles de genres dillérens.

Dans le système linućen, le genre IInîtue, trop largement circonscrit, renfermoit les élémens de: plusieurs bons ge"res qui ont été successivement proposés et adop'és. C'est ainsi que Bruguière extrait d'abord les genres Spondyle, Peigne, Pernes, et plus tard les genres Avicule et HIonlelte, et laissa pressentir le genre Gryphée, qui fut établi par Lamarck, en 1801 , dans le Systeme des Animaux sans ertèbres. Antérieurement à Bruguière, Adanson, dans son excellent onvrage des coujuillages du Sénégal, a ramené, d'après la cunnoissance de l'animal, le genre Huître à ce qu'il doit être, et est tombé d'accord avec Lister.

Outre le yenre Gryphée, Lamarck a encore extrait des Huitres de Linné les genres Plicalule, Vulselle, Marteau et Limes. Plus tard, le mêmé auteur en a encore créé deux autres, les Pintadines et les Pudopsides; ainsi onze coupes génériques, toutes plus ou moins nécessaires, presque toules admises par le plus grand nombre des au. teur's, ont été établies aux dépens des Huîtres de Linaé. 'Tel qu'il est aujourd'lui, ce genre, avec lant de coupures, reste encore fort nombreux en espèces. Leur irrégularité, la facilité qu'elles ont de s'adapter pour ainsi dire aux accidens locrux, d'en recevoir et sans doule d'en conserver une loule de modificatious, forment une multitude de nuances entre lesquelles il est souvent clifficile de 
se fixer, et d'où il est quelquefuis impossible de sortir, saus l'arbitraire que donue l'babitude et un coup-d'œil exercé.

Nous allans maintenant eulrer daos quelques détails sur l'anatomie des IIuitres; il sera suffisaut, je pense, de Iracer les faits les plus iapurlans de leur organisation.

La forme de l'Huitre est généralement ovale, quelquefois arrondie on alongée, suivant les espèces, assez régulière, wais non régulièrement symécrique; l'animal est placé dans sa coquille, doat il ne présente pas à beaucoup près les irrégularités; la partie autérieure de sa téte correspond aux crochels et au ligament qui réunit les valres; sa partie postérieure, élargie, répood à leur bord libre. Comme tous les Acéphalés, les Huîtres soat pourvues d'uu mauleau fort ample, doat les denx lobes sont séparées dans presque toute la circonférence de l'animal, excepté antérieurement ou au-dessus de la bouche, où il forme une sorte de capuchon qui la recouvre. Epaissi dans sez bords, le manleau est pourva dans cette partie de deux rangs de cils ou de tenlacules, qui paroissent doués d'une grande sensibilité, qui sont rétractiles au moyeu de petits muscles qui ront en rayonnant du muscle adducteur; de ces deux lignes tentaculaires, la prewière, ou l'ialeree, ne se compose que d'un seul rang de cils; la seconde, ou l'externe, a des tentacules moins grands, qui forment une espece de fiange à deux ou trois rangs : il est formé de deux feuillets, puisque c'est dans leur intersalle que se lépose on se sécrèle la malière juune qui est les cufs, d'après l'opinion la plus gćcéralement reçue.

Les Huitres vivant fixées aux corps sous-unarias, n'avoient aucun besoin d'organes lucomoteurs; aussi ne leur tronre-t-on aucune trace tu pied des autres Conchilères; elles n'ont au reste, comme un certuin nombre d'en:r'cux, gu'un seul inuscle adducleur, nixis qui e,t très-puissunt el divisé en deux parties, auxy'uelles on a assiuné des usages dillíreus. Ce wuscle est subcentral; il lic fortentent l'auimal à sa coquille. Les organes de la autrition se conposeat d'une bouche placée antérieurement duas la duplicalure du manleau, en dedass de l'esjecce cée capuchon qu'il forme dans l'endroit de la junction de ses lobes : cette bouche est grande, simple, très-dilalable, garnie de deux paires de tenlacules assez yrands et lamelliformes; la paire stipérieure représente cenx des Mollusques céplualis, les denx iuférieurs ont une struclure furt semblable à celle des branchies. Cetre bouche aboutit sans aucun intermédiuire à uue porbe on estoṇac dont les parois sont très-miuces, placíe dars l'épaisseur du foic, anguel elle adhère daus tout son pourlour, el présentant intérieurement des ourertures en assez grand nombre el de grandeurs difírentes, qui sont les orifices qui postent dans l'estomac le produit de la sécrétion biliuire. De la partie postérieure de cet organe part un intestin grêle, qui, après plasieurs grandes circonvolulions dacs le foie, se dirige vers le muscle adducteur, remonte ensuile vers le dos, où il se termine dans la partie moyerue par un orifice fluttant infundibuliforme. Le foie est assez volumineux, brun, embrassant l'estomac et une partie de l'iotestin; il verse directement le produit de la sécrélion dans l'eslomac, sans l'intermédiaire de vaisseaux biliaires, et par les grands pores que nous avons mentionaés précédemment.

Les branchies, ou organes de la respiration, se composent de deux paires de feuille!s inégaux en longaeur, les externes étant les plus courts, et les internes les plus longs. Les premiers prenneat origine aux tentacules externes, pour se continuer en entourant le corps jusque vers l'orifice de l'auus; l'autre paire de lames branchiales part des tentacales iuternes et aboutit à pen près au même poinl, en remontant un peu plus baut. Ce point de réunion des feuillels braochiaux est aussi celui où le mantean vient preadre a vec eux une adbérence inlime; celle adbérence sépare en deux portions inégales la grande onverture du manieau: l'une d'elles est dorsale, c'est la plus courte, et l'autre est ven'rale; dans celle deinière on ne voit aucune trace de l'ourerture qui s'y remarque dans les antres Couchifères, de manière que l'on peut dire que la masse viscérale est placće dans l'Huitre eu dessus et en aranl.

L'appareil de la circulation est fort ítendu, suriout la partie qui a rapport a la respiration : il se coropose d'un cueur aboc son urtillelte; il est placé dans son péricarde en avant du ruscle adductear, entre lui et la masse des viscères : ce ce qui le fait remarquer facileunent est la couleur bran foncé de son oreillelle. Ce cœur est pyriforme; par la pointe il dune naissance i uu gros tronc aurlique qui se dirige en avant, et se dirise presçu'à sa sortie en trois branches principales. La premiere se dirige vers la bouche et les tentacules, sur lesquels on voit ses sous-dirisions; la seconde fournit au foie et aux oryanes digestifs; ia troisicme eufin derient postérieure, puur se ramifier dans toute la partie postérieure du corps.

De la base du coeur naissent deax gros troncs très-courts, qui réunisseut et font communiquer l'oreilletle avec le cœur; celie-ci est d'un brus presque noir, quadrilalere, recerant dans son épaissear un bon nombre de pelits vaisseans; de ses deux angles posiérieurs naisseut de chaque cótk un gros tronc qui se suns-divise presque iumédiatement en trois brancles; les deux liranches exterues se rapprocbeut pour s'anastomoser et produire un seul gros Ironc; ces cinq troncs principaux s'abouclient aux vaisseaux branchiaux, qui, régulièrenent disnosís, sout formés de cing 
branches priacipales, qui de leurs parties latérales en fouroisseat un très-grand nombre qui s'anastomosent régulièrement. Nous ne voulons point catrer dans les détails de cet appareil de circulation; cela nous entraineroil à nae description beaucoup trop longue, et bors des bornes de cet arlicle. Nuus renvoyons au magnifique ouvrage de Poly, auquel on doit une connoissance plus parfaite de cet appareil, et les figures excellentes qui le représenteni.

Les Huitres, pour se reproduire, ne paroissent avoir quin seul sexe, le sexe femelle, comme au reste fous les Acéphales; mais dans les animaux qui nous occupent, il ue paroît pas mieux connu quue dans les autres. Il en est de même du sysı̀̀me nerveux, aे la connoissance duquel les auleurs wodernes n'ont rien ajoult; mais on doit fortement présumer qu'il a beaucoup d'analogie avec celui des autres Mollusques bivalves.

Les Huîtres aiment à virre sar les côtes, à peu de piofondeur et dans une mer sans courant et tranquille. Quand ces circonstances se présentent sur une grande élendue, alors elles s'y accumulent, et forment ce que l'on numme un banc d'Iluitres; il est de ces bancs qui ont plusieurs lieues d'élendue, qui paroissent inépuisables, el qui même ae semblent pas diminuer, quorqu'ils furnisseut à une cousommation ćnorme. Al'exemple des Anciens, les Modernes ont aussi établi des parcs à Inuiires, où on lês laisse grossir, où elles sont emmagasinćes pour les besoins : on leur fait aussi subir une préparalion dont on connoit da cause; c'est celle qui les rend verles.

Comare nousl'avons dit précédemment, le genre lluire de Linné a été successivenent divisé en d'autres genres: de tous ceux-ci, le genre Grypliće esı, sans contredil, celui qui présente le moins de bons caractères. Aussi MI. Cuvier (Règne animal) n'a aduis ce genre de Lamarck que comme scus-geare des Jutuitres : ce que nous croyons devoir admellre pour plusieurs raisons; car, cutre une structure analogue daos la formation dı test, on remarque aussi un passage insensible eutre les deux geures, à tel porint qu'on ne sait pas si quelques coquilles be doivent pas plutùt être placćes dans liun que dans l'autre. Pour décider la question, il Eaudroil modifier les caracières de l'uu ou f'autre gcnre, pour les y faire rentrer; it n'y a point de inotif raisonnable alors pour ne pas les y inetire toutes. Que l'on fasse entrer dans les Gryphées, par exenple, des coquilles aplatics de laut en bas, adhérenles par leur valve inlérieure, seulement sur cetle toible considération d'un crochet latéral touró́ un peu ea spirale, engagé dans le bord, on sera forcé, par analogie el pitr la dégradation insensible de ce caractère, it y faire reutrer toutes les IIuîtres. Il en sera de mè̀ne, sil'un veut faice entrer ces mêmes coquilles dans le genre Iluitres : alors nécessairement toutes les Grypbées derront venir s'y ranger. Il suit de là que, pour bien faire, il faudroit fondre les deux genres en un seul, et élablir parmi ses nombreuses espèces des groupes assez bien circonscrits pour pouvoir les y rapporler sans difficulté. Quoiqu'on ait dit que les Gryphées étoient des coquilles libres, on doit cepeadant noter qu'un assez graud nombre des espèces qu'on y rapporte soni constamment adhérentes à toules les époques de leur vie, et que tonles ont adhéré dans le jeune àge. Celle observation duil encore plus les laire rapprocher des Iluitres, qui, pour un certain nombre, sont dans le même cas. Le mode d'accroisseweut de certaines Gryphées a dû les forcer à se délacher assez promplemenı du corps oì elles étoient adhérentes, puiscque celle adlérence ne se fait le plus souvent que par le sommet du crochel.

Un des deroiers motifs qui doivent porter ì confondre les deux genres, est l'observation de plusieurs individus de la Gryphée vivante; celte coquille, très-rare, adhère par une assez grande surface de la valve inférieure; mais ce qui est très-remarquable, c'est qu'elle prend ou ne pread point de crocbet, suivant les circonstances de son habital, et noos avoos vu la même espèce de cognille dont on auroit pu placer un individn dans les Gryphées et un autre dans les liuitıes. En comparant ensuite les antres caractères des Huitres et des Gryphées, nous trouvons une charmière absolument semblable, éprouvant les nềmes znodificalions, selon les circonslances, capalıles, comme le mode et l'étendue de l'adhérence, d'apporter dans cette parlie des changemens et des variations. Entin la forme et la posilion de l'impression musculaire n'uffrent aucune différence dans les dcux genres, et l'une et l'antre ont, quant à la structure el à la nature du test, une ressemblance parfaite. Nous restons convaincu que le genre Huitre doit comprendre dans son ensemble les Gryphées. Il est arrivé pour ce grand nombre de coquilles ce qui a eu également lieu pour plnsieurs autres genres aussi numbreux en espèces: on a transformé en genre les extrêmes d'une mểme série, les espèces intermédiaires ayant élé négligées ou élani restécs inconnues; wais une fois mises en place, ces espèces forment un passage, une transition iusensible d'un geare à l'autre.

Nous croyons qu'un bon genre, très-nombreux en especes, tel que celui qui résulte de la réunion des Huitres et des Gryphées, peut avec autant d'avantage être divisé en plusieurs groupes d'espèces, que parlagé en geare lait d'une manière arbitraire, et reposant sur de mauvais caractères.

Aux géologues habitués à citer des Gryphées, il importera pen que colle dénomination s'applique à un sous-genre, ou à une des section des Huî́res, ou à un geare distinct de celles-ci; mais il est nécessaire pour que le zoologisle, élranger 


\section{3}

H l’ I

à tou:e antre considéralion que celle déduite des caracières des corps organisés, fasse l'application jigourense des priacipes de la science, el ríunisse dans un mére geare tous les érres qui oal le méme caractère.

Les Gryphées, commeles Huilres, serencoattent à létat de pétrilication duas les terrains très-anriens : ces coquilles sont con:emporaines dans le plas graad oomure des coucles de la terre; il est irèz-rare de trouver des Gryplices sans Huitres, ou des IIuitres sans Gryphées, daus l'étenc'ue d'uue mène cocche. On a cru long-temps qu'elles étoient propres a cerfaiues formations, qu'ulles pur ical servir a les rcconnoitre; mais nous ne savuus s"il existe des donoées suffisantes pour décider cclie question, qui, au reste, a perdu me pirlie de l'intérét qu'elle pouvoit avoir, jar la décourcrie réceate des Gryphiées dans les couclues les plus modernes des terrains tertiaires. Ce fut uous, d'ahord, dans nos recherches a Valmoudois, qui en trouràmes une espèce biea distincle, e: MI. Bertránd Geslia, ensuile, Co déconrril une antre espèce noa moins biea caractérisée daus les collices subapeonines de l'Italie.

\section{Les Huâtres proprement dites.}

\section{CAT.ACTERES GEIRIQUES.}

Corps comprime, plus ou moins orbiculaire; les Lords du mantear épais, uon adiárens et líiractiles, puurras d'uae double ragyée de lilameus tentacu! aires courts el nombrenx; les deux paires t'appeadices labiaux triaugulaires ct alungées; un muscle subceotral bipartite. Coyuille aduérente inéquiralve, irrégulic̀re, a crochels écartćs devenant très-istégaux avec l'áge et à ralre supéricure, se déplaçant peodant la vie de l'animal; charniere sans dents; liganteot demi-intérieur, s’insérant dans une fusselle cardinale des valves; la losolte de la rulre iuférieure croissanl avec l'inge, comme son crocket, et acquérast quelquefuis une griade longuear.

1. Hritne comestible. Ostrea edidis.

o. testâ ovato-rotunduti, basi subattenuatá; membruris imbricatis, undulatis; valos superiore planiá.

Ostran edulis. Liss. GxeL. pag. 535 f.

List. Conchy l. tab. $19 \overline{\bar{j}}$. fig. 30.

Gestt. Test. tab. 102. fig.a.b.

Pessast, Zool. brit. tom. 4. tab. 62. fig. 70.

Cuzzs. Conch. tom. 8. tab. 74. fig. 682.

Excrch. Fl. 184 . fig. 7.8.

Far. Testi uniauriculatz.

Tar. Testicatation collum elongasum basi frudecti.
II U I

Lasx. Anim. s. vert. tont. 6. pag. 205. $n^{n}$. 1.

Coquille très-abondamment répandue sur presque tout le littoral de l'Océan européen, lormant des bancs coosidérables, exploités ríguliẻrement pour la consonanation énorme que l'on en fuil daos yresque toule l'Lurnpe. Celle espéce est grande. dilatée, arrondie, subırigone, écaillense eo delıors et sonreut ayant Is valve inférieure chargće de cótes rayonoantes, inégales, coupces trausversalement par un grand uombre de lames. Ces la ines sont irrérgulic̀res, plus un auoins rapproclaées, plus ou moins nnubreuses; clles sunt iubriquées sur la valve supérieurc. Cetle valve est plate; en ciedans clle est d'un blanc lailcux, el préscnte vers le asi. lieu une impression musculaire semi-lunaire. I. talon est triaggulaire; il est court, élroit, ayant dans le milieu une goutrière dans laquclle est in. sćré le ligameat. Il existe plusieurs variélés de cette coquille : uous en possẻdons une qui vient des có:es de la Hullande, et qui est remarquable par le grand oombre de fevilléts ćcailleux el relevés yui cuurrea! ses deux valves; elle a ude forme un peu plus transerse que celles qui vireat sur nos côtes. Une autre variélé se trouve à La Rc. chelle cı jusque dans la Manclac; elle est alongée, étroite cl prísente une très-urande ressemblance, quant à la forme, arec l'Ótrea virginica; sna talon est tris-ulongé, poiniu, éiroil, absolument comone dams toiltes les especes lon:rues. Les plus grands irdividus de celle espece n’unt guc̉re que 11 ou 12 centicuetres de dirucusion.

L'Ostrea bellosacina a laat de ranporis aves celle espèce, quion pourroit croire quelle $0^{\circ} \mathrm{cos}$ cst qu'une variétć.

2. Hcirse pied de cheval. Ostrea hippopus.

o. testi notundati, magná, crussi, vahia superiore planá; lamellis tnunviersis, creberrinis, uppressis.

LAมx. Aniun. s. zer.. tom. 6. pag. 20,3. $2^{\circ} .3$.

Cetie espèce est parfaitemeut distincte de la précédlente, el il suffiroil de voir son volume habituel, la largeur de son Ialon et l'épaisseur de ses valies, pour ére bieatót couvaiaca que leur séparatiou est nécessaire. Colle-ci est arrondie, ovale, irréguliere, couverte en dessas el en dissous de lawes a peine saillantes, concentriques, coulipliées, surtout vers les bords; la valve irdirieure, tovjours plus épaisse, plus boubúe el plus grande que la supérieure, est cluaráe de còies irrégulières, longriludiaalcs, que les laraes ćcailleuses transverses cuupent ea trarers; l'intérieur de la coquille est lout blanc; sa surface est uo pea bojselée ou onduleuse; l'iøpression musculaire, semiluaaire, est proportiounelleasent plas grande yus dans l'espéce précédente el esi conslamoneal placée plus antérieurement. Le taluo des :alves eś toujours prolongé, larģe; celui de la ralve infériére profoudecoeo: creusépar uae givulière múdione, Lurúc: 
bordée cúc charque côté par un bourrele! décurrent; celui de la vilve supérieure est plas aplati, la fouttiere est superficielle et les deux bourrelets ne sout qu"indiqués. Quelques vieux individus de cette espece ont quelquelois plus de quatre pouces d'épaisseur lorsque les valves sont réunies. La cavité occupe par l'animal a à peine sept à huit lignes duns sa plus grande profondeur. A voir des coquilles si considérables, il se:ublerni: qu'elles ont un poids proportionné; , elles sont, au contraire, lrès-légères, étant formécs de lames li’ézminces, qui laissent toujuurs entr'elles des espaces vides. Celte coquille vit, avec la précédente, dans l'Ocćan européen; quelques personncs nous assurent l'avoir vue dans la Méditerrance. Elle a is ou 16 cenı. de long, sur 12 ou 13 de lapge.

3. Huitre beauvisine. Ostrea bellovacina.

O. testâ oblongo-cuneatâ, supernè rotunduti; valvi majone basi radiatim salcuti, alters plants.

LAsX. Ann. du Mus. tom. 8. pag. $159 \cdot n^{\circ} .1$, el torn. 14 . pl. 20. fig. 1. a. b.

Buntis, Oryctographie de Brux. pl. 10. fig. a. et $p l .11$.

Noв. Descript. des Coq. foss. des cnv. de Paris, tom. 1. pl. 48, et 49. fig. 1. 2.

LAux. Anim. s. vert. tom. 6. pas. 218, no. 23.

Var. A.) Non. Test 1 motunduti, regulariter et rudiutim sulcutá; sulcis squamosis.

Ceule grande espèce a leaucoup d'abalogic avec les deux précéclentes; unais elle en a davintage alec l'Osirea edulis gu'aver lou:e autre. Elle est arroodie, lantót suborbiculatire, quelquefois un peu uvalaire. La valve inférieure est toujours plus grande et plus profunde que la supérieure. Celle Vulve est irrégulièremens rayonnée par des cótes longitudinalcs que coupent en travers uo grand nombre de feuillets écalleux, minces, quelque$f$ is très-saillans, surtout sur les parties latérales; en dedans, celte vilve préseate une impression musca. laire assez grande, oblique, ovaluire, submédiane et superliçiclle. Le crochet de cctle valve o'est guère plus grand que celui de la valve supérienre; il est crensé duns le milieu par une gouttière étroite, profonde, bordée de chaque còté par un perit bourrelet péu saillaut; la vilve supérieure est aplatie; en deliors, elle oollie jamais que des stries lamelleuses, irréguliceses el transverses: elle prend une épaisseur assez considérable vers le crochet. Celui-ei, plus court que dans l'antre valve, a sit goutrière plus superticielle, et les deux bourrelets sont remplacés par deux surfaces trian. gulaires et aplaties. La variélé que nous indiquons est constanie; elle est remarquable par sa régularité et surtout par les cồtes longitudinales rayunuantes qui ornent sa valve iuférieurc. Ces còtes, qui sont souvent écailleuses, sout quel-

Hist. Nat. des L'ers. Tome II. quefois aussi seulement rugneuses iransversalement. Celle belle coquille est comınunc aux environs de Paris, a Bracheux, à Noailles, daus les linnites du Soissonuatis; elle se retrouve aussi co Belgiejue, aux environs de Bruxelles et de Gand. Les plus gratuds individus ont 14 cent. de longucur, sur 12 de large.

\section{Ilvita dentelíe. Ostrea denticulata.}

o. testi depressa, ov'uto-rotundutá, glabrü; valví superione convexis, inferiore pland, amphore; limbo interno ad peripharram denticulato.

Var. Limbo pmpe cardinem denticulato.

Ostrea denticulata. Bon s. Mus. tab. 6. fig. g. 10.

Excrec. $p l .183$. fig. 5. 4.

Lanx. Anim. s. vert. tom. 6. pag. 206. n०. 15.

Belle coquille nuancée de couleurs assez vives, et loujours facile a recomnoitre par les dentelures gui se voicnt sur le bord, vers la cbarnière. Cette counille est arıondie, f́laléc, assez éprisse, ayant la value infíricure plus profonde et plus grande que la supérieure. Celle valve, adhérente par presque toute sa surface, présente vers ses bords un grand nombre de lames qui résultent de ses accroissemens. Le crochliet est excavé à l'intérieur; il est triangulaire, peu saillant au-dessus du bord; sa face supérieure est assez aplatie, creusée dans le milieu d'uo sillon superficjel, bordé par des bourrelels presque aussi litges que lui; la valve supérieure est pourvue en deliors d'un très-grand nonbre de lanes irrénulières, se recouvrant mutuellement d'un brun olscur passant au violutre foncé vers le crochet. Celui-ci est petit, trèsaplati, et la gouttière n'est indiquée que par deux petits sillons peu marquućs; en dedans, les valves sont d'une nacre peu brillante, blanche vers les hords, et d'un rouge très-toncé, bleuâtre ou brunatre à l'intérieur des crochets, et dans le aulieu des valves; limpression musculaire est subceolrale, très-yrande, ovalaire, subtraosverse; elle est ordinairement dine couleur encure plus foucée que le reste; les bords sout simples, si ce n'est ver's la cliarnière, où ils sont dentelés assez piofundément. Cette Huitre vieot, dit-on, des mer's du Scinégal. L'individu figuré par Born est plus graud qu'ancun de ceux que nous ayons eacure vus; il a 10 cent. de dimension.

\section{Hoitra très-large. Ostrea latissima. Nos.}

$O$. testâ ovazo-rotundatî, irregulari, incrassatâ, sublirsigatá; umbonibus latis, triangularibus, foves îtrangulari latissimâ exaratis; marginibus parte superiore grunuloso-plicatis.

Noв. Descript. des Coq. foss. des environs de Paris, tome 1. pl. 52, et pl.53. fig. 1.

Cette espèce est la plus grande qui soit conaue 
j-atu'- présen: ace earirsos de Paris; elle es! zussi rae des esjeeres fosolís los plus remarguaWles : elle est arropdie ou oralaire; sa ralve inférienre, adhirsu! par preszae docte sa surface, es: zp'arie. et ses bords sa relèreat presçue perpeadiculairezent à sa pactie ialfrrievrs. Cette valre est 1rès-íprisse, lisse $\varepsilon a$ dedajs, irtérulière=ea: la=ellevse ea debors; soa boră sapériear, qgui est assez large. se prologge ea da talou court, large, iriangulaire, présenias dacs sos =ilion az large sillod aplali, trizarulaire 2assi, ecro=pagaé de chaque cóté d'ua bourrelet a plati. Li=pressioa rousculaire est grande, subcentrale, on per sopériegre; elle es? irroadie, as pen saill. lante rets son burd iaféreur, warguée de zones Irassterses gui indicjaenl ses accrnissezess j a lears ferlies sopérieures en rers la charaière; les bords s0at crínelés e! lécrèrezeal plissés irzostersaleDeai; la ralre spptrieure, ua per bosbrie ea debors, a ses bords releris, siaples, 1raschans, Ei crécelés supériensesens contae ceus de la value iaf́rieure; $C D$ debors celte ralre ex irségalièrezeut lamelleuse. sts lazes snal conrles e: se =ostreat pracipale cen: rers les borts: 12 charaiére el l'iapression Dasculaire sos? semblables à ce les de la ralre inierieure. logs de cranoissoss easore qu'us pelit sombre d'iadiridas de celte espèze, qai cå élé iroorés à Chat=00:, et lioz d'enx Étois e vore s dhéres: al ro cher scr leguel ji a roil récu.

Loaguea: 17 centi=ètres, largent 25.

6. Hrirar dthoide. Ostrea detoided. Sow.

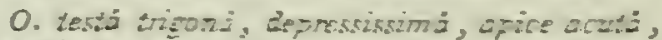

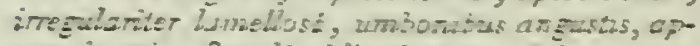
Frorimstis ; fossulz obligut, trpartid.

Sor. Wistr. conci. Fl. $2 \div 8$.

Ostrea delioidea? Lixe. Lin \&u Mas. tors. \&

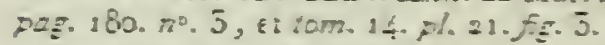

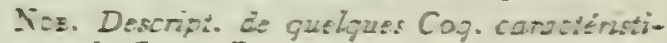
gives, , th. 15.5 .5 .3$.

Il est très-frobable qqe lHuire décrite par Lasarch dass les Arrales bu Múusem, soas le

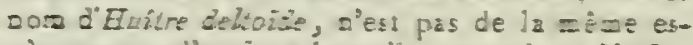
pèce que celle-ci, a laguelie cepeadand h. So-

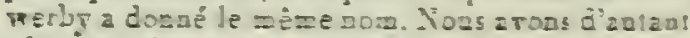
plus de raison pour croire que ces coquilles ap.

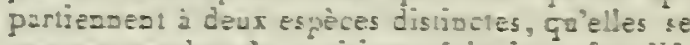
reacontreat dass des positions géolugigues fort différezier, el gue celle de Lacarch préseale coe!ques cartatères qquì ne se tronteat pis dazs l'autre.

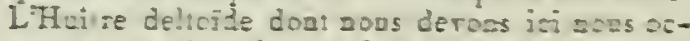
cupez en: celie qui a élé figurte par M. Suwezby, et aco celle de Li=erci.

Cette cogille es: 1rès-?:=xryazble par sus ex-

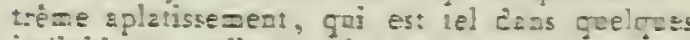
indiritus, gae l'on a peise a cosceroir co=aes:

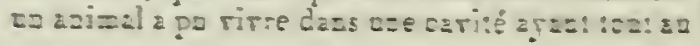

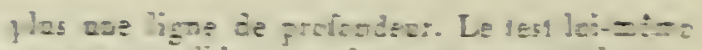
F51 Duace, solide repeodsat, et tow-Re; Il z woe

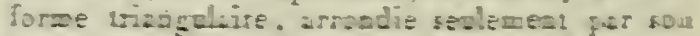
bord infériés. A l'enlérien:, el szx:00 a la talte ivferieure, on rois an frand zozbre de lazes irréculières dizcroissz=exi gei se aulipliest

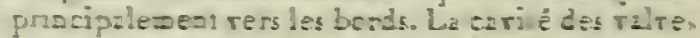
présente cae serfece plos trizege aire tecose goe J"enlineor, ce gqui prorient de Telargissment

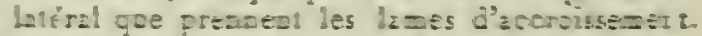

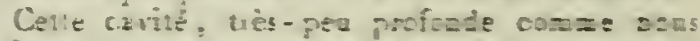
l'arous dil, es: loale lisse; a y remerdye doe i=-

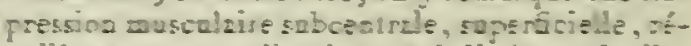

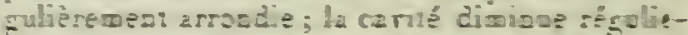

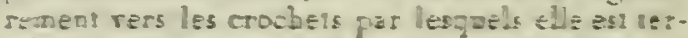

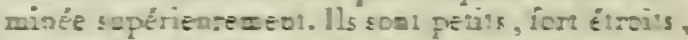
poiatzs, ires-rzpprocbés; its siacliesol ca peu

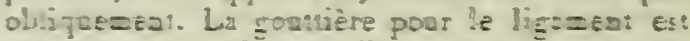
Élroliz, pea profonde; elle est axrozpaguie de

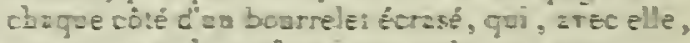
occupe locle la surface id:erge des crocbels.

Crile coquille, irks-dishico de isules centes

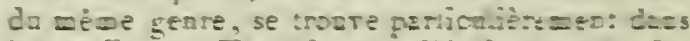

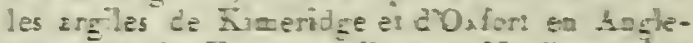
lerre, es du Harre en Frase. M. Broopmato

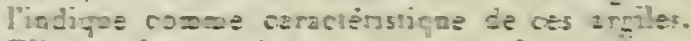

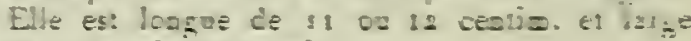
de 1 i cezila. e: de=i.

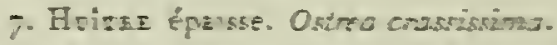

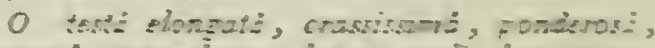

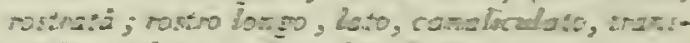

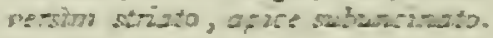

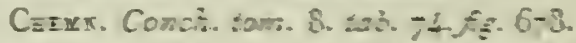

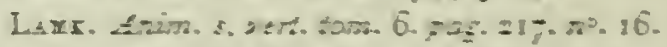

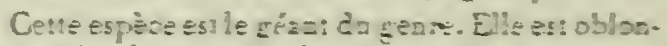

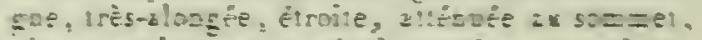

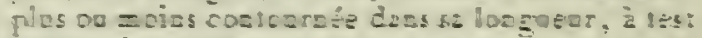

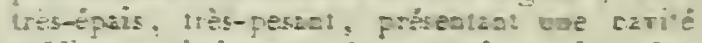

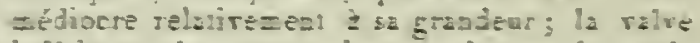
inforieare, beacoup plas friade que la ropor-

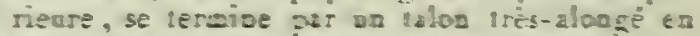
hee, doul la saflace caperieare, prufoultoten e:

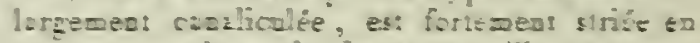
irevers; ec boerrele: latse el saillau zucompagoe de chajue cósé la guartière. Ces bosire-

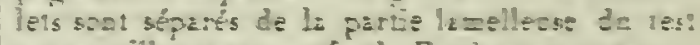

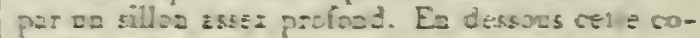
uguille préseute des zccroistezezs scaltsifs:=ts zsez do abretu, 1 rès-szill! $z=s$, surloet rers le crochel; ils soa: dfoospts par on gread soubre de

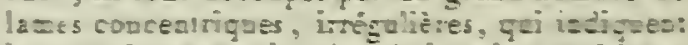
les amoroiseneas; le izloo de li relre sepérizcie

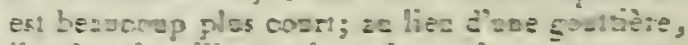

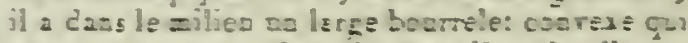

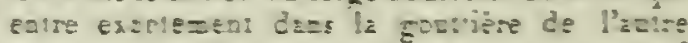

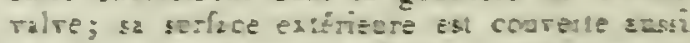

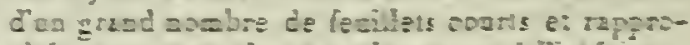

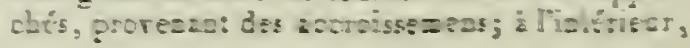


Jes valves sunt lisses, ondulées, et présentent à leurs parties latérales el subinférieures une intfucssion musculaire arrondie, médiocre, marquée de zones nombreuses daccroissemcnl; les bords des valves snot simples dans leor étendue. Celle curquille curiense a, quanl à sa forme, de l'analogie avec l'Ostrea virginica. Un individu que nous pussédons a 3 décimètres el demi de longuenr, c’esl-à-dire plus d'un pied, et 14 centim. de large. Nous a vons vu des individus jus prands encore; nous ignorons dins qual lieu ils se trunvent.

8. Huithe Jong bec. Ostrea longirostis.

O. testâ valp’a inferiore crussá, subcucullutí, rostro Longissuno, contorto.

Ostrea longinostris, La ux. Ann. du Mus.tom. 8. pag. 162. $n^{6} .9$, el lom. 14. pl. 21. fig. 4 .

llid. Anim. s. vert. tom. 6. pag. 217. $n^{\circ} \cdot 17$.

Cetle espéce, parliculièle aux environs de Puris, tonjours pius petite que la précédente, n'est jas moins remarquable gyu'elle par la longucur considérable de sur cruclset, cumparée à la carilé des valves. 1 ta valve inf'erieure est alongée, éltoile, le crochet tait is peu près ta moitie de sa longueur; il est allénué au sommet, large, aplati vers la base; une très-large goultière, atcumpagnée de cliaque côté d'un bourrelet aplati, le parconat daus :onte sa longueur. La cavilé de celle valve est assez prolonde, s'entunce un peu sous le crochet; elle cst ovale, arrondie, it bords simples; l'inuression musculuire est arrondie, subrentrule, e: inarquíe de zones numbrenses d'atcroisservebi. Ël deburs, cellc espèce est Furt intréguhère; clle est couverte, daus toute son étendue, de lames aunces, assez saillantes, irrigulières, très-rapproclices; le lest est assez épais, composé de lames séparées lcs unes des aulres, el qui, ordinuirement, se fractureut à l'iutérieor avec une grande facilić. Ia valve supérieure esl généralewent moins épaisse; son croclset, au lieu de la goutlière, est ununi d'un bourrelel saillanı qui y correspond; du reste, sa surlace extérienre est de axeme ucciapéce par de nombreux feuillets diaccroissement. Un ne tonnoil eucore celie espeece qu'a l'élat fussile, et aux environs de Paris seulerucut. La valve iuférieure a 13 centimét. de loor et 40 millim. de Jarge.

\section{Huitre callifíre. Ostrea callifera.}

O. testi ovato-rolundata, hinc prope busim callo crusso subuuratú; valva majore crassissimâ, intius irregulariter excrivatâ.

Ostrea hippopus, Lamx. Ann. du Nus. tom. 8. pag. $15 \mathrm{~g} . n^{\circ} .2$, el tom. 14. pl. 21 . fig. 1.

1Lid. Anim. sans vert. tom. 6. pag. 218. $n \cdot 19$.
Ков. Descripl. des Coq. Juss. des eno. de Paris, tom. 1. pl. 40. fig. 1, el pl. 41 . fig. 1 el 2.

Iamarck aroit d'abord confondu celte esperce avec l'Ostrea hippopus, qui vil actuellement sur uos cótes; mais un examen plus approfondi lui a fait recommitre l'errenr qu'il avoit cummise, $e t$ il l'a rectiliée dans son ouvrage des Animaux sans aertebres; en consóquence, il lui a donné le: nom 'ju'tllo conserve achellement. Cette espèce est parliculière anx envirous de l'aris; elle prend quelquefuis une épansseur considérable; clle est ovale, oblongue, a crochels conts, triangulaires, dont la gouttière médiane et superficielle, cilroire, est suirie de deux bourelets aplatis; lit caviré de la valve inféricuse est assez graode, profonde, se prolongeant un peu an-dessous du cruchel; sit surface est lisse, et l'impression musculare que que l'on y voit est peifle, Iransverse, oviale, et situce pers le tiers inférieur de la cavilé; en dehors les valves somi couvertes d'un grand nombre de feuillets irréuliers, plus rapprochés et plus noubreux sur Ta valve supérieure. Celle vaive supirieure est operculiforme, aplatic, beanc:onp woins śpaisse que l'aulre; son crochel es! court, et la goullière du liganaenl est à peine indiquéc.

C'esl aux environs de Versailles, dans les inarnes supérieures aux k:ypses, que: l'nn trouve cetle espèce; on la reucontre aussi à Lonjumeau. Un individu, que nous devons à l'oblizeance de II. Huot, a 14 centimètres de Inng, 85 millia. de la ge, el la valve inférieure seule a 80 millim. a’cipaisseur.

10. Huitra vésiculaire. Ostrea z'esicularis.

o. testá semi-globosâ, basi relusâ, lorvi; valı́â inferiore ventricosâ, hinc subarur:culatá; supenore plano-concava, operculformi.

l.Амк. Ann. du Mus. tom. 8. pag. 160. no. 5, el tom. 14. pl. 22. fig. 3. a. h.

Ibid. An. sans vert. tom. 6. pag. $219 \cdot n^{n} .28$.

Nicson, Petr. suecana. fur. cre. pag. 29. $\mu l .7$. fig. 5 , et $\mu l .8$. fig. 5 .

Bnosg. Descript. géol. des envir. de Paris, lab. 3. fig. 5. a. d.

Coquille très-communémenl répandue dans la craie, qui, allectant des furmes assez diverses, álté prise quelunefois pour une Gryphée: elle est arrondie, sa valve inlérieure est tres-profodde et beancoup plus grande gjue la supérieure; elle cst ordinaircuent miace, sulsauriculée d'un cóté sealement, el sou point d'adbérence est souvent très-pelil, quelquuelois ménıc disparoissubt eutjèrement, ce qui faut présuner que celte espèce pouvuit vivre sans cure lixée. En dehors, cellc valve est ordinairement lisse; on $y$ remarque quelques accroissemens irréguliers qui, dans las vieux individus, deviennent lamelleux vers les bords. La valve supérieure est concave en dessus $\mathrm{O}_{2}{ }^{*}$ 
et convexe en dedans; comme l'auire clte est lissc, nu striée par quelques accroissemens. Le talon de la valve est fort court; il présente une surface large et trianguiaire, an milieu de laquelle est creuséc une petite fossette :riangulaire aussi, qui recevoil le ligamen!; en dedans, les valves sont parfailemeot lisses: l'impression musculaire, qui s'y voil trčs-près du croclıel, est arrondie, sublalérale el très superficielle. Les bords sont minces, Iranchans, simples dans toute leur élendue, si c'e n'est sur les côlés de la charnière, où ils sont légèremen! crénelés.

Celle coquille ne s'est rencontrée, jusqu’à présent, que dans la formalion craycuse, en Ftauce, en Allemagne, en Angleterte et en Scanie. Les grands individus ont go millim. ds diamètre.

11. Hoitre biauriculée. Ostrea biauriculuta.

O. testâ semi-globosá, basi truncatâ, biauriculatâ; valuá inferiore ventricosissimâ; superiore planulat $a$, operculifomi.

I. ам. Ann. du Mus. tom. 8. png. 164. $\pi^{0} .4$.

Ibid. Aniss. sans vert. toms. 6. pag. 219. $\pi^{\circ} \cdot 29$.

Coquille qui a de la ressemblance arec la précúdente; elle est orbiculaire, très-bombée cn dessous, aplatic el même concave en dessus; sa valve inférieure est extrêmement épaisse, profonde, sillonnée en dehors par des accroissemens jrréguliers, se prolongeanı un peu en bec à son bord antérieur; la cluarnière esı druite, très-large, forl étroile; elle se prolonge de cluaque côlć en deux orreillelles irrégulières, comparables, jusqu'à un cerlain point, avec celles de cerlaincs espèces de Peignes: elles ne scnl séparées du resie de la surface que par une sinuosilé plus ou moins profonde. Le talon des valves, Irès-élargi, occupe presque tout le bord cardinal; on voil cians sou milieu nne large tossette triangulaire, dépriméz, dont la base faitsaillie en demi-cercle à l'intérienr, et accompagnnée de cliaque cóté par une dépression latérale qui n'en est séparée que par les bords mênies de celle cavité. A l'intérieul, les valves s'ut lisses, irréguliẻrement bosselćes; la valre iufé. rieure, qui csi extrêmement éprasse, est creusée vers son cenlre par unc impression musculaire artondie, diune médiocre élendue, sillonnće par des accroissemens; la valve supérieure, operculiforme, aplalie quelquefois, concave cn dessus, esı auriculée comme la valve inférieure : son impression musculaire est superficielle, et les accroissemens qui se voient à sa surface extéricure sont généraleınent plus marqués. Quvirque celle coquille ait quelquefois près de 2 pouces d'ćpaisseur, l'animal n'occupe environ que la sixième partie, et presque tonte l'épaisseur du test apparlient à la valve inférieure. Les plus grands individas que nous connoissions on! 80 millim. de diamètre.

\section{H U I}

12. Iloitre dorsale. Ostrea doreata. Noв.

O. test $\hat{i}$ orbiculati, utringuè gibbosis, in medio subangulatá; valvá inferiore profondí, extus irregutariter laniellosá, striatì; valvi superione angulo acuto bipartitâ, lamellis nris elatis ornalâ, striis tenuibus longitudinalibus devaricatis instructs; marginibus supemè crenulatis.

Noв. Descript. des Coq. foss. des env. de Paris, tom. J. pl. 55. fig. 9. 1 a. 11 .

Coquille irès-distincte de toutes les espèces connues à l'étal fossile. l.es deux valves, très- Jonbées en dehnrs, sont quelquefors l'une et l'autre anguleuses dans le milieu, mais quelquefois aussi li valvé supériente, e!le senle, oflire ce caraclèrc; la valve inférieure esı profonde, arrondie, adbúrente dans une parlie de sa longueur : on n'y aperçoil exlćrieuremcnt que des stries sublamelleuses qui résultent de ses accroissemens; son crocliet, pen proéminent, est trianģulaire, courbé snr lé côté, aplati en dessus, largc à la base, et offrant dans son milieu un large sillon Irès-aplati. qui donnoit allaclie au ligament; la valve supérieure est consiamment anguleuse el bossue dans le milieu, a la manic̀re de certaines Bucardes de la section des Hémicardes, mais tuujours irrégulicrement; la surface exlérieure est ordiuairement étagée par un nombre plus on moins considerable de lames transverses d'accroissement. Ces lames, assez épilisses, sonl irrégulic̀rement découpées à leurs burds; des stries nombreuses, fines, divergentes, souvent bifurquées, naisseul do crorbet el de clıaque côlé de lis carèue, el descendent eu ondulant jusque sur les bords. A l'intérieur, celle valve supérieure ollire vers son côlé cxlêne une inpressinn musculaire semi-lunaire superficielle, qui correspond exaclement à celle de la valve inl'śricure. Lues bords sont légèrement renversés en deliors; ils sont simples inférieurement, et forlement crénelés a leur parlie supérieure, de cliaque côté de la charajère. Celle espère curieusc se :rouve aux environs de P'aris, à Munneville et à Valmondois, Ellle est longue de 50 millim.

3. Huirne fausse came. Ostrea pseudo chama. I.AML.

O. testî irreguluriter orbiculatá, valvá inferione gibbosấ, longitudinaliter subplicatâ, transwersim lamellis concentricis irreguluribus instructa; vicilvâ superiore planâ; umbonıbus minimis, recurvis; fossulì ligumenti minimá, angustâ.

LAnk. Ann. du Mus. ton. 8. pag. $162 . n^{\circ} 6$, et tom. 14.pl. 22. fig. 1. a. b.

Noв. Descript. des Coq. foss. des env. de Paris, tom. 1. pl. 55. fig. 1.2.3.

Le nom que Lamarck a donnć à celle espèce indique la ressemlılance qu'il lui a Irouvée daus sa forme exlérieure avec celle des Comes. Celte coquille est orljiculare, peu couvexe; la valve in- 


\section{H U I}

férieure, plus grande et plus profonde que la supírieure, présente en deliors des sillons à peine marqués, souvent caclués par des fevillets trans. verses e: assez nombreux, produils par les accroissemens irréguliers; le crochet de cette valve est trc̀s-court, très-étroit, presque toujours incliné sur le cóté antérieur; la goultière du ligament qui le sillonne dans sa longuenr est étroile, peu profonde, et les bontrelets quil'accompagneot sont eux-mèmes aplalis et à peine distincts; la valve supérieure est operculiforme, quelquelois conrave en dessus; sa surlace extérieure ne présente jamais que des lames transverses d'accroissement; ces lanes sont minces, très-nombrcuses et fort rapprochées; le talon de cette valve est extrêmeunent court: à l'intérieur, la coquille est lisse, subnacrée. L'impression nausculaire qui se roil vers le ceatre est semi-lunaire, transverse et arunée dans sa longuenr.

Celle espèce, que l'on trouve assez fréquemment aux envirous de l'aris, à Lonjumeau, à Versailles et à Montmartre, a 60 millim. de diamitre.

14. Huitre élalće. Ostrea extensa. Nов.

O. testî̀ orbiculatí, depressissimâ, longitudinaliter plicuti.j; marginibus integris; umbonibus minimis, planis, for'eolù triangulari exaratis; impressione musculıri magná, orbiculari.

Non. Descript. des Coq. foss. des env. de Paris, toin. 1. pl. 76 . fig. 1. 2.

l'Huitre élalée esı une coquille d'une médiocre étendue, remarquable par l'extrêrne aplatisseuneut de la valve inférieure, la seule qui nous soit connue. Celle valve présente en-dessus un large surface à peine dépasséc par la saillie des bords; en dessous clle est adhérente dans presque toute son étendue, et la partic libre est ornće de larges sillons rayoonans, assez régnliers, presqu'égaux, gui modilient à peine le bord, qui reste simple, épais, légèrement renversé en deliors dans toute sa lnngueur; le talon, qui termine supérientement la coquille, est couri, triangulaire, oltus, strié en travers: il n'offre presquaucuue trace de la cannelure du ligament. L'impression musculaire est très-grande, orbiculaile, centrale, légèrement déprimée. La surface interne est loule lisse, ayant quelques ondulations peu constanles.

Cette coquille ne s'est encore trouvée qu'aux environs de Paris, et spécialement à Valmondois. Ellc a 85 millim. lle diamètre.

\section{Hivitre étroile. Ortrea angusta. ов.}

O. testí elongatâ, angustissina a , apice attenuati, depressî́; valvâ inferiore longitudinaliter subplicatâ, transversin lamellosä; lamellis distuntibus; valvâ superiore minore, striis concentricis brevibus numerosis ornatá; umbonibus prelongis, attenuatis, fossulâ profundà exaratis.
Noв. Descript. des Coq. foss. des env, de Paris, tom. 1. Fl. 58. fig. 1, 2. 3.

Coquille qui a de l'analogie, quant à la forme, avec l'Ostrea virginica; mais elle est encore proportionnellement plus étroile. Sa valve inférieure, nn peu approfondie, est plus grande que la supérieure; elle est alténuce vers le sommet; sa surface extérieure, irrógnlièrement plissée dans sa longueur, est traversée par des lauses saillantes, distantes, Iransverses, irrégulières, onduleuse sur les bords; le crochel est fort alongé, pointu, assez large à la base, creusé en dessus d'une large et profonde gouttière, accompagnée de cliague côté par un pelit bourrelet élroit. la cavité in!érieure sélend au-dessous dn talon; elle est lisse, et présente à sa parlie supéricure et lalérale une impression musculaite fort grande, suloovalaire et presque longiludiuale. La valve supérieure est aplatie, mince; son talon, plus court que celui de l'aurre valve, offie dans le milieu un bourrelet saillant qui correspond à la gouttière de la valve inférieure. la surface extérieure est ronverte d'un grand nombre de stries lanelleuses, subregulières, Iransverses; la surface intérieure est lisse, et les bords sont simples.

Celte espèce, assez rare, ne se trouve quaux env.rons de Pariset anx environs de Soissans. Elle est longue de 12 centim. el large de 50 millim.

\section{Huitre enflée. Ostrea infata. Nob.}

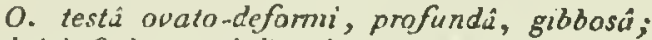
valva inferiore rariplicatá; umbone angusto, fos. sulá ligamenti angustî, marginibus supernè crenatis.

Nов. Descript. des Coq. foss. des env. de Paris, tom. 1. pl. 58. fig. 4. 5, el pl. 5g. fig. 1. 2.

Celte espèce d'Huíre est reconnoissable à sa forme ovalaire, à son irrégularité, à la profondeur considérable de sa valve inférieure: celle valve, qui est la seule connue, ne présente ordinairement qu'un petit nombre de plis longindinaux, étroits, subcaténés, interrompus par des lames transverses d'accroissement. Ces lames sont irrégulières, plus on moins nombretises, multipliées, surtout vers le bord. Le crochet est triangulaire, poinlu au sommet, à loase assez large, ayant en dessus un canal étroit et superficiel pour recevoir le ligament. Les bourrelets qui accompagnent cette gouttière sont superficiels, aplatis, el ordinairement dépassés par le bord mince et tranchant, qui se continue avec celui de la valve; à l'intérieur sa cavité se prolonge un peu on dessous da crocliet; on voit une impression musculaire semi-lunaire alongée transversalement, un pen courbée, très-superficielle, et marquée de quelques accroissemens; les bords de la valve sont simples, si ce n'est vers la charnière, oì ils sont assez finement crénelés.

On trouve cette coguille nox environs de Paris, 
à Valmondois, oủ elle est assez rare. Sa longueur est de 60 million. et sa largeur de 45.

17. Hoirne lingulee. Ostrea lingulata. Noв.

O. testá elongato-angustissimá, subcylindracế, cucullats; umbone parvo, obtuso; marginubus integris; extus striis irregularibus, numerosis.

Noв. Descript. des Coq. foss. des env. de Paris, tom. 1. pl. $5 \mathrm{~g} \cdot \mathrm{fgg} \cdot 13.14$.

Petite coquille fort singulière, qui ressemble à nne goutrière dermi-cylindrique, alongée el fort étroile; sa cavité est profonde, se prolongeant un peu sous le crochet. Jes bords ciui la furment de clıaque cóté sont élerés et sioples, taudis qune le loord inférieur, très-court et tranchant, n’est point relevé, el continue la gourlièı que préseate toute la cavité de la coquille; le crnchet est court, olstus atu sommet, apliati en dessus, muni d'une goultière très-superficielle, triangulaire, très-nettement séparée des lourrelets qui l'accompaguent par l'angle que forment ses bords. La valve inlérieure, la seule qui nous soil connue, est striée en dehors d'une manière très-irrégulière par les accroissemens; son test est mince, compacte, solide, et d'une couleur unifurme d'un brun-noiralte.

Cette coquille curiense ne s'est encore renconthée qu'aux environs de Paris, à Valurondois. Elle est longue de 48 uillim. et Jarge de 13. तовв.

18. Huitre multistriée. Ostrea multistriata.

O. testá ovatâ, utrinque gibbosá, tenui, fragili; valvá inferiore subluvigatâ, convexá; valvá superiore dorsatá, striis tenuibus numerosis bifidis ornatí; umbonibus minimis, brevissimis.

Celle espèce présente quelqu'analogie avec l'Ostrea divaricata, mais elle se disingue par sa forme et la disposition des stries de la value supérieure; eile est nvaluire, à ralre presquéyale went convexe; liuférieure, très-bossue, est lisse ou marquée de quelques plis longitudiuaux tres-peu marques; les stries d"accroissement sont rares el peu indiquées; le croclset, très-court et triangalaire, a daus le milìeu une petile fossette aplalie, suivie de chaque côté de petits bourrelets bien arrondis. A l'intérieur celle valve est lisse; l'impression musculaire que l'on y vait est tellement superlicielle, que ce n'est qu'avec peine quon l'aperçoit; la valve supérieure est presqu'aussi convexe que l'autre; son crochet esi plus court, et sa surface extérieure est couverte de petites stries nombreuses, serrées, rayonanantes, Lifides, se dirigeant en cudulant du crochet vers les bords. A l'intérieur celte valve est d'un blanc subaacré; son impression, un peu plus marquée que celle de l'autre valre, est snblatérale, pe:ite, ovalaire et trunsperse.
Celle espèce se Irouve à Válmondois, dums lu bassin de Puris. Elle a 35 coillim. de long, sur eo de large.

3. Huitre incertaine. Ostrea incerta. Nob.

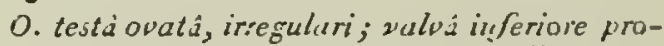
fundi, gibbosa, incrassatá; striis lumellosts, mumenusis, irregularibus, trunsversis; umbone angusto, triangulari, fossuli angustu exarato; marginibus integris.

Nuв. Descript. des Coq. foss. des env. de Paris, tom. 1. pl.57. fig. 1. 2 , e: $p l .58$. fig. 6. 7 .

Celte coquille, que l'on truave liéquemment à Valmondois, est embarrassauze par son extrêco variabilité, qui ae permet pas de la reconnoitre a l'enseable de ses formes, comue on peut le faire assez facilement pour d'autres espéces. Comare on ne la trouve jandis avec la valve supérieure, on unangue de ce cólé de plusieurs bons caracières spéciliques, de sorte qu'il est difficile de lui en assigner d'assez conslans pour quon puisse la reconuoitre facileuent. La valve inférieure est généralemeut ovale, arrondie, profonde en dedans, très-convexe el bossue eu dehors; la surlace extérieure, qui offie des traces d'adliérence plus ou moius élendues, est striée très-irrégulierement en travers; les stries sont serrées, suuveat suljlamclleuses; les cruchets sont triangulaires, pcu prolungés, pointus au sommet, creusts dans le wiliea par une gunitière superticielle ct lort étrcile; la surlace intérieure es! lisse, ondulense, un peu prolongée suus le crochet, et muaic vers te cemse et un peu latéralemeat d'une impressian musculaise, semi-lunaire et peu profonde; les burds de cette valve iuléreure sont simples et épais; rurement on aperçait d'un côté seulentem, vers la charnière, quel ques crénelures obsolètes. Cutte coquille a 65 asiliar. de longueur.

20. Huitre ovale. Ostrea ovata. ов.

O. testâ ovatâ, irregulari, multilamellatá; valvâ inferiore gibbosá, lamellis numerosissimis irregularibus erectis instructâ; umbone prolonga, depresso, supernè planulato; valvá superiore planâ, striato-lamellosâ; marginibus incrassatis, integris.

Noв. Descript. des Coq. fass. des env. de Paris, tom. 1. pl. 60.fig. 1. 2. 5 .

La valve infírieure de celle coquille est ordinairement adhérente par une très-grande élendne de sa surface, ce quila rend habicuellement trèsirréguliere; cependant l'ensemble de sa furme reste ovalaire ou arrondie, les parties libres de la surface extérieure sont chargées d'un Irès grand nombre de lames iransverses très-irrégulièrement découpées par le bord libre; le crocbet est gracd, triangulaire, irrégulièrement contourné, ayant 


\section{U I}

stpériearement une surface plane creasce au wilieu par une gouttière superlicielle qui occupe le tiers de la surface environ, les bourrelers qui l'accompaguent élant aussi larges qu'elle; ces bourrelels sont aplatis, séparís du reste de la coquille par un sillon superficiel; tuutes ces parties sont strićts en iravers; la value supérieure est plane ou convexe seloo les individus, et relalivement à la profonclenr de la valve infírieure; sa surface exlérieure est seulement striée en travers; les stries ne devienneot lamelleuses que vers les bords et dans les plus vieux individus; son crocher, beancoup plus conrt que celui de la valve ioférieure, a dans le milicu, au lieu de la gouttic̀re, un bourrelet ussez saillant qui y correspond, et, au lieu des bourrelets latéraux, denx gouttières superficielles, dans lesquelles sont engagés les bourrelets de la valve inférieure; la surface intérieure des valves est lisse, et prísente ver's le milieu une grande impression musculaire, semi-lunaire, transverse, Leaucoup plus large que lungue; les bords des valves sont fort épais, reaversís en lebors, sionples dans toute leur éleudue.

C'est à Lonjumeau et à Versailles, dans le lieu dit la Ménagerie, quil faut cliercher celle espèce, qui esi longue de 90 millim. et large de fo.

\section{Huítae sonore. Ostrea sonora. Noв.}

O. testá ovato-depressâ, incrassatâ, extùs irreguluriter striato-Lumellosâ, aliquandd sublavvigulî; umbonibus subarqualibus, latı, depressis, upice valde acuminats; inipressione musculari mediocri, ovuto-semilunari, trunsversâ.

I.e nom de celle espèce a élé donné par MI. De. france, dans sa collection; elle le mérile à toras égards, car la compacité du test est assez considérable pour lui permettre d'être assez sonore et serublahle, sous ce rapport, à des éclats de certaios silex. Celte coquille est ovale, obronde, lort déprimée, à valve inférieure un peu plus graude et plus profonde que la supérieure, adhérente par un pelit point du crochet, quelquefois très-solide et très épais se dans les vienx individus, striée en dehors on irrégulièremeot lauelleuse, quelquetois toute lisse; elle se termine supérieurement par un grand crochet Irès-large, poinlu, iriangnlaire, dépassé de chaque côté par les lames d'accroissement, et creusé dans son milieu d'une grande et large Cossette accompagnée de cluaque còté diun buurrelet assez saillaot et demi-cyliudrique; la valve supérieure est plave en dehors, presque toujours lisse, ayant le crochet presqu'aussi grand que celui de la valve inférieure; elle est irès-aplatie, et sa surface ne présente presquaucune trace ni de la goutlif̀re, $\mathrm{ni}$ des bourrelets; la face interae des valves est lisse, jamais prolongée sous les crochets; on y voit une iapressiou musculaire, médiocre, ovale, semi- lunaire, soperficielle, Iransverse, el siluće vers le licrs inférieur de la longueur : cette impression est toujours sillonnée par les accroissemens mul. tipliés. Celte espèce ne s'est encore rencontróe qu'aux environs de Valognes, à Ranville, où elle est assez commune. Elle est longue de plus de 11 centim. et large de 95 millim.

\section{Huitre oblongue. Ostrea parasitica.}

O. testâ tenui, oblongâ, rectú, glabrâ, apice netusâ, albo violacescente; valvâ inferiore ampliore.

Ostrea parasitica. GMEL. $n^{n} \cdot 115$.

Rомрн. Mus. tab. 46. fig. 0 .

Kleis, Ost. tab. 8. fig. 17.

An Cheах. Conch. tom. 8. tab. 74. fig. 681?

Gasar. An.sis. Sénég. tab. 14. fg. 1.

Exстсц. $p l .178 . f g r .1 .3$.

Vétan. Adans. Sénég. tab. 14. fig. 3.1

ENCYCL. $p l \cdot 185 \cdot f g .2$.

LAsk. Anim. s. vert. tom. 6. pag. 205. no. 14.

Lamarck rapporte à celte espèce une coquille décrite par Aduuson, qui, nous le croyuns, en dillère d'une manière sulfisante pour en ĉtre facilement dislinguéc; car celte espèce d'Adanson étant tonjours aplatie, ayant toujours les crochets plus larges, et ayant en outre une autre couleur, venant aussi diatres régions, sera vraisemblablement séparée par la suite de l'espèce qui nous occupe. Cette espèce est alongée, étroite, à valve inférienre, prolunde, un peu en bareau, adlú. reote par une grande parlie de sa surface, presque lisse, ou marquce seulement de quelques cóles obtuses, rares et irrígulières; son crochet est pointu, triangulaire, tantót droit, lantôt inlléclıi sur le cóté; la gouttière médiane cst à peine indiquée; elle est t'c̀s-étroite, tanclis que les bourrelets qui l'accompagneat sont furt élargis; la valve supérieure est aplatie, operculiforme, lamelleuse en debors; snn talon est. très. court, et ne présente ni groullière ni bourtelets latéraux; le ligawent est fixé sur le bard, légc̀. rement llexueux, et saillant dans le milieu; en dehors les valves sont teintées d'un viulet obscur, mais en dedans celle conleur est d'une teinte plus éclataute; et auancée de blanc nacré el guciyuefois de rougre; l'impression inusculaire est petile, latérale, obroude et toujours violette. Celle coquille a 65 millim. de long et 35 millim. de larro.

\section{Huitae nacrée. Ostrea margaritacea.}

O. testâ ovato-acutâ, recurvâ, rostrntâ et cucullatâ, operculo glabro, sublanelloso, mar. garitaceo.

Escrcs. pl. 181. fg. $1-3$. 
Layk. Anim. s. vert. tom. 6. pag. 208. no. 26.

Coquille qui a de l'analogie avec l'Ostrea cornu copice, mais qui se disliague de celte espèce en

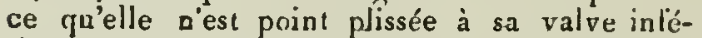
rieure. Elle est alongée, étroite, linguifurme, éprisse, lamelleuse en dessus comme en dessous, ayant la valve inférieure prufonde, assez fortement creusée en dessous du talon. Celui-ci est prolongé, triangulaire, presque plat, la gonutiere médiane da ligament étant ì peine creusées. Les lames dont se compose la valve supérienre sont plus courtes et généralement plus régulières. Celte valve est aplatje, terminée supérjeurement par un talon pointu, triangulaire, dont la surface est encore plus aplalie que celle de la valve inlérieure; l'impression musculaire des valves est sublatérale et alongée; une belle nacre brillante forwe le test lui-même; elle est rosce, irisante vers le bord inférieur. Cetie coquille, assez rare, se trouve dans les mers de l'Amérique mćridionale. Elle a I I centim. de longueur et 60 millim. de large.

\section{Huître étroite. Ostrea virginica.}

O. testâ elongatâ, angustâ, subrectá, crassâ, lamellosâ; valsâ superiore planulatâ.

Lister, Conch. tab. 201. fig. 35.

FAVANa, Conch. pl. 41 . fig. c. 2.

Excrcl. pl. 79. fg. 1-5.

Ostiea virginiana. GмгL. $n^{\circ}, 113$.

Lister, Conch. tab. 200. fig. 34.

Petiv. Gazoph. tab. 105. fgo. 3.

LAMx. Anim. s. vert. tom. 6. pag. 207. no. 18.

Grande espèce qui nous vient des côtes de Virginie, et que son étroitesse et la couleur violette de son impression mnsculaire rendent toujours facile à distinguer de ses congénères. Elle est alougrée, étroite, altéuuée vers le sommet; la valve inlérieure est concave, blanche en dedans, teinte de violet-rougeảlue vers son bord inférieur; l'impression musculaire est semi-lunaire, transverse, étroite, arquée daus sa longueur, placée vers le milieu des valves; elle est coujours d'un beau violet pourpré; le talon est étroit, prolongé, pointu, creusć dans le milieu d'une large goultic̀re neu profonde, bordée de chaque cóté par un bourrelet peu saillant; la valve supérieure, fort aplatie, a le talon généralement moins prolongé. Celle partie est légètrement convexe, et la gouttière da ligament est à peine creusée en dehor', l'une el l'autre válve sont convertes de lames écailleuses, irrégulières; leur couleur est d'un fauve-rougeálre, nuancée de bleu et quelquefois de brun. Celle coquille prend quelquefois des dimensions assez considérables; nous en avons vu qui aroient plas de 2 décimetres de longeur (environ 8 pouces), sus 10 ou I 2 centim. de large.

25. Hoitrne corne d'abondance. Ostrea comu copia.

O. testá ovato-cuneiformi, apice rotundatâ, subtìs margineque plicatí; valvâ inferiore cucullatâ.

Favane, Conch. tab. 45. fig.e.

ExcrcL. pl. 181. fig. 4. 5 .

Chems. Conch. tom. 8. tub. 74. fig. 679 .

LAMx. Anin. s. vert. tom. 6. pag. \&10. $n^{\circ}, 33$.

Lamarck a séparé celle espèce de l'Ostrea cucullata sur des caractères qui paroissent de peu d'importance. Le principal consisteroit en ce que, dans la Cucullatu, les bords sont dentelés, tandis que daus celle-ci ils ne le sont pas. Cetle espèce est alongće, conique, arrondie vers le bord inférieur, atténuée au somniet, où clle se termine par un long talun triangulaue et pointu; au-dehors la valve inférieure est très-bossue; elle est pilissée longiludinalemeat, les plis partent en rayonuant du crochet; ils sont aigus, irréguliers, peu nowbreux, et correspondent à des dentelures plus ou moins profondes, qui découpent le bord. En dedans celte valve est très-protoncle, et sa cavié se jurolonge dans presque toute la longueur du cru. chet; la surface extérieure de celui-ci est aplatic, assez large dans quelques individus, trćs-étroites dans dautres; ditus queliques-uns le sillon du ligitment est étroit et peu prufond. La valive sujérieure est plate, plissée en dehors, et ses bords sunt dentelés de manière à s'engraintr arec ceux de la valve inférieure; son crochel est forl cour\% Extérieurement celle coqujlle esı d'un vialet asuez foncé; en dedans elle esı subnacrére, d'un be:u viole! vers les bords, et d'un blanc pur dans te reste de son éleudue. L’impression musculaire :e prolonge sur le côté dans une grande lunguedr de la valre inlérieure. Cette espece vienl des ne:s del'Inde; elle a 90 millim. de lunguear.

\section{Huitre en pochelte. Ostrea cucullata.}

O. testâ ovali, intùs succiformi; valuá inferione plicati, cucullatá; marginibus enectis, plicatoangulatis; linabo interno denticulato.

Ostrea cucullata. Bon. Mus. tab.6. fig. 11.12. EncrcL. pl. 182 . fg. 1. 2.

LAsx. Anins. s. vert. tom. 6. pag. $210 . n^{\circ} .34$.

Cette espèce n'est peut-être qu'une varićtć de la précédente; sa forme est àpen près semblable, sa valve infórieure est aussi profonde, et sa curin? se prolonge sous le croclet; elle est plissée en dehors, et ses hords sont dentelés; sa valre supérieure est operculiforme, lígèrement bonlbée en dehors, plissée comme l'iufér:eure, et ay ant conme 
elle les bords dentelés; les crochets sont géuérulement un peu moins prolongés et plus larges que lans l'espéce précédente; en dedans les valves, d'une aacre violette surles bords, sunt d'un blancjannâtie ; au centre l'impression musculaire est petite, d'un violet noir, semi-lunaire, sublatérale, et ayant le bord iulérieur obtus, mais saillant; vers la charnière, les bords sout de claqque côté fincuent créuelés on denticulés.

Cette coquille, peu commune daus les col'ertions, vit dans les nic̀mes ners que la précédente, et a lis ajêcoes dimensions.

27. Huitre llabellule. Ostrea fabellula.

O. testáoblongâ, cuneati, supernè rotundatâ, suburcuatí; plicis longitudinalibus, nugosis; nate alters productî.

Chama plicata ultera. Brand. Foss. Lanton. $n^{\circ} .85$.

Lanz. Ann, du Mus. vol. 8. p. 164. $n^{\circ}, 16$, el tum. 14. pl. 20.fig. 3. 4. b.

Ibid. Anim. s. vert. tom. 6. pağ. 215. $n^{\circ}$. 6 .

Petice coquille que l'on trouve fréquemuent aux environs de Paris dans les calcaires grossiers. Eille est ovale, oblongue, rítrécie vers le sommet, oi elle se termine ordinairement par un crochet poiulu, se prolonue.nnt avec l'ìge. La valve int:"liture est plus grande que la supérieure, quoique déprincée elle est plus profoude; extérienremeut elle est couverte de côtes arrondies, longitudinales, subéranillenses, qui plissent le bord en y aboutissant; le talinn présente ure surlice un peu aplatie, dont le sillun wédian n'est pas tricprutond, et bordé de cinaque côté par denx bourrelels élroils, séparés du bord par une strie prolunde; la valve supérieute ust assez épaisse, elle est plate, el l'on pourioil croire quelle apparliem à une autre espece, si l'on n'avoit d'aulres exemples de ceite dillirence singuliere entre les valres d'une nième espèce. Au liéu des cỏles longritudinales, sa surlace est occupée par un grand noubre de lanes uransverses, lappurochíes, peu saillantes et irrégulières; le talon de celle valve est pius court que celui de la valve inférieure; les burds sube simples, ayant deux ou (r. is crénelures à leur partie supcrieure, mais jumais plassés ai même viduleux. L'impression unusculisire est arruadic, subceratrale, che médiocre écndue, et toujuars superticielle.

Les plas grauds inclivitus de ceite espice ont 50 atilian. de longuear et jo de large. Lucalités, Griznon, Courtaynon, Chuanont, P'araes, ilouchy, Valmondors, etc.; aux euvirous de Paris; les turruns de Gaod, de Valougnes el de Lisucites.

20. Ilditre cucnllaire. Ostrea cucullaris.

O. testî oblong.i, cuneato-spathuluti, basi ostrutí; nate infenure pinfundé cucullutu.

Hist. Nat. des I'ers. Tone II. o. cochlearia. Laš. Ann. du MIts. tom. \&. pag. 162.

Lasrx. Anim. s. vert. tom. 6. perg. $219 \cdot n^{0} .27$.

Noв. Descript. des Cog foss. des env. de Paris, ton. 1. pl. 56. fig. 2. 3, et pl. 49. fig. 3. 4 .

Coquille diversiforme, fort irrégulière, dont nous ne connoissons, jusqun"à présent, que la valve inférieure. Celle valve est alongée, étruite, alténuée au somuet, élargie, quelyucfois spalulée is sa partic inlérieure. Le crochet est alcngé, pointur, étroit, triangulaire; sa surface supé̉iente est plane, striée en travers; la gnutlicre médiane est superlicielle, ei les bourrelels quil'accompignent sont très-peu saillans; ils sont séparés du reste du lest par un pelit sillon profond qui les suit jusqu'an sommet. La cavité est assez profonde; clle s'ćtend en dedans du crochet dans presque tourta sa Inngueur; el'e est lisse, el préseate, vers sit partic ioléricure et externc, une impression musculatre ovale, sub!ongriucidaale et très-superlicielle. Les bords de cetle valve sont simples, irrégrulièrement découpés, ce qui tieat a l’irrégularité nême de la coquille; en dehors elle est irréunlièremunı lamelleuses, à lames courtes (t serirées.

Cetı coquille se tronve à Belz et ì Valunondois. Elle est Jungue de 65 millia. et large de 30.

29. Huira élígante. Ostrea elegans. Nur.

O. testá ovato-arbiculati, infernè gibbosâ, supernè pluns; valví infériore rugis subregularibus. longrtudinalitios ornalá; valva superiore planá, strus concentrices imgularilus instructa, ad

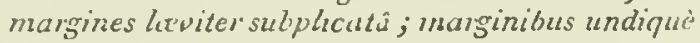
2'aldè crenatis.

Ков. Descript. des Coq. foss. des eno. de Paris, tom. 1. pl. 5o. fig. 7. 8. 9 .

Cette especce est sur la limile des IItitres dont la valve iuféricure est plissée, tandis que ia supé rieure reste plane el sans aucune strie; car dans celle-ciles phlis de la valve superrieure se montrent sculement vers les bords, el dans un étal pour ains: dire rudimentaire: la valve inférieure est toujours plus grancle que l'autre; elle est fortcment convexe en debors, souvent irréguliorement bossue, stun qu'elle esr adhérente par une surfice plus ou ancins grande. Daos les individus les plus rézuitiers, la sulface extécieure ressemble un peu à celle d'un l'eigne, étant converte de sillons longitudinaux asscz reryliers, quelquelois bilides dans le asilieu, se terminanl le plus sonveat pat un angle aigu. Ces sillens sont coupés ordinarr ment en iravers par des stries sululamelleuses d'accrnissement. Parvcrnu sur le bord, ils le plissen assez finement; mais ces plis ne sont point artic: lés arec la valie supéricure, qui est coujours tresp courte pour les alteind re; le crocbet de celle valie cst ordinirientent fort court, aplati en desstis, I'p* 
triangulaire, à base larıe, ayant dans son milieu uve gontlière élroile et lrès-superficielle; la valve supéricure est presque toujonis plane, Irès-rarement bombée en dehors, épaisse dans les vieux individus, se terminant supérieurement par on crocliet subtronqué, lurge, cuult, à surlace touta-fajt plane, olliabt à peine quelıues Iraces du sillon pour le ligament; eu deliors elle est, dans toute sa partie suprérieure et royenne, couverte de stries concentriques, nombreuses, peu saillantes, qui font place peu à pen à des plis trèsaplatis, qui occupent le limbe et correspondent aux crénclures nombreuses et sailantes qui se roient sur les bords. Ces crénelures de la valve supúrieure correspondeut sur la valse inlérieure à ile petits enfoncenens punctilormes. Liimpression musculaire est sublitérale, ovale, transverse, trẻs-superficielle et marupuée d'accroissemens noubreux.

Cetle coquille ne s'est encore rencontrée quiaux environs de Paris, ¿a Claumont et à Valmondois, où il eșt excessivement rare de $]_{1}$ rencontrer les deux valves rétures: Les plus grands individus on 60 soillins. de diamètre.

\section{†† Espices dont les valies sont plissées.}

3o. Huîrne crếte de cog. Ostrea crista galli.

O. testâ rotundatâ, submutic $\hat{\imath}$, plicntissimtá; plicis longitudinalibus, angulutis, latescentibus, ad extremum maximis; limbo interno scabro.

Mytilus crista gulli. Lis. Gred. pag. 3350.

Ruмрн. Mus.tab. 47. fig. $d$.

Dahgenv. Conch, tab, :0. fig. d.

Goalt. Test. tah. iof. fig. e.

Knorr, Del. tab. b. 4. fig. 8.

- Jergn. tom. 4. tab. 10. fig. 3-5, e! tom. 5. tab. 16.fig. 1.

Cuesx. Conch. tom. 8. tab. 75. fig. 683. 684. Excrcs. $p l$. 18g. fig. $\mathfrak{3}-5$.

Lamk. Anim. sans vert. tom. G. pug. 213. $n^{\circ} 45$.

Belle espèce d'Huitre, recherchee des amateurs a cause de sa Corare et de sa raretć; clle est ovale, olsronde, ordinairement un peu plus large que longue. Ses deux valves sont presqu'également bo nbées; l'inférieure est a peine plus grande que la supérieure; l'une et l'autre sont plissées lon:iundinalemenl; un ou deux plis principaux desceudent du crochet à la base, et c'est de leurs parties latérales yue naissent les autres plis au nombre de trois ou quatre de chaque côté; chacua de ces plis, en aboutissant sur le bord, s'y termine en autant de dentelures grandes et profondes, dont les plus grandes sont a la partie moyenne du bord iufé. rieur; le bord supérieur est presque droil. Le ı- lon est tris large, très-court, à peine proł́minan:; le liganent est porlé daas son milieu dans un sillon très-large, mais superficiel. L'impression musculaire est sublat ́ŕrale, forl grande, semi lulunaile; les hords sont finement créaclés daus toute leur éteudue; ces crénelures sont quelquefois à plusieurs rangs sur le bord inférieur; extérieurement les valves sont couvertes d'uu grand nomlire de stries granuleuses, onduleuses, irrégulìres, aflectant en génúral la direstion longitudiuale. Celte coquille est d'un bleu-violet bruvître à l'extérieur, et d'uu beau brun marbré de jauue doré à lintérieur.

Cetle espèce vit dans les mers de l'Iade; elle a 75 à 80 millim. de longueur.

\section{Huitre imbriquée. Ostrca inbricata.}

O. testâ rotundutâ, plicatissimâ; plicis angulatis, ad extrenum maximis; dorso lamellis imbricato, squamisque tubulosis echinato; linbo interno glabro.

Ruмрн. Mlus. tab. 47./ig.e.

DARGENT. Conch. coq. rar. pl. 2. fig. $f$.

Favanne, Conch. $p l-45 . f i g . e$.

Exстс⿰. $\mu l .186 . f i g .2$.

Lank. Anim. sans vert. tom. 6. pag. 213. $n^{n} \cdot 46$.

Celle cocpuille esı noe des espèces de la section des Huitres plissées qui prenneat le plus grand volune; elle est arrondie presqu'égalcuent, convexe des deux côtés, et ornée de plis longitudinaux nowlreux très-prolonds, aigus à leur sonsnet, imbriqués par des écailles nomlireuses et redressées; les bords sont dentelís dans toute leut éteudue; les dentelures sunt protundes, sans tılicrcules; le bord supérieur ssl presque droit, déprissć par un talon triaıgulaire fort sailiant, creusé daus sa longueur d'une large goullıre bornce latćralement par des bourrelets peu saillans, mais presqu'aussi larges qu'elle. $\Lambda$ l'interieur, celle coquille est blaache, subnacrée; on voit a son centre une tres-grande impression musculaire subcentrale, ovale, trausverse, saillante pitr son bord inférieur; elle est ordinaivement d'un brun-roux, et ses accroissemens sont marruís par des zones d'une teinte plus foncée. A l'exlérieur, celle coruille est d'un violet lonce, couleur qui se répète sur le bord incérieur des ralves.

Celle coquille vient de l'Océan des GrundesIndes, principalement des mers de Java. Elle a quelquefois plus de 2 décin. de diamère; son lest est très-épais et très-pesant.

\section{Hứtre rateau. Ostrea hyotis.}

O. testâ opatâ, plicatâ, lumellosâ, squamis subtubulosis putulis echinatâ; lcibro interno glabro. 
Irj tilus hyotis. Lix. Gatec. pağ. 3550 .

Guast. Test. tab. 10 j. fig. $a$.

Cuess. Cunch. tom. 8. tab. 75. fig. 685.

Lierrec. pl. 186 . fig. I.

LAms. Anim. sans vert. tom. 6. pag. 215. $n^{\circ} \cdot 47$.

C'ente belle espèce a de l'analogie avec les précédeıstes; elle preod quelquetois un aussi graud volume que l'Ostrea imbricata; un pourtoil mène la conlondre avec elle si l'on ae faisoil allention qu'elle est constamment tubulense, tandis que celle arec laquelle nous la compitrons esl loujuars ćcuilleuse; elle est ovale un arrunile, chargíe de liuit a dix gros plis anguleux, prolunds, dont le biatut est hárissé, à des distunces inégrales, de grandes écailles spatulées au sommer, lubu!euses, redressées, sonvent inlundibulilismes : on en compre cinq ou six dans la longuenr de chacun des plis. Les valves som prexçu'égales; la supérieure est us peu bombée; l'une cillaulte se ternirent supéreurement prar un crochel puiotu, cuurt et large a la base; le sillon du ligament tit a peine creusé, et lez deux bourreles yui l'accornprarnent sout fort peu saillaus; les loords ne sont créuelćs dans aucune purtie de leur étendue; a l'intérieur, les valves sout hlanclices vers le centie et biones sur les bords. L'irupression musculaire est suidalerale, grande, arrondre el ordinairement roussitre. En dehors, la coquille est d'un brun funsí; elle n"tst puiut striée cumut l'Ostrea crista galli; on n'y voit que tes stries d'asciroissement.

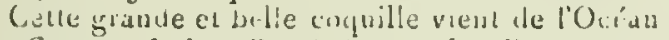
te, Granctes-Iodes, diapres Lamarck; clle est pres'jh'aussi grande que la prćlcideule.

5.j. II vitre à côtes rares. Ostrea raricosta. NuB.

$O$. lestá elonguli, angususid, apice altcnualı; watos tnferiore profinds, costls ruribus radianttbus ornata; supertore plana, imbricato-lamelloji, vialaceo-marmoralt, mitis albî.

Cocquille singulière que nous croyons nouvelle. Elle est alongée, étroite furieneut alténuée au sonmel, qui se prolonge en un long talon śtrual et prialu, cuncare a la valve supérieuse. la valve inférieure est beancuap plus graude que l'autse; eile est eymbulaire, mace; sa cavité se prolonge un peu en dessous du bord cardinal; eıle tsi ornée en dehurs de sid a sept furies cùles rayunnumtes, élroites, siuples, dont les deux uédialies sont les plus grusses. Cés cótes décumient le burd, qui est inince, non crénelé et aun línlé. La valve supáneure est operculitorme; elle est yiate, sars colles qu currespondent a celles de la vulce ulírieme; ses borws sunt simplt:s; el.e ist curerte de lames concentriyues très-r.npprocléés et imbriqua es comme dans l'Ustrea odlulss. Ln iehor's, cetie espece est blanche vers les croiłe:s, warbiée de rivlet vers los bords; en dedans, clle est d'un blunc naeré. l'inapression musculaire est ovale, oblongue, longitudinale, superlicielle, el de la mêmé couleur yue le reste. Nous ne counoissons jas la patrie des enquilles de cette espece, dont lis lougueur est de 85 trilliw. et lu largeurde 40.

34. Huitre geutille. Ostrea pulchella. Noв.

O. testâ elonguto-recurvi extiesque violuscorile, apice allemuals, longitudinuliter tenuc plucilt; plicis inbricato-landellssis, inaqualbus.

'Irès-jolie petite cogaille d'un voluase conjunrs médiucre, ayant nu test épitis et convert cn deliurs d'un grand numbere de plis irréguliers el lomuinadiauux, découpés par un yraud nombre d"éc:ailles lamelleuses et triasverses. La valve inléricure est plus grande que la supéricure, et se prolune supéricurcement en un grand talus printu, croit, creusé dans sii longncur par the gountise prolonde el fítroite. Ein dedins la ciavilé de celle valve se prolunge en dessours du talon; elle esi profonte, d'un ulanc-viulálre inardsć de laclies brunes et violetles plus funcéces. L'impression nus. culaire est asrondie, sublatérale, el ses accroisseinens sumt wartgués pir des zones violelles; les bords sont décuuprés en deacelures petiles et inégales, qui correspundeat a celles de la valve supét'teure; celle-ci est fort épaisse, ذ̇ peine conrcese eu deliors, couverte, comme l'uure, dle plis jlicígullers; sou bord interne est créuclé daus toute son élendue; sa couleur est, à l'intírieur, d'un volet-brau beaucoup plus imense el plus nniluma yue dans la valve inférienre. Celle coguille cst, à l'intéreur, d'un violet lonncé. Elle a élí rapportée du P'érua, et elle n’u gae 45 williur. da lingueur.

\section{Huitne llabelluide. Ostrea flabelloides.}

O teslá sublrigonà, crassè pliculi, plicis magrais, dorso aculis, subimbricalls, luterolibus, obliques.

K.ion , Pelrif. 4. part. 2. d. i. pl. 56. fig. 3.

Lseyci. fl. 185 . fig. $6-9$.

Vur.?' Plicis maximis. O. depentila.

KNORR, l'etrif. 4. purt. 2. d. i. pl. 56. fig. I. 2. ExescL. pl. 1 ij. fig. Jo. 11 .

l, амк. Anime salls vert. tom. 6. pag. 215 . $n^{\circ} .4$.

Espcee comnue a l'ćast de pótrificalion seniement, el qui ‘ beascoup cl'anulogie, quant a la lorme des plis dout elle ust couver:e, àvec i'Ostrea crista galli, que nuus avons précédemment héerite. Lile est arrondie, caurbée dans sa longueur, se prolongeant ordmairemena un peu vers sun extrémité antérieure. De gros plis longiludinaux lrès-aigus, au nombite de huit ou dix, descendent en rayonnant du sumuet tes valies vers les bords. $\mathrm{P}_{\mathrm{P} 2}$ * 
Les values sont presqu'égales; la supérienre, ordinairemeut botnbée, est le plus souveut écailleuse vers le bord. Ces écailles résultent des accroissemens. Les crochets sont peu prolongés, presqu'égaux, obtus et superficiellement sillonnés dans le milien, pour recevoir un ligament qui deroit ćtre petit. A l'intérieur, les valves sont boursouftlées et oaduleuses, comme dans l'Ostrca crista galli. L'impression musculaire est oblongue, supérieure, un pert saillante inférieurement, et les bords sont déconpés en autant de grandes dents triangulaires qu'il y a de plis à l'extérieur : ces dents se reçoivent réciproquement; elles sont triangulaires, très-aiguës, et leurs bords sont tranchans.

Cette belle espèce se trouve dans divers lieux, principalement dans les argiles inférieures à la craie des environs du Havre. Elle a go millim. de longueur, et i l centimètres de large vers le bord.

36. IIuitre groupée. Ostrea greganea. Sow.

O. testâ ovatâ, subobliquâ, longitudinaliter multiplicatî, apice subtruncatâ; plicis numerosis, furcatis, divaricatis, transversim striatolamellosis; marginibus complicatis in ultrâque valuâ.

Sow. Miner. Conch. pl. I11. fig. I et 3 .

Noв. Descrip. de quelques foss. caractéristiques, pl. I j. fig. 2.

L'Ostrea gregurea est une coquille ovalaire, peu oblique, subtronquée au sommet, et la valve inférieure est convexe en dessums et assez profonde en dedans; la supérieure est plus petile, plus aplatie, et ayant un talon plus court que Iinférieure. Dix-buit à vingt plis descendent obliquement et en rayonnant da sommet vers les bords; un plis médian, qui, vers le milieu de la longueur des valves, commence à se bifurquer, partage tous les autres en antérieurs et en postérieurs, qui aboutissent au bord chacun de leur còté en clivergeant; ces plis latéraux sont plus petits que ceux rui rísultent de la bifurcation des plis médians, et qui occupent tout le bord inférieur de la coquille; les plis de la valve inférieure sont semblables à ceux de la supérieure, seulement ils sout plus profonds; ils sont tous anguleux, subcarćnés, un peu tuberculeux, et marqués de stries transverses, sublamelleuses, qui indiquent les accroisscmens; le talon des valves présente intérieuremeut une gouttière peu profonde, accompagnée de cbaque côlé d'un bourrelet aroudi.

L'Huître groupée avoil l'habitude, comme cela a licu pour un certain nombre d'esficces, de s'attacher les unes aux aulres, et de former ciusi des masses plus ou moins considérables. Celte espèce, lonģue de 60 millim. et large de 40 , se trouve principalement dans les argiles du Ilavre.
37. Huitre plicatule. Ostrea plicatula.

O. testâ rotundutâ, pulvinatâ; plicis longitudinalibus, subobtrisis et transversè nugosis, radiantibus.

Ostrea plicatula. Garel. $n^{\circ}$. III.

Gual't. Test. tab. 104. fig. $a$.

Curems. Conch. tom. 8. tab. 73. fig. 674.

Encrel. pl. 184. fig. 9 .

Var. plicis subinbricatis, angulatis.

Gualt. Test. tab. 104. fig. d.

Cuems. Conch. tom. 8. tab. 73. fig. 675 .

Var. Plicis nurginalibus, in disco nullis.

Var. Plicis obtusis, perpaucis.

Var. Testâ oblongâ, lateribus plicatâ; dorso irregulari, convexo.

LA ик. Anim. s. vert. toni. 6. pag. $211 . n^{\circ} .41$.

Coquille variable, mais qui ne l'est pas autant que l'a pu croire Lamarck; elle est généralement arrondie, aplatie, rougeâtre ou brunảtre, ayant des plis plus ou moins nombreux, plus profonds à la valve iulérieure qu'à la sujérieure; l'adhírence de la valve inférieure se faisant par une grande surface, les plis ne se montrent gucre que vers les bords, qui ordinairement se relivent ferpendiculairement; la valve supérieure est apliaiie, rarement bombée eu dehor's; ses plis currespondent à ceux de la valve intérienre, et ne se montrent qu'en niêase lemps qu'eux; les deutelures des bords sont pen norbbreuses, triangulaires, peu élevécs et à base large; la charnière est petiie, fort étruite; les talons des valves sont courts, tri's - petits, pointus, dépassaut à peiue le bord, et ollrant une surface plate divisée en trois parties presqu'égales par deux sillons; l'irnpression musculaire est subcentrale et médiocre, arrondie e: superficielle; les bords de clacepe côtú de la charnic̀re sont finement granuleux; la couleur du delıors est rougeâtre ou brunâtre, passant quelquelois au viulet; en dedans elle est blanche, sulinacrét, teintée de jaune sur les bords.

Cetre coquille vit dans ies mers de l'Inde; elte a 50 à 55 millim. de diamètre.

58. Hoitre tougeâtre. Ostrea rubella.

o. testẩ oblungì, parasiticá, rubello-ziolacescente, latcribus plicata; costá dorsali incequali, elevatí.

An Mytilus frons. Lrs.?

Bons. Mus. test. pag. 121 . vig. fig.t.

LАмк. Anim. s. vert. tonı. 6. pag. 2 เo. $n^{\circ} .36$.

Julie petite coquille régulièrennent plissée, tant à sa valve supérieure 'qu'à l'inférieure. Elle est ovale, oblongue, un peu alténuće vers le Isommet; sa valve inférieure, un peu plus pro- 


\section{H U I}

fonde que la supérieure, s'attache au moyen de crochets que produit l'animal à mesure de son accroissearat sur les branches de gorgone, de fucns, etc. Las plis qui couvrent cette valve sont divergens, et partent de chaque côté du poiut de l'aủhéreoce. Lorsque cette adhérence cesse de bonve heure, les bords se relèvent et les rides devienuent rayonuantes; ces rides sont arrondies, assez saillautes, marquées par des stries longitudinales produites par les accroissemens; elles formeut sur le bord des dentelures aiguës, triangulaires et réciproques pour chaque valve; la valve supérieure, un peu bombée en delıors, a des plis moins réguliers et moins profonds; ils ne se monirent guère que vers les bords pour y produire les dentelures qui s'engaugent entre celles de la valve inférieure. Le lalon des valves est court, érroit, et coutient le ligument dans une petite rigole triangulaire tı̀s-superlicielle. En dedans cette coquille est nacrée, d'un blanc-rougeatre, mais le plus souvent d'ur blancjaunâtre; les bords vers la charnière sont finement crénelés, et les crénelures suivent le contour des dentelures qu'on y voit en dehors. Toute celle cuquille est d'uu rouge-violacé unilorme.

Celle espèce vit dans l'Océan américain; elle a 40 millim. de longueur, sur 25 à 27 de large. Nов.

3. Hoitre d̀ petits plis. Ostrea tenud plicata.

O. testâ ovato-elongatá, apice attenuatâ, depressâ, plicis angustis nugafomibus radiantibus utrâque 2'alvâ ornatâ; umbonibus longis, acutis.

Noв. Descript. des Coq. foss. des env. de Paris, tom. 1. pl. 5o. fig. 2. 3. 4. 5.

Coquille fort déprimée aplatie, à test mince et fragile; les valves sant inégales; la valve inférieure, un peu plus protonde que l'aure, se lermine supéricurement par un talon assez prolungé, triangulaire, pointu au somonet; la gouttière du ligument est très-large et profonde; elle est acconjagnée latéralement de bourrelets peu convexes ét fort élroits. A l'intérieur, qui est lisse, on remarque une grande impression musculaire, ovale, arrundie, placée vers le bord antérieur; extérieurement cetle valoe est ornée d'un grand nombre de plis étroits, rayonnans, subnoduleux, inćgaux, fort petis; à la parlie autérieu:e de lá coquille ils sdplatissent et disparoissent vers les bords, qui sont seulement ouduleux; la valve supéricure est tout-à-lait plate; son talon est beaucoup plus court que celui de l'aure valve; il est comvexe en dehors, et cette convexite fort lare s'cnfunce dans la gouticice de la valve inférieure; à l'intérieur, celle valve est lisse, et ses bords snat simples dans tout leur pourtour; en delors clle est couverte de plis longiludinaux serublables à ceux de la valve inférieure, seulement ils sont un peu moins élevés.
Cette espèce se trouve liabituellemeut dans les terrains à lignites du Soissonnais el de la Champagne; elle est longue de 65 millim. et large de 40.

40. Huitrue couleuvice. Ostrea colubrina.

O. testâ elongatâ, angustâ, arcuatâ, plicatâ; valvis semi-complicatis, dorso carinatis; lutere exierno convexo.

Knona, Petrif. 4. part. 2. d. II.pl. 58. fig. 5-7.

LАмк. Anim sans vert. tom. 6. pag. 216 . $\pi^{\circ} \cdot 10$.

L'Huitre couleuvrée a beaucoup d'analogie avec l'Ostrea carinata; on la distingue cepeudant au premier apercu par ses plis transserses, qui sont constamment plus gros et plus obliques, du reste, la forme de la coquille est la wếrae; elle est en conséquence fortement courbée dans sa longueur, comprimée sur les côtés, attćnuće vers son exirémité inférieure, et obcuse ou subtrouquée à son exłrémilé supérieure; les valves sont tort épaisses, anguleuses, et c'est de l'angle que naissent les plis trunsverses et obliques qui descendeut sur les parties lutérales du test; ces plis sont très-carénés, ont l'angle trauchavt, et produisen sur le bord des valves de grandes dentelures triangulaires et trc̀s-aiguës qui se reçoivent: réciproquement; le nombre de ces plis transverses est à peu près mailié maindre dans dos individus de même taille que dans l'espicece suivante; les crocliels sont obtus et presqu'égaux; leurs ialons peu prolongés complètent leur ressemblance.

Cette espèce se trouve dans la craie, dans les mêmes lieux que l'Ostrea carinata, mais elle y est plus rare. Elle est longue de 95 millim., non compris la courbure; elle a 50 willim. d'épaisseur, et 30 ou 35 de largeur vers le milieu des valves.

\section{Iuitae carinće. Ostrea carinata.}

O. testâ oblongâ, utrinquè subacutâ, lateribus complanata, arcuatâ; valvis complicatis, dorso curinatis; plicis transversis, tenuibus.

Evcrci. $p l .: 87 \cdot f g \cdot 3-5$.

Lамк. Ann. du Mus. tom. 8. pag. 166, et tom. 14. pl. 23. fig. 1. a. b.

Ihid. Anim. s. vert. tam. 6. pag. 216. n०.9.

Non. Descript. de quelques foss. caractéristiques, pl. 13. fig. i.

S werat, Miner. Conch.pl. 365.

Вronc. Géol. des env. de Paris, pl. 5. fig. II.

Cette coquille très-remarquable, avec quelques autres espèces voisines, constitue une section bien tranchée parmi les Huîlres; la longneur des valres, leurs courbures, les plis nombreux ct 
traosverses qui les courrent, sont les caractéres qui distinguent celte section.

L'Huitre carinée est alongíe, étroite, fort épaisse, recourbće duns sa longueur, ct comaie plice en deux, lorsque, par l'äge, tlle a pris tiut b $\diamond$ accrissetuent; elle est très-aplatie sur les cótés, cc qui, joint à la carérie non caubaliculée qui forme l'angle des valves, constilue les caiaclères yui, au premicr abord, distinguent cette espere de celles qui l'avoisinent. Le sumuet est le plus souvent I ronqué, el quelquefois a ccompagué d'une petite oreillette sur le côté antéricur : du summet part une cıélc longitudinale liès proéminéale, qui suit toule la longueur des valves el les partage en deux parties presçu'ígales, en parcouranı leur courlure. Cette carène donne baiss.nuce a un grand nombre de plis diveruens el latciraux, un peut obliques, quelquefois perpendiculaires, dont le nusbre valie suivant láge des iadividus; ils sont furtemed anguleux, et, en aboutissint sur les houds, ils y produisent de nombreuses dentelur's triaugnulaires et très-aiguës, sewblables à celles d'une scie; ces plis sunt stricis latéralewent, quelquefois d'une nanière régulière; les valves sont extrêmement épaisses, et l'aniual n'y occupoit qu'une lorte petite cavilé. Daus un individu dont les valves rémuies out d'uoc carène a l'autre plus d'un pouce d'épaisseur, la cavité de l'animal a à peine deux lignes de profondeur; l'inupression unsculäirs est assez graude, latérale, ovalaire, placée Irès-haut près de la claarnière; sur la valve supérieure, le talon présente une goutrière obl:gue el profonde, et sur l'inférieure un Lourreler tyalement oblique, correspondabi a la goulliere cle l'aulue valve : ces parties finement striées els liavers domnoient allache au ligament.

L'Huitre carinée se trouve, à ce qu'il parnîl, exclusivement dans la craie glauconiense : on lia rite à Rouen, dans la craie de la Touraine, à la perte du Rlıône; en Belgique, aux envirous de Alons; en Angleterre el en Sianie, pres de Christidna.

Cetle espèce est longue de i 2 rentim. la cour1 ure comprise; elle a quelquefois 70 milliusctres d'épaisseur, et elle a environ jo willim. de large vers le milieu des valves.

$\dagger \dagger+$ Espèce dont le crochet est élev'é en dessus ou tourné latéralement en spirale (geure Giyplée La

\section{CARACTERES GEXERIQUES.}

Coquille inéquivavle; la valve ioférieure graade, concave, teruince par un croclset suillant, ccnibé en spirale involute; la valve supérieure pelite, plane el operculaite; charriete sans dents; une fosselle cardinale, oblongue, arquée sous le cruchet pour le ligarient.

\section{L I}

42. Huirse colowbe. Ostrea coluinba. Las:s.

O. testu ovato-rotundatô, dilutati, pmfundt, gibbosissimâ, glabri; umbonibus minmmis, retortis, lateralibus; cardine simplici; lisamento luteralı.

LamK. Anim. sans vert. tom. 6. pag. 198. $n^{\circ} .2$.

Konn, Petrif. part. 2. D.3. pl. 6\%. fig. 1. 2.

Suw. Miner. Cunch. pl. 383. fig. 1. 2.

Brogx. Géol. des env. de Puris, pl. 6. fig. 8. a. b. . .

Coquille renarquable sous plus d'un rappori, pouvant être cunsidérée d'un cóté comnae an des points extrêmes de la grande série des Huitres, et, d'uue autre, comme présentaut, par la josiliou du ligarment, des analogies avec les Canaes: analogies assez élcignćes au resle, puisçue les Cames ont deur impressions wusculantes, el que celle Gryplée n'en a qu'une.

La Gryphée colombe est une grande et be!le corpuille ovaluire, arrondie, un f'u plus lenglie que large, à valve iulérieure profunde, tièsconvexe en telıors, et très-bossue surlout vers le erochet. Celui-ci est plus on unoins grand, selun les iuclividus; il est saillant en dessus cu bord cardinal; il se conturne lalíraleuscut, ch if firme un lour ou na lour el demi de spire; il se lat aine par une poinle assez aiguë, sur laquelle cu trouve lunjuars une lace de íadlicience cte la cogrille dans le jeune äge; le rrochec est turjiru.s iullécli sur le cirlé antérneur de la coguatle. Ceile. ci est inciguilatérule; le cólé antéricur est le plus court, et il présente constannacrit ane sinuosité peu profunde, yai lorase d'une parric ua lobe arrondi. La valve supérieure est plithe, opercilliturme, furt épaisse aux bords puslerieur el supérieur, mais tres-mince dins toul la reste de sun élendue; inclinée obliguement vers le livpu antéricur de la mêne aınière que celui do la valve iulćrieure, son crocher lair atussi un torr c un t:ut et deni de spirale, uais il n'es proit:t saiblant, el il reste compris dans l'épaisseur de ba valve. En dehors celle vialve est marquće, surtou: sur le cólé postérieur, de liney stries lanelleuses; en dedaus elle est lise, d'un blanc subnacré, et on voit, sur fe cólé antérueur, une inpression musculaire d'une taille médiocre et pét prolonde, le bord cardinal présente une gouliter trangulaire, décurceste sur le lourd ublique, et commençual au soumet; elle est burmée a l'sttéricur par ua pelit bourrelet saillant qui la suit dans sa lungueur; une guntière seublable se von sur la valve iulárieure, seulenent elle est plus profonde, domince el en fartie cachée par la saillie du bord externe, de sorte yue le ligament devoil ctre pou: ata:i dire eucuissé, et purvitite peu à lexlérseur.

On tronve quelduefois des individis de cette 
coquille f́counas pour la conservation de leurs couleurs. Ces couleurs consistent en lnngues hammules onduleuses, érroilıs, longiludinales, bifurquées, irrégulières, d'une couleur orangéerougeảtre, passant quelquefois vers le brun sur un fond blanc. Nous avous vu plusienrs individus culurús de celle wanière; tuais ce qui nous semble siugulier, c'est que la valve supérieure restoil véaumoins toute flanche, ce qui uous porte d cruire qu'il en étoit de mêune pendant la vie de l'animal.

L'Huitre colombe est répandue très-ibondamment dans presque tous les terrains de cruie, mais cunjours daus la craie tulfan ou inférieure. Il n'est presque poiat de localité de ce termin où l'un ne la rencontre, suil en France, soit en Allemagne, soit ea Angleterre. Elle a 8 ou 9 centiun. de diamètre.

43. Hoitne dilatée. Ostrea dilatata. Sow.

o. testâ ovato-rotundâ, dilatutâ, subdepressâ; valvầ infenore convexâ, classá; superione operculiformi, concavâ, lamellosá; umbone magno, pralongo, valdè recurvo, culceiformi, tripartito.

Sow. Miner. Conch. pl. 149. fig. 1. 2.

Noв. Descript. de quelques foss, caractéristiques des terrains, pl. 8. fig. 7 .

Var. B. Noв. Testâ profundiore, angustiore; umbone nuagis recurvo.

Var. C. Nuв. Testâ sublobatâ, depressiore; umbone longissimo.

Nous pourrions ajonter encore quelques varielis, car celle coquille prend des lormes assez. diverses; tantôl elle esi profonde, Irès-convexe en dissous, et son crochel, fortement relevé, se recourhe au-dessus de la charnjère de manière à la cacher; d'auties fois ce crochet se prolonge en un long talon peu recourbé, bien semblable par sa structure a celui de certaines Huitres; quelquefuis la coquille, lrés-aplatie, est plus ovalaire; finelyues individus enfiu, oulıe qu'ils sont plus cuurts et plus ípais, ont le croclies saillant en dehors du bord cardinal, el mon an-dessus de lui, comme cela a presque toujours lieu : le prolongeurent du crocliet de la valve inférieure de cette corjuille, sa forme. la manière donl le lingament y ćloit plucé, la moditication qu'il a fail ćpouver a celui de la valie supérieure par sa courbure, loul dénonıre sa grande analogie avec les Huitres. Sil'on courbuil de la même inanière que daus celle Gryphice le talon de l'Ostrea crassissima, on ol)liendroil use Gryphée don! le crucsel seroiı ıou seablable a celui de celle espece. La valve inféicure, grande, concave, épaisse au crochel, devient plus ınince et se dilite vers le hord inféricur; elle est inéquilatétale; le cóté antérieur vers lequel le crochet s'inlléchit an peu est le plus ccurı. Le crocliet esi grand, saillant, recourbé, presque perpendiculairement au-dessus de la charuic̀re; dass quelques individus, le sommet du crochel est trongué par suite d'une adhérence plus ou moge. Ensins la dessous du crochel el ile soo sommet nait une large et profonde goutliere. striće régulièrement dans sa largeur; sa forme esl triangulaire, et sa base, plus ou moins clargie, est sinueuse latéralement; celle surface est pautaźcéc en trois parties, une aćdiane, large et profunde, et deux latérales plas étroiles et plus superficicl!es; la valve supérieure 'st plane, assez souvent concave an-dessus el convexe en dedans; ses borl. supérienr et postérieur son: les plus épais, le supéricur surroul, qui comprend la charmitice, si. quiert une épaisscur considérable : il est le plus ordinairement à angle droit avec le plan horizout:l de la ralve, et assé fréquemment aussi cet angle est ouvert, de sorte yue le plan du talon, :u lieu d'üre à peu prés horizontal, devicut perpendiculaiie. Ce talon de la valse su prérieure esi parlaugé en trois parties, qui correspondent a celles de valve inféricure; mais ce ciui est tres-remarguable dans les individus no peu vieus, c'est gue la pratrie moyenue fait une saillie en deliors du bord, du maviere a devenir comparable a la grande slent des Myes. A l'intérieur celte coquille est lissé et polie; ress le nilieu, on voil uac jupressinn musculaire, arrondie, peu profunde, gquelquetois rugneuse el covverte de potits tubercules, dont quelques-uns prennent sisuvent la lorme el lit disposition des perles. En dehors l'une el l'aulre valves sout irrounlicrement lanielleases, el les lames sont p:lus serries sur la valve supribienre. On rencontre celle coquille en abondance daris les argiles du Havre el d.ıns presque toules ceiles ๆui sont de la unêue époque róologique.

Les grants individus on 11 ou 12 centincitres de longueur.

44. HOÎtвE arquée. Ostrea urcuatu. Lask.

O. testá ovalo-oblongì, valdè recurvi, subsymetricâ, apice obliqun, trunswersim nigosí, "mtice sublobalü; unco magno, ir.torto, regulari : valva superore mininu, operwlari, plana.

Gryphace arcuatu. L.ssx. Anim. sans sert. torr. $6^{\circ}$ pag. $198 . n^{\circ} .4$.

Gryphcea incurva. Suw. Miner. Conch. pl. 11:. fig. 1. 2.

Pasxissos, Organ. rem. tom. 3. fug. :00. tab. 15. fig. 3 .

Bodnguet, Pëtr.f. pl. 15.fig. 92.

De Br.arst. Malacol. $p l$. $5 \mathrm{~g} \cdot \mathrm{fig} \cdot 4$.

DEF. Dict. des Scienc, nat. tom. 10. pug. 5̇

Coquille Irès-commune, dont la lurace régulière, fortement arquée, el en apparence syuctrigue, se rapprocbe assez de celle de cetrairs nautiles; mais c'es! Ja seule ressemblance jue l'ua 
puisse lui troover avec ce genre. Cette coquille est ovale, oblongue, déprimée latéralement; la valve inférieure, très-grande, est régulièrement arquée; sor somalet, puiatu, est fortemeal incliné en dessus, contourné en spirale, et osontrant uce très-petice surface d'adlićrence; il s'ipcliue obliquement vers le cóté antérieur. Ce cuté antérieur est iudiqué par une sinuosité plus ou moins profonde, selon les individus, re qui le sépare en un lobe semblable à celni d'autres espèces. (ee lobe est étroit, el, outre le sillon longiludial qui le sépare, il est indiqué par la sinuosité qu'urfrent les stries d'accroissement. La surface supérieure du crucluet présente un espace triangulai:e, élroil, linement strié en travers, trilobé, donnant attache au ligament, et indiquant ses nombreux accroissemens. Le bord inférieur de celte surlace est sinueux, de manière à recevoir exucterseut le talon de la valve supérienre. Aulani la valve inférienre est grande el bombée, antiant la supérieure est petite, aplatie et opercaliforme; elle est ovaJaire, subcarrée, peu épaisse, le plus suuveut conrexe en dedaus et concave en dehors. Le hord supérieur, qui n'est guère plus épais que les autres, est tronqné et coupé en ligne droite, avec une légère saillie médiane, qui le rend un peu sinuenx; cette saillie correspond à la base de l'cspace triangulaire fort court qui donanit insertion au ligament. Celte surface triangulaire est simple, non irilobée, striée en thavers, et circonscrite de claque côté par na sillon assez prolond. La surtace intérieure est ondulcuse, lisse et polic; un remarque sur le côté antérienr, fort près du torrl, une petite impression musculaire arroodie ei saillunte; en dehors cetle valve est couverle de siries conceutriques qui indiquent les accroissemens; ses bords sont épais, conpés perpendiculairemen,, si ce n'est dans le jenne âge qu'ils sont miuces. l.a surface extérieure de la valve inférienre est, comme la supérieare, couverte de silits d'accroissement ardinairement lamelleuses, el se chargeäut quelciuefois en silloas plas on Havies réguliers, ce qui constime une valiéié assez constante dans l'espèce. La cavité intérieure de la valve inférieure est petite relativeneut à sa gran. deur; tout le crochet est rempli pir la maticre calcaire qu'y a déposée l'animal, de surte que daos Jes grands et vieux individus, celte partic du test occupe les trois quarts de son épaisseur; en'dedens, elle est lisse, et elle présente une impres sion musculaire semblable à celle de l'autre valve.

L'Huitre arquée est une des coquilles les plu: communes que l'on conroisse; tile se irouve daus ceriains lieux en telle abondance, qu'elle ser: à parer les routes; el!e est éminemmeat ra. ractéristique de la lormation du liais ę des argiles, qui l'accompagne. Partoul en Enrope vi: celle formation a été ouservée, on y a rencoutr: la Gryphée arquée. Nons paurrivis citer cin. qquaute localités où on la troove eu liance, e: nous pourrions facilement angmenter celle liste de celle bon moins nombreuse d'Allemarne tt d'Angleterre. Longueur 70 millim., largeur 45.

45. Hoitas de l'Adelaware. Ostrea ameriсатис. Ков.

O. testâ magnâ, oıbiculatá, subtùs convexissima, superne plund; valya inferion extús lumeblosia ; lumellis distuntibus, undulatis, tenuibus; umbone magno, valde netorto, luteruli; valvs superione pianâ, transversin tenué lamellosî; umbone depresso, spirato.

Très-belle espèce d Huitre appartenant ì la sectiou des Gryphées, et se rupprochant beancoup par sa lorme du Gryplacea columba el autres espèces voisines; elle est très-graode, à test épais, solide; sa lurme est orbiculaire, très-convexe en desscus, plane en dessus. La valve iuférieure, de beacoup plus grande que la supérieure, esl très-couvexe en dessous; bon crochet, grand et proéminent, se reaverse sur le cóté, oì il se tourae en spirale; la surlace extériejue est obsruréuent plissée dans sa longueur, et constamment couverte par un assez graud nombre de lames transverses suillantes, onduleuses, 1inbriquées, et assez distantes entrelles; la sur:face supérieure da crocliet est réciuite co uz: simple guntiere trus-oblique, comprable a relle de la clarnière des Cames, dans layjuelle cependant un retrouve les parties qui consituent celles des Iluires, parties qui ont suli des modilionlions dépendana de la lurne el du renversumo: du crocliet. Ainsi, on y reironve nue grouniirte médiane suivie de claque cóté par un bumreiet dont l'extćricur est le plus long; la groutiaère est érroite et profonde, elle reçoit un hourrulet correspundani de la valve supérieare, comme nous avons va que cela a voit liea daos toutes les Huitres. Ja valve supérieure est aplatic, operculiforue, concave en dessus, légerenicat conviate en dedans; sa surface extéricure est claargée d'nia très-garand nomise de lames conceutrigues irrtgulieres; ces lames sunt fines, trés-ralprochét et saillantes, surtcut vers les bords. Le crociset, forleumat tourué en spiraie, est engagé da:s l'épaisseur de la valve, et ne tait aucune saillie sur le bord cardinal; celui-ci prćsente une surface ablique, suhtrianguluire, assiz epaisse, cretstic ea gontlicre, el Lonte inferieurement par une callusilé décunente, strice en travers, qui s'enrane dans la cavité de la rilve inférjeure. La sarfuce interne des valves est lisse, lígirement lowseléc; un y remarque, a la paric mojeme et supéricure, anc grande impression nusculate orticuiaire, superticielle dans la valve inférieurc, assez prolon de dans la supérieure; les lurds sumt simples, tranchaus, queiqueluis cenx de la vilve supériture reibvés intévilurer.ent. Cente grance

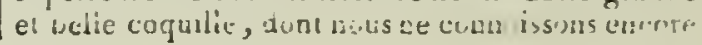


que les individus que nous posséduns, a été tronvíc daus les creusemens du canal, entre SainiGeorge et Philadelphie, dans l'útat de Ladelawire, Amérigue septentrionale. Elle a I 2 cent. et demi de diamètre et 65 millim. d'épaisseur.

D'après les reuseignemens que nous avons eus, et surtout d'apres li nature tu sable qu'elle contient, nuts croyons que cette corjuille est terliaire.

Nов.

46. IIvitre grypluoide. Ostrea gyphoides.

O. test $\hat{\jmath}$ ovat, utrinquè planulat $\hat{\hat{s}}$, supernè concavi, lateraluter valdè contorti, longitudinaliter plicalá; valus superiore concavi; umbone depresso, spirali.

Nов. Dict. class. d'Hist. nat. tom. 8. pag. 38g.

An Ostrea plicata? lasus.

Il est bien certain que celte coquille et quelques autres qui lui sont anilngues font le passage entre les Ifnitres propreuent dites et les Grypluées : dans ce deruier genre il est des espèces qui, avec la valve inlérieure très-grande, ont les crochets inclinés latéralement el celui de la valve supér:eure evgagé dans son épaisseur, tout eu farmant une spure quelquelisis de plus d'un eour; dans la copulle qui nous occupe les deux valves étant très-aplaties et les crochets élant tortemert inclinés, sont en wagís dans l'épaisseur du lest dans l'une et l'autre valve. Cutte espece est ovale, oblongue, arquée daus la longueur; da valve iulérieure, piane en dessous, ordinuirenient adliérente pur nne très-large surface, a son hord supérieur relevé presque perpendicul. ircinent; elle est plus grande que la supérieure; son cruchet, fortement iucliné sur le bu:d antérieur, s'engage dans l'épaisseur du lest, et lorme environ un tour e! demi de spirc. Extérieurement, celte valie est converte de gros plis irréguliers, flus on moins largement espucés, génćrálement peu saillans; its renden les bords onduleux; la valve supérieure est plane ou concave en dessus; son bord supéricur, heaucoup plus épais que les autres, est onduleux dans sa fonguenr", fortement a:qué, sc terminaut par un crocbet fortement spiré, et ne dépassant jamais l'épaisseur du tes!: eu deliors celtc value est irrégulièremeut plissée dans sa longuenr. La charnière consiste pour l'une et l'autre valve en une goutière longue et érroite, arquée, loornée en dehors par la saillie du bord, et en dedans par un petit bourrelet décurrent. L'inlérieur des valves est lisse; l'impression musculaire que l'on y voil est grande, latérale, légèrement creuscé dans la valve supérieure et superlicielle dans l"inlérieure.

Cette coquille se trouve aux environs du Mans, dans la partie supérieure de la furnation nolitigue; elle est longne de $9^{5}$ millim. et large de 80.

Hist. Nat. des Fers. Toun: II.
47. IIvitre uni-angulaire. Ostrea uniungularis. Noв.

O. testî elongato-ovati, angust $\hat{i}$, profundí, infernè uniangulati, supernè planâ; umbonibus minimis, lateralabus, valde contortis.

Cocguille ovale, oblongue, dont la valve iuférieure, beaucoup plus grande qne la supérieure, est trés-épaisse, arquée dans sa longueur, et carénée dans le milieu du dos; celte carène abtuse s'étend du crochet jusquà l'extrómité inférieure, et partage ainsi en deux parlies presque égales la suiface extéricure de cette valve. Celte surlace est presque lisse; on y remarque cependant des stries irrégulières d'accroissemeat pru proéminentes. Le crochet est assez grand, légèrement relevé à sa base, et fortement incliné latéralement à son sommet, qui produit noe petile saillie en dehors et qui présente une petite surface d'adhérence. La surface cardinale de ee crochet esi inclinée comme lui; elle est triungulaire, conrte, crensée an milieu par une gon:iière assez large, bordée de chaque côté par un pelit bourrelet très-étroit, dont l'externe est beaucoup plus court que l'autre : 'cetle surface est striée en travers. La valve supérieure est operculiforme, lamelleuse en dessus, à bords minces, si ce n'est le supérieur, qui s’épaissit en un talon obligue continué en un crochet un pen spiral el aplati; la surface interne des valves est lisse; l'impression musculaire que l'on y voit est latérale, arrondie et superficielle; dans l'une et l'autre valve les bords sont simples. Nous re savons d'où vient cette espèce, qui fait un passage bien évident entre la seciion des Huitres gryphoïdes et celle des Gryplices proprement dites. Elle est longue de 75 millim. et large de 50.

\section{Iuitre italique. Ostrea italica. Nов.}

o. lestâ ovatî, gibbosî, convexâ, cymbiformi, profundu, sublovigat $\hat{y} ;$ umbone magno, supernè recurvo; fossuli cardinali depıessî, triangulart, striati; marginibus integris, aculis, supernè granulutis.

Ostrea navicularis? Broccar, Conch. subap. tom. 2. pag. 565. no. 6.

Il est tiès-probable que cotte coquille, qui nous a été comraniquée par M. Bertrand Gésin a son retour d'llalie, est l'espèce décrite par Brocchi, la descripliun de l'auteur italien correspondant assez exactement aux earacières qu'elle présente. Elle est ovile, oblongue, à valve inlérieure beancoup plus griande que la supérienre, très-convide en dessus, cuncave en dedians, se terminant supérieurement par un croclet arqué relevé en dessus de la charnière, teujonr's tron. qué abliquemert par une surface d'adbérence plus ou moius Jarge, ordinairement d'une petite

$\mathrm{Q}_{\mathrm{I}}$ * 
citenlur; ce relevement du crochet rend perpendicnlaire la surfuce du talon, comue cela a lieu dans le plus grand nombre des Gryphées vérit.bles. Ce talon est court, triangulaire, creusé d'une goultière superficielle accompagnée de cliaq̧ue côté d'un bourrelet très-aplati, limité par' un sillou de peu de profondeur; la surface extéricure de cette coquille est prestue lisse; les stries d'accroissement que l'on y aperçoit sont rares, ̀̀ pcine lamelleuses et jamais suillantes. La valve supéricure est toujours concave en dessus; ses bords sont furtemeat relevés, ce qui lui permel de descendre assez profundément dans la cavité de la valve inférieure; elle est presque lisse à l'extérieur, rarenent foliacée ver's le bord inférieur; à l'intérieur les valves sont lisses, polies. Limpression musculaire qu’elle présente est sublatérale, petite et très-superficielle.

Cette coquille a dans sa forme el ses caractères de l'analogie avec les jeuoes individus de l'Ostrea. dilatata (Gryphoea Lamk.); mais on reconnoit facilement qu'elle appartient à une autre espèce : quoique dépendant du terrain terriaire, elle doit donc Taire partie des Gryphées proprement diles. Elle se trouve dans les argiles du Plaisantin. Sa longueur est de 80 millim. el sa largeur de 60.

49. Huitre en bameçon. Ostrea uncinata. Non.

o. testâ ovato-angustâ, infernè gibbosâ, convex $\hat{i}$, supernè plani, lovigatí; valv $\hat{a}$ inferiore convexia, recurvi, unbore maximo unciformi retorto terminatá; valvi superiore planí, substriatâ.

Noв. Descript. des Coq. foss. des env. de Paris, tom. 1. pl. 47. fig. 4. 5. 6.

Déjà nous avons renarqué une espèce d'Huître d'ltalic appartenant aux Gryplées proprement dites : celle-ci plus quaucune antre duit en faire partie, car par sa forme elle se rapproclse de l'Ostrea ancuata; elle est particulière anx environs de Paris. Elle est orale, ollongue, étroite; ses valves sout très-inégales; l'inférieure, fortemeat arquée dans sa longueur, est très-convexe, atténuée au sounuet, terminée par un trochet très-grand, fortement relevé au-dessus de la charnière et inclinés sur le côté antérienr. La surface extérieure de certe valve est presque lisse. Son crochel a une surface plane en dessus, fortement relevée, subtrilobée, striée en travers; cette surface donnoit attache au ligament. La valve supérieure est petite, suborbiculaire, Irèsplane, mince vers les bords, un peu plus épaisse supérieurement; de ce côté supérieur elle montre une petite surface triangulaire, un peu oblique, striée en travers, qui correspond au talon de la valve inférieure. L'intérieur des valves est complétement lisse; elles offrent une impression musculaire, sublatérale et inférienre, petite, ovalaire, longitudinale; la cavité de la valve infé- rieure se prolonge un peu sous le crochel; les bords sont simples, ainces et tranclauns.

Celle coquille, excessivement rare aux environs de Paris, ne se trouve qu'à Valmondois. Elle est longue de 40 millico. et farge de 23.

5o. IIvitre virgule. Ostrea virgula. Def.

O. testâ elongatâ, angustâ, apice contorto spiratâ, valvâ inferiare gibbosâ, dorsatâ, longitudinuliter striatâ; striis undulalıs, irregularibus; valvâ superiore planâ, sublovigatâ.

DEF. Dict. des Scienc. nat. art. Huitne.

Nов. Descript. de quelques Coq. caractéristiques, pl. 5. fig. 12. 13.

L'IJuitre virgule es! une pelite coquille olslongue, étroile, oblique, coutournće au sormet, lequel, en se tomaant eu spirale, est projelé en dehors de l'axe lungitudinal du test. Ce contournement de la partie supérieure donne assez bien à cette coquille la forme d'une virgule. La valve inférieure esl convexe, bossue, assez profonde, montrant vers le cruchet des points d'adhérence. Le crochet, assez grand, est peu saillant au-dessus du bord; il sincliue fortement sur le côté antérieur, et lait un tour de spirale visible platót en dessous qu'en dessus. La valve supérieure est plane, quelquelois même elle est concave en dessus; elle se contourne comme l'inférieure, elle est seulemeat plus courte, et son crochet, quaigue tourné en spirale, ne fait point saillie tn deliors: comme l'inférieure, elle est ornée de stries longitudinales, mais beacoup moins prononcées. Dans un assez grand nombre d'individus ellessoat ì peine visibles à l'oil uu. Les stries de la valve inférieure sont nombreuses, serrées, onduleuses, irrégulières, quelquelois interrompues ou plicilormes; le crochel en est souvent déponrva; des accroissemens irrégulièrement espacés formeat, surtout sur la valve irférieure, plusieurs étages. La clarnière, sur l'une el l'aurre valve, consiste en une goutlière triangulaire, peu profonde, oblinue, larye à la base, donnant inserion au ligament : celle goultière est bornée en dedans par une côle sai!lante, obligue, et ('n delsors par le bord de la valve, yui la domine. Le test est épais, surtout sous les crochets; il est lisse en dedans, et présente vers le milieu de la longueur et presque toucliant au bord antérieur une petite impression musculaire, seni-lunaire ou ovale, peu profonde.

Cette coquille se trouve en Frauce, dans les marnes inférieures à la craie. Elle est longue de 20 à 25 million.

51. Huitra gondole. Ostrea cymbiuns. Lasr.

o. testâa ovatâ, subøquilaterâ, ad apicens acutâ, recuvvâ, angustâ; valvâ inferiore valdè convexâ, aliquantisper subdepressấ, dilatatá; 


\section{Ii L I}

alterü concevi, tenitier transwersim strati; cardanc angöuslo, in utrûyue valvó trilobato, lrianb'tiluri.

Grophara cymbium. Laus. Anim. s. vert. tom. 6. prag. $193 \dot{3} \cdot n^{\circ} \cdot \overrightarrow{5}$.

Kisunu, Petrif. part. 2. B. 1. pl. 20. fis.7.

l: c:cs. $p$ l. 189 . fig. 1. 2? Mala.

ínв. Descript. de qualques Foss. caractérisristiques, pl. 12. fig. 1.2.

lisprece bien dislincic de lontes relles ciu méne genite. Llluitre gondole se reconudit it sa forme crale, trigone; clle est presepu'ćcpulatírule, et sin crochet priutu se recourlue au-dessins de la charnito saus jatsisis la cuavir. L’extrémité de ce croulat priscule loujours une surface d'arbéreace filus ru moius large, quelquefois a peine perceptible. la valve inlúrieure est plus ou morins cunvexe, selon les individus; elle n'esl pus riesépaise, nême sous les crochels, ce qui n'a pas lieu ditus le plus grand nombe des espèces; la lice interne du crochel cst ocinućc cu entier par la at:arnière, qui sllie, comane dans toulcs les Hritres, un talon trilolí. La goutièe occupe le valieu; elle est piofonde, lrigone, et unssi large a tlle seule sue les deux buurelels qui l'accompantucot. Celle goulliere et ces brurrets sont actieraent séparés du burd par un sillon rirvil, el lort régulièreutent strés en travers. La valve suprieure est ovale, rigrone, plus courte que 1..rile; elle cost concave en dessus, el so: terinine eti privle au somolel. Ce sommet est occupsos, c.mume dans laume valve, pirr lis sillons dic lat charaiere. Las surlace extéricula de celle vislve c'st est occupée flat un żrand nombre de slries régnlicres, concentripues, lransverses, el qui se niul1i,l:eni, surtout ver'sles burds. Ces stries sont, dans le plus grand nombre des individns, interrompues far des accroissenens irrégulicrs. A l'inlérieur la coquille est lisse, et ne présente jamais, comme dans l'Ostrea dilatata (Griplecea Lamk.), cel élargissenuent supérıeur occasıonné par l'accruissemcut de la coçuille. On retrarqque sur l'une e: l'iutre valve une imp:ession musculaire orbiculare, latciale, antérieure, superticielle dans la valve iulciseuse, bealucoup mieux marquée dans 1. supériture, élanı enluulíc d'un bord saillant.

Ceile cuquulle se rencontre assez communéda:ss loulite supé:ieur, en France, anx eovirons de Cien, et eo Angleterre. Elle est longue de 9 i 10 centim. es large de 7 .

52. IIciтresublobée. Ostrea sublobata. Ni в.

o. testá ovato-elongatá, irregulari, anticè sublobata; walva inferiore magna, crassa, umbone obluso, valdé recurvo, terminati; valvâ superiore plańá, operculiformi, irregulariter lame!losá; inipressione musculari parvi, projuniá.
Cuquille covale, oislongue, peu rénlière, voisine, pur ses rapports, de l'Ostrea arcuata, inais ayant le crochet plus oblus et moins crand. La ralve infíreure, ròs-épuisse, est divisće ea deux lobes inćnaux par une dépressinn latérale antćrieure, qui descend au boud inlérieur; sil surface extérteure, tres-counrese, est iuc'culierement bosselée el irrógulièrement \&lagke par dos accroissemens : le croclet, qui la termine sugi rieurement, rost relevé au-dessus de la charuicre; il est Irès-ublus; sal surface sujuéricure cst or'cujúc par une rigole médiane, étroile el asscrz pulunde, Loriće de claciue cólé par un petil bourrelet aplali. Ja valve supérieureest opercnlifunac; ses accroissemens et les lames qui en résullent sunt plus nombreux que ceux de la valve infúrienre; son liord supericur est oldiquement trouqué, el la subface qui en résulie, subrrilubce et triangulisite, correspond il la surlace cardinale de l'aulle rulve. A l'incericur, la coquile est lisse; dans la valve inféricure, l'impression musculitice, siluíe à sa partre médiane est cxlerne, prufinde, pelite, arrondie, cu légc̀recoeut inclinée; ce!le de la valve supérieure est superficielle, et ses boris sunt seulement un peu boursotiflés; les burds sont simples, trunchaus i la valve inlé rieure, épais el oluhus à la supéricure.

Celle copuil'c se trouve dans l'oolite fermonineuse inférieure; wais il paroit quelle y cstrare. Sa longuear est de 80 millimètres et sa largeur de 50 .

53.). Huitre angraleuse. Ostrea angulata. Iosy

O. testi oblongo-ovati, subtis costis trious longiludinalibus angulato-cainatis instruct. violuscente; unco magno, subobliquo, retorio; impressione musculari violuces.

Gryphrea angulata. LAvis. Anim. s. vert. tom. 6. pag. $198 . n^{\circ} .1$

Coquille rarissime, diapres Lamarck; la seule des espicres de son genre Gryphée qui soit connue il'élat vivant. On n'a encore vu de cetle coquille que deux individus complets; l'um dars la collection da Muséum, el l'autre daus celle de l'Eicole des mines. Nous en possédons quelques vilves inférieures; elles sont fortement arquies, très-convexes en dessous, bossues, plus ou moius régulières, très-prolondes en dedans, se teruinant par un crucliet for' grand, relevé, contourné sur le róté antérieur, présentant, comme dans toutes les Givpliées, une surface supérieure cardinale, striće en travers, creuséc d'une gouilière médiane, lacjuclle est accompagnée de chaque cóté d'un bonrelet asse $z$ saillan et étroit. En dehors, cette valve inléricure présente, dans ie milieu du dos, 1 ruis fortcs carènes, anguleuses, irréguiières, qui décuapeat le bord en trais plis inégaux. La valve supérieure est operculiforae, concave en dessus, fuliacce, lisse en dedans; $\mathrm{Qq} 2^{*}$ 
scs bords snnt simples, traachans, ayant trois ondulations inférieuremeut pour s'interposer duns les plis de l'autre valve. A l'intérieur les valves sont blanches, sobnacrées, teiotées de violet, ayaut antérieurement une petite impression musculaire constamment violette. On ne sait quelle est la patrie de celte coquille; on nons a assuré cependant qu'elle venoit des environs de Bayonae. L'individu de la collection du Iluséran a 1 décim. de longueur.

\section{HUITRE ÉPINEUSE.}

Nom vulgairement donné par les marchands aux coquilles du genre Spondyle et à quelquesunes du geare Came. Voyez Spondre et Cane.

\section{HUITRE FEUILLETÉE.}

Les marchands nomment ainsi la plupart des coquilles dépendant du geure Came. Voyez ce mot.

\section{HYALE. Hyalea.}

Le geore Hyale que Forskal a le premier fait connaitre, maigré les renseignemens quall en a donués, il cst vrai fort obscurs, et sovvent inintelligibles, a été confondu par Linaé parmi les Térébratules dans son genre Anomie. Lamarck, qui, le premier, a séparé en genre les Mollusques qui nous occupent, à l'exemple de Linné, les a laissés parmi les coquilles bivalves, ce dont il est facile de s'assurer en consultant le Système des Aninıaux suns vertébres, publié en 1801 .

1I. Cuvier, dans sca Tableau élémentaire de zoologie, avoit eu la même opinion, quoique Furskal ait dit que ce Mollusque, en considérant sa c squille, avoit quelques rapports a vec les Patelles. Il semble que Bruguière avoit eu la même idéc, car on ne trouve pas les Hyales figurées avec les Anomies, daus les planches de l'Encyclupédie, et il n'ea donne pas la description à l'article Anomies du même ouvrage. Il est possible aussi qu'il les ait préférablement laissées avec les 'Térébratules. Quelque temps après les premiers travaux de Lamarck, 11. Cuvier fit l'anatomie des Hyales; il les rapprocba alors des Clios et autres genres analogues, et en forma une classe particulière soos le nom de Ptéropodes. Dès-lors on ne dut plus avoir d'hésitation sur la place du genre; on n'en conserva que sur la manière dont on envisageroit la classe ou l'ordre nonvean. M. de Roissy, le premier, daos le Buffon de Sonnini, a adopté ce nouvel arrangement, que tons les zoologistes modernes ont également suivi. Voyez P'téraPODES.

Lamarck a $\nabla u$, dans ces Mollasques, an type particulier d'organisalion, ce qui les lui a fait envisager comme un terme moyen ou de transition entre les Mollusques conchifères et les Mollusques propiement dits. Cette idée, qu'il mani-
Testa d'ajord dans sa Philosophie, il la conserva dans lous ses autres ouvrages.

Pérov et le Sueur, auxquels on doit une monographie de ce genre, publiée avec figurcs dans le tone XV des Annales du Muséum, ajodtèrent quelques fails nouveaux sur l'organisation des Hyales; mais ils en rapprochèrent à tort quelques genres qui sonı étrangers à cclui-ci. M. Cuvier (Règne animal) divise les Pléropodes en deux suus-ordres, ceux qui ont la lête distincte, et ceux sans la tête distincte. Le genre Hyale, $\dot{a}$ lui seul, forma celte secoude division. Les iravaux de M. de Blainville sur les Ptéropotes, et surtout son article HraLE, daus le Dictionnaire des Sciences naturelles, sont venus infirmer, d'une manic̀ı lort puissante, les opinions reçues jusqu'à ce jour sur ces Mollusques. M. de Blainville en donna la description la plus complète; il en fait connoître avec détail tuntes les parties, et il a occasion de rectifier plusieurs faits mal vus par Péron ct le Sueur, et par M. Cuvier lui-même. C'est ainsi qu'il fait voir qu'on avoil éludié l'animal renversé, c'cst-à-dire que l'ox aroit pris la face dorsale pour la veatrale, et celle-ci pour la dorsale, ce qui rétablit, dans l'ordre ordiuaire pour tons le's Mollusques en général, la position de l'anus et des orifices de la génération. M. de Blainville fait remarquer aussi que ce que l'on avoit pris pour des branchies n'en est réellement pas, mais seulement le pied singulièrement disposé prour la natation. Ce dernier tast reste d'autant plus incontestable, qu'un véritable peigue branchial se trouve sur le cóté droit de l'animal, et communique direciement arec le fluide ambiant pal une large fente du manteau. Le cœur, qui est fort gros, est au côté gauclie, en avant des branchies, comme dans tous les Mollusques; il est composé d'une oreilletle et d'un ventricule; l'oreillelle recoit le saog des veiues pulmonaires. Le cœur donue origine par la pointe à un gros tronc acrtique quii se divise presquimmédiatemcnt en deux brauches, l'une antérieure el l'autre postérieure.

Une antre reclification que $M$. de Blainville a faite est relalive aux organes de la genération; il paroitroit que ce que $\mathrm{N}$. Cuvier a pris pour le testicule ne seroit autre chose que l'oviducte, semblable à ce que l'on nomme la matrice daos les Hélices. Il résulteroit de ce fait, aussi bieu que de l'existence du !esticule à la base de l'organe excitateur mâle, que ces animaux auroieut un double accouplement, uo accouplement réciproque, comme celui des Hélices et de beaucoup d’antres Mollusques céphalés : ce qui reporte ceux-ci beaucoup plus haut dans la série. Ce qui doit confirmer davantage celle opinion, c'est l'existence de véritables tentacules, que $M$. de Blainville croit même oculés, sans pourtant l'affrmer d'nae manière positive. Ce qui a pu faire commeltre plusieurs erreurs relativement ì ces 


\section{H U I}

Mollusques, c'est sans doute la forme singulière du pied el du manteau : il étoit naturel de penser que ces prolongemens, ces lanières charnues flotlant dans l'eau, pouvoient porter les organes de la respiration; cela sembloit d'autant plus probable, que la manièce dont on avoit considéré l'animal, à l'inverse de la véritable position, rendoit plus ditficile la recherche du vérilable organe de la respiralion. Le manteau, dans les Hyales, est assez grand, et surtout fort dilatable. et fort rétractile, étant pourvu de muscles puissaos qui le foat rentrer presque complétement dans la coquille. Celte eaveloppe es! fort mince dans sa partie moyenne, où elle est adhérente, et plus épaisse daus les bords y̧ui avoisincal l'ouverture de la coquille. En dessus il se prolonge comme la supérieure, et en dessous comme la lame inférieure de la coquille; il est plus épais sor les parties latérales, où il se partage en deux lèrres qui ne sont poiat leadues. C'est à l'extrémilé pası́rieure de leur réunion qüil existe, du moins dans quelques espèces, une lanière qui n'en est sans doute qu'uo appeodice.

D’après ce que dit Forskal de ce!te partie du manteau, il paroit qu'elle est susceptible, peudant la vie de l'animal, d'une extension considérable, au point même de devenir translucide. Le maoleau n'est ouvert qu’à la partie a alérieure, surlout en dessus et de chaque côté; il n'existe aucune ouverlure correspondanl aux leates latérales de la coquille. Le pied est formé par deux ailes antérieures, qui paroissent nailtre de la léte, qui se Irouve au fond de l'angle qu'elles préseatent : ces ailes, épaisses à leur base, sont trèscharaues; elles reçoivent plusieurs plans de libres destinés à leur contraction.

M. de Blainville, comparant et rapprochant les Hyales des Bollées, a vu dans cette forme singulière du pied une simple modilicaliou gui ne pouvoit détruire le rapprocbemeut qu'il proposoit; il est certain que ce seul motif seroit insuffisant pour combaltre l'opinion de ce savant zoologisle. La coquille mince, translucide et cornée de l'Hyale est formée de deux parties, que les ancieus aoleurs ont considérées comme des valves soudíes; c'est 6ans doute pour celte raison quils les oot placées parmi les Anomies ou les Térébratules.

La parlie supérieure est la plus plade; elle est ordinairement rayonnée par des côtes ou des stries symétriques; elle se prolonge antérieurement en une lèvie courbée, trancbaule, terminéc par uoe ou plusiears pointes; à la partie postérieure elle se termine par une ou deux pointes, selon les espèces. La pointe da milieu est celle qui reste constamment dans loutes; elle est creuse et percée à son extrémité; clle donne insertion au muscle principal de l'animal, celui que M. de Blainville nomme columellaire. Ce genre, qui a été trouvé à l'état fussile, a été caraclérisé de la manière suivante par M. de Blaioville.

\section{CARACTÉRES OEंXERIQUES.}

Corps subglobuleux, formé de deux parties distinctes: la postérieare, ou abdominale, larire, déprimée, bordée de chaque côté d'uue double lèvre du manteau, quelquefois prolongée, contenue dans nue coquille; l'antérieure, dilatêe de chaque côté en aile ou nageoires alrondies; têle non distincte, pourvae de deux tentacules contenus dans une gaine cylindrique; ouverluıe buccale avec deux appendices labiaux décarrens sous le pied; anus à la parlie postérieure de la double lèvre du manteau au côté droil; Lranclıies en forme de peigne du même côlé; termioaison de l'oviducle à l'endroit de séparation des deux parlies du corps; celle de l'organe mâle tout-àlait antérieure, en dedans et en avant du tentacule droit. Coquille extérieure fort mince, transparente, symélrique, bombée en dessous, plane en dessus, fendue sor les cótés pour le passage des lobes du mantedu, ouverte en fente eu avaut pour celui du céphalolorax et tronquée an sommet.

M. de Blainville a fait, dans le Joumal de Physique et a reproduit dans le Dictionnaire des Sciences naturelles, la monographie complète du genre Hyale; il comprend aujourd'bui treize espèces, dont la plupart sout à peine counues dans nos collections. Celle qui est la plus répandue est la suivante :

\section{II Yale iridentée. Hyalea tridentatu.}

L.sм. Anim. s. vert. tom. 6. pag. 286. no. 1.

Anomia tridentata. Forsr. Faun. anab. pag. 124 ; et Icones. tab. $40 . f g . b$.

Anomia tridentata. Gмек. no. 42.

An Mrusculus teleucus. Lin.?

Hyalaea Forskali. Businv. Dict. des Sciences nat.

Covier, Ann. du Mus. tomt. 4. pag. 224. pl. 59 .

- Exстск. же́тв. pl. 464. fig. 5.6.7.

Pénon el Lesueur, Ann. de Mus. tom. 15. pl. 3. fig. 13.

Hyale papilionacée. Hyalea papilionacea. BORY DE ST. VINCENT, Voy. aux quatie principales iles d’4frique, tom. I er. pag. 137. pl. 5. fig. 1.

Coquille très-commune qui fut long-lemps la seule conuue des naluralistes, et que Linué plaça dans son geare Anomie, comme nous l'avons vu précédemment. Elle est ovale, globuleuse, cornée, mince, transparente, formée de deux parlies juégales sondées entr'elles, mais laissanl sur le côté deux fentes longues et étroites, et aoté- 
rieucrent vae onserture ovaldic a levrestrésinćarales; la partie supérieure csı lı̀s-g!ubuleuse; liatéticure est au contraire très-aplatic, et se prolonge antíricurement cu un bec large, relevé en arant de l'ouverturc et lermine a son hord libre par donx pointes pen frolungres. Sur le milieu de celle partie on remarciue trois côles longitudinales, rajonaantes, dont la médiane est beaucoup plus litrage que les aulres; postérienr ment, et à la jonction des denx partics de la coquille, le bord est elargi et découpé symétriquement en trois pointes : la médianc, plus yrande et ordinairement tronquée an sonmel, donne aitache, à lintérieur, an muscle colımellaire de l'adimat.

Cette coquille est tres-commune dans torle la Médilerrauée, dans l'Océan ri'Alirique, au Sinéদral. mais elle est beaucoup plus rare sur les cólcs cie lOcéan. Elle a 17 milliun. de longr.

2. Hyale trois épines. Hyalea trispinosa. Lest.

H. testà ovato-elongatâ, depressá, albıdî, tenuissimâ; aperturâ ovato-angustâ, marginious subaqualibus rinuls tenuissimis lateralibus continuatî, posticè irispinosâ; spiná mediunẩ

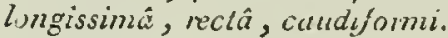

Lesceva, Jourtal dos Sciences de Philadelphie, tom. 3.

'Très-jolie espèce, fort remarquable par son aplatissement : les deux parties qui la composent sont presqu'fuales; l'iaférienre se reconncit à iu partie de l'ouverture gni lui appartient, gui est un pen plus saillante que l'autre; la converié raédiane de ce côté offie trois cóles Irès-aplalics, qui rayonnent du sommet à lis base. Liouverture tst pelite, étroite, subovalaire, se terminant aux conmissures el se prolongreant en deax lentes latérales irés-étroites, qui s'étendent jusqu'it la lisse des épines latérales; la parlie supuriense će la corruille est toute lisse, réculièrearent consexe; elle se joint postérieu:ement avec l'anlle your former l'extrémité postéricu:e. Celle extrémilé se prolonge en une pointe médiaue trèsgriele et très-cissante, qui est aussi longue que la coquille elle-même. A sa base, et de claquue côlé, aaissent sywétriquerneat deux épines couries et très-aiguës; ces épiues latérales, ainsi que la pointe poslérieure, sont projetées dans le plan forizontal de la coymille.

Nous ne savons d'où vient c.ctte espèce, qui est Jongue de 9 millim. lorsciue la pointe póstéricure esi fracturie; clle tieni plus du duabie lorsqu'elle est intacte.

\section{Hy te de Rang. Hyalea Rangii. Гов.}

H. testá globulosá, ovata, posticè trispinosî, anticè urcuatá; lubro elevato, tenui, fraglt ; aperturi minimi, profunda, angustissima; $n$ - mulis lateralibus brevibus; spinâ postical, medianí, recurvi.

C'est, nous le pensons, M. Rang le premier guii a rajporté celle espcoce; elle est une des plus ploluleuses, el parvitruit, par l'ensemble de sa forme, n'ĉue qu'une varicite de l'Hyalea trider:talce; mais sun ourerture el la forrie de la levie intérieure présentent des caractères tcllement lras. chis, quil est impossible de la contiondre avec eltu.

L'Ilyale de Rang est petile, globuleuse, mince, fragile, transpriente, d'ü Liun-counć clair; sa partic supćrieure exirêmemeut bombée; l'ouverture étroile, Iransverse, el profoudément cachée par le relèvement de l'exiréuité cle la partie inférieure; ce relévenuent est presque ferpoucliculaire, il se soude de chayue cỏć́ aux cowuizsures de l'ourerlurc, the conmunaique forut avec les rimules latériles: crlles-ci soul cocrles, "ues-élroites; tlles parvieanent jusqu'a la base des épines latérales. I.e cỏté postérıcur se teruide par trois pointes très-aigruës, dunt la médiane esi lä plus prolonǵ́e; elle se recourbe iulérieurement, tandis que les autres se relivent un peu en dessus; la face infíieure est régulièremeat ruyounce pir cinq côles symélriques qui partent de la poiale médiane.

Celle jolie espèce vient des mers d'Afrique; elle a 8 un 9 nilliru. de loligutur.

\section{HYALES (Les).}

Pelile famille yu'a proposte M. de F'erussac dars ses Tableaux sjstémaliques des Mollusques fun une partie des gentes de l'ordre des l'íropudes de M. Cuvicr el de lamarck; il y comprend les senres IIyale, Cllodore et Cyw!sulie. M. de Blaıviile, dans son Truité de Malacologie, a à peu près adopté cetle lamille en lui dounant le oom de Thécosome; il y a tuil entrer le genre l'yrgo, yui apparlient indubitablement au genre Biloculine de la famille des M!iliulites. M. Rang, dans son Manuel des Mollusques, en adoptant la famille ate: Ilyules, l'a augmentée de vilusieur's gentes voirins des Cléodores. On y comple les sept geares suivans : Cymbulie, Limacine, Ifyale, Cléodore, Cuvicrie, Euribie el Psyclé. Cos deux derniers geures laissint encore quelque doute sur leurs rapporls, l'arrangemeul de celle famille telle qui I'a présenté M. Rang nous semble préférabié a ce qui a été fait avant lui, et nous l'adoptons, ajues la confirmations des deux genres encore incertains. Voyez les nols des genrts que oous venons de ciler.

\section{HYDATINE. Hydutina.}

Genre tont-à-fait inutile, élabli par M. Scluumacíer pour quelques Bulles dont la Buila hydutus fail partie, ainsi que quelques amtres gui en sont trés-roisines.

si l'on continue à érablic des geures sur des 


\section{II $\mathrm{Y} \mathrm{G}$}

taraclères d'une si fuible importance que cenx de celui-ci, bientôt il faudra substituer le mat de gerıre à celui d'espece, et les multiplier ainsi d'une wanic̀re irralionnelle. Foyez BuLle.

\section{IYYDOBIE. Hydrobia.}

Celles des l'aludines de Lamarck qui ont la spire alongée et pointue, ont êté séparées en yenre par M. IIarman, qui lui a imposé le nom d'Hydrobie. Ce genre, qui ne repose sur aucun caraclère essentiel, ne peut être adoplé. Voyez Palomine.

\section{HYGROGÉOPHILES. Hydrogeophila .}

Sous-ordre prnposé par M. Nenke dans son Synopsis Conchyliorum, pour une partie des geores de la famille des Auricules de M. de Ferussac. Ce sous.ordre comprend les genres Carichie, Scarabe et Auricule. Voyez ces mots.

\section{HYPOBRA:NCHES. Hypobranchia.}

M. Menke, dans son Sinopsis methodic Molluscorum (page i1), a formé sous celle dénominatiun un ordre qui correspond à celui dics Inférobrauches de N. Cuvier. Vojcz IsféroBraxenes.

\section{HYRIE. Hyria.}

Genre que Lamarck a proposé dans sou dernier ouvrage pou: une coquille démenibrée du genre Unio. Depuis que l'on connoit les étonuante's modifications de forme que peuvent éprouver les espèces de ce grenre, les IIyries de lamarck ne peuvent plus être cousidérées que comme vu des nombrenx intermédiaires entre les espèces alongées et les espc̀ces raceourcies. Voyez $110-$ LETTE. 


\section{B $\dot{\mathrm{E}}$}

\section{IBÈrE. Iberus.}

Ce geore, que Montfort a propnsé pour une section des Hélices, dont l'Helix. gzcalleriana sert de type, a'a point été admis; il rentre dans les Carocolles de Lamarck, qui elles-mêtnss ne sonı $q y^{\prime u n e}$ division artificielle des Hélices. Voyez C.linocolle et Hélice.

\section{ICHTHIOSARCOLITES. Ichthiosarcolites.}

Gente établi par M. Desmarest, pour des trongons articulés de moules intérienrs de coçuilles dunt la nature resta long-temps incertaine. Connus seulement à l'état de pétrification, dépouillés de toutes les parties qui pouvoient en facilitcr l'étude, ces corps problémaliques furent rangés par les auteurs parmi les coguilles muitiloculaires, a côté des Spirules; leur développeunent en spirale très-large et à tours dijoints les rapprochoit en effet de ce genre. On étoit encore conduit à ce faux rapprochement par les loges transverses et simples dont la cavité intérieure des Ichilliosarcolites sembloit partante; mais d'après un examen plos allentif des pièces yui nous lurent comonuniquées par M1. Roulant, officier de unarine très-distingué, nous pûmes nous assurer que le freure dont nous nous occupoos avoit été fortué avec des moules intérieur's d'une coquille bivalve appartenant très-probablement an genre Caprine de M. d'Orbigny. Nous sonmes cunvaincu e'galawent que quelques-unes des espèces d'Iclithiosurcolites provienaent du moule iuterne de l'exirtmité inléricure de quelques Hippurites. 11 est donc impossible de conserver un genıe fundé sur de tels élémens, et nous renvoyons en conséyjence alu articles Hippurtte el Spherulite.

\section{IDOLE.}

Nom rulgaire douné par les anciens conchyliologues à l'une des plus gr.undes espeeces du genre Anpullaire. Voyez ce mol.

\section{JDO'THEE. Idothea .}

Ea établissant ce genre, Mi. Schumacher a fait un double eaploi pur lequel il reproduit le genre Corbeille de M. Cuvier. Voyez ConBEILLE.

\section{II.OTE. Ilotes.}

Gerle proposé par Montfort pour un pelit corps mulciloculare que Lamarck a placé avec raison dans son geure Onbiruline sous le num d'Orbiauline numismale. Fojez Orarcolisil.

\section{IMBRICAIRE. Imbricaria.}

Quelques espèces de Mitres, qui ont la forme. des Côues, ont deax fois servi à l'établissement de genres qui ne seront point adoptés. L'un d'eux, sous le nom de Conelix, a été proposé par II. Sowerby dars son Genera; et l'autre, sous le nom d'Imbricaine, par M. Schumaclier, daus son Système de Conchyliologie ( page 236, pl. $2 \mathrm{t}$, fig. 5). Celte division des Mitres ne peut être reçue, car les espèces qu'elle renferrne se lient avec le reste du genre par des nuances insensibles. Voy. Nitre.

\section{INCONPARABLE.}

Nom vulgairemunt donné à nue belle espèce de Cyberce, Cytherea erycina des auteurs. Voy. Crthérie.

\section{INÉQUIVALVE. ( Coquille).}

On donne ce nom, d'une unanière générale, à coutes les coquilles dont l'une des valves esi plus grande que l'autre. Foyez le mot CuQuiche dans le premier volume de ce Dictionnaire.

\section{INËQUIVALVES. Inaquivalvia.}

11. Latreille, dans ses Familles naturelles dic Règne animal, page 204, a donné ce nom is la seconde faulle de ses Brachiopodes pédonculés. Celle lámille ne comprend qu'un seul geure, celui des 'I'érébratules. Il est à présumer que celte lamille ne sera point adoptée, car les caracteres sur lesquels elle repose sont de très-peu de valeur. Voyez Brachiopodes et T'́réshatule.

\section{INPEROBRANCIIES. Inferobrunchiata.}

Nom proposé par M. Cuvier pour nae classo de Mullusques gastéropodes, qui cumprend les genres Pluyllidie et Déphyllide. Vojez ces in ts et Mollusques.

\section{INFCNDIBLLUM.}

Section gćnérique que Klein a proposée dans snn Traité des Coquilles pour quel jues espèces de 'Troques et de Calyptrces. Depuis, cette association a été de nouveau reproduite par $\mathbb{N}$. Sowerby, dans son Mineral conchology; mais clle ae pouvoit étre adoptée, bien que Lamurck ait donne l'exemple de la réunion des mêmes coguilles dans son geare Tioqua. Voy. Calytrte. et 'liropue. 
INOCÉRAHE. Inoceramus.

CARACTÉRES GÉNE⿱宀㠯IQUES.

Coquille griphoide, ioéquivalve, irrégulière, subéquilatérale, d̀ lest lanelleux, non lihreux, puiutue au sommet, élargie à la base; crocliets opposés, pointus, fortement recourbés; charnière courte sur le côté supéro-postérienr, diruile, composée d'une série de crénelures graduellemeni plus petites, pour recevoir un ligament wulliple; impression musculaire inconnue.

Ce yenre, à peu près aussi incerlain que celni des Catillus, nous scmble cependant avoir plus de rapports avec ceux de la famille des Malléacées quelui : nnus avons trauvé dans celui-ci des cuquilles aplaties ou cordiformes, mais équivalves et régulières, ce qui n'alieu dans aucun des geures des Ilallćacées; dans le genre qui nous orcupe, au contraire, nous observons des coquilles irréguliẹres, inéquivalres, comme toutes celles des greares environanas. Pour qu'il ne restât plus de doute à leur égard, il faudioit cuunoitre l'impression musculaire, et fludier plus soigneuseaient encore la charnière. Un unnlif nous lait présumer que dans les Inocerrames il ne dnit y avoir qu'une scule impression musculaire. Tuntes les coquilles dimyaire: irrégulières sont adbérentcs; une coquille irrégulière, libre, rentre dans les conditions organiques de toutes celles qui sont dans le unerue cas. 'Tontes les coquilles irrégulières, libres, sont monomyaires. Nous pouvons done couclure par analogie que les Inocćrames ne tun! pas exception à cette règle génćrale, puisquils ont libres et irrénulicrs.

$\mathrm{Si}$, d'uu côté, le test lamelleux et les autres caractères des Inocéranes les font rentrer dans le voisinage des Pernes; d'un autre, l'absence de la plupart de ces caractères jetle du doute sur les Catillus, \& rend plus uifícile j justifier l'opinion que l'on a gévéralemeat sur ces curps.

Les Inocérames sont des coquilles minces, qui ont une forme analorgue is celle des Gryphées. La valve supérieure, q̨noique plus petile que l'infericure, est cependant moins operculitorme que cellc de ce genre; los summets sont pintus, recourbés en crochel, saillans, plus grauds et plus pro?miaens pour la valve inférieure. La charnière placće sur le côlé superienr el pustérienr est courle, droile, occupe un espace triangulaite divisé en créneiules longiandinales, peu profiondes, séparées eutr'elles par de pelites lignes saillantes très-étroiles; ces crónelntes donnvient insertinn à uu ligament nulliple, subinteroe, comme celui des Pernes. On ignore eacore si la coquille éluil bäillante, de manière à donner pasaage à un byssus. Le mauvais ćtal de conservalion de ces coquilles s'est opposé à ce que l'on puisse se déciler à ce sujet.

Le genre Inocéraue a élé créé par M. Sinwerby, Hist. Nal. des Vers. Tome II. dans le Mineral conchology; mais dans l'origine il n'a pas été circonscrit tel qu'il l'est aujnurd'hui, car l'auteur y avoit réuni les Calillus. Tous les auteurs systématiques ont conservé la division qu'en a faite MI. Brongniart, \& tous se snnt accoldés avec lui pour le placer à côlé des l'ernes et des Crénatules.

J.es Inocérames, réduits à deux espèces, sont pour la craje glauconieuse ce que les Catillus sont pour la craie blanche; ils sout caracléristifues de ces couches et des argiles qui les accompagnent. Jusqu"i préseot on ne les a jawais trouvés ui audessous, dans les terrains jurassiques, ni au-dessus, dans la craie blanche ou la craie arénacée.

Inocérame sillondé. Inocemmus sulcalus. PARK.

I testâ ovato-elongatâ, apice acutâ, inflatâ, valde longitudinuliter sulcatí; sulcis distantibus, elatis, acutis, carmatis, rudiantibus; umbonibus recurvis, aculis, oppositis.

Parkixson, 'Trans. de la Soc. géol. de Londres, tom. 5. pag. 5g. tab. 1. fig. 5.

Sowerbx, Mlnerul conchol. pl. 506 . fig. I i 7 .

Alex. Bhovgrzant, Géngnosie des terrains de Paris, pl. 6. fig. 12.a.b.

Coquille alongée, subovale, printue au somnut et très-rétrécie, arrondie inlírieuremeut, inéquilatérable, !rès-inéquuivalve; elle est bombée et très-convexe des deux côtćs. La valse inférieure, plus yraude que la supérieure, a le spochet beaucoup plus alnngé, $\mathrm{ct}$ domide celui de liautre valve de la niçme aranière que dans les Gryphres: ces crochets sinclinent vers le bord antérieur; ils dunnent origine à huit ou neuf yrosses côles rayounantes, dunt lcs trois ou quatre anlérieures soni les plus grosses, les plus distantes el les plus saillantes; elles snnt aiguès, carénées, et quelquefois un pen plissétes un strifes eu travers par des lames assez régulières d'accroissemens. Les cúles, en parvenant au bord, le déconpent en festons ou en crénelures, en aussi grand nombre yu'il y a de côtes. Le bord cardinal est eu ligne druite; il est incliné postérienrcment el se confond avec le bord postéricur; il est court, et occupe un espace triangulaire dont la base cst sous le crochet, et le somruet à l'extrémité du bord. Cet espace, leaucoup plas grand dans la valve infírieure que daus la superreure, est orcupé par la chilrnière, qui présen!e dix à douze crénelures guadnellomen! plus courtes. II est trèsrare de tronver cette coquille avec son test; il disparoit entièrement : ce qui n'auroit pas lieu s'il avoit une couche corlicale fibreuse; celle-ci résistercit a la dissnlulinn. On la trouve dans un grand nombre de localitís, tant de France que d'Allemagne, et surlout d'Anglcterre, on elle n'est pas rare a Folkstoue, ctc. Ce qui est remarR $r *$ 
quable, c'est que l'Inoceramus concentricuss l'accompagne partout, et peut, par conséguent, la remplacer comme caractérisique.

\section{IPHIGENNIE. Iphigenia.}

Dans son Essai d'un systeme de Conchyliologie (pag. 155, pl. 17, fig. 4), M. Schunacher a élabli ce genle, toul-à-fait inutile, pour quelques espèces de Douaces, telle que la Donax lavigata de Chemnitz, qui avoit servi depuis lang-lemps à Lamarck, comme type de son genre Capse. Voyez ce nol.

\section{IRIDINE. Iridina.}

Les lacunes encore nombrenses que laiscent les connoissances anatomiques des Mollusques, rendent incertaines, dans plusieurs de leur's parties, les méthodes de classification les plus récentes, et proposées par les savans dnnt les travaux son! justement regardés comme classiques. Ce qui prouve combien il est dilficile de bien asseoir et invariablement upe mélbode, c'est qu'une seule olservation suffit pour renverser une partie du système établi avant que celte observation ait étć faite; il en est même qui détruisent des rapports qui semblest d'autant plus incontestables qu'ils ont été sanctionnés par tous les zoologistes, puisque, comme cela est constaté pour les Mollusques acéphalés, les anılogies des coquilles conduisent souvent à l'erreur: aussi, quand il faut toucher à re que le raisonueunent et l"habitude ont consacié dans les sciences, ce n'cst plus en leur opposant des raisonnemens nouveaux et différens que l'on doit proposer des changemens, mais en apportant les observations et les faits lá nù ils manquent. C'est cette mélhode que naus nons plaisons a suivre dans nos rechercles; c'est celle qui nous a dirigé dans un travail qui a l'lridine pour sujet: l'observation qui en lait l'objet principal prauve pour les Mollusques conchiferes nu acéphales combien la connoissance de l'animal devient nécessaire.

Jes Iridines sont des coquilles lacustres, trèsrares josqu'à ce jour dans les collections, et dont on a'avoit point eu occasion d'observer l'animal. Le peu d'individus qui étoient conuus venoient, disnit-on, de la Chine, et les conclyyliulogues durent apprendre avec surprise que M. Caillaud, auquel nous devons des recherches si précieuses sur les antiquités d'Egypte, en avoit rapporté de ce pays. C'est dans le canal de Joseph qu'il eut occasion de les observer et d'en recueillir plusieurs beaux exemplaires. Ce fait curieux a èté rapporté dans nne nole publiée par M. de Ferussac sur les Ethéries; elle est insérée dans le premier volume des Mémoires de la Socièté d'histoine naturelle.

Autrefnis on contondoit les Iridines avec les Mulettes et les Anodontes, que l'on nommoit des moules d'eau douce. Humphrey cependant les en avoil distingurs sous le nom de Barbala dans le calalngue de ta collection de M. de Calonnes, comme M. de lierussac l’a fait voir à l'article BarBeLLe du Dictionnaire clussique d'Histoire naturelle. Bruguière conlundit celle coquille avec les aulles esperes dont il avoit fait snn genre Anoduntile, dans les planclies de l'Encyclopédie. Tous les auteurs, et Lamarck lui-même, jusquà la publicatiun du sixième volume de l'Histoire des Aniniaux sans vertebres, suivirent l'opinion de Brugruière, qui sembloit, au reste, confirmbe par ce que les analogies peuvent uffir de plus certain. Cependant Lamarck, d'après la considération de la charnière el la forne générale de la coquille, s'éloignanı un peu de celle des Anodontes, instilua le gente Iridine dans la première partie du tome Vf́ de l'ouviage pré.cité, publié en 1819 . Outre que l'antériorité de ce genie fut contestée à Lamarik, comme nous l'avons dit précédemment, la valeur de ses caractères ne le lut pas moins, et le plus grand nombre des concliylinlogues ne l'adopièrent point. Ainsi, N]. de Ferussac, dans ses Tableaux systématiques des Animaux mollusques, en tail le deuxième suus-genre des Abodnntes, en le metlant en rapport aver: les Lastènes, Siropbiles de M. Rafinesque, el Dipsas de M. Leach.

M. de Blainville eut une opinion semblable; il réunit les Iridines aux Auodnntes, comme on peut le vnir daus son Thusté de Malacologie, pag. 533. M. Latrelle enfin (Fainilles nuturelles du Regne animal, pag. 214) le conserva; et, à l'exerople de lamarck, il le considéra conme très-voisin des Anodontes, puisqu"il le plaça inmédialement après celles-ci. Nuus ajouterons que M. Suwerliy a nranifesté la mêrne opininn que vel!e cle M. de Ferussac, dans le Journal de Zoologie.

M. de Ferussac, dans la nulice que nous avons cirée, considère avec juste raison l'l ridine trouvée par M. Caillaud, comme élanı de la tuême espèce que celle de la Chine; il pense mêue que la coquille qu'Adanson avoit fait connoître sous le nom de Mutel, peit se rapporter aver quelyue cerrilude au genre et à l'espece qui nous occupe, quoique M. Sowerby ail eu une autre opinion. La dilférence principale qui existe entre les individus de la Chine el ceux d'Egypte, e'est que les uns ont une charnière crénelée dans toute sa luugueur, tandis que les autres, an rapport de ii. Caillaud, n'olfient que très-rarement ce carac. tère, d'où M. de lierussac avoil été purté à réunir avec heaucoup plus de certilude les Iridines aux Anodontes. L'analogie des coquilles est en effet si grande, qu'il étoil permis de penser que l'animal devoit être entièrement semblable à celui des Muletles et des Anodontes. Quoique, par le fait, il il n'en soit rien, et que, loin de confirmer l'opinion la plus généralement admise, l'anatomie de l'animal la détruise entièrement, cornme nous le verrons lientót, il seroit injuste de blàmer les 
aufeurs que nons avons cilćs; ils ont cóconciui!s prar los anilogies les plus forles, el il leur ćloil iaprosible de prévoir qu'une cuy uille scomblable ('u loul aux Anoduntes contieodruil un animal entièıencril différeat; ceci esı d'uutant plus excusable que l'on n'aroit point encore renceutré parmi les Conchulères une ancmalic semblable.

1!. Cuil!aud avoil eu le soin de recueillis dans l'espiri-de-vin deux jeunes indıviolus de l"Iridine du Nil, airsi que quelques-uns de l'Anodonía mbens Lawark, quelques Muletes et wue Cyrinc : cesavanl voyageur vuulut bien nous comnunitgucr ces richosses znulougiques; 1l eut la bunté de nous abandomnco une des deux lridines, et wous confia la seronde punr mous scrvil pendanl nos re:chelches analoriques. Il wous conanuniqua eyalement un madividu bien conservé des aulıes espéces. Nous reçuours a vec d'aulant plus de plaisir et de recomuoissance la comnancation de M. CailIsud, que nuus aperciunes bifntôl que l'unimal de l'Anodontu rubens, ries-vuisin de celui de l'Iridue, devnit entrer dans le utềe gente.

l'our que l'un soil mieus à móne d'apprécier les dilférences qui existenı entre l'aximal que nous allons décrire, les Anodoutes el les Mutetles, il ne sera pas liors de fropos de rapportor sommairement les rails proncipaux d'orgamisation de ces riewx genres, que Puli a Irumbis entiorement semLialdes quant a l'aninal; ce quil a pié confirmé Licpris par tuutes les personnes gui les ont comyariós.

l.e manteau des Minlentes est findu dang $10 n 1$ son cuntour; il ne présente, postéricurement, ni iubces sii sipluons; a lencrmat oi ils exis'cul daus les antres Concliffores, le manteau est plas épatis cut salmi de frangnes tentaculanes; la sépraration des cour lobes se conlunue méne jus jue vors le dos de l'animal, suss le ligamrut, oì se trouve une éclıancrure profonde, en cul-ite-sac, daus laynelle aboutit l’anus, et gui n'est síparre du reste par aucune brile; elle peut a petine èlre liunsidćrúe comare une seconde ouveriure paliéile; el, sous ce rapport, les genres yui nous ocrupent ne devioient pas laire pratie cle l'ordre des Biforrpalla de M. Lalle elle.

Lis branchies des Mulelles el des Anodontes se riuminsent au-dessus de l'unus; elles soni, comine dans tou. les Conchilires, au nombre de qualre, deux de chayuc cóté, la paice anlícure étanı lá plus pelite; clles st: teruirient vers le dos de l'aninal posténicurement, en se rćunisiant par les vaisseaux brancliaux juscju'a l'origioe du pied, et se divisant de clayue chité de cetle purtie jusqu'au foie, où elles sinsèrcnt intérienemcu!, ariusi qu'a la base du pied; l'ınerrion de l'exalrómilé antérieure est cachée en partue par les uppen. dices labiaux, qui sont libres dans presyue lous leurs contons. Entre les deux fenillets irancliaux du côté droit, dans l'endroit où ils se ráunissent e: pustćrieurement, on renargue, quelquelois avec: assez de difficul'f, deux petils orifices qui sout ceux des oviductes. Poli les avoient signalés en indiquint, par une ligrnre grossic, leur position dansles brancluies. I e pied est assez épais, sécurifurme, plus épais à la base; c'est entıc lui et le inuscle adductenr antérieur des valves, dans la ligne médiane, que se vuil un pelit orilice ovale, arrondi, qui est l'ouverture de la bouche.

M. de lierussac, a l'article A sodonte du Dictionnaire classique d'Histoire naturelle, en caractérisant cc grente, dil que la coquille eft exactement close, si ce n'est à l'endroit des siphons, oir elle est líante. Celle expression de siphons, appliqucie aux Anoulootes, nuus a jeté dans un loute qu'il appaticn: a M. de Ferussac lui senl le lever, en nous apprenant ce qu'il entend par siphons, dans les Anodoutes. Nous avons épronvé uı eubarras et un doule lien plus graud à l'egard de ve que .11. Ralinesque nomme siphons, dabs les Mulelles de l'Uhiu. Mulhcurcusenent, la Conchyliologie n'a point encore de vocabulaire généralemenl adoplé, surloul pour l'étude des animany. Les dillirens autenrs donnent a cerlains mots des signilications dillirentes, d'où résultc nécessairement une confusion dont il est sonvent impossible de sortil. Jci, sans savoir d'une manière claire et precise ce que M. de Rafinesque nomme siphons, nous devous douler que ce ne soient les auênes partics que les zoologistes liancais nomment ainsi. Comne l'aniunal de l'] ridinc ést pourvo de vérilables siphons, il est bien essentiel d'examiner en détail la Description des Unio de l'Olio, par M. Rafinesque, pour ne point laisser de doute sur la ressemb!ance ou la tifilirence dorganisaion entre les aniuaux qui nous occupent. Voici tex:mellement ce que dit M. Ratincsque, apres avoir averti que les animaux des genres et sous-genres de sa fauille des Pédifères uiffient que de trèslígères dillérences de cuuleurs, dimensions et proportions : "Aniual blanc un un peu incarnat; " Dantcan wince, lisse, tapissant les valves, " bilobé et cichancré postérieurement, sans fran„ ges; second manteau intérient brancbial, strié " "bliquenent, mince, lilubé postérieurement, "Leacoup moindre que l'extéricur, et enve"Ioppant le pied; pied comprioné, musculenx, "coriace, oblong, dilatable; boucbe antéricure; n anus posı́ıieur a l'extrémilé du ligament; "siphons antérieurs, lutéruux, égaux, un de * chaque cúlé, derrière la buuche, en forme " de tubercule pefforé; el cocore plus en arriòre, " également de chaque cóté, un appendice bila* mellaire oblus, à lames inégales, plates, ovales n et oblongues, l'intérieur plus grand. Ce sont "apparemment les organes de la génération. "

Si celle description est exacte, comme on ne sauroit en douter, puisque MI. Rafinesque cn a véritié les détails sur púus de vingt espc̀ces et sur trois centsindivitus, il est certain que l'nninual des Mulctles de l'Ohio diffère de celıi des Mu$\mathrm{R}_{12}$ * 
letles d'Europe et d'Afrique; mais peut-être pas autant qu'on pourroit le penser au premier a perçu.

Nous voyons d'abord que le manteau est fendu dans tonle sa longueur; qu'il forme au-dessous de l'extrémité du ligament une écbancrure ou une sorte de cul-de-sac, ce qui le rend absolument semblable à ce qui se voil daus nos Muleltes; qu'il est dans celle partie postérieure dépourvu de franges : nos Muleltes, au contraire, en ont loujours. Cette disposition du manteau fait voir bien évidemment que l'animal des Mulettes de l'Ohio n'a pas de véritables siphons, qui g'exjstent jamais sans la réunion postérieure des deux lobes du manteau.

Ce que M. Rafiuesque nomme second manteau, n'est autre chose que les brancbies, coume il l'a reconnu lui-même : elles ont bica probablement une organisation senblable à celle de nos espèces; reulement, elles paroissent siluées plus antérieurement et envelopper plus parliculièremcn: la base du pied; le pied et l'auus sont absolument semblables à ces parties dans les espèces d'Europe : mais pour ce qui concernc les siphons, placés, comme le dit M. Rafinesque, de chaque côté de la bouche, en forme de luhercule perforé, nous ignorons complétement ce que l'on doil entendre par ces organes, que nous ne trouruns dans aucane de nos espèces. Nous pouvons affirmer et répéter de unuveau, que ces parties, quoique non conoues, ne sunt pas de véritables siphons.

Les appendices hilamellaires striés, placés de chaque côté de la bouche, et que M. Rafinesque prend pour des organes de la géuération, ne sont évidemment que l's palpes labiaux ou appendices baccaux qui existent dans tous les Mollusques acéphalés dans un état plus ou moins complet de développement et d'adhérence.

Après celte digression assez longne, mais nécessaire pour s'entendre sur l'existence des choses et la valeur des mols qui les retracent à l'esprit, il sera facile d'apprécier les différences notables que nous allons signaler daus l'animal de l'lridine. La coquille de l'Iridine, dont il existe de bonoes figures ( comine celles de l'Encrcicpédie, pl. 204 his, fig. a. b.; celles du Voyage de M. Caillaud, tome 2, pl. 6o, fig. 11, qui représentent la variété que nuus possédons; et enfin celle du Genera of Schell, de M. Sowerby), est transverse, étroile, beaucoup plus large que longue, inéquilatérale, le côté antérieur bcaucoup plus court que le postérieur; crochets petis, peu saillans, se voyant à peinc au-dessus du bord cardinal, peu inclinés; bord cardinal ou supérieur presque droit, lisse, simple, préseutant sur la valve druite et immédia:ement sur le crochet nne saillie à peine sensible, reçue dans une légère dépression correspondante de la valve gauche; le ligament est très-long, il occupe presque tout le bord supérieur; l'extrémité antérieure est étroite, la pristérienre est plus large et subarquíc; le bord inférieur est un peu oblique, quelyuefois un peu sinuenx vers le nulieu, comme il arrive dans plusieurs espèces d'Unio, et notamuent daus celle du Rlia, Unio margaritifera; les bords antérieurs, postérieurs el inlérieurs, sont minces et trauchans; le rest est assez épais, solide, d'une nacre puurprée, irisée, très-belle ì l'intérieur; au-dehors, il est revètu, comme toutes les coquilles lacustres, d'un épiderme d'un brun-verdảitc plus ou moins écorché sur les crochets : les valves, à l'intérieur, olfrent une impression palléale furt large, surtout postérieuremenl; elle est sans écliancrure postérieure; elle se rend directement de liinpression unusculaire antérieure à la postérieure. Les impressions musculaires doivenl être divisćes en deux sortes, d'après les usages des muscles qu'elles reçoivent: les premières, ou les plus grandes, donnent allache aux muscles adducteurs des valves; l'une est antérieure et l'autre postérieure. Les secondes sont plus nombrenses, et destinées à l'insertion des muscles rétracteur. du pied: elles se divisent en antérieures et en postérieures; les antérieures sont au Dombre de trois principales, et de deux ou trois autres, fort petites et variables. La première tient par son bord antérieur au bord postérieur de la grande antérieure, vers son milieu : la seconde est plus petile, placée presque sous le crochet; elle est entièremeat isoléc : la troisième, enfiu, est immédiatement sous le crochet, et dans sa concravité; elle est inéuale, raboteuse et transversalement oblongue. La grande impression musculaire postérieure n'est accompagnée que d'une seule pelite inpression; clle lui est supérieure et antérieure, et en est eutièrement isolée. Lorsqu'on réunit les deux valves, on s'aperçoit facilement que la coquille est bâillanle autérienrement pour le passage du pied, et postérieurement pour celui des siphons.

L'animal conlenu dans la coquille que nous venons de décrice a une furme semblable, c'esta-dire qu'il est alongé , étruit, assez épais du cỏlé du dos, plus mince vers son bord inférieur, placé duns sa coquille comme le plus grand nombre des Mullusques ać́phales; ainsi le dos correspond au bord cardinal, le ventre au bord inférieur, la Louche au côté antérieur, et l’anas au cóté puslérieur.

l.'animal sorti de sa coquille, et avant d'avoir subi aucune préparation, présente les parties suivantes : le manteau, enveloppe mince, subtransparente, rougeâtre, est parsemé de nombreux vaisseaux; son bord antérieur se termine par nn limbe épaissi, assez large, jaunâıre, plus large et plus musculeux postérieurement qu'antérieurement; vers la partie postérieure les tibres musculaire: devienoent obliques, plus serrées, plas épaisses en se divigeant vers le bord postérieur. Vers le des le manteau, après avoir courert les organes 


\section{R I}

I R I

pruncipaux de l'animal, lels que le foic, une parlie de l'ovaire, le rectum, le cœur, se dirigre vers la ligne médiane, où il rencoutre le bord de l'autre lobe, s'y unit intimement, el donne uaissance à une lame très-mince, médiane, qui s'interpuse eutre les bords cardinaux de la coquille. C'est dans l'endroit où le manteau se réunit à la base des branchies que se voit une grande veine palléale, oblique, qui reçoit tous les vaisseaux dislribués sur sa surface. Le mauteau présente, depuis le muscle antérieur jusque vers les deux liers de son bord inférieur, une grande ouverunre pour le passage du pied; mais vers le tiers poscérieur les deux lolves se réunissent el lorment ainsi une grande puche : celte réunion se contiuue au bord postérieur, el elle donne seissance dans cel endroit à deux tubes courts nu sipbons, dont le plus grand communique directement avec; la cavité du manteau, et le plus pelit est destiné à l'uscus. Ces siphons, dans l'élat de coutraction de l'auiral, ne depassent pas les bords du mantean, et sont mème plus courts que lui : ils sont d'un gris - bleuâlre, rugueux, et probablemenı pourvus de palpes, conme des tubercules charnus coniraciés le fonl soupçonner. A la parlie antéıieure el supérieure de l'animal on voit un muscle épais, graud, brun-rougeâtre, c'est le muscle adducleur antérieur; au-dessous on apercoil plusieurs autres petits muscles jaunâlıes, qui iont les muscles rélracleurs anlérieurs du pied; ils sont disposés antour d'un organe d'un grisbrunatie ou verdatre, qui est le fivic; l'un d'eux, le plus postéricur, se voil à travers le manteau, très-unince duns cel endrnit, et se prolonge audessus du borl du fuic pour sorlir sur le dos de l'auimal. C'est lui qui s'insère dans l'impression que nous avons fait remarquer dans la cavité du croclet, sous le bord cardinal.

Au-dessuns de ce muscle se remarque un pelit orgaue d'un rouge-briqueté assez vif; il occupe Ia cavité des crochels que le muscle a laissés liLres. Eufin, Inul-à-fait postérieurenient, se voit le muscle adducteur postérieur plus grand que l'untérieur, en avant duquel se trouve l'extrémité du muscle rélracieur postérieur du pied; une reine, qui se contourne sur le bord du toie, dans l'épaisseur du manteau, donne aaissance aux vaisseaux antérieurs de cette enveloppe. Telles sont les partics que l'on peut a percevoir sans aucnne dissection, et en les laissant toutes dans leurs rapports naturels. Nous allons maintenant délacher le manteau du côté droit de son insertion torsale, couper le siphon branchial sans rompre l'adhérence des deux lobes du manteau, done nous laisserons uc lambeau renversé à droile, de manière à meltue à décnuvert et la face interne du limbe palléale, et la cavité du sipbon. Par celte préparation fort simple, nons verrons dans leur position nalurelle différens organes, doni le plus considérable est le pied dans un élal de cou-
Iraction; il est absolument semblable à celui des Mulelles el des Anodontes.

Entre celte partie et le auscle adducteur autérieur, el dans la ligne médiane, se voit une pelite ouverlure sisuéc profondément, c'est la bouche; et l'on obscrve une lc̀vie supérieure et une lèvre inférieure dant les borts se continnent de cliaque côté à deux appendices plats, subco. riaces, rougeâtres en dehors, et blancs jaunâtres pour la face interne, qui est très-finement strík en travers. Ces organes sunt les palpes labianx; ils son: libres seulement par leur bord infé, ieur; le supérieur ou dorsal s'insère presque totalement an bord du fuie.

De chaçue cóté du corps de l'animal el de la base du pied, on remarque les deux lames brancliales placées olsliqueuient; elles s'insc̀reut au bord postérieur du foie, elles se réunissent par leur base, et descendenl jusqu'au-dessous de l'extrémité postérieure da pied, où la paire droite se réunit a la gauclse dans la ligne médiane jusqu'audessous de l'exirémité postérieure du muscle adducteur postérieur; les feuillets brauchiaux externes sont les plus grands et recouvreat les internes, excepté vers l'insertion au foie où ils forment une sorte d'écbancrure dans laquelle les feuillet: internes peuvent se voir.

Les branchies ciestinées à la respiration reçoivent deux ordres de vaisseaux doni la disposition et la distriloution sont absolument semblables à ce que Poli a décrit et figuré sur ces parties des Mulelles dans son magnitique ouvrage, les Testacées des Leux-Siciles.

Si l'on écarte les deux feuillets branchianx du côté droit, nn verra, quelquefois il est urai ave. assez de difliculté, deux petites ouvertures placées l'une au-dessus de l'autre vers le tier's anterieur de la lougueur des branchies, et situées tout-à-fuit au fond dans l'endroit de la réunion des deux feuillets.

Ces onvertures, dont Poli n'avoit point indiqué les usayes, puisqu'il dit qu'elles condnisent à la cavité abdominale, ne sont, comme l'a trèsbien dit M. de Blainville, que les orifices des oviductes, qui, nae fois reconnas, se retrouvent sur les autres Mollusques acéphales tonjours du même côté, senlement plus ou moins Laut.

En enlevant d'un côlé les branchies, en disséquant le foie et l'ovaire, en délachant tout le reste du manteau du même côté, en conpant par le milieu les deux siphons, on s'aperçoit d'abord que le bord postérieur du manteau déborde les lubes, que le tube branchial est plas grand que l'auus, et qu'il en est profondément séparé.

Les organes de la digestion se composent d'une onverture buccale qui abontit directement à l'es. lomac, à moins que l'on ne veuille nommer asopbage le canal extréceraent court qui se renfle bientôt en noe cavité stomacale, aplatie de haut 
eu bas, pyrifurose, à parois très-minces, adhérente au fuie qui leaveloppe, eu recevant par des cryples très-grandes le produit de la sécrélion hépalique qui s'y rend sans l'intermédiaire de cauaux particuliers. De la piroi inférieure ou aldominale part, au-dessus d'un perit cul-de-sac, un iutestin cylindrique qui desceud daus la base du pied jusqu'au-dessous du auscle adducteur pustérieur de cet organe, se courbe, remonle en cunservant sun dianètre jusque dans le foie, vủ il seufle en une surle de vessie, en lormant uue anse cachée en parlie par l'estomac; il gagne cusuite la ligne médiane et dorsale. C'est apiès ĉtre parvenu à celte région, vers le milieu de la Junguerr tolale de l'animal, que l'intestin, que l'on peut nommer rectum, passe a travels le casur eu couservant la duection moyenne et dorsile; il parvient ainsi jusqu'à la partie postérieure dú rorpis, ou il se coube en se renflant el s'ipaissisṡat uu peu; il passe entre les extrémilés dus nuscles rétracteuis postérieurs du pied, derriçre le muscle adducteur pustérieur, el il se ternine par un élraugleaenı sphinctéroíde surmonlé d’u petit pavillon, au milieu duquel se voit très bien I'ouverture de l'anus. Cette exlréailé de liulestin se trouve placée immécliatement daus la cavité a siphou aual et au-dessus de sun unverlure extérieure.

En ouvrant lalgemeat la paroi dorsaie ou sujérieure de l'estomac, on reconnoit la dispositiou des cryptes biliairs, ainsi que la foruse arrundic cle louverture pylocitye.

Nous nous abstiendrons d'entrer dans les d $\therefore$ la . dorganisation et de distribution du systeme ut rirculation; n'ayant eu qu'un seul individu à noire disposition pour la dissection, nous n'avuns pu fiudier ce système dans tontes ses parties; muts ce que nous avons vu a tant d'aualogic, nuus jocrions nıeme dire tant de ressemblance avr.c celui des Mulettes et des Anodonies, que nons perasons qu'il seroit fastidieux de faire cles descripllows qui se retrouveront nalurellement à íaticle Muletre auquel nous renvoyons. Nous n'avous piss cherché non plus à éludier entièrenent le systeme nerveux, le plan dorganisulion de l'aniwal qui nous occupe diffère trop peu d'aulres types déja bien conous, pour qu'il puisse présenier quelquanomalie notable dans sa disposition ou ses rapports et sa distribution.

La génération des Iridines doit s'opérer de la unéme manière que dans les Mulentes, puisq̨n'ou relcouve les mêmes organes el dans les mémes d'apports. La question de l'isermapisuditisme complet, contesté pur les observations de M. Prevost de Genève, mais non encure résolu, est d'une telle importance daus l'élude des Mollusques acéybales, que l'on doit suspendre sou jugement jusquà ce que de nouveaux laits scient reus éclairer les observatenrs.

Qjoique M. P'revost ait découvert les zoo- spermes dans cerlains iudividus de Muletles, test eu vain que $M$. de Blainville, ce savant alialuaniste, et qui sail si bien manier le scalpel, a recherché sur un très-rrand nombre d'individus l'orgace inâle qui devort eu produire la sécrérion. La cranuissance que nous avıons de ce lait nous a engagé à faire sur l'lridine des recherches a cet égard; mais nous n'avons rien découvert qui put jeter quelque luaière sul celle importautt que siiun.

D'aprés ce que nous vemons de dice de l'Iridine, nous lévus eu résumé les obseıvalions suıvaules :

10. Le mauteau est rès-dillírent de celui des Muleltes $\epsilon t$ des Anodontes; il préseule, comae dans la famille des Pyloridés de 11 . de Blainville, la réaniona des deux lubes, qui laissent le prassage du pied et dunnent nassance a deux luwes ou siphons.

$2^{\circ}$. Dans les Mulettes e! les Anodontes, le leuiller branchial externe est le pius petit; dans l'Jridine il est le plus grand.

30. Les palpes fabiales, dans los Iridines, sout grauds, égaux, corraces, adhérens par tuut le bord supérieur; el, daus les Mulettes, ils sunt plas petıls, l’aterne plus pent que l'externe, aous et adbérens, stuleuent par la partie antérieure du bord sipélieur.

$4^{n}$. Les urtices des uviducles des lidines sont placés plus anténeureuent gue dans les Mulente.

$5^{\circ}$. Le systcue de la digestion se compose des uièmes organes dans les deux genres; seulenient duas l'iritine les circonvolutious ues iucsilus sunt plus grandes, et le rectum se proiunge asvanlage, pour porter l'anus jusque dars la cavile riu siplivis. Cel orlice aual se lisslugue auss:

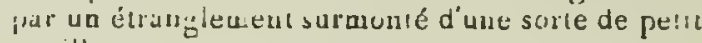
javillon.

60. Le système musculaire des deux genres est absolunieat seablable, si ce n'est que les uuscic autélieurs du pied sont síparés autour the la pallle anrérieure du fure, el lillssent sur la cum quilic des inapressiuas que n'unt pas les Mulettes, et gue souvent ces auscles riums en un seul lals-

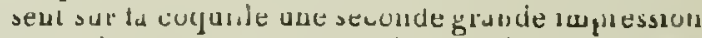
muscularce antideute que rioul fis les Mulettes te: les ìuuvules.

$7^{\prime \prime}$. Le pued, l'ouverture de la bunclie, sa forise et sa pisition, ce que llous avons vu des systeaes artérıels et veineux et du systène nerveux, we nous unt pout offert de dillérences notables.

Pusgue laviual de liridine présente une organisation sı Gilléreote de celle des Muleties et des Anodoures, il n'est plus pussible, tualgré lia resseusulance des coquilles, de le lasser daus la uièue lanalle.

A sumve riguuleusenent les indicaions que nuus donueut les connuissances analomaques yue nous venons d'açjuérit, ce seroil dans la famule des Conques de Linnarck, et peut-êlre dans celie des Pyluridés de M. de Blasuville, en en rao- 


\section{R I}

I R I

difian: un peu les caractices, qu'il seroil convenable de faice rentrer ce genre.

A la fin du Mémoire que nous avons donné sur le gense qui vieut de nous occuper, Dous avious annoncé qu'il semit wécessaire d'élablir un geure nouveau pour l'Anodonta rubens, qui, rapportée en meme irmps que l'Iridine, par M. Caillaud, nous sembloil présenter des carractères suffisans ponp sa séparation. Ċn exameu approfondi de lanimal de cet Anodonte oous a pleineuent convaincu qu'il appartenail au genre Iridine; la seule dilléreoce qui exis!e, en effet, consiste en ce que le manteau n'a les lobes soudés que dans une boaindre élendue. L'organisation, quant au resle, est identiquement la nuème. Nons avions pensé qu'ude assez grande coquille, que l'on Irnuve rossile au val d'A ino, appartenoit au genre Iridine, et se rapprochoil de l'Iridiza rubens par sa forme et ses autıes caractères : ouıs en avions jugé par l'examen dı bord cardinal; mais, depuis, ayant eu orcasion de voir d'une manière couplète l'intérieur des valses de celle espève, nous nous sommes assuré, par la di position des impressions musculaires, qu'elle appartenciil au geore Awodonte.

II est une autre coquille rapportée du Nil par M. Caillaud, mais dont nous o arons pas encore v'u l'animal, qui, d'après les dispositions de ses impressions musculaires, nous semble devoir clitrer au nombre tles Iridines; cependunt, duns l'incertilude nit uons sommes encore à son ćrard, nous ne la mentionnerons qu'co traitant du geare Minlette, aucjucl nous réunissonsles Anodontes d̀ tilte de sectiun sous-générique.

\section{CARACTERES GÉNERIQUES.}

Animal nvale, comprimé latéralement, ayant les deax lobes réunis postérieurement, et prolongé en deux tubes disincis; nuscles rélracteurs des lubes non saillans dans le limbe du manteau; pied grand, épais, sécurifurme, tranchant à sou hord; nuverture luccale, ovalaire, garnie de chaque cóté de denx palpes grandes, strices en dessinus, lihres dans une grande partie de leur êteadue; braucbies longues, étroiles, disjointes, formant deux feuillets litléraux inégaux.

Coquille ovale, oblorgue, inéquilatérale, à charaiere droite on légèrement arquée, saas dents, quelyquefois irrógulièrement grenue, ayant toujours sous le truchel une petile inllexıon, trais impressions ausculaires Irès-grandes, el une quatricume, postérieure, plus petite; les deux inpressions ausculaires anlérieures très-rapprocluécs, presqu'égales; les deux impressions postérieures inérialt's, la supérieure très-pelite.

Les caracleres que uous donuons an genre Iridine dilfèrent d'une manière notable, comme on le voit, de cenx que lui avoil imposés la marck. La principale différebce que cet auteor avil trouvéc entr'elles et les Anodontes, consistoit en ce qüil regaraoit, comene priocipal raractère, les crunelures du bord cardinal, tandis rue nous, lappréciant à unc plas juste valeur, par suite d'olsservations plus uullipliées, mons la regardons comare de lrès-peu l'imporlance; el l'on en seru convaincu comme nous, si l'ou fail allention que ces crinelures du bord manquent ou existent dans la méme. espece, selon les circonstances lncules : ainsi, on sail, par exemple, que les individus qui vieanent du Sénćgal ont presque toujnurs la charnière cri:nelée, landis que ceux du Nil l'ont Inujours siuple; et cependant il est impossible, apri's l'exami'n le plus scrupuleux, de trouver d'autre dillérences que celle-la entre les iodividus de ces deux lncislitús. Nous ae suivrons donc pas l'exemple de M. Sowerlay, qui élalilit uue seconde espéce suns le nom d'Iridina nilotica, pour les individus venant d'Egypte. En rejetant le caraclère de l.amarck, nous nous allachons davantage à celax que l'on peut tirer du nombre et de la position des impressinns musculaires. Cest ainsi que, dans les espèces que nous avons pu examiner, nous en avons vu loujours quatre indiquant l'allaclee de's adducteurs. Ces inuressions sont grandes; les deux antérieures sont presqu'égales, placées irc̀s. près l'une de l'autre, la plus exierne cobliquement, la plus interne en travers, et presqu'au méme niveau; elles sont ovales, el généralemicnt superficielles; les deux impressions poslérienres sunt inégales, la plus petite esı au-dessus de l'autre; enfí, comme dans les Mulettes et les Anodontcs, on voit une impression placée dans le crochet ovale el profonde, el donnant allache au muscle rétracteur du pied. Ainsi il y a véritablement cinq impressions musculaires dans la coquille des Iridines; quelquefois, el surtout dans l'espèce la plus ancieonemen! conoue, l'impression unsiculaire antérieure et interne est décomposée en denx on Irois antres gruupées à la méme place que devroil avoir l'unique que l'on y trouse habitucl. lement.

1. IrIdise exolique. Iridina exotica. LAmx.

I. test $\hat{\imath}$ ovato-angustî, subdepress $\hat{i}$, anticè laviter hiante, angustione; candine simplici, vel crenulato, recto, in medio leviter inflexo; impressione musculari antrcá et interna, bipartilá; sub epidermifusco-vinente, margaritaceú, purpurascente. Nов. Mém. de la Soc. d'Hist. natur. tom. 5. pl. I, pour l'auimal.

Anodontites. Brug. Encycl.pl. 204. fig. 1. 1. b.

Iridina nilotica. Sow. Zoolog. Journ. $n^{n} .1$. pl. 2.

Anodontu exotica. DE Buainv. Malacol pog. 5 8. pl. 66. fig. 2.
LAsx Anm. sans vert. 1om. 6. pag. 89. no. 1. 
Le Alutel. Adass. Sénég. pl. 17. fig. 21. pag. $234 . n^{\circ} \cdot 21$.

Iridina nilotica. Calleaud, Voy. à Méroé, tom. 2. pl. 6o. fg. 11 .

Celle espèce ful loogr-temps précieuse, parce yu'on ne connoissuit pas le lieu où l'on peut la chercher. Naintenant que, rapportée en assez granıl nombre du Nıl par M. Cuilland, elle a été répandue daus les collections, elle deviendra plus commune encore à mesure gue nus communications avec l'intérieur de l'Afrique seront plus fiégrentes.

Cetle helle coquille est grande, ovale, transverse, étroite, d’une belle nacre-rosée à lintérieur, revétue à l'extérieur d'un épiderme d'un brun-verdâtre plus ou moins intense, suivant l'ige de l'animal, ordinairement écorché vers les croclueı. Lorsque les deux valves sont rapprochées, elles Jaissent entrelles un petit bäillenent intérieur pour le passage du pied; le côté antérieur es! beiucoup plus court que le postéricur, il est aussi plus ćtroit; les croclsets, très-courts et a prine saillans au-delà du bord, s'inclinent de ce cólé antérieur. A l'interieur, la coquille esı d'une vì̀sbelle couleur pourprée; elle est lisse, brillanle, et prísente turjoursà sa partie antérieure les de:ix impressions musculaires, dout l'iuterne est presque tonjours diviśe en deux ou truis plus pclites, dont la situation est parfaitement semblable a l'impression unique que l'on voit dans quelques individus. Le bord cardinal est presque droit; 11 est formé dans piesque toute sa longueur pal un buurrelet arrondi, simple, quelquefuis crénclé, inujours légèreaent flexucux au-dessous du crochet.

Quelques anteurs odt cru que c'étoi: en Chine que vivoit celte coquille; quoique l'on g'ail pas lil certitude du contraire, on peut supposer, avce yuelque raison, qu'elle habite exclusiventem les grands fleuves du centre de l'Afrique. L mogucur iti centimères, largeur 60 millimères. Il y a dies individus plus grands que celui dout nons dunnous ici la mesurc.

\section{Irtdine rougeâtre. Iridina rubens. Noв.}

I. testà ovatâ, utrinquè obtusá, crassá, intìs rubente, extùs epidernii fusco induta, posticè sublamellosí; cardine arcuato; impressionihus muscularibus quinque, anterioribus magnis, crqua. libus.

Anodonta rubens. Lauk. Anim. s. vert. tom. 6. pag. 85. $n^{\circ} .6$.

ENCrCL. pl. $20 \mathrm{I}$. fig. 1. a. b.

Caircaod, Voyage à IIéroé, tom. 2. pl. 60. fig. 12.

Cette espèce est celle dont nous avons vu l'asimal pour lequel nous nous proposions d'établir un nouveau gente; mais, comme nous l'avons dit, un examen ultérieur nous a fait changer d'opinion à cet ćyard, et nous la reportons définitivement an genre Iridine. L'lridine rougeâtre est ovale, arrondie, obtuse à ses extrémités, iuéquiIatérale; son test est épuis, solide, revêtu en debor's d'un épiderme brun, yuelquefois verditre, presque toujours écorché sur les cruchets, prósentunt des zones étroiles et transverses, plıs piles, souvent lamelleuses, qui indiquent les accroissenens de la coquille; sur le cóté postérieur l'éprderme se relive en lames nombreuses et serrées, qui augmentent de longueur à mesure qu'elles s'approchenl du bord inférieur; à l'intérieur la coquille est d'une belle nacre rongeâtre-pourprée; on y voit cinq impressions musculaires, dont les les deux antérieures sont presqu'égales, rapprochées, oralaires; la plus interne est transverse; la postérieure est irés-grande, superficielle, et, au-dcssus de son angle supérieur, on en remarque une autre petite ei arroudie : à l'iutérieur des crochets, et dans la partie la plus profonde, existe la cinquiène impression, qui est ovale, oblonge et profondément creusée dans l'épaisseur dn test. Le bord cardinal est arqué, légère inent flexueux, simple, court, et n'ayant jamais présenté jusqu'a prísent les crénelures accidentelles que nous avons vues dans l'espèce précédente.

L'animal qui habile celte coquille ue diffèro pas d'une manière très.essentielle de celui de I'l ridine exutique, il est seulement plus ovale, plus épais ; son pied a'st proportionuellement plus grand, et son manteau est feadu plus profonilcment.

Cetle coquille se trouve abondamment dans le Nil. Les plus yrands intlividus ont 14 centimetres te long et 80 millimètres de large.

\section{ISABELLE.}

Nom vulgaire donué tantô à une Porcelaine, tantôt í un Cóne. Voyez ces mois.

\section{ISOCARDE. Isocardia.}

Ces t:nquilles laisoiı $n$ antrefois partie des Cames. nu des l’étoncles des anciens auteurs. Lorsque Linné iustilua des geores, il le lit avec une grande réserve, et il dut souvent réunir dans une mêrne coupe des matiriaux assez hétérogènes. Son genre Bulle en est un exemple; les Cames pourioient en ĉtre un autre. ("est avec ces dernières qu'il confon. dit les cocquilles qui nous oecupent. Bruğuière, qui, le premice parmi nous, rélorma les genres de Linné, sentit que des coquilles aussi régulières que les Isocardes ne p uvoient rester ilans le nuême genre que des cơuilles adhérentes, irrégulières el de formes diflérentes; il saisit trieslijea leurs rapports. En les plaçant parni les Cardites, il marqua leurs affinités avec les yenres environuans. Cejendanı le genre Cardite de Bruguière aroit besoin lui-mêrné de réforme. Lamarck 
les opéra, des conpes qui en résultèrent nne a úté consacrcée à l'établissemens du geore Isocardc. Caractérisé d'abord sur les coquilles seules, il fut admis par presque tous les zoologistes, et depuis coufirmé par les savantes recherches de Poli, daus son grand ouvrage des Testacées des Deux-Siciles, oi on ea trouverat une bonne description et d'excelleutes fiurures. Cest sons le non de Glossoderme qu'il le décrit. Quoique J'on puisse remarquer dans l'ouvrage de Ḱlein (Tent. meth. Ostrac. page 138 ) un genre antérieurement établi sous le nom d'Isocandia, on seroit fortement dans l'erreur si l'on croyoit qu'il a des l'apports avec colui-ci, on quie c'est le même; car Ḱlein y rémit tontes les coquilles bivalves qui présentent à l'œil la forme d'un cœur : anssi il ne renferme presqu'uniquement que des Bucardes, presque toutes les espèces connues du temps de cet autcur, et accidentellement une seule espèce d'lsocarde, l'Isocardia cor des anteurs; il y aurnit donc de la mauvaise foi ou de l'ignorance de dire gue Kolein est le créatenr du genre Isucarde : il a rassemblé sous cetle dénomination des coquilles cordiformes de quelques genres qu'elles fussent, et Lamarck a établi le genre Isocarde tel que nous l'entendons aujuurd'bui.

Quant à la place que les amleurs systématiques ont assiguée aux Isucardes, elle a assez varié. Lamarck les a d'abord mis dans sil famille des Cardiacćes a vec les Bucardes, les Cardites, etc.

M. Cuvier (Régne animal, pag. 478) les considere comme un sous-genre du genre Came, Chana, ce qui rompt les rapports étahlis par lo's autres auteurs. L'opinion de M. de fierussac est différeate de celle çne nons venons de ciler; mais elle se rapproche davantage de celle de Lamarik. Lin conserrant la famille des Cardiacées de ce dernicr, il en a élorigné les Cardites, les Cypricardes et les IIyatelles, domt il a fait, avec les Véniricardes, la famille des Cardites; il n’a conservé dans les Cardiacées que les Bucardes, les Hémicardes et les Isocardes.

M. de Blainville, dans son article Monuvsque du Dictionnaire des Sciences naturelles, a conservé à peu près la manière de voir de M. Covier, c'est-a-dire que les Isocardes sont dans la lamile des Camacées, avec les Cames, les Dicérales, les Ethéries, les Tridaces et les 'Trigonies. Nous nous somones pluieurs fois demandé pourquoi ces genres étoieut réuuis, et nous avons vaıtement cherché à répondre à cette question; carles caractères de la famille sunt tellemeat étenclus, qu'il seroit possible d'y faire entrer la plus grande partie des Conchiféres.

L'opinion de M. Latreille (Fainilles naturelles, pag. 217) est entièrement la niéme que celle de Lamarck; seulement i] réunit avec juste raison le genre Vénéricarde à cenx qui composent les Curdiacées. Voici les caractères qui peuvent servir à faice recounoitre le genre Isocarde.

$$
\text { Hist. Nat. des Vers. Tome II. }
$$

CARACTĖBES GÉNÉRIQUES.

Animal à corps fort épais; les bords du manteau finement papillaires, séparés dans la partie iuférieure noyeune seulement, et réunis en arrière par une bande transverse, percéc de deux orifices entourés de papilles radiées; pied petit, comprimé, trancliaut; les appendices buccaux ligulés. (Blainville.)

Coquille équivalve, cordiforme, ventrue, à crochets écartés, divergens, roulćs en spirale; deux dents cardinales aplatics, intruntes, dout une se courbe et s'enfonce sous le crochet; nne dent latérale alongée, située sous le corselet; ligament extérieur fourchu du côté antérieur.

Le nombre d'espèces connues d'Isocardes est peu considérable.

1. Isocarde glubuleuse. Isocardia cor.

I. testâ corduto globosâ, lavigatô, fulvî̀ natibus albidis.

l.AMk. Anim. sans yert. tom. 6. pag. 31. $n^{\circ} .1$.

Chama cor. Lis. GreL. pag. 3299.

Cardita cor. Brug. Dict. encjcl. $n^{\circ}$. 1 , ct pl. 23z. fig. 1. a. b. c. d.

PoLI, Test. des Deux-Siciles, tom. 2. tab. 23. fig. 1. 2.

Caemn. Conch. tom. 7. pl. 48. fig. 483.

Zoologic. Joum. pl. 15 du Supplém. avec l'avimial.

Broccar, Conch. subap. tom. 2. pag. 5 rg.

Scinla, de Corporib. marinis lapides, tab. 6 . fig. $u . a$.

Isocurdia fraterna? S $1 \mathrm{Y}$, Mém. sur les Fossiles du Muriland, dans le Journal de Philadelphie, tom. 4. pl. 11. fig. 1.

Var. b. LAm . A crochets plus courts et moins divergeus.

Espèce très-répandue dans les collections; elle porte vulgairement le nom de Cœur de bouf, de Curur a vulute; elle se tronve vivante dans les mers d'Europe, et nolamment dans la Méditerranće. Sisn analogne idenlique se rencuntre daus presque tons les lieux à tossiles de l'Ttalie et cD Calabre. Ce qui doit surprendre, c'est que l'analogue fossile se retrouve parmi ceux du Mariland, en Amúrique. La variété est particulière aux environs de Bordeanx, quoiqu'elle se rencontre aussi en Italie; il fatudra en faire peut-être une espèce distincte. L'lsparde globnlcuse ayant été décrite dans le premier volume de ce Diclinunaire sous le num de Cardita cor, nous y renvoyons. 
2. Isocarde des Grandes-Indes. Isocardia molt. kiancr.

1. testâ cordatî, subtrigonâ, inaquilaterî, oblique sulcutâ; valvis carinatis; latere antico, hrevivie, depresso, lovigato.

La ax. loc. cit. no. 3.

Cardita moltkiana. Bnug. Encycl. pl. 233. fig. 1. a. b. c. d.

Elle est extrêmement rare et très-distincte de la précédente. Nous renvoyons pour sa description au premier volume de ce Dictionnaire, à l'arlicle Candite.

Les autres espèces, telles que l'Isocandia baso chiana (Der. Dict. des Scienc. nat.), n'étant que des inoules intérieur's, ue peuvent s'en rapproclser que par analogie de forme, et non sur les caractères de la charnière, que l'on nc connoît pas. C'est pour cette raison que les espèces tignrées par Sowerby, dans son Mineral conchology, pl. 295 , ne doivent être admises qu'avec doute. Nous ajouterons l'espèt:e fossile que l'on trouve aux environs de Paris. Níв.

3. Isocarde parisienne. Isocardia parisiensis.

I. testâ globulosî́, valdè cordifonni, longitudinaliter striatâ; striis tenuibus, d'stantibus, convexis, subdepressis, numerosissimis.

Noв. Descript. des Coq. foss. des env. de Paris, tom. 1. pag. 189. pl. 3o. fig. 5.

Par les stries lougitudiniles dont clle est ornée, celle coquille a quelques rapports avec l'Isocandia arietina figurce par Brocchi; ma's dans celte espéce les stries sont bien moins nombreuses que dans la nôtre, et d'autres difiérences se remarquent aussi dans la forne.

L'Isocarde parisienne est d'uu volume médiocre; elle est ovale, obronde, très-oblique, très-inéquilatćrale; ses cruchets, assez grands, écartés, très-cordiformes, s'inclinent en avant, où ils font un tour et deai de spirale; en dehors la coquille est couverte d'un grand nombre de stries, qui commencent au crochet et vont se terminer eu rayunnant sur les bords des valves; ces stries convexes et pen saillantes sont lisses. très-régulières, et séparées par des intervalles qui leur sont égaux en largeur; le lest est très-mince, et par conséquent très-fragile.

Nous ne pourons rien dire de plus sur cette coquille, dont nous ne connoissons ni l'intérieur ni la clarnière; cependant le moule intérieur et les fragmens du test, que nous avous observés, sont tellernent caractérisés, que nous ne couservons aucun doute el sur le genre et sur l'espèce dont il est question. Cette espèce, extrêuement rare, ne s'est encore trouvće qu'aux environs de Paris, à Lernes et à Moucliy; nous en devons la comoissance à M. Grave, dont les communications obligeantes ont été si utiles à notre ouvrage sur les euvirons de Paris. Longueur 38 millim., largeur 30.

\section{ISOCARDIA.}

Suns le nom d'Isocarde, Klein a rassemblé la p!upart des corquilles globuleuses, dont les crochets saillans leur donneat la forue d'un cœur; c'est ainsı que des Bucardes, des Péloncles, dey Arches, ct l'Isocarde elle-méme, furent compris dans celte division, qui ne pouvoit être adoptée.

\section{ISOGNONON.}

Le Perna isognomon de Lamarck a donné à Klein l'idée d'ua genre palliculier pour celle coquille, d'une lorme assez singulic̀re : le geure n'a point été adopté. Voyez Perne.

\section{IVOIRE. Ehurnus.}

Le Buccinum glabratum de Linné, qui est devenu le type du genre Eburae de Lamarck, a été aussi employé par Montfort (Conchyl. syst. tom. 3, pag. 5o6) pour le genre Ivoire, qui fait double emploi avec celui de Lamarck, plus getqérilement adoplé. Voyez Eв UR 


\section{J A B}

$J_{\triangle B E T}$

Adanson (Coquillages du Sénegal, pl. 18, fig. 3) apprelle ainsi une pelite espere d'Arche que Linné a désigníe sous le nom a drca afru, et que lanariti úa pas rapporiće parmi les espèces qu'il a décriles.

\section{JABIK.}

Daus son Voyage au Sénégal, Adanson décrit sous ce nom une conpille qui apprartient an gente Ranelle, el qui n'est point, comme l'a dit M. de Blainville, le Murex scrobiculator de Linné, mais que ce dernier a rapporté, bien ì tort, selon uous, au Mlurex girinus. Nous pensons yue l'espèce d'Adauson, qui n'a pu être examince d'une manic̀re spéciale, est corcore doutense. Voyez MANELLE.

\section{JAGON.}

Il est difficile, ponr ne pas dire impossible, de rapporter ce le espece d'Adansou (Coqul. du Sénég. pl. 18) à son véritable getre; mais il est probable que c'est un Cardinm, pusque dans sa descripliun il dit que la clamière est semblable à celle du Kanan, qui est bien cerlainement un Cartium.

\section{JAMIAR.}

Linné avoit rapporté le Cône Jamar l'Adanson (Coquil. du Sénég. pl. 6, fig. 1) à sun Contis genumus; mais ce Cône ne pouvoit être admis par la synonymie, car ou voil qu'il y a confondu plusieurs espèces dislincles. (Cé serult an Cóne papilionacé de Lamalck qu’il se rapunorteroil; mais nous doutons beacoup que le Jama suil la mème espéce.

\section{JAMBLE.}

Daprès Dargenville, on nommeroil ainsi sur les cótes de Poiton, les Palelles vulgaires qui souvent servent de nourtatuce aux habilans pauves de ces pays.

\section{JAMBBON.}

Les marchands donnent habituellemen! ce num à la plupart des espè es du geure Pinna. Voyez PISNE.

\section{JAMBONNEAU.}

Nom sous lequel Adanson a réuni plusieurs genres, tels que Monles, Mudioles et Pinnes, et :̨ui n’a pas ćlé admis. Ou donne plus particulierc- ment le nom de Jambonnean aux coquilles du genre Pinne. Vojez ce mol.

\section{JANIRE. Janiru.}

Démembreasent irutile fait par Mi. Sclumacher pour quelques especces de Peignes dont MI. Drunet avoit lait de son côté un gente qual rapproche de la lanille des Arelies. Ce genre, anquel il donne le nom de Núbité, a été rejeté et relizi de M. Scliumacher le sera égalenent. Voyez l'ricse.

\section{JANTHINE. Junthina.}

Connu depuis très-long-tenps, ce genre n'en est pas moins restá vilcillant dans les míthodes, comune nous le verrons bientôt. Le premier aulcul qui en ait parlé est, à ce gu’il paruî, Faljus Columua (de Purpura, pag. 13, fig. : ), dout l'onsrage lut publié en $16: 6$. La finure giui accompange sa description est trés-bonne punt le temps oil clle ful luite. Lisler, dans son granl ouvrage (Synops. conchyl. pl. 572), a donne la ligute de a crquille et de l'animal, frubablement d'après Fabius Columa, qualil a soin de ciler. Breynius, en joo5, sans ciler Colunma ui Jister, donna de nouveau des figures de l'animal de la Jantbine; mais ces figures sont mauraises. D'alllwe anteurs, tels que sloune, en 1707 , Brown. en 1750 , cl Rumplitus, thas des ouvrages qui ont pi:ur but la connnissance des productions de certams pay's, on domé la firure de la coquille sealement du gense qui nous occupe.

Un ouvrage qui auroil dî avoir noe grande inlluenre sur l'es; ril des zoolönistes, esi celui de liorsahl, oi l'on truave de bonnces ligures d'un assez grand nombre de Mollusques. Pnblié plusieuss aunces avant la treizieme élition du Systema nature, il auroit pu servir à y apporter plusieurs nodilicatious importantes, si lid direclion imprinéce alors aux sciences naturelles p'en̂t été différeute. Lianialal de la Janthine, bien connu daus sa configuraliun exlérienre, ainsi que dans sa manire de vivre, n'auroit pas dú élue confondu avec les IIélices, el l'on doit s'élonner" que Liané ait comasis une prateille crieus. Aussi le genre Junthine, que Lamarck proposa dans ses premiers liavaux, fut-il adopté sur-le-champ. Depuis, Bosc donna de nouveau la figure de l'an. mal dans son 'l'ruité des Coquilles, el y ajouta une bonne description. Néunmoins, comme l'ubserve M. Curicr, on ne connoissoit point encore assez les rapports des formes extćrieures arec l'organisation, pour lixer invariablenent la place. de ce genre. C'est dans l'intention de décider celte question que M. Cisvier entrepril l'anatourie $S_{s} \because *$ 
de la Jantkine, ayant eu à sa disprsilion plusieurs individus de mếme espece, riplpurlés de uers fort éluiguées. Malgré celte anatuuie, nous ne voyons pas encore les auteurs d'un accord nnanime sur les rapports de ce genre.

M. Cuvier le place dans ses Concinylies avec les Phasiauelles et les Ampullaires.

Lamarck en liait une faraille à part, qu'il tient isolée entre les Néritacées et les Macrostomes.

M. de Ferussac le rapporte à la famille des 'Trochoïdes, dans laquelle il rassemble aussi bien les Janthines que les Mćlanopsides, les Nérites, les Scalaires, eic.

M. de Blainville, sans adopter absolument l'opinion de Lamarck, en a une qui s'en rapproche plus que d'aucune de celles de ses devanciers; il propose eu ellet, dans son second ordre des Asiphomobranclies, une cinquième famille sons le nom d'Oxistones, pour le genre Janthine lui seul. Celte nuuvelle famille se trouve immédiatement après celle des Hémicyclostomes qui correspond enticirement à celle des Néritacées de Lamarck.

M. Latreille enfin, dansses Familles naturelles, a manifesté une opinion differente de toutes celles que nous venons de onentionner. L'anteur établit six familles dans la seconde section des Pectinibranches; la seconde, sous le nom de Turbinés, est cousacrée aux genres Turritelle, 'Turbo, Anpullaire et Janthine. Celle dernière opinion, dans laquelle on aperçoit quelques similiudes avec celle de MMI. Cuvier el de Ferussac, n'est point entièrconent semblable à celle de ces deux zoologistes; elle leur est p!utôt internédiaire. Paruí toutes les opinions que nous venons de rapporter, celle qui nous paroít se rapproclier le plus de la vérité, est celle de Lamarck et de M. de Blainville; c'est elle que nous adopterions de préférence. D’après les travaux de MM. Cuvier et de de Blainvilie, on peut caractériser le geure Janthine de la manière suivantc.

\section{CARACTERES GÉNERIQUES.}

Animal de forme ovale, spirale, pourvu d'un pied circulaire, concave, en lorme de ventouse, accompañó d'une masse vésiculaire subcartilagineuse, ề de chaque côté d'espèces d'appendices natatoires; tête fort grosse, tentacules subulés, peu contractiles; les yeux portés au-dessuns ıé l'extrémilé d'assez longs pédoncules silués au côté externe des tentacules, et paroissant en faire partie; lıouche à l'extrémité d'un mafle fort gros, proboscidilorme, entre deux lèvres verticales, subcartilagineuses, garnies d'aiguillons qui se continuent jusqu'à la base d'un petit renflement lingual; organe de la respiration formé par deux peignes brauchiaux; l'ovaire se termioant daus la cavité respiratoire; lorgane excilatenr mâle assez petit et non rétructile. (De Blainv.)

Coquille ventrue, conoidale, miuce, transparente; ouverture triangulaire; columelle drvile, dépassant la base du bord droit, celui-ci ayant un sinus dans son milieu; opercule remplacé par une masse vésiculaire subcartilagineuse attachée sous le pied.

I.es Janthines sont de jolies coquilles minceq, transparentes, r'ès-fraphiles, toutes dun beau violer plus ou moins loncé; elles sont globuleuses, turbiniformes. Livuverture, très-grantle, est sewilunaire, un peu oblique à l'axe, ayant le bord druit très-mince et tıés-trauchant, el toujours sinueux dans le milieu; la columelle est droice, miuce, en filel tordu sur lui-mème, el se terminant inférieurement à sa jonction avec l'extré. milé du borí par un angle assez saillant et renversé en dehors. L'aniunal des Janıbines a une manière de vivre particulière; suspendu renversé i la surface de l'eau, au moyen des vésicules a riennes attachées ḋ son pied, il est constamment flottant, et ne peut jamais descendre au fond de la mer, à moins que celle vésicule a'ait été arrachée : de celle manière, il peut êlre transporté, à la suite de veuts ou de tempêtes, à de irès-grandes distances du lieu qu'il luabite; il peut, comnie tous les corps flattans, être entrainé par les conrans. Cela explique pourquoi quelques espèces de Jauthines sont répandues dans loutes les mers.

Ce genre ne routient encore que trois espèces; tomles sont vivanles, el nous ne connoissons rien, même dans les terrains les plus nouveaux, qui puisseut s'y rapporter. Quoique deux espèces soient abondantes dans la Mrditerrante, et que, d'après la nature des terrains de la Sicile, on puisse cruire qu'elle y a élé enfouie comme le reste des habilaus de celle nier, cependant elle ne s'est point encore reucontrée dans cette sorte de terrain.

3. Janturae, commune Janthina communis. LAM $\mathrm{B}$.

$J$. testá ventricoso-conoideâ, longitudinaliter subrugosâ, trunsversim temue striati, violacei; ultimo anfiactu magno, subangulato; spira apice obtusiusculâ.

Lasx. Anim, sans vert. tom. 6. pag. 206. $n^{\circ} \cdot 1$.

Helix Janthina. Lss. pag. 3645. no. 103.

Lister, Conch. tab. 572. fig. 24.

Rимгн. Mus.tab. 20. fig. 2.

Gualt, Test. tab. 64. fig. O.

Stoax. Jam. tab. 3g. fg. 2.

Fonsk. Descript. anim. pag. 127. $n^{\circ} \cdot 7^{5}$.

Dargenv. Conch. pl. 6. fig. 5.

Chemn. Conch. tom. 5. tab. 166. fg. 1577 1578 . 
Junthinu fragilis. ExicycL. $p l$. 456. fig. 1. a. b.

Cuvier, Ann. du Mus. tom. 11. Ménr. sur la Janthine, fig. $1-8$.

Janthina fragilis. DE Buaisv. MIalac. pag. 447. pl. 37 bis. fig. 1 .

Var. A.) Nов. Testá majore; striis transversis, numerosionbus; testî undiquè violascente.

Depuis long-temps celle cuquille est conoue, il sullit pour ainsi dire de l'indiquer. Sa forme extéricure est cellc de certains 'Turbos; sa spire est assez proémineute, obtuse au sommet, formée de quatre ou ciuq tours légèremeat convexes, à suture simple, peu approfondic; le pourtour du dernier tour est subangulenx, et cet angle obtus correspond à la sinuosiıé du bord droit. La columelle est ea filets très-minces, tordue sur ellemême, et terminée inférieurement par un angle subauriculiforme renversé en dehors; en dessus cette coquille est ordinairement d'un violet pâle blaochâtre, terminé d'uoe manière trancláe par l'angle da dernier tour; loute la base est d'uo violet-bleuâtre fort intense. Des stries longitudinales, assez serrées et nombreuses, sont produites par les accroissemeus; d'autres stries transver'ses irrégulières, plus nombreuses en dessous qu'en dessus, coupent les prowières à angle dioit. Dans quelques indivilus les stries traosverses manqueat tout-à-fait en dessus. La partie vésiculaire desséchée ressemble à un peu de mucus buursoutflé en cellules nombreuses. La variété que nous avons sigualée est conjours plus graude, plus striee, et d'use teinte plus uniforme que les autres ialividus : clle vient des mers d'Afrique. Celte espèce se trouve dans presque toutes les mers. Nous la connoissous aussi bien de l'Océan européen que de la lléditerranée, dcs mers d'Amérique, du grand Océan du sud, ainsi que du cap de Bonuc-Espérance.

Les plus grands individus ont 45 millim. de diamètie.

2. JaxrmuE naine. Janthina exigua. LaMx.

$J$ testá ovato-conoided, tenuissimá, subhyalinâ, longiludinaliter elegantissimè striatá, violaceấ; spirá apice acutâj ultino unfructu obtuse angulato.

Lasur. Anim. sans v'ert. toms. 6. pag. 206. $n^{\circ}, 2$.

ERTCYCLOPĖDE, pl. 456. fig. 2.a.b.

Cette petite espèce est bien distincte de la précédente; elle reste constamment beaucoup plus petite, et les stries longitudinales très-élégantes dont elle est orn ́e la rendent bien distincte du jeune âge de l'espèce arec laquelle nous la comparons. Elle est glubuleuse, à spire conoide et pointue, formée de cinq tours, doot le dernier est plus grand que tous les antres; ils sont arron- dis, convexes; leur suture est profonde; ils sont ornés d'ua très-grand nombre de stries longitudinales et obliques, sublamelleuses, sinueuses dans le milieu du dernier tonr. L'ouverture est grande, subsemi-lnoaire; son bord droit, fortcment écbancré dans le miliea, présente l'origine d'une petite fente bien comparable à celle des Pleurotomaires, fente que l'on peut suivre sur le milieu du dernier tour par la sinuosité brusquement anguleuse des stries longitodinales; en dessous, le delnier tour est bombé, percé au centre d'un pelit ombilic caché derrière la columelle. Celle-ci est droite, perpendiculaire, d'un blanc-violâtre, et cermincé par un aogle peu saillan. Toute la coquille est d'un beau violet, quelquefois un pen plus intense en dessous qu'en dessus, mais sans que celte différence soit nellement tranchée an pourlour du dernier tuul. Cetle coquille se trouve dans la Miditerrance, et M. Lesson en a rappotté quelques individus du Chili, qu'il nous a communiqués a vec la plus grande bienveillance. Les plus yrands individus on environ 7 millim. de diamètre et 8 millim. de hauteur.

\section{Jaxture prolongée. Janthina prolongata.} De Brarnv.

J. testâ ovato-glohulosâ, apice obtusâ, lavigatâ; anfractibus convexis, saturá profiundi separatis; aperłurâ magnâ, ovatû, busiprolongutâ; margine dextro loviter sinuato.

De Braint. Dict. des Scienc. nat. tom. 24. pag. 155 .

Payraudeau, Cat. des Annel. et des Moll. de l'ile de Corse, pag. $121 \cdot \mathrm{n}^{\circ} 154$. pl. 6. fig. 1.

Sow. Genera of Schcll. no. 5. fig. 3.

Espèce éminemment distiocte des deux précédentes. Elle est trc̀s-globuleuse, reutrue, à spire courte et obluse, formée de cinq todrs, dont le dernier, beaucoup plus grand que les antres, n'est jamais angulenx à $s a$ circonférence. Ces tours de spire sont très-convexes, lisses ou à peice marqués de quelques accroissemens; la suture qui les sépare est profonde, subcanaliculée; le dernier tour, très-convexe à la base, ae préseute qu'une pelite fente ombilicale eotourée de quelques stries à peine perceptibles, et cachées presque complétement par le renversement du bord gauche. L'ouverture est graude, ovalaire, plus baute que larye, ayabt sou bord droit légèrement sinneux dans le milieu; la columelle est arquée, d'un blanc-violátre, un peu épaisse supérieurement, se prolongeant à la base, à sa jonction a vec l'extrémité du bord droit, en uo angle obtus pea renversé en dehors.

Cette coquille ne s'est encore rencontrée que dans la Méditerraoée, à l'ile de Corse, en Sicile, et dans l'Adriatiquo; elle paroît surtout commune 
à l'ile de Corse. Elle a 15 millim. de large et 20 de long.

\section{JARDINIER,}

Nom vulgaire de l'Helix aspersa. Voyez $\mathrm{H} \dot{\varepsilon}-$ LICE.

\section{JATARON.}

C'est le nom générique qu'Adanson a proposé (Coquill. du Sénég. pl. i5) paur des cuquillcs que Lawarck a réunies sous le non de Cames. (Voyez ce mo:.) Le même auteur a nommé Caine annelée, Cltama crenulata, l'espéce décrite el figurée pal Adaason.

\section{JATOU.}

A danson (Coquill. du Sénéo. pl. 9, fin, 21 ) a ainsi nomıné une coquille du genre Murex ; c'est le Murex gibóosus de Lamarck, et le Murex lingua vervecina de Camailz. Voyez Murex.

\section{JAUNE D'CEUF.}

Dénomination employée par les marchands pour désigne: une beile espèce de Natice, Natica albumen. Toyez Natice.

\section{JELIN.}

Adanson (Coquill. du Séıég. pl. 11, fig. 6) rapporte à soo genre Vermet un Tube teslacé qui, s: nous sunble, esı une vérituble Serpule. Limné l'a placé dans ce geare suus le noun de Serpula ulltestinulis. Voyez Serpule el Vermet.

\section{JENAC.}

Nom sous lequel Adanson a décrit une pelite espèce de Crépidule que Linué a désignée sous le nom de Patella goreensis, et qui n'est probablenient qưue variété de la Crépidule unguiturine ce Lamarck.

\section{JESITE. Jesites.}

Mooıfurt a placé parmi les Pulythalames (Conchyl. syst. tom. 1, pay. 102 ) un corps adhérent euruulé comme un Spirorbe, nuais divisé par plusieurs cloisons. Soidaui avoit déjà lait connoître ce corps; il est figuré dans le Testacea microscop. de cet auteur, pl. 30, var. 140,10 , éalement parmi les Polythalames. Quviquel'on sache aujourd'hui que plusieurs especes de Céphalupodes vivent adhérentes a la manière des Spirorbes, celui-ci en a si bien le puil et la structure, que l'un doit rester dans le donte jusqu'a ce que des ubservathors nouvelies viennent coofirmer ou détruire 'opioion de ces auteurs. On suit d'ailleurs gria'l existe un assez grand nombre de Serpules ou iplutút de Vermels qui se cloisounent par suite des accroissenens de l'animal; plusieurs Siliquaires sont dans ce cas : il n'est done pas impossible cie penser que ces petits corps apprittienneat à des Mollusques, qui se sout irrégulièreasent clıisonués. lic duule que MI. de Ferussac a conservé en rapportant ce genre aux Céplalopodes puurroit servir à coufirnier notre opinion.

\section{JESON.}

Adaxson, Coq. dus Sénég. pl. 15. fig. 8. Syn. de Cardita crassicosta. Lamarck. Voyes Cardite.

\section{JODAMIE. Jodamia.}

M. Defrance, dans le Dictionnaire des Sciences naturelles, a élabli ce genre, qui nous semble a voir les plus grands rapports avec les Sphérulites et les Radiolites : nuus le mentionueruns ea traitant de ces geares. Voyez Spákulites el RADIOLITES.

\section{JOL.}

Tel est le nom qu'Adausoa a donué ì une petite espèce de Buccin de la section des Nasses; mais le preu de nelteté de la figure ne peraet pas cie pouvoir la rapporter a une des especes décrites par les auleurs.

\section{JOUANNETIE. Jouannetia.}

M. Desmoulins, daos le Bulletin de la Société linnéenne de Bordeciux, a proposé, suus ce nun, 11u petit genre dédıé à N. Jouannet, observatex: for babile, pour une petile coquille perluraate yut appartient, selon nous, au geure Pholade. Elle est du nombre des espèces de ce genre qui sont pourrues d'un tres-grand écussun enreluppant la presque totalité des valves. Voy. PhOLADE.

\section{JOCRET.}

Nuus ve sonnues pas de l'opinion de Gmelin, qui a rapporté à la Venus maculata (Cytherea maculuta Lamk.) le Jour't d'Adanson (C'oq. du sénég. pl. 17) qui nous semble une espèce bicu distucie, que les iuteurs a'ont poiot encore mentioudée d'une manière satisfaisante.

\section{JULAX.}

Nom donné par Adanson (Coq. du Senég. pl. 19.) a uoe pellte espèce de Pbolade indiquée par Lioné sous la dénumination de Pholas strista. 


\section{K A C}

KaCinn.

Adanson (Voy. au Sénég. pag. 187, pl. 12, fig. 9) donne ce nom à une coquille de son genre Turbo, qui paroît appartenir au Turbo tuber de linné. Voyez 'TuRвo.

\section{KALAN.}

Démominalior sons laquelle Adanson (Foy. au Sénég. pl. 9, figr. 3o) désigne une coquille du genre Sirombe, qui pourroit bien être le Stronıbus Lenlıginosus de Linné. Pour arriver à celle déterwination, il faut moins s'cn rapporter à la figure et à la synonymic d'Adanson qu'à sa description, qui ne laisse guère de doute à l'égard de lespèce. Voyez Strombe.

\section{K.ALISON.}

Une pelite espèce d'Oscalirion a reçu ce nom d'Adauson. (Voy, au Sénég. pl. 2. fig. 11.) Lauarck ne l'a point ruppoilée dans sa sy'nonymie, et MI. de Blainville pense que ce n'est qu'une variété de l'Osiálrion tuscirulaire; mais nous ne partageous pas sull opinion: il nous secoble, d'apres l'exaruen altentif de la description d'Adanson, que cel O,cabrion constalue une espèce bien distucte de toutes les autres. Voyez OscaBR,OX.

\section{KAIIAN.}

Une bclle espèce de Bucarde, Cardium exo. ticum des auteurs, a été nomaiée de celle andnière par Acianson. (Voy. au Sénég. pl. 18.fig. 2.) Voyez Bucarde.

\section{KAMBEUL.。}

Adanson (Froy. au Sénég. pl. 1) a donné ce num à une coquille terrestre du Sénégral que La- marck a comprise au aombre des Bulimes, et que M. de Ferussae a placée parmi les Agatlioes : l'une et l'autre de ces opinions pcut être justifiée; car la coquille est de celles qui par ses caractères se placent sur la limite des genres et en font la jonction. Les deux auteurs ont conservé à celle espèce le num de Kambeul, imposé par Adauson.

\section{KAURIS.}

On écrit quelquefois de celte manière le nom de la Porcelaine Cituris, vulgairement connue sons la dénomination de Mounoie de Guinéc. Voyez $\mathrm{C}_{\text {aunus }}$ et Yorcelaine.

\section{KISE'T.}

Dinomination sous laquelle Adanson ( $F o y$ a a Sénég. pl. 13, fig. 5) fail connoilre une coquille du genre Nérite. 11 est difficile de savoir à ifuelle espcece des auteurs elle peut être rapportéc. ( $\nu_{0 y}$. Nírtes.) Ginelin la nomue Neritci Magdelenip; mais on est loin d'êlre certair: si celle essèce: devra resler.

\section{KRAKEN.}

Dans le Buffon de S'onnini, Montfort, se livraut davantage à l'aldeur de sou imagioation qu'a l'élude des tirits, a raconté l'histoire d'un Youlpe yiganiesque capable d'allaquer el de fuire nallfritger ua vaisseau de hall-ford. Celle histuire, qui u'a rieu d'authentique, a'auroil pas pernis' $\dot{a}$ un autre observateur que Montfort létablissenent d'un genre fondé sur des relations mensongitres, et nun sur l'examen de l'aniual lui-même.

Voyez l'arlicle Poulpe, dans lequel nous reviendrous sur les animaux d'une grande taille doul la présence est quelqquefuis luneste it l'bomme lui-toêıne. 


\section{A B}

\section{Labarin.}

Now donné par Adanson (Yoy. au Sénég. pag. зo5, pl. $7, f$ fig. 2) à une trìs-belle espèce de Pourpre, qui est le Purpurea coronata de Lamarck.

\section{LACUNA.}

Sous celte dénomination, M. 'Turton a proposé une petite coupe générique qui correspond \& l'une des nombreuses sous-divisions du genre Turbo. Vojez ce mot.

\section{LAGAR.}

Dénomination imposée par Adanson (Voy, au Sénég. $p l .13$ ) à une espèce de Nérà dont Gmelin, dans la treizième édition de Linné, a fait sa Nerita promontorii. Cette coquille pourroit bien n'être qu'une des nombreuses variélés de la Nerita polita.

\section{LAGEYA.}

Geare proposé par Klein (Tent. meth. Ostrnc. pag. 49) pour des coquilles du genre Buccin, principalemeot pour celles qui, selon lai, oni la forme d'une bonteille. On ne doit pas ére étonné qu'un genre pareil n'ail élé adopté de persunce.

\section{LAGENULE. Lagenula.}

Montfort a proposé de former ce genre (Conch. sist. tom. 1, pag. 3iI) pour un petit rorps fort singalier, figuré depuis long-lemps dans le bel currage de Soldani. (Test. microsc. tab. 120. r'as. 248.) Il ressemble à un petit ouf supporté par un pied composé de plusieur's petits calices ajustés les uns aux autres. Il est fort dontenx que ce corps, qui se trouve dans les sables de la mer Adrialiquo, doive étre conservé parmi les Mollusques.

\section{LAMBIS.}

Nom sous lequel les marchands désignent particulièrement une espèce de Ptérocère, Pterocera lambis Lamk.; ils donnent aussi le nom de Lambis de la grande espèce au Strombus latisimus Lin.; de Lambis ailé de la moyenne espèce au Strombus gigas Lin.; de Lawbis marbré au Strombus lentiginosus Lin.; el enfin de Lambis non ailé de la grande espèce ai Stro:nbus lucifer Lin.

\section{LAMELLAIRE. Lamellariu.}

Montagu, par un double emploi, a dunné le nom de Lamellaine au genre Pleurobranche d M. Cuvier. Voyez Pleunobraxicae.

\section{LA IIELIIBRANCHES.}

C'est à MI. de Blainville que l'on doit la création de cetle nouvelle dénomination pour rassercbler en une senle divisinn tous les animaux mellusques doat les branchies, par paires trés-larges el en lames aplities, sont placies entre le corps et le manteau. Presque tous les Concbifères ou coquilles bivalves doivent rentrer dans cette division, dont nous repalerons à l'article MouLUSQUE, auquel nous renvoyons.

\section{LAMELLES. Lamellata.}

M. Latreille, dans ses Familles naturelles du Règne animal, pag. 202, a propusé ce nom pour remplacer celui plus dillicile de Polyplasiphore, dnnné par M. de Blainville aux Oscabrions. V'oyez Oscabrion.

\section{LAMPADIE. Lampas.}

Petit genre établi par Montfort, pour une coquille nicroscopique qui apparticnt ab genre Robuline de M. D'Orbigny. Voyez Roveluse.

\section{LAMPAS. Lampas.}

Genre proposé par M. Schumacher, dans son Essai d'un nouveau systeme des Coquilles, pour le Alurex lampas de Linné. Celle division correspond au genre Triton de Lamarck, depris long-tcmps établi; elle ve peut donc être conservée. Poyez 'Тнгто.

\section{LAMPE ANTIQUE.}

Nom que l'on donne vulgairement à quelques espèces d'Hélices qui ont l'ouverture irès-évaséc, et principalement à celles dont Lamarck a fait son genre Anostome. Voy. Hélice el Axostome.

\section{LAMIPSILIS.}

Suus-division établie par Rafinesque pour queliques especes de Muleules qui currespondent d'une manière assez exacte au genre Mulette de Lamarck. Ce gente de Rafinesque ne peut últe adopté, pas plus qune ceux proposés par Ml. Say dans le nême gene. Loyez Munette.

\section{I.AMPUSIE. Lamprsia.}

A l'exemple de Montfort, M. Scliumacher a porté 


\section{A N}

portć trop loin le desir de faire des genres. Celuici est un déucmbrement inutile du genre Triton de Lamarck: il a pour type le Triton pileare. Vojez Triton.

\section{LANGÜE.}

Nom vulgaire donné à des coquilles de genres divers. On noume Langue de cliat une jolie espèce de Telline, Tellina lingua felis Lamk.; 1.angue d'or, Tellina foliacea; Linngue de tigre, Tellina scobinata; el Langue de veau, le Murex vitulinus. Voyez Telline et Rocaea.

\section{LANIOGÈRE. Laniogerus.}

C'est à M. de Blainville que l'on doit la création de ce noureau genre. Dès 18,6 il fut connn par l'extrait d'un mémoire qui fut publié dans le Bulletin de la Société philonatique pour celte année. M. de Ferussac, dans ses Tableaux systématiques des Aniniaux mollusques, a adopté ce genre et l'a placé dans les rapports indiqués par son créateur, c'est-à-dire qu'il l'a rangé dans les Gastéropodes, dans la famille des Polybranches, à côté des Eolides et des Glauques, entree lesquels il sert de passagre.

MI. de Blainville a reproduit ce genre dans le Dictionnaire des Sciences naturelles, dans l'aulas duquel il est figuré, et en a moutré les rapports à l'aricle Morrosque du même ouvrage, en le ran. ge.ınt rout près des Glauques et des Cávolines.

Voici les caractères que M. de Blainville assigne à ce genre.

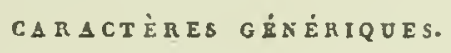

Corps an, alongé, convexe en dessus, plane en dessous, terwiné par une surle de queue; la tête assez distincte; quatre tentacules fort petits; les Lranchies en forme de longues lanières molles, llexibles, disposées en un seul rang de chaque cốté du corps; l'anus el les organes de la génélution à droite, dans un tubercule commun.

$\mathrm{Si}$ on vent comparer ces caractères à ceux du genre Glauqque, on verra que les Laniogères s'en distinguent très-bien, quoique très-voisins. On n'en connoit encore qu'une seule espèce, que 3. de Blainville a vue dans la collection din Museum britannique. Nous ne la connoissons pals, et il nous est impossible de douper sur elle de plus amples détails.

\section{LANIS'TE. Lanistes.}

Montfort (Conchy. syst. tom. 2. pag. 122) a Établi ce genre avec le Cyclostoma carinata d'O. livier, qui n'est autre chose que l'Ampullaria carinata de Lamarck. Cette coquille appartient véritablement aux Ampullaires. Voyez ce mot.

Hist. Nat. des Vers. Tome II.

\section{E D}

\section{LANTERNE.}

Nom vulgaire d'une trc̀s-belle et rus coqquille, dont Lamaick a fait le type de son gente Auatine. Voyez ce mot.

\section{LAPLYSIE. Laplysia.}

Lamarck, par suite d'une erreur, a écrit de cette manière le nom générique des Aplysies. Voyez ce mot.

\section{LAPLYSIENS (Les).}

Nous avons traité cette famille à l'article Aply. SIENS, a aquel nous renvoyuus.

\section{LASTENA.}

B1. Rafiucsque a établi ce sous-genre pour une division du genre Auodonte de Lamarck. Ce genre Anodonle se fondant d'une manicre insensible dans le grand genre Mulette, et ne présenlant point de caractères suffisans pour être conservé, à plus forte raison celle division de Rafinesque doit-elle être rejetée.

\section{LATIRE.}

Dénombrewent des Fuseaux établi à tort eu gence par Monifort (Conchyl. syst. tom. 2 , pag. 531 ), sur le simple caractère dun ombilic intundibulilorme, plus grand qu'il ne l'est ordinairement dans les Fuseaux. Foyez ce arot.

\section{LATONE. Latona.}

Genre proposé par M. Schumacher pour quelques coquilles du genre Donace de Lainarck. Ce genre, qui a pour type le Donax cuneata, n'x aucnn caractère qui le justifie; il doit donc être rejelé. Voyez Donace.

\section{LAVIGNON.}

MI. Cuvier a proposé sous cette dénominalion un sous-genre de Macıres qui réunit plusieurs des Lutraires de Lawarck. (Voyez Lutraire.) M. de Ferussac, dans ses Tableaux, a élevé ce sousgenre au titre de genre, dans la famille des $\mathrm{Nlac}$ tracées. Nous pensons que si on conserve celle coupe, elle doit étre considérée comme sousgenre des Lutraires de Lamarck. Voyez ce mot.

\section{I.ĖACHIE. Leachia.}

Depuis long-temps le genre Calmaret de Laraarck a voit été étalıli, lorsque M. Lesueur lui imposa le nom de Léachie, qui ne doit pas être adoplé. Vojez Poulpe.

\section{LEDA. Leda.}

L'Arca rostrata de Chemnitz, qui depuis longtemps est comprise dans le gebre Nucule de La- 
marck, et qui ne présente aucun caractère qui l'en puisse faire sćparer, a cependant servi de type à c:e nouvean gen re de M. Schumacher (Ess. d'un nous. Syst. pag. $17^{2}$, pl. 19, fig. 4), qui doit ètre rejeté.

\section{LÉGUMINAIRE. Leguminaria.}

Sous ce nom, M. Schumacher (Ess. d'un Syst. pag. 126, pl. 7, fg. I) a proposé un genre qui comprendroit celles des espèces de Solens de Iamarck, qui, avec une chalnière subrnédiane, unt une côle intérieure et transverse qui la soutient. Ce genre ne peut êtrc adoplé. Voyez Solen.

\section{LEN'TICULACÉES (Les).}

Cette famille fut proposée par Lamarck dès sog, dans sa Philosophie zoologique; il y comprenoit les geores Miliolite, Gyrogonite, Rotalite, Rénulite, Discorbite, Lenticuline et Nuormulite. Depuis celte époque, Lamarck a senti que celle association de genres n'étoit rien moins que naturelle, et il l'abandona pour une nouvelle distribution qu'il proposa dans l'Extrait du Cours et dans son dernier ouvrage.

\section{IENTICULAIRES OU PIERRES LENTICU. LAJRES.}

Nom que l'on donne quelyucfois aux Leuticulites et anx Nuamulites. On donae particulic̀rement le now de pierres lenticulaires à celles qui contiennent un grand noubre de ces corps agrégés par an cimcal solide.

\section{I.ENTICULINE a LENTICUIJTE.}

Ce genre, que l'on confondoit autrefois avec les Camérines ou Nummulites, a élé créé par Lamarck, pour de pelits curps lenticulaises polythalames, qui ue diffërent des Nummulites quue par les cloisons qui s'ércudeal jusqu'au centre de la coquille, et par l'ouverture, qui reste visible lorsque celle des Nuumulites disparoit constamment. Ces caractères ont paru suffisans à la plupart des zoologistes pour conserver les deux genres, et les placer dans des fanilles dillérentes. Une étude comparative des espèces de ces deux genres, et surtout de celles qui ne sont pas pétrifiées, auroit fait apercevoir une structure absulumeul semblable dans les deux genres; si quelques légères différences s'y remarquent quelquelois, elles se lient toujours par des auances insensibles. Nous traiterons de ces corps au mot Nomulites. M. d'Orbigny a senti, comine nous, la nécessité de réunir les deax genrcs Lenticulite et Nummulite; mais ayant connu une de ces coquilles à l'élat vivant, il a donné au geure le nom de Nummuline, que nous avons adopté. royez ce mot.

\section{IENTIGO.}

Klcin (Method. ostr. pag. 100 ) propose de réunir dans le genre qu'il nomme ainsi, toules les coquilles dont les tubercules aplatis et arrondis ressemblent plus on moins à des lentilles. Dc pareilles geures ne méritent pas unême d'èrre examinés.

\section{LENTILLAIRE. Lencillaria.}

La coquille que $\mathrm{N}$. Schumacher a prise comme type de ce geore lentillaire, est la Venus punctatu de Chemnitz, que Lamarck avoit coml.rise dans son genre Cythèrée. Par un examen uliérieur, nous nous sommes assuré que cette espèce, ainsi que quelques autres avoisinantes, doivent entrer dans le genre Lucine; le geure Lentillaire devient, par cela même, un double emploi des lucines. Voyez ce mot.

\section{LËOPARD.}

Nom vulgaire que l'on donne quelquafois anx espèces tigrées de Cônes et de Porcelaioes. Voyez ces mots.

\section{LÉPADIENS.}

M. de Blainville, daus son Traité de Malucologie, a nommé de la sorie une famille fort nalurelle, qui correspend exactemeat à celle que Lamarck, antérieuremeut à lui, avoil faite sous le nom de Cirrhipèdes pédonculés. (Voyez $\mathrm{Ca}_{1-}$ uHip̀̀ne.) M. Rang, dans son Manuel de Conchyliologie, a adopté la faunille et la dénomination de M. de Blainville; il y a introduit le gente Alèpe, Alepas, pourl' Anatifaunivalvis des auteurs. Celle famille se trouve alors composée des six geares suivans, auxqucls nous renvoyons: Alèpe, Gymnolćpe, Anatile, Pollicipède, Polylèpe el Jiitholèpe.

\section{LÉPAS ou PATELLE.}

On donne vulgairement l'un de ces noms comme synonyme de l'autre, à toutes les coquilles qui sont patelloiiles, telles que Cabochon, Calyptrée, Crépidule, Patelle, Fissur elle, etc. Le mol Lepas est plus particulièremént employé actuellement pour dísigner les animaux qui sont rangés dans les genres $\Lambda$ natife et Balane de Linné.

Quelques personnes nomment encore Isépas fluviatile, les coquilles du genre Ancylc, Lépas percé, celles du genre Fissurelle, et Lépas chambré, la plupart des Calyptrées.

\section{LĖPAS.}

Conservanl la dénomination vulgaire, Adanson (Voy. au Sénég.) a rangé dans un senl et même yroupe qui porre ce nom les coquilles ben-sculement des Patelles, mais encore des Crúpidules, 
de: Calsochons, des Calyptrées, des Fissurelles, I des Oscabrions et mèrue des Siphonaires. Ce genre, qui correspond à plusieur's des lamilles actnelleauent reçues dans les métlodes, n'a pu être conservé, et le num qui le désignoit n'a plus la mếrne valeur.

\section{I.EP'TCENA.}

Ce geure a élé proposé par N. Dulman; mais comme il correspond exariement all genre Sirygocéphale de $M$. Defrance, et que ce genre n'a point de caractères suflisans pour èlre distingué des 'T'érébratules, nous reavoyous aux mots l'ruDUCte el 'TÉréra atur.e.

\section{LEPTOIODE. Leptopoda.}

Daus sa classificalion naturelle des Mol!usques, MI. Gray a proposé sous ce num l'ordre troisième de sa classe des Conchophores : cet ordre renferme les denx genres Nactre el Nusule de Wamarck.Sans doute gua a ae considérer qu'un seul point des coquilles, on peut faire c'c ritpprochement, puisque, daus les unes et dans les autres, le liganent est porté sur un cuilleron inlérieur; mais si l'on fait alteution à la très-yrande dillírence qui existe daus tous les autrescaractices, on ne pourra que difficilement se rendre compte des motils qui ont dirícé M. Gray, dans ce rapprochement qui nous parvit tont au moiuss bizarre. La fumille des Macuracćes, caractérisée comme elle l'est actueillement par des avimaux qui ont deux siphous postérieurs, ne pourroit êlıe xodıliée pour y laurs earer le genre Nucule sans que la valeur de ces ensactères ue füt presque consplétement détruite. V́ojez Nactracés et Arciacres.

\section{LEPTOXIS.}

Geore proposé par M. Rafjuesque et non adopté parce qu'il correspond au genre Limuce de Lamarck, antérienre.uent établi. Vayez Linsì.

\section{J.EVANTINES.}

l.es conrbyliologues du dernier sièrle désignoient ainsi plusieurs des coyuiles bivalves du genre Vénus, qui sont habiluellement rapportées des mers du Levanb. l.amarck a conservé ce nora a use belle espece de Vínus, Venus levantina. fooyez Vixus.

\section{LIBITINE. Libitina.}

1I. Schumacher n'ayant sans dunte pas reconnu le genre de la coquille qu'i! nomme Lililine, en a fait un genre nouveau, quoiqu'elle fint comprise depuis lons-temps au nombre ries Cypricardes de Lauarct. Vojez CrrutCARDE.

\section{LIBOT.}

Isamarrk a eu bien raison de ne rapporter qu'avec donle le Libot d'Adanson (Foyage au Sénégal, pus. 27, pl. 2) au Patella unibella de Linné. Il existe des différences notables, si l'on compare la description du Libot à celle de l'espèce que nous venons de citer; l'une est bleue en dedans, d'un noir-grisultre en delor's, fandis que l'aulre est contamment rose. Ce qui a pu produite l'erem, c'est que, dans sa synonyaie, Adauson cite la figure 21 de la planche 538 de Lister, qui est douleuse, et que les autcurs rapportent génélulement au Patella imbella. Le Libot d'Aclanson est donc une espèce qui n'a point encare élé reconoue.

\section{LICOPHRE. Licophris.}

Muntort introduisit ce genre parmi les Mullusques, et cl'après son exemple le plus grand nombre des auteurs l'adoptèrent. Cependant il ace falloit que l'examiner avec quelque soin pour. 'tecomboire qu'il appartient au genre Nurrmulite do Lamarck. Toyez ce mol.

\section{LICORNE. Monoceros.}

M. de B!ainville, dans le Dictionnaire des Sciences naturelles (tom. 24), altribue la création de ce grore a Montlor!; cependant nons trouvons dans la Zuologic phlosuphique de Lamirrck, publice quelques années avant louvrage de Montlurt, le geure Monoceros, élabli dans la tamille des Purpuracées, catre les Pourpres et les Concholépas, où est sa place uaturelie; nous le relrourons, dans l'Extruit du Cours, dans la famille des Purpuriferes, sous la même dénomination et dans lés mêmes rapports.

Ionifort a dü puiser à celle source pour la furmation de ce gene dout il a traduit le non en liançais et changé la dénomination de monoceros en celle d'unicornus. Ce genre, extrait lles Punipres, a eusuite élé adopré par le plus grand noushre des conchyliologues. MM. Cuvicr, lierussac e: de Biajsiville lont admis comme sousgenie des Pulpres, dont il présente la forne génćcale et la coluatelle aplatie. Voici les caracteres que lui donne Lamark.

\section{CARACTÉRES GE் NERQUES.}

Coquilie ovale; nuverture longitudinale, se tcrminant intérieuremeut par une échancrure oblique; une dent coniçue à la buse interne du bord druit.

Le seul casaticre important qui sépare ce genre des Peurpres est la deut cunique consinte, plus ou moins longue, qui se voit à la base cuu bord droit. Cecte deut, dunt an IL $2 *$ 
ne connuit pas le mode de formation, pourroit être produite, à ce que pense M. de Blainville, par l'organe de la génération, dont le passage est vers cet eadroit. Cetle idée prendra quelque solidité si l'on fait attention que les Licoraes ne sont pas les seules coquilles qui ont ane saillie sur le bord droit : nous en avons reconau ane presque scublable, ou du moins très-analogue, dans trois espèces du genre Turbinelle de Lamarck, et an véritable Fusean rapporté par l'expédition de la corvette la Coquille, présente ce caractère aussi constammeat et d'une manière aussi tranchée que les Licornes. Ce caractère, s'appliquant à plusieurs genres, devient beaucoup uooins certain pour celui qui nous occupe, el pourroit apporter de la confusion dans divers genres, si on vonloit en faire l'application exacte et rigoureuse. On doit entendre par Mlonoceros les coquilles qui, avec tous les caractères des Pourpres, out de plas une dent sur le bord droit. Parmi les espèces de Monoceros de Lamarck, on rcmarque une très-bclle espèce qu'il a nommée MIonoceros cingulatum, qui montre que le caractère de ce geure n'a que fort peu d'importance, comme au reste on peut le pressentir d'après ce que nous avons déja dit. Cette coquille a la columelle arrondie et plissée à la munière des Mirres ou des Turbinclles; elle devroit donc faire partie de l'un de res genres, selon que l'on attachera plus d'importiuce à l'un on à l'aurre de ces caractères. Dans le genre Mlonoceros on pourroit donc placer tout à-la-fois avec les espèces qui en tont le type des Fuseaux, des Pyrules, des 'Turbinelles ou des Mitres. Si l'organisation des animaux compris dans ce geare étuit connue, il est à présumer qu'il ne resteroit pas dans la inétbode, es que des divers démembremens seroicat portćs aux genres que aous veaons de mentiuncer.

1. Licorse tuilée. Monoceros imbricatum. LAs.

M. testì ovalâ, ventricosâ, scabriusculi, cinere i uut griseo-nufá; costis transversis, confertis, imbricalo-squamosis; anfiactibus convexis; spiria brovi; uperturâ ovata, albu; labro cremulatc.

Lask. Anim. sans vert. tom. 7. pag. 251. $r_{4} \circ .2$.

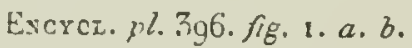

Buccirum monoceros. Brog. Dict. encycl. $2^{\prime \prime}$. 11,

Marrisi, Conch. cabin. toni. 3. pl. $6 \mathrm{~g}$. fig. 761 .

Favasie, Conciz. ol. 27. fig. d. 1.

Kхон, Vergn. 4. tab. 3o. fig. 1.

Manтxs, Conch. tom. 1. fig. 10.
Palias, Spicil. zoolog. fasc. 10. tab. 3. fig. 3. 4 .

Cress. Conch. tom. 10. tab. 154. fig. 1469. 1470 .

DE Braist, Malacol.pag. 412.pl. 22. fig. 3.

Unicomus typus. Montr. Conch. syst. tom. 2. pag. 454 .

Purpura monoceros. DE Rosss. Buff. de Sonn. tom. 6. pag. 24. $\pi^{\circ} .3$.

Nов, Dict. class. d'Hist. nat. tom. 9 , article LICORNE.

On trouve cette coquille, la plus commane du genre, figurée dans le magnitique ouvrage de Ilurtyns; une autre espèce que Lamarck y rapporte égalemeat s'y voit, planclue 5o, c. Si on les compare avec le soin nécessaire, on voit qu'elles appartienneot à deux espèces très-distinctes, et la seule figure qui représente la $\mathrm{Li}-$ corne, traitée dans cel ouvrage, est celle de la planche $10, e$. C'est une coquille ovale, à spire courte, composée de quatre à cinq tours dont le dernier est très-grand. Ils sont couverts de côtes transverses, bérissées d'écaillles serrées, ce qui rend la coquille rade au toucher. Elle est de couleur bran-lanve, plus ou moins funcé, selon les individus; ea dedans elle est blanche; sa columelle est arquée, comme dans les Pourpres, et aplatie de même. Au bas de la lèvre droile se voit une dent courbée, grande, pointue, dont la base assez large se contiaue en dedans par une côte saillante.

C'est dans les mers Magellaniques que se trouve cetre coquille, qui a quelquefois jusqu'ì trois pouces de longueur.

\section{Liconxe striée. Monoceros striatum. Laxx.}

M. testâ ovatâ, ventricosâ, transversim unduluto-striatá, subdecussatá, rufo-castaneâ; anfractibus convexis, ultinio anterius obtuse angulato; spirá brevi, apice albâ; aperturî lcevigatâ, albicante.

L. иx. Anint. sans vert. tom. 7. pag. 251. $n \circ .3$.

Monoceros narval. ExcrcL. pl. 396. fig. 3.

Cette coquille ressemble, sons plus d'un rapport, à la précédente; elle est ovale, oblongue, d'un brun peu foncé ea dehor's; son ouverture est ovalaire, blanche; son bord droil ess toujours simple et entier; la dent placée à sa base est longue e! très-aiguë; la columelle est fort large, aplatie, jamais perforée à la base par un ombilic, et presque jamais le bord gauche ne se reléve au-dessus d'elle. Les tours de spire, au nombre de quatre ou cinq, sont a:rondis, courts, le dernier, ljeaucoup plus grand que tous les autres réunis, est couvelt comme eux d'un grand nombre de stries transverses, saillantes, légète- 


\section{I C}

ment onduleuses, qui quelquefois sont coupées en travers par des accroissemens assez réguliers. Sur les premiers tours, deux ou trois de ces stries, un peu plus saillantes que les autres, les rendent anguleux à leur partie supérienre. Celte coquille, assez rare, vient, à ce que l'on assure, de l'Océan indien. Elle a 45 millim. de longueur.

\section{LAMx.}

3. Liconne glabre. Monoceras glabratum.

II. testâ ovatâ, lơvigatâ, rufo-castaneá; anfractibus convexis, ultimo basi unisulcato; spira exertiusculâ; labro tenui intius loevigato, fulvorufescente.

An buccinum narval? Brug. Encycl. meth. $n^{\circ} .12$.

Monoceros glabratum. LamaK. Encycl. pl.3g6. fig. 5. a. b.

LAMr. Anim. sans yert. tom. 7. pag. 251. $n^{\circ} .4$.

Peut-être l'espèce que Lamarck a séparée sous ce nom n'est qu'une variété de celle qu'il a nommée Munoceros crassilabrum, et que nous allons décrire. Nous avions pensé d'abord que cette réunion devoit s'opérer sans liésitation. Nous croyions que le peu d'épaisseur du bord droit, indiqué comme caractère spécifique, étoit dû au jeone âge; mais depuis les voyages fréquens qui se sont faits au Pérou, nous arons pu réunir un assez grand nomlire d'individus de tout âge de la Licorne lèvre épaisse, et nous nous sommes assuré de cette manière que le caractère de celte dernière espèce étoit coustant daus les divers états où elle se trouve.

La Licorne glabre est une coquille ovale, oblongue, à spire plus ou moins saillante, composée de cinq tours convexes, dont le dernier est plus rrand que tous les autres. Ces lours de spire snnt lisses, et le dernier présente à la base un seul sillon qui correspond à la position de la dent sur le hord droil. L'ouverture est ovale, subsemi-lnnaire, longitudiuale; elle esı d'un blanc-jaunâtre en dedans; son bord est simple, tranchant, généralement peu épais, et garni à la base d'une dent courte et acérée. La columelle est très-aplatie, légèrement renversée à la base, où elle est un peu saillanie.

Cette espèce vient du Péron; elle a $\mathbf{4 0}$ millim. de longueur.

4. Liconne lèvre épaisso. Monoceros crassilabrum. LAMx.

III. testâ ovata, crassâ, laevigatá, aliquantisper transversim costatá, fusco-albicante vel cınereo-nigrá; anfractibus convexis ; spirâ exsertiuscula; lubro crasso, anticè patulo, simplici; dente basis brevi, acutissino.
Larx. Anim. sans vert. tom. 7. pag. 252. $n^{\circ} .5$.

Buccinum unicorne. Bruo. Encycl. méth. $n^{\circ} .13$.

Monoceros crassilabrum. Lam. Encyclop. méth. pl. 3g6. fig. 2.a.b.

Nous nous proposiuns de renvoyer pour cetle espèce à la description de Bruguière, dans le premier volume de ce Dictionnaire, où il l'a fait connoître sous le nom de Buccinum unicorne. Sa description, fort exacte, est incomplète cependant, parce que cet auteur, si exact d'ailleurs, ne connnt pas un assez grand nombre d'individus pour donner tous les détails que nous pouvons présenter aujourd'hui.

Nous avons apporté quelques changemens daus la phrase caractéristique de cette espèce, parce: qu'il nons a semblé que Lamarck ne l'avoit connue que d'unc manière incomplète, ou plutôt n’en avoit étudié qu'un trop petit nombre d'individas. Cette coquille est aussi variable que le Purpura lupillus qui vit abondamment sul nos côtes. Sous le rapport des couleurs, on la voit passer successivement d'un gris-noir très-foncé au blanc presque pur; on lui voit aussi prendre inseusiblement des stries ou des côtes transverses en très-petit nombre d'abord, et finir par en êtle couverte.

Cette coquille est ovale, nblongue, quelquefois très-ventrue, cornposée de cinq tours, dont le dernier est beaucoup plus grand que tous les autres. Ces tours de spire sont peu convexes, surtout les premiers, qui sont très-pla's; ils se joignent par une suture simple et superficielle. Dans le jeune âge ils sont couverts de côtes ou de stries transverses plus ou moins serrées qui, daus le plus grand nombre des individus, disparoissent avec l'age: une on deux de ces côtes, ordinairement plus saillantes, persistent davantage et viennent former une double carène sur le dos de la coquille. Dans quelques autres entin toutes les stries ou les côles du jeune âge se montrent jusque sur le dernier tour, et aboutissent jusque sur le bord; des stries longitudinales, plus ou moins nombreuses et rarensent régulières, se voient sur la surfacc du dernier tour. L'ouvcrture est très-petite relalivement a la grandeur de la coquille, ce qui est dû à l'épaississcment viaiment très-remarquable de son bord droit. Ce bord est aplati en avant, un peu incliné, et terminé al l'intérieur par un angle aigu, qui le linite d'une manière trèsnetle de ce côlé. A la base se trouve une petile dent courte et irès-pointue. (ielle ouverture est loute blanche. Nous possédons, sous le rapport de la couleur, quelques variétés intéressantes: l'une d'elles est d'un brun-noir, uniforme; une aurre a des bandes de la même couleur sur un fond d'un fauve pâle; une troisième est partout d'uo jaune-orangé; une quatrième est d'un brun 
vineux peu fancé; et une cinçuième enfin est toute blanche. Celte coquille se lroure au Pérnu, aù elle paroît fort commune. Les plus grands individus ont 45 millim. de longueur.

\section{Liconse monocanthe. Monoceros monocan-} thos. Bносc.

MI. testâ solidâ, longitudinaliter costato-nodosá, transversim substriati, spiru brevi; uperturâ ovatâ; labro intùs crenuluto, busi spinâ brevi instructo; columelli subperforatô, uriuatâ.

Buccinum monocanthos. Brncc. C'onchyl. foss. subap. tom. 2. pag. 331. $n^{\circ}$. 13. pl. 4. fig. 12.

Cette espèce est la seule de ce genre qui soit connue à l'état fossile. Elle est ventrue, ovalaire; sa spire est très-courte, composée de quatre ou cinq tours, dont le dernier est beancaup plus grand que lous les autres. Ce dernier tour est chargé de six à sept grosses rótes longitudinales, clbtuses, irrégulièremenat espacées; dans quelques individus elles sont lisses; dans d'autres elles sont coupées en travers par des stries, et quelquelois ces stries, largement espacćes, limitent des rangées de tubercules qui les surmontem. La base de la coquille est ordinairement ouverte par un ombilic assez vaste, entouré lui-mêuıe par"un sillon étroit et profond qui vient aboutir à l'exriémité de la lèvre droite, à la base de la dent qui s'y voit. L'unverture est ovale, oblongue, rélrécie par l'épaississement du bord droî qui est crénelé dans toute sa longueur; la columelle rst aplatie, relevée à la base senleınent; la dent du hord drcit est conrte et fort pointue. Nous possédons un individu de cette espèce qui a cunservé des traces de sa coloration première; il est d'un fauve pâle; des stries poncunées de fanve-roux altiernent avec d'autres qui sont blanches.

Cest en Iialic stulemeut que celle espece se rrouve à !'élat fussile. L'indivilu figuré par Brocaii a 55 nilim. de longueur; ceux yue nuus ¿veas vus sout plus petits.

\section{I.IÉVRE.}

On donne vulgairement le nom de Lièvre on r.e Pecu de lièvre à une grande el belle espèce de Puicelaine, Cyproca testudinariu des auteurs. Toy: Porcelaine.

\section{IIEEYRE MARIN.}

Ce nom est donnć sur nos cóies de Lá Rochelle e: de la sléditeranie unx arimaux dn genre Apriysie qui, dans l'élut de rontraction, vut de la ressemblanse, quant à la furme du cur ps ut ¿ cclle des teniacuites, a un liève on à un chat ancroupi. Ceste dernière comparaison lenr a valu aussi, de la part des rririss, le von de Chat ds nier. Iogez Agrrsie.

\section{LIGAMENT.}

On entend par ce mot, en roncbyliulogie, la partie corrée et solide gu: sert à lier les deux valves d'une meeme coquille. Il y a plusieur's sorles de ligamens; on en trouve ordiuairement un seul, quelquelois il y en a denx, et, dans cerlaius gertres, ils se divisent en un grand nombre de parties, et ulors on le nomme ligament multiple. Relativercent à sa position, le lignuent est externe ou inlerue, ou interno-exterae Lorsqu'il est cxterne, il est hombé en dehors et supporté sur des apcplyyses oblongues plus ou moins saillantes, que Linné a nombrées les nymphes, expression qui est restée dans la science. Lorsque le ligaınent est intérieur, il est compris dans un espace plus ou moins resser ré de la cbarrière, qui lail une suiluce plus ou moins consiclérable dans l'intérieur' et qu’a cause de cela on a nonmé cuilleron. Quand ce ligameut intérieu est placé de celle maniere, qu'une partie de san extrémité est visible au-dehors, on le nomone interro-cxterne. Enfu, lorsqu'avec uu ligameat interne $1 \mathrm{en}$ existe in autre presque rudimentaice à l'extéricur, on dit ilors que le ligament est double. Quant a la struciure du ligament, nous renvoyons a l'article Coqurle de Braguiète, où il eu est falt mention.

\section{LIGAP.}

Nom donuć par Adanson ( Voy. au Sén. pag. 253. pl. 10, fig. 6) à une cociualle du gence Turbo, Turritellu de Lismarcb. C"est la Turrtella terebra de cet auteur.

\section{LIGULE. Ligula.}

Le genre Ligule a été proposé par II nnagı:, mais Lamarck n'en ayant pas eu cumbuissance, le proposa de nouveaus solls lo $110 \mathrm{~m}$ d'Anphidesme, qui a flé généralement idupté dep̧us. Voye $z$ A

\section{IIUACE. Limax.}

An:ınax molısyues, gastéropodes, de la famille res Limacées dé Lamarth, dans l'ordre des Pulursacis terrestres. Les Limaces, comme lc.s Hélices, furent connues des anciens; Arisiote ct l'line les mentionnèreal; d'uutres auteurs, tels que Muralt, Ray, Hardur, Redi, Swammerdim, cherchereni, jar une écnde plus a puprofundie, a éctairer l'bistoire des Lienates et dés Limaçons, donuereui sur leurs mours, leur accouplemeut $t$ ! leur anatomie, des détails curieux qui ne furero pas toujours exempls d'erteur. Lister, dans soa Jynnpsis, donue, d'apres Redi, plusietirs planches oil des trítall, analomques sant représerılé:. Dans leur indication, un retarque plnsieurs erreurs que le siraut Swamasercian, dant les truvaux sosta antérieur's, ae connenit pas. Lister lut

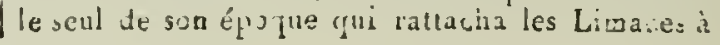




\section{I iI}

son syslème g〈uóral de conchylinloggie; les autres anleuis, jusqu'a l3ruguière, ne los mentionntrent jas, on les éluigucreal des Mollusques dans la classe des Vers nus; en un mol, ils ne les regardèrent pas comme voisines des Hélices. Nous devons en excepter cependant Dargenville, qui plaça les Limaces à la lin de ses Coquilles terresires, qui font i la suite de son système une partie séparée. Nous en excepterons également Muller, qui, dans son Histoire des Vers terrestes et fluviatiles, commença les 'Testacées, gens testaceu, par les limaces, quil fit suivre des Ilélices, ct dont il décrivit un assez bon nombre d'espèces.

Linné, dans son système, n'ınita pas le bon exemple de Muller. II Élablit, comme on le sait, trois clisses dans les Vers, les In!esinaux, les Mollusques, et les Testacés. Ce fut dans la classe des Mollusques, avec les Téthys, les Doris et les Aplysies, que ful placé le gente Limace, lorsque les Hélices, qui ont, par l'urganisation, Iańl d'analogie avec clles, fureut portées parmi les 'Yestacés, à côté des Nériles et des Turbos.

l.es auteurs qui suivirent le systeme lunnéen à la lettre, comme Bruguière el les savaus anglais du mème tcmps, aduplèrent entièrement cel arrungement délectueux. M. Cuvier, qui, dèsı 798 , proposa, daus son Tableau élénentaire d Histoire naturelle, d'heureux changemens dans la classe des Mollusques, Mliţ̧a les Limaces en tête des Gastèropodes, mais les tint cncorc assez éluignces des II élices.

Lamalck, dans son Systène des Animaux sans vertébres, suivil l'opinion de M. Cuvier. Le déliuul de coquilles des Limaces lut la cause de l'erreur dans laquelle lumbèrent aussi bieu Linné el Broguièc que les deux sivans zoologistes que nous venous de ciler. Draparnaud, dans son Histoire des Mollusques terrestres et fluviatiles de la France, fut le premier qui reprodusit l'opinion de Muller, c'es'-j-dire qu'il remit, à l'exemple de ce savint, les Limaces piès des Hélices.

Lamarck ne inanqua pas de saisil cet heureux rapprochemenl; aussi voyuns-nous que, dans sa Philosophie zonlugique, il rappioclia sa famille des Limacéens de celles des Colimacées, el qu'ainsi se trouvèrent beaucoup mieux en rapport les deux genres Limace el Hélice.

M. de Roissy, dans le Buffon de Sonnini, ayant presqu'entièreinent adnpté le premier système de Lauarck, Laissa les Limaces avec les Mollusques nus, et par conséquent forı loin des Hélices. Il faut dire que l'ouvruge de M. de Roissy est antéricur de plusieurs années à la Philosophie zoologique, et que, le publiant daus le mêne teaps que l'onvrage de Draparnaud, son savant aulcur n'aura pu profiter des travaux de ce dernier. Comme uous l'avons luit remarquer, M. Cuvier, apiès avoir éloigué les limaces des Ilélices, fit voil, par sou excellent Mémoire anatomique sur ces deus genres, qu'il existoit à peine des différences suffi- sinles pour les séparer à l'avenir, quoiqu'en apparence lort disscmblables. M. Cuvier, ayint recoonu dans les travaux des premiers naturalistcs des erreurs et des lacunes, entreprit, malgré ceux de Sivammerdam sur le même sujet, de rendre complétcaient l'anatouie de ces Molluscyes: en donnant de meilleures figures que ses lievanciers, ainsi qu'une descripliou lu's - exacte et plus complète, M. Cuvier a rendu un grand service à la science. Il cst naturel de penser que la nouvelle opinion que $\mathrm{M}$. Cuvier se tit des Limaces dut recevoir son application disns la classification yu'il proposa dans le second voluane du Regne animal. Nous trouvons, en ellet, les Linaces daus les l'u monés terreslres à cótá des Hélices, et il établit le passage des deux genres par les deux sous-genres Testaceile et Parmacelle, qui out des coguilles rudimentaires; counme, at reste, Lamarck l'avoit rait dans l'Extrait du Cours, lout en couservant loujours les Liuares el les Hélices dans deux falmilles el dans deux sections différentes, mais voisines. Cet arrangement resta le mềne dans son grant el deruici ouvrage, les Aninzaux sans pertèbres.

M. de Ferussac, dans ses Tableaux systématiques, adopta entièrement l'opinion de MI. Cuvier, seulement au lieu de laire des Liinaces et des Hélices des genres il en fit des familles; il sépara aussi du genre Limaces les Arions sur la simple dillérence d'ùn pore nuqqueux à l'exllémitc du corps. Ce genre, ce nurs semble, ne sauroil être adopté autrement que comme sous-gente, ou comme une simple section dans le genre; notre opiuion à cet égard est conlorme à celle de $\mathrm{Ml}$. de Blainville dans son arlicle Molzusques du Dictionnaire des Sciences naturelles.

M. I,atreile, dans sou dernier ouvrage intitulé : Fam. nat. du Règn. aninı, a rapproché, à l'exemple de M. Cuviertl de :H. de Ferussac, les Limaces des Hélices, quoiqu'il en fasse, commece deruier, deux familles dont l'arrangement ollie des différences de peu d'imporlance. Vojez Pulasosés et NuDIIIAACES.

Le corps des Liuaces étant très-contractile doil être d'une forme trés-lariable; cependant nn lui rccannoît ane forme ovale, alongée, plus obtuse antérieuremenl que postéricurement, où il se tcrmine en poiute carénće, quelquefois arrondie; le dos des Limaces est bombé, convexe, plus que demi-cylindrique, plus épais antérieurement, où l'un remarque nn disquc charnu, épais, ovale, plus ou moins grand, phus ou unoins forlement sépraré da reste de la peau, et sous lequel la tète peut se rélracter ; celte parrlie se nomme chirasse. La face inférieure de la Limace est entièrement plane; elle estaussi rraude que l'aninal et lui sert a la progression; le pied déborde in peu sur les cótćs le corps de l'anional, et surtout en ilvant. A sa jonction arec la tite. 
on remarque un sillon assez profond qui la sépare. Quoiqu'un peu renllée, la têle se distingue fort peu du reste du corps : elle porie deux paires de tealacules contractiles; ils sont cylindriques, terminés par un renflenent. Le reallement de la prenière paire est seulement transparent; celui de la paire supérieure laisse voir un point noir, qui est l'wil. Ils sont, sous le rapport de la structure et de la manière dout ils se contractent, absoIument semblables à ceux des Húlices. I,a bouche est placée en avant et en dessous de la tĉte; c’est uce ouverture infundibuliforme, plissée dans son coniour, et qui présente à la lèvre supérieure une dent cornće solide. Sur le côté droit du corps se voient trois ouvertures. La première, assez peu apparente en géntral, est placée à la base du tearacule droit; elle se roit sur une surte de bourrelet, et donne passage aux organes de la génératiou : Ia seconde, beaucoup plus grande, est placée dans une échaucrure du bord du bouclier du côté droit ; elle denne passage à l'air qui entre ou sort de la cavité Iurancluiale : la troisième ouverture est fort petite; elle est percée sur le bord pastérienr de l'orilice de la respiration; c'est la terminzison de l'intestin ou l'anus.

La peau des Limases est chayrinée, rugueuse, très-semblable à celle des Hélices; elle est fort épaisse, très-sensible, très-coutractile, continuellement invisquée par one humeur muqueuse, abondante, qui sort d'une grande quantité de cryptes ıuaqueuse, dont une plus considérable et plus enf ncée, placée à l'extrémité postérieure, en dunue une quantilé assez notable. Toutes les Limaces n'ont pas cette crypte, ce qui a porté M. de Felissac à distinguer comme gen ze celles des Linaces Lui la présentent.

La locomotion s'opère dans les Limaces de la méme manière que dans les Hélices; les muscles disjosés sous la pean y forment une couche dont il n'est point facile de distinguer les faisceaux; cette couche musculaire est plus épaisse à la face inférieure, où est le pied, que partou: ailleurs. Oitre le système musculo-cutanć des Limaces, elles offrent encore des miscles propres au wouvement de certaines parties : c'est ainsi que la masse buccale, les tentacules et la verge en ont qui leur sont particuliers. Les teatacules sont des cylindres creux formés par la peau revètue en dečns de fibres musculaires circulaires; la contraclion de ces libres suffit probableneut pour produire l'alongement de ces parties : leur rétraction s'opére par un muscle longitudinal gui part du grand muscie médian de l'animal. Ce muscle se bifurque, unvoic une partie de ses fibres au tentacule supérieur el l'autre à l'intẻrieur; il contienı le nerf aptique dans son milieu, et il s'insère ea s'épanouissant un rieu à l'origine du renllement des tentacules. Les onuscles propres de la masse buccale unt une disposition entièrement semblable à celle des Hślices, c'esı-i-dire qu'il y a plusieurs mus- cles cont"s assez épais qui sont destinés à la mastication; ils se réunissent à un long faisceau musculaire qui s'insère an plan locomoteur, et qui est destiné à retirer cn arrière, et sous le bouclier, coute la tête et ses dépeudauces. Nous parlerons du muscle propre de la verye lursque nous décrirons les organes de la génération. La bouclie est assez graude; elle est almée à son bord supérieur d'une dent coinée qui dillère de celles des Hélices en ce qu'elle u'est pas dentée; la partie inférieure présente une langue épaisse, alongée, murie d'une plaque assez ure. Dans la cavité buccale, et de chaque côté, aboulissent les canaux excréteur's des glandes salivaires; ces glandes, dans Ies Iimaces, sont beaucoup plus courtes que dans les Hélices. De la bouche nait un asopbage fort étroit, assez cullt, qui se renfle bientót en un vaste estonıac qui présente un cul-de-sac à son extrémité postérieuice; c'est vers cel endroit que viempent aboutir les canaux biliaires, qui sont fort considérables. Cet estomac est dans sa pusition naturelle d'avant en arrière et de droile à gauche; l'intestin est beaucoup plus étroit, il nait postérieurement de l'estoruac, et fait plusieurs circonvolutions accompagné et enveloppć des lubes du foie : il se reploie en avant pour sc terminer, comme nous l'avons vu, près de l'orifice pulmonaire. Le foie est luri grand, divisé ea deux lobes, l'un droit et l'autre gauche ct postérieur : celui - ci contient l'ovaire. L.es orifices des canaux biliaires sont si grands, dit M. de 13lainville, qu'il sulfit d'insuffler l'eslomac pour gonlle $\mathrm{l}^{\circ}$ tous les lobes hépatiquues avec la plus graude facilité.

I.e systeme de la circulation se compose d'artères et de veines; le cuur est placé presque sur le nilieu de la cavité du poumon; il est enveloppé d'un péricarde qui adlière à la paroi supérieure de cette cavité. La coquille, qui reuferme la cuirasse, est placée de unanière à protéger cet organe, puisqu'elle est située immédiatement audessus. Le caur est ovale, et la pointe se dirige ev arric̀re et en dessous; l'oreillette s'y insère par sa face supérieure : celle-ci a la forme d'un croissant, dont les pointes s'étendent en avant et rassemblent toutes les veines pulmonaires qui $y$ aboutissent au bord externe et convexe.

On n'a point encore découvert de valvules à l'entrée de l'aorte : ce vaisseau important se distribne d'une manière presque semblable a celle des Hélices; il n'y a même de différence sensible que dans la position du second tronc, qui se rend au foie, à l'intestin et aux autres riscères: ce cbangement de position est dú à la manière dont les organes de la Limace snnt rassemblés, au lieu d'être portłe dans une coquilie spirale.

M. Cuvier fait observer que la couleur des artères de la Limace est d'un beau blanc de lait, ce qui les fait reconnoitre facilemen l et produit l'effe: d'une injection des plus délicates. 
Quand on examine par deduns l'enveloppe grinerale de la Limace, dit M. Cuvier, dans son excellent Mémoire, on voit de chaçue cóté un grand vaisseau longitudinal qui grossit en avant. II recoit heauconp de branches de l'enveloppe unêue, et l'on voit sur sa longueur des trous par les juels elles lui viemuent des viscères; les trois principales sont tout-i-fait à la partie autérienre. Ces deux vaisseaux sont les deux veiues-caves; ils eanlrassent clacun de lenr cólé le contour de la cavitć pulmonaire dans tout ce cercle, par lecquel la cuirasse ou wanteau se joint au dos proprement dit; il en part daos ce circuit une inlinití de petites branches, qui sunt les artères pulmonaires, et gui dunnent naissance à ce beau réseau dunt la cavilé de la respiration est tapissée; réseau qui reproduit à sun tour des vénules, lesquelles aboutissent toutes en dernière analyse dans l'oreiliette du cour.

Le réseau vasculaire dont nous venons de parler. tapisse la cavilé pulunonaire, qui est presıue ronde; il couvre de wailles a peu près semblables les parois de cetle cavité, à l'exception de l'eadruit occupé par le péricarde. Le bouclier et la placgue osseuse qu'il contient, dans le plus grand numbre des Limaces, sont placés au-dessus de relle cavilé, de madière à la protégcr; la fáce inlërieure est formée par une sorte de cloison unusculeuse qui la sépare des viscères, et que l'on is comparée a ua diaphragme.

Noous avons dit précédemment où étoit placée louverture qui fait comanniquer la cavité palmonaire à l’air atmosulrérique : cel orifice est susceptible de contracition et de dilatation, stiiviut les besoius de l'uniual; il paruit que ses mouremens sont produits par les muscles communs de la peau, car jusqua'à présent personne u'a décrit de libres propres pour les ooérer. Les radicules veineuses qui naissent du réseau pulnouaire se réunissent, d'après M. Cuvier, en plusıur's troacs qui aboutisieat sćparémeat daus l'oveillette, ce qui a déterminé sa forme en croissaut : d'après 11 . de Blainville, elles formeroient un seul trouc, qui se readroit isolément à l'oreillette.

M. Cuvier nomme organe de la viscosité el M. de Blainville organe de la dépuration uricaire un organe qui entuare ce péricarde, et forwe autour de lui un cercle prescyse complet. Il est rerê:u au-dehors d'une membrane lisse et grisâtre; à l'intérieur, il est counposé d'un grand nombre de lames très-minces, qui adhèrent aux parois par un de leurs bords : le canal excréteur tait le même contour qque l'organe lui-même; il s'adosse au rectum pour surir a côté cle lui sur le bord de l'ouverture de la respiration.

Les organes de la géuération different peu, en général, de ceux des Hélices; cependant ceux-ci out de plus les résicules multifides et la poche du

$$
\text { Hisi. Nut. des Fels. Tome II. }
$$

dard. Les orgaues générateurs de la Limace se compasent:

10. D'un ovaire situé dans le lolse postérieur dı fuie, dans lequel il est presqu'entièrement caché; il est granuleux, et on en voit naître par des radicules un canal ou oviducie, d'abord trèsmiace et très-étroit, reployé sur lui-même uu très-grand noubre de fois; son diamètre angmeute insensiblement eu se rapprocbant de l'organe que M. Cuvier nomme matrice.

$2{ }^{\circ}$. Cetle matrice, dont les parois sont épaisses, est boursouftlée, composće intérieurement de cellules assez régulières, qui sont remplies d'unc abondarte viscosilé. A près plusieurs inllexions, elle sc change en uu canal plus étroit, cyliudrique, à parois lisses, épaisses, et qui se realle un jeu avant de se terminer dans le cloaque.

$3^{\circ}$. Unc solte de vessie ou un sac à une seule ouverture se voit à côté clu cunal da second oviducte; ses parois sont épaisses, elles se rérlícissent en un col très-court, qui s'insère sur lo vagin, peu avant qu'il n'entre daris la cavitú commune de la génération : certe pente poche, que l'on retrouve dans les Hélices, les Awbrettes et plusicurs at:tres Mullusques, pourroit bien ètre: comparée à la vésicule copulative des insectes; elle est habiluellement remplie d'un fluide jauautre et épais. Ces dilléreutes partjes cunstituent l'apparesl femelle de la génération. Nous lerues remarquer que l'organe que NI. Curier nomme matrice, M. de Blanaville le désigne sous le non de seconde partie de l'oviducte.

L’appareil nuâle est composé d'un testicule pau dillérent de celui des Hélices; il est pourvu dinn canal déférent qui, au poiut oi la matrice el luviducte se réunissent, se joint intimement à enx, ainsi que le tesicule. Un organe granulenx, eis lorme de bande blanche, se remarque le long de la mitrice, et l'accompagne en grossissant. Celle partie, que M. de Blainville compare ì l'épididyme, se prolonge au-delà de la portiou boursuuflée de l'oviducte; c'est seulement de cet endroit qu'on en voit naitre un canal, d'après II. de Blainville, qui se recourle en se prolongeant assez loin pour aboutir à la base de la verge. La verge est plus courle que dans l'Hélice; el!e est plus large en arrière qu'en avant, où elle s'amincit peu à peu; elle est creuse dans toute sa longueur; elle lorme par conséquent un long sac, dont les parois, assez épaisses, sont musculaires; les fibres qu'on $y$ remarque sont annulaires: ces Gbres annuluires ont le même usage que celles des tentacules, c'est-à-dire que lorsque le pénis entre en action, il sort en se renversant et se retournant absolument comme les tentacules. II est fixé à sa base par un nuscle épais, assez court, qui, lorsque les organes de la génération et sur" tout la verge ont rempli leurs fonctions, la retire en dedans, et en la retournant agisseat de mémc que le muscle rétracteur des tentacules. Ce muscle

$$
\mathrm{V}_{\mathrm{v}} \text { * }
$$


s'insère postérieurement sur la cloison charnue que nous avons vue précédeminent séparer la cavité respiratrice de la cavité viscérale.

Le système nerveux ne différant pas essentiel. lement de celui des Hélices, nous renvoyons à ce mot pour les délails que nous en avons donnés. On doit sentir cependant que la distribution de quelques filets a dî sc trouver légèrement modifíe dans les Hélices par là position des viscères. Les organes des sens, chez les Limaces, paroissent être aussi peu actifs que chez les Hélices. Le toucher paroît, dans les unes et dans les autres, d'une grande délicatesse; mais la vue paroît nulle, quoique Swammerdam ait trouvé toutes les parties qui constiluent l'œil. Elles sont dépourvues de l'audition; unais elles goûlent et elles odureat, puisqu'elles sont attirées par une bourriture qui leur plaît, et qu'clles se rassemblent en assez grand nombre sur les plantes ou les matières qu'elles préfèreat. Cependant le goût doit être obtus, si on en juge d'après l'étai de la langue et d'une partie de la bouche, qui sont cornés.

Les Limaces, coinme les Hélices, cherchent en automne un abri contre le froid : elles paroissent y être moins sensibles que les Hélices; car on en voit encore lorsque tontes celles-ci ont disparu. Elles s'enfoncent dans la terre, se cacheat dans les vieux murs, ol paroissent préférer les vieux troncs d'arlures pourris, dans l'intérieur des. quels il y a du terreau produit de leur pourriture. Arrivées dans l'endruit qu'elles jugent convenable, elles se contractent autant qu'elles le peuveat dans le sens de leur longueur; quelquefois elles le sont au point de présenter une foraue presqu'hémisplérique. Elles passent l'hiver dans un état presque complet d'engourdissearent; a mesure que la clıaleur revient, elles sortent de leurs trous, lorsque déjà les plan'es ont commencé à pousser : c'est aussi à cettc époque, vers le commencement de mai, que les Limaces s'accouplent. On n'a point encore de détails suffisans sur leur accouplement. Les Aaciens avoient eu connoissance de quelques-uns des faits qui y sont relatifs, puisque Redi, et d'après lui Listel, ont tiguré des Limaces dans ce moment. Depuis il n'y $a$ eu que les abservations eucore incompletes de M. de Werlich; elles sont dans l'Issis de Oken, et M. de Ferussac, dans son grand ourrage, les a rapportées dans leur entier. Nous ne pouvons les reproduire ici, mais nous engageons beaucoup les aaturalistes qui sont a portée de faire ces sortes de rechercbes dobserver le plus exactement possible l'accouplement des Limaces; c'est un fait très-intéressant, et qui manque encore puur plusieurs points.

Les Limaces pondent peu de temps après l'accouplement, ordinairement a la fio de mai ou au commencement de juin; elles déposent les œufs, qui sont jaunâtres et arrondis, dans des endroits abriiés du soleil; elles en placent quelques-uns dans le même endroit, et vont chercher un autre lieu pour en déposer quelques autres.

\section{CARACTÉRES OÉNÉBIQUES.}

Corps ovale, oblong, muni d'un pied dans toute sa longueur; la peau partout fort épaisse, nıais surtout a la partie antérieure du dos, où elle forme un écusson plus on moins grand, nu bouclier coriace, contenant dans son épaisseur un rudimeat de coquille plus ou moins évident; cavité pulmonaire siluée au-dessous de l'écusson, et ayant son orifice plus ou moins avancé sur le bord droil; anus au bord postéritur de cet orifice; tête peu distincte, séparée du pied par un sillon transverse, peu profond, portant quatru tentacules, dont les deux supérieurs soni plus graands et oculés a leur exirémité.

Les Limaces rechercheat les lieux humides, et vivent habituellement de végétaux pourris ou à dewi pourris; elles dévasteni souveni les jardins en altaquant les jeunes plaves ou les fruits qui ne préseutent pas une résistance aussi grande que celle de la plupart des végétaux : elles sont quelquefois tros-abondanles et difficiles à détruire, en ce qu'elles se cachent et s'abritent peudant le jour, et se soustraient áinsi aux recherches vigilantes de l'agriculteur.

\section{Limace grise. Limax cinereus. tru.}

L. corpore elongato, cinereo, diverse maculato; carinâ posticuli, acutâ, albidâ, proelongấ; tentaculis rubescentibus; clypeo postice acuminato, scutiformi.

SWAMмERDAM, Biblia nat. torn. 1. pag. 158 . tah. 8. fig. 7. 8. 9 .

Limax cinereus. List. Phil. Trans. tom. 9 . 1674. pag. 96. tab. no. 14.

Limax cinereus. Lis. Faun. suec. pag. 365. $n^{\circ} .1278$.

Liniax maximus. Syst. nat. pag. 1081 . no. 4. Muller, Hist. Verm. pag. 5. $n^{\circ} .202$.

LIN. Gmel. pag. $3100 . n^{\circ} .4$.

De RoIssy, Buff. de Sonn. Moll. tom. 5. pag. $18 \mathrm{t}$.

Drap. Hist. des Moll. de France, pag. 124. $n^{\circ}$. 4. pl. 9. fig. 10.

I.амх. Anim. s. vert. tom. 6. pag. 5o. no. 3.

Preiffer, Syst. anond. pag. 20. $\pi^{\circ} .3$.

De Brainv. Dict. des Scienc. nat. tom, 26. pag. 430 .

Limax anticonm. Feros. Hist. des Moll. pag. 68. no. I, et pag. 96. \$. ph 4. pl. 8. a. fig. 1. pl. 8. d. fig. 5.

Cette espèce est la plus grande qui soit conoue 
ca Europe; elle est anssi une des plus agiles du grenre lorsqqu'elle marche. Elle est très-alongée, cylindracée, auténuée à ses deux extréunitłós, surtout à la postéricure; elle se termine de ce côté en une sorte de pyramide triangulaire, une carène posírieure et supéricure se trouvant dans la ligne médiane et dorsilc. Cette carène, qui se protunge ordinairement jusçuau quart postrírieur de la lungueur tutale, est quelquefuis onduleuse a son burd libre; elle est imujours blanclie ou d'une cuuleur uoins foncće cyue le reste de l'animal. Lis cuirasse est ovale, ollongne, courte, arsez épaisse, s'avançant jusque vers la lête, et se terwinant postérieurewent par une pointe obluse; sur sur côté droit on remarq̣ne une ouverInte avalaire assez grande qui sert d'ortice i la cavitú respiralrice. La tête, bies détachée pendant la markibe, est beancoup moins saillante dans l'élat de repos; elle est d'une couleur roussàtre, no peu étroile antéricnrement. Les deus tentacules supérieurs sont fort grands; à la base de celui du côté droit se voit un petit tubercule, qui indique l'issue dles or"ganes de la génération; les tentacules inférieurs sont courts ế yrêles. La couleur de cet animal tost assez variable : il est ordinairement d'un gris-vineux on blanchâtre, quclqquefois rougeâtre, sur lequel se dessinent des tackes d'un beau ocir disposées en bandes, au combre de quatre, le plus ordinairement; quelquefiris elles sunt éparsıs et irrégulières, d’autres fuis ausi l'animal est d'un gris-noirâtre, inesquiunifurrue. Les taches de la cuirasse ne sont que tuès-rurement dispróes par bandes; tlles frinent des marbrures a tarbes filus on morns grandes et plus un moins confuses. Si on regarde la peau à la loupe, on la lrouve couverte d'un grand nombre de petites rides onduleuses, souvent anastomusées, sublongirudinales, qui parrissent à peine pendant la marche de l'itnimal, et qui snnt beaucoup plus visibles dans sun état de coatraclion. Celle grande et helle espèce se tronve dans presene toute l'Europe, dans les forêts, dans les lieux les plus bumides et les plus ahrités.

l.es plus grands individus ont 16 ou 17 cent. de longueur.

L.e test rudimentaire que l'on trouve dans l'épaiscur de la cuinasse est onguifinme, assez Epais, comme cristallsé; dans les vienx individus il est blone, un peu ćpaissi, postérieurement arrondi, el obtus a sa palle antírieure. Il n'a guère que 10 ou 12 aillim. de longizeur.

2. Linace tachelée. Limax variegatus. Drap.

L. corpore lutescente, vel grisen, tentacults nigncuntihus, maculis numerosts, mitmoruto; cl, feco ovato, maculis rotundatis ornato.

Drapans. Hist. des Moll. pag. 127. " $\|^{\prime} \cdot 9$.

Frace. Hist. des .troll p!. 5. fg. $1-6$.
Dargesy. Conch. pl. 52. fig. 29 .

Lix. Garel, pag. 3ro2. $n^{0} \cdot 7$.

Bruc. Encycl. méthod. pl. 85. ftg. 2.

De Roissy, Buff. de Sonn. Moll. tom. 5. pag. 182.

Lianace blonde des caves. Brand, Hist. pag. 116.117.

La Limace lachetéc est une des espèces les plus répundues en Europe; clle cst moins grande que la mécédente, et sa couleur est ordinairement différente; elle uanque d'ailleurs de la carène postérieure, ce qui, an premier aperçn, la disingue sullisamment de la Limace grise. Lolsqu'elle marche, cette limace esr alungée, semicyliudrique, allénuée à ses deux extrémitćs, mais surtout postérieurement, oì elle se termine en pointe aiguë; la cuirasse est ovale, oblongue, courle, olstuse postérieurement; l'ouverture de la respiration est grande, ovalaire, et sur son bard on voit l'ouverture de l'anus; la lête est cnurte, peu saillante au-dessous de la cuirasse; elle esi divisée en deux parties par une linne d'un fauve foncé qui règne duns toute sa longueur; les rentacules supéricurs sont assez lonus : ils sont noirúlres, snurent blenútres; les inférieurs sont rrès-cuurts, el de la même conleur que le reste de l'animal. La pean est couverte de pelites ruyosités, qui, vues à la loupe, ont une régularité assez remarcqualıle; el'es consistent en rides longitudinales, courles, recinurbies les unes vers les autres, et s'anastomosant á leur extrémité. La conleur cst ordinairement d'un jaune-fauve rougeatle; elle est assez variable. On trouve des iudividus qui sont d'uo gris-jaunútre peu foncí. Sur le fond se dessinent des taches ublongues, blanchâtres, quelyuefois confuses, mais ordinairement nellement séparées; le bouclier présente des taches d'un jaune pále, arrondies et toujours nettement séparées; l'osselet intérieur est ovalaire, blanc, assez mince, arrondi à ses deux extrémités.

Draparnaud avoit cru que celle espéce se trouvoit particulièrement daus le midi de la lir.ınce, il pensoit mêue qu'elle y étoit rare; mais il étoit daus l'erreur, car" on la trouve presque partont, surtout dans le vorisinage des labitations et dass les caves, où elles s'uturitent pendant l'hiver. D'après M. de Ferussac, elles sernient communes cu Angleterre, en Hollande, en Suède, en Frunce, duns liile de Chypre, et même aux EtatsUnis. Elle a 12 à 13 centim. de long.

\section{LIMACE a greste. Limax agrestis. Lis.}

L. corpore rufescente vel griseo, aliquando maculis longitudinalibus griseis ornato; clyparo postice rotundato; carinâ postivali, brewi et obliquâ.

Lister, Philosop. Trins. toms. 9. 1674. pag. g6. tab. $n^{\prime} \cdot 15$.

V v 2* 
Thid. Synops. tah. 101. fig. 101. a.

Limax cinereus immaculatus. Liv. Faun. suec. pag. 366. $n^{\circ}$. 1279 .

Dargenv. Conch. pl. 32. fig. 27.

Pennant, Brit. zool. tom. 4. pag. 41. no. 19.

Muleer, Verm. Hist. pag. 8. no. 204 .

Lin. Griel. pag. 3101. $n^{0} .6$.

Brug. Encycl. méthod. pl. 85. frg. I.

Draparn. Hist. des Moll. pag. 126. $n^{\circ} .5$. pl. g. fig. 9 .

Limax reticulatus. Menc. Vern. Hist. pag. 10. $n^{\circ} \cdot 207$.

ScHEFFE, Vels. Mitschnecken, tab. I, et tab. 2. fig. 1. 2. 3.

Limax reticulatus. DE Rorss. Buff. de Sonn. Moll. tom. 5. pag. 182,

Limax filans. Hor, Trans. Lin. tom. I. pag. 183.

Ibid. Swayas. loc. cit. pag. 185.

Ibid. LathaM, Trans. Lin. tom. 4. pag. 85. pl. 8. $\operatorname{fg}_{g} \cdot 1-4$.

Cetle Limace, beaucoup plus petite que les précédentes, est alongée, étroite, pointoe postérieurement, et rounie de ce côté d'une carène dorsale médiane peu saillante, courte, et ordinairement oblique. La cuirasse est oblongue, plus grande proportionnellement que dans la plupart des espèces; elle couvre une partie du corps, duquel elle se détache profondément à son extrémité postérieure. La têle se dégage aettement de dessous cette cuirasse : elle est étroite, el porte deux tentaculessupérieurs marqués extérieurement d'une ligne d'un brun foncé; les inférient's sout très-courls et très-grêles. Sur le côlé droit de la tête, entre les deux tentacules, nn voit un petit tubercule blanc, quelqnefois seulement l'indice d'uo pore, qui montre la place des organes de la génération. Le corps de cette Limace est recouvert d'nn grand nombre de rides longitudinales, subrayonnantes, sur lesqnelles sont placées, dans la même direction, des tacbes blanchâtres sur un fond d'un gris assez intense ou d'un roux-fauve. La cuirasse, épaisse postérieurement, est marbrée de taches plus ou moins nombreuses, quelquefois confuses, d'une teinte plus obscure que celles du corps. La tête est en dessus d'un fauve foncé; elle est blancbe ou grisâtre latéralement.

On a cité no fait assez remarquable relativement aे cet animal, habitant les forêts, grimpant souvent le long des arbustes : on l'a vu desceudre des branches suspendu à un fil, comme le font certaines cheuilles; on a cru qu'un organe sécréteur particulier fournissoit la matière de ce fil; mais un examen attentif de cette espèce et de la manière dont s'opère sa chute a proupé que la suspension étoit due à la muscosité du pied qui sert labituellement ì fixer l'animal aux corps sur lesquels il marcbe. Cetle mucosisé ćtaut plus visqueuse et plus-épaisse dans cette espèce que dans les autres, produit un fil assez fort pour soutenir l'aninal pendáol une certaine durée de sa chate; mais il se brise lorsqu'elle devient trop longue.

Cette observation a été faitc sur uue variété d'un blanc-grisâtre de la Liuace agreste, variété qui se remarque encore par me laille toujonrs plus petite. Dans son extension, cette espece a. 60 millim. de long.

4. Liarace jayel. Limiax gagates. Drapar.

L. corpore elongato, nigro-virescente, postice cariná brevi dorsuli instructo; clypeo undato, gnanuloso; sulco marginali minimo.

Limax gagates. Draparn. Hist. des Moll. pag. 122. pl. 9. fig. 1. 2.

DE Rorss. Buff. de Sonn. tom. 5. pag. 180. $n^{\circ}$. 1 .

Feros. Hist. des Moll. pag. 75. no. 5. pl. 6. fig. 1.2.

Nous donnerons de cette espèce la descriptioe qu'en a faite Draparnaud, n'ayant pas en occasion de l'observer en nature. Elle est à peu près de la taille de la précédente, mais toujours d'un noir loncé, passant au gris sous le pied. Les tentacules supérieur's sont assez longs, effilés veis le sommet, renflés et rapprochés à leur base, les inférieurs sont très-courts; la cuirasse est tinement granuleuse et quelquelois bossue dans son milieu; le corps est strié longitudinalement par des ligoes qui s'anastomosent; ses parties latérales sont ordinairement d'un noir moins foncé que le milieu du dos. Celui-ci est carếné dans une parlie de sa longueur; la carène est souveut trèssaillante; le bord du pied est circonscrit en deliors par un sillon pen profond; le trou de la iespiration est placé à la partie postérieure et droite du bonclier. Lorsque l'animal est contracté, il est demi-sphérique; lorsqu'il est alongé, il a 50 millimètres de longueur environ. Cette espèce paroît propre à la fírance méridionale.

5. Limace rousse. Limax rufus. Lis.

L. Corpore elongato, gibboso, colore variabili, granuloso; tentaculis nigris; clyparo oblongo, posticè attenuato, suhlavigato; marginibus lineolis nigris tnansversis ornatis.

LAs K. Anim. s. vert. tom. 6. pag. 49. $n^{\circ}$. 1.

Limax ater. Mouc. Verni. Hist. pag. 2. $n^{\circ}$. 200.

Lin. Gmel. pag. 3ogg. $n^{\circ} .1$.

Draparn. Hist. des Moll. pl. 122, no. 2, pl. g. fig. $3-5$.

Limax rufus. DaAparn. Hist. des Moll. pag. 123. $n^{\circ}$. 3. pl. 9. fig. 6. 
Limax succineus. Muld. Verm. Hist. pag. 9 . $n^{\circ}, 203$.

1bid. Lrw. Garel. pag. 3100. no. 3.

Swamar. Bibl. nat. tom. 1, pug. 162, tab. 9. fig. 1.

Lima.r subrufus. Lister, Anim. angl. Append. tab. 2. fig. 1.

Ibid. Conch. tab. 101. fig. 103.

D) ARGNv. Conch. tab. 33. no 30 .

DE Rorss , Buff. de Sonn. Moll. tom. 5. pag. $181.73^{\circ} \cdot 2$.

Cov. Ann. du Mus. tom. 7. pag. 140.pl. 9 .

Celte Limace, très-commune, est certainement l'une des plus variables qui soient connues. Passaut du noir le plus foncé au rouge-orangé, et souvent à d'autres buances, on ne peut la reconnoître que par l'ensemble de la forme do corps el quelquues caractères que nous allons mentionner. l'eut-être conviendroit-ı!, comme l'ont fait Drapanaud et quelques autres auteris, de séparer en plusieurs espèces ceux des individus qui présenteut quelques caractères constans. M. de Ferussac, dans son grand ouvrage sur les Mollusques lerrestres, a rassemblé neuf variétés, au moyen desquelles il montre un passage successif d'une couleur à l'antre. Il s'attache, pour démontrer qu'elles appartiennent à un même type, à deux seuls caractères qui lui semblent les plus importuns, et qui le seroient en effet par leur constance; ce sont les tentacules qui restent tonjours noirs, et le bord du pied toujours marginé et marqué de linéles alternativement noires et jaunes. Ce dernier caractère cependant sembleroit de peu d'imporlance, malgré ce qu'en dit M. de Ferussac; cal une Limace qu'il comprend an nombre des variétés de celle-ci, et gu’il a figurée, ne le montre pas du tout: aiusi il resteroit donc, pour seul caractère essentiel, la coulear noire des tentacules, et nous ne pensons pas qu'il soit d'une telle importance qu'on doive le faire passer en première ligae. Nous croyons qu'il sera nécessiire, pour recononitre lout ce gue M. de Ferussac considère comme appartenant à une seule espèce, que l'anatomiste étudie avec soin la structure intérieure de chacune des principales variétés, et sapplique surtout à la comparaison minutiense des urganes de la génération.

Le Limax rufus a été placé par M. de Ferussac duss son geare Arion, genre sur lequel nous avons dit notre manière de voir. Si les animaux qui olfrent le caractère sur lequel il esı fondé avoient une organisation un peu différente des autres $\mathrm{Li}$ maces, si ce caractère entrainoit avec lui une modification qui se montrât dans les mœurs et dans la manière de virre, on pourroit supposer que le scalpel est impuissant pon' nous dévoiler des differeaces organiques; mais il n'en est pas ainsi : tout frouve au contraire, par la similitude des mours et de structure, que le pre muqueux des Arions n'est qu'un accident de très-peu d'importance dans leur organisation, car il n'a d'autre but que de readre plus abondante la sécrétion muqueuse, au moyen de laquelle les Limaces et les IIélices se fixent sur les corps qui les sup. portent.

l'esp̣èce qui nous occupe est généralement plus épaissè que toules celles du mênue genı ; sın corps est proportiounellemeut plus large, il esi atténué aux deux extrémilés, il est dépourvu des carène dorsale anguleuse; mais, à sa place, se trouve souvent uue ligne blanchatre on verdatre légèrement saillante. Le pied est large, bordé extérieurement. La bordurc est plus large à l'e >tićunité postérieure qu'à l'antérieure; elle est sillonnée transversalemeut, et les sillons sourt ordinairement uoirs ou bruns. La cuirasse est ovale, oblongue, alténuće postérienrement, lisse ou à peine greaue, très-nettement séparée du reste du corps. L'onverture respiratoire est fort grande, arrondie, très-antérieure. La tête est peu saillaute an-dessons de la cuirasse; elle est étroite, et ses tentacules sont toujours d'un gris-noirâtre ou tontà-fail noirs. La peau du corps est coriace, épaisse, chagrinée par un assez grand nombre de tubercules oblongs, onduleux, presque toujours isolés, et généralement fort saillans. Le pore muqueux postérieur est triaggulaire, blanc, assez profond. La couleur de celte espèce est variable, comme nons l'avons dií; elle passe du jaune-orangé à une teinte d'un poir foncé uniforme, en admellant tnutefois que les variétés indiquées $p a r$. M. de de Ferussac dépendent toutes de la même espèce.

Celle Limace est très-commune dans toule l'Europe, dans les jardins, dans les bois, préférant les lieux ombragés et humides, se trouvant généralement sur les plantes en putréfaction. Les grands individus out quelquefois 14 centimètres de longueur.

\section{Limace blanche. Limax albus. Muxc.}

L. corpore albo, elongato, marginato; murgine uurantio; clypceo oblongo, subgranuloso; tentaculis albis.

Arion albus. Feros. Hist. des Moll. pag. 64. no.2. pl. 2.fig. 3.

Limax albus. MoLn. Verm. Hist. pag, 4. 120. 201.

Lin. Grel. pag. 3100. $n^{\circ} .2$.

Brug. Encycl. méthod. pl. 84. fig. 3.

M. de Ferussac signale plusieurs variétés de celle espèce, qui paroit propre aux régions septentrionales de l'Europe. Cet auteur est porté ì croire que cette espèce n'est encore qu'une variété du Limax rufus. Nous ne voyons pas pour quel motif il s'est abstenu de l'y faire rentrer. Noes 
arons va, en décrivant précédemment la Limace que ricus renons de ciler, que le caractère distioctil est pris principalemen! des linéoles noires qui se montrent sur le bord du pied; nous arons vu que le caractère disparnissoit quelquefois, el que M. de Ferussac avoit ligruré une variélé dans laquelle il ce se montre plus : il pourroit en être de même de la couleur des tentacules, et alnis la Limace blancbe ne préseniernit flus aucun des caractères extérieur's qui fút li luire distinguer de la précédenle. On est encore plus porté à cetre conclusion par les variétés de cuuleurs qui se montreat aussi dans celle espèce : le plus souveut elle est blanclie, il est vrai; wais on en trouve cependant qui sont d'un jaune pale.

Celle Limace est alongée, demi-cylindique, pointue, postérieurement pourve en dessus de l'extrémité du pied d'une cryp̧e muqueuse triangulaire. Le pied est large, bordé en debors par un bourrelet plus large postésieurement qu'antérieurement. Ce bourrelet est d'un beau jauneorangé; il est lisse el dépourvu des linéoles noires que nous avous remarquées dans l'espèce précḱdente. Le bouclier est médiocre, ovalaire, percé vers le unilieu de son bord dioit par le irou de la respiration; la tête est Llanche; les grands tentacules conservent la même coulear et sont alténués à leur extrémité; la peau est coriace, épaisse, chagrinée de la même manière que dans le Limax rifus; les tubercules sont cependant plus serrés et plus nombreux; le bouclier es! presque lisse ou légèremeut chagriné. Cctte espèce habile le nord de l'Enrope, en Norwège, en Scanie, dans la Russic méridionale; elle est Ingue de II ou I2 centimètres dans son élat cie développement.

\section{I.IMACELLE. Limacella.}

Genre que M. de Blainville a Établi pour no Mollusque de la famille des Limacinés, qu'il a cu uccasion dohserver dans la collection du Muséuan britannique. Quoigue ce Mullusyue ait la turtue des Limaces, il eu diffère cependant eu ce que le pred est séparé du manteau par un sillon qui fuit tout le tour dir corps. Toici les caractèrtes que M. de Biainville a clunnf́s a ce genre dans sun aricle Molluspoes du Dictionnuire des Sciences naturelles.

\section{CARACTÉRE GENERIQUES.}

Corps alongé, sıbcylindriçue, pourvu d'un pied aussi long et aussi litrge que lui, dont il n'est séparé que par un sillnu, enveluppé dans une peau épaisse, formant à la partie intérieure du dus une sorte de Louclier protecteur de la cavité puliuonaire, dunt l'orifice est a son bord droit; les orifices de l'appareil générateur distans, celui de l'oviducte a la parlie postérieure du cóté dioit, et commaniquant par un silloa à la terninaison de l'urgane mále sitné à la racine du tentacule droit. La seule espèı e conmue de ce genre avnit d'aburd élé nommíe par $\mathbf{1 1}$. de Blainville Limacclle lactescente, Limacella lactescens; mais depuis il lui a substilue le nom de limacelle d'Elfort, Limacella elfortiana, espèce qui n'est ni décrite ai liguréc.

La singularité des caractères de cel animal at paru telle a M. de Blaiuville, 'qu'il a ajouté l'observation suivanle qué uas extrairuns texluelleneut:

"Celle combinaison de caractères nous paroit ") si aumale, que nous cloutuns réellewent que n nous ayons bien observé le Mollusque sur lequel "nous avuns élabi ce geare."

\section{IINACES.}

Famille de Mollusques gastlropodes nulmonés, terrestres, déja átablic sous le num de Limaciens ( voyez ce mot) par lamarck, à laquelle N1. Fe russac, en y liaisant des changeme-s assez notables, a donné le nom de Limaces. Cette famille, qui fait partie de l'ordre des Géophiles de cet antenr, est divisée de la manière suivaule :

A. Lintièrement cuirassíe; tentacules contractiles.

1. Dicères. Onchide, Cnchidies.

2. 'l'étracères.

Vaginule, Plilomique, Euzulle, Fironıcille.

B. Cuirassées antérieurenent; quatre tentacules rélractiles.

Liwaceile, Arioo, Limace, Parmacelle.

C. Unitestacées avec cuirasse sans collier. Testacelie.

Larrangement de celle famille couduit iosensibleinent des Licoaces aux Limacous par lintermédiaire des Plectrophores et des 'l'esiacelles yul avois.nent les Hélicarions et les Vilrioes. Cet ordict nous semble le plus naturel, el mous l'adopterious de prélérence à tout autre s'il ne conteuvil quelques genres très-iucertains de M. Ratinesque. Nous renvoyons, pour plus de délails, aux dilléreus genres qui entrent dans la composition de celle tacuille.

\section{LIMACIEIS.}

Famille élablie par Lamarck dans la Zoologie philosophique, pour les genres Onchide, Licauce, Paımacelic, Vilrune ct 'Testacelle. Lawarck a reproduit la uêtue lanille snus le mêure nunı, et sans aucun changement, dans l'Extrats du C'our: ainsi yue dans les Anmaux sans vert., inm. 6 , pag. 42. En consuliadi les mots survans, Lima- 


\section{I II}

çoxs, Lisacelles, Lisaces, Liuacixés et PulNONÉs, nn aura une idée suffisante des changemens apportés à cette fawille par les divers auteurs.

\section{LINACINE.}

11. Cuvier (Règne animul, tom. 2) a créé pour un animal, lrès-voisin dos Clios, un genre çüil a nommé aiosi. Lamarck, en l'adoplant, a livit sentir que ce nom, en rappelant l'idée d'une Linace, ne pouvoit convenir, puisque la Limacine est pourvue d'une cuquille spirale régulière. 11. de Blainville a clıangé ce nom pour celui de Spiratelle que nous adoptuns, et auyuel nous renvoyous.

\section{LIMACINES (Les).}

Famille proposée par M. de Ferussac dans ses Tableaux systématiques des Anin. mollusques, pour deux pelits genres de la clasie des Plérupodes. Ces yeares sont comus sous le nom de $L_{i}$ macine et d'Atlante; ils ont quelques rappor's tutr'eux, surtout à l'égard des coquilles. Mais M. Rang a prouvé, par un très-bon travail anatumique sur l'Aılante, inséré dans le tome 4 des Hèmorres de la Société d'Hiftoire naturelle, que ces rapports ne sunt pas aussi intines qu'on l'avoit généralement pensé. Les Allantes appartiennent à Ia classe des Gastéropodes, tandis que les Limacines doivent rester parmi les Ptérupodes. La famille qui rassembloit ces deux geures ne doit donc pas èıre conservée, el quand mêane elle devroil l'êrre, il faudroit substituer un autre nom à celui si pen convenable que lui a donné $\mathrm{M}$. de Ferusvac. Al, Rang, daos son Munuel de Conchyhologie, a formé pour le genre Allanle la lamille des Ailantides (voyez Atrante), et il a laissé le genre Limacine a côté des Cymbulies dans la fumille des Hyales. Voyez Hyare et Lisacine.

\section{LIMACINÉS.}

Famille établie par M. de Blainville (arı. Moz. Lusques du Dictionn. des Scienc. natur.) pour les Hélices et les Limaces des auteurs. M. de Blainville a été conduit à la réunion de ces denx familles probablement par la difficulté de placer plutôt dans l'une que dans l'autre certains gentes qui, par les transitions qu'äls présentent, laissent duos le doute à l'égaı́d de la famille à laquelle jls doivent appartenir. M. de Mlainville a distribaé de la mauièie suivante la lamille des Limacinés.

† Le bond antérieur du manteau renflé en bouyrelet et non en boucher.

Une coquille.

Ambrette, Bulime, Agathine, Clausilie, Maillot (qui comprend les genies Partule et Ver tigo ), Tomugère, Hélice.

\section{I II}

It Le bord antdrieur du manteau élargi en une espece de bouclier.

Coquille aulle ou presque meabraneuse.

Vitrine (qui renferme les geares Helicolimax el Helicaron Ferus.), Testacelle, Parmacelle, Limacelle, Limace, Onchidie (qui conurend 'e gente Véronicelle Blainv.). Voyez tuus ces mots.

\section{LIIIACONS.}

Celce expression, synonyune d'Hélice dans le plus grand nombre des auteurs, a pourtant ceté employce par d'autres d'une manière plus unénérale pour désigner tuules les coqquilles enroulées, soit imarines, soit terrestres, dont la forme, plus on mains globuleuse, présentait quelques rapports avec celle des véritables Hélices. Dargenville est un de cenx qui la génćralisèrent le plus. Ad:uascin l'appliqua à la première section de ses coquillages univalies sous le nom de Limacons univalves. I y raugea douze genres divisḱs en ring familles: l'une d'elles, la troisième, comprend le genre Limaçun, qui ne renferne que des coquilles vérilablement terrestres, lorsque tous les autres genres de la section des Limaçons ne comprennent que des coquilles d'eau douce on marines. Les auleurs plus moderues, en conservaut le nom de Limaçon, le restreignirent beaucoup, et ne l'appliquérent plus qu'aux seules coquilles terrestres.

\section{LIME. Lima.}

Ce genre, créé par Bruguière dans les planches de l'Encyclopédie, n'avoit point été caractérisé par lui. Lamarck, dans ses premiers travaux, l'adopta, lui imposa le premier ses caractères génériques, et depuis il fut admis par la plupart des zool gistes. Bruguière avoit placé ce genre à la suite des Peignes, et c'est avec eux en effet qu'il a le plus de rapports.

Lamarck, dans le Systeme des Animaux sans vertebres, 1801 , le milégalement eo rapport avec ce genre et les Houlettes. Lorsque Lamarck établit des familles parmi les Mollusques dans sa Philosophie zoologique, il counpril dans celle des Byssifères la Lime, la Houlelte, et d'autres genres qu'il sépara des Peignes, qui furent placr's dans la famille des Ostracés. Cet arrangement resta alısolumeat le même dans l'Extrait du Cours, publié en 1811 ; mais, lians son dernier ouvrage, il apporta quelques changeriens, institua la faaille des Pectinides, qu'il forma d'une partie des gentes de ses Ostracés et des Byssifères de l'Extncit du Cours, et rétablit ainsi les rappor's uaturels des Limes avec les Peignes, les Houlettes et les Plagiostomes.

M. Cuvier, Règne animal, conserva le genre Huitres à peu près tel que Lioné l'avoit fait; les 
Limes, les Peignes, etc., s'y trouvoient compris it litre de sous-yeure. M. de Ferussac n'adopta pas à cet égard le sentimeut de M. Cuvier, il prélíra l'opiuion de lamarck; il admil la famille des l'es: tinides, et le genre Lime y fut compris. I. do Blaiuville, dans sou Truité de filalucologie, admit par le fait la famille des Pectinides de Lamarck en lui donnant le nom de Subostracés. II la reforma en en éloignant denx genres, celui de la Line y resta. M. Latreille conserva l'opinion de II. Cuvier en élevant au titre de famille le gemre Huître de ce zoologiste; il le divisa en deux Iribus, dont la seconde répond assez bien aux Pectinides de Lamarck : c'est dans celle ltibu des Ostracés yue se trouvent les Limes.

D'après ce que nous venons d'exposer, il est facile de voir gu'il n'existe que deux opinions sur le genre qui nous accupe. Doil-il rester dans les Ostracés ou faire parrie des Pectiuides? Tuate la question est là. Si l'oa considère les dillérens caractères des Limes, ct si on les compare it ceux des l'eignes, on leur trouvera beancoup plus de rupports qu'avec les Huîtres. Si, avec Poli, ou s'attache plus spécialement à l'animal, on lui trouvera biea des rapports avec les Huiltres et les Avicules, mais on lui en trouvera plus encore avec les Peigues. La coquille des Limes s'éloigae certainewent beaucoup de celle des Huitres proprement dites; elle est régulière, solide; non foliacée, non adhérente, si ce n'est par le byssus que porte l'anizal; elle a des oreillettes cardinales comme les Peignes, seulement elles sont plus courtes, et le ligament est placé de même dans une fosselle cardinale triangulaire.

La principale différence entre ces genres, dilféreuce que II. Latreillea parfaitement saisie, ģuisque c'est snr elle qu'il les a séparés dans deux fa malles vuisines, est l'existence du byssus dans les Limes, lur'squ'il manque presque toujours dans les l'eignes. Nous croyons que $\mathrm{M}$. Latreille a douné a ce caractere trop d'imporiance, et nous conservous l'o jinion de Lamirek, en laissant ce genre duus la famille des Pectinides. Poli, dans son bel ouvrage des Testacés des Deux-Siciles, a donoé l'anatuwie d'une espèce de Lime que l'on trouve trèstréquemmeut daas la Méditerranée; il lui a reconou tant de ressemblance avec l'animal de l'Avicule, qu'il n'a pas cru devoir les séparer en deux genres. Dans sa méthode, ses deux genres réunis forme celui qu'il nomme Glaucoderme. II we peut être adınis tel quíl est, car la dilférence untre les coquilles senles est si grande qu'elle a sulfi depuis long-temps à tous les auteurs pour les séparer. Voici de quelle manière Mr. de Blainville caractérise ce genre.

\section{CARACTÉRES GÉNÉRIQUES.}

Corps médiocrement comprimé, subsymétrique, enveloppé dans un manteau fendu dans presque tcute sa circonférence, très-finement liangé sur les bords, et sans aucua indice de siphon; houche entourée de lèvres fraugées et de deux paires d'appendices laliaux; un appendice aldoniual (le pied) rudinentaire, avee un byssus.

Coquille ovale, flus cu mains oblique, jresqu'équivalve, sulauriculée, régulièrement bâillanle à la partic antérienre du hurd inférieur; les sominets antéricurs el écartés; cliaruic̀re buccale, longitudinale, sans dents; ligament arrundi, presqu'estérieur, iuséré daus uue excavation de chaque valve; impression musculaire centrale partagée en trois parties distiactes.

Un genre voisia des Limes, que Lamarck a proposé sous le nom de Plagıostome, a cíté adimio par presque tous les unteur's. liormé de coquilles prour la olupart a l'ćlat de pétritication, il étoit difficile de vérificr dans lous les cas la valeur des caractères donnés par Lumarck; cependant si l'on s'ćtoit moins altaché aux furmes extérieures, on auroit pu se convaincre tacilement que les Plagiostomes olfient pour la plupart les accidens ŗui caractérisent les Limes : aiasi on ponvoit s'apercevoir qu'ils sont bäillans du côté antérieur, qu'ils sont pourvus de chaque côté dn bord cardinal de petites ortillettes semblables a celles des limes; enlin, que ce bord curdinal lui-même est drait et absolumeut semblable à ce gui a lieu dansle gente que nous venons de citer. Il ne resloit donc, pour sendre la comparaison complète, que de voir la charaière des l'ligiostomes, el de s'assurel si ce point icoportunt ollivit des dillórences rcelles a vec les Limes, et si ces diflérences étoieut suffisantes pour justifier ce genre. Nuus avons pn examiner la charnic̀re de plusieurs espéces de Plagiostomes, wéue de celles qui servirent de type au gemre, el nous pouvons assurer qu'il n’existe pas la plus petite dilférence entre ces carjuilles et les Limes. Relativement à la forrue, on ne peut trouver le mnyen de former avec elles uu groupe sciparté, car les Limes, sous ce rapport, se lient aux Plagiostomes par des auances insensibles.

Les limes sont des coquilles marines minces, solides, bäillantes sur le côté antérienr, et quelqueluis aussi sur le postérieur; elles se terainent supérieurement par un bord cardinal dreit taillé en facette oblique comparable à celle des Spondyles, ordinairement d'une forme triagulaire, á peiue dépassée au sommet par la saillie du crochet. Cetre facette est creusée dans le mo. lieu par un sillon aplati, triangulaire, á base lurge; légereacnt saillante à l'intérieur, et donnunt insertion au lirament : $\tan$ tôt le bord cardinal est perpendiculaire a l'axe longitudinal de la coquille, tantôt il est plus ou moins incliné. Une seule impression musculaire est placée très-hau daus l'intérieur de la coquille; elle est arrondie 


\section{I, I M}

ou uvaluire, très-superícielle, et visible seuleuxcnt daus les vieux individus.

l'armi les coquilles fossiles, il en est quelquesunes de très-épaisses et de très-gruades que l'o a cluerclié à introduire dans ce gente, et que d'autres auteurs ont vonlu comprendre au nombre des Aricules et des l'intallines; mais il est biea certuin qu'après l'appreciation convenable de leurs caractèrez, elles conviennent micux an gente qui nuas occupe ‘fu'à tnut autre. 11. Sowerlyy, daus s on Mineral concholngy, est celui des auteurs qui Iss a placées al nombre des Limes.

Au nombre des Plagiostomes, Lamarck aroil counpris quel gues coquil! ces épineuses d'une forme particulièce, ouvertes sous les cruchets, inćquivalves, quel queluis irrégnlic̀res, et qui ne présentent ancun des vrais caractères des Plagiontomes. Ces copquilles, don ou a une trés-bonue idée parle Plagriostoma spinosa, ne pouvoient rester daus le genre Plagiostome, el devaient encore moins êire iotrodnites au nombre des liines. M. Defrance pensa Gqu'il éloit nécessaire d'en faire un genre à purt, et le proposa suas le nom de Pachyte dans le Dictionnaine des Sciences naturelles. Avant qu'it ne parût, il l'àvoit communiqué à M. de Blainville, lorsqun'il publia dans le mème ouvrage l'article MnLI usque. Par une erreur assez singulière, $\mathbf{M}$. de Blaıville uansporta aux Plagiostounes le now du noureau genre de M. Defrance, cunservaat pour les coquilles de ce genre l'ancienne dénominativa. l.es savans que nous vcoons de citer ne lirent pas attention, en consacraut un gente nouveau pourles cuquilles dont nous parlons, que ce genre avoil li plus grande ressemblance, on pourrit mêrne dire la flus parfaite identité, avec celui établi par ladwarck sous le nom de Podopside. Il auroil donc: snlli de rejeter des Plagiostumes daos le genre Podopside les coquilles du gore Pachyte; ce genre, eutièremeut iautile, n'auroit pas alors été pnrté par M. de Blainville dans la finaille des 'T'rébratules, où il est déplucé; d’un autre cỏté, le geare Podopsis lui-même devant être rayé de la méthode eutraiue avec lui les $\mathrm{Pa}$ cliytes daus le genre Spondyle. (Voyez ce mot.) Ainsi, des rélormes aécessaires purrai les genres dont il vient d'ctre question, il résnle quon peat réduire à deux le nurnbre qui esl convenable, puisque, avec les limes, nons mettons les Plagiostomes, et avec les Suundyles les Podopsides et les Pacliyies. Nous ne parlons pas de deux genres de M. S wwerlyy que l'on a reconnus ĉrre des démembremens inutiles des Pudopsides, et par cunséquenı des Spondyles.

Le nombre des Limes, tel que nous comprenons actuellcment ce genre, est peu considérable en espèces vivantes, an is il,contient en revanche beaucoup d'espèces fossiles répandues d'unel manière assez constante dans les terrains divers, soit terliaires, soit secoodaices. La formalion crayense en recè.e uu bon nombre d'espèces, dont quelquesHist. Nut. des Tiers. Tone II. unes sont fort curieuses, en ce qu'clles présentent quelques points cl'analugie avec celles qui sont vivantes aujourd'hui. Dons les terrains inléricurs ì la craie, et surtout dans ceux d'oolite, se rencontrunt en aboudance les grandes espèces que nous avons mentionnées précédemment; elies ne se mantrent jamais au-delà des limites de cette formation: il en esi de mène des espèces yue l'un trouve lans le lias et le muscliclkack; elles y sont constantes, au point qu'elles peuvent tris-lien scrvir de caracières zoologịnes à ces terrains.

1. Lixe commune. Lima squamosa.

L. tcstâ ovali, depressâ, anticè quasi ubscissâ; costis squamosis, uspervimis; curdine obliquo, margine plicato.

Ostrea lima. Lrs. Gael. no. 95 .

Dargenv. Conch. tab. 24. fig. c.

Rомгн. Hus. $t a b$. 44. fig. $d$.

Gualt. T'est. tabl. 88. fig. $e$.

Chems. Conch. tom. 7. tab. 68. fg. $63 \mathrm{~s}$.

Excyec. pl. 206. 19.4 .

L.Air. Anim. sans vert. tom. 6. pag. 156. $n^{\circ}$. 2.

DE Blainv. Malacol. pag. 526. pl. 62 . fig. 3.

Coquille ovale, oblongue, trouquée antérieurement, rétrécie clu côlé des cruchets, élargie, spatulifurine, araincie el déprimée du côté inlérieur, généralement déprimée. La surface extćrieure est clitrgée de vingt à vingt-cinq côtes lungitudiaales, arrondies, distantes, élroites, saillauies, armécs de longues érailles inclioées, aplalies, subimbriquées; les oreillettes sont fort inérales, les postérieures sont plus grandes que les antérieures; outre quatre ou six rayons écailleux longitudinaux qui les couvrent, elles sont encore oruces d'un grand nonbre de stries transverses, assez. régulières, mais iaterrompues. Le côté autćrieur est a plali, sulstronqué, et prósente, lorsque les valves sont réunies, un bâillement étrout, lancéolé, pour le passage du byssus. Supérieurement on y voit les orcillettes, qui sont trèscourtes et strićes conne les postérieures; les stries transverses se montrent aussi sur tont le côté antérieur. Les crochels sont petits, poiotus, droits, opposés, à peine saillans au-dessus du talon qui termine les valves. La charnière est oblique à l'axe de la coquille ; à l'intérieur les côtés de l'exlérieur se reproduisent et ocrasionnent sur les hords des crínelores aussi nombreuses gu'eux. Celle corquille est tonte blanche; od la trouve daos la Méditerranéc el dans l'Océan indion. Nous possédons som analogue fassile, provenant des terraios terliaires de la Sicile. Cette espèce est

longue de zo i 80 millimètres.

$\mathrm{Xx} *$ 
2. Lime enfléo. Lima infiata.

L. zestâ obliquâ, ovatâ, valdè tunidá, utınque latere hiante, auriculis minimis; cardine obliquo; margine subintegro.

Lister, tab. 177. fig. 14.

Goalt. Test. tab. 88. fig. FE.

Cenun. Conch. tonı.7.tab́.68. fg. 649. litt. $a$.

ENcrcz. pl. 206. fig. 5.

LАмк. Anim. s. vert. tom. 6. pag. $156 . n^{\circ} .1$.

Certe coquille est ovale, oblongue, rérrécie supérieurenent, obliquement ćlargie à sa partie inférieure; elle est entlée, mince, très-convexe en deliors, bâillante des deux côtés, et présenlant un assez grand nombre de petiles cótes subanguleuses, longitudinales, fort étroites et distantes, plus nombreuses à la partie antérienre qu'à la postérieure; le côté antérieur est arroodi, jamais tronqué, le bâillement qui s'y voit est assez considerable. Les oreilleltes son t presqu'égales, la postérieure est eependant un peu plus grande rque l'autre; clles sont lisses ou presque lisses; le talon des valves est assez prolongé, très-oblique, e! laisse entre les crochets une distance assez con. sidérable; le bord cardinal est obliquement inclioé à l'axe lungitudiual, la saillie médiane qu'il présente colrespond à la goullière qui reçoil le ligament. A l'intérieur, la coquille est blanche, lisse, quelquefois présentant la réprórition des côtés de l'extérieur; les bords sunt légèrement crénelés, excepté l'antérieur, à l'endroil du bàillement des values. La lime enllée, commune dans Is Méditerranée, se irouve aussi fussile dans les terrains tertiaires de l'ltalic; elle est longue de 50 millimètres.

\section{Lime linguatule. Lima linguatuld.}

L. testâ tenui, pellucida, exalbidâ, oblongoarcuatâ, undiquè hiante; radiis tenuibus, undulatis; auriculis parvis.

Var. B.) Testâ striis transversis, semi-lunaribus, longitudinalibus, decussantibus.

Ostrea hians. Grex. $n^{\circ} \cdot 97$.

Scurart. Einl. in Conch. tom. 3. tab. 9. fig. 4 .

Lamx. Anim. s. vert. tom. 6. pag. 157. n०. 6.

Pelite espèce qui a beauconp de rapporls avee la précedente, mais que l'on distingue facilement au premier aperçu, par le plus grand aplatissement des valves \& par le bâlllement considérable qui les laisse onvertes aussi bien du côté ánlérieur. que du postérieur. Le bâillenıent antérienr surtout est remarquable en ce que si l'on regarde la coquille de ce côté, elle ne manque pas de ressemiblance avec quelques Fistulanes.

La Lime linguatule est ovalaire, oblongue, étroite, déprimée, très-oblique, obliquement tronquiuée du côtú antśrieur; clle est tonte lilaoclee, suburansparente; sa surface extérieure eft orme d'un grand nombre de stries rayonnantes tiesfioes, partant du croelset \& alleignant les bords, sur lesquels elles forment de perites crénelurrs. Ces stries soul lraversées par des lignes d'aceroissement plas ou moins nunbreuses, quelquelivis assez régrulicites. Le liord cardinal esi court, obliquement incliné sur l'uxe longitudinal; il esi parlagé en deux parties presqu'égales par la saillit: du crochet. Lus oreillettes soni égales, lisses; les postérieures, beaucoup plus déprimćes \& rapprichices que les autres. Le bord antérieur eft arrendi, épaissi, un peu évasé en dehors; le postérieur largement écbancré, surtout à sa partie inférieure, est nince \& tranchant. Lorsque les valves sont réunies, elles ne se couchent que par le loord rardinal, \& une très-petite partie du bord inlórieur.

Launarck donne pour parrie à celte espère le littoral de la terre de Van-Diémen; elle se trouve aussi dans la Médilerrance. Nous aurious eu peine à croire qu'il fût possible de rronver à des distances si considérables des individus idenliques d'une méme espèce; nous en avons fité couvaincu tiependaut en comparant ceux que nous avons de la Miditerranée avec ceux du cabinet de Lamarck, rapportés par Labillardière.

Longueur 34 millin. I.es individus de la Miditerranée sont un peu plus petits.

\section{I. ме gíante. Lima gigantea. Noв.}

L. testá trnuissimâ, semi-lunari, notundatâ, anticé truncatá, excavatâ, hiante, longitudinaliter striata; striis depressis, ad margines evanescentıbus; auriculss minimis, inarqualibus, antica breviore; candine obliquo.

Plagiostona gigantea. Sow. Miner. conch. pl. 77 .

Trigonia. Encycr. pl. 238. fig. 3. a. b.

Lima gigantea. Nor. Descript. des Foss. caractérist.pl. 14. fig. 1 .

Si l'on compare la figure de l'Encyclopédie à celle donnée par M. Sowerby, on reconnoîtra que toutes deux reprisentent la mêaie espice. Celte coquille est arrondie, subsemi-lunaire, oblique, ronquée anlérieurement, assez bombée \& un peu cordilurme; sun côté antérieur est fortement lronqué, \& Corme une grande lunule en cœur, excavée, qui montre entre les valves un baillcmeal supérieur pour le passage d'un byssus. Lies crocliets sunt opposés, petits; ils partagent le bord cardinal eo denx parties inégales, dont l'anisricure est la plus courte. Le bord cardinal est droil, fort court et ineliné sur l'axe longitudinal; il est formé par deux très-petiles oreillelles, dont l'antérieure est si courte qu'elle paroît ne pas existcr; la postŕrieure est un peu comprimée el 
légrirement sinueuse à son bord postériellr. Cu gratud nombie de stres fines, peu profundes, sou veut onduleuses, parleut en rayonnant des crochets, descendent en s'alluillirsant peu à peu, et tinissent par disparoilte avant d'avoir altyint les inorls. Dans yuelques individus, ces stries, au hen d'etre régulicrement distribuées sur toute la f.allie supéilcure de la cocjuille, sont partingées un deux parties, l'une antériense \& l'aulie pustétienre, de waniere à laisser le centre de la cocuille entièieasent lisse; le cóté antérieur, plus un couins excavé, survaut l'ảge des iudividus, est rellen.cril linité par un anglt ariondi, au-dessous duquel se muntrent quelgues stries plus étroites "t plus enliuncées que les autres.

Celle coyuil!e, rres-répandue daus le lias, tanı en Erance qua'en Allenagne et en Angleterre, a yguelqueluis plus de 6 pouces de longueur.

\section{Lime plissée. Lima plicata. Lanx.}

L. testâ ovato-oblongi, aprce altenuati, incequiluterali, longitudinuliter costato-plicatô, antluci truncatá; costis stmplicibus, numerosis, converis; auriculis inoqualıbus, antica brevissimâ.

L.isk. Anim. s. vert. tont. 6. pus. 158 no. 3.

Nов. Descript. des Coq. Joss. des env. de Puris, tom. 3. pl. 43. fig. 4. 5 .

Cielle espèce n'est peut-êlre qu'une variété de 1. Lime commune; elle présente une forme trèsanahgrue, mais elle a tuojours une taille beaucoup plus petile : ce qui la disungue surtous, - 'es: que ses cóles sont constammeni dépuurvues 1. ¿̇iues écaillenses; elle est ovale, oblongue, cn i su ue de spatule, rétrécie a somut, géníralenent déprimée. Oo compte sur la surface extérieure vingt-lrois un vingl-quatre côtes longitudirales, élroies, aplaties en dessus, glabies. Le côté antérienr est tronqué, aplati, quelquefors excuvé, présentant torjunrs un petil baillement Isncicoé ; le bord cardunal est incliué sur l'axe I sngitudinal de la cupqulle; il se prolonge longitudinalement en un ralos plus ou noins alongé, selou l'age des ind vidus. Le laton triungrulaire est airisé dans le aihien par une goultière assez large, qui fait une saillie it la base, el qui étoil destinee a rectroir le ligament. Les areillelles sont for inćgales, l'autérienre est extrènement courte; la postérieure est dé orianie et chargfe de stries r.younantes; les hoids sont crénelés dans presugue toute leur élendue. L'intéricur des valves es! lisse, et l'on y roil la répélition des côtes de lextírieur.

Cette coquille n'est encore connue qu'à l'élat fossile; elle fin trouvée d'abord dans le faluns de 1. Tuuraine, et eosuite nolis la découvrimes aux environs de Paris, à Valmondois, où elie esı exressitement rare. Les plus grands individus ont 42 coillim. de longueur.

\section{I M}

6. Liae oblique. Lima obliqua. Lask.

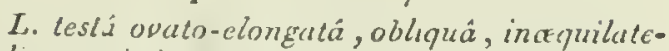
rali, tenuissind, fiagali, stris longiludinalibus angulatis omati; stris anticis remoluusculis, subarqualibus.

Lssк. Anin. du Mus. tom. 8.pag. 462. no 3 .

Nов. Descript. des Coq. Sors. des env. de Paris, tom. 1. $p l$. 43 fig. 9. 10. 11.

11 nous est impossilje de cunceroir combuent Lamarck a pu confoudre celle espéce aver la précédente, dans son dernier ouvrage; elles sont rellemear distinctes, que nous ne croyons pas nécessaire d'en donner d'aulrés prenves que la description mise en rejard de l'autre. La Lime oblique est une forl petite coguille ovale, oblongue, rétrécie supérieurenen!, très-mince, très-fra translucide el très-convexe en dehot's; la surlace exlérieure estordéc d'un yrand nombre de stries anguleuscs, longitudinales, simples, partan: du crochet et aboutissant en rayounant ver's les horts, qu'elles rendent onduleux. Le bord cardinal est étroii, assez fortement incliné sur l'axe longitudinal de la coquille; il est dominé par un crochet assez saillant el puintu, dont le sumnet le partage en deux parties presquégales. Le lulon en est trés-conrt, el sa surface est 'n parlie occupéc par une fosselle liiangulaire très-large el trèssuperficielle. Les oreillelles sont presqu'égales; elles sont lisses et fortement séparćes du reste par un angle assez profund. La surface intérieure des values est lisse el brillante; le test est si mince que les stries se répietent à l'intérieur jusyu'au sounmel. Nons ue connaissons encore celle espèce qu'aux environs de Paris, à Parnes, à Grignon el à Monchy-le-Châtel. Les plus grands individus ont 10 inillim. de longueur et 6 de large.

\section{Lise flabelloide. Lima flabelloides. Nob.}

L. lestâ ovato-angustâ, longitudinaliter costatá; costis tenuibus, squamulosis, convexis; latere untico supernè oblique truncato, valde hiante; in hiatu margine refle.ro, simplici; margine infe. iiore crenalo.

No . Descript. des Coq. foss. des env. de Paris, tom. 1. y/l. 4.̄ं. fig. 6.8 .

Vur. a.) I.B. testî angustzore, costis numerosioribus instructs.

Loc. cit. fig. 7 .

Coquille fort remargualife, que nous avons découverte aux environs de l'aris, dans la localité intéressaute de Vulmondois; elle a une forme qui la fait reconnoitue facilement, ćtant la plus longue et la plus étroile des especes du genre; e!'e est assez fortement déprionée vers le bord inférieur; sa sulface extérieure, peu convexe, est ornće de douze à quinze cúles longiludinales, 
étroiles, saillantes, couveres, chargées d’un grand nonbre d'écailles courtes el relevces, qui rendent la coquille rude au toucher; sur le côté antéricur, les côtes sont beaucoup plus fines et beaucoup moins élevées; le côté antérieur est obliquement tronqué à sa partie supérieure. Dans cet endroit il présente un large bâillewent, dont les bords éprais et arrondis sont fortement renversés en dehor's. Le bord cardinal est un peu oblique; il se continuc en un tulon court et obstus, dont le milieu est occupé par la fossette duligameus. Le crocbel est pelit, à peine saillant au-dessus du bord. De cbaque côté sont les oreillettes, dont l'antérieure est beaucoup plus grande que la postérieure; les bords soat simples, si cc aest l'iuférieur, qui esı frnement crénelé.

I a variété paroît assez constante. La coquille est plus étroite et plus langue proportionnellement; les côles Inngiludinales dont elle est ornée sont plus nombreuses, plusétroites, et les écailles dout elles sout chargées sont plus courtes et plus nombreuses. Celle jolie coquille est longue de 35 millim. et large de 27 .

\section{Lrae obscure. Lima obscura. Nob.}

L. testî̀ nvato-depressâ, incequaliterâ, obliquâ, longitudinaliter tenuè sulcutâ; umbonibus proeminentibus, uppositis; latere cardinali brevissimo; auriculis subcequalibus.

Plagiostoma obscura. Sow. Miner. conchol. pl. 114 . fig. 2.

Nов. Descript. de quelques Foss. caractérist. pl. 8. fig. 6.

Coquille ovalaire, obronde, presqu'aussi large que longue, peu enllíe, fort oblique, très-izéquilatérale. Le côté antérieur est le plus grand; il est à peine tronqué, et l'espace lunulaire est de peu d'étendue. Le bâillement que l'on y remarque à la partie supérieure est fort ćlroil et presque linéaire; le côté postérieur est arrondi, cuurt et dćprimé perpendiculairemeal. Ce qui read celle espice de Lime facile à recunncitre, c'est la brièvelé du bord supéricur ou cardinal; ce bord, assez fortement incliné, est partagé en deux parties égales par la petite saillie que forine le cruchet. lies oreilleltes sont semblables et de même taille; petites, obliques et déprimées. Toute la sorface extérieure cst couverte de stries nombreuses, longitudinales, rayonnantes, très-Ĺnes, égales, peu profondes; ces stries, un peu plus saillantes du côté postérieur, manquent complétemeat sur le côté antérieur. Quclques lignes d'accroissernent irrégulièrement espacées coupent en travers les stries longitudinales. Cette coquille se trouve parliculicrement dans les marnes argileuses d'Oxfort; elle passe dans le calcaire à l'olypier's, au-dessous dnquel elle a'uxiste plus. Elle a 50 aillim. de longueur.

\section{I . II}

9. Lime poncluée. Lima punctata. Ninb.

L. ¿estâountì, obliquissimsâ, dilutatû, depressâ, longitudinaliter strintâ, unticè obliquè tıuncatú; striis confertis, tenuibus, punctutis; cardine angusto, obliquo; auriculis minimis, incequelibus.

Plagiostoma punctata. Suw. Mineral conchol. pl. 113. fig. 1. 2.

Celle espèce est une de celles dont nons arous pu étudier tacilement les caracières, quoiqu'elle fût à l'état de pétrification. Nous sommes parvenu, sur un individu, à découvrir la cbarnière, couverte par la pierre oolitique, gui sert ordinairement de gangue à celle espèce. Nuus a vonः vu que celle charraicre étoil idenliquement la même que celle des Limes. Cotle coquille est ovale, semi-lunaire, déprimée, très-nblique, fortenent dilutée inferieurement et très-rérrécie au contraire à sou extrémité supérieure; le côté anlérieur est presque droit, tronqué, souvent excavé, présentant loujours à sa partic supérieure un petit bâillement long el étroit; le vôté prostćricur est arrondi et fort court; la surlace externe est oruée d'un très-grand nombre de stries rayonnantes du sonmet à la base. Ces stries, quelquelois ondulenses, sont ponctuées dans les inicrvalles qui les séparent; les ponctuations sont nombreases, très-fines, et se voieul beaucoup plus sur le côté postéricur que partout ailleurs; le bord cardinal est court el oblique, prolongé en un talon triangulaire, divisé dans le milieu par une goutlière superficielle, triangulaire aussi, et lígèrement saillante à la base. Le crochet fait pera de suillie au-dessus du bord; les oreilleltes sont inégales; l'antérieure est plus courte et plus oblique que la postérienre : celle dernière est légèreinent sinueuse à son bord postériens.

Cette coquille, commune aux environs de Caen, dans l'oolite ferrugineuse, a 65 ou 70 millim. de longueur et 55 à 60 de largeur.

10. Lime cordiforme. Lima cordiformis. Nan.

L. testâ opatî, antice truncatâ, gibbosâ, cordiformi, lunuli pnofundissima hiunte instructâ, striis longitudinalibus distantibus antice posticéque ornatâ; umbonibus subcarinatis, nuaxinis; cardine brevi, obliquissino.

Coquille fort extraordinaire, que l'on preodroit pour une Bucarde de la section des Hénicardes, tant elle est aplatie sur le côté antérieur. Elle est de forme ovalaire, semi-lunaire, très-aplatie du côté antérieur; la surface en eft fort large, cordiforme, et présente à sa partie supérieure un enfoncement lunulaire considérable, séparé dn reste par un angle obtus. Celle lunule, à sa partie supéricure, est baallante : elle est, comme le restc de la surface antérieure, oroée d'un grand nombre de stries simples, étroites, et assez distantes les 


\section{I II}

unes des autres. res crochels sont grands, arquiés, cordiformes, anguleux et carénếs à leur partie supéricure; ils sont opposés et se teranineat sur le bord cardiual, qu'ils parlagent en deux putties presqu'úgales. Le bord cardiual est très-court, tellement oblique, qu'il esı presque parallèle à l'axe longiludinal de la coquille. Les oreillettes, yui se termineat sur les côlés, sont fort conrtes; l'antérieure l'est un peu plus que la postéricure: le milieu de la coquille esı lisse; son côlé postérieur ne présente que quclques stries obsolèles qui se conlinueut sur l'oreillelle de ce côté.

Cette coquille, dont nons ne connoissons pas la localicé, provient, à ce qu'il paroit, d'aprics la nalure de la roclie qu'elle contient, de la formation du lias el des aryiles qui en dépendent. Elle est longue de 85 millin. et large de 50.

11. Lise lunulaire. Lima lunularis. Nов.

$L$. testâ ovato-oblongâ, obliquâ, subarcuatâ, conve.râ, tenuè striatâ; striis undulatis, dorso evanescentilus; latere antico brevi, obliquo, profunde sinuato, lunulato; auriculis brevibus, incequalibus; cardine obliquissinun; marginibus integris.

Fort julie coquille, qui provient des oolites des environs de Caen, el dont nous ne trouvons la descriplion daus aucun auteur. Elle est de taille médiocre, ovale, oblongue, atténuée supérieurentent; elle est très-bombée et convexe en deliors; sa surface, qui paroit presque lisse, est ornće cependant de stries très-fines, onduleuses, apparentes, principalement sur les parties latérales, et disparoissant presque toujours sur le milieu du dos; le crocher est bombé, saillant, au-dessus du bord cardinal et incliné sur le côté antérieur. Ce côté est remarquable, en ce qu'il est non-seulemeat tronqué, mais encore excavé par une luaule subcordilorme dans laquelle l'oreillette antérieure est comprise. Ce côlé antérieur est limité par un angle obtus et arrondi. Le bord rardiual est court, étroit et oblique. L'oreillette antérieure est assez courte, et elle l'est davantage que la postérieure : l'une el l'autre sont striées dans leur longueur; la postérieure plus fortement que l'autre. Les bords sont simples, tranchans et ne paroissent pas avoir été bâillans dans aucun point de leur étendue. La Lime lunulaire provient des environs de Caen; elle a 40 mill. de longueur.

12. Liase de Hoper. Linia Hoperi. Nов.

L. testâ ovato-subtrigonâ, transversâ, depressâ, locvigatâ, supernè attenuatâ; cardine brevi; auriculis minimis, subaqualibus, aliquandd longitudinaliter striatis.

Plagiostoma Hoperi. Sow. Min. concñ. pl.38o.

Celte espèce de Lime est remarquable par son extrême aplatissement : elle est ovale transversa- lement, plus large que liante, leraiucée à sa partic supericure par un angle peu aigu que forme le crochet; clle ell tronquíe antérienrement, el sa troncalure est très-courte; la lente qui s'y voit esi linéaire. La charnicre est trés-élruile; sa surface supérieure est courte el présente la fosselle qui caractérise les Limes. Les oreillelles sont presqu'ćgales; l’antérieure est la plus courte: l'nue el l'autre, el surtout celle dernière, sont fortement séparcées du reste de la su:face laj ur sillon profond. La surface extérieure cst lisse, ou presque lisse, car on n'y remarque le plus ordinairement que quelques stries irrégnlicres d’a:croissement. Daus quelques individus, le ciolé ancérieur el le postérieur, ainsi que les oreillelles, sout ornés de stries longitudinales rayommantes. Iues bords sont entiers, très-nuinces el tranchans.

Celte corquille ne s'est encore rencontríe que dans la craic, où elle est ussez rare. Les plus grands inclividus ont 36 mill. de long et 43 de Parue: ces proportions sont un peu variables.

\section{Lime transverse. Lima transversa. N⿴囗.}

L. testî̀ ovato-transversâ, maximầ, depressî̀,

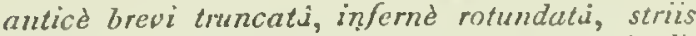

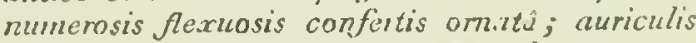
brevibus, inaqualibus; cardine obliquo.

An Plugiostoma transwersa? Lasк. Anim. s. vert. tomt. 6 . page $160 . n^{\circ} .1$.

La phrase caraclérislique que donne Lamarck a son Plagiostome transverse convient, en partie, à l'espèce que nous allons décrire. Le défaut de synonymie et de ligure nous empêclue de nous assurer si ce sont des types bien distincts. Nutre espèce est une des plus grandes du genre; olle est ovale, transverse, plus large que liaute, termiuée à sa parlie supérieure par un angle presque droit dont le sommet est formé par le croclyet et deux des côtés par le bord antérieur et le postérieur.

Cette coquille est déprimée; sa surface extérieure est couverte d'un grand nombre de stries ou de sillons longitudinaux, flexueux, convexes, peu élevés, présentant, sur leur's parties latérales, de fines stries obliques, très-courtes, qui parlent da fond des intervalles qui les sénarent entr'eux, et remontent jusque vers le milieu de la largeur, de chaque cốlé. Le côté antérieur est contr, oblique, tronqué, excavé à la partie supériemre, où il présente une petite fente très-courte et fort étroite. Le bord postérieur est plus oblique et plus court que l'antérieur. Le bord cardinal est fort conrt; il estétroit, et les oreillelles, quile prolongent de chaque côté, sont inćgales; l'autérieure est la plus courte : l'une et l'autre son! striées dans leur longuear.

Cette grande espèce se tronve particnlièrement anx environs de Caen et de Bayeux. Elle a 12 ou 13 cent. de long et 14 ou 15 de large. 

กัов.

14. Lame uniauriculée. Lima uniauriculala.

L. testâ ovutu-oblong $\hat{\jmath}$, incoquilater $\hat{\jmath}$, anticè auriculat $\hat{\imath}$, lavigatu; auricula posticuli nuilá; cardine obliquato, pratongo.

Celte espèce n'apparticnt peut-être pas au genre lime, puisqu'elle n’a qu'une seule oreillette antérieure et que la postérieure est remplacée par la continnation déprimée du bord curctioal. Elle est ovale, oblongue, trćs-inéquiratérale, à cror hets assez grands et gihbeux; le reste de la cuquille est déprimé. Le côté antérieur est un peu oblique, nou trongué, et ne paroît pas avoir été bâillant; il se termine, à sa jonction avec le bord supérieur, en oreillette assez large et déprimée, sinueuse it sa base. Le bord cardinal est assez lurge, lógèrement arqué postérieurement et déprassé par le crochet; son extrémité postérieure se conlund avec: le bord supérieur en produisant un angle obtus. l.e bord inférieur est arrondi; il est mince er t:anchant; la surface extérieure, bombíe seulenient vers le crochet, est déprimée vers les hords: elle est toute lissc.

Cette coquille, que nous ne connoissons qu'à l'élat de pétrification, paroit proveoir du muschelkalck. Nous ne connoissons point la nature de sa charuière: aussi ne la placerons-nous qu'avec doute au numbre des Limes. Elle est longue de 55 millim. et large de 45.

\section{Lime rustique. Lima ristica.}

L. testâ ovato-oblongì, supemè attenuatâ, anticè valde et oblique truncata; candine angustissimo, auriculis brevibus temmnato; costis longitudinalibus, depressis, latis.

Plagiostoma rusticum. Sow. Miner. conchol. pl. 381 .

Coquille ovale, oblongue, étroite à la partie supérieure, tronquée antérieurement et sublunalée; sa suiface extéricure est assez convexe; on y voit un assez grand nombre de cóles lougiludinales, souvent onduleuses, déprimées, rayonrantes, plus étroites sur les cốtés antérieur et postérieur. I.e côté antérieur est court et oblique, légèrement bâillant à sa partie supérieure; il est quelguefois excavé et prend alors la forme d'une lunule lancéolćc. Le bord cardinal est tIès-coult, obliquement incliné sur l'axe longitudinal de la coquille; les crocliets le partagent en deux parties presqu'égales. Les oreilletles sont extrêmenent courtes, l'antérieure surtont se voit à peine: l'une et l'autre sont striées dans lcur longueur.

Connue seulernent à l'état de pétrification, nous n'avons pas encore vu dans son enticr la cliarnière de celte espèce; mais d'après l'euseuble de la forwe; et surtout celle des oreillettes, nous ne doutous pas qu'elle n'appartienue au genre auquel ncus la rapportons. Elle a cté trouvíe cu
Angleterie, aux environs d'Orforl, dans le salfle veri. Líndividu que nous possćdons vieut de Gundershoflen; ila 70 millim. de long et 50 de large.

16. Lime lingulie. Iima lingulata. NoB.

L. testá ovato-oblongi, angustá, obliquissimi, tenuissime striutá; strus punctatis, longitudinallbus; latere aníco truncato, excuvato, laviter arcuato, striis lationbus ornato; cantune brevissimo, perobliquo.

Petite coguille qui, pour la forme et la grandeur, a de l'analogie avecil'espece vivante nowmée Linne linguatule par Lamarck, et que nous avons précédemment décrite. Celle-ci esi uvale, oblongue, étroite, déprimée, presqu'aussi large à son bord supéricur qu'à l’iuférienr; sa surfuce extérieure est nonce d'une multiıde de stries excessivement fines, à peine visilles à l'ail uu : elles sont régrulières, longitudinales et très-finement ponctućes. L.e côté autérieur est presque parallèle au postérieur; il $\epsilon$ st tronqué, excaré, légèrement ar'qué dans sa longueur; les strits qui s'y voient sont en général plas grosses que les autres; un biillement peu considérable, commençant au-desscus de l'oreillette, se prolonge jusque ver's le milieu de sa longueur. I.e bord cardianl est extrêneneat ohlique et furt court; il est at peine dépassé par la saillie du croche!. L'oreillette antricieure est lort petite, e! plus olilique que la postérienre : celle-ci est sépatrée flar un sillon assez profond. Les boris des valves sont munces, tranchans el siuples.

Celle petite conuille provient des oolites des environs de Caen. Elle paroit assez rate. Eilie eś longue de 20 uill. -et lulbe de 11 .

17. Lrme subéquilatérale. Lima glacialis.

L. testá ovali, depresso-converi, subcequitaterâ, hinc hiunte; ladis numerosts , tenuibus, subusperis; margme non placuto.

Ostrea g!acialıs. Gmer. " ${ }^{\circ} \cdot 90^{\circ}$.

Lister, Conch. tab. 176. fig. 15.

Knurr, Vergn. tom. 6. tab. 38 fg. 5.

Chema. Conch. tom. 7. tab. 68. fig. 652.

ExстcLor. pl. 206. fig. 2.

Var. b.) Testi radiis nitioribus, tenuissumis.

Chens. Conch. tom. 7. tab. 68. fg. 653 .

Excyulor. pl. 206. fig. 3.

Lank. Antm. s. vert. tom. 6. pase. 157. n'. 5.

Cette coquille se reconnoit avec la plus grande facilite; tlle est de forme ovalaire, oblonglat, spatulre, rétrécie à son extrémité supérieure, déprinée latéralement; sa surface extérieure esi occupée par un lic̀s-gland nombre de stries lièsfiaes, très serrées, longitudinales, nrnées de grauulations owlongues e: saillantes, disposées avec 


\section{I II}

assez de symélrie pour les faire prendre pour lles stries ubliques traversant les premicres. Le bord supćrieur est fort court; il est droil, non incliné sur l'axe longilunal, divisé en deux parties presqu'f́gales par la saillie du croclet prolongé en un petit talon; il porte dans le milieu une petite tosselle Iriangulaire qui donne insettion au ligament. Le cólé antélieur n'est point tronqué, il se ternine superieurement par un bäillement assez considérable dont les bords, iris-épaissis, sont fortemenl renversés en dehors; il se continue avec l'oreillette antérieure, ce qui clonne à celle-ci plus d'étendue qüà la postérieure. l,es loords des valves sont minces, tranchans, très-finement crénelés. La surface ablếlieure de retle coquille est d'un beau blanc à l'extérieur; on la trouve presque toujours de cette couleur, mais cela n'a licu que lorsquelle est dépouillée de son épid'rme, qui est d'un biun peu inteuse. Nous possédons une variété de celle espòce dont les stries, gúnéralement plus larges, son ícailleuses au lieu d'être luberrulenses. D'après Lamarrk, cetle coquille vil dans les mers d'Amérigne. Elle esi longue de 65 willim, el large de 45 .

\section{Lu átrcile. Lima fragilis.}

L. testí oblongo-angusti, necti, subarquiluterí; sulcis longitudinulibus, muticis; auriculis sub. requalibus.

Ciess. Conch. tom. 7. tab. 68. fg. 650 .

Excycz. $\rho$ l. 206. fig. 6.

Var. b. ; Ostrea bullata. Bors. Mus. tab. 6. fig. 8.

L.Amк. Anim. sans vertèb. toni. 6. pag. 157 . $n^{\circ} \cdot 5$.

Nous devons à l'obligeance de M. Quuy la connoissance exacle de celle espèce intéressante. Elle oflie des rapports extrêmement grands avec des coquilles pétrilices qui se trouvent aux environs de Caen dans la formation oolitique, ainsi quaux environs de Maëstricht dans la craje supérieure. Une autre espece, le Lima bulloides, qui se trouve aux envirous de Paris, a aussi de l'analogie avec celle-ci, mais elle reste conslamınent heaucoup plus petile. La Lime érroite est une coquille ovale, oblungue, équilatérale, étroite, à test mince, parloul d'un blanc-laileux, Elle est convexe el bossue en dessus; son crochet, qui-dépasse le bold cardinal, donne naissance à un assez grand nombre de stries longiludinales f rt étroiles, convexes, et rendues légèrement noduleuses par des stries lransverses d'accroissement assez nomJreuses. Sur le côlé postérieur les stries sont plus fines, et quelquefois hifides. Le côlé autérieur est à peine baillant; il est tout lisse. Le bord cardinal est droil, non iucliné sur l'axe; il est oc-cupé en grande parlic par une large fosselle triangulaire, superficielle, qui fait saillie à l'intérieur des valves, Les oreillelles qui terminent ce bord sont pelites, ¿gales, séparées Ialéralement par une pelile sinuosilé, Le bord jufúricur seul est finenient crénelé.

Celte coquille, forl rare dans les collections, vient de l'ile de Nicobar . d'après Lamarck. Celle que nous devons à l'ubligeance de $\mathrm{M}$. Quny a êté tapportée des mers australes; elle a 24 millin. de long et 14 de large.

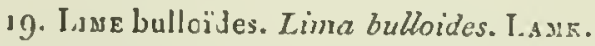

$L$. testâ ovatâ, convexi, in nedio striutij; sitris longitudnalibus, confertis; curdine recto, "litgusto, anriculss minimis, aqualibus.

Laав. Anal. du Mus. tom. 8. pug. 40.7. $n^{\circ} .3$.

Nov. Descript. des Coy. foss. des env. de P'uris, tont. 1. pl. 43. fig. 12.13. 14.

Coquille qui a beaucoup d'analogie avec la préćrdente, dont elle ne paroit dilférer que par la laille; mais ce u'est pas le seul caractere qui duive l'en séparer. Elle cst orale, oblunguc, trèsmince, très-fragile, équila!érale, très-comvexe, et puint bâillaule sur les còtés. La surface ex'erne est ornée, dans le nilieu seulenient, de stries longitudinales, fines et angulenses; elles aboulissent toules sur le bord inférieur, el elles y produisent de fines crénelures qui se reçois ent rúciproquement daus les deux valves. Le licrd carcibal ou supćrieur est droil, élroit, el divisé en denx parties évales par la saillie du croclsel; il prísente un talon fori court, creusé dans le milieu d'une goullière triangrulare-dont la base est très-large et un peu saillañte à l'intérieur des valves. Les oreillelles sont grandes, fyales, lisses, non sinueuses à leur base. Les bords sont simples, tranchans, si ce n'esı l'inférieur qui est crénelé, comale nous l'avuns vu.

La Lime bulloide, fort rare aux environs de Palis, sans doule á cause de son extrêne li'agilité, ne peut êlre confondue avec une autre espèce. également fossile, qui se trouve en Sicile. C"esi principalement dans les sables que l'on fait lomber de lintérieur des grosses coquilles provenant du Griguon, de Moucliy, de Parnes el de Courlagnon, que l'on a quelques chances de reeueillir. celle espèce dans son intégrilé. L.es grands individus ont 8 millim. de long. et 5 de large.

20. Liмe bossue. Lima gilbbosa. Scw.

L. testâ ovato-oblongâ, gibbosâi, tenwi, ctquiquiluterali; dorso longitudinaliter sulcato; Interibus lavigatis; auriculis cequalibus, latis.

Sow. Miner. conch. $p l$. 152.

Var. a.) Nов. Testä latiore, striis numeroviuribus, crenulatis. 
Cellc espèce, comme nous l'arons indiqué en parlant de la Lime ćtroite, a beancoup d'analngie arec l'espèce vivante que nous venons de men-tionner. Celte analogie n'est pourtant point parlaite, et il reste des caracteres suffisans pour bien les distinguer. Celle eoquille est oblonğve, mince, fragile, très-bonbée, régulierement ovale, à ebarnière droite el trourle; sa surface extérieure est ornée, sul le milieu du dos, de douze ou treize sillons longitudinaux, qui partent du crocbet el se rendent en rayonnant au bord infericur, sur lequel ils produisent uu nombre égal de crénelures. Les parties lalírales sont constamment lisses; la postérieure est plus large que l'autre. Le crochet, incliné sur le bord cardinal, le divise $\in$ n denx parties tgales. Le talon, court, assez forlement incliné en delors, est divisé lui-mêne par une goultière large et superficielle qui donnoit attache an ligument, Les oreilletles sout égales, courtes, peu déprimées, toutes lisses et point sinueuses sur leurs parties latćrales.

La variété que nous avons indiquéc se recon ucit à un peu plus de largenr, à quelques côtes de plus, ei surtout aux crénulations produites sur Ies côtes parle passare de stries d'accroissement tratsverses régulières.

Cette coquilie, fort commune dans les onlites ferrugineuses, se trouve particulièrement aux curitons de Caen; elle est éralement en $\mathrm{An}-$ gleterre el en Allemagne. Elle est longue de j.j millim. et large de 20.

\section{Lime dilatée. Lima dilutata. Lanr.}

L. testí ovato-rotundatâ, subtrunsversá, tenui,

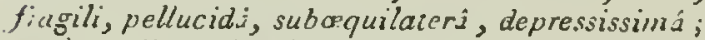
exlus stris radiantibus tenuibus ornatá; candine angusto, brevi; auriculis minimis, incqualibus, aritica breviore.

Lamk. Ann. du Mus. tom. 8. pag. 464. n.. 4 .

Ibid. Anim. sans vert. tom. 6. pag. 158. $n^{\circ} .5$.

Nов. Descript. des Coq. foss. des env. de Paris,

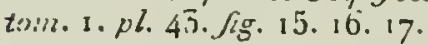

Jolie coquille que son extrême fragilité rend assez rare dans nos collections; elle ressemble beaucoup, quant a la lorme, au Plagiostome trunsverse que nous avons dicrit précédemment sous le nom de Lima transversa. Il y a cette différence eotre éles. de la taille d'alsord, et ensuile de la posilion de la cliarnicre. La Liuie diatce est ovate, arrondic, un peu plus large yrue longue, très-mince, très-fragile, transpatrente, ug peu oblique, presque équilacérale; le củića alćricur uı peu plus grand ģue le postérienr; elte est tris-dépriuncé el couverle extćrieurement $C$ inn assez grand nombre de cótes longitudinales, rayonuantes, obsolcles, disparcissant vers les cro- chets. Les bords en sont à peine modifiés : le bord cardinal on supéricur est extrêmement court, iो est perpendiculaire à l'axe longitudinal; le eroche le domine un peu, et il se termine de chaque côté par une petite oreillelle, neltement séparée par un sillon anguleux. Les oreilletles sont lisses, très-déprimées; l'antérieure est la plus courte. A l'intćrieur, la coifuille est lisse el brillante; son borl antérienr, par une petie siunosité, indique qu'elle devoit être brillante.

Cette petite coquille, connue à l'élat fossile seulement, se trouve à Grignon, Courlagnon, Parnes, elc., aux environs de Paris. Elle est longue de 10 millizn. et large de II.

\section{Lime spatulće. Lima spatulata. Lamx.}

L. testi ovat', depressâ, supernè attenuatá, longitudinaliter multi-costatú; costis squumosis; interstitiis tenuiter et oblaquè striatus; latere antico oblique truncato, hiante; uuriculis aqualibus, striatis; candine recto.

Lasr. Ann, du MIus. tom. 8. pag. 463. $n^{n} .1$.

Ibid. Anim. sans vert. tom. 6. pug. 158 n?. 1 .

Nов. Descript. des Con. foss. des env. de Paris, tom. 1. $\mu l .43$. fig. 1. 2. 3.

Cette espèce de Iime est la plus grande que nous connoissions aux environs de $\mathbf{P}$ aijs; flle est régulièrement ovalaite, déprimée, peu cunvexe, oinée à l'extérieur d'un grand nombre de cóleg longitudinales, rayonuantes, plus ou moins rayprochées, sclon les individus, arrondies el chargées de nombreuses écalles. L'intervalle des cútes, examiné à la loupe, présente un caractère que nons ne retrouvons dans ancune autre espèce ; ce sont des stries obliques, très tines, qui descendent du bord untérienr vers l'inférieur; elles snnt trèsrégulières. Le bord cardinal est droit, non incliné sur l'axe, il se prolonge en un talon divisé dans sa longueur par la goutlicere étruite el assez profonde du ligaınent. Le côlé antérieur est tronqué à sa partie supérieure; il présente dans cette partic un hâilleonent considérable lancéolé, dont les bords épaissis snnt tortement renversés en dehors. Ce bord se continue avee l'ureillelte, ce gui la prolonge et la limite par un sillon profond. L'Dreillette pastérieure est la plus petile; elle est déprimée el couverte de stries rayonnantes, coinme l'antérieure; les bords sunt crénelés tans loute leur éteudue, si ce n'est l'antéricur à l'endroit du baillemeni. Cette cocpulle se troure assez abondament aux enrirons de Paris, à Grignon, à Parnes el surtout à Chaumont, d'vù proviennent les plus grands et les plus beaux individus, mais aussi les plus fragiles. Sa longueur est de 43 milim. et sa largear de $3 j$.

23. Lrue prohoscidće. Lima proboscidea. Sow. L. testâ ovato-rotundaiâ, crassí, costis longidinulibus 
tudinulihus rudiuntibus undulatis exaratấ; costis rolundatis, irregulariter squamosis; margimbus crenulats; cordine recto, anriculis subatuctlibus icuminato; latere antico oblique truncato, hiante.

Sow. Minor. conch. pl. 264 .

Ostrucites pectiniformis. Scmuornem, die Potrefic. pag. 23. $n^{\circ}$. 1.

Cence espèce est la gúaule dis lines; elle provient des territas secundairus suprients à l'oolile. Eile est ovale, arrundie, pertimitirne, assez bundréc en delscrs, et clargée extérieurenent de onze ou douze grosses côtes lonģiludinales qui se dirigent des croclitets, nù elles prenneut naissance, vers les luords, sur lesquels elles se lerminont eu. produisant autulut de grosses crénelures: res cóles sont uadulonses et grrossièrement écailleuses. Les crochets sonl peu suillans, ils parlagent le loord cardinal co deux pirties presrgue égales. Ce loorl cardinal ou supćrienr est droit, alongé, non incliné sur l'uxe longitudinal, prolongé eu un talon quelquefois fort long dans les vieux individus, présentaut dans le inilieu une large gouttiere assez prcfonde, suillante à l'intérieur par sa base; le côlé antCrient est ob'iquement tronqué, largeinent bivillant; sujuélieurement les bords de ce hỉllemeut sout épaissis et renversés en dehors, comme nous l'avons ru dans plusienrs autres especes. Ce burd se continue arec l'urtillelle, ce qui la rend beaucoup plus saillante que la postéricure. Celle-ci est forl grable, diprimée, peu siuucuse à son cốlé postúlieur; elle es! lisse ou marquie de quelques accroissemens trumsverses. A linlérieur la corquille est lisse; l'un y voil une "ìs-grande impression muscnlaie, subcentrule; Je test est tućs lopais et très-solide.

Nous avons rouvé celle coquille aux environs de Saint-Milicl dars une conche d'oolite blanclie qui contieat un lurt graud nombre de belles Iókrificaliuns; elle a été également ubservée en Angleterre aux enviruns de Weymoull. Elle est loogue de 16 centimètre el large de 13.

\section{Nioz.}

24. Lise de Dujardin. Lima Dujardinii.

L. testî̀ ovatâ, supermì attenuatâ, depressâ, costis mduntubus numerosis angustis convexis squaniosis ornutâ, anticè truncatá, excavatâ, hiante; auriculis bresibus, incequalihus.

Coquille ellegante qui a quelques rapports éloignés avec la Lime commune par la disposilion de ses côtes et des écailles qui les rendent rudes. Cette espice est ovale, ubronde, rétrécie supérieurement; elle est déprimée, presque équilatérale et tronquée anlérieurement; sa surface exlérieure est ornée d'un grand nombre de côtes régulières, arrondies, rapprochées, sur lesquelles soat disposées avec assez de régularité des ćcaillos

$$
\text { Hist. Nat. Lers. Tome II. }
$$

courtes, plas rapproclices et plus saillantes sur le côlé antélieur que partout ailleurs; le côté supérieur est ́lroit, à peine incliué sur l'axe longitudinal, el parlagé en deux parties presque égales par la saillie du crochet; ce bord se prolonge latíralement par des oreillettes courles el déprinées, donl l'antérieure est la plus pelite. I.e côté anlérieur est obliquement trouqué, excavé et un peu liaillant à sa partic supélicure; ll est nellement linaíc a sa partie externe par un angle aign prorluit par lat dernière côte; la surlace de ce conté est linensent striće en Jung, et les stries sont interrompues pard'ilutres l'ansversus; l’ureillette postérieure est lisse.

Cente upuce, dont nous devons la commoissance a M. Dujardin, naturiliste dislingué auquel on doil plusieurs Mémoires interressans sur les lossiles de lit craie de Tonruine, a élé trouvíe pour la première fuis par lui, el nous nous firisons un plaisir de la lui didier. Elle provient des environs de 'lonrs, d'une craie sablense qui a de l'analogie arec celle de Maèstricht. Sa longucur est de 57 millim. el sa largeur de 32 .

\section{LIMICOI,AIRE. Limicolaria.}

Sous ce nom, M. Schumacher propose un genre qui n'est print recevable; il a pour 'ype le Bulimus flammeus des autents, coquille qui appartient bien cerlainement an genre auquel on la :apporte, el qui n'a aucun calactère propre à la distinguer dés vérisables Buliues. Voyez ce mot.

\section{LINNACÉS.}

M. de Blainville, dans son Traité de Malacologie, donne ce nom à une fumille qui correspond exactement à celie des Lymnéeus de lauarck; i] la compuse des genres Limnée, Pliyse et Planorbe, qui sont les seuls yui se voieat aussi dans Ia lamille de lamarck. Nous n'adoplerons pas la dénomination de M. de Blainville, puisque celle donnće au nıême groupe par Lamarck existoit long-temps auparavant. Voyez Lymnćens.

\section{LIMNEE. Linnea.}

Genre de la famille des Pulmonés aquaciques de M. Cuvier et ıle celle des Limnéens de Lamarck, définitivencal établi et caractérisé par ce deraier zoologiste.

Aucun des conchyliologues qui ont précédé Lamarck n'a pensé à faire des Limnées un geare séparé; ainsi, après avoir été confondu tanlôt avec les IÍ́lices, les Bulimes, et plus généralement avec les Buccins, dénomination giil leur fut consacrée par Lister, Geullirui, Muller, elc., elies furent enfin rassemblées sous de bons caractères daus le Sy'stème des Animaux sans vertèbres. On doit s'śtunuer que les naturalistes qui précé- 
ddrent celle époque n'aient pas senti la nécessité de ce geare; car Muller, Geoffruy el Lister luimême, qui connoissoient l'aoimal, ne pouroient, sans rompre les rapporis les plus évidens, les ranger parwi les antres coquilles, soit terrestres, soit marines. Bruguière surtout, qui avoit commencé à opérer quelques réformes dans le système linnéen, pouvoit mieux que personne établir ce genre; mais, entrainé frar le caractère lrop vanue yu'il avoit imposé aux Bulimes, il confondit les Limnécs, conme beaucoup diutres coquilles étrangères à ce genre.

Le genre Limnée créé, Draparnaud le premier l'adupta, et ce savant, qui joignoit ì une cunnoissance exacte des Molluseyes, un esprit judiciellx quilui en faisoit saisir les rapports, ne manqua pas de rapprocher les limnées des Physes et des Planorbes, ce que Lamarcl n'avoit pas fait dans sou premier ouvrage. Cet illustre savant ne tarda pas à sentir la justesse de l'jdée de Draparnaud; aussi, peu de tenıs après l'époqne que nous venons de citer, dans l'Extrait du Couss, il rappiocla, comme :1. Cuvier l'avoit aussi indiqué, les Linımées des autres Pulmonés aquatiques. D'auties zoulogistes, tels que de MMI. de Blainville et de Ferussac, adoptèrent entièrement cette mauière de voir. Les rapports qui unissent les Lymnées aux autres genres voisins sont donc justes, puisqu'après quelques divergences, toutes les opinions se sout réunies en une seule, celle de Draparnand.

Les Limnées sout des coqnilles lacustres généralement niaces, subvitrées, assez fragiles, qui se plaisent surtout dans les eaux stagnantes, où elles se muliplient souvent considerablement.

Les Limaécs habitent toutes les récrions de la terre, vers les póles comme sous la zone torride, et dans les deux hémisphères.

L'animal, observé depuis long-temps, a élé anatomisé par M. Cuvier, dont l'excellent tra. vail est inséré parni les Mémoires du Museum. V. de Blainville en fit aussi la bissection, et ses reclierches conlirment celles de $\mathrm{Ml}$. Cuvier; enfin, nous - même l'avons Egalement faite, el nous arons vu tout ce que les deux anatomistes avoient d'abord observé sur la structure de ces animatux.

Le corps des Limnées, contenn dans une coquille plus ou moins alongée, souvent ovale, venirne, et toujours en spirale, prend lui-même ces diverses formes, snivant l'espèce; il ressemble en cela \& tous les autres Mollusques trachélipodes, auxquels celni-ci appartient. Il :emplit ordinairement compléterneni la coquille, quelquefois même il a de la peine à y être entièrement contenu; il est pourvu d'un large pied ovale, lié par un pédoncule au reste du corps; il s'y insère sons le col, et le manteau qui l'enveloppe, aussi-bien que la parie antérieure de son corps, se fixe d l'inscrliun du pied en prenant plus d'ćpaisseur ver's son bord libre. Sa lête est large, non séparée du reste par un col, pourvue de deux tenlacules contractiles; les yeux, non pédonculés, snnt insérés à la base au còté interne de ces tentacules; ils sont triaugulaires, ćpais, un peu alnngís. Un voile charnu, échancré dans le nulieu, forme denx larges ajppendices, un de chaque côté, ce qui donne beascoup d'ampleur ì la lête; la bouche est antcirieure, mobile, et sa masse esı assez considérahle: elle prend des formes assez dillérentes. M. Curicr.r dit qu'elle a de la ressemblanre aves: une bour:lic humaine; M. de Blainville, qu'elles la forme d'un Trenversé Cette bruche est armée de deux clenis, ou urieux d'une den une échancrure mnyenne; au fund, s'aperçort ntie langue charnue tiès-unrosse, et au-dessis l'ouverture de l'cesophage. Celui-ci, peu renfli, est accompagné de deux glandes salivaires, dunt les canaux excrétenrs aboutissent aux parties latcrales de la bouclie; il continue à s'avancer sans augmenter de volume, et parvient à un estonac très-cbarnu, très-épais, comparable pour la struclure an gésier d'on oiseau. L'inlestin qui en surt est grêle, d'une grosseur uniforne et assez lung; ; i) fait plusieurs grandes circonvolutions dans le fuie, reçoil à l'orifice pylorique les vaisseaux biliaires, et se termine à l'anus. Le foie est trèsgrand, grenu; il occupe la presque tutalité des tuurs de spire.

La cavité de la respiration est plus profundément enfuncée que dans les Hélices, et son orilive extérieur en dillère aussi par une languelle yui peut la bnucher, et qui se contourne en goultière dans le temps de la respiration; da reste, elle a beaucoup de ressemblance avec celle de ces dernières pour la distribution des vaisseaux. Les systèmes veineux et artériel, pour la circulation générale, ne présentent rien de particulier; ils sont en cout analugues à ce qui se remarque dans les Mullusques du même ordre. Les oryanes de la généralion ont également beaucoup de ressemblance avec ceux des Hélices; ils sont presque aussi compliqués : ils se composent d'un organe mâle et d'un organe femelle; l'organe mále cumprend deux parties, un organe excitateur qui sort au-dessous du tentacule droit, et à la base cluquel vient aboutir un canal déferent qui prend son origine au testicule; l'organe femelle se corpose d'un ovaire, d'un oviducle, d'une pocbe à viscosité et d'un orifice extéi ieur. L'ovaire est granuleux, jaunátre, acculé au foie, avec lequel il reuplit les premiers tours de -spire; il en nait l'oviducle, conduit membraneux d'abord assez large, contourné plusieurs fois, se rétrécissant ensuite beaucoup; il traverse noe partie du fuie, gagne le testicule, à travers lequel il passe pour gagner ensuie le renfement cylindrique on la poche à viscositć. Ellc est plissée transversale- 
ment et assez rêulièrement; elle est destinćc à recrevoir les aufs et à les invisquer de matierc glaircuse avant qu'ils ne puissem être pondus. Le reullement se termine à uo canal plus étroit, qui reçoit celui d'une petite poche ou vessie dunt l'usage n'est pnint encore bien connu; peu apri's, il almulit à lomlice extórieur, qui se voit rrèsprofundément placé à l'endirit vi le pédoncule clu pred se réuoil au corps. Jaes deux vritices de la génération se trouvant fort fluignés, cela nécessite ile la part des Lymaćes un mode d'accouplement siugrulitr qui a'est pas le mêune que celui (les llélices. Dans ce genre, deux individus sullisect; ici il en faut trois, celui du milieu ayissant lui seul comme málc el comme femelle, les dcux autres uagissant que conne màle ou coume lemelle seulement. Souvent à ces deux individus viennent s'en accuupler d'autres, ce qui quelquefois constitue de lort longues trailuées llottantes à la surface des eaux, dont tous les individus agissent à la fois comme comme nuäle el comme Semelle, excepté les deux dcs extrérnités.

Le système nerveux a beaucuup de ressemblance avec celui des autres Blollusques trachélipocles; l'anneau asopbagien, ou le cervean, est composć supérieurement de deux ganulions réudis par. un tronc médian transversal, inférieuremeot de trois autres ganglinns, dont les deux lateraux sont iutimement liés aux deux premiers. De ces ganglions partent des filets dont la distribution générale ne présente rien de particulier; elle est semhable à ce qui existe das les Mullusupue dil unème ordre.

Les Limnées sont généralement de couleur luun foncé ou brun-verdátre; lour peau lisse, sans tubercules, mulle et visqueuse, paroit plus sensible encore que celle des Hélices on des Liuaces, car au moindie alloucliement elles se contraetent, rentrent loutes leurs parties dans la coquille, et devenant d'unc pesauleur spécifique plus considérable, elles tumbent au fond de l'eau. Comme elles suni furcées de venir respirer l'air en nature, elles ne peuvent rester très-longr-temps au fond de l'ean; mais pour revenir à sa surface elles sont ublignés de ramper sur le fond jusquà ce qu'elles alteiguent le bord, ou de ramper le long des tiges des plantes aquatigues : ce qua elles funl avec assez de rupiclité. Lorsyu'elles sont à la suface, elles se lienneat dans une position renversée, la face inférienre du pied dirigće en haut et la coquille en bas, plongée dans l'eau. II paroit que daos celte position, l'animal pent ramper à la surface de l'ean: on suppose alors quiune couche irès-mince de liquide sert de point l'appui aux elforts musculaires de sun pied; mais cela est difficile a concevoir, car on sait qrie l'ean ne peut servir de point d'appui pour opérer des mouvemens que lorsqu'elle est frappée promptement et par une surface assez large, et celte condition, si nécessaire à la natation, est loin de se rencon- trer ici. Vuici les caractères qui conviennent à ce geure.

\section{CA ACTËRES CÉNËIQUES.}

Animal ovale, plus ou moins spiral; les bords du roanteau épaissis sur le cou; le pied grand, ovale; la têtc pourvuc de deux icntacules trianguluires, aplatie, auriforme; les yeux sessiles au côtrí interne de ces tentacules; bouche avec denx ap pandices latéraux considérahles, et armće d'unc denı supéricure lilide; l'rritice de la cavilé pulunnnaire en forme de sillon, prercé au côté droit, et bordé inl'rieurement par une sorte d'appendice auriforme pouvant se plier en goultière; orifice des organes de la génération distans; celui de l'oviducte à l'entrée de la cavité pulınonaire, celui de l'nigane má.e sous le tentacule droit. (De Blainv.)

Coquille oblongue, quelquefois turriculée, is spire saillante; ouverture entière, plus longuc: que large; loord droit trancliant; la pastie inférieure remoutant sur la columelle, el y formant un pli très-oblique en revtrant dans l'ouverlure. Point d'opercule.

On trouve un assez graad nombre de Limnées a l'élat fussile : toutes appartiennent, jusqu'à présent, aux terrains tertiaires; qurilgues-unes oltient le phénomène remarquable d'une répartition uniforme dans an graod nombre de lieax furt éloignés les uns des autres.

Ces coquilles se trouvent indistinctement dlans les terrains marinseldans les terrains d'eau douce. Dans celte première sorte de terrains, où elles forment quelquefois des comches assez éteodues, on ne peut pas en conclure que des envahissemens successifs de la nuer ou des eaux donces ont eu lieu sur une nême surface, car il est certains endrcits oi il faudroit supposer les altermances d'aclims répétées un trop grand nombre de fuis pour établir en principe leur réalité; ce sont cependant des observations de ce genre qui out conduit M.I. Cuvier et Brongniart à une explication pen admissible des laits ciui s'observent, tant aux environs de Paris que dans un grand nombre d'autres lieux. La réfutation qu'en a fait un géologue anssi savitnt que judicienx, M. Constant Prevost, a rendu très-facile l'explication d'un phénomène ' qui avoit f.it supposer jusqu'à trois irruptions de la mer sur les continens. Il ne faudroit pas se boroer à supposer trnis irruptioos, mais un bien plus grand nombre; carles alternats se montrent quelquefois en couclies aultipliées et très-minces, et il fandroit supposer ponr clincuu d'eux une nouvelle irruption marine. Il est bien plus simple et plus aaturel de supposer que les phénomenes qui ont eu lieu autrefois cians les bassins que nous observous a la surface de nos contineas, sont les mêmes que ccux qui se passent aujourd'ıui $\mathrm{Y} \mathrm{y}^{\star}$ 
sous nos yeux. Nous voyons que les fleuves entrainent peudant leur crue une partie des matériaux que leur lit contient, rejelteut au loin dans la mer les plantes et les coquilles que leur littoraux ont nourries. Etendus en couciles plus ou moins grandes, ces malériaux peuvent être purs de tout mélange, ou bien, s'ils ne sont point considérables, se conlondre avec les corps marios. On conçit alors qu'un nombre considerable de conches déposées dans la mer, à l'embouchure d'un grand cours d'eau douce, peuvent alternativemeat ne contenir que des corps d'eau douce ou des corps ararios, ou un mélaoge, selon que les circonstances aurout rendue prédomiante, suit l'influence du caurs d'eau douce, soit celle de la ner. Les observations, qui se multiplient journellement dans les divers bassins tertiaires de l'Europe, prouvent d'une manière évidente que leurs couches sont dues aux causes que nons renons de mentionner.

Partout on observe les trois sortes de couches, et lorsqu'elles n'existent pas simulıanément, on trouve des mélanges dans lesquels prédominent soit les corps marius, soit les corps d'eau douce ou terrestres. Il est ane autre sorte de terrains, ce sont ccux qui ont été déposés tranquillement au fond des grands lacs; ceux-là ont le caractc̀e particulier de ne présenter que des corps orgavisés d'une mème nalure : res cerps sont terrestres, et n'ont pu vivre en aucune façoo daas les eaux saumâtres ou marines. Ces dépôts, qui surviennent à la suite des terrains marius de mélange, indiquent une autre série d'actions, et se distiuguent toujours des preaniers avec lacilité.

Cette digression étoit naturellement amenéc au sujet des Limnées, qui ont servi dans l'une et l'autre hypothèse de point d'appui à ceux qui les soutiennent; dans l'une, on croyoil prouver le séjour tranquille des eaux douces à la surface dans lous les cas où on les tronve; dans l'autre, on établissoit une distinction qui modilie d'une manière considérable la valeur du caracière. Sorsque les Limnées sont répandues dians des couches intercalées entre des dépôts mainas, elles ne prouvent autre chose qu'un aftluent d'eau douce dans la mer; si, au contraire, elles sont seules ou avec des corps terrestres, on ne peut douter que leur dépôt n’ail eu lieu daos une eau douce, sur laquelle la mer ne pouvoit avoir aucune iuluence. Il résulte de ce qui précède que, selon la valeur que l'on voudra donner aux caractères zoologiques des fossiles, on pourra arrirer à des conclusinns fort différentes : il n'appartiènt qu'à l'lomme doué d'un jugement sain et d'une grande babileté d'observation, de choisir celles qui s'acicordeut avec l'universalité des faits, et qui pcut rendre compte d'un plus grand nombre de phéuouènes.

Nous arons vu au commencenent de cet ar- ticle que Bruguriere avoit compris les Lamean dans soo geare Bulime; la descriplion qu'il a donnée de plusieurs espèces appartenant à cu genre, nous dispense de les reproduire ici. Nous prierons le lecteur de consulier l'arlicle Bulase, dans le premier volume de ce Diclionarire, et il y trouvera, sons les noms de

Bulime de Dombey, Bulimus dombeyanus, la Limáe de D.nolsey. Noв.

Bulimus palustris, la Limnaea palustris. Bulimus stagnalis, Ia Limncea stugnalis.

Bulimus radix, lit Limna a ariculuria.

Bulimus peregrus, la Limnara peregra.

Bulimus glutinosus, la Limnace glutinosa.

Bulimus tnucatus, la Lininaa minuta.

Nous avons rapporté l'Auricula dombeyana de Lamarck au gente Liannée, parce qu'elle pré. sente tous les caractères essentiels à cegnenre, et non pas ceax des Auricules. L'ouverfure forl anple, oblique, de cette coquille, le pli columellair: saillant et tordu qu'elle olfre, Ini donne la plus grande ressemblarce avec les Limnces. La seule objection que l'ou pourroit firire a ce rapprocliement, scroit relative à l'épaisseur du test, qui, dans celle espèce, est plus considérable que dians aucune autre; mais aussi on sail combien est peu important ce caractère qui n'est jamais employé comme caractère de genre.

1. Linśe effiée. Limna longiscata. Broxg.

L. testa clongatâ, subturritû, acuminat $\hat{\imath}$, luvigatô; aperturi ovato-acutô, basi subdilatat.ı; columellâ marginutá; plicâ columellari minimi.

Brovg. Ann. du Mus. tom. 15. pug. 272. pl. 22. $f g .9$.

Limnée effilée. Bпапр, Ann. du Mus. tom. 14. rl. 27. fig. 14.15.

Noв. Descript. des Con. foss. des eno. de Paris, pug. 92. pl. 11. fig. 3. 4.

Cetle limnée est bien caractćriséc; elle est alougée, subturiculée, étroile, très-lisse, conaposée de sept à luait tours de spire assez rapproclués, peu bombés, séparés par une suture peu profonde. linuverture est ovale, alnagée, un puu dilatée à la base, rétrécie supérienrement; la lèvre est ariace et tranchante; le pli colum llaire est peu saillant, petit, arrondi; la columclle est bordée. Ja bauteur de l'ouverture r'śgule pas tout-á fail la moiliée de la bauteur totale de lit coquille. Longuen. 30 millim. I.es individus fignres par MI. Brongraiat, loc. cit., scut plus grands, ils ont 37 millim.

2. Liмxée élancée. Limmaca strigosa. Brong.

L. testâ clongato-subturritâ, lovigatô, aliquan. 


\section{I M}

tisper substriatî̀; aperturû non anıplà, lrasi dilatutü; colunellì "ix maıginatì; plicá columelluri eminente, valdè tortuosâ.

Brosg. Ann. du Mus. tom. 15.pug. 575. pl. 22. fig. 10 .

Nob. Descript. des Con. foss. des env. de Paris, pag. 92. pl. 11. fig. 1. 2.

Si l'on possédoit des individus aussi entiers de cettc espèce que de la précédente, il est bien à présumer que l'an reconnoiltroit que ce n'est qu'une variété. Quoique commune daos la localité que nous indiquerons, la marne qui la renlerme ia présente on très-conprimée et déformbe, ou seulement le moule iutérieur, ou des firgmeos dissémiués. Núanmoins, quoique présentant une forme très-analonne, voici la différence que nous avons aperçue : elle est généralemeat plus perite, un peu plus renflée vers le milien; elle est plus souvent lisse, el quelquefois les stries d'accroissement paroissent répétées régulièrement, ce qui la feroit prendre pnur une espèce distincte, si l’on D'en vayoit lous les intermédiaircs; son ouvertire est plus dilatie à la base; le bord columellaire à peiue coarqué: mais le pli est Irès-tortueux, hien sitillant é épais à la base. Loogueur 25 millim. Fossile de Pantin, près Paris.

3. Lıмx́e pointue. Limnara acuminata. Brovg.

L. testá ovato-acuti, pyntmidali, subventricosâ, lwoigat $\dot{j}$; anfractibus septenis subconveris; upertuiz ovcitu, ampliz; columellí marginatâ; plicà columelıri perspicû́.

Bnoxg. Amn. du MIus. loc. cit. pl. 22. fig. I I.

Kerussac, Mèm. géol. loc. cit. no. 4.

Nuв. Descript. des Coq.foss. des env. de Paris, pug. 9j. $\mu l .10 . f i g .20 .21$.

Sous plus d'un rapport, celle espèce duit laisser du duute. D'abord, la figure de M. Brongniart a'est pas eatic̀rement eo rapport avec sa discription. Il dil que le dernier tour est trèsgrand et lrès-l'enflé, et que le pli columellaire est fort unarqué, ce qui n'exisıe pas dans la figure, car à peinc y vait-on un pli columellaire; et lé dernier lour, quaique plus renflé que daas la Liminara strigosa, ne l'est pas beaucoup plus. Celle que nous avuns fait figurer n'a pas les tours de spire aussi convexes et la suture aussi profonde; mais son dernier tour est très-grand, l'ourerture elle-même est fort ample, dilatée à sa base. Le pli culumellaire est tordu, saillant, et se fond insensiblement eu une columelle lisse et bordée. Longueur 30 millim.

4. LI ม x É des grès. Lymnaca a.rnularia. BRARD.

L. testá ovato.acuninatâ, lcevigatâ; anfrac- tibus septenis, convexiusculis; aperturi ovati, peroblici; plicá colunellari obliquâ, minimú, subproninenti.

Br.a.d, Ann. du Mus. tom. 15. pl. 24 . fig. 5. 6. 7 .

Fenussac, Mem. géo. loc. cit. no 15 .

Nов. Descript. des Coq. foss. des env. de Paris, pug. $93 . p l \cdot 1$ เ fig. $7 \cdot 8$.

Nayant eu en notre possession que quelques individus mutilés, il nous seroit difficile de faire une description parfaitemeot exacte de cette espèce; elle est ovale, oblongue, acuroinće, assez. Irrge à sa base, quelquelois marquée par des accroissemeds assez réguliers. Ce qui la caractérisc le micux est son ouverture, qui est fort ullique à l'axe, ovale, étroite, et présentant une colnunelle longue; un pli columellaire petit, tordu sur luiréue, peu saillant et court. La spire assez longue, acumioée, est cornposée de sept tours peu canvexes; la suture est médiocrement profonde. Longueur 24 millim., largeur $ı$.

\section{Iruñ́E leucostome. Limnora leucostoma.}

L. testi elongato-turrita, longitudinaliter et tenuissime striati, fusco-nigricante; anfractibus septenis, convexis; aperturi abbreviat.:; narginibus intus albidis.

Bulimus leucostoma. Porret, Prodr. pag. İ7. $n^{\circ} \cdot 4$.

Lymincus elongatus. DRAPARX. Mloll. pl. 3. fig. 5.4 .

Preiffer, Syst. anord. $p l .4 \cdot$ fig. 26.

L.sмк. Anim. sans vert. tom. 6. p. 162. no. 1 I

Jolie coquille, la plus turriculée des rimnées; elle est alongce, pointue, formée de huit tours légèrement convexes, dont le dernier est proportionné aux autres; la suture qui les réuoit est simple et peu profonde; ces tour's sout légèremeot striés dans leur longueur : les premiers manquent ordinairemeat, ayant été rungés ou brisés; le deraier se termine par uue pelite ouverture ovalaire une peu oblique, dont le bord drcit, garni à lintérieur d'un petit bourrelet blanc ou jaubátre, se joint i la base avec la columelle, ea sinfléchissant ver's elle. Celle dernière est blauche, courte, produite par un pli très-oblique, rentraut dans l'ouverture; le bord gauche est très-court, très-mince et appliqué daus toute son éteudue eutre l'extrémité supérieure de l'onverture et la base du pli columellaire.

La Limnée leucostome avoit été nommće Limnous elongatus par Draparnaud, et nous ac voyons pas pour quel motif Lamarck a échangé cette dénomination ponr celle que tous les auteurs adoptent d'après lui. Cette petite coquille se 
llouve en France et en Allemagne. Nous arons temarqué que les individus étoient généralement plus grands, d'une couleur plus funcée dans le nord que dans le midi. Cette cuuleur est un brun clair, corné, quelquefois grisáıre, trausparente, laissant anercevoir antour de l'ourertnre le péristome iutérieur. Les grands individus sont lougs de 20 millim., larges de 6 , et resseaublent i certaines Mélanies.

\section{Lișx́́ naine. Limnoca minuta.}

L. testâ ovato conicá, tenui, pellucidâ, longítudinaliter striatu, cineren-fucescente; anfructibus quinis, convexis; sutioris excavatis.

Buccinum truncutulum. MuLLER, Verm. pag. 130. $n^{\circ} .325$.

Le petitBuccin. Grozp. Coq. $75 . n^{\circ} .2$.

Bulimus truncatus. Brug. Dict. $n^{\circ} .20$.

Helix truncatula. Gues. pug. 365g. $n^{\circ} 132$.

Bulinus obscunes. Porret, Prodr. pag. 35. $n^{\circ} \cdot 3$.

Lymneus minutus. Daspara. Moll. pl. 3. fig. $5-7$.

LAMK. Animl, sans vert. tom. 6. pag. 162. $n^{\circ} .12$.

Pfeifeer, S.jst. anord. pl. 4. fig. 27.

On preadroit cette espèce pour un Cyclostome, wi plutôt pour un Bulime, à cause de la lorue de l'ouverture dont les bords sont presque réuois. Elle est ovale, oblongue, pointue au sommet, et formée de cinq tours de spire très-convexes, à siture simple el profunde. Le dernier tour, un peu plus grand proportionaellement que les autres, occupe à peu près la anoitié de la longueur de la coquille; il est perforé à la base par un pelit ombilic arrondi. Liouverture est régnlièrement ovalaire, droite, à peine évasée à la base; te hord droit est simple et tranchant. La coluroelle, arquée dans sa longueur, est simple, lisse, arrondie, et se continue avec un bord ganclie appliqué sur noe petite partie de l'avant-dernier tour, et libre el renversé dans tout le reste de son étendue. On remarque extérieurement des stries longitudioales, nombreuses, serrées et irrégulières, qui résultent des accroissemens. La conleur de cette coquille est d'un brun-fauve jassant au noiratre sur les premiers tours.

Cette Limnée se tronve en France, en Allemague, el en Angleterre, daus les ruisseaux. Elle Est longue de so willim. et large de 5.

7. LIMné de Lesson. Limnara Lessoni.
Noz.
L. testì ovato-ventricosâ, globulosâ, pellu-
cidá, fragilissımâ, substriatâ, viridulá; spirâa

brevi, acutî ; aperturâ magná, ovali ; margine dextm simplici, acuto; columella contortâ.

Nor. Magas. de Conchyl. par M. Guérrs, pl. 16.

Coquille remarqua!le que nous devoos à l'obligeance de ootre ami M. Lesson, auleur de la Zoulogie du Voyage de la corvette la Coquille, autguel nous nous fásons un plaisir de la dédier. Celle espèce de Limnée a une forme qui la rapproche un pcu de la Linnncia auricularis de Lamark. Elle est ovale, globuleuse, arnpullacée, exressivement mince et fritgile; el!e a la couleur et la transparence de la corne bloude qui seroit légèrement teintée de vert. La spire est courte, pointue, composée de ciny tours, dua! le dernier, beaucoup plus grand que les autres, olfie, ainsi que le précédent, un petit méplat vers la suiure. La surface extérieure parnit lisse ou seulement striée par des accroissemens; mais, vue à une fnrte lonpe, elle prósente des stries longitudinales extrêmement fioes et très-serrées, coupres en travers par d'autres non moins liues, transverses, et plus écartées que les premières. L'ouverture est ample, ovalaire, évasée à sa base, un peu rétrécie supérieuremeut; la lèvie droite a'est pas renversée en dehors, elle est simple et très-ınince; le bord ganche forme une lanc exc:essivement mince, qui s'uppliciue sul l'avant-dervier tour le long de la columelle. Celle-ci est en tilet trèsétroit, tordu, et formant un pli oblique par celte tursion. Cette coquille, fort rure, vient de lis Nouvelle-Hollande; e'le est longue de 27 millim. et large de zo.

\section{Liมné substriće. Limncea substriata.}

L. testá ovato-elongatâ, subventricosâ, striatú; strus ninimis, subregularibus; anfructibus septenis, convexis; spiriexserti, acuminati ; aper. turá ovatá, obliquá ; plıcâ columeluri magnà, tortuosá, prominenti.

Noв. Descript. des Coq. foss. des env. de Paris, pag. 94. pl. 11 . fig. 5. 6 .

Celte Limnée a des caractères distinctifs asse 2 faciles à saisir; elle est ovale, ulongée, acnminée, striée longitudinalement; les stries sont fines, rapprochées, assez régulières, peu prolondes; la spire est lien saillante, elle présente six à sept tours convexes, dont le dernier est quelquefois un peu bossu et jamais plus grand que la moitié de la longneur totale de la coquille; l'ourertnre est ovale, un peu oblique, longitudinalement rótrécie; la columelle est langue, bordće; le pli columellaire, quoique miuce et grêle, est fortement tordu, ce quale fait saillir dans l'iolérieur de l'ouverture.

9. Linnéz cornée. Limnea cornea. Brong.

L. testâ ovato-ventricosî, lavigatâ, nigis 


\section{I II}

accretionis irregularibus; anfraclibus quinis, certoexis, ultimo magno; upertura ovata, amplì; columelli marginatâ; plicê colunellari magnâ, vix torluosá.

Brong. Ann. du Mus. loc. cit.pl. 22. fig. 12.

lier. Miém. géol. loc. cit. no. 5.

An Limnée cornée? Brard, troisième Mémoire sur les Fossiles terrestres et d'echl douce des environs de Paris.

Ков. Descript. des Coq. foss. des env. de Paris, pag. 94.pl. 11. fig. 13. 14.

La Limnée cornée nous paroit suffisamment distiacie des autres espèces du même genre; elle est grande, ventrue, ovale, compasée de cinq tours seulement, dont le dernier et le plus grand occupent les deux tiers de la hauteur tutale. Elle est lisse ordinairement, et d'autres fois sillonnée irrégulièrement par les rides plus on moins grossières de ses accroissemens. Livuverture est grande, ovale, à bord droit très-mince; la columelle est submarginée, et ae se cunloud pas avec le pli columillaire qui, quoique gros el fart élargi à la partic qui rentre dans la coquille, est peu saillant et peu tordu sur lui-même. Celte coquille, dout on trouve partoul le moule, et quelquefois le test changé en silex, comme l'observe M. Bronynart, paroit appartenir sfécialement aux silex lacustres supérieurs. Longueur 30 a 35 millim. largeur 14 à 16 .

10. L.MNÉE ovale. Limña ovala.

L. testî̀ subanipullaced, ovali, longitudinaliter striatá, albidi; anfructibus quinis; spirâ brevi, acutí; aperturâ ovato-oblongâ.

Gualt. Test. tab. 5. fg. $n . n$.

Helix terr. Gmer. pag. $3667 . n^{\circ} .217$.

Bulinus limosus. Polret, Prodr. pag. $3 \mathrm{~g}$. $n^{\circ} \cdot 7$.

Limneus ovatus. Drap. Moll. pl. 2. fig. 3o. 3r.

LAsrx. Anim. sans vert. tom. 6. pag. 161. $n^{\circ} .8$.

PFEIFFER, Syst. anord.pl. 4. fig. 21.

Celle espèce a de l'analogie avec la Limnée auriculaire, mais elle est moins grande, plus fragile, et sa spire est consta nnment plus alongée. C.rmme son nom l'indique, celte coquille est "vale, oblongue, acuminée au sommet, à spire courte, composée de quatre on cinq lours convexes, à suture simple et profonde; le dernier tour, beaucoup plus grand que tous les antres, est ouvert à la base d'une fente ombilicale; il se termine par une ouverture fort ample, peu oblique, dont le bord droit est extrêmement mince et tranchant; elle est dilatée et versante à la base. $\mathrm{L}_{2}$ columelle est presque droite, à peine inflérbie dans le milieu, et depoarrue da gros pli lorda qui existe dans la Limnée auriculaire. Le bord gauche est mince, court, appliqué dans toute son étendue, si ce n'est au-dessus de l'ombilic. La surface extérieure ne présenle que des stries d'accroissement; elle est souvent revétue d'une couche uoirâtre qui resseıble à un épiderme, mais qui nocn est pas un véritable; au-dessous de cetle couche la coquille est d'un blanc-jaunâtre, transparent et corné.

Cette espèce se rencrntre principalement dans les eaux stagnantes; elle est longue de 2.5 rill 24 nuillim. et large de 14 on 15.

11. LAMÉE pyramidale. Lymnaa pyıanidalis. Brard.

L. testâ ovato-acutà, ventricosâ, lơvigutút ; aperturí magnâ, dilatat ; columell 2 marginut $\hat{\hat{2}}$; plicâ magna, obliquâ, in medio subbipartits, callosà.

Brard, Ann. du Mus. tom. 15. pl. 24. fig. 1. 2.

FER. Méll. géol. pag. 6o. $n^{\circ} .3$.

Nов. Descript. des Coq. foss. des env. de Paris, pag. 95.pl. 10. fig. 14. 15.

Cette Limnée est grande, ventrue, toute lisse, pyramidale, comme son nan l'indique, compesée de sept loars de spire, dont le dernier est presqu'aussi grand que les six autres; ils sont légèremeat bombés el séparés par une snture simple tt peu profonde. L'ouverture est graade, évasée à sa partie inférieure; le bord colunellaire est bordé, et le pli qui y aboutit obliquement est saillant, calleux et très-souvent subdivisé par un pelit enfoncement longitadinal qui en marque en mème temps la tursion. Longueur 43 millimètres, largeur 17.

12. LIMNÉE des marais. Liñnea palustris.

$L$. testà ovato-oblongâ, longitudinaliter et te-

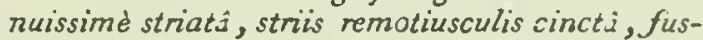
cescente, interdum albido carrulescente; spirâ conico-acutấ; aperturî̀ ovatâ.

Helix fragilis. Lis. Gmer. pag. 3653. $n^{\circ}$. 129.

Buccinum palustre. HOLLER, Verm. pag. 13 t. $n^{0} .326$.

Lister, Conch. tab. 124. fig. 24.

Goalt. Test. tab. 5. fig. c.

DarGeNv. Conch. pl. 27. fig. 6. figurà quartî.

FAVAKNe, Conch. pl. 61. fig. f. g.

Cgems. Conch. tom. 9. tab. 135. fig. $123 \mathrm{~g}$. 1240.

Bulimus palustris. Brog. Dict. $n^{0} .12$.

Helix palustris. G MEL. pag. 3658. $n^{\circ} .131$.

Ejusd. Helix corvus. Pag. 3665. no. 203. 
Limneus palustris. Drapars. Moll. pl. 2. fig. 40-42, et pl. 5. fig. 1.2.

Helix palustris. MostaG.

Preirfer, Syst. anord. Fl. 4. fig. 20.

Brosg. Ann. du MIus. tom, I5. pl. 22. fig. 15.

Fer. Mtém. géol. sur les terr. d'eau douce de la France, pag. 19. $\pi^{\circ} \cdot 12$. 461 .

UEFr. Dict. des Scienc, natur. tom, 26. pag.

Nов. Descript. des Coq. foss. des envir. de Paris, tom. 1. pag $95 . \mathrm{pl}$. 11. fig. 9. 10.

Lamx. Anim. sans vert. tom. 6. pag. 160. $n^{\circ} .3$.

Coquille qui n'est pas moins abondanle que la Limnée stagnole que l'un trouve toujours a vec elle. Elle est ovale, oblongue, subturriculée, peu venirue, à spire poinlue, composée de six lours arroudis, dout la suture est simple. La surface de ces lours paroît lisse; nais, examinés avec une furte lcupe, on les trouve fincmeat et très-régulièrement striés. Le deraier tour, vn peu plus grand proporlionuellemeut que les autres, préseule presque toujours quelques plis transverses irréguliers à la base. Ce cernier tour a une petite fente omvilicale, sourent cachée dans les vieux individus, par le renversement complet du burd gauche. L'ouverture est un peu oblique à l'axe; elle est wédiocre, ovale, oblongue, alténuée a lis partie supérieure; son bord droil est mince, trancliant, non dilaté à la base; il se joint à la columelle un peu obliquement. Cette colunelle est courle, elle est murie dans sa longueur d'un pli très-oblique, rentrant dans l'ouverlure. Le bord gauche est court, mince, appliqué depuis l'angle superieur de l'ouverture jusqu'a la base du pli columellaire.

La Limnée des marais est variable pour la couleus et la taille; tille est petite et blancbille, ou d'un corné-grisâtre dans les parlies seplentrionales de l'Europe; elle devient beaucoup plus grande, d'un biun foncé, vineux, dans la France méridiomale et en Italie; les stries gui la couvrent varient avec les autres caractères : elles sont d'autant plus régulières qu'on les examine sar les individus provenant des pays cbauds. Dans notre ouvrage sur les Fossiles des environs de Paris, nous avons indiqué l'analogue lossile de celte espèce. On ne peut douter en effet que ce ne soit lui. Nuus avons comparé à diverses reprises les raritéćs soit vivautes, soic lussiles, el nous leur arons toujours trouvé une parfuile ressemblance. Les plus yrands individus de cetle espèce sont longs de 33 arillim. et larges de 15 .

33. Linné anticulaire. Limnaca auricularia.

L. testâ am ullacế, z'entricoś́, ovatá, tenui, diaphanâ , pallidè fulvô; stris Iongitudinalzbus, tenuissimis, confertis; spiri brevissima, corcuminutâ.

Helix auricularia. Iis. Gsen. pag. 3662. $n^{\circ} \cdot 147$.

Buccinum auricule. MuleER, $5 \mathrm{~cm}$. pag. 126. $n^{\circ} . \bar{j} 22$.

Bonvani, Recr. 3. fig. 54.

Lister, Conch. tab. 125. fig. 22.

Gualt. Test. tab. 5.fig. $f \cdot g$.

DARgext. Cunch. pl. 27.fig. 7.pl. 28. ffg. 22; et Zoomorp. pl. 8. fig. 6.

Favanne, Conch. pl. 61. fig. e. 3. e. I1.

Le Radis ou Buccin ventru. Geoff. Coq. pugg. 77. $n^{\circ} \cdot 3$.

Helix auricularia. Privant, Brill. zool. tom. 4. $t a b .86$. fig. 158.

Bors. Mus. tab. 16. fig. 20.

Chems. Conch. tom. 9. tab. 135. fg. 1241. 1242.

Bulinus auricularius. Brug. Dict. $n^{\circ} .4$.

Limmeus auricularius. DRAP. Moll. pl. 2. Jig. 28. 29 .

Preiffer, Syst. anord. pl. 4. fig. 17. 18.

Lamk. Anm. s. vert. tum. 6. pag. 161. no. 7 .

Celte espèce cst la plus remarcpuatile dn genıe parsa furme extraordinaire; elle est orale, arrondie, globuleuse et vésiculaire, à spire exces. sivement courte, formée de quatre lours couvexes dont le dermier est extrêmement grind; la sulure qui les réunit est simple, mais profonde, quelquefois subcanaliculée. Le dernier tomr, trćsconvexe en debors, olfre à la base une fealc ombilicale constamment ouverte; il se termine par une ouverture peu inclinée à l'axe, trèsample, auriculifurme, ovale et oljonde. Le bord droit, très-mince el très-tranchant, est fortement renversé en delıors; il est dilatć et se joint olyiquement a la base de la columelle en rétrécissar. un pen l'ourerure. La colunelle est lougae, droite, tordue sur elle-neéme, ce qui produit nn pli arrondi et assez saillant; le bord gauche est court, furmé par une lame très-mince appliquf́e dans toute sa longueur jusqu'à la fente ombilicale, au-dessus de laquelle elle se relère. La surface extćrieure du dernier tour est luisante et paroit lisse; mais, examinée avec plus d'attention, on la troure couverte de stries trés-fines qui résulient des accroissemens. Le test de celte coquille est irès-mince, fragile, d'une conleur uniforme, d'un jaune ambré, transparent. La Limuéc auriculaire balite presque tontes les eaux douces de France, de la Hollande, de l'Allemagne et de l'Angleterre. Elle est longue de 28 millim. et large de 24.

14. ListE: 


\section{I M}

14. Lannée féverole. Limnaca fabula. Brong.

L. testî ovato-v'entricosâ, levvigatâ, acumimutä; anfructibus quaternis, subconvexis; aperturì ovato-oblong(î; plicá columellari tortuosâ, ud junctionem dilutntâ.

Bnovi. Ann. de .Ius. loc. cit. pl. 22.fig. 16. FER. Me'm. géol. loc. cit. $n^{\circ}$. 15.

UEE. Dict. des Scienc. nat. tom. 26. pag. 462 .

Noв. Descript. des Coq. foss. des env. de Paris, pag. $96 . p l .11 . f i g .11 .12$.

lerite corguille peu remarquable, et qui paroit assez dislincte comme espece; elle est ovale, ronirue, à spite assez courte, composée de quatre tours seulcment; ils sont peu convexes, el la suture est peu protionde; le deraier lour est proportionnellenent beaucoup plus yrand que les autres. Liouverture est longitudinale, ovale, rétrécie à sa base; le pli columellaire, autant qu'on peut eu juger diajrés des moules, devoit être fortement tordu sut lui-mêune, saillant daus l'ouverture, ap!ali et élargi à l'endroit de la jouction avec la colunclle. Longueur 10 a 12 millimètres, lugeur 5 à 6 .

\section{Li M⿻上丨 obluse. Limncea obtusa. BRARD.}

L. testá ovato-subventricosî, spiná brevi, obtusú; arifructibus quinis, convexis, vulde sepurutis, ultimo magno; uperturî longâ, ovutâ. 5. 4 .

Band Asun. du Mus. tom. 15. pl. 24 fig.

Fin. Mém. géal. loc. cit. no. 14.

Nos. Descript. des Coq. foss. des env. de Paris, fag. 96. pl. 10. fig. 16. 17.

Celle limnée est bien nommée, el suffisamnent distincle comme espèce; elle est ovale, arrondie, ventrue, lisse. Sa spire est peu saillaute, arrondic et obtuse au sommet, le plus souvent cumposée de ciuq cours; quelquefois il y ea a qualie sculement: ils sont convexes, presqu'en escalier, fortemeal séparés par une sulure profonde. L'ouverture est longiludiuale, grande, ovale, d'aprés la figure citée de M. Brard; la columello est lisse, bordée; le pli columellaire fart ınıce, à peine saillant. Ne possédant que des moules intéricurs de celte coquille, et pư entiers du côlé de l'uuverture, la descripiron de cette purtie de la coquille pourroil se trourer incomplète. Lounueur 20 milliwètres, largeur 13.

16. I.тмёе ovoide. Limnaca ovum. Brovg.

L. testâ avata-ventricosá, acuminatâ, sublavigatâ; anfiuctibus sex, converis, ultimo niagno;

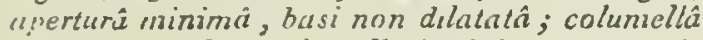
murginatâ; plìđá columelluri minimû́, subrectâ.
Brong. Ann. du Mus. loc. cit.pl. 22 fig. I3. a. b.

Fer. Mém. géol. loc. cit. $n^{\circ}, 6$.

Nов. Descript. des Coq. foss. des env. de Paris, pug. 97.pl. 11. fig. 15. 16.

Quoique cetle espèce ait quelqu'analogie avec la Limmáa cornea, elle en a plus, d'après M. Brongniart, avec la Linunaea peregra de Draparnaud: cepeudant il y a trop de dissemblance avec cette dernière pour établir ce rapprochemeut. Elle est composée de six à sept tours convexes, bien séparés par une suture simple, mais assez profunde; le dernicr tour est grand, uccupant la muitié de la lauteur de toute la coquille, mais l'ouverture n'cst point évasée; elle est plutôt rétrécie, soit supérieuremeat, soit inférieurement. La coluunelle est assez longue, bordée; à l'endroit de sa jonciion avec le pli columellaire, le lord yauche offie une petite languette qui fait lćgirement saillie; le pli columellaire est peu tordu sur lui-même; il est peu saillant et généralement fort mince. Longueur 25 millim., largeur 15.

17. Lıณn's symétrique. Lymmaa symetrica. BAARD.

L. testâ ovuto-globosâ, subcylindricà, acuminati, laviusculiz; spiri minimi; anfirictibus quaternis, ultimo niagno, superne subnuarginato; aperturá ovato-acuti.

Brard, Ann. dus Mus. tom. 15. pl. 27. fig. 9. 10.

EER. Mém. géol. loc. cit. $n^{\circ} \cdot 9$.

Nов. Descript. des Con. foss. des env. de Paris, pag. 98. pl. 11. fig. 19.

Cotte espc̀ce n'est peut-ètre qu'une variété de la I,vonuée cyliodrique, avec lacjuelle elle a beaucoup d'analorie; cependant elle est plas étraite et plus alon zée que celle-ci, sa spire est plus ćleréc, ses tours sont muins convexes et séparés par une suture moins profonde. Le dernier tour est fort graod; il occupe à lui seul les deux tiers de la hanteur totale de la coquille. Vue du côté du dus elle semble presque symécrique, la saillie inférieure que faic l'onverture de la coquille étant peu prononcée. L'ouverture est ovale, oblongue; Ia culumclle est lisse, et le pli columellaire est petil, peu saillant el presque droit. Longuenr 10 millim., largenr 6.

18. Lısie cylindrique. Linnoca cylindrica. BRARD.

L. testâ ovato-cylindricá, globulosâ, lavigatâ; anfractibus quinis, subscalaribus, suturâ pmfundâ separatis, ultimo anfractu ingentissimo; aperturâ opatá ; plicí columellari abbicviatâ, crassâ. 
Brard, Journ. do Phys. 181, pl. 2 fig. 6. 7 .

FEa. Mém. géol. loc. cit. $n^{\circ}, 16$.

Nов. Descript. des Coq. foss. des env. do Paris, pag. 98. pl. 10. fig. 18. 19.

Espèce bien distincte de toutes celles du même genre, à l'exception de la prícédente, avec laquelle elle a une ressemblance assez grande. $\mathrm{Ce}$ peadant elle est plus veutrue, sa spire est encore plus courte et presque scalarifurme. Les tours en sont bien séparés par nae sulure profonde; ils sont lisses et subcylindriques. Ire dernier tour occupe plus des trois quaris de la bauteur totale. L'ouverture est assez grande, ovale, évasée à sa partie antérieure; la columelle est simple, et le pli columellaire est droit, court, pyramidal, peu saillaat, quoiqu'assez fortement tordu sur luimême. Longueur 13 millin., largeur 8.

19. Limsée renflíe. Limnaz inflata. Brona.

L. testầ ovato-glabosâ, lcevigatâ, minimî̀; unfractibus quinis, convexis; suturî profiundi; aperturi ovat', subobliquí; plscâ colunsellari magnâ.

Brostg. Ann. du Mizs. loc. cit. pl. 22. fig. 18.

An Limnéc renllée? Bnand, Ann. du Mius. tom. 15. pl. 27. fig. 5. 6. 7.8.

Fer. Mém, géol. loc. cit. $n^{\circ} \cdot 7$.

Nов. Descript. des Coq. foss. des env. de Paris, pag. 98. $p l$. 11. fig. 17. 18.

II est lien à présumer que MM. Brard et Brongraiat ont désigné une seule espèce snus la même dénominatinn; on aurail lieu d'eu douter d'après l'examen seul des tigures, nuais d'après la description elles ont beaucoup plus de ressemblance; et, si l'on fait attention çu'elles vienneut des mêmes lieux ou du même gissement, et qu'elles sont de même taille, on aura bien des présonptious de plus pour croire que c'est une mêare espc̀ce. Cetle petitc espèce est globuleuse, trèsveutrue, à spire assez élevée et printue, composée de cinq tuurs, dont le dernier est trèsgrand, de la moilié anssi haut que le resle de la coquille. L'ouverture est assez régulièremeut ovale, oblique à l'axe; la columelle est trèscourte, tandis que le pli columeltaire est fort long, pen tordu et peu saillaal. Longueur 8 a to millim.

20. Lumée ventrue. Limnaca ventricosa. Brong.

L. testâ avatâ, ventricosissimâ, lavigutâ; anfructibus quinis, convexis, ultinıo magno; aperturá amplâ, subrepandâ; columellá marginatâ; plicâ colunzellari minimâ.

Brovg. Ann. du Mus. loc. cit. pl. 22. fig. 17. Fer. Mlén. géol. loc. cit. $n^{\circ}$. II.
Nin. Descript. des Coq. foss. des env. de Paris, $p a g \cdot 99 \cdot p l \cdot$ : 7. Jig. 1. 2.

Celle espèce u'est pas beaucoup plus grande que la Limncea cylindrica; comme elle elle est ventrue, mais elle est ovale au lieu d'être cylindrique; ses lours de spire, au noubre de cing, sont convexes; la suture est peu prolonde; le dernier est trìs-grand, il forme près des trois quarts de la cocquille. L'ouverture est grande, turt ample, 'vasée; la columelle est bordie, et le pli columellaire est fort long, peu tordu, assez grêle. Longueur 12 millim., largeur 8.

21. Lıané de Virgivie. Limną virginiana. LAMK.

L. testî ovato-ventricosâ, tenuissimâ, diaphanâ, longitudinaliter striat $\hat{\text {, }}$, transversim inaequaliter plicata, grisced; anfructibus quinis, ultimo oblongo, spiri longione; aperturs ovati, basi repandi; columellá contorto-plicatâ.

Ls ux. Anim. sans vert. tom. 6. pag. 160. $n^{\circ} .4$.

Cette Limnée est ovale, oblongue, ventrue, acuminie au sumnet, ayant une spire courte a laquelle on ne compte que qualre tou's, clont le dernier est inlioiment plus grand que tous les autres. Le test est mince, transparent, d'un blancjaunatı ou grisåtre; il est excessivernent liagile; la surface extérieure est occupée par un yrand nombre de stries longitudinales, subrégulières, iuterrompues par des plis transverses, irréguliers, variables dans chaque individu. L'vuverture est très-gr'ande, ovale, oblongue, évaste à la hase, u peu rélrécie à sa parlie supérieure; le bord drnit est très-mince, tranchant, pellucide. La columelle, qui est en lilet très-étroit, est tardue sur elle-mêrne, ce qui produil un pli peu saillant; le bord gauche est fort court, appliqué daus toule sa loggueur, et ne laissant ouvert ni owbilic ui fente ombilicale.

Cette coquille, assez rare dans les collections, se Irnuve en Amérique, daus les eaux douces de la Virginie; elle a quelques rapports avec la Limnée ovale, et surtout avec la limnée voyageuse. Elle est longue de 25 millim. et lárge de 12.

\section{LIIMNÉENS (Les).}

Les geures gni composent cette fanille sont réunis par de très-bons caractères, tirés principalement de l'organisation de l'appareil de la respiration. Quoique vivant dans l'eau, les animaux de ces genres sont obligés de venir à sa surface respirer l'air, qui porte son influence salutaire sur un réseau vasculaire, semblable à celui des Colinacées.

Les anciens auteurs donnoient le nom de Buc- 


\section{J M}

cins à la plupart des coquilles qui sont plarées anjurd'lui dans eete lanille. lister domnuil ana llanoflies la dénominalion de tourpres, it i) les avoit assez lien circonscrits. Cependant Linuć länges indistinctement les Planorles et les Jimnces parmi les llélites, ce qui rénnissoit dius un mine grinre des animanx lint dillireos el des coqualles clun aspect qui devait laisser pen de douse sur lour onigrine. Muller, en créant le renre l'lanorbe, a rempli une indicalion trisjus!e; aussi tous les conoligliulonues, excepté les savans anglois qui se suni tenus a la letire de Liuné, l'ont adonté. On doit s'étonner, après la ríalion de ce premier genre, que jersmne n'ait s nge à ćtablir nne coupe pour les liannies, qui sc trouruient dans le móne cadre d'oliservaliun, el Muller, qui avoil sćparé si judicicusement les l'lanorbes, confondit celles-ci arec les Buccins. Bruguière les relira des Hélices de Linnó, les riogea dans son genre Bulime, ou elles u'étuien! pas nijeux placées, et où tlles restèrent jusqu'a l'époque nù lamarck, dans le Système des Animaux sans zertébres, cría le guture lymnée, qu'il éloigna d'abord des Planorhes, mais qu'il en rapproclia enivite, en 1811 , dans l'Extrait du Cours. Dans l'intervalle, un nonvean genre trèsanalngue aux limućes, qui avoit été créé depuis long temps par Adanson sous le nom de l3ulin, list reproduit de nouveau par Draparnaud sous r clui de Physe, qui a été adopté. Les trois genres l'anorbe, Limaíe et Physe constituent aujuurd'hui, pour lamarck, la famille des Limnéens, que M. Cuvier n'a point adoptće, mais dous il it liait ses l'ulmonées aquatipues, en y joignant quelques genres dent l'organisation n'est point encore bien cannue. Euliu, M. le Ferussac l'adupta d'apres lamarck; il y groupa plusienrs ucnres tout-a-fait nouveaux ct lifen incertaius dc Rulinesque, en y ajoulant le genre Ancyle de Geolliry; c'est nutme le scul changenent important que ce savant ait appotté dans les limnéens. l.amarck, qui avoil placé ce genre parni cenx des Calyptraciens, il est vrai, avec tust le doule que l'on peut meltre pour motiver une opinion aussi incertuine, y avoit été conduit, sans doute, par l'analugie des formes du test. Cependant, d'après de nouvelles ohservations, il est presquinconiestable que les Ancyles soni pulinonées, puisqu'elles viennent assez frćquemment à la surface de l'eau, et dans les temuss de sécheresse peuvent rester dans la vase humide en atteudant les pluies. Ce qui, outre cela, pourroit donner quelque poids a cette opinion, c'est la furme semblable du petit canal respiratuire à celui des Limnées. Au reste, malgré tout le doute que doit laisser cette question jusqu'a la connoissance plus parfaite de l'animal, nous pensons 'ju'étant fluviatile, il est toujours mieax placé pirrmi des coquilles de même nature qu'avec des cuquilles marioes.

\section{IJINOCOCHI,IDES. Limnocochlides.}

N. Iatreille a institné celle fantille daus ses Fumilles naturelles du Regne animal. Lille est Ia troisième des Gastéropodes pulmonés. Il la compose de denx choses qui semblent fort dillérentes, les Auricules et les limnces. Celle réunion ne pent être appoyce sur une similiınde d'organisalicn dans les animaux qui y snot rassemblés : il laut donc en revenir aux familles instimés par lamarck el moditiées par M. de [3]ainville, dent l'une, les Auriculacéc's, conyjrend les genres $\mathrm{C}$ iarichées, Scarabe, Auricule el Pielin; el la seconde, celle des Limnécrns, qui ne conlient toujours gue les rois genres Limnée, Physe et Planorbe. Nous renvoyuns aux articles qui Iraitent de aes deux familles et à ceux des genres qu'elles contiennerst.

\section{LIMNOPIILE, Limnophila.}

Dins son Catul. méthod. des Moll., M. Menke a formé un suus-ordre auquel il a donné ce nom, dans lequel il réunit les nểues genres gue ceux ¿ui composent la famille tes lymnóens de lazarack, auxquels il a joint quclques geures dumteux ou inutiles de M. Rafiuesque, tels que ('ycléunis, Espipliyla, elc. Voyez Lranéns.

\section{LINGULE. Lingula.}

Seba avoit figuré depuis lang-temps la Lingule complète avec sun pédicule, mais il l'avoit cousidérée comme une espèce d'Anatile, ce qui est ciase probableantal du peu d'attemtion que l'an donne a sa cilalion; car Lirnó, ef Gineliu après Jui, n'ayant vu sans doule gue dés valves séparées de cente coquille, en firent une Patelle. Rumplius, par les mêmes motifs que Linué, se trompa égalumrnt; il pensoit que c'étoit l'osselet de quelque espèce de Limace; ce que Favanne avauça aussi d'après lui. Cliemnitz, qui vit la coquillé counpléle, la plaça parmi les Pinnes: probablement qu’il ignnoroit l'existence du pédicule, sans quoi 11 n'auroit pas commis une pareille erreur.

Bruguière fut le premier qui établit un genre particulier pour celte coquille, qui étoit restée long-temps incerlaine entre des familles et des genres très-dillérens. Brugnière avoit établi ce genre daos les planches de l'Encyclopédie, mais il ne put le caractériser, la mort l'ayant enlevé aux sciences avant qu'il ait pu achever son ouvrage. Ce fut Lamarck, le premier, qui le caractérisa dans le Système des Aninz. sans vert.

M.Cuvier, anquel nous empruntons la plupart de ces délails, fit l'anatomie du ces Mollusques, et les trouva si difléreos des autres Acéphales, qu'il fit alors pressentir qu'il seroit nécessaire d'en faire on ordre à part avec les Orbicules +t les Térébratules : ce que Lamarck oe tarda pas à réaliser dans la Philosophie zoologique, en établissant sa 


\section{I N}

famille des Brachiopodes, qu'il composa des Irois geares que nous veoons de mentionner.

M. de Roissy, dans le Buffon de Sonnini, suivit l’idée de M. Cuvier el de Lamarek; mais il alla plus loin qu'eux en réuaissant aux trois genres des Brachiopodes les Cirrhopodes des auteurs, c'est-àdire les Anatifes, les Balanes, les Coronules, ete., qui, certainement, s'en éloignent d'une coasière notable. Lamarck, dans l'Extrait du Cours, Iaissa la famille des Brachinpodes composée telle qu'elle se trouvoil dans la Philosophie zoologique.

M. Cuvier (Règne animal) laissa également les Biacliopodes composés des mêmes genres. Lamarck, dans son deroier ouvrage, n'apporta non plus aucun changement i la famille des Brachiopodes, et le gente Lingule la terainant se trouve le deraier des Acéplaales, et par conséquent sur la limite de ceux-ci et des véritables Mollusques.

M. de Ferussac, dans ses Tableaux systématiques, proposa quelques eliaggemeos dans les Brachiopodes; il les distribua en plusieurs familles, parce qüil y joignil les genres Canie, Tbécidée et Mlagas : il auroit pu y joindre, ce nous seable, les Productes de Sowerby.

M1. de Blainville, dans son article Moluvsque du Diclionn. des Sciences nalur., fit aussi de grands changemens dans celte famille: entre les trois genies de Lamarck et de M. Cuvier, ainsi que ceux admis par M. de Ferussae, on Irouve à lilre de division des Térébratules les genres faits, à leur dépens, par Sowerby, et, de plus, les genres Strophomène de Rafinesque, Plagiostome, Diancliora ct Podopside. M. de Blainville, dans l'opinion où il est que les Lingules sout fort voisines des Patelles, aux poiuts principaux de l'organisation, termine la elasse des Céphalés par celles-ci, et commence la elasse suivante, les Acéplaalés, par les Lingules, voulaat ainsi établir uo passage presqu'insensible entre les deux classes par ce rapprocheueat, qui paroît singuhier.

M. Latreille, dass ses Fam. natur., a divise les Brachiopodes en deux ordies et en plusienrs familles. Vans le premier ordre (les Pédonculées), nn trouve une première famille, les Equivalves, gui ne comprend qu'un seul genre, qui est celui de la Lingule. La secunde famille, les Inéquivalves, se compose aussi d'un seal geare, les 'Térébratules. Le second ordre des Sessiles ne reaferme gu'une seule famille établie sous le nom de Fixipalves; alle se compose des genres Orbicule, Cranie, et avec doute des geores Radiolite et Sphérulite.

En examioant la famille des Osıracés du même auteur, on rerrouve plusieurs des genres que M. de Blainville avoit fait entrer dans ses Bracliopodes, tels que Producte, Podapside, Dianchora, Plagiostone. Cette vacillation fait voir que ces geares ont besuin d'être examinés avec tout le soin nécessaire pour décider de leur véritable place.

\section{I N}

M. de Blainville, qui a eu oecasion d'observu l'animal de la Lingule a a Muséum britannique, ne se trouve pas eatièrement d'accord avec la description faile par M. Cuvier; le point le plus capital est ce qui est relatif auecur. M. Cuvier a rcconıu deux de ces organes, et MI. Blainville peuse yue ce que MI. Cuvier a considéré comme deux cours n'étoil autre chose que deux oreillettes qui aboulissoienı à un ventricule unédian qui donnait naissance à une artère aorte : ee n'est, nous croyons, qu'une présomption fondée sur une abalyse qui peut tromper. Il uous semble, comae le dil M. de Blainville lai-même, que le fail est assez important pour avoir besoin d'être vérilié.

Nous ne pourons entrer jei dans tous les détails analomiques d'organisation des Lingules; ces détails sout aujourd'hui counus de tout le monde, depuis la publication de l'excellent Mémuire de M. Cuvier dans premier volume des Annales du Musém. Nous y reovoyons avee toute la confiance que doiven inspirer les travaux d'un aussi célèbre zoologiste. Voici les caractères que l'on doil donnci' aujourd'Lui à ce genre.

\section{CAR $\triangle$ CTÉRES GÉXÉRIQUES.}

Coquille subéquivalve, aplatie, ovale, oblongue, tronquée à son sommel, un peu en poiule à sa base, élevée sur un pédicule charnu, tendineıx, tixé aux corps marins; charnière saus denls. Animal déprimé, ovale, un peu alongé, cumpıis entre les deux lobes d'un manteau lendu dans loute sa moitié antérieure ou céphalique, et portant des branchies pectiaées, adbérentes à la fiace interne; bouche siuple, ayaut de chaqne côté un long appendice teotaculaire, cilio dans tout snn bord externe, et se rétractant eo spirale dans la coquille.

On oe connoissoit antrelois qu'une seule espèce de Lingule : quelques personnes ont prétendı depuis qu'il en existoit une seconde at l'útat vivant; mais nous pensons qu’elle n'est qu'une variété dé la Lingula analina de Lamarck. Il n'en est pas de même de quelques espèces fossiles dicouvertes en France et en Aoglelerre, et que l'oo pent ajuuler à la suite de ce geore. De ces dernières une seule nous est connue, et nous l'ajouterons is la description de l'espèce vivabte.

\section{Lixgore anatine. Lingula anatina.}

L. testâ ovato-elongatâ, angustâ, apice allcnuat $\hat{i}$, laviter convexâ, aquilater $\dot{a}$, sublavigatî, viridi; apice aperto; ligamento cardinali prriongo, cylindraceo, fusco.

Patella unguis. LiN. GMEL. $n^{\circ} 9^{5}$.

R имн. Mus. tab. 40.fig. L.

Sева, Mus. tom. 3. tab. 16. fg. 4. 
Cuv. Bulletin, n०. 52 .

Ann. du Mus. tom. 1. pag. 69 .

Caess. Conch. tom. 10. tab. 172, fig. 1675. $\$ 677$.

Excrez. pl. 250. fig. 1. a. b. c.

LАмк. Anim. s. vert. tom. 6. pegg. 258. $n^{\circ} .1$.

DE Businv. Malacol. pag. 5og.pl. 52.ffg. 3.

Scuum 1 caer, Ess. d'un syst. pag. 104. fig. 3.

Cetle coquille est extrêmement connue, à peine est-il nécessaire d'on faire une description; cependant, pour qu'il n'y ait point d'équivoquc dans le cas ot une espece dillérente vieudroit à être déconverte, nons en donoerons ici les principaux caractères.

Elle est ovale, oblongne, terminée en pointe assez aiguë à sa partie supérieure, coupée presque carrément inférieurement, lérèrement bombée en dessus, parfailenrent symélrique et équilatérale, à somut poinlu, médiocre, bâillant, et s'inséraut dans un long pédoncule cylindracé un peu alténué à son extrémité, coriace, teudiueux et même subcorné. ('e pédoncule remplace le ligaroent, et sert à fixer l'animal aux cnrps sous-marins, comare le sont les Auatifes. Le test de la coquille est mince fragile, d'une belle couleur verte en deirurs, nuancée transversalement par des zones d'un vert-brunâtre; à lïntérieur, la coulcur verte ne se voit que vers les bords, le miliea des valves ćtant occupé par une grande fache blanche, opaque, sur lacpuelle se distingue très-netlement une grande impression mnsculaire cordiforme, subcentrale, es an-dessus deux autres trc̀s-superficiolles, à peine indiquées. A l'intérieur on ne remarque que quolques stries irrégulières d'accroissemeut, et vers le sommet deux ou trois rides longitudinales tuherculeuses, qui s'élendent à peine au quart de la longueur.

Cette crquille provieut des mers de l'Inde, surtout de l'Océan des Moluques. Elle est longue de 45 millim. et large de 23 .

2. LiNgule myliloïde. Lingula mytiloides. Sorr.

L. testâ ovati, tenui, depressí, supernè angulati, infernè subliante, transpersim substriatâ.

Sow. Miner. conchol. pl. 19. fig. 1, 3.

An. eadem Lingula ovalis? Sow. loc. cit. fig. 4 .

Il est à présumer que l'espèce nommée Lingula ovalis par M. Sowerhy est la même espèce que cellc-ci: distinģuée seulensent sur un moule et sur un caractere de très-pen d'importance, tout porre à croire quielle en est une variété à forme un pen uvalaire. Cetle coquille est petite, ovale, oblongue, un peu spatulée; elle est très-iléprimée, très-mince, atténuće an sommet; les crochets sont très-petits, rapprochés; la surlace extérieure est striée transversalement par des accroissemens multipliés et assez réguliers.

Ce fossile curieux a été trouvé d'abord en Angleterre, et décrit par M. Sowerby; depuis, la même espèce a été découverte en Alsace par M. Voliz. Les plus grands individus que nous ayons vus ont 20 millim. de longueur et 10 de large; ils sont einpâtés dans un calcaire brunàtre ou bleuitre, qui paroit appartenir à la furcuation clu lias.

\section{LINGULES (Les).}

Sous le nom de Pédonculés Equivalves, M. Latreille avoit proposé, dans ses Familles naturelles du Règne animal, une famille parliculière pour le gente Lingule lui seul. M. Rang, dans son Manuel de Conchyliologie, vonlant conserver un arrangement à peu près semblable, a adoplé la famille de M. Latreille, en lui donnant le nom de Lingules. Nous ae pensons pas qu'il soit nécessaire de séparer les Lingules des 'Térébratules et de quelques antres genres voisins de ceux-ci. Quoique dans leur orgazisation intime les 'Térébratules soient fort peu conoues, cependant ce que l'on en sail suffit pour les tenir très-rapprochées de la Lingule. Voyez ce mot et Bracaiopodes.

\section{IINGUI,INE Lingulina.}

Gence établi par M. d'Otbigny, dans son travail général sur les Céphalopodes, pour de petites coquilles microscopiques très-voisines des Nodosaires par leurs rapports. Ce geare est compris dans la famille des Sticostègues, et il est placé entre les Frondiculaires et les Rimulines. Dans l'arrangement que nous avous proposé à l'article CÉphalopodes de ce Dictioanaire, nous avons pensẻ qu'il convenoit de distribuer les genres dc Ia famille que nous venons de citer d'après d'autres caractères, tels que la forme et la position de l'ouverture. De cette manière, le grenre LinguLINE, dont l'ouverture est terminale, a été adjoint aux Nodosaires pour former la première section des Sticostègues.

\section{CARACTYRES GE் ERIQUES.}

Coquille alongée, déprimée latéralement, formée d'une seule série de loges recouvrantes, dont la dernière est ouverte au conire; ouverture eu fente longitudinale.

Les Lingulines sont de petites coquilles d'une forme très-remarquable; elles sont ovalaires, déprimées, composées d'une série de loges transverses emboitúes les uoes sur les autres : la deroière, terminée supérieurement par un diapliragme déprimé et anguleux sur les côtés, est légèrement ironquée au sommet. Celte troncaturc est ogcu- 
píe toul entière par l'ouverture : celle - ci est alongée en feute ovalaire, pointue à ses extrémités.

Le pelit nombre d'espèces qui sont connues proviennent, pour la llupart, de la mer Adrialtiique. Ayant éte ligurés dans le hel ouvrauge de Suldani, l'espèce suivanle, que nous a! tous dérire, est la seule que nous ayons trouríe ì l'état fossile dans les sables des enviroris de S.eane.

\section{Ling oLing cariuée. Lingulina carinata. D'ORB,}

L. testá ovatî, cxtremitatibus atteruati, lorvigati, latevibus curinata; loculis transversis, simbplicibus, primis numerosis; ultmo margine sinuato; aperturi angusti, rimuliformi.

D'Ons. Mérn. sur les Céphal. Ann. des Scienc. nat. toin. 7 . pag. $257 \cdot n^{\circ} .1$.

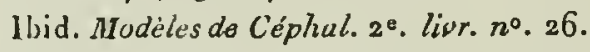

Soldan, Microsc. tom. 4. tab. 12. fig. P. p.

Petice coquille tonle hlanche, ovaluire, allénuée à ses deux extréınités, plus large autérieurewent que postérieurcuent. Les loges transverses sont très-multiplićes au sommet; elles sont sinıples, fortement arqućes et très-boubées; la dernière, beaucoup plus grande que les autres, est sinueuse à son bord postérieur, et terminće en pointe unédiane trooquée pour l'ouverture. Les côtés de cette coquille sont carénés daos toule leur étendue; cetle carène la divise en deux parties parfailement symétriques.

M. d'Orbigny donne les Antilles pour patrie à cette espèce, et Soldani l'avort recueillic dans les sables fossiles des environs de Sienne. Elle est loogue de 1 millim.

\section{LINTHURIE. Linthuris.}

Démembrement iuulile proposé par Nontlort, dans sa Conchyliologie systématique (tom. 1, pag. 254), pour une petite coquille qui appartient an geure Cristellaire. Fojez ce mot.

\section{LIPIN.}

Dénomination imposée par Adauson ( Vojag. ars Sénég. pag. 125, pl. 8 , fig. 18 ) is une cuquille nomusée Murex afer par Linné, et placée duns le genre Euseau sous le nom de Fusus afer par Lamarck. (Anim. s. yert. tom. 7. pag, 131. $n^{\circ}, 29$. )

\section{LIPPISTES,}

Genre proposé par Montfort pour une coquille mariue que Fichlel avoit placée parmi les Argonautes, mais qui doit bien plutôt appartenir aux Daupbinules, dont elle a les caractères. Voyez DAUPHINULE.

\section{LIRI.}

Nom donue par Adansnu ì une petile coquille qu'il rapporte is son genre Lépiss, el qui n'esi frorliablement antre chose gu'un Cabochon. (imelin (Liv. 13". édit. pag. $5714, n^{\circ}, 110$ ) Ini a dumué le nom de l'alclla perversa.

\section{LIRIA.}

A. Gray a donné ce non à une coupe gínérique déruenthré des l'arciles par M. Siverhy sons le nou de siphonaire, pu col géncirule:uent adopté. Voyez Sipgonatre.

\section{LISOR.}

M. de Blainville ( Dict. des Scienc. nut.) pense que le Lisor d'Adansun (Voyag. au Scricg.pl. 17, fóg. 16) a élé rapporté à tort, par Gurelın, au Mlactra stultorum, el que c'esl probablenent une Vénus, el peut-ôtre la I'enus lacta. Nous ue pratlageons par l'opunion de M. de Blainville; car en lisanu la description d'Adanson, pang. 233 , nous voyons que, le ligansent est iulérieur, placé dans une fosselle entre des deuls lamelleuses, el qu'il y a de plus, à la charnière, des dents lalcórales également larmelleuses : caraclères qui coavienneuı essentiellement aux Mactres, et mon aux Vénus. Sil'on joint á cela la ressemblance dans la couleur, la disposition des rayons el le biillemicnt des valves, un sera porlé i croire ipue le Lisur est bien la mềne coquille que le Mactra stuliorum.

\section{LISPE.}

Adanson (Voyag. all Sèngg.pl. 11, fig. 2) is placé sous ce nom, dans son genre Vermet, une agrégaliun de sules calcaires contuumćs irrégnlièremest, el qui ajpartient probablement à ce gence, puisque l'on trouve des cloistrus a l'int:rieur. Linné lui a donné le now de Serpula glomerata. Voyez VEH

\section{LISTERA.}

MI. 'I'urion a fail un double emplui en établissant le gente Lislera jour des coquilles bivalves, que M. Cuvier avoil dislinguées sous le nom de Lavignon, et qui ne sont autre chose que les Luraires de Lamarck. Voyez Lavignon et LuTRAIRE.

\section{LITHODOME.}

M. Cuvier (Règn. anim. tam. 2) a proposć uu sous-gente sous ce nom pour des coquilles du genre Modiole, qui ont la propriélé, coume beancoup d'autres Mlullusques acéphales, de prrcer la pierre ou les polypiers pierreux. On a prétendu que les Mlodivles se creusoien: des luges a ussi biea dans le grunit que dans les roches calcaires: ce fail n"est pas encore bien cerlain. Quoi quil en scit, ce suus-genre be sauroit être conservé, puisque l'anatomie des animaux ne diffère 


\section{I, \ T}

ell rien de celle des autres Modioles, et que la corjuille elle-míme ne prósente pas de dillíventes sullisantes pour légilimer celle coupe. Voyez Modtole el Lirnophages.

\section{I.ITIOPIIAGES.}

Les Mollusques litbophages ae se rencontrent que prarmi les Accipladés on Conclifléres. On a rémi sous celle dénomination lous ceux qui ont la singulière propricilé de ronger les pierres calcaires pour se loger al se mellre il l'aluri des chocs uxlómeurs. Presyue tioutes les fauilles des Conchifires ont des nenrcs rui perfortent, soille bois, soil la pierre; nous en parlerous ì mesure yue l'occasion sc présentera. Nous ue les considéruns jas num plus ici comme une famille particulière, mais curume offrant une propriété qui leur est conımune. On a eu des opiniors fort différentes sur la manière dont ces animaux peuveat percer les pierres: quelyues personnes penseut que l'animal clmisil le's pierres dans l'ćcat de mollesse, parce qu"elles ont vu des Pholades dans quelques dépôls Puseux, blancs, peu consistans, quielles auront regarlés conını une pierre comroençante; mais cel!e opinion ae peut supporter le moindre eximen approfundi, car s'il fwut une pierre tendre a l'animal lorsyu'il s'y introduit, il laut qu'elle reste dans le inème élat pendant locie la durée de sa vie; si elle vient à durcir, Il ne trouve plus les conditions convenables pour vivre, il doit néressairement pririr. Il seruit impossible alors de trouver un Luhoplage vivant dans one pierre dure : ce qui est loin d'être vrai.

On a supposś yue l'animal, par des mouvemens nultipliés eı les frullemens nombreux des aspéritcis de su coquille contre les parvis de son érroite prison, étvil dans le cas d'angmenter lentement la cavité qui le contient. Mass ce moyen, tout ınécanique, trnuve des objecrions puissautes:

10. Les Perfurans se trouvent coujours daus des pierres d'une dureté et d'une densité quelquefois plus grande que la coquille elle-inême, qui est d'ailleurs survent fort minces.

$2^{\circ}$. Les aspérités quelconques de la coquille ae sauroient seıvir à augrmentel la cavité qui la con. lient, pusyue l'on devroit les Irouver émoussées ou usćes par les frotlemens; mais il r'ea est pas ainsi, car toutes s'y trouvent dans une très-belle conservation, méme dans les lames ou les aspérités les pius délicates qui quel quefois les couvrent. Uo granl nombre de coquilles perforantes sont entiereaient lisses, et dans l'ienpossibilité de se relourner dans la cavité qui les contient, car elles sont relenues par une crêle pierrense qui s'enlonce dans la rainure que laissent les crochets des deux valves.

M. Fleuriau de Bellerue, qui a fait on grand noubre de recherches sur ces animaux, a observé que les l'holades étoient constamment enveloppíes d'une liquear épaisse, noire, qui sans doute ćtoit une liqueur corrosive. Ayaut observé anssi que ces aniuaux étoient phosplıorescens, il pensa que ce pouvoit bien être à l'acide plosphoreux qu'écoil due la propicélé de comoder la prierre qui est parliculicre aux Lilhophages. Supposer aux I'erforans une liqueur currusive, il faut ćgalement en supposer la sécrétion el son organe sécréteur : je dis supposer, parce yu'on a cherché inutilearent cet organe.

M. lileuriau a pensé que ce devoit être le pied qui en devuil fournir le plus; mais si l'on fait allenlinn que les Saxicaves, pal exemple, el les Mudioles lilhodomes ont cet organe entièrement rudireulaire; que les animaux de ce premier gense ont le mancau a peine ouvert à l'eoäroit du pied, on se demandera, puur ceux-la au moins, où pourroit étre placé l'organe sécréleur. Si l'urgane qui produit la liqueur corrosive des Lilhophages n'est pas connu, il ne s'ensuit pas qu'il n'existe pas, et celle seule objection raisonnable contre l'opinion de M. lileuriau de Bellevue ne nee seinlsle pas suflisanle pour la détruire. Il est à présumer yue la liqueur est acide, car les Lishophages vivent loujours dans les pierres caliaires. On n'a puint encore une observation constatce qu'ils puissent virre dans des pierres d'une nalure différente, et ce fail confirme leaucoup l'opinion du savant observateur que nous venons de citer. Nous n'admettrons donc pas l'opinion de M. de Blainville, qui pense que la raccíralion de la pierre par le mucus de l'anitual est dans le cas de la dissoudie lentement. Il doone à l'appui de son opinion les Patelles, qui se creusent sur les rocbers une place qu'elles adoptent; mais il faut dire que c'est sut une pierte culcaire teadre que cela se remarque. II faudroit que le même phénomène se répétál sur les calcaires les plus durs; et l'ohservation manque Il seroit difficile de concevoir au reste, même à un chimisle, comment un morceau de pierre calcaire exposé à une longe macération dans un unucus de Mollusque qui ne contiendroit aucuu principe dissolvant, pourroit cependant se ramollir, se dissoudre on se désagréger. On voit par les doutes nombreux que la question qui nous occupe est loin encore d'ètre résolue; il unanque une foule de conditions avant d'arriver à une solutioz complète : ce seroit d'examiner les mucosités des Lithophages par les moyens chimiques, de chercher sur un grand nombre et dans tous les geares les organes de sécrétion, qui sont probablement placés dans les bords du mauteau; s'assurer que ces animaux ae peuvent rivre quc dans les pierres calcaires, elc. C'est ainsi ciue l'on pourroit préteudre résoudre une question inléressante et importaute tont à la fois.

\section{LITIOPE. Litiopa.}

Pelit nenre qu'a établi M. Rang, dans sun Manuel de Conchyliologie, ponr un auimal fort curieux, observé, pour la première fois, par 
M. le capitaine Bellanger. Cet animal, qui porte une coquille analogue par ses rapporis a celle des Phasianelles, a la singulière propriété de se sospeadre dans l'eau, comne le lint certaines cheoilles, au moyen d'un fil de soie. Cette progrićté est due à ce que l'animal porle à l'estréwilé de son pied un organe vésiculcux, rempli d'une mucosité assez tenace, el qui ne se délaie ciue lentement dans l'eau. Ne connoissant ces délails que d'après ce qu’en dic M. Rang, n'ayanl point d'ailleurs la coquille sous les yeux, nous ne pouvons eatrer dans plus de détails à l'ígard de ce genre.

\section{LITTORINE.}

M. Ferussac, dans ses Tableaux systématiques des Animaux mollusques, a divisé le genre $\mathrm{Pa-}$ ludiue des auteurs en cing sous-genres, dom le dernier a reçu le nom de Littorine. Ce sousgeare, sans présenter une division très-nalurelle, est pourtant utile à conserver, en ce qu'il réunit un assez grand nombre de petites coquilles lluviatiles ou marines que l'on plaçoit lantôl daus les Cýclostomes, tantöı daus les Turbos ou d'autres genres dont elles s'éloiguent Égalemenı. Yoyez Paludine.

\section{LITUACÉS. Lituacea.}

Famille établie par M. de Blainville, dans son Traité de Malacologie, pour quelques genres quue l'on est élonné de trouver rassemblés. Ce sout les suivans: Ichthyosarcolite, Lituole, Spisule, Hamite et Amononocératice. Deux seuls gentes de celle fanille ont entr'eux des rapports, ce sont les Lituoles et les Spirules. Le genre Ichthyosarcolite, comme nous l'avons vu en traitunt de ce genre et à l'occasion des Hippuriles, a élé fait sur des parties de coquilles bivalves ì l'état de pétsification. Qurant aus gebres Hanite el Amnubocératite, ils appartiennent a la fumille des Ammonés par lous les caracteres, et l'uu d'eus doit être supprimé comme double emplui de Jiautre. (Fojez Hasire.) Le genre Spirule, tel que M. de Blainville le compose, n'est puint admissible, puisqu'il $\mathrm{y}$ introduit des coquilles uicroscopiques qui a'ont gnère, avec la Spirule, d'ulitres rapporis que. ceax des formes extérieures. La famille des Lituolées ne peut être conservée, à moins qu'on ve veuille y apporter les flus notables changemens; et daus le cas où on voudroit les opérer, elle aurvit encore l'inconvévient d'être un double emploi de celle des Nautilacés. Voyez ce mol.

\section{l.ITUITE.}

Ce genre, proposé par Monifort (Conch. syst. tom. "2, pag. 273.), restera vruisemblablewent dans la science. Malheureuseacent, comme on wo feut se fier à suculue des descripitions dounées par cel auteur, il est diffic:?e de le placer dans la série. Deux ritisons s'y opposent : la prenieienc est relative a la position du siphon; Montfort le dome courue ceniral, et un grand nombre d'observations uous portent it croire qu'il devoit être latéral, comme dans les Spi:ules; la seconde est relative à la lorme des cloisons : est-il bien certain qu'elles son: simples coume le prétend Monifort? La forme de la coquille, l'enroulement complet de ses premiers tours, nous font penser qualle pourruil dépeuslre de la lumille des Amnunés, et apparienir à l'espèce d'Hamite figurće par M. Philips, duss son ouvrage sur les lossiles caractéristiques.

Il est donc difficile, dans l'état actuel des olservations sur 'e genre, de rien décicler avant que ces caracic̀res aieutélé de nouveau confirmés.

\section{LITUOL.ACEES.}

Lamarck, dans sa Philosophie zoologique, avoit proposé une famille à laquelle it a donné ce nom. Elle étoil composée des six geures: Lituolite, Spirolinite, Sprule, Orthocére, Hiplurite el Bélemnite; depuis il s'aperçut du peu de liaison qui existoit entre ces genres, il réforma la famille, dans l'Extrait áu Cours, e: la réduisant aux trois premiers gentes, il lui à donné le nom de Lituolés. Celle lanille, qui couprend des genres micruscopiques, des corquiltes siphonces et même des cocpuilles bivalves, n'éloit paint admissible, mène après la réfurme qu'elle a subie. Lamarck l'a cependant conscrvée dans son dernier ouvrage.

Voyez les genres précédemment cilís el l'arlicle Cépualopodes.

\section{LITUOLE. Lituola.}

Ce genre fail double emploi avec celui nommé Spiroline par Lamarck. Admis par quelques auteurs à côté des Spirules, et mêune confondu avec elles par M. de Blainville, nnu-seulemen: il ne peut rester dans son voisinane, mais it doit étre latusporté dans uo autre ordre et laire partic d'une fatulle particulière, comme nous le verrons à l'article Sprkolise auquel nous renvoyous.

\section{IITTCOLEES (Les).}

Lorsque Lamarck eut réformé la famille des I.ituolacées (poyez ce mot), il laisia subsister celle-ci pour les trois genres Spirule, Spiroline et Liluole. Elle v'est pus plus admissible que la première. Vojez ĊérHaL podes.

\section{J,ITUOLITE.}

On a donné ce nom åux Litucles à l'êla! fnusile ou de pétrilication. Ces terminaisons en ite, que l'on avoit érablies pour dislinguer les especes fossiles des vivantes clans un mème genre, sont abandonnées avec juste raiss. Foyez lituore. 
LIVON.

Le Turbo pica de Linné et c'e Lamirck a ćlé ainsi nommé par Adanson. ( $V, y . a u$ Ién' $g$. $\mu$ !. 12. $\left.f_{g} \cdot 7.\right)$ Voyez Turao.

\section{I.IVRÉE ( La).}

MI. Geolfroy e! les auteurs de concliyliolngie du dernier sièrle donnent ce nom à l'Ilelix hortensis ou à l'Helix nemoralis. Yojez ces mols.

\section{LOBAIRE. Lobaria.}

Döjit un gnenre Lobaire avoit été fait par MI. de Blainville pour un animal voisin des Acéres, lorsque M. Schumacher, dans son Essai de Conchyliologie, proposa, suus le uêruc nom, un greare parmi les cuquilles bivalves. Ce double ernploi iies! pas ce que l'on duive reprocher le plus à l'aulcur, mais c'est qu'il ait conni le nom de Lobaire à une coquille qui, dès $180 \mathrm{I}$, a servi de type au gem:c Sabruizolaire de Lamark. Poyez SAvicinolatre.

\section{LOBAIRE. Lobaria.}

Ce nom esı le qualrième que reçoit ce genre. Décrit d'abord par M. Cuvier sous le noun d' $A$. cére, emprunté à Moller, el ensuile reproduil par M. Mrkel sous les nouns de Doridıum el de Bullidum, MI. de Blaiville l’a caractérisé de nouvcau dans son Traité de Malacolngie, cu lai imposant le nom de Lobaire, que nous n'adnptons qu'autant que ce genre n’ayant point é:é décrit aux arricles Acére el Donrane, il luisseroit une fáclicuse lacume dans la connoissauce des rapporis yui lien! les divers groupes de la famille des Bulléens. L'animal des Lobaires a de Ia ressemblance avec celui des Bulles, et surtout des Bullées, mais il en dilfere d'one nuaière lris-notable par l'absence absolue de toute espèce le rudiment lestacé. On le prendroil aussi voloutiers pour une petile $A$ plysie; mais si on l'examine de près, on ne retrouve plus la feute pallíale qui peraset à l'eau de se répandre lucilement sur les uranchies. La description que fait $\mathrm{M}$. Cuvier du Bullea camosa nous donne a ponser fo'elle peut sappliquer à un animal provenant de la Sicile, et qui nous sembluil d'abord devoil constiver uu gearc parriculicr. Si cel animal, que nous possiduas, apparticut ráclletnent un gacare Lubaire, nous trouverions avec lui ct la description de M. Cuvici cles difiérences assez notables, telles que, par cxemple, l'cxistence d'un très-petit rudiment testacé à la partie postéricure, el d'autres dillérences daus les proportions des lobures qui divisent l'animal. Dans le doute où nou nons trollvons à l'égard des Iabaires, nous nous contenterons de rapporter ce que NI. Cuvier en a dit dans son Mémoire plein d'intếrêt publié dans les Annales du MLséuns. Lc's ruseignemens que nous nous altendions à Hist. Nat. des Vers. Tome II.
- Ironver dans les arlic!es de MI. de Blainville (Dict. des Scienc. nat.) nous manquent calièrement, car tout ce ?!: y a rapport consiste en quelques articles de reuroi qui pe traitcut pcint du genrc au lond. D.ans le Dictionnaire clussique d'Histoire naturelle, M. de lierussac n'a traité non plus, ¿̀ l'article Acirre, que de 'a firmille qui porte celte dénominalion daus ses Tableaux systénıatiques. Croyant que le geare Arère avoil été traité d'une manière complète par l'aliteur que nous venons de citer, nous y renvoyianes de l'article Doride, lorsque plus tard nous fúanes chargé de la conlinualion des asticles Mozroseues de ce Dictionnaire. Voici, cu pen de muts, ce que M. Cuvier dit du Loharia qualriloha.

" J'ai dil que j’appellerois Acéres proprement $n$ diles, les espéces cnticrement dépourvues * de coquilles. Je n'en connois qu'une jusqu'í - présent, et je ne l'ai rue que dans l'esprit-de"vin. Cest wu cabinet imperist de l'lorence que * je l'ai observéc, et que j'en ai obtena quelques " individus pour nolre Musíum. Elle vieut de la " Méditerrunée; mais je n'ai pu ea découvric " d'indices dans auc:un auteur. Le nom de Dulla n carnosa lui convicndroit à merveille, car elle " tepréscnte for bien un Bulla, comine l'Aperta, - par exemple, cont la coquille se seroit éra"nouie, et ñuroit laissé que des chairs qui l'en"veloppaient. Ces claairs ou ce mantua ont mèue * absolument la forme l'une corjuille, et sc con" lournent de mêrne eu spirale par derrière. "Quand on en fend la peau extśrieure, on trouve * sous elle un vide pcssible, uue solution de con" tinuilé entre deux membranes, dans larpuelle n pourroit ĉtrc lnģic une cociuille très-semblable "a celle de l'Aperta; mais cet intervalle n'est » occupé par rien; il a'a pas méme cette lame * cornće cl llexible qui tient lien de coquille dans

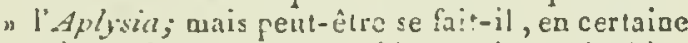
* saisun, dans cet espace vile, quelque sécrética n dinne nature calcaire, comae il arive daos "certaines Linaces.

"Son caraclc̀:e extérieur le plus marqué, c'est " que l'ouverture par où l'ean yénctre aux brann chies, et les orifices de l'arus et lle la géné"ration, sont plus en arrière ţuc dans les espèces " précédentes (Bull, lignaria, Physis, etc.), et n que le sillon qui va de l'organe femille à l'ori" lice de la verge est par conséquent plos long. * Les denx lubes lacéraux du pied qui, dans - Ia Bulla apritic, remoulent et forment de * cluaque côté du dos une proćcinence charnuc, * sont ici winces ct aplutis et ed forre de nan geoires, ce qui donue à l'animal ur rapport n sensible avec l'Aplysia. I.e disque teataculaire * est en revanclie plus élvinnos des formes de " l'Aplysia que dans les autres Bulles; il esı ovale - et ne mootre nulle séparation, nulle prócmin nence qui indiqne des tentacnles; deux points - Liuns placés prés de ses angles antéricurs anA a a * 
- nourent proba'lement la prísence des yeux * que j:- n'ai pu toutefois distinguer. Ce pelit "animal s'a guère qu'un pouce à 18 lignes de "longueur."

Avant de donner quel ques détails sur l'organisation du Lobaire, nous lerons remarquer l'expression que nous avons sonlignéc dans la description de M. Cuvier: un vide possible est encole une chose iléale, et pourrcit jeter dans l'esprit quelque chose de douteux sur l'ubservation de M. Cuvier, si elle n'éloit expliquée de manière i ne point laisser d'ambiguité. Nous cruyuns qu'il existe à la fartie pastéricure de l'animal une cavilé qui reste vide, el dout les parois sont constainueut en contact. Lorsque l'on vient à fendie la peau coriace du Lobaire, on lrouve une masse charnue antéricure quicontient la bouche et ses annexes. Cetle masse charnue, après un Etringlemeni œsophagien fort court, cominurique avec un estomac irrégulier fort court. Cet estomac se continue rn un intestin grẻle, cylindracé, entuuré prestjue complétement par un foie sublobé, irrégulier, ussez gros, qui verse le prodnit de sa sécrétion par de pelits vitisseaux biliaires qui entrent dans l'estonarc à l'origrine de l'intestin. L'ouverture de l'anus, à laquelle l'intestin se termine, est situće à la partie postéricure du corps, à la base de la liranchie; dans le systène digestif, les glandes salivaires semblent nanquer: M. Civier, du moins, n'en fait point meution. A l'extrénité du foie se trouve un ovaire d'une pelite dimension, dua al part un uvidicte lorlille, assez court, qui va joiudre le lesticule. Celui-ci est assez gros, vésiculaire, el ne parvit avoir ancune communication iutéricure aver l'uryane excilateur placé le lonir du côté guauche, el communiguant á l'exté-

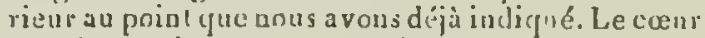
est silué à la partic postérieure et presque terminale de l'aniual; il est alongé, petit, tringunlaire,-et contenu dins un péricarde tres-mince. I.es branchies consistent en un pelit paquet formé de bait à dix lames courtes et longiudiuales, placées à l'exiériaur en clessous du rebord du manteau. Un sillon longiludiual qui rènne sur le côté rauche de t'aniaral, depuis l'orilice de l'orume cxcilatcur, placé inmédiatement au-clessous de. Ia tête, joint l'organe mûle arec l'urgane femelle, qui, comne nous l’avoos vu, s'ouvre à l'extrémité postérieurs du c:orps.

L'espèce qui a serri aux anatomies de $\mathrm{M}$. $\mathrm{Cn}$ viel a été nownée Lobaire charnue, Lobaria camosa; c'est un animal ovalaire, don! le pied est dilaté latéralement eo espèces de uageroires, et rlon! le clos est divisé en deux lobes, dont liantérieor représente micus le manteau que le poslérieur, ćtant séparé de la masse charaue par un bord mince et flexueux, comme cela se voit daus un assez giaud nombre de Mollusques nus; le lobe postérieur est arroodi, un pen ovalaire, Ironqué postérieurcment, el il n’est sćparć dú
Jaje antérieur et des bords du pied que par un sillon superficiel dnut la trace esi angmeotée pat un changement daus la couleur. Cette couleur est d'un gris assez funcé sur les lohes et sur les parlies latérales du pied, mais blancluâtre daos les iutervalles qui séparent ces diverses parties. 11 est à prisumer yue cette couleur est le résulıat d'unc aliération qu'aura subie l'aniınal par suite de sun séjour prolongé daus l'alcool.

\section{LOMAN.}

Nom donné par Adanson (Voy. uu Sénég. pl. 6,fg. 7) au Conus textilis de Linné et de lidmarik. Il est connu sous le uom vulgaire de Drop dor. C'est une espẻce qui varie beaucoup, avec laquelle on eu a lait plusicurs.

\section{LONASTONE.}

Genre proposé par M. Rafinesque dans le Journal de Physique, mais trnp inconuplétemeut connu pour décider si il doit élre adoplé et mêıne dans quel rapport on doit le mettre dans la méthode. Ceprendanı il semble être un double euplui des Limuées.

\section{LONIER.}

Gmelin, dans la ıze. éditiou du Systema naturce, a donné au Ioniter d'Adansnn (Yoy. au Sénég. pl. I2, fig. 6) le nom de 7rochus griseus. Voyez 'Tодиe.

\section{LOPHYRE.}

Poli, dans son grand uuvrage des Testacés des Deux-Siciles, a donné ce nom aux animaux des Oscubrions. Voyez ce mot.

\section{LORICATA (les Armurées).}

Dans le Système conchyliologique de M. Sclunmacher, les Uscabrions forment la seronde division des coquilles multivalves; rette division porle le nou de Loricata. Ce qui est siugulier, c'est de la trouver entre les Bulanes et les Tarets. lorsque l'on savoit depuis long-temps par les analumies de ML. Cuvier et par les systèmes de Iramarck combien ces animaux snnt éloignés de cenx entre lesquels M. Schumacher les place. Poyez Oscabrion.

\section{LORIPE்DE.}

L’animal de la Lucine lacı́ce qui a servi à Poli pour l'établissement de ce genre est probablement scmblalile à celui des autres Lucines, autant qu'il est possible d'en juger par l'identité des caractìres des coquilles comparés ertr'eux. Nous ne pensuns pas, d'après reela, quil snit ntecessaive de séparer en deux genres des coquilles analogues jusqu'á mowent où la connoissance de l'auimal 
d'une autre Luciue soit renue confirmer ou démire l'analogie que nous royons maintenant sullisammeat fondée. Voyez Lucis.

\section{L.OTOIRE.}

Monifort, qui, dans sa Conchyliologie systematique, a proposé va lrès - grand numbre de ¿ncures, avoit ćtabli celui-ci a lont pour un déusenibrement des Murex de I.inné, que Jamarck ay oit élabli sous le nom de Triton. Vuyez ce nos.

\section{LOZET.}

Adunson (Voy. au Séneg. pl. 9, fig. 33) nomme ainsi une perile copulte yui doil appartenir an gente Fuscau, el que Gmulin a plartée dans les Murex, sous le nom de Murex fusiformis. (Sjst. nat.pag. 3549. $n^{\circ} .88$.)

\section{LUCINE. Lucina.}

Linné avoit confondu leq Jucines en partie avec les Vénus, en parlie avec les Tellines; clles ue présentent cepeudant jamais les caracteres de ces deux geures, guoiquelles s'en rupprocheat. Aussi Bruguière les sépara dans les plunches de l'lunyclopédie, et, sans le caractériser, indiqua re grrupe aux zoologistes; lanarck l'adopta dans le Système des Animaur sans verlébres, et lui donna des cararteres génériques yu'ol reproduisit duns les Annales du Muséum. En publiant l'E.rtruit du Cours, ce celècure naluraliste n'apfurta aucun changemear dans la composition du zorure, et n'adopla pas le lonipide de l'uli. l.e prenicer et le seul démenbremeut a cité pupusé sous le nom de Fimbria par Héuerte, el ensuic sons celui de Combeille par Cuver, dans le Règne animal; re renre, avec celle dernière déuomination, a ćlé fúnéralement adopté des conchyliologues, et entr'autres par lanıarck, M. de lierussac, ctc. Le démenubrement des corleilles étoit le seul qu'on pouvia faire en l'appuyant sur de bons caraclères; car, mágré la varitabitité des caractères extérieurs des coquilles des Lncines, il cst impossible, du moins dans l'élat de nos connoissances, d'en fuire plusieurs coujes groúriplues, et c'est sans cloule, d'uprès celle analonie, prur ainsi dire forcée, qui lie les espiecrs de re gemre, que hamartk, et plus récemment eucore N. de Btainville, y onı réuni le Loripiede de Poli. Elllectivement, la Tellma lactea de Linné, "qui seut de yye au genre du suvint zooloriste napolition, ņrésente tous les caractèı es exlérieurs des Lorines; ce qui prote it crnire que relles-ci nul les mocmes caraclères zoolngịne-de celle-là, qui est idenique et par la charnière, et par les impressions des muscles on din ruantean.

M. de Blainville, dans son article Mozrusque, ne sest pas contenté de réunir ce senl geurc aux lucines, il y a ajouté les Amphidesmes el joinl les Corbeilles, que M. Cuvier avoit séparces; quant à ces dernières, peul-ĉtre est-ce en juger trop prémalurément, puisqu'on ne connuit point l'animal, et que les coquilles n'ont qu'un seul trais de ressenublance, l'exislence des dents latéralet à la charnièrc. Il suffit de comparer les caractères de ces deux genres pour se convaincre de leur différence. Quant aux Amplidesmes, rlles nous paroissent rapprochées des Lucines d'une manićre plus forcée eucore, outre qu'clles ont le ligament intériear comme quelques Lutraires ou l'Arignon de H. Cuvier, el colles entriautres qui se rapprocteat de la Calciuclle d'Adanson, caraclères que ue présentent jamais les Lucines, quoique quelques-unes aient le ligament très-enloncé cntre des nymplacs saillantes qui se caclent en partie au-dehor's. les Amphidestoes n'ont pas nou plus les irapressiuns musculaires des lucines, et limpression du manteau est profondément sinueuse : ce qui annonce l'exisience de grands siplions el d'uo pired lanellitorne, plutôt searbluble a celui des 'Tellines gu'à celui des Lucines. Nous nous abstenons donc d'admeltre ce cliangement, considérant, avec le plus grand nombie des concliyliologues modernes, que les Lucines forment à eiles seules ur groupe naturellement caractérisé par l'impression des muscles el le détaut de pli urrénulier : ce qui les dislingue des 'Tellines par le linament extcricur', l'iapression des muscles el du cuauleau, ainsi que la disposition des dents cardinales, et les sépare des Anplidesaes; cr erfin par la forme des crochets des dens cardinales, la position et la constance des dents latérales: ce gui, juint aux autes caractères, les éluigne des Cintheilles. Ce genre esl caractérisć de la mauitre suivante.

\section{CARACTÉRES CÉNÉRIQUES.}

Corguille suborbiculaire, inéquilatćrale, à crochels petits, pointus, olligues; deux dents caldimales diverinentes dom une bifide, el qui sont variables ou disparoissent avec l'àge; deux dents latćrales doot une est quelqueluis avoitée, la postćrienre plus rapprochée des cardinales; deux impressions asusculatres très-séparées dont la postérieute furme un prolnngement cu fascic; l'impresinndu inantean est simple; ligament extérieur.

Si l'un reut adneture le Loripede de Poli conne une víritable lucine, alors on pourra caractériser l'animal de la inanière qui suit :

Curps orbiculaire, symétlique, comprimé, enveloppé par un manteau sinueux sur les bords, entičrcucnt fermé, si ce nest antérieurement et en arrière où il se terouiue par un assez loug tulie unique; appendice abdomisal fort alongé, Aarrellifurme; les branclies à demi réunies en un scul lobe de cbaqque cóté; bouche sans appendices labiaux.

On uc comoit pas encore un très-grand nomLre d'espitces vibustes appartenant à ce geore; 
il est eaccre plus nombreux en espèces fossiles, et les cuvirons de Paris en offient plus à eux seuls que tous les autres terrains tertiaires connus, si on cu juge d'après les collections et les ouvrages publiés juscin'anjourd'hui. Nous en avous décrit et figuré ringt-deux espèces dans notre Description des Coquilles fossiles des environs de Paris, et nons les avons partancées en plusienrs groupes dout les caracteres periveat également convenil aus especces virantes. Nous proposerons plasieurs changemens en les sonmeltant loulcfois aux conclyyliologues; ciest de replacer dans le genre qui nous occupe phrieurs corquilles que les auteurs rangent habituellewent parmi les Yenus de Linné ou les Cythérées de La:uarck : ce sunt, pour les espèces vivantes, las Cylbérées borll rose et tégérine; et, pour les fos. siles, celle que dernièremeat MI. de Basterot a oommée Cytherea leonina, dans sou Mémoire sur les fossiles des euvirons de Bordeaux, el une autre espèce encore inélite de la roême lncalité qui a beaucoup de rapports avec la précédente. Si nous examinons ces espèces avec lont le soin nécessaire et comparalivement avec les Lucires, dous leur trouverons tons les caractères de ce genre: des cocquilles aplaties, orbiculaircs, rayonnantes, qui rout jamais plus d'une cu deax dents à lá charaière; une dent latérale plus éloignée que dans les Cythérées, qui présen'ent conjours ane grande impression musculaire antérieure en forme de languello; une impression du manicau simple sans la siuuosité plus ou moins profonde qui se remarque dans les Cylliérées a cu cúić posićrieur, et crui indique dans ce genre l'exis!ence des siphons; eufin l'intérieur de la cociuille parsemé de puints enfoncés, eatuurés d'un cercle plus ou moius régulier : caractice qui se retrouve dans presque tontes les Lucines, ct gुui iient bien probablement it une organisalion farticulice du manteau. Les cociuilles qui présentent tous ces caraclères appartenant si essenticl!ewent aux Lucines, ne peuvent en aucuse manière rester parmi les Cyiluérées. La seule objection five l'on pourioit faire, c'est que les quatre espèces que nous proposons de joindre aux Lacines noflient jamais qu'une dent latérale au lieu de deax qui caractériseat ordinairement les Lucines; nais celte anomalie, dans ces espèces, ne sauroit être un obslacle pour les remettre dans lenrs rappoits aturels, puisquelle a licu assez fréçueminent pour d'aulres cspàces qu'on n"a pas nacios rangées dans ce genre. Nous eiterons pour exemple la Lucina edentula, qui $\mathrm{L}^{\circ}$ it $\mathrm{ni}$ dents cardiallas, ni desls latérales; nous pourrions ajouter la $L_{i 2}$ cina Mlenardi, espèce fo-sile qui est dans le nème cas, et plusieurs autres. Si ces espèces restent parmi les Lucines, lorsque, à la rigucur, elles ea prézentent moins les caractères, pourquoi celles que nous proposons d'y introduire n'y seroient-elles pas admises?
La Lucina carnatia Lamarck ne peut rester paruni lcs lancines; elle n'ea présente pas les caractères, elle a bien plutót ceux des Tellines, parmi lesquelles on la reportera indubitablement Jorsqu'on l'aura examince avec rquelyue soin. Ce qui l'éloigue du premier alsord de ce greare, est l'impression siaueuse du mantea, qui a une échancrure trc̀s-profonde; ce qui l'en ćloigne encoste, c'est ru'elle est dépourvue de l'impiessiun musculaire linguiforme, antéricure; enlin elie a sur le côté l'iullexion ou le pli des Téllioes, il est vrai, très-fnibleweat prononcé, mais il n'en existe pas acoius.

\section{Lucise édeutée. Lucina edentula.}

L. testâ orbiculcso-ventricosá, subglobosá, intùs favescente; cardine edentulo; ano ininumo, hinceolato; striis concentricis, rugaformibus.

Venus edentula. Liv. Garr. $n^{\circ} .80$.

Lister, Conch. tab. 260 . fig. 96.

Cress. Conch. tom. 7. tab. 40. fg. 427-429.

LaMx. Anim. s. vert. tom. 5. pag. $540 . n^{\circ}, 3$.

Eücycs. 28f. fig. 3. a. b. c.

Vulgairement aummée l'Abricot, celle coquille est remarguable eutre les Lucines par sa charnière qui manque entièrement de dents cardiaules el latérales; elle est arrondie, lenlicnlaire, boubce en dehors, mince, d'une couleur fauveorangie, plus intease a l'intérieur des valves qu'au-dehors; les crochets sont médiocres, recuurbés sur le côté antérieur, el dominant une petice lunule dépriasèe, lancévlće, conprise alars une autre beaucoup pius grande, sulucordiforune, saillante au centre, $\epsilon \hat{t}$ vaguement indiquée par une sinuosité peu profonde. La surface extéricure est occnpée par ua grand nombre de stries fines et concentriques, souvent interrompues, el readues irrérrulières par des accruigseıncns assez grossiers. Le bord cardinal est étroit, arijué dans sa longueur; il ne présente ancune liace de dents artioulées. Malgré celle circonslance, on ae peut douter que celle espèce n'apfrartienge au genre Luciue, car on trouve dans l'intérieur des ralves les impressions ulusculaires tout-à-fait semblables à celles de ses congénères. Liimpression antérieure est très-grande, trèsélrcite; elle se prolonge depuis l'exlrémité du borll cardinal jusque vers la partje inférieure da bort antérieur; l'impression du manteau est simple comme dans toutes les Lucines; les bords s.is ilanchans et saas aucune dentelure. Cette jalie coquille provient, d'après Lamarck, des mers l'Anérique; les plus grands individus ont 55 millimètres de long et 60 de large. 1l existe aux environs de Bordeaux et de Dax une coquille fossile qui a beancoup de ressemblance avec celle. ci, mais qui néanmoins nous semble constiluer une espèce distiacte. 
2. Lucrese globuleuse. Lucina globulosa. Nob.

I. testi orbiculatâ, condiformi, globulosî, subspharicâ, tenui, fragili, tenuitcr striat $\hat{s}$, marqulatcrí; cundine edenlulo; intùs nargimobus longitudinaliter substriatis.

Cence Lucine fussile est la plus globuleuse de tontes celles que nous connoissons; ses ralses forment un héaispliére presque régulier; les crochets soul assez grauds, cordiformes, iuclicés en avant, au-dessus d'un enfoncenent 'unaire qui n'est paint limité en dehors, et se confond ainsi avec le reste de la surface extérieure. Celle surlace est cbargéc d'un graud numbre de stries transrerses, lives et rénulicies, très-serrées, qui sont le résultat des accrnissetocns; à l'intéricur, les valres sunt liuement ponctuées, et sur les bords on remarque quelques rides longiludiuales olssolètcs. L’impression musculnire antérieure est tròs-alongée, Jaciniće sur ses bords, arquéc dans sa longueur, et se dirigeant obliquement vers l'intćrieur des valves. Limpression musculaire postérieure est ovale, arrondie; le bord cardinal, arqué daos sa longueut, ne présente aucune trace de dents, soit cardınale, soit latérale; sa partie pustérieure est occupéc par une gontlière peu profonde, cachée par le reburd du corselet, et destinée ì donner altaclıe à un ligamont marginal alongé.

Cette coquille a de très-grands rapports avec la Lucina edentula, mais on la reconnnit a premier aperçu par sun extrêtne convexilé; elle est fossile des environs de Bordeaux. Sa longucur est de 45 millim. el sa largeur de 47 .

\section{Lucrne géante. Lucina gigantea.}

L. testấ hutissimâ, orbiculatâ, lcevigati, aliquandò subradiatá, intùs puncticulutâ; cardine edentulo; nymphis maximis.

Noв. Descript. des Cuq. foss. des env. de Paris, pag. 91. pl. 15. fig. 11. 12.

Cette coquille, la plus grande des Lucines, n'est pas connue depuis long-temps à son état parfait. Plus jeune et plus pelite, on pouvoil la confondre arec la Luciue changeante; aujourd'hui cette erreur est impossible : elle est lisse, ou seulement marquée circulairement par des stries d'accroissemeut qui sont craisćes par d'autres stries rayonaantes et superficielles qui s'aperçnireat à peine. Son crochet est petit, et la lunule à peine marqquée; la cliarnic̀re est sans dents. Des nymphes grandes et fort saillantes étoient destinées 2 donner insertion à un ligament qui devoit être très-puissant; le bard est lisse, mince et iranchant; tout le test est mince aussi. Tonte th surface intérieare comprise entre les iLpressions musculaires et celle du maateau, est pointillée irrégulièrement comme cela a lieu dans un grand nombre de Lucines; le reste de la surface inté- rieure est lisse; les impressions musculaites sont grandes, et celle du manteau est plus large quelle ne l'est ordinairement. Quel que soil l'âge de celte espece, jamais la charniere n’a de denis cardinales ou latérales. Je possede une vilve de celle coquille qui est couturnée sur cllc-méme de maničre a présenter assez bien la furme de la grande valve de la 'Tírébratule bisinuata.

Longueur 96 millimètres; la largeur cst de 98 envirua 3 pouces 7 lignnes.

4. Lucrese changeante. Lucina inutabilis. LABR.

L. testî̀ ovato-trunspersầ, conpressi, inarquilaterâ, oblaqua, lerviguti; cardine edentulo; numphis magnis, prominulis; umbonitus minimis, acutis; intus valvis radatim striatis.

Venus mutabilis. I.AMк. Ann. des Mus. tom. 7 . pag. bi. et tom. 9. pl. 32. fig. 9. a. b.

Lucina mutabilis. Ibid. Snim, s. vert. tom. 5. pag. 5 fo. $n^{\circ} .4$.

DEF. Dictionnuirc des Sciences naturelle's toni. 27 .

Noв. Descript. des Coq. foss. descno. de Puris, pag. 92. pl. 14. fig. 67 .

Trompé par une analogie de furme, Lamarck a confondu une seconde espèce avec celle-ci, ce qui lui a fait dire qu'étant jeune celle coquille avait des dents a la clarnière, quelles disparoissoient avec l'ige. Nais, conme l'observe MI. Defrance, qui le premier a fait comnoitre l'erreur, ce seroit le scul exemple que l'on pourroil cité d'une telle anomalie. Il est lacile de s'ussurer du fait, et j'ai réuni dans ma collection une séric d’individus de celte espèce à peu près à tous les ages, et aucun d'eux ne m'a offert de dents à la charnière. D'un autre cúté, en y portant sulfisamment attention, on saperçoit bientôt des diflérences constantes qui sépaı́nt les deux espìces, ce que l'on peut véritier en comparant la Lucina contorta à celle-ci. La Luciue cbangeante est grande, lisse, cu seulement marquée par des accroissemens quelquefois irréguliers; elle est ovale, obronde, inéquilatérale, déprimée, saus lunule; les crocliets sont petits, paintus, peu saillans, la cbarnière est sans dents, e!, comme dans l'espèce précédente, les nymphessont grandes et saillantes; mais proportionnellement elles le sont moins. 'Tout l'espace compris dans l'impression du mauteạu est comme haché par des stries fines, rapprochées et divergentes, qui rendent l'aspect de cette surface intérienre fort remaiquable. C'est la seule espece que je connaisse qui offre ce caractère. L’impression musculaire antérieare est fort langue et étroite; l'impression du manteau est indiquée par la terminaison des stries sar le hord, qui est tout lisse. Ce calactère des stries intérieares est saffisant pour faire recon- 
noilre l'espèce au premier coup-d'œil; car les plus jeuoes individus les aftrent aussi bicn que les plus grands. Longuenr $7^{5}$ nillim., largeur $9^{8}$.

5. Lucrix bossue. Lucina gibbosula.

L. testá ovato-obliquá, subanguluti, gibbos.i, luevigatâ; cardine subedentulo; dentibus lateralibus nullis.

Lamx. Ann. du Mus. toni. 7.pag. 239, et torn. 12. pl. 42. fig. 8 .

Der. Dict. des Scienc. nat. tom. 27.

Nов. Descriot. des Coq. Joss. des env. de Paris, pag. 95̄. pl. 15 . fig. 1.2.

On reconnoit facilenent celle espèce à sa forme peu régulière, subangulaire, à son manque de lunule, qui est remplacée par une lígère dépression. Les crochets sont petits et poinlus; sa surface extérieure cst lisse, ou seulement ınarquée par des accruissemens; sa clıarnière est quelquefois sans dents : on en voit cependant une petite cardinale sur quelques individus. les dents latérales manquent conslamment; le bord est mince, Iranchant, étroil; l'impression du nanteau est plutỏ indiquée qu'elle n'est maıquée; les impressions musculaires sont petites, el l'antérieure étroite et peu prolongée. Celle coquille est assez coormune, surtout à la Chajelle, près Senlis, où il n'est pas très-rare de la truuver complète. Elle est longue de 20 nillim. et large de 22.

6. Locise rénulée. Lucina renulata. Lask.

L. testâ suborbiculatâ, ventricosâ, licevigatâ, rquilaterali; cardine subbidentato; dentibas lateralibus nullis.

I.Awx. Ann. du Mus. tom. 7. pag. 239. $n^{\circ} \cdot 7$, et tom. 12. pl. 42. fig. 7. a. b.

Der. Dict. des Scienc. nat. tom. 27.

Nов. Descript. des Coq. foss. des env. de Paris, pag. 93. pl. 15. fig. 3. 4 .

Petite coquille très-lisse, ventrce, souvent diaphane, sans lunule, à crrcliet eullé, courbé, jroéminent, à cbarnière presque saus dents, me ou deux cardinales trés-peilies, rudimentaires, les latérales manquant loujours; les impressions musculaires sont petites, l'antérieure est tièstiroite et tres-pres du bord; celui-ci est lisse, très-entier et assez mince. Lamarck avoit considéré celie coquille comine l'analogue en pelit de la Lacina edentula; mais elle préseote aver. celie-ci des différ ences qui ne permettent pas de les réunir. Il n'en est pas de mème d'une espèce dun: je possède un individu complet, vivant: il ressemble tellement au fossile, que, sans la conleu: un peu plus jaunầre de celni-ci, il seroit absolument impossible de les distinguer. Je les considère donc comme des analogues parfaits; malheureusement j'ignore la patrie de la roquille vivante. Longueur 16 millim., largeur 18.

\section{I.ucrse lisse. Lucina lavigata.}

L. testá orbiculuri, depressâ, lasvigatâ; lunulâ nullâ; dente card!nal magno, profunde bipartito; dentibus lateralidus nullis.

Nar. Descript. des Coq. foss. des env. de Pans, pag. 94. pl. 15. fig. 9. 10.

Petite coquille lenticulaire très-distiocte dos espèces qui l'avoisinent, et surtout de la précédente, avec laquelle on pourroit la confondre. Elle est lisse et seulement marquée par quelques accroissemens; sa lunule n'est pas marquée; son crochet est très-petit, pen saillant; la lame cardinale est étroite, elle porte dans le milieu et sous le crochel deux dents cardinales, dont unc est fort petile, quelquefuis avortée, l'untre grande, profondément bifide; il n'y a point de deusis latérales. Les impressious musculaires sont petites; l'antérieure est presqu'aussi large que la pusiérieure, mais elle est plus longue. Le bord est sinple, large et mince. Elle est lougue et large de 12 millim.

\section{Jucrue de Mlínard. Lucina Menardi.}

L. testâ magnâ, orbiculatâ, subventricosí, aquilaterali, lavigatí; intiss puncticaís ruris, irregulariter spassis; cardine edentuls.

Noв. Descript. des Coq.foss. des env. do Paris, pag. 94. pl. 16. fig. 13. 14 .

Grande et belle espèce de Lucine : Irès-facile à recannoitre par la nanitre dani la lunnle el le corselet sont malquís; sa surface exlírieure test lisse; les stries qui sy voient ne sont que des accroissemens irréguliers. Le crochet est assez grand, et il paroît l'ŕtre plus par la manière doni il est délaclié de la luuulc el du corselet. l,uuvle grande, saillunte, indiquée par une ligne enfoncéc; corselet phus grand que la lunule, délaché comme elle par une linge profonde. La cliarnière dass tous les ázes est sirns dents cardinales el sans deats latérales; la nymulue est peu saillante et peu enfoncée. l.e bord est mince, Iranchaust, élroit, séparé parl'impression da nanteau, qui foruse unc bandelette assez large. Le reste de la surface interne est assez lisse; on y remarjue, cornme dans beaucisup de Lucines, des points épars et saillaus. Lianpression nusculaire intérieure est fort grande, placée assez près du bord, dont elle suit la direclion. Longueur 78 millim., largeur 84 .

\section{Lucine lacté. Lucina lactea. Lam}

L. testâ lentiformi, gibbâ, alhâ, pellucidu, transversim tenuiter striulá; umbonibus tumudis, uncinates; cardine dentilus duobus cardinalı! us instracto; lutetalibas nullis. 
I.Asx. Anim. s. vert. tons. 5. pag. 542. no. 12. Tellina lactea. Lis. Gurs. $n^{\circ} .69$.

Gualt. Test. tab. 71. fig. D.

Снемs. Conch. tom. 6. tah. 13. fig. 125 .

Excre1. pl. 284. fig. I. a. b. c.

Loripes. Pout, Test. tab. 15. fig. 28. 29.

Lucina lactea?" Paynaudeav, Catal. des Annal. et des Mfoll. de C'orie, pag. 41. no 67 .

Jamarck, dans snn dernier oustage, a placé celte coquille dans deux genres dillirens, dans les Auphidesmes el dans les loutraires, en cilant pour l'un et l'autre les mêmes ligures de b'oli : le double emploi est bien évident, et il a été occasionné par un caracicre auguel Lamarck a dnnné (rap) de valeur. Nous a vous vu, par la deseriplion de plusieur's espèces de Lucines, que le liganient, quoique véritahlement extórieur, f́toil cependant raché en dehors par le reloord du corselet, qu'il couvre presur'cntièrcment; cela est remarquable surloul dans les Lucina edentula, tigeruna, punctalu, elc. Dans relle-ti le liganent est encore plus cnfuncé el plus caclié que daas les espèces yue nous avons citćes: c'est celle circonstance qui aırra sans doute déterıniné Lamarık à placer parmi les Amplaidesmes cerlains individus, ct a en conscrver cerlaios aulres au nombre des Lascines. Puar nous, ces deax sortes d'individus conslituent deux espèces bien distinctes, appartenant au gente Lutirie; en les décriraut l'un et l'aulre unus ferons sentir lear dillérence, et l'on évilera ainsi lunte espèce de confusion à leur Buard.

Ia Lucinc laclée est une coquille orbiculaire, mince, blanche, diaphane, boubée, équilatérale, a crochets assez grands, oblique nent inclinés sur le còtć antéricur sur lequel il n'y a aucnue trace de luaule. la surface extćrieure est occupée par au grand nombre de stries irrégalières, trèsTines, trunsverses, plas nombreascs sur les crochets ejue partont allieurs, et souved interrorapues par des accruissemens. Le corselet recouvre en parlie le ligament; cependant il le laisse beancoup y'us à dicunvert que dans la plupart des espécés. Cieligament est assez lung, porté sur des nymples étroiles el visibles au dehors; les bords sunt simples, nunces et tranchans; la charnière est très-élroite, arquée dans sa longueur; elle préseate sous le cruchet deux petites dents divergentes, dont l'antéricure est bifide sur la valve gauche, tandis ģne c'est la postćrieure qui l'est sur la valve droile. A l'intérieur les valves sont lisses; l'impression palléale esl simple, ret les impressions musculaires sont presqu'éxales, fort lungues el pius larges que dans la plupart des espèces.

Celte coquille est le véritable Loripes de Poli, et il ne parait pas que l'espèce indiquée par
II. Payraudeau soil la même. D'apris le peu qu'il en dit, il est à présnmer que celle qu'il a eu en vue est le Lucinu radula de Lamarck: on peut in juger par la phrase suivante, qui est extraite de sou ouvrage: "Coquille convexe, épaisse, forle" ment striée en travers, les stries étant un peu " lamclicuses. "Cela ne peut s'accorder arec la descriprion que nous venons de donner, el ne peut convenir non plus à l'espèce suivaute.

La Lucine lactée est répandue dans tontc la Méditerianéc, el parnitroit exister aussi dans l'Océan enropéen; unais il seroit possille que par suice de la confusion à l'égard de celle especce, lcs auteurs y aieni rapparlé la suivante, glai se trouve en ellet daus mos ners.

Lamarck cite celle cspece à l'étal fossile, dans les fuluns de la 'Tourinine. Nous ne la conncissons pas de celle localité, mais nous lia possidons identiqucment senublable it celle achucllemeat vivante des terrains tertiaires de la Sicile. Longueur 23 millim., largeur 25.

10. Lucrse amphidesonoide. Lucina amphidesmoide's. Nив.

L. testâ orbiculatâ, locviter depressâ, lentiformi, albâ, substriatâ, cardine edentulo; fossula ligamenti obliquá, subinternâ ; intùs striis obsoletis radiantibus; impressione musculari anticẩ, angustâ, pràlongîa, obliquatî.

Amphidesma lactea. Lasr. Anim. s. yert. tom. 5. pag. 4 y. $\pi^{\circ} .3$.

Celle espice se rapproche de la précédente par sa forme extćrieure, mais elle est toujours moins bumbée, moins ablique et moirs inéquilatérale. Elle est arroodie, équilatérale, blanclıe, assez épaisse, subtransparente, et conrerie en deliors d’un grand noubre de stries irrégulières d'accroissement. Les crochets sont très - petits, à peine proéainens au-dehors, el renversés andessus d'une impression lunulaire très-petile, très-étroite et lancéolée; les valves à l'iutérieur sunt ponclućes; clans le centre et vers les bords on reunatque des stries obsolètes et rayonuantes, qui de se moutrent jauais dans la Lucha lactea. L'iapression nusculaire antérieure est ćtroite, arquée dans sa longuear; elle suil à sa partie supérieure la direction da bord, elle s'en délaclee casuite paur se porter olliquenent e tn dedans des valves. La charnière ne présente aucune dent cardiale, à moius qu'on ne puisse nommer ainsi un pelic labercule à peine saillaat, silué suas le crochet; sa partie postérieme est formée par une goullière oblique, assez profonde, cachée presque cumplètement au-deliors par le bord extérieur du corselet. Celte disposition particulière du ligament, ainsi que le manque total de deuts cardinales, suffisent seuls pon' distinguer celle espèce de la précédente.

La Lucire amphidesmoïde se troure aussi biez 
dans l'Océan européen que dans la Mécilerranée et dans les mers du Sénégal. Nous la connoissons fussilc dans les faluns de la Touraine, à Bordeaux, à Dax, en Piémout et en Sicile. Elle a 25 willim. de diamètre.

11. Lucrse divergente. Lucina divaricata. LANE.

L. testâ orbiculari, subglobosâ, albâ, antiguatá, tenui, bıfariäm obliquè striuts.

Tellira divaricata. Lis. Guel. $n^{\circ} \cdot 74$.

Boxsani, Recr. J. Jig. 349 .

Caens. Conch. tom. 6. pag. 134. tab. 13. fg. 129 .

ExcrcL. pl. 285. fig. 4.a.b.

Lucina divaricata. LAy . Ann. du Mus.tom. 7 . pag. 239 .

Ibid. Animl. sans vert. tom. 5. pag. $541 . n^{\circ} \cdot 7 \cdot$

Drf. Dict. des Scicnc. nat. tom. 27.

Parraudeau, Cat. des Ann. et des Moll. de Ciorse, pag. 42. $n^{\circ} .69$.

Curdium arcuatum. Mostage, Brit. zool. pag. 83. tab. 3. fig. 2.

Var. a.) Testâ crussiorc, dentibus lateralibus, cminentioribus.

Var. b.) Testá mininıá, strïs maximè undulatis.

Lucina undulata. Layx. Ann. dis _IIis. loc. cit. no. I1.

Lucina divaricata. Basterot, Mém. sur les env. de Bordeaux, Mém. de la Soc. d'Hist. nat. de Paris, pag. 86. $\pi^{\circ} .2$.

Sow. Miner. conchol. pl. 417.

Nos. Descript. des Coq foss. des env. de Paris, tum. I. pag. 105. pl. 14. fig. 8. 9 .

Espécc vraiment étonnante par sa dispersion presqu'universelle, tant à l'état vivaut qu'à l'état fossile. Elle est orbiculaire, lentilorme, assez ylobuleose, miace, blanche, et toujours facilemeat reconnoissable à la disposition particulière de ses stries; elle est écuilatérale; ses crochets sont petits, peu saillans; dès leor sommet un commeace à apercevoir des slries très - fines ployées dans leur longueur, dont une partie, plus courte, s'intléchit sur le côté autérieur, et l'au!re, plus alongée, se dirige obliquement sur le postérieur: ces stries sont profondes, plus on moins rapprochées selon les individus, souvent interrompues par des accroissemens plus ou woins maltipliés, qui divisent la surface en élages irréguliers. On n’apcrçoit aucane trace de lunule; le ligament, prolongé sur le bord, est presqu'eniièrement cacbé par le rebord du corselet; à l'intérienr les valres sont lisses et brillantes; l'impression palléale est presque toujours poncticulée;
L U C

les impressions musculaires sont égalcs, érroitcs, supcrticielles, l'autérieure plus oblique, el sc dirigeant vers l'intérieur des valves. Le luord cardinal est Etroit, arqué daos sa longueur; il présente sous le crocliet use petite dcat cardiuale sur la valie droite, et deux pelites dents divergentes sur la gauclue. Dans la plupart des individus les dents latéralcs manquent toet-à-fait, ou l'on n'en retrouve que les rudimens. Dans quelques variétés fossiles qui olfreut un tcst beaucoup plus épais et un bord cardinal plus larue, on tronve les dents latérales bicn distinctement forarées; dans d'autres enfiu, evalement fusiles, la dent latérale antérieure seule existe, la postcirieure est obsolćte ou manque eulièrement.

Nous aurions pu indiquer un plus grand nombre de variétés, mais comme les variations nont lieu qu'à l'égard des stries qui sont plus ou moins noznbreuses et de l'existence des dents latérales, assez variables, comme nous l'avons vu, nous croyons qu'il suffit d'iadiquer ces éléreas de variation dans les caractères pour qu'ils ne portent aucun obstacle à la dútermination de l'espjèce et de ses variétés.

On trouve cellc coquille dans l'Ocćan européen, dans la Méditerraucé, dans l’Océan indieu, dars les uners du Brésil, et jusque dans l'Océan austral. A l'état lossile il a'est presque point de terrains tertiaires en Europe où on ne la rencontre eo plus ou moins grande abondance; elle est combune en Frauce aux environs de Paris, de Valoznes, de Bordeaux, de Dax, de Monspellier, de Perpignar, et dans lus laluos de la Tuuraine. On la trouve aussi en Belgique, en Allemagne, aux environs de Baden, de Vienne et en Silésie, én Angleterre, dans l'argile de Londres. Oa la retrouve encore aux environs de Nice, dans le l'sémont, à Asti, dans tous les terrains terlinires de l'lalie et cenx de la Sicile. Celle espice est, commc on le voit, une de celles qui pourroieut le roieux caractériser l'ensemble des terraios tertiaires; ce qui est dù à l'étoonante lacilité qu'elle avoit autrelois, comme actuellemeat, de supporter des variatiuns de climat fur coosidérables. Loogueur 28 millim., largeur 30.

12. Lucrve écailleuse. Lucina sqquamosa. Lazx.

L. testa suborbiculatâ, tumids, incequlcaterali; costellis radiantibus, ambricato-squamosis, squamis minimus, numerosissimis; wuo vulusque excastatis.

LAuk. Anim. s. vert. ton. 5. pag. $5 \dot{42 .} n^{\circ} .11$. Escrcs. pl. 285 . fig. 3. a. b. c.

Lucina reticulata!" Parraud. Catal. des atma. et des Moll. de la Corse, pag. $4 \overline{3}$. no 70.

Nous présumoas que la figure que donde Bruguière dans les plancbes de ce Dictionnaire représente celte espèce grossie, car nous ne l'avcug jamais 


\section{U C}

janıais vue aussi grande que celle représentće; peut-être que la Lucina reticulata de H. "'ayraudeau est la même que celle-ci; on peut le cruire, du moins d'après le peu qu'il en dıt : il serrit possible aussi que ce lút une variété de la Iancine réticulée de Lamarck. La Lucine éc:ail!euse est une jolie coquilie d'un beau blanc de lait; elle es! oıbiculaire, inéquilatérale, un peu plus large que longue; ses crocliets sont très-petits; ils doninent cependaut une petite lunule ovale, lancéolie el déprimée; la surface extérieure est régulière nocnt réticulée par des côles longitudinales, layonnanles, coupées en travers par un grand noubre de stries écailleuses, ttès-fines et ırèsrapprochées; à l'intírieur la coquille est loute blaoche; l'impression musculaire antérieure est extrèuncment élroile, arquée clans sa longuenr el fort alongre; la charniére est étroite; on voit sous le crocliet deux uès-petites dents cardinales, divergentes, et aux extrémités du bord cardinal une dent latérale, saillante et pointue; la dent latérale antérieure est un peu plus écartée que la postérieure; les bords sont simples ou à jeine crénelés dans equelques individus.

Ceite coquille, rare sur nos cótes, est plus commune dans la Mediterrance; elle se trouve priacipaleruent en Sicile : nous l'avous fossile du uérue endioit.

Les plus grands individus que nons ayous vus ont 16 millim. de longueur et 18 de larye.

13. Lucine muli-lamellée. Lucina multilamellota. Noв.

L. testá magnâ, subrotundat $i$, lentiformi, conve.2nusculd, striis lamellosis numberosis transversis ornatá; unbonxbus acutis, recurvis; lunula minimi, pmfundissims, lanceolatâ, ano sinuoso; malginibus integris; cardine bidentato; dentubus latcrulibus mullis.

Nous n'arons encore vu qu'un seul iudividu de certe belle rsjece : il est fossile des envirous de Bordeaux. Il est arrondi, leuticulaire, régulièrement cnorexe, et orné à l'extérieur d'uo grand nombre de lames concentritgues, minces, relevées, mulippliées, surtout rers les bords, où elles devienneut plus irrégulières par suite des accroissemens; les crocbets soot proéminens et pointus, inclinés intérieurement au-dessus d'une perite lunule lancéolée, très-profondénent excauśe; le cólé postérieur est occupé par un corselet indiqué par une sinnosité qui s'étend jus. ṛu’à l'extréninté du bord inférieur, dans laquelle lus lames transverses s"ufféchissent; les bords sunt simples dans toute leur étendue; dans le milieu des valves on temarque, irrégulièrement épar'ses, un assez groud nombre de ponctllations entourées d'un cercile un peu dépriané; l'impiession musculaire antérieure est extréoment longue, fort étroite, courbée dans sa longueur; la charnière Hist. Nat. des Vers. Tome II. est dépourve de dents latérales; elle ne porte que deux petites dents cardinalcs, divergentes; la nymphe du ligament est courte ef saillante. Ce ligament étoil caclié en grande partie par le bord supéricur du corseles, creusć à l'intérieur en une large rignole destiuéc à le conteuir.

Cetle belle ct rare coquille est une des grandes espèces du geure. Voici les diacusions d'un individu complet que nous possédons : longueur 83 williu., largeur 8 1.

14 Lucine albelle. Lucina albella. Lasк.

$L$. testâ orbiculatâ, reniformi, subcompressí, lceviusculá; lunula minimà, depressá; cardine bidentato; dentibus lateralibus perspicuis.

I.Aхк. Ann. du Mus. tom. 7. pag. 240. $n^{\circ} .8$, et tom, 12. pl. 42. fig. 6. a. b.

Def. Dict. des Scienc. nat. tom. 27.

Nов. Descript. des Coq. foss. des env. de Paris, pag. $9^{5}, p l, 17 \cdot$ fig. 1.2.

l'etite coquille peu remarquable, assez aplatie, lenticulaire; sa surfice extérieure est lisse, sillonnée de quelques accroissemens; ses crochets sout petits, peu saillans, acumines; la lunule est ¿́galement petite, lancéolée, entuncée; le corselet est simple, oon saillant; la charnière a dans le milieu une ou deux petites dents cardinales; les dents latérales sont constantes. L'impression musculaire antérieure cummence trèshalit, presquan-dessous de la lunule; elle est petile el souvent divisée en deux parties dans sa largeur. Lamarck avoit fait une variété avec des individus un peu plus déprimés; je ne pense pas que celle seule différence suffise pour la conserver. Longueur 13 millim., largeur 15.

\section{Lucre subuigone. Lucina subtrigona.}

L. testi depressâ, ląvigatâ, subtrigoná; lunulâ ovatâ, subdepressá; cardine bidentato; dentibus. latemalibus nullis.

Nов, Descript. des Coq. foss. des env. de Paris, pag. $95 . p l .16$. fig. 15.16.

Pelite coquille très-déprimée, d'une forme subrrigone, ayant le crochet petit et courbé, toute la suıface extérienre lisse, une lunule ovale marquce par une ligne eofolscée; le bord est entier, étroit, séparé de la surface interne par l'impression du manteau; la clarnière est étroite, saus dents latérales, jrésentant deux petiles dents cardinales, divergeutes; les impressions musculaires sont écartées, petites, et l'antérieure est fort étroite et assez courte. Longneur 12 millim., largeur 84.

16. Lucise calleuse. Lucina callosa. Nов.

L. te:iâ obliquè trigonâ, lavigatâ, intùs callosá; umbonobus prominulis, recurvis; lunula $\mathrm{Bb} \mathrm{b}^{*}$ 
nuagnâ, cordatá; cardine obsoletè bidentato; impressione musculuri anticâ, transversâ.

Venus callosa. Lamx. Ann. du Mus. tom. 7 . pag. 130 , et toma. 9. pl. 32.fig. 6. a. b.

Ibid. Anim. s. vert. pag. 608. $n^{\circ} .5$.

DeF. Dict. des Scienc. nat. tom. 27. pag. 272.

Noв. Descript. des Coq. foss. des env. de Paris, pug. 96. pl. 17. fig. 3. 4. 5 .

Lamarck avoit à tort placé cette coquille parmi les Vénus; elle porte tous les caractères des Lucines. M. Delirance a donc eu raison d'iadiquer sa place daus ce genre; mais, malgré scs rapports a vec la Lucine bossue, son épaisseur et sa forme plus a:! guleuse ne sulfiroient pas pour la distinguer, sil ne venoit se joindre plusieurs caracières plus inportans à ces premiers. Ainsi, le crochet est loujours plus proéminent, la lame cardiuale plus large, plus épaisse; il y a constamment une lunule fort grande, cordiforme; le corselet est indiqué par une dépression aussi constante gue la lunule, ce qui n'a jamais lieu dans la Lucine bossue. La cliaroière présente des deots cardinales au nombre de deux; elles sont quelquefois eflacées dans les vieux jadividus, mais jamais au point de ne plus en trouver les vestiges. Un autre caractère non moins saillant est la position transverse du muscle antérieur, qui, dans aucune autre espèce de Lucine, ne l'est autant que dans celui-ci; elle est aussi remarquable par les callosités de inatières calcaires qui s'observent dans l'intérieur des valves.

Longaeur et largeur 15 millim.

17. Lucine élagée. Lucina scalciris.

L. testầ orbiculatí, convexî, crebris striis lamellosis ormutâ, sapè interruptis accretionibus scalariformibus; umbonibus minimis, subrectis; cardine bidentato; dente laterali unico.

Nов. Descript. des Coq. foss. des onv. de Paris, pag. 96. pl. 15. fig. 7. 8.

M. Defiance avoit uinsi nommé depuis longtemps celte espèce dans sa colleclion. Recueillie d'abord dans une localité où elle est consıamment étirgée par des accroissemens parallèles à ses bords, elle nous avoit d'abord paru constituer une espècé particulière; mais depuis, l'ayant comparće avec une espèce que l'on rapportoit à la Circinaire, nous avons reconnu une espèce distincte, qui a beaucoup de rapports avec la Lucine élégante, dont on la distingue néanmoins avec facilité. D'abord, celle - ci a'a point de lunule, elle est moins mince, moins convexe; son crochet est plus droit et moins grand; ses stries sont muins nombreuses et moios régulières; la lame cardinale est plus large; elle présente, immédiatement sons le crochet, deux pétites dents abliques; des dents latérales, l'antérieure est bien prononcée, la postérieure est souvent indiquéc par un petit mamelon; du côté de la lunule on remarque quelquefois, et cela n'a rien de constant, une ligne déprimée, oblique, plus ou moins irrégulière, que l'on pourroil prendre pour une véritable lunule, mais qui n'en est point une. Longueur et largeur 22 nullim.

18. Lucrne sillonnće. Lucine sulcata. Lamк.

L. testâ orbiculatâ, sublongitudinali, transversim sulcati; umbonibus uncinatis, recurvis; lunula nullâ; dente curdinali unico, variabili; dentibus lateralibus nullis.

Lasr. Ann. du Mus. tom. 7.pag. 240. no.12, et tom. 12.pl. 42. fig. 9. $a . b$.

DEF. Dict. des Sc. nat. tom. 27.

Nов. Descript. des Coq. foss. des env. de Paris, pag. 97. pl. 14. fig. 12. 13.

Le facies de cette coquille la fait reconnnitre très-facilement, car elle est la seule, parmi les espè̀:es fossiles de ce geare, qui ait plus de lıngueur que de largeur; elle se reconnuit aussi par ses stries rígulières, concentriques, émoussées, non !nelleuses, quelquefois interrowpues par des accroissemeos; son test est fort épais; son croclsel petit et recourbé; la charnière ne présente qu'une seule deat cardiuale qui n'existe pas dans tons les individus; les dents latérales manquent toujuurs; l'impression musculuire antírieure est fort étroite et peu longue; le bord est légèrement plissé à l'endroit de l'impression dı manteau. Lungueur 18 millim., largeur 16.

19. Lucine divisée. Lucina bipartita. Der.

L. testâ orbiculatâ, convexâ, luteâ, bipartitâ; umbonibus inflatis, recurvis; lunulá nullâ; curdine obsoletè, bidentato; dentibus lateralıbus nullis; callo magno, fusco ad impressionem muscularem anticam.

Der. Dict. des Sc. nat. tom. 27. pag. 276.

Noв. Descript. des Coq. foss. des env. de Puris, pag. 98. pl. 16. fig. 7. 8. 9. 10.

I a Lucine divisée est très-remarquable; elle est la seule, parmi loutes les espèces du genre, qui ait la singulière propriété de se dédoubler, comme le funt quelques Corbules; son test se parlage dans son épaisseur en deux parlies: l'une, très-nince, jaunâtre, extérieure, striée, trèscaduque et très-tiagile, ne se voit en place que très-rarement; l'autre, au contraire, plus éprisse et blancbe, murquée par des accroissemens, constitue la coquille; elle est arrondie, réniforne, très-convexe; les crocbets sont recourbés, assez grands, et d'une couleur brun-rosé lorsque la couclse extérieure manque; la charnière n'uffire que denx petites dents cardioa'es, et jamais de dents latérales; les impressions musculaires son 


\section{U C}

petites, l'antérieure n’est guère plus grande que a pustérieure, arais elle présente cela de remarquable, qu'clle est placée canstanacent sur une callosité brun-lauve qui s'ćteud jusqu'au-dessous du crochet. Longueur 23 nillius., largeur 25.

20. Locine virginale. Lucina virginea. ов.

L. testâ orbiculari, depressí, albî, transversim stricato-Lumcllosa, longztudinaliter argutissime struti ; unubonibus minumis, cacutis; lunuli cordut $\alpha$, inedio exsertiuscula; ano simplics, roseo tincto.

Coquillc élégante, doal nous se trouvons nulle part la ligure, et qui prubableruent est nouvelle; clle a quelques rapports avec la Lucina radula. Elle est urbiculaire, lentiforme, déprimée, équilatćrale; ses crochets sout petits, pointus, cuntuurnés au-dessus d'une luaule médrocre, comprimce et cornme piacée, saillante dans son militu, et indiquice au-dehors par un pli sinueux. Le corselet est simple; ses bords couvrent en parlie le ligament, et ils sout teintés legèremeat de rose. Lia surface extérieure est couvelte d'un très-graud nombre de stries lamelleuses, élégantes par lcur régularité. Si l'on exanine cette surlace avec une lurte loupe, ou y observe un nombre considérable de strię longitudinales trèsfines et très-serrées; à l'intérjeur tout le centre des values est ponclué à la manière de la Lucine de la Jumaique. L'impression musculaire antér.eure présente celle particularité remarquable, de remonter sur uoe parlie du bord cardiaal sur leyuel elle creuse une fossette ublongue. Nous croyons que cette espèce est la seule qui présente ce fait curieux. La charnière est assez large; on y trouve suus le crochet deux petites dents curdinales divergentes, olssolètes; anlérieureasent, le bord supérieur de la fosselte du muscle s'ćlève et sert de deat latérale; la dent latérale postérieure nanque; les bords sont simples, mintes et tranchans. La couleur de celte espèce es! uniformémeat d'un blanc pur en dedans el en dehors, si ce r'est vers le crochet, où se trouve une tache rose.

Celle coquille a été recueillie à Amboine par notre arni M. Lesson, qui a eu la bonté de nous Ia communiquer. Elle est longue de 49 millim. et large de 5 .

21. Lucıne de la Jamaïque. Lucina jamaicensis.

L. testí lentiformi, scabrâ, sulcato-lamellosí, intius subluted; lumellis brevibus, concentrucis; lutere antico utrinquè angulato.

Venus jamaicensis. Cresn. Conch. tom. 7. pag. 24. tab. 3g. fig. 408.409 .

Ibid. tab. 109. fig. 1943.1944.

Excres. pl. 284. fig. 2. a. b. c.

ListsR, Conch. tab. 300. fig. 137.
Ecden b.) Testâ intìs flavî̀, scabrî.

Eadem c.) Testiminore, intus extusque candils. Lams. Anim. s. yert. ton. 5. pag. 5og. "n. 1 .

La Lucine de la Jamaïque cst une coquille suborbiculaice, yuelyuefois ovale tratsversalement, déprimée, régulierrnut couvexe, à test peu épuis; la surlace ex:ćrieure es! chargée de stries lanclleuses, tansverses, irrégulières, qui soot le tésultat des acceroisseareos; les crocliets sont pctits, lisses, peu suillaus au-dehors du bord cardinal; la lunule est grande, lancéolée, saillante dans le milieu, indiquée par use dépression qui, autérieureusent, lurme un adrle obtus en se joignant avec le bord antérieur. Le corselet est très-graad, limité, comase la lunule, par une dépression, mais plus ueltement indiqué à cause du sillon qui le termine. $\Lambda$ l'intérieur les valve's présentent dans le nilieu da limbe un graad nombre de petites ocelles sailiantes, déprimées au centre par un peint enfoncé. Limpression musculaire antérieure est lort alongée, peu écarlée du bord; la postérieure est arruudie. La charnière ollie sous le cruchet une seule deat obsolète sur la valve dioile, et deux petites den:s divergentes sur la gauclıe; les deuts Iatérales soni très-prouoaćes, l'antérieure surtout, qui est la plus rapprocbée des cardinales, est Jort saillante, oblongue, sa base faisanı une légère saillie à l'intírieul: Le ligaaient est grand, caché presque complètement par le rebord supériear du corselet. La couleur de celle coquille est peu variable; elle est d'un beau jaune d'abricot, surtout à l'intérieur et vers les trurds. Ceux-ci sont simples dans tonte leur étendue. La seconde variété indiquée par Lamarck est toute blanche. C"est principalement dans les mers de la Jamaïque que se truuve cette espèce, l'une des plus cominures di1 genre. Les plus gradds individus ont 70 millim. de loog et 87 de large.

\section{Lucine ratissoire. Lucina radula.}

$L$. testâ orbiculat $\hat{a}$, lentiformi, convexâ, albidi, lamellis concentricis numerosis regularibus ornatâ; striis raduntibus, obsoletis margine interiore valvarum; lunulâ lanceolatî, depressa; cardine bidentato; dentibus lateralsbus nullis.

Lank. Anim. s. vert. tom. 5. pag. 541 . no. 5.

Tellina radula. Moxtagu, Test. brit. tab. 2. fig. 1. 2.

Maтно, Act. Soc, linn. tom. 8. pag. 54. $n^{\circ}$. 12.

Pet1v. Gaz. tal. 93. nc. 18.

Coquille que l'on Ireuve sur une grande partie du littoral de l'Océan européen. Nous la connoissons depuis les côtes de Norwègre jusquà celles d'Espagne. Malgré cetle grande dilférence dans sa siluation, Dous l'avons trouvée lrès-peu $\nabla a-$ $\mathrm{Bbb}_{2}$ * 
riable, même ponr la taille. Cette coquille est route blanche; elle est orbiculairc, lentiforme, régulièrement bombée; ses crocliets sont petits, très-peu saillans an-dessas da bord; on les voit s'incliner au-dessus d'une perite lunule enfoncée, Jancéolée et toule lisse. Le corselet est fort grand, légèremeut indiqué par un sillon peu approfondi, qui, en aboulissaut sur le bord, y produit une petite sinuosité. Ce corselet contient supérieurement un ligament alongé sul le bord, presquantièrcment recouvert par" le bord saillant du corselet. La surface extérieure est ornée d'un grand nombre de stries lamelleuses, conceniviques, régulières, fines, dans l'intervalle desquelles on remarque souvent des stries transverses extrêmemen I fines. A l'intérienr la coquille offie quelques stries longitudinales, obsolètes, beaucoup plus marquées sur les bords que partont zilleurs. La charnière est étroite; elle est dépourvue de dents latérales, et elle porte sous les crochets une seule dent sur la valve gauche et deux petites dents divergentes sur la druite. L'in. pression musculaire anterieure est furt étroile, et se dirige obliquement dans l'intérieur des valves. Les plus grands iodividus out 42 millim. de diamètre.

\section{La $\mathrm{AT}$.}

23. Lucine concentrique. Lucina concentrica.

L. lestâ orbiculatâ, lentiformi, subconcexâ; lamellis concentricis, elevutis, distantibus; striis longitudinalibus, ad interstitia minutissimis; lunulâ vix perspicuâ; nynuphis profundissimis, tectis.

Lucina. Excrce. pl. 285. fig. 2. a. b. c.

Lamк. Ann. du NTus. tonv. 7. 238, et tonz. 12. 20l. 42. fig. 4. a. $b$.

DEF. Dict. des Scienc. nat. tom. 27.

Noв. Descript. des Coq. foss. des env. de Paris, pag. 88. pl. 16. fig. 11. 12.

Belle coquille de forme lenticulaire, dont les crochets sont fort peu saillans; elle est ornée extérieurement d'un grand nombre de lames élevées, concentriques, assez régulièrement espacées, distan!es, entre lesquelles s'aperçoivent des stries longitudinales très-tines, qui ne se voieot bien qu'i l'aide d'une loape; le bord est assez large et assez régulièrement plissé, dans les vieux individus, à l'endroit de l'insertion du mantean; la lawe cardinale est large, elle porte sous le crochet deux dents cardinales, une dent latérale antérieure très-forte, et une dent postérieare toujours avortée; les nymphes sont obliques, peu proéminentes, très-enfoncées dans le corselet, qui les recouvre presqu'entièrement. Longueur et laryeur 40 millim. Coquille fort commune dans tous les dépôts coquilliers du calcaire grossier du bassin de Paris.
24. Iucixe contournée. Lucina contorta. DEF.

L. test $\hat{~}$ orbiculato-subtransversâ, angulutâ, depressâ, striato-sublamellosâ; striis distinctis, separatis; lumulà lanceolatâ, pmfundá; pube prominenti; cardine bidentato; dentibus lateralibus nullis.

DEF. Dict. des Scienc. nat. tont. 27.

Var a.) Testí sublwevigatî, parte anteriore striati.

Và l. ) Testâ sublarvigatâ, unsbonibus mina. ribus, lunulâ zix perspicuá.

Nов. Descript. des Coq. foss. des env. de Paris, pag. 99. pl. 16. fig. 1. s.

C'est avec juste raison que Mt. Defrance a séparé celle espèce de la Lucine changeante; elle oflre en effet des caraclères assez constans pour qu'on la distingue désormais a vec facilité : elle est moias trausverse et moins inéquilatérale; les crochets sont plus suillans; elle est presque toujours colsverte de stries lamelleuses, on du moins elles y existeut constamment à la partie antéricure; il y a une luaule prufonde et constante. Le corselet est indiqués par une dépression, et il est saillant. La charnière a constamment, depuis le plus jeune àge juscyü la plus grande taille, qui est tonjours beaucoup moindre que dans la Lucine changeaute, deux dents cardinales bien marquées, jamais de dents latérales, des nymphes qui sont moins saillantes, reccuvertes profoudément par le corselet. A ces différences spécifiques, on peut ajonter que jamais la Lucine contonrnée a'a à l'iotérieur les stries divergentrs et harhées que présente consta wanent la Lucine clangeante. Liorpression musculaire est aussi moins longue et plus large inférieurement : ce qui est l'inverse dans l'espèce à laquelle nons la comparons.

La variété a ne se distingue que par un peu plus de grandeur, et par ses sllies, qui ne sont bien marquées qu'i la parlie anlirienre, le reste de sa surface élant presque lisse. La variété $b$ pourroit peut-être constituer une espèce, car elle a les crochels plus pelits, la lunule à peine sensible, la lame cardinale plus étroite, et sa surface est presque lisse. Longueur 45 millimètres, lasgeur 50.

25. Locrie des pierres. Lucina saxorum. Lasx.

$L$. testis orbiculatí, anticè subangulate, lentiformi; striis tronsversis, tenuissinis, vix separatis; umbonibus mininis, recunvis; candine bidentato; dentibus lateralibus subnullis; nymphis inagnis, prafundis, tectis; lunulá et pube proemirentibus.

Lucina circinaria. Laar. Ann. du MLus.tom. 7 . pag. 238.

Ilid. Dep. Dict. des Scien. nat. tom. 27.

Var. a.) Testâ compressiore, striis absoletis. 
Lacina saxomm. LAmк. Ann. du Mus. loc. cil. $n^{\circ} .4$, et tons. 12. pl. 42. fig. 5. a. b.

Noв. Descript. des Coq. foss. des env. de Paris, pag. 100. pl. 15. fig. 5. 6 .

Après un examen attentif de la Lucine des pierres el de la Lucine circinaire, il est impnssible, lorsqu'on les a l'une et l'autre en bun élat, de tronver une diflérence suffisante pour en faire deux espèces. En comparant la description qu'eu a donnce Lamarck dans les Annales, on verra que les dillërences principales proviennent des localités et surtout du gissement, et j'en suis d'antant plus persuadé que jai comparé les types des denx espèces dans la collection de M. Defrance. La I ucine des pierres est orbiculaire, lenticulaire, subangulcuse antérieurenent et un pen simneuse postérieurement, assez aplatie, élé.ọmment striće; les sties sont très-fines, régulières, très-rapprochées; les crochets sont petits, courbés; la lunule est saillante, ainsi que le corselet : ils son iudiqués par une liune déprimée; la cliarnière porte deux dents cardinales et une dent latérale antírieure, le plus souvent avortée; la nyauplie est grande et reconverte par uue portion du corselet. Lu variété ne differe que par un peu plus d'apiatissement et par des stries un peu moins nombreuses. Longueur et largeur 27 millimètres.

26. Locine élégante. Lucina elegans. Dep.

L. testà orbiculatâ, striatâ, compressâ, tenui, sappd intùs puncticulatâ; umbonibus minimis, recunvis; lunulâ nuinmâ, profundissimâ; curdıne edentulo.

DEF. Dict. des Scienc. nat. tom. 27.

VAr, a.) Testä compressiore, latiore, suborbiculatâ.

Lucina complanata. Laxis. Ann, du Mus. ton. 7. pag. 24l. $n^{\circ} \cdot 12$.

Nов. Descript. des Coq. foss, des env. de Paris, pag. 101. pl. 14. fig. 10.11.

Depuis long-temps Lamarck avoit établi, dans les Annales, une espèce, sous le nom de Lucine uplatie, pour une coquille dont il u'avoit vu qu'une ou denx valves; il l'avoit caractérisée par conséquent d'une manière incomplète; depuis, cette espèce ayant élé retrouvée plus purfaite et plus grande, M. Defrance a cru pouvoir la distinguer sous le nom de Lucine elégante; mais ayant sous les yeux les igpes de la Lucine aplatie de Lamarck et de l'élégante de M. Defiance, nous zvons pu juger, aprés un examen altentif et scrupulenx, quelles devoient constituer une mêtre espère, dont la Lucine aplatie n'est qu'une variété. La Lucine élégante est circulaire, couverte extérienrement de fines stries lamelleuses, bien distinctes et fort régulières, d'autant plus fines qu'elles se rapprochent des crochets; ceux-ci soat petits, conrbés obliquement; la lunule est petite, ovale et lrès-eufoncée; le corsclet est simple, non marqué; la charnière présente quelquetois une très-petile dent cardinale et jamais de dents latérales; à l'intérieur on rcmarqque des poinis saillans comn:e dans beaucoup de Lucines, Longueur 19 millim., largeur 20.

\section{Lucrie agréable. Lucina grata. DeF.}

L. testî urbiculatí, tenui, depressá, tenuissimi et regulariter striutá; lumulì minimâ, depressia ; cardine bidentato; dentibus laterulubus obsoletis.

DEF. Dict. des Scienc. nat. tom. 27.

Noв. Descript. des Con. foss. des env. de Paris, pag. 101. pl. 16. fig. 5.6.

Coquille agréable par la fiuesse el la régulariló de ses stries Iransverses; clie est fort nince, trc̀sliragile, de forme orbiculaire el très-déprimée; son cruchet est très-petit, ainsi que la lunule, qui est enfoncée; le corselet n'est indiqué par aucıne dépression; la clarnière a le plus souvent deux dents cardinales, quelquefois il n'y a qu'une des deux dents latérales; la posiérienre mauque presque toujours, et l'antérienree st snuvent radimentaice ou manque tolalement, quoiquion la trouve d'autres fois dans tout son développement; l'impression musculaire antérieure est demi-circulaire. Ce u'est peut-êtle qu'une variêté de l'espèce précédente. Longueur et largeur 27 à 28 millim.

\section{Locine ambiguë. Lucina ambigna. DrF.}

L. testâ orbiculatâ, lentiformi, spissâ, striatá; striis transversis, tenuissimis, distinctis, subbamellosis; umbonibus minimis, recurvis; cardine subtridentato; deritibus lateralibus nullis; nymphis profundissimis, tectis; lumulà et pube lineâ subdepressâ indicatis.

DEF. Dict. des Scienc, nat. tom. 27.

Nов. Descript. des Coq. foss. des env. de Paris, pag. 102. pl. 17. fig. 6.7.

Cette espèce est intermédiaire entre la Lacine concentrique et la Lucine de Fortis; elle a la même taille, mais elle se distingue facilement de l'une et de l'autre : ses stries son plus nombreuses, plus rapprochées el muins lamelleuses que dans la concentrique; elles sont aussi nooins régulières. La lunule et le corselet sont proéminens, mais foiblement indiqués par une ligne déprimée. La lame cardinale est large, non séparée par la cavité du crochet, qui est nulle; elle est munie dans le milieu de trois dents cardinales; elle ne porte point de dents latérales. La nymphe est grande, arquée, très-profonde et enlièrement recouverte par le bord du corselet, à tel point que dans l'élat frais, le ligament devoit être entic̀rement caché. L’impression musculaire antérieure est plus grande, plus large et moins oblique; elle se distingue de la Lucine de Fortis principalement en ce que celle-oi est plus convexe à la luaule et le corseles 
bien plos grand, les strics obsolètes et la charnic̀re sans dents. Elle est longue ct large de 43 millim.

29. Lucre de Fortis. Lucina fortisiana. Det.

L. testá orliculatâ, convèrá, obsoletè striatâ; lunulì ct pube proeminemibus, scparatis lineâ profundâ; cardine edentalo; imipressione pallii plicalú.

DEF. Dict. des Scienc. nat. tam. 7 .

Non. Descript.des Coq. foss. des env. do Paris, pag. 102. pl. 17. fig. 10. 11.

Je conserve quelqnes doutes al l'égard de celle caquille; ce puurroil étre une forte variélé de la Lucine de Ménard, mais je ne puis en avoir la preuve, nayant sous les yeux qu'une seule valve de celle especce. Je la duis à l'oblineance de M. Defrance, qui a bicu vonlu me la communicuer. Elle est de forme circulaire, et beaucoup plus convexe que la Lucine de Mlénard; elle est couverte extéricurement de stries irrégulières, interrompues par des accroissemens. La furme du croclict de la lunule et du corselet est à peu prés la mêrue. La charaic̀re ne prósenie qu'une seuie jecite deat rudimentaire et poirst de dents latérales. A l'intérieur elle est lisse el paroit dépourvee des points épar's que nous avons remarqués dans la Lucine de Ménard. L'ieupression muscnlaite antérieure est lon't grande, bieu plus étroite c: en saillie; l'impression du manteau est irrégulièrement plissee. Longuenr el largeur 50 milliu.

50. Lucine à crocbet. Lncina ancinata. Dez.

L. Lestâ suborbiculatâ, dcpressú, fragili, tezisissimè striatá substrutáve; umbanibus magris, uncinatis; cardine unidentulo; dente bifido, dente laterali antico variabii, postico nullo; rismphiss profundis, tectis; lunulâ ovatâ, profirnda.

DEF. Dict. des Scienc, nat. tom. 7 .

Noв. Descript. des Caq. foss. des envinons de Parjs, pag. 103. pl. 26. fig. 3. 4.

La forme de celle coquilte la fait facilement reconnoille; ses grands cruclets courbés véritablement en crochets, sa lunule petite et profonde, sa surface couverte de stries très-fines, quelquefois obsolètes, sa charnière qui ne porte qu'une seule dent cardinale bifide, sont les caracteres principaux quila dislingueut des autres espèces du méme genre. Des denis latérales, l'antérienre seule existe; tantôt ellc est assez bien prononcée, daatres fois elle est rudimentaire. Les nymphes sont grandes, saillantes, courbées, très-profondes, et entièrement cachées par le bord dn corselet : entre elles et ce bord, on voit nne goultière assez profunde dans laquelle étvit placéle ligament, qui pouvoil à peine s'apercevoir iu-dehors lorsque les valves étoient fermées. L'im. pression musculaire antérieare est assez grande, érvite et peu courbée. Longueur 30 millinètres, largem. 52.

\section{Lucine concave. Lucina concava. DEF.}

L. testis orbiculato-canvexâ, tenui, irregulariter striutá; strïs minimis, aliquantısper obsoletis; lunula munuma, pube pracminents; card:ne bidentato; lateralibus dentibus perspicuis.

DEF. Dict. des Scienc. nut. tom. 7 .

Non. Descript. des Coq. Soss. des env. do Paris, pag. 104. $p$. 17. fig. 8. 9 ,

Les caractères de celte coquille sunt faciles a saisir; elle est obbiculaire, convexe extérieureutut, concave à l'intérieur; elle est mince; sa surlace extéricure est couverte de stries Irès-fines, irrégulières, quelquefois appareutes; le crochet est petit, ainsi que la lunule, qui est lancéoléc et assez superficiclle; le corselet est próminent, indiqué par un léger pli; la charnière est étruile; elle présente dans son milicu deux dents cardiuales, dont unc est plus lorte, et deux dents latírales; l'ioppression musculaire antérieure ess étroile, submargiuale el drute; le burd est lart étroit, miote et tranchant. La longueur es la largeur sont de 19 millimétres.

\section{I.vCine naine. Lucina minutu.}

L. testá orbiculati, numutü, subglobosâ, cordutí, crassissimó, tenutssimé striatú; umbonbus minimis, arcaul.s; cardme bidentato; denubus lateralibus munimis; lunulà monmmá, profundt.

Nuв. Descript. des Cog. foss. des env. de Paris, pag. $104 \cdot p l .17 \cdot$ fig. 15.16.

Ce!te petite coquille est pisiforme, globulense, très-épaisse, à crocbets et a lunule petits; sa surface extćrieure est trc̀s-linement strice transversalement, suuvent étugée par des accroissemens; la concavité de ses valves ne répond pas a lcur convexité; clles sont presque planes, tt les impressions musculaires, aussi bien que celles du mauteau, s'y voient en creux. Liimpression musculaire est fart petite, très-étroite; la charnière présente deux dents cardinales, petiles, très-courtes; les dents latérales sunt constantes, quoique très-petites; l'antéricure est la plus grosse et li plus rapprochéc des deux. Longueur el largeur 10 millimétres.

33. Lucin E trigonule. Lucina trigonula. Nos.

L. testâ subtrigonâ, transversà, incrassati, depressâ, lavigatá; umbone aculo, uncinato; lunula lanceorula, profunda; cardine bidentuto.

On ne peut comparer celle espèce quavec la I,ucine callense qui est tossile des enviruns de Paris. Celle-ci, connue seulement à l'état fossile 


\section{U C}

des environs de Bordeaux, est constamment plus grande que celle avec laıuelle nous la comparons. Elle est inéquilatúrale, triangulaire, lisse en dehors, très-déprimée, et cepcudant à test furt épais. Le crochet est saillant et pointa, peu incliné au-desius d'une pelite luuule très-prorunde, lancéolce. Le corselet occupe le burd supérieur et postérieur; il est bossu et limité en dehors par un angle peu pronoocé; le bord inlérieur est légèrement sinueux antérieurement, et produit un angle obtus i la jonclion de ses extrémités arec les bords antéricur et postérienr. A l'intérieur les valves sont sulsugueuses; clles présentent ce fait remarguable d'avoir les impressions musculaires et du manteau en saillic, au bieu d'être creuseses, comme cela a licu ordinairemcal. L'inipression musculaire antérieure est extrêmement étroite. A près avoir suivi le bord antérieur dans une partic de son étendie, elle se recourbe en fornant un angle presque droit pour soivre la direction du bord inférieur, a fort peu de distance de l'impression palléale; elle se termiae presqu'a la usoitié de la longucur de ce bord inférieur. L'impression musculaire postérieure est ovale, oblongrne, placée très-près du bord; elle douoe aaissauce pär son extrémité inférieure à une ligne saillante, irrégulièrement tuberculeuse, qui suit le bord inférieur, et qui n'est autre cliose que l'impression du manteau. La clıarnière est courı; clle est dépourvue de deots latérales; sous le crocbet, on voit deux petites dents divergentes, et derrière elles commence une nymplie assez saillaste, cn partie cachée par le bord du corselet, et donuant attache au ligament.

Nous n'avons jamais vu que deux valves de celle espèce, toutes deux fossiles des euvirons de Bordeaux, et présentant les caractères si remarquables de cetıe espèce. Longueur 26 millim., largeor 3 i.

\section{Lucise épaisse. Lucina pensylvanica.}

L. testi lentiformi, ventricosâ, tumidia, cras$s \hat{u}$, albâ; humellis concentricis, membranaceis; valvâ magnâ, condutâ, dcpressi; marginibus integris.

Lamz. Anim. s. vert. tom. 5. pag. 54a. n’2. Venus pensyluanica. Lis. Gmer. $n^{\circ} \cdot 7 \mathbf{I}$.

Luster, Conch. tab. 305. fig. 138.

Bonx. Nus. cass. vind. tab. 5. fig. 8.

EscrcL. pl. 284. fig. 1. a. b.c.

Coquille vulgairenent oommle ha Bille d'ivoire par les unarchands; elle est trc̀s-globuleuse, trèsventroe, extrèmement épaisse, toute hancbe, exléricuremeal couverte de lames caduqnes, concentriques, très-fines, et distantes entr'elles; le cóté anı́́rieur est occupé par use graode lunule cordiforme, déprimée, aplatie, séparée par un sillon assez profond; elle est surmontce à sa parlie supérieure par la saillic des croclicts qoi vienneat s'inllechir vers elle. Le corselet est trésample, il occupe tout le cúté postérieur de la coquille; il est très-saillant au centre, et le sillon qui le limite à l'extérieur produit une petite siauosité sur le bord lorsquil y parvienı. l,e teat de celte espèce est unifurmément blasc, il est extrêmement épais, et ressemble à dı inatbre dans la cassure. La charnière est légèrement arquée dans sa longueur; clle se compose, comme dans la Lucina jamaicensis, d'une dent cardinale médiane sur la valve droire, et de deux petitr-s dents divergentes sur la gauclic : les denis latirales sout petiles, furt érartées des cardinales, la postérieure plus gue l'antérieure; elles sont cornprioúes, comme pincées el oblongues. I.e ligament est prolongé et caclié en grande partit: par le rebord du corselet. liimpression muscinlaire antérieure est fort étruite, elle comunen:er au-dessous de la dent lalérale du mème cuité, et descend jusque ver's le bord inférieur; les bords sont simples dims lcute leur étendue.

Celle espèce, que l'on trouve dans les oners d'Amérique, est allssi lungue que large; elle u 45 millim. de diannitre.

35. Lucre colombelle. Lucina columbella. Lame.

I. testâ albâ, suborbiculatî, convexo-gibbosé, transversim multilumellatá; lunulâ magnâ, cordalá, sulco profundo separatá; ano mogno, ovato, hamelloso; sulco distincto.

Lamx. Anim. s. vert. tom. 5. pag. 543 . n?. 15.

Basterot, Mérn. géol.sur les env. de Bordeaux, Mém. de la Soc. ¿thist. nut. tom. 2. pag. 88. pl. 5. fig. 11.

Cetle espèce, connue d'abord à l'état fossile, uous a été comonuniquét vivaste, provenant des wers équatoriales de l'Afrique, par M. Gray, savant zoologisle anglais, conservatcur du Muséum britanuique. 11 n'est point d'anilogie plus parfaite que celle qui existe cntre l'inuividu vivant et le fossile. On n'apercoit aucune diflérearce dans la disposition des lawes extéricures, dans la forwe si remarquable de lia linule et du corselet. Cetre coguille est arroudie, globuleuse, fort épaisse, trés-rapprocliée par ses rapporis de da Lucina pensylvanica; ses crochets sont assez saillans, opposés, obliquement iocliaés sur le côté antérieur, qui est occupé par une grande lunule cordiforme un peu déprimée, el fimiléc cı dehors par un sillon assez profond. Le corselte est alongé, ovalaire, saillant au centre, et nellement distingué du reste de la surface par un sillon semblable à celui de la luaule, qui desceud ju:qu'à la jonction du bord inférieur avec le puslerieur, en produisant dans cet endroit uoe situcosité assez profonde. A l'extérieur de la coquille 
viranic, od troure un graud nombre de lames concentiques, régulicies, papyracées, fragites et caduques, qui ne laissent sur les fussiles que de perits sillons qui n'en sont que les traces. A J'intérieur la coquille est d'un blanc pur; ses bords, fort épaissis, sunt tiès-finement crénelés dans toute leur érendae; la charnière est épaisse; les dents cardinales qui soat sous le crochet sont presque toujours avortées, les denis latérales sont au contraire lı̀̀s-saillantes; l'autérieure est la plus rapprochée, et la postéricure, sur la valve droile, est creusée à la base d'une petile fosselle qui reçoit la dent de l'autre valve.

Cetre coquille se trouve a l'ítat fossile dans les faluas de la Touraine, aux environs de Dax et de Bordeaux. Dans celte dernière localité elle présente le plus grand díveloppement; elle a 29 mikim. de long et 25 de large.

\section{Lucris orangée. Lucina aurantia. Noв.}

L. testầ orbiculalâ, convexo-turgidi ; transversim tenuiter strutá ; lunula depressá, ovatâj uno magno, ovato; margmbus intcgris; umbonibus albidis, fasciis uuruntius rimarginibus zalparum.

Cвемr. Conch. cab. tom. 7. tab. 37. fig. $3 \mathrm{~g} 6$.

Chemnitz a confundu celle belle et rare ruquille avec la Cytherae punctu!a, espèce pourtant bien différente. Celle coquille a des rappurts avec la Lucine colornbelle el la Lucine épisse; elle est orbiculaire, globuleuse, épaisse, subcordiforme, équilatérale, ayant les crocheis assez grands et proéminens, contourués au-dessus d'une lunule cordilorme, ovalaire, légèremen et limitée au-debors par un sillon assez profond. Le corselet est très-gründ, il occupe tout le còté postérieur de la coquille, à la liunite duquel il produit un pli sinueux plus prutond à son extréunité inférieure que vers les crochels. La surface extérieure est couverte d'un grand nombre de stries sublamelleuses, concentritjues, plus serrées ters les bords que partont ailleurs, et souvent interrompues par deз accroissemens multipliés.

La conleur de celle coquille la fail reconnoître très-facilement; elle est blanche sur les crochets, mais d'une belle couleur orangée sur tout le reste de la surface et plus foncée vers tes bords : cette couleur est disposée, dans quelques individus, en zones plus loncées qui correspondent aux accroissemens. A l'intérieur la coquille est finement ponctuée; elle est blanche an centre, et le limbe, ainsi que les impressions musculaires et la charnière, sont teintées d'orangé. L'impression musculuire antérieure est alongée, oblongue, linguiforme, la postérieure est ovalaire; la cbarnière ollire sous le crochet denx petites dents cardinales divergentes, et a ses exiréwités une deot latérale, oblongue et
saillante.
Nous ȟe sarons d'où vien! cette lielle coçuille, que nous n'avons encore vae que dina un trespetit numbre de collections. Elle a 28 milliu. de dianèure.

\section{Locise ligérine. Lucina tigerina.}

L. testâ lentiformi, convexiusculî̀, decussatim strutá, alba; intus murgine inferiore pupureo; ano trigono, impresso, minumo; impressione inusculari anticâ, prolong.i ; impressione pallii simplici.

Venus iggerina. Lxs. Grzu. $n^{\circ} .69$.

Runph. Mlus. tab. 42 fig. $\mathrm{H}$.

Listra, Conch. tab. $337 \cdot$ fig. 174 .

Goalt. Test. tub. 77. fg. A.

Cuess. Conch, tom. 7. pag. 61, tab. 37. fig. 3 go. 391 .

Excrct. pl. 277.fig. 4. a. b.c.

Var. 2.) Testà intùs penitùs albâ.

Var. 3.) Testî̀ exasperatâ, subgranosá ; strï transversis, emunentioribus.

Cytherae a tigerina. Lask. Anim. s. vert. fom. 5. pag. $574 \cdot n^{\circ} .53$.

Lorsque l'on examine celle coquille, on lai tronve tous les caractc̀res des Lucines et non ceux des Cythérécs, au numbre ciesquelles tous les auteurs l'ont mise à l'exemple de Lamarck. Elle esı orbiculaire, déprimée, à test assez épais; ses crochets sont petits, poiutus, et dowinent une lunule très-petite, très-enfoncée et cordiforme; les crochets donnent naissance à un grand nombre de stries lougitudinales, diveygentes; ces stries sont coupées en travers par un grand nombre d'autres non moins régulièses, mais lines et granuleuses, ce qui établit sur la surface extérieure un réseau fort élégrant. A l'iutérieur la coquille est blanche au centre, teintce d'un beau rose-pourpré sur tous les bords. L'impression musculaire antérieure, l'impression du mantean sont identiquement semblables à ce que l'on voit dans tun:es les Lucines. La charnière a bien quelques rapports avec celle de certaines Cytuérées; mais on doit se snuvenir que celle parlie étant très-variable dans les Lucines, ce ne peut êlre dans ce genre qu'un caractère secoudaire. Dans cette espèce, elle se cumpose d'un bord un peu sinueux dans le milieu; il porte sous le crocliet deux petites dents cardinales divergentes, et, près d'elles, une dent latérale furt grande qui, par sa situation, a quelque ressemblance avec celle des Cythérées; la dent latérale postérieure manque tout-à-fait.

Autrefois on polissoit celte coquille pour faire paroitre au-dehors la belle couleur rose dont ses bords sont tcints. Dans cet état, les amateurs et 
les marchands lui donnoient le nom de MIouchoir do Trims.

Celle coquille, commune dans l'Océan ind'en, se troure aussi dans celui d'Amérique. Lille a $63^{\circ}$ millin. de long et 70 de larue. Nous en possétlons unc varićlé toule blanche au-dedans, dout les stries longitudinales sout presque cll'acécs, el qui provient des ancrs du Séuégal.

38. Luctse bord rose. Lucina punclata. NoB.

L. testâ lentiformi, orbiculatî, convexiusculâ, crassâ, ponderosá, longitudinaliter sulcrutâ; sulcis plunulutis; limbo incerno roseo; disco luteo, subpunctato ; impressione musculari anticâ, angustú, preclongâ, obliquatâ.

Cytherara punctatu. LAxx. Anim. s. vert. tom. 5. pag. 574. $n^{\circ}$. 5千.

I'enus punctatib. Lin. Gmei. $76^{\circ} \cdot 74$.

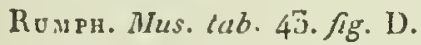

Guast. Test. $t a b .75$. fig. D.

Caesx. Conch. tom. 7. tab. 37. fg. 397. 398 .

Exсхст. pl. 277. fig. 3. a. b. c.

Comne la Cythéréc tigérine, celle espèce doit venir se placer dans le genre Lncine; elle a, de plus que celle que uous cilons, uu caractère prupre aux espreces de ce genre, celui des ponctuations dans l'iutérieur des valves. Celle coquille est arrondie, fort épaisse, très - solide, d'unc forme lenticulaire régulièrement bombée en dessus : ses crochets sont assez proéminens; ils son: poiutus et inclinés au-dessus d'une lunule cordifurme, petite et enfuncée. Sur la surface extérieure, on remarque an assez grand nombre de cóies rayonuantes, aplaties, iriégulières pour le nombre, et se dirigeant des crochets jusque sur les bords. Ces bords n'en sont point mudifiés, c'est-à-dire qu'ils restent simples dans toute leur circonférence. Cette surface extérieure de la coguille est d'un blanc pur, si ce n'est vers la lunule, qu'elle prend une teinte rosée. A l'iutérieur, tout le bord, justgu'i l'impression palléale, est d'un beau rose; le centre des valves est jaunátre, et l'on y remarque un grand nombre de poncluations comparables à celles qui sont dans la Lucine de la Jamaique. L'impression musculaire anterieure est alongée, étroitc, linguiforme et dirigée obliquemeot du bord supćrieur vers l'inférienr. La charnièie est portée sur un très-large bord; elle présente deux dents cardinales divergentes, $c t$, sous la lunule, une dent latérale conique et oblongue.

Celle bolle coquille, recherchée des amateurs, surtout lorsque, par le poli artificiel, on a fail paroitre au-debors sa belle couleur rose, se tronve dans l'Océan indien, et il en existe une variété plus dépriouée et plus petite dans les mers du Sénégal. Les individus d'une taille ordinaire on! 75 millim. de long et 80 de large.

Hist. Nat. des Vers. Tome II.
T.a variélé que nous venons de signalcr se trouve fossile aux envirous de Dax el de Bordeaux.

39. Locine rude. Lucina scabra. Lank.

L. testì orbiculari, depresso-convexâ, alhâ, subpellacidid costellis sifuamosis, radicntibus; inties punctis impressis.

Excrex. pl. 285. fig. 5. a. b. c.

Chems. Conch. tom. 1 1. tab. 199. fig. 1945. 1946.

LAMx. Anim. s. vert. tom. 5. pag. 542. $n^{\circ} \cdot 9$.

Celte jolie coquille est une des plus rares du genre; elle est orbiculaire, déprimée, lentiforme, ornée à l'extćrieur d'un grand nombrc de stries rayonnantes sur lesquelles sont arrangées, avec beaucoup de régularité, un grand nombre d'écailles triangulaires et imbriquécs; entre ces stries principales, il s'cn trouve unc plus petite et plus tiuenuent écailleuse. Le crochet est trèspetit, pointu, à peine saillant au-dessus dn boud cardinal. La lunule, qui est au-dessous de lui, csı alongée, lancéolée, saillante, et indiquée dans soa cootour par un petil sillon étroit. Le corselet n'est renda sensible que par les stries longiundinales qui, sur lui, sont plus fanes et plus serrées. A l'interieur, la coquille est finement ponctuée; ses bords sont occupés par des stries obsolètes qui correspondent à celles qui sont à l'extérieur; les bords, et surtout l'inférieur, sont finement crénelés. La charnière est étroite, arquée; une seule dent cardinale avortée se voit sous le croclict. Ises dents latérales sont trc̀s-prononcées; l'une et l'autre fort écartées des cardinales, et l'antérieure est la plus prolongée.

Celle jolie Lucine, qui vient, à ce que l'on présume, des mers d'Amérique, esı toute blanche en dedans et en dehors. Elle a 23 millim. de diamètre.

\section{LUISANTE (La).}

M. Geoftroy, dans son petit Traité des Coquilles des environs de Pliris, a donué ce nom à une petite espèce d'Hélice, que Muller a nommée Helix cellaria. Voyez Hélice.

\section{LULAT.}

Une Modiole, fort commune au Sénégal, et qui probablement forme une espèce distincte du IIytilus modiolus de Linné, a été nommée de cette manic̀re par Adanson. (Voyage au Sénégal, $p l$. 15.) Cetre espèce n'a point été mentionnée par Lamarck. Voyez Modiole.

\section{LUNA.}

Une coquille qui paroit appartenir an genre Calyptré, et qui est probablement le Calyptraea trochiformis, a servi de type au genre que

$$
\text { C c c } *
$$


Klein (Tent. method. ostr.pag. 10, pl. 1, $n^{0} .20$ ) a nommé de cette manière. Ce genre ae pouvoit ètre adopté; il est tomué dans l'oubli.

\section{LUNOT.}

La Venus senegalensis de Gmelin (pag. 3282 , $n^{n} .67$ ) est la même coquille que le Lunot d'Adanson. (Vojage au Scinégal, pl. 17. fig. II.)

\section{LUPON.}

Le Lapon d'Adanson (Voyage au Sénégal, pl. 5 , fig. 2) est une petite coquille du geure Porcelaine, qui seroit la Cyprea lota, d'aprìs M. de Blainville; mais Lamarck n'indique pas $\Lambda$ danson dans la synonymie de celle espèce, à laquelle, au reste, la description d'Adanson ne convieut pas eatièrement. Voyez Porcelasine.

\section{LUTRAIRE. Lutraria.}

Linné avoit confondu les coquilles de ce genre parmi les Mactres et les ityes. Bruguière ne les sépara pas non plus de ce genre, on plutót il les mit toutes parmi les Macires. Lamarck sépara le premier ces coquilles et en forma le genre qui nous occupe sous le nom qu'il porte encore anjourd'hui; c'est dans le Système des Animaux sans vertébres qu'il le caractérisa.

II. de Roissy l'adopta dans la continuation du Buffon de Sonnini, et le plaça, comme Lamarck, à côté des Mactres. Dans sa Fhilosophie zoologique, Lamarck établit la famille des Mactracées, dans laquelle ce gente fut compris, avec les Erycines, les Ongulines, les Crassatelles et les Mactres. Dans l'Extrait du Cours, celte famille et les rapports des Lutraires ne changèrent pas. M. Cuvier n'adoptc pas cet arrangement, et le genre Lutraire, dont il sépara une partie sous le nom de Lavignons (2nyez ce mol), fut pour lui un sous-genre des Myes, qui elles-mêmes font partie de la famille des Enfermés : elles furent donc séparécs des Mactres. Dans son dernier ouvrage, Lamarck apporta quelques changemens dans la famille des Mactracées ( עnyez ce mol), mais il laissa toujours les Lutraires en rapports avec les MIactres. M. de Blainville eut, à l'égard des Lutraires, une opinion à peu près semblable à celle de $\mathrm{M}$. Cuvier, c'est-à-dire qu'illes sépara des Mactres : celles-ci, sous le Dom de Lutricole, se trouvent dans la famille des Pyloridés; celles-là, dans celle des Conchacés, avec les Vénus, etc. M. Latreille a également séparé les Lutraires des Mactres, sans les mettre dans leurs rapports anatomiques; il les a transportés de la famille des Mactracées dans celle des Myaires, qui se trouve composée des geares Lutraire, Anatine et Myes.

Le genre Lutraire, à ne considérer que l'animal, est certainement beaucoup plus voisin des Myes que des Mactres; mais, si on s'altache plus particulièremen: aux rapports que peuvent offrir la charnicre, il sera incontestablement très-voisin des Macires; ce soat ces deux différentes manières de considérer ces Mollusques qui ont fait naitre les diverses opinions que nous venons de rapporter. Quelle que soit celie que l'cn adopte, voici de quelle manière cc genre peut être caraclérisé et d'après l'animal et d'après la coquille.

\section{CARACTÉRES GÉE⿱ERIQUES.}

Animal très-comprimé; le mantean fendu dans tout sou bord in férieur, lerminé en arrière par un long tube, un pied subautérieur, petit et sécuriforme; coquille inéquilatérale, Iranspersalement oblongue ou arrondie, bàillante aux extrémilés lalérales; charnière ayan: une dent comme pliée en deux, ou deux dents dont une est simple, et une fossette adjointe, deltojde, oblique, saillante en dedans; dents latérales nulles; liyament intérieur fixé dans les fossetıes cardinales.

Les passages insensibles qui existent entre les Lutraires et les Mactres se muntrent non-seulement dans les coquilles, mais aussi dans les anjmaux. D'un côté, nous voyons dans les coquilles les dents latérales qui caractérisent les Mactres s'effacer de plus en plus, et finir par disparoître dans la plupart des Lutraires. Quant aux animaux, la progression est la même, et les différences résident dans le développemeat plus ou moins considérable des siphons: dans les Mactres ils son: en général courts, et restent réunis en uue seule masse cylindroïde; dans les Lutraires, an contraire, ils s'alongent considérablement à l'égal de ceux des Myes. Quant aux formes extérieures des espèces, les passages insensibles d'un genre à l'autre ne sont pas moins évidens : si, d'uu côté, les Mactres présentent des formes assez constammont triangulaires, il en est d'autres qui sont ova. laires, et c'est cette dernière forme qui domine parmi les Lutraires. Il n'y auroit donc point de motifs ralionnels pour tenir séparés deux yenres dont tous les caractères se conviennent lorsyu'ils sont pris dans leur ensemble. Cependant, comme les genres doivent être faits aussi pour aider le naturaliste dans ses recherches, nous conserverong celui-ci comme un de ceux auxquels il manque quelques interınédiaires pour opérer leur jonction détinilive

Les Lutraires sont des coquilles qui vivent dans les sables; eiles s'y enfoncent à la manière des Soleas, des Myes, eic.; elles ne font saillir au dehors que l'extrémité de leur tuyau. On en trouve quelques-unes à l'élat fossile, répandues dans les terrains tertiaires en plus ou moins grande abondance; elles manquent jusqu'à présent aux environs de Paris, et se montrent surlout dans le bassin de Bordeaux et dans les terrains subapennias. 
L.dis.

L. tcstî oblong.j; striis trunsversis, nugaformibus; latere antico pratongo, apice rolunduto, vulde hiante.

Mya oblonga. GMex. pag. 3221.

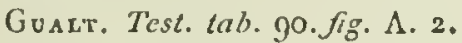

Dacosta, Conch. hrit. pag. 3o. tab. 17. fig. 4 .

Cin.us. Conch. tom. 6. tab. 3. fig. 12.

Lad K. Anim. s, vert. tom. 5. pag. 468. $n^{\circ}$. I.

Lutricola solenoides. De Buarv. Malacol.pag. 566. $p$ l. 77. fig. 3.

La Lulıaire solénoide est une grande coquille qui vil sur nos còtes de l'Océan, dans la Mléditerranée, et jusqu'an Sénégal. Elle est alongée, ovalaire, trés-inéquilatérale, légèrement arquée dans sa lungueur. Les crochets sont petits, aplatis; la surfacce extćricure est couverte de grosses rides transverses, indices des accroisseuens; un épiderme mince, bı un, écailleux antérieuremeut, revêt la coquille, çui est blanche ou jaunátre en dessous; en dedans la coquile est toute blanche. Limpression inusculaire antérieure est la plus grande, et l'impression palléale est fortement écbancrée du côté postćrieur. La charnière est coure, elle fait par son burd inférieur une saillie assez considérable dans l'intérieur des valves; elle présente un grand cuilleron nhlique, à la partie antérieure iluquel sout placées deux dents cardinales, divergentes, sur la valve droite; la plus antérieure de ces dents est profundément bifide; sur la valve gauche e'est la dent postérieure qui présente ce caractère. Celle coquille est très-lsâillante lorsque ses valves sont réunies : le bảillement antérieur est le moins considérable.

II existe en Sicile une cnquille fossile qui a de très-yrands rapports avec celle-ci; tlle seubleroil taire l'intermédiaire avec la Lutraire elliptique et l'espèce qui nuus occupe : la charnière est un pen diflírente, les deux dents cardinales diver. yentes se rćunissant à leur sommet en forme de $V$. Celle Lutraire prend quelquefois d'assez grandes dimensions. Sa longueur est de 50 millim. et sa hurgeur de 10 centimètres et demi. Nous en avons ru des individus qui avoient au moins un tiers de plis.

\section{L. $1 \times x$.}

2. Lutraias elliptique. Lutratia elliptica.

L. testâ ovali-oblongâ, lavinusculâ; strïs transs'ersis, exiguis, lateribus rotundatis, postico longiore.

Mactra lutraria. Lir. Gees. pag. 3.5Q.

Lister, Cunch. tab. 415. fig. 259 .

Pennast, Zool. brit. tom. 4. pl. 52 . fig. 44.

Cнема. Conch. tom. 6. tab. 24. fig. 240.241.
Tar. a.) Antico latere altenuato, oblusè acuto.

Lask. Anim. s. vert. tom. 5. pag. 468. $n^{n} \cdot 2$.

On distingue facilement cette cspèce de la prícéclente par sa forme plus élaruice, par son test plus mince, et génciralenent plus déprimé. Elle est ovale, rrunsverse, assez mince, inéquilatérale, blanche ou jannatre. Scs cruchets sont très-petily, à peine inclinés sur le cùté antérieur. La surface exlérieure est rendue un peu rugueuse par des stries d'accroissenıent plus marquées sur le côté anlérient que partont ailleurs. Elle est revêtue d'un épiderme d'un lu un-grisittre trés - mince et caduque; à lintćrieur elle est d'un blanc par. L'impression du mantean est très-profondément excavée jusqu'au nireau de la charnière. Celle-ci est légèrement arquće, saillante à l'intérieur; elle se compose d'un grand cuilleron un peu oblique, dounant allache it un fnut ligament; en avant de ce cuilleron on voit sur la valve ganche une dent fort saillante en forme de $V$, et sur la valve droite derx deats lamelleuses très-étroites, divergentes, dans l'intervalle desquelles vient s'interposer la dent de l'autre valve. I,e cỏté anlérieur est court et obtus, légèrement biillant; le postérieur est egralement artondi, mais il est plus prolongé ct beancuup plus baillan: que l'autre. I-es bords sont simples el tranclians dirns toute leur étendue. Nous possédons a l'état fossi!e l'analogue de celte espèce; il provient des sables jaunes de l' $\Lambda$ slesan. Aux envirans de Bordeaux on trouve une trèsgrande coquille qui a leancoup de rapports arec ceile-ci, mais qui nous paroût en dilférer d'une manière assez constante pour que nous dussions la tenir séparée. Les plus grands iudividus que nous ayons vus ont 62 millin. de longueur et 11 centim. et demi de laigre.

3. Lutrata ridée. Lutraria nigosa. Lamk.

L. testâ ovati, alhido-flavescente; striis longitudinalibus, elevatis, transversis ninius elevaiss, decussantibus.

Mactra rugosa. GuEz. pag. 3261.

Chess. Conch. tom. 6. tab. 24. fig. 236.

Everce pl. 254 . fig. 2. a. b.

Var. b.) Striis longitudinalibus, posticis, , ario. ribus, magis elevatis.

La.ux. Anim. s. vert. tom. 5. pag. 46g. $\pi^{\circ} .3$.

Celle espèce est l'unc de celles qui peut servir d'intermédiaire entre les Mactres et les Lutraires. Elle est ovale, très-enflée, épaisse; ses croclsets sont graads et protubérens: le băillement des valves, tant antérieureunent que postérieuremeat, est peu considérable. La surface extérienre esé ornée d'un grand nombre de cótes longitudinales, rayonnantes; elles sont étroites, très-nottes, e: rendues légèreusent tuberculcuses par des accrois$\mathrm{Ccc}{ }_{2}$ * 
semens transverses plus ou moins nombreux : ces cótes longitudinales sont remplacées sur le côté antérieur par des stries fines et olssolètes; le côté postérieur reste entièrement lisse. A l'intérieur, les valves sont profondes; on y remarque deux impressions musculaires fort grades, dont la postćrieure est lout-d-fait circulaire. L’impression palléale est largement échancrée, la cbarnière forme une saillie assez considérable dans l'intérieur; elle est épaisse el solide. A côté d'une grande fosselte en cuillerun, pour le ligament, on voit sur la valve gauche une pelite dent en forme de $V$, très-comprimce, et en avant une pelite deul oblique et pointue, folt étroite, qui rcpiésente la dent latérale antérieure des Mactres. Sur le côté postêrieur de la charnière on voit aussi une dent très-élroite, alongée et fort saillante, qui correspond aussi à la dent latérale postérienre des Mactres. Sur la valve dioite en avant du cuilleron, on trouve une pelite caviśs destinée à contenir la dent en forme de $V$ de l'autre valve, et en avant deux petiles dents divergentes dans l'intervalle desquelles vient se placer la deut latérale antérieurc. Sur le côté postérienr on tronve également la cavité destinée à recevoir la dent latérale. Celte charnière est tout-à-fait celle des Mactres; il n'y a de différence appréciable que dans la position des dents latérales qui sont beaucoup plus rapprochées que dans les espèces du हente que nous cilons: elles offreat encore celle dilférence peu importante d'être plus courtes ct p!us épaisses. Celle coquille vit dans la Méditerranée et dans l'Océan indien, et se tronve fossile aux environs d'Asti, en Pićmont. Sa longueur est de 62 millim. et sa largeur de 83.

L. 4.

L. testẩ tenui, compressî, rotundato-trigonâ, squalidi, transversè striata, intus alb ì; fossulà ligamenti trigonâ, basi latấ, anticè duobus dentibus obsoletis, parallelis; marginibus integris.

Lister, Conch. tab. 253. fig. 88.

Dscosrs, Conch. brit. pag. 200. tab. 15. fig. 1 .

Excrer. $p l \cdot 257 \cdot f g \cdot 4$.

Ligula compressa. LeAcH.

An Mactra Listeri? Grec. pag. 326I.

Cresx. Conch. tom. 6. tab. 3. fg. 21.

Lasx. Anim. s. vert. tom. 5. pag. 46g. no. 4 .

Celte Lut:aire est une de celles qui rentrent dans les Luvignons de M. Cuvier. II est assez prohable qn'elle n'est qu'une variété de la Calcinelle d'Adansoo, dont elle ne paroit différer que par la couleur. On trouve cette espèce en très-grande abondance sur ront le littoral ocćaniçue de la France et de l'Angleterre. Ellc s'éloigne des autres Lutraires par sa forme et la grande obliquité de son ligniment: ausii plusieurs auteurs avoient pensé qu'il Étoil nécessaire de faire, avec elle ct quelçues antrcs qui lui resseablent, un genre à part, sous le nom de Liguic, p:oposé par Leach, ou celui de Luvignon, proposć par M. Curier. Il seroit prssible que ce genre devial nćcessaire plus tard, lorsque l'on aura fait une comparaison toinutieuse des anianax des Lotrairez propreıneut dilcs et de celle-ci.

La Lutrairc compriance est uue coquillc ovale, sublrigone, transverse, striée en lravers irléğtrlièrement; elle est presque équilatérale. Ses crochels sont extrîuement petils, et ne font aucune saillie au-dessus du bord. A l'intérieur, les valves sont d'un bliuc mat. L'impression du manteau, qui est très-raste, s'élargit considérablemeut dans l'untéricir des valves, và elle présente un conlour un peu sinueux. La charnic̀re est courıc, saillante, à lintérieur; le ligameut est porié sur uu cuilleron court, obliquement inclinć du côté postérieur et fort large à la base. Sur le bord antírieur de ce cuilleron on apercoit sur la valve droisc deux trèspetites dents parallèles, obsolètes, dans l'intervalle desquelles est reçue une petile dent de la valve opposée. Outre lé ligament placé à l'iutérieur des cuillerons, il en est un autre gui paroit n'en ètre que la continualion, et qui est tixé, à l'extérieur, daus un peti: sillon qui représente les nymphes. Si celle coquille avoil des dents latérales, elle devroit entrer dans le genre Amplidesme. Cetle coquille vit dans les sables, de la mème mauière que les autres Lutraires. Elle est ordinairement d'un blanc-grisálre ou d'un jaune sale. Longueur, 56 millin., largeur 43.

5. Lutraire calcioelle. Lutraria piperata. LANK.

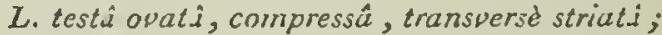
dentibus minimis ; foveolâ nragnâ, obliquatá.

Mactra piperata. Gues. pag. 3261.

Calcinellu. Ansxs. Sénég. pag. 232. tab. 17. fig. 18.

I,Aux. Anim. sans vert. tom. 5. pag. 469. $n^{\circ} .5$.

Comme nous l'observions à l'écrard de l'espdce précédente, celle-ci n'eu est très-probablement qu'une varićté; elle n'en diffère, en efle:, que par la couleur, qui est ici constaruaseut blanche, et par une forme un peu plus alongée et plus ovalaire. Celte coquille est très-compriméc, toute blanche, lisse en dedans, striée irrégulièrement en travers en dehors : ces stries sont très-fines et très-serrées. Les crochets, pointus et excessivement petils, ne fon $t$ ancune saillie au-dessus du bord. La charnière, les impressions musculaires, limpression du manteau, sont semblables à celles de la Lutraire comprimée. Les caructères essentiels 


\section{U T}

de l’espèce se trouvent conséquemmeot les même dans l'une et dans l'autre: ce qui fait voir la nécessilé de leur réunion. L.e bâillement des valve: est tris-petit; les bords sont simples, tranchaus daus toute leur étendue.

Celle espèce vil dans liz Médicrranée ct dans les nieis du Sénégal; elle est longrue de 30 urillinn. et large de 40.

6. Lutraine de Coltard. Lutraria Cotturdi. PAYAAOD.

L. testâ ovali, trigonâ, compressâ, pellucidâ, nitidâ, subaquilaterî̀, postice subangulati, anticed rotundutî, albî, transwersim lavviter striatâ; urnbonibus acutis, minimis; fossulí ligatmenti minimâ, obliquâ; dentibus candmalibus obsoletis.

Payraudeau, Cat. des Annel. et des Moll. de Corse, pag. $28 . n^{\circ} .35 . p l$. 1. fig. 1. 2.

Jolie coquille, qui a de l'analogie arec la Ioutraire calcinelle : elle est ovale, oblc. rrue, transverse, toute blanclic en dedans et en dehors; elle est très-comprimée et légèrement bâillante de chaque côlé; postérieurcunent, alle préscote un pli comparable à celui des 'Tellioes et se termine par un angle oblus : antérieurement elle est arrondie. Les crochets sont tres-petits et a peine saillans; ils s'inclineot antéricurement, et l'on voit, au-dessous d'eux, sur la cbarnière, une très-pelite dent obsolète. A côté de celte deut, on aperçoit uu cuilleron épaissi, profondément creusé par une fosselle triangulaire, oblique, large à $3 a$ base, en partie recouverte par le bord posićrieur et destinée à donner altuche à un ligament fort épais. La surface extérieure paroît lisse, mais examinée avec une forle loupe, on la trouve finement strié, surtout \& son côté antérieur. A l'intérieur, les valves sout lisses et l'impression palléale fort grande, sinueuse et anguleuse à son extrémité postérieure. Cette coquille s'est trouvée dans la Méditerrance, aux eqvirons de l’ile de Corse, et en Sicile. Ce qui est trís-remarqualile, c'est que MM. Quoy et Gaymard l'ont recucillic dans lear voyage à la Nouvelle-Zélande. Nous avons sous les yeux les individus des deux localités, et ciest en vain que nous roudrions y trouver des dilférences. Les grands individus out 24 millim. de longueur et 33 de largeur. Non.

7. LUtranke très-large. Lutraria latissima.

L. testâ ovato-ellipticâ, complunatâ, inaquiluteri, anticè rotundatâ, posticè subangulatâ, inansversim tenuiter striatá; cardine producto, dente laterali postico minuto instructc.

Coquille fort remarquable par sa graodeur et son ćlargissement : elle a des rapports avec la Lutraire elliptique, mais elle est bien plus comprinéc el plus large. Sit forme est elliptique; ses croclıets, légèrement proéminens, sont extrếmement petits el sont à peine saillans : le côté autérieur cst llès-court, il est arrondi, obtus; le cólé postérieur se termine par un angle obtus. La surface extérieure est couverte de stries transverses qui sont plulôt le résultal des accloissemens qu'une disposition particulière : l'intérien: cles valves est lisse, peu profond. L'impression palleale que l'on y remarque est tic̀-vaste, et remonte prescue au niveau de la charoielc. Celle-ci est épaisse, saillante à l’intérieur; clle se compose d'un large cuilleron triangulaite, en araul duquel est siluce, sur la valve gauche, une dent très-sulltule, en forme de V, et, sur lit valve droile, deux dents divergentes lamelleuses, daus l'intervalle desquclles se place la dent de l'autre valve. Sur le côlé postérieur du cuilleron, an voil une petile dent londimentaire obsolète, olvique", qui n'est que la trace de la dent latérale postérieure des Mactres.

Celte coquille est celle que probablement M. Basterot a prise pour la Lutraire elliptique. Il sulit de voir combien elle est comprimée et les différences qui existent dans la charnière pour s'assurer qu'elle constitue une espèce dillérente.

Celle coquille se trouve fossile aux environs de Bordeaux; elle est longue de 73 millim. et large de 12 centim.

\section{Lur'raire grimace. Lutratia sanna. Bast.}

L. testâ ellipticâ, transversim elongatì, incequaliterá, irregulariter striatâ, artice rotundatâ, posticè attenuutâ, infermè arcuatâ; cardine dentibus lateralibus obsoletis instructo.

B.st. Mérn. sur les en'. de Bordeaux, Mlén. de la Soc. d'hist. nat. de Paris, tom. 2. pag. 94. $n^{\circ}$. 1.pl. 7 . fig. 23 .

An Lutruria crassidens? LАмк. Anim. s. vert. tom. 5. pag. 47 1. n०. 12.

La phrase carastéristique que donne Lamarck ì la Lutraria crassidens, qui se trouve fossile dans les lialuns de la 'Touraine, peut convenir, ì certaius égards, à l'espèce qui nous occupe, et nous l'y tapportons avec cioute. La Lutraire griuace a aussi des rapporls avec l'Elli; tique; mais sa petile taille el sis forme palticulière l'cu séparent net. tement. Elle est ovale, alongrée iransversalemen!, assez gonfíe vers les crochcls; sou côlé autéricur estlrès-court, obtus et arrondi; le côté postérieur. s'alténue peu à peu, et se termine en un angla obtus; ce côlé esı bâillant presqu'autant que dân la Lutrairc solénoide; le côlé antéricur l'est beaucoup moins. Le bord supérieur ou cardinal est droit dans presque tonte la longueur de la corguille; mais le bord iuférieur est arqué régulièrcment, de nanière à faire paroîlre la coquille courbéc dans sa lougueur, quoiquielle ne le soit réclle- 
meot pas. La charnière est assez étroite, peu saillaste dans l'intérienr des valves; elle est presçue semblable a celle de la Lutraire ridée; wais les dents latérales sont encure plus rudimentaires. A côté d'un cuilleron profond et épais, oo vuit aotérieurement sur la valve gauche la dent en forme de $V$, et parallèlement au burd la petite dent latérale antérieure; uue autre petite dent latérale postéricure se trouve de l'autre côté du cuilleron. A l'intérieur, les valves sont lisses; l'impression musculaire antérieure est oblongue et courbée; à l'extérieur, elles sont irrégulièrement striées en travers. Cette coquille se troure fussile aux environs de Bordeaux, particulièrement à Saucaız, où elle est assez rare. Elle est longue de 28 millim. et Iarge de 47.

\section{Intratre étroite. Lutraria angusta. Nob.}

L. testâ ovali, transversìm elongatâ, angustâ, incequiluterâ, posticè subangulatâ, hiante, antice obtusâ, brevi; siriis longitudinalibus, irregularibus; marginibus tenuibus, sumplicibus.

Pelite espèce de Lutraire que l'on prendroit pour une variété, soit de la Solénoïde, soit de l'Elliptique, mais qui se distingue de l'une el de l'autre par des caractères coustans. Elle est ovale, tres-alongée, furt étroise, très-équilatérale, à côté autélieur court et oblus, tandis que le postérieor est alongé, aiténué et nn peu en bec à son extrémité. La coquille est fort déprimée; on voit en debors an assez graud nombre de stries irrégulières, serréc 3 vers les bords, qui sumt les traces des accroissemens. Les rrocliets sont petits, pointus, très-peu saillans. Le bord supérieur est presque droit; il préseute une charaière peu proéminente à l'intérieur. Celte charnière est composée d'un petit cuilleron triangulaire, el sur son bord antérieur de deux dents divergentes sur une valve, et d'une petite dent ployée en deux sur l'autre.

Les plus grands individus de cette coquille ont
24 millim. de long et 48 de large. E.lle se troure fossile anx euviruns de Bordeaux et de Dax.

\section{LUTRICOLE.}

Dénomination sous laquelle M. de Blaiaville, dans son article Miollosque du Dictionnaire des Sciences naturelles, range le geore I,igule de Leach, et le genre Lutraire de Lamarck. Il est bien probable, du muins autanı quion en peut juger d'après le petit noubre d'espices, que le trenre Ligule de Leaclı n'est point du tout le même ģne celui de Moulagn, puisque celui-ci correspond aux Amplidesmes de Lamarck. Voyez AmpaIDESME et LIGULE.

\section{LYMNÆA pour LIMNÆA.}

C'est à tort que plusieurs auteurs ont écrit ce wot a vec un $y$, et il en est peu sur l'orthographe duynel on ait plus varié. Vuici les exemples qu'en rapporte M. Basterat dans son intéressant Mémoire sur les fossiles du sud-onest de la France, inséré parmi ceux de la Société d'bistoire naturelle de Paris. Iymnara, L.amarck, Deshayes; Linneus, Sowerby , Bronguiart ; Lymneus, Draparaaud, Brongniarl, Defrance ; Lymncea, Sowerby, de Blainville; Lymmoeus, Cuvier, Bawdick; Ly'ninaus, Montfort; Limnaca, Desmarets, Ierussac. C'est cctle deruière mauière qui est la plus cunvenable.

\section{LYMNIEM.}

M. Ocken, dans son Traité de Zoologie, a élabli sous ce nom un genre qui correspond au gende Mulette de Lamarck. Voyez ce mot.

\section{LTRE DE DAVID.}

Les marchands donnent encore quelquefois ce nom à une belle coquille fort rare du genre Harpe, Harpa imperialis de Lamarck. Vojez HARPE. 


\section{A C}

\section{Machurite.}

Genre proposé par Lesueur, dans le ier, volune des Mémoires de l'Académie des Sciences naturelles de Philadelphie, pour une cuquille pétriliée qui reotre parfaitement dans le genre que M. Sowerby avout proposé long-temps avant dans le Mineral conchology sous le aom de Eumphalus. Voyez ce wot.

\section{MACOMA.}

Nons trouvons lindication de ce genre de Leach dans l'article Mloluuspoe di Dictionnaire des Sciences naturelles, au geure Vénus, dont il fuit une des numbreuses sous-divisions. La coquille qui lui sert de type nous est inconnue; nous croyons même qu'elle n'a jamais été figurée, et nuus ne conmoissous riea de ce genre que la phrase suivante, par laquelle M. de Blaiuville l'a caractérisé :

"Coquille épidermée, striće, comprimée, ^ovale; les sommels peu proéminens; deux - deots bifides sur la valve droile, une seule sur ¿ la gauche."

\section{MACONNE.}

Les conchyliologues du dernier siècle donnoient ce nom à une varićté du Trochus agglutinans, qui se couvre de pelits cailloux au lien de coqquille, comme cela a lieu le plus ordinairement. Ce nom est resté parmi les marchands, qui désignent ainsi la mème corguille. Voyer l'miptére et 'Troque.

\section{MIACRODITE.}

Genre proposé par Montfort pour ane coquille microscopique, que MM. lierussac et de Blainville oat rangée dans les Lenticulites (voyez ce mot), et qui, suivant notre opinion, s'ea dislingue assez bien par l'ampleur de l'ouverture. La manière doot Mloutfurt a observé ce corps laisse beaucoup de doule sur ses rapports; il n'est pas sûr si l'ouverture est tolalement fermće, et il ignore sil existe un siplon, ou une rimule, on une fente. Ce corps n'élant connu que par la description et la mauvaise ligure de cet auteur, il est fort difficile de statuer à son égard.

\section{MACROSTOME. Macrostoma.}

Lamarck a réuni dans celte famille les genres de coquilles qui offrent une très-grande ouverture. Rassemblés d'après des caractères tirés plutôt de la cognille que de l'animal, après on examen plus approfondi, ils ne purent resier dans les mêmes rapports; ainsi M. de Blainville en porta une partie dans sa famille des Otidés (voir ce mot) el une autre dans son ordre des Chismobranches. M. Cuvier, avant M. de Blainville, avoit déjà sćparé les Sigarets des Haliotides; M. Latreille a suivi cet exemple: dans ses Familles du Regne animal, il a eu soin, en les plaçant dans deux ordres différens, de les rapprocher le plus possible, ce que a'a pas fait M. de Blainville. Celte fanille, créće dans la Philosophie zoologique sous le nom de Siomalacés, recnt de son auleur le nom qu'elle porle aujourd'hui dans l'Extrnit du Cours. Elle éproura dans ce: ouvrage des cliangemens uotables : composée primilivemert des trois genres Haliotide, Stomate et Stomatelle, elle ne renferma plus que les deux derniers; les Haliutides furent portées arec les Patelles, et les Sigarets restèrent dans la famille des Aplysiens.

Dans son dernier ouvrage, Lamarck recomposa sa famille des Macrostomes sur son premier plan, et n'y fit d'autres changemens que d'y joindre le genre Sigaret: elle se compose donc aujourd'hui des geures Sigare!, Stomatelle, Stomate et Haliotide.

A ne voir que les coquilles de celle famille, il est incontestable qu'elles se joignent par des caractères communs, tels que la forme de l'ouverture, qui est extrêmemeat ample; le raccourcissement de la spire, qui est tonjours très-courte; enfin la courbure de la columelle, et la manière dont elle se développe en laissant apercevoir à l'intérieur cornme à l'extérieur toutes ses circonvolntions. Mallieurensement les caractères des coquilles ne coïncident pas dans tous les genres avec l'organisatios des animaux; d'un côté nous royons les Sigarels passer d'une manière iasensible aux Natices, et montrer d'un autre des dégradations vers les Stomates, les Stomálelles et les Vélutines. Les Haliotides restent isolées par la nature de l'animal, dont les braochies ont une situation tout-à-fait particulière.

Si l'on conserre la famille des Macrostomes, il faudra, à l'exemple de MI. de Blainville, en écarter les Haliotides et la former de plasieurs genres, dont la composition seroit conçne de la manière suivante: si lon se souvient que les Natices développent sur leur coquille un large mantean qui les enveloppe complétement, mais que l'animal retire à sa volonté, il faudra en rapprocher cenx des Sigarets qui se trouvent à pen près dans le même cas, c'est-à-dire ceux qui sont aे demi-intérieurs : ces Sigalets correspon- 
dent n: renre Cryplosiome de $\mathrm{NJ}$. de Blainville. J.e secrais degr'é, gui russembleroit les Siurarcts jroprement dits, ne comprendroit que ccux qui, constamment enveloppis de leur rasir manteau, ont toujours leur coquille cachée à l’intírieur : ce groupe correspond an genre Coriocelle de M. de Blainville. Un troisičme groupe ne conliendroit que ceux des Sigarets qui montrent tonjours leur roquille entière à l'extérieur, el qui font ainsi yassage aux Vélulines: ce genré correspond à ce que M. de Blainville nomme Sigaret. Enfin viendroil le genre Vélutine, qui, pourvu d'une coquille extérieure et épidermée, fait le passage vers les Stomates et les Stomatclles.

Ces divers groupes que nous renons d'indiquer sont, il faut le dire, formés d'une maniče arbitraile, au moins pour le plus grand nombre; nous ne pensons pas que ce soit la de bons genres, nuisqu'on retrouve dans chacun d'eux les degrés riir.rs d'uae même organisation. Il faut en exropier peut - être le genre Vélutine, qui manque d's...reule, et les genres Stomatelle et Stomale, doni les animanx sont actuellement inconnus, ei itcu: on ne peut établir les rapports que d'apres jes coquilles.

La plupart des geares qui sont compris dans la famille des Macrostomes se trouvent à l'élat fossile; il faut en excepter le seal genre Stomate. Voyez les noms des gerres que nous avons cités dans le cours de cet article.

\section{MACROSTOMES. Macrostoma.}

M. Latreille, dans les Familles naturelles du Regne animal, pag. 199, a admis la famille proposte par Lamarck, en la modifiant de telle sorte qu'elle se trouve réduite aux genres Sigurel, Cryptostome et Lamellaire, landis qu'il a rejeté dans la famille suivante les Auriformes, qui loat partie d'une autre classe et d'un autre ordre, les genres Haliotide, Stomale et Stomálelle. Nous arous vu, en traitant de la famille des Macrostomes de Lamarck, que l'on ne pouvoit rationnellement en rejeter que le seul gente Haliotide. Voyez l'article précédent et Morluseue.

\section{MACTRA.}

Klein (Meth. ostrac. pag. 171, pl. $11, f i g .73$ ) avoit appliqué ce nom, auquel depuis un a donné une autre signification, à des coquilles qui, d'après l'indication de Rumphius ( $p l .44$, fig. L.), doivent appartenir au geare AлcH

\section{MACTRE. Mactra.}

Genre de la famille des Mactracées de Lamarck, établi par Linné, qui y réunissoit des coquilles dont on a fait plusieurs autres genres. Le mot de Mactre fot employé poor la première fois par Bonanai, qui a désigné aiosi une espèce d'Arche.
Jinnć l'emplaya pour le genre qui nous occuje; Bruguierc i'actopla sans y apporter de changenurus; Lamarck le réforma en le débarrassant d'alunrd des Lutraires, de plusieurs Ciassatelles et de quelques Lucines: ainsi modifić, le genre Mactre de Linné présente une coupe uaturelle que tous les zoologistes admeltent cumme genre dans leurs clussilicalion; nais tous n'out pas élé d'accord sur la place gu'il devuit occuper dans la série des Acépluales ou Conshiferes. M. Cuvier reconout la ressemblance qui existe entre l'animal des Macires et celui cles Vénus; ausi estce dans sa famille des Cirdiacés qu'il plaça ce genre. Cependant, reconnoissant aussi les rapports iutiwes qui lient ce genre aux Lutraires et aus Bjocs par la coquille, il les tapprocha le plis yu'il put, en terminant les Cardiacés par les Mactres, ei cu commençant sa lamille des Enfermés par les Myes et les Lubaires. M. de Ferussac adopta celle opiniou en la mndiliant un peu, d'après les derniers travaux de Lamarck. M. de Blainville rapprocha les Mactres des Vénus bien plus que ne l'avoient fail les auteurs que nous venons de ciler: il fut en ccla parfaicment d'aciord avec Poli, qui réunil l'animal des Vénus et celui des Maclres dans un scul el même genre. Ce motif l'engagea, dans son arlicle Muruesque du Dictionnaine des Sciences naturelles, à placer les Mactres entre les Cyprines et les Vénus. Que'le que soit l'analugie des animaux, analogie qui peut êlı'e cootestće sur quelques poiuts, les rapports évidens des coquilles doiveut cependant entrer aussi pour quelque chose dans la place que l'on fait occuper à un genre. Les Mactres, qui sont des coquilles peu épaisses, épidermées, baillantes, qui ont le ligament interne et les dents latérales lamelleuses, pourroient bien être conservées dans la mĉme famille que les Vénus; mais présentan: le passage le plus évident avec les Lutraires, c'est sur les limites de ces denx familles que, d'après l'opinion de M. Cuvier, elles doivent se Irouver. M. Latreille, dans son ouvrage (les Familles nuturelles), a suivi la manière de voir de Lamarck; il a eu sans doute quelque motif pour cela. Quelle que soit la dissidence des opinions sur ce gente, voici de quelle manière il peut ètre caractérisé.

\section{CARACTERES GÉNEIQUES.}

Coquille transverse, inéquilatérale, sub:rigone, un peu bâillante sur les côtés, à crochels protubérans; une dent cardinale comprimée, plissée en goultière sur chaque valve, et auprćs une fossette en sailie; deux donts laterales rapprochtes de la cbarnière, comprimées, renirantes; ligament intérieur inséré dans la fossette cardinale; ligament extérieur très-petit.

Les espèces de ce geare sont nombreuses, et elles viennent de toutes les mers; elles ne présentent, par leur forme assez semblable, que peu de 
morens de les sous-diviser; cependant M. de l3läinville les a partagées en cioy section;, dont les caractères sont lirés de la charnière : il en existe plusicurs espèces lossiles; MI. Defrance encile huil, mais nous en connoissuns un plus grand nombre.

Lorsque nousavons trité du gen'e L,ubaire, nous avous fait aperecvoir une degradılion insensible eatre les especies de ce genre et colles des Mactres; décruadation qui est telle, que quelques espéces pourroica indillé:emment apjartenir à l'un ou à l'autre. Les mêmes nuances se reconnoisscat aussi dans les avimaux de ees espices; il faut donc, de toute nécessité, que si l’on conserve le genre Lutraire, il soil entrainć à la suite des Xlactres, et compris dans la même ficaille. Comme nous veaous de le voir, ces rapports ont été sentis par la plupart des auteurs, par Lauarck surtout, qui en a peut-être exaçéré la valeur dans l'arrangement de sa fanille des Maciracéces. M. Cuvier, qui, en suivant les inclications de Poli, a rapproché les Mactres des V'́nus, auroil dú faire eatrer dans la même famille les Lntraires et quelques autres geares avoisioans. La principale dilférence sur laquelle on a établi une aussi grande séparation dans certaiues métlodes, entre les Lutraires et les Mactres, consiste en ce que dans les premières, l'animal a les tubes réunis eu un seul siplion, tandis que dans les autres les siphons, bejucoup plus courts, sont toujours séparés.

L'avitral des Mactres est généralement trigone, collé, variable, au reste, selon les espéces; il est composé d'un mavteau fort mince, dont les deux lobes sont onverts dans tonte la partỉe inférieure du bord; ils se réunissent supćrieurement lorsqu'ils alteignent au moscle adducteur antérieur; inféricurement, ils se joigneat beaucunp plustôt, et formeat un assez grand cul-de-sac percé à sa partie médiane de deux trous inégaux, prolongés en dehors eu denx cubes plus ou moins courts. La plus grande des ouvertures est la branchiale; clle est la plus inférieure: l'autre est trèspetite. Les siphons sont retirés en dedans par deux muscles adducteurs fort epais, qui laissent dans liatérienr de la coquille une irupression échancróe qui se continue avec celle du mantean. Lc pied est fort grand, courbé dans sa longneur, et terminé en pointe à sou extrémité antérieure; il est très-charnu et adhère à la masse viscérale par vne grande surlace. A la partie antérieure et múdiaue du pied, au-dessous du nuscle rétracteur antérienr, se tronve une petite onver:nie, qui est celle de la bouche. Flle est munie en dessus el en dessous d'une lèvre courte, dont les extrénuités se terminent à droile et à gauche eu deux paires de palpes triangnlaires très-fiuement striées en dedars; de chaque côté du pied et adhérens à sa : ase sont placés les feuillets brabchiaux, qui sont trèsmioces, fort grands et inéyaux; l'externe étant le plus graud. Ces feuillets se réunissent à la base clu pied, et se prolongent na peu daus la cavité du Hist. Nat. des Vers. Tome II. siplion liranclial. L'inus esi placé au-dessous d'eux, immédiatement au-dessus du unuscle rétracleur postérueur.

La dispusition iutérieure des organes est fat senublable à celle des Vénus, qui, du restc, a Leancoup d'analogie avec ce qui se voit dans les animaux du lype res Conchifères réguliers. Nous avous éludic sur une grande espece de Mactres, la Mactre fauve, qui vit en abondance sur nos côtes, le système nervonx de ce genre; nous l'avons Irouvé formé d'un double granglion cérébral situé au-dessus de l'ouverture buceale, idhérent à la fuce interne du muscle adductenr antérieur. Celte paire de ganglions fouruit en rayonnant des branches qui se reudeni à la bouche, au foie et anx antres viscères, et une pare plus considérable que l'on voit se terminer en un petil ganglion, duguel naissent plusieurs flets quise distribueat aux denx paires de palpes. Des parties laté rales et inféricures des ganglions cervicaux nai une branclie plus considérable qui s'enfonce dans la masse des viscères à sa jonction avec le pied. Elle suit la même direction jusqu'à la latuteur du caur el du rectum; elle remonte vers eux pour les suivre jnsquan muscle adducteur postćrieur, sut le milieu duquel le aerf de chaque côté vient se joindre, pour furmer un ganglion d'oris'échappent un assez graad nombre de filets qui se jetten dans l'épaissenr des bords du manleau, dins la masse charnue des siphons, et celle de leurs muscles rúlracteur. Des braaclıes que nous n'arons pas mentionnées précédemmeal ont leur origine an bord anlérieur el supérienr des gangrlions cervicaux, et se répancleut de là dins toute la partie antérienre dn manteau. Dans les reclserclies qui ont été faites jusqu'i présent dans les Mollusques acéplales, le système nerveux avoit échappé aux analowistes. Quelques-unes de ces partics, entrevues par Poli, avoieat été prises ponr des vaisseaux lymphaliques; uons sommes les premier qui, dins le Ditionnaire classique d'Histoire naturelle, ayons décrit le système nerveux d'nne manière précise dans plusicurs genres, el qui en ayons déduit des considérations générales à l'article Mozrusque du même ouvrage.

Les Mactres soat des coquilles généralement minces, bâillauıcs des deux côtés, mais beancoup moins que les lutwaires. Parmi elles, Lamarck avuit placé une coquille fort remarquable, qu'il nomma Mactre donucic: elle ne présente pas les caractères de ce geure; sa charnière offre au milieu de denx denis divergentes un cuilleron assez grand, destiné an ligameot; elle se rapproche donc de certaines Amptidesues, el nous avoos cru nécessaire de faire avec eile un genre particulier soas le nom de Mésodesme. On trouve a l'élal fossile un assez yrand nombre de Mactres; elles sont mo:ns noubreuses que les espèces vivantes: elles ne se ont eucore montrées que dans les terains teriaties.

$D d d *$ 
1. Macta giante. Mactru gigantea.

MI. testâ magnâ, solidâ, albido-fulvâ, transversim substriala, intrì nates hiunte; fovea cardinali maximi, cordata.

Evcrcl. pl. 25g. fig. 1.

Cиeах. Conch. tom. 10. tab. 170. fig. 1650.

L. Mх. Anim. sans vert. toni. 5. pag. 472. $n^{2} \cdot 1$.

Celle coquille est la plus grande du genre; elle cst ovalaire, sultrigone; son test est assez épais, d'un blanc-grisâtre à l'intérieur, et revêtue en dehors d'un épiderme d'un brun sale, assez intense, légèremeut foliacé, sous lequal la cocjuille est de la même couleur qu'à l'intérieur; les crochels sonl grands et prolubérans; la charnière est très-puissante, clle offre dans le milieu un trèsgrand cuilleron, de chaque sólé duquel se voient deux grandes dents latérales très-rninces, lamelIclises sar la valve droile; les dents latérales sont doubles, le rebord postérieur se relevant presqu"ì l'égal des latérales elles-mêmes; la dent cardinale en forme de $V$, qui est un des caractères les plus essentiels des Mactres, manque ici complélement. Cetle coquille, sous ce rapport, sert donc de passage aux Lniraires, quoique par sa forme et le peu de bâillement de ses valves elle a ppartienne véritablement au genre Mactre. Les impressions masculaires soat très - grandes dans celte espèce; clles sont lisses et brillantes; l'aatérieure est ovalaire et la postérieure au peu plus arrondie; l'impression du manteau ne présente postérieurement qu'une fort petite échancrure; le bâillement antérienr de la coquille est peu considérable; le postérienr, un peu plus grand, est quelquefois partagé en deux légères sinuosités qui indiquent la position des siphons.

Celte grande coquille se trouve particulièrement dans les mers de l'Amérique septentrionale, surtout an banc de Terre-Neuve, où elle paroit assez commune. Elle est longne de go millim. et large de 125 . On en connoit de plus grands individus que celui dont nous donnons les dirnensions.

2. Mactre de Spengler. Mactra Spengleri.

$M$. testá trigonì, lovvi; valvó planâ; natibus distantibus, aperturí lunatâ separatis.

Mactra Spengleri. Gatex. pag. 3256. no. 1.

Cuess. Conch. tons. 6. tab. 20. fg. 199-201.

Excrcz. pl. 252. fig. 3. a. b.

SpeNGler, Catal. tab. 3. fig. 1-3.

LAnx. Anim. sass vert. tom. 5. pag. 473 . $n^{\circ} \cdot 2$.

Cuquille des plus singulières, dont la charnière présente le fait particulier de laisser béante eu dessous du crochet la cavitú du ligament. Nous ne connoissons ancune disposition parmi les
Mollusques appartenant à la classe des Acéplualés qui offie un fait de celle aalure.

Celle coquille est assez grande, d'un blancroux, miuce, subtransparente, à crochets assez grands, mais fort écartés, duminant antérieurement un grand espace lunulaire, qui est boroé à sa parlie supéricure par celle cavité toujonrs ourerte du ligament. Le corselet "st subcordiforme; il occupe lout le côlé postérieur, et il est nellement séparé de cliaque côté par nne carène peu saillante. La surface extérieure est légèrement el irrégulièrement striće par les accroissemens mulcipliés. A lu clarvière, on recoarque sous le crachet un cuilleron peu saillant à l'intérieur, très-profondément creasé, et toute sa paroi post\}rieure manque. Le ligament, dans toute l'étendue de celle fente, se trouve par couséquent à découvert. A la partie antérieure du cuilleron on voit une petite dent en forme de $V$, mais en partie avortée. La surface intérieure est lisse et polie; les impressions musculaires sont médiocres, ovalaires, el l'impression du manteau forme postérieuremeal une échaacrure profonde, mais étroile.

Cettc coquille, rare et précieuse, vient, d'après Linné, des mers du cap de Bonne-Espérance. Sa longueur est de 65 millim. et sa largeur de 85 .

\section{N ACTRE carinée. Mactra carinuta.}

$M$. testâ trigonâ, pellucidâ, albâ, convexâ; vulvâ angulis lamellâ clevatû carinatis cincumscriptâ; natibus lacuibus.

Guslit. Test. tab. 8j. fig. $f$.

Ksora, Vergn. tont. 6.tab. 34. fig. I.

Exc rcL. pl. 251. fig. I. a. b. c.

An Mactra striata? G GeL. pag. 3257 .

LAM1 . Anim. sans vert. tom. 5. pag. $47 \overline{3}$. $n^{\circ} .4$.

Coquille El'́gante, d'une forme remarquable, et bien facile à reconnoilre parmi toutes ses congénères. Elle est avale, trigone, tonte blanche, très-mince, transpar'ente, presqu'équilatérale. Ses crochets sont médiocrement saillans; ils sont étroits et fortement incliaés sur le côté antérieur; le cóté postérieur est subıronquê, aplati, et occupé en entier par un très-vaste corselet bordé et limilé en clehors par nne carène lamelleuse, fort saillante à son exırémité inférieuwe; les bords de ce corsclet laissent entr'enx un báillement assez considérable. La surface extúrieure paroil lisse et pclie; mais, examinée à la loupe, on la trouve converle d'une très-grande quantité de stries transverses d'accroissemeat. La charnière est étroite : dans le milien on trouve un cuilleron d'une méliocre étendue, à la partie antérienre duquel est située la dent pliée, dont un des côtés est avorté. Les dents latérales soot minces, la- 
melleuser, fort courtes; la posterieure surtout est fort petice, et plus rapprochée du cuilleron que l'autérieure. Liimpression du manleau n'a qu'une lrès-petite échancrure postérieure; les impressions unsculaires sont très-petites, relativement à la yrandeur de la cocpuille.

Cette espèce, recliercliée des amateurs, est woins grabde que celle de Spengler, et paroit provenir des mểnes mers. Sa lougnueur est de 60 millian. et sa largeur de 80.

\section{Mlactre albine. Mactira albina. Nов.}

III. testâ ovato-subtrigonâ, inflatâ, tumyidâ,

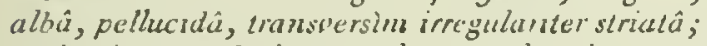
umbonitus cordatis, regulanter plecatis; ano magno, ovito, busi sinuoso.

(irande el belle coquille dont nous ue trournas nulle part ni descrijation ni fiğure; elle présente, comme quelques autres especes apparlenant à dillirens genres, ce fait remarquable de vivre au Sénrigal el de se retronver à l'élat fussile and enviruos de Dax el de Bordeaux. Lile est ovalaire, sulutrigone, jresque cordiforme, par conséquent très-enllée; ses crochels sont assez curauds, saillans, inclinés furtemeut sur le sôté ancérieur, qui est díprourvu de luusle; ses crochets sunt tantót lisses et tautôt ornés de rides ou de plis Iansverses plus on moins nombreux, selon les individus; la surlace extérifure est occupée par ur) très-griuld noubre de stries transverses tıćs-fines et ubsulètes, qui se multiplient d'une manic̀re irrégulic̀re vers les bords. Le corselel wcupre tout le côtć postéricur; un angle obtus le limie à l'cxtérieur; il esı légèrement sinucux à son exIrémité inférieure; lés stries qui s'y voient sunt seablables a celles qui sont sur la face exterae; la clarniere est large, mais, raccourcie, on y voit das le milien un grand cuilleron dépassanı le bord à sa base, à côté duquel est placée antérieurement la dent cardinale, qui, dans ruelques individus, est réluite à un de ses côtés. les dents latérales sont cuurtes, lamelleuses, cumprimées ci très-saillantes. Les impressions musculaires nc répondent pas, quast à la taille, à celle de la coquilie: elles sint pe!ites, ovalaires; la postérieure est un peu plus grande que l'autre.

Cette lielle coquille est lungue de 85 millim. cl large de gú.

\section{Mactax grande taille. Mactra grandis. Nov.}

M. testâ magnâ, ovato-trigonâ, trunsuersâ, antice substmuosâ, allenwatâ, albo-griseâ sub efidermi fuscuto; stris sulcisve irregularibus; lunulâ ovatâ; cardine brevi; dentibus lateralibus minimis.

Il ne faut pas confondre celle coquilke arec la Mactrc géante; elle constitue une espèce eminemment distincte par tous ses caractères, n'ayant guère de cominun avec celle que nous venous de ciler que sa grandeur et sa coulcur. Sa forme est ovale, triangulaire; clle est comprimie, presqu'équilatérale; son côté postérieur est plus gran.l que l'antéricur : celui-ci, à parlir des crocliets, cst légèrement excavé, ce qui le rend plus étroit et le fait terminer en pointe obtuse à sa jonction avcc le bord inféricul. Les crochets sout peu saillans, obliqueneut conlourués an-dessus d'nue luaule ovaliare assez grande; celle luaule, légèrement déprimée, esi séplarée jar un silion pea profond. lie corselet occupe tout le cỏlć pustilicur; il est indiqué f:ar un sillon qui s'approlondit en descendiut, et gqui produit une sinuosicé sur le bord, an point où 1 y arrive. Tiextrémité postérieure cst furreanent biallante; les loords de 1,âilleuent sunt plus épais que les autres. La surface extérieure cst cliargée d'un assez grand nombre cic sillons on rides transverses irrégulières, quii s'accuniulent et se grossissent vers le bord inlérieur; celle surface, dénudúe aux crochets, csı revêtue d'un épiderme grossier, foliacé, d’úa brun très-loncé. La chinricie diflère beancoup de celle de la Mactre gúaute. lie cuillcron en est beaucoup moins grand; il est accompagné antérieurement d'une dent cardiuale en forme de $\mathrm{V}$, qui manque loujours dius l'espice que nous citons: celle deut cirliuale est lics -fo:te, el se voit également sur les deux valvès; senlement, sur la valve droile, son cốé posiérieur est trèscourt, el l'auléricur, très-prolongé, se confund par sa lrase avec le loord. Les dents latérales, qui, dans la Mactre géante, sonl très-grandes el trèssaillaoles, soni ici extrêmement courtes et ì peine suillantes. Les impressions musculaires sont assez grandes, et l'inpression du manlean a une échancrure postérience large et peu approlondie.

Cetle espece, dont nous ignorons la patrie, est longue de go williw. et large de 120.

\section{Mactre fauve. Alactra helvacea.}

II. testà ovato-trigonô, pallidè albî, fulvo radrata; vulvi lanuluque convexis, iufis; denubus lateralibus remolis.

Mactragluuca. G.ues. exclusi Borniisynonymo.

Mactra helvacea. Cuenx. Conch. tom. 6. pag. 2.34. $4 a b \cdot 23$. fig. 252.233.

ENcrcr.pl. 256 fig. 1. a. b.

Pol.r, Test. tom. 1. tab. 18. fig. I -3 .

l.amk. Anim. sans vert. tom. 5. pag. 473 . $n^{\circ} .5$.

Cette grande espèce rit abondanument sur nos côtes; elle a quelque ressemillance avec la Mactre géante, mais néanmoins s'en distingue facilewent. Elle est ovale, subtrigone, inéquilatérale, un peu baillante à ses deux extrémités, mais plus à la postérieure qu’à l'antérieurc; ses crochets sont pelits, obliquereut inclinés audessus d'une espace lunulaire lancéolé, indiqué D d d : * 
par nne légère dépression; une ride pen prononcée limite sur le côté postérieur la surface du corselet; la surface extérieure est lisse sur les crochets et finement striée dans le reste de son étendue : elle est revêtue d'un épiderme d'un brun-fauve légèrement lamelleux, surtout vers les bords des valves. En dessous de cet épiderme la coquille est ornée sur un fond d'un blanc-fauve de lascies rayonnaules d'un fauve plus foncé, dont on aperçoil des traces à l'intérieur. La charnière est assez large; sa partie médiane est occupée par un cuilleror qui ne fait aucune saillie sur le bord; la deat en forme de $V$ qui est placée à sa artie antérieure est fort grande et complète. Les dents latérales sout très-remarquables par leur grande élévation et leur peu d'épaisseur; la manière dont elles s'cngagent reud difficile leur conservation, si l'on veut ouvrir la coquille sans précaution.

Cette belle coquille se rencontre aussi bien sur les côtes d'Angleterre que sur celles de France. Elle est longue de 80 millim. et large de 112.

\section{Mactre lisor. Mactra stultorum.}

Mr. tes:â ovato-trigonầ, lavi, subdiaphanâ, pallidè fulvâ; radiis albidis, obsoletis; facie internâ albido-purpurascente.

Le Lisor. Adaxs. Sénég. tab. $17 \cdot f g$. 16.

Pour, Test. toin. 1. \$ab. 18. fg. $10-12$.

Cenzin. Conch. tom. 6. tab. 33. fg. $224 \cdot 225$.

ExcrcL. $p l$. 256. fig. 2. $a . b$.

Var. b.) Testâ minore, pallidiore; natibus albidis.

Lамк. Anim. sans vert, tons. 5. pag. 474. $n^{\circ} \cdot 7$.

Liané a nommé cette coquille MIactra stultorum, parce que son abondance altirant presqu'exclusivement les regards du commun des observateurs, elle est presque la seale coquille qu'ils rapportent de leurs excursious sur le littoral de l'Océan. Celte coquille est d'une médiocre grandeur; elle est subtriangulaire, assez eutlée, cordiforme; ses crochels sont grands, proéminens, obliquement inclinés en dessus d'un espace lunulaire à peine indiqué; la surface extérieure ne présenie d'autres stries que celles des accroisse. mens; le test est très-mince, fragile, transparent, d'un fauve-violacé en delıors, avec des zones transverses, presque brunes et irrégulières, sur lesquelles s'aperçoivent très-distinctemeat des linéoles obscures, blanchàtres, longitudinales et rayonnantes. A l'intérieur la coquille est d'un violet assez intense, surtout vers le bord postérieur; la charnière est étroite, alongée, remarquable en cela que la fossette da ligament est fort petite et les dents latérales fort grandes.

Cette coquille se trouve également dans la Méditerranée, sur diftérens points de l'Océan atlantique, an Sénégal, et est très-abondante dans tout l'Océán européen. Sa longueur est de 44 millim. el sa largeur de 54 .

8. M

MI. testâ trigonâ, solidâ, ulbâ; striis transversis, tenuibus, subfurcatis ; facie internâ maculis violaceis nebulosis.

An Mactra glabrata? G MEx. $\pi^{\circ} \cdot 7$.

Cremn. Conch. tont. 6. tab.22.fig. 216.217.

Lamx. Anim. sans vert. tom. 5. pag. $47^{5}$. no. 10 .

Coquille d'un médiocre volume. Elle est blanche en dehors, ornée quelquefois de quelques rayons d'un faure peu intense, et en dedaus de taches nébuleuses plus ou moins graades et violettes. Elle est triangulaire, presquinéquilatérale, un peu gonflée; son test est solide et épais; les crochets, peu bombés, sant peu inclinés; le corselet est assez grand, lancéolé, orné d'une tache semi-lunaire violacée, et l'on y voit des stries fines et régulières d'une grande èlégance; des stries semblables se trouveat sur l'espace lunulaire, qui, du reste, n'est point séparé en delors, et ces stries se continuent sur tout le côté antérieur de la coquille; elles se prolongent jusque vers le milieu de la surface de la coquille, où elles s'arrêtent et se bifurquent. La charnière est étroite; le cuilleron qui porte le ligament est fort pctit et obliquement incliné du cốté postérienr; les dents latérales sont grandes, extrêmement minces, et la postérieure est la plus prolongće.

Cette coquille a ćté rapportée des mers de la Nouvelle-Hollande, et ne manque pas de rapports avec une des espèces fossiles du bassin de Paris, que Lamarck a nommée Muctre deni-sillonnée. Il existe cependant des dilférences assez grandes pour qu'on les lienne séparées en deux espèces. Longueur 82 millim., largeur 44.

\section{Mactre plicataire. Mactra plicataria.}

M. testâ albâ, diaphanâ, transversè rugosoplicatá; vulvá planiusculá; ano depresso, oblongo.

Chern. Conch. tom. 6. tab. 20. fig. 202. 204.

Excrcs. pl. 255. fig. 2. a. b.

Mactra plicataria. GMEL. $n^{\circ} .2$.

Lauk. Anins. sans vert. tom. 5. pag. 476 . $n^{\circ} 14$.

Cette espèce de Mactre est ane des plas déprimées qui soient connues dans le genre; elle est encore facilement reconnoissable par les gros plis transverses irréguliers dont elle est ornée. Elle est subtriangulaire, inéquilatérale; le côté postérieur étant le plus court, ses crochets sput peu saillans; ils sont coarts et dépassent à peine lo 
bord cardinal; une grande lunule lancéolée, toute lisse, occupe la presque totalité du bord antérienr; le côté postérieur est subtronqué, lisse, séparé par une carène lamelleuse, très-saillante, yni limite la surface du corselet. Le test est extrêmement mince, et les sillons transverses réguliers dont il est orné en dehor's se répètent à lintérieur, où ils sont aussi saillaus. La cbarnière est assez large, portée sur une lame cardinale trèswince, dont le milieu présente une cavité trèssuperficielle destinée à l'insertion du ligament. La deot cardiuale en forme de $\mathrm{V}$ est petite et fort singulière, en ce que de la base de son côté antérieur nait une petite apophyse qui remonte obliquement et se termiue en pointe. Les dents latéralcs ont le caractère particulier d'être fort courtes, extrêmement minces, et de laisser entre elles sur la valve droite une cavité très-étroite d'abord, et qui s'élargit furtement en dessous. On ne connoît encore qu'un très-petit nombre d'individus complets de cette espèce, qui est si rare que l'on a même de la peine à s'en procurer des valves détachées. Elle provient de l'Océan indien, d'après Launarck. Sa longueur est de 53 millim. et sa largeur de $7 \mathfrak{t}$.

10. Mactre lactée. Mactra lactea.

MI. testâ ovatû, trigonâ, subturgidâ, tenui, pellucidâ, albâ; fascuis lacteis; striis transversis, tenuissimis.

PoL1, Test. tom. 1. tab. 18. fig. 13. 14.

An Mactra lactea? Gael. n०. 10.

Lasx. Anim. sans vert. tom. 5. pag. 477. n..19.

Parraud. Cut. pag. 3o. no. 3g.

La Macıre lactée est l'une des espèces que l'on troave dans la Méditerranée; elle est très-distincte par sa forme enflée, triangularre, et snrtont par la blanchear constante de son test; les crochets sont opposés, pen inclinés au-dessus d'un espace lnnulaire très-grand, cordiforme, à peine indiqué au-dehors par un angle très obtus; le corselet est plus nettement séparé, il occape tout le côté postérieur; la surface extérieure est lisee, substriée irrégnlièrement vers les bords; ¿ l'intérieur la coquille est d'un blanc lacté extrêmement pur; la charnière, supportée sur une lame cardinale étroite, est pourvue dans le milieu d'un cuilleron dont ta base fait une légère saillie à l'jutérienr. Les dents latérales sont longues, lamelleuses, et assez épaisses à leur point d'insertion; la dent latérale postérieure est plus longne et plus rapprochée da cuilleron que l'antérieare; les impressions muscalaires sont arrondies, superficielles, et l'échancrure de l'impression palléale est extrêmement courte. La longuear de cette espèce est de 52 millim. et sa Pargeur de 64 .
11. Muctre blanche. Mactra alba.

II. testâ obtusd trigonâ, turgidâ, subpellucidâ, albâ; striis transversis, minimis; lineis longitudinalibus, raris, obsoletis.

An Mactra lactea, etc.?' Ceesiv. Conch. tom. 6. tab. 32. fig. 320. $32 \mathrm{I}$.

Encrelop. pl. 354. fig. 5. a. b.

Lamk. Anim. sans vert. tom. 5. pag. 477. no. 22.

Celte coquille a des rapports avec la Mactre australe; cependant on la reconuoit au premier coup d'œil, parce qu'elle manque à l'intérieur des tacbes violelles qui se voient dans l'autre espèce. Elle est ovale, subırigone, presqu'équilatérale; elle est mince, transparentc, toute blanche en dedans, d'un blanc-roussaitre ou grisatre en dehors, et couverte de ce côté d'un grạd nombre de stries très-fines, transverses, assez régulières, quelquefois interrompues par des accroissemens grossiers. La lunnle est à peine indiquée; le crochet qui la domine se recourbe un peu obliquement au-dessus delle. Le corselet est grand, ovalaire, et séparé par un angle très-obtus qui descend en s'effiçant jusqu"is la jonction du bord inférieur et du bord postérienr. La charnière est portée sur une lame cardiuale fort étroite; la fossette du ligament est petite, obliquement inclinée du côté postérieur; la dent cardinale, en forme de $\mathrm{V}$, qui est placée à sz partie antérieure, est fort grande et assez épaisse; les dents latérales sont courtes, oblongues et épaisses. Celte coquille, fort rare daus les collections, se trouve darrs les mers de l'Iude, et quelquefois dans l'Océan pacifique. Sa longueur est de 35 millim. et sa largeor de 43.

12. Mactre solide. AIactra solida.

II. testâ trigonâ, opacâ, loevussculâ, subantiquatî.

Mactra solida. Liv. Syst. nat. pag. 1126 . G a $n^{\circ} .13$.

Var. a.) Testá unicolore, albido-cinorascente aut flavescente.

List. Conch. tab. 253. fig. 87.

Pennant, Zool.brit.tom. 4.tab. 51.fg. $45 . a$.

EкстсL. pl. 258. fig. 1.

Cueus. Conch. tom. 6. tab. 23. fig. 230.

Var. b.) Testa cingulis olivaceis fuscis aut conileis pictá.

Dacosta, Test. brit. tab. 15. fig. 229.

Cивак. Conch. tom. 6. tab. 23 . fig. 229 .

LaMr. Anim. sans vert. tom. 5. pag. $477 . n^{2}$. 23.

Payradd. Cat. des Ann. et des Moll. de Corse, pag. 29. n०. 38 . 
Dorovas, Brit. sleeli. tont. 2. 4ab. 61.

Donset, Cat. pag. 32.tab.6.fig. 6.

Coquille extrêmement abondante dans tout l'Océan européeu, sur prescque tous les points de la Méditérranée, et qui se retrouve, nous a.t-on assuré, jusque dans les mers du Sénégal. Elle est ovale, subtrigone, solide, épaisse, ordinairement blanche, et quelquefois aussi ornée de zones transvel'ses, jaunâties ou bruaâtres; sa surface extérieure est couverte de stries multipliées, transverses, obsolètes : on y remarque de plus les étages plus ou moins nombrenx qui rósulfent des accroissemens. Les crochets sont médiocres, pen enllés. La lunule, qui est au-dessous d'eux, est grande, ovalaire, superficielle, élćgamwent striée dans presque toate son étendue, priucipalement à sa partie supérieure. I.e corselet occupe presque tout le côté postérieur; il est grand, ovalaire, et strié de la mêue manière que la lunvle; le bord cardinal est assez étroii, sı ce n'est daus le milieu, où il est élaryi par la saillie que produit sur sou bord la base de la fossette du ligament. La dent cardinale plojuce est petite et comprimée; les dents latéláles sont assez prolongées; elles sont égales et finement sirıées de haut en bas. Ce deruier caractère est très-bor pour reconnoître l'espèce, car il n'y en a gu'nn petit nombre qui le piéseuteat. L'écLancrure postérieure de l'impression palléale est lurt étroite et peu profonde. Les rariétés de celte espèce ne different de type que par quelques zunes transrerses, taotót fauves, tautút bruadtres, qui suivent babituellement les traces d'accrcissement.

Nous possédons na individu trii vien! des mers du Ford, qui a la plus parfaite analogie avec d'autres à l'état fossile, qui pruvienuent du crag d’Augleterre. Longueur $35^{\circ}$ aillim. , Largeur 47 .

\section{Mactre déprimée. Mactra depiessa.}

II. testá subovati, tenui, pellucidi, candidi, convexi; disco lavi, depresso; lateribus stria:opticatis.

Crems. Conch. tom. 6. tab. 24. fg. 234 .

L_ve. Anim. sans vert. tont. 5. pag. 479. $7^{\circ} \cdot 29$.

Cozuille dont la forme sort on peu de celle qui est habituelle aux Macires : tile pourroit, cowne la Lutmaric rugosa, servi: d'iutermédiaire entre les Mactres et los Lutuires. Elle est ovale, oblongue, t:ansrerse, uéquila!́́rale, toute Llauche, mince, t:ansparen:e. Les crochets sunt petıls, a peice saillaus au-dessus du bord; au-dessous b'eux e: antérieuremeat se voit un espace lunúaire très-pelit et lancéulé. La surface extérieure uss orcúe d'un tris gı gra nomb:e de stries extrêmement fiaer, résulieres, interlompaes à des upuces inégats pur des accroinsemens plus cu moins nomlreux. Le cóté antérieur est plus court et plus étroit que le postérieur; celui-ci est arrondi, obıns, légèrement bâillant. Iıa charnière est portée sur une lame cardinale très-éuoite: la fossette du ligament est étroite, mais protunde. Un des côtés de la dent cardiuale est oldinairement avorté; des dents latérales, la postérienre est à peine saillante; l'autérieure est courte et pointue. Limpression palléale est largement et profondécueat écuancrée du côté postéricur.

Nous ignorons d'où vieat cette coquille, que Lamarck croil provenir des mers de l'Inde. Eille est longue de 28 millim. et large de 42 .

14. Mactre delloïde, Muctra deltoides. Lams.

II. testâ ovato-trigoná, incequilaterá, albá; latere postico breviore; vulvâ anoque eleganter plicatis.

Mactra seni-sulcata. Lıмx. Ann. du Mis.

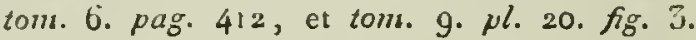
a. $b$.

Ibid. Layr. Anim. s. vert. tont. 5. pag. 479. $n^{\circ} .52$.

IIactra semi-sulcata. Noв. Descript. des Coq. foss. des euv. de l'ario, tom. 1. pag. 31. no. 1. pl. 4. fig. 7-10.

Nons ne sarons si l'espéce vivante que Lamarck a comparée avec la lossilc des envilous de Paris, lui est réellemcnt ileutique : ce que cous avons pu viri jusqu'ici ne vous cunfirme pas dans cette opinion, que nous aviuns cependart adoptée dans notre ouvrage sur les Fossiles des environs de $P_{a r i s .}$ L'espèce vivante qui semble àvoisiner le plas ia Mactue deltoide est celle que nous avons précédemnent décrite sous le nom de Mactre australe; il sullira de mettre en rapporl les deux espéces pour se convaincre que leur analogie n'est pas aussi parlaile qu'on doit l'exiger pour ces sortes de comparaisuus. La Mactre deltoide est mince, cassaute, orale, subirigone, très-déprimée, presque équilatérale; à crochets petits, peu courbés, au-dessous desquels se voit uae grancle luarle oralaire, remarquable par les stries élégantes dont elle est oruée. Le corselet occupe la presque totalité du côtć postćrieur; Il est plus graud que la lunule, et il est séparé par un abogle du reste de la surface; celle-ci cst finement sirıée en travers. Ia churaiére est fort étroite; la fossetle du ligament, fuit ublique e: très-profonde, est accompagnée antérieurement de sa dent cardinale, en fortue de $\mathrm{V}$, qui caractérise le gente. Ceste dent caldur. le est furt courte et très-étroite; les dents latprales sunt assez prolongées, Lamelleuses, trèssailiantes, e: la postérieure est un peu plus conive que l'antérienre. Cetre coquille fossile se truure en alıondauce aux euvirons de l'aris et de $V_{2}-$ lognes. Les plus grrauds individus sunt longs de 33 millin. et larges de 47. 

Noв.

15. M

M. testâ trigond, transuersâ, depressâ, lavigatâ, antice laviter arcuati; cardine angusto, bievissimo; dente cardinali simplici; lunulis lavigaiâ.

Noв. Descript. des Coq. foss. des environs de Paris, tom. 1. pag. 32. no. 2. pl. 4. Jig. $11-14$.

Coquille qui avoisine beaucoup la précédente, que l'on trouve quelquefois daus les mêmes localités, et que l'on ue confuadra pas a vec elle si l'on fuit alteution à ce caractère, bien facile à observer, de la lunule lisse, tandis qu'elle est constamment striée dans la Mactre précédente. La Mactre déprimée est ovale, truasverse, triangulaire, trèsdéprimée, comme son nom l'indique. Ses crochets sout très-petits, à peine sailluns; ils s'inclineut au-dessus d'une lunule d'une médiocre étendne, ovalaire, sublancéoléc, lisse, léyèrcment déprimée et séparće par un sillon simple. Le corselet est subsinueux à sa partie supérieure : il est irrégulièrement ruguenx, et il occupe rout le côté postérieur. La surface extérieure est presque lisse; on y remarque yuelques stries d'accroissement. Lat charnière est très-courte et fart étroite; elle se compose d'une très-petite cavité qui reçoit le ligament, en avant de lacjuelle est située la dent cardinale, qui est réduite à une seule lame oblique par l'avortement de son côlé interne. Les dents latérales sont très-courtes et très-peu saillantes. Les bords sont minces, tranchans, simples dans toute leur longueur, et l'impression palléale a une échancrure pastérieure extrêmement petite. Cette espèce, plus rare que la Mactre deltoide, se trouve priacipalement aux environs de Senlis, dans les grès marins supérieurs; elle est longue de 37 millira. et large de 50. Il existe, aux environs de Dax, une espèce très-voisine de celleci; mais qui en diffère d'une manière notable, nonseulement far la charnière, mais encore par les stries de la luaule et du corselet.

\section{MAFAN.}

Il paroittoit, d'après Adanson ( Voyage au Sénégal, pag. 93, pl. 6, fig. 4), que ce Cône seroit une des nombreuses variétés du Conus cmiralis des auteurs. Comme ceux-ci n'ont pa's rapporté cette espèce daus leur synonymie, on doit conserver du doute jusqu'ail moment oì on aura pu l'ćtudier de nouveau, la figure d'Adanson étant insuftisaute pour décider la grestion.

\section{MAGAS.}

Genre proposé par Sowerby (Min. conch.pl. I ig) pour une petite coquille bivalve, fossile, que l'on trouve dans la craie de Neudon, ainsi que dans celle de Maudesley-Norwich, en Angletcre.
Lamarck l'avoit mentionn'e dans son deruier ouvrage parmi les Térébratules; elle ca présente, en effet, les caractc̀res extérieurs. Sowerby, ayant eu occasion d'examiner sa structure iutíricure, a cru devoir, d'après cela, proposer le noureau genre; ajais il n'est pas admissible. Voyez 'Генв́ватUL.

\section{MAGILE. DIagilus.}

Ce fut sous le nom de Campulote que Guetrard (Ménı. tom.111, pl.71,fig. 6) réunil les $M_{\text {id- }}$ giles aux Vermets en un seul genre: ce qui, d'apris les connoissances acquises par l'ouvra d'Adanson, devoit porter ce genre parmi les Mollusques. Cependant on ne tint pas, depuis, compte de cette opinion; car les Magiles furent confondues avec les Serpules. Montfort, dans sit Conchyliologie rystématique, revint à l'opinion de Guettard, reporta la Magile parmi les Mollusques, la sépara des Vermels, et lui donna le nom générique qu'elle porle aujourd'hui, et qui est généralement adopté. Lamarck ne mentionna pas ce grenre dius l'Extrait du Cours; il ne l'adopta définitivement que dans son dernier ouvrage, où il le plaça à la fin de la famille des Serpulées. M. Cuvier (Règneanimal) ne mentionna ce genre ni parmi les Mollusques, ni parmi les Annelides. M. de Blainville leur Irouva assez de rapport avec les Vermets pour les admettre, ainsi que les Siliquaires, parmi les Mollusques; cette opinion n'a point élé adoptée par M. Latreille, qui a conservé celle de M. Lamarck. On voit, par ce qui précède, cumbien il existe encore de doutes à l'égard des Magiles. Les deux opinions penvent étre également soutenues avec avantage; cal les zoologistes qui pensent que ce corps doit resler parui les Anoelides ont une figure de Pallis qu'ils rapportent à ce genre, et qui pourroit bien être une Serpule. Les per'sonnes qui croient que les Mariles sont des Mollusques, s'appuieut sur des analogies assez bien fondées de la forme de la coquille. Nous sommes dorc forcé, jusqu'à ce que l'on connoisse bien l'animal des Magiles, de llotter pour ainsi dire eatre deux opinions différentes.

Les Magiles ont une singulière manière de vivre; elles sout engagées dans des masses madréporiques daus lesquelles elles se creosent une cavilé pour y être contenues assez justes et sans avoir la moindre adhérence : elles commencent par former une coquille spirale héliciforme, qui se continue par un tube assez dioit, onduleux, à une seule carène. A mesure que l'animal grandit, il abaudonne la partie de la coquille et de son tube qui ne peut plus le contenir; mais an lieu d'y laisser des cloisons, comme le font les Vermets, il remplit entièrement cet espace par uue matière calcaire, compacte, diaphane, dure, pesante, semblable en quelque sorte dans sa cas- 
sure a de la calcédoine blonde. Taunarck caractérisc le geare Magile de la mauière suivaste.

\section{CARACTÉRES OÉKÉRIQUES.}

Test ayant la base contournée en une seule spirale cuurte, ovale, héliciforme, à quatre tours contigus, convexes, dont le dernicr est le plus grand et se prolonge en tube dirigré en ligne droite ondée; le tube convexe en dessus, caréúe en dessous, un peu dépriané el plissé sur les cơtés, a plis lamelleux, serrés, ondés, vericicaux, plus épais d'un côté que de l'autre. Aniujal inconnu.

Il a'y a encore qu'une seule espèce de Mugile qui soit connue, car celle rapportée par l'íron ve nous scoble pas distincte; c'est un jeune individu de l'espèce que Lamarck nomme Magile antique, Magilus antiquus. On De connoît encore à l'état fossile rieu qui puisse se rapporter à ce geare.

1I.agre antique. Magilus antiquus. Lask.

Lanx. Anim. s. vert tami. 5. pag. 374.

Campulote. Guetrard, Mém. tom. 3. pag. 540. pl. $7^{1 .}$ fig. 6 .

De Blainv. Malacol. pag. 433.

Moxrf. Conch. tam. 2. pag. 43.

Cette coquille est certainement l'une des plus singulières que l'on ait encore abservée. M. de Blainville a Lien saisi ses rapports en la plaçant à cúté des Vermets et des Siliquaires : ces rapports deviennent moins incertains depuis que l'on sait que la Siliquaire appartient à la grande série des Mollusques gastéropodes : comme dans ces deux genres, la cuquille du Magile commence par s'enrouler en spirale un assez grand nombre de fois, et se termine par on tuyau druit légèrement Ilexueux. A mesure que l'animal s'accroît, il remplit derrière lui le vide de sa coquille d'une matière dure, diaplane, qui, dans sa cassure, resscmble à un marbre cristallin. Cette coquille est sillonnée transversalement; à la base elle est pourrue d'une dépression ombilicale, ordinairement obstruée par un dépút calcaire. Cet ombilic est formé par noe cóte saillante qui paroît le résultat du canal on de l'échancrure dont la corfuille étoit jourvue dans le jeune âge : le bourrelet qui forme ret ombilic se continue en dessons dn tuyau, et y forme une vive-arête qui s'avance jusqu'd l'onverture. Les stries transverses que nous avons fait remarquer sur la spire se prolongent un peu audelà, mais bientôt elles sont effacées par des stries longitudinales, lamelleuses, extrêmement serrées, crépues, et surtout irrégulières. L'ouverture a les bords simples; elle est ovalaire et de peu d'étendue. Nous avons vu, dans la collection de M. Marmin, une variété remarquable de celle coquille; Elle a la spire subturriculée, alongée comme celle d'us Buliue, et très-cbtrse au sommet. Celle espèce vit, à ce quill paroit, dans les mers de I'sle-de-France. Elle esi toute blanche, et acquiert quelquefuis près d'un pied de longneur.

\section{MAILLOT. Pupa.}

3. Avant les travaux de Draparnaud, aucun auleur n'avoit bien saisi les earactères de ce greure, puisque les coquilles qui le composent étaient disséminées dans des genres diffétens : presque tontes, parmi les Hilices, et plusieurs dans les' Turbos, dans le système de Linné; parrai les Hélices et les Bulimes, dans celui de Bruguière, etc. Dès que le genre lut bien circouscrit par Draparnaud, dans son Prodome, Lamarck l'adopta immédiatement après dans le Système des Animaux suns vertèbres. Quoique terrestre, il le classa dans sa méthode loin des IIélices, entre les Scalaires et les Turritelles; mais il ne tarda pas à modifier son opizion et à remettre les Maillots dans leurs rapports naturels en suivant l'exemple de Draparnaud. La famille des Colimacées de la Philosophie zoologique contient en effet ce genre avec les Ilélices, Bulimes, Agathiaes, etc.; mais il paroît qu'alors lamarck a'avoit point encore considéré le genre Clausilie comme nécessaire, puisqu'il ue le mentionna pas. Roissy, dans le Buffon de Sonnini, suivit l'exemple de Lamarck. Montfort adopta les Maillots, et il n'admit pas non plus le genre Clamsilie : ce qui doit étonner de la part de cet autelic qui établissuit des genres sur de très-petits caractères. Celle omission ne fut point encore réparée par Lamarck dans l'Extrait du Cours, mais seulement dans les Animaux sans vertèbres, après que MI. Cuvier lui-même ent proposé son genre de Nompareille, qui répand aux Clansilies de Draparnaud : les Maillots furent alors associés aux Clausilies dans la famille des Colimacées, augruentée de plusieurs autres genres. M. de Ferussac, dans son Systeme de classification du genre Helice, adopia à bien dwe le genre Maillot, en le réduisant au titre de souggenre et en lui danuant le now de Cochlodonte (vayez ce mot et Hónice), et sans changer rien de bien important dans l'énoncé des calactères. M. de Blainville a adopté ce genre, et le plaça, comme Lamarck, en rapport avec les Clausilies, les Agathines et les autres genres de Colimacées. (Voyez ce mot.) M. Latreille, dans son dernier ouvrage, a conservé l'opinion la plus généraloment reçue, c'est-à-dire qu'en adoptant le geure Maillor, il l'a mis dans les mêmes rapporis que Lamarck et M. de Blainville. L'animal des Maillots paroit être semblable à celui des Ilólices, d'après M. de Ferussac. Cependant, la première paire de tentacules est beaucoup plus courte; les dilférences les plus essentielles sont dans les formes de la coquille, la position de l'ouverture, et, le plus souvent, les plis lamelleux qui garnissent l'ouverture. Il paroîtroit étonnant, d'après ce que nous avons ru dans les Hélices, que 
les diflérences extérienues gui se manifustent dans les Nuillots ne se traduisissent pas à lintérieur par des diflérences organiques comparables a celles que nous avous remarquées dans les Bulimes, les Ambrelles el les liétices. Nours ne dontons gucre yue, lorsque l'on anra fait l'anatnasic des Maillots, on ne trouve des curaclires sullisaus romindeus avec cenx de la cogiville pour justilie. la cricilion din genre et sa cooservation.

1)'après la manière de vivre des Maillots, et la forme crérieure des parties du corps que lion a ¿tudir, it est évident qu'ils appartieunentau graod type des llélices, dout ils ne sont qu'une simple undilication. Les véritables Maillots sont des coquilles cylindrcides, ovales, obtuses an snumer, a lours xcrrés él nombrenx, lisses on plissées tongitudiualenent, jamais striées ou plissces en travers, du moins nous n'cu conioisons ancuu exemple; l'nuver(ure est arrondic, bordíe, aussi luurte que large : ce qui la dislingue éninemment de celle des Illilices, c'est quelle est dans une prosicion parallèle à l'axe, au lieu de lui êue diversement ou plus ou unoins ioclince.

Les. Uaillots vivent dans les forêts, sons les buis. sons, dans les lienx ombragés, où ils se tiennent cachés pendant lardenr du suleil : ils surtent de lcur retrailc pendant les pluies douces du printemps ou de léti; alors nn les trouve assez altondamment, quelquelois le long des arbres, des moliers on des vieilles murailles. Il est à présumer quils passent lihiver, comme les IIélices, dans un état d'engourdissement. Les caracetères suivias sont ceux que Lamarck donne à ce gerie.

\section{CA ACTÉRE GÉNÉRIQUES.}

Coquille cylindracée, en géuéral épaisse; ourerture irrígulière, demi-ovale, arrondie et subanguleuse inlúrieurement; à bords presqu' ćnaux, rélléchis en dehors, disjoints daus leurs parties supéricures; une la me columellaire tout-à-lait applitucie, sinterposant entreux.

A l'article Malsot, du Dictionnaire d'His. toire naturelle, MI. de Blainville les a divisćs d'une manière liacile à saisi", d'après le nombre et $1 \alpha$ position des dents de l'ouverture; mais, dans son arlicle Morrusque du mème Dictionnaire, ce zoologiste a propnsé de nuuvelles divisions d'uprìs í forme générale et d'après des coupes déji proposées par d'autrcs auteur's; c'est-à-dire qu'il $y$ fait rentrel les geures Gaknalle (Cuv.), Gibee (Munt,), Vertico (Mull.), et Partule (fer.). Ces dillérens genres réuuis aux Maillots augmentent le nombre des espéces, et roalgré ces divisions, on pourroil encore admettre, au besoin, celles qui reposent sur le nombre et la position des plis de l'ouverture.

La plupart des espèces coanues sont petites, ou Hist. Nat. des Vers. Tome II. de taille médiocre; elles sont d'Eurọ e et d'Amérique : on en trouve aussi en $A$ sie, et plusieurs espèces aux iles de kitance el de Bourbon.

S'il est vrai que le gente Clausilie ait des caractères insuffisans pour être crnservé, et qu'il duive renir par la suite se confondre aroc les Mirillats, il en est plusieurs autres le cenx que 1]. de 13!ainville confond aveceux, tels que les grenres Vertigo et lartule, gui ont des dilférences assez considérables pour être iloignćs; ie gence l’artule surtout, plus voisin des Bulimes que lont aure grenre, présente une organisation qui, comme nous le verrons, sullit pour [u'll soit desermatis conservé dans la méthode.

Brnguicre, dans le premier volume de ce Dictionnaire, a décrit, sous le nom de Bulime, plusienrs espèces de Maillois : nous renvoyons aux espriuces sinivantes:

Bulimus manica, $n^{n}$. 87. Pupa manica. L.s.s:x.

Bulimus u’a, no. 88. Pupa uva. LAмr.

Bulimus sulcalus, $\pi^{\circ}$.7. Pupa sulcata. L.1мк.

Bulimus fusus, no. 86. Pupa fusus. I.A u.

Bulimes similis, $n^{\circ}, 96$. Pupa cinerea. Lasik.

Eulimus tridens, $n^{\circ}$. go. Pupa lisiens. 1.Ask.

Bulimus quadridens, $n^{\circ}$. 91. Pupa quadrichrn, LAM $\mathrm{K}$.

Bulimusavenaceus, $n^{\circ}$. 97. Pupa apena. LA

Bulimus musconum, $n^{\circ}$. 65. Pupa unbilicata. LANK.

1. Maturot seigle. Pupa secale.

P. testî́ cylindraceâ, allenuulo-oblusinscula, striule, pallide fuscâ; aperturu septom rel actodcnlustâ; lubro margine reflexo.

Pupu secule. Da ap. MIoll. pl. 3. fig. 49. 50.

Helix secale. DAud. Hist. des Moll. $n^{\circ} .488$.

LA ыг. Anim. s. vert. tam. 6. pag. $110 . n^{\circ} .21$.

Petite coquille qui a une très-grande ressemblance avec le Pupa frumentim; elle est is peu près de la même taille, mais tonjours ylus étroite; les tours de spire sont aussi plus larges th moins nocabreux dans une même étendue; cnlia la disposition des dents de l'ouverture présente des dilfirences assez constantes pour qu'on la puisse distinuner à défaul des autres caracières. Cette coquille est alongée, turriculée, poiutue au sowmet, cyliudracée, formée de dix tours aplatis, ì sulure simple et superlicielle. Ces tours sont hinement striés dans leur longuear; les stries sont trísnombreuses, léguliêres, el disparaissedt quelquefois sur les derniers tours. A la base, on trouve un petit ombilic iufundibuliforme, profont; le bord ganche le recouvre a peine; l'ouverture est putite, nn pen plus haute que large; son péristome est blanc, épaissi, irès-peu reaversé en dehors. On compte daus sa longueur neuf deats

Eee * 
presggu'égales, prolongées jusque dans le fond de loaverture; on en compte trois ou quatre sur la columelle; truis appartiennent au bord gauche, et les trois deruicres, qui sont les plus graudes, sont réparties à cles espaces égaux daus la lonzuracur du bord druit. Des dents columellaires, la supíricure exterue est quelquefois bifide, ou plu. tò: iccomparnce d'un petil tubereule à sa base. l’armi les deuls du bord droil, la supérieure s'avance jusqu'au bord du périslome, en face de celles de la columelle.

Cette coquille, d'un brun-coraé foncé, se Irouve presque partout en lirance, sur les rocbers, daus les mousses, dans les lieux frais et ombragús. Les plus grands individus ont $\mathrm{g}$ millin. de longueur.

\section{Marllot fronent. Pupa firmentum.}

$P$. testá cylindraccâ, uttenuato-subacutá, tenuissimè striuta, cinereo-rufescente; apertuia octodentatá; labro margine albo, reflexo.

Pupa fiumentum. Drap. Moll. pl.3. fig. 5 г.52.

Helix frumentum. DАบрев. Hist. des IIoll. $n^{\circ} .487$.

Laxx. Anim. s. vert. tom. 6. pag. $109 . n^{\circ} 20$.

Le Pupa frumentum est use petite coquille subcylindracée, puintue au sommet, formée de dix tout's très-étroits, très-rapprochés, un pen convexes, à sulure simple et peu profonde; ils sont obliquement striés dans leur longueur; les s.ries sont fines, très-nombreuses et peu rígu. lières. T.e dernier lour est pourvu à sa base d'unc petite fente onılilicale, très-śtroite, recouverte presquenlièrement parle bord gauche; le dernier tour est très-court; l'ouvertare qui le lermine est patite, arrondie, presqu'aussi haute que large; son péristome est blauc, épaissi, reuversé en dehors, et garui daus sa lonjueur, surtout dios lefond de Fouverture, de sept à buit dents lamelleuses, très etroites, dont deux appartiennent à la colnmelle; deux autres, les plus grandes, à la base du boid gaucbe, et les autres au bord droir. Liune des dents columellaires, ordinaireunent bifille, est situéc à l'insertion du bord droit, et en forme le point d'appui. Cette petite coquille, très-commune en France et en Allemagne, est de la grandeur et à peu près de la couleur d'un graí de fromeat; elle est partout d'un brun-corné clair; son test est mince et diaphane. Elle est longue de 8 millian.

3. Malleot polyodonte. Papa polyodor.

$\boldsymbol{p}$. testá cylindraceo-turyidald, smóacutd, siriatî, corneo-fucescente; apertunî angustati, nsultidentatá; labro margine reflexo.

Pupa polyodon. Dnap. Moll. pl. 4. fig. 1. 2.

Helix polyudon. Daud. Hist. des Moll. $n^{\circ} .490$.

Layk. Anim. sans vert. tom. 6. pag. 109. $\pi 0.18$.
Pelice coquille qui babite la France múridiuvale et une partic de l'Italie. Elle est alongée, lurriculće, subfusiforme, pointue au sommet, et un peu plus rétrécie vers l'ouverture que dans le milieu; sa spire est formće de dix tonrs trèsrapproclıés, à suture simple et peu approlondie; ils sont régulièreusent striés dans leur longueur, les stries sont lines, rapprochées et obliques; le dernier tour préscute à la base une fente ombilicale assez longue; elle est en patlie cachée parle reuversemeni du bord gauchic. L'unverture est petite, ovaluire, longitudinale; elle est très-remarquable par le numbre considérable do petites dents lumelleuses très-fines par lesquelles elle est pres que fermce. On comule quinze de ces denis dans son pourtour; quatre seulemeut a ppartiennent a la columelle.'Touies ces den is ue soni pas égales; sept d'entr'elles sont plus saillantes que touies les autres; les deux gui sont placées à la liase de la colunelle, à l'origine du bort gauche, sont, parmi ces deruières, celles qui font le plus de saillie. Toutes ces dents sont blanches, ainsi que le péristome, qui est légérenent śpaissi en dedans, et ua peu renversé en dehors. 'Tuute la coquille est d'un brun-coorné foncé ea debors; elle esi wince, fragile et Irausparente. Sa longueur est de 10 millimètres.

\section{Maillot obtus. Pupa obtusa.}

F. testâ brevi, turgidi, cylindraceâ, obtusâ, obliquè striatâ, ulbs; aperturis edentuld; labro murgine subrofexo.

1'upa obtusa. Drap. Moll.pl.3. fig. 44.

I.Aмк. Anim. sans vert. tom. 6. pag. 108. $n^{n} \cdot 14$.

Celte espèce est l'une des plus cylindriques e: des plus obtuses qui soit dans le geare. Ele est alungée, forméce de buit tours gradués entreux, dont les premiers sont extrêmeineat obrus, toujours lisses, assez convexes, tundis que les suivans sout plus aplatis, striés obliquemeat dans leur longueur, et réunis par une suture simple, legèrement approfondie. L.e dernier tour ne présente jarais à la base la moindre irace d'ombilic; il se termine autérieurement par une petite onverture un peu oblique a l'axe, plus longue que large, doni les bords sont désanis, ì peine renversés en delıors, et épaissis en dedans par un petit bourrelet blanc. La columelle est tris-courte, arrondie, un peu tordue. Celte ouverture est toujours dégarnie de dents, et l'espèce pourroit, par cousćçuent, se placer sur la limite du genre pour servir de passage arec les Bulimes. Le Maillot obtus est noiformément d'un blanc-grisálte passant quel. quefois au brun, surtont vers le sommet de la spire; il est blanc a l'incériear. Draparnaud avoit crn qure celle espèce se trouvoit en France; mais il étoit dans l'erreur, car, malgrt les recherches multiplices d'un grand nombre de zoologistes, on 
ne l'y a janais rue, et elle a tié constamment trouvćc en Dalmatie. Sa lonsucur est de iz millim.

\section{Majzot ovilaire. Pupa ovaluris.}

$P$. testâ ovalo-turgidî, apice ubus $\dot{j}$, glubri, alba; aperturi sexdentati; luhn murgine reflexo.

Eulimus ovalaris Ourv. Voy. pl. 17. fig. 12. a. $b$.

Terligo ovalaris. DA D DEB. Hist. des MInll. $n^{\circ} \cdot 9$.

I. Am. Anim. sans vert. tom. 6. pag. 103. $\pi^{3} \cdot 13$.

Petite coquille fort remarquable qu'Olivier, le premier, a fait connaitre dans son $L^{\prime}(y)^{\prime}$ ge u Lev'cunt. Elle a de l'analogie, quant à la firme, avec quelquacs-unes des es pèces qui se tronvent en France, el notamment avec le Pupa dolium. Elle est orale, obluse, à spire courte, à lacuuelle on compte sept ì huit tour's rapprochés, convexes, à suture siuple, un peu protionde el subcanaliculée. Ces tours sont légèrement striés dans leur longueur; ils sunt blancs, quelquefuis grisittres; le dernicr est percé à la base d'un ombilic petil et poloud; il se termine antérienremeut par uae ouverture à bords épaissis, renversés en dehors, presqu'aussilongue que large, et abstruée par six dents fort saillantes, qui ne laissent à l'unimal, pour son passage, quiuse fente fortement contournće. De ces six dents, deux seulement sont placíes sur la columelle; une trnisième est à la base du hord gauche à l'endruit te son insertina; les trois autres appartienneat au bord droit. 'Toute ceite onverture est blanche.

Celle petile coquille, assez rare dans les collections, a 6 i 7 millim. de lungueur.

6. Mallot zèbre. Pupa zebra.

P. testá cylindrace $\hat{a}$, attenuato-obtusî, albi, lineis luteo-rufs longitudinalibus intermptis or nats; aperturâ tridentuto; lubro margzine subreflexo.

Bulinus zebra. Osıv. Voy. pl. 17. fig. 10. a. $b$.

Helix zebriola. Davd. Hist. des Moll. $n^{\circ} .455$.

L.sux. Anim. sans vert. tom. 6. pag. 107. $n^{\circ} \cdot 9$.

Jolie coquille cylindracée, qui a de l'analogie, cunme nons le verrons tont is l'heure, avec le Pupu tridentata. Elle cst alongée, turriculée, porntue au soamet, un peo enflée dans le milies, muis géaéralemeot cylindracée; on comple à sà spire douze à quatosze tours très-étroits, serrés, à peine convexes, marqués par quelques stries d'accroissemeut irrégulières, et oroés, sur un food bla ac, de llammules longitudinales d'ua lorun assez iutense : ces flammulles sont plus ou moins rapprochées, selon les individus. L'ouverture est petile, plus haute que large. Derrière elle, $t$ ea partic cachée par le bord gauclie, se trouve une petile fentc ombilieale. Dans les vieux imlividus, le p'ristome est rendu complet par un bonrelet olslique, qui renunle de la base du hord gauche vers l'extrémité du borl droit. lies bords sont épaissis, légèrement renversís; le druit porte ver's son milieu une dent abıse, le granche en prúsente éralement une, mais siluce verssa base. La columelle en présente aussi une placice obliquement en face de celle du bord droit, de manicre à ne laisser entr'elles qu'un in ervalle extrêtnement étroit. A l'inlérieur, luuverture est blanclie.

Celle espèce, qui habite le centre de l'Asie, est longue quelqueluis de plus de 30 aillim.; on la trouve ordinatirement plus petite.

\section{Mallot lrideuté. Pupa tridentatu.}

$P$. teslî simistrorsâ, cylindruceâ, alternutónacut $i$, sublavigatá, ulbs; st:iis longitudinalibus, obsoletis; aperturs nufescente, tridentuti; dente columellari unico; labro margine abbo, reflexo.

Gualt. Test. tab. 4. fig. e.

Helix tournefortiunu. D. U DEB. Hist. des Moll. $n^{n} \cdot 457$.

l.Aмk. Anin sans vert. tom. (j. pug. 106. $n^{n} \cdot 7$.

La figure donnée par Gualtieri est insu Risante pour reconnoitre cetle jolie espece, qui a beanconp d'analogie ave le Pupa zebra, dont alle sembleroit n'être qu'nne variélé tuuraće ì gauche et sins couleur. Cette coquille est du pelit nombre de celles qui, dans le genre, tournent à gauche. Si les deuts de l'utverture élviont mains êpaisses, elle devroil reatrer parmi les Clansilies. Llle est lurriculée, alongée, pointue, forusée de onze à douze tou's aplatis, tric's-rapplochés, lisses, i sulure sımple, un pen eufuncée, quelquefois submarginée par un petit bourrelet légèrement plissé, qui se montre priucipalement sur les derniers lours; la base de ce deraier tonr est percée d'une petile fente onbilicale, peu profonde, recouverte par le renversement du bord gauche. L'ouverture est petite, uralaire, un peu plis haute que large; ses bords sciat épaissis, l'́gèremeat renversés, blancs, loujoul's désunis dans tonte la longneur de la columelle; le divit est beauconp plus long que le gauche; dans son milieu il est muri d'uae dent obtuse et assez grosse, placte de telle sorie, qu'elle correspond an milieu de l'iatervalle qui sépare la dent colomellaire de la dent du bord gauche. C'est sur le milieu de la columelle qu'est située la deat comprimée dont elle est muaie. L'intérieur de l'ouverture est d'un jaune-safrané pále; tout l'extérieur de la coquille est blans.

Celle coquille, assez lare, se trouve en Perse, dans le midi de la l'uiquie; elle est longue de 27 willim. 
8. Maillot orientul. Pupa labrosa.

p. testâ ovato-cylindraceâ, obtusî, glabiâ, subpellucid.d, obsoleld striatâ, albid's-corneấ, aperturî edentuli; labro murgine reflexo, dilatuto.

Bulimus labrosus. Otı. Foy. pl. 31. fig. 10. a. $b$.

Iielix lubrosa. Daud. Hist. des Moll. $n^{\circ} .419$.

I,six. Anin. sans vert. tom. 6. pag. 106. $n^{n} \cdot 5$.

Tıc̀s-belle espèce qui fait évidemment le passage des Maillots aux Bulimes; cllc ne diflere de ces deraiers que par un reaversement considérable du péristome, et un pli columellaire assez gros et olatus. Celle coquille est alongée, ovaluirc, à spire obtuse et cylindracée, compnsée de sept à huit tonrs très-pen convexes, dont les premiers sant très-rapprocliés; la suture qui les unit est simple et superticielle. La surface des tours' paroit lisse, mais, vue à la loupe, on la trouve couverte d'un assez grand noubre de stries récrulières, produitas par les accroissemens. Le dernier tour occupe un peu plus de la moilié de la lungueur tntale; il se termine antérieurement par une ouverture ovale, obronde, à peine inclinée sur l'axe. Derrière cette ouverture, à la base de la conquille, se trouve une petite fente ombilicale cachée par le renversearent du bord gauclse. Le péristome de l'nurerlure est :out blauc; il est complet dans les vienx individus; dans les jeunes, il existe un intervalle entre les deux points d'insertion du bord : interva!le qui, dans la suite, est occupé par une callosité décurrente. Le pli columellaire descend ol,liquement; il a quelcques rapports avec celui d'autres espcces, mais il en a davautage avec ce que l'on voit daus quelques Bulimes, que l'on n'a jamais songé d transporter a m milien des Maillots, comwe celte espèce. Il est donc à présumer que dans un arrangement général des coquilles, elle sera remise à sa vérilable place. $\mathrm{S}_{a}$ couleur extérieure est uniforme, d'un blanc-corné, transpareat, devenant plus opaque et plus blanc vers I'ouverture. La longueur des grands iodividus est de 3o millim. Cette coquille, jusqu'à présent, n'a été rapportúe que par Olivier, de son voyage ea Perse.

9. Manlot striatelle. Pupa striatella. Fer.

P. testâ ovatâ, albâ , fusco variegatâ, apice obtusâ; anfractibus planulutis, longitudinaliter striatis; striis regularibus, longitudinalibus; suturis undulatis; aperturâ nvato-rotundâ, fusccâ, marginatâ; columellâ dente minimo instructâ.

Pupa striatella. Guérte, Icon. du Règne aninial, pl. 6. des Moll. fig. 12.

Quoique nous tronvions cette espèce indiquée sous ce nom par M. de Ferussac dans l'ouvrage

\section{Ni A I}

que nous venons de ciler, nous ne la vayons cependant pas dans le Prodiome de cet auteul, uù nous espérions en trouver l'indication. Celte espèce se reconnoît avec facilité; voisine du Pupa uva, ayant une forme analogne, on la distingue au premier aperçu, par la finesse de ses plis et par les taches en llammules qui ornent les lours de la spire : elle est ovale, oblongue, obluse au sommet; on lui comple dix ou onze tour's, dont les premiers sont irès-rapprochés et très-étroits; ils sont aplatis et réunis par une sulure très-superlicielle, rendue onduleuse par la terminaisou des stries longitudiuales. Ces stries sont assez saillanles, en forme de plis; elles sont ordinairement blanches, tandis que les intervalles qui les séparent sont bruns. Souvent sur le fond blanc de la coquille se montreat des fámınules longitudinales, nombreuses, plus ou moins larges, d'un brun foocé, qui coupent les suries un peu obliquement: le deraier tour préseate à la base un ombilic ınédiocre, contourné et caché en grande parlie derrière le bord gauche. L'ouvercure ressemble beaucoup à celle de certains Cyclostomes; clle est presque ronde, trc̀s - peu modifiée par l'avant-deraier tour; ses bords soal épaissis en un bourrelet aussi saillant en dehors qo'en dedans. Ce bourrelet est lylanc, ou tcinté d'ua brun clair; les points d'inserlion du péristome sont réunis par un bord gauche fort épais, de la même coulcur que le reste da péristome. Sur la culumelle, à pea près vers le tiers supérieur de sa longueur, se trouve uu très-pctit pli, très-coult et tranchant au summct. Nous avous acquis cette conuille avec d'autres qui provennient de l'ile de Cuba : nous sapposons qu'elle vit dans ce pays. Elle a 28 mill. de longneur; sa largeur est un peu variable, comme cela arrive, an resle, dans presque toutes les espèces du greare Maillot.

ı. Mainlot cylindrique. Pupa cylindrica. Miceiun.

P. testâ ovato.cylindraceâ, apiceobtusâ, corneâ, longitudinaliter tenué et eleganter striata; umbilico patulo; aperturû ovatâ, alhâ, octo vel noven plicatâ; columellâ plicis duobus panullelis instructâ; marginibus incrassatis, reflexis.

Micraud, Descript. de quelques Coq. viv. Bull.

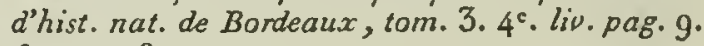
fig. $17 \cdot 18$.

Cette jolie espèce nous a été communiquée par l'auleor, qui, le premier, en a donné la description. Elle est ovale-oblongue, tnrriculee, très-obtuse au sommet, un peu renflée dans le milieu et formée de douze tours convexes, trèsrapprochés, très-étroits, et oraés dans leur longueur d'une multitnde de tines stries longitudinales, très-régulières. A la base du dernier tour se trouve un large ombilic en entonnoir. 


\section{A I}

I'ouverture est fort singulic̀re; elle est blanche, ses bords sont épaissis, légèreunent reaversés. On comple dans leur longneur livit à neuf plis fort saillaus, dont deux ou trois seulement appartiennent à la columelle : lorsqu'il n'y a que deux plis, ils sout placés tout près de l'angle supérieur de l'ouverture, et tellement rapprochés qu'ils se confindeut par leur lase; ils sont inégaux; le plus petit est le plus interne. Si un troisième pli culumellaire se montre, il est situé à la base du bord gauclıe; les autres plis de louverture sont distriTanés dans la longueur du bord droit: Irois de ces plis sont plus saillans que les autres.

Celle coquille, nince, Iranspareate, parlout d'un fauve clair, a été déconverte par M. Michaud, aux environs de Firguières et de Bascara; elle a 9 millim. de longueur.

\section{I1. Matllot mousseton. Pupa muscorum.}

$\boldsymbol{P}$. testâ minimâ, cylindracea, obtusâ, lavi, corneo-fuscescente; anfractibus canvexis; suturis excavatis; aperturî unidentatî; labro margine reflexo.

Turbo musconm. Lix. Gmel. pag. 361 I. n. 94 .

Helix muscorum. Muldea, Vermi. pag. 105. $n^{\circ}$. 304 .

Dargent. Zoamorph. pl. 9. fig. II.

Le petit Barillet: Georr. Coq. pag. 58. $n^{\circ} \cdot 20$.

Cиemsitz, Conch. tonz. 9. tab. 123. fig. 1076 . a. $b$.

Pupa marginata. Drap. Moll. pl. 3. fg. 36-38.

Helix inuscorum. DauneB. Hist. des Moll. $n^{\circ} \cdot 475$.

LAxк. Anim. sans vert. tom. 6. pag. I11. $n^{\circ} \cdot 27$.

Cette espèce est l'une des plus petiles qui soient conoues; elle est ovale, cylindracée, à spire courte et obtuse, à laquelle on compte sept tour's conrexes légèremeat striés daus leur longneur et réunis par une suture peu approtondie; à Ia base du deroier tour, on voit un petit ombilic, arrondi eu partie, recouvert par l'épaississcment assez considérable du bord gauche. L'ouverture est très-petite, surbaissée, aussi longue que large. Les bords sont épaissis en un bourrelet marginal anssi saillant en debors quen dedans; le bord est simple, blanc, sans dents, et se prolonge quelqucfois, à ses poinıs d'insertion, en un bord gauche qui complère l'ouverture. Sur le milieu de la columelle se trouve une très-petile dent, irès-courte et tranchante au sommet.

Cette petite coguille est partout d'un brun clair opaque. Elle babite en France, en Allemagne, dans les lieux ombragés et humides; sa longueur est de 3 millim.

\section{A I}

12. Mallou baril. Pupa doliam.

$P$. testâ brevi, cylindraceá, irflatâ, oblusi, striati, cornen-fuscescente; aperturi unidentuti; labro margine aibo, reflexa.

Pupa dolium. Dнаранs. Moll pl. 3. fig. 4ij.

Felix dolium. Ds vовв. Hist. des Moll. $n^{\circ} \cdot 477^{\circ}$

L.Asx. Anim. sans. vert. tom. 6. pag. 110. $n^{\circ} .25$.

Il y a une analogie de forme entre cette espèce et le Pupa oblusa; comme lui, il est cylindricyue et préseute nue spire extrêmement obluse; il est proportionaellement beaucoup plus large que les aulies cspices. Sa spire est forméc de dix tours très-couris, un peu conrexes, à sufure simple et superficielle : de ces tours, les premiers sont enticrement lisses; les suivans sont couverts de stries klcgantes, inépalcs. Ces stries sont fines, sert'fes et loncritudinales. T,e dernier tour est pourvu, à la base, d'uoc longue fente onbilicale; l'ouverture ggui lc termine est ovalaire, blanche. Ses bords sont légèrement rencersés en delıors, on peu épaissis à l'intélieur, et n'offrent jaıais aucun pli. Lal columelle, elle seule, est pourvae d'noc lamelie transterse qui s'enfonce profondément dans l'iutérieur, et qui est placée vers l'angle supéricur de l'ouverture.

Cette petile coquille, asse $z$ rare, est d'un bruncorné foncé, quelquetois grisâtre. Elle se tronve dans la France tuéridionalc, aux envicoos de I,you et de Montpellier; elle a 5 à 6 millim. de longreur.

13. Malceot grain. Pupa granum.

$P$. testâ cylindraceí, attenuato-aculì, griseí aut fuscescente; striis longitudnalibus, minutissimis; aperturi quadidentuti; lubro margine albo, refexo.

Pupa granum. Dnap. Moll. pl. 3. fig. 45. 46. Helix granum. Dav D. Hist. des Moll. n $n^{\circ} .483$.

Lamx. Aninu. sans vert. tom. 6. pag. 110. $n^{\circ} \cdot 23$.

On reconnoîl le Pupa granum i la disposition particulière des dents de l'ouverture, qui sont groupées en trois parties bien distinctes. Cette petite coquille a beaucoup d'analogie, quant à la forme el à la grandeur, avec le Pupa secale; il est cependant plus pointu el plus ćtroit. Sa spire est formbe de buit à neuf lours convexes, tlèsfinement striés dass lcur longueur; le dernier, assez largement ombiliqué a la base, se terminc par une ourerture subarrondie, un peu plus baute que large; daos son iotérieur on compte sept plis lamelieux, dont deux columellaires sont paral. lc̀les, très-rapprochés, celui qui est vers l'au.jle de l'ouverture étant plas grand que l'autre. Les plis de la columelle sont aussi an nombre de deux; souvent ils se joiguent par une petite callosité, 
et se confondent en un seul bourrelet. Enfin il en existe trois sur !e bord droit : ils sont parallèles, e't l'an d'eux, ordinairement le médian, est trèspetit el quelquefois manque tout-a-fatit.

l.a couleur de celte coquille cst d'un bruucornć foncé; son test est aunce, translucide et fingile; l'ourerture est blanche; les bords, un peu ćpaissis, sont renversés en dehors.

Celte espece, que l'on trouve presque partaut en Irance, dans les lajies el dans les buissous, a 8 à 9 orillim. de longuenr.

14. Marloot fragile. Pupa fragilis.

$P$. testá sinistrorsâ, elongatí, altenuato conicá, pellucidi, lutco-fuscescente; columelli subunidentali.

Turbo perversus. Lix. Guer. pag. $5609 . n^{\circ} .88$.

Caess. Conch. tom. 9. tab. 112. fig. 959. a. b.

Pupa fragilis. Drap. Moll. pl. 4 . fig. 4.

Helix perversa. Da U DEв. Hist. des Noll. $n^{\circ} .5$ I 1 .

LAsk. Anim. sans 2ert. tom. 6. pag. 110. $n^{\circ} \cdot 24$.

Cetle coquille ressemble plus à une Clausilie qu’à un Ma!llot; el e tourne toujours à gauclie, el ce caractèrc, joint à celui d'une seule petile dent obsolc̀te ì l'unverture, peut aider à reconroitue l'espèce. Cette coquille est alongée, turriculée, poialue au sommel; sa spire, longuement conique, est composíe de douze lours très-peo convexes, dont la suina est siaple et pea pro. fonde, et qui sont linement et ílígamment striés en longueur. Ine deruier lour est percé à sa base d'un trou ombilical, pelit, en parlie caché par le bord gauche. L’unverture gui le termiue est petite, presquaussi longrue que large, dont le péristome est presque continu, laujnurs mince, l'́gèrement évasé en dehors, blanc ou blanchàtre, el dépourrue de dents daas laule son étendue. l.a columelle seule en présente une très-petite à sa partie supcrieure, vers l'angle de l'onverture. Tuute la coquille est mince, transparente, extrimement fragile, d'un bıaa-corné clair.

Cerre espèce vil dans la partie méridionale de la France; elle est longue de 10 mi!lia.

\section{MAILLOTTIN. Pupina.}

M. Vignard, amatemr zélć d'histoire naturelle, a proposé de doaner ce nom à une perite coquille wariae fort singulière, rupportée des terres australes par 11. Lesson. Cetle petite coquille est transparente, cylindracée, comse blanche, et pourroit être prise pour un Maillot, si on be liaisoit attention à ua pelite échancrure qui se tronve ì la base da demier tour. Cette échancrure a'est point prolongée par un canal; elle semble faite par un empurte-pice, qui, en eflieurant le bord, y auroil produit eu même temps upe très-petile feate. Malgré la singularilé de ce caractère, la forme arrondie de l'ouverture et les autres accitens de la corguille, nous n'y voyous "fu'unc simple modilication des Buccius, qui ne sernicnt pas plus claignés de ce genrc que le Buccin aéritoide, par exemple. Si le genre Buccin u'avoit élé traité par Brugnaière dáns le premier volume de ce Dictionnain, nous aurions lait du Pupiana nne section parliculière; limicé conime nous le snmoses pour terminer la conchyliologie de ce Dictionnaive encyclopédique, nous me pouvons domer sur cetle corquile des détails plus étendus, tet nuas renvoyons is la note the II. Vinnard, que l'an trouvera daus les Annules des Sciences naturelles.

\section{IIAJET.}

Nom donné par Adaason (Voy. au Sénég. pl. 5 , fig. 1) à une l'orcelaine assez commune, Cjprau stercoruria. Voyez Horcelarae.

\section{MILACOLOGIE.}

Daus son Système de Terminologie, M1. de Blain. ville a proposé cette dénomination, que prubable. ment on acloptera par la suile, paur désigner la science qui lraire des Mlollusques. Pendani cout le lemps que l'on se borua à l'étude des coquilles, saas porter une attention aussi grande qu'on le fait aujoard'hui anx animaux qui les produisent, le nom de conclıyliolugie avoit paru sulfissut, et l'halitude que l'on contracta de l'employer d'une manière plus géniriale à mesure que la science lit des prourès rendit moins sensible la privation d'une expression technique qui lüt jropre, par son étymolugie, à exprimer la nature de la science à laquelle efle doit s'appliquer. M. de Blainville ayant donné le nom de Malacozoaire a cous les animanx mollusques d'après l'indicalion d'Aristote, le noun de Malacolngie devenoit tris-convenable à la scieace qui traile de ces animaux. Oa doit souhailer que ces nonvel!es dénominalions, auxquelles on n'est point encore assez luabitur:, soit adoplées par tous les auteurs systénatiques, puisque les classilications actuelles prenuent leurs bases principales dans la commoissance approfondie de l'organisation des Mollusques.

\section{MALACOZOAIRES.}

Dénominalion proposée par M. de Bluiuville pous remplacer, dans son Sjstène, le mot Mollusque. Cependant c'est a ce dernier mot qua M1. de Blainville a fait son arlicle géuérul surles Hollusques. $V_{0 j} \varepsilon=$ ce mot.

\section{MALENTOZOAIRES.}

Suivant son Système de Terminologie, M. de Blainville, dans son Traile de Mulacologie, a cionné ce nor à sun sous-type des Mcliusyues, qu'il avoit aussi désigné sous le nom de Mollusques arlicalćs. Ce sous týpe comprend tous les animaux 
que Lamarck avoit réuuis dans ses Cirrlipèdes (voyez re mol), et de plus, daus une farille parifculière, le's geores Oscabrion et Oscabrelle. Ce lapproclienient, fondé sur une analogie peu admiesiljle selon potre manière de voir, ne sela sans iuute pas adopté lorsque l'on aura vu, par des ana:omies multipliées, que l'organisalion des Oscaldrions n'a rien de semlulable dans la disposition fondamenta'e des nrganes à celle de tous les animaux des Cirrlipèdes. Vojez Cinuarines et Mulrusques.

\section{MATALEACEES.}

Famille de Mollusegues acéphalćs, Cublie par lamarck pour une parlie des genres faits aux déperss des Iluitres de liunć. P!usieurs des genres cui composent anjourd'bui la famille des Mallíacies étuient compris dans celle des Byssifères du même auteur, dans ses premières familles de la Philosophie zoologique et de l'Extrait du Cours. Depuis, les Byssiferes furent partagées en deux parsies: l'nne qui forme la facnille des Pecriuides (xoyez ce mol), et l'autre celle qui nous occupe. Elle est couposée des geures suivaus: Crénatule, Perne, Marteas, Avicule et Pintadice, auxguels nous rervoynns. M. de Blainville, saus adopter le nom de Milalléacées, a pourtuat admis la famille es y faisant quelques changemens et en y ajoutaut quelques genres. C'est à l'article Marganiracés que nous les ferons counoitre. M. Latreille a fait de même que M. de Blainville, t'est-à-dire qu'eu conservaol les mêues genres dans un même groupe, et en y faisant de très-petits changemens, il a cru nécessaire de clianger la dénomination de Malléacées pour celle d'Oxigones. Voyez ce mot.

\section{MIAMELON.}

Notn vulgaire que donoent les marcliands à plusieurs coquilles appartenant particulièrement au gerare Nalice: c'est aiasi qu'ils nomment Mamelon blanc le Natica mammilla; Memelon à columelle voire, le Nastica melanostama; Mawelon fauve à grand ombilic, le Natica albumen.

En conclyyliologie, on donne assez urdinairemeat le nom de manielon à l'extrémité oLtuse et un peu saillante de certaioes coquilles appartenant particulièrement aux genres FusEav, Vosore, ete.

\section{MIANIIA.}

Sons le nom de Mamma, Kleis (Tent. meth. ostrac. pag. 21) a lormé un genre pour la plupart des coquilles globuleuses, sans faire la moindre atteation aux caractères essentiels qu'elles pouroient offrip. Ce geare contient, a vec des Nalices, des Nérites, des Tonnes, des Buccins, etc. Il soffit de citer celte rénnion de genres pour faire penser troe elui-ci n’a jamais été adopté.
MAMMELLE. Maninilla.

Dans sou Essai d'un nouvcau système des Coquilles, M. Sclumacher a donué ce nom à un dériembrement inutile du genre Natice, dont le Natica melanostoma ist le type. Ce genre, qui repose uniquemenl sur une pelile dillérence dans la lorme de l'uabilic, ne peut être adopté. Voy. Natrce.

\section{MANCIIE DE COUTEAU.}

Nom vulgaire donaé aux grandes espèces du geure Solen. Voyez ce mot.

\section{MANÉIOU.}

Dans guelques ouvrages de conchyliologic mais surtout dans les relations des voyageurs, il est rapporté que les Indiens ont pour idole une grande et belle coquille, que long-lemps on ne comnt que par leurs récits. Depuis, ayant é é apportée, on a reconnn qu'clle dépendoit du genre Ampullaire, et elle a ćté dérrite sous l." goun d'Ampullirire idole. Voyez Asipulaarae.

\section{MANTEAU. Pallium.}

Lorsque l'on ouvre une coquille bivilve dans laquelle est encore l'auimal guri l'a construite, on trouve que le corps de cel animal ést envelopié d'une peau wince, fendue par devant, que l'on a comparée à un mantean dont il seroit revêtu. Celle comparaison, ussez juste, a élé portée des animaux bivalves à ceux qui n'ont qu'une seule coquille, et même à ceux qui n'en ont point du tout, pour désigner l'enveloppe charnue, l'espèce de collier à travers lequel il passe pour sortir de la coquille. Dans les Mollusques nus, le nom de manteau a étć douné spécialement à la peau plns ou moins curiace qui couvre le dos, et qui quelquefois se prolengre de tous les côtés en une peau llottante qui déborde tout l'animal. Les formes diverses que prenuent cetle partie, dans les différentes classes de Mollusejues, lui ont fait donner quelque valeur dans les caractères de classitication, et surtout de la pirt de Ml. Latreille, qui, daus ses Familles naturclles du Règne animal, a formé plasieurs divisions principales parmi les Mollusques acéplablés à l'aide de ce moyen.

A l'arlicle Mollusques, où nous passerons en revue les diverses modificalions que les Mollusques éprouvent dans toutes leurs parties, nows examinerons jusqu'a quel poiat on peut se fier aux caractères que peut fournir le manteau aux classificateurs. Voyez Moluusques.

\section{MANTEAU. Pallium.}

M. Schumacher a établi soas cotle dénominaliou un geure aux lépens des Peignes, pour celles des especes qui onl quelques dentelures su: le bord cardioal. Déjà une aulre persones, M. Drouet, 
sü las cractire scallable, avoit établi pon:

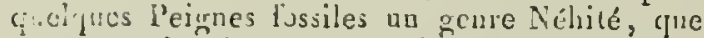
yersonne u'a adopté, et celui die H. Schimacher restera dans "oubli à cause de son inutilité. Voy. Pergaie.

\section{MUNTEAU DUCAL.}

Lin joli Peigne, le Pocten pallium, recherché cies amateurs à cause de la beauté el de la liaírheur de ses couleurs, a reça depuis long-lemps le ram de Marleau ducal, sous lequel il est actnellement inscrit dans les catalonues des conchyliclogistes. Voyez PEIGNE.

\section{MANTEAUY BIFORÉS. Biforipalla.}

Daus les Mollusques acéphales, M. Latrcille a eraployé le nombre et la forme des ouvertures du manteaa prur élablir parmi ces animaux des divisions primaires, dont l'une, sous le nom de $B i$ foripalla, est divisée eu deux familles : les Mytilacés et les Nayades. Bien que ce rapprochement soi: assez naturel, on peut dire cependant que les animaux qui y sont reofermés n'ont pas deux cuvertures au manteau; car on pourroil regarder ciue les Nayades surtout n'ont point d'ouverture jostérieure, puisqu'une simple bride, siture andelii des bords charnus du mantean, sépare l'anus de la cavite brancliale. Ces deux familles rentiervient donc par conséquent dans l'ordre des mantcaux ourerts, si d'autres caractères ne se juirnoient à celui-là pour lui donner une plus grade valeur. Voyez Mrtuacé et Narade.

\section{1:ANTEAUY OCVERTS. Patulipalla.}

Tel est le nom que II. Latreille donne au premitr oide de ses Mollusques acéplialés; il renforme, divisé en quatre fauilles, tous les animaux duat le arateara est ouvert dans toute son étendtie. D'après ce caractè:e, MI. Latreille est obligé de partager cet ordre en denx sections : daus la prenière sont rangés les tuéphales à ur seul unosule, et dans la seconde ceux qui ont deux auciscles. Tiauleur s'est vu forcé de mettre dans 17 raug inférieur ce caractère da nombre des ui:.scles que Lamarck aroit tonjours considéré ( $\cdots$ une de première valeur; cela fait sentir de whis en plus combien il est aécessaire de poser cefia les bases $f$ indameatales de la classification, ¿2u readant à chacun des points organiques qui duirent y étre employés sa véribalile valeur. Cies çuestinas, qui sembleut de jou d'iatérêt, soat cependant frudamezta'cs', comme nons le verrous ì l'article Morctsegrs. I.es quâtre familles comprises dans la section des Patulipalla sont les saivaales : Ostracés, Pectinides, Oxigones el Arcacés. Voyez ces mols.

MANTEAUX TRIFORÉS. Triforipalla.

Ce troisieme ordre des Mollisţues acéphalés de M. Salueille donue une preuve Lien convainrante que la valeur qualil donne a la forme du ananteau est biec arbitraire, puisqu'il est obligé de séparer dans une famille et dans un ordre les deux seuls genres 'Tridacue el llippope des Carmes et autres genres qui ont ígalewent trois ouveriures au mantean. ('e n'est douc plus d'après ce caractère priucipal du mantean triforé que cet ordre a élé formé, mais d'après d'autres considéraiions, qui, quoique mises en seconde ligne, ont cependant une iraportance telle qu'eiles ont dominé la pensée de l'auleur, et lui ont fait faire dis groupes autres que ceux qui devoient être le résultat des caractères principanx de cet ordre. Ainsi, en raisunnant d'a près les donoćes de M. ?atreille, il auroit fallu rćunir daus cel ordre des Triforipalla, non-seulement la famille des 'Tridacnides, mais eocore celle des Cauncess, el successivement par des gradalions da méme caractère, celle des Cardiacés. M. Latreille ne l'a pas fait, parce qu'il a été retenu par des molifs pnisćs a une antre source, tels que les dispositions branchiales des animaux, le renversement complet des uns, qui paroissent a voir le dos du cutté du bord libre de's valves, tandis que les antrea restent dans la posilion normale, elc. On voit done pap là que des caractères qui unt semblé plus iraportans que celui du mantean l'ont retenu malgré lui dans les limites d'une famille naturelle indiquée depuis longr-temps. Voyez'Turdacsites et Mollusques.

\section{MANTEALX TUDULEUX. Tubulipalla.}

Cette division, que M. Latreille a proposće parmi les Mollusques acéphales, ne sera probablemeut pas adoptée; car il existe entre les animanx qui ont le unanteau triforé el ceux qui ont celte partie prolongée en deux siphons postérieurs des auances inseusibles qui ne permettent pas de fixer entr'eux une limite naturelle. Ceta est si vrai que M. Latreille, ici comme à l'égard de la famille des Triforipalla, a plus tenu coropie d'autres caractères que du principal, qu'il a mis en avant. Cela devient évident quand on trouve parmi les Manteaux tubuleux les Camaceis et les Cardiacés, dans lesquels les siphons sout nuls ou excessiveoneat caurts. Pour faire concider le num de l'ordre avec les êtres qu'il doit contenir, il auroit fallu se borner à y rassembler tous ceux dont les siphons, réunis en une senle masse ch, pnue, semblent se cootinuer du cólé postérieur par un seul tabe cylindracé plas ou muins proúminent. Cet arraugement eût été peut-être préférable, mais il n'cut pas été naturel, puisque le caraclère sur lequal il se fonde préseule aussi une série de dígradalions, an milieu clescueiles il est presqu'icapossible de poser une limitc. Il y a donc deux risons principales pour rejeter les diicers ordres fondés sur les caractéres du manteco : dans le premier nous voyous les ilolius jues dimysires 


\section{A R}

myaires intercalés an milicu des monomyaires, parce qu'ils ont le mantcau fendu dans toule son ćlendue; dans le second ordre on trouve des auimaux dimyaires dont le manteau est fendu Éalemeut dans toute son étendue, relenu seulement an-dessus de l'anus par une bride yui ne lui appartient pas; le troisic̀me ordre est évidemment séparé sur des caractères autres que ceux qu'indiquent son nom; le quatrième, enlin, est un mélange d'animaux de diverses sorles ras- emblés sur un caractère qu'il est impossible de leur appliquer à tous. Nous reviendrons sur ces divisions primaires à l'article Moleusques.

\section{MANTELET.}

Adauson (Voy. au Sénég.), trompé par quelques différences que présentedt les animaux et les coquilles des Porcelaines jeunes avec les vieilles, avoit formé un geare pour les premières, auquel il avoit donvé ce nom; quelgues auteurs, sans l'avoir examiné assez altentivement, l'on! adoplé à tort. Voyez Porcendune.

\section{MAPPEMONDE.}

Une belle espèce de Porcelaine, que quelques persooves nomment aussi Carte de géonraphie, reçoit ce nom de la plupart des marclıands, et elle est connue dars les calalognes sous le nom de Cyproca mappa. Voyez Yorcelaine.

\section{MARGARITACÉS.}

Faroille nouvellement proposée par Mr. de Blain. ville pour remplacer celle des Mallíacées de Lamarck. Ce sont à peu près les mèmes genres qui ont servi aux deux zoologistes pour la formation de ce groupe ; seulement les Margaritacés cunliennent plus de genres que les Malléacées, parce que, depuis la publication de l'ouvrage de Lamarck, ils ont été établis et adoptés, et soot veous naturellement se ranger dans leurs rapports aver les anciens. Un changemeat heureux que $\mathbf{~ I l}$. de Blainville a fait, c'est de rapprocher les Vulselles des Marteaux, dont elles sont fort voisines, bien plus que des Huitres, près desquelles Lamarck les avoit laissées. Ia famille des Margaritacés esı composée des genres Vulselle, Marteau, Perne, Crénatule, Inocérane, Cutille, Pulvinite, Gervilie et Avicule, auxquels nous reavoyons.

\section{MARGINELT,E. Marginella.}

Genre de la famille des Columellaires de Iamarck, qui se trouve dans les Pectinibranches baccinoïdes de M. Cuvièr : c'est à Adanson que l'on doit sa création; il le nomme Porcelaine, en conservant le nom vuluaire de Pucelare aux coquilles qui portent aujourd'hui celui de Porcelaine. Il y confondit les Olives, ce qui prouve que les animanx qu'il avoit vus sont bien roisins.

Hist. Nat. des Vers. Tome II.
N A R

Malgré l'élablisseroent de ce genre, Linné n'en rangrea pas moins les Marginelles au numbre de ses Volutes, ce que Bruguière imila. Lamarck, en dénombirat le gente volute de linné, el par suite le genre porcelaine d'Adauson, donna à celui-ci le nom de Porceluine, qui lui est resté. Depuis ce monent, ce gente a été adopté par la plupart des zoologisies.

Quoique les animaux ne different de celui des Porcelaines gue par un peu moius d'ainpleur dans les lobes du manteau, les coquilles en olfieat assez pour être distinguées facilement : elles servent mêrne de point intermédiaire entre les Volutes et les Enroulés, aluxincls elles ionchent par les espèces dont la spire n'est pas saillan:e; clles s'en rapprochent edcore par' le bourrelet marninal du bord droit, el souveni par les plis columellaires qui accompaguent tout le bord gauche. Voici les caractères de ce genre.

\section{CARACT⿱亠凶禸RS G ÉNÉRIQOES.}

Coquille ovale, oblongue, lisse, à spire courte et à bord droit garni d'un bourrelet ex debors; base de l'ouverture à peine échancrée; des plis presqu'égaux à la columelle.

I.es Marginelles sont des coquilles lisses, de taille médiocre, agréablement coloriées, qui viennent toutes des mers équatoriales des deux mondes; elles peuvent se diviser en deux groupes, corme l'a proposé Lamarck. M. de Blainville a voil adopté celte division dans son article MARGINELLE du Dictionnaire des Sciences naturelles; mais à l'article Mozrusque il proposa ua troisième groupe pour le genre Volvalre (vayez ce mot), ce qui détruit, il est vrai, une partie des caractères imposćs aux Marginelles, mais qui a l'avantage de grouper d'une manière naturelle des 仓́tres qui se ressembleat, et de supprimer un grenre inutile ou à peu près, dont ua assez bon noubre d'espèces éloient de jeunes Marginelles. Le mêtne zoologriste dit que Klein avoit établi ce genre depuis long-temps sous le non de Cucumis; nous trouvons bien effeclivement nn genre de ce nom dans Klein, mais en vérifiant les citations, nous le trouvons composé d'un plus grand nombre de Nitres et de $V 1$ ". 'es que de véritables Margioelles.

Le nombre des Marginelles est. assez considérable; on en trouve presqu'autant à l'état fossile qu'à l'étal vivant. Toutes celles qui sunt connues appartiennent, jusquà préseot, aux terrains telliaires.

1. Marginelde veigense. Marginella glabella.

M. testầ ovato-oblongâa, griseo-fulvâ, zonis mifo-rubescentibus cinct $\dot{a}$, maculis minimis albis udspersâ; sparia brevi, conica a , apice obtusâ; columellá quadriplicatá. 
Voluta glabellu. Lss. Grax. pag. 5445. n०. 32. Lister, Conch. tab. 818. fig. 29 .

KLEIx, Ost. tab. 5. fig. 92.

Adans. Sénég. pl. 4. fig. I. La Porcelaine.

KNonk, Vergn. tom. 4.tab. 21 . fig. 3.

MaRini, Conch.tom. 2. tab. 42.fig. 429.

Escrce. pl. 377. fig. 6. a. b.

LA

Celte Marginelle, après la Marginella bullata, est celle qui prend les plns grandes dimensions. Elle est alongée, ovalaire; 3 s spire, assez prolongée, est pointue, composée de sepı à butt tour's sérrécis, peu convexes, dont le dernier est beaucoup plus grand que les autres. Tous ces toars sont lisses, polis, et leur suture est bordée en dessous par une linne d'un fauve-brun interrompu à des distances inégales par des taches blanches irrégulières. L'ouverture est alongée, étroite, un peu oblique, terminée à la base par nne échancrure assez large et peu profonde; sar la columelle qui est droile, on compte quatre plis presqua"égaux, dont les deox inférieurs sont beanconp plus ubliques que les deux supérieurs. Le bord droit est épaissi en un bourrelet arrondi, saillant en dehors, d'un bran-fauve. Surle bord de ce bourrelet on remarque quelques petites crénelures plus grosses dans le jeune âge que dans les vieux individus. Sur la surface extérieure de la coquille, qui est d'un brun plus ou moins iutense, soni Éfarses un grand nombre de petites taches blanches, irrégulières et dans lear grandear et dans leur positiou. Nous possédons one variété dans laquelle les taches blanches forment une zone médiane sur le dernier lour, dont la surface est presyue rouge. Cetle belle coquille est commude au Sénégal; elle est longue de 40 millim.

\section{Marginatex aubéculée. Marginella nube-} culata.

M. testâ ovato-oblongâ, subturbinatâ, albidâ, fammulis longitudinalibus undatis, pallide fulv is, uno latere nigrinis, ultimo anfractu superius obtusè angulatâ; spirà brevi, conicd, obtusiusculú; columellâ quadriplicatá; labro intùs lavi.

Lister, Conch. tab. 818. fig. 32. 435.

Martint, Conch. tom. 2. tab. 42. fg. 4504.

EncrcL. pl. 377. fg. 2. a. b.

LaMr. Anim. sans vert. tom. 7. pag. 356 . no. 3 .

Var. a.) Teștâ minore, maculis uxdulatis triseriatis cincta.

La Marginelle aubécalée a des rapports arec l'espèce précédente pour sa forme et u grandear; mais sa spire ayant un angle qui marque chacon de ses lours, il est facile, ¿̀ l'uide de ce caractère, de li distinguer. Elle est ovale, oblongue, altćnuće à ses deux extrémités; sa spire est couposée de cinq à six tours extrêmement lisses, et comme vernissés; leur suture est peu apparente, simple et superficielle. Le dernier tour, beancoup plus grand que les autres, se termine antérieurement par une ouverture alongée oblique, dont le bord droit est légèrement détaché de la spire par une petile échancrure. Le bord droit est blanc, ćpais, reaversé en dehors; la columelle porte quatre gros plis blancs, dont celui de la base se contouraent pour rejoindre l'extrémité de l'échancrure. Sur la surface polie de celte coquille, dont le fond est d'un blanc-grisátre ou roussâtre, se dessinent des taches irrégulières, nuageuses, dun gris assez foncé, ordinairemeut bordées de brun d'un côté. La variété que nons avons indiquée est remarquable en ce que la lèvre druite est toujonrs plus épaisses, et que les taches, un peu onduleuses, sont disposées sur le dernier tour en trois fascies bien distinctes. On ignore où vit celte espèce; elle a 35 à 40 millim. de longueur.

\section{Marginelle rayonnée. Marginella radiata.}

M. testâ ovato-oblongâ, albidâ, strigís luteonufis Longitudinalibus angustis undulatis crebris radiatim pictä; spirá brevi, conicá, obtusâ; colunuelle quadriplicatá; labro intùs lavi.

Leac日, Miscell. zool. tom. 1. tab. 12. fig. x.

I.amx. Anins. suns vert. tom. 7. pag. 356. $n^{\circ} .2$.

Jolie coquille ovale, ventrue, à spire trèsconrte, a laquelle on compte quatre oo cinq tours à peine convexes; le dernier est infuiment plus grand que tous les autres; l'ouverture qui le termine est alongée, plus large à la base qu'au sommet; sur la columelle on compte quatre plis presqu'égaux, dont l'inférieur est très-oblique; le Lord droit est fort épais, lisse, Llanc en dessous, orné de tacbes noabreuses d'un brun très-intease sur le cóté externe. Les taches sont transverses, linéaires, et plus ou moins serrées. A l'extérieur, qui est d'un très-beau poli, d'un blauc-grisattre ou jaunátre, on voit un assez grand nowhre de linéoles très-étruites, longitudinales, onduleuses, d'un jaune-brunâıre plus ou moins intense. Celle jolie coquille, fort rare jusqu'à présent dans les collections, est longue de 32 millim. Sa patrie est inconnue.

4. Mangraler cing plis. Marginella quingue. plicata.

M. testâ ovato-oblongâ, squalide albidj, immaculatä; spirá brevissimâ, apice obtususculi; plicis coluniella quinis; labro intùs lavi.

EscrcL. pl. 376. fig. 4. a. b. 


\section{A R}

I.AMx. Anim. sans sert. tom. 7. pag. 356. $n^{n} .5$.

Martixi, Conch. demier Suppl. de Wagner, tub. 225. fig. 4008. 4009 .

Coquille remarquable par sa spire excessivement courte, et les ciuq plis qui sonl coustimment sur la columelle. Ia spire est tellement obtuse que l'extréruité du bord droit en alleint sourent le somunet; quand elle n'est poiut ubstruće par unc callosité, on la trouve formée de yuatre a cinq tours très-étroits et aplatis. Ja coquille a l'extérieur est unifurmément a'un blancgrisătre; elle est ovalaire, polie, brillante; son uuverture esı aussi longue qu'elle est élruile; son bord droit, délacbé au somaet par une sinuosité assez profonde, est bordé d'un bourrelet rosâtre légèrement crénelé au bord interne, et prescju'aussi saillant en dedaus qu'en dehors; li columelle porte ciny gros plis presqu'également distans, et dont le premier remonte à peu près à son tiers supérieur. Nous possédons une coquille qui qui o'est peut-êlre qu'une variélé de celté e.pèce; el'e est cependant plus ćtroite; ses plis sont plus obliques, et il y en a un sixième ajouté aux cinq autres. L'ouverture est léùènent teintée de rouge, ce qui na pas lieu, lıabiluellenınt, dans les autres individus de la méune espèce. Cette coquille, assez rare, [rovient, à ce qüil paroit, des mers de l'Iude, et n'a guèie que 25 à 30 mill. de longueur.

5. Marginelle bleuaitre. Marg:nella comulescens.

MI. testâ ovato oblongh, albido-carulescente; spirs brevi, subacutá; labro intùs castanco, margine interiore lavigato; columellâ quadriplicatâ.

I.rster, Conch. tab. 817. fig. 28.

Adaxs. Sénég pl. 4.fg. 3. L'Egoued.

Mlartivi, Conch.tom.2.tab. 42 .fig. 422.423.

Voluta prunum. Gxex. pag. 3446. n०. 33.

Esсrсx. $p l .376$. fig. 8. a. b.

La3r. Anim. s. vert. tom. 7. pag. 356. $n^{\circ} \cdot 4$.

Cette espece est l'une des plus commuoes du genre. Elle est ovale, alougúe, étroite, partout d'une même couleur, d'un gris-bleuâtre; quelquefois, mais rarement, ornce de yuelques zones Jongitudinales blanchirres. Sa spire est extrêmement courte; on y compte cinq lours arrondis, dont le derujer est beacoup plus grand qu'eux. L'ouverture est fort alongrée, d'un brun foncé en dedaos, très-élroites à sa partie supérieure, où le bord droit est fortement détachó par une échancrure profonde; ce bord droit est blanc, terminé en bourrelet obtus, furtement renversé en dehors; la columelle a quatre plis obliques, dont les deux inférienrs sont très-rapprochés et quelquefois confondus par leur base.
M A R

Cutte coquille est fort commune dans les mers du Séuégal; clle a 35 millim. de longueur.

\section{Marginele rose. Marginella rosea.}

MI. testâ ovatâ, albo roseoque tessellutá; spirâ conoideâ, obtusá; labro intùs laevi, extiss varice transuersim rubio lineato; columellà quadriolicat.j.

l.ANк. Anim. sans vert. tom. 7. pag. 557. $n^{\prime \prime} \cdot 7$.

Cette coquille pourroit être confondue avec la Marginelle nubiculíe, sj l'on ne lisisoit attention aux lackes régulières de son loord droit et au défuut d'angle à lis parlie supérieure du dernier tour; elle est uvale oblongue, à spire assez saillante, obluse, furmće de guatre à cinq tours convexes, lisses, polis, ornés t'un grand noubre de petites iaches blancuátres ou grisâtres, quelquefois bordées d'une ligne brupe très-fine d'un côté seulement. Ces taches, un peu nuageuses, se dessinent sur un fond d'un beau rose. Louveriure est plus ample que tlans la plupart des espèces; son bord droit est à peine diślaclié; supérieurement, il est blanc, assez épais, orné à l'extérieur de linéolcs transverses, d'un brun-noir, plus ou moins nombreuses, selon les individus. La columelle présente quatre plis petits, peu obliques, placés à dés intervalles égaux.

Ceile espèce se trouve dans les mers du Sénégal; elle a 25 millim. de longueur.

7. Marginelle bifasciée. Marginella bifasciata.

M. test $\hat{i}$ ovato-oblongi, nitidâ, anterius longitudinaliter costulatí, griseo fulvâ, fasciis duabus fuscescentıbus cinctâ; pancílis nigrinis per series transversas . dispositis ; spirâ exsertiuscula; labro intús crenato; columellâ quadriplicati.

An Martivi, Conch. tonz. 2. tab. 42.fig. 431?

EscrcL. pl. 377, fg. 8. $a .6$.

Laux. Anim. sans vert.tonı. 7.pag. $357 \cdot n^{\circ} .8$.

La Marginelle bifasciée ressemble extérieurement à une petite Volute; elle est ovale, veatrae, à spire pointue et conique, dont les tonrs, au nombre de cing, saut urués de petits plis longitudioaux d'une grande régularité; le deroier luur est un peu allénué à la base. l'ouvertare est oblique, subseari-lunaire, plus large dans le milieu qu’à ses extrémilés. l,e bourrelet du bord droit est blanc, denticulé intérieurement daos toute son étcndue; il est presque aussi saillant en dedans qu'au-dehors. La columelle est droile, très-pointue à la base; les quatre plis qui s'y voient sunt fort gros et obliques. A l'extérieur, la coquille est ornée, sur un fond d'un blancgrisåtre, dune multitude de ponctuations disIf $f_{2} *$ 
posées en ligoes traosverses; a la partie supérieure du dernier tour, immédialeueal au-dessous des côles qui s'y trouvent, est sitake ane première zone transverse d'un brun foncé. A la base de ce dernier lonr, on remarque une seconde zone plus obscure, formée de laches subonduleuses.

Cette coquille, assez rare jnsqu”à préseat dans les collections, vient, d'après Lamarck, des mers du Sénégal. Les plus grands individus sont longs de 28 millim.

8. Mirgivelle féverule. Marginella faba.

M. testá ovato-oblongâ, anteriüs longitudinaliter costulutá, albidí, fulvo-nebulatí, nigro punctatâ; punctis sapiuis oblongis, per series transversas longitudinalesque digestis; spiná exsertiuscuhi; labro intùs crenulato; columellá quadriplicats.

Voluta faba. Lix. Gxex. pag. 3545. .70. 31.

Petit. Gaz. tab. 10. fig. 5.

Gusir. Test. tab. 28. fig. $q$.

Adsys. Sénég. pl. 4.fg. 2. Le Narel.

KroRr, tergn. tom. 4. tab. 17. fig. 6.

Martisi, Conch. tom. 2. tab. 42. fig. 432. 433.

Evcrce. pl. 377. fig. 1. a. b.

Laxx. Anim. sans vert. tom. 7. pag. 357. n०.9.

Cette espèce a de l'analogie avec la Marginella bifasciata. Sa spire est plus pointne et plus alongée; elle est formée de six taurs légèrement conrexes, sur lesquels sont disposées très-régnlièrement de petiles côles obtnses, conrtes, qui, snr le deraier tour, ae se prolongent pas au-delá de son tiers supérienr. Ce dernier lour est alténué a la base; l'ouverture qui le termine est fort étroite, et son bord droit, assez gros, est finement dealelé dans presque toure sa longueur. A sa partie supérienre, jl est détaché de l'avaatdernier tonr par une échancrure étroite. L'onvertare est toute blancbe, et la colamelle porte quatre plis égaux. A l'extérieur, cette coquille, sur un lond d'an blanc-jaunătre, est arnée de buil on dix rangées transverses de paints bruns, oblongs, quadrangulaires. Les premiers lours de spire présenteoi seulemeni deux ranus de ces taches, l'ua à la base et l'antre an sommet.

Celle petice coquille, fort rare, provient, saivant Lamarck, des mers dn Sénégal. Nons soupçonnons, d'après la forme de l'ouveriare, exaciement semblable à celle de la Naryinelle birasciśe, que celle-ci n'en est qu'une variélé. Longuenr 24 millim.

9. Magersele double-varice. Marginella bivaricosa.

M. Lestâ ovato oblongi, albi; varicibus duotus utrisque luteo-aunantiis, spirá adnatis; lubri sarice alinrum, altero latoro opposito; spini brevissimá, acutá; columellà quadriplicata.

Voluta marginata. Bors. Mus.tab. 9.fig. 5. 6.

Fataxise, Conch. pl. 2g. fg. e.

Carss. Conch. tom. 10. tub. 150. fg. 1421.

Voluta marginata. Gres. pag. 3449. $n^{\circ}$. 42 .

EхстсL. pl. 376. fig. 9. a. b.

LAuк. Anim. s. 2'ert. tom. 7. pag. 558. no. 1.

Var. A.) Noв. Testâ griseo-auranticu, varicibus crassissimis.

Var. B.) Nов. Testi subcarneoli, majori; labro dextro latissimo.

Coquille assez commune et rariable, tant dans ses couleurs que dans la largenr de son bord droil; elle est régulièrement ovalaire, atténnée à ses deux extrémités; sa spire est très-courle, poinine, et son côté antérieur est garni d'une vaste callosité, très-se mblable à ce qui se voit dans cerlains Buccins. Celte callosité, remodlant jusqqu'zu sommet de la spire, la cacbe dans ane grande partie de son étendue. L'onverlure est oblongue, droite, et extrêmement étroite; elle est brune en dedans. Le bord droit est ordinairement blanc à sa partie inférieure; il est très-épais, aussi saillant en dedans qu'en dehors, lisse, arrondi, divisé vers scb bord dorsal par un sillon profond, de sorte qu'il paroit être composé de denx bourrelets l'un snr l'autre : a l'extérieur, le bourrelet est ordinairement bordé d'un jaune-orangé assez intense. Dans la première variété, la coquille, qui est grisátre, a le bonrrelet d'an faure-brun. Dans la seconde, la coquille, beaucoup plus grande, est d'an blanc légèrement teinté de rose, et le bonrrelet est de la même nuance. Il y a cinq plis sur la columelle; les deux inférienrs; plus obliques et plus rapprochés que les autres, se confundent par leur base.

Cette coquille, commune, se trouve eo abondance dans les mers du Sénégal. Longuenr 26 mill.

30. Margivelte longure-varice. Narginella longivaricosa.

$M$. testá ovato-oblongâ, nitidí, pallide fulvi, maculis albis ninimis irnegularibus adspersá; labri varice longo, usque ad apicern spine adnato, luteo-maculato; spirí brevissima; columelli quadriplicati; labro intus obsoleté crenato.

LAyx. Anim. s. vert. tom. 7. pag. 358. no. 12.

Celle Marginelle a à peu prés la forme de la précédente; mais elle esi constammenı dépourvue du duuble bourrelet sur le có:é droit. Elle est orale, oblongue, à spire conrle et obluse, souvent cachée jar une callosité brunàtre. Sa surface extérieure, d'un fauve peu foncé, est parsemée d'un grand nombre de lacbes blanches irrégulièrement espacées. L'ouverture est presque aussi longue 
que la coquillo, le bord alroit remontaar juaqu'au comenet de la spire. Le bord droit est épais, blanc dans tonte son étendue, et orné de deux seules taches transverses, étroites, d'un brun foncé. La colomelle est on peu arquée dans sa longueur; elle porte, à sa partie inférieure, guatre petits plis obliques et tort rapprochés.

C'est encore au Sénégal où celte espèce se troure : elle y paroit assez rare, à en juger du moins d'après nos collectious. Elle est Pongue de 22 millim.

11. Marginele monche. Marginella muscaria.

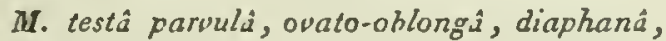
alb $\hat{a}$, interdùm luteo-aurantiâ, spira exsertiusculâ, obtusâ; columella quadriplicatâ, labro intius lovi.

LAmx. Anins. sans vert. tom. 7. pag. $35 \mathrm{~g}$. $n n^{\circ}, 13$.

Cette espèce a beancoup d'analogie avec l'une de celles que l'on trouve le plus abondamment aux environs de Paris, Marginella eburnea. Eille est ovale, oblongue; sa spire alongée est forc pointue : on y comple quatre à rinq cours convexes, don: le dernier est beaucoup plus graud que tous les autres. Ce dernier tour est renflé à sa partie antérieure; il est terminé par une onverture alongée, étroite, dont le bord droit est un peu plus enflé dans le milien que dans le reste. de son Élendue, ce qui donne quelque ressemblance à celte espèce avec une Colombelle. La columelle est droite, munie de quatre plis obliques. Toute celte coquille est lisse, polie, blanche ou jaunâtre. Lamarck dit qu'elle est si commnne dans les mers de la Nauvelle-IIollande, près de l'ile Maria, qu'on peut la ramasser à poignée dans cet eadroit. Elle est Iongue de 13 milliw.

12. Marginele dentifère. Marginella dentifera.

M. testâ fossili, panvî, gracili; spirâ elongatà, subpyramidali; habro brevi, intis unidendato.

Marginelle dentifera. Ann. ibid. $n^{\circ} .2$.

LAмx. Anım, suns vert. tom. 7. pag. $35 \mathrm{~g}$. $n^{\circ}, 16$.

Il n'y a presqu'aucnne différence entre celle espèce et la précédente; elle est toujours plus pelite, plus élroite, et son bord droit présente à sa parlie supćicenre une petile dent saillante à la partie interne de l'ouverture. Quant au reste, cette coquille est parfaitement semblable à la Margiuelle éburnée. Eille est alongće, étroite, lisse, polie, à suire langue et pointue, ayant la coluavelle légèrement arquée, et garnie dans sa longneur de quatre plis un pen moins obliques que daos l'espèce avec laguelle nous la comparoas.
Cetto potite coquille est plus rare que l'autre; on la trouve particulièrementà Grignon, à Parnes et à Courtagnon. Elle est longue de 5 millim. Nous en possédons nn indi vidu dont la spire tourne à gauche.

\section{Alarginelle éburaée, Marginella ebumeu.}

MI. testâfossili, parvâ, ovato-oblongâ; spirid exsertiusculâ, marginibus anfractuum confluenubus ; columellâ quadriplicatá ; labro mutico.

Marginella eburnea. Lamx. Ann. du Mus. tom. 2. pag. $61 . n^{\circ}$. 1 .

Lamx. Anim. sans vert. tom. 7. pag. 30̣!. $n^{\circ} .15$.

Petite eoquille extrêmement commune dans les calcaires grossiers du bassin de Paris. Elle est alongée, oblongue, à spire plus prolongée que dans aucune autre espece. Celte spire est formée de cing tours légèrement convexes, it suture simple; le dernier est étroil, atténué vers la base; son ouverture est longue, étroile, aussi large à une extrémitć qu'à l'autre; le bord droit simple, un peu plus épais dans le milieu; il est séparé de l'avant-dernier tour par une très-peti'e échancrure. La columelle est droite, les quatre plis qui s'y trouvent sont très-obliques, trèsétroils. Eu dehors, cette coquille est parfaitcment lisse, polie, brillante.

Nous connoissons une variété de celle espèce remarquable par sa grande taille; elle vient des terrains tertiaires du Val de Ronca et de la Superga, près de Turin. Nous n'apercevons, entre les individus de Paris et cenx que nous renons de citer, aucune autre différence que celle de la taille. Dans ceux-ci la longneur des plus grands individus esı de 20 millim. Celte espèce se trouve anssi aux environs de Valogaes. lata.

Mi. testâ nbovatâ, apice retusâ, albidâa, purictis rufis quadiutis transversim seriutis tessellatá, plicis procipuis quinis instructâ, supri aliis duobus seu tribus minimis; labro intùs cre. nulato.

An Voluta porcellana? Cвемx. Conch. tom. 10. tab. 15o. fig. 1419.1420.

Gmel. pag. 3049. $n^{\circ} \cdot 139$.

Lank. Animt. sans vert. tom. 7. pag. 36 1. $n^{\circ} \cdot 24$.

Isa Marginelle parquetée n'est Irès-probablement qu'une variété de l'interrowpue. Ces deux coquilles ont identiquement les mêmes formes et les mêmes caractères; elles ne diffèrent que sous le rapport de la coloration. Celle petile espece est ovale, déprimée, très-obtuse au somatet; 
sa spire est entièrement cacirée par une callosité à la base de laquelle s'insère le bord droit; celuici est fort épais, très-large en dehors, et quelquefois partagé en deux ou trois parties par des sillons semblables ì celui que nous avous remarqué dans la Marginelli bivaricosa. L'ouverture est extrémement étroite, et ressemble, à cause de cela, à celle de la plupart des Porcelaines. le ború droit, renversé en dessus, est crénelé dans tou:e sa lon rneru; il est quelquefois blea, mais plus souvent tacheté de brun. La columelle, caurbée parallèiemeat au bord droit, est ralleuse rers son milieu, toujours blancbe, et garnie dans les deux tiers de sa longueur de neuf a dix plis très-petits, graduellement décroissant de la base au sommet; l'avant-dernier plis, le plus grand de tous, est bifide. La coloration de cette corquille consisle en rangćes transverses trìsserrées de ponctuations lquadrangulaires, d'un brun-rougcátre sur un fand blanc. Sur le milieu et rers la base du dernier tour, il existe deux zones de ponctuations plus grosses.

Cette espèce est assez commune an Sénégal; elle vit dans les mèmes lienx que la Marginelle interrompue, et, comme elle, est assez variable. Nous ne doutons presque pas qu'on ne les réunis.e un peu plus tard, lorsque les variétés intermédiaires auront été observées. Longueur 15 millim.

15. Marginelde interrompue. Marginella interrupta.

MI. testâ parvâ, obovatâ, apice retusá, allodi, lineis transversis confertissinis interruptis purpure is pictâ; columellâ subquadriplicâ; labro intüs obsolelè creaulato.

Le Dechoo. Anans. Voy. au Sénég. pag. 61. pl. $4 . f g .5$.

LAмг. Anim. s. vert. tom. 7. pag. 362. $n^{\circ}, 25$.

Cette coquille, comme nous le disions en décrivant la Marginelle parquetée, n'en diffère réellement que par la coloration. On retrouve exactement les mêmes caractères; seulemeot dans celle-ci le bord droit est plus généralement blanc, plus large et plus souvent étagé à l'exiérieur; les lignes de points soot plus nombreuses, beaucoup plus fines; elles forment aussi deax zones transverses qui, dans quelques individus, sont remplacées par de grandes taches subarticulées. La calumelle et le bord droit sont semblables dans cette espèce et dans l'autre; l'avantdernier plis est bifide et plus gros que ceux qui le suivent.

Celte coquille, d'après Adaason, est foṛt commune dans les mers du Sénégal, à l'ile de Gorée surtout. Elle est longue de 15 millim.

16. Marginelde rayée. Malginella lineata:

M. testâ obovatâ, upice retuso concarấ, albat; lineis spadiceis remotiusculis propd labrumi subramosis cinctá; columelli swbseptemplicatis labro intics striato.

Voluta persicula. (Var. b.) Lır. G sеr. p. 3444. $n^{\circ} \cdot 29$.

Lister, Conch. tab. 8o3. fig. 9 .

Petiv. Gaz. tah. 8. ffg. 10.

Bonani, Recr. 5. fig. 2.38.

Gualt. Test. tab. $28 . f i g . b$.

Adans. Sénég. pl. 4. fig. 4. Le Bobi.

K Norr, Vergn. tom. 6. tab. 21. fig. 6.

Martivi, Conch. toni. 2. tub. 42. fig. 49. 420.

Excycr. pl 377. fig. 4.a.b.

losix. Anim. sans yert. toln. 7. pag. $36 \mathrm{r}$. $n^{\circ} \cdot 23$.

Cette espece a beauconp d'analogie avec la suivante : on lai retrouve la mêne forne et presque tous les autres caractères, la principale dillérence se moutrant surtout dans la coloration. Nous soupconnons, d'après quelques variétés que nnus possédons, que relle espèce n'est qu'uue simple variétć de la Marginelle ligrine. Elle est ovale, globuleuse, tres-obtuse au sommet, qui est tronqué et quelquefois concave. La lèvre droite est plus longue que la coquille; elle est blapclue, épaisse, surtout dans la nuilieu: quelquefois elle est crénelée à son bord interne; quelquefois aussi, dans les individus les plus vieux, les crénelures disparoissent, et il ne reste plus sur la levre droite gue quelques stries transverses. La columelle est arquée dans route sa longuenr; on y trouve ordinairemeot cing à six plis graduellement décroissant, plus perits et plus étroits que dans la Marginelle tigrine. L'ouverture est étroite, courbée, un peu dilatéc a la base. A l'extéritur, rette coquilie est lisse, brillante, toute blanche, ornée sur ce fond de linéoles transverses irés-étroites, au nombre de dix ou douze, d'un beau rouge pourpré. Une des variétés, que nous possédons, montre, à l'extérieur, des ponctnasions asscz semblables à celles de la Marginelle ligrine, mais réuaies entr'elles par des linéoles transverses plus multipliées que dans la plupart des individus de la mème tspèce. La Maryinelle rayée se trouve abondamment daus les mers da Sénégal. Longueur 22 millia.

17. Marginele tigrine. Marginella persicula,

M. testì obovata, apice retuso-concavi, albá, punctis laters confertis a tspersa; columell $\hat{\dot{b}}$ septemplicatí; labro intus crenulato.

Foluta persicula. LIN. G MEL. fag. $5444 \cdot n^{n} .29$.

Lister, Conch. tab. 8oj. fig. 10.

Petiv. Gaz. tab. 8. fig. 2. 


\section{A R}

Boxsxi, Recr. 3. fg. 246.

Gualt. Test. tab. 28. fig. c. d.e.

Mantixi, Conch. tom. 2. tab. 42. fig. 421. (Bona.)

EscrcL. pl. 377. fig. 3. a. b.

Laxx. Anim. s. vert. tom. 7. pag. $361 . n^{\circ} .22$.

Nous avons chorché à trouver des différences suffisantes entre la Marginelle tigrjue et la Marrinelle aveliue de Lamarck; nous n'avous vu, entre les deux espèces de cet auteur, que dé simples variétés, appartenant au méme type, et dont on trouve facilement les passages, à l'aido d'nn grand noubre d'individus.

La Marginelle tigrine est une jolie coquille qui a, quanı à la forme et à la plupart de ses caractères, une grande analogie avec la Marginelle cornée. Elle est ovale, élargie, très-obtuse, à spire aplatie, et même concave. Le bord droit dépasse la longueur de la coquille; il est blanc, arqué, épaissi, lisse, quelquefuis légèrement crénelé. L'íchancrare qui le sépare du sommet est pen profonde. La columelle, arquíe parallèlement au bord droí, est nu pen dépirimée et subtranclianle; elle ptésente, dans les deux tiers de sa longneur, sept à huit plis régulièrement décroissant de la base au sommet. Ces plis sont étroits et pressés les uns an-dessus des autres. L'ouverlure est étroite, arquée dans sa longueur, un peu plus large à la base quau sommet; elle est toute blanche eu dedans. A l'extérienr, cette coquille, sur un fond blanc ou d'un blanc-jaunàtre, est ornée d'un grand nombre de points rouges ou fauves, qui, dans quelques individus, son' plus multipliés, et affectent quelquefois une disposition telle, qu'ils furment deux zones transverses, oì ils sont plus petils et plus unultipliés.

On trouve celle coquille assez abondamment dans l'Océan allantique austral. On assure aussi quelle se rencontre dans les mers du Sénéural. Longueur 22 milliun.

18. Marginelle cornée. Maiginella comea.

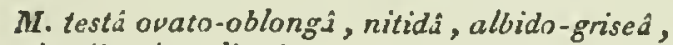
zonis tribus luteolis obscurè cincta, apice obtuso; labro intus crenato, anterius apicem superante; columella septemiplicatí.

Lams. Anim. sams vert. tom. 7. pag. 360. $a^{\circ} \cdot 20$.

La Marginelle cornée est une des espèces. les plus remarquables du genre : elle fait un passage incontestable vers les Óvules. Elle est ovale, trèsobtuse au sommet, un peu plus étroite a la base; elle est d'un gris-corné clair, et elle est ornée de trois zones très-obscures, d'un fuuve très-clair. Louverture, qui est fort étroite, est arquée dans sa longueur, la courbure de la columelle se trouvant paralléle à celie du bord droit. Cetle onverture est toute Llanche. La lèvre droite, qui est épaissie en on bourrelet assez saillant audehors, est plus longue que la spire; elle est fortement séparée du sommet par une échancrure profonde. Son bord interne est finement crénelé dans toute son étendue: les crénelures se prolongent \& l'intérieur en pelites côtes qui s'étendent assez loin dans l'ouverture. La columelle, fortement arquée, est chargée de sept plis, également espacés, mais inégaux. Ils dicuinuent graduellement de la base au sommet.

Cette coquille, fort rare, n'est conoue que dans un petit nombre de collections : l'individu que nous possédons provient, à ce que l'on nous a assuré, des mers de la Nouvelle-Hollande. Il est plus grand et plus frais que celui de la collection de Lamarck. Longueur 25 millim.

19. Marginelte ballée. Marginella-bullatu.

M. testâ ovato-oblongâ, cylindracế, albidì, fasciis crebris angustis rubro-lividis cinctá; apice cbtuso; columellá quadriplicató; labro intùs lavigato.

Listar, Conch. tab. 803. fig. נi.

K попn, Vergn. tom. 4. tab. 23. fig. 1, et iab. $27 \cdot f g \cdot 1$.

Mantixi, Conch. tom. 2.tab. $42 . f i g .424 .425$.

Voluta bullata. G BEL. pag. $3452 . n^{\circ} \cdot 129$.

Excrci. pl. 376: fig. 5. a. b.

Lama. Anim. sans yert. tom. 7. pag. 360. no. 19.

Nous ne dontons pas que, suus ce nom, Lamarck n'ait confondu deux espèces parfaitement distinctes: la première, que l'on reconnoitra facile. ment par les figures que nous citons dans la syncnymie, et la seconde, qui a été ligurée par Cbemnitz (tons. 10. tab. 150. fig. 1409. 1410 ). Cette dernière, qui acquiert toujours un volume très-considérable, comparativement à l'àutre, devra, par la suile, recevoir un nom particulier.

La Marginelle bullée est uoe petite coquille qui a rarement plus d'nn poure de longueur: elle est ovale, obtuse des deux cólés, et surtout a sommet. I.a spire est entièrement cachée. Louverture est alongée, étroite, un pen évasée a la base, $t \mathrm{t}$ aussi longue que la coquille elle-même. Le bord droit est blanc, épais, peu saillant au-dehors, légèrement infléchi dans son milieu : une petite É.hancrare le sépare de l'avant-dernier tour. La columelle porte à sa base quatre plis inégaux: le quatriène, on le dernier, ne paroît être qu'use bifurcation du troisième, qui est le plus grus de tous. L'ouverture est blanche en dedans, et la columelle est d'un blanc-jaunâtre. Le bourrelet du bord droit s'étale largement sur le cóté antérieur de la coquille; il devient d'un fauve-brunâtre vers ses limites. A l'extérieur, la coquille est d'an brun-cendre, quelquefois très-pâle et passiat 
au blanc-grisaitre. Sur celle couleur se dessinent an grand noubre de zones transverses bruoes, sonveat interrowpues par des fascies longitudinales irrégulières, qui paroissent être le résultat des ascroissemeas : les zones transverses, elles-mênes, n'ont rien de régulier daus leur nombre et leu. largeur.

Celte coquille, assez rare, vient de l'Océan indiea. Elle est longue de 25 à 28 millim.

20. Marginelle ovulée. Marginella ovulata.

II. testá fossili, parvâ, ova:â, spirâ brevissimá; labro intùs sulcato; columellà quinque seu sexplicatâ.

Lamr. Anim. sans vert. tom. 7. pag. 359. $\pi^{\circ} \cdot 17$.

Marginella ovulata. Ann. ibid. $n^{\circ}, 3$.

Cette Marginelle, par sa forme, se place aaturellemeat sur la linite de la première section des Marginelles, qui renferme toutes celles qui ont la spire sailaute au-dehors. La forme de cette espèce cst assez régulièrement ovale; sa spire est très-courte, presque complètement enveloppée par le dernier tour, doat l'ouverıure est à peu près aussi loogue que la coquille elle-mêrue. Cette ouverture esi étuoite, un peu plus élargie à la base qu'au sommet; le bord druit est peu Epais, rarement bordé en dehors, et toujours légèrement strié en dedans dans ipute sa lungueur. La colnmelle, qui est droite, offie tonjours cinq à six plis graduellement décroissant de la base vers le sommer; la surlace extérieuse est couplétement lisse.

Cette petite coquille ne se trouve pas moins abondamment que la Margioelle élurnée aux envirous de Paris et de Valognes. Elle est longue de $14^{\circ}$ millim.

Nous aurions pu ajouter la description d'un assez grand nombre d'espèces, soil vivantes, suil fossiles, à celles qui précèdeat, car nous comptons actuellement irente-cinq espèces dans la premic̀re section et dix-huit dans la seconde, ce qui porte à plus du double le nombre des espèces connues de Lamarck.

\section{MIARGINULINE. Marginulina.}

Ce genre éroit autrelois confondu parmi les Orihocères, avec lesquels il a en ellet beaucoup d'analogie. Linné, qui meltoit indistinctement toutes les cuquilles cloisonnées dans son gente Nitutile, donua le nom de Nautilus raphanus à nne petite coquille multiloculaire, qui servit depuis de type an genre qui nous occupe. Comme nous le verrons is l'aricle Nodosane, Lamarck confondit dans ce genre, ainsi que parmi les Orthocères, un grand nomisre de coguilles apparteount à des gepres bien différens.
Le Nautilus raphanus de Linné fut compris an nombre des espèces de ce dernier genle, quoiqu'en effet il a'en présentat pas tous les caractères. Nous n'entrerons pas ici dans les détails qui seroient nécessaires pour fuire counoitre tous les changemens de rapports qui se sont faits surcessiveunent dans les diverses méthodes depuis celle de Lamarck. Nous avozs donné à l'article Ci.pha ropode une partie de ces déluils; oous oous proposons de les readre plus cumplets lorsque nous traiteroos des genres Orthocert et Nodosaires.

Le genre Marginuline est compris, par M. d'Orbigny, dans sa premiere familie des Foraminiferes, les Sticostègues; elles sont placées entre les Vagiaulines et les Planulaties : elles ont des rapports principalement avec ce premier genre, et elles ae s'en distinguent que par un caractère doat nous aurons à apprécier la valeur. Nous voyons que dans les Nodosaires M. d'Orbigny a counpris des coquilles tronq̧uies an sommet et à ouverture centrule, d'autres qui ont également l'ouverture centrale, mais qui ont cette partie prolongée plus ou moins fortement. Dans ce genre, M. d'Orbigny n'a poiat douné d'imporlance à ce caractere de la forme de l'ouverture. Dans le genre qui nous occupe et celui qui le précède, on trouve des coguilles identiquement semblables, et qui ne présentent d'autres différences que celles que nous avons mentionnées entre les espèces de Nodosaires : ainsi, par un arbitraire que l'on ne peut aduettre actuellemeat dans les sciences d'observation, MI. d'O:bigny doone à un nême caractère une valeur qu'il augmente ou diminue à son grć. Si le prolongewent de l'ouverture dans les Nodosaires ne suffit pas pour faire un geare, pourquoi suffiroit-il pour séparer les Marginulines des Vaginulines? II. d'Orbignay, à ce curactère des Marginulioes, ea juint un autre qui ne nous parait pas plus important, et qui, nous n'en duutous pas, se rencontrera égalemeur dans quelques espèces-de Vuginulines: nous voulons parler du commeoment de spire que $\mathrm{M}$. d'Orbigay a observé dans les Jarginulines. 11 résulte pour nous, des observations précédenies, que les deux genres que nows venons de comparer devront être réunis, et les espèces groupées en deux seclions, d'après la furme de l'ouverture. Quant à l'importance réelle que nous dounous à la position de l'uuverture, nous croyons qu'elle est assez graade pour délerminer la lorcanation des genres daus la fasille des Siicostègues, comme daus la pluparı de celles qui sont comprises dans l'ordre des Foramiaifères.

La réunion des deux gevres qui nous occupent nécessile quelques changemens daos la phrase caractéristique que $\mathrm{Ml}$. d'Ôbigny avait imposée a chacun d'eux : en leur conservaut le nom de Marginuline, bous les caraciérisons de la manière sulvaute. 


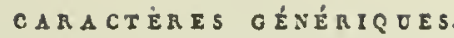

Coquille alungée, conique, dınite ou lénèrement courlsee, ayant quelquefois atu sommet an commencement de spire, cloisonnće transversulement, quelçuefois un peu obliqueurent dans son étendue; ouverture arrondie, taulót simple, tantót prolongée, placée sur la dernière cloison, à son angle antérieur.

Les coquilles que aous renfermons daus le genre Marginulane sunt micruscopiques; clles sont alongécs, coniques, tantôt subcyliadracées.et un peu aplaties sur les côtés, tantût régulièrement triaugulaires et pyramidales. Les cluisons plus ot covins noinbreuses qui partagent leur test daus sit longueur sont généralement un peu obliques, tandis que, daus les Nudosaires, elles sont loutà-fait transverses. Le sonmet est ordinairement aigu, et il l'est surtout dans celles des espèces qui nont aucun rudiment de spite; il est au contraire plus obtus et un peu inlléchi dans cellès des espèces où l'on en truuve un. Dans ce dernier cas, les coquilles sont ordinairemeut un peu courbées dans leur longneur; les cloisons sont indiquées à l'extérieur par des stries superficielles parallèles, ou par des étranglemeus plus ou moins profonds. L'uuverlure, siluće, comme nous l'avons dit, à l'angle antérieur, est toujuur's arrondie, tantò: simple, tantôt prolongée; mais, eatre ces deux états, il existe des passnges inseusibles au woyen desfuels on peut se convaincre que ce caractère du prolongement de l'ouverture n'a réellement aucune importance; car il est certaines espèces dont l'ouverture est seulement un peu bordée, d'autres qui l'ont un peu prolongée, et d'autres enfin qui l'ont située à l'extrémité d'uu petit tube assez saillant. Il est impossible, ce nous semble, de choisir une limite entre ces divers degrés. Il en est de mêue par rapport au commencement de spire relativenent i ce genre, aussi bien que pour plusieurs autres.

Nous indiquerons quelques-unes des principales especes qui peuvent faire partie du genre MIargrauline; nous les diviserons en deux groupes.

\section{Especes dont l'ouverture est sans prolongement (genre Vaginuline D'ORB.).} NoB.

I. Marginuline elégaute. Marginulina elegans.

M. testâ elongatâ, conicâ, subrectâ, albâ, nitidà, basioblique truncatî, lateraliter depressâ, dorso cristato-curinatî, transversim et obliquè costatì; aperturí minima, mitundâ, simplici.

Vaginulina elegans. D'Orв. Tab. méthod. de la class. des Cesphal. Ann. des Scienc. nat. tom. 7. pag. $257 \cdot n^{\circ}$. I.

Ibid. Mod. de Céphal. 3e livr. n॰. 54. .

Hist. Nat. des Fers. Tome II.
Celle petile coquille, gue nous avons recueillie dans les sables de Rimini, a été très-lieu reprlsentée par M. d'Orbigny dans ses jolis Modéles de Céphalopades. Eille est alongée, conique, déprincé de chaque cúlé, parfaitement régulière et symétrique; sun sommet est obtus; sa base, obliquement tronquéc, présente, à sa partie la plus élargie et la plus élcvéc, une très-petice onvcriture superticielle, ronde, et sans le moindre prolongement; sur le cóté postérieu, aiusi que sur les parties latérales, se trunve une série de côtes transverses, parallèles, très-régulières, qai, en indiquant les cloisons, montrent les ancieunes traces des parties que l'auimal a successivement abandonnées; sur le milieu du dos est siluée une carène assez saillante et légrement arquée dans sa longueur. Les cûtes transverses aboutissent à sa base, en s'atıénuant insensiblement.

Les plus grands individus de celle espèce n'ont que 2 millim. de longueur.

2. Marginuline gousse. Marginulina legumen. NoB.

MI. testâ elongatâ, conic $\hat{\hat{A}}$, utroque latere depressâ, angulatâ, basi obliquè truncatâ, lavigatâ, apice submucronatâ, laviter recurvij; carinâ dorsalı majore.

Vaginulina legumen. D'Orв. Tab. méth. des Céph. Ann. des Scienc. nat. loc. cit. $n^{\circ} .2$.

Nautilus legumen. Lix. pag. $3373 . n^{0} \cdot 22$.

Orthocera legumen. Laxк. Anim. sans. vert. tom. 7 . pug. $5 \mathrm{~g} 5 . n^{\mathrm{o}} \cdot 6$.

ENcrcL. pl. 465. fig. 3. a. b.c.

Plancus, de Conch. minus. not. tab. 1. fig. 7 .

M

Guait. Test. tab. ' 9 . Jig. P.

Montagu, Test. brit. Suppl. tab. '9. Jig. 6.

LeUder. Mlisc. tab. 8. fig. G ?

Cette espèce est une de celles qui, se trouvant le plus abondamment dans les sables de l'Adriatique, et qui ayant un volume un peu plus considérable que la plupart des coquilles wicroscnpiques, a puétre observée facilewent par un plus grand nombre de personnes, et figurée dans un plus grand nombre d'unvrages d'Listoire aâturelle.

La Nautilus legumen de Linné est une petite coquille alongée, conique, pointue au sommet, obliquemeut tronquée i la base; elle est blanche, lisse, transparente dans les intervalles des cloisons, qui sont indiquées par des lignes opaques, mais non saillantes; ces lignes sont obliques et parallèles à la cloison de la base, La coquille est déprimée sni les parties latérales, un peo moins épaisse du côté du dos, où elle se termiue insensiblement par une carèue médiane assez élevée

$$
\mathrm{Ggg} *
$$


et ISgèrement courbso dans sa longneur; une autre carène plus obtuse et plus courte est placte sur le côlé ventral, à l'opposé de la première. I'ou vesture est très-petite, arroudie, située trèsprès du bord, et à la partic la plus élevée de la dernière cloison.

Celle cuquille se trouve, avec la précédente, dans les sables de Rimini, et, d’après Alontaru, dans ccux de la côle d'Angleterre. Elle a gưtrjuefois près de \& ligaes de longuéur, enviton 4 millim.

3. Mangnudre tricarióe. Murginulina tricarinata. Noв.

MI. testâ elongatâ, pyrrmidali, triangulari, lavigatâ, nitidâa, culba ; angulis margine obtusu instructis; apice acutissimo; busi trigonô, obliqua; “perturấ rotundatá.

D’Onв. Model. de Céph. a re. liv. no. 4.

Petite coquille très-remarrquable par sa forme pyramidale. Celte pyramide est à face presqu'ífiales; la base est un peu oblique, et les angles, occupés par un bourrelet qui les suit dans toute leur longueur, sont obtus et arrondis. Les trois côtés de cette pyramide sont lisses, brillans; on y voit des stries transverses et obliques qui indiquent la position des cloisons; lat dernière, légèrement enfoncée au-dessous des bords du test, est percée à son angle le plus aigu d'une petite ouverture ronde et simple. Tonle celte coquille est hlanche; les iniervalles des cloisons sunt translucides, et l'us n'aperçoit au somıet, qui est trèspointu, aucune apparence de spire.

Cette espèce vit, a vec les précédentes, dans lia iner Adriatique, et se trouve particulièrement à Rimini, oì clle est rare. l.es individus que nous avons vus n'a voieut guère plus de 2 millim. de longueur.

\section{Espèces dont l'ouverture est située au bout d'un prolongenzent de la dernière loge (genre Marginuline D'Unв. ).}

4. Marginelne radis. Marginulina raphanus. D'ORB.

M. testâ elongatâ, letteraliter depressâ, apice

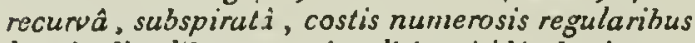
longitudinalibus ornatâ, albâ, nitida, basi truncatâ; uperturâ rotundata , prcelongâ.

D'Ояв. Tub. des Céphal. Ann. des Scienc. nat. lö. cit. pag. 258. $n^{\circ}$. 1 .

Ilid. Modèl. de Céph. Ire livr. an, 6 .

Nantilus raphanus. Liv. pag. 3372. $n^{\circ}, 16$.

Orthocera raphanus. Lasr. Animt. sans vert. toms. 7. pag. 593. $n^{n}$. 1 .

Sold ans, Test. microsc. tam. 2. tab. 94. fig. N. P. Q. R. X. Y.

\section{A R}

Cette espèco est encore l'une de celles qui fut connue de Linné; elle est alongrée, conique, wè̀régulière, légèremont courbée au suaraet, qui présente un commencesnent d'entoulement spiral; elle est un peu déprimée sur les côtés; elle est ornće de dix cótes tongiludinates continues, très. régulières et symétriques, suillantes et tranchanles au sommel; la côte dorsale est un pell plus éle vée que les autres; dans les intervalles de ces côles, on aperçoir les races des cluisons transverses, qui ne sont jamais globuleuses, mais tonjours aplaties. A la base celle coquille est tronquée, raais elle n'est point oblique, comme duns les espèces que nous a vous précédemment décrites. La dernière cluison est légèrement concave; son extrémité se prolonge en un petit tube cylindracé au bout duquel est siluée une ouverture arroudie. Celle coquille est d'une couleur d'un blanc-yrisàtre; les côtes \& les cloisons sont opaques, le reste est translucide. Elle se trouve, avec lof précédeutes, daus la mer Adrialique; elle est longue de 2 à 5 millim. On la trouve aussi fossile it Castel-Arquato.

\section{MARGARI'TANE. Margaritana}

Sous ce nom, M. Sctumacher a proposé, dans son Essai de Conchyliologio, un genre puar anselques-uns des Unro qui ont la dent cardinale supérieure obsulète. Ce geure ne pcut êure adopté; il avoit d'ailleurs déji écé proposé par M. Leach, et ña été cité par les auteur's qu'à itite de sectiou sous-géuérique. Voyez Mulette.

\section{MARGARITE. Mfargarita.}

M. Leach a voit proposé ce genre pour une partie des Avicules de Bruguière; Lamarck lui a douné depuis le nom de Pintadine; Mégerle l'a voit aussi locmé, dès 1811 , sous le nom de Margatitiphore; et Klein enfiu l'avuiı, bien avant cout cela, assez bieo indiqué sous le nom de Mater perlarum. Vuy. Pintadine el Aticule.

\section{MARGARITITES.}

Les Anciens ont donné ce nom. a des corps arrondis, pérrifiés, qu’ils ont crus être des perles. On n'a puint de certitude à cet érrard. Il u'en est pas de mềne d'une perle véritable que nous avons trouvée en vidant ime Avicule tossile de Bordeaux, Avicula phanelacea Basterot, dontles deux valves étoient encore réunies. Ce corps, parfaitement rond, d'uoe ligae de diamètre environ, avoit conservé une partie de l'éclat de la nacre.. ....

\section{MARMITES, Ollata.}

Nom donné par M. Schumacher à la seconde section de son systène de conchylioluyie. Elle renferme la plupart des geares des Cirrlaipèdes sessiles de Lamarck. Il nomme ces genres Balane, Diadème, Tétraclite et Verrue. Voyez ccs mots. 
MARNA'T

Alanson nomme ainsi (Voy. au Sénég. pl. 12. fog. 1) une cóquille du genre Turbo, dont Linné ¿ tail un espèce particulière à laquelle il a donné le num de Turbo punctatus. (Syst. nat. 130 édit. tom. 1. pag. 3597. $\left.n^{\circ} \cdot 37 \cdot\right)$

\section{MARRON ÉPINEUX.}

Nom vuleraire que les marchands donnent ì un espece de Cime, Chama arcinella des auteurs. V̆ojez Cabie.

\section{NARSYAS.}

M. Oken, dans son Manuel de Zoologie, a subslituć ce non à celui d'Aurjcule, consacré bien lung-tcmps avant par les truvaux de Lamarck. Ce genre fait don: un double emploj qui ne sera point adopté. Voyez Auricule.

\section{NIARTEAU. Malleus.}

Liané confondoil les coquilles de ce genre jarmi les lluitices, comme heauconp d'autres qui en dillërent cependant d'une manière essenticlie. Bruguièıe, dans les planclıes de l'Encyclopédie, sépara des Huities de liuné sun genre Avicule dans lequel il piaça les Marteaux; enfin Lamarck en fit un renre particulier anquel il donna le nom de MIarteau, à cause de la folme des corquilles qui a quelçues ressemblance a vec cet instument des couvreurs. Ce fuldans les Animaux sans vertibres, $180 t$, que ce geare se tronva élabli pour la première fois; depuis celle époque, il fut adunis par le plus nrand noabre des conchyliolonges: ils ne varient pas sur la nécessité de l'admettre, mais sur la place qu'il doit occuper dans laséric. C'est ainsi que son auleur lui-méme, après l'avoir placé près des Vulselles et des Avicules dans le Système des Animuux sans vertébres, quelques années après les en sépara pour les porter dans la taruille des Byssilëres, 'andis que les Vulselles restèrent dans la famille des Ostracfes. Le savant auteur de l'Extrait du Cours el des Animaux sans vertèbres conserva ces rapporis dans ces deux ouvrages; cependant, daus le dernier, il sépara de ses Byssifères la fauille des Malléacées (voyez ce ruot), dont il crut devoir exclure encore les Vulselles : les Marteaux se trouvèrent voisias des geures Crénatules, elc.

MI. Cuvier, Règne animal, n'a point imité Lamarck; il a luissé les Marteaux près des Vulselles. M. de lierussac a conservé la famille des Malléacées; il y a apporté quelques changemens : c'est ainsi quil en ôte les Crénatules pour y subs. tituer les Vulselles, qui sont mises en contact avec les Marteaux.

I. de Blainville a conservé le genre Martean, l'a mis près des Vulselles, et a donné le nom de Mlargaritacées (voyez ce mot) à la famille des
Malléacées, en y faisant les changemens nécessaires. On ne connuit point encore-l'animal du Mallcan; on sait seulement quill saltache par un bjssus. Voici les caracteres de ce genre.

\section{CARACTERES GÉXERIQUES.}

Corquille subéquivalve, rabotcuse, dillorme, le plus souvent alongée, sublobrc à la base, à crochets petits; diver iens; clurnière sans denis; une fosselte alongće, conique, située sous les cruchets, truversint obligivement la lacelte du ligameot; celui-si presquextérieur, šinsérant sur Ia lacelie courte el en talus de chaque valve.

Les Marteaux sunt des coquilles singulières par la lorme habiuelle gu'elles ellectent : leur bord supétieur se prolonge de chaque colé en deux longues auricules étroites, qui, placécs à angle presque druit sur le corps de la coquille, lui donnent une grande ressemblance avec le marteau dont se serveles ouvriers couvreurs.

Le corps de la coquille est alongé, étroit, diversement onduleux ou plissé sur ses bords; it lintérieur on lemarque en dedans de 'impression du colps une grande et vasle impression musculaire, ovalaire é très-superticielle : toute la surface comprise dans cette impression est une nacre d'un blanci-violatre, tandis que le reste de la coquille, c'est-à-dire à peu près les deux tiers inlérieurs de son corpset ses deux oreillctles, sont complétement dépourvas de parties varcrées, et paroisseut être protuits par les expansions du cuanteau.

Toutes les especes de Miarteau ne sont pas pourvues sur leu partue latérale des longues oreillelles qui appartienneat seulement à deux ou trois espéces; mais si ce caractère manque, il peut étre lacilement suppléé unn-seulement pour la distiaciion des espèces, mais cncore pour la déterminalion du genre à l'aide de la charuière, qui oflre des caractères constans. Siluće perpenciiculairement sur l'axe longitudinal de la coquille, elle est toujours en ligne droite, ses loords sont taillés en biseau, en une sorte de talon comparable à celui des Pintadines ou des Limes. Ce talon est creusé dans son wilieu d'une gountière oblique, triangulaire et profonde, dunt la base falt une saillie demi-circulaire à lintérieur des valves. En arant de celle fossette se tronve une sinuosité plus ou moins protunde, selon les espèces, qui, comparable par sa position, sa forme et son usage à celle des Avicules, est destinée à donner passage à un petit byssus. 11 cxiste donc-dans les caractères des Marteaux une extrêne ressemblance avec les Avicules : on retrouve le même ensemble dans l'un et l'autre gente, et celui-ci n'en diffère véritablement que par l'irrégularité des coquilles et leur forme bizarse. Un autre genre avec lequel les Marteaux ont une grande analogie est celui des Vulselles, que Lamarck a laissé dans la lamillo Ggg $2 *$ 
des Ostracées, probablement parce qu'il n'a point reconau aux.Vulselles d'échancrure pour le byssus, comme cela a lieu dans tous les genres de la lamille des Malléacées. A part ce caractère, qui certainement est d'une graude valeur, les Vulselles ont saus contredit beaucoup d'analogie avec les Marteaux : nous voyons que dans ce genre la charaière est composée de la mếne manière, seulement elle est plus généralement oblique; aussi les auteurs qui ont traité de ces genres, après Jamarck, ont eu suin de les rapprocher autant qu'ils ont pu : ce ¿qui sera ane amélioralion dans celles des métbodes riont les arrangemens seront basés sur d'autres principes que celle de lamurck.

Les espèces de Marleaux sont encore peu noml)reuses; elles vivent, à ce qu'il paroît, à une jrofondeur assez considérable. fixées aux rochers de l'arcbipel indien. C'est dans les mers de l'Inde, en effet, où l'on a constamment recueilli les plus grandes et les plus belles espèces. Oa n'en counoit encore aucuue à l'état fossile.

1. Marteau blanc. Malleus albus.

M. testâ trilobà; lobis luteralibus baseos proelongis; sinu byssi nullo aut à foveâ ligumenti non distincto.

An Lister, Conch. Lab. 219. fig. 54 ?

Lask. Anim. sans vert. tom. 6. pag. 144 . no. 1 .

Coquille très-connue des amatears, et fort recberchéc par eux à cause de son extrêne rareté. Sa forme est celle d'un grand $\mathbf{T}$ dont une des branches supérieures seroit un peu plus courte que liutre; les oreillettes sont alongées, étroites, placées à angle droit sur le corps de la coquille; l'oreillette antérieure est un peu plus courte que l'autre. A sa base se voit une petite échancrure pour le byssus, échancrure qui remonte vers le bord cardinal et a son issne à côté du sommet. Le corps de la coquille est alongé, linguilorme, plus ou moins régulier, très-ćtroit, présentant constamment sur les bords el de cbaque côté deux ou trois grands plis sinueux, semblables à ceux de certaines Huitres. La surface extérieure est toute blanche, mais d'un blanc-jaunâtre ou corné. Cetle surface est couverte de grosies rides et de lamelles ransverses qui sout le produit des accroissemens. A l'intérieur la partic supérieure la plus concave, occupée par le corps de l'animal, est netlement séparée par la couclie aacrée dont elle est revêtue. Cette nacre, d'un blaoc brillant, présente souvent des taches irrégulières d'un violet obscur. L'impression musculaire, qui est oblongue, sublatérale et longitudinale, est constamment de cette conleur. Le reste de la surface intérieure est polie et d'un blanc-coroé counne l'extérieur.

Cette coquille acquiert quelquefois en vieillissan upe épaisseur et une solidité remarquable : nous avons vu un individu qui avoit plus d'uu pouce d'épaisseur à la parlie inférieure des valves. Ia longueur de cette espéce est de 7 à 8 pouces : les oreillettes ont une longuear un peu moiudre.

\section{Marteau commun. Malleus vulgaris.}

M1. testâ trilohâ, extùs intìsque scepissimb nigra ; sinu byssi à foveâ liganenti sepunato.

Ostrea malleus L1s. Garex. $n^{\circ} \cdot 99$.

Ruмгн. Mus. tab. 47.fig. $h$.

Dargenv. Conch. tab. 19.fig. $a$.

Gustr. test. tab. 9. fig. d. c.

KNовR, Vergn. tom. 3. tab. 4. fig. 1.

Caems. Conch. tom. 8. tab. 70 . fg. 655.

EncycL. pl. 177. fig. 12,

Var. b.) Testâ albidâ, lobis latenalibus baseos brevissimis.

Caema. Conch. tom. 8. tab. 7o. fig. 656.

Eiverec. pl. 177. fig. 13 .

Lasx. Anim. sans vert. tonı. 6. pag. 144. $n^{\circ} .2$.

Le Marteau vulyaire a une grande ressemblance, quant à la forme, avec l'espèce précédente: on le reconuoit par sa charoière, dont l'écbancrure est plus grande et située beaucoup plus près de la fussette du ligament; il se reconnoît encore en ce que la coquille est seulement onduleuse dans sa longuenr et jamais plissée régulièrement sur les cô:és. Si l'on joint à ces caractères priocipaux ceux de la couleur, de la forme de l'impression musculaire, ainsi que celle de la tacbe aacrée, on dislinguera très-facilement les deux espèces, quand mếne il arriveroit, comme cela a lieu en ellet, que les variétés de coulenrs pourroient amener à les confondre. Le Martean commun est généralemeat plus grand que le Marteau blanc; son test est plus foliacé, beaucoup moins compacte; les oreillettes son plus larges, l'antérieure généralement plus grande; l'impression du corps est proportionnellement plus courle et plus ovalaire; litapression ausculaire est plus grande et plus ovale; la couleur enfin est presque cuostamment d'un violet très-foncé à l'inlérieur, presque noirútre au-debors. La variété que nous signalons, d'après Lamarck, est blaoche, et pourroit par conséqueut se confondre avec l'espèce précćdente; mais si l'on fait altention qu'elle conserve tuus les caractères que nous venons d'assigner à celle-ci, il sera difficile de commettre la moiadre méprise à sun égard.

Cette espèce a 8 on 9 pouces de longuenr : les oreillettes ont ordinairement autant de longueur que la coquille elle même.

\section{Marteau volsellé. Malleus vulseilatus.}

MI. testâ elorigatâ, planulat, , fragili; latenum 
marginibus subparallelis; basi inaquali; lobo obliqué porrecto.

Ostrea vulsella. Garel. $n^{\circ} .100$.

Cuens. Conch. tom. 8. tab. 70. fig. 657 .

Excrec. pl. 177. fig. 15.

L. 31. Anim. sens vert. tom. 6. pag. 145. $n^{\circ} .4$.

Il sembleroit que cette coquille n'est que le jeune ìve du Nulleus vulgaris; mais celui-ci, avant d'être arrivé à sun développement, a les deux appendices auriculaires, dont l'espèce que nous allons décrire manque constamment. Elle est alongée, étroite, irrégulière, foliacée à l'extérieur, très-aplatie, presqu'aussi large à sa partie inférieure qu'à la supérieure. Le bord cardioal est un peu incliné sur l'axe longitudinal; sur son cóté antérieur se voit l'échancrure pour le passage du byssus. Cette échancrure est beaucoup plus profonde. L'impression nacrée intérieure est petite, obronde, ordinairemeut limité par un bord saillant; elle est blanche, et contient vers le cealre uue petite impression mosculaire presque circulaire. Le reste de la surface interne est irrégulièrement boursonfflée, toujours d'un violet très-intense. A l'extérieur, la sarface est occupée par un girand nombre de launes irrégulières d'accroissement. Ces lames sont très-fragiles et sauvent très-saillantes.

Cetle petite coquille vient, d'après Lamarck, de la mer Rouge, de Timor, et de la Nouvelle-. Ho:lande. Elle est longue de go à 100 millim.

\section{MARTESIA.}

Genre élabli par Leach pour des Pholades raccourcies, cunélilormes, bâllantes, avec plusieurs pièces accessoires, l'une dorsale et moyenne, et deux marginales inférieures. M. de Blainville, à l'article Morrusque du Dictionnaire des Sciences naturelles, a admis ce geare comme sousdivision des PLolades. Voyez ce mot.

\section{MASIER.}

Nom donné par Adanson à no Tube calcaire earoulé en spirale, et qui appartiedt sans donte an genre Vermet. Voyez ce mot.

\section{MASQUE. Persona.}

Dans sa Conchyliolcgie systématique, Montlort a établi ce genre pour quelcutes-unes des cogailles les plus bizarres du genre Murex de Linné. Lamarck les comprend, dans son genre Triton, sous le nom de Triton grimaçant. Depuis les recherches de MN. Quny et Gaymard, il paroit que l'animai qui habite celle coquille est semblable à celui des Casques. Voyez Trison.

\section{MASSUE D'HERCULE.}

Nom vulgaire d'une espèce commone de Ro- cher, Murex brandaris. I.es marchands nomment aussi grande Mlassue d'Hercule le Nurex cormutus. Voyez Rocher.

\section{MATADOA.}

Adanson ( Voy. au Sénég. pä. 239 et 250 , $p l .18, f g .5)$ nomme ainsi une coquille quil rapporte à son genre Telline, lequel répond aux Donaces des auteurs modernes. Il est fort difícile de décider du genre de cette coquille d'après la description et la seule figure d'Adanson; il dit, page 239 , que le Niatadoa a de la ressemblance avec la Calcinelle, dont il a le ligament intérieur placé un peu plus au-dessous des sommets. Ce n'est donc point une véritable Donace, re n'est pas non plus une Vénus, comme l'a pensé Linné, ce seroit plutôt une NIactre. Comme on le voit, on est dans l'impossibilité de décider la question avant de revoir en nature la cocpuille d'Adanson.

\section{MATER PERLARUM.}

Dass son Tentamen Methodi ostracologica, Klein a formé, sous celte dénomination, un yente qui correspond assez bien à celui commé depuis Pintadine par Lacoarck. Voyez Pintadise.

\section{MAZZA.}

Ce geare, que proposa Klein, est, comme l. plupart de ceux qu'il a formés, composé d'une réuvion de coquilles diverses qui doivent être réparties aujourd'hui entre les genres Fusen, Pyrule, Ampullaire, etc.

\section{MÉGAPTÉRYGIENS. Megaptery'gia.}

M. Latreille, dans ses Familles naturelles uu Règne animal, a divisé les Ptéropodes en deux ordres. Le premier, qui porte le nom de Mégaptérygiens, comprend deux familles, les Procéphales et les Cryptocépbales. Cet ordre ne pourra étre adopté, non plas que les familles qu'il renferme, à cause des changemens nombreux que les travaux récens de $M$. Rang ont introduit dars l'arrangemen: des Ptéropodes. Voyez Prínopndes et Mollosques.

\section{MEGARINA.}

Rafiuesque (Journ. de Physiq. tont. 8, pug. 427) a proposé sous ce nom uu genre quil séparé des Térébratules, sur des caractères de trop peu de valeur pour qu'ils puisseut être adoptés. Yoyez TÉrébrattule.

\section{MÉLAMPE.}

Montfort a formé sous ce nom, dans sa Conchyliologie systématique, un genre qu'il a séparé des Auricules. Lamarck l'a adopté en lui donnant le nom de Conovule. Enfin, ce savaut a fini 
par rizair les Corovales aux Auricules, doat elles

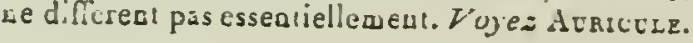

\section{MÉLAXIDES.}

Fanille que JI. Lalreille a proposéespour réunir p'usieurs genres qui aroisiued åssez les Méldnies, et quil met en contact arec elles; ce sont les silvans: Pbasianelle, Mélanie, Mélanopside, Pyréce, el Plaare. Celle famille ne répond pas ea:ièrement anx Múlauiens de Lamarck; on y troure de plus les.genres l'Lasiaueile el l'lunaxé. Peut-étre le premier n'est-il pas dans ses rapports naturels. Les Phasianelles soot très-roisiues des Ampultzires, près desquelles AIM. Curier et de Biaiavil!e les ont conslamment placées. M. Latreille dcane les caractères suivans a la familice des Mélauides : les bords de l'ouverture de la c:ogulle sont désnnis; le droit s"éléve au-dessus de la columelle, et laisse entrelle et lui an vite formant u angle. Cetle columtile n'ulfre ai plis ri dentelures. Ces caractices ne peurent s'appliqtier, comme on le roit, à tous les genres contenus danis cetje famille. Les Plasianelles et les Niélanes nout pas l'angle a la base de la columelie comme les aures. Il y a une raison pour faire entrer les Mélanies daus la mème famille que les M lanopsides; mais elle n'existe pas a l'egard des Phasianelles : nous vonlons parler de l'opercule et de la structure des avimaux. Quant à la réunion des Planaxes aux Mélanopsides dans Ia fa anilie des Nélanides, anus la regardans comme un cbangement heureux. Depuis loug-lemps nous arions l'opinion que les Planases sont des Mélanopsides marics, et nous espérons que leur anatu gie riendra guelque jour couliraer nolre manive cie roir.

\section{M!ćlaNIE. Melunia.}

Geore de Is famille des Mélaniens de Lararck et des Conchylies de \$1. Cuvier. Lister a vait placé depois fort l yo-temps les Nelacies avec les Limnées dans les Buccins d'eau dusce; mais it les aroit séparées d'āprès leur analogie de furme, sans pourlant changer leur dénomination. On roil, far les plancbes 108 a 124 de son graud ouvrage, qui ne prósentent que des Nélanies el des Mélanopsides, qu'il avoit fort biea saisi les caractères d'easemble de ves coquilles, qu'ıl a voit séparées des eoquilles terres'res, arec lesquelles, plus rard, ou les confondit.

Iusulier ful exempt de celle fate dans laquelle voxa Liané, qui plạça les Mélanies iudistincıe-" metat parmi les Hélices. Bruguière commit une ETreur non moins grare que celle de Linaé, et d'autant moins pardonabie au célèbre auteur de l'Encjelopédie, qu'il avoit étndié a Hadagasear l'animal d'une grande espèce te liélanie, ce qui ne l'empêcha pas de les confondre dans son genre Pullime, taujours entrainé par des caractères arti- ficiels et peu restreints. Lamarch enfia, dans ses premiers Iraraux, créa le genre Mélanie, quall plaça d'abord dans le systèue près des Limnéés es des Hélices, et quil en éluigna ensuite à mesure que les geares environnans fureat mieux connus, et qu'un put mieux conséfquemment en établii les rapports. Cependant ces rapporis n'aroient point été justemeut appréciés, ear adus royons que ces deux zoologistes, qui ont le plas étudić l'anatumie des Mullusques MN. Cuvier el de Blainrille, s'accordent parlaitement sur la place de ce gearc: le premier, ea le considérant comme sousyenre de scs Conchjlies (2ojez ce mol), dans lesquelles il ajuute les Ampulaires et les Pbasiznelles; et le second, eu lus raggeant dans la fanille des Ellipsostomes avec les geures que nous venons de citer. M. de Ferussac n'a point admis celme opiaiou. Nues vojons, dans ses Tablecur. systématiques, le genre qui nous occupe forter un des sous-geares des Paludines. Calle opiaion nous semble susceptible de discussiun. M. La:reil!e ae l'a point actoptée; ce savant a plutul arlanis celle de M. Cuvier, en la modifiant. (Foyez MÉlaxides.) Ce yeare, dont on ne connoil qu'ımparlaitenent l'anatomie, d'apres ce qu'eu a dit Bruguière, peut étre caractérisć ainsi.

\section{CARACTERES GIXERIQCES.}

Animal trachélipode, dioiqne, ayaut le pied liringé dans la circunférence; deux tentacules bliturmes; les yeux à leur base exterae; ua auna praboscidiforme. Caquille turriculée; oureıllue entière, ovale ou ublonge, évasée à la base; columelle lisse, arquee en dedans; un opercule coraé.

Les Mélanies sont tuutes des caquilles d'eau douce des pays chiuds; on ne les trucure plas virantes en France, quoiquielles y aient récu autrefois en très-giand nombre. Tos dépóts coquilliers, suit lacustres, soit marins, en offreat un grand nombre d'espèces. Quelques-unes, d'apies leur gissenent, leur abondance el leur constauce dans les terrains marins, secublent avoir récu dans un lluide salé avec un grand numbre de geares esseniielleweot anarins. Ce fait, qui a parte guelyues personaes à élablir des liypotbèses sur la salure moins grande de la mer a une époque trés-reculée, celle ou se dépasoitles fossiles des environs de Palis, a'esi pas suffisacs pour prouver celle opinion. Nous iruavons en effet dans la Mréditerranée une petite coquille brillatite dont l'analogue lussile existe eu Italie, l'Helix subula Biocihi, qu'on ne peut, d'après la coquille, rapporter qu'au genre Mílanie, el qui, d'après l'animal, pourroi: ểre un aurre yenre. A cetle espece pourruil se rallacber an ceriain numbre de celies des terrains marins; il seroit donc essentiel de pouvoir en étudier l'animal.

te geare Rissad, g̨ui est élab!i cepais fort peu 


\section{E L}

de temps, ćlcit placé parmi les Mélanies; et comas il est rarin, il a pu contribuer à former l'upinion dunt nous venons de parler.

Ce genre Rissoz a été considéré par M. de Ferussac comme soirs-genre des Paludines, et il le plaça près des Mélanies. M. de Blainville l'admet comme genre, et le fait suivre les Melanies. Si l'on convieut de couserver ce genre, qui, de l'aveu le M. de Blainville lui.nềme, est assez. artiliciel, il seroit pent-être cunvenable au isi d'en élablir un pour la Meíunia custellati, gui n'est point une véritable Mélanie, ni une Rissua, et pour la Melania murginatu, qui se trouve dans la mêrne circonstauce. Nuus pensons qu'il faut taire de ce genre comme de celui des Néiles, yui a des espéces lacustres et d'autres marines, dont on aroil essayé de faire des genres distincts, el qu'on est forcé aujourd'Lui de réusir.

\section{Mélane de Cuvier. Melanía Cuvieri.}

31. testî́ pyramiduto-turritâ, transversinz striatî; anfmictibus subconvexis, parte superiore subcurinatis, longitudinaliter costatis; costis distantrbus, penultimo et ultimo anfraciu cuspidutis; uperturi ovuto-oblongú; columella uncuatâ, marginut $\dot{x}$.

Nов. Descr. des Coq. foss. des env. de Paris, pag. 104. pl. 12. fig. 1. 2.

'Très-belle et très-rare coqquille, l'une des plus grandes et des plus remarquables du gense; clle a beauconp de rapports avec la Pyrcha spinosa (Lamarck, Anim. s. vert. tom. 6, pag. 170, no. 2) quanta la forme el a la disposıtiou des côtes; mais elle en diflère essentiellement, a'apparteuant point au mêtue genre.

Cette orrunde coquille tarriculée, régulièremcot pyramidale, est élégannent stríéc en travess; ses stries sont plus distantes et plus profondes à la base; elle est ormée de côtes longitudiaales soillantes, peu obliques, pointues á leur sommet, mais qui, sur l'avant-dernier et le dernier tour, s'élèvent et se prolongent en unc forte épine szillante. Les tours soni peu convexes, subcarénćs supérieurement; ils purlent chacun six à sept côtes, et sont séparis entr'eux par uae suture qui remonte et les embrasse assez haut : elle est indiquée par une stric large ot onduleuse sur le plat. Les stries qui sont súr la carène sont fiocs et trìs-prolondes. Longueur go millias:

3. Méravie souilléc. Melania inquinata. Def.

II. testi elongut:, turvitỉ, busi striutä; an. fractıbus subconvexis, in medio anguhtis; tuberculis depressis, sernatis vel striä proeminentiore; aperturs ovuta, busi dilatatâ.

Def. Dict. des Scienc. nat. torn. 29. pag. 469.

Cerithum melunoides. Sow. Mineral. conchol. pl. $147 \cdot f_{g} \cdot 6 \cdot 7$.
Var. a.) Tests anfructibus bisirialis, tuberult: nunierosioribus.

Var. b.) Testâ tuberculıs bỉfariam separatis.

Var. c.) Testâ majore anfractibus tristriatis, stria inferiore aliquantzsper subtubcrulatî.

No . Descr. des Coq. foss. des cnv. de Paris, pag. 105. pl. 12. fig. 7. 8.15. 14. 15. 16.

Ihid. Noв. Mago. de conchylo, par Guériu, pag. 13. pl. 13.

M. de Ferussac et onus, possèdons l'abalogue vvant de crelte espèce, et surtout de uotre variété $c$. Elle vient, à ce qu'il nous semble, de la partie miridionale de l'Asie ou des Philippiues. On troure en Angleterre, à Headen-Hill, lanalorne fussile que Sowerby, à canse du mavais état des iadiridus qu'll a eus à sa disposition, avoil rangé dans le genre Cérice. Cette espèce est assez graude, turriculée, alténuée au soumet, on no pell tronquée; clle ollie dix à onze lours d.c spire légèrement convexes et súparés par nue suture superficiells. Cbaque tour de spire préseate, un peu au-de:sous du milieu, me rangée de tubercules saillans, un peu aplatis et assez aigus; le reste est lisse dans le plus grand nombre des individus. A la base, on remarque ciuc ou six siries saillantes. L'ouverture est ovale-oblongue, la lèvre droiic entière et simple. La variété $A$ se reconnuit à des tubercules plus nombreux et plus serrés, aplatis plutôt longriludinalement que transversalement. A 11-dessus, il y a çeux stries saillantes el distantes. La variété $B$ esı singulièro par les tubercules qui se troureat divisés transversalement dans leur niilieu par uue strie prolunde. La variété C riest pas moius remarquable que la préceédente. Les IIIbercules sont presque ullacés : a leur place, il y a une strie proeminente qui oflice des tubercules très-petits, à peine saillans; all-dessus de cettc strie il y en a ordinairement trois autres simples. Cette variété, qui paroit dépeodie de la localité où on la trouve, es! plus grande que les atres, et est généraleasent plus larye à la bast. tongueur 45 millim., longueur de la variêté C: 50 millix.

\section{MÉlanie trooquée. Mlelunia truncatu.}

MI. tesiâ turritâ, upice truncatâ, solidi, fusconigircante; costulis longitudinulibus, superioribus eminentiorilus; striis transversis, ciebris, costulls decussantibus; anfructrhus pluno convexis.

Bulimus uter. Rrchan D, Actos de la Soc. d'Hist. nat. de Paris, pag. $126 . n^{\circ} .18$.

Melunia semi-plicata. Excrce. pl. 358. fig. 3. a. $b$.

LA Mx. Anim. s. vert. tom. 6.pag. 164. $n^{\circ} .2$.

Coquille alongée, lurriculée, Ironquée ordinairement au soamet; elle est d'un brun-noir, à spise fort alcagée, lormée de buit à deuf cours 
aplatis, à suture tanlót simple et superficielle, Iablôt plus profonde et crénelée; ce qui a lieu principalement sur les premiers toul's. Ceux-ci scat coaverts, dans toute leur étendue, de stries t'ansverses rapprochées, nocobreuses, convexes, dont les supérieures sunt coupćes en travers par des cótes longitudioales qui n'occupent ordinairement que la moitié inférieure de chaque tour, si ce n'est au sommet où elles s'éleodent d'une suture à l'autle. L'ouverture est ovale, pointue supérieurement; elle cst blanche en dedaus, évasée à la base; sa lévre droite est mince, trauchante, ua peu recouvraote. La columelle est peu Épaisse, coulournée et arquée à sa base, et cuntinuée supérieuremeut par un bord gauche peu épais à l'extérieur. Celle coquille est taute rioire, ou d'un brun-noirâtre. Elle se trouve, d'apiès Lamarck, dans !es rivières de la Guianc. Elle est longue de 55 à 60 millim.

\section{Mélanie thiare. Melania amarula.}

MI. testâ ovato-conoideâ, solidâ, longitudinaliter costulata, transversin striatâ, fusco-nigricante; costulis in spinas rectas porrectis; anfractibus supernè angulato-planis; angulo margıne spinoso; spirs exsertá; aperturâ albocarulescente.

Helix amarula. LiN. Gmes. pag. 3656. no. 126.

Buccinum amarula. HuLLer, Verm. pag. 137. $n^{\circ}$. 33o.

lister, Conch. tab. 1055. fig. 8.

RoMpe. Mus. tab. 33. fig. f. f.

Petrv. Amb. tab. 4. fig. 3.

DARGenv. Conch. pl. 61. fig. g. 2.

SEBA, Mus. tom. 3. tab. 53. fg. 24. 25.

Giel. Conch. tom. 9. tab. 134. fig. 1218.1239.

Bulimus amarula. Var. B.) Brug. Dict. $n^{\circ} \cdot 19$.

Melania amaiula. Excycr. pl. 458. fg. 6.a. b.

Lamr. Anim. s. vert. tom. 6. pag. 166. $n^{\circ} \cdot 10$.

De Blainv. Malacol. pl. 35. fg. 7. a.

Bruguière ayant conlondu avec cette coquille plusieurs espèces fort distiuctes, il notrs semble ácessaire, après en avoir retranché les variétés, d'eo donner de nouveau la description. La Mélanie thiare est une coquille ovale-oblongue, ventrue, à spire le plus sonveat tronquee, composée de sept à hait tours convexes, dont le dernier est presque aussi grand que tous les autres. Ces touls sont étagés par une rampe un peu oblique, qui est limitée a l'extérieur par une rangée d'épines qui couronoe chacun des tours. Ces épines, plus ou moins longues, selon les individus, sont tubuleuses et s'appuiedt, parleur base, sur de pelites cóles qui se prolongent à la partie supérieure de cliaque tour. Des stries obsolètes, transverses, assez grosses a la base du dernier tcur, soot disséminées sur la surface extericure de celle coquille. Celte surface est revélue d'au épiderme épais et tenace, nniformément noir. Quand on parvient à enlever cet épiderme, le test est d'un brun-roussâtre. Liouveriure est assez grande, ovalaire et subdilatée à la base; elle est blanche en dedans. La colunelle est assez épaisse et arrondie.

Cette cocquille se trouve abondamment dans les eaux douces de l'Inde, et dans les iles de l'Océan indien. Elle est longue de 45 millim.

\section{Mílanie granifère. Melania granifera.}

M. testâ ovato-acutâ, striis transversis crassiusculis granosis cinctâ, luteo-yirescente; ultimo anfractu ventricuso; spira anfractibus planis; aperturá albâ.

EncrcLop. pl. 458. fig. 4.a. b.

Lamz. Anïn. suns yert. tom. 6. pag. 167. $n^{\circ} .13$.

La figare de l'Eacyclopédie ne donne pas une idée trés-exacte de celle espèce; elle la représente-beaucoup plus large qu'elle ne l'est habituellemeat. Cette coquilie est turriculée, trèspointue au sommet; on comple neuf tours à la spire; ces tours sont a platis ou légèrement convexes; leur suture est simple et suivie d'une petite rampe fort étroite formée par une rangée de granulations un peu plus grosses que les autres: de chacune de ces granulations descendeat de pelites côles lougitudinales qui s'élendent d'une suture à l'autre, et qui sont profondément coupées en travers par cinq sillons qui découpent ainsi la surlace en granulations presqu'égales. A la base du dernier tour, aux granulalions succèdent des côtes transverses, simples. L'ouverture est ovale, alongée, pointue supérieu. rement et un peu dilatée à la base; elle est blanche ea dedans; à l'extérieur, la coquille est couverte d'un épiderme d'un lorun-jaunatre.

Cetle espéce, longue de 25 à 50 millio., se trouve, d'après Lamarck, dabs les eaux douces de l'Inde et de Timor.

6. Mílanie flammulée. Melania fusciolata.

MI. testâ oblongo-subulatá, basi ventricosá, tenui, diciphaná, tenurssimè decussatá, albzdä, flanmmlis longitudinalibus luteolis ornatâ; anfractibus convexis, subdenis; suturis impressocavis; spirâ peracutá.

Melanoidesfasciolata. Oniv. Voy. pl. 31 fg. 7. LAM Caillaud, Voy. à Méroé, tome. 2. pl. 6o.fig. 8.

Celte espèce, qui vit abondamment daos le Nil, est alongée, turriculée, très-pointue, à spire très-longue, formée de douze à treize tours légèrement convexes, à suture siaple et foement striés 
striés su: toute leur surface; les stries snnt distintes, convexes, simples; celles de la base du dernicr tour sont plus serrées el plus grosses; des stries longitudinales très-fines el trés-serrées se voient dans les in'e valles des stries transverses. l'ouverture est ovale, oblongue, plus évisće, en g'suéral, que dans la plupars des espèces, se rapprochaul par ce caractere de yuelcyues l'aludines. l.a surface extérieure est revếtue d’uu épiderne d'un brua.faure, très-mince, qui laissc a percevoir des flammules longiludioales d'un jaune-orangé, qui descendent en oudulaut d'uue sulure i l'autic. Sur le dernier tour, el surtout vers la base, les Ilanmules sont remplacées par des lignes ile poiuts de la mérne couleur qu'elles. Cette cuquille a le test très-ınince el trinsparent. Nous présumons que c'est elle que Martiui a figurée ( $p l$. 136, fig. 126t, 1262) dans snu graud ouvrage sur les coquilles. Longueur 35 milliun.

7. Mélanie éplineuse. Meluniu setosa. Siram.

M. Lestâ ovatâ, ventricosâ, apice tıuncatâ; anfractibus supernè planulutis, spintis, spinis acutis coronutis, trunsversin striatis; aperturî ovatâ; coluniellấ latâ, depressâ.

Sivar. Fascic. de Zool. no. 4.

GraY, Zool. juum. no. 2. pl. 8. fig. 6.7.8

Mantsi, Conch.pl. 134.fig. 1220. 1221 ?

Celte belle espèce de Mélanie a beancoup de ressemblance, quaat à la forune, avec la Melania amarula. Elle est ovale, ventrue, toule noire; sa spire est courte, irunquée au sommel, composće, lorsqu'elle est entière, de huit à neuf cours courts, à sutare simple, raualiculés en dessus, et couronnés d'un rang de longues épincs aur l'angle externe. Ces épines, qui ont une struclure particulière que M. Gray a fort bien décrite dans fa note qu'il a publiée dans le Zoological Journal, sont rapprochées les unes des autres, et leur base se prolonge souvent en autant de côles lougitudinales qui, sur le dernier tour, parvienneut jusqu'a la base. En debors, celle coquille est cuuverte de siries transverses; l'une deelles, placée au-dessous de la suture, est plus large que les suivantes; celles qui sont a la base du dernier luar sont ordinairement plus yrosses que toutes les autres. L'ouverture esi uvale, oblongue, blauche en dedans; la columelle est fortlarge, aplatie à la base, assez épaisse et légètement saillante à sun extrémité iuférieure. Celle coquille, rare jusqu'ü présent dans les collections, nosus a élé comununiquée pa: notre ami, M. Lesson, qui en a recueilli quelques exemplaires à l'ile Waigion. Elle est longue de 32 millim.

8. MÉranir semi-croisée. Melania semi-decussata. Laxx.

M. testâ turritâ, longitudinaliter semi-plicatâ, Hist. Nat. des Vers. Tome II. transversè rugosá; anfractuum parte inferione decussatâ, plicuto-crispâ; apertur i ovato-oblongá.

Melania cormgata. Lamx. Ann. da MIrs. tom. 4. pag. 431. $n^{\circ}$.6, et tom. 8. pl. 60. fig. 3. a. $b$.

Ibid. DEF. Dictionn. des Scienc. nat. tom. 29. pag. 468.

Melania semi-decussata. LAst. Anin. sans vert. tom. 7. pag. 545. $n^{\mathrm{n}} \cdot 6$.

Nов. Descript. des Coq. foss. des env. de Paris, pag. 106. pl. 12. fig. 11. $1 \%$

Cette espèce est fort remarquahle, alongée, turiculée; elle a, en général, la forme ct le port de la Melania laciea. L'ouverture a aussi beaucoup d'analngie avec celle de celle dernière; unais elle est plus étroite, plus alongée, le sinus de la base plus profond; elle a huil à neut tours de spire. Toute la copuille est couverte de stries Irausversales, assez grossières, quoique rígulières, et toule la parlie inférieure de cbaque tour est en outre plissée longitudinalement, de manic̀re à couper les strics iransverses à angle droit, ce qui élablit un réseau sur la partie iufúrieure de chaque tour, lorsque la partie supérieure n’est occupée que par les stries Iransverses. Les stries lougiludinales se prolongent quelquefois d'uu suture ì l'autre; coute la coquille alors est treillissée, excepté à sa bise, oì les stries transuerses existent seules. Celle espèce se trnuve Cossile à la ménagerie dans le parc de Versailles. Longueur 3.) aillim.

\section{Mélanie laclée. Melania lactea. Tasix.}

M. testâ turritâ, elongutâ, aliquantisper. subventricosí, solid $\hat{i}$; anfractilus convexiusculis, superioribus lavigatis, inferioribus longitudinaliter plicutis.

Lsmx. Anim. s. vert, tom. 7. pag. 544. $n^{\circ} .2$.

Ibicl. Ann. du Mas. tom. 4. pag. 430. $n^{\circ} .2$, et tom. 8. pl. 6o. fig. 5. a. b.

DEF. Dict. des Scienc. nat. tom. 29. loc. cit.

Bulinus lacteus. Bnuc. Encycl. pag. 324. $n^{\circ} .45$.

Var. a. ) Testi minore, anfractibus transucrsè striatis.

Var. b.) Testâ undiquẻ lavigatâ.

Var. c.) Testâ magis ventricosâ, ultimis anfructibus plicis mujaribus.

Melania Stygii. Al. Brovoniagt, Mémi. surles terrains calc. trap. du Vicentin, pag. 91. pl. 2.s fig. 10.

Noв. Descript. des Cog. foss. des ens. de Paris, pag. 106. pl. 33. f.g. 1. 2. 3. 4. 5.

An Melania influta?" Bonson, Rém. de l'Acad. de Turitr; tom. 26. pag. 386. pl.2. fig. 14. 
Forris, della tialle di Rocca. tav. 1. fig. 7 .

Var. d.) Teslús minore, ulinuis anfractibus clathratis.

Cette coquille cst très-alıondammont répandue dans le bassin de Paris, et, ce qui est remarquaHle, c'est qu'elle ne s'y rencontre pas dans les terrains d'eau douce, mais constamment el en très. grand nombre dans les terrains marins: ce quia fait penser qu'elle avoit vécu dans la mer; et c'est aussi l'opinion que nous en arons. Celle espèce, que l'on ne peut rapporter qu'an genie Milinie, puisqu'ellc en a cous les caractères, est turriculíe, alongée, présentant neuf à dix tours de spire peu convexes, à snture simple el superlicielle; les tours superitur's sont lisses, les quatre ou cing inférieurs étant plissés longitudinalement. L'ouverture est ovale-oblongue, présentant à sa base un sinus assez approfondi; la lèvre droite est naince, Irancluable; la gauche est renversée et hordant la columelle. A l'angle inférieur, oì se rénissent les deux bords, on renarque, dans un assez graud nombre dindividus, surtout ceux qui viennent de Lisy et d'Ermenonville, un bourrelet columellaire. La varićté $c$, dont N. Broggniart a fait une espèce particulière, se trouve aussi aux envisous de Paris, surtout à la Chapelle, près Senlis. Elle cst plus ventrue, et l'extrémité de la spire préseate des plis plus gros. C'est a vec douse que nous rapportons l'espèce de Borson, la figure f́tant trop mauraise. Notre variété $b$ est très-reconnoissable en ce qu'elle est toute lisse; les derniers tours ne présentcat aucun pli ni aucune sırie. La variété $a$ est constamment plus petite et striée transversalement sur toute sa surlace; elle vient de Grignon et de Maule. La variété d est aussí plus petile : on la trouve ì Maulelle, près Houdan. J'extrémité de sa spire est chargée de petits plis longitudinaux coupés par des stries tratsverses qui disparoissent insensiblement vers le cinquiène cour. Nous possédons un individu de celle espèce dont l'angle inférieur de l'onverture est délaché accidentellement, ce qui lui donne beaucoup de ressemblance avec la Mplaniu costellata. Longueur 40 millin.; de la variété a, 20 milliu.; de la variété $d, 22$ millim.

10. MÉrante très-lisse. Melania lavissima. Sow.

M. testâ oblonga, conicá, solidj; anfruclibus convexiusculis, lavissimis, olivaceis, longitudinaliter internupte fusco fascialis; aperturi ovato. acutâ, supernè incrassatâ, basipatulâ.

Sow. Zoolog. Journ, no. 1. pag. 6o. $n^{\circ} .5$. pl.5. fig. 5.

Celle espèce a quelques rapports avec celle si commune aux environs de Paris, connue sous le nom de Melania lactea. Elte est épaisse et solide, inrriculée, conique, a spire poiolue, compostc de sept tours à peine convexes, très-lisses et sé- parés par une suture superficielle et simple. Sous un épiderme d'un veri-brunàtre, les tours sont

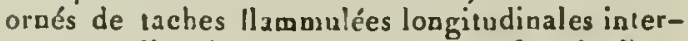
rompues d'un brun-rongeátre assez funcé; l'ouverture est ovale, oblongue, pointue au sommel, évasée, et versante à la base. Le bord drnit est légèrement épaissi en dedans; mais le bord guuche, ordinairemeat mince et peu apparent dins la plupart des espéces, est daus celle-ci épaissi et subcalleux à sa parlie supérieure. La columelle est d'un blanc-jaunâtre, quelquefois d'un rouge assez vif.

Celle coquille vient, à ce que dit M. Sowerby, de la petile rivière de la Guayra, Nouvelle-Espayne, oì elle est très-abondaute. Sa longueur est de 35 aillia.

I1. MÉla NiE brunatre. Melunia fuscata. Non.

M. testâ elongatâ, turritâ, nigricunte, lavigatâ, apice aculd; anfractibus planulatss, submarginatis, ultimo hasi mullistriato; aperturầ brevi, ovato-acutâ, infernè valdè dilatatâ.

Helix fuscatus. Burs. Mfus. cas. vind. pl. 16. fig. 17.

Crems. Conch. pl. 135. fig. 1129?

Nons meltons un point de doute à la figure que aous indiquons dans l'ouvrage de Chemnitz, pares que la coquille auroit la lèvre gauclıe de la même couleur que la surface extérieure, landis que dans celle qui va nous occuper, celle parlie est constamment blanche. Ne seroit-ce pas une fante de la part des culoristes? ('ette espèce est alongre, turriculée, à spire très-longue, étroite et pointue: on y compte douze a qualorze tonrs lorsquelle est entière; mais elle est ordinairement trunquée par les érosions qui arrirent si fréquemment aux enquilles d'eau douce. Les lours de spire sont aplatis, larges, lisses, si ce n'est le deruier, qui, à la base, présente tonjours des stries transverses, nombreuses. Ia suture est assez profonde et suburarginée dans la plupart des individus lionverture est trés-renarquable dans celle espòce : elle est courte, pointue au sommet, el tellement dilatée à la basse, que quand on la regarde de re côté, on aperf̧oil l'enroulement de la columelle jusqu'à l'avant-dernier lour. I,e bord droit, légèrement sinueux, est oblique à l'axe longitudival; il est miace, tranchant, d'un blanc-bleuàtre a lintérieur; le bord columellaire cst aplati, formé dine zone blanche fortement contournée et arrondie. A l'extérieur celte coquille est d'un brungris très-foncé, et mếrse noir. Elle est longue de 65 millim. On ve sait quelle est sa patrie. Nos.

12. MÉLANie baguette. Alelania kympanorum.

M. tcstá elongato-conicá, apice acutá; an- 
fractibus iranswersim laviter striatis, supernd muricato spinasis, fusco vittatis, subvividibus; spimis lutenuliter depressis, apice obtusis; "perturi ovalo-angust $\hat{i}$, utrinqué attcnuat $\dot{i}$; labro simplici, sinuoso.

Strombus tympanorum. Chexs. torn. 9. tab. 136. frg. 1265.1266.

An Buccinum! fuscatum. List. Conch. $p l .121$. fig. 16. 17 ?

Celle espece de Mllanie, que l'on trunve dans les rivières de la Sẻnégrambie, est une des plus remarquables du genre. Sins la torme de sun nuverture, no pourroit la prendre pour un Cérice. Elle est alongée, Iurriculíe, pointue ati sommet; sa spire est lougue, conique, composcie, Iorsqu'elle est entière, de onze on douze ton's, dont les premiers sont fortenient sillonnés en tritvers et plissés dans leur longueur; les tours suivaus sont presque lisses, mais a leur partic supérieure se trouve une rantre de grands ubercules spinifurmes, aplatis latéralenent et obłus au somnet. On comple cinq ou six de ces tubercules sur cliacun des tours de spire. liouverture est médiocre, ovale, oblique, alténuće à ses deux extrémilús; le bord droil est mince, tranchint, sinueux supérienrement, et se juirgnant à la coluwelle en furmant une sinuositě un peu anguleuve. Cette columelle, ainsi que l'intérieur de l'unverture, cst blanche; elle est un peu tordue a la base. Ia coulcur de cetle cuquille est assez variable; revẻtue d'un épiderane d'un brun-verdûtre, elle est quel quefuis de celle senle cou'eur; mais, le plus souvent, elle est ornée, sur un fund blauc, de fascies iransverses plus ou moins nombreuses, d'un beau rouge foncé. Celle belle espéce, rar'e encore dans les collections, semble farre un pas. sage vurs les Pyrènes ou les Cétites. Bille a 50 aillim. de longueur.

15. Mélarie subulée. Melania subulata. Nopa.

$M$. testi elongato-turriti, angusti, acuminat $x$, subulati, fuscá; anfractibus longotudinuliter placatss, transwersint striatis, convexiusculis; suturis nuarginutis; apertur brevi, basi inaxime dilatati; columelli valdè contortá.

La Mélanie subulée est alongée, fort étroite, très-poinıtue, très-alténuée au sommet; sa spire est composée de onze ou douze tours légérement convexes, plissés longitudinalenent, et striés assez profondément en travers; les sutures, assez aporofondics, sont acconjpagnées d'un pelit bourrelet granulenx : sur le dernier cour les plis $s^{\prime} a r-$ rétent au niveau de l'angle supérieur de l'ouverture, tandis que le; stries transferses se coniinuent jusqu'à la hase. Lourerture est semblable a celle de la Melania fuscata; elle est cependant eacore plus dilatće a la base. La columelle, trés. iurtement tordue, laisse aperceroir, eu la re- gardant parla lase, un ombilic intérieur profond, dans lçuel on p:eut apercevoir l'enroulement dé plusieurs tours. Celle columelle est blanclıe, ainsi que l'intérieur de l'uuverture; en debors la coquille est d'un brun pâle, plus foncé an soramet. Sa putrie est iguorée. Elle est longue de 56 millim.

14. Mflane de Say. Melania Sayi. Nob.

M. testâ conicá, turrita, apice acutâ, hreviculi, virescente, lavigatia; anfractibus medin e.x. cuvatis, uitiono aliquantisper hasi carinâ granulosá instructo; aperturâ obliquâ, utrinquè altcnuatí, valdè sinuosâ, busi subcaniculati, albí.

Cette Mćlanic prísente un passage vers les Cirites cl ccrtaines Turrilelles fussiles des envirous de Paris, par la forme reajaryuable de son ourerture et le prolongenent considérable de l'cxlrémilé inféricule dü bord droit, occasionné par ses deux grandes sinuosités. Nous dédions cetle espèce à M. Say, naluraliste distingué de Plitadelphie, auquel les sciences sont redevables de la connoissance d'un grand nombre d'objets curicux, propres à l'Amérique septentrionale. Cette coquille est alongée, turriculée rúgulièrement, conique, plus courte que la pluparo des espèces, proportiumuellement à sa largeur. Elle est lisse, polie, diun vert plus ou moins foncé, pa:sant au brun oy au jauátre; ses tours de spire, au nombre de dix ou douze, int une suture simple et peu profonde. Les premiers sout aplatis, trèsétroils, mais les derniers sont fortement excavés dans le milieu. Dans quelques individus la base du deruier tour est circonscrite par one catène tuhercukuse. L'ouverture est wédiocre, trèsoblique, alténuée à ses extrémités; la base est subcanaliculée, et ressemble beaucoup à celle de certains Cérites dépendant du genre Potamide de Ml. Brongniart. Le bord droit test mince et tranchan!; îl est profondément siuueux à sa partie supérieure; il domine l'ouverture par le frolonyemenı de son extrémité.

Cecte coquille se trouve abondamment dans l'Obio et ses affluens. Elle est longue de 35 millim. et large de 16 i la base.

15. Mélanie scalariforme. Melania scalariformis. Nos.

MI. testá elongato-turritá, angustâ, longitudinaliter costatí; costis regularibus, distantubus, ungustis, continuatis; suturis profundis, crenulatw; anfractibus planulatis, ultimo basi striato.

La Mélanie scalariforne est une coquille proveuant du terrain oolitique des environs de Caen; elle appartient bien certainement an genre anquel. nous la rapportons, et elle n'est pas la seule qui provienne du mèase lieu. Elle a l'aspect d'un Scalaire, a cause de la continuité des cỏtes longitudinales qui se correspondent d'un lour à l'auire, absolument corame cela se présente dass les 
coquilles du genre que nous citons. Elle est alongée, turriculée, étroile, poiutue au sonımel, formée de onze ou dauze tour's aplatis, ì sulure enfoncée, subcanaliculée, el crénclée dans toute son élendue par la saillie de l'exirémité des côles. Celles-ci sont lon ritudinales, droiles, se correspondant les unes aux antres de manière à former des varices continues du sommet i la base de la coquille; ces côles, au nombre de uenf sur chaque tour, sont étroiles, distantes, convexes et peu élevées; la hase du deruier cour, sur laquelle les côtes disparoissent, est occupte par des stries transverses, serries el régulic̀res. L'ouverture est petite, ovalaire, rétrécie supéricurement, et diJatée à la base. Nous avons une coquille qui n'est peut-être qu'une variété de celle-ci ; ses còtes, moins régulières, sont plus nambieuses, el elles sonl coupées en travers par plusien's stries transverses, profondes. Les plus grands individus que nons ayons pu nous procurer oat 25 millim. de loogueur. FER.

16. Mécantr grain de blé. Melania triticea.

M. testâ ovato-conicá, turrití; anfractibus convexiusculis, lcevigatis; aperturấ ovato-acutâ, hasi dilatata.

Non. Descript. des Coq. foss. des env. de Paris, pag. 107. pl. 14. fig. 7. 8.

Quoique nous n'ayons point tronvé l'indication de cetle espèce dans les ouvrages de M. de Ferussac, nous trouvons pourtanl la nole suivante donnée par M. Delirance dans te Dictionnaire des Sciences naturelles (tom. 29, pag. 471, is

"M. Daudebard de Ferussac a trouvé, dans le * bassin d'Épernay, avec la Mclania inquinata, \# une antre espèce de Mélanie voisioe de la $\mathrm{Me}$ "Lania hordacea, à laquelle il a donné le noin " de Melania triticea ". Nous avons verifié, dans la collection de M. Defrance, que l'espece qui nous occupe est bien celle qui a été ainsi nommée par M. de Ferussac. Elle est petite, conique, turriculée, assez large à la base; sa spire préseule six ton's pou convexes el entièrement lisses. L'ouverture est ovale, grande, dilatée à la base; la levre droite est simple et tranchante; le bord gauche se renverse sur la colunelle : il est appa. rent, surtout à la base de la coynille. Longueur 8 millim. LAMx.

17. Mésanıx glaia d'orge. Melania hordacea.

$M$. testá turritâ, crassâ, tenuè striatá; striiis transversis; anfractibus vix convexis; aperturâ minimâ, basị subsinuatâ.

Lamx. Anim. s. vert. tom. 7 . pag. 544. $n^{\circ} .4$.

Ibid. Ann. du Mus, pag. 431. no. 4 .

DEr. Dict. des Scienc. nat. loc. cit.
Bulimus chuatus Laxx. Ann. du Míns. pag. 293. $n^{\circ} .8$.

Var. a.) Testá sublarvigatâ.

Var. b.) Testá basi lutiore, striis tenuissinis.

Vir. c.) Testá striis crassioribus, anfractibus supernd subangulatis.

Var. d.) T'estâ anfractibus convexiusculis, laxvibus.

Nов. Descript. des Coq. foss. des env. de Paris, pag. 108.pl. 13. fig. 14. 15. «2. 23.

La Mlćlanie grain d'orge se trouve à peu près dans les métres rirconstances que la Melania lactea. On a génciralement l'opiuion que celte espièce étoit marine, ou vivoit däns les eatix suunâtres, car c'est principalement dans les couche's de múlange qu'elle se trouve le plus abondamment. Celle petite coquille est presqu'aussi variable dans la forme que dans les stries doul elle est le plus souvent couverte; clle est alangée, conique, ́praisse; ses sutures sunt peu profondes; les stlies sout assez fines. On en remarque assez constamment ane plus hrosse vers la farlie supériére des laurs, ce qui leur donne une furme lígèrement anguleuse; les siries de la base sont mains profondes et moins sensibles. L'ouverture est petite, proportionnellemeut à la grandeur de la coquille; elle est peu dilatée à fa base, on elle oftice un sinus peu profond; la lèvre droile est simple et tranchante; la gaucbe est renversíe su. la columelle qu'elle borde. Les stries de la variété $a$ sont à peine apparentes, quoiqu'on retrouve sur ses tour's l'augle furmé par la plus grosse d'entr'elles. La variété $b$ est très-r'econnoissable par sa base plass large, son ouverure plus grande eı des stries plus lines: elle se trauve à Maulette et à Tancrou. La variété $c$ présente des stries grosses et profondes; elle paroît plus anguleuse que les autres : elle se rencontre plus fiéquemment ì Mauleute. Enfin, la variété $d$ est plus alongée, plus étroite; ses tour's de spire sont plus convexts, plus détacbés 'et entièrement lisses. On la trouve à Pierre-Laye, à Abbecourt et à Valmoudois.

Lorsque, par la complaisance de $M$. Defrance, nous púmes exaniner les Bulimes que Lamarck a nomunés sur les individus de la collection de ce savant, nous reconnúnes plusieurs erreurs, et entr'autres celle qui a rapport au Bulimus clavatus, qui u'est rien autre chose qu'un jeune individu de la Melania hordacea. Longnear 9 millim.

18. Mílante caniculaire. Melania canicularis. LAMx.

MT. testá.turritá, subulatâ, lavviter transversed striatâ; anfractibus convexis; aperturâ minimá, ovatâ, basi vix sinuatá.

LAMr. Ann, du Ifus. tonנ. 4. pag. 43ı. n०. 5. 
Jbid. Anim. s. verl. tom, 7. pag. 545. no. 5.

DET. Dict. des Scienc. nat. loc. cit.

Var. a.) 'Testâ strïs majuribus basi vix perjpicuis.

Non. Descript. des Con. foss. des env. do Paris, pag. 10g. pl. 13. fig. 16. 17. 26.27 .

On ne trouve que rarement celle petite espèce, qu'il faut notamment reclurrer dans les sables de Grignon. Ellc est asser mince, fragile, étroite, alongée, subulée; scs lours de spire, au unmbre de dix, sont bien détacliés, convexes, striés en traver's; les stries sont lines et serrées: elles sc voient aussi hien à la base que sur tout le reste de la coquille. L'ouverture est petile, ovale, un peu oblique à l'axe, et peu sioueuse à la base; le bord droit est tress-mince et Irauchant: la variété $a$ est un peu moins alongée, et ses stries sэat plús profondes et plus larges; elles disparoissent presqu'entièrement à la base. Longueur .9 millim.

19. Mérante lisse. Melania Levigata.

M. testâ turritâ, conoideâ, làvigatd; anfiactibus convexis; apertuni ovatâ.

Nов. Descript. des Coq. foss. des ent. de Paris, pag. 110. pl. 13. fig.'18.19.

Il est assez difficile d'assigner les caractères de celle espece; elle a heaucoup de rapports avec la variélé lisse de la Mélanie grain d'orge : cependant on la distiague ea faisant attention que la Mélanie grain d’orge est plus étroite, plus élancée; que ses tours de spire sont à peive séparés, quils sont peu convexes. Ici la base est plus large, l'ouverture y est moins saillante, el ne présente que très-lniblement le sinus qui se voit dans l'hordaces. Le bord gauche n'est point refléchi à la base, et à peiue sensible sur la coluunelle; les tonrs de spire sont lisses, convexes, séplarés par une suture assez prolonde. Longueur 7 millim.

20. MÉluNze brillante. Melania nitida. LaMr.

$\boldsymbol{M}$. testâ subulatâ, acutissimá, lavissimâ, nitidi; anfractibus planulatis; suturis minimis; uperturâ ovato-oblongâ.

Lasв. Ann. du Mus. tom. 4. pag. 432. no. 8, et tom. 8. pl.6o. fig. 6. a. b.

Ibid. Anim. sans vert. tom. 7. pag. 546. $n^{\circ} .8$.

Helix subula. Brocc. Conch. subap. tons. 2. pag. 305. tab. 5. fig. 5. a. b.

Var. a.) Testâ basi latiore; suturis profundjoribus, perspicuis.

Nов. Descript. descog. foss. des env. de Paris, pag. 110. pl. 13. fig. 10.11.12. 13.
Voici encore un exemple d'analogie parfaile entre les individus qui se trouvent en lialie, it Bordeaux, à Haulcville et anx envirnes de Paris. Rien n'est plus facile que de reconnoître cette espèce, composíe de treize ou qualor'ze tour's despire : elle est très-aiguë au sommet; elle est sululée, alonure, très-lisse, polie, brillante; ses tours de spire ne sunt indiqués que par une strie trćspeu apparente, à peine si on les aperçoit a l'uil nu. Louverture cst petile, ovale, alongrée, saillantc, et sinueuse à la base : la lèvre droite est. simple, trauchante; la gauche est l'́gèrement reuversée sur la columelle. La varićlć a cst tir peu plus grande; elle est plas large a la base; ses tours snut lígèreacont convexes, et ses smtures plus appareates.

Brocchi, en rapportaut à son Helix nitidu la Melania nitida de Iamarck, a commis une erreur dépendant des figures des Annales qui sont grnssies sans que ce grossissement soit indiqué. L'Helix nitida du uaturaliste italien est une espèce furt différente, conslamment plus graude, dout on tronve l'analogue vivant dans la Médilerrauée, tandis que son Holix subula est bien l'aualugue de l'espèce que nous veuons de thécrire.

21. MÉLAxIE tortue. Melania distorta. DEF.

M. testà subulatâ, lccvigatá, nitida, in axe ancuatá; aperturâ ovato-oblongá; labro dextron infernè linea proeninenti ternunato. 468.

Der. Dict. des Scienc. nat. tom. 29. prtg.

Nов. Descript. des con. foss. des env. de Paris, pag. 131. pl. 13. fig. 24.25.

On avoit confondu celle espèce, fort remarquable, avec la Menalia nitida, avec laquelle elle n'a de rapport que par le brillant et le poli de sa surfacc extérieure. M. Defrance, le premier, reconnut que celte coquille devoit former une espèce particulière, el mous avons adnpté son opiuion à cause de la constauce et de la solidité de ses caractères distinctifs; elle est en effet conslamment arquée sur elle-même et dans le sens de l'are, et cette courbure est quelquefois biv'n plus forte que dans l'individu que nous avons fait finurer. Sa spire se compose de neuf tours aplatis, non convexes, it sulure à peinc visible, lisse et brillante; l'ouverture est fort singulière, ovale, oblongue, proéminente et fort sinucase à la base; la lèvre droite est mince et tranchante; dans l'endroit où clle s'appuie snr l'avant-dernier tour . c'est-à-dire à l'angle ioférieur, elle se continue par un petit bourrelet qui se voit le long de Ia spire, qui se reploie même au sommet poar se conlinuer du côlé opposé, et au-dessous duquel se remarque quelquefois un petit canal. Jongucur 6 milliw. 
22. Mícarie plicatelle. Melania tenuiplica.

II. testâ minimâ, tenui, fragilissimà, subulatâ, longitudinaliter tenuissime plicata; anfractibus convexis; aperturî̀ obliquâ, ovato-mlundatâ.

Noв. Descript. des Coq. foss. des env. de Paris, pag. 11 .

C'est en clierchant à la loupe, dans les sables de Pierrelaye, que l'on peut espérer de rencontrer celle petite espèce. Elle est nince, fragile, subulce, formíe de sept tours de spire arroudis, bien distincts entr'eux par une suture assez enfoncée; ils sont finement striés ou plissés lungitudinalement, carachẹ̣e qui rend l'espèce trèsfacile à reconnoìtre. L'ouverture est oblique, ovale, aırondie, peu sinueuse ì la base; la lèvre gauche est légèrement réléchie, le bord droit est sruple. Longuear 3 millim.

23. MÉzante fragile. Melania fragilis. Lamr.

M. testâ ovato-turritâ, fragilissimî, tenuissione striata; striis regularibus, elegantissimis; anfracthilus rotundatis, valdè suturû profundâ separutis; aperturâ magnâ; margine basi reflexo.

LAмк. Ann. du Mus. tori. 4. pag. 433. $n^{\circ}$. 11. Ibid. Anim. s. vert. tom. 7. pag. 546. $\pi^{\circ} .11$. DEr. Dict. des Scienc. nat. loc. cit.

Noв. Descript. des Coq. foss. des env. de Paris, pag. 112 . pl. 13. fg. 6. 7 .

Cetre jolie petite coquille est fort rare, et sa grande fragilité est une des causes qui la rendent Jilus diffcile à reaconirer. M. Duchitel nous en a donné un individu venant de Grignon, et M. Defrance nous en a contié un autre plus grand pour le faire dessiner. Ils sont ovales, oblangs, tuiriculés, très-minces, très-fragiles, formés de six tours arrondis, séparés prar une suine profonde, presqu'ea canal, et couverte de stries fines, serrées et un peu contuuraúes en S. L'ouverture est grande, régulièrement ova'e; son bord droit est très-mince, tranchant, rélléchi à la base; le bord gauche est peu sensible, il se reploie dans la columelle. Longueur 5 millim.

Q4. Mécanie Ireillissée. Mlelunia decussata.

M. testà conoiden-turritâ, striis transversis et costulis longitudinalibus decussatd; aperturi nagnâ, basi effusâ et sinuata.

Bulimus decussatus. Lam r. Annales du Mus. tom. 4. pag. 294.

Ibid. Anim. s. vert. tom. 7. pag. 537. $\pi^{\circ} .13$.

Bulimus decussatus. Def. Diction. des Scienc. nat. tomi. 5. Supp. pag. 124. $\pi^{\circ} .12$.

Nов. Descript. des Coq. foss. des env. de.Paris, pag. 112 . pl. 14. fig. 9. 10.

Lamarck, en caractérisant cette petite coquille dass les Annales du Muséum, et en la plaçant parmi les Bulimes, a manifesté des doutes sor son genre, et présumoit alors qu'elle devoit faire partie des Mlélanies : cette rectification devenoit nécessaire par les nombreux retrancheonens que nous avons laits dans le genre Bulime. II n'est pas douteux, au reste, d'après la forme ile l'ouverture de celte coquille et l'érasement de sa base, qu'elle ne doive se placer parmi les Milanies. La Mélanie treillissée est petite, conique, turriculée, à base assez large; sa spire a neul touri subconvexes, treillissés par des stries transverses, assez fines, qui coupent à angle droit de peliles côtes pcu saillantes et régulières. L'uuverture est grande, ses bords sont érasés et fortement réléchis à la base dans les plus grands individus, qui ont 6 millim. de longueur. Il est à remarquer que l'analngue fossile de cetle copece se trouve a Valognes, département de la Mlanclie.

25. Méranue à petiles côtes. Melania costellata. LAMK.

MI. testâ turritâ, subulatú, transversim striatú; anfractibus convexiusculis, costis curvis crebrisque ornatis; aperturâ ovati; angulo inferiore soluto inciusque cunaliculato.

Liмk. Ann. dis Mlus. tom. 4. pag. 430. $\pi^{\circ}$. I, et tom. 8. pl. 6o. fig. 2. a.b.

Ilid. Anim. s. vert. loc. cit. pag. 543. $n^{\circ}$. 1 .

Def. Dict. des Scienc, nat. loc, cit.

Var. a. ) Testû costis majoribus; striis transversis, subnullis.

Var. b.) Testá subvaricosá; costis obliquis, minoribus; -striis transversis, majonbus, creberrimis.

Branc. Mtérn. sur le Vicentin, עar. Roncana, pl. 2. fg. 18.

Var. c.) Testì apice costatâ; strriis transversis, grossiusculis, eminentioribus.

Mlelania variabilis. DEr. Diction. des Scienc. natur. loc. cit.

Noв. Descript. des Coq. foss. des cnv. de Paris, pag. 113. pl. 12. fig. 5. 6. 9. 10.

Lorsque, dans cette espèce, les côtes longitudinales préduminent, les stries Iransversales s'atfoiblisseut et disparoissent presqu'entièremeat; lorsqu'au contraire les cótes dimiuuent, les stries transverses se développent et finissent par prendre un arcroissement consilerable : ansi, si l'ou ne vayoit que les deux extrèmes de la série, on pourroit faibe deux espèces; cest ce qui est arrivé à M. Defrance; l'erreur n'est plus possible dès yue l'on voit la sélie des variétés que nous venon; d'établir. La Múlanie a petıtes côtes est grande, turriculec, poiutue au sommet; ses tours, au numbre de quatorze ou quinze, sont peu convexes, ils sont crargés de côtes lougitudinales, traversées par des stries tines et assez nombreuses. L'ouverture seule caractćrise celte ospèce; ello 
est fort remarquable par l’aggle inférieur délaché de l'avant-dernier tour, et loujours canaliculs en dedans; à la base elle est sinuense assez profondément. On trouve dans les faluns de Valognes l'auloguse de la variélé $c$ seulement. Longueur 58 millim.

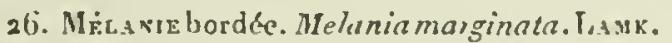

MI. test's turriti, conic j; unfroctibus planulutis, suturib subcanalacuti separalis, quinque stricttis; striis regrlusitus, remotiusculis; aperturi uvat $\hat{x}$, obliquâ, valdè marginat $\hat{x}$.

Bulimes turricula. Brug. Encjel. pagr. 2.34 . $70^{\circ} \cdot 44$.

Melunia marginata. Laxx. Ann. Lis Mrus. tom. 2.p. 430. n०.3, et tom. 8. pl. 60. fg. 4.a.b.

Ibid. Anim. s. vert. loc. cit. $n^{\circ} .3$.

1)EF. Dict. des scienc, nut. loc. cit.

Var. a.) Testi minore, anfructibus septem stricatis, suturâ non canaliculati.

Noв. Descript. des Coq. foss. des env. de Paris, pag. 114. pl. 14. fig 1.2. 3. 4 .

Celte coquille, fort commune dans les colleclions, se reconnoit facileanent par sa furme turriculke, conique; par ses lonrs de spire aplalis, présentant cinq stries régulières et distantes sur chacun d'eux, et séparés par une suture assez proloude, subcaualiculée, formant atrour de la coquille une rampe réńrulière; les stries, aussi bien que le bord de la suture, somt trancliantes; l'onverture est ovale, oblique à l'axe, à lèvres épaisses; angle inférieur subcanaliculé; base arrondie et subsinueuse; la lève droite est épaisse, arrondie, largemelt bordée par un bourrelet márginal qui a jusqu à 5 unillinètres de largeur. Le bourrelet est régulièremeut strít dans sa lungrueur; il se rétrécil a la base, el se continue prour former le bord gauche, qui esı lui-mêtne assez épais. La variété est loujours plus pelite; peut-ìtre mème pourrviton en faire une espèce pour la coustance de ses caractères. Elle a six ou sept stries sur chaque tour, et ceux-ci ne sout point séparés par une suture en caual on rampe. Le bourrelet de la lèvte droite est plus étroit, tandis que le bord gauche est constamment plus large et plus étalé sur la columelle. Longueur 36 millim.; longueur des plos grands iadividus de le variété 20 millim.

27. MÉrame petits plis. Melunia plicata.

M. testỉ turrito-conicá, longitudinaliter tenuè plicatâ; anfractibus subconveris; suturis simplicibus; apertunâ os'ulis, obliquâ, marginatá.

Nов. Descript. des Coq. foss. des env. de Paris, pag. 115. pl. 14. fig. 5. 6.

Quoique très-voisine de l'espèce précédente par la forme de l'ourerture, elle s'en distingue facilement; elle est constamment plus petite que la variété; clle n'est point stríé en trarers, mais ses tours, qui sont légìrement convexes, sunt converts de petils plis longitudinaux assez serréz et bien resuliers; les sutures sont simples, non canaliculće; l'ouverture est oblique à l'axe, fortement simeuse à sa hase, et canaliculée à son angle inlirieur. La lère droite est épaisse, Lordée, mais le bourrelet est plus ćrroit que dans la Melunia marginala. I,e bord gausihe est épais, il lorme une sorte de callusité sur la partie inférieure de la colurnelle. Longueur 12 millin. Certe espèce est très-rare el très-liugile. Elle vien d'Abbecourt, près Beauvais.

\section{MÉLANIENS.}

Certe fanille, créce par Tounarck, d'abord sous le nom d'Auriculucees, dans la Philosophie zooLogique, parce tgu'il y aroit joint les Auricules, a été reproduite par lui dans l'Extrait du Cours et dans l'Hi:toire des Animaux sans vertèbres sous la dénoaniation de Mélanions; il y réuuit les trois genres Mlélanie, Mélanopside et Pyrène. Les auteur's qui, depuis la lormation de ce groupe, écrivirent sur les Mullusques, ne le conservèrent pas. On remarque dans leurs classiticatiuns mélhodiques les gences qui y sout réuais placés dans des groupes différeus, comıne nous le verrous en traitant chacnn d'eux en particulier. Nous observerous que le genre l'yrène, réuni aux Cérites par 11. de Blainville dans son Traité de Malacologie, l'avoit sté antérieurement aux Mílanopsides par M. de Ferussac duns sa Monographie des Melunopsides, insérfe dans le prerrier volume des $M e ́-$ moires de las Sociélé de Histoire naturelle de Paris. De ces rapprochemens, le second est celvi que nons adopterions de préférence. Oa voi: en ellet un très-grand nombre de points de contact entre eux, non-seulement dans les circonstances d'habitation, mais encore dans les formes, dans l'épiderme qui les couvre, dans la position et la forme da canal de la base. La seule dillérence notable se truuve dans l'existence d'une échanciure profonde au sonımet de la lèvre.

La famille des Mélaniens, en adoptaa la réunion des Pyiènes aux Málanopsides, ne conliendroil dune que deux genres. Nous croyons qu'il sera bon d'en ajouter un troisième, celui des Planaxes, qui nous paroît avoir autant de rapporls a vec les Mélanopsides, que les Nérites et les Néritines eu ont ellir'eux. La famille des Mlelauiens, composée des trois genres Mélanie, Mélınopsidé et Planaxe, pourra peut-čtre s'augrnenter encore du genre Rissoa. Ce genre cependant se lie avec les Litlorines, el pourroit, à cause de cela, entrer dans la famille des Turbos. Voyez les difléreas genres que nous a vons mentionnés.

\section{MÉLANOPSIDE. Mélanopsis.}

Les coquilles qui foot aujourd'bui partie dus 
genre Mélanopside étoient, ponr la plupart, connues des ancicns concliyliologues, on de ceux de l'époque oì Linné a clonné les dernières édiions du Systema naturce. L̇u joignant aux MÍlanopsides les Pyrènes de Lanrarck, comme l'a proposé dans ces derniers temps N. de terussac, on en trouve quelques espèces tigurées daas lister parmi les Buccins d'eau donce avee un assez grand nombre de Mélanies. Liané les a conlondues toutes avec les Sirnubes, les Buc:cins et même les Hurex; ce que Gmeiin et Delwynes out égalcunent fait. Bruguiere en a nis partie dans les Bulimes, partie dans les Cérites. C'est à $M$. de Ferussac que l'on doit l'établissenent du genre.

M. de Blainville cependant, sans citer les sources, dit, dansle Diciionnaire des Sciences naturelles, que Lamarck l'avoit proposé plusieurs années auparavant. Níanmoins nous voyons que ce zoolouiste le prenier l'a adopté; nous le trouvons dans la Philosophie zoologique, dans la famille des Auriculactes, cntre les Auricules et les Mélanies; nons le retrouvons également danss l'Extruit da Cours du mine auteur, mais dans la famille des Mélaniens, entre les Múlanies et le genre $\mathrm{P}_{\mathrm{y}^{-}}$ rène, proposé pour la première fuis. Cettc assuciation futcouservic la mêrae par son anteur dans son dernier ouvrage, les Animaux sans vertebres.

Montfort, en adoptant ce genre, en a cliangé, on ne sait trop pourquoi, le nom pour celni de Faune, qui est maintenant presqu'nublié; et on ue sait pas davantage pourquoi it l'a placé entre 500 gence Ruban, qui esı déniembré des Agallives, et le genre Terobra. M. Cuvier n'a point adopté ce genre; il pe le mentionne pas dans le Régne animal. Il a'en est pas de wème de M. de Blainrille, qui, en l'adneltant, tend à faire sentir la nécessité de le rapproclyer des Cérites : il propose mérne de placer les Pyrènes comrae sous-genre des Cérites, et de mettre les Mlélanopsides comme gente distinct inmédialcıneıt anrc̀s cèlui-ci. II. de Ferussae aroit en une opicion à peu près semblable, conme on peut le voir par ses Tableaux systématiques. Cependaat, réunissant les deux genres Mélanopsis et Pyrène, et plaçant le groupe is la fia de la famille des Trochoides, il differe en cela de M. de Blainville, en ce qu'il les met moins immédiatement en rapport avec les Cérites.

M. de Ferussac a publié, en 1823 , dans le premier volume des Ménoires de la Société d'histoire naturelle, la monographie des Melanopsides. Quoique nous ne partagious pas les curséquences que l'auteur a tirées des faits relatifs aux analogies nombreuses que préseate ce genre entre les espèces vivantes et les tossiles, on n'en doit pas moins apprécier les nombreuses observations pleines d'intérêt qui prouvent que c'est dans des régions plus méridiouales qu'il faut aller cliercher less analogues virans des cspèces que nous trouvons
N E L

fossiles en France et en Angleterre. Autrefuis, très-alsondamment répandus dans ces deux pays, comme leur test fossile le prouve, les Mélanopsides ne s'y rencontrent plus. C'est en Espagne, en Asie, en Grèce, en Afrique, et jusque dans l'Inde, qu'ils vivent aujourd'hui. Si l'un troure encore quelques Mílanopsides daas le nord de l'Allemigne, cela est Jî́a à des circonstances parliculic̀res. C'est ainsi que M. C. Prevost en a recueilli une espèce dans des caux therwales des envirous de Vienne.

Ce genre, déjà assez nombreux en espèces, peut être caractérisé de la manière suivaute.

\section{CAR $\triangle$ CTERES GÉNÉRIQUES.}

Animal dioïque, spiral, trachélipode; le pied court, arrondi, pourva d'un opereule corné; la tête portant deux gros tentacules coniques, assez peu alongés, incomplétement contractiles, ayant les yeux sur un renllement assez saillant, situć à leur base externe; la boucbe à l'extrémité d'une sorte de mufle proboscidiforme; lis cavilé respiratrice aquatique, conteoant deux peignes branchiaux inégaux, et se prolongeant en un tube incomple: à son agule antérieur et externe. Coquille alongre, fusiforme nu conicocylindrique; sommet aigu; tours de spire plus ou moins nombreux, le deınier ayant souvent les deux tiers de la longuear tutale; ouverture ovale, oblongue; columelle calleuse supérieurement, tronquée, sćparće de la lèvre droite à la base par un siuns profund, une callosité plus ou moins considérable, on un sinns à la réunion de la lèvre droite sus' l'avant-dernier tour.

Lorsque l'ou coasidere dans leur ensemble les espèces des genres Mélanie el Mélanopsidé, on voit combien ils ont entre eux de rapports par les nuances insensibles qui établissent un passage entic eux. Yarmi les Mélanies il en est quelquesunes, tclles que les Melania lactea, tympanorum et Sayi, qui ont à la !jase de l'unverture une sinuosité étroite qui devieut un peu anguleuse dans l'une de ces especes, et qui montre le passage aux Mélanopsides par les l'yrénes de Launarck. Dans la Melania tympanorum, le toord druit, prolondéruent siqueux a sa parlie supérieure, est uue transition par ce caraclère vers le méne gento Pyténe de Lamarck, qui, comme l'on sail, ne differe des Mélanopsides que par l'écbancrure profonde qui se voit à la partie supérieure du bord droit. Si wous prenons d'uutres coyulles, nous trouverons encore un autie passage entre les Mélanies et les Mélanopsides, par la manière inseasible avec laquelle se muatre l'éclianerure de la base. C'est ainsi que clans les Melanopsis abtusus, Parkinsoni et ri'antres espèces vitantes de l'Ohio, l'échancrure est à peiue indiquée par un très-petis renflewent de la base de la culumelle. Dahs d'autres espèces, telles que le Dlelanopsis costaia, 
l'ćclancrure de la base est döjà devenue plus prolionde, et enfia elle s'approluadit encore daus toutes les autres espèces jusqu'aux Pyrcines. Il y a done, relativemeat à la lisisun iutiace qui existe eatre les deux renres que anus venons de comparer, des raisons bien sullisuntes pour les réunir dans une nểme fanille. Nuus n'avours insisté í cet ćnard d'une manicre si particulicre, que parce gue nous vnyuns dirns l'uuvrage de M. de Blainville ces deux genres jetés dans deux fimilles dilférentes fort éloignées l'une de l'aure. Sans doure que les Mólanopsides, an moyea des Planaxes, peuveat se lier aux coquilles marines dites cichunciées ou canaluculées à la base; mais nous pensons que celte haison est une puissante raison pour meltre la fauille des Mćliuiens sur la limile des deux grands groupes, par conséujuent immédiatement avant lés Siphonostomes de M. de Blainville, dans le cas où l'on suivroit l'ordre général de Lamarck, ou immédiatemed après les Angistomes, dans le cas cù l'ou suivroit on ordie inverse.

L'aniral des Mélannpsides, d'aprc̀s ce que l'on cn connoit, c'esi-à-dire d'après les caracteres exlérieurs seulement, ceux de l'opercule compris, a heauconp de ressemblance aves celui des Mélanies; c'est une autre raisun qui vieut à l'appui de leur rémnion duas un méae groupe. Les llélanopsides sont les liabitans des eaux douces des pays chauds, avec les Mélanies, les Néritines, eic. Leur associalion avec les genres que nous venons d'inclıquer se monire la unèıe dans les lerraius uà is ant tossiles. Dans ces sortes de terraios, ils siat encore accompagnés de corps ararins en plus ou moins grande abondance, qui ser"ent de preuve à l'ophininn adıise aujourd'hui, que ces rerrains, diss d'euu douce, se sont déposés dans la mer aux alflueas des cuurs d'eaux terrestres.

\section{Miranopade de Dufresne. Mclanopsis Di- fresnii.}

M. testâ elonguto-turrita, fisiformi; ar fractibus plarulutis, lavoigatis, ultimo tuberculis tribus «ainrnato; suturi subcanaliculatá; lineâ depressâ, murginats; colurnells tortuosi, callosâ; lubbro dextro....

Nos. Descript. des Coq. fuss. des env. de Paris, pas. 120. pl. 12. /is. 3. 4 .

Nous avons dédié celle belle et nouvelle especce à M. Dufresae, qui, depuis maintes années, recueille avec soin nos lossiles parisiens, el qui a contribué puissammeat à repandre le çuût de leur riude. Il a bien voulu mettre sa riche el belle collection à notre disposition : nous nous plaisons à lui en témoigner notre reconnoissiace.

Celte belle et grande espèce de Milanopside est remarquable ausant par sa taille que par les iruis cútes tuljerculeuses qui se voient à sa base sur le

Hist. Nat. des Vers. Tome II. dernier tour, le reste de la spire étant lisse, sans còtes ni tubercules. Les sutures sont légèrement saillantes, inbriquées", subcanaliculées, un plưot indiguées par une surie profonde; elles sont marginées par une ligne un peu enlonçe et pen marquće, qui est placćc au-dessug et qui les suit. L'onveriure ent ovale, arrondic. la culumelle est tronquée à sa base, turtement arquée dass son milieu; le bord gauche la revèt et y lorme une callosité; le bord droil u'est pas entier sur l'individu unique que uous possedons, le seul qui soit conau. Il nous seruble, d'aprés quelques stries d'accroissement, qu'il devuit êlre sinueux vers l'angrle inlérieu; alors celle espèce rentreroil daus la section des P'yréues. Longueur 80 inillimètres.

2. Mécaxupside buccinoïle. Melanopsis buccinoides. lins.

MI. testâ ouato conicâ, acuth, lcevigatî; anfractibus subcinaliculatis, ultimo alteris longiore; suturis subregularibus; aperturâ ovatî; columellấ callosâ, arcuatâ; labro dextro tenui, simplici.

Melania buccinoidea. OL.1v. Voy. au Lev. p!. 17. fig. 8.

Melumopsis buccinoidea. FER. Mém. géol. pag. 64. $n^{\circ}$. 1 .

Ibid. Monogr. Mérn. de la Soc. d'hist. nat. tom. 1. pag. 148. pl. 7. fig. 1. a. 11, et pl. 8. fig. 1. a. 4.

MClanie de Soissons. Brand, $4^{\theta}$ MIÉm. Joum. de Plujs. avill 1812, fig. 9. 'I'rès-mauvaise.

Bulimus antediluvianus. POІret, Coquilles terrest. et fluv. pag. 36.

Bulimus antediluvianus. Lavк. Ann. du MIus. tom. 4. pag. 2 yj.

Jlid. Anim. sans vert. tom. 7. pag. 538. $n^{\circ} .15$.

Nos. Descript. des Coq. foss. des env. de Paris, pag. 120. pl. 14. fig. 24. 25. 26. 27 , et pl. 15 . fig. 3. 4 .

Nous n'avons pas voulu reproduire ici tonte la synonymic de celte espèce; nous a'en avons rapporlé que ce qui est nécessaire pour que l'on puisse facilement la seconunître; nous renvnyons pour le reste \& la Monograplie de $\mathbf{M}$. de Ferussac, ois elle est présentie dans son ensemble. Les dillérentes localités que noos désignerons ne présentent pas toutes les variélés que M. de Ferussuc a indiquées; c'est ainsi que les individus que nous caractériserons ici doivent être rapportés à sa variété $g$ et l'autre à sa variélé a. Malgré le grand nombre que nous en avons recueilli daps les divers endroits que nous citerons, nous n'avoas pas trouvé nécessaire d'ajonter de nouvelles variélés : celles que aous possédons reotreat dans celles de l'onvrage de M. de Ferussac, où toutes ont été par$\mathrm{Ii}$ * 
failement saisies. Les individas de la variété $g$ soat ovales, coniques, assez grands, lisses; leurs tours, at uombre de sept; sont presque plals, peu convexes, à sulure peu marquée, quoique bien apparente et souveat irrégulière pour le deraier lour : celui-ci est plus grand que tous leș autres. L'ouverture est de moyenne grandeur, ovale; la columelle est fortement courbie, tronquéc à la base, présentant à sa partie inférieure nac callosité très-forte. La lèvre droice forme, en se réunissant à celte callosilé, ua canal élroit; cette lèvre est extrêmement nuace, très-fíagile : aussi sur des milliers d'individus que nuus avous vus d Éperaay, nous n'en arons trouvé qu'un seul qui ail celle partic assez hien conservée. La variéré a est toujours plus pelite, sa callu sié columellaire est moins lorte, et le deruier tour'de spire est moins grand que lous les autres réunis. Ces variétés se retrouvent à l'ille de Wigt, ea Angleterre, avec des coquilles semblables à celles de cos terrains. Longueur 29 millim., longueụr de la variété a 12 ou 15 millim. Cetle coquille vit actuellèment en Espagae, dans l'archipel de Grece, en Turqquie, etc., et se trouve fossile en Italie, en France, aux environs de Paris et en Angleterre dans le bassin de Loadres.

3. Mér.avopside a acillaroïde. Melanopsis ancilluroides. Nов.

M. testâ ovato-subcylindricâ, ventricosâ, lavigatâ; spiri conico-abbrevatá; anfructibus planulatis; suturis nullis, callo tectis; aperturâ ovato-oblongấ; columellâ parte inferiọre callosâ.

Noв. Descript. des Coq. foss. des env. de Paris, pag. 121.pl. 15. fig. 1.2.

Celle corjuille m'a été doonée comme provenant des eavirous de Meaux; elle est remplie d'un calcaire d'eau douce que je crois siliceux, qui est particalier a bassin de la Marae; ce qui m'a fait ajouter foi à celte indication. Il seroit possible de la confondre a vec une des nombreuses variétés de la Baccinoide, mais oa pourra la séparer par les caractères suivans: elle est plus ventrae, plus cylindriqge; sa spire est plus régulièrement conique; elle est aussi beaucoup plus courte. Mais ce qui la reod très-remarquable et ce qui lui a vala le nom que nous lui avons imposé, c'est que, comme dans les Ancillaires, les sutures soot couvertes par la matière calcaire que l'animal y a déposće et polie. Les tours de spire sont indiqués au-dessous de ce calus par une légère dépressioa. L'ooverture est plas grande, plus alongée gue dans le Irelcznopsis buccinoidea; la columelle est moins caurbée; son calus inférieur est aussi considérable, mais la gouttière qui le sépare du bord droit est mains apparente; le bord droir est très-miace, tranchant plin proéminent. Longueur 25 millimètres.
4. Mrlaxopside à coles. Melunopsis costala.

M. testâ ovato-oblongâ, acuminatî, aliquantis per oblusâ, longitudinuliter costatâ.fuscâ; anfractibus convexis, ullimn alleris longione, in medio depresso; aperturí albâ, mininấ; callo magno.

Melinia costuta. Ondv. Voy. au Levant, pl. 31. fig. 3.

Melunopsiscostala. Laмк. Encycl.pl. 458.fig. 7 .

Melanopsis costuta. Fer. Mém. géol. pag. 64. $n^{\circ} .2$.

Ilid. Monngr. Mém. de la Soc. d'hist. nat. de Puris, lom. ier. pag. 156. pl. 7.fig. 14. 15.

Ibid. Lask. Anim. sans vert. tom. 6 pag. 168. $n^{\circ} .1$.

Ibid. Dex. Dict, des Scienc. nat. tom. 29. pag. 479 .

Nов. Descript. des Coq foss. des env. de Paris, pag. 122. pl. 19. fig. 15. 16.

Celte Mélanopside se Iroave vivante en Turquie et en l'erse, et fossile ea Italie et anx environs de l'aris. Il a'existe presque aucune différence entre les individus qui sont dans ces deux étals.

Le seul individu que nous possédions, et que wous avons recueilli aux environs de Soissons, se rapporte à l'une des variétés de l'espèce, et celleci ne varic gaère moins que le Melanopsis buccinoidea. Il est ovile, à spire courte, subironquée, furróe de quatre tours visibles, seulement le dernier enveloppant presque entièrement tous les autres; ils sont convexes, subdéprimés vers le milieu et chargés de côtes assez grosses, en géaéral peu régulières. L'ouverlare esı pelite, ovale; la columelle est très-arquée el le calus inférienr est granul; l'angle inférieur est subcanaliculé; la lèvre droite est simple et iranchante. Longueur 16 millimètres.

\section{Mélayopside de Parkinson. Melanopsis} Parkinsoni. Nos.

I4. testâ ovato-tarritâ, lavigatâ; anfractibus convexiuseulis, parte superiore nodulosis; aperturâ ovatá; columellà subcallosá, vix basi truncatá; sinu nuniwo; labra dextra subcrasso.

Nов. Descript. des Cón. foss. des env. de Paris, pag. 123. pl. 17. fg. 3. 4.

Melanopsis brevis. Sow. Min. canch. tab. 523 . fig. 2.

Je ne conapis encore que trois individas de cette espèce remarquable, denx dans lą collection de fossiles du déparlemeat de l'Oise que possède M. Grave, à Beauvais, et le troisiène est de la collection de M. Defrance, où je l'ai irouves désigoê sous le nom de Bulinas Parkinsoni. C'est à la complaisance de ce deraier savant que je dois 
duavoir pu le décrire et le figarer. Celfe espèce cst uvale, oblongue, subvearrue, lisse; la spirce est assez courte, composíe de sept it huit tours convexes; sur les supérieurs se voil une rangée de tubercules coniques el émoussés; lc derrier et l'avant-deruier tour eo sont dépourvus. L'onverture est ovale, oblongue; la columelle est jeu ćpaisse, peu tronquée à la loise; le camal de la lase n'est Jui-mêare que peu prolond; la callosilú inféricure de la coluaselle est unlle; lu lèvie droite cst épairse près de sun bord, qui est trancliant ct en bisean. Lungueur 18 millimètres.

6. Minaxopside obluse. Melanopsis oblusa.

II testì ovato-glohosâ, inflati, solidi, crassâ, lovigatä; anfirscibus convexis, aprce erosts; aperturs ovatu; columellâ recurva, bust subtruncatâ, vix callosia; labio dextro crasso.

Noв. Descript. des Coq. foss. des env. de Paris, pug. 123. pl. 14. fig. 22. 23.

Cet!c espéce de Mélanopside est furt singulière par sa forme ovale-ventrue; clle présente une épraisseur qui ne se vuit pus ordinairement dans les coquilles du genre. Sis spire, très-courte, est ubluse; elle se compose de cinq lou's arrondis dont le teruier est plus prand que lous les autres: le somalet est rongé, comme cela se voit trèssouvent dans les cuyuilles lacustres. fiouverture est ovale. La culumelle forme un arc de cercle assez rézulier, elle est tronquée à la base; mais celle truocature est muins apparente eu ce yue le canal de la base lini-mêtme est feu profond; la rallosité est petite; lia levrot druile est épuisse. Longuenr 2.3 uilliòires. Cette curieuse espece, qui se truave rarement dans le Suissonnais, a seaucoup d'analogie, quaut à la furme de sa colamelle, avec quelyues-unes qui viveut dans les lleuves de l'Auériyue sepleutrionaie.

7. Mrinavopside de Bouś. Melanopsis Bouei.

MI. testá ovatâ; anfirctibus sex ad septem, ultumo venuricoso, costis munimis longuludznulibus munito, infernè iwberculato, spinoso; apperturi ovata; callo repando; columelli crassú.

lieros. Monogr. da gen. Melanop. loc. cit. p. 159 .

Ilid. Hest. des Moll. Melanop. foss. $21 \%$ Liv. pl. 3. fig. g. 10.

Cettc julie espècc, yui fut découverte par M. Buné dans ses ruyagres géuluginues en Allemanne, a quelques rapports de lurme avec le Mclanopsis Martmii. Flle est ovalaire, courte, à spire conique et pointue, régulière, composée de six à sept tours aplatis, rapprochès, dont le dernier est plus graod que tous les autres. Les trois on quatre premiers tours sant lisses; les suivans sont ornés de petites cútcs longiturdinales, yui se terminent sur l'angle des tours par de petits lubcrcules pointus qui forment tone seule série. L'ouverture est petite, ovale, oblique, rétrécie it ses extrémites; elle se contiune à sa parlie supérieure par une pelite gonttière creusée cotre la callosité columellaire el l'extrćaité snpéricure dn hord clroit. L'échancrure de la base est petite et ublique. Le boud droit est wince, tranchant, légcremca! simenx i la parlie supcrieure. la columelle est lisse, arquućc dans tome sa longucur, ct pouvue, a sa partic supérieure, d'une callogitó assez large, qui, linitce au-dehors par un petit sillon, constitue le bard gauclse.

Cche coquille élégante, que M. de Ferussac : dédiéc à l'un des géologucs les plus distingués, dont les immenses reclicrches se sont ćteadues sur presque toutc l'Europe, s'est Iruuvie particuliercment pres de Bisentz, dans la vallée de Marsch, en Moravie, ainsi que piès de Schardik, dans les a arnes argileuses superposíes, d'après M. Boué, aux argiles plustiques.

8. Méraxopside à peti:es cóles. Melanopsis costellata.

M. testí ovato-oblongâ, olivaceá; spirá lmevi; ultimo anfractu reliquis triplo; costus longıudinalibus, numerosis, prope suturim lineam nodosam formantitus.

Fercssac, Monogr. dil gen. Mélanop. loc. cis. Rag. 157 .

Melanopsis costuta. IEnos. Mém. géol. pag. 54 . $n^{\circ} .2$.

Murex cariosus. Lix. Syst, nat. tom. I2. pag. 1220.

Gmex. pag. 35 q1.

Dillwis, Descript. cat. pagr. 712.

Var. a.) Mujor et elatior, fisciata. Buccina maroccunc. Cuess. Conch. tom. 10. tab. 210. $f_{g} \cdot 2882.2883$.

On dislingue facilement celte espice de toutes eclles du mćme geimre; clle cst ovale, pointue au summct; sa spire est courte, étagée par un angl. assez saillant, situé a la partie supuérieure des tours; ceux-ci, au nombre de six ou sept, sont courts, aplatis, ornés d'un ussez grand nombre de peliles côtes longitudinales, qui forment un pelit tubercule ev passant sur l'angle supérieur. Le dernier tour, bcaucoup plus grand que les autres, est oroé, comme eux, de cótes longitudiaales qui s'ellaceut ell descendant el finissent par disparoitre à la base. L'ouvertare est ovale-obroude. Le bord droit, mince et tranchant, est un peu sinueux vers son extrémité supérieure, à l'endroit qui correspond au rang des tubercules. La columelle est-Iégalic̀rement arquée; elle est lisse, brillante, blanche inférieurement, et pourvue d'une callasité rosàtre à $s a$ partie supérieure.

Celte coquille, en dehors, cst revêtue d'ua Iii 2 * 
épiderme d'un brun-verdâtre, au-dessous duq̣nel on distingue nellement, dans certains individus qui furment la variété, deux bandes étroiles et transverses d'un brun foucé.

On rencoutre, d'après $M$. de Ferussac, celle espèce en très-grande quantité dans l'aqueduc de Sérille. La variété se trouve påliculièrement dans les eaux douces des environs de Maroc. Longueur 25 millim.

9. Mélanopside à gros nouds. Melunopsis nodosa.

IT. testâ opato-acutâ, solidâa anfractibus septem ad octo, ultimo ventricoso; costis nodosis longitudinalibus munito; nodis vulde notatis, lineas tres transversales formantitus; aperturá ovatá; callo albo, repando; columellâ crassâ, lutâ, albâ, nitidá.

Ferussac, Monogr. du gen. loc. cit. pag. 158. pl. $1^{\mathrm{re}}$. fig. 13.

Melanopsis affinis. FEr. Mèm. géol. pag. 54. sp. $n^{\circ} .3$.

* Fossilis. Feros. Hist. des Moll. 15 . livr. Melanops. foss. pl. 1. fig. 13 .

Var. a.) Cylindracea fossilis. FER. $21^{e}$. livr. Moll. foss. pl. 2. fig. 13.

Celte coquille a bearcoup d'analogie avec la Melanopsis costata, dont elle u'esi peut-ĉtre qu'une variété; elle paroît cependant assez constante dans ses divers caractères. Sa forme la rapprocbe de la Mélanopside buccinoide. Elle est ovale, pointue, à spire conique plus on moins alongée, formée de sept à huit tour's aplątis et rapprochés, dont la suture est simple; les premiers sont lisses; les suivans sont creusés à leur partie supérieure d'une gouttière superticielle courōnoée, principalement sur le dernier tour, par un double rang de tubercules obtus et courts. L'ouverture est oblongue, ovalaire. Le bord droit est simple, tranchant, fragile, un peu sinueux supérieuremeut, et formaat, avec la callosité columellaire, une petite rigole prolongée et très-étroite. L'échancrure de la base est médiocre. La columelle est régulièrement courbée; elle est épaisse, bordée par un bord gauche qui devient calleux à sa partie suptrieure.

Cette coguille, que l'on connoît vivante et fossile, est, dans le premier cas, blanche en dedens et brune en dehors, et, dans le second, constamment blanche. Elle vit en abondance près de Bagdad, et se trouve non moins abondamment à l'élat fossile, entre Otricoli et le Vigne, dans un terrain de mélange, où elle fai découverte par Mesnard de la Groye, que les scicaces ont trop tôt perdu. C'est ì ce savant, anssi modesle qu'érudit, que nous devons quelques exemplaires de cette espèce. Longaeur 23-i 25 millim.
10. Mécanopsior alongée. Melanopsis aciculuris.

$\boldsymbol{M}$. testâ subulatâ, lovigatâ, nitidâ, solidî; atro-fuscâ; fasciô flavescente, suturis cinctâ; unfructibus octo ad decem, complanatis, sensim deciescentibus; aperturá ovali, utrinquò albi; callo indistincto; colunella apice attenuatâ, acut $\dot{i}$, vìx enıarginatâ et cannliculatâ.

Fer. Monogr. du genre Mélanop. loc. cit. p. 160 .

Ibid. Além. géol. pag. 54. sp. $n^{\circ} .5$.

Var. A.) Minore, unicolore. Mel. Audebarii. Prevost.

Var. B.) (iorneo colore.

- Fossilis. Melanopsis subulatus. Sow. Min. Conch. tab . 332. fig. 3 ?

Ou duil la connoissance de cette espéce curieuse de Mćlanopside à M. Constant Prevost, l'un des hommes les plus distingués parmi les géolognes lrancais; il la rencontra dans une circonstance particulière, qui vient pronver d'une manjère irrćcusable que, si les races de Mélauopsides, de Mélanies, de Néritines, et sans doute de beallcoup d'autres genres et espèces, ont été anéanties sur la plus grande surface de l'Europe, uù on ne retrouve plus que leurs débris fussiles, cela n'est dû qu'à un cbangement de tempérałure dont d'antres preuves ne sont pas moins palpables : c'est, en ellet, dans l'enceinte artificielle d'une source cliaude que M. Prevost a observé, isolée sur un point extrêmement circonscrit, celle espc̀ce de Mélanopside, accompagncé d'une Néritinc, analogue à celle qui se Irouve aujourd'hui dans les parlies les plus méridionales de l'Europe. Il est ćvident que cette espèce n'a dô sa conservarion, au miliea de la destruction de ses congénères, qu’à cette circonstance fortuite de son habitation dans une eau thermale.

La Mélanopside alongée se rapproche beancoup de certaines Mélanies, telles que la Melania tactea, par exemple, par sa forme turriculée, l'épaisseur de son lest, et surlout par le pea de profondeur de l'échancrure de sa base: ce qui en fail, comme nous l'avons déjà dit, un passage remarquable, sous plusieurs rapports, enlre les Mélauies et les Mélanopsides. On compte huit tours à la spire des plus grands individus. Ces tours sont aplatis, assez larges, lisses; ils ont une suture simple, linéaire et très-superficielle. L'ouverture qui termine le dernier tour est ovale-oblongue; elle est taniôt blanche, tantốt brunátre. Sun bord droit est mince, Iranchant, et la columelle, arquée dans sa longueur est à peine échancrée à sa base. Sa partie supérieure est loujours dépourvue d'une callosité Elle est accompagnée, dans toute sa longueur, d'un bord gauche mince et appliqué. Les plus grands individus ont 22 millim. de longueur: 
11. Milanopside térébrale. Melanopsis atra.

U. testâ tumito-subulatâ, vertice acutissimâ, larigatí, subnitidî, ferè opacâ, fusco-nigrî̀ vel badia; anfractibus sexdecim ad duodeviginti contiguis, sensim decrescentibus, planulatis; suturis arista et sulco lineari notatis; aperturî̀ albidi, ovatâ, utrinquè emarginatá; latere exteriore sejuncto, extenso; margine v'a'de urcuato, acuto; culuniellí incurvâ, subulatô; callo repando, nediocri.

FER. Monngr. dugen. Mélanop. lac. cit. p. $16 \mathrm{r}$.

Melanopsis atra. Fer. Méni. géol. pag. 54. sp. $n^{\circ} \cdot 7$.

Strombus ater. Lis. Syst. rat. pag. 1213.

Mlus. Lud. Ulr. pag. 624. n०. 289 .

Scanoter, Fasc. pag. $371 \cdot n^{\circ} .168$.

Ibid. Einleit. tons. 1. pag. 449.

Свемк. Conch. toni. 9. 2e. part. pag. IgI. tab. 135. fig. 1227.

GeL. pag. 3621 .

Diluwis, Descr. cat. pag. 676 .

Strombus dealbatus. GMEL. pag. 3523.

SEBA, Thes. tom. 3. tab. 56. fig. 13. 14.

Scrr. Einleit. tom. 1. pag. 462. Strombus, $n^{\circ} .32$.

Nerita atra. MoLl. Verm. Hist. pag. 188. $n^{\circ} .375$.

Cerithium atrum. Brog. Encycl. meth. pag. 485. $n^{\circ}$. 18.

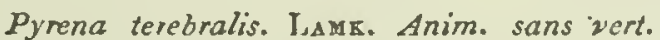
$2^{e}$. édil. tom. 6. .2. part. pag. $16 \mathrm{~g}$.

Lister, Synops. tal. I 15. fg. 10.

Rомрн. $t a b$. 30. fg. 7 .

Petrv. Amb. $t a b .13$. fg. 16.

Mantev1, Berlin. mag. tom. 4. tab. 9. fig. 41 .

KLEIN, Ostrac. \$. go. sp. 2. $\pi^{\circ} .8 . p a g .34$.

Junior buccinum acicula. Gsez. pag. 3503.

Iistr., Synops. tab. 1055. fig. 7.

Scra. Einleit. tom 1. pag. 407. Buccinunt, n०. 191.

3. 4 .

2.) Fossilis? Dessr. Crust. foss. pl. 6: fig.

Iier. $21^{\text {e. livr. Melanops. foss. pl. } 2 . f i g .7 .}$

Pyrène de Madagascar. DE Buaisz. Malacol. pl. $2 \mathrm{~s}$. fig. 2. a. a.

Bruguière ayant décrit, daus le premier volume de ce Dictionnaire, cette espèce de Mélanopside, qu'il confondit avec les Cerites, sous le nom de Cérite fuviatile, il n'est pas nécessaire de la décrire de noupeau ici : il suffit d'en aroir présenté la synonymie la plus complète et de renvoyer a la page $485, n^{\circ} .18$, pour la description très-exacte de l'espèce.

12. Mílavopstde Épineuse. Melunopsis spinosa.

MI. testá turrit $\hat{u}$, vertice erosi, truncatí; crassi, nigro-opaca; anfractibus septem ad tredecim inferne tuberculato-spmosis, prope suturtm planulatis et sulcis linearibus notatis, ultimo supernd sulcato; aperturâ canileâ, ovatoacutâ, utrinquè emarginatá; latere exteriore scjuncto, in medio extenso, emarginato, partito; latenc inlerione distincto, crasso, repando, integı, columelli adnato; peristomate fisco; cullo non distincto; rimâ umbilicali distinctâ.

lierussac, MIonogr. du gen. Melanops. loc. cit. pag. 162 .

Buccinum funineurn. GмЕL. pag. 3503.

Listen, Synops. tab. 118. fig. 13.

MIART. Berlin. mag. tom. 4. tab. 10. fig. 52.

Scвпот. Einleit. tom. 1 ex, pag. 405. Buccintmm, $\pi^{\circ} .183$.

Helix cuspidata. Dillwin, Descript. cat. pag. 949 .

Pyrena madagascariensis. LA пк. Encycl. méth. pl. 458. fig. 2. a. b.

Pyrena spinosa. Laxx. Aninz. sans vert. tomi. 6. $2^{\mathrm{e}}$. part. pag. $170 . n^{\circ} .2$.

Long-temps la Mélanopside épineuse a été recherchée des amateurs, à cause de son extrême rareté. Elle n'est poiut rare cependant dans les eaux douces de Madagascar, et uu jeune voyageur, M. Goudot, dout le zèle mérite de l'encouragement, en a rapporté un assez graud nombre de son voyage dans celle ille. Celle coquille est alongée, turriculće, ordinairement tronquée au sommet. Sa spire esl composée de douze à quatorze tours assez larges, finement striés en travels, et ornés de cútes longitudinales plus ou moins nombreuses, qui, dans la plupart des individus, se prolongent, à la partie supérieure des tours, en tubercules épiueux. Ces cótes, en aboutissaut sur la suture, la rende crénelée; les stries transverses de la base sont beaucoup plus grosses que les autres. L'ouverture est ovale-obronde; elle est d'on bran-Cauve à l'intérieur. Le bord droit est fort saillant; il est détaché à sa partic supérieure par une échaucrure assez profonde, et à sa base, par une antre, qui l'est an pen moins. La columelle est régulièremeat arquée dans toute sa longueur; elle est lisse, arrondie; elle se relève en un bord gauche, saillant, surtout à sa base et à son summet. A l'extéricur, celle coquille est d'un noir foncé ; elle est très-variable sous lc rapport de la disposition de ses còtes et des tubercules qui les sarmontent. 'Tantôt la partie supérieure des tours 
forme ane rampe spirale horaće en dehors par un angle assez aigu, couronné régulièrement par les tabercules; tantót les tours unoins anguleux ont des tubercules beancoup moins saillans; quelquefois les cubercules manqueut tout-à-fait, et alors les tours sont régulièremeat convexes. 11 est enfia d'autres individus qui, après avoir produit une des truis variétés précédentes, la issent sur leur coquille des cspaces plus ou moins grands, déponrvus de côles, et sur lesquels on a'aperçoit plus que les stries transverses.

Les grands individus de celle belle espèce de Mélanopside ont quelquefois plus de 60 millim. de longueur.

15. MÉla mopside semi-granaleuse. Melanopsis semigranulosa.

M. teslà ovato-oblusâ; spirâ breviculâ; anfractibus supernè granulutis, infene lcevigatis, fusco-vinidibus; aperturá ovatá, basi vix emarginatá; colunitha rotundatá, superne callosú.

Cette espèce de Mćlanopside est l'une de celles qui viennent se placer parses caracières sur la limite du geare du cóté des Mélacies. Eile est ovale, ventrue, à spire ob:use et peu prolongée, formée de six à sept lours légèrement convexes, à suture simple, dodt les premiers sont lisses, et les derajers couronaćs par deux ou truis rangs de tubercules obtus, subquadrangulaires, assez régulièrement disposés sur le dernier. 'Tus ces tubercules occupeuc le tiers supiérieur. Tuut le reste de la sarface est complètement lisse. L'ouverture est petite; elle est ovale-oblongue, oblique, rétrécie à ses extrémités; elle se prolonge a sa partie supérieare en une pelite goutlière assez large, entre la callosité columellaire et l'exırémité du bord droit. Celui-ci est mioce et tranchant dans toute son étendue; il se joint à la base de la columelle en faisant une petite inflesion qui remplace l'échancrure qui se voit dans les autres espèces de Mélanopsides. La columelle, régulièremeot arquée dans sa longueur, est á peıne échancrée à la base. A sa partie supérieure se troure une callosité assez épaisse : celle callosité est blanche, ainsi que loute l'ouverture. Uo épiderme d'un brua-verdàıt très-funcé couvre loute la coquille à l'extérieur. Celte espece, que l'on trouve daus l'Ohio, avec une quanité reconarquable de Muleltes dont les forntes sunt extrémement variées, ne prencl jamais de grandes dimensions, les plus grands radividus a'ayaui pas plas de 25 i 28 millian.

14. Mínanopside aéritiforme. Melanopsis neritiformis. Nов.

01. testâ ovato-globnsi, nerilformi, apice obtusissimá, fisco-nigrbcante; aperturd ovatosemilunari, basi zix elinarginats; columelda con- cortâ, supernè callosâ, in medio dipressá; labro dextro bisinuato.

Coquille des plas singalières, qui vient se placer dans la série des Mélanopsides, a cóté des Melanopsis obtasa et semignanulosa. Sa spinre est tellement courte et obtuse, qu'on la plactroit parmi les Niratines, si un ne voyuil sud ouverture. Elle est ovale, globuleuse, quelquelois subsphérique. On comple cinq lours a la spire: ces tours sont courls, coutiuus, el le dernier est beaucoup plus grand que 10 us les autres; ils sont lisses, revétus a'un épiderme coriace, caduc d'un biun-foncé. L'onverture est des plus bingulières. La columelle, droite a la parie supérieure, se recourbe assez subitement à la base; ce qui lui donne quelque ressemblauce avec celle de certaines Natices. Elle cst garnie à sa partie supérieure d'une callosité assez épirisse, qui est séparée de l'extrémité du bord droit par an canal assez proturd. La coluuclle, avant de se recourber vers le tiers inférieur de la longueur, s'aplatis seusiblement et s'écale, à la base du deruier tour, de manière à en couvrir l'ombiic par un bord gauche appliqué. L.e hord drcit est assez épais; il cst couvexe à sa partie supérieure, et échancré largement à sa paric iutérieure, de uıanière qu'il se joint à la base de la coluaelle en formant un angle un peu sallant. L'échancaure qui existe dans les Mélanopsides est ici seulemeut indiquée; car elle consiste uaiquenent ea ce y'ue l'exlsémité de la colunieile fail une lógère sailise en dessus da bord dicit, à sa jouctiun. Lu dedans, celte coquille est d'un brun-ruugejtre. Sar la levere droite, qui est d'un bruo un peu blanchatre, on voit, daas lit plupart des individus, quarre lascies d'un bruarouge, qui ne saperçorient pas au-debors de la coquille.

Ou trouve cette Mélanopside curieuse, avec la précédeote, dans l'Ubio el ses afflueas. Eille a 20 millim. de lougueur et 16 de largeur.

15. Miranopside de Dufout. Melanopsis Dufourii.

- MI. testá ovato-conicá, solidi, nitente, bruncá, yel viridè lutescente, vel griseâ, maculis rufis aspersá; anfractibus octo, ultimo ventricoso; costis tiansversalibus tribus nolatis cincuniscriptu; upertura ovato-elongata, lutere exteriore elongato, adversis callum infexa; cullo ulbe, convexo, nitıdo; culuniellá crassí, ulbá, nitids.

Fer. Nonogr. dugen. Mélunop Mém. de laSoc. d'Hist. nut. de Paris, tum. I"r. pag. $155 . p l .8$. fig. 5.

Buccina maroccuna. Cвenr. Conch. tom. 10, tab. 2 10. fig. 2078-208t.

Var. b.) Nugná et olata, hervi et fusciati. Cerars. fig. 2076. 2079. An species?"

Var. c.) Mlagná, carinû elevatu propé suluram cinclâ. Cuews. fig. zo8̈o. 2081. 
Dans sa Monographie des Mélanopsides, M. de Ferussac a, selon nous, confoadu deux espèces qui nous paroissent parfaitement distinctes : les coquilles qui se trouveot à Dax, à l'état fossile, nous paroissent avoir des caractères suffisans pour être séparées du type vivant que nous réservous seul, sous le nom de Melanopsis Dufurrii. Cette coquille a quelque ressemblance avecla Melanopsis buccinoidea. Elle est à peu près de la même taille, ovale, pointue, à spire conigne assez longue et étagée; elle est composée de sept tours réguliers, convexes à suture simple et un peu profonde; le dernier, beancoup plins grand que les autres, est lisse comme eux : à sa partie supérieure, il est creusé diune rigole plus ou moins profonde, qai suit la suture, au-dessous d'un bourrelet convexe. Cette rigole aboutit sur le bord droit, et y produit uoe inflexion dans le sens de sa longueur. L'onverture est ovalaire, rétrécie à ses exirémités, d'un brun assez foocé en dedans. Le bord droit est mince, trancbant. Le bord columellaire est blanc, brillaot, régulièrement arqué, et muni à sa partie supérieure d'uoe callosité épaisse. L'échancrure de la base est assez large, mais peo profonde. Sous nn épiderme verdâtre et très-mince, cette coquille est blanche, ornée de taches ou de fascies d'un brun plus ou moins intense. Ce n'est qu'a vec doute que aous avons rapporté à cette espèce la figure de Chemnitz, dont nous avoos fait notre variété (b); elle sembleroit appartenir plutôt à une variêté de la Mélanopside bucciooide. Longueur 25 millim. Elle vit aux environs d'Alicante.

16. Mrínopside de Martini. Melanopsis martiniana.

M. testâ ovali, subpyniformi, lacvi, solidâ; anfractibus septem ad octo, ultimo ventricoso, costis transversulibus duabus notatis circun. scriplá; et in nuedio sulco excava to ; spirâ torulosâ ; aperturî̀ ovato-elongatâ, superno contractâ; latere exterinre clongato, adversius callum inflexo; callo magno, repando; columellá crassâ.

Fer. Monogr. du genre Mélanop. Loc. cit.p. 155, pl. 2. fig. 11-13.

W $\triangle$ Lca, Petrif. de Ksorr, tom. 2. tab. c. 11 . fig. $1-5$.

Pyrunifossilis monstruosum. Martin, Conch. tom.2 pug. 203. tab. 94. fig. 912-914. Cochlis pyriformi, lavi, edeniula, fossili; labro calloso, sex spiris excavatis.

Buccinam fossile. Gare. Syst. nat. pag. 3485.

Fra. Hist. des Moll. $21^{\mathrm{e}}$, livr. Melanop. foss. pl. 2. fig. 11.12.13.

An purpura retusa? Lamx. Anim. sans vert. tom. 7. pag. 248. $n^{\circ}$. 44 .

La Mélanopside de Marlini est une fort belle espèce, conone d l'état fossile seulement. Elle ressemble à un Buccio; elle est ovale, alongée plus ou moins, sclun les variétés. Son test est treesépais et fort solide. Sa spirire, plus ou moins clancée, est formée de cinq à six tour's rapprochés, aplatis, subtronqués au sommet, crensés dans leur milieu d'une goultière peu prolionde, limités iuférieurement par un angle obius et saillant qui couronne la partie supéricure du dernier tour. Cclui-ci est beaucoup plus graud que tous les autres réunis. L'ouverture qui le termiue antérieurement est assez courte, ovalaire, et se conlinue à sa partie supérieure par un petit canal creusé entre l'extrémité du bord droit et la callosité columellaire. La colurnelle est arquée dans sa longueur, profondémentéchliancrée à sa base; elle est arrondie, épaisse et garnie à sa partie supérieure d'une grosse callo. sité, qqui peut très-bien se comparer à celle qu'on remarque dans certains Buccios. La surface extêrieuse est lisse et iuterrompue à des distances ióegales par des accroissemens irréguliers, quelquefois mème grossiers. La surure qui sépare les tours, régulière d'abord dans le jeune âge, tioit par être lurt irrégulière dans les vieux individus, par suite des accroissemens.

Cette Mélanopside est très-variable; il en est quelques-uns dont la spire est tellement obtuse, qu'elle se trouve àu niveau du deruier toar. Entre cette variété et celle dont la spire est plus élevée, il existe un si graud nombre de auances, qu'il n'est presque pas possible, sous ce rapport, de trouver deux individus identiquement semblables.

Cette espèce se trouve très-abondamment, à ce qu'il paroît, dans les terrains tertiaires des environs de Vienne en Autriche, de Baden, et en général dans presque tous cenx de l'Autriche et de la Prusse. Longueur 40 millim.

\section{MÉLAR.}

Daos son Voyage au Sénégal ( $\mu l .6, f g .2)$, Adaasou donne ce nom à uue belle espèce de Cône connue sous le nom vulgaire de Cône écorché, Conus striutus des anteurs. Voyez Cûse.

\section{MÉLAS.}

Nom que Montfort, dans sa Conclyyliolugie systématique, a donné anx coquilles du genre Mélanie. Cet auteur is mis ce geure en rapport, on ne sait trop pourquoi, avec sou genre Mélampe (Conovule lamk.) el son gevie Cliton, démembré des Núritines. Voyez Muzaxiz.

\section{MÉLĖAGRE. Mcleagris.}

Genre que Muntfort a proposé dlans sa $\mathrm{Con}$ chyliologie systématique (tom. 2, pag. 206), pour une sons-division des Turbos de Linni, ceax dont la coquille est ombiliquée. Le Turonon pica lui aest de type. Personne, comme an peut bien le penser, n'a adopté ce geare. 


\section{NंÉLIDE்.}

M. Rang, dans son Manuel de Conchyliologie, a proposé d'établir sous cetté dénomination un reare nouveau très-voisin, à ce qu'il paroit, des 'Thélliys de Linné. M. Rang n'ayant donné sur ce nouveau geare que peu dexplications, n'en ayant présenlé uon plus aucune figure, nous nous contenterons de répéter textuellement la caracléristique qu'il en donae daus l'ouvrage précité.

"Animal pélagien, gélatioenx, transpareat - et limaciforme; la têle distincte et compreant - un voile membraneux, contourué en forme - d'entonnoir, garni iotérieurement de cirrbes * dirigés à l'extérieur, et du milieu duçuel s’é- lève une pelite trompe terminée par la bouche; " tentacules au nombre de deux, situés à la base "du voile, très-alongés, coniques, terminés par n une petite capsule, de laqnelle sort un organe * conique et rétractile; pied aussi long que l'a" nimal, mais extrêmement étroit, en forme de - sillon; brauchies furmées de deux stries peu ^ nombrenses de massues oblongues, arrondies à * lenr sommet, pédiculées à leur base et recou* vertes de perits tubercules; organes de la gín nération réunis au côté antérieur; anus plus en * arrière. *

A ces caractères, MI. Rang joint les observaticns suivantes: "Ce Mollusque est sans contredit * Irès-voisin des T'héthys, avec lesquelles nous * l'arions d'abord contondu; mais l'ćlude que - nous avons laite depuis de ce dernier, sur un - iodividu vivant, nous a engayé à leur affecter

* une différence générique fondée sur l'organi.

* sation toute différente dés branchies. La Mé-

" libée, qui aage très-bien en agitaut de cóté et

"dautre la partie postéricule de son corps,

¿ babile sur des plabtes errantes dans les mers

* du cap de Bonne-Espérance, où nous avoos

\ pu l'aliserver vivante peadant assez long-temps.

"Nous arons remarqué que les branchies tom-

* boient facilement pour peu qu'on les touclat.

n L'espèce qui sert de type an geare est la Me-

- libea rosea. Peul-être faudra-t-il y joindre

" quelques pelits animaux découverts par M. d'Or-

- bigny sur les côtes de Ia Rochelle, é qui pré-

" sentent pour organes de la respiration de j:e-

- Lites massues disposées sur deux rangées lon-

* gitudinales et dorsales."

Tels sont les seuls dérails dans lesquels nous puissions entrer in l'égard du genre Méiluce; nous prósumons que pilus ard il sera rémi in genre Théthys à titre de snus-genre, mais nous Jevons desirer que M. Rang lt lasse coubcilde d'une manière plus coaplète.

\section{MÉLINE. Melina.}

C'est ainsi que M. Schumacher nom me le genve Perne, institué depuis loog-temps par Lay!arck.
Celte nouvelle dénomination ae peut étre adoptée. Voyez l'ERnE.

\section{MELON.}

Nom vulgaire d'une très-belle espèce de Volute, Volpta melo des auteurs. Vojez Vouutr.

\section{MÉLOXGĠNE. Melongena.}

Daus son Essaid'un Systènze de Conchyliologic, M. Schumacher a proposé sous ce nom un démembrement tout-à-fait ioutile du genre Pyrale, auquel il donne pour type le Pyrula melongenu de Lamarck. Quand on songe que le genre Pyrule se lie d'une manière intime aux Fuseaux. et que probablemeat il sera supprimé, à plus forte raison les démembremens de Montfort et de M. Schumacher doirent-ils être rejetés. Voyez Pyrule.

\section{MÉLONIE. Melonia.}

Lamarck, dans son dernier ouvrage, a établi ce geare pour des coquilles mulitloculaires fossiles, que long-temps avant Fortis a voit décrites sons le nom de Discliolites, et dont Busc, dans sa Conchyliologie, avoit formé le geare Alvéoline. Il éloit nécessaire, en rendant justice à Bosc., d'adopter exclusivement Je nom qu'il avoit inposé al genre. (Vojez Alvéoline.) Celle dénomination de Mélonie, préférce par Lamark avoit l'inconvíuient d'avoir déja été employée par Muntfort pour d'autres coquilles appartenuat i un aotre genre.

\section{MÉLONIE. Melonis.}

Montfort, sous ce nnm, a proposé un petit genre de coquilles anuliloculaires cjui ne peut être adopté, étant le mèıe que cenx qu'il arnit deja faits sous les nnms de Cancride, Florilie, Clurysole, etc. Ce genre est compris dans celui des Nonionices de M. d'Orbigny. Iroyez SiaNIONINE.

\section{MEMNONITE.}

Nom que les anciens conchyliologues dnasoient i une coquille que l'on appeloit Volute memnonite, et qui appartient au genre Cọnce. Céroit le Conus virgo, ou une autre espèce que Bruguière. a nommée Conus distans, et pour laquelle Lamalck a censervé en françás la déuomination valgaire de Củne memnonite.

\section{MERCENAIRE. Merenaria.}

M. Schursiaclier, dans son Essai de Conchyliologie, a donué cornme nouveau yenre la Vemus merccnana de Liuné, qui ne dilfere ea rien des autres especes du genre dars lequel tous les auteurs la placent, We tels dímeriviemens a'cat 


\section{NI E S}

pas besoin d'être discutés; il suffit de les ciler pour qu'ils soient rejetés d'une bonne mérliode. Troyez VÉNus.

\section{MERE-PERLE. Perla mater.}

N. Schumacher a donnć ce nom aux coquilles que Lumarck avaut lui a réunies é genre, sous le now de Pintadines. Ce genre Piuladine se lie d'une manière insensible aux Avicules, et nous l'y arons joint. Rejetant le genre de Lamarck, nous n'adoptons. pas non plus celui de M. Sclaumacher.

\section{MÉrétrRICE.}

Nom que Lamarck a d'abord donné, au gense qu'il démembra des Vénus de Liané, êt auquel il donna plus lard la dénomination plus convenable de Cythérée. (Voy. ce mut.) MI. de Blainville, dans l'article Morzusque, a couservé ce nam pour une de ses nombreuses divisions des Véuus. Vojez également ce mot.

\section{MÉROÉ.}

Déjà Mr. Mégerle avoit proposé le démembrement des Donaces pour celles des espéccs qui, telles que le Donax meroe, mangruent de la dent latérale postérienre. Nous avons vin à l'urticle Dosace, aucquel nous renvoyous, que ce caraclère est de peu d'importance et complétement insuffisant pour la formation d'un genre. Celui qui dous occupe, proposé par M. Schumacher, est un double emploi du genre de M. MIérerle; daus tous les cas il ne peut être adopté. Voy'ez Donace.

\section{MIÉSAL.}

Nom donné par Adanson (Voy, au Sénég. $p l$. 10) à nne coquille qu'il place à tort dans sun genre Cérite; efle appartient aux 'Turritelles. Les auteurs ne l'ont point eacore mentioméé. C'est pourtant une espèce intéressaute, en ce gu'elle pourrait servir de passaye entre les Turritelles et le genre Proto, proposé par NI. Defrance. Voyez Tukrutelde.

\section{MÉSODESHE. MIesodesma.}

Depais long-temps nous nous étions aperç quilil existuit une grande conlusion parmi les éspìces des genres Crassatelle, Erycine et Amphidesme. En éludiant la cause de celte conlusion, nous reconnûnes qu'elle dépendoit d'une tausse appréciation de quelques caractères dont l'importance avoit échappé à Lamarck et à la plupart des auteurs qui le suivirent; ces caractères, surtout cenx du genre Erycine, furent cumpris de tclle sorte que quelques personues, et notamment N. Sowerby dans son Genera, allribuèrent à ce genre des coquilles qui ne lui ont jamais apparHist. Nat. des Vers. Tome II.
M $\mathrm{E} \mathrm{S}$

tenu, et cue Tamarck avoit rangées au nombre des Crassatelles; quelques espreces de Mactres se trouvoieut aussi dans le cas des Crassatelles que nous venous de mentionacr; enlin, des Amphidesmes, ct notamment celles conaues sous le bora de Donacilles, n'offroient pas les carantive propres au neure dans lequel elles c....nt corrporises. Cé qui nus étonna, c'est que cos coquilles, prises dans les genres Crassaletle, Mactre el Aaphidesme, frúsentent ideniquetront les nuêmes caractères, et en voulant faire acc:order ces cataclères avec ceux d'un rente déji connu, nous fû̀es bientût convaincu que cela élcil impossible, a uroins que d'éteadre les caracic̀res de quelques - uns d'entr'cux, el de remplacer aiusi une confusinn existante par me autre surle de difficulté. Nuns cruyons donc nécessirire pant les coquilles que nous venons de ciler, ainsi que pour plusieurs antres dont la connoissance est due aux recherches de MII. Quoy el Gaymard, d'établu' un nouveau genre auquel uous avons clonné le nom qui est en tếe de cet arlicle à cáuse de la dispositiun particutière que présente le ligameut. Nous conservions encore quelque durte surla nécessité de ce genre; nous desiriuns, avaut de le puilier, de connoitre l'animal, eł de nous assurer par ce moyen quil ne seroil pas rejeié comme sil avoit élé lait nniquement d'après lits coquilles.

II. Quoy, dnat le nom est déjâ placé lort haut dans la science, et qui, avec une grande modestic, la cultive d'une manière désintércssée, a bien voulu se dessaisir d'un animal du gente nouveau glue nous nous proposiuns de farre pour que nous puissions le caractériscr complétement, el que l'un ne pât en conséquence fatire d'objections séricuses à son établissement, deveru indis. pensabie.

L'animal du genre Mésodeswe oftie des caractères qui sont suffisans pour l'élablissement du geare. Il se distingue à la fuis des Mactres, et sans doute des (irassatelles, mais surtout de ce piemier par la briéveté des sipbous, qui scai tellecont cousts qu'à peive s'ils lont saillie en dessous du bord du manteau. Nous allons, all reste, donner la description extérieure de l'animal; on poul'ra du moins le comparer avec celui des genres près desquels il devra se placer. Cet animal est ovale, obloug, déprimé ; il est revếtu d'ua manteau mince, lransparent, dont le bord étroit, charau, forme nee bande continue qui s'ćlend du muscle postérieur à l'antériear. Les deax parties du manteau sont soudées dans les deux tiers postérieur's de leur étendue; ils forment ainsi un cul-de-sac assez considérable à l'extrémité duquel se trouvent les deux petits siphons, dont l'inférieur ou anal est beaucoup plus petit que l'autre. Ces siphons sont relirés en arrière par deux petits muscles rétracteurs, subtriangulaire, qui font a peine saillie dans le limbe du mantean et dont $\mathrm{Kk} \mathrm{k}$ * 
limpression sor la coquille est très-médiocre. Le pied est comprimé, subquadrangulaire, coriace, ua peu pointu en avant. Dans la direction de l'ouverture palléale, à la parlie médiane, dans un enfuncement silué entre la base du pied et le muscle adductenr antérieur, se trouve, entre deux petites lèvres charnues et transverses, une petite ouverture ovalaire, qui est celle de la bonche. Ces lèrres se continuent de cluaque côté cn une paire de petites palpes charuues, ovalaires, libres dans presque toute leur étendae, striées à lear face interne, et situées sur les parties supérieures da pied. La paire de palpes supérieure est plus grande que l'ioférieure, et partagée en deux prarties distiactes, dont l'une, l'inférieure, est plus raeubraneuse que l'anlre.

Nous avons vu, en décrivant les parties extérieures de l'animal, que son manteau présentoit à son extrémité postérieure deux petitcs ouvertures peu prolongées, représcntant les siphons. Lursque I'on a renversé le mantean en dehors, après l'avoir fendu jusqu'à l'origine du siphon branchial, on trouve à l'intériear, autour de ces ouverlures palléales, une petite frange ondulée un peu saillante, qui augmente, d'une manière assez notable, l'étendue des siphons. Celte frange est plus épaisse et plus courte pour le siphon branchial que pour celui de l'anus, car celui-ci est prolongé à lintérieur en un véritable tube continu. Cette disposition tieut certainement à celle des branchies.

En consultaut les divers ouvrages dans lesquels ont été représentés ou décrits des animaux a pprartenant aux Lamellibrancbes, on verra que leurs branchies se continucnt ordinairement au-dela du pied, se joigneat duns la ligne médiane et horizontalemens. Lorséue l'on examine l'animal placé sur le dos, cetle réunion des branclites se fait immédiatement au-dessous de l'extrémité postérieure du pied. Quelquefois, lorsque l'animal est pourvu de longs siphons, ces branchies se prolongent dans leur cavité, cumme on peut le remarquer dans les Pholades, les Myes, etc.

En voyant l'extrềne raccourcissement des siphons daus l'animal qui nous occupe, nous compticas trouver une disposition analogue des branchies à ce que nous connoissions dans des cas semblables; nais il n'en a pas élé ainsi : au lieu de se prolonger en arrière, les branchies sont comme tronquées à leurs parties postérieures, et leur soudure se lait sur le bord tronqué, qui a une direction perpendiculaire relativement à l'axe longitudinal. L'anus est situé immédiatement auçessous de l'extrémité supérieure de ce bord, à lendroit de sajooction avec le corps. Les brancbies sont inégales; le feuillet externe, un peu auriculiformc, est beaucoup plus petit que l'autre. Ces branchies sont striées de cbarque côlé, l'iaterne presque longitudinalemeat, l'externe obliquement. Entre les deux branchies du cúté droil, à peu près au tiers antérieur de leur longueur, on remarque une petite fissure dans la partie la plas profonde de leur jonction.: celte fissure est l'ouverture de l'oviducte. N'ayaut qu'un seul animal de Blésodesme à nntre disposition, nous n'avons pu en faire une dissection complète ll eût élé important de voir quelle espèce de modificalion les organes de la circulaliou ont éprouvée par suite de l'arrangement particulier des branclies.

D'après ce qui précède, bous pouvons caractériser le genre Mésodesme de la mauière suivante.

\section{CARACTERES GÉNÉRIQUES.}

Animalovalaire ou suburigone, aplati; les lobes du manteau réunis dans les deux tiers postérieurs de leur longuenr, et ponrvus à leur extrémité postérieure de denx ouvertures très-courtes, prolongées à l'intérieut par une rnembrane très-mince; pied très-aplati, quadrangulaire, couvert à son extrémité postérieure par les branchies, tronquée's et soudées à leur extrénité postérieure; brauchies externes obliques, très-courtes, subauriculees; branchies internes quadrangulaires; anus placé au-dessous des brunclies. Coquille ovale, transverse ou triangulaire, épaisse, ordinairenent close; charuière présentant dans son unilieu une lussette étroite et triangulaire pour le ligament, et de claque côté une dent oblongue et simple.

Les coquilles qui appartiennent au geare Mésodesmes sont généralement épaisses, solides, transverses, parfaitement closes, si ce u'est duas une espèce dans laquelle l'extrémité postérieure est un pen bâillante; leur cbarnière est très-remarquable, épaisse, solide: on y troure dans la partie moyeaue une calvité souvent en forme de cuilleron. laquelle donase insertion à un ligament fort épais. De cbaque côté de celle cavité est placée une grande dent oblique, qui sengage dans la valve opposée daus une cavité véciproque crensée immédialement au-dessous du bord.

Nous ne connoissons encore que des espèces vivantes dans ce genre; la plupart sout originaires des mer's ausirales; il en est une cependant que l'on trouve dans la Mléditerranée et sur wos côtes de l'Océan, où clle n'est pas extrêrnement rare. Nous donnerons la description de celles qui sunt venucs à notre conuoissance.

\section{Noв.}

M. testầ elongato-transversâ, trigonâ, posticè valdè truncatá, donaciformi, striis exilibus transversis ornata, albo-fucescente; marginisus integris; umbonibus minimis.

Mactra donacia. Lasr. Anim. sans vert. tom. 5. pag. 479. $n^{\circ} \cdot 28$.

Celle coquille, par ses caractères, n'appartient par certainement au genre Mactre, dans lequel 
Lanarck l'a placée. Par sa forme, elle se confondroit facilement avec les Donaces; car, comme laus ece genre, le cólé postérieur est furtement tonque. Eillc est dépriacée, lrausverse, triang"laire, épaisse, solide, très-iuéquilatćrale; le éôté justérieut extrömenent court, trongné un pen obliquenent; la surface extérieure est lisse, brillanle, d'une jaune-corné, quelguefois verdatre; des stites d'accroissement tiues et aullipliées, zo is peu rigulières, se voient sur celte surlace, qui est revóue d'un épiderme mince, non ćrail. leux. A liutéricur la coquille est blanche; le euilleron dn ligameot fail unc saillie peu considérable a l'ualérieur des valves; il est profund. Au-dessus de lui est silué une pelite değ triangulaiie à côté de laquelle te ligament se prolonge eo dessous du crochet jusquà l'extćrieur, où il se montre dans un point de peu d'tendue. Ia dent cardinale postéticure est cuurte, furt étroite; la dent luté* ale antérieure, ou plutól supérieure, est alongéc sur le bord, et a au mcins deux fuis la longueur de l'autre. La surface interne est Llanclie, lisse, polie; l'impression palléale est assez large, surtout à son extrémité antélieure. L'éclubcrure qu'elle forme à son extrémité postérieure est peu prulunde; elle l'est plus cepentant qur dans la jlupart des autres espèces.

Celle coquille, que l'ou troure à la Nouvelle. 'L! lande, est restée rare jusqu'à présent dans les callections. Le iluséum, long-temps, n'en posséda 'iu'une valve. Longueur 70 millia. Il existe des individus plus grands.

2. Mìsodesaz de Clıemuitz. Mesudesma Chemnitzii. Nов.

D1. testâ ovato-oblongá, transversâ, suharquilatterá, crussâ, soludi, luteo-virescente, lavigata, intus alba; cardine incrassuto; fossuld ligainenti profundi, bast producti; dentibus cardinalibus subcqualibus.

Cazar. Conch. cab. tom. 6. tab. 3. fig. 19. 20.

Lorsque cellc espèce fut rapporléc, dans ees deroiers temps, par les expéditious scientifiques fuites par ordre dil gouvernement, il sembla qu'elle étoit nouvelle, et cependant depuis longterops elle avoit été ligurée dans l'ouvrage de Chemaitz, qui la confondit avec des Myes; elle s'eo distingue cepcudad éminemment, et tous ses caracières la portabl an nombre des espèces da notre nouveau geore. Elle dillère de ses congrénères par sa forme orale, transverse, et par l'épaisseur remarquable de son test; elle est jresqu'équila:érale, jamais bäillante; sa surlace extérieure est revétue d'un épiderme d'un jauneverdatre assez mince et transparent, au-dessous duq̣uel la coguille est blancbe; les crochets soat très-petiıs, à peine saillans au-dehors. An-dessous d'eux, el sur le bord cardinal, se présente une carité étroile et profonde donnant insertion à un ligament fort epais, qui, par son extrémité supérieuse, se montre un peu à l'extérieur : la base de re cuillecon, qui ressemble is une goulière miangulaire, fuit une saillie assez considcrable dans l'intérieur des valves. De chaque cólé sc trouve une dcol ípuisse el divergente, légèreasent clugrinée sar les parties latúrales; sur la valve ganche se trouve une petite dent cardinale, raduneulaire; sur le tôlé aotérieur de l'autre elle cost produite par le relivenient assez considérab!e du bord du cuilleron. A l'in ćricur, celle coquille est blanche. Limpression pallíale est large, mais son échancrure postérieure est très-courte.

Celle espèce a ćté recueillic dans l'Océan indien, à Amboinc, ainsi que sur plusieurs points de l'Océan pacifique. longueur 34 millim., largeur 62.

\section{Mísodesme de Quoj. Mesodesma Puoji.} Nus.

MI. testá ovato-trigonâ, transversâ, obliquè truncata, trunsversin irreguluriter striatá, fucescente; latere postico breviori.

C'est l'animal de celle espèce que nous arons pu examines, et au unoyen duquel nous avons pu caractériser le genre d'une manière plus complète. Elle a quelque ressemblance avec la Mésodesme donacie. Lillc est ovale, trignone, plus large proportiunoellement que cette dernière: son cólé postérieur est fort court, tronqué, ce qui la rend très-inéquilatérale; son extrérnilé autćrieute est arrondie et obtuse; les valves, partaiteruent eloses, sont épaisses, d'un brunroussatre, légèremeal striées par des accroissemens muliipliés el irréguliers. A l'intérieur elle est lisse, polie, d'un bla oc-grisálre. Sa charnière est plus étroite que duns l'espèce qui précède; la dent cardinale postérieure est courte et épaisse; l'aotérieure, plus prologgte, s'étend sur une partie du bord supérieur; l'impression du manteau est large, surtout du côté antérieur; l'impression du rélracteur des siphoos est très-cuurte. II.I. Quoy el Gayruard out recueilli cetle espèce dans les mers de la Nouvelle-Zélande. Longueur 27 millim., largeur 43.

4. Mlésodesme striée. Mesodesma striata. NoB.

NI. testâ triboni, compressâ, albâ, crassí, strus transversis crassis sulciformibus ornatí; umbonbus minimis, lavigatis.

Mactra striata. LıN. pag. 305̃7. $n^{\circ} .5$.

Crassutella striata. Lami. Anim. s. vert. tom. 5. pag. 483. $n^{\circ}$. II.

Erycina striata. Sow. Gen. of Shells. $n^{\circ}, 10$. fig. 2 :

Chexs. Conch. tom. 6. tab. 22. fig. 22a. 223.

Escrex. pl. 254. fig. 4. 
Cette espèce, comme on le voit, a été transportée daus des genres divers; selon la manière dont on a envisingé ses caractères, elle ne peut rester dans aucun des gen:es indiqués par la synonymie, landis que ses caracteres la placent très-bien au nombre des Mésodesmes. Celle coquille est équilatérale, triangulaire, aplatie, blanche; son test est épais; il est orué en deliors d'un grand nombre de stries transverses, régulières, concentriques, çui disparoissent sur les crochats, qui sont entičteneut lisses. A l'intéricur Ia coquille est blanche, lisse, polic; les iupressions musculaires que l'on y voit sunt petiles et ovalaires; la clıarnière est assez étruile. Sur la valve droite, de charue côlé d'un cuilleron trèscourt en goatlière, sunt placées les deux deuls cardinales divergentes, dont la postérienre est un peu plus lonoue que l'äulre; sur la valve gauclie, entre le cuillecon et la dent cardinale postéricure, se trouve une dent cardinale étroite ei courte, qui suil la direction de la prenière. Celle troisième dcut à la churnière de cette espèce de Mésodesme suthroit, an déliut d'autres caractères, pour la distinguer de ses congénères. On trouve celte coquille daos les mers de la Nouvelle-Hallande. Eile est longue de 17 mill. et large de 21 .

5. MÉsodesme donacille. Mesodesma donacilla. Noв.

M. testî avato-trigonâ, transversâ, inaquilateri, utroque latere ob́tusâ, lavigutí; albidofulpo fusconue varicgatâ, intùs albâ; cardine incrassato.

Mactra cornea. Pour, Test. des Deux-Sic. tom. 2. tab. 19. fig. $9-11$.

Amplidesma donacilla. LAмк. Anim. s. vert. tom. 5. pag. 490. $n^{\circ}$. 2.

Erycina plebeia. Sow. Gen. of Shells. n॰. 10. fig. 3.

Lorsque Lamarck proprosa le genre Amphidesme, il prit cette coquille pour type, et lii imposa le noon de Dozacille; depuis il joignit à ce genre plusieurs autres espèces qui présentent des oaractères diflérens, et l'Amplidesme panachée peut en donner l'idée. Conme le genre Amphidesme cortenoit en outre d'autses coquilles qui pouvoient rentrer lacilement dans d'inutres grenres, nous sentimes la nécessilé de le réfurmer, et par suile la coquille qui nous occupe fut reportée dans le genre Mésndesme, où elle se truave nalurellement en rapl ort par lous ses caractères avec les au:res espicces du toême genre. Celte coquille es: crale, trigoue, oblongue, transverse, inćquilatérale, furt épaisse, lisse, ohtuse ì ses extrémités, le plus souvent blanche, et ornće de taches ordinairement rayonnantes, d'un brun plus ou moins foncé; elle est quelquefnis roussâtic ou rougeâtı ; à l'intérieur elle est d'un blanc-cornć; l'impression palléale est assez large, et son échancrure postérieure est courte et en demi-cercle; la charaière est épaisse; la fosselle du ligament est très-profonde, étroite, en gouttière, et il peine saillante à la base; ses bords se relčcent d'une manière remarquable, et il semblervit, a cause de cela, qu'il existe quatre dents carclinales sur chaque valve, quoiqu'en réalité il "y'y en ail que denx. Ces denls cardius?es sont épaisses, triangulaires; l'antérieure esı un peu plus courle que la postérieure.

Celle eoquille se lirave dans la Médalerranée et dans l'Océin curopéen. Elle est longue de 14 millim. et latge de 23.

6. Mesonesure de Gaymard. Mesodesma Gaymardi. Noв.

M. testâ ollongî, trigönâ, posticè truncalâ, brrvissimi, inacquiluterâ, anticè obturâ, alhâa, substriata; cardine bievi; fossula ligamenti obliqua.

Julie corquille que nous nous faisons un plaisir de dédicr à M. Gaymard, auquel la zoologie est redevable de tant de laborieuses recherches faites avec ardenr et on dédain de tous les périls. Celle coqquille lut trouvée à la Nouvelle-Zélande; elle ressemble à une Donace, et présente quelques rapports avec la Mésodesme de Quoy; mais elle dillère de toutes les espèces que nous connoissuns actuellement. Elle est triangulaire, oblongue, tıansverse, tronquée fortemeat à son cưlé postéricur : ce côté est extrêmement court, ruguenx ou irrégulièrement strié; le côté ancériour est obtus, trc̀s-arrondi, large; le bord inférieur est presque parallc̀le au supéricur; la jonction de ce bord inférieur avec le postéricur produil un aogle assez aiun; les crochets sont très-petits; la surface extérieure est toute blanclie, sous un épiderare d'un jauue-verdâtre très-caduc. A l'intérieur cette coquille est d'un blanc laileux trèsbrillaul; limpression palléale est assez large, et son écliancrure postéricure est fort courte; la charuièré, placéc au-dessous des crochets, présente un cuilleron en gouttière, dont $l_{2}$ base est saillase daus l'intérieur des valves et obliquement t'ouquée. Cette fosselle du ligament est elle.même ohliyue; elle est accompagnée de chaque cólé d'uue dent cardinale, épaisse, dont la postérieure est de moilié moins longue que laatre. Le seul individu que nous possćdions de celle espèce rare a 15 willin. de long et 25 de large. Noв.

7. Mésodesme trigone. Mesodesma trigona.

M. testâ ovato-trigonâ, subinaquilaterâ, inflatâ, crassâ, irreguluriter striato-rngoosâ, albâ, posticè subargulatâ; natibus productis, subcordatis.

Cette espece a beaucoup d'analogie avec la 


\section{E T}

Ilísodesme striéc: elle est triangulaire, subinéquilatérale; son côté postérieur, un peu trongqué, est termine par un angle assez aigu à sa jonction a vec le bord inférieur. Les valves sont !rès-épaisses et lrès-solides; leur surface extérieure est tantôt lisse, tautôt couverte te sillons iwréruliers et transverses; à l'intéricur clles somt blaucluce. L'impression palléale, assez large, est à peiue éclıanç̣éc à son extrémité posiérieure; la charnière est épaisse, courte, comme dans la llésodesme donacille; les bords de la cavité du ligameat se relèveat au niveau de la lame cardinale, et produiseat sur le bord quatrc deasts sur la valve droite et deux sculement sur la gauche, parce cue les bords dont nous parlons soni beaucoup moins saillans sur la valve de ce côlé. Les dents cardinales sont iaégales; lu postćrieure est courte et pyramidale.

Celle coquille, qui est répandue dans les collections depuis longr-temps, nous paroît inédite; nous l'avons toujour's vue placée parmi les Crassatelles. Notre ami, M. Lesson, nous a assuré qu'elle se trouvoit au port Praslia, Nourelle-Jullande. Les graods individus ant 28 millim. de long et 33 de large.

\section{MÉSOMYONE. Mlesomyona.}

M. Latreille, dans son ouvrage intitule Familles naturelles du Règne animal, a proposé de remplacer par cette dénoxination celle de Monomyaire qu'avoit proposée Lamarck. Il est vrai que la graude secrion des Mollusques acéphales, à laquelle M. Latreille applique la nouvelle dénomination, ne correspond pas entièrement aux Monomyaires de l'auteur des Animaux sans vertèbres; elle représenteroit plutôt celte partie des Mollusques que M. Cuvier a désiguée sous le nom d'Ostracées à un seul muscle. Nous verrons à l'urticle Moncuspues quelle distribution devà êtse préférée.

\section{MÉTAPTĖRE. NLtaptera.}

Geare proposé par M. Rafioesque dans sa Monographie des Coquilles de l'Ohio, insérée dans les Annales générales des Sciences de MiM. Bory de St. Vincent et Drapiez, pour un démembrencut des Unio, quill caractérise de la manière suivante: coyuille ovale, triangulaire, dilatée en aile postérienremeut; ligameat incliné sur l'aile; dent bilobée, créaelée; deat lamellaire courbée, détachée du bord de l'aile; axe extra-médial; contour à peine épaissi; truis impressions musculaires; Mollusque semblable à celui de l'Unio. Ce genre, établi sur des formes extérieures et surtout sur le prolongement en forme ciaile du côté postérieur, ne peut être conservé; à peine pourroit-il former une division très-secondaire parmi les Mulettes. Voyez ce mot.

\section{I L}

\section{MICROPODE. Micropoda.}

M. Gray, dans sa Distribution méthodique des Mollusques, inserréc daus le Bulletin des Annonces scientifiques, a donné ce noun à une famille qui ue correspond pas, comme l'a cru M. do I'erussac, aux Dimyaires la mellipedes de Lamarck, mais bien à une pirtie de ses llonomyaires ostracćes et pectinides. Daus cet ordre des Micropodes, M. Gray plase les genres Pejgae, Initr. et Anomye, dont les animax ont en ellet le pied réduit à l'élat rudimentaire, ou n'eu unt poina du tout. Nous ue pensons pas que celle division soit adoplée; les lamilles proposées par Lamarck élaust caraclérisées d'une ranière plus complète, sont par cooséruent prél'érables. Voy. Ostracées el Pecrinides.

\section{MICROPTERYGIENS. Micropterygia.}

M. Latreille nomme ainsi le second ordre quäil propose dans la classe des Ptéropodes. Cet oidre ae renferme qu'une seule famillo, celle des Pueumodermites, qui elle-même ne contient que les deux geares Gastéroptère et Pneumoderne. Cet ordre ne nous parcit pas nécessaire, les animaux pumr lesquels il a élé institué ne présentant pas, à ce qu'il nons semble, des caractères sulfisans pour être si fortement séparés des autres Ptéropodes. Voyez Prénoredis.

\section{MICROSTOMÆ.}

M. Menke, dars son Catalogiue raisonné des Mollusques, a désigné de cche manière une section parmi les Agatlines; elle contical celles des espèces qui nal l'ouverture étroite, ei dont Montfurt avoit fait son geure Liguus. Foyez AcsTHINE.

\section{MIGA.}

Adanson (Foy. au Sénig. pag. $116, p l .8$ ) donue ce nom à une espèce bien caractúriséc du geare lbuccin. Brugnicre, dans le $1^{\mathrm{cr}}$. volume de ce Diclionnaire, lit decrite suus le non de Bus:cin miga, denominatiou qui a été adoptée par Lamarck. Voyez Buccis.

\section{MILIOLE. MIilivla.}

Sous ce nom, Lamarck avoil cré: un genre pour de petites coquilles microscopiques unultiloculaires, hizartes par le mode d'enrouleneot des loges. Dans ce genre, Lamarck conlondoit plusieurs types particuliers que M. d'Orbigny distingua, ce qui l'amena à former une famille avec les groupes qui sortirent des Milioles de Lamarck. Il donna à certe famille le com d'Agatbistègues. Voyez ce mot et Céphalopodes.

\section{MILIOLITE.}

Geare établi par Montfort pour une coquille 
qui appartient au genre Mlélonie de Lamarck. Voyez ce mot, dinsi que Alvéolise.

\section{MILLĖPES,}

Klein (Method, ostrac. pag. 99) a lormé ce geare pour une sous-division des Sirombes, yui répond ties-bieu au genre Plérocère. Voyez ce m.ol.

\section{MILLEPORITE. Milleporita.}

M. Latreille (Familles naturelles dus Règne animal) a divisé l's Polythalames décapodes en quatre tribus : la dernière, qu'il a désignée sous le nom de Milleporite, renlerme un assez grand nombre de genres qui nous semblent bien bétérogènes. Voici comment ce groupe se trouve caractérisé : la coquille n'offre plus de siphon apparea!, ni d'ouverture extérieure, ou, si elle cxiste, clle est entièrement appliquée sur le tour précédent, l'exlrémité externe du dernier s'avanģant et se confondant avec lui, L'intérieur de la coquille est divisé en une infinité de petites loges, où elle est plutôt poreuse que celluleuse; la forme est tantôl discoidale et très-aplatie, lantôt presque globulause et presque ovcille. Les genres compris dans ce groupe, au nombre de seize, y sont distribués de la manière suivante. Quoique M. Latreille se soil abstenu de citer les genres de Montlort qui Ini ont semblé douteux, il u'en a pas moins admis quelgues autres qu'il est impossible d'adopter.

I. Coquille ayant une ouverture, mais appliquée sur le lour précédent et cachée.

a. Iatfrieur de la coquille roulé en spirale.

1\%. Un ombilic ou un manelon a centre.

Archidie, Ilote.

20. Poiut d'ombilic ai de mamelon au centre.

\section{Hélénıde.}

7. Intérieur de la coquille rayonaée.

$$
\text { Cellulie, Célibe. }
$$

1i. Coquilie n'ayant aucune trace douverture.

a. Cuquille subglobulerse ou sutoroide.

$$
\text { Borklie, Miliolite. }
$$

$$
\text { Clausulie, Gyrogonite. }
$$

f. Coquille discoidale.

c. Coquille rayonnée.

$$
\text { Roialie, Ėgéone. }
$$

d. Corquille à cercle concenırique.

\section{I S}

Tinopore, Sidamlie, Nummulie.

\section{Licophre, Discolıte.}

Parai ces genres de Moutfort, qui presque tous peavent être des sujets d'opinions diftéreates et de discussion, nous remarquerons que les Cellulies et les Célibes ne sembleut avoir aucun rapport cntre eux, si l'on en juge d'après sa description. Nous ferons observer également que le geare Gyrogosite ayant élé tccomu pour une graiue de chara ne doil plus se trouver ici, et nous ajonterons que les trois geures Borélie, Miliolıte et Clausulie de Nonlfort ont été laits pour trois especces d'uu même geare que lamarck a nommé Mélonie, genre quavant Lamarck Bosc avoit établi sous le uom d'Alvéoline. (Voyez ce mot.) Quant au dernier gronpe, il présente des Clémens tout-à-fait bélérogénes : d'abord, les yeures Tinopore el Sidćrolite n'en doivent former qu'un seul; ils ont des rapport avec les Nummulies. Ce dernier comprend-il les Lenticuliles de Lamaick? Cela est probable, mais M. Latreille ne le dit pas. Les deux autres geares sont reconnus pour des duu. bles emplois, le premier du genre Nusacute, et le second d'un Polypier pierreux foramiuifere, plus connu sous le nom dOrbunte. Nous reuvoyons, pour d'aulres détails, aux wots des yenres cités dans cet article.

\section{MINARET.}

Nam vulgaire que l'on donne quelquefois aux espèces alongées de Nitres. Voyez Mitru.

\section{MINIME.}

Dénomiuation valgaire d'une espèce de Cỏue que les auteuis ont décrile sous le mêne nom. Vojez l'art. Cóns dás le ier. volume de ce Dicliouudire.

\section{MINJAC.}

Nom donné par Adanson (Voy. au Sónég. pag. $109, p l .7)$ a une coquille du grand genre Buccin de liuné, Buccınum oleaıum, qui reatre aujơr. d'lyui daus le genre Tonne de Lamarck. C'est le Dolium olearium de cel auteur.

\section{MIRAN.}

C'est ainsi qu'Adanson (Yroy. au Sénog. pağ. 5o, $p l .4$ ) nomme une coquille qui est un Buccin pour les auteurs modernes, Buccinum niutabile de Bruguière, représentée avec son animal; elle a servi de type au gente $V$ is, établi par Adanson ot adopté depuis par la plupart des auteurs pour d'aulres coquilies géuŕralemen: plus alongées. Voyez Vis.

\section{MIISILE.}

Genre proposé par Moulfort (Conch. syst. tonı. 1, pug. 295) pour un petil corps fort singulier 
qui se trouve virant dans l'Adriatique et fossile aux eavirons de Sienne. Ce genre est caractérisé de la taanière suivante par son anteur.

\section{CAR ACTÉRS GÉ NÉRIQUES.}

Coquille libre, univalve, cloisonnće, droite et formée en cruche un pen aplatic, carénée et arunée sur un des còtés; bouclie ovale, ouverte; cloisons unies; siphon inconıu. Le Mlisile noumıé Misile aquaire, Misilus aquatifer par Montfort, est un pelit corps ovale, aplati, muni d'une crêle profondément découpre, qui s'étend seulement sur un des còtés. Ce pelit corpss paroit si singulier et si anomal, que quelqques anteurs ne le rangent qu'avec doute parmi les Mollusques.

\section{MITRE. Mitra.}

Il est peu de genres parmi les Mollusques qui offrent des coquilles dont les formes soient plus agréables et les couleurs plus vives et mieux distribuces; voisines des Volutes, les Mitres, quant à l'animal, doivent en différer pen : quoiqqu'il ae soit point encore connu, les rapports des coquilles sont si grands qu'il est impossible de nier leur anulogie. La plupart des auteurs anciens connurent dus coquilles de ce genre, mais, n'établissant de distinction parmi elles que d'après les formes, ou mème les accidens extérienrs, ils les confondirent indistinctement avec des genres fort différens, principalement avec des Buccios. Linué lui-mème les rangrea dans les Volutes, ce que fitent Bruguière et ses autres instateurs. La. marck est le premier qui ait séparéles Mitres des Volntes de linné daus le Système des Animaux sans vertébres, 1801 . Il le conserva depuis dans ses autres uuvrages. Monifort, d'après les formes extérieures seulement, divisa le genre Mitre de Lamarck en deux autres, les Minaress et les Mitres. Celte division n'est poiot motivêe par de hons caractères; aussi la plupart des auteurs n'adoptèrent pas cente opinion, et le genre Mitre resta dans son entier jusqu'au momeni où MI. Sowerby proposa d'en démenbrer, sous le now de Conelix, un perit geure contenant toutes les espèces qui ont à peu près la forme d'un cône on d'une olive, et qui ont un assez grand nombre de plis à la columelle. Ce démembrement, à notre avis, ne peut, pas plus que celui de MInntfort, Ére admis comme genre, mais seulement comne des sousdivisions favorables à la déterminatiun des espèces. les rapports des Nitres avec les Volutes sont si évidens, que l'on a généralement fort peu varié sur la place que ce genre devoit occuper dans la série.

Cinfondı, comae nous l'avons dit, par Linné et Bruguière a vec les Volutes, Lamarck, en le créant, le laissa tout près de ce genre. M. De Roissy, dans le Buffon de Sonnini, adopta l'opinion de Lamarck, et l'appuya judicieusement.
Dans sa Physiologie zoologique, Lamarck conserva les mêmes rapports que dans le Systeme; ce qu'il fit aussi dans l'Extrait du Cours et dans son dernier ouvrage, où il retiat sa famille des Columellaires. Montfort plaça les Minarets après les Pleurotomes et à cöté des Turbit:elles, qu'il rapprocha des Mlitres, en rompant ainsi les rapports les plus naturels. M. Cuvier, en conservant le genre Volute de Linné, dut y apporterdes clanagemeos d'après les travaux les plus modernes; il Te sous-divisa en plusieurs sous-genres, dont l'un est consacré aux Mlities de Lamarck. M. Ferussac, dans les Tubleuux syslématiques des Nollusques, a conservé les Mlitres dans le voisinage des Volutes, et, de ces deux genres avec celii des Vis, il en a fuit la famille des Volutes, qui est loin de répondre à la famille des Columellaires de M. Lamarck. M. de Blainville (Traité do Malacologie) a réuni les Mires, les Volutes et plusieurs autres genres dans la famille des Anrystomes; et MI. Latreille, dans ses Familles du Règn! animal, a conservé sans clangemens la funillo des Columellaires de Lamarck : les Mitres sy troulvent cunséquemwent dans les mêmes rapports.

Les Mitres sont des coq̨uilles qृui habitent principalement les mers équaroriales; el'es diminuent et disparoissent à mesure que l'oo s'éloigne des mers chandes. Quoique les collioes subapenniennes présenteut à létat fossile plusicurs grandes espèces, on n'en relronve plus anjourd'bui que de petites dans la Méditerranée, d'espèces dillérentes, et elles y sont fort rarcs; les environs de de Paris eu offient aussi un assez grand nombre dont on ue connoit plus les analogues vivans. l.e genre Mitre peut se caractériser de la inaniùre suivante.

\section{CARACTERES GÉNÉRIQUES.}

Animal inconnu, mais probablement voisin de celui des Volutes; coquille turriculée, subfusiforrae à spire pointue au sommet, à base échancrée et sans canal; columelle chargée de plis pirrallèles eotr'ux, trinsverses, et dont les inti"rieurs sont les plus petits; loorl columellaire mince et appliqué.

Il est impossible de conlester la grande analsgie qui existe entre les Mitres et les Volutes. Quoiqgue dans la plupart des espèces la constance des caracteres sort suffisante pour les distiaguer lucilcmeat, il en est quelques - mes cependant qui, comme dans la plupart des antres genres, éclappent à la règle commune, et viennent se placer sur lenrs limites. Dans ces coquilles les phis, all lieu d'être inégaux, sont parfaitement egaux entr'eux, de sorte que lon ne sauroit dire si ces espéces sont plutót des Mitres que des Volutes, relativement anx forates extérieures. La plupart des Mitres sont parfaitemeat reconuoissalsles, 


\section{4 年门}

parce qu'clles son génírucrnent plus étroiles, plus alongées proportionucllement que les Volules. Mlais il est encore, sour ce rapprorl, des espices dans les deux genres qui les lient d'une manière inline; il esi mème quelques - naes des espèces de Mlitres qui semblent faire le passage vers les Cónes taut leur forme les rapproche de reux-ci. Celte forme, aux yeux de quelques anteurs, a paru assez bizarre pour mériter la création d'un genre particulier, que les uus, avec i1. Schumacher, nonmeat Imbricuire, et les autres, avec NI. Sowerlyy, nomment Conalix. (ie démembrecrent, qui se lie d'une manière inlime aux Nlitres, ne peut être reçu; à peine s'il derroit former une division sous-géaérique de la moindre valeur.

Le genre Mlitre, nalurel dans son ensemble, contient un très-grand nombre l'espèces, loutes rcasarquables par leur's formes elégantes et la richesse étonnan!e de leurs cuuleurs. Les terrains terliaires, qui recèleui un si grand numbre de corps organisés, renferment aussi un assez bon nonbre d'espèces du geare Nlitie, dont la plupart participeat par leur élégance à la beauté du genre.

\section{Nов.}

1. Mrtre de Lamarcl. Mitra Lamarckii.

M1. testâ elongato-turritâ, acuminatâ, alhâa, maculis mfis quadratis quinque seriatim cunctá; sirrïs transversis, obsolctis, punclatis ; aperturá subsemilunari, clongatá, alba; columelli quadriplicatâ.

Très-belle espèce de Mitre que nous croyons nauvelle, et que nous dédiuns a la mémoire de l'illusure Lamarck. Elle a queligues rapports a vec la Mitre cardinale, mais elle cn dillere d'une uanière essentielle, tant par l'alongement plus considérable de sa spire que par une disposition particulière de ses couleurs; elte est alongée, subturriculée, pointue au sommel, ayant le dernier lour un peu ventru et un peu plus long que le reste de la spire; celle spire est formée de huit tours légèrement convexes, ornés principalemen: ì leurs parties supérieures el inférieures de stries obsolètes, transverses, punctuées finement dans toute leur longucm. La suture est simple, peu profonde. L'ouverture est alongće, un peu oblique, atténuée supérieurement: elle est toute blanche en dedans; son bord droit est simple el tranchant. La columelle porte dans sa longueur quatre plis obliques el inégaux. Eu debor's celle coquille, sur an fond blauc laiteux, esi ornée sur le dernier tour de cinq rangées de grandes taches tan ves quadrangulaires de grandeurs inégales. Les tours sui$\checkmark a n s$ nofirent que deux rangées de ces tacbes.

Cette belle coquille, extrêmement rare jusqu'à présent dans les collections, est longue de $7^{\circ}$ millim. Sa patrie est inconnue.

\section{I T}

2. Mitre cardinale. Mitra curdinalis.

II. testí suato-acuti, transversim striatá, puncirs minutis perforati, alba; maculis spadiceis et plurimùn tessellatis, seriatis; columelli quinque plicatô.

Lister, Conch. tab. 858. fig. 65.

Gualt. Test. tab. 53. fig. 9. ad dexteram.

SEBA, MILs. tom. 3. tab. 5o. fig. 50. 51.

Kxora, Vergn. tom. 4. tab. 28. fig. 3.

Voluta pertusa. Bons, Mus. tom. 9. fg. II. 12.

Martixi, Conch.toni. 4. tab. 147. fig. 1358. 1359.

Voluta cardinalis. Gares. pag. 3458. no. $n^{3}$.

Evcres. pl. 369. fig. 3. a. b.

Mitra cardinalis. Ann. ibid. pag. 199. $n^{\circ} .6$.

LAIx. Anim. sans vert. tom. 71. pag. 301. $n^{n} .6$.

Ia Mitre cardinale est généralemeut plus ventrue que l'espèce que nous avons précédemment décrites. Sa spire conique el pointue est composée de neuf à dix tours presque plats, à suture simple, et couverts dans toutc leur étendue de stries superficielles el transverses, distantes, très-finemeut ponctuées; le demier tour, plus rrand que le reste de la spire, est lui uiêtne strié conune celui qui précède; l'ouverture qui le terusine est alongée, élroite, altéuućt à ses deux extrémités. Le bord droil, épaissi daus loute sa lougueur, est armé d'un graud noubbre de dentelures forl aiguës, qui correspondent par leur base aux stries de lextérieur. La columelle est oblique, suivie d'un bord gauche calleux à la base, et garnie de cinq plis inégaux : celte partie est toute blanche, ainsi que l'nutéricur de l'ouverture. Ea dehor's, cetle Mitre présente, sur un lord blanc, quelquefois un peu nébuleux de violâure, douze a qualorze séries de ponctualions quadrangulaires, dont l'une, plus large, est située sur. le milieu du dernier tour.

Cette coquille, assez rare dans les collections, est longue de $6 a$ à $6 j$ aillim. Elle vient de l"Océan indien.

\section{Mrtre fleurie. Mitra versiculor.}

M. tostâ subfusifonni, lutescente, albo-nifo fuscoque maculata et nebulosá; stris trunsversis, puncticulatis ; labro crenulato; columellá quadriplicati.

Mitra versicolor. MIARTrNs, Conch.fig. 23.

Voluta nubils. G мьL. pag. 3450. n०. 145.

Lamx. Anim. sans vert. tom. 7. pag. $30 z$. $n^{\circ} .8$.

Mitra versicolor. Ann. ibid. $n^{\circ} .8$. 


\section{I T}

Celle espèce de Mitre a de la ressemblance avec la Mitue cardinale; clle est cependaut plus ulongée, moins ventrue; le dernicr lour est proportionnellemeat plus courl; la spirc conique et pointue cst composce de dix tours convexes, is suture simple, et couverts de stries superficielles rapprochées, Irc̀s-finemeut ponciuces; l'ouverture est toute blanche; le bord droit tranchant ct garni de pelites dentelnres dans toute sa longueur, lesquelles, par leur base, correspondent aux stries extérieures. La columelle est arrondie, oblique; le bord gaache qui la suit est très-court, en bourrelet, décurrent; elle est garnie de quatre plis inég jux et obliques. Les couleurs à l'extérieur sont un pen variables; elles cousistent en taclies brunes el assez grandes, irrógulières, situées à la partie supérieure des tours; une zone plus obscure de taches qui se confondent davantage se voit a à la base du deraier tour. Outre les deux zones, on remarque dans leur intervalle un grand nombre de petites taches irrégulières, brunes, accompagnécs et souvent bordées d'autres taches blanclies.

Il existe une variété plus longuc dans laquelle les taches brunes sont très-prédominantes et deviennent la couleur du fond; elles sont alors nuageuses et transversalement parcourues par des taches blanches oblongues.

Cetle jolie coquille, au moins aussi rare que la précédeate, est presquanssi grande quiclle; elle cst longuc de 56 à 60 millim. Ëlle vit dans l'Ócéan indica.

4. Mitre épiscopale. Mitra episcopalis.

II. testâ turritâ, lavi, albi, rubro maculutj; muculis inferionibus quadratis, transversim serica. tis, supcrioribus irreguluribus; infractumo margine superiune integro; columelli quadriplicat $\hat{\text {; }}$; labro postice denticulato.

Voluta cpiscopalis. Lry. Gares. pag. 3459. $n^{\circ} \cdot 9$ 4.

Listea, Conch. tab. 839. fig. 66.

Bonani, Recr. 3. fig. 120.

Rомр日. Mus. tab. 29. fig. K.

Petiv. Amb. tab. 13. fi. 11 .

Gualt. Test. $t a b .53$. fg. G.

Dargeny. Conch. pl. 9. fig. C.

Favane, Conch. pl. 3ı. fig. C. 2.

SEBA, Mus. tomı. 3. tab. 51. fig. 8-19.

Kковя, Vergn. tom. 1. tab. 6. fig. 2.

REGEN. Conch. tom. 1. tab. 3. fg. 33.

Mantini, Conch.tom. 4. tab. 147. fig. 1360. 1360. $a$.

Excres. pl. $36 \mathrm{~g}$. fig. 2 et 4.

IItia episcopulis. Lasx. Ann. duslus. tom. 17. pag. 197. $n^{\bullet} .1$.

Hisk Nat. des Vers. Tome II.
Lasx. Anim. suns vert. tom. 7. pag. 299. $n^{\circ}$. 1 .

Quoiqne furt commune, celte coquille n'en est pas unins remarquable par sa grande taille et la vivacité de ses couleurs. Elle est très-alongée, subturriculée, très-élroite, relativement à. sa grandeur. Dans les grands individus, la spire est formée tle onzc tours peu convexes, assez larges, ì sthture simple, dont les premiers sont charges de stries assez fines, profondément pouctuées, qui s'effacent peu à peu et disparoissent vers le cinquième ou sixième tour. Le dernier occupe à peu près la moitié de la longueur; il se termine antérieurement par une ouverture longue el étroite, d'un blane-rosé à l'intérieur, sinueuse, échancrée même quelquefois à la partie supérieure de la lèvie droite. Cette lèrre droite est assez épaisse, tranclante cependant, et armée dans toute sa longuear de lincs dentelures; le bord gauche se relève, surtout à la base de la coquille; il est ua peu calleux à sa partie supérieure. Sur la columelle on compte cinq gros plis, dont le dernier, à la base, est peu prononcé. Sous un épiderme très-mince et jaunâtre, celle coquille, sur ua fond blanc, présente plusieurs séries de taches d'un rouge vif, dont la première, placée immédialement au-dessous de la sulure, en offre constaonment de beaucoup plus plus grandes, bilurquées à leurs parties iuférieures.

Cette belle coquille, qui vit dans l'Océan indien, a guelquefois 150 millim. de longueur, enviton 5 pouces et demi.

5. Mitre papale. Mitra papalis.

MI. testâ turritâ, crassâ, ponderosâ, strïs inspresso-punctatis renotiusculis cinctâ, albâ, rubro nucuculatâ; maculis irnegularibus, iransversim seriatis; anfianctuum margine superiore plicis dentiformibus coronato; columella subquinque plicatâ ; labro anticè denticulato.

Voluta papalis. Lis. G.uex.pag. 3459. $n^{\circ} .195$.

Lister, Conch. tab. 839.fig. 67 .

Bonani, Recr. 3. fig. 119.

Rusip. Mus. tab. 29. fig. I.

Petrv. Anbb. tab. 13. fig. 12.

Gualt. Test. tab. 53 . flg. I.

DARGENV. Conch. pl. 9. fig. e.

Favañe, Conch.pl.3ı.fig.d. a.

SEBA, Mus. tom. 3. tab. 51. fig. $1-5$.

KNorr, Vergn. tom.'1.tab. 1. fig. I.

REGENF. Conch. tom. 1. tab. 1. fig. 1.

Msatini, Conch. tonz. 4. tab. 147. fig. 1353. F354.

EncreL. pl. 370. fig. 1. a. b.

Mitra papalis. Lask. Ann. ibid. $n^{\circ} .2$. 
T.AMr. Anim. sans vert. tum. 7. pag. 299. $n^{\circ} .2$.

Cette belle esprèce a beauconp d'analogie avec la précédente ponr la laille, la forme et mêne les conleurs. Elle est alnngée, épaisse, solide, subcurriculée; les lours, au nombre de duuze, sont, à leur partie supérieure, forlement crévelés; les cténelures sont spiniformes, dressées et appnycées contre le tour précédent. Ces tours, peu convexes, sont sillounćs en travers; ces sillons sont larges et convexes, ponctués sur les premiers tours seulement : le dernier, ordinairencut lisse sur le milieu, présente à la base des sillons seablables à ceux du sonmet. L'ouverture est alnngée, étroite; le bord droit tranchant est denté dans toule sa longueur; le bard gauche, redresse à la base seulement, est épais dans tonte son étendue. La coluaclle présente cinq plis inégaux et inćgalement espacés.

Comme l'espèce précédente, celle Mitre est blancile en dessus et ornée de tacbes diun rouge vif. Ces laches, disposées par zones transverses, sont beaucoup plus multipliées; le dernier tour en porte jusqu'à quatorze rangs.

Celte espièce est plas rare que la précédente; elle vient comme elle de l'Océan indien et de l'Octean des Moluques. Elle est longue de i2 ou I5 centiàtres, plus de 4 pouces et demi.

\section{Mrtre pontificale. Mitra pontificalis.}

IU. testá ovato-turritâ, strïs impressis cinctû, punctis majusculis pefforata, albâ, maculis aurantio-rubris irregularibus pictá; anfractuurn margine superiore elevato, taberculis crassis coronato; cohumellâ quadripl:catá.

Lister, Conch. tab. 840. fig. 68.

Petiv. Amb. tab. 9. אgg. 15.

Goact. Test. tab. 53. fig. 1. ad dexteram.

Sгba, MIus. tom. 3. tab. 51. Fgg. 47. figura quatuor.

Knов , Vergn. tom. 4. tab. 28. fig. 2.

Martini, Conch. tom. 4.fig. 147.tab. 1355. 3356.

Excrci. pl. 37o. fig. 2. a. b.

Lamx. Anim. sans vert. tom. 7. pag. 300. $n^{\circ} \cdot 3$.

Mitra pontificalis. Ann. ibid. pag. 198.

On pourroit prendre celte espèce pour de jennes individus de la Mitre papale, mais clle a des caractères assez constans ponr en être facilement séparée. Elle est constamment plas petite; elle est alongée, pointne; ses tonrs sont droits, crénelés à leurs parties supérieures, et distingnés entre eux par une sorte de rampe spirale que forme lear saillie. Ces tours sont an nombre de dix on onze; ils sont courts, les premiers striés et ponctués, les saivans sont lisses. Liouvertare est alnngée, pointue an sommet, dilatée à la base; le bord droit, épaissi à sa partie supérienre, est finement dentelé à sa parlie inférieure seulement; la columelle porte quatre plis, l'inférieur est trc̀s-obliqne, fort petit, el se distingue it peine; le bord gauche est mince, relevé a sa partie inférieure. L'ouvertare est d'un blanc-fauve à l'intérienr. En dehors cette espèce est, cocone les précídentes, ornée de taches d'uu bean rouge sur un fund blanc; une série de ces taches, plus grando que les autres, est située autour de la suture, et l'autre est placée vers la base du dernier tour.

La Mitre pontificale se trouve dans l'Océan des Grandes-Indes. Les plns grands individus ont 70 millim. de longueur, plus de 2 pouces et demi.

\section{Mitre pointillée. Mitra functiculata.}

$M$. testî̀ ovata-acutâ, trinsversim striatâ, luteo-rufescente, inferné albido zonatû; flammulis fuscis longitudinalibus picti,; striis impressis, punctutis, subdenticulatis; anfractibus tuberculato-coronatis; columellì quudriplicatú.

SEBA, Mlus. tom. 3. tab. 5o. fig. 29. 30.

Favanne, Canch. pl. 31. fig. d. 3.

L.AME. Anim. s. vert. tom. 7. pag. 300. $n^{\circ}$. 4.

Mitra puncticulata. Ann. ibid. $n^{\circ} .4$.

Coquille aussi rare que belle, fort recherchée des amateurs. Elle est ovale, oblongue, atténuée à ses deux extrémités. La spire est aussi longne que le dernier tour; elle se compose de Luit tours peu convexes, subétagés, et rendus très-distiucts entre eux par une rangée de tubercules pnintus et subépineux, dirigés en dehors, qui snivent les sutures; trois on quatre stries transverses, assez fortemeat ponctuces, se voient sur chacnn des tours supérieurs; des stries semblables se voient sur toute la surface du dernier; elles sont ordinairement subdeutelées, et quelquefois les ponctuations devienneut obsolètes. Liouverture est alongée, très-étroite, un peu oblique, et trèsrétrécie à ses extrénités; le bord droit est épais, a peine crénelé, et l'on y remarqne quelques linćoles branes qui correspondent à la terminaison de quelques-unes des stries dn dehors. La columelle est oblique, et l'on y compte qnatre plis, dont les deux premiers sont assez gros et fort écartés. L'ouverture est d'un blanc-jannâtre. A l'extérieur, celle coquille présente sar la spire, qui est d'un jaune peu foncé, des llamrales irrégnlièrement espacées et longitndinales, d'un brun assez intense, dans l'intervalle desquelles sont placés, d'une manière irrégulière, des points blancs assez grands et quadrangulaires. Sur le dernier on trouve dans le milieu une fascie transverse fort large, sur laauelle les flammules n'existeat plus, mais où l'on remarque des poiots blancs 
en lien plus grand nombre. La base de ce dernier cour est d'un faurc-orangé, assez foncé, sur lequel les flammules brunes reparoissent.

Cette jolie coquille, doot on ignore la patrie, est longue de 43 militim.

\section{Mitre limbifère. Mitra limbifera.}

MT. testa ovato-fusiformi, lavigati, basi rignsi, aunantio-fulvi; anfractuum inferiore limbo planiusculo; coluniellà quadriplicatâ.

An Marisi, Conch. ‘om. 4. tab. 150. fig. 13g5. 1394?

An Voluta aumantiu? Gnex. pag. $3454 \cdot \pi^{\circ} .60$.

LAs. Anini. sans vert. tom. 7. pag. 316. $n^{2} \cdot 49$.

Mitra limbifera. Ann. ibid. pag. $214 . n^{\circ} .49$.

Celte espèce de Mitre auroit pu êlre nommée Bicolore, puisqu'elle est en effet partagée en deux couleurs très-neltement l'ancbées. Elle est ovale, oblungue, fusiforme; sa spire pointue est formće de sepl tours très-aplatis, dont le dernier est ux peu plus grand que les autres. Ces tours scut lisses, si ce n'est le dernier qui est ridé à la base; ils sont réuois par uoe suture simple, peu approfondie. L'nuverture est assez large, rélrécie au sommet, dilatée à la base; son bord droil est un peu épais, simple dans loule son éteudue. La columelle, un peu excavée à sa parlie supérieure, est blanche et prósente tualre plis de la méme conleur. L'ouverture est d'un blanc-jauvitre a l'intśrienr. Au-deliars la cuuleur de celte espece consiste en une larne bande brunc qui occupre les trois quarts inférieurs du dernier tour, qui irancbe d'une manière trèt-nette avec la couleur blanclie de la spire.

Cette coquille, tres-rare, est longue de 52 ¿ 38 millim. Sa patrie est inconnue.

\section{Mitae oraugée. Mitra aurantiara.}

M. testi ovati, trunsversiln sulcatá, aurantij, alho zonutí; columella quadriplecatá; lubro crenulata.

Exicrct. $p l .575$. fig. 5.

Laмk. Anim. suns sert. tom. 7. pag. 516 . $n^{n} \cdot 50$

Hitra aurantia. Ann. ibid. nº. 50.

Coquille fort rare, qui provient des oners de Ia Nouvelle-Z?lande. Un tress-bel iadividu nons a été communi quśs par M. Quoy, l'un dus royageurs naluralistes qui on illustré dans ces derniers temps la unarine frauçaise. La Mitre orangée est conique, pointue, plus courte que le dernier tour; elle est formée de huit toursapplatis, légèrement élagés. à suture siaplú, mais un peu pirlunde. Ces tours sunt étrnits, et ornés de cinqa six stries traosverses très-tioes, ćcartćes et assez
M I T

profondes; elles sont simples, et sur le dernier lour elles se continuent jusqu’à la base, où elles se cluangeut en rides iransverses. Ces rides sont plus rapprocliées que les stries. L'ourerture est alongée, fort étroite, rétrécie à ses denx extrémités; lc bord droit est épaissi, crénelé en dedans dans toute sa longuenr. La columelle est pourvue dans son milien de cinq plis graduellement décroissans et toujours blancs; au-dessus de ces plis le bord gauche est extrêmement mince et appliqué, mais il se reldve et s'épaissit dans tout le reste de la longueur de la colnmelle. Ce bord gauche est blane, tandis que l'intéricur de l'ouverture est d'un hlanc-rosatre. En debors ce!te coquille est d'une belle couleur orangée, et la paltie supérieure des tonrs est ornće d'une zone blanche assez large. Celte zone occupe ordibairenent trois ou quatre stries. Celle coquille est longue de 40 millin.; elle est ordinairement plus petite.

10. Mitae tricolée. Mitra texturata.

II. testá nuato-acut.j, albnfèrugıneoque vaijegatâ; sulcis transwersis, impressis, distuntibus: interstitiis nugaformubus, grunosis; striis longitudınalibus, impressis, confértis; columellâ quadriplicatá.

Lister, Conch.tab. 8ig.fig. 36.

Escrcz. pl. 372.fig. 2. a. b.

LA $\$$. Anim. s. vert. tom. 7. pag. $515 . n^{n} \cdot 47$.

Mitra texturata. Ann. ibid. $n^{\circ} .47$.

I.a Mitre tricotée est courte, mais n’a fjue des rapporis Ćlnignés, quaut ì sa lorme, avec les $\mathrm{Mi}$ tres crénelée el daciyle. Elle est orale, oblongue, ventrue, à spire assez longne et acuminée, folmée de sepl tours arrondis à sulure profoude el crénelée trés-tinemeat; ces taurs, dont le dernier est plus yrand que les autres, sont lorteutent sillonnés en iravers, et crénelés par des stries longitudinales muins profondes et moins larges que les sillons transverses. L'ouverture est d'un blanc-roussátre, pointue au sounet, dilatée à lit base; le bord droit est obtus et fortement crénelé dans toute l'ślendue de son bord interne. La columelle est enflée dars son milieu dans l'endroit même où sont silués quatre plis inégaux el fort étroits. A l'extérieur celte coquille est d'une couleur blanche marbrée de taches rousses furt irrégulières, qui forment deux zones priucipales, dont l'une est au sommel et l'autre a la base du dernier tour.

Celle coquille, extrêmement rare, est longue de 35 millim. Sa patrie est inconnue.

11. Mitra crénelée. Nitra crenulata.

MI. testâ cylindraceá, striis impresso-punctatis cincti, albi, luteo-riebulosá; suturis labroque crenulutis; spila brevibimá, conicá; columellí octoplicatâ. 
Volutu crenulata. Caems. Conch. tomi. 10. tab. 150. fig. 1413,1414 .

GMEL. pag. $3452 . n^{\circ} \cdot 130$.

ENcych. pl. 372. fig. 4. a. $b$.

LamK. Anim. sans vert. tomi. 7. pag. 315 . $n^{\circ} .46$.

Mitre crenulata. Ann. ibid. pag. 213. $n^{\circ} .46$.

Celle-ci a beaucoup de rapports avec la Mitre dactyle; sa spire est proportionnellement plus courte, et elle est beauconp plus cyliadracée et plus élroile; elle est ovale, oblongue et formée de sept tours très-courts, dont la suture est finemeot créneléc. Le dernier toor est si grand qüil constilue à lui seul presque toute la coquille. I'ouverture est aussi grande que lui; clle est très-étroite; son bord droit est oblus, simple dans toule son éleodue. La columelle est droite, si ce n'est à sa base, oì elle est tronquée un peu obliquement; elle porte huit petits plis presqu'égaux, subimbriqués. La surface extérieure est converłe diun résean élégaut de stries longitudinales et transverses trèsrégulières et également espacées; cette surface, sur un foud blanc, offie de graodes taches longitudiaales, noageuses, d'un jaune-brunâtte.

Celte coquille, non moins rare que la précédente, a 35 millim. de longueur.

12. Mitre dactyle. Mitra dactylus.

IX. testâ ovato-turhinatâ, striis impressis obsoletè punctatis cinctâ, albidâ, fulvo-nebulosâ; spirấ brevissimâ, subdecussatâ; columellá sexplícatâ.

Voluta dactylus. Lin. G MEL. pag. 3443. n०. 25. Lister, Conch.tab. 813.fig. 23.

SEBA, AIus. tom. 3.tab. 53. fg. 5.

Chess. Conch. tom. 10. tab. 150. fig. 1411. 1412.

Excrch. pl. 372. fig. 5. a. b.

LAsx. Anim. sans vert. tom. 7. pag. 314. $n^{\circ} .44$.

Mitra dactylus. Ann. ibid. $n^{\circ} .44$.

Coquille reararquable par sa forme; on la prendroit facilement pour un Cône si on ne lui trouvoil des plis à la columelle. Elle est ovale, obıuse, à spire courte, formée de sept à huit tours, dont le deraier l'emporte de beaucoup sur les autres. Le sommet de ha spire est un peu granulenx, subtreillissé; mais la plus grande partie du deraier tour est seulement striée en travers. Les stries sont fines, distantes, superficielles, peu profonces et très-régulièrement espacées; elles sont bruoes dans les individus frais. Looverture toute blancbe; elle est très-longue; son bord droit est épais, oblus, un peu sinueux à sa partie supérieure el lisse dans le reste de son Etendue. La columelle est un peu oblique; ì sa partie moyenne commencent les six plis gradués qui descendeat jusqu'à sa base. Iue bord gaucbe commence à la huluteur du troisième plis; il est fort aplati, renversé jusqu'ì l'extrémité de l'ouverture. A l'extérienı, cette coquille est oblongue ct oruée de taches rousses nuageuses, affectant ordinairemeat une disposition en baudes transverses au nombre de qualre.

Cette coquille, d'après Lamarck, vient du golfe du Bengale; elle est très-rare dans les colleclions. Sa longueur est de $\mathbf{4 2}$ millim.

33. Mrtre strialule. Mitıa striatula.

M. testâ subturritâ, acutâ, striis elegantisind cinctâ, albido-fulvâ; anfractibus margine superiore oppressis; columellâ quinque seu sexplicatâ.

Lister, Conch. tab. 819, fig. 33.

EvcrcL: pl. 372. fig. 6.

Lamk. Anim. sans vert. tom. 7. pag. 313. $n^{\circ} .38$.

Mitra striatula. Ann. ibid. $n^{\circ} .38$.

La Mitre striatule est nne coquille de médiocre grandeur; elle est alongré, très-ćtroite, trìspointue au sommet, ayant la spire un peu plus longue que le deraier tour. Celle spire est formée de huit à neuf tours conjoints, très-aplatis, à sutare simple et superficielle; ils sont ornés en dehors d'nn grand nombre de stries d'une extrême élégance par leur régularité; ces stries sont ajguès, très-nombreuses et serrćes les unes contre les autres. L'ouverture est subtriangulaire, trèsétroite au sommet, èvasée à la base; elle cst d'un brun-faure dans loules ses parties. Le bord droit est mince, tranchant et simple; la columelle est oblique dans toute sou étendue; elle présente cinq ou six plis très-rapprocbés et subiunbriqués. La base de la coquille est courte, comme tronquée. La surface extérieure est d'un beau branfauve uniforme, avec quelques pelites taclies blanches irrégulièremeut éparses.

Cette coquille vient des mers d'Amérique; elle est longue de 40 millim.

14. Mitre jaudátre. Mitra lutescens.

M. testâ subturritâ, basi vix emarginatâ, lacvi, comeâ, lutescente aut pallide fulvâ, immaculat $\hat{\text {; }}$; columellà triplicatâ.

LAMx. Anim. sans vert. tom. 7. pag. 312. n०. 37 .

Mitra lutescens. Ann. ibid. no. 37 .

Payr. Catal. des Ann. et des Moll. de Corse, pag. $164 . n^{\circ}$. 330. pl. 8. fig. 19.

Coquille assez variable, que l'on trouve communément dans la Méditerranée, en Sicile, en Carse et sur les côtes occidentales de l'Afrique. 
Elle est alongée, oblongue, toole lisse, à spire aussi lougue que le deraier tour; cette spire est poinlue, et formée de sept ì huit tours légèrement convexes; les sutures soat simples et peu profondes. Liouverture est alongée, rétrécie supérieuremeni; son bord droit est simple, tranclaaot, blanc à l'iatéricur. I a colnanelle est obli(que; clle présente dans son nilieu trois plis fort obliques, traachaus, subion liquués. Dans les griands individus on remarque quelquefois un qualrieme pli obsolète au-dessous des trois premiers. Le bord gauclue est blanchítre, mince, élalé, et recouvre une petite fente ombilicale. Cctie coquille est d'une couleur uniforıne, d'uu brun-jaunâtre peu foncé. Sa longnenr est de 53 millim. Lindividu liguré par M. Payraudeau a 42 millim. de longueur.

15. Mitre lactíe. Mitra lactea.

MI. testâ fusiformi, sublievigatâ, pellucidâ, albá; striis transversis, obsoletis, subpunciviulutis; columellâ quadriplicutâ.

Caems. Conch. tom. I1. tab. 179. fig. 1735 . 3736.

ExcrcL. pl. 371. fig. 2.a. b.

Lass. Anim. s. vert. tom. 7. pag. 3 I2. $n^{\circ} .35$.

Mitra lactea. Ann. ibid. pag. 2 Io. n०. 350.

Il est bien facile de reconnoitre celle espèce, puisquelle est lisse et toute blanche. Elle esi alungfe, fusiforme, à spire pointue plus longue qoe le dernier tour, próseutant quelques stries obsolètes alı sommet, lesquelles sont ponctuées assez tinement. L'ouverture est blanche comme le reste; elle cst étroite; son bord droit est mince, trunchant, simple, et l'ou trouve sur sa columelle quatre plis ioégaux rapprochés, subimbriqués; Je bord gaucbe a'est visible qu'a la base de la columelle: il est tres-court.

Cetle espèce, qui vient des mers d'Afrique, a 35 milliar. de longueur; elle n'est peut-être qu'une variélé de la Mitre cornicalaire de Latnart:k, qui provient des mémes uners, et qui n'ea diffère que par quel(jues taches irrégulières roussûlres, et par des stries qui ue sout poiut ponctuées.

I6. Mitre filifére. Mitru flosa.

MI. testấ fusiformi, tenuissinè cancellatâ, cinguliferi, stramineá; cingulis elevatis, angustıs, crebis, intcnse rubris; columellà quadiiplicatá.

Guazt. Test. tab. 53. fg. h.

Voluta filosa. Bor. , Mus. tab. 9.fg. 9. Io.

Favaxie, Conch.pl.5̃.fig.c.7.

Toluta filosa. G mel. pag. 3465. $n^{\circ}$. I I J.

L.1 x. Anim. s. vert. tom. 7. pag. 3 ı I. no. 35 .

Mitra filosa. Ann. ibid. pag. 209. no. 33.
Coquille des plus remarquables par l'ólegance et la régularité des stries dont elle est ornée, ainsi que par la disposition particulière de sa coloration. Elle est alongée, na peu plus veatrue que celle qui précède; sa spire est un peu plus courtu que le dernier tour. Elle est composée de dix lours très-convexes, subétagés, à suture assez profonde: sur les tours on observe un réscau irès-fin de stries longitudinales et transverses; des cordeletles transverses, élloites, d'uoe extrême régularité, font saillie au-dessus de re réseau, et sont d'une couleur d'nn brun-pourpré sur un food blanc lorsque la coquille est déponrvae de son épidermc, et brunâlre lorsqu'ellc en est eocore revêtue. L'ouverture est d'un blanc laiteux; son bord droil est assez mince, crénelé dans toufe son élendue, $6 \cdot t$ le fond de chađgue crénelure est marqué d'un poini brun; il correspond à chacune des linćoles de l'extéricur. La columelle est renflée dans le milieu; elle prósente dans cet endruit qualre plis subimbriqués et tranchans. Le bord gauche ust blanc comme le reste de l'ouverture, ef nettement trauché dans toute son étendue.

Celle jolie espice nous a été communiquée par. MM. Quoy et Gaymard; elle provient des mess de la Nonvelle-Zélande. Elle a 35 ì 40 millin. de longueur.

\section{Mitre fendillée. Mitra fissurata.}

MI. testấ fusiformi, lavissimấ, pallidè griseá : lineis albis, obliquis, reticulatimn cancelletis, fissuras cemmluntibus; columellâ quadriplicatô.

Excrcs. pl. 37!.fig. 1. a. b.

lamк. Anim. sans vert. tom. 7. pag. 311 $n^{\circ}, 34$.

Mitra fissurata. Ann. ibid, $n^{\circ} .34$.

Espèce très-jclie et recherchée des collectionneurs, autant par sa rareté que par la singularité de ses couleurs. Elle est très-alongée, fort étroitc. toute lisse, brillante, si ce n'est à son sommet oi elle est pourvue, sur les premiers tours, de deux ou trois stries supcrficielles finement ponctuces; le deraier tom est na pea plas graud gucle reste de la spire. Celle-ci se compose de doure ton rs à peine convexes, à sulure simple. L'ouverture est alongée, fort étroite, terminée is sit partie supérieure par une petitc goultière ent:e l'extrémité du bord droit et l'avant-detuier tour. Le bord droit est mioce et tranchant, il est un peu sinueux supérieurement; il est d'un brun-fant ce à lintérieur. La coluorclle est excavée au-desslis des plis. Ceux-ci, dans les vieux individus, sotst au nombre de six; ils sont étroils, tranchalis $\in$ lurtement imbriqués; ils sont blaucis sor une columelle bruaâtre. Il a'y a aucune trace de liord ganche. La couleur de l'extérieur est d'un bea. brun-fauve pen foncé sur les trois quarıs infértelirs du dernier tour, le reste est d'un blanc-jaunâtut, qui est la couleur dominante de la spire. Sui cé 
deux couleurs est placé un réseau de linéoles blauches, anguleuses, très-fines et obliques; ces linéoles ressemblent à de petites fissures : elles n'ont rien de régulier ni de constant dans les individas.

Cette très-rare espèce, dont Lamarck n'a conau qu'un petit individa un pen décoloré, est longue de 2 ponces, 55 millim. Les individus que nous possédons viennent de l'Océan indien.

\section{Mitre sangsue. Mitra sanguisaga.}

M. testâ fusiformi, transuersin impressostriatá, longitudinaliter costatá, fulvo-coinlescente, albo zonatá; costis granulatis, sanguineis; columellà quadriplicatâ.

Poluta sanguisuga. Lix. Grex. pag. 5450. $\pi^{\circ} .50$.

Lister, Conch. tab. $821 . f g .58$.

Petiv. Gaz. tab. 4. fig. 5.

An Guact. Test. tab. 53. fig. $f$ ?

SEBA, Mus. tom. 3. tab. 49. fig. 11. I 2. เ5. 36 .

Martixr, Conch. tom. 4. tab. 148. fig. 1373 1374 .

Exстс2. pl. 573. fig. 10.

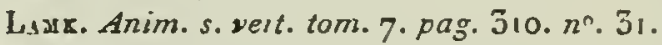
Mitra sanguisuga. Ann. ibid. no. 31 .

Cette coquille avoit élé confondue, arant Lamarck, avec la suivante; rais elle s'en distingue éminemment. Elle est alonğée, fusiforme, à spire très-pointue et plus longue que le dernier tour. On y compte dix tcars légçrement convexes, à suture profoode et onduleuse, et dont les premiers sont brunâtres. Ces tours sont chargés de cótes longitudioales, serrées, finemeut découpées en travers par des stries prufondes; ces stries se cbangent en rides à la base du dernier tour. Jicuverture est oblongue et étroile; son bord droit est simple, brunâtre à l'iotérieur, el strié dans presque toule sa langneur. La columelle est d'un bruo fuocé, et les qualre plis inéganx et obtus qui s'y trouvent sont blaochâtres. Le bord gauche est mince, à peine saillint à la base.

Cente coguille est très-élégante par la disposilion de ses couleurs; ses cótes sont d'un rouse de sang, tandis que les interval'es sint d'un blanc-yrisûtre uu brunâlre : lursque c'est cctle dernière coulear gui existe, le dernier tour présente une ou plusieurs fuscies blanclies.

Cette belle et rare espèce vient de l'Océin indien; elle est longue de 38 millim.

\section{Mitne stigmataire. Mitra stigmataria.}

M. testâ cylizudraceo-fusiformi, transuenim inplesso-siriatí, longitudinalier costatí, cine- reo-crerulescente, lineis punctatis sangwineis cinctid; costis granosis; columelli triplicati.

Rсмвн. Mlus. tab. 29. fig. 8.

Petiv. Amb. tab. 13. fig. 9 .

KNoRn, Vergn.tons. 4.tub. 11. fg. 4 .

Regenf. Conch. tom. 1. tab. 1. fig. 5.

Martisi, Conch. tons. 4.tab. 148 . fg. 1567. 1368.

An voluta granosa? Cenxs. Conch. tom. 10. tab. 151 . fig. 1442.1443 .

1. Auk. Anim. sans vert. tom. 7. pag. 511. no. 32 .

Mitra stigmataria. Ann. ibid. $n^{\circ} . \mathbf{5} 2$.

Espèce noo moios remarquable que la précédente, mais qui en est constammeot distiocte par ses caractères; elle est toujours plus grande, et ses cótes de sont pas rougres dans toute leur étendue, mais seulement oraées de deux zones de taches sanguinolentes. Cette coquille est alongie. étroite, subturriculée, à spire très-pniatue, plus longue que le dernier tour. Eille se compose de onze lours convexes, à suture bord́e et ondnleuse; ils sont pourvus d'un très-yrand nombre de cóles longiludiaales, étroiles eî serrées, crénelées par des stries trausverses, profondes, qui les dćcoupent fortement; ces stries, i la base du dernier lour, sont beaucoup plus élroiles, plus serrées et plus prufundes que tontes les autres. L'onverture est ilnn rée, allénute ì stes deax extrémités; le bord droit est aince, blanc-brim en son limbe intćrieur, blanchitre au fond et strié dans son miliea; le bord gaucbe est mince, bran, et à peine relevé à la base. la columelie est de la méme couleur que lui ; elle est pourvue de truis plis seulement. A l'extérieur cette julie cuquille est d'uu blanc-jaunitre on rcsaire. Sa base et son solumct sont bruns : sar le dernier tom ou voil deux zones de laches d'uu louge vif; sur les côtes longiludina!es ces tacbos soni oblongues et quadrargulaires. La première zone, située vers le tiers supérieur du deruier tour, se continue sur le milieu de ceux yui précèdeut.

Celle espèce, recherchée des amaleurs, habite lOcéan indien; elle est longue de 55 willim.

20. Mitre renardine. Mitra vulpecula.

11. testá fusifoıni, transwersim impresso-striatâ, longizudinaliter et obtusè costat $a$, luteo-ryfescente, fisco zunatis; apice hasique nigricalltisus; columellis quacriplicata; labro intis siriulo.

Foluta vulfecula. Lix. Gsed. pag. 3451. no. 54

Ruмва. Miws. tab. 2q. fg. $r$.

PETIF. dmí. iab. ¿5. fig. 6.

Gualt. Test. ¿lió. 5i.fig. b.c. 
SEBA, MLus. tonx. 3. tab. 49. fig. 27. 28. 29.30. 39. 40.

KNoRa, Yergn. toin. 3. tab. 15. fig a et 5 , et tab. 16 . fig. 3 .

Mantivi, Conch. toin. 4. tab. 148. fig. 1366.

Evcrex. pl. 373. fig. 2.

Lask. Anim. s, vert. tom. 7. pag. 5og. $n^{\circ} .29$.

Mitra vulpecula. Ann. ibid. $n^{\circ}, 29$.

Cette Mitre, variable dans scs couleurs, est unc des plus jolies espèces du genre. Elle est alongée, étroite, pointue au sommet, ayant une spire alongée, à laquelle on compte onze tours à peine convexés, ornés de côtes longiludinales, iraversées par des stries superficielles distanles, ұui disparoissent ordinairement sur le dernier tour, ao moins sur la partie médiane. Ce dernier tour est aussi dépourvu, dans la plupart des iudividus, des côtes gni sont sur ceux qui précèdent. Louverture est fort alongée et très-étroitc; le bord droit est blanc en dedans, brum à la base, et ayant deux taches hlanches dans le reste de sa J. nngueur. Ia columelle est d'un blanc-jamitre; son bord gauche, très-peu saillant, se icrmine à sa partie supérieure par uoe callosité presque noire. Les quarre plis qui se voieat sur la colume!le sont très-oblus et blanchäres. La couleur de rette espèce est ordinairement d'un jaune-urangé foucé uniforme. Dans quelques individus, le dernier tour présente une des deux lascies brunes furt ohscures; dans d'autres enfin la cognille est d'un jaune-blancbàtre, et son dernier tour est orné de deux zones d'un brun foncé très-net et très-distinct.

L'Océan indien est la patrie de celte espèce, qui est longue de 50 millim.

\section{Mrrne nc̀gre. Mitra cafra.}

M. testâ fusiformi, medio loevi, zonis alternatim albo luteis et rufo.fucescentibus ornutî; basi transversè rugosá; spirâ longitudinaliter plicatâ transuersimque striatá; columellâ quadriplicatî.

Foluta cafra. Lis. Gmex. pag. 3451. no. $5 \mathrm{~J}$.

Gostr. Test. tab. 55. fig. e.

SeBA, MIus. tom. 3. tab. 49. fig. 21. 22. 41.

Kмонв, Vergn. tons. 5. tab. 19. fig. 4 . 1370.

Martint, Conch. tom. 4. tab. 148. fig. 1369.

Encres. pl. 373. fg. 4 .

Lamx. Anim. sans vert. tom. 7. pag. 310. no. 30.

Mitra cafia. Ann. ibid. pag. 208. no. 30.

Espèce trc̀s-distincte de toutes ses congénères. Elle est fusiforme, à spire longne et pointue, à laquelle on compte onze lours à peine convexes. Les premiers sont chargés de petites côtes longi- ludinales régrulières qqui s'effucent insensiblement, et linissent par disparoitre sur les demiers tours; les sulures sont submargineres ef superficielles. Le dennier tour est à peu près atussi long que la spirc; il est ridé transversalerrent et alténué à la base : l'ouverture qui le termine a le bord droit Epais, brun, aveci denx taches blanches dans sa longueur; il cst blauchatre en dedans et finement strié. Lil columclle est brunâlte et les quatre plis qui s'y trouvent sont blanchatres; ils sont oblus, et le supérieur, qui est le plus gros, est tout-ì-fait transverse. La couleur de celle coquille est assez variable : les individus que lou rencontre le plus frécquemment sont d'uu hrun foncé et ornés de deux znnes transverses jaunitres ou blanchâtres; dans d'aulres ces zones s'élargissent, el la supérieure gannc la sulure, tandis que l'inlérieure reste très-nette; daus d'autres enfin cclte seconde Fascie s'ćlargit elle - mêcone et passe au bron par des nuances insensil)les.

Celte coquille, fort rare, vient de l'Océan indien; elle a 60 mıllim. de logugueur.

22. Mitae mélongène. Mitre melongena.

M. testâ fusiformi, albidâ, rufo-fucescente, fasciatâ; costellis longitudinalibus, creberrimis; striis transversis, infrà suturas profundioribus; spirì peracutâ, columellầ quadriplicatâ.

Excycs. pl. 373. fig. 9 .

L.Am. Anim. sans vert. tom. 7. pag. 309. $n^{0} \cdot 27$.

Mitra melongena. Ann. ibid, $n^{\circ} \cdot 27$.

La disposition des coulcurs de cette jolie Mitre rappelle un peu celles de la Pyrule mélungèoe, ce qui, sans doute, aura déterasiné le choix de cette dénomination que lui a donnée Lamarck. Ele est alongée, étroite, fusiforme, attenuée ì ses deux extrémilés. Sa spire pointuc se compose de dix tours arrondis, à sutore crénelée et un peu bordée. Ces tours sunt chargés de cótes longitudiualcs, étroites, très-régulières, courbées dans leur longuenr. On remarque des stries fincs à leur partic supérieure; sur le dernier tour les stries reparoissent au-dessous du milieu, et se changent peu à peu en rides sur la base. L'ouverture est alongée, flroite; son bord druit est mince, simple, lisse à l'intćrieur, brunâtre en dedans. La colnmelle, qui est brune, est munie dans son milieu de quatre plis blancs et tranchans. La couleur extérieure de cette espèce consiste en deux fascies blanches sur un fond brun assez foncé : l'une d'elles, située à la partie supérieure du dernier tour, se continue régulièrement sur ceux qui précèdent; la seconde, par son bord sapérieur, se confond insensiblemenr avec la coulear brune qui domine dans celte espc̀ce. La Mitre mellongène se tronve aussi dans l'Océan indien. L'individu que nous possédons a 30 millim. de longueur. 
23. Mrtae sanglée. Mitra cinclella.

M. testâ fusiformi, transversè striatá, albidâ, zonis lividis lineisque aliis rubris, aliis cartleis cinctá; costis longitudinalıbus infernè obsoletis; unfructibus supernè oblusè angulutis; columellí quadriplicatá.

L.Axk. Anim. sans vert. tont. 7. pag. 5og. $\mathrm{n}^{0} .28$.

Mitra cingulata. Ann. ibid. pag. 207. n०. 23 .

Celle espèce de Miue est assez variable dans sa coloralion, wais elle est facilement reconnoissable par les stries fines et nombrcuses dont tle est ornée à l'extétienr. Celte espèce a des rapports avec la Mitre costellaire; clle est alontrée, étroite, allénuée aux deux extrémités; sa spire est conique, pointue, pyranuidale, loriace de nuze à douze tours, légèrement convexes, à suture un peu ondaleuse, et clargés, surtout sur les premicrs, de cótes longitudinales nombreases, obluses, arrondies, qui, sur le dernier cour, sou: lésèrement cuberculeuses à leur sompet, et ne s'étendent pas ordiatirement jusqu'à la base. Oalre ces cóles, on remarqque sur la surface extérieure un grand noubre de stries transverses, t'és-fines et régulières, qui, à la base du dernier tuar, sc changent ed rides plus ou moins nombreuses. L'ouverture est oblongue et trés-étroite; ses deux bords sont parallèles; le droit est échancré supérieuremeat, un peu à la manière des Ylearolomes; it est simple et obius dans loute son étendue : le bord gauche est mince et appliquá; il se termine supéricurement par une callosité assez épaisse, sur laquelle rieat s'up. puyer l'ëx trémité da bord droit. La columelle est presque droite; elle porte dans son milieu quatre plis inégaux, transperses et toujours blancs. L'ouverture à l'iatérieur est de la mêtme couleur, si ce n'est la columelle qui est biunáire. Les conleurs de cette Mitre consisteut en fascies transverses, inégrales, blanches ou brunâtres, entre lesquelles soni placées des lignes ferrugiueuses, au nombre de quatre sur le desnier tour.

Cette coquille, assez rare, se troure dans l’Océan indien. Elle est longue de 55 willim.

24. Mrtre costellaire. Mitra costellaris.

MI. test'́ fusiformi, transversè striat $\hat{a}$, fuscat $\hat{\text {, }}$, albo fasciaté; costis longiludinalibus, crebris; unfractibus supeinè angulutis, ad angulum crenuto-muricatis; columellâ quadriplicatá.

Gratt. Test. tab. 54. fig. d.

Cakss. Conch. tom. 10. tab. I51. fg. 14306. 1437 .

Excycl. p 6. 373. fig. 6.

Vur b.) Costis laxioribus.

I.As: k. Amm. s. vert. tom. 7. pag. 308. no. 25.

Intra costellaris. Ann. ibid. fag. 206. no. 25.
Il est doaleux que la figure de l'Encyclopédie représente la inéme espéce que celle indiqnée dans Chemnitz. Nous arons sous les yeux deax coqailles qui paroissent assez biea s'accorder anx caracières assigués par Launarck à celle-ci, dont l'une ressemble fort bien a la figure de l'Encyclopédie, et l'autre à celle de Cliemaitz, et qui nons paroissent ofanmoins constituer deux espèces bien distincies. Sons le-nom de Mitre costellaire, nous ne prélendons indiquer que celle qui se rapporte à la figure de l'Eacyclopédie; clle est alongée, subfusiforme, alténnée a ses denx extrémitás, formée de deux cônes presqune égaux, posés base à base. La spire est formée de douze tours, don: les premiers sont bruas, à peine convexes, ct les suivans sont plas blanchatres et anguleux a lcur partie supérieure; ils sont ornés de côtes longitudinales, nombrenses, étroites, noneuses à la partie supérieure des tours. Sur le dernier lcs côtes se prolongeat ì peine, et sout en général plus grosses que sur les lours précédens. Ces cótcs sont traversées par des stries tines, peu profondes, et distantes. Sur la base de la coquille, ces stries se changent en rides ondalenses. L'ouverture estalongée, étroite; la lèvre droite est brune à son bord, blanche et striée en dedans. Sur une columelle d'un bran foncé se tronvent quaire plis blancs, dont le premier est le plus gios et bifide.La base de la coquille se prolonge davanlage que dans la plapart des espéces; elle se relére vers le dos, comme cela se voit dans quelques Fuseaux.

Cette espece vient encore de l'Océan indies. Elle est longue de 62 millim.

\section{Mitre en lyre. Mitra lyrata.}

M. testá fusiforni, angustâ, nuticá, albidá, fasciis spadiceis cinctá; costis longitudinalibus, angustis, creberrimis; interstitiis transversè strintis; anfractibus supernè obtusissime angulatis; columellí quadriplicatá.

Cuess. Conch, tom, 10. tab. 151. fig. 1434 . 1435.

EscycL. pl. 373. fig. 1. a. b.

LAMs. Anint sans vert. tom. 7. pag. 3c8. $n^{\circ} \cdot 26$.

Mitra subdivisa. Ann. ibid. $n^{0}, 26$.

Cette jolie coguille est fort rare dans les collections : on la reconnoît très-facilemeut par sa furme alongée et le pea de largeur de son dernier tour. La spire est très-longue, pointue; on y comple douze tours peu convexes, à suiare légérement ondouleuse. Ces tours sont ornés de côles longitudinales, lisses, très-étroites, et d'une extrếne régularité : dans les intervalles on trouve des stries transverses très-fines, qui, à la base du dernier tour, se changent en rides assez grosses qui découpent les cỏtes longitudiales en granu- 
latisas régulic̀res. L'ouvertare de celle coquille est al ongée, très-étroile; le bord droit est sinueux à sa partie supérieure, et légèrement rentlé; immédiatement au-dessous de celte sinuosité, il est lisse, un pcu arrondi; el manidans a longueur de trois taches bruoes. Ce bord droit, blanchàtre à l'iatérieur, est strié dans presyue toute sa longneur. La columelle est d'un brun peu intense; les quatre plis obtus et étroils qui s y trouvent sont de la méme coulear. En dehors cette coyuille est d'un blanc-grisátre; elle présente, à la partie supérieure des tours, une ligne brune, et, sur le dernier, deux autres beacuup plas étroites, dont l'une est médiane et l'autre vers la base.

Cetle Mitre, fort Elegante, vient, comme les rpécédertes, de l'Océan indien, si riche en belles especes. Elle est longae de 52 willim.

\section{Mrtae plicaire. Mitra plicaria}

$M$. testi ovato-fusiformi, Longitudinaliter pli. catá, albidi, fusciis fusco nigris interniptiscinctí; plicis elevatis, renrotiusculis, anticè subspinosis; anfractibus superne angulatis, ultinio zond lividí cincto; colunselli quadizplicatá; labro intús striato.

Ioluta plicuria. Lrs. GMeL. pug. $3452 . n^{\circ} .55$.

Listea, Conch. tab. 820.fig. 37 .

Bossssı, Recr. 3. fig. 65.

Petrv. Gaz.tab. 56. fig. I.

GosLt. Test. tab. 54 . fg.f.

Dargexv. Conch. pl. g. fg. q.

Farasis, Conch.pl.31.fig. 1. 4 .

SEBA, Mus. tom. 3. tab. 49. fig. 23. 24.

Kscra, Vergn. tom. 1. tab. I5. fig. 5. 6, et toin. $\overline{3} \cdot t .2 b \cdot 27 \cdot$ fig. 4 .

Martisi, Conch. tom. 4. tab. 148. fig. 1362. 1363.

Eзстсг. pl. 3ך3. fig. 6 .

Lак巨. Anim. sans vert. tom. 7. pag. 307. $n^{\circ} .23$.

Nitra plicaria. Ann. ibid. pag. 205. $n^{\circ} .25$.

Celle roquille a quelques rapports avec la Mitra toniata; elle se recunnoit au premier abord a sa forme plus ventrue et à sa spire moins prolongée. Elle est ovale, fusiforme, atténaée à ses deux extrémités, ornée à l'extérieur de plis longitodinaus fort réguliers, anguleux à leur partie supérieure, ce qui conronne les tours de spire d'un seul rang de pelits tubercules. Le dernier tour est aussi grand que la spire elle-même; il est ridé transversalement a sa base. L'onverture est alongée, très-étroite; ses deux bords soat parallèles; le bord droit est épaissi, siquenx à sa partie supérieure, lisse, seulement on peu strié àl'insúrieur. La columelle est bordée dans toute sa longaeur diun bord garche on pea calleax sapé-

Hist. Nat. des Vers. Tome II. riearement, et peu saillant à sa partie inférieare. La columelle oflre quatre plis sur son unilieu; de ces plis, le premier oa supérieur est fort gros, bipartite; le quatricme, celui de la base, est très-petit et se distingue à peine. Cetle ouverlure est d'un blanc-grisáıre à l'intérieur, et le bord droit présente loujours trois tacbes d'un brun foncé, qui correspondent aux zones de la mérne couleur qui parcourent la surface. Celle surface cst d'un blanc-grisátre; sur elle se dessinent nettement trois fascies d'un brun très-iotense. Liuae d'elles, sitaée à la parrie supérieare du deroier lour, se relrouve à la base de lous ceux qui prícèdent; elle est quelquefois réduile à une rangte de points Iransverses qui se voient senlement dans les interralles des côtes. La fascie médiane est furt large, on peu plus păle, et dans quelques individus bordée de claque côté d"une linne presque noire. Celte coquille, qui vit das l'Oćéan iadien, est longue de 50 millim.

\section{Mitre ridée. Mitra corrugata.}

M. testá ovato-fusiformi, longitudinaliter plicatí, transversè rugosá, albidi; fasciis cingulisque fuscis; anfractibus supernè angulatis; ultimi anfructu angulo:submuricato; colunelli quadriplicatâ.

Rемрв. Mus. tab. 29. fig. 5.

Periv. Ainb.tab. 13. fig. 7 .

Gus it. Testac. tab. 54. fig. a.c.

SEBs, Mus. tom. 3. tab. 49. fg. 31. 32. 35. 36. 38. 43.44 .

Escrc1. pl. 373. fig. 8.a. b.

Mitra conugata. LAm . Ann. $n^{\circ} \cdot 24$.

Var. b.) Testá rubente, zonis albis.

Kxorr, Vergn. tom. 6. tab. I 2. fig. 5.

ManIIxI, Conch. toni. 4. tab. 148. fg. 1364.

LАмк. Anim. saus vert. tom. 7. pag. 308. $\pi^{\circ} \cdot 24$.

La Mitre ridée se dislingueroit à peine de l'espèce précédente, si l’on ne trouvoit dans ses caractères, peu importans en apparence, une constance qui doit les faire apprécier à ane juste valeur. Cette coquille est, en général, plas petite que celle qui précède; elle est ventrue, subfusilorme, à spire conique et pointue; ses toors, au nombre de neuf, sont convexes, arrondis, si ce n'est le dernier, qui est caréné et tuberculeux a sa partie supérieare. Ces lours sont ornés de côtes longitudioales fort régulières, traversées par des rides médiocrement suillantes et plos rapprochées à la parie supérieare des cours qu'à lear base; le dernier toar est plas graod que la spire; les rides de sa base sont grosses et oaduleoses. L'ooverture est alongée, étroile, d'un bruo-blanchâtre à l'intériear, ayazt le bord droit simple, épaissi, eь

M mm 
piesentant deux taches brunes qui correspondent aux zores extérienres. La columelle, brune, offre trois gros plis blancs, suburansverses dans son milizu. Un quatrième, très-petit, se voil à la suite des autres. A l'iatérieur, celte espèce est d'un blanc-grisâtre, teinte de jaone. Deux fascies brunes parcourent le milieu du dernier tour, et sout sourent bordées d'une fascie obscule d'on janne-orangé.

Cetle coquille, plus rare que la précédente, vit comme elle dans l'Océan indien. Elle a 40 millim. de longueur.

\section{Mitre serpenline. Mlitra serpentina.}

$M$. testâ subfusiformi, albâ, aurantıo zonatâ, lineis spadiceis tongitudinalibus undatis pictâ; striis transversis, excavato-punctatis; colunzellà quinque seu sexplicatâ.

ExcrcL. pl. 370. fg. 4. a.b.

Lamx. Anim. s. vert. tom. 7. pag. 306. $n^{\circ}, 21$.

Mitra serpentina. Ann. ibid. $n^{\circ} .21$.

Très-jolie coquille fort rare daus les collections. Elle est ovale, oblongue, pointue au sommet, assez étroile. Sa spire est formée de buit lours convexes; le dernier est un peu plus grand que les autres réunis. Ces tours sont garnis à l'extérieur de grosses rides transverses, au nombre de quatre ou cinq et fortemeat poncluées. Des taches régulièrement espackes, blanchcs et bordées de brua, forment à la base de chaque tour une zone conlinue; elles sont disposées sul un fond d'un blancjanaâtre. Sur le dernier toar de la partie inférieure de ces taches naissent des linéoles onduleuses, festonnées, fort étroites, bordfes habituellement de points blancs plus ou moins prononcés. L'ouverture de cette jolie coquille es! alongée, un peu dilatée à la base; elle est d'un jaune pâle, un peu rosâtre; son bord droit est finement crénelé dans toute sa longueur. La columelle, dans les vieux individus, préseute six plis inégaux; on u'en trouve que cinq dans les individus plus jeunes. Le bord ganche se mcntre seulement à la base de la columelle; il est mince et appliqué.

Celte jolic coquille vient, à ce que pense Lamarck, de l'Océan indien. Longueus 40 millim.

29. Mitre rubanée. Mitra toniata.

M. testâ elongat $\hat{a}$, fusifonni, angustâ, zonis altẹrnatim luteis et albis ornatâ, earundem mur. ginihus nigris: costis longitudinalibus, obtusis; interstiis transversè striatis; columella quadripli. catâ; labro internè striato.

Caems. Conch. torn. 10. táb. 151. fig. 1444. 1445.

Escres.pl. 373. fig. 7.a. b.

Laur. Anim. sans vert. tom. 7. pag. 307. $n^{n} \cdot 22$.
Mitra taniala. Schubert et Waona, Conch. tab. 225. fg. 30g4. 30g5.

Cette Mitre est une des belles espèces du genre, et en même temps nne des"plus rares. L'individu figurépar Chemnitz est très-remarquable par sa grande taille et par sa riche coloration. Cette coquille est alongée, poiutue, très-étroite, turrirulée; sa spire est en alène : on y compte douze ou ueize tours subanguleux dans leur milieu, quelquefois arrondis; ils sont munis de côtes régulières, longitudinales, obtuses, à base lárge, daus lintervalle desquelles se montrent bien distinctement de fines stries transverses. L'ouverture est alongée, tiès-étroite, remarquablè en cela que son bord droit, comme dans les Colombelles, fuit une inflexion à l'intérieur. Le bord droit est oblus, lisse, strié intérieurement. La columelle est un peu tordue; elle présente cinq plis, et elle se prolonge à la base un peu à la manière des Fuseaux; elle est suivie dans toute son étendue par un bord gauche, court et obtus, un peu calleux à sa partic supérieure. Les cooleurs de celle espèce sont assez variable; tantôt elle est brane, avec des zones transverses blancbâtres, très-nettement sćparées; quelquefois elle est d'un blanc-grisâtre arec une zone blanche bordée de brun clans le milieu du deraier lour. La partie supérieure de celle zone se montre à la base des tours qui précèdent. D'autres fuis eufin Ia coquille est d'un jaune-orangé avec une large bande blanche bordée de brun sur le dernier tour. Lindividu liguré par Cbemniı a près de go millim.; ceux que nous avons eu occasion de voir n'en ont guère plus de la moitié. Elle se trouve dans l'Ócéan indien.

3o. Mrtre granatine. Mitra granatina.

M. testâ fusiformi, longitudinaliter striatâ, albidâ, subfasciatâ; cingulis elevutis, angustis, granulutis, albo spadiceoque articulatis; columellâ subquinque plicatâ.

Ruмг. Mus. tab. 29. fig. $t$.

Petiv. Amb.tab. 9. fig. 18.

Evcrcs. pl. 371.fig. 4. a.b.

LAMк. Anim. sans. vert. tom. 7. pag. 306. n०. 19 .

Mitra granatina. Ann. ibid. $n^{\circ} .19$.

Espèce non moins rare que la précédente, et qui a avec elle assez de rapports. Elle est trèsalongée, pointue, lormée de opze tours convexes à suiure simple; elle est ornée de rides transperses plus étroites, et en général plus espacées que dans la Mitra scabriuscula. L'intervalle de ces rides est occupé par des stries très-fines que traversent d'autres stries non moins fines et longitudinales. Le dernier tour, qui forme à peu près la moitié de la coquille, présente à ses parties supérieure et inferieure deux zones diun brun assez 


\section{I T}

foncé, dans l'intervalle desquelles les rides transverses elles seules sont ponctuées de la même couleur. L'ouverture est toujours blanche ou d'un blenc-rosé; son bord droit, mince et transpareut, est fucment crénelé dans toale son élendue. Ia coluaclle présente dans son milieu cing plis inégaux; lc bord gauche est très-court, fort mince et appliçué dans toute son élendue.

Celte coquille, rare et précieuse, a 65 millim. de longueur. Elle vient de l'Océan des GraudesIndes.

31. Mita à créneaux. Mitra crenifera.

II. tost $\hat{i}$ fusifomi, albà, spadiceo seu fusco fasciati; fascis margine superione lobatis; rugis transversis, granulatis; coluniellà quadriplicata.

SEBA, MIns tom. 3. tab. 49. fig. 19. 20.

Excrclp. $p l .370$. fig. 3. $a . b$.

Lask. Anina. sans vert. tom. 7. pag. 306. $n^{\circ} \cdot 20$.

Mitra crenifera. Ann. ibid. pag. 204. $n^{n} \cdot 20$.

Comme nous le ferons observer tout à l'heure, celte éspece n'est probablement qu'uae variété de la. Mitre scabriuscule. En elfel, on retrouve une disposition très-analogue daus las rides transverses, les strics qui sont entr'elles, la forme de l'ouverture et les plis de la columelle. I,a différence principale porte sur la coloratioo, et deja nous avons lail observer qu'elle étoit très-variable dans l'espèce avec laquelle nous comparnos celle-ci. Dans la Mitra crenifera, il existe dans le milicu du dernier lour une zone de tarhes brunes irrégulières, de la partie supérieure de laquelle s'éliveol avec assez de régularilé des llammules anguleuses qui ressemblent assez bien, comme l'a senti Lamarck, anx créneaux des vieilles fortilications. Une zooe plus régulière de la même conleur qua la prenière est placée audessous delle à la base du dernier tour. Loayueur 48 millim. Elle habite l'Océan indien.

32. Hitre olivairc. Mitra olivaria.

MT. testâ ovato-fusiformi, lceviusculâ, albidî, fusco fasciutà; striis tmansversis, obsoletis; coluwelli quinque plicatá.

I.Ister, Conch. tab. 813. Jg. 23. $a$ ?

Encrec. pl. 371 . fig. 3. a. b.

Layr. Anim. sans vert. tom. i7. pag. 505. $n^{\circ} \cdot 17$.

Mitra olivaria. Ann. ibid. no. 17.

Espècc de Mitre extrêmement rare, qui, par sa forme, se rapproche des olives, comme l'exprime le nom que lai a imposé Lamarck. Elle est nvale, oblongue, ventrue; son deroier tour est beaucoup plus grand que tous les antres réuris. Les stries traosverses qui se voient à leur surface
MI I $\mathrm{T}$

sont obsolètes, surlout sur le dernicr tour, oit elles ne sont plas indiquées que par des points bruas. Liouvcinure est alongée, d'ua blanc-rose, étroile à ses deux cxtrémitćs; son bord droit, mince et tranchant, est muni dans sa longuem de points hruas un peu saillaas, qui carrespondent par leur position à ceux de l'extérienr. Ia coluniclle parte ring plis ubliques subimbriquués et ranchans. A l'cxtéricur, sur un fond bleu, lc deruier toul est orné de llenx zones d'un brun foncé, transverses, irrégulières, quelquefois interrompues. lintervalle qui sépare ces deux zoncs est occupé par les lignes de points dont nous avons pallé, et qui sout quelquefois réudies par des livéoles longiludinales.

Celte espècc peut se joindre à la Mire daclyle, créneléc, cıc., el former ainsi le passage entre tes Mitres proprentent dites et le geure Cóne helix de MI. Sowerby.

Cette espèce vient, d'apuès MM. Quoy et Gaymard, des mers de la Nouvelle-Zćlande. Elle cst longue de 40 à 50 millim.

\section{Mitns scabriuscule. Mitra scabriuscula.}

MI. testâ fusiformi, longitudinaliter striat, transversè rugosi; rugis ut plurimum aibo fuscoque anticulatis; anfiactibus convexis; columell $\hat{s}$ quadriplicatâ, perforat $\hat{\jmath}$; labro crenulato.

Voluta scabriusculu. Lin. GMEL. pag. 3450. $n^{\circ} .48$.

Mitra sphoralata. Mantyns, Conch. 1. fg. 21.

ExсуCL.pl.37'/fig. 5. a. b.

I, мuк. Anim. sans vert. tonı. 7. pag. 305. $n^{\circ} \cdot 18$.

Mitra scabriuscula. Ibid. Ann. pag. 203. $n^{\circ} .18$.

La Mitra crenifera de Lamarck n'est peut-être quiune variété de celle-ci, car elle paroît trèsvariable dans sa coloralion, selon les mers où ello se trouve. Elle ne l'est guère moins clans sa laille, el quelpucfuis dans la pioportion da dernier tour par rapport à la longueur de la spire. Cette spire est formée de neuf lours, dont le deraier est plus grand que tous les auties; ils sont légèrcmeat convexes, à suture peu profunde mais créaeléc; ils sont chargés dans leur Inngueur de cinq on six rides, dans l'intervalle desyuclles ou sompte deux ou trois stlies très-fines. Ces rides et ces stries sont rendues granuleuses par des stries longiludinales qui les l'aversent; stries qui, comme les premières, ont une extrême r'́gularité. Sur les rides trausverses sont placées des taches d'un brun-rongeat:re, quadrangulaires, alternant avec des taches blanches égales, et les intervalles de ces rides sont blancs ou jaunâtre. 'Telle est la disposition de coloration des individus les plus beax. Daas d'autres, les ponctuations brunes sont moins Mm m 2 « 
marqués; le fond blanc ou jannâtre esı aliéré par des taches nuageuses d'un rouge pále. L'ouverture, qui est pelite et élroite, est ordinairement d'un jaune-safraué assez foncé, el d'aulres fois d'un blanc-jaunâtre. La columelle présente dans son milieu guatre plis, dont le dernier est trèsrapproché du précédeni, et beaucoup plus petit que lni.

Cette espèce, fort rare, babite l'Océan indien et l'Océan pacifique. Ses variétés dépendent, à ce qu'il paroit, des localités où on les trouve. Elle est longue de 55 millim.

\section{Mitne bicolore. Mitra casta.}

II. testâ turritâ, lavvi, bruneâ, albo fasciatâ ; spira fasciis scriatim punctatis, subplicatis; columellâ sexplicatâ.

Mitra fasciata. Marxys, Conch. 1. fig. 30.

Volutacasta. Caenn. Conch.tom. ıо. pag. 136. vig. 20. fig. c. d.

GMex. pag. 3453. $n^{\circ} .137$.

Lamx. Anim. sans vert. tom. 7. pag. 3०4. $n^{\circ} .15$.

Mitra casta. Ann. ibid. $n^{\circ} .15$.

Coquille fort remarquable par la disposition de ses couleurs. Elle est très-alongée, turriculée; sa spire, très-aiguë, est formée de onze ou douze tours aplatis, dont les premiers sont ornés, à leur partie supérieure, de deux ou trois series profondément ponctuées. Ces stries, dans quelgues grands individus, se prolongent jusque sur le dernier tour; celui-ci, plus court que la spire, offie, sur un fond blanc, une large zone d'un brun foncé, dont on n'aperçoit que le bord supérieur sur les deux ou trois tours suivans. Liouverture est oblongue, très-étroite, fort rétrécie et sinueuse à sa partie supérieuse; elle est blanche à l'intérieur, et la zone fauve s'y répète dans une nuance woins foncée. La columelle est presque droite et chargée de quatre plis tranchans dans les jeunes iodividus, et qui se montrent au nombre de six dans ceux qui ont atleint tout leur développement.

Cetle coquille, rare et précieuse, se trouve dans l'Océan pacifique ct dans l'Océan indien, sur les côtes septentrionales d'Amboine. D'après les figures de Chemnitz et de Martyns, elle auroit un peu plus de 2 pouces de tongueur. Les individus que nous possédons et ceux que nous avons vus sont plus petits de moitié.

\section{Mirne granulée. Mitra granulosa.}

M. testá sublurritâ, decussatâ, granosâ, rufofucescente; granis confertis, crassiusculis, transversim et longitudinaliter ondonatis; columellâ quadriplicatá.

Martyss, Conch. 1. fig. 19.

MARTist, Conch. tom. 4. tab. 149. fg. 13 go.
Excych. $\mu l \cdot 370$. fig. 6.

LAMX. Anim. sans vert. tom. 7. pag. 304. $n^{\circ} .14$.

Mitra granulosa. Ann. ibid. $n^{\circ}, 13$.

On a rarement, dans les collections, de grands individus de celle coquille. On la trouve cornmunément petite. Elle est alongée, turriculée ; pointue au sommet, composée de luit tours, légèremeut convexes, doat le dernier tour est plus court que la spire. Ces tours sont découpés à leur sarface par des sillons transverses el longiludinaux, égaux, très-réguliers, et un pen plus espacés à la base du dernier tour que sur les précédens. L'ouvertn:e est pelite et fort étroite; le bord droit est mince, tranchaut, légèrement crénelé dans toute son étendue. La columelle ést von peu tordue dans sa longueur; les quatre plis qu'elle offre sout inégaux et rapprochés. Le bord gauche est à peine sensible à la base de la columelle. A l'intéricur, l'ouverture est d'un blanc-roussâtre; la nême couleur se répète au-dehors de la coquille d'une manère uniforme, mais il est des individas qui sont d'un biun foncé.

Celte espèce vient des mers de l'Inde et de la Nouvelle-Zélande. D'après Lamarck, elle aninit à peu près 50 millim. de longueur; mais l'individu figuré daus le bel ouvrage de Martyns a presque le duuble.

36. Mirre rôtie. Mitra adusta.

MI. testâ fusiformi-turritâ, albido-lutescente, maculis nifo-fuscis longitudinalibus ornatâ; stris transversis, impressis, remotiusculis, puncticulatis; suturis crenulatis; columellâ quinque plicatá.

Lister, Conch.tab. 822. fig. 40.

SEBA, Mus. tom. 3. tab. 5o. fig. 49 .

KNoRr, Lergn. tomt. 2. tab. 3. fig. 5.

Martini, Conch. tom. 4. tab. 147. fg. 1361.

Voluta pertusa. Gmex. pag. $3457 \cdot n^{\circ} \cdot 9^{2}$.

ENcrcL. pl. 369. fig. 5. a. $b$.

Lam. Anim. sans vert. toms. 7. pag. 3o3. $n^{0} .32$.

Mitra adusta. Ann. ibid. $n^{\circ} .12$.

Var. b.) Testá breviore, ventricosiore; maculis nigricantıbus.

La Mitre rôlie est une belle coquille alongée, étroite, subturriculée, dont la spire, composée de buit tonrs, est coniqne et pointue. Les tonrs sont aplatis, et la suture qui les joint est subétagée par un bord finement et irrégulièrement crénelée. Cette corguille est entièrement couverte de stries transverses, nombrenses, simples, sans ponctuations, légèrement convexes, plus distantes ì la base du dernier tour que partout ailleurs. L'ouverture est alongée, étroite; son bord droit est épais et un peu renversé en dehors dans toute son éten- 
due; il est chargé de crénelures qui correspondent aux strics extéricnres. La columelle est un peu oblique, et elle présente cinq plis inégaux, doni le dernier est le plus petit, quelquefois peu appareat. Le bord gauche se relève seulement a la base de la columelle; il est wince et renversé au-dessus de son axe.

Celtc cotquille est ordinairement revêtue d'uu Épiderme d'un brun assez fonci'; on aperçoit audessous de lui de grandes laches longitudiuales d'un brun foncé sur un fond d'un blanc-jaunaitre. Le deraier tour a ordinairemen:, un peu au-dessous de sa partic moyenne, une zone sans taches au-dessous de laquelle elles reparoissent pour s'éteadre jusqu'à la base.

Cette coquille n'est point rare dans les collections. Elle habite les mers de la Nouvelle-Hollande, de Timor et d'Amboine. Elle est lougue de 70 millin. I amarck ea cite une variété qui nous est inconnue.

37. Mrtre ferrugineuse. Mitra ferniginea.

MI. testâ ovato-fusiformi, albá, aurantio vel ferrugineo maculutâ; sulcis tminsversis, elevatis; columellâs sub quinque plicatâ.

An Martini, Conch. tom. 4.tab. 149. fig. 1380 ? 1581 ?

Var. b.) Testí elongatâ, subturritâ.

Voluta mitra abbatis. Caens. Conch. tom. I1. tab. 177. fig. 1709. 1710.

L.Mr. Anim. sans vert. tom. 7. pag. 303. $72^{\circ} \cdot 10$.

ATitra femiginea. Ann. ibid. $n^{\circ} .10$.

On distingue la Mitre ferrugineuse à l'élancement de sa spire. Elle est alongće, poiotue, étroite, formée de dix ou onze tours aplatis, oraés en dehars de cinq à six sillons iransverses, profonds, anguleux, sans ponctuation. Les sntures sont simples, quelquefois subétagées, le sillon 'jui se trouve prés d'elles ćrant un peu plus élevé que les autres. L'ouvertare est petile, forl étroite; le bord droit, épaissi dans presque toute sa longueur, est plissé en feston à sa partie supérienre. La columelle est fort oblique, ellc est droite dans le reste de sa longueur, et présente quatre plis; elle est dépourvue de bord gauche. En debors, cette coguille, sur un fond blanc, est marbrée de grandes taches d'un roux ferrugineux, interrompues vers le milieu du dernier tour; elles reparois. sent à la lase.

Cette coquille, dont nons ignorons la patrie, est longoe de 40 millim. Nous en possédons une variété qui a la partie médiane dn dernier tour entièrement lisse.

38. Mrtre conronnée. Mitra coronala.

$M$. testá ovato-fusiformi, striis excavato-punc- tatis cincî́a, fulvâ vel spadiceâ; anfractumu limbo superiore albo subcrenato; calumellâ quin. yue plicatâ.

Voluta coronata. Caems. Conch. tom. I1. tab. 158. fig. 1719.1720.

EncrcL. pl. 37 เ fig. 6. a. b.

LA и. Anim. s. vert. tom. $7 \cdot$ pag. $317 \cdot n^{\circ} .5:$.

Ititra coronata. Ann. ibid. $n^{\circ} .52$.

Celte Mitre est une jolic espèce. Elle est ovale, fusiforme; sa spire est alongée, poinlue. Les tours, au nombre de sept, sont aplatis, mais neltenumt distingués par un rang de petites taches blanches et courtes placées à leur sommet. Quelquetiois ces taches blanches sont irrégulières et clangées en petits tubercules par lesquels la sutore en est rendue onduleuse. Les tours sont chargés de stries transverses, superficielles, très-régulières, ponctués dans leur Jongueur. L'ouverture est alongée, étroite, d'un blanc-rougeâtre à l'intérieur; son bord droit est abtus et simple dans toute sa longueur. Cing plis se roient sur la columelle; ils sont inégaux, tranchans, subimbriqués. A l'extérieur, cette coquille est d'un jaune-orangé, quelquefois d'un jaune-rongeâtre. A la partie supírieure des lours se trouve une zone d'un blanc por immédiatement au-dessous des crénelures.

On ne sait où vit cette coquille très-rare, qui est longue de 30 millim.

39. Mitre zébrée. Mitra paupercula.

M. testâ avato-oblongâ, lovigatâ, basi striatú, albâ, lineis spadiceis longitudinalibus radiatim pictá; columellâ quadriplicatâ; labro sinuoso.

Voluta paupercula. Lin. GMeL. pag. 3447. $n^{\circ} \cdot 37$.

Lister, Conch. tab.819.fig. 35.

Gual. Test. tab. 54. fig. l.

KNORR, Vergn. tomı. 4. tab. 26. fig. 5.

Martini, Conch. tom. 4. tab. 149. fig. 1386. 1387 .

EncreL. pl. 372. fig. 8. a. b.

Mitra zebra. LAar. Ann. pag. 215. $n^{\circ} .53$.

Var. b.) Testâ penitìs transvesim striatâ, lıbbro non sinuoso.

Enexcr. pl: $37^{2}$. fig. 7.a. b.

LAMK. Anint. sans vert. tom. 7. pag. 317. $n^{\circ} .53$.

La Mitrc zébrée est une espèce bien facile ì reconnoitte. Elle est ovale, oblongue, un peu ventrue, obtuse au sommet. Sa spire est plus coorte que le dernier tonr; elle est formée de sept tours légèrement convexes, entièrement lisses, si ce a'est le dernier, qui offre quelques stries à sa base. L'ouverture est alongée, étroite, blanclic à l'intérienr. Son bord droit est un pea oblus et 
d'nne couleur brune; ce bord est sinueux i sa partie supśrieure. La columelle porle dans son milieu quatre plis; elle est suivie dans toute son étendue par un bord gauche fort mince, appliqué dans sa partie supérieure et relevé à la basé de la columelle seulement. A l'extérieur, cclle Mitre est blanche, ornée d'un très-grand nombre de flammules longitudinales, onduleuses, d'un bruo foncé, quelquefois rougeâtre.

Cette coquille n'est point rare dans les collections; elle vient de l'Océan indien, et MM. Quoy el Gaymard en ont rapporté nne petite variété des mers de la Nouvelle-Hollande. El e est longue de 30 à 35 milliw.

\section{Mitne cucumérine. Mitra cucumerina.}

MI. testá ovatí, ventricosî, sulcis elevatis cinctí, aurantiá; ultimo anfractu fuscia albâ subinterruptá cincto; spirí apice obtusa; columellú quadriplicatú. 1399.

MARTisi, Conch. tom. 4. tab. 150. fig. I3g8.

ExстсL. pl. 375. fig. 1.

LAMx. Anim. sans vert. tom. 7. pag. 317. $n^{\circ} .54$.

\section{IItra cucumerina. Ann. ibid. 54.}

Cetle Mitre est arale, ventrue, alténuée à ses deux extrémités. Elle a un peu le port de certaines Colombelles. Sa spire est aussi longue que le dervier tour; on y compte buit tours arrondis, fortement sillonnés eu travers; ces sillons sont simples, anguleux, très-réguliers, jamais poncıués; ceux de la base sont un pell plus petits que ceux de la partie supérieure des tours. Louverturc est oblique, pointue à ses deux extrémités; sa lèvre droite épaissie, principalement dans le uilieu, est fortement crénclée dans toute sa longueur. La columellc est rìs-oblicque dans sa partie supéricure, un peu plus redresséc à sa partic inférieure. L'on trouve quatre plis, dout le supérieur est très-gros. Le bord ganche, qui est à peine relevé, ne se montre qu'à la hauteur des plis de la columelle. Toure l'ouverture est d'un jaune pâle tirant sur le faure. En debors, cette Mitre est d'une belle conleur rouge-orangée, avec une fascie de taches blanclies plus ou moins régulières sur le millieu du dernier tcur.

On ne sait où vit celle espèce, qui est longue de 28 millim.

\section{Mitre patriarchale. Mitna patriarchalis.}

II. testâ ovatî, transversè striatâ, basi granosi, albâ, fiu vo vel spadiceo zonutí; anfractibus supperne angulatis, longitudinaliter plicatis, nodosis; nndis albis; spirs apice obtusa; columellì quadripicicata.

\section{NI I T}

Caens. Conch. tom. 10. tab. 150. figt. 1425. 1426.

Voluta patriarchalis. G MEL. pag. 3460. $n^{\circ}$. 158.

EncycL. pl. 374. fg. 3. a. b. è specimine juniore.

I.AMK. Anim. suns vert. tom. 7. pag. $3: 8$. $n^{\circ} .55$.

Mitra patriarchalis. Ann. ibid. pag. $216 . n^{\circ} .55$.

Petitc espèce fort extraordinaire par sa forme. Elle est ovale, à spire obtuse, cuulte, étagée et onduleuse : elle se compose de six à sept tours extrêmewent courts, dout le dernier est aussi grandque les autres réunis. Ces tours sont nonseulemen t noduleux à leur partie supérieure, naais encore plissés longitudiualement, et le dernier ridé en travers. Ces plis et ces rides produisent à l'extérieur des tubercules obtus, blancs, dont une rangée, celle du milien, est ordinairement d'un brun intense. Une rangée de petites taches brunes se voit entre les lubercules qui couronnent la spire. L'ouverture est courle el étroite; son bord droit est obtus, et il a dans son milieu nne lache brune qui correspond à la zone extérieure. La columelle est oblique; les quatre plis qui $s^{\circ} y$ trouvent sont très-inéganx : le premier est trèsgrand, mince et sublamelliforme.

Cetre jolie petite coquille, assez rare dans les collections, vient, à ce que l'on assurc, de l'Océan indien. Elle est longue de 20 million. Nous pensons que la firure citée de l'Encyclopédie appartient à une auire espèce qui a des caracteres non moins constans que ceux de celle.ci.

\section{Mitre muriculée. Mitra muriculata.}

MI. testî ovatî, transversè sulcato-granosâ, aurantia; anfructibus superne angulatis: angulo tuberculis coronato; spirâ brevi, columellí quadiiplicutî.

Cuems. Conch. tom. 10. tab. 150. fig. 1427.

Lank. Anim. sans vert. tom. 7. pag. 318. $n^{\circ} .56$.

\section{IItra muriculata. Ann. ibid. $n^{\circ} .56$.}

l'etite coquille non moins singulière que la Mlitre patriarchale : elle est ventrue, conique des deux cútés, à spire assez courte et obtuse, dont les tours, al nombre de quatre ou cinc, sont conrounés par un seul rang de gros tubercules obtus; au-dessous de ces tubercules, et sur le dernier tour, se trouvent des sillons transverses très-réguliers, peu profonds, mais assez larges; ils sont simples et non ponctués. Louverture est alongcé, extrèmement étroile; son bord droit obtus, crénelé dans tonte sa longueur. La columelle est un peu bossue dans le milieu où sont sitnés quatre petits plis tranchans; cette onverture es! d'un blanc-jaunâlte. Cette coquille, ea 
dehors, est d'une couleur uniforme, d'un jaunefauve clair; les tubercules sont quelquelois un peu blanchâtres au sommet.

Nous ne savons d'où vient celte coquille rare, qui, d'aprc̀s Lamarck, auroil 20 millim. de longucur; liadividu que nous possćdons est long de 15 millim. seulemeut.

43. Mitre réluse. Mitra retusa.

M. testâ obovati, infernd transversiın striatâ, albâ, lineis longifudinalibus spadiceis radiatin pictấ; ultimo anfractu fusciâ albâ linecrs decussınte; spinî brevi, obtusâ; columellâ quadriplicatâ.

Scroztren; Einl. in Conch. tom. 1. tab. 1. fig. ?.

Var. b.) Lineis rubris.

Lasx. Anim. sans vert. tom. 7. pag. 3ıg. $n^{\circ} .61$.

Mitra relusa. Ann. ibid. $n^{\circ} .61$.

Petite espèce qui sembleroit n'être qu'une varićté de la Mitra paupercula, mais qui en est coustamment distincle et par sa laille et par le renflemeut du bord droit. Elle est ovalaire, courte, un peu ventrae, à spire très-courle et sonvent obtuse, quelçuefois aussi acuminée. Cette spire est formée de sept tours un peu convexes, à suqure simple, très-courts, dont le dernier est beaucoup plus grand que tous les antres; celui-ci cst finement strié à la base; le reste de la coquille est parfailement lisse. 'L'ouverture est alongée, extrêmement étroile; elle est d'un blanc-brunấtre, quelquefois tonte bruae; sa lèvio droite est obtuse, lisse, et présente constamment, vers sod tiers supérieur, un renflement intérieur assez considérable. La columelle offie quatre plis; son bord ganche est très-court à l'extérieur. Celte petite Mitte est ornée, sur un fond blanc, d'un grand nombre de flammules d'un brun-rouge et Tangitunales. A la parlie supérieure da derniẹ tour toutes les fammules sont interrompues par une zone blanclie, étroile el continue.

Celle espicce se trouve assez communément dans les mer's de l'Inde. Sa longueur est de 17 millim.

44. Mitre pelites zones. Mitra microzonias.

M. testù ov'atâ, longitudinalıter oblusèque costutâ, busi trunsversè nugosâ, fusco-nigicante, fasciis albis angustis subinterruptis cinctâ; columellâ triplicuti.

ExcrcL. pl. 374. fig. 8. a. 6 .

Lamx. Anim. sans vert. tom. 7. jag. 320. n०. 62 .

Mitra microzonias. Ann. ibid. pag. $218 . n^{\circ} .62$. Petite coquille très-facile à distinguer. Elle est ovale, oblonguo, a spire ordianiremont un peu plus longue que le delaier tour. Celte spire est formée de sent à buit tours fort courts, légèrement arrondis et subplissés dans leur longueur. Leur sulure est simple ou onduleuse; l'ouverture est courte ; le bord dioit est blanc el strié à l'intérieur; la columelle est trc̀s-brune, et les quatre petits plis qui s'y trouvent sont parfaitementblancs. A l'extérieur, cetle espècc est toute noire ou d'un brun foncé. A la partie supérieure du dernier tour setrouve une seule ligne étroite de points atrondis, quelquefois quadrangulaires, qui se touchent par deux des angles: celte ligne ponctuée se conuuue à la base des cours précédens.

D'après Lamarck, cet:e coquille se tronve daus l'Océan indien; nous sommes assuré qu'elle vit aussi dans la Médicrmuée. Elle est longue de 21 millim.

\section{Mitre cloporline. Mitra oniscina.}

MI. testî ovato-acutâ, decussatâ, granosâ, fusco alboque fasciat í ; columellâ quadruplicatá.

Lamx. Aniint. sans vert. tom. 7. pag. 323. $n^{\circ} \cdot 78$.

Mitra uniscina. Ann. ibid. $n^{\circ} \cdot 7^{8}$.

Petile coquille fort jolie qui provient, d'après Lamarck, de l'Océan intien. Elle est alongée, sublusiforme; sa spire, conique et pointue, cst aussi longue que le dernier tour. Elle se compose de sept à buit tours conrexes, sur lesquels sont disposées, avec une grande régularité, des côtes longitudinales, obtuses, assez saillantes, dans lez intervalles desquelles on voit de fines stries transverses, assez distantes les unes des autres. La suture est onduleuse, et les côtes du tour inféricur correspondent aux intervalles de celles du tour sopérieur. L'ouverture est conrte, étroite; son bord droit est mince, tranchant et simple dans toute son éteudıe; le bord gaucbe présente à sa partie supérieure une petite callosilé sur laquelle l'extrémité au bord droit vient s'insérer. La columelle est un peu gonflée dans son milieu, et elle est pourvue, dans cet endroit, de trois petits plis très-inégaux. A la base du dernier tour, immédialement au-dessus de l'échancrure, on remarque trois rangées de petites granulations trèsrégulières. Les couleurs de celte espèce consisteut en (rois bandes, d'un brun asıez fonać, sur un fond blanc pur. Ces trois fascies ne se voient que sur le dernier tour; la supérieure, seule siluée contre la sulure, se continue sur les tonrs suivans.

Celte petite coquille, assez rare dans les collections, es: longue de 14 millim.

\section{Mırre bâtonnet. Mitre bacillum.}

M. testâ fusiformi, subcylindricá, transverse sulcatâ, fucescente, albido undatâ; spirâ brevi, obtusiusculá; columellâ sexplicatâ. 
LAsic. Anim. sans vert. tom. 7. pag. 321 , $n^{\circ} .66$.

Mitra bacillum. Ann. ibid. $n^{\circ} .66$.

Celte espèce de Mitre présente cet intérèt particulier, de former le passuge entre les Mitres proprement dites et celles dont M. Sowerby a fit son geare Cone helix. Elle ressemble en eflet a uo petit Cône à spire forl loague, et dont les tours sonl arrondis à leur partie supérieure; elle cst oblongue, alongée, subcylindracée, à spire conique et paintue, plus courte que le dernier tour Elle est composée de buit lours courts, légèrement élagćs, convexes vers les sulures, a platis dans le reste de leur étentlue; ils sont clargés de qualre à cing gros sillons transverses, subaaguleux, doat l'un, ordinairemeat plus gros, est situé immédiatemeut au-dessous de la sulure. Ces sillans sont simples, non ponctués, même dans le jeune âge. Le dernier tour est conoïde; il cst régnlièremeut sillonné, comme ceux qui précédent. L'ouverture, qui le termine antérieureısent, ressemble entièrement à celle des Cônes, et rotammeat à ceux de la section des Bàtonnets; elle est longue et étroite; le bord droit est mince, trauchant, un peu échancré à sa partie supérieure, légèremeat ondulé dans sa longueur par les sillons qui y abontissent. La columelle est droite, parallèle an bord droit; elle popte dans son milieu six plis tranchans, subimbriqués. Celte coquille est assez variable quant à la couleur ; tautôt elle est grisâtre, tantôt d'un jauneorang $\ell$, et quelquefois rougeâtre. Sur ces diverses couleurs se dessinent assez netlement des flamaurles longitudinales blanches, tantôt droites, rantòt onduleuses.

Cette coquille, fort rare, provient à ce qu'il paroît des mers de la Nouvelle.Hollunde. Elle est longue de 24 millim.

47. Mitre de Péron. Mitra Peronii.

NI. testá ovato-conicá, transversé sulcatá, aurantiâ vel fuscá; anfructións fasciâ aloidấ cinctis; columellâ quadriplıcatá.

Var. b.) Testá breviore.

Layx. Anim. sans vert. tom. 7. pag. 322. $n^{0} \cdot 71$.

Mitra Peronii. Ann. ibid. $n^{\circ} \cdot 7 \mathfrak{r}$.

Petite coquille fort remaquable, ea ce qu'elle conduit aux Colnmbelles par l'épaississement de son burd droit. Elle est ovalaire, assez cuurte, ayant la spire fornée de six à sept tours aplatis, conjoints, et finement striés en travers. Les stries sont superficielles, distantes, très-peu profondes, tantôt simples, tantôt très-finement ponctnées. Le deraier tour est plus grand que tous les autres; il est convexe, alténué a la base, où les stries se changent progressivement ea rides. L'ouverture est diongée, fori élroite et rélrécie, d'une manière remaquable à sa parlie supérieure, par an rentlement assez considérable du bord droit. Ce Lord est obtus dans uno partie de son étendue; il est miace et crénclé à la base; il est blanc á l'intérieur, ainsi que la columelle. Celle-ci est épaissie dans son milieu, et elle présente quatre plis presque transverses el inégaux. A l'extćrieur, celle coquille est partout d'un brun-orangé. Le dernier tour, à sa partie supérieuse, est orné d'une ligue blanche très-étroite et très-netle, laquelle se continue à la base des lours qui précèdent, la suture se faisant immédiatement au.dessous d'elle. Cette Mitre curieuse a été rapport́e, pour la première fois, par Péroa, de son voyaue aux terres australes. Elle a 20 à 22 millim. de longueur.

Dans la collection de Lamarck, avec plusieurs individus de l'espèce que nous veuons de décrire, il s'en trouve un autre qui a avec eux beauconp de ressemblance, mais qui cependaut, par ses caractères, devira conslituer une très forte variété, peat-être même une espèce distincte de celle avec laquelle Lawarck l'avait confondue.

\section{Mirne petites côtes. Mitra crebricosta.}

M. testá ovata-fusiformi, costis crebris, langitudinalibus, infernè obsoletis; colunielli quadriplicatá.

LaMK. Anim. sans vert. tom. 7. pag. 324 . $n^{\circ} .1$.

Mitra crebricosta. Ann. ibid. tom. 2. pag. 58. $n^{\circ} .1$.

Coquille fusiforme, à spire assez longue et poinlue, formée de neuf tours subconvexes, chargée d'an grand nombre de pelites côtes longitudinales pliciformes, sur lesquelles passent, i la partie supérieure des tours seulemeal, des stries trés-fines et onduleuses. Le dernicr tour est aussi graud que la spire; les côtes qui s'y trouvent sont lort réculières, et diminuent pen à peu vers la base, où elles disparoissent quelquefois. L'ouverture est alougée, alténuée à sés deux extrémités; le bord droit est sinueux à sa partie supérieure et renflé, au lier's supérieur de sa loggueur, en une deut ubluse el intérieure. La columelle est bordée dans sa longueur par un bord gauclie, saillant a la base seulement. Cetie columelle présente, sur un petit reallement médian, qualre petits plis presqu'égaux, transversaires, qui s'avaucent sur presque touie la largeur du bord gaucbe.

Cecte coquille, élégante par sa forme, se trouye fossile aux euvirons de Paris et de Valogaes. Lougueur 27 million.

49. Mitre monodonte. Mitra monodonta.

MI. testâ ovato-acutâ, laviusculì, supernè longitudinaliter striatâ; labro intùs unidentato. 
L.suk. Ann. sans vert. tom. 7. pag. 304. $n^{\circ} .2$.

Mitra monodonta. Ann. ibid. $\mathrm{n}^{\circ} .3$.

La Mitre monodonte est une petite coquille along'e, fusiforme; le dernier lour est un peu plus grand que la spirc. Celle-ci est conique, pointue, composke de sept tonrs. Ces tours, tièsjeu convexes, sunt sinueux à leur partie supélicure, immédiatement au-dessons de la suture; lcur surface est cuuverte d'un tin réseall, produit frar de petites côtes longitndinales, traversées par des stries beaucoup plus lincs, onduleuses, plus aırquées à la partie supérieure des tours que su: leur partie moyenue. lionverlure est ovalaire, assez évasće; le hord droit est épałssi, lisse, et préseote sur son côté intérieur une petite dent asscz snillante et aiguë. La columelle est trèsoblique à sa partie supéricure; elle porte à sa partie moyenne gualre pelits plis très-élroils, à peine ohliques; le bord gauche u'est visible que dans quelques iudividns; il est fort mince et appliqué daos laute sou étendue.

Cette coquille se trouve fossile aux environs de Paris, notamment à Grignon, aiosi quaux cnrirons de Valognes, à IIauleville. Longueur i5 millius.

50. Nitre margidée. Mitra narginata.

MI. teslâ ovalâ, laviusculì; anfiactubus margine viriculoso crenulatoque subduplicatis.

Lask. Anim. s. vert. Lomb. 7. pag. 324. no. 3.

Mitra marginata. Ann. ibid. $n^{\circ}, 3$, et tom. 6 . pl. $44 \cdot$ fg. $7 \cdot a b$.

l'etile espèce qui devroil rentrer dans le genre Cöne helix de M. Suwerby, dans le cas où ce genre seroit adunis. Elle a lapparence d'un petit Cóne a spire élancée. Celte spire est plus courte que le dernier tour; elle est conique, et on y comple neul' à dix cours convexes tiès-comrts, dont la suture est marginée par une pelite côte décurrente qui la snit. Celle petite côte, dans la plupart des indiviclus, est finement plissée ou légèremeut ponctuie. l.e dernier lour est conique, très-alténué à la base; sur celle parlie, il présente toujuars quelques stries transverses. L'onverture est alongéc, fort élroite; les deux bords sont parallèles; le droit est mince, traachánt dans route son étendue, ct la columelle présente toujours cinq plis submosverses très-étroits. Nous posséduns une variété assez semarquable de cette cspèce, dans laquclle toule la surlace extériẹre est ornée de stries transrerses très-réguliçres. Le bord des sulures est snivi d'une double côle.

Cette petite coquille, assez rare aux environs de Paris, se trouve à Parnes et à Grignon, aiusi qu'aux environs de Valognes, d'où vient la variété. Les plus grands individus ont 17 millim. de longueur.

Hist. Nal. des Vers. Tome II. 5r. Mitre plicalelle Mitra plicatella.

M. lestâ fusiformi, Invigatá; anfractibus margine subplicatis; columella quadriplicatî.

Lanx. Anim. sans vert. Lom. 7. pag. 324. $n^{\circ} \cdot 4$.

Mitra plicatella. Ann. ibid. $n^{n} .4$, et tom. 6 . pl. 44 . fig. 8.

Celte coquille est alongíe, fusiforme. Sa spirc est presqu'aussi longne que le dernier tonr; elle est conique, pointue, romposée de onze lours convexes, lisses on presque lisses, irès-finement plissés près des sutures : relles-ci sont simples et assez profundes. Le dernier tour, un peu ventru à sa partie supérieure, est très-alténué à sa partie iulćrieure. l'onverture est oblongue, subsensilunaire, à bord droit, mince et tranchant, et toujour's dépourvue de bord gauche. La columelle est droite; elle porte dans son milien quatre petits plis obliques très-étroits, sublamelliformes et trèsdistans les uns des antres. La base du dernier toue est légèrement striée en travers. Les stries sont simples, et les iuférieures sont beaucoup plus fines que les autres.

Nous possédons une variété de celle espèce tonjours plus étroite, à spire conjours plus longue proportionuellement, et ayaot la suture bordéc d'un très-petit bourrelet sur lequel sont placés les petits plis que nous avons remargués dans d'autres individus.

Celle coquille se trouve fossile aux envirous de Paris et de Valngnes. I,es grands individus ont 30 millim. de longucur.

52. Mrtae labiatule. Mitra labrutula.

M. testâ ovato-acut à, laviusculà, supernè costulis striisque transversis decussatá; labro crasso, marginato.

LAmк. Anim. sańs vert. tom. 7. pag. 325 . $n^{\circ} .5$.

Mitra labratulu. Ann. ibid. $n^{\circ} .5$.

Encres. pl. 392. fig. 3. a. b.

Espèce remarquable par la furme singulière de l'ouverture, qui lui donne quel que ressemblance a vec de petits strombes. Elle est ovale, ventrue, a spire conique et pointue, un peu plus courte que le dernies tour, formée de dix tours à peide convexes, nn peu sinuenx à lem partie supérieure, tantôt lisses, tautôt chargés cont à la fois de petites côtes longiludinales et de fines stries transverses. Ces stries wanquent ordinairement sur le dos du dernier tour pour ne se présenter qu'à sa hase, où elles sont obsolètes. Cette base du dernier tour se relève à l'endroit de l'échancrure, vers le dos de la coquille, beaucoup plus que dans la plnpart des espèces. L'ouverture est alongée, assez étroite. Le bord droit est epais, lenflé, renversé en deliors, souvent sinueux à sa partie supérieure, Nin $*$ 
et ruelçuefuis renfé à sa parlie interne en une dent craisse et obtuse. l.e bord gauche est visible dans lou!e son étcndue; il est calleux à sa partic supérieure, mince et appliqué dans tout le reste sur la columelle, qui est arquée forlement. A sa partie supéricure on voit quatre plis transverses, dont les Irois supérieurs sont égaux, et l'inléricur leaucoup plus petit.

La Mitre labratule est assez rarialıle, relatirement it la taille et à la forme de l'ouverture. Cette dernicre est quelquefois d'une couleur corníe simple; d'antres fois elle est blanche, luisante, à lèvre très-épaisse, fortement renversée en deliors, et présentant une dent obtuse très-large à sa parlie interue. Oa voil quelquefois des indiviclus de celle espère qui ont conservé quelyues traces de leur primituve coloration : ces traces consistent en flammulcs d'un rougc ferrugineux; e'les sont longituninales, distantes à la partie supérieure des tours. Il existe à Courtagnon et auprès de Valounnes une variété constante ifui a des stries transverses dans toute son étendue.

Celte coruille se troure fossile dans presque tout le bassin de Paris et aux envitons de Valogres. Les grands individus ont 33 millim. de longrueur.

53. Mitre côtes rares. Mitra raricosta.

MI. testî̀ ovato-acutâ, costis longitudinalibus, distantibus, angustis, acutis; labro crasso, nuarsinato, intius subunidentato.

Volute lubiata. Свемnitz, Conch. tom. I1, tab. $212 . f_{s} s .3008 .3009$.

L.ANE. Anim. sans vert. tom. 7. pag. 325 . $n^{\circ} .6$.

Mitra raricosta. Ann. ibil. $n^{\circ} .6$.

Coquille qui, par sa forme, se rapproche de la précédente. Ellc est ovale, oblongue, ventrue clans le uilieu, ayant la spire couique, pointue, plus cuu:te que le dernier tour. Cette spire est formée de huit tours très-convexes, à suture onduleuse, sinple, légèrement déprimés ì leur partie supéricure, et chargés de còtes longitudiaales saillantes à leur somnet plus qu'à la base où elles disparoissent pcu à peu. La disposition de ces cótes, dout on ne comple que sept à hail sur chaque lour, rend la suiure ondulease. La base du dernier tour est lisse; elle est rulevée vers le dos. L'ouverture est subseni-luaaire; le bord droit est épais, renversú cu delurs, sinueux ì sa parlie supérieure, ct préscnle au lie:s supérienr de sa longueur un renflement peit considérable. A la partic interne la coInmclie est asicz forlement renllée; ditns son ralicu on y campte rinatre plis subtransverse; dont le deruice est le plus oblique of le plus petit.

Ceme corpille, assez rare, se troave fossile à
Parnes et à Grignon, aux environs de l'aris. Elle a 34 millim. de longueur.

\section{Mitae mixte. Milra mixla.}

MI. testâ fusiformi, laevigatî, basi apiceque obsoletè striata; aperturâ עlx emarginutá.

Lanx. Anim. sans vert. tom. 7. pag. 325 . $n^{\circ} \cdot 7 \cdot$

Mitra mixla. Ann. ibid. pag. 5g. $n^{\circ} \cdot 7 \cdot$

Coquille régulièrement ovalaire, atténuée à ses leux extrémités, ayant la spire aussi longue que l'ouverture. Celle spire est forméc de huit tours très-per convexes, à suturc simple et superlicielle, enlićrement lisse; un y remarque quelques stries longitudinales d'accroisscment. Le dernier tour est oblong, alténué à la base, où il est liṣe comme le resle de la surface. L'ouverture est oblongue, semi-lunaire. Le bord droit est mince, obtus, non-renversé en dehors. La columelle est puurvue à la base de quatre plis égaux, de sorle qu'il seroit difficile de dire si certe coquille est plutôt une Volute qu'une Mitre. Ces plis sont tranchans, également distans entr'eux, et s'étrndaat jusqu'à l'extrémilé du bord gauche, gui n'est visible quà l'extrćmité de la columelle.

Celle coquille est assez rare anx environs de Paris; clle se troure à Grignon et à Parnes. Sa longueur est de 25 millim.

\section{Mitre cancelline. Mitra cancellina.}

MI. testâ subfusiformi, lavigat ; labro internè striato; aperiura basi subintegra.

Nitra cancellina. Ann. ibid. $\pi^{\circ} .8$.

LAUI . Anim. sans vert. tom. 7. pag. 325. $\pi^{\circ} .8$.

On pourroit facilement confondre celte pelile coquille avec un Fuseau, à cause de sa forme et par le prolongement assez considérable de sa base, qui est subcanaliculée. Cette coquille est alongée, étroile, à spire plus longue que le dernier tour; formée de sept à huit tours peu convexes, à sulnre simple et superficielle. lie dernier tour esl allénué à la hase, où il se prolonge en un canal court, terminé par nne échancrure peu prófunde. Celle base est légèrement striée en dehors; le resle de la surface esi tont-ib-fail lisse. Louverture est assez courte, oblongue, semi-lunaire, étroite. Sur le milien de la columelle on trouve quatre petits plis, dont les denx médians sonı les plus distans el les plus saillans. Le bord druit est mince, tranchant el linement strié en travers dans toute sa longueur.

Cctte petite roquille se troure fossile à Parnes, à Grignon et à Senlis, aux cnvirons de Paris; elle se rencontre aussi dans les faluuicres de Valogoes. Elle est longue de 12 millim. 
56. Mrtre tarière. Nitra terebelhum.

M. testâ fusiformi-turritâ, luevigat $\hat{z}$, infernè striutá; "uperturâ basi subintegrâ.

Excrce. pl. $3 g^{2}$. fig. 2. a. b. c. d.

IAask. Anim. sans vert. tom. 7. pag. 325 . $n^{n} \cdot 9$.

Mitra terebellum. Ann. ibid. $n^{\circ} \cdot 9$.

P'elite coquille d'une forme très-remarquable; elle est ceriainement, de toutes les espècics du uenre. la plus étroite proportionnellement à sa longueur. Lille est alongée, turriculée, à spire lungue et pointue, et ayant la base du dernier tour prolongée en un canal à la manic̀re des fuseaux. Sa spire subulée est formée de buit tours aplatis, assez larges, á sulure sionple et superticielle. Le dernier tour est beaucuup plus court qu'elle. Une dépression considéruble indique en dehors l'origine du canal: celui-ci porte à la lase quelcues sillons transverses, juclquefois onduleux. Liouverture es: petile, oblongue, élroile, un peu arquéc dans sa longueur; le bord droit est très-mince, tranchant, sinucux supérieusement, et gुuelquefois très-légèrement strié á l'intérieur. La columelle est tordue dans son railieu; elle porte, dans cet endroit, cing pelis plis obtus et inégaux. L'écbancrule de la base est peu profoode.

Celse pelite coquille, curieuse par les modifications de l' rase quelle prísente, se trouve fossite anx euvirons de Paris, à Parues, Grignon, Courtagnnn, Houcliy-le-Chùtel, etc. Elle est longue de 18 millirn.

\section{Mita fuselline. Mitra fusellina.}

MI. testầ ovuto-fusiformi, lavi, minutâ, basi trunsversim stiatâ; anfractibus supernd marginatis.

Laxx. Anim. sans vert. tom. 7. pag. 326. no. 10.

Mutra fusellina. Ann. ilis. no. 10.

Celle pelite Mitre lient anx deux précédentes especces par sa forme générale qui la rapproche des Fuseatux. Elle est firt petice, alongre, úl roi'e, à spire conipue, proislue, plus longue que le dernier tour. Celui-ci se prolonge à la base en un canal court, terniné par une échancrure peu profonde; relte base présente quel ques stries proloudes très-fines : tout le reste de la coquille est parlaicenneut lisse. Les cours de spire sont légèrement convexes; ou en comple huit, ils sont nettement sćparés par une sulure assez profonde, hordét d'un pelit bourrelet décurreu!. L'ouverture est oblongue, ćlroile, pointue ì ses extrémités; le bord droit est mince, trauchant, un peu siuuenx à sa partie supérienre. La columelle (st simple, dépourrue de borl gauche. Sur son milieu on trouve cioq pelits plis, dont les second el troisième sout les pilus gros.

Celle pelite corgille se tronve aux environs de Paris, à Griguon, l'arues, Moucliy-le-Chàtcl. Elle est longue de 7 is 8 millim.

\section{Mrtue graniforme. MIitru graniformis.}

MI. testâ ovatâ, longitudinaliter costulat $\hat{\imath} ; a n-$ fractibus marginatis.

Mitra gran!formis. Ann. ibid. $n^{\circ}, 11$.

I.AMr. Anim. sans vert. tom. 7. pag. 326 . $n^{*} .11$.

Peite coquille fort élégante de la section des Cônes helix. Lille ressemble en ellet à un pelit Còue dont la spire seroit prolongée. Elle cst ovale, conique, ventrue; sa spire, plus courle que le dernier tour, est régrulièrement conoide; on y coapte six tours peu convexes, extrênement courts, un peu sinueux en dessous des sutures, lesquelles sont bordées d'un bourrelet assz gros, lisse et conlinu. $\Lambda$ u-dessous de ce bourrelet naissent de pelites côtes longitudinales, très-nombreuses et très-serrées, lesquelles, sur le dernier tour, se prolongent régulière ment jusqu'à la base; elles sont pliciformes. L'ouverture est alongée, élroite, tout-ì-fait semblable à celle des Cônes; les deux côtés en sont parullèles. Le bord droit est mince, trimchant dans toute son étendue; la columelle esı dípourvue de bord gauche; clle est arrondie, et porte sur son milieu cinq plis tranchans, inégaux, subimbriqués.

Celle jolie perite corquille est assez commune daus les sables de Parnes et de Houchy-le-Chitel. Les plus grands individus on 9 millin, de longueur.

59. Mitax mutique. Mitra nutica.

M. testâ ovato-acutî, lovvigatâ; anfractibus undique simplicibus; plicis columella quaternis.

Encrce. pl. 3g2. fig. 1. $a . b$.

LAMx. Anim. sans vert. tom. 7. pag. 326 . $n^{0} .12$.

Mitra mutica. Ann. ibid. pag. 60. no. 12.

Il semblerost que cette conjuille n'est qu'une variélé d’âge de la Mitre labratule; mais, lorsquion en examine plusieurs individus, on peut se convaincre de la consiance de ses caractères, et par consćquent on peut l'adrollse comme une tspèce particulière. Elle est alongée, ventrue, subfusiforme, un pen enllée dans le milieu. Le dernier tour est aussi long gue la spire; celle-ci conique el pointue, est composée de neuf lours forl courts, très-convexes, dont les premiers portent quelques côtes obsolètes qui disparoissent rapidement et laissent lcs turrs suivans tout-à-fait lisses. A la base du dernier tour on aperç. quelques stries trìs-fines, serrées et nomlicitics. 
Jiviverlure estalungre, subsemi-lunaire, érroite; le boril droit en est simple, sinueux un peu à la manière des Pleurolomes. La columelle esi dioitc; on compte daus sa longueur cinq plis, dont le Ilernier est rudimentaire. L'échancrure de la base est étroile et peu profonde.

Celle coquille, assez rare aux environs de $\mathrm{Pa}-$ ris, se trouve à Grignon et daos les localités enviroauantes. Eile est longue de 21 millim.

6o. Mrtre alongée. Mitra elongata.

MI. testâ fusiformi-turritâ, lavigutâ; columelli subquinque plicatá.

DaRGENv. Fass. pl. 29. (Buccinite, $2^{\mathrm{c}}$. fig. du n ${ }^{\circ}$. 6.)

(b.) Eadem striis transversis, vix perspicuis.

Laxx. Anim. sans vert. tom. 7. pag. 326. $n^{\circ}, 13$.

Mitra elongata. Ann. ibid. $n^{\circ}, 13$.

Belle et grande espèce de Mitre particalière, jusqu'à présent, au bassin de Paris, où elle est assez commune. Elle est alongée, étroite, fufiforme, à spire longue et pointue, aussi longue que le dernier tour : eile est formée de neuf tours convexes, à suture simple et un peu profonde; le deruicr tour est lisse comme les précédeas. A sa base on trouve nn assez grand nombre de stries très-fines, onduleuses, qui disparoissent presque complétemeat dans certains individus; dans d'autres, au contraite, elles retnootent jusque sur le dos du deraier tour : c'est ce qui constilue la variété notée. L'ouverture est alongée, oblougue, plus étroite is sa partic supérieure qu'à l'inféricure; le bord droit est très-miace, tranchant et lisse à l'intérieur. La columelle lisse, presque droite, a des plis qui se voient sur le milieu; le premier, scul, est très-marqué, les quatre autres sont trèsobliques, très-courts et à peine marqués.

Cette coquille se trouve particulièrement à l'arués, à Mouchy-lc-Châtel, à Contragnun et aux eavirons de Moutmirail. Les grands individus ont 2 pouces 9 ligues de longueur, $7^{5}$ millim. Noв.

61. Mrtee de Brongniart. Nitra Brongniarti.

MI. tèstâ clongatâ, fusiformi, acutâ, longitudinalier crebricostatí; custis supernè undulosis, lon-itudinulibus, basi evanescentibus; anfructibus convexis, superne tenuè striatis; aperturâ clongat $\hat{a} ;$ colunelli subquadriplicatâ.

Cette Mitre est la plus grande des espèces connues aux euvirons de Paris, et, parmi les fossiles, une des plus grandes du genre; elle est trés-ilongée, étroite, fusiforme, ì spire longue et rointue, plus longue que le dernier tour; on y cumpte dix ou onze tours convexes, fanement sticés à leur part e supéricure, immédiátement audessous de la suinre; ces tours sont ornés, dans leur longueur, de côtes pliciformes, petiles, cuurtes, plus ou moins nombreuses, selon les individus, et manquau quelquefois sur le dernier tour. Celui-ci, atténué à la base, est ordinairement mulique, et présente rarenient de ce côté quelques stries obsolètes. La base de la co!umelle cst circonscrite par un bourrelet tordu sur luimême, dont le centre est occupé par une fente ombilicale gue le bord galuche recouvre ordianirement dans une partie de sa longueur. L'ouverture est longue, étroitc, un peu plus large dans le milieu qu'a ses extréantés; le bord droit en est mince, trancliant et sinueux à sa partie supérieure. En se joignant à l'avant-dernier lour il forme une échancrure angulense assez profonde. La columelle est presque droite; sur le milieu elle porte deux à quatre plis obscurs, dont le deraier surtout est presque toujour's à l'élat rudimentaire. Le bord gauche est mince ct appliqué dans toute son étenduc.

Celte belle et rare espèce de Mitre se trouve à Parnes, Liancourt et Nlouchy-le-Châtel. Elle est heaucoup plus grande que la Mitre alongée, avec laquelle on ne siut:oit la confondie. Elle est longue de 3 pouces 3 ligues, 85 millim.

62. Mrtae scrobiculée. Mitru scrobiculata. Brocchi.

M. testâ elongato-angustâ, fusiformi; spirâa proelongâ, acutâ, transuerstm sulcatâ, valdè puncticulatá; aperturi elonguta, angustâ; columella quadriplicatú.

Brоссн. Conch. subap. tom. 2. pag. 317. pl. 4. fig. 3.

Bast. Bass. tert. du sud-ouest de la France, Mém. de la Sac. d'Hist, nat. tom. 2. pag. 44. $n^{\circ} \cdot 2$.

Cette Mitre est la plus grande des espèces fossiles connues. Elle est trćs-alongée, subulée, pointue; la spire est plus longue que le deruier tour. Elle est composée de quatorze cours à peine convexes, dont la suture simplc est finement canaliculée en dessus; ces tours sont chargés de sillons transverses, nombreux, qui, dansles grands individus, disparoisseat sur le milieu àu dernier lour : ces sillons, plus ou moins profonds, selon les individus, sont quelquefois anguleux et quelquefois aplatis. Quelle que soil leur forme, on observe toujours dans les intervalles qui les séparent des stries ou lamelles longitudiaales qui les font paroître coume percés. A la base du deruier rour les sillons sont beaucoup plus larges et subonduleux. L'ouverture est forlt alongće et très-étroite; le bord droit en est mince, tranchant; la columelle lui est parallèle, el le bord gauche qu'y s'y voit n'est saillant qu'à sa base, où il recouvre une petice fente oubilicale. La columelle est arrondie, presque droite, et elle ve porte jamais plus de quatre plis. 
Ce r'est qu'avec doute que nous mpportons à celle espèce la variélé indiquée par M. Basterot, poul s'ĉtre trouvéc aux environs de Bordeaux. Dans celte rariété, en elfet, la columelle présente toujours cinc plis; le dernier tour est beaucoup plus ventru, et les ponctuations qui sont au foud des sillons sont inliniment plus fines, et souvent n'existent pas dn lout : ces différences paroîlront peul-êlrc sulfisintes pour séparer comme espèce distiucte les individus de Bordeaux. Longueur 3 pouces 9 lignes, 102 milliw. Nous en avons vu des individus plus grands que celui dunt nous donnons les dimensions.

63. Mitre de Dufresne. Mitra Dufresnei. Bast.

MI. testá ovato-oblongâ, crassâ, subventricosâ, superne locviter striatu, lavigutâ; anfractibus convexiusculis, ultimo magno; aperturä elongứâ; columellà quinque vel sexplicatâ.

Bast. Bass. tert. du sud-onest de la France, MIém. de la Soc. d'Hist. nat. tom. 2. pag. 44. $n^{\circ}$.1. pl. 2. fig. 8.

M. Basterot n'a connu que de fort petits iadividus de cette espèce, qui est une des plus belles qui soit connue dans ce genre. Elle est ovale, oblongue; sa spirc est courte, obluse au sommet, formée de six ou sept lours arroudis, convexes, dont les premiers sont striés en travers; ces stries finemeat poncluées disparoissent assez rapidemeat, et les tours inférieurs sont tout-à-fait lisses. La su:ure est simple et assez profonde; le dernier tour, plus grand que tons les autres, est ntlénué à la base, et relevé dans cette partie à l'endroit de l'éclıancrure. L'ouverture est alongée et fort Etroite; le bord droit en est simple, mais oblus, et rapidement épaissi à l'iutérieur. La columeile ést un peu renllće daus le milieu, où sont situés les cinq ou sir plis qu'elle présente; cette columelle est bordée dans toute sa longueur par un hord ganche fort saillant et fort épais à sa base, ct recouvrant à peine une fente ombilicale assez lurge qui se trouve à sa base. En dehors, la coqquille devoit être ornée de vives couleurs, à en jiger par les traces qui en demeurent sur certains individus : on les truuve, en effet, d'un rougeocracé parcouru de lignes (ransversales blanches; ces lignes se mauifestent quelquefois par des ponciualiuas.

Celle coquille ne s'est encore tronvéc qu'aux environs de Burdeaux : elle est, avec la précédenle, la plus grande du genre. Si longueur est de 97 milliw.

64. Mrtre striatule. Mitra striatula. Brocchr.

MI. testâ fusiformi, glabcrimâ, striis flifor mibus, distantibus, loviter crenulatis, transverse succinctâ ; columellầ triplicatâ.

Bноссп. Conch. subap. tom. 2. pag. 318. $n^{\circ}$. 18. pl. 4. fig. 8.
Celte Milre pourroit bien n'être qu'une variété de la Scrobiculée. Elle est alongée, fusiforme, très-étroite, à spire plus longue cque le dernier tour; on y comple neuf it dix lours legèrement canrexes, couverls, dans toule Jcur étendue, de petits sillons arrondis, filiformes, dont les intervalles sont finement ponctués. L'onverture est fort courte; son bord druit cst mince et trauclrant; sa columelle est droite, ct elle n'offie jamais que trois plis obliques el inégaux. Le bord gauclie ne devient seusible cqu'à la base de lie columelle; il se renverse forlement pour cacher uoe petite fente ombilicale qui est à sa base.

Cette jolie coquille se troure fossile en Italie. Elle n'a guère plus de 40 millim. de longneur.

\section{Mitre pyramidelle. Mitra pyramidella.} Broccr.

MT. testî fusiformi, lavigatâ, apice larviter costulatâ; anfructibus planis, numerosis, ultimo brevi, basi prolongo; aperturâ angustí; columellâ subquadriplicutú; labro intùs striato.

Вroccr. Conch. subap. tom. 2. pag. 318. $n^{\circ}$. 19. pl. 4. fig. 5.

Celle espèce ne s'est encore rencontrée qu'à l'état fossile. Elle est alongée, étroite, rrès-pointue au sommet, et se prolongeant à la base en un canal semblable d̀ celui des Finseaux. Les lours de spire sont au nombre de dix; ils sont aplatis et réunis par une suture onduleuse, subcamaliforme. Les premiers tours de la spire sont chargés de petites côtes longitudinales, distiactes, étroites, pliciformes, qui disparoissent sur l'avant-dernier et le dernier tour; celui-ci, sur la longueur de son canal, offie en dehors quelques stries obsolètes. L'ouverture est alongée, étroite, subsemi-lunaire; le bord droit est mince, tranchant, sinueux à la partie supérieure. La columelle présente trois plis très-l'approchés, tranclians, subimbriqués.

Celte coguille, assez rare, est longue de 25 millim.

66. Mrtre plicatule. Mitra plicatula. Broccur.

M. testá elongatá-fusiformi, apice acutá; anfractibus convexiusculis, longitudinaliter ob. solete plicatis, ultimo anfractu basi recto, brevi; aperturâ subsemilunari; columellầ quadriplicata.

Broccr. Conch. subap. tom, 2. pag. 318. $n^{\circ}$. 2a. pl. 4. fig. 7 .

Cette coquille est très-voisine de la précédente, et n'en est probablement qu'une variété. On lú distingue néanmoins par des caraclères assez coostans, dont il faudroit voil les passages pour la réunir avec la première; elle est alongée, trèspointue an sommet, fusiforme; son dernier lour est plas petit que le reste de la spire. Collc-ci se 
compose de dix à onze touis, à peine convexes, à suture simple et profonde; les tonis sont nombreux, courts: tantôt ils sunt presquue lisses, tantôt on y trouve de petils plis longiludinaux, irréguliers, quant à leur nombre \& a leur position; le deruier tour, assez ventru à sa partie supéricure, s'alténue assez fortement à la base, où l'on trouve quelques stries transverses. L'ouverture est plus large que dans l'espèce précédente. Le bord droit est mince, mais non contourné. La columelle est courte, presque droite; on y trouve toujours quatre petits plis subimbriqués. La face interne du bord droit est finement stiée en travers.

On trouve cette coquille fossile dans les terrains subapennnins, aux environs de Parme. Elle est longue de 25 millia.

67. Mitre cupressine. Mitra cupressina. Broc.

MI. testá turriti, angustầ, fusiformi, elegunnter cancellati, busi elongatâ, flexuosis; columelli triplicati.

Broccr. Conch. subap. tom. 2. pag. 3tg. no. 2t. $p l$. 4. fig. 6 .

Ou distingue cette jolie coquille de toutes ses congúncres par les cardclèes suivans : elle est alonirée, subulée, élroile, turriculée. Sa spire, furt longue et pointue, se compose de douze tours un peu convexes, orués d'un fin réseau, produit par des côies longiludinales ftroites, très-régulieres et flexucuses, coupées en travers par des stries fines el profondes qui y produisent des crénelures; les deus stries qui sunt pres des sulures, plus laiges que les autres, la bordent dins toute sa lungucur. l.e dernier tour est très-court; il se prolonge en arrière en un canal étroit, sur lequel les strics transverses seules se voient. La coluzaelle est presque droite, un peu tordue, et se présente jamais que trois plis presqu'égaux et subtranswerses.

Cente jolie espièce se tronve fossile en Italie; elle a 25 à 30 militu. de longueur.

$D^{\prime}$ aurés les tiưres de Brocchi, elle deviendroit gilus longues d'ur tiers euviron.

68. Mrrre fusiforme. Mitrafusiformis, Brnc cur.

II. testâ elongato-fusiform, subangustá, lavigatâ; spirä aculâ; anfractibus convexiusculis; uperturâ brevi, angusti; labro simplici, acuto; columellầ quadijulicatś.

Broccr. Conch. subap. tom. 2. pag. 3!З. $n^{\circ} \cdot 16$

En décrivant cette espèce, Brocchi y a rapporté une ligure de l'Encyclopédie, qui appartient sans le moindre doute à lit Mirra elongata de Lamarck. Quoiqu'il y ait, sans contredit, tne très-grande ressemblance eratre l'espèce des environs de Paris et celle des collines subapenuines, on trouve cependant entielies des caricitires sul- fisans pour les séparer; ce tui restreiat cucose l. nombre des analogues fossiles entre les deux formations.

Cette espèce est alongée, fusiforme; elle est assez ventrue au dernier tour. Sa spire est assez lungue, pointue, conposće de scpl à Luit tours légèrement convexes, complétemeut lisses: le dernier tour est aussi grand que la spire; il est assez large à la base, où il se relève au-dessous do l'écbancrure. Le bord droit est mince, tranchant; le bord yauche est appliquć dans toute sou étendue : il ne se relève que loibleneut à la lase de la columelle pour recouvrir une petite leute ombilicale dont elle est percée. L'uuverture est droite, ì bords presque parallèles. La columelle est un pe u renflée dans sa partic moyeaue, et préscnte en cet endroit quatre plis, dout les deux yremiers sont les plus gros, les autres sont obsulètes.

Cette espèce de Mitre se trouve en même tewus dans les collines subapennines, aux environs de Dax et daris les laluns de la 'Tourine. Elle est longue de 45 milliu.

69. Mrtae parisienne. Milra parisiensis. Noz.

M1. testà ovato-oblongâ, utrâque extremitate ullenuatâ; spirí pyrumiduli, aculâ; unfinuclıbus subplanis, medio depressis, obscure nodosocostalis, ultimo anfiaclu ventricoso, costis grossiusculss longitudinalibus instructo; uperlurê elongato-angustâ; labro obluso, supernè luber. culo unico instructo; columelli medio turgidz, quadriplicati; plicis muximis, subaequalibus.

Coquille rarissime, dont nous n'uvons jamais vt! que deux individus, provenant de la riclie localicé de Parnes, dans le bassin de Paris. Celte coquille forme le passagre entre les Mires e: les Volutes, tant par sa forne que par les plis presqu'ígaux et trés-saillans qui sunt sur la columelle. Cette coquille est ovale, ventrue, atténuée à ses deux extrénités. Sa spire est conique, pcintue, forméc de sept tours aplatis, subcanaliculés ou plutút déprimés dans lenr milieu, un peu couvexes à leur base. Sur ces tours, le dernier exceplé, se truuvent des cólcs nouerises, obscures, convexes, intégulièrement placées, comme sont les varices des Tritons. Le dernier tour est aussi grand arue la spire; il est muni de côtes longitudinales fort grosses et arrondies, qui se terminent à leur partie supérieure par un tubercule gros et obtus. Ces côtes sont plus régulières quc sur les tours yui précèdeut. Elles diminuent assez rapidement et disparoissent à la base, où elles sont remplacées par quclqques stries transverses à peine nuarquées. L'ouverture est oblongue, étruice. La lèvre druice est a ropé dans sa longucur; elle est simple, olutuse, et el!e est pourvue a l'iutéricur, vers le quart supéricar de sa longueur, d'un tubercule écrast? et rirculaire. Lạ colunelle est excavée à sa partic supcricare, reul!éc à sa parlie moyeanc et suivio 
dans conte sa longueur d ua Lord gauche mince at appliqué. Sur le renflement columellaire se trouvent quatre gros plis presqu'egaux, doat le dernier seul est un peu plus petii que les précédens. La longueur de cette espèce est de 47 millin.

\section{MITRUIAA.}

Duns su classification naturelle des Mollusque, M1. Gray a proprosé de dianner ce nom à un geore démewlué des Calyplrées, qui, tels que le $\mathrm{Ca}$ lyptrae chinensis, l'atella chinensis de Liané, ont le sommet à peine en spirale et à l'intérienr une lause obliquemeut décurrente sur le côté. Comme ce groupe de Calyptrées se lie diune manière intime par des nuances insensibles aux espèces trochitormes et tout-à-fait spirales, nous ae pensons pas que l'on doive admeltre le genre de M. Gray, avec d'autant plus de raison ģüil n'y a rien dans la structure de l’animal qui le justifie. Voyez Caryptáe.

\section{MITRULARIA.}

M. Schumacber a proposé sous celle dénomination un démembromeat des Calyptrées de Lamarck, pour celles des especces yui ont à l'intérieur une lame en demi-cornet. Celle division pourroit être admise à titre de sousgenre, el ne pourroil l'être à litre de genre quautant que l'organasalion des animaux viendroit à en prouver la nécessité. Voyez Calyptré.

\section{MODIOLE. Nodiola.}

T.amarck, auqquel on doil ce dínembrement des Mou'es de Liané, l'a fondé sur un caractcice de trop peu d'importance pour être d'́sorraais conservé. Les Modioles ne diflërent cn effel des Moules que parce que les crochets ne sont pas tout-a-fait terminaux comme dans celle-ci. La valeur de ce caractćre est d'aulant rovindre quil existe calre les deux genres une foule de nuances qui servent de passage de l'un a l'antre : ces nuances se remargquent surtont parmi les espèces fossiles. Quant au genre lithodome, †'ui n'est aussi qu'un démembrement artificiel des Modioles, il est nécessairement entraiué aver. ellos i la suite des Monles. A l'imitation de M. de Blaiovilie, nous rúunissons au genre Moule les Modioles et les Lithodomes. Toyez Mour.e.

\section{MOFAT.}

Adaasou ( Foy. au Sénég. pl. 18.) n rangé sous le nnon grénérirure de l'éloncle les Burardes et les Arches : le Mufat appartient au second de ccs genres. Cócst une des especes les plus rares et les plus intéressantes, en ce qu'plle complète un petit groupe des Bacardes. Elle a teçu le nom de Busarde grimacieve, Carlium ringens, de
Lamarck. (Anim. s. zert. tom. 6.pag. 4. no. 3.) Vojez Bocarde.

\section{MIOLAN.}

Nom imposé par Adanson (Voy. au Sćnés. pl. 19, fig. 3) à une pelile espèce de Solen que Linné rapporte itu Solen legumen. II paruît assez probable que la citation est exicte, autant gu'il est possible d'en juger d'apiès la courte descripion et la firure médiocre d'Adanson. Vojez Solex.

\section{MOLETTE.}

Nom vulgaire que l'on donne à plusieurs espèces des genres Trocbus, Monodonte et 'Turbo, parce que leur forme aplatie et les épiues dont le dernier tour est armé leur donne asstzz de ressemblance avec la Molelle d'un éperon.

\section{MOLLUSQUES. Mollusca.}

Les Mollusques occupent par leur organisation la première place entre les Iuvertebrís. Les rapports qui existent entre cenx qui sont le unieux organisés et les derniers échelons des Vertébrés sont si évideos, que los naturalistes n'ont contesté la prééminence des Mollusques sur les autres classes que pendant le teons où ils en ignoroient l'auatomic. Aujourd'hui que des savans du premier ordre ont jeté sur celte partic long-temps négligée des sciences naturelles tout l'éclat de leurs hiborienses recherches, cette question a éé complétement rísolue. Aussi nous n'accumalerous pas ici les preuves de l'opinion génćralcment reçue, elle se déduira facilement de ce que nons exposerons plus lard sur les Mollusques.

A l'arlicle Conchylologe que Bruguière a traité dans le preucer volume de ce Dictionnaire, l'histoire de la science a éćc lajle en grande partie. Bruruière s'est conienté de présenter, dans ure stírie de lableanx, toutes les anciennes méthodes el celles plus modernes qui parurent avant lui. Cette marche, lurt bonne en elle-mćme, oll: $e$ quelques inconvíniens, el entr'autres cclui de laisser (rop de vague daus l'appréciation des fails qui cnncourent à l'avauscement de la scicnce; d'un autre cóté, cet avancement n'a pas été provoq̨ué seulemeut par les roélliodes, celix des auteurs gui ont bien observé et bien décrit !es faits y nnt aussi puissammen: contribué, et il y auroil de l'injuslice it ne pas les citer pour ce qu'ils lui nat fait faire de progrès : c'est dans lc lant de compléter, sous ca rapport, l'article très-rcinarquable d'ailleurs de Bruguière, que nous reprenons, dans un écrit anssi concis que possible, l'histaire de la science, en évitant des détails superflus sur ceux des allteurs dont les méthodes ont ćlć dunnées dans l'arlicle que nous venons de citer. 11 csi done iudispensable de renvoyer le lecteur a cel article; il $y$ acquerra des connoissances prćliminaires méces- 
saires a l'intelligence des sujets divers que nous avous à traiter acluellement.

L'ćtnde bien faite et systératique des Mollusques, considér'́s non-seulement d'après leur eaveloppe, mais encore d'après les connoissances natcmiques, est toute moderne; on ne trouve dans les anciens auteurs que des recherches isolées, incomplètes, et pour ainsi dire des essais perdus et sans application. L'esprit ne s'arrétoit dans ces temps, à ces sortes de recherches, que par. pure curiosité, par admiralion pour les ceuvres de la nature, sans penser à leur utilité réelle; aussi toutes les connoissances que nous transmettent les auteurs anciens sont-elles entachées de ce vice radical qui s'est opposé si long-temps à leur perfectionnement.

Plnsieurs travaux cependant doivent marquer leur époque dans la scieace, quoiqu'ils aieat été publiés fort anciennement: c'est ainsi que nous citerons l'ouvrage de Belon, de Aquatilibus libıi duo cum iconibus ad vivum, publié ea 1553 , et dont quelques parties sont consacrées aux Mollusques. Lcs planches de cet ouvrage, ainsi que du suirant, se resseatent nécessairement du temps où elles ont été faics. Rondelet, de Piscibus, 1554 , esi supéricur à Delon pour l'exactitude des obscrrations sur les Mollusques, dont il a décrit un plus grand nombre. Les coquilles sont gruelquefois représentíes avec l'aninal et l'opercule: lis liynres, quoique grassières, ne laissent pas d'ètre assez exactes pour que l'on reconnoisse assez facilement plusieurs espéces. 11 a séparé en deux parties ce qui a rapport aux Mollusques: dans la prewière sont réunics les coquilles bivalres, parmi lesquelles se tronve l'Oreille de mer, et dans la seconde sont rassemblées toutes les coquilles univalves. On reconnoit chaque jour com. bien sont exactes la plupart des observations que Rondelet, daus son style simple et naif, a consigutes dans scn ouvrage, qui restera l'un des plus recommaudables de cette époque.

Lionrrage de Gesuer, intilulé ; De Piscibus et Aquatilibus libri tres, ijojo, n'est qu'une compilation daus laquelle on retrouve exposées les idées des Anciens sur les Mollusques et les coquilles; cet ourrage, sous ce rapport, est fort semblable à celni d'Aldrovande, de Animalibus exsanguibus, etc., 1606 , où sont rapportées les opinions des Anciens : des figures la plupart recopiées, trèsgrossicies, permettant à peine la reconnoissauce des objets représentés, accompagnent le texte, qui a ujourd'hui n'est que ratement consulté.

Qucique publié pen de tcmps après celui d'A!drovarde, le Traité de la Pourpre de Fubius Colis ma en diflëre hien essentiellsment sous tous les rapirorts : ce pelit ourrage, fart rare, publié à Rome eu 1616 , est très-remarquable par l'esprit qui a dirigé sur autenr. De tons !cs traités anciens, cest sans cort:edit celui qui a été fait dans le but le fil: costenabie pour lavancemerit de la science, et malgré l'imperfection des figures, il sera toujour's recherché comme devant faire époque daus I'histaire de la concbyliologie.

Ce ne fut que long-temps après, vers la fin du mêne siècle, que parurent plusieurs ouvragess d'anatomie sur les Mollusques; d'alonrd, en 1678 , l'Historia Animalium Anglice de Lister, dont la plus grande partie est cousacríe aux Mollusques terrestres et lluvialiles de la Grande-Bretagne, et sur lesquels il a dontué de honnes ohservations utiles encore à consulter. Ce ne fut que plusieurs années après que Lister, que l'on peut considérer comme le père de l'analomie des Mollusques, publia en $1694,1695,1696$, plusieurs mémoires d'anatomie: le premier est consacré surtout aux coquilles terrestres et aux Limares, dont les anatomies, bien impalfaites sans doute, sont représentées dans huit planches gravées; le second des mémoires traite de l'anatomie des Buccins marios et d'eau douce, c'est-à-dire des Lymnées; le troisième, enfin, comprend l'anatomie des coquilles bivalves d'ean douce et de mer: mais ce sont en général des dissections très-imparfiates qui ne peuvent presque plus être utiles dans l'état actuel de la scicnre. Enfin, dans le tom. 19 des Transactions philosophiques de Londies, Lister a inséré l'anatomie du Peigne avec des figures; mais, comme les frécédences, elles laissent beaucoop à desirer. Nous ne parlerons pas du Synopsis conchyliorum du nêtme autcur : il en a été rendu comple à l'article Concuy liorngie du prenier volume de ce Dictionnaire : nous y renvoyons. Daus le même teropss, Muralt donnoit, daus le Recueil des Curieux. de la Nature, 1689 , les observations anatonicgues sur la Limace rouge. Harder, ea 1679, daus san Prodromus physiologicus, publioit son Examen anatomicum Cochlece terrestris domi-porla; et enfin Reiselius, égaleweut dans les Miscellanea Curiosoruna natura, pour les années 697 et 1698 , publioit son Ilémoire de Limace in ovo; de sorle que, surtout sur cette partie des coquilles terrestres, on possédoit un assez grand nombre de dozumens qui ne se rattachoient cepeudantalors ì aucun systèuc, et qui long-tenups fareut oubliés et ne profitèrenc que peu on poividu toutanx auteurs qui suivirent: car, en ellet, ce ne fat que fort long-temps apris que l'on songea à établir un système basé sur les rapports des animanx. Il étoit assez naturel, à reste, que l'éiude anatomique des Mollusques commençát par cellx qui nous entourent, que nous voyors it chaque instant, et sur lesque!s nous pouvons facilement multiplier nos recherches et nos observations.

Rumphius, qui le premier nous donna une frgutc de l'aninal du Nantile, figure bien insuffisante tt bjen imparfaite, mais qui peut cependant être de quelçu'utilité ì l'aide des notes que l'auteur publia, augmenta par ses divers travaux le cliamp de l'obscrvaliou, et éclaircit en plusieus endrnits 
les connoissances sar les Mollusques. Ce fut principalenent dans le grand Recueil des Miscellanea Curosorum nalurex, prour les annćes 1684 à J688, que cet autcur inséra les Mlénoircs dout oous venoos de parler. Nous ne mentionnous pas ici son onrrage sur l'ile d'Ainboioe, que Valentyn connpléla, l'ayant déjà lait à l'article Coscuy ziolugre.

Réaumur, auçuel les sciences sout redevables de taut de lravaux, qui répandit sur plusieurs de ces parties, et notamuent sur lcs insectes, toutes les lumières de ses savantes ubservations, s'occupa aussi des iflollusques, sur lesquels if publia plusieurs observations que le lemps a confitmécs. Il existoil cntre les savaus une discussion it l'egarde de la tormation du test tles Mollusques: les uns prélcndoient que celte partie sulicle prenoit son accroissement par inlussnsception, comme les os des vertébrés; les autres, a contraire affirmcicnt, avec beaucoup plus de raison, que la coquille n'étoit lorméc que par superposition de couches. Réan anur entreprit des expériences qui pusseut décider la question, et il en fit un assez grand nom!re pour la mettre hors de doute; aussi toutes les persounes qui les out connues, et qui a'ont point eu d'injuste prévention, se rangèrent de son avis. Outre ce sujet, qui fut savamment traité par Réaumur, cet illustre académicien s'occupa aussi de diverses antres rechercbes sur les Mollusques. En 1710 parat son Mémoire sur les mouvemens progressifs des Mollusqques, et sur quelques autres de leurs mouvemens; Mémoire dont la suic ne fut publiée qu'en 1712. Non-seulement cet habile observateur fait connoître le mécanisme des mouvemens des Mollusques de divcres classes, mais encore ceux des Étoiles de mer, des Oursins, etc.

Un auıre Mémoire, non moins intéressant que le précédent, inséré comme lui dans les Mémoiles de l'Acadérnie, pour l'anaée 171 , est consacré aux différentes mavières dont plosieurs espèces d'auimaux de mer s'attachent au sable, aux pierres, ct les uns aux autres; le fait principal qui s'y tronve déreloppé est relatif a la formation des byssas de la plupari des coquilles bivilves yjui se fixent par ce moyen.

Non-seulemeut Réaumur s'occupoil avec succès d'observations longues et difficiles d'Listoire aatorelle propremeut dite, mais il savoit aussi se saisir des sujets d'application; c'est ainsi qüil s'occapa de la leinure pourpre, que l'on peut olstenir d'une coquille désignće alors sous le nom de Buccin, à laquelle Lamarck a donné le nom de Purpura lapiilus, espèce fort commune sur nos côtes, et qqui lournit une liq̣ueur purp̧rée, dont il seroit peut-être possible de tirer parti.

Des deux deraiers Mémoires de Réisumar dont nous ayous à parler, le premier, de 8717 , est consacré aux Pinnes marioes et à la formation des Perles, et le second, de 1723 , tritite des merveilles des Dails (Pholades), et de leur

Hist. Nat. des Vers. Tome 11 . phosphorescenee. Celte propriété des Pholades, qui est conune de puis très long lemps, a ćlé le sujet de plus d'une recherche. Nous en traiterous à l'article de ce geare.

Les travaux mulipliés du savant auleor des Vémoires sur les insectes eurent une inlluence des plus marquées sur l'esprit des observaleurs de cetle époque; il répandit le goût de l'observation, et son esprit plein de justesse, de sagacité et de philosophie, put servir d'exemple it ses successenrs pur continucr à parcourir avec succès les routes qu'il avoit cuvertes.

Ce fut dans le mêrue temps que Pétiver donna, en 1713 , son vurrage intitulé Aquatilium Amboince icones et nominc; ouvrage conlenant de buunes plauches et d'excelleutes obscrvations : il est un complémeut nécessaire aux travaux de Rum. phius el de Valentyn son continuatcur.

Un animal qui ravage et qui détruit tous les bois employés à la constucion des digues maritimes, qui les perce en tous sens, a étć bien naturellement le sujet de plus d'one observation; il fulloit elfectivement les multiplier pour bien cunnoître un ennemi aussi redoutable, et pour apporter remède anx destructions quail occasionne, si cela est possible. C'est dans cette intention que fut publiée, dans l'année 1720 , la Dissertation de Deslatodes, dans les NJémoires de l'A cadémie, et plus tard, 1733 , celle de Roussel, intitulée: Observation sur l'origiae, la constitution et la nature des Vers de mer qui perceot les vaisscaux, les piliers, les jetćes et les estacades. Ce fut la mêrne année. 1733 , que Malouet publia à A msslerdaun ses Recherches iutéressantes sur l'origine la formation, etc., de diverses espèces de Vers à ınyaux. Ces auteurs, aussi bien que Sellius, qui ne fit paroître que vingt ans après son Histaria naturalis Teredinis, etc. , commirent des erreurs graves dans les descriplions qu'ils firent des Tarets; et, puisque nous sommes sur ce sujet, nous mentionverons sur-le-clamp le Mémoire de l'babile observateur Adanson, qui le communiqua, dès l'anuće 1756 , à l'A cadémie, mais qui ne fut inséré parmi les Mlémoires de celte société savante que trois ans plus tard. L’anteur, après avoir décrit avec exactitude le 'Taret qu'il avait observé au Sćnégal, réfute les opinions des auteurs qui ont parlé du Taret, et démontre jusqu'à l'évidence, et en se fondant sur la plus juste analogie, que l'on a voit toujours pris pour la têle de l'animal son pied, et réciproquement; et que l'on avoit eu tort de taire de ce coquillage une classe a part, car il a la plus grande ressemblance avec les Pholades. Aussi, depuis le Mémoire d'Adauson, tous les anteurs se rangèreat de son avis, et aujourd hui encore, c'est son opiaion qui est adoptée par les auteurs modernes et classiques.

Pour reprendre la série chronologique tgne nous avons interronpue a sujet des Tarets, nuus parleruns d'un ouvrage qui lait époque dans plusieurs 


\section{$4 ?+\frac{1}{4}$}

M O L

parties de Ia zoologie, le Biblia naturce de Swammerdam, dans lequel on trouve peu de chose, il est vrai, sur les Mollusques, mais qui contient cependant sur les Hélices et les Liaraces des anatomies très-bonaes, on peut dire les seules que l'un pût consulter avec avantage avant la publication des excellens Mlémoires de M. Cuvier.

Comme on l'a dû remarquer, le goút de la saine olsservation se répandoit de p'us en plus; on seatoit le besoin de multiplier les faits, de sonder les profondeurs de la aature, pour baser enfin des théories à peine ébauchées. Ce goút, il faut le dire, étoit dî surtout à Réaumure età plusieurs des observaleurs que nous avons cités.

Nous ne nous arrêterons pas à quelques mémoires publiés à la même époque, qui, qunique très-intéressans, ne sont point assez importaus pour nous occuper, tels que les expérieuces de Duhamel du Mouceau sur la pourpre, IIémoire de l'Acadénuie des Sciences, 1739 ; le travail de Moehriog surle poisson de cerıanes Monles, publié en ${ }^{1742}$; les observations sur les Huittres par Edmann, publiées en 1744 dans le recueil de l'Acadeniia scientia Comment.; ainsique le mémoire intitulé Pisciculi testis Ostrearum inherentes, par Heyke, inséré dans le même recueil et dans la même année. Ce fut aussi à peu près dans le mĉme temps, 1739 , que Plancus publia la première édiliou de son important travail sur les coquilles microscopiques : par ses observations nn nonvean monde, pour ainsi dire, lut connu, et produisirent pour les coquilles ce que l'ouvrage de Muller sur les animaux microscopiques ellecina dans les autres parties de la zoologie. Ce furent lí les premières observations dont le microscope enrichit la conchyliologie : elles furent secondées plus tard par l'infatigable micrographe Soldani, dont nous avons parlé a l'article Cépraropode. L'ouvrage de Plancus ent une seconde édition beaucoup plus complète que la première et fut publié à Rome en ${ }^{7} 760$. Cet ouvrage, ainsi que celui de Soldani, sont encore les seuls qui puissen! servir anx recherches oécessaires à ceux qui s'occupent des Polytbalames en particulier; d'auires ouvrages, d'une bien plus grande importance pour l'étude et la classitication des Mollusques, se préparoient.

Guettard, rassemblant les fuits épars publiés snr les Mollusques, et apercevant les défauts de ses devanciers, fat le premier qui développa, dans son mémoire intitulé Observations qui peuvent servir à former quelques caractères de coquillage, l'exccllente méthode qu'on négligea quelque temps encore, mais qui fut adoptée comme la seule convenable. Il propusa d'établir des genres non-seulement d'aprés la coquille, comme l'avoieat fait quelıues écriviins, nais encore d'après l'animal, qu'il considère avec juste raison comme deraat donner los caractères les plus essentiels. C'est ainsi qu'il est arrivé à des coupes vraiment
NI O L

naturelles : on doit singulićrement regretter qu'il a'ait point étendu davautage ses observations, 11 forme plusieurs geares dont le premicr est pour la Limace; le second le Limaçon (genre Helix); le troisième le Buccin terrestre, qui realerme des Clausilies et des Maillots; le quatrièune n'est qu'un déuneunbrement peu uécessaire des Hélices pour celles qui sont aplaties el omliliquées; le cinquième, qui cuntient le Limaçon terrestre à opercule (Cyclostone), a été justement conservé; le sisième renferase les Planorbes; dans le septième, sousle nom de Vigneau, il rassembla les cuquilles connoes sous les noms vulgaires de Demowelle, Limaçon, Vivipare fluviatile. Guettard, comase on le voit, avoit itès-lors séparé des coquilles que Inng-temps encore après lui on tint réunies, et que daus ces derniers temps Draparnaud sépara sans le citer, quoique cependant il soit le véritable auteur du genre Vivipare (Paludine Lamarck); dans le liuitième genre il établit les earactères propres aux Buccins, qu'il nomune anssi d'après!e vulgaire Moine, Cornet ou Pourpre. C'est sur l'observation de l'aoimal du Purpura lapillus Lamarck que celte division est établie. Le genre suivant, le neuvième, est consacré aux Nérites, genre conservé depuis; le dixième est destiné aux 'Troques, qu'il nomme Guiguette; le onzième, auquel Guetlard conserve le nom de Patelle ou Lépas, douné par les autenrs, renferme effectivement les véritables Patelles; le donzième genre caractérise trèsbien le genre Lernée de Linaé (Aplysie des auleurs moderne); l'avaut-dernier geare, le treizième. sous le nom de Conque, Buccin fluviatile, réunit les Lymń́es; le quatorzième enfin est destiné au genre Valvé. D’après cel essai, que l'on peut considérer comme la première application que l'on ait faite ponr les Mollusques de véritables principes zoologiques, on doit voir combien Guellard pensoit juste; mais on nauroit qu'une foible mesure de son savoir, si nous ne rapportions textaellement un passage de son Némoire, dans lequel on trouve en peu de mols l'indication des caractères qui peuveat circonscrire de bons geares. Après avoir justement blàmé des auteurs de son époque qui ne voyoient dans cbaque être qu'un individu isole de lout autre voisin ou congénère, après avoir blànéé les idées mélaphysiques quui accompagnent presque de rigueur les observations publiées alozs, il adresse les questions suivantes:

"Qui peut en eflet se refuser aux divisions qui » on tété faites en différens genres, des corquil" lages dont il a été question plus baut? Pourrais"je avec raison conlundre les coquillages don: les " yeux sont posés au bout de ces espèces de ๖ luyaux auxquels on a dooné le nom de corae - avec ceux qui les ont à la base de ces tuyaux? n Les coquillages qui n'ont que deux de ces cor- nes, peuvent-ils se confondre avec ceux qui en - ont yguatre? Ceux qui oat ces espèces de cylin. ndies attachés aux cornes, et quii porlent chacun 
" nn cil, tandis que ces cornes en manquent, ne

" duivent-ils pas égalewent être rangés sous un

n genre dillśśrent de celui où sont placés les autres?

n Metlrai-je les coquillages qui n'ont que deux

* yeux pusés intérieurement avec ceux qui les unt

" à l'extérieur, d'autant plus que les cornes de cos

* coquillages sont aplaties et Iriangulaires? Outre

n cela, ces coquillanes, qui ferment leur coquille

* d'une partie qui li bouche exactcment, el qu'un

- appelle comaunément opercule, ne doivenı-ils

- pas être éloignés de ceux qui n'unt jas cette

" partie? Ne pourroit-on pas nuéco dire que les

- coquillages dont l'opercule est cartilagineux,

- soat séparés naturelletnent de ceux où l'opercule

- est dur el conme osseux? ('e ne sera, au reste,

- qu'en faisant attention aux plus petiles dilfe-

- rences qui se trouvent daos ces animaux, qu'on

* parviendra à découvrir, autant qu'il peut nous

- l'être permis, cet enchainemen! que les étles

- ont les uns avec les autres. "Personde, nous le pensons, ne disconviendra que les vrils principes de la conchyliologie ne suient dès-lors pnsés par Guetlard. Ces principes, qui furent si souvent méconnus après lui, trouvèrent cependunt des hommes qui les employèrent habilement au profit de la science, et teutèrent, en agrandissant le champ d'observatiou, d'établir sur ces priucipes des systèmes complets; systèmes que l'un apprécie d'autant plas aujoutd'hui qu'ils sont restés plus longtemps dans l'oubli. Tels lurent Linaé et ddanson, ๓ais ce deruier surtous.

Uu esprit d'aualyse et de philosoplie s'est montré dès le temps de Linné, et a commencé même avant lui, pour plusieurs parties des sciences natorelles; mais lioné, don: nous ve saurions trop étudier la méthode, a élé le véritable fundateur de la rélurıne, le premier qui ait recherché à rattacher à un système naturel toutes les connaissances acquises par ses prédécesseurs et par lui-même, et à les cuortonnel d'après des bases olides, appuýes sur la saiue observation.

Pour les Mullusques, Adanson l'a précédé, et l'ouvrage de cet auteur, encore classigue anjourd'hai, fut d'un grand secours au professeur d' $U_{p-}$ sal, qui y trouva rassemblíes une fuule d'observations plécises, rigoureuses sur une suile considérable de geares; il y trouva des genres faits d'après l'animal des coyuilles, comme Guellard en aroit dunné l'esemple.

A l'article Coscaylologie il n'a été donné qu'un léger apercu de l'ouvrage d'Adauson: vous allons entrer à son égard dans plus de lśtails. Adauson ne se contenta pas d'un caractère pour l'établissement d'un seul systène, il essaya toutes les combinaisons; d'abord, pour la coquille seule, puis, puur l'uniaral, et divisa d'abord toutes les coquilles en Limaçons et en Conques. Dans les Limacons ou coquilles univalves, il considere six clioses : $1^{\circ}$. les spires; $z^{\circ}$. le sommet; $3^{\circ}$. l'ouverture; $4^{\circ}$. l'opercule;
$\mathrm{M} \mathrm{O} \mathrm{L}$

50. la vacre; $6^{\circ}$. le périoste. Ces six parties principales devienuent, par leurs diverses comhinaisons, le sujet de onze tableaux systénutiques, dans lesquels il les a épuisées toutes. Pour les conques ou coquilles bivalves, il luit le mêrae travail; mais il y trouve sept parties principales: $1^{\circ}$. les ballaus; $2^{\circ}$. les sonimets; $3 \bullet$. Ia charnicie; $4^{n}$. le ligument; 50. les atlaches; 60 . la nacre; $7^{\circ}$. le pétioste. Sept lableaux donnent une idće des diverses combinaisuns de ces sept choses principales. Adanson cousidere les divers rapports lirés de l'animal. Il y trouve cing choses principales, qui sont: $1^{\circ}$. les cornes; $2^{\circ}$. Ies yeux; 30 . Ia bouche; $4^{n}$. la traclıée; 50 . le pied. Nuus allons donner les titres seulement des tableaux qui concernent celle partie pour faire juger do leur utilile. Le premier, sur le nombre descornes, divisé en trois sections: les Limiçons qui n'en ont point, ceux qui en ont deux, et cenx qui en ont quatre. Le second : figure des cornes (tentacules), Limaçons dout les cornes sont conifjues ou cylindriques, divisés en ceux qui out un renllement à la base des tentacules, et ceux qui en sout dépourvus. Le troisième : sur la situation des cornes a la racine de la tête ou à l'extrémité de cette partie; deux tableaux sont consacrés à la place des yenx, soil sur la tête, soit sur les tentacules. Une première division renferme ceux qui n'ont point d'yeux; une seconde pour ceux dont les yeux sont sur la têle, au côté interne de la base des tentacules; la troisième, ceux qui, avec la même disposition, ont les yeax à la base externe.

Dans le second tableau, les Mollusurues sont divisés en quatre classes: $1{ }^{\circ}$. ceux qui ont les yeux au côté extel'ne à la base des tentacules; $2^{\circ}$. ceux qui ont les yeux au côté externe, un peu au-dessus de la base; $3^{n}$. ceux qui ont les yeux au côté externe, vers le milieu destentacales; $4^{\circ}$. enfin, ceux dout les yeux sont au sommet des tentacules. La bouche n'a été considérée que de deux manières, les Limaçons à bouche sans trompe avec $\mathrm{dcs}$ mâchoires, et ceux qui on t une trompe sans mâchoires. La forme de la trachée ou canal respiratoire n'a olfert que deux manières d'être, ou présentant une siunple ouverture sur le côté de l'animal, ou laissant sorlir de son dos un long canal qui se relève vers lui. Quant au sillon du pied, $A$ danson a aussi pour cela for né un tableau dans lequel est une division puur les Mollusques qui n'ont point de sillons au pied, et une seconde pour ceux qui en ont un sur la partie antérieure.

Les Cunques, cunsidérées d'après l'animal seulewent, n'aut présenté que quitre parties principales : le manteau, les trachces, le pied, et les fils ou byssus.

Le inanteau est considéré de trois manières: $1^{\circ}$. entièrement divisé en deux lobes; $2^{\circ}$. divisé d'un côté seulement en deux lobes; $3 \circ$. formant un sac ouvert seulement dans les deux côtés opposés. Pour les trachées ou siphons : $1^{\circ}$. il y ea a 
une seale, en forne d'ouverture; $2^{\circ}$. il $\mathrm{g}$ en a deux, également en lorme d'ouverture; $3^{\circ}$. il y en a deux alongées ea tuyaux réunis. Quant au pied, les Conques ne présentent que trois circonstances: $10^{\circ}$ on elles a'en ont pas; $2^{\circ}$. ou elles en ont un 'Iui ne paroît point au-dehors; $3^{\circ}$. ou elles en ont un qui paroit au-dehors. Les fils ou le byssus, à l'égard des Conques, n'offre que deux choses, celles qui en ont et celles qui en snnt dépourvues.

C'est ainsi qu'Adanson, avant d'entrer en matière, combine une fusule de systèmes différens: basés sur un caractère unique, et par cela même insuffisant pour faire des coupes naturelles, quelques-uns de ces systèmes servent encore aujourd'bui pour l'établissement de grandes divisions, comme dans les Conques la forme du manteau, dans les coquilles univalves l'existence ou l'absence de lopercule, etc. Nous renvoyous, pour la connoissance du système d'Adanson, au tableau qui en offre l'ensenble, donné à l'article Conchy rologiz. On remarquera, dans ce système, plasieurs défauts; ils dépendent surtout de ce que les groupes ont été formés d'après nn seul caractère. C'est pour cela que les Oscabrions se trouvent pour la première fois rapprochés des Patelles, les Haliotides des Limaçons terrestres; les Pinnes, les Moules, les Avicules confondues en un seul genre; mais ces defauts, quelque graves qu'ils paroissent, sont rachetés par uae foule d'excellentes observations et de justes rapprochemens, comme celui des 'Tarets et des Pholades, par exemple, que, malgré cela, Linoé a tcnu séparés et très-éloignés; les Pholades dans les Multivaves, et le Taret dans les coquilles univalvẻs à spire bon régulière.

Ce seroit ici le lieu de parler des ouvrages de Linné; mais comme il a été rendu comple de son système conchyliologique à l'article ConcryLIOLOG1E, nolls y renvoyons pour mentionner l'onvrage de Ginani, publié dans les années 1755 à 1757 , sur les coquilles marines de l'Adriatique, et celles terrestres et fluviatiles du teritoire de Ravene. Ce travail, accompagné de nombreuses et bonnes figures, est fort rare à Paris, et ne peut être consulté antant qu'il le mériteroit. Ce ne fut que plus tard, en 1761 , que Bobatsch donna son ouvrage intilulé : de quibusdam Aniinalibus marinis, dans lequel il tut dirigé par de vrais principes de zoologie, tellement qu'on le consulte encore maintenant avec fruit. On y trouve des anatomies bien faites et bien représentées par de bonnes planches. Les Mollusques dont il est question soat : l'A plysie, la 'Théthys et la Doris.

L'ouvrage d'Adauson et les observations de Guettard avoient fait sentir le profit que l'on pourroit tirer de l'étude bien faite des opercules; Ils devinrent le sujet de plusieurs Mémoires, dont un des plus importans est celui de Iférissant, inséré dans les Mémoires de l'Acadénie de Paris, e. 1766 .
A cette époque une forte inpulsion a túté clunnée aux sciencęs naturelles; Bulfon et linné en avoient répandu le goût; et si déjì, avant eux, quelques hommes avoient commencé à frayer à la science de nouvelles routes, ces deux célèbres Ecrivains la placèrent tout-à-fuit hors de l'empire des anciennes routines, et créèrent pour elle une ère aouvelle, dans laquelle l'école françoise surtout sut lui faire laire de rapides progrés. Il ue s'agissoit plus alors d'entasser d'iuatiles ou d'incomplètes observations; il ne s'agissoit plus de procéder à l'élude de la nature avéc cet esprit de métaphysique qui avait gâlé les écrits des Anciens, mais de rassembler les faits, do les coordonner, d'établir avec le moins de lacunes possible cet enchainement admirable des êtres, de saisir les rapports qui les lient, de poser en uo mot les écbelons de cette composition organique croissante depuis l'être le plus simple jusqu'is celui qui est le plus composé : toutes les partic's de la zoologie sentirent les utiles elfets de cotte benreuse réforme.

Pallas, pour les Mollusques, posa dès-lors, en homme de génie, les premiers fondemens de l'éd:fice que l'on devoit bientôt continuer; c'est dans les Miscellanea zoalogica, surtout au sujet des A phrodites, que l'on peut s'assurer de la justesse et de la sagacité de cet jllustre observateur, lorsqu'il démontre combien Linné lui-même, en s'altachiut plus spécialement aux caractères des coquilles (ju'di ceux des animaux, s'élcigne de l'orche naturel; il fait voir, contre l'opiuion du professeur d'Upsal, que les Limaces, qui comprennent pour lui un grand noubre de Mollusques, doivent être placcirs parmi les Mollusques univalves. Il divise au resle tous les Mollusques en deux grands órdies, les Mollusques univalves et les Mollusques bivalves, dans lesquels, à l'exemple d'Adanson, il fait rentrer les 'Tarets et les Ascidies.

Ce fut l'anaée suivante, 1767 , que Geolfioy, dans son petit Traité des Caquilles terrestres et fluviatiles des environs de Paris, ít de nouveau l'application des priacipes de conchyliologie élablis avant lui; il se servit de l'animal pour caractériser les genıes qui, quoique peu nombreux, sont pourtant restés.

Muller, ce savant anteur de plusieurs ouvrages impurtans pour la zoologie, outre sa Faune disnoise, donna aussi un Systeme de Conchyliologio et un Traité sur les Coquilles terrestres et fluvicutiles. Ce dernier ouvrage est plus parfait que celui de Geoffruy; il divise ses Mollusques en trois sections, de la manière suivante :

$$
\text { † Caquilles nulles. }
$$

Tentacules linéaires.

Gente Liace.

$$
t+\text { Coquille univalve. }
$$

«. Tentacoles linéaires: 
10. Au nombre de quatre.

2०. An nowbre de deux.

HeLtx.

Vertigo.

B. Tentacules tronques :

10. Les ycux en dedaus.

$2^{\circ}$. Les yeux par derrière.

Ancrle.

Cartchie.

$\boldsymbol{\gamma}$. Tentacules triangulaires. Buccis.

ઈ. Tentacules cétacés :

10. Les yeux en deliors.

$2^{\circ}$. Les yeux en dedans.

3o. Les yeux par derrière.

Nérite.

Praxorbe.

VaLVÉ.

\section{tt+ Coquille bivalue.}

Siphons doubles:

10. Court.

20. Alongé.

3॰. Nulle. donte).

Modre (Ano-

Temine ( Cyclade des auteurs).

Mre (Mulettes des auteurs mo. dernes).

Outre ce système particulier pour l'arrangement des Mollusques terresires, dans lequel Mullcr a profité habilement des idées de Gueltard et de Geoflioy, on est redevable au puême auteur d'un systèrne général de Cunchyliologie, dont un tabteau a été présenté à l'article Coschýlonogre do premier volume de ce Diclionnaire. Il s'en faut de beaucoup que ce systène général soit aussi bien fait que le premier : il ne présente pas les perfectionnemens que l'on devuit espérer après la publitation d'un ouvrage tel que celui d'Adinson par exemple.

Quelques ouvrages publiés dans le même temps apportérent quelques aatériaux à la science, celui de Forslial (Descriptiones animalium, avium, piscium, amphibiorum, vermium, insectonem, quae in itinere orientuli observavit $177^{5}$, et les planches du même ouvrage, publiées l'année suivante); celui d'Othon Fabricius (Fauna groenlandica, etc. 1780); les divers Mémoires de Dicquemarre sur plasieurs animaux Mollusques. Its sont tous insérés dans les Transactions philosophiques de Londres, et dans le Jounal de Physique pour les années 1779 a 1786 . Les Observations de Murray surla reproduction des parties enlevées aox Limacons et aux Limaces, 1776 ; question curieuse etimportante que Spalanzani annonça le premier, et qui fut contirmée par Bonnet et George Tarenne en 1808 , dans son Trailć dc Cochliopérie, comme nous l'avons dit à l'arlicle HÉrice.

Enfin, nous arrivons an temps où Bruguière donna en France une nouvelle impulsion à l'étude des Mollusques par son travail de l'Encyclopédie; mais, il faut lavouer, ce savant écrivain ne profita pas autaat qu'il l'auroit pu faire des travaas qui l'avoient précédé; il aaroit dû moins s'atiacher à la lettre de Linaé, et, quoiqu'il ait perfectionne sou système, il le laisse encore lous de ce qu'il aurout pu devenir entre des ruains aussi habiles. Nous voyons eu ellet qu'il confond, dans son ordre troisic̀me, les Vers mollusques, des êtres fort étrangers les uns aux autres, et qui sont loin de se trouver, daus leurs rapports maturels, avec de véritables Mollusques. On y troure des Polypes, des Hydres, des animaux subarliculés, des animaux radiaires, et même un genre de poissons. Il sépare cepeudant dans un ordre suivant, sous le nom de Vel: échinoderines, les Oursins, que Linné avoit coufondus avec les Vers mollusques. Son ordre cinquième, les Vers teslaciés, est divisé, à la manière de Linné, en trois sections : la première, les Mlultivalves; la seconde, les coquilles bivalves; et la troisième, les coquilles univalves. La première de ces sections contient neuf genres, qui, comme on peut le penser, réunis d'après la scule considération du nombre des pièces, doivent être forr étrangers les uns aux autres. Elfectivement, is côté des Oscabrions, nous trouvons les Balances et les Anatifes, $\dot{a}$ côté de ceux-ci, trois genres parfaitement groupés, et que réunissent des carractères naturels : les Tarets, les Fistulanes (gemc nouveau), et les Pholades : ce qui est évidemment imilé d'Aclanson. Après ces trois genres, vient celui que liruguière nomma Cluar, Gioemis (voyez ce mol), établi, comme on l'a recomu depuis, sur une sapercherie de l'italien Gioeni. Les deux derniers genres de celle section, qui re sont pas plus en rapport avec les précédens que ceux que nolas venons de mentionner, sont lcs geures Auomic el Cranie. La deuxième section, qui comprend les coquilles bivalves, est divisée en deux parties, l'une pon les coquilles irrégulières, la seconde pour les coquilles régulières. Les six genres suivans se montrent dans la prenuère : Acarde, Came, Huître, Spondyle, Placube, Perne. On sail aujourd'bui que le genre Acarde a élé établi sur des épiphyses vertébrales de certains poissons. Dans la seconde, il y a treize yenres élablis dans l'ordre qui suit : Mye, Sjlen, Pinne, Moule, 'T'clliue, Bucarde, Mactre, Do. nace, Vénus, 'Trigonie, Arche, P'eigne, 'Térebratule. La troisicme section, qui reuferme l.s Univalves, est séparée en deux grandes divisions, à la mauière de Breyne : les coquilles uniloculaires et les coquilles multiloculaires. Les premières sont divisécs en coquilles sans spires régulières, qui renferment six genres qui n'ont entr'eux presqu'aucuns rapports, Fissurelles, $\mathrm{Pa}$ telles, Dentale, Serpule, Arrosoir, Siliquaire; ot en coquille à spire régulière, qui comprennent vingt-trois genres; ce sout les suivans: Cốne, Par. celaine, Ovule, Volute, Buccin, Pourpre, Casque, Strombe, Murex, Fasean, Cérite, Vis, Toupie, Sabot, Bulle, Bulime, Hélice, Planorbe, Nalice, Nérite, Haliolide, Argonaute. Les genres 
de coquilles mutiloculaires, qৃui ont été si multipliés dans ces derniers temps par Montfort et d'autres, ne sont, dans Bruguière, qu'au nombre de quatre : Camérine, Ammonite, Nautile, Ortbocérate.

On ne peut disconvenir que Bruguière n'ait appporté des amélioratious bien sensibles dans le système de Iinné, que les genres plus numbreux n'y soient mienx circonscrits el mieux caraclérisés. Outre ces changemens favorables, Bruguière en opéra encore d'aulres parl'arrangernent des figures qui accompagnent ce Dialionnaire; te fut là qu'il institua plusienrs geores, que la mort prémalurée qui l'enleva aux sciences l'empêcha de caractériser, mais qui tous ont été adoptés par Lamaick, qui en a démembré plusieurs.

Pendant que Bruguière publioit de son côté le commencement du Dictionnaire encycinpédique, Gmelin donnoit du sien la treizicme éditiou de Linné, dans laquelle il ne produisit presqu'aucuns cliangemens notibles: cependant les ger res sont un peu mieux en rapport, et il en adopte quelques-uns de Forskal et un de Nuller. Du restc, pour les Testacés proprement dits, il ne fait qu'en indiquer un plus rrand nombis: d'espèces, parmi lesquelles il a coumis un granci nombre d'erreurs de synonymie et beaucoup de doubles emplois. Ce ne fut que la même année que l'on introduisit en France, par' une traduction, l'onvrage de Molina, iutitulé : Essai sur l'Histoire naturelle du Chili, dont l'origine date de $178 \mathrm{e}$. Plusieurs des objets décrits dans cet ouvrage ne furent retrouvés que dans ces derviers terups par les naturalistes pleins de zèlc et de savoir qui accompagncerent le capilaine Duperrey dans son voyage de circum-vavigatiou.

Un auteur, auquel la conchyliologie doit d'immenses recherches anatomiques, qui le premier tenta de caractériser les geures des Mollusques d'après les Mollusques seuls, abstraction faite de la coquille, qui cliercha à établir sur ce sysıème une classification méthodique, l'oli, médecin italien, commenca, en 1791 , la publication de deux volumes de son ouvrage, qui fut termiué en 1795 . Ces deux volumes comprennent les Multivalves et les Bivalves, dout l'arrangement est le suivan!:

\section{TALLEAU de l'arrangement systèmatique des Mollusques acéphales, d'apiès PoL1.}

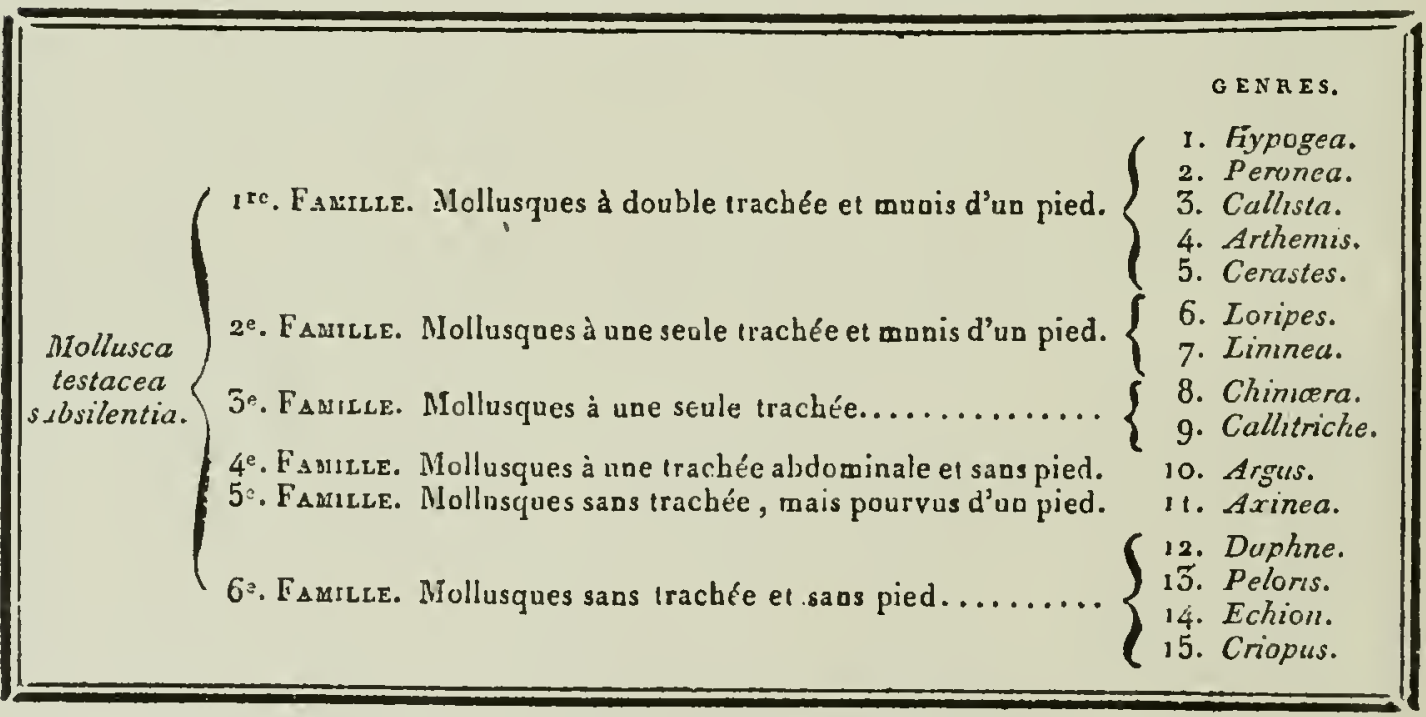

Le premier de ces geares, Hypogea, rassemblo les Solens, les Pholades et le Tellina incequivalvis de Linn'.

Le second, Peroncea, les Tellines de Linné.

Le troisième, Callista, les Vénus de Linné.

Le quatrième, Arthemis, Venus exoleta Linné. Cythera exoleta Lamk.

Le cinquième, Cerastes, le genre Cardium Liuné.
I.a seconde famille contient deux genres qui nons seinblent devoir s'ćloigner beaucoup. Le prenier, Loripes pour le Tellina lactea Linné, Lucina lactea Lamk., à laquelle se rattachera sans doute par la suite une grande parije ou la tolalité du genre Luciue, et Limnea pour les genres Mulette Brug. et Anodonte Lamk.

Les deux genressuivans, Chimara, pinna Lin., et Callitriche (les genres Muule, Modiole Lamk. 
et Lithodome Cuv.) forment une famille trèsnaturelle. Le geure Argus, gui correspond aux Peignes, aux Spondyles et aux Limes, forme d lui seul une facuille; il en est de même du genre Axinea (genre Pésoncle Lank). Iles quatre dernier's genres, le geare Daphné répond à une partie du genre Arche; le geare Peloris aux Huitres Lamk.; le geare Echion aux Anomies, et le genre Criopus à I'Anomia impeforata, Cranie Lamk. Celte manière dont Poli a envisagé les Mollusques l'a conduit à des groupemens très-nalurels; ses familles sont basées d'après la considération d'organes importans à l'animal, et nullement d'après les coquilles : il suivit donc une méthode diamétralement opposée à celle de la plupart de ses prédécesseurs. C'est ainsi que par des travaux de celte importance s'accumuloient les matériaux qui bientôt devoient servir à la nouvelle ère à laquelle nous touchons. lin résumant les travaux des hommes qui ont établi et saisi les vrais principes zoologiques, et qui en ont fait uae heureuse application, on tronve d'abord Guettard et Adanson, qui ont démontré la nécessité de considérer tout à la fois dans l'établissement des genres, et l'animal et la coquille : ce dernier a parlaitement défini toutes les parties de l'animal, et avec ce langage bien appraprié, il étoit facile de s'entendre sur tous les points de la connoissance des Mlallusques. Linné, de soa côté, créa presqu'en même temps tout le langage de la conchyliologie ou de l'élude arrificielle des coquilles, et une méthade qui, malgré ses imperfections, mettoit cepcudant la conchyliologie an rang des autres sciences et dans la voie de son perfectionnement. l'allas ne s'atlacha plas à la présence de la coquille, mais bien à Jarganisation intime des animaux, pour rapprocher et placer parmi les Mollusques des êtres que Linoé en avoit séparés, et ce perfectionnewent est nae suite des principes que ce célèbre observateur a voit si judicieusement employés dans d'autres parties de la zoologie. Bruguière, en s'attachant à la méthode lianćeane, lui donua un développement et une précisinn qu'elle n'avoit point encore eus, ramena en France le goốt de la conchyliologie, dont l'étude fut readue plus facile par les déterminations spécitiques, que l'on trouve dans l'édition de Gmelin, qui rasseublis, par une conpilation quelquefois mal faite, tontes les espèces décrites avant lui; tandis que Poli, suivant uue route différente, proposa enfin nne méthode naturelle, a ppuyée sur de nombrenx faits aualomigues.

Depuis la publication de l'ourrage de l'oli jus: qu'à l'apparition du Tableau élémentaire de l'histoire naturelle des Anmaux, 1798 , par M. Cuvier, rien ne parut sur les Mallasques. La uouvelle classification proposée par ce savant dans l'ouvrage précité, est le résultat non-seulement de ses propres observations; mais encore de celles faites avant lui, et des principes justement appréciés des Guettard, des Adanson, des l'allas, des
Poli, etc. M. Cuvier, le premier, rapprocha conveaablement les Mollusques des poissons, et les releva ainsi d'un degré dans la mélhode, ce i quoi il fut conduit par les comoissances anatomiques. Il ne considéra plus la coquille coanue iuuispensablement nécessaire pour éiablir les rapports, et l'existence ou l'absence de ce corps protectenr ne le détermina plus à sép̧arer les vers mollusques des vers testacés, comme l'avoient fait Linné et Bruguic̀re après lui ; il suivit en cels l'opinion de Pallas, qui, depuis ce moment, fut toujours adoptée.

Dans ce premier e:sai de M. Cuvier, les MolJusques sont divisés en trois grands ordres, les Céphalopodes, les Gastéropodes et les Acéphales. Les Céphalopodes contiennent quatre genres, les Seiches, les Poulpes, les Arganaules et les Nautiles. Ces derniers, outre les vrais Nautiles, renfermeat aussi comme sous-genre les Ammonites, les Orthocératites et les Camériaes de Bruguièré. Les Mollusques gastéropodes sont divisés ea uus et en testacés; c'est dans la première de ces divisions que l'on trouve rénais, pour la première fois, les vrais Mollusques sans coquille, que Linné et d’autres avoient séparés sans autres motifs des Mollusques testacés. Nons trouvons ici avec les Limaces, les. Théthys, les Ap!ysies, les Doris, les Tritonies, ayant pour sous-geares les Eolides, les Phyllidies, les Scyllées, les 'Thalides et les Leroées. Les Gastéropodes testacés sont divisés en cinq parties; dans la première on trouve le genre Oscabrian lui seul, parce que sa coquille est composée de plusieurs pièces. L'opinion d'Adanson, qui, le premier, avoit proposé ce rapprochement des Oscabrions, des Patelles et autres genres voisins, quoique peu fundée peut-être, fut admise alors par M. Cuvier, et, depuis, presque tous les auteur's l'imitèrent. Dans la seconde, sous la dénomination générique de $\mathrm{Pa}$ telles, il rassembla toutes les coquilles patelloïdes, qu'il distingua cependant en plusieur's groupes principaux, quel'on pent considérer comme pouvaut servir d'origine à antant de genres qui fureat adoptés depuis. Dans le premier groupe sont les véritaliles Patelles; dans le second les Cabochons; dans le troisième les Crépidules, arec lesquelles sont coufondus les Navicelles; dans le quatrième sont rassemblées les Calyptrées à appendice intérieur; dans le cinquième les Calyptrées à la me spirale; et dans le sixième enfin, les Patelles perforées au sommet, dont Bruguière avoit fait son genre Fissurelle.

la troisième division des Gastéropodes testacés compread huit geares rénnis, il fauı le dire, surdes caractères beaucoup tropétendus, qui sont: coquille d'une scule pièce en spirale, à bouche enlière, sans échancrure ni canal. Les genres Ormier, Nérite, Planorhe, Hélice, Bulime, Bulle, Sabot, 'Toupies en font partic. Ce genre Bulime est divisé en trois sections, gui comprenneut distinc- 


\section{0}

M. $\mathrm{O} \mathrm{L}$

tement la première, les Lymnées et les Mélanies confrodues; la seconde les Anricules; la troisième les Agathines. Le gente Sabot est partagé en six sections: la première pour le genre Scalaire, lit seconde pour les Dauphinules, la troisième pour les 'Inurielles, la quatrième el la cinquième pour les 'lurbos proprement dits, et la sixième pour le genre Eperon, Calcar de Montfurt. Le genre 'Toupie est sous-divisé en qualre parties: la première pour les Cadrans, la seconde pour les Monodontes, la troisieme pour les Roulettes, e: la quatric̀ue pour les Fripières. Daus la quatric̀me sous-division des Molluscques gastćropodes testacés, sont rassemblés tons ceux dont la coquille a un canal i la base. Sous le nom générique de Murex, sont réunis les genres Cérite, Fusean, Rocher de Bruguière et Pyrule. Sous le nom de Stiombes, on trouve les vraies Strombes et les Ptírocères. Celle division contient encore les Cistapues. la cinquième et deraière division des Gastérnjodes dont li. coquille est munie seulement d'une échavcruse, comprend les Buccins, avec l'iodication des geures 'Tonue, Licorne, Harpe, Riciuule, Eburue $t$ Tis, les Volutes, les Olives, les Porcelaines et les Cornets. Quoique plusieurs de ces yenres, surlout dius la troisième sous-division, soieat assez liétérogènes et peu en rapport, on doit roir cependant une amélioration bien sensible dans le sysième, et surtout duns ses divisions priucipales.

Le truisième ordre des Mollusques, ou les Acéthales, renferme, comme dans les Mollusques céphalés, une première division, pour ceux qui sout sass coquille; on y trouve deux genres: les Ascirlies et les Biphores, dont Jamarck, plus tard, a fait un ordre à part sous le nom de Tuniciers. la seconde division renferme les Acépbales testacés, sans pied, et à coquille inéquivalve, les genres Huitre, Spondyle, Placune, Anomie el Peigae. Dans la troisième, ou troure les Limes, les Perpes, les Avicules, avec l'indication des geures Pintadine et Marleau, les Moules, les JamLonneaux, les Anodoniles (Brug.), les Unios; el, ce qui est assez étonuant, lorsque l'uuvrage de Poli est publié depuis plusieurs añées, on y 1rouve aussi les Tellines, les Bucardes, les Mactres, les Vénus, les Cames, avec l'indicaliou des Tridacnes et des Cardites (Brug.), et les Arches. Cette division est certainement celle qui, dans l'ouvrage de M. Cuvier, contient les élémens les plus hétérogènes.

Les Acéphales testacés de la quatrième division sont tous pourvus d'un pied; les valves son c ćgales, la coquille est ouverte par les deux bouts, le manteau est fermé par devant. Les Solens, les Myes, les Pliolades, les Tarels, et comme sons-yeare de ce dernier, les Fistulanes (Brúg.), sont les senls qui s'y trouvent rassemblés d'une manière fort nuturelle.

La section suivante n'a pas beaucoup de ranporis avec celle-ci : elle cuntien:, en eltet, les

\section{$\mathrm{MO} \mathrm{L}$}

Acéphales testacés, sans pied, munis de deti.. tentacules charnus, ciliés, roulés en spirale.

Cette section, qui conduit assez naturellement. à la suivante et dernière, contieut le genre Térébratule, dans lequel se retrouve la roquille de. l'Ilyale et, avec donte, celle de la Critaie; le genure tingule, établi par Bruguèere, et le genre Orbicule, découvert par Miller et contondu jusque là parmi les Patelles sous le nom de Patella anomala.

La dernière division des Acépliales testacts comprend des êtres dont on a fait depuis un ordre à part, sous le nom de Cirrbipèdes. M. Cuvier n'y admet encore que les deux genres. de Bruguière, les Anatiles et les Balaniles. Enfiu, dans le nouveau systeme de M. Cuvier, disparoît pour jamais cette division artificielle d'unjvalves, de bivalves et de mulivalvcs; disparuit aussi celle séparation arbitraire des Mollusques mous, des autres Mollusques à coquille, ct conmeuce à s'établir un véritable arrangement mélbodique, on peut même dire philosophique, des MIollusques.

Sans doute que celte métbode étoit susceptible de perfectionuement, et le teups est veau ou bientôt elle les recevra en fuule, surtont par les travaux de Lamarck, qui, depuis 1794, étoit professeur de zonlogie au Jurdin des Plantes. Notre illustre Linué français commença sas ouvrages sur les Mollusques pur un Mémuiro sur les Seches, dans lequel est démontrée la nécessité de séparer les Sèches de Linoć en trois genres, les Sèches, les Calmars et les Poulpes. Ce fut parmi les Mlémoires de la nonvelle Société d'Hisloire naturelle que cel!ni-ci fut inséré, aussi-bien que le suivant, qui re parut que l'annce d'après. Ce Mémoire iunpoltaut, qui est le prodrome de la nouvelle classification que Lamaick proposa, en 1801 , dan lo Système des Animaux sans vertébres, présente des dífinitions génériques beaucoup plus rigon. reuses que celles qui a voient été faites jusqu'alor's; et quoique Lamarck se soit pluà suivre la méthode de Bruguière en la perfectionnaut, il doubla tout d'un coup le nombie des genres de l'Ecy'clopédie; et, tout en se serrant des observations de MI. Cavier sur les auimaux, il conserva cependant es:core, et on peut dure, saus inotif, la division liunéenne de coquilles univalves, Livalves ot multivalves.

Lamarck ne se conten!a pas d'imiter Brugaière sur ce point, il ie suivit encore dans les principales divisions; ainsi les coquilies univalyes sont divisćes en uniloculaires et en muliloculaires : ces premières sont parlagées ensuite, d'après la torme de l'ouverture qui est versante, canaliculée ou échancrée à la base, on qui est entière : ce que n'avoit pas fait Bruguière, mais ce qui avoit été partaitement indiquépar M. Cuvier. On trouve ies genres nouveaux suiraas, parmi ceux dont 12 
bouche est versante, échancrée on canaliculée: 'l'arrière; l'ysule, séparće des Bulles; Ancyle, aujourd'bui Ancillaire; Colombelle, Marginelle, Aacillaire, Turlinelle, séparée des Volules; les Fuseanx, les Pleurotomes, les Fasciolaires des Rochers; les Nasses des l'uurpres; les Harpes des Buccins; les Ptérocères et les Rostellaires, des Strombes.

Dans les coquilles ì ouverture entière, il sépara les Cadrans des Toupies, les Monodoules des Scalaires, les 'Turritelles, les l'yramidelles, les Cyclostomes des Sabots; les Iĺlicines, les Sigarets et les Janllines, qui étoient coulondus avec les Hélices, en sont judicieuscment retirés; les Agathines, les Lyunées, les Mílanies, les Ampullaires et les Auricules qui faisoient autant desous-divisions du geare Bulime de Bruguière, sont élevés à la qualité de genre : il sépara encore les Stomates des Haliotides, les Crépidules et les Calypirées des Parclles. Mais, ce qui est singulier, c'est que Lamarck rejette encore a la fin des coquilles unilocnlaires, et, comme dans un incertar sedis, les genres Ventiale, Siliquaire, Vermiculaire, Arrosoir et Argomaute, qui n'ont entr'eux aucun lien, aucun rapport.

Les genres de Multiloculaires sont augmentés des Spirules et des Ortliucières, démembrés des Nautiles, ainsi que des Planorbites, des Bitculites et des Orthocératites, qui forment autant de genres nouveaux.

Les coquilles bivalves offreat un certain aombre de genres uouveaux; elics sont divisées, comme dans Bruguière, en régulières et en irrégulières: daas ces dernières, il n'y a que deux genres nouveaux, Vulselle et Marteau; parui les premières, il s'en remarque un plus grand nombre: les Glycimc̀res, démeinbrées des Myes; les Sanguinolaires, des Solens; les Cyclades, les Tellines, Mérétrices ou Cythérées, des Vénus; Lutraire, Paphie, Crassatelle, des Mactres; Isocarde, des Cardiles (de Bruynière); ITippope, des Tidacues; les Pétoncules et les Nucules des Arches; Modioles, des Moules; et séparant ensuitc les Anomies et les Cranies des Multivalves, il les reporte, avec juste raison, parıni les coquilles bivalves irrégulières; les gentres Calcéole et Jingule sont également séparés des Anomies. Par la réforme que nous venons de meutionner, la section des Mulivalves se trouve moius hétérogène; quoique nou nalurelle par son arrangement, elle est ici séparée en trois groupes couvenables.

Ce système, dans lequel Isamarck n'a pas su profiter convenablement des travaux antérieuremeat publiés, deroit recevoir un peu plus rard un pertectionuement considérable dans l'ouvrage quil publia cn 180 i sous le titre de Systeme des Animaux sans vertèbres.

Lamarck employa avec avantage alors les observations de M. Cuvier et de Puli, et en fit l'application ì son système en y rapportant dass

Hist. Nat. des Vers. Tome II. un ordre assez naturel les nouveaux genres quil avoit proposés. Le tableau ci-coutre sera plus propre ì donner une juste idée du systène de l'auteur at à en présenter l'ensemble. Däns ce système, où il est facile de remarquer un asscz graad noubre de perfectionuemeus, on voil d'abord qu'it lexemple de BI. Cuvier, Lamarck met les Mollusques au premicr rang parnil les Invertébrés, et les divises dés-lor's en deux graods ordres, d'après l'existence ou l'absence de la têle; ce qui avojt été plutố iudiqué par Puli et par M1. Cuvier d'après lui cqu'établi délinitivement; et de celle maniere, Lamurck a encore admis, d'aprćs M. Cuvier, les Mollusques sans coquille, dont il tait une division à part aussi bien daus les Céphalés que dans les Acéphal'́s. Dans les Céplıalés, ils sont divisés d'après le mode de locomotion, ce qui n'aroit pas encore été lait; ils reuferment d'ailleurs plusieurs nouveaux genres, et assez bizarrement les Oscabrions, qui sont bien loin d'être nus, mais que Lamar'ck a placés près des Phyllidies, cntraîaé sans doale par les rapports qu'il leur trouvoit. Les Mollusques céphalés sout divisés en deux grandes fanilles, ceux qui son! nus et les conchilères. Nous a vons parlé des juremiers, et les seconds sont sousdivisés en trois parties, ceux qui ont une coquille point en spirale el qui recouvre l'animal, comme les Patelles. On trouve ici les Conchulépas, qui ne suut autie chose que des Pourpres. Mais si daos cctte occasion Lamarck les a mal placés, c'est à lui aussi que l'on doit d'avoir saisi leurs véritables rapports dans un autre cle ses ouvrages. La seconde division contieut les coquilles uniloculaires spirivalves engainant l'animal. On retrouve ici deux sous-divisions d'apsès la forme de l'ouverture, comme H. Cuvier le premier en avoit montré l'exemple : on elle esi éclancrée ou canaliculée à sa base, ou elle est entière. Dans ces deux grandes familles, nous voyons uue sé:ie assez nombreuse de geurcs qui ne sont pas toujaurs dans leurs rapports nalurels, et qui forment dans cbacane de ces tamilles no séric simple el continue. C'est à la fin de la seconde que se voient encore, après les Haliolides, les genres Vermiculaire, Siliquaire, Arrosoir, Cariaaire, démembrés des Al'ononautes pour la première fois. Les Argouautes les Dentales ne s'y trouvent plus, quoiquelies aient dû bien plutot rester parmi les Mollusques que les Vermiculaires, par cxemple.

La troisieme division, qui renferme les coquilles multiloculaires, est encore bien imparfaite, quoiqu'elle contienae un geure de plus, Hippurite, qui lut iatroduit bien à tort dans certe section, car ce sont des coruilles bivalves.

Les Mollusques acéphalés sont divisés, comme les Céphalés, en nus et couchifères : les premiers, outre les genres Ascidie et Biphore, contiennent de plus le genre Mamuaire de Müller; dans les seconds, ce n'est plus de l'animal que sont tirés les priocipaux caractères, mais de la coquille

$\mathrm{P}$ P p * 
seule : ainsi ces deux grandes divisions reposent sur l'égalité ou l'inégalité des valves. Dans les coquilles équivalves sont introduite les Pholades, séparées des 'larets malgrú l'opinion si connue et si juste d'Adanson; les coquilles de cette division forment du reste une masse sans coupure dans buquelle les genres sont arrangés dans un ordre souvent peu naturel, mais décroissant.

Les coquilles inéquivalves, qui contiennent aussi les Cirrbipedes, sont divisées en trois groupes : dans le premier, par une erreur asse $\iota$ grave, l,amarck, considérant le tube des Tarets et des Fistulanes comme le développenent d'uue valve, les place dans les coquilles inéquivalves, quoique ce lube, comme l'avoient fait voir Spengler et Adanson, contienue deux valves égales. Dans le second groupe, caractérisé par deux valres inégales opposées ou réunies en charnière, se voit encore le genre Hyale, et après lui, pour faire passage à la section suivante, sont placés à la fín les Orbicules et les Lingules, comme l'avoit fait M. Cuvier. La dernière section contient les Anatifes et les Balanes.

Ce système, qui, dès l'époque de sa publication, fut généralement adopté, fut long-temps le seul suivi pour l'arrangement des collections, et quoiqu'imparfait sous bien des rapports, il a cet avantage d'être facile à comprendie. Jusqn’à présent, depuis l'époque de Linné, nons n'avons point $\nabla u$ s'établir de faunille parmi les Mollusques; des séries plas ou moins naturelles de grenres groupés d'après ua caractère très-étendu, voilà ce que nous trou. vons. C'est encore à Lamarck que l'ou doit, comme nous le vercons plus tard, l'introdnction de cette amélioration.

Malgré ces changemens favorables dans la méthode, plusieurs auteurs n'en liennent presque pas compte, et s'attachent à la lettre de Linoé ou au système linnéen perfectiunné pal Bruguière, et cherchent à $y$ intruduire quelques genres plus ou moins bien faits. Busc, daos le Buffon de Déterville, est dans ce cas, puisqu'il conserve la métlıode de Bruguière, dans laquelle $i$ ajoute les geores Fudie, très-voisin des Ascidies, et Oscaoe, près des '’atelles; et dans les hivalves, les genres Onguline, Erodone et Hiatelle, adnptés de Daudin. Ce fut la même anuée que M. Cuvier donna son Méruoire sur l'aoatomie du Clio borealis. Il ne trouva dans cet animal aucun des caractères de ses Cépbalopodes avec lesquels Lamarck l'avoit provisoirement placé; il y rencontra des condiiions d'orgaaisation particulic̀re, ayant plus de rapports avec celles des Gastéropodes qu'avec celles des Céphalopodes, et daprès cela, il sentoit la nécessité de ne point appliquer le nom de Gastérupode à cet être, poisqu'il n'avoit point de pied pour ramper, et il ne le fit pas alors; ce ne lut que deux aos après, lorsqu'il eut recueilli de nouveaux matériaux du voyage de Pérou, qu'il cut coous l'animal de l'Hyale et celui dont il tit son geare Proumo- derne, qu'il iostitua un ordie noureau snns le nom de P'éropodes. Ces auimaux ont en effet, sur les parties latérales du corps, des nageoires en forme d'ailes, qui servent à leur locomotion.

A peu près à la même époque (1803), Draparnaud publia le prodrowe de son graud ouvrage sur les coquilles terrestres et fluviatiles de France, ouvrage qui ne parut qu'après sa mort. Guidé par de très-boos principes de zoologie, Draparaand n'admit et n'instilua que de buus genres. Your la distribution générale, il suivit la méthode de M. Cuvier; il établit ou adopta les genres Vitrine, Clausilie, Ambrelte, Physe tt Valvée. On doit aussi à cet auteur d'avoir été le premier à abandonner la manière pcu naturelle dont Linné considéroit les coquilles pour la dés:gnation de leurs diverses parties : c'est en les plaçaut dans la position qu'elles conservent sur l'animal marchant devant l'observateur que l'on doit les étudier; et cette méthode rationnelle, convenable surtout pour les coquilies bivalves, a été généralement adoptée.

En 1802 commença à se publier, dans le Buffon de Sonnini, la partie des Mollusques par Montfort : quoiqu'il en ait donné quatre volumes, ì peine si on peut la considérer comme commencée, puisque ces qualre volumes sont consacrés uniquement à l'histoire des Sèches, des Poulpes, des Calonars, et de quelques coquilles muliiloculaires. M. de Roissy, qui contiaua ce travail, et qui le termina en deux volumes, qui parureat en 1805 , rassembla et recueillit les faits nouvellecuent acquis dans la science, et les rattacha, d'une manic̀re fort convenable au système de M. Cuvier, qui lui servit de base fondamentale, dans lequel il fit entrer tous les genres de Laınarck; le nouvel ordre des Ptéropodes de M. Cuvier, qu'il plaça cntre les Céphalopodes et les Gastéropodes, ainsi que le venre Daudin, adopté par Bosc, et ceux nouvellement établis par Lamarck sous les noms de Coronule et Tubicinelle, démembrés des Baluues de Linné.

M. de Roissy ne fit aucun genre nouveau; il proposa seulemeut de changer le num d'Ancille, douné par Lamarck à un déncmbrement des Volutes de Liuné, en celui d'Anaulace, parce que Geolliroi avoit dójà donné le naùn d'Ancille à ur aı.tre genre; ct de substituer le nom d'Euérie à celıi de Gulathée, employé par les entomologistes. On présumoit déjà, par la description de Rumphius, que les coquilles des Pulythalames appartenoient aux Céphatopodes, mais le fait avoit besoin d'èrre confirmé ; et c'est ce que fit MI. de Roissy par la description qu'il domna de l'animal de la Spirule, que Yéron avoit rapporté de son vuyage autour du monde, et qüil eut occasion d'examiner avec soin. L'ouvrage de M. de Roissy est rempli au reste d'cxcelleutes observations, d'aperçus ungínieux, bien capables de favoriser l'avameeroent de lá science. La seconde édition du Traité élémen- 
taire â Histoine naturelle, par M. Duméril, parut en 1807. On y put recueillir les nouveaux faits publiés sur les Mollusques. Celte partie, quoirque traitke en peu de pages, contieut cependant une iunovation qu'il est bon de mentionner. En admellant le systrme de M. Cuvier, il en conserva les principales divisinns; seulement, dans les $G a s-$ téropusies, il se sert des organes de la respiration pour les diviser en truis groupes : le premier, les Dermobranches, ont les branchic's externes on forme de lautes ou de panaches, et il renferme les Doris, les Tritonies, les Scyllécs, les Eolides, les Phyllidies, les I'arelles, les Ilaliolides et les Oscabrions. Il est bien cerlain que les IIulintides n'apparliennent nullement à cette famille. Le second groupe est nommé Adélobranches; les animuax quil couticnt ont un trou propre à l'admission de l'air sur les branchics; et les Aplysies, que nous trouvons en première ligue, sont bien lain d'avoir ces caractères, car elles ont le manteau feudu largement, portent des branchies en panaches et ne respirant pnint l'air. MI. Dumbril y place aussi les Sabots, les Nérites, et probablement tous lcs genres dont la coguille a l'nuvertuée entière; et certes ancun ne respire l'air eu nature. On y trouve aussi les Limaces, les 11 'lices et les Planurbes, les seules qui puissent réelletneal rester dans cette division.

Le troisième groupe des Gastéropocies, qu’il onmme Siphonobranche, est beaucoup plus naturel que le précédent; it répond parfitement à la qualrième division des Gastéropodes du premier systican de M. Cuvier.

Dans les Acéphalcs, au lieu d'y rímir les $13 a-$ lanes et les Anatifes, il en fait juste:nent un ordre a part, sous le nam de Brachiopodes, daas lequel il admet à tort les Lingules, les Orbicules et les 'l'éríbiatules, sur l'anaingie desquels il étoit ditfrcile de cammeture une erreur, puisque Poli, dans les belles planclies de son ouvrage, avoit donné l'anaromie des uus el des autres.

Le savant voyageur Olivier ae se con!enla pas de rassembler une foule d'ubservations curienses sur flusieur's branches d'histoire naturelle; il en recuillit aussi sur les Mullusques, et enrichit la science d'un assez graud nombre d'especes uourelles.

Ce fut dans la même anaée (1807) que II. de Ferussar fils donaa une nouvelle édition d'un opuscule de son père; et quoicju'il n'y soit question que de coquilles terrestres et lluviatiles, nuns derons dire que ce petit ouvrage cuatient plusieurs fails curienx ef deux nouveaux genres: le genre Mllanopside, fait avec les coquilles nomunées Mćlanies, par Olivier; et le genre Septaire, confondu avec les Crépidules, et qui en est certainement bieu distinct.

Lamarck cependant, cherchant toujours à perfectionner le système des Mollusques, dans lequel, comme nous lavons fait apercevoit, on n'avoit point encore ćtabli de familles, fit enfin celle amfliotation importante dans sa Philosophie zoologique, publiée en 1809 . II partage le rigne auima! en plusieurs degrés d'organisation; ce qui groupe d'uhord les êtıes analnģrues d'une manic̀ plus ou moius exacle. Dans le quatriène degré sint cn:npris les Crustacés, les Annelides, les Chirrlipedes et les Mollusques. Ces deruiers sont cependant beancoup plus avancés dans l'organisation que tons les autres. Les Cirtipipèdes ne comprennent ioujours que quatre genres, les 'lubicinelles, les Coronules, les Balanes el les Anatifes. Pour établir le passage de rette classe à la suivante, Lamarck suit nne marche progressive, et comarence par les Mollnsques acéplales, yui font le premier ordre des Mollusyues, qu'il conmence par une famille a laquelle il adapte, d'une maniere fort convenable, le nom de Brachio. podes, appliqué par M. Duméril aux Cirrbinèdes et aux Braclinpodes mélangés et confondus. Ici celte famille des Brachiopodes comprend les trois genres Lingule, 'Térébratule et Orbicule. Ia seconde famille, les Ostrucés, qui correspond asscz bien au genre Huîre de Linné, renlerme onze genres dans l'ordre suivant: Radiolite, Calcéole, Crarie, Anomie, Placune, Vulselle, Jluître, Gryphée, Plicatule, Spundyle et Peigne. Celle famille, assez hétérogène dans ses ćlémeus, a été divisée depuis en plusieurs autres. La suivan!e ou la troisième a été désignće sous le nom de Byssifères; elle renferme, par ce seul caractère d'un pied propre a filer un l,yssus, des geares fort analognes, que Poli avoit rapprochés les uns tles autres. Cette famille, d'après l'iadication de M. de Roissy, se trouve interposée entre les Huîtres et les Auodontes, que M. Cuvier avoit rapprochées; clle se compose de neuf genres : Houlette, Lime, Pinne, Moule, Modiole, Crénatule, Perne, Marteau, Avicule. La quatrième famille, celle des Camacées, contient, avec le genre Came, les genres Ethérie et Dicérate, tons deux nouveaux, et, de plus, hors de lcors rapports naturels, et seulement sur le seul caractere de l'inégalité des valves, les deux genres Corbule et Pandore. Les deux genres Mulette et Anodonte forment à eux seuls la cinquième famille, les Nayades; elle est suivie de celle des Arcacées (genre Arca de Linué), qui auroit été naturellement composéc des geures Nucule, Pétoncle, Arche et Cuculée, auxquels se trouvent réunie: les 'Trigonies, qui g'out point avec eox de rapports sulfisans. La septième famille, les Cardiacces, est encore composée de genres dunt les rapnorts ne sont pas trop bien établis; les genres Tridacne et Hippope sont beaucoup plus vuisins des Cames que des Cardites, qui diffèreot à peine des Véuéricardes, et surtout des Isocardes et des Bucardes, les deux seuls genres qui soient assez voisins. Les Conques, qui constituent la huilième familie, sont formées des genrez 
Vénéricarde, Vénus, Cythérée, Donace, Telline , Lucine, Cyclade, Galatbée, Capse. A l'exception du genre Véncericarde, lous les autres constituedt une famille assez baturelle, et il en est à peu près de mêtue de la suivante, les Mactracées, où l'on trouve les genres Erycine, Onguline, Crassatelle, Lutraire et Mactre. Lé genre Erycioe est ici érabli pour la première fois; et, pour la première fois aussi, Lamarck adopte les Ongulines de Daudin. Les Crassatelles et les Mactres, malyré le ligament intérienr et d'autres rapports quiles lient aux Lutraires, sont plus voisioes des Vénus, d'après l'opinion la plus généralement reçue aujourd'hui. La famille des Myaires, qui est la dixième, se compose des genres Myes, Panopée et Anatine. Ces deux derniers sont nouveaux : l'un, les Panopées, établi par Ménard de la Groye, à son retour d'Italie; et l'autre, les Anatines, proposé par Lamarck, et adopté depuis.

Dans un ordre bien naturel viennent, après les Myaires, les Solénacées, qui, outre les trois genres Sanguinolaire, Sulen et Glycimère, contiennent aussi, et dans des rapports très-naturels dans le voisinage des Pholades, les genres Pétricole, Rupellaire et Saxicave; les Pholadaires les suivent, et elles pourroient fort bien être séparées en deux groupes, l'un pour les Tarets et les Pholades, l'autre pour les Fistulanes et les Arrosoirs. Ce singulier genre, que nous avons vu précédemment confondu avec les Serpules, a été examiné avec beaucoup de soin par M. de Roissy, qui, le premier, a jugé qu'il devoit se rapprocher des Fistulanes. Il trouva en effet sur le inbe des Arrosoirs rleux petites valves incluses dans l'épaisseur du tube, lorsque ces deux valves sont libres dans le tube des Fistulanes; la découverte que l'on fit depuis du genre Clavagelle a confirmé celle opinion. La deraière famille, la douzième, est consacrée tout entière aux Acéplalés nus, qui sont réunis sous le nom d'Ascidiens, qui se composent toujours des trois genres Ascidie, Biphore et Mammaire. Le denxième ordre des Mollusques est consacré aux Cépbalés, divisés en trois grandes sections : les Ptéropodes, les Gastéropodes e: les Céphalopodes. Les Ptéropodes ve se composent tonjours que des trois genres Hyale, Clio et Poeumoderne. Lamarck, qui ordinairement cherche à établir les rapports et les passages aussi bien entre les grandes divisions qu'enire les crenres, auroit dû suivre les iodications de M. de Roissy, qui pensoit, avec juste raison, que les genres voisius des Patelles et les Patelles elles-mêmes faisoient cetle transition d"un ordre au suivant. Les Gastéropodes vieanent immédiatement après les Ptéropodes; ils sont subdivisés en trois sections : la première, pour ceux dont le corps est droit, réuni au pied dans presque toute sa longueur. Cette section contient quatre familles, qui renferment tous les Mollusques nus. La première, les Tritonieos, conticnt les genres Glaucie, Ez- lide, Scyllée, Tritonie, Théthys, Doris. La seconde, les Phyllidéens, réunit les Pleurobranches, les Phyllides, les Oscabrions, les Patelles, les Fissurelles, les Emarginules. Celle seconde fasille est peu naturelle; les Oscabrions d'abord en sont tout-à-lait étrangrers, aussi bien que les Patelles, les Fissurelles et les Eroarginules. Dans les Laplysiens se truuvent, avec les Laplysies et les Dolabelles, les Bullées, lurt éloiguées des Bulles, et les Sirrarets, qui n'ont avec elles aucun rapport. Lcs Limaciens, qui suivent, se composent des Onchides, des Limaces, des Parmacelles, des Virrines et des Testacelles.

Les Gastéropodes qui ont le corps en spirale, et qui n'ont point de siphons, sout partagés en liuit familles: $1^{\circ}$ les Colimacés, qui suiveni les Limacéeus pour marquer les rapports des deux familles. On y tronve les geores Hélice, Hélicine, qui s'en éloignent, puisqu'ils sont operculés; Bulime, Amphibulime, qui ne different point des Ambretles de Drapainaud, Agathine et Maillur. $2^{\circ}$. Les Orbacées, les quatre genres Cyclostome, Vivipare, Planorbe, Ampullaire. 30. Les Auriculacées, famille composée de genre peu en rapport, les Auricules, les Mélanopsides, les Mélanies et les Lymnées. $4^{\circ}$. Les Néritacées : celle-ci est tout-à-fait naturelle; elle a été conservée par les auteurs; elle renferme les genres Níritine, Nacelle (Septaria Ferussac), Nérite et Natice. Quoique l'on ne connût alors en aucune maDière l'anatomie des Navicelles, Lamarck cependant, par ce tact purticulicr qui lui avoit fait deviner des rapports si intéressans, ne s'étoit point trompé dans celui-ci, car l'anatomie l'a confirmé depuis. $5^{\circ}$. Les Stomatacées, groupe naturel des genres Haliotide, Stomate el Siomatelle: ce dernier, nouvellement proposé et publié pour la première fois. $6^{\circ}$. Les Tuibinacées, dont les 'Troques et les Cadrans sont éloignés fort à tort, comprenuent les genres Phasianelle, Turbo, Monudonte, Dauphinule, Scalaire, Turritelle, Vermiculaire (Vermet d'Adanson). $7^{\circ}$. Les Hétéroclites portent justement le nom qui leur est imposé; car quels rapports y a-t-il en effet entre les Volvaires, les Bulles et les Janthines? 80. Les Calyptracées réunissent des genres dont les caractères sont évidemment mal appréciés; les Crépidules et les Calyptrées ont des rapports entr'eux, mais ils n'eu ont nullemeut avec les Trochus et les Cadrans, qui cependant sont voisins l'un de l'autre. La troisième division des Gastéropodes qui ont le corps en spirale et un siphon n'est partagée qu'en cinq familles. La première, les Canalilères, contient le genre Cérite, Pleurotome, 'Turbinelle, Fasciolaire, Pyrule, Fuseau et Murex. Le geare Clavalule paroit être oublié. La seconde, les Ailées, les genres Rustellaire, Pıerocère, Strombe. La troisiene, les Purpuracées, les genres Casque, Harpe, Tunue, Vis, Eburae, Buccio, Concholépas, rapporté à sa véritable 
place, Monocéros, Pourpre et Nasse. La quatrième, les genres Cancellaire, Marginelle, Colombelle, qui o'a cependaut noint de plis à la columelle, Mitre et Volute. Enfin la cinquieme, les Enroulées, famille très-naturelle qui contient les six genres Ancille, Olive, T'arrière, Ovule, Porcelaine et Cône.

La troisième graode division des Nollusques est consacrée aux Céphalopodes, dans l'arrangement desquels nous trouverons des changemens notables. Divisés en trois groupes, le premier pour les tesis muliloculaires, le second pour les tests uniloculaires, et le troisieme pour ceux qui nont point de test. Ils présentent cinq familles, dont les trois premières pour le premier groupe, la quatrième pour le second, et la cinquième pour le troisième.

La première famille, sous le nom de Lenticulacées, renferme les genres Miliolite, Gyrogonite, Rénulite, Rotalite, Discorbite, Lenliculiue et Nummulite. A l'exception des genres Rotalite et Nummulite, tons les autres sont nouveaux. La seconde famille comprend les genres Lituolite, Spirolinite, Spirule, Ortboccre, Hippurite et Bélemnite. Les deux genres Lituolite et Spirolinite sont nnnveaux. La troisième, les genres Baculite, Turrilite, Ammonocératite, genre nouvean, Ammouite, Orbulite et Nautile. Les Argonautacés ne sout nullement des Céphalopodes; ils réunissent très-aalurellement les Cariaaires et les Argonautes. Enfin, Ia dernière fa mille, les Sépialeses, qui u'ont point de test, ue présente toujours que les trois genres Poulpe, Calmar et Sèche.

Tel est le systène que Lama:ck donna en 1809 : quoiquil présente beancoup moins d'imperfection que le premier, il n'est cependant point saus défaut, et nous les avons signalés ì mesure que nous les avons rencontrés. Nous avons rendu compte d'upe mauière assez détaillée de ce système, parce qu'ayant servi de base à ceux que Lamarck a proposés depuis, bous a'aurons plus, par la suile, qu'à indiquer les perfectionnemens que son auteur y aura apportés. Nous ne vous arrêterons pas à ıendre louguement compte de l'ouvrage de Denis Montfort, qui parut en 1809 et 1810. Ce travail, purement conchyliologique, 11 'a d'autre mérite que d'avoir multiplié les genres des Mulciloculaires microscopiques d'après l'ouvrage de Soldani et celui de Fichtel et Moll : il a particulièrement dirigé l'attention du conchyliologue vers celte partie long-lemps négligée, et a rendu par là un véritable service pour la parlie des coquilles nultiloculaires. Partant d'un principe faux et faisant de ce principe une application rigoureuse, il a dû tomber dans beaucoup d'erreurs. Toutes les coquilles qui, daosles genres, ne s'y rapportent pas rigoureusement, ou qui présenteat avec le type de ce genre la moindre différence, Montfort en fait en genre distinct. Nous pouvons citer un exemple de cela dans le gente
Rocher, qu'il divise en douze genres, d'apiès le nombre des varices, la longuear du canal, la forme plus on moins arrondie ou rétrécie de l'ouverture, ou autres caractères d'aussi peu de valeur. Cepeudant il y a dans cet ouvrage plusieurs genres à conserver, car depuis ils furent proposés sous d'autres noms, et généralement adoptés.

Lamarck, continuant toujours à perfectionner sa méthode, y fit des clangemens asser notables, et voulut prendre acte de ces améliorations; if publia en conséquence une petite brochure intitulée : Extrait du Cours de Zoologie, elc., l'aris, 1812. Avant de parler de cet ouvrage, nous devons nentionner le Mŕmoire de Péron et Lesueur, inséré dans le tom. XV des Annales du MIuséum. Dans ce MIémoire, les auteurs confondent tous les animaux qui, nageant librement dans les eaur, et n'étant point céphalopodes, sont munis, soit de nageoires latérales, soit de nageoires verticales placées ou sur le dos, ou sur le ventre: des étres de types fort différens fureat associés, et la plapart des nouveaux genres que les naturalistes projosèrent ne purent rester jarmi les Ptéropodes, où ils croyoient deroir les placer.

N. Cuvier avoit donné, dans les Annales die Muséum, píusieurs Mémoires anatomiques sur les Mollusques, et ceux dont l'organisation fut entièrement dévoilée ne aurent plus laisser le moindre doute à Lamarck: ces matériaux, habilementréunis, contribuèrent pujssamment aux perfectionnemens et aux modifications rưiil apporta dans son système. Les Mollusques sont taujours dévisés en deux ordres, les Mollusques acéphalés et les Mollusques céplialés.

Les Mollusques acéphalés sont eux-mêmes divisés en testacés et en nus. Comme dans le premier système, il les partage eu Monomyaires et en Dimyaires; les Monomyajres contiennent sans nul changenent les familles suivantes: $\mathrm{Bra}$ chiopodes, Ostracées et Byssifères. Les Acéphalćs dimyaires sont divisés en inéquivalves et en équivalves. Dans les inéquivalves on ne troure qu'une scule famille, les Camacées, qui renlerme loutours les Corbules et les Pandores. Les équivalves contiennent le même nombre de familles: $10^{\circ}$. les Nayades; $2^{\circ}$. les Arciacées; $3^{\circ}$. les Cardiacées, dans

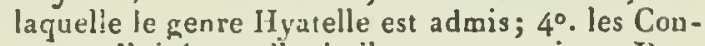
ques, äivisées en llaviatiles et en marines. Dans ces deraières on trouve les deux genrcs Cypriue et Donacille qui sont entièrement nouveaux. $5^{\circ}$. Les Mactracées; $6^{\circ}$. les MIyaires, desquels on a éloignć le genre l'anopée pour le reporter' ì la suivante; $7^{\circ}$. les Solénacées, desquels est démembrée la buitième fanille, les Litlophages, entièrement nouvelle, composée des quatre genres Rupicole, Saxicave, Pétricolle, Rupellaire. Celui-ci est nouvean. 8०. Les Pholadaires, parmilesquels est introduit le genre Clavagelle, qui fuit le passage des Fistulanes aux Acrosoirs. I.es Acéplia. lés nus n'ont éprouvé aucun changement. 
Dans les Mullusques céphalés, on remarque un plus grand nombre de clangemens, et ils sont ixportans. D'abord, au lieu de lrois on y voil cinq sections, qui sont dans l'ordre suivant : $1^{\circ}$. les Ptéropodes; $2^{\circ}$. les Gasléropodes; $3^{n}$. les Trachipucles, section nouvelle; $4^{\circ}$. les Céplalopodes; 5’. les Hétéropodes, secilion nuuville.

Les Ptérupodes au lieu de truis genres en uffient cinq: les genres Cléodore et Cymbulie sunt adoptés de Péron. Les Gastíropudes sont dislingués des Trachélipodes, d'apres le-lieu de linsertion du pied sur tout le veutre dans les premiers, seulement au col et par un pédicule dans les seconds. Les Gastéropodes contiennent, outre les familles iodiquées dans le précćdent système, les Tritoniens, les Pliyllidiens, sípasés en nus el en conchylifères; ces derniers, composés des Oscabrions, des Onbrelles, nuvvexu zenre des l'atelles et des Haliotides, mais avec uu point de doute; et de plus, les Calyptracieus, qui se trouvent ici justement parmi les vrais Gastropodes débarrassés des genres Cadın et 'Troclus, mais contenaut de plus les geures Cabochon, pris de Monifurt, Fissurelle el Eurarginelle, séparés des Pliyllidieus. Les Laplysiens contiennent les Acères du M. Cuvier, et les Bulles rappro chées des Bullées; les Sigarets, qui y sunt à tort; les Dulabelles et les Laplysies; entin, les Liunaciens. Les Trachélipudes coutiennent tous les Mollusques à coquille spirale, avec ou sans sifhon. Ils sont pariagés $\in$ n deux grandez secilions, les 'Trachélipodes sans siphon et les 'Tracbélipodes avee un siphon. Dans la première se voient dix familles : $1^{\circ}$. les Colimacées, dans lesqucls sont iutroduits à tort, puisquils sont operculés, les Cyclostones, les Hélicines, ainsi que les Auricules; $2^{\circ}$. les Lymnéens, fa mille nouvelle taite avec les Lymuées, rapprochées des Physes, des $\mathrm{Pla}$ norbes et des Conovules, mais ceux-ci, arec juste raison, suivis d'un point de doute; $3^{n}$. les Mf́laviens, faurile nouvelle, dans laquelle sont rassemblés les genres Mélanie, Mlélaunpsirle el l'yrène, gonre nouveau; $4^{n}$. les Péristonieus au lieu d'Orbacées, desquels on a ốé les genies Plauorbe \& Cyclostome ponr y melltre le geure $\mathrm{V}^{\top}$ alvé; $5^{\circ}$. les Fiélilacées; 60. les Agallines, furnant à elles seules une famille sans nom particulier; $7^{\circ}$. les Plicacées, famille rouvelle dans laquelle se trouvent les deux nouveaux genres Tornatelle et Py:amidelle; $8 \%$ les Scalariens, également famille nourelle faile arec les genres Vermet, Scalaire et Dauphinule, démembrés de la famille des Turbinacées; $9^{\circ}$. les Miacroptères, encore nouvelle famille pour les fienres Stomate et Stomatelle, sépartís, oul ne sait trup sur quels motifs, des Haliolides; $10^{\circ}$. enfin, les T'urbinacées, auxquels sont joints les $\mathrm{Ca}$ drans et les Troques, séparés des Calyptraciens.

Les Trachélipodes à siphon saillant, dont la coquille est munie à la base d'un canal ou d'une riciancrure, coniconent les familles suivautes:
10. Les Canaliféres, où sont rétuhlies lus Clav. tulcs, oulglicées dans le précédent systime, it de plus les deux genres nonveanx Ranelle et Siruthio. taire, démembrés des Rochers que Montlort avoit indigués le prenuer snus le le nom d'Apolle et de Crapaud; $2^{2}$. les Ailées; 3 c. les Purpuriferes a vec les deux noureaux genres Cassiduire dénerr. bré des Casques, el Ricinule des Prurpres; 4". les Columellaires, dans lesjuels lamarcls a lon judicieusenent placé les Vulvaires, qui faisoient antérieurement partie des Ilírúrclie; 50 . les Enroulies ou les Ancilles ont changé lcur nona en celui d'Ancillaire.

Les Mullusques céphalopodes sont ıojonrs divisés en Tes!acés muliilocula:res ou polythalanes et en Céphalopodes non testacés. Les Cíplialupodes multiluculaires renfermeut les Orthoccíes, dont la coquille est druile na prescyue droite é saus spirale; il s'y trouve les genres bétrmnite, Orthocère, Nodosaire, geare nouveau, el Hippurite. Les Lituolés, doni la coquille est en partie spirale, le devier tour se terminant en ligne droile; elle ne contient gue les trois crenres Sirirule, Spiroline, Lituule. Jes Criotucíes, limille nouvelle, furmée des genres Ruaulite, Crisitllaire el Orbiculine; ces deus derniers estièrement nouveaux. La qualrième famille est nouvelle; sous le nom de Sphérulíes, elle renferme, Miliulite, Gyrogunite el Mélonite, gende uouvenu. La cincuiène, las Radiolées, est créce pour la premicre fois pour les genres Rotalie, Lenticuline et Planatule: ce dernier n'avoit point encos été fait. Les Nautilacées ne conticnuent plus que les coquilles dont les cloisons sont simples: dans ce nombre sont les Discorlites, les Sidérolites, genre nouveau, Nummulite et Nautile. Ia dernière famille, les Ammonées, est consacrée aux coquilles, dont les cloisons sunt protindement sinueuses, et nous y trourons depuis les coquilles discoïdes jusçu'i celles qui sont droites, les genres Ammouite, Orbulite, Turrilite, Ammonocératile el Baculite. La seconde division des Céplaropodes, celle qui ne contient que des coquitles monothalames, renterme un seul genre, le geure Argonaute. La trcisième division cst destince aux Céphalopodes non testacís, qui, outre les truis gemres que nous avons indiqués dans le premier systeme, renferme de plus le genre Calmarct, nouvellement instituć. $\mathrm{La}$ cinquième et dernièrs seclion des Mollusques, que Lamarck regarde comme celle qui cunlieur les animaux les plus par. faits des Intertébrés el les plas voisins des poissons, contre l'opinion la plus généralement reçue, a été dislinguée par le num d'Ethéropodes; elle ne renferme que les trois geares Carinaire, Firole et Playllireë : ces deux derniers confondus par Péron et Lesueur parmi les Ptéropodes, dont ils diffèrent essentiellement.

Dans ce systeme de Lamarck, où l'on Hourc des cliangemens notables, surtous daus les Mul- 
1p sques céphalís, et parmi ceux-ci dans les Céphalopodes, où la méthode s'cst accrue d'un assez grand nombre de genres, de familles mieux circonscriles el dans un ordice plus aaturel, ce savant zoologiste a su profiter des travanx faits avant lui; loio de négliger la connoissance des Mollusques, il a cherché, au contraire, à s'appayer sur leur organisation pour créer ses divisions principales souvent de plus secondaires, conme les farbilles, et le plus souvent en ne fuisant le genre que d'après la coquille seule, quoique cependanl un grand nombre se soicnt confirmés par l'anatounie. Il faut dire que Lamarck avoit eu pront arriver à ce perfectionnement des matériaux bien précieux, les excellens Mémoires de NJ. $\mathrm{Cu}-$ vier sur les Mollusques, répaudus dans les $A n-$ nales dı Muséum, depuis le commencement de la publication de ce recucil important. Ces Mémoires furent recueillis et réuois à d'autres qui n'avoicat point encore été publiés, et ils formèrent un volume intitulé : Mémoire pour servir à l'histoire et à l'anatomie des Mollusques, qui a paru en 1817 , et dont nous rendrons cumpte lorsque nous serons arrivé à celte époque.

Nous n'avons point de travaux bien importans à mentionner. Quelques Mémoires qui oné éclairci plusieurs points d'anatowie aséritent d'être cités: en 1813, le Mémoire de Mekel sur les Mollusques plenrobranclies, ainsi que celui sur l'ordre des Pléropodes; en 18 r 4 el anaćes suivantes, plasieurs Mémoires d'anatomie comparée, dans lesquels il est souvent questiou des Mollusques, par sir Everard Hom : ils sont inserés dans les Transactions philosophiques; en 1816 , le Mémoire d'Erman sur le sang de quelques Mollusques, publié à Berlin; en 1815 , celui de Lesuear et Desmarest, sur le Botrylle étoilé de Pallas, et inséré dans le Journal de Phisique, tom. LXXX; celui de Stibel, intitule : Dissertatio anatome Limnei stagnalis, Goëlt. en 1815. Un travail beaucoup plus important, qui parut dans le Journal de Physique en 1814 , est cului du savant professeur N. de Blainville. Il fut le prernier qui donna une importance réelle et justement appríciée aux organes de la respiration. Dans la uéthode de classilication, il reconooit que la coquille, pour les Mollusque's qui en ont, est un corps essentiellement protertcur de ses organes: il distingue les Mollusques d'après la symétrie au la non symétrie des branchies, ce qui entraine la symétrie ou la non symétrie de la cnqnille; et d'après cette considération, romme d'après celle de la position et de la forme des branchies, ce savant zooloyiste établit pluvieurs ordres nouveaux, qui plus tard deviareus le sujet de plusieurs Mémoires uarticnliers qui fureal insérés dans le Bulletin de la Société philomatique; ils sont sur les. Ptérodibranches, Cyclnbranches et Inferrabranches. Quelques genres nouveaux furent en mêrne temps proposés.

On a dú remarquer que depuis l'époque de Bru- guière, c'cst-à-dire celle où la conchyliologie a pris en France un nouvel et plus puissant essor, nous n'avions eu aucune occasion de ciler des cuvrages systématiques produits par des savans étrangers; c'est qu'ed effet en Angleterre anssi bien qu'en Allemagne, on eut uu si grand respect et une si grande vénération pour les travaux du grand Linné, qu'ils devinrent pour ainsi dire l'ob. jet d'un culte. On auroit regardé comme sacrilége la main qui y auroit tonché. Il cst bien facile de sentir le résulial de l'applicalion d'un tel priucipe: la science resta stationnaire, et ce n'esi que depuis un pelit noubre d'années que l'Allemagne a produit quelques ouvrages dans lesquels leurs auteurs ont cherché à faire adopter les améliorations apportées dans la science. L'onvrage d'Oken se présente le premier. L'auteur, cnırainé par une idée première, celle de la combinaisnn quartenaire, y a moulé son système des Mollusques; ainsi, on y trouve quatre ordres dans la classe, dans chaque ordre quatre tribus, dans chaqué tribu quatre familles, et dans chaque famille quatre genres. On prévoit d'avance quel a dû être le résulial d'un pareil système, qui, en opérant une diminution considérable dans le nombre des geores, n'a pourtant rien apporté d'utile à la conchyliologie. On y trouve des changemeos dans des nonıs génériques adoprés depuis long-temps en France, et quelques changemens de rapporis qui sont loin d'être tous naturels; quelques familles même présentent uue confusion dont il est difficile de se reudre compte : une, entrautres, qui contient les Anomies, les'Térébratules, les Lernées et les Balanes; nae autre celle des Sépiaćes, qui réunit la Cymbulie, le Clio borealis, les Argonantes et les Sèches. Cependant, il faut le dire, toutes les farnilles ae sont pas de même, et l'on cn trouve qui sont assez nainrelles. Les nouveanx genres qni se remarquent dans ce système sont ou manvais, on peu importans; ce sont en général des démembremens de genres déjà faits, et qui n'eo avoient nullement besoin: nous pourrions les ciler presque lous pour prusuer ce que anas venons de dire.

En 1814 parul à Palerme le Traité de Somto. Ingie, de Rutinescjue, où il proposa quel ruues changemens dans l'arrangement des Nollusques, e. quelques nouveaux genres, dont le plus important est le genre Ocythoé pour les Poulpes dont la paire supérieure des pieds est élargie en une membrane assez large, comme cela se remarque dans la poulpe de l'Argonaute, qui s'en sert, dit-on, comme de roile pour voguer à la surface des eaux.

L'élude des Mollusques agrégés avoil été longtemps aégli rée, ou, pour mieux dire, on ne connoissoit eucorc presque rien de positif sur ces animaux singuliers, lorsque Lesueur et Desmarest publièrent leurs travaux sur cette partic des Mollusques. Ce fut d'abord Lesucur qui démontra que le geore Pyrotome, qu'il avoit établi conjoin- 
tcment a vec Péroo, n'étuit que l'assemblage d'un graud nombre de petits anneaux : ce quil confrrma ensuite avec Desmarest par l'examen des Botrylles. Savigny, doat l'ouvrage est de 1816 , donne uce nouvelle importance à cc sujet, par son excellent travail sur les Alcyons que l'on désiguoit ordinairement par le noun d'Alcyons à double uncerture, et qui sont des réunions d'une foule de petits animaux voisins des Molluiques par leur organisation. Nori-seulement Sarigny jeta un jour noureau sur ces êtres, mais il élendit encore son travail à tous les Mollusques agrégés qu’il partagea eo deux crdres : les Ascidies tithides el les Ascidies thalides. lies premic̀res sont partagées eo deux familles, selon qu'elles sont fixées nu qu'elles sont libres : cette famille, sous le nom de Théthy's, est divisée en Théllyys simiples et en Théthys composées qui renferment un grand unmbre de genre nouveaux. La deuxieme fanille, J's Lucies, est également divisée en Lucies simples et en Lucies composćes; mais il n'y a que de cette deraic̀re seclion, qui contient à elle seule le genre Pyrotone. I,e deuxième crdre ae contient qu'une seule lamille, les ThaIides, qui elle-même renferme le seul geure $\mathrm{Bi}-$ phore et ses deux sous-gentes.

Nous touchousenfin à une époque où les premier's zoologistes français, MIM. Cuvier et de Blainville, proposèrent aussi, soit particulièremeot des traraux sur les Mollusqques, soit un système général pour s'accorder anx autres branches des conouissuoces zoologiques. Ces deux savaos, aprés avoir douné les preuves les plus éclatantes de leurs connoissances approfondies sur presque toutes les parties de la zoologie, étoicnt peut-être plus que persoone en état de faire une application juste et rigoureuse des principes zoologiques entrevus par les Ancieas, et qu'ils développèreat ciune manic̀re aussi solide que brillante.

M. Cuvier, counme nous avons déjà en occasion de le dire, publia, dès le promicr rolume des Annales du Muséum, en 1 Bo2, les Mémoires sur les Mollusques : la manière claire et précise dont il Jes décrit, l'histoire du geare dont il traite, qu'il ajoute à son travail, et les anatomies quii sont faites avec une perfection et une clarté dont Poli lui seul avoit donné l'exemple; ces N'émoires, dont on a fait un précieux recueil, doivent servir de modèles à tous les zoologistes qui, jaloux de faire faire à la science des progrès a ssurés, voudront s'occuper des mêmes matières. Ce ne fut qu'en 1816 que ces divers Mémoires de NI. Cuvier furent rassemblés. Nous allons les iodiquer sommairement :

$1^{\circ}$. Sur l'animal de la Lingule; $2^{\circ}$. sur celui de la Bullaca aperta; $3^{3}$. sur le Clio borealis, $4^{n}$. sur le genre Tritonie (ces quatre Mémoires publiés en 1802.); $5^{\circ}$. sur le genre Aplysie ( 2n 18nj et 1804); 6०. sur la Phyllidie et le Dleurobranclie; $7^{\circ}$. su: la Dolabelle, la Testa- celle et la Parmacelle; $8^{\circ}$. sur l'Oncliydie (en 1805); $9^{\circ}$. sur la Scyllée, l'Éolide, le Glaucus (avec des additions au Mémoite sur la Tritonie, en 1806 ); $10^{\circ}$. sur la Limace et le Colimaçon, sur la Ly mnée et le Planorbe (eo 1808); $11^{\circ}$. sur le genre Théthys; $12^{\circ}$. sur la Janthine et la Phasjanelle; $13^{\circ}$. sur les Vivipares d'eau douce, les Turbos, les Trochus, etc; $14^{\circ}$. sur le Buccinum unduturn (en 1810); sur les Acères ou Gastéropodes sans tentacules apparens.

A ces divers Mémoites furcunt ajoutés, lors de la publication da recueil, plusicurs autres Mérnoires : celui sur les Haliolides, les Sigarets, la Patelle, la Fissurelle, l'Einarginule, la Crépidule, la Navicelle, le Cabocbon, l'Óscabrion et la Ptérotrachée; celui sur les 'Whalides et les Biphores, et celui sur les Ascidies.

Ces précienx matérianx donnés à la science furent bientôt uis en auvre par leur savaut anteur; ils servirent de base pour établir le système des Mollusques qui fitit partie du Règne animal, et doot nous donnons icile tableau.

Les Mollusques snnt divisés en six ordres: les Céphalopodes, les Ptéropodes, les Gastéropodes, les Acćphales, les Brachiopodes, et les Cirrhopodes. Ces ordres, qui soat placés sur la wême ligne, devroient présenter entr'eux des degrés égaux d'organisation, soit en remontant, soit en descendant. Persoune cepeodant ne disconviendra qu'il existe une plus grande distauce entre les Gastéropodes et les Acéphales, par exemple, qu'entre les Ptéropodes et les Gastérnpodes; qu'il n'en existe également enre les $A$ céphales et les Cirrhopodes qu'entre les Acéphales et les Brachiopodes. Les Céphalopodes ue sont point encore divisés en Décapodes et en Octopodes; ils présentent seulement une série de sept genres. Les Ptéropodes, qui suivent, sont parlagés en deux sections: la precière, pour ceux qui ont une tête apparente, et la seconde pour ccux qui sont sans celte prtie. On y trouve le seul genre Hyale, qui, d'après M. de Blainville, est pourvu d'une véritable tête.

Les Gastéropodes sont divisés en sept familles : les Nudibranclies, les Inférobranches, les Tectibranches, les Pulmouées, les Pectinibranches, les Scutibrauches et les Cyclobrancbes : divisions qui sout établies essentiellement sur l'organe de la respiration, sul la position, la forme et la nature du fluide, gu'il assimile. Dans les Nudibrauches, nous trouvons deux geures nouveaux démembrés des Doris, et qui ea sont voisios.

Dans le Traité d"Anatomic comparée, les $\mathrm{Pa-}$ telles étoient placées arec les Phyllidies daos la mêtme fanille; elles en soot justement rejetées ici, et les Intérobranches ne se composent plus que des Phyllidies et des Diphyllides; cc dernjer gente est nouveau. Dans les Tectibranches on trouve un nouveau geare, le Nctarche, avec les Acères de 
Mïller, qui comprenneat les deux genres Bulle et Bullíe.

Les l'ulmonés se divisent en Pulinonés aquatiques at en Pulmonés terresires, d'aprés la nature du lluide dans lequel ces Mollusques vivent: tous respirent l'ail Dans les Pulmonés terrestres, on remarque l'Oachidie, l'suricule, le Mlélauje, l'Actén et les Pyramidelles, qui ont une orgataisution assez dilfércate des Planorlues, des Lyunnces et des l'hyses, th moins pour ceux de ces genres dout l'organisation est connue.

Les P'ectiuibranches se distinguent en 'Trochoides, Buccinoïdes et en Cachés; les 'Trochoilles, avec les gentes Sillot, 'Toupic et Nérite, coutiennent aussi le genre Concliylie, qui présente, d'une unanière peu rationnelle et it titre de sous. geore, les Ampullaires, les Múlauies, les Phasianelles et les Janthines. Daas le genre Sabot, et comane sous-genre, nous trouvans les (iyclostomes terrestres, qui, quoinue pourvus d'une cavité pulınonaire dans lạguelle ils reçoivent l'air, ont du reste beaucoup de rapports par lopercule surtout a vec les autres Mollusques Pectinibrauches de ce geare.

La sixième famille des Gastéropodes, les Scutibrauches, est aouvelle. Ces Sintibranches sont divisés en sytuélriques et en non syméiriq̨ues : dans ces deruiers se trauveat les genres líorinicr, Cabochon et Crépidules; et dans les secoods, et bien à tort, hurs de tous les rapports, les genres Septaire, Curinaire et Calyptrée, avec les liissurelles et les Linarginules. Dans les Cyclobranclies, nouvelle et derniére fanille des Gastúropades, on voit les gences Palelle et Oscabrioo. De ce picmier genre, M. Cuvier inalque dins use nole qu'il faudra en séparer les genres $\mathrm{Pavoiz}$ et Ombrelle; ce qui a voit déjá élé fait par Montfort et par Lamarck. Il est certain que les Oscabrions préscnteal de grandes dilficultés dans lear clissification, et dans l'apprécialion de leurs rapports. Nous y reviendions plus tard.

Les Acépbaies, comme dans l'origine, sont divisús en Testacés el en aus. Les Testacés, l'après la méthode de lamarck, se partagent en ceux qui n'ont qu'un muscle et ceux qui en ont deux : les premiers sont contenus daus la seule Camille des Ostracées; les seconds le sunt dans gruatre familles, les IIytilacés, les Béuitiers, qui font partie des Monomyaires de Lamarck, les Curdiacés et les Enlernés. Les Acépbales sans coquilles préscntent deux sections, qui ne sout poiul basées, comarne Savigny l'avoit proposé, sur la fixation ou la liberté de ces animaux, alais bien d'après leur manière d'être : aiusi, les premières contienuent les Biphous et les Ascidies, et les seconds les Botrylles, les Pyrosomes et les Polyclinum, adoptés, la plupart, de Lesueur, Desmarets et de Savigny; les genres de ce dernier surlout restreints à un fort petit nombre.

Hist, Nal. des Zrors. Tome II,
Les Brachiopodes n'offrent rien de nouveau; ils torment l'avant-dernier ordre ou le passage des Acéphales aux Cirrhopodes, qui terminent les Nollusques et établissent fort bien le passage anx animanx arliculés. Ce systerae des ilollusques, que M. Cuvicr auroit pu rendre plus parfait sil avoit profité clavantage des travaux de Lacnarck, est firndi sur co que l'ulservation a cle plas précis et do plus positif; il dillère essentielment de ceux proposćs par Liunarck, el la raison én est fitcile à comoitre : Lamarck a alticlié une importance asse 4 grande anx curacteres de la cogrulle; au contraire, N. Cuvier ne les a considérís que tres-secuallitement. Lina a admis des sousgenres; l'autre, plus rationullement peut - ctre, d'apres aolre manière de penser, n'en a print fait : ce qui, nous lc croyons, est micux pour la simplicité d'un systeme.

Cé fut ve.s lat mème époqne que Mi. de Blainville publia ses Ménoires sur les Mollusques dans le Journal de Physique, en les rablachant cegendaut à son Système général du Règne animal. Il conmence J'abora par détucher des Hollusques, comane devant lormer un seul type qui lait le passage des auibaux arlicnlés aux Mlıllusques, les Cirrliopodes; ce qui aroit ćlé filit avaat lui. Il proposa d'en raf'procber les Oscabrious, qui, sous bien des rapports, sont éloignés des Patelles el des Pbyllidies. Dans le's vrais Mollusques, M1. de Blainville admet, suus lit dénomination de C'ćplatophores et d'Acéplcáophores, Ja division de lacrarck de Céphalés et d'Acéplaalés. Les auties divisjons, comue nous l'avons déjà dit, sont tirces de la symérie ou de lis non symétrie de l'orgare de la respiralion et de la cuquille. Les (Céphalaphores sont partagés ca trois sections ou ordres, toujours d'après la lorme et la disposition des organes de la respiration : lo premer, les Pallioiranclies; le second, les lamellibranches; et le troisième, les Húlćrobrauches.

Par une singularité qu'il est difficile d'expliquer, la plupart des Mullusques l'térépodes et Ilétéropocies, d'après l'opiuion du savao: dont nous citous les lavaux, avoient été éludiés a l'envers, c'est-i-dire que l'on avoit constamment pris la lace abdominale pour le dos, et réciproquement. Ceile opmion, appuyée sur l'analogie te posilion des urganes dans les Mullusques, paroit bien probable pour beacoup de ceux dont il est ici question. Pour la Carinaire cependant il paroil qu'al n'en cot pas ainsi que le dit M. de Blainville. Nuos apportons d'abord les observations de notre savant ami, M. Bory de St.-Vincent; celle de l'éron et Lesueur, confirmée par une autre qui nous a été communiquée manuscrite par Mi. Marnia, amateur fort distingué de couchyliologie, qui lui-mème l'avoit reçue d'un pharmacien de Nice, lequel lui envoya iout à lit tois l'animal, la coquille, les dessins faits sur le vivar et en couleni, ainsi que plusieurs obserQqq* 
valions que la méne personne fil pendant la vie de l'animal, qu'il vit nager et se tenir constamment dans la wème position. Ia coquille toujours en bas, ainsi que le cœur, les branclices, clc., qu'elle contient, et la nageoire, que M. de Blainvilie considere comme une modification du pied, est constanment tournée en laut. Il seroil bien nécessaire, et les voyageurs seuls le pourroient facilement, de recueil it de buavelles obscrvalions sur celte question assez inportante. Quoi quil eu suit, les obscrvations ale M. de Blanville, en ramenant la discussion sur ce point, n'en sont pas moins jutéressantes U: même aécessaires.

Dans un Némoire publié par le méme auteur sur l'ordre des Polybranclies, il y rapporte le genre Glaucus, qu'il décrit compllétemeut, et ajou:e dans celle lamille le nouveau genre Laniugère, interméliaire entre les Glaucus et les $\mathrm{Ca}$ volines.

Dans deux auties Mémoires, le premier, sur les Cyclobranclıes, qui réunissent les Doris et les Onchidics, on trouve un nanveau geare, trèsvoisin de ce deruier, sous le nom d'Onclidore. Daras le second, sur les Inférobranches, dont les Oscabrinns ne font plus parlie, un nouveau genre y est établi sous le nom de Linguclle. Nous pourrions ajouter aux divers travaux de M. de Blainville les articles qu'il a publiés dans les volumes du Dictionnaire des Sciences nalurelles, parmi lesquels on en remarque plusicurs oì sont décrits, pour la première fois, des Mullusques nouveaux, peu ou mal conuus. Poar ceux-là, nous anrous occasion un peu plus lard d'en parler et de les rapporter.

Si, à ces divers travanx, nons ajoutons ceux de Leach sur les Cirrbipèdes, oì le test de ces animatux est soumis à une rigoureuse analyse, et pour lesquels plusients genres nouveaux sont établis, nous connoitrons à peu près tont ce qui a été publié d'important sur les Mollnsques avant que le derniev ouvrage de Isamarck ait paru: ainsi, ce grand zoologiste, dans l'établissement de son nouveau système, put profiter d'une fuule do bons travaux, et son esprit, plein de justesse et de saỵacitó, sut s'emparer de ces matériaux, les coordonner, pour arriver enfin à un système qui, en admettant les counoissances anatomiques nonvellement acquises, n'a pourtant pas eu le tort de rejeter tout-à-firit les rapports des coquilles, surtout lorsque ceux des animanx eux-mêmes manquoient. Quoiqu'on trouve encore quelques imperfections dans celte cuvre da protond génie et du vaste savoir de Isamarck, la lucidité de ce système est telle qu'il y a fort peu dle savans en France qui ne l'ast atlopté; et il a décidé, en Angleterre et en Allemagne, la réforme que plasieurs hommes sefforçoient en vain de fajre arriver parmi les seclateurs trop zélés de l'immortel Linne.
D’abord, Iarmarck a séparé des MIsllusqques, sous le nom de. Tuniciers, les Nullusques acéplalés nus, que tous les auteurs avoieut adınis parmi eux : non-seulernent il en fait une classe à part, mais il los éloigne de tous les animaux articul's. Celle uétbode, qui a été blìnée récemment par MI. ile Blaiaville dans sou Traité de Mralucologie, est pourlant appuyée, de la part de Lamaick, de fails nombreux et de judicienx raisnnncmens. Forcé, dit-il, de conserver une série simple, et de coordonner les divers animaux d'après les deugrús d'organisation, quoique récllement la nature ait produit deux séries, il étoit évilient que les 'Tuniciers étoient très-rapproclús des liacliaires fistulides, et avoient me organisation bien noins avancée que les vers et les insectes.

M. de Blainville convient qu'il existe de grands rapports eatre les Actinozoaires et les 'Tuniciers; et s'il en existe, conme cela n'est pas donleux, entre ceux-ci et les Mullusques, il cst bien évident qu'en admettant une série simple, Lamarck se trouroit dans la nécessité de rompre des rapports, soit en rapprochant les T'uniciers, et avec: eux les Actinnzodires des Nollusques, suit en éloignant les Tuniciers pour les rapprocher des Actiaies : ce qui lui a paru plus conforme i lis nature. Lamarck est lnin de rejeter les rapports qgui existent entre les 'Tuniciers et les Mollusçues, mais il faudroit les délaclier en rameau litéral; pour le pronver, nous rapporterons textuellement ce qu'il dit (tom. 3, pag. 9o, Aniniaux sons vertebres ): Ainsi se montre la séric des ani* maux inarticulés, commençant par les Infu* soits, se continuant par les l'olypes, les Tuni* ciers, les Acéphales, et sc terminant avec les "Mallusques, duot les derniers ordres sont les "Céplıalopodes et les Hétéropodes.

Lamarck a aussi séparé des Mollusques, et dans des classes de la mêure valeur, les Cirrbipèdés et les Conchifères, les Acéphales de ses précédrntes néthodes. Il en a été question aux deux aiticles de cet ourrage qui les concernent, et nous y avons ajouté un tableau des familles d'apris Lamarck. Ainsi, sous la dénomination de Mollusques, ce savant zoologiste n'entend plus que les Mollusqres céphalés, dont nous piésentons ici le tabieau. En comparant ce tablezu avec ce que nous avons dit précédemment du système établi dans l'Extrait du Cours, on se formera une idte suffisante des chaugemens qui ont été apportés dans la méthode, changemens qui sont presque tous des amćliorations. Quoi que l'on puisse dire et quoique les bases du système paroissent quelquefois artificielles, il n'en est pas moins constant que, de toutes les méthodes, c'est celle de Lamarck qui est la plos naturelle, celle qui offre les râpports les mieux établis, celle $q^{\mathrm{D}}$ est la plus simple, d'une application plus facile, et dont la mémoire se charge sans la fatiguer : elle présente l'avantage 
de la méluode linuéenne, quoiquid'e suil sans comparaison beaucoup plus complète el qu'clle wlice un nombre considérable de genres. Le défaut le plus grave yue l'on zit ì reprocher à la ınélho te de Laruarck, c'ésı de a'avuir pas employé des caraclères de aiêue valeur pour séparer tinus les genres. O: r vail en ctlel quelyues mónalités rue le terps et de aouvelles observalivus fervat disparoitre.

Daurres zoolog's'es, comme nous l'arons dit, reprochent à Lanarck d'avoir donné trop d'importance aux caractères des coquilles, ce qui est - Vrai pour plusicurs genres; nais il faul ajouier que la plupart de ceux-lit sunt peu ou point comus sous le rapport de l'organisalion des animaus. Eufin, il laut ajouter que la presque tolalité des Mollusques du grand ouvrane de Lamarck a été publiće lorsque déji le cólébre professeur, à la suite de ses lungues et laborienses reclierclies, étoit lombé dans la cécitć la plus absolue, ce qui l'a empéthé de revoir par lui-mêtue scs travalux à inesure de leur pullication, el d'y apporter les changenens que les décunveiles réceutes rendoieut nécessaires.

Peadant que l'ouvrage de Lamarck se contiauoit et se terminoit, M. de fierussac publiout un tresgrand ouvrage génćral sur les Mollusques terrestres El fluvialiles: cel ouvrage non icrminé, est composé d'une suite de livraisons de plauches adinirablement exéculées par MII. Huel el liessa, nos plus labiles peintres d'histoire naturelle, el gravées par M. Coutant, planches dont l'ordre est difficile átablir, puisque dis le commencement il s'en tronve de supplémenldits, el gui souvent ne sont point accompagaées du texte exilicatif : plusieurs parties du texie, dans les dernières livraisons, servoient déja de suppléaıent à ce qui a été dil daıs lis précédeutes. Un systìme nouveau pour le geure Iélice lui seul, anquel on ríunit tous les genres qui en ont été successivement démembrés par les zoologistes nodernes, en leur donnaut de nouveaux noms formés des raciues helico et cochlo, auxijuels sont ajoutées des épithèles caractéristi¿ques; el plus que lous céa un système gúnćral des animaux Mlollusques créé pour établir les rapports des Hélices et autres gentes terrestres et fluviatiles; avec le reste des Mollusques : tel est l'ensemble de cet ouvrage, gue l'vo peut considérer comme for uré de deux parties, celle des Mollusques terrestres et fluviariles, qui n’est point leraniué, et qui a besoin de l'èlre pour pouvoir être juslemeut appréciée; l'antre, qqui est lormée d'une suite de tableaux systématiques des animanx mollusques, partie eutière:neat achevée, et dont nous rendlons comple succinclement.

Comaue dans la première mélhocie de Lamarck, tcus les MIollusques sont divisés ea deux graodes sections, les Céphalés et les Acéplatés. Les Céplatés olfrent irois classes, les Cépla!upodes, les Ptéronodes et les Gastéropodes: les Cóphalopodes sont divises, d'arries M. Leach, en Décapudes el en Octopodes. Par une singularité difficile expliquer, et que B. de Blainville avoit lurt bien remarquie, on trouve, sur IJ seule analo ie thes $S_{\text {irisules, }}$ loutcs les coquilles pulyilalancs sabs eaception parmi lcs Dicapodes; les Octapudes ne contieureal que les l'oulpes et les $\Lambda$ romartes, et, à l'égard de ces derniers, nous pensou;, comme H. de lblaiuville, que le Poulpe que l'on rouve quelquet is dans celle élégante cuçuille a'en cst guian habiant parasie. Après la première famille des Décapodes, les Aanon'es, on troure une fanille pour les lliphpurites seules el les Batulites de Montfurl, qui n'en sunt qu'un démeubrement fort inutile. Outre que les Hippurites ne sont peint de vériables Cluisonués, M. de Fernssac lii mène arroit indi. qué d'une anajère furl a'jrénge, il faut le dire, les rapports de res corps arec les Spluérulites de Laauarck. La troisième lanille des Décapodes est consaciée tour entière pour le seul genre Bélenaaite. La quaticase, arec le geare Ichthycsarcolite, qui est un type paticulier de cocjuilles bivalics, se truuvoit zéunie arec les Raphauistres, les Orthocéralites el les Nodosaires, qui n'ont presque poiat de rapprort entre eux. Ia fanille suivante, qui est initéc de Lamarck, les Li:iiles, est beaucoup pins nalurelle. MI. de Ferussac a voulu y fuice l'addition d'un gente de Moutfort, et le choix n'est pus heureux, fuisque c'est sur le genre Canope qu'il est tombé. La sixième fanille, les Discorbes, ne conticnt que les trais genres Clistellaice, Discorlie e: Rutalie. Mais la septième, dans lagnelle sont s'juaríes les Lenticuliues, pout les placer avec les Nauliles ei les éloierner des Nummulites, avec lesquels elle ne devroil former qu'un seul et même genre, rompl évidemmeat !es rapports les plus maiurels.

Lamarck avoit le preuier donnés l'exemple du rapprochemeat des Nummulites et des Ninutiles; mais il existe entre ces deux geares une diférence qui na poiat été suffisammeut sentie : les Nautiles sont contenus dans la dernic̀re loge de leur coquilles, les Nummulites sont au contraire des os intérieurs dars lesquels l'animal ne peut uullenent rentrer. Il est dilli:ile de cuncevoit pourquoi, clans la famille suivaute, 11 . de Ferussac a réuni avec les Numanulites et les Sidérolites les Orbiculites, qui sen Ćloignent deja, el surtout les Mćlonies, qui en diflerent notab!caneut, puisque ce sont des coquilles essenticllement pureuses. Dans la séric gúnérique, 11. de lierussac ne s’est pas toujours istreint a álablir les rapprochemens des gcures qui terainent el qui commencent les fanifles : nuus demauderons d'abord quels rappurts il existe entre les Baculites et les Batolites, cnire les Rotalies el les Lenticulines, entre les Mlélonies et les Pićnulines, enfin entre les Aréthuses el les Siches, çui terminent, avec les Calmars, la grande scrie des Décapodes? Partout ois 
I. de Ferassac a imilé lilléralement, il a conseıvé dans cette classe des rapports naturels; mais aussirút qu'il a voulu innover, il les a détruits pour la plupart.

La classe que M. de Ferussac fait suivre est celle des Ptéropodes, imitée presqu'entièrement de M. Cuvier et de Lamarck, dans lesquels il a ajouté le genre Gastéroptère le Mekel, que M. de Blainville considère comme Irès-voisin des Acères de Müller, et le genre Pliylliroë, adopté de Péron.

Les Gastćropodes sont les mémes Mollusques que dans M. Cuvier; is contiennent par consé'puent les $\mathrm{G}$ astéropodes, les 'Trachélipodes et les Hritéropodes de Lamarck. Ces Gastćropodes sont parlagés en neul ordres clont la surcessiou est absolnment la même que daus l'arangrement de M. Cuvier; seulement ce que relui-ci nomrue familles dans le Règne anumal, M. de lierussac en fait des ordres. II y en a sept dans N. Cnvier; on eo trouve neul daus M. de Ferussas, dont no incertain pour le geure Atlas, et le second ponx les Pulmonés, qui sont divisés en operculés et en non uperculés. Les Nudibranches, ontre les genres de M. Cuvier parlagés en sous-ordres et en familles, contiennent les Irois genres Onchydiore et Laviogère de M. de Blainvilie, et le genre Doto de MI. Oken.

Les Inférohranches sont divisés de manière à rénnir les Phyllidiens et les senu-Phyllidieos de Jamarck, qui font ainsi deus sous-ordies : le premier ne contient que les deux genres Phyllidie et Diphyllide de M. Cuvier, le second réunit les Ombrelles dont M. de Blainville avoit reconnu les rapporls avec les Aplysie, les Pleurobrauches, extraits des Tectibranches de $M$. Cuvier, et de plus le genre Linguelle de M. de Blainville, qui, d'aprés le savani zoclogiste que nous venous de citer, et qui est l'auteur du genre, devroit se trouver près des Pliyllidies dout il diffère à peine. L'ordre snivant est incerlain : il avoit élé proposé par M. de Blainville pour le genre Allas sous le nom de Ciliobranclie; mais depuis, ce zoologiste a reconnu qu'il avoil commis une errenr, et que ce gente Ctoit fort voisin du genre Gastéroplère, proche, selou lui, des Acères.

Les Tectibrancbes, à l'exception des Pleurobranches, coutienuent les mèmes genres que dans 1I. Cuvier; on y irouve cependant le gente Actéon de Ol.en pour 'Mp.rysia viridis qui n'a que denx tedtacules, un reure Bulline trís-artificiel pour les bulies don: ?a spire est saillante, et enfin le Sormet llidianson.

L.es Puilnonés, comme nous l'avon dit, sont sćparés en deux ordres d'après l'opercule : ceux qri sont sans cettc pièce forment le quatrième ordre. Cec ordre n'ust pas divisé, comme dans M. Cuvier, d'après l'babitation des Pulmonés en terrestres el llavistiles, mais bien en quatre fa- milles : la première, les Limaces, parmi lesquelles se voit le pouveau genre Vaginule, qui ne diller e pas d'une manière essentielle des Véronicelles de IJ. de Blainville, indiqué avec doute; les genres Pliylomique et Eumèle de Rafinesque; le genre Ariou, démembrés des Limaces sur un caraciére d'une importance secoudaire; le geare Plectrophore, interı́diaire entre les Parmacelles el les Testacelles.

1,a seconde famille est formée par les Limacons. M. de lierussac la commeace par son genre nouveau Ifélicarion, qui pourroit à peine Jormer un sous-geore du suivant, Hélicolimace (Vitrine Draparnaud). On y lruuve également le genic Parlule, dénembrenent des Bulimes qui pour:ra rester. Ce que $\mathrm{M}$. de Fernssac a le mieux faic daus celle classe, e'est d'avoir séparé en u groupe bien circonscrit les véritables Auricules, avec lesquelles on cunfondoit les coquilles terrestres da gente Hélice, et gue d'aillears M. Cuvier avoit placés indistincteureat parmi les Pulmonés aqualiques. Cenx-ci sont réunis et forment la quatrième famille, les Lymméens, qui, outre les genres de M. Cuvier et de Lamarck, renferme de plus quelques genres incertüins de Ralinesgue, et le genre Ancyle de Genflioy, qui certaiuement n'est point là à sa place. I'our les Pulmonćs operculés est établi un nouvel ordre de Gastétropodes, et, il faut l'avoner, cette innovation n'est pas heureuse, puisqn'elle éloigne los Cycilostomes terrestres des Yaludines, ce que l'on a voil justement reproché à Lamarck. On ne trouve dans cet ordre que les deux gentes Hílicine et Cyclostome. Cét alraugearent a forcé M. de Ferussac de commencer lordre suivant, les Pectinibrancbes, par les Puludines; ce qui rompt un peu moins les tapports. Ces Pectiaibranches sont divisés en quatre sous-orlres sur la considćration de de l'opercule : le premier, les Pomastomes, pour cenx dou l'onercule ferme exactement l'ouverture de la coquille. Ils présentent deux familles dont les genres sont bien loin d'être rangés dans un ordre Daturel. Ces familles sont basées sur le nombre des tentacules, el cependant à côté des Valvées se tıouve le genre Natice, dont le Pitonille de Montfort fait un suus-genre, quoiqu'il soit le même que le geare Héliciue. Il y :apporte aussi les Kouletles de Lamarck, quoinda'on n'eu connoisse pas l'opercule. Ainsi, ce genre Natice se trouve séparé des Nériles, avec Jesquels tous les auteurs lui ont reconna les plus grands rapports, rapports confirmés par l'observation des animanx.

Dans la seconde famille, avec les Nérites se trouvent les Ampullaires, les Janthines qui n'ont point d'opercule, les Pbasianelles, les 'Toupies avec un grand nombre de sous-genres, les Pleurotomaires, el immédialement après les Scalaires; et enfin, pour lerainer un si bel ordre, le gente Mélauopside. 
I.e dcuxic̀me sous-ordre, les Ilémipomastomes, comprend les Nollusques canalifêres de Laruarck, du moins la plus grande partic, et la plupart des gerres de MI. Cuvier deviennent des familles: ainsi, il y en a une pour les Cériles, une pour les Buccins, une troisèua pour les Pourpres, diviscis en Puurpres, Culombelle, Rocher, Fuseau, Rostellaire, Strombe ct Cónes, sous-divisés en une foule de sous-genres plus on woius bien rapprochés. Dans le traisième sous-ordie sont tassemblés tous les Mollusques sans opercule, et ils offreut trois lamilles, les Enroulés, les Volutes et les Couronoes : celle dernière pour un seul gomre démeabré des Volıtes. Enfin, le quatrième sousordre, sous le nom d'Adélodermes, renferme les Sigrarets sur un caractère mal apprécié, que le coquille est dans le manteau; mais il y ea a, comme le dit M. de Blainville, qui noot point de coquille et d'autres qui l'ont complétement à l'extćrieur. Outre ce genre Sigaret, se trouvent aussi les genres Cryptostome el Lamellaire. Les Scutibranctes offrent un arrangement très-voisin de celni de N. Cuvier : la première famille représente complétement celle des Macrostomes de Lamarck, ì l'exception des Sigarels qui en sont relirćs.

La seconde est formé des deux geares Cabochon el Crépidule. La troisième, caractérisće par la symétrie de la coquille el des organes, comae l'avoit proposé M. de Blainville, coutient encore le geore Septaire, Navicelle, que lamarck aroit justeraent jugé être très-voisin des Nérites, et les Calyptrées, qui ne sont uulletnent symétriques, et dont les organes ne le sout point non plus; les gnenres 'Trémésie, Notrème de Rafinesque, geares très-mal et très-incomplétement olsservés.

Vieat easuite une famille qui n'a ancun rapport avec ce qui précède ou ce qui suit, les Ilétéropodes, qui se trouveat intercalés entre les Calyptries ci les Patelles.

Je huiticme ordre, les Cyclobranches, est absolutuent le même que daus M. Cuvier. La grande série de Mollusques gastéropodes se tepmine par les Oscabrions, el sans doute pour se conformer tout à la fois à l'opiuion de M. Curier. cl à celle de M. de Blaiaville; et au lieu de transpurter les Polyplaxiphores près des Cirrhipides, M. de Ferussac rapporte au contraire ceux-ci immédiatement après les Mollusques céphalés e! avant les Nullusques acéphalés, rompan! ainsi sans molif les conuexions et les rapports des êtres. Par mue singularité plus grande peut-être, $M$. de lerussac place les Cirrhipèdes, que tous les zoologistes ont regardés comme un type bien distinct d'organisation, parmi les Acéphalés, sous le iitre de classe au méue degrés que les Brachiopodes el les Lamellibranches : ce qui est évideroment lirux et erroné. Dans les Brachiopodes, les genres Balane et Anatile cle Bruguière devienuent des familles dans lesquelles soni gronpés les nouveaux genres ¿ tablis par Lamarck et par M. Leach.
La seconde classe des Acéphalés, les Brachiopodes, contient, de plus que dans M. Cuvier, le genre Magas de Sowerby, décombréldes Téribralules; et on ne sait pourquoi alors M. de Ferussac u’a point adinis la plupart des autres genres séparís du mêne genre par le nếme autcur: le ñenre Cranie que M. de Blainville le premier proposa d'en rapjrocher, el le genre Thuécidé de i1. Delianace.

La dénominalion de Lamellibranche imposée at la troisiome classe des Acéphalés est empruntíc ì $\mathrm{N}$. de Blainville; la distribulion des ordres est prise le M. Cuvicr, dont les cing tamilles sont élevées à ce degré. Dans cet arrangement sont adaptées, d'une maničı assez naturelle, la presque totalité des familles de Latnarck, dans lesquelles se remarqueat peu de changemens notables. La quatrième classe enfin est deslinéc aux Acéphalés aus des auleurs. M. de Ferussac a adup̣té le nom de Tunicier imposé par Lamaıck, et, du reste, suit en tous points la méthode de Sarigny.

'I'el est l'ensemble de ce système, ou plutùt de cet arrangement que son auteur a qualitié de $f a-$ milles naturelles. Ce titre paroillia trop ambitieux saus doute anx yenx des personaes qui saperceviont du peu que l'autenr a ajoulci a ce qui avoit été fait avant lui, des changemens pen favorables qu'il a introduit dans sa méthode, lesquels ne sout pas en rapport avec l'éat de lá science lors de sa publication. Nons arons de plus de cet auten une excellenle Monographie des Mélanopsides, auxquelies il réunit juslement les I'yrénes de Ianarck. Ce fut aussi en 1820 que Sibweigger publia en Allcıngne un Tiaté sur les Animaux sans vertébres inarticulés : Ics Mollusques y snnt distribués d'après le Règne animal de II. Cuvier, onsis dans un ordete inverse, c'est-à-tlire croissant en organisation, dass lequel il a introduit les genres de Lamarck. Quelques nous nouveaux, particulièrement pour dúsigner les ordres des Gastéropodes de il. Cuvier et pour quelques genres, sont les seules choses notables qu'il $y$ ait dans cet ouviage, qui, du reste, pour les Mollusques, n'a apporié aucun fait nouveau.

Nous pourrions presque en dire antant de la mćthode de M. Goldfuss; elle est cependant beaucoup plus parfaite et présente l'introduclion d'un principe qui scroit fort bon s'il pouvoit s'appliquer rigoureusement à tous les Mollusejues : c'est de la lurane dn pied que sont tirées les principales divisions; aussi ce savant zoologiste a-t-il soin d'adopter toutes les divisions qui ont été faites antéricuremeut par les auteurs d'après ce caractère. II conserve douc les Céphalopodes, les Ptéropodes, les Brachiopodes, les Gastéropodes et les Cirrhipodes, auxquels il ajoute les Pélicipodes pour les Acéplales testacés, et les Apodes pour les Acéphales aus; eafin, les Crépidopodes pour l'or- 
ấre qu'il établir uniquement pour les Oscabrions. On dait blâtoer M. Galdfuss d'avoir fait une innovation peu beureuse, celle d'avoir place hors de lous les rapports les Brachiopodes entre les Plérepodes et les Gastéropodes; quelques autres i.anorzions plus heureuses, parmi les Gastírojoncles surtont, et sun ordre des Pélicipodes, se remarquent daus celle mélliode.

l'iusienrs Mémoires de différens auteurs out fia à peu près à la mêue époipue. Eo lialie, i:n trics-beau travail de M. Ramzaui sur les Mullusyues arliculćs et le's Acéphales. En Aruérique, alix Liats-Unis, les Mémoires de Siy, ceux de l.csucur, qui habile maintenant ce jay's, vi il a décourert plusieurs geares nouveaux parmi les Céphalopodes, quelques autres parmi les Nuclécoluancles, et un grand nombre d'espèces nouvelles. Le mème auteur a donné aussi, dans les Tis'moires de lu Société des Sciences naturolles de l'hilatelplie, nne anatomie détaillée et bien faite de la Firule. Nous purarions citer aussi le Nímoire de Rafinesque, insíré dans le tnone 4 dıs Annules des Sciences naturelles de Bruxelles, daus lequel sont poussées á l'extrçare les divisions hEáriques dans les genres Muletle et Aoudonie de Lawarck, et sur de simples modilications dans les lormes qui varient heaucoup. Eu Angletere, nous pouvons mentionner les diffírens ouvrages

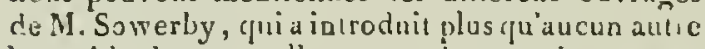
les wélhodes nonvelles, en adoplant les geures ac Lamarck daus le Nineral concliology, qui renferme un assez grand nowbre de gemres nou. veaux qui seront cunservés; et ensuite, daus le Genera of Shells, ou il fat connoilte, par de Jonnes tigures et des descriplious bien fuiles, tous les genres qui ont été publiés jusqu'ici, à moins que ces genres ne soient trop arlificiels : it en :jacte même quelques-uns qu'il propose, tels que P'auladonye, Ouiscie, Conelix, Piléole, Siphoraire et Astarté (Crassine Larnk.). 1.e premier de ces genres est un dos plus intéressans it tous cyards; il fait connoitse prositivement la place que doivent occuper, dans la sirie générique, lise quantité de coquilles pétrifiées des terruins secondaires dont on ne savoit que faire. lae seroud est moins important, jI cst dónembré des Cassidaires de Lamarck; il en de méme du troisieme, établi pour les Mitres qui ont la forme d'an cône. lie quatrième est fort voisiu des $\mathrm{Na}$ vicelles, et intermédiaire cntre ce genre et les Núritines. Le cinquière csl démembé des $\mathrm{Pa}-$ reiles; il cst ćrabli sur de lons caractères, et il ca est de mème du genre Aslarté . q̨ie Lüarcls a jroposé depuis suns le nom de Crassine.

LiAncrleterre duit atissi à M. Gray nue classificaion méthodique des Mollusques d'upres leur strucicre interne. Ce futien $182:$ qu'elle fur inséJéc dans le London medic. reposit. Cetle mlthode Gui, nous pourons l'assurer, ne sera jumais a dopltie a cause de la longueur et de la difficilié des coms, divise les Mollusques en sept classes: 10. les Antliobirechoonhura (Céplialopudes); 20. Gasteropodophora (Gastínpudes); 30. Gusteropterophora; $4^{\circ}$. Stomatopterophora ('lúropides) ; 5n. Saccophora (A céplalís nus); $6^{n}$. Conchophou (Acreplatís icstucés); $7^{\circ}$. Spurobrachrophora (13raclitopodes). Ces widres répondent à ceux de 11. Cuvicr; il n'y esl pas questiua das Cirrliopodes; mais les Gastén npocies sont divisís en deux ordies, Gasteropodophora pour la presyuc: tolalitó des Guslćrnpades, et les Gasteropteiophora pour le genre l'térotrachée, quij lassemble les Caminares et les Argunatules. Un autre changenset.t gue l'on doir remarquer, et qui est loin d'être ralionoel, est d'avuir placé les Acéplalís nus arant ceux qui ont une co:juille, et de les avuir unis ainsi en rapprert avec le ternier orde des Niollusques, les l'tíropodes. La plupart des sous-divisions de ces ordes soul ćlablis d'apris la cunsideration des organces de la respiration; et les groupemens de genres ou les fanilles, surtout parmi lcs Gastéropodes, sont fnrmćs ascez rignureusement sur l'opercule, ce gui cunduit â des rapports fort naturels.

Nous ne pourons rendre comple complétement de celle méllode, qui, du reste, n'offre pas d'antres apercus nonveaux : on y remaryue plusieurs genres oou connus, tels que Phythia pour l'Auricula myosotis de Drapalnaud, genre give nons crejons inutile; Bithynia pour quelques Yaludines; Ielutina pour la Bulla velutina; Mitrales pour la Patella chinensis, aujourd'hui dans les Calyptrées; Diodora pour la Patella apertura; Laminarica pour quaclicies I'leurobranches.

Dans le wème teunpras M. Gray publioit l'on. vrage dnnt mous venons de parier, il paroisscit dans le Joumal des sciences, de la littéruture et des ants, ¿ Loncres, les genres des conguilles de lamarck, daus l'excellente in!entiou de fairc adop'er, des zoolngristes anglais, les divisions nouveles, fl de les sabstiuer au système de Linué, q̨ui cst presqu'uaiquement suivi.

Des travaux gुui n'oot qu'un julérêt local, duri les bases sont les ménes que celles dé Draparand, ont étć entrepris an 1821, l'un puilr la Sucde, l'autre pour l'Allemagne, sur les coquilles terrestics et fluviatiles de ces deux pays. Lianteur din pueunice est Nilson; snn ouvratge porte le tilre d'Histoire des MIollusques terrestres at fubiatiles de la Suède. Celui du secnut es! de Placiller, dont l'currage est intilulé : Arrangement systématique des Coquilles terrestres at fi:umulles de l'Allemagne. De bunnc's plauches, où plusieurs animaux sunt représentis, ainsi que roo:es les coquilles de l'Allemanze, cinoique le prius granil nombre ait ćté liguré par Dranarnaud, accumpagnent le texte; on y trouve méase un nouveau genre sous le nom de Pisidium, pour quelques Cyclades dont les siptons sont ia peine saillans. 
De retrua d'un voyage long el périlleux. pentant le.pel ils avoient rasseniblé d'immenses collections zoologriques, qu'ils eurent Ja dusleur de perdie an annient de venir en enrichir leur patrie, MII. Quny el Giaynari rapporcèrent semuntint quelpues deloris présienx pour les Mollungues; ils les décrivirent ei les livent figated duss le maruitipue Altas du Voyage de l'trunie. la plupast furent cornmuniqués par enx à .H. de Blainvilie, gyiu en fit de bonnes anatomies qui se trouvent disus le mêtne ouvrage : lés gentes Ilipiranice, Cóne, Vulute, Ovale, Parculaine, Vis, Ricinule, P'térocère, i"avicelle, sont depuis Inrs sullisamment connus. Les yeures Cliotite et 'l'inorienas lurent établis sur des Mlollusıues nouveaux, l'un trèsvaisin ues Clios, l'autre peu éloigná des Biphores. Nous ne parlins pas i.i tes espeèces nouvelles dont ils enrichirent plusicurs genres, surtont celui des Hélices el celui des Biphores.

Lues mêmes naturalistes ont publić successivement, et princinalement dans les Annales des Scionces nuturelles, plusieurs .lémoiressur divers Mollusques, mais surtont sur ceux des classes inférieures que Lamarck a réunis sous le nom de Tuniciers, extraits de l'ouvrage précitć. Pendant la mêure anıée parurent, à quelquues mois de distance, dleux ouvrages importans sur les Mollusques: le premier, l'article Mocuosque du Dictiunnaire des Sciences naturelles, par.J. de Blainville; le second est un Tableau systématique des Mollusques, par le célèbre entomnlngistc M. Laatreille, qui le communiqua d'abord à l'Académie des Sciences, et le publia casuitc dius le tome 3 des Annules des Sciences naturelles. Ces deux ourrages impurlans furent complétés plus tard par leur anteur.

M. de Blaiaville, de son article Mornusque, aurquel il apporta des changemens notables, fit son Manuel de Malacologie, qui ne parnt qu'en 18:5; et M. Latreille fondit son'Tableau dans les Familles du Regne a nimal, qüil pứlia également en 1825 .

Nons rendrons compte d'ahord du Systeme de Malacolosie proposé par M. de Blaioville, dans l. quel ce savant auteur cherche à fatre accorder les caractères des coymilles arec ceux des M.nllusques qui les hahitent. M. de Blainville donne le nom de Malacosouire aux Mollusqnes, et celui de Malacologie a la science qui en traite; il rasscmble dans celte classe des êtres les mêmes animaux que MI. Cuvier : il nomme type des.Mollusques les virais Mollnsques, c'est-i-dire les Cépbalés et les Acéphal'́s de M. Civier, et sous-type les Cirrhopories du mêrne auteur, quili nomme Malentozoaires on Mollusques arliculés. Les Malacozoaires sont divisés en trois classes on en trois degrés d'organisation : la première, les Céphalophores (Céphalopndes); la seconde, les Paracéphalophores (les Gastéropodes), et la troisième les Acćphalophores (les Acéphales). La première classe, les Céphalophores, est divisće en trois ordres : les premiers, les Criptodibranches, reaferment deux familles caractérisées d'après le nombre des tenlacules ou des pieds; la première, sons le norn d'Octocere, renferme les Poulpes avec les sous - divisions des Elédones de leach et des Ocyllios de Raliaesque; la seconde funille, orr les Décacìres, réunit les deux geures Calmar et Sèche, dont le prenier est divisé en six soussections pour les zenres Sépiole, Cranchie de Leach, les Onjechothentis de Lichlenstein, les Calmars llèches, Plumes e! Spiotenthis de M. de: Blainville. Le zenre Sèche n'il aucunc sous-di:ision; ce premier ordie, très-nalurel, ue renferme aucun corps sur lequal M. de Blainville eut conservé le moindre doule. Il a séparé, dans le second nodie, qui porte le nom de Cellulacées, presque toutes les cuquilles poly lualames que M. de Ferosiac avoil placícs parmi les Décapodes. Ces Ceilulacées sont parlagés en trois fanilles, les Splsérulacées pour les geores Miliole et Mélonie, Saracéncire el 'Tuxtulaires, tous deux nouvenux genres proposis par M. Defrance poar de petiles coquilles lossiles.

C'est eu vain "fue nous avons cherché les rapports des Miliules et des Mćlonies, soil d'apres le mode d'enroulement, suit d'après la structure; la forme sevle a quelque rapprort. Les deux autres gentes en ont aoius peut - être encore que les deux premicrs; car ils be sont point enroulés, mais a loges alternes : ces deux geares, an reste, aulant du mains que lon pent ea jugrer d'après les figures, pourroient bien n'en faire qu'uo senl; el le petit gence que M. Defrance a trouvé à l'état fossile dans les sahllez d'Italie, se trouve vivant dansles mers de l'Inde, et nous pouroos assure. que la dernière cloison est ouverle. La seconde famille, les Planulacées, contieat les denx geores Rénuline de Lamarck, et Pénérople de Monifort, anxquels sont rapportés, dans le premier, le genre Frondiculaire de M. Defrance, et le second sonsgeare Plauulaire. La troisième famille, les Numanulacés, c. ntient des geures plus naturellement groupés : 10 . les Niummulites, parmi lesquelles soat rapportés les Licophores de Montfort, qui soit des Polypiers. $2^{\circ}$. Les Héliciles de Gaelırd: les espèce: dout la surface est marquée d'oudulations profondes, et dont la structate interae est la mêtune que celle des Nummulites. Il g rapporle aussi l'Egéone de Deais Montfort. 30. Les Sidérolites, auxquels sont rapportés les Tinophores de Montfort. $4^{\circ}$. L'Orbiculine, qni rassemble les genres llote, Hélénide et Archidie de Montfort, qui bous paroisseat des coquilles cellulées asse? éloignées des Nunmulites. 50. Le Placeatule, dans lequel se trousent les genres Eponide e! Florilie de Montfort, doot l'onvertare est à la base comene dans les Rolalites, et non symétrique sar la carène comme daus les Nummulites. $6^{\circ}$. Enfin, les Vorlicia. 
les, qui comprennent les genres Cellulie, Théméone, Sporulie et Andromède de MIonifort. liordre troisièue des Céphalopodes porte le noun de Polythalamacés; il est divisé en sept familles, les Orthuećrés, qui compreanent les Bélemnites, les Conulaires, nouvean genre propusé par Niller, les Conilites pour les geures Achóloïle, Animome el Thalamule de Moniforl. Les Orthocères, qui avec: les coqguilles qui apparlieunent véritableaent à ce genre, rúunisseut encore les Nodusaires, les Ríophages et les Molosses, qui oat une organisation diffêrente. Les Baculites se trouvent ici lormer le dernier genre de cetle fanille, quoiqu'elles appartieunen t bien plutồt, ce nous seuble, í celle cies Ammonées. Isi seconde famille, celle des Liluiscées, est parlagée en deux sections; la première, pour les gemres dont les eloisoas soni simples, et la seconde poar ceux dont les cloisons sont sinueuses. Ainsi, dans la prenière se tronvent les genres Ichalyosarcolithe, geure eucorc mal counu et d'une oryanisation particulière; Lituole, Spirule, auquel sont rapportćs les gemres IIortole de Montfort; Spiroline et Lituite. Daas la seconde section se i'ouvent, sur un caractère mal apprécićselon nous, come pour les baculites, les genres Laruite, A nmonocéralite. Il nous semble qu'il seroit natturcl de séparer les Cloisoná́s en deux parties qui ne devioient jamais se confondre, ceux dont les cloisous sont simples, qui formeut une sírie dans laquelle coules les formes, depuis la discoïde jnsqu'à la droite, se rencontrent; et l'autre pour ceux dont les cloiscras sont siuneuses, et qui offient tue série non inoirs complète. La troisième facaille est relle des Cristacés; elle renferme des corps dont les cloisons sont siaples, et qui n'ont p'us que des rapports fort éloignés avec les couguilles yui termineat la famille précédente. l.e genre Crépiduline est nouveau; il contieut, d'une nanière furt naturclle, les geares Astacols, Cancride et l'énérople de Mont furt. Le yenre Oréade, aduplé de Montfort, ainsi que le genre Liuthirie, ciui représente sans doule ici les Cristellaires de Lamarck, et dont se trourent séparés pour être reporlés dans une autre lamille les genres Sphinctúrule, Hérione, Rhinocure et Lampadie, qui ort pourtant avec lui les rapports les pius intimes.

Lil quatrième famille de cet ordre, les Ammonacées, n'est plus caractérisée à la manière de Lamarck, d'après le mode d'articulation du test; ¿ussi, comme dans les liamilles précédentes, elle reaferme des geares à cloisoos sinuenses et à cloisons unies, tels que le premier geare, par exemple, les Discorbites de Lamaret, proposées par lui pour une eqquille microscopique de Grignon, qui, outre qu'elle mançue the siphon, cruclere très-essentiel que .11 . de Blaiaville semb) sor, et re pouvuit conséquemment contenir l'anicual ni en partie ni en totalité. Après se genre vaent celui des Scaphites, qui a'a avec lui aucua rapport, mais qui avoisine les Ammonites qui suivent. Ensuite vient celui des Simplégudes, adoplé de Montforl; genre qui n'a pas les cluisuns simples, puisqu'elles sont sinueuses, et mêrne subarticulées. A ce geare est joint, et véritablement burs de tons les rapports, le genre Anmonic du míme auteur, élabli, comme lout le inonde sait, pour les Nautiles ombiliqués. Le genre Plinulite s'y trouve ́́yalement réuui; et a l'égard des cloisons de celle coquille, que Montfurt dit être simples, nous avons quelques motifs d'en douter, d'autant que ce seroit, ce nous semble, le seul cxemple d'un Niulile à siplion marginal, ct j'avoue u'en avoir point encore $v \%$

Il en est de même du genre Ellips slite, uni est si voisia des Ammoniles. Comment M. de Blaiuville s'ea est-il unique oneut rapporté à Moutfort, lorsque les belles planches de l'nuvrage de M. Brongniart sur les eavirons de Paris fone voir les cloisons des Ellipsolites plus prolundément découpées que clans la plupart des Ammoaites? Le genre Amalthé de Mloniturt est encore ajoutć a vec les pré. cédens parrai les Simplégades, peut-être avec plus de raisou, si la description el la figure de Mlontfort sout suffisament exactes pour qu'on doive y avoir une contiance entière. 'I'uujour's conduit par les cal'actères tirés de la forme du lest, M. de Blainville rassemble, dans la cinquième liamille, les Nautilacées, des genres assez hètérogènes : aiusi, on y trouve le genre Orbulitc de Lamarck, dans lequel sont rapportés les Aganides el les Pélaguses de Maatlort. Le genre Orbulite n'est qu'un déunembrement très-artificiel tles Ammonites, qu'il termiue oǹ commence la série. C'est ì tort qu'est rapporté is ce geure le Nantilus regius, qui doit rester parmi les véritables Nauriles. Le genre Nautile vient après celui de l'Orbulite. Dans ce genre, M. de Blainville réuait justemeut les Angulites et les Océanies de Montfort, ainsi que son Bisiphite, qui ne porte point deux véritables sipl:ons, trisis qui ollie, sur le retour de la spire, une dépressiou médiane qui, dans la séparaicion des clvisons, se cusse toujour's dans les especes pétriliées, et ollie ainsi l'apparence de deux siphoas, quoiqu'il rien existe réellement qu'un seul, cornme ious nous en somules assuré plusicurs fois.

A côté dles Nautiles, et dás la mêerne famille, se truave le genre Polystumelle, adopté par Lamarci, qui rassemble les genres Géopune, Pélore, IIphide, Phonème, Chrysoleet Mélonic de Mlontfort: genies dont aucun n'est siphoné, muis seuloanent perloré. Celle famille se termine par le genre Leuticuline, qui ne peut être adopté, pnisque c'est absoinment le même que les Nimmulites, et dans lequel M. de Blaiuville accumule un graad nombre de geures de Hontfort, dont les uns sout perforés, les autre ne le sont pas. II nous sullicu de les citer pour muntrer qu'ils sont loin d'ètre dans leurs rapports aalusels : Palrocle, Nonione, Macrodite, Rubule, Laupadie, Pharame, Anté- 
nor, Clisiphonte, Rbinocure, Hérione, Splinctérule.

La sixième famille contient deux geares seclement, les Cibicides et Rotalites. Ce dernier renficrme, outre le Rotalite trochidiforme de Lazarck, les genres Storille, Cidarolle et Cortale. la dernjère famille enfin est pour le genre Turrilite, qui est un des derniers degrés des coquilles siphonophores a cloisons sinueuses, qui se rrouve ainsi isolée de ses véritable rapports naturels.

Il est bien évident, d'apiès ce que nous venons d'exposer, que $\mathbf{M}$. de Blainville a pris ses caractères sur des choses trop variables pour arriver à des coupes naturelles; il a dooné trop d"impor. tauce à la forme extérieure, d'ou il résulte un assez grand nombre de rapprochemens forcés; et n'ayant aucunement pris garde à la présence ou à l'absence et à la position du siphon, caractères que nous pensuns devoir étre de première importance, on voit dans une même famille des coguilles qui diffèrent anssi essentiellement que d'avoir ou d'être privées de siplion, de l'avoir marginal, central ou abdoninal. En un root, M1. de Blainville pour celte première partie de sun sy'stème, faisant en quelque sorte abuégation des sages et Inmineux principes quil a posés dans la science, a porté toute son allétion sur les formes extérieures, et ayant négligé les caracic̀res si essentiels de la structure des coguilles des Céplialopodes, il estarrivé à tout confondre dans cette classe si importante des Mollusques.

$\mathrm{La}$ deuxième classe des Malacoroaires est nommée $\mathrm{Paracéphalophore;} \mathrm{elle} \mathrm{représeute} \mathrm{les} \mathrm{Mollus-}$ aues gastéropodes de M. Cuvier, el elle comprend trois sous-classes, les Paracéphalopbores diciques, les Paracéphalophores monoiques, et les Paracépbalophores berı́aphodites. Cette division est certainement une des meilleures, car elle indique d'une manière claire et précise des termes particuliers dans l'organisation. La première sousclasse contieat deux ordres, les Sipbonoloranches, qui équivalent aux Pectjuibranches buccinoïdes de iI. Curier, et renferment toutes les cocyuilles catnaliculées ou éclancríes à la base, et les Asiphonobrauches, qui contienneat toutes les coquilles it ouverture entière.

Le prenier ordre des Siphonobranches se compose de trois familles: la première, les Siphonostowes, comprend dans l'ordre suirauı les genres Pleurotome avec la Clavatule; Rostellaire, qui a cerlainement plus de rapporis avec les Strombes: l'anioal étunt inconau, on ponvoit suivre rigoureusement l'indication des coquilles; Fuseau, Pyrule, Fasciolaire, 'Turbinelle, qui ont tous entre eux les rapports les plus éridens.

Les genres qui ont un bourrelet persisiant au hord druit sont, dans celte fanille, les Colombelles, qui nous paroissent bien plutốt appartenit anx corfiilles écbancrées; Triton, dans lequel sont confondus, il nous semble à tort, les Siru-

$$
\text { Hist. Nat. des Fers. Tome II. }
$$

thiolaires, qui avoisinent les Rostellaires par la manicre dunt le canal de la base se termine; Ranelle et Roclier.

Ia seconde famille de l'ordre esi consacrée aux Entomostomes, qui rassemblent les geures suivans: Cérite, dont uotre genre Tristome, le gente Nériué de M. Defrance, ainsi que les $\mathrm{I}^{\prime} \mathrm{y}$ rènes de Lamarck, font partie, a titre de sous-sections dans le geure. De ces dilléren!es conpures, le genre Potamide seul nous semble rapproclié naturellement. Notre gense 'Tristome, qui offre la particularité remarquable d'avcir une ouverture dorsale sur le dernier tour, qui a cerlainemeut des rapports de forme avec les Cérites, pouvoit cependaut bien en être sépaté d'après ce caractère. Le genre Nérioé est plus rapprocbé des Pyramidelles que des Cérites; le genre Pyrène enlin a une analogie beaucoup plus murquće avec les Mélanopsides qu'avec tout autre genre. Les Mélanopsides, il est viai, viennent aprés, aussi bien que les Planaxes, qiji ne sont peut-êtres que des Mlelanopsides marins. I.e genre Alène est noureau; mais nous arons fait voir à l'article qui le concerve qu'il étoit absolument inutile, et que la connoissance de l'animal ve fisisoit que confirmer le genre Vis de Lanıarck. Après les Vis viennent les genres Éburne, Bucciu, Harpe, Tonne, Cassidaire, Casque, Ricinule, |Cancellaire, Pourpre, Coucholépas.

La troisième famille est consacrée anx Angistome. Sons celle dénomination sont réunies toules les coquilles à ouverture étroite : on y trouve d'abord les Strotulses, auxquels sont réunis les Ptérocères, et par l'analogie qu'il y a entre les jeunes coquilles des Strombes avec les Cónes, on arrive à ce genre. Cette comparaison n'est certainement poiot exacte : les coquilles doivent se comparer pour en établir les rapports sur des indiridus de mêtne âye, puisque tous les zoolugistes savent combiea, dans certains genres, elles offient de différences. Les Cônes vienuent donc après les Strombes, les Tarrières, les Olives, les Ancellaires, les Mitres, les Volutes, les Marginelles, les Périboles, que $\mathrm{MI}$. de Blainville a reconnus depuis avoir été faits pour de très-jeunes Porcelaines; les Porcelaines et les Ovules suivent dans l'ordre que nous venons d'indiquer.

Le second ordre, les Asiphonobranches, reaferme tous les Pectivibranches trochoïdes deM. Cnvier. Ils sont divisés en cinq facilles : la première, Goniostomes, renferme le geure Cadran, auquel sont réuais les gerres Eucaphale de Sowerby et Maclurite de Tesueur, qui sont absolument semblables, et Toupie, où se tronvent rapportés les genres Entonnoir , Fripière, Eperon de Mlontfort, Roulette de Lamarck, Tectaire, Télescope et Canibaride de Montfort. Parmi ces geares, nous pensuns que les Roulettes doivent être conservées en genres; que les 'Télescopes, ayant un très-grand sinus sur la lévre droite, sinus qai caractérise Rrr * 
plugieurs especes de Cúriles, et que les Truchus virfient jamais, duivent bien juluôt faire partie le ce genre. Quant aux Candiarides, elles ont des rapporls avec le Virnau, comme l'a indiqué M. de Ferussac, el ce dait êlle vers le genre LitInriae que re démembrement duit se trouver.

La secande lanilic, qui rassembie les coquilles ì ouverture rooke, porte, à cause de sela, le non le Cricostone. Le prenice gurace est celui des Sabols, qui rémit les Monnduntes, les Lillorines de MI. de lierussac, ct un assez grand nombre d'autres sous-divisions; vienoent ensuile les genres Pleuratomaire, dont les coquilles sont aussi lieu trachilinmes que turbinifurmes, Dauplinule, 'imritelle, Proto, Scalaire, Vernet, Siliquaire, Macrile, uns deux, ponr la premiere fois, rapprochés des Vermets, avec lesquels ils nul sans contredit de l'analogie; Valvée, Cyclostone, Paludine, et on arrive ainsi a la troisième famille des Ellipsostrmes, qui se compose des genres Mßlanie, Rissnaire, Pbasianeile, Ampullaire, Hóliciue et Pleurocère.

Les Hémiclostomes, qui forment la quatrième fanile, se composent des genres Natice, Nérile, Jes genres Nériline Lamk. el Piléole compıis dans ce dernier, el Navicelle. Celle famille, comme on le voit, est absolument semblable à celle des Nérilacées de Lamarck. Aiosi se sont cunfrués lts rapports que Iamarck avoil indiqués depuis long-lemps entre les Néritines et les Navicelles, rapports que nous avions adaptés contre l'upiaion de M. Cuvier el M. de Ferussac, el que ce deruicr a rivement defeudue contre naus. Le grente Jautline, qui forme a lui seul la famille des Oxistames, qui est la cinquic̀ne et dernière de l'ordre, présente effectivenent, scil dans sa coquille, soit dans son animal, des traits parriculiers qu'il est trìs-difficile de mettre ed rapport arec les autres Mollusques.

Ici commence la deaxième sons-classe, qui est deslinée aux Paracéphalopbores monoiques; taus les individus portent les cleux sexes, mais ils ont besain d'un accouplement réciproque.

Deux grandes sections parlagent cette sousclasse : la première, pour les Mollusques dout les organes de la respiration el la coquille, quand elle existe, ne sont poini syné!riques; la secuncte, pour ceux dant les organes de la respiration sont symélriques, et par suite le corps protecteur lorsqu'il existe. Tro:s ordres partageot celle première section : $1^{\circ}$. les $\mathrm{Palliobranches} \mathrm{(Pulmonés} \mathrm{terres-}$ tres et (luviatiles, Cuvier); $2^{\circ}$. les Chismobranches; $3 \circ$. les Monopleurobranches.

Les Pulmobranches concieanent trois familles: la première, les Lymancées, correspond exactemeat aux Lymnéens de Lamaick, et elle renferme les mèmes genres, Lymnée, Pbyse eı Planorbe. La seconde famille, les Auriculacées, est bien sćparće des autres l’nlmonés, comme M. de Ferussac en a donné l'exemple. Nous ne troupons ici rue les grenres Pictin, auquel sont rapportés les geares' Turaatelle et Conavule; Auricule, renferinant les genres Scarabe et Carychie; enfin. les Pyramidelles, qui soot rapprochées des Auricules, aussi, à l'exeaple de M. de Ferussac, seulement d'après quelyues a aalogies tirées des coquilles, car l'animal a'est point counu. Isa troi. sième famille est celle des Limacinés : elle e:t d. visée en deux seclions. La première renfolum: les Mollusques dont le bord antérieur da mantean est reuflé en bourrelet et non en bonclier; ils ont une coquille: les genres Ambrette, bulime, AgaIlius, Clausilie, Maillar, qui comprend les Girnailles de M. Cuvier, les Gibues de Montfort, les Vertigos de Muller , el Parıules de M. de Ferussar; ce dernier genre nous semble plus voisin des Bulimes, 'Tomogère (Anosiome Lanık.) el Hilıce. I al seconde sechion est pour les Mullusques dont le bord antérieur du manteau est clarui en une espèce de Louclier; la coquille est nulle ou presyue mealraneuse. Les genres qui com jonsent celle section sont les suivans: Villine, auquel est réuni le grenre Hélicarion de M. de lerussa c; 'Testacelle, Parmacelle, Limacelle, geare nouveau, mais douteux, de M. de Blainville, conme il se plait it l'avouer lui-nıème; Limace, renfermanal le genre Arion de M. de Ferussac, écabli sur uu caracic̀re de trop peu de valeur, et les deux genrcs Philnmique et Eumè'e de Ratinesque; Oochidie, anquel sont rapportés le geure Véronicelle de $M$. de Bldinville, et jar conséquent le genre Vaginule de M. de lierussac : M. de Hlaiuville, ne pouvant admeltre ce que dil Buchanan que son Onchillie du Typha a les sexes séparés, avoue, au resle, qu'il a pn se tromper sur l'existence de lit coyuille.

L'ordresecond, les Chismobranclies, ne contient quiun fort petil nombre de genres: Coriocelle, genre nouveau élabli par M. de Blainville, et fort voisin du Sigaret qui suit. Celui du Cryptostome vient ensuite; il a ćté également proposé pour un Mallusque, voisin du Sigaret, par MI. de IBlaiuville; le genre $\mathrm{Oxinoé} \mathrm{de} \mathrm{Rafinesque,} \mathrm{gente} \mathrm{don-}$ teux comue le plus grand noubre de cenx quil a propnsés; Stomatelle. qui n’y est rapportć que par analogie, car l'animal en est inconnu; enfin, le geure Vélutine, proposé par M. de Blainville et par Gray sous le même nom, termioc cet ordre.

L'ordie suivant, qui est le trnisième, les Monopleurobranclies, commence par la famille des Subaplysieus, qui se compose des genres Bertelle, genre uouveau proposé par M1. de Blainville pouv le Bulla plumata de Donavau; Pleurobranclic, Pleurobranchidie, également genre nouveau, élaLli par M. de Blainville pour un Mollusque voisin des Pleurobranches, mais qui a'a point de cuquille.

La seconde famille de cet ordre, sous le nora d'Aplysiens, est consacrée aux genres Aphysie, Dolabelle, Bursatelle, nouveau genre des uers de 
l'lnde, qुui u'a aucune trace de caquille; Nistarche, qui n'en a point non plus; et Elysie, genre ubservé d’alord par MI. Risso, et rapporté par lui au genre Nolarche, mais que M. de Blainville en sépare provisoirement sur le doute qu'il conserve a l'égard de la terminaison de l'aus et de l'organe wâle.

La troisième fanille est celle des Patell: i.les; elle coulicnt les genres Orabrelle, Siphunaire, dernierement proposte par Siswerly, et auquel M. de Biainville rapporte le Aumet d'Alausun; 'lj lodine, senre duuleux de Rafinesque.

Lés genre's Bulle, Bélérouthe, Bullée, Lobaire, Sormet, adopté d'Adanson, Gasterrptère el Allas comprosent la quatrième lamille, cellc des Acires, yui ternine la prenière section de la denaiène sous-classe. La deuxième sectinn, qui conticut des

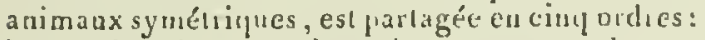
le premier, les Aporobranches, correspond assez liven aux P'f(ropodes de A]. Cuvier; il contiens les geores Hyale, Cléodore . Cynbulicer Pyrgo, nonveau genre proposé par \$l. Defrauce, qui le met parai les Polythalanes, et que M. de Blaiuville rapporte ici a me place molus convenaisle. Les genres que nous venons de citer forment la jutmiere fumilie de l'ordre, los Thécosomes.

La seconde famille, les Gyunosounes, est compisée des genres Clio, qui cuntient le gature Cliudite de Quoy. et Gaymard, et P'neumoderme. La troisière famille, les Psilosomes, est cuuposcie d'un seul genre, du genre P'lyylliroé, què Lamarck place dans les Jlétéropudes a vec les Carinaires et les biroles. Les Pulybranches comprisenat le second urdre; ils son divisés en doux lanilles daprès le

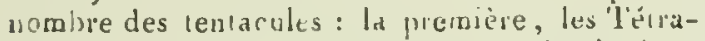
cères, renferme les genes Glaucus, laniogère, geure uouvean proposé par M. de Blainville jour un Moll:ssque de la collertion britaunique ; Tergipe. Caroline, Eolide. Ta seconde familie, les Diccires, cuntiem les penres Scyllée, Tritonic et 'Thály's. L'ordie troisiène, celui des Cyclubrancles, est lorrá des genres Doris; Oachidiore, ¿eure nouveau observé a Loodres par M. de l3luin-

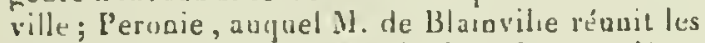
Onchydics marines de 11 . Cuvier. Le quatrième ordre, querique :enlermani les deux genies $\mathrm{P}_{\mathrm{L}} \mathrm{y}_{\mathrm{H}} \mathrm{l}$ lidie et Linguelle, est licis-diflírent de la famille des Phyllidiens de Lamarct. Le genre Linguclle est lort curieux; il est vojsin des Plyjllidies, et M!. de Blainville, qui l'a établi pour la premiere fuis, jrésume que ce pourroit bien être le mène que le grente Diphyliide da M. Curier.

L'ordie cincuième, les Nincléobranches, qumique piéscutani des animaux symérígues, semlile assez éluigoé. quaul à l'organisation, des Nollusqgues précédens, car ceud-ci sont essentielleaent nageurs; les aures, au contraire, pour le flus grand onmbie au moins, rumpent sur un pied jlus on moins graod. La première fumille de cet ordre porte le pom de Nectopode, et reprósente les
IIérćropodes de laanarck, moins le genre Ply lliroć que nous arons va ailleurs. 11 reste dans relle-ci les genres firole el Carinaire; les genres Firoloitle el Sagitlelle de Lesueur sont rapporlés à ce premier. Le nom de Pléropodrs, donné ici a la seconde famille, ne s'applicye plus do tont aux animaux gue X. Cuvier ef Latmark avoicat dísignis sous ce nom : puisuju'elle renterme lis genies Allunte, diruarert par Tiesueur, Spiratelle, genre limacine de Lamarc li, óté de ses cinuexiuns indiquies par ce zuologiste, avec les Clio, l's Clédores, ponr être reporté iciavec le gerre que nous venons de citer, et les Argonautes ifue, d'après l'analogie de la coqualle, $\mathrm{M}$. de Blaiuville rejulle des Cúphalopodes.

La lroisième sous-classe des Mlullusques parace:phalophores contient cetux qui sout her asiphiredilcs; et pour lier celle sons-clasie a la précidente, elle commence par coux des animax qui s'y rapportent, qui snnt symél:iques, et dunt la lorane clu corpis alongé a quelques rapports avec ceux qui cerancul le dernicr ordre: celle suus-classe se divise aussi, comone la précédente, cu Mollusques symétriques et en Moliusyues uon symétriques. Liordre premier de la première section, les Cirrhobranches, contient celui de tous les Mollusques qui es! !e plus syenćtrique, el dont nous avous fail conuoitre en détail l'anatomie singuliere; nous voulons parler dn gcure Dentale, dunt l'intestin médian et droit se terunioe à la partie postćrienre et médiane de l'animal. Nous reuvoyons an mot DeNTaLe pour plus de dálails. L’organisation de ce genre est si particulièı on peutle dise eu passint, que c'est Lien justement que $\mathrm{MI}$. de Blauville en a fait un ortre particulier, et son examen ultériear nous a conlirmé dans la place qu'il lui a assignée.

Le second ordre reuferme les Cervicobrabclics, et la premicre famille, suns le nom de Rétifères, contient le genre Patelle lui seal. M. de Blainville, dont nous n'aduettons pas l'opinion, crut qque lit série de lames qui s'ut daus les Patelles entre le pied el le mantean ve sont priat des organes branchiarax, qu'il tronve, à ce qu'il prélend, dans les parois de la cavilé cervicale en forme de petites lignes très-liues qui s'entre-croisent, et qui ne paroissent étre que des filres nusculaires. Laa seconde famille, suus le nom de Branchiferes, rassemble nalurellement les yenres lissurelle, Emarginale et Parmopliore. La ilcuxième section de certe sous-classe u'a qu'un scul ordre, les Scutibranches, qui est pariagé en plusicurs fanilles: $1^{\circ}$. celle des Otidís, coinposée des genres Haliolide el Ancyle rapprochrís, peut - élre pas trèsnaturellement, corno $\mathrm{Mi}$. do Blainville le lit laimème, mais il l'a fait daprès la considération des Branchies, qui sunt placées du mêrne côté, c'esta-dire à gauche; $2^{\circ}$. Its Calyptracées, famille adoptée de Lamarck, et lomée des genres Crépidule, Calyptrie, dont nous aroos doané nne 
anatomic; Cabochon, Hipponire et Notrème, ce dernier fort douleux, proposé par Rafinesque; mais les précédeus, suriout les Calıoclions et les Hipponices, forment le passage le plus naturel enire les Univalves el les Bivalves, rapports qui avoient été déjà sentis par H. de Roissy dans le Buffon de Sonnini.

Les Acéphalophores, ou la troisième classe des Mollusques, renferment les nêmes animaux que dans la métbode de M. Cuvier, à l'exception des Cirrhopodes, c'est-à-dire qu'ils réunissent les Conchifères et les Tuniciers de Lamarck. Cette classe est divisée en quatre ordres de mêtme valeur; le premier, sous la dénomination de Palliobranclies (Brachiopodes des anteurs), rasseuble en deux secrions, pour les coquilles symétriques et non symétriques, les geures lingule, 'l'érćbratule, Thécidée, Strophomène, Pachyle, nonveau gense de M. Defrance, dérnembré cles Plagiostomes pour ceux qui paroisseat symétriques; Diancliorc, nouvean geare de Sowerby, bien voisin du précédent; et Podopside pour la prenièere section; Orbicule ct Cranie pour la seconde. Nous ferons nbserver que les genres Pachyse, Dianchore et Podopside sont des doubles emplois inutiles des Spondyles, et que le genre Plagiostome doit rentrer dans celui des Limes.

Liordre saivant correspond i la famille des Ru. distes de Lamarck, et il en porte le nom ; les Sphérulites, les Hippurites qui en sant rapprochées, ainsı que les Radiolites, qui ne sont qu'un seul et même genre, comnse nous l'avons démontré dàns une nole où nous établissons le même rapprochement que M. de Blainville avant que son traitć eût paru; Birostrite, qui est le moule intérieur de la Spbérulite, et Calcéole, qui est une coquille libre et beaucoup plus régulière que les précédentes dont la plupart vivoient fixécs. Ce dernier genre sera probablement rapproché des Cranies.

Le troisième ordre, le plus considérable, qui contient la presque tolalité des Acéphales conchifères, est distribué en familles d'après la forme du manteau surtout, en y combinant aussi la présence on l'absence du pied, etc. La première lamille, les Ostracés, correspond assez bien à celle à laquelle Lamarck a donné le même nom. Elle renferme les Anomies, Jes Placnnes; le genre Harpace adopté de Parkinson, wais donblement à tort, car il a élé établi pour une espèce de Plicatule, et doit en conséquence appartenir à la famille suivante : celle-ci se termine par les deux genres Huitre et Gryphée. La seconde famille, les Subostracés, se rapporte fort bien à celle que Lamarck a nommée $P$ ectinide. Les caractères tirés de la disposition des branchies qui ne cachent pas entièrement l'abdomen, el ceux tirés d'un pied rudimentaire et lyyssifère, réunissent trèsbien et invariablement les geares Spondyle, Plicatule, Hinnice, genre nonveau proposé par M. Defrance pour des coquilles adhérentes et in- termédiaires entre les Spodyles, les Plicatules et les Peignes; Peigue, Houlelle et Lime. La famille des Margaritacées, qui est la troisième, est la même que les Malléacés de Lamarck : elle admet ici quelques geures de plus proposés nouvellement, et en nutre le genre Vulselle, justement rapproclié. Outre les genres Vulsulle, Marteau, Perne, Crénatule el Avicule, comprenant le genre Pintindine, on trouve les genres Inocérame, Catille, Pulvinite de M. Defrance, et Gervilie du mêrac auteur. Ira quatrième lanille, les Mytilacées, est anssi semblable à la même de Lamarck; elle conticnt les Moules, auxqnelles sont réunies les Mnclibles et les Piunes. Dans ces quatre lamilies, M. de 13]ainville a suivi presque rigourcusement l'arranremenı de Lamarck; mais pour le cinquième il s'en écarte notablement, puisqu'clle est formée par les Arcacées, qui contienneal le mêare nourbre de genres, à l'excepilion du genre Cucullée, qui est placé comme seclion purmi les Arches. La sixième famille, les Submytilacées, compreud, sous le seul caractère du manteau fendu el d'une onverture pour l'anus, des genres qui, par leur aspect, sembloient s'ćloigner beauconp : Lamarck a voil cru devoir les séyarer, malgré l'exemple de Poli. M. de Blainville revient à l'idée da zoolagiste italien, mais il a soin de diviser cette famille en deux parties : la première, gui comprend les Nayades, et la secoude nue partie des Cardiacés. Les Nayades sont réduiles à deux genres, les Aundontes et les Mulelles; parmi les premièrts figure le genre lidine, dont nous avons vu l'anirnal que nous a communiqué le savant voyagreur Caillaud, et qui, par l'organisation de son manteau, est fort dillérent des Anodontes puisqu'il a deux siphnns. Dans le genre Muletle, les Hyries et les Castalies de Lamarck y sont rapportées. La seconde section de la famille est formée du genre Cardile lui seul; il est vrai qu'a ce genre sont rattachées les Vénéricardes et les Cypricardes de Lamarck.

Quoique les Acéplıales dont les lobes du manteau ae sont point réunis se terminent ici, celle particularité si remarquable, qui semblervit sullisante ponr élablir pour eux une division, n'est nullement indiquée, el elle ne l'est pas non plus pour ceux qui suivent, qui commencent à avoir réunis en plusieurs endroits les bords du manteau. La famille des Cawacées, qui est la septième de l'urdre, se compose de coquilles régulières el irrégulières : les irégulières comprennent les genres Cames, Dicérate et Ethérie; les régulières contiennent le geare Tridacne et Hippope qui y est rapporté; mais nous pensons que c'est à tort que ce genre se trouve dans celte famille, car, outre quil est réellement monomyaire, la charnière présente anssi des différences considérables, et la régularité des valves doil l'éloigner aussi des Camacés. Il en est de même, ce nous semble, des genres Isocurde et Trigonie. La huitième fa- 
mille, retle des Conclaacés, correspond à plusieurs de celles de lamarck : elle est sous - divisće en rrois secions; la prenière renferme les coquilles régulières à dents latérales écartćes, et la forrme du pied n'est pas prise en cousidération pour la séparation des groupes, comme l'avoit fait Lamarck. Le genre Bucarde, qui commence, se truuve à côté des Donaces, des Tellines, qui renlerment le geare Tellinide de Latmarck; Lucine, auquel est justerneut ré:nni le 1.0ripes de Poli, mais à tort, selon nuus, l'Awphidesune, et plus à tort le geare Carbeille; Cyclade, qui présente comme sous-sectiou les genres Curnea de Mlégerle, Cyrène de Lamarck, et Galathće du mème. Dans cetle unème section se trouvent enrore les genres Mactre, Cyprine et Liycine: ainsi, le caractère du ligameat interne, ou externe qui avoit servi à Lamarck puur étublir des rapprochemens assez naturels, n'est pas employé ici; et la seconcle section, qui est destinée aux cưvilles r'śgulières suns dents latéralesécartées, comnence par le genre Crassatelle, qui est suivi du grand genre Véuns, dans lequel on trouve seize gruapes, dont les genres Cylhérée Lamarck, Astarté Sowerby, Micorna el Nicania de Léach foat partie.

La troisième section renferme les coquilles irrégulières, et on y tronve rassemblés, certainemeat d'une manière peu naturelle, les genaes Vénérupe comprenaut les Saxicaves, Coralliuphage, genre nouveau formé aux dépens des Cypricardes de Lamarck pour celles qui sont perforantes; Clutbo, établi par Fanjas, tous trois naturelleınent groupés, mais don ton a rapproclée à tort les Corbules, les Spliènes et les Ongrulines.

Dans la neuvième fámille, les Pyloridées, M. de Bluinville s'est servi du ligameut interne et externe prour y établir deux groupes : dans le premier, où sont rassemblées les coquilles à ligauent incérieur, on troure les genres Pandore, Anatine, 'Thracie, deux geares sur lesquels nous avous des observations curieuses relatives à la charnière; Mye et Lutricule, nouvelle dénomination pour rassembler les gearas Ligule de Leach et Lutraire de Lamarck.

Dans la seconde section, pour les coquilles dont le ligament est extérieur, on trouve le genre Psammocole, déaomination nouvelle au moyen de laquelle les geores Psammobie et Psammotée sont réunis; le genre nouveau Solételline, démembré des S.lens pour les espèces ovales voisiacs des Tellines et des Psammobies; sanguinolaires Solécurte, également geare nouveau démembré des Solens pour les espèces ovales dont le Solen strigillatus lait partie; entin, les genres Solen, Solémye, Panopée, Glycimère, Saxicare, Byssomie Cuvies, Rhomboide, geure nouveau établi sur 'Hypogaca barbata de Poli, Hyarelle, Gastrochène (Fistulane Limarck), Clavagelle et Arrosoir. Ces deux derniers genres, qui ont, quant à la coguille, une organisation si particulière, s'ć- lojgnent par leurs rapports des genres précédens, et peul-êtıe que le genre Fistulane devroit ètre compris arec les deux autres.

La deruière famille des Acéphalophores testacés, sous le nom d'Adesaracés, rémin d'une manière fort naturelle des geares dont lamarck, avec les trois derniers de la précédente famille, avoit luit denx lamilles assez hélćrogènes. Ces genres soat: l'liolade, 'Térédine, Taret, Fistulase, pour quelques espéces du inême genve do Launarck, el Clnisonuare. Nous ferons observer que le genre Fistulane tel qque MI. de Blaiuville le conçuil ne devra pas être conservé : on en verra les inatifs it notre anticle Fistulane de cet ouvrage, auquel uous reovoyons.

C'est ainsi que se termue ce grand ordre les I.amellibranclies, dans l'arrangement duquel il y a des améliorations nombreuses, des rapprochemens fondés sur une grande connoissance des Mollusques, mais aussi des erreurs asse\% graves.

Le quallième ardre contient les Mollusques acéplaalés aus, sous le nom d'Hétérobranclies; ils sont divisés en deux familles, les Ascidiens et les Salpiens. L'une el l'aulre de ces lamilles est partagée ensuite en denx tribus : clans la lamille des Ascidiens, la prenière rribu est ponr ceux qui sont simples; on y trouve les geures Ascidie, Bipapillaire, Fodie, genre établi par Bosc : daus la seconde tribu, qui ne contient que des Ascidiens agrégés, on y rencontre les genres Pyute, Distome, Butrylle, auquel sont rapportés les genres Diazoma, Polycline de Savigny, Palycycle de Lamarck, el Sinoïque, qui rénuit les genres Aplidium, Eucclium el Didermum de Savigny. Les Salpieus ue contiennent que deux genres, tt chaque genre lorme une tribu: la première pour les Salpiens simples, qui renferme le genre Biphore, divisé en huit groupes, parmi lesquacls se voient les genres Monoplore el 'Timorieme de MN. Quoy et Gaymard. Les Salpiens agrégrís contieunent le gente Pyrosome lui seul.

Le sous-iype des Mollusques, que M. de Blainville nounme Malentozoaire ou Molluscarticulés, se compose de deux classes fort différeates d'êtres: les animaux que renferme la prenière sont intermédiaires eutre les derniers Acéplales et les Eutumozoaires, tandis que ceux de la seconde, dans l:quelle M. de Blainville rapporte les Oscabrions, lie les Mollusques céphalés aux Entounozuaires. Voici à cet égard ce que dit ce zoologiste, page $59^{2}$ de son Manuel : « Le passare des Malacu" zoaires anx Enlomozoaires se fait dans deux * lignes, des Malacozoaires acéplalés aux Entu" mozoaires hétéropodes par les Nétnatopodes, ct » des Malacozoaires céphalés aux Eutonuzoaires » chétopodes jar les Polyplaxiphores : en sorte " que les deux classes que nous rénnissons dans " notre sous-type des Malactozoaires sont néces- sairement fort différentes.

La classe première porte le nom de Néunato- 
podes et correspond aux (irulipodes des autears, et celle-ci est divisée en deux larmilles qui coïucident arec les geares Anatife et Balane de Bruguière. Dass la première se voient les genres Gymnolèpe de Leach, auquel est joint le genre Cineras du même auteur; Pentalèpe qui réunit les genres Pentalasme et Polycipède de Leach ; Pulypède, qui est presque le uêne que le Scalpellum de Leach, et enfin Litholèpe, genre nouvellement propnsé par Sowerby. La fauille des Balanides contient les geures Balane, Oihthosie, nonveau genre de Ranzani, Conje, Crensie, Chihanale, ćtabli par Ranzani, el Coronule. Ce dernier gence est sous-divisé en Cluénolobie de Luach, Céropire de Ranzani, Diadème Ranzani, el Tubicinelle de Lamarck.

La seconde classe, sons le nom de Polyplaxiphores, ne contient que le seul geurc Oscalrion, ancjuel est ríani le genre Oscabielle de Laurarck.

De Inus les sysiènes étai lis jusqu"a ec juur, c’est sans cootredil celui de M. de Blainville qui repose sur le plus graod nombre d'observalions analouiques, les seules sur lesquelles on doive a l'avenir liire de nouvaux essais. II a reudu de rrès-yrands services à celle parlic des stiences nalurelles, en faisant eonnoître un grand nombre d'animaux sur lesquels il restoit du duute, et, quuitguil en existe encore un certain numbre sur lesfucls nous n'arous que l'ignorance la plus complère, ou quelques donuées incertaines, nous devons consictérer le Manuel de Malacologie con me une nine précieuse dans laquelle les zoolagis!es puiseront d'utiles matériaux, el troureront une mélhode yui, à l'exception de quelques rapports de détails et de 'juelques autres 6 videmment lurcics, suivant notre uanicre de voir, comme nous l'avons fait reunarquer, restera à la science coume une base solide a laquelie on pourra rattacluer désormais les fails nonveaux, el fera honnenr aussi lien à sun auteur cu'au siecle qui l'a produie. Ce qui se remarque aussi avec plaisir, est la bonne foi que M. de Blainville a mise dans la rérlastion de sun Genera; re qui doil inspirer plus de confiauce aux zoologistes. On reccnnoit aussi, dans la marclie ıju'il a suivie, la route bien Iracće par les Adanson, les Lamarck et les Cuvier, el guil a partout cherché à appliquer les principes pos's par ces grands mâtres; principes que $\mathrm{Ml}$. de Blainville a reudus plus certains et plus rigonrenx.

Nous nous p:oposions de rendre cumple de la muéthode de $\$ 1$. lutreille de la mêıne manière que nous l'avons liait prur celle de M. de Blaiuville; mais cela nous eutraineroit lrop loin, et nous craignons déjà d'avoir trop élendu celle partie de notre article. Nous uous contenterons de donner le tableau analyique de la methode de ce suraut, gui, du reste, rentre assez dans eelle de Isamarck sous leauconp de rapports : on pouria lacilement coinpater ce tableau avec ceux qui sont à la fin de cel aricle.
Deux ouvrages importans furent publićs à peu de distance sur le même sujet; l'ur parut à Leyde en $1825 ; M$. de Haan ev est l'auteur; il a pour vitre Monographice ammoniteorum et goniatiteorum sfecimen : l'aul re a paru en 1826 dans les Anoales des sriences walurelles; r'est un grand iravail de M. d'Orbigny fils sur les Cóphalopodes et suriout ceux qui ont une coquille nicroscopique. Ces deux ouvrages, les plus inırorlans gur aient jaru dans res deroiers lemps sur les Ciplialopodes, méritoient uo exatnen rout particulier, ct c'est à l'arncle Ciparopodes, au fuel nous reuvuyons, qu'étoit naturellement sa place.

l'our terminer l'examen cilique des travaux importans publies sur les Mollusigues, il nous reste deux ouvrages donı nous donneronsl'anılyse la plus coneise qu'il nous sera pussible. Le prenitr de ces ouvrayrs, le $\boldsymbol{N}$ anuel de Conchyliologie de N. Rang, publié co 1829 , nous artêtera unoios que le second, la seconde édition du Règne animal de N. Cuvier, dans lajuclle il a préstrné des changemens importans dans la méthode de classification des Mollusques: changemens que nous devons examiner avec toute l'allention fil la défiance de nous-même que doivent inspirer les travaux d'un zoologiste aussi expérionenté.

M. Rang, dans sun Manuel de Conchyliologie, admet cing grandes divisions ou classes dans le yrand iype des Mollusques, dans lequel sont compris les Acéphales nus el les Cirrbinèdes. Ces classes sont disposies dans l’ordre suivant : Céphalopodes, l'lércpudes, Gastérupodes, Acépliales el Cirrhipèdes. Cel ordre est à peu près celui yui fut suivi par M. Cuvier dans la première édition du Règne animal. Deux choses sont cependant it remarquer: la preniere, c'est que les l'téropodes sont mainterus immédialement après les Cćpbalopodes, et se trouvent ainsi entre celle grande classe el celle des Gastérupodes; la secunde consis'e à avoir supprimé l'nne des grandes divisions de M. Cuvier, celle des Brachiopodes, et de l'avoir réunie aux Acéjubales testacés à titre d'urdre seulemenl. Cé dernier cbangement ramène les Brachiopondes aux rapports qui Jeur out élédonnés, soil par Lauarck, suit par Ill. de Blainville. Relativenent aux Fićropotes, nous ne pensuns pas qu'ils puissemt, par lemr organisaliun, s'approcher duvantage des Ciéplialopodes que les Gastćropodes cux-uímes, duml l'organisation, dans son ensemble, est intiniurent plus complèle. Il n’est pas à présumer que les l'téropodes aient été ainsi placŕs, parce quils sont, de ious les Mollusques, ceux yui ongent le mieux. Ce molil ne peut entrer que d'une nanicre bien secondaire dans les arrangemens gínéraux des animaux, el particulicremunt de ceux qui, comme les Mollusques, sont soumis à des circoustances de vie si diverses.

Il existe, il faml en conveur, une assez grande lucune eatre les Céphalopodes el rous les autres Moliuszgues; ils cousiblueot, dans ce grand em- 
brancliernent desanimaux sans veric̀)es, un ordre palfatement distinel et nel'ement circonscrit prar lous ses caractères. Puisqu'ıls sont, de fuus les Mollusques, les mieux organisés, il nous semble que, pour suive an décroisstront gratuel, on dnit mellre inmédialement apres cux ceux dics Miollusques qui ont l'orgunisulion la plus complele. Celle narche, que M. de Blainville a suivie dans son 7'railé de Jlalacologie, dun c̀lre prétérée à celle de M. Rang.

Nous no dirons rien ici de l'arrangement des Céplablopndes, M. Rangr ayant adoplí, sans y appoiter le moindie chaugement, l'arlungement proposé par M. d'Orhigny dans son Iravail grénéral sur celle classe. Nous en avous donné l'anilyse il l'arlicle Cépancopodes, anguel nous renvuyons. La classe des Ptéropndes est pallayec en deax faunilles, les Hyales et les Cloos; on Irouve dans l'arrangement des gences de lit premicre, des cbangeruens importans qui sout dis aux observations de M. Rang, auquel on doit des travaua remarquatles sur la classe des Plérnpodes. Lin trailant de la fanille des Hyales (voyez ce mol), nous avons donné à ret ŕgard dies délals gqui nuus dispensent de les reproduire ici.

Les Gastínodes cuuliennent la plus grande partie des Mollusques céphalés; leur division en ordres et en fumilles est fort dilficile, parce que lon a un grand nombre de modificaliuns oryaniques à concilier ei à meltre en lıarmnnie, et yue, jusqu'à présent, nu n'a pas eu un guide fidèle pour se conduire au nilieu de's nombreuses tentilives et des olsservations mulippliées qui ont été failes jusqu’à présent sur celle classe si considérable des êlres. Dans l'arrangement de cetle clasic de Mollusques, l"arbitraire qui s'est introduil dans la tormation des ordres et des familles cst plus remarquable que dans l'ordre général de distriluution des classes; on a pu voir par ce qui précède qu'il n'existe à cet égard presqu'aucuue harmonie dans les divers sysièmes dont nous avons rendu comple. Dans celuide $M$. Rang, la distribu. lion des ordres des Gastéropodes diflère encorc, sur plusieurs points importans, de tout ce qui a élé fait jusqu’à présent. Les ordres, au nombre de dix, sont distribués aiusi qu'il suit : Nucléobrancbes, Nudibranches, Inférobranclies, Pectibrancbes, Pulmonés inoperculés, Pulmonés operculés, Pectinibranches, Scutibraucbes, Cirrhobrancbes et Cyclobranches.

I.es Ptéroprodes se Irourant à la suite des Céplalopodes, il falloit bien, ponr snivre des rapports très-naturels, meltre immédiatement après eux ceux des Gastéropodes qui ont avec eux des rapports si intimes, que pendant long-temps ils furent confondus. L'ordre des Nucléobranches se troure ainsi dans la métbode de $\mathrm{M}$. Rang entrainé a la tête des Gastéropodes, quoiqu'il contienne des animaux inférienrs. Les Nodibrancbes, qui viennent après, sont liés anx Nucléobrancbes, e: par conséfucut doivent sc trouver après enx. Une luis que lun a admis la place des Xuclioharches, is conduiseat d'unc maniere naluclle anx hulerobranches et anx l'oclinibranches, et cet arrangement pouroit i!re asdoptr. On pourmit encore lassser a lour suite ís l'ulmonés operculís cl innpreculés; mais les l'eulinibranclies, qui renferment des animanx a sexe séparé, ne devruient pas se tronver a lemr suite dans l'nmlro décroissant adoplé par M. Rang. Ieı nous ripílerons notrc observation, quel,s l'celinibranclies

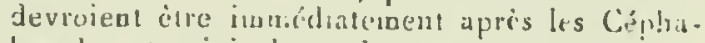
lupodes et suivis des ordies que nous vennus de menticnner et de cenx dunt nons avons encore a parler. Les Sirn'ibranclices pournicnt se licr aves: les 'Tectiblanches: ccrie liaison les mellmit dans des rilppris plus convenables quavec le 3 demicres liamilles des l'ectimibranclues, et l'on n'auroil pas le désagrément, dans une classificalion simple ou liuéaire, de voir, entre des animaux d'un degré ćlevé daus l'organisalion, d'anres gui le sont beaucnun moins. En comparant le; S: unibranches, les Cirrlphranches el les Cyclobraucles aver: les l'actinibrauches, on reconnoit que sous plusieurs rapports ces diver's ordres se tombent et se lient. Mais daos noe méthode naturelle, ce n'est pas seuleınent quelques points de l'oromanisalion qui drivent décider de la valeur des ralpports, wais l'nrganisation tout entière, appréciće dans lous les systemes organiques.

Avant d'exaniner les divers ordies des Acéphalés, mous jellcrons un coup d'ail rapide sur les nombrenses famil!es qui divisent les Gasıćropodes. C'est pridici!riament dans ces groupes tgue M. Rang a approrté des ancíliorations qui sunt dues en grande partie aux travaux fairs avant lui, mais mienx appréciçs, et aussi à sa sagacile et à ses unmbreuses observalions. Nous devons ajouter, et M. Ranğ le reconnoit lui-nême, qu'il a fail des einprunts iuportans au Trailé de Maluco. logie le M. de Blainville, dans lequel sont rassemblćs ex plus grand nombre que dans aucun autre onvraye des observations sur les animanx Mollusques. Déjà M. de Blainville, dans l'ouvrage que nous venons de ciler, avoit séparé les Nucléu. branches des H'téronodes, cı les avoil rapprocluis da type d'organisation auquel ils appartiennent. M. Rang, sous ce rapport, a imite M. de Blainville, et comme Ini il a admis dans cet ordre deux familles auxquelles il donue le nom de Firolides et d'Allantides. La composition de ces litwilles diffère de celle de M. de Blitinville en ce que les Argonaules sont maintenus parmi les ( $:$ phalopodes et les Limacines ou Spiratelles au nombre des Ptéropodes. Nous avons dit, à l'occasion des Firolides et des Allantides, ee que nons pensions des rapports indiqués par M. Ravg, et nous y reviendrons d'une manière plus générale is l'article Nocríobraveres, auquel nous renvoyons. 
Les Nudibranches renferment cinq familles: les Ptérosomes, les Glauques, les 'Tritonies, les Doris et les Placobranches: deux familles sont nouvelles, la première et la dernière; celle des Ytérosomes ne contient qu'un seul genre élabli par M. Lesson, dans la partie zoologique du Voyage de la corvette la Coquille. Ce genre curieux, encore incamplétement connu, a bien certainement quelques rapports arec les Glauques; mais il est difficile de l'admettre dans l'ordre des Nudibranclies, puisque M. Lesson lui-mêtne avoue que l'appareil de la respiration n'est point connu, et qu'il a'a pu trouver la terminaison postérieure du système digestif, deux condilions trèsessentielles, ce nous semble, pour décider de la place de ce genre curienx. Eafin, un iroisième motif qui doit retenir le zoologiste, est fondé sur l'ignorance où l'on est de la dispusition des organes de la génération.

La faunille des Placobranches étoil plutôt admissible que celle que nous venons de citer; elle ne renferme non plas qu'un seul genre proposé par M. Van-IIasselt, sous le nom de Placobranche, mais caractérisé d'une manière sufisamment détaillée pour donner la preuve que le ganre s'éloigue de tous ceux qui sont connus, et qu'il doit constituer noe famille dont il est difficile de fixer, quart à préseut, les rapports naturels. les Tectibranches formeut un ordre très-naturel divisé en deux familles, les Aplysiens et les Acères. 11 n'est pas besoin de revenir sur une question que nous avons déjì discutće allx articles Apt.Ysıers et Acrirns. (Voyez ces mats.) Quant aux Inférobranches, dans lesquels M. Rang admet aussi deux familles prises de Lumarck, mais en partie modifiées, nous pensons qu'elles ne pourrunt être admises dans leur comprosition. C'est ainsi que la Diphyllidie, par exemple, rapprochée des Phyllidies à cause de la disposition des branchies, en diffère sous tant d'autres ranports, qu'elle derra probablement constituer une finille à part. Quant à la famille des Semipliyllidiens, dans laquelle on voit les geares Ancyles, Pleurobranchée, Pleurobrauche, Ombrelle, Spiricelle et Siphonaire, elle ne sera sans doute pas conservée, du moins éloignée comme elle l'est par quatre grands ordres des Sculibranclies, avec les genres desquels elle se lie d'une manière naturelle.

Nous n'admettons pas, avec MI. Cuvier et ses imitateurs, la dénomiaation de Pulmonés pour ceux des Mollusqnes qui ont des branchies aeriences. Nuus croyons, avec Lamarck, qu'il est important de conserver, dans les dénominations caractéristiques, des termes qui représentent le véritable érat de l'or'ganisation; il est évident, pos" quiconque a voulu rélléchir sur la condition d'organisation qui eotraîne avec elle un poumon rérituble, que les Mollusques, quels qu'ils soient, ae peureat avoir de poumons. Dans de pareilles questions, il faut toujours avoir recours aux d⿳⺈hinitions. Quand on aura rigoureusement défini un pournon, il sullira de chercher à l'appliguer à la partie nommée poumon dans quelques Mollusques, et l'on ponria s'assurer, par ce moyen si sicuple, qu'il n'y a point de Mollusques pulmonés; et celte démonination devra en consé(quence disparuitre de la nomenclature de la malacolorie. Les Pulmonés, dans l'ouvrage de AI. Rang, sout divisés de la mème manière que dans celui de MI. de Ferussac, en Pulmonés sans opercules, et en Pulmonés operculés. Celte distinction est bonne en elle-mêue, en ce qu'elle sépare, d'une mauière furt nette, des animaux quie généralemeut on avoit trop rapproclıés dans la plupart des méthodes. Les Puluonés inoperculés sont divisés en quatre familles : les Limaces, les Limaçons, les Auricules et les Lymáens. La composition de ces lamilles est prise, pour la plupart, dans les méthodes antérieures à celle que nous examiuons; elle a subi cependant quelques moditications de dérail dont jl a été question aux divers articles qui les concernent. Quant aux Pulmonés operculés, ils semblent faire le passage aux Pectinibranclues; et, en les conservant, c'est en effet les seuls rapporls qu'ils puissent avoir. Leur distribution est prise de la méthode de $M$. de Ferussac, el l'on y trouve par conséquent les deux familles Hélicines et Turbicines; ce qui rapproche les Cyclustomes des Paludines, au lieu de les confondre, comme l'avoit fait II. Cuvier parmi les Pectinibranches : ce qui étoit une contradiction aussi bien avec la définition de cet ordre des Pulmonés, puisque les Cyclosıomes sont pulmonés, qu'avec celle des Pulmonés eux-mèmes, puisqu'on n'admelloit pas parmi eux un Pulmoné véritable. Les Pectinibranches renfermeut un très-grand nombre de Mollusques; les uns ont une coquille dont l'ourerture est entière; les autres ont l'ouverture soit caniculée, soit échancrée à la base : ce sont ordinairement les deux principales divisions que l'on trouve dans les méthodes, el souvent on y en ajoute une troisième, démembríe de la seconde, pour les coquilles qui sont simplement échancrées. Ces divisions ont élé admises par M. Rang; mais il en a ajouté une t:oisiẻme pour la famille des Sigarets, qui se voit immédiatement après les Volutes, et suivie des Huliotides. Nous croyons qu'à l'égard dẹ ces nouveaux rapports, M. Rang a a pas assez apprécié la liaison des Sigarets avec les derniess genres de la fauille des 'Turbinés, el nous sommes persuadé que celte famille des Sigarets n’auroit pasété ainsi déplacée sansle desir qu’avoit M. Rang de lier les Scutilranches avec les Pectinibranches; mais, comme nous l'observions lout à l'beure, celte liaison pcut se trouver au moyen d'un autre arrangement, qui s appuie d'ailleurs sur les observalions auatomiques actuellement connues. Les trois groupes proposés par M. Rang dans les Peclinibranches 
tiniliranches ne soot pas fondés sur les caractères de la corquille, mais sur ceux de la lorme du manteau qu la produit, ce qui revient à peu près au méme. Dans la première section on de trouve que deux launilles, les 'Turbinés et les Trochoïdes, qui rassemblent tous les Pectinibranches à coquille dont l'ouvertare est entière. On compte six familles dans la seconde division; ce sint les suivantes: $\mathbf{1}^{\circ}$. Cérites, pour le genre Cérite lui seul, ce qui n'est peut-être pas admissible quand on pense à ses rapports avec le genre Pleurotome. $2^{\circ}$. Pourpres, qui correspund assez bellecuent a la famille des Antomostomes de M. de Blanville. $3^{\circ}$. Strombes, pour le genre Sirombe lui seul, auquel les Ptérocères sont réunis comme section. Si nous admeltions celle fauille, ce seroit en y ajoutaut les Rostellaires, et peut-être les Struthiolaires. $4^{\circ}$. Les Cônes ne comprennent que deux genres, Cónes et Alène. Ce dernier genre, comme on pourra s'en assurer en consuliant l'article qui le concerne, est un double emploi parfaitement iantile du geare Vis de Lamarck; et quand mème oul l'adopternit, on ne pourroit lui trouver la moiudre a alogie avec. le genre Cône, dont il est artificiellement rappraché. 5". Enroulés. Nons n'admettons pas cette famille telle que M. Rang la propose. Les genres qui peuvent en faire partie sont généralement caractérisés par la roquille lisse et polie, ionjours dépourvue d'épiderme, telle que celle des Porcelaines, Ovule, Volvaire, Marginelle, Olive, Ancillaire el 'Tarriere; les genres V'is et Mitre que M. Rang y ajoute parnissent appartenir, le premier à la fimille des Pourpies, et le second à celle des Volutes. $6^{\circ}$. Volutes. Celle famille ne se compase que de deax genres, Volute et Yet. Ce deraier est un dímembrement des Volutes de Lamarck, qui probablement ne sera pas admis, parce qu'il exisle catre le genre Yet et les Volutes propreinent diles, an grand nombre de nuaoces qui les lient d'une unanière intime.

Inmédiatement après celte famille des Volutes vient celle des Sigarets, la seule admise par M. Rang dans la irnisiéne section des Pectinibranches. Cetle famille est naturclle quant anx genres quiclle r'nferme, mais elle nous semble isolie el hors de ses vérilables rapports. M. Rang a voulu, par son moyen, établir ane liaison entre les Peclinibranches et les Scutibranches. Ceux-ci, en effet, commencent par la famille des Ormiers, qui ne contient que le genre Ilaliotide, qui est ainsi rapprocbée des Stomates, Stomatelles, etc., de la lanille des Sigarets.

La fauille des Calyptraciens de Lamarck avoit besoin d'être réformée. On y trouvoit à la fois des animaux symétriques et d'autres qui ne le sont jamais. M. de Blainville, le premier, fit celle réforme, et $M$. Rang l'imita. La fámille des Cabochons contient les geores non symétriques, et celle des Patelloides les genres symétriques. Le

$$
\text { Hist. Nat. des Vers. Tome II. }
$$

neovième ordre des Gastéropodes a été emprunté de M. de Blainville par M. Rang, sous le nom de Cirrhobranches. Il ne renferme quive scule famille, celle des Deotales, laquelle, elle-même, ne contient que le seul genre Denıle. Enfin, le dernier ordre des Gasiéropodes, est celui des Cyclobranches. Cet ordre renferme deux familles, celle des Patelles pour le genre Patelle lui seul, et celle des Oscabrions, 6galement pour le senl geare Oscabrion, dont les Oscabrelles sont rapprochées à litre de sous-geare. Nous ferous observer que déjà, daus les Inférobranclıes, il exisle dans la famille des Phyllidiens un genre Phyllidie qui est véritablement Cyclobranclie comme les Patelles et les Oscabrions; a assi, quoiqu'il soit dépourva de coquille, et encore parce que son oroanisation differe beaucoup de celle des Diplayllidies, il conviendroit mieux de le rapprocber des Oscabrions dans l'ordre des Cyclobranches. Nous ferons remarquer en outre la grande différence qui exise entre celte manière de voir, relativement aux Patelles et aux Oscabrions, avec celle de M. de Blainville, qui croit que les lamelles latérales des Patelles ne sont pas destinées à la respiration, et qui a vu, dans les Oscabrions, une organisalion assez différente de celle des autres Mollusques, pour en faire ce qu"il a oommé un sous-type, dans lequel il a joint les Cirrihpèdes. N. Rang, en se rapprochant de la mélhode de Lamarck à l'égard des deux genres dont il est question, est rentré dans l'opinion la plus géocralement reçue, qui est aussi celle que dous préférons. Relativement à la place que M. Rang donne à cet ordre des Cyclobraoches, nons pensons qu'il ne fait pas aussi bien le passage vers les Acéplalés que le feroil l'ordre des Scutibranches; et il est bien à présnmer que l'anteur dont nous examinons la méthode l'a lai-mème bien seuti; mais nous avons va que, dans le desir de lier les Pectinibranches à la snite des Mollusques, il avoit été obligé, d'uv côté, de placer la famille des Sigarets à la suite des Volutes, el d'en rapprocher les Sculibranches, à cause des rapports intimes qui sont entre ces deux groupes.

La quatrième classe du système de M. Rang circonscrit toos les Mollusques acéplıalés. Lamarck, qui avoit ru dans ces abimaux une orgauisation assez différente de celle des Mollusques céphalés, en avoit fail un embranche meot à part, compris dans sa méiliode au même degré que les Mollusques. Si cette manière de voir avoit l'inconvénient de irop isoler les Acéphales des autres Mullusques, la plupart des méthodes actuelle ont l'inconvénient do trup les en rapprocher et de les meltre an mème degré que les Ptéropodes, relativement aux Gastéropodes; ce qui proave que l'on ne s'est pas assez atlaché à mesarer dans leur valeur réelle les caractères que fournissent ces organisations diverses. On ne disconviendra 
pas sans doute quil existe une difference infaniment plus gran le entre les Cépralapodes et les Ptéropodes qu'entre ces Jerniers et les Gastéropodes, et qu'il n'existe pas mains de différence catre les Gastéropodes et les Acẹphalés qu'entre les deux premiers ordres. Lamarck, dans ses premières méthodes, avoit sis éviter la plupart de ces inconvérieos, en établissant dans les Mollusques deux grandes divisions primordiales : l'une couteuaut les Nollusques céplialés, et l'autre les acéphalés; ce qui élablissoit une parité convenable dans les caraclères de ces grandes divisinos. Dans la méthode de M. Rang, celte parité n'exisie plus, et elle est encore à un moindre degré daus l'arrangement de M. Cuvier et des auteurs qui l'ont suivi.

M. Rang admis, d'après M. Cuvier, denx divisious principales daus les Acéphalés; elles reposent sur l'ubsence ou la présence d'une coquille, ce qui est beaucoup plus important ici que dans les Mollasques propreneot dits; car dans ceux-ci les geares d'une même famille, et quelquefois les espèces dı ancue genre, possèdent le corps testacé, ou en manquent eutiòrement. 'Trois ordres se trouvent dars les Acćpbales à coquilles, les Brachiopodes, dont M. Cuvier fait use classe à part, les Rudis:es et les Lanjellibrauches. Les Brachiopodes, jusqu'à présent, sont en petit nombre; HJ. Rang y admet trois familles: $1^{\circ}$. celle des lingules pour le genre I ingule lui seul. $2^{\circ}$. Celle des Térébratules ponr les genres T'érébratule, Strophomène, Thécidée et Calcéole. Naus croyons que ce deruier, d'après ce que nous ea connoissons, est plus vaisin des Ciranies que des 'Térébratules, et nous l'adeuaturions plutôt dans celte deraière famille. $3^{\circ}$. La famille des Cravies contient les deux genres Cranie et Orbicnle, qui ont en effet entreux de très.grands rapports.

Liordre des Rudistes est un de ceux sur lescynels il a existé pendaat long-temps le plus de doutes et de variations; les observations que nous avons faites à ce sujet ont jeté quelque jour sur la structure des singulieres coquilles qu'il renferme. M. Rang, quoiqu'il les connût, a hésité à changer la marche de la plupart des mérhodes, et il s'eo est tenu, à cet égard, à ce qui avoit élé fait avant lui. Cependant il y a introduit des améliorations considérables doni il a puisé les élémens dans le travail de M. Desmoulins sur les Sphérulites, et dans les diverses notes que Dous avons publiées sur le mème sujet. Selon nous, les Rudistes ne forment pas on ordre, ou du woins, si l'on croit que cet ordre doit être adopté, il naus semble que sa place ne seroit pas entre les Brachiopodes et les Lamellibrancbes. Au reste, ce qui nous fait dire que cet ordre des Rudistes doit être repoussé, c'est que nons ne royuns des animaux acéphalés à denx muscles latéraux que parmi les Lamellibranches, et ce caractère, qui se retrouve d'une manière évidente daas les Radistes, les entraine dans le, roisiange des Cames, où ils peaveat constituer une famille, mais non un ordre.

L'ordre le plus considérable de la classe des Acéphalés est celui des Lamellibranches; M. Rang le partage à pen près à la manière de Lamarck en deux divisions principales, les Monomyaires et les Dimyaires : division qui a été abandonnée r.́. cemment par M. Cuvier, comme nous le verrous bientôt. I.es Mnnomyaires reaferment quatre familles : les Ostraciés, les Pectinides, les Malléacés et les Avicules. Dans les Ostracés nous trouvous le genre Harpace de M. Parkinson, lequel est un duuble ewpl.i du geare Plicatule. Quant a la famille des Peclinides, nous y voyons les Pudopsides et les Dianchores, qui ne sont autre cbose que des Spondyles mal reconous, et Plagiostomo, qui est un dédoublement inutile du genre Lime. Nous cherchons en vain les molifs qui ont pu déterminer M. Rang à séparer une famille des Aviculés pour le seul genre Avicule. Celle famille nous parait entièrement inutile, puisqu'il n'y a rien dans l'organisation de ce genre qui puiss le faire éloigner des Marteaux et autres genres de la famille des Malléacés.

M. Cuvier a loujuurs cherché à rapprocher les Arches des Huitres, parce qu'elles oni le manteas fendu dans toute sa longueur; il avoil établi des Ostracés à un muscle et des Ostracés à deux mar cles, et c'est dans le secoud groupe que les Arches étoient comprises. La plupart des auteurs ont faut des efforis pour coucilier les rapports donnés par M. Cuvier avec ceux que Lamarck a voit assignés, et vonlureot trouver un juste milieu entre ces opinions opposées. M. Rang n'a pas renoncé à set essai, et pour ŕaliser ses tentatives il a mis la famille des Arcacés en tête des Acéphales dimyaires, immédiatement à la suite de la famille des Avicules, quoiqu'en réalité, pour suivre l'ordre des rapports, il auroit fallu meltre la famille des Mytilacés à la place de celle des Arcacés. Ce sous-ordre des Lamellibranches dimyaires contient sept familles, ce sont les suivantes: Arcacés, Mytilacés, Submytilacés, Camacés, Conchacés, Pyloridés et 'Tubicolés. Nous ae dirons rien, quant à préseot, de la compositious de ces fir milles; nous avons en occasion, aux diverses arlicles qui les concernent, de donoer à leur sujet des développerens assez considérables. Nous arrivons à l'ordre des Hétérobrancbes, le seul qui soit dans les Acéphalés sans coquille. Cet ordre avoit ésé rejeté des Mollusques par Lamarck, qui, sous le nom d'Ascidiens, en a fait une classe à côtó de celle des Radiaires. Lamarck s'étoit fondé snr des considéralions dont la valeur n'a pas été appréciée, et la plupart des auteurs, après lii, ont préféré, a l'exemple de M. Cuvier, et d'après les indications du beau travail de M. Savigny, les conserver à la suite des Mollusques acéphalés, dont ils ne paruissent être en effet que des modifications. Denx familles se voient dans les Hétérobranches, et 
elles sont fondées sur la maniçre de virre des unimaux qu'elles contienuent. Dans celle des Ascidiens sout renfermés les Hétérobrauches counposés, ou pluıôl agrégés; dans la lamille des Salpiens, sont ceux qui vivent libres, ou dont les anrégalious peuvent être délrujtes saus faite resser la vie. Dans celle lamille, qui ne renfermoit autreforis que le genre Biphore, M. Rang a iutroduit trois genres, 'Timorienne, Monoplive tt Phylliroé. Ce deruier genre avoit été mis à cơlé des Carinaures par Lamarck, tet nous crnyons ine le rapprochearea de $\mathrm{M}$. Rang esi plus beuleux et sera sans doute adoplé de prélérence.

La cinquième classe de la méthode de M. Rang eat celle des Cirrbipèdes, et elle est divisće, comme dans la méthode de Lamarck, en dcux fat roilles qui correspondeut aux genres Lépas el Malane de Linné. M. Rang a adwis dans liune et l'autre de ces familles les mêmes genres que $\mathrm{Ml}$. de 13lianville, et à peu près dans un ordre semblable.

On a pu s'apercevoir que dans la méthode dont nous veuons de donner une courte analyse, il se trouve quelques changeuens heureux, yuclques rapprochemens qui n'avoient pas été aussi Lien sentis, mais que sa marche géućrale repose ea grande partie sur les trois systènes principaux les plus wodernes, que l'auleur à cherché à conciiier, et dans lesquels il a introcluit quelaues a móliorations sensibles.

11. Cuvier, auquel on est redevable de travaux si immenses sur luutes les braguhes de la zouloğe, a élé un des premiers anatomistes qui se suit occupé d'une manièle spéciale de l'urgauisation intérieure des Mullusyues. De nombieux Ménoires publiés dans les Annales du Muséum peuvent servir de modèles aux recherches de ce genre, et M. Cuvier les a fait précéder de la publication d'une métbode pour l'arrangement des animaux de ce grand type. Celte mélbode, qui tait partie de la prensere édilion de l'ouvrage classique, le Règne animal, a été analysée précédemment a vec quelques détails. Depuis 1817 , les recluerches sur les Mollusçues se sont muliplices sur prestue tous les points de la surface du glube; des entreprises scientitiques ont eu tes résultats les plus heureux pour l'avancement des sciences naturel'es en général, et particulièrement encare pour les animaux dont nous nous occupons. II existoit de telles lacunes dans les connoissances a na tomiques nécessaires à une bonne méthude, que l'on ne devoit pas s'altendre, à celle époque, que les arraogemens proposés pussent subsister longremps, et suffire aux laits nonbreux et nouveaux apportés de toutes parls dans la science; il devoit arriver ur moment oi l'on regarderoit cumme arlificielles les méthodes qui avuient été précédemment admises sans restriction, et que l'on cherchervit, si ce n'est à les rejeter tout-à-fait, du moins à $y$ apporter de très-graods change- mens. La prewiere roćlıode de M. Cuvier étoit deveuue insulfisante sous plusieurs rapports; Icus les oaturalistes desiroient yuc ce grand zonlugiste la wit en harmonie avec los faits nonterux, et leurs voux ont élé accoinplis prar la putlicatiun :écente de la seconde éclition da Régrne animal. L'analyse que nous avous fuite do la partic des Mollusques dans la première édilion de cet ou-

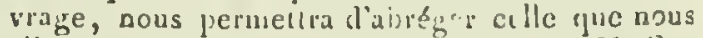
allous présenter, et les charige.zens que .1. Cisvier a apportés dans sit classilication u'étant pas aussi nombreux que nous nous y étions d'ationd alleadu, il nous sulfira donc thind que: e: de disculer ceux des points où ces villírences se montrent.

M. Cuvier, dans cette nouvclle toéthode, conserve les six divisions priucipales qu'!l avoit proposćes précédcomment; leur urlíc de rappor: sont exacteatent les mêmes. I.cs shangencus que sous aurons a examiner tornbermat sur des divisious secondaires el sur des délails coccle plus rnıutieux. Nous ne reproduirons pas ini l'ypizinn que nous avous émise dans diverses occasions, ef notamment en parlant de la méthode de Mi. Bayg, que les divisions principales doirent être fondíes sur des caraclères d'une égale valeur. Les six divisions de M. Cuvier ne sauroient ètre assimilées entr'elles sous ce rapport, el çnclques-uncs, telles que les Ptéropodes et les Brachiopojes, ne paruisseat pas suivre la progression décroissante que M. Cuvier a adoptée thans tous ses arrangernent systématiques.

Dans les Céphalupodes, MT. Crvier n'almel coujnurs qu'un trés-petit nombre de genres, et celui de la Seche correspond it lordie des Ciryplodibıanches de M. de Bláinville, et embrasse tout à Ia fois, sans aucune distiaction, les Octopodos et les Décapodes, ainsi que lous les gentes que l'on rassemble dans les deus familles. Quand même on devroit regrarder le geu:c Seche comme une famille, on regretletoit cuc re que M. Cnvier ait omis celle distinction fondamentale, d'arnès le nowbre des bras, el qu'il n'ait pas du moins établi deux groupses parmi les sous-yeares; nous voyons ici, comme sous-grenres les Sèches, les Puulpes, les Argonautes, les Bellćroptes, les Calmars, les Onycotheuthis, les S'pioles, les Sópiotheutis et les Sèches proprrement dites. If $\mathrm{y}^{\prime}$ a donc, relativement ì ce genre Seclee, des changemens importaus, puisque, d'use part, les Argonaules y sunt rapportés, lursquils faisuicnt auparavant un genre à part, placé à la fin de la grande série des Cépbalopodes; ifue les Belléropbes en soirt rapprochés, aussi bien que les Onycotbeuthis, les Sépiales et les Scipiotlieutis. 11. Cuvier a donc senti la nécessité d'aumetue dans la série ces divers geares, qui présentent en effet des types constans parmi les Céphatoporles; mais lintroduction de tant de matcriaux daos le genre Sèche lui seul, quelle que soit la valeur que 
l'on donne à cette dénomination de genre, ve nous paroit pas une trande amélioration dans le système, d'autant plus que des travaux tels que ceux de M. de Haan et de M. d'Orbigny avoient mis sur la voie des améliorations, et qu'il étoit facile de les perfectionner encore en suivant leurs erremens.

M. Cuvier, en ne reconnoissant pas notre genre Béloptère, que probablement il ne vit jamais, et qu'il continua à confondre avec des becs de Sèches, se priva du moyen le plus sûr de lier d'une manière évidente les Nautiles aux Sèches, d'un côté pa: l'intermédiaire de ce genre Béloptère, et d'un autre par celui des genres Bélemnite, Orthocérate, Lituite, etc. Aussi dans sa méthode, les Nantiles viennent-ils sans transition immédiatement après les Sèches; mais la composition du genre a éprouvé d'utiles changemens, puisque l'on n'y trouve plus plusieurs sous-genres de Céphalopodes microscopiques; ainsi les Lenticuline, Rotalie, Discarbe, Planulite, etc., sont entièrement supprimés, et l'on ne trouve plus à leur place que les cinq sous-genres qui suivent: Spirule, Nautile proprement dit, Lituus, Orthole et Orihocératite. La composition de ce geure correspond assez exactement à celle de la famille des Nauilacées de Lamarck et de quelques autres auteurs. Le geare Bélemrite vient à la suite des Nautiles; mais les Ilippurites qui, dans le système de 1817 , venoient immédiatement aprc̀s elles, ont été reportées à uue place plus convenable parmi les Acéphalés, et ont été remplacées par le geure Actinocamax de M. Miiller, qui n'cst, selon nous, qu'une sous-division des Bélemnites. A la suite de ce genre Actinocamax vient encore, sans aucuu intermédiaire, le genre Ammonite, qui représente, à l'aide des sous-genres qu'il renferme, la famille des Ammonées de Lamarck et de la plıpart des auteurs. Celte famille des Ammonées est tellement aaturelle, qu'elle a passé intacte ì travers toutes les métloodes proposées jusquà présent, si ce n'est dans celle de M. de Blainville, oì elle a unalbcurcusement ćlé démembrée. On trouve dans le genre Ammonite de M. Cuvier, el placés sur la même ligne, plusieurs sous-genres dont les caractèzes ont infiniment plus de valeur dans les uns que dans les autres; c'est ainsi que les Cératites et les Orbulites, qui ne sont que des modifications des Ammoniles, modifications dans l'enroulement des tour's de spire sculement, sont suivis des genres Scaphite, Baculite, Hamite el Turrilite, dont les distinctions génciriques reposent sur des caractères d'une valenr beaucoup plus grande.

Sur la même ligne que les Sichlics, les Nautiles, les Bćlemuites, les Actinocamax et les Ammonites, se trouvent les Camérines, genre dans lequel sont rassemblés ces nuyriades de coquilles miscroscopiques parmi lesçuclles II. d'Or'- bigny avoit judicieusement élabli des familles et un grand nombre de genres. Mais M. Cuviel s'est borné à indiquer comme sous-genres les familles du laborieux observateur que nous venons $d_{c}$ citer, ce qui rend le genre Camérine le représentant d'un ordre tout entier, dont plusieurs parties n'appartiennent peut-être pas aux Mollusques. A l'égard de ce genre Camérine, il existe une disparite évidente avec ceux qui le précèdent. On conçoit les rapports qu'il y a entre les Nautiles, les Bélemnites et les Ammoniles, considérés comme genres ou comme familles. Les différences qui séparent ces groupes sont comparables entrelies, et sont d'une valenr à peu près égale; mais il s'en faut de beaucoup, selou nous, que les Camérines soient à leur égard dans les mêmes proporiions. Ies Céptalopodes foraminifères ne sont rattachés aux Mollusques que d'une manière un peu incertaine. La structure de leur coquille et le peu que l'on connoil des animaux donnent it penser à ceux qui ont fait une longue étude de celte partie difficile de l'histoire naturelle des Mollusques, qu'ils doiveu: former, non un geare, non une famille, mais un ordre, el peut-être une division plus londamentale encore. Daus tous les cas, la séparalion que $\mathrm{M}$. Cuvier a faite en un seul groupe de tontes les coquilles microscopiques qui, dans la méthode prócédente, encombroieut les genres et les déparoient, est une amćlioration fort grande, puisće, au reste, dans les travaux de N. d'Orbigny et dans ceux de M. de IIaan.

La seconde grande division des Mollusques est celle des Ptéropodes. MI. Cuvier les avoient divisés d'aburd en Ptéropodes à tête distincte el en Piéropodes sans iĉte. Dans celte nouvellc édition de sa méthode cette distinction est supprimée, ct l'ordre des rapports entre les genres a subi quelques modifications. Ces genres sont disposés de !a manière suivante : Clio, Cy wbulie, Pueumoderne, Limacine, Hyale, Cléodore et Pyrgn : le genre Cléndore est divisé en cinq sous-ğcnres qui cnirespondent aux genres nouvellenent propusís par 11. Rang. Le genre Pyrgo, proposé par M. Deliance, apparticndroil, d'après M. ciOrbigny, au genre Bilncu' ine de sa famille des Agatlisligues, dépendant des Céphalopodes foraminifères. Nuus croyous que celte place convient mieux à re gente que celle indiquée par 11. de Blainville, duras le's Ptéropodes, et adoptée par M. Cuvier.

Relativement à la grande série des Gastéroporles, M. Cuvier a introduit des cl:an remens assez inportaus daus l'ensemble de leurs divisious; ct c'ent ainsi, par exenuple, que les P'ulmodés se tronverit à leur lête, au lieu d'être, comuse précédemment, à la suilc des Nudibranches, des Inférubrauclies et des 'lectibranches. Cette mansposilion est une amélioration, sans donte; car elle net au haut de la série des animaux d'une organisatiun plus cum- 
plćte quise ceux qui s'y trouroient d'ahord: mais ces animaux, qui ont uno génération bermaplrodite, sont-ils les plus avancés de tous les Gastéro"odes? Si la séparation des sexes est une preuve non équivaque d'une organisation plns compliquée, il nous semble que si l'on tient à suivre un ordre décroissant des systemes oryaniques, on doit mettre avant les Pulmonés ceux des animaux Nollusques qui préseutent la séparation des sexes : cet ordre seroit sans contredit plus rationnel que celui suivi par M. Cuvier; et il faudroit, pour qu'il fût interverti, qu'il existât dans cerlaines particularités de l'organisation des molil's sulfisans paur ne pas snivre l'ordre qui paroit le plus aturel. Il faudroit donc que les motifs fussent pris dans le système d'orgaues le plus fondameutal detous, c'est-à-dire le système uervenx. Les Iravaux de M. Cuvier lui-même ont mis hors de doute que les systèmes nerveux des Gastéropodes pulmonés et des Gastéropodes pectinibranches dinïques ne différoient pas d'uue manière essentielle dans leurs distributions et leurs rapports; et dès-lors, pour former les divers degrés de la mélbode, il a fallu se fouder sur d'autres appareils organiques d'nne moindre importance, el s'arrêter, par conséquent, sur ceux de la génération, qui certainement offient des caracteres infiniment plus élevés que ceux que pourroient présenter soit les organes de la resjiration, soit tout autre appareil organique quelconque. C"est par celle observation que nous cherchon: à justilier l'opinion que nous venons d'émellre sur la transposition qui a élé faite par M. Cuvier, des P'ulmonés en têle des Gastíropodes: nous aurions desiré y trouver les Pectinibrancbes buccinoides, qui nous semblent plus rapprochés de la perfection organique qu'aucune autre famille des Gastéropodes. Quoi qu'il en sait, nous ferons remarquer que la distriluation des Yulmonés est semblable à celle du prewier systère, et que l'an y trouve les Pulmonés terrestres et les Pulmonés aquatiques: de ces deraiers out été retranchés les genres 'Tornatelle et Pyramidelle pour les transporter, en admettant eutin l'opinion de lamarck, dans les Pectinibranches trachoides entre les Nélanies, les Janthines e: les Natices. A la suite des Yulmonés se reprósentent dans l'une et l'autre méthode, dans un ordre exactement semblable, les Nudibranches, les Inférobianches et les'l'ectibraucbes. Daus le premier des ordies que nous venons de mentinarer, celui des Nudibranclies, on trouve plusieurs genres danı les uns on ćté établis depuis 1817 et sumt déja connus, et dont les antres paroissent pour la première fois; c'est ainsi que les Unchidores, les Laniogères, les Cavolines et les Placoluranches sont venus prendre leur place dans le système, et que les Plocamocères, les Flabellines et les Busiris s'y présentent pour la prewière fuis. Il résulte de ces additions que l'ordre des Nudibranches renferme quinze gentes au licu de huit.

Les Inférobrancles n'ont subi aucun changement; il n'en est pas de même des 'Tectibranches, dans lesquels an roit de plus quauparavant les genres l'leurobranches, Bursatelle, Gastéroptère et Ombrelle: ce dernier genre avoit ćlé précédemment confondu par M. Cavier parmi les I'atelles.

Le ciuquième ordre des Gastéropodes a élé adopté de Lamarck; c'est celui des Jlétéropodes, que M. Cuvier a introduit pour la première fois dans sa méthode : cet ordre comprend non-seulement les genres que Lamarck y avoit introduits, mais encore les genues Allante, Timorienae et Monopbore. Les genres de cet ardre ont subi, dans le Traité de Malacologie de M. de Blainville, des rapports différens, dout nous avons déjà parlé, et dans la mélhode de Rang ces rapports sont encore changés, et ils nous paroissent préférables à ceux autérieurement proposés, et même à ce que M. Cuvier présente aujontd'hui. Il est incontestable, par excmple, que les genres Carinaire et Firole ont entreux la plus grande analugic; tnais on peut douter, avec juste raison, qu'il en soit de même à l'éyard dess genres Timorienne, Monophore et Phylliroé. Dans le preanier, on ne conuoit ni les branchies ni la masse des viscères: il en esı de même dans le second; mais comme il existe un canal qui traverse l'animal daus tonte sa longueur, ourert seulement à sa partic antérieure, ses rapports avec les Biphores paroissent mitux ćtablis qu'avec les auimaux de l'ordre des Héléropodes. Relativement aux Phylliroés, il y a certainement plus d'analogie entr'eiles et les Carinaires qu'avec les genres qui précèdent : leur urganisation paraît plus avancée que celle des Biphores; car, à l'exception d'un organe respiratoire que l'on n'a pu encore reconnaître, les auinaux de ce genre ont de l'analogrie avec les Mollusques. Mais si l'on met une si grande importance dans la distribution des animaux à l'organe de la respiration, nous demandons pourquoi l'on feroit à l'égard des Playlliroćs une exception aux règles généralement adoptées, et si l'on ne feroil pas mieux d'en laire un ordre ou une famille à part, plutôt que de le faisser au usilieu d'animaux auxquels il ne ressernble pas autant qu'on doit le desirer dans une mítbode vaturelle. Si l'observation de M. Laureillard, à l'ćgard de la génération des Carinaires, est juste, et que ces animaux aient les organes généraleur's séparés, ce sernit une raison de plus pour en éloigner les Phylliroés, les Timoriennes et les Monnphores, et peut-être même aussi les Atlantes, sur lesquelles M. Rang a fait des observations anatomiques très-précieuses par leur grande précision.

Les raisong qui nous ont déjà engaró à ne 
pas admettre en lête des Gastírnpodes les Pulmonés et les ordres qui suivent, subsistent ici rout eulières pour les rapports de l'ordre des Hétéropodes aveo ceux qui précident et celui qui suit. Nons ne croyons pas aécessaire de revenir sur une question qui sera éclaircie un pea plus tard par les considéralions que nous pourrons déduire de l'anatomie comparte des Alullusques.

Le sixième ordre des Gastéropodes, les Pectinibranches, cst le plus considerable de cous. a]. Curier les divise en trois famılles, celle des Truchoides, qui reste à pell près semblable à ce qu'elle étoit dans la première édition du Règne animal; celle des Capuloïdes, qui est nouvelie, et que nous examinerons bientôt; enlin celle des Buccinoides, qui renferme assez exacternont les mêmes genres gue précédemmen!. L'ancien genre Sibot, de M. Cuvier, est divisé en deux, c'est-àdire, qu'il a adwis le gcare 'loupie, Tiochus de Ianarck. Ce genre Troclius contient buit scusgenses, au nombre desquels nous voyons les Ruulelles, qui paroissent cependant dillćres notatument des Troques; et les T'́lescopes, qui appartieudent, sans aucun doute, au genre Ciérite. Relativement aux Cadrans, qui coustituent eucore un des sous-genres des 'Toupies, on pourroit, ell s'en rapportant à la forme singulic̀e de l'opercule, les regarder comme an genre bien distinct; mais il faudroit que l'animal fút connu pour que celle question fít décidée. Il y a néanmoins flus de présomption pour croire que le genre Cadran devra rester que pour l'opinion contrare. Du genre Sabot, nous reunarquons que plusieurs genres qui y étoient autrefois confondus en sont áctuellement retirés, et forment autant de genres ¿̇ part. D'un autre côté, nous observons que le genre Pleurotomère a étć joint aux Sabots a titro de sous-genre, quoiqu'en réalité il dit des caractères aussi fondamentaux que la plupart des yeares que M. Curier a séparés des Sajols.

Si, dans les Pulmonés, la considéracion de l'organe respiratoire les a lait mettie en tête de's Gastéropodes, il nous semble que ces mémes considérations, qui ont pour eux tant de valeur, auroient dú en conserver pour ce qui est relatif au genre Cyclostome, puisque ce geare est égraleweut pourvu d'un réseau branchial propre a respirer l'air. Malgré celte circonstance si particulière dans ce genre, N. Cuvier le maintient toujours à titre de sous-geure des Turbos, eatıe les Scalaires et les Valvées. Il se fonde, pour justifier cet arrangement, sur ce que les Cyclostowes n'ont que deux tentacules; que les yeux sont portés à l'extérieur, a leur base; que la cavité respiralrice est largement ouverte au-dessus du cou, comme dans presque tous les Pectinibranches; et qu'enfin l'organe excitateur mâle, an lieu d'être rétractile, se reploie ordinaireme ot dans le sac biachial. Ces moifs de rappruclez: les $\mathrm{Cy}-$ clostomes des Pectinibranches ont certainement une graude force; wais si, dans les arrangemens mélludiques, un preud pour rènle générale que $t \in$ sysic̀ne d'organes devra lournir les caractères prip: cipaux des ordres ou des familles, noug crojons qu'il faut subir toutes les consć́fuences d'ua piincipe une lois posé, el qu'on ae doit admettre aucune exception à ce priscipe. Ici surtout il est très-facile, ce nous semble, d'éviter l'exception; car, qu'y a-t-il d’important à considérer pour meitre en rapport un aninal comme celui des Cyclosiomes? Est - ce la leute de son orgaue respirateur ou cet organe lui-même? est-ce la forme des tentacules et Jeur nombro qui est en nénéral irès-variable? est-ce enfio la position de lis verge? Si ces caractères, considérés comaı secondaires dans la plupart des genres et des familles, out pour celle qui anus occuje plus de va eur que la modificalion de l'organe respirateur, cela prouveroil que les zuologistes peuvent encore prendre arbitrairement les caractéres dec des geures et des familles, et leur donner nue importance dópendant en partie de leur caprice.

Les genres Paludine, Lillorine, Mlonodonte, Phasianelle el Acopullaire viennent is la suite des Sabols et de ses sous-genres. Nous ferons observer que les Monodontes dillèrent à peine de certains 'I'royues, et qu'ils se joiguent aussi aux 'Turbos par une disparitiun insensible vers l'un et l'autre genre des caractires qui leur ont été assignés par les auteurs. Nous aurions dô nous allendre à irourer plutól les Mlunodontes parmi les sous-yentes des Sabots que les Pleurotomères et les Cyclostomes, par exeuple, qui dillerent infiniment plus du iype des 'lurbos que le genre qui nous occupe. Le genre Ampullaire est divisé en quatre sousgenres; ce sont les suivans : Laniste, Hélicine, Ampullize et Olygire. Les persones qui soccupent de cnnchyliologie seront étonnées sans doure de trouver, comme sous-yenre des Acopullajres, le genre llálicine, qui en diflère d'uae manière si essentielle, ct surtont de le retrouver sous trois noms dillértens. Les Ampultines el les Olygires ne sunı en ellet que des doubles emplois des Hélicines. Helativement a la place de ce dernjer genre, nous ne partagerong pas l'opunion de M. Cuvier, et nous troyons qu'il doil se rapprocher des Crclostomes, puisque l'uaimal respire l'air el quail est operculé.

On ne retrouve plus dans la nouvelle méthode de AI. Cuvier le genre Conchylie, qui rassembloit les Ampullaires, les Mélanies, les Phasianelles et les Janthines. Ces geares sont diversement répartis, et déja nous ávons vu les Phasinelles et les Ampullaires; et nous trouvons a près elles les Mélanies divisées en trois sous-genres, Rissoaire, Mélanopside el P'yrène, lesquels sual suivis des genres Actéon, Yyramidelie, Jantbine et Nérite. Les Actéons ou 'Tornatelles de Lamarck étoient, dans la première méthode, à la saite des Auri- 
cules, dans ics Pulmonés aquatiques. Lamarck les avoit tonjours mis à la suite des Pecciniloranches, dont la coquille a l'ouverture entière et ferrée d'un opercule. L'abservation a démontré combien étoient justes les prérisions de ce profund zoologiste. M. Cuvier se conforme à celle opinion, en mettant ces deux genres dans les nouveaux rapports que nous vennns d'indiqu'r. Le genre des Janthines diffère tellennent, dans presque tous les points de son organisation, des antres Mollusques pectinibranches, que quelques zoologistes ont cru nécessaire d'en faire une famille à part; et cette manière de voir est pentêsre préférable, puisqu'elle évite l'inconvénient de rejeter d'une place à l'autre le geure Jantbine, dans l'incertitude où l'on est pour le placer d'une manière rationnelle. A la suite de ces genres, qui lerminent la série assez considérable des Pecinibraucbes trochoides, vient se ranger la famille des Capuloides, dont les genres éloient auirefois, pour la plupart, compris dans les ScutiLrancbes. On comple dix genres dans celle famille des Capuloides, et ils snnt disposés dans l'ordre qui suit : Cabocbon, Hippouice, Crépidule, Pileole, Septaire ou Navicelle, Calyptrée, Sipuonaire, Sigaret, Coriocelle et Cryptoslome.

Deux réllexions se présentent an sujet de cette fumille, l'une relative ì ses rapports quant à son ensemble, l'autre au rapprocbeanent de la plupart des genies qui la constituent. Si nous en croyons les anatomies faites par M. de Blainville, des genres Cabnclion et Hipponice, l'organisation de ces animaux les rapprocherait, sous plus d'un rapport, des Acéphalés, et ils devraient servis en canséquence de passage enıre les Mollusques céphalés et les Acéphalés. Les Sigarets, Coriocelles et Cryptoslomes, au contraire, ue semblent que des moditications du type des Natices, et devroient se rappracber de ce genre plutôt que de cenx avec lesquels il est mis en contact. Si, d'un côté, les Capuloïdes montrent quelque ressemblance arec les derniers genres des Trochoïdez, cette analogie lient plutôt à la confusion des genres qui y sont introduits qu'd des rapports véritablemenı naturels; d'un autre côté, les rapports sont évidemment rompus entre les derniers genres des Capuloides et ceux de la famille qui suit les Buccinoides. Cette famille, qui commence par les genres Cône, Porcelaine, Ovule, etc., n'offie oertainement qu'une analogie très-éloignée avec les genres Cryptostome, Coriocelle, Sigaret, etc.; mais il en est de même à peu près dans toutes les familles proposées par M. Cuvier, qui semble à dessein en avel fait autant de groupes isolés.

Dans la famille des Capuloides, cinq genres seulement nous semblent deroir y rester : ce sont les Cabocbons, les Hipponices, les Crépidules, les Calyptrées et les Siphonaires; encore ce dernier genre pourroit-il prendre ane place plus con- venable, soit à côté des Ombrelles, soit d̀ côté des Fissurelles. Pour le genre Piléole, ce n'est qu'une modilication des Nérites, et il en est de méme du genre Na vicelle, d'une manière plus évidente encore, puisque l'on trouve un rudiment d'opercule comparable à celui des Nérilines. Pour ce qui est relatif anx genres Sigaret, Curiocelle et Cryplostome, qui sont pourvus d'un opercule corné rudimentaire, analogue à celui des Natices, c'est vers ce genre que uons croyons que dcvroient se trouver ceux que nous renons de citer.

La grande famille des Buccinoïdes diftere peu, dans sa composition, de ce qu'elle étoit dans la pre: mière édition de l'ourrage de M. Cuvier; elle renferme toujours les Pectioibranches dont la coquilie est échancrée à la base, et ceux qui ont rette coquil!e prolongée en un canal plus on moins long: nous ne :rouvons de difference que relativement à l'jntratuction de trois surs-genres, celui des Volvaires à la suile des Olives; crlui des Concholépras, à la snile des Ricinules et des Pourpres; et enlin celui des Siruthiolaires, dass le geare Rncher, à la suite des Fuseaux el des Lathirey. Nous n'avous rien autre chose a dire de celle famille. Le sepièzne ordre des Gastéropodes est nourellement introduit dans la méthode par 11. Cuvier: il donne à cet ardre le nom de Tubulibranches; il le compose des genres Vermet, Magile et Siliquaire. Antérienrement an Traité de Mralucologie de M. de Bluinville, le genre Vermet, fui seul, avoit étć admis an nombre des Mollusques, d'après les observations d'Adanson. Concluit flar une analogie bien lundée, M. de Blainville a rapprocbé de ce genre les Magiles ét les Siliquaires, compris autrefois parmi les Annelides. En se contiant dans la justesse des obserrations d'Adanson, et en s'en rapportant également à l'analugie des opercules, le genre Vermet devroit se rapprocher des Turbos, aiusi que des Turritelles et des Scalaires. Ces rapports, une fuis admis, on étoit eotraíá à rapprocber les Magiles et les Siliquaires des Vermets, et il devenoit naturel d'en faire un groupe ou une famille qui ne füt pas éloignée de celle des Turbo: II. Cuvier a vu dans ce groupe une organisation assez à part pour l'isoler presqu'entièrement des rapports que nous venons d'indiquer, et le placer entre les Pectinibranches buccinoides, qui se terminent par le genre Sirombe et les Scutibranches. Relativemeut à ce dernier ordre, qui commence par les Haliotides, il y a bien en elfet quelques rapports avec le nouvel ordre; mais, il faut en convenir, ils soat extrêmement éloignés, et consistent priacipalemeat en ce que dans les $\mathrm{Ha}_{\mathrm{a}}$ liotides, comme dans la plupart des Siliquaires, la coquille est percée latéralement d'un nombre plus ou moins considérable d'ouvertures régulières, pour transmettre le fluide ambiant sar les branchies. Si l'ordre des Tabulibranches est ad- 
mis, nous croyons qu'on le changera de place, et qu'on le reportera vers les Pectiaibranches troclioides.

- Lordre des Sculibranches a subi des changemens notables à cause de l'établissement de la farnille des Pectinibranches capuloïdes; il ne forme plus qu'une seule série, et celte division en symétriques et non symétriques est disparue. Ils se réduisent actuellement à quatre geures : les Ormiers, les Fissurelles, les Emarginules et les Pavois. Le premier de ces geares nest pas symétrique, et l'animal a cela de particulier, d'avoir les branchies à l'ioverse des autres Mollusques gastéropodes; elles sont en elfet situées sur le cóté gaucbe. Les trois geares qui suivent sout au contraire symétriques, ei leurs branchies participent à celle régularité. Celle réunion de geures dans un même gronpe ne paraitra pas naturelle à ceux des zoologistes qui donnent ane grande imjuortauce aux calractères tirés de celle symétrie; jls savent en ellet que presque tous les systemes d'organes diffèreat daos les animaux pair's et dans les animaux non symétriques. A part le geare Haliolide, l'ordre des Sculibranches correspondiat d'une mavière assez velte ì la famille des Branchiferes de M. de Blainville, il pourroit éıre -onservé moyennant l'éloignement de ce genre, qui, généralement, a été séparé des Emarginules, des Pavois et des Fissurelles, par les auteurs de conchyliologie et même par les zoologistes.

Le dernier ordre des Mollusques gastíropodes est celui des Cyclobranches. Cet ordire n'a subi aucun changement, et l'on y trouve toujours les deüx genres Patelle et Oscabrion. Ce gue nous arons dit précédemment de cet ordre, eu parlant de la méthode de M. Rang, nous dispeuse de le reproduire ici.

Nous arrivons actuellemedt à la quatrième grande division des Mollasques, celle des Acéphales: M1. Cuvier les partage, comue précédemmient, en deax grandes séries aduplées par M. Rang, les Acépliales testacés et les Acŕphàles sans coquilles. La preaière division est untiniment plus considérable que l'autre, et eile est, comme précédemment, divisée en cinq facailies, qui diffèrent fort peu de ce qu'elles étoient aupararant. Ainsi la troisième famille porte le nom de Camacés au lieu de celui de Bénitiers qu'elle avoit d'abord; quant anx autres familles, elles ont conservé et les mêmes noms el les mémes rapports. Dans leur composition elles out subi quelques changemens que nous allons faire connoitre.

Les familles dans lesquelles sont distribnés les Mollusques acéphales correspoudent pour la plupart aux ordres que MI. Latreille a établis parmices êtres: on se souvient sans doute que l'habile entonoologiste s'est servi de la for une úu manteau pour la circonscription de ces ordres. Les dénomina- tions de manteaux ouverts, de manteaux biforés, de Manteauxtriforés, de manteaux tubuleux, indiquent sur quel caractèı e ces divisions principales sont fondées. Il est remarquable que les famille élablies par M. Cuvier cojncideni d'une madière fort exacte aux ordres de M. Isatrei!le; re que l'on ne peut altribuer, non à une ocuvelle combinaison de sa part, mais au talent particulier qu'il eut de mettre en saillie le calaclère qu'ıl donna comme plus important; car, par le fail, les grandes divisions de $\mathrm{N}$. Latreille, à l'exception de quelques délails de peu d'importance, se retrouvent sous d'antres noms dans la preuiere édition du Règne animal de M. Cuvier, et y sout reproduites entièrement dans la seconde.

La famille des Ostracés, Ia première des Acéphales testacés, n'est plus divisée, comme aulrefuis, en Ostracés à un muscle el ea Ostracés à deux muscles; elle forme une senle série, dans laquelle on compre ac:uellement dix-luuit genres au lieu de dix qui s'y trouvoient dans la precuière méthode. Le geare Acarde, de Bruguière, est reproduit, et il représente une partie des Rudistes de Lamarck. On y roit, comme sons-genres, les Radiolites, les Sphérulites, les Calcéules, les Hirpurites et les Bátolites. Quoique ce soit nne amélioration d'avoir admis parmi les Acéphales las genres dont nous venous de parler, ce n'est cependant pás la seule que l'on doive espérer; car, d'un côté, les genres Radiolite et Sphérulite doivent être réunis, et il doit en êire de même des genres Batolite et Hippurite. Ce sont les deux senls que nous admeltrions dans les Acardes, con. sidérés comme famille, et cette famille devroit être transpurtée à côté des Camacés; tandis que les Calcéoles, par leur structure intérieure, se rapprochant des Cranies, doivent entrer préférableuent dans l'ordre des Brachiopudes : ainsi, le geare Acarde a besoin lout à la fuis de réforme dans sa composition et dans ses rapports.

Le genre Huitre, à l'exception du genre Acarde, qui en tournit un sous-genre dans la precoière méthode, n'a éprouvé aucun changement; mais au lieu d'être suivi par les Anoanies, on trouve aprés lui les genres Itinnite, Plagiostome, Paclayte, Dianchore et Podonside. Nous avons fait observer, dans une note publiée depuislongtemps daus les Annales des sciences naturelles, que le genre Plagiostome contenoit à la fois un grand nombre de coquilles analognes aux Limes, et quelques autres semblables aux l'odopsioes, dont M. Defidace a fait son genre Pacliyte. Nous avons fait condoitre que le gebre Pachyle, ainsi que les Dianchores el les Podopsides, n'eroit autre chose que des Spondyles dus un élat particulier de fussilisation. Nous pouvons donc dire Tue ces genres, quoi qu'on les retrouve dans la méthode de M. Cuvier, doivent être rejelés, puisque les Plagiostonjes rentrent daus les Lines, er les trois aurres dans les Spondyles. Nous arri- 
vous au gemre Perne sans remargyuer de changement dans la composition et l'arrangement des renres Anomie, Placune, Spondyle, Martean el Vulsellc. Anx Pernes, II. Cuvier ajoute cinq sous-genres, qui sunt: Crénatule, Gervilie, Inocérame, Catille et l'ulvinite. Ces sous-urenres sont, pour la plupart, adouis dans la famille des Malléactes de Lamarck, on celle des Margarilarés de M. de Blainville. Jusqu'à présent, les genres que nous avons cilés dans la famille des Osiracés appartienuent à la section des Monomyaires. l.a plipart de ceux, cn plus pelit nombre, qui nous restent à mentiunner, sont contestís pour quelques-uns; car Lamarck les avoit compris dans ses Monomyaires, tandis que M. Cuvier et yuelques autres zoologisles les adunettent au nombre des Dinyaires.

On ne devoit pas s'attendre à trourer à la suite des Pernes le genre Éthérie de Lamarck, qui, bien qu'ostréitorme, présente des caractères telleunent différens de ceux des Ostracés en général, mème cnvisagés à la manière de M. Cuvier, qu'aucun zoologisie jusqu’à présent n'avoit songé au rapprocliement proposé par cel auteur. Les Ébéries suut des coquilles très-irrégulières, dont les individus adherent indistinctement par une valve on par l'autre; leur tcst est boursonfllé, revêtu en dehors d'un épiderme et jamais d'une crồte fibreuse, comme dans les Pernes, les Avicules et les Pinnes. A l'intérieur des valves on trouve deux très-graudes impressions musculaires, dont l'une surtout, probablement l'antérieure, est fort longue et fort étroite. L’adhérence immédiate de ces coquilles ne permet pas de supposer qu'elles sont pourvues d'nn byssus; elles n'offrent d'ailleurs aucune trace de passange de cet organe; leur charnière, quoique comparable jusqu'ì un certain poiut avec celle des Hinnites ou des Marteanx, a cependant une disposition loute particulière que l'ou ne retrouve dans aucun autre genre. En suivant un ordie de rapports yui nous semble plus naturel, nous croyons que l'opinion dc Lamarck, qui melloit les Elluéries à côté des Caunes, est préférable à celle de M. Cuvier; et, quant à nous, nous l'adopterons jursyu'à ce que la connoisance des animanx soit venue l'sufirmer. Les trois deruiers genres de la fumille des Ostracćs nont point subi de changement, si ce n'est que les 'Trironies, qui constituoient uu suus-genre des Arches, lorment actuellement uu genre séparé, a leur suite.

La famille des Mytilacés est augmentée de qnelques genres : celui des Moules est resié le inçme. Les Anodontes ont acquis les deux sousgenres Iridine et Dypsade. Nons observerous que M. Cuvier, daus ceste farnille des Myrilacés, a cherché à réunir tous ceux des genres des Acciphales qui ont deux ouvertures an nantean. Elle correspond à l'or:lre des Biforipalla de M. Lailireille. Le sous-geure Iridine, mis à la Hist. Nit. des Vers. Tume II. suite des Anodontes, lait une grave exception aux caractères de la famille, puisque l'animal a le manteau véritablement triforé. Ces exceptions, donı nous avons déjà renıarqué plusicurs, prouvent deux choses : ou que les rapprochemens sont lails d'une manière arbitraire, on que les caractères imposés aux ordres et aux familles ne soat pas choisis dans les organes qui paurvient en offiri de plus solides. Nuus ne pourrons que rípéter ici qu'il fiu opter entre un principe el sa rigoureuse applicalion, ou bien laisser au hasard le soin de dŕcider des rapports. P'uisque la famille des Myiylacés est fondée sur le carnctère priacipal de deux ouverlures au unatea, caractère qui est cause de la séparation des Pinnes et des Mloules et du rapprocliement artiticiel, selon nous, des Cardiles, Cypricardes, Vénéricardes, elc., il nous semble que ce caractère auroit dû́ être pratique à l'égard des Iridiues, el eiles anroient dû, llans son application rigoureuse, être trausportées, comme l'a fait M. Rang, dans la lamille des Cardiacés.

Les Muleties ne se distinguent véritublement pas des Anodontes par leurs caractères cssentiels; les animaux des deux geures ne dillèrent en aucune maniè:e; et quant aux coquilles, il y a eutr'elles un passage insensible qui les rénnit d'une manière évidente. N. Cuvier a joint aux Mulettes, it titre de sous-genre, les genres Hyrie et Castalie de Lamarcli; entre lés Cardites et les Crassatelles, qui, dans la nućlhode précédente, éloient les deux genres qui terninoient la famille des Mytilacés, nous trourons les Cypricardes, les Coralliopbages el les Vénéricardes. Nous avons démonlré (')une nanière irrévocable, à ce que nous croycus, à l'arlicle Candite, que les Véuéricardes ne diffèrent en aucune mauière de ce genre; elles feroient alors ici double emploi; quant aux Coralliophages, elles ne sunt qu'ine bien foible modification des Cypricardes, et nous les aduellous d'autant mojus dans cetle famille, que l'on remarque que l'impression paléale est écliancrée postéricurcment; ce qui met hors de doute que l'auimal est puurvu de siphons postérieurs: ce qui n'a pas lieu, bien certainemeut, n: daus les Cardiles ni daus les Vépélicardes.

La troisième fanille des Acéphales testacés est celle des Caunacés; elle se réduit, pour M. Cuvier, i un seul genre, celui des Cames, dans lequel sont l'éunis, à titre de sous-genre, les Tridacnes, les Hipponcs, les Cames proprenent dites, tes Dicérales et les Isocardes. Celle famille des $\mathrm{Ca}_{-}$ macés remplace celle des Bénitiers de la piemière ćdition du Régne animal; mais elle est plus complète dans sa composition. le grenre Came, rqui faisnit partie de la famille des Cardiacés, a été replacé d'une inanicre plus convemable, el les lsiscardes ont íté entrainées à sa suite.

D'après les caractères de la famille des Camact's, elle devroit renfermer tous ceux des Mollusques 
acépbales qui ont trois ouverturcs an manteau, Inais dont les deux ouvertures postérieures ne sont pas proloogées en tube. Si ce caractère éloit nellement tranché, jl seroil sans aucun donte préférable à tout autre; mais la nature se jone de nos mélhodes et des distribntions que nous voulons imposer parmi ses productions. On Irouve bien, en effet, dans la famille des Camacés des a nimaux qui out le manteau perforé postérieurement; majs peu a peu ccs perforations se prolongent, et finissen!, par des transitions insensibles, par se changer en véritables siphons. Il est donc difficile, impossible pent-être de déterminer une lianie au milieu des êtres ainsi nuancés; si des limites doivent être posćes, il faut nécessairement que re soit par d'autres moyens. Déjà, à l'nccasion de l'ordre des Triforispalla de M. Lalreille, nons avons fait sentir l'inconvénient qui résulte de l'emploi de la forme dn manteau pour les divisions primaires parmi les Mollusques acéphales; on en reconnnit toute l'imporlance ì des faits tels que cenx que nous avons déjà rapportés pour le genre Iridine et la famille des Camacés en génćral.

Nous remarquons également fort peu de changemens daus la famille des Cardites, qui vient après celle des Camacés. Lee principal, que nous avons déjà mentiouné, consiste dans le transpont du geare Came dans la famille qui porte son nom : au genre Cyclade sınt ajoutćs les trois sous-rgenres Cyrène, Cyprine et Galathée, el entre les lucines et les Vénus on voit de plus le genre Onguline de Lamarck; entin, parmiles sous-genres des Vénus a été ajonté le genre Astatté de Sowerby, ou Crassine de Lamarck. Celle famille des Calldiacés ne nous arrêtera pas davantaģe.

La famille des Enfermés est la dernière des Acéphales testacés : clle est plus consiclírable dans cetle mérbode que celle qui l'a précédée; elle commence de même par le genre Mye, dans les sous-genres duquel le genre Sulémye, lui seul. es? ajouté. A cet égard, nous pouvons assurer d'une manière irès-posjlive que M. Cuvier a ćté dans lerreur en dunnant à ce genre de tels rapports; car, d'apri's l'animal que nous avons sous les yeux, il appartiendroit plutốt à la famille des Cirmacés, puisque son mantean ne présente à son extrémilé postérieure que deux trous sans prolongenens : le genre Solénye devient donc une prenve de plus que la distribution, d'après les accidens du unanleau, ne pent supporter un examen approfundi. M. Cuvier a santi que les Gastrochines se linjent aux Fistulanes et aux Claragelles, et au lieu de les roeltre à la suile des Myes coume précédemment, on y voit les gentes Bissonye, IIyatells e! Solen. Ce dernier est le seu! de ces truis genres "jui ait eu it stiplorter quelyues changemens daus sa composition; car a scul smas genre Sunguinolaire qui y étoit anuexć aulrefuis sont joiuts aciuellement les grentes l'sammulice el l's rumo:é, que Tamarck plaçoil aves plus de raiscn, ce nou semble, daus le voisinage des Tellines. $\Lambda$ la sui (. des Solens se montreni les genres suivans : lrs Pbolades, les Tarets, les Fistulanes, les Gastrochènes, les 'Térédines, les Clavagelles et les Alrosairs; ces trois derniers genres n'avoient point encore été admis dans les méthodes de M. Cuvier, si ce n'est les Arrosnirs, qui étoient parmi les Annelides. Nous avons deji fait plusieurs observalions sur les genres Fistulaoes el Gastrochènes ; il suffira de renvoyer le lecteur aux artirles qui conrernent ces deux genres, et surtont à l'articlc Tusrcolées, pour le convajncre que l'un des deux duit êlre supprimé. M. Cuvier, au reste, y a apporli: des cluanuemens qu'il est bou de noter. Les caraclères des Fistulanes, dans son dernier ouvrage, lendroit à n'y admeltue que des coquilles lont-àtuit semlilables aux 'Tarets, telles que la Fistulana grggatu, et la Fistutuna lagenula. S'il en est ainsi, il est évident que le genre Fistulane est un double emploi des Tarets, et par consf́quent le genre des Gastrochène, seul, doit rester dans la mélbnde. Les 'lérédines intercalćes entre les Gastrochènes et les Clavagelles ae sont pas à leu. place; elles ont tous les caractères des Pliolades. unais de plus elles sont pourrues d'un tube posit:rieur qui les rapproche aussi des Tarets; ce sont des Tarets à valves fixées, et nous avons des raisons bien fortes pour croire que pendant la vif des animaux qui les ont produiles elles n'étoient point dans l'état où on les voil aujourd'bui, et les observations rue nous avons faites à ce sujet sont consignées dans nolre ouvrage sur les fossiles dr? environs de Paris, ainsi qu'à P'article 'TÉr f́orxe du Dictionnaire chassique d'Histoire nuturelle. Non४ les reprodujrons au mèmo article de ce Dicrionnuire.

Depuis trente ans Lamarck avoit mis les Arrosoirs dans les Mollusques; il est vrai que d'abord la place qu'illeur assigna n’étoil pas irès-nalurelle; mais des qu'ıl ent observé le genre Clavayelle, il n'luésita plus sur les rapports qui convennient aux Arrosoirs, et les conserva constamment dans les Tubicoles, quoique son opinion ait éćc souvent contredite, et telle est la supériorité de cet observateur cúlèbre, que, saus autre donnte que celle des rapports exlérieurs, il a préva la plisc que devoit ocsuper ce genre, et que ses prévision: sont aujourd'hui justifáes par les observations que M. Ruppel a failes sur les Arrosoirs de la nu: Ronge, ce qui a délerminé N. Cuvier à remellre enfir ce genie dans des rapports plus aaturels que dans sa méllode précédenle.

Nous auruns liurt neu de chose à dire sar la seconde grande division des Acéphales nomri t's Acéphales suns coquilles, puisque $\mathrm{M}$. Cuvier $\mathrm{n}$ ': introduit dans leur arrangement et leurs rapporta a ucun chaugement; nnus arriverus donc aur Brachiopodes, qui forment la ciucuiène grande division des Mullusgyres. Tris-pen d'auteurs ont 
adais celte division an mèune degré que $11 . \mathrm{Cu}$. vier; les aubaux qui sont daus cet ordre se lient d'une manic̀re bien évidente avec les aulres Acéphales testacés, et ils sont supécrieur's dass l'organisation aux Acépluales saus coquilles que N. Cuvier place a vant eux : nous les retrunvons toujours formés des genres Lingule, 'lérébratule et Orbicules. Dans les 'Túróbratules, M. Cuvier admet deux sous-genres, les Spirifires et les 'Ihtécidées: les Spirileries ne constilueut pas un bon genre, les caractères qui les séparent n’ayant pas été choisis d'une manière couvenable, puisque tous les Bracliopodes sont spiriferes propremeut dits. Aux Orbicules sont écralement juints deux sousgrares qui n’en faisoient pas partie précédeosirent, les Discines, qui sont un double emploi des Urbicules, et les Cranies, que Poli a fait conuoitre sous la dénominalion de Criopus.

Tel est l'enseuble du système de M. Cuvier. pour ce qui concerne les Mollusques proprement dits, tels gu'ıls sont adonis dans la presque tolalité des unétlodes; les Cirrhopodes dont il nous reste a parler constiluant, soit une classe, comme dans Ja'narck, snit un sous-type, comme daus N1. de B!ainville. Ici les Cirrhopodes sout considérés comne un embrabchement des Nullusques, et sont au méne degré, relalivenent aux Brachiopodes et aux Acéphales, que ceux - ci avec les Gastéropodes, les Ptéropodes el les Cúphalopodes; la disparité eotre la valeur de ces groupes se montre, à l'égard de celui-ci, d'une manière non moins évidente que pour quel fgues - uns des autres. Quni qu'il en soit, M. Cuvier a considérablenent a mélioré leur distribulion en y introduisant un assez grand nombre de sous-genres qui we figuroient pas dans sa première méthode : c'est ainsi qu'au lieu da geure lépas, divisé en quatre sous-genres, qui constituoil les Cirrlıopodes à lui seul, on voit maintenant les deux genres Anatife ou Pentalasmis et Gland-de-mer : ces deux geores correspondent aux deux fanilles érablies précédemmeut par lamarck pour les mênes animaux, sous les dénominations de Cirrhipèdes pédonculés et Cirrlipièdes sessilcs. Dans le premier gente on irouve les quatre sons-genres Poncepied, Cinéras, () thion et 'ítralas nis: ce dernier sous-geure est nouveas; on le doit à M. Cuvier, qui le propose pour ceux des Anatifes qui n'ont que quatre pièces an lieu de cinq qu'on leur troure habiiuellemen:. M. Cuvier a eu sois de dúbarrasser de ce groupe d'animanx des divisions douleuses qui y ont élé introduites par divers auteurs. Le genre Gland-de-mer correspond aux Balanes de Bruguière; il est divisé en dix sous-genres dans l'orddre suipant: Bulane, Acaste, Conic, Asème, Pyrgome, Ochthosie, Creusie, Corunule, 'Tuljicinelle et Diadème : tous ces sous-genres ne sont pas éralement admissibles, ne reposant pas tons sur des caractères de méune valeur. Nous poutrions citcr les genres Asème, adopté de Raazani, (t les Dislènes, qui ue sont qu'ua díloublement inulile des Corounles. Les Acasics ne sont, à bien tire, que des Ballanes vivaut dilus des éponges; clles sunt donc, re!aliveucont à celles-ci, dans un degró inféricur. Ia plupart de ces sous-gentes sont fondés sur d'ussez bnos caractíres, le nombre des pieces qui formeat la coquille : clles ne sont géméralement valiables que dequatre à la ait; mais leur disposition el le tisara celluleux plus uu moins ¿́pais qui se développe dans keur épaisseur, a Culirni quelyues bons caractères pour des divisions, que l'on peut admellre, et que II. Cuvier n'a pas rejelies de sa méthode.

Telles sont dans lear enseıble les diverses méhodes qui par lear imporlance méritojeat ua examen particulier. Eu les soumettant à la critique, nous avons voulu non alıérer en quoi que ce soit l'estiose que leurs auteurs méritoient, ni diminuer l'importance des services qu'ils on rendas à la science, mais provoquer où clles sout possibles des amćliorations, et fixer sur certuius points cuntestés l'atteution des zoologistes qui pourront les éclairer par des observations unuvelles. Une critique n'est utile qu'autant qu'elle est laite dans l'iutérêt de la science ét dans le but uuique de favoriser ses progrès. Avant d'en venir a celte partie de notre article, dans leçuel nous donnerons quelques délails d'anatomie counparée sur les Mollusques, nous devons discuter dans son application aux animanx qui nous occupent la question de l'unité de conposition; discussion y'ii nous conduira à savoir si les Mullusques sont des animaux vertébrés.

Il est une question très-importante que nous sommes ubligé, par la nature de notre sujet, de discuter de la manière la plus fundamentale que nous pourruns; celte question est celle qui est relative a la comparaison des animaux vertebrés avec ceax qui sonı sans vertèbres, et notamment avec les Mollusques. M. Geoffroy SaintHılaire est le premicr qui ait agité la question: dans son Systeme d'unité de composition oryanique, il devoit chercher à trouver les mêues Elúmens dans tout le règne animal; il a donc saisi avec empressement lous les points d'anaIngie qui se sont présentés à lui, et il a cherclić à en faire une application à son système, application qui, seton nous et bieu d'autres zoolaristes, est évidemmeat forcée, quelquefois même portée à l'exayération.

Pour bien étudier la question, il faut revenir, corne daus la plupart de celles qui sont en discussion, au point de départ, sans lequel il n'est point pernis de s'entendie, c'est-à-dire une rigourense défuition de ce qui doit être examins. Puisqu'il s'agit ici de comparer un auinal vertébré avec un animal sans vertèbres, il fult défnir ce que sont ces animaux.

10. L’unimal vertélré est celui qui est pourvu, $\mathrm{T}+12 *$ 
à l'intérieur, d'un squelelte ariculé qui sert de poiut d'appui on de voyen de protection à tous les organes; il est toujours muni d'un cerveau et d'une moelle épinic̀re.

$2^{\circ}$. L'animal iuvertébré est celui qui est toujours dépourvu d'un squelette articulé intéricur, et qui n'a ni masse wédullaire antérieure (cerveau), ni moelle a!ongée.

11 n'est pas douteux, quand on examine l'enscinble des animaux vcrtélurés, que l'on aperçoit, comme NI. Geoffioy Sain-Hilaire, le plan unique d'organisation que la nature a employé à leur égard. Il y a pour ellx, selon l'expression le M. Geollioy, unité de composition. Celle unité doit s'entendre, non d'une similitude exacte le toules les parties des différeus animaux, mais d'une analogie incontestable qui existc entre eux tous sur un grand nomlure de points londamentaux de l'organisalion. Ainsi, que l'on veuille comparer un mammifère à un poisson on tous autres animaux, en apparence aussi différens que ceux-là, on rctrouvera toujours chez eux des points non équivoques de ressemblance: ainsi une enveloppe extérieure, des mearbres appropriés à la manière de vivre, une têle réceptacle des seos principanx; un cerveau contenu daus celle tête, lestiné à donner de cos sensations, la perception à l'animal; un squelette arliculé contenant les viscères, modifié selon des circonstances d'habitat, loujour's inlérieur et protégeant dans une colonne verlébrale un appendice considérable du cerveaus : voilà les points principaux de ressemblance que l'on trouvera entre les animaux, tout éloignés qu'ils paroiftent; et certes ces puints de ressemblance sont ceux qui sont fondanentaux dass les animaux vertébrés, puisqu’ils se retrouvent daus lous, quelles que soient les modifications extérieures qu'ils aient éprouvées.

Dans toule celle grabde série d’atamaux rertélurés, on truive, comme dans toutes les produclions de la nature, des nuances, des modificalions, des dégradations qui élaljlisseut de continucls passages entre les divers iyjes dont elle se compose : on voit cetle force de la nature se montrer dans la créalion des être en allant du plus simple au plus composé; on la voit astreinte à des lois qualil ne nous est pas toujours permis de deviner, tant il est difficile, malgré la persévérance des observations, de pénétrer dans ses acics les plus secrets. Il a étć permis a l'homme, placé au suprême degré de l'éclielle animale, de découvrir déja des lois fondamentales de la nalure: c'est at moyen de ces découvertes qu'il a pu établir un ordre régulier dans l'arrangement des faits qu'il a observés. Cel ordre, qui n'est point indifférent en lui-même, doit représenter, aulant que nous pouvons l'espérer, la marcbe progressive de la nature ellemème. Lorsque dans cet ordre nous iroupous des lacunes considérables, lorsque nana veyenns cntre deux ordres de chuses ćlablis un esparce que nums n'avons encore pu franclice, ou plutcil dians leçuel la nature n'a encore rien placé, nons devons nous arrêtcr pour resier dans le chann! de l'abservation, et éviler soigneusenent le vilgue des suppositions, des liypoibèses quedes firits ve vienueut pas appujer.

Entre les aniaraux vertélićs et sans vertèbres il existe une de ces grandes lacunes; aussi nous n'almettuns le sysième de M. Gcullroy' SaintHilaire, c'est-à-dire l'unité de compusition, qué pour les animaux vertébrés eux seuls, pensant qu'ils furment dans leur enscmble un lype tcllement à part, quil n'y a plus entre eux et le restc du règne animal que des ressemblances infiniment plus éloignées que celles qui se truuvent entre les groupes les plus disparates de celle premic̀re série.

S'il y a unité de composition pour les vertébrés, nous pensons qu'il y a unitć de composition pour les invertébrés; encore dans celle deraière parlie du règne animal est-il probable qüil existe plusieurs grands emhranchemens, pour chacun desquels la même loi d'unité de composition est mise en pratique par la nature.

S'il existoit une lui unique pour tous les êtres vivans appartenant au règne animal, il n'y auroit véritablement aucune linite pour la comparaison, et l'on devioil, de toute uécessitć, reIronver dans les animaux les plus simples tous les élémens organiques de ceux qui sont plus composés. On sent combien servit ridicule lit comparaison d'un animal radiaire, par exemple, ou d'un infusoir, avec un animal vertébré quelconque.

Ce seroit en vain que l'on chercheroit à diminuer le ridicule de la comparaison en jetant dans l'intervalle la série d'animaux invertéliress, qui viendrait comme un intermédiaire entre les deux points comparés. Nous verrons bientôt quut: cet intcrmédiaire ne peut être admis, parce qu'il noffire aucun des poinls de comparaison recevables. Il y a, ce nous semble, dans une question comme celle-ci, une marclie logique à suivre, sans laquellc on ne peut que s'égarer; quand on veut comparer deux choses, il faut qu'il y ait entr'elles des termes comparables, pour que l'or puisse en déduire une ressemblance quelconqur. Nous pensons que pour comparer les animanx vertébrés à ceux qui sont sans vertèbres, il faut prendie dans ceux-ci les moins avancés en oruranisalion el dans ceux-là cellx où cette organisation est la plus complète : c'est le mnyen de diminuer l'espace qui exisle entr'eux, et d'avoir le plus grand point de conlact que l'on puisse espérer. Celte marche auroit sans doule ós suivie; mais il fallut bien s'apercevoir, malgré lonte la tendance gue l'on avoit à trouver des unalogies, 


\section{$\mathrm{MOL}$}

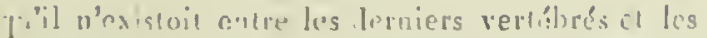
W'anjers invertébrés qu'une ressemblance extrêincment éloignéc, et qu'il existoit un grand hialus entre les deux classes. C'est alors que l'on chercha dans des animaux inlíriears des termes de comparaisons que l'un uc pouvuit rrouver ailleurs; c'est alor's que M. Geoiliuy, sautant au-dessus de trule lit clasce tes Mollusques, alla trouver dans lis aninasux articulés la contirmalion et la preuve, sclon lui, de sit lui universelle d'unicé d'orgnanisation. Il a dnnc lallu que l'auteur prit l'animal verćluré le plus inférieu qui, couver's d'une carapace solide, semblent avoir le syutence deliors, pour le comparer avec un cruslacé on tout aulre anional articulé. Nous répéterons encore que pour étre convenililement faile, les termes d'une comparaisun doivent être comparablus; aussi, nous le demandons de bonne fui, quand on aura fait des efforts considbrables pour lrouver de la ressemblance entre ces deux êtres, aura-ton empêclié que l'un reste véritablement avec un squelette et l'aulre avec la peau durcie qui sert d'enveloppe a ses organes? Nous ne croyons pas que l'cn contestera que l'enveloppe des animaux articulés snit autre chose qu'une peau durcie; nous renvoyous celles des personnes qui en pourroient djuter aux iravaux des naluralistes qui se sont le plus occupés de cette classe d'animaux. Il nous suffira d'une seule preuve, c'est que les animaux arliculés, par leur organisation, changent de peau, ce qui a'arriveroit pas si cette partie éloit un squelelle exlérieur. On voit un cerlain nombre de vertébrés de la classe des reptiles changer de pean a certaine époque de l'année, mais viton jamais un animal vertébré changer de squelette, comme il Caudroit que cela arrivit pour élabli. sur ce point ure parité entre lui et l'animal arliculé?'Il est de toute éridence que l'on ne peut coupare une peau avec un squelelte, car de cette comparaisun an ne peat arriver qu'a une seule conséquerce, la dissemblance la plus parfaite: les deux séries de choses comparées sont, d'un côté comme de l'aurre, dans leurs rapports tellement uaturels, que l'on ne peut les en distraire sans se jeter dans des difficultés insurmontables. Quc dans les vertébrés on compare, squelette à squelette, une série d'organes all'ectés à ccrtaines frictions, on trouvera toujours, comme la raissn l'indiqne et comme l'obserration le démontre, des points similaires qui rendent celle comparaison très-jusle; mais est-jl convenable da comparer un squelette avec une peau durcie, avec une corquille qui est moins cncorc que cette peau, car e!le est le produit d'une sécrétion d'une pelite partie de la surface cutante des Mollusques? Oa sent bien qu'en présentant de celte manicre la question, elle devient a jamais insoluble, ou plutôt elle se résout ea une impossibilité de comparaison. Sous le rapport du squelette il
Mi C I

n'est done pas nécescaice d'insisier davantitue, prisque l'ou ne peut que réporler : ici il y a symu. lelle, la il n'y enl a pas; icil les organes sant appuyés sur une charpente osscuse, lonjours julérieure, conlenue dans la peau, li ils sont dépourvus de celle charpente et enfermés dans la pezn, comme dans tous les aulles animanx, sculenent elle est ducie et brisie par segmens, pour lat fasilité des mouvenuens. (In sait que dans les animaux vertébrés le norntuse des verlèlses cs: illimité en quelquc surte, que leur nature varie; mais on n'a pas vu un aninal récluit à un triespetit nombre, ou níne $\dot{a}$ une scule vertelur:,

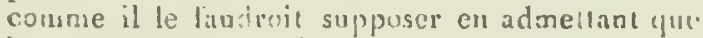
la coquille d'un Mollnsque est me vertèbre di:génćrée. Nous reviendrons lientót sur cell.. conparaisun. Quand méme on pourroit surmanie: celle dilliculté, que nous croyuns invincille, du squelette, il n'en restervit pas moins l'oryanisation tout eulière, qui viendroit mettre obstacte a uae compraison plus étcudue. Il est bien vrai que daus les preniers des animanx invertébrics. il existe uu systènue nerveux, des organcs ds. circulation, des organes digestils, des organe: du mouvement, etc.; mais cet ensemble a mu arrangernent tollement diflérent, des rapports si peu semblables, que nons ne vayons pas pius di: moyens de comparaison que daus le squelell:. Le cerveau e! le système ner réduits à une simplicité qui les éloigne considé. rablement de ce cu'il $s$ a de plus simple dans les animanx vertébrés. Le système nerveux, qui est la base d'une orgauisation quelconque, sulfirat a lui seul pour pronver la disscrmblance cntre les deux types. C'est de ce système que découlen tous les actes d'un animal; aussi nous vojons duns le vertébré qu’il donne lieu à l'intelligcuce. tandis que dans tous les invertébrés on n'observc. aucune aclion qui pût la laire supposer.

Quand on a examiné ainsi la question dans la série des animaux articulés, en supposant même: qu'elle füt résolue d'une manic̀re inconlestable en faveur de la loi d'unité de composition, on n'a:1roit en délinitive que reculé les limites de lintpossible, et il fant toujours arriver à cette granile série d'animaux inférieurs, dont l'organisation est si simple que la plupart des naturalistes, d'un conseotement unanime et presque tacite, loin de chercher à les rapprocher des animaux les plus élevés, n'ont vu de terme comparable que dant les plantes : de cette coraparaison est résultée l.1 dénominalion de zooplites, sous laquelle ils sont généralement cunnus. Il s'élève donc à la tiaite de cet ordre d'animaux un mur d'airain infranchissable, devant lcquel viennent se briser lous les efforts infructueux des naturalistes qui admettent la loi de l'unité universelle. Que cet obstacle soit un peu plus haut ou un plus bas dans la série des êtres, il n'en existe pas moins. Ne vaut-il pas caienx le reconnoître là où l'observa!ion yous 
prouve que la naiure l'a jacé, que de tálier 1.mileaent de le lianchir ou de le reculer?

Revenaot à la questiva, uous vayons yue la rnmparaison se fail, non-sculemeal entre des jartics uon comparables pour les funclions, mais jous voyons aussi que, par un abus de raisonneruent, on en est venu a comparer uhe partie avec ın lour : aiusi, posanı à cólé des auimaux crus1 acés ceux qui, vers la série des Mollusques, ont le plus d'analogie arec eux, nous parlons ici des tirrlipèdes, on a díduit entreux el les premiers une ressemliauce au moyen de laquelíe on a pu lire, les Cirrlipèdes sou $t$ très-aualugues aux Cruslacés; les Crustacés sont vertébrés, donc les Cirrbipides le sont aussi. Mais on n'a pas fait attenliou que celle comparaison ne pouvoil être adunise, puisquion a été obligé de convenir de primeabord que dans les Cirrhipèdes il n'existoil plus yu'une seule veltébre; on ne pourroil douc espéa er que l'on souliendroil avec avantage la comparsison d'un animal vertébré tout entier avec un iutre n'ayant plus qu'une seule vertèbre: on sent que les difficultés s'accumulent, que la question se complique à mesure que l'on reut pousser plus Ioin les investinations, et que l'on cherche à surmonter des diflicultés qui soni sans doute invincilles.

Quant à la comparaison des animaux vertélırés et des Mollusques sur laquelle on a moins insisté, è qui n'a élé trailéc que pa: un naturaliste qui s'éloit peu occupé jusqu'alors de l'organisaiion des Mollusques, il est facile de concevoir qu'elle préseutoit bien d'autıes diflicultés que celle avec lef animaux articulés.

On se souvient du travail intéressanı que M. Latreille a publis il y a quelques années dans les IIémoires de la Société d'Hist. naturelle sur celle comparuisou des Poissous et des Céphalopodes; on se souvient aussi des payes éloquentes du beau Mlémoire de M. Curier sur les puèues animaux; et au sujet de celle coroparaison, ces zoulogistes, conséquens àvec le raisonnement, n'onl point cherclié d'autre comparaison entre deux ordres d'auimaux différens ģue celle qui pouvoit résulter nalurellement des faits et des observations connus; ils se sont bornés à déduire de leur comparaison la distauce immense qui existe enlıe les deux séries et le très-pelit nombre de points par lesquels elles se rapprochent. Celte marche, la seule rationaelle, n'a point été suivie par l'auleur du Mémoire présenté à l'Académie sur le méme sujet. M. Robineau Desvoidy a élé prendre son terme de comparaison parni les Mollusques les plus inférieurs, parai ceux que M. de Blainville net en quelque sorte $e n$ debors de celte classe d'animaux a laquelle il donne le nom de Mollusques articulés, el qui sout plus généralement connus sous le nom d'Oscabrions. De ce que ces animaux sont pourrus d'un cerlaiu nombre de pièces tesiacícs quiles pro:t́gert a lis auaière des carapaces des
Talous, on a cru pouvoir manlrer dans les diverses parties dont ces pluques sunt conposics, loutes celles qui constituent les vertèbres, psais déforruces, suudées, el pour ainsi dire uéconroissables à cause de l'usage auyucl ces vertèbres sont désormais destinées. Icj, comme dans les autres points de la comparaison, on n'a pas fail alledion au point fondaneutal de la question; si les Oscabrions en cflet sont couverts de vertcbies, ils doivent avoir un systçme nerveux en rapport arec les vertèbres. La condition d'un animal vertébré est d'être poursu d'une moeile alongrée: point d'animal vertélurésans celte condition: peuton dire quelle se rencontre daus les Oscabrions? Sous le rapport du systcme nerveux, ces animaux appartiennent évidemment au grand lype des Mollusques, puisque ce système est ganglionnaire, irrégulier, et qu’il ne présente wême pas, comne dans les Crustacés, un cordon médullaire médian; dou aulıe côté, les picces testacées des Oscabrions ne peureal être comparées arec des ver!c̀bres, car elles sont, comme loutes les coquilles, le résulıaı d'une sécrétion cutanée, dont les accroissemens se funt par superposition de couches, el non par inlussuception, comme elle a licu dans les os des animaux vertébrés. Dans ces deraiers, les pièces osseuses reçoivent chacune un cerlain nombre le vaisseaus destiués à en opérer la formalion dans le foetus, l'accroissement el la réparation; ces os reçoiveut également des parlies du système nerveux, el rendent à la circulation la partie du sang superllue par uz système veioeux considérable. Rien de tont cela, qui est cependant la base fondamentale d'un sysic̀ne osseux, ne se rouve dans les pièces d'un Oscabrion, ni dans un corps testacé quelconque provenanl des animaux mollusq̣ues : ici, conséquemuent, la comparaison ne peut pas se faire avec plus d'avantage que dans les Crustasés, ct moins encore peul-êlre; car les termes de la comparaison sont encore plus éloignés. Nous avons vu que dans les Crustacés on comparoil une vérilable peau durcie avec un squeletle intćricur. On discit: L'animal vertóbré porte en dedans ce que le crustacé porte en debors. D'un 'ôlé il est contenu, de l'autre il est coutenan!. Quaal aux Mollusques, on ne pourroit faire le même raisonnement, car ce n'est même plus d'ure peau durcie dout ils snnt couverts, mais d'une excrétion de celle peau, ce quiles éloinne encore plus des vertélyrés que les Crustacés eux-mêmes : que celte excrétiou soil en une ou plusieurs parties, clle n'en est pas moins fondamentalement, sux ycux de lout homme qui pense juste, uac dépeudance de la pesa el non un sysic̀ne osseir.

En remontant des O.calprions vers des animaux mulluspues donl l'urananisalion est plus avancée, ou saperçoit, par le peu de constance des pièces testacćes qui les couvrent, combien elles ont pen 
d'impor!ance dias leur nrganisaticn : on vuil, par la plare qu'clies occupent dans crrains de ces animaus, soit à l'iulćrieur, soit à l'extérieur, qu'elles sont destintes, comme l'a lrès-bien dit 11. de Blainville, à protégrer une série d'organes, ceux de la respiration el de la circulation, yui ea sont, en quelque sorte, ure dépendance.

On ne peut dire que cetle circonstance existe au mếme degrés dans le système osscux des vertélirés: sans doule que le squelelle sprouve de grandes modilicalions; Il suflit, pour s'en assuer, lie mellre l'un à côlé de l'aulre des squelelles de poissons el d'oiseaux, de reptiles et de unamınifires; mais enfin le squelelle existe loujours sans aucune exception. It n'en est pas de mène dans les Mollusques, dont un grand nombre mangue coristamment de copuille.

Dans les Mollusques les plus compliquís de ıus, les Ciphal spodes, la coyuille, quoique souvent incérieure ou subintérieure, quoique souvent anssi parlagíe en un grand nomlure de cloisons simples ou compliquées, n'en est pas moins une coquille, en cont comparable, porir sa formaion el sa nature, à celle des Mollusques plus inférieurs. I.es coquilles se refusent, par ies mêmes prinripes, a une comparaison avec les vertèbres : s'jl exisle des analogies entre les animaux yui les produisent et ceux qui sont placés dans la sćrie leaucolip au-dessus d'cux, les aualogies ne se montrent que dans l'ensemble de la composilioo rganique, qui, comme uous l'a vons déja piésenté, laisse entre enx un imanense hiatus.

Par un moyen iogéaieux, un jenne analomiste a préseaté, il y a peu de lemps, la comparaison d'un auimal verrébré très-simple avec l'un des Céplialopoles le mieux connu, le l'oulpe; il a supposé l'animal verlébré dépourvu de sysic̀me ossenx d’abord, et ensuite ployé par le milien du dus, de manière à faire toucher la léle au bassin. Par ce renversement, il trouvoit mnyen dexpliquer le rapprochement du tube anal de la base dı col dans les Céplualopoles et quclques antres phénomènes de leur ormanisation; wais M. Cuvier, dans le rapporı qu'il a lail à l'Acad'́mic sur ce travail, remarquable d'aillcurs, a démnntré d’une manière bidente que ce n'éloit point par le clos qu'il falloit ployer l'animal, mais bien par le ventre, pur que la comparaison fut aussi complète que possible. Malgré tout ce qu'a d'ingrénienx relle comparaison, les puints fondamenlaux lui manquent lonjonrs, ciest-i-dire que ce Céplialopode n'a ni squelelte, ni syslime oerreos qui suil approprié.

Il nous semble, d'aprés ce qui vient d'ètre rlit, sur la question d'analngic entre les Vertébrés et les Invertibrés, que l'un peut conclure que les deux "randes prarties du rigne animal sont nettement sreparies, et sont daus des conditions d'organisalion entièrement différentes. Celle dillïrence est celle, qu'elle rend impossible, entre eux, une conparaison minulieuce, et que dars recrain; d'enlre eux, ils n'ont plus rien de commun qik. parce quils sout également des conps vivans. Enir: ces aumaux simples et ceax qui sont placís an haut de l'échelle animale, il y a une dillérence: inliniment plus grande quícnlie eux er le véućtal. Comme janais un n'a cherclić a trouver d'ablie analogie entre les v'égéliux e! les animanx, qu: celle qui découle des conditions priwordiales dl: la vie, nous ne perisons pas que l'on puisse dísar. ntais, avec araulage, tenter de nourax stlor: pour tronver de la resscmulance entre des érre qui dillirent antant entre eux que les deux grall-des parlies des êlres vivans, les végúlaux el les animanx.

Nous lerminercns ici ces considérations sur urat question inléressante el importante foul a la foris; If nous a sulfi de montrer en rúsumé quels ét ient les poinls de départ qui ont servi de base au: raisonemens que nous avons combatlus, cu leu: opposant avec d'aulres raisonuemens des principes qui nous semblent justement déduits de: fails, jusqu"à préseal adınis daus la science. 11 nous paroît jusle de ne comparer des systènies d'orgagisalion qu'aulant qu'bl y a cu ellet entle eus. quelgues points comparabliles: nous avons dû rejeter celle comparaison l'un système osseux et d'un système culané, parce que rien, en effei, n'esl comparable, et rentrant dans une jus:e limite, Dous avons arlmis, en la restreignant aus. seuls animaux oi clle soil verilablement applim quable, la loi d'unité de comprasition.

lorsque l'anatomic comparée des animaux sans. vertchres scra aussi avancice que colle des animaux vertébrés, on y lrumvera les fondemers d'une loi semblable ì célle découverte par M. Geo!froy, en cela qu'clle démontrera que dans ces arimax la nalure a suivi un mode de formalion clilfírent de celui qu'elle a mis en pralique pon. les animanx supérieurs. Il sen laul bien mallienreusement que l'anatomie comparée des animaux inrerlćbrís soit aussi avancée quil le faudroit pour en déduire des Inis ginérales dorganisalicn; a peine si quelques-unes des parties de la scienct. sont ébaucliées sous ce rapport. Les animaux arliculés sont, sans contredit, les mieux ccnnus, et quoique leur nombre soit considérable, ils re formeut cependant qu'une peite parie de la grande série des Invertélmés. I'our ce qui est dis Mlollusques, presque lout cst a faire, el jusqu'a présent, des observations anatomiques liailes à leu sujet, on n'a pu établir un corps de doctrine, a cause des lacunes nombreuses qui se rencontrent dans les connuissauces acquises a leur sujel.

Nous nnus proposons, dius un résumé aussi concis quil nous sera possible de présenter, fic melle en regard les observallions consignces dans la science jusqu'à ce jour, en y ajoulaut, loisque nous en aurons le moyen, les considérations géníales nui pourrone se dédnite de l'enserable des 
ficis. Nous n'avons pas la prétention, dans un essai comme celui-là, de donner une anatomie comparée complète des animaux mollusques: comme nous le disions, bien des matériaux nous nauquent encore; mais il ne sera pas inutile, nous l'esperons, de présenter un tableau abrégé des modilicatious assez nombreuses qu'éprouvent les divers systèmes d'organes dans celle séric d'auimaux. Nous pourrons, par des olsservations qui nous sont propres, remplit plusieurs des lacunes qui existent dans les connoissances analngiques des Mollusques; wous indiquerous celles qui resient encore dans le but d'exciter sur elles les recherches des naturalistes.

Nons prendrons pour terme de comparaison celui des Mollusques dont l'organisation est la plus complète; elle nous servira de mesure à laquelle nous viendrons sucçessivement préscnter tous les autres animaux compris dans la même graude division, et nous anuoterons les dilléreuces observées. Ce sera par conséquent un animal céphalopode qui nous servira de point de départ; nous supposerons cet animal sufisamned connu dans toule son organisation, et celte supposition est gratuite de notre part, puisqu'en eflet l'anatnmie des Céphalopodes est plas avancée dans ses détails que la plupart de celle des autres familles.

Dans l'examen rapide que nous ncus proposons de faire des clivers organes qui coustituent les Mollusques, nous ne les prendrons pas au hasard, nous examinerons chacun des grands systèmes organiques affectés à des finactions bien distinctes dans leur ordre d'importance : $1^{\circ}$. système nerveux; $2^{\circ}$ organes di nestifs et des sécrétions qui en dépendent; $3^{\circ}$. organes de la génération; $4^{\circ}$. organes de la circulalion et de la respiration; $5^{\circ}$. système musculaire général et particulier; $6^{\circ}$. enfin organes des sensations.

\section{S. I r. Système nerveux.}

Le système nerveux, comme nous l'avons dit ailleurs ct comme cela est prouvé depuis longtemps, est la base fondamentale de toute organisation. Des animaux les plus simples, eux senls paroissent déponrvus de système nerveux apparent : aussi la plupart des zoologistes pensen! ciue dans celte série dinimaux, la malière nerveuse est égalemeat répartic dans loute la masse; ce qu'ils supposent pour pouvoir rendre compte de quelçues phénomènes de leur vilalité. Quelle que suit l'opiuion que l'on puisse avoir à cet ćgard, it reste certaiu gque l'organisation des animaux est d'autant plus parfaite que le systime nerveux est plus complet, et qu'il se trouve toujours en harmonie avec la composition organique de chacun d'eux.

Dans les MIullusques, Ie systeme nervenx est essentiellenent ganglionaite; il représente en quelque sorte le sysicuc du grand trisplanclinigue des animaux vertébrés, sans que cependant celte comparaison soit exacle dans toutes ses parties.

Néanmoins, si ou veut trouver de l'analogie evtre le système nerveux des Mollusques et celui des Vertéprés, ce sera plutôt avec le grand sympathique qu'clle se montrera qu'avec le système nerveux général, dépendaut du cerveau et de la moelle alangée. Ce qui vient ì l'appri de ce qui précède, c'esi que les Mollusques n'ont pas un cerveau proprement dil : l'anneau osoplaagico, composé de quuatre ganglious rémnis, remplace daus ces animaux le cerveau des verlébrés, en ce qu'il est un centre plus actif de perceptions que les autres parties du sysième; mais il ue constitue pas un véritable cerveau, à moins que l'on ne modifie et que l'on n'altère d'une manière très-grave la définilion du cerveau dans les Vertélorés. De l'absence du cerveau dans les Mollusques, il en résulie nécessairement l'alssence d'ıne moelle épinière : voilà donc un système nerveux de la plus grande importance, qui entraine avec lui l'existence d'un squelette dans les animaux qui en sont pourvus, quı manque entièremeut dans les Mollusques et lout le resie des animaux sans vertèlures. Ce seroit bien vainement, comme on le voit, que l'on feroit la tentative de cbercher l'unité de composition dans des animaux aussi dilléremment organisés que les Vertébrés et les Mollusques, puisqu'il faudroit, avant tout autre fait, prouver qu'il existe dans ces derniers un cerveau, une moelle alongée et le système nerveux qui en dépend.

Considéré dans son ensemble, le système nerveux éprouve des modificalions remarquables dans la séric des Mollusques; on peut y trouver deux manières d'être fondamentales, l'une qui apparlient aux Mollusques céphalés, et l’autre aux Mollusqques acéphales. Ces deux grandes divisions du système nerveux a voicat engagé Lamarck à séparer comme classe les Acéphiles des autres Mollusques, et à les placer an mêne degré dans sa méthode. Peut-être les méthodistes reviendront-ils plus tard à celle idée, qui ne doit pas être définitivement rejetće.

Du cerveau ou annead cesophagien. En suivant rigoureusement la définition que les anatomistes donnent du cerveau, les Mollusques seroient privés de cette partie si essentielle du système nerveux. Plusicurs \%oologistes ont senti d'apics cela quil éloit nécessaire de donner un nom particulicr ì la masse principale el antérieure du système nerveux des Mollusques, et comme elle affectc la forme d'uu amneau à travers lequel pusse l'uesophlage, ils unt proposé le nom d'annecaze asophagien, qui est cortameuent prélérable $\vdots$ celui de cerveau. L'annear oesaphagien, daus les Mullusques, est le phus ordinibeinent composé de qualre gauglions principaux réunis entr'eux par des ucrls transierses, ordinatrement gros et courts, gui se rendent de l'un in l'autre. Ces ganalions 
r̈:Oons sent disposís de manicre qu'en supposant iruiasal asarchat sur ua plitn horizuntal devat luhserrateur, deux sont suprificurs et deux sout infírieurs; ils sont symétripues, cest-à-dire que l:s deux supérieurs ainsi que les deux inléricurs suat semblaules.

10. Dansles Céphalopodes, l'aunean asophagien est proporionnellement plus considirable gue dans les autres Mollusques. 11 est tormé de guatre grus ganglions yu'il est assez diflicile de tisinzue Iris-justennent, parce que les branches qui les rómissent snnt l'is-grosses. Ces bianches de jonction sont au norubre de deux seulemeal; elles sont grosses et courles: les ganglions se touchent cians la liune usédiane par leur bord interue, les supériemrs eotr'cux ainsi que les inficricurs : outre res qualre ganglions principaux, on en trouve denx autres fort considérables, auxym Is M. Cuvier a donué le nom de ganglions en patte àose. On vout un de ces ganglious de chaque coté de la tive; ils sont destinés à fournir quatie ou cimy - losses branclu's qui se rendeut aux bras gui muromnent la léte des Céphalopudes : ils ne loulnincont que quatue brauches dans les Ciphalopules octopucles, il y en a cinq dans les Décapudes.

Le centre nerveux principal est protégé, dans les Céplualopudes, par un andeau cartulagineux ussez sulide qui l'enveloppe eu partie, el qui est fercé de l'ous porr le passage des nerfs : ce carlilutre nest puinı un vérulable critine, il a'a quoue ressemllince fort úluignée avec le cułne des vertébris; et cela se concevra rrès-facilcuent, pussqu"il ne contient pas un véilable cervean. Il est nuvert à sa base, et son sommet sert d'appui aux hras. Il est peu régulier; il est creusé lácérulement de deux cavités auditives, rudimentaires, qui n'ont aucuac issue à l'extérieur, et il fournit une insertion solicle i la connée opaque de l'uil, qui semble n'en être qu'une expansiun latérale. II n'csı fermé par le bas que par un rissu cellulaire assez serré, qui lie avec lui lés organes cuntenus dans le sar.

Sous avons vu, en rendant compte de la méthocle de M. Rang et de celle de M. Curiu:, seconde édition, quil étoit rationnel, en suivant l'ordre décroissant comme eux, de placer immédiatement après les Cóplıalopodes les Gastéropodes monoiqques on à sexes séparés : c’esı lia l'ordre adopté par Ml. de Blainville dans son Traité de Aralacologie; et sil'on veut y faire allention, c'est aussi la disposition que Lamarck a donoèe à ses familles, quoique dans un ordie inverse. I1 tiut ajouter, pour ćtre juste, que la marche adoptée par Lamarck, bien que naturelle, n'éloil pas appuycé sur les faits, et cette considération si imprrtante des sexes n'étoil entrée pour rien dans les molifs qui ont déterminé l'ordre de sa méthonde.

2". Dans les Gastéropodes dioïques, l'anneau Hist. Nat. des Ters. Toms II. œsoplazgien est moins considérable proportunneslenent pine duns les Cipplablopodes; les ganģ lions sout grincialement plus isolés, les filets tunsverses rui les jugrani (1ant plus grëles et plus alougrís. Nums allons indiuguer les principales modilicutions de celle partie du sysltue nervenx daus celle sćrie assez considirable des Mollusques.

Dans la faunille des Enroulés, dont les Cónes doivent être sépurés, le genre l’orcelinine seul nous est connu. Quant a l'urganisation des aniunaux dans ce geture, l'anncilu asoplagieu rst assez consićralle; il est plus étendu proportionnellemeat que dans les Fuseaux el les Rochers : il est composé de deux ganglions suprérieurs, oblongs, pulpeux, accolćs is ieur partic antérieure, et prolongés latétalenient sur les côlés de l'oesopliage. Deux lilets latéraux les joinnent à deux gun gun lious intérieurs qui sunt à peine de la moitić de la gros. seur des premiers. Une bande médiane, transverse, large el courte, rónnit les deux gangliuns inférieurs ét conulète l'anucan cesoplacrien.

Les âulaes gences de la fanille des Euroulés ne sont pas encore connus perur la plupart de leurs détails anatomiques. Les (jvules el les Olives, caracterisés par $\$ 1$. de Blainville dans son 'Traité de Malacologie, sont les seuls sur lestuels on ait quelques renscimner.ens, 110p incomplets encore pour fare paric d'un t'avail génćral c'unatomie. Il fu est de mème anssi des genres counpria dans la famille des Columellaiies de Lamarej; les Mlizes, les Colonbelles, les Tuluies, les Marginelles et les Volvaires, comus dars leurs formes extélicures, ne le sont allcunement dans leul analtomic profonde. Bientít, par la publication des importans travaux de 11. Quoy, la science possidera rons les materiaux nécessaires pour renplio celle lacune si considérable. Nous pourrons donner des détails étendus sur plusicus gerres de la famille des Purpurifères. Eu zénéral le cerveau, on plutôl l'anneau asoplagicen, est encore plus réduil que dans les genres de la fanille des Enroulés ou des Céphalopodes. Dans les Cassidaires, les cleux ganglions supérieurs sont oblonrrs et guidiangulaires, accolés dans la ligne médiane, et réunis à deux petits ganglinns inférienrs par denx très-pelites branches latérales el une bride médiane qui complèıe l'anneau. Une lranclie extérieure, gui naîl de l'angle supérieur du ganglion droit, donne raissance à un petit ganglion pour les organes de la génération.

Dans les Pourpres il est lort difficile d'apercevoir le cerveau, tant il est petit et enveloppé d'uu tissu cellulaire dense et serré ; c'est du moins ce qui existe dans le Purpura hemastoma, que nous ayoos examioé. Dans cet animal on observe quatre ganglious arrondis, graniformes, qui communiquent entr'eux par des lilets latéraux et inférieurs extrèmement déliés. Nous n'avons aperçu aucun gangliou particulicr pour les organes de la génćralion. L’aniual de la Harpe, dont M. Raynaud TV * 
a dumné une loone analonie, esi das le mîme cas que celui des l'ourpres; le ccrvenu y est tiespetit, et ce n'est qu'avec peine qu'ou parvieut à le déconvrir an-dessus d'une léle qui, elle-même, est exirêmement pelile: quatre giains I ulpelıx, dont les inférient's sont plus petils que les supérieur's e! plus éloig̣ués entr'eux, for'ment l'auaeau a'sophagieu avec les filets de joaction.

Le genre Bucciu est beaucoup mieux connu que ceux rue nous venons de meulionner. l.e inérnoire cle M. Cuvier ne laisse rien à desirer sur la conmoissance exacle de son organisation; les ganglioas supérienrs sont proportionnellemeat plus frrands que dans les genres Harpe el l'ourpre; ils sout ovalaires, oblongs, placés lungiludiualement de cliaque cóté de l'osophage, et réunicà lenr partie antérieure par une branche grosse et courte; les ganglions inférieurs sout petils, ciuadragulaires, et réunis aux supérieurs par de, brauclues lacérales, courles, mais fort ninces; le ganglion supérieur du cólé droit fournit plusicurs filets qui donacnt naissance an ganglion des organes de la grúrération. De celle famille des Purpuriferes il resie à connoître les genres Casque, Ricinule, Licorne, Concluolépas, Youne et Vis: les rapports des Casques avec les Cassidaires font présomer, avec quelque raison, quils ont une ormanisation semblable. On peut avoir la même présompiou bien fondée à l'ćsard des genres Ricinule, Licorne et Conclinlćpas par r.pport aux lourpres. Quant aux Tonnes, leur analowie avec les Harpes el les Buccius parait lus éloịnnée, el c'est de loas les g, cares compris dans les l'urpurifères le plus important à bicn councître.

A l'exception du Postellaria pespelicani, dont l'animal est coonu à l'extéritu:, fous les autres a aimaux apparlenan ì la fumilie des Ailées de Lamarck sont jusquı'à présent restús inconnus dans leurs détails analumiques. Le Rostellaire, que nons renons de citer, est trop abondamment répandu dans nos mers pour quill reste long-temps iaconau dans ses délails anatowiques.

Le genre l'tćracère a été figurć par MII. Quay et Gaymard dans l'sitlas de leuz premier voyagre de circumnavigation; ils nont dunné nalbeureusemeut aucun délail sur ce grenre curieux, quaique très-répandu áas presque toules les mers: les Strombes sont eucre moins connus que les Ptérocères. A l'égard des Côncs, que plusienrs anatomistes rapprochent, d'après la coquille, des genres de la lamille dont nous nous occupons, on conaoît mieux leur strucıre : dans ce grenre, l'anneau œsophagien est, comme à l'ordioairc, formé de quatre ganglions, les deux supérieurs sont quadrangulailes, aplatis et réunis sur la ligne médiane dans toute leur loogueur ; plusieurs lilets qui parteat de l'aogle inférieur de chaque cóté passent en dessous de l'osoplage pour aller former les deux ganglions inférieurs, qui sont pres- que rudimentairç. On trouve dans ce genre, comme dans les Buccius, les Porceluines, Ac., un petit ganglion pour les moganes de la génériltion, ganglion gui nuit d'un lilet déraché de l'angle supérieur du ganglion du cơlé droil.

l'armi les gevies de la famille des Canalifères, on a'eo compte qu'un petil noubre qui soit complélement counu; quelques-uos cepeudant sout abondanment ripaudus dans uos mers, et il est diflicile à concevnir comment on ne s'en est pits encore occupé. I,es genres Cúrite, Pleurolome, Turbinelle, Cancellaire, Fasciolaire, Sirulliolairc, Ranelle el'l'riton, connus à l'extérieur, ne le sout pas encore dans leur anatomic; if est viai qrae plusicurs de ces gentes snnt artiliciels, que les liuscaux et les Pyrules noflreut aucune distinction fondamentale : il en est de même des Rochers, des Ranelles et des Tritons.

Plusieurs Fuseaux ont quelqu'analogie avec les Buccins par le raccourcissement considírable du canal, qui est placé à la base de la coquille. Les animaux de ces cspèces participent, anssi bicn que la coquille, à la ressemblance avec les Burcins; ainsi le luseau du Nord nolfre presquaneune différence, quant à l'animal, avec celui du Buccinum undantum; le cerveau est disposé de la nuême manière et présenle à pư prés la aê.x.c forme; les ganglions dont il est formé sont proporlionnellemeat un peu plus petils, embrasaant l'asophage plus étroilement, et fomraissant d'ailleurs des branclies pour le gangnliuu de la gúcúraliun. Il seroit à desirer que l'organisation des espècus de Fuseaux rui oat a la base un canal tris-long, soit complélement conaue puur pouvoir la cuniparer avec celle des especes que nous menlionnons.

I.es Rochers ont un animal Jont le cerrean differe peu de celui des liuseaux. Le docten. Leibeln a donnć, dans le ione 14 des Annales des Sciences naturelles, une anatomie forl complète du Murcx brandaris. Ce Mollusque, qui fouraissoit aux Aaciens la belle couleur pourpre. est 1 rés-abondant dans certaios parages de lat Médilerranée; son cerveau ne semble formé quc de deux graglions, ee qui tient à la nanière dunt les deux paires sont réuaies intimement dans lat ligne médiane; les deux supérieurs, dans leur. ensemble, furment une plaque subyuadrangulaire assez miuce, dont il part un très-grand nombre de filets, et entroulres, de la partie antrírieure, deux latírax tıès-lius qui se rendent aux gauglions inféricurs : ceux - ci sont à peine du cinquième des supérieurs, et ils ne fouraissent qu'un petil nombre de filcts destinés principalcmeal aux parties antérieures de l'animal.

Il n'existe pas une aussi grande différcuce qu'on pourroit le croire eotre les Mollusques uvi ont la coquille canaliculíe ou éclıancrée à la base, c't ceux qui on la coquille enlière : daus ces derniers, en effet, l'animal fait saillir aussi un lcnur 
luyau charnu destiné à porler l'cau sur l'appareil brauchial ; muis comne ce turau ne fait sal]lie runc momentanément, il ne laisse sur la cuquilie aucune trace de son passage, ou plutôt elle "iien est aucunement nodifié, tandis que, dans des Mollusques à coquil!c échancrée ou caralicaléc, ce tuyau charau étant constamment en s.illlice a modilié par sa présence la lurne de la basc de la coquille, et y a produit, selou șa longueur, une écliancrurc ou un canal. Tout en réduisant à sa juste valeur le caracière des coquilles enticices ou canaliculées, il faut aéannoius convenir qu'il est l'indice extérieur de modifications plus profundes dans les animaux : nous apercevrons quelques-unes de ces modifications dans le système nerreux, et nous les verrons se continuer dans les autres systèmes organiques.

Nous avons va, en général, que plus les animax out un systc̀me nervenx parfait, et plus les diverses parties qui constituent l'anueau aesophagien sout resserrées et ont une tendance à se co:luodie: il n'est pras étonnant, en passant d'un ordre de Mullusques dont l'organisalion est plus parfaile, vers un autre ordre dans lequel les organes de la génération surtout sont considérableineut modifiés; il nest pas ćtonnant, disonswous, de voir un syslème nerveux avoir une tendauce à se simplitier el a se rapprocher de celui des Mullusques acéphales.

La famille des Turbinacées de Lamarck se compase de plusieurs genres qui, puur la plupart, sont connus dans leur anatomie; nous cilerons les 'Troques, les Munodontes, les Turbos et les Phasianelles. Le cerveau, dans ces geures, est réduil, d'ałrès NI. Cuvier, aux cleux ganglions supérieurs, très-ćcartés el juints par un fllet transverse, long et mince. L'anneau œsophagien est complété par un filet simple qui s'étend d'un ganglion à l'autre, en passant en dessous de l'osuphage. Celle disposition des parties du t:crveau est si différente de ce que nous avons vu précédemment, ģu’il est nécessaire de la noter avec soin pour la voir plus lard se mellic en accord avec les antre's systemes d'urrancs. On remarque peu de différence en général daus le cervean des quatre genres que nous avous menlionnés : les deux ganglions sont ou arrondis, ou ovalaires, fort petits relativement à la grandeur des animaux, et sinés sur les parties lacúrales de la masse bucale, où ils donneut des lilets rayonnans; le ganglion des organes de la génération parait manquer constamment, et ne se montrer de nouveau que dans le type des Irélices et des limaces. Si la présence de ce ganglion doit avoir quelqu'influence sur les rapports à donner aux Mollusjues entre eux, il n'est pas douteux que lés IÍlices ou plutôt les Pulmobrauches, nc doiveat, dans l'ordre de la méthode, venir se placer li-s premiers après les. Mollusques dont la coquille csi caoaliculée ou écbancrée à la base. Ce carac- tire rest pas le seul, comme ncus le verrons plus lard, qui soit tavorable à cet arrangement.

Les Scalaires et les Dauphinules, qui forment, avec les Vermes, la fanille des Scalariens de Lamarck, appartiennent, par leur organisation, a la famille des 'Tubiuacés, dont in us avons parlé précédenment; les Dauplinules ac sont qu'une très-légère modilicaticu des 'Turlans; et les Stalaires paraisscul se rapprocher des 'lurrirelles, du moius par l'ojercule. Nous espérions pouvoir donuer sur les Sralaires des délails d'organisation, mais nous en sımme privé par suile de la pourriture des individus de la Méditerranée sur lesquels nous complions.

De la famille des Macrostomes de Lamarck, famille qui doit être nécessairement réformée, deux geures seulement nous sont actuellement connus quan à lenr anatomie, le Sigaret ct l'Haliulicle.

Les Sigarets se lient aux Natices par des nuances insensibles, depuis les especes qui ont la cocunille intérieure cutièrenenl cacbée dans l'ćpaissenr du manteau jusqu'a ccux qui ont celle coquille subépidermée el en partie décurnerte. Lour anatomie moutre cntre enx et les Natices quelques diffisrances peu considérables, il est vrai, mais quil est nécessaire d'apprécier pour la distiaction dos genres.

Dans les Sigarets, les filamens du système nerveux sont d’une grande ténuité, les ganglions œsophagiens sout eux-mêmes furt pelits; les deux supérieurs sont rappruclés, subtrigones, et communiquent entre eux par une branche large et cuurte. Les gauglions inférieures sont plus petits que les supérieurs; ils sont subgraniformes et accolés dans la ligne médiane; ils sont juints aux supérieurs par des brauches latérales, grêles et assez longues.

Le genre IIaliolide diflère considérablernent de tous ceux que nous avons exandinés jusquà présent : l'anneau osophagien est très-grand, composé de trois ganglions seulement, deux sont antérieurs el situés de chaque cúlé de l'osophage, it la base d'une masse bucale, assez large, qui les tient fort écartés; une branche sirnple, arquée en avant, sert à joindre sopérieurement les deux ganglions. De leur extrémité inlérieure, qui est profondément bifurquée, partent, de cla aque côté, deux braches profondes, fort alongées, qui gauncnt, en se courbant l'une vers l'autre, le point de jonction du muscle central, avec la partie antérieure du pied. C'est dans ce point que se trouve le truisieme ganglion, qui est sous-œsopbagien : les branches nerveuses qu'il fourait sout destinces, pour le plus grand noubre, à la grande masse mosculaire du pied, et quelques auties aux viscères. De tons les Mollusques à coquilles spirale, celui des Haliolides s'approche lc plus des Mollusques bivalves, par la grande $\checkmark \vee \vee 2$ 


\section{$52 i$}

II O L

étendue de l'aunean cesophasien et, comme nous le verrons plus tard, par la disposition du coent.

Les Janlhines, fort éloiguŕes des Haliotides et de la plupart des Mollusques qu'on a mis dans leur voisinage, ont les ganglions asophagieus fort pelits, ei l'anneau doat ils font partie est fort étendu : ce qui tient viaisemblablement au diamètre très-cousidérable de la masse bucale et de l'usoplarge. Les deux ganglions supérieurs sout sublatéraux; ils soat quadrangulaires, et la branclıe qui les réuait est langue et grêle. Les ganglions iuférieurs sont rapprochés, arroudis, et se touchent dans la ligne médiane par un point de leur circonférence; il commuoiquent aux précćdens à l'aide d'une branclıe anastomotique, longue, mais très-ténue. Les Natices, que Lamarck a placées dans le voisinage des Jauthines, dans son ordre mélhodicjue, s'en Gloignent beaucoup, en cela da moins que l'anneau esophagien est très-étroit. Les deux ganglions supéricus sout oblongs et à peine séparćs; ils fournissent des filets nerveux en grand nombre, taut aux parties antérieures qu'aux parties postérieures de l'animal; les ganglions inférieurs, rénais par une cummissure médiane, sont plus petiis que les premiers, et ils sont joints à eux par des branches latérales, grosses et courtes.

Il es: a présumer que dans les Nériles, si voisioes, par leur corjuille, tés Natices, le systeme nerveux n'oltie pas de griandes diflírcuecs. Nous ne pouvons douner aucon détail sur leur structure intéricure, et nous passons a la lamille des Faludines, su laquelle M. Cuvicr a donné de précieux détails. Dins les I'aludiucs, le systéme nerveux, assez leveloppé, ne présente cepeudant que deux ganglioas autérieurs assez consiltínbles; M. Cuvier oe décrit ni ne ligure les ganglions inférieurs, cc gui feroit supposer qu'ils n'existent pas dans ces animaux. Une anomalic si remarcjuable auroit été certainenueut précisée pau ce savant anatomiste, si elle eût eu lieu; mais elle n'existe pas, et nous avons pu nous assurer, par de nombreuses dissections, que les Paludines ne faisoient pas exception à la régle si générale, dans les Mollusques céplualés, d'un aoneau cesophayien formé de quatre ranglioas. Les deux yauglions supérieurs sont fort gros, subovalaire, séparés, et se communiquent par une branche médiane, grosse et conrte; deux petites brauches lapérales, courtes et grêles, conduisent aux ganglions inlérieurs, qui sopt fort petits, granifurmes, ei joints par leur angle supérieur. Les nerfs qui partent de cet amaeau esoplagien sont furt nombreux, et nous aurons loccasion de. Jesimentiouner plus tard.

Les Ampullaires ne diffèrent presque en rien des Paludines, et leur système nerveux n'offrant aucune modification particulière, nous nous dispenserons d'en donaer la descriplion.
MOL

Les Pulmonćs aqualiques sont comnus pour la plupart : les Lymućes et les Plaworbes, si aomdaus dans les eaux douces de l'Europe tempéríc, appartiennent à celle famille. Daus le prenier rle ces gemres, l'anncau wsophagien est très-ćpliti; les ganglions réunis par des branclies si grossts, qu'ils semblent se confondre dans une seule mass: nerveuse. Cependant on voit distinctement tot ganglions antérieurs, qui ont lis lorme de dcus petils renflemens sublriangrulaires; les augles aulírieurs et internes se réunissent, tandis que lts angles antérieurs et postérieul's se joignent aux gavglions inlé:ieurs. Ceux-ci, à peine indiqués, se réunissent iulimemeat dans la liunne médianc. Dans les Planorbes, dont l'anneiu oesnphagien est couvert par une sulistance glanduleuse, les ganglions sont plus isolés que dans les Lyunuées; il: n'en diffèrent au reste que par les branches de réunion, qui sont plus grêles et plus longues.

Le graud type des Hélices est parfailement connu depuis les belles anatomies de M. Cuvier. Dans ces muimaux, sur lesquels nous avons lit:t aussi des recherclies assidues, l'anneau cesopliagitu semble lorné de deux gros ganglions seulemen!; ce qui provient de ce que les deux paties a!e gnat?glioas sont soudées par leur bord interue dans i: Jigne médiane : on distinguecejendant plus facilement les deux ganglions antérieurs que les postérieurs, qui forment ube sen!e masse arrondic. Les ganglions antérieurs sont tort gros, aplittis, trausverses, lournissant, par lcur extréalité anli:rieure, un grand noubre de brasules irradices;

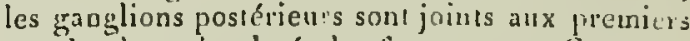
par des branches lalérales furl grosses. Ces grillglious rénnis formeat une pelite masse ienticuPaire, des bards de lacquelle nzissent un grancl nowbre de lilets. I'espèce d'Hélice que M. Cuvier a disséquée a'est pas la senle qui juésente $11: 1$ anneau œsoplagien composé de la sorle; nous avons pu nous assurer, sut un grand nonble d'e:pèces, qu'il restoil conslamnient le méme. Il re dillère pas non plus, dans la plupart des geure.s séparés du grand genre Hélice de Linné; c’esl ce dont nous avous pu nous assurer pour les venres Bulime, Agaluine, Ambrelte et Carocole. Eu passant à la fanille des limaces, on u'apercerit non plus aucune modification inportante dans le syslème nerveox comparé à celui des Hílices. Dirns les Parnacelles cependaut les ganglions $\propto 3 u-$ phitgiens sont généralement plus étruils et flus pubaun'es, tandis quils sont plus épais et plis: arrondis dans les Testacelles. Dans les Onchidies, animaux marins, limaciformes et respirant l'air, le système nerveux y est dans un développement considérable, et néanmoins, il est très-analornte à celui des Limaces et des Hélices. La principale différence consiste en ce que les ganglions aulérieurs sont proportionnellement plus grands et plus aplatis, et paraissent fournit un nowatie de Elets considćrables. 


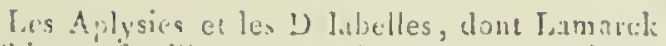
a lait une fumille, De constituent, prour quelctues auteurs, qqu un seul gemre; et en ellet, l'organisulion des Dolatelles ne diffère en aucune manicire de celle des $\Lambda_{\text {plysies, et }}$ Ml. Raug, dans son grand liavail, a nis le lait hor's de doute. 1)ans ces animanx, lanneau asophagien est très-large, et il se compose de trois ganglions sculemenl; l'un cst antérieur ct médian, il représente les deux ganglions antérieurs des autres Mollusques; les denx autres sont sublatéraux et inféricurs. Le gangtion antérieur c'sl quadrangulaire; de son bord antérieur il donne, de claqgue côté, une branche, qui remoute au-dessous de l'esoplage pour se jeler dans un ganglion cesophagien supéricur, pelit et Iransverse. Des augles inférienr's naisseal les branclies de commanaication avec le's ganglions inférieurs; elles sont grosses et assez. longues. Ces granglions infér ieurs sont suhtriatngulaires; une branclict très-grosse et transverse les fait communiçuer, et leur bord postéi ienr furrnit au système rnuscula re un nombre de hrancles très-consitlérable.

Les I'leurobrauches, gui avoisineal les Aplysies sous plusieurs rapports, ont anssi un anneau osophatgien extrèneureent laryng; il difficre de cului des $A$ plysies en ce qu'it $y$ a deux ganglions antérieurs et sualement un petit ganglion puslérieur. Daus les 'l'héthys, an contraire, lés deux gringlions antéricurs, intimement réunis, forment une large plaçue ovalaire, yui cousunnique par des pelits filets latéraux, aveci une paire de petils ganglions inferieurs. 11 en est it peu près de uĉtue daus les S'yllées; cependaut le gros ganglion supérieu: cst sublubé, andis que dans les Doris, il ne differe pas dinne manieve trés-nolable de celui des 'Thútilys. Les 'Titonies, si voisines de tous les animaux mous dlont burs venons de parler, en ciiffretat d'une tanaère trćs-aotable par la structure de l'anneau ocsophagien. T.es wauglions sont sibglobuleux, assez gros, et adhérant entr'eux par une pretile partic de leur circonférence. l.es deux supérieur's sont rínilormes, tandis que les deux autres sont glubuleux. Les branclies trés-numbreuses qui naissent de ces renllenens nerveux, partent presque toutes de leur surlice interne.

l.a famille des Acères de II. Cuvier tient à celle des Aplysies par un grand nombre de points dans l'ensemble de l'orginisation; le système nerveux en dilfere ceppendant sous quelques rapports : c'est aiusi çu'au lien des trois ganglions des Aplysies, il n'y en a plus que deux, réunis en dessus el cn dessous de l'osophange par des filets transverses, pont constituer l'annean esophagien. Un troisième granglion, destinć aux visceires, est produit par la réunion de deux filets gui partent des ganglions laléraux pour se porler vers la base de P'estomac. il n'en est pas de mème dans d'aulres genres que l'ou avoisine de ceux-ci, tels que les Calyptrés, les Caboclions, les Rarmophores, «c.
MiO L

It existe deux surtes bien distincles duta: lea Moilusques couver's d'une coquitle palelionde: les uas sont symétriques, les autres sunt irrignliers, ct celle symótrie ou cette irrégualarité cntraine des nodifications notalles dans l'organisittion. C'est ainsi, par excuple, que le systènce nervenx n'est pas plas symétrique dans les genen Calyptré, Ciépidule, Cabochon, Oubriclle, Siphonaire, que dans les Mnllusques pourms d'une coçuille spirale, tandis quil est precsyre complétetncnt symútrique dans les Emarginules, les Patelles, les Oscabriuns, les Parmopliores, \&2. Dins ces genres, la seule branclie viscérale n'est pas symétrique. 'Dans les animaux que nous venons de mentionner, l'anneau osophagien eit largement ouvert, les ganglions en snnt pelit, les antérieus fort écartés el les postérieurs réunis dans la ligne médiane. Cente disposition se retrouv? aussi bien dans les grenres Caly prtré et Ombrelle qui sont irré́ruliers, que dans les Parmophores, les lissurclles, les Eirürginules, \&c., qui sont sy'méIriques. Ces genres dillïrent ensuite essentie!lumein, cornase nous le verrons plus tard, frar la distribution des trinclies nerveuses, ainsi giat: par dlautres points non moins essenticls de l'org:uisutiou.

11 existe, sans contredil, noe trìs - grant? lacune entre les Mfullusques céphalés et Irs Mlollusques acéphalés. L'organisation de ces deur grands enaluanchemens est assez dilférente, selon nous, pour justifier l'opinion de laimark, qui a lait de l'un et l'autre denx classes distinctes, tandis que les autres zoch, gistes les ont constammeut réunies, conme a!nfartenant à un seul et naçre type. Sans dorie yu'il existe, co:mme dans beaucoup d'autres clusses, des points de contact, ou des rapporis qui sont incontestables; mais ces rapporis re sont pas d'uu ordre tel qu'on doive réunir datis un wêtne cadre des organisations aussi dillérentes. Lorsque nous avons examiné les diveries classifications, et en pariculier celle de M. Cuvier, nous avons lait remarquer que les carıclères sur lesquels étoient londées les divisions primordiales u'étoient point d'une égale valusu, et nous avons liat vair qu'il y avoit moins de distance, par exemple, entre les Ptéropodes et les Gastéropodes, qu'cntre ces derniers et les Acéphales. Ncus allons ici acçuérir la preure: de ce que nous arancions alors, et on la trunvera, non seulearent dans le systime nerveux, mais aussi dans lous les autres systemes ci'orgaues.

Dans les Mullusques acćphales, il n'exis's plus d’anneau cesophagien, le cerveau est réduit à denx ganglions dont les branches sont irradiécs sur les partics latérales du corps, tnais dont aucune ne se rejuint au-dessous de l'c:sophage ni même à la partie antérieure de l'anitru!. A l'upposé des ganglions antérieurs, au-dessus de 
l'anus, se truvent deux yanglions géúcialeacnt plus petits que ceux de la partie antérieure, el qui sunt joints entreax par un petil filet transverse, ordinairement très-court; les ganglions antérieurs el postérienrs, c'est-ì-dire les deux parlies principales du systène nerveux, communijuent evtr'elles à l'aide de deux longs filets latératix qui parcourent toute la longueur da corps, depuis les angles inférieurs et postérieurs des gauglions cérébraux jusquaux ganglions postérienrs. Quoigue par celte disposition il y ait un aonean nervenx complet, il n'a rien ceperdant qui puisse le fatire comprarer avec l'annear osaphagien d'un Mlollusque céphalé quelconque. Outre ces ganglions, il exisle encore, dans la plus grande partic des Acéphales, nne paire de ganglions latéranx placés dans l'épaisseur des bords du manteau; tontes les parties du système nerveux sont dans le plus grand nombre parfaitement sy'métriques : caractère qui n'est pas moins essentiel à noter que la non-symétrie de celụi de la presque totalité des Mollusques céphalćs. T)e celte symétric parfaite do systène mervenx a découlé celle du reste des animanx.

En examinaut les diverses familles que i'on a élablies daos la classe des Acéphales, nons aurons à remarquer, dans les pallies priacipales du système nerveux, bien moins de variations 'jue dans celles qui coustitueat les Mullusques cépbalés.

Aucune anatomie de Mullusques n'est plus difficile que celle de la famille des Bracliopodes; b en que l'on possède des animaux de T'érćbram!e, bien que M. Cuvier ait dommé une anatnmie de la Lingule, on d'a rien eurnre sur le système nerveux de ces animanx. Poli, qui, sans l'avoir reconnu, avoit depuis long-lemps figuré claus son bel onvrage le système nerveux des Mnllusques livalves, n'a donné sur les Cianies aurun délail qui ait rapport à ce système; de sorte que celte famille si importante est une des moins connues dans son organisation. II n'cu est pas de mème de la famille des Ostracées, dans laquelle il ne faut compter que les genres IHuitre et Gryphé réunis, Placnne et Auonie. De cet trois genres, deux seulement nous sont conuus; ce sont les Huitres et les Anomies.

Poli ni aucun autre anatomiste, à notre connoissance, n'ont mentionné le système nervenx des Iuitres; celit tient pent-être à la difficulté que l'on éprouve a le mettre à découvert par la dissection. Ce système, dans ce genre, consisle en denx pelits gnanglions situés à la base des palpes labiaux; ces ganglions sont subquadiangulaires, et fourvissent, de leur angle inférienr, une branche latérale qui se porte vers le muscle d'attache, où ils produisent un pelit ganglion érnilé, donı les filets se distribuent principalewient alix branclies et au ceeur. Cette partie posté- rieure dn sysièa nerveux des lfiatres n'est point sjuétrigue : celle circonstabce est importante a noier; car nons verrons quelie se repríseute dans lous cenx des Mlollusques bivalves qui sont mononyaires. On remaryoe une disposition sesnblable daus les Spondyles, les Peignes, \&ic.

La famille des Pectinides, pour les genres dont les animanx sont connus, differe tress-peu de celle des Osiracées. Cependant le systeme Derveux des Spondyles est généralement mieux comnu et plus facile à apercevoir que celui des Huitles : il se compose d'une paire de ganglions antérieurs placós au-dessus des palpes labiaux, et d'un ganglion central caché derrière la base dn picd el applíjué snr le muscle d’atlache. Celre disprosilion est semblable dans les Peignes; mais il arrive que, dans les espèces à valyes égales, les filets qui donnent naissance an ganglion central sont parfitement semblables, et que le ganglion est situé d̀ égale distance des extrémilés du muscle; ce qui a a pas lien dans les autres espercs. l,e genre lime, yıi est compris dans la neéme famille que les Peigues, a le systìme nervéux disposé de la néme maviéte que daus les l'vigues a valies émales.

lis famille des Malléncées renferme des cocguilles pour la pluparr irif́guhères, beauconp tnoius cependant gue dans celles des Ostracées: un seul genre en est bien connn, c'est celui des Avicules; les autres, Crínatule, Perne, et Marleau, n'en sont rapprochés que par aualogie. Dans le genre Avicule on commence a trouver des rapports fort grands avec les Noules : dans ces ginres, il existe uu rès-grand muscle d'attache subcentral on postcrieur, et de plus un trèspelit unscle antérieur, rodimentaire; il existe donc, par ces genies et quelques autres, an véritable passage entre les Mollusques à un nuscle el ceux qui en onl denx. Ie systeme nervenx participe à cette modalication du systime musculaire; il est beaucoup plas syonéricige, et il existe à la fois deux ganglious antérieurs el denx postérienrs: les antérieurs sont, comnie à l'ordinaire, silnés à la base des palpes labiaux; mais les grands lilets latéraux, au lieu de converger ver's le veutre du muscle postérieur, se titunent consiamment ćcartés e: dounent naissance de chaque côté, un peu au-dessus de latlache du muscle, a nu pelit ganglion qui communicue arec son congénère par nne branche transverse assez grossc. Nons observons une disposition alssolument seml) able dans l'arimal des Muules, avec celle difference cependant que les gauglions postérieurs sunt moins feartés. Il en est de nuême dans l'animal des Pinnes, dans lequel les ganglions postérieurs, par leur grosseur et le nombre considérable des rameanx qu'ils répandent, pitroisseor la partie la plus considérable du système nerveux : ces deux ganglions sont encore plus rapprochés que dans les Moules. Nous ne 
parlons pas du genre Modiole, qui cst tonta-lisit ar tlicsel.

la famille des 'J'ridacnécs, formée de deux. genres sculement, n'est pas encore cunnue; yuaut i la struclure des animaux qu'clle confient, on a sur eux quelyues détails des furmes extérieures, mais ccla est insullisaut puur le but gne nous nous proposuns actnellemens. C'est it tes yenres oi se lernine, daus fe systeme de Lanarck, la grande division des Conchifères nonoryyaires, et déju nous pouvons remarguer que ceux des auteurs qui n'ont pas adoptí sa mélliode el qui n'ont point admis, duus les Munomyaires, les $A$ vicules, les Moules, ete, ont eu ratson, puisque le sysièrne nerveux de ces gentes a plus d'analogie avec celui des Mollusques dimyaires ciunec celui des Alollusques monomyaires. l.es deux graudes divisions que l'on pourra à l'avenir élablir dans la classe des Conchilères devront êlre basćes ci'après le uombre el la disposition des ganglions postérieurs. Les discu sions qui se sont ćlevics sil l'cyard de certains genres que les autcurs, sclun leur opinion, ont placés lantôt daas les Monvayyaites, lantôt dans les Dimyaires, cesseront dès liusıant

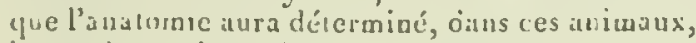
le noubre el la position des ganglions.

le systène nerreus, dans les Conchifères dimyatres, ne prisente yue bien peu de nordilicalions : la principale consiste en ce que les ganplions prostérieurs se rappruelicnt au point cie se loncher par leur bord, et de se souder quelguelois, romme reta a lieu dins les ganolions supserieurs des Moliuitjues cépula!és.

Il sera curicux de dumer, sur le systime nerveux dus Cames et des biluéries, des déluils yui banqueat encore à la science. Il est à frésuaser que ces genres de la famille des Camaccécs ont un systcme terveux semblable ì celui des autres Conclialères diungaires; cependant l'irrégularilé des auiuaux et leur nanque de symélate duit livire supposcr quelqu'anomalie dans leur systime nerveux. Sil arrivoit que le genre blhéric appartint is une autre famille, comme NI. Cuvier l'a suppjosé, dans la dernière édliton du Règne animal, 't que ce Mollusque, quoique dinyaire, ast rependant les lobes du mantcau divisés dans coute leur lunguenr, on derroit Irouver dans un type si farticulier d'organisation un systc̀me nervenx diliérent de es que nous arons noté jusquà l'ísent.

Ln joignant à la famille des Nayades de Lamarck le geure Castulie, on a un ensemble de genres qui téconlcut lous d’un nême Iype, el quii divent constiluer un seul grand geure ou une facollle, suirant l'exleution tịue l'ou aura donuce à ce mot de genre. Le systene nerveux, dans celte ímille, est très-régulier, et compasé des deux paires de fanglions untérieurs et postérieurs; les grangrions postéricurs snut très-petits, très-rapprurliés, et fournissent á́anmo:as un grand noubre cic lilets. l.e geare Trigouie n'est connu que depuis peu; quant à son intinial, e'est aux rechicrehes de I.M. Quoy el Gayinard que l'un est redevable d. sa décunverte. Cel aniaral a les formes extéricurrs de celui des Nulclles; un peut done supposer guc: le systeme nerveux a une disposition semblaile dans ses parties principales. Il n'en est pas di: méme des animaux de la lanille suivate, cells des Arcacées de Lamarck; ou lrourc clicz cus, en ellict, un système nervenx très-considérable, qui présente, dans les Arches notamment, uuc: disposition que nous ne recourguons daus ancun autre geure: les ganglions antéricurs sont trèspetits, et n'ont point entre eux de communicaticu; les pustérieurs au contraire constitucnt la partic la plus considérable du système : ils doment uaissance, de chaque côté, à six grosses branclies principales et à un filet de communication asse\% urros el court. Dans les l'éloncles, le systiont: nerveux n'est pas moius considirable que diats les Arches : les ganoglions antérieur's sont éraleineut les plus pelits, et dans le reste de sadishibulion, un n'apercert poirur de différences cunsilirables. On voit que cres deux genres, auxyucls il faut joindre les Cucullées par: analogie, apparticn-

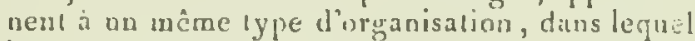
le sysième nerveux a un dévelopienent plus cunsiderable que dans la plupart des antres Nolli:ques acépliales. On n'a sur le grone Nincule jue des renseignemens incomplets, et il est improssivi. de dire si, par sou organisation, il appartient à ha famille des Arcacées.

Le genre Vénéricarde, que Lamarck a compris dins sa lamille des Conques, n'est ('n'un dédonbenent artificiel des Cardiles de Brnopuicre. Jin récinissaut ces deux grenres, il reste à décider s’ll devront être introduits dans les Con yues ou da::s les Cardiacćes. D'après les anatomies que Poli en if fuites, le gen re Carditen'appariendrait ni a l'une ui a l'antre de ces familles, puiscjue le mantean, fendu dans toute sa longueur, est semblable à rel:ai des Muleltes et non à colui des liucardes, dont les lobes sont snudés et perfurés, postérieuren:ent. cle deux Irous. Isa partie du systène nerveux que l'ou conooit dans les Cardites parvit justifier l'opinion de ceux des zoologistes qui rémissent les Cardites anx Mulcties ef autres genes de la famille des Nityades. Il faudroit cependant, ata: de décider complétement ce poin de conrroverst, que des andtrmies plus complè!es fussent faids sur ces deux renres.

Dis que l'on a retranclié des Cardiacées les Cardites el les llyatelles, celle lanille reste composée des trais genres Jucardes, Cipricarde et Isocarde, qui ont eatre eux des rapporis incontestables. Dans re groupe dianinaux, le systeme nerveux niest pas très-considérable; il se réduit à deux petils ganglions antérieurs, dont il est trisdillicile de voir la jonclion avec les deux gillglicns postérieurs, qui sont śgulercat trés-pelit. 
(ies gan jions postúieurs sont complétemeat soudís, el na fuumissent que deux paires de nerís ponr les parties postérieures de l'animal. Les animaux cooproris dans la lamille des Conques a'unt pas nou plus un système nervenx considérable; rependant on y trouve de plus aue dans les Con- hifères dimyaires à maulean dont les lobes sont complátement séparés, un petit ganglion particulier flacé dans l'épaisseur ćes lobes du manteau, ordinairuirement an-dessus de leur commissure. (ic ganglion a élé indiqué d'une maniòre positive par Poli, dans sa belle anaronie du Sulen. C'est iinsi qu'il n'existe point de modifraliurs un peu importanles, dans les furmes extésicures des animaux, situs qu'on n'en retrunse prolindément la cause déterminante. A l'excepticn de cet accruisseurent dans le système nerveux des Mollnsques dont le unatean se prolonge en siphons postérieurs, nous ne lui trouvons rien qui vaille la peine d'êire noté dans les fa inilles suivantes te Lamarck, Nynplackes, Lithopłaces, Corbnlées, Mactracées el Myaires. Quant aux Səlenacécs, on trouve dfax gangliuns anlétieurs quadrilatères, aplatis ct turt grands, très-ćcartés entre eux, et se conmuniquant parr un filet intermédiaire très-long et tries-mince. Ces ganglions, outre les deux lifets de comunnication avec les gan glions postérieurs, donnent naissanre i plasicurs brancles latérules qui se jellent dans les hords du aranteau, et vont tormer les gauglions litcíraux, u:a peu au-dessus de la commissure. Les gancilions postéricurs sunt plus pelits gre ceux dont nous venons de parler; ils sont suljobés et accolés par le wilien : les lirunches qui en naisseat sont assez oonbreuses et se distribueat aux branclies el à toules les parties yostérieures de l'auimal. l,a famille des Pholudaires devia être composée d'une manière difiérente que dans l'cuvrage de Lamarck; les 'Térédiues et les 'Tarets devront en faire partie, landis que les Gastrochènes, double emploi des Fistulanes, devront être reportés dans la famille des Tubiculées. Ainsi modiliée, celte fanille présentera des animaux d'uue sliucture assez particulière et trèsrapprochés, quant au système nerveux, de celle des Solenacées. Dans le genre Pbolade, le rapprochement des nuscles adductcurs des valses a été cause de celui des deux parlies du systeme nerrenx; les brunches latérales, déja raccourcies dans les Solens, le sont davantage dans les Pholades. Ces branches partent de deux pelits ganglions antérieurs, assez rapprochés, et communquant par une branche transverse d'une grosseur médiocre. Ijes gangrlions posterienrs sont gros, ovalaires, soudés daus la ligae médiane, et fournissant de cliaque coté 1 rois grosses branchies principales yui se distribuent aux branchies et aux siphons.

Les genres de la famille des 'l'ubicolées ne sont ųu'incompléteraent connus; nous ne pouvons donnèer sur eux aucuns détails.

'Te!'s sont, dans leur ensemble, les mndifications qu'épronvent les parlies principales du sysiem? uerveux dans les denx grands eubranchemen: des Mlullasques. Nons répéterons encore que plas l'urgauisution est complète, et plus ces parties principales du système nerveux sunt lices. Nous lis voyons former un vrai collier dans les Céphalopodes, se dćtacher en qualre gannlions souvent réunis dans les Gustéropodes monoigunes, se sépitrer en guatre ganglions constamment distincts et juints par des lilets transverses plus ou moins lungs diuns les Gastéropodes dioïnes; nous les trouvons nièroe réduils à deux gaıglious latéraux, furt écartés, dans quelque-uns de ces Gistéropudes. L'ecartement des ganghons devient encore plus grand dans des Mollosyues plus simples, tel; y.se les Aplysies, les Donahelles, etc. Eulin, dan: les Mollnsques conchiferes, les gan lions divisen! le système nerveux en deux prries distinctes, qui ont pou distance toute la longueur de l’animal. De ces parlies principales du système nerveux naisent deux sorles de verfs, les uns autérieurs, les aulies postírieurs. Nous allons examiner d'abord les brimclies nervenses qui, dans les Molluques ciplialis, sc distribuent aux parties antétieures du corps.

On peut distinguer, dans les brancles nerveores antéricurcs, celles qui sont destinécs iux sens et celles qui sunt réparies daus les aulres sys!èmrs d'urganes. Dans les Céphalopodes, les nerls desiués a l"organe de la rue sont très-gros, et naisseut de la partie moyenue el auterieurs des denx gros gabglions supérieurs; ils som! gros et courts, passeml a travers l'envelope cartilagineuse qui protece la partie postérieurs du globe de l'ceil, el lit s'épauouissent en un énorne ganglion pulpeux dont les tile:s innombrables tormentune vériable rétine. Nous verrons plus lard que ce développeasent extraordinaire du nerf optique, dans les Céplualopodes, est cur rapport avec la perfection de l'organe de ia vue. D'autres nerfs, qui parlents aussi de la parlic anlérieure de l'anneau asoplangien, mais proportionnellement heaucoup morins considérables, se rendent à la fuis aux glandes salivaires, à la masse bucale et à la langue charnue contenue daus les mandilunles. On trouve, dass ces Mollusques, ct ce sont les seuls qui nous l'offriront, na nerf auditif, assez gros at foll court, qui s'épanouit en une sorte d'ampoule, daus une: cavilé audilive rudimentaire, creusée dans l'épuisenr du cartilage céplatique. Les ganglious sublatérax, yue NI. Cuvier noune ganglions en patte d'oic, sont destinés à lounir les nerfs du touclier el du mouvement aux quatre on cincs paires de bras clout la tête des Céplaalopodes est cunronuée. Ces branclies communiquent entre elles, et forment un anneau complet supérieur au moyen de rameaux latéraux qui s'anastomosent earre eux. Enfin il existe quelques autres file's antéricurs deslinis ì la peau, qui couvreal la teite e! ses a p!endices. 
R.es Molliasçues grastéropodes a'ay'ant ui les r:" ganes do l'audition, ni les longs bras teulaculuices res Céplualopodes, doivent nécessairerneal manquer des branches nelveuses destinées à ces parties. Les branches aurérieures des ganulions osophayiers soat cependant assez nombreuses, et se disinguent aussi, en celíes destinées aux organes des seas, celles pour les urganes de la géućration, cl enlin celles pour les aut:es sysième d'orgunes; les verfs opliques sont en général grìles el trisalongés, surtuut dans celix des Moliusques qui cut les temacules rétractiles. Le sens de la viee, dans ces aniarux, éant beaucoup moins partait que daus les Céphalopodes, le nerf qui s'y reod est proportionuellement beaucoup moins gros. Nous le trouvons dans lous les Mollusques gui soust purvits d'un œil, tel ruchmentaire que snit cet urgane; ii exisie dans toute la série des Mollosques céphalés; nous ne conaraissons du moias aucune exception.

Les lílers destinés a la masse bucale, dans la séric des Miollusques céplailés, sont ordinairement a tr 1 onl,re de deux ou truis de chacine coté : ils existent constamment; ils ne varient, dans les fuailles ou les nenres, que par le nombre ou le poiat de leut origine. Lin de ces filets est particulièrement destiaé à la paire iaférieure de tentacules. Lorsqu'elle existe, une autre se porte sur les parties litlérules de la lềie, el la troisieme est desliabe purtichlièremeat a la langue et aux glandes salivaires. Les modifications qu'éproureut les filets nerveux, dans les diverses familles des Mallusques céplalís, on trop peu d'importauce poor être minutieusecont volées; il en est de wème aussi de celles destinées aux organes de la génération. Ces organcs, placés généralement sur le cólé droit de l'anmal, recoivent leurs aeif́s du gangliou supérieur du ateine có:é. Ce uerf, taniút simple, et tamıỏ bifurqué on décomposé en plusieurs filets, se reud aux organes de la géuération, ordinaireroent $a_{i}$ lis itvon produit un renflement ganglionnaire peu cunsidérable, silué rens l'orifice extérieur de ces vinanes. Daus un peril nombre des r.lollusques, ce gan se distribuent imuédiatement dans les organes auxquels ils sunt destinés. Les Mollusques conchifíres, viduls, à ce qualil parilit, à áàvoir plus que l'organe du toucher, vout plus de aerls antériears aussi noublreux : ceux des yeux et de la tée manqueut, puisigue ces purties inanquent elles-mênes. Les gänrlions antét ieurs lournissent coustamment deux filéls, qui se répandent dans les palpes de la bouche; d'autres se jelteut daus la partie antérieure du manteau, et la bride trausverse quijoint les ganglions, placéc inúédiateneat au-desses de la bouclie, complete, dans ces Riollusques, la portion antérieure du systeme uerveux. Nons arons ru précédemment que la position des ganglions autérieurs n'éprouvoit que de très-forbles modifications, tant dans les Mollusques irrégu-

$$
\text { Hist. Nat. des Vers. Tome II. }
$$

liers, que dals cenx qui scrol parfutement symitriques. Ou ne retroure pas non plus, dans les aninaux qui bous occupent, la moindre trace des nerls propres aux organes de la généralion.

Les brauches uerveuses posterieures qui naissent de l'anneau croplagien sont destiáes aux orsanes de la locomolion, de la dicestioa, de la respiration et de la circulation. Ces nerls sont plus ou moins considírables, selon le déreloppenient des organes anxquels ils se rendent. Les ganglions julérjeurs lourvissent ordianirement les filets acrreux destinés aux organes de la locomorinn. Lans les Céphalopodes, il exis'e unc exceprion à celle règle assez génúrale; car les nert's çui se rendeut aux hras, olganes locomoleurs, naissent des ganglions en paltes d'oie, qui sunt antérieur's el supérieurs. Les muscles du saci, dans les Ceplaalopodes, recoivene un irc̀s-grand nombre de filets que lear distribue, ainsi qu'aux tégumens, une paire de finglious laiéraux, que

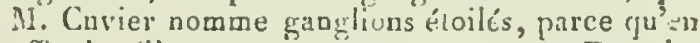
eflet les lilets en partent en rayomnant. Dans les Gastéropodes, la distribution des filets cutanés ou musculaites na rien de trís-constaut; taolút ces filets forment un ganglion, qui se roit reis la partic médiane du plin locomorenr; d'autres fuis ils se distubuent immédiatemeat aux ruscles columellaires et à ceux de l'covelope extérieure. Dans les Mollasçues gui son prolégés par une coquille dans lacquelle ils peuvent renirer en exlier, les netfs des jués à lappareil unusculaire et en méme tempis au touclier sont peu considérables, laudis qu'ils le deviencent bien clavanlage dans les Mollusques ans, ou qui ont la coquille í l'intérieur. Aussi, ontre les brancbes infórieures, ou troure constamment des branches latérales qui se rendeut dans l'épaisseur de l'euveloppe musculocutauke des Mollusques nus.

Les Mcllusiques acéphales se divisent eu deux ordres, par rapport aux mouremens qu'ils exécuteni; tous, sidos exception, ont un on deux muscles destinés à rapprocher les deux paries dont la caquille est composée; mais les uns, fixis coustamment par une de leurs valres, ou altachés au sol an moyen d'un byssus, n'ont point de locomolion pioprement dile : ansis ils u'ont ancun oryane de mouvement, ou il est réduit à l'élat rudimentaire el reste sans usage, taudis que las autres, libres et pourvus d'ua organe de lucomolion, peuveal se déplacer arec plus ou moins de faciitié et p'us ou moius de rapidité. Ces deux condílions dans la vie des Míllusques acéphales doivent produire, dans leur organisation profonde, des moditications qu'il est important d'éludier: dans les Hnitres, par exemple, les nerfs dn monrement sont aussi cenx dn loucber; car ils se distribuent égalenent daus les muscles rétracteur's du manteau et des palpes qui le bordeot. Il en est de méme dans les Anomies et les Spondjles. Quoique daus ce deraier gense on 
commence à aperceroir ua pied rudinentaire, nous g'avons pu nous assurer si ce pied recevoil des filets nerveux particuliers; mais cela nous paruit peu probable; car nous a'iwons pu, non plus, les découvri: daus les l'eignes. Dans ce geare, qui renferwe des coquilles libres, le pied est sans usage pour la locumolion : son usage est borné dans quelques espèces à líler un très-petii byssus. I.e pied est réduit à la même inactirité dans tous les Mollusques byssifères; aussi on ne voil prendre un peu de développement is cet argaue que dans ceux des Mollusques acéphalés qui sont entic̀rement libres: alors se montre en mĉne temps deux branches nerveuses assez grosses, qui paitent du ganglion autérieur pour se rendre a la base dn pied et se distribuer dans son épraisseur. Il n'est aucun genre pourvu d'un pied qui manque des tilets nerveux dout nous venons de parler: ils sont remarquibles, surtout dans les Solens, les Pholades, les Mactres, les Vénus et les Bucardes; ils sont plus réduits dans les Mollusques que Lamarck uomme 'lénuipèdes, parce qu'en effiet ils ont cetle partie lort mince.

Les Mlollusques conchifères siphones ont de plus que ceux qui u'ont poiat de siphons, des filets nerveux qui naissent des ganglions postérieurs, pour se rendre anx muscles réıracteurs des siphons; d'autres filets, que fournissent ordinairement les nerfs du maoteau, se porteat dans l'épaisseur du tissu musculo-cutané des siphons, jusque dans les palpes, ordinairement nounbreuses et très-sensibles quien couronneat les ouvertures.

Lorsqu'il existe de véritables siphons daus les Mollusques acéphales, les lobes du manicau soni soudés postérieurewent daus une étendue plus ou moins grande : c'est dans cette circonslance particulière de leur organisation que se montre le gapglion litkral dont nous avons en uccusion de parler. Ce gauglion, situé un peu audessus de la conmissure, est produit par quelques branches paléales lalé:"ales, qui formeat quelquefois une sorte de plexus, d'ou partent les tilets nerveux qui se distribuent dans les bords musculeux et épaissis des lobes du manteau. Celle manière d'êlre de ces nerfs a été très-bien représentée clans les Solens par l'anatomiste célèlre Poli : nous l'avons retrouvéc dans les Mactres, les Lutraires, les Pholades et les Vénus.

Le ccur et l'organe de la respiration sont liés d'une manière intime dans leurs fouctions; ve sont des organes d'une haule importance dans les animaux, et la vilalite $y$ est plus grande que dans la plupart des autres appareils organiques; elle y est puissamment eatreteaue par des nerl's nombreux, qui ont ordinairement une même origine. Dans les Céphalopodes, ces nerfs sont fort gros; ils naissent de l'angle inférieur des ganglions supérieurs; ils ont une distribution parliculic̀e dans ees animaux, parce qu'il y a deux cœurs; ils se bifurquent et se partarent éalemer de cliaque côté entre le coeur et sun orvillette el la branchie. Ces nerfs devienneu plus simples dans les Gastéropodes, et ils sont pairs ou impars, selon que le caur on les branchies sont ou ne sunt pas synétriques. 'l'ous les Mollusquics çui out une coquille non symétrique, soil extéricure, soil intérieure, n’ayant janais les organes de la circulation et de là respiration symétriques, les nerl's q:i s'y rendent, par une conséçuence naturelle de la loi de symérrie, ne sont jamais pairs. Ces nerl's naissent du burd postćrieur des yanglions supúrieurs; ils suivent ordinaivement l'oesopliage jout se jeter, an numbre de deux ou trois, sur le cera. et les branchies; quelgnefuis, unais celit arrive assez rarement, les nerfs destini's aux trlgates de la digestion forment, avec ceux de la circulation, un ganglion, ou un petil plexus dont les filets se distribuent, en rayonnant, a tous les orgines contcuns dans la cavité spirale de la lisquille. Dans les Mollusques symítiques, comme nuus le disiuas, le cour est placé dans la ligne médiane, et les branchies sont également dans la ligne médiane, on disposees par paires sur les parlies latérales du corps. Les Oscaluions, les Yatelles, les l'billidies, etc., peureat donner une très-bonne idée de cel arrangement, dans les $\mathrm{Mlol-}$ lusques céphalés. Dans ces genres, les nert's qui se renclent au caur et aux branchies maissent, au nombre de deux paires, du bord postérieur de l'anneau asophagien : sous ce rapport, ces Molluscyues se rapprochent beaucoup des (jonchifères, dans lesquels la teadance à la symélrie se montre de plus en plus. Ein elfel, ì l'exeeption d'un petit numbre, les Mollusques acépliales, mérae ccux dont la corquille est irrłgulière et qui u'ont qu'un seul muscle ceatral, ont les orgaues de la circulation et de la respiration conplótement symétriques. Le cour, clias cette séric d'animaux, est silué daus la ligne médiane et dorsale. La litmille des Ostracées liait seule exceplion à cette régle grénérale : les nerfs qui se reudent aux orghane de la circulation el de la respiration dans les Nollusques acéphales ne.sont connus que dans un petit nombre de geares. Dans les Pholudes, par exemple, le ganglion postérieur fournit use paire de nerl's qui descendent de chaque rôté du corps el s'ealoncent a la base des brauclies, en suivant la base des artères et des veines branchiales : il en est a peu près de uême dans les Solens et presqus lous les autres gentes dont les Mcllusques aont réguliers, ¿̀ manteau fermé par derric̀re. Dansles Molínsques sycoélriques à mantean ouvert, le ganglion postérieur fournit anssi les rameaux destinés aux brancbies. Outre ce rameaux, il existe dansles Arclies, par exemple, des branches spécialement destinées au cour, lesquelles paissent aussi du ganglion posterieur; mais, à l'exception des genres de la famille des Arcacées, on ne sait pas s'il existe, dans les Alollusqnues des familles suitantes, des 
nerfs propies au cceur. Il est à prúsumer que quelyques lilets, assez wiaces pour avoir échappé aux rerilierches des anatomistes, naissent des grandes branches latérales pour se diriger sur l'urgane circulatoire.

Dans la lamille des Ostracées, où le système nerveux paroit si peo dércloppé, on trouve un diet aerveux a la base cle claque paite de brauchies; Insis. on ne sait pas eacore si les nerfs donoeut des tilets au cour, ou si cet orgaoc en reçoil d'autres rameaux. On voit qu'en général il reste beaucoup de recherches a faire sul le système nerveax des Ilollasplues ascéphalés, et que, néaumoins, Jes parties principales en sout assez connues pour :ervir de fondement aux conpes priucipales à étaBhr daus la classification.

Les organes de la digestion et des sécrétions recoivent aussi des Jranches nerveuses plus ou muias considćrables, selon leur élat de développeceot; les aerls ne sont juarais symélriques, et on le corcevru fucilement, puisqu'il n'est aucua Mlollusque conu où les organes digestifsaieat une symétrie parfaite: c'est loujours de la partie inféireure des ganglions cérébraux que naissent les nert's qui se distribueat aux orifanes de la digestion; ils se jeltent sul l'osophage, desceadent avec lui, et se distribucut a tous les viscères qui cuocourent à l'acte de la digestion; ils fournissent constumment une braoche assez forte, qui se rend zu foie, une autre, très-line, se rend aux glaudes salivaires. Il arrive quelquefois, comme nous l'avons déjà fait remarquer, que les nerfs des viscères produisent, en se réunissant, un ganglion qui, non-seulement donae les braaches destinfes aux organes de la digestion, mais eucore celles qui se rendent au coear et aux branchies, ainsi qu'à la partie postérieure des organes de la généralion. Cette disposition générale des nerfs des viscéres, bien que variable dans les Allluscjues, n'a rien de bien constant dans les familles qui paroissent les plus naturelles; ils ne peuveat donc servir en riea comme moyen de classification. Si les Mollusques céphalés, sous ce rapport, préscotent des variations contiauelles, il a'en est pas de même des Mollusques acéphalés, dans lesquels nous observerons beaucoup plus cle constance. Ainsi, dans les Mollusques acéplülés irréguliers, à un seul muscle, Jes nerfs des visciéres sont constamment fournis jar le ganglion postérieur : on n’a pu encore canaoitre dass lout son détail la distribution de ces filets uerveux, qui sont excessivement ninces et échapjent facilement aux recherches les plus assidues; mais on peut du moins les suivre depuis lcar oriyiae jusqu'ála masse viscérale qu'ils doirent animer. Dans les Mnllusques conchiteres dimyaires, les nerfs des viscies naissent ea partie des ganglions antérieurs, el en partic des postérieurs. C"est aiusi que dans les Muleltes, par exerople, les ganar!: o::3 antérieurs furnissent des
Lräucles à J'estomac et au foie, tandis gue les ganglions postérieurs donuent naissance a quelques minces filets, qui se portent à l'intestin et à la base du pied, qui contient une partic du foie. Dans les Arches, Je ganglion postérieur fournit toutes les branches principales destiuées ì la série d'organes dout nous uous occupons. Dans ce genre, ainsi que dans les l'ćtoncles, Je foie, les intestius, l'estounac, et même les ovaires, reçoirent leurs nerl's du ganglion postérieur. Dans les Conques et touses les autres familles qui suivent celle-lia, la distribution des norfs de la digestion est semblable, à peu près, à ce que nous avons va dans les Mulettes, éest-à-dire que les lilets sont également produis par les ganglions antéricurs et postérieur's.

Les organes de la génération sont tiès-variables daus les Mollusques; ils ont une grande importance áans l'étude analomique de ces êtres. C'est par leurs moyens quion a pu les distribuer eu grands ordres, et probablement qu'ils donneront plus tard coux de les arranger en familles ou en genres. Il est probable arême que, par une étude très-approfondie, on parviendra, par leur moyen, à déterminer rigoureusement l'espèce; car c'est par eux qu'elle se propage duns l'espace et daus le temps. Il s'ea faut de beancoup, malheureusement, que les olsservations analomiques sur Jes Mollusques scient assez mulipliécs pour donner, à cel éyard, des corollaires généraux au moyen desquels on ponrroil enfin arriver à la délinition exacte et rigoureuse de l'espèce. Il nous semble que cette question, des plus fondamentales, ne peut être déliailivement traitée qu'après les recherches les plus multipliées sur tout ce gui concerne les organes genćrateurs. Ces orgaues sont, en gf́néral, peu développés daas les $\mathrm{Alol}$ lusques céphalopodes; il semble que daas ces Mollusques, dont l'organisation est, par son ensemble, beaucoup plus complète que dans tous les autres, on auroit dâ trouver les organes de la génération en rapport avec le développement organique. Il n'en est rien ceperdant, car ils ne sontp̧as plus complets que dans la plupart des Mollusques céphalés; aussi l'appareil nervenx qui se rend d ces organes est peu considérable; il consiste en une branclse très-méliocre que fournit le gavglion inférieur du cótć daroit, laquelle se distribue aux organes máles : l’ovaire, qui est placé à l'extrémitć postérieure du corps, recoit ses nerl's des lranches visçérales dont nous avons puécédemment parlé. Les Mollusques gastéropodes offreut, presque sans exception, une disposition particulière dans les branches nerveuses de la génération; dans les uns, qui ont les organes séparés, c'est-à-dire qui sont monoïques, les nerfs prennent naissance du ganglion supérieur du côté droil, el se rendent, dans les máles, à la verge et à ses annexes, et daus les femelles à l'oviducte et a l'ovaire. Dans ceux qui scnt dioïques, les filets nerreux, su nombre de $\mathrm{X} \times \mathrm{x} *$ 
deux ou trois; nutissent également du ganglion cervical du cûtú droit, se porient du nuêno eôté vers les oreanes de la génésation, el produisent, près de l'endroit de laiar sortie, un pelit ganglion dont les lïlets se rendent on partie aus oryanes mâles et en parlic aux organes femelles. Ceux-ci pénètrent jusqu'à l'ovaire, en suivaut le premier el lc second ovidacte; dans quelcrues MInllusques de celle série, les galuglious inférieurs fournissen? les nerfs de l'ovatie, iandis que ceux de la verge naiscul du ganglion supéricur: c'est ainsi que cela s'observe daos les Aplysics et dans quelque autres geures qui s'enl approulient.

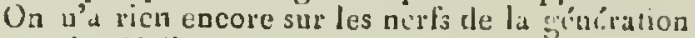
dars les Mollusques acúphales: dans cis auimaux les organes de la gúbération sont extrimernent simples, puisqüils consisient uniçuement, à re ‘n'il paroit, en an ovaire el son ovidacte. I.opsqu'il exisie un pied, el tque ce piad acquiert ua cerıin degré de développeracnt projse à Ia locomotion, il contient dans sa base, relenue par un appareil musculairc très-puissant, une partie nes viscères, milis princi uleroen! une jartie du foie et l'ovaire. On suit quía la base' de ce pied se troureat deax branclics nerveuses, qû́ s"iniroduisent daus sur epaistenr; mais on ignore complétement quelle es: leur distribution; on pent supposer, avec quelque raison, qu'elles donnent des branches anssi bien a to foie el à l'intestiu qu'à l'uvairo et à l'enveloppe mnsculo - culanée commune. Ce que uous venons de dire pent s'appliquer aus animanx compris dans les Conchiléres dimyaires de Lamarek.

I a partie la plus imporiante du systime nervenx des Mollusques est, sans contredit, celle à laquelle on a conné le noun de cerveau; c’est d'après elle crue l'un pourra conlitmer la distiaction de ces êtres eu deux grandes classes, comene l'avoit proposé Lamarck. D'an côté, en eflet, nous trouvons un centre nerveux unique; et de l'autre, deux centres dien évidens. La dispersion de finfluence nerveuse dans des contres éloignís, indique une dígradation évidente dans l'orginisation où ce pbénomìne se présente.

\section{\$ II. Organes digestifs et de's sécretions qui en dependent.}

Les organes de la digestion sont en géoéral furt simples dans les Mollusques; ils suivent, pour leur développenent, les proportions que I'on remaryue dans les animaux plus élevés. C"est ninsi qu'ils ont plus d'étendae dans ceux qui se uourrissent ảe subslances végétales que dans ceux qui s'alimentent de matičres animales. Celte règle, pour ếre générale, n'est cependant pas sans exception; nous verrons unème qu'il existe des variatious assez notables dans les fardilles, les grcarcs, quelcinetois mèze jusque u?ns lco espéces. l.appareil organique prnpre aux fucctions digeslives sé compuse de plusien:s partit's, qu il sera bécessaire dexaminer séparémeat : 10 . It bouche et les glandes salivaires qui en dínendeul; $2^{\circ}$. l'cusophage, l'esinmac et l'intes'in; à̃. la fuie; 10. La booche. Cet!a partie, duns les Mlollusques, est tris-raniable; elle forme ordinairement une masse plus on moins considirable, dans laquelle se tronve, dars un élat plin ou unoina urand de développement, l'appareil dentaire os lingual, corné, propre à saisit la ma ibre alimentaire; nous ailons examiner celts partie dans coule la série, en commen:ant par les Cóphalopodes. Dans ces Nollusqucz, l'ouvertu e bucale cist munie de deux mandibules corníes, quie l'on a trìs-juslemenl comparées à celles d'un perroquet. Cence comparaison, exacle sous inns les rapports, ue l'est pas quant à la sitmation des patrries, c'est-i-dire que la y raode mandihule, dans les Céplialopodes, est inférieure, tand's qu'elle ent supérienre dans les oiseanx, el daus les perroguters notamment. Ces forlez máclioires son! pnnvues d'un appareil musculaire fort considirable, et conlienuent dans leur cavilé me lan ne tipiosse et charnue, armée de crocbets colués, trèsactrés. Par une comparaison qui nous semble fort juste du bec corné des Cóphalopodes que norrs cunnoissons actuellemenl, avec lo bes calcaire (rhiucolite), que l'on tronve à l'ial fossile depuis les terrains teritajes jusque dirs l.'s couches du Muschelkalck, on a conclu qare les bees calcaires aroient apparlenu i des Cíphalupodes, dont nous ne ponvous conncilre que les díponillez teslacces. On a pu supposer que reilaines esjuires de ces becs appartenoient d̀ certaines cispèces de Bólemnites, d'Anmoniles on de Niutiles, parce qu'elles se sont trouvées assez constamment dilnz les mèmes dépôts. Il csi qualqures-uns de cer bees lossiles qui, à part leur éprissen: et !eur nalure, ont la plus grande analogie, quan! is leur structure, arec ceux des Céphalopodes aciuels : lel ét notamment celui trouvé danz le caltaire jurassique de La Rochelle, et dícril par N. d'()rbigny fils dans les Mlemoires du la Societé d' Histoire naturelle. Cet organe si puissan de masticalion, dans les Céphalopudes, se rédnit ì quelques plaques cornces, ou à une langne de lis mime nalure. Dans la plupart de's Ciasiérupodes, quelqnes-uns, et botammeat ceux qui se nourrissent de cliair, ont la boucle prolongte en une trompe exsertile, plus ou moins lougue, mobile, armée de crochets cornés, qui scil de suçoir. Une propriélé dout jouissetil les Mollusques pon 1vus de trompes, est celle de percer les coquilles des Mollusques bivalves sumtout, en dissolvant, à ce qu'il paroit, la maliire ealcaire sur laquelle des organes mons ou corrals n'anroient aucune prise. Celle action chimique eat remarquable surlout dans les Rochers, qui niellen irès-pcu de temps à perlore: des coguilles quelt 


\section{MO I}

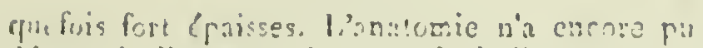

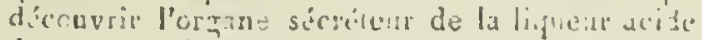

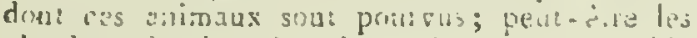

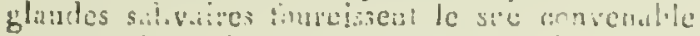

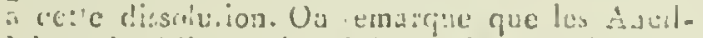

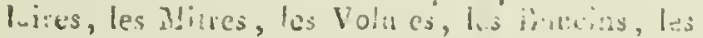

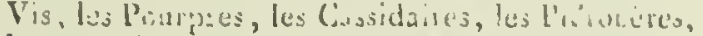

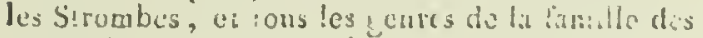

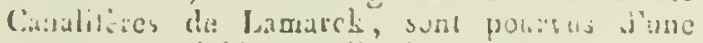
(1"sure sembable a ccile des Racicis: tous,

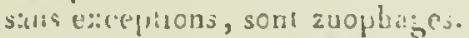

'luns les ilatres Molusquats, qui ont une c:oquaile à euverture entide, qui ont cette coyplit.e

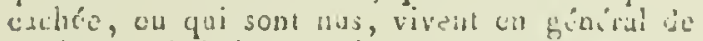

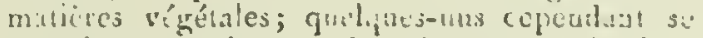

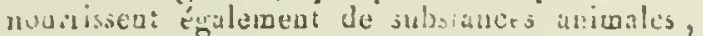

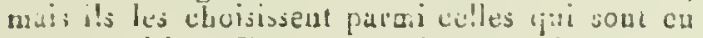
décomposition. Dans ces animitax, l'oaverture de la boucbe est garuie, a liućácur on sui les bords, de plaques coraées plas of möns ércind.es, sticíes ou guruites de surres de perits cro-

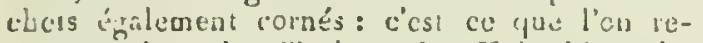

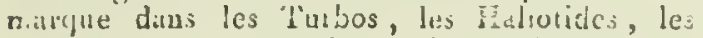
Jambines, etc. Daus d'autres l. buuche est ale; mais, dans son fond, au-dessous cle l'cotrie de l'wsophage, est placte une dent cornce, robile,

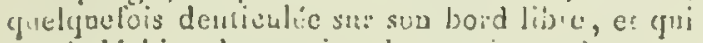
scir à déchirer les partirs al mestaires; ceest particulistement dans liz Il:ilices et les autres Pulmorés que l'on apericoit reic mod:linition de l. mas:e burale. Au lieu de cerie langue simple, certains Molinsquez gastéropoles sunt pourvas d'une très-lonarue langue urticulic, ganale de petits crachets, et qui c'st roulée, dat!s istatt de repos, en spirale, duns la cuviás stumarale ou dams un sic particulicr, siouć na-dessons de l'wsophrge : telle est celle des Panlles, les Uscabrions, elc. 'Yous les ilallusques que nous venons de unenionaer, c'es:-it-dic cons les Mulliszucs ciptalís, suss ciception, ont de chaque côtú de l'cesopbage, qu! çuctuis immidiatemeut derriere la masse bucale, ean flandes sulivaires plus on woins díveloppées, el dont les ci-nzux,

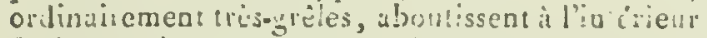
de la boache, en percunt obleflement sus parvis la:érales. I.es modificutions qu'tpreavint ces ghlaudes salivares noat aucure unporizace si on on routort s'en servir conune luse de chasiticatiun; cal elles out des furtoes liés-didireasts dan des repres évitionment lart voi.ins. Lus Moilus-

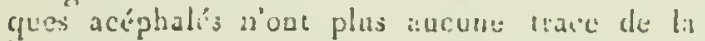
langue conte on des uppilteils dentuites di,ers que unous arous vus a ceur pourrus dinc iête; l's glandes salivaires disparoisseat aussi, l'ustuenac se trouvant enveloppé irnmédiatement par le fuie, et l.t mastication nayant plus liei. L'ouverture bucile, ditus les Acéplálés, consisie en un trou rond uu ovalaire percé il la partie onoyenae, supúrieure et antérieure de lit masse viocúrale, fecurvorte par la partie antériente des lobes du

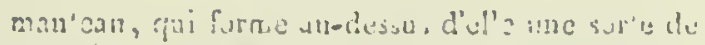

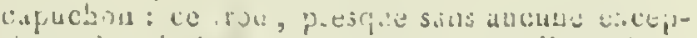

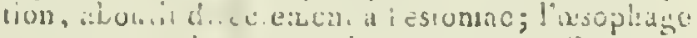

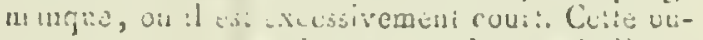

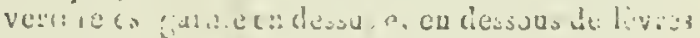

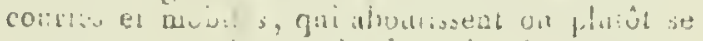

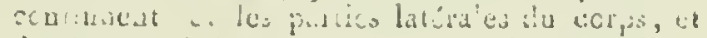

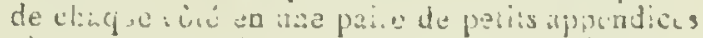

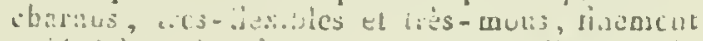

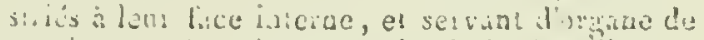

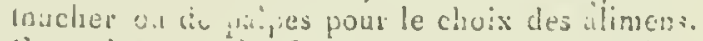
lies paijes un. lies formes assez ccas!....ies d..iss

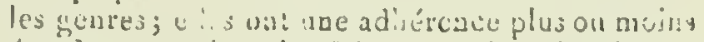

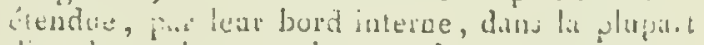

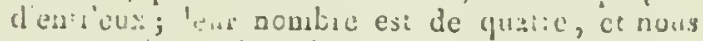
ne conno.jsanj jusqu'd prisent cil ..ne sculo ex-

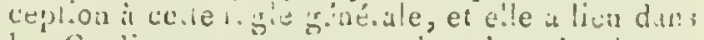
les Corditis, qui cu ont trois puiles de chatpue có. Luas les tiat ins, les palpes labiates ocut

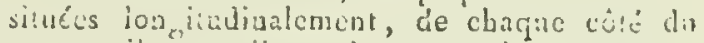

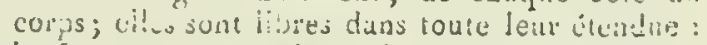
les Limes on! res pallyes Irès-conrles, soudíc's sar" les partics latiates du corps, daus :on ce létr

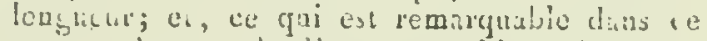

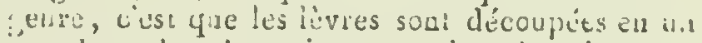
prasd nom!se de pe its lentacules, doat le nowbie est çäl de cbarque cúté. Los Peiguts et hs Spundyles ollicint une autre modification non moiris remarquable: outre les palpes labialios, qui sont soadées earrel!cs par leur bord interne, l.: lives sout grandes, circuluites et lobies; de: manice que duns lacte de lit prébension des alimens, ces partitis peuvent s'ulongar et prendic la forme d'ur eitonurir, au fond duqnel est sitia l'ouveriate bucale. Dans les Moules et la plupart des gentes des Concbifires dimyaires, les paiper labialus sont risasulaires, soudies sur les par'it's la éralos du cirps, el réunies eatrelles par paidies da:rs les deux tiers supéteurs de leur bord intern:. Dau; cis zenres comme daos ceux que dous avo:3 déji exicoisís, les palpes sont suriées il leur sur.-

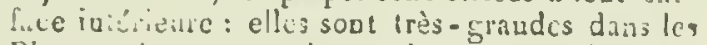
Pinnes, beacucoup plus petites et ì stliez plo"s furtus daus les Avicules; les Juletres les ont usscz grardes col lijues dans unc plos grande partie des

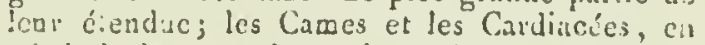

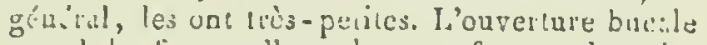
prend la forme doue longue feuce, lans les Arehes et lés Pétoncles: les lèves sont très-saillintes ut les galpes fort courtes; e!les deviennent fo:t louges et fort étroites dins la plupart des neures r 1 i ont les lobes da wantena réunis, tels que ic's Vínus, les Donaces, les Tellines, cic. Dans les Soleas ct les Pholadez, les lèrres sont ir:s-saillantes, font longues, et les palpes sumt ćro:tés el éralement prolongées.

Le la cari.ćbucale, dans !es Iollusques céphnlís, part un caral dont lez propcrtions sont ass: $z$ variables : ce caad est l'osophagc. Il est sim:l-, meobrancux, cylind:ique, quelf̧refois uclle se: 
séparé de l'estomac par on étrangalement ou cardia; d'autres fois s'élargissant insensilulement, de manière qu'il est très-diflicile de déterminer l'endroit dii commence l'estomac. Ces valiations dans la lougueur et le diamètre de celle partie a'uat yu'un foible intérêt, et nous en reparlerons en examinant les modifications que présente l'estomac.

$2^{\circ}$. De l'estomac. Cet organe, dans les Ríllusques, est extrêmement variable, ordinairement mince et membraueux; il est quelguefois trèsépais et très-charau, comparable en cela au gésier Ales oiseaux; quelquefois séparé en plusieurs poches par des étranglemens, et contenant des appareils plus ou moins considérables, osseux, cartilagineux ou cornés, destinés au broiement de la matière alimentaire. Dans les Céphalopodes, l'cesoplage se read dans un estomac membraneux, que M. Cuvier nomme le jabot: ce premier eslomac, dilaté sapérieurement, comae dans quelques Gallinacées, est revêtu à l'intérieur d'une ıembrane muquense, plissée longitudinalement; après un étranglemeat peu considérable, cet estomac aboutit à uae cavité très-musculaire, et que l'on peut très-lien comparer an gésies des Galliuacés. Cette comparaison est d'autant plus exacte, que cet organe est revêtu à l'intérieur, comme dans les oiseaux, d'une membrane carlilagineuse furt solide. Un troisième estomac, tourné en spirale, est ouvert immédialemeat au-dessous du gésier, et commuaique avec lui par un canal exırcomement court et élroit; cet estomac est garni à l'iotérieur d'une lame spirale qui en ayrandit la surface: c'est derrière les replis de celte meabrane que sont placées les ouvertures de vaisseaux hépatiques. Celte cavité n'est donc point uu cœenm, comme l'a dit M. Curier, mais seroit plutôt comparable au duodenum des aoiwaux rertébrés. L'intestia, qui est gros et boursoufflé, aait de ce troisième estomac; après avoir fait un grand anse, il recononte pour aboutir à l'entonoir, dans lequel il s'ouvre.

Dans la plapart des Mollusques pourvas d'une coquille en spirale, l'appareil des organes digesiifs est moins considérable que celui que nous venons d'examiner: l'estomac consiste ed une peche membraneuse, fusiforme, revêtue à l'inlérieur d'une muqueuse, dont les plis ou les stries sont plus ou moins saillans; elle se termine ordinairement par un cul-de-sac dont l'étendue est raiable, vers lequel se dirigent les vaisseaux biliaires; l'intestin qui nait de ce cul-de-suc est grêle, contenu dans l'épaisseur dı foie, et présentaat dans quelques genres un reullement cœcal plus on moins considérable : c'est ce que l'on remarque dans les Buccins, les Pourpres, les Cassidaires, les Rochers, etc. L'estomac esi plus simple dans les animaux dont la coqnille a l'ouverture entiere, il est fusiforme, simple, et l'in-

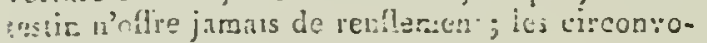

lutions que cet intestin produit sont plus nombreuses que dans les Mollusques qui ont la coquille canaliculée ou échanocréc à la base, et cela sa remarque notamment dans la famille des Hélices et des Limaces, aussi-lien que dans cellc des Néritas et des Natices. Ia fumille des A plysiens, ainsi que celle des Acc̀res, présente un.t disposition particulière très-renarquatsle des orgrunes digestil's; dans les Aplysies, prar exemple, l'wiophage, assez court et étroit, se rend à un premicr estomac formé de deux parties séparées par un etranglement médiocre : cet estumac esi complétement membraneux; il conmunique à un secund estomilc, ou gésier, par une uuverture assez large. Ce gésier est subcyliadriciue, composé d'une zone musculaire fort épaisse, a l'intérieur de laquelle sont implantées, au nombre de lauit ou dix, des pyranides subquadrangulaires, d'un cartilage trés-solide; elles sont dispusées assez régulièrement eu quiconces. Ce gésier est lurt dillérent de celui des Cépbalopodus, et a'cst plus comparable avec celui des oiseaux; il conviendroit sals doute, à cause de cela, de lui clonver un autre nom. Un troisième estorac, membraneux, à parois plus épaisses que le preunier, s'ouvre imasédiatement dans le gésier, et u'en est séparé que par un étranglemeot médiocre. Sur les parois de cet estomac sout disséminés, d'une manière irrégulière, des crochets cartilagincux ou osseux, dont la pointe est dirigéc vers l'ouverture supérieure; un prolungement assez étroit et cylindracé termine inférieurement le troisième estomac; la paroi inlérieure et postérieure est percée d'une ouverture pylorique, garnie d'une espèce de valvule, et recevant dans son épaisseur de nombreux vaisseaux biliaires, dout les ourertures sont fort grandes. L'intestin qui suit est cylindracé, assez égal, enveloppé en grande partie d'un foie très-volumineux, dans lequel il fait plusieurs grandes circonvulutions; il se termine à l'aoos, situé à la partie droite et postérieure du corps. Les Dolabelles présentent la nême disposition que les Aplysies, mais il u'eu est pas cout-à-fait de méne des Bulles; claus ce geure, l'csopliage charau et cyliudrique se rend à un seul eslomac, fort charmu, très-épais, el cuntenant daus son intérieur, solidement fixés dans ses parois, trois osselets calcaires, fort grands, qui ont été pris par Gioeni pour un aniwä complet, dont il a décrit les mours et les babitudes. Quelques auteurs, et Bruguière notannent, confiant dass la description éviderment mensongère de l'auteur italien, donnèrent à ce soi-disant geure le nom de Char (voyez ce mo!). Ces plarques osselises, dans les Bulles, sont si grandes que l'on a quelque peine á conceroir comment elles penvent être logées dans un animal d'uu médiocre rolume. Un duodenum, légèrement boursouflé, nait de la partie inférieure et pes:érienre de cet estomac, et se contiaue inssn- 


\section{C L}

slulement eu un intestia grêle, assez court, qui lail quelques petiles circunvolutions dans un foie issez cousidérable. L.es Bullées, qui on une coquille intérieure, sont semblables aux Bulles par In disposition de leur estomac.

Dans les 'Tritonies l'oesophage ost si ample, qu'il paroîr teniv lieu de l'estomac; il est membraneux, cylinctrique, pourvu à sun extrérnitś postérieure d’au cul-de-sac assez considérible, duquel part un iotestin dont la cavice est tort irréyuliète; il s'élarrail ordimairement, vers sun liers postérieur, en un crecuu assez ćtendu, duquel nait un rectum gros et cout, qui se termine au cóté dioil du corps. Dans les Duris, l'oesopluage est formé de plusieuıs boursuufllures irrégutières; l'estomac semble en être un prolongrement, car il s'y termine sabs étranglement; les canaux Liliaires y soat ouverts tris-largement daos de grandes cryptes dont les parois sont parsemées; l'intestin nait de la partie du côté droit le l'estomac; il forme no grand circuit soudé au lourd du foie, dont la masse est considérible. Cet intestin est furt gros, pourou d'étranglemens ir reuulièrement espacés, ce qui le rend comparable au gros intestin des auimaux verlétrés.

Un genre roisin de ceux.ci, celui des Pleurobranclies, oftie une série de quatre estomacs, dout le premier, mince et membraneux, peut É:re comparé au jabot des Ga!linacées; le secoond, subglobuleux, est épais et charau: c'est le gésicr; il est séparé du premier par un étranglement dans lequel on remarque l'ealice des vaisseaux biliaires; le troisième, également subylobuleux, est garai en dedans de feuillets longindioaux trèsépais et saillans; le quatrième entin, membraneux et de la mème forme que les précédens, en est séparé par un étranglement très-court, et dunae naissance a l'iatestin, çui fait une courte circonvolution dans le toie, et se termine aı côté droil de l'aritnal. Le foic est pen volumineux, subbilubé, et situé à li partic la plus pustérieure de la cavité abdomialc.

Un genre curieux, celui des Linguelles (Brasis $\nabla_{0}$ ) ou Diphyllidies (Cov.), ollie un estomac a parois très-minces, tqui s'étend dars toute la longrueut du corps; il en occupe la ligne médiane; il est fusiforme, et contient à sa partie postérieure un stylet calcaire extrèmemeot délié; à son tiers antéricur, du cóté droit, nait un intestin extrèmcarent court, cylindracé, qui est complétement isolé du foie, et qui se rent eu ligne droile ì l'ourerture anale, siluéc au riel's postéricur, du côté droit de l'auional. Aucun Mollustue n'a présenté juscqu'à présent dans les organes dizestifs rien qui soit comparable à ce que l'on voit dans celui-ci : le foic a subi une modification non moios remarquable que l'estomac et l'intestin; il forme noe masse isoléc, assez volumineuse, presque cylindrique, divisce transversulemeat en

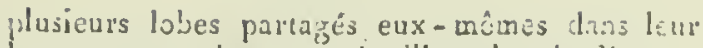
longueur par deux grands sillons log gitadiany. au fond desquels rentrent les vaisseaux biliatires; ccux-ci se rénnisseat pour l'ormer ua trona priscipal, qui se divise biestôt en diux brancles. dont l'ume gange l'estomac et le perce vers la: wilieu de sä longueur, landis que l'aute, tine et plus longne, se dirigne vers l'extrécilé cée l’intestin el seulance dans son Épaisseur, ua pes avant sa terminaison anale.

Les Mollusques ptéroporles, dont ane partit wlle que les firoles et les Carinatives, rentru: dans les Gasléropodes de M. de Blainville, s. divisen ea ellet, par leur organisatioa, en deur groupes bien nellemeut séparés. Dans les Vuclér. branches, qui cumpreanent les geares Carinai:'c Firole et Argonaule, l'intérieur de la bonrha. est revêtu de grandes plaques coraées, coupu.sées de segmens arliculés et munis de leux: :"ngrées de grands crochets doot l'extrúmité est tirigée en avant. Cet appareil très-mobils, qu: l'animal peut faire saillir au-dehors ct rentro: rapidement, lui sert il la tois de maichoires et ct langue : un apparcil musculaire cousidérable é! destiué à opérer ces mouvemens. Des glande: s.l. livaires, petiles et isolées, placées de chaque cól: de l'es!onac, donoent naissance it des canaux s:ilivaires très-grếles et fort loags, qni percent lés parois latérales de la masse bucale. L'osoplsays cst membraneux et cylindrique; il se dila:e en u. estomac assez longr et cylindrigue aussi : ì so:ı entrée il est pourvu d'une valvule subcartilag. neuse forace de trois parties triangulares. Un intestin très-grêle termine postérieurement l'estomac; il se read d'aloord en ligne droile au pédicule qui sépare le nocléus du corps ale l'auimal; il le perce dans a longueur, reacontre le licit, dans lequel il fait deux petiles circonvolutions, el se termine au bord droit el postéricur dı nuclé:us par un aus llottant situé à la base de la branchie.

Les Hyales et les autres Mollusques ptéropodes que Lamarck avoit considérés counme nu passagc des Mollusques céphalés aux Mollusques acsipàless, présentent en effet une disposition fort an zlogue à celle des abimaux de cet ordre : l'iesıphage est très-court, l'estomac furt ample et enveloppé de toute part par un loie volumineu. jui verse divectement, par des ouvertures nombreuses, le suc biliaire daos sa savité; l'intestin est grile. et forme un circuit sur les bords du foic. La Clis boréale, sur laquelle M. Cuvier a donné un trèsbon mémuirc, présente une disposition loutis semblible.

Il est nécessaire de faire remarquer que tous les Conchiferes unt les organes de lin dignes'i n disposćs d'une maaière particulière; l'esionac, ordinairement globuleux, est, sins exception, enveloppé du foic; les canaux hilinires manquent eatic̀rement, et les produits de la sícréticusont 
versés directement p.r r des cyyp!es pilus on moins randes el plus nu moinis nombrenses. Nous arous ril yue dias celle classe de Miullniques l'aropliage rasupoil presque constamnent; nous aurots snin de farre remaryuer ceux das ficures ou on obscrve celle partie. Ce que nous vornous de dire d'lase mauiere générals peut s'apiliyuer en partionlier aux animase de la famil!a des Os'racés; I intestin est cyliudrique, assez couı, t)mant une ou deux griades circonvolutious din.; l'épisisueur du foie el deloride, reventint eı.. suite sur la ligue médiane et dorsale, où il clerieu: symétrique, et se termiue à l'txtrémité postúdicute de l'animal. Daus la lamille des Pect.nides, el notamueut dius les geares Peicne ci

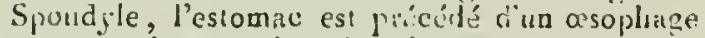
count el large, riclé jurreureaseut; lintestin nat de la partie postélietile el supérieure do l'estnmac, et, apres une grande circonvolution dans le toic, yagne le bord dorsal et se contourne ensuite sur le muscle central, ois il se tcluine par un anus follant. Le genre Pinne, qui ajpartient à la famille des Bytilacćes, póéscnte un esophagne très-étroit el très-ioust, qui aboutit a un renflement stomacal trè-globuleax, lequel se prolonge postérieurement en une cavilé cylindruide qui, aprés un éiranģlemert pyloriyue, doune naissance à uo inlesilu, cqui présente un reullement cocil assez cosidéiable: cet intesin, tres-simple et lort court, n'a qa'une seule circonvoluticn dans le livie, et il se .rmine par un autre reullcunent da rectum qui priciede de très - peu l'anus.

Nious avons vu que dans les Cardies les palpes laliales étoient divisées en six lobes de chaque colé; l'ouverture bucale quelles garaissebt est furt petice et prolongée en arricle par un orsophare asse\% long mais tris-étroil ; il souvie dans un eslomac globuleux doul l'ouverture pylorique cst assez grande : l'iniestin est court, ne fait dans le fuie quiune seule patite citconvolution, et se porte immédiatement vers le dos pour se teraines a l'ouvertuse postérieure du corps.

Il exisle, dabs un certain nombre de Mollusques acéplialés, uoe partic dont l'usige n'est point eacore connue : clle consiste ditas un appan. dicr: vermifcrme, concé, nexible, pointu à l'uue de ses extrémités, foxé dans les parois de l'estomaci pall l'autre, et contenue duns uxe cavité unembiaueuse annexée à l'estomac. Les Tridacaes présentent notannıcat celle or:sanisation, et chnz eux cet appendice corać est fort long; nous l'obserrous également dans les Arches, les Péloncles, los C jlúrées, les Vínus, les Bucardes, les Tel. lines, les Mactres et les Myes, muis il manque dins les Muletres, les Mloules, les Pinnes, les Solens et les Pliolades. On avoit cru que la présence de cet appendice corné pouvoit serrir à faire des rapprochemeus naturels entre les genres; mais on fiut remarguur qu'il se troure ou quil man- que lans des animaux qui apparienneol évidemment au méme groupe natulel.

Duas les Mollusques acépla!és qui sont muais d'uu pied assez grand pour se mouvoir, la base de ce pricd contient une partie des viscétcs, notanacmi use petile parlie diu foic et presque tout luvale; l'intestin s'y prolonge plas ou moins, scina que lit masse viscérale est plus ou moins prolongéne dans l'épaissem de ce pied. Uu nppaieil musculaire assez compliqué est destiné à soutenir la nussse viscérale el la liej intioneuncnt a l'organe cliarna qui l'enveloppe. Ia plupart des genies ponrvus d'un pied préscutent un intestin dont le développement est bieo plus considérable que daus ceux qui manquent de celte partic.

Ainsi, nons voyons que daus les Cylberies, los Donaces, les 'lellines sultout, et notammeut encore dius les Bucardes, les iutestins formeat une mul:iade de circonvolucions presqu'inextricables dans l'epuisseur de foie el de l'ovaire; ces circonvolutions deviennent beacoup plus sitaples dans les Sulcas et les Pholades. Dans $1011 \mathrm{~s}$ ces Mo:lusques, comme ceux que nous avons ex:minés précédemment, le rectum gagone cunstamment le bord dorsal de l'animail, le suit dans loute son éiendue, et se termile, soil dans le siphon anal lorsqu'il existe, ou eaire les lobes du manteau lorsqu'ils sunt súparés dans toute leur érenclue. L'importance qu'vat les orgaues de la digestion daus les animaux de tous les ordres est telle que les classilicatears ont ja, das les er.branchemeas du regue animal, employer aree avantage leurs diverses modifications pour cilconscrire des groupes ou des lamilles naturelles. Il seroit à souliaiter que cet exemple fút suivi pour ce qui a rapport aux Mollasques: d'après le peu que nous conuoissous su: ces animax, nous pouvons cependant concevoil l'espérace que l'on trouvera dans les olganes de la digestion d'excellens unoyens de classification. Il est remarquable déjà que tous les apimaux du grand geute Murex. de Tiune ont les organes de li: digestion disposls de la vićme manière; il n'est pas moins remarquablo de vriu dáns les Mollusques acóphialés ceux de la plupart des geures naturels offrir une arssi grunde coustauce. Les donnces incumplètes que lous possédons acluellemeut duivent encourager les acatomistes à dirigncr parliculièrencat leurs rccherches de ce cóté; elles seront liès-utiles à l'aviucemeat de celte partic de l'auatomie corpựéc.

\section{\$ III. Organes de la génération.}

Les Céphulopodes ont les organes de la génération peu eu rapport avec le reste de leur orgauisation. Il a été tacile de remarquer que de tous les Mollusques ils sont les plus avancés vers les vertéblés; aéanuoios ils appartienaent au grand Iype des Millusiucs, et saliout par les organes de la géuéralion. 


\section{$\mathrm{MOI}$}

Gónćralion, qqui ne diflèrent pas beaucoup dic ce yu'ils snnt dans les Mollusques diö̈ques. M. Cuvier, dans son Mémorre sur les Poulpes, a donné des diails fort intéressans sur les organes génétalcul's de ces animallx. Ils sont diojques, c'estu-dire qua'il y a des individus máles et des individirs femelles; les armanes femelles comprennen un wrand ovaire divisć en yrappes d'oulis plus ou moins grandes, contenucs dans uile poche séparié du périoune, ¿ laguelle ils adhèrent en un seul point par un grand nombre de pédicules. Celle poche est ouverte par un oviducte cylindrigue, court et assez large, qui se divise bientòt ca deux oviductes semblables, musculeux, mais charaus au moment de la ponte; ils sont cylindiiques, irrégulièrement boursouftlés, et présentent à leur base une glande vaste, revé:ue à l'intérieur d'un grand nombre de feuilles membraneux. M. Cuvier compare cette glande à celle qui, dins les Raies, est destince i revêlir les œufs d'une roque. I,es oviductes sont aussi tapissés d'une nauqueuse plissée longriludiaalemeut, et dont les tenillets sont dentelés sur leur hord libre.

l,es oryanes males ont beanconp d'analogie par leur position avec les organes femelles, le testiatule suitont diffère peu de l'ovaire par sa structure; il est formé de deux parlies glanduleuses, dont l'une est subgraualeuse, et l'autre divisée en lanieres, plusieurs tois bifurquées. Cet appareil est contenu dans une poche péritonéale particulicre, de laquelle nait un canal deférent, très-long et très-grôle, qui, après un très grand nombre de circonvolutions, alsoutit à une sortc de vésicnle sćminale qui se joint à une glande très-semblable pour l'aspect extéricur, à un aprendice cocal, et que $\mathrm{N}$. Cuvier désigne sous le now de prostate. Au-dessus du point de jonction de ces deux parties se trouve l'ouverture d'un sac rempli d'animaux soermatiques qui sont tellement grands qu'on peut les apcrcevoir il l'ail nu; ce sont des lilamens animés qui ont cinq à six liugnes de lungueur, el qui sont entassés el pressés dans Ia cavilé qui les recièle. C'est à Néédham que l'on doit la déconverte de ces animaux on de ces fameuses anguilles qui ont été, dans le temps, le sujet d'une vive conltoverse. Un canal particulier de cette poche aboutit à la base de la verge, tandis qu'un aune canal, faisant suite à la résicule séainale, vient aboutil vers son sommet.

Les organes de la ginération, dans les Gastéropoçes dioiques, sont en général composés à peu prés de la méme manière que dans les Céphalopodes. Dans les individus femelles on trouve un oraile silué à l'exırémité la plus reculée de la masse viscérale; cet ovaire est formé de granulations, quelquetiois de digitations rassemblées par un lissı cellalaire peo serré; un canal fort étroit nait de cet orgage; après s'ètre tortillé sur le bord du foie, il se renlle en une surle de mailice, et vient aboutir, sur le cỏlé droit de l'a-

Hist. Nat. des Vers. Tome $I I$.
MO I

uival, à un csifice llotant dans la cavić́ respiralrice : celle disposition se remaryue sullowt dins les renres Cóne, Porcelaine, Buccin, Puurpre, Rocher, Triton, Fuseau, elc. Les organes mâles consistent en un iesticule plucé comme l'avaire à l'extréconité la plus reculée des viscères, et donuant naissance à un canal déférent, extrèmement tortillé et lrès-grêle, qui se dilate pen à peu cu aboutit à la lase d'une verge énome, constamuent saillante, sur le côté droit du cou, dans l'intésieur de laquelle il est contenu, fortement cortillé sur lui-même. l.es animaux cles genres qui appartiennent aux Mollusques aronoipues ont la verge plus ou moins développíe : en général elke est tris-grosse, toujours exsertile et reploýce, dans l'élat de repos, dans l'intérieur du sac branchial. 11 est certains Mollasques, tcls que les Pourpres et les Cônes, qui ont le canal déférent excessivement long; dans les Purpres surtout, il a une ténoité capillaire, et il est d'une extrêtuc longueur.

Les Mallusques monoiques ollient sur cliaque individu la réunion des deux sorles d'organes, et leur jonction a lien ordinairement à la plartie anlérieure et droite du corps; dans quelques-uns, cependant, les organes mâles et femelles ont chacun une issue séparée, et toujours aussi sur le côté droit du corps. Quelques Mollusques appartenant à la famille des Ptéropodes avoient paru faire exception à cette règle générale à la position des organes de la génération; mais M. de Blainville a fait voir que l'on avoit étudié ces animaux dans une posilion renversée, et qu'en les rélablissant dans celle qui leor est naturelle, on trouva les issues des organes générateurs à la place qu'elles daivent avoir sur le côté droit de l'animal. La combinaison qui résulte de l'association de deux sorles d'organes épronve des madifications assez consilérables et constantes, selon les geures que l'on examine : si l'on en croil les observations de M. Cuvier, les sexes seroieat encore séparés dans la plopart des Mollusques pourvus d'uae coquille à ouvertare entière; cependant les olservations de $\mathbf{M}$. Quog viendroient inlirmer cette opinion, qui, au reste, a été parlagée par M. de Blainville. Uans celte série de Mollusques, les arganes de la génération paroissent disposés de la même manière que dans celle qui précède; cependaut, en général, l’ovaire prend un développement très-considérable, tandis que les organes mâles cnt une tendance à devenit plus pelits; c'est ce que l'on remarque principalement daos la verge, qui, dans les Turbos, les 'Troques, les Phasianelles, les Ampullaires et les Paludines, a proportionnellement beaucoup moins de volume que dans les Buccins, les Pourpres, les Rochers, etc. Ceux des Mollusques qui respiren: l'air en nalure, c'est-à-dire les Pulmonés terrestres et aquatiques, ont les organes de la gédération composés des organes mailes et fe$\mathrm{Y} \mathrm{y}^{\star}$ * 
melles; les organes femelles consistent en un ovajre plus ou moins développé qui cccape ordinairenıent l'cxtrémité des viscères accolé au foic; uil oviducte, ordinairement très-fin et fortement torlillé sur lui-même, naît de cet organe, et vient aboutir à un renflement plus ou moins considérable, qui est la matrice : celle-ci se contiuue par un canal ordinairement fort court, sur lequel on près duquel s'insère le canal de la vésicule copulatrice. Lorsque cette vésicule ne s'ouvre pas dans le canal de la matrice, il s'ouvre dans n a cluaque ou poche commune de la génération, dans lacjuclle vient s'insérer aussi l'extrémité de la gaine de la verge. Les organes mâles sont composús d'un testicale qui est une glande cylindroide plus ou moios alongfe, donnant uaissance par sa base à un caual détérent, qui tantôt est libre et tantôt soudé à la matrice; ce canal vient aboutir à l'extrémité d'une gaînélibreuse, cylindracée, dans laquelle il se tor'ille considérablement: cette gaine reuferme la verge, à l'extrémité de laquelle se sonde ce canal déférent : cette disposition se remarque priacipalement daos les genres Lynuée, Plauorbe, Ambrette, Agathine, Bulime et Limace. Dans les Hélices le canal déférent, au lieu de se rendre à l'extrémité de la verge, perce cet organe plus ou moins haut sur sa partie latérale. Dans ces animaux les organes de la génération sout compliqués par quelques parties qui manquent dans les autres Mollusques; ils sont en effet pourvus de vésicules multifides, dout les branches sont assez nombreuses et variables selon les espèces. On ignore quel est l'usage de ces vésicules: elles sont a a axées aux organes femelles, car elles sinsèrent sur les parois du canal de la matrice; une cavić particulic̀re aux Hélices contient un dard calcaire, très-aiggu, destioé, d̀ ce qu’il paruît, à l'excilation géuératrice. Cette cavitć, nommée poche du dard par M. Cuvier, a son issue dans le cloaque; elle se renverse au-dehors pendant l'acte de la génération, et les animaux s'excitent mutuellement en se lançant le dard qu'elle contient sur les parties de la pean qui avoisinent l'issue des organes de la génération. Il paroît qu'il n'existe aucune connexion entre les organes mâles et femelles des Aplysies et des geores qui les avoisinent; la vcrge est isolée sur le côté droit du cou; elle est complétement rétractile, comme dans les Pulmonés; clle sort au-dehors par une ouverture qui s'aperçoit au-dessons du grand tentacule droit; son extrémité póstérieure, un peu tortillée et amincie, est retenue par un tissa cellulaire assez serré sur le côté droit du corps, et complétement en dehors se voit un canal ou plutôt nne simple rainure creusée dans l'épaisseur de la peau, qui s'élend depuis le tron extérieur de la verge jusque vers l'extrémité postérieure dn corps où s'onvreat les organes générateurs femelles. Quoique l'organe excitatear ne soit pas lié d'une manière directe au resie des organes de la génération, il u'en existe pas moins ug irros tesicule, forwé d'un canal spiral, surmonlé d'une épididyınc, el aboutissant par ua conduit très-court à un camal commun, ou cloaque de la génération. L'organe lemelle consiste en un très-grous ovaire lolé, du milien duquel nait an oviducte très-mince à sun origive, mais se renllant et se tortillant a nusure qu'il s'avance vers le testicule : écst lorsqu'il est parvenu a cet organe qu'il prend une forme cylindracée, et qư̈il reçoit d'un côlć une vésicule copulatrice assez grande, et d'un aulre un appendice simple et cyliudroiode, qui ressenble ì une branclie isolée de la vésicule mulifije des Limaçons; une antre partie, qui paroîl ylanduleuse, probablement uoe prostale, nomné par M. Cuvier corps en forme de grappe, est lixtée au cluaque, dans le voisinage du canal de lis vésicule copulatrice. On igruore complélement l'usage de cet organe. La séparalion si complète de la verge des autres organes de la géuéıation pruuve, ce nous semble, d'unc manière évidente, que cet organe est simplemeat cxcilaleur, et ne remplit qu'accidcutellement, en quelque sorle, le rôle de transmettre le fluide lécondant. I,es Aplysies ne sont pas les seuls animaux où cellc particularité se remarque; on la retronve dans les Dolabelles, dans les Ácéres, les Notarches, ctc. Nous l'avous également observé dans les Calyptrées et les Crépidules.

Dans les Mollusques compris dans les Ptéropodes de Lamarck, et que M. de Blainville a rangés dans son ordie des Aporobranches, ainsi que dans celui des Nucléobranches, les organe; de la génération sont généralement peu connus; il n'en est pas de même dans les Doris et geures roisins, sur lesquels M. Cuvier a donıé quelques détails. Dans ces animaux, les organes de la génératiou sont séparés à peu près à la manière de ceux des Linuaces; les organes femelles se composent d'un gros ovaire, cuntenu dans l'épaisseur du foie, d'un oviducte tortillé sar lui-même, assez long, aboutissant au testicule, sur lequel il se cclle intimement; la vésicule copulatrice a mn canal assez long, qui présente ce fait particulier d'être bifurqué: l'upe de ses branches, la plus grêle et la plus courte, se rend au tesiicule, au point où s'insère l'oviducle; l'autre, plus grosse. aboutit à la base de la verge. Le testicale est fort gros, irrégulier; dı point où s'insère l'oviducte part un canal cylindracé el assez gros d'abord, qui samincit et se tortille avant de parvenir ì l'extrémité de la verge, oì il s'ouvre : ce conduit est le canal déférent; la verge est très-longue, complétement rétractile, st elle sort au côté droit du corps, immédiatemeut à côté de l'ouverture des organes femelles. Il est à présumer que les geores qui avoisinent les Doris, et qui sont moins conaus dans leur anatomie, tels que les Glauques, les Eolides, les Scyllées, etc. : présen- 


\section{$\mathrm{MO} \mathrm{O}$}

reat un arrangemeut tis-semblable a celui dos Uuris.

Il existe un petit nombre de Mollusques à coqquille univalie qui sont complétement liermaphrodites, et qui font par conséquent le passage (nit:e les Mollusques monoïques et cenx que contiernent les coquilles bivalves. Dans ces cires un seul organe persis:e, c'est l'orgune lemelle, et dies-lor's chaque individu se suliit à lui-même : un ovaire assez yros forne la partie postérieure de la masse der riscères; cet ovaire est pourvu diu ovifucte rui aboutit au-deliors dans le sae branchial. Les Cubuchons, les l'atelles, les Dentales, les Finsurelles, et, d'apres .II. de Blainville, les llalictides et les Calyptrées, mais à tort pour ce lemier genre, sout les senl genres que lon cite intueilemeat duas los Mlollusques céphalés liermiuphradites.

Dans loule la grande série des Mo!lusqques acéplialés nons trouverons une disposition rès-anaIngue dans les orraues de la génération: dans tous cés lanellibranclies un ovaire très-grand oteupe Ia partie supérienre de l'animal, et s'enfonce dans l'épaisscur du pied loripue eer organe existe; cet oraire fournit de sa partie antérieure un oviducte forl court, qui s'ouvre entre les fenillets branclsiaux extérieurs du côté droit; celle ouverture se présente plus ou moios liaut, selon les genres: cente sirnplicité des organe de la génération a élé contestée par des observateurs labiles, qui se sant fundés sur les expériences pluiôt que sur l'inspectiva anatomique. A en croire NI. Prevast, de Geneve, on parviendroit par l'isolement de certains individus, de Mulelles, par exemple, a rendre les atutres infécunds; il y aurait donc des individus mâles el d'aulres femelles. Il appuic ceite première doanée par d'autres observalious; il prétend qu'en exprimant en quelque sorte certains individus des Julettes de nos rivières, on aperçoi: dass la liqueur un graud nombre d'uninaux miernseopiçues très-analogues anx animaux spermaliques des animaux vertébrés; il y auroil donc rérit.ablenent, si les observations de M. l'rerost sout justes, non pas seulement des organes générateur's des cleux sexus dans un mème indivilu, mais même leurséparation complète, comme duns les Mollasques les mieux oryanisés. Pour qu'un fait si important soit mis hors de doute, if faudroil d'ahol'd qu'au moyeu d'analomics bien filites on parviut à connoilre les individus mâles et les individus ferelles; mais cont ce que l'on a pu obtenir jusqu’a présent, et malngé les recherches les plus asidues, on u'a jamais pu décourrir la moindre diflérence entre tous les individus d'une même espèr:e: on doit néanmoins vivement desirer gun un observa!eur aussi habile que M1. Prerost donne suite à ces recherclies, qui ne penvent manpuer de le conduire a des résultats du plus haul intérét.
M O T

S. IY. Organcs de la respiration et de la circulation.

La liaison intime qui existe entre les orgranes de la respiration et de la circulation nous it déterminé a examiner simultaníment les modilications qu'ils éprouvent. 'Tous les Mollusques, sins exception, respirent par des branchies : dans quelifues-uns les branchies sum modiljces de maniere à recevoir immédiateurent le contact de l'air; mais ces animaux ne sout pas poul cela pulmonés, comme on l'a dil impropremenl: une cavité tapissée d'un réseau vasculaire ne peut être comparée à un poumon, si l'on conserve la définition exacte et rigoureuse donnce par les amatomistes.

La circulalion, dans les Mollusques, se fait d'une mauière plus simple que dans les auimaux. vertébrés; elle a lieu dans un cercle simple: viusi les veines apportent des différentes parties du corps le sang vers la branchie; il s'y vivific, passe dans les veiues brancluiales et arrive au cœur, gui est composé d'une ureillelle et d'un veutricule; il passe à travers cet organe d'impulsion; et il est porté à toutes les parlies de l'atuimal par le système artériel. Dins les Céplablopodes, où il existe une Irès-grande branchie de chaque côté du corps, il existe deux cours, et chacua d'eux est pourva d'ube oreillette : ces Mollusques sont les seuls qui offie ce fait singulier d'oroanisation. Ces cours latéraux sont propies à claqgue organe branclial, mais ils n'ont aucune intluence sur la circulation artérielle, qui se fajt au moyen d'un eœur médian, duquel nait le sy'stème artériel, dont la partie priucipale est une antle considérable. Une particularité remarquable propre au système veineux des Céphalopodes consiste en un grand nombre de glandules spongieuses llotlant daus la cavité du sac branclial, el allhérant aux veines, dans lesquelles elles s'onvrent par un grand nombre d'ouvertures. M. Curiex pense, avec juste raisou, que ees glandes sont destincées à suppléer à la respiration, ou du moins à la rendre plus aclive; d'aulres analomistes pensent que ces glandes transmelleat dans les veines une certaine quantité de fluide ambiant, après lui avoir fuit subil quelqu'altération : eette opinion se fonde sur ce qui a lieu dans les Aplysies, dont nous aurons à nous oceuper plus tard. La position des branchies, dans les Céphalopodes, ollie celle anomalie d'ćtre contenues dans un sac situé en dessous du corps; elles présentent de plus une symétrie parfaite, ce que nous ne retrouverons plus que dans des Mollusques d'un ordre très-inférieur.

Dans tous les Gastéropodes pourvus d'une coquille spirale, les branclies ne sont jamais symétriques, elles sont laujonrs situées dans une carité formée par une duplicature du manteau, el situées au-dessus du cou de l'animal. Celle branclia est 
taniút simple, tantút double, le plus ordinaire. unent clle se cumpose de deux peinnes brancbiaux, donl l'un, toujours licaucoup plus petit, est placé à la base de l'autı e. Celte disposition est tellement géuérale duas les Gastćropodes à coquille spirale, yu'il est iuutile de donner à cet égard des délails plus éteodus : nous ajunterous sculement que celle branchie esI formće de filamens plus ou moias ipais et plus on moins nombreux, selon les genres. Lc nom de l'ectinibrauches, donné à celle grande séric des Mollusques, est conveuable en ce qu"il représcule un pount esscatiel de leur organisation; il a cependant linconvénient de ae pouvoir être d'une application générale, car il n'est point de Mollusque qui ne suit vérilablement pestinibranclıe, mais celle dínominalion ne s'appliyue qu'à ceux qui le sout d'uue mauic̀re plus évidente que tous les autres.

Un cœur d'un volume médiocre es: silné constamment à la base de la brauchie dians les Pectinituraaclies. Le sans veineux, apriés avoir traversé la branchie, est porté dans tuul l'animal par le système artériel qui naí du ventricule : que les Nollusques soien! siphonobranclies ou asiphonobranches, selon les expressions de MI. de Blainville, les organes de la respiration et de la circn. lation n'éprouvent que de légères modifications; ses organes sonı donc peu propres à déterminer de perties coupures dans la méthode, mais ils peuvent très-bicn s'employer à la délimination des grands ordres ou des graodes familles de la classe des Mollusques. Lia lungue sćrie des Pectinibran. ches pourrnit comprendre tous les Mollusques qui, dans la méllıde de Lámarck, soot distribués dans ses treize deraières farnilles; il est à remarqquer cependant, que les genres Haliotide, et très-probablement les Stomates et Stomatelles, ont les organes de la respiration el de la circulalion dans un arrangement parliculier qui doit les fairc sor'a tir de l'ordre dans lequel ils se trouvent actuellement. Dans ces animaux, ev effet, la branchic, ainsi que le cœur, sont situés à gauche de l'ani. mal; ce qui est, comme on le voit, le contraire de ce qui a lien dans tous les antres Mollusques céphalés : outre ce dérangement considérable, le cour a subi une modification dont nous ne retrourons plus d'exemple ique dans les Mollusques bivalves, c'est-à-dire que, quoique pläcé à la base de la branchie, il est néanmoins traversé par l'intestin, dont l'extrémité vient floller dans la cavité branchiale. Nons avons déjì vu que le système ncrveux des Haliotides présentoit des anomalies non moius remarquables que celle que nous venons de sigualer; ce genre doit donc, par l'ensemble de soa organisation, constituer uae famille très-distincle, car il semble s'isoler de toutes parts des autres Mollusques. Il seroit pentêtre possible que par un examen minutieux d'un hrand nombre d'espèces de cbaque geare, de déterminer d'une manière positive dans ceux-ci les modifications que penvent éproures les organes de la respiralion el de la circulation : ce seruit le mnyen de décider s"il est pussible de se servir atilement, duns tons les cas, de cette partic de l'urganisation pour la déterminalion des coupes secondaires. Si l'on puluvoil s'assurer, par exemple, que dans les Buccins les bramc hies sont roujours molles et composées d'un nombre déterminé de feuillets, tandis que, dans d'autres genres, elles servieat consla amment décomposćes en minces filets subcarlilagineux, on ponrroit alors s'iider de la déteraination des geures dans jes espères douteuses par l'examen facile de celle parlie de leurs organes; mais le nombre des observations faites jusqu"i présent, el la ncigligence qu'ur.t apportée, jusque dans ces derniers temjis, lcs voyageurs naluialisics a la recherche el à la conservalion des aniwaux mullusques, s'uppose à c $\mathrm{C}$ que l'on puisse poser des içgles génćrales ì cct égard; on pent tout au plus indiquer quelques fails isolés qui ne prendrent de l'imporlance qu’à mesure qu'ils scront joints à des obscrvations Douvelles.

Dans les Pectinibranches proprement dits, les branclies sont contenues, consue nons l'avons déjà dit, dans un sac silué an-dessus du cou de l'animal; la situalion de l'organe branchial reste la méze, après avoir éprouvé une modification importanle dans les Gastéropodes fulmobrauches. Ces aoimaux, qui reçoiveat sur leurs branchies l'air en uature, ne présenteot à la place d'une brauclie pectinéc qu'un réseau vasculaire considérable dans lequel le sung est régénúré; re réseau, qui occupe une surface plus ou moins étendue, ne peul ètre comparé ni dans sa structure, ni daus sa nature, à ua véritable ponmon, tel que l'on conçoit cel organe dans les adimaux verlébrés. Il n'y a de la part des Nullusques pulmobranclics aucua effurt pour l'inspiration et l'expiration du fluide respiré, no trou ourert sur le côté droit du corps, dans la partie épaisse du manteau, que l'on nomme le collier ou la cuirasse, selon les geares, permet, par sa dilatalion ou son occlusion, à l'air anıliaat d'arriver et d'être cunservé plus ou moins long-temps sur le réseau branchial. Malgré celle tnodification importante dans la forme de la branchie, la circulation en général, et le creur en particulier, n'en ont point éprouvé d’assez considérables pour mériler une description parliculière.

Les Aplysiens et les Dnlahelles nous offient un fait des plus singulicrs dans certaines parties da système vascalaire; un antre fail qu'elles servent à démontrer aussi bien que tous les Nollasques qui ont une coquille rudimentaire, c'est que celle coquille est essentiellement destinće, comme nous aurons occasion plus tard de le démontrer, à protéger les organes de la circulation et de la respiration. Dans les Aplysies, ces organes ne son' plus situés, comme duns les Peclinibranches 
roprement dits, à la parlie antúrieure de l'animal; on les trouve en ellet sous une sorte de bouclice cartilagincux ou calcaire, silué à la partic mnyenne ou postérieure du corps, et cuclıl's sous les lobes épáis d'un manteau llottant. Deux hrancbies inćgales, pectinilormes, molles, regrivent le sanér quileur est apporté p.a le système veineux; mais la veine branchiale, lrès-large, arant d'arriver a la base de la branchie, a ses parois farmées par un réscan musculaire, dont les mailles sant assez étendues pour perusellie une libre communicalion culre la ciavité de la veine et la poclse commune qui cuatient les "rgaues; de sorte que l'on peut concevoir ou yie le sang s'épanche librement de la veine dius celle cavilé, ou que la veine peut almeltre utue partic de liquide gui y est contenue. II est à présurer cependant que duraut la vie de l'animal I. contraction du tissu musculaire de la reine eupéclic sa libre communication daus un sens ou daus l'autre; car sans cela on ne pourroit guère expliquer la circulatjon de ees anituanx.

'Tous cenx des Mlullusques qui sint dépourvus te coguilles offreut des moditicatious particulives dans chacun des genres : c'est une raison peul-èrre pour faile croire qüil en est de mème dans les Mollusques qui sont pourvus d'une coyuille. L'armi les Mollusques qui ont la coguille paleloide, on reoralijue daus les organes de $I_{a}$ ruspiralinn plisieurs modifications furt importintes: les unes, par exemple, se lient aux Pecrinibranches, parce qu'ils ont la cavilé branchialc situé au-dessus du con, et que leurs branchies ne diffirent en aucune marière de celles des animaux de cel ordre: telles sont les Calyptrécs, les Ciépidules, etc. Dans d'autres, un peigue branchial, unique, extérieur, et protégré par une coquille jrrégulière, est placé ccpendant comme dans un grand nombre de 1 lallusques nus; ils doivent donc se joindre à ceux-ci : dans quelgues autres, dont la corpuille est parlaitement symétrique, les organes respirateurs sont situés dc deux manjères; dans les uns, Fissurelle, En.rginule, Parmopliore, etc., les branchics situées in-dessus du cou, dans une cavité comparable à cclle des Pectinibrauches, sont égales et parfaitemeut symétriques; dans d'autres, Patelle, Osculurions, ces orirabes, décomposés en lamelles, sont situés autour du corps, à la base du pied. Chacuoc de ces modificalions en entraine avec elle unc autre dans l'orgaue de la circulation: c'est aiosi que dans les Culyptrées il est situé comme dans tous les Pectinibranches, landis yu'il devieat symétrique dans ceux des animaux clont les branchies le sont égralcmeut; duas ce cas il est pourou de deux oreillctles, ce qui est un fassage des plus évidens vers les Mollusques acéphalếs. Les Unbrelles, qui ont plus d'une abalogic avec les Pleurobranches, ont le coeor situé à peu prìs de la mêne manière, c'est-à-dire placé it la base đe la lunanchie, à l'origine du con, du côté droit. Il existe une séric de Wo!lusques sans coquilles, yui ont les franchies nectinétes parfailement symétriques, mais diversement situées; e'est ainsi que dans les Doris, elles sont rasscmblées autour de l'anus, à l'extrénulté postéricure et médiane da cupps, le cuur est situé immédialement au-dessous d'elles; landis que dans d'aulres genres, tels gue la Scyllée, ha 'Trilonie, le Glauque, lir 'Tiuéliyss, la linguclle, le cour est placé plus ou moins haut daus la ligne médiane et dorsale, parce que les branchies son l distribuées égalcanent de cluaque côté du corps, soit en lanières, soil en arbuscules, suit en licaclles ou peigues branchiaux plus ou moins élendus; mais il est à remaryucr "juc toutes les fois que le caun est silné dans lit liguse médiane, il est coaposé d'un ventricule et de deux orcillelles, et qu'il est toujours situé vers le point de l'animal qui se rappioche le plus d: l'origine des branchies.

On a cru que dans les Nucléobranches, tel'es que les liroles et les Carinaires, amimaux qui parvissent parlailement symétriques, le cour et la brancbie participoient a celle rígularite; mais 1 n'en est rien : le nucleus yui conlient la ranse principale des oryanes n'est point syunéllique comme le reste du corps, el le coul, sicué $a ! 1$ côlé droit, cst il l'origine de la branthie, qui gaugne en s'alléuuant le côté ganclue, formant aíasi unc frange à dentilions décroissantes sur le côlé antérieur du nucleus.

Quelques zoologistes pensèrent que dans un certain nombre d'animaux mollusques, qui furent nommés Pı́́ropodes par M. Cuvier, la respiraticn se faisoit au unoyen de certaines parties de la peau, divisée par un I rès-grand nombre le stries; ces stries, à re qüil paroit, sont dues anx libres musculaires superficiels; car MI. de Blaiuville a trouvé daus les IIyales et les Cléodores m peigue branchial, qui araot lui avoit ćchappé aux olservaleurs, et situé dans une cavilé respiralıice fort petite, mais comparable à celle des Gastéropodes. C'est ce qui a déterminé le zoologiste que nous venons de citer à uodifjer d'une inivière si importante la classitication des gentes que nous venous de menlionacr, et de tous les l'éropodes en général. Il est certain, en cllet, que des aniasux qui n'ont qu'une senle branchie non symétrique, un ceur avec une seule oreilletle, s'eloignent bien davanlage des Mullusques bivalves que Lamarck ne l'avort cru. Il laut rapprocher des animaux de celle grande classe ceux qui dans la classe précédeute ollirent avec eux des points d'analogie plus nombreux : ce sera, sans contrediı, d'un cólé les Haliotides, a causc de leur anzeau cesopbagien trc̀s-élendu el da passage du rectura à travers le coeur; d'un autre côté a vec les animaux symétriques, soit nus, suit a corguilles, parce qu'ils ont les branchies égales, la coeur médian ef pourva de deux oreilile!ts:, 
C.'st disia gue l'arganisalion se modifie diune maniere renarquable, lorsque l'on arrive at la limile de denx classes d'animaux qui ont entr"eax beaucoup d'analogie.

'lous les Mollusques lamellibranches ont, sous le rappont de la respiration et de la circulation, une organisalion quileur est propre, el qui n'olfie qu'un tres-pelit nombre de moditications : c'est aiusi yue tous, sans exception, ont de charrue cólé du corps ane paire de feuillets branctiaux réunis entreux dans la ligne médiaue, soit dans tonte leur étendue, comme dans les Mollusques sạns pied, soit à leur extrémité pastérieure seulement, lorsque le pied existe. La structure de ces branchies est à peu près la même pour tous; elles sont formées de deux feuillets charaus, it la base desquels sont placées les artères brancliales d'un côlé, et de l'uutre les veines du mème noin. Ces vaisseaux fournissent des braoches nombreuses, parallìles, très-tines, qui s'anastomosent it leur sommel; les veizes brauchiales aboutissent a noe vreillelte, ordiaairement triangulaire, qui s'insère sur les parties latérales du coul, par un pédicule assez court; le ventricnle, ordinairement oblong, tusiforne, est quelquefois arrondi; les fibres musculaires dont il est formé sont distribués en petits faisccaux peu épais : à travers sa capacité passe l'iatestin rectum, sur lequel sont accolés les gros vaisseaux aortiques qui se distribuent snil à la parlie antérieore, soit à la parlie postérieure du corps. Nous allons examiner quelles sont les modifications connues qui font exception à celle disposition générale. C'est ainsi que dans les Iuîtres, le cœur n'est point silué sur le milieu du dos, el a'est pas traversé yar l'intestin; il est placé à la partie supérieure du muscle central, il n'a qu'une seu'e oreilletle, qui est fort grande, subsymétrique, quadrangulaire, et communiquant an cœur par deux troncs très-courts et fort gros; les vaisseaux brancbiaux communiquent avec rellc oreillelle, non à la maniere des LamelliLranches, mais par trois branches de chaque côté, qui se rendent à chacun des grands vaisseaux branchiaux. Nous ne relrouvons cette manière d'être dans aucun des autres gentes, snil séfuliers ou irréguliers, des Lamellibranches. ("est ainsi qu'en passant à la famille des l'ectinides, on trouve le cœur médian et traversé par l'intestin; dès-lors aussi le coeur est symétrique et pourva d'une oreillelte de chaque côté. Dans lu lamille que nous cilons, le cœur est à la parlie postéricure du grand couscle; il est arrondi, dirisé en six lobes à peu près égaux; les oreillettes sont soudées immédiatement à sa face postérienre : elles sont assez charnues et épaisses, et elles reçoiront les veines branchiales pur leur extrémité inlérieure. Dans les Monles, le cœur est submédian, petit; les oreillettes forment de chaqne côté un pelit sac, à l'extrécoité antérieure duquel est siluć un vitisseau simple, qui se jette dans la reire lirancliale, vers son liers antívieur. Dans les Punes, qui ont le systèue vasculaire extrimement développé, le veutricule est fort gros et furt épais; il est séparé des oreillelles jar uu pédicule court : celles - ci sout semblat.les, subtrilobées, globuleuses ei ćpaisses; elles reçoivens claus leur milieu deux grosses arteres braucluialce, lortenent cnntaurnées it leur partie antérieure. L'aorle, cqui suit la ligne mćdiane et dursale, se dirise à la parie anléricure en deux grandes branclies, qui suivent dans toute lcur étendue hes Lords du manteau, en lournissant à cette partie un très-grand nomble de vaisseaux, divisés d'une manière assez réguličre sur son limbe. L'aorte postéricure est destinée à fournir le sang aux viscères; ellc se partage en un grand nombre ste branches, dont deux jurincipales soot destinces a l'estomac, anx iutestins et à l'ovaire. Les oreillettes sont en ónćral uoins sćprarées du caerur et des vaisseaux braachiaux dans les Molluscyues dimyaires que dans les monomyaires; cependau: les Arches font exceplion à celle rćngle, car ciles snat pourvues de deux cours, munis chacan te deus oreillc!tes : ces cours sont petits, parfaitement semblables de cliaque côté; ils sont subglobuleax, charans, à peiue séparés des oveibleltes; l'uue d'elles, l'externe, est furmće par le renllement de l'artère branclivile; l'interne, beatscoup plus pelite, à peine séparée par a érranglement, se voit à l'urigine de l'aorte, qui torme une anastumose direcle entre les deux caurs. C'est de la courlumre antérieure de ce vaisseau que naissent les brancbes qui se distribuent à coutes les partics aalérieures de l'unimal. Liaorie est bilurquée un peu au-dessous de son origine; les branches infétienres se dirigent l'nne vers l'autre, et de leur joncrion, yui a lieu dans la ligra médiıne. résulie une grosse aorte descendante, qui ne se partage en rameanx nowbreux qu'à son extrémilé infíricure.

On a généralement l'opinion que le genre P'́loncle est us démembreasent assez inuule des Arches; il est ì remarquer, cependant, quili $\mathrm{cm}$ differe sous plusieurs rapports, non-seuleunent par la forme du pied, par relle de la coquille, mais par d'antres points beaucoup plus esseotiels de l'organisatinn. C'est ainsi que le çeur est unique, traversé par l'intestin, el pourvu de clrạue côté de deux vastes oreillelles subtriangulaires, qui reçoivent les vaisseaux brauchiaux par leur extrúmilé intérieure; c'est à leur angle supćrienr quaboulisscal les veioes qui proriennent des diverses partics di corps. Il seroit à désirer que l'on connût l'anatonise exacle d'un grand nombre d'espcces apparlenant aux deux genres; ce seroit le unyen de s'assurer s'il existe dans les orcanes de la circulation une sćrie de modilicacions, qui formeroient un passage entre les aniwaux, comme il a lien pour les coquilles.

Les Mollusgnes lamellibranches, qui, comme 
ceux-ci, on deux nusciles et les lolies du man. ceau complétemeut désunis, en dillèrent béanmoins par les oreranes de la virculalion; c'est ainsi que dans les Muletles, le cour, silué rers le milieu de l'animal, est simple, fusitorme; les oreillelles, qui ne sout qu'un reullement de l'artc̀re branchiale, sont alongées, triangulares, et com. numiquent avec lui par un pédicule yros et court. Les petites artères lıranchiales aluutissent clircctemeut dans l'oreille!te, aussi-bien que dans l'artcre branchiale principale, qui eu est la contimation. La méme disposition se représente dans jresque tous les Mollusques dimyaires, qu'ils strient ou non poulvus de siphons postéricurs; il l'y a de dillérence à leus égard que daus la posilion relative du coenr, qui est plus ou moins médiau. Nous pouvons citer, comne appurtenant t cette modilication organique, un grand nombre de gerres, lels que Bucarde, Isocarde, Vénus, Cyrène, Lucine, Telline, Donace, Saxicave, Vínćrupe, Mactre, Lutraire, Mye, Solen el l'holade; c'est-à-dire tous les types principaux des familles établies dans les Conchilëres dimyaires. Les Cardites se lient aux Conchifčcs nunomgaires et aux dimyaires par une modifivalinn parliculière; le cœur est globuleux, les creillettes sont snudées immédiatement sul ses cúlús: ces orcillettes sont assez grandes, et reç.sivent à leur extréunité antéricure l’artère branvaliale, qui nait de la partie interne el antérieure de l'artère branchiale principale, sur laquelle sinsèrent les artérioles qui parcourent les branchies. Ainsi ce genre dillère des Mulelles et des autzes dimyaires, et se lie un peu, soil aux Fétancles, soic aux Moules, et mĉme aux Peignnes.

Il esi a renarquer qu'à mesure que les animaux conchilères ont les siphnns plus alongés, les branchies ont une tendance à se porter vers l'exIrúmité pustérieure du corps el à se prolonger, plus ou noin3, dans la cavité du siphou, qui lear est destinée : ceci se remarque aussi bien dans les Solens que dans les Pholades, les Saxicaveo, etc. 'Tulles sout, quant à présent, les comnoissances acquises sur celte parlie de l'organisation des Mollusques; elle a besnin, comme presque tonles les autres, d’être approfondie par un graud nombre d'observations. On pourroit limiier quelques ordres ou quelques lamilles en s'appuyant sur les caractères organiques que fournissent la respiration et la circulation; mais il seroit à craindre qu'en en faisant un usage trop obsolu, on ne comait des erreurs graves à cause des connoissances qui sont eucore nécessaires pour établir, d'une manière à peu près celtaine, des lois générales.

\section{S. V. Systdme muxulaire général et particulier.}

I.e sysièmemasculaire, dans les Mollacques, doit être considéré de deux manières : il est géné. ril et duit déterminer le mouvement; il est particulier el destiné à certaines fonctions. Ie système: grénéral est variab!e selon les types des Malinsques dius lesquels on l'examine; ils constitue plusicur:s parties distincles que nous amtons successiveuient a examiner : 10 organes locomoteurs. Ils sont dc deux sortes dans la plupart des (éplialnpedes. Ces animaux portent sur la tête huit ou dix lanières llexucuses, entièrement musculaires, destinćcs a la locomotion et a la préhension de la proie; chacun de ces bras est formé de quatre fuisceaux de muscles, dont la base s'insère solidement sur uue plaque cartilagineuse, qui forme la partie sulide de la téte; des ventouses pourvues de muscles propres sont disposées en double séric ou en sćrie simple le long de ces loras, et servent à rerenir, de la manière la plus solide, le corps 'qu'elles saisissent. L'enveloppe cutanée des Céphislopodes, qu'ils soient ou non pourvus d'une coquille interne, est épaisse, charnue, et coosposée presque entièrement de fibres musculaires entrecroisées dans toutes les directions : ces fibres se continuent dans les nageoires, lorsqu'elles existent, comme dans les Sèches et les Calmars; un grand nombre d'entre elles se réunissent en deux laisccaux supéricurs et laléraux, qui joigoent la tête au corps, et servent a retirer celle-ci vers le sac ou à permetlre son alongement; deux autres inuscles moins importaus, parallèles à ceux que nous venons de meotionner, se trouvent à la face inférienre de la tête el du cou, se jetleat dans les piliers du sac, et se lient ajnsi à l'enveloppe générale. Ces unuscles représentent ccux qui, dans les Mlollusques pourvus d'une coquille spirale, se nomment muscles columellaires. Celte analogic fait supposer que si les Céphalopodes que l'on trouve habiluellemen! dans la coquille de l'Argo. paute en étoieut les constructeurs, les muscles verceroient la peau pour venir sallaclier sur les parois de la coquille, comme cela a certainement lieu dans les Nautiles; mais l'animal parasite de l'Argonaute ne s'y trouvant lié par aucune moyen, peut en sortir à volonté : ce qui rend inexplicable et la formation du test qu'on lui altribue, ct sa symétrie parfaitc.

II y a voe très-grande différence entre le système musculaire des Céphalopodes el celıi des Gası́éropodes proprement dits; il faudroit placer. entr'eux sans doule, comme l'ont fait au reste plusieurs zoologistes modernes, ceux des Mollusques qui. après les Céplıalopodes, on le plus de liacilité dans leuss mouvemens et sont olghanisés pour la natation. Les Ptéropodes, ainsi yue les Nucléobranches, remplissent fort bien celte condition; mais ils sont si inférieurs aux Gastéropodes sous tant de rapports, qu'il n'est guère rationnel de faire prévaloir, à leur égard, les modificalionns du système musculaire, qui ont bien peu de valeur comparativement à celles qui conchent à des systèmes d'organes dont l'impo:tance a $<c^{\prime}$ incou- $^{-}$ 
trstallement admise par tous les zonlagistes, On concevia sans peine que ce qui tonclie an système nervenx, aux organes de la génćration, etc., "st d'une bien autre importance gue les noditicalions do système musculaire, très-variatıle dans les Mollusques. Les Ptćroprodes, et en gínéral les Mullusques aageurs, ne deviont prendie place dans les classifications, non comme on lia fait jusqu'a présent, d'après lenr faculıé de rager, mais d'après l'enserable de leur organisation.

Les Gastéropodes ont en génćral uoe démarclie lente, ce qui tient à ce qu'ils sont obligés de ramper sur un disque charnu, plus ou moins érenda; ce plan locomoteur, auquel on a donné le nom de pied, quoiqu'il n'ait ancune analogie avec cette parlie d'aucun animal rertébré quelcontue, est plus ou moins éleuda e! plus on moins délaché du corps, selon la lurme de l'animal. Dans les Mollusques pourvas d'une cognille spirale, le pied lorme une rasse charrue assez épaisse, qui se lie au reste du corps au rooyer d"un pédicule gros ct court, qui sinsère urdinairenent alr-dessous du cou. Cette circonstance avoit para sulfisante à I,anarct pour laire de tous les animaux qui l'ollirent ua ordre a part, auquel il donne le nom de Trachélipodes; mais si l'on fait attention an passage qui existe entre ces animaux el ceux qui sont limaciformes, et qui sont réellement gastéropodes, comme l'entend Lamarck, on sera bien ublizé de rejeter cette division artificielle, quoiqu'elle ait paru d'abord assez utile. Dans tous les Gastéropodes, le pied est formé d'un plan musculaire, dont les libres sont enlacées d'une manière inextricable: on peut en distinguer cependant de longitudinales, croisíes par d'autres lransverses, yui tou!es deux sont enlacées par des tibres oblirues. 11 existe en outre des libres perpendiculaires qui s'étendent de la face inlérienre à la supérieure du pied, et détermiuent son aplatisseuent; ces fibres sont ton!es réunies par un tissu cellalajre plus on moins serré. Ceux des Mollnsques gastéropodes qui ont une coquille spirale sont fortement attachés à ce corps protecteur par un muscle puissant, qui part de la partie antérieure du pied, avec lequel il est intimement confandu, passe à travers le pédicule et va s'ınsérer sur la partie la plus solide de la coquille, c'est-à-dire la columelle : tantôt ce faisceau musculaire est simple, lantôt il est divisé à son point d'altache en plusieurs petites lanières. Plusieurs zoologistes prétendent que c'est à cette circonsrance de peu d'importance que sont dî les plis que l'on remarque sur la columelle de certains genres; mais il est une objection à faire à cetle upinion, c'est que les p,lis columellaires se prolongent bien au-rlelà du point d'insertion dı muscle, ce qui n'auroit pas lieu, si le causcle éloit lui-même la cause de leur production. Nous avons la convicion que ces plis ont lieu par suite d'une modifica'inn du manieau, car c'cst lui qui est chargé de la formation de toutes les parties de la coquille, et le muscle columellaite n'est divisé que parce que la columelle elle-biène est chargée de plis plus on moins saillans : il est à présumer qu'ici, comme daus plusieurs autres cas, l'ellit is élé pris pour la cause. l.e muscle columellaire éprouve d'autres mudilications dans ceux des Mlul. lusques qui ont la coquille interne ou qui l'ont patelliforme : dans les preniers, la forme du muscle est en rapport avec celle de la coquille; si elle est spirale comme dans les Sigarets, il ressemble Leaucoup à celui des autres Gastérupodes à coquille extérieure : cependant il est plus aplati et a une tendance à se courber en forme de fer à cheval; mais ceci n'a pas lien dans les Bulles, dont le muscle columellaire est en tout semblalile i celui des autres Nollusques. Lorsque la coquille interae est en bouclier, elle a'a ordinairement aucun rapport avec les muscles; et les Dolabelles, les Aplysies, les l'leurobranches, aussi bieu que les Iimaces, manqueut complétement de wascle columellaire, comme ceux des Mollusques gastćropodes rui sont compléternent dépourvus de coquille; dans ces animaux; les inuscles rétrac!eurs de la tête remplacen: le muscle columellaire, comme nous aurous occasion de le voir plas lard. Les Oabrelles, les Pattelles, les Cabochons, et en général tous les Mollusigues qui ont la coquille patelliforme, s'attachent à cette coquille au moyen d'un muscle qui vair des parties latérales du pied, s'étend en demi-cercle ou en forme de fer ì cheval sur les parties latérales et postérieures de l'animal, et va s'insérer, en conservant la même forme, sur la partic moyenne de la surface interne de la coquille. Lorstuue l'animal est symétrique, les deux parlies du muscle sont semblables, quand un les parrage dans la ligne mécliane : le muscle est irrégulier, c'cst-à-dire qu'il n'est point symétrique dans ceux des animaux qui n'ont pas les parlies paires; c'est ce que l'on remarque principalement dans les Ombrelies, Cabochons, Calypirées, etc. Ces modilications du muscle columellaire et de l'appareil locomoleur dans les Gastéropodes proprement dits be peuvent servir que de moyen secondaire dins uoe bonne classilication; cependantil ne lant pas négliger leur emploi, et il faut sivoir l'allier a celui que nous donue les autres parties de l'organisation.

L'apparareil musculaire a reçn de profondes moditications dans ceux des Mollusques qui soot destinés à la natation : celle de ces modifications que nous devons citer la première, se montre daus les Carinaires et antres Nucléobranches; guoique le pied soit changé en une véritable nagreoire, on reconnoit néanmoins le lissu musculaire coriace, particulier aux Gastéropodes, et on retrouve une trace de l'ancien usage de cette partic daus on petit espace ou disque musculaire, qui sert, à ce qu'il paroit, à fixer l'animal. Chez 


\section{O L}

res animand lont quelques-uns manquent de coquilles, le nussile columeilaice manque aussi ou il est réduit à l'état rudmueulaire; 1 l n'est pas étonnant, d'après rela, ru il soil improssible, quclque stoin que liou y prenue, de trouver la trace de son adhírence sur les Cisrinaires, par excmple, dunt la coquille est d'ailleurs si mince.

l.es l'téropndes, au lieu d'un pied on d'une nugevire méliane gui le remplace, ont sur les prities latérales du corps des appendices musrolaires qui leur servent de nageoires; ces appendiees sont pairs el symétriques; il y en a ordinurement deux, comme dans les IIyales, les C'éndores, les Civinbulies, etc. Ces nayeoires $r$ auplarent complétement le pied, dont il n'existe pius la innindie trace.

Les modilicatinns du système musculaire sont bien plus frappautes, lorsque l'on vient à examiner les Mollusques bivalves: dans les uns, on ne trouve quiua seul inuscle central qai sert à rapprocher les valves; dans d"autres, il existe deux muscles destinés au même usage, l'un est antérieur, l'autre proflérieur : lorsqu'il n'existe véritablement qu'un sen muscle, le pied mangue tout-à-fait ou il est udinentaire; mais celle partie se montre et grandit à mesure que les inuscles se séparent et deviemeat égaux. Lorsqu'il est à l'élat rudiment.jire, le pied n'a d'autre usage que de filer le byssus. Ou crnçoit que celle partie soil à peu Jrès inulile, dans des animaux qui vivent consIdument fixés, tandis ru'il devient un moyen de progression aussitôt que l'aoimal devient lỉre. Le pied des Nollusques acéphales u'a presqu'aucun lapport arec celui des Molluscjues céplabés; il est dipourvu de la surlace aplatie au noyen de layuclle se fait la reptation; il a la forne d'une lugue on diu appendice cylindroide dont les usiges paroissent étıe ceux du levier. Il faut ca escepter rependant quelques Mollusques tqui paruissent aroir ld faculié de ramper: tels setoient, par exempie, les Nucules el les 'Trigonies, si les ubserralinns luiles à leur égard sont justes. Il faut excepter encore ceux des Mollusques qui vivent eafoncés daus le sable ou crui pertorent la pierre pour s'y loger : duus les Silens, par exeniple, le picel se lermine par un empalteureat subdiscoide, ' l'animal, par l'élar.sisement de ce disque, se fixe solidement aux parois du nou cylindrique upuil babite. Dans les Pliolades et les Gastrocilenes, le pied est purté en uvant; il est tronqué, rerminé nar une larse surface circulaire au inoyen de laquelle l'aniosal peut adlséter, comne par une venlouse, à la cavité qu'ıl babıle. Parmi cend des Miollusques qui liabiten: dans les pierres, quelqueuns, comne les Yéncrupes, ont le pied encore assez développé; tandis que dars d'autres, tels que les Saxicaves et les P’élicoles, le pied est réduit à l'étal rudinentaire et peut à feine sortir du manceau y". l'enveluppe.

Le preil des Mullusques acéplıalés est formé d'un Hist. Nut. des Fers. Tone $I I$.
Mi O L

lissu misculaire très-dense el réritublement incxtricable; les libres s'eutrecrnisent dans tous les sens: cependant, comme dans la plupart, une parlie des viscères est contenue à la base du pied, et entre ses parnis il existe, pour les protécrer ct les retenir, un grand nombre de pelits muscles cylindrirues que Poli a noumés muscles funiculaires, c'est-á-dire en forne de cordelettes. Ces muscles, qui passent d'une paroi à l'antre du pied el qui quelquefnis s'étendevi de sa partie antérieure à la postérieure, concourent d'une manierc Irès-elficace à la solidité de cet organe : il est pourvu, en outre, de muscles rétracteurs qui lui sont propres. Il en existe ordiaairement unc paire antérieure dont l'insertion a lieu dans le voisinage du muscle adducteur antérieur : l'autre pairc est postérieure; elle se fixe à la partie supérienre de l'umpressinn musculaire postérieure; quelquefois, enlin, on trouve une troisième paire de ouucles réuracteurs du pied, et ils vont siusérer daus l'intérieur du crochel des valves.

Il est possible, au moyen des impressions que laissent les muscles dins les coquilles bivalves, de listribuer cette classe en groupes assez nalurels; il laut se souvenir de l'accurd qui existe cutre la disposition du système nerveax el le nombre et la pnsition des must les: les vrais Munomyaires, en ellet, n'ont qu'un seul ganglion postérieur, non symétrique, landis qu'ıl en exisle deux dans ınus les Mollusegues dimyaires. Ia difficulé que l'on a ¿prouvée relalivement a certuins genres pour les placer soit dans une série, soil dans l'autre, pourra être facilement détruite aufi - bien par l'examen des coquilles que par celui du système nerveux : il est beaucoup plus difficile de se servis d'une manière conveuable des impressions que laisse le systène nusculaire, dans les coquilles uniralves. Dans celles qui sont en spirale, J'impression musculaire est profondément enfoncée et ne jeut être vue que lorscque la coquille est brisée; elle est d'ailleurs ordinairement superticielle et peu facile a divtinguer; elle est très-visible, au contraire, et facile à étudier dans toutes les coquilles patellitarmes, et il a été possible de la faire entres pour qquelque chose dans les caractéres de quelques familles et des genres qu'clles renterment.

Le systène musculaire parliculier est celui qui est destiné au mouvement de certaines parties ou de ceıtains organes; i] est gínéraleurent lort simple dans les Mallusques; car les parties susceptibles de nisuveneas propres sont en fort petit nombre : t:eux de ces mouvemens qui se manifestent le plus sont propres a la léle $t$ a ax appendices qui la surmontent. Nous n'aurons pas it parler ici de ce qui a lieu dans les Céplalopodes, puisque les organes du mouvement sont chez enx placés sur la tète. Les Gastíropodes, qui on la facilité de rentror dans une coquille et d'en sortir, qui ont tous la téte uobile et saillante, ont des muscles propres à ces mouvemens: ces muscles, au nombre de dew 
daos la plupar, se nounment rélracleurs de la léle; ils s'insercul ordinatrenent sur les parties latérales de la masse bucale, el vout ensuite se conlondre soil dans les filores du plan locomoleur commun, suit avec celles du muscle co! umellaire : ces deux muscles, ell se con'raclaut, fout rentrer la lête sur clle-méme, en la rctournatul conme un doigt de gant. 'Tous les Mollusques gastéropocles qui liabilent unc roquille spiralc sont, sans exception, pourrus das muscles rútracten's de la têle; ceax jui sun! sins coquille en sent éralement pourvus, mais ils sont plus petits, et s'insercerat toujours dans

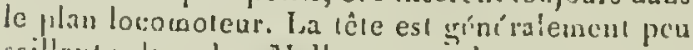
saillante dans les Mollusques qui sont couverts d'une roquille patelliforme; aćanunins tette partic leut saillir en dehors di bouclier: les muscles qui serrent à re mourcment scint fort pelits, et vont ïinsérer, de chaque cóić, dans les libres du auscle d'al!ache.

Uncertain no:nlore de Hollnsques portent sur la léte des appendices charnus, auxquels on a donné le non de teolacules. Ces tentacules sont de deux sortrs: les uns, simplement contractiles, peureni se diriger dans tous les sens, s'alonger ot se raccourcir; d'autres ont les wêmes faculiés, mais, de plus, peuvent renirer complétemeut ì l'inlírieur, ct alors ils sont rétractiles. Les wuscles yui sont propres à ces tentacules sont disposús en rajson des funclions guils ont it remplir; ils consistent ordinairement en un seul petit muscle pour chaque tentacule: lcs mouveniens propres se font à l'aide du lissu musculaire sons-cutane, qui est composé de filstes rirculairces el de libres lungiludinales. Le muscle propre anx tenlacules, lursqquils sont sculement coulractiles, consiste a les raccourcir sans les faire rentrer: mais lorscju'ils sont en même temp:s rétractiles, ils sont comoue de longs luryaux dans le centre desquels passent les muscles qui s'allachant il lear sonuct, les ientrent un dedans en les retourant sur eux-méanes par leur confraction. Dans les Mollusigues acéplalís, nii la têle manque, on ne trouve, en consépuence, aucun unuscle destiné it res mouvemens; mais la louche est pourrne de pralies mohiles, dont les unouremens, à c'c qu'il purnit, s'operrent au moyen de fibres confonducs cans leur ćpaisscur' car un n'ap̧erçoit aucun fuisceau musculaire distinct qui leur snit propre.

Dans les Gustéropoles qui apparliennent anx deax premières classcs de 11 . de Blain rille, c'estù-dire dans reux qui sont nunoïfues el dioïgne's, l’organe míle de la génération cst prourvu diun muscle spécial, ce muscle est le rélrateur de la verge; ses fonctions sont semlitiles à celles des muscles des teutacules: c'est ainsi que lorsque la verge n'est point rétraclile, qu'clle est constaunmeot caillante au-dehor's, le mussle cst borné a la raccourcir et à la rcjeler dars l"intérieur du sac Jxüaclial; lorsfr'an contraire la verge es! rélrac-

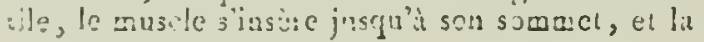

fait rentrer en la retolirnant sur cilc-mune, is la wanic̀re des tentacules. Ce inuscle cost, en góncírul, pelil, situé sur les parijes lalórales du cou, au cuté droil, se confondial par sa base arece les libres de l'euveloppe commune, cl ajant le somuet insćlć dans l'ćpaisseur de l'i.ruane dunt il dirige les muavemens. Dés que les Mollusques devicunent hermaphrodies, aves les organcs mailes disparvit nécessairement le aussle qui low est particulier : tonte la classe des Acćplalís est complétemest lans celle catégoric.

la préhension et le broienen des alimens a licu chez les Alollusques céplialés au noyera diun apparcil musculaire, plas ou moins rowiligai", qui corme la masse laucale. Cet appareil te aiuscli's cal motifié selon la nıanière dom l'aninal peut vivre; il est, pour ainsi dire, pelommé duns le's Cóplialopodes munis, comme on le sait, de tris. fortes mitchoires cornécs. Il se proknge en uns: trompe plus on moins rétractile don; ia plupa:t des Gastéropodes qui vivent de chair, tamdis qu'il se réduit à favoriser le déchirument des anittières vígéales en putrilaction clans cens des Mullusques qui vivent de ces ualicies. Eulin, il devient nul dans les Mlullusques arciphalés clunt lonverture bucale béante recoibl les particulcs nutritives en suspension daus l'tau.

On ne peut déduire prestiaucune rífo de classification d’aprecs les must les particnlieis anx oryanes que nous venons de wentiomer, puisyne ce sont les organes eux-unémes, dmut les monlitications habilenent observés peurcnt seivir de base à une bouse méthode.

\section{S. VI. Orgunes de's sens.}

Les sensations paroissent en gíuéral lort al:tuses daus les Mrollusqurs, si ce inest colle du toucher, qui semble plus exquise qu'ancune aure. Nous examiacrons successiveusen! les organe: de la rue, de l'ouje, du goit el du toncher.

Les anatomies de Swaunuerdam ont dínontré depuis long-temps eque les yeux des Minllustjues avoient la mêne compositiou que renx des aniua ux vertélurés, et c'cst a ce rúlilure anarouiste que l'on doit aussilat prearière desmiptiou dlatailíe de l'ceil si fonnant des Cóplablopodes, is lapuelle 11. Cuvier a ajouté, aveo d'eacclientes ligures, des délails nouveaux el plus précis. lacs analomistes ont dú ćtre ćlonnés de remontrer dans un aniobil mullusine des yeux d'unc structurc plus parlatle que daus beacoup d'animaux vcrićbrés. On lrouve dans ret coil tout ce qui est nécessatire à la visimn la plus parlaite, et l'ou ne peut donter ciue les Cóphalopodes ne jouissent de la ruc à un ausji haut degré que les poissons. Il n'en est peut-ĉtre pas de même daus les Mlollnsçnes wastéropodes, dont les yeux sont extrêmement petits, en érard à la frandeur des animaux; ils somt, malgré leur petitesss, composés de manicre $i$ donner ì l'aximal ta a cr- 


\section{O I}

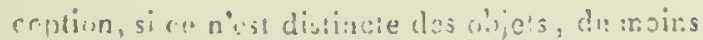

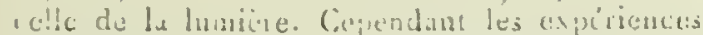
nubluplife; qui ont éle fatics sm les Hilires sunt

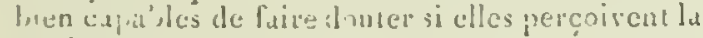

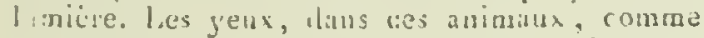

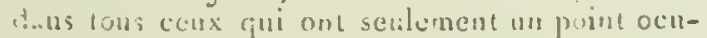
lille, combenment, dans une envelopie commune, 11. cristallin, une huncur vitrée et me expausion a.erreuse probuice por un rert oplique qui y pineve. Ilalgó Ia complicalion de cet oruane de la vie, on pent douter ares raisum qu'il remplisse it s Encriuns bien parlaites, quand on peuse sur- ul a la masicre désavantagense dunt il est jucé dins un assez grand nambre de Mollusques. On 1.rastrue, d'aillecrs, que cet oryane manque en-

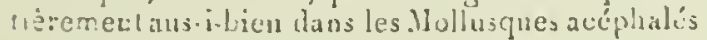
q re daas quelques-uns de ceux qui out une têle s:illante. Si l'un vuuluit citablir des rapprochearens 1'aprcs la perfection plus ou moins grande de cet -rane, il est cortain que les Culinaires, par tremple, derroicut sc ueitre a cóté des Céphalopodes, landis que t'on metroit après clles les Gas1:ropostes disuyues, dnut la plupart ont les yeux ! !rs crunds et plus paifuits que les autres Mollisspues. On peut donc dire, qu'à l'exception des cíphalopodes, la vue est vinluse ou mancue complétement dans les Mollusques.

L'onie est une sensalion encore plos incertaine. Oa ne trouve d'oryane propre gue dans les Cíphai jpodes, et il y est tellenient ruclimentaire, et suitou si prolündément cáché, (ju'il cst naturel l'e douser qja'll puisse donlier à l'animal la moindre ferception des sons. Celle trace de l'organe de laudition disparoit complétement dans inus les autres Mollusques. Aussi voiton ces anianax r:omplétement insensibles à tnute espèce de hruit, à moins (:u'il ne soit assez intense pour imprimer des viluations sensibles anx milieux yuils haldient; wais alors, ce n'est plus au moyen de l'culition yu'ils les percoivent, uais par le tomclier.

De toutes les scusations qu'épronvent les Mollusjues, c’est sans centredil celle du touclier qui paroit la plus parlaite: on voit en ellet les parties de ces animaux se contracter an moindie contact; l'eflleureanent le plus léger d'un corns élranger suftit ponr déterniaer la coutraction de la partic qu'il tonche, et celle contraction ne peut aroir lieu cu'après la perception de la sensation qui la fait éprouver. Il est facile de conceroir qu'uue peau molle, contractile et nerreuse, soit appropriée aux functions du tact leancoup plus que celle qui est coriace ou protégée par des parties dares. 'Fous les Mollusques cenendant ne doivent pas avoir le tact aussi forterneut développé. C"est ainsi que, dans certains d'entr'eux, on troure une peau dure, rugueuse et coriace, gui ne peut perme:tre que des sensations obscures; c'est ce qui a lien probablement dans quelyues Doris, des Phyllidics, etc. Dans les Mollusques acéplıalés qui on: cout le corpsenveloppé dans an test sulide,

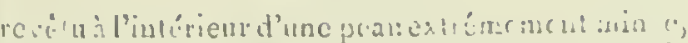
le turtier est trés-délicat dans les parties cortinairement alsitées de tout conlibt: atussi voil-t:t cliez enx une contraction lics-vive all mome:t d'un contact u'cs-fuil)!e. Il cest fatile d'observer cente sensilfilite exquise dans tous les Hullusques livalves: celle sensibilité paroit ( plus grande daus certaios d'entreux, qui sultt puturus dorganes propres à un louclier ou tum? sensalion donl nous ne pouvons glière unus renclrc: compte. Les Mollusques dont le mintcau se prolouse en deax siphuas postérieurs, ont, à l'entrée decessiplions, un ou plusieurs rangs de peties palpes destinées, par le toucber le plus exquis, it repousser de l'iatérieur du unanteau les corps rui pourroient êre nuisibles is l'unimal; elles remplissent peut-ĉtre aussi la fonction de groutiel les matières alimentaires qui púncitrent jus.ju's la bouclue de l'animal, en passant à travers $11:$ le ces sip!nons. Quelgues pliysiologistes out prirendu que la perception des odeurs, dians les Mollusques, a lieu au moyen des mérucs par. lies que le toucher affecte; mais celle opiniou est luin d'être démoutrie: on a dit, pour l'apjuyer, que la peau des M] olluscrucs, tusjours molle et enduitc de urucosić, ressembloit, it beaucoup d'égards, à la membrane piluitaire de la plapart des animaux vertílućs. Si celle explication peut avoirson application pour ceux des Mollusfues qui virent il lair libre, il neu est pas de mérae pour coux qui vivent daus l'eau. On a remarqué que, daus l'un el l'auiro cars, la p'upall des Minllusijues ćloient allirés do loin vers la proie on vers la maticre alinentaire qui lear convient; nuas on n'a pu encore expliquer par quel nogen ils percoivent uxe scnsation pour laquelle on ne cuunuit aucur organe spécial. On peut done dire que si les Molluşues perçoivent les o:lcurs, on ignore pa quel moyen, à moins que l'on ne veuille l'expliquer en disanc, avec quelques physiologistes, $\mathrm{q}_{\mathrm{i}} \mathrm{uc}$ l'udorat n'est quiune modification de tact.

Si l'cin eu juge par lia structure des orgarics, lc tôht doit être fort olltus dans la plapart des Nolluspues. Nous voyons en ellet que, dans la plopart, la cavité de la bouche est revétue du platpues carlilaginenses ou cornécs : cela se trouve mêne chez les Cíphalopodes qui ont des michoires cormies et dont la langue, guoigue charnue et épraisse, est recouverte d'une peau cartilaggiveuse, armée de petits crorhels. Les Gastéropodes zoophages, quisont, pour la plupart, munis d'une trompe flexuclise, ont, à l'inlćrieur, une langue cornée, arrace de crorkeis plus un moias longs, el qui ne paroit aucunement propre a la perception du gout des ilimens. Les Mollusques gui viveat de matières vígétales paroissent avoir le gout plus développé; cependant il en est un certain nombre clont la cavitć bucale cst en-

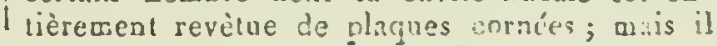

$$
2.222 \text { k }
$$


en est d'autres, comme les IJ̈́lices, les I.imaces, elc., equi ont celle parlie lout-a-fuir nue, et plus susceptible, par couséquent, de guûtcr les alimens. Aussi l'ou voil ces aniuaux cluvisir leurs alimens et les prendre, de préfédence, parui les Jórumes et les firuits sucrés: on les voil se jeter sur les jeunes puusses des plantes, el les dívarer avee assez de prompitude. Ces animas, , nui clıoisissent ainsi leuts rualières alimentaires el yni marejuent pour cerlaiues d'emrelles des prélérences non équiroques, sonl, a ce qu'il parail, peu nombreux, si du moins on s'en rapporte aux observaliuns failes jusqu'a ce jour. Il faut remarquer une coincidence asucz singulière entre les matieres alinemaires prises par les animas el la forme yu'ils domnent à leur coquille. Ciest ainsi que l'on peru adinelle arec Lanurck, mais d'une manière moins absolue, que les aninaaux zoophages ont, ea gínćral, la corguille caualiculte it la base, landis que cenx qui se nomrissent de végétanx ont une coquille dont l'ourerture est entière. Il servil difficilc de décider si les Mol. lusques bivilves ont lorgane du goút bien leveloppés : sils percuivent celtc sensalion, ce ne pent être que d'ur:e manic̀re fort dillérente de celle des autres animaux; car ils snt dép,ourrus de cavité bucale, et par conséquen l privés de lruyer et de goúter les alimens. Mais ce qui semble cliez eux tenir lieu te l'orgauc du goút, ce sont les palpes labiales et les lévres winres qui entourent la buncbe. D'un antre côlé, l'observation directe de la manière doat les alimens se preunent élant impossible, à cause de la siluation profonde de la bouche, on ne pent guère avoir que des plésomplions plus ou mains bien fondúes sur les perceptions sensitives de ees aminaux. Au resic, comme on peut facilement le déduire de ce que nous venons de dire, les seusations chez les Mallusques sont, en général, peu développées; ceux de ces animaux sliez lesquels on en apercyoil quelques-uues à un degré plus éminent que les autres foul excepion à la résle générale, comme les Céphalopodes pour la vue, et les Culimacées pour le guût ; mais lous, presque sans exceplion, sont doués du toucher le plus délicat, qui semble chez eux remplacer les autres sensations.

On a employé ntilemeat, dans la plupart des méthodes, la disposition particulière des organes de la vue ou ceux de la mastication pour circonscrire d'une manière naturelle des familles on des geares. Adanson avoit remarqué que dans certains groupes de Mollusques les yeux étoient silués de la mêne manière, taolôt portís sur un pédicułe situś à la base el au côté externe des teatacules, tantôt à la base interne de ces mêmes tentacules, quelquefuis a leur base pustérieure, quelquefoit enfin, suit à leur sommet, soil dans une des parties de leur lono'ueur. A l'aide de ces combinaisons, il avoit élabli un tableau dans lequel les Mollusques qu'il a voit observésćtoient rangés d'une manite firt conreuable; mais il avoil ang 311 un trop pelit numbre pour que l'un puit déduire quelques iegnles de ses observations. Nums :"erions plus rard quel farit on peut lirer, pour une fome mcibude, des caracièes yue foumissent les yeux.

'íls sunt les fails courus d'une manière airsolue dans l'organisalion des Mrollusques; en les r'assenblant de la manicre la plus concise, notre lut a élé surlout de urontrer les nombeuses lacunes ylie leur anatomie prósente; c'est plutôt une indiciolioo pour les observations à venil, gu'un lbulí: complet de l'unalomie comparée de ces aumanx : mous tâclıerons nćanmoirus, après un essai de certe nalure, d'coployer anssi util'ment qu'il nous scía possible ce peu de malcriaus a l'élablissement d'une classiliation yuc nous nous cli. lurcerons pur li de rendre muius ativitrire yue quelques-unes de ce!les qui sont dans le domane de lit science.

\section{De la mélhode.}

l’our qृu’une méllode suit bonne, il esı nóressaire qu'elle melle daus leurs rapporls les anianux dont elle s'ociupe d'après l'ensemble do leur onganisation, et il faut bien en:endre qu'elle ne dort repousser aucuue des paries, quelles quie:lı 3 sjient, de celle organisation; mais cile duil sivoit choisir ct classer, dans un urdre trèsrignunreux el Ingique, les divel'ses parties d'une or ra- $^{-}$ uisalion pour en déduire avec súreté des caraclères el la valeur de ces caraclères. Ce u'est qu'en suivant une roule tracte par la logique que le zoologiste évitera d"introduire, daus une méhode de sa création, liabitraire qui a présidé a l'arrangement de la plupart de celles qui existent; c'est en cherchant avec constance dans l'organisation les parlies les moins variables qu'il puura lracer des divisious yui, lien qu'arlilicielles prour la aalere, sont cependant uliles, nécessaires mêa:e pour l'élude de ses nombrenses proluctions. II sera évideut, pour loul espril juste, qu'une bonce aćlbocte ne peuı être faile que lorsque l'on a acquis une connoissance exacle tet miuulieuse de cous les faits qui constiluent la science; de celte condicion nécessaire à une bonue méllude, il s'ensuit que pour être faite il laudroit que ia science n'ait plus rien à demander à l'observation: on sent ţue, dès-lors, une bonue mélbode est presqu'iupossible, puisque chaque jour des observalions nouvelles apportent des nıáeriaux qui peuvent la modifier. Mlais de ce quiune mélbode parfaite seroit acluellement inupussible, il ue s'ensuit pas que lon doive abandonner !a science sans guide, et cüil ne soit pas nécessaite de cherclıer à la perlectionner : c'est la tâche que doit remplir l'observaleur minutieux qui a rissemblé par de longues éludes les nombreux matćriaux que la science possède; e'est toujours de cetle 
manive qu'en ont arri les tialualistes les plus rélibres; ciest l'excrijle dume par les liume, les lamarck, les (iuvier : ces grands loummes, gu ont su eruirasser par laur viste savoir tumes les liranches de l'hislorire naturelle, out rendu d"ionmenses services a celle partie des eronnossances humaines; ils ont su conrdonner l'cnsemlile de la science, ils lui on donnél'inpulsion plitosophifine qui convient si sminemment i untre fpoque. C'cst à ceux qui, comme nous, livris à une scule pautie des scicnces dont ils on! embrussé l'érendue, it nuliplicr leurs ellurls pour perlectionuer leurs ianneuses lavaux.

Nous le répéterons, après l'avoir dit plusicurs luis, gue le systc̀me nerveux est la base tondauentale de toute organisation; ses modilications sont donc de la plus haute iuportan:e quaml il s'agrit de déterminer les limites qui sépationt les glands groupes d'animanx. Dans les auinaux verléfris, le systeme nerveux est lout a la lois rachithen et grouliomaire. Dans les Mollusques, qui dans l'ordie de dígradaion suivent imuédialement, tout le systćme rachidien manque compléterient; il ne leur reste plus que le seul systène f.rmglimaire, qui continue à se montrer avec des modilications plus on moins grandes, dans dos classes d'animaux qui sont au-dessnus d'enx, jusiju'an tuoment on il disparoit entin dans les itres les plus simples. l'ris dans son cosemble, le sysième nerveux n'éprouve donc, dans tout le leyne animal, que deux grandes modifications : aussi existe-t.il une llès-grande lacnue entre les deux sortes d'anionaux que lamarck a si judiciensement délininés par les noms de Vertébrés et d'Iuver!' ébrés.

() a long-temps discuté, les zonlogristes dis:utent cncore, sur l'urdre général que l'on doit d nner au règne animal. Les uns veulent le dispuser en allant des animaux les plus élevés vers les plus inférieurs, el ils fondent leur opinion sur ce que les animaux les plus élev'́s sont les mieux connus, el qu'il est par conséquent lies-nalurel de comorencer un ordre tres-méthodique par les irres qui nous sont le plus familicrs; les autres, au contraire, se fondent sur une plitosopbic plus clevée sans doute, et, cherchant a saisir l'urdre de créstion qu'a suivila nature, ont voulu, dans leur méthode, imiter sa marche; ils ont vu que la nature procédoit, dans ses pluductions, du simple au composé. On voit que partont où commeoccut les ètres organisés, ils suut d'une simplirité pour aiosi dire élémentaire; que le lait se montre à l'origine des deux graodes parties des êtres vivans, et que c'est à ce point qu'ils se touchent. Quoiijue la génération de ces étres simples soit encure un probleme pour un grand nombre, c'est toujours par eux que l'on voil comuneacer les êlles organisés, el c'est toujours daos leurs simples élémens que sont réduits les êtres les plıs parfaits lorsque nous les soumellous à une analyse profnude. Pour le philosophe qui contemple la hatme dans ses actes, qui cherclie a sainir lis moyeus qu'vlle emploie, on pluió les lois qu'elle race en usanc, il est une verité incontestalle, prouvée aussi-bicn par l'ohscrvation des êtres asclupllement vivans que par les déprouilles, aujourd'hui lossiles, de ceux qui on vécu les preniters ¿ la surface de la torae. Quels sont, en ellet, los animanx dont on tronve les déponilles dins les teulaios les plus anciens? ce sont en grumiral dea auinaux simples, on des plantes qui ont la ménc: simplicité de structure; el à mesure que l'on remonte daos les dípols, on y trouve successivement des êlres de plus en plus composés, et eulin on arrive a l'époque actuellc dont l'lomme, l'animal le plus parlait, est contempnrain. Si telle a é!ć la marche qu'a suivie la nalure, il est assez naturel que l'on cherclse à l'imiter en disposant ses produits daus l'ordre gu'elle semble avoir indiqué.

Lorsgne l'on traile de l'analomie comparée en génćual, c'est-à-dlire quand on conıpare inute lat série des animax au type le plus parlait d'ol'gaaisation, il est tout simple de suivre les dégradalions successives qui se montrent dans la série, et de cumparer aussi ce qui est le moins connu à ce qui est connn plus complétement : celle mawière de procéder, pour une science loule dt: comparaison, ne doit pas sappliquer, ce nous semble, à une autre science qui est loute de aréthode et de raisonnement, Lien qu'clle ne suit que la consćquence de l'autre.

Pour ce qui a rapporl aux Mollnsqnes, ce que nous venons de dire nous a décidé daus la mófhode que nous suivrons; nons avons emplové l'urdre décroissant pour la comparaision anatomique des Mollusques, el nous meltrons en pratique les principes de l'ordre naturel jour ce qui concernc la móthode : on ne pourra pas al'sucer, à l'égard des animaux qui nous occupent, que les uns sont mieux conous que les autres. Sous ce rapport, il ne peut y avoir de prétérence, et l'cn ne peut être déterminé daus son choix que par des raisons plus élevées.

Nous avons vu que le système nerveux des Mollusques offjoit en général deux unodificalinns fondamentales : d'un cúlé an anneau csoplangien ef quelques ganglions irrégulièrement épars; d'un autre côté, point d'auneau osophagien, et un systime nerveux à ganglions symétritues. Ainsi se trourent nettement séparés, et à des deyrés comparables el d'ćgales valeurs, les Minllusques céplialés de ceux cui sont acéplates. Sans admeltre, avec Lamarck, qu'il soit nécessaire de laire de ces derniers nne classe parliculière du règne animal, nous pensons que l'on ne doil pas adopter la manicre de voir de M. Cuviei et de ses imitateurs, qui les oat mis daas leur métbode au mème degré que les Céphalopodes, par rapport aux Piéropodes ou aux Gastérop jiles: i! raut 
disc diviser le grand embrancliement des MInl-

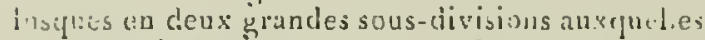
cn finurroit donoer le non de chesses; chacune d'elles pourra recevoir des sous-divisions fundies sul des caractères pris dans des oryanes dillérens, si l'on veut; car il peut bien se litire que ce jui seroit de première ionportance dans la premiere casse n'auroit plus qu'une valeur secondaire dans la seconde.

Le système nerreux peut servir à former des divisions plus secondaires que celles que nus venons d'abord de pnser. C'est ainsi, par exemple, que dans les Mollusques bivalves, en exceptant les Brachiopodes, on peut se servir de sa sumélrie, de sa non-symétrie, pour les partager eil deux grands ordres. Il est remarquable, comme rous l'avons déjà fait apercevoir ailleurs, que ces deux modifications coincident d'une manière exacle à la présence d'un ou plusieurs inuscles d'artache de l'animal à sa coguille: ainsi, cette dirision fondamentale que Lamarck y avoil judicieusement éla!slie, doil rester dans la méthode actuelle, mais tn la modifiant de manière à faire rentrer dans l'une d'elles celles des familles que l'observation pourra prouver y appartenir.

Jaes Brachiopodes, dont malheureusement l'urviuisation est incomplétement connue, quoique le sysic̀me nerveux soil symétrique, on ne peut en louter, par la disposition de l'ensamble c̈e l'ar ganisalion, que ces animaux ne duivent luite, daus les Mullusques bivalves, une truisiène grasde division egale aux denx premières; mas cet ar-

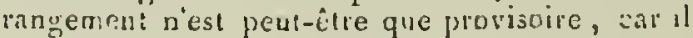
pourroit arriver, lorsegue l'on sera parvenu à entsnoitre prarfaitement l'oreranisation des Braclinijucles, que l'on soil obligé d'en livire une Iroisiernce rlasse au même degré que les Mollusques criphalés el accíphales. Si nous passons a l'examen des Boliuseques céplalés, nous verrous qu'i l'aide dia système nervanx on pent aussi y élablit deux grandes divisions principales, doat l'une comprend tous les Gasléropodes, el l'autre les Céphalopodes. Dans les premiers, l'anneau cesophagien est composé de ganglions tnujours distincts, plus ou moins rapproclićs, joinls par des fileis alténués, el jamais réunis eu une seule masse nervense; c'est, au contratire, ce gui a lieu d'une manière conslante dans les Cíphalnpodes, dont l'anneau asophagien est formé de ganglions conrondus. Ainsi le système nerveux jeut déjà servi: à diviser, d'une mauière égale el comparative, tous les Mollnsques en cinq grandes divisions, qui sernnt pour nous des sous classes.

Finus donnons ici le tableau figuratif de co. divisions primordiales, pour que l'on en fuiss: saisir lacilement l'ensemble.
Ire. CLASSE.

HOLLUSCUES ACÉPIALS.

Point d'anneau cesophagien.

Une coquille bivalve.

I Ie. CL $\Lambda$ S S E.

MOLLUSQUES CE்PEAIÉS.

Un anneau csoplagien.

Une coquille onivalse lorsqu'elle existe. ire. Sous-classe.

Système nerveux, symói ricjue.

LES Diaranes Lamk.

2e. Sous-clitsse.

Systeme nerveux, non symérrisgue.

LES IIONOMYIRES Larok.

\section{3e. Sous-classo.}

Système nerveux? sgmétrique.

BIA A BIO PODES Lamk.

Ire. Sous-classe.

Anneau cesoplagien, ì ganglions distinces

LES GASXÉRODES.

2e. Sous-clisse.

Anceau csophagien, à ganglions confondus. LES CEP I $\triangle$ LOPODES. 


\section{Iil () i}

P'our ćlablir des sous-ordres, les organes anxjuels on devroit s'ullacher seroient, dans liurde 1 allurel dimportance, cenx de la dizcstion; mais leurs modifications nonbreuses sont comules dins un trop pelit nomlare d'especes paur gue l'on puisse ulilement les emploger quant it prent: 1 liaul done s'altaclacer a des caracieres de moindre valeur, lels, pal exemple, gue la rigularicé on lirrégularió du corpes yui conlidue arec clle colle de la corguille; il faut se servir aussi, cumbe. Il de lilaimvilluen à denné l'exemple, des oreranes de lat genération; mais dans les Mullusques ils ne pervent être emplnyés que pour colix qui sout

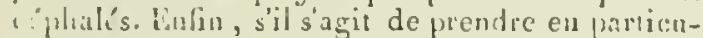
ler chacuve des cing grandes divisions, il faudra clescher, pour chacuue d'elles, dis calaclères propres pour lenr division secondaice : on duit frílérer les cardelères equi se déduisen le plas ficilearent, soil des formes extúricures, suit de crles de quelirues organes apparens au-dehors, I:rscjuc ros furiues on ces organes sunt en rapport afece liomanisation profunde.

Vinus avans reorarquí que dans les Mullusques a'élualís, le mantcau ou l'enveloppe extérieure $\therefore$ ii ou complé:enent síparé con deux parties

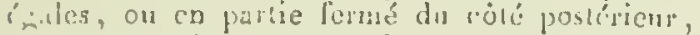

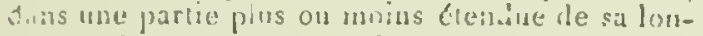
Eneur. Nous alvous ru aussi gue chlle réunion des fates du manteau coincidnit à l'exisence d'un fringlicu nerveux, situs vers lin eommissure; riasi, il esl possible de partance le premier orde tes Mullusanes accplialés on deux scitius, dont l'une compeudroit oos cenx yui ont le mancau mopléremeat nuvert, et l'au!re seux cui sut purrus de deux siphinas plus ou moins al nogés. Chacuuc de res divisinns comprentra deux sections : diuns la preniere, scrut réunics les ro-

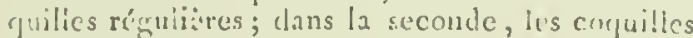
irchulieres. Lutin les fanilles pourront se cir-

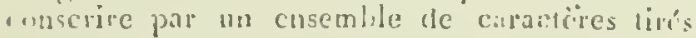
iussi-lion de la roquille que de lanimal, mais surlout de ce dernier. Il est dimirile d'craploper la longueur des siphons, car ou voit rutils se accoursissent inscnsililenent cu passaut d'un

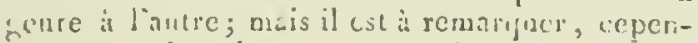
lisot, que leur longueur est géníralcment proporlionnéc à l'ouverlure du oiantesu ; its sont en eltet d'autaut pliss alongés que celle ouveriare du mantear est pius perile, et ils finissent purr n'orre plus en quelque sorte que do simples trous, Iorsegue celle curculure est très-grandie. Si la longueur des siphons est variable, il n'eu est pals de mère de leur réunion, qui parcit constaule rans un assez grand noaslure de Miollusques; si ce caraclice a uue wrode constance, et sfuil coincide, comme nons le croyons, au biillerren: postélieur assez comsidérable de reraines coyuilles, on pourra établir dans les coguille's biralres régulières deux tribus, au moren des-

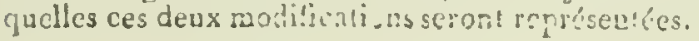

De lelles durivons ue prourtont s'úlalulir que dislicilerocut dans les Mollusques rénulier's sat:s siplouss dans gaclyues - uns, cependant, le :1plion anal des atulres Nullusines est res risenti fiar une bribe qui résule de la soudune de parlia inférieure des bramchics avec le uansein: mais on 1.e pent regarder ectue légere moditcation comane un siphon vériable, el le catricte.

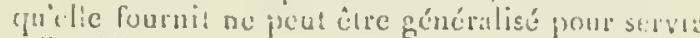
is l'olublissement d'une tribu on d'un sous-ortre.

Comme dans tous les articles qui contcrneni les familles prupasces jusqu'a re jour par les antcurs nous avons donné des détails éleadus sı: Ghacune d'elles. Clque neus avons chert bé il h. rirconscrire d'une manicye natmelle, gue nan:s avons aussi indiqué les rítormes quelles devoicut subir dans l'élat acenel de la science, nous res:voynos aux aricles yui les concernent, et nous amuons le tibleau suivant, qui représente lea. crisemble.

Les Mollusques acéphalés dic la scconde livile sion, c'est-ídire ceus qui sont nonomyilires, se composent d'un petil nombre de lamilles at de zentes; ce qui paroil les listinguer de la mat nière la pius fontlatmentale, c'est l'esistence on l'alsence dun pied : ce caracière, lacile ì saisia, peur délerminer detix ordres très-distinces : clanrun de ces ordres ne conicut gुn'u seule lumilie liclativenutent atux Bratiopodes, on ne jeut si: servir que de la coquilde, puisyue les aniana: sout si peu connus; clès-lors on poura les civiser. soit a lat maniete de Lamardi, en rapproctinnt

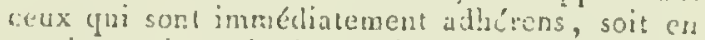
a:mployant le mode de ríunion des valtees. Aiasi, d'un côté on pourroit faire un ordre de ionte: - elles cui on: wue charaiere ariculée, el un autre de celles dun les ralves soni libres; ci dans aldarune de ces clivisiuns, les lanilles s'biblarien b'apres l'alinurace médiate on irmódiate de la coyuille.

l.es chnngemeas que nous nous propnsans dans

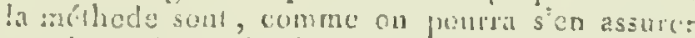
par le tablean ri-joiat, de deux rablutes ditiirentes: les uns proricnuent des principes winó

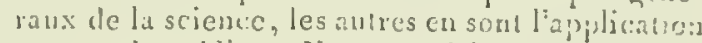

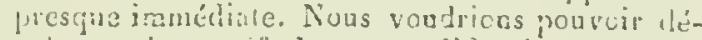
volojper los on lifs de ces modilitarions, en pas-

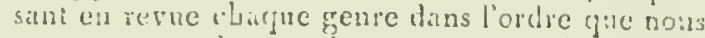
Juposons; mis restreint comne nous le sommis dans cal ourrane, il nous est iwpossible d? not:

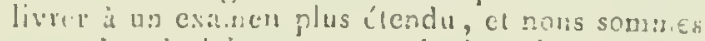
onmbuint de ldisser aus zoologistes lo soin an-

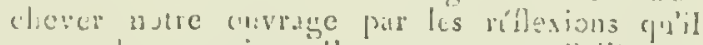
foutra leur suscies. Ils tronreront, Litilenes,

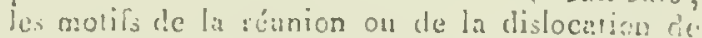
cerlanes lamilles, de rertains genres, dans le: anicles rui les concernent en puriculicr.

1.orsyue les caractires qu'on pouvoil tirer des

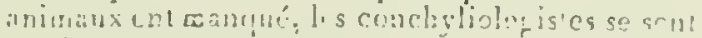

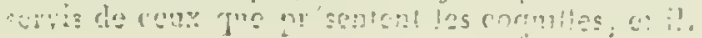


unt cli lisi de prefrente ceux çui paroissnier t le filus intianement liés à l'urranisaliou. 'La cinaniète, d.ıns les coquilles bivalves, a servi trésuitileseot pour la tormalion des farvilles el des ñcnres. La unélhode de Lamarck est en graucie parlie londée sur ces caractères : quelyues persunnes en ont rejeté l'imporıance, et leur uoril semble être assez plausible, puisçuil esı vrai que la charnière est furmée par une lamelle trés-mince du man'ean, qui s'introduit dans ses anfractunsilés. Il est néanmoins un fait incontestable, dout l'observation déuiontre claque jour l'importance, c'est qu'il n'existe ancuae modilicalion un peu iusporlante dans les accidens de la charnicre, sans "lu'elle ne coïncide avec wae modificatiou éyuivalente dans l'orgunisation: s'il n'en étoit ainsi, il n'y auroit point de raison pour que des animaux d'une structure diffirente ne fissent des charnières seublables, et on sait que le coutraire a heu, puisque la charaière est eonstante dans claque bon grenre on dans chacgue fawillc. Il nous sulfira de rappeler quel gues bons gcures, tels que les Crassatelles, les Vénus, les Bucardes, etc., poir couvaincre co:nbien sont déccssaires les curaclires pris de la charaière pom la dislincriou des genres. Il ne faudruit pas cependant voular leur donuer plus d'impuriance qu'ils ae méritent; car si dans quelapues genres ils ont une cunstance à peu près absolue, dans d'autres ils sont susceptibles de variations cousidérables, et dès-lors its ne doivent être emplnyés que très-seconduiremeut. C'est ainsi yue dans les Mulettes, par exenzple, auxqueiles i) est forcú aciuellement de joindre les greares Hyrie, Castalie et Anodunle de lamarck, on ironve sur des a jimaux semblables des coguilles qui non-senlement ont des lormes très-diverses, mais eucore une charnière très-rariable, en cela qu'elle commence par ére liućaire el aon-articulée, et qu'elle fuit, par des modifications successives, par être deutée très-fortement. Ce genre a'est pas le seul que nous pourrions citer : les Lucines, les Lutrairos, les Sulens, etr., sont daus le taêne cas; mais lorsque les caractères importans de lit charaière vienuent à manquer, il resle toujour's des caractères dans les coquilles propres à chaque yenre, et c'est alors sculement que la sagacité du zoologiste chéterwise le rapprochement des espères.

La distribution des Mollusques céphalés est extréarement dilficile lorsqu'il s'anit d'y établir des divisions fundamentales; c'est principalement pour ce qui a rapport aux Gastéropodes que les élémers de classilication manquent, et que le zoologiste est forcé, en attendant l'observation cles fails, de se livrer à l'arbitraire et à sa sagacité.

Nous suivrons pour les grades divisions les donaces de M. de Blainville, en les modifiant néanmuins selon les observations qui cnt élé faites depuis la publicalion de son Traité. Ainsi, ces Hlollus rnes sercut partagés eu trois grands ordies, d'apres la nature des ngganes de la génération: ics uns sont en eillet herwapirodites, aussi complétemeat que les Mcllusques actéphulés; les autres sont herinaphrudites, naais ils unt besoin du rapprocheneat de deux individus pour upérer lit grućralion; lus antres, enlin, out ua sexe séparé juus chacjuc iudividu. A ces carriction générnux, pris daus les animaux, sen joignent d'autses que t'un peut trouver sur la coujuille; c'est ainsi yue coules les coquilles échancrées ou canaliculées a la Lase paroisseat appartenir à des animanx nonurques, tandis que celles qui ont l'ouverture enticre ajpitrliendroient, a ce gu'ıl paroit, aux Mollusques diusques. La limice de celle derwic̀ı série de Mulluscjues avec ceux qui sont hermaphrodites n'test pas concore aussi netlemeat arréćc que celle des deux autres; il faudivit. pur yu'il n'existát plus de dunte à cet énard, un asse $<$ grund nombre dobservations a a alomiques sur des gemes que nous ne conmoissuns pour ia plupart que par leurs corpuilles. Ces genres restecura danc incertains, el nous auruns sojiu de les indiyuer comme tels.

P'isiens auteurs múhodicues ont clierche; dans cus demiers temps, sitl étuit possille de déduire quelques régles générules dourantrisation in muger de lopercule. Ils se sont bien aperçus que celle partic n'existuit que dans un certain nuinbre de Mullusques, et ils ont remarugué quien úénéral les Pectinibranches en étoient pourvus; wais, comne il existe des exceptions, la valeur de ce caractère est considćrablement rćdaite, et oD a dû se borner ì en laire une anplicalion beaucoup monins générale. l'ćlude bien fuite de celle partie peut être for ntile a la distiaction des renres; ccpendant, nous devons dire qual he laut pas lui donner plus d'imporlance qu'elle ae uerite; car, s'il est conslant clans sa furme et dans ses rapporls avec l'ouverture de la coquille, il est très-variable dans d'autres, lant par sa nature que par la manière dont il clos l'ouverture. L'opercule est, ì l'igard d'un cerlain nonbre te Mollusques univalves, à pea prés de la mêne imporlance que la chardière dans les coquilles bivilves. Relativement à sa nature, il est tantót corné, tantót pierreux; daus certains geares on ne trouve que l'une ou l'autre de ces modificafions, tandis que dans d'autres elles se présentent toutes deux it la lois: ce qui pronve qu'il ne faut pás donner trop de valeur a la nature de l'opercule, et qu'il funt s'altacher davantage ì sa structure. C'est, en tllet, à l'aicle de ce moyen que l'on a pu faire d'heureus rapprocbemens dans des genres dunt les espéces ont une tendance à se contondre, corarae les Pourpres, les Buccins, etc.

Les opercules sont roulés en spirale, au formés de conches appliquées les unes sur les autres et se débordant; on y reconncit une surface assez régulic̀re, qui est le puint d'insertion du muscle qui l'allacbe à l'anional. Celle insertion est assez variable; 



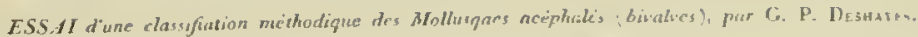

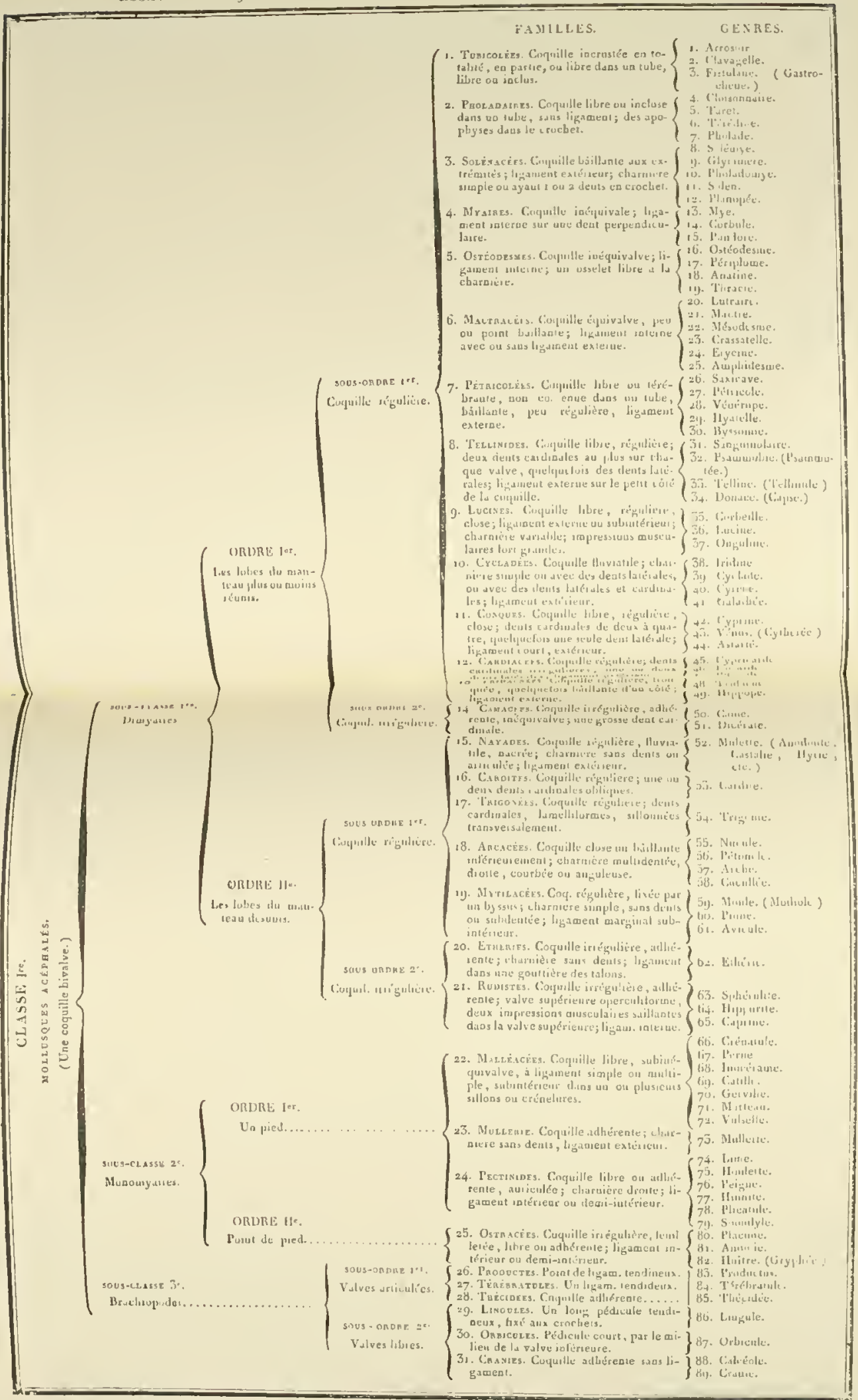





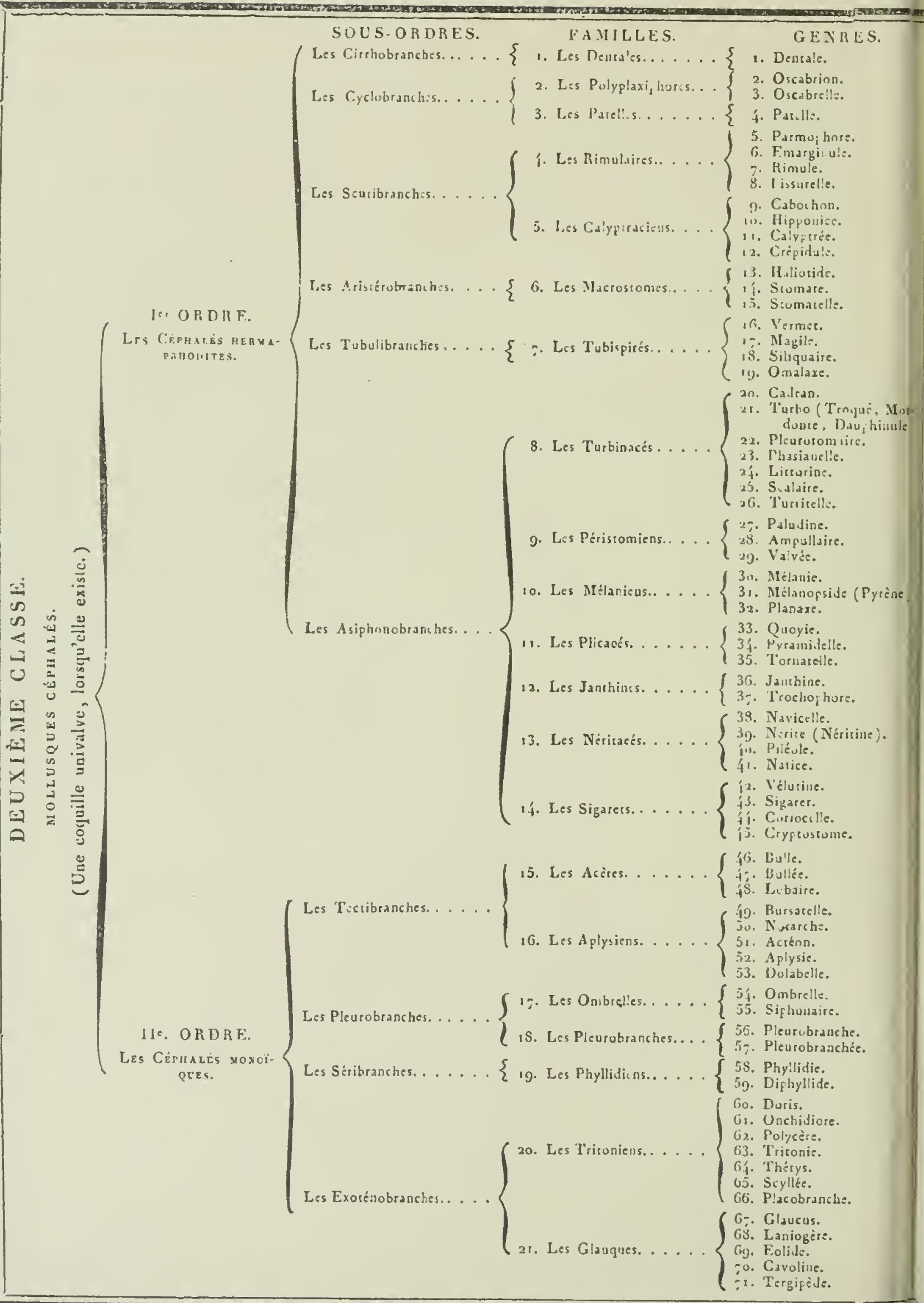




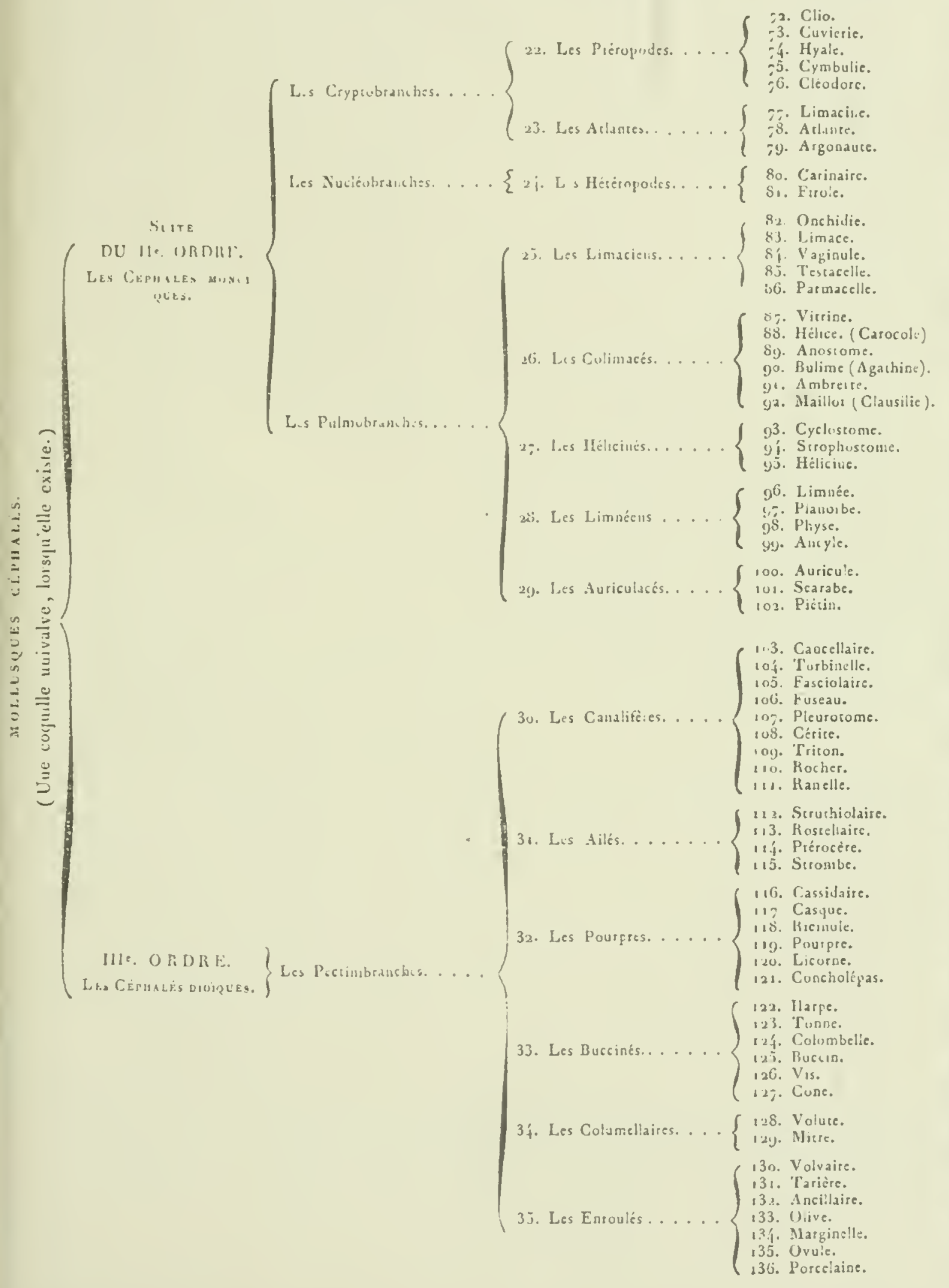




\section{$\mathrm{MOL}$}

rariable; elle est arrondie ou oralaire; elle occupe quelquefois presque tonte la surtace interne de l'opercule, et d'autres fois elle ne se moutre que sur une pelite partie de son étendue; la forme du point d'altache coincide avec celle de l'opercule. Ainsi, dans ceux qui sont arrondis et spirés, elle est toute différente de celles des opercules squamcux ou onguliformes; néanmoins, il est difficile de se servir de ces caractères, puisque l'on a l'upercule tout enlier pour en tenir lieu. Ou a re:narqué que tous ceux des Mollusques qui soni dioingues ont l'opercale squameux el corné lorsquil existe, tandis que cette partie prend différentes formes dans les Mollusques monoiques. Dans ceux qui sonl hermaphrodites, l'opercule ne se rencontre que dans un très-petit nombre de genres, et celle exceplion laisse encore du doute sur leur nature. Ces geares ont, au reste, une forme tcllement anomale, quil ne faut pas étre surpris s’ils ollient des anomalies dans plusicurs points de leur organisation : ces genres, dont M. Cuvier a fait sa famille des Tubulibranclies, avoient été compris daus les Serpules par Linné, ê daus les Annelides par Lamarck; à cette indication on reconnoit les gcores Vermet, Siliquaire et Mugile.

Les élémens de classification dont nous venons de parler sont les mojens que nous avons employés de la manière qui nous a paru la pins converable pour élablir la classification comprise dans le tableau ci-contre.

Nous nons proposions, si l'espace ve nous eut manqué, de donoer à cel essai les développemens nécessaires pour faire bien comprendre jes raisons qui nous ont délerminé dans l'arrangement des genres et des familles; nous avons voulu, autant que possible, indiquer leurs rapports naturels par les rapproclemens que nous avons fails. L'arrangemenl lioéaire, tel quill est adopté daus les mélhodes modernes, cuncilie difficilement les caractères de certaines familles; un roil qu'il existe four elles des embranchemens latéraux qui de$1 \mathbf{r}$ jient les faire entrer les unes à cóté des aurres, dans une ligne horizontale, et non ies unes audessous des autres, dans une ligne perpendiculaire. Les persunnes qui ont long-temps étudié cctle partie des sciences naturelles dout nus nous occupons, reconanitront facilement ces familles, qu'il est si diflicile de bier placer dans l'ordre linéaire; elles verınt aussi quen suivont l'ordre des rapports, on arrive toujours à des larunes plus ou noirs niandes, lorsque l'un louche à la lízite des grands groupes.

\section{MOLOSSE. Molossus.}

Blumembach, daus son Specimen Archarologia Teliuris, etc., pag. $21, p l .2, f i g .6$, a mentiouaé et bguré un corps fort singulier, qual a raugá dacs les Orthocéralites, sous le nom dOrshacera-

Hist. Nat, des Feis. Torze $\mathrm{K}$. tites gracilis; c'est arec ce corps que Montfort a fait son genre Molosse, qu'il caractérise à sa manière, c'esi-à-dire peu courenablement.

Coquille libre, univalve, cloisonnée, droite, conique, listuleuse et intersectće; cloisons unies, faites en tambour; siphon latéral, continu, rond, servant de bouche; somnet pointu; base horizonılale. Celte coquille, clıangéc ea fer sulfuré, est-elle dans son entier? le test a-t-il ćlé remplacé par la matière étrangère? les cloisons seules existent-elles le test ayant disparu, ou bien l'inverse est-il arrivé? Il faudroit répondre i ces questinns d'uue manière satisfaisance pour pouvoir se faire une idée exacte des Molosses. Te seroil-ce pus un corps semblable à ceux figurés par Schlolbeim dans son Petrefactenkunde, 3o cahier, $p l$. 19, f. 8,9 , sous le nom de Tentaculites, et qui auroit été mal figuré ou mal vu par Blumembach, et par suile plus mal recopie pal Morliurt? Lamarck a'a pas mentionné le Molosse; M. Cuvier a imité Lamarck. M. de Ferussac l'a placé daus la fanille des Nodosaires; M. de Blainville, daus son Traité de Malacologie, a reporté les Molosses, ainsi que les Nodosaires, dans le genre Orthocère; ce qui le rend, à bien dire, un incertce sedis, jual les dilférentes coquilles qu'il renferme. M. Latreille a mentionné les Molosses dans sa tribu des Orthocérates, à la fin, daus la dernière section, qui compread les coyuilles noucuses ou anaulées transversalement. Ils sont en rapport avec les Echidues, les Raphanistres, Réopliages, Nodosaires el Spirolines. On ne peut guère doutcr actuellemeot, d'après les travaux de MM. de Haan e! d'Orbigny, que le Molosse ne soit un double emploi des Orthocérates. Nous renvoyons à Orthocirate, Orthocías et Nodosalies.

\section{MONIATE-DU-DIABLE.}

On nomme quelquefois de cette manière les pierres lenticulaires, ou Nummulites. Foy. Nus\&ULITES.

\section{MONYAIE-DE-GUINĖE.}

Num vulgaire diune Porcelaine fort commune, Cyproa caurica, qui servoil autrefois dans le commerce des esclaves. Fojez l'orcelaine.

\section{MONNAIE-DE-SAIIT.-PIERRE.}

Autre nom vulgaire des Nummulites. Voye: ce noul.

\section{MOYOCONCHA.}

Cette section, dans le système de Klein ( $M e$ thod. Ostruc. pag. 114), réunit comme passań des Uairalves aux Bira.res toutes les coquilies 
patelloïdes; c'est encore aujourd'bui l'opiaion des plus savans zoologistes.

\section{MONOCULUS.}

M. Menk, daus son Catalogue raisonné des Mollusques, a rappelé, ì l'égard des Hyales, que linné en avoit conlondu une espèce avec ses Monocles, sous le num de Monoculus telemus. Vugez Irales.

\section{MONODACTYLE. MOnoductylus.}

Klein, et la plupart des auteurs du dernier siècle, donnoient ce uom à ceux des Strombes ujui se prolongent postérienrement par un seul appendice du la lèvie droite. Voyea Strome.

\section{MONODONIE.}

Ce gerre, crós par Lamarck, eit un des plus artiliciels quait proposé le savant auteur des Animaux sans vertébres; il l'a démenubré des 'L'urbos et des Troques, et il a pris dans ces deux gentes de Linué toutes les espèces dont le bord gauche est séparé du bord droit par une et que!quefois par plusieurs éminences, ou deals colnwellaires. Ce genre est d'autaut plus artificiel, que l'on a reconna depuis sa créalion que les animaux ne différoient eu rien de ceux des 'Turbos ou des T'roques. Cet unique caractère d'une ou plusieurs deuts columellaires ne peut servir, en en joignant d’autres tirés de la forme, qu'à établir dans les genres Turbo, Monodonte et Trochus réunis, différens groupes, que l'on pent arranger de mavière à arriver insensiblement de la torme des Turbos à celle des Troques, par tous les intermédiaires. Voyez Turbo el Tropue.

\section{MONOMYA.}

M. Menk a traduit en latin, de celte manière, la dénomination de Munomyaires imposée par Lamarck à une des grandes divisions des Mollnsques acéphales. Celte division de M. Menk correspond assez neltement aux Ostracés monomyaires de M. Cuvier. Voyez No Nom Ya1нes, Ostracés et Moliusques.

\section{MONOMYAIRES.}

Lamarck a dirisé les Conchifèros en deux grands ordres, les Dimyaires et les Nlonomyaires. Cette division est fondée sur le nombre des impressions unusculaires que l'on observe dans l'intérieur des valves, el qui indiquent si l'animal qui les habitoit avoit un on deux muscles adducteurs. Cette méilsode, qui semble ne pouvoir donner lieu à allcune discussion, est pourlant susceptible de controverse à l'égard de plusieurs genres que Lanarck range parmi les llonomyaires, et d'autres anteurs purusi les Dimyaires. Il $y$ a peu de na- turalistes qui aient adopté celte division de Lamarch. Voyez Conculfiras et Molrusques.

\section{MONOPHORE. Monophora.}

Genre encore incertain, pröposé par MII. Quny et Gaymard, dans la zoologie de leur premier voyare; il paroit avoir beaucoup de rapports avec les Biphores, et M. de Blainville pense même que la seconde ouverlure a écbappé à ces observitteurs, et qu'il convient, en attendant de nouveaux renseignemens, de placer ce genre dans la même famille. M. Cuvier, dans la seconde éditıon du Règne animal, n'a point parlagé l'opinion de MI. de Blainville, et il a mis en rapport les Mlonophores arec lcs Nucléobranclies. Celle opinion ue peut être adoise quautant qu'elle sera conlitrée par une anatomie complète de l'animal dont il est question.

MONOPLEUROBRANCIIES. Monopleurobranchiata.

Ce mot, qui signilie animal portant une seule branchie sur le côté, a été proposé el enaployé par MI. de Blainville, dans son Traité de Malacologie, pour son troisième ordire des Mollusques, quil caraetrise de la manière suivante : oryaues de la respirarion branchiaux, situés au côté droit du corps, et nis à couvert plus uu moins counplćternent par une partie du manteau operculiforme, dans laquelle se développe souvent une coquille plane, plus ou moins involvée, à ouverture très-yraude et constamment entière; tentacules nuls, rudimentaires ou auriculiformes. M. de Blainville partage son oràe des Monopleurobranches en quatre familles: la prenière, sous le nom de Suluap!ysiens (voyez ce mol), renferme les genres Berthelle, P'leurobranche et Pleurobranchidic; la seconde famille, les Aplysiens, contient les genres Aplysie, Dulabelle, Bursitelle, Notarche el Elysie; la troisième, les Pallelloides, comprend les Irois genres Ombrelle, Siphonaire et 'Tylodine; le quatiième, enfin, sous le nom d'Acère, renferme les yentes Bulle, Bellćrophe, Ballé, Lobaire, Sormel, Gastéloptère et Allas. Nous renvoyons, pour plus de délails, a ux fawilles et aux diver's geure, quelles renferment.

\section{MONOTHALAMES.}

Expression synonyme de coquille uniloculaires. Voyez Coquilles el Mollusques.

\section{MONO'TIS.}

M. Brown, dans un Mémoire insćré daus le Jouınal géologique de M. Keferstein, a proposé de former sous ce nom na gente particulier, pour une coquille connue à l'élat de pétrification seulemeut, et rapportée au genre Peigne par la plupart des conchyliologues. Celle coquille a été 
$\mathrm{NO} \mathrm{L}$

dísignie par 11. Sclilobeim sous le nom de Peclen salmarius. Nous avons pu examiner plusieurs ćchautillons asse 2 complits de cette espèce, et nous a vous pu nous convaincre qu'elle appartenoit au genre Avicule, et qu'elle devoit entrer parai celles qui n'unt point d'appeodice postérieur.

\section{MORILLE.}

Nom marchand du Murex hystrix de Linné, qui appartient aujourd'hui au geore Puurpre. Vojez ce wot.

\section{NORIO.}

Nom latin donné par Montfort à son genre Heaulne, ou plutòt Haume, qui n'est rien isutre cliose que le gente Cassidaire de I,amarck, généralement aclopié. Voyez Cassidatre.

\section{MORULE. Morula.}

Genre inutilement démembré des Ricinules par M. Schumacher, pour celles des espèces qui, telles que le Ricinula inorus, sont garnies à l'extérieur de tubercules arrondis. Ce genre ae peut être adupté. Vojez Ricisule.

\section{MOULE. Mytilus.}

Quoique Rondelet, dès 1555 , ait distingué les vérntables Noules d'autres genres, cela n'a pas empéchlé des aureurs plus modernes de confondre indistinctement, sous le même nom, des coquilles entièrement différentes et de lormes et d'babitation. Lister, en séparant les Moules véritables ou marines de celles quil nomme d'eau douce, a commis une faute, de ne pas les désigner aussi par des aoms dilléreus; et les auteurs qui suivirent n'auroient eu aucun prétexte de confondre des coquilles qu'il est si facile de distinguer. Cette erreur, qui depuis ce moment est restée dans la science jusquu'à l'époque de Linné, qui plaça les Nluletles ( parani les Mlyes, est passée dans le vulgaire, gü désigne encore nos ALulettes et nus Auodontes par le num de Iloules de rivières. Poupart et Réaumur, dans les Mléwoires de l'Acallémie, Dargenville et Favanne, dans leurs ouvrages, suivireat l'opinion comnune, qu'Adanson commença à rectifier, ainsi que Linn̊. Le premier de ces auteurs confondit avec les Pinnes, les Mloules, les Modioles et les Avicules. Linné ne tomba pas dans la mème faute; il réserva le noin de Pınne à une seule des especces d'Atauson, et donna le nom de Noule, pris du vulpraire, aux espèces de ce genre qui vivent dans la mer seulerment: des Houles d'eau douce, il en fit des Mlyes; ce qu'adoptèreut ses imitateurs, jusqu'à Lamarck; Brnguière, autant qu'on en peut juger par les caractères quïil donna à sor geore Minule, aima mieux le cocoposer comase Daryenville et d'autres, et le caraclúrisa, en conséqquence, comme il suit, dans les talıleanx qui sont en iêle du premiel volume de cette Encyclopédic : coquille fermée partout, charnière non dentée, ou composée d'une ou deux dents. Depuis, Bruguière sentit que des élémens si diftérens ne pouvoient composer un mème grenre, et, dans l'arrangement des flancbes de l'Eucyclopédie, il institua le genre Muletles, qui fut adopté depuis par les savaus, qui virent bientòt coulien elles dillíroient des Myes. Bruguière, eu instituant les genres Avicule et Perne, aux dépeos des Moules de Linné, opéra un ebangement très-utile, qui le rendit bien plus naturel. Lamarck a'eut qu'à adopter les travaux de Bruguière, auxquels il n'ajouta que le genre Modiole, qui est très-artificiel.

Lorsque l'on compare, en effet, les coquilles du genre Modiole avec celles des Mloules, on est bienlôt convaiacu que la seule différence apprécishle eatre les deux genres, consiste uniquement en ce que dans l'un, il existe un bord antérieur qui dépasse un peu les crochets, iandis que dans l'aulie les crochets sont terminaux. On pourroit peut-être altribuer à ce caractère une importance quail est loin d'avoir, puisqu'il est vrai, d'abord, que les a ni una $x$ des Modioles sont entierement semblables à ceux des Moules, et ensuite, qu'il n'est pas difficile de s'assurer que ce caractere s'ellace insensiblemeat et dispratuit d'une manière si peu brusque, qu'il est certaines espèces que l'on ne sait si on les placera dans l'un ou l'autre genre. Sous ces denx considérations, le genre Modiole ne peut donc étre reçu; et, à l'exemple de M. de Blainville, nous le joignons à celui qui nous occupe.

Un sous-genre a été proposé par M. Cnvier; il l'a démemlaré des Noules de Linné, et il l'a proposé sous le nom de Lithopbage. Ce sousgenre, dont M. de Ferussac a tait un genre particulier, ne peut être admis que comme une division l:es-secoudaire, ou comme groupe d'espéces. La coquille, modifiée par la manière de vivre fle l'a ainual, présente tous les caractères des Nodioles, et l'animal lui-orême leur est identique. Ce sous-geure doit donc de tuute aécessité ère cntrainć dans les Muules arec les Modioles elles-mêues.

On a assez varié dans la place quón assigne aux Moules dans la série générique. lorsque Lamarck eut propes de paituger les Mollusques acéphales d'après le nombre des impressions musculaires, en examiaant les coquilles des Muules, il ne fit point sans doute altention à la petite impression antérieure, qui es! assez visible: ce qui le détermiua à placer ce genre parmiles Monomyaires. M. Cuvier n'eut pas la méme opinion que Lamarck, et, effectivement, on troure, en le cherchant avec soia, un petit muscle antérieur; ce qui le place, sous ce rapport, dans la liroile des deux fawillcs. 
M. de Bluinville a conservé la manière de perser de M. Cuvier; ce que M. de Ferussac a fait égalemeni. C'est véritablenent parni les Dimyaires que doit maintenant se placer le genre Moule.

Lianatornie des Noules a été faite depuis furt lung-temps. Comme certaines espèces sont très-abondantes dans nos mers, qu'elles sout un alinent assez agréable à l'lomme, on a cherché a comaitre en délail un animal ulile, liacile a obseıver par la quantité considérable que certaius parages en fournisscut. Nous ne citerons pas les travaux qui ont précédé ceux de Poly et ceux des zoologistes modernes; ils conlienuent des erreurs el sont peu complets quant à l'anatomie. Comene tous les Lamellibrauches, les Monles ani ont une coquille syrnétrique et équivalve, sont également syrnétriques dans leurs parlies, le manteau a les lobes égaux, les bords sont libres, excepté sur le dos, où ils se réunissent; cette réudion se prolongeant au-de! de la longneur du ligament de la coqnille pour donner naissance à une ouverture complète, qui est celle où se décharge l'auus; au-dessous et postérieurement les bords des lobes sont assez épais, garnis de tentacules, et leur rapprochement simule assez bien l'ouverture du siphon branchial : cependant on ne peut nommer cette partie un siphon, puisque le mantean reste ouvert depuis l'anus jusqu'à la partie untérieure de l'animal. Les bords de cet organe sont épais, charnus, fortement adhérens au limbe de la cognille; le reste des lobes est celluleux et souvent ehargé d'une substance d'un blancjannâtre qui remplit toutes les cellules. Le système musculaire se compose de deux parties distinctes: les muscles adducteurs et les muscles du pied; les adducteurs sont fort inéganx, l'antérieur étant très-petit, comme nous l'avons dit, comparalivement au postérieur, qui est aussi grand que l'impression qu'il laisse. Les rauscles dn pied se partagent en trois faisceaux principaux: les muscles autérieurs, qui se lixent presque dans la cavité du crochel; les muscles noyens, que l'on pourroit nommer muscles intrinsèques du pied, qni se bifurquent et sont, pour ainsi dire, $\dot{a}$ cheval an centre de la masse commune, à l'endroit de la réunion de tuus, et concourent priucipalemeut à la formation du pied; les postérieurs, enfin, forment une masse assez considérable, divisée en trois faisceaux fibreux qui s'attachent, en rayonnant, à la coquille, depuis le muscle adducleur postérieur, en remontant, jusque vers le milieu de la longueur du bord : ce muscle donne principalement naissance au byssus qui sort ì a base du pied, dans l'endroit où les fibres des rétracteurs antérieurs et des postérieurs se réunissent el s'eutrecroisent d'une manière iuextricable, en donnant un grand nombre de fibres an pied proprement dit.

Les organes de la digestion se composent d'une ouverture hucale, cachíe par des plis labianx transverses, qui se continuent à des palpes, une paire de chaque côté, assez urands, charnus, linement stries. Par un cesopliage très-court, on arrive à une cavité slonacale ovalaire, remplie de lames ou cryples hépatiques. Cet orgaue, aussi-bien que la plus grande partie des inteslirs, est enveloppó par le fuie de la même manière que daus les aulres Lanellibranclıes. liutestin, après plusieur's circunvolutions, remonte vers le dos, où il se place dans la ligne uiédiane, oì il est enveloppé pror le cour et se termine par un orifice qui se décharge par l'onverture anale du unateau. Les organes de la circulation sont secoldables à ceux des aulres Lamellibranches: un caur fusilurue sur le rectun, denx oreilleltes lurt uninces, deux aortes, ctc. Comme dans les autres Mollusques du même ordre, les dranclies se composent de deux paires de feuillets très-minces el faciles ì díchirer transversilement; l'externe est plus yraud quel'interne. Les organes de la génération sont semblables à ceux de autres laurellibranclies. (I'oy. MozLUSQOes. ) I.e système nervenx a ćté examiné par 11. de Blainville, et it l'a trouvé composé de trois ganglions. Nous avons rapporté textuellement ce que dit ce savant anatomiste, daus notre arlicle Molcusques, à l'occasion dú système nerveux considéré d'une manière générale dans les Mollusques bivalves : nous y renvoyous.

Les Moules vivent ordinairement par bancs, sonvent cousidérables, dans le voisinage des côtes, fixées les unes aux autres, ou au sable ou aux galets du tond de la mer: le plus souvent elles préfèreat les endroits ai les basses matées les tiennent à découvert quelquefois cinq on six heures; mais celles-là, pour la nourtiture, sont moins estimées q̨ue celles qui resteal constamront couvertes par les eaux; certuines espèces, vivant plus isolément, s'attachent dans le creux des rochers oit elles se tiennent suspendues par leur lyyssus.

La coquille des Moules est d'un tissu serré, compacte, composée quelguelivis d'une trèsbelle nacre, le plus ordinairement d'une matière calcaire violette, plus ou moins foncée, revêtue d'un épiderme brun, corné, tenace, très-adtérent ì la coquille; quelquefois il est d'un beau vert, ou il n'existe pas du tout, sur les espèces surtout qui oat de tines stries. Le genie Moule est caractérisé de la mauière suivante:

$$
\text { CARACTÉRES CÉNÉRIQUES. }
$$

Animal ayant un corps ovalaire plus ou moins convexe. Le manteau ouvert dans tout son bord inférieur, depuis le sommet jusqu'à l'ouverture anale, simulant un siphon par son ípaississement. 
garmi de toutacules dans cet cudroit seulcment; appendice abdominal linguiforme, canaliculé dans snn milieu, mu par plusicurs muscles rérracteurs, yui donnent altaclie ì un liyssus placé ì la partic postíricure de la base du pied; bouclie sinple, falsiée, garrie de palpes épaisses el granıies.

Coquille longiludinüle, équivalve, rézuliere, a crochels tantót Icruinatux et poinius, Inntôt dépassés par un très-pelit cólé antérieur, se fixant par un byssus; charnière latélále, le plus sonvent tdentée, quelcuelois une nu denx dents ubsolètes sur le crochet; ligament marginal subintericn ; une inpression musculaire alongée en massue postćrienre, une autre très-petite antéricure sous les crochets.

l.es Moules sont presque tontes des coquilles marines; quelques-unes cependant vivent dans las lleuves: on en tronve une dans le Danulie; quelques autres habitent les eaux peu salícs de l'combouchure des rivières. Quclijues localités où on troure des Moules, uniquement avec des coquilles d'eau douce lossiles, font présumer arec jusic raison, malgré leur grand nombre, qu'elles ont vécu diuns l'ean douce. () Irouve des Mnules dans presque Ioutes les wers; mais les plus grandes especces sont propres aux climats chauds.

Nous partagerons le genre Moule en trois groupes d'espèces qu'il sera bieu facile de reconnoître, puisquils sercnt désignés par les caraclères imposés au genre Nodiole de larnarck et au sous-grenre Lithophage de N. Cuvier. Nous clisposerons les espéces de manière à montrer les passages d'un groupe à l'autre.

\section{Moules proprement dites.}

1. Moure alongée. Mytilus clongatus.

11. zest is angusto-elongatí, rectu, infernè posticèque albầ, aluirdè violacea; latere pastico depresso; basi bidentatâ.

Mytilus elongatus. Cuess. Conch. tonı. 8. ub. 83 . fig. 738 .

Favsixe, Conch. lab. 50. fig. I.

ENcrcL. pl. 2!g. fig. 2.

Lsur. Anins. sans vert. tom. 6. pag. 122. $n^{0} \cdot 12$.

La Moule alongée se rapproche, sous quelques rapports, d'une espèce quii vit abondamment sur nos côtes, mais qui est loujours plus petite qu'elle. Ce caractère seroit de peu d'importance, s'il ne s'en joignoit d'autres que l'on pourra apprécier par la description. Elle est alongée, ovalaire, ujès-pointue au sommet; son côté inféricur est droit', parallèle à la moitié inféricure du cóté supérieur, lequel se conlinue par une courbure insensible avec le bord cardinal, qui sinfléclit asscz fortement rers les crochets, yui eux-mérnes sont ioclincs co avant. Ces crochers sont pointus; ils portent, en-dessous, deux dents sur la valre dreile et une seule, plus épaisse, sur la gauche. Lc sillon du ligament est trés-alungé; il est subinlúrieur et assez large à sa lansa; i] occupe toute la lungueur du bord cardiual. Eu dedans, cefle cocpuilie est d'une uacre d'un blanc-crisitre a la prartic supérieure el anterieure; elle est d'un leau violet dans tnule sun catrémité postélicure. En debors, celte coquille est lisse, sous un épiderme asscz épais, d'un brun très-foncé; elle est d'un violet obscur, si ce n'est vers les crochets, oì elle est blanche. Le test de celte coquille est grénéralement asscz épais; elle est. peu bombée en deliors, et la cavité des valies correspond, par lear peur de profondeur, it cette forme extérieure. Ceile coyullle est cilíe de l'Amérique méridionale, par Lamarck. M. Lesson nous en a communiqué no individir provenant des mers du Chili. Sa longucur est de 13 centimètres et demi.

\section{Movle large. Mytilus latus.}

$M$. testâ oblongo-ovatâ, subepiàeme palli $\dot{c}$ violaceâ; striis concentricis, crebuis, pastico latcre recto.

Exстед. pl. 216. fig. 4.

LaMr. Anim. sans vert. tom. 6. pas. 122. $n^{\circ}, 13$.

Grande coquille ovalaire, oblongue, plus large proportionnellement que la plupart des especes; elle est médiocrement bombée, mais elle l'est surtout vers ses crochets, qui sont subcarinés. Ces crochets sont petits, pointns, fort rapprochés, courbés antérieuremeot; le côté antérieur est droil, subtronqué à sa parlie anlérieure; le postérieur lui est presque parallèle; il est déprimé à l'endroit de sa jouclion avec le bord sunérieur ou cardial. Celui-ci est légèrement courbé dans su longuenr; il préseute un canal assez profond, qui donue altache au ligament. Le crochct est épais, à pcine creusé en dessous; il présente constamment une dent cardioale peu élevće; en derlans, les valves son: peu concaves; tout le linne du manleau est d'un blanc assez pur, lcs bords sont simples et violets. Celte couleur est plus intense dans l'impression musculairc. Eu dehors, celte coqnille est couverte d'un épiderme coriace, d'un brua-uoir, au-dessous duquel elle est d'un viole:grisâtre passaat au blanc sur les crochets. On remarque un grand nombre de sillous ou plutôt de rides transverses, irrégulières, gui sout les iraces des accroissemens. Celle coquille, assez rare, vient des mers du Péron. Elle a 148 willias. de longueur.

3. Move zonaire. Mytilus zancrius.

.11. testi oblongi, antiquat $\hat{i}$, albizi; zonis 
concentricis, riolaceis; latere postico sinuato, depresso, albo.

Excrec. $p l .217$. fig. I.

Lamr. Anim. sans vert. tom. 6. pag. 123. $17^{\circ} \cdot 14$.

La Moule zonaire est celle qui a de l'analogie a rec la Noule alongré, et que l'on trouve quelquefois sur uos côtes de l'Océan, ainsi que dans la Mléditerrance, si nous voulons en croire quelques conchyliologues qui habitent les côtes de celle nier. Celle espèce de Moule est alongée, ovalaire et étroile; elle est légèrement courbée dans sa longneur, régulièrement convexe, à test mince et souvent étagé par des accroissemens assez réguliers. Le crochet est inclioé sur le côté antérieur; il est petit, pointu, assez épais en dedans, et ne présentant jarnais de deut cardinale. Le bord cardinal est, selon les individus, plus on moins c urbé dans sa longueur; il présente une fosselle cardinale peu profonde et fort étroile. En dedans J a coquille est blancbe vers les crochets et violette dans le reste de son étendue; en dehors elle est revêtue d'un épiderne d'un brun foncé, et lurs(qu'elle est polie, elle est oruée de zones transverses, violeltes et blancbâlres.

Cette coquille, fort commune, est longue de 110 à 120 millimètres.

\section{Movle à crevasses. Mytilus rimosus.}

M. testâ lovigatâ, planiusculâ, subcurvatâ; cardine edentulo; natibus terminalibus rimâ cardinali separatis.

L. Азк. Ann. du Iflas. tom. 9.pl. ग7. fig. 9.

DEF. Dict. des Scien. nat tom. 33. pag. $15 \mathrm{I}$.

Ñoв. Descript. des Coq. Joss. des env. de Paris, tom. 1. pl. $40 \mathrm{fgg} .3$.

Il est extrêmement rare de rencontrer celle coquille duns son ćtal d'iotćgrité; sa fragilité la rend peu commune dans les cullecions. Elie est alengce, ovalaire, toute lisse; les crochets soat wa peu enllés, terminaux, obliques; au-dessous d'eux et sur le côté antérieur la coquille se relève un peu el présente une petite sinnosilé qui indique le passage du byssus; les bords sont riuces et ıranchaus; l'antérieur est droit et paralèlle à l'axe longitudinal; le postérieur est courbé régulièrement das toute sa longrueur, el par cette courbure il se joint au bord inlérieur, qui est obtns et arrondi; le bord supérieur on cardinal produit, par son incidence sur l'axe longitudinal de la coquille, un angle peu aign. Ce bord cardinal est creusé d'une grontlière issez profunde, qui, lorsque les dcux valves étoicat réunies, devoil laisser un hiatus ussez considćrable dans lequel étoit placé le ligannent. Lail surface extérieure de celle coquille est lisse, ou dn moins elle ne présente quic des stries d'accroissemen!; la face interne est iacrís, co daus les vieax iudividus, la cavité se prolonge an-dessous des crochets. Elle s'est trouvic d'abord dans la célébre localité de Grignnon; nous en avons recueilli une valve presque entière dans celie non moins connue de Courtagnon. Elle est longue de 63 millim. et large de 36 .

5. Movle épaissie. Mytilus incrassatus. NoB.

MI. testâ ovato-elongatâ, incrassatâ, apice aculâ, lavigatá; cardine subrecto, anticè septıfero, subcalloso; umbonibus acutis, retortis.

Nов. Descript. des C'oq. foss. des env. de Paris, tom. 1. pl. 40. fig. 1. 2.

Nuns avious d'abord pensé qne la Moule que nous allous décrire n'étoil qu'nae valiété de la précédente, mais en ayant vu uu certain nombre d'individus à des âges différens, nous avons pu nous convaincre de la conslance de leurs caractères : ce qui nous a déterminé à en faire une espèce dislincte.

Cette coquille est ovale, alongée, bossue et subcarénée vers les crochets; son côté antérieur est large et rentrant. On renarque sur le côté, entre des stries d'accroissement longitudinales, de petiles stries transverses, irrégulières. La surface extérieure est lisse ou étagée seulement par des accroissemens irréguliers; les crochets sont pointus, entièrement terminaux et conlournés un peu en spirale sur le côlé antérieur. Au-dessuus de leur sommet, on trouve une sorle de talon ou plutôt une cloison calleuse et épaisse, striée en traver's, an-dessous de laquelle la cavilé des valves se prolonge. Le bord antérienr est un peu courbé en dedans dans sa longueur; il est épais, simple, un peu sinueux supérieurement. Le bord postérieur est presque parallèle à l'antérieur; il est peu courbé dans sa longueur. lee bord inférieur est réguliérement arrondi et obtus; le bord casdinal ou supćrieur produit, avec la linne longit aclinale de la coquille, un angle beaucoup plus aigu que dans l'espèce précédente. Ce bord est est élargi, très-épais, et partagé dans sa longueur. par une goullière qui donnoit altache au ligament. La cavilé intérieure de cette espèce est profonde; sa surface est lisse et nacrée.

Celle coquille, fort rare aux environs de Paris, n’a esscore élé trouvée que dans deux localités, à Valmondois et is Senlis. Sa Jongueur est de $7^{5}$ millim. et sa laryeur de 40.

\section{Movj.e treillissće. Mytilus decussatus.}

M. testî ovato-trigond, longitudinaliter sulcatí; striis transversis, incrqualibus; natibus acutis, cuwis, interno latere canaliculatis.

Favane, Conch. pl. 5o. fig. r. 1.

Lanx. Anim. sans vert. tom. 6. pagr. 120. $n^{\circ} .4$.

Cctle cnrquille a beancoup d'analogie avec la Moule de Mägllan; el!e est presque aussi grand: 


\section{If $\quad$ U U}

gu'clle. Ellc est alongée, ovale, pointue, un peu coarbée dans sa langueur, légc̀rement déprimée vers son extréxité postérienre; elle diffère principalement de la Moule de Magelian par ses cótts longiludiuales, qui sont beaucoup moins saillantes et plus onduleuses : ces côtes sont traverśes par des accroissemens bien marqués, sulpresuliciers, qui produisent sur la surface un réseau à largon naille. Les cûtes qui sont sitnées sur le còlú antérieur sont beaucoup plus lines que tontcs les autres, el sont légerement graunleuses; lit surface interne des ralres est lisse, dime nacre brillante, d'un violet prourpré à la base, et d'un blanc-rrisátre dans les crochels. A l'extérienr, la corquille est revètue d'un épiderme asse épais, (i'un brun-noir, au-dessous duquel elle est d'une belle couleur violelle, que l'ou read très-brillinte par le poli artiliciel.

Celue espèce est un peu plus rare que la Moule de IIagellan; elle se trouve dans les neetrues mers. Sa longueur est de 100 a 110 millim.

\section{Movre velue. Mytulus hirsutus.}

11. testi. subtrigona, epiderme hirsutissimat; sulcis longitudmahbus, tenuibus; hatere postaco depresso, husnte.

Var. B. Testâ angustiore, infernè lateribus depressis.

Lasr. Anim. sans vert. tom. 6. pag. 120. $n^{\circ} .5$.

Nous devons la connoissance de cette espèce à III. Quoy et Gaymard, qui l'ont rapportée des mers de la Naurelle-Hollande. Elle est toujours d'une taille médiocre, ovale, alongée, pountue au sommet, dilatéc à sa partie supérieure; trèsconvexe el très-bossue, sa surface extérieure est revêtue dun épiderme velu, assez caduc; elle est chargée d'un liès-graud nombre de stries longiludinales, profondes et serrées, très-lines et trèsçroantes par leur régularité; elles disparoissent ordınairement sur la partie supérieure du côté autérieur : ce côté antéricur estaplati, courbé en dedans, et forlement siaucux à son bord, de manière que les deax valves étant réunies, clles laissent entr'elles un bàillement assez considérable pour le passage du byssus. A l'intérieur, la suface est parfaitement lisse, d'un blanc-grisatre dans la:s crochets, mais d'une nacre très-brillante, réfléchissant les plus beaux ćclas métalliques à la hase. Ea delıors, celte espèce est partout d'un lirun trìs-foocé, si ce n'est vers les crochets, on elle est blanchatre. Les bords de cette coquille sont très-légèrement créoelés, et le supéricur, ou cardinal, est assez large, et contient un ligiluent ģi lui-même est fort large et fort épais.

Cette coquille, assez rare, provient, comme nnus l'arons dit, des mers de la Nnuvelle.IIullaude; sa longueur est de $5 j$ à Go unilliw.
3. Mover doblie. Mytilus exustus.

$M$. testâ oblongù; longitudinaliter strint:i; 2 cntri angulo tumido; marrine crenuluio.

Mytilus exustus. Lrs. (inel. $n^{\circ}$. ?

Lister, Conch. lab. 505. /ig. .05.

Cuens. Conch. tom. 8. tab. 84.fig. 754 ?

Viscric. pl. 220 fig. 5 el 4 .

(2) Var. Testiungustione; anlicè zix angutusti.

l.Амк. Anim. sans vert. tom. 6. pag. 121. $n^{n} \cdot 6$.

Crquille très-voisine de la Mnuie velue gui, probablement comme celle-ci, est couverie d'un épiderune de mème nalure, mais qui étant plus cacu :, ne se monire pas habiluellement sur les individus de nos collections. Cetle coquille e:t ovale-oblongue, plus étroite propnrtionnellement que la plupart des espéces; elle est trèsmince, fragile, déprimée, assez régulièreme:ı convexe, el ordinairement un peu déprimée es dilatce à l'eudrnit où les bords superieur et poshirieur se joignent. La surface extérieure est orrite de stries longitudiaales nombreuses fort réguličces, tinement crínelées et presque conjours bifídes vers le bord des valves. Les crochets sont très-petils; ils ae sont pas lout-à-fait terminaux, mais légèrement dépassés par une petite extrémité antérieure, dont le bord est assez fortement créne!c. Le côté antérieur est saillant. Daos le milieu, en y voit une petite fente lancéolée, pour le passage du byssus. Le bord cardinal est presque droit. La goutière du ligrament est fort étroite et le ligament lui-nıêne est peu épais. Fa dehors, celte coquille est d'un brun-noirâtre, d'une tein!e qui approclıe de celle du café brúlé. A l'intérieur, sa nacre est brillanie, d'un brun pourpré. Ses bords son: linement crénelés daos toute leur étendue.

La variété ne differe que par un peu moins de largeur; ce qui est dî à ce que le côtć postériena. est à peine dilaté. Nous pensons, à l'igard de la cilation de la figure de Chemuity, qu'on ne pent la rapporter quavec doute à celle espèce; cile nous semble convenir davantage au Modiolu subcuta, représenté une seconde luis dans le aûrne ouvrage $(p l .8 \bar{j}$. fig- 760$)$.

Celle jolie espece de Moule vient des mers d'Amórique. Elle est longue de 42 millimètres.

\section{Mover septifère. Mytilus bilocularis.}

M. testa ovato-trigoná, posterihis depress.;, longitudinaliter sulcatá; sulcis tenuibus, cremilatıs, subgranosis; valvis basi sepliferis.

Var. A. Mytilus bilocularis. Is. Gsex. $n^{\circ} .3$.

Caean. Conch. tom. 8. tab. 82. fig. 736 a. b.

Encrel. pl. 218. fig. 5. a. b.

Var. B. Testi minore, epiderne viris. 
Chess. Conch. tom 8. tab. 8: fig. 737 .

Var. C. Testâ extìs intivique fuscâ.

Var. D. Testâ extüs forrugineâ, intùs albidi.

Alytilus exustus. Bors. Mus. tab. 7. fig. 5.

Cueys. Conch. tom. 8. tab. 83. fig. 744. a.b.

Excycl. pl. 220. fig. 1. a. b.

Lank. Anim. sans vert. tom. 6. pag. 121. n. 7 .

Coquille fort remarquable, et qu'il est toujours tiès-fiacile de distinguer de ses congénères. Elle est ovale, oblungue, courbée ordinairement dans sa longueur, quelyuefois aplatie, quelquelois aussi extrêmeneat bombée, bossue et subcordiforme. Ses couleurs ne sunt pas moins variables que sa furine : tantôt elle est d'un brun plus ou moi:1s inteuse; quelgnefois, euliu, elle est presque tunte ruagre. Celle derniorre couleur est peut-être due ¿̀ l'exposition assez prolungée des individus, cui la présente aux vicissitudes atmosplériques.

Cette coqnille est ovale-oblongne, couverte en ducluors d'un très-grand nombre de stries fines, extrêmement régulières, souvent onduleuses, bifides et granuleuses dans toute leur étendue. L.es cruclıets sunt petits, très-pointus, entièremeat terminaux; au-dessous d'eux, et du côté interne des valves, se voit une petile cloison transverse, cunparable à la cloison des Crépidules, et qui cuurre une partie de la cavité du crochet. Celte cloison est blanche et plus ou moins prolongée, selon l'âge des individus. Le bord cardinal est c.urt, et la gou tière da liganent dontil est creusé orcupe un peu plus de la inoitié de sa longueur; eile est étroite, mais prufonde : le côté antérieur est ordinairenıent droit, quelquefuis recourbé en dedans, et il offre toujour's vers son milieu une perite fente pour le byssus: ce bord antéricur b'e'st point crénelé, tandis que le reste de la circonfúrence des values l'est très-linemeut. A l'inzérieur, cette espéce est toujours lisse, d'on blanc tantût verdaitre et tantôt brunâttre.

On trouve cetle coquille dans les mers de l'Inde et de la Nouvelle-Hullande; sa longueur est de 45 millims. nicus.

10. Movrx de Magellan. Mytilus nagella-

MI. testî oblongî, infernè angulatì et albida, supernic purpureo-violucescente; sulcis longitudirualtbus, crassis, undatis; natibus acusis, subrectis.

Lister, Conch. tab. 356. fig. 193 J.

FavaNie, Conch.tub. 5o. fig. r. 2.

KNORR, Vergn. tom. 4. tab. 5O. fg. 3.

Crems. Conch. tom. 8. tab. 8j. fig. 742.

Excycr.pl. $2: 7$. fig. 2.
Yar. 2. Testâ minore, antiquatú; valvis cochleatis.

Var. 3. Testâ minore, subplicata, intùs argenteâ.

Chens. Conch. tom. 8. tab. 83. fio. 743 .

LaMK. Anim. sans vert. tom. 6. pag. 119. $n^{\circ} .1$.

Belle espèce de Moule, qui n'est point rare dans les collections, et qui se rcconnoît assez fücilcment parmi les espéces du genre. Elle est alongée, étroite, un peu courbée dans sa longaeur, pointue au sommet, ayant les crochels acuuinés un peu contournés sur eux-mêmes et un peu calleux à leur base. Le milieu de la coquille est convexe et bossu, elle est dilatée vers le tiers inférieur de sa longueur; sa surface extérieure, revêtue d'nn épiderme d'un brun foncé, présente de gros sillons longiludinaux et onduleux peu régulieis, qui s’atlénuent ordinairement vers la" base de la coquille, où il se terminent sur le bord, qu'ils rendent légèrement onduleux. Le côtó antérienr, daas les grands inclividus, est arqué; les sillons qui sont sar ce côté sont toujours plus lins yoe sur le reste de la surface; la partie supérieure en est tout-à-fiait dépourvue. Le bord cardinal ou supérieur est arqué en dehors dans sa lonuneur; il est assez épais, creusé d'une rigole subinterne, gui doune atlache à un ligament très-ćpais. A l'intérieur, les valves sont lisses, d'uue nacre d'un blanc éclatant, nuancé de larges zones violettes : dans la plupart des individus, une tache très-grande de celte dernière couleur occupe toute la base. Lorsque cette corquille est dépouillée de sun épiderme, elle est d'un violet foucé, lantôt rouğcûtre et tautôt noirâtre. Les crochets présentent dans celle espèce un caractère assez particulier : celui de la valve gauche est creusé d'une petite gouttière, dans laquelle s'enfonce un bourrelet arrondi et assez suillant, qui se trouve sur le crochet de la valve opposée. Cette cocuaille, commune dans les collections, vient des mers d'Amérique, et nolamment du détroit de Mlagrellan. On en trouve aussi une varićlé constanment plus petile dans les mers d'Afrique, au cap de Bonne-Éspérance, d'oì elle a ćté rapportée par feu Ladande. Les grands iudividus out 125 i 150 militin. de longueur.

1. Movre à canal. Mytilus canalis.

M. testâ oblongá, lexviuscula, cornileo-nigricante; margine antico canalifero; postico planulato, albo.

Listra, Cunch. tato. 360. fig. 199.

Var. 2?" Testi lutiore, natıbus brevioribus.

Excyce. pl. 215.

LAME. Anum. sinns yert. tom. 6. pag. 123. $7 i^{\circ}, 15$.

Celte 
Celte coquille se reconnoit facilement entre ses connénères par son élargisserneut, et surtout par le caral peu profond grii se voila a la partie supérieure du cólé antérieur.

Cetie coquille est ovale-oblongue, pointue au sonumel, a crocluts carénés et bossus; ie côté antérieur est subtronqué, et sa partic supérieure jrésente une dépression décurrente, qui coruespond a une fonie lancéolce situce sur le bord, et dunnaot passane au byssus. Ce côté antérieur est droit, le postérieur lui est presque parallèle; il est dépriné, et un angle obtus résulte de sa jonction avec le bord cardinal : celui-ci es! droit bu à peine courbé; il est wince, et la rigole du ligament est presque aussi longue que lui, mais étroile et peu prufunde; les crochets sont sans dents. A l'utérieur, les valves sont, à leur parlie supérieure et moyenne, d'uu blanc subaacré; les bords sout d'un beau violet. A l'extérieur, lorsque celle coquille est polie, elle est blancte sur les crocbets, d'un violet peu intense au cóté antérieur, mais d'un violet très-foncé sur tont le reste de la surface. Lorsqu'elle est revêtue de sou épiderine, elle est partout d'un brun trèsfuncé. D'après La marck, celle coquille viendroit de la Jamaique. $S_{3}$ longueur est ordinairement de 110 i 115 millim.; il en existe cepeudant des iudividus plus grands.

12. Novte opale. Mytilus opalus.

AI. testi elongati, curvati, posteriùs arcuatosinuati; epiderme fusci; caldine unidentato.

An Lister, Conch. tub. 363. fig. 204?

Lasx. Anim. sans vert. tom. 6. pag. 124. $n^{\circ} \cdot 18$.

Cette espèce est une des plus grandes et des plus belles du genı Mloule. Eille est ovale, alungée, fort étroite, poinlue an sommet, légèrement courbée duns sa longueur; les crochets suat fort épais, écartés, juclinés sur le rôté antérieur, et présentant toujours sur la valve d:oite deux dents divergentes, entre lesquelles vient se rlacer un bourrelet obtus de la valve gaucbe. Le côté antérienr est un peu courbé dans - Iongueur; le bâillement pour le passage du byssus est alongé, assez grand et lancéolé. Le bord postérieur est presque parallèle à l'antérieur; il est régulièrement courbé, et se continue insensiblement avec le bord cardiaul : celui-ci, à sa partie antéricure, est profondément canaliculé derricre les dents cardinales; ce canal, qui conlient une perite parlie du ligament, se continue ea ane goultière très-longue et ćtroite, qui donae insertion au ligament. En dedans, celte coquille est diune nacre blanche, irisée des plus belles couleurs de l'opale; en dehors elle est brune, et son épiderme prend une teinte verdâtre vers les Lords. Lorsçu'on lui a douné un poli artiticiel, Hist. Nat. Fers. Tome II. les teintes irisics de la nacre sont cncore plas brillantes quáa l'iatéricur.

Cetle coquille, rare et précieuse, a quelçueluis prés de deux décimètres de lungueur; elle sc trouve dans les uers australes, aiosi que daus l'Ucćan indien.

15. Nocte d'Afrique. Mytilus afer.

H. tcst $\hat{\jmath}$ oblongo-trigniz $\hat{x}$, supernè dilatati, lincis angulatis picti; eprderme flavo-virente; latere posticon versis basim tumido.

Mytulus afer. Guet. $z^{\circ} .28$.

Favana, Conch. tab. 5o. fg.f. 2.

Kконя, Vergn. tom. 4. tab. 15. fig. 5.

BоRx. MIUS. tab. 7. fig. 7 .

Chesx. Conch. tont. 8. tab. 83. fig. 7339 à 741 .

Escrce. pl. 218. fig. 1.

Var. B.) Test $i$ angustiore, litturis nullis.

L.s $n^{n} \cdot 21$.

Cette Moule est assez variable dans ses conleurs, el on seroil tenté de faire des espèces disincles des individus qui ont conservé leur épiderme el de ceux qui en sunt dépouillés; mais ces individus sont réunis par des caracic̀res comnuuns, et lous doivent être rapportés à un seul type.

Cette coquille est alongée, très-aiguë au sommet, obtuse inférieurement; san cóté antériear est presque droit, il est bossu à sa partie supérieure; le hord postérieur est fort court, beaucoup plus court que le bord cardinal, ce qui est l'inverse daus le plus grand nombre des espèces. Les crochels sont pointus, à peine inclinés; ils ont toujours deux petites teats cardinales sur une valve, et une seule intrante sur le côté opposć. La surface exterieure est revĉtue d'un épiderme souvent transpareal, d'un brun-verdâtre, an-des. sous duquel on aperçuit un grand nombre de linéoles ruusses, transverses, fortement angaleuses ou en zig-zag: dans d'autres individus, l'épiderme est d'un vert foncé, orné de zones fauves, au-dessous duquel la coquille est violátre ou ornée de zones purpurines. En dedans, celle coquille est ornée d'une nacre d'un blasc-rougeátre, tantôt pâle et tantôt très-loncé.

Celte coquille n'est point rare dans les collections; elle vient des coites de Barbarie. Sa longueur est de 110 ou 115 millim.

14. Moele agathine. Mytilus achatinus.

M. testầ oblongo-trigoná; epidernse fulvo-rufescente; anteriùs conıpresso-angulatâ, posterius tumidulâ, -intús splendidissima, livido-violacescente.

Yar. a.) Testá elongatá, anticè nuinùs angulatô. $\mathrm{Bbbb}$ * 
(hens. Conch. tom. 8. \& b. 84 ffŏ. 748 .

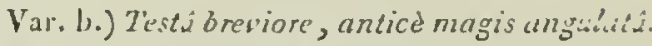
Mytilus versicolor. Ga EL. $n^{n}$. 30 .

Ciness. Conch. tom. 3. tab. 84. fig. 748 .

ExcrcL. pl.218. fig. 5.

Іанк. Anim. suns, vert. tom. G. pag. 125. $r^{2} \cdot 22$.

fa Muole agathine a des rapports avec le Mytilus ")er d'un côté, et le Mytilus smarugdnus d'un aıiıc. Eile est ovalt-ırigone, alongée, assez larğe, ¿ sommet pointu et lérèterueut incliné antérieuzenuent. Le côté antéricur est légèrement conrexe ذ̇ sa partie supérieure; il est limilé à l'extérient par un angle tiès-obıus, qui rend les crochess subcarónés. Le côlé postérieur est déprinaté, el produit un angle obtus à sa jonction avec le luond supérieur; ce borl est à peitic ar.jgé dans sa longneur: la groullière du ligament est presque anssi longue que lui; et ce qui la rend remarquable, c'est quc s ubord interne est fi:entent créuelé daus toule sa longueur. A l'extélieur, la coquille est sillonnéc par des acrorvissenens irréguliers; elle est revêtus d'un épiderine d'un brun funcé, jaunálie sur le còté antérieu et rerdâtre sur les bords. A l'intérieur, les va!ves sont d'une nacre brillante, blanche antérieurement, et al'un rouge vineux irisé dans le reste de leur étenduc. Les rrocilets, peu épais, préscuteut lonjours deux petiles dents sur chaque value.

Celte belle coquille, assez rare dans les collections, vient des aner's d'Amérique; et la variélú, toujoors plus petite et beauconp ululus épaisse, a été rapportée des mers de la Nonvelle-Zélande pa. MM. Quoy et Gaymard. Sa longueur est de ioj unillim.

15. Moure comestible. Mytilus edulis.

11. testi oblongî, anteriùs curví, compressoangulatâ, posteviùs retusá, versùs basim tumiduld; dentibus subonatomis.

Mytilus edulis. Lix. Gaed. $n^{\circ}$. II.

Var.a.) Tesiâ corruliscens, raduis obsoletis aut mullis.

Iusten, Couch.tab. 362. fig. 200.

K. von , Vergn. torn. 4. tab. 15. fig. I.

Pexnaxt, Zool. Brit. tom. 4. tab. 65. fg. 73 .

Chenx. Conch, tom, 8. tub. 34. fig. 75 s.

Vincrel. $p l .218$. fig. 2.

Vur. b.) Testâ pellucidâ, viáatceo-madiati.

. Mytilus pellucidus. Matox, Act. soc. Linm. tom. 8. pag. 107.

Crexs. Conch. tom. 8. pag. 84. fig. 751.

Laxx. Anim. s. vert. tom. 6. pag. $126 . n^{\circ} .29$. Cette coguille est l'une des mieux connues du gen:e, ćlant très-abondanımen: répandue sur tont Fe litural de France. Elle sert à la nouriture des liabilaus des cóles, et souvent elle est transportéc au loiu comme le sont les Huitres: son abondance: est telle dans certaines localites, que lion s'en sert quelquefois en guise d'emprais sur les terres qui ne sonı point éloigncées cies cóles.

Celle rroule reste tcujours diun rolume médiocre; elle est ovale-oblungue, étruite, convexe, déprimée antúrienrement, où elle est un peu loaillatue pour le passage du byssus. Le cólí antérieur est dioit, rarement courbé, le postérieur lui est parallele; le lord supéricur ou cardinal est a peine courbe, il est occupé dans toute sa lon„ueur par la gouttière superliciclie du liganeal; les crochels oot quelquetuis deur pelites dents cardinales. A lintáricur, celle Moule est blanche et ses bords sont vinlets; en deliors, elle estrerêtue d'un ípiderure d’u brun rrès-foncé : lorsque cet épiderroe est enlevé el la cucjui!le polie, elle csi partout d'un violet obscur. Ia valiśté se distingue par son test for mince orne de llaumules longitu. dinales d'un violet foncé sur un tond l'une même. couleur beaucouj: moins intense : celte varićlé est ordinarement plus titroite, propurtionacllement, que le type de l'espèce. On lrcuve relte coquille, nun-seulement sur les côles de lirance, mais aussi sur celles d'Angleterre, de la Ilullande, et justure dans les mers de la Russie el de la Norwige. Ces claangemens de teapéralure lui font íprouver quelyues modifications gu: ne soot pas assez consiúrables pour qưun puisse eu apprécier la valeur. Les grands individus de celte espéce unt 80 ou 85 millim. de longueur. N.

6. Mover acuminle. Mytilus acuminatus.

M. testâ ovato-elong.ltî, depressá, unticè acut $\hat{s}$, angusti, supernè dulatati, striis longitudinalinus tenuissimis ornuti; lutere antico brevissimo, subrostruto; umbonibus minmis, vi.t: prominentibus.

Modiola acuminata. Nos. Descript. des Coq. foss. des enu. de Paris, tom. 1. pag. $262 . p l .40$. fir. 9.10 .11 .

Nous derons la conmoissance de celle belle espire de Muule à notre confrire et savant ani M. J. Desnnyers, connu si homurablearent par ses આavaux géologiques.

La Mou!e acumince olf:e encore on passage eutre les Modioles et les Moules.

Elle est de forme ovale-oblongrue, pointuc et étroice autérieurement, élargie et arrondie postérieureueut. Les bords supérieur et inféricur sont droits, et leur incidence au summet produit un angle aigu. La coquille est aplatic, peu bonilée et déprimée, surtouı vers l'angle supérieur et postérieur. La suiface externe est couverte d'un grand nombre de stries tines et longitudinales; 


\section{$\mathrm{MOU}$}

ties sont arrendies, simples, pen suillaates, ct layonocut des crocliets vers les bords sur lesquels tles produisenı de fumes crénelures: elles ne naisscat pas immédiatenicat du sonmet, car il est lisse. En declans la caquille est luisante, et on s'aperçoit aux cassures qu'elle devoit çıre nacrée.

D'apris un groupe de celle espèce que posside M. Desnogers, on ne peut douter qu'elle a'ait eu la mêrae manière de vivre que les autres Moules, car les individus sout disposés ea chapelet comme sont les Manles larsqu'elles s'altachent les uncs .ux autres par leut hj'ssus. Longueut 23 million., largeui 10.

17. Mocle en hache. Mytilus hastatus. NoB.

il. testầ ovato-elongatá, subulatí, valdè recurvi, dorso oblique ungulatis, longitudinaluter striataj; striis anticis ct posticulubus divariratis, spatio mediano lievigato separatis, margine antuco brevi, profundè crenulato.

Modiola hastata. Nuв. Descript. des Coq. foss. des envir. de Puris, tom. 1. pag. 261. pl. 58. fig. 13. 14.

II y a beaucoup de rapport cutre cettc espèce cl la précéllente : elle se rapproclic aussi du $M y$ tulus sulcatus pour la dispresition des stries, mais elle se distingue de l'une el de l'áutre de ces espèces.

Nous avons donné le oom de Monie lasiéc à crite coquille par la ressemblance de sa lorme $\therefore v: c$ un fer de hache. Elle est ovale-oblonirue, pointue antérieurement, arrondic et dilatée poslérieurement, courbée dans sa longueur, et se levminaul antériearement par un bec court. Sou extrémité antérieure el postéricure se termine aussi par un augle saillant résuliant de la jonction des bords postérieur cl iuférieur. Eufia, un angle superieur ohlus est produit par la junction des bards sunérieut et postérieur. I,c dos est lombé et saillanl; un angle obtus le narcourt obliquement du sommet a l'angle inférieur et pustérieur, et partacre ainsi la coquille en deux parties inf́gales. Les siries longiludinales, nomfucuses, serrées el obtuses, qui couvreut la partie postérieure de la cogurille, sonı limit́es par cet angle, au-dessuus duciucl commence l'esprace lisse antérieur sur lequel on ne voit que des ar:- roissemens transrerses peu róruliers. licxtrómitú antérjeure est munie de quelques stries qui partent en rayonnnat tes crucliets et produisent des "rénelures profondessur lebord. Les crocluers sont petits, peu saillans atu-dessus du bord cardioal: -elui-ci est en ligne dinile, incliné obliquemeot sur l'are de la coquille; il est simple. l.e bord posiélieur est linement crénclé dans loute sa louwreur. En dedans celte coquille est narré, mais :llc est maie. Limpressicn musculaire antérieure est semi-luarive et assez graulc.

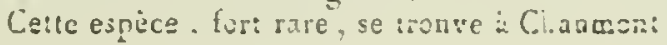

$\mathrm{MOT}$

563

et à Mbbecrumt. Elle est Iongue de 5 million. cl laige de 33.

18. Moore angulaire. Mjtilus angularis. NDE.

II. testí ovato-clongatâ, recurvi, gibbosi, duso oblique anguluts, supernè depressâ, diluts; strus tcnuibus, obsuletis, longiludinalulus ornati; umbonıbus minimis ; masginabus ciemilatis.

Modiola angularis. Nов. Description de's Cnet. foss. de's cnv. de Paris, tom. 1. pag. $260 . p l .4$. fig. +. 5 .

Il exisle dans les mers de l'Inde me pelite espéce de Moule ( $j u i$ a arec celle-ci des rapporls de forme, mais qui, étant plus grande et sunjours lise, ne sauroit être confundue avec elle. La Moule angulaire est assez grande, ovale, pointue antérieuremcnt, courlsée dans sa longueul et boosbée en dessus. Son test est mince, fíagíc ct nacré a l'iutérieut. I.e horil antéricur est trescurrt ét déjusse peu le crochet; le bord inférieur. un peu bombé en deliors antésieurement, se courbe assez fortement en dedans à sa partic mayenne; le bord supricur on cardinal se reléve à son exliémité postérieure de manière à former un angle saj!lant a sa jonction; le bard postérieur est arrondi. Si cen'est à la partie mayenne du borl inléricur, tout le resle du coutcar des valves est crénelí; en dessus elles sontoraces de stries lines, longitudinales, pen ćlevées, obsoléres, et disparoissant vars les crochets. Depuis l'extrénité dos cracbers jusque vers le milieu du bard inféricur descend un augrle saillant qui séparc nelteroent tom!e la partic antérieure de la coçuille : an-dessous de cet angle, et en avant de lui, les strics sunt plus fines et plus obstures.

Celle crquille, rare et fragile, ne s'est caccrc rencontrée qu'd Toailles, dans les salıles inferieus au calcarire grossier. Sa longuears est de 25 wi!!. et sa largeur de 15.

19. Motre pectinée. Mytilus pcclinatus. Layt.

ML. levlí orato-aculá, antiré acuminatâ, dorso gibbosu, longrtudinaliter strialj; striis minerosis, elegantis, posticè uliquandó bifilis; umbombus minimis, subteminalsbus; margme it, feriore subsivitato.

Modinlu pectinatu. I.Asx. Ann. du Mus. t. 6. pag. 225. $n^{\circ}$. 5, et tom. 9. $\mu l .17$. fig. 12. a. b.

Motiola pectinata. Non. Descript. des Con?. foss. dis ens. de l'aris, tom. 1. pag. $25 \mathrm{~g} \cdot \mu l .5 \mathrm{~g}$. fig. 6.7.8, et pl. 41.f.g. 1.2. 3.

Vat. a.) Nos. Testá majore, posticè bisinuata, depressiusculá

letic coguille trés-úlégante, qui fait évidemrien: le passage cntre les Monles el les Mndıoles. Son creclacies: presque terminul, el lebudanti$\mathrm{B} b \mathrm{LL}:$ 
rieur est aussi court que dans cerlaines espèces placées par Lamarck au nombre des Moules. Celle petile espèce est ovale - ablongue, pointue antérieurement, élargie du còté postériear, oblique, assez fortemen bombée ou bossue à sa parlie moyence, déprimée vers le bord poslérieur, et surlout à la jouction de ce bord avec le supérieur. Le crocliet, qui est tiès-petit et à peinc sailiaut, est cout lisse : c'est à une petite distance que commencent à paroitre les stries longitudinales, arrondies el fort él'́rantes, qui couvrent touse la coquille el gagnenı, en grossissant graduellement, les bords sur lesquels elles produisent de pelites crénelures. Ces stries, et surtout les posiérieures vers le milieu de leur longueur, se bifurquen! : presque toutes les sulies antérieures sout plus fines que les autres. Dans quelques individus bien frais les stries d'accroissement sont marquées dans l'iatervalle des stries longiludinales, et lorsqu’elles sout r'ćgulières la coquille paroît treillissée. Le bord antérieur est lrès-court; l'iaférieur est un pea sinneux dans sa longueur, et reatre légrement en dedans; le postérieur est arrondi et obtas, et le supérieur, très-obliquement incliné à l'axe de la coquille, est droit et creusé en dedans par le sillon do ligament.

La variété que nous avons tait figurer est fort remarquable par la double siauosité du bord postériéur el par l'aplatissement plus considérable de la cogaille : cette variété paroît assez constaute, car nons en arons vu plusieu's exemples.

Cette coquille, mince et firagile, se trouve à Parnes el à Grignon, aux environs de Paris. Elle est longue de 8 unilim. el large de 5. Noв.

20. Moure pectiniforme. Mytilus pectiniformis.

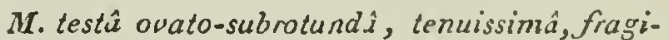
lissimâ, intìs argente $\hat{a}$, longitudinuliter costatâ, pectiniformi, profundâ; costis cribris, rotundatis, latis, rudiantibus; apice minimo, lutere "intico brevissinio, crenulato; lunuld intùs arcuatà, lcevigatî.

Modiola pectiniformis. Nов Descript. des Coq. foss. des emp. de Paris, tom. 1. pag. 263. pl. 39 . fig. 14.15 .16$.

Aucune espèce ne peut ètre comparée à celleci, soit pour la lorme, soit pour ses autres caractères; aucune, en elīel, n'est aussi arrondie, n'esı aussi courte : elle a de la ressemblance avec un pelit Peigne manquant des oreillelles. Celle coquille est ovale-oblongue, presqu'aussi large que longue; elle est convexe, arrondie, subcordiforme lorsque les valves sout réunies; le bord antérieur est extrêmement court et crénelé; le bord cardinal est un peu courbé, simple et assez cuurl; le bord inférieur est fort court lui-méme, il est courisé ers dedans, et la partie de la cqouille à laquelle il correspond est tonte lisse : tout le reste de la circonférence, c'esi-à-dire au moins la moitié, est occupé par le bord postérieur, qui est crénelś ou plutôt onduleux dans toute sı longueur. Les côtes longriludinales, nounbreuses, rayonnilutes, arrondies, obluses, peu distantes, subcrénelćes par des accroissemens, descendent des crochets à la circonférence : une seule petite partie du côté inférieur en est dépourvue, et elle sépare, comme dans les aut:es espèces, les côles autérieures des postérieures. Ces cốtes antérieures, au nombre de quatre ou cinq, produisent des crénelures, ou plutôt des dentelures saillantes sur celle partie du bord qui lear correspond. Le lest est si mince que les cótes du dehors se répètrent en dedans : cle ce côté celte coquille esı nacrée.

Celle espèce se trouve à lloudan, aux enviroms de Paris. Elle est lorgue de 11 millim. et large de 9 .

2I. Moule profonde. Mytilus profundus. NoB.

M. testî ninimá, tenuissima, frugili, dorsa'á, profundi, extus termissimie strutid, umbone minimo; latere postico subdalatato; murginibus subcrenulatis.

Modiolı profunda. Nов. Descript. des Coq. foss. des env. de Paris, tom. 1. pag. 264. pl. 4 1. fig. 12. 13. 14.

Petite coquille très-mince et très-fragile, que nous n'avons sćparée comme espèce qu'apiès en avnir exaniné flusieurs individus qui nous ont toujours semblé différens des autres espèces du même genre, et qui n'avoient point de ressemblance nou plus avec le jeune âge des espèces que nous avons observées. Elle est ovale, atténuée du côté antérieur, un peu plus longne que large : la cavilé des valves, d'une nacre brillante, est profonde et lisse; en dehors la coquille est trèstombée; el!e paroîl lisse, mais, examinée à une forte loupe, on aperçoil des stries extrèmement fines, très-nombreuses el liès-seriées; les croche!s sont assez saillans, ils dépasseut un peu le bard antérienr, qui est fort court, ce qui rapproche celle espèce des Moules proprement diles; le bord cartinal esi un pen plus épais que les autres; les bords paraissent lisses, mais ils sont irès-linement crénelés par les stries qui y aboulissed:

Celle petite coquille se trouve à Parnes, anx eovirons de Paris. Elle est longue de $\overline{3}$ ou 4 millimètres.

22. Movee des Papoux. Mytilus papuanus. LIN.

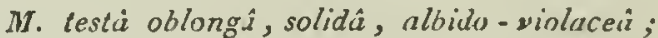
antico latere obliquè dilutato; unbonibus tumidis, obtusè angulatis.

Dargesp. Concli. tab. 22. fig. c.

An Lulat? Adsxs. Sénég. tom. 15. 
Pexsast, Zool. Brit. tomb. 4. tab. 66. fig. 77. Cвемx. Conch. tom. 8. tab. 8j. fig. 75ั7.

Excrce. pl. 219. fig. 1.

FAvaiNe, pl. 5o. fig. 6.

Modialu pupurna. Lasx. Anim. sans veri" tom. 6. pag. $111, n^{\circ} \cdot 1$.

Fort belle espèce de Moule dont Lamarck aroit fuit le type de son genre Modiole. Cette coupuille est ovale-oblongrue, à test fort épais, solide; elle est obluse au sornmet, très-convexe, el pilurvue ì son cóté antérieur d'une dépressiou dont l'extrémité correspond a la terminzison du bíilile. ment qui donne passane au byssus. les crochets sout peu préomineus, ils sont courbés au-dessus d'un cỏlé antérieur très-court et très-Qbıus; le côté inférieur est presque droit, le pastériear est rénuliçrewent coubé, et se joint iusensiblement au bord cardiual; celui-ci est épais; la grouttic̀re du lirrament est large et profonde clle s'appuie à l'inícrieur sur une côte décurrente, pen saillante. A l'intérieur, la coquille est quelquelois d'un blanc livide, mais le plus souvent d'un hlauc nacré, avec une tache d'un riulet peu loncé vers le bord inférieur. liimpression sousculaire antévieure est plus grande que dass la plupart des espèces. Elle est oblongue et parallèle a u bord inférieur. En debors, celle coquille cst revélue d'un épiderme assez coriace, d'un hrun assez loacć, au-dessons duquel, par le poli, elle se trouve d'un beau violel peu foucé, avec des zones transverses blanchatres.

Cetle coguille n'est point irès-rare dans l'ozéan Allantique austral, à la terre des Papoux, dont elle a conservé le nom. Lamarck dit (qu'elle est longue de 98 millim.; cette mesure est celle des petits individus. Nous en possédons un qui a 155 pillim., et nous en avons vu de plus grinds.

\section{Movre tulipe. Mytilus tulipr.}

M. testî oblongí, tenui, supcrnè coariłali, sinuatu, infernè compressi, ulatí, albu, purpureo suadiccoque partim radiati.

An Mytulus modiolus? Lrx. Grec. no. 14.

K.овк, Tergn. tom. 4. tab. 15. fig. 3.

Cuвм. Concin. tom. 8. tab. 85. /fg. 758.759 .

liscres. pl 221. fig. 1.

Vas. a.) Testi angrustiore, roseo radiats.

Modiolu tulipa. Lasx. Anim. s. vert. torn. 6. pag. $111 . n^{\circ} .2$.

Relativeasent is la forme extérieure, cette espèce a beaucoup d'aualogie avec ceile qui pricecde, mais elle reste toujours beaucoup plus pelite. Eille est ovale-oblongue, lénèrement arquée dais sa longueur, obtuse an:éricurement, plus larre et subililatée à son còté postérieur : elle est mince, sublransparente, rrès-convese, subcurdifurme lorsqua'on la regarde du cótć anlérienr; les crochels sont assez grands, inlléchis sur un còté anlérieur très-court; le bord cardinal est mince et reçoit le liganeut dans une goullière à peine creusée; le hord anterieur est un peu inlléchi dans le milieu, nùil préseute un trìs-petit bàillement pour le passage du byssus. La su:face cxlérieure est revèlue d'un épiderne simple d'un brun-jaunảtre; cet épiderme est très-caduc; audessous de lui la cuquille est d'ua blanc-grisitice oul blenatre, et ornée d'un grand nombre de llammules on de rayons longiludiuaux d'un bean violet; en dedans, les valves sont lisses, d'un blauc-violitre, et l'on $\mathrm{y}$ aperçoit, surtout vers les bords, les lignes violelles de l'inlćricur.

Cette petite coquille, assez comınue dans les collections, vicut des mers d'Amérique.

Uoc coquille, figurée par Adanson sous le nom de Lulat, a été rapportée par quelques persunnes à celte espèce de Moule; mais il sulfit d'en lire altentivement la descripion pour s'apercevoir qu'elle ne peut lui convenir: l'erreur a élé comnase d'abord pitr Gmelin, dans la 13 e. élition da Systema naturce, et reproduite ensuite par M. de Blainville dans le Dictionnaire des Sciences naturelles. Longueur 75 à 80 williu.

24. Moole de la Guianc. Mytilus guianensis. MI. lestî̀ oblongâ, infernd wix carinati, e.xtrorsùm lutescente; fusciâ obliquâ, bicolorutî̀; ligamento cardinali pralongo.

Mytilus bicolor. Brug. Catal.

Modiolo guianensis. LAмx. Anim. sans yert. tom. 6. parg. 112. $n^{\circ}$. 4 .

Julie espèce de Moule, remarquable par l'élargisseınent de son coté postérieur. Elle est subnralaire, obloggue, alténuće antériearement; dilatée et obluse du cólé poslérieur, son cóté intérienr est très-court; les crochets qui le cominent sont fort petits, pen saillans au-dessus du bord, et sulicarénćs à leur arigine. Celle carène des crochets se prolonge obliquement en s'alourissult, et disparoit entièrement au milien du dos. Le borrl cardinal est trc̀s-long; il occupe ì peu prìs les deux liers de la longueur tolale de la corpuille: il est fort mince, et creusé dans toute celte lonzucur d'une petite gontlière superficielle, trèsćlroite, qui donne allache à un ligament trèsilungé. Le test de celte Moule est très-miace, aransparent, d'une nacre blanche asssez lorillante à l'intérienr, et préseutant au-deluors des stries transverses d'acs roissement assez multiplices. Lia cuulcur exiéricure se partage en deux parties rès-distincles: l'une occupe le côté aolérieur de la coquiile, elle est d'un brun fauve; et l'uutre, gui se voit sur lonle sa partie postéricure, est d'un heau rert, netenont tracolé sur loa:tie couleur. 
('elic coçuille, ossez rare, rient des mors de la Guiane, d'apries lanarck. Suivanl cel autear, tle auroit 8o aillimèıres de Inngueur. l.es iudividus que nous pusséduss en ont $\hat{b}_{0}$.

\section{Mccre coubée. Mytilus cinnamomcus.}

11. testâ subcylindricâ, ventricosí, ammati, utráque cxticmutute retusi; natilus subpromimulis.

Mytilus cinnamonucus. Ciners. Conch. tom. 8. tab. 82 . fig. 73 1.

ExcrcL. pl. $231 . f i g .4$.

Var.b.) Ead. miner. Testâs subepidermie alhidá. 1.Ist. Conch. tab. 'jig. fig. I97.

Modiala cinnamomea. L. An K. Amim. sans z'ert. trm. 6. furg. $114 \cdot 12^{n} \cdot 13$.

Fort jolie coquille cylindr áe, ovale-blongntue, .r courhere daus sa longueur ; clle est obluse a ses licux extrénitís el elle u’est guvère plus large diun tôlé quede l'aulre. les crochu!s sont assez grands, wurnés en spirale antŕrieurement, re qui remd - rule confulle cordiforme lorsyuion la regarde de ce cobté. Ia surlace cxtericure est converte l'une inulitude de slides transverses exlrêaement lines et rérulières: cfs slries, par leur trsesse, donoent une apparence soyeuse à celle surface. le loord inferieur est courbe dans sa lingrues:r; le supúricur l'est ́́gulenent, et il lui es parallèle. Le loord cardinal est mince, courbŕ, -i le sillon du lịament est exlıêmement éircit. l: bord postériem est oilus, arundi, épuissi, -ornine cila a lieu dass la Modinle lithodome -1 la pllupart des espéces qui, conme celle$\therefore$, vivent dans l'intúfut des prerres ou dos vałrénores. A l'intérirur les váves, yui smut ixtrêmeatcul minces, sont d'un banc al'genlin; i) l'sxtirieur elles sont d'un brun-fauve, d'use tinle unifoune.

Cene coquille, asscz rarc: se trouve dans les mers de llle-de-liance claus l'Océan iudicn. la lonnueur des plus grauds individus est de 37 millimetres.

La vacicité prustrnit bien constituer une espice d.fỉrente : num-seúcuent tle reste toujours plos pelite, unis encore elle est constwment dun hrun prescite noir et manque des ilics fines el rroblicies qui caracléusent si lien les individus qui funt le tyje de l'espiere.

26. Novie sillunute. Mytilus sulcatus. Lank.

TII. testầ elurgntâ, spathulat $\hat{a}$, obliquâ, depressi, anicè posticèquc iongitudinaliter sulcutâ, "ll meaio lervigata; mmbonlus minimis; mirgrne antico bievissimo, crenulats.

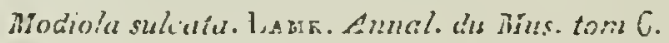

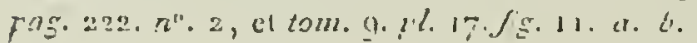

Nous anrions dú chabger le nom de cetle esprice, car une autre coquille vivaule, qui n'cst pnint son analogue, le porte également; mais com'ne c'est l'espèce lossile qui a reçu re mon la proniile, nous croyons que la vivante doit en changer de préférence. La figure de tanarck, "fue nous venous de ciler, donne une trés-mauraic: idie rle celle coquile; car il sembleroit qu'il existe des stries transverses passant sous les longiludinales pour aller produire les créneines dil Loud supḱrieur, landis que ce sont les stries longiludimales qui les lunt, comme sur les autres bords oi clles aboutissent.

Celle coguille est ovale-oblongue, élargic postérieuremenl, ce qui lui donne la for'une d'une sparule; elle est très-aince, tràs-fragile el nacrée à l'intritieur. Les crochels sont petils, feu saillans et in :linés anfirieurement of obliguement. L'extrómité antéricure est un peu en liec et déplasse les crochets. Lit surface extrrieure est parlagéc en deux parlies lien disliucles : l'une midiane, qui descend obliqucment du crocliel jusqu'au bord inférieur, dont elle occupe la partie nrédiane; elle est lise "u marquée d'accroissemens transverses, et clle sćpare les parties autérieure et postólienre qui somt oruces de sillons longitudinaux : les antć. rieurs sont on pelit nombre, et les postéricurs courrent en rayonnant coule la partic postórieure de la coguille. Eu parvenaut sur les hords, ces sillous y produisent de perites erinelures profundes et rapprochées à l'endroit la lonrd anlćriem qui avoisine la cluarmière. C.elleci est sinıple, el le ligancon! citoil portó dans une guntière subinternc, que l'on recomnoit facilement le long du borl supírieur.

Celle conuille, par la disposition de ses stries, a de l'analonie avec les Mytilus discrepans et discors ; mais sa lorme la distingue trés-lan:ilement. Celle coguille se truive aux environs de Iaris, à Griguon, Manle el à Parnes. Sa lon nurueur est de 23 tnillimétics et sa largeur de 15.

27. Movte spatulíe. MJ tiius spathulatus. Ninn.

MI. testá ilongatá, angust $\hat{j}$, depressi, termissimâ; antiré margine anticn, linevissimo, rostriformi, terminats; postice latione; cxirnmituti anticas et paríi posticali sulculs; parte intermediá larngutâ.

Modialu s, athulata. Nas. Descript. des Coq.

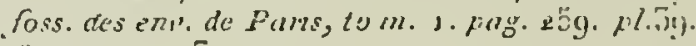
fig. $11,12.15$.

Celle espice pourrnit être prise pour une varićló de la prícédente, si elle ćinit moins constante dans sa forme et sa taille. lille est oblongue, alungce, peu bombie, très-ciroite trés-mince, très-fraule, ayant l'extrémité antéricure lieauconp plus émile que la postériente, et terninte frit ub locid artérieur iris-court, silicané en 


\section{$\mathrm{MOH}$}

Iresus, riénclé et s'avaucant en bes, qui est rendu fibs sensile par la sinuosić́ diu boral infitieur. I.es crochers somt tres-pelils, pen s. 1llans ei intlimís nbliquement sur le córí anlirieur. Ie cóté postérieur est plus larye : eu dessus, il est cnuvert de stries lunpilidinales tiès-fines, onduleuses, qui descentent des croalicts et qui se terminent sur le brorl pro aulant de petites cránclures. Comme dans l'uspere priccideulo, ces stijes manquent sur la partic mojenne de la coquille, qut est lisse nu striée senlement par quégues accroissenens. Lisc dijession longitudina!e livise cet espate lisse de I. curuille en deux parties intigules. L'intŕriem ust tris-lisse e: diune macre tres brillsule. lin delucrs cette cociuille est blanche. Son bord snpérieur on cardinal est alqué daus toute sa lungueur.

Celie petile coquille, assez rare, se Irouve inalement aux euvirons de Páp, a Parnes et li:s Groux. Fille est longue de 13 militiacises "l large de 5.

\section{Mouce Huetle. Mytilus discrepnns.}

II. testî oborulâ, minimi, temui, ririduliz; "rnis lateralabas longitudiralibus, medianas trans. cersis.

1) scosta, Cunch. bril. Lab. 17.fig. 1.

Modiola discrepans. I, $\mathbf{3 x}$. Anim. sans vert. iom. 6. pug. $114 . n^{\circ} \cdot 15$.

Cente Moule a de la ressemblance arec une espèce Gíi vit ảuns les mers de la Nouvelle-Z̈́lande et arec une auire que l'un irsure fossile aux environs de l'aris. De ces deux especes, la fussile est celle qui se distingucroit plus liacilement; car celle de la Nouvelle-Zélande nous smble une siouple variéré de colle qui rit daus la Médilerrace, la seule que Lamarck ait connue. Cetle Moule se reconnoit trés-farilement; clle est ovalaire, lrés-bombie, cortifurme, lorsquion la regarde antérieureuent. I.e cóté antérieur est plus obius que le postérieur; il est arrondi et dominé par les crocbets yui s'inclioent au-dessus de lai. La surlace $\mathrm{cx-}$ lérieure est divisée co trois parlies: l'une, médiane, parfaicment lisse, sur laquelle on apercoit quelyues stries daccroisscment; les deux aulies, autérieure el postérieure, fineuent sillounées longifudinalement, sont séparíes par la première. I.es bords sout linement crénelés lans toutes les parties yui correspondent anx espaces sillonnés ì l'exlérieur. Le hord cardinal est atqué dans sa longuenr; il offie, dans une goutlière trcs-supeaficiclle, tu ligament court el étroit. A l'intérieur, les valves sont d'une nacre d'un blanc-grisàtre, Guclguefois violatrc; en dehors, elle; sont revîucs d'un cpiderme ordinairenent vert, quelquelois d'un vert-bruuaire ou jaunáre.
II O U

Celle cormille nacquicu jamass un in in i wilune. Le's plus yrauls imlividus que nutus ajons sus out 108 milliaietres de longucut.

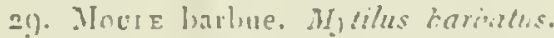

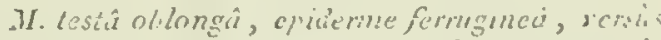

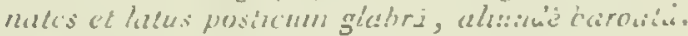

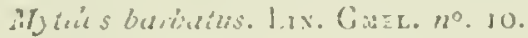

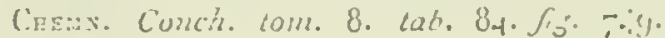
Non ínes.

Excres. pl. Ji8. fis. 6. id.

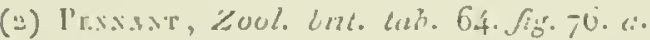

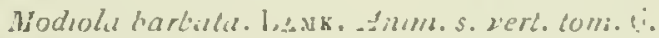
pug. 114 . no. if.

La Mou'c harl ne es! une coquille assez conmune da: s la llédilerranc; clice ressemble bealicoup plus aux rsfices de la serlion précidente: qua une Mindiole propreaneut dive. Elle cot ilcngie, ovalaire, funtue autricusement, ayant les croctets prosface termiuar. In: Somi cardinil, grii est truil, prulnit, aves l'ase lo:atudical de la coquil!e, un angle un pen aigu. L.e bord est assez épatis, court, el purte un ligams n: assce. large et sulintérienr. I.e colé autúblin dépasse a peine les croche:s, taut il cet coun" le cưlé inférient est un peu baililant et simmux vers son unilicu; le Lorul supérieur lui esi parallile: cclui-ci, par sa jonction asce le bord cartinal, produil un angle obtus, vers lequel la cojulli. est défriméc. Lus surface extérieure est reccirverte d'un épiderne assez épais, extrèuen:ent velu, au-desons duquel on tronve me surfire logerement strice en travers, d'un liruu formi, gielequelnis violitre i l'inicirieur.

Cicte esjece est d'une uacre d'un brun rincux foncé, assez brillante. Les bords sont sirnfles et liés-tuticts.

Celle espice est lungue de 50 millimères.

30. Movre hache. Mytilus securis.

II. lestî oblongâ, incuuvâ, unfernè carinato-nculis; epiderme fusco-rugricance; milis violaced.

Modiolu securis. Lamk. Anim. sans 2 cit. com. 6. pug. 1 15. nn. 12

La Nonle hache a une forn.c remarpualse; clic est alongée, trçs.étroile antérieurement; dilillét et courbée fartement dans le nulieu de sa longneur, elle est carénée rers le milieu du dos. Lai carène, qui part du crochet, est arrondie, et disparoit vers l'exlrémilé antérieure et postérieure te la coquille. Le bord inférieur est fortement concave; le bord supérieur est, au coutraice, fort convexc, et se continue avec le loord cardinal quj est presque droit; il est alongé, étroit, el le ligament $1 \cdot s 1$ aussi long que lui. Les cruche!s

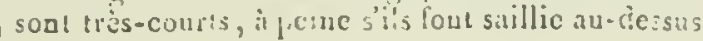


du hort. A l'cxterient cette espece est rerétue d'un épiderme d'un brun fauve, au-dessous ducquel la coquille, par le poli, acquiert une nacre brillante d'un assez beau violet. En dedans, la nacre est blanche à la partie supérieure et violette à l'inférieure. Les bords sont sioples et très-entiers.

Celle coquille, fort rare, provient des mers de la Nonvelle-Hollande et se trouve aussi à 'Timor. Elle est longue de 60 millimètres.

31. Movre subcarénée. Mytilus subcarinatus. La is.

MI. testâ ovato-oblongá, in medio incunvatá, antice subacuminatá, posticè latiore, lavigat'́; striis accretionis notatâ; umbone minimo, recurvo, subcordiformi; margine superiore producto, subcarinato.

Modioule subcarinata. Isamr. Ann. die MItus. t:mt. 6. pag. 222. $n^{\circ} \cdot 1$, et toin. 9. pl. 17. fig. 10. a. $b$.

Jbid. Anim. sans vert. ton. 6. pag. 116 no. 1 .

Mlodiola subcarinata. DeFr. Dict. des Scienc. nat. tom. 31. pag. 514 .

Noв. Descript. des Coq. foss. des env. de Paris, tom. 1. pag. 256 . pl. 39. fig. 4. 5.

Nous ne comprenons pas dans la synonymie de cetle espèce la Madiola subcurinata de M. SowerLy (Miner. conchol. pl. 2;0.fig, 1), parce que, comme cet auteur l'a lui-wêcre, du reste, senti, il y a des différences notables entre les denx coquilles. La plus considérable, outre les proportions différentes dans la forme, consiste an ce que dans l'une (celle d'Angleterre), le somuct, encore plus court yue dans la nôlre, s'avance jusqu'au niveau du bord antérieur; ce qui rend celui-ci proportionvellement plus large et plus obtus.

La Modiole subcarénée est oblongue-ovale, attónuée antélieurement, plus large postérieurement, assez furtement arquée, courlıée dans sa longueur et surtout vers l'extrémité postérieure. Le crochet est petit, très-oblique, contourné sur lui-ınême à son extrúmité et subcordiforme; il est dépassé par l'extrémité antérieure, à peu près comme cela se voit dans la MIodiola tulipa. Le bord supérieur ou dorsal, droit à son extrémité antérieure ou cardinale, se relève en s'arrondissant et en s'aplatissant latéralement, de sorte que la coquille semble avoir été pincéc et comprimée dans ce: endroit. Le bord inféricur, convexe autćrieurement, devient fortement concave dans sun milieu et se termine en s'arrondissant avec le bord postćricur. Les bords sont minces, trancbans et tont-á-fait lisses. La charnière consiste en une guutière oblique, soutenue sar wae crêle saillante à l'intćricur, arrondie, donnant insertion an liganent, qui devoit étre presque toialement caché par la saillie du bord.
Cette corpuille, toute lisse en deduns, l'est presque aussi en dehors; car la surface exlérieure n'ollie que des stries peu régulières d'accroissement, qui sont plus multiplices sur la partie auterieure que sur la postérieure.

Celte Midiole est mince, nacrée en dedans, très-liragile e! très-rare; el le ne s'est juscqu'ü présent trauvée qu'à Grignon, el on n'eu cocuoit en:ore qn'un pelit nombre d'exemplaires.

Queliques personnes ont crit trouver l'analogue fossile de cette coquille dans le Mytilus modiolus de Brocclia; nais il s'en liut de beacoup qu'il eu soit ainsi. Nous avons comparé avec soin les deux cognilles, que nous a vons dans ce moment sous les yeux, et nous pourons assurer qu'clles constituent deux espèces furt distincles. Longueur 28 millim., largeur 63.

52. Moose plicatule. Mytilus plicatulus.

$M$. testâ oblong $\hat{a}$, extrorsimm obliquè dilutatí, longitudinaliter sulcati, extremitatis anticd lumbo interno plicato.

Excycc. pl. 220. fig. 5. a. b.

Modiola plicatula. I, 1 r. Anim. sans vert. tom. 6. pag. $11 \bar{j} \cdot n^{2} \cdot 10$.

La Monle plicatule ne sauroit se confondre avec la sillonnée, nou-seulement parce que sa taille esl toujours beancoup plus grande, mais encore par une forme qui lui est particulière. Elle est alongće, étraile, courbée dans sa longueur, alténuće à ses deux extrémités, mais surtout à l'antérieure qui est beaucoup plus étruile que l'autre; ses crochets sont à peine dépassés par le côlé antérieur, qui est très-court et doot le bord est très-fortement crénelé; la convexilé des valves est peu considérable, surtout du crité postérieur, oì elles sont déprimées. Le bord inférjeur, qui est Latillant vers le milieu de sa longuenr, est concare en dedans; il est simple duns toute sa partie supérieure, il est crénelé seulement à son extrénité pastérieure : le bord cardinal ou supérieur est d:oil, assez épais, el ne présente jamais les denlelures qui caractérisent la Moule sillonnée. A l'intérieur, les valves sont d'une nacre d'un hlanc livide, avec des reflets verdâtres vers l'extrémité postérieure; en delıors, elles sont ornées d'un graud nombre de sillons longiludinitux, subrayonmaos, un peu onduleux, el souven bifurqués vers les bords. Sur le cúté aotérieur, ces sillons sont extrêmement fins, et quelquefsis ils manquent cou:-à-fait. L'épidertne qui recourre cette espèce est d'un brun-verdàtre, quelquefois jannâtlee.

Celte coquille, assez rare, provient des mers de l'Amérique septentrionnale, de New-Yorck ou de Philadelphie. Sa lougueur est de 85 millim.

35. MOOLE sillonnée. Mytilus sulcatus.

II. testá oblongi, suttùs elevato-angishíá; sulcis 


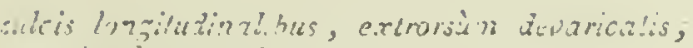
"m "give ligumenit crenaso.

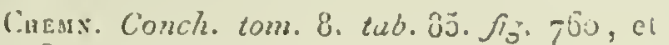
tuu. 34. fig. 754 .

Fisrci.. frl. 220. fig. =.

Mudinlu suícata. I.Axk, Anim. saris werl. toin. $0 . p a g .113 . n^{n} \cdot g$.

Coquille lort reconnoissable par lit diatzison en aile de sun côté snpérjeur; elle est oräle, alongée, obtuse aux deux extúunités, et ayaut le bort untricur extrêmement court et subrostré; le inrd infirieur est sinueux vers le milieu de sa longueur; le cóté supérieur produit, à la junction le l'estrémité du bord cardinal, un angle aign, ssillaat, vers lequel la coyuille est fortement déprimée. Les crocbets sant extrónement petits; i!s stsu! uu per bossus, subcaréaés, et serveat de pint cle deipart, ainsi que la carc̀ne qu'ils formeat, a un grand nombre de sillous longitudinax, rayunains, réguliers, quelquetois bifurqués lans li ur longueur, el aboulissent sur le bord des vires, qu'ils rendent crénelés dars toute leur étendıe. C'es bords suat minces, irauchans, el le carcliasl on supérieur est rematquable sous deux rapports; il est tont-a-fait dreit et de plus finearent crénelé ou plutót dentelé daus toute sa Jüjucur, de sorte quil ne manque pas de ressemblance avec celui des Arohes, les crénelures de rune des valves étant reçues dans les interralles L̀e celles de l'autre. Cette coquille, à l'extérieur, est revétue d'un Épilerue d'un jaune-verditre, an-dessous diuguel on voit bieu distinctemen! des zones liansverses, ou seulement des taches, soit violitires, soit bleuátres. A l'intérieur, on trouve wue nacre irillante, nuancle de ces deux cieraières cuuleurs.

1.a Aloule sillonnéc, assez commune dans les collections, luabite les wer's de l'índe; elle est longue de $j \mathrm{j}$ millim.

54. Modre arborisée. Mytilus pictus.

M. testid cybindmce i, extrorsiun depresso lutescente, tenui, $12 \mathrm{f} i$, maculutá, loneolijfuscis vuriè scripti.

Excres. pl. 221 . fig. 2.

Modiolu picta. J.1 sx. Anint. sans vert. tont. 6. pag. $112 . n^{\circ} .8$.

Cивик. Conch. tab. 198. fig. 2016 et 2017.

Coquille fort curieuse et extrêmemeat rare; elle est très-inince, subpapyracée, cxtrêmement fragile; elle est oblonưue, rétrécie antérieurement, plus large et déprimée à son extrémité postérieure; elle est légèrement arquéc dans sa lonsueur, ce qui se remarque priacipalement dans les grands el vieux individus; son extrémité aniéricure est subrostrée, très-courte; les crochels, qui sont très-petits et à peine saillaus, snnt presque Hist. Nut. des Fers. Tome II. ieroimux. I.a smeruce extéricule est lisse, polic, l.rillante, on y remarcue à peme quelques strics d'accroissement; snn côté antérienr cst d'un jannerougcalre, présentant quelynefois de glandes taclies irrégulières, nuagenses, d'un lauve-roureitre. I,e cuté postriricur est peint d'une manic̀re tres-ćlGgante de longues llammules brunâtres, cuduleuses et dirisécs, qui alsoutissent sur le bord. A l'intéricur, cette espèce est d'un blaac nacré jur, qui ressemble a de l'argent non poli. Lu's tond sont extréuement minces, et le cardinal, qui n'est guère flus tur que les autres, reccit, tans une rignle exlrènement étroite, un liganent subiutéricur : rès-foib!e.

Cette jolic coguille provient, d'après Lamarek, de l'Ocrín allantigye : guelques persunues assurent quelle vit dans les rochers i la maniere des Mudioles liiliodomes. Sa longueur est de 70 mill.

53. Mou ce étui. Mytilus vagina.

M. testâ ohlong $\hat{\imath}$, rectâ, depresso-cylindrace $\hat{a}$, cenul, fingilissini:; striis transwersis, clegantissimis; epiderne costata.

Modicha curenarius. Runpr. Mus. tab. 46. fig.e.

Nodiold vagina. LAмк. Anim. s. vert. tom. 6. pag. $112, n^{\circ}, 7$.

Rare el précicuse coquille gue l'on troure dans les mers d'Ambuine, gui fail le passage entre les Monles de la section des Modioles el celles de la section suvanle des Lilhodomes. Elle vit cependant à la mauière des autres Moules, c'est-à-dire qu'elle ne rreuse pas la pierre ou les argiles durcies. Elle est ovalc-oblongue, obrise à ses cxirćmilés, r'́guliérement convexe et subcylindracée. A l'exlér'’eur, elle est revếlue d'un épiderme unince d'un brun corna, sublecailleux vers le bord inférieur; le côté antérieur est assez laige, bien arrondi, et plus grand en général que dans la plupart des especes de eelte section. Les crochets, qui s'inclinent au-dessus de lui, sont grands, saillaws, subcorditormes; ils sont lisses, randis que le reste de lu surface extéricure est finemeat striée en harcrs; le bord inléricur est un peu concave daus sa l'nguteur, surtout vers son extrémité postérienre; le lord cardinal est tres-mince, trìałongé, et lit gonttìre qui supporte le ligament est trés-alongée et très-étroite. Le test de cette coquille est extrêmeınt mince; il est nacré d l'intéricm, et celle aacre, blanche supérieurement, est pourprée à l'extrémité postérieure. En deloors, la coquille est dua brun-marion foncé, passant au brun-faure sul les crochets, qui, à leur extrémilé, sont quelque fois blanchâtres.

Cette espèce est longue de 70 a 80 millim. L'individu que possc̀de le Muséum a une diurensión plus grande encore.

36. Moure demi-nue. Mytilus semi-nudus. Noв.

11. testâ ovatá, obliquè cordatâ, tenuisimin, $\mathrm{Cccc}$ * 
fragili, tumidi, striis longitidinalinus tenuibus ornats; stris spatio submediuno lavigato separatis; unbonibus minimis, subterninulubus.

Modiole semi-nuda. Nos. Descript. des Coq. foss. des env. de Paris, tom. 1. pag. 264. pl. $3 \mathrm{~g}$. fig. 20. 21.22 .

Si nous étions moins scrupnleux sur les analogies, nous pourrions donuer celle espèce comme sex xblable au Modiola discrepans Lamx., qui vit daos la Méditerranće et dans l'Océna earopéen. On ne peut contester la grande analogie qui existe eotre ces coquilles, mais on conviendra qu'clles uffreat quelques différences, et cela suffit pour que nous les admetlions à litre de subaualogues seulement. Dans la lorme, l'espèce tossile dillère un peu de la vivante : cllc est plus régulièrement orale, les crochets sont un peu plus saillans. Le lord cardiaal est plus saillant à l'intérieur, ce qui, dans la jonction des valves, rend le crochet plus profond. Quant au reste, le nombre et la forme des stries, la proportion entre la surfice qu'elles occupent et la pritie lisse de la coyuille, le nombre de ces stries sur les côtés de la coquille, etc., tout est semblable dans la virable et la fos ile.

Celte petite coquille est très-mince, très-fragile, boubée régulièremeat eo dessus, ayanı le côté antérieur plus graod que dans les espèces précédentes, et dépassant a peiue le crocbet, ce. qui rend la coquille très-inéquilatérale. On remarque, comure daus le Mytilus discors, deuz faisceaux de stries lougitudiniles snr la surface extérieure, un antérieur plus petit, et l'autre postérieur; ils sont síparés par un espace lissc qui comprend à péioe le tiers de la surface : cet espace est strié par quelques accroissemens transverses, quil se contiauent et se voient sur le resto de la coquille. Le sommet est borubé el incliné sur le bord cardinal: celui-ci, à l'endroit où il le touche, est lígèreurent écliancré. Le bord antérieur et le postérieur sont finement crénelés, et leur peu d'épaisseur correspond ì l'extrême ténaite du test.

Nous d'avoos jamais vu sle celte coquille que deux valves, dont l'une a été brisée; cclle qui nous reste est longue de 7 miliim. et large de $4 \mathrm{~J} / 2$. Elle se trouve à La Chapelle, près Senlis.

37. Movre arquée. Mytilus arcuatus. LAmx.

$M$. lestâ elongalâ, subaquilaterî, in medio profundè sinuatá, arcuatâ, bilobatí, lavigatí, tenuissimâ, fragili; umbonibus minimis, recurvis; cardine sineplici.

Mudiola arcuata. Lamz. Ann. du Mus. tom. 9. w. 18. fig. 1. a. $b$.

Modiola ancuata. Nов. Descript. des Coq. foss. Les env. de l'aris, tom. 1. fag. 265. pl. 40. fig. 4. 5. 6.

Nons ayons ea beaucoup de peine à nons déci- der à introduite cetle petite et dizarre coquilic dlans le genre Moule : elle auroil étr mieux peut. ére parmi les Saxicaves, et c'est là dú nous l'auriuns placée, si elle eût montré guelgues tracc: de dents ì la charaière. Cette petite coquille ise ressemble guère aux antres espèces du grenre; elle est alongée, subéquilatérale, le côté antérien: éluut presqu'aussi grand que le postćrieur. Una wrofonde sinuosité sépare les valves en denx lobes intgaux. Il sembleroit qu'étant mulle, cctle croquille a été ployée en deux; elle est toute blanche, non a acrée à l'intéricur; sa surface extérieure est lisse et brillante: on y aperçoit queltyes stries d'accroissenent. Les crochets sont fort petils, submédiaus, el vienneat s'inclines obliquernent sur le borel cardinal, qui est siuple, et ne présente qu'une petite écliancrue nédiane, comme nous l'avons vu daus d'auties moules. M. Defrance observe que celle conjuille aruit probablement une maniere de vivre particuliere; car on la trouve toujours bivalve dans les cuquilles turriculcés. La courbure des valres pourroit sans cuntredit lavoriser l'ascension de cctte coquille le long de la coluarelle, dans une spire cutruite.

Celte petic coquille se trouve à Grignun, it Parnes el à Mouchy, aux eovirons de l'aris; si longueur est de 6 milliw.

38. Mours étruite. Mytılus ungustus. Nов."

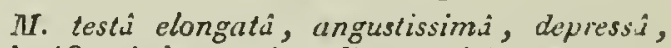
soleniformi, laxngutâ, politâ, cunticè ungustiare; umbonibus subrullis, subtemunalibus ; marymibus integris.

Modiolu angustu. Nов. Descript. des Cong. fisss. des env. de Puris, tom. 1. pag. 266. pl. 41. fig. 6.7.8.

Voici encore une petite coquille qui probablement a'appartient pas an genre Moulc. Cumanc punr la précédente, oous ne voyons pas cependant oì elle pourroit être mieux placée; elle a plus Ifuce lat Noule arguce les caractères dil genre : par sil forwe, elle se rapprodle da Myctus lichophayus; clle est alongée, étroite, aflatie, ayart ses borils supérieur et inférieur parallèles; elle est rrìsinćquilatérale. Sun côté antérieur est très-cuutt, anais il l'est moios en proportion que dans lit piupart des Moules : ce côté antéricur est un peu plass étroit que le postérieur. I.e crochet se contond avec le lurd; il est indiqué sculument, et non saillant. En arant de lui le bord ollie me petite flexion intérienre; mais cela ve ressemlle en aucuue manière à une charnière articulée. Le reste des burds est simple et lisse; la surface extérieure est tout-à fail lisse et polie; l'utúrieure est blanche non nacrée.

Cette petite coquille est assez rare, sans doute ì cause de sa fragilité; elle se trouve aux environs de Paris, à Parnes el à Mouch y. Sa longueur ust de 3 millim. et sa largeur de 9 . 


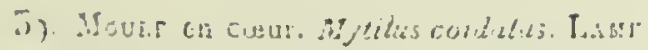

MI. tenticlonguti, cylundraceá, a:cuati, tumidi, Iivtgatis; umboninus inflatis, antici inflexis, cordsils, subspiratis, prominentibus.

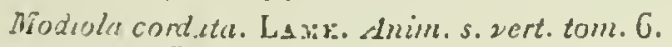
pug. $117 \cdot 11^{6} .3$.

1'iul. Alnn. du Nus. tom. 9. pl. 18. fig. 2.a.b.c.

Inodeola cordata. Non. Descript. des Coq. foss. dine ellv. de l'aris, tom. 1. pug. 268. pl. 3g. fig. 17. 18. 19.

Les pursonues qui connoisseat le Modiola cinnamomea de Lanarcl peuvent se litire un tresboaus adéc de retle espèce; car elle ne paroî ille yue son diminulif. Lumarck a confondu a vec l'espece fussile des environs de $P$ aris une autre voquille, lrouvée par Mesnard de la Gruye aux exvitons du Maus, dans des terrains aociens, et 'jui duit être lotalement séprarce de la première.

I. a Moule en cour est une pelite coquille alonÉfe: lrasverse, courbée médiocrement dans sa f.jnưuer, étroite, cylindracée, obtuse à ses c'xirécrités. Les crorliets, un peu gonflés, sont obliquecont contournés sur le cólé antérieur, qu'i's dépassent ioujouls; ils sunt un peu en spirale : auss:, fuand on voit la coquille par devant, elle a l'aspect d'une petile Isocarde. Le bord antérieur esı fort cnurt, arrondi el limité en dessus par un petit angle très-ohtus. L'extrémité postéricure est un peu plus déprimée que l'antérieure; le bntd supérieur ou cardinal est arqué, convexe en dessus; il est simple, seulement un peu flexueux audessous du c:ochet, à l'eudrait de sa jonction a vec le bord antérieur. I.e bord inférieur est arqué à l'inverse du supérienr; il est convexe en dedans de la coquille. Le-bord postérieur est arrondi; il est plus épais que les autres parties de la circonfï:ence; il reinonte ollliquenent pour joindre l'extrémité du bord supérieur, avec lequel il fait uo angle peu sailiant. Toute la surface extérieure de la corpuille est lisse: quelques individus sont comme ćlagés par des accroissemens. En dedans elle est nacrée, peu brillante; la nacre dont elle est composée n'a de l'éclint que dans les cassures. C'est en cassant les grosses coquilles du calcaile grossier, et surtaut les tronçnns du Céritc gúant, que l'on trouve celle coquille très-l'ragile, dans les localités de l'arıes, Grignon et Courtagnou; elle a 8 millim. de long et 15 de large.

40. Muve argentine. Mytilus argentinus. Noв.

MI. testá elongatâ, cylindraceâ, angustá, tenuissimá, frugili, margartaceâ, lavigatâ, arcuati; umbonibus recurvis, cordatis, pritninulis.

Modiala argentina. Nов. Descript. des Coq. foss. des env. de Parts, tom. I. pag. 269. pl. 42. fig. 1. 2. 3 .

Ibici. Mém. sur les foss. de Falmondois.

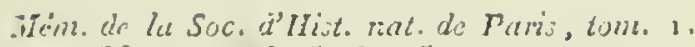

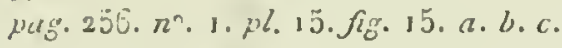

Nous ponvons assurer que l'analogic entre les inclividus du bassin de Paris el cenx de Dax cst aussi complète que peuvent le desirer les persomes les plus scrupuleuses; l'identice est si parfaice, qu'il devicadroit impossible de distiaguer les individus des deux localices si on venoic à les millanger dans une même boile.

P'cut-ćtre avons-nous eu tort de stparer cetlc espice de lit précédente: elle a avec elle tant d'unalogic, fue l'on pourroil la regarder commc une lorte variété. Nous l'avons maintenue comarc espèce, palice que nous ne connoissons encorc aucun intermediaire eatre ces coquilles.

La Moule argentine dillere de l'espèce cqui précède, en ce qu'elle est toujours proportinnnellement plus lungue et plus étroite, sensiblement plus courbie; son test est taujours heaucoup plus fragile; son extrúmilć postérieure cst plus alténuće, moins armondic, et le bord qui la terminc n'est point spaissi. I,es crocliets sont plus saillans; le coilé antéricur est plas court et plus incliné inférieureneul; entin, le bord cardinal est gćnéralcment plus saillant au-dessus de la cavité iulerne des valves.

Ces cntactères qui, pris isolément, a'auroient qu'une foible importance, en prennent davanlago par leur cnsemble, ct leur valeur totale ne pou:ra élle détruite quautant que l'on trouvera des intermédiaires qui auront à la fois des caractères de l'une et l'autre espèce.

La Noule argentine semble formée d'une feuillc d'argcnt polie et brillante à l'intérieur, et conscrvéc au mat à l'extérieur. Ou la trouve à Valmondois, particulic̀rement dans les galets de calcaire d'eau douce. Elle n'est pas très-rare, mais elle le devient extrêmement dans nos collections par la dıfficulté de l'extrairc enlière des pierres oi elle vécut autrefois. On la troure également à Dax; sa longueur est de 7 millitr. et sa largeur de 18 . LAMB.

4i. Moune lithophage. Nytilus lithophogusa

M. testâ elongatâ, cylindraceâ, rectî̀, anticè tumidione; extremitatibus oblusis; striis longitudinalibus postice brevibus; striis transversis irregularibus, decussatis.

Modiola lithophaga. LAмx. Anim. sans vert. tom. 6. pag. $115 . n^{\circ} \cdot 22$.

Mytilus lithophagus. Lis. Gure. pag. 355 เ. n०.6.

Ruмpa. Mus. amb. tab. 46. fig. F.

Listen, Conch. tab. 427. fig. 268.

Dargenv. Conch. tab. 26. fig. K.

Gualt. Test. tab. 9o.fig. D.

Favanne, Conch. $2 a b$. 5.fig. H?

Cecc 2 * 
Petrv. Amb. lab. In. fig. i5.

Tors, Mhus. Cues. vind. tab. 7. fig. 4.

Cuem.x. Conch. tom. 3. tab. 32.fig. 729. 7 Jo.

ExicycL. pl. 22.fig. 5. a.b.

Lithodomus. Covier, Règ. anim. tom. 2. pag. $47 \%$.

DE Braisv. MIalacol. pag. 532, fl. 64. fig. 4 .

Modiola lithophuga. Noв. Descript. des Coy. fuss. des env. de Paris, tom. 1. pag. 267. pl. 58. lig. 10. 11.12.

Aucun des auteurs que nous venons de citer dans notre synonymie ne mentiunne celle coyuille à l'éra fossile. Brocehi est le seul qui en firle, et encore n'est-ce qu'avec daute, puisyu'il ue connut que le monle d'une coquilla qu'il rapporta à l'espèce qui nous occupe.

Nous avons long-lemps douté que la coquille fossile que nous avons découverte aux environs de Paris fût l'analogue de celle qui se trouve ahondamment dans presque toute la Méditcrrauée, l’Océan indien, eu Amérique, etc., jusyn'au momeat où nous avons pu la comparer avec des individus vivans, dépouillés de leur épiderme. C'est alor's seulemeat que nous nous somraes assuré de l'identité parfaite qui existe entr'eux.

Ta Moule lilhophage est une coquille alongée, très-étroite, cyliadracée, à crochets presque lermioaux; elle est plus alténuée et plus déprimće du côté postérieur que de l'antérieur. Le cáté antúrieur est obtus, très-court, dépassant à peine Je crochet. Le bord iuférieur est alongé et presque parallèle au côté supérieur, qui se relève un peu ver's le milien de sa longueur. Les crocliets sont petits, pen saillans, contournés à côté du bord, et non rétléchis au-dessus. Le bord cardinal est lègérement infléchi an-dessus de la cavilé de la valve; il est simple, droir, er la rainure du ligament est très-étroile. La surfuce extérieare, par la disposition des stries, se divise en deux parties, l'une antérieure el inférieure, yni est courerte de slites longitudioales; l'anlue supérieure el postérienre, qui est lisse, on quir du moins n'offie que des stries transverses d'accroissement. Les stries longitudinalıs antórienres ascupeut tou:e la longueur de la coguille; mais elles diminuent graduellement en suivant la diagonale qui couperoit également la coquille en Jeux. Ces stries sont scrires et nombreuses, snnvent bilurquées, yuelquefuis onduleuses ou oblliques, ou rendue's subgranuleuses par !'interruption que leur fout les accroissemens.

On trouve celle coquille vivante slans la Ilćdirerranée, l'Océan indien, Amboine, les iles Philippines, etc.; el linsile en Italie, à Bordeaux et aux environs de Palis, à l'arnes, vi nous n'eu connoissons jusçưi présent qu'un seul individu, daris un fragment du Certhium gigunteum. Sa loggueur est de a millim...et sa lingeur de 3-f.
42. Nuvle papyracée. My tilus papy raceus. No

31. testà ovato-transwersâ, oblupuissina, rnntuces oblusi, postice attenuati, supernè ungrilats, inflat $\dot{a}$, convexâ, lievigati, tenuissim i, frugl lsssimi; umbonibus minims, inflatis, prom:nenubus.

Mrodiola papyracea. Noв. Descript. des C'oy. foss. des env. de Paris, tom. 1. pag. 270. $\mu l .41$. jig. 9. 10. 11 .

Ibid. Mém. sur les Fossiles de Falmonderis. MIém. de la Soc. d'Hist. nat. de Paris, tom. 1. pag. $257 \cdot n^{\circ}$. 2. pl. 15. fig. 16. a. b.

Celte espèce est perforante comine les juécídenles; elle lient un peu par se's caractires iat Mytilus lithophagus, mais plus encore aux deux espèces gui précèdent. Elle est vrale-olılongue, transverse, oblique, subcylindrucée, un peu attónuée à ses extrémités; elle est très-gon!lée, très-convexe, extrémement mince, et par suite d'une fragilité excessive; elle est plus étroite à ses extrémités qu'à sa partie moyenne; l'extréruilé postérieure surtout est la plus altímuce. Je còté antcrieur es: for: court, il est obtus el dominé par un pelit crochet per gonflé et contonruć en avant Irès-obliqueuseut. Ce crnchet !ait pen de saillie en dehors du bord cardinal : ce bord est peu arqué; il s'incline obliquement sur l'axe transverse de la coquille, ce qui read saillante son extrérnité postérieure, qui forme un ande par sa jonction avec l'extrénilé du bord pusicerieur. Le bord inférienr est presque druil, ou légéremeut courbé en dehors. La surficte interne est tout-î-fait lisse. Sur l'extéiteur un voit d's stries d'actroissement irrégulières.

Nous aviuns d'abord trouvé un seul individu te celle espèce; depuis, nous en arons recueilli de besucoup plus glands, contenus dans un prlypier lossile de Valmondois. Nous n'urons pu en conserver que quelques valves entières; la plus grande est langue de 17 aillim.

\section{Mocle caudigère. Mytilus candigerus.}

11. test: ohlongâ, cylmdruces, lenu, mtis

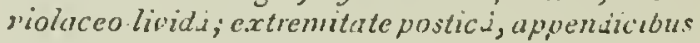
anjustatis subcauduti.

Excres. pl. 221. fig. 8. u. b.

Modiolu caudigeria. Losk. Anim. sans de'rt. tom. 7. pag. $116 . n^{n} \cdot 23$.

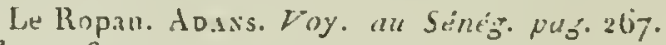
pl. 19. fig. 2.

On avoit long-temps conservé du doute sur la corjuille nommée Ropan par Adanson; on ne suvoit si elle devcit faire partie des 'Jarets, quoique l'auteur dise, d'une manière positive, guielle n'apparlient pas it ce genre; ou bien enter parmi les lholades, surrant loprinion de Buse; ou ćtre placée au nombre des Gastro- 
ribnes on Fistulanes, suivant calle de $M$. de lislainville. Cette dernière opinion nus paroissuil préférable; wais aucune de celles gue nous vód:ons de rapporter ne uous semblnit pnuvoir êlre almise qu'après de nouveaux renseignemens sur la enquille qui y a donné lieu. Ne possédant pis la Modiole caudigère lorsque nous écrivines l'arlicle Ropax du Dictionnaine classique d'Histoire nulurelle, il nous fut impossible de reconnoilre suu identicé avece la descriplion d'Adanson. Cette lescription, quoiqu'incomplète, est cepenclant issez precise, yuand on a l'objel sous les yeux, hour éviter lonte espìce de méprise. M. Kurng, a $u$ recour d'un voyage au Súnéga!, a alppris d'une vanière prsilive gue le Ropan u'est autro closs que le Mytulus comdigens.

I,a Modiole caudig̨ère est unc coquille alongée, cylindroide, obluse antérieureasent et terminée du cité postérieur par deux appendices assez proInngrís, gni se croisent lorsque les valves sont lumces. I,es cruchers sont si courls, cu'à peine sits lunt saillic au-dessus du bord : ils sunt preşue terminaux. Le còté antérieur cst arrondi, olstus : et les deax côtís, Minférienr el le supérieur, soni parallèles. Le bord carlinal est extrêmenent :roil; il est court, cl présente une goullic̀re trèsCirvile pour le lızament. L'exirćmité pastérienre u:st allínuée el lerniuéc, comme nous l’avons dil, liar un appendice, en forme de bec, inféricur sur la valve droile el supéricur sur la ganclic. De celie dispositien résulle le roisement des deux appendices, lorsciue la corprille cst complétement termée. Ia surface exlćrieure est enlièrement lisse, d'un blanc-grisàte, et dépourve d'épiderne. I l'intéricur, elle est d'un blanc-subnacré.

Celle pelite coquille, assez rare dans les collections, vil, à la manicie des autres Lilliodomes, en s'enfonçant dans les rochers caliarts, dans les polypiers piemeux el même dans les "rroupes de Bulares. Ce qui a pu contribuer à conserver du dowle à son égard, c'est qu'elle a la faculté de s'envelopper, cumme les Fistulanes, d'un lube calcaire, incrusté à l'intérieur du trou quieile balive.

Cetle espèce, avec nne autre que nous avous découverle dans les polypiers picrrenx des ouers de l'Inde, son! les seules, jusq̨u'a préscut, connues gui se coastruiseut uo tube adlárent. Longucur 25 à 50 mill.

\section{MOUI.E. Wy:ilus.}

Confondant, comme liané, les Moules, les Modicles el les Ancdnuies, M. Schuinacher, dans son Essui de Conchyliologie, n'a pus tenu comple des amćliomations faites par Bruguiere el par lamarck dans ce gemre, el y a laissé une coufusion inadonissible aujurdhui. Foyez Mlovi.e.

\section{MOUI.E FLLVISTLE.}

Un nombe vulgairezen de celle wanicie les coquilles des genres Linio et Anodonte, que lion trouve abondamment dans presque toutes les caux douces. Voyez Hunetre.

\section{MOURET.}

Adauson, dans son Voyagse au Sénegal, p!. . . a donné ce nom à une coquille que les autrurs ont placie dans les lalelles, mais qui apnarlient lien plu:ôt au grearc Siphonaire, nouvellement crós par Sowcrlyy. Vojez ce mor.

\section{MOUSSOLE.}

Tel est lc nom qu'Adinnson a inuuć, daris le Topage au Sénégul (pugr. 250, $\%$ l. 18 ), i une copuille bivalve nnmmée Arche de Noć par les aulcurs. Voyez Arine.

\section{MOVIN.}

On ne sanroit donter, d'après la descriplion d 1 danson (Toyage au Sënegal, pag. $246, \mu 1 \%$ \&) . que la coquille qu'il nomme Mlovin n'appartiot an zenre Bucarde; mais les auleurs modertes ne l'ont pas mentionnée daus leurs caltilognes.

\section{MULETTE. Unio.}

Abondammeat répandues dans ros riviires, les Molenes farent connues par les Anciuns. Rondelel, dans son Histoire des Puissons, les désigna sons le nom de Mloules dean douce, ponk les séparer des Monles de mer; mais 11 paroit coufondre, sous le nom de Monles d'eau donce, et les Anodnutes et les Muletros. Isister en figura un assez graad nombre; Gualicri eu représeuta quelques-unes. Lisler sćpara, comne Rondelel, les Moules d'eau douce des marincs, mais confondil comme lui les deux genres. L'eutére devroiton attribuer à Klein leur sépiltation; mais, si l'on considere que le gun:e Matidilus' de cet autenr conlient itussi-bien des Auodontes que des Muleltes, on devia restilucr à Briguière le márile de les avoir nellemenl síparés dans les planches de l'lincycloprídie; car linniá parlagrea les cognilles des Mulelles et des Aurndontes pitrtie entre les Moules el parlie tutue: les Myes. Qunique Bruguière cûl séparé ros deux genres, Poli les réuni: de nouveau scus te noun de Lymnara. D'après les caraclives de l'orginisalion, il nexiste en eller ancume différence entre l'animal des Anodontes et cellii des Mulclles, comme nous le verrons loul it l'heare. Cetle opinion de Poli, appuye cependint sur l'aualonic, n'a pas prévalu. leituarck a adopulé les deux grenres de Bruguicre. II les plara d'abord dans le Systeme des Amimam suns vertibres, $18 n 1$, entrc les Modiules et les Moules, n'ityant. puint cncore établi la séparation des Mlonnmyaires des Dimyaires. M. de Roissy, dans le Buffon de Sommme, n'imia point lamelrek : 1cu: en conscrvaul les ilcux gures, il dii güls 
nun: élé séparés que d’après les coquilles, et il les place non loin des Perues, Crénalules et autres genies analogues. Daus la Phlosophie zoologique, la fanille des Nayades fut créée pour. les deux geares Mulette et Anodonte, et elle fut placíe entre les Camacées et les Arcacées, rap. ports qui furent conservés les mêmes dans l'Extrait du Cours. H. Cuvier (Règne arimal) les plaça plus convenablement à la suile des Moules, daus les Acéphalés à deux muscles. Mais ce qui étonne, c'est que MI. Cuvier ait adopté les deux geures á titre de genre, quoique ce savant zoologiste reconnút la similitude des auimaux de l'un et de l'autre. Lamarck, dans son dernier ouvrage, a démembré des Anodontes le genre lridine, qui est venu auymenter la famille des Nayades, placée toujours dans les mêrnes rapports. 'Tous les auteurs qui ont suivi Lamarck l'ont blâué d'avoir créé ce geure Iridine sur des caractères en apparence de peu de valeur; mais ces personnes ètoient loin de peuser que, sons plusieurs rapports. l'animal des Iridiues dilléroit entièrement de celui des Mulettes, comme nous l'avons fait voir dans notre Mlémoire andtomique sur les lridines. Ralinesque, dans le tome 5 des Annales de Sciences de Bruxelles, a adopté le nom de MIulette pour les espèces qui paroisseut appartenir à ce genre, el qu'il a trouvées daus l'Ohio. Ces espéces, très-nombreuses, ont été clivisées par lui en plusienrs gemes et sous-genres; cגr l'auteur ciont nous parlons a fait une lamille des MIulettes : il lui a doná le nou de Pédifèr's. (Voir ce mol.) Le genre Muletle devient le premier de cetle nouvelle famille; mais si l'on considère que l'auteur a poussé beaucoup trop loin le desir d'établir de nuuveaux genres, ya'il les a fondés sul des caractères de peu d'inportance, on sera forcé de rapporter non seulement le genre Mulette de Ratinesque, mais eacore la famille tout entière au gemre Mulette des anteurs. Si les figures qui accompannent le Mlémcire de Ralinesque avaient élé bonnes, on aliroit pu sans doule juger des différences organiques qni existent entre les animanx des Muleltrs de l'Ohio et celles de l'Europe; mais elles sont tellement mauvaises, đqu'on est obligé de s'ea rapporter uniquement a la description. D'aprés celte description, elles different assez notablement des Mnlelles de l'Europe, et on peut en juger par la propre plirase de Rafinesque, que nous rapportous textuellement: "Corps blanc ou un peu in" carnal; manteau nince, lisse, tapissant les " valves, bilobé et échancré postérieurement, * sans franges; second manteau intérieur bran" chial, strié obliqquement, mince, bilobé postén rieurement, beaucoup moindre que l'extérieur, » et enveloppant le pied; pied comprimé, musw culeux, coriace, oblong, dilatable; bouche " antérieure; anus postérieur, à l'extrémité du "ligament; siphons antérienrs latéraux égaux, x: un de chaque cólé derrière la bouche, en íornce
" de taberculc peifóré, ct encure plas en arrière, n Éyalemeut de chaque cóte, un appendice bulaD urellaire, obtus, à lames inégales, plates, " ovales on oblongues, l'intérieurc plus grande.

* Ce sont apparemmeut les organes de la gúné"ralion."

Ratisesque ajoule: "D'après cette description » exacte, el ulue j'ai vérifiće sur plus de vingt - espèces et trois cents indivicus, un verra qu'sl y - a une dillérence nolable eatre les Mollusques tt "ceux des Unıo européens, tels yưils sont décitis * par les auteurs, el notamment par MI. de Fl"russac (Essuid'une Méthode conchyliologique), " qui se pique d'une scrupuleuse exactitude dans " l'́nonciation des caractères de Mollusques flu* viatiles. \# Celte description de Rafiucsque, que l'on peut croire exacte, puisqu'il dit l'avoir tuile d'après l'examen de plus de vingt espécts et sur plus de trois cents individus, nous fait voir que les Mnlettes de l'Ohio ont un mantean seinblable à velui des nóres, si ce n'est qu"il n'est pas frangé postérieurement. Les branchies paroissent peu dilléıer aussi: cependant elírs semblent un pea plus autéricues, et plus crveloppant le pied; ce pied cost très-seusblable a celui de nos espèces. La bouche et l'anus sont situés de mene; mais pour ce qui segarde les siphons placts de chaque côté derrière la bousile, eo forme de tubercule pertoré, nous jgaorons 10talement à quoi rapporter ces organes qui ne sont point de véritables siphous, lels que duus les enlendons ordiuairement. Il n'y a rien dans nos Mulettes qui puisse nous douner à cel égard la moindre analogie. Quaut aux appendices bilamellaires que Ralinesque prend pnur les organes de la génération, nous ne pouvons douter que ce. ue soient siuplement tles palpes labianx. Niuus verrons bieniôt que de fausies dénominations ont donué lieu à ces incertiludes de Rafinesque et aux erreurs qui en sont la suite; malgrci cela, oous adinellrons loujours les genres e! sous-genres des Mluletles de cet auteur, et lis presque totalitéde sa famille des Pédilëres, dans le genre Mulette. M1. de Ferussac, davs ses Tableaux sjstématiques des animaux moliusques, a opéré celle réunson; ce que bowerlyy a tait, après lui, dans le Zoological journal. Ces denx auteurs ont admis, is titre de sous-genres, plusieurs des genres de Ralinesque, et ontcherché ú élablir une chaine non interrompue depuis les Nulettes jusqu'iux Anodontes: le prenier, conservant cependant les Anoduntes et les Mulelles a titre de genre, ce qui n'est point rationuel. M. de Blaiaville ('Truité de Malacologie, page 539 ), sous le nom de Submytrlacécs, réunit daus uue même famille les Anodontes et les Mulettes avec les Cardites; il adaet aussi, comme Bi. de Ferussac, les deax gremres ae Bruguière; il dit cependant, dans la cintactéristique du genre Mulette: "Animal en"lierement semblahle i celui des Anedontes. 
11. de Blainville, après avoir établi sa classificaliou d'après les aniuaux, abandonte pour ce fonre un principe qqu’il étoit plus nécessaire que pirtout aillears tie meltre rn pratique. Les ciaractères de ce gentre sont les suivius :

\section{CARACTERES GEXEHIQUES.}

Auimal plus ou moins ovale, plus ou moius ipais; le manteau is bords libres el épais, le plus suuveut sinples, quelquelois ciliés, ouvert dans toute son élenduc, sans forner une ouverture prarticulière pour l'anus, celte ouverture de l'anus ítant uniquement produite par l'adlsérece de la base des feuilles Lrancliaux au tnantean, el nullement par les lobes du manleau entre cux. La partie postérieme de t:cs lobes épaissis, tiangés el imitant le siphon branchial des Mollusugues siphonifères.

Coquille transverse, équivalve, inéquilatérale, libre, à croulhets écorchés, presque ronges; quatre impressions musculaires, deux grandies pour les muscles adducteur's, deux perites ì côté des yrandes pour les muscles rélacleurs du pied. Charnière varialle, tantót à deux dents sur chaque valve, l'une cardinale, couste, irrégulière, simple ou divisce en deux, substriće; l'autre ulongrée, conprinée, latćrale, se prolungeant surrs le corselet; quelquefois une scule deut cardinale anlírieure, tuatôt une seule dent prostéricure; quęlquelois entin aucures dear ì la charnière. jigauent extéricur.

Nuns ferons olsserver que, d'après notre opinion, M. Lalreille, lians ses Fumilles naturelles, a eu tort de placer les Mulelles daus la lamille des Uanteaux hiforés; car il n'existe, en cffel, qu'uae seule ouverture continue, depuis lo muscle adductcur' ansérieur jusqu'a l'anus, c'est-à-dire justgue sur le dus de l'animal. On a comparé la cavité uù se décliarge l'auns, dans les Muletles, au siphon aval des Moules; mais il y a une gräade dittérence : les Mloules offrent une vćrilable: cammissure, unc entière réunion des deux lobes, ce rui sépare tetlement le siplon anal de la prande ouverture pallíale; mais, dans les Nluletres, celle commissure, celle réunion des deux lobes n'a pas lieu : l'espéce de cavilé en cul-de-sac dans lacuelle abontit l'anus étaniformće parl'adhésion de la base des hrunchics au manteau, et nullement prar la réunion de ses denx lobes, circunsiance d'organivali: n quili faut bien distinguer; car elle tendruit à fance rapprocber les Mulenics des Arubes et a les mellic avant les Moules, en raisonuant d’après le système de M. Cuvier.

11 est fort difficile de distinguer entre elles les espoces de Hulettes: les transitions presque inseusibles par lesquelles on passe de l'una à l'autre teroient presque croire à une espèce unique, variant a linlini selon les cliarats et les localités. Un passage pareil existe entre les .lulelles et les
Anodentes, par des nuances inseasibles, depuis les Mulettes qui ont la coquille la plas épaisse et la charnicre la mieux prononcée, jusqu'à celles equi deviennent ninces et qui ollrent it peine quelyues traces rudimentaires de la charvière; et l'on arrive aux Anodontes, qui n'en ont plus du tout. L'identitc de l'aumal des deux grenres devoit faire prévoir ce résultal; résultat dont nous prarrions trouver d'autres exemples dans des familles de la unçme classe.

Toutes lus Mulettes sont nactées à l'intérienr, le plus souvent d'une nacre argentine; quelquetiois cette nacre a !es conleurs les plus belles el les plus Irillantes, en pourpre ou en rose plus on moins foncé; quelquefois, d'unc teinte brunâtre et cuivreuse. Eu dehors, elles sont revêlucs d'un épiderme brun-noirâtre, jresque toujours écorché sur les crochets, où la coqnille est ellc-même plus ou moins profondément cariéc. On pourroil diviser les Muleltes en plusieurs groupes, d'après divers caractères; mais il faut pour cela en avoir sous les yeux nn rrès-grand nombre de divers pays; ce qu'al ust fort difficile de rassembler dans nos collections.

Une discussion iuléressante s'est élevée, il y a quelque lenıs, au snjel de la génération des Muleltes. MM. Prévôt et Dumas ont tenté ure suite d'expériences dont le résultat se trouveroit en contradiction avec tout ce qu'on avoit cru jusqu'alors sur la génération de ces animaux. Aiusi, selon eux, il y auroit des individus mâles et des individus fenelles, quoique jusqu'i prísent les moyens d'observations analomiques aient été insuflisans pour déconvrir ces organes. Leurs expériences consisten! à avoir placé isoléı $\in$ at des individus femelles, et avoir empêché par cet isolement la fúcondation des ouls. Les individus mâles ne produisirent rien, ut la fécondalion ne put avoir lieu que lorsqu'ils fureut placeis dans les mémes vases que les individus lemelles. Cetle expérience, toute condusante qua elle paroisse, et quoique faite par des hommes liabituśs à de minuticuses observations, pourroit étre admisce sans dilficulté, si les auteurs, i la suite, avoient donné des délails anatomigues convenables sur les organes asâle et léeuelle des Muleltes; mais loin de là, car ils lurent obligés de convenir qu'ils n'apercevoient d'autrcs dillérences entre les individus nounmés par eux mâle’s et femelles, que colle résultant des développemens de l'ovaire cl de ses annexes. D'un autre cólé, uas habite antlomiste, Ml. de Blainville, a chercbé, au sujet de ces expériences, les oryanes de la génération, et il u’a non plus rien trouvé. Il faut donct iltendre, sur cette question importanle, de nou. vellcs expériences et de nouveaux faits qui puissent la dicider.

Un anatomistc anglais, M. Jacobson, et quelques autres observateurs après lui, ont piétendu qu'il existoit dans les branchies des NIrletles nae très-pclite corjuille, quils reyardèreat comanc pia- 
1:sile. et suils dúvivirent comme tclle dans les duces ciéla Socrété hunéenne de Londres.

M. de Blainville ne pallagea eu aucune facon l'opinion du suvant anglais; il ne vil, avec juste raison, dass ces soi-disant parasiles que les oufs éclos dans l'ovaire des Muleutes elles-mèmes. Il n'est pas très-liare de voir des Mollu:q ies dunt les auls éclosent aiusi duns liutéricur de l'organe qui les produrt. On putirroit ciler, chez les Vivipares, les r'aludines et les Partules.

Louservaliuu de M. Jacobson rentre donc, sous ce rapport, daas un ordice de laits doot on n'a pu, depuis long-teups, apprécier l'importance zooloğígke. Il n’est pus plus étunnant de voir ces Bollusques ovipares être accidentellemeat vivipares, yue beaucoup d'autres animaux daus lesquels ce púfnowène se remarque.

Les aniusux des Bulettes sont actuellement bien conaus dans leurs diverses parlies, depuis les Jelles anatomies laites par Poli, dans son griand ouvrage des Testacés des Deux-Siciles. Comparables, sous quelques rapports, avec ceux des iboules at des Cardites, its en sont cependant assez dillérens pour en être, ce nous semble, plus fortement séparés gưils ne le sont dans lá plupart des méthodes. Pour laire apprérier cotie diflérence, nutas donnerons quelques dérails sur l'analomie des MIuletles, et nous lís comparerous à ce qui existe dans les Cardites.

Dans notre Mémoire sur l'Jridine, ainsi yu'à l'article IrIdate de ce Dictionnaire, nous avous réfuié quelques-unes des assertions de M. Rainaesque, qui, dans son Mémoire sur les Coquilles de l'Olio, présente quelques détails sur les aniunaux qui produisent les singulières coyuilles babiant les lleuves de l'Amérigue seprentrionale. Celle rétutation, qui étcit fondée seulemeut sur des prísonptions, est aujonrd'Lui justifiéc; car nous avous pu nous assurer de visu que les animaux étoient idintiquement les mèmes que ceux qui peuplent nos rivières. Cette similitude vient confirmer la justesse de l'opiuion des zoologistes qui pensent gu'il est impossible de rien clérnembrer dans le grand genre des MuJettes, et que toutes les modificatious de liume que l'on y remarçue, ne doiveat entrer que comme élémens tres-secondaires dans la limitation des genres et aême des sous-genres des gruupes d'espèces.

$\checkmark$ a description yue nous allons donner de lorgauisation des Bulettes peut s'appliquer aussibieu aux Anodontes qu’à lous les autres genres et suus-genres qui ont ćté réceuament proposés dans le genre Mulette par quelyues auteurs.

Les animax conteuus dans les copuilles du genre Muletre sont diversitormes, c'est-à-dire que la furme de leur corps correspood exactement i celle de lintétieur des coquilles : nous dississ de l'incíliciur des coquilles, parce que quel- ques-uzes d'elles ont le test tellement épais, cu'il $n^{2} v$ a plus ou presque plas de rapports eatre lat lor we extérieure et celle de l'intérieur des valves. Ces animaux sont en général ovales-oljlongs, quelquelois arrondis ou subcordilornes; ils se cumposent, conme lous les auimaux acépliales, d'un raateau membracexx, épaissi sur les Lords el dont les lobes suat désuais dars toute leur cifcunlérence; tes loles sonl égrax, symétriques, tuajours déponrvus de siphons postélieurs, arais seulemeat épaissis et liangés dins celle partic où les siphous existent ordinairement. Le pied est assez unince, un peu en forme de hacbe; il se prulonge très-peu du côté postérieur; il est pourvu, de ce même côté, d’un petit muscle rétracteur, qui s’insère sur la cogulle, inmćdiatement au-dessns de la graule impression musculare postérieure. Lor'sque l'on reaversc les lobes du ranteau en arlière, on aperçoil, eutre la partie supérieure du pied et inmédialement au-dessous du muscle adducteur a. lérieur, une petite ouverture transverse, oralaire, yarue en dessus et ea dessous d'une petile levre churnue; c'est l'ouverture de la boucice : les livves se contiuucal de chưgue côlé à une paire de palpes mollisses, ovalaires, libres dans une parlie de leur ćtcudue, adletrentes au unanteau par leur. Lord supérieur; la palpe externe, un peu plus grande que l'autre, est la contination de la levre supúrieure; les palpes 'sont finemeat linmelleuses sur celles de leurs surfaces qui se touchent. La petite ouverture bucale dunt nous avons parlé conduit dans un estomac pyriformt. cunplétement enveloppé pa: le fuie, qui y verse, par cies cryptes noonbreuses, les produits desa sé. crélion. Une plus grande ouverture que celles des riryptes, siluée à la parties iul'śricure et supétieure de l'estomac, conduit à l'intestin; celte ouvertuc est celle du pylore. L’intestin, d'abord légerement rentlé à sa surite de l'estomac, devient plus gréle et reste eylindrique dans tont le reste de son éteudue. Il iait truis inllexions dans l'épaisseur du luie, et vient se porter cusuite dans la ligne nuédiane et dorsale, passe à travers le cour et se teraiue par un anus silué daus un solte de caual formé par la réunion de l'extrémité inléricure des brauchies. l.e foie, qui est assez volumineux, occupe toule la cavité des crocbets des valves, et il est accompagné diun petit orgine rougeatre doat l'usage nest point encore connu. Le foie, l'estomac el l'intestin constituent la principale partie de lit masse viscérale, et ils son compris a la base du pied daus un dédoublement charnu de cet orgaue.

Les branchies sont composées de deux feuilleis inégaux de claqgue côté du corps, le fevilitet externe est plus court que l'interne; ils sont demicirculaires par leur bord libre; supérieurement ils se soudent sur les parties latérales du pied, et au-dessous de cet organe la paire brabchiale d'uu 
Evié se riunit a celle de l'alulre. Ces feliil!c!s hranchianx sout linement strićs con trarera; chacune des stries repl:tiscule des vaiseaux transverses d'unc exllếne rérularití. Ces vaissseaux sout de deux ordies: les uns proviennent de la circulation ácuélule, ce sont les artères brauchialcs; los idutres se dirigent vers le cour, ce sont les veines du miène noun. I,e raur est situé à la parlie médiune et dorsale de l'auianal. Lorsque l'on a suivi la directiou de l'intestin jusquáa rectum, on monve vers son inilieu un pelr: reullement liusifirme qui l'eubrasse dans tout son pourtour, et ce renllemeut est le cour. Cel organe, formc d'un ventricule oblong et fusiforme, est libreux, quoique ussez mince, et il donne naissance, de cliaque cóte, a une grande oreilletle membraneuse et tresmirce, qui recrit immédiatearent les veines branchisles et tratusmet le sang au cour par un étranzlemeut assez considérable, à l'entré duquel on ne trouve aucune vilvule. Le caur done uaissance antérieuremeut à un vaisseau aorlique considérable, qui, Jjentôt après sa sortie, produit une petile brunclue qui se jelte dans l'ovaire et la base du pied. Le trouc principal remonte duns la ligue médiane et dorsale, fournit de nombreux rameaux au foic et à la masse viscérale, ct se pallage enfiu, atu-dessus de l'ouverture bucale, en plusicurs branches principales, qui sc distribuent au manteau el principalement a ses bords charaus. Sur la surlice du aıanteau existe ın réseaı visculaire, résulıant de la division des troncs dont nous venons de parler, et qui, se dirigeant vers sa parlie postérieure, vont se jeter dans une grande veine brauchiale, siluce à la base des brancliies.

Tout ce que l'on connoit des organes de la sínèration consiste en un ovaire assez considéiable. compris dans la masse viscérale et reafermé spécialement à la basc du pied vers son extrémité posterieure. Cet orgaue est pourvu l'un orifice extéricur, situé entre les deux feuillets brancliaux du cótć droil, vers le quart supéricur de leur lougueur. Cet organe communique aussi directement avec. les branchics, car, à l'iustant de la ponte, les oufs s'accumulent eutre les deux meubranes dont chaque feuillet est formé, et ce n'est qu'après leur sćjonr plus ou moins prolongé dans celle partie qu'ils sont rejetés au-dehors. Nous avous vu précédemment que les observations de WJ. Prevost, de Genève, tendoient à faire croire que les Mulettes étoient pourvues des deux sexes séparés, comroe cela a lieu dans les Mollusyues dont l'organisation est la plus avancée. Les recluerclues anatomiques que l'on a pu faire jusqu'alors, pour rendre évidentes les observalions cle ce naturaliste, ont élé sans succès, et il seroit a desirer que des analomistes habiles s'emparassent de ce poiat de controverse et le missent enfin burs de doute.

I.e système nerveux des Muletles est encore Hist. Nut. des Vers. To:ne II. pen connu; ce que nous en avous vu a la pli:s grande analigie avec celui des auties Laucllibran. lies jóguliers. A l'arlicle Mlacrue, nous a vons donné quelques détails sur le sy'stène nervenx de ce genre, et dans sa distribution grenćrale, celui du geme qui nous occupe y a leanc up de rapports; cependart le canglion postérieur, quirísulte de la rúunion des deux g:andes branches latérales, fournit un bien plus urand nentre de branibes quie dims les Macires, et mème les Monles. Les brunclues sont an monble de qua:re principales, les postérieures se distribuen: autour de l'aums, ct elles donnent naissance à deux filels assez considérables, qui se jettent dans la parlie postédieurc du maleur, celle qui esı la plus épaisse et tonjours garnie de papilles. Les autres branches du gangliou postérieur se réprandent, les moyeunes dans les branchies, et les antérieures paroissent remunter vers l'anus et le cour.

Si nous couparons cetle organisation avec celle des Cardites, nous trouverons des différences assez considérables pour que ces gentes ne snient pas à l'aveuir autant rapprochés quon le fait acluellemeat. Dans les Cardites, le manteau a une disposilion analogue à celui des Mulettes, mais les branchies sont beaucoup moins postérieures, et eaderassent le pied dans toute sa base. Celui-ci est genéralement plus ótrnit que dans les Mulettes, et forsque l'aninal marclie, il se prolonge beaucoup pius en arrière. Louverlure bucale a une furme Lien dilléiente de relle des Muletles, elle est arrondie, el garnie latéralenent d'un grand nombre de palpes dispastes en deux paquels latéraux. L'osuphaze est très-long, taudis que dans les Mulettes il est tellement court que l'on peut dire que la bouche est immédiatement l'entrée de l'estomac. L'estomac, dans les Cardites, est arrondi et gloluleux; on y trouve deux ou trois grandes cryples biliaires, et dans son bas-lond, l'ouverture pylorique. Lintestin est grêle et cylindrique dans luute son étendue, les circonvolutions sont perz noubreuses, et il se termine, comme dans lous les Acéplialés réguliers, en un reclum droit et médian, passan à travers le cour. Ce dernier organe est très-dillérent de ce que nous avons vu dans les Mulettes; le ventricule est gros el globuleux, de ses parties latérales et un peu inférieures naissent les oreillelles, qui clles-mêmes sont cautes, et ne reçoirent à leur estrémité qu'une seule veine branchiale, dans laquelle se sont portés tous les auties vaisseaux branchialax. Dans ce genre, les nreillettes ne sont donc pas, comme dans les Mulelles, la continuation des vaisseaux branchiaux. Quant au reste de l'organisalion, comme elle est à peu près semblable dans tous les Acéphalés, il n'est point élonnant de lui trouver de lanalogie dans les deux genres que nous comparons; cependant, dans ces deux genres, tous les organes principaux diffèreat, et notamment ceux de la digestion et de la circulation, les plus 
mporlans, sans conlreait, daus la classe dont les Cardices et les Mulettes foul partic. Il restcroil actuellement à discuter si uuelafues points de ressemblance extérieure doiren! l'emporter sur des diffirences aussi grandes daus l'ensemble de l'nrganisation : celle question, yue nous avons trailce ¿l'artirle Noltusques, n'a pas besoin d'être reproduilc iri, et nous renvayous le lecteur à l'article général que nnus venons de mentiunner.

Les Mulettes vivent dans prestyue tomes les caux douces qui sont répandues sur la surface du slobe; elles sout cependant hien plus nombreuses dans les régions septentrinnales on tempúrées que dans la zone équatoriale : elles se plaisent aussi Lien daus les eaux couraules gne daus les caux Iranquilles des lacs et des éla ags; elles seatoncent un partic dass le salile ou la rase, sur lesquels elles marchent dans une posirion presque verliciale à l'aide de leur pied musculeux et eu y creusan un sillon plis ou woins profond.

Quoique très-abondaument répandues actuellement en Europe, ce genre ne s'y rrouve que très-raremeat à l'ćlat fossile. Celle abseuce, gne l'on ponroil comparcr à celle presque aussi alısulue des régious les plus chaudes du rylobe, devicrat une raison de plus pour penscr yue lat teinpéralure de l'Europe centrale est at'tusllement bien diflírente de ce qu'elle éloit pendint la période de formalion des terrains tertiaires. Ce que mons remarquerous entore, c'est que dans les réginas équatoriales, on trouve plus spécialement des Auadontes ou des coquilles qui leur ressemble, et que c'est ígalement des coquilles de ce gemre quelion rencontre, soit en Italic, an val d'Arno, soit aux environs de l'aris, dans les lignites du Suissonnais; mais daus ce dernier grissenent, les coquilles dont aous parlons y sont en quelque sorte supposées, car on n'a ju, jusqu'à présent, en recueillir autre chose que des fragnens. Ces rapparts de distribution gíographique ne laissent pas d'avoir quelqu'inporiance et devenir concluass, yuisqu'ils se joignemt a wo granti vambre d'autres fails qui, tous, êndent à la même conclusion.

Parmi les genres de la lanille des Nayades de Lamarck, il n'en es: qu'un seul, celui de l'lridint, que nous ne réunissons pas aux Muleltes. Nous prenons également, dans la famille des Triggonées, le gente Castalie pour le juindre à celui qui nous occupe, parce qu'en effet il en a les caraclères f riocipaux. Enfin, nous y réunissons aussi noosculement les genues et sous-grenres de M. Rafinesque, mais encore ceux qua proposés deruièrement M. Lea dans sadt intéressant ouvraye, publiéà Philadelpbie. Une rénnion si considérable d'espèces, don l les formes et les accidens sout si divers, rend nécessaire, dans le genre Mulette, an yiand nombre de sous-divisions ou de groupes, qunil convient de caractériser plutôt d'après les accidens de la charnière, que d'après des formes ex:cieares extrêrezent vainbles.
3. Muretre à plis rares. Unio rariplicata.

V. testá ouatí, subalùîa, crassi, postico liatore $p$ licis obliquis raris simuosá; pube clevatá, compresso-carinatî.

1. Аик. Anim. s. 2eit. tom. 6. pag. $71 . n^{\mathrm{c}} .5$.

l, Unio rariplicata est nne des jlus grandes espèces du yenre; son épaisseurnc la rend pas moins temarquable que ses autres calacteres. Flle est ovaleoblougue, épaisse, subcordilorme, tris-inécpui. latéralı; ; les cruchets sont assez grands, opposts, et inclin's sur le côté antérienr, qui esı fort contt et lort obtus; la surface exlćrieure, qui est recou. verle d'un épiderme noil el très-épais, est ornée. de quatre à cing gros plis très-larges el oblus; ccs plis, dans le jeume àne, aboutissen jusqu'aux bords, et les rendent sinueux, tandis que, daus les individus adules, ces plis se termineut en s'aduncissout vers le côté postérieur, et ne produisent sn. les borls aucume modification; le cóté pusićricur est subtronqué, un pen oblique, formant un angie abıus ê ouvert avec le côtú supérieur. Celui ci est aninci, un peu élevé en aile, et présente claus toute sa longueur un liganeul arrundi, trés-épais et rès-puissant : à l'ült́lieur, là nacre est parlunt d'un l.lanc argenté légèrement irisé. la charuirire est des plus fortes; elle se compose, sur la vahe droile, d'une petile dent antérieure, en crèle, et d'unc únorne clent cardinale, Jy'r midale el comne hachée sur route sa surlace supérieure; une cavité assez profonde se voit à côlé de celle dent. La grawde tent postérieure est comprimée, saillante et lranchante sur son bord; elle est rugueuse dans conte son f́lendue, et subplisste à son exllémilé postélicure. la vaive gुauclue préscule deux dculs cardinales assez érroites, séparées par une grande cavilé qui recoit la deut le l'autre valse, to jrofondínent découpées dans route leur étendue; deux lanıes saillanles laissent entı'elles une cavić lliangnlaile, profonde, destinéc à recevoir la grande dent postérieure de la valve droite. J'impression musculaire antérieure est semi-lunaire et très-profonde; Ia postéricure est arrondie et superficielle.

Celie grande cuquille, qui se trouve assez liéquemneal daus les fleuves de l'Anćrique septentrionale, et principalement daus l'Obio, est longue de 10 cemina. et large de plins de 14.

\section{Muzetre en hache. Unio securis.}

$U$. testî̀ subtriangulari, obliqua, inequilaterali, in medio depressi, per umbones saldé complanata; latere pustico depresso, plunate; valvis crassis; sulepidemide fusco-lutescente lineis puncticulatis, njgrescentrluss, ornatî; cardine imsussato, unidentato, altero budntato; dentibus obliquis, pryfuncle rngosis.

l.E. , Observ. sur le genre Unio, pug. $51 ., 0^{\circ}$ 1.j. pl. 11. fig. 17 . 


\section{II $\mathrm{L}$ i}

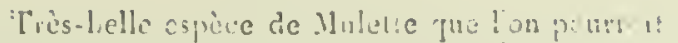
peodre par la forlsc entericule, scil pou une Crassatelle, soit pour une lénus, nais sinriout pour une coijuille de ce premier genre. Elle est suburigone, très-nlalicgue, a crochels assez grandis et rappruchús, tròs-obliqulies; le côté antŕricur est rcurt, arronti, assez larse; le cotó postérieur est fortement séparé de la surfice supérieure par un ar:gle ipui part de l'extrénitć postéliente du croche! , et qui descend oblique nent jusqu'i l'extrímité iuféricure de la coquille, qui lorme un an le olitus par la joncion du bord supérieur et die l'ibfélicur. Le ligament est grand et solide, placé a la partie supúrieure du cốté post rieur. La surlice exterue est irrégalièrcuent sillannée par des accroissemens; elle est coaverte d'uu épuderine mince. transparcnt, d'un brua-jaunalle, ala-dessous ducjuel se vaient des lignes élroites, rryonanos, lérement arquées daus leur lon„ricur, et formés de points quadrangulaires al. fernalivement d'un brun-nair el jaunâtre. A l'inbiscur, la corruille ent d'une belle nacre argentcie, irisée. La charnièse est très-large et très-sulide; elle es: fortement artquée dans sit longueur, et les lens partics qui la constituent sont séparées par ua talge espace médian, aplati et liès-lısse; on roii sur la valve droile une grande dent cardinale, obtuse, pyramidiale, llianguluire, profondínent découpée, et de claqque côté une fossette peu profonde el tres-rugueuse. Sur la valve gauche se trouvent denx furtes denls pyramidales, divergentes, protundément cariées, obluses au sommet, et séparées par une large cavité coniquae; Ix rlent lamellaire postérieure esł légèrement cuurbée diuns sa longueur; elle est large à lat base, obruse au sommet, et rugueuse a son extrémité pistérieure. Les impressions musculaires sont assez rundes, l'antéricure est subovalaire, Irẻs profonde, et rugneuse dans piesque toute son étendue; la posí́lieure csl-arrondie et plus superficielle.

Cetle belle espèce, fort rare jusqu'à présent, vit dans l'Ohio. Les grands individus ont 65 muillas. de lougueur et 70 de large.

\section{Mulette arrosće. Unio irroruta.}

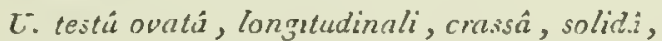
cordiforme, obluqux́, trunswersim sulcatâ, noduhs obtusis lines planci, obliqua, longitudinali internuptis; epidermide viridi, puncticulis numerosissimis irrorato; cardine lato, in medio profunde inflero, pluno; dente cardinali unico, prafund: rugosa, obtuso, in altero dentibus duobus, angustis, divaricatis.

L.E., Observ. surle genre Unio, pag. 11. $n^{3} .5$. vl. J. fig. 5 .

Cuquille remarcuable par sa forme ovale-oblongue et longitudinale. Elle est très-eollée, cordif́rae, sillouréce an-dehors par des accroissemens
Mi L I

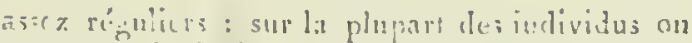
troure, puncipalement du cisć posté ieur, des lubercutes oblus, irréguliçrasul disposes; lem seric est iuterrompue par une zone longitudinale, submédiane, aplatic, qui en est constamnent dépourvue. Sous un épiderme d'uu vert - jumature, lrasparent, on voil une multitude de pelits points d'un rert luncé, disposés quelqueluis en zune lomgitudinate dans les endroits vui ils sont le plus rapproclićs; les croehets sont grands et ubliques, presque tcrminaux, presque toujours profondément rungés. A l'incériear, lat connille, dust le test est tres-épais, est d'une tris-belle nacte, d'un blanc argenté; lat cliarnic̀re est très large et trèsrpaisse, furtement courbéc daus son milien; la latne cardinale est aplatie et lisse sur ce point. On trouve sur la parlie antérieure de la charnière, sur la valve droite, une grande deut cunéfforme, luugitudinale, rugueuse, et conune hachée; elle est eirconscrite de chałjue côlé par une petile cavité divergente : sur la valve gauche se trousear deux dents apluties, longiludinales, divergentes et très-ruguneuses, séparées par une grande cavité conique; la dent lamellaire postérieure est lígèrement courbée dans sa longueur; eille est courte, peu suillanle, frès-large il la bise, et rigrueuse dans presque loule sou élenduc. Les impressions aruscularites sonttrès-pelites; l'antérieurc: est sena-lunaire, trés-profonde; la pustérieure est un pen cxcavée et arrundic.

Cette coquille, qui vil dans l'Ohio (Amérique septentrionale), est assez rare dans les colleclions. Elle a 50 nuilina. de longr sur 42 de large.

\section{Mulette sinuce. Unio sinuata.}

$U$. test $\hat{a}$ ovato-oblong $\hat{\imath}$, supemie coarctatí, s:-

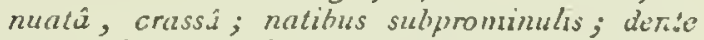
candinali crasso, lobato, striato.

My'a margaritifera? Lix. Gsiel. pag. 3219.

Listen, Conch. tab. 149. fig. 4?

Kхоя , Ve'gn. tom. 4. tab. 23. fis. 2.

Schroet. Flusc. tab. 4. fig. 1.

Drap. Hist. des MIoll. pag. $132 . p l$. 10. fig. 8. 16.19.

Everce, fl. 248. fig. 1. a. $b$.

I.A $\mathrm{x}$. Anim. sans vert. tom. 6. pag. 70. $n^{\circ}$. 1 .

Celle coquille est la plus grande des espèces qui existent en Europe. Elle est ovale-oblungue, sinueuse dans le milieu, son cóté antérieur est obtus et court; les crochcls sont médincrement saillans, plus ou moins rongés; la surface extérieure est irrégulièrement sillunnée par des accroissemens multipliés, et revềlue d'un épiderme épais d'un brun-noir. A l'intérieur, celle cơpuille est d'un blanc nacré très-lrillant; on obserre $d$ la charnière, sur la valve droite. une dent antérieure, coniq̨ue, très-épaisse, sillonnée jusqu'an 
snmmet, et le lungr da bord supécitar uae dert alongée, lígerencut tranchante et rugneuse. Sur la valve gauclee on trouve denx dents cardinales, séparées par une grande cavić́; a la place de la dent postérieure on trouve une cavité oblongue, rugueuse: dans laquelle vient se placer lat dent poslérieure de l'autre valve. Les impressions musculaires sont profondes, principalement dans les vieux indivilus, les antérieures surtout sont remarquables par les rugosités dont elles sont atmées; le ligament est très-saillant, Irés-épais et prolongé dans presque tonte la lengueur du borl supérieur.

On trouve cetle espèce dans la plapart des urands lleuves de l'Europe iempéríe, dans le Rhin, le Danube, la Gronde, ete. Elle a 13 a 14 centim. de larke; sa nacre, trés-ćpaisse, est souvent employée dans la fabricativa d'objers d'arl.

\section{Molette navifurne. Unio naviformis.}

$U$. testá transwersim oblong $\hat{\jmath}$, rect $\hat{j}$, anteriùs angulatâ, compressâ, subemurginutì; sulcis transversis latis, lateris antici undulatis.

An Unio cylindricus? SAY, Encjcl. amér. Conch. pl. 4. fig. 3.

LANк. Anim. suns, 2ert. tom. 6. pag. 75 . $n^{\circ} .20$.

Il est bien à présumer que l'Unio cylinaricus de Say est la même coquille qua: celle que Lamarck nomrue Muletle navitorme. Celle coquille remarquable est alongée, trés - inéquilatérale, subrylindroile, et ressemble, par sa torme extérieure, à certaines Arches, et plutùt encore aux Cypricardes; san côté anfúrieur est très - court et arrondi, le côté pustérieur est obliquement tronı̧ué et sinuenx dans sa longueur; les bords supérieurs et inférieurs sont droits et parallèles; les crocỉets opposés ont de la ressemblance, quand ils son bien conserves, avec ceux de certaines Bucardes, c'est-à dire qu'ils forment à peu prìs un demitour de spire : au-dessous d'eux on remarque une luaule assez profonde, sublancécolée. Le corselel est comprimé a son extrémilé postérieure; il esı Loraé par uoe légère dépression qui gagne obliquement l'angle inférieur et postćricur; le ligament, qui est peu épais, s'élend d'un bout à l'autre du corselet. Lit surface extérieure, outre des lignes daccroissement et des stries lines el assez rigulières, est partagće en deux parties par un ansle obtus ct oblique qui s'élend depuis l'extrémité du crochet jusquau-dessous de l'angle postérieur; cet angle est couronné par ltois ou đquatre gros tubercules déprimés et obtus. Suns un épiderme très-fin, d'un vert-brunatre peu funcé, on remalrque un grand nombre de peties taches triangulaites d'un vert intense, qui forment tanlôt

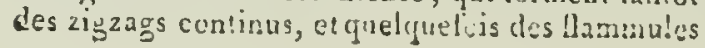

isolées. A l'intérieur, la coquille est d'une nıcrc blanclic; la charnière est formée, surla valve druite, d'une seule dent antérieure, pjratnidale, asse 2 large et profondément découpée : la denı lamelluire postérieure s'élend dans loute la longueur du bord supérienr; elle est étroile, tranchante, ('trugueuse à son extrémité postérienre. 11 existe deux denis cardinales, divergentes, sur la ralre yauche; elles sont découpées cumme celles de liause valve.

Cerce coquille, assez commune dans les fleures te l'Amérique sepreutrionale, a le lest trós-éplatis et irès-solide. Sa lougueur est de 36 millım. et sa largeur de $9^{1}$.

\section{Mulette littorale. Unio littoralis.}

$U$. testâ lutè ớutî, subquadratâ, pube sulco nuarginale utrinque distincti; natubus rugosis.

Unio littoralis. Syst. des Anim. sans vert. p.'5. 114.

Scrnoft. Flusc, tah. 2. fig. 3.

Drap. pag. 133. $n^{\circ}$.3. pl. 10. fig. 20.

Excycl. pag. 248. fig. :.

Act. Soc. lin. tom. 8. tul. 3. a. p. fig. 3.

L.мк. Anim. sans vert. tom. 6. pag. 76 . $n n^{\circ} \cdot 25$.

PFEtFfFr, Syst. anord. pl. 5. Sig. 12.

Coquille tres-commune dans les rivières de l'Europle tempérée. Sa furme est assez variable; elle est ovale-oblongne, quelqueluis subquadiangulaire; elle est aplatie, inéquilatérate, un peu oblique, élruite, antélieurcasent plus large tet subanguleuse du cốć posiérierr; sa surface exlérieure est souvent silloudce par des accroissemens irréguliers; elle est revérue d'un épiderme d'un brun loucé nuirâtre, yqui unanyue ordinairement sur les crocbess. A l'intérieur, la coquille présente une nacre blanche, quelquefois rosatte ou grisâtıe. Lia charnièe est assez élroite, at le bord cardinal présente un sinus assez profund vers le milieu de sa longueur. On trouve une dent cardinale sur chaque valve : elle est grosse it pyramidale sur la valve ciraite, plas petite et plus obtuse sur la gaucbe. La dent lamclleuse pustérieure est fort étroite, saillante, lamelliturme, el courbée duns sa longueur; elle est reçue dans une cavilé correspondante de l'autre valve. Il arrive que, dans le vieux individus, cette dent pastérieute disparoit complétenent, atussi-Lien que la cavité qui doit la recevoir : dés-lurs celte coquille, selon son îge, cniteroit suit dans les Mulelles, soit dans les Alasmiduntes, si l'on admeltoit un gente comme ce dernier.

II sernit possilile que l'Unio que nous avons dédić à Draparmaud sous le nom d̛ Unio Duracarnakli, ne soit qu'une variété hiangultire de cefleci; il y a cepecdan! dos du!freres si uotubles, 


\section{L L}

¿jue nous conserverons les deux especes jusqu’ irmeal oi nous aurons vu les passages de liune à l'sutre.

1.a Mule:te littorale est une des concuilies les plus aloondalites des rivières de France; les grands individus ont 45 milliu. de lang et 60 ou 65 de large.

\section{Mulftete rayonnée. Unio radinta.}

$U$. testî́ obovatâ, convero-depressâ, tenmissimè transtersim striatâ, antico latere latissinı ; epiderme flavicante, longutudinaliter radiati.

Mya radiata. GuEs. pag. 320.

Lister, Conch.tah. 152. fig. 7.

Unio ochraceus. Encyc. amér. Conch. pl. ‥ fg. 8.

Var b.) Testâ majore, paulo crassiore, anteriùs nagis producti.

LАнк. Anint. s. vert. tom. 6. pug. $75 . n^{\circ}$. 13.

Cinquille d'un médiocre volurae, ovale oblongue, inéquilatérale, arrondie antérieurement, subangu. leuse postérieurement, el un peudilatée en aile du côté supéricur; les croclets sont médiocres, ordinsirement rongés; le reste de la surtace extérieure est recouvert d'un épiderme d'un vert-brunatire, all-dessous duquel on apercait un graud nomlse de s'ayons élroils, el irrégulièrement espacés, d'un vert-brun foncé; a l'intérieur la cocuille est rosàtre et irisée en vert mélallique. La clarnière esst assez étroite; elle se compose, su la valve droite, d'une dent cardiuale, sublobée, pyranidale; d'une dent postérieure pu'u saillante, rurneuse à la partie postérieure. La ralve gauclie Alie deux dents cardinales inégales; l'antérieure rat la plus grande : les deux lamelles postérieures sint étroites, rapprochées, subcrénelées au somInet; elles laissent entre elles une goultière trianganlaire dans laguelle se loge la dent postérieure de l'autre valve. L'impression musculaire antérieure est assez profonde, arrondie et lisse; la postérieure est arrondie et superficielle.

Cette coytuille, assez rare, habite les lleuves et les lacs de l'Amérique septentrionale; elle est longite de 40 à 45 millim. el lurge de 70 à 80 .

\section{Mulette resirée. Unio coarctalia.}

U. testî ovuto-oblong $\hat{\imath}$, convexo depressî́, anterius subungulutâ, supernè coanctuto -sinuati, intius livedo purpurascente.

Var. 2.) Epiderme radiis.longitudinalibus obltpuis pictî.

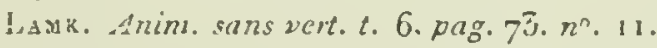

Celte espece se reconnnit facilemeal à sa forme nvilaire, transverse, et à son aplalissement. Flle est ablongue, liès inf́rpilatérale; le côté antr."ieur est arrondi; le cós g stóricur, trungué ob!i-
II I

うั่

quemeut, se termine inférieurement par un augle nbtus; le loord supérieur est légcrement arqué, et le ligament occupe presque toule sa longueur; le burd inféricur est droil, un légèrement sinueux ditus son milieu; les crocliets sont très-peu saillaus, prolodónent rongés : de lcur côté postérieur natil un angle ohtus yui descend obliguement juscgu'à l'angle postérieur el iuférieur. has surface exlćrieure, revêtue d'un épiderme épais, d'un brun-nuiritre, est clargéce de sillons ilrćguliers d'accroissement. A l'iutéricur, celte coguille est d'une nucre violette, pourprée, quelqueluis livide. On trouve it la chamiere, sur la valve droite, une seule dent pyrarnidale, obliguc, dont la lace supérieure est coune bacliée; sua la valve gauclie se voient deux petites denis divergentes, séparées pa! un sinus profond, dans letguel sinsere la deal de la value opposée; la dent lamellaire postérieure est grande, arsez mince, arqucie, allénuée et rugueuse à sou citrémité postérieure; les lauelles qui la reçorvent sur lautre valie sont égales et saillanies. Limprcssion musculaire an!érieure est grande et arronilie, peu profonde; el'e est accoinpagníe d'une petile impression semi-lunaire placte alldessous d'clle; l'impression musculaire postérieure est arrondie, un peu plus longue que larre.

Celte coquille labite les rivières de l'Amérique septentrionale; elle est luagne de 42 millim. el large de 8z.

9. Nulette purpurescen:e. Unio purpurascens.

$U$. testî ovato-oblongâ, convexi, postcrits subanguhitâ, superné depiessa, medio sulisnuatis, intùs purpurascente.

Uno purpuieus. Encje. amér. Conch. pl. 3. fig. 1.

Var. b.) Testä tenui, intus albo-rnbescenie.

Var c.) T'estâ crassiore, intùs alliclì.

L.MN. Anim. suns vert. tom. 6. pag. 7.7. $n^{\circ}, 12$.

Cette espèce avoisine la précédente par ses ritpports. Elle est ovalaite, transverse, très-inérguilatérale, assez épaisse, enllée, quoique les crochels soient lort peu saillans. Son extrémité antérieure est arrnudie, plus étroite que la postérienre, qui, étant obliquement trouquée, se termine inférieurement par an angle très-obtus. La surface extivicure, sillonue par des accrnissemens irréguliers, esl revêtue d'un épiderme noir, rcailleux, rongé sur les crnchels. A l'intérieur, Ia cacre est d'un beau violet pompreci, irisé dte nuances d'un vert míallique. Il existe denx dents cardinales sur chargue valves, ce qui distingues éminemment celte e.pèce de celle qui prócéde.

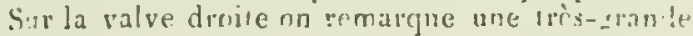
dent cardioale, ly'ramidale, rujutuse a sa sict 


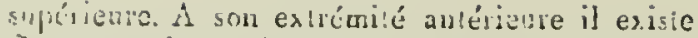
Lte untr: dent très-petile, placće le long du bold; les dents cardinales de la valve gaduclic sont presqu'égales, divergentes, rugueuses, et síparées par une fossette prolonde et sillonnée; la dent lamellaire postérieure est épaisse, assez. courte, crénelée dans sa longnueur, el reçue entre deux lanes épaisses, également crépelćes ì teur sommel. L'impression musculaite atntérieure cst semi-lumaje, assez protiondc, ciricic, et accompagnce d'une aulse impression trés.citrite, fort petite, placée imaédiatement alt-dessous d'elle. L'impression musculaire postéricure est grande, superficielle, ovale, oblongue. La variélé diflère en ce qu'elle est plus comprimće et d'unc nacre blanchâtre, légèement poururéé.

Cette espèce habile les riviéres de l'Amérique septentrionale; elle est lougue de 5o millim. et large de 90 .

\section{Mulette noire. Crin atra.}

$i$. testû ovati, inequilaterali, transvers.î, ventricosissinit ; umbonibus tumidis, recun'is, crosis; epidernide nigricante; dentibus carainalibus binis, erectis, obliquis; dente posticali magno, subtnuncato, rugoso; margariti, purfuruscente.

LEA, Observ. sur le genre Unio, pag. 40. $n^{\circ} \cdot 7$. w. $7 \cdot f \mathrm{~g} \cdot 9$.

Celle coquille est fort rare, et liune des plins Lelles dn genre. Elle est ovale, trìs-enllće, et ressemble à certaines Bucardes par la proémiuence de ses crochets; son côté antérieur est trèscourt, plus étroit que le postérieur; il est olstus et arroudi; le cólé postérieur est dilaté, subironqué, plus obtus que l'antćrieur. La surluce extérieure est largement étagée par des accroissemens assez réguliers; elle est revêtue d'un épiderme épais, d’un nnir foncé, passant au brua vers les crocliels. A l'intérieur, la nacie est d'une belle couleur de pourpre pen intense, irisće d'une teinte bleuatrc et de ronge dc feu. La charuière est assez épaisse; ellu est oblique et courbée dans sa longueur; elle présente sur la valve druile denx dents infogales, divergentes, et tout-à-lait antérieures. Ces denis sont très-ruguenses à lentr surlace interne. Les dents de la valve gauche sont beaucoup plus grosses; elles soat presfure égales et diriớées antérieurement; la dent lumellaire poslérienre est grosse, épaisse, courte, atténnée postérieurement, tranchante et crénelíe à sun sommet; elle est reçue entre deux lames inćgales de la valve opposée : la plus courte et la moins saillante de ces lames est la supérieure. l'impression musculaire antérieure est très-profonde, subsemi-lunaire, divisée en deux parlies inćgales par une côle saillante; au-dessous d'elles on remarque une seconde inpression beancoup pins petite, arrondie et tres-profonde; l'impres- sicin musculaire posicrieure est grande, semilunaire el superficielle.

Celte belle espc̀ce, qui rit dans le Mississipi, a 80 millim. dans sa plus grande longruenr et 118 de large.

\section{Muletre australc. Linio austialis.}

U. testâ ovato-oblongî̀, depressi, tenui, intì. carulescente; laterum extremtatibus rotunduts.

L.suk. Arim. sans vert. tom. 6. pag. öo. $n^{\circ} \cdot 46$.

De relour de son voyage, M. Lesson nous corrmuniqua une Mulette qu'il avoit recueillie à l.t Nouvelle - llollande. Ses caractères s'accordect asscz bien avec ceux que donnent Lamarck à la Mulelte aplatie; et sans avoir toutefois la preur: immécliale que notre coquille soit identiquement la máae, bous pensons qu'el'e n'en est qu'uric rarićlé. Elle est oblogne, transverse, subornlatire, inéquilatérale, miure et déprimée, obtu=e et arrondie dı còlé antérieur, subtronquée $t$ obseuríment anguleuse du côlé postériemr. Lid surlace extérienre est irré.julièrement striće jat des accroissemens; elle est revêtue d'un épidcure đ'un heau brun très-intense et rongée sur les crochets. A l'intérieur, celte coquille est d'un blaucjaunatuc dans le nilieu des valves, et bleuarte vers l'esuréu ité postérieure. La charnière ullic ir son extrémilé autérieure, sur la valre droire. unc clent oblique, subauriculiforme, $\dot{a}$ la base de laquelle on en remarque une seccude, très-courte, et lisse comme la première. Sur la valve gauclie la deut cardinale est coute, pyramidale, et sul:divisće à son extrémilé postérueure; la deat lamellaire postéricure est fort courte, peu saillante, subitement lronguéc à son extrémilé postéricurt, qù elle est chargée de rugosilés nombreuses. L'impression ausculaire antéricure est fort granule, arroudic, superficialle, irrégulicrement sinueuse sur les bords. L'impression musculaire postéricare n'est pas plus graude que l'autérieme; eils est tris-superficielle et atrondie.

Celte copuille, rare, à ce qu'il paroit, dans les collections, est longue de 35 millim. et large de 57.

\section{Mvцzтte grenue. Unio granosa.}

$U$. testa obovatî, convexo-depiessi, fuscorufescente, postuce latrom rotundatâ; striis oblsquis, graniferis; granis conferlis.

Unio grailosa. Bnug. Journ. d'Hist. nat. tom: 1. pag. 107 . pl. 6. fig. 3. 4 .

ExсrсL. pl. 249. fig. 2. a. b.

LAנк. Anim. sans vert. tom. 6. pag. 79. $n^{\circ} \cdot 37$.

Petile coquille, remarquable en ce qu'elle es: cartunt chargée de lines granulatiuns, caractire 
que l'on ne remarclue dans aucune antre estèce. Sirugrière, le premier, en a donne la desriprion. Eile est urale, arrondic, un pen plus large riu cơlé prstírient que de l'antéricur; ctle est ris-inciquilatérale, nblique; sen bosd supéricur el poslérieur est un pen velevé en aile; sa suldace exlérienre, couverle d'un épiderme brun foncí atssez eprais, est clargće d'un grand norubre de lines granulations rapprocluces, wais irrérulièrenent dispersées. A l'inténeur, la nacie esi d'un blanc-bleuatre, avee des rellets irrsés jantmilles vers les burds. La charuicre est trèsilloire, arquéc; elle préseute sur la valve droile une dent antéricure, rugneuse, sublameilaire, et, "ur la valve gauche, deux dents très-olliques, siparces par une goullière assez profonde. lai dent postérieure est alongie, furt étroite, peu saillanie, ringueuse, el atlénuée à son exlrémité pusterieute; elle s'engage entre daux lituelles rris-miuces de la valsue opposée.

Cette coquille a élú trouvće dans les vivières de fa Guiane, à quel ques lieucs de distance do leur "ulboucluse dans la aer. E!le a 24 millim. de lunguear et 40 de large.

13. Mulette aviculaire. Unio avicularis.

U. testi stotriangulari, obligud, subarquilatitid, postice angulato carinati; umbonibus magnis, lavigatis; mangine superiore recto, Int:Ci posticèque condatim producto, latere postiro acuto, sinuoso; dente cardinali, antico, tripartito, sulcats.

Hy ria avicularis. I.suk. Anim. s. vert. tom. 6. rag. $80.1 \pi^{2} \cdot 1$.

.Vy a sjmatophora? Lis. GMer. vag. 3222.

1.rsten, Synops. Conch. zab. 160.fig. 16.

Nous plaçons, dans le genre Muletle, celle coguille dont lasuarck a lait son genre Hyrie; nous atrous ru puur quelle raison ce genre ne pouvoit atre admis, el la deseription qui va suivre en deviendra la preuve la plus 6́vidente. La Mulcte aviculaire est une coquille singulière par sit forme extérieure; elle est subtriangulaire, très oblique : moins inéquilatórale que la plupart des espèces; ses crocbets sont assez grands et obliques lorsyu'ils ue sont pas rongés; le côté antérieur est illénué, amiaci en coinz; son angle supérieur se prolonge en une oreillette courte, indiquéc par uy sinus profond. Le colá postérieur est le plus dilaté; il se termine inléricurement par un angle ab) ars; du cóté postérieur des crocliets part un angle caréné, oblicgue, qui descend jusqu'à l'angle postérievi el inférieur de la eoquille. An-dela de cet angle, on remarque une force dépression qui, eu atténuabl cette partic de la coquille, lui dome une lorme comparable à celle de l'Unio ralutu et autres espèces analogues. l.e bord sujériem on cardinal est dioit; il se prolonge il son extrémite postéfieurc en une oreilletie contcume, plas ¿rrande çue l'antéricurc; la surface cxićrieure est lisse un sillonmée par des aecroissemens. L'egriderene qui la revêt est d'uo brun-verdâtre, obs'we; il l'uléricur, la coquille est d'une nacte d'un blane argentó; sa charnièse, coubée dans sa longnemr, présente ce fait particulier dans les Mulelies, d'uvoir la dent aucérienre divisée en truis den!s inc'gulles, divergentes, strites de chaque cúte. Si, clans celle espece, la troisième el la plus petite des dents eardinales n'existoit pas, on be pnurroil trouver la moindre ditference avec, ioules colles des Nuletles que Lamarck a placées clans sa seconde sccion. I,a dent lamellaire pus. lómeure ne diffère en rien de celle des autres Muleties; elle esi légerement courbée dans sit lon.

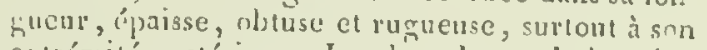
catrénité postrírieure. Les dcux lames de la valve gnamclic entre lesquelles clle est reçue somı d'inégale

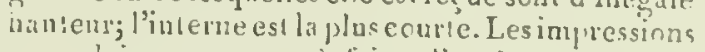
musculatres sont tout-a-fait celles des antres MluIclles; l'antérieure est arroudie, légèrenent crensće; la postérieure est oblongue, longitudinale, et très-superlicielle.

Certe copmille rare habite, à ce que lion prisume, les rivières de la haule Asic. Sa longnear, dans les individus de moyenne taille, est !e $\left.y^{\prime}\right)$ millim., el sa largeur, d'un angle à l'uturs, cs cie 75 .

\section{Nunetre ailée. Unio alata.}

$U$. testâ enagná, ovato-trigoná, transterviori strintî; pube in alam muxumum clevati: walvis margine conatis; ligamento ccculurbu.

Unio alatus. Sax, Encyclop. amer. C'onet. 11. 4. fig. 2.

Lank. Anum. sans 2ert. torm. 6. Aligg. jij. $u^{\prime \prime} .28$.

LeA, Obsern. sirr le genre Uno, fage. tiz. (S.minphynota alata).

11. Lea a proprosé, dans l'niruage rue nous vcruons de citer, m genre Symphyuote, jui nous parôí inadmissible, ('n ce qu'il est londé. non sur les carraclères de l'animal, non plus sur. ceux de la charnière, mais sur un accident de pen d'importance, de la réunion inmédiale des valves au-dessus du ligamenı. Si l'en observe la clipposition toute particulicre de l' lineo cilcslu, cu de çrelques autres cspices analogues, on remarque ciue le prolongement aliforae gur cources le ligament est soudé dans ses deux parties fru la matière crétacée elle-mème, de sorle yne l'aciiüu du ligament se joint à celle de l'ćlasticilé du test poul' s'opp ser à laction musculaire. Ce qui est curicux dans les espececs qui oflrent ret accident, e'est gue la charniere n'est pas moins raralile que rans les autres Juleties. Ainsi, nutus m

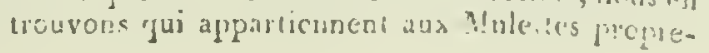




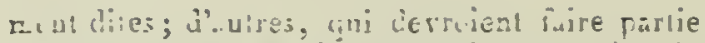
l'cs soudunles, el äjutres colin des Alasmidoa!es, sionadueltoil ces divers gendes; mais on est furcé de les rejeter, aussi-bien que le gerse Symplignote lui-méme, qui d'olfire aucud bou caracière.

La Muletle ailée est une espèce des plus remárquables; elle est ovale-subirigone, aplatie, asstz ưince, très-inéquilatérale, àvant le cỏé zniérieur arrondi, très-éltoil, el le cưté prstélieur, également arrondi, mais beaucoup plus large. Le bord supérieur el postérieur, forlcueat cunprimé et Iargenent dilaté en aile subtriangulaire, légèremeat sinueuse à son bord postérieur et cuupranl enljèrement le liyament, goi est ảu reste tont-à-fail semblable à celui des autres especes de Mulettes. La surface extérieure, irrégulièrement sillonnée par des accroissemens, est recétue diuo épidera:e épais, d'un brun trisfoncé. A lintérien la cnquille est d'uue tresLelle nacre pourprée, irisée par des rellets d'an ruuge billani et d'un beau vert métallique. I a charnière est couposée de deux dents cartinales dont la saillie fait on angle presque droil arec le bord supélieur. Il existe deux déts cardinales sur cliacune des ralves: celles de la ralve droite sont forl inégales, l'antérieure est presque sıdimentaire et trés-oblique; l'autre est graude, pyracoidale, fort ́́paisse et rugueuse à son somret: sur la valre gaucle, la dent antérieure est la plus grande; elie est comprimée laléralement, forl aiguë, el séparée de la postérieure par une carilé piofonde. La deat lamellaire postérieure est lénèrement arquée dans sa Jongueur; elle est tréssailiante, lamelliforme, fortement ironquée à son extrémitć postérieure. Cette dent ue commence à s'élever que vcrs le milieu du bord cardiual : les lames entre lesquelles elle est reçue sont inćyzles, paralleles : l'iolerae est à sa base moias saillante que l'autre, tandis qu'à son extı lomité postérieure elle la dépasse en longueur el en hauleur. L'impression musculaire anteriecue est lort grande, sub-ovalaire, et dirisée en deax parties distinctes e inégales par une cóte saillante; l’impression mus. culaire postélieure est trés-yrande superficielle, el son exlrémité supćrieuie se confond avec T'impression da muscle rétracteur postérieur du pied.

Cetıe zrande et belle coguille ril dans les grands amas d'eau douce de l'Acaérique septentrionale. Elle est longue de 11 à 12 centimètres de l'extréwiié snpérieure de l'aile au bord inférieur; les zrands indrvidus un jusqu'à 60 millimètres de large.

\section{Muletie obtnse. Linio bctava.}

li. testá ovatá, tumidi, è vindi lutescente, radiatá; latere postico trevissimo; antico oblicus curvo, critemitate rotundato.

\section{ii L L}

Scr:OET. Flusc. tub. 5. fis. 5.

Excrer. F.l. 248 . fig. 5 .

Mya butuva. MItos, $n^{2} .8$.

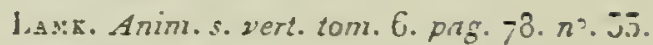

Pferffer, Sjst. anord. pl. 5. fig. 14.

Coquille très-distincte de la Muletle des peintres, mais assez visine de quelyuues variélés de la. Ilulette litlorale; elle se distingue uéu aruoins de l'une te de l'autre. Elle est ovale-transverse, inéquilatérale; son les! est assez mince; ses croclie!s assez saillans el dépouillés de leur épiderme; ses extrémitis sont arrondies et obluses, l'antérieure est но рец plus étroite que la postérjeure. En dehors, celte coquille est lisse, marquée, à des distancesinégales, par des accroissernens peu seusibles; son épideraie es! d'un Lrun-jaunâtre $\in t$ quelquefois d'un vert foncé: le plus souveat il est d'une teinte uniforme el quelguefuis interrompue par des rayons jaunatres, élroits, qui se montrent particulièrement sar le còté postérieur. A l'intérieur, la coquille es: d'une nacre d'un blanc argeoté, quelquelois d'u jaune pâle. La charnière est étroile, courbée dan; sa luugueur comene le bord supérieur dont elle suit la directinr. La valre droite offie une deut cardinale, saillaute et aiguë, sillonaée à sa face supéricure el dentclé a son bord libre. Sur la valve gauche, il exisie deux dents cardinales dirergentes, rugueuses, el dun! la postérieure est comme ployée en deux. Ia dentlamellaire cst lisse, très-étroite, trancluable, troncuée subitemect à son extrémilé postérieure; la cavilé qui la reçoil est étroile te: profondc: elle est formée jar deux lames parallẻles assez minces el saillagies. I,impression musculaire anlérieure est ovale, seni-lunaire, frofoade et rugueuse vers san bord interne; au-dessous d'elle, on remarque unc aure pelite impressiun ohlongue, courlúe dans sa longuear. L'impression muscoiaire postérieure est arroadie et très-superficielle.

Oo tronve comonámeul celle Mulet:e dans les rivières de Frauce et d'Allemagne. E!le est longu de 25 ailliacires et large de 50.

\section{Mulette ridée. Cinio corrugata.}

$U$. testí voato-rlıombed, tenui, viridi; umbnnibus rugosis; rigis angulato-flexuosis, sub longitudinalibus.

(a) Testá ziridi pubis carinatj, lovigatä. Mya corrugata. Mull. Grez. $\pi^{\circ} .15$.

Cesxs. Cunch. tont. 6. tab. 3. fig. =2.

Escrel. pl. 248. f.g. 3. a. b.

Testä fulvo-zirescente, pubis carinä rugasá.

Mya rugosa. Griel. n०. 32.

Caeas. Conch. tom. 10 tab. 170. fig. 1649 .

Excres. pl. 248. fig. 6. 
Lxwä. Anim. suns vert. tom. 6. pag. 70 . n?. 34 .

Petite corpuille, fort rare encore dans les collections. Elle est assez régulièrement ovale, iuécuilatćrale, obrusc et arroadie antéricureasenı; flibs large, et obscurément anguleuse du cóté postéricur. l.es crochets sont saillans, subanfrizleux. Du cólé postérieur, ils sont reunarquables, in ce qu'ils sont couverts d'ure multilude de pclits plis rayonnans, qui se joigneat souvent cntreux, Ge manière a former des zigzags dont les angles sunt très-aigus; ils se prolongeat, en s'atténuaat, jusque vers lc tiers de la surface extérieure, et se prolongent généraletnent davantage sur le cỏté postérieur. Le restc de la surface est lisse, converte d'ua épiderme d'un vert tendre, aliernant ver's le hord avec des zones jaunatres. A l'intérieur I coquille est d'une nacre argentée ct brillante, irisée du côté postérieur. La charnière, courbée d.ıs sa longueur, présente, sur chaque valve, ure seule dent cardinale alongée et la nelliforme, sur laquelle on remarque des rugosités irrégulières. La dent lanellaire postérieure est peu étendue. Elle est médiocrement saillante et s'attónue insensiblement à son extrémitć postérieure; c.le est simple sur la value droite et accompagnée sur la valve gauclie d'une seconde petite lamelle, (qui lui est parallèle et qui est beaucoup plus courte. Les impressions musculaires sont petites: l'antérieure est ovale et assez profonde; les postérieures sont confluentes et très-superticielles.

La longueur de l'individa que nous possédons est de 24 millim. el sa largeur de 36.

\section{Morette du Nil. Unio nilníica.}

C. testá ovato-oblong $\hat{\imath}$, subdepress $\hat{\alpha}$, striat $\hat{2}$; fusco-viente, antice vbtusî, posicè obscurè ingulatâ, incus purpurei; cardine bidentato, angisto, recurvo.

Calumata, Voj. à Méroé, tom. 2: pl. $6 \mathrm{t}$. fig. 8. 9 .

Coquille ovale-oblnngue, 1ransverse, nblique, inéquilatérale, subdéprimée, à crocliets peu saillans. Le cólé antérieul est atrondi et oblus, plus étroit que le pastélieur, qui est termiaé paj un anrrle olsscur. Le cóté supérieur est déprimé et lígèremeat dilaté. La surface extérieure est irrégulièrement striée; l'épiderme qui la recouvre est d'un brun-vert trés-foncé ou d'un brunnoirátre, manquaal ordinairement sur les crochets. A l'intélieur celle coquille est d'une belle couleur rose-pourprée. La charnière est trèsEtroite et courbée dans sa longueur; elle se compose sur la valve droite de deux dents trèsinégales, abliques, dont l'iulerne est la plus graade : toules deax sont rugueases et denticulces sur le bord. Sur la valve gauche, les deux dents sont tyalemeat inégales, mais elles sunt l'une ¿ la suile de l'autre, au lieu d'étre parallèles Hist. Nat, des Fers. Tome II. comme daus la valve opposíe. L'anténeure est sabpyramidale, assez étroile, rugueuse et denliculée. La postérieure cst beaucoup plus petite, sublamelliforme et rugueiuse d'un côté seulement. La dent lamellaire postérieure est assez épaisse; elle cst courte, tranchante, lisse et subtronquée posléricurement.

Celle coquille, assez épaisse et solide, vit dans le Nil, comme son nom l'indique. I.es individus de moyenne taille sont longs de 30 inill. ct larges de 48.

\section{Muzette laocédlé. Unio lanceoluta.}

$U$. testâ transversìm elongatâ, inequilaterali, antice obtusâ, posticè rostratâ; valvis tenuibus, compressis; umbonibus vix proeminentibus; caldine bidentato, altero unidentato; dente candinali acuto, obliquo.

LEA, Observ. surle genre Unio, pag. 8. $n^{n} .2$. pl. 3. fig. 2.

1) y a quelques rapports de forme entre celle cspece et la Mulctle rostr'ée des rivic̀re d'Europe, mais ces rapports se bornen! à l'extérieur; car la cliarnière des deux espèces est entièrement différente. L'espèce qui nous orcupe est alongte, étroite, trabsverse, très-inéquilatérale, déprimée. Ses crocliets sont peu saillans, subanguleux du côlé postérieur. Cet angle des crochets se continue sur le côté postérieur et supérieur, et il sert de limite à une dépression, au sommel de laquelle est placé le ligament. L'extrémité antérieure est arrondie ; l'extrémité postérieure est alongée en bec. La surface cxlerne est sillonoée par des accroissemens, ct revêtue d'un épiderore écailleux, d'un lurun-noirátre. A liutérieur, celle coquille est d'une nacre-jaunâtre on rosée, irisée de plusieurs nuances. Sur la ralve droite, la cliarnière préseate deux dents obliques inćgales: l'antélieure, qui est la plus petice, est placée sur le bord, dont elle suil la direction; uuc cavilé profonde la sépare de la postérieure. Celle-ci est grande, pyranidale, aigü̈ à son sommel, et denticulce sur son bord. II u'existe qu'une seule grande dent cardinale, pyramidale et pointue, sur la valve gaucbe; la dent lamellaire postéricure est très-mince, assez saillante, finement rugueuse, et obliquement lionquée à snn extrémité postérieure. Les lames de la valve gauche, entre lesquelles elle est reçue, sont inégales : la supérieure est la moins alongée ei la moins saillante.

Celle coquille sare se tronve dans la riviere de Tarborough, Anérique sepledtrionale, d'après M. Lea. Les grands individus ont 32 milliw. de longueur el 74 de large.

19. Mulette mytiloïfe. Unio mytiloides.

$U$. testâ elongatá, transversâ, obliquâ, inaquiluterali, inflatâ, virescente, intus aloa, Eee * 
margaritacế; cardine bidentato, altcro unidenlato; lamellầ posticali, angusistâ, truncaía.

ENCTCL. pl. 249. fig. 4 .

La forme exlírieure de cette espèce la rapproche des Moules de la section des Miodioles. Eille est alongée, transverse, un peu inlléchic du côlé postérieur, très-inéquilatérale, subcyliudruilde, à croclıets obliques et peu saillans; le coté antérieur est très-coult ut arrondi; le côté postérieur esi légèrement alténué et obtus à son extrémité. la surface extérieure est chargée d'accroissemens irréyuliers, el elle est revétuc d'un épiderme trèsmioce, lisse, d'un vert très-tendre. A l'intérieur, celte coquille est d'une nacre d'un blanc argeuté; sa claaruic̀re est courte, milis assez épaisse antérieurement; on y voil sul la valve droite une seule dent nyramidale, triangulaire, obtuse, légèrement deuticulée à sou sommet, et sur la valre gatuche deux dents obliçues, carites, séparées par une cavité assez larege: la dent la mellaire poslérieure est très étroite, tracchante, peu saillante, et subitementlronquée à son extrémité postérieure. Les impressions musculaires sont médiocres; l'antérieure est assez prolonde et semi-lunaire, la postérieure est arrondie el très-superficielle.

Cette petite coquille rare, dont nous ae connoissons pas la patrie, a 18 millim. de long et 35 de large.

20. Molette des peintres. Unio pictomem.

$U$. testâa ovato-oblongî, posterius rhombeoaltenuali, extremitate obtuse acuti, natibus subvaricosis.

MJa pictorum. Liv. Gries. pag. 3218 .

Bonaxs, Recr. 2. fig. $40.4 \mathrm{I}$.

Gualt. Test. tab. 7 I. fig. c.

Senroet. Flusc. $t a b$. 4. fig. 6.

Excrec. pl. 248. fig. 4 .

Stura, Fuun. 6. $n^{\circ} \cdot 2$ pl. $a . b . c$.

Var. b.) Natibus undato-rugosis, subtuberculosis.

Mya ovalis. Mlontagu.

Myce ovata. Maton. $n^{n}, 10$.

Lam r. Anim. s. 2'ert. tom, 6. pag. 77. $n^{\circ} .32$.

Drap. Moll. terr. et Ruv. de France, pl. 11. fig. 1. 2. 3. 4?

Preiffer, Syst. anort. pl. 5. fig. 9. 1 o.

La Mulelle des peintres a beaucoup de rapports avec l'espèce suivante. Elle est ovaleublongue, étraite, assez aplatie, très-inéquilatérale, obluse aotéricurement, atténuée et sulsanguleuse du côlé postérieur, et divisée de ce côté par un angle obtus qui s'étend du crochet vel's l'angle postéricur. I/z surface extérieure de cette corguille est couverte d'un épiderme d'un brun-vert trìs-pálesur les crochets; en dedars elle est d'une nacre blanche très-brillante, devenant quelquefois rosée, ou d'une belle couleur jaune safianée. La cliarnière est très-étroite, ua peu sinueuse dans le milieu : la dent cardinale est lamelliforne, cariée, un peu oblique, el plus épaisse que dans l'Unio rostrata; elle est recue daus la valve op)posée entıe deux dents très-inćgales, lauselliformes, dont la supérieure est fort petite. La dent postérieure est lamellilorme, tranchante, presque anssi longue que le bord supérieur de la coyuille; clle s'insète entre deux lames non moins ćtroiles de la valve gauche. Les impressions musculaires sout arrandies; l'antérieure est assez prolunde, la postćrieure est très-superticielle.

Cette coquille est très-alındanment rópaudue dans toutes les rivièles de l'Europe tempéríe. Sa longueur est de 25 is 30 milliun. et sal largeur àe 55 i 60.

\section{Molette rostrée. Unio rostrata.}

$U$. testâ trunsversim clongat.i, pos:erius uttenuato-rostrutu, extremitate subtruncatú.

Lister, Synops. Conch. tub. 147. fis. 2?'

Lasi. Anilis. s. vert. tom. 6. pag. 77. no. 31.

l'reiffer, Syst.anordon. $p l .5$. fig. 8.

Il est probable que cette espèce u'est qu'une variété de l'Unio pictorum; elle ollie cependunt quelques dillérences assez constintes, qui, au reste, ne sont peut-être que des muditications de localités. E!le est oblougue-alongée, étroile, un pen cylindracée, très-inéquilalérale; sun rest est mince, revêtu en debors d'un épiảerme très-lin, d'un vert peu foncé; le côké autérieur est coutt tet arrondi, le posterieur se termiue par un angle assez aigu : il est formé par la jonction des bords supérieur et inléricur qui se dirigeut obliquement l'un vers l'autre. Les croeliets sont assez saillaus, its divisent le bord cardinal en deux parlies inégales. La charnière est très-étroite; elle préscate, sur l'une et l'autre valve, une dent antérieure ou cardinale très-étroite, lamelliforme, relevée le long du bord lunulaire. La dent postérieure n'est pas moins étroite que l'antérieure; elle se prulonge dans presque toute la longueur du bord supérieur : elle est fort saillante, lauselliforme, très-tranchante à son snmuet; elle est reçue entre deux lamelles non moins minces el très-rapprocliées de la valve gauche. A l'iotérieur, celle coquille est d'un Llanc-nacré jaunâtre ; les impressions musculaires sont médiacres el superficielles.

Cette coquille, que l'on trouve dans les grand. neures de l'Europe tempérée, mais principalement dans le Rbône et dans le Danulse, est longue de 33 millimètres et large de 78 . Nous avons ru quelques individus plus grauds que celui dont nous dozaons la dimension. 


\section{T L}

z2. Méerre égyplicune. L'rio eźptiaca.

$U$. testi ovatu-oblongâ, inequiluteria, turgidí; lutere postrco lato, drialato; caldure angusto, budenlulo; lanncll + 'postucula angustissimá, acuti; epidemindo fusco-nudi, subradiato; margariti albo-rosea.

Var. Testá minore, posticé dilutatá, subalutá, migricurite.

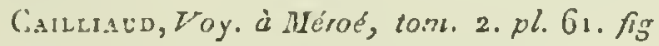
6. 7 .

C̈est i M. Cailliaud que l'on est redevalile de la connuissance de celtc belle espjece de Mulette, qui vit dans le Nil. Fille est ovale-oblongue, tiunsverse, inérualatriraic, enllée, subcordilorue; ses croclsets sont grands et proémineus, quelquefois anberculeus, rareusen ron gés; le côté antérieur cst arrondi el obtus, plus étroil que le postérieur qui, supérieurement, est comme pincé et légèsement diluté en aile; la surface extérieure est irrégulièrement sillonnée par des arcroissemens; l'épulerme qui la revît est lisse, d'un vert foucé, çuel quefois brunâtre, interrompu irrógulièrement par des tuches jaunes daus lesquelles on apercoit ordinaireıneui queløues rayons élruits. A l'intérieur, la coquille est d'un rose pâle. La charnière est très-étroite, interrompue sous le crocbet; on $y$ voit anterieurement sur la valve droile deux dents lamellitormes le long du bord: l'iaterne est plus grande et plus saillanie que l'externe. Sur la valve gaucbe on remarque une grande dent trèsétroite et sillonnce, égulement placée le long du bord, à la base de laquelle an en voit une seconde beaucoup plus courte. Ia dent lamellaire postéricure est droite ou à peine courbée ; elle est lanelliforme, très-étroite, trancbante, légc̀rement plissée vers son sommet; elle s'engage entre deux lames très-ineguales de la valve gauche : celle de ces lames qui est supérienre est Ja plus courte. La coquille est mince, les impressions musculaires peu profondes, et les deux antérieures, aussi bien que les postérieures, soat coolluentes. La variété se listingrue par un rovindre volume, par son bord supérieur dilaté et amiaci, et surtout par un épiderme noir trés-écailleux.

Les grands individus de cette espèce out 38 millim. de long et 60 de large.

23. Muletre margiuale. Unio marginalis.

i. Lesti ovato-oblongr. subrhambeâ, tenui, intis corulescente; fascits transversis, marginalabus; dente cardinuli parvo, compresso.

Excrce. $p l 247 \cdot$ fig. 1. a. b.c.

Var. b.) Testi minore, breviore.

J.Asx. Anim. s. 2ert. tom. 6. pag. $79 . n^{\circ} .4 \mathrm{I}$.

Celte eapece cstovale, transverse, inćquila térale, à lest mince, revêtu d'un épiderme d'un brun foncé, isterronpu vers les bords par des zones transverses
II U L

d’un jaune-verdåtre assez príce; l'extrúmité antérleure est arrondie, obluse, un pen plus étroite que la postérieure, qui se teruine par un angle assez saillaut. Le bord supérieur et pustéricur est comprimé et un peu dilaté en aile; il cst séparé vers le crochet par un angle postérieur qui se continue jusqu'au sommet. A l'intérieur, celte coquille assez mince unais solide, est d'une aacre d'un jaune peu fonce, très-brillante, avec des rellets rougeâtres et bleuâtres ver's l'extrémité postérieure. La charnic̀re est extrênemeat étroite, légèreanent arquuée dans sa longucur; clle se compuse, sur la valve droite, d'une dent cardinale, oblongue, en crête, rugueuse à sa face ialerne, et créoelée à son bord lib̆re; elle est accompaýnée extćrieurement d'un petit bourrelet décurrent qui limite la cavité dans laçuelle dloil être recue la dent de la valve oppusée. Sur la valve ganche ou rematque deux dents obluses, dont la postérienre, plus courte, ne commence à s'úlever ru'à l'csirúmilé de l'autre. La dent lamellaire postérienre est alongée, ałquée, étroile, irunchante, rưrucuse et trouquée à son extrémité posiérieurc; clle est reçe entre deux lamelles iuégales de la valve gauche: elles sont inégales par leur longueur et par leur bautcur.

Cetre coquille habite les rivières du Bengale, mais particulièrement, à ce qu'il paroit, daus les rizières. Elle est longue de $46^{\circ}$ millimèlt. et large de 84.

\section{Mulette fragile. Unio fragil:s. Sar.}

$U$. testâ transiersim oblongâ, posteriùs prodisctá; natibus retusis; cardinis dentibus angustis, vix prominulis; margaritầ roseâ.

S. r, Mém. de l'Acad. de Philadelphie.

Coquille fort remarquable, qui fait un passage très-êvident aux Avodontes par l'état rudimenlaice de ses deals cardinales. Elle est ovalaire, trausverse, très-inéquilatérale, obtuse et arrondie ; du cóté antérieur elle est obscurémeat aoguleuse postétieurement, et coupée obli fuement de cet angle postéricur jusqu'au bord supérienr : celuici est droit, et le ligament s'étend dans toute sa longueur; les crochets sont à peine saillans andessus dn bord cardinal. Toute la coquille est aplalie, surtout du cóté antérieur; elle est miuce et fracrile, sillonnée par des accroisscmeos irréguliers, et recouverte d'un épiderme d'un brun sille, jaunatre. A l'intéricar, la nacre est d'un rose-pourpré d'uae très-belle nuance; la charnière présentc ì sa partie antúrieure une seule dent, peu saillante et fort étroile, sur la valve clroite, et un petit bourrelet à peine saillant sur la valve gauche. La dent lamellaire postérieure n'occupe que le tiers postérieur de la longuenr du bord cardinal; elle est assez saillante, lamelliforme, lisse et trunchante : elle est recue entre deux lamellez, couries et peu saillates, de la valve gauche. Eee e ${ }^{\star}$. 
I'impression musculaire anlérieure est semi-lunaire, fort grande, yeu profunde; au-dessus d'elle on remarque une autre impression assez grande, ovale, légèrement arquée et dentelée sur ses bords. l'impression mosculaire postérieure est superficielle, arrondie, et se caufond, par son extrémité supérieure, avec l'impression du rétracteur posté. rieur du pied.

Cette coquille habite les grands fleures de l'Amérique septentrionale. Sa longueur est de 60 millin. et sa largeur de 100.

\section{MULLERIE.}

Genre établi par M. de Fernssac dans le preoier vulure des Mémoires de la Société d'Histoire naturelle ( par. 368 ), à la suite d'une Notice qu'il publia sur Tes Ethéries découvertes par M. Cailliaud, de Niates.

La coquille qui a servi à l'élablissement de ce genre eside la collection de M. le dus de Rivoli.|Elle i l'aspect extérieur de l'Éthérie plombée Lamarck, et pourroit se confondre avec elle si elle n'étuit, à ce que dit M. de Ferussac, d'une autre facoille, puisqu'elle seroit monomyaire, aurnit un ligament marginal semblable à celui des Anodontes ou des Mulettes, et auroit une charaière crínelée à peu près semblable à celle des Crénatules : elle ne peut être placée dans la famille des Malléacées de I amarck à canse de cette disposition singulière du ligament, et surtout parce qu'elle se fixe sur les corps sous - marins ì la manière des Ifuîtres. Vuici les caractères que M. de Fernssac donoe is ce genre :

\section{CARACTÉRES GÉNÉRIQUES.}

Coquillc adhérente, inéquivalve; valves réunies par un ligament extérieur, court, latéral, et par une charniere sinueuse munie de fossettes obliques dans lesquelles s'emboîtent des proéminences correspondantes l'éunies les noes et les autres par un appendice ligamenteux.

M. de Ferussac ne dunnan! point de nom spécifique $a$ l'unique espèce de ce genre, nous praposons de la dedier à MI. de Rivoli, qui ea est possesseur.

\section{MUITILOCULAIRE.}

Nom donné aux coquilles cloisonóes, que l’on nomme aussi Polyllalames. Voyez Coquilse et Molnesques.

\section{MULTIVALVES,}

Quand on chercha à former des divisions parmi les Mollusques, un des premiers caractères qui frappa fut le nombre des parties constituant l'ensemble de la cuquille : de la les dénominations d'univalves, bivalves et multivalves. Ces deux gremières décominalions pourroient rester dans la

\section{U S}

science, mais la dernière a dû rassembler des êtres furt différeas; c'est ce que l'oa sentit à mesure que les connoissances s'agrandirent: aussi on y apporta successivement des cbangemens. Dargenville y avoit d'abord fait eatrer les Oursins, Linné les réduisit à trois geares, Bruguière en angmenta beaucoup le numbre, et Lamarck les détruisit en remeltant dans leurs rapports nalurels les êtres qui composoient celle agglomération informe.

\section{Voyez Conchrhorogie et Mlullusques.}

\section{MIURE.}

On donne vulgairement ce nom à des coquilles tuberculeuses d'une lorme assez semblable à celle du fruit du cốrier. C'est ainsi que les Cerithium. morus, Ricinula morus, Purpura mansinella, etc., et plusieur's autres Pourpres, ont reru ce nom des marchands.

\section{MUREX.}

Klein, dans sa métbode, avoit élabli une classe sous celte dénouniuation, qui est scientitiqueıeut eaployée paur désigner le genre Raclier. ( $V$ oyez ce mot.) Cetle classe répond assez bien au gnenro Murex de Linoé. Il la divise en deux genres : le premier, Murex frondosus, renferme les coquilles rameuses ou à longues épines; le secand, Murex costuosus, comprend seulement celles dun mêmc genre qui n'ont pas les varices armées d'épines. Ces caractères très-vagues l'out porté à réunit dans ces genres un bon nombre de corguilles qui ne pouvolent y coovenit.

\section{MURULE. Murula.}

Ce genre a été proposé par MI. Schumaclies dans son Essai de Conchyliologie, pag.2 27, puats quelqques espèces du genre Ricunule de Lamarck, icls que le Ricinulis morus, aspera, etc. Ce gense, qui ne repose sur aucun bou caractère, peut d'autant moins être adopté, que le genre Ricioulo lui-ıếme pourroit bien par la suite être réuui aux Puurp:es. Voyez Ricisuse.

\section{MUSCADE.}

Noเn vulgaire que les marchands donoent 2 lo Bulle ampoule, Bulla ampoula.

\section{MUSCULUS.}

Klein, dans son Tent. method. ostia., pag. 127, a donné ce nom à une classe de cuquilles bivalves, daus laquelle il réunit trois genies, Musculus acutus, Musculus litus, et Misculus mamsmarius. Ces trois geures correspondent au genre Mytilus de Linné, et comprenuent à la fois des Moules, des Modiules et des Anodonies. Les genres et la famille de Klein ne peurent être adoptés, et on ne pert nou plas les considérer coame 
l'origine des dé membremens que Bruguière et lamarck out fuits dans le genre Mytilus. Vojez Nové.

\section{MIUSIQUE.}

Plusieurs espèces du genre Volute qui offrent des lizpes parallèles sernblables à la port́ce sur laquelle sisut placées les notes, et des points plus ou muins mullipliés, ont préseaté qirelque ressemblance avec la wousique écrite, d'où le nom que les marchands donnent surtout au Voluta musica. On a désigné, sous le nom de Musique de GuiHíe, le Voluta guianica Lamarck; de Musique lisse, le Voluta lovigatu Lamarck; de Musique murbrée et de Musique rouge, deux valiélés du roluta musica; enlia, la Musique verte est le Volute polyzonalis.

\section{MUTEL.}

On ne peut presque plus douter que le Mutel d'.1danson ( Voy. cue Sénég., pag. 234, pl. 17) ne svit une jeune coquille du gente Iridine; et, ce qui tend à le faire croire, c'est que la description qu'Adanson en doune se rappurte entièrement i de jeunes individus de l'Tridine que le M. Cailliaud a trouvés duus le Nil. Voyez Iridrive.

\section{NYACEA.}

Duns son Synop. meth. Mollusc., M. Menke dunne cenom is une famille qui correspond en parlie a celle des Mlyaires de Lamarck; mais les geares qu'il $y$ ajnute ne nous sembleut pas naturellement placés, et nows ne pensons pas qu'on inive y laisser les geures Sulénye et Pholadomye. TOJez MYALES.

\section{MYAIRES.}

Lamarck, le premier, a iostitué la famille des Myaires dans la Philosophie zoologiquo; il la romposoil alors des geures Mye, Yanorpe et Anatine, qui certainetoent ont entr'eux des rapports. Senlement les Myes et les Anatines ont le ligament interne. Celle lamille est bien placée entre les Mactracées et lez Solénacées; elle tient de l'une et de l'antre. Dans l'Extrait du Cours, où les lacolles sont mieux caractéristes, surtout d'uprès la position da ligameat, cette famille ue se compose plus que des deux genres Iye et Anatine, les Panoryes, mieux étudiées, ayant été l'appu:lées dans la famille des Solénacées. Le dernier ouvrage de Lamarck offie des rapports et la composition de celle famille entierement semblables.. M. Cuvier ne l'a point adoptée. Les teux genres Mye et Anatine font partie de la famille des Euferaús, et sont des sous-genres des Myes, aussi-bien que les Lutraires, les Anatines, les (ilycimères et les Pandores. M. de Ferussac, en admettant la famille de Lamarek, y a apporté plusieurs changemens; il y a ajouté les zerres l.utraires et Solémye : c'ést le deraier de ces deux genres qui est le moins rapproché. M1. de Blainville, dans son Traité de Murucologie, n'a point adopté la famille des Myaires de Iamarck; les genres qu'elle renferme sont compris dans la neuvieme lauille des Lamellibranclies, qu'il a nommée les Pyluridés. (Voy. ce mol.) Cel:e lusnille, divisée en deux sections, la piemicre, pon: les coquilles dont le ligament est interne, ot la seconde pour celles dont le ligament est extérieur, représente presque darus leur entier les Mactracées, les Myaires et les Solénacées de Lamarck. M. Latreille (Fams.nat. du Règ. anim., pug. 222.) a adopté, comme M. de fierussar., la famille des Myaires, à laquelle il a joint les. Lutruires, suns y meltre les Solémyes, comme M. de Ferissac: ce qui est le plus ralionnel. M. Latreille a tait tenir à celle famille les mêmes rapports çue I a marck entre les Mactracées, dout la famille des Ampliydesmides est séparée, et les Solénides, qui répondent aux Solénacées de Lamarck. Depuis ces divers travaux, nors avons observé le gense Analine dans ses détails; nous avons trouvé que tontes les espèces étoient pourvues, dansleur élat complet, d'une dent mobile et caducue à la charnière. Nous avons reconnu que celle dent, ou plutót cet osselet, a voit une forme constanle selon les groupes d'espèces; ce qui nous a déterminá à démembres les Anatines en plusieurs genres, et a faire avec elles une famille particulière. (Voyez Anatine.) Ainsi la famille des Myaires, dans le cas où on l'adupteroit, se trouveruit léduite aux deux geares Mye et Lutraire, qui ont beaucoup d'analogie, soit pour le test, soit pour l'animal. Lamarck caractérise ainsi celle lamille :

Ligament intéricur une dent ćlargie en ua cuilleron, soit sur chaque valve, soit sur voe seule, dnmant attache au ligament. La coquille est bâillante aux deux extrénités latérales ou it une seule. Voy. Myz, Anatine el Lotraire.

M. Meukc a proposé, dans son Synops. method. Mollusc., un nouvel urrangement de la famille des.Myaires, à laquelle il donae le nom de Myacrer. Il la compose de six genres, dans l'ordre suivant: Lutraire, Anatine, Thracie, Mye, Solérnye, ct Pholadumye. De ces six geares, les deux derniers n'appartienseat eu aucune wanière à cette $f_{a-}$ mille; les Pboladomyes se rapprochent, cnmme on le sait, des Panupées et des Solens; les Solémyes, au contraire, ont une organisation tellement distincle, qu'elles devront peut-être constituer à elles seules une famille. Quant an genre Analine, bien que Lamarck l'ait placé dans les Myaires, se liant par des caractères insensibles a vec les genres Thracia, Periploma, elc., il sera probablement nécessaire anssi par la suite, en continuant les observations yue nons avons déjł failes ì son égard, d'en constituer une petite famille intermćliaire entre celle des Myaires el cos 
Curbules : ainsi la farille des Myaires, en suttarhant aux principaux caractères que lui a donnés Lanarck, se trouveroit réduile aux gedres Mye et Lntraire; mais nous croyons que celle lamile doit recevoir une extension assez considúrable pour adonettre d'un côté les Mactıes, qui se lient aux Lutaires, el, d'ua autre, les Corbules, qui ont tant de ruppoits avec les Myes. Nous ieuvoyous à cel égard is l'arraogremen! que nous avous proposé à l'arlicle Moluuspues.

\section{MYE. Mya.}

Les coquilles qui ont servi à l'établissement de ce genre étoient peu conaues des Anciens. On peut croire que la coquille nommée Chama peloris par Rondelet, ainsi que le Chama glycumeris, appartiennent a ce genre. On pourroit eucore, en conservant quel ques doutes, y rapporter la figrure $26 \mathrm{~g}$, pl. 423 de Lister, qui i que!qu'inalugie avec le Mya truncata; inais on ne peut plus y conserver la figure de Gualrieri, que Iamarck cite, parce qu'elle appartieot bien plutô: ¿ l'upe des grandes Anulines. C"est donc Dargeaville, dans sil Zoomorphose, et Chemuiz, qui, les premiers, ont donné de bonnes figures de quel pues espèces du grenre Mye, sans que cependant ils les distiaguassent d'autres couquilles bipalves. Linné, Je premier, institua ce genre, mais il y coulondoit uu grand nombie de cuquilles étrangèeses, qui on furent successivemeot retranchúes par Bruguière, qui établit le genre Anodonte; et par Lamarck surtout, qui en déuembra les Anatines, une partie des Lulraires, le's Glycimères, les Vulselles, et en sépara la plus grinde par:ie des espèr:es, qu'il réduisit à quatre, encore faut-il en ôter une, le Myca solemycalis, ıni doit appartenir à notre nouvean gente Tétrugronoste (voyez ce mot), et pent-èlie laudia-t.il un sćparer aussi le Mya erodona. M. Mínard de la Groye reliancha encore noe espece des Hyes de linó, pour en faire le ngenre l’anopée; c’est le $\boldsymbol{M}$, a glycimeris qui a servi de type au nouvexu genre. Linné jlaça les Myes eutre les Pholades et les Sulens, lni laisant suivre les Multivalves et conmencer la grande sćrie des Bivalves. IBrugaiere ue l'iajita pas, et sépara diluantage ce genre des Mulivivalves; il commenca la série par Ta seclion des conuilles irrégulières, et celles qui sont régulic̀res vinrent après; les líyes en forment le premier genre. Lamarck, dans le Système des Animaux sans vertêbres, les mit entre les Glycimères et les Solens; et, uи peu plus tard, en élahlissant la funille des Myaires, il les mit en rapport avec les Auatines et les l'anopées, non loin des Sulens, rapport ru'il cooserve dans ses autres ouvrages. M. Cuvier adopla le genre Nyc; mais ce getrre représente plutôt une fitmille par le grani nombre de sous-gentes qual contieni.

3.. Cisy, dans s.l chassificaion naturelle des
Mullusques, fait, de la famille des Myaires, nn deuxième ordre de ses Conchopho'a; il nowne cet ordre Puchypoda, et il le coupose des genres Mye et Corbule, rapports qui sont assez natarels d'uprès la seule considéralion de la charvièrt. M. de l'erussac a justemeot rapproché les Lutraires des Myes, coume B1. Cuvier l'avait lat le premier. MIl. de Blainville et Latreille les ont ituités. L'organisation des Myes dillère assez do celle des Mactres sous plusicurs rapporta; mais elle est très-vaisine de celle des Lutraires avec lesiquelles elles ont la plus graade analogie. Les Myes sont fortement épiderinées; le mauteau est leriné presque dans lout son coutour; denx tube; tris-longs réunis sous une mêne enveloppe revilue d'un épiderme rugueux teriniment l'unimal postćlieurenent et lui donuent ane comanunicalion avec le lluide ambiant; nne troisième onverture antérieure très-petile se trouve vis-à-vis le pied adionentuire, et a a peine yoelques ligntes d'étendue. Les bords du minteau sont épais tit charnus, mais, dansle resie de son étendue, il est extrêconeut maluce el trassparenl; postćricu. rement il conlieat le muscle rayonné rélracteur des siphons; le muscle adductenr antérieur est fort onince, ćlroit, alongré sous le bord, et son impressicu se conlinue avec celle du bord du mauteau; le wuscle postérieur est cylindrique, plus pais. sant que l'antérieur, et placé entre le bord et l'origine des cabes. Quand on a feadu le mantcau dans la coumissure inférieure, on voit nn pied gréle en lorme de languetle, sans courbure; il aubliere à la conasse abdominale; il est coriace, et a des muscles rétracteurs á peine sensibles. L'anverture de la bouche est petite, cachée eatre deux lèvres sous le muscle adducteur antérieur : ces lèver aboutissent a deox paires de palpes labiaux, une de clarque côté; elleq sont langues, pointues, épaisses, non appligućes l'ane contre lautre : leur lince interne est conue veloutćc pal un graud nombre de lamelles trunsverses, très-fines, fort suillantes; les lames qui revètent (es palpes soot absolument semblables dans les Mactres: le systèrne digestil ne dillère pas cle celui des autues ('onchilêres. (Voyez Nonrusques.) Les brancibies sont peu étendues; elles s'étendent de chargue cóie de la enasse ahdomioale, principalement ì sa partie pustérieure, où elles se rérltrisseat et deviennent Hotlan'es jusque vers l'orilice interne du tube branchial. La lame externe du feuillet externe se prolonge notablement audeli du puint de réunion des branchies, se repliant vers le pied comase les autres leuillets bratacliaux , et llutlant postérieurement avec eux, de manière que l'aninal est pourva réellement de trois lénillets brancbiaux de cluaque cóté, l'interne le plus grand et le truisiène le plus petit. Cette dispositiun est essentiellement caractélistique de ce gente, ajusi que d'un autre qui en est vaisio, el ucus ne pensoas pas que personoe ait men:ionnó 
ce fait intéressant et trics-ficile à rúulfer. Yous l'avons obscrué daus los denx espèces se nos cótes, la Mje tronguie et la Mye de's sables. Quaique licrdie des Labellibranclies ail cté caractérisé de manière a ne tenteruer que les Iluliusques it deux paices alc branclais, nous pensons que celle? paire !e plus dans les dyes ne doil pas empéclier de mutre ce genrc duns les necures rapluorts, justenactil apprécrés ites zoologistes, et yu'il n'est pas

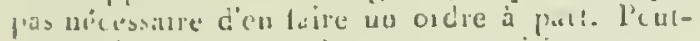
ile "n'en observan! les genres avoisuans avec allention, conme les Lutraires, on trouveral de ciwo former une famille walurel.e sur laquelle il ne icstera plus le nuadre douie. Nuus pouvous anuonecr cue ce caractere se rencontre igileliant dans les Mactres, arais point dans les 'l'el. lanes, ni les V'́nus, les l'lolades, les Donares, etc. Nous ne parlerons proint din systéme de la circulation, qui doitétre furt semblable, pour oc point dice idcutique, à celui des antres Mullusques lamellibranches. l'our le systène bicrveux, on aperçoit facilement les gatuglions antineur et postćreur. Le premies, plité sur l'assJhage, et immédiatement sous le muscle adduetcur antrieur, donne deux branclies antérieures qui descendeut le long de la face interne du musale adducteur anquel elles foumissent quelques filets, gagneu! le vord spais du mautea, el sy distribueut; deux branches latérales assez grosses qui se perdent dans les palpes labiaux : quelques felits lilets postérieurs en purtent pour se reudre vers l'estonac, le foie et les iniestins. Entio, deux petits filets sortent des angles postéricurs du hauglion, descendent latéralement de cliaque côté de la masse abdowinale, et se rendent probublement au ganglion postérienr; mais leurexliême ténuité nous a empiechlé de lessuive jusque li.. Le ganglion postérieur est appliqué sur la face interne dn muscle adducteur postérieur; il fournit yuatse branclies, deux postérieures, cui gaguent le bord du manteau pour s'y réprandre apres avoir donué un filer prour les siphuns: les deux brauclies antérieures temontent de chaque còlé du corps ¿ la base des brauchies, auxryuelles elles distribuent probablenent des filets nombieux avant de lourair les branclies d'anastomose avec le ganglion antérienr. D’après ce cjue nous venons d'exposer, le genre Nye peut être caraclérisé de di manière suivaute.

\section{CARACTÉRES GÉNÉRJQUES.}

Animal ovale, plus ou moins épais, pourvu de deux tulses réunis, !ng et revêtus d'un épiderme brun et ruguenx. Les lohes du manteau réunis ne laissent quine très-petile onverture antérieure. l'ied yetit, linguifortae, rudnsentaire; palpes labianx épais, pointus, prolondénent striés à leur lace interne. 'Trois feuillets brauchiaox de claque côté: l'interae le plus graod, l'externe le plus latit; its se réunissent posterieurencm, c: la or inasse llotle dans la cavité du nanteau. Cocquille

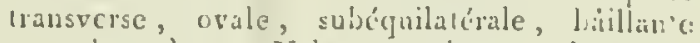
cux deux bouls. Valve gatuche numie d'une dent cardinale, grande, comprimce, arrondie, sirllante presepue verticalcment. Une fosiclie

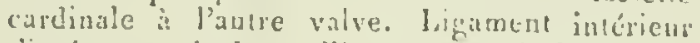
s'insérant sur la dent saillaute et dans la fossetle de la valic opposće.

les Myes vireut enfoncées claus le salile, pres des cúles. Lilles y sont plactécs les lubes ou siplions co haut ef l'omrerture de la bonche en bas. Il dout la ú tre fort difficile de quitter celle posilion, on de se reuscr un noureau trou, lorsqu'elles sont arraclices de cclui où alles ont pris leur accroissemen. On ne troure gu'un tri's-petit nombre de Myes a l'état fossile, et clles appartiennent aux terrains les plus modernes, tels que le crag d'Angleterre el les terrains récens de la Norwège.

Quelques especes de ucejuilles, qui se trouvcrit aux environs de Dax et de Bordeaux, semblen: loire un passage, d'un cólé arec les Anatines, ol de lautre asec les Corl ules. Ce dernier genra surtout a des rapports furt intimes avec les Myes. lls sout lels que tuamarck avoil placé parmi ulles une grande el lelle espèce de Corbule, sous le nom de Mya croduna.

\section{Mre lronquée. Mya tinncata.}

M. testâ opatî, ,entricosâ, posteriùs truncatí; cardinis dente antrorsim porrccto, rotundato, integerimo.

Mtj a truncata. Lix. Syst. nat. pag. I112. GMxx. $n^{0} \cdot 1$.

Gualt, Conch. tab. 9' fig. D.

Pensant, Zool. brit. tom. 4. $\mathrm{ml} .4 \mathrm{r}$.

Chess. Conch. tom. 6. tab. J, fig. I, 2.

LincrCl. rl. 229. fig. 2. a. h.

LAM . Anim, sanszert. tom, 5. pag. 461, no. 1 .

Il est extrimeneut facile de reconncilue celle espece ; elle cst ovalaire, conrle, inćquilatórale, inćquivalve, rentlíe, subcorditorme, arrondic et olscuse antérieurement, tronquée du côté postírieur, cù elle est fortement bûillante. Ce cóté postérieur est beaconp plus rourt et plus étrnit que l'antérieur : les bords du baillement considérable qưil présente sont épaissis à l'intíricur et un pen ruversís en dehors; les crochets sont asscz grands, obliques. Sur la valve gauche, on trunve, a la chamière, un grand cuilleron perpendiculaire, creusé en goultière el séparé autérieuremeut, par un sillon oblique, d'une dent obsolèie un diune sorte de lobure, qui lui sert de point d'appui, de ce cóté, sur le bord cardinal. Sur la valve droite, on voit un cuilleron petit $\in t$ profond, incliné clans la cavité du crocleet : son extrémité inféricnce fait une légère saillie dans la cavilé de la valve; son cóté antéricur porto n:e 
pelile saillie oblique, qui s'enfunce dans le sillon que nous aroos fail remarquer, à la basc du cuille. ron de l'autre valve. L'impression musculaire antérieure est fort longne ırès-étroite, el arquée dans sa longueur. L'inipression postérieure esi pe. tite, semi-lunaire, et elle est jointe à l'antérieure par l'impression paléale, largement écbancrée postérieurement.

A l'extérieur, les valres préseotent an grand nombre de sillons et de stries irrégulières d'accroissement : elles sont d'un brun-grisâtre, quelquefois ochracées. I'épiderme qui les couvre est assez solide, d'un brun peo foncé, et se proionyeaut sur le tube charmu, fort alongé, qui constitue jes siphons. A l'intérieur, les valressont d'u bruzgrisâtre complétenent lisses. M. Brongniart a rapjorté cette espèce fossile de Udvalla, près de Goteborg en Norrège. Elle habite les saliles de l'Océan europécn. Sa longueur est de 42 mill. et sa largeur de 58.

\section{MrE des sables. Mya arenaria.}

MI. testâ ovatô, anterius rotundatâ; cardinis dente denticulo, laterali, acuto.

Mya arenaria. Lis. Syst. nat. pag. 1112, GIEL. $n^{\circ}, 2$.

Bast. Op. subs. tom. 2. pag. 6g.tab.7.fig:1. Curns. Conch. tom. 6. tab. 1. fig. 3. 4 . Excrcl. pl. 229. fig. 1. a. b.

Pexnaxt, Zool. bitit. tom. 4. pl. 42.

I.A. $\mathrm{x}$. Anim. sansvert. tom, 5. pag. $461 \cdot n^{n} \cdot 2$, DE Brarv. Malacol.pag. 565. $) / 77$. fig. 1.

Coquille ovalaire, assez épaisse, équiralve, suluéquilatérale, très-bảillante à ses extrćmités, (-l surtout à la postérienre. Le côté antérieur est ostus. Les crochets sont pclits, peu coorbés, et jmmédiatemeat au-dessous d'eux se voit, sur le bord cardinal, une très-grande dent, saillante jerpendiculaireaeut sur la valve gauclse, ct une cuvité oblique intérieure sur la valve droite. Ia lent cardinale, ou le cuillernn, est partagée en deux parlies très-joégales: l'une, la plus grande, tunne insertion à uu très-fort ligament; elle est lígèrement creusée en cuilleron: l'autre consiste ca une deat bifide, longue et étroite, obliqucment décorreule à la base du cólé postérieur. La charnière de la valve droile consistc en un grand ruilleron profond, renversé dans la carilé du rrochet lui-mime. Sur le cóté postérieur de ce cuillernn se montre nne petile surface plane, çuelquefois un peu saillanie, qui correspond à̀ la dent oblique de l'autre valve : celle disposition de la charnière de celte espèce cst extrêinement analogue à ce que l'on voit dans les Corbules; et certainement celle coquille riendroit se placer dans ce geare si clle troil inéquiralie el zuoins buillante. A lextériens, les ralves snnt couverles de siries transrerses ficu rógulières, mais trés-nomloreuses : l'épiderme qui les revêt est mince et d'un brun-grisåtre. En dedans, elles sont d'un blanc-grisátre. L'imprcssion musculajre antérieure est très-étroite ct fort lungue, et l'éclıancrure de l'impression paléale est profunde et assez large.

Celle coquille vit dans les sables de l'Oréan d'Europe. Sa longueur est de 57 mi!l. et sa largeur de 102 .

II existe, dans le cray d'Angleterre, une Mye fossile qui a la plus grande analogie avec celle-ci. M. Sowerby lui a conservé le nom de Mya arenaria, el, en effel, ce seroil bien l'analogue de l'espèce dont il s'agit, si la dent ublique du cuilleron n'étuit obsolète; mais ce caractère est de peu d'importance.

\section{Mys tugon. Mya tugon.}

II. testí globosá, anticè obtusi, posticè brevi, oblıquè t-uncatâ, hiante, longitudinaluter striatí, subdecussatí, albì, pellucidì.

Iya anatina. LIx. Garl. pag. $522 t$.

Le Tugoo. Anass. Voy. au Sénég pl 19.fig. 2. Свам. Conch. tons. 6. tab. 2. fg. 15-16. ExстcL. $p l .229 \cdot$ fig. 5. a. b.

Anatina globulosa. Laмr. Anim. sans vert. tom. 5. pag. 464. no. 5.

Fossilis. Mya urnata. Bast. Mém. de la Soc. d'Hist. nat. tom. 2. pag. 95. pl. 4. fir. 21.

Celle coquille appartient sans contredit au genre Mye, et non aux Anatines, comme Lamarch I'avoit cru. Elle est très-reınarquable en ccla que, vivant an Séaćgal, ellc se relrouve, fossile, aux environs de burdeaux el de Dax. Celle petite espèce ne manque pas d'analogic, quant à la forme, el surtout à sã truacature postérieare, avec le Mya cruncata. Elle est ovalc, gloludeuse, un peu plus large que longue; clle est Irès-eallée, ¿ crochets grands et subcordifuranes. Son cóé postérieur est très-court, tronquí, étroit et forteınenı båillant. Le cóté aniérieur est subdilaté et régulièremeus arrondi. Sur la value gauclie on troure, sur le bord cardinal, ua petit cuilleron oblique assez prolondémeul creusé en gountic̀c. A la base, et dı cóté postérieur, se truuve in jelit lobc, qui cn est sćparé par un angle sailla $7 .$. Le cuilleron présente, avec celui des antres Myes, velle dllúrence d'être un peu incliné à l'intérifuat des valves; ce qui mnntre na vérituble passage des Myes vers los Anatines. Sur la valre droile, un voil également ua pelit curllcron senfonçaı dans la cavilé du crochel; mais il y est moins cortement enfoncé que dans les autres espćces du méne geare. Son bord postérieur présente one sorte de dédaublement qui est destirś à receroir I pe:iie dent que nous aroos ficil remar- 


\section{Y T}

Tyuer sarl'antre valve. Le bord postérieur cst court, trunqué, Irès-bâillant, un peu épaissi et assez furtement renversé en delıors. La surface extéyieure de cetle coquille est ornée d'un grand nombre de stries longitudiaales, onduleuses, subtreillissées par des stries transverses irrégulières d'accroissement. Ces stries longitudinales sont situées priacipalenent sur le côté postérieur; on en voit rarement sur le côté aotérieur. A l'intérieur, les valves sont lisses, ct l'impression musculaire pos:érieure est tellement petite, qu'elle se distiugue à peine de l'extrémité de l'ionpression paléale don l'échancrure est peu profonde.

Celte coquille, soit rivante, soit à l'état fossile, est très-rare dans les collections. Elle est longue de 23 i 25 millim. et large de 28 a 30 . Les individus fossiles sunt un peu plus petits.

\section{MOCONQUE. Myoconcha.}

MI. Sowerby est l'auteur du genre Myoconqne. Il l'a établi pour ane coquille fossile de l'oolithe ferrugineuse supérieure, quel'on trouve aussi bien en Augleterre qu'en France, et ayant, par sa forme, qucldues rapports avec les Modioles, mais se rapproclıant singulièremerıl des Curdites parses autces caraclères. Ce rapprochement devient évicent, quand on met à còté de celte coquille la Curdita phrenetica. Aussi nous avous la conviction riue ce genre Myoconque ne sera point adopté, et que, malgré la forme myrilurde de la coquille, il sera joint aux Cardites. M. de Bluiaville, dansson Truité de Malacologie, n'a mentionné re genre que dans les additions et correctious; ve le cansluissant, dit-il, que d'après la figure et la caractéristique de l'auteur anglais, il lui esi impossible de lui assigner des rapports dans la série méthodique. M. Menke, dans son Sinopis Molluscorum, a placé ce genre dans la famille des Crassatelles, avec les genres C'russina el Crassatella, quorqu'en yéalité il n'ait avec eux que des rupports fort éluignés.

\section{MYSCA.}

M. 'Turton a proposé ce gente inutile pour quelçues espèces de Muletles qui ont la dent antérieure comprimée. Le peu de valeur de ce caractère doil faire repousser ce gense d'une bonue máthode. Voyez Musetre.

\section{MIYSIA.}

Doulle emploi qu'a fait M. Leach pour le genre Loripes de Poli, étabh de puis fort long-temps, et qui, par conséquent, doit être préférublemeat couservé. Voyez LoRapede et Locine.

\section{MYTILACÉES. Mytilucer.}

La famille des Mylilacées futcréée par M. Cuvier, dasusle Régne animal. Il y renferma tous les Mol- lusques acépliales testacés qui ont deux ouvertures au manteun. Cette famille représente les Biforipalla de M. Latreille, et elle contient Jescinq genres Moule, Anodonte, Mulefte, Cardite eı Crassatelle. Le genre Moule est divisé en trois sous-genres: les Minules propres, les Mudioles el les Lilbodonus. Dans son premier Tiaitésystématique des Aaimaux sans vertèbres, Lanarck mit les geores que nous venons de citer dans d'autres zapports. C'est ainsi que les Moules et les Modiules se Irouvent près des Piunes, à cốté des Mulettes el des Anodontes, les Cardites étant rejetées plus loin. Dans la philon sophie zoologique, les Moules el les Modiules funt partie de la lamille des Byssifères, avec les Houlettes, Limes, Crénatules, elc., tandis que les Muleltes ei les Anodontes, de la linialle des Nivades, et les Cardites font partie de la lamille d=s Cardiacées. Cet arrangement est resié absolument lc méme dans l'Extruit du Cours. Mais, dans son dernier ouvrage, Lamarck a adopté la faunille de 11. Cuvier, en la moditiant. II n'y laisse en elfet que les trois genres Piune, Mudiole et Moule, mais il la range parmi les Monomyaires; ce que n'ont pas fait la plupart des zolngistes qui ont suivi de préférence l'opinion de M. Cuvier. M. de Ferussac a adopte la fanille des Mytilacées; en la conposant des Modiales, des Moules et des Libodomes, il ea sépara le genre Pinne, pour le porter dans la fanil e des Avicules. M. Gray, dans sa classification des Mollusques, a associé les Mloules avec les Arcbes et les Avicules. Il est facile de concevoir des rapports entre les Moules el Avicules; mais avec les Arches, cela est un peu plis diffeile. M, de 13lainville a suivi rigoureusement Lamarck: il a admis les Mytilacées sans autres clrangemens que de faire des sous-genres des Moules a vec les Modioles el les Libudomes. M. Latreille a imité complétement M. de Ferussac.

Dans le Dictionnaire classique d'Histoire naturelle, nous avons complétement adopté la lamille des Mytilacées de Lamarck. Depuis, de nouvelles observalious nous ont lait sentir la nécessité d'y apporter quelques cbangemens. D'abord, il faut reconuoître, avec M. Cuvier, que les genres de cerre famille sont dimyaires. Ils ont le système nerveux parlaitensent symélrique, et celte raison, jointe à la présence de deux muscles, dont l'un est très-petit, il est viai, doit les faires confondre daos la yrande série des Acéphalés di myaires. Nous avons fait seatir, à l'arlicle Noves, la nécessilé de suppriner les gemres Modioles et Lithodome, et de ue les admeltre qu'à titre de sections dins: les Moules. Les rapports dans l'nrganisation des animaux nous out déterminé à former ia famille des Mytilacées des genres Moule, Pinne et Avicule. (Voyez ces mots.) Aux Moules sont joinis les Modioles et les Lithurtumes, et aux Avicules nous arons réuni depuis long - templs les Pinladines. 
MYTILICARDES.

M. de Blainville anmme ainsiun des sous-genres des ('ardites (Truité de Mulacologic, pag. 540), dans lequel il comprend les espices alungées, un peu échancrées ou bâillantes au bord inlérieur, ayant le sommet piesque cépbalique et le liganieut caché. La Cardite grosse-côte, Cardı́ta crassicosta, sert de type à ce sous-gerre. Nayez Cardite.

MYTILOÏDE.

Geure proposé par M. Brougniart dans sa Géc- logic des environs de Paris, $2^{\circ}$. édit., pour des coquilles de la crie, que M. Surverby a reconnu depuis apparteniv au mèue genre que les Calilleь. Voyes ce mol.

\section{MYTUI.O-PECTINCULUS.}

Genre que K!ein a pris de Fubius Columna. II: représente parfuitement le genre Placune de Lamarck, que Lister confondoit avec les P'eignes, quoicqu'il en ail fait one pelite seciou. Foyez Pracune.

Fin du Tome second: 







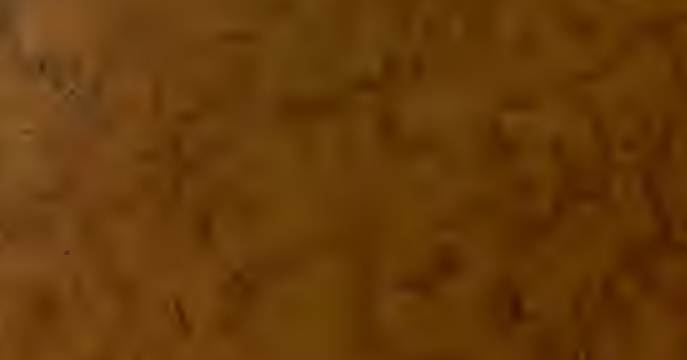

A.

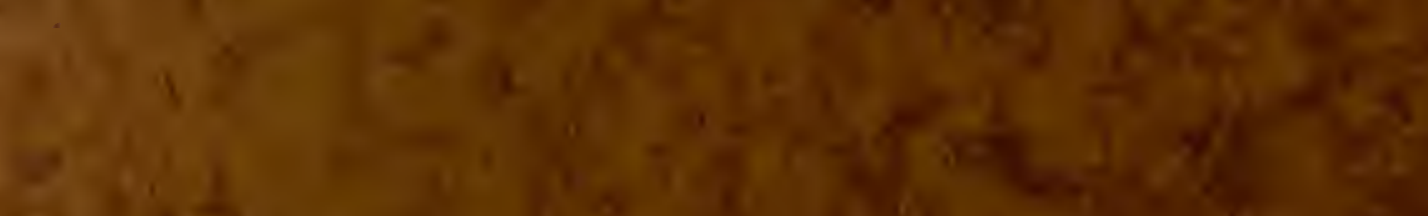

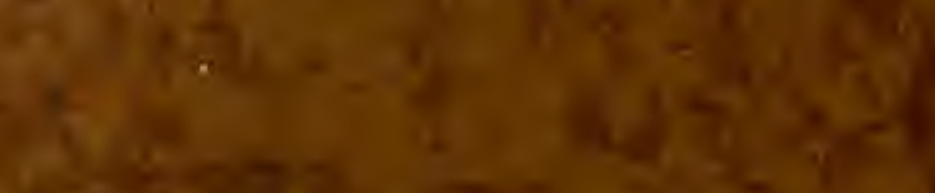

cosis?

axexing

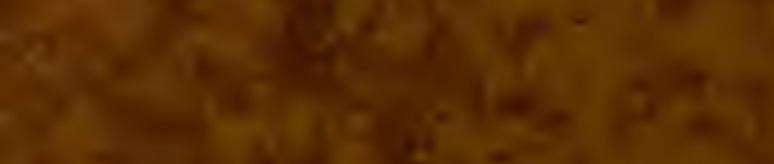

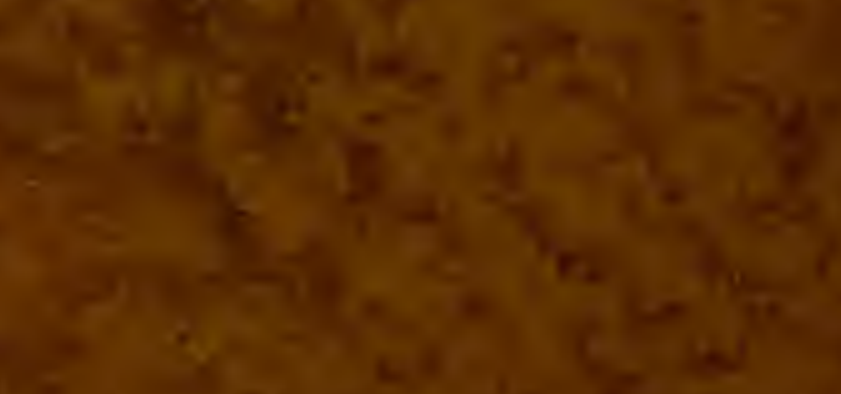

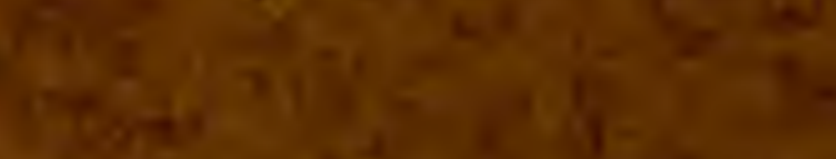

en
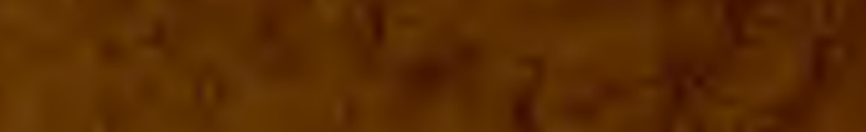

$$
\frac{2 x+4}{4}+5
$$

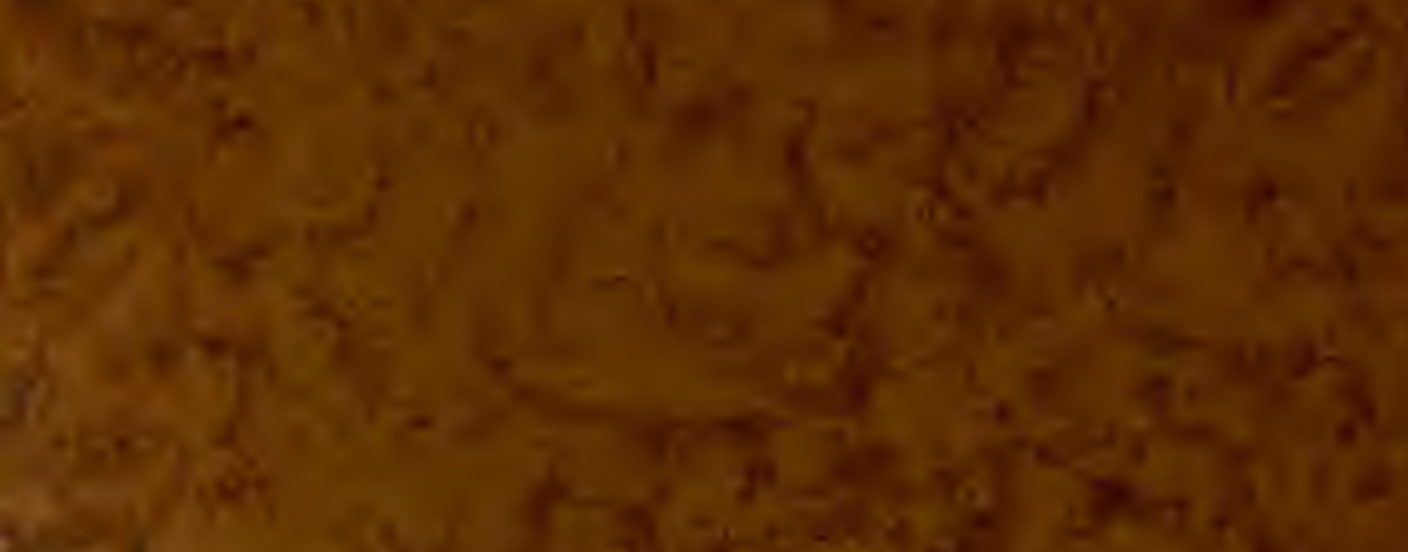

aidesting

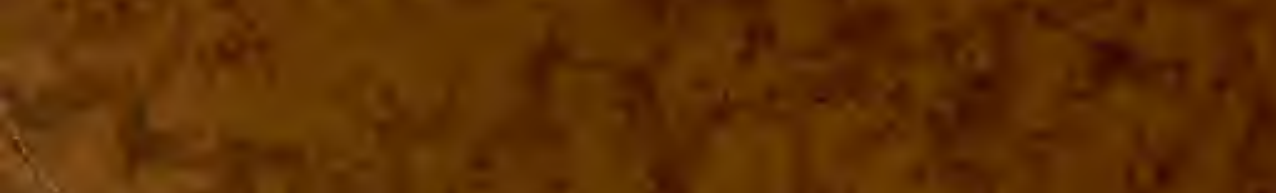

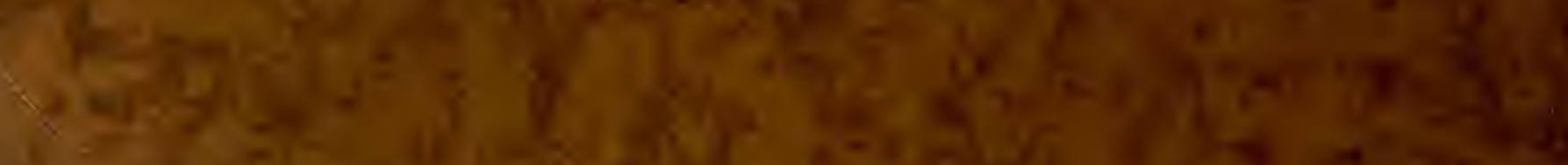

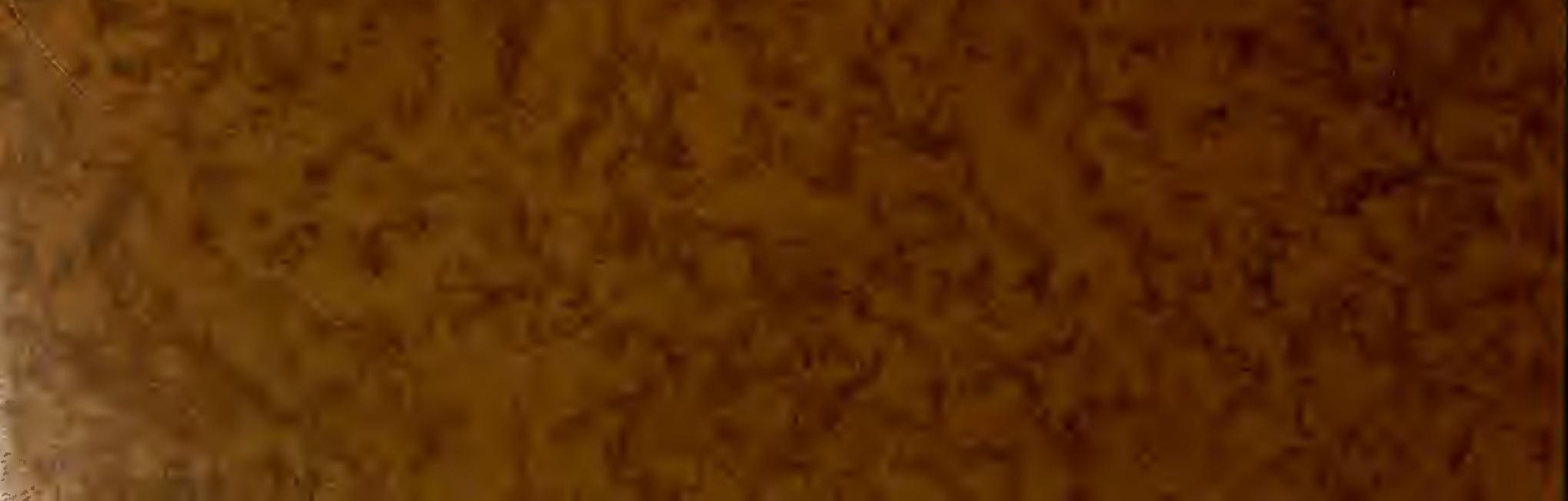

